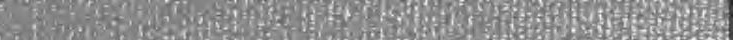

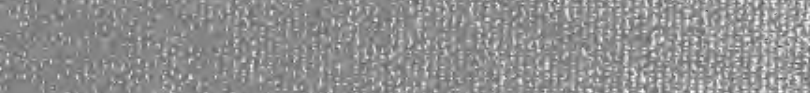

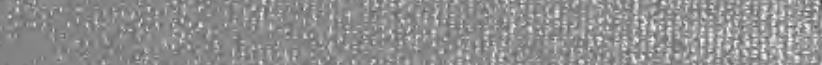

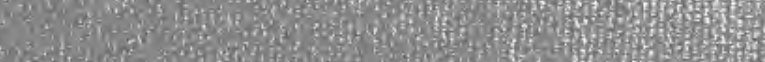

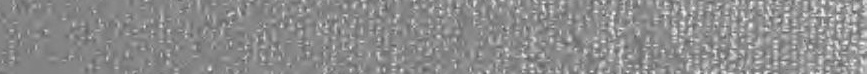
c. s. 32 (2)

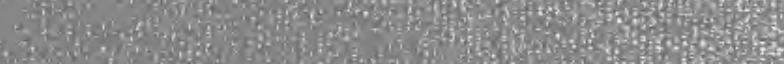
at

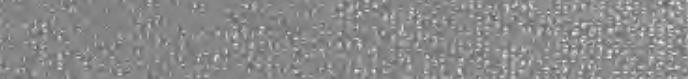

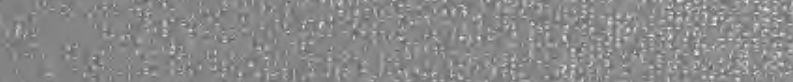
2.

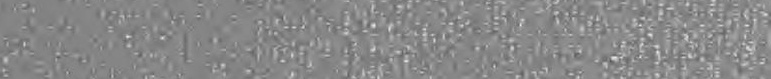

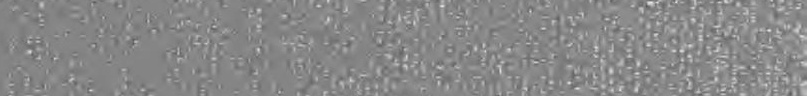

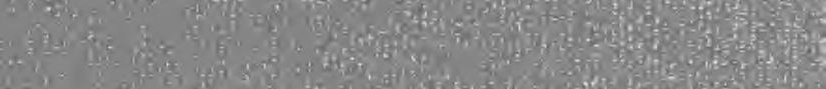

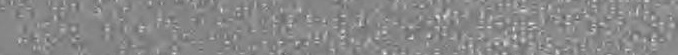
$4010 \%$ a Alin

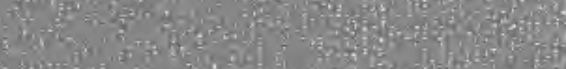

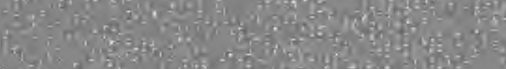

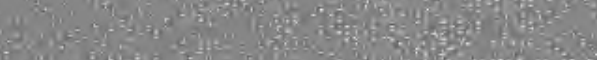

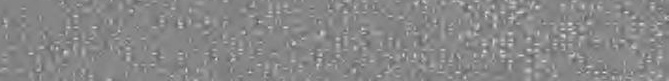

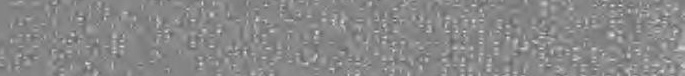
(6.17)

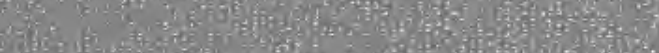

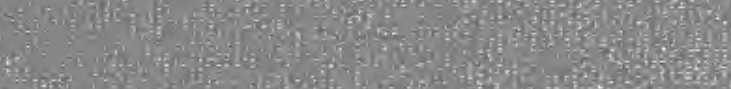

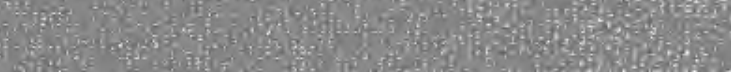

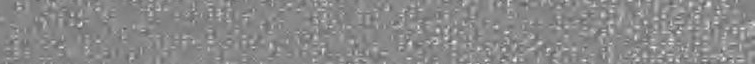

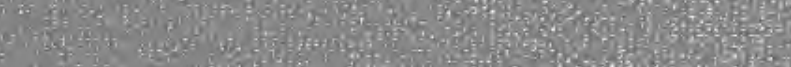

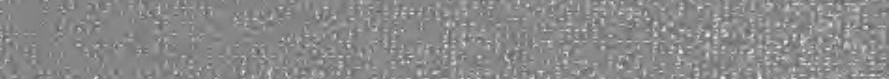
Q6.

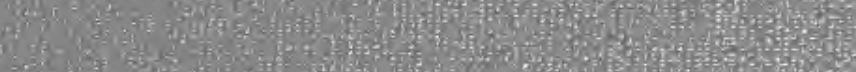
a.

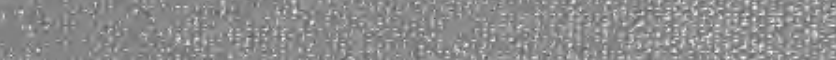

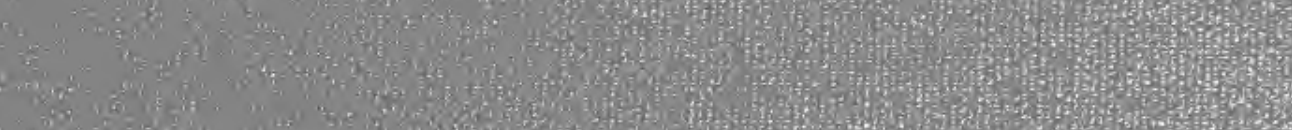
S. w.

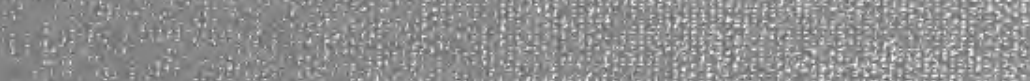

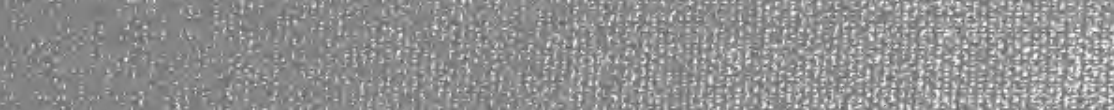

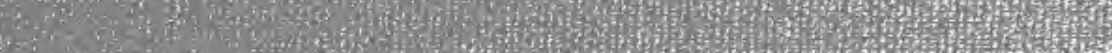
Ans

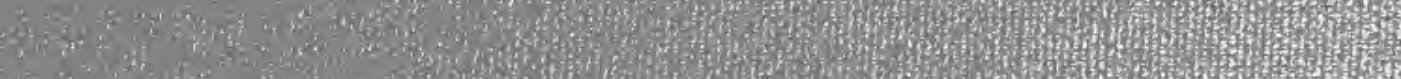
$\therefore$ and if (2) (5.) 






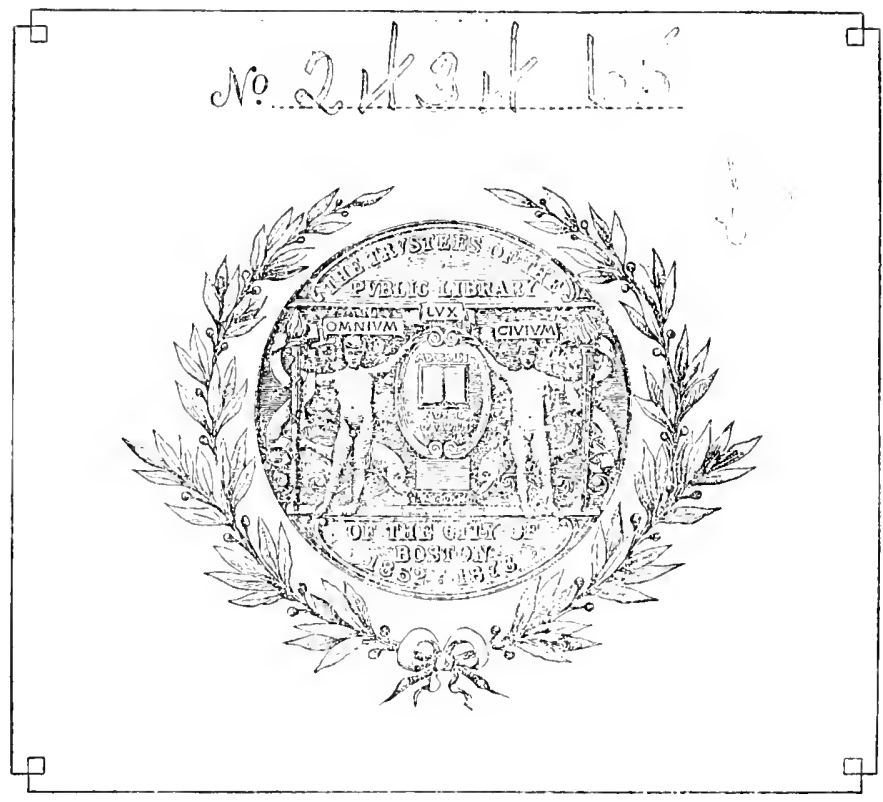




\section{ALPHABETICAL DICTIONARY}

oF

\section{Coats of Grms}

BELONGING TO

FAMILIES IN GREAT BRITAIN AND IRELAND;

FORMING AN EXTENSIVE

\section{O R D I N A R Y}

DF

\section{BRITISH ARMORIALS;}

UPON AN ENTIRELY NEW PLAN,

IN WHICH THE ARMS ARE SYSTEMATICALLY SUBDIVIDED THROUGHOUT, AND SO ARRANGED IN ALPHABETICAL ORDER

THAT THE NAMES OF FAMILIES WHOSE SHIELDS ARE FOUND ON Buldings, Monuments, seals, Paintings, plate, etC., WHETHER MEDIEVAL OR MODERN, CAN BE READILY ASCERTAINED.

BY THE LATE

JOHN W. PAPWORTH, F.R.I.B.A., EDITED FROM PAGE 696 BY

ALFRED W. MORANT, F.S.A., F.G.S.

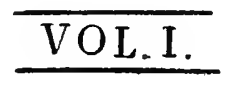

JONDON.

T. RICHARDS, 37, GREAT QUEEN STREET.

1874.

Al: ighte roservec. 


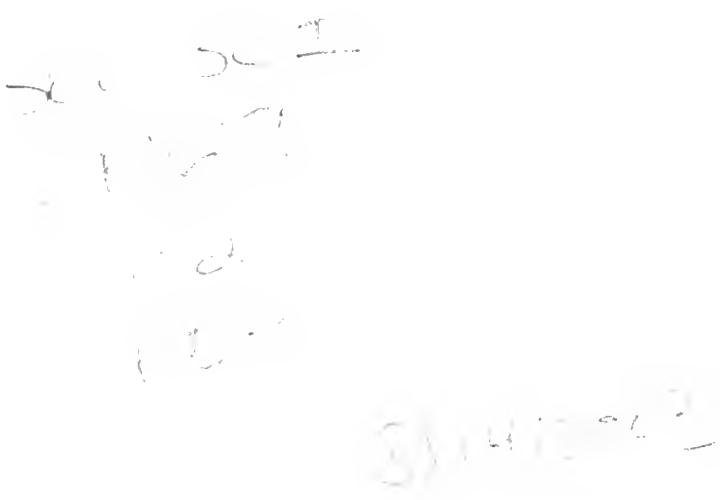




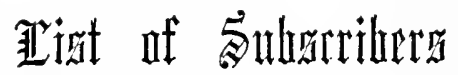

To the Work under the final arrangement for completing it.

The Print Department of the British Museum

The Department of Science and Art, South Kensington

The Library of the Corporation of London (Two copies)

The Society of Antiquaries, London (Two copies)

The Archæological Institute of Great Britain and Ireland (Two copies)

The Birmingham Library (Two copies)

The Chetham Library, Manchester

The Historic Society of Lancashire and Cheshire

The Kent Archæological Society (Two copies)

The Kilkenny and South-East of Ireland Archæological Snciety

The Leicester Permanent Library (Two copies)

The Lincolnshire Diocesan Architectural Society

The Liverpool Free Public Library

The Liverpool Library (Two copies)

The London Institution (Two copies)

The Middle Temple Library

The Sheffield Library

The Somerset Archæological and Natural History Society (Two copies)

Trinity College, Cambridge (Two copies)

The Wiltshire Archæological and Natural History Society

Mrs. Stackhouse Acton, Acton Scott (Two copies)

Rev. H. Addington, M.A., Henlow Grange, Biggleswade (Two copies)

William Adlam, Esq., Chew Magna

W. A. Tyssen Amhurst, Esq., Didlington Park (Two copies)

John S. Anderson, Esq., Old Broad Street (Two copies)

Messrs. Asher, Berlin (Two copies)

Arthur Ashpitel, Esq., F.S.A., F.R.I.B.A., the late (Two copies)

C. C. Babington, Esq., M.A., F.R.S., F.S.A., Cambridge (Two copies)

C. G. V. Bayly, Esq., Davies Street (Two copies)

L. R. Baily, Esq., Liverpool (Two copies)

John Batten, Esq., J.P., Aldon, Yeovil (Two copies)

William Beamont, Esq., Warrington (Two copies)

Rev. W. K. R. Bedford, M.A., Sutton Coldfield (Two copies)

James Bennet, Esq., the late, continued by Mrs. Bennet, The Close, Salisbury

Beckford Bevan, Esq., Bury St. Edmund's (Two copies)

W. H. Blaauw, Esq., M.A., F.S.A., the late

H. Blenkinsop, Esq., Warwick

Edward Blore, Esq., D.C.L., F.S.A., Manchester Square (Two copies) 
Miss Bockett, Bradney, near Reading (Two copies)

J. R. Botham, Esq., Birmingham

E. M. Boyle, Esq., Torquay (Two copies)

Edward K. Bridger, Esq., Berkeley House, Hampton, Middlesex

Thomas Brightwen, Esq., Grent Yarmouth

Sir Bernard Burke, Ulster King of Arms, Dublin Castle (Two copies)

W. R. Callender, Esq., jun., Rusholme (Two copies)

John Calver, Esq., Harleston

G. A. Carthew, Esq., F.S.A., East Dereham (Two copies)

R. Redmond Caton, Esq., F.S.A. Ryefield House, Ayrshire (Two copies)

John Inglis Chalmers, Esq., Aldbar

Mrs. E. Cole, Doddington, Lincoln (Two copies)

Rev. the Lord Alwyne Compton, M.A., Castle Ashby (Two copies)

Thomas Coombs, Esq., Dorchester (Two copies)

Rev. G. E. Corrie, D.D., Master of Jesus College, Cambridge

J. Ross Coulthart, Esq., F.S.A.Scot., Ashton-under-Lyne (Three copies)

Rev. G. H. Dashwood, M.A., F.S.A., the late (Two copies), continued by Captain Bulwer, East Dereham

James Dearden, Esq., the late, continued by Mrs. E. C. Waters, Upton House, Poole

William R. Emeris, Esq., Louth

John Evans, Esq., F.S.A., Hemel Hempstead (Two copies)

Rev. C. J. Evans, M.A., Ovington, Thetford (Two copies)

Miss ffarrington, Worden, Preston (Two copies)

John Fetherston, Esq., F.S.A., High Street, Warwick (Two copies)

A. W. Franks, Esq., M.A., Dir.S.A., Victoria Street (Five copies)

Gilbert.J. French, Esq., F.S.A., the late (Two copies)

H. H. Gibbs, Esq., St. Dunstan's, Regent's Park

W. Gray, Esq., F.G.S., F.R.A.S., York (Two copies)

H. S. Grazebrook, Esq., Pedmore (Two copies)

Rev. H. T. Griffith, B.A., Felmingham, Norfolk

F. S. Growse, Esq., Bildestone

Edward Haillstone, Esq., F.S.A., Walton Hall, Wakefield

James H. Harrison, Esq., Great Yarmouth

William Harrison, Esq., F.G.S., F.S.A., Samlesbury Hall

R. S. Harvey, Esq., Nottingham Place (Two copies)

E. Hawkins, Esq., F.S.A., the late (Two copies)

Miss Frances M. Hext, Lostwithiel

R. R. Holmes, Esq., F.S.A., Windsor Castle

D. D. Hopkyns, Esq., F.S.A., Weycliffe, Guildford

Rev. John Horner, M.A., Mells Park, Frome (Two copies)

J. C. Hotten, Esq., the late (Two copies)

J. J. Howard, Esq., LL.D., F.S.A., Dartmouth Road, Blackheath

Edward Hussey, Esq., Scotney Castle, Kent

R. C. Hussey, Esq., F.S.A., F.R.I.B.A., Harbledown, Canterbury (Two copies)

Henry Jackson, Esq., Sheffield

Rev. J. E. Jackson, M.A., Hon. Camon of Bristol, Leigh Delamere

(Four copies)

William Long, Esq., Wrington, near Bristol

Rev. W. C. Lukis, M.A., F.S.A., Wath, Ripon

Kev. S. Lysons, M.A., F.S.A., Hempsted Court (Two copies) 
Edgar MacCulloch, Esq., Guernsey (Two copies)

G. W. Marshall, Esq., LL.D., F.A.S.L., Hanley Court, Tenbury (Two copies)

John H. Mathews, Esq., Harley Street (Two copies)

The Rt. Hon. the Lord Monson, M.A., F.S.A., Belgrave Square

A. W. Morant, Esq., F.S.A., F.G.S., Leeds (Four copies)

Rev. H. G. Morse, Lorrimore Square (Two copies)

C. R. Scott Murray, Esq., Caveudish Square

John Nealds, Esq., Guildford (Two copies)

Alexander Nesbitt, Esq., F.S.A., Oldlands, Uckfield

J. D. T. Niblett, Esq., Staniforth, Gloucester (Two copies)

John Iltid Nicholl, Esq., the late (Two copies)

J. Gough Nichols, Esq., F.S.A., the late

The Most Noble the Marquis of Northampton, Castle Ashby (Two copies)

W. J. O'Donnavan, Esq., University Club, Dublin (Two copies)

Frederick Ouvry, Esq., F.S.A., Lincoln's Inn Fields (Two copies)

A. Paget, Esq., the late

John H. Parker, Esq., F.S.A., Oxford (Two copies)

J. A. Pearson, Esq., LL.D., F.S.A., the late

H. Peckitt, Esq., Carlton Ousthwaite, Yorkshire (Two copies)

Hugh Penfold, Esq., Middle Temple (Two copies)

Charles Penruddocke, Esq., Compton Park (Two copies)

Charles S. Perceval, Esq., LL.D., Tr.S.A., Eccleston Square (Four copies)

Rev. G. Pinder, M.A., Hartford House, Bournemouth (Two copies)

J. H. Plowes, Esq., York Terrace (Two copies)

Ambrose Poynter, Esq., Dover

B. Quaritch, Esq., Piccadilly (Four copies)

T. Richards, Esq., Great Queen Street (Four copies)

Joseph Rix, Esq., M.D., St. Neot's (Two copies)

G. Roots, Esq., B.A., F.S.A., Ashley Place, Victoria Street (Two copies)

R. R. Rowe, Esq., F.S.A., F.R.I.B.A., Cambridge (Two copies)

James P. St. Aubyn, Esq., F.R.I.B.A., Lambe's Buildings, Temple (Two copies)

Rev. E. J. Shepherd, M.A., Trosley Rectory, Maidstone (Two copies)

E. Philip Shirley, Esq., Lower Eatington Park

R. H. Shout, Esq., Upper Park Road, Haverstock Hill

H. A. M. Waldo Sibthorp, Esq., Chester Square (Three copies)

Messrs. Simpkin and Marshall, Stationers' Hall Court

Rev. E. H. Mainwaring Sladen, M.A., The Gore, Bournemouth (Seven copies)

Rev. Walter Sneyd, M.A., Keele Hall, Newcastle

Rev. John H. Sperling, M.A., Westbourne Rectory, Emsworth

R. J. Spiers, Esq., F.S.A., Oxford (Two copies)

Lady Steele-Graves, Mickleton Manor House

Messrs. Stevens and Sons, Chancery Lane

John Sykes, Esq., M.D., Doncaster

James Thomson, Esq., F.R.I.B.A., Devonshire Street, Portland Place, (Two copies)

W. Thorn, Esq., M.D., Harrow Road (Two copies)

The Ven, the Archdeacon Trollope, M.A., F.S.A., Leasingham, Sleaford

Charles Tucker, Esq., F.S.A., Heavitree, Exeter (Two copies)

Rev. S. Blois Turner, M.A., F.S.A., Halesworth, Suffolk 
W. F. Vernon, Esq., Harefield Park, Uxbridge (Two copies)

Weston Styleman Walford, Esq., F.S.A., Middle Temple (Seven copies)

R. S. Warrington, Esq., Garrick Street

Albert Way, Esq., M.A., F.S.A., the late (Three copies)

Col. Gould R. Weston, Hunterston, Ayr (Two copies)

John Whichcord, Esq., F.S.A., F.R.I.B.A., Queen Victoria Street

Rev. R. Vernon Whitby, B.D., Lechlade (Two copies)

Alfred White, Esq., F.S.A., West Drayton (Two copies)

W. H. Whittemore, Esq., Boston, Massachusetts

W. Winkley, Esq., Harrow

C. J. W. Winter, Es'́., Great Yarmouth

William M. Wylie, Esq., M.A., F.S.A., Blackwater, Hampshire

Joseph S. Wyon, Esq., Regent Street (Two copies)

John Yarker, jun., Esq., Manchester (Two copies)

R. F. Yarker, Esq., the late 


\section{P R E F A C E.}

In consequence of the decease of Mr. Papworth in July 1870, after a painful illness of several years' duration, it was found that this Work could not be completed according to the original scheme of publication, and the Subscription list was therefore finally closed.

As, however, there was a general desire among the Subscribers that the Work should be completed, the continuation of it was entrusted to Mr. Papworth's relative and friend, Mr. Alfred W. Morant, whose qualifications for this undertaking were not unknown to some of them. It may therefore be sufficient to mention here that his taste for such subjects had led him to take a friendly interest in this Work almost from its commencement, and to watch and further its progress; and he had, in the course of his own heraldic pursuits, arranged a large collection of foreign coats of arms on a similar plan, and compiled several other manuscripts on this and kindred subjects.

It was at that time ascertained that at least three-fifths of the manuscript had been published in the 696 printed pages; and the remaining two-fifths of it were left by Mr. Papworth sufficiently arranged for reference. Mr. Morant, besides the necessary and laborious technical revision of the press from p. 696, has had to insert in their proper places the remainder of the coats contained in the several Rolls referred to under the letters $A$ to $Z$, copies of which Mr. Papworth had prepared for the purpose: and also to arrange and enter numerous additional coats collected in the course of many years by Mr. Papworth. Mr. Morant has likewise added the coats of some new creations, together with a number of others from his own collections. The manuscript also required the necessary preparation for the press, and in parts some rewriting to adapt them to the author's final plan as carried out in type. This plan has been adhered to throughout the remainder of the Work, mainly through the kind assistance of Mr. Weston Styleman Walford, whose appreciation of it in the first instance is noticed in the Introduction. He has kindly supplied many special details connected with the arrangement of the coats, and his willingness in affording advice has been extended to the Editor and to Mr. Wyatt Papworth, thus ensuring, it is hoped, the same degree of accuracy in their revision as was attained by the author. Only the revision of the type, and the matters connected with the publication were undertaken by $\mathrm{Mr}$. Wyatt Papworth.

The unpublished portion contained very few references to the authority $W$ (Withie's additions to Glover's Ordinary, contained in a copy in the British Museum); an omission considered not important. 
It has been thought advisable to reprint Mr. Papworth's original Introduction, with such alterations only as were deemed necessary, rather than to insert an elaborate essay by another hand.

Many inquiries having been made whether an Index of Names was to be supplied, it may be well to record that Mr. Papworth had no such intention. This Dictionary of Coats of Arms having been originally founded on the Encyclopædia of Heraldry published by Sir Bernard Burke, which comprises a Dictionary of Armorials wherein the Names are given alphabetically followed by the several coats of arms, the two works will doubtless be much used together, especially as the latter is to a great extent an Index to the former. The additional entries from the Rolls and other sources into this Dictionary, although numerous, hardly appeared to need an Index to themselves, many of the names being merely variations in the spelling of those to be found in the Encyclopædia.

The two Tables which will be found at pp. xvii and xix have been inserted in order to facilitate the use of the Work.

A List of the Subscribers to the Work, under the final arrangement that was made for completing it, is appended, together with the number of copies which their payments entitled them to receive. As anticipated in the scheme for continuing the publication, the balance then in hand, though somewhat increased under that arrangement, has been found insufficient to defray the expenses. The sale of the remaining copies will probably repay Mr. Wyatt Papworth the amount advanced by him for the purpose of completing the publication, and may, it is hoped, eventually yield some remuneration for the great labor and time expended by his late brother in the preparation of the manuscript, and in the collection of the material. The assistance, however, of the Subscribers in extending a knowledge of the Work is earnestly requested.

Additional Title-Pages have been furnished for the convenience of those who may be desirous of binding the Work in two volumes.

Mr. Wyatt Papworth has only to add his thanks to the Subscribers for their patience during the long, and at last fatal, illness of his brother, which tended so much to retard the progress of this publication; and for their support of the scheme proposed by him for the completion of the Work now happily achieved.

33, Bloomsbury Street, W.C., July 1874.

** It is requested that where the words "Pole, Devon.," occur, they may be altered to "Collinson, Somerset." 


\section{INTRODUCTION.}

THE object of this Work is to enable the generality of persons, though but slightly acquainted with heraldry, to ascertain with facility the names of the families by whom any given coats of arms are, or have been, borne. For this purpose a very large number of coats have been for the first time arranged in alphabetical order, so that any of them may be readily found; and the names of the respective families are attached:

The Plan of the Work is simply this: the arms are blasoned (i.e., technically described), and are arranged in alphabetieal order by the names of such of the respeetive enarges as are first mentioned in the blason; so that the inquirer has but to blason the coat, and the first charge that he names shows under what title in this Dictionary the coat is to be sought. When trow is no charge, the tincture of the field is to be considered as the charge, and such a coat will be found under the head of that metal, color, or fur. Again; when there is no charge, if the field be party, the ordinary employed to designate the direction of the partition gives the place of a coat of this kind in the alphabet; thus, for example, per bend will be found under BEND. In like manner, when there is no charge, coats that are barry, bendy, gyronny, paly, etc., will be found respectively under BAR, BEND, GYRON, PALE, etc. Coats which are billety, crusily, or otherwise semy, follow a similar rule; for if there be no other charge, those of which the field is semy are regarded as charges; but they are considered as parts of the field when there is another charge.*

In a few cases, the different modes of blasoning of which arms are capable may make it necessary to refer to more than one title.

Some of the charges, such as the ordinaries and others much in use, form heads so comprehensive, that several divisions and subdivisions became indispensable: there it will be seen that further alphabetical arrangements have been observed; sometimes by the tinctures only, and sometimes by the charges

* This, it will be observed, is confined to the field; on the contrary, charges which are billety, crusily, etc., are regarded as surcharged. 
also. This part of the Plan will be best learned by inspection; for it is hardly possible to express it precisely in a few words. It may, however, be stated, that when the coat has only one charge, or charges of one kind, the second alphabet is by the tinctures; but in more complicated cases there is an alphabet of those charges or surcharges which fall under that part of any division or subdivision, which makes it to differ from a preceding onc; and as often as such a charge is a chief, quarter, canton, or base which is surcharged, there is a further alphabet of these surcharges; and in every case there is finally an alphabetical arrangement of the coats by the tinctures. It will be observed that under some subdivisions the coats appear to be not in alphabetical order by their tinctures. It will, however, be found that they are arranged in groups according to some of the charges named in the blason; and that each group has the coats in it alphabetically arranged by their tinctures. A new group begins as often as a variation either in kind or

- in number occurs in the charges. The apparent irregularity is due to the absence of headings to the several groups. All beasts, birds, fishes, flowers, fruits, etc., though specially named, come together in their respective places, just as if the jroper headings, according to this Dictionary, had been inserted. As .. $s=$ not easy without practice to supply those headings mentally, a cuat may often be more readily found by looking at once for the tincturs of the field; for these subdivisions rarely contain many coats, and it does not in general take much time to run the eye over all the first named tinctures

It will be seen that of several objects constituting a charge or surcharge the first in the order of blason, and of a complicated charge or surcharge the in. important portion, have respectively been taken for the alphabetical words.

The usual marks of cadency, when employed merely as modern differences, are not to be regarded as charges or surcharges for any of the above purposes; and the occasional difference, the bordure, is not to be relied on as a distinctive charge, except in the simpler coats: arms within one may often be found in this Work where they would have been if there had been no bordure. Charges over all form no element of subdivision.

For those who are moderately conversant with Heraldry the preceding explanation might suffice; but to render the Plan more intelligible to persons who are less skilled in the technical description of arms, and to assist the memory of others, such of the RULES OF BLASON as are applicable to the subject are subjoined, with some remarks in further elucidation of the method observed in this Work.

1. The tincture, if but one, of the field is first to be noticed.

2. If the field be of more than one tincture, the partition is to be named 
with any peculiarity, such as indented or the like, and then the tinctures; as for example, party per pale indented arg. and gu.

The word party is generally omitted in this Work, and only por fess, per pale, etc., used in such cases. Instead of per cross the term quarterly, as being more commonly understood, has been employed; and such coats without charges are to be found under that head. When the arms in question consist of two or more coats marshalled quarterly, they are to be sought separately. The arrangement as to such arms as are barry, bendy, paly, etc., and also as to such as are semy as regards the field, has been explained above.

3. Next comes the principal ordinary (not being a chief) or, if none, the central charge (if any) on the field, with any peculiarity and its tincture; as arg. a chevron engrailed gu., or arg. a lion rampant gu.

4. Then should follow any other charges on the field, between or within which such ordinary or other central charge is placed, as arg. a chevron betw. three mullets az.

These two rules have been carefully observed; although it is not unusual to say, for example, arg. between two cotices an anchor gu., in this Work the blason is arg. an anchor between two eotices gu. In like manner a "bend coticed", is a "bend between two cotices". The other diminutives have been treated in the same way; and a "bar-gemel" is reckoned as "two bars". The word between is sometimes omitted, for brevity, in the blason of such coats as are referred to in rule 4, when the accompanying charges are of different kinds; as for example, arg. a fess gu. in chief two mullets az. in base a fleur-de-lis vert.

5. If the principal ordinary or other central charge be itself charged, then on is to precede it; but the surcharge on it is not to be named till after the other charges (if any) on the field, between or within which such ordinary or other central charge is placed; as arg. on a chevron between three mullets gu. an estoile or.

There are, however, some ill-devised complicated coats of modern date, which, to avoid obscurity, are generally blasoned by naming the surcharge immediately after the charge on which it is placed. There are also coats of earlier date, in which an ordinary is surmounted by another of the same liind; these are sometimes blasoned, for example, thus: gu. a fess or surmounted of another az. between three crescents arg.; but they will here be found in accordance with the rule, as gu. on a fess or betw. three erescents arg. another fess az. Marks of cadency or the like used as differences will be presently mentioned.

6. If there be no central charge, the charges on the field should be mentioned mediately after it, as they may be placed, regard being had to the rules ich follow; as arg. three mullets gu. two and one (or in pale, in bend, in fess, the like). 
In describing the places that charges occupy, such terms as in chief, in base, between, and within, frequently occur, and are used in the subdivisions of the larger heads in this Dictionary. There are other terms hardly less common, such as in bend, in fess, in pale, etc., indicating the relative positions of charges when there is no such ordinary in the coat; but the arrangement of this Work does not in any way depend on them.

7. Charges in chicf and in base are to be named after those in the middle of the field; and those in chief before those in base, but subject to the next rule.

In general, a chief is not understood to be a charge in chief; that ordinary being in the nature of an addition to the field. But for the purpose of the methodical distribution of the arms under the more important heads, it has been found convenient to use the term in chief in an extended sense, and to comprise under it, not only charges properly so designated from their position, but also a chief itself, whether surcharged or not. It is essential to bear this in mind, and also that in base is used in its utmost latitude.

8. A chief, quarter, or canton with its surcharges (if any) is to be named after the charges (if any) on other parts of the escucheon.

9. All charges and surcharges inclosed within a bordure are to be named before it.

When a bordure is the sole or primary charge, the coat will be found under that head in the Dictionary.

10. A chief, quarter, or canton overlying a bordure must be named after it.

11. In like manner, any charge over the others, or as it is termed over all, must be mentioned after them.

When one ordinary or other charge is on the field, and another over all, such arms are often to be found represented and blasoned differently ; so that it becomes uncertain which is the primary charge. This occurs occasionally even where a lion or other beast is debruised by a bar, a bend, or the like. It is therefore expedient, when there is a charge over all, and the coat cannot be found under what appears to be the primary charge, to turn to that which overlies it, as if that were on the field. In blasoning such coats the word surmounted should be avoided, as it may lead to a coat of this kind being mistaken for a surcharge on a charge only.

12. The marks of cadency, when used as modern differences to distingui: younger sons and junior branches of families, and also the mark of Baronetcy, are to be named last.

From what has been said it will be evident, that to find any given ec the course is to observe the charge which is first named in blasoning it, a 
to turn to that title in the Dictionary.*. If the charge be of a kind but rarely used as a primary one, it will form a head which is divided only according to the number of them borne in the various coats in which it so occurs; and under these divisions such coats follow in alphabetical order by their tinctures: so that if the coat be a simple one, consisting of any number of charges of that sort only, it is readily found.

Should the first charge be one of more frequent occurrence, as for example mullets, then instead of the division only according to the number in different coats, there will be found divisions according to the manner in which they are borne as primary charges with others accompanying them, following a method of distributing the various coats under the larger heads, which is observed throughout this Work; and suppose the coat in question to be, for example, gu. five annulets arg. a canton erm., then under the division "five annulets and in chief" (for a canton is always borne in chief), follow the class of coats to which this belongs, in alphabetical order by the names of the respective charges in chief. A reference to the Work itself will furnish numerous examples of such cases, and of others analogous to them.

The principal ordinaries and other charges of most common occurrence form such comprehensive heads, that the divisions and subdivisions under each of them are numerous; and it will facilitate the use of this Dictionary, if the Plan of it, in this respect, be noticed with more particularity, as it extends more or less to all the important charges. It is obvious that if a charge occupy the centre, or indeed any other part of the field, whatever charge or charges accompany it must, speaking generally, be either upon, above, or below, or on one or more sides of it, that is, in heraldic language on it, in chicf, in base, or on the dexter or the sinister side; or it will be between or within them; or it may be within a bordure, orle, or tressure. The cases of the dexter and the sinister side, as well as some other possible ones, may be for the present purpose disregarded: the rest enter largely into the method of distributing the various coats. The head Pale, for example, may be made to show, as fully as any other, the scheme or method which has been devised; and this may be most effectually done by bringing all the divisions and subdivisions under the eye at once in a tabular form, premising only that, though they are chiefly derived from the various conditions in which a Pale, charged or not, or palets may stand in relation to other charges, the partition of the field in the direction of a pale or palewise has supplied the divisions Per Pale and Paly. $\dagger$

* Or to the more general title under which that charge is comprised.

$\dagger$ The PALE was selected by the author for the purpose of exemplifying the scheme, and it has been thought best to retain it, though the coats arranged under this head in the Work have not required all the subdivisions here mentioned. 


\section{PALE}

PER PALE

1 PALE

...... and in chief

....... and in base

...... between or within

$\ldots \ldots \ldots \ldots$........... and in chief

$\ldots \ldots \ldots \ldots \ldots$ and in base

ON 1 PALE

....... and in chief

....... and in base

...... between or within

$\ldots \ldots \ldots \ldots$ and in chief

$\ldots \ldots \ldots \ldots \ldots$ and in base

PALETS $\left\{\begin{array}{c}\text { These are divided aecording to the number, with in each } \\ \text { case subdivisions as above. }\end{array}\right.$

PALY

Under each of the above divisions and subdivisions follow the arms answering to it in alphabetical order by the charges and the tinctures, or if no charge, according to the tinctires only. The mode in which this has been accomplished will be best understood from an inspection of some of the examples given under the head PALE, or under the more comprehensive heads, Bend, Chevron, and Fess. More, indeed, will be learned by running the eye over the several subordinate headings under those heads than could be communicated by any description. It must be remembered that in chief comprehends every charge there, even a chief itself. PER PALE and PALY are not subdivided; for, as has been explained, when there are charges on such fields, these coats do not come under the head PALE, but under those respectively of the several primary charges. A bordure does not form a distinctive charge in the above arrangement, except where the word within occurs: some coats consisting of a primary charge and one in chief (or in base) within a bordure are" placed under between or within and in chief (or in base, if such is the case). It will be observed that over all forms no subdivision; the consequence of which is, that though a coat with a pale (for example) only on the field may become comparatively complex by reason of a charge ovcr all being itself charged; still it is to be sought under A PALE, and so in analogons cases. Paly and also barry, bendy, etc., are not confined to even numbers of the pieces, because in early heraldry coats occur, intended for the same, which have the number sometimes even and sometimes odd. As one of the consequences of the diminutives of the principal ordinaries not being distinguishable inter sc in carly coats, under BeNo cotices will be found as bendlcts. 
In general, the terms of the blason point out very clearly under what division or subdivision a coat is to be sought; but occasionally this is more readily suggested by the coat itself or a sketch of it. Thus a pale billety falls under ON A PALE, since "billety" is "charged with billets exceeding ten." Again, a pale and three charges, say for example mullets, whether two and one (the arrangement when nothing more is said), or in chief, in bend, in fess, or in base, come under ON A PALE BETWEEN; for one of the mullets is on the pale, and that is between the two others. The same remark is applicable to such a coat as per fess gu. and or a pale counterchanged and three eagles displayed of the last. The PILE would have furnished examples similar to those furnished $b_{y}$ the PALE. Should the unskilled inquirer hesitate by reason of the omission of the word between in such coats as arg. a fess gu. in chief two mullets az. in base a fleur-de-lis vert, a glance at the coat as tricked (i.e., sketched) will remove all difficulty.

Those that have had but little experience in early heraldic examples, to say nothing of the more recent, know how difficult it often is to determine what species of beast, bird, fish, flower, fruit, monster, reptile, or tree, a charge was intended to represent. This has led to all kinds being brought together under the respective titles of BEAST, BIRD, FISH, FLOWER, FRUIT, MONSTER, REPTILE, and TREE, and there distinguished by their several special names: so that different species may be sought for at most within a few pages, instead of having to turn to several remote parts of the volume. Demi-animals come under the same head as the entire animals of the same kind, and have precedence of them; so that, for example, demi-lions come before lions. With the exception of demi-animals, all parts of animals, including those of the HUMAN FIGURE, will be found under their heraldic designations; and a similar rule has been applied to all parts of vegetables. Heads comprise not only those of animals, but also those of inanimate objects, as, for example, spearheads. Fleurs-de-lis (not being lilies proper or lis of the garden) are not ranked as flowers, but as FLEURS-DE-LIS; nor are cinquefoils, which, as also ioils of all numbers, are to be sought under Forls; and in lien of tre, quatre, cinque, etc., the figures, $3,4,5$, etc., are used to distinguish the several kinds. Bezants, etc., are to be found under the general term RoundLE; and several other charges which it seemed expedient to class under general heads are arranged under such heads.

The inconveniences which wouid otherwise have arisen from such classifications are, it is hoped, obviated to a great extent by the Table which is given at p. xix, showing under what general titles in the several alphabets the various species of classified charges are to be sought, when this does not appear above, or by cross references in the Work itself. 
In early heraldry there are some charges of different kinds which have been often confounded and variously blasoned. Thus the distinction between the diminutives inter se, and sometimes between them and the principal ordinary itself, was not recognised; as, for example, a bendlet and a cotice, and also a bendlet and a bend (as we now regard them), were often identical, there being no rule for the proportion of such charges. So roses and cinquefoils or quatrefoils, lozenges and fusils, a fess indented and lozenges or fusils in fess, a fess indented and a fess engrailed, masculy and lozengy, vair and nebuly, and some others, have been mistaken for each other. Such causes of uncertainty in the charges give occasion to search being made for very early coats under different heads; which is an inconvenience no classification could avoid.

The author's idea of this Work was not altogether new : almost simultaneously with his completion of his arrangement, but without any knowledge of the undertaking, W. S. Walford, Esq., F.S.A., advocated in the Archocological Journal* the necessity for some publication of the kind. That gentleman's patient investigation of the Plan of the proposed Work led to so favorable an estimate of it, as to induce him to promote its appearance, not only in the usual manner, but also by giving valuable advice whenever the author had occasion to ask his assistance.

The author always deprecated a hasty opinion of the Work: for though, in an attempt so novel and so laborious, he could not expect to produce one that was faultless, he was convinced that by a careful examination of it, many, if not all, objections that may occur on a superficial view will be satisfactorily removed.

* Remarks on Mediceval Heraldry, with a view to an Ordinary of Arms, etc., 1848, vol. v, p. 9-17. 


\section{LE OF THE ALPHABETICAL TITLES}

minler which the Arms are arranged.

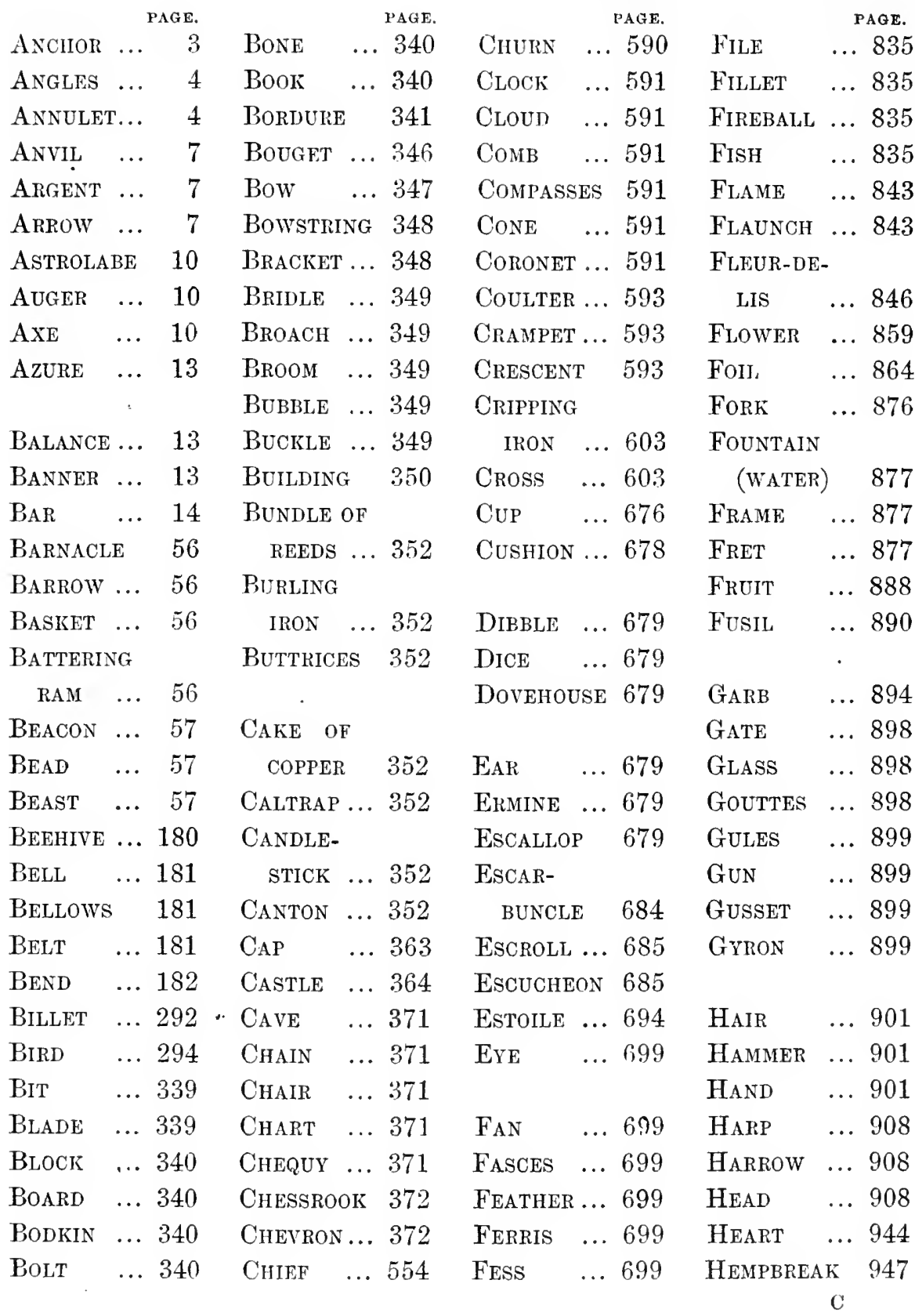


TABLE OF THE ALPIIABETICAL TITLES.

\begin{tabular}{|c|c|c|c|c|c|c|c|c|}
\hline & & $\mathrm{GE}$. & & PAGE. & & & & \\
\hline ILL & & 947 & MUllet & ... 989 & REST & $\ldots 1045$ & TASSEL & \\
\hline Iook & $\ldots$ & 948 & & & Ribbon & $\ldots 1045$ & TeEth & $\ldots 1111$ \\
\hline OIN & & 948 & JAIL & ... 998 & Rock & $\ldots 1045$ & TELESCOPE & a...1111 \\
\hline IoRSESH & & 951 & Nest & ... 999 & ROLL & $\ldots 1046$ & Tent & $\ldots 1111$ \\
\hline IUMAN & & & Numeral & 999 & Roundle & $\ldots 1046$ & THREstle & $\ldots 1111$ \\
\hline FIGURE & & 952 & & & RuDder & $\ldots 1056$ & THUNDER- & \\
\hline & & & OAR & ... 999 & & & BOLT & $\ldots 1111$ \\
\hline ICLE & & 955 & $\mathrm{OR}$ & .. 999 & SABLE & $\ldots 1056$ & TIARA & $\ldots 1111$ \\
\hline NKMOLIN & & 955 & OrLe & ... 999 & SADDLE & $\ldots 10$ & ToP & $\ldots 1$ \\
\hline NSECT & & 956 & & & SAIL & $\ldots 10$ & Torch & $\ldots 1$ \\
\hline NSTRU- & & & PACK & $\ldots 1001$ & SALTIRE & $\ldots 10$ & TOWER & $\ldots 1111$ \\
\hline MENT & & 957 & ALE & $\ldots 1001$ & CARPE & $\ldots 1088$ & TREE & $\ldots 1112$ \\
\hline & & & & & & $\ldots 10$ & $\mathrm{E}$ & $\ldots 1$ \\
\hline$E Y$ & $\ldots$ & 958 & Pee & $\ldots 1$ & CYTHE & $\ldots 10$ & TRIA & $\ldots 1$ \\
\hline $\mathrm{ILN}$ & $\ldots$ & 959 & $\mathrm{FN}$ & $\ldots 101$ & LL & $\ldots 10$ & TRI & $\ldots 1$ \\
\hline NIFE & $\ldots$ & 959 & ON & $\ldots 10$ & & $\ldots 10$ & TrI & $\ldots 1119$ \\
\hline NoT & & 959 & Pile & ...1021 & HOT & ...1093 & TUB AND & \\
\hline & & & & $\ldots 1$ & HUTTLE & $\ldots 10$ & & $\ldots 1119$ \\
\hline ABEL & ... & & PIPE & $\ldots 10$ & SLING & $\ldots 10$ & TURs & ...1119 \\
\hline ADDER & $\cdots$ & 960 & Pitc & $\ldots 1032$ & PADE & $\ldots 10$ & & \\
\hline AMP & $\ldots$ & 960 & Pla & $\ldots 1032$ & PEAR & $\ldots 10$ & VAN & ...1119 \\
\hline $\mathrm{EAF}$ & $\ldots$ & 960 & Plol & ...1032 & SPECTACL & 1095 & VAIR AND & \\
\hline EG & ... & 962 & Pol & $\ldots 1032$ & PHERE & $\ldots 10$ & & $\ldots 1$ \\
\hline ETTER & $\ldots$ & 965 & PoL & ...1032 & PINDLE & $\ldots 10$ & ERT & $\ldots 1120$ \\
\hline $\mathrm{OCK}$ & ... & 966 & Portculi & LIS1032 & SpooN & $\ldots 10$ & VIOLIN & $\ldots 1120$ \\
\hline OZENGE & & 966 & Pre & $\ldots 103$ & SPUR & $\ldots 1$ & & \\
\hline URE & ... & 973 & PURSE & $\ldots 1033$ & SQUARE & $\ldots 10$ & & $\ldots 1121$ \\
\hline & & & & & & $\ldots 1$ & & $\ldots 1121$ \\
\hline & $\cdots$ & & $Q U_{t}$ & $\ldots 1$ & StafF & $\ldots 1096$ & WHIP & ...1122 \\
\hline ANTLE . & $\ldots$ & 973 & Quartert & LY 1035 & Stilt & ...1099 & WHIRLPOOI & L 1122 \\
\hline ASCLE & $\cdots$ & 973 & QUIVER & $\ldots 1043$ & STIRRUP & $\ldots 1099$ & WING & $\ldots 1122$ \\
\hline $\mathrm{AST}$ & & 977 & & & StONE & $\ldots 1100$ & WORKING & \\
\hline AUNCHI . & $\ldots$ & 977 & RAFT & $\ldots 1043$ & Sugar-Lo & DAF1100 & CARD & $\ldots 1124$ \\
\hline ILL . & 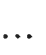 & 979 & Rainbo & $\ldots 1043$ & Sun & $\ldots 1100$ & WREATH & ...1124 \\
\hline ILLPICK. & ... & 97 & Rake & $\ldots 1043$ & Sword & $\ldots 1101$ & & \\
\hline ITRE . & & & $\mathrm{RAY}_{\mathrm{A}}$ & ...1048 & & & YOKE & $\ldots 1125$ \\
\hline & & & Reel & $\ldots 1043$ & & ...1110 & & \\
\hline ORTAR & & & Reptile & ...1043 & TARGET & $\ldots 1111$ & ZULES & $\ldots 1125$ \\
\hline
\end{tabular}




\section{TABLE OF CERTAIN CHARGES WHICH ARE TO BE FOUND UNDER MORE GENERAL TITLES.}

This is supplemental to the cross references in the Work itself : it does not include the Charges which are shown by those references to be comprised under other Titles.

\begin{tabular}{|c|c|c|c|c|c|}
\hline Charge & & Titles. & Charges. & & Titles. \\
\hline Acorn cup & & Cup & Bezant & . & Roundle \\
\hline Adam or & Naked & & Bible . & . & - Rook \\
\hline $\operatorname{man}$ & . $\quad$. & Human Figure & Big wheat & - & - Fruit \\
\hline Addice & & Axe & Birth fish & - & - Fish \\
\hline African or & Indian & Human Figure & Bishop & • & - Human Figure \\
\hline Albanian bo & onnet. & Cap & Bittern & & . Bird (Heron) \\
\hline Aider or & Elder- & & Blazing star & & - Estoile \\
\hline Almond sli & & $\begin{array}{l}\text { Fruit } \\
\text { Tree }\end{array}$ & & & $\begin{array}{l}\text { - Flower } \\
\text { - Ship }\end{array}$ \\
\hline Anchor & & Letter also & Boat hook & & . Hook \\
\hline Antelope $(H$ & Leraldic) & Beast (Antelope) & Bonfire & - & Beacon \\
\hline Apollo & . $\quad \cdot$ & Human Figure & Bonnet & - & . Сap \\
\hline Archer & . $\quad$. & Human Figure & Bourdon & - & - Staff \\
\hline Armillary s & phere. & Sphere & Bowl $\therefore$ & & - Cup and Platter \\
\hline Armour & . $\quad$. & $\begin{array}{l}\text { Human Figure, } \\
\text { Head, Leg, etc. }\end{array}$ & $\begin{array}{l}\text { Brambling } \\
\text { Branch }\end{array}$ & & $\begin{array}{l}\text { Tree } \\
\text { - Tree }\end{array}$ \\
\hline Arrow head & & Pheon & Brig . & . & - Ship \\
\hline Ash & . & Tree & Britannia & . & - Human Figure \\
\hline Astrolabe & . & Sphere also & $\begin{array}{l}\text { Brize } \\
\text { Broach }\end{array}$ & & $\begin{array}{l}\text { - Insect (Gadfly) } \\
\text {. Instrument }\end{array}$ \\
\hline Bacchus & - & Human Figure & Brogue & & - Leg \\
\hline Backgammc & & & Broom (Plar & nt) . & Tree \\
\hline table & & Board & Brunsay or & Gadfly & Insect \\
\hline Bag $\dot{ }$ & & Purse & Bunch of & grass & \\
\hline Bag of mad & ider & Cushion & and reeds & & - Tree \\
\hline Balm . & $\cdot$ & Tree & Bundle of a & arrows & s Arrow \\
\hline Barberry br & ranch . & Tree & $\bar{D}$ & cotton & Knot and Pack \\
\hline Bark & $\cdot \quad \cdot$ & Ship & Bunten or B & unting & g Bird (Finch) \\
\hline Basilisk & - & Monster & Burdock & • & - Leaf \\
\hline Basnet & - & Head and Human & Burdon & - & - Staff \\
\hline Baston & - & Bend & Burgonet & & $\begin{array}{l}\text { (Human } \\
\text { figure) }\end{array}$ \\
\hline Battle axe & $\cdot$ & Axe and Spear & & & \\
\hline Bay . & - & Tree & Cannet & & - $\quad$ Bird (Duck) \\
\hline Beaver & & Beast (Beaver) & Canton void & ded & - Square \\
\hline Bell (Hawk & k's) & Bell & Carbuncle & - & - Escarbuncle \\
\hline Belt . & . & Belt and Ribbon & Carnation & - & - Elower \\
\hline Bend . & - & Ribbon also & Casque & - & . Head \\
\hline Betony & - $\quad$. & Leaf & Cavalier & & . Human Figure \\
\hline
\end{tabular}




\begin{tabular}{|c|c|c|c|c|}
\hline Charge & & Titles. & Charges. & Titles. \\
\hline Cedar . & & Tree & Digging-iron & Spade \\
\hline Centa.ur or & Sagit- & & Dirk . . & - Sword \\
\hline tarius & & Monster & Dock leaf . & . Leaf \\
\hline Chakot or $\mathrm{C}$ & halbot & Fish & Doe & - Beast (Deer) \\
\hline Chaia shot & & Shot & Door . & - Building \\
\hline Chal"ce & . & - Candlestick \& Cup & Dove . . & - Bird (Pigeon) \\
\hline Chapeau & • & Cap & Dove house & - Building also \\
\hline Chaplet & . & Wreath & Dung fork . & - Fork \\
\hline Charity & & Humar Figure & Dyke . . & - Building \\
\hline Cherub & & $\begin{array}{l}\text { - Head and Human } \\
\text { Figure }\end{array}$ & Eagle. . & Bird \\
\hline Chess rook & & Zules also & Ear of rye. & Fruit \\
\hline Chevalier & & . Human Figure & Ear of wheat & - Fruit \\
\hline Cheval tra & & . Caltrap & Eel spear . & . Spear \\
\hline China Coka & & . Tree & Effet, Eft . & - Reptile (Lizard) \\
\hline Chough & & - Bird (Crow) & Eight foil. & - Foil \\
\hline Church & . & . Building & Elder berry & - Fruit \\
\hline Cinquefoil & . & . Foil & Elephant . & - Beast \\
\hline Civic crow & & - Wreath & Escucheou voided & Orle \\
\hline Coat of ma & & - Human Figure & & \\
\hline Cock and I & Ien & . Bird (Cock) & Fabulous animal & - Monster \\
\hline Cold well & & . Building & Fasces & . Axe also \\
\hline Collar (Do & 's) & - Belt & Fencock & - Bird (Heron) \\
\hline Compasses & & - Instrument also & Fermail & - Buckle \\
\hline Coot & . & . Bird (Coot) & Ferral or Verule & - Annulet and Orle \\
\hline Cormorant & - & . Bird & Ferris . & Instrument also \\
\hline Corn . & & - Fruit (Wheat) & Figure or Numera & Letter \\
\hline Cornet & & . Horn & Fire brand. & . Torch \\
\hline Cornish $\mathrm{Ch}$ & ough . & - Bird (Crow) & Eirepan . & - Beacon \\
\hline Cost or Co & & . Bend & Fish pot & · Wheel \\
\hline Cote . & . & - Building & Flaming bush & . Tree \\
\hline Cotton & & - Tree & Flax comb. & . Comb \\
\hline Cotton (bu) & ale of) & Pack & Float, Flote & - Instrument \\
\hline Crawfish & & Fish (Crevices) & Foine . . & - Beast (Fitch) \\
\hline Crequer pl & ant & - Tree & Forest : & - Tree \\
\hline $\begin{array}{l}\text { Crevices } \\
\text { Creyke }\end{array}$ & . & $\begin{array}{l}\text { - Fish (Crawfish) } \\
\text {. Bird (Raven) }\end{array}$ & Fountain & $\begin{array}{c}\text { - Building and Well } \\
\text { also }\end{array}$ \\
\hline $\begin{array}{l}\text { Creyke } \\
\text { Cronel or }\end{array}$ & Coronel & $\begin{array}{l}\text { Bird (Raven) } \\
\text { Head (Spear) }\end{array}$ & Fox . & Beast \\
\hline Cross . & . $\quad$. & Saltire also & Frasier & Flower \\
\hline Crossbow & . & Bow & Fusil. & Spindle also \\
\hline Crow . & . & . Bird & 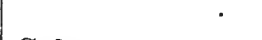 & \\
\hline Crown & & - Coronet & Galtrap & Caltrap \\
\hline Crowned h & eart & . Heart & Ganape & Bird (Turkey Cock) \\
\hline Crutch & - & . Staff & Ganapie & Bird (Cormorant) \\
\hline Cubit arm & . & Hand & Garlic & Fruit \\
\hline Culverin & & . Gun & Garter & Belt and Bend \\
\hline Currier's s & lave & . Instrument & Garvin & Fish \\
\hline Curry com & & . Comb & Gateway & Building \\
\hline Cygnet & & - Bird (Swan) & Ged . & Fish (Pike) \\
\hline Cypress sp & & Tree & $\begin{array}{l}\text { Glazier's snippers } \\
- \\
-\end{array}$ & Instrument \\
\hline Dagger & & . Sword & iron & Instrument \\
\hline Danish Wa & rrior . & . Human Figure & Gletven or Trefoil & \\
\hline Dart . & . $\quad$. & - Alrow and Spear & grass & Foil \\
\hline Declescent & . & - Crescent & Gourd & Fruit \\
\hline Deer goat & . & - Monster (Heud) & Grapes & - Fruit \\
\hline Die $\quad$ & . & . Sotce & Grass . & Tree \\
\hline
\end{tabular}




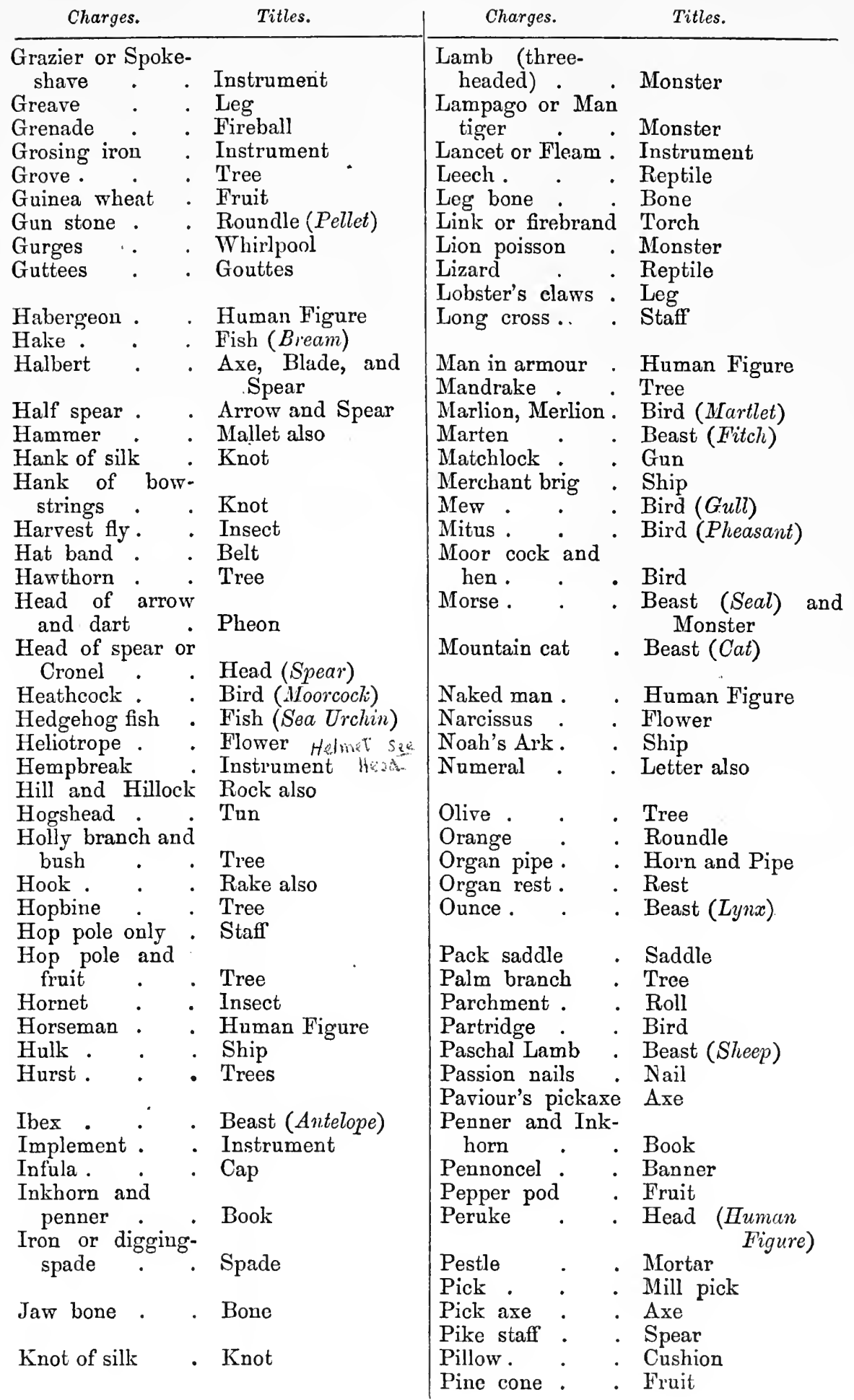




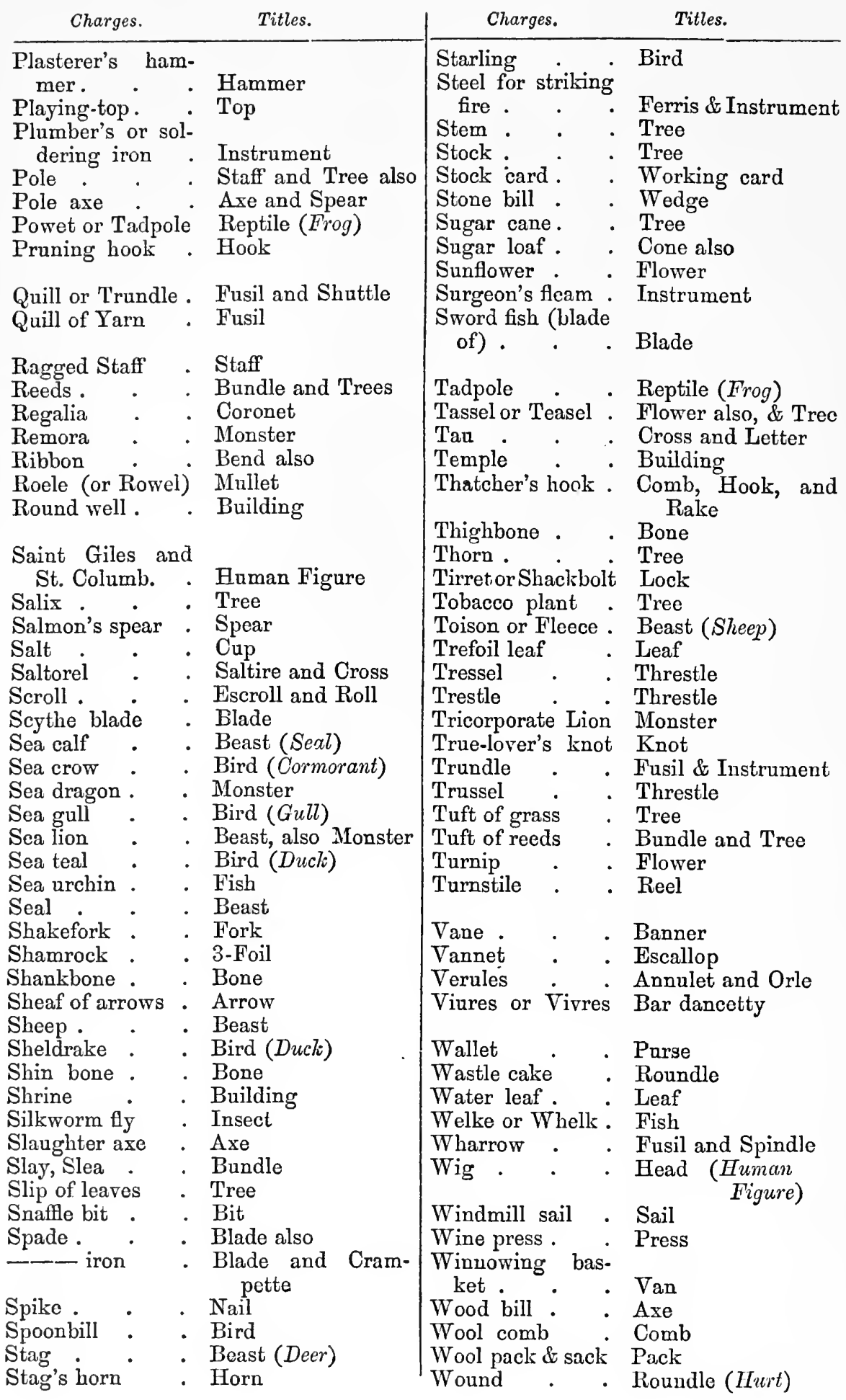




\section{PAPW ORTH'S \\ ORDINARY OF BRITISH A R M O R I A L S.}




\section{ITALIC CAPITALS IN THE BODY OF THIS WORK.}

A. Acre Roll, dated A.D. 1192 (but ? later). Ashmolean MS. 1120; Harleian MS. 6137.

B. Roll, circa A.D. 1240-45. Printed by Nicolas, 8vo., London 1829, from MS. I, 14, in the College of Arms.

C. Roll, circa A.D. 1256-66. Printed in Leland's Collectanea, 8vo., Oxford 1707 , ii, 610 ; Harl. MS. 6589.

D. Roll, circa A.D. 1286. Harl. MS. 6137.

E. Roll, circa A.D. 1277-87. Harl. MSS. 6137, and 6589.

F. Roll, circa A.D. 1262-92. Harl. MS. 6137.

G. Roll, circa A.D. 1296. Harl. MS. 6137.

H. Falkirk Roll, A.D. 1298. Harl. MS. 6589.

I. Roll, circa A.D. 1299. Harl. MSS. 6137, and 6589.

$J$. Roll, circa A.D. 1300. Harl. MSS. 6137, and 6589.

K. Caerlareroc Poem, A.D. 1301. Printed in Grose's Antiquarian Repertory, 4to., London 1779, ii, 107-284, from Cotton MS. Caligula A, 18; and by Nicolas, 4to., London 1828, from the same MS. and from another in the College of arms: Harl. MSS. 6137, and 6589.

L. Dunstable Roll, A.D. 1308. Harl. MSS. 6137, and 6589.

M. Roll, circa A.D. 1300-12. Harl. MS. 6589.

N. Roll, circa A.D. 1308-14. Printed by Mores, 4to., Oxford 1749, from Queen's College (Oxford) MS. 158, and from Bodleian MS., Dodsworth 1455086 ; in Grose's Antiquarian Repertory, 4to., London 1780, iii, 86, from Borret's MS.; in Palgrave's Parliamentary Writs, fol., London 1827, i, 410 ; and by Nicolas, 8ro., London 1828, both from Cott. MS. Caligula A, 18: Ashmol. MS., Wood F, 33: Harl. MSS. 4033, 5803, 6137, and 6589 ; Lansdowne MS. 855 .

O. Boroughbridge Roll, A.D. 1322. Printed in Palgrave's Parliamentary Writs, fol., London 1830, ii, Appendix 196, from Wynn's MS. Ashmol. MS. 831.

P. Roll, after A.D. 1338. Printed in Nichols's Collectanea Topographica, 8vo., London 1834, ii, 320, from Grimaldi's MS.

Q. Calais Bannerets, A.D. 1345-48. Printed by Mores, 4to., Oxford 1749, from West's MS.: Ashmol. MS. 1120: Cotton MS. Tiberius E 9; Harl. MSS. 6589 and 6595.

R. Calais Knights, A.D. 1348. Harl. MS. 6589.

S. Roll, circa A.D. 1392-97. Printed by Willement, 4to., London 1834, from Newling's MS.

T. Rouen Roll, A.D. 1418. Ashmol. MS. 1120: Harl. MS. 6137.

$U$. Parliament Roll, A.D. 1512. Cole MS. 30 : another, A.D. 1515, printed by Willement, fol., London 1829.

V. Glover's Ordinary, Cotton MS. Tiberius D, 10 ; Harl. MSS. 1392, and 1459.

W. Withie's additions, to the last-named, in Harl. MS. 1459.

X. Jenyn's Collection, Harl. M.S. 6589.

$Y$. Jenyn's Ordinary, partly printed by Nicolas, 8 vo., London 1829, from MS. in the College of Arms ; but of greater length in Harl. MS. 6589.

$Z$. Sandford, Genealogical History, fol., London 1707; the numerals which follow this letter refer to the pages in that book.

$V^{*}$. Coats, incorrectly given in the printed Glover's Ordinary, which have been copied into books of reference and probably used as actual coats.

All those coats for which no authorities are cited have been derived from heraldic works of repute, and trustworthy other sources. 


\section{PAPWORTH'S}

\section{ORDINARY OF BRITISH ARMORIALS.}

ACORN see Fruit.

ADDER see Reptile. ALANT seo Beast.

ALCE see Monster.

ALIERION see Bird.

ANCHOR

(including Grappling-iron);

palewise unless otherwise described.

Arg. an anchor az. surmounted by a maunch sa. charged with three crosses patty of the field. Colpoys.

Arg. an anchor without a stock ppr. environed on the centre with the letter $\mathrm{C}$ or. Clement's Ins.

Arg. an anchor sa. SKIPton.

Az. an anchor arg. OFFEr, Scotland, $W$.

Az, an anchor or. Fere, Scotland, W. Fero.

Barry of six arg. and az. over all an anchor with two cables fixed to the ring roded and pendent or. ALLEN, London.

$\mathrm{Gu}$ an anchor arg. the ring or. Z Z ACHERT.

Gu. an anchor arg. the stock or. Goadefroy. GOODREED, Ribstan, co. York. GoODrood.

Gu. an anchor or. FaIR, Scotland.

Or an anchor az. DUTONGE.

Or an anchor gu. FaIRHOLM, Craige Hall, Scotland.

Or an anchor gu. quarterly with arg. a boar's head erased sa. all within a bordure az. Farrholm, Greenbill, recorded 1757 .

Or an anchor sa. Chappele, London, Her. off. MSS. Vincent, No. 154. Chappell, London, $W$.

Or an anchor sa. charged with a fleur-de-lis arg. for diff. CHAPrelu.

Per fess or and arg. an anchor sa. Harrison, London.

Vert an anchor az. (but? arg. or ppr.) LeTEurs.

\section{Chief}

1 ANCHOR and in chief....

Arg. an anchor az. a chief gu. MIA, Ireland. on a Chief..... Coronet

Az. a cabled anchor supported by a lion ramp. or on a chief wavy erm. an eastern crown of the second betw. two lions' heads erased sa.

Richardson, London.

$$
\text { ....Escallops }
$$

Arg. an anchor sa. on a chief wavy gu. three escallops of the first. JASPER, London.
1 ANCHOR and in chief.... cont.

on a Chief.... Flowers

Gu. an anchor arg. on a chief or threä roses of the first. Dr. GIBson, Hatton Garden, Londou, 1716. MAGER or MaJor, Southampton; and the Isle of Wight, Her. Off. Hants. c. 28. MAYOR, Rugby.

$\mathrm{Gu}$. an anchor or on a chief of the second three roses of the field. MAYER or MAYOR, Island of Jersey, granted temp. Henry VII.

$$
\text { ..... Hend }
$$

Or an anchor sa. on a chief crenelly gu. a leopard's head betw. two estoiles arg. Tivitoe, London, granted 13 March, 1761.

$$
\text { ....Roundles }
$$

Gu. an anchor or on a chief of the last three tor. teaux. Hersham, London; and Stagenhoe Park. co. Herts.

$$
\text { Mullet }
$$

Az. an anchor arg. in chief a mullet of six points betw. two crescents or. Ferrie, Glasgow.

1 ANCHOR betw. or within....

\section{Anchors}

An anchor betw. two smaller ones within the beam and fluke. NAVY OfFice seal.

Beasts

Or an anchor sa. between two lions pass. gu. Delme, Lord Mayor of London, 1724.

Or an anchor fesswise (but? in fess) sa. betw. two lions pass. gu. OWEN.

$$
\text { Birds }
$$

Gu. an anchor betw. three martlets or. CAIRNS.

Escallops

Az. an anchor betw. three escallops arg. GreEN or GREENE, Ireland.

Fishes

Arg. an anchor betw. two dolphins haurient respecting each other ppr. Colston, Colston Hall, co. Lincoln; Filkins Hall, co. Oxford ; and Roundway Park, co. Wilts. Coulson, Cottingham Castle.

Or an anchor betw. three fishes naiant az. HABGOOD.

\section{IIullets}

Arg. in a sea in base ppr. an anchor az. betw. two mullets in fess of the last. BARSANE, Edinburgh. Arg. an anchor az. placed in the sea ppr. betw. two mullets of the second all within a bordure arg. (but? of the second). Barton, Edinburgh. Gu. an anchor or betw. two mullets in fess arg. FAIR. 
1 ANCHOR betw. or within.... cont.

Sword and Flower

Arg. an anchor az. ringed or over all a fetterlock containing on the dexter a sword erect of the second bilt and pomel gold on the sinister a rose gu. Town of BEWDLEY, co. Worcester.

1 ANCHOR betw, or within.... and in chief.... on a Chief

Erm. an anchor az. betw. three escallops gu. on a chief wavy of the second a naval coronet or. PARKer. Harburn, co. Warwick, bart.

Az. an anchor or encircled with an oak wreath vert betw. three mullets pierced gold on a chief paly of seven of the last and gu. a mural crown arg. Dickson, Hardingham Hall, Norfolk, Bart.

\section{ANCHORS}

Two anchors in saltire with the cables interlaced. VICTUALIING OFFICE seal.

\section{ANCHORS between....}

Arg. two grappling-irons in saltire sa. betw. four pears gu. STOFORD, Stoford, co. Devon.

\section{ANCHORS}

An anchor with another smaller on each side within the beam and fluke. Navy OFfice seal. Or three anchors sa. MARChant, co. Devon.

3 ANCHORS aud in chief....

Arg. three auchors sa. a chief az. Lovegrove.

3 ANCHORS betw. or within.... and in chief....

Arg. three anchors sa. in pale betw. two palets vert a chief gu. DarWeLl.

\section{ANGEL see Human-figure.}

\section{ANGLES}

(sometimes called Chevrons-couped, or Crossescouped, but probably instruments made of metal; see Glover.)

Arg. three pairs of angles interlaced fesswise at each end an annulet az. W AstLEY.

Arg. three pairs of angles interlaced palewise with a ring at each end gu. WASTLAY, $V$.

\section{ANNULET}

(including Gem-ring):

see Escarbuncle, Orle, Whirlpool, and Wreath.

Reference for coats, in which the annulet is a common difference, must be made to the charges which it accompanies.

Arg. an annulet sa. Pym, Sidford, co. Devon.

Az. an annulet ensigned with a cross patty and interlaced with a saltire couped and conjoined at base or. Borough of Southwark.

Chequy az. and or an annuletgu. Prothero.

Gyronny of eight arg. and gu. an annulet counterchanged. LETCH.

Gylonny of eight gu. and or. an annulet counter. changed. LoNSDALE.

Gyronny of eight sa and arg. an annulet counterchanged. Dootan, Ireland.

Or. fretty gu. in the middle an annulet interlaced az. John Meld, Godsall, co. Stafford, $V$.

Per chev. gu. and arg. in base an annulet of the first. LaMaN or LyMaN, Harl. MS.1458. LamoN, LANAM, LyMON, or LyNAM.

1 ANNULET and in chief....

Sa. an annulet environing a crosier the foot enwrapped by a snake in chief two coronets arg. Benedictine Abbey at BARDNEY, co. Lincoln.
1 ANNULET and in base....

Arg. in chief a gem-ring gu. out of a mount in base three trefoils vert. Dorrien, Haresfoot, co. Herts.

\section{ANNULET betw, or within....}

Bordure

Gu. an annulet or within a bordure engr. sa. Blankensop, Cumberland.

Compasses

Arg. an annulet betw. the legs of a pair of com. passes sa. Hadley, $V$.

Escallops

Arg. an annulet betw. three escallops gu. Tupner, co. Dorset.

Fleurs-de-lis

Arg. an annulet suspending two buckets saltirewise sa. betw, three fleurs-de-lis gu. Banister. Flowers

Gu. an annulet or betw. three roses arg. SIPLING. co. York.

\section{Harrows}

Erminois an aunulet interlacing three trian. gular harrows conjoined in the fess point.... REDMAYN, co. York.

Lozenges

Az. an annulet betw. three lozenges arg. HoLE. Az. an annulet arg. betw. three lozenges or. Hor. Ebberly House, near Great Torrington, co. Devon, quartering gu. two bars or.

\section{ANNULET betw. or within....} and in chief....

Az. an annulet environing a barrulet betw.two bars and in chief a cross patty fitchy or. Holte, $V$.

\section{ANNULETS}

Arg. semy of 3-foils ppr. two aunulets braced in the nombril point sa. EATON. ETon.

Quarterly or and gu. in the second and third quarters an annulet gold over all a bend sa. BORGILION.

Quarterly vert and arg. in the second and third quarters an annulet gu. BEECROFT, Bishop Wearmouth, co. Durham.

\section{on a Canton}

\section{ANNULETS and in chief....}

Arg. two annulets and a canton az. Brearber, London.

on a Chief

Erm.two rings interlaced sa. on a chief of the last three crosses formy ar. Wy chING HaM, Norfolk.

Erm. two annulets linked together sa. on a chief of the second three crosses patty arg. WitCHINGHAM.

\section{ANNULETS betw. or within.... Crosses}

Arg. two annulets linked together gu. betw. three closses formy sa. Thornhagh, co. Notting. ham, confirmed 4 Feb. 1582 .

$$
\text { 3-Foils }
$$

Arg. two annulets conjunct sa. within an orle of 3-foils slipped vert. John EToN, $V$.

\section{ANNULETS}

Arg. three annulets az. RichaRds or Rychens, Kent; and Swannington, Norfolk. Richers, Norfolk. Riches, V. Rithers, Wrotham, Kent.

Arg. three annulets gil. Hirton (that Ilk). Rosseter or Roster.

Arg. three annulets each enclosing a 5 -foil gu. a mullet for diff. Sir Pont RED, $V$. 


\section{ANNULETS.... cont}

Arg. three annulets sa. BasiLL, $W$.

Arg. three annulets vert. HARGENILL, Harl. MS. 1458. HARGONELL.

Az. three annulets arg. AnLett, $V$. Ayidet.

Az. three annulets or. ANLETT. Bysetr. John de Pechani, $A$.

Barry of six arg. and az. in chief three annulets of the last. Cramlington, co. York.

Barry of six arg. and az. in chief three annulets sa. Cramlington, $V$. Cramlington, Westmoreland. Cromlington, $V^{*}$.

Barry of six arg. and sa. three annulets or. Seamarke.

Barry of six arg. and sa, in chief three aunulets of the second. Cookes, $V^{*}$. Tylueck.

Barry of eight erm. and az. over all three annulets or. Harries, Cruckton, and Tong Castle, co. Salop.

Barry of ten az. and erm. three annulets or. Harris, Cork ; and Park's Grove, co. Kilkenny, 1685.

Barry of ten erm. and az. three annulets or. Harris.

Erm. three annulets gu. two and one. Besills.

Erm. three annulets interlaced in triangle gu. Mandere, $V$.

Erm. three annulets one within the other gu. Sir Jolin FrtTon, $V$, his daughter m. Holward.

Gu. three annulets arg. Michelston.

Gu. three gem-rings az. (? arg.) Michilston.

Gu.three gem-rings arg. stoned az. Mxchilstan, $V$.

$\mathrm{Gu}$. three annulets each inclosing a 5-foil or. Sr. . Danecke or Da MEKe, $V$.

$\mathrm{Gu}$. three annulets or stoned az. Eglinton, Eglinton, Scotland, quartered by Montgomery.

$\mathrm{Gu}$. three gem-rings or stoned of the first. Mychelstan, W. Mrchilstan, $V *$.

$\mathrm{Gu}$. three annulets engr, or. Everard, Harkdown, Suffolk.

Or three annulets gu. Hutron (that Ilk).

Per bend az. and arg. three annulets counterchanged. WhistLEFord.

Per bend sinister wary arg. and az. three annulets counterchanged. PoLlardBy.

Per chev. arg. and gu. in chief three annulets of the last. Layman.

Per chev. gu. 'and arg. three annulets counter. changed. Layman. Schicke. Harl. MS. 1458. Schyкe. Skike, Suffolk.

Per chev. gu. and or three gem-rings counter. changed. William Grace, $V$.

Per chev. indented gu. and sa. three annulets arg. WeEkes, Surrey.

Per chev. gu. and sa. three annulets or. WeEks.

Per chief indented arg. and gu. three annulets counterchanged. AMERviLe.

Per fess dancetty (or indented) arg. and gu. three annulets counterchanged. Sir Thomas Amervile, Norfolk, $V$. Arvill, $V^{*}$. Mongodene or Nongedene, $V$.

Per fess az. and arg. three annulets counterchanged. Whiselford, Harl. MS. 1458.

Per fess dancetty az. and arg. three nnuulets counterchanged. AuBERvi, Suffolk.

Per fess az. and or. three annulets counterchanged. WHISTELFord.

Per fess indented gu. and arg. three annulets counterchanged. Monckton, Mongton, Mongdene, or Monkton, co. York. Mondegon, Harl. MS. 1458.

Per fess or and az. three annulets counterchanged. Orseys, co. Worcester.
3 ANNULETS.... cont.

Per fess or and gu. three annulets counterchanged. Criens.

Per saltire az. and gu, over all three annulets or two and one. ANHelet, $V$.

Sa. three annulets arg. Jawdreld. Michelstan, Michelstane, or Michelston.

Sa. three annulets or. Michelstone.

\section{ANNOLETS and in chief...}

\section{Beast}

.... three annulets and in chief a greyhound courant gu. RHODES.

Canton

Arg. three annulets and a canton az. Brambud. Brember, London.

Arg. three annulets az. a canton of the last thereon a mullet of the field for diff. Sir Nicholas Brambull, or Brember, $V^{*}$.

Arg. three annulets sa. a canton of the last thereon a mullet of the field for diff. BREMBER, Lord Mayor of London, 1377, 1383, 1384, and 1385.

Az. three annulets arg. a canton of the last thereon a mullet gu. for diff. Brember, London. Chief

Gu. three annulets and a chief arg. with (for augmentation) a canton or charged with the rose of England. AyLet, Howells, Essex.

Per saltire gu. and az. three annulets or two and one a chief of the last. BLanson.

on a Chief.... Beast

Az. three annulets or on a chief arg. a greyhound courant gu. collared of the second. liHODEs, Little Eden. Rodes.

$$
\text { .....Fret }
$$

Per saltire az. and gu. three annulets or on a chief arg. a fret sa. Blanson, $V^{*}$.

Per saltire gu. and az. in the first three annulets or on a chief arg. a fret sa. Blanson, $V$.

$$
\text { ..... Fretty }
$$

Per pale gu. and az. three anuulets or two and one a chief of the second fretty sa. Blandson.

Per saltire az. and gu. over all three annulets or a chief of the last fretty vert. BLanson, Harl. MS. 1458 .

Per saltire gu. and az. over all three annulets or a chief of the last fretty sa. BLanson, $V$.

Sa. three annulets arg. a chief of the last fretty of the field. HeLton, co. York.

Sa. three aunulets or a chief of the last fretty of the field. HeLton.

\section{Quarter}

Arg. three annulets az. a quarter of the last thereon a mullet of the field for diff. Sir Nicholas BrambuzL, or Bremiber, $V$.

\section{Saltires}

Sa. three annulets or in chief two saltires arg. John Helton, co. Westmoreland, $X$.

\section{ANNULETS betw. or within.... \\ Bordure}

Arg. three annulets within a bordure gu. BEsILLs. co. York.

\section{Colises}

Arg. three annulets in bend betw. two cotises sa. within a bordure engr. gu. Selwyne.

\section{5-Foils}

Arg. three annulets within an orle of 5.foils sa. Walker, Mansfield, co. Nottingham.

Per chev, arg. and az. three annulets within an orle of 5 foils all counterchanged. WaLkER, Eastwood, co. Nottingham. 
3 ANNULETS betw. or within.... cont.

Heads

Az. three annulets in fess arg. betw. as many bull's beads erased of the last attired or. BuLI, co. York; Hockwold, Norfolk ; London; brass to Josias Bull, ob. 1621, in the church at Sutton Coldfield, co. Warwick.

\section{ANNULETS betw. or within...}

and in chief....

Sa. three annulets in pale betw. two palets or a chief arg. Mant.

\section{On 3 ANNULETS}

Sa. three annulets arg. each charged with seven torteaux. Dicwand, $V$ *. Dicward, $V$. Diewand.

\section{ANNULETS}

Arg. three annulets two and one conjoined to a fourth in the centre by a fillet sa. BERLINGEr.

Erm. four annulets ..... CANTwELL.

Gyronny of eight az. and arg. four annulets or. ANLETT, Harl. MS. 1458.

Gyronuy of eight or and az. four annulets of the first. Ambetr.

Per saltire az. and gu. four annulets or. AnLetr, $V *$.

Per saltire az. and gu. four annulets in cross or fretty sa. Blunson.

Per saltire gu. and az. four annulets in cross arg. ANLET, co. York.

Per saltire gu. and az. four annulets or. ANneles.

Per saltire gu. and az. four annulets in cross or. Anlet, temp. Edward IV, $V$. Anlett.

Quarterly per fess indented arg. and gu. four annulets counterchanged. BRACKINGTON.

4 ANNULETS and in chief....

Per saltire gu. and az. four annulets or on a chief of the second a fret vert. BLANson.

\section{h ANNULETS}

Arg. five annulets one within the other az. Gorges, $V$.

Arg. five annulets conjunct az. Gouges.

Arg. five annulets one within the other az. alternately oppressing a cross engr. sa. Robert GIFFORD, Harl. MS. 6137.

Arg. five annulets one within the other gu. Chellery, $V$.

Az. five annulets one within the other arg. Rauf de Gorges, $E$.

Erm. five annulets in chev.gu. WARDHAN, London.

Gu. five annulets or two two and one. SKrPown.

Or five annulets one within the other vert embracing and depressed by a cross engr. gu. Robert GyFFARD, $A$.

5 ANNULETS and in chief....

Gu. five annulets and a canton erm. Cantwell, Ireland.

Gu. five annulets or a canton erm. Whiтte.

Gu. five annulets or two two and one a canton erm. Cantweld, Ireland, $V$. Rayling Whitte, $V$.

\section{ANNULETS}

Arg. six annulets gu. Aveneli, co. Gloucester. Sir John de Plessis, $B$. De Plessis, $Y$. John Plessis, $Y$.

Arg. six annulets gu. two two and two. Sir Hughe Piacis or Plessy, $V$.

Arg. six annulets gu. three two and one. Avery, Haddon, co. Derby. Giffourd. Lowther, Ireland. Plasses, co. Oxford, Harl. MS. 1458. Playce, co. Oxford; and co. Salop. Plecy or Plessetis, Earl of Warwick. Plessey or Plessis, co. Oxford. Hue de Pressis, $E$. Sire Hugue de Plessis, $J$.
6 ANNULETS..... cont.

Arg. six annulets gu, three and three. PLECY, $S$. Arg. six annulets sa. LANGthorne. Henry Luzer (? Luther), $Y$.

Arg. six annulets sa. three two and one. BexweLL. LANTHON, Harl. MS. 1458. LOWDES, of the North. Manvers, $W$.

Az. six annulets arg. three two and one. Ronron. Az. six annulets or. De Musgrave, $Y$. Thomas Musgrave, $Y$.

Az. six annulets or two two and two. Sir Thomas Musgrave, $V$.

Az. six annulets or three two and one. Sir John Folyotr, Kent, $V$. Musorave, Hayton Castle, Cumberland; and Barnsley Park, co.Gloucester, Bart. Musgrave, Edenhall, Cumberland, Bart. Musgrave, Norton Conyers, co. York, created Bart. 20 Oct. l638. Musonave, Myrtle Grove, co. Cork; and Tourin Cappoquin, co. Waterford, Bart. Musgrave, Musgrave Hall, Penrith ; and Clea, Cumberland; Ashby, Ashby Mus grave, and Hartley Castle, Westmoreland; Westminster, 1716. Thomas Musgrave, $S$. Pecham. Petham.

Gu. six annulets arg. Avenell, Netherhaddon, co. Derby; the co-heiress, temp.Johnm. Vernon and Bassett.

Gu. six annulets in pale arg. CARDOYLL, Harl. MS. 1458.

Gu. six annulets arg.two two and two. Sir Raufe de KaRD OILL, $V$. Kardoyle.

Gu. six annulets arg. three two and one. Cantwell. Kardaile or Kardoyle. Newport.

Gu. six annulets or. Sir John de Crombwele, $M$. Sir John Cromwell, $I$. John Cromweli, $Y$. Sire Johan de Cromwelle, $N$. Musgrave. Newport. John de Vepount, $P$. Vipont or Vipount. John de Vipoent, $B$. Sir Nicolas Vipount, $I$.

Gu. six annulets or a label az. Sir John de Vepount, $M$.

Gu. six annulets or two two and two. Sir Robert de VIPoUnT, co. York, $V$. (three two and one, $W$. ) $\mathrm{Gu}$. six annulets or three two and one. CANTWELI. Cronwell, Cambridge. Vipont, Westminster, 1716 ; and co. York. VYroINT.

$\mathrm{Gu}$. six annulets conjoined in pairs or two and one. Clench.

Gu. six annulets embraced or two two and two. Bracer.

Gyronny of six az. and arg. on each an annulet counterchanged. MEARNS.

Or six annulets az. three two and one. Londres. LONSDALE, in S. Sepulchre's church, London.

Or six annulets gi. Cromwf.LL. Newport. John VEPONT, Westmoreland, Y. Sire Nicholas de Vepound, $N$. Sir Nicol Vepount, $M$. Vipoint. De Vipointe, $Y$. Sir Nicolas Vipount, $I$.

Or six annulets gu. two two and two. Sir Roger Cromwell, $V$. Lowder. Sir Henry Lowder, $V$. Or six annulets gu. three two and one. VIPoNT; and with a label az. Sir John de Vipont, $L$.

Or six annulets sa. Loucher, Y. Hugh de LOWTHER, $Y$.

Or six annulets sa. two two aud two. OLound or Oulond, $V^{*}$. Sir Hugh Olouner, $V$. Ouland. Or six annulets sa. three two and one. LANGTON. Lowther, Earl of Lonsdale. Lowther, Swillington, co. York, Bart. Lowther, Pontefract; Mask, co. York; Cockermouth, Cumberland.

Per bend sinister wavy or and az. six annulets counterchanged. Sir John PoLLU (? PoLLewE), co. Devon., Harl. MS. 2021, fo. 17 b. 


\section{ANNULETS.....cont.}

Per saltire and per fess arg. and gu. six annulets counterchanged one two two and one. TIDDEMAN.

Quarterly or and gu, three annulets arg. in each of the second and third quarters over all a bend sa. BORgulion, Burgonyon, or Burgulion.

Sa. six annulets braced palewise in pairs arg. two and one. Anderton, Anderton, co. Lancaster. Harl. MS. 1459, fo. 4.

Sa. six annulets or. John de LeEke, $Y$. De LEKE, $Y$.

Sa. six annulets or two two and two. LODER. Lotнer. LOUders, Scot]and, Harl. MS., 1458. Lowrнer, Northumberland. Sir Hugh de LOWTHER, $V$.

Sa. six annulets or three two and one. Lathay. LEEK.

\section{ANNULETS and in Chief....}

\section{Carton}

Giı. six annulets or a canton erm. Ireland, $V$. Cauntweli, Ireland. Chief

Arg. six annulets gu. a chief chequy sa. and or Plecy or Plesstis, Upwinborue-Plecy, co. Dorset, temp. Edward I.

Gu. six annulets or conjoined in pairs two and one a chief of the second. Clench, Harksted, Suffolk.

$\mathrm{Gu}$. six aunulets interlaced palewise in pairs and a chief or. CLENCH, $V^{*}$. on a Chief

Or six annulets sa. three two and one on a chief arg. three mullets of the second. Elitngton.

6 ANNULETS betw, or within....

\section{Bordure}

Arg. six annulets sa. within a bordure engr. gu. Bexweld, Harl. MS. 1458. BoXWell.

Arg. six annulets sa. three two and one within a bordure engr. gu. Bexwell, $V$. Beywell, $V$.

Gu. six anuulets or within a bordure engr. arg. Thomas Blinkensop, Helbecke, $Y$. Cronwell.

Gu. six annulets or three two and one within a bordure engr. ar. BLANKENSOP or BLENEENSOP, Cumberland. Blinkensopp. Helebeke.

Gu. six annulets or a bordure compony arg. and az. CROMWEIL.

$\mathrm{Gu}$. six annulets or a bordure compony arg. and sa. CromwelL.

Gu. six annulets or three two and one within a bordure engrailed compony arg. and az. Croumweri, $V$.

Gu. six annulets or three two and one all within a bordure engr. (? of the last). BLankensop, $V$.

\section{ANNULETS}

Gu. seven annulets conjoined in pale arg. KENDALL.

\section{ANNULETS}

Arg. nine annulets in saltire interlaced five gu. and four az. Hatchet or Hatchets.

\section{ANNULETS}

Gu. ten annulets or four three two and one. BIPONT.

Or ten annulets sa. four three two and one. LOUTHER.

10 ANNULETS and in chief....

Sa. ten annulets arg. four three two and one on a chief of the last a lion pass. of the field. Bridgliman, Norfolk.

\section{ANNULETS}

Sa. twelve annulets divided into three chains of four each palewise arg. two and one. ANDERTON, Claiton, co. Lancaster, Harl. MS. 1468, fo. 96.

\section{ANNULETS unnumbered}

Arg. semy of annulets within each a lion ramp. and an eagle displ. alternately sa. in the interstices a lesser annulet of the last. YvaIN.

Gu. fretty or on each joint an annulet az. MEI.工. Quarterly gu. and arg. annulets and crosses patty alternately in bordure counterchanged. ALT, Loughborough, $\mathrm{co}$. Leicester.

\section{ANT see Insect. ANTELOPE see Beast.}

\section{Az. an anvil or. ARNULFE்.}

\section{ANVII}

Gu. an anvil arg. ArNoul.

Gu. a smith's anvil arg. AnvaIre or ANvIL.

\section{ANVILS}

Per chev, arg. and sa. three anvils counterchanged. Surth, Abingdon, co. Berks; and London, 1634; Her. Off. London, c. 24, fol. 3 b.

\section{APE see Beast. APPLE see Fruit.}

\section{ARCH see Building.}

\section{ARGENT}

For Argent quartering a charged field (with or without a charge over all) see Quarterly the second and third charged with....

Arg. simple. Boguet, Normandy.

Arg. in chief dexter a crescent and sinister an annulet sa. BrDAII, Harl. MS. 2021.

ARK see Ship. ARM see Hand.

\section{ARROW}

(including Bird-bolt, Dart, Half-spear, and Broadarrow which sometimes means a Pheon);

palewise and point downward unless otherwise described;

see Bow, and Quiver; and for Arrow-head see Pheon.

Arg. an arrow erect or supported betw. the forelegs of a demi-buck gu. DEcker, London, granted 6th August, 1616.

Per pale embattled gu. and az. an arrow in bend or barbed and feathered arg. point upward. Cugler. Curler, St. John's Lodge, co. Hertford, Bart.

Vert an arrow arg. point upward. (The ancient coat of) M'ADAM, Waterhead, co. Kirkcudbright; and Ballochmorrie, co. Ayr.

Vert an arrow in pale or feathered and headed arg. Standard, Whitehill, co. Oxford.

\section{ARROW and in base....}

Vert an arrow fesswise in chief and a dexter hand apaumy couped in base arg. LoughnaN, Ireland.

\section{ARROW betw, or within...}

For 1 Arrow betw. the attires of a stag's head see 1 Head and in chief, and so in analogous cases.

\section{Beasts}

Quarterly erm. and gu. an arrow in bend sinister point upward.... betw. in the first and fourth quarters a lion ramp.... Fosketr, Rosehill, Ábbot's Langley, co. Herts.

\section{Feathers}

$\mathrm{Gu}$. an arrow with on each side where the feather should be three ostrich feathers (? in pale) arg. the barb erected or. Bocken or BorCkEN. 
1 ARROW betw, or within.... cont.

Heads

Or an arrow betw. three boars' heads gu. DANNERE, Scotland.

Horns

.... a broad arrow .... feathered .... betw. three harts' horns .... HALL, co. Devon.

Arg. a barbed arrow .... feathered or betw. three bugle-horns sa. Hawlex, co. Devon.

Arg. an arrow or feathered gu. betw. three bugle. horns stringed sa. and interlacing the lower one. Haule, co. Devon, $V$.

Wings

Gu. an arrow point upward betw. two wings conjoined in base arg. ZINGEL, $V$.

Gu. a broad arrow between two wings (? arg.) ZiNGELL.

1 ARROW betw, or within.... and in chief....

on a Chief.... Head

Vert a dart betw. two garbs or on a chief az. a cherub's head ppr. betw. two estoiles arg. THACKERY.

Vert a dart betw. two garbs or on a chief purp. a cherub's head gold betw. two estoiles of six points of the last. THackeray.

$$
\text { ..... Mullets }
$$

Arg. a dart fesswise piercing a heart gu. on a chief az. three mullets of the first. Douglas, Bads, Scotland.

Arg. an ar'row fesswise piercing a heart surmounted with a royal crown ppr. on a chief az. three mullets of the first. Dougras, Chilston House, Boughton-Malherbe, Kent.

$$
\text { .....Pheons }
$$

Gu. an arrow betw. two wings conjoined in lure arg. on a chief of the second three pheons of the first. ShingleHurst, London.

\section{ARROWS}

....two arrows in saltire, enfiled with a ducal coronet.... Town of SouthwoLD, Suffolk.

Az. two arrows in saltire enfiled by a coronet or. Benedictine abbey at Bedertcsworth, Edrundestow, or S. Edmundsbury, Suffolk.

Arg. two darts gu. pointed and feathered of the first piercing a heart of the second. YEoman, Dryburgh ; granted 1668.

Arg. gutty de sang two darts points upward gu. featbered of the first piercing a heart of the second. YEOMAN.

$\mathrm{Gu}$. two arrows in saltire arg. over all a fess chequy of the second and first. Macaulay.

Per fess embuttled arg. and gu. two arrows fess. wise counterchanged feathered az. OckLeshaw, co. Lancaster.

Sa. two broad arrows in saltire arg. Pearle.

\section{ARROWS and in chief....}

Sa. two broad arrows in saltire arg. feathered or in chief a plate. Pearre, Harl. MS. 1458. Perle, $V$.

2 ARROWS and in base....

Per fess arg. and sa. in chief two arrows in saltire ppr. surmounted by a heart gu. ducally crowned az. and in base an anchor with chain etc. all .... Pritzler.

\section{ARROWS betw. or within.... \\ Buckles}

Gu. two arrows in saltire points upward arg. sur. mounted of a fess chequy of the second and first all between three silver buckles. M'C
2 ARROWS betw. or within.... cont.

Gu. two arrows in saltire arg. surmounted of a fess chequy of the second and first betw. three buckles within a bordure indented or. M'ArLA, Edinburgh. Macauley, Alderman of London, ob. 1788

\section{Fleurs}

Az. two arrows in saltire arg. betw. four fleurs-delis or. RicharDs, Heath, co. Hauts.

5-Foils

Arg. two arrows in saltire points upward a\%. between four 5-foils of the last. JAMESON. Heads

Gu. two broad arrows in saltire or feathered arg. betw. four lion's heads erased and crowned of the second. Arrowsmyte, Huntingfield Hall, Sutfolk.

\section{Roundles}

Gu. two arrows in saltire arg. headed or betw. four plates. GoODALL.

Sa. two broad arrows in saltire arg. betw. four plates. Pearle.

Sa. two broad arrows in saltire.... betw. nine plates. PERKE.

\section{ARROWS}

....three arrows.... Richard ARCHARD, $V$.

Arg. three broad arrows az, HaLEs, co. Stafford.

Arg. three arrows palewise in fess az. surmounted of a fess or. Hutcheson.

Arg. three arrows in pale az. surmounted by a fess or. Hutchison, Edinburgh.

Arg. three bird-bolts gu. John Boson, $S$. Sire Peres Bosoun, N. Bossum, Norfolk; and Boulton, co. York, Harl. MS. 1458. Raf Bozun, $F$.

Arg. three bird-bolts in fess gu. Bolton. Raufe de Boulton, $V$.

Arg. three bird-bolts in pile gu. Rauf Bouzrn, $E$. Arg. three bird-bolts gu. feathered or. Bussham, co. Lincoln, Harl. MS. 1458.

Arg. three bird-bolts gu. the feathers purfled or. Rauf Bozun, $E$.

Arg. three bird.bolts gu. garnished or. Bozom or Bozun.

Arg. three bird-bolts gu. headed or and feathered of the first. BowMan, Wissingset, Norfolk.

Arg. three bird-bolts gu. headed and feathered or. Busham, Baroby, co. Lincoln.

Arg. three broad arrows gu. HENDER, Cornwall. Arg. three broud arrows bendways sa. two and one. CoRBaLly, Ireland.

Arg. three bird-bolts sa. Rispon, Bableigh, in Parkham; Winscott, co. Devon; and Risdon, co. Gloucester. RisDon, $V$.

Az. three arrows in pale arg. ARcher.

Az. three bird-bolts arg. Bosome, Cornwall. Bosum, V. Busham, Cornwall, Harl, MS. 1458. Speccott or Speckott.

Az. three bolts in pale arg. BozoN.

Az. three arrows or. ARCHARD, Harl. MS. 1458. Simon Archer, Tamwortb, co. Warwick, 1619, $W$. CADicotr, East Whiteway, co. Dorset. GrANDORGE.

Az. three arrows enfiled by a coronet or. Benedictine Abbey at Bedericsworth, EDMUNDEstow, or S. Edmundsbury, co. Suffolk.

Az. tbree arrows in pale fesswise or points to the dexter. Bolton, Serjeant, ob. 1787.

Az. three arrows palewise or. Chamdecotre, Quarleston.

Az. three arrows or feathered arg. Chaldecotr, Harl. MS. 1458. 
3 ARR0WS.... cont.

Az. three arrows in pale or feathered arg. Charles HaLE, 1716.

Az. three broad arrows or. Archer, Baron Archer of Umberslade, co. Warwick.

Az. three bird-bolts or. Borand, co. Devon. Bolton. Boulton, Stixwold; and Moulton, co. Liucoln, quartering Fonster.

Az. three bird-bolts of as many points or. Bozom or Bunsam.

Gu. three arrows arg. Bagsshadr, $V$. Baysshaw, $V *$ LEE.

Gu. three arrows arg. barbed or. Nicolas Hales, $V$. HAILES.

Gu. three bird-bolts arg. Boltesham, Northumberland. Sire Thomas de Boltesham, $N$. Sir Thomas Botlesham, co. Northampton, $V$. Bosome, Norfolk. Bozon.

Gu. three bird-bolts in pale arg. Bothesham, Northumberland.

Gu. three bird-bolts in a parcel arg. banded az. one in pale and two in saltire. John Joskyn, Essex, $V$. Joskyn.

Gu. three quarrels arg. BAGGSHAMr, $V$.

Gu. three arrows double pointed or. HaLEs, W.

Gu. three arrows or feathered arg. Sir Bartholomew Hales, co. Warwick, Kt., 1619, quartering arg. a lion ramp. and a bordure engr. sa., $W$.

$\mathrm{Gu}$. three arrows or feathered and barbed arg. Hales, Woodchurch, and Hales' Place, Canterbury, Kent, Bart. Hales, Beaksbourne, co. Kent; and Brymore, co. Soinerset, created Bart. 12 June, 1660 . Halles.

$\mathrm{Gu}$. three arrows or feathered and bearded arg. Jones, Bwlch Gwent, co. Cormarthen; Good. rich, co. Hereford.

$\mathrm{Gu}$. three broad arrows or feathered and headed arg. Hales, Coventry, co. Warwick ; and Tunstall, Kent.

Or three bird-bolts gu. nooked and pointed of the first a label gu. BERUM.

Per pale gu. and az. three arrows or barbed and feathered arg. ARcher, co. Lincoln. granted $24 \mathrm{March}, 1684$.

Sa. three bird.bolts in pale arg. Colseshan, quartered by Throgmorton.

Sa. three darts one in pale and two in saltire held in a hand couped at the wrist arg. Lowle, co. Somerset; and Yardley, co. Worcester.

Sa. three broad arrows in pale or. Lawrus: Picardy.

Vert three arrows (or ?) barbed and feathered arg. (The modern coat of) M'ADAM, Waterhead, co. Kirkcudbright; and Ballochmorrie, co. Ayr.

\section{Chief}

\section{ARROWS and in chief....}

Az. three arrows and a chief or. Hrcon or Hrcun, $V$.

Az. three arrows in pale and a chief or. HEYTon, Heyton.

Az. three broad arrows or a chief of the second. Hicicombe. on a Chief.... Head

Arg. three darts pileways az. on a chief of the last a boar's head couped or. Hutcheson, Scotland.

Arg. three arrows meeting in point sa. on a chief az. a boar's head erased or. Hutcheson, Scotland.

.... Heads

Az. three arrows barbed and feathered... on a chief or three blackamoor's heads ppr. Camplin.
3 ARROWS and in chief..... cont.

$$
\text { ....Heads cont. }
$$

Az. three broad arrows or two and one feathered arg. on a chief of the second as many man's heads couped sidefaced ppr. Watres, Collington, Holbroke, and Shunks, co. Somerset; Her. Off. Dev. Som. and Wilt., c.22.

Az. three arrows or feathered and headed arg. on a chief of the second three Moor's heads couped sidefaced sa. WATTS, co. Somerset; and Hanslope Park, co. Buckingham.

$$
\text { ..... Mullets }
$$

Or three arrows sa. headed and barbed arg. on a chief of the second as many mullets of the field. BusBy, Addington.

\section{ARROWS betw, or within.... \\ Axes}

Arg. three arrows in fess sa. in the middle point betw. two halberts endorsed gu. Crinan, Cringan or Crinzian, co. Dumfries.

Birds

Arg. three arrows gu. one and two between as many Cornish choughs ppr. two and one. Crastein. Scrace.

$$
\text { 3-Foils. }
$$

Arg. three arrows gu. two in saltire and one in pale feathered or betw. six 3 -foils slipped of the second two in chief two in fess and two in base. Littlejohn, England.

\section{ARROWs betw, or within.... Heads}

Az. a sheaf of arrows or betw. three boar's heads couped of the second. Gordon, Tacachie.

\section{Flowers}

Arg. a sheaf of five arrows barbed az. betw. four roses gu. MaCkenan, Edinburgh, granted 1794 .

Sprigs

Arg. a sheaf of arrows gu. betw. three holly branches each of as many leaves ppr. banded of the second. Invine, Murthill, Scotland.

Arg. a sheaf of arrows gu. betw. three holly branches each of as many leaves vert banded of the second all within a bordure of the third. IrviNe, Bieldside, Scotland.

\section{ARROWS}

Az. three pair of arrows in saltire each pair environed by a ducal coronet or. Town of Bury SaInt Edmonds, Suffolk. Benedictine Abbey of BeDERICsworth, EDMUNDStow, or Bury Saint Editonds, Sufioll.

\section{ARROWS}

Arg. seven half spears sa. headed az. three one and three. Docker.

\section{ARROWS}

Az. eight arrows interlaced in bend dexter and sinister arg. headed and featbered or fretting a bowstring in fess of the second. Town of SHETFIELD.

\section{ARROWS or 3 SHEAVES of ARROWS}

Gu. three bundles of as many arrows arg. Brest, co. Salop.

Gu. three sheaves of arrows points upward arg. JoskIN or JoskYN.

Gu. nine arrows three in a parcel two in saltire and one erect arg. Joskyn, $V$.

$\mathrm{Gu}$. three bundles of as many arrows arg. feathered and banded or. Brest, $V$.*

Gu. three bundles of as many arrows or feathered and banded arg. Biest, Atcham, co. Salop, granted 1586, $W^{\prime}$. Brest, Harl. MS. 1458. 
9 ARROWS or 3 SHEAVES of ARROWS ... . cont.

Gu. three bundles of as many arrows two in saltire and one in pale or feathered headed and tied in the middle with a string arg. BEIST or BIEst.

\section{ARROWS and in Chief.... Chief}

Gu. nine arrows or three in a parcel i. e. each parcel having two in saltire and one in pale or barbed arg. a chief dancetty erm. Bestuand. on a Chief

Arg. three sheaves of as many arrows ppr. banded gu. on a chief az. a bee volant or. PeEL, Drayton Manor, co. Stafford, Bart. PeEI, Brookfield, co. Chester, descended from William Peel, Oswaldwistle, co. Lancaster, great great grandfather of the present Baronet.

\section{ASHEN-KEY see Fruit.}

ASKER, and ASP see Reptile. ASS see Beast. ASTROID see Estoile, and Mullet.

\section{ASTROLABE}

Az. an astrolabe ol. Astrolt.

Per fess or and gu. an astrolabe ppr. held in the dexter paw of a lion ramp. counterchanged armed and langued az. Middeten, Frazerburgh.

\section{ATTIRE see Horn.}

\section{AUGER}

Gu. three augers arg. handles or. Bungald or BONGHOLE.

\section{AUK, and AVOSETTA see Bird.}

AWL

Sa. three awls points erect arg. hafts or. AULE.

\section{AXE}

(including Addice, Battle-axe, Bill, Broad-axe, Carpenter's-axe, Danish-axe, Fasces, Halbert, Hatchet, Hew, Lochaber-axe, Pick-axe, Poleaxe, Slaughter-axe, and Wood-bill);

palewise, unless otherwise described.

See Spear, and Sword; and for Brick-axe see Implements.

Arg. an ancient battle-axe handle gu. top. az. beld of a stork ppr. by the dexter claw. BILL.

Az. a battle-axe arg. and lance or in saltire. Garband.

Az, a battle-axe arg. lield by a lion ramp. or. Hethersett. Pyeingham.

Az. a battle-axe or headed arg. OLdmixon, Oldmixon, co. Somerset.

Az. a battle-axe or headed arg. the edge to the sinister. Heynaeston, $V^{*}$. OLdmixon, $V$.*

Az. a halbert or the edge to the sinister its lancehead arg. Heyngeston, $V$.

Barry of ten arg. and az. a battle-axe or held by a lion ramp. gu. Alexander, Dover, Kent.

Barry arg. and az. a battle-axe or held (after the Norwegian fashion) by a lion ramp. gu. Alexander, co. Chester, 1535, $\mathrm{T}^{\mathrm{T}}$.

Gu. a battle-axe held by a lion sejant on a chair arg. Alexander.

Gu. a battle-nxe arg. held in the dexter paw of a lion ramp. or. Sansun.

Gu. a battle-axe held by a naked arm conped arg. Hindeston, co. Devon.

Gu. a battle-axe held by an armed arm arg. Hinston, co. Devon.

Gu. a Danish battle-axe arg. held by an arm in armour Ipr. Hingston, Dodbrooke House, co. Devon.
AXE.....cont.

Gu. a pick axe arg. Rous, $V$. Rous or Rowse.

$\mathrm{Gu}$. a battle-axe erect held by a naked arm embowed issuing from the sinister ppr.

Hingenson, co. Bricks.

Sa, a battle-axe or headed arg. Oldmixon, Old. mixon, co. Somerset.

Vert a halbert grasped by a lion ramp. arg. Partyn, co. Salop and co. Stafford.

\section{Arrow}

\section{AXE and in chief....}

Az. a halbert in bend sinister arg. head upward or oppressed by a tilting spear in bend dexter gold headed of the second in chief a silver broad arrow barways to the dexter feathered and pointed as the third. Garband, $V$.

Az. a battle-axe and tilting spear in saltire arg. headed or in chief an arrow barways of the second headed and feathered of the third, Garband, $V^{*}$.

Az. a pole-axe and lance in saltire or headed arg. in chief an arrow of the second headed and feathered of the third. GarBand or Garbrand. Or a battle-axe in bend sinister surmounted of a lance in bend dexter and in chief a dart barways pheon-headed and feathered all ppr. GarbRAND, Jamaica, granted 28 Oct. 1768.

\section{Balances and Hand}

Arg. a Roman fasces and sword saltirewise ppr. in chief a pair of balances held by an armed arm az. Hoseason, Zetland; and Jamaica, 1808, quartering Bituce.

\section{Mullets}

Gu. a battle-axe lield by a dexter arm in fess issuing from clonds on the sinister in chief two mullets arg. Petwet.

\section{AXE betw, or within...}

\section{Bordure}

Arg. a battle-axe head downwards held by a lion ramp. guard. ppr. within a bordure az. Crackneli, De Cracknell, or Crakenele, Devonshire House, near Bath, co. Somerset; Cracknell, Isle of Wight ; and Burwall S. Mary, co. Cambridge, quartering Phinlips.

\section{Heads}

Arg. a Lochaber-axe betw. three boar's heads couped gu. RANKINE, Rochelle; descended from Rankine of Shields.

Gu. a Lochaber-axe betw. three boars' heads erased arg. RANKen, Scotland.

\section{Leaves and Horn}

Ar'g. a battle-axe betw. three holly leaves in chief and a buglehorn in base vert garnished gu. Burnet, Aberdeen, Scotland.

Roundles

Arg. a battle-axe gu. betw. three ogresses. Morse. Arg. a battle axe ppr. betw. three ogresses. Morse.

\section{AXE betw. or within...}

and in chief....

Az, a battle-axe in bend sinister surmounted of a tilting spear in bend dexter betw. four cannons or on a chief of the second a fleur-de-lis of the first enclosed by a demi rose couped in pale gu. radiated to the sinister gold and by the stump of a tree eradicated and couped at the top as the third. Morris, $V^{*}$. Sir Christopher Moures, Master of the Ordnance, $V$.

\section{AXES}

Arg. two halberts in saltire az. Ecches, Kildonnan, Scotland. 
2 AXES..... cont.

Arg. two battle-axes in saltire sa. Sir Lionell Maddison, Newcastle, Knt., descended from Madidison of Ellergill, granted 6 June 1635, quartering MARLEY.

Az. two battle-axes in fess or. Edw. Baynbrige, $V$.

Az. two halberts or. BaynBridge.

Az. two battle-axes in saltire ppr. Morris.

Erm. two battle-axes in saltire sa. MaIdestone, co. Lincoln.

Erm. two battle-axes in saltire sa. that in bend dexter oppressed by that in bend sinister which has the head dowuwards. Maydeston, Wardall, $V$.

Erm. two halberts in saltire sa. MAYDEsTon or Maydston, co. Lincoln, Harl. MS. 1458.

Gu. two halberts or. Bayndryg. Harl. MS. 1458. Gu. two halberts endorsed or. Pavin, Harl. MS. Pavyn or Pavys.

Or two battle-axes in saltire sa. headed arg. Maidstone, Boxsted, Essex; granted 1614.

Sa. two battle-axes in saltire arg. BellingFord. Hewgill, Smeaton and Hornby Grange, co. York.

Sa. two battle-axes in saltire arg. that in bend sinister next the field with its head downwards. Belixngford, Norfolk, $V$.

Sa. two bills addorsed in saltire arg. BILLIngFord, Norfolk and Suffolk.

Sa. two halberts in saltire arg. BeLlingford.

Sa. two pole-axes in saltire arg. ducally crowned or. Fletcher, Candover, co. Salop.

\section{AXES and in chief....}

on a Chief..... Beast

Per chev. embattled or and gu. in base two battleaxes in saltire arg. on a chief az. parted from the field by a fillet wavy a demi lion ramp. naissant of the third holding in both paws a trident of the first. Drce.

Or two axes addorsed handies az. blades sa. on a chief gu. a lion pass. guard. of the first. MaLebar, co. Derby.

$$
\text { ..... Mullets }
$$

Az. two battle-axes in fess arg. on a chief or as many pierced mullets gu. Christopher Barninidge, Bishop of Durham 1507, Archbishop of York 1508, and Cardinal.

Az. two battle-axes in pale arg. on a chief or two pierced mullets gu. BATNBRIDGE.

Az. two pole-axes or headed arg. on a chief of the second two mullets of the first pierced gu. BAYNBRY, co. York.

$$
\text { ....Palo }
$$

Erm. two battle-axes in saltire ppr. a chief az. charged with on a pale betw. two pelicans' heads erased arg. vulning themselves a rose gu. Bill, quartering HonsFaLl.

Erm. two wood-bills sa. with long handles ppr. in saltire a chief az. charged with on pale or betw. two pelicans' heads erased at the neck arg. a rose gu. barbed and seeded vert. William BIL, D.D., ob. 15 July 1561, tomb in Westminster Abbey; the heiresses m. Samwell, co. Northampton; and Haydock, co. Hants.

\section{Fire-ball}

Per chevron embattled or and gu. two battle-axes in saltire arg. in chief two bombs fired ppr. DYCE.

\section{Mullet}

Gu. two halberts .... over all a fess chequy .... and .... in chief a mullet.... CHarston, Scotland.
2 AXES and in base....

\section{Beasts}

Arg. in chief two battle-axes in saltire in base two boar's erect standing on one hind leg combatant ppr. MaC Swrnie, Ireland.

\section{Crescent}

Gu. two battle-axes addorsed in base a crescent. or. Fernandes.

Cross

Per fesse embattled gu. and az. in chief two pick. axes and in base a cross moline or. Pickwick, Bathford, co. Somerset. $V$.

\section{AXES betw, or within....}

\section{Arrows}

Arg. two halberts addorsed gu. in the middle fess point three arrows in fess sa. Crinan, Cringan, or Crinzias, co. Dumfries.

\section{Bird and Flower}

Arg. two Lochaber-axes in saltire heads upward betw. a cock in chief and a l'ose in base .... Matheson, Bennetsfield.

\section{Birds}

Gu. two pole-axes in saltire or betw. four martlets arg. PICKMIAN.

\section{Bordure}

Arg. two halberts in saltire az. within a bordure per bordure indented or and gu. EkLEs.

Az. two battle-axes in fess wishin a bordure engr. or. Bainbridge. Edward Baynbrige, quartering gu. a squirrel or on a chief arg. two mullets of the field, $V$.

\section{Mullets}

Gu. two pole.axes in saltire or headed arg. betw. four mullets of the last. Pitman or Pittman, Woodbridge, Suffolk. Pitrman, East India House, London.

\section{AXEs betw, or within....}

and in chief....

Az. two slaughter-axes addorsed in saltire arg. handled or betw. three bull's heads couped as the second armed of the third viz. two in fess and one in base on a chief silver a boar's head couped gu. betw. two block brushes (i.c. bunches of kuee holly or butchers' broom) vert. Company of Butchers, London, and Company of Butchens, Exeter.

\section{AXES}

Arg. three battle-axes paleways....two and one. KEENLYSIDE.

Arg. three addices az. handles or. ADDICE.

Arg. three battle-axes az. Batten, co. Devon.

Arg. three battle-axes gu. Dannes, co. Devon; Deverston, Harl. MS. 1458. Daverston or Denerston, Suffolk, quartering arg. on a chev. sa. a cross crosslet or, $V$. Lint.

Arg. three Danish-axes gu. two and one. Reney, France.

Arg. three halberts gu. two and one. Danerston, Suffolk.

Arg. three halberts in pale gu. Daverston or Danderston, Suffolk.

Arg. three hatchets gu. Rencre, France, Harl. MS. 1458.

Arg. three pick-axes gu. Pikworth. Pyckworth, $V$, or Pycott, $V$. Thomas Pikworth, $S$.

Arg. three pick-axes gu. an annulet for diff. Robert Picworth, $S$.

Arg. three pole-axes gu. Denarston or Deversion. Arg. three battle-axes ppr. Hicks, changed the name temp. Elizabeth to Gwavas, Gwavas, in Sithney; the co-heiress m. Veale and Carlyon. 


\section{AXES.....cont.}

Arg. three pole-axes in fess ppr. Hodoer, Hoddersfield, co. Cork, quartering Moore.

Arg. three battle-axes sa. Sir Henry GibBes, Honindon, co. Warwick, 1619, $W$. Grtwies, Elmeston, Kent. Grves, $V^{*}$. Hall, $V^{*}$.

Arg. three battle-axes in fess sa. Gybers, co. Devon, Harl. MS. 1458, GibBs, Suffolk.

Arg. three battle-axes in pale sa. GrbBes, co. Devon. GibBs, co. Derby, and Stoke, Suffolls. Gibis, Sainthurst, co. Gloucester.

Arg. three battle-axes in pale barwise sa. Hales.

Arg. three halberts sa. Grves $V$. HaLL, co. Chester, $W$.

Arg. three halberts in fess sa. heads turned to the sinister. GIBBE.

Arg. three halberts sa. beaded az. Hoodar or Hodner.

Arg. three bews or miner's pick-axes sa. William Chare, in Trinity College Chapel, Cambridge.

Arg. three pick-axes sa. PECK.

Arg. three pole-axes sa. Gibns, Elmeston, Kent.

Arg. three wood.bills in pale sa. Gibies or Gibis.

Az. three axes arg. William Hurstal, $F$. William de Hursthale, $E$.

Az. three ases arg. handles or. Axtell. Denys, co. Devon.

Az. three battleaxes arg. Batten, $V *$. Hani, W. Russein. WRight, Scotland.

Az. three battle-axes in fess arg. HaLL.

Az. three battle-axes arg. hafted ppr. WRIGHT, Scotland.

Az. three battle-axes alg. handles ppr. studded or. Batten.

Az. three broad-azes arg. WnIGHT, Scotland.

Az. three carpenter's axes arg. WRIGHT, Scotland.

Az. three halberts in fess arg. GiBBEs. HaLd, Kennington, Kent.

Az. three pole-axes in pale arg. garnished or. GibBs, co. Herts.

Az. three battle-axes or. BaInbrige, $V^{*}$. Sir Robert Dennes, co. Devon, Harl. MS. 1458. Denzs or Dennis, Orley, co. Devon. Gibbes, $V^{*}$. HALL, $V^{*}$.

Az. three battle-axes in fess or. Edward HaLI Bybrool, Kennington, Kent; granted by Cooke, $1588, W$.

Az. three battle-axes or staves arg. BAINBRIDGE.

Az. three halberts in fess or John Grobes, Starford, co. Herts; granted by Cooke, $W$.

Az. three halberts or headed arg. Denrs, co. Devon.

Az. three pick-axes or. PAcrwood, co. Warwick, quartering Ponter.

Az. three pole-ases in pale or. HaLL, Kent; granted 1588.

Az. three battle-axes ppr. headed arg. hanāles garnished or. BATTEN.

Erm. three battle-axes gu. DEnnes or DonneEs. Denns, Holcombe Burnell, Isle of Wight.

Erm. three battle-axes in pale gu. Dennis, Cornwall; Bicton, co. Devon; and the Isle of Wight.

Erm. three battle-axes sa. WeEres, Hurstper. point, Sussex, quartering HaMPTON, CAREY, Aston, co. Oxford, and MACE. WrKes, Cocktree, co. Devon.

Erm. three bills sa. Dennys, Holcombe, co. Devon.

Erm. three pole-axes sa. Weckes or Wries, North Wylie, co. Devon.

Gu. three axes arg. AxAll or AxEson.

\section{AXES.... cont.}

Gu. three battle-axes arg. AINswortr, Smithills Hall \& Moss Bank, co. Lancaster. Arneswonth, co. Lancaster. Aynisworth, $V$. Hakelevett. LEWDSon, Harl. MS. 1458. Lewiston, co. Dorset; Durham ; and co. Huntingdon. Peter LEWSTON, $V$.

Gu. three broad-axes arg. Sire .... de Rentr or Riton, Harl. MIS. 6137.

Gu. three pick-axes arg. Bawdwy Pigot, $S$.

$\mathrm{Gu}$. three pole-axes arg. Lowdston.

Gu. three pole-axes in fess arg. over all a fess chequy of the second and first. Foshauch. FosmaUgB.

$\mathrm{Gu}$. three battle-axes or.

Ainelietts or Hakelets, Harl. MS. 1458. Hacket, co. Salop. HackuUYt, Yatton. Hakelett, $V^{*}$.

Gu. three battle-axes in pale or edged arg. Lewston, co. Dorset.

Gu. three broad-axes or. Sire .... de Renti, $A$. Gu. three hatchets or. Hackelititz, co. Salop.

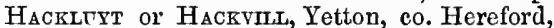
and co. Salop.

Gu. three pole-axes or. Sir Walter Hakelett, temp. Edward I, $V$. Haket, co. Salop.

Or three Danish-axes gu. MaRTELL; and with a label of tive points az. MARTELL.

Per fess arg. and erm. three battle-axes sa. Grbes, Fackley, co. Oxford, Bart.

Sa. three battle-axes arg. Dancrs. Sir .... de Daneys, $V$. Daveys, London. Thomas HaLI, $V$. HaLl, Bradford, co. Wilts. Elys de Thornetonrust, $P$.

Sa. three battle-axes in fess arg. GIbBes, co. Warwick; and HaLle, Harl. MS. 1458.

Sa. three battle-axes in pale arg. GibBs, Honington, co. Warwick.

Sa. three broad axes arg. Sir John Porter, Harl. MS. 1458.

Sa. three Danish-axes arg. Daynes. Dennis, co. Devon.

Sa. three hatchets arg. Daneys, $S$.

Sa. three pick-axes arg. Honde, $V$. Picketr. Piggott, Cambridge. Geffray Pigot, Melmoreby, $P, X$. Randolf Pigot, $S$. Pigott. Pycotт, co. Bedford, $V$. Sir Randolph Pygot, $V$. Pуgотт, Gravenhurst; Stratton; and Holme, co. Bedford. Pygot, Melboreby; and Carleton, co. York.

Sa. three pole axes arg. HALI, Bradford, co. Wilts. LowDEN.

Sa. three battle-axes or. Sir William HALL, Kent, $W$. Hasc, Bradford, co. Wilts, $W$.

Sa. three pick-axes or. Pigotr, co. Nottingham. Sa. three pole-axes in pale or. H HLL, Kent.

Vert three hatchets (or pole-axes) erect or. HONEERVILIE.

\section{Chief}

\section{AXES and in chief....}

Gu. three battle-axes or a chief erm. Shepard, Bucks. Sheppard, London and Bristol. on a Chief.

Erminois three pole-axes erect az. two and one on a chief gu. three bendlets arg. Jennings, Westminster; granted 1760), to Robert Jennings, Auditor of the Eschequer.

\section{AXES betw, or within....}

\section{Bordure}

Arg. three battle-axes sa. within a bordure gu. Dennis. Dinnes, Scotland,

Arg. three halberts sa. within a bordure ermines. GiBbs, South Parrott, co. Devon. 
3 AXES betw, or within.... cont.

Az. three battle-axes arg. within a bordure or. Gibis, Comberton Magna, co. Worcester; and London, 1645.

Az. three battle-axes arg. within a bordure engr. or. WRight, Edinburgh.

Erm. three battle-axes within a bordure engr.gu. Daneys, co. Devon. Denys, co. Devon, $V$.

Erm. three pole-axes within a bordure engr. gu. Dennes, co. Devon, Harl. MS. 1458. DennIs.

Sa. three pick-axes within a bordure arg. Pigotr, Bedford; Marsham, co. Berks; Bechampton, co. Buckingham; Weston, co. Not. tingham; and Abington-Pigotts, co. Cambridge.

\section{Fleurs}

Gu. three battle-axes in fess arg. betw. as many demi fleurs-de lis and the same number of mullets or. TREGOLD.

Heads

Arg. three battle-axes and as many boar's heads couped gu. with a 4 -foil vert in the middle point. Ranken, co. Perth.

\section{Mullets}

Gu. three broad-axes arg. a demi fleur-de-lis joined to each handle. withinside or betw. as many pierced mullets of the last. Thomas TREGOLD, $V$.

\section{AXES betw, or within....}

and in chief....

Sa. three pick-axes in a bordure arg. a canton az. Pigotr, Abington-Pigotts, co. Cambridge, quartering Foster.

\section{AXES}

Arg. five pole-axes in fess ppr. Hodden, Ireland. Gu. five Danish-axes palewise in saltire arg. Roger MACHADO, Clarenceux King of Arms, temp. Henry VIII. ob. 1516, $V$.

Gu. five axes in saltire arg. M'HADo, Scotland.

Gu. five axes or three and two. M'Hud, Scotland.

\section{AYLET see Bird.}

\section{AZURE}

For Azure quartering a charged field (with or without a charge over all) see Quarterly the second and third charged.

Az. simply. Berington, Bradwell, co. Chester. Harl. MS. 1535, fo. 8. DE Barge, Ville sur Sans, Lorraine. Les seigneurs de St. Chaumont.

Az. a 5-foil arg. (? for diff.) Besington and Bessington.

Az. a 5-foil or (? for diff.) Besington.

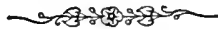

\section{BADGER see Beast.}

BALANCE and in Base....

Arg. a pair of balances held by an arm in armour az. in base a sword and Roman fasces in saltire all ppr. Hoseason, Zetland; and Jamaica; quartering BRUCE.

BALANCE betw, or within....

\section{Bordure}

Az. a pair of balances supported by a sword in pale arg. hilt or pomel or within a bordure of the last. Justice, East Creichton, Scotland.
BALANCE betw, or within.....cont.

Estoiles

Az. a pair of balances or scales within an orle of eight estoiles or. Starr.

\section{BALANCE betw, or within....}

and in chief....

Gu. a pair of balances held betw. three garbs or by a hand and arm embowed ppr. vested of the first cuffs gold issuing from clouds affixed to the upper part of a chief barry wavy of four arg. and az. Company of BAKERs, Exeter: the same with the addition of the clouds radiated and two anchors of the second in the chief. Company of Bakers, London.

\section{BALISTA see Sling.}

\section{BALL}

see Bead, Bubble, Fireball, Mound, Shot, Sphere, and Roundle.

\section{On 1 BANNER}

(including Colours, Flag, Pennon, and Standard). Bird

Gu. on a knightly banner flowing to the dexter arg. an imperial eagle. GarBetr, 1486; Huntington Park, co. Hereford, 1790: the staff garnished sa. Garbetr, Acton-Burnell, co. Salop : the staff twisted arg. and sa. GARBED or G $\mathrm{G}_{\triangle \mathrm{BIT}}$, Rigbton, co. Salop.

Gu. on a banner or an imperial eagle charged with an escucheon arg. the staff held by a griffin segreant of the last. GarbetT.

\section{on a Canton}

$\mathrm{Gu}$. on a banner displ. arg. a cauton az. charged with a saltire of the second. BANNERMAN, El. sick, Bart. quartering or a cross moline az. a bordure engr. arg.

\section{Cross}

Gu. on a standard arg. fringed or in saltire with a broken spear of the second a cross of the first. Sмxтн, Balhara, Scotland, granted 1765 , quartering az. a cat salient arg. with BLAIr and Drummond.

on a Cross

Gu. on a banner arg. a cross betw. sixteen escu. cheons of the first and charged with a lion pass. guard. or the flag affixed to a sword erect held by a dexter arm embowed in armour issuing from the dexter all ppr. A coat of augmentation to LAKE, Bart.

On 1 BANNER and in chief....

Quarterly sa. and arg. over all a representation of the colours of the Thirty-first Regiment (.... two laurel branches saltirewise .... below the union-jack) in bend sinister the first quarter occupied by a lion ramp. of the second. BxNG, Earl and Baron Strafford.

On 1 BANNER betw, or within....

Gu. on a banner displ. arg. a canton az. and a saltire of the second all in a bordure as the last charged with four buckles of the third alternating as many holly leaves vert. BANNERMAN.

\section{BANNERS}

Az. three banners bendwise in pule flowing to the sinister or. KINGDoM.

Or three pennons in chief sa. LoGIE, Scotland.

3 BANNERS betw, or within....

Arg. three standards (another vanes) sa. in an orle gu. VYrNeY, $V$. 


\section{BAR}

(including Closet and Barrulet); see also Fess.

Arg. a bar az. Burken. Burkin, London, 1730. Arg. a bar dancetty in chief az. Robert FIrz. Elys, Newton, $X$.

Gu. a bar or surmounted by a staff raguly arg. DruitT.

Gu. a bar indented on the upper edge or. Thorleys.

Paly of six arg. and gu. in chief a bar indented or. Gousley, $V$.

\section{Beast \\ 1 BAR and in chief....}

Arg. a bar wavy and a demi otter issuant sa. armed langued and crowned with an antique crown gu. Merprom, quartered by Seton.

Beasts

Arg. a bar and in chief two lions ramp. gu. CALSTON.

\section{Birds}

Arg. a bar dancetty gu. in chief two martlets sa. Norton, co. Devon.

Chief

Arg. a bar indented sa. a chief gu. Burhfrend.

Az. a bar dancetty and a chief or. Monsire Jobn de Stonor, $Y$.

Or. a bar chequy sa. and gu. a chief indented az. WODDISBURY.

on a Chief

Az. a bar or on a chief of the last three escallops gu. Clerke, $W$.

1 BAR and in base....

Az. a bar arg. in base three apples transposed or. HARKWYN or HARLEWYN, co. Devon.

Az. a bar arg. in base three apples erect ppr. Harleton, co. Devon.

\section{Bars}

\section{BAR betw. or within....}

Or a barrulet betw. two bars gemels gu. over all three escucheons vair. GAMOLLE, temp. Ed. ward III.

Or a barrulet betw. two bars gemels gu. over all six escucheons vair three two and one. Gamol.

Flowers

Gu. a bar betw. two fleurs-de-lis stalked and leaved in chief and an annulet in base or. Kellock, Scotland.

1 BAR betw, or within.... and in chief....

\section{on a Chief}

Vert a bar countercompony arg. and az. betw. three cuirasses of the second on a chief silver as many buckles of the third. Baldberney or Baldbirney, Scotland.

\section{Cross}

Az. a harrulet environed with an annulet betw. two bars and in chief a cross patty fitchy or. Holte, $V$.

Fish

Gu. a bar engr. arg. betw. three suns or in the collar point a demi-salmon naiant from the fess of the second. AULD, Scotland.

On 1 BAR and in chief....

Per chev. or and az. a bar fusily of the first each fusil being charged with an escallop gu. in chief two fleurs-de-lis of the last. EDGAR.

\section{Garb}

$1 \frac{1}{2}$ BAR and in chief...

Az. a bar and a half arg. in the sinister quarter a garb or. SCHEFFELD, $V$.
BAR. $1_{\frac{1}{2}}$ BAR and in chief.... cont.

on a Quarter

Arg. a bar and a half az. on a quarter of the last a 5-foil or. Pauf PIPARd, $Y$.

Arg. a bar and a half gu. on a quarter of the last a 5-foil arg. John Denwentwater, $X$.

Arg. a bar and a half sa. on a quarter of the last a 5-foil or. Richard TWYFORD, $Y$.

\section{BARS}

...2 bars nebuly....Y Yeovinton.

Arg. two bars az. Hackbeach. Hillton, Sussex. Hilton, Hilton, co. Durham; the coheirs m. Musgrave, Younghusband, and Briscoe. Hriton, South Shields, co. Durham; Sussex; co. Leicester; London; and Jamaica; descended from Hilton of Hilton. Hilton, co. Gloucester; Rhea Hall, co. Stafford; and London, 1716, quartering arg. three daggers diverse gu. Le Baron de Hilton, $S, Y$. Le Sire de Hilton, $Y$. Sir Robert Hilton, $V$. Robert de Hilton, $E, F$. Sir Robert de Hyltone, $H, N$. Venables, co. Lancaster.

Arg. two bars az. over all a lion ramp. gu. WALTON.

Arg. two bars az. over all a lion ramp. gu. crowned or. Willesifose, Willesmot, or Wilmescot, co. Gloucester.

Arg. two bars az. over all a lion ramp. or holding in the dexter paw a rose branch gu. Tudman.

Arg. two bars and a bend az. Martingdale or Martindale, Montford, $V$. Mountford, $V *$. Arg. two bars and a bendlet az. Mountford, co. Warwick.

Arg. two bars az. over all a bend chequy gu. and of the first (another gu. and or). LEGG.

Arg. two bars az. over all a bend compony.... and gu. LEA or LeIGH, Bradley, co. Lancaster.

Arg. two bars az. a bend compony gu. and or. Leigh, Ridge, co. Devon. Leigh, Bardon, co. Somerset, 1595, descended from Leigh of Ridge.

Arg. two bars az. on a bend gu. three arrows of the field. Dawne, co. Chester. Venables, co. Lancaster. M. Richard de Venables, $S$.

Arg. two bars az. on a bend gu. a bezant. GreY, Horton, Northumberland.

Arg. two bars az. on a bend gu. three chaplets or. GREY, co. Hereford.

Arg. two bars az. over all an eagle displ. with two heads gu. Sir Joln Spe ke, $V$.

Arg. two bars az. over all an escarbuncle of eight points gu. Blount.

Arg. two bars az. over all an escarbuncle gu. nowed or. BLocnt, Gloucester.

Arg. two bars az. over all an escarbuncle of eight points gu. bezanty. Blount, Mangerfield, $V$.

Arg. two bars az. over all an escarbuncle of eight rays gu. pometty and floretty or. BLounr.

Arg. two bars az. over all an escarbuncle of eight rays or. BLounT, London and Gloucester.

Arg. two bars az, over all a buck's head gu. WooDWARD.

Arg. two bars az. over all three bucks' heads cabossed or. WOODWARD, London.

Arg. two bars az. over all a saltire gu. Port or Deporte, Sheepshead, co. Leicester.

Arg. two bars engr. az. A AHULL, $V$.

Arg. two bars fusily az. Faconbreate. William de Fauconberge, $F$.

Arg. two bars wavy az. Delariver. Samford.

Arg. two bars wavy az. on a cherron gu. three bezants. EsTer. 
BAR.

2 BARS.....cont.

Arg. two bars wavy az. three demi lions gu. Milligan or Mulumine, Scotland.

Arg. two bars embattled erm. BuRney or Burneby, co. Devon, $V^{*}$. Burney, Kensington, Middlesex.

Arg. two bars wavy erm. Lacr, Enfield, Middlesex.

Arg. two bars gu. Bery, co. Devon. Bomford, co. Lancaster. Bynde, Sussex. Chanry. Denton. Ewer. Foxall, London and Ireland. Limesie. Mainwaning, Over Peover, co. Chester, Bart., quartering az. six garbs or for Kivelioc, Earl of Chester. Malntaring or Manwaring, Peure, now Orer Peorer, co. Chester; Kermincham, co. Chester; Ightfield, co. Salop; and Whitmore, co. Stafford. Mainwaring, Oteley Park, co. Salop; and Bromborough, co. Chester, derived from Mainwaring of Whitmore, quartering KINASTON. Sir Richard MANWARING, co. Chester, $V$. Wil. liam Manwaring, $P$. Walter Maldust or Malduist, $C$. Mandut or Manduit, co. Warwick, and Somerford-Manduit, co. Wilts. . William Manduyt, $X$. Martin, Athelhampston, co. Dorset, and Long Melford, Suffolk ; Baronetcy, 28 May, 1667. Martin or Martyn, Exeter, co. Devon., derived from Martin of Athelhampston. M Martin, Exeter; and Kemeys, co. Pembroke; temp. Henry I. MARTin, Hemingston, Suffolk, Colston Basset, co. Nottingham ; Anstey Pastures, co. Leicester; Worsborough, co. York. Sir William Martin or Martyn, $H, I, L, X$. Monsire William Martin, $Y$. William MarTyN, $Y$. Martyn, co. Devon, $V$. Mlauduit, Hanslope, co. Buckingham. William MaUdy , $B$. Maunduit. Saint Clere. South, Ferraby, co. Lincoln, confirmed 22 June, 1602.

Arg. two bars gu. over all on an escucheon of the first a saltire of the second and chief erm. Deane, Baron Muskerry, m. Fitzmaurice.

Arg. two bars gu. on the upper one an amnulet or. Mantyn.

Arg. two bars gu. a crescent for diff. BRADSHAW, co. Chester. Martyn, Saint Dominic, Cornwall; Parkpale, co. Dorset; Saberow, co. Somerset; and Oxton, co. Devon; and with a mullet in chief sa. SourH.

Arg. two bars and in chief a crescent gu. BARRYE, co. Devon.

Arg. two bars gu. a label az. Monsire Nichol le Fitz-Martin, $B, X, Y$. Wintershale, $E$.

Arg. two bars gu. on a label of three points az. nine plates. Sir William Martin, $V$.

Arg. two bars gu. on a label of three points of the last nine bezants. Martyn.

Arg. two bars gu. a label of five points of the second bezanty. Marlyn. Martyn.

Arg. two bars gu. a label vert. Mornton. Thomas MuLTon, $Y$.

Arg. two bars gu. over all a lion ramp. of the first. BICKNELL, London.

Arg. two bars gu. over all a lion ramp. double queued or pelletty. Brandon, Chamberlain of London.

Arg. two bars gu. a bend az. Martindale. Martyndall, $V^{*}$. Mountford, co. Warwick.

Arg. two bars gu. a bendlet az. Martindall, $V$.

Arg. two bars gu. a bendlet or. ManNwaring, Croxton, co. Chester, derived from an illegitimate son of Mainwaring of Over Peover, 1546.

Arg. two bars gu. a bendlet sa. MoLton.

Arg. two bars gu. on a bend az. three mullets of the first. WeLchinan, Brackley, co. North. ampton; and Kineton, co. Warwick.

\section{BAR. 2 BARS.... cont.}

Arg. two bars gu. on a bend of the second three trefoils slipped of the first. PALMER; but slipped or, Pat,mer, $V$.

Arg. two bars gu. over all a long cross (sometimes a crosier) in bend sinister or. Gilbertine Priory at Sempringham, co. Lincoln.

Arg. two barrulets and as many endorses gu. BARE. Arg. two bars gu. over all an escarbuncle of ejght points flory at the end gu. bezanty. Edward Blount, Maugerfield, co. Gloucester, $V$.

Arg. two bars gu. a maunch of the second. UNDERSHOT.

Arg. gutty de larmes two bars gu. Chaury, $V$. Chawrey, $V$. Chawry.

Arg. two bars dancetty gu. GAINE.

Arg. two bars embattled gu. ENYs or Evys. Euys. Janies, Ightham Court, Kent, derived from Van Haestrect from the vicinity of Utrecht, quartering Grevis. James, Wilsborough, Kent, and Ryegate, Surrey; quartering arg. three millrinds barwise sa.; with barry wavy of six arg. and az. on a chief or three swallows volant sa.

Arg. two bars counterembattled gu. JaMES, Chrisball, and Manewden, Essex.

Arg. two bars engr. gu. Anables, AnNabell, or AnNabi.es.

Arg. two bars fusily gu. Rauf Raul or Rool, $E, F$.

Arg. two bars engr. below gu. Undershot, $V$. Arg. two bars indented gu. HaMiLIN.

Arg. two bars nebuly gu. John Champion, Kent, $V$. Arg. two bars nebuly gu. on a bend engr. sa. a rose betw. as many mullets or. CHrswell London, granted 13 April, 1714. ChIsweLL quartering FrENCH, granted 10 Dec., 1773 to to Muluman, Debben Hall, Essex.

Arg. two bars nebuly gu. on a bend sa. three plates. Goulstone. Gulston, co. Hertford, co. Leicester, and London.

Arg. two bars voided gu. over all a bend sa. Burton.

Arg. two bars wavy gu. ENGIAND, Ireland. Goldingram, Norfolk, $V$. Gouldingham, Norfolk.

Arg. two bars wavy and a baton gu. Sir Roger d'Amors, $L$.

Arg. two bars sa. Sir William Breneton, Brereton, co. Chester, $V$., the beiress m. Holte, Aston, Bart. Brereton, Malpas, co. Chester, descended from Brereton of Brereton. BrERETON, Burros, co. Denbigh; Eccleston; Wetenhall; Tatton; Honford ; Wolvesacre, and Barrell ; all descended from Brereton of Malpas. BREREToN, quartering sa. two banners arg. BREWERTON. Bruerton. Brereton, Ireland. Deane, co. Huntingdon. Ellesfield. Garby or Garbin. Ildoerton. Geffre de Meremond, Harl. MS. 6137, fo. 97. Pelcot or Pelott, Ireland. Penrey, Norfolk. Pillet, Ireland, $V$. Pillett or Pillott.

Arg. two bars sa. a label gu. Garden, co. Cambridge. Sir Thomas GARDYN, $N$.

Arg. two bars sa. a label of three points gu. Breton, co. Cambridge.

Arg. two bars sa. a label of five points gu. GarBYN, co. Cambridge. Gardinis. Sir Thomas GARDYN, co. Cambridge, $V$.

Arg. two bars sa. a crescent gu. (? for diff.) Bradshat, co. Chester.

Arg. two bars sa. a mullet between them for diff. Brereton.

Arg. two bars sa. a bend erm. Finchair. 


\section{BAR.}

2 BARS.... cont.

Arg. two bars sa. a bend gu. Ashton. Lynde, $V$.

Arg. two bars sa. a bendlet gu. Sir Robert AsHToN.

Arg. two bars sa. a baton gu. Sir Robert de Ashton, Constable of DoverGastle, $V$. Lrnde, $V$.

Arg. two bars sa. on a bend gu. three mullets or. Dransfield.

Arg. two bars sa. over all a cross formy flory gu. Breneton, Honford, co. Chester, Bart, descended from Brereton of Malpas, temp. Henry VIII.

Arg. two bars sa. over all a maunch gu. ManBy.

Arg. two bars embattled counter-embattled sa. Bervers, Essex.

Arg. two bars dancetty sa. Dorinng, North, in the Isle of Purbeck, co. Dorset, granted 1613. Ginkeli, Earl of Athlone.

Arg. two bars engr. sa. Facombrige or Faconberge. Henry Fauconberge, $Y$. Kirkby. Kirkley, co. York. Rous, $V$. Row. Rows, Stockly Parva, co. Huntingdon. Starnes. Stains. Stanes, Essex. Stayne, co. Lincoln.

Arg. two bars engr. sa. a label gu. Stapney or STAPUE.

Arg. two bars fusily sa. Faconberge. Sir....de Fauconberge, $V$.

Arg. two bars lozengy sa. Fauconberge, $Y$.

Arg. two bars masculy sa. Fauconberge, $N$.

Arg. two bars nebuly sa. a label of three points gu. M. Robert de Zevelton, $S$.

Arg. two bars nebuly sa. a bend gu. Poner, Cornwall.

Arg. two bars nebuly sa. a bend or. Power, Bletchington, co. Surrey, granted 8 June, $160 \mathrm{~L}$.

Arg. two bars sa. voided of the field. Canswell.

Arg. two bars wavy sa. Elchefield. Sire Johan de Elchesfejd, $N$. Sire Jolian Lessend, $L$. Monsire Richard de Stapleton, $Y$. Basset, Lord of Sapcote. Zevelton.

Arg. two bars wavy sa. a label gu. Zenelton. Zevelton.

Arg. two bars vert. Ayburg. Delaval, Northumberland. Harthale, co. Derby. Sir Richard Harthull, co. Derby, temp. Edward I, $V$. Hershull or Herthald. John Herthild, $Y$. Sire Richard de Herthulle, $N$.

Arg. two bars vert over all a lion ramp. gu. Chaloner, co. Stafford, $W$.

Arg. two hars vert over all a bendlet gu. Herthali.

Az. two bars arg. Burdett. Hirton. Kinderton, LeigH, co. Chester. Venables, Lord Vernon, quartering VERNON, and VERNON of Haslington. Sir Thomas Venables, Baron of Kinderton, co. Chester, $V$. Wilbratair, Woodhey and Delamere, co. Chester.

Az.two bars arg. with a martlet for diff. VenABLEs, Andover, co. Hants ; visitation 1634.

Az. two bars arg. a bend chequy or and gu. Willian de LeEgH, $X$.

Az. two bars arg. a bend compony of the last and gu. Lea or LeE, co. Cumberland.

Az. two bars arg. a bend compony or and gu. LEGH or Leigh, Adlington, co. Chester, $V^{*}$. LEGH or LEIGH, Isell, Cumberland, temp. Edw. II.

Az. two bars arg. a bendlet compony or and gu. LEGH, Adlington, co. Chester, $V$.

Az. two bars arg. over all a bend counter-compony or and gu. Leigh, 1369. LEGH, of the North, $I^{r}$. LEGH, Isell, co. York, $V$.

\section{BAR.}

2 BARS.... cont.

Az. two bars arg. over all a bend gu. Done. LEe, Plaistow, Essex; and Ratcliffe, co. Leicester. LEgH, Norbury Booth's Hall, co. Chester. Lergh. Tenables, $V *$.

Az. two bars arg. over all a bendlet gu. LEGH, Bothes, co.Chester, $V$. Sir Alexander Venables, temp. Edward II and III, $V$.

Az. two bars arg. on a bend gu. three arrows of the second. Done, Utkinton, Flaxyards, Duddon, and Oulton, co. Chester.

Az. two bars arg. on a bend gu. three arrows or. Dawney. Donne or Doan, co. Chester.

Az. two bars arg. on a bend gu. three arrows or in pale with the bend feathered and headed of the second. DAwne, co. Chester, $V$. Sir John Done, Utkinton, co. Chester, $W$.

Az. two bars arg. and a bend or. PoLe.

Az. two bars arg. on a bend or three pheons gu. LEGH, $V$. LEIGH, $V *$.

Az. two bars arg. on a lozenge sa. a lion's head erased or. Darman, co. Chester.

Az. two bars dancetty arg. Sir Jobn de la Ryver, co. Berlis, $V$.

Az. two bars nebuly arg. Del See or Dolsey. William Poole, $V$. Martin Del See, co. York, $V$. SeE. Sey.

Az. two bars wavy arg. Brooksbank. Delapole. Halsweli, Halswell, co. Somerset. Pole or De la Pole, Kingston-upon-Hull. SEe.

Az. two bars erm. HamiLl, Ireland.

Az. two bars embattled counter-embattled erm. William Burnby, Burnby, co. Devon, $V$.

Az. two bars counter-embattled erm. Burnaby, co. Devon.

Az. two bars nebuly erm. Sir de Holcain, $V$. HOLCAN.

Az. two bars wavy erm. Holkham. Holcam and HOLCAN.

Az. two bars erminois over all a bend counter. compony of the second and gu. LeE, London.

Az. two bars or. Bradr, co. Cambridge. Sire William Bordet, $N$. Monsire Richard Bundet, $Y$. Burdett or Bordet, co. Leicester. Bundetr, Bramcote, co. Warwick; Formark, co. Derby; and Ramsbury, co. Wilts, Bart. Richard Burdett, $Y$. Sir William Bundett, co. Leicester, $V$. William Pauncefot, $F$. Pembruge. Pipard. Prvers, co. Berks.

Az. two bars or over all a lion ramp. gu. Hatcliff, $V$.

Az. two bars or a bend chequy of the last and gu. LEE, Hartwell, co. Buckingham, Bart.

Az. two bars or. a bend gu. Bundetr.

Az. two bars and a bend or. Leigh, Preston, co. York. Patte. PotT or Potts, London and Norfolk. Potrs, Mannington, Norfolk, Bart., created 1641, descended from Pot, who had a grant of arms in 1583. Potrs, Chester. Potrs, South Shields, co. Durham.

Az. two bars and a bendlet or. Pотт, Bentham Hill, Kent, quartering gu. three swords erect ppr. with gu. a cross engr. betw. four plieons arg. Az. two bars or on a bend sa. three crescents of the second. Twithair.

Az. crusily two bars or. BlackenhaM or Blakenhadr, Suffolk. Sire Thomas de Blakenhai, $N$. Blonientam.

Az. two bar's dancetty or. Delamere or Delamore, co. Berks. De la Rever or Dejariver, co. Berks. Sir William de la Reven, co. Bucks, $V$. Richard de Rineres, $F$. Sir John de la Rifere, $L, N, Y$. Rivers, co. Berks. Ryneli. 


\section{BAR. 2 BARS....cont.}

Az. two bars embattled or. BarneBY.

Az. tro bars lozengy or. ElLAcott, co. Devon.

Az. two bars nebuly or. Delapoole. Rrven or De la Rrver.

Az. two bars wayy or. Delariver. Poole. Sir Walter de la Poole, $Q$.

Az. two bars vairy erm. and gu. Renald de Brenuse, $A$.

Chequy arg. and az. two bars gu. Lеснсне, $V$. LECHECHE, $V^{*}$.

Chequy or and az. two bars arg. Town of OKenampton, co. Devon.

Erm. two bars wavy az. over all a crosier in bend or. Augustinian Abbey at Missenden, co. Buckingham.

Erm. two bars gu. Banant. Bavant. Sir Walter Bruant, $V$. Johan le Fitz W..., $F$. Sir Wanter Huntercombe, $J$. Roger Manduit, $Y$. Mandut or Mandurt, Northumberland and co. Stafford. Sir Roger Manduyt, $M$. Sire Roger Maudut, $N, Y$, or Maudyut, $O$. Nugent, Mar. quess of Westmeath. Nugent, Carlanstown, co. Westmeath, Earl Nugent. Nugent, Ballin. lough, co. Westmeath, Bart. Nugent, Essex. Nugent, Moyrath, Streamstown, Tefferman, Culvin, Braclilyn, Drumcrce, New Haggard, Dysert, Ballinacorr, Donore, Carlanstown, Coolamber, Killasonna, Robinstown, the Rosse, Pallas, etc., Ireland. Whishorth. Workshali or Worshall. Geffry de Wrokeshalle, $Y$. Wroxhat,, Wroxhall, co. Dorset.

Erm. two bars and over all three crescents gu. Waterton.

Erm. two bars gu. orer all three escocheons or. Sir .... de HALI, $V$.

Erm. two bars humetty gu. Dabridgcourt, co. Warwick. DamberNort or DanBREMORT.

Erm. two bars nebuly gu. FoLIot.

Erm. two bars voided gu. Hunterconbe.

Erm. two bars or over all a lion ramp. az. Bagnali, co. Stafford, and Wales. BickNoli.

Erm. two bars purp. Roger Mandite, Cumberland, $V$. MAUDIT, $V^{*}$.

Erm. two bars sa. Francis.

Erm. two bars wavy sa. over all a crosier in bend or. Augustinian Abbey at Missendes, co. Buckingham.

Erm. two bars vert. Defaval, Seaton Delaval and Ford Castle, Nortbumberland. Sir .... de la VALE, Northumberland, $V$. John de la Valie, $X$. Devali.. Hawks. Vale. Walies, $V$.

Gu. two bars arg. Chalon. Chalons, co. Devon. Fonesiex. Foxley, co. Berks. Foxiex, $V$. M. John de Foxlee, $S$. Sire Johan Foxide, $N$. Krrkefton. Martyn, co. Dorset. Pusey.

Gu. two hars and a bend arg. WALIIS, WELCH, or WeIsH, Wanlip, co. Leicester, $7 \mathrm{Edw}$. I.

$\mathrm{Gu}$. two bars arg. on a bend or three leopard's heads sa. Higgat, Suffolk.

$\mathrm{Gu}$. two bars arg. on a bend or a torteau betw. as many leopards' faces az. Highgate, Hayes, Middlesex; and Rendlesham, Suffolk. Heygate, Southend, Essex, Bart. Hygate, $V$.

Gu. two bars arg. over all a millrind erm. Pannerton, co. Stafford.

Gu. two bars embattled arg. Coffin, co. Somerset. Gu. two bars embattled on the top arg. Sir Thomas Coffys, $V$.

Gu. two bars dancetty arg. William Asmant, $V$. Gu. two bars engr. arg. Grasseil. Rouse.

Gu. two bars fusily arg. Preston, $V$.
BAR. 2 BARS.... cont.

Gu. two bars voided arg. on a bend of the second a castle az. THORNHILr, Ient.

Gu. two bars compony arg. and az. BurIey, $V$. Roche.

Gu. two bars erm. Botelan or Boteinand. Boteler,Cumberland, $V$. Nugent, $V *$. Panton. Sir Hugl Pantone, Beamanton, $V$. Pantulf, Baron of Weme, co. Salop, the heiress m., temp. Henry III., Boteler of Oversley, co. Hereford. ThornemL, co. York.

Gu. two bars and in the dexter chief a milhind erm. Sire Hugh de Pauntone, $N$.

Gu. two bars erm. a bend of the first. WorkshaLI or WoRshaLI.

Gu. two bars erm. over all a bend engr. sa. Pentolph, co. Salop.

Gu. two bars wavy erm. Hurding, co. Dorset. LACr, co. Oxford and co. Somerset.

Gu. two bars indented arg. and az. Hugh Freneyes, $Y$. Monsire de Freir, $Y$.

Gu. two bars indented az. and or. Rauf Freyne, $Y$. Gu. two bars or. Harcourt, Earl Harcourt. Harcourt, Ankerwycke, co. Buckingham, descended from Harcourt of Wignell, Sussex, and of Stanton Harcourt, co. Oxford. Sir Robert Harcourt, co. Leicester, $V$. John de Harcourte, $C$. Sir John de Harcourt, $I$, and with a label of three points az. his son Jobn, $I$. Sir Jobn de Harecourt, $L, N$. Le Conte de Harecourte, $I$. Sire de Harecourte, Y. Hils, Suffolk.

Gu. two bars or on a label of three points az. nine plates. William de Harcourt, grandqueur de France, 1410; glass in Evreus ca. thedral.

Gu. two bars or over all a lion ramp. arg. PeVereil.

Gu. two bars or orer all on a bend arg. three talbots' heads erased sa. GoDnen, Leyborn Castle, 1574, and Finchden, Tenterden, Fent.

Gu. two bars dancetty or. Asamuz. Asnantes. SAMLER.

Gu. two bars wavy or. Brewer, co. Devon, $V$. Bruer. Bruvere. Rivers, River, or De ia Piver, co. Berks.

Gu. two bars per fess indented arg. and az. Hue de Frene (or Frecha), $E$. M. .... de Frent, $V$. Gi. two bars vair. Castell. Hugh de Fren, $V$. Frene. Grimstead or Grimsted. Grimsteed, co. Dorset. Grinstead, co.Somerset. Moreton. Mortemer. Robert Mortimer, $A$. Hugh de Mortemer, $K$. Robert de Mortiner, $D, E, F$. Sir Hugh de Mortymer, $H$. Hugh Morton, $Y$. John Mortymer, $Y$. SAY, Richard's Castle, co. Hereford, $V$. TALBOT, Castle-Richard, $V$. William Talbor, $Y$. Sire Richard Talebot, $O$; and with a pierced mullet arg. in the dexter chief for diff. M. Gilbert TauBot, $S$.

Gu. crusily or two bars vair. William de Mortimer, $F$. Mortymer.

Gu. two bars vairy or and az. Hugh Mortimer, $J$. Gu. two bars vairy vert and or. GrImsted, co. Dorset.

Or two bars az. Asre, co. York. BURdetT. Crehall or O'Crehali, Ireland. Fitz-Ralph, temp. Henry III. Hackebecke. Sir Robert HaKebEch, $V$. M. Reynald Hakenbeche, $S$. HAKBEECH or HAKEBECHE. HARKEYN. Harmartie. Hernentale. Poole, co. Derby. Or two bars az. over all a lion ramp. guard gu. Oxburgh or Oxborough, King's Lynn, and Emneth, Norfolk. 


\section{BAR.}

2 BARS.... cont.

Or two bars az. over all a bend gu. QuaPLED, Quapelade, or Quappelad.

Or two bars az. an eagle displ. gu. Garnegotr.

Or two bar's az, orer all on a chev. gu. three mullets of six points arg. TaLwORTHE, $V^{*}$.

Or two bars wavy az. P'OLE or PALE, Norfolk. Poole, Norfolk.

Or two bars bendy of six gu. and az. JAKYs, $V$.

Or two bars wreathed bendy of eight az. and gu. JAKTS, $V^{*}$.

Or two bars gu. Cameron, Nea House, Christ Church, co. Hants. Chalmers, Scotlaud. Chalun, 1 . Halbecke. Sir .... deHarmanvill, $V$. Harcourt, $E$. William Harecourt, $Y$. William HARECURT, $F$. John de Harcourt, $G$. Sir John de Harcort, $N$. Richard de Harecourt, $B . \quad$ Richard Harecourt, $P$. Thomas Harecourte, $S$. Harold. Manvoysin or Mansyne. Petney, Ireland. Bartholomew de Sulee, $D$. Sulley. Robert Surler, $Y$. Wintersell, co. Wilts.

Or two bars gu. a label of five points az. Harcourt.

Or two bars gu. a label of three points sa. WINTERSHALL, I'.

Or two bars gu. a label of five points throughout sa. Wintershall, Wintershall, Surrey, and Little Stoke, co. Oxford.

Or two bars gu. over all a lion ramp. of the second. Breners.

Or two bars gu. a bend az. Wane, Kent.

Or two bars gu. a bendlet az. WAKE, Kent, $V$.

Or two bars and a bend gu. Palmer.

Or two bars gu. a bend of the first. WAKE, Kent.

Or two bars dancetty gu. HARIEN.

Or two bars indented gu. Derncoorte.

Or two bars invected above but engr. below gu.

Boxle, $V^{*}$. Boxle Axabelies, $V$.

Or two bars nebuly gu. a bend az. LoNel.L.

Or two bars wavy gu. in chief a label of three points of the last each point charged with a martlet arg. Rawry, Essex.

Or two bars per pale indented vert and az. Sustan, $V$.

Or two bars per pale indented vert and gu. Sutston.

Or two bars sa. Deynes, Norfolk. Sire de Dist, D. Penrer, Norfolls. Pever, Norfolk, $V$. Pueray.

Or two bars with a label of five points sa. John de Wintershulie, $E$.

Or two bars sa. in chief a pierced mullet gu. Geffry Mereitone, $A$.

Or two bars sa. on the uppermost a mullet. Penrey, Norfolk.

Or two bars sa. a mullet ar. Pevere.

Or two bars sa. on the uppermost a mullet pierced ar. Pever or Piner, Norfolk. Piver.

Or two bars sa. a pile counterchanged. ENGHAM or ENgleham, co. Norfolk.

Or two bars engr. sa. Brantwart.

Or two bars vairy arg. and sa. Liтcotт. Lrdcotтe, co. Buckingham; Woodburcot, co. Northamp. ton; and Surrey. Lттсот, co. Buckingham; Stratford-Langthorne, Essex; and Maulsey, Surrey. Stone, V*, qualtering with gu. two bars vairy or and sa., or three fleurs-de-lis $\mathrm{gn}$.

Or two bars vairy arg. and sa. in chief a mullet. Ly'TCOTT.

Or two bars vert. ABEck or Habick. Arbreth, co. Lancaster. Herthall or Herthuld.
BAR. 2 BARS.... cont.

Per chev. sa. and arg. in chief two barrulets of the last. Allerton.

Per fesse az. and gu. two bars or. Holt or Holte.

Per fesse embattled az. and gu. the base masoned sa. with crosses botonny of the last, $i, e$. Joopboles as in fortifications, in chief two bars wavy arg. over all in pale a sword of the last hilt and pomel or on the blade a key. City of Bath, co. Somerset.

Per pale arg. and gu. two bars counterchanged. BarRet, $V$.

Per pale .... and .... two bars nebuly .... John de Dauntesey's seal, $V$.

Per pale arg. and gu. two bars nebuly counter. changed. DANDsey, London.

Per pale arg. and or two bars nebuly gu. William DANCY, Alderman of London, $V$. Walter DaUndesey, $V$.

Per pale arg. and sa. two bars dancetty counterchanged. ENDERBIE.

Per pale az. and gu. two bars or. John HoLte, co. Jancaster, $V$.

Per pale or and gu. two bars counterchanged. Derpatrick.

Per pale or and sa. two bars vert. Harthill.

Per pale vert and or two bars counterchanged. Tregender, Tregender, Cornwall; the heiress m. Nanspian.

Sa. two bars arg. Sir John Brerton, F. Fowkes, London. Sir Robert Toune, co. Cambridge, $V$. Tonket.

Sa. two bars arg. an annulet of the second. Moston. Sa. two bars arg. a label of three points gu. Zenelton, $V$.

Sa. two bars engr. arg. Roos or Rossf, Rous or Rouse, Letton, Norfolk; and Rouse-Lench, co. Worcester. Rouse, Ml arket. Harborough, co. Leicester; descended from Rouse of Rouse-Lench.

Sa. two bars bumetty arg. CAMBrIDGe.

Sa. two bars nebuly arg. MARTYN, co. York.

Sa. two bars arg. voided gu. Rogerway.

Sa. two bars wavy arg. ELLESFIELD.

Sa. two bars arg. corded or wreathed gu. WAY or WAYE, Great Torrington, co. Devon, con. firmed 1574.

Sa. two bars wreathed arg. and gu. Roger WAYE, $V$.

Sa. two bars nebuly erm. Sir Robert Spencer, $V$. Spencer, Spencerscourt, co. Devon, $Z, 333$. Sa. two bars wavy erm. Spencer, co. Devon.

Sa. two bar's or. Benet de Blakeham, $E$. Beges de Blakelig, $F$.

Sa. two bars or on a bend arg. three escallops gu. LAYTon. Leighton.

Sa. two bars engr. or. HenryGraseli, $V$. Grassell. Sa. two bars wavy paly wavy az, and arg. Rogerway.

Sa. two bar's vair. Hackon, Norfolk.

Sa. two bars vairy arg. and vert. BARKeley. Brakeley. Brakley, $V$. Hallom, Northumberland.

Vair two bars gu. Ingerham. WaIkINGame, Ridmer, Harl. MS., 0589. WalkInghaM, Farnham, co. York. Allain de WALKINGHAM of Redmer, $Y$. John de WalkinghaM, $Y$. Sir Jobn de Walkingham, $M, N$.

Vert two bars or. Corayne.

2 BARS and in chief....

(Some of the following coats should probably be blazoned Barry..... and on a chief....)

Annulets

Arg. two bar's and in chief three annulets az. Cramington, Newcastle-on-Tyne. 


\section{BAR. 2 BARS and in chief.... cont.}

\section{Annulets cont.}

Arg. two bars sa. in chief three annulets of the second. Burdeaux. Burdeux, $V$.

$\mathrm{Gu}$. two bars arg. in chief three annulets of the second. Gregory de Ank, Y. ANkE, $V$. ANke or Antey. Auke, $V$. Deane or Deanre. Girgon. Grigson. Grigson, Saham Toney, Norfolk. Michell de Sparding, $Y$.

Sa. two bars erm. in chief three annulets or. CaLIEYS.

\section{Beast (Dog)}

Arg. two bars gu. in chief a greyhound in full course az. Rosmer or Rosumers, Cornwall.

Arg. two bars gu. in chief a greyhound pass sa. SKIPWITH, co. Lincoln.

Sa, two bars arg. in chief a talbot pass. of the second. Hayward, Tandridge Hall, Surrey. Hewarde or Hartard, London; and Tonbridge Court, Surrey.

\section{(Lion)}

Arg. two bars gu. in chief a lion pass. of the second. Buenby. Louche or Lowche.

Arg. two bars gu. in chief a lion pass. guard. of the secolld. BurnabY or Burneby, Watford, co. Northampton; the co-heirs m. Bathurst and Langham. Burnaby, Baggrave Hall, co. Leicester; Evington, co. Leicester; derived from Burnaby of Watford. Burnis, $V$.

Arg. two bars gu. in chief a lion pass. guard. per pale of the second and vert. BurNaBY, Broughton Hall, co. Oxford, Bart.

Arg. two bars sa. spotted erm. in cluief a lion pass. gu. Hul, St. John's, co. Wexford.

Az. two bars wavy arg. in chief a lion pass. guard. or. Tayler or Taylor, London; granted 1592.

Erm. $t w u$ bars gu. in chief a demi lion ramp. of the second. Draton, $V$. Drayton or Draton. De Freign. Frenye or Freyne.

Gu. two bars erm. in chief a lion passant or. Costomer, Yarmouth. Gifford. Gyssard. Hinl, Bury S. Edmund's, Suffolk. Hill, Yar. mouth and Lynn, Norfolk.

Gu. two bars erm. in chief a lion pass. per pale or and arg. HruL, Dennis, co. Stafford; Blaenavon, co. Monmouth. HiL, Hales, Norfolk.

Gu. two bars or in chief a lion pass. arg. HuL, co. Somerset, $V$; and Suffolk.

Gu. two bars and in chief a lion pass. or. HuL, $V^{*}$; Robert Tregoz, $V$. John Torington. $V$. Torrington, $V *$.

Gu. two bars and in chief a lion pass. guard. or. TREgoose or TREgOOZE, $V *$.

Or two bars az. in chief a lion pass. of the last. GreGory, co. Leicester, and Stivic Hall, near Coventry, co. Warwick. GREGORY, descended from Gregory of Stivic Hall, quartering DYMOKE, LudLOW, MARMion, etc.

Or two bars az. in chief a lion pass. of the second crowned of the first. GrEGORx, Lastingham, co. York.

Or two bars az. in clief a lion pass. of the last ducally crowned gu. GREGORY, Greenwich, Kent, and Westminster, Middlesex. WADE, co. Oxford.

Or two bars az. in chief a lion ramp. of the second. Gregory, Stockwith, co. Lincoln.

Or two bars az, in the simister point a lion ramp. sa. on a cauton gu. a chaplet arg. Hounes.

Sa. two bars wavy arg. in chief a lion pass. guard. , of the last. Mouxd.

Tert two bars arg. in chief a lion pass. guard. or Greenhil, Greenhill, Middlesex.
BAR. 2 BARS and in chief.... cont.

Beast (Lion) cont.

Vert two bars erm. in chief a lion pass. guard. or. GREENHLLL, London, granted 1698.

Beasts (2 Lions)

Gu. two bars arg. in chief as many lions ramp. of the last. SPENCER.

\section{(3 Lions)}

Sa. two bars or in chief three demi lions ramp. of the second. Wendover, Salisbury, confirmed 14 June, 1615.

Arg. two bars sa. in chief three lions ramp. of the second. Howland, Cambridge; London; and Streatham, Surrey; granted 1584.

Az. two bars or in chief three lions ramp. of the second. BRADY.

\section{Bird (Eagle)}

Gu. two bars or over all a bend engr. vair in chief an eagle displ. of the second. LEE, Ebford, co. Devon ; granted 1759.

\section{(Falcon)}

Sa. two bars vairy arg. and vert in chief a falcon close or betw. two bezants. Hacon, Ipswich, and Whiteacre, Norfolk.

\section{(Martlet)}

Sa. two barrulets vairy arg. and vert in chief a martlet.... betw. two plates. HACON, Topecroft, Norfolk.

\section{(Swan)}

.... two bars wavy ... from the npper one a swan issuing close .... MADDOCK.

\section{Birds (2 Martlets)}

Arg. two bars sa. in chief as many martlets of the last. Denton, $V$. Englenton de Hibernia.

$$
\text { ( } 3 \text { Cocks) }
$$

Arg. two bars gu. in chief three cocks of the second. Badcock. Blakestone, $V *$ * Blackstone, Castle Priory, Wallingford, co. Berks. Sir Mattbew BLakiston, Lord Mayor of London in 1760, Baronetcy 1763. BLAKIsTon, Blakiston, co. Durham; and its branches, Gibside, Newton Hall, old Malton, Seaton, and Thornton Hall. Plackeston, Newcastle-on-Tyne, $V$.

Arg. tro barrulets in chief three cocks gu. Biaxton, Sussex.

Arg. two bars sa. in chief three cocks gu. Blaxton.

\section{(3 Martlets)}

Arg. two bars and in chief three martlets gis. Anstabeth, $V$. Anstaboth. Anstalboth, $V$. Denton, Ainstable; Cardew, co. Cumberland, 1686, desceuded from Denton of Denton. Mocles, $V$. Moncles.

Arg. two bars gu. in chief three martlets sa. Weeding. Sir Rauf de Wedone, N. Sir Rauf Wedone, co. Buckingham, temp. Edrard I, $V$. WEEDON, WeETON or WetON, co. Buckingham, co. Dorset, and co. Lancaster, temp. Henry III.

Arg. two bars and in chief three martlets sa. Aglionby, Aglionby, Carlisle, Nunnery, and Newhiggin Hall, Cumberland. AgLionby of the North, $V$. Carill, London. Eagleby. Eglionby or Egleby, co. Warwick.

Gu. two bars and in chief three martlets arg. Washington. Weshington. Weishington, $V$.

Gu. two bars erm. in chief three martlets or. SACRE, Kent, granted 1614. SARE, Norton, Kent, confirmed 7 Feb. 1613-4.

Sa. two bars or in chief three martlets arg. HAWEESFORD.

\section{Buckles}

Arg. two bars sa. in chief three buckles az. Butler. 
BAR. 2 BARs and in chief.... cont.

\section{Buckles cont.}

Arg. two bars sa. in chief three round buckles az. Butler. Luther, Myles's, Essex, temp. Henry VIII; the co-heirs m. Fane of Wormsley, and Taylor. Luther.

\section{Canton}

Arg. two bars and a canton az. Byngler or Bynley. Lathbury. Pipard ol Pypald. TwrFond, London, temp. Richard II.

Arg. two bars and a canton az. charged with a martlet of the first (another or). LAthBury, Holme, co. Derby, visitation 1011. LAthbURY, $V^{*}$. Lathebury, $V$.

Arg. two bars az. on a canton of the last $a$-foil of the first. Peperde.

Arg. two bars az. on a canton of the last a 5 -foil or. Prcard. Sir Rauf Pipand, G.J ; or Pypard, $F$. Piper.

$\Lambda$ rg. two bars az. on a canton gu. a 5 foil or. Rauf Pipart, $E$.

Arg. two bars az. a conton sa. Paul or Paule, Norfolk ; and Lambeth. Surrey.

Arg. two bars az. ou a canton sa. a 5 foil or. PrPard, co. Worcester.

Arg. two bars and a canton gu. Berdsey. Cistercian Abbey at BITLESDEN, co. Buckingbam. BoIs, $V^{*}$. Bors, $E$. Ernand de Bors, $F$. Nicol de Borse, E, Harl. MS. 6137. Ernald de Boyes; Arnald del Boris, $C$. Ernaud de Boys, $B$. John de Bors, $A$, or del Bores, $D$. Sir Robert Boys, co. Lincoln, $V$. Boys, Lincoln. Broughton, co. Lancaster. Bynley. Copland. Corbet, V. M. Robert Corbet, $S$. Deane, Yatton, co. Hereford. Fuller, Norfolk and Suffolk. KIRBY, Nottingham, temp. Elizabeth. Kimkebr. Stakeland. Strickland. Sir Walter de Strikjande, $N$.

Arg. two bars and canton gu. a label of three points of the first. M. Robert Corbet, the son, $S$.

Arg. $t$ tro bars gu. on a cauton of the last a cross moline of the first. limby. KirkBy, Kirkby, co. York; Powcliff, co. Lancaster; and Cum. berland.

Arg. two bars gu. on a canton of the second a cross moline or. HEaDworth. KIPBY, Nottingham. M. Richard de Kyrkeby, $S$. Sir Poger KirkBy, Kyrliby, co. York, $V$. Kyrkebr, co. York, $V$.

Arg. two bars gu. on a canton of the last a 5-foil pierced or. CoRBet.

Arg. two bars gu, on a canton of the last a mullet of the first. Bors.

Arg. two bars gu. on a canton of the last a mullet or. Kirkey.

Arg. two bars and a canton gu. over all a fillet sa BoIs or de Boys, 1315; in Ingham church, Norfolk.

Arg. two bars and a canton gu. over all a bend az. Copland. Sir John Coupland, $V$.

Arg. two bars and a canton gu. over all a bend sa. Copland, Boston, co. Lincoln. Sire Johan du Bors, N. Boys, Hoston, Norfolk.

Arg. two bars gu. debruised by a bend sa. over all a canton of the second. CopelaAnd, London; and Bootle, Cumberland.

Arg. two bars and a canton gu. a bendlet sa. M. Roger le Boys, $S$.

Arg. two bars sa. a canton erm. Marshali, Lord Mayor of London, 1745.

Arg. two bars nebuly sa. a canton gu. Bronesby, Sholey, co. Leicester. Escanton or Stanton, co. Leicester.
BAR. 2 BARS and in chief....cont.

\section{Canton cont.}

Arg. two bars and a canton sa. Benley, Bentuey or Benley, $V^{*}$. Benly or Bently, $V$. James de Bors, $E$. Bor. Boys, Lincoln. Dubors, $F$. Az. two bars or a canton sa. Hill, London.

Erm. two bars and a canton gu. Borse or Borsey. Boyes. Nicol du Boyse or Bors, $E$.

Gu. two bars and a canton arg. Deane. De Dene, $V$. Dene, co. Hereford. Dent.

Gu. two bars the upper erm. the lower arg. a canton of the second. Harowdon, $V$.

Gu. two bars and a canton erm. Harowdon, $V *$ * Gu. two bars or a canton erm. ST. JoHN.

Gu. two bars voided or a canton erm. Briggs, Norfolk.

Or two bars and a canton az. ScARBorough or Scarburgh, Norfolk. Skarborough, $V$.

Or two bars az. a canton erm. Goucell.

Or two bars az. and a canton erm. in chief a fleur-de-lis sa. GowcEL, Dinner, Norfolk.

Or tiro bars and a canton gu. Bors, Lincoln. Bramishow. Corbet. Fitzwallen, Essex.

Or two bars and a canton gu. over all a bend sa. Coupland.

Or two bars sa. a canton erm. Wescomb, co. Somerset.

Sa. two bars nebuly arg. a canton gu. BRokesby: and with a mullet gu. on the canton, Sir John Brokesby, co. Leicester, $V$.

Sa. two bars or a canton erm. Westcombe, Bart. Vair two bars gu. a canton or. Pynon. on a Canton.... Beast (Deer)

Sa.two bars arg. on a canton of the second a buck of the first attired or. Buxton, Buxton, co. Derly; Brassington, co. Leicester.

(Lion)

Arg. two bars gu. on a canton of the first a lion pass .... Bellingham.

Arg. two bars gu. on a canton of the second a lion pass. of the field. Boyes, Claybroolie, co. Leicester.

Arg.two hars gu. on a cant. of the second a lion pass. guard. of the first. William de Lancaster, $V$.

Arg. two bars gur. on a canton of the last a lion pass. or. Baron, $V$ * The Baron of Barton, $V$. KENDALL.

Arg. two bars gu. on a canton of the second a lion pass. guard. or. Jolnn de Lancaster, a Baron in 1299. LanCASTER, Crackhouse, Cumberland; and Rainhill, co. Lancaster. Sir John Lancaster, $V$. Roger de Lancaster, $E$.

Arg. two bars gu. on a canton of the second a lion ramp. or. IJANCASTER.

Arg. two hars gu. on a cunton of the second a lion ramp. guard. or. Sire Johan de Lancaster, $N$.

Az. two bars arg. on a canton of the second a lion ramp. gu. GREY.

Or two bars az. on a canton of the last a lion pass. of the first. Wilson, $V$.

$$
\text { .... Beasts }
$$

.... two bars .... on a canton .... two lious .... pass.... Baron.

$$
\text { .... Billets }
$$

Or two bars az. on a canton arg. five billets sa. Jugler, Ryegate, Surrey. Jugler.

$$
\text { .....Bird }
$$

Gu. two bars arg. on a canton of the last a martlet sa. Rocult, co. Hants.

$$
\text { .....Buckle }
$$

Arg. two bars sa. on a canton of the last a buckle or. TwIFORD or TWYFond, co. Leicester, Lord Mayor of Jundon, 1388. 
BAR. 2 BARS and in chief.... cont. on a Canton .... Castle

Arg. two bars .... on a canton .... a tower tripletowered. CAsstLE.

Gu. two bars arg. on a canton of the second a castle sa.

Sire William del Chastel, $N$. Duncastue, co. Warwick.

Gu. two bars arg. on a canton of the last a tower triple-towered sa. Sir William CastelL, or de Chastela, co. Warwick, $V$.

Gu. two bars arg. on a canton sa. a tower of the second. Chasteld, $Y^{*}$.

\section{.... Chess rook}

Arg. two bars sa. on a canton of the second a chess rook or. BRAYlFond, $V$.

$$
\text { .....Chevron }
$$

Az. two bars arg. on a canton sa. a chev. betw. three pheons of the second. HILL, London.

Az. two bars arg. on a canton sa. a chev. of the secoud charged with a griffin's head erased of the third betw. two mullets gu. Hirl.

Gu. two bars or on a canton sa. a cher. betw. three pheons arg. charged with a wolf's head erased betw. two mullets of the first. HILI, Lord Mayor of London, 1519. HrLL, co. Salop.

\section{.....Cross}

Arg. two bars gu. on a canton of the last a cross couped.... Latrier.

Arg. two bars gu. on a canton of the second a cross of the first. BRENTON. BRUNDON or Broughton, $V$. Broughton, Broughton, co. Stafford; Doddington Hall, co. Chester, Bart. Broughton, Lowndham, co. Nottingham ; Tunstall Hall, co. Salop; descended from Broughlon of Broughton.

Arg. two bars gu. on a canton of the last a cross crosslet fitchy of the field. MobeerLey.

Arg. two bars gu. on a canton of the last a cross engr. of the field charged with an annulet az. for diff. BrotghtoN.

Arg. two bars gu. on a canton of the second a cross avellane or. KrRKBY, Cumberland; Row. cliff, co. Lancaster; and Kirkby, co. York.

Arg. two bars gu. on a canton of the second a cross crosslet or. KYRBY.

Arg. two bars gu. on a canton of the second a cross fusily or. KIREY.

Arg. two bars gu. on a canton sa. a cross engr. of the field. Brotughton.

Arg. two bars sa. on a canton of the second a cross formy of the first charged with an annulet gu. Bingley, co. Nottinglam.

Alg. two bars sa. on a canton of the last a cross moline of the first. KIRkLaY.

Or two bars az. on a canton gu. a cross flory arg. ATton.

\section{.... Escucheon}

Arg. two hars gu. on a canton of the last an escucheon of the first. Martyn, Durham.

$$
\text { ....Fess }
$$

Arg. two bars az. on a canton or a fess gu. in chief three lozenges of the last. SAMrord.

$$
\text { ..... Fish }
$$

Gu. two bars aro. on a canton az. a dolnhin em. bowed or. Panton, Sussex, granted 1615 .

$$
\text { ....Fleur-de-lis }
$$

Arg. two bars gu. on a canton of the second a fleur-de-lis or. Vixcext, Firby and Warmsworth, co. York.

\section{.....Flower}

Arg. two bars az. on a canton of the second a rose or. Sir Ralph Pip.urd or Pítand $F, G, J$.
BAR. 2 BARS and in chief....cont. on a Canton .... Flower cont.

Arg. two bars gu. on a canton of the second a rose of the first. DAWEST. DERWENTwATEl. DRINKWATER.

Al. two bars gu. on a canton of the second a rose or. Dawentwater, $V$. Derwent, $V$. DerwentWater, $V$. DRINKWater. Sir Thomas LANCASTER, $Q$.

Or two bars az. on a canton erm. a rose gu. Holmede, co. Chester.

$$
\text { ....3.Foil }
$$

Arg. two bals gu. on a canton of the second a 3 -foil slipped or. VINCENT, co. York.

$$
\text { ....5-Foil }
$$

Arg. two bars gu. on a canton az. a 5-foil or. Prpard, co. Gloucester, temp. Henry II.

Arg. two bars gu. on a canton of the second a 5-foil of the first. Beckingmam, co. Berks and Essex. Derwentwater, $V$. Lancaster, Richmond, co. York. Preston, Preston, co. Lancaster, $Z, 363$. Preston, $r$. Sometimes the canton arg. and 5 -foil gu. Durant. Water or Drinkwater, London.

Arg. two bars gu. on a canton of the second a 5-foil or. Lancaster, Richmond, co. York. William Lancaster, Hertsep, $V$. Preston, $V$. Preston, Cumberland. Ppeston, Preston Richard, Preston Patrick, and Nether Levens, Westmoreland; from which sprang the Prestons of Furness, Holker, and Ellel, co. Lancaster. Preston, Flasby Hall, co. York. Preston, Moreby, co. York. Prestox, co. Lancaster, and Up.Ottery, co. Devon.

Arg. two bars gu. on a canton of the last a 5-foil pierced ol. Corbet. M.John Derwentwaten, $S$.

Arg. two bars sa. on a canton of the last a 5.foil of the first. TWIFORD or TWYFORD, co. Leicester.

Arg. two bars sa. on a canton of the last a 5.foil erm. TWYFORD.

Arg. two bars sa. on a canton of the second a 5 -foil or. TWIFORD or T'WYFORD, co. Leicester, and Frostdyke, co. Lincoln. TwyEord, Trotton, Midhurst, Sussex. TwYFord, quartered by Jolliffe. Sir Johan de Tuxforde, $N$. Sir Robert TwYFORD, $T$. TWIFFORD or TWYFORD, $L$.

Arg. two bars sa. on a canton of the second a 5 -foil pierced or. PIPARD or Pipant. M. Robert TwYFord, $S$.

Erm. two bars gu. on a canton of the second a 5-foil or. Sir Richard PREston, Hestmoreland, $V$.

$$
\text { ....Garb }
$$

Arg. two bars sa. on a canton of the last a garb of the first. Wever or WeEver, Ternhill, co. Salop.

Sa. two bars arg. on a canton of the last a garb of the first. Wever, co. Chester. Edward Wyrel, co. Chester, $V$.

Sa. two bars arg. on a canton of the first a garb of the second. WeEver, Weever, co. Chester. Sa. two bars alg. on a cantun of the first a garb ol. Wever. Wever, Wever. Weverhair. Wiver, Wiverton, co. Chester. Wever, Aston, co. Chester, with due diff., Harl. MS. 1535, fo. $287,296$.

Sa. two bars arg. on a canton of the second a garb betw. four passion nails or. DEDwood.

Sa. two bars arg. un a canton gu. a garb or. WeVER. 
BAR. 2 BARS and in chief.... cont.

on a Canton cont. Hand

Arg. two bars az. on a canton gu. a gauntlet grasping a broken sword ppr. hilt and pomel gold. StamFord, Derby : quartered by Caldwell.

$$
\text { .... Head (Beast) Boar }
$$

Arg. two bars gu. on a canton of the second a boar's head couped arg. (another or). Pakeman. .....Lion

Arg. two bars gu. on a canton of the second a fion's head erased or. KinBy, Meophtham's Bank, Tunbridge, Kent. KIRBY, Waterford. KYRBY.

\section{....Wolf}

Arg. two bars az. a chief of the last on a cauton sa. a wolf's head erased of the field. WiLBraham, Nantwich and Rode, co. Clester; descended from Wilbraham of Delamere.

Az. two bars arg. on a canton sa. a wolf's head erased of the second. Sir Richard Wilbram, $V$.

Az. two bars arg. on a canton sa. a wolf's head erased of the second langued gu. WILBrahar. .... Ink-moline

Gu. two bars erm. on a canton sa. an ink-moline arg. Layard. Panton, Bishopwearmouth, Dur. ham. Panton, co. Denbigh and North Wales.

Gu. two bars or on a canton sa. an ink-moline erm. Panton, North Wales, and co. Denbigh. .... Lozenge

Arg. two bars gu. on a canton of the second a lozenge arg. (another ol'). Derwentwater, $V$. .... Mascle

Arg. two bars sa. on a canton of the last a mascle of the first. Marshe or Marsh, co. Lincoln.

$$
\text { .....Maunch }
$$

Arg. two bars gu. on a canton of the second a maunch of the first. Bardesey, Bardesley, or Bardsey, co. Lancaster. Berdesey, Berdsey, and Berdesley. Bardey or Berdsay, co. Lancaster, $V$. Bradsey, co. York.

Arg. two hars gu. on a canton of the last a maunch or. BARzey, Shrewsbury.

$$
\text { ..... Mullet }
$$

Arg. two bars az. on a canton of the second a muilet or. M. Avery Britchebury, $S$.

Arg. two bars gu. on a canton of the second a pierced mullet or. LANCASTER, Stockbridge.

Arg. two bars nebuly sa. on a canton gu. a mullet or. BROKESBY.

Arg. two bars nebuly sa. on a canton gu. a mullet pierced or. BRACKESBY.

Arg. two bars sa. on a canton of the second a mullet or. TwrFord, Millward, co. Salop.

Erm. two bars gu. on a canton of the last a mullet or. GWERRY.

\section{....Pheon}

Arg. two bars sa. on a canton of the second a pheon of the first. Bingley, co. Flint and Middlesex, 1605.

$$
\text { .....Saltire }
$$

Arg. two bars gu. on a canton of the first a saltire of the second. Broughton, Henley, co. Salop.

$$
\text { ....Wreath }
$$

Arg. two bars sa. on a canton of the second a chaplet or. 'T'wyFord, $V$.

Or two bars az. on a canton arg. a chaplet of laurel ppr. HoLme.

Or two bars az. on a canton gu. a chaplet arg. in the sinister point a lion ramp. sa. Holmes. Chief

Arg. two bars wavy az. a chief or. BIDEFord.

Arg. two bars and a chief gu. MoIgne.

Arg. two bars sa. a chief gu. Moynes.
BAR. 2 BARS and in chief.... cont.

\section{Chief cont.}

Az. two bars and a chief arg. Newbald. Newbold.

Az. two bars arg. a chief erm. Barton.

Az. two bars arg. a chief gu. Hugh DaNYeIL, $Y$. Hugh Seinttue, $Y$.

Az. two bars arg. a chief per fess indented erm. and of the second a canton or. Hotham, $V^{*}$.

Az. two bars dancetty or a clief arg. STonor, Stonor, co. Oxford, Baron Camoys, quartermg Camoys.

Az. two bars dancetty and a chief or. Sir William Stoner, $V$. John Stonere or de Stonor, $Y$.

Az. two bars and a chief indented or. HaIR or HARE, Scotland.

Az. two bars or a chief per fess indented erm. and arg. and a canton or. Hотнам:

Gu. two bars voided and a chief arg. over all a bend sa. Thornhill.

Gu. two bars arg. a chief erm. Thompson, Pelham Raytor, Kent.

Gu. two bars or a chief indented arg. HAnE, Suffolk.

Gu. two bars and a chief or. PICHMOND.

Gu. two bars and a clief dancetty or. HARE, Harl. MS. 1078, p. 17.

Gu. two bars or a chief indented of the last. Colrane. Sir Nicholas Hare, Hemerfield, Suffolk, $V$. HARE, Stow Bardolph, Norfolk, Bart., quartering Crane. HARE, Earl of Listowell. HARE, Lord Coleraine. HARE, Docking Hall ; Stanhoe Hall, Norfolk, descended from Hare of Stow Bardolph.

Or. two bars az. a chief gu. Manners or Mannors. Manners, Ethale or Etall, Northumberland. M. John Maners, $S, Y$. Maners, Lord Roos, $Z$, 395. Sir Robert de Manners, $M$. Sir Robert Manners, $V, Y$. De Manners, $Y$. Manners, Long Framlington, Northumberiand.

Or two bars and a chief gu. Bery. Harcourt. Or two bars and a chief indented gu. MontagH.

Sa. two bars and a chief arg. Frognall.

Sa. two bars or a chief arg. Froghall or Frognatu, Kent. John Frogenhall, Kent, $V$. Frognali, $V$.

on a Chief.... Annulets

Az. two bars arg. on a chief of the second three annulets gu. Cooks, Charcellor of the Exchequer in Ireland, granted $20 \mathrm{July,} 1612$. De Grey, Baron Walsingham.

Az. two bars arg. on a chief of the second three annulets sa. Cramlington, Cromlington, $V$.

Or two bars dancetty (anotber indented) sa. on a chief az. three annulets arg. BECKE, co. Berks and co. Lincoln. Thomas Beke, Arley WhiteKnights, co. Berks, $V$.

Or two bars dancetty sa. surmounted by the fasces in pale ppr. on a chief az. three annulets arg. BECK, Creeting St. Mary and Needham Market, Suffolk; descended from Becke, co. Lincoln.

Or two bars dancetty sa. on a chief az. three annulets of the first. Thomas BekE, $V$.

$$
\text { .....Beast (Dog) }
$$

Arg. two bar's az. over all three buck's heads cabossed or on a chief of the third a taluot gu. betw. two annulets sa. Woodward, co. Buckingham.

Arg. two bars gu. on a chief of the last a greyhound courant per pale or and erm. St. Albons. William Skipwrth, St. Alban's, $V$.

Sa. two bars arg. on a chief of the second a greyhound courant of the first. SkIPwith, Norfolk. 
BAR. 2 BARS and in chief.... cont. on a Chief cont. Beast (Lion)

Arg. two bars az. on a chief gu. a lion pass. or collared of the second. Demardeston, Suffolk.

Arg. two bars nebuly az. on a chief per pale of the first and sa. a lion pass. guard. counterchanged. TYNGILLON, $V$.

Arg. two bars gu. on a chief of the last a lion passant or. Deverson.

Arg. two bars nebuly (or wavy) sa. on a chief gu. a lion pass. guard. or. Le Staple, $T$.

Arg. two bars wavy sa. on a chief per pale of the first and second a lion pass. counterchanged. Tingleton.

Az. two bars arg. on a chief of the second a demi lion ramp.issuing gu. Egrenhall or Egrevale.

Az. two bars arg. on a chief gu. a lion pass, or. DEnEston, $V *$.

Az. two bars arg. on a chief gu. a lion pass. guard. or. Denardeston. Sir Piers Denardeston, Suffolk, temp. Edward I, V. Sir Pere de Dennardestone, $N$. Jamerdeston, Suffolk.

Az. two bars wavy arg. on a chief or a demi lion ramp. sa bezanty. Smyth.

Az. two bars arg. on a chief or a lion passant gu. WALDRON.

Az. two bars wavy erm. on a chief or a demi lion ramp. issuant ermines. Snytr, West Ham, Essex, and Stoke Prior, co. Worcester.

Az. two bar's wavy erm. on a chief or a demi lion ramp. gu. Suith, co. Worcester.

Az. two bars wavy erm. on a chief or a demi lion ramp. issuant gu. Sмrтн, Hough, co. Chester; confirmed $7 \mathrm{July}$, 1579. Sмтт, Loudon.

Az. two bars wavy erm. on a chief or a demi lion ramp. issuant sa. Sir James Smith, Kt., Alderman of London. Sir Thomas SmrTh, Hough, co. Chester, $V$. Ferdinando Dudley Lea.Smith, Halesowen Grange, co. Worcester, the senior co-heir to the title of Baron Dudley, quartering Lea Lord Dudley, and ninety-nine other coats, including Ward, Sutton alias Dudley, Someril, Paganel, Tiptoft, Holland, Plantage. net, and Lyttelton. Sirth, Upton, Essex, Bart.

Erm. two bars gu. on a chief of the last a lion pass. or. GIFFORD.

Erm. two bars gu. on a chief of the last a lion pass. guard. or. Osberne GLFFARD, $E, Y$. Osborne GIFFORD, $V$. OsBORNE, $V *$.

Gu. two bars arg. on a chief of the last a lion pass. of the first. Sir Adam Jowthe, $V$.

Gu. two bars arg. on a chief or a lion pass. az. INGLEFIELD, co. Warwick.

Gu. two bars arg. on a chief or a lion pass. gu. Marpray, $V$.

$\mathrm{Gu}$. two bars engr. erm. on a chief or a lion pass. guard of the first. SToRrs, Newcastle on-Tyne.

Gu. two bars wavy erm. on a chief or a demi lion ramp. issuant sa. armed and langued gu. Sirth, EImshurst, co. Stafford; derived from Smith, Heath End House, near Newcastleunder-Lyne; Visitation 1614.

$\mathrm{Gu}$. two bars or on a chief of the second a lion pass. of the first. Marbury.

Or two bars gu. on a chief of the last a lion pass. of the first. FERINGTON. Forington.

$$
\text { .... Sheep }
$$

Arg. two bars az. on a chief of the last a golden fleece pendant betw. two millinds erect or. BarchaUd.

$$
\text { ..... Bird }
$$

Arg. two bars gu. on a chief sa. an eagle displ. or. Harrison, Ireland.
BAR. 2 BARS and in chief.... cont.

on a Chief cont. Bird cont.

Sa. two bars erm. on a chief indented per pale or and arg. an eagle displ. of the first. BARLOW, Sheffield.

Sa. two bars or on a chief of the last an eagle displ. of the first. William Catenis, $V$. Catenis, Catenys or Catnes.

$$
\text { .... Birds }
$$

Arg. two bars gu. on a chief of the last three martlets of the first. WARD.

Gu. two bars arg. on a chief of the second three martlets of the first. Anstalboth, $V$.

$$
\text { ....Book }
$$

.... two bars wavy .... on a chief .... an open music-book between as many swords in saltire .... The Acadeny of the Muses, London.

$$
\text { ..... Buildings }
$$

Vairy arg. and sa. two bars or on a chief of the last three dovecotes gu. LydcotTe, Chicken. don, co. Oxford.

$$
\text { ....Caltraps }
$$

Erm. two bars sa. on a chief of the last three caltraps or. Browne.

$$
\text { ... Castle }
$$

Gu. two barrulets arg. on a chief of the second a tower triple-towered az. THORNHILL.

Sa. two bars wavy arg. on a chief of the second a castle of the first. Rawson.

\section{..... Crosses}

Arg. two bars nebuly sa. on a chief of the last three crosses patty fitchy or. HaRvy, $V$.

Arg. two bars wavy sa. on a chief of the second three crosses patty fitchy or. HARBY, or HaRvy, Lord Mayor of London, 1272 and 1273.

Arg. two bars sa. on a chief vair three crosses patty or. OWENDELIE, or OWYNDALE.

Arg. two bars sa. on a chief vert three crosses patty or. OWENDELLE or OWYNDATE.

$$
\text { ........ Cups }
$$

Or two bars gu. on a chief arg. three open bowls of the second the insides of the third. HALGHTON.

$$
\text { ....Cushions }
$$

Az. two bars arg. on a chief of the second three cushions of the first, tasselled or. Fieming, co. York.

$$
\text { ..... Escallop }
$$

Az. two bars arg. on a chief of the last an escallop betw. two mullets of the first. MADDER, or Mather, Scotland.

Az. two bars or on a chief of the last an escallop betw. two rnullets of the field. Mather, Lanton, co. Roxburgh. .... Escallops

Arg. two bars gu. ou a chief az. three escallops ppr. Boyse, Bannow, co. Wexford, 1658.

Az. two bars arg. on a chief or three escallops gu. HAZARD.

Az. two bars or on a chief of the last three escallops sa. CraRke, Sandford.

Gu. two bars arg. on a chief or three escallops of the first. HASSARD.

Or two bars az. on a chief of the last three escallops of the first. CIERKE, $W$.

$$
\text { ..... Escucheon }
$$

Or two bars gu. on a chief az. an inescucheon erm. Norton, London, 1611; and Stretton, co. Salop.

$$
\text { .... Estoile }
$$

Arg. two bars wavy az. on a plain chief of the last an estoile betw. two escallops or. Alles, Viscount Allen. ALIEx quartered by Proby. 
BAR. 2 BARS and in chief.... cont.

on a Chief cont. Estoile cont.

Arg. two bars sa. a label of five points throughout gu. on a chief az. an estoile of sixteen points or charged with a plate thereon a cross of the third betw. a human skull in a cup on the dexter side and a basket of bread i.e. wastell cakes all of the fifth on the sinister side. Royal Hospital of BEтHLEHEM, London, founded as a priory 1247-established as an hospital for lunatics 1446-and refounded 1546.

$$
\text { ..... Fleurs-de-lis }
$$

Az. two bars arg. on a chief or a fleur-de-lis betw. two roses gu. Bradshaw.

Or two bars az. a chief quarterly of the second and $\mathrm{gu}$. the first and fourth quarters each charged with two fleurs-de-lis gold the second and third each charged with a lion of England. Maners, Lord Roos, Earl of Rutland, Z. 395 ; the chief being an augmentation granted to Thomas Manners, Etall, co. Northumberland, and Belvoir, Lord Ros, created Earl of Rut. land, 1525: and with a crescent for diff. Manners-Sutton, Baron Manners, Foston, co. Lincoln.

$$
\text { ....5 Foils }
$$

Or two bars az. on a chief of the last three 5-foils of the first. Stocrwith, East Meare, co. Hants ; Visitation 1634 .

Or two bars gu. on a chief of the second three 5-foils of the first. EMERY, Kent.

Or two bars sa. on a chief of the second three 5-foils of the first. Maney, Kont.

$$
\text { ...6-Foils }
$$

Arg. two bars gu. on a chief of the last three 6 -foils of the first. Watram Mortimer, $Y$. Walran Montymer, $Y$.

$$
\text { ....Head (Beast) }
$$

Erm. two bars gu. on a chief of the second a leopard's bead or. GIFForD.

\section{.....Heads (Beasts) Deer}

Gu. two bars or on a chief arg. two buck's heads caboosed of the second. Barendes, $V^{*}$.

Az. two bars or on a chief sa. three hart's heads of the second. HAREFORD.

Az. two bars or on a chief sa. three hart's heads couped of the second. HartFond.

Or two bars wavy az. on a chief sa. three buck's heads of the field. HARTFORD, co. Bedford.

$$
\text { .... Leopard }
$$

Arg. two bars az. on a chief of the last three leopard's heads of the first. Wright, Bickley, co. Chester ; confirmed 18 Dec. 1853.

Arg. two bars nebuly and a bend sa. on a chief gu. three leopard's beads or. Clement, Kent, $W$.

$$
\text { ....Wolf }
$$

Arg. two bal's gu. on a chief of the first three wolf's heads couped of the second. LETON, $V *$. WOBREW, $V^{*}$.

$$
\text { .....Birds }
$$

Ar. two bars wavy gu. on a chief purp. as many eagles' heads erased ppr. Dons, London.

$$
\text { ..... Horns }
$$

Or two bars nebuly az. on a chief arg. three buglehorns stringed sa. SwTthen, $V$.

$$
\text { .....Lozenges }
$$

Az. two hars arg. on a chief of the second three lozenges gu. Fleming, Wath, Cumberland, John Flemyng, $r$. FLeMYNG, $V$.

$$
\text { .....Mullet }
$$

Gu. two bars or on a chief of the second a mullet Sa. STODEw or STOWDOW.
BAR. 2 BARS and in chief.... cont.

on a Chief cont. Mullets

Arg. two bars gu. on a chief of the first three mullets of the second. WAssington, $V^{*}$.

Gu. two bar's arg. On a chief of the last three mullets of the first. Grigson.

$$
\text { .....Palet }
$$

Or two bars sa. on a chief of the second a palet (sometimes called a billet) betw. as many base esquires of the first an inescucheon charged with a fess and chief erm. Butrer.

$$
\text { ..... Palets }
$$

Az. two bars or on a chief of the first two palets (sometimes blasoned pellets) betw. as many esquires based dexter and sinister of the second an escucheon arg. BLANCKFront.

Gu. two bars or on a chief of the first two palets betw. as many esquires based dexter and sinister of the second an escucheon gold. Hogerey.

Or. two hars sa. on a chief of the first two palets (sometimes blasoned a billet) betw. two esquires based dexter and sinister of the second an escucbeon .... (? sa.) charged with a fess and chief ern. (or else an escucheon barry of four erm. and .... (? sa.) Bưtuer.

\section{.....Pheons}

Az. two bars wavy or on a chief of the Jast three pleons of the first. Blatchford, Oshorne, Isle of Wight.

$$
\text { ....Roundles (Bezants) }
$$

Arg. two hars gu. on a chief vert three bezants. Angevile, or ANGevirie, Thethelthorpe, co. Lincoln. ANGEVYNE, co. Lincoln.

Arg. two bars sa. on a chief of the last as many bezants. JoHn, Penzance, Cornwall.

$$
\text { ....(Torteaux) }
$$

Arg. two hars gu. on a chief of the first three roundles of the second (?). ATwins, Highfield, co. Cork, 1682 ; the heiress m. St. Leger.

$$
\text { .....suns }
$$

Az. two bars erm. on a chief arg. three suns ppr. Nicholson, co. Lancaster; Cumberland; aud London.

\section{Cherron}

Arg. two bars and a chev. in chief sa. Holbeame.

Az. two bar's and a chev. in chief or. SPrIE, SPRy, or Sprye, Spryeton, co. Devon, 1437, confirmed in 1619; the heiress $m$. Gregory. SPRY or Sprye, Tillond, Place, and Tregolls, Cornwall; quartering Trenowth, Trejago, Trewithenick, Cheynduit, Nanfan, etc. Spry, or SpRYe, Gutcrewe, Trewinny, Millbrool, Ugborough, Plymouth, and Stoke Damarell, with due diff. SPRy, or Sprye, Tencrelse, Cornwall ; descended from Sprye of Tillond, Visitation, 1620, with due diff. SPRy, or Spre, Mawnen, Cornwall; descended from Sprye of Tencreke, with due diff. SPRY, or SPRYE, Mevagizzy, Cornwall; descended from Sprye of Cutcrewe, Visitation, 1620, with due diff. SPRY, or SPRYE, Blisland, Cornwall ; presumed to have descended from Sprye of Cutcrewe, with due diff. Spry, Boyton, and Lannceston, Cornwall; con. sidered a branch of Sprye of Cutcrewe, with due diff. Spry, Truro, Cornwall. Spky, or Sprye, Bodmin, Cornwall; and co. Devon ; a supposed branch of Sprye of Devonshire and Cornwall, Visitation, 1620. SPRy, Exeter, London, and Bath; a presumed descendant of Sprye of Devonshire and Cornwall.

Crescent

Arg. two bars and in cliief a crescent sa. Randolfe. 
BAR. 2 BARS and in chief.... cont. Crescent cont.

Gu. two bars and a crescent in chief or. Muschamipe.

\section{Crescents}

Arg. two bars and in clief as many crescents gu. Nonwers, or Nowers.

Arg. two bars aud in chief three crescents gu. Nanvers. Nevers. Nonwers, Norwers, or Nowers, Noonwers. De la Nouers, or Nowers, Gothurst, co. Buckingham, temp. Henry III. Sire de Nowwers, $N$. Sir James Nowers, co. Buckingbam, temp. Edward I, $V$. Sir John Nowers, $V$. Pridham.

Az. two bars or in chief three crescents arg. Cheltenham.

Gu. two bars and in chief three crescents arg. Sir Robert Wetesham, Suffolk, $V$.

Gu. two bars arg. three crescents in chief or. Frampton, Dorset.

Or two bars sa. in chief three crescents gu. Ex_oTt, Godalming, Surrey, $W$.

\section{Cross}

Az. two bars and in chief a cross formy fitchy or Holr, Aston, near Birmingham, co. Warwick, Bart.; the heiress m. Bracebridge. Holte, Frdington Hall, co. Warwick.

Az. two bars and in chief a cross patonce or. Holte, Aston, co. Warwick, quartering Erdington, de Wolrey, Castells or Castles, Grimsarwe or Grimshaw, Maidenhach, Colting, Comberford, Knight of Baschurch, Willington of Barcheston, Ferrers of Tamworth, Bradbourne of the Hough, Brereton, Malpas, Barons of Malpas, Egerton of Malpas, Corbet, Orrebj, Strange, Cleobery of Bradstone, and Lister of Whitfield.

Gu. two bars and in clief a cross erm. Panton. Crosses

Az. two bars or in chief three crosses croslet of the second. Carpenter, London.

Az. two bars and in chief three crosses formy or. Bathurst, Leachlade, co. Gloucester, Bart.

Or two bars az. in chief three crosses formy gu. Winstanley, Winstanley, co. Lancaster. Winstanley, co. Lincoln. Winstanley, Braunston, co. Leicester; derived from Winstanley of Lancashire; quartering Holt, Prideaux, etc. Winstaniey, Woolton Lodge, co. Lancaster. Winstanley, $V$.

Sa. two bars erm. in chief three crosses patty or. Bathurst, Earl Bathurst. Bathurst, co. Hants ; Kent; and London. Bathunst, Lydney Park, co. Gloucester. BatHuRst, Richmond, Scutterskelf, Clintz, and Arkendale, co. York, derived through Batburst of Horsmanden, Kent, from Bathurst of Cranbrook, temp. Hen. VI ; the coheirs married Sleigh of Stockton, Turner of Kirkleatham, and Forster of Buston. Cups

Az. two bars dancetty arg. in chief three covered cups or. LAGAGE.

2 Escallops

Arg. two bars az. in chief as many escallops gu. Sir .... de Haulton, $V$. John de Hylton, $Y$. 3 Escallops

Arg. two bars and in chief three escallops az. Errington, Cassina. Erington, $V^{*}$. Errington, Errington and Beaufront, Northumberland. ErRINGton, Walwick Grange and High Warden, Northumberland; and Hele, co. Wilts; derived from Errington of Errington. ERrington, Ponteland, Northumberland. John Eryngton,
BAR. 2 BARS and in chief.... cont.

\section{Escallops cont.}

$X$. Eyringham, co. Devon : and with a crescent for diff. Enington, Denton, Northumberland.

Arg. two bars az. in chief three escallops gu. Sire de Halton, $Y$.

Arg. two bars gu. in chief three escallops. .... Roger de Melese, $F$.

Al'g. two bars and in chief three escallops gu. Eliyngton, $V$. Menles, or Melies.

Arg. two bars and in chief three escallops sa. Fitz, Truro, Cornwall. Fitz-Pen, alias Phippen. Phippen, Truro, Cornwall.

Az. two bars arg. in chief three escallops or. HAITON.

Az. two bars erm. in chief three escallops or. Bringhurst, co. Leicester.

Gu. two bars and in chief three escallops arg. Sir John Backhouse, or Bayous, $R$. Bayhouse, or Bayouse, co. Lincoln. Sir Walter Bayons, co. Lincoln, $V$. Sir William Bayons, or Bayows, $L$. Sir William Bayons, temp. Edward I, $V$. William de Bayous, $\boldsymbol{Y}$. Monsire de Barous, $Y$. Sir William de Barouse, $N$. Brawmse. Rayhouse. Timare.

Gu. two bars arg. in chief three escallops or. Clatke, co. Hereford.

Or. two bars and in chief three escallops az. Clarke, co. Gloucester; and Loudon, 1586. Clarke, M.D., $W$.

Or two bars az, in chief three escallops gu. Clark, Shipley, co. Somerset. Clenke. Valentyne Clerke, London, and his son Roland Clarke, Kt., $V$. Holand, $V^{*}$. Holland.

Or two bars az. over all a horse's head erased erm. in chief three escallops gu. John Clanks, Bishop of Bath and Wells, $W$.

Or two bars az. depressed by a nag's head erased or in chief three escallops gu. Clarke, Ipswich, Suffolk.

Or two bars and in chief three escallops gu. Harcourt.

Sa. two bars or in chief three escallops. .... Marriott; quartering Pearson and Bosworth. Escucheon

Arg. two bars and in chief an inescucheon $\mathrm{gu}$. Auberville, or Othberville, Essex, and Suffolk, temp. John. Dernall, or Derrali.

Gu. two bars and in chief an escucheon or. Hagelle.

Or. two bars gu. in chief an escucheon bendy of eight of the first and az. Rony, France.

Or two bars gu. in chief an escucheon of the second. Seigneur le Stratton, $R$.

\section{Escucheons}

Arg. two bars and in chief three escucheons sa. Clowfield.

\section{Estoiles}

Arg. two bars and in chief three estoiles sa. MoYne.

Fleurs-de-lis

Or two bars and in chief as many fleurs-de-lis sa. Goulton, co. York.

Arg. two bal's and in chief three fleurs-de-lis gu. Sentliz, $V$. St. Liz, $V$.

Chequy arg. and sa. two bars gu. in chief three fleurs-de-lis or. Sentis, $V$.

Gu. two bars and in chief three fleurs-de-lis arg. Mortener.

Gu. two bars erm. in chief three fleurs-de-his or. Gilbert, Northirlingham, co. Norfolk. Gilbert, Cantley, Postwich Hall, and Chedgrave, Norfolk, 1694. 
BAR. 2 BARS and in ehief....cont.

\section{Fleurs-de-lis cont.}

Or two bars and in chief three fleurs-de.lis sa. GoLton, Ipswich, Suffolk. TOVEY.

\section{Flower}

Az. two bars or in chief a rose betw. two buglehorns. .... Martin.

\section{Flowers}

Erm. two bars engr. one az. the other gu. in chief three roses of the last on a canton of the same a lion pass. or. Lancashire, Polefield, Prestwich, co. Lancaster; the coheirs $\mathrm{m}$. Scholes, Tetlow, and Greaves.

Gu. two bars or in chief three roses arg. DaLton. 3-Foils

Arg. two bars indented and in chief three 3 -foils slipnetl sa. Costineld, Brand.

Arg. two bars and in chief three 3.foils slipped vert. SOAMES.

Or two bars gu. in chief three 3-foils slipped vert over all on a bend az. as many boar's heads erased arg. Copeland, Lord Mayor of London in 1836.

4-Foil

Arg. two bars sa. in the dexter chief a 4 -foil or. Sire John de TwYFond, $O$.

\section{5-Eoils}

.... two bars and in chief three 5-foils .... Thomas de Trentram's seal, 15 Edward II, Cotton MS. Julius, $F$. viii, fo. 58.

Arg. two bars and in chief three 5-foils gu. Denton, co. Buckingham; co. Lancaster; aud co. Oxford. Stokeyth or Stokwyth, $V$.

Arg. two bars gu. in chief three 5-foils sa. Denton, Denton Hall; and Warnell, Cumberland; the heiress $m$. Copley. Sir Richard Denton, $V$. Eastfield. Lefevre, Southampton.

Gu. two bars and in chief three 5-foils arg. Delancex, or Delancy.

Gu. two bars and three 5-foils in chief (? arg.) Mortimer.

Sa. two bars and in chief three 5-foils arg. WALDEN, $V$.

Sa. two bars erm. in chief three 5.foils pierced arg. WALDEN. M. Alexander WALDEN, $S$.

Sa. two bars and in chief three 5-foils or. Wellysham. Welyshan, $V$. Garb

Sa. two bars arg. in chief a garb or. Wever. Hand

Sa. two bars arg. in chief three gloves or two and one the latter being between the bars. Monsire Walter HuNGERFORD, $T$.

Head (Beast) Deer

Sa. two bars chequy or and az. in chief a stag's head cabossed betw. two suns in splendour of the second. NicHolson, Ashton-under-Lyne, co. Lancaster.

$$
\text { .... Leopard }
$$

Az. two bars and in chief a leopard's head arg. TOTEHYLL, $V$.

Az. two bars arg. in chief a leopard's face or. Wright, Cranham Hall, Essex.

Az. two bars and in chief a leopard's face or. WRIGHT.

\section{Heads (Beast) Leopard}

Az. two bars arg. in chief as many leopard's heads or. Wriget, Bellenden, Essex; granted 1767.

$$
\text { .....Boar }
$$

Erm. two bars wavy gu. in chief three boar's heads couped sa. BAYon, co. Chester.
BAR. 2 BARS and in chief. .. cont.

\section{Heads (Beasts) Deer}

Az. two bars and in chief three buck's heads cabossed or. Thomas WymberLey, Bitchfield ; and Spalding, co. Lincoln; granted 16 May, 1588.9.

\section{.....Leopard}

Arg. two bars and in chief three leopard's heads gu. Jessop, Gillingham, Chilcomb, Chickwell, and East Chequerell, co. Dorset. Jessope, JEssopp, and JESSUP.

Arg. two bars gu. in chief three leopard's heads sa. Poulteney, co. Warwick.

Az. two bars arg. in chief three leopard's heads or. Wright, Wrightsbridge, Hornchurch, and Dagenham, Essex ; granted 20 June, 1509. Wrighte, Cranham, Essex, Bart.; Gayhurst, co. Buckingham.

Az. two bars engr. arg. in chief three leopard's heads or. Wright, Essex.

Or two bars and in chief three leopard's heads gu. Jessop, Butterly Hall, co. Derby, derived from JEssop, Longford. Jessop, co. York. Jessop, Doory Hall, co. Longford. Jessope, Gillingham, Chilcomb, Chickwell, and East Chequerell, co. Dor'set. JEssopp or Jessup.

Sa. two bars erm. in chief three leopard's faces or. Feltham, London.

$$
\text { .... Lion }
$$

Arg. two bars and in chief three lion's heads erased sa. Worge, Sussex.

$$
\text { ...W Wolf }
$$

Arg. two bars and $\because n$ chief three wolf's heads couped gu. Leton; co. Buckingham, $V$. WOBRWE (sic), $V$.

Arg. two bars and in chief three wolf's heads erased gu. Lellow, LeLoN, or Lelow, co. Buckingham.

Gu. two bars and in chief three wolf's heads couped arg. KNIPE, London; granted 16th Nov. 1616. KNIPE, co. Lancaster; and Westminster.

Gu. two bars and in chief three wolf's heads erased arg. KNIGHT, Piddington, co. Northampton; and co. York. KNIGHT, or KNITE. INYGHT, or KNYTE, $V$.

$$
\text { ..... (Fish) Whale }
$$

Or two bars wavy and in chief three whale's heads erect and erased sa. CoLBEck, co. Bedford.

\section{.... (Monsters) Griffin}

Gu. two bars or in clief three griffin's heads erased of the second over all a bend compony reg. and sa. GREMAN.

\section{Hearts}

Erm. two bars and in chief three hearts gu. ANNAT, or ANNOT.

$$
\text { Horns }
$$

Arg. two bars wary and in chief three buglehorns stringed sa. Swythair.

\section{Horseshoes}

Gu. two bars and in chief three horse shoes arg. BAKEPUCE, co. Putland.

Gu. two bars arg. in chief three horse shoes or. Sire Johan de Bakepuce, $N$. Sir John Bakepuce, co. Cornwall, $V$. BacPuce, co. Rutland, $W$.

\section{Inkmoline}

Gi. two bars arg. in the dexter chief point an inkmoline erm. PANToN, co. Lincoln; and co. Stafford.

Gu. two bars and in the dexter point an inkmoline erm. Sir Hugh Paunron, Cumberland, $V$. 
BAR. 2 BARS and in chief.... cont. Insects

Arg. two bars and in chief three gadflies sa. Fleming, co. Lancaster.

Keys

Gu. two bars or in chief three keys arg. KInkLEY.

Gu. two bars or in chief three keys arg. wards upward. KERKELE, $V$.

Mascles

Az. two bars and in chief three mascles or. Sperling, or Spurling, Weston, co. Hertford; granted 1586 .

Monster (Griffin)

Arg. two bars and in chief a demi griffin issuant sa. Cahurta.

Arg. two bars sa. in chief a griffin segreant az. LANDAwarnick, Landawarnick, Cornwall. Mullets

Arg. two bars gu. in chief as many mullets pierced Sa. Bale.

Arg. two bars and in chief as many mullets sa. Mawgan, Cornwall.

Az. two bars and in chief as many mullets arg. Venables: and with one in the centre for diff. VENABLEs, Autrobus, co. Chester.

Az. two bars arg. in chief as many mullets or. Hilton.

Az. two bars and in chief as many mullets or. BurdetT.

Gu. two bars and in cbief as many mullets arg. Sir Jobn Cantone, co. Leicester, temp. Edward I, $V$. Sire Johan de Cauntone, $N$. Wassington. Wessington.

Gu. two bars vair in chief as many mullets or. Costes, $V$.

Sa. two bars and in chief as many mullets arg. Spylman, Kent.

Sa. two bars arg. in chief as many mullets or. Spelian, or Spmiran, Essex.

Arg. two bars and in cbief three mullets of six points az. EsIJNGToN.

Arg. two bars az. in chief three mullets gu. Bridleshate.

Arg. two bars voided az. in chief three mullets gu. BredLashaw, co. York.

Arg. two bars az. in chief three mullets pierced sa. Mallam.

Arg. two bars and in chief three mullets gu. Judrin, Heyford, co. Northampton. St. Low. Nicholas de Moeles, $B$. Washington, co. Lancaster; co. Leicester; co. Northampton; co. Buckingham ; and Kent. Geo. Washington, of Bridge's Creek, Westmoreland, Virginia, U.S., descended from Washington, of Sulgrave, co. Northampton ( 30 Henry VIII); Warton ; and Whitfield. Wassington, co. Lancaster, $V$. Wedon, co. Buckingham.

Arg. two bars and in chief three mullets pierced gu. Wassington. William de Wassington, $S$. Wessington.

Arg. two bars gu. in chief three mullets pierced sa. WEDON.

Arg. two bars and in chief three mullets sa. Aliten, Suffolk; and Sussex. Fogge. Morgne or Moyne. William Moyse, $V$. William OWGAN, $Y$.

Arg. two bars and in chief three mullets pierced sa. MaJOR, co. Leicester; granted 1646. Major, Brampston, co Nottingham.

Arg. two bars and in chief three mullets of six points sa. MoIgn, $V$. Willinm MoIgne, $S$.

Arg. two bars sa. in chief three mullets vert. KEMrson, lreland.
BAR. 2 BARS and in chief.... cont.

\section{Mallets cont.}

Az. two bars and in chief three mullets pierced arg. Venables, Woodhill.

Gu. two bars and in chief three mullets arg. Canton, or Canntoun, co. Leicester. William de Wessington, $X$. Wrishington, $V$. Wassington, $V$.

Gu. two bars and in chief three mullets pierced arg. Mallory. Sir Constantine Mortimer, $V$.

Gu. two bars arg. in chief three mullets of six points pierced or. Awsthwarte, Awsthwaite, Uumberland; the heiress m. Stauley.

Or two bars gu. in chief three mullets .... Denton.

Or two bars and in chief three mullets vert. Kenpson, Ireland.

Sa. two bars and in chief three mullets or. Frene, Ewern Courtney, co. Dorset; and Hanniugton, co. Wilts. Freke, West Bilney, Norfolk; descended from Freke, of Ewern Courtney, co. Dorset; the heiress m., 174l, Evans. Freke, Baron Carbery, quartering Evans, with Stafford of Blatherwick, Stafford of Bromeshall, Bagot, Toeny, Vernon, Belliol, Malbank, Walkelyn, Hastang, Burdett, Camville, Garshall, Aylesbury, Keymes, Basset, Pabenham, Engaine, Bellew, Fogge, Tame, and Redman.

\section{Palet}

Arg. two bars gu. in chief a pale of the last charged with a boar's head couped of the field. Pakenhalr.

Or two bars and in chief a palet a dexter and a sinister gyron gu. over all an escucheon or. Hogelex.

Per pale az. and arg. two bars and in chief a pale bet. as many esquires based dexter and sinister all counterchanged an escucheon of the second. "This is the true compounded coat of Mortymen as $I$ have seene it in a very owld glass windowe in the parish churche of Hagley, in Worcestershire, per Yorke H" (Brooke); Harl. MS. 807, fo. 106 .

\section{Palets}

Arg. two bars and in chief as many pales az. on an inescucheon or two bars sa. BREcke.

Arg. two bars and in chief as many palets gu. on a canton sa. a boar's head couped arg. Pakeman, $V$.

Arg. two bars and in chief as many palets sa. Chirchman or Churchman, co. Salop. Chirchman, $V$. Kirkman.

Or two bars and in chief as many pales sa. an inescucheon gu. BeverLey.

Sa. two bars and as many palets in chief arg. Churchian.

\section{Pheons}

Arg. two bars embattled counter-embattled and in chief three pheons reversed gu. James. Pile

Or two bars sa. from the chief a pile counter. changed. Englemart.

\section{Quarter}

Arg. two bars and a quarter gu. Ernald de Boys, $P$. Henry de Boys, $Y$. John de Boys, A. Striciland. Boysy.

Arg. two bars and a quarter gu. a label alg. Sire John Conbet, $O$.

Arg. two bars and a quarter gu. over all a bead sa. Boys, Hoston, Norfolk.

Arg. two bars and a quarter sa. Monsire de TwIFORD, $Y$.

Gu. two bars arg. a quarter erm. M. Giles SAINT.JoHn, $S$. 
BAR. 2 BARs and in chief.... cont.

on a Quarter..... Beast

Arg. two bars gu. on a quarter of the last a lion pass. guard. or. Juhn Lancaster, Helgill, $Y$. M. John de Lancastre, $K$. Roger de Lanciastre, $X, Y$. William de Lancastre, $B$.

$$
\text { .... Castle }
$$

Gu. two bars arg. on a quarter of the second a castle sa. CAsteL, co. Berks.

$$
\text { ..... Chevron }
$$

Az. two bars arg. a quarter sa, charged with on a chev. betw. three pheons of the second a wolf's head erased betw. two mullets gu. HIL.L, $V . *$

Az. two bars arg. a quarter sa. charged with on a chev, betw. three pheons of the second a wolf's head erased sa. betw. two mullets gu. Sir Rowland HruL, Alderman of London, $V$.

$$
\text { .....Cross }
$$

Arg. two bars gu. on a quarter of the last a cross of the first. John de Broghton, $X$.

$$
\text { .....Cushion }
$$

Arg. two hars gu. on a quarter of the last a cushion of the first. Le Sire de Derwe NTWATER, $Y$. John Derwentwatre, $Y$.

$$
\text { ....5-Foil }
$$

Arg. two bars az. on a quarter of the last a 5-foil or. Rauf Pipard, $Y$. William Swynford, $X$. John TwIFFord, or TwyFord, $L$. John de TwyFond, $Y$. Richard TwyFond, $Y$.

Arg. two bais gu. on a quarter of the last a 5 -foil arg. John Derwentwater, $X$.

Arg. two bars sa. on a quarter of the last a 5 foil or. Richard TwYFond, $Y$.

\section{Roundle}

Gu. two bars or in chief a bezant. LutrerelL. Roundles

Az. two bars arg. in chief as many plates. Bradwell, co. Chester. Venables, Bradwell, co. Siafford.

Sa. two bars .... in chief as many plates. ABLE.

Arg. two bars sa. in chief three roundles ... RuppingaLl.

Az. two bars the upper arg. the lower or in chief a plate between two bezants. Pусот, Deding. ton, $V$.

\section{....(3 Bezants)}

Az. two bars or in chief three bezants. Dodingron. Elworthy. Pecketr, Carlton Husthwaite, co. York. Pericot, or Percot. Monsire John Picot, or Pigot, Dodington, $Y$. Pigot, Dodington, co. York. Sire Baudwyne, Prcot, $N$. Sir John Pygot, Ayton, co. York, temp. Edw. I, $V$. Pygott, $V^{*}$. WAKE, $F$.

Az. two bars dancetty or in chief three bezants. RYvers, Lord Mayor of London, confirmed 2 May, 1581.

Az. two bars dancetty or in chief three bezants. Rrvers, Chafiord, Kent., Bart., quartering as an augmentation az. on a fess engr. betw. three swans arg. a bar gu. charged with as many roses of the second.

Gu. two bars or in chief three bezants. GarLAND, co. Lincoln. Garland, or Garlant. Goband, GoBond, or GoNBAND, co. Lincoln. GoLAND. Monsire le Goband, $Y$. Sire Johan Gobaud, $N$. Monsire Gobaud, $Y$. Sir John Gouband, co. Lincoln, $V$. Lotereli, $V$. Hugh Wake, D.

Sa. two bars embattled or in chief three bezants. Barnes or Bernes, co. Cambridge.
BAR. 2 BARS and in chief.....cont.

Roundles cont. (3 Hurts)

Arg. two bars az. in chief three hurts. CARNaBY. William Carnaby, $X$. Robert de HaLton, $Y$. Karnabie, Northumberland. Karnabye. Sire de Kernaby, $V$. Kernaby or Kernby. Wrttlebury, co. Warwick.

Arg. two bars az. in chief three hurts on a canton of the first a lion ramp. of the second. KaRNABYE. ....(3 Ogresses)

Arg. two bars az. in chief three ogresses. Watrs. John Watrs, Alderman of London, granted 1596, W.

Arg. two bars gu. in chief as many ogresses of the second on a canton sa. a boar's bead couped of the first. Pakeman, $V^{*}$.

Arg. two bars per pale indented az. and gu. in chief three ogresses. DoDwell, Dublin; granted 10 March, 1662.

Arg. two bars sa.in chief three ogresses. AlLERTON. Arg. two bars embattled sa. in chief three ogresses. Barnes. Berns, Soham, co. Cambridge.

$$
\text { .... (3 Plates) }
$$

Az. two bars arg. in chief three plates. Hungerford, Farleigh Castle Chapel. Walter HUNGERFORD, $Y$.

Gu. two bars arg. in chief three plates. HALSTED. De Moeles. Molston. John Monles, co. Devon. $V$. Otby, Otteby, and Otterby, co. Lincoln. Sire Randolf de Otteby, $N$. Pycott, $V^{*}$. Sire Huge Wake le Oncle, $N$. Wake, temp. Edward I, $V$.

Purp. two bars arg. in chief three plates. Sir Randolf OtBY, co. Lincoln, $V$. UTteBY, $V^{*}$. OTTSBY, $V^{*}$.

Sa. two bars arg. in chief three plates. ADAM. Sire Adam Fitz JoHn, co. Lincoln, temp. Edward I, $V$. Sire Adam le Fitz JoHn, $N, Y$. FrTz-JoHn, co.Lincoln. Sir John HungerFord, $V$. HungerFord, Down Ampney and Winrush, co. Gloucester; and Farley Castle, co. Somerset; a Baron in 1426. Hungerford, Caher. more, co. Cork; a branch of Hungerford, of Farley Castle. Hungerford, Dingley, co. Northampton; quartering HoLDICH. Hungerford, Calne, co. Wilts; quartering Hungerford of Heytesbury. John de Riginghale, $D$.

Sa. two bars arg. in chief as many plates over all on a bend gu. a lion's bead erased of the second. Segar, or Sugar, Tilney, Norfolk.

Sa. two bars or in chief three plates. John ABELL, $Y$.

\section{....(3 Torteaux)}

Arg. two bars gu. in chief three torteaux. Angevrne, co. Lincoln. Bluworth, or Blurproth. Colland. Menles. Monsire de Meubes, $Y$. Moels, Baron Moels, a Baron in 1292 ; the co-heirs m. Courtenay and Bottreaux. Sir John Moelds, $I$. John Moels, $Y$. Roger de Moels, $Y$. Moels, or Mules, Sumbridge. Mole, Tringeg, co. Bedford ; and Northampton. Roger de Moles, E. Morles, co. Somerset. Johan de Moules, $J, N$. Sir John de Mornes, $H$. Mules, Honiton, co. Devon. Mules, Errsborough, co. Devon; and Cadbury, co. Somerset; derived from the baronial family of Moels. Mules, Ilminster, co. Somerset; a younger branch of Mnles of Swimbridge and Cadbury. Mukis or Mulis, co. Devon. Trechingham. Monsire John de Treningham, $Y$. WAKE, Decping, co. Lincoln. Sir Robert WELLE, $V$. 
BAR. 2 BARS and in chief.... cont.

Roundles....(3 Torteaux) cont.

Arg. two bars gu. in chief three torteaux, over all a baton sa. CRERINGHAM.

Arg. two bars gu. in chief three torteaux over all a bend sa. Treningham, $V^{*}$. Treinenham. Trikenham, $V^{*}$. Trykingham, $V^{*}$.

Arg. two bars gu. in chief three torteaux over all a bendlet sa. Walter de Treningham, co. Lincoln, $V$. Trikinghad, co. Lincoln, $V$. Trukinghair, Trylinghain, $T$.

Arg. two bars sn. in chief three torteaux. Mould, Appleby, co. Leicester.

Or two bars gu. in chief three torteaux. WAKE, Clevedon, co. Somerset, Bart. Le Sire de Wake, $Y$. WAKE, Lydell, $Z, 110,215$. Bald win WaKe, $A, D, E$. Hugh WaKe or le WaKe, $B, P$. Sir John $\mathrm{W}_{\mathrm{AKE}}$ or De WAKE, $G, H, J, N$; Sir Hugh de WaKe, co. York, temp. Edward I, $V$. and with $a$ baton az. Sir Hugh WAKE, $N$.

Or two bars gu. in chief three torteaux over all a bend sa. Waces, $V^{*}$.

Or two bars gu. in chief three torteaux over all a bendlet .... Waces, Norfolk, $V$.

\section{Suns}

Az. two bars .... in ehief three suns. Spratrey.

Az. two bars erm. in chief three suns or. NichoLL, Greenhill Grove, co. Hereford. Nichols. Nicholson, Thelwall Hall, co. Chester. Nicholson, co. Cumberland; and co. Lancaster. Nicholson, London; confirmed 1596.

Az. two barrulets or in chief three suns ppr. Jeniinson, Watton, co. Derby; baronetcy 1685 .

Gu. two bars erm. in ehief three suns in glory or. Nicholson, Ballow House, co. Down; derived from Nicholson of Cumberland; quartering STEELE.

Wheel

Az. two bars or in chief a catharine wheel betw. as many buglehorns arg. Mertins, Lord Mayor of London, 1725.

Wreaths

Arg. two bars az. in chief three chaplets of roses gu. Basteed. Sir William de Basset, $V$. Sir William BASSET, $N$.

2 BARS and in base....

Or two barrulets in chief az. an eagle displ. in base gu. Cossans, Jamaica, granted 1767.

2 BARS betw. or within....

(some coats, placed here in compliance with a customary method of blason, will also be found in the divisions to which they properly belong.)

\section{Annulets}

Gu.two bars betw. three annulets arg. RYkHIL, $V$. Sa. two bars betw. three annulets in chief and a fleur-de-lis in base or. Burdus, Middlesex; granted 8 Aug. 1720).

Az. tro bars or betw. six annulets of the last three two and one. Cruden.

\section{Beasts}

Az. two bars arg. betw. three lions pass. in pale or. Minterin or Minterne, Batcombe, co. Dorset; and Thorpe, Surrey.

$\mathrm{Gu}$. two bars humetty arg. betw. tbree lions pass. in pale or. Gibson, Teede, co. Lancaster.

Az. two bars gu. betw. nine lions pass. guard. or. Bradshaw, co. Buckingham, 1506.

\section{Billets}

Ar. two bars wavy betw, three billets sa. HoNE, co. Devon.
BAR. 2 BARs betw, or within....

\section{Billets cont.}

Az. two bars betw. six billets or. Howe, Ireland. Gu. two barrulets erm. betw. six billets or. $M_{A x}$, Stoke, Suffolk; granted 4 June, 1687-8.

Birds.... (3 Ducks)

Arg. two bars wavy betw. three ducks arg. SHIRLEY, $V . *$

$$
\text { ....(3 Eagles) }
$$

Ar. two barrulets and three eagles displ. sa. Sir Jolnn SPEncer, Lord Mayor of London, 1594. .... (3 Martlets)

Arg. two bars betw. three martlets gu. two and one. Richard W $W_{\text {ARDE }} V$.

Gu. two bars betw. three martlets arg. (another or). BRIGFORD.

Or two bars az. betw. three martlets gu. PAYNell.

Or two bars gu. betw. three martlets in pale sa. ANKYRSLEY.

Or two bars betw. three martlets sa. SalKyns, London.

Sa. two bars wavy betw, three martlets or. ToDD, Bray, co. Berks.

Sa. two barrulets betw. three martlets or. two and one. Muttlebury, $W$. ....(3 Pigeons)

Az. two barrulets or betw. three doves ppr. Barrett, London; granted 1773.

$$
\text { ....(3 Swans) }
$$

Az. two bars wavy betw. three swans arg. two and one. Shinley, $V$.

Or two bars sa. betw. six birds gu. three two and one. William Paynell, $A$.

$$
\text { ....(6 Martlets) }
$$

Arg. two bars betw. six martlets gu. three two and one. Rokinge. Roringe, $V$.

Arg. two bars sa. within an orle of six martlets gu. Paynell, co. Hants; and Sussex.

Arg. two bars betw. six martlets sa. three two and one. MI'Cor, Scotland.

Arg. two bars vert betw. six martlets gu. three two and one. ATMORE.

Az. two bars erm. betw. six martlets or. MIAw, co. Lancaster; and Suffolk.

Gu. two bars betw. six martlets arg. three two and one. Chalons, co. Devon. Eiseldon. Sir John Eland, co. York, $V$. Eland or Eyland, co. York. Elland, Yseidon.

Gu. two bars betw. six martlets arg. two two and two. EgLAND, or EyLAND, co. Lincoln.

Gu. two bars or betw. six martlets .... LeEKS.

Or two bars az. betw. six martlets gu. three two and one. Thomas Paynell, $A$.

Or two bars betw. six martlets gu. three two and one. Marley.

Or two bars sa. betw. six martlets az. three two and one. Creich, or Creigh, Scotland.

$$
\text { ....(8 Martlets) }
$$

Arg. two bars sa. betw. eight martlets gu. three two and three. PANELL, $V^{*}$. Sir William PoWele, $V$.

Arg. two bars betw. eight martlets sa. Furlong. Gu. two bars betw. eight martlets arg. three two and three. Challons, co. Devon. Dankyrsley, co. York. Sir Thomas de Elande, $S$. Extend. SHETHELEY, $V$.

Gu. two bars betw, eight martlets or three two and three. Chalons, co. Devon.

Or two bars az. within an orle of eight martlets gu. PAYNeli, co. Hants.

Or two bars az. betw. eight martlets gu. three two two and one. Thomas PaYneLL, $Q$. Sir Thomas Paynneli, co. Hants, $V$. 


\section{BAR. 2 BARS betw, or within.... cont.}

\section{Birds cont. (9 Martlets)}

Arg. two bars engr. az. betw. nine martlets gu. Mone, Taunton, co. Somerset; and Heytes. bury, co, Wilts.

Arg. two bars az. betw. nine martlets vert three three two and one. Moore.

Arg. two bars betw. nine martlets gu. Mone, co. Bedford.

Arg. two bars betw. nine martlets gu. three three and three. Frater. Moore, Wichford, co. Hants; Visitation I (i34. Poringe.

Arg. two bars engr. the first sa. the second az. betw. nine martlets gu. three three and three. Mone, Suffolk.

Arg. two bars vert betw. nine martlets gu. three three two and one. Mone, co. Hants; and co. Somerset, $V$. Paneid.

Arg. two bars betw. nine martlets vert. ALLARD. Mone.

Gu. two bars arg. betw. nine martlets.... ETwaLL.

Gu. two bars betw. nine martlets arg. Challows.

Gu. two bars betw. nine martlets arg. tliree three two and one. Sir John Chalons, $V$.

Gu. two bars betw. nine martlets arg. three three and three. T'ankersley.

Gu. two bars betw. nine martlets arg. four three and two (another, four two and three). SMETHLEY.

Gu. two bars arg. betw. nine martlets or three three and three. SMethley.

Gu. two bars vert betw. nine martlets arg. three three and three. Chatons, $V^{*}$.

Or two bars betw. nine martlets gu. three three and three. Chalons.

Or two bars sa. betw. nine martlets az. three three and three. Creech, Edinburgh.

Arg. two bars az. an orle of martlets gu. William Panneli, $F$. William Paynell, $E, Y$.

Arg. two bars sa. an orle of martlets gu. Sire William Payneli, $N$.

Az. two bars or an orle of martlets gu. Monsire Roger BURdeT, $Y$.

Gu. two bars ur an orle of martlets arg. Sire John de HoLAND, $O$.

Gu. two bars and an orle of martlets or. John Blande, $Y$.

Or two bars az. an orle of martlets gu. Thomas Painel, $E$. Sire Thomas Payneli, $Q, X$.

Or two bars within an orle of martlets gu. Mordey or Merley, France.

\section{Bordure}

Arg. two bars az, and a bordure engr. gu. OLNEY.

Arg. two bars az. within a bordure sa. PARR.

Arg. two bars az. a bordure engr. sa. Sir Gilbert de Halsall, co. Lancaster, $V$. Parr, Parre, co. Lancaster; and its branches, co. Derby; co. Leicester; Horton, co. Northampton; Kempnall ; Eccleston ; etc. PARR, Stonelands, co. Devon; quartering Codrington. PARr, Kendal, co. Westmoreland, $Z, 490$; quartering the coat of augmentation granted by King HenryVIII to the family of his queen, Katherine Parr-or on a pile gu. three roses of York betw. six of Lancaster. RANNE, $V$,

Arg. two bars az. a bordure engr. sa. a crescent for diff. PARr, Liverpool, co. Lancaster; Honn, West Derby; Lythwood; and co. Salop, derived from Parr of Kendal.

Arg. two bars az. within a bordure engr. sa. bezanty. Parr, Bacliford, co. Chester; derived from Parr of Kendal.
BAR, 2 BARS betw. or within.... cont.

\section{Bordure cont.}

Arg. two bars az. on a bordure engr. sa. eight escallops of the field. PARR, granted 1590 derived from Parr of Parwich, near Warrington, co. Lancaster; with several quarterings. PARR, Fir Grove, in West Derby ; Grappenhall Heyes, co. Chester; derived from Parr of Ormskirk.

Arg.two bars gu. within a bordure engr.... PEENET, $V^{*}$. KnotTISFORD, $V^{*}$. Kot'TISFORD, $V$.

Arg. two bars nebuly gu. within a bordure az. Constabie.

Arg. two bars gu. within a bordure engr. az. Sutton, co. Stafford.

Arg. two bars within a bordure gu. Heligsal, or Helingsale. Helingsaie, $V$. Lawfui.i. Pigmeyne, al Pigveney.

Arg. two bars gu. within a bordure engr. pean. Sibthorpe, Can wick Hall, co. Lincoln; quartering WALDO.

Arg. two bars gu. within a bordure sa. GiвтHoRp, GiLTHORPE or GythoRPE. GibThoRPE, $V$. William Siвthorp, Thorpe, $V$.

Arg. two bars gu. within a bordure engr. sa. Benett, co. Stafford. Bennetr, Dublin; quartering az. three plates. CoKesford, Launton, co. Oxford; confirmed Feb. 1611. Cottesford, co. Oxford; and co. Devon. Gibthorpe, $V^{*}$. Martyn, co. Devon. Parre, $V^{*}$. Sibthorpe, $V^{*}$. Sybthorpe, St. Alban's, co. Herts; and Ladham, Norfolk.

Arg. two bars gu. on a bordare engr. sa. eight bezants. COTTESFORD.

Arg. two bars nebuly gu. within a bordure sa. Scarshall. Sharshail.

Arg. tiro bars gu. within a bordure sa. charged with eight cunquefoils or. Preston, co. Bedford; and Chilwick, co. Hertford; granted 1629.

Arg. two bars sa. within a bordure gu. BaraBY, Lincoln. DEANE.

Arg. two bars sa. within a bordure engr. gu. William de LoNDE, or Loude, Y. William de Wivile, $E$. W yvel. William Wrvil, $V$.

Arg. two bars sa. within a bordure invecked gu. Winrey, Wimley, co. Hertford.

Arg. two bars sa. within a bordure engr. or. CronTELL, $V$. WINLE.

Arg. two bars sa. within a bordure of the second charged with eight fleurs-de-lis or. STOKEs.

Arg. two bars and a bordure sa. Rodeley.

Arg. two bars and a bordure engr. sa. Wyvite.

Az. two bars within a bordure arg. gutty desang. Amarle.

Az. two bars arg. a bend gu. within a bordure compony of the second and third. LeE.

Az. two bars arg. over all a bend gu. within a bordure engr. gobony of the second and third. IsALL. LEY, co. Buckingham.

Az. two bars wavy arg. within a bordure or. Brooksbank, Eland, Halifax, co. York; and Hackney, Middlesex.

Az. two bars or within a bordure engr. gu. LavalL. Az. crusily and two bars or a bordure engr. gu. Jolnn de $\mathrm{P}_{\mathrm{AR}}, K$.

Erm. two bars and a bordure gu. Bedman.

Gu. two bars within a bordure arg. Deane, Syeston, co. York.

Gu. two bars and a bordure erm. ABriscourt, co. Oxford. M. Nicol Dabrichcourt, $S$. Sansett Dabrichcourt, $S$. Dabrichcourt, or Dambreticourt, $\boldsymbol{V}$. Sir Johu Dapscourt, T. 
BAR. 2 BARS betw. or within.... cont.

Bordure cont.

Gu. two bars dancetty or within a bordure sa. Ashmell, Asmall, and Aspinwald, Northumberland.

Or two bars and a bordure erm. AnRIscourt, co. Oxford.

Or two bars gu. over all a bend sa. a bordure az. FAUtikner.

Or two bar's nebuly gu. within a bordure compony of the second and arg. DAUnCEY.

Or two bars glk. within a bordure sa. Deynes, Coddenham, Suffolk.

Or two bars and a bordure vert. ABriscourt, co. Osford.

Sa. two bars and a bordure arg. Byncks. LAyот, London, formerly of Flanders, 1633.

Sa. two bars arg. within a bordure gu. DEane, co. Berks.

\section{Castles}

Sa. two bars engr. betw. as many towers tripletowered in chief arg. and three crescents in base or. Bragge, or Braig, Nether Augeshark, Scotland. BragGe, Scotland.

Sa. a bar gemel or betw. three towers tripletowered arg. Claver, co. Buckingham.

Sa. two bars or betw. three tower's arg. Cleaver.

Sa. two barrulets arg. betw. five towers two in chief and three in base or. Brogg, Scotland. Coronets

Or two bars az. betw. three ducal crowns gu. two and one. Genevel, or Geneville. Genevill, Northumberland. Geneweld, $V$. Grenewell. GreenwerL, Greenwell Ford, co. Durham. Grenwert, Grenwell Hill, co. Durham, $V$. Crescents

Arg. two bars gu. betw. three crescents sa. WaLTON.

Or two bars betw. three crescents gu. two and one. William Wodert, $V$.

Or a bar gemel betw. three crescents gu. WODELL.

Arg. two bars wavy az. betw. six crescents.... three two and one. Hornbrook, Tavistock.

Arg. two bars betw. seven crescents sa. three three and one. Hewes.

\section{Crosses}

Arg. two bars betw. as many crosses crosslet fitchy in chief and an anchor in base sa. LOGHLAN or Losack, Scotland.

Az. two bars wavy arg. betw. as many crosses crosslet fitchy in chief or and a swan with wings endorsed in base of the second. LachLaN. LAUCHLAN.

Az. two bars dancetty erm. betw. six crosses crosslet or three two and one. HaIRsnet.

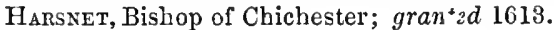
Harsewitt, Norvell.

Or two bars sa. betw. six crosses crosslet gu. three two and one. Mellent, or Mellert.

Az. two bars betw. seven crosses crosslet or. Sir Thomas Blakinghadi, Suffolk, $V$. Blaknys, Norfolk.

Az. two bars betw. seven crosses crosslet or three three and one within a bordure engr. gu. Bay.

Gu. two bars vair and seven crosses crosslet.... three three and one. Mortimer alias Zover. HARSNET.

Gu. two bars vair betw. eight crosses crosslet or four three and one. Will. de Mortimer, $V$.

Az. two bars dancetty erm. betw. nine crosses crosslet or. HARSNET, Sussex.
BAR. 2 BARS betw. or within.... cont.

\section{Escallops}

Gu. two bars betw. three escallops arg. Sire William Bause, $O$.

Gu. two bars erm. betw. six cscallops or three two and one a bordure of the second. Sir .... Dabrigecounte, $V$.

Or two bars gu. betw, eight escallops az. Prew or Prue.

\section{Estoiles}

Sa. two bars betw. two stars of six points or. Tivining, Bryn, co. Pembroke.

Arg. two bars betw. three stars of six points pierced sa. Douahtr.

Arg. two bal's sa. and six estoiles gu. Prierse, $V^{*}$.

Arg. two bars sa. betw. six estoiles gu. three two and one, Pearse, Court, co. Devon; granted 12 August, 164l. Pearse, Dulverton, co. Somerset.

Az. two bars erm. betw. six estoiles arg. three two and one. Harrison, Copford Hall, Essex, quartering Fiske. Harrison, Dow Hill, Kent.

Az. two bars erm. betw. six estoiles or three two and one. Harrison, Essex; Reisby and Burton-Stath, co. Lincoln.

Fish

Or two bars wavy betw. three shrimps in pale gu. Atsea, $V$.

\section{Flaunches}

Gn. two bars arg. betw. on each of as many flnunches erm. a cross crosslet of the field. Marshall, Ardwick, and Penwortham Lodge, co. Lancaster; quartering EARNsHaw.

Arg. two bars humetty gu. betw. as many flaunches of the second three garbs in fess counter. changed. Fryer.

Sa. in chief a bar gemel betw. two flaunches arg. ARTHAWE.

Fleur-de-lis

Gu. two bars or betw. three fleurs-de-lis arg. ELsING.

Az. two bars dancetty erm. betw. six fleurs-de-lis or three two and one. Cademan, Norfolk and London; granted 1633.

Vert two Lars betw. six fleurs-de-lis or three two and one. Styles, Kent and London.

Sa. two bars erm. betw. nine fleurs-de-lis or. Farrant, Kent.

4-Foils

Az. two bars betw. six 4 -foils arg. VINCENT, $V$. 5.Foils

Arg. two bars betw. three 5 -foils sa. Bartiett, Weston in Branscombe, co. Devon.

Sa. two bars erm. betw. six 5.foils arg. three two and one. Robert Browte, $V$.

Arg. (another or) two bar's betw. eight 5-foils gu. four three and one. Lanvoys.

Fruit

Sa. two bars erm. betw. fifteen wheat ears or five five and five $a$ bordure of the second. STokes, $W$.

Guttys

Arg. two bal's gu. betw. eight gutty's de larmes four three and one. CHAURY.

Arg. two bars gu. betw. nine guttys az. three three and three. CHAwny. CHOwRey.

Hands

Az. two bars wavy erm. betw. three dexter haads couped at the wrist apaumy arg. SEagood.

Heads (Beasts) Bear

Arg. two bars betw. three bear's heads erased gu. Letton, or Lxtтon, co. Hertford. 
BAR, 2 BARS betw. or within.... cont. Heads (Beasts) Boar

Or a fess gemel gu. betw, three boar's heads erased at the neck sa. Jenkinson, Norfolk.

$$
\text { .... Dag }
$$

Per fess erm. and az. two bars engr. betw. three talbot's heads erased counterchanged. Burton, quartering RoBINSON.

$$
\text { ....Horse }
$$

Or two bars gu. voided betw. three horse's heads erased sa. Jenkinson, Norwich; granted 1687.

$$
\text { ..... Leopard }
$$

Vert two bars engr. arg. betw. three leopard's heads or. Child, London, and Newton, co. Northampton.

Vert two bars engr. betw. three leopard's faces or. Curnd, Surat, East Indies; and Dervil, Essex; Baronetcy 1684.

\section{(Human Figure)}

Az. two bars arg. betw. three close helmets or. Gabriel AnMuger, London; and North Creake, Norfolk, 1730.

Az. two bars or betw. three helmets arg. Almiger. Armiger, Norfolk, 1716.

(Beasts) Leopard

Az. two bars betw. six leopard's heads or three two and one. Shrimpton.

$$
\text { .....Lion }
$$

Arg. two bars betw. six lion's heads cabossed gu. Musketr, Intwood Hall, Norfolk; descended from Muskett, Haughleigh, Suffolk, temp. Henry VIII.

Or two bars betw. six lion's heads erased gu. Goodwin, Hammersmith, Middlesex.

Or two bars sa. betw. six lion's heads couped gu. three two and one. Kearsley, or Kearsiy, co. Lancaster; and London; granted 2 Oct. 1622 .

\section{Insects}

Arg. two bars betw. three bees sa. Flemings, $V$. Arg. two bars betw. three butterflies volant sa. Flemings. $V^{*}$.

Sa. two bars betw. seven bees arg. three three and one. CомвE, co. Somerset.

\section{Lozenges}

Gu. two bars or betw. six lozenges arg. three two and one. Comвe, co. Devon; and London; granted 2 July, 1603. Goonwin or Goodwyn, Streatham, Surrey, $Z, 424$; Dorking and Guildford, Surrey; and Lewes, Sussex. GooDwr, Sussex; granted by Camden, $W$.

\section{Mascles}

Arg. two bars betw. six mascles sa. three two and one. Barnes, co, Berks; Baron.

Az. two bars betw. six mascles voided or three two and one. Darnelu, Heylings, co. Lincoln.

Arg. two bars betw. nine mascles sa. three three and three. BARON.

\section{Mullets}

Arg. two bars betw. as many mullets sa. pierced or. Doughty, Louth, co. Lincoln; Theberton Hall, Suffolk.

Sa. two bars arg. in chief two mullets or in base an annulet of the last. Spmaran. Splliman, Waldon, $V$.

Sa. two bars arg. in chief as many mullets .... in base two annulets or. Spelman, or SpHman, Essex.

Arg. two bars nebuly gu. betw. three mullets sa. Kennan, Ireland.

Arg. two bars betw. three mullets of six points pierced sa. Philip Dodghty, Westminster, 1730.
BAR, 2 BARs betw. or withir.... cont.

Mullets cont.

Arg. two bars betw. three mullets of six points sa. pierced or. Doughty, or Doutey, Esher, Surrey; Snarford Hall, and Boston, co. Lincoln.

Gu.two bars betw. three mullets arg. ScarysBroke.

Az. two bars arg. betw. six mullets or three two and one. Felgate, or Fellgate, Yaxley, co. Suffolk.

Arg. two bar's az. betw. nine mullets .... three three and three. JEPHSON.

\section{Pheons}

.... two bars .... betw. three pheons reversed .... Frilder, Little Horkesley, co. Eussex.

Arg. two bars betw. three pheons gu. Colegrave. Az. two bars betw. three pheons or. SмIтE, or SHYTH, London.

\section{Reptiles}

Arg. two bars gu. betw, as many serpents vert. REFUGE.

Roundles (Bezants)

Per pale gu. and az. two bars or betw. three bezants in chief and a pheon in base arg. Gowland, Durham; granted 1749.

(Ogresses)

Arg. two bars sa. betw. three ogresses within a bordure engr. of the second. Almenton, co. Devon.

Or two bars sa. betw. three ogresses within a bordure engr. of the second. AYLBERToN.

\section{(Plates)}

Sa. two bars arg. betw. three plates. Hunger. (Torteaux)

Arg. t.wo bars gu. betw, three torteaux over all a baston sa. Sire Walter de Thurkingham, $O$.

Arg. two bars gu. betw. three torteaux a bordure sa. Crekinghant.

\section{Stones}

Arg. two bars wavy betw. three honestones az. Hones, Ottery, co. Devon.

\section{BARS betw. or within...}

and in chief....

\section{Birds}

Arg. two bars the first engr. on the upper side the second on the under side az. betw. three roses gu. stalked and leafed vert two martlets of the third betw. the roses in chief. Holyman.

Canton

Arg. two bars a bordure engr. and a canton gu. CORBET.

on a Canton.... Sword

Erm. two bars within a bordure engr. gu. on a cantor of the last a dagger erect ppr. pomel and hilt or. Nugent, Waddesdon, co. Berks, Bart. Nugent, Donore, co. Westmeuth, Bart. Chief

Arg. two bars gu. betw. six ogresses a chief of the second. Blankeley, $V$.

on a Chief..... Fleurs-de-lis

Or two bars az. on a chief quarterly of the second and gu. four fleurs-de-lis two lions pass. guard. of the field all within a bordure wavy compony arg. and sa. Manners, Hanby Hall, co. Lincoln; and Buckminster, co. Leicester; baronetcy 5 Jan. 1793.

Heads

Gu. two bars or a bordure arg. in chief three griffin's heads erased of the secoud. Greman.

\section{Monster}

Arg. two bars az. a bordure engr. sa. in chief a griffin pass. gu. Litler, Tathwell, co. Lincoln. 
BAR, 2 BARS betw, or within....

and in chief.... cont.

\section{Mullets}

Arg. two bars a bordure and in chief three mullets sa. Sir Hugh Bossard, $O$.

Roundles (Ogresses)

Arg. two bars gu. a bordure "recersily" sa. in chief three ogresses. Thomas Wake, Epine. $Y$.

Arg. two bars within a bordure engr. sa. in chief three ogresses. Allerton, $V$.

\section{....(Torteaux)}

Arg. two hars az. within a bordure engr. sa.in chief three torteaux. PARR, Kempnall, co. Lancaster.

Arg. two bars within a bordure engr. gu. in chief three torteaux. Thomas WAKE, Blysworth, $V$.

Arg. two bars gu. within a bordure indented sa. in chief three torteaux. WAKE. Sir Thomas $W_{A K E}$, Blithesworthe, $O$.

Arg. two bars gu. a bordure "recersily" sa. in chief three torteaux. Monsire Thomas Wake, Blisworth, $Y$.

\section{Annulets}

\section{On 2 BARs}

Arg. on each of two bars gu. an annulet.... M Intin, co. Dorset.

\section{Beasts}

$\mathrm{Or}$ on two bars gu. three lions ramp. arg. two and one. Dannett, co. Leicester.

\section{Birds}

Arg. on two bars gu. three martlets of the field. Cranber.

Arg. on two bars gu. three martlets or two and one. WiLLET.

Arg. two bars engr. gu. on the upper as many martlets or and on the lower three escallops of the field. ToLL.

Az. two bars or on the upper bar three martlets gu. Sire Robert Bondet, $N$. Sir Robert Burdett, co. Leicester, temp. Edward I, $V$.

Az. on two bars or three martlets gu. M. John Burdet, $S$. Burdett, co. Leicester.

Erm. on two bars gu. three martlets or. WARD, Houghton Parva, co. Northampton; granted 31 Mas, 1695.

Erm. on two bars vert three martlets or two and one. Willey. WILLY, W.

Arg. on two bars az. four martlets of the first two and two. More, co. Somerset.

Arg. on two bars gu. four martlets of the first two and two. John WARDE, $V$.

Arg. on two bars gu. four martlets or two and two. WARD.

Az. on two bars or five martlets gu. three and two. P.... Wriaeley, $F$.

Arg. on two bars gu. six martlets or. TEMPLE, Burton Dasset, co. Warwick.

Arg. on two bars sa. six martlets of the first three and three. TEMPLE, Lord Nugent.

Arg. on two bars sa. six martlets or. BINDE. Temple, Viscount Palmerston. Temple, Temple, co. Leicester. Temple, Stowe, co. Buckingham, Bart.

Az. on two bars arg. six martlets gu. Cranber. Cranbura, $V$. Craneburne.

Az. on two bars or six martlets gu. three and three. M. John Burdet, $S$. Roger Burdett, $Y$. The old coat of BurdetT, Bramcote, co. Warwick; Formark, co. Derby ; and Ramsbury, co. Wilts, Bart. Bundert, co. Warwick, and co. York. Burdett, $V$. Wrialife or Wriley.

Erm. on two bars sa. six martlets or. TEBrLe.

Gu. on two bars arg. six martlets sa. LongCroft, co. Worcester.
BAR. On 2 BARS.... cont.

Birds cont.

Or on two bars gu. six martlets arg. three and three. Bynde, Sussex, $V$.

Or on two bars gu. six martlets of the field three and three. Bynde, Sussex. Byne.

Or on two bars sa. six martlets arg. three and three. Criegh, Scotland.

Vair on two hars gu. six martlets or. WAIIINGHaMr. Bougets

Or on two bars gu. three water bougets arg. Willoughby, Risley, co. Derby ; Grendon, co. Northampton; Wollaton, co. Nottingham; and co. Stafford. Willoughby, Middleton. Sir Henry Willoughiy, Wollaton, co. Nottingham, $V$. M. Edmund WrloughBy, $S$.

Or on two bars gu. three water bougets of the field. Wnuloughby, co. Warwick.

\section{Buckles}

Arg. on two bars sa. three square buckles of the first a 5 -foil for diff. in the centre. BoDErrey.

Arg. on two bars sa. three round buckles points in fess to the sinister or two and one a 5 -foil in the centre gu. for diff. BODdelley, $V$. Bodelley, $V$.

Erm. on two bars sa. three round buckles or two and one. Bodley, Streatham, Surrey. Combs

Erm. on two bars sa. three comls arg. Lucas. Coronets

Arg. on two bars az. as many coronets or. GENEVIIL.

Or on two bars az. three ducal coronets of the ficld. Hakebeche, Emneth, co. Norfelk.

\section{Crescent}

Or two bars counter indented gu. on the uppermost a crescent and mullet arg. MAIR, Scotland.

\section{Crescents}

Arg. on two bars sa. tbree crescents two and one arg. Fitzsimonds.

Or on two bars gu. three crescents of the field. Eцiот, Fiyot, Elyotт, Surrey.

Cross

Arg. two bars sa. on the uppermost a cross formy of the field. Deden, co. Huntingdon.

\section{Crosses}

Arg. on two bars gu. three crosses formy or two and one. Martin, co. Somerset; and co. Devon. Martyn, Totness, co. Devon.

Arg. on two bars (gu. another) sa. three crosses patty fitchy or. John FELL, Bishop of Oxford, 1678 , ob. $10 \mathrm{July}, 1686$.

Or on two bars sa. three crosses patty fitcby arg. two and one. FELL.

.... on two bar's .... six crosses patty .... Richard (? Poone) Bishop of Chichester 1215, of Salisbury 1217, of Durbam 1228-37.

Arg. on two bars az. four crosses patty or two and two. Sir John de Den, $V$. OUndell, $V$.

Arg. on two bars gu. six crosses crosslet or three and three. Dandeleigh. Philip Daundelegh, $V$, or Daundeleghe, $Y$. David.

Arg. two bars gu. crusily or. Philip d'ANDELEGH or Daundeleigh, $X$.

Arg. on two bars gu. six crosses crosslet fitchy or three and three. WiLes, Sussex.

Arg. on two bars sa. six crosses formy of the field three and three. Deane.

Arg. on two bars sa. six crosses patty or three and three. Den, co. Huntingdon. Dene, co. Huntingdon, $r$. Deane, Oundel, $V$. OWNDELL, $V^{*}$. 


\section{BAR. On 2 BARS.... cont.}

\section{Crosses cont.}

Arg. two bars sa. crusily patty or. Sire John de Deen. $O$. Sire .... de Den, $N$. Escallops

Arg. two bars sa. on the upper one as many escallops of the first. Fiset, London.

Arg. on two bars az. four escallops or two and two. HALTON.

Arg. on two bars sa. four escallops of the first two and two. Flote, $V$.

Arg. on two bars sa. four escallops or two and two. Banning, London, 1588.

Or on two bars sa. four escallop shells of the field two and two. Sir Paul Banning, London, granted $1588, W$. Bayninge, London.

Arg. on two bars gu. six escallops or tbree and tbree. Palmer, Hill, co. Bedford.

Arg. on two bars sa. six escallops of the first three and three. Flecke, Surrey. Flote.

Erm. on two bars humetty gu. six escallops arg. three and three. Dabridgcour, co. Warwick. Escucheon

Arg. two bars gu. on the first an escucheon erm. Martyn, co. Hertford.

Or two bars gu. on the first an escucheon erm. MARTYN, Lord Mayor of London, 1492.

\section{Escucheons}

Erm. on two bars gu. three escucheons or. Hall. HALLE.

\section{Fish}

Or on two bars gu. as many shrimps naiant arg. Asea.

Or on two bars wavy gu. as many sbrimps of the first. Sea. AtSEA, $V^{*}$.

Or on two bars wavy gu. three shrimps of the first two and one. ATSEA, $V$.

Fleurs-de-lis

Arg. on two bars sa. three fleurs.de-lis or. Hort, London; granted 22 March, 1663.

Arg. two bars humetty vert three fleurs-de-lis or two and one. William RotheLEY, $V$.

Or on two bars gu. four fieurs-de-lis arg. two and two. RichaRDs; granted 1613. RicharDs, Fringe, Norfolk.

\section{Flowers}

Arg. on two bars gu. three roses of the field barbed vert seeded or two and one. OrLebar, Hinwick Honse, co. Bedford.

3-foils

Or on two bars gu. six 3-foils arg. three and three. PaLmer, $V^{*}$.

Or on two bars gu. six 3-foils slipped of the first three and three. Palmer, Earl of Castlemain, and Baron of Limerick, 1730.

\section{5 -foils}

Arg. on two bars az. three 5-foils of the field. Teverrey. Whitney. Wiiloughby. Witney.

Arg. on two bars az. three 5-foils or. STAPLEFond, co. Derby, and co. Nottingham, temp. Henry III. Richard de Willoughby, $Y$.

Or on two bars sa. three 5-foils arg. two and one. Coward, Wells, co. Somerset.

Arg. on two bars az. six 5-foils or. Willouging.

Arg. on two bars engr. az. six 5-foils or three and three. Lenche, Wych, co. Worcester. Lenche or LENCH.

Arg. on two bars gu. six 5-foils or three and three. Painer, co. Bedford.

\section{Fretty}

Arg. two bars gu. fretty or. Clopton or Crotton. St. Lyz, $V$. Cistercian Abbey at SAltrey, Saltix, or Sawtrey, co. Huntingdon.
BAR.

On 2 BARS.... cont.

\section{Garbs}

Arg. on two bar's sa. three garbs or. KNIGHTBRIDGE, Clielmsford, Essex.

Guttys

Az.two bars engr. arg.gutty de sang. Rous, London.

Erm. on two bars sa. six guttys d'or three and three. STokes.

\section{Heads}

Arg. on two hars az. as many lion's heads erased or. Harpur, $V *$ *

Heads (Beast) Boar

$A z$. on two bars engr. or three boar's heads erect couped sa. two and one. The modern coat of TWEMLOW, co. Cliester.

Az. on two bar's engr. or three boar's heads'erect couped sa. two and one with a crescent in chief for diff. Twentow, Arclyd, Hatherton, and Northwich, co. Chester: and with due diff. its branch, Tweniow, Alsager; and the Elms, Betley, co. Stafford; quartered with the ancient coat, arg. a chevron or betw. three squirrels sejant gu.

$$
\text { ..... Dog }
$$

Arg. on two bars az. tbree greyhound's heads erased or. HARPER, Bambury.

$$
\text { .....Leopard }
$$

Arg. on two bars sa. three leopard's heads or two and one. Shoobridge, Uclifield, Sussex; granted 16 April, 1662.

Arg. on two bars sa. three leopard's heads or jessant fleurs-de-lis of the first. MorLand, $W$. ..... Lion

Arg. on two bars betw. three lion's heads erased or two and one. Harpur, Bambuly, $V$.

$$
\ldots .0 x
$$

Arg. on two bars sa. three bull's heads cabossed of the field. Stonestreet or Stonestreete, Hurstmonceaux; and Westham, Sussex; the heiress m. Griffin. Stonestreet, Halton, Sussex; and Stondon Hall, Essex.

$$
\text { ..... Leopard }
$$

Gu. on two bars or four leopard's faces sa. two and two. Pinner, Bury St. Edmund's, Suffolk; granted May 2, 1612; and Sussex.

\section{Leaves}

Erm. on two bars sa. six elm leaves or three and three. Erranies, Allerton Hall, Liverpool. Elmiss, Stantield, co. Lincoln.

Erm. on two bars sa. ten elm leaves or five and five. Elmes, V. Elmes, co. Lancaster; and Lilford, co. Northampton.

\section{Lozenges}

Gn. on two bars arg. six lozenges of the first three and three. GEERING.

\section{Mascles}

Az. on two bars arg. three mascles gu. Darnell or DaRNHILL, co. Lincoln.

\section{Monster}

Arg. two bars sa. on the upper one a wivern volant tail extended of the field. Manfeld, $V$. inullet

Arg. two bars sa. on the uppermost a pierced mullet or. Pever.

Or two bars sa. on the uppermost a mullet .... Penrey, Norfolk.

\section{Mullets}

Arg. on two bars sa. as many pierced mullets or. Hopton.

Arg. on two bars az. three mullets or. John de ÉSSEBINGTON, $Y$.

Arg. on two bars gu. three mullets of the first two ard one. Amys, Essex. Maynwaring, $V$. 
BAR. On 2 BARS.... cont.

\section{Mullets cont.}

Arg. on two bars gu. three mullets or. AMYAS, Essex.

Arg. on two bars sa. three mullets or two and one. HOPTON.

Az. on two bars arg. three mullets gu. two and one. Kimperley.

Az. on two bars or three mullets gu. two and one. KNIPELL. KNYPERLE, $V$.

$\mathrm{Az}$. on two bars or three pierced mullets gu. KNyple, $V$.

Arg. on two bars sa. six mullets or three and three. Hopton, co. York. Lenthall.

Arg. on two bars sa. six pierced mullets of the first three and three. Robert Hopton, $X$. Hopton, Ermeley Hall.

Arg. on two bars sa. six mullets of as many points or three and three. Hopton, co. York. John Hopton, Bishop of Norwich, 1554-9.

Erm. on two bars gu. six mullets or three and three. IValter Bavant, $Y$.

Erm. on two bars gu. six pierced mullets or. Bavant.

Erm. on tivo bars sa. six mullets or three and three. Sir Arthur Hopton, $V$. Hopton, co. Somerset; and Blithbon, Suffolk.

Erm. on two bars sa. six pierced mullets or. Hopton, Armeley Hall, Leeds.

Erm. on two bars sa. six mullets of as many points or. HOPTON.

Palets

Sa. on two bars wavy arg. six palets wavy gu. three and three. WAy.

\section{Roundle}

Arg. two bars sa. on the first a bezant. Pellat, Peliet, or Pejlot, Bignall Park; and Bolney, Sussex. Pillett or Pillott.

Roundles (3 Bezants)

Arg. on two bars gu. three bezants two and one. Martyn, co. Gluucester. Willovghyy, eo. Nottingbam.

Erm. on two bars gu. three bezants two and one. Pearson, Moulton Park, co. Northampton. Pearson, Tankerton; and Maize Hill, Greenwich, Kent; descended from Pearson of Sprat. ton, co. Nottingham, ternp. Richard III; quartering Radford. Tenet, $V$. Tennant.

Erm. on two bars each per pale sa. and gu. three bezants two and one. Tennant, Chapel House, near Skipton, co. York.

Or on two hars gu. three bezants. CLERKE, granted by Camden, $W$.

$$
\text { ....(3 Plates) }
$$

Erm. on two bars sa. three plates two and one. Pennant.

Or on two bars gu. three plates. Willovghey, Nottingham and Wollaton, co. Nottingham.

Vert on two bars gu. three plates. ClanKE, $V^{*}$. .. (4 Bezants)

Or on two bars az. four bezants two and two. Utber or Uteer, Norwich and Hoo, Norfolk.

$$
\text { ....(6 Bezants) }
$$

Arg. on two bars gu. six bezants three and three. Matitin, co. York. Sir Walter MartiN or Martine, co. Gloucester, $V$. Martyn, co. Gloucester.

Or on two bars gu. six bezants three and three. Martyn, Cambridge.

$$
\text { ....(10 Bezants) }
$$

Arg. on two bars gu. ten bezants five and five. Deweli, De Welie, or Dewill.

Arg. two bars gu. bezanty. Sire Wary Martin, N. Martyo, Cambridge.

\section{BAR. On 2 BARS and in chief}

\section{Beast.... Dog}

Arg. on two bars sa. three 3-foils slipped of the field in chief a greyhound comrant of the second. PALMIER, Warden Street, co. Bedford; and Lad. brooke, co. Warwick. Palmer, Cheam Park, Surrey. William Parmer, Ladgrave, co. Warwick.

Arg. on two bars sa. three 3-foils slipped of the field in chief a greyhound courant of the second collared or. Palmer, Waulip, co. Leicester, Bart.; quartering Hudson.

Or on two bars gu. six 3-foils arg. three and three in chief a greyhound courant sa. Palmer, Suftolk; temp. Edward II. SirThomas PaLmer, Wingliam, Kent (Barorietcy 1621, since of Dorney Court, co. Buckingham), from whom descended Roger Parmer, Earl of Castlemaine. Palmer, Boyne House, Tunbridge Wells. Palmer, V. Palmer, Sussex.

$$
\text { - ....tion }
$$

Arg. on two bars gu. six 3-foils or three and three in chief a lion ramp. sa. Palmer.

Or on two bars gu. six 3.foils of the field three and three in chief a lion pass. ppr. Palmer, Great Farmouth; and Loddon, Norfolk.

Or on two bars gu. six 3 foils slipped arg. tbree and three in chief a lion pass. sa. Palmer, Holt, $V$.

\section{Canton}

Gu. on two bars arg. six mascles of the first three and three a canton erm. Geary, Surrey.

Gu. on two bars arg. six mascles of the first three and three a canton or. Gerrey or Geere, co. Hereford.

on a Canton.... Anchor

Gu. on two bars or tbree mascles az. two and one a canton arg. charged with an anchor sa. Geary, Polesden, Surrey ; since of Oxonhoath, Kent, Bart.; quartering arg. a chev. voided betw. three fleurs-de-lis within a bordure gu.

$$
\text { ..... Chief }
$$

Erm. on two bars sa. three bezants two and one a canton arg. charged with a chief of the second thereon a cross patty betw. two martlets of the third. Tennant, Little Aston Hall, Shenstone, co. Stafford.

$$
\text { ... 5-Foil }
$$

Az. two bars or the upper eharged with three fleurs-de-lis the lower with three martlets gir. on a canton of the third a 5-foil arg. PEPPARD, Cappagh, co. Limerick.

$$
\text { .....Hand }
$$

Arg. two bars engr. gu. on the upper as many martlets or and on the lower three escallops of the field a canton az. charged with a dexter hand in bend of the tirst. ToLl, Grewell, co. Hauts.

Arg. two bars engr. gu. on the upper three martlets and on the lower as many escallops or a canton az. charged with a dexter hand apaumy in bend of the first. Christopber ToLL, co. Gloucester, $H$.

$$
\text { .... Head }
$$

Gu. on two bars arg. six mascles of the first three and three a canton or charged with a leopard's face az. William Gere, Brakway, $V$. Geary, Geere, or Gery, Bushmead Priory, co. Bedford; descended from Gery of Royston, co. Herts, 1509 ; the coheirs m. Milnes, Milnes, and Wade.

Gu. on two bars or six mascles az. three and three a canton of the last charged with a leopard's head of the second. GERRY, co. Lancaster. 
BAR. On 2 BARS and in chief.... cont. on a Canton.... Head cont.

Gu. on two bars or six mascles az. three and three a canton of the second charged with a leopard's head of the third. Geane, co. Devon. Gene, Heavitree; and Kenney, co. Devon.

Gu. on two bars or six mascles az. three and three a canton of the second charged with a leopard's head of the first. GEARE, Gillingham, Kent; and Heavitree, co. Devon.

$\mathrm{Gu}$. on two bars or six mascles of the first three and three a canton az. (sometimes sa.) charged with a leopard's face of the second. GEaring or Gering, Winterton, co. Lincoln.

\section{Chief}

Or on two bars az. as many barrulets dancetty arg. a chief indented of the second. John SAWBRIDGE of Olantigh, co. Kent, Lord Mayor of London, 1775. Sawbridge, East Haddon, co. Northampton. Sawbridge, North Kilworth, co. Leicester; all descended from Saunders, of Hill Morton, co. Warwick, ] 037.

Arg. on two bars gu. six 5 -foils or a chief indented of the last. Fanra, Norfolk.

on a Chief.... Flower

Az. on two bars or as many martlets each betw. a pair of fleurs-de-lis of the first on a chief of the second a rose gu. seeded gold barbed vert betw. two fleurs-de-lis of the field. Jenkes.

$$
\text { .....Tail }
$$

Or on two burs az. as many barrulets dancetty arg. a chief indented of the second charged with au ermine spot or. SAwERIDGE.

$$
\text { ....Tops }
$$

Sa. on two bars arg. three water bougets vert two and one a chief gu. charged with three playing. tops of the secoud. Topp.

\section{Crosses}

Sa. on two bars erm. as many annulets and in chief three crosses formy or. BATHURST, Isle of Wight.

\section{Flowers}

$\mathrm{Gu}$. on two bars or as many crosses bottony of the field in chief three roses arg. barbed vert seeded gold. DALFOy, Ireland.

Head (Beast) Boar

Arg. two bars gn. the uppermost charged with three mullets or in chief a boar's head couped az. IrLaxd, Baruban, Scotland.

$$
\text { ....Dog }
$$

Sa. two bars erm. billetty of the first in chief a homnd's head erased betw. two chaplets or. HALL, Salop.

Sa. two bars erm. billety of the first in chief a talbot's head erased betw. two chaplets or. Joln HaLI, Evers, co. Salop, $V$.

\section{Heads}

Arg. on two bars gu. three hounds courant of the field in cbief as many wolf's heads erased of the second. LEION or LELOW.

\section{Tops}

Sa. on each of two bars arg. a water bouget vert in chief three tops of the second. Towpis, $Y$.

\section{Billets}

\section{On 2 BARS betw.....}

$\mathrm{Or}^{\circ}$ on two bars sa. betw. three billets gu. two and one five martlets (? arg.) three and two. Keluey, Kelly, or Kíylley.

Or on two bars betw. as many billets lying fesswise gu. six martlets arg. three and three. KELE, London.

\section{BAR. On 2 BARs betw...... cont.}

Billets cont.

Or on two bars sa. betw. three billets lying fess wise gu. two and one six martlets arg. three and three. Thomas Keyce, London, $V$.

Or on two bars sa. betw. three billets gu. two and one five mullets (? arg.) three aud two. KELLEY, KELLY, or KEYLLEY.

Bordure

Gu. on two bars within a bordure arg. four martlets in pale sa. ALdwen, co. York, $V$.

Erm. on each of two bars az. as many crosses patty or a bordure engr. sa. charged with four escallops and as many crosses alternately arg. and gu., granted in behalf of the Rev. Dr. Samuel PArr, Prebendary of St. Paul's.

Or on two bars gu. within a bordure vert eight escallops arg. Pryer, France.

Arg. on two bars gu. within a bordure of the second three 3-foils or. PaLmEr.

Az. two bars and a bordure arg. all gutty de sang. Adiarle. Armarle, $V$.

\section{Flaunches}

Or on two bars humetty gn. three leaves of the first two flaunches of the second. Frrer, Thornes, co. Stafford.

\section{Fleurs-de-lis}

Az. on two bars dancetty or betw. three fleurs.de lis arg. two mullets in chief and a crescent in base gu. HARKNess, Scotland.

Heads

Arg. on two bars az. betw. three leopard's faces in pale gu. six bezants. Arson, Chester.

\section{On 2 BARS betw, or within....}

and in chief....

\section{on a Canton}

Erm. on two bars sa. four crosses patty or two and two all witbin a bordure engr. of the second charged with roses and escallops alternately arg. on a canton of the third six bees volant ppr. BisH.

\section{Cross}

Arg. on two bars gu. six martlets or three and three all within a bordure engr. sa. in chief a cross flory betw. two fleurs-de-lis az. WARDE, Bastchurch, Hinton, and Newton, co. Salop.

\section{BARS}

.... three bars .... over all a lion ramp .... Thomas Atte La'THE's seal, Willinghall, Norfolk, 27 Edward III.

Arg. three bars az. Burt or Burtt. Carfrae, Glenbog, Scotland. Elricht, co. Leicester. Grey. Maguire, England. St. Phinibert.

Arg. three hars az. over all a lion ramp. gu. crowned or. Wiluescotr. Sire Henri de Willemescote, $N$.

Arg. three bars az. a bend gu. GAUnt, Lord Lindsey.

Arg. three bars az. over all a bend masculy gu. GreY.

Arg. three bars az. on a bend gu. as many leopard's beads or. Gray.

Arg. three bars az. on a bend gu. as many bezants. Green. Grex.

Arg. three bars az, over all an eagle with two heads gu. armed or. Speke, Cornwall.

Arg.three bars az.over all a saltire gu. DELAPort.

Alg. gutty-de-sang three bars humetty az. Adrarle. Armarle, $V$.

Arg. three bars lozengy az. Faconberge.

Arg. three bars wavy az. SAMFOND, 1295. SANDFORD. 


\section{BAR. \\ 3 BARS.... cont.}

Arg. three bar's wavy az. over all a lion ramp. of the first. BuLBECK, Kingston, granted 24 April, 1559.

Arg. three bars wavy az. over all a crescent gu. Seaman.

Arg. three bars erm. KinKerton.

Arg. three bar's nebuly ermines. William Moreis, $V$.

Arg.three bars gu. Bartley. Bohun (?). Bussey, as quartered by Viscount Townshend. CAMERoN, Lochiel; the branches of Lochiel were Cameron, Letterfinlay, styled Mac-Vic-Vartin; Strone; Glenevis; Caluart ; Errocht and Drimnassallie; Glendessary and Dungallon; Fassifern, etc. Champney. William Crepin, $C$. Coatsworth, Newcastle. Egremond. Garmon. Grey. Martin, Bodmin, Cornwall; the co-beirs m. Trefusis and Winter, temp. Henry IV. Moltone, K. Molton or Moulton. Tebaud de Moletone, $A$. Thomas de Molton, $J$. Sire Thomas de Moltone, $N$. Sire Thomas de Moulton, $B, I$. Sir de Moulton, Egremont, $V$; quartered by Ratcliffe, Lord Fitzwalter, $U$. Le Sire de Moulton, Gillesland, Y. Rafe Mutron, Egremond, $Y$. Thomas de Multon, $K$. Muschampe, Surrey. Pashiey, co. Berks. Scerloga, Wales. Scowlage. Scowrlage, $V$. William Soules, $V$. Wollaconbe, Wollacombe, co. Devon; the beiress $\mathrm{m}$. Stafford.

Arg. three bars gu. a label of five points az. Motzton or Multon, Baron of Gillesland, temp. Edward I; the label vert, Thomas Movlton, Gillesland, $Y$; the label sa. Thomas de Moulton, le Forestier, $B$.

Arg. three bars gu. in chief a mullet sa. Wollacombe, co. Devon, 1611. Arg. three bars gu. a mullet for diff. Wollcombe, Hemerdon and Ashbury, co. Devon; derived from a com. mon ancestor with the Wollacombes of Wollacombe.

Arg. three bars gu. a bend sa. Multon. Rosse. THORPE.

Arg. three bars gu. a bend engr. sa. Newelr. Rosse, $V$. Sire Johan de Ros, $N$. Thorpe, $V$.

Arg. three bars gu. on a bend of the last as many escallops or. Mencaster.

Arg. three bars gu. on a bend sa. as many escallops or. Mencaster, Essex. Sir Walter Moncaster, Essex, temp. Edward 1, V.

Arg. three bars and over all as many castles gu. Alyne, $V$.

Arg. three bars gu. over all as many towers triple towered or two and one. ALLEN.

Arg. three bars gu. over all a fleur-de-lis sa. Staveley.

Arg. three bars gu. over all a crosier in bend staff arg. head or. Gilbertine priory at AlviNGHADr, co. Lincoln.

Arg. three bars gu. over all a long cross in bend sinister .... Gilbertine priory at MALTON, co. York.

Arg. three bars dancetty gu. BAALUN or BaLduN, $V^{*}$. Bassetr, Cornwall, $V^{*}$. Bassetr, North Levenham, and Umberly, $V$.

Arg. three bars embattled on the top gu. Sir John BarRYs, $V$.

Arg. three bars embattled gu. BARRY.

Arg. three bars enarched in the middle gu. HENCKELI, London.

Arg. three bars engr. gu. William Crepyn, $C$.

Arg. three bars bumetty gu. Denne, Syeston, co. York.
BAR. 3 BARS.... cont.

Arg. three bars indented gu. Boline.

Arg. three bars nebuly gu. Champayne. Champney, Kent. Danmare. Linning, Scotland. Arg. three bars nebuly gu. on a bend sa. as many bezants. GOLOVER, $V$.

Arg. three bars wavy gu. Bassetr, $Z, 449$. Champaine. Robert de Chamipanie, $A$, Harl. MS. $6 \mathrm{L37}$, fo. 90 . Champney. Sir Johan de Chatumpayne, $N$. Dalby. Drummond, Cargill; and Stobhall, Scotland. Garmon. Polmervy.

Arg. three bars wavy gu. on a bend sa. as many mullets or. CHISSELI or CHUSSELL.

Arg. three bars sa. AFFLECI, Dalham Hall, Suffolk, quartering Dolben, Mulsho, Aston, Vincent, Bernak, Paas, Dive, Wigtoft, Proctor, etc. Atjchenleck, that Ilk, co. Angus; the co-heirs $\mathrm{m}$. in 1499 Cunningham of Craigends, and Boswell. Bushe or Busse, Heather, co. Lincoln. BusHY or BusHey. Bussey. Le Sire de Bussy, $Y$. John Bussy, $S, Y$. Sire Huge de Bussye, $N$. Careswell. Frogenhati, Faversham, Kent; on the cloisters of Canterbury cathedral. HogesDon or Hogsdon. Hotham, co. York. Houghton, co. Lancaster, $V$. Houghton. Marshail, Head. ingly, co. York. PoLKInghorne, Polkinghorne, Cornwall ; the heirs m. Williams and Glynn. Porter, $V$. Raymond, Marpole, co. Devon; and Langley Park, Kent. Raymond, Saling Hall, Essex. Raymond, Valentine House, Essex; Baronetcy 3 May, i 774 . Trevery, $V$. Arg. three closets sa. ANCHILECK, Scotland. Arg. three bars and a crescent sa. Haughton. Arg. three bars sa. a bend erm. Finchant, Cam. bridge, and Norfolk. Fyncham, Norfolk, $V$.

Arg. three bars sa. over all on a bend gu. as many escallops or. SPRUSE or SPREUER, $V$. Spreuse, $V^{*}$.

Arg. three bars sa. over all a cotton hank or. CotTon.

Arg. three bars sa. over all as many cotton hanks or. Cotron, $W$. HaWARD, co. Gloucester, $\boldsymbol{V}$.

Arg. three bars sa. on a pale of the second as many plates. Sмrтtн, co. Hereford; and co. Hertford; granted 1563.

Arg. three bars sa. a maunch gu. Hugh de MAGNEBY, $P$. Hugh MANBY, $Y$. John de ManBy, $Y$.

Arg. three bars humetty sa. Byncks. Lamott, London, formerly of Flanders, 1633.

Arg. three bars indented sa. SHIrFord.

Arg. three bars nebuly sa. Sir Rauf BASSET, $J$. ECLESFIELD.

Arg. three bars nebuly sa. a bend or. Poore, co. Oxford.

Arg. three bars voided sa. BURKTon, Norfolk.

Arg. three bars voided sa. over all a lion ramp. gu. MAYTr.

Arg. three bars wavy sa. Sir Rauf Basset, $J$.

Arg. three bars vert. Frie. Fnxs, V. Grinsteed, co. Dorset. Sotjthatr. Virtue, co. Berks.

Arg. three bars vert over all a lion ramp. gu. CASE, Barwick.

Arg. three bars nebuly vert on a bend of the first as many torteaux. Goulston, co. Hertford.

Az. three bars arg. Lucas Chani, $E$. Cramiborse. and Crambirme. Sir Rauf de Cramburne, $V$. Ilesley. Josley. Kawn, co. Chester. Lucas. 'T'AME. Lucas 'TANE, Essex, $V$. TANeY or TANy. TANner. Sire Johan TANy, $N$. Monsire de TANY, $Y$. John TANY, $Y$.

Az. three bars humetty arg. Hutron, co. York. 
BAR.

3 BARS.... cont.

Az. three bars nebuly arg. Mantin, co. York. MARTYN.

Az. three bars wavy arg. Browning, $V$. Browning, Cowley, co. Gloucester. Bulbeck. Delamare. Martyn, Stanton, Suffolk and co. York. Saiford. SandFord. Henry de Sandford, Bishop of Rochester, 1227-35. SANDFord, Ireland; certified May 1779. WestLake, Kirlihampton. Cistercian Abbey at Woburn, co. Bedford.

Az, three bars wavy arg. over all a bend gu. Halswell, Halswell and Wells, co. Somerset.

Az. three bars nebuly erm. Sir .. de Holcam, $V$.

Az. three bars or. College of St. Mary at Maidstone. Seymour, Ireland. Spygurneli, $V$. TAME. Tany.

Az. three bars or a label gu. Merton.

Az. three bars or a bend arg. Stanhowe,

Az. three bars or over all a bend compony arg. and gu. LeIGH, co. Chester.

Az. three bars dancetty or. LoNgden. Loveday, Essex. Sire Richard Loveday, $N$. Loveday, Suffolk, $V$. LOWDEN.

Az. three bars nebuly or. FaINFond.

Az. three bars vairy erm. and gu. Brewes.

Erm. three bars wavy arg. Moreis.

Erm. three bars az. Colter or Coulter, Scotland. Offeweil. Oswell, co. Devon; the heiress m. Orwey. Tyrreis.

Erm. three bars az. a bend gu. Fromantrum, $V^{*}$.

Erm. three bars az. a bendlet gu. Fromiantrel, $V$.

Erm. three bal's gu. Fotheringham, Pourie, Scotland. Henry Heuse, A, Harl. MS. 6137, fo. 91. Sire Henry Husee, $N, V$. Monsire Thomas Husee, $X$. Le Sire Husee, $Y$. Thomas Husee, $Y$. Henry Hussi, A. Martin, Ireland. WhISHIRTS.

Erm.three barrulets gu. EDEFYn, co. Worcester.

Erm. three bars dancetty gu. Barlo.

Erm. three bars humetty gu. Abriscourt, co. Oxford. Dabrichcourt or Dambreticourt, $V$. Dabridgcourt, Strathfield, co. Hants, $16 * 9$. Sir John Dapscourt, T. M. Nicol Dabrichcourt, $S$. Sanseti Dabrichecourt, $S$.

Erm. three bars nebuly gu. Folior.

Erm. three bars or. NoRrington.

Erm. three bars humetty or. Abriscoort, co. Oxford.

Erm. three bars sa. Barley. Emerick. Francies. Francois. Francoys, $V$. Ratkes.

Erm. three bar's nebuly sa. Mares, $V$.

Erm. three bars wavy sa. BaILEY. BarLey. Barlo, Essex.

Erm. three bars wavy sa. a crosier in pale or. Augustiuian Abbey at Missenden, co. Buckingham.

Erm. three bars vert. FazakenLEy, Fazakerley, co. Lancaster. Fitz-AkerLey, co. Lancaster. Gaskeli or Gasilll, co. Lancaster. Vale.

Erm. three bars nebuly vert. FASAKYR, $V$.

Ermines three bars nebuly arg. William Mones, $V$.

Ermines three bars nebuly sa. BarLey, co. Hertford, $V$. Mores, $V^{*}$.

Gu. three bars arg. Sir Richard Bellinghan, Essex; temp. Edward I, $\boldsymbol{V}$. Bensted, $V$. Berlingham. Categny. Foxley. Karkenton or Karkington. Kirkenton, $V$. Thomas de Moleton, $E$. Thomas de Molton, $F, J$. Le Sire de Moulton, Fraunkton, 1 . Puser, Pusey, co. Berks, quartering Bovverie.
BAR. , 3 BARS.... cont.

Gu. three bars dancetty arg. Basset, co. Devon, $V$. Catenham, $V$. Tottenham, Ballyduff, co. Waterford, temp. Queen Elizabeth; Tottenham Green, co. Wexford. Totrenham, Baronetcy 1780, now Loftus, Marquis of Ely. TotTenHam, New Ross, co. Wexford; Ballycurry, co. Wicklow ; and Glenfarn Abbey, co. Leitrim.

Gu. three bars embattled on the top edge arg. Monsire Robert Barre, $S$.

Gu.three bars embattled arg. Barry, Roclaveston Manor, co. Nottingham.

Gu. three bars eugr. arg. Giffard.

Gu. three bars humetty arg. Heligsal or Helingsale. Helingsade, $V$. Lawfulit. Pigmeyne or Pigveney.

Gu. three bars voided arg. BARry, co. Devon. BENSTED.

Gu. three bars wavy arg. CHore, Abingdon.

Gu. three bars wavy arg. on a beud sa. three bezants. Golofer or Golofry.

Gu. three bars chequy arg. and az. BAnRy, Devon. Gu. three bars compony arg. and az. Barry. Morisire Thomas BARR, quartering barry of six or and az. a bend gu. $S$.

Gu. three bars compony arg. and sa. BARBEY or Barrey. Barre, $V$. Bayre. Barré.

Gu. three bars erm. Beverley. Gifiard or GIFFORD, Yester or Gifford Hall, Scotland. Margaret Huse's seal, 1243. Matilda HusE's seal, 1304. Monsire John de Kinketos, $Y$. Kirkenton, Kirkton, or Kerton, Kirton, co, Lincoln. Sir John KYRKETON or KYRKLINGTON, $V$. KYnkToN.

Gu. three bars dancetty erm. Catenham.

Gu. three bars humetty erm. Bedman.

Gu. three bars nebuly erm. Sir Walter Goldingham, $V$.

Gu. three bars or. Beaumont. Berry, Crediton; descended through BERry, Molland; from Berny, Berry Narbor, East Leigh, Lobb, etc., co. Devon. Ralph de Bury, Bury Narbor, temp. Henry III; the heiress, 1708, m. Kirkham. BLACKFORD Or BLAKFORD. BLAKEFORD, $V$. Cameron, Glendessary. Muschampe, Peckham, Surrey. Poynings. St. OWen.

Gu. trois barres d'or diaspres. Le Counte de le IluE or del Ille, $C$, and Harl. MS. 6589, p. 48.

Gu. three bars dancetty or. MANDUT or MANDUYT. Gu. three bars humetty or. ABriscourt, co. Oxford.

$\mathrm{Gu}$. three bars wavy per fess wavy or and erm. over all a saltire of the first. CHeston, Mildenhall, Suffolk.

Gu. three bars vair. Castell. Le Sire de Castee, $Y$. Thomas Chaston, $Y$. Gemsted, $V^{*}$. Sire Andrew de Graunstede, $N$. Sir Andrew Gremsted, co. Somerset, $V$. Ingeham, $V^{*}$.

$\mathrm{Gu}$. three bars vairy arg. and sa. Frene.

Gu. three bars nebuly vert a chev. erm. RoLston.

Or three bar's az. Conan de AsHe (Port), Y. Ash. Conan de Ask, $P$. Aske, Aske, and Ousthorp, co. York. Constable, Halsham, co. York. Coyle, Ireland. Thomas Mandevine, $Y$. Mandevulue. Panbinge. Pembrdige, co. Salop.

Or three bars az. an annulet in the centre point for diff. Aske, Aske, co. York. Richard Áske, Aghton, co. York, 24 Henry VI, V.

Or three bars az. over all a lion ramp. gu. Mownes.

Or thrce bars az. a lion ramp. gu. crowned or. WILLEMSCotT, $V^{*}$. Sir Henry WILLMEscotT, cu. Gloucester, temp. Edward III, $V$. 


\section{BAR. \\ 3 BARS.... cont.}

Or three bars az. a bend gu. Elyand. Penbrug, $V$. QUaPLED, Quapelade, or QuaPPElad.

Or three bars az. on a bend engrailed of the field as many escalloys sa. SAXBY, Norfolk.

Or three bars az. over all an eagle displ. gu. beaked and armed or. Jernegan Fisz-HuOH, Tanfelde, $P$.

Or three bars az. over all an eagle with two heads expanded gu. WaLrond, Alboune, co. Wilts. Or three bars az. a saltire gu. DE Port, lord of Basing, co. Hants, the heiress $\mathrm{m}$. Saint John.

Or three bars wavy az. Samford. Stamford.

Or thiree bars gu. Bohun. Bournetr. Datbie or Dalby. Sir Brian Fitz-Aleeyn, N. FitzAlteyne. Martyn. Meschines. Mostone, Valone, Ireland, $W$. Movlton, $V^{*}$. Muschairp, $V$. Muschampe or Muschamp, Horsley, co. Surrey; the heiress $m$. Vesey, of Ireland. Sir William de Muschanrp, of Barmoor, Northum. berland, 1267, son of Stephen, third son of Thomas de Muschamp, Baron of Wooler; the heiress m. Ford, Strathearn, and Huntercombe. Mustian. Oldenburg, $Z$, 55.4. Raf de Seint. Owen, $F$. St. OWen. Penrise. Stowers.

Or three bars gu. surmounted by a bend az. Brandeston. Sir Hugh de Bravndeston.

Or three bars gu. over all on a bend sa. as many escallops of the first. Lightroot.

Or three barrulets gu. over all a saltire of the last. BEWIE.

Ortbree bars dancetty gu. Deyncourt. Delayare, co. Bedford. De la Mare, $V$. Mare or De LA M ARE.

Or three bars nebuly gu. Sir Salathiel Loveld, Baron of the Exchequer 1708. Lovel, Harleston, co. Northampton; the heiress, m., 1742, Badcock. Sire Johan Lovele, $J$.

Or' three bars wavy gu. BASSET, Baroness Basset. Basser, Hedington, the direct descendents of the Chief Justice. BASSET, Cornwall and Devon. Dansey. Dansie. Sire Johan LoveLL, $J$ : and perhaps William EDENDON or Edington, Bishop of Winchester, 1346-66.

Or three bars wavy gu. quartering or a liou's head erased within a double tressure flory counterflory gu. as a coat of augmentation. Drommond, Uxbridge, Middlesex; and Charing Cross, London. Drumand, Denham, near Uzbridge, Middlesex; and Drumtocby Castle, co. Perth. Drumuond, Cadlands, co. Hants. Drumand, Stanmore, Middlesex; all as descended from Drummond, Viscount Strathallan, slain in 1745, and attainted; the dignity was restored in 1824.

Or three bars wavy gu. Drcmond, Duke of Melfort (Earl of Perth, Baron Stobball, etc., temp. James II); quartering or three bars wavy gu. and as a coat of augmentation az. a lion ramp. arg. within a double tressure of Scotland, for DRummond of Melfort, with Montefichet, D'Audibert, and De Berenger.

Or three bars wavy gu. a mullet surmounterl of an anrulet. Drummond, Carlourie, Scotland.

Or three bars wayy gn. over all a naked man naiant in pale grasping in the dexter hand a sword and having bis sinister hand and feet in action all ppr. Drummond, Kildies, Scotland.

Or three bars wavy gu. with a scimetar in pale arg. hilt and pomel of the field. Drumsind.

Or three bars wavy gu. in the centre a buman beart counterchanged. Drumond, Cultmalundy, Scotland.

Or three bars sa. TORDEANE.
BAR. 3 BARS.... cont.

Or three bars sa. on an escucheon of the first a canton gu. Comrays.

Or three bars and two pales sa. BErmiey or Bermely.

Or three bars sa. a pile az. Growse.

Or three bars dancetty sa. Shelford. ShImFord. Or three bars nebuly sa. BLUnt.

Or three bars wavy sa. Lakington, Washbourne, co. Devon. Mountuoy. Vidler.

Or three bars vair. Acton.

Or three bars vert. BraY, $V$. FrIE. Fris or Frise. Sir Sohn Molgne, $V$. MoIGne or Moygne, $V^{*}$. Molton, Kent. Multon, St. Clare's, Kent.

Or three bar's vert a lion ramp. gu. DoRseley. Or three bars vert a bend gu. Puninge.

Or three bars vert a baton gu. Sir Michael PoYninges, L; Harl. MS. 6137 .

Or three bars vert over all an eagle displ. sa. Prannell or Pranele, Martin Wothy, $c 0$. Hants; London; granted 1584. Prannell, Rudsmill, co. Hertford. Henry Pranseli, Alderman of London, 1584, $W$.

Paly of six arg. and az. three bars gu. BurLey.

Per bend sa. and az. three bars or. Kenan, Scotland.

Per pale arg. and erm. three bars gu. Moulton, Plymouth, co. Devon; Visitation 1620.

Per pale or and arg. three bars nebuly gu. Monsire John Dandeseye, $S$. Danncey.

Per pale or and arg. three bars wavy gu. DANDESEY.

Sa. three bars arg. Eaton, Worcester. HaUghton. Richard de Hoghton, $X$. Sire Adam de Houghton, co. Lancaster, $y$. Monsire Richard de Hovghton, $S$. Hovghton or Haughton, Haughton, co. Chester; Petersfield, co. Hants; Lancaster, and Sussex. Hovghton, Alderman of London, d. 31 Dec. 1596. LEA, Lea, co. Lancaster. Porter, co. Warwick. Sir William Scharlow, $V$.

Sa. three bars arg. a label of three points gu. Richard de Houghton, $S$.

Sa. three bars arg. a mullet of the first. John de Hoghton, $X$.

Sa three bars arg. in chief a mullet of the last. Hodahton, Mayfield, Sussex.

Sa. three bars humetty arg. Rodeley.

Sa three bars nebuly arg. Estbury.

Sa. three bars wavy arg. ETHELfIELd.

Sa. three bars wary erm. Bayfierd, Bayfield.

Sa. three bars indented or. LOVELES, co. Berks.

Sa. three bars wavy or. LogIE, that Ilk.

Vair three bars gu. Beamont, $V^{*}$. Cany. Cancey. Castell. Caynes, co. Wilts, $V$. Kenis, $V$. Kenys. Keynes or Keyneto, T'arent, co. Dorset; temp. Henry I. Sir Robert de Keynes, $V$.

Vairy erm. and gu. three bars az. Bruce. De BREYs, co. Brecon.

Vairy gu. and arg. three bars or over all a lion ramp. of the second. Peverell.

Vert three bars erm. a lion ramp. az. Bagnali. Vert three bars humetty or. ABriscourt, co. Oxford.

3 BARS and in chief....

(Some of the following coats should probably be blasoned Barry..... and on a chief....)

\section{Annulets}

Arg. three bars az. in chief as many annulets gu. GRAY or GieY, Ireland; granted 1612. 
BAR. 3 BARS and in chief....cont. Annulets cont.

.... three bars az. in chief as many annulets gu. COOKE or COKE.

Farmbill, co. Gloncester.

Or three bars sa. in chief as many annulets gu.

VISNEL.

Sa. three bars and in chief as many annulets gu. Moston. Moulton, $V^{*}$. SirJohn de Multon, $Y$.

Sa. three bars arg. in chief as many annulets or. SEYHARK, $V^{*}$. SEYNEES, $V^{*}$.

SEYNCRS, SEYNKES, or SCYNKS.

Sa. three bars and in chief three annulets or. Multon.

\section{Beast (Dog)}

Arg. three bars gu. in chief a greyhonnd courant. Sкrpwith, Skipwith, Hever, and Ormesby, co. Lancaster ; Showers, Norfolk.

Arg. three bars gu. in chief a greyhound courant sa. collared or. KерWITH, co. Warwick. Skipwith, Prestwould, co. Leicester, Bart.

Gil. three bals arg. in chief a greyhound in full course per pale or and erm. collared az. Skipwith, St. Alban's, co. Hertford; granted 1507.

$$
\text { .... (Lion) }
$$

Or three bars az. in chief a demi lion issuant double queued sa. Sutrie, Adinston, Scotland.

Erm. three bars az. out of the uppermost a lion issuant .... Fruen, London.

Erm. three bars and in chief a lion ramp. issuant gu. Freyne, $V^{*}$.

Gu. tbree bars arg. in chief a liou pass. or. Hemslex, Queen's County, Ireland. Heirsey.

$\mathrm{Gu}$. three barrulets erm. in chief a lion pass. guard. or. HruL.

Or three bars az. in chief a lion pass. gu. on a chief of the second three mullets gold. STEILLYs, Scotland.

Or three bars and a lion pass. in chief gu. Ormenod, Ormerod, co. Lancaster; quartering LEGH ; the heiress m. Hargreaves. Ormenod, Chorlton, co. Chester, and Tyldesley, co. Lancaster. Ormenon, Tyldesley, co. Lancaster, and Sedbury Park, co. Gloucester; derived from Ormelod of Ormerod, 1588; quartering JoHnson of Tyldesley, Wareing of Walmersley, Crompton of Hacking Hall, and Nutall of Walmersley. Oruerod, Huntspill; visitation of Somerset, ]623.

Sa. three bars .... and in chief a lion pass arg. Cyfferwest, Cowarne.

$$
\text { ..... (Wolf) }
$$

Arg. three bars gu. in chief a wolf courant az. Reskymer or Roshyder, Reskymer, Cornwall; the co-heiress m. Trelawney, Mohun, Courtenay, and Lower. Roscomouns, $V^{*}$.

Arg. three bars gu. in chief a wolf pass. az. Reshinner, Hailsford, Cornwall. Roscomours, $V$.

\section{Beasts}

Erm. three bars and in chief as many lions gu. KNyut, Knill, co. Herefurd.

Bird (Eagle)

Az. three bars wavy erm. in chief an eagle displ. betw. two ducal coronets or. KingFord, Youlkston, Cornwall ; granted 169].

$$
\text { ....(Martlet) }
$$

Or three bars wavy and in chief a martlet betw. two crescents gu. Drummond, Edinburgh.

Paly of six arg. and az. three bars sa. a martlet or. Mildi:
BAR. 3 BARS and in chief.... cont.

\section{Birds (3 Martlets)}

Arg. three bars az, in chief as many martlets gu. Sir William PayneLL, $I$.

Arg. three bars gu. in chief as many martlets az. MolTon, Norfolk.

Arg. three bars sa. in chief as many martlets of the last. CACEL. Carrill, Tangley Park, Surrey. Carrill, Bentons, Sussex; the coheirs m. Viscount Molyneux and Lord Morley. Carrill or Carrell, Harting, Sussex. Richard CARryli, created Baron Carryll by King James II at St. Germaius: all descended from Sir John Caryul, Warnham, Serjeant at Law to Henry VIII.

\section{(Owls)}

Sa. three bars and in chief as mauy owls arg. WAKEFELD, $V$. WAKEFIELD, Kingston-uponHull, co. York. WAEEFLELD, $V^{*}$.

\section{Canton}

Arg. three bars gu. a canton erm. Apesiey, Surrey and Sussex. Apeele. John Aspelle, V. Molton. Motton.

Arg. three bars and a canton gu. Briggs. Bryggs. Fuller, Roselill Waldren; and Aslldown House, Sussex; quartering Frayton, Eliott, Parker, and Parier of Ratton. Fulier, Tanners Waldren, Sussex. William Futwer, Bishop of Limerick, and of Lincoln, ob. 1675. Fulwer, London. Fulwer, Sandridge Court, Surrey. Hollenshed. Multon, $V$. Arg. three bars gu. a canton sa. EToNe.

Arg. three bars sa. a canton erm. MARShaLL, Fiskerton, co. Lincoln.

Arg. three bars nebuly sa. a canton gu. KeBLe, West Creting, Old Newton; and Stowmarket, Suffolk.

Arg. three bars wavy sa. a canton erm. KeByLL.

Arg. three bars and a canton sa. Branche, Westmorelaud. Branshath, Bramspath, Branspeth, or Branspauche. Branspath, co. Westmoreland, $\boldsymbol{V}$. Braunspath, $V^{*}$.

Gu. three bars and a canton sinister arg. Fuller, Ireland.

Gu. three bars arg. a canton erm. WALSHE, $V$.

Gu. three bars arg. a canton or. Marshall, Abbot's Anne, co. Hants.; Visitation, 1634.

Or three bars az. a canton erm. Newman.

Or three bars gu. a canton erm. Robert Caunsfeld, 1386 ; Vincent's Baronage, p. 180. Ganfield. Gaulfield. Gaynsford. Martyn. Sr... de Martyn, $V$. Moujden, Stalenborough House, Kent; and co. Lancaster.

Or three bars nebuly gu. a canton erm. LOVEI, $V^{*}$. Or three bars gu. a canton sa. BRIDGEs, Norfolk. Ur three bars nebuly sa. a canton gu. Folvilue, co. Leicester.

Sa. three bars and a canton arg. Burton, Lindley, co. Leicester. Haughton. Marshali, co. Hants. Rothington, $V$.

Sa. three bars arg. a canton or. MarshaLr, Abbots Anne, co. Hants; Visitation, 1634.

Vairy arg. and sa. three bars gu. a canton erm. ASPLEY.

on a Canton.... Beast (Lion)

Arg. three bars wavy az. on a canton gu. a lion pass. or. HoLites.

$$
\ldots(0 x)
$$

Gu. three bars arg. on a canton of the second a bull pass. of the first. Irane.

$$
\text { ..... Beasts (Lions) }
$$

Or. three bars arg. on a canton arg. two lions pass. gu. Routhe, $V$. 
BAR. 3 BARS.... cont.

on a Canton cont. Bend

Gu. three bars arg. on a canton erm. a bend of the field. WELCH or WELSF.

Gu. three bars arg. on a canton erm. a bend lozengy of the first. WALshe, $V$.

Gu. three bars arg. on a canton erm. a bend lozengy or and of the first. WaLSHaLL.

Gu. three bars or on a canton erm. a bend lozengy az. and or. VALEHEY.

Or three bars gu. on a canton erm. a bend engr. of the second. Stephen WaLEYs, $V$.

$$
\text { .... Billets }
$$

Or three bars az. on a canton arg. five billets sa. INGLOS.

$$
\text { .....Bird }
$$

Arg. three bars az. on a cariton of the second a martlet or. LATHEBURY, $V$.

$$
\text { .... Book }
$$

Arg. three bars gu. on a canton of the second a book or. Fulwar, Cork, Ireland ; granted 26 Feb. 1635.

$$
\text { .... Castle }
$$

Arg. three bars gu. on a canton of the last a tower (or castle) or. Fuliter, Isle of Wight. Fulter or Fulwer, co. Hants; Visitation 1634.

Gu. three bars arg. on a canton of the last a tower triple-towered sa. Drale, Feversham, Kent.

$$
\text { .....Crescent }
$$

Arg. three bars sa. on a canton of the second a crescent of the first. BuckTon, Hull, co. York.

Arg. three bars voided sa. on a canton of the last a crescent gu. Burkton, Brome, Suffolk.

$$
\text { ....Cross }
$$

Erm. three bars gu. on a canton az. a cross engr. arg. Huttoft, $V^{*}$.

Erm. three bars gu. on a canton az. a cross engr. betw. four pheons arg. Henry Hutroft, co. Hants, $V$.

Erm. three bars gu. on a canton az. a cross engr. arg. betw. four pheons or. HutтoFts, co. Hants; and Salisbury, co. Wilts.

Arg. three bars gu. on a canton sa. a cross formy or. Ecton.

Or three bars gu. on a canton erm. a cross formy of the second. GarfeILD, Tuddington, Mid. dlesex. Garfielid.

Az. three bars or on a canton gu. a cross patonce arg. AtTon, $V$.

Or three bars az. on a canton gu. a cross patonce arg. De Aton, Baron 1324.

$$
\text { .....Fess }
$$

Arg. three bars az. on a canton or a fess and in chief three lozenges of the second. StaINFORTH.

Arg. three bars az. on a canton or a fess betw. six lozenges sa. Stainforth.

Arg. three bars az. on a canton or a fess sa. in chief three mascles of the last. STAMFord, Hadley, Middlesex; granted 2 May, 1542; and co. Stafford.

Or three bars az. on a canton arg. a fess sa. in chief three mascles of the last. Crever, co. Hertford, 1684 .

$$
\text { .....Flenr-de-lis }
$$

Arg. three bars az, on a canton gu, a fleur-de-lis or. MarRIOT.

Arg. three bars sa. on a canton of the second a fleur-de-lis or. Meryett.

Per pale arg. and gu. three bars counterchanged on a canton of the second a rose crowned or. Barrett, Castle-Barrett, co. Cork.

\section{BAR. 3 BARS....cont}

on a Canton cont. Flower

Sa. three bars arg. with the augmentation of a - canton or thereon impaled the rose of England and the thistle of Scotland. HoghtoN, Hoghton Tower, co. Lancaster, Baronetcy 1611, quartering BoLD.

$$
\text { ....5-Foil }
$$

Arg. three bars gu. on a canton az. a 5-foil or. Pipare, $V *$. Raufe Pipart, $V$.

$$
\text { .....Fountain }
$$

Or three bars wavy gu. on a canton arg. a fountain az. Drummond, Innermay, Scotland.

$$
\text { .....Hand }
$$

Arg. three bars az, on a canton gu. a gauntlet or grasping a broken sword of the first hilt aud pomel sa. Stamiond or Staunford, Rowley, co. Stafford; granted 25 June, 1544.

\section{.....Head (Beast) Leopard}

Arg. three bars gu. on a canton az. a leopard's head or. Allard, $V^{*}$.

$$
\text { ....tion }
$$

Or three bars az. on a canton gu. a lion's head erased arg. Thomas Cox, Physician to Charles II. Daniel Cox, M.D., 1730. Cox, Dunman. way, co. Cork, Bart. Cox, Chichester, Sussex, descended from Cox, Monmouth.

Or three bars wavy gu. on a canton arg. a lion's head erased enclosed by a double tressure flory counterflory of the second. Drommond, Maderty, Scotland; and with a crescent for diff. Drummond, Machary, Scotland.

Or three bars wavy gu. on a canton of the first a lion's head erased enclosed by a double tressure flory counterflory of the second. DRUMmond or Drumond, Scotland.

\section{.... (Monster) Dragon}

Arg. three bars sa. on a canton or a dragon's head erased of the second. Brawne, London and Surrey, 1604.

\section{.... (Human Figure)}

Gu. three bars erm. (another or) on a canton arg. a maiden's head ppr. Baretri, India.

$$
\text { ....Hnman Figure }
$$

Sa. three bars or on a canton gu. a demi woodman holding a club over the dexter shoulder gold. Wood, North 'Taunton, co. Devon.

Sa. three bars or on a canton gu. a demi woodman erased holding on the shoulder a club of the second. WOOD, co. Devon.

Arg. three bars gu. on a canton .... a man ppr. Wood, North Taunton, co. Devon.

$$
\text { ..... Insect }
$$

Or three bars gu. on a canton az. a harvest-fly displ. of the first. Muschampe, Cork, Ireland.

$$
\text { .....Mullet }
$$

Arg. three bars nebuly sa. on a canton gu. a pierced mullet or. BrokesBy, co. Leicester, $V$. ..... Saltire

Arg. three bars sa. on a canton gu. a saltire of the first. BranspetH, co. Lincoln, Harl. MS. 1436. Braunspath, $Y$. Brawne.

$$
\text { .....sword }
$$

Arg. three bars sa. on a canton gu. a dagger of the first. GAISFORD.

$$
\text { .... Wreath }
$$

Or three bars az. on a canton arg. a chaplet gu. Holmes, Gawdy Hall, Norfoll.

\section{Chief}

Arg. three bars az. a chief gu. NewbFry, London.

Arg. three bars wavy az. a chief gu. on a canton erm. a mullet of the second. Henry Barley, Abberly Hall, co. Hertford, $V$. 
BAR. 3 BARS and in chief.... cont.

\section{Chief cont.}

Arg. three bars wavy sa. a chief per pale erm. and gu. Barley.

$\mathrm{Az}$. three barrulets and as many endorses fretted in cross arg. a chief dovetailed or. Pickrord.

Az. three bars or a chief dancetty gu. THFOBALD, Archbishop of Canterbury, 1139.61.

Or three bars sa. a chief paly erm. and gu. Birdey.

Sa. three bars wavy arg. a chief or. WA'nin, St. Alban's, co. Hertford; and Slipton, co. North. ampton.

on a Chief.... Annulet

$\mathrm{Gu}$. three bars wavy arg. on a chief or an annulet betw. two bull's heads cabossed sa. through each of their nostrils an annulet of the last. Bulman, Northumberland.

\section{.....Beast (Greyhound)}

Gu. three bars arg. on a chief of the second a greyhound in full course sa. Siтrifith, co. Lincoln.

$$
\text { ....(Lion) }
$$

$\Lambda z$. three bars arg. on a chief of the second a demi lion ramp. issuaut gu. Egrenhall, $V$. EGRevale.

Az. three bars wavy erm. on a chief or a demi lion issuant sa. in the dexter chief a crescent gu. Smith, London.

Arg. three bars gu. on a cliief az. a lion pass. or. INQLEFIELD.

Az. three bars arg. on a chief or a lion pass. guard. gu. WALLERON, $V$.

Az. three bars nebuly arg. on a chev. sa. as many martlets or a clief gu. charged with a lion pass. guard. betw. two anchors gold. Fordian, $V^{*}$. FREMAN, $V^{*}$.

Az. three bars or on a chief arg. a lion pass. guard. gu. OxFord.

Erm. three bars humetty gu. on a chief az. a lion pass. guard. arg. CURRER.

Or three bars az. on a chief of the last a lion pass. of the first. Tregosse.

Or three bars sa. on a chief of the second a lion pass. of the first. Fuamsted, Ruston and Denton, co. Northampton.

$$
\ldots(0 x)
$$

Sa. three bars wavy arg. on a chief gu. a bull pass. or. Bullatan or Bullman. John Bulman, $V$.

$$
\text { ....(Wolf) }
$$

Arg. three bars gu. over all as many stag's heads cabossed or on a chief'sa. a wolf pass. betw. two plieons of the third. WOODWARD, co. Worcester.

Arg. three bars gu. over all as many stag's heads cabossed or two and one on a chief of the last a wolf pass. of the second betw. two pheons sa. Woodward, Dean, co. Gloucester.

$$
\text { .....Fleurs-de-lis }
$$

Or three bars gu. on a chief arg. as many fleursde-lis sa. Norman, Lord Mayor, London, 1453.

Or three bars gu. on a chief of the last three fleurs-de-lis of the field. Norman.

$$
\text { ..... Flowers }
$$

Arg. three bars wavy az. on a chief quarterly gu. and or in each of the first a lion of England in each of the last two roses counterchanged on an inescucheon erm. a sceptre gold. CoMpany of New French Merchant adventurers.

$$
\text { .....Foils }
$$

Arg. three bars dancetty sa. on a chief of the last as many 5 -foils or. Rigey.
BAR. 3 BARS and in chief.... cont. on a Chief cont.

\section{.... Heuds (Beast) Leopard}

Arg. three bars nebuly and a bend sa. on a chief gu. as many leopard's faces or. Chenent, $V^{*}$. .....Lion

Arg. three bars az. or a chief of the last as many lion's heads erased or. Hikjinge.

....Wolf

Gu. three bars arg. on a chief of the last as many wolf's heads erased of the first. WoLFe, $V^{*}$. WOLF, $V$.

\section{....Landscape}

Arg. three bars gu. on a chief embattled of the last the representation of a castle with broken walls of the field on a canton of the last a medal of Talavera or suspended from a red ribbon with blue edges. Fulder.

Gu. three bars or on a bend erm. a sphinx betw. two wreaths of laurel ppr. on a chief embattled a view of a fortified town with the word ACRE thereunder. Camsron, Fassifeln and Callart, co. Argyll ; and Arthurstone, co. Angus, Bart. ....Mullets

Arg. three bars sa. on a chief of the second two mullets of the first. HaUghton.

$$
\text { ....Pale }
$$

Az. three bars arg. on a chief of the second a pale betw, two gyrons (also called piles) of the first over all an escucheou gu. charged with a cross croslet fitchy as the barss Benedictine Abbey at WinchCombe or Winchelcomb, co. Gloucester.

\section{....Palets}

Az. three bars or on a chief of the first two palets betw. as many esquires based dexter and sinister of the second over all an escucheon arg. Sir Roger Mortimer, $W$., Roger de Mortymer, $E$; the escucheon erm., Roger de Mortiner, $E$; the escucheon or., Roger de Montenter, $F$.

Az. three bars or on a chief of the first two palets betw. as many esquires based dexter and sinister of the second over all an escucheon arg. five billets sa. three two and one. Henry de Mortiner, $F$; the escucheon arg. three nails points in base sa. Robert Mortimer, $V$.

Az. three bars or on a chief of the first two palets betw. as mary esquires based dexter and sinister of the second an escucheon arg. over all a bendlet gu. William de Mortimer, $E$.

Az. three bars or on a chief of the first two palets betw. as many esquires based dexter and sinister of the second an escucheon arg. over all a saltire gu. Gefrai de Montruer, $E$.

Gu. three bars or on a chief of the first two palets betw. as many esquires based dexter and sinister of the second over all an escucheon arg. Sir Hugh Mortimer, co. Hertford, $V$. John Montiuer, $E$.

Or three bars sa. on a chief of the first as many palets betw. two esquires based dexter and sinis. ter of the second over all an escucbeon gu. charged with three bars arg. Symon Burcay, $X$.

Sa. three bars or on a chief of the last two palets (sometimes blasoned billets or pellets) over all on an escucheon erm. two (auotber three) bars gu. BuRLEY.

Sa. three bars or on a chief of the first two palets betw. as many esquires based dexter and sinister of the last over all an escucheon arg. Rafe de Montiner, $F$; arg. charged with five billets sa. three two and one. Richard de Bors, $F$. 
BAR. 3 BARS and in chief.... cont.

on a Chief cont. Palets cont.

Sa. three bars or on a chief of the first two palets betw. as many esquires based dexter and sinister of the last over all an escucheon erm. Richard du Borse, E, Harl. MS. fi584, but corrected to Richard de Borler, E, Harl. MS., 6137.

$$
\text { ..... Saltire }
$$

Arg. three bars sa. on a chief gu. a saltire or. Watungton, Caldicott Hill, co. Hertford.

Erm. three bars wavy sa. on a chief gu. a saltire or. Wallington, Cheltenham and Peers Court, co. Gloucester.

$$
\text { .... Tops }
$$

Sa. three bars vert on a chief indented gu. as many tops arg. Topp. ..... Wheels

Gu. three bars arg. on a chief az. three catharine wheels or. Lexton, Kepwick, co. York. .... Wings

Az. three bars arg. on a chief of the last as many pair of wings conjoined gu. FIeming. Crescents

Arg. three bars gu. in chief a crescent sa. charged with another or. BERY, co. Devon.

Gu. three bars alg. in chief as many crescents or. Frampton, $V$. Framton. Molton, Francton. John Multon, Franketon, $Y$.

$\mathrm{Gu}$. three bars and in chief as many crescents or. Robert Frampton, Bishop of Gloucester, 168191.

Sa. three bars arg. in chief as many crescents or. Framipton, Upway, co. Dorset.

\section{Cross}

Az. a barrulet environed by an annulet betw. two bars and in chief a cross patty fitchy or. Holte, $V$.

\section{Crosses}

Az. three bars and in chief as many crosses patty fitchy or. Stow or Stowte, $V^{*}$.

Or three bars and in chief as many crosses patty fitchy az. STOwTE, $V$.

Or three bars and in chief as many crosses patty fitchy sa. Sirte, Lested Lodge; and Maidstone, Kent. Smyter, Boughton Monchelsea, Kent; granted 14 Sept. 1605.

$$
\text { Cups }
$$

Arg. three bars and in chief as mauy covered cups gu. HAUGHTON.

\section{Escallops}

Arg. three bars wavy az. surmounted of a lion ramp. or in chief two escallop shells of the second. Ficld, Heaton Hall, Helmesley Lodge, and Weston House, co. York, quartering Wilmer, Thweng, Bruce, etc.

Erm. three bars humetty gu. in chief as many escallops or. Dabridgecourt or Dabriscourt.

$\mathrm{Gu}$. three bars wavy or over all a dolphin embowed naiant arg. in chief three escallops of the second. Town of Poole, co. Dorset.

\section{Escucheon}

Or three bars gu. over all in the dexter point an escucheon erm. Sir .... de Martyn, $V$. Martin, Kent; and co. York. Marton, Capernwray Hall, co. Lancaster; derived from Paganus de Marton, Lord of East and West Marton, in Craven, quartering arg. on a cross gu. five escallops of the field within a bordure vert with arg. two chev. the lowermost rompu sa. between three chaplets gu.

\section{Estoiles}

Arg. three bars wavy and in chief two estoiles az. 'I'ESHMAKER.

\section{BAR. 3 BARS and in chief.... cont.}

\section{Estoiles cont.}

Az. three bars and in chief as many estoiles or. Pitss or Pytts, co. Worcester.

Or three bars wavy gu. in chief as many stars az. Drumand, Colquhalzie, Scotland.

Or three bars and in chief two estoiles sa. Wybergh, St. Bees, Cumberland; and Clifton Hall, Westmoreland, quartering ENGAYNe and HILTON.

\section{Fleurs-de-lis}

Az. three bars wavy arg. in chief as many fleursde-lis or. Movlt, co. Nottingham, granted 1686 .

Az. three bars erm. in chief as many fleursde-lis or. Denn, Temsford Hall, co. Huntingdon. Denne, Adsham, Kent. Denne, Denne Hill, Kingston, Elbridge, Bishopsbourne and Lydd, Kent; and Winchilsea, Sussex ; quartering az. three leopard's heads affronty couped at the neck or with arg. two flaunches sa. each charged with a leopard's face or.

Or three bars wavy az. in chief four fleur-de-lis sa. on a canton of the field a bend gu. charged with a crescent arg. RoBINson.

\section{Flowers}

Sa. three bars arg. in chief a rose or. HougHton, King's Clyff, co. Northampton; and co. Rutland. 5-Foils

Gu. three bars or in chief as many 5 -foils of the second. Emery, Kent.

Or three bars sa. in chief as many 5 -foils .... Emeris, Louth, co. Lincoln; seal.

Sa. three bars arg. in chief as many 5-foils of the last. Phillimore.

Sa. three bars or and in chief as many 5-foils.... EMERIs, Louth, quartering ATKinson, of Fanthorpe Hall; seal.

Sa. three bars and in clief as many 5 -foils or. Robert Filmer, East Sutton, Kent, $W$; granted 1570 ; Baronetcy, 1674. Head

Or three bars wavy and in chief a boar's liead erased gu. DRunimond, Pitkellanie, Scotland. Heads

Arg. three bars az. in chief as many lion's heads erased of the second. HICKLING.

Arg. three bars gu. in chief as many lion's lueads erased of the last. Love, Basing, co. Hants; Visitation, 1634 ; the heiress m. Beckford.

Az. three bar's or in chief as many lion's heads erased of the second. Hickuring, Green's Norton, co. Northampton.

\section{Lozenges}

Arg. three bars az. iu chief as many lozenges gu. Dalton. Flandrensis.

$$
\text { Mullet }
$$

Gu. three bars wavy arg. in chief a mullet of six points of the second. Basire or Basier. Mullets

Arg. three bars sa. in chief two mullets of the last. HolToN.

Arg. three bars sa. in chief two pierced mullets of the second a crescent for diff. Haughton or Hawton, London; Her. Off. c. 24.

Arg. three bars sa. in chief two mullets pierced of the last the horns barry of the first and second. Houghton, London.

Gu. three bars arg. in chief two mullets of the last. Rafe.

Or three bars vert. in chief as many mullets of the second pierced of the first. Kempsos or Kempston, co. Stafford; and Ardens-Graftun, co. Warwick. 
BAR. 3 BARS and in chief. .. cont. Pale

Arg. three bars dancetty sa. in chief a pale erm. ENDERBIE.

\section{Palets}

Az. three bars and in chief two palets or. Morisimer, Auchenbray.

Or three bars and in chief two palets sa. over all an escucheon barry gu. and erm. BURLEy, co. Salop.

Or three bars and in chief two palets sa. over all an inescucheon gu. BewLEY.

Or three bars and in chief two palets (sometimes blasoned pellets) sa. over all on an escucheon gu. three bars erm. Beverley. Borley.

Per pale or and az. three bars and in chief as many palets counterchanged over all an escu. cheon arg. HagLeY.

Arg. three bars with in chief two palets and as many gyrons dexter and sinister sa. over all an escucheon of the first. IKBOROUGH.

Az. three bars with in chief two palets betw. as many esquires based dexter and sinister arg. over all on an escucheon of the last a cross croslet gu. Benedictine Abbey of WinchComB, co. Gloucester, $V$.

Az. three bars with in chief two palets betw. as many gyrons or. Town of RADNOR.

Per pale or and az. three bars with in chief two palets and as many cantons counterchanged over all an inescucheon arg. HaGLEY.

Or three bars with in chief six palets sa. over all an inescucheon of the second. Beverley. Pile

Or three bars az. in chief a pile betw. a gyronny of two pieces of the second over all an escucheon elm. MoRtymer. Quarter

Or three bars gu. a quarter erm. Gansell. on a Quarter.....Beasts

Or three bars az. on a quarter arg.two lions pass. gu. Routh or Rowth.

$$
\text { .... Bend }
$$

Or three bars gu. on a quarter arg. a bend fusily gu. and of the first. GANFIELD, co. Leicester. .... Castle

Gu. three bars arg. on a quarter of the last a "torele" or castle sa. John DENE, $Y$.

$$
\text { ....Head }
$$

Or three bars az. on a quarter arg. a lion's head couped gu. Cox, Beamonds, co. Hertford.

\section{.....Pheons}

Erm. three bars gu. on a quarter az. a cross engr. arg. betw. four pheons or. Hutroft, $V *$. Henry Hutort, co. Hants, $V$.

$$
\text { Roundles.... (2 Plates). }
$$

Vert three bars erm. over all a lion ramp. gu. murally crowned or in chief two plates. Freniantle, Siranbourne, co. Buckingham, Bart.

\section{....(3 Bezants)}

Az. three barrulets arg. in chief as many bezants. Atrins, co. Stafford and London.

Az. three bars arg. in chief as many bezants. Atryns, Great Berlkhampstead. and Much Hadham, co. Hertford; and Clapham, Surrey, Bart.

$\mathrm{Gu}$. three bars or in chief as many bezants. GarBAND, co. Lincoln.

$$
\text { .... (3 Hurts) }
$$

Arg. three bars az. in chief as many hurts. Basset, $W$.

Arg. three bars gu. in chief as many hurts. Atrins, co. Hertford.
BAR. 3 BARS and in chief.... cont.

Roundles cont. (3 Ogresses)

Arg. three bars sa. in chief as many pellets. Humberston, Walkerne, co. Herts; and Norfolk.

$$
\text { ....(3 Plates) }
$$

Az. three bars arg. in chief as many plates. Nicholas Erington, $V$. Evington, $V^{*}$.

Gu. three bars vert in chief as many plates. Clarke, Middlesex.

Sa. three bars arg. in chief as many plates. Fitz-JoHn. Moston, Northumberland.

$$
\text { .... (3 Torteaux) }
$$

Arg. three bars az. in chief three torteaux. Alkins. Jolun Grey, Bishop of Norwich 1200-14. Arg. three bars gu. in chief as many torteanx over all a bendlet sa. Sir Walter de Chirchingham, $R$.

Arg. three bars nebuly gu. in chief as many torteaux. Amery or EMery, Little Baddow, Essex.

Or three bars gu. in chief as many torteaux. GORE. GOWER.

Saltire

Az. three bars arg. in chief a saltire or. George Foudras, $V$.

Az. (another gu.) three bars arg. in chief a saltire engr. or. Fondrass or FonNDE, France. Tops

Sa. three bars nebuly vert in chief as many playing tops arg. TopP.

\section{Trivets}

Arg. three bars sa. in chief as many trivets of the last. Revett or Rivetr, co. Cambridge; and Crettinge, Suffolk.

\section{BARS and in base.}

\section{Fleurs-de-lis}

Per fess or and gu. in chief three barrulets sa. in base as many fleurs-de-lis of the first. Stone, Kent.

3 BARS betw. or within.

(some coats, placed here in compliance with

a customary method of blason, will also

be found in the divisions to which they properly belong.)

\section{Beasts}

Az. three barrulets dancetty betw. two lions pass. alg. Delmar, Kentield, Kent.

Birds.... (3 Martlets)

Arg. three bars betw. as many martlets sa. Careill.

$$
\text { ....(3 swans) }
$$

Sa. three bars wavy betw. as many swans arg. Waters, Lenham, Kent.

$$
\text { .... (4 Martlets) }
$$

Arg. three bars humetty gu. betw. four martlets in pale sa. AldMen. Aldwen, co. York, $V$.

$$
\text { ....(8 Martlets) }
$$

Arg. three bars gu. betw. eight martlets or a bordure az. SoMervil.L.

Arg. three bars betw. an orle of martlets gu. Sire Rauf de Royinge, $N$. Royniger or Roynger, Norfolk.

Or three bars within au orle of martlets gu. Romyng.

\section{Bordure}

Arg. three bars embattled .... a bordure engr. az. over all an escucheon gu. Straiton, Montrose, Scotland.

Arg. three bars az. within a bordure gu. Augustinian Priory at Olveston, Ossulveston, or Owston, co. Leicester. 
BAR. 3 BARS betw. or within.... cont.

Bordure cont.

Arg. three bars gu. on a bordure az. eigbt dores or over all a tower triple towered of the first. Town of Morpeth, Northumberland.

Az. three bars or a bordure engr. arg. Andrew Hake, $X$.

Az. three bars or within a bordure erm. ARNeFord, $V$. ARNFord.

Az. three bars or within a bordure gu. Newborough.

Erm. three bars gu. within a bordure of the second. Fotheringham, Bandon, Scotland.

Gu. three bars wavy arg. within a bordure of the last. CHOKE.

Gu. three bars arg. within a bordure engr. or. Carfrae, Scotland.

Or tbree bars az. within a bordure (sometimes the bordure engr.) gu. Asise, co. York.

Or three bars az. a saltire counterchanged a bor. dure engr. gu. Diffort.

Or three bars az. over all a saltire counter. changed within a bordure invecked gu. DiPFord or DitForD, Londou.

Or three bars gu. within a bordure of the second charged with eight martlets of the field. Ronryng.

Or three bars wavy ga. within a bordure az. DROMMOND, Rickarton, Scotland, quartering arg. a lion ramp. az.

Or three bars wavy within a bordure gu. Drummond, Carnock, Scotland. Drummond, Hawthornden, Mid Lothian, Bart.; quartering Forbes as grand quarters : in the second and third paly arg. and gu. a saltire also paly counterchanged on a chief invecked az. a crescent of the field betw. two spur-rowels gold.

Or three bars wavy gu. a bordure of the last charged with eight crescents of the first. Drummond, Midbope, Scotland.

Or three bars wavy gu. within a bordure wavy of the second. Drummond, Logiealmond, Scotland.

\section{Closets}

Arg. three bars closeted gu. Bensted.

Sa. three bars erm. closeted compony or and arg. Honwood, co. Huntingdon, $V$.

Sa. three bars erm. closeted or. Horwood, co. Huntingdon.

\section{Escallops}

Arg. three bars gu. an orle of eight escallops sa. William and Robert Moulton, co. York; and London, 1571,W. Moulton, co. Gloucester; Kent; London; and co. York ; granted 1571.

\section{Estoiles}

Az. three bars raguly humetty arg. betw. as many estoiles or. TEshmiaker.

Arg. three bars gu. betw, eight estoiles sa. one three and one. LIONNEL.

Flaunches

Or three bars bumetty sa. betw. two flaunches gu. three garbs in fess counterchanged. FRYER.

\section{Flears-de-lis}

Arg. three bars betw. ten fleurs-de-lis az. four three two and one. HAILARD.

Arg. three bars betw. ten fleurs-de-lis az. three three three and one. HayLord. Sir.... de HAYLARD, $V$.

\section{3-Foils}

Gu. three bars humetty arg. betw. as many 3-foils or two and one. Palmer.
BAR. 3 BARS betw, or within.... cont.

\section{5-Foils}

Arg. three bars sa. betw. as many 5 foils gu. I'reIsb, Levethan, Cornwall; the heiress $\mathrm{m}$. Morshead.

Arg. three bars sa. betw, as many (? pierced) 5-foils per fesse gu. and sa. Treys, Cornwali. Keys

Az. three bars betw. eight keys or three two two and one. William Screen, temp. Richard II, Henry IV, and Henry V. Harl. MS. 980, fo. 300 .

\section{Leaves}

Sa. three bars engr. betw. ten elm leaves erect or. Elmsali, Thornhill, Wakefield, co. York, quartering Greaves. Mullets

Sa. three bars betw. as many mullets or. Wyburne, Cumberland.

\section{Plough}

.... three barrulets wavy betw. a plough in chief and two spearheads erect in base.... Norris, Basing Park, co. Hants.

\section{BARS betw, or within.... and in chief....}

\section{Beast}

Arg. three bars gu. a bordure compony or and az. in chief a greyhound courant sa. SkIPwirH, Stayne, co. Lincoln.

Arg. three bars gu. a bordure sa. in chief a greyhound courant of the last. SKIPwITH, Skipwith, Hever, and Ormesby, co. Lancaster ; and Snowers, Norfolk.

\section{Canton}

$\mathrm{Gu}$. three bars erm. betw. ten crosses formy or three three three and one a canton of the last. Hadsor, London.

on a Chief.... Fish

Sa. three barrulets wavy arg. betw. as many plates on a chief or two dolphrns erect and endorsed betw. as muny anchors az. Curteis.

$$
\text { ..... Palets }
$$

Az. three bars or on a chief of the first two palets betw. as many squires based dexter and sinister of the second all within a bordure erm. an escucheon alg. BLANCHFRONT.

\section{Estoiles}

Or three bars wavy and a bordure gu. in chief as as many estoiles az. Drummond, Monedie, Scotland.

\section{Roundles (Ogresses)}

Arg. three bars sa. within a bordure engr. of the second in chief as many ogresses. Allerton. (Torteaux)

Arg. three bars sa. a bordure erm. in chief as many torteaux. BloodwortH. Sir Thomas BLuDworth, Leatherhead, Surrey, Knt., Lord Mayor of London, 1666.

\section{Annulets} On 3 BARS

Arg. three bars az. in the centre two anrulets

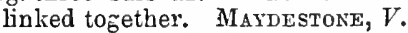

Or three bars bumetty sa. charged with as many annulets arg. Ambrose, co. Lancaster.

\section{Birds}

Gu. on three fesses wavy sa. as many birds arg. Menadarva or Mathadaria, Menadarva, Cornwall.

$$
\text { ....(3 Martlets) }
$$

Arg. three bars wavy az. on the middle one as many martlets or. PenNant, Lord Mayor of London, 1750 . 


\section{BAR. On 3 BARS.... cont.}

Birds cont. (3 Martlets) cont.

Arg. on three bars sa. as many martlets of the first. C CACEYLI.

Arg. on three bars sa. as many martlets of the first two and one. Carill, $Y$. Carill, $V^{*}$. ....(3 sheldrakes)

Arg. three bars wavy az. the one in fesse charged with three sheldrakes of the field. YswitTan WYDDELL.

\section{....(3 Swallows)}

Gu. on three bars wavy sa. as many swallows or. Mathadarda, the heiress m. Beville.

$$
\text { ....(5 Martlets) }
$$

Arg. on three bars gu. five martlets in saltire or. WARDE, Pilton, co. Devon; confirmed $21 \mathrm{Jul}$;, $1614 ;$ Her. Off. London, c. 24.

$$
\text { ....(6 Martlets) }
$$

Az. on three bars arg. six martlets gu. three, two, and one. Crambura or Crambury.

$$
\text { ....(9 Martlets) }
$$

Arg. on three bars sa. nine martlets of the field three three and three. Trehane, Trehane, Cornwall; the co-heirs m. Scawen, Kendal, and Verman.

Gu. on three bars wavy arg. nine martlets sa. three three and three. MarLand, Kent.

Gu. on three bars wavy or nine martlets.... three three and three. MorLand.

\section{Bougets}

Arg. on three bars gu. six water bongets of the first two two and two. Strange, $V$.

\section{Buckles}

Erm. on three bars gu. as many buckles or, Fotmeringhant, Lawhill, Scotland.

\section{Crescent}

Or three bars dancetty gu. the first charged with a crescent and estoile arg. MaIR, Glassels.

\section{Crescents}

Az. three bars arg. on the upper bar two crescents of the first. CARFRAE, Edinburgh.

\section{Crosses}

Arg. on three bars gu. six crosses croslet or. Sir Richard Daudeley, $V$. Daundley, $V^{*}$.

Arg. on three bars gu. seven crosses croslet or. DaUndeleigh, $V^{*}$.

Arg. on three bars gu. nine crosses croslet or three three and three. SANDELBY.

Erm. on three bars gu. nine crosses patty or three three and three. Clereeck.

\section{Escucheon}

Or three bars gu. on the dexter point of the first bar an escucheon erm. Martye, $V^{*}$.

\section{Escallops}

Or on three bars wavy gu. as many escallops of the field. Drunmond, Blair, Scotland.

Erm. on three bars humetty gu. six escallops or three two and one. Sir .... DabRigecounte, $V$.

Erm. on three bars humetty gu. nine escallops or three three and three. Monsire John de Dabrichecourt, $S$.

\section{Fish}

Gu. on three bars wavy or as many shrimps of the first. ATSEA, $V^{*}$.

Or on three bars wavy gu. as many shrimps of the first. SEA.

\section{Foils}

Arg. on three bars sa. six 5-foils of the field three two and one with a crescent on a mullet for diff. Darrell, all Souls' College, Ox. ford.
BAR.

On 3 BARS..., cont.

\section{Flowers}

Arg. three bars sa. on the upper bar as many roses of the field. Darrell. Paul Dayrell, $V$. Pole. Pooley.

\section{Fruit}

Erm. on three bars humetty sa. fifteen wheatears or five and five. Stokes, $W$.

Sa. three bars humetty arg. on the uppermost as many mullets of the first. Sir Hugh Bossard, $O$. Saltires

Gu. three bars wavy or on each as many saltires sa. Mariand.

\section{on a Canton.....Bird}

\section{On 3 BARS and in Chief}

Arg. three bars sa. on the first a lion pass. gnard. betw. two martlets second three 5 -foils and third as many escallops all or a canton gu. charged with a bird wings expanded like the field. Thunston, $V^{*}$.

$$
\text { .... Saltire }
$$

Sa. three bars arg. on that in fess point three martlets az. a canton gu. charged with a saltire of the second. FYNCH; quartered by Tamworth, Harl. MS. 1436.

on a Chief.... Bars

Or three bars gu. charged with as many martlets of the field two and one on a chief az. two bars nebuly arg. Crimes or Crymes, Buckland Monachorum, co. Devon; Peckham, Surrey.

Or on three bars gu. as many martlets of the first a chief of the second charged with two bars nebuly arg. Grimes, London; granted 1575 .

$$
\text { .....Gun }
$$

Arg. three bars wavy sa. each charged with as many plates; on a chief gu. a culverine betw. two anchors or. Gonston, Essex and London.

\section{BARS}

(two bars gemel are counted as four bars)

Arg. four bars az. William FeYce, $V$. Sir Joln Horbury, 32 Edward I.

Arg. two bars gemel az. Pearse or Peeres.

Arg. four bars az. over all a lion rump. gu. STRATFORD.

Arg. four barrulets az. over all a griffin segreant or. BARWELL.

Arg. four bars gu. Firz-Arured, Ireland, $W$. SONLEY or SOULIEY.

Arg. four bars gu. over all a lion ramp. or ducally crowned per pale of the second and third. Brandon.

Arg. four bars gu. over all a lion ramp. sa. crowned or. Wasthouse.

Arg. four bars gu. over all a bend az. Mulcaster, Charlwood, Surrey; Visitation 1662; derived through Mulcaster, Carlisle, from MulCaster, Taperham, temp. William II. Mulcaster, Charlton Place, near Canterbury.

Arg. two bars gemel and $a$ bend gu. Bylesdon.

Arg. four bars gu. a bend sa. CHaworth.

Arg. four bars gu. over all a cross croslet sa. GOWER, co. York.

Arg. four bars gu. over all a fleur-de-lis sa. Staveley.

Arg. four bars gu. over all a saltire or. MaUbanie, co. Dorset, $V$.

Arg. four bars nebuly gu. Dolseby.

Arg. four bars wavy gu. over all a saltire or. Malbank, co. Dorset. Malbouck.

Arg. four bars wavy gu. over all on a bend sa. three bezants. Sir Jolin Golafre, ob. 1442, tomb in church atFy field, co.Berks. GaLoren, co.Oxford. 
BAR.

4 BARS.... cont.

Arg. four bars sa. Treryge, $V$. Treyge.

Arg. four barrulets sa. GOLDFORD.

Arg. two bars gemel sa. CARE swelt. Sire Johan de Guldeford, $N$.

Arg. two bars gemel sa. over all a lion ramp. gu. Adam de Monhaut, $E$.

Arg. two bars gemel sa. over all a lion salient gu. armed and langued az. Monmouth, Monmouth Castle, temp. Henry III.

Arg. four bars sa. over all a lion ramp. or. Cocker, Croft, co. Lincoln.

Arg. four bars dancetty sa. DoLrsa, Worth, co. Dorset.

Arg. four bars counter-embattled sa. an escucheon gu. Straiton, Laureston, Scotland. Straton, Scotland.

Az. four bars arg. Demamarche or Delamarch. Thomas de la Lond, $V$.

Az. two bars gemel arg. Syperwast, $V$.

Az. four bars or. City of SALISBURY, or NEW SARUM; Visitation, 1565 .

Az. four bars dancetty or. ORLYANS.

Erm. four bars gu. SouLSBY, Hallington Hall, Northumberland; Bessingby, Bridlington, co. York. SUlbIE. Sir John Sulby, K.G., $V$. SulLY, K.G., $o b .1388$.

Erm. two bars gemel gu. Huntercombe. Sire Wauter de Hontercombe, $N$. Honterecombe, $K$. Wat de Honterimumbe, $G$. Sir Wauter de Hountercombe, J. Walter Hunterconi, $V$. Rauf de Huntercomb, $E$. Le Sire de Huntercombe, $Y$. Walter de Huntercombe, $Y$. Sire Walter Huntercombe, $G, I$. Sir Wauter Huntrocoump, $H$.

Erm. four bars or. WENTIAS, $V$.

Erm. two bars gemel sa. Huntercomb, $E$. Huntercombe.

Gu. two bars gemel arg. John BARRY, $Y$.

Gu. two bars gemel and a bend arg. Monsire Thomas WALSHE, $S$.

$\mathrm{Gu}$. two bars gemel and a bendlet arg. WaLshe, co. Leicester. WELSH, Worslip, co. Leicester. WESHE, $V$.

Gu. two bars gemel arg. on a bend of the second a lion pass. sa. FarNebr.

Gu. four bars arg. over all a bend or. SockwelL.

Gu. two bars gemel arg. on a bend or a lion pass. of the first armed and langued az. Farneby, Kent.

Gu. four bars dancetty arg. Totenham, $V$.

Gu. two bars gemel or. Roald de RicHDiond, $Y$.

Or four bars as. Asie, co. York. Pembridge.

Or two bars gemel az. Fueshing.

Or four bars az. over all an eagle displ. gu. GaRNEGAN, temp. William I, $V$.

Or four bars dancetty az. OrLyans.

Or four bars nebuly az. PaUly.

Or four bars gu. Fitz-Alured, Ireland.

Or four bars sa. on three escucheons arg. as many church bells of the second clappers of the first. HaLl, Essex.

Or two bars gemel sa. GULFORD or GUILDEFord, co. Stafford and co. York.

Or four barrulets wavy sa. a bend arg. Poole, co. Oxford.

Per pale arg. and gu. four bars counterchanged. Barrett, Essex.

Per pale or and arg. four bars wavy gu. AnutesLy, co. Gloucester.

Per pale or and az. four bars counterchanged. Brans, $V$.

Paly of six arg, and sa. four bars gu. Barré.
BAR. 4 BARS.... cont.

Quarterly gu. and vert in each of the last two bars wavy arg. Peverell.

Sa. two bars gemel arg. Kirkrand.

\section{BARS and in Chief}

Beast

Erm. four bars az. in chief a demi lion ramp. issuant ppr. FreweN, Ilmer, co. Buckingham; and Northiam, Sussex; descended from Richard Frewen, bailiff of Worcester, 1473. Accepted Frewen, Bishop of Liclifield, etc., 1644; Archbishop of York, 1660.64. FREWEN, Brickwall House, Northiam, Sussex; and Cold Overton Hall, co. Leicester.

Erm. four bars gu. in chief a demi lion ramp. issuant gu. Sir .... de FrEYNe, $V$.

Erm. two bars gemel gu. in chief a demi lion ramp. issuant of the last. Freyne.

Arg. two bars gemel and in chief a lion pass. gu. Faringe, Lucas de Feringes, $A$. Richard Feringes, $A$.

Az. two bars gemel and in chief a lion pass. guard. arg. Wat de Neivile, $E$.

Az. two bars gemel and in chief a lion pass, or. Tregos, Hylford, Cornwall. Tregoze, Goring, Sussex, temp. Edward II and III, the heiress $m$. D'Oyly. Henry Tregos, $F$. Henry Tregoz, A.

Az. two bars gemel and in chief a lion pass. guard or. Tregos, $Y$. Henry 'Tregoz, $E$. Sir Rauf Tregoz, $V$. Sire Henri Tregoz, $N$. Sir Henry Gragor, temp. Edward I, $V$. Tregoz, Sussex, $Y$.

Az. two bars gemel and in chief a lion ramp. or. Sir Henry TREGOZ, $X$.

Erm. four bars and in chief a lion ramp. gu. Frenye.

$\mathrm{Gu}$. four bars and in chief a lion pass. guard. or. Sir .... de SpYgornele, $V$.

$\mathrm{Gu}$. two bars gemel and in chief a lion pass. guard. or. SpRIGnell, Highgate, Middlesex; confirmed 10 Sept. 1639 . TREGOZ, $E$.

Or two bars gemel gu. and in chief a lion pass. guard az. TREGOZ, $Y$.

Or two bars gemel and in chief a lion pass. gu. John TrEgoz, $A, J$.

Or two bars gemel and in chief a lion pass. guard. gu. John Tregos, $D$. Tregosse or Tregoz, E. Jon Tregous, F. Tregos, Sussex, $Y$. Geoffry Tregoz, $C$. Sir John Tregoz, $H, Y$.

\section{Beasts}

Arg. two bars gemel and in chief two lions pass. gu. FARINGE.

\section{Canton}

Arg. four bars gu. a canton of the first. INGLEFIELD.

Arg. four bars az. a canton gu. Hотнuм, Hothum, co. York, temp. Edw. II.

Arg. four bars and a canton gu. FATRFAX, Deeping Gate, co. Lincoln.

Gu. two bars gemel arg. a canton erm. Thorniey, London.

Gu. four bars or a canton arg. FECBuRy or FeKSBURy.

$\mathrm{Gu}$. four bars and a canton or. FECBURY or Fensbury.

Or four bars sa. a canton arg. TaLLant.

on a Canton.... Bend

Arg. four bars gu. on a canton of the first a bend fusilly of the second. WALSHE, $V$. 
BAR. 4 BARS and in chief.... cont.

on a Canton.... Bend cont.

Arg. four bars gu. on a canton erm. as many fusils in bend of the second. Waleys, co. Dorset.

\section{.....Billets}

Gu. two bars gemel or a canton arg. billetty sa. InGLOYs, Norfolk.

\section{.....Crescent}

Gu. two bars gemel or on a canton sa. a crescent of the second. Briggs, Haughton, co. Salop. ...5. Foil

Arg. four bars gu. on a canton of the second a 5-foil of the first. Beckinghai, $V$. Bekinghair, $V^{*}$.

Arg. two bars gemel gu. on a cauton of the second a 5 -foil of the first. Beningham, $V$. ....Garb

Arg. four bars nebuly gu. on a canton of the second a garb of the first. Becre, $V *$.

\section{Chief}

Az. two bars gemel and a chief or. CypHerwast, $V^{*}$. Sir Nicolas Menel, $I$. Sir Nichole de Menil, $J$. Sire Nicholas de Mexnel, $N$. Mexnili, $V^{*}$. Nevill. De Sifrewast, $E$. Richard de Sipherwast, $E$. Syferwast, $V$. De Syffrewast, $F$.

Erm. two bars gemel and a chief gu. John Drchaunt, $X$. Robert Drchant, $Y$.

Erm. two bars gemel and a chief or. John de la Vale, $Y$.

Gu. two bars gemel and a chief arg. THornel, $V$. Bryan Thonnehm, $Y$. Monsire Bryan de ThornhmL, $Y$. ThornhmL, Thornhill, co. York; the heiress m. Saville. Thonnhil, Riddlesworth Hall, Norfolk; and Fixby Hall, co. York; derived from Thorzhill of Thornhill, 1734 .

Gu. two bars gemel arg. a chief of the second charged with a mascle sa. for diff. THORNHmL, Stanton, co. Derby; descended from Thornhill of Thornhill.

$\mathrm{Gu}$. two bars gemel arg. a chief indented erm. INGPEN, Galaker, co. Hants, 27 Edward III; Visitation, 1634.

$\mathrm{Gu}$. two bars gemel and a chief arg. over all a bend sa. ThornhLL, $V^{*}$.

Gu. two bars gemel and a chief arg. over all a bendlet sa. THоRNHшL, $V$.

Gu. two bars gemel or a chief arg. Pichiond, co. York.

Gu. two bars gemel or a chief erm. INCKPEN, Golaker, co. Hants.

Gu. two bars gemel or a chief indented erm. HinkPenN, $r$. InCKPEN or InCKPENy, White. house, co. Hants. INCKPEN or INKPEN.

Gu. two bars gemel or a chief invected erm. INKPEN, $V$.

Gu. two bars gemel and a chief or. Richrond, Highead Castle,Cumberland, temp. Henry VIII; and Catterlen, the heiress, $m$. Hutchinson. Ronald de Richeirond, $P$. Poald de Richenond, $Y$. Thomas de Richemont, $K$. Roiaunt de Richemund, $E$. Roald de Richmond, $V$. Monsire Rohaine de Richmont, $Y$. Sire 'Thomas de Rugemiond, N. Roald. Rowald. Rugemond or RugeMONT.

Gu. two bars gemel and a chief or over all a crosier arg. Premonstratensian abbey of $\mathrm{S}$. Agatha at EAsBx, co. York.

Gu. four bars a chief and over all a crosier or. Benedictine priory of S. Martin at RICHMOND, co. York.
BAR. 4 BARS and in chief.... cont.

Chief....cont.

Or two bars gemel gu. a chief indented arg. Hare, Norfolk.

Sa. two bars gemel and a chief arg. Walter de Melsanbx, $X$.

on a Chief..... Barnacles

Arg. four bars wavy az. on a chief gu. three pairs of barnacles or. Snith, Suffolk. .....Beast (Leopard)

Erm. two bars gemel az. on a chief gu. a leopard pass. guard. or spotted sa. IsHerwood, Windsor, co. Berks; granted 1764.

$$
\text { ....(Lion) }
$$

Arg. four bars gu. on a chief of the last a lion pass. or. Osberne Gifford, A, Harl. $M S$. 6137 ; but arg. two bars gemel gu. on a chief of the last a lion pass. or. Osberne de GIFFORD, $A$, Ashm. MS. 1120.

Erm. two bars gemel az. on a chief gu. a lion pass. guard. or spotted sa. IsHerwood, Windsor, co. Berks ; granted 1764.

$$
\text { .... Buckles }
$$

Arg. two bars gemel gu. on a chief of the second tbree round buckles or. STRIPLING, London; granted 4 May 1663.

$$
\text { ....Castle }
$$

Gu. two bars gemel arg. a bend of the last on a chief of the second a tower az. Thornhml, Barbadoes; and Kent.

$\mathrm{Gu}$. four barrulets or on a chief sa. a tower arg. THoRNHILI, Kent.

$$
\text { ..... Escallops }
$$

Gu. four bars arg. on a chief or three escallops of the first. HASARD, co. Gloucester.

$$
\text { ....3-Foils }
$$

Gu. two bars gemel arg. on a chief of the last five 3 -foils az. three and two. NEALE.

$$
\text { ..... Heads }
$$

Aig. two bars gemel gu. on a chief az. three leopard's heads or. Wright, co. Oxford; granted 11 Feb. 1686.

$$
\text { ..... Lozenges }
$$

Az. two bars gemel arg. on a chief of the second three lozenges gu. Sterling. Sir Thomas Sterlyng, $V$.

\section{.... Mullets}

Sa. two bars gemel arg. on a chief of the last three mullets of the first. MEDLEY, co.Warwick.

Sa. four bars arg. on a chief of the last three pierced mullets of the first. MedLer, co. York, $V$. Midlex, $V$.

Sa. two bars gemel arg. on a chief of the last three pierced mullets of the first. MedLex, $V^{*}$. MIDLEY, $V^{*}$

$$
\text { ....Wheels }
$$

Sa. two bars gemel or on a chief of the second three catharine wheels of the first. MIDGEIEx, Midgley and Clayton, co. York.

$$
\text { Chess-rook }
$$

Or four bars sa. in chief a chess-rook betw. two mullets of the last. MarshaLL, Blewbery and Windsor, co. Berks.

\section{Cross}

Or two bars gemel gu. in chief a cross of the second. LABorer or LABruer.

\section{Crosses}

Or two bars gemel gu, in chief two crosses couped of the second. LABORER, $V$.

Heads (Beast)

$\mathrm{Az}$. two bars gemel arg. in chief three lion's heads erased of the last (another or.) Newarke, Akham, co. York. 
BAR, 4 BARS and in chief.....cont.

\section{Heads cont. (Monster)}

Sa. two bars gemel or in chief three griffin's heads erased of the second. Mrsters, London.

\section{Mullets}

Arg. two bars gemel az. in chief three mullets gu. Bridle hall, Bridleshali or Bridleshaw, co. Lincoln and co. Lancaster. Sire Gilberd de Briddeleshale, $N$. Sir Gilbert Buddeleshali, co. Lincoln, temp. Edward I, $\boldsymbol{V}$.

Arg. two bars gemel and in chief three pierced mullets sa. Meduey, Iver, co. Buckingham; descended through Meduey, Buxted, Sussex, (the heiress m. Evelyn), from Benedict MEDLEY, Clerk of the Signet to Henry VIII.

Piles

Or four bars wary alternately gu. and vert three piles issuant from the chief sa. CALDwell, Caldwell, Scotland.

Or four bars wavy alternately gu. and vert three piles issuant from the chief sa. each charged with a fountain ppr. CALDWELL.

Roundles.... (Ogresses)

Arg. two bars gemel sa. in chief three ogresses. Hildeslex, $V$, Hildesley or Hilsley, Cromers Gifford, co. Oxford; Brinton Benam, co. Berks ; and Kingston, Surrey.

Or two bars gemel sa. in chief three ogresses. Itsley or Illshey. Ilsley, Ilsley, co. Berks.

4 BARS betw. or within....

\section{Anchor and Beast}

Arg. two hars gemel az. in clief an anchor sa. betw. two martlets respecting each other vert and in base a lion pass, guard. gu. FYDELL, Morcott, co. Rutland.

Arg. four bars sa. in chief an anchor of the last betw. two martlets respecting each other vert in base a lion pass. guard. gu. Fidoe.

\section{Birds}

Arg. two bars gemel betw. three eagles displ. sa. SPENCER, London.

\section{Bordure}

Gu. four bars arg. on a bordure of the last eight martlets sa. M ARLEy, Ireland, quartering or a chevron .... . betw, three martlets ...., with arg. three lambs....

\section{Escallops}

Arg. two bars gemel betw. three escallops gu. Dene, quartered by Hadley. Dyne, Westfield, Sussex.

Gu. two bars gemel betw, three escallops alg. Rawlinson, Cark, in Carknell, co. Lancaster; Carke Hall, $Z, 452$; granted 1662. Rawlinson, Lord Mayor of London, 1706. Rawlinson, Greenhead, co. Lancaster; the coheirs m. Crackenthorpe and Moore. Rigge, Wood Broughton House, co. Lancaster.

\section{Flowers}

Sa. two bars gemel betw. six roses arg. three two and one. Lethbridge, co. Devon.

\section{Heads (Beast) Boar}

Or two bars gemel gu. betw. three boar's heads couped sa. JFNkıNson, Norfolk.

Or two bars gemel gu. betw. three boar's heads erased at the neck sa. JENisinson, Tunstal, Norfolk; and Oulton, Suffolk.

$$
\text { ..... Deer }
$$

Arg. two bars gemel betw. three buck's heads cabossed sa. Jermin, Wickham Bishop, Essex; granted 9 Aug. 1664.
BAR. 4 BARS betw, or within.... cont.

Heads (Beast) cont. Deer cont.

Az. two bars gemel arg. betw. three buck's heads erased or all betw. two flaunches of the last. Parker, Warwick Hall, Carlisle. Parker, Petterell Green, Cumberland.

$$
\text { .... Leopard }
$$

Az. two bars gemel arg. betw. lhree leopard's heads or. Cromy.

$$
\text { ....Lion }
$$

Az. two bars gemel betw. three lion's heads erased arg. Newarke, Dalton.

$$
\text { .... Tiger }
$$

Or two bars gemel gu. betw. three tiger's heads sa. two and one. Jenkinson, $W$.

\section{Monsters}

Az. four bars arg. betw. three sea horses or over all on a chevron crenely of the last five gouttesde-poix. ToOKER.

\section{Mullets}

Arg. two bars gemel az. betw. three mullets gu. BRIDESHaLL, co. Lincoln.

Arg. two bar's gemel sa. betw. three mullets gu. JUMPER.

\section{BARS betw. or within....}

and in chief....

Arg. two bars gemel gu. betw. three columbines az. stalked and leared vert on a chief sa. three duck's heads erased of the first. WISE, I'horn. bury, co. Gloucester.

\section{On 4 BARS}

Arg. four bars bumetty gu. on the second a leopard's head or. HALL.

\section{BARRUIETS}

Arg. five barrulets gu. over all a lion ramp. crowned and sustaining a battle axe or. ALEXANDER.

Arg. five barrulets sa. over all a lion ramp. or. Cocker, Crompton, co. Leicester.

Az. five barrulets arg. over all twelve martlets in orle gu. Conte de Pembrok, $G$.

Erm. five barrulets gu. Harris, co. Hants. Whiтchurch, co. Hants.

Erm. five barrulets gu. over all three escucheons or two and one. HalHEad. HaLL, Ipswich, Suffolk, confirmed 8 Fel., 1587; Coggeshall, Essex; and co. York. With a mullet for diff., HaIL, Barkham, co. Berks; and co. Oxford.

Or a barrulet betw. two bars gemel gu. over all three escucheons vair. GaliolLE, temp. Edward III.

Or a barrulet betw. two bars gemel gu. over all six escucheons vair three two and one. GamoLL.

5 BARRULETS and in chief....

Arg. five barrulets and a canton gu. Cosard, Cosard, co. Hants.

Gu. five barrulets and a canton or. BERBURA.

\section{BARRULETS betw. or within....} Birds

Al'g. five barrulets gu. betw. three martlets in chief and as many tilting spears paleways in base az. M'CAIZIEN.

\section{Bordure}

Arg. five barrulets gu. on a bordure az. ten mart. lets or. MerLey.

\section{BARRULETS.}

Arg. six barrulets az. Walter de Munchanecr, $E$; but William, Harl. IIS. $613 \pi$.

Arg. six barrulets az. over all three lions ramp. gu. Rauf de Woneburh, $E$. 


\section{BAR. 6 BARRULETS.... cont}

Arg. six barrulets and over all a bend az. Mulchester.

Arg. six barrulets az. over all a bend gu. GaUnt. Arg. six barrulets az. over all three chaplets gu. Rauf Fitz-William, $G$.

Arg. three bars gemel az. Ceiferwast. Sir John Cyfrewast, $V$. Monhault, co. Lancaster. Pipard, Larkbear, co. Devon; the heiress $\mathrm{m}$. De Lisle. SifERWAST.

Arg. six barrulets gu. Robert de Stotevire, $E$.

Arg. three bars gemel gu. Banry, Saint Dunstan's in the West, London, 1709: a junior branch about 1756 took the name of BARNET or BARNETT, Easingwold, co. York; and Blackheath, Kent; an elder branch now bears the name of BAYLEY, Allerton, co. York. Gerald Barry (Giraldus Cambrensis) Bishop of S. David's, 1199-1203. Benisted, Benington, co. Hertford. Caster, Norfolk. Forcer. Fountney or Fontenny. Monthaut. Moushall, co. Lancaster.

Arg. three bars gemel gu, over all a lion ramp. sa. Thomas Famfax, 1716. Sir Thomas Fairfax, Walton, $V$. FaIrFax, Torcester, Northumberland; Askam, Walton, and Gilling, co. York; created Viscount 1625. FAIRFAX, co. York.

Arg. three bars gemel gu. a lion ramp. sa. armed and membered az. FaIrFax, quartered by Erskine.

Arg. three bars gemel gu. over all a lion ramp. sa. crowned or in the dexter chief point a trefoil slipped az. FaLrfax, Caldeck, Cumberland.

Arg. three bars gemel gu. a bend az. Mulchester.

Arg. three bars gemel gu. a beudlet az. Mulchester, $V$.

Arg. three bars gemel gu. over all on a bend or a lion pass. of the second. Farnabr, Kippington, Kent, Baronetcy 1726; this was a coat then quartered by FARNABY, and is therefore inac. curately ascribed to LLOYD.

Arg. six barrulets gu. over all eight martlets in orle vert. Pairs or Patrick de ChaUns, $F$.

Arg. two bars sa. each closeted of the same. Sir Henry Bisbery, $V$. Bishbery or Bisbury. Guldeford, Cumberland and Northumberland.

Arg. three bar's gemel sa. Sire William Arcalon, $O$. John Carestille, $X$. William Caneswell, $V$. Monsire Pers de Carew, $S$. Caswall, quartering Towne, Pryor, Whiting, and Clarke. Caswerl, Hampton Court, Middlesex. Creswell, co. Hants, temp. Edward I. Ercali. KikKaton, Kinklay, or KirkLayne. Kirkeley or KiRKIAND. KiRILLAND or Kirkiey. Sir William KyrKalane, $V$. Le sire de lírkalon, $Y$. Richard Kirkalon or Kirkton, $Y$. Kyrkalon, $V$. Trevery, $V^{*}$.

Arg. three bars gemel sa. over all a lion ramp. giı. Mawde. Adam de Monhault or Monthaut, A. Monhault, West Riddlesden, co. York, Visitation, 1584 . Adam de Monhaut, $E$. Monthalt, co. Lincoln. Monthault, temp. Edward III, $V$. Sire James de Mounaut, $N$. Adam de Munhaut, $Y$.

Arg. three bar's gemel sa. over all a lion ramp. gu. charged on the shoulder with a cross croslet fitchy or. Maude, co. York; Kendal, Westmoreland; and Blawith, co. Lancaster.

Az. three bars gemel or. Milnel or Milvel.

Gu. three bars gemel arg. Bense, Benst or Benstead.

Gu. three bars gemel arg. over all $a$ bend of the last. WALSHE, $V^{*}$.
BAR. 6 BARRULETS.... cont.

Gu. three bars gemel arg. over all a bendlet of the last. John W ALSHE, Onlep, co. Leicester, $V$.

Gu. three bars gemel or. Beast. BeE. Bense or Benst. BENSTED, $v$.

Or six barrulets az. BraUz.

Or three bars gemel az. Menel. Meynel. Nicholas Mrnelu, $V$.

Or three bars gemel gu. over all a lion ramp. sa. FAIRFax, Baron Fairfax.

Or three bars gemel sa. over all a lion ramp. git. charged on the shoulder with a cross croslet fitchy or. MawHOOD, certified May 1779.

Per chev. sa. and or three bars gemel arg. the bottom one passing behind the chev. point. AI.LERTON, $V$.

Per pale arg. and gu. six barrulets countercbanged. Barrett, Kent.

Sa. three bars gemel arg. Careswetr. Carsweli, co. Stafford.

\section{BARRULETS and in chief.... \\ Beast}

Az. three bars gemel and in chief a lion pass. or. Henry Tregoz, $A$.

Or three bars gemel and in chief a. lion pass. gu. Robert de TrEgoz, $B$, although the blason therein is gu. three bars gemel or in chief a lion pass. gu.

Beasts

Arg. threc bars gemel and in chief as many lions ramp. sa. WILlet, Walthamstow, Essex. Willet or Willett. Willetr, Combe, Portbill, and Tapeley, co. Devon.

Az. three bars gemel and in chief as many lions ....sa. Northin, London.

\section{Canton}

Arg. three bars gemel gu, a canton erm. Bardewelt. Berdwel. Berdewell, $V$.

Arg. six barrulets and a canton gu. James de Pantone, $F$.

Arg. three bar's gemel and a canton gu. Cowrield. Panture.

Arg. three bars gemel sa. a canton gu. TEnBY, $V^{*}$.

Arg. three bars gemel and a canton sa. BucKETon. Robert Buketon, $V$. Bukton, $V *$.

Gu. three bars gemel and a canton erm. Robert BafDEWFil, $V$.

Gu. three bars gemel or a canton arg. FirzOsborne, Suffolk.

Gu. three bars gemel or a canton az. BRIDGES.

$\mathrm{Gu}$.three bars gemel or a canton erm. BARDEWELL, $V$. Brigges or Briggs, Saul, Norfolk; and Haughton, co. Salop, created Baron 1641 ; the coheiresses m. Chandler, Brooke, and Chethan.

$\mathrm{Gu}$. three bars gemel or a canton sa. BrIGGs, quartered by Thompson. Brigas or BrYGGE, Norfolk.

Sa. tbree bars gemel and a canton arg. Buckton. on a Canton.... Beast

Arg. three bars gemel az. on a canton gu. a lion pass. of the field. Standon. Staundon, $V$.

Arg. three bars gemel gu. on a canton az. a lion pass. guard.or. Fountain, Bawcombe, co.Devon.

Arg. three bars gemel or on a caiton az. a lion pass. of the second. Fountayn, $W$.

$$
\text { .... Billets }
$$

$\mathrm{Gu}$. three bars gemel or on a canton arg. five billets sa. two one and two. INGELose or Ingloss. Inglehouse, $V$. Sir Henry Inglos, $V$. Inglish, Suffolk. Sir Ingo Lefes, $T$. 
BAR. 6 BARRULETS and in chief.... cont. on a Canton.... Billets cont.

Gu. three bars gemel or on a cantou arg. six billets sa. INGLISH, Norfolk.

$$
\text { ....Crescent }
$$

Arg. three bars gemel sa. on a canton of the gemel last a crescent of the field. Buckton.

Gu. three bars gemel or on a canton sa. a crescent of the second. Briggs, Haughton, co. Salop.

Sa. three bars gemel arg. on a canton of the second a crescent of the first. Bacton. Btckton or Buketon.

$$
\text { .....Cross }
$$

Arg. three bars gemel gu. on a canton sa. a cross patonce or. Sir John Erton, 3 Henry VI, $V$.

$$
\text { .....Lozenges }
$$

Or three bars gemel gu. on a canton arg. five lozenges in saltire of the second. HIrdie, Heveringland, Norfolk.

\section{Chief}

Arg. three bars gemel and a chief gu. Girrand.

Az. three bars gemel and a chief arg. CYFEn or

Syfer. Robert de Creseques or Cresignes, $C$.

Az. three bars gemel aud a chief or. MEIGNILI. or Mesnill. Menel. Monsire de Meneli, $Y$. Le Sire Menill, $Y$. Nicol de Menili, $E$. Tremon de Menyld, $B$. Mexneld, North Kilvington, and The Fryerage, near Yarm, co. York; derived from MENELL, of Hilton, 1203; quarteriug Catterich, Catterich (ancient), 'T'empest, Umfraville, and Salcocke. Sir Nichol de Meynill, $H, V$. Meynit, quartered by Darcy and by Lord Conyers, $U$.

$\mathrm{Gu}$. three bars gemel and a chief arg. THorkeli, Suffolk, $V$.

Gu. three bars gemel and a chief indented erm. Hyipden or Hympen, co. Hertford.

on a Chief.... Barrulet

Arg. three bars gemel az. on a chief gu. a barrulet dancetty or. John HAIDON, Sheriff of London, d. 1583. HAYDON, Boughwood, Ebford, and Cadhay, co. Devon, temp. Edward IV ; and Crewkerne, co. Somerset. HAYDON, Woodbury, co. Devon; London; and Surrey.

Arg. three bars gemel az. on a chief gu. a wivre (viure) or. Haidon, co. Devon.

$$
\text { .... Reast (Lion) }
$$

Erm. three bars gemel sa. on a cbief az. a lion pass. ar. Currer, Kildwick, co. York, represented by Currer, Eshton Hall, quartering Richardson. Curner, Clifton House, co. York, 1806 , quartering Roundell.

Erm. three bars gemel sa. on a chief az. a lion pass. guard. arg. Currer.

$\mathrm{Gu}$. three bars gemel arg. on a chief or a lion pass. sa. Malefaunt.

Arg. three bars gemel az. on a chief sa. a wolf pass. or. Burthogge, co. Devon.

\section{Heads}

Az. six barrrulets arg. on a chief gu. three leopard's heads or. Henry Burrele, $V$.

Az. three bars gemel and as many lion's heads erased in chief arg. Nemarie or Newharke.

Az. three bars gemel and as many lion's heads erased in chief or. WHITE.

\section{Quarter}

Gu. three bars gemel or a quarter arg. BARDWELL or BARDWELly .

\section{on a Quarter}

Gu. three bars gemel or on a quarter arg. five billets sa.two one and two. Joln INGLEHOSE, $V$. Sir Henry IngLose, $V$.
BAR.

7 BARRULETS

Arg. seven barrulets az. William de MunchanesY. $F$.

Arg. seven barrulets az. over all a chevron gu, Bartholomew de la More, $F$, or Mare, $E$.

Arg. seven barrulets az. over all three chaplets gu. Rauf le Fitz-Willian, $E$.

Or seven barrulets sa. Porchester.

\section{BARRULETS}

Erm. four bars gemel compony or and sa. Horwood.

Erm. four bars gemel sa. Tomkinson.

Gu. four bars gemel and a bend arg. Walleys, Alep, co. Gloucester. WeLsH, co. Gloucester.

Or eight barrulets gu. Sir ... Porchester, $R$.

8 BARRULETS and in chief....

\section{Canton}

Arg. four bars gemel sa, a cauton gu. TenBy, $V$. on a Canton

Az. four bars gemel or on a canton arg. a demi lion ramp. gu. Waldis, Dublin.

Chief

Az. four bars gemel and a chief or. Menela or Meyneli, co. York.

Gu. four bars gemel and a chief arg. Thornhill, Owston, co. Lincoln.

Gu. four bars gemel and a chief or. Sir Thomas de Richemond, $M$. on a Chief

Gu. four bars gemel arg. a chief of the last charged with five 3 -foils az. three and two. Pendock, Tollerton.

\section{BARRULETS}

Arg. three bars closeted gu. BENSTED.

Sa. three bars erm. closeted or. Horwood, co. Huntingdon. The six barrulets compony or and arg., Honwoon, co. Huntingdon, $V$.

\section{BARRULETS}

Arg. ten barrulets gil. over all a lion ramp. sa. Robert de Estotevile, A, Harl. MS. 6137, fo. 94.

10 BARRULETS and in chief....

Gu. in base ten barrulets wavy arg. and az. a demi horse ramp. issuant arg. TrEVILLIAN, $V^{*}$.

\section{BARRULETS}

Per pale arg. and gu. twelve barrulets counterchanged. BARrett, Ireland.

\section{BARRULETS and in chief....}

Az. six barrulets gemel and a chief or. Menelt or Meynell, co. York.

\section{BARROLETS}

Arg. seven barrulets gemel az. INGERSALEMr.

\section{BARRULETS and in chief...}

\section{Canton}

Sa. eight barrulets gemel and a canton arg. Buckton or Buketon, co. York. on a Canton

Arg. eight barrulets gemel az. on a canton gu. a lion pass. or. HAYLE.

\section{BARRULETS unnumbered}

Per pale or and arg. barruly wavy gu. Sire Richard de Auntesheye, $N$.

\section{BARRY of 4}

See also a Fess and in chief....

Barry of four arg. and gu. per pale counterchanged. Barrett, Bellhouse, Essex.

Barry of four counter-escalloped arg. and gu. each scale nailed sa. Armourer.

Barry of four az. and arg. Gonston. 
BAR. BARRY of 4 .... cont.

Barry of four gu. and arg. SAlkeld. Moure, co. Northampton.

Barry of four gu. and or. BRewse.

Bary of four or and az. Mortiner, first Earl of March.

Barry of four indented or sa. or and az. Richard Nitford, Bishop of Chichester 1389, Salisbury 1396.1407.

\section{BARRY of 5}

Barry of five eacb per fesse embattled (? formerly vaily) arg. and sa. Stratoun, Scotland.

\section{BARRY of 6}

Barry of six (?or) and (? sa.) Reginald Boulers or Buther, Bishop of Hereford 1451, Lichfield, etc., 1453-9.

Parry of six arg. and az. Aske, Chowhent, co. Lancaster. Baymond. Beauchampe. Conenor. Cotron. Henry de Grai, $K$. John de Gray, $E$. De Gray, $D$. Le S. de Graye, $T$. Richard de Graye, $A$. Sire Henry de Grex, $J$. Johau de Grey, $F$. John Grey and le S. Grey de Codnor, $S$. Reynauld de Grex, $G$. Sire Richard de Grey, $N$. Richard Grey, $Y$. GreY of Wilton, $Z, 341$. William Grey, Bishop of Ely 1454.78. Walter de GREY, Bishop of Worcester 1214-16. Sir Henry Grex, Codner, co. Derby, $V$. Richard Grey, Y. Grey, Southwick, co. Durham; Sir Arthur GREY, Wilton, temp. Elizaluetl. Earl de GREY, quartering Robinson. GReY, Earl Stamford and Warrington, quartering Booth. Newbald. Newbold. VACHELL.

Barly of six arg. and az. a fleur-de-lis or for diff. Grey.

Barry of six arg. and az. a label of three points gu. Grex, Sherland, $V$.

Barry of $\operatorname{six}$ arg. and az. on a label of three points gu. niue bezants. Gray. Grey, Saudiacre, $V$.

Earry of six arg. and az. label of five points gu. lieigraald de Graye, A, but Bernard, Harl. MS.6137, fo. 94. Reyoauld Grex, D. Renaud de GReY, E, but Edmund, Harl. MS. 6137. Sir Peignaula de Grex, $J$. Sir John Grex, Wilton, co. Hereford, $V$. Henri de Grex, $G$. M. Henry Grey de Wilton, $S$.

Barry of six arr. and az. a label of five points gu. on each point three bezants. Gner, KingstonMereward.

Burry of six arg. and az, a label gu. Sir Raignold de Gray, $H$. Sire Johan de Grer, $N$.

Barry of six arg. and az. a label gu. bezanty. Richard GreY, Sandiacre, $I$.

Barry of six arg. and az. indented the one into the other. Oliver Todenham, $E$.

Barry nebuly of six arg. and az. Symond Basset, A, Harl. MS. 6137, fo. 95. Browning, $V^{*}$. 1)ANMARE. Sir .... Gillbert, Baron of Sandford, $V$. Samford, $T$. Gilebert de Saunford, $F$.

Barry wavy of six alg. and az. Allen Basset, Lord of Wycombe, descendant of Thomias second and eldest surviving son of Chjef Justice Basset. Symond liasset, A. Jrowning, Cowley, co. Gloucester. Dansey, co. Heleford. Gilbert. Sir Gubert Baron of Samford, $V$. Gilebert de Sauniord, $F$. Sandford.

Barry of six arg, and elminois. Pallant, Redgrave, Sutfolk.

Bary of six arg. and gu. Lord BARRer, Ireland, V. B.ARny, Earl of Barymore. Barry, Lem lara, co. Corli. Batinx, Marbury Hall, co.
BAR. BARRY of 6 .... cont.

Chester; and Foaty, co. Cork, quartering gu. on a chev. or betw. three bezants as many crosses formy fitchy sa. quarterly with Heluz. Banky, Ballyclough, co. Cork, Lisnegar, near Rathcormac, descended from William de Barizx, who m. Augharad, daughter of Rhys-ap-Griffith. Barry or Bery, Winscot and Bendon, co. Devon. Bayouse, $V$. Multon. Roger Talebot, $A$.

Barry of six arg. and gu. per pale counterchanged Peat or Peit, Scotland. Peyto, $V^{*}$.

Barry of six arg. and gu. per pale indented counterchanged. Petoe or Peyto, Chesterton, co. Warwick.

Barry of six arg. and gu. per pale indeuted sinister collnterchauged. PeYTo, $V$.

Barry of six arg. and gu. per pale kavy counterchanged. PEAT, Scotland.

Bary dancetty of six arg. and gu. Walter de Balun, $E$. Balun, $V$. Basset, Typidy, $V$. Thomas Basset, Cornwall, $Y$. Basset, $Y$.

Barry bendy of sis arg. and gu. AnEry.

Barry of six arg. and gu. indented the one into the other. John TUdenhaM, $E$.

Barry nebuly of six arg. and gu. Laurence Bassett, $E, F$. Bassett. Robert de Champaine, $F$. Champayne. Sir John Champneis, $V$. Robert D'Aminare, $A$, Harl. MS. 6137 , fo. 94. Sir Richard Damerey, $Q$. Sir Jolın D'Amory, $V$. Danmare. Germon, Kent.

Barry nebuly of six arg. and gu. a crescent for diff. Jenico, $V$.

Barry nebuly of six arg. and gu. a label of three points az. Alten, co. Lancaster. Goldingham, Suffolk. Goldngton, Sussex.

Barry nebuly of six arg. and gu. a label of five points az. Pers AcHARD, $E, F$. The label or, Nicoll de Bape (? Bathe), E. The label sa., Robert de Amanri, $F$.

Barry wavy of six arg. and gu. Baps. John Basset, North Imffenham, co. Rutland, a descendant of Thomas second and eldest sur. viving son of Chief Justice Basset. Laurence Bassett, $E, F$. Bassett, co. Leicester. Robert de Champate, $F$. Robert de Champayne, $A$. Robert D'Aimiare, A, Harl. MS. 6137, fo. 94. Dalbie, Brookham, co. Warwick. Damerey. Sir Richard Damory, Q, Harl. MS., 6589. Daumary, $Y$. DannceY, or Dauncey, Dansey, Brinsop, co. Hereford. Dartois or Dartoys, Ireland. Dolby, Brizes, Essex. Loveld, co. Somerset. Valeignes, Kent.

Barry wavy of six arg. and gu. a label of five points az. Pers Achard, $E, F$. The label or, Nicoll de Bape (? Bathe), $\boldsymbol{E}$. The label sa., Robert de Amanri, $F$.

Barry of six arg. gu. and az. Brens.

Barry of six arg. and sa. Bussey, co. Lincoln and co. Cambridge. Sir Myles Bussey, $V$. Clifford. Frognall. Sir Raufe Hosterley, $V$. Hosterly. Oxon. 'Tanie. Sire Robert Touk, $N$.

Barry of six indented arg, and sa. Gise, co. Gloucester.

Barry of six arg. and sa. indented the one into the other (i.e. barry bendy lozengy). Gili, 1732.

Barry nebuly of six arg. and sa. Simon Bassett, $E$. Blount. Cherfield. Sir Gilbert de Ellesteld, $V$. Ellesfield, $V^{*}$.

Barry nebuly of six arg. and sa. a label of three points gu. Severton. 'T'he label of five points, H., or liuuf, Bassett, $E$. 
BAR.

BARRY of 6 ....cont.

Barry wavy of six arg. and sa. Ashfieid, co Oxford. Ashfield or Estrield, Suffolk. Simon Bassett, $E$. Ralph Basset ; descended from William Lord of Sapcote, youngest son of Richard and Mand. Eclesfiein. Elchefiesd, co. Oxford. Ellestield, $Y$. Stalton or STAYlToN.

Barry wavy of six arg. and sa. a label of three points gu. Sir Ralph Basset of Chedle, a younger son of Basset of Sapcote. The label of five points gu. H., or Rauf, Bassett, $E$.

Barry wavy of six arg. and sa. gutty d'eau. Mornis.

Barry wavy of six arg. and sable bezanty. John Basset, New Place, a younger branch of Chedle.

Barry of six arg. and vert. Harthell. Marshe. VANYS, $V$. Vigerous, quartering .... three pine-apples vert.

Barly of six az. and arg. Chann. Cham. De Gray, D. Richard Grey, $Y$. Poyntz.

Barry wavy of six az. and arg. Cistercian priory at Owbourne Bernard, i.e., Woburn, co. Bedford.

Burry dancetty of six az. and arg. Tonenhasr.

Rarry nebuly of six az. and arg. Kenel.

Barry of six az. and erm. V. co. Berks, quartering or a cbev. betw. three cocks sa.

Barry of six az. and or. Merton. Mons. Fitz Rafe de Multon, $Y$.

Barry of six three az. and three vairy gu. and erm. Brewes, Harl. MS., 6589. Reignold Brewes, $Y$. Reinold de Brewys, $Y$. John Gristey, $Y$.

Barry of six erm. and az. VAchel, co. Bedford; Colley and Windsor, co. Berks; and North Marston, co. Bucks.

Barry nebuly of six erm, and arg. Manes.

Barry of six erm. and ermines. Thomas Bradwandin, Archbishop of Canterburs, 1349. Bradwardye, $V$.

Barry of six erm. and gu. Baxbe. Beaunont, co. York. Carcy. Henri Hese, $E$. Husee, $V$. Hussey, co. Dorset; Essex; Suffolk; co. Salop; Sussex; and co. Wilts. Husser, Wyrley Grove, Lichfield, co. Stafford; quartering Fourke, Wybaston (?), and Jesson. Hussey, Nasb Court, co. Dorset; and Salisbury. Kirton, co. Lincoln. LavaLL.

Barry nebuly of six erm. and gu. Sir Geoffry Folyot, $V$. Folyot, $V^{*}$. M. Alezander Goldingharr, $S$. Lacy, co. Northampton and Northumberland.

Barry wavy of six erm. and gu. Forriot, co. Northampton. Folliot or FolitotT.

Barry of six. erm. gu. and az. Brewes.

Barry of six vairy erm. and gu. and az. William de Breuse, $E$.

Barry of six three per fess erm. and gu. three az. Griseley, $V$.

Barry of six erm. and sa. gutty d'eau. Thomas Bradwardin, Archbishop of Canterbury 1349.

Barry nebuly of six erm, and sa. SPENCER.

Baryy nebuly of six erm. and vert. FASAKYR, $V^{*}$.

Barry wavy of six ermines and arg. Morris.

Barry of six ermines and erm. Bradwarden.

Barry of six gu. and arg. Sir John BerLing Ham, co. Essez, $Y$. Kirketon or Kerketon, Kirketon, co. Lincoln, temp. Edward II. MoIGNe. Peser.

Barry nebuly of six gu. and arg. Goldingham. JENICO, $V *$.

Barry nebuly of six gu, and arg. a crescent for diff. JENico, $V^{*}$.
BAR.

BARRY of 6 ....cont.

Barry wavy of six gu. and arg. De Anmore, $L$, Harl. MS., 6137. HAMOND. Sir Richard HaMORY or de HamoRy, L, Harl. MS., 6589.

Barry of six gu. and erm. John BEAmonn or Beaumond, co. Devon, $Y$. Le Sire de Beamont, co. Devon, Y. Husser, in Farleigh Castle Chapel.

Barry nebuly of six gu. and erm. Nowers.

Barry wavy of six gu. and errn. LACY, Northumberland.

Barry of six gu. and or. Bery. Harcourt. Poyntz, co. Gloucester. John de St. Owen, E. Barry dancetty of six gu. and or. Thomas Baioun, $Y$.

Barry of sis gu. and vair. Beaumont, co. Devon. Thomas Coucy, $Y$.

Barry of six or and az. Constable, Tixall, co. Slafford; and Burton-Constable, co. York, Bart.; quartering Clifford. Constable, Halsham and Burton-Constuble, Holderness, co. York; quartered by Maxwell. Sir John Constable, Halsham, co. York, $V$. Robert Conestable, Holderuess, $Y$. Le Conestable de Holderness, $Y$. Copcotr or Copecott. Fitz-Eustace, Ireland, Viscount Baltinglas, quartering gu. a saltile or. Gawsell. Holderness, co. York. Oray or Oyry. Pembruge, $V^{*}$. Sir Fulke de Penbrugge, $V$. Henry Pembryge, $A$, or de Panebrigge, Harl. MS., 6137, fo. 95. Richiond.

Barry of six or and az. a label of five points (and with a bendlet instead of the label) gu. Henry de Penbrugge, $F$.

Barry wavy of six or and az. Basset, Cornwall. Claude.

Barry of six or az. and gu. Karnes, co. Leicester. Barry of six or and gu. Sir Bryan le Fitz ALeyn, $J$. Henry Fitz Allen, $A$. Bryan Fitz Alien, A, Harl. $M S ., 6137$. fo. 95. Bery. Chanard or ChanNard. Hoole. Part of the arms of Lautereurg, $Z, 871$. Owen. St. Owen, co. Salop; and Gerneston, co. Hereford. Seynt Owen, $V$. Richmond. Roger Talebot, $A$, Harl. MS., 6137, fo. 95.

Barry of six or and gu. in chief a label of five points arg. Stovin, co. York. The label sa., Stovin. Barry of six or and gu. bezanty. Connter.

Barry dancetty of six or. and gu. M. Piers de la MaRE, $S$.

Barry of six indented or and gu. MaIr, England. Barry nebuly of six or and gu. BaDcock. Philip Bassett, $D, E, F$. Sir Philip Bassett, $V$. Dolseby, London. Lovell, $V^{*}$. Le $\mathrm{Sr}$ LOVELl (de Lovel et HollaNd, $S$;) quartering az. flory .... a lion ramp. guard. arg. $T$. Lovelu, Baron Lovell, of Tichmersh, and Viscount Lovell. Mountroye.

Barry nebuly of six or and gu. a label of three points az. Lover., $V^{*}$. The label of five points, John Lovel. , $E, F$.

Barry nebuly of six or and gu. a label of five points $\ldots$ BAPE, $V$. With each point a\%, charged with three mullets of six points or. John Lover, $G$. John Lovel, of Tichmersh, Lord of Dakkyng, m. a daughter of Basset of Wycombe. Barry wavy of six or and gu. Atsoe. Ralph Basset, Chief Justice temp. Henry J. Basset, Cornwall. Basset, Heanton Court, Umberleigh, and Watermouth, co. Devon; descended from Jobn, elder son of Sir John Basset; quartering Davie. John BAsseT, Heanton P'unchardon, co. Devon, 1716. Phelip Basset, 
BAR.

BARRY of 6 ....cont.

$D, E, F$. DALBY, co. Leicester and co. Warwick. Dalby, Castle Donnington, co. Leicester. LoverL, Seigneur de Tichmarch, $Y$. Thebaude de Valoynes, ob. 1209, $P$, (but ? paly.)

Barry wavy of six or and gu. a label of five points az. John Lovel, $E, F$.

Barry wavy of six or and gu. a label of five points az. on each point three mullets of six points or. Johan Lovel, $G$.

Barly of six or and sa. EMErick, Norfolk. John Emeryke, $V$. EMrich or EMrike. MariotT. MaRRIOTT, co. Northampton. Marriott, Avonbank, co. Worcester; The Leases, co. York; derived from Augustine Marriot, of London, 1989. Marriott, co. Derby. Marriot. Maryet or Maryot, co. Berks; Preston, co. Gloucester; Bredfield, Sussex; and Whitechurch, co. Warwick. MENET or Menett. Sire Johan de Meriet, $N$. Meriet, co. Wilts, $V$. Meryott, co. Somerset. Pembridge or Pembruge, co. Leicester.

Barry of six or and sa. per pile counterchanged. William Engham, $V$. Sir Jolın Gros, $V$.

Barry dancetty of six or and sa. Roger Lovedai, $E$.

Barry nebuly of six or and sa. Stephen Blount, Ixworth, Sutiolk, the heir of the elder branch m. temp. Henry III, Mary Blount of Saxling. ham, Norfolk, heiress of the younger branch. Blount, Grendon, co. Hereford, descended, like Blount, Baron"Mountjoy, and Earl of Devonshire, from Sir Walter BLounT, slain 1403 at Shrewsbury, a son of Blount, Soddington, co. Worcester. Sir William Blount, co. Warwick, $V$. Edmund Blunt, Uxbridge, 1716. The Blount family used other coats also on seals, but this coat in war was preferred by BLount, Belton, co. Rutland. Blunt, London, since of Clery, co. Hants ; and Croydon, Surrey, Bart. Williarn le Blunt, E. Ellesfield, $V^{*}$. Mountjoy, co. Devon. Panley, co. Oxford.

Barry wavy of six or and sa. William BLount, $Y$. William le Blunt, $E$. M. John Blunte, T. Mountuoy.

Barry of six or and vert. Bray. Mowlton, Kent. Moygne, $V$.

Barry nebuly of six or and vert. Hawberk. Sir Nicholas Haweerke, V. Hawerk. Hawkirke.

Barry of six three per fess erm. and gu. three az. Griseley, $V$.

Barry of six sa. and arg. Haughton, co. Chester; and co. Lancaster. Robert Touke, $Y$.

Barry nebuly of six sa. and arg. LAWARD.

Barry wavy of six sa. and arg. Estbery.

Barry of six sa. and erm. Bradwarden or Bradwarder.

Barry of six sa. and or. Fintey. Logie, Scotland.

Barry of six sa. and or per pale counterchanged. Scurfield.

Barry of six vail and gu. Baxmont or Baymont, co. Devon. Sir Thomas Beamont, Cornwall, $V$. Beaumont, co. Devon. M. John Beaumont, $S$. Chinn, Hampton Park, co. Gloucester. Sire de Coсну, $D$. Ingelram de Coucy, Earl of Bedford, temp. Edward III, V, Z, 178. Robert de Coucr, E. Gaines. Ghisnes, Chokes, co. Northampton, 33 Henry III. Inglefieid. KeMISHE. KENNIS.

Barry of six vairy arg. gu. and az. BRrce.

Barry of six three vairy erm. and gu. three az. Giles de Braose or Brewse, Bishop of Hereford 1200-16. William de Breuse, $E, F$. Sir William Brewes, Brecon, $V$.

\section{BAR.}

BARRY of 8

Barry dancetty of eight (? arg.) and gu. John de Colenham, $Y$.

Barry of eight arg. and az. De la March. Feyce, $V^{*}$. Greenstrreet, $V^{*}$. Grey, Horbon or Horbyn, co. York. Knighton, Bayford, co. Herts. And with a label of four points gu., Grey.

Barry of eight arg. and gu. Fitz-Aluned, $V^{*}$. Fitz-Awry, Ireland. Baray, Ireland, $W$. Chaworth. Hungary, as borne by Margaret of AnJou, $Z, 299$; and by Mary of Lorraine, $Z, 5 \div 4$.

Barry of eight arg. and gu, a label of three points sa. GobIon, co. York.

Barry of eight arg. and gu. a label of five points sa. GoByns, co. York.

Barry of eight arg. and gu. indented the one in the other. John de 'Гudeнam, $Y$.

Barry of eight indented arg. and gu. John de Balun, $A$.

Barry of eight arg. and sa. Treryge, $V^{*}$.

Barry of ejght az. and arg. De la Lond, $V^{*}$. Queroualle.

Barry wavy of eiglit az. and arg. KenNell.

Barry of eight az. and or. Sir Conan de Aske, $V$.

Barry of eight erm. and gu. Kinton, co. Lincoln. Sulby, $V^{*}$.

Barry of eight erm. and or. Wentuas, $V^{*}$.

Barry of eight gu. and arg. Barry, $V^{*}$. Bury, co. Devon. Clynke.

Barry of eight gu. and or. Brian Fitz-Allen, Bedalle, $P, Y$. Sir .... de Yoinz, V. Sir Nicholas Poynes or Poyntz, $L$. Poyntz, $V^{*}$. Drogo Firz-Pons, temp. William I, his elder son Richard, of Clifford Castle, founded the Cliffords; and the younger, Osbert, that of Poyntz. Poynz, Iron Acton. Poyntz, Ryegate, Surrey; Midgham, co. Berks; and Cowdray Park, Sussex; the coheiresses m. Clinton, Spencer, and Cecil. Stedon. Stodow.

Barry bendy of eight gu. and or. Holuand, co. Lincoln.

Barry pily of eight gu. and or. VANCE, Ireland.

Barry of eight or and az. Fitz-Alan. Danske. Henry de Penebruge, $E$.

Barry of eight or und gu. Sir Brian le Fitz Alain, E. Sir Brian Fitz-Alan, Buron of Bedale, co. York, $y$. Brian FITZ-ALAN or FITZ-ALEYN, Lord of Bidall. Fitz-AlLan. Richard Beaumes, Bishop of London, 1108-28; and (with a crescent) Richard de Beaumes, Bishop of London, 1152-62. Sir Nicholas Pornz, Baron of Cory Malet, $V$. Hue Porntz, $K$. Sir Nicholas Poynes or Poyntz, L. Poynes, North Okingdon, Essex; and Alderley, co. Gloucester. Romely, Skipton, co. York, temp. Henry I.

Barry of eight or and gu. in the dexter chief point a inullet sa. Fitz.Alten.

Barry pily of eight or and gu. Horrand, co. Lincoln.

Barry of eight or and sa. Selby, The Mote, Kent, 1667. Sir Henry Selby, Knt., Serjeantat-Law, 1715. Charles SeLey, Bayhall, assumed the name of Amherst, d.s.p. 1745; the heiress m. Browne, now (1784) SElBy, Whitley, Essex, 1833. SEliby, Swausfield, Alnwick, Northumberland. Henry V, Duke of SAxONY, $Z, 69$.

Barry nebuly of eight or and sa. Blount, Tittenhanger, co. Herts. M. Walter Blount, $S$. Charles, co. Devon.

Barry wavy of eight or and sa. Pavely, co. Oxon. 
BAR. BARRY of 8 .... cont.

Barry of eight sa. and or. SELBy, Biddleston, Northumberland, temp. Henry III; quartering Perchay, Lounde, Fauconberg, Darcy, Tujte, etc. Selby, Baron de Selby, Denmark, descended from SELBY, Biddleston. SELBY, Winlaton, Durham; and Twizel, Northumber. land. SELBY, Earle, Nortbumherland, presumed to be a younger branch of Selby of Biddleston.

\section{BARRY of 10 .}

Barry of ten arg. and az. a label of nine points gu. ANGIE.

Barry of ten arg. and gu. Barry, Lord Barry, $Z, 350$. Thornell, Suffolk, $V$. Whinfieid.

Barry of ten arg. and gu. a label of five points az. Gobion, Gobion, co. Bedford; an heiress $\mathrm{m}$. Le Boteler, temp. Edward I.

Barry of ten arg. and gu. in chief a label of nine points vert. EwE, temp. Rich. I.

Barry of ten arg. and purp. Eve.

Barry of ten arg. and sa. Barrall.

Barry of ten az. and or. Dargie.

Barry of ten az. and or per pale counterchanged. BARNABAS or BARNETBY, impaling the reverse in St. Peter's Church, Barton-upon-Humber; Havl. MIS. 6829, fo. 84 .

Barry of ten gu. and or. Bokelton, Kent. Bokylton, $V$.

Barry of ten or and arg. (? az.) Mildes or Milds, Shelford, co. Cambridge.

Barry of ten or and az. Copcote.

Barry of ten or and gu. Fitz-Alien. Bekelton. Berry, Berrinkerber. Sir Nicholas Poyntz, $L$. Rian.

Barry of ten or and sa. Botevile, alias Thynne, co. Salop; quartering arg. a lion ramp. tail nowed gu. Thxnne, Marquis of Bath. Thynne, Baron Carteret.

Barry of ten or and sa. a label of five points az. Boteville.

\section{BARRY of 12.}

Barry of twelve arg. and az.

Brancey. Ingrahar. Montchansey, Montchanseye, or Mountchansey, Suffolk.

Barry of twelve arg. and gu. Manwaring, Chester. Meneleswaring. Stutrile, co. Somerset.

Barry of twelve arg. and gu. in chief a label of five points az. SoMerill.

Barry of twelve az, and arg. INGERHAM.

Barry of twelve per pale az. and arg. counterchanged. Moore, the Moore, co. Salop.

Barry of twelve or and az. Brambors. Brans. Mountford. Selby, Kent.

Barry of twelve or and sa. Botfreid, Hopton Court, co. Salop; a branch of the ancient Shropshire family of Botfield or Botevrue, Botevyle, near Church Stretton. Botfield, Decker Hill, co. Salop. Botfiesd, Norton Hall, co. Northampton.

\section{BARRY of 14}

Barry of fourteen arg. and az. Hugh Le Bron, Earl of the Marches of Aquitaine, father of William de Valence, Earl of Pembroke, $V$. Hotham, $V^{*}$.

Barry of fourteen arg. and gu. Robert de Stotevile, $E$. Stutevile, Baron of Cotingham, $V$.

Barry of fourteen arg. and gu. a label of five points az. Hue Gobrun, $E$. The label of the second, Sir Hugh Gosyon, $V$.
BAR. BARRY of $14 \ldots$... cont.

Barry of fourteen az, and or. BEAUBRAs, $V^{*}$. Porchester, $V^{*}$.

Barry of fourteen gu. and arg. a label of five points of the first. GOBYON, $V^{*}$.

Barry of fourteen or and az. Sir Robert BEaUBras, $V$. Henry de Pembridge, $D$. Sr .... de Porchester, $V$.

Barry of fourteen or and sa. Selby, Kent.

\section{BARRY of 18}

Barry of eighteen arg. and az. Frtz raues, $V$. Barry of elghteen arg. and gu. a label of five points az. Hugo GoMON, $F$.

\section{BARRY of 20}

Barry of twenty arg. and az. Brun.

\section{BARRY unnumbered}

Barry arg. and az. Fitz-Ralph, co. Berks. Sir Henry le Gray, $H$. Richard de GraY, $B$. Aymer de Lesignan, Bishop of Winchester, 1250-60. Le Count de la Marche, C. Marshe. Monchensy. William Monchensye, $Y$. Sire William de Monchensi, $N$. Seymour.

Barry arg. and az, a label gu. John de Gray, $B$. Sire Randoulf de Monchensi, $N$. The label or, Sir Henry de Grex, $O$.

Barry wavy arg. and az. Brownung. Sire Nichol Percy, $O$. Thomas Samford, $Y$.

Barry arg. and gu. Bassetr. Patrick de Chaurcy, $B$. Sir Thomas de Molton, $H$. Snith-Barry, Marbury Hall, co. Chester; and Foaty, co. Cork, quartering gu. on a chev. or betw. three bezants as many crosses formy fitchy sa. with az. a fess betw. three urchins ar. Stuteville.

Trornhild, Suffolk.

Barry arg. and gu. a label az. Sire Huge Gobyoun, $N$.

Barry bendy arg. and gu. CRIsPIN.

Barry indented arg. and gu. John BaLun, $X$.

Barry bendy lozengy arg. and gu. QUARM, Dartmouth, co. Devon; Nancor, Cornwall. WenhaMr or WinehaM, co. Chester.

Barry wavy arg. and gu. Piers Achart, $X$, or Acharte, $Y$. Sire Richard Ammori, $N$. Richard DamoRx, $Y$. Nicolaus de MANForD or Manfort, $C$. William de Samford, $B$.

Barry wavy arg. and gu. a label az. Piers Acharte, $Y$. Sire aleyn de Goldingham, $N$. The label gu., Nicholas de SAmFord, the son, $B$.

Barry bendy lozengy arg. and sa. CrispiN or Crispine.

Barry wavy arg. and sa. Sir Johan de Elcheffeld, N. Gillert de Elleffieid, $Y$. Sire Gilbert de Elmesfeid, $O$. WARD.

Barry wavy arg. and sa. a label gu. Gilbert de Elscheffeid, $N$.

Barry dancetty az. and arg. TURBervine.

Barry wavy az. and arg. Kenel.L.

Barry erm. and gu. Hugh de Huse, $C$. Hugh le Hussey, $C$.

Barruly gu. and arg. Robert Stutevile, $X$.

Barry wavy gu. and erm. Sir John de LAcy, $N$. Barry wavy gu. and or. William Basset, $Y$.

Barry or and az. Beanbras or Beaubras. VERnON.

Barry dancetty or and az. Loveday, co. Leicester. Barry or and gu. Sir Bryan le Fitzalayn, $H$. Bryan Fitzaleve, $K$. Alayn le Fitz Brian, $B$. Sir Hugh Poyns, $H$. Sire Nicholas de Poyss, $N$. Robert le Savage, $B$.

Barry bendy' or and gu. Beruingham. 
BAR. BARRY unnumbered.... cont.

Barry wavy or and gu. Philip Basset, $P$. Sir John Lovel, $H$. Sire Johan Lovel, $N$. Thomas Loven, Tichmarshe, $Y$.

Barry wavy or and gu. a label of three points compony az. and arg. Sir William Loven, $R$.

Barry or and gu. fretty arg. Hernol dela WEDE, $C$.

Barry bendy lozengy or and sa. CANCELLor or CaNCELOR.

Barry nebuly or and sa. Blount, Milton Ross, co. Leicester; Mapledurham, co. Oxford ; quartering Ayala, Castile, and Beauchamp.

Barry wavy or and sa. Sir William le Blound, $L$, or le Blount, $N$, or Blunt, $R$. William Blount, $Y$. Poneley.

Barry wavy sa. and arg. Robert de la WARde, $Y$. Richard Stapilton, $Y$.

Barry bendy lozengy sa. and or. IPRE.

\section{BARNACLE}

Arg. a barnacle in bend sa. Barway.

Arg. a horse-barnacle sa. BarNack, co. North. ampton.

Arg. a horse-barnacle closed in pale sa. BARNAKE, $V$.

Arg. a horse-barnacle sa. Porse, Castlezance, Cornwall.

Az. a horse-barnacle in pale or. Horsuran or Horswman, Sleaford, co. Lincoln.

Gu. a horse barnacle arg. Wyatr, Kent.

Per fess az. and gu. a horse-barnacle closed in pale arg. Wyatr, $V$.

Per fess az. and gu. a horse-barnacle arg. the ring or. Wyat, Sherwell, co. Devon, and Bexley, Kent.

Per fess gu. and az. a barnacle arg. Wyatr, co. Devon; and Kent.

1 BARNACLE and in chief....

Az. a horse-barnacle in pale arg. a chief gu. Wrotr.

Az. bezanty a horse-barnacle or on a chief of the first three 4-foils pierced arg. Horsman, Sussex.

1 BARNACLE betw..... and in chief....

Az. a horse-barnacle arg. betw. three plates on a chief per pale indented of the first and purp. two estoiles of sixteen points or each charged with a rose of the second. Horsman.

Az. a horse-barnacle closed in pale or betw. three plates on a chief per pale indented of the first and purp. two estoiles of sixteen points of the second in the centre of each a rose arg. Horseman. Horsman, $V$.

Az. a horse barnacle.... betw. three plates on a chief indented erm. three roses.... Horsman.

Az. a horse-barnacle or betw. three plates on a chief indented per fess of the first and purp. three roses arg. Horsman, Norfolk and Sussex.

\section{BARNACLES}

Arg. two barnacles in pale sa. Barnake.

....two open horse-barnacles.... Brayie, $V^{*}$. 3 BARNACLES

Arg. three horse-barnacles open in pale gu. Orenge, Foscott, 0 . Somerset.

Arg. three horse-barnacles in pale tied tightly gu. two and one. Donert, Renham, $V$.

Arg. three horse-barnacles in pale gu. tied loosely or two and one. Donett, $V$.

Arg. three horse-barnacles sa. Barnake, co. Northampton. Brnnake, co. Leicester. William Bernak, $X$.
3 BARNACLES.... cont.

Or three barnacles or brays expanded in pale sa. Brayte, $V$.

Arg. three horse-barnacles opened at the top sa. PADley, co. Derby ; the heiress m. Eyre.

Per fess gu. and az. three horse-barnacles arg. Wyot.

3 BARNACLES and in chief....

Az. three breys or on a chief arg. a demi lion gu. Simon de Genevile, $B$.

Az. three-horse-barnacles expanded in pale or on a chief erm. a demi lion ramp. issuant gu. Geffry Genevile, $D$. Geffray de Genevile, $B, C, E, J$. Geneville, Earl of Ulster, $V$. Sir Geoffrey Granevil, $V$. GeneviLL, Ludlow Castle, co. Salop, and Trim Castle, Ireland, temp. Edward I; the heiress m. 1301, Roger Mortimer, Earl of March; Sir Simon de Geynvili.e, her uncle, a Baron in Ireland, 3 Edward II, left five co-heiresses, $m$. to $\mathrm{Cu}$ sack, Hussey, Loundres, Cruys, and Delahyde. GENEVILLE. JAIIVILE or J ANIVILLE.

Az. three horse-barnacles in pale or on a chief erm. a demi lion ramp. gu. crowned of the se. cond. Genevill.

Az. three brayes or on a chief erm. a (? demi) lion ramp. gu. Geffry Geinvme, $X$.

\section{BARREL see Tun. BARROW}

Sa. a hand barrow betw. nine roses or. BEARwELL.

\section{BASKET see also Van}

Az. a basket of fruit ppr. betw. three mitres or. Thomas $J_{A N E}$ or $J_{A U N}$ Bishop of Norwich, 1499.1500 .

Per bend gu. and az. a fish-basket weel or eelpot in bend or on a chief az. a wolf's head erased sa. betw. two ogresses. WheEler, co. Wor. cester, $V$.

\section{BASKETS}

Az. three baskets or. GARDEN.

Gu. three covered baskets or. Augustinian Priory at Pertney, Norfolk.

Sa. three wicker baskets with handles arg. Sir John Littiaborne, $V$. Littlebury.

Sa. three baskets full of bread arg. Middueton, Abbot of Midgeley.

Sa. three baskets (sometimes of bread i.e. wastell cakes) arg. Benedictine Abbey at Middeten, also called Milton-AbBats, Dorset.

\section{BASKETS betw, or within....}

Az. three cross baskets in pale betw. a prime and a cutting knife in cbief and an iron and an outsticker in base. CoMPanY of BasketMAKERS, London.

\section{BAT see Beast. BATON see Bend, and Staff. \\ 3 BATTERING-RAMS}

Arg. three battering-rams az. BARTEY.

Arg. three battering-rams armed and ribbed or headed az. Berffie.

Arg. three battering-rams barways in pale ppr. headed and garnished az. Bertie, Duke of Ancaster, and Marquis of Lindsey. Bertie, Earl of Lindsey, Baron Willoughby of Eresby, Lord Great Chamberlain of England. Bertie, Earl of Abington. Baron Norris of Rycot, quartering sa. a shattered castle triple-towered arg. With due diff., BErTIE, Waldershire, Kent; Bertie, Creton, co. Lincoln; and Bertie, Uffington, co. Lincoln.

Or three battering-rams az. ERrser. 
3 BATTERING-RAMS betw, or within....

Arg. three battering-rains fess-wise in pale ppr. headed and garnished az. a bordure of the last. Bentie, Nether Hall, Essex, Baronetcy, 1812.

\section{BATTLE-AXE see Axe. \\ BAUTEROLE see Chape. BEACON}

Arg. a firepan sa. inflamed ppr. a crescent for diff. HaYwood, co. Stafford.

\section{BEACONS}

Az. three beacons or fired gu. Gervis, $T$.

Az. three beacons with ladders or fired gu. Genvays.

Sa. three beacons fired or the flames ppr. Dauntre or Dauwte.

Sa. three beacons with ladders or fired gu. Daunt, $V$.

Sa. three beacons with ladders fired ppr. Daunt, Ireland.

\section{BEADS}

Vert eleven round beads in chev. surmounted in the centre by a cross pendent to the two end beads a tassel all or betw. three 5.foils arg. Wimidush.

\section{BEAN-COD see Frnit. BEAR see Beast.}

\section{BEAST}

\section{For Reptiles sea that article, and for} Fabulous-beasts see Monsters.

\section{ALANT see Dog.} ANTELOPE including Ibex

Arg. an heraldic antelope gu. tusked horned maned and hoofed or. ANTILUPE.

Az. an antelope pass, arg. attired tufted and un. guled sa. Bugaine.

Az. an ibex ramp. arg. horned or. SteinMan, Croydon, and Peckham, Surrey.

Az. an antelope pass. or. LoAne, Kent.

Ermines an antelope rainp. or. EDwaros, Lalant, Cornwall.

Per pale arg. and gu. an antelope pass. counterchanged. Dighton, Sturton, co. Lincoln.

Sa. an antelope ramp. arg. armed or. Harris. Harris, Cornwall, $W$.

Sa. an antelope salient arg. attired tufted and maned or. Harris, co. Devon; and co. Monmouth.

\section{APE}

Arg. an ape sejant on a heart holding a palm brauch ppr. VAULT.

Vert an ape sejant holding up the paw braced round the middle and chained to the sinister side of the escucheon arg. APPLEGH.

\section{ASS}

Sa. an ass arg. AssIL.

\section{BADGER including Brock}

Arg. a badger pass. sa. Broc.

Or a badger pass. sa. BADGER.

\section{BAT}

Arg. a bat displ. ppr. Stainings.

Arg. a bat or reremouse displ. sa. Batster or Baxter. Baxter, Scotland. Stenynge, Honyuote, co. Somerset; and Suffolk. Stenynges, Erlsome, $W$.

Arg, a bat displ. sa. a label gu. Stainings, Honycott, co. Somerset; and Erlsone, Suffolk.

Or a bat volant gu. ATTON.

Or a bat displ. vert. AtTon, $W$.

Per bend sinister or and gu. a bat displ. sa. Josue.

\section{BEAST.}

\section{BEAR}

Arg. a bear sa. BEAREFORD.

Arg. a bear sa. with a skean piercing his loack and coming out under his belly handle gu. blade az. Dnunberck, Drumbreck, Scotland.

Arg. on a mount vert a wild bear sa. cliained and armed or. KELLET, Ripley, Surrey, confirmed 1 Oet. 1550.

Arg. a bear pass. sa. Fitz-Ounse.

Arg. on a mount vert a bear pass. sa. Berens.

Arg, a bear pass. sa. muzzled or. Apulton, co. Lancaster.

Arg. a bear ramp. sa. Bear, $I^{*}$. Beare, Cornwall, $V$.

Arg. a bear ramp. sa. muzzled gu. OATES.

Arg. a bear ramp. sa. muzzled or. Bannard, $V$. BARNARD, Abbiugton, near Northampton. Barnard, Cave Castle, Howden, co. York; quartering GeE. Barnand, Lord Mayor of London, 1738. Barnard, Bartlow House, Linton, co. Cambridge. Bernard, Norfolk; co. Cambridge; co. Huntingdon; Nettleham, co. Lincoln; and Nether.Winchendon, co. Buckingham. Bernard, Castle Bernard, King's County.

Arg. a bear ramp. sa. muzzled and collared or. Bernard, Nettleliam, co Lincoln.

Arg. a bear ramp. sa. muzzled collared and chained or. BEREsFORD, $V^{*}$.

Arg. a bear salient sa. BEARE, Killigarth and Bryn, Cornwall ; the heiress $m$. Beville.

Arg. a bear salient sa. armed gu. muzzled collared and chained or. BERESFORD, Beresford, co. Stafford; and Bently, co. Derby.

Arg. a bear salient sa. crowned or. APELTON Appelton aud Aprotion, Apleton, co. Lancaster.

Arg. 'a bear salient sa. muzzled or. Barnard, Upton Leonard.

Arg. a bear salient sa. muzzled collared and cluained or. BAYceFord. BAYRTORD. Beresford, Bentley, co. Derby, $V$. Beresford. Kent, $W$.

Arg. a bear sejant ramp. sa. muzzled gu. GaII.

Barry of six or and arg. a bear ramp. sa. muzzled gold. Barnard, Ham, Surrey.

Or a bear pass sa. Fitz-Ourse. Fitz-Urse, $V^{*}$. Or a bear ramp. sa. muzzled collared and lined gu. Mulnes, Ashford, Dunston, Aldercar Park, and Cromford, co Derby ; confirmed 1795 ; one beiress $m$. Gell.

Or a bear ramp. sejant sa. Berneck.

Or a bear statant sa. Fitzunse, $V$.

Per fess sa. and arg. a bear ramp. counterchanged muzzled gu. LyNDSEY or LyNDEsEY. LYNSEY, $V^{*}$.

Per fess sa. and arg. a bear salient counterchanged muzzled gu. LyNsey, $V$ :

Sa. a bear erect arg. chained and muzzled or. Mylles, co. Hants.

Sa. a bear ramp. or. ORLY, France.

\section{BLOOD-HOUND see Dog.}

BOAR including $\mathrm{Hog}$, etc.

Arg. a boar puss. gu. Trewarthen. Trewarther. Arg. a boar pass. gu. armed or. TREwALTHEN.

Arg. a boar statant gu. armed or. Trevartheam, $V^{*}$. Trevalithean, $V$.

Arg. a boar passant .... the head gu. Mruric-GOCH, Dyved.

Arg. a boar pass. sa. Brytaen. M'Carthy, or Maccarthy, Ircland. Priot. 


\section{BEAST. BOAR....cont.}

Arg. a boar pass, sa. armed gu. PERotT.

Arg. on a mount vert. a hoar pass. sa. crived or. Keidet, Lota, co. Cork, Bart., quartering or a cross gu. in the first quarter a flenr-de-lis of the last.

Arg. a boar pass. sa. enraged and unguled gu. Perrot.

Az, a boar arg. Goche.

Az. a boar chained to a tree arg. Llwch Ltawen VAwr.

Az. a boar pass. or. Burbidge.

Barry of six arg. and gu. over all a boar ramp. az. Borelands, Edinburgh.

Erm. a boar pass, sa. Burbridge.

Gu. a boar arg. armed bristled collared and chained or tied to a holly bush on a mount in base ppr. OWen, co. Pembroke.

Gu. a boar pass. arg. Boor or Bore.

Gu. a boar pass. arg. collared and chained to a holly bush vert. OWEN.

Gu. a boar pass, arg. tusked or. RANDOLFE, Norfolk.

$\mathrm{Gu}$. a boar salient arg. collared and chained or. Eyre, $V^{*}$

Gu. a boar statant arg. armed or. Bore, $V$.

Gu. a boar pass or. BAtrD, Auchmedden, Scotland.

Gu. a boar pass. ppr. Hennessy, Ballymacmoy, co. Cork; derived from Mac Ennis, Iveagh, co. Kerry.

Or a boar pass. gu. Bratrle. O'MALY, Ireland. Or a boar sa. Gylpin, $T^{*}$. OELdon or Oldon.

Or a bog lying fesswise a raven feeding on his back sa. DANSKINE, Scotland.

Or a boar pass. sa. Gilpin, Scaleby, Cumberland ; and Westmoreland. GilpiN, Bungay, Suffolk.

Or on ground vert a boar pass. sa. OHENLOYNE (Hibernicus Sylvestris), $V$.

Or on a mount vert a boar pass. 8a. OLdon or OLton.

Or in a pond vert a boar pass. sa. Siluestris, $V^{*}$.

Or a boar statant sa. Gilpin. Gurlpin, $V$.

Sa. on a mount under a holly bush vert a boar pass. arg. collared gu. LHWARCH LHAwEN VAUR.

Sa. a boar pass. or. Alvey or Allvey.

Vert a boar pass. arg. Pollard, co. York.

Vert on a mount in base a boar pass. erm. O'HANLAN, Ireland.

Vert a boar or. BOAR.

\section{BUCK SEe DEER.}

\section{BUFFALO, BULL, and CALF, see 0x.}

\section{CAMEL}

Arg. a camel passing through a ford of water ppr. CAmelford, Cornwall.

Az. a camel pass. arg. Camer, Bury Pomeroy, co. Devon.

Az. a camel statant arg, CAmelt, $V$.

Sa. a camel pass. arg. CAnEL, Bury Pomeroy, co. Devon.

Vert a camel arg. FaLLowes, co. Chester; Harl. MS. 1535.

Vert a camel or. Fallowes, Fallowes Hall, and Haywood Hall, co. Chester; removed to co. Derby; descended from Aldford of Aldford.

Vert a camel statant or. Falwitz, Alderley, co. Chester.
BEAST.

DEER

including Buck, Doe, Hart, Hind,

Reindeer, and Stag

Arg. a demi buck gu. between his forelegs an arrow erect in pale or. Decker, London, granted 6 Aug. 1616.

Per bend sinister arg. and chequy or and az. in the dexter chief point a demi buck sa. Primouth or Primout, Surrey.

.... a stag .... Foumkes, Merton, co. Flint.

.... a buck springing or. DE RInzy, Du REnZy, and De RenzI, Clobemon Hall, co. Wexford; descended through Sir Mathew de Renzy, from George Castriotes Scanderberg; and quartering az. on a cross arg. five escallops gu. a bordure or.

Arg. a buck az. attired or. Hertington, $V *$. HoLAIE.

Arg. a hart statant az. attired or. Hertington, $V$.

Arg. a hart trippant az. Hertington.

Arg. a field and river ppr. on the field a buck gu. drinking in the river. BanNevelt.

Arg. a buck lodged gu. Griffith ap Griffin, $V *$. Arg. a stag lodged gu. PorQuYN, Cornwall. Griffith ap GrifFin, $V$.

Arg. on a mount ppr. a stag lodged gu. HaRthilt. Arg. on a mount vert a stag couchant gu. Town of Hertrord. TaLLaNd.

Arg. a stag couchant gu. horns and hoofs or holding in its mouth a blanch vert. Llewellyn Ychan ap LLEWELLYN.

Arg. a stag salient gu. armed or. KIncH.

Arg. a stag sejant gu. attired or in the month a trefoil slipped ppr. Bowen.

Arg. a stag. statant gu. HoLme, co. York.

Arg. a stag statant at gaze gu. Gryffydd Gwrr.

Arg. a buck trippant gu. HoLme.

Arg. a hart trippant gu. BLyтhe, co. York.

Arg. a stag trippant gu. CARTE.

Arg. a buck trippant gu. attired or. M'CARTY, Earl of Clencare, temp. Elizabeth. M'C $\mathrm{C}_{\Lambda \mathrm{RTnY}}$ Lord Muskerry and Earl of Clancarty. Macartney, $V *$.

Arg. a stag tripp. gu. attired or. Donel Macartiemone, Earl of Clancare, $v$. Sir Donicius, Ireland, $V$.

Arg. a buck trippant gu. attired and unguled or. M'CARthr, Carrignaver, co. Cork; descended from Cormac M'CARTHr, Lord of Muskerry.

Arg. a stag trippant gu. attired and unguled or. Holne, co. York.

Arg. on a mount vert a stag lodged within park pales and gate ppr. Town of Derby.

Arg. a hart pass ppr. attired or. HoBYN.

Arg. a stag salient ppr. armed or. KIRCH.

Arg. a stag statant ppr. attired or. HoLMs, Beverly, co. York, $V$.

Arg. a stag trippant ppr. attired and unguled or. Holme, Beverley, co.York. Parkhml, Scotland. Arg. a stag sa. LaHr and Clettemberg, $Z, 871$. Arg. a hart sa. attired or. BARDwELl.

Arg. a hart pass. sa. Hertington.

Arg. a stag springing sa. over all a fret vert. WARnet, Hampstead, Sussex. And with a label of three points .... WARnET, Surrey.

Arg. fretty vert over all a stag springing sa. Warnett, Framfield, Sussex; Visitation 1633. WAnNITS.

Arg. fretty vert over all a stag springing sa. attired or. Warnetr, Sussex, $V$.

Arg. fretty vert on each crossing of the fret a crescent or over all a buck springing sa. attired or. WARnetT Or WARnitz, $V^{*}$. 


\section{BEAST.}

DEER

z. a stag arg. with an arrow stuck in the back and attired or. Bowes, Kittle Hill, and Swar. sea, co. Glamorgan.

Az. on a mount vert a stag reguard. arg. HeNDLEY.

Az. a stag conchant arg. Downes, co. Chester.

Az. on a mount vert a hind grazing arg. HENDLEY, Hendley, co. Lancaster.

Az. on a mount vert a bind lodged arg. HendeEy, Hendley, co. Lancaster.

Az. a hind pass. arg. Chettle, Suffolk.

Az. a buck springing arg. attired or. GETHrN, Ireland.

Az. a buck salient arg. crowned or. GETHIN, Pejton, co. Brecknock; and Southweld, Essex.

Az. a stag standing at gaze ary. Lowe, co. Derby.

Az. a hart trippant arg. Lowe, Alderwasley, co. Derby; quartering Fowne (a helress m. Hurt) and descended from a younger branch of LowE, Denby, and Locko, co. Derby, originally from co. Chester, and quartering Rosell.

Az. a stag trippaut arg. Lowe, Derby; and London.

Az. a reindeer trippant erm. WALstone.

Az. a stag in full course or pursued by a brace of dogs arg. all bendwise and at random. YARDIEY.

Az. a stag and two hounds courant in bend or. JAliDELAY.

Az. a stag in full course or pursued by three greyhounds arg. all bendways and at random. YARDELEY or YaRDLEY.

Az. a buck pass. or. Strahan.

Az. a hart springing or. StrathallaN.

Az. a stag trippant or. Strachan.

Az. a stag trippant or attired and unguled gu. Strachan, Teddington Grove, Middlesex, descended from Strachan, Thornton, co. Kincardine. Strachan, Glenkindie, Scotland.

Erm. a biud tripping gu. Cowels.

Gu. a hind couchant arg. on a mount within water banked all $\mathrm{ppr}$. Hindmarsh.

Gu. on a mound vert a bind couchant arg. HINDMARCH.

Gu. a stag statant arg. collared and chained or. Bois, co. Brecknock. Willians, Velyn-Newydd, co. Brecknock.

Gu. a stag standing at gaze arg. attired or. Jones.

Gu. a buck trippant arg. Popkrn, co. Glamorgan; and Scotland.

Gu. a hart trippant arg. Lowe, Derby.

Gu. a stag trippant arg. Ćor, Scotland. Davys. Mackinlay, Edinburigh.

Gu. a stag trippant or. Daviuson, North Wales ; confirmed 12 June, 1586 . Davison.

Gu. a stag at gaze ppr. O'KENNELLY.

Or. a hart standing at gaze az. attired sa. Strachan, Thornton, Bart.

Or a stag ramp. gu. VIOLETte.

Or a stag couchant ppr. gorged with a collar az. thereon a mullet arg. betw. two crescents of the first in the dexter chief point a rose gu. for diff. Sсотт, Kew Green, Surrey; Baronetcy 9 Aug. 1653.

Or a buck trippant ppr. THomas.

Per pale gu. and az. on a mount in base vert a stag trippant arg. Strachan, Leven, Scotland.

Sa. a stag couchant arg. Downes, co. Chester.

Sa. bezanty a buck in full course arg. BuckeleLI, co. Devon.

Sa. a buck lodged arg. Downes, Downes, co. Chester.
BEAST DEER

Sa. a stag lodged arg. Chorler, co. Chester; and co. Lancaster.

Sa. a stag lodged arg. attired and unguled or. Downes.

Sa. a stag pass, arg. Gwilim Twyaf.

Sa. a buck pass. arg. attired or. Jones, Esthall, co. Oxford.

Sa. a hart pass. arg. attired or. Hedd Molwynog, Lurd of Uwch Aled; from whom descended Lloyd, Havod-Dinas, co. Denbigh; Lloyd, Ilwyn y Maen, co. Salop; Iolo-Goch; and REYS AP IEvan, Chwibren.

Sa. a buclispringing arg. attired or. Downes, $V^{*}$.

Sa. a stag springing arg. attired or. Downes, co. Chester, $V$.

Sa. a stag statant arg. Hedd Molwynog. Lloyd, Pale.

Sa. a stag statant arg. armed or. Monwynog, Uwch-Alid, Wales.

Sa. a stag standing at gaze arg. attired and un. guled or. Jones, co. Monmouth.

Sa. a hart trippant arg. attired or. LLOYD, Harod-Dinas, co. Denbigh.

Sa. a stag standing at gaze or. Morris, co. Calnarvon.

Vert a buck arg. in the dexter chief a crescent for diff. Fowberx, $V^{*}$.

Vert a bnck couchant arg. Downes.

Vert a hind couchant arg. PEYTON, co. Brecon.

Vert a stag couchant arg. attired or. RAY, co. Gloucester.

Vert a stag courant arg. armed or. GerHIN, Gethinsgrott, co. Cork, and Percy Mount, co. Sligo, Bart.

Vert a stag pass. arg. attired or. Fowbery, Bluntisham, co. Durham; and Newbald, co. York. Fowberr, co. Huntingdon. Llywarch HoWLBWRCH.

Vert a stag pass. reguard. arg. Cynvraig VycHaN.

Vert a buck salient arg. ducally gorged and attired or. Gethin, Ireland.

Vert a hind springing forward arg. Felbury. GILSILAND.

Vert a hart statant at gaze arg. ENRIGHT.

Vert a stag tripp.arg.in the dext. chief a crescent for diff. George Fowbery, Newbald, co. York, $W$.

Vert a stag trippant arg. attired or. LlowancH, Holbwreh.

Vert a buck or. Morris, $V^{*}$.

Vert a stag or. Morris.

Vert a buck pass. or. Moris, Suffolk.

Vert a hart pass. or attired arg. GeLstable.

Vert a hart salient or. GeLYSALE or GELLISDALE.

Vert a stag springing or. GILsLand. Gisland.

Vert a stag at gaze or. SOMIERFord, co. Stafford.

Vert a roebuck trippant or. Monris, London, $W$.

Vert a stag trippant or. Crarkeson, co. Notting.

ham. SPARRow.

Vert a stag pass. ppr. O'ConnoR, Coramore, Ireland.

Vert a buck ramp. ppr. PARKer, co. Chester.

Vert a stag trippant ppr. Clarkeson, co. Nottingham. Parry, Madryn, co. Carnarvon.

\section{DOE see Deer.}

$$
\text { DOG }
$$

including Bloodhound, Greyhound, Hound, and Talbot

.... a talbot pass. or collared gu. Ashberton.

Arg. a greyhound courant $g u$. in front of an oak tree on a mount vert. LanBERT, Mount Ida, Norfolk, Bart. 
BEAST.

DOG....cont.

Arg. on a mount vert a greyhound pass. gu. in front of an oak tree ppr. Lambert, London and Paris.

Arg. a hound pass. gu. Strethley, Stretly, co. Stafford; granted 1583.

Arg. a talbot pass. gu. Ousley, co. Stafford. Wolserey, Wolseley, co. Stafford, Bart.

Arg. a talbot pass. gu., with a crescent for diff. Wolseifey, Mount Wolseley, co. Carlow, Bart.

Arg. a greybound salient party per long. sa. and of the first. De la Fonde, Iver, co. Bucks, $V$.

Arg. a greyhound springing per pale sa. and of the first. DE LA ForDE.

Arg. a greyhound in full course sa. HoLrord, co. York.

Arg. a greyhound courant sa. Moreton, Moreton, co. Chester: originally Lostock, quartering Davenport, and Massey; of this family came William Moreton, Bishop of Meath; his sun and heir, Sir William Moreton, Recorder of London, ob. 1763. Williams, 'Treworgy and Trebane, Cornwall; the co-heirs m. Prudeaux and Stackhouse.

Arg. a greyhound in full course sa. collared gu. Morton.

Arg. a greyhound courant sa. collared or. Holford, co. Chester, $V$.

Arg. a greyhound courant sa. collared vert rimmed of the first. Morton, co. Chester.

Arg. a greyhound pass. sa. Belvale. Holford, Weston Birt, Tetbury, co. Gloucester, formerly of Holford, co. Chester, quartering Stayner, Nutt, and Lade; a heiress m. Cholmondeley.

Arg. a hound pass. sa. SHERington.

Arg. a greyhound pass. sa. collared or. HoLFord, co. Lancaster.

Arg. on a mount vert a greyhound pass. sa. collared or. Holford, Kilgwyn, co. Carmarthen, quartering Gwynne.

Arg. a talbot pass. sa. ears and collar or. KeYne, Cretingham, Suffolk. And with a crescent for diff., Keyne, Rowlesby, Norfolk.

Arg. a greyhound skipping in bend sa. ATwood.

Az. a talbot arg. Hubbert, Cork, Ireland; and Isle of Teneriffe.

Az. a hound courant arg. Burgoy or Burgoyne, co. Oxford.

Az. a hound pass. arg. Burgorgne,co. Cambridge; and co. Devon. Burgon, Long Stanton, co. Hereford.

Az. a talbot pass. arg. Borgoine. Borgronge. BuRgoIgNe.

Az. a talbot pass arg. in chief a mullet or pierced sa. (? for diff'.) BORGON.

Az. a talbot pass. arg. collared gu. ALberton, Plympton.

Az. a taluot pass. arg. collared gu. lined or at the end of the line a knot. Borgorn.

Az. a talbot statant arg. collared gu. lined or at the end of the line a bundle orknot. Burgoyne, $V$.

Az. a talbot pass. or. Burgoigne.

Barry of six arg. and gu. in chief a greyhound in full course sa. MACEPOWDER, co. Devon.

Barry of eight arg. and gu. per pale counterchanged a greyhound courant sa. divided between the two chief quarters silver. SkYpwrth.

Barry of eight arg. and gu. per pale counter. changed in chief a greybound iu full course sa. SкIPWITH.

Erm. a talbot pass. sa. Preston, Melton, co. Leicester.

Gu. a talbot pass. arg. Comberford, Comberford, co. Stafford.
BEAST. DOG....cont.

Gu. a talbot pass. or. Charfin or Chafin, Chetle, co. Dorset.

Gu. a talbot pass. or collared and line reflexed over the back sa. KEENE, Ireland.

Or a grevhound courant sa. Pantrickson, Cumberland; granted 1592 .

Or a talbot pass. sa. Courteene, Aldington, or Aunton, cu. Worcester. Couritin, Loudun.

Or on a mount vert a greyhound statant sa. Stecher.

Per bend sa. and or a hound pass. counterchanged. Staber.

Per pale or and arg. a hound gir. Annelsme.

Sa. a greyhound salient arg. Powerton.

Sa. a dog conchant on a cushion or. Alaband.

Vert a greyhound courant in bend arg. collared gu. studded or. Brome, Abergwilly, co. Car. marthen; Seven Oaks, Kent; London; aud Cobham, Essex.

\section{ELEPHANT}

Arg. an elephant pass. sa. Sutci.trfe, co. Lancaster; from the Low Countries. John SUTCLifre, Groom of the Bedchamber to Charles I. Matthew Sutchiffe, Dean of Exeter.

Gu. an elephant arg. Elphinston.

Gu. an elepliant pass. arg. armed or. Elphinston or Elfinston. Elpington.

Gu. an elephant statant arg. armed or. Elphinston, $W$.

Per pale gu. and vert an elephant arg. on a mount ppr. bearing on his back a castle or. Town of Coventry.

Perpalegu. and vert an elephant on his back a tower triple-towered or. CoventRY, co. Warwick.

Vert an elephant arg. Butron, Ichleford, co. Hertford; granted 15 Dec. 1769.

\section{FLEECE see Sheep. \\ FOINE see Fitch. \\ FOX}

Arg. a fox sa. enraged gu. MaLston, co. Devon. Gu. a fox pass. or. GaVENor.

\section{GOAT}

Arg. a goat ramp. sa. the head and part of the neck of the first armed vert. DE BUCKTon, $V^{*}$.

Arg. a goat salient parted per fess at the neck of the first and sa. armed vert. John De BuckTon, $V$.

drg. a goat salient sa. attired or. BuckTon.

Az. a goat pass. arg. Gaveregan or Gavergan, Gaveregan, co. Cornwall.

Gu. a goat climant arg. attired or. Barwei.L.

Gu. a goat pass. arg. Bager. BAKEn, Nortulk.

$\mathrm{Gu}$. a goat pass. arg. attired or. BAKER, $V^{*}$, BARDWELL, Norfolk.

Gu. a goat salient arg. armed or. Bensted, $V$. Bensteed.

Gu. a goat salient arg. attired or. M. William Bardwell, $T$. Bardweil, Norfolk. Beawsted. BREDWELL, Suffolk.

Gu. a goat statant arg. attired or. BaKer, $W$.

Gu. a goat salient or. M. Williarn BEDWELr, quartering or an eagle displ. vert. T. M. Peris de Boughton, $S$.

Sa. a goat arg. armed or. Bokethey, Cornwall. Celynis, thirteenth century. Davis, Elmley. LLOYD, Dolobran.

Sa. a goat pass. arg. attired bearded and unguled or. CARnsew, Carnsew, and Bokelley, Cornwall, the heirs $\mathrm{m}$. Prideaux and Godolphin. The family of Thomas, an purchasing tire barton of Carusew, adopted the name and arms of Carnsew. 
BEAST. GOAT....cont.

Sa. a guat ramp. alg. Burton, $V^{*}$. Tremhaie, Trethale, Cornwall.

Sa. a goat ramp. arg. armed or. Bonleigh, $V *$ *

Sa. a goat salient arg. Burton, co. Devon, $H$. M.Cleverty, England. 'Trethicke.

Sa. a goat salient alg. attired or. BoDLEIGH, co. Devon, $W$. Boletery, Cornwall.

Sa. a goat arg. attired or stunding on a child ppr. swaddled gu. and feeding on a tree vert. DiviEs, Hope, co. Montgomery, and Marsh, co. Salop.

Vert a goat climant arg. FELuURy, Northumberland.

\section{GREYHOUND see Dog.}

HARE including Coney

.... a coney sejant .... Duke.

Arg. on a mount vert a hare salient ppr. Harvey.

Az. a hare salient arg. round the neck a hunting horn sa. stringed gu. Kineiland, Monkland, Scotland.

Az. a hare salient arg. round the neck a bunting horn vert garnished gu. Cleland, That Ilk, co. Isanark, hereditary forester to the Earls of 1)onglas, the descendants were settled at Laird Braes, co. Wigton, Faskine, Moukland, Cartness, in Scotland; $\Lambda$ bingdon, co. Berks; and Ballymagee, Rath-gael House, and Newtownyards, co. Down. Clemand.

Az. a hare courant and an eagle pouncing on it or. DENSEINE, Scotland.

Az. a hare salient or collared gu. to the collar a bugle horn pendent sa. Cleveland or Cleviand, Tapley, co. Devon; the heirs $m$. Ibbetson and Saltren.

Gu. \& hare salient arg. HASE, Berkhampstead, co. Hertford.

Gu. a hare arg. seized by a goshawk or. DENSKrn, Scotland.

Vert a coney arg. Penhallow, Penhallow, Cornwall. HART see Deer. HEDGEHOG see Urchin.

\section{HIND see Deer. HOG see Boar.} HORSE including Mule

Gu. a demi-horse arg. hoofed and maned or issuing out of water in base ppr. Trevelyan, Nettlecomb, co. Somerset, Bart.

Gu. a horse arg. armed or coming out of the sea party per fess wavy az. and of the second. Trevelyan, Netherwitton, Northumberland, quartering Thornton, and descended from Trevelyan of Nettlecombe.

$\mathrm{Gu}$. the base barry of five arg and az. therefrom a demi-horse issuant of the second maned and hoofed or. Trevelyan, Cornwall.

Per fess gu. and barry wavy of ten arg. and az. a demi-horse ramp. jssuant of the second. Sir William Trevilitian, to. Devon, $V$.

.... a horse courant fretty caparisoned carrying a man armed cap-à-pie bearnng a shield charged with France quartering England the dexter arm extended and holding a sword erect the pomel fastened by a chain to the gurget over the helmet a cap of maintenance thereon a lion statant guard. ducally crowned .... Seal of the Town of WALLINGFORD, co. Berlis.

Arg. a horse (bay colour) pass. holding in his mouth a tulip slipped ppr. AтнектоN, $V^{*}$, it is given by Glover as a quarterng of ATHERTon, Atherton.

Arg. a horse pass. gur. bolding in the mouth an oak syrig vert acorn or. Ashton, Ashton in Markerfeild, quartered by Atherton; Harl. MS. 1549, fo. $15 \mathrm{I}$.

\section{LEAST, HORSE.... cont.}

Arg. a horse pass. sa. bridled and saduled or. Postlings, $V$.

Arg. a horse standing sa. Bromfaling.

Gu. a horse carrying a chevalier armed at all points with sword erect arg. Moncurre, Slayne, Scotland.

Gu. a horse in full career. Hanover, $Z, 87 \mathrm{I}$.

Gu. a mule pass. arg. Moile, co. Devon. Moyle, St. Anstell's, Cornwall.

Per fess arg. and sa. a horse salient counter. changed. SPILLER, co. Wilts.

Per pale arg. and sa. a horse pass. counterchanged. Spiller, Sussex.

Per pale sa. and arg. a horse counterchanged. Spllter, Bodmin, Cornwall.

Per pale sa. and arg. a horse courant counterchanged. Splluer, co. Stafford.

Sa. a horse pass. arg. bridled gu. Trotr, $W$.

Sa. a borse pass. arg. spancelled in both legs on the near side gu. PERcrval, Lambourne Hall, Essex; quartering Lockwood, Cutts, and Dowdeswell. Percivall, co. Hants.

Sa. a loorse upright arg. bridled or. CABELL, Buckfastleigh, co. Devon.

Sa. a borse carrying a man armed at all points brandishing a sword arg. NEvoy, That Ilk.

Sa. a horse carrying a man in full armour with halberd ppr. ARGANOR.

Vert a horse thereon a man in complete armour in the dexter hand a sword ppr. Maguine, Prospect Hill, co. Fermanagh; derived from the Maguires, Lords of Fermanagh.

\section{HOUND see Dog}

\section{IBEX see Antelope. LAMB see Sheep. \\ IEOPARD}

Some of these are probably Lions.

Arg. a leopard ramp. guard. az. Braytort, co. Lincoln.

Arg. a leopard pass. gu. Qtiarlton.

Arg. a leopard ramp. gu. Horne.

Arg. a leopard salient guard. gu. JERMY.

Arg. a leopard ramp. sa. LINCOLNE.

Arg. a leopard ramp. vert. WALTON.

Az. a leopard pass, arg. Hun.

Az. a leopard ramp. arg. Hun.

Az. flory aud a leopard ramp. arg. Holland.

Az. a leopard ramp. arg. crowned or. Genand. OrTON Or ORTUN.

Az. a leopard ramp. or. Etheresset.

Az. a leopard segreant or. HETHERFIELD.

Gu. a leopard pass. arg. crowned or. Gerard.

Gu. a leopard ramp. arg. Marney, Essex.

Gu. a leopard ramp. arg. armed of the field. AstLey.

Gu. a leopard ramp. arg. crowned or. DEYLEY.

Gu. a leopard pass. guard. or spotted sa. ARLOTE or ARLOTT.

Gu. a leopard ramp. or collared az. Lancaster. Or a leopard ramp. sa. armed arg. Lincolne.

Per pale gu. and az. a leopard ramp. with a lion's tail arg. collared per pale of the second and first. Causton, Oxted, Surrey.

Per pale or and gu. a leopard pass. arg. armed az. Playse, Norfolk.

Per pale sa. and gu. a leopard pass. arg. Fresh. Quarterly per fess indented gru. and or in the chief quarter a leopard arg. BEsAYNT or BESANIT.

Quarterly or and gu. in the first quarter a leopard pass. sa. SAY.

Vert a leopard ramp. reguard. arg. CotTon. 


\section{BEAST.}

LION

.... a demi lion ramp. conped gu. Hofner.

Arg. a demi lion ramp. gu. Betirye, $V^{*}$. Sir Betkyne Denet, $V$. Dennet, $V *$. Malory, $V$.

Arg. a demi liou ramp. sa. Mervin, co. Cambridge. Mervyn, co. Wilts., $V$. And charged with a fleur-de-lis or for diff. Mervin, Pertwood, co. Wilts. Mervyn, Trellick Castle, co. Tyrone.

Az. semy of fleur-de-lis or a demi lion ramp. arg. Merevall. Morenill or Morvile, France.

Az. semy of fieurs-de-lis arg. a demi lion ramp. or. Morvile, $W$. Morvyle, $V$ *

Az. flory or a demi lion ramp. arg. and a bend gu. Sire William MIORELe, $O$.

Az. semy of fleurs-de-lis or a demi lion ramp. of the second. Monvile or Morknill, France.

Erm. a demi lion couped az. collared or. CARD or CAIRD.

Gu: a demi lion ramp. arg. Denet.

Gu. a demi lion ramp. erased arg. LUTwIDGE.

Gil. a demi lion erect in a tun arg. HOPTON.

Gı. a demi lion ramp. arg. crowned or. GRAvE. GreEN, $W$.

Gu. a demi lion ramp. arg. tail forked. Stokes.

Or a demi lion ramp. az. issuiug out of a chair resembling a nural coronet reversed arg. Talstock, $V$.

Or a demi lion ramp. az. in a mural crown reversed arg. TALsTOCK, $V^{*}$.

Or a demi lion issuant from a tun gu. Hopton.

Or a demi lion ramp. enhanced double-tailed gu. William MAULARE, $E$.

Or a demi lion ramp. sa. Talstock.

Per chev. sa. and arg. in base a demi lion couped gu. Piciereneli.

Per chief gu. and arg. in the first a demi lion ramp. of the second a 5 -foil of the first for diff. WeIdon, Cookhami, Bray, and Shaftesbroke, co. Ber'ss; and Northumberland.

Per fess arg. and vert in chief a demi lion ramp. gu. GIse.

Per fess gn. and arg. in chief a demi lion of the second armed or langued az. WELDon, Kent.

Per fess or and gu. a demi lion ramp. vert. Wharton.

Sa. a demi lion ramp. arg. Pulfani, $V$.

.... billety .... a lion pass. Robert Hayton, c. 1424, brass at Threddlethorpe, co. Lincoln.

.... semy of 3 -foils slipped .... a lion pass. .... crowned .... John de LisLe, Lord of Burlee, temp. Edward III; seal $V$.

.... a lion pass. guard .... Town of Milbourneport, co. Somerset.

.... a lion pass. guard. toward the sinister side .... (Attributed to) William, Earl of Gloucester, ob. $1183, Z, 48$.

.... a lion ramp.... Ralph Botiler, 1275, in Badminton churchyard.

Arg. a lion ramp..... quartering per pale arg. and gu. over all a lion ramp....., with or a lion ramp. ...., and .... a chevron .... be. tween three serpents erect wayy . .. tails barbed. Mahoney, Dromore Castle, co. Kerry: an old seal.

.... a lion ramp. .... with seven quarterings. 'Thomas Jefrry: seal, 1 Feb. 1635.

.... a lion ramp. .... holding a baton .... (The ancient arins of) Trevelyan, Nettlecomb, co. Somerset, Bart.

.... a liou ramp. sa. over all a bend sinister or. Menedith, Oswestry, co. Salop.

... crinsily patty .... and a lion ramp. ... Tuche T, 1301.

\section{BEAST. LION.... cont}

.... a lion ramp. .... crowned .... KEIGwin, Penzance, co. Corriwall.

Arg. a lion pass. guard. az. debruised by a pale gu. Tennant.

Arg. a lion ramp. az. Sire de Ardene, $A$. Birneli, co. Lincoln. Bremond. Piers Brurs de Skelton, $Y$. Piers de Brus, $B$, or de Bruys, $P$. Bruse, Kent. Courtney, quartering or three torteaux. CREIGHTon, Earl of Erno, quartering arg. on a chevron az. betw. three sprigs of laurel vert as many boar's heads of the first. Creighton, Crum Castle, co. Fermanagh. ERne. Monsire de Faconberge, $Y$. Sir Walter de Faconbrige, temp. Edward I, $V$, who $\mathrm{m}$. a coheiress of Peter Brus, Lord of Skelton, $V$. Falconbridgk, quartered by Nevill and Conyers, $U$. Fauconberg, temp. Edward I. Sir Walter Fauconberge, $I$, or Wauter Faucounderge, $N$. Le S. le Faukonberge, $S$. Fauconberge, $Y$. FaUconbridge or Fatconbridge. Ferquilar and FARQUhar, Scotland, quartering az. a sinister hand apaumy arg., with or a galley sa. flags gu., and arg. a tree vert, over the quarterings a crescent gu. Galloway, Lord Dunkell. GunbY, $V$ *. Hamon. Handeloe, Williamstrip, co. Gloucester. Hanlow. KING, co. Hereford. Kylche. Lisle or Lile. Mitchenson or Michenson. Steede or Stead, Warham, Northall, co. Norfolk; quartered by D'Oyley. WANDFORD, co. Nottingham.

Arg. a lion ramp. az. a label of three points gu. FAWCONBERGE.

Arg. a lion ramp. az. a label ga. Colvule. Isle of Fly. John Corvyeise of Marshland, Y, but in pencil NevilL.

Arg. a lion ramp. az. a bend compony of the first and gu. FulTON.

Arg. a lion ramp. az. over all a bendlet compony erm. and gu. Fulton.

Arg. a lion ramp. az. over all a bend compony gu. and or. Sir Ricbard Dockesey, co. Salop, temp. Edward III, $V$.

Arg. a lion ramp. az. over all a bend compony or and gu. Dockeley. Dockesey, $V^{*}$. Dorksey, co. Salop. Fawconbridge.

Arg. a lion ramp. az. a dexter baton compony or and gn. Sir Richard de Dockesseve, $N$. M. Walter de Faconberge, $Y$. Sir Waultre Faucomberge, $M$. Sir Walter Fauconderge, $N$. Arg. a lion ramp. az. over all a bend gu. ARDERne. Augustimian priory at Gisborne, Giseburn, or Gysburgh, co. York. Totr, co. York.

Arg. a lion ramp. az. depressed by a bend or. FAUCONBRIDGE.

Arg. a lion ramp. az. over all a bendlet gı. Sire de Ardene, $A$. Gerard. Tokett or Tockette, Tocket, co. York.

Arg. a lion raınp. az. debruised with a bendlet or. Clifton. Sir Walter Fauconbridge, Essex, temp. Edward III, $V$.

Arg. a lion ramp. az. over all on a bendlet gu. three escallops of the field. TAYLOR, Dublin, $W$.

Arg. a lion ramp. az. debruised with a fess gu. Sutton, Essex.

Arg. billetty a lion ramp. az. Huntington.

Arg. crusily of crosses croslet gu. a lion ramp. az. Montford. Sire de Montfort, $N$. Thomas de Mountford, $P$. Thomas Mountford, $Y$.

Arg. crusily fitchy gu. a lion ramp.az. Mountfond, co. You'k.

Arg. flory and a lion lamp. az. Bratost. 
BEASR. IION.... cont.

Arg. a lion ramp. az. in his dexter paw a thistle ppr. Gallaway, Scotland.

Arg. a lion ramp. az. armed gu. Braytoft. Clifton.

Arg. a lion ramp. az. armed and langued gu. Broce, Carnock, Scotland; quartering or a saltire and chief gu. Crichton, That Ilk, co. Fdinburgb, Lord Crichton and Viscount Frendraught; quartering arg. a saltire and chief az. over all on an escucheon az. three stars arg. within a double tressure flory counterflory or. Crichton, Cairnes, Scotland, cuartering Cairnes. Crichton, Sanquhar, Earl of Dumfries, a cadet of Frendranght, quartering Stewart. Fatconbridge. Fitz-Rery. Lron, Scotlaud.

Arg. a dragon vert and a liou az. crowned gu. combatant. Tame, Fairford, co. Gloucester.

Arg. a wivern vert combating with a lion ramp. az. crowned or. TAME, co. Oxford.

Alg. a lion ramp. az. crowned or. Fitz-Kery, Ireland, $V$. Picierixg,

Arg. a lion ramp. az. ducally crowned or. Picisering.

Arg. a lion ramp, az. crowned with a coronet of four balls or. (?) Ralph de MaIDstone, Bishop of Hereford 1231.9; or (?) Hugh de Mapenore, Bishop of Hereford 1216-19.

Arg. a lion ramp. az. crowned gold depressed by a fess compony or and of the second. Mrid, $V^{*}$.

Arg. a lion ramp. tail forked az. FAconberge, Lord of Shelton. WAUDEFORD.

Arg. a lion ramp. double tailed az. WoNDESFord. Arg. a lion ramp. with two heads az. MAson, Irelind.

Arg. a lion ramp. guard. az. Brattoft, co. Lincoln.

Arg. a lion ramp. barruly gu. and .... Hesse Cassel, $Z, 566$.

Arg. a lion ramp. chequy az. and or. Coвsнad, V. Coвнait.

Arg. a lion ramp. chequy az. and or armed gu. CoKEHAM.

Arg. a lion .... chequy or and az. CoBE⿱一𫝀口, $V *$

Arg. a lion ramp. chequy or and sa. Sire Rauf de CobHami, $O$.

Arg. a lion ramp. chequy or and vert armed gu. CoKeHAM.

Arg. a lion ramp. erm. gorged with a collar or. Guil.LIM, Westbury and Minsterworth, co. Gloucester, 1571.

Arg. a lion ramp. ermines collared or. GwLLInt, co. Hereford.

Arg. a lion ramp. ermines armed sa. collared or. A gUILIIIARS.

Arg. a lion pass. gu. Clare or Clarke; the heiress m. Peake about 1400. Petit, $V$. Petit, Ardevora, Cornwall; the coheirs m. Aruudel, Sayer, and Killigrew. Quesnes.

Arg. a lion pass. gu. over all a pale az. Dring.

Arg. on a mount vert a lion pass. gu. against a tree ppr. Perraro.

Arg. a lion pass. crowned gu. Darchington.

Arg. a lion pass. gu. crowned or on a mound az. environed with a circle and ensigned with a cross avellane of the third. OGILVI, Glashaugh, Scotland.

Arg. a lion pass. guard. gir. Catte. OgInvie, Boyne, Scotland, Bart.; quartering Eamiston; over all dividing the quarters a cross engr. sa. for Sinclair, Deskford. Quarieton, $V$. Quarliton. Querieton.

\section{BEAST, IION.... cont}

Arg. goutty de sang a lion pass. guard. gu. BIRN or Brin, Ireland.

Arg. a lion pass. guard. gu. armed and langued az. crowned with an imperial crown ppr. Ogilvie, Milltoun, Scotland, certified 2 Sept. 1779; quartering per fess or and az. a galley of the first masts sails and tackling ppr. in the dexter chief point a dexter hard couped in fess holding a dagger in pale gu. in the sinister chief point a cross patty fitchy of the last, and Sinclair.

Arg. a lion pass. guard. gu. ducally gorged or. OGILey.

Arc. a lion pass. guard. gu. crowned o:. Sir Warren de Lisle, $R$. Ogiluvy, Lord Banff; quartering arg. three popinjays vert beaked and membered gu.

Arg. a lion pass. guard. gu. cromued with an antique crown or. ANGUs, Scotland.

Arg. a lion pass. guard. gu. royally crowned or. OgIIVIE, Rothemay, Scotland; quartering Eamiston, over all dividing the quarters a cross engr. sa. charged in chef with a crescent arg.

Arg. a lion pass. guard. gu. imperially crowned ppr. Grant OGILviE, Earl of Seafield; quartering Sinclair'; second and third grand quarters, Grant. OGIIIE, Earl of Findlater, with the same quarterings.

Arg. a lion pass. guard. gu. crowned with an imperial crown and collared with an open one or. OGILVie, Earl of Airlie, Alyth, and lintrathen. OGilvie, Innerquharity, co. Forfar, Bart., quartering Ramsay. OGLuv, Balbigno, Scotland, with the same quartering within a bordure az.

Arg. a lion ramp. gu. Angas or Anges.

Arg. a lion ramp. gu. Ashley. Aslie. Atwood. Balditngton. Beamish, Cork. Braumont. Bloner, Cowley, co. Gloucester. Bokenham. Brunfold. Buckingham. Champnex, co. Devon. Chetwood, $\boldsymbol{V}$. Cramriond, Scotland; quartering or a dexter hand couped fesswise holding a cross croslet fitchy gu., with per fess or and vert in chief a galley of three masts oars in action sa. in base a salmon naiant arg., and arg. a tree eradicated vert, in surtout an escucheon az. charged with a bend betw. three pelicans in their nests arg. DonaLd, quartering or an ar'm in armour fesswise ppr. holding a cross croslet fitchy gu., with or a galley oars in action sa. flags gu., and vert a salmon naiant arg. Dundas, that Ilk. Edridge, London, and Shipdham, Norfolk. EDrik. Egerton. Etтrick, High Barns, co. Durham. Fergus. Ieuarn Gadarn. Gerard. Gerney, Norfolk. Gray, Ouchester. Havering, co. Wilts. Hulton, Donington, co. Lincoln, and Parke. Hulton, Hulton. Ivye, co. Oxford, and West Keynton, co. Wilts.; quartering arg. a fess embattled gu. betw. three annulets sa. JERMrN. Jones, Nass, near Lydney, and Hay Hill, near Newnham, co. Gloucester. Joye, West King. ton, co. Wilts. Larare. Legh, High Legh, co. Chester; quartering Cornwall, Mortimer, Lenthall, Grey, and Basset. LEIGH, Dublin; certified 6 Feb. 1677. LEIGH, co. Chester, $V$. Leon, as borne quartered with Castile, by Eleanor, Queen of Edward I. Lyons. Macalester, Loup and Kennox, Scotland; derived from Augos Mor, of the Isles; quartering or a dexter arm in armour couped fesswise 


\section{BEAST.}

LION . . . . cont.

lolding a cross crosslet fitchy gu., with or a galley oars in saltire sails furled sa. flags gu., and vert a salmon naiant in fess arg. Macal.estels, Rosehill and Barr, Scotland, with the sane quarterings. Macalisten, Glenbarr. co. Argyll, derived through Macalister, Strathaird, from the Lords of the Isles, with the same quarterings. MAC DANIEL, Ireland; quartering arg. a liand couped in fess holding a cross croslet fitchy gu., with or a lymphad sa., and gu. a fish najant ppr. M'Donald, St. Martin's ; quartering or a hand in armour holding a cross croslet fitchy gu., with or a lymphad sails furled sa., and per fess arg, and vert a fish naiant in fess .... Bosville MaCdonald, Baron Macdonald, Slate; quartering or a hand in armour holding a cross croslet fitchy gu., with or a Jymplrad sails furled sa., and vert a salmon naiant in fess arg., second and third grand quarters Bosville. Macdonald, East Sheen, Surrey, Bart., with the same quarterings. M'Donain, Kippoch, co. Inverness, with the same quarterings. M'LEAN, Ardgour, quartering az. a castle triple-towered arg. flags displ. gu., with or a dexter hand couped fesswise gu. holding a croslet fitchy az., and or a galley sails furled sa. flag gu. on a sea vert a salmon naiant arg. M'Lochlan. Morgan ap Meredith. Petit ol Petyt, Cornwall. Pettit or Petyt. Talbot, Upper Lyne, co. Devon. Hugh de Torbervile, A, Harl. MS. 6137, Turbevire, $D$, Turbervile, $E$, De Turbervile, $F$. VANDERNOT, co. Lincoln, quartering arg. three chev. gu. VERDON, co. Chester. VINYAN, co. Cornwall. $V$. Wall. Laurence Womack, Bishop of St. David's, 1683.6. WooD, co. Stafford. Thomas Wood, Bislıop of Lichfield, 1671-92. And with due diff., Dundas, Blair Castle, co. Perth, descended from Dundas, Dundas, quartering Airth, Bruce, Henderson, Lauder, El. phinstone, Drummond, Spital, Leslie, Lord Lindores, etc. And with a label of three points az. each charged with two bezants. Beaunont. And with a mullet for diff. LEIGH.

Arg. a lion ramp. gu. M'Donald, Bowie, Scotland; quartering az. a dexter hand couped fesswise holding a cross croslet fitchy arg., with or a galley oars in saltire sa., and per fess wavy arg. and vert in base a fish naiant of the first, all within a bordure quarterly gu. and arg.

Arg. a lion ramp. in bend sinister gu: VIvian.

Arg. a lion ramp. gll. facing the sinister side. Vivian, Cornwall, $V$. Vinyan, Cornwall, $V$.

Arg. a lion ramp. gu. on a mount in base vert. Vivian, Cornwall.

Arg. on a mount in base vert a lion pass. gu. in front of a tree of the second. Winton, Scotland.

Arg. a lion ramp. gu. over all on a bar sa. three crosses croslet fitchy of the field. Colbrooke, co. Devon.

Arg. a lion ramp. gu. over all a bendlet of the first. Sir Richard Egbaston, $V$. Oswalstre, $V$.

Arg. a lion ramp. gu. debruised with a baton of the first. EDGEBASTON.

Arg. a lion ramp. gu. over all a bend az. AsHeLson. EDGebaston, co. Leicester. Eschelaston.

Arg. a lion ramp. gu. depressed by a bendlet az. Edgebarston EgGebarston or Eggebaston, quartered through De Boudon by D'Oyley.

Arg. a lion ramp, gu. debruised with a bend com. pony az. and or. SCHARINGTON or ScHEVINGTON, V. Sherington, Shrimpling, co. Norfolk.
BEAST. LION....cont.

Arg. a lion ramp: gu. over all a bendlet (a bend $V^{*}$ ) compony of the second and or. Lusyon, $V$.

Arg. a lion ramp. gu. over all a bendlet compony or and az. Lukin, co. Lincoln; and co. Oxford. Lunis, Dunmow, Essex. Lunis, Hythe, Kent.

Arg. a lion ramp. gu. over all a dexter-baston compony or and az. Piers Lucien, Y. M. de Lucion, $Y$.

Arg. a lion ramp. gu. over all a bend compony or and of the second. Lucion. Lusion, $V^{*}$.

Arg. a lion ramp. gu. over all a bend raguly or. Striward, Nolfolk, $V^{*}$. Steward, co. Cambridge; Stantney, Isle of Ely; Gestwait, Heseldon, and Swardeston, Norfolk; and Suffolk; granted 10 March, 1586.

Arg. a lion ramp. gu. over all a bendlet raguly or. Steward, Norfolk, $V$.

Arg. a lion ramp. gu. over all a bend sa. Branche, $V *$ * EveringhaM.

Arg. a lion ramp gu. over all a bendlet sa. John Branche, Norfolk, $V$. Flefte, Kent. Fleets.

Arg. a lion ramp. gu. over all a ribbon sa. ABERNETHY.

Arg. a lion ramp. gu. over all on a bend of the second three crosses croslet fitchy of the first. WATTON.

Arg. a lion ramp. gu. on a beudlet of the last three crosses croslet fitchy of the first. WATFORD.

Arg. a lion ramp. gu. over all on a bendlet of the first three crosses patty fitchy sa. GibBins, $W$.

Arg. a lion ramp. gu. over all on a bend or three crosses patty fitchy .... GibBens. GibBines. Gibbings. Giebins.

Arg. a lion ramp. gu. over all on a bend sa. three crosses croslet fitchy of the field. WADDON, Plymouth. Walton, Addington, Kent. Watton, Adliugton, Kent.

Arg. a lion ramp. gu. or a bend sa. three escallops of the first. SPENCE, Brinsten, Scotland.

Arg. a liou ramp. gu. on a bend sa. three 5 -foils arg. Branche, $\boldsymbol{V}^{*}$.

Arg. a lion ramp. gu. over all on a bendlet sa. three pierced 5 -foils arg. Sir Philip Branche, Norfolk, $V$.

Arg. a lion ramp. gu. on a bend of the first three mullets sa. EgBaston, $V^{*}$. Oswalstre, $V^{*}$. Arg. a lion ramp. gu. over all on a bend sa. three mullets or. Fleet or Flote. De Fleete, $V^{*}$.

Arg. a lion ramp. gu. over all on a bendlet sa. three mullets or. Sir Laurence de Fleete, co. Lincoln, $V$.

Arg. a lion ramp. gu. over all on a bend az. three bezants. Bukenham or Bokenham, Norfolk.

Arg. a lion ramp. gu. on a beud sa. three bezants. Egrevale or Egrewall. Egrivall, $V^{*}$.

Arg. a lion ramp. gu. over all on a bendlet sa. three bezants. Sir Robert Egrrvall, $V$.

Alg. a lion ramp. gu. a dexter baton sa. bezanty. Sir Edmond Cornwalle, $L$.

Arg. a lion ramp. gu. over all a chevron az. Harris, Ireland.

Arg. a lion ramp. gu. over all a chevron or. Harres. Harries or Harris. Harris.

Arg. a lion ramp. gu. over all a fess or. RochFori, Wexford.

Arg. a lion ramp. gu. over all on a fess or three crosses patty fitchy sa. CALBROKE. KIIRINGTON. Kirlington alias Colbroke, $V$.

Arg. a lion ramp. gu. on a fess sa. three crosses formy or. CoLbrooke.

Arg. a lion ramp. gu, a saltire sa. BoAtfield. 
BEAST.

IION .... cont.

Arg. billety a lion ramp. gu.

Sir Roger de Bolmere, $N$. Bulmer or Bullmer. Joan de SaPi, E. 'Thomas T'urbervile, $Y$.

Arg. semy of crosses botonny a lion ramp. gu. GIFTORD.

Arg. crusily and a liou ramp. gu. Walter Bukeshuld, $Y$. William Giffard, $E, Y$.

Arg. crusily fitchy and a lion ranp. gu. BRETT, London. FaUnt or Fant, co. Leicester.

Arg. crusily sa. a lion ramp. gu. William GIFFORD, $F$.

Arg. semy of escallops sa, a lion ramp. gu. (? William MadBe, A, Harl. MS. 6137.)

Arg. flory az. a liou ramp. gu. Thonpe, Thorpe, oo. York.

Arg. a lion ramp. holding betw. the paws a star gu. over all a bendlet az. FaInLy, Bread, Scotland.

Arg. a lion ramp. gu. holding up an esquire's helmet az. Cleshan, quartering arg. a heart gu. royally crowned ppr. within a bordure az. charged with eight buckles or on a chief of the fourth three mullets of the first.

Arg. a lion ramp. holding betw. the paws a human heart gu. in the centre chief point a crescent az. thereon a mullet silver for diff. Dundas, Richmond, Surrey; and Llanelly, co. Carmarthen, Bart.

Arg. on a mount vert a lion ramp. looking to the sinister gu. supporting an orange tree leaved and fructed proper. DE LA Motte.

Arg. a lion ramp. gu. unarmed or. AlBone.

Arg. a lion ramp. gu. armed or. LIGHTON, Ullishaven, Scotland. Macdonatd, Mayderty, Scotland, quartering or a dexter hand couped fesswise bolding a cross croslet fitchy gu., with or a lymphad .... in base a salmon naiant in sea vert, and arg. an oak tree vert surmounted by an eagle or.

Arg. a lion ramp. gu. armed az. over all a bend sa. Branche.

Arg. a lion ranmp. gu. armed az. over all on' a bend sa. three 5-foils of the field. Branche.

Arg. a lion ramp. gu. armed and langued az. Ashenden. Bokenhar, Stoke Ash, Norfolk, 1716. Hulron, Hulton, co. Lancaster. Lighton, Sweden, descended from Scotland.

Arg. a lion ramp. gu. armed and langued or. Astiey. Astley or Asteley, co. Stafford.

Arg. a lion ramp. gu. armed sa. Vrvyan, Trelo. warren, Coruwall, Bart.

Arg. a lion ramp. gu. collared of the field. REDdish, Berifield, co. Berks. Sir Richard STAKPoll, co. Gloucester, temp. Edward I, $V$.

Arg. a lion raunp. gu. collared or. AsHENDEN, $V$. Eyseldon, co. Devon, $V$. Eysseldon, co. Devon. (? Sir John de Havering, H.) Rediche, Redicbe, co. Lancaster; confirned 15 May, 1587. Reddish, Redishe, co Dorset; Redishe, co. Lancaster; and Mayden, co. Wilts. StackPole. Sir Richard de Stakepol, $N$. Stakepowle Stake Poole or Stakepoll, co. Gloucester.

Arg. a lion ramp. gu. gorged with a collar or charged with three ogresses. AsHdoun or AsHDOWN.

Arg. a lion ramp. gu. collared and chained or. ASHENDEN.

Arg. a lion ramp. gu. collared and chained or crowned with an antique crown of the last. UnE, Scotland.

Arg. a lion ramp. crowned gu. Monsire d'Erelington, $Y$. Henry Hentlington, $Y$.
BEAST. LION.... cont.

Arg. a lion ramp. gu. ducally crowned or. Constable. Sir .... de Hirton, co. Lancaster, $V$.

Alg. a lion ramp. gu. crowned or. BAVEnt, Halton, co. Lancaster. Hinton, co. Lancaster and co. York. Hotton. Hulton, Hulton. Luxemburg, $Z, 489$. Napton, co. Warwick. St. Paul. Earl of Poitou, $Z, 95$. Hugh Turbervilte, $Y$.

Arg. on a mount vert, a lion ramp. gu. crowned or. Mount, Kent. Mounte, Kent, $W$.

Arg. a lion ramp. gu. crowned with an antique crown or. Roche, Ireland. Sloan.

Arg. a lion ramp. gu. crowned or a crescent for diff. Turbervile, Saudford Peverel, co. Devon, and Beere, co. Dorset.

Arg. a lion ramp. gu. crowned or on a dexter baston sa. three mullets of the third. Sire Geffrey de Cornewayle, $O$. Jeffry de Cornwale, $Y$.

Arg. a lion ramp. gu. ducally crowned or over all on a bend sa. three pierced mullets or. Sir Geoffiy de Cornwall, $V$.

Arg. a lion lamp. gu. crowned or over all on a bend sa. three nullets or. Sire Geffry de Curteneye, $O$.

Arg. a lion ramp. gu. ducally crowned or over all on a bendlet (bend $V^{*}$ ) sa. three bezants. Sir Edmund de Cornewall, $V$.

Arg. a lion ramp. gu. crowned or over all on a dexter baston sa. three bezants. Monsier Symon de Connwale, $Y$.

Arg. a lion ramp. gu. crowned or over all on a bend sa. three bezants. CornwaIL, co. Oxford. De CoRnewali.

Arg. a lion ramp. gu. crowned or over all on a bend eng. sa. eight bezants. CoRNwaI.L.

Arg. a lion ramp. gu. crowned or over all a bend sa. bezanty. Sire Edmon de CoRnewailue, $N$. Sir Edmond de Curteneye, $O$. But with a dexter baston bezanty instead of a bend, Sire Edmond de Cornewailis, $O$.

Arg. semy of crosses croslet a lion ramp. gu. crowned or. Sire Stevene Barret, O. Brewes, co. Buckingham. Brewes, Stinton, co. Norfolk, descendant of the Lords Braose of Bramber. Brewse, Suffolk.

Arg. a lion ramp. gu. crowned or armed and langued az. Hxuton, Farnworth, quartering Hall.

Arg. a lion ramp. gu. crowned and chained or. URRTE.

Arg. a lion ramp. gu. crowned sa. M. de LovetoFt, $Y$.

Arg. a lion ramp. gu. on his head a helmet az. Clapharr, Scotland. Clephan, Carslogie, Scotland.

Arg. a lion ramp. gu. enraged az. EтнrIck, Earl of York.

Arg. a lion ramp. gu. incensed az. Morgan ap Meredith, Lord of 'Tredegar, co. Monmouth; his heiress $\mathrm{m}$. Llewellin ap Ivor, Lord of St. Clere, ancestor of the Morgans of Tredegar.

Arg. a lion ramp. gu. langued az. ArueniA, jmpaling Jerusalem, and az. three bars arg. over all a hon lamp. gu. langued az. all tierced, Harl. MS., 6829 , fo. 46 .

Arg. a lion ramp. gu. langued az. holding betw. his paws a man's heart ppr. Dundas, Duddingstoun, West Lothian; descended from Dundas, of that Ilk; quartering Hamilton, Lynde. sey, Crawfurd, Dreghorn, etc. And with a cres. cent for diff. Dundas, Manner, Scotlanil. 


\section{BEAST. LION....cont.}

Arg. a lion ramp. gu. langued sa. Vinyan, Corn. wall, $V$.

Arg. on a mount vert a lion ramp. gu. crowned or tail arg. Mount, $V^{*}$.

Arg. a lion ramp. tail forked gu. W. de Bavesor, F. Brewer. Brewse, Norfolk, temp. Edward III. Havering. Richard de Haveringes, $E$. William de Havering, $Y$. Monsire de Haveringe, $Y$. Mountford, $V$. Nuvant, co. Devon. St. PaUl, co. Lincoln. WaIders, co. Leicester.

Arg. a lion ramp. double tailed gu. Havering. Hulton, Bevis Mount, co. Hants., and Wrexham Hall, Norfolk. Mountford, $V^{*}$.

Arg. a lion ramp. donble tailed gu. one of the tails coward. WALLIS, quartered by Danvers.

Arg. crusily a lion ramp. tail forked gu. William de Breuse, Bishop of Llandaff, 1266-87. Sire Robert le Venour, $N$.

Arg. crusily a lion ramp. tail forked and renowed gu. Sire Giles de Breouse, $N$.

Arg. crusily fitchy a lion ramp. tail forked gu. M. John Brewes, $S$.

Arg. a lion ramp. tail forked and nowed gu. col. lared of the first. Havering, co. Dorset. Sir Pichard Havering, Halton Park, $V$. Sir John Havering, co. Wilts, $V$.

Arg. a lion ramp. double tailed gu. collared of the first. Havering, $V^{*}$.

Arg. a lion ramp. tail forked gu. collared az. Sire Johan de Havering, $N$.

Arg. a lion ramp. tail forked and renowed gu. collared or. Sir John BencLer, Suffolk, temp. Edward III, $V$.

Arg. a lion ramp. double tailed gu. collared or. BENCLER, $V$.**

Arg. a lion ramp. tail forked gu. crowned az. BERG, $Z, 489$.

Arg. a lion ramp. tail forked gu. crowned or. St. Paul, Snarford, co. Lincoln. Luxemburg, $Z, 313$

Arg. a lion ramp. tail forked gu. crowned ppr. Peter, Earl of St. Paul, surnamed of Luxenburg, $Z, 407$.

Arg. semy of crosses croslet .... a lion ramp. tail forked .... H H HERING, co. Wilts.

Arg. a lion ramp. guard. gu. Cattesby. Germy, Suffolk. GERney, Suffolk. Horn. Horne. Horon. Sir Gerarde Horun, $V$. Jermy or Jermyn, Antingham, Merlingforth, and Wyton, Norfolk; Brightwell, and Stutton, Suffolk. JERMYN, $V$.

Arg. a lion ramp. reguard.gu. Agrnal, Cresseley.

Arg. a lion salient gu. Felbridge. Lrghton, Scotland. Petit, Ardevore, Cornwall; the coheirs m. Arundel, Sayer, and Killigrew. Peтiт, Cornwall, $V$. Petrit, Cornwall. Werdon.

Arg. a lion salient gu. collared or. Erseldon. Radish, co. Lancaster. Yseldon.

Arg. a lion salient guard. gu. JERMy.

Arg. a lion ramp. lozengy or and az. Cockham.

Arg. a lion ramp. per fess gu. and sa. Joan de Lovetot, $E$, or Love'Tof, $F$. Lovetort, $V$. Lovetort Lovetot or Livetot, co. Huntingdon, and Worksop, co. Nottingham, temp. Henry I. De Lovetot or Luvetot, Lord of Hallam, co. York, in Sheffield church. Lovetost, $V *$ * Lovetr.

Arg. a lion ramp. per fess sa. and gu. John Lovetor, $Y$.

Arg. a lion guard. with two bodies counter. ramp. per pale gu. and sa. Davy HoweL, $V$.
BEAST. LION.... cont.

Arg. a lion pass. ppr. Deane, co. Leicester, $W$. Arg. a lion pass. reguard. ppr. Smrth, $V^{*}$.

Arg. on a mount vert a lion pass. reguard. ppr. Smrry of the Exchequer, $W$. Smith, co. Salop, $W$. Smyth, co. Hertford; Crednall, co. Hereford; Askham, co. Nottingham ; and Overton, co. Salop; granted 1590.

Arg. a lion ramp. ppr. Deane, Nortonpetrach, co. Devon, $W$. LAsCYE, co. Lincoln, temp. Edw. I. Arg. a lion ramp. guard. ppr. Den, $W$.

Arg. on a mount vert a lion statant guard. against a tree ppr. Town of ANDOVER, Hampshire.

Arg. a lion pass. purp. Deane, co. Leicester. DENE.

Arg. a lion ramp. purp. Balderston, co. Lan. caster. Richard de Baldreston, $Y$. Bayousse, co. Huntingdon. Deane. Deane, Dedan, or Dene, Newton Patrock, co. Devon and co. Leicester. Sir Johan de Dene, $N$. Sir John Dene, co. Leicester, temp. Edward I, $V$. Dene De Den or Dedene, co. Leicester. Sir Roger Fitz Roger, $V$. Sir Robert le Fitz-Roger, $J, Y$. LEON, $Z, 70,129,179,250,260,378$, 475,499 . Wood, alias Deane. Wood, Hiltwood, co. Stafford. SIrIpton.

Arg. a lion ramp. purp. over all a bend or. SANDACRE.

Aig. a lion ramp. purp. over all a bend vert fretty or. Sandacre, $V$.

Arg. a lion ramp. purp. over all a dexter baston vert. Monsire de SANDACre, $Y$.

Arg. a lion ramp. coward purp. Amand. Rowch. Arg. a lion ramp. purp. gorged with a ducal co. ronet or. Story, London, 1634.

Arg. a lion ramp. purp. crowned or. Sir John Clemsby, co. Leicester, temp. Edward I, V. Sire Johan de Creursby, $N$.

Arg. a lion ramp. crowned purp. Roche or Roch.

Arg. a lion ramp. tail forked purp. SHoREY. STory, co. Salop.

Arg. a lion ramp. tail forked and double nowed purp. Sir William Storey, $V$.

Arg. a lion ramp. with two tails purp. SturRey or Stury, Rossall, co. Salop.

Arg. a lion ramp. double tailed purp. crowned or. Hugh Folrot, Bishop of Hereford, 1219-34. Folliot, Pyrton, co. Worcester.

Arg. a lion ramp. double tailed purp. ducally crowned or on the neck of the lion a crescent for diff. FoLrrotr, Ballyshannon, created Baron Folliot, 1619, descended from Folliot of Pyrton; the coheirs m. Foley, Walker, Powell, Jones, and Bangh.

Arg. a lion ramp. reguard. purp. St. Quinrin. Herbert St. Quintin, $Y$. Panthe.

Arg. a lion ramp. reguard. purp. the tail reflexed from betw. his legs over the back. Derouch. Sir Amand de Roucu, $V$.

Arg. a lion ramp. reguard. purp. crowned of the second. Eman, Windsor, co. Berks.

Arg. a lion pass. sa. Bali, Scotto, co. Norfolk; granted to Robert Balde by Cooke, $W$. Bentley, $V^{*}$. Blunden, Bishop's Castle, co. Salop. Breton, quartering sa. a mullet arg. Delafold, $V^{*}$. Jenkin Llwyd. Lenpy. $V^{*}$. Pynock, $V^{*}$. Stapleton, $V^{*}$. Wakefare, $V^{*}$.

Arg. a lion pass. sa. over all two bills (battle-axes, $\left.V^{*}\right)$ in saltire the staves gu. headed of the first. Gibon, $V$.

Arg. a lion pass. in bend sa. depressed by a bend gu. (N.B. The lion above the bend only ap. pears.) Henry Cresset, $V$. 
BEAST.

IION.....cont.

Arg. a lion pass. sa, over all two tilting spears in saltire gu. headed of the second. Gybons, co. Lancaster, and Darsham, Suffolk.

Arg. a lion pass. sa. in the dexter paw a trefoil slipped vert. BLUNDEN, Ireland.

Arg. a lion pass. sa. the forefeet fettered or. Madoc ap Adda Moel.

Arg. a lion pass. sa. the forefeet disarmed. Ro. bert Suith, Surrey, 1623, $W$.

Arg. a lion pass. disarmed sa. Smrth, $V^{*}$.

Arg. a lion pass. coward sa. Herweil.

Arg. a lion pass. guard. sa. Buunden, Bishop's castle, co. Salop. Humphreys, HuMphries, Humphris, Hunphrys, and Humphryes. Humphries, Ham Frith, Essex, quartering sa. three nag's heads erased arg. St. Quintis. William de Stone, $F$. Cadivor VAwr.

Arg. a lion pass. guard. tail forked sa.. Fretwick.

Arg. a lion pass. reguard. sa. Sмrт, Honington, co. Worcester.

Arg. a lion ramp. sa. Ap Meredith, Wales. Ashby. Borgentyn. Chitwood. Bovile. Botfust, Suffolk. Branas. Casamajor, Potterells, co. Hertford, quartering with sa. a crescent arg. Cressy, Cressy Hall, co. Lincoln. Leoline ap Madoc ap Elis, Bishop of St. Asaph, 1357-75. FAwconbridge. Sire Johan de Fenes, $N$. Sire de Fienes, $A$; and so Fineles, $A, H a r l$. MS. 6137. Fineaux. Foulk, Cilain and Pentre Morgan. Fynes. Girardot, Allestrey, co. Derby; quartering gu. a chev. arg. Gouls, Duntish, co. Dorset, temp. Edward II. HARPER, Kent. Henston, co. Lancaster. Huxhad, co. Devon. Kinaston, Ruyton, co. Salop; quar. tering erm. a chev. gu. KrNaston, Otley, co. Salop; derived from Iorwerth GocH, Lord of Mochnast, younger son of Meredith ap Bleddyn, Prince of Powis; a heiress m. Mainwaring. Lentston. Lloyd, Crogen. Long, Scotland. Lostock, quartered by Atberton. Maesmore. Mathew or Mathews, Hensol Castle, and Castle Menych, co. Glamorgan; the heiress m. Talbot. Mathers, Upton Grey, and Alton, co. Hants. Maurice, Bryn y Gwalie, Barons of Pale yn Edeirnion. Madoc ap Meredith, ob. 1160. Mompesson. Morgan, Dudelston, co. Salop. Morgan, Tredegar and Mauchan; i.e. Morgan ap Llewellyn (ap Iror Lord of S. Clere) ap Llewellyn ap Ivor ap Bledry ap Kadivor Vawr. Newton, Suffolk. Paske. Pomeroy, Berry-Pomeroy, co. Devon. Powys, Lord Gifford. Rhys, Rúg. John Fitz Roger, $A$, but Robert, Harl. MS. 613\%. Sir Herbert St. Maris, $L$. Sempy, V. Sarte, Southwark. Sir Miles de Stapeltone, $N$. Sir Nicholas Stapleton, $Q$. Sir Bryan Stapleton, Carleton, co. York, $V$. Stapleton or Stapylton, Baron Stapleton, 1313; the heirs m. Metham, and Dolman. Stapleton or Stapylton, Wighill, co. York; descended from Stapleton or Stapylton, Carlton, co. Fork; derived from Miles, first Lord Stapylton; a heiress m., 1783, Chetwynd. M. Miles de Stapulton, $S$. Stapleton, Baron Beaumont. Stapleton, Thorpe Lee, Chertsey, co. Surrey. Stapleton, Baron Le Despencer, quartering Fane, Neville, and Spencer. Stapleton or Stapylton, Myton, co. York; created Baronet 1600 ; descended from Stapylton, of Wighill; the heiress m., 1770, Bree. Stapylton, Norton, co. Durham; a brauch of Stapylton of Myton. VAughan, Duddleston, co. Salop; derived through David
BEAST.

LION.

ap Madoc of Peutemorgan, from Bleddyn, Lord of Diumael, third son of Owen Brogyntyn, Lord of Edeirnion, Dinmael, and Abertanat. Wakeford, Norfolk. Sir Robert WaKe Fure, $V$. Walkfare, Norfolk. Welles. Whitestones(?). Whitson, Scotland. Williams. Wynn, Dud. dleston, co. Salop. Wynne, Plas Issa.

Arg. a lion ramp. sa. over nll a label of one point gu. Bagecroft, Beccles, Norfolk, 1730.

Arg. a lion ramp. sa. a label of three points az. BotFust, Suffolk.

Arg. a lion ramp. sa. a label of three points gu. M. Robert de Morlee, $S$.

Arg. a lion ramp. sa. a label of five points gu. BuRNell.

Arg. a lion ramp. sa. a dexter baton az. a 5.foil erm. Sire Richard de Egebastoun, $O$.

Arg. a lion ramp.sa. over all a beud cornpony gu. and of the first. Browne, co. Chester. Fawcett. Arg. a lion ramp. sa. over all a dexter baton gu. Burnell, Ireland, and Essex. Hue Burneli, E. Philip Burneli, $D$. Monsire de Pierpoint, the nepbew, $Y$.

Arg. a lion ramp. sa. debruised by a bendlet gu. Burnell. Fines. Wat de Gry, $F$.

Arg. a lion ramp. sa. a dexter baton or. Sir Robert de Perponest, $M$. Sir Robert Perpoynt or Pierpont, $L$; and also, but a mistake, Sir John de WeYlande, L, Harl. MS., 6137.

Arg. a lion ramp. sa. on a bendlet gu. three martlets of the field. Phelip Bunners, $F$.

Arg. a lion ramp. sa. over sll on a bend gu. three round buckles or. Wat de GeI, $E$.

Arg. $\Omega$ lion ramp. sa. over all on a bend gu. three escallops of the field. Burnesu, Ireland, $V$, and Essex.

Arg. a lion ramp. sa. over all on a bend gu. three escullops or. Burnel, Ireland, and Essex. Philip Burneli, $E$. Gayeon. Gibbon, $V^{*}$.

Arg. a lion ramp. sa. on a bendlet gu. three escallops or. Burnell. Gibbon, $W$.

Arg. a lion ramp. sa. debruised with a fess chequy az and or. Burley. Milde.

Arg. a lion ramp. sa. over all a fess chequy of the second and first. MILDE.

Arg. a lion ramp. sa. over all a fess counter-com. pony az. and or. Milde, Suffolk. MrLd, $V$.

Arg. a liou ramp. sa. over all a fess gu. Howell ap Bennet. Benet ap Howell, $V$.

Arg. a lion ramp. sa. over all a fess engr. gu. Poweld, Filworth, Surrey. Ap-Howeld, co. Gloucester. Powell, quartered by Davies, Moor Court, co. Hereford.

Arg. a lion ramp. sa. on a fess or three crosses croslet fitcly of the secoud. KIKINGTON alias Colbrooke.

Arg. a lion ramp. sa. over all on a fess az. three bezauts. Punchas, co. York.

Arg. a lion ramp. sa. over all on a fess of the second three bezants. Thwaytes, temp. Henry VI, V. Thawits, $V$.

Arg. a lion ramp. sa. debruised by a saltire gu. Deli. Gotisle.

Arg. a lion ramp, sa. over all a saltire engr. gu. Gotesley or Gotysby. Gotisle, $V$.

Arg. a lion ramp. sa. over all a saltire engr. gu. charged with a crescent for diff. GOATLEx, Canterbury.

Arg. a lion ramp. sa. holding in the dexter paw a fireball ppr. BaLL, co. Chester.

Arg. a lion ramp. sa. Lolding in the paw a rose vert. 'TraNte. 


\section{BEAST. LION.... cont.}

Arg. a lion ramp. sa. bolding a baton in pale az. WILIISBX, $V$.

Arg. a lion ramp. sa. supporting a ragged staff az. WILLISBY.

Arg. a lion ramp. sa. in the dexter paw a torteau. Lunt.ow.

Arg. a lion ramp. sa. holding in the dexter paw a chaplet vert. Trout, co. Devon; granted 1588.

Arg. billetty sa. a lion ramp. of the last. Planche, co. Leicester. Planges or Plaunches, co. Worcester.

Arg. billetty sa. a lion ramp. of the last crowned or. Pranche, co. Buckingham. Sir.... de la Plaunche, $N$.

Arg. crusily gu. a lion ramp. sa. Robert LINET or LIVET, $A$.

Arg. crusily and a lion ramp. sa. Sire William Bukemynter, $O$. Thomas Hautevile, $Y$. HighaMr. LiNNET.

Arg. semy of crosses croslet fitchy and a lion ramp. sa. Hantvile or Handvilie, co. Devon and Kent. M. de Hautevile, Y. Levetr, Salehurst, Sussex ; granted Dec. 1607.

Arg. semy of crosses patty and a lion ramp. sa. Handvme, Ulcombe, Kont.

Arg. semy of escallops gu. a lion ramp. sa. Wil. liam MaUBe, $A$; MaUfe, altered in to Maube, $A$, Harl. MS. 6137 , or Manfe, $D$. Sir William MAUFEE, $N$.

Arg. semy of estoiles and a lion ramp. sa. Buckimster, co. Northampton.

Arg. semy of fleurs-de-lis and a lion ramp sa. Sire William de Bocministre, $N$. Monsire de Bocemnster, $Y$. Bokemynster. Buckminster, Peterborough; granted 24 March, 1578.

Arg. semy of 5 -foils gu, a lion ramp. sa. OrReiL. Parkville or Pierrepotnt. Pierrepont, Holme Pierrepont, co. Nottingham; created Earl of Kingston 1028; Visconnt Newark, Baron of Holme Pierrepoint. Pierrepont, Earl Manvers.

Arg. goutty de sang a lion ramp. sa. Scriven, Stapleford, co. Cambridge; Frodesley, co. Salop; and co. Worcester.

Arg. goutty de poix and a lion ramp. sa. Jake de la Plance, $G$. Delaplanch, co. Buckingham.

Arg. semy of mullets gu, a lion ramp. sa. Pierrepont, Earl Manver's.

Arg. a lion ramp. sa. armed az. Honston, co. Lincoln.

Arg. a lion ramp. sa. armed gu. Sir Nicholas Stapleton, $Y$.

Arg. a lion ramp. sa. armed and langued gu. Madoc ap Meredith, last Prince of Powys-Fadoc; and his son Owen Brogrstro ; from the latter descended, nsing the same arms, besides Hughes, G werclas; Li.oYd, Dolyglessyn ; LLoyd, Crogen; Morris, Pale, the heiress m. Lloyd; Brana8, Branas ; Foulke, Cilan; Owen, Plas Issa, the heiress m. Lloyd; the Barons of Crogen and Branas, the heiress m. Ievan, Baron of Kymmer; RHYs, Baron of Rûg, the heiress $m$. Salusbury; Matsmon, Maesmor, the heiress m. Morris; Wynn, Pentre Morgan; (? John Wynne, Bishop of St. Asaph 1715, Bath, etc., 1727-43); Vaughan, Duddleston; and Lloyd, Ebnal; the Barons of Cyniark, the Barons of Hendwr; and Lroyd, Tyfos. Hughes, Gwerclas in Edeirnion, co. Merioneth, and Peny.Clawdd, co. Denbigh, quartering Cilin ap y Blaidd Rhudd; Madoc, Lord of Mawddwy; Elystan Glodrydd; Tudor Trevor; Ievan ap
BEAST.

LION.... cont.

Llewelyn; Horrel, Lord of Nannau ; Philip ap Uchdryd; Ednowen ap Bradwen; Vychan ap Llowarch Goch; Rogers; Cadivor ap Gwaethvoed; Tudor ap Griffith Vychan; Rhys ap Tudor; Llewelyn ap Griffith; Philip ap Ivor; Griffith ap Sir Howel; $\mathrm{Hwfa}$ ap Kendrig ap Rhywalon ; Howel ap Ieuaf; Llewelyn ap Ynyr ; Sannde Hardd; Oren Gwynedd; Eledyr ap Rhys Sais; Kendrig Sais; Marchweithian; Llewelyn Aurdorchog; and Trahaern; a heiress m. Lloyd. Madoc ap Jeyan. Lloyd, Glansevin. Lodlow. Mowat, Balquhollie, Scotland. De Monte Alxo, 1252. John Ap Rhys, Saeth Marchog-yn-Eideirnion, co. Merioneth; derived from Griffith Goch, son of Rhys-apIevan, Baron of Kymmer, Crogen and Branas, in Eideirnion; the heiress m. Salusbury. Idio WyLT, before 1100 . Lloyd WILLIAMS, Gwernant.

Arg. a lion ramp. sa. armed or. BAGEcrort, Bexwell, Norfolk. Morley or Morle, Morle, Norfolk. Burnell. Lovell. M'Donald, Stellen, quartering az. a dexter hand ppr. holding a cross calvary patty sa., with arg. a galley erm. in the sea vert oars in saltire and sails furled sa.. and per fess wavy arg. and vert in base a salmon naiant ppr.

Arg. a lion ramp. sa. langued gu. armed and unguled or. Monsire Nicholas Stapleton, $Y$.

Arg. a lion ramp. sa. armed or langned gu. FarquHar, Mornie, Scotland, quartering az. a sinister hand in pale couped arg., with or a galley and .... masts and tackling sa., and .... an oak tree vert.

Arg. a lion ramp. sa. collared or. Denton. Wyrrali, Forest of Dean, co. Gloucester.

Arg. a lion ramp. sa. gorged with a ducal coronet or. LinCOLNE.

Arg. a lion ramp. sa. collared and cheined or. AMEREdith, co. Devon.

Arg. a lion ramp. sa. gorged with a collar and chain affixed thereto reflexed over the back or. Meredirh, Radnor, Wales; granted 1574.

Arg. a lion ramp. sa. ducally gorged and chain reflexed or. AmerdLey.

Arg. a hion ramp. sa. collared and lined or. Phillits, Yeovil, co. Somerset. Philuips, Netley, co. Salop.

Arg. a lion ramp. sa. dncally gorged (? gu.) and chained or. PHmIPps, Penty Park, Dale C'astle, and Mabws, co. Pembroke. Phiriprs, Picton Castle, co. Pembroke (derived from Cadivor VAWR ) created Baronet 1621, and Baron Milford, 1776. Philipps, Brides Hill, co. Pembroke; descended from PHilipps, Sandyhaven. Philsipps, Middle Hill, co. Worcester, Bart., 27 July, 1821.

Arg. a lion ramp. sa. ducally crowned gu. OwEN. Arg. a lion ramp. sa. crowned gu. Beauchamp, Essex. Midlame. Powell. Rochrord, $Z$, 487. Sir Herbert de Smareis or Desmiareys, $L$. Arg. a lion ramp. sa. ducally crowned or. Lluellyn, South Withiam, co. Lincoln, 1654. Morgan, Arkston, co. Stafford. Morgan, Blackmore, co. Hereford; granted 27 May, 1602. Morgan, St. Bennet Finck, London; author of the Sphere of Gentry, ob. 27 March, 1693. Segrave, Sealford, co. Leicester.

Arg. a lion ramp. sa. crowned with an antique crown gu. Rhys Grug, South Wales.

Arg. a lion ramp.sa. crowned or. Asnuey, Lowesby, co. Leicoster. Sir Edward Burneli, temp. 
BEAST. LION.....cont.

Edward I, $V$. Sir Edward Burnell, $I$; or Burnel, $N$. Sir Nicholas Burnell, $V$. Philip Bunneli, $G$. The Barons Burnell. Herlington. William de Morle, $G$. Sir Robert de Morle, $O$. Syr Roberte Morler, $Q$. Le Sire de Morley, $S$. Le Sire Morley, $T$. Morley, Droxford, co. Hants, cc.1670. Morley, Norfolk. Powelil. Salisbury.

Arg. a lion ramp. sa. ducally clowned or over all three bars gemel gil. Fairfax, Fowlington and Walsingham, Norfolk; and Setton, co. York.

Arg. a lion ramp. sa. ducally crowned or over all a fess chequy az. and gold. WILLOck.

Arg. a lion ramp. sa. crowned or over all a fess counter-compony az. and gold. Midlesrve.

Arg. a lion ramp. sa. ducally crowned gold over all a fess counter-compony az. and or. WILLOCK, $V$.

Arg. billetty or (? az.) a lion ramp. sa. crowned of the second. Delaplanch, co. Buckingham.

Arg. billety and a lion ramp. sa. crowned or. Sire .... de la Plaunche, $N$.

Arg. a lion ramp. sa. crowned or almed gu. Syr Roberte Morley, Q. George Morley, Bishop of Worcester, 1660 , Winchester, $160(2-84$.

Arg. a lion ramp. sa. crowned and armed or. Le Sire de Morleys, $Y$. Morley or Morle, Morle, Norfolk. Frtz-Rery, Ireland.

Arg. a lion ramp. sa. collared chained and ducally eromned or. Phillips, London, 1634.

Arg. a lion ramp. sa. collared and crowned or. DAREL, in Brodsworth church, co. York. St. GEORGE, in Meltou church, co. York.

Arg. a lion ramp. sa. surmounted by an esquire's helmet and chained or. PHIr.IPS.

Arg. a lion ramp. sa. langued gu. Dundas. Sir Nicholas Stapleton, $Q$.

Arg. a lion ramp. sa. head paws and end of the tail of the field. Sir Nicholas Wildiams, Ed. winsford, co. Carmarthen; the heiress m. Ham. lyn. Wrillams, Lee, Kent; and Carmarthen; derived from Williams of Edwinsford.

Arg. a lion ramp. sa. the tail introverted the head paws and brush of the tail of the field. LLOYD, Glanseven. co. Carmarthen; descended lineally from Idio Wyllt, Lord of Llywel, co. Brecon, son of Suthrie, Lord of Desmond in Ireland.

Arg. a lion ramp. sa. the head paws and half of the tail ash colour. GWILT, GWYLLT or WyLLP, Idio, South Wales.

Arg. a lion ramp. the tail elevated and turned over the head sa. Buxton, Shadwell, Norfolk, Bart.

Arg. a lion ramp. sa. tail forked or. Morant.

Arg. a lion ramp. tail forked sa. BaGEcroft, Norfolk. Sir Thomas Banynton, temp. Edward II, $V$. Sir William de Crescr, $N$. Sir William Crescr, $I$. William de Cresse, $E$. Cressi, in Milton church, co. York. Cressy or Creswick, Birken, co. York. Sir William Cressy, Essex, temp. Edward III, $V$. Thomas Crecy, but in a later hand "modo Clifton de Hodsocke," Y. Monsire de Cuessie, Seigneur de Horlesake, $Y$. Sir William de Morlex, $H$. Havering. Sir Rafe de StanladF, $L$, or Stanlow, $L$. Stanlow, co. Stafford.

Arg. a lion ramp. double tailed sa. Barrenkton, co. Leicester. Cressy, $V$ *. Monlenet.

Arg. a lion ramp. tail forked and nowed sa. Stanlaw, co. Stafford.

Arg. a lion ramp. tail forked and renowed sa. Sir Rauf de Stanlawe, $N$.

\section{BEAST. LION .....cont.}

Arg. a lion ramp. tail forked and double nowed sa. Sir Raufe Stanlawe, co. Stafford, temp. Ed. ward I, $V$.

Arg. a lion ramp. tail forked sa. a label gu. Sire Roger de Crescy, $N$.

Arg. a lion ramp. tail forked sa. a label of three points gu. Sir Roger de Cressy, co. York, $V$.

Arg. a lion ramp. double tailed sa. a label of three points gu. Cressy, $V^{*}$.

Arg. a lion ramp. tail forked sa. a bendlet compony of the first and second. Bavent.

Arg. a lion ramp. double tailed sa. armed and langued gu. Cressey or Cressie, temp. Hen.II. Cressy. Newton, co. Chester, and co. Oxford.

Arg. a hon ramp. tail forked sa. collared or. DENTON.

Arg. a lion ramp. double tailed sa. gorged with a chaplet or. Newton.

Arg. a lion ramp. tail forked sa. crowned or. Sire .... de Morlee, $N$. Sir Robert de Morley, $V$. Morley, Norfolk. Stanlaw, co.Leicester. But double tailed, MorLEy, $V^{*}$.

Arg. a lion ramp. guard sa. Cadivor VAUR. Lincolne. Protheroe Prytherch or Ap Rhydderch, Dolwilym and Plas Landra, co. Carmarthen, and Bristol.

Arg. billetty sa. a lion ramp. guard. of the second crowned or. Delaplance.

Arg. a lion ramp. reguard. sa. Hewes or Hues, Bromham, co. Wilts. JenkIN, Folkestone, co. Kent, descended from the Jenkins of the north. Jenkin, Minster, Kent. JenkIN, Stowling Court, Kent, and Warbleton and Burwash, Sussex. Mathew or Matrhew, Castle-Mangoh, co. Glamorgan. St. Quintrin. Herbert St. Quintre, $Y$. Meredith, Crediton, co. Devon. Arg. a lion ramp. reguard. sa. langued gu. Price, Glangwilly, co. Carmarthen; quartering sa. semy of 3 -foils ...., with sa. a boar pass. arg., az. a wolf ramp. arg. armed and langued gu., sa. three scaling ladders betw. the upper ones a spear's head arg. its point embrued on a chief gu. a tower triple-towered of the second, and gu. a chev. betw. three roses arg.

Arg. a lion salient sa. Altham, Essex. Ellereck, Felierdag. Honston, $V^{*}$. Hontston, co. Lincoln, $V$.

Alg. a lion salient tail forked sa. Clifron, Hodstock.

Arg. a lion sejant sa. MEgGrson.

Arg. a lion ramp. vair with a .... CaLTOFT, $Y$.

Arg. a lion pass. vert armed gu. Tоuсн.

Arg. a lion pass. reguard. vert. Sherborne, quartering vert an eagle volant arg. armed or.

Arg. a lion ramp. vert. BUGGE, Scotland. BULBECK. Creeton. Jones, co. Salop. Lron, Appleton Hall, co. Chester; quartering Fairclough. Lyons. Robsert. Roseberry. Sherborne, Ribleton, co. Lancaster ; quartering vert an eagle displ. of the first. Sherburne, Stonyhurst, co. Lancaster, Bart.; the heiress m. Weld. Sire Johan Spring, $N$. Sir John Springs, co. York, temp. Edward I, $V$. Touch, that Ilk. WALTON, co. York.

Arg. a lion ramp. vert a label gu. Senton.

Arg. a lion .... tail forked vert crowned or. Hindmarse or Hendmarsh, Kent. Hindiarsh Hendrarsh or Hyndmarsh, Scotland.

Arg. a lion ramp. guard. vert. CotTon. SHERBORNE; quartering vert an cagle displ. of the first. WALTON. 


\section{BEAST. LION.... cont}

Arg. a lion ramp. guard. vert crowned or. Hindmarsh.

Arg. a lion ramp. guard. tail forked vert crowned or. Hendmarsh, Kent.

Arg. a lion salient vert armed gu. Touch.

Az. a lion pass. arg. Lyband. Pagrave, $W$. Palarave, V. Palarave, quartering Marasse. Ithel VYchaN.

Az.a lion pass.arg. crowned or. EBenstein, $Z, 871$.

Az. a lion pass. guard. arg. Sir Guy de Astrey, V. Blomfield or Bloomfield. HuN.

Az. semy of crosses croslet or a lion pass. guard. arg. Astrey. Robert Asteley, $Y$. Monsire de Astly, $Y$. Sire Robert de Dalton, $O$. Monsire Henry de Holiand, $Y$.

Az. semy of crosses bottony or a lion pass. reguard. arg. AstLey.

Az. semy of escallops .... a lion pass. guard. arg. Sir Richard de Houraund, $O$.

Az. a lion ramp. arg. ALLYE, Tewkesbury, co. Gloucester. Alre; co. Gloucester. ARNOLD. Athwat. Atlee, $V$. Atlee, Sussex. Auchteriony, Kelly, Scotland. Cadrod Calchirnedd. Cadwgan, Ystrud Flur. Champney. Baron Coedmore. M. Johm Colvyle, S. Couell, East Somerton. Crew, Nantwich, Pulcroft, Holt, and Aston, co. Chester. Nathaniel Crew, Baron Crewe of Stene, co. Northampton, Bishop of Oxford, 1671, Durham, 1674-1722. Cnew, Crew, co. Chester. Crew, Durham. Crewe, London. Cadrgan ap Grono. Hurpur-Crewe, Caulke Abbey, co. Derby, Bart., quartering Harpur. Hethenfield or Hethensett. M. Heniy de Heton, $S$. Orton or Horton. Hiatt. KynNersiey or KynNaRdsleye, Loxley, co. Stafford. Lamont or Lamond, Scotland. Love. M'Dowall, Garthland, Scotland, 1630. M'Dowall M'Dougati, M'Dugall or M'Oul, Lord of Lorn; quartering or a lymphad sa. with a beacon on the topmast ppr. MackneI. Scotland; quartering arg. a sinister hand couped fesswise in chief in the base wavy az. a salmon naiant of the first, with or a galley oars in action gu. on a chief of the last three mullets of the first. M'NE匹, Fear Fergus, Scotland, with the same quarterings. MaUdE. Viscount Hawarden; quartering arg. three bars gemel sa. and over all a lion ramp. gu. charged on the shoulder with a cross crosslet fitchy or. Roger de Mohant, G. Monhazit. Monhault, co. Lancaster. Sir Roger de Monhalt, Lord of Hawardin, $V$. Monhault, an escucheon to Stanley, Earl of Derby, $U$. Montalt, Baron to the Earl of Chester, and of Montalt Castle, co. Flint. Monthait. Roger de Monthalt, $B$, or Munhaut, $D$, or Monhaut, $E$, or Munhaute, $I$. Sir Robert Mohaut, $H$. Robert de Montaut, $K$, or Mouhaut, $F, N$, or Munhaut, $Y$. Muhant. Ochterlony, quartered by Lyon. O'KeEFE, Mount Keefe, co. Cork; quartering gu. a knight on horseback ppr., with or a peacock in pride ppr., and vert three lizards or. John de Orton, $Y$. Palgrave, Norwood Barningham, co. Norfolk. Pikenham. Powel. Robsert. Pochfort, Ireland. Richard de WILLES, $F$. YENA, London.

Az. a lion ramp. arg. a label of three points gu. Colvine, $V^{*}$. Sir Geffrey Colvilu, co. Leicester, temp. Edward I, $\boldsymbol{V}$. Glanfield, $V$.

Az. a lion ramp. arg. on a label of three points gu. nine bezants. Covel, London. Cowelt.
BEAST.

LION .... cont.

Az. a lion ramp. arg. a label of four points gu. Colmerley or Colmerby.

Az. a lion ramp. arg. in chief a label of five points gu. AoLUITE, quartering or three chess rooks gu., with arg. on a fess az. three bezants.

Az. a lion ramp. arg. and label gu. Sire Geffrei de Colevile, $N$. Colvilue, co. Cambridge, and co. Lincoln. Couell, East Somerton.

Az. a lion ramp. arg. a label or. John Munhaute, $Y$.

Az. a lion ramp. arg. over all a bend compony of the last and gu. Beaunont.

Az. a lion ramp. arg. over all a bend compony erm. and gu. Beaumont.

Az. a lion ramp. arg. over all a bend gu. Boyland, Suffolk; quartering sa. an eagle displ. arg. Colvile, Suffolk. Colvill, $V^{*}$. DonewILl, Ireland. GERARD. HEYLAND, Suffolk. W AYLAND, Kent. Wayland, $V *$ * Sir Johu Weyland, $L$. Az. a lion ramp. arg. over all a bendlet gu. Sir John Colvill, Suffolk, $V$. Sir John WaYLaND, Suffolk, temp. Edward III, $V$. Roger de WELONDE, $E$.

Az. a lion ramp. arg. over all a dexter baston gu. Sir John Weyland, $L$. Monsire de Weland, $Y$. Sir Johan de Wertande, $N$. Roger de Welonde, $E$. The baton or, Sire Richard de WEYLANDE, $N$.

Az. a lion ramp. arg. a bend indented gu. Tinners, co. Hereford.

Az. a lion ramp. arg. over all on a bendlet ( $a$ bend, $V^{*}$ ) gn. three escallops of the second. TayLor of the north. $W$.

Az. a lion ramp. arg. over all a bendlet or. WEYLAND, Suffolk.

Az. a lion ramp. arg. over all a fess per pale arg. and gu. WaLshe.

Az. a lion ramp. arg. over all on a fess or three roses gu. Harwand, Merrow, Surrey.

Az. a lion ramp. with two hends arg. holding betw. the paws a crescent or. Mason, Beel-House, co. Berks, quartering Pomeroy.

Az. a lion ramp. arg. supporting with the forepaw a cross formy fitclyy or. Peckingham.

Az. a lion ramp. arg. welding a sword of the last. JULIEN.

Az. a lion ramp. arg. brandishing in each of the forepaws a sword ppr. Hertigan.

Az. a lion ramp. arg. resting his dexter hindfoot on the letter H. Town of Horsham, Sussex.

Az. billety and a lion ramp. arg. Grammer, Ware, co. Hertford.

Az. crusily bottony a lion ramp. arg. Braytoft, co. Lincoln.

Az. semy of crosses croslet a lion ramp. arg. Braytoft, co. Lincoln. Holland. Howland. Dalton, Croft. Kinersley, co. Stafford; and North Cleobury and Badger, co. Salop. Kinardsey. Richard de Kunardsleie, $E$. Sire Huge de Krynardeste, $N$. Kynardeseye. Kynnensiey, Leighton, co. Salop.

Az. crusily or a lion ramp. arg. Monsire de Dalton, $Y$.

Az. semy of crosses croslet fitchy or a lion ramp. arg. Dalton, Myton, co. Tork.

Az. semy-de-lis and a lion ramp. arg. Holmand, Weare, Shipwash, and Upcott Avenel, co. Devon; the beiresses m. Coham. Sir John Holtand, Quidenham, Norfolk, Bart., 1730. Sir Robert Holland, I. Pole, Shute House, co. Devon, Bart. Poole Pole or Pull, co. Chester. 
BEAST.

$$
\text { LION.... cont. }
$$

Az. semy of fleurs-de lis a lion ramp. arg. over all a bend gu. HoLland, London.

Az. semy of fleurs-de-lis or a lion ramp. arg. Dalton, co. Lancaster. Meverell. Pole. Wellesley, Baron Maryborough; quartering Wellesley and Colley. Robert PuLL, alias Pools, Lord of Barretspoole, 1280. Sir James Poole, of Poole; baronetcy 1677; the heiress m. Blencowe.

Az. a dragon ramp. or and a lion ramp. arg. combatant. DANNEY or DANCY.

Az. a lion ramp. arg. armed and langued gu. Rochfort, Westmeath, Ireland, temp. Henry II. Robert Rochгонт, Chief Baron of the Ex. chequer, 170\%, from whom descended RocHFORT, Gaulstown, Earl of BeLvedere; and Rochfort, Clogrennan, co. Carlow.

Az. semy of crosses croslet or a lion ramp. arg. langued and armed gu. KINARDISIEY.

Az. a lion ramp. arg. collared gu. Domvile, co. Salop. Donville, Templeogue, and Santry House, Dublin, Bart. Domvile. Donvili, $V$. Detmvill or Dounvill. Dorvilise, $V^{*}$. Gerard, Crewood, co. Chester.

Az. a lion ramp. arg. gorged with an antique clown or. M'DowaLL, Logan, Scotlaud.

Az. a lion ramp. arg. gorged with au eastern coronet or. MACDONALD, Scotland.

$\mathrm{Az}$. a sea in base in it a rock ppr. on which stands a lion ramp. arg. gorged with an open crown or. M'Dowall or M'Dougall, Garthland, Scotland, 1604 .

Az. a lion ramp. arg. gorged with an open crown or holding betw. the paws a man's heart ppr. M'Dowall, Stodrirlge, Scotland.

Az. a lion ramp. arg. collared sa. Lokyer, Much Wenlock.

Az. a lion ramp. urg. maned or collared sa. LoKyer, Idbury, co. Oxford, and co. Salop.

Az. a lion ramp. arg. erowned or. ALaN, Gallo. way. Alain, Sire de Grlloway, Y. Alilan, Scotland. Ammeny. Dalton, co. Lancaster. Daytent. Degalloway. Dovglas, Dule of Douglas, the Iordsbip of Galloway; quartering Abernethy, Wishart, and Stewart, over all an escucheon of pretence for Donglas. Douglas, Bridgeford, Scotland, with the same quarterings within a bordure indented or. EBERstein, $Z, 871$. Le roy d'Erbeny, $Y$. Galaway. Fregusiue, Sire de Galloway, $V$. M'Dowall, Garthland, Scotland, 166il. Moreville. Orton, 1730. Tregusius, $V^{*}$. Sir Walter Wentwage, $Q$.

Az. crusily fitchy or a lion ramp. arg. crowned of the second. SALISBURY.

Az. a lion ramp. arg. gorged with an antique crown and imperially crowned or. M'DowaLI, Freugh, Scotland.

Az. a lion ramp. arg. the tail .... Monsire de Brune, $Y$.

Az. a lion ramp. tail forked arg. Atree, Sussex. Monhault, co. Lancaster. Payne, quartering gu. a cross flory or.

Az. a lion ramp. tail forked arg. armed and crowned or. Pechey or Peache, Chichester, Sussex.

Az. a lion ramp. tail forked arg. crowned or. Crombwell. John de Cromwell, $K$.

Az. a Jion ramp. guard. arg. Robert de DaLton, $Y$. Hun or HunNe, Essex and Kent; granted 8 Sept. 1572. LeE, Fitchworth, Sussex. Powell. Thornes, Edge, afterwards Shelvock, co. Salop.

\section{BEAST. IION .... cont.}

Az. semy of crosses croslet a lion ramp. guard. arg. Dalton, Thurnham, origivally of Bispham, co. Lancaster; the beiress $m$. Hoghton. Dalton, Curbridge, co. Oxford, afterwards Stanmore, Middlesex.

Az. crusily or a lion ramp.guard. arg. S. Robert DalToN, $Q$.

Az. semy-de-lis and a lion ramp. guard. arg. Holland, Quidenham and Harleston, co. Norfolk. Sir Robert Holland, $L$, or de Holand, $L$, Harl. MS. 6137, or de Hoylanee, $N$. Sir Thomas Holland, $Q$. M. Jolın de Hollande, $S$. Otes and Thomas Holand, S. Heury de HOLAND, $Y$. The original coat of HoLAND, Earl of Kent, and Duke of Surrey, $Z, 205,217$. Az. semy of fleurs-de-lis and a lion ramp. guard. arg. over all a bendlet (bend $V . *$ ) gu. HOLLAKD, Denton and Cliston, co. Lancaster, $V$. Honland, Sutton, $V$.

Az. semy of fleurs-de-lis a lion ramp. guard. arg. on a bend gu. an ostrich feather of the second betw. two bezants. HoLland, London, grented 18..

Az. semy of 5-foils a lion ramp. guard. arg. HOLLAND.

Az. a lion ramp. guard. arg. the feet gu. Hur, $V$. Az. a lion ramp. guard. arg. armed gu. $H_{\triangle F}$.

Az. crusily or a lion ramp. guard. arg. langued gu. S. Robert Dalton, $Q$.

Az. a lion ramp. guard. arg. crowned or. Gerard. Horton. John de Orton, $V$. Orton or ORtun. Az. crusily a lion ramp. guard. arg. crowned or. DaLTON, co. Lancaster; quartering barry of six arg. and az. in chief three lozenges gu.

Az. semy of fleurs-de-lis and a lion ramp. guard. arg. langned gu. Sir Thomas HollaND, $Q$. Sir Oiths Holiand, $Q$.

Az. a lion ramp. guard. tail forked arg. crowned or (another adds, langued gu.). Sir Walter WeTWage, $Q$.

Az. a lion ramp. reguard. arg. Loyd.

Az. a lion ramp. reguard arg. crowued or. CALTON, Catsworth, co. Huntingdon.

Az. semy-de-lis or a lion ramp. reguard. arg. Dalton, Norroy King of Arms, 1553.

Az. a lion ramp. barry of six arg. and $\mathrm{gu}$. HuLton.

Az. a lion ramp. chequy arg. and gu. Richard WIKES, $E$. WYKES.

Az. a lion ramp. erm. Armeny. Brompton, Norfolk. Sr. Fitz-Simon, co. Leicester, temp. Edward III, $V$. Sr. Rauf FITz-Simon, $N$. Fitz-Symond, co. Lincoln. Sr. de Gerard, co. Lancaster, $V$. Monck, Newcastle-on-Tyne. URRYEN. URWYN.

Az. crusily or a lion ramp. erm. JoHNS.

Az. fretty arg. a lion ramp. erm. collared gu. supporting a pillar of stone pyr. Clulow, Echingham, Sussex.

Az. a lion ramp. erm. crowned or. Fitz-Gerard, co. Lancaster. Gerard, Bromley, co. Stafford. Gerard, Etwall, co. Derby. Peach or Pechey, Kent.

Az. a lion ramp. erm. ducally crowned or. JARRETT, Camerton Court, co. Somerset; quartering Stepheus, and Ridley.

Az. a lion ramp. double tailed erm. PeEcH, $V^{*}$. Az. a lion ramp. tail forked erm. crowned or. Gerard. Peche, Lullingstone, Kent. Gilbert de la Pесне, Baron, 13 Edward II ; the heiress m. Hart. M. John PeEche, S. Sir John PeEch, Kent, $V$. 


\section{BEAST. LION ....cont.}

Az, a lion ramp. guard. erm. Gerard.

Az. a lion ramp. erminois ducally crowned or. Dureli, St. James's Westmiuster; confirmed 10 Sept. 1771.

$\mathrm{Az}$. a lion ramp. lozengy arg. and gu. Wrkes, Morton-Jeffrey, co. Hereford.

Az. a lion or and a dragon arg. erect and combatant. DANCEY, co. Berks.

Az. a lion pass. or. Llewelyn Atr-Dorchog, (with the Golden Torques) Yale. Bromfield, Lord Mayor of London, 1637. LoANE, Kent.

Az. a lion pass. guard. or. Astley. BekMinster. Bromfield, co. Stafford ; from Wales. Sir John Bromfield, Suffolk Place, Southwark, 1730. Llewellyn Aur Dorсноок, Yale, Wales. Thоmpson, London, 1730. John Tномson, Auditor to Queen Elizabeth, $W$. THоmson, Shalfield, Essex; and co. Lincoln.

Az. on a mount vert a lion pass. guard. or. Fitz-AER.

Az. a lion pass. guard. coward or. Hanmer, Porkington, co. Salop.

Az. a lion ramp. or. AgAR, Ireland, and Cranham Hall, Essex. Beckingham, 1730. Bellesine. Brampton. William le Breouse, A. Brewse. Browne. Champney. Chense, Ridgebourne, and Huntington, co. Ilereford; quartering Watkins. Cosys, co. Dorset.

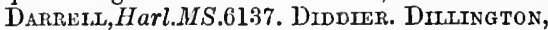
co. Hants. Ethersall, co. Lancaster. Frtz-Syatond. Foster. Garsey. Gerard. Grasay or Grassey. Hampnes. Hetherfield. Hothersell. Hughes, East Bergholt, Suffolk, Bart. Hughes, Wells, co. Somerset. Ivas. Lluoyd, Wales, and Maryland. Lloyd, co. Hants. Meredith, Pentrebychan, co. Denbigh; derived from Hugh Meredith, of Wrexham and Pentrebychan. Meredith, Stansley, co. Denbigh, and Leeds Abbey, Kent; derived, through Meredith ap David, of Alington, from Eunydd Gwerngwy. Joan de NeIvile or Nervle, $E$. Hugo de Nevile, $C$. Sir Hugh Nevill, $I$, or de Neyville, $N$. Sir Hughe Nevil, Essex, temp. Edward, I, $V$. John de Nevile, Essex, Y. Monsire le Nevilu, Essex, $Y$. Nevil. Nevill, Essex, and co. Nottingham. Orton. Peckham. Philipse, Philipsburg, America. Pickinghanr. Prkenham, V. Ripars. William de Rode, $A$. Rowley. Anthony RudD, Bishop of St. David's, 1594-1615. SAMBORNE. TUDOR. WHTTTLE. WILFORD.

Az. a lion ramp. to the sinister or. Part of the arms of GeLDREs, $Z, 326$.

Az. a lion ramp. or a crescent for diff. HothersenL. St. Bride's, London, 1615.

Az. a lion ramp. or a label gu. Colvile or Colwerl, co. Cambridge.

Az. a lion ramp. or a label with five points gu. Colviue, Lullington, and Daffeld Hall, co. Derby, formerly of Carlton Colvile in Suffolk, and Newton Colvile, co. Cambridge; with fifteen quarterings.

Az. a lion ramp. or a bend compony of the last (another vert) and gu. BEAUniont.

Az. a lion ramp. or a baton erm. Calthorpe, Norfolk.

Az. a lion ramp. or a dexter baston gu. M. Wil. liam de Roves, $D$.

Az. a lion ramp. or depressed by a bendlet (bend, $V^{*}$.) sa. with an erm. spot arg. in the dexter chief of it. Sir John Calthonpe, $V$.

Az, a lion ramp. or over all a fess gu. WrLlock, $V$.
BEAST.

IION.....cont.

Az. a lion ramp. or over all on a fess sa. three crosses croslet fitchy gu. William Barons or Barnes, Bishop of London, 1504.5.

Az. a lion ramp. or holding a battleaxe arg. Hethersett. Pykinghair, $V$.

Az. a lion ramp. or supporting in the paw a cross formy fitchy arg. William Rysom, co. York, $V$. Rysom or Ryson, co. York.

Az. a lion ramp. or holding in the dexter paw a hind's leg erased at the first joint arg. Champanty.

Az. billetty and a lion ramp. or. Brun. William Brune, $Y$. M. William Bur, $S$. Gesors or Gessors. Jeffry. Nassad, Prince of Orange. NASSAT, $Z, 606,607,609,685$. NASSAU, Earl of Rochford; quartering Dietz, with Vianden, and Catznellogen, over all an escucheon for Zuleistein.

Az. semy of crosses croslet arg. a lion ramp. or. Bretrt.

$A z$. semy of croslets and a lion ramp. or. $M$. William de Breouse, $D, N$, or Brewase, $E$, or Breowse, A, Harl. MS.6137. Breus, F. William de Brus, $B$. M. Thomas le Brewse, $S$. Sir Juhn de Brewes, co. Buckingham, temp. Edward I, $V$. Brewse or Brewen, Wagford, co. Buckingham. Goodrich, Seling Grove, Essex. Jordan, co. Dorset. John Jordan, Gatewick, 1302, Aubrey, Surrey, 1719, iv. 261. JorDAN, Catwick and Charlwood, Surrey.

Az. crusily fitchy and a lion ramp. or. Mousire de Brewse, $Y$.

Az. semy of fleurs-de lis a lion ramp. or. Le Sr. BEAMIONDE; quartering az. three garbs or, $T$. Beaumont, Stoughton Grange, co. Leicester, 21 Feb. 1660; since of Cole Orton, Bart. desceuded from Henry de Beaumont, made King of the Isle of Man for life, temp. Edward I. Le Sieur le Beaumont, $S$, or de Beaumont, $Y$. Lewis de Beaunont, Bishop of Durham, 1:18-33. Beaumont, $Z, 113$. Beaunont, Gracedieu, co. Leicester, descended from Beaumont, Coleorton. Beaumont, Barrow, co. Derby. Francis Beaumont, Master of the Charterhouse, 1619. CoHAM, Coham, co. Devon, quartering Holland, Metsted, Bickford, and Árscott. Dalton, Kyrkby Mysperton, 1563. Holland, Weare, Shipwash, and Upcott-Avenel, co. Devon; the heiress m. Coham.

Az. flory and a lion ramp. or over all a bend compony arg. and gu. Beamond, $V^{*}$. Richard BeAUMONDE, but a note says, M. Louys Beaumont, $Y$. And with a bendlet, Beaumont, Lord of Folkingham. Sir Henry Beamond, $I, V$, or de Beaunund, $M$. And witls a dexter baston, Sire Henry de Beaumund, $M$; or Beumond, Haneret, $O$. Sire Henrl de Beumond, $N$.

Az. semy of fleurs-de-lis and a lion ramp. or over all a bendlet (bend, $V^{*}$ ) compony erm. and gu. Beaumont, $V$.

Az. Hlory with a lion ramp. or a dexter baston compony of six pieces gold and gu. Monsire de Beaumont, $Y$.

Az. flory and a lion ramp. or over all on a bend gu. three keys wards upwards gold. Benedictine priory at HoLAND or HoLLAND, co. Lancaster.

Az. flory and a lion ramp. or over all on a bendlet compony of six pieces arg. and gu. three mullets sa. Beaumont, $V$.

Az. semy of roses and a lion ramp. or. OWEN. 
BEAST.

LION.... cont.

Az. a lion ramp. or armed of the field. Beaunont.

Az. a lion ramp. or armed and langued gu. ALMIER. John Aldror, temp. Henry VII, derived from Efnydd ap Gwenllian. Morgeneu, Dyffryn Clwyd. Evnydd ap Morien.

Az. semy of crosses croslet gll. a lion ramp. or armed and langued of the second. Broase.

Az. a lion ramp. or crowned arg. Dayrell, Lillingston Dayrell, co. Buckingham; quartering arg. on three bars sa. six 5 -foils of the field three two and one. Darrel, $Z, 334$. Dayrell. Shudy Camps, co. Cambridge, descended from Dayrell of Lillingston Dayrell, 1579.

Az. a lion ramp. or crowned arg. supporting a cross croslet fitchy of the third. DarReLL, Sussex.

Az. crusily and a lion ramp. or crowned gu. Sir John (another, Thomas) Breves or BrUex, $Q$.

Az. a lion ramp. or armed langued and crowned gu. William de OrReLl, and his descendants. Darrela Darell or Dorrell, Sesay, co. York; a heiress m. Dawney; Cale Hill and Scotney, Kent; Littlecote, co. Wilts, quartering Calston; Pageham, Sussex ; Trewornan, Cornwall. etc.

Az. a lion ramp. ducally crowned or. CriLer. Darell. Darrecl, Bengal, and Richmond, Surrey, Bart. Sir Francis Dayrel, Castle Camps, co. Cambridge, 1730. J JRRETt.

Az. a lion ramp. crowned or. Schwarzenberg, $Z, 489$.

Az. a lion ramp. murally crowned or. VILLETTES, Bath, co. Somerset; granted 31 Dec. 1766.

Az. billety and a lion ramp. crowned or. Montbliard.

Az. crusily and a lion ramp. crowned or. Brewis. Brewse.

Az. semy of crosses croslet or a lion ramp. crowned with an antique crown of the second. Breawse.

Az. a lion ramp. tail forked or. Bromhall. Broneall, $V$. Sir Robert Stapleton, co. Stafford, temp.Edward III, $V$. Stapleton, co. Leicester, and co. Stafford. Robert de STEPELTONE, $E$, or Stepeltone, $N$, or Stepleton, $G$. Sir Robert de Stepredon, $L$, or Stapleton, $L$, Harl. MS. 6137. Monsire de StaptetoN, $Y$. John Stepleton, $Y$.

Az. a lion ramp. double tailed or. Bromealc, $V^{*}$. Stapleton, $V^{*}$.

Az. a lion ramp. tail forked or crowned ppr. GELDRES, $Z, 155$.

Az. a lion ramp. tail forked or unguled armed and crowned arg. Monsire de Montryveld, $Y$.

Az. a lion ramp. guard. or. Britley. Evans, Rhyd-y-Carw, co. Montgomery; derived from Llewelyn Aurdorchog, Lord of Yale; the heirs m. Davies and Owen. Etheresset. Assigned to Robert Fitz-Hamion or Fitz-Hamond, Lord of Gloncester, temp. William II, $Z, 45,48$. Fitzhamon, $V$. Hatherfield. Hetherfield. Hetherset. Hethersete, $V$. Pagrave, $V$. Hewes, co. Wilts. Sherborne.

Az. semy de lis a lion ramp.guard. or. HolLAND, Earl of Kent.

Az. a lion ramp. guard. armed and crowned or. Horton.

Az. a lion rump. guard. or incensed gu. Robert Fitz-HaMron, Lord of Cardiff.

Az. a lion ramp. guard. tail forked or. LEE, Lee, Sussex

Az. a lion salient or. Brinley, co. Berks. Ro. bert SNowden, Bishop of Carlisle, 1616-21.
BEAST. LION.... cont.

Az. crusily fitchy and a lion salient or. Thomas Breatse or Brewse, $Y$.

Az. a lion salient guard. or. Paringham.

Az. a lion segreant guard, or. Hetherfield.

Az. a lion statant or. Edmund Bromfeld, Bishop of Llandaff, 1389-93.

Az. a lion ramp. per fess gu. and arg. Betsworth.

Az.a lion ramp.per fess or and arg. BETTESWORTH, Tyning, Sussex.

Az. a lion ramp. vairy arg. and gu. Hulton.

Barry of four az. and arg. in chief a lion ramp. or. MAdeston or MADEsson.

Barry of four erm. and or over all a lion ramp. az. BaGNaLl.

Barry of four gu. and erm. in chief a lion pass. or. GrFFond.

Barry of four or and az. a lion ramp. counterchanged. KuCKFIELD.

Barry of five arg. and az. over a lion ramp. gu. WaLTON.

Barry of five arg. and az. over all a lion ramp. gu. crowned or. WIILESMOSE WILLESMot or Wilatescot, co. Gloucester.

Barry of five arg. and az. over all a lion ramp. or holding in the dexter paw a rose-branch gu. TUDifan.

Barry of five arg. and gu. over all a lion ramp. of the first. Breknelu, London.

Barry of five arg. and vert over all a lion ramp. gu. Chaloner, co. Stafford, $W$.

Barry of five az. and or over all a lion ramp. gu. HATCLIFF, $V$.

Barry of five erm. and or over all a lion ramp. az. BAgNalu, co. Stafford, and Wales. BickNoll.

Barry of five gu. and or over all a lion ramp. arg. Peverell.

Barry of five or and az. over all a lion ramp. guard. gu. OXBCRGH or OxBOROUGH, King's Lynn and Emneth, Norfolk.

Barry of five or and gu. over all a lion ramp. gold. Breners.

Barry of six arg. and gu. orer all a lion ramp. or. AdDars.

Barry of six arg. and sa. a lion ramp. gu. MAUD, Hargood Hill, co. York.

Barry of six arg. and vert over all a lion ramp. gu. CASE or CASSE. CASE, quartering gu. a chev. betw. three helmets arg., with gu. a chev. betw. three men's heads couped ppr., gu. a Saracen's bead erased at the neck arg. wreathed round the temples of the second and sa., sa. three horses' heads erased arg., and .... a fusil sa. within a bordure of the last.

Barry of six az. and gu. over all a lion ramp. erm. armed or. WAKELYN.

Barry of six erm. and az, over all a lion ramp. arg. Thenger.

Barry of six erm. and gu. a lion ramp. sa. crowned or. Snyth, Newcastle-under-Line, co. Stafford; granted 1561.

Barry of six erm. and sa. a lion ramp. or. Gibson. co. Lancaster; London; and co. York.

Barry of six gu. and az. a lion ramp. erm. WALKELIN, Radborne, co. Derby; the coheirs m. Chandos and Stafford.

Barry of six gu. and erm. in chief a lion pass or. Giffard.

Barry of six or and erm. (another sa.) over all a lion ramp. az. BAGNaLl, Kent.

Barry of seven .... and .... over all a lion ramp. .... Thomas Atte LATHE's seal, Willinghall, Norfolk, 27 Edward III. 


\section{BEAST. LION.... cont.}

Barry wavy of seven arg. and az. over all a lion ramp. of the first. BuLbeck, Kingston; granted 24 April, 1559 .

Barry of seven arg. and az. over all a lion ramp. gu. crowned or. Wilmescott. Sire Henri de Willemescote, $N$.

Barry of seven arg. and vert over all a lion ramp. gu. CaSE, Barwick.

Barry of seven or and az.over all a lion ramp. gu. Sir de Mouns, $V$. Mownes.

Barry of seven or and az. a lion ramp. gu. crowned or. Wirlemscot. Wilicascot, $V^{*}$. Sir Henry WillatescotT, co.Gloucester, temp. Edw.III, $V$.

Barry of seven or and vert a lion ramp. gu. Dorseliey.

Barry of seven vairy gu. and arg. with or over all a lion ramp. of the second. Petereli.

Barry of seven vert and erm. a lion ramp. az. BagnaIL.

Barry of eight arg. and az. over all a lion ramp. gu. crowned or, Marsh, Middlesex. Washous.

Barry of eight arg. and gu. over all a lion ramp. sa. Estotteviule.

Barry of eight arg. and gu. over all a lion ramp. sa. crowned or. EgManton, co. Lancaster.

Barry of eight az. and gu. a lion ramp. erm. Fitz-Wakelin. Walkeiyn, $V^{*}$.

Barry of eight or and gu. a lion ramp. arg. JACKson, Loch house, Scotland.

Barry of nine arg. and az, over all a lion ramp.gu. Stratford.

Barry of nine arg. and gu. a lion ramp. or ducally crowned per pale of the second and third. Brandon.

Barry of nine arg. and gu. over all a lion ramp. sa. crowned or. Wassthose, $V$. Wasthose, $V^{*}$. WASTHOUSE.

Barry of nine arg. and sa. over all a lion ramp. or. Cocker, Croft, co. Lincoln.

Barry of nine az. and gu. over all a lion ramp. erm. Waliselin, $V$.

Barry of ten arg. and az. a lion ramp. gu. Guyling, $V^{*}$. Hawling, $V^{*}$. Jackson, Scot. land. Henry de Luconburg, $D$. Lusignan (Cyprus), $Z, 407$. Stratfond, Farmcott or Farnscott, Gusling or Nether Guiting, and Hayling or Hawling, co. Gloncester, 1623, $W$. Stratford, Earl of Aldborough. Stratford, Nuneaton, co. Warwick.

Barry of ter arg. aud az. a lion ramp. gu. holding a battleaxe or. Alexander, Dover, Kent.

Barry wavy of ten arg. and az. a lion ramp. or. Elton alias Serborne, co. Hereford. Seborne, co. Hereford.

Barry of ten arg. and gu. a lion ramp. or ducally crowned of the second. Charles Brandon, Duke of Suffolk, $V$.

Barry of ten arg. and gu. a lion ramp. or ducally crowned per pale of the first and second. Brandon, Suffolk. Brandon, Duke of Suffolk, $Z, 536$.

Barry of ten arg. and gu. over all a lion ramp. sa. Robert de Estotevile, $A$. Ostotevill or OSTOTENVYLL.

Barry of ten arg. and sa. over all a lion ramp or. Cocher. Cocker, co. Chester, $W$.

Barry of ten or and gu. over all a lion ramp. arg. Stratfolid, Coventry.

Barry of eleven arg. and gu. over all a lion ramp. crowned and sustaining a battleaxe or. Alexander.
BEAST.

IION. ...cont.

Barry of eleven arg. and sa. over all a lion ramp. or. Coclier, Crompton, co. Leicester.

Barry of twelve arg. and az. over all a lion ramp. gu. Ciprus, Sir Payne Delamarch, $\boldsymbol{V}$. Dela Miarche.

Barry of twelve arg. and gu. a lion ramp. arg. BRANDON.

Barry of twelve arg. and gu. over all a lion ramp. sa. Sir Robert Estotevire, temp. Edward I, Essex, $V$. Estotvile.

Barry of twelve arg. and sa. a lion ramp. gu. Chansey.

Barry of twelve or and arg. a lion ramp. gu. Sir Geffrey Lisedian, $F$.

Barry of twelve or and gu. over all a lion ramp. sa. Stutvile, Essex.

Barry of fourteen arg. and gu. a lion ramp. sa. over all a bendlet or. Henry Pinpund, $E$.

Barry of sixteen arg. and gu. a lion ramp. sa. a baston or. H. Perpund, $F$.

Barry of twenty-one arg. and gu. over all a lion ramp. sa. Robert Destotvine, $A$, Harl. MS. 6137.

Barry of twenty-two sa. and arg. a lion ramp. gu. Thomas de Chansi, $G$.

Barry arg. and az. a lion ramp. gu. Lesianch. Namalu.

Barry arg. and gu. in chief a lion pass. of the second. MaLefont.

Barry arg. and gu. a lion ramp. sa. Robert le Stotevile, le Normand, $B$. Sire Robert de Estotevile, $N$. Robert de Stutrevilie, $O$.

Barry arg. and gu. over all a lion ramp. sa. crowned or. WAsher, Lyneham, near Chudleigh, co. Devon; and Sunbridge, Kent.

Barry or and az. over all a lion ramp.gu. RoNORDY or Ronoriy.

Bendy of six arg. and gu. a lion ramp. or. EnNys.

Bendy of six arg. and sa. a lion ramp. gu. YoNGe, London.

Bendy of six az. and gu. over all a lion ramp. or. ENDAS or ENEAS.

Bendy of six or and vert over all a lion ramp. sa. Donynge, Chichester, temp. Henry VII.

Bendy of seven arg. and sa. over all a lion ramp. gu. Cutler, Ipswich, Suffolk, confirmed 2I July, 1612 .

Bendy of seven or and sa. over all a lion ramp. gu. Cotrer, Chantry, Suffolk.

Bendy sinister of eight or and vert a lion ramp. sa. Dunyng, Rye, Sussex.

Bendy sinister of fourteen or and purp. over all a lion ramp. sa. Dunning, Lord Ashburton.

Bendy sinister or and vert a lion ramp. sa. Donning.

Chequy .... and .... a lion ramp. .... Howr. Chequy arg, and gu. a lion ramp. or. SHergold. Chequy or and arg. over all a lion ramp. sa. LYON's InN, London.

Chequy or and az. a lion ramp. gu. M. John de Armenters, $D$.

Chequy or and gu, a lion ramp. arg. Hoy, Midanbury, co. Hants, Sheriff of London, 1812-13.

Chequy or and gu. a lion ramp. erm. Skarle't.

Chequy or and gu. a lion ramp. (another ramp. guard.) of the first. Pocock.

Chequy or and gu. a liom ramp. per fess erm. and sa. SharietT, $V$.

Chevronelly of five arg. and gu. over a lion ramp. sa. Winthorp, Groton, Suffolk.

Chevronelly of seven or and gu. over all a lion ramp. of the last. HASARD, Syngleton, Essex, 
BEAST. LION.... cont.

temp. Edward III. Hashiard, $V^{*}$. Singleton, Essex, temp. Edward III. Sir Hasbard de Sineleton, Essex, temp. Edward I, $V$.

Erm. a lion ramp. az. Elidyr ap Rhys Sars, living 1050. Robert Creighton, Bishop of Bath, ete., 1670-72. Crichton, Innerneity, Scotland. Decras, inyton. Eaton Eaten or Eiton. Eyton, Eyton, co. Denbigh. Eyton, Gaddesby, co. Leicester and co. Northampton; granted 1577. Hardness, Kent. Lewis, Galthorpe. LIBby, Stolie Prior and Bromsgrove, co. Worcester. SirJohn de Lylie, $V$. Meddop, Meddop Hall, co. York. Medshope, $Y$. Medehor, Trenant, Cornwall. M. James le Primering, S. Piciening, Threlkeld, Cumberland. Sutton, Sutton.

Erm. a lion ramp. az. crowued or. Mithorpe. Mydhope, co. York. Pickering, Thorpe's Lodge, co. York. Thomas Prikeringe, Y. Sir John Pilening, Thirkeld, $V$. Pichering, Winderwath, Westmoreland; Gretton; and (temp. Elizabeth) Tichmarsh, co. Northampton; quartering Lascells. Pickering, Paxton, co. Huntingdon. Picrening, $V^{*}$. Sir Henry Pickering, Whaddon, co. Cambridge, 1648; Baronetcy 2 January, 1660-1. And with a crescent on a crescent for diff. Pickering, Tableburst and East Grinstead, Sussex.

Erm. a lion ramp. az. ducally crowned or. Pickering, Hartford, co. Chester.

Erm. a lion ramp. az. crowned or. armed gn. Pickering, Old Lodge and Clapham, Surrey; quartering Umfreville, Meres, and Weld.

Erm. a lion ramp. az. crowned and langued or. PICKERING.

Erm. a lion pass. gu. Drew, South Broom, co. Wilts. Dnew, $V$. Humphry EliLs, Kent; granted by Cooke, $W$. Jegat, $V$. Leger. Simon de Segre, $E$. Simon Segre, $Y$. Segrey.

Erm. a lion pass. gu. crowned or. Secretye Segretty or Segrety. Segirti, $V *$. Segriti, $V$.

Erm. a lion pass. tail coward gu. Elils, co. Flint.

Erm. a lion pass. guard. coward gu. Elnyfed ap Cynvrig ap Rhiwal.Lon, living 1073. Brovghton, Broughton. Elis, Alhray. Powel. Alrhay.

Erm. in chief a lion ramp. gu. Sтоск, Ireland.

Erm. a lion ramp. gu. Brerehouse, Norfolk. Estengrave. Joan de Estengreve, E. Sire John de Estengreve, $J$. John Estengreve, $Y$. Griffeth. Jennence or Jennins, Bosmangan, Cornwall, and co. Salop. Jennings, Harlington, co. Bedford; Cornwall; and co. Salop. Legat, Essex, Kent, and Norfolk. Legett. Thomas Logat, $V$. Stangrave, $V$. Thorp, Gateshead. Turberille, Whitchurch, co. Devon. Woorley or Wouley.

Erm. a lion ramp. gu. over all a bend sa. bezanty. Bryan, co. Chester and Cornwall.

Erm. a lion ramp. gu. over all a cherron or. Robert de Hardres, $A$.

Erm. a lion ramp. gu. crowned or. Fanhope, co. Devon. Hertington. Patishall. Monsire de Pateshill, $Y$. John Pateshull, $Y$. Turbervue, Beere, co. Dorset. Turbervill, $V$.

Erm. a lion ramp. gu. crowned or armed and langued az. James Tureerville, Bishop of Exeter, 1555-9.

Erm. a lion ramp. gu. tail forked. Brewse, Norfolk, temp. Edward III.
BEAST. LION .... cont.

Erm. a lion ramp. double tailed and nowed gu. Bruss, $V^{*}$.

Erm. a lion ramp. tail forked and renowed gu. Sir Ricluard de Breouse, $N$.

Erm. a lion ramp. tail forked and double nowed gu. Brewes, $V$. Sir Richard Brus, Norfo'lk, temp. Edward HII, $V$.

Erm.a lion ramp.guard.gu. cromned or. WoORLEY or Worley, Dodington, Kent.

Erm. a lion ramp. reguard. gu. OxMan, Rutland.

Erm. a lion salient gu. WorLey, 1730.

Errn. a lion salient tail forked gu. Warley or Werley, London. Henry Worley, Alderman of London, $V$.

Erm.a lion salient guard.gu. crowned or. WARLEY or WERLEY, Loudon.

Erm. a lion statant guard. .... (?gu.) Simon de Segre, added in a later hand, $F$.

Erm. a lion ramp. purp. crowned or. Broy. Broye, $V$. Panfuil. Patishall. Payteshed, $V$.

Erm. a lion pass. sa. Wither.

Erm. a lion ramp. sa. Broughton. Bulmione. Edwards, Baron Kensington. Davies, co. Denbigh. Enwarns, Haverfordwest, co. Pem. broke. Hanton, Ireland. Baron Jefreeys, Chief Justice. Jones, Llwynon, co. Denbigh, derived from Tudor Trevor, Lord of Whitting. ton; since 1780 Jones-Parry, Madryn, co. Carnarvon, and Llwynonn; quarterng Parry. KENDRICK, London, W. KENWRICKE or KENRICK, co. Berks, co. Lancaster, co. Northampton, and Ower, co. Salop. Kenrick, Lord Mayor of London, 1652. Kendrick, Reading, co. Berks. Kenurych, $V^{*}$. Lamibe, Troston, Suffolk. Richard Leger Legot or Lazor, Lord Mayor of London, 1345. Pritchard, Campston Hall, co. Monmouth; now Swansea. RoberTs, Hafod-y-Bwch. Cynfrig ap Rhrwallon, lilled 1073. Kenury ap Rywallon. Rywallon, $V^{*}$. Sonlly, Sonlly. Stapleton.

Erm. a lion rarnp. sa. crowned or. Turbervilu, $V^{*}$. Erm. a lion ramp. sa. armed and langued or. EDWardes, Baron Kensington; quartering Rich.

Erm. a lion ramp. vert crowned and ducally gorged or. Dukes, co. Salop; quartering arg. a chev. gu. betw. three gillyflowers slipped and stalkel ppr., with az. three falcon's beads erased arg., arg. three buglehorns stringed sa., and sa. three pheons arg.

Ermines a lion vass. gu. Sir Edward Drewe, Kyllerton, co. Devon, Serjeant-at-law; confirmed 1593; from whom descended DRewe, the Grange, Broadhembury, co. Devon; now quar. tering Prideaux, Frencb, Wynard, Huckmore, Fotheray, De Baronia, and Champernon. Dnew, Drew's Court, co. Limerick.

Ermines a lion ramp. gu. Enwards, co. Huntingdon, and co. Salop.

Erminois a lion ramp. az. surmounted by a fess gu. TODman.

Erminois a lion ramp. gu. VAUGHAN, Nannau, Wengraig and Hengwrt, co. Merioneth, Bart.; quartering gu. a lion ramp. erminois; descended like VAUGHaN, Rûg and Hengwrt, co. Merioneth, through Howell, second son of Ynyr Vychan, Lord of Nannau, from Cadwgan, Lord of Nannau.

Fusily or and vert a lion ramp. arg. GiLl, co. Devon. 


\section{BEAST. LION....cont.}

Gu. a lion pass. arg. Casheld. Delayache, co. Buckingham. Thomas de Heton, $Y$. Hulghton. Massey, Allerborough, co. Chester; quartering or a mullet sa. William de Menc' or Mert', $F$. Nowbray, $V^{*}$. Neale Nele or Nealle, co.Lincoln. Neale, Norfolk. O'Toole, Ireland. Playter or Platt, Norfolk. Howell ap IORWERTH O VON.

Gu. a lion pass. arg. collared az. Delamare.

Gu. a lion pass. arg. crowned or. Diepholtz and purt of BieckHausen, $Z$,87I. Fitzgerol.d. Sire Warin del I DLE, Baneret, $O$. L'IsLE. King. ston Isle, co. Berks. L'IsLE, Isle of Wight, temp. Henry III. Liste, Earnley, co. Northampton, and Northumberland. WokINGDon, Essex.

Gu. a lion pass, guard. arg. Delabrare. Neale, Norfolk. Redesdali, co. Lincoln. Ridesdale. Redeshali, 1730. Riddesdali, $V$.

Gu. crusily and a lion pass. guard. arg. Sir John del IDLE, $O$. Pedenton, quartering or crusily a lion rump. az.

Gu. crusily or a lion pass. guard. arg. De Lisue. $\mathrm{Gu}$. crusily fitchy or a lion pass. guard. arg. Gerard de LisLE, $Y$.

Gu. a lion pass. guard. arg. ducally crowned or. LYSLEY or LISLE, Harew ood, Lyley, Kirkheaton, Rothwell, and Warmfield, co. York; Mimwood, co. Hertford; and Pewsham, co. Wilts ; quartering or a fess betw. two chev. sa., with gu. a lion pass. guard. arg. ducally crowned or in chief three pierced mullets arg.

Gu. a lion pass. guard. arg. crowned or. Warin le Fitz-Gerald, $B$. Fitz-Gerold. Gerard. Gerard de LiLe, A, Harl.MS.6137. M.Gerard de Lisle, $D$. Sir Waryn de Lisle, $L, V$. Sir John (alii Gerard) de Lisle, $L$. Sir Waryn del Yle, $N$. Sir John de Lisle, $R$. Le Sr. de le Lisle, $S$. Gerrard de L'IsLe, $Y$. Lisle, Brackley, co. Northampton; and Felton, co. Nortbumberland. GERARD, Lord Lisle, $Z, 448$.

Gn. crusily and a lion pass. guard. arg. crowned or. Sire Gerard del YLE, $N$.

Gu. crusily or a lion pass. guard. arg. crowned gold. Sire Robert del YLE, $N$.

$\mathrm{Gu}$. a lion pass. guard. arg. crowned with an antique crown or and girt round the waist with an annulet of the last. OgILVY or OgILvie, England.

Gu. a lion ramp. arg. ATwood. Augustinian Hospital at BURTON-LAZER, co. Leicester, impaling arg. a cross gu. Cormet. Diras. De Duras. Ellis, Plas Yolyn. Everingham. Randolf Gernons, fourth Earl of Chester, $X$, (another the tail "estroict"), $Y$. Gilchrist, Earl of Galloway. Gernet. Gervies or Garvies, Pratling Magna, co. Leicester. Hum. phrey Hunphreys, Bishop of Bangor, 1689 ; Hereford, 1710-12. Kifrin, Essex. Conte de Leycestre, $G$. Lycke, London. Mackmorough, Ireland, $V$. Mackemore. Mandevilue. Marchweithian. Markoe. Ingram del Merk, C. M. Simon de Mountford, D. Moubray. Sir John de Mowbray, $L$. Mowbray, Earl of Northumberland. Sire Johan Moubray, $N$. Sire Johan de Moubray, $J$. SirJohn Mowbray, $M$. Robert de Muwbray, $F$. Roger Moubray, $P, Y$. Moubray or Murray, Bambugle, Scotlaud. Roger de Moubrey, $A, C$, or Mumbrey, $A$, or Moubray, $B$, or Mowdray, $E, G$. Mowbray, quartered by Howard, Duke of Norfolk, $U$. Monsire de Mowbray, $Y$. Mlowbray, Lord of
BEAST.

LION .... cont.

Axholme, $V$. Mowbray, Duke of Norfolk, Lord of Axholme, $Z, 110,205,208$, quartered by Howard, $Z, 358,496$. Nottingham. Le Counte Patriz, C. Price, Foxley, co. Hereford, Bart. Price, co. Denbigh. Price, Rhiwlas. Price, Spring Grove, Richmond, Surrey, Bart. RanulpH. Salisbuay, co. Northampton. W $_{\text {ALLACE}}$, Craigie, Scotland, quartering Lindsay. Dunlop WALLACE, Craigie, co. Ayr, Bart. Sir William Wastney, $I$. Roger le Ware, $A$. WaLlace, Wallace-Craig, Scotland. Walleen, London, and Shepperton, Middlesex; quartering or a grenade sa. fired ppr. over all a fess countercompony gold and az. WYNne, Voelas. Gu. a lion ramp. arg. a label of three points az. Mowbray, co. York.

Gu. a lion ramp. arg. with a mullet for diff. W ALI.ACE, Ingliston, Scotland.

Gu. a lion ramp. arg. in the dexter chief a mullet of the second. W $\triangle$ LLACE, Bergen; quartering gū. a fess chequy arg. and az. all within a bordure engr. or.

Gu. a lion ramp. arg. over all two bars sa. SaIclitffe, co. York. Wallace.

Gu. a lion ramp. arg. over all a bend of the second. Churchild, quartered by Mohun.

Gu. a lion ramp. arg. over all a bend az. Tylitot or TILLOT, East Bardsale, Suffolk, and co.York. Gu. a lion ramp.arg. and bendlet az. TyLLIoLl, $V^{*}$. Gi. a lion ramp. arg. and dexter baston az. Piers TILYole, $X$, or TILIOLL, $Y$. Sir Robert Tillyolf, $M$, or Tyliol, $N$, or Tyilioll, $V$.

Gu. a lion rump. arg. over all a bend compony of the second and az. Walter de Wessington, $Y$.

$\mathrm{Gu}$. a lion ramp. arg. over all a bend erm. FALCRON.

Gu. a lion ramp. arg. over all a bendlet erm. Filchett.

Gu. a lion ramp. arg. a dexter baston sa. William de WaRe, $G$.

Gu. a lion ramp. arg. a bend engr. sa. Sir Phillip de Mowbray of Scotland, $\boldsymbol{M}$.

Gu. a lion ramp. arg. over all a bend vair. Aston, Enfield, Middlesex. Aston, co. Gloucester, $V$.

Gu. a lion ramp. arg. over all on a bend sa. three crosses croslet fitchy of the second. Robert de OLDEFELDE, $Y$.

Gu. a lion ramp. arg. over all on a bend sa. three crosses potent fitchy of the second. OULDFEILD, $V^{*}$. OUL,DFIELD.

Gu. a lion ramp. arg. over all on a bendlet sa. three crosses potent fitchy of the second. OOLDFEILD, $W$.

Gu. a lion rump. arg. over all two bendlets or. Playstow.

Gu. a lion ramp. arg. and two bendlets or the uppermost under the lower over him. Playstowe, $\mathrm{J}$.

Gu. a lion ramp. arg. over all on a chev, or three escallops sa. ScHNEIDER.

Gu. a lion ramp. arg. over all a fess voided sa. WAILIACE.

Gu. a lion ramp. arg. over all a crosier or. BAYEN. Gu. a lion rawp. arg. over all a crosier in bend sinister or. BAYEN. ODo, Bishop of Bayeux, Earl of Gloucester (half-brother of William I). Cistercian Abbey at Byland, co. York. Odin, Kent. Odin, Boston, Pennsylvania.

Gu. a lion ramp. arg. in the dexter paw a crescent of the second. Salispury.

Gu. a lion ramp. holding. in the dexter paw a pen arg. Grey. 
BEAST.

IION.... cont.

Gu. a lion ramp. holding in the dexter paw a sword erect arg. Bergaigne, 10 Feb. 1631.

Gu. a dragon or and a lion ramp. arg. combatant. Danncey, co. Gloucester.

Gu. a lion ramp. arg, supporting a wivern erect vert. Danncey or Dauntesey, West Lavington, co. Wilts.

Gu. semy of annulets or $\mathbf{\Omega}$ lion ramp. arg. LoNG.

Gu. billety or a lion ramp. arg. Sire Johan de Creppinge, $N$. Grammer, London and co. Warwick. Willian GramaRY, $Y$.

Gu. crusily botony a lion ramp. arg. Henry GRAMIARY, $Y$.

Gu. semy of crosses botony fitchy and a lion ramp. arg. Delawarr. Laware or Jawarre. WARRE. Johan de la WARE, $G$.

Gu. crusily and a lion ramp. arg. DaLTON; quartering Bright; Mouument of Lady John Murray, ob. 1765, in Sheffield Church. LawarRe. Hantvill. HaUterill. Kinardesley, co. Salop. Penleaze, High Cliff, Cluristchureh, co. Hants. Joan de la Warre, $E, L$. Sire Johan de la WARE, $N$. John la WARE, $Y$. Roger de la Wane, $K$. Foger La Ware, $A$.

Gu. crusily and a lion ramp. arg. a label az. Sir John de la Warre, $L$.

Gu. crusily fitchy a lion ramp. arg. DELAwARR, co. Gloncester and co. Warwick. WarRe, Chapleigh, co. Somerset, sometimes charging the lion with a crescent gu. Joan de la WARRE, $E$. Sir John la Warre, I. John de la Ware, but in the margin Robert de la WASE, $Y$. Monsire La Ware, $Y$. (? John de la Ware, Bisluop of Llandaff 1:51-56.)

Gu. crusily fitchy a lion ramp. arg. a bend engr. sa. Delawarr.

Gu. semy of crosses croslet fitchj or a lion ramp. arg. Ashwy. Foulkes.

Gu. crusily fitchy or and a lion ramp. arg. over all a dexter baston engr. of the second. Monsire Roger de Weston, $Y$.

Gu. semy of fleurs-de-lis a lion ramp. arg. Sire Johan Deywille, $N$. Sire John de Euyle, $O$. Poole.

Gu. semy of 5 -foils and a lion ramp. arg. GRACE, London.

Gu. semy of acorns or a lion ramp. arg. Atwood. Chenduts. Pengelley, Cornwall.

Gu. semy of mullets and a lion ramp. arg. LISTER.

Gu. semy of nails or a lion ramp. arg. BRYN.

Gu. goutty .... a lion ramp. arg. thrust througb with two swords in saltire liilts downwards ppr. Walters.

Gu. goutty d'or a lion ramp. arg. John de CRepinge, $G$.

Gu. bezanty a lion ramp. arg. Monsire de Hewick, $Y$. Hewikes. Nichol Hewik, $r$. Malthain Ratcliff, $Y$.

Gu. semy of ogresses a lion ramp. arg. CuIfton. Gu. a Jion ramp. arg. armed az. Astiex. Marchweithian, Lord of Is-aled, from whom descended besides Tudor ap Robert Fychan, Berain; (the heiress m. Salisbury, Clough, Wynne, and Thelwall); Price, Boch-y-raiadr; Wynn, Llangynhafal ; Panton, Colesbill Manor; Parry, Tywysor and Pistill; Price, Rhiwlas, Pant Glas, Giler, and Voelas.

Gu. a lion rump. arg. armed and langued az. Mowbray. Price, Phiwlas, and Gilir, co. Merioneth.
BEAST. LION.... cont.

Gu. a lion ramp. arg. armed and langued gu. WYNne, Voelas,co.Denbigh; the heiress m.Finch. $\mathrm{Gu}$. a tricorporated lion issuing ont of three points of the escuclieon all meeting under one head in fess arg. armed and langued az. EDMOND.

Gu. a lion ramp. arg. collared az. Durneys.

Gu. a lion ramp. arg. collared of the field. Boxworth.

Gu. a lion ramp. arg. crowned az. Marnham.

Gu. a lion ramp. arg. crowned or. Clifton. Cuisson. Fourches. Furches. Grey.

Haliewton. Halilington or Hallowton. Sir Thomas de Halweton, $R$. Hambly. Haward or HaWERD. HaYwaRd or HEYwaRd, of the North. Howel ap IEva. Morgan, Mellhouse, co. Durham; Visitation, 1615. Musard, co. Devon. Paslew, co. York. WakINDON, $V^{*}$. Pershall. Sir.... Wakyndon, $V$. Wayseter. Weysandon. Wifrenton. Michael Wisringdon, corrected in the margin to Nicholas WoKunGDON, L. Sir Nicholas WYLFRINGDON or de Wifringdone, L. Woringdon, Essex. Nichol de Wokendene, $G$. Sir Nicholas Woringdon, $L$, or De ToKingdone, $N$. Monsire de WoKing Don, $Y$.

Gu. a lion ramp. arg. ducally crowned or. HAWARD HaYwaRd or Heyward, Brocton, co. Salop. WorTnDon.

Gu. a lion ramp. arg. crowned or over all a bend. let sa. WiCKENDEN.

Gu. a lion ramp. arg. ducally crowned or holding in each forefoot a bezant. BrinkHurst.

Gu. a lion rainp. arg. crowned and langued or. SalWaY.

Gu. a lion ramp. arg. enraged az. MowBRAY, Duke of Norfolk.

Gu. semy of acorns slipped or a lion .... tail coward arg. Cheyndute.

Gu. a lion ramp. tail erect arg. Randolph de Gernonirs (? son of Randolph de Meschines) fourth Earl of Chester; m. Maud, daughter of Robert, Consul of Gloncester, son of Henry $\mathbf{I}$.

Gu. a lion ramp. tail forked arg. Brinton. Thomas de Brinton, Bishop of Rochester, 1373.89. Brinton, $\Gamma$. Le Conte de Leister, $B$, or Lejcestre, $N$. Moundford. Conte de Mounford, $F$. Simon Montfort, Conte de Leicestre, $Y ; Z, 87$. Montfort, Earl of Leicester, temp. John. Simon Montfort, Earl of Leicester, temp. Edward III, $V$. Wauter PAYNe or PayveIey or Payveli q quartering az. a cross flory or, $X, Y$. M. John ATtewode, $S$. Wood. And with a label arg. Pbilip de Mountront, $C$. Gu, a lion ramp. double tailed arg. Atwood, Broughton, co. Salop. Atwood. $V^{*}$. BoHemid, Harl.MS.6829, fo.46. Brynton, $V^{*}$. Montford, co. Leicester. Stokes, Tetherton Locas, co. Wilts. Gu. a lion ramp. tail forked and nowed arg. ADwOoD. ATwood, $V$. BoHEMIA, $Y$.

Gu. a lion ramp. tail forked and double nowed arg. Simon de Montfort, fifth and sixth Earl of Leicester, through Allicia de Bellomont.

Gu. a lion ramp. tail forked arg. armed az. Hamlet Sнетншіск, released all right in this coat to John Atwoov, Worcester, as having properly belonged to Sir John A twood (Pat. 6 Henry VI), Ashmolean MS. 835, fo. 365 .

Gu. a lion ramp. tail forked arg. armed or over all a bend (another a fess) az. Eruls.

Gll. a lion ramp. tail forlied arg. langued az. Elles or Ellis. 


\section{BEAST. LION.... cont.}

$\mathrm{Gu}$. a lion ramp. tail forked arg. crowned or. Bohemia, $Z$, 194. Luxembourg, as quartered by Anne of Austria, daughter of the King of the Romans and Bohema.

Gu. a lion ramp. guard. arg. ATwood. John de la Mare, $Y$. Marnay, Cornwall. Marney, Coruwall. Marney, Norfolk. Marny, $V^{*}$. $M$. Robert Marny, $S$. Sir Henry Marney, $V$. Saint Marney, 1730. Meschines, Earl of Chester. Wood. And with due ditf. Manney, Essex.

Gu. a lion ramp. guard. arg. a label of three points or. M. William Marny, $S$.

Gu. a lion ramp. guard. with one head and two bodies arg. Kellum or Kellak.

Gu. semy of crosses croslet or a lion ramp. guăd. arg. Astley. Asteley, $V$.

Gu. semy-de-lis and a lion ramp. guard. arg. DEwUL, co. Hertford.

Gu. a lion ramp. guard. arg. armed of tbe field. Astuey.

Gu. a lion ramp. guard. arg. crowned or. DENLE, $Y$, or Deiley. Deyiny. Fitz-Gerand, co. Lancaster. Heywarde, Lord Mayor of London, 1570.

Gu. a lion ramp. reguard. arg.. GAY. CADogan, Earl Cadogan. LLOyd. Loyd. Robert MORGAN, Bishop of Bangor, 1666-73.

Gu. a lion "rampant sautant embelif d'argent." Robert de Mere, $Y$.

Gu. a lion salient arg. Dewilse. Salisbury, 1730.

Gu. a lion salient arg. in the dexter chief a cres. cent (? for diff.). Thomas Salisbury, co. Northampton, $V$.

Gu. a lion salient arg. crowned or. Worrngdon.

Gu. a lion sejant on a chair and bolding in the paws a battleaxe arg. ALEXANDER.

Gu. a lion stataut arg. crowned or. Gerard Lyite, $A$.

Gu. a lion ramp. barry of six or and az. WOIIINGDON, $V$.

Gu. a lion ramp. barry of seven (another of eight) arg. and sa. Hospital called Eising Spital, Hospital or Priory the Virgiu for Canons Regular, near Cripplegate, London, and now SION COLLEGE.

Gu. a lion ramp. barry of ten arg. and az. Desney. Woringdon, Essex.

Gu. a lion ramp. barry of ten or and az. DESNEy, $V$. WoKIngdon, Essex.

Gu. a lion ramp. barry arg. and az. Sire Thomas de Wokingdone, $N$.

Gu. a lion ramp. barry or and az. Disney. WoKINGDON, $V^{*}$.

Gu. a lion ramp. bendy wavy of eight arg. and az. HaROWDEN, $V$.

Gu. a lion ramp. chequy arg. and sa. BLaCKBolene.

Gu. a lion ramp. chequy erm. and sa. ducally crowned or. BIACKBURN.

Gu. a lion ramp. chequy or and az. Dernestode or Dernford. Dornford.

Gu. a lion pass. erm. Nereforo, Norfolk.

Gu. a lion pass. guard. erm. Astley, $V^{*}$. Brins, $V$. Robert Briwys, $Y$.

Gu. a lion pass. guard. in chief erm. Brynse.

Gu. a lion ramp. erm. ATwood. Sir John Basford, R. Berford. Bradford. Brampton. Mereford or Meriford, London. Nereford or Neryord, temp. Edward III. NEIRFord or NeErford, Norfolk. William Neuneford, $A$, or de Nerefolid, A, Havl. MS. 6137 ; and $E, F$,
BEAST.

LION .... cont.

or de Neirford, $N$. William Neirford or de Neirforde, $Y$. Monsire de Nerford, $Y$. Neyrfond, temp. Edward III, $V$. Sir William Nerfond, $V$. Norford, $V^{*}$. Noweford or NeirFord. OLdeHaIL. Sir Raufe de Sherlinghadi, $V$.

Gu. a lion ramp. erm. over all a chev. or. Hardres, Kent, $V$.

Gu. flory or a lion ramp. erm. MAREs, Salisbury, and Steeple-Ashton, co. Wilts.

Gu. a lion ramp. erm. gorged with a collar gemel az. therefrom pendent an escucheon of the last charged with a mullet arg. Pownaru, Pownall, co. Chester, and Liverpool.

Gu. a lion ranup. erm. crowned or. Sir John HAMELYN $, L, O$; or HaMLYN $L$. Sir Joban de Hamelyn, $N$. Sire John Hamlyn, co. Leicester, temp. Edward III, $V$. Hamelys, $V^{*}$.

Gu. a lion ramp. erm. crowned with an antique crown or. HaMLIN.

Gu. a lion ramp. erm. ducally crowned or. Hamelyne or Hameise, co. Buckingham. Hamin or Hamelyne, co. Leicester.

Gu. a lion ramp. tail forked erm. Adam do Brinton, $F$; or Brintone, $E$. Neirford or NeERFord, Norfolk. Sparshall. Stores, co. Berks. Stores, co. Devon.

Gu. a jion ramp. double tailed erm. Brampton, Norfolk and Suffolk. Nerfond, $V^{*}$. SPARCoLise, $V^{*}$.

Gu. a lion ramp. erm. tail forked over all a chev. or. Harnres, Kent.

Gu. a lion ramp. tail forked and nowed erm. Nerford, $V$. Sir John de Sparsolle, $\boldsymbol{V}$.

Gu. a lion ramp. tail forked and renowed erm. NERFORD, $V$.

Gu. a lion ramp. erminois. Stote, Jesmond, Northumberland.

Gu. a lion ramp. salient erminois. Bulmer.

Gu. a lion couchant or. Euworth.

$G$ a a lion pass. or. Hugh le BIgot, $B$. Hugh Bigot, $C$. Vatence or Valomes.

$\mathrm{Gu}$. in chief a lion pass. guard, or. Sir Amias Brett, the son, $Q$.

Gu. a lion pass. guard. or. Aquitaine, $Z, 2$. GUYEN, $Z, 487$; said to have been added in the arms of England on the marriage of Eleanor dau. and co-heir of William fifth duke withHenry II. Barnard. Brett. Le Brett. Waines. Gu. crusily arg. a lion pass. guard. or. Asteley, $V$. Astrky. Monsire Gerard de Lisley, $Y$.

Gu. in chief a lion pass. guard. or. langued az. Sir Amias Bretr, the son, $Q$.

Gu. a lion pass. guard. or. crowned arg. L'IsLE, Rugemont, co. Bedford, temp. Henry III.

Gu. a lion pass. guard. crowned or. GERARD.

Gu. a lion pass. reguard. or. Brett or Bret.

$\mathrm{Gu}$. in chief a lion pass. reguard. or. Bretr.

Gu. a lion ramp. or. Albynetro. Efnydd ap Gwenllian, quartering Rhys ap Marchen. D'Albany, Earl of Arundel, $V$. Le Conte d'ARUNDElL, $B, Y$; or ARUNDel or ARENDEL, $E$. Conte de Arendel, $G$. Richard, Earl of Anundel, $K$, or Arondell, $Q$. Le Conte d'ARONDELL et de WARREN, quartering Warren, $S$. Le Counte de Arundel, $N, P$. Earl of Arundel. Thomas Aruniel alias Fitz-Alan, Bishop of Ely 1374, Archbishop of York 1388, and Canterbury 1396-1414; quartering chequy or and az., Maidstone church, and this quarterly coat, with over all a surcoat arg., Radulphus de ARUNDEI, Lansdowne MS. 872. Deler, Mentry. 
BEAST.

LION.... cont.

Berewashe. Meredith ap Bleddyn. Bolebec. Borne. Bromwich. D'Albany. Daulbeny or Dawbeny. John de Eston, added in a later hand in $F$. De Meschines. Fatieron. Fitchett. John le Fitz-Allen, $A$; or FitzAlain, $A, B$. Sir Pichard Fitz-Aluain, Counte de Arundell, $H$. Fitz-AIJIAN, quartered by Lord Willoughby, $U$. Fitz-ALan, Earl of Arundel, $Z, 111,225$. Forth. Grey. Ivey, Exeter. Lincolne. Le Sr. Matrevers, quartering sa. a fretor, $T$. Meredith. Northmore, co.Somerset, and Cleve, co. Devon. O'Kenney, Ireland. M. Robert de Passele, S. Price, co. Denbigh. Prxce. Stantun. Waldace, Craigie, quartering Lindsay. WALtaCE, Helmston, quartering gu. a fesse chequy arg. and az. WaLdace, Ellerslie, Neilstounside, Cairnhill, and Kelly.

Gu. in chief a lion ramp. or. Bretr.

Gu. a lion ramp. or a label of five points az. Herbert de Borgheise, $A$. Bertb. Burghense, A, Harl. MS., 6137.

Gu. a lion ramp. or a label of six points az. Johan de Muchegros, $G$.

Gu. a lion ramp. or over all three bars az. Desney. Disney.

Gu. a lion ramp. or a bend arg. Fychet, Spax. ton, co. Somerset.

Gu. a lion ramp. or a baton in bend erm. FICHET or Fitchet, co. Somerset.

Gu. a lion ramp or over all a bend erm. FALCoN, $V^{*}$. Falcron, $V$. Fichet, $V$. Halton, $V$.

$\mathrm{Gu}$. a lion ramp. or over all a bendlet erm. (The ancient arms of ) MALET.

Gu. a linn ramp. or over all a bend vair. Aston, co. Gloncester. Sire Richard de Astone, $N$. Sirnmester or Skryusher, co. Nottingham and co. Stafford.

Gu. a lion ramp. or a bend vert. Askewe. Sire Richard Aston, co. Gloucester, temp. Edward III, $V$.

Gu. a lion ramp. or over all on a bend arg. three crosses flory sa. John Gyeon, D.C.L., $V$. PAyne alias Gybon, confirmed 24 Nov. 1570.

Gu. a lion ramp. or over all on a bend arg. three crosses formy sa. GrBons or GibBons, co. Glamorgan; Ditley, co. Oxford; and Newhall, co. Warwick. Gibon. PAYNe.

Gu. a lion ramp. (? arg.) surmounted with a crosier in bend sinister or. Cistercian Abbey at Belleiand Begeland or Byland, co. York.

Gu. a lion ramp. or over all a long cross or pil. grim's crutch in bend sinister of the last. Augustinian Priory at NEwBergH, co. York.

Gu. a lion ramp, or over all on a bend arg. a torteau betw. two crosses croslet patty fitchy sa. Gibbons, Stanwell Place, Middlesex, Bart.

$\mathrm{Gu}$. a lion ramp. or in the dexter paw a battleaxe arg. SANSUN.

Gu. a lion ramp. holding an Irish axe or. Nonway, $Y$.

Gu. a lion ramp. or holding a battleaxe sa. NoRwAy, Harl. MS. 6829 , fo. 46 .

Gu. a lion ramp. or supporting a staff raguly of the last. Forth.

Gu. a lion ramp. or in the dexter paw a cutlass arg. hilted of the second. Durand.

Gu. billety and a lion ramp. or. ANTHONY. Bolmer. Sir Rauff de Bulmer, $M$, or Bolmere, $N$. M. Rauf Bulmer, $S$. John Bolmer, Bulmer, $Y$. Bulmer or Bullmer, Essex, and co. York. Bulmer, Wylton. Augustinian Priory at MARTon, co. York.
BEAST. LION.... cont.

Gu. billety and a lion ramp. or a label of three points compony vert and az. Blaumester, $V$. Blaminoster.

Gu. crusily arg. a lion ramp. or. Joan d'Elstone or D'Estone, $E$. Hoburne.

Gu. crusily and a lion ramp. or. CAPEll. Corbet. Hopton, Hopton, co. Hereford. Wat Hopeton, $E$, or De Hopton, $F$. Knel, co. Oxford and co. Gloucester. Sire Wauter de Optone, $N$. Oxton.

Gu. crusily fitchy and a lion ramp. or. KNeLl. KNILL, co. Hereford. KNrLL, co. Hereford.

Gu. replenished with estoiles and a lion ramp.or. SEYLEX.

Gu. semy de lis arg. and a lion ramp.or. Davall. London, 1650.

Gu. semy de lis and a lion ramp. or. Marks, Steeple-Ashton.

Gu. goutty and a lion ramp. or. Johan do Bolmere, $G$.

Gu. a lion ramp. or armed and langued a\%. ARUNDELL. ALBINI of Arundell, surnamed Pincerna, extinct temp. Henry III.

Gu. a lion ramp. or armed and langued az. holding in the dexter paw a scimitar arg. Scrymgeor, Dundee; created Viscount Duddop and Lord Scrymzeor, 15 Nov. 1641.

Gu. a tricorporated lion issuing out of the three corners of the escucheon all meeting under one head in the fess point or armed and langued az. Edmond Plantagenet (Crouchiback), Earl of Lancaster, temp. Edward I.

$\mathrm{Gu}$. crusily fitchy a lion ramp. or armed and langued az. Le S. la Warne, $S$.

Gu. a lion ramp. or collared arg. Benyngton, Benyngton, co Lincoln.

Gu. a lion ramp. or collared of the field. Sir William Boxworth, co. Cambridge and Suffolk, temp. Edward I, $V$.

Gu. a lion ramp. or crowned arg. HaJu, $V$. HaYe, $V^{*}$. HeYwaRd, co. Salop.

Gu. a lion ramp. or crowned az. Degremont. Disgremond. Egcenon. HaLl.

Gu. a lion ramp. crowned or. Aigremont. HaLi. Furtho, Furtho, co. Northampton. Wokingdon. Gu. a lion ramp. crowned or holding in the paws a battleaxe arg. Norway, $Z, 276,554$.

Gu. a lion rampant crowned or holding a Danish battleaxe arg. handled of the second. SWEDEN. Gu. a lion ramp. or enraged az. Fitz-Alan, Arundel, Sussex.; and Clun, co. Salop.

Gu. a lion ramp. tail forked or. Barewashe, Kent. Brinton. Sir Berth. de Borways, O. Bartholomew Burwashe, $Q$, or Bourgheyche ard Borewache, $S$. Burghershe, $V *$. Burgersh or Burwash. Burghersh, $Z, 383$. Sire Bartilmeu de Borouash, $N$, or Burhesse, $Y$. John Bourghershe, $Y$. Sir Stephen Burẃash, $L$. Havering (in Wrightwell Church, Suffolk). STOAKes, Artleborough, co. Northampton, 1630.

Gu. a lion ramp. tail forked or a label of three points az. Burwash, Kent.

Gu. a lion ramp. double tailed or. BORGHERSH, Norfolk, and co. Devon.

Gu. a lion ramp. double tailed or over all a bend az. Burewash, Kent.

Gu. a lion ramp. tail forked or over all a bend sa. WARE.

Gu. a lion ....t tail forked or armed az. Borewashe, Ireland.

Gu. a lion ramp. tail forked or crowned az. CoMberton. 


\section{BEAST. LION.... cont.}

$\mathrm{Gu}$. semy of crosses croslet fitchy and a lion ramp. or crowned and langued az. KNELI.

Gu. a lion ramp. guard. or. Conbet, $V$. Everingharr. Trinitarian or Maturin Priory at Hounslow, Middlesex. Fitz-Hamon. Lancaster. Price. Masters, Lolldon, 1730. Roberts, Bow, Middlesex.

Gu. a lion ramp. guard. or a crescent for diff. Blanty, Kinshum, co. Hereford.

Gu. a lion ramp. guard. or impaled with az. three demi hulks of ships joined to the impaled line of the last. Town of IPSWICH, Suffolk; confirmed 1561.

Gu. a lion ramp. guard. or over all a bend az. Poldegrew or Pollitcrew.

Gu. a lion ramp. guard. or holding a rose arg. stalked and leaved vert. WASTER.

Gu. billety and a lion ramp. guard. or. Augus. tinian Priory at Marton, co. York.

Gu. crusily and a lion ramp. guard. or. Agruald.

Gu. a lion ramp. guard. or collared az. Sir Tho. mas LANCASTER, $Q$.

Gu. a lion ramp. guard. or collared arg. over all a (bend, $V^{*}$.) bendlet or rather a dexter baston az. PoLDEarewe, $V$.

Gu. a lion ramp. guard. or gorged with a collar az. charged with three fleurs-de-lis of the second. Sir Thomas de LANCASTER, $V$.

Gu. a lion ramp. guard. or crowned arg. HALL, co. Leicester.

Gu. a lion ramp. guard. double tailed or. Master, Willesborough, Kent.

Gu. a lion ramp. guard. tail forked or supporting betw. the paws a rose of the field stalked and leaved vert. Master, Kent; and Cirencester and Knole Park, co. Gloucester. MAster, co. Oxford; granted Dec. 1568.

Gu. a lion guard. with two bodies counter-ramp. or crowned az. the tails passing betw. the legs and reflexed over the back. Comberton, $V$. John Northampton, Lord Mayor of London, 1381. Harl. MS. 1349, fo. 9 .

Gu. a lion ramp. reguard. or. Amenedith, Marston and Tamerton, co. Devon. Braney, co. Hereford. Buaney, Esham. Bowen, Troedyraur, co. Cardigan. Fitzgenald. Elystan GLODRUDD, living 970 , father of CADWGAN. Gwynne, Garth, co. Brecon. Meredith, Henbury, co. Chester. Maurice. Morrice, Betshanger, Kent; descended from Ethelystan Glodrydd, Prince of Ferlys ; quartering Tudor, Trevor, Cadwgan, and Chadwick. Morice, Werrington, co. Devon, with the same descent: Baronetcy 1661; the heiresses m. St. Aubyn and Molesworth. Pryce, Newtown, co. Montgomery, with the same descent; and its branches, Pryce, Manariefed, co. Cardigan; Bodfach, co. Montgomery, and Glan Miheli. Thomas, in Chobham Church, 1570.

Gu. a lion ramp. reguard. or. Beddoes, Cheyney Longville, co. Salop. Cadogan, Earl Cadogan, Lloyd, Ludlow, co. Salop. Lloyd, Cefndyrrys, and Ferney Hall, co. Salop. Morris, co. York. Powel.L, Boughton-Monchensy, Kent; Ednop and Newton, co. Salop; Ewhurst, Sussex; and Brampton Ralf, co. Somerset; Baronetcy 1661. All quartering arg. thiee boar's heads couped sa. two and one, as derived from Elyston Glodrudd.

Gu. a lion ramp. reguard. or armed and langued az. John Lloyd, Bishop of St. David's, 1636 . 87.
BEAST. LION.... cont.

Gu. a lion salient or. Dulungton, KnightonGeorge, Isle of Wight ; Visitation 1634; Baronetcy 1628 .

Gu. on a mount vert a lion sejant guard. or. OLDES.

Git. a lion ramp. per bend eru. and ermines. Timberley, Suffolk. Tymperley, Suffolk, $V$. TyMPLEY, $V^{*}$.

Gu. a lion ramp. the head arg. divided by a line indented or erased from the body of. Grace, $V$.

Gu. a lion ramp. per fess arg. and or. Grace, Beaconsfield, co. Bucks. Grace, Grace Castle, co. Kilkenny, Bart., and Knole House, Sussex; descended through Grace, Ballylinch Castle, co. Kilkenny, and Shanganagh (now Gracefield), Queen's County, from GRACE, Barons of Courts. town, and Lords of Grace's country; derived from Raymond Fitzwalter, surnamed Le Gros; quartering with gu. a saltire arg. betw. twelve croslets or for the ancient arms of Grace alias Windsor, with Butler, and Sheffield. Grace, Mantua House, co. Roscommon, quartering Windsor, Butler, Fitzpatrick, Walsh, Sheffield, Dowell, and Hussey.

Gu. a lion ramp. per fess arg. and sa. crowned or. Green.

Gu. a lion ramp. per fess arg. and sa. ducally crowned or. Sir John Grene, Essex, $V$. And with a 3 -foil vert for diff. GreENe, Alderman of Chester, $V$.

Gu. a lion ramp. per fess indented arg. and or. Grace.

Gu. billety gold a lion ramp. per fess or and arg. William Butumen, Gilsland, co. York, $V$.

Gu. a lion ramp. per pale arg. and or. DHLke, co. Leicester, co. Stafford, and co. Warwick; granted 10 January, 1514. Dyukes.

Gu. a lion ramp. guard. per fess or and arg. Trinitarian or Maturin Priory at Hounstow, Middlesex.

Gu. a lion ramp. sa. Timperley, Timperley Buckford, and Longumdale, co. Chester; the beiress m. Massy; Harl. MS. 1535, fo. $28,43$.

Gu. a lion pass. vair crowned or. Marney.

Gu. a lion ramp. vair. Adam de Benerguam, corrected in a later hand to EveringHair, $F$. Sir Adam Everingham, $I$. Sir Adam de Everingham, $M, N, X$, co. York; temp. Edw. I, $V$. John de Everingham, $Y$. M. Reynold de Ev'yNGHAM, quartering sa. a bend betw. six croslets arg., $S$. Everyngham, Pontefract, Rockley, and Birkin, and in Arksey-with-Bentley church, co.York. Marmyon, co.Gloucester. William Marmyon, $Y$.

Gu. a lion ramp. vair a dexter baston or. Monsire Thomas de Everingham, $Y$.

Gu. a lion ramp. vair crowned or. Everingham, Berkinge, and co. York. Monsire Adam D'Everingham, $Y$. Adam de Everingham, $E$. Marmon. Sir William Marmyoun, $L$, or Marmion, L, co. Leicester, temp. Edward I, $V$.

Gu. a lion salient vair. Everingham, co. York; Barton-upon-Humber, co. Lincoln. Marmyon. Gu. a lion vairy or and az. Comberton.

Gyronny of eight arg. and vert a lion ramp. guard. or. Evans, Allestree Hall, co. Derby.

Gyronny of eight erm. and ermines a lion ramp. or. Sir Trevor Williams, Langibby Castle, co. Monmoutb, Bart., 1730. 
BEAST

LION.... cont.

Gyronny of eight erm, and sa. a lion ramp. or. Roger Willians, Llangibby Castle, co. Monmouth; confirmed 1575; Baronetcy 1642; descended through Rhys Goch, Lord of Ystradyw, co. Brecknock, from Caradoc Vreichvias; a heiress m. Adams.

Gyronny of eight gu. and sa. a lion ramp. or. Mathew, $W$.

Gyronny of eight or and az. a lion ramp. erm. Mocklow, co. Worcester.

Gyronny of eight sa. and gu. over all a lion ramp. or. Matthew, co. Northampton.

Lozengy arg. and vert. a lion ramp. of the first. Gill, co. Devon.

Lozengy az. and erm. over all a lion ramp. gu. WELUES.

Lozengy erm. and az. over all a lion ramp. arg. WELLES, London.

Lozengy erm. and vert over all a lion ramp. gu. Sir John Welles, Lord Mayor of London, $1431, V$.

Lozengy or and arg. a lion ramp. guard. gu. GrL, Ansley, co. Hertford.

Lozengy or and gu. a lion ramp. arg. GiLL.

Lozengy or and vert a lion ramp. arg. SALFORD. SAWFORD, $V^{*}$.

Lozengy or and vert a liou ramp. guard. arg. Gylle, $V^{*}$. GiLIE, London, and co. Warwick.

Lozengy or and vert a lion ramp. gu. GıLL.

Lozengy sa. and erm. a lion ramp. gu. Welles.

Lozengy vert and erm. a lion ramp. gu. John Welles, Lord Mayor of London, 1431.

Lozengy vert and or a lion ramp. arg. SAwFoRd, $V$.

Lozengy vert and or a lion ramp. guard. arg. Gylite, $r$

Or a lion pass. az. Thompson, co. Buckingham.

Or a lion ramp. az. Algernon, $V$. Boynton or Bonton. Alice of Brabant, second wife of King Henry I. Sir Piers de Brerson, $L$. CADWGan, Lord of Nannau, co. Merioneth, younger son of Bleddyn ap Cynfyn, King of Powys; from him descended the early Barons of Nannau, the heiress m. Rhys ap Jevan, Baron of Kymmer; NANNEY, Cefn Denddwr, the heiress m. Ellis; Nanney, Nannau, and Mues. y-Pandy; Luwrd, Cwm Bychan and Ceerwys; Vaughan, Nannau (Bart.), Rúg, Hengwrt, and Dolmelyullyn. Courtaey, co. Devon; quartering arg. three trefoils slipped sa. Cromwell. Le Counte de Detenyschire, $N$, $i$. e. Devonshire, $Y$. Fulton. Gyssors. Ie Conte del ILE, $B$. Counte Vernon del Ildie or de Ildie, $D$. Conte de Lisle, $E$, or Lille, E, Harl. MS. 613\%, G. JoNes, London, and Clifton, co. Gloucester; impaling Creswick. Jones, Trewythen. Jones, Pentre Mawr, co. Denbigh. Jones, Larkhill, co. Lancaster; quartering gu. a fess dancetty erm. betw. six crosses croslet arg. KaTz, quartering az. sim. ple, with purp. on a mount vert a tree ppr., and arg. on a mount in base vert a fox springing ppr. 'The Reverend Ino and Reverend Angarad Lloyd. Richard Loveli, $B$. Lovain, $V^{*}$. Jo. celinus Lovainensis, $V$. Lovain. Louvain. Lovayne, Brabant. Mahon, Ireland. Mac Mahon, Ireland. Nanney, Maes-y-Nenadd, co. Merioneth; derived through Wynn, Glynn, co. Merioneth, from Osborne Fitzgerald, Lord of Inys-y-Maengwyn. Percy, $V$. Le Conte de Northumberiand, Sr. de Lucy; quartering Lucy, $S$. Benedictine Priory at St. BeEs, Cumberland; quarterly with Lucy. Sr.Henry
BEAST. LION.... cont.

de Percy, $H, J$, nephew of Earl Warren, $K, N$. Pency, Duke of Northumberland; quartering Lacy, second and third grand quarters, Percy. Percy, Earl of Beverley, with the same quar. terings. Pency, Baron Prudhoe, with the same quarterings, and a crescent for diff., and $\mathrm{Hugh}$ Pency, Bishop of Rochester, 1827; Carlisle, $1827-56$, with the same diff. PERCY, Guy's Cliff, co. Warwick, with the same quarterings, the centre point charged with a crescent arg. thereon a fleur-de-lis gu., adding as second and third principal quarters Greatheed and Bertie. M. Thomas Percy, $S$. Sire Pency, $Y$. Monsire de Pencye, $Y$. Percy, Lord of Alnwick, $Z$, I11, 235, 345, 346. ReDvers, Earl of Devon. Richard Ridvers, $Y$. De Riparis, $Z, 419$. Ridvers or Rivers, Cornwall. Baldwin de Rivers, Earl of Devon and Lord of the Isle of Wight, $\boldsymbol{V}$. Rodney. Roney. Rowlands, Carew, Isle of Anglesea. Anian de Schonat, Bishop of St. Asaph, 1268-93. Sutton. Vaughan, Wengraig, Rûg, and Dol-y - Melynllyn. WANDFORD. WINDESFORD. And with a crescent for diff. Percy, Earl of Worcester, ob. 1403.

Or on a mount vert a lion ramp. az. Jones, co. Hereford, and Rowe, Middlesex. Joanes, Brim. sey, co. Somerset. Jones, quartered by Hogg. Or a lion ramp. az. a label of three points gu. Henry Percy, $S$.

Or a lion ramp. az. a label of five points gu. Joan de Monhault, $E$.

Or a lion ramp. az. a bend compony arg. and gu. Fulton, $V^{*}$. Sutton, $V^{*}$. Sutron, Essex. Or a lion ramp. az. over all a bendlet compony gu. and arg. Sr. de Fulton,.Holt, $V$. Sire Johan de Sutton, Holderness, $V$, but with a dexter baston instead of the bendlet, $O, Y$.

Or a lion ramp. az. over all a bend gu. Doxey. JOYRE. VESSEY.

Or a lion ramp. az. debruised with a bendlet gu. Dokesley. Vescy, $V$. Vesey, $V^{*}$.

Cr a lion ramp. az. a dexter baston gu. William Vesey (but Percy in the margin), $Y$.

Or a lion ramp. az. oppressed with two bendlets gu. Brusell.

Or a lion ramp. az. over all on a fess gu. three martlets arg. DaMrEND, $V^{*}$. DaMENOR. Sir Gerard Damener, $V$. Daminer.

Or a lion ramp. az. on a fess sa. three bezants. Porches, London.

Or a lion ramp. az. bolding in the dexter paw a long cross gu. M' $\mathrm{C}_{\mathrm{raw}}$, Scotland.

Or a lion ramp. az. thrust through with a sword of the last entering at the breast and issuing beneath the tail. WOODALI.

Or billety and a lion ramp. az. Dangle. Guis. cardus de Engolisiro, Earl of Huntingdon, temp. Richard II, $V$. HUNTINGDON or Huntington. KichaRd.

Or crusily and a lion ramp. az. Hopton. Sir de Lovelx, Baron Lovell, Castle Cary, co. Somerset, $V$, summoned to Parliament, 1348 . Lovele or Luvel, co. Somerset. Sir Richard Luveli or LOVELI, $I$, or LOVELL or Louwell or Lupelt, $L$, or Lovel, $N$. Monsire Richard Loveli, $Y$. MonsireAlexander de Montfort, $Y$. Or semy of estoiles and a lion ramp. az. Galehault.

Or semy of hearts gu. a lion ramp. az. The old arms of LUNEBURG, $Z, 8 \pi l$.

Or a lion ramp. az. armed gu. Rivers, Earl of Devonshire. 


\section{BEAST.}

LION.... cont.

Or a lion ramp. az. armed and langued gu. MAHON, Baron Hartland.

Or a lion ramp. az. crowned of the first. Clendon.

Or a dragon vert and a lion ramp. az. crowned of the first combatant. TaMe, co. Oxford.

Or a lion ramp. az. crowned gu. Clevedon, Essex. Clyvedon. Sire Johan de Clevedone, $N$. Sire Johan Clyvedon, Essex, temp. Edward I, $V$.

Or a lion ramp. with two heads az. Simon MASON, Great Gransden, co. Huntingdon, 1730. Mason, Hunningford, co. Huntingdon. Sir John Mason, $V$. Mason, Cuckney. Mason, Masonbrook, co. Galway; descended from Mason, Sion, Middlesex.

Or a lion ramp. az. langued gu. Brabant.

Or a lion ramp. az. maned gu. Argernon.

Or a lion ramp. tail forked az. Sr. de Bonton, $V$. Buckilele. Bulzaleel. Lisle. William de Percy. Wadisford, Wanbore, co. York. Christopher WANDESFORD, Kirtlington, co. York, $V$.

Or a lion ramp. double tailed az. Bonton, $V^{*}$. WANDESFORD, $V^{*}$. WANDESFORD WANDFORD WANSFORD or WAWSFORD, Kirklington, co. York, Bart. WandysFord.

Or a lion ramp. double tailed az. ducally crowned gu. Bentali, Bentall, co. Salop.

Or a tricorporated lion guard. issuing out of three corners of the escucheon all meeting under one head in the fess point az. the lion at base ramp. to the sinister side. Nashe, $W$.

Or semy of hearts and in chief a lion ramp. guard. az. Gothes, now JuTI.AND, $Z, 554$.

Or a lion ramp. reguard. az. ARgall or Argnall. Agreveri, Chesley.

Or a lion salient az. Munford.

Or crusily aud a lion salient az.

Loveli, $Y$.

Or a lion ramp. erm. Firz Symon.

Or a lion ramp. erm debruised by a bendlet gu. Voyce, Sulbury, Sussex; and London.

Or a lion pass. gu. Charlton, $V^{*}$. Ap Wenunwin, $V^{*}$.

Or a lior pass. gu. crowned az. KatzenELLENBOGEN, $Z, 606,607,619$

Or a lion pass. gu. a label az. Hastings, co. Oxford.

Or a lion pass. guard. gu. Games or Garmes, Newton, co. Brecknock. RoDonick.

Or a lion hopping in a tun gu. Hopton.

Or a lion ramp. gu. quartered by the Duke of Bavar1a, 1342, $Z, 113$.

Or a lion ramp. gu. Ap Griffith. Le Conte de Arondel, $F$. William Blethin, Bishop of Llandaff, 1575-90. BledDyn Ap CrnfFin. Bolebec. Blount. Bosworth. Blythe, co. Lincoln. Guy Carieton, Bishop of Bristol, 1672-9. Le S. de Charleton, $S$. Le Sr. Charleton, $T$. Chariton, quartered by Tibetot and by Sutton, Lord Dudley, $U$. Sir John Charlton, $V$. Charleton, Apley, co. Somerset, $Z, 397$. ChaRLeton, Charleton Tower, Hesleyside, and Longlee, Northumberland; Baronetcy 1645 ; quartering Widdlington; the heiresses m. Charlton, Talbot, and Sherburne. Charleton, Lea Hall, Nolthumberland. Charlton, Ludford, co. Hereford ; and Witton, co. Salop, Bart.; a heiress m. Lechmere; de. scended like Cuariton, Powys Castle, co. Mont gomery, a Baron 1313-53, from Charlton, Apley Castle. Thomas Cherlton, Bishop of Here. ford, 1327-44. CoHEN. Col.Ey. Colitey,

\section{BEAST. LION....cont.}

Ireland. D'Audibert. DANIEL, Westbrook House, co. Dorset; quartering az. an arm embowed issuing from clouds in base ppr. hold. ing in the band a cross croslet fitchy gu., with vert a lymphad or. DELAFold, Ireland, $V$. Monsire Delapoole, $Y$. Dorsedly. Duff, Ireland. Egerton, co. Chester. Farquharson, Invercauld, co. Aberdeen; descended from the Thanes of Fife; quartering arg. a fir tree growing out of a mount in base fructed ppr. on a chief gu. the royal banner of Scotland displ. a canton of the field charged with a dagger also ppr. point downwards. FarquHarson, Langton Honse, co. Dorset. Felbryge, Norfolk, and co. Huntingdon. Sir Robert de Felaridie, $J$. Sir Roger Felbrige, $R$. M. Simond Felbrige, $S$. Mounsyer Felderidge, $T$. Gould, Ireland. Ecvan ap Grifit, $F$. Griffiths, Thorn Grove Park, near Worcester. GutBRIE, that Ilk, co. Forfar; quartering az. \& garb or. Guthry, Lunan, Scotland. Gwenwynwxy, Prince of Powis Wenwynwyn, derived from Bleddyn ap Cynfin, Prince of Powys. Holland, $Z, 143$, 158, 310. Hasbrough or Hasburg. LaCy. LEIGH, West Hall, High Legh; and Twemlow, co. Chester; quartering Joddrell; derived from Thomas de Leigh, West Hall, Lord of a moiety of Lymme in 1305, eldest son of Ricl. ard de Lymme, by Agnes, heir of Richard de Leigh. LeIGH, now Trafford, Oughtrington, co. Chester; derived from Leigh, West Hall; quartering arg. a bend lozengy su. LEIGH, Charlestown, South Carolina, Bart. M'BEAN, Inverness, Scotland; quartering arg. a dexter hand couped apaumy gu., with arg. a sword in pale within a bordure indented gu., and or a lymphad oars in saltire sa. M'ClaUCHLaN and M'Cladughian; quartering arg. a dexter hand couped fesswise holding a cross patty fitchy gu., with arg. in a sea in base vert a lymphad sails furled oars in saltire sa., and per fess arg. and vert in base a salmon naiant ppr. M'DONALD, Slate; quartering arg. a dexter hand couped fesswise gu. bolding a cross croslet fitchy sa., with arg. a lymphad oars in saltire sa., aud per fess wavy arg. and az. a salmon swimming in base ppr. MACDONALD ; quartering or a nalied arm issuing from the sinister in fess ppr. holding a cross croslet in pale gu., with arg. a galley az., and vert a salmon naiant in fess or ; all quartered by Lockhart. M'DoNNEIL, Earl of Antrim; quartering or a dexter hand couped in fess holding a cross croslet fitchy gu., with or a galley oars in saltire ...., and az. a dolphin naiant.... M.DUFF. MACDUFF, Earl of Fife; quartering Duff. M'Farquhar; quartering arg. a fir tree growing out of a mount in base vert in the sinister chief point a sinister hand gu. MackintosH, IKillachie,Scotland; quartering or a dexter band couped fesswise holding a dagger palewise in chief gu. and a galley oars sal. tirewise inbase sa. Macrintosh, Connadge, Scotland, with the same quarterings within a bordure vair for diff. MackintosH, Mackintosh, co. Invervess; derived from Shaw, living in 1163 , second son of Duncan in'Duff, Farl of Fife, Baronetcy 1812; quartering alg. a dexter hand fesswise couped at the wrist and holding a human heart gu., with az. a boar's head couped or, and or a lymphad sa. surmounted by two oars in saltire gu. Mackintosh, Abeirardure, Scotland, with the same quarterings, all within 
BEAST LION..... cont.

a bordure gu. charged with eight annulets or. Mackintosh, Kinrara, Scotland; quartering or a lymphad oars erect in saltire sa., with az. a boar's head couped or. M'Lachlan, Kilchoan; quartering arg. a dexter arm fesswise couped gu. holding a cross patty fitchy sa, with per fess wavy arg. and vert a galley sails furled sa. flags gu., and per fess or aud vert in base a salmon naiant arg. M'Latichlan, Scotland; quartering arg. a dexter hand fesswise couped gu. holding a cross croslet fitchy sa., with or on a sea in base a galley sails furled and oars in saltire sa. flags gu., and arg. on a sea in base a salmon naiant ppr. M'LachLaN, Trinidud, granted 1787 ; quartering arg. a dexter hand couped fesswise gu. holding a cross formy fitchy az., with arg. in base the sea thereon a galley oars in accion and sails furled sa. Hags gu., and per fess arg. and az. a fish naiant in base or; over all dividing the quarters a leopard's face gold. MariLORY or Mallonié, Papwurth, co. Cambridge, and Kirkbie-Mallorie, co. Leicester. MaDoc, Lord of Mawddwy, co. Merioneth, younger son of Gwenwynwyn; quartering Athelystan Glodrydd and Tudor Trevor; the heiress $\mathrm{m}$. Iorwerth, eldest son of Owen Brogyntyn. Je Counte Mareschald, $J$. Randolph Meschines, third Earl of Chester, $X$. M. Robert Muschgros, $D$. Jobn Musegros, $Y$. Owen, Adbrightly, co. Salop. David ap Owen, Bishop of St. Asaph, 1503-13. Petrtt. Le Sire de la Pole, $N$. William Poole, $Y$. Powis. Panulph. Mervin ap Rhodri Mawr. Rowland, Carew, Isle of Anglesea. St. Chere, Suffolk. Serbridge. Srnclair, Mey, Scotland; quartering az. a ship at anchor within a royal tressure or, with az. a ship in full sail or, over all dividing the quarters a cross engr. sa. Streche. Hughe Turbervile, $A$. Vaugean. Vivan. Vivian. WALE. WeEMr, Riris, Scotland; quartering Forbes. Griffid ap Weninwyn, E. Griffith le fitz Wenonwen, $Y$. Ap Wenunwin, Lord of Powys, $V$.

Or a lion ramp. tail erect gu. Randolph Meschines, Earl of Chester, temp. William I, $Y ; Z, 47$.

Or a lion ramp. gu. debruised by a bend arg. Fyfie, Earldom, Scotland.

Or a lion ramp. gu. over all a bendlet compony of the second and first. March.

Or a lion ramp. gu. over all a bend sa. Cokeley. Delapoole. Hokeley, $V$. Poole or Pooley, co. Chester. Sir Lewis de la Poole, co. Chester, temp. Edward III, V. Steuart, Fothergate, Scotland.

Or a lion ramp. gu. over all a dexter baston sa. Sire Lowys de la Pole, $N$.

Or a lion ramp. gu. surmounted by a ribbon sa. A bennethy, of that Ilk, co. Fife, temp. Robert I; the coheirs $m$. Stewart, Lindsay, and Lesly. Abernethy, Rothemay, created Lord Saltoun of Abernethy, 1455.

Or a lion ramp. gu, over all a bend sinister sa. Faterley or Fareley.

Or a lion ramp. gil. over all on a bend sa. an alrow arg. SPENCE, Kerbuster, Scotland.

Or a lion ramp. gu, on a bend sa. a buckle betw. two mascles arg. Spence, Wormeston, Scotland.

Or a lion ramp. gu. over all on a bend indented sa. au oval buckle tongue upwards betw. two mascles arg. SPEnce, Edinburgh.
BEAST. LION.... cont.

Or a lion ramp. gu. over all on a bend wavy sa. an oval buckle tongue upwards betw. two mascles arg. Spence, Edinburgh.

Or a lion ramp. gu. over all on a bend sa. three lozenges or. Spens, Craigsanquhar, co. Fife ; descended from Spens, Lathallan; quartering gyronny of eight or and sa.

Or a lion ramp. gu. over all on a bend embattled counter-embattled az. three mascles of the field. SPENCE, London.

Or a lion ramp. gu. over all on a bend raguly az. three mascles arg. SPENCE.

Or a liou ramp. gu. over all on a bend az. three bezants. Bockinghair, Suffolk. Boкynнair, $V^{*}$. Buckingham, Lord Mayor of London, 1705.

Or a liou ramp. gu. over all on a bendlet az. three bezants. Bozynham, Suffolk, $V$.

Or a lion ramp. gu. over all two bendlets sa. ABERNETH.

Or a lion ramp. gu. surmounted by a fess az. MAcFie or M'PhIE, Scotland.

Or a lion ramp. gu. over all a fess chequy az. and arg. Stewart, Scotstoun, Scotland, New Register.

Or a lion ramp. supporting a saltire engr. couped gu. John Wolton, Bishop of Exeter, 1579-94.

Or billety and a lion ramp. gu. VIAN.

Or crusily and a lion ramp. gu. Long, London.

Or crusily fitchy and a lion ramp. gu. (?) Lewis de Cherleton, Bishop of Hereford, 1361.9.

Or the field replenished with estoiles az. a lion ramp. gu. Gallyealt.

Or a lion ramp. gu. armed arg. Delafield, Ireland.

Or a lion ramp. gu. armed and langued az. FaRquHARSON, Haughton, co. Aberdeen; quartering Cuming and Ogilvie. M'Duff, Earl of Fife. SHaw, Rothiemurchus, Scotland ; quartering arg. a fir tree growing out of a mount in base vert on a dexter canton of the field a dexter hand fesswise couped holding a dagger all ppr. Wenyss, Bogie, co. Fife, Bart., quarterjng arg. a lion ramp. sa. Wenrys, Dennesfort, co. Kilkenny.

Or a lion ramp. gu. armed and langued of the field. BLEDDYN-AP-CYNFYN, King of Powys, and, by usurpation, of Nortb and South Wales, heir of Mervyn, King of Powys, third son of Rhodri Mawr, hing of Wales; from whom descended the Princes of Powys-Fadoc; Griffith Maelor, Bromfield; Owen Brogyntyn, Edeirnion, Dinmail, and Abertanat; Cynric Efell, Eglwys Egle; Linion Efell, Cynllaeth; through the Princes of Powys-Wenwynwyn (the heirs $\mathrm{m}$. Charlton and Iorwerth ap Owen Brogyn. tyn) Foulk ap John ap William, Lord of Mawddwy, co. Merioneth, temp. Edward I, the beiress m. de Burgh; Rhywallon ap Cynfyn; Iorwerth Goch, Mochmont; and through $\mathrm{Ca}$ dwgan, Nannau, Jones, Trewythan and Rhiewport, co. Montgomery; quartering sa. three nag's heads arg. VaUGHan, co. Carmarthen.

Or a lion ramp. gu. collared arg. BeMreler, Suffolk. BeynClere, Suffolk. BoswortH. Sir William de Boxworthe, N. Boywarke. Matrony, Studley and Houghton-Conyers, co. York.

Or a lion ramp. gu. gorged with a crown arg. Beaucler, Suffolk.

Or a lion ramp. gu. collared of the first. MaLony, co. York. 
BEAST,

LION.... cont.

Or a lion ramp. gu. ducally gorged of the field. Culex.

Or a lion ramp. gu. gorged with a ducal coronet ppr. Corney.

Or a lion ramp. gu. collared and chained of the field. AsHENDEN.

Or a lion ramp. gu. crowned az. Cieveden.

Or a lion ramp. gu. ducally crowned az. DiETz.

Or on a mount vert, a lion ramp. crowned gu. Mount.

Or a lion ramp. gu. crowned gold. Bleddyu ap Cinfin. Cheygne, Harl. MS. 6137, fo. 44.

Or a lion ramp. gu. crowned gold over all on a bend sa. three bezants. CoRNewaIL, quartering Pourcell, Harl. MIS., 1449, fo. 102.

Or a lion ramp. gll. couped in all the joints of the first. Mitaitand, Lethington, Scotland.

Or a lion ramp. tail erect gu. Randolph de Meschinfs, first Earl of Chester and Cumberland, $Y ; Z, 47$.

Or a lion ramp. tail forked and nowéd gu. Sir Roger de Chaundos, co. Chester, temp. Ed. ward III, $V$.

Or a lion ramp. tail forked gu. Bruens. Henry Burwash or Burghursh, Bishop of Lincoln, 1320.40. Bartholomew Burwashe, Q. Candishe, co. Chester. Caundis. John Chandos, $Y$. Chandoys or Chandoz, co. Chester. Mr. Antoyn MALLORY, S. MaLORY, co. Leicester. Powis. Trane, temp. Henry IV.

Or a lion ramp. double tailed gu. Beneler. Chaundos, $V^{*}$. Malloky, $V^{*}$.

Or crusily and a lion ramp. tail forked gu. Sir Robert Venour, co. Lincoln, temp. Edward III, $V$,

Or a lion ramp. tail forked coward gu. Caundis.

Or a lion ramp. tail forked gu. and armed az. Bartholomew Bunwashe, the King's Chamberlain, $Q$.

Or a lion ramp. tail forked gu. collared arg, Anthony Malory, $V$. Belmer. Bencleder or Benyeler. Beynclere, Suffolk. Mallory, Stodley. Sire Johan de Seincler, $N$.

Or a lion ramp. tail forked gu. collared or. Bencleder or Benyeler.

Or a lion ramp. tail forked and nowed gu. collared arg. St. Cuere, Suffolk.

Or a lion ramp. double tailed and ducally crowned brandishing in the dexter paw a falchion allgu. $P_{A \cup L}$ Middlesex; granted 1758.

Or a lion ramp. guard. gu. Bauzon. Creswick. Horon, 1730. Roberts, Wales.

Or a lion l'amp. guard. gu. collared arg. Bencher. Boxworth, co. Cambridge. Boxwrey.

Or a lion ramp. reguard. gu. FERNS, Ireland. Guthrie, Halkertoun, Scotland. Guthry, Forfar, Scotland ; quartering az.three garbs or, all within a bordure indented arg. RoBerts, 1730.

Or a lion ramp. reguard. gu. holding in the dex. ter paw a cross croslet fitchy az. GUTHRY, Kingsedward, Scotland.

Or a lion ramp. reguard. gu. seizing with his mouth the top of a spear in bend sinister sa. Dias.

Or a lion 'embeljf' gu. John Felbrigge, $Y$.

Or a lion salient gu. Felpridg. Ferbrige. Sire Roger Felbrigge, $N$, or Felbrige, temp. Edward III, $V$.

Or a lion salient respectant gu. Morish.

Or a lion ramp. per fess az. and gu. Sir Ralph SADLEIR, temp. Henry VIII and Elizabeth;
BEAST. LION .... cont.

his descendants were SADLEIR, Standon, co. Hertford, the heiress m. Aston; Sadiein, Everley, co. Wilts; Sadier or SadLIER, Arle Court, co. Gloncester, and Purton, co. Wilts; Sadieir, Temple Dinsley, co. Hertford, and Apsley Guise, co. Bedford; baronetcy 1661; the heiress m. Moody. Sadiein, Sopwell Hall and Sadleir's Wells, co. Tipperary; a heiress in. Bury and Prittie; descended from Sadiein, Sopwell, co. Hertford; the heiress m. 1662, Saunders.

Or a lion ramp. per fess gu. and az. SadiER, co. Hertford, 1730.

Or a lion ramp. per fess gu. and sa. Monsyer John ChENEY; quartering chequy or and az. a fess gu. fretty erm., T. Lenstofte. Lovetort, co. Huntingdon, $V$.

Or a lion ramp. per fess sa. and gu. De Lovetoft De Lovetot or De Luvetot, Lord of Hallam, co. York, in an old house and the Priory at Worksop. Priory of Augustinian Canons, ulso called Radford Priory, at Worksop, co. Nottingham.

Or a lion ramp. purp. Lacy, $V^{*}$. Lincoln's InN (of Court), London. Le Counte de Lincolne, $Y$. Neale alias Nigill. Conte de Nicol,e, $G$. Henry de Lacy. Counte de Nichole, $H, J, N$. Henry Earl of LincolN, $K$. Le Conte de Nichole, $P$. Henry Lascy, Earl of Lincoln, temp. Edward III, $V$. LAcy, Earl of Lincoln, $Z$.

Or a lion ramp. ppr. Deane, Cobsall, co. Not. tingham, $W$.

Or a lion ramp. purp. collared arg. Sir William BASKWORTHE Or BOLKWORTHY Or BALKWORTHY, $L$.

Or a lion pass. sa. Dingham. Pynock, France. Pynoke, London, 1730 . LloYd, co. Montgomery; quartering purp. three falcons or, with gu. three horse's heads erased arg., and purp. a falcon or. LUdLow, co. Salop. Twist. TUDER, $V$.

Or a lion pass. guard. sa. Twist.

Or a lion pass. guard, sa. crowned gu. Beauchanpe, Essex.

Or a lion ramp. sa. Barker. Beton or Betune. M. Robert de Betune, D. Bromwyck. Renud de Clivedone, F. Creswick, Sheffield. Erpingwold. Finanders. Robert the Frison, Earl of Franders, $Z, 313,402 . \quad$ Griffith. Gwaethanoed, King of Cardigan and Prince of Gwent. Hadlow. Henauli, $Z, 113,158,316$. Julich or Juliers, $Z, 216,326,489$. Langton, Windsor, co. Berks. Sir Christopher de Ludlow, $R$. Ludlow, Stokesay and Hodnet, co. Salop, $Z, 319$. Mathew, Thomastown, co. Tipperary; created Baron Mathew and Earl of Llandaff; quartering Jestyn ap Gurgant. Sir David ap MATHEw, Lord of Llandaff, co. Glamorgan, Standard-hearer of England, temp. Edward IV; descended through Aeddan, Lord of Grosmont, co, Monmouth, from Gwaethvoed, King of Cardigan and Prince of Gwent; quar. tering Russell, Clare differenced, and Flenung; tomb in Llandaff cathedral. Sir William Mathew, Radyr, his grandson, quartering Jestyn ap Gurgant. MaThEW, Stansted, Sussex. Mathews, Linton, co. Hereford. Mathew, Birkeswell, co. Warwick. Mathews, Bonnetstown, co. Kilkenny, Ireland. Tobias MatHew or Matthew, Bishop of Durham 1595, Archlishop of York 1606.28. (The moderu arms 
BEAST.

IION..... cont.

of Mathew or Mathews, Hensol Castle, and Castle Menych, co. Glamorgan; descended from Sir David ap Mathew; the heiress m. Talbot; from this branch descended Mathews, Upton Grey, and Alton, co. Hants. Mathews, Cadiz. Matthew, Ireland. Morton, Camma, Scotland. Nertost, Essex, temp. Edward I. Piningham. Poley, Poley, co. Hertford; Boxted and Badley, Suffolk. Poley,Boxted, Suffolk, $V$. Poole, Lord Powis. Powlex, Radley, Suffolk. Rolls. Benedictine Priory at St. Bees, Cumberland; quarterly with Lucy for PERcy. Monsire de Staniow, Y. Stanton, Ireland. Staunton. Wakeford, Norfolk. Welles, Grebby Hall, co. Lincoln; quartering Dymoke, Ludlow, Marmyun, Kilpec, Hebden, Rye, Welles, Engayne, Waterton, Sparrow, Talboys, Fitzwith, Umfraville, Kyme, and Waterbouse. WaLkFare, Norfolk. Wenrts, Unthank. WoLvey. Wood, Codshall, co. Somerset.

Or a lion ramp. tail erect sa. M. John LudLow or Ludlow, $Y$, or de Lodlowe, $S$.

Or a lion ramp. sa. a label of three points gu. DAMPIER.

Or a lion ramp. sa. a label of five points gu. Beton or Betune. Daupiers.

Or a lion ramp. sa. over all a bend compony gu. and arg. Sir Robert Bavent, $V$. FaUssetT, Rochester, and Heppington, Kent; quartering Bryan, Godfrey, and Toke. Fonsert, $V$. Fonset or Folssett, Middlesex, 1611. Fawcett.

Or a lion ramp. sa. over all a bendlet compony gu. aud arg. Forssett, $V$.

Or a lion ramp. sa. over all a bend gu. Franders.

Or a lion ramp. sa. over all a bendlet gu. Flote.

Or a lion ramp. sa. over all on a bend gu. three escallops arg. Gibins. GybBons or Guybon, Stratchet, Norfolk. Gubyon, $V^{*}$.

Or a lion ramp. sa. over all on a bendlet gu. three escallops arg. Gubyon, Norfolk, $W$.

Or a lion ramp. sa. over all a fess gu. Powedt, Sandford, co. Oxford. SutTon, $V^{*}$.

$\mathrm{Or}^{*}$ a lion ramp. sa. on a fess gu. three mullets of the field. Casaubon, quartered by Purdun.

Or a lion ramp. sa. over all on a fess az. three bezants. Porches. Sir William Punchas, London, $V$.

Or a lion ramp. sa. orer all on a fess of the last three bezants. Thwartes, Ireland.

Or a lion ramp. sa. in the dexter forepaw a fleurde-lis az. IJAFFAN, Bart.

Or a lion ramp. sa. in the dexter paw a torteau. Gatile Gattey or Gatty.

Or a lion ramp. sa. supporting a ragged staff az. WILLISBY.

Or a lion ramp. sa. thrust through with two swords in saltire ppr. WaLTERs.

Or billety and a lion ramp. sa. Brabodch or Brubouch. Brubouche. Cosars. Imbert. YMBERT.

Or billety and a lion ramp. sa. over all a bend gu. Cosars.

Or crusily gu. and a lion ramp. sa. Deravache. Roche.

Or crusily and a lion ramp. sa. Rondulf D'AR. DARNe or ARderne, $E$, or ARdern, $F$. Bonel, Duffield, co. Derby, origiually from Flanders; the beiress m. Colvile. Brewes, co. Gloucester. Bronnse, co. Gloucester.

Or a lion ramp. sa. armed gu. Clynde.

\section{BEAST. \\ LION. . . . cont.}

Or a lion ramp. sa. arned and langued gu. LudLow, Morehouse, co. Salop.

Or a lion ramp. sa. chained of the first. Philisips, Newport House, Cornwall.

Or a lion ramp. sa. collared gu. and chained of the first. Sir T. Pbillip ap Meredith ap Bladerike, $V$. Meredith, $V^{*}$.

Or a lion ramp. sa. collared and chained of the first. Phillips, Wales. Phuilipps.

Or a lion ramp. coward sa. LudLow.

Or a lion ramp. sa. ducally crowned arg. Sir Hugh Cirvedon, $V$.

Or a lion ramp. sa. crowned arg. CHENDon or Chenedon.

Or a lion ramp. sa. crowned gu. Beadchamp, Essex. Beauchampe, Fyfeld, $V$. Sir Johan de Beuchamp, $N$. Clendon. Clindan or Clindon. Sir John Cliffon, $L$. Remund or Renaud de Clivedon, $\boldsymbol{E}$. Reymond (in margin Renauld) de Clivedon, $V$. De Namur.

Or a lion ramp. sa. armed and crowned gu. CLISDON.

Or a lion ramp. sa. crowned gu. pearled of the second. Beauchamp, Fifield, Essex.

Or a lion ramp. cromned sa. Cleevedon.

Or a lion ramp. tail erect sa. M. John Ludlow or Ludlow, $Y$, or de LudLowe, $S$.

Or a lion ramp. tail forked sa. Brockas. Broyer or Bruyeres. Cressy, lissex. Stanlaw. Gerard Stantlowe, $Y$. Adam de Welle, $K, Y$. Sir Adam de Welles, $N$. Sir Adam de Veiles, $H$. Wells, Kent; and Grimsby, co. Lincoln. Le S. de Welles, $S, Y$, or Weils, $T$. Adam Dominus de Welles, $\boldsymbol{V}$. John Lord Wells, $Z$, 417.

Or a lion ramp. double tailed sa. Dewelues. De WELLES, $V^{*}$

Or a lion ramp. tail forlked sa. a label gu. Cressr, Essex.

Or a lion ramp. tail forked sa. over all a bend com. pony gu. and arg. Banent.

Or a lion ramp. double tailed sa. over all a bend compony gu. and arg. Bavent.

Or a lion ramp. double tailed sa. over all a bend gu. Bures.

Or a lion ramp. tail forked sa. over all a dexter baston gu. Sire Felip de Weutes, $N$.

Or crusily and a lion ramp. tail forked and renowed sa. Sir Peres de Breouse, $N$.

Or a lion ramp. tail forked sa. armed and langued gu. WELLES, quartered by Lord Willought by, $U$.

Or a lion ramp. guard. sa. Lewis, St. Pierre, co. Monmouth; descended through Llewellen, Lord of St. Clair and Tredegar, from Cadivor, Prince of Divet, co. Pembroke.

Or a lion ramp. guard. sa. armed arg. Lincolnt. Or a lion ramp. gnard. sa. armed gu. VOYDE, Gwaythe, co. Cardigan, Wales.

Or a lion ramp. guard. tail forked sa. Brockas.

Or a lion ramp. reguardant sa. GcaY. Cadivor ap Gwaethyced, Lord of Cardigan Iscoed. Gwaethyoed, King of Cardigan, and by mar. riage Prince of Gwent, head of one of the royal tribes of Wales. Jenis, Higher St. Columb, Coruwall. Jenkins, Bicton Hall; descerıded from Jenkins, Abbey Foregate, co. Salop; quartering Bagot and Muckleston. JENkINs, co. York. Jenkyns, York and Rusby, co. York. Jenixy, Trekening, Cornwall; the co-heirs m. St. Aubyn, Slaming, Trelawuey, and Cary. William LLOYD, Bishop of Llandaff, 1675 , Pe- 


\section{BEAST.}

LION.... cont.

terborough, 1679, Norwich, 1685-91. LoyD or Lloxd, co. Stafford; Keyswin, co. Merioneth; and Marington, co. Salop. Robert Morgan, Bishop of Bangor, 1606-73. Moxt. Price, co. Carnarvon. Pryse, Gogerddan, co. Cardigan; derived through Rhydderch ap Ievan Lloyd, from Gwath-Voed, Lord of Cardigan; the heiress m. Loveden. Vaughan, Ireland. Gwaithvoed VAWR, ob. 1057. WELLS.

Or a lion ramp. reguard. holding betw. the fore paws a fleur-de-lis .... Pryce.

Or a lion ramp. reguard. sa. armed and langued gu. Jones, Lancych or Blaencych, co. Pembroke, and Pennar, co. Cardigan, quartering Lloyd.

Or a lion salient sa. Felbridge, $r$.

Or a lion ramp. vair. Monsire Wakehide D'ARDerne, $Y$.

Or a lion ramp. vair a dexter baston gu. Monsire Ruufe de Beaupre, $Y$.

Or a lion vert. Bortraux.

Or a lion pass. vert. Bantrair.

Or a lion ramp. vert. Robert Bertrair, $E$. Bartram, $V$. Botreux. Buret. Darderne. Dudlex. Grace. Pollymore. Richard de Poltimore, $F$. Robesard, $V$. Robsart, $V$. Robesarde, $V^{*}$. Rollymore. Richard Sutton, $V$. Sir Richard Sutton, $I$, or de Sottone, $N$. WALKINGTON. WaILINGTON. WaRd,

Or a lion ramp. vert and a label gu. Sire Johan de SortTone, $N$.

Or a lion ramp. vert and a label of five points gu. Senton, co. Lincoln.

Or a lion ramp. vert over all a fess arg. Sutron, co. Berks.

Or a lion ramp. vert armed and langued gu. Primrose, Dalmeny, Scotland; quartering arg. on a fess az. betw. three primroses vert as many mullets or.

Or a lion ramp. vert armed and langued gu. over all on a fess purp. three primroses of the field. Primirose, Carrington, Scotland.

Or a lion ramp. vert crowned gu. Robsart.

Or a lion ramp. crowned vert. Hendiarsh.

Or a lion ramp. tail erect vert. Waklin de Arderne, $G$.

Or a lion ramp.tail forked vert. Duduey. Dudury, Earl of Northumberland, $Z, 338,442,537$. Dunrey, Earl of Leicester, Baron Denbigh. DudLey, twentieth Earl of Warwick. Sutron, Dominus Dudley, $V$. Sir Richard SutTon, co. Lincoln, $V$. Sctron, Sutton, co. Chester, and Knight Grange.

Or a lion ramp. double tailed vert. William Dudley, Bishop of Durham, 1476.83; quartering .... a cross moline .... with .... two lions pass. .... Sutron, co. Lincoln. Sutton, $V^{*}$. Sutron, Over Haddon, co. Derby, temp. Henry VI; descended from Sutton, Sutton, co. Chester.

Or a lion ramp, tail forked vert over all on a fess arg. three torteaux. James Sutron, co. Chester, $V$.

Or a lion ramp. tail forked vert armed and langued gu. Sir Edward SutTon, Lord Dudley; quartering Paganel with Malpas and Tibetot with Charlton, $U$.

Or a lion ramp. guard. vert. RoBsent.

Or a lion ramp. reguard. vert. Hume, England, 1730.

Or on a ground in base vert a lion salient of the last royally crowned az. Hastie, Scotland.
BEAST.

IION .... cont.

Paly of four or and az. over all a lion rainp. counterchanged. Clopton, co. Warwick. Sir Hugh Clopton, Lord Mayor of London, 1491, $V$; quartering per pale or and az. a cross formy fitchy counterchanged. He built the great stone bridge at Stratford-upon-Avon. CockField, Essex, $V^{*}$. Cockfesld, Essex, $V$.

Paly of six gu. and or a lion pass. guard. arg. (The ancient arms of) MaLLET, Enmore, co. Somerset.

Paly of six gu. and or a lion statant guard. arg. MaLLet.

Paly of six or and az. a lion ramp. counterchanged. Clofton, co. Warwick.

Paly of six sa. and erm. a lion ramp. arg. Danielt, co. Gloucester.

Paly of eight arg. and az. a lion ramp. gu. Nicholas Stratford, Bishop of Chester, 16891707.

Paly of eight arg. and gu. over all a lion ramp. sa. Griffith MaELon, Lord of Bromfield, eldest son of Madoc ap Meredith, last Prince of Powys-Fadoc; from whom descended Owen ap Griffith Vychan, Lord of Glyndwrdwy, co. Merioneth, the Owen Glendower of English writers, $Z, 224$; the heiresses $\mathrm{m}$. Adda ap Iorworth, Scudamore, Croft, Ruthyn, and Mornington. Tudor ap Griffith VYCHaN, Lord of Gwyddelwern, co. Merioneth, brother of this Owen; the heiress m. Griffith ap Einion. Mayland.

Paly of eight gu. and arg. a lion ramp. sa. Owain GLXNDOWR. Griftith MAELOR, a son of Madoc ap Meredith.

Paly of eight or and vert a lion ramp. sa. DonINGE.

Paly gu. and sa. a lion ramp. arg. crowned or. Bellere.

Per bend arg. and az. a lion ramp. counterchanged. Venour.

Per bend sinister arg. and az. semy of ermine spots or over all a lion ramp. of the last armed and langued gu. LLoyd, co. Cardigan.

Per bend arg. and gu. a lion ramp. counterchanged. Freskereld, $V$.

Per bend arg. and sa. a lion ramp. counterchanged. OWEN, Wales. KIHFORD. RadFord or RATFORD. Ritford.

Per bend arg. and sa. a lion ramp. tail forked counterchanged. RATFORD.

Per bend az. and arg. a lion ramp. counterchanged. Francis, co. Derby, $W$.

Per bend sinister wavy az, and arg. a lion ramp. counterchanged. VENour.

Per bend az. aud or a lion ramp. counterchanged. Frances.

Per bend wavy'az. and or a lion ramp. counterchanged. VENNOR or VENOR.

Per bend az, and vert a lion ramp. arg. SchefiezD.

Per bend sinister erm. and ermines over all a lion ramp. (? arg.). LLOYD, Rhagatt, co. Merioneth; Berth, co. Denbigh; derived from Tudor Trevor.

Per bend erm. and ermines a lion ramp. or. EDWARDs, Brislington, co. Somerset. Lloyd.

Per bend sinister erm. and ermines a lion ramp. or. Davies, London, and co. Salop. Davis, co. Denbigh. Dyноск, co. Warwick; granted 1581. Dумоск, Penley Hall, co. Flint; and Ellesmere, co.Salop; descended through David ap Dai Madoc, whose name, by mutation, became David Damoc or Dymock, from Rhys Sais. Dymoke, $V$. Edwardes, Chirk. Edwards, 
BEAST.

LION.....cont.

Exeter. EDwands, Northowran, co. York. Enwalios, Farncott, Liddome, and Lea Castle, co. Salop; Welham, co. Leicester; and Chirk, co. Denbigh ; descended from Tudwr Trevor. Hosier, Croukton, co. Salop. Jones, $V$. Matthew Mawson, Bishop of Llandaff, 1739 ; Chichester, 1740; Ely, 1754.70. Lloyd, Lexton Inolls and Pealey. Mostrn, Baron Vaux; quartering Vaux. Mostyn, Mostyn Hall, co. Flint, Bart. Mostin, Pengwern, Llanwnda, North Wales; descended from Mostyn, Mostyn. Pennant. John Trevaur, Bishop of St. Asaph, 1352-7; and another, 1395.1402. Richard 'Ilievor, Bishop of St. Darid's, 1744 ; Durham, 1752-71. Trevor, $V$. Tudor-Trevor. Tuther, $V$. Sir John Trevor, Brynky nalt, co. Denbigh, 1730. Yonge, $V$. Young. Wynne, Eyarth.

Per bend sinister erm. and ermines a lion ramp. or a crescent for diff. JENkENS or JENKYNS. Mostyn, Talacre, co. Flint, Bart.

Per bend sinister erm. and ermines a lion ramp. or armed and langued gu. EDWARDS, London. Pennant, Bagilt. Pennant, Jamaica, of which were the late Lord Penrbyn; Dawkins Pennant, Penrhyn Castle, co. Caernarvon; quartering Dawkins, with Yswittan Wyddel], Philip Phichdan, and Gruffyd Lloyd; and Pennant, Holywell; all branches of PenNant, Downing and Bychton, co. Flint; derived through Madoc ap Meilir, from Rys Sais, living 1066, great. great grandson of Tudor Trevor. Trevor.

Per bend sunister erm. and erminois a lion ramp. or. Edpows. Hill Trevor, Viscount Dungannon; quartering Hill. Tudor Trevon, Lord of Whittington, co. Salop, living 924 ; from whom descended ErTos, Eyton, Erddlis and Bersham ; derived from Eyron, Rhiwabon, the beiress of Rhiwabon m. Evans; Mostyn, Mostyn, co. Flint, Bart.; Mostyn, Bryngwyn; Mostyn, Segrwyd; Mostyu, Talacre, co. Flint, Bart.; Mostrn, Bodscallan, co. Anglesey, the beiress in. Wynn; Mostrn, Kilken, co. Flint, the heiress m. Edwards; Pennant, Bychton and Down. ing, co. Flint; and Pennant, Lord Penrhyn.

Per bend sinister erm. and ermines a lion salient or armed and langned gu. John Trevaur, Bi. shop of St. Asaph, 1352.7.

Per bend sinister erm. and pean a lion ramp. or gorged with a wreath of oak vert and supporting in the dexter forepaw a sword erect ppr. pomel and hilt gold. Lloyd, Lancirg, Sussex, Bart.

Per bend sinister erm. and sa. a lion ramp. or. Penant, $V$.

Per bend gu. and arg. a lion salient counterchanged. Rossie, that Ilk.

Per bend nebuly gu. and az. a lion ramp. or. WORMngton, Dublin.

Per bend sinister or and arg. a lion ramp. counterchanged. Dasiock.

Per bend sinister dovetailed or and az. a lion ramp. double tailed erm. Stucker, Weston, co. Devon; granted 1759.

Per bend wavy or and az. a lion ramp. counterchanged. VENOUR.

Per bend sinister wavy or and az. a lion ramp. counterchanged. Texour, $V$.

Per bend or and sa. a lion ramp. counterchanged. Francis, co Derby. Francis, $V *$. Simpson, co. York.

Per bend invecked or and sa. a lion ramp. coun. terchanged. Frenci, lershore, co. Worcester.
BEAST. LION.... cont.

Per bend nebuly or and sa. a lion ramp. counterchanged. Sinpson, Foston Hall, co. York. Simpson, Stainford, co. York. Symson, Poddinghall Garth, co. Durham. Sympson, Polton, co. Bedford. Thomas Syrpson, co. Rutlaud, $V$.

Per bend (?) or and sa. 'embelif' a lion ramp. counterchanged. Adam Fraunces, $Y$.

Per bend sinister or and sa. a lion ramp. counterchanged. Adan, $V^{*}$. Frances. Adam Francis, $W$. Fraunceys, Lord Mayor of London, 1352 and 1353. Simson. Sympson, Kent.

Per bend sinister or and sa. a lion ramp. counterchanged holding betw. the paws a gauntlet az. Edward Simpson, Lichfield; granted ....

Per bend sinister or and sa. a lion ramp. coun. terchanged armed and langued gu. Simson, Lamarsh, Essex.

Per bend sinister or and sa. a lion ramp. double tailed counterchanged. Sympson, Winkton, co. Hants; quartering Walcott.

Per bend sa. and arg. a lion ramp. counterchanged. Sir Henry RatFord, $V$.

Per bend sinister sa. and arg. crusily and a lion ramp. all counterchanged. LODGE.

Per bend .... and .... semy of roundles with a lion ramp. counterchanged. LODGE, Ireland.

Per bend sa. and az. a lion ramp. counterchanged. RATFORD, $V^{*}$.

Per bend sinister sa. and erm. a lion ramp. or. Enwaros, Henslow, co. Bedford, and London.

Per bend sa. and or a lion ramp. counterchanged. Frances. Sir Adam Francis, $V$. Sir Edward Francis, co. Derby, $W$.

Per bend sinister sa. and or a lion ramp. coun. terchanged. Adam Francis, Lord Mayor of London, 1352. M. Adam Franceis, $S$.

Per bend wavy sa. and or a lion ramp. counterchanged. Simpson or Simson. Srmpson.

Per chev, arg. and az, a lion ramp. connterchanged (sometimes collared or). GILEs or Gyles, Bowden, co. Devon; Visitation 1620; the heiress m. Gipps.

Per chev. arg. and purp. a lion ramp. counter. changed. Giles, co. Devon.

Per chev, az. and gu. a lion salient erm. Howard.

Per chev. az. and gu. a lion salient erm, crowned .... Howard, $V^{*}$.

Per chev. gu. aud az. a lion ramp. erm. ducally crowned or. Herward, Wenlock, co. Salop.

Per chev. gu. and or a lion ramp. barry nebuly arg. and az. LaNGLer, $V^{*}$.

Per chev. gu. and or a lion ramp. vair. Langiey, $W$.

Per chev. or and az. a lion ramp. counterchanged. LaNE, co. Northampton. Sir John LaNe, $V$.

Per chev. engr. or and sa. a lion ramp. counterchanged. Barker, $W$. Barker, Hurst, co. Berks; and Warwick.

Per chev. nebuly or and sa. a lion ramp. counterchanged. Barker, Essex.

Per chev. nebuly (or rather wavy) or and vert a lion ramp. counterchanged. BARKER, $W$.

Per chief az. and arg. over all a lion ramp. gu. Aston.

Per chief az. and arg. over all a lion ramp. gu. on an escucheon of the second three ducal coronets or two and one being an angmentation given by Gustavus Adolphus, King of Sweden. Sir Henry St. Geonge, Garter King of Arms, ob. 1644. Sir Thomas St. GEorge, Garter King of Arms, ob. 1702. 
BEAST

LION.... cont.

Yer chief az. and arg. over all a lion ramp. gu. crowned or. George, $V^{*}$. Sir William de Seyn Jorge, $N$. St. George, co. Cambridge, $V$. St. Geonge, Hatley St. George, co. Cambridge; Tyrone, co. Galway; and Carrick, Ireland. Baudewin St. Georige, $Y$.

Per chief az. and arg. over all a lion ramp. gu. ducally crowned or armed and langued of the second a crescent .... for diff. St. George, Woodsgift, co. Kilkenny, Bart.

Per chief az. and gu. a lion ramp. tail forked or. Robert Hastang, $Y$.

Per chief az. and or over all a lion ramp. tail forked (double tailed $V^{*}$ ) gu. Sr. .... de Aston, $V$.

Per chief erm. and arg. over all a lion ramp. az. TrotTer, Skelton Castle, co. York, granted 16 Feb. 1587. Trotter, Helmdon, co. Durbam, quartering Burden.

Per chief gu. and az. over all a lion ramp. arg. Hastang, $V$. Sire Felip de Hastang, $N$. Humfrai Hasteng, $E$. Humfrey Hastange, $Y$. Sir John Hastings, $L$, or de Hastinges, $L$, Harl. MS. 6137.

Per chief gu. and az. over all a lion ramp. double tailed arg. De Hastang, $V^{*}$.

Per chief gu. and az. over all a lion ramp. tail forked and nowed arg. Sir Philip de Hastang, co. Stafford, temp. Edward III, $V$.

Per chief gu. and az. over all a lion ramp. or. (No name but meant for Humfrai Hasteng, $E$, Harl. MS. 6137.) Sir Robert Hastang, $L$. Sire Roberd de Hastang, $J, N$. Robert Hasting, $G$. Hastang or Hastings, co. Stafford. Hastang, Leamington; and Newbold, co. Warwick, temp. Henry II. Monsire de Hastage (? Hastange), $Y$. Sotton, $V^{*}$.

Per chief gu, and az. a lion ramp, or and a label arg. Sire Johan de Hastang, N. Sir Thomas de Hastank, $O$.

Per chief gu. and az. over all a lion ramp. or and a bend arg. Hastang, $V^{*}$.

Per chief gu. and az. over all a lion ramp. or and bendlet arg. Sir Richard HASTANG, co. Stafford, temp. Edward III, $V$.

Per chief gu. and az. over all a lion ramp. or and a dexter baston arg. Sir Nichol de Hastanges, $L$. Sir Richard de Hastang, $N$.

Per chief gu. and az. over all a lion ramp. tail forked or. Sire Robert Hastang, co. Stafford, temp. Edward III, or de Hastang, $N$.

Per chief gu. and az. over all a lion ramp. double tailed or. HastaNGE, $V^{*}$.

Per chief gu. and or over all a lion ramp. az. Sir John Sotton, Essex, temp. Edward III, $V$; or de Sottone, $N$. The lion or, Sutton, $V^{*}$.

Per chief gu. and sa. over all a lion ramp. arg. Wood, co. Lancaster. Wood, Hackney, Mid. dlesex, confirmed 20 June, 1634. Thomas Woon, Bishop of Lichfield, etc., 1671-92, con. firmed 1634 .

Per chief or and arg. over all a lion ramp. az. debruised by two bendlets gu. M. John Thornebyrye, $S$. Thornebury, $W$. But with cotices instead of bendlets, James Brusel, $V$. Brussel, $V^{*}$. Thornbery, $V^{*}$.

Per chief or and az. over all a lion ramp. erm. GoldWell, Godinton, Kent.

Per chief or and az. over all a lion ramp. of the first. Aston. Huntercombe.

Per chief or and az. over all a lion ramp. tail forked of the first. Aston.
BEAST. LION....cont.

(Per chief ?) vair and or a lion ramp. gu. Sir John de Sutron, $M$.

Per fess arg. and az. in chief a lion pass. of the second. WALL, Ireland.

Per fess arg. and az. in chief a lion pass. guard. of the second. VALE.

Per fess arg. and az. a lion ramp. counterchanged. Richardion.

Per fess arg. and az. a lion ramp. gu. Roger de Mowbray (name erased), $A$.

Per fess arg. and gu. a lion ramp. counterchanged. William Wryne, $V$.

Per fess arg. and gu. a lion ramp. per fess sa. and of the first. PERCY, Scotton, co. York.

Per fess indented arg. and purp. in chief a lion ramp. of the second. SKIPTon.

Per fess arg. and gu. a lion ramp. per fess sa. and of the first collared and chained or. PERcY.

Per fess arg. and sa. a lion ramp. counterchanged. Kiffin, Knolyrante, co. Salop. LLoxd, Ipswich, Suffolk. Powers, Wales. Vaughan, co. Northampton, 1716.

Per fess arg and sa. a lion ramp. reguard. counterchanged. VAUGHAN, Earl of Carberry.

Per fess az. and arg. over all a lion ramp. gu. crowned or. M. Bawdwyn St. George, $S$.

Per fess az. arıd or a lion pass. guard.gu. Brasham. Per fess wavy az. and or on the first a lion ramp. arg. gorged with an antique crown vert. M'DowaLL, Neilsland, Scotland.

Per fess az. and or a lion ramp. counterchanged. Francis, Colchester, Essex. Goodlake, Letcomb Regis, co. Berks; quartering Garlard. Henry Mechell, $V$. Goodlake, Wadley House, and Shellingford, co. Berks; quartering Mills.

Per fess erm. and arg. a lion ramp. az. depressed by two bendlets gu. Thornbery, $V$. Thornbury, $V^{*}$.

Per fess erm. and arg. a lion ramp. sa. Kinwelmarch or Kilmalich.

Per fess erm. and az. in chief a lion pass. guard. of the second. WALL, Hoxton, Middlesex; granted 1613 .

Per fess erm. and az. a lion ramp. with two heads counterchanged. MasoN, Greenwich, Kent; granted 1739. MASON, Aldenham Lodge, co. Hertford.

Per fess erm. and az. a lion ramp. per fess gu. and arg. Geffry Genville or de Genville, $A$. Per fess erm. and ermines a lion ramp. counterchanged. KendLemarsh or KeNDLEMarch. KIIUING MARCH, $V^{*}$.

Per fess ermines and erm. a lion ramp. counter. changed. KirI.ingmarch, $V$.

Per fess gu. and arg. a lion ramp. az. Thonnbery.

Per fess gu. and arg. over all a lion ramp. double tailed or. Burrish.

Per fess wavy gu. and arg. a lion pass. sa. pierced through with a dagger in bend $\mathrm{ppr}$. entering at the shoulder hilted or. SMdLL, Curriehill, and Cornhall, Scotland; quartered by Keir.

Per fess gu. and az. a lion ramp. arg. over all a bend or. Humfray Hastyng, $F$. Rothings.

Her fess gu. and az. over all a lion ramp. arg. debruised by a bendlet (bend $V^{*}$ ) engr. or. Rothinge, $V$. Rothinges, $V^{*}$.

Per fess gu. and az. a lion ramp. or. Hastang, $V^{*}$. Mowgarle, $Y$. Mowgrale or Mowgrill. Nowgatie, $V^{*}$.

Per fess dancetty gu. and or in chief a lion pass. arg. a crescent for diff. GLENEster. 


\section{BEAST LION.... cont.}

Per fess gu. and arg. a lion ramp. arg. and sa. crowned or. Greene, $V^{*}$. Grene, Essex, $V$.

Per fess gu. and or a lion ramp. counterehanged. Wident or Widout, co. Hereford.

Per fess gu. and or a lion ramp. vair. Langlex.

Per fess gu. and sa. a lion ramp. arg. semy of crosses croslet of the first. LODGE, Leeds, co. York.

Per fess or and arg. a lion ramp. az. Rickards. Tedeurne, co. Devon. Thornbery, $V$. Thornborough or Thornbury. Thornbury, $V^{*}$. IERBURY, originally of Batcombe, co. Somerset; Shirebampton, co. Gloucester; and co. Wilts. YERBURY or YERBINE, co. Gloucester, and 'l'rowbriage, co. Wilts.

Per fess or and arg. a lion ramp. gu. Robert Powell, Park Hall, co. Salop, 1647, great-greatgrandson of Robert ap Howel, illegitimate son of Gritfith of Abertanat, eighth in descent from Einion Efell, ob. 1196, illegitimate twin son of Madog ap Marchudd, Prince of Pawis Fadog.

Per fess or and arg. a lion ramp. guard. gu. Powell, Newicke, Sussex.

Per fess or and arg. a lion ramp. guard. gu. over all a fess vert. Whitinghair, co. Lancaster, and Whitingliam, co. York.

Per fess or and arg. a lion ramp. sa. and gu. Pentine, Pentire, Cornwall.

Per fess or and az. a lion ramp. gu. Gurreon or Gurrien.

Per fess or and erm. a lion ramp. az. Ford, Abbey Field, co. Chester.

Per fess or and gu. a lion ramp. counterchanged. Kirke. Mason, co. Yurk; quartering or a lion ramp. with two beads az., with arg. a chev. gu. betw. three snails sa.

Per fess wavy or and gu. a lion ramp. counterchanged. Drummond, London.

Per fess or and gu, a liou lamp. counterchanged armed and langued az. holding in the dexter paw an astrolabe ppr. MiddLeton, Frazer. burgh, descended of Fettercairn.

Per fess or and gu. a lion ramp. reguard. counterchanged. Adam Krrk, $V$. Krrke, $V^{*}$.

I'er fess or and gu. a lion ramp. sa. and arg. De Lovetot or De Luvetot, Lord of Hallam, co. York, in Ecelesfield church.

Per fess or and gu. a lion ramp. sa. and erm. SkarletT.

Per fess or and gu. a lion salient vert. Wharton.

Per fess or and sa. a lion ramp. connterchanged. Barker. Francis, W. Yerbury, co. Oxford, and co. Wilts.

Per fess sa. and arg. Edionds or lidmondes. EDwards, Ness Strange, co. Salop, derived through Thomas ap Llewelyn, from Einion Efell, son of Madoc last Prince of Porys-Fadog. EDwards, Dolsery, co. Merioneth; quartering Owen. Gethis, co. Salop. Gethr, co. Montgomery; extinct 1803. TrFfin alias Waghan, co. Salop. Lloyd, Oswestry, co. Salop. Picbard Vaughan, Earl of Carbury, Baron Taughan of Evelyn, 1730.

Per fess sa. and arg. a lion ramp. counterchanged armed and langued gu. Einion EFELL or EVELL; Lord of Cynllaeth, living 1182-91, son of Madoc, last Prince of Powys Fadoc; from whom descended EDwards, Ness Strange: KYFFin, Glascoed; the heiress $m$. Williams: KrFfis, Bodfach, co. Montgomery; the heiress m. Price: livitin,Maenan,co.Caeruarvon; the coheiresses

\section{BEAST. LION.... cont.}

m. Lenthall, Nanney, and Kenrick: LuoxD, Aston, co. Salop: Madrice, Lloran, co. Denbigh, and Pentrekenrick, co. Salop: Meredith, Abertanat: Roberts, Llangedwin: TANAT, Abertanat, co. Salop; the coheir m. Godolphin : Tanat, Blodwell: Vaughan, Golden Grove, co. Caermarthen: VAUGHaN, Lord Carbery: WYNN, Plas-yn-Moliwrch: and Wynn, Plas Newyddyn-Bodlith; the heir m. Middleton.

Per fess sa. and arg. a lion ramp. reguard. counterchanged. VAUGHAN.

Per fess sa. and arg. \& lion ramp. reguard. tail forked counterchanged crowued or. TrLGHaw, Snodland, Kent.

Per fess sa. and or a lion ramp. counterchanged. Luls.

Per fess vert and arg. a lion ramp. counter. changed. GrenFord.

Per fess vert and arg. a lion ramp. guard. erm. William de la March, Ar. Walliæ, $V$.

Per fess vert and arg. a lion ramp. or and of the first. St. Grorge, co. Cambridge.

Per fess embattled vert and erm. a lion ramp. or. Suffield, Wells, Norfolk; granted 1732.

Per fess vert and or a lion ramp. counterchanged. Greenrord. Grenrord, $V$. St. George.

Per pale arg. and az. a lion ramp. gu. Elford, Beckham, co. Devou, Baronetcy 26 November 1800.

Per pale arg. and gu. a lion ramp. of the first on the sinister side supporting a tree eradieated ppr. on the dexter. Wynstone, co. Brecknock.

Per pale arg. and gu. a lion pass. counterchanged. Pereley. Pyreley, $V$.

Per pale arg. and gu. a lion l'amp. counterchanged. Blouyle, Suffolk. Punsey.

Per pale arg. and gu. a lion ramp. erm. Monsire de Nonwrz, $Y$.

Per pale arg. and gu. a lion pass, or. Pearley. Playse.

Per pale arg. and gu. a lion ramp.sa. Bladweld, Suffolk. Glindore. Owen Glyndour, $V$. OWen. Roberts, co. Salop; Rristol; Westerley, co. Gloucester; and Dublin. Roberts, co. Gloucester, Middlesex, and Bristol, $V$. RoBERTs, Sutton-Chanell, co. Leicester ; confirmed May 1614.

Per pale arg. and or a lion ramp. per fess gu. and sa. Stanbury or Steynbury.

Per pale arg. and or over a lion pass. sa. Perely or Pirly, $V$.

Per pale arg. and or over all a lion ramp. sa. Perley, $V$. Prrley, $V$ *. Stanbery.

Per pale arg. and sa. a liou .... counterchanged. Baldwin, co. Salop.

Per pale wavy arg. and sa. a lion ramp. gu. EI.TED.

Per pale wavy arg, and sa. a lion ramp. gu. crowned or. ELFORD, Cornwall; quartering Eu. three stirrups arg.

Per pale arg. and sa. over all a lion ramp. or. Bynghai, $V$.

Per pale arg. and sa. a lion ramp. or armed gu. (another the lion crowued gold.) Binghas.

Per pale arg. and sa. a lion ramp. guard. gu. and or. Champers, Kent.

Per pale arg. and vert a lion ramp.gu. PowLyar.d. Per pale wavy az. and arg. a lion ramp. or and gu. Lontr, co. Somer'set.

Per pale az. and gu. a lion ramp. arg. HaLton, Samford, Essex, Bart. Roberts. 


\section{BEAST.}

IION.... cont.

Per pale az. and gu. a lion pass. arg. over all a bend or. Rothings or Rothinge.

Per pale az. and gu, a lion ramp. arg. Norwich. College of the Virgin for Secular Priests at RaveninghaM, afterwards atNorton-SoUpecors, Norfolk, removed to Metring Bam, Suffolk.

Per pale az. and gu. a lion ramp. arg. armed of the second. Arderne ARden or Ardren, Ireland.

Per pale az. and gu. a lion ramp. double tailed arg. Cons.

Per pale az. and gu. a lion ramp. erm. Sir John de Norwich, $R$, or Norwich, $Y$.

Per pale az. and gu. a lion ramp. or. ARDAN. Arderne, Ireland, $V$. Halton, Greenthwaite Hall, Cumberland, temp. Richard II; and South Winfield, co. Derby. Oulton or Owlton.

Per pale az. and gu. billety or a lion ramp. of the the last. Werche.

Per pale indented az. and gu. a lion ramp. or. Robert Drayton, Norfolk, $V$.

Per pale indented az. and or a lion pass. guard. counterchanged. Crofron, Baron Crofton.

Per pale az. and or a lion ramp. counterchanged. Manning, Stanbury, Cornwall. Michell. ORPEN, Glanerough, co. Kerry; derived from Robert Orpen or Erpen, Erpingham, Norfolk. OrPen, Ardtully, co. Kerry ; derived (like OrPeN. Dublin, quartering Millard), from ORPEN, Killowen. Stanbury or Stanberie, Stanberie, Cornwall; the heiress m. Manning; a younger branch was of West Stanberie, and another of Cliff.

Per pale az. and or a lion ramp. per fess gu. and sa. Henry Stanbery, $V$. Stonbery, $V^{*}$. Stanbury, $V$.*

Per pale az. and or a lion ramp. sa. Stainsbury.

Per pale az. and purp. the field replenished with crosses croslets arg. a lion ramp. of the last. Tidmarsh.

Per pale az. and purp. a lion ramp. erm. Frognall. Sir William Oldhali, $V$.

Per pale az. and sa. a lion ramp. arg. Tremargan, $V$. Tremorgan.

Per pale az. and vert a lion ramp.or. Clayton, $V$.

Per pale erm. and az. a lion ramp. counterchanged. Marke.

Per pale erm. and ermines a lion ramp. or. Young, Poulton-cum-Seacomb, co. Chester ; confirmed 10 Jnne, 1625, and co. Flint.

Per pale erm. and gu. a lion ramp. counterchanged. Withie, London, $W$. Withis, $V^{*}$.

Per pale erm. and or a lion ramp. gu. John Withie, London, 'Armes Painter,' $W$.

Per pale erm. and or a lion salient gu. WichIE or Withre. Withie, Wotton, co. Devon; granted 1612. WithiE, Wootton-Basset, co. Wilts; confirrned 12 June, 1615. WıтнIE, London.

Per pale erm. and sa. a lion ramp. or bolding in the paws a cross patty fitchy of the last. STRUDWICK.

Per pale gu. and arg. a lion pass. guard. counterchanged. Osilby.

Per pale gu. and az. over all a lion pass. arg. and a bend or. Rothinges, $V^{*}$. Rothing or Rothings.

Per pale gu. and az. over all a lion pass. arg. debruised by a dexter baston or. Rothinges, $V$.

Per pale gu. and az. a lion ramp. arg. Newrort. OIDTON or OLton. RoseWLLL, co. Somerset, co. Wilts, and co. Devon. Roswel.u.
BEAST. LION.... cont.

Per pale indented gu. and az. a lion ramp. arg. BELLERS.

Per pale gu. and az. a lion ramp. arg. supporting betw. the paws a tree eradicated vert. Wynston, co. Hereford; and Paynswick, co. Gloucester.

Per pale gu. and a7. semy of crosses croslet or a lion ramip. arg. armed and langued of the third. Hutchinson, Boston, co. Lincoln, and Boston in America.

Per pale gu. and az. a lion ramp. arg. crowned or. Bellarneys. Sir William Northam, $V$.

Per pale gu. and az. a lion ramp. tail forked. arg. Roger le Rous, $E$, or Rus, $F$. Rowseweil or Rowswell, Ford Abbey, co. Devon; Norfolk; and Bradford, co. Somerset.

Per pale gu. and az. a lion ramp. erm. Esmons, Cornwall. Sr. .... Norteyn, $T$. Norwiche, $V$, co. Northampton, $W$. Norwich, Essex; Norfolk; Brampton, co. Northampton; and Suffolk; temp. Edward II. Sir John de NorwTCH, Metyngham, Sutfolk, a Baron in 1342.

Per pale gu. and az. a lion ramp. erm. a label or. Sire Johan de Nonthwyk, $O$.

Per pale gu. and az. a lion ramp. erm. crowned or. Bellers.

Per pale gu. and az. a lion ramp. erm. crowned or a label gold. Bellers.

Per pale gu. and az. a lion ramp. or. Fremargan. Olton, $V$. Oughton. Oulton, $V^{*}$. Owlton, $W$. Per pale indented gu. and az. a lion ramp. or. Drayton, Norfolk.

Per pale gu. and az. semy of crosses croslet and a lion ramp. or. Hutchinson, Cornforth, 1570, and Whitton House, Durham.

Per pale gu. and az. a lion ramp. guard. or. Sir Henry Halton, $V$. Holion.

Per pale gu. and ermines a lion pass. guard. .... Neale.

Per pale gu. and or a lion ramp. arg. Beler. Augustinian Priory at Kirkby Beliers, co. Leicester.

Per pale gu. and or a lion ramp. counterchanged. Manning, Stanbury, Cornwall.

Per pale gu. and purp. a lion ramp. erm. Oldhali.

Per pale gu. and sa. a lion ramp. arg. Beler, Eye-Kettleby, co. Leicester. Bellars, Berkhampstead, co. Hants. M. James Bellers, $S$. Beluers, Criche, co. Derby. Fleet. Kirkby, co. Leicester. KYRBY or KYRKBY. LEEKE, co. Leicester, $r$. Mulbery or Mulbury.

Per pale jndented gu. and sa. a lion ramp. arg. Bellers, Stoke, $V$.

Per pale gu. and sa. a lion ramp. crowned arg. Keitelby, co. Gloucester.

Per pale gu. and sa. a lion ramp. arg. crowned or. BELLER, co. Leicester and co. Nottingham. Bellars. Bellers. Billers, Lord Mayor of London, 1734. 'Thomas Northas, $\boldsymbol{Y}$, or de Northam, $Y$.

Per pale gu. and sa. a lion ramp. arg. ducally crowned or. Bellers, Keytilby, $V$.

Per pale gu. and sa. a lion ramp. erm. Cowne.

Per pale gu. and vert a lion ramp. arg. Sir John Bevereche, $V$. Beveridge. Sir Thomas de Beugham, $O$.

Per pale or and arg. a lion ramp. sa. Meredith, Upper Weld, co. Buckingham. Moore alias Meredith, co. Bedford and co. Buckingham.

Per pale dancetty or and az. a lion pass. guard. counterchanged. CROFTON. 
BEAST.

LION .... cont.

Per pale indented or and az. a lion pass. guard. counterchanged. Cronton, Mohill Castle, co. Leitrim, Ireland, Bart. Crofton, Lougford House, co. Sligo, Burt.

Per pale or and az. a lion ramp, couterchanged. Stone, co. Lancaster and co. York.

Per pale or and gu, a lion pass. arg. Hillis, $V$. Plaise. Sir de Plaiz, Norfolk, temp. Edward I, $V$. Playz, temp. Edward III. Playse or Plaiz, Tofte, Norfolk. Monsire Richard Place, $Y$. Sire Richard de Plays, $O$. M. John Plars, $S$. Richard PlaYCE, $Y$.

Per pale or and gu. a lion pass. gnard. arg. Sire Gyles Plays, $N$.

Per pale or and gu. a lion pass. guard. arg. armed az. Plaxse, Norfolk.

Per pale or and gu. a lion pass. guard. counterchanged. Place, Weddington Hall; co. Warwick; descended from Playse or Place, Dinsdale, co. Durham; quartering Halnath.

Per pale or and sa. a lion ramp. counterchanged. Stone, London; granted by Segar.

Per pale or and vert a lion ramp. gu. over all a baton arg. Rauf BIGOD, $E$; but with a bendlet, F.

Per pale or and vert a lion ramp. gu. Brgot. Brgod, le Conte Mareschal, $P, V^{*}$. Bigod, Earl Marshal, $V$. Roger Bigot, Counte Mareshall, $H$; but Conte de Nortolk, $X$. Mons. Roger BIgod, Counte de Norfolke, $Y$. Le Counte le Mareschal, $N$. Augustinian Priory at Carthele or Kertarele, co. Lancaster, Marshall, Earl of Pembroke. Marshall. Newton-Kyme, co. York. Le Conte Mareschall, $B, G$, or Mariscale, $E$, or Mareschal, $F$. Henry Marshall, Bishop of Exeter, 1194-1206. Counte de Pennebrok, C, Harl. MS. 6589. William Marshal, Earl of Pembroke, $Z, 87,96$. Cluniac Priory at Thetfond, Norfolk. Vigod.

Per pale or and vert a lion ramp. gu. incensed az. Marshal, Earl of Pembroke.

Per pale or and vert a lion ranup. or and gu. Le Counte de Pennebror, $C$.

Per pale purp. and arg. on the dexter side a lion ramip. respectant on the sinister side an oaktree vert. O'Conor, Sligo, Irelaud.

Per pale sa. and arg. a lion ramp. counterchanged. Edward VaUghas, Bishop of St. David's, 1509 . 22.

Per pale sa. and arg. a lion ramp.gu. Champanays, $V^{*}$. Champnays, $V$.

Per pale sa. and az. a lion ramp. arg. RowseweLd, Vasterne, co. Wilts.

Per palesa. and az. a lion pass. guard. or. NeILL, England.

Per pale sa. and gu. a liou pass. guard. arg. Fresh. Neal, $V^{*}$. Neale ol Nerll, Essex; Yeldon, co. Bedford; Wollaston and Hanging. Houghton, co. Northampton. John Neale, Wollaston, co. Northainpton, $W$. NEale, Allesley Park, co. Warwick; descended from Neale, Deane; quartering Vansittart. Ne山, Scotland. VILIIERs.

Per pale sa. and gu. a lion ramp. guard. arg. crowned or. Besney, co. Hertford.

Per pale sa. and gu, a lion statarit arg. Neale, Dean, co. Bedford; and Allesley Park, co. War. wick.

Per pale sa. and gu. a lion statant guard. arg. a mullet for diff. Ralph, third son of John Neale of Wollaston, co. Sorthampton, usurped by Neale, Loudon.
BEAST. LION.... cont.

ler pale sa. and gu. a lion ramp. erm. crowned or. Sir John Norwice, $V$.

Per pale sa. and gu. a lion pass. guard. or. Pich. ard NeIL ol NexLe, Bishop of Rochestcr, 1608, Liclifield, etc., 1610.14.

Per pale sa. and purp. a lion ramp. arg. (some. times erm.). Norwich.

Per pale vert and gu. a lion pass. arg. Felton, co. Gloucester.

Per saltire ajg. and sa. a lion ramp. counter. changed. Payne, co. Lincoln, $V$.

Per saltire az. and gu. a lion pass. guard. or. Richard Young, Bishop of Bangor, 1400, Rochester, 140\%-18; grauted by Dethick.

Per saltire az. and or a lion ranıp. guard. of the first. GoLD, London.

Per saltire az. and or a lion ramp. counterchanged. Gound, Exeter, temp. Edward III; Combe in Staverton, temp. Elizabeth; Hayes and Downes, co. Devon; the cobeirs m. Buller and Tuckfield; the heiress of GouLd, Lew Trenchard, $m$. Baring. Gould, Fleet House, co. Dorset. GouLD, London, $W$. GouLD, Dorchester; Staverton, co. Devon; and Edmonton, MLjd. dlesex.

Per. sultire erm. and sa, a lion ramp. arg. Grafton. Per saltire erm.and sa. a lion ramp.or. Grafton, $V^{*}$. Grafton, 1605 .

Per saltire or and az. a lion ramp. connterchanged. Goold. John Gould, Broadnemett, co. Devon, 1730. Gould, Staverton, co. Devon. Gould, Londou, 1730.

Per saltire or and erm. a lion ramp. az. Sir Ralph Bagenholt, co. Stufford, $W$.

Per saltire sa. and erm. a lion rarnp. or. Garston, London, 1584. Grafton, London, $V$. Grafton, Shrewsbury; Little Missenden, co. Bucks ; co. Chester ; London; and co. Worcester.

Per saltire sa. and erm. a lion ramp. or armed and langued gu. Grafton, co. Worcester and co. Statford, temp. Henry VIII.

Per saltire sa. and or a lion ramp. counter changed. Gould, Worcester.

Purp. a lion ramp. arg. Lyons. Mackmore, Ireland. Wimbishe, Nocton, co. Lincoln.

Purp. a lion rump. arg. oppressed with a fess or. Mackirone or Mac MoRE, Ireland.

Purp. a lion ramp. or. Paylow, $V^{*}$. Pashlex, Kent, V. Sr. ... de Payled, V. Payton.

Purp. semy of crosses croslet and a lion ramp. or. Lamorat.

Purp. a lion ramp. or collared gu. MaJlory, co. Northampton.

Purp. a lion ramp. or crowned arg. Pashley.

Purp. a lion ramp. tail forked and nowed or crowned arg. Sir Richard Pashley, $V$.

Purp. a lion ramp. double tailed crowned or. PASHLEY, $V^{*}$.

Quarterly arg. and az. in the first quarter a lion pass. gu. Sir William Ponscyn, N. Ponseyn, $V^{*}$.

Quarterly per fess indented arg. and az. in the first quarter a lion pass. gu. Crofts. Croftes, $V^{*}$. Herbert Croft, Bishop of Hereford, 1662 . 91. Sir Hugb Crofre, $V$, co. Salop. Cross.

Quarterly indented arg. aud az. in the first quarter a lion pass. gu. CrofT, 1730.

Quarterly per fess indented arg. and az. in the first quarter a lion pass. guard. gu. Sir Richard Crofte, co. Hereford, $V$.

Quarterly arg. and az. in the filst quarter a lion ramp. gu. Sir William Ponseyn, co. Hereford, $V$. 


\section{BEAST. LION.... cont.}

Quarterly arg. and az. in the first quarter a lion salient gu. Ponseigne.

Quarterly indented arg. and az. in the second quarter a lion pass. or. Crofts, co. Salop. Sire Huge de Croft, $N$.

Quarterly arg. and gu, in the first quarter a lion pass. guard. az. SAY, Suffolls.

Quarterly arg. and sa. on the first a lion ramp. of the second. BREToN.

Quarterly az. and arg. in the first quarter a lion of the second. Ponsryn, co. Hereford.

Quarterly per fess indented az. and arg. in the first quarter a lion pass. of the second. Sir Hugh Crowt, $L$. Jennyss, Middlesex.

Quarterly per pale indented az. and arg. in the first quarter a lion pass. guard. gu. Crofts.

Quarterly per fess indented az. and arg. in the first quarter a lion pass or. Sir Hugh Croft, $L$.

Quarterly per fess indented az. and arg. in the first quarter a lion pass. guard. or. Croft or Crofte, Castle Croft, co. Hertford. Croft, Croft Castle, co. Hereford, Bart. Crofts, co. Salop and co. Heroford. Sir Hugh Crort, $L$. William Crofte, co. Hereford, $V$.

Quarterly az. and gu. over all a lion ramp. arg. Holton. Huning, Suffoll, $V$. Morgan. Sir John Olton, co. Chester, $V$. Olton, Wetnall, to. Chester, Harl. MS. 1424, fo. 116.

Quarterly indented erminois and gu. in the first quarter a lion ramp. guard. sa. CRoft, Stilling. ton Hall, co. York. Croft, Hutton Buscel, co. York; quartering Bowes.

Quarterly per fess indented gu. and arg. in the first quarter a lion ramp. of the second. Crofts, Norfolk.

Quarterly gu. and arg. in the first quarter a lion pass. guard. or. Bowden, co. Oxford.

Quarterly per fess indented gu. and az. in the first quarter a lion pass. guard. arg. Crofts.

Quarterly go. and az. over all a lion ramp. arg. Morgan. Newport.

Quarterly gu. and erm. in the first quarter a lion ramp. or over all an eagle displ. of the last. HuGHSON.

Quarterly gu. and or in the first quarter a lion pass. arg. Town of ALTRINGHAM, co. Chester. Massey, Dunham Massey, co. Chester, Baron to the Earls of Chester. Mascy, Dunbam, co. Chester, $V$. Massy, $V^{*}$.

Quarterly gu. and or in the first quarter a lion pass. arg. (another, of the last) over all a crosier in pale head to the sinister ..... Benedictine Prioly at Birkenhead or Birketwoon or Burket, co. Chester.

Quarterly engr. gu. and or in the first quarter a lion pass. arg. Besrin.

Quarterly per fess inderited gu. and or in the first quarter a lion pass. arg. BegFyn. Besyn, $V$.

Quarterly per fess indented gu. and or in the first quarter a lion pass. guard.arg. BeLsin. Besny. Besanit or Besaynt. Besney or Besyn, $V$. LanGley, Kent, $V$.

Quarterly gu. and or in the first quarter a lion ramp. arg. Hamond MASCY, $Y$.

Quarterly gu. and or in the first quarter a lion pass. of the second. Massy, co. Chester.

Quarterly gu. and or in the first quarter a lion pass. of the last a label of five points arg. Massy, co. Chester.

Quarterly gu. and or in the first quarter a lion pass. of the second (another arg.) over all a
BEAST.

LION..... cont.

crosier in pale liead to the sinister .... Benedictine Priory at Birkenelead or Birketwood or Burset, co. Chester.

Quarterly per fess indented gu. and or in the first quarter a lion pass. guard of the second. Besvilie, $V^{*}$. Besvylue, $V$.

Quarterly gu. with vairy or and az. over all a lion ramp. arg. Pevereli or Peverel, co. Nottingham, temp. William the Conqueror.

Quarterly gu. with vairy or and vert over the whole a lion pass arg. Pevereic, co. Nottingham, $V$. Pevereli, Lord of Nottingham.

Quarterly gu. and vert over all a lion ramp. arg. Owleton. Sir John OwLtoN, Harl. MS. 1535, fo. 24 and fo. 396 .

Quarterly or and az. over all a lion ramp. arg. Hunez, Add. MS. 5798, fo. 153 .

Quarterly or and az. a lion ramp. counterchanged. GREENFORD.

Quarterly or and az. in the first quarter a lion pass. gu. Ponnsdon, co. Hereford.

Quarterly or and az. in the first quarter a lion .... gu. Gerconly.

Quarterly or and az. in the first quarter a lion ramp. gu. Raffe de Marconvile, $A$. M. Davy JTRkANVILE, $D$.

Quarterly or and az. in the first, quarter a lion ramp. sa. M. Henry Inglous, $S$.

Quarterly or and gu. in the second quarter a lion pass. arg. MASSEY, Dunbam; co. Chester.

Quarterls per fess indented or and gu. in the first quarter a lion pass. guard arg. LANGLEY, Kent, $V^{*}$.

Quarterly or and gu. in the first quarter a lion pass. az. SAy, Tilney, Norfolk; and Suffolk.

Quarterly or and gu. in the first a lion pass. az. SORREY.

Quarterly or and gu. in the first quarter a lion pass. az. in the second a fret of the first. SAY. Quarterly or and gu. in the first quarter a lion pass. guard. az. Sire .... de $\mathrm{S}_{A Y}, N$. Sire SAy, Essex, temp. Edward III, V. Sore, V.

Quarterly or and gu. a lion ramp. counterchanged. Manston.

Quarterly per fess indented or and gu. in the first quarter a lion pass. guard. of the second. Croft, Cowling Hall, co. York; and of Dod. dington, Kent, Bart.; descended from Croft of Stillington.

Quarterly or and gu. in the first quarter a lion ramp. of the second. Gerconiyle. INGLISH.

Quarterly or and gu. in the first quarter a lion pass. guard. sa. SAY.

Quarterly or and sa. in the first quarter a lion pass. gu. Boyvili, Suffolk. William de Boyvile, $C$.

Quarterly sa. and arg. in the first quarter a lion pass. guard. of the second. Bowdon.

Quarterly sa. and arg. in the first quarter a lion pass. guard. of the second crowned or. Sir Edward Prerne, $V$.

Quarterly sa. and arg. in the first quarter a lion ramp. of the second. Byxg, Viscount Torring. ton. Brxg, Wrotham Park, Middlesex.

Quarterly sa. and arg. the first quarter occupied by a lion ramp. of the second over all a repre. sentation of the guidon of the Thirty first Re. giment (.... two laurel branches saltirewise .... below the union-jack) in bend sinister. Byng, Earl and Baron Strafford.

Quarterly sa. and arg. on the first a lion pass. guard, or. Breton. 
BEAST.

LION.....cont.

Quarterly sa. and or in the first quarter a lion pass. arg. Bowden. Bowden, co. Chester. Bowdon, $V$.

Quarterly sa. and or in the first quarter a lion pass. arg. Iangued gu. Bowdon, Beighton Fields and Southgate House, co. Derby ; quartering Erdeswick. Bowdon, Pleasington Hall, co. Laucaster; descended from Bowdon, Southgate House, co. Derby; quartering Butler.

Quarterly sa. and or in the first quarter a lion pass. guard. arg. Bowdon.

Quarterly sa. and or in the first quarter a lion pass. of the second. Bowden, Bowden, co. Chester.

Quarterly sa. and or in the first quarter a lion ramp. guard. of the second. BrNG, Kent.

Quarterly vair with gu. three bars or over all a lion ramp. arg. Peverell.

Quarterly vert and gu, over all a lion ramp. arg. Awing, Suffolk, $V$. Hunninge, $V^{*}$. Huninges, co. Chester; and Carsam, Suffolk. Oulton, co. Chester, 1572, Harl. MS., 2151, fo. $85 \mathrm{~b}$. OLdington or OLton.

Quarterly vert and or over all a lion ramp. arg. OULTON.

Sa. a lion pass. arg. Bichingfield. Sir John Stormy, $R$. Taylor, Cumberland; Lyme, co. Dorset; and Denbury, co. Devon. Tayiour, co. Cambridge; Haleston Grange, co. Glouces. ter; and Bradley, co. Hants. John 'TAYLor, London, $W$. VERDON, Northumberland. VERNON.

Sa. semy of annulets and a lion pass. arg. Fulthorpe, $V$.

Sa. a lion pass. arg. crowned or. LeE, Wales, $W$. LEIGH. Huston, Cornwall.

Sa. a lion pass. guard. arg. Stormy or Sturmy. Redeshall, co. Lincoln.

Sa. a lion ramp. arg. Arbouin. Bratton. M. Henty de Breban, D. Cassamiajor. Churchill. Cronwels, Hinchinbrooke, co. Hants; descended from Williams, Wales. The Lord ProtectorOliver Cromwell. Cromweld, Theobalds, Cheshunt, co. Herts; the heiress m. 1831, Russell. Deverdon. EDGar, Wadderley, Scotland. Engharad, daughter of Meirich ap Dynfwal ap Arthen ap Sybsilt, King of Cardigan, and wife of Rhodri Mawr. (?) Silvester de Everdon, Bishop of Carlisle, 1247-54. Roger de Evendon, seul 24 Edward III, Harl. $M S .818$, fo. 43 . Eble de Genevre, $B$. Holmes. LEwrs, Lanishen Court, co. Monmouth ; quartering sa. a chev. betw. three spear-heads arg. with sa. a chev. betw. three fleurs.de-lis or, and or on a canton gu. two lions pass. of the first; and Lanishen House, co. Glamorgan; both descended through Lewis, the Van, co. Glamorgan, from Ivor ap Meurig, known as Ivor Bach, living temp. Hen. II ; the heiress $m$. Windsor. Hall, Essex. Herfford. Kilche. Sir Johan de Kinkeston, (? the lion or), $J$. Mackmorocgh, Ireland. Maithiard. Tobias Matthew, Bishop of Durham, 1595 ; Archbishop of York, 1606-28; quartering gu. three chevronels arg. with a crescent in the fess point .... Matthew, co. Dorset. Matthew, Stansted, Sussex. Moducote, Whitley Hall, co. Salop. Morle or Moriey, Morle, Norfolk. Pendle. Henry de Penedoke, E. Plank, Essex. Sandford. Scuray. Segrave. Nicholas de Segrave, $A$. Thorne. Thornes, co. Salop. Thorney, $V$. Torney or Tourney. Vardon, Norwich. Sir Thomas de VERDoN or de Verdoun, $N$. Sir John Verdon, $R$. Sir Tho-
BEAST.

IION .....cont.

mas de Verdon, co. Northampton, temp. Edward I, $V$. WARDEN, $V^{*}$. WARDON, $V$. Wastness, quartered by Greasley. Wastneys. Sir William Westeney, I. Wilimams, co. Huntingdon; and Denton, co. Lincoln. Williams. Sa. a lion ramp. arg. a label gu. Polmore, Polimore, co. Devon. Nicholas de Segrave, $K$.

Sa. a lion ramp. arg. depressed by a bend compony of the second and gu. Thomas Marche, $V$.

Sa. a lion ramp. arg. debruised by a bend compony or and gu. Croxton, Croxton, co. Chester, temp. Henry III ; the heiress m. Mainwaring, an illegitimate descendant of Mainwaring of Peover. Croxton, Ravenscroft, extinct 1696. Marshe. Presland or Prestland, Thoby, Essex.

Sa. a lion ramp. arg. over all a bendlet compony or and gil. Croxton, $V^{*}$. Scharington, $V^{*}$. Schevington, $V^{*}$.

Sa. a lion ramp. arg. over all a bend gu. Couviue, Suffolk. Chinchil, $V$. Chirkehill, $V$. HOLME.

Sa. a lion ramp. arg. over all a bendlet gu. Churchill, co. Somerset; and Churchill-Henbury, co. Dorset. Sir J ohn CHuRcHil, Churchill, co. Somerset, 1730.

Sa. a lion ramp. arg. over all a dexter baston gu. Monsire Robert de MonLey, $Y$.

Sa. a lion ramp. arg. over all a bend or. VESSEY, Isham, co. Cambridge.

Sa. a lion ramp. arg. oppressed with a bend engr. or. Segrave.

Sa. a lion ramp. arg. over all on a fess or three crosses patty fitchy (another, crosses croslet fitchy) of the field. CoLbroke.

Sa. a lion ramp. holding betw. the forepaws a 5-foil arg. LUARD.

Sa. a lion ramp. supporting a garb arg. KTRKEBY.

Sa. a lion ramp. arg. holding in the paw a garb or. KYRBY or KYRkBy, Essex.

Sa. semy of annulets and a lion ramp. arg. Fulthorp. Sir Roger Fulthorpe, $V$. Molton. Sa. semy of annulets or a lion ramp. arg. Fulthorp.

Sa. billety arg. a lion ramp. of the last. Sire Johan Neyrmyst or Neyrnuyt, $N$. Wartoft. Sa. semy of crosses bottony and a lion ramp. arg. Hantevinl or Hautevili, co. Devon.

Sa. semy of crosses croslet and a lion ramp. arg. Sire Geffrei de Hautevilue, $O$, Hautevile, $N$. LoNG, Wraxall, co. Wilts ; Draycot, co. Wilts, quartering Cerne; and Wansted, Essex, Bart., extinct 1805, quartering Popham, Seymour, and Child; the heiress m. Pole. Lorg, Preshaw, co. Southampton; descended through LoNG, Devizes, like LoNG, Monkton Farleigh and Baynton, co. Wilts, through LoNg, Rowde Ashton, co. Wilts, quartering Long, from LoNG, Little Cheverell and Potterne, co. Wilts. Long, Melksam, and Collingbourne Kingston, co.Wilts. Sir Gefferay Watevile, L, Harl.MS.6137.

Sa. semy of escallops and a lion ramp. arg. HOLLAND.

Sa. semy of 5 . foils and a lion ramp. arg. Clifton, Clifton, co. Nottingham, Bart. Pierpont.

Sa. semy of 5. foils and a lion ramp. arg. langued gu. Seal of Gervase Clifton, Treasurer of Calais, 36 Henry VI, Harl. MS.6829, fo. 23.

Sa. the field replenished with acorns or a lion ramp. arg. ATwood.

Sa. goutty de larmes and a lion ramp. arg. Chantry. 
BEAST.

$$
\text { IION.... cont. }
$$

Sa. a lion ramp. arg. armed and langued gu. Kyddy. Williams, alias Cromwel, temp. Elizabeth.

Sa. a lion ramp. arg. armed or. John Vendon, $Y$. Sa. a lion ramp. arg. armed and unguled or Monsire John de VERDoN, $Y$.

Sa. a lion ramp. arg. collared gu. Gasteneys. Verdon. WAstneys, co. Chester, co. Leicester; Hedon, co. Nottingham; and co. Stafford. William le Wasteneis, $E$, or Wastneys, $\boldsymbol{F}$. Edmun Wasteney, G. Sir William Wastneye or Wastneys, $L$, or Wasteners, $N$. Sir William de Wasteneys, co. Stafford, temp. Edward I, $V$.

Sa. a lion ramp. arg. collared or. WEst, Suffolk; quartered by Gresley, Colton, co. Stafford, $Z$, 341 .

Sa. a lion ramp. arg. crowned gu. VERDON.

Sa. a lion ramp. arg. crowned or. Brockest. Chaucombe, co. Warwick. Dagworth, Alding. ton, Kent. Segrave, co. Leicester and co. Lincoln. Dominus Segrave, co. Leicester, $V$. Le Sire de Segrave, $K, Y$. Monsire de Segrave, $Y$. Segrave, $Z, 207$. Sir Jobr Segrave, $H$, or de Segrave, $J, K$. Sir Johan de Segrave, $N$. Segrave, co. Leicester, temp. Edw. I. Twichet. Westropp, co. Limerick and co. Clare.

Sa. a lion ramp. arg. ducally crowned or. Seagrave, Castle Ashby, co. Northampton.

Sa. a lion ramp. arg. crowned or and a label az. Sir Nicholas de Segrave, L, Harl. MS., 6137, but corrected to gu. in L, Harl. MS., 6589.

Sa. a lion ramp. arg. clowned or and a label gu. Sr. Nichol de Segrave, $H, K, L, N, O$.

Sa. a lion ramp. alg. crowued or a label of five poiuts gu. Nicholas de Segrave, $G, J$.

Sa. a lion ramp. arg. crowned or over all a dexter baston gu. Henry de Segrave, $G, N$.

Sa. a lion ramp. arg. crowned or over all a dexter baston engr. gu. Sire Johan de Segrave, $N$.

Sa. a lion ramp. arg. crowned or a dexter baston of the last. Sire Symon de Segrave, $N$.

Sa. a lion ramp. arg. ducally crowned or collared gu. JaRrat JaRratr or JARRETT.

Sa. a lion ramp. arg. crowned ppr. Segrave, $Z$, 208.

Sa, a lion ramp. coward the tail reflected over his back arg. MATHEw, Wales, $V$.

Sa. a lion ramp. arg. incensed gu. KAREDIG, Wales.

Sa. a lion ramp. tail forked arg. Metrond. Wastneys, co. Stafford. Monsire de Wastnes, $Y$. Sire Edmon Wasteneys, $N$, co. Stafford, temp. Edward 11I, $V$; but Robert, $Y$.

Sa. a lion ramp, double tailed arg. Moulent, $V^{*}$. WASTENEYS, $V *$.

Sa. a lion ramp. tail forked arg. and a label of the last. Sire Johan de Kyngestone, $N$.

Sa. a lion ramp. tail forked and nowed arg. Moulent, $V$.

Sa. a lion ramp. tail forked and nowed arg. within the tails a fleur-de-lis arg. Metford, $V$.

Sa. a lion ramp. donble tailed between the tails a fleur-de-lis arg. Metrond, $V^{*}$.

Sa. a lion ramp. donble tailed arg. collared gu. Wastneys, Hedon, co. Nottingham.

Sa. a lion ramp. tail forked arg. collared or. Sir John Wastenys, Heydon, co. Notting. ham, $V$.

Sa. a lion ramp. double tailed arg. collared or. WAsteneys, $V^{*}$.

Sa. a lion ramp. tail forked arg. crowned or. SEgrave.
BEAST. LION.... cont.

Sa. a lion ramp. guard. arg. Stormyn. Thorne. Melverley and Shelvolk, co. Salop. Thornes, formerly Shelvock, now Edge, co. Salop. Robert Atte Thornes, Shrewsbury, temp. Edward III. Wastneys, co. Lincoln and co. Stafford.

Sa. a lion ramp. guard. tail forked arg. WASTnEYs, co. Stafford.

Sa. a lion ramp. reguard. arg. Morgan, Abercothy, co. Carmarthen ; and Biddlesden Park, co. Northampton.

Sa. a lion salient arg. Scurmy, $V$. Stormy, Dromonby, co. York; quartered by Constable, $W$. John STuniye, $Y$.

Sa. a lion ramp. barry of six arg. and gu. Horme. Sa. a lion ramp. barry of eight arg. and gu. Caster. Holme, $V$.

Sa. a lion ramp. bendy of six arg. and gu. Hotmes. Hampoll, co. York.

Sa. a lion ramp. bendy arg. and gu. Whetley.

Sa. a lion ramp. erm. Aguillon. Lough, $V$.

Sa. a lion ramp. erm. with a collar genel az. therefrom pendent an escucheon of the last charged with a mullet arg. Pownall, Liver. pool, co. Lancaster; and Pownall, co. Chester.

Sa. a lion ramp. erm. crowned or. WesthoRP, Cornburgh, co. York.

Sa. semy of fleurs-de-lis or a lion ramp. erm. crowned of the second. Phinur, Lord Mayor of London, 1463.

Sa. a lion ramp. double tailed erm. Stokes, co. Gloucester. Stokes, Hean Castle, co. Pem. broke; descended from Peter de Stok, Caen, in Normandy, temp. John.

Sa. a lion pass. or. Field, 1730. PiNoke or Pinnock. Tentavile. Tayior, 1730.

Sa. a lion pass. guard. or. EkEnEy.

Sa. a lion pass. guard. coward the tail reflected over the back or. Genkins, co. Chester.

Sa. a lion pass. reguard or. Browest.

Sa. a lion ramp. or. Archer, co. Salop. Nicol le Archer, $E$. Banent. Brabant, $Z, 143,402$. Brocas or Brockust. Bromell. Bromhali, Levington, co. Bedford. Flanders. Sir Johan de Kinkeston (but? the lion arg.), $J$. KeterLdGe, London; granted 1593. Kingston, co.Bedford. I uddlow. Makemore. Narstoft Nartoft or Nartost, co. Devon, and Essex. Nartoft, $V$. Neymist, $V$. Neymyst, $V$. Norman, England. Nortofr, Essex. Sir Adam Nortoft, Essex, temp. Fdward I, $V$. Sire Adam de Nortost, N. Pirtun. Polimore. Lucas de Poltimor, $A$. Ricbard Pultonor, A, Harl. MS. 6137. Samborne. Samburn, $V^{*}$. Sir Joln SAMBURNe, $V$.

Sa. a lion ramp. or over all a bend. erm. Fiтcher or FitchetT.

Sa. a lion ramp. or holding in the paws an escucheon arg. charged with a cross patty fitchy gu. Kenling, Newcastle-ınder.Iive, co. Staffiord. Keling, Hackney, Middlesex; granted 30 April, 1632.

Sa. a lion ramp. or holding betw. his paws a mullet arg. LEWARD.

Sa. billety arg. and a lion ramp. or. Narstaffe, Essex.

Sa. billety and a lion ramp. or. Frlesworth. Nartoft. West.

Sa. goutty d'eau a lion ramp.or. Kingston,London. Sa. goutty d'or a lion ramp. gold. Picton, Wyvill Court, co. Berks and co. Chester.

Sa. a lion ramp. or crowned arg. holding a cross crosslet fitchy of the last. Darreld, Sussex. 
BEAST. LION.... cont.

Sa. a lion ramp. crowned or. Gilbert de SEgrave, Bishop of London, 1313-16. Segrave, co. Worcester.

Sa. a lion ramp. or armed and langued gu. BramhalL, co. Chester, and London; confirmed 21 Nov. 1628.

Sa. a lion ramp. or crowned gil. The Palatinate of the Rhine, $Z, 564,566,569,575,875$.

Sa. a lion ramp. tail forked or. KING, co. Buckingham. Sir Nicholas Kingston, co. York, $\boldsymbol{V}$. Sir John Kingston, temp. Edward IIl, $V$. Kingston, Wendover, co. Buckingham. Sire Johan de Kynestone, $N$. Thomas Kingston, $Y$.

Sa. a lion ramp. double tailed or. Kingston, $V^{*}$. KING, Charlestown, co. Roscommon, Bart. Morlent.

Sa. a lion ramp.tail forked or a label gu. KINGSTON, co. Berwick. Sire Nicholas de Kingestune, $N$.

Sa. a lion ramp. double tailed or a label of three points gu. KNYsToN.

Sa. a lion ramp. double tailed or and a dexter baston gu. Sire Walter de Kingestone, $N$.

Sa. a lion ramp. tail forked and nowed or. Sir Bartholomew Burghershe, Kent, temp. Edward III, $V$.

Sa, a lion ramp.guard. or. Brocas, $V^{*}$. Brocas, Beaurepayre, co. Hants; the beiress, temp. Henry Vil., m. Pexhall. John Brocas, $Y$. Brockas or Brokas. Brookhurst. Brocas, Alton and Beaurepayre, quartering Brocas. Brocas, Lord Mayor of London, 1730. Sir Barnard Brokas, $V$. Brocas or Brockust, quartering Roches, with gu. six ragged staves palewise, three two and one arg., Banbury, and Morell. Syr John Brockas, Q. M. Bernard Brokas, $S$. Fletwicke.

Sa. a lion ramp. guard. or and a label of three points gu. M. Bernard Brocas, $S$.

'Sa. a lion ramp. guard. or armed gu. Syr John Brockas, $Q$.

Sa. a lion ramp. reguard. or. Evans. GWYN, Maeslech, co. Brecon. Lloyd, co. Brecon. Storaryn. Story.

Sa. a lion ramp. reguard. or ducally crowned of the last. Brockuurst, London.

Sa. a lion ramp. per fess arg. and erminois. Lloyd, Cynfell, co. Merioneth ; granted 1734.

Sa. a lion ramp. per fess or and arg. Wellsand or WELLISAND.

Sanguine a lion ramp. arg. Wymbish, Harl. MS. 6829 , fo. 57.

Varry or and gu. in the dexter corner a lion pass. guard. of the last. Ferrers.

Vairy or and gu. a lion pass. guard. gold ' a lau. treme pointe d'escue.' Robert Ferrers, Baron of Wemme, $Y, i . e$. in the dexter canton, $Z, 263$.

Vert a lion pass. guard. arg. Hervy.

Vert a liou ramp. arg. Beveridge, Scotland. Bolbeck. Hugh Boleber, $B$. Le Baron sire Hugh de Bolbecke, $Y$. Bulbeck, $V$. Campbell-Hune, Purves Hall, co. Berwick, Bart. quartering Pepdie, and quarterly with gyronny of eight or and sa. within a bordure gu. charged with eight escallops of the first a canton gyronny of eight of the third and erm. quartering az. on a f'ess betw. three mascles arg. as many 5 -foils of the first, with .... three piles engr. az. with arg. a cross engr. az and over all in surtout an inescucheon arg. charged with an orange slipped and imperially crowned all ppr. Clinch. Helton. Heron. Heyton. Sir Adam de Heyton or Heton, $V$.

\section{BEAST. LION.... cont.}

Hockleton, co. Salop. Home, Todderich, Scotland: quartering .... a popinjay vert beaked and membered gu. HoME, Spot, Scotland; descended from Home, Dunglass, 1424, quartering arg. three roses gu. slipped vert. Home, Thát Ilk, quartering Pepdie. Home, Longformachus, with the same quartering. Home, Merestoun, with the same quartering, over all a crescent gu. Home, Aytoun, Scotland; descended from Lord Home, with the same quartering, over all a rose gu. Номе, Westertoun, with the same quartering over all a rose within a bordure gu. HoME, Eccles, Scotland, quartering Pepdie and Hume. Howe, Wedderburn, Scotland, quartering Pepdie and Sinclair. Home or Hume, Lumisden and Rentoun, Scotland, quartering Pepdie, Forrester, and Elme. Home, Kames, with the same quarterings, all within a bordure engr. gu. Hume, Humewood, co. Wicklow; descended from Hume, Baron Polworth, quartering l'epdie. Hume, Hutton Hall, Scotland, with the same quartering, all within a bordure arg. Hume, Earl of Dunbar, with the same quartering and Hume, over all in surtout Dun. bar. Hune, Wormlebury, co. Hertford, Bart. Hume, Salisbury. John Hume, Bishop of Bristol, 1756, Oxford, 1758, Salisbury, 176682 , Add. MS. 5i98; quartering az. on a chev..... three mullets ....

Vert a lion ramp. arg. surmounted by a fess gu. JoY.

Vert a lion ramp. grasping a halbert arg. PARTyN, co. Salop and co. Stafford.

Vert a lion ramp.holding a dagger arg. DEMPSEx, Ireland.

Vert a lion ramp. arg. armed and langued gu. Bulbeck, Essex. Holme, Scotland. Home, Earl of Home, quartering Pepdie, over all an escucheon for Landell. Hume, Earl of March. mont, quartering Pepdie, Polworth, and St. Clair, over all in the centre an escucheon arg. charged with an orange ppr. stalked and slip. ped vert ensigned with an imperial crown ppr. Hume, Coldinghamlaw, Scotland.

Vert a lion ramp. arg. the head feet and tail gu. Gwaith VoED, living 9\$21.

Vert a lion ramp. arg. crowned gu. John Beeston, $Y$. Beston, $V$. Monsire de Beston, $Y$. Ralphe Menvile, $Y$.

Vert a lion ramp. arg. crowned and armed gu. Benston. Orton, Orton, co. Cumberland; the heiress $\mathrm{m}$. Skelton.

Vert a liou ramp. arg. crowned or. BeEston. Boston. Conner, Ballybricken, co. Cork.

Vert a lion ramp. guard. arg. Sir Walter CotTon, $V$. Walton, Cutton, $V$. De Cotton, $V^{*}$. Herton, co. Lancaster. Love, quartered by Alchorne; Visitation of Kent, A.D. 1619. Sir John Sherborne, $Q$. Sherborne, Sherborne, co. Lancaster; quartering Bailey, Harl. MS. 1549, fo. 86. Sir Richard Sherborne, co. Lancaster, $V$.

Vert a lion ramp. guard. arg. armed az. Sir John Shenborne, $Q$.

Vert a lion ramp. reguard. arg. Cotton.

Vert a lion ramp. erm. over all a fess gu. JEwE, co. Devon.

Vert a liou ramp. or. Monsire Wakeline d'Arderne, $Y$. Bigotr. Conner. Farrell, Connaught,Ireland; descended from the Princes of Annaly. Farrell, Skeffington Hall, co. 


\section{BEAST. LION.....cont.}

Leicester, quartering Brome; derived from Farrell, Dublin, and co. Chester; a heiress of Farrelt and Dod, Lower Hall, Brocton, m. Worthington and Bonnor. GoODENoUgH. William de Gienefeld, Archbishop of York, 13(16-15. Grenteld, co. Wilts. Hardde. Lewis. Lloyd, co. Salop. Mac Neıl, Barra, Inverness, chief of the Macneills of the Western Isles: quartering arg. in base the sea with a castle above the sea ppr., with or a lymphad sails furled sa., and or a dexter hand erect couped gu. within an orle of nine fetterlocks.... Sr..... de Montenak, $V$. Montenake, $V *$ * Morgan, co. Monmouth. Thomas Newton, Bishop of Bristol 1761.82, Add. MS. 5798. Sire James de Nortone, $N$. Norton, South wick, co. Hants, quartering White; the heiress $m$. Whitehead. Norton, Rotherfield, co. Hants, Baronetcy 23 May, 1622; quartering az. on a fess betw. six crosses croslet or three escallops gu., with az. a fess nebuly betw. three crescents or ; the beiress $m$. Paulet. O'Ferrall, formerly Princes of Annaly, now co. Longford. Randes. Robbesart. Robsart, $V$. Rohantred. Sandiff. Shaen, Great Kew, Surrey, Bart., 1730.

Vert a lion ramp. sinisterwise or. Connour. Conor, King's County.

Vert a lion ramp. or over all a baton az. Beaupree.

Vert a lion ramp. or depressed by a bend gu. Beaupere, $V *$. Rafe de Beaupre, $Y$. Beaupere, Cornwall. Dxper or Diprey, Cornwall.

Vert a lion ramp. or and a bendlet gu. Beaupere, $T$.

Vert a lion ramp. or oppressed with a bend engr. gu. Dxper or Diprey, Cornwall.

Vert a lion ramp. or a bendlet engr. gu. Dirre.

Vert a lion ramp. or over all on a fess sa. a cres. cent arg. betw. two mullets of the second. Dalisone, Scotland.

Vert flory arg. a lion ramp. or. HELY.

Vert semy of broomslips and over all a lion ramp. or. Sandde HARDD, Lord of Morton, the modern Burton, co. Denbigh, from whom descended Puwell, Horsley, Bart.; Ievan ap Iorwerth, Llanwyllyn, co. Merioneth; and Llewelyn ap Ynyr, Yale.

Vert a lion ramp. or armed and langued gu. Arderne. Newton.

Vert a lion ramp. or armed and langued gu. over all a fess of the second. Thomas J $J_{\text {ANE }}$ or $\mathrm{J}_{\mathrm{ANN}}$, Bishop of Norwich, 1499.1500.

Vert a liou ramp. or cruwned az. Arderne.

Vert a lion ramp. or crowned gu. ALDElNE, $V *$ * ARDERNE, $W$.

Vert a lion ramp. crowned or. O'Connor, co. Kerry, Ireland. Trson.

Vert a lion ramp. tail ereet or. GRENEForde, $Y$.

Vert a lion ramp. tail forted or over all a bend gu. Banprey, Weele, Norfulli.

Vert a lion ramp. double tailed or over all a baton gu. Beaurre, Wells.

\section{OTTER.}

Arg. a demi otter sa. issuing out of a loch in base ppr. Lithgow, Drygrange, Scotland.

oX.

Arg. a bull pass. az. CHItтoke, Suffolk.

Arg. a bull statant az. Chiтok, Suffolk, W.

\section{BEAST. $\quad 0 \mathrm{X}$.....cont.}

Arg. a bull pass. gu. Bevill, Cornwall. Bevint Bevan or Bevin, Cornwall. Billesley. Ridley, Northumberland.

Arg. a bull pass. gu. on a mount vert. RIDLEY, co. Oxford, co. York, and Tekett and Westwood, Northumberland.

Arg. on a mount with bulrushes ppr. stalked and leaved vert a bull pass. gu. RIDLEY.

Arg. an ox pass. gu. through reeds ppr. Rioley. Arg. a bull gu. armed or. BEvelex, $V^{*}$.

Arg. a bull pass. gu, armed or. Bevil, Cornwall. Cole. Gonowers or Gonwers. Gower or Gowers. Torell, $V^{*}$.

Arg. on a plain vert a bull statant gu. Riduex, $V$. Sometimes attributed to Nicbolas RIDLEY, Bishop of Rochester, 1547 ; London, 1550-3, Add. MS. 12443, fo. 217.

Arg. a bull statant gu. armed or. Sir William TORELI, $V$.

Arg. on a mount vert a bull standing gu. armed or. RidLer, Alkington and Linley, co. Salop. Sometimes attributed to Nicholas RidLey, Bisbop of Rochester, 1547; London, 1550-3, Add. MS. 12443, fo. 188.

Arg. a bull statant gu. armed or the tail betw. the legs. Bevyley, Cornwall, $V$.

Arg. a bull pass. gu. armed and unguled or. Beville, Killegarth. Bevill, Cornwall.

Arg. an ox gu. armed and unguled or passing a ford of water in base ppr. City of OxForD.

Arg. on a mount vert a bull pass. under an oak all ppr. Verrall or Verreli.

Arg. a bull pass. sa. Bellely. Meredydd Bwt. Lamelin, Lamelin, Cornwall; the heiress $\mathrm{m}$. Trelawny.

Arg. on a mount vert a bull sa. armed gu. RiDLey, $V^{*}$.

Arg. a bull pass. sa. armed or. Bennet, Abington, co. Cambridge.

Arg. a bull sa. armed and nuguled or. BoLL, Wales: Bwla, 'Гregothlave, Cornwall.

Arg. an ox sa. unguled or passing a ford ppr. Jolin de OxFORD, Bishop of Norwich, 11751200.

Arg. a bull statant sa. armed and hoofed or. Gwrs, co. Calmarthen.

Az. a bull pass. arg. Crittock or Chitrocke. Az. a bull pass. or. Chetroke, Dickleborough.

Bendy wavy arg. and az. an ox gu. passing over a ford ppr. City of OxFORD.

Erm. a bull pass. gu. BEveILLE, co. Huntingdon. Bevill.

Erm. a calf gu. Cavatu.

Erm. a calf pass. gu. Cavell, Cornwall ; the coheirs $m$. Vivian and Hole.

Erm. a bull gu. armed arg. Beurl or BEVILL, $V *$.

Erm. a bull pass. gu. armed arg. Bevylu, Woltún, $V$.

Erm. a bull pass. gu. armed and unguled or. Bevilu, Cornwall.

Elin. a bull pass. sa. Winter Witer or Wither. Wintter, Ashurst, Sussex.

Erm. a bull statant sa. armed gu. Wyter, $V$.

Gu. a bull pass. guard. or. D'ElLBeUf.

Or a bull gu. Argahast.

Or a bull pass. gu. Banon. Boron, $W$. Boyon. TORELI, or 'T'ARELL.

Or a lull pass. gu. over all a pale ermine. Broke, Serjeant-at-Arms to King Henry VIII.

Or a bull pass. gu. attired of the first. BaptistBrowne. 


\section{BEAST.}

ox....cont.

Or a bull pass. sa. collared and belled gold. Hur., Child-Ockford, co. Dorset, temp. Henry III.

Or a bull pass. sa. horned arg. Trecarne, 'Trecarne, Cornwall; the heiress m. Glynn.

Per hend sinister sa. and arg. a bull pass. reguard. erm. SHERWOOD, co. Warwick.

Per bend sinister sa. and arg. a bull pass. reguard. erm. and ermines attired gu. SHERwood, $V$.

Per fess vert and or a bull counterchanged. Hastings.

Per fess vert and or a bull salient counterchanged. Sr. Drew de Hasting, $Y$.

Per pale arg. and gu. a bull pass. counterchanged. Coles. (Cooper, Dicham Grove, near Petersfield, co. Hants?)

Per pale arg. and gu. a bull pass. counterchanged attired or. Coledran, Merriott, co. Somerset.

Per pale indented gu. and arg. a bull pass. counterchanged. Collinay.

Per pale indented or and gu. a bull pass. counterchanged. Carlore.

Per pale vert and or a bull salient counterchanged. De Hasting, $V^{*}$.

Sa. a bull pass. arg. Wood, Fulborne, co. Cambridge; and Sneterley, Norfolk.

Sa. a bull pass. or. Fitz-Geffrey, co.Bedford; and Ruslidon, co. Northampton. Fitz-Gefrry, $V^{*}$.

Sa. a bull statant arg. the tail between his legs. Fitz-GeffRey, co. Bedford, $\boldsymbol{V}$.

Vert a bull arg. armed and unguled or. BEstar. Vert a bull pass. or. RDLESDALE. RIDLEWORTH.

\section{PORCUPINE see Urchin.}

\section{RABBIT see Hare. RAM see Sheep.} SHEEP, including Fleece, Lamb, and Ram.

Arg. on a base wavy az. a lamb triumphant sa. John de OxFORD, Bishop of Norwich, I175-1200.

Arg. a ram statant sa. armed or. Layton, co. Devon, $W$.

Arg. a paschal lamb pass. or. Dunrze, Rockbere House, and Playford, co. Devon, Bart.

Az. a golden fleece quarterly with or a castle gu. betw. two fleurs-de-lis in fess vert over all a fess erm. Plowes, Wakefield, co. York, granted 12 December 1823.

Gu. a ram. pass. arg. WinRaM, Woolstone, Scotland.

Gu. on an altar-tomb a lamb pass. guard. arg. carrying a banner of the last charged with a cross of the first resting the dexter forefoot on a mound or. Augustinian College of Bons. hornmes at AsHERUGGE or AsHridge, co. Buckingham.

Or on a mount betw. two lesser ones vert a lamb sa. holding with the dexter foot a banner erm. charged with a cross clechy gu. Grose, Richmond, Surrey; granted 1756.

Per chev. erm. and gu. in base a golden fleece. FunEaUX.

Vert a lamb arg. Lambert, Carnagh, co. Wex. ford, and co. Kilkenny; quartering erm. an eagle displ. gu.

Tert a lamb pass. with three heads guard. and reguard. arg. TRIPPET.

Vert a ram pass. arg. YEa, Pyrland Hall, co. Somerset, Bart.

\section{SQUIRREL}

Arg. a squirrel sejant gu. cracking a nut or. Hartford, co. Chester. Nutshald, Nutshall, co. Lancaster, $W$.

Arg. a squirrel sejant gu. cracking a nut ppr. Haltford, $V^{*}$. Nutshali, $V^{*}$. Squire, $V^{*}$.
BEAST. SQUIRREL.... cont.

Arg. a squirrel sejant gu. cracking nuts ppr. Sevire, co. Devon and co. Worcester.

Arg. a squirrel sejant gu. supporting a hazel branch vert fructed or. NuTSHALL, Nutshall, co. Lancaster.

Az. a squirrel sejant or. Walters, Piercefield, co. Monmouth.

Erm. a squirrel sejant gu. Squire, the heiress m. Mervyn.

Or a squirrel sejant gu. SQuire, Suffolk, $V$.

Or a squirrel sejant gu. cracking a nut .... Orton, Kent. Orton, $\boldsymbol{V}$.

Or a squirrel sejant gu. holding a sprig ppr. Napleton.

\section{TIGER}

Arg. a tiger reguard. at a mirror az. SIBELLS.

Arg. a tiger statant reguardant coward gu. at a mirror on the ground az. handled or. Stbbelis, Kent, $V$.

Arg. a tiger reguard. at a mirror gu. Sibeld, Kent. Arg, a tiger or reguard. at a mirror az. SIBELLS, $V^{*}$.

Arg. a tiger pass. reguard. at a mirror ppr. BARDis, co. Oxford.

Arg. a tiger ramp. ppr. collared and chained or. O'Halie.

Arg. a tiger pass. sa. Bold. Daniell.

Az. a tiger statant or. LoANE, Kent, $V$.

Az. a tiger pass. or. LoAne. Lone, Kent; Warlingham and Ellour, Suffolk. Love, Sevenoaks, Kent.

Or a heraldic tiger pass. gu. LuTwyche or LUTWICH.

Or a tiger .... gu. Luтwrch, $V^{*}$.

Or a tiger pass. gu. Lutwyche, Lutwich, co. Salop.

Or a tiger statant gu. LurwxcH, Lutwych, co. Salop, $V$.

Or a tiger pass. sa. Dyor, Lichfield, and Freeford Hall, co. Stafford; confirmed 20 February, 1562.

Or a heraldic tiger pass. sa. STAckpoore.

Per pale az. and gu. a tiger ramp. erm. John de NORWICH, $X$.

Per pale gu, and az. a tiger pass. arg. MaBB.

Per pale gu. and az. a tiger statant arg. John MABB, Chamberlain of London, $1560, V$.

Vert a heraldic tiger pass. or mane and tuft of the tail arg. Love, Kirksted, Norfolk; granted 10 December, 1663.

\section{URCHIN, including Hedgehog and Porcupine}

Gu. a porcupine arg. collared or. Hrer, London.

Gu. a hedgehog salient collared and chained arg. Sir Simon EYre, Lord Mayor of London, $V$.

Gu. a porcupine salient arg. quilled and chained or. Eyre, Lord Mayor of London, 1445.

Gu. a porcupine erect arg. tusked collared and chained or. Simon Exre, Lord Mayor of London, 1445.

\section{WOLF}

Gu. a demi wolf ppr. issuing to the sinister feet erected each side of the head arg. BeтwILL. .. a wolf pass. ppr. Trembleth, Trembleth, St. Ervan, Cornwall; the heiress m. Arundel. Arg. a wolf pass. gu. WoLFEsLex or WolsEnEY. Arg. on a mount vert a wolf (pass. $V^{*}$ ) statant gu. Sinth, $W$.

Arg. a wolf issuing from a wood ppr. CaLLAGHAN or O'CALLAGHAN, Ireland.

Arg. a wolf sa. enraged gu. Malston, co. Devon. Arg. a wolf pass. sa. WaLSALL. WaLsalt.e, $\breve{V}^{*}$. Wolleshali, Wolleshall, co. Worcester. THOLSTON. 
BEAST.

WOLF....cont.

Arg. a wolf ramp. sa. collared or. Wood, $V$.

Arg. a wolf salient sa. ATwood. FORD, Frating, Essex. WoLfe, Easton-Manduit, co. Northampton. Wood, co. Stafford.

Arg. a wolf salient sa. collared gu. Woon.

Arg. a wolf statant sa. Walsaile, $V$.

Az. a wolf pass, arg. Blaidd RHYDd. LoE. Surgan. Surgeon, $V^{*}$.

Az. a wolf pass. arg. armed and largued gu. Gellyn ap BLAIDd RHCDD.

Az. a wolf ramp. arg. Brees or Breeze. Sir John Doos, $V$. Henry Dwns. Dun, $V^{*}$. Lewis. Lloyd, Bronwydd. Lloyd, Crickadarn, co. Brecon. Oliffe. (Tydwail, Gloff, co. Brecon?) Watkins, Llangorse, co. Brecon.

Az. a wolf ramp. arg. collared gu. chained (gu. $\left.V^{*}\right)$ or. Sir Morgan Iitwally, $V$.

Az. a wolf salient arg. Clece. Clere, $V$. Davies, Pentre, co. Pembroke; quartering Saunders. Don, Donn, or Doon. Donne, Picton. Howell. Lloyd, Bronwydd, co. Car. digan; and Kilrue, co. Pembroke; descended from the ancient lords of Dyfed. Maenyrch Goch, lord of Brycheinog.

Az. a wolf salient arg. collared gu. KidweLL.

Az. a wolf salient arg. collared and chained or. KYNDWELL.

Az. a wolf salient arg. langued or armed gu. Downe.

Arg. a wolf statant arg. John Surgon or Surgun, $V$.

Az. a wolf salient erm. Davis, Kent; proved June, 1752.

Az. a wolf salient or. Donne, Mattishall. Dunn, Bircher, Leomiuster; quartering sa. three ronnd buckles tongues downwards or.

Az. a wolf salient or collaredaz. bezanty. KIDwELL, Wales.

Barry of ten or and vert a wolf ramp. arg. WoLf, $V *$. WOLFE, $V$.

Gu. a wolf issuing out of a rock from the sinister side of the escucheon all arg. Whilians, co. Devon; and Denton, co. Lincoln. Williams, The Friars, Chichester, Sussex. Wumianis, Clapton, co. Northampton, Bart.; the heiress m. Fonnereau.

Gu. a cave ppr. therefrom issuant a wolf at full speed reguard. arg. Williais.

Gu. a wolf pass. arg. Low, London, 1684 ; quartering arg. a hunting-horn stringed sa. betw. three crescents of the last, with arg. on a fess betw. three crescents gu. as many mullets or. Low, Alderwasley. Sir Edward Low, New Sarum, co. Wilts, 1730. Lowe, $V^{*}$. Lowe, Sbrewsbury, co. Salop; and Calne, co. Wilts. Lowes, Pidley Hall, co. Northumberland.

Gu. a wolf preyant arg. Lowe, New Sarum, co. Wilts.

Gu. a wolf statant arg. William Lowe, co. Salop, $1586, W$.

Gu. a wolf salient or. ALBANGE.

Gyronny of eight arg. and or a wolf saliant sa. ATwOOD.

Gyronny of eight az. and gu. a wolf ramp. or armed sa. langued of the second. HANKE, Mayor of Chester; granted 6 September, 1580.

Or a wolf salient sa. armedgu. Louth or Lowth, co. Lincoln.

Or a wolf salient sa. armed of the field. Louth or LowTH, co. Lincoln.

Or on a mount vert a wolf statant sa. under a tree prir. Wood, co. Lancaster, 1582.
BEAST. WOLF.... cont.

Per pale gu. and az. a wolf salient arg. HaNkEY, Churton, co. Chester. Henry Hankey, Mayor of Chester ; granted 1572.

Per pale sa. and arg. a wolf salient (of the last bendwise. Fresche, $V^{*}$ ) counterchanged. French.

Per pale sa. and az. a wolf pass. arg. FnEnCH. But salient. Fresh. Frenche, $W$. Fresche, $V$. And statant. French, $W$.

Sa. a wolf ramp. arg. Lours.

Sa. a wolf salient and in the dexter chief a crescent (for diff.) arg. LOUnE Louthe or Lowth, Castle Hedingham, Essex; Cretingham, Suffolk; Sawtrey Beaumys, co. Huntingdon; quartering Mulso.

Sa. a wolf ramp. or. Louthe, $V$. But salient. LouTH or LowTH. Robert Louth, Bishop of St. David's 1766, Oxford 1766, London 1777-87. Sa. semy of estoiles a wolf salient or. WLLSON; granted $18 \ldots$

Sa. a wolf saljent reguard. or. LOADEs, London; granted $30 \mathrm{July}, 168 \%$.

Vert. a wolf pass. pierced with an arrow the point coming out of the mouth arg. Bleddyn ap Maenyrch, 1090. Powell, Castle Madoc.

Vert a wolf salient arg. GAmBOw; impaling arg. three mulberry leaves vert two and one.

Vert a wolf ramp. or. WOLFF.

ANTELOPE and in chief....

\section{on a Chief..... Crosses}

Per pale gu. and arg. an heraldic antelope pass. counterchanged on a chief divided as the field or and az. two crosses croslet fitchy also counterchanged. Robert DigHTON, Stourton, co. Lancaster, $V$.

$$
\text { .....Escallops }
$$

Or an antelope pass. gu. on a chief of the second three escallops of the first. DERYcotr.

BEAVER and in chief....

Erm. on a mount vert a beaver ppr. a chjef az. charged with an anchor erect cabled or betw. two eagle's heads erased arg. beaked gold. Hose, Kentish Town, Middlesex; grauted 3 February, 1806.

\section{BAT and in chief....}

\section{on a Chief.... Palets}

Arg. a bat displ. sa. on a chief gu. three palets of the field. Stainings, co. Somerset. Staynings, Honycott, co. Somerset.

\section{5-Foils}

Per chev. az. and arg. in base a bat displ. in chief two 5 -foils counterchanged. Blake.

Per chev. az. and arg. in base a bat displ. sa. in chief two pierced 5 -foils or. BlaKe, $V$.

Canton

BEAR and in chief....

Arg. a bear ramp. sa. a canton erm. BERE, $V^{*}$.

A rg. a bear salient sa. a canton erm. Bere, Kent, $W$.

Arg. a bear in pale salient sa. armed gu. a canton erm. BEARE.

Arg. a bear sa. and a canton gu. BERE, Kent; and Oakenham, co. Berks.

Arg. a bear ramp. sa. and a canton gu. BEARE or Beere, Kent, 1586. Beere, $V^{*}$.

Arg. a bear salient sa, a canton gu. John BeERe, Kent, 1580, $W$.

\section{on a Canton.... Bird}

Az. a bear salient arg. on a canton or a cock gu. Denhany.

Az. a bear sejaut with the fore paws salient arg. on a canton or a cock gu. Dehaney, London. 
BEAST, BOAR and in chief....

\section{Beast}

Per cher. or and gur. in base a hoar pass, in chief two lions pass. guard. counterchanged. EAson.

Per chev, or and vert in base a boar pass. of the first in chief two lions pass. guard. gu. M'DoNagh, Irelaud.

on a Canton.... Sword

Gu. a sanglier pass. or and for diff. a canton erm. charged with a sword palewise ppr. BaIRD, Newbyth. And with a crescent .... surmounting the sword. BAIRD, Saughton Hall. Castle

Az. in base a boar pass. or. in chief a castle with two towers arg. Cazalet.

on a Chief.... Mullets

Erm. a boar pass. az. on a chief or two pierced mullets of the second. Forster.

Erm. a wild boar pass. az. bristled armed and unguled or langued gu. oll a chief of the third two mullets of the fourth. Bacon, Newton Cnp, co. Durham, and Stewart Pile, Northumberland; granted 1752.

Per pale sa. and arg. a boar pass. counterchanged on a chief az. three mullets of the second. Doran, Ireland.

\section{....Roundles}

Arg. a boar pass. gu. armed and bristled or on a chief az. three plates. Punceid, Cromlyn, co. Dublin; a branch of Purcelr, Croagh, co. Limerick.

\section{Crescent and Estoile}

Gu. in base a boar pass. or in chief within an increscent an estoile of eight points arg. on a canton erm. a sword erect ppr. pomel and hilt gold. Baind, Feruton, co. Perth, Bart., de. scended from Auclimedden.

\section{CAT and in chief....}

on a Chief.... Banner

Az. a cat ramp. arg. on a chief the standard of St. Andrew and a claymore point downwards in saltire ppr. Sirth, Loudon.

\section{Crescents}

Erm. a cat pass. and in chief two crescents sa. DUANE, London, and Ireland.

\section{Bird}

DEER and in chief....

Sa. a buck lodged reguard. arg. betw. the attires a heathcock volant or. MonTort, Norfolk.

Sa. a hart lodged and betw, the attires a beath. cock volant or. MonLisht or MontoFt.

Sa. a buck lodged reguard. and betw. the attires a heathcock volant or. Montort, Norfolk.

Sa. a stag lodged reguard. and betw. the attires a bird or. Nortost, Norfolk.

\section{on a Canton.... Lozenges}

Arg. a hind trippant gu. on a canton of the second three lozenges of the first. Agras.

$$
\text { .... Ship }
$$

Arg. a stag pass. gu. on a canton az. a galley or. Parker.

Chief

Az. a stag trippant or a chief arg. Bertrand.

Or a buck ppr. and a chief gu. Srarhow, $V^{*}$.

Or a hart trupant ppr. and a chief gu. Spanuow, Essex, $W$.

Sa. a buck trippant and a chief indented or. Hamblex. Richard Hunble, Alderman of London 1626, in St. Savions's church, Sonth. wark. Humble, Stratford, Essex, and London, 1634. Huabie, London, Burunctcy 1660.
BEAST. DEER and in chief....cont.

Chief cont.

Sa. a stag tripp. erm. and a chief or. WaLeston. on a Chief.... Beast

Arg. on a mount a buck couchant under a tree all ppr. and for augmentation on a chief az. a mount vert thereon a lion in the act of tearing the standard of the Mahratta prince Holkar and beneath the word "Madripore." Hislop, Tothill, co. Devon, Bart.

$$
\text { .... Beasts }
$$

Per pale vert and arg. on the first a buck pass. ppr. on the second a boar pass. per pale sa. and ppr. on a chief or two lions ramp. combatant gu. supporting with their fore paws a sword entwined with a serpent. O'Sullivan, Ireland. .....Bird

Sa. on a mount in base vert a buck salient or a chief of the third charged with a blackcock ppr. MARTOSET.

Sa. on a field in base vert a stag courant or a chief arg. charged with a beathcock ppr. MorTofFe, Norfolk, 1609.

Sa. on a mount ppr. a stag lodged or a chief of the third charged with a moorcock of the second. Mortort, Itringham, Norfolk; confirmed October 1606 .

\section{..... Birds}

Sa. a stag trippant or attired and unguled arg. on a chief of the same three falcons ppr. EDWARDS, originally of Maes yr-hen-Uys, co. Denbigh, subsequently of Gouldgrieve, co. Flint, and now of Old Court, co. Wicklow.

\section{....Castles}

Gu. from behind bushes vert a stag courant arg. on a chief az. three castles of the field one and two. James, Cathedine, co. Brecknock.

\section{.....Crescents}

Gu. a stag trippant or on a chief of the second three crescents of the first. Peeriran.

$$
\text { ....3-Foil }
$$

Sa. a stag trippant or on a chief dancetty arg. a 3 -foil vert. Humble, Cloncoskoran, co. Waterford, Bart., quartering Nugent.

$$
\text { ....5-Foil }
$$

Or on a mount a stag lodged in a grove of trees ppr. on a chief gu. a 5 -foil betw. two mullets of the field. Fernie, Scotland.

$$
\text { .... Flower }
$$

Or. a stag trippant az. on a chief of the last three roses arg. Fruid, Scotland.

$$
\text { ....Mullet }
$$

Arg. a stag couchant ppr. on a chief vert a mullet of the field. Doherty.

$$
\text { ....Mullets }
$$

Arg. a buck at full speed .... on a chief vert three mullets of the first. O'Doherty, Ireland.

Arg. a stag courant ppr. on a chief vert three mullets of the field. Doherty.

$$
\text { ....Wings }
$$

Arg. a stag trippant surmounted br a tree eradicatel vert on a chief az. two wings expanded and conjoined of the field. Renny.

\section{Crescents}

Arg. on ground in base a stag lodged betw. two trees vert in chief three crescents.... HisLor or HisLope, Scotland.

\section{Cross}

Arg. on a mount a stag lodged in a grove of trees vert in chief a cross croslet betw. two mullets or. Ferner, Scotland. 
BEAST. DEER and in chief.... cont. Crown

Arg. a stag trippant ppr. hoofed and attired or betw. the attires a royal crown ppr. being an augmentation granted by King John. Wrurass, Eltham, Kent; baronetey 2 November 1674; and Gwernevet, co. Brecknock. Wrimans, Islington, Middlesex.

Az. a stag pass, arg. attired or betw. the attires a regal crown ppr. Davies, Brecon. Davis. Powell, co. Brecknock.

Az. a stag trippant arg. collared and lined or betw. the attires an imperial crown ppr. PRrTHERcH, Abergele, co. Carmarthen; originally ap Rhydderch; descended from Rhydderch ap Gwilyn, of the line of Cradoc ap Gwilyn, Lord of Tal. lyn; quartering gu. on a chev. betw. three men's heads couped in profile arg. five gouttes de sang.

Az. a stag trippant arg. unguled attired and bear. ing betw. his horns an imperial crown or. Owain Gethin. Lewis, Gilfach, co Carmarthen ; quartering az. a chev. betw. three eagle's heads erased or. Prytherch, Abergele.

\section{Estoiles}

Gu. a stag arg. lodged in a thicket of trees vert betw. the attires three stars of the second. Fatrnie, Farlogie, Scotland.

\section{Flower}

Arg. a stag trippant with wings attached to the buttocks and hind legs ppr. betw. the attires a rose or. Jones, Tredustan, co. Brecknock. 5 -foil

Sa. a buck couchant arg. attired or in the sinister chief quarter a 5 -foil of the last. Downes, Evenwood, co. Durham.

\section{Insects}

$\mathrm{Gu}$ a buck trippant arg. in chief two bees volant or on a chief nebuly of the third a Lorraino cross as the field betw. two eagles displ. sa. Goodhart, Langley Park, Kent.

\section{Mullet and Crescent}

Az. a stag tripp. arg. in the dexter chief a muliet of six points and in the sinister an increscent of the last, Strachan, Tarrie, Scotland.

\section{Mullets}

$\mathrm{Gu}$. on a mount in base a stag pass, arg. in chief two mullets or. CRIspie.

Gu, a stag lodged arg. surmounted by a crosier or betw. the attires three mullets of the second. Farre, Nig, Scotland.

\section{Roundles}

Per chev. engr. or and sa. in base a hart trippant of the first in chief three ogresses. HARTstrong, South Repps, Norfolk.

\section{Buckles}

DOG and in chief....

Sa. a talbot pass, or in chief three round buckles arg. Carter, co. York.

Canton

Arg. a greybound courant sa. a canton erminois. JaCOBS.

Chief

Arg. a greylound pass, and a chief sa. CArpenter, Sussex; and Cobham, Surrey ; granted 4 March, 1663.

Gu. a talbot pass. or a chief erm. Chaffin, Warmiuster, co. Wilts. Thomas CHaffin, Chettle, co. Dorset, 1730.

on a Chief.... (Beast) Lion

Sa. a talbot sejant al'g. on a chief gu, a lion pass. guard. betw. two Heurs.de.lis or. Town of Sudeury.

\section{BEAST. DOG and in chief.....cont.}

\section{on a Chief..... Crosses}

Arg. a talbot pass. sa. collared or on a chief az. three croslets of the third. KEene, Norfolk.

Arg. a talbot pass. sa, eared and collared of the field on a chief indented az. three crosses cros. let (another, botonny) of the first. KEyne, Suffolk.

Arg. a talbot pass. sa. collared or on a chief indented az. three crosses croslet of the third. Edmund KeEne, Bishop of Chester, 1752; Ely 1771-81.

Arg. a talbot pass, sa. eared and collared or to the collar a ring of the second on a chief indented az. three crosses croslet of the third. KENE, Starston, Norfolk.

Az. a talbot pass. or on a chief arg. three crosses croslet sa. Kene, Ipswich, Suffolk.

Az. a talbot pass. or on a chief indented arg. three crosses flory sa. KeEn, North Cove and Thanderston, Suffolk; granted 3 May, 1562 .

\section{.... Fleurs-de-lis}

Arg. a greyhound pass. sa. on a chief az. three fleurs-de-lis or. HiLFord, Wistow Hall, co. Leicester; Baronetcy 164], ex tinct 1780.

Arg, a greyhound statant sa. collared or on a chief az. three fleurs-de-lis of the third. HaLford, Paddock House, near Canterbury, a branch of the preceding.

$$
\text { ..... Flower }
$$

Arg. a greyhound pass, sa. on a chief az. a rose arg. for angmentation 1827 betw. two fleurs-delis or and as further angmentation on a canton erm. a staff entwined with a serpent ppr. and ensigned by a coronet composed of crosses patty and fleurs-de-lis .... HALFORD, Baronetcy 27 September, 1809.

$$
\ldots \text { Key }
$$

Arg. a spaniel dog pass. ppr. on a chief embattled az. a key paleways the wards upward betw. two crosses croslet or. MaIrE.

$$
\text { .....Mullets }
$$

Or a talbot pass. sa. on a chief of the second three mullets of the first. Alwaye, Streetley, co. Bedford.

\section{.... Roundles}

Arg. a greybound in full course sa. on a chief of the second three bezants. BLACKWELT.

Arg. a greyhound courant sa. on a chief dancetty of the last three bezants. BLackweld, Ampney Park, co. Gloucester.

Arg. a greyhound in full course sa. collared chequy or and gu. on a chief dancetty of the second three bezants. BlackwaLL, Blackwall, in the Peak, co. Derby, Henry III.

Arg. a greyhound conrant sa. on a chief indented of the last three bezants. BLackHald, Exeter. BlackWall, London.

Arg. a greybound courant sa. collared or on a chief dancetty or indented of the second three bezants. Blarwell, co. Derby, $V$.

\section{Crescents}

Arg. a talbot sejant sa. in chief three crescents gu. Furnese Furnes and Furness.

\section{Fleurs-de-lis}

Sa. in base a greyhound pass. and in chief three fleurs-de-lis arg, HAWFORD, co. Leicester. Horn

Or a greyhound comrant in bend sa. in the dexter chief a hunting horn stringed of the last. JAGO. 
BEAST. DOG and in chief.... cont.

\section{Lozenges}

Per fess erm. and sa. a talbot pass. or in chief two lozeuges of the second. DANIEL, Trelissick, Cornwall.

\section{Pheons}

Vert in base a talbot pass. and in chief two pheons or. Grape, New Windsor, co. Berks; granted 1764 .

\section{ELEPHANT and in chief....}

\section{Canton}

Or an elephant az. on bis back a quadrangular castle arg. masoned ppr. on the sinister tower a flagstaff and banner gu. on the dexter corner of the banner a cantou silver charged with a cross gu. the dexter corner of the escutcheon quarterly France and England. Royal African CoMPanY, incorporated $20 \mathrm{Jan} .1662$.

on a Chief.... Heart

Gu. an elephant erminois on a chief or a human heart ppr. betw. two horseshoes az. PitT, Priorsley and Shiffuall, co. Salop; granted 1758.

Erminois an elephant statant az. on a chief of the last the sun betw. two beehives ppr. i.e. or. HEACock, Newington, co. Middlesex; granted 1746 . HАYcock.

\section{FITCH and in chief....}

Arg. a foine (or fitch) sa. on a chief indented gu. three escallops or. Marten, Sussex, descended from those of Aquitaine, 1386.

GOAT and in chief....

Arg. a goat salient sa. and a chief vert. Buketon or Buciton. Buckton, Bellingham, Northumberland.

\section{HARE and in chief....}

on a Chief..... Swords

Az. a hare salient arg. with a bunting horn vert hanging about the neck garnished gu. or a chief arg. a sword fesswise az. hilt and pomel or. Cleland, Fasline, Scotland.

\section{Suns}

Az. a hare courant and in chief tbree suns or. John WATsoN, Bishop of Winchester, 1580-4. Add. MS. 12443, fo. $131 \mathrm{~b}$.

\section{HORSE and in chief. ...}

on a Chief.... Escallops

Barry of four .... and .... a demi-horse issuant .... on a chief .... three escallops .... Ralph of Shrewsbury, Bishop of Bath, etc., 1329-63; or Ralph ERGHUM, Bishop of Salisbury 1375, Bath, etc., 1388-1400.

$$
\text { ..... Mullets }
$$

Vert a horse arg. caparisoned or on a chief of the second three spur-rowels gu. STUDHOLME, Studholme, Abbey Holme, co. Cumberland, ternp. Henry II.

\section{Cross}

Arg. on ground in base vert a horse pass. sa. saddled and bridled gu. in chief a cross croslet fitchy of the third. Torrie.

\section{Estoile}

Arg. on a mount in base vert a borse trotting sa. furnished gu. in chief a star of the third. Trotter, Scotland; Workman's MS.

\section{LEOPARD and in chief.}

Erm. a leopard ramp. reguard. and in chief three flies volant ppr. Zacharial Pearce, Bishop of Bangor, 1747; Rochester, 1756-74.
BEAST, LION and in chief....

\section{Annulet}

Arg. a lion ramp. and in the dexter point an annulet gu. LEIGH, Leigh, Cornwall.

Az. a lion ramp. arg. clowned or an annulet of the second. MaLton.

Sa. a lion pass. arg. langued gu. in chief an an. nulet or. TAYLOR, London.

\section{Birds.... Falcons}

Arg. a lion ramp. tail nowed gu. gorged with an eastern coronet or in clief three falcons ppr. Bewes, St. Neots, Cornwall.

$$
\text { .....Martlets }
$$

Arg. a Jion ramp. gorged with a ducal coronet or in chief three martlets .... BewEs.

\section{Canton}

Arg. a demi lion ramp, and a canton az. Kernaby.

Arg. a lion ramp. sa. a canton chequy or and gu. Jeffryes, Brecon and Abercywieg, co. Brecon.

Arg. a lion ramp. and a canton sa. OWen, co. Salop, Kent, and London. Owen, Woodhouse, co. Salop; descended from Owen, Llunllo; the heiress m. Kynaston and Mostyn. Owen, Bettws Hall, co. Montgomery, of like descent. Owes, Condover, co. Salop, of like descent; the heirs m. Mytton and Smythe.

Az. a lion ramp. arg. a canton or. RudD.

Az. a lion ramp. and a canton or. RuDD, Abergavenny, co. Monmouth; and Higham-Ferrers, co. Northampton. Rudd, Newton Kyme, co. York; and Thorne, Doncaster; quartering Sutherland.

Chequy or and gu. a lion ramp. erm. and a canton az. Scarletr, West Bargholt and Copsford, Essex, Jlill.

Chequy or and gu. a lion ramp. sa. a canton arg. Skarlett, East Dereham, Norfolk.

Erm. a lion ramp. az. a canton sa. Edwards, co. York.

Erm. a lion ramp. and a canton sa. JefFrers, Acton, co. Denbigh ; and Whiteford, co. Fliut; derived from Tudor Trevor. Jeffrevs, Lord Jeffreys, of Wem-the Judge Jeffreys; descended from Jeffreys, Acton, co. Denbigh; the heiress in $1720 \mathrm{~m}$. Fermor. JEFFREYS, Wem, co. Salop. JefFries or JefFereys.

Gu. a lion couchant arg. a canton or. JoNEs, Fakenham, Norfolk.

Gu. a lion ramp. arg. a canton erm. Sтотт.

Gu. a lion ramp. arg. crowned or a canton erm. GREY.

Gu. a lion ramp. arg. a canton or. Whetstone, Essex.

Gu. a lion ramp. and a canton erm. of the last. SCARINGBORNE.

Gu. semy-de-lis or a lion ramp. and a canton erm. Marks or Markes, Suffolk.

Gu. a lion ramp. or a canton erm. SCARINGBORne,co. Lancaster. Scharingborne, $V$. Scharingbourn, $V^{*}$.Sharburne or Sheringburne. SHarnborne, Sharnborne Hall, Norfolk.

Gu. a lion ramp. tail forked or and a canton erm. Sherrorne, Norfolk, and co. Northampton.

Gu. a lion ramp. or a canton per bend sinister erm. and sa. LANDEN.

Or a lion ramp. gu. collared arg. a canton az. Macrory, Mobberley, co. Chester, temp. James $\mathrm{I}$; the heiress $\mathrm{m}$. Leigh; derived from Sir William Mallory, Studley, co. York.

Or a lion ramp. and a canton gu. Bruers. Powell. Puwts, Sutton, co. Salop. 
BEAST. LION and in chief.... cont.

Canton cont.

Or. a lion ramp. vert a canton erm. Sutron, Edenhall, co. Stafford. Sir Richard Sutron, 1619 , one of the executors of the will of Thomas Sutron, founder of the Charter House, London.

Per bend sinister erm. and erminois a lion ramp. or a canton sa. for distinction. Pennant, quartering Douglas.

Per chev, arg. and or a lion ramp. sa. a canton gu. Meredyth.

Per pale arg. and gu. a lion ramp. counterchanged a canton sa. Hethrington, Ireland.

Per pale gu. and az. crusily or a lion ramp. arg. a canton erm. Hutchinson, Skirsgill and Crossfield House, Cumberland; Newbiggin Hall and Appleby, Westmoreland; the heiress m. Martin.

Per pale or and vert a lion ramp. gu. a cunton vairy or and gu. William Marshali, Earl of Pembroke.

Sa. semy-de-lis or a lion ramp. arg. ducally crowned of the second a canton erm. PHillups. on a Canton.... (Beast) Boar

Barry of ten arg. and az. a lion ramp. gu. on a canton of the last a boar pass. of the first. $\mathrm{J}_{\mathrm{ACKSON}}$, Edinburgh.

\section{.....Lion}

Or a lion ramp. gu. surmounted by a bend engr. sa. on a canton of the second a lion ramp. arg. SPENCE, Edinburgh.

$$
\text { .....Bird }
$$

Erm. a lion ramp. guard. az. on a canton gu. an eagle displ. with two necks or. EDwands, London.

Erm. a lion ramp. az. on a canton or an eagle displ. sa. Enwards, Lord Mayor of Lorıdon, 1679.

Erm. a lion ramp. guard. az. on a canton or an eagle displ. sa. EDwards, Tyrington, Norfolk.

Erm. a lion ramp. gu. on a canton or an eagle displ. sa. EDwards.

Erun. a lion ramp. guard. gu. armed az. on a canton or an eagle displ. with two necks sa. EDWARds, Kent, and co. Salop.

Gu. crusily and a lion pass. guard. or a canton arg. charged with an eagle displ. sa. on the breast an escucheon gold charged with three bars az. Asteli, co. Leicester.

$$
\text { .... Castle }
$$

Barry of six erm. and sa. over all a lion ramp. or on a canton gil. a castle of the third. Gisson, Ireland.

Chequy or and gu. a lion ramp. erm. on a canton az. a castle triple-towered arg. Scarietr, Baron Abinger. Campeesi, Baroness Stratheden, a daughter of Lord Abinger.

$$
\text { ..... Chevron }
$$

Arg. a lion ramp. sa. ducally crowned or on a canton az. a chev. of the third betw. three acorns slipped and erect ... D Du CANE,'London ; and Braxted Lodge, Essex; granted 1730.

$$
\text { ..... Cross }
$$

Az. a lion pass. or on a canton arg. a cross gu. JASON, $W$.

Gu. a lion ramp. or on a canton arg. a cross sarcelly vert. REson or Reason, Essex.

Gu. a lion ramp. or on a canton of the last a cross croslet vert. Resine, Essex, temp. Edward I.

Gu. a lion ramp. or on a canton of the second a cross patonce vert. Sir John Resone, lissex, $V$.
BEAST. IION and in chief....cont.

on a Canton.... Cross cont.

Sa. a liou ramp. arg. on a canton of the second a cross gu. Churchill. Churchill, Duke of Marlborough; quartering Spencer; over all in chief for augmentation on an escucheon arg. a cross gu. debruised by on an escuclieon az. three fleurs-de-lis or.

$$
\text { .....Cup }
$$

Per bend sinister dancetty erminois and sa. a lion ramp. counterchanged on a canton gu. a covered cup arg. Simpson, Glover's House, Sittingbourn, Kent; quartering erm. a chev. gu. betw. three pheasant cock's heads couped az. with arg. on a fess dancetty gu. betw. three torteaux a tleur-de-lis or.

$$
\text { .....Escallop }
$$

Arg. a lion ramp. gu. on a sinister canton az. an escallop or. LEIGH, Northam, co. Devon, $W$.

Arg. a lion ramp. gu. on a sinister canton of the second an escallop or. LEIGH, Borough in Northam, co. Devon; derived from Leigh, High Leigh; the co-heiresses m. Basset and Bury.

Per bend sinister az. and vert a lion pass. reguard. or on a canton arg. an escallop gu. Cranke, I.ondon.

Per bend sinister erm. and ermines (? erminois) a lion ramp. or and for distinction on a canton sa. an escallop arg. charged with a cross flory of the fourth. Trevor.

$$
\text { ..... Flower }
$$

Arg. a lion ramp. sa. with an augmentation of a canton erm. charged with a rose.... Whitestones ; granted 22 Sept. 1586.

Az. a lion ramp. double tailed sa. a canton az. thereon a rose of the first slipped ppr. OwEN, Wrexham, co. Denbigh; quartered by Rogers Harrison.

$$
\text { ....5-Foil }
$$

Arg. a lion ramp. sa. on a canton gu. a 5-foil erm. Whetstone, Woodford Row, Essex.

$$
\text { -.... Fret }
$$

Gu. a lion ramp. arg. on a canton sa. a fret or. BuCKLAND.

$$
\text { ....Garb }
$$

Erm. a lion ramp..... on a canton.... a garb... GisBone.

Erminois a lion ramp. sa. collared arg. on a canton vert a gurb or. GisBorne, Yoxall Lodge, co. Stafford; and Horwick House, co. Derby.

Or a lion ramp. reguard. sa. on a canton of the second a garb of the first. Price, Kingstonupon-Thames, Surrey; confirmed 1602.

$$
\text { ....Guns }
$$

Per saltire az. and or a lion ramp. guard. of the first on a canton arg. two pot guns az. (another sa.) GoLd.

$$
\text { .... Harp }
$$

Barry of eight arg. and vert over all a lion ramp. .... with an eastern crown or armed and langued az. on a canton az. a harp or. Lighton, Mejville, co. Dublin, Baronetcy 1 March, 1791.

$$
\text { ..... Head }
$$

Az. a lion ramp. alg. gorged with an antique crown or on a canton arg. a hart's head cabossed gu. M'DowaL, Crichen, Scotland.

$$
\text { ....Horn }
$$

Or semy of oak-leaves vert a lion ramp. az. on a canton gu. a buglehorn stringed of the first. Patch, Tiverton, co. Devon.

$$
\text { ......Key }
$$

Gu. a lion pass. or on a canton arg. a liey palewise sa. Loban. 
BEAST. LION and in chief.... cont.

on a Canton.... Mascle

Per bend sinister dovetailed or and az. a lion ramp. erm. on a canton of the second a mascle of the first. Stuckey, Hill House, Langport, co. Somerset.

$$
\text { .... Mnllet }
$$

Az. a lion ramp. double tailed erm. on a canton arg. a mullet pierced gu. Peachey, Baron Selsey.

Az. a lion ramp. double tailed erm. crowned or on a canton of the third a mullet gu. PECHE, Sherowall, co. Derby, and co. Lancaster.

Az, a lion ramp. erm. ducally crowned or on a canton of the last a pierced mullet gu. Peacrey, North Bersted, Rumbolds Wyke, and South Mundham; descended from Peachey, Shripney, 1614.

Az. a lion ramp. or on a canton arg. a mullet gu. KIRBY.

Barry of six arg. and gu. over all a lion ramp. sa. armed or gorged with a crown arg. on a canton of the second a mullet of the first. WASSE, Kirkhill, co. York.

$$
\text { .....Pheon }
$$

Arg. a lion ramp. gu. on a canton az. a pheon or. PETYT, London; granted 1688.

Az. a lion ramp. arg. on a canton of the second a pheon.... Iorwerth Sais MARchog.

Erm. a lion ramp. gu. armed and langued az. on a canton of the last a pheon or. РетYT, London, and Ackworth Park, co. York; confirmed 1810.

Sa. a lion pass. or on a canton gu. a pheon of the second within a bordure engr. erm. TAYLER.

$$
\text { .....Piles }
$$

Az. a lion ramp. arg. ducally crowned or on a canton of the second three piles gu. M'Dowall, Edinburgh.

\section{....Roundle}

Or a lion ramp. gu, a canton of the last thereon pendant from a mural crown of the first by a riband of the second fimbriated az. a represen. tation of the gold medal and clasp presented for services in the Peninsular war. MACDONALD, Dalchosnie, co. Perth; descended through Macdonald, Kippoch, from Alexander, son of John, Lord of the Isles; quartering arg. a dex. ter arm embowed in armour ppr. garnished or the hand grasping a dagger point downwards also ppr. pomel and hilt gold, with arg. on waves of the sea ppr. a ship her sails furled sa. in base a salmon naiant also ppr., and or an oak-tree growing out of a mount in base ppr. surmounted by an eagle displ. sa. over the whole a fess counter.embattled gu. thereon two swords in saltire points npwards arg. pomels and hilts or betw. a representation of the Spanish cross of distinction on the dexter and the Portuguese cross of distinction on the sinister both ppr.

Or a lion ramp. gu. and a canton sinister charged with gu. ten bezants quarterly with az. on a mount vert a lion pass, guard. or. CHARLToN, Apley Castle; and Wytheford Hall, co. Salop.

Sa. a lion ramp. arg. holding betw. the paws a mural crown or a canton erm. thereon pendent by a riband gu. fimbriated az. a representation of the medal presented for services subinscribed Waterloo in letters sa. Churchill.

$$
\text { ... Ship }
$$

Az. semy-de-lis or a lion ramp. of the last on a canton arg. a ship in full sail $\mathrm{ppr}^{\text {. PooL or }}$ Poole, co. Chester.
BEAST. LION and in chief.... cont.

on a Canton.... Ship cont.

Az. semy-de-lis or a lion ramp. guard. of the se. cond on a canton arg. a ship in full sail ppr. Poox, New Shoreham, Sussex ; granted 1648. ..... Staff

Per fess or and sa. a lion ramp. counterchanged armed and langued gu. on a canton of the last an Esculapius's rod palewise entwined with serpents arg. M'WHIRTER.

....sword and spear

Az. a lion ramp. per fess or and arg. on a canton of the last a sword pomelled gold surmounted of a speal of the last. 'Thomas Bettesworth, Chidden in Hambledon, co. Hants, 1665.

$$
\text { .....swords }
$$

Per pale vert and az. a lion ramp. arg. crowned or on a canton erm. two swords iu saltire sur. mounted by a fasces impaled within a wreath all or. DoBede, Soham, co. Cambridge.

\section{Cantons}

Arg. a lion ramp. guard. sa. in chief two cantons the dexter or a griffin segreant sa. the sinister arg. three bull's heads cabossed sa. armed gold. Morgan, Langston, co. Monmouthi ; derived from Philip Morgan, second son of Morgan ap Llewellin, Lord of St. Clere and Tredegar.

\section{Castle}

Gu. a lion ramp. arg. a castle in the dexter point.... Castilion, Benham Valence, and Woodspene, co. Berks, 1565.

$\mathrm{Gu}$. in base a lion pass. guard. or in chief a castle surmounted with a tower arg. City of NonwicH.

Per fess vert and gu. in base a lion pass. guard. or in chief a quadrangle of castles walled arg. Town of LANCASTER.

\section{Castles}

Per chev. gu. and or in base a lion ramp. az. in chief two castles arg. Panton. Penton. Chief

Per fess or and gu. a demi lion ramp. vert a chief of the first. WHARTON.

Arg. a lion ramp. az. a chief gu. Brossell. WALTHEOF.

Arg. a lion ramp. reguard. ermines a chief vert. Marsh or Marshe, Wales.

Arg. a lion ramp. gu. a chief erm. Monchief, that Ilk.

Arg. a lion ramp. gu. armed and langued az. a chief erm. Moncrief, Culfalgie. Moncrieffe, Tippermalloch, co. Perth; Bristol and Loxton, co. Somerset. Wellwood Moncrieff, Tullibole, co. Kinross, Bart.; quartering arg. an oak issuing out of a well in base ppr.

Arg. a lion ramp. and a chief gu. Dundas, Scotland. Etrtrick, London.

Arg. a lion ramp. gu. a chief per fess indented of the first and sa. Hyetr, Wotton, co. Somer. set, 1573 .

Arg. a lion ramp. gu. a chief sa. Russeri, $W$.

Arg. a lion ramp. sa. a chief erm. Trotter, Helmden, co. Durham; Visitation 1615.

Arg, a lion ramp. sa. a chief gu. AsBBY, co. Leicester. Ashley. Botterell or Botriell. Syward, Ear] of Northumberland.

Arg. crusily and a lion ramp. sa. a chief gu. MOUNTFORD.

Arg. a lion ramp. sa. a chief lozengs or and gu. LOWDE.

Arg. a lion pass, and a chief sa. Rishton, Dunkinhaw and Sparth, co. Lancaster.

Arg. a lion ramp. and a chief indented sa. Hyetr, co. Gloucester. 
BEAST. LION and in chief.... cont.

\section{Chief cont.}

Arg. a lion ramp. sa. a chief per fess indented of the first and gu. HyELT.

Arg. a lion ramp. sa. a chief per fess indented of the first and second. HYATT.

Arg. a lion ramp. sa. a chief indented point in point of the second and first. Hiet.

Az. a lion ramp. arg. a chief erm. Philirs, co. Worcester.

Az. a lion ramp. arg. a chief erm. a label gu. Colvile.

Az. a lion ramp. arg. a chief or. Huninges.

Az. crusily and a lion ramp. arg. a chief nebuly sa. and of the last. DALTON, Croft.

Az. crusily or a lion ramp. guard. arg. a chief barry nebuly of four of the last and sa. DaLton, Bispham, co. Lancaster. DalTon, Kingstonon-Hull, Hawkeswell, Bedale, and Sleningford, co. York; Visitation 1666.

Az. a lion ramp. guard. arg. a chief erm. Phillms, Ickford, co. Buckingham.

Az. a lion pass. or a chief erm. Kent.

Az. a lion pass. guard, or a chief erm. KENT, Thatcham, co. Berks. Kent, co. Berks, co, Gloucester, co. Lincoln, co. Warwick, Duvis, co. Wilts, and co. York; granted 1600-35.

Az. a lion ramp. or a chief gu. Gower. Sir Robert Hastang, $L$. Querion or QuerRyn.

Az. a lion ramp. tail forked or a chief gu. Hastings, co. Stafford.

Az. a liou .... and a chief or. Dicoy.

Az. a lion ramp. and a chief or. Dicer, $V^{*}$. Dixx, Lord Mayor of London 1585. Dixie, Bosworth, co. Leicester,Bart. Ponton, Scotland.

Gu. a lion ramp. arg. a chief chequy or and az. WARREN. John WARREN, Bishop of St. Davids 1779, Bangor 1783-1800. WARREN, London, $V^{*}$.

Gu. a lion pass. and a chief or. HICKEY.

$\mathrm{Gu}$. a lion pass. guard. and a chief or. Barnett.

Or a lion ramp. az. a chief gu. Sutton, Essex.

Or a lion ramp. tail forked gu. a chief az. AsHCOMB or AIsHCOMB, co. Berks. 1612.

Or a lion ramp. tail forked gu. armed and langued az. a chief of the third. Arscomb, Liford, co. Berks.

Or a lion ramp. and a chief gu. Farquhatison. M'CoMbie.

Or a lion ramp. gu. a chief vair. Sr. John de SutTon, $M$.

Or a liou pass. sa. a chief gu. Rushton, co. Lancaster and co. Stafford.

Or a lion ramp. sa. a chief gu. a label of five points arg. Thomas DAMPIER, Bishop of Ro. chester 1802, Ely 1808-12. Dampier, Colingshays, co. Somerset.

Or a lion pass. sa. a chief indented of the last. Wheller, Dorking, Surrey.

Or a lion ramp. and a chief sa. Phurrs, Tam. worth, co. Warwick.

Or a lion ramp. vert a chief gu. Dixy, co. Huntingdon and London.

Sa. a lion pass. arg. a chief indented or. Margesson, Offington, Sussex; descended through Maraetson, Rotherham, from Margesson or MaRgetson, Wakefield, co. York; quartering Whitebread.

$\mathrm{Sa}$. a lion pass. guard. arg. a chief engr. or. MARGETSON.

Sa. a lion ramp. and a chief or. Brion. Buttery, co. Northampton. Foulk Buttery, Marston, $W^{F}$; given to Cressant Buttry alias Matany, Laurence-Marston, co. Northampton; by Cooke; $W$.
BEAST. LION and in chief.... cont.

on a Chief.....Anchor

Az. a lion ramp. arg. supporting a rudder or on a chief of the second an anchor sa. betw. two 3-foils ppr. Henley, Waterpery, co. Oxford.

Paly of six or and gu. a lion pass. ppr. on a chief az. an anchor of the first betw. two martlets arg. Usborne, Cooling, Suffolk.

\section{..... Annulets}

Or a lion ramp. double tailed sa. on a chief gu. two annulets interlaced of the field. WeLLS, East Allington, and Portlemouth, co. Devon.; quartering Bury and Fortescue.

$$
\text { .....Arrows }
$$

Or a lion ramp. vert on a chief of the second three demi darts of the first. TRIgGs or TrYgG, co. Devon.

\section{.....Axes}

Arg. a lion pass. gu, on a chief of the last three pole-axes of the first. JACKson; quartering or three bars wavy az. on a canton gu. a lion pass. guard. or. J ACKson, co. Derby, and co. Stafford. J ACKson, Bubnell, co. Derby; Visitation 1662. JACkson, Glanbeg, co. Waterford.

$$
\text { .... Beast }
$$

Chequy arg. and gu. a lion ramp. guard. or on a chief of angmentation wavy az. a seahorse naiant ppr. betw. two Eastern coronets or and above the word "Havannah." Pocock, Hart, co. Durham, Bart.

$$
\text { .....Beasts }
$$

Erm. on a mount vert issuing from park palings with gate ppr. a lion ramp. or holding in the dexter paw a scimetar all ppr. on a chief in. dented sa. two lions ramp. arg. Bune; quartering Davis, Higford, and Scudamore. .....Bendlet

Az. a lion pass. guard. or on a chief erm. a bendlet sa. O'H HCKIE, Ireland. .....Bendlets

Arg. a lion couchant tail reflexed between the legs over the back gu. on a chief of the first two bendlets of the second betw. three fleurs-de-lis bendwise in bend sinister az. Trelawarren, quartered by Bevile, Harl. MS., 1079 , fol. $37 \mathrm{~b}$.

Arg. a lion pass. gu. on a clief of the first two bendlets betw. three fleurs-de-lis of the secoud. Trelowarnen, Trelowarien, Corriwall; the heiress m. Beville.

$$
\text { ..... Billets }
$$

Sa. a lion ramp. or on a chief of the last seven billets az. Normand, Scotland.

$$
\text { .....Bird }
$$

Arg. a lion. ramp. gu, on a chief erm. a martlet of the second. MoncriefF, France.

\section{....Birds}

Arg. a lion ramp. ..... on a chief az. two doves ... Formby.

Or a lion ramp. gu. on a chief az. two doves rising arg. Writams, Boston, New England; granted 1767.

Az. a lion pass. or on a chief arg. three Cornish choughs ppr. RoFfey.

Gu. a lion ramp. arg. ducally crowned or on a chief of the last three Cornish choughs ppr. ColebrookE.

Vert. a lion pass. gu. on a chjef az. three doves close arg. RoFr.

Or a lion pass. sa. on a chief of the second three eagles displ. of the first. Sidex, Bures St. Maryes, $1530, W$. 
BEAST, LION and in chief.... cont.

on a Chief.... Birds cont.

Arg. a lion ramp. az. on a chief sa, three martlets of the first. MaNBr, co. Lincoln, $W$.

Az. a lion ramp. or on a chief sa. three martlets arg. Manby.

Gu. a lion ramp. erm. crowned or on a chief of the last three martlets sa. CoLebnoks, Ash. well, co. Herts.

$\mathrm{Gu}$. a lion pass. erm. on a chief of the last three ravens ppr. RoFFEx, London, granted ....

\section{.... Book}

Erminois a lion ramp. az. on a chief per pale erm. and gu. a book open ppr. betw. two roses of the fourth and arg. ManT.

Gu. a lion ramp. guard. or holding in the dexter paw a key erect arg. on a chief wavy az. an open book with clasps ppr. surmounted of a crosier gold a canton arg. charged with a cross gu. betw. four crosses patty fitchy at the foot sa. Bishopric of QUEBEc.

\section{.....Canton}

Arg. a lion ramp. gu. a chief wavy az. on a canton or an eagle displ. sa. Russeld, London.

$$
\text { .... Castle }
$$

Arg. a lion ramp. sa. collared or on a chief az. a tower triple-towered of the field betw. two bezants each charged with a cross formy gu. STockwen, Blackheath, Kent.

Gu. a lion pass. arg. on a chief sa. a tower tripletowered or. Chastelper.

Gu. a lion pass. or on a chief sa. a tower arg. Chestlyer, $V$.

Or a lion ramp. sa. on a chief of the last a tower triple-towered of the first betw. two bezants. Stocket, St. Stephen's, Kent ; and London.

\section{.....Coronet}

Arg. a lion pass. sa, on a chief of the second a ducal crown or. Jones, Kevill, co. Wilts; granted by Cooke, $W$.

Arg. a lion pass. sa, on a chief of the second a marquis's coronet or. Jones, co. Wilts.

Arg. a lion pass. sa. langued gu. armed or on a chief of the second a ducal coronet of the last. Jones, Revell, co. Wilts.

Az. a liou ramp. supporting a cabled anchor or on a chief wavy erm. an eastern crown of the second betw. two lion's heads erased sa. Richardson, London.

$$
\text { ....Coronets }
$$

Az. a lion ramp. arg. supporting the sword of the City of London ppr. upon a chief of the second three oriental crowns two and one the points alternately radiated gold encircled by two branches of olive also ppr. Domvince, St. Albans, co. Hertford, Bart., Lord Mayor of London, and Baronetey 1814; quartering Domvile, Baronetcy 1686, extinct 1768 , with six lozenges conjoined in bend sa., and arg. five lozenges ennjoined in pale gu.

Or a lion pass. sa. on a chief of the second a ducal crown of the first. JoNEs, $V^{*}$.

$$
\text { .....Crescent }
$$

Arg. a lion ramp. gu. on a chief of the last a crescent betw. two mullets or. FYFE, Scotland. FyFfe, Dron, Scotland.

Gu. a lion ramp. arg. on a chief of the second a crescent betw. two mullets az. LigoNien, France.

Gu. a lion ramp. or on a chief arg. a crescent betw. two annulets az. IIGONIER, London, and Cobham, Surrey.
BEAST. LION and in chief.... cont.

on a Chief..... Crescent cont.

Or a lion ramp. gu. a chief tortilly gu. and vert charged on the first with a crescent arg. betw. two mullets of the last in the second. Macritchie, Edinburgh.

Or a lion ramp. gu. armed and langued az. on a chief of the second a crescent betw. two stars of the first. FirE.

\section{....Crescents}

Az. a lion ramp. or on the head a naval crown arg. a chief of the second charged with two crescents of the first. Punling, Hatton Garden, London; granted 1759.

Az. a lion ramp. crowned with an eastern coronet or on a chief of the last two crescents gu. Puritng.

Arg. a lion pass. gu. tied to an oak tree ppr. on a chief az. three crescents of the first. Ronald. $\mathrm{Gu}$. a lion ramp. guard. or on a chief arg. three crescents of the field. DEane, London.

Per bend or and gu. a lion ramp. counterchanged on a chief vert three crescents arg. Simpson, Ireland.

Per fess az. and arg. a lion ramp. counterchanged on a chief potent or three crescents per pale gu. and of the first. Moxos.

$$
\text { .....Cross }
$$

Or a lion pass. az. crowned .... on a chief arg. a Jerusalem cross betw. four croslets gu. and on each side a sword of the third handled gold. A coat of Sir Richard ClOUGH, ob. 1570.

Or a lion ramp. sa. on a chief az. a cross croslet betw: a mullet on the dexter and a rose on the sinister side arg. a mullet of the second for diff. Fargus.

Per bend sinister gu. and or a lion ramp. counterchanged on a chief wavy arg. a cross raguly couped of the first. Simpson.

Per bend or and arg. a lion ramp. az. on a chief of the last a cross patty fitchy of the second between two mullets of the first. Matthew Basquer, Flytte, Isle of Wight, $V$.

Per bend or and arg. a lion ramp. az. on a chief of the last a cross patty fitchy between two mullets of the first. BASKER or BASQUER, $V^{*}$.

Per bend or and arg. a lion ramp. az. on a chief gu. a cross patty fitchy betw. two estoiles of the second. BASQUER, Isle of Wight.

$$
\text { ....Crosses }
$$

Arg. a lion pass. gu. on a chief az. three crosses croslet of the field. LitTuEdare, White. haven.

Arg. a lion pass. gu. on a chief az. three crosses croslet or. IITTLEDAIE.

Arg. a lion pass. sa. on a chief of the last three croslets croslet of the first. Edward LoNGE, Monkton, co. Wilts; granted by Cooke, $W$.

Az. a lion ramp. or on a chief of the last three crosses patty of the first. JoHNs.

Sa. a lion pass. arg. on a chief of the second three crosses croslet of the first. LoNG, Rowde Ashton, co. Wilts; granted 1589.

Sa. a lion pass, arg. holding in the dexter paw a cross croslet fitchy or on a chief of the second three crosses croslet of the field. LoNG, Longville, Jamaica; and Hampton Lodge, Surrey, (descended from LoNGE, Netheravon, co. Wilts, ob. 1630); quartering Tate, Zouche, and St. Maur. LoNG, Baron Farnborough, descended through LoNG, Carshalton Park, Surrey, from LoNg, Longville, Jamaica. 


\section{BEAST. LION and in chief....cont.}

on a Chief.... Crosses cont.

Sa. a lion pass. arg. armed and langued gu. on a chief of the second three crosses croslet of the first. LoNG.

Sa. a lion pass. or on a chief arg. three crosses croslet of the field. LoNG.

$$
\text { .....Escallop }
$$

Gyronny of six or and az. over all a lion ramp. erm. on a chief arg. an escallop betw. two fleurs-de-lis sa. Mutcow, co. Gloucester and co. Worcester.

Gyronny of eight or and az, a lion ramp. counterchanged on a chief arg. an escallop betw. two fleurs-de-lis sa. Macklowe. M'Lowe.

Gyronny of eight or and az. a lion ramp. erm. on a chief arg. an escallop betw. two fleurs-delis sa. MackLow or MuckLowe. William Mucktow, co. Worcester, $V$.

Gyronny of eight or and az. a lion ramp. erm. on a chief arg. an escallop betw. two fleurs-de-lis sa. a canton gu. MockLow, Broughton Soulney, co. Nottingham.

Gyronny of twelve gu. and az. a lion ramp. erm. tail forked on a chief arg. an escallop betw. two fleurs-de-lis sa. Mockuow or MuckLaw, co. Worcester.

\section{....Escallops}

Arg. a lion pass. gu. on a chief az. three escallops or. Diblo or Dibloy.

Arg. a lion ramp. gu. on a chief sa. three escallops of the field. KEMP. Rosseli, Duke of Bedford. Russell, Earl of Bedford, $V$. Russeli, Lord Russell, $Z, 354,357$. Sir John Russel, co. Dorset, $V$. Russelt, Earl of Orford, 1713. Russeld, Moore Green, King's Norton, co. Worcester. Russelu, King's Heath, co. Worcester, Esa.; the heiress m. Bailey.

Arg. goutty de sang a lion ramp. gu. on a chief of the last three escallops or. Patison, England. Patisison or Patison, co. Berwick.

Alg. goutty de poix a lion ramp. sa. on a chief az. three escallops of the field. Patrison, Glasgow.

Bendy of six or and az. a lion pass. arg. on a chief gu. three escallops of the first. GoBrss. ..... Estoile

Arg. a demi-lion ramp. naissant out of the base gu. armed and langued az. on a chief indented sa. a star betw. two crescents of the first. Mitchelson, Middleton, co. Edinburgh.

Arg. a lion ramp. az. on a chief gu. an estoile betw. a cross croslet fitchy and a rose lof the field. Fergusson, Craigdaroch, Scotland.

Erm. on a rock in base ppr. a lion ramp. gu. on a chief wavy az. an estoile or betw. two plates the dexter charged with a sword erect also ppr. pomel and hilt gold and the sinister with an anchor sa. Sтотт, Quebec, granted ....

$$
\text { .....Estoiles }
$$

Az. a lion ramp. arg. on a chief engr. of the second three stars of the first. INGLIs, Newtounleyes, Scotland.

$$
\text { .....Feathers }
$$

Or a lion ramp. az. on a chief of the second three ostrich feathers arg. Pranes, Westbury, co. Buokingham.

Or a lion ramp. az. on a chief of the last an ostrich's feather of the first betw. two others arg. Prunes, Westbury, co. Buckingham.

Or a lion ramp. reguard. sa. on a chief wavy az. three ostrich feathers arg. Roberts, Stepney, Middlesex.
BEAST. LION and in chief.....cont.

\section{on a Chief.....Flenr-de-lis}

Erm. a lion ramp. guard.az. on a chief embattled gu. a fleur-dle-lis or betw. two boar's heads couped erect arg. TAYLOR, Pennington House, co. Hants.

Gn. a lion pass. gnard. or on a chief az. a fleurde.lis of the second. Town of Lancaster.

Vert a lion ramp. arg. on a chief gu. a fleur-de-lis or betw. two castles of the second. PLAyFord, Kent, Norfolk, and Suffolk.

Vert. a lion ramp. arg. on a chief or a fleur-de-lis gu. betw. two castles ppr. Playfaip, Meigle, Scotland.

\section{....Fleurs-de-lis}

Gu. a lion ramp. or on a chief of the last three fleurs-de-lis of the first. GrwLow.

Or a lion pass. sa. on a chief gu. three fleurs.delis arg. GlasBrook. .....Flower

Arg. a lion pass. guard. gu. tied to an oak tree ppr. on a chiof az. a rose slipped betw. two crescents of the first. RonaLD, Montrose, Scotland.

Arg. a lion pass. guard. gu. on a chief vert a rose betw. two crescents of the field. Smimson, London.

Arg. a lion ramp. gu. on a chief erm. a rose of the second. MoncriefF, Readie, Scotland. And with a crescent for diff. MoncriefF, Murnyfray, Scotland.

Per pale indented az. and or a lion pass. guard. counterchanged on a chief arg. a rose betw. two fleurs-de-lis gu. CRofton. Dewin.

$$
\text { ..... Flowers }
$$

Arg. a lion ramp. gu. on a chief sa. three roses of the first. Rússell, Fordham, Suffolk; the beiress m. Dyer; descended from Thomas Russel., Yaverland, Isle of Wight; ob. 1438, through Russer., Chippenham, co. Cambridge; and Checquers, co. Buckingham; Baronetcy 19 January 1628-9, extiuct 1804 ; the heiress $\mathrm{m}$. Greenhill. Greenhill Russei., Checquers, co. Buckingham; Baronetcy 15 September, 1831, extinct 1837. Frankland Russelu, Thirkelby, co. York, and Checquers, co. Buckingham; Baronetcy 24 December, 1660; quartering Franliland. Russex, Laugherne, co. Carmartlien, $Z, 371$. Russeld, Workington, Cumberland. Russect, Swallowfield Place, co. Berks ; Baronetcy 1812.

Arg. a lion ramp. gu. on a chief sa. three roses of the field seeded or barbed vert. Russele, Laugherne, co. Carmarthen; Baronetcy 1660; descended from Russell, Chippenham; the heiress m. Cotton and Somerset. Greenhill Russell, Checquers, co. Buckingham; Baronetcy 15 September, 1831, extinct 1837 ; quartering vert two bars arg. in ehief a lion pass. of the last; and erm. on a chief gu. a lion pass. arg. Az. a lion ramp. arg. on a chief of the last three roses of the first. Gillow.

Erm. a lion ramp. gu. collared arg. on a chief az. three roses of the third barbed vert and seeded or. Russeli, Ilam Hall, co. Stafford; and Biggin House, co. Northampton; quartering Watts.

Sa. a lion ramp. arg. on a chief of the second three roses of the first. GLLOCK.

Vert a lion ramp. or on a chief of the last three roses gu. Newton, Newton, co. Haddington, 1377 , Bart.

$$
\text { ....3-Foil }
$$

Or a lion pass sa. on a clief of the second a 3.foil slipped arg. Rushton, co. Lancaster. 
BEAST, LION and in chief....cont. on a Chief.....3-Foil cont.

Or a lion pass. sa. on a chief of the last a 3.foil slipped of the field. Rishton, Elswick, co. Lancaster; derived through Richton, Holmes Wood, and Rishton, Dunkenhalgh, from Henry de Blackburn, whose grandson Henry assumed the name of Rishton. ....5-Foil

Arg. a lion ramp. ermines on a chief gu. a 5 -foil betw. two crosses croslet or. Huxhasi, Plymouth, co. Devon, and London; granted November, 1750 .

$$
\text { ....5.Foils }
$$

Arg. a lion ramp. sa. on a chief gu. three 5-foils of the field. BALLETT, London; granted 1582-3. But the 5-foils or. Balletr, Hatfield, Essex. ....Fruit (Acorn)

Or a lion pass. reguard. az. on a chief dovetailed vert three acorns slipped and leaved of the first. JoHNSON, Warrington, co. Lancaster, 1741. ....(Corn)

Erm. a lion ramp. gu. on a chief az. an ear of bigwheat couped and bladed or betw. two estoiles arg. Bigneli, Salisbury; and London.

$$
\text { .... Garbs }
$$

Arg. a lion ramp. sa. armed and langued gu. on a chief az. three garbs or. JoNEs, Glyn Arthur; and Llanerchrugog, co. Denbigh ; quartering Bleddin ap Cynffn, Wood, Smallman, Bwla, Jones, Talbot, Trevor, and Gellyn ap Blaidd Rhudd.

$$
\text { .... Hand }
$$

Vert a lion ramp. or on a chief arg. a hand erect gu. Maginnise, Ireland.

$$
\text { ..... Hands }
$$

Az. a lion ramp. arg. on a chief or two dexter hands couped gu. Magennis, Ireland.

Or a lion ramp. az. on a chief arg. two dexter hands couped gu. Crosey.

Or a lion ramp. gu. on a chief of the last three dexter hands apaumy of the first. M'BEAN, Scotland.

$$
\text { .... Harp }
$$

Arg. a lion sejant in a wood ppr. on a chief wavy gu. a harp betw. two anchors or. Wood, Ireland.

\section{....Head (Beast) Boar}

Arg. a lion pass. gu. on a chief az. a boar's head couped or betw. two spur rowels of the first. FinLason, Scotland.

Arg. a lion pass. gu. on a chief az. a boar's head couped or betw. two pierced mullets of the field. Fincayson, Scotland.

$$
\text { .....Deer }
$$

Erm. a lion ramp. sa. on a chief engr. vert a stag's head cabossed betw. two garbs or. PHILlips, Whitmore Hall, Coventry.

$$
\text { .... Leopard }
$$

Chequy erm. and sa. a lion ramp. gu. on a chief of the second a leopard's face betw. two crosses croslet fitchy or. Cooke.

Erm. a lion ramp. az. on a chief sa. a leopard's face arg. betw. two crosses croslet or. CLARK, Buckland Tout Saints, co. Devon.

Gu. a lion ramp. arg. on a chief wavy of the last a leopard's face betw. two 5 -foils .... LANGMEAd, co. Devon.

$$
\text { ....(Human Figure) }
$$

Vert a lion ramp. or on a chief arg. a man's head couped at the neck and bald ppr. betw. two ducal coronets of the second. Mulladay, Meath, Ireland.
BEAST. LION and in chief.... cont.

on a Chief.... Heads (Human Figure)

$\mathrm{Gu}$. a leopard ramp. reguard. arg. pierced in the side with an arrow in bend sinister of the last on a chief or three Moor's heads in profile erased at the neck ppr. Moneav, certified May 1770.

$$
\text { ..... Keys }
$$

Arg. a lion ramp. sa. armed and langued gu. on a chief of the second two pairs of keys con. joined and addorsed palewise of the first. Hide or Hyde or New-Minsten Benedictine Albey, co. Hants, $U$.

Arg. a lion ramp. az. on a chief of the last three lozenges of the first. CRICHTON, Ruthven, Scotland.

Arg. a lion ramp. sa. on a chief crenelly gu. three lozenges or. Buttery or Buttry.

Arg. a lion ramp. sa. on a chief of the second three lozenges or. Foulk Butreny, Marston; given to Cressant Buttry alias Matany, Laurence-Marston, co. Northampton, by Cooke, $W$.

Or a lion pass. guard. sa. on a chief gu. three lozenges vair. Goodwis, London.

Sa. a lion pass. guard. or on a chief of the last three lozenges of the first. Westmore, Middleton; and Preston, co. Lancaster.

$$
\text { ....Mascles }
$$

Or a lion pass. guard. sa. on a chief gu. three mascles vair. Goodwin, Arlscot, co. Warwick.

Or a lion ramp. sa. on a chief of the last three mascles of the first. Peters, London; granted 1748.

$$
\text { .....Monster }
$$

Arg. a lion ramp. gu. on a chief sa. a salamander in fire ppr. DUNDAS, Kinkevil, Scotland.

$$
\text { .....Mullet }
$$

Arg. a lion ramp. gu. on a chief erm. a mullet of the second. Moncrief, Rapness, Scotland.

Az. a lion ramp. or on a chief arg. a mullet gu. betw. two torteaux. Sиiтн, Hammersmith, Middlesex. Sir John Surth, Middlesex, Bart.; quartering gu. two chevrons and a bordure arg. 1716.

Gu. a lion ramp. or on a chief arg. a mullet betw. two crescents az. LigonIER, Earl Ligonier.

Gu. a lion ramp. or on a chief of the last a mullet of the field betw. two hurts. Sнутн.

$$
\text { ..... Mullets }
$$

Arg. a lion ramp .... on a chief az. three pierced mullets of the field. MiMurray, Worriston, Seotland.

Arg. a lion ramp. gu. on a chief sa. three mullets of the first. Whitney, Ireland, $V$. Witley, Ireland.

Arg. a lion ramp. sa. on a chief az. three mullets of the first. HyNdasyd or Handyside, Gains Park, co. Huntingdon; and Scotland.

Arg. a lion ramp. sa. in the dexter forepaw a 3 -foil slipped vert on a chief az. three mullets or. O'CONNELr, Ireland.

Arg. a lion pass. sa. on a chief of the second three mullets of the first. BaLL, co. Northampton; granted 1613

Arg. a lion ramp. sa. on a chief of the second three mullets of the first. WHITNEY, $V^{*}$.

Arg. a lion ramp. sa. on a chief indented of the last three mullets of the first. PAnIse, Guuwin in Lelant, Cormwall.

Az. a lion ramp. arg. on a chief of the first (? second) three mullets gu. BLAck. 
BEAST, LION and in chief.... cont.

on a Chief.... Mullets cont.

Az. a lion ramp. arg. on a chief or three mullets of the field. INGLIs, Edinburgh.

Az. a lion salient arg. on a chief or three mullets of the first. InouIs, Cramond, Scotland.

Az. a lion pass. arg. on a chief engr. or three mullets sa. Stayner; quartered by Holford.

Gu. a lion ramp. arg. on a chief or three mullets pierced az. Joburn, Newton Hall, Northumberland.

Gu. a lion ramp. arg. on a chief or three mullets sa. Whatiey, Mayor of Bristol, 1768. Whatrey or Wheatley, Whatley, Frome, co. Somerset.

Gu. a lion ramp. or on a chief arg. three mullets sa. WiскнAп, Ireland.

Or a lion ramp. gu. on a chief az. three mullets arg. Mrluan, Scotland.

Or a lion ramp. gu. on a chief az. three pierced mullets of the field. FIFFE.

Or a lion ramp. sa. armed and langued gu. on a chief of the last three mullets of the first. Chanceler, Shieldhill, Scotland.

Or a lion ramp. sa. on a chief per fess of the first and gu. three mullets arg. M'MilLaN, clau Buchanan.

Per bend sinister erm. and ermines a lion ramp. reguard. erminois on a chief az. three mullets of. six points arg. Davis, London and Westminster, granted 1746 .

$$
\text { ..... Pack }
$$

Per saltire arg. and gu. a lion ramp. guard. or on a chief wavy az. a woolpack of the first betw. two bezants. Back. ....Roundle

Arg. a lion ramp. gu. on a chief sa. a bezant betw. two escallops of the first. Russer., co. Dorset. ....Roundles (Bezants)

Or a lion ramp. az. on a chief indented gu. three bezants. Raven, Bramerton, Norwich.

Or a lion ramp. double tailed az. on a chief indented sa. three bezants. Raven, granted 15 October, 1561 .

$$
\text { .....(Plates) }
$$

Arg. a lion ramp. gu. on a chief of the last three plates. HutroN, Ireland.

Or a lion ramp. az. on a chief indented gu. three plates. RAven.

$$
\text { ....(Torteaux) }
$$

Az. a lion ramp. or on a chief arg. three torteaux. Sir Thomas Sirte, Clerk of the Council, $W$. Smith, Parson's Green, Middlesex.

$$
\text { ..... Saltire }
$$

Arg. a lion ramp. gu. on a chief erm. a saltire engr. of the second. HICKEY.

Arg. a lion sejant guard. gu. armed and langued az. holding in his dexter paw a thistle ppr. and in his sinister a shield of the second on a chief az. a St. Andrew's cross of the first. LYoN-Office or OfFice of Arus at EDINBURGH.

Gu. a lion pass. or on a chief arg. a saltire engr. az. charged with a lion pass. guard. of the third. HickIE, Billing, co. Northampton.

$$
\text { ..... Saltires }
$$

Arg. a lion ramp. sa. on a chief dancetty of the last three saltires couped or. GwiLt, co. Montgomery; Surrey ; and Westminster.

Bendy of six az. and or (or and az. $V^{*}$ ) a lion pass. guard. arg. on a chief gu. three saltires couped of the third. Sir Hugh Gosion, $V$.

Bendy of six or and az. a lion pass. arg. on a chief gu. three saltires or. GobyNs.
BEAST. LION and in chief.... cont.

on a Chief..... Sprigs

Arg. a lion pass. gu. on a chief .... three oak sprigs bearing acorns ppr. JoHnson.

Gu. a lion ramp. or on a chief of the second three laurel hranches erect ppr. Brooke Pechell, Pagglesham, Essex; Aldwick, Sussex; and Twickenham, Middlesex, Baronetcy 1 March, ]797.

\section{....sword}

Gu. a lion pass. arg. combatant with a snake which entwines round his body ppr. a martlet or for diff. on a chief embattled of the second a sword erect ppr. hilt and pomel gold. betw. two laurel branches ppr. inclining towards the sword. Ga1Tskitl.

Sa. a lion ramp. reguard. arg. on a chief em. battled or a sword erect ppr. hilt and pomel gold enfiled with an eastern crown gn. betw. two tiger's faces also ppr. FLoyd.

\section{.... Swords}

Arg. a lion ramp. sa. on a chief gu. two seaxes (i.e. Saxon swords) in saltire of the first hilts and pomels or. Gom, Clerkenwell, Middlesex; granted 24 January, 1761. Gomme, High Wy combe, co. Buckingham.

$$
\text { .....Trees }
$$

Arg. a lion ramp. gu. on a chief of the last three oak branches of the first. WooD, Oxford.

Coronet

Arg. in base a lion pass. sa. in the dexter chief an imperial crown upon a cushion ppr. O'KENNELIY, Irelard.

Gu. a lion ramp. or armed and langued az. over his head a ducal coronet gold. HumFrex, Dublin; and Honfrex, Rishangles, Suffolk; confirmed 26 January, 1638 . HUMFREY or Humphrex, Holbroke and Dunkstone, Suffolk. Gu. a lion ramp. .... holdirg in the dexter forepaw a crescent .... in chief a ducal coronet .... O'KegGaN, Ireland.

\section{Crescent}

Arg. a lion ramp. gu. in the dexter chief a crescent of the last. Dundas, Fingask, Scotland.

Arg. a lion ramp. tail forked sa. a crescent in dexter chief.... Newton, in East Mascall church, Sussex; 1578.

Az. a lion ramp. and in chief a crescent arg. Agar, Earl of Normanton.

Az. a lion ramp. arg. crowned or in chief crescent of the second. M'Dougati, Castle Semple.

Az. a lion ramp. or a crescent (? for diff.) . . . Hotherseld, St. Bride's, London, 1615.

Gu. a lion salient (ramp. $V^{*}$ ) and in the dexter chief point a crescent arg. Thomas Salisburx, co. Northampton, $V$.

Per pale sa. and gu. a lion pass. guard. and in chief a crescent arg. NEALE.

\section{Cross}

Arg. a lion ramp. and a cross croslet gu. Havering, co. Wilts.

Arg. a lion pass. gu. in chief a cross croslet fitchy sa. Seabrook.

Arg. a lion pass. coward sa. in chief a cross formy fitchy gu. Hizard.

Gu. a lion ramp. double tailed and crowned or in the dexter chief point a cross croslet fitchy arg. Peasley, Kildare, Ireland.

Gu. a lion ramp. or in the first quarter a cross patty vail. REson or REAson. Sire Johan de Resoun, $N$. 
BEAST. IION and in chief....cont.

Cross cont.

Or a lion ramp. sa. in chief a cross croslet betw. a mullet of six points on the dexter and a rose on the sinister.... Fearguson, Ireland.

Crosses

Per chev. embattled az. and arg. in base a lion pass. sa. ducally crowned gold in chief three crosses patty fitchy or. SuIth, Bristol, co. Somerset; granted 4 July, 1766.

Escallop

Sa. a lion pass. arg. in chief an escallop betw. two estoiles or. 'TaYLOR, Portsmouth, co. Hants; granted 1750.

\section{Escallops}

Barry wavy of seven arg. and az, a lion ramp. or in chief two escallop shells of the second. FiELd, Heaton Hall, Helmesley Lodge, and Weston House, co. York ; quartering Wilmer, Thweng, Bruce, etc.

Arg. a lion ramp. gu. in chief three escallops sa. Clutterbuck, Stanmore, Middlesex.

Az. a lion ramp. and in chief three escallops arg. Clutterbuck, Newcastle; and Warkworth, Northumberland; descended (like Clutterbuck, Ireland; and Marazion, Cornwall, through Thomas Clutterbuck, Archdeacon of Winchester) from CuUtTersuck, Eastington, co. Gloucester; derived from Clotterbooke, King's Stanley, ob. 1591. Sir Thomas Clitterbeck, Alderman of Liondon, 1669. Clutterbuck, Newark Park, Ozleworth, co. Gloucester. Clutterbock, Harnish House, co. Wilts. Clutterbuck, Lippiat, co. Gloucester.

Az. a lion ramp. arg. in chief three escallops or. Clutterbuck.

\section{Escroll}

Arg. a lion ramp. az. holding in his dexter paw a chaplet of laurel vert in chief a scroll sa. thereon the word EmManuel or. Emmanuel College, Cambridge, founded 1584 by Sir Walter Mildmay, Chancellor and Treasurer of the Exchequer.

\section{Estoiles}

Per fess az. and gu. on the second a lion pass. on the first two stars arg. NEwron, Dalcoif, Scotland.

Az. a lion ramp. and in chief three stars arg. INGLIs, Manners and Mannerhead, Scotland.

Gu. a lion pass. and in chief three stars arg. Newton, Scotland.

Or a lion ramp. and in chief three stars gu. Fairlie, Bruntsfield, Scotland.

Vert a lion ramp. and in chief three estoiles or. O'MORE, Leix, Ireland.

\section{Tishes}

Or in base a demi lion couped and in chief two fishes naiant az. Mervys, Ireiand.

Fleur-de-lis

Sa. a lion ramp. tail forked and nowed arg. within the tails a fleur-de-lis arg. Metrond, $V$.

Sa. a lion ramp. double tailed between the tails a fleur-de-lis arg. Metfond, $V^{*}$.

$$
\text { 3-Foils }
$$

Arg. a lion ramp. gu. in chief three 3-foils slipped vert. GAYNER or Gaynor, Ireland. 5-Foil

Arg. a lion ramp. double tailed sa. in the dexter canton a 5 -foil gu. Cressy.

Per fess az. and gu. a lion ramp. or in the dexter chief point a 5 -foil arg. HEBER, Marton, co. York; confirmed 1569 ; the last male heirs of this family were Richard HEBER, of Hodnet
BEAST. IION and in chief.... cont.

5-Foil cont.

and Marton, ob.1833, and his brother, Reginald Heber, Bishop of Calcutta, ob. 1826.

Flower (Rose)

Per chev, vert and or in base a lion ramp. reguard. az. in chief a rose of the second betw. two fleurs-de-lis arg. Gidon, London, and Spalding, co. Lincoln.

$$
\text { ....(Thistle) }
$$

Arg. a lion pass. guard. gu. gorged with an open crown and crowned with an imperial one ppr. holding in the dexter paw a sword of the last defendirng the thistle placed in the dexter chief point vert ensigned with a crown or. OGIIVIE, Barras, co. Kincardine, Bart.

\section{Flowers}

Erminois a lion ramp. double tailed gu. issuing from an antique crown az. in chief two thistles ppr. Galliohtly.

\section{Hand}

Arg. a lion ramp. in the dexter chief a dexter hand in sinister chief an increscent gu. KEoaH, Ireland.

Per pale or and gu. a lion ramp. in the dexter chief a right hand couped and in the sinister a cross croslet fitchy all counterchanged. M'Laughian, England.

\section{Hands}

Arg. a lion ramp. and in chief two dexter hands gu. Magawly, now Magawley Cerati, Princes of Calry, co. Westmeath. Field-Marshal Philip Henrr Magawly was made a Count, 1631, by Charles VI, Emperor of Germany.

Arg. a lion ramp. and in chief two dexter hands gu. over all a fess or charged with as many lions ramp. counter-rampant supporting betw. them a third hand couped all of the second. Burrard, Bart.

Arg. on a mount vert in base a lion ramp. ppr. in chief two dexter hands couped ga. O'BRENON, Jobh, Duach, Ireland.

Arg. a lion ramp. sa. in chief two dexter hands couped and erect gu. CrosbIE, Lord Brandon and Earl of Glandore; the heiress m. Talbot; descended from Crosbie, Bishop of Ardfert. Crosbie, Ardfert Abbey, co. Kerry. Crosite, Maryborough, Queen's County; Bartcy. 1630.

Per fess arg. and or a lion ramp. per fess gu. and sa. in chief two dexter hands of the third. DaLY, Benmore, and Dunsandle, co. Galway.

Az. a lion pass. guard. or in chief three sinister hands arg. JoLLEY or JoLLY, Hatton Garden, London; granted 1692.

\section{Heads}

Or a lion pass, and in chief three esquire's helmets sa. KNAPP; quartering Hambly.

Sa. a lion pass. and in chief three helmets or. KNaPPE, Woodcot, co. Oxford; granted 2 Sept. 1669.

Gu. a lion ramp. arg. ducally crowned or in chief two spearheads of the last. Macnamara, Langoed Castle, co. Brecon; and Caddington Hall, co. Bedford; descended through Macnamara, Irelaud, in common with the O'Briens and the Macmahons, from Cormoc, second son of Olioll Ollon, a descendant of Milesius.

$$
\text { Hearts }
$$

Al'g. a lion ramp..... in chief two human hearts ppr. Corker.

\section{Insects}

Erm. a lion (another a leopard) pass. .... and in chief three bees ppr. Peance, Bishop of Bangor, 1747, Rochester, 1756-74. 
BEAST. LION and in chief....cont.

\section{Insects cont.}

Erm. a lion (another a leopard) ramp. reguard. and in chief three bees volant ppr. Zachary Pearce, Bishop of Bangor, 1747, and of Rochester, 1756-74. Pearce.

Erm. a leopard ramp..... in chief three bees vo. lant sa. Pearse.

Erm. a leopard ramp. guard. ppr. in chief three bees volant sa. Pearce.

\section{Lozenges}

Gu. a lion pass, and two lozenges or. Robert ThornHaM, $X ;$ i.e. Robert (nephew of Michael de Turnham) founder of Bayham Abbey, Sussex. N.B., as this blason is indecisive, see Lion betw.....LLozenges.

\section{Mullet}

.... a lion pass. guard. on an antique ship in the sea with one mast sail furled and pennon flying in chief on the dexter a mullet on the sinister a crescent.... on the sinister side an escucheon of St. George. 'Town of Newtown or Frantile, co. Hants.

Az. a lion ramp. tail forked erm. crowned or a mullet pierced gu. PECHE, Kent.

Az. a lion pass. guard. and in chief a mullet or. THOMPSON.

Or a lion ramp. gu. in chief a mullet of six points az. betw. two boar's heads couped of the second. BraCE, London.

\section{Mullets}

Arg. a lion ramp. az. armed and langued sa. in chief two mullets gu. CRICHTon, Easthill, Scotland, a cadet of Ruthven.

Arg. a lion ramp. and in chief two mullets gu. a chief erm. Moncrief, Edinburgh, Scotland.

Arg. a lion pass. gu. in chief three mullets sa. WitLEY.

Arg. a lion salient gu. in chief three mullets sa. White, $V^{*}$. Whyte, Ireland, $W$.

Arg. a lion ramp. ppr. in chief three mullets gu. Drane.

Az. a lion ramp. and in chief three mullets arg. Anderson, Scotland.

Az. a lion ramp. and in chief three mullets arg. in the centre chief point a crescent for diff. INGLis, Scotland.

Az. a lion ramp. and in chief three mullets arg. in the centre chief point a mullet of the last. INGLEs, Stewart Boone.

Az. a lion ramp. arg, in chief three mullets or. ENGLISH.

Gu. a lion pass. guard. arg. ducally crowned or in chief three pierced mullets of the second. JyLer, Fulham, Middlesex ; quartering Pitt.

Or a lion ramp. sa. in chief three mullets az. MaC MrLuan, Dunmore.

Vert a lion ramp. erminois in chief three pierced mullets of six points arg. Dalmer, London.

\section{Pheon}

Arg. a lion ramp. az. in chief a pheon of the last betw. two mullets gu. M‘CouL, Scotland.

Arg. a lion ramp. gu. in the dexter point a pheon sa. Petyr, Cornwall; London; and co. York.

Gu. a lion ramp. and in chief a pheon betw. two lion's heads erased arg. EDIDGE, Pockeredge House, co. Wilts.

\section{Piles}

Or a lion pass. and in chief three piles sa. LoGGAN or LoGoN, Upton, co. Gloucester; Staverton, co. Berks; co. Oxford; and co. Buckingham. Capt. John Logan, Ibury, co. Oxford, 1730 .
BEAST. IION and in chief.... cont.

\section{Quarter}

Gu. a lion ramp. or and a quarter erm. Andrew de Sharingburne, $Y$.

Roundle (Bezant)

Or a lion ramp. vert collared..... in the dexter chief quarter a bezant charged with a fret gu. Sutron, Renton, co. Lancaster.

$$
\text { .....(Ogress) }
$$

Or a lion ramp. double tailed sa. in the dexter chief point an ogress. WeLis, Holme House. Roundlos

Az. a lion pass. gu. in chief two bezants. O'FLYs, Ireland.

Barry of seven vert and erm. a lion ramp. gu. murally crowned or in chief two plates. Fremantre, Swanbourne, co. Buckingham; Baronetcy 1821.

Sa. a lion ramp. arg. in chief three bezants. Traby.

Sa. a lion ramp. arg. collared vairy az. and ermines in chief three bezants. TreBy, Goodamoor, Plympton, co. Devon.

Sa. a lion pass. or in chief three bezants. Hawkins, Kent.

Sa. on the waves of the sea ppr. a lion pass. or in chief three bezants. Hawrins, Lewell, co. Dorset.

Sa. on a point wavy a lion pass. or in chief three bezants. Sir John Hawkins, Plymouth ; granted 1565 ; with an augmentation of on a canton or an escallop betw. two palmer's staves sa.; granted 1571.

Az. a lion ramp. erm. in chief three plates. Rad.PHSTon, Dublin ; granted 8 Aug. 1674.

Arg. a lion ramp. az. in chief three torteaux. CAIRD.

Arg. a lion ramp. tail forked gu. in chief three torteaux. HaRvaGe.

Arg. a lion pass. vert in chief three torteaux. ToUgr, Scotland.

Arg. a lion pass. gu. on a chief of the second seven plates four and three. MEager.

Ship

Arg. in base a lion pass. gu. and in chief a threemasted ship sails set.... O'Le arIE, Ireland. Sphere

Az. a lion ramp. arg. in chief a sphere betw. two estoiles of five points or. DRYDEN.

Az. a lion ramp. and in chief a sphere betw. two estoiles or. Dryden, Canons Ashby, co. Northampton, Bart. Dryden, co. Northampton, $W$. Tre $\theta$

Or a lion ramp. gu. in chief three fir trees eradicated vert on a canton arg. a flag az. charged with a saltire of the fourth. FARQUHARSON, Finzean, co. Aberdeen; descended from Donald, son of Findla More Farquharson, ob. 1547.

Wreaths

Gu. a lion pass. guard. and in chief two chaplets of laurel (another, civic wreaths) or a chief wavy cliarged with a ship of war before Algiers ppr. PelLew, Viscount Exmouth; granted 1817 .

\section{OTTER and in chief}

on a Chief..... Bird

Arg. on a mount vert in base an otter ppr. a chief gu. charged with a dove of the field betw. two crosses patty fitchy or. William Hart Coleridge, D.D., Bishop of Barbadoes.

Flowers

Arg. in base au otter issuing from water ppr. in chief two roses gu. LithGow, Scotlaud. 
BEAST. $\quad 0 X$ and in chief....

on a Chief..... Bird

Arg. on a mount vert a Pembrokeshire ox statant ppr. a chief gu. charged with a falcon arg. belled betw. two stag's heads erased or. Jones, Pant-glâs and Landovery, co. Carmarthen.

$$
\text { .....Canton }
$$

Arg. on a mount of bulrushes in base ppr. a bull pass. sa. a chief pean billety or with a canton of the last. Scotr, Stourbridge, co. Worcester, and Great Barr, co. Statford.

$$
\text { ..... Flower }
$$

Vert a bull arg. attired and unguled or on a chief erm. a rose gu. Boscoan.

$$
\text { .... Roundles }
$$

Per pale or and arg. a bull sa. on a chief of the last three bezants. CoLE, $V^{*}$.

PANTHER and in chief....

Per fess erm. and sa. in base a panther pass. of the first in chief two mascles of the second. Daniell, Truro, Cornwall.

\section{Birds}

\section{SHEEP}

Per fess wavy az. and arg. in base on a mount vert a ram couchant sa. armed and unguled or in chief three doves ppr. PuJolas, Middlesex; granted 1762.

on a Canton.....Piles

Gu. a lamb arg. on a canton of the last three piles sa. BazETT.

on a Chief.... Insects

Az. in base on ground vert a lamb pass. arg. on a chief of the last three bees ppr. GAUSEN.

$$
\text { ..... Mallets }
$$

Az. a fleece or pendent from a chief sa. charged with three mullets in fess arg. Town of LEEDS.

$$
\text { .....Gouttes }
$$

Az. a fleece arg. in chief six gouttes d'eau. GEDEON.

SQUIRREL and in chief....

Gu. a squirrel sejant cracking a nut or on a chief of the last three fleurs-de-lis az. Stokes, $V$.

\section{on a Chief.....Crosses}

TIGER and in chief....

Arg. a tiger statant sa. on a chief az. three crosses formy of the first. EwER, Bishop of Llandaff 1761 , Bangor 1769-74.

Or a tiger statant sa. on a chief gu. three crosses patty arg. EwER, Luton, co. Bedford, and Lees-Langley, co. Herts.

\section{Mascles}

Per fess erm. and sa. a heraldic tiger arg. in chief two mascles of the second. Daniers, Lymington, co. Hauts.

\section{Chief}

WOLF and in chief...

Arg, a wolf pass. sa. a chief gu. Wood, $V^{*}$. WooD, Islington, co. Middlesex; granted Feb. 1606.

Arg. a wolf salient sa. a chief gu. Wood, W.

Az. a wolf ramp. and a chief arg. DuN; granted 10 Feb. 1605.

Az. a wolf salient and a chief arg. Donne, granted 1605

\section{on a Chief.....Birds}

$\mathrm{Gu}$. a wolf pass. or on a chief crenelly arg. three martlets az. BurgOYN, $V^{*}$.

Gu. a wolf statant or on a chief crenelly arg. three martlets az. John Burgoyn, Sutton, co. Bedford, Auditor, $V$.
BEAST. WOLF and in chief....cont.

on a Chief.....Cross

Az. a wolf ramp. arg. on a chief dancetty of the last a cross croslet fitchy gu. betw. two escallops az. Brooke.

\section{....Crosses}

Arg. a wolf statant sa. on a chief az. three crosses formy of the first. EwER; quartered by Hogg. John Ewer, Bishop of Llandaff, 1761, Bangor, 1769-74.

Az. a wolf pass. or on a clief of the last three crosses patty of the first. EwER. ....Palo

Sa. a wolf salient or on a chief of the last a pale of the first charged with a fleur-de-lis arg. betw. two pellets. Wruson, Highbury Hill, co. Middlesex; Massingham, Norfolk; and Stowlangtoft, Suffolk.

\section{....Roundles}

Arg. a wolf salient sa. collared or on a chief az. three bezants. WOOD, London.

\section{Crescents}

Erm. a wolf pass. and in chief two crescents sa. O'Duane, Ireland.

\section{Crosses}

Az. a wolf ramp. arg. collared and cbained or in chief three crosses patty fitchy of the second. Bushe, co. Wilts.

Sa. a wolf salient and in chief three crosses.... fitchy arg. Rushe, co. Wilts.

\section{Escallop}

Gu. a wolf pass. reguard. and in chief an escallop betw. two horseshoes or. Smrth, East Bourne, Sussex; granted 1758.

\section{Estoiles}

Sa. a wolf salient or in chief two estoiles arg. on a canton.... a cross.... WiLson, Melton, and Rudding Hall, co. York; quartering Fountayne. Christopher WILsoN, Bishop of Bristol, 1783-92.

Sa. a wolf ramp. per fess erm. and erminois in chief two estoiles or. Wrison, Flatt, near Blewcastle, Northumberland; confirmed 3 November, 1773.

Az. a war-wolf pass. and three stars in chief arg. Dickison, Winkelstoun, Scotland.

Sa. a wolf ramp. and in chief three estoiles or. Wirson, Eastbourne, Sussex, Bart. WIIson, Eshton Hall, co. York; derived from WiLson, Brigsteare, Westmoreland. Wrson, Ive's Place, Maidenhead, co. Berks ; and Eshton Hall, Gargrave, co. York. Wilson, Bromhead, co. York. Edmund WiLson, Willen, co. Hertford, $V$.

Sa. a wolf ramp. and in chief threepierced stars of six points or on a canton arg. an eagle displ. with two heads. sa. Wrison.

Sa. a wolf salient or in chief three stars arg. WILsox, Inverness; and Fingach, Scotland. Wilson, co. Hertford.

Sa. a wolf salient and in chief three estoiles or. Wirson. Wusson, Stralby, co. Lincoln; Forest Hall, near Long Benton, Northumberland; Eastbourne and Shesfield, Sussex; and Elton, co. York. Wilson, Field House, Brancepeth, and Lumley Castle, Durham. Wirson, Melton, co. York. Thomas Wirson, Bishop of Sodor etc., 1697.1755.

\section{Fleur-de-lis}

Arg. a wolf ramp. vert on a chief sa. a fleur-de-lis betw. two estoiles or. Wrison, Abbot Hall, Westmoreland. 
BEAST. WOLF and in chief.....cont.

Fleur-de-lis cont.

Sa a wolf salient or in chief a fleur-de-lis betw. two bezants. Wilson, Baron Berners; quartering arg. a bend plain within a bordure engr. sa. WusON, co. Leicester.

Eleurs-de-lis

Vert in base a wolf pass, and in chief three fleursde-lis arg. WoIfe, Hatherton, co. Chester.

Vert a wolf pass. ppr. in chief three fleurs-de-lis arg. VAN WoLF.

Vert a wolf pass. ppr. in chief three fleurs-de. lis or. VAN WOLFF.

\section{Flower}

Sa. a wolf salient or in chief a rose ppr. betw. two estoiles gold. Wuson, Knowle Hall, co. Warwick; quartering Fitzgerald, Newsham, Shepperd, Harries, and Jordan.

\section{Monster}

Per fess gu. and or in base a wolf pass. reguard. vert holding in the mouth a fish of the third in clief a griffin pass. arg. KYERKWALD. Mullets

Sa. a wolf salient or in chief three mullets arg. Wircson, Charlton-Kings and Stroud, co. Gloucester.

Sa. a wolf salient or in chief three mullets of six points arg. Christopher Wuson, Bishop of Bristol, 1783.92.

BOAR and in base....

Or a boar pass. az. in base a crescent gu. Tringham.

\section{CAT and in base....}

Per fess az. and vert. in chief a cat couchant coward tail reflexed over the back in base a pierced 5-foil arg. Catharne, co. Pembroke, $V$.

\section{Annulets}

\section{DOG and in base....}

(Arg. ?) in chief a greyhound courant and in base three annulets gu. RHoDes.

Tree

Gu. in chief a greyhound courant arg. collared or in base an oak tree eradicated of the second. RyMer, Scotlaud.

\section{Axe}

LION and in base....

Quarterly sa. and or in the first quarter a lion pass. guard. in the fourth a battle-axe surmounted by a tilting spear in saltire of the second. Bowden, Stroud Green, Croydon, Surrey.

\section{Birds}

Arg. in chief a lion pass. az. in base two raveus pendent from an arrow fesswise sa. Mackie, Bargally, Scotland.

Arg. in chief a lion pass. guard. az. in base two crows pendent from an arrow fesswise sa. Mackne, England.

Per fess ..... and .... in chief a lion couchant .... in base three birds (? martlets). Peter Walles; seal attached to an order dated 1 February, 1655, to Col. Robert Phaire and Thomas Woodliffe, Esq., to repair to Dublin about the soldiers lands in Cork.

$$
\text { Castle }
$$

Gu. in chief a lion pass. or in base a castle arg. Castilia, from Spain.

\section{Crescents}

Arg. a lion pass. and in base two crescents gu. Cavanagh. Cavenagh. Kavanagh, Borris, co. Carlow, the family of the native kings of Leinster, descended from Cahir Mac Art Kavanagh.
BEAST. LION and in base.... cont. Crosses

Gu. in chief a lion pass, or in base three crosses patty arg. two and one. Staynton, $V^{*}$. Sir Robert Steynton, $V$.

\section{Flear-de-lis}

Az. a lion pass. and in base a fleur-de-lis arg. Fuandringeant.

Az. a lion pass. and in base a fleur-de-lis or. Flandringe or Flandringham.

$\mathrm{Az}$. in chief a lion pass. guard. and in base a fleur-de-lis or. Flandringham, $V^{*}$. Fladondringham, $V$.

\section{5-Foil}

Per fess gu. and arg. in chief a demi-lion issuant of the last and in base a 5-foil of the first. Weldon, Swanscombe, Kent.

\section{5-Foils}

Or in the dexter chief a lion pass. in the sinister chief and in base a 5 -foil sa. Aureichier, $V$. ACRTICHER. AURTICHIER, $V^{*}$.

\section{Fret}

Erm. in chief a lion pass. guard. sa. a fret gu. Huddleston, Upwell Hall, co. Cambridge.

Per chev. or and gu. in chief a lion pass. sa. in base a fret arg. Madefont or Matesaunts.

\section{Garbs}

Gu. in chief a lion pass. and in base three garbs arg. Roter or Rother, co. Chester. Rotier, $V^{*}$. Rotyr, $V$. Rotyer, co. Chester, $V$. Rutrer, Stratford-upon-Avon, co. Warwick, $W$. RutTer, co. Chester, and co. Gloucester.

Gu. in chief a lion pass, or in base three garbs arg. ROTER or ROTHER.

\section{Gun}

Per fess wavy gu. and az. a lion pass. guard. or beneath the feet a musket lying horizontally ppr. semy of fleurs-de-lis confusedly dispersed of the third. HockIN, Lydford, co. Devon; granted 1764 .

Head

Sa. in chief a lion pass. guard. in base a leopard's head jessant-de-lis or. Moreland. Mordand. Heads

Arg. in chief a lion pass. guard. gu. in base three leopard's heads sa. two and one. FILLODE, co. Salop. Fouldelode, co. Salop, $V$. Fyurlode, $V^{*}$.

\section{Inkmoline}

Arg. a lion salient in the dexter base an inkmoline sa. Crespigny; quartering az. three bars arg.

Arg. a lion salient sa. armed and langued gu. in the dexter base a pierced fer-de-moline of the second. DE Crespigny, Crampton Lodge, Camberwell, Surrey; and King's Row, South. ampton, Bart.; quartering az. three bars arg.

\section{Mullets}

.... in chief a lion ramp. and in base two mullets gu. HurRx.

\section{Roundles}

Per fess or and az. in chief a demi-lion rampissuant sa. in base six plates three two and one. M. Deggar SeEs, $S$.

\section{Swords}

Per fess embattled az. and gu. in chief a lion pass. arg. in base two faulchions in saltire blades of the third hilts and pomels or on a canton erm. a mural crown or and suspended therefrom by a ribbon gu. edged az. the Corunna medal gold. Darlina. 
BEAST. LION and in base.... cont.

Tree

Per fess wary gu. and arg. in chief a lion pass. guard. erminois in base on a mount vert a fig-tree ppr. MintuE.

Per saltire az. and gyronny of eight or and sa. in chief a wounded lion couchant arg. pierced by a spear behind gu. his head resting on a shield gyronny of eight as above in base a bolly bush or surmounted by a crook and bugle horn saltirewise silver on a chief gu. within a bordure arg. the white horse of Hanover between two Eastern gold crowns. Burnes, descended from Campbell of Burnhouse.

SHEEP and in base....

Arg. a paschal lamb couchant with banner arg. staff and nimbus or in base the letters P. P. of the last. Town of Preston, co. Lancaster.

ANTELOPE betw, or within....

Heads (Beast).... Leopard

Arg. an antelope pass. betw. three leopard's faces gu. Dicton, co. Lincoln.

\section{Pheons}

Sa. an antelope arg. maned and tufted or betw. four pheons ppr. HARRIS, co. Gloucester; quartered by Williams.

\section{Bordure}

ASS betw. or within....

Arg. an ass pass. within a bordure sa. bezanty. Core, Bokeish, Woolfardisworthy, co. Devon.

Gu. an ass pass. within a bordure arg. Moyse, Kent.

BEAR betw, or within....

Gu. a bear ramp. arg. collared of the field betw. three mullets of the second. Crarke, Ashgate, and Norton Hall, co. Derby.

Gu. a bear ramp. erm. gorged with an eastern crown or betw. three pierced mullets arg. Crarke, Elm Bank, Leatherhead, Surrey.

\section{Bars}

BOAR betw, or within....

Arg. a boar pass. .... betw. two bars .... MAC CAN, Ireland.

\section{Bows and Ship}

Arg. a boar pass. gu. crined or betw. three long bows charged with arrows and bent pointing in centre one in chief and a skiff with oars sa, betw. the two in base. O'MaLiex, Rosehill. co. Mayo, Baronetcy 2 July 1804.

\section{Crescents}

Arg. a boar pass. sa. betw. three crescents gu. NutTer.

\section{Crosses}

Arg. a boar pass. betw. three crosses croslet or. O'Crulite, Ireland.

Fleurs-de-lis

Sa, a boar pass. betw. six fleurs-de-lis arg. Meredydd GAM, Dyvod.

\section{3-Foils}

Az. a boar betw. ten 3. foils slipped arg. APPRYAND, $V$. Gryfrith, $V^{*}$. Griftith Luoyde, $V$. Mullets

Arg. a hoal pass, gu. armed or betw. three mullets of the second. Trevarthian, Trevarthian, Cornwall; the heiress m. Reskymer.

CAMEL betw, or within...

Or a camel pass. betw. three cloves sa. Crove, co. Wilts.

\section{Flowers}

Per pale sa. and gu. a mountain cat betw. three roses arg. LIMPENIE.
BEAST. CAT betw, or within.... cont. 3-Foils

Vert a cat (pass. $V^{*}$ ) statant tail crect arg. within an orle of eight 3 -foils slipped or. VAQHAN, $V$.

Vert a cat pass. arg. betw. nine 3-foils slipped or. VaUGHaN.

\section{Bells}

DEER betw, or within....

Sa. a doe pass. betw, three bells arg. DoobeL, Faurmour, Sussex; granted 1695.

Sa. a hind pass. betw. three bells arg. Walter Dobeis, Falmere, Sussex ; confirmed 1604.

Gu. a doe statant betw. three bells arg. DoBLE, co. Somerset.

\section{Bordure}

Or a stag trippant within a bordure gu. MacARTney, Belfast, co. Antrim; derived from George Macartney, Blacket, Scotland, 1630. Macartay, Lish, co. Armagh, Baronetey 22 July 1799.

Or a buck trippant gu. attired arg. within a bordure of the second. Macantrex, Mickle Leatbes, Auchinleck, and Blacket, Scotland. MACARTNEy, created Lord Macartney of Lissanoure 1776, Earl Macartney 1794; descended from Macartney, Auchinleck, Kirkcudbright, Scotland. Macartney, Lissanoure Castle, co. Antrim.

Sa. a stag statant arg. attired or within a bordure quarterly erm. and erminois. Jones.

Vert a buck pass. ppr. attired arg. within a bordure engr. of the third. Somerfokd, Somerford, co. Stafford, 1583.

\section{3-Foils}

Per fess arg. and vert a stag ppr. betw. three 3 -foils counterchanged. CoNmeLL, Ashtown, Ireland; granted 1668.

Per fess vert and arg. a stag trippant betw. three 3.foils counterchanged. O'Connell, Iveragh, Grena, and Derrynane Abbey, co. Kerry, Powers.

Vert a buck trippant within an orle of trefoils slipped or. RoBInson, London; Cranford, co. Northampton; and Stretton Hall, co. Leicester, Bart.; Baroretcy 22 Juve 1660; borne next to a coat of augmentation granted 1633.

\section{Pheons}

Az. a buck arg. betw. three pheons or within a bordure engr. of the last charged with eight burts. Parker, $V^{*}$.

Az. a buck statant arg. attired or betw. three pheons within a border engr. of the last charged with eight hurts. Parker, Cambridge, $V$.

Az. a buck trippant or betw. three pheons arg. within a bordure engr. of the second hurty. Parker, co. Cambridge.

Gu. a hind courant arg. betw. three pheons or within a bordure of the last pellety. HunT, $V$. Gi. a hind betw. three pheons or. LINwood.

Gu. a hind betw. three pheons or within a bordure engr. .... platy. Livwood.

Gu. a hind trippant betw. three pheons or within a bordure engr. arg. pellety. Hunt, $W$.

Gu. a hind trippant betw. three pheons within a bordure or pellety. HUNT, $V^{*}$.

Quarterly gu. and vert a buck statant betw. three pheons arg. within a bordure engr. or. Buck, $V$.

Sa. a buck pass. arg. betw. three pheons or within a bordure eng1. of the second pellety. Parier, Northleach, co. Gloucester.

Roundles

Sa. a buck arg. betw. three beznnts on cacl a pheon of the first. Fostrin, $J^{\prime}$. 
BEAST. DEER betw. or withir.... cont.

\section{Roundles cont.}

Sa. a hart trippant arg. betw. three bezants on each a pheon of the first. Foster, $W$.

Sa. a buck trippant arg. betw. three bezants on each a pheon of the field within a bordure compony or and gu. Forster.

Sa. a hart trippant arg. betw. three bezants on each a pheon of the first (? az.) within a bor. dure compony or and gu. Thomas Fonster, r. Foster, London.

Vert a stag arg. having in the mouth a sprig or betw. three bezants. ReDshawe.

DOG betw. or within....

Bars

Or a greyhound in full course betw. two bars sa. BAKER, London, and co. Worcester. George BAKER, Surgeon to Elizabeth, London, $W$.

Per pale erm. and gu. a greyhound courant betw. two bars.... BaEER, Bay fordbury, co. Hertford.

Birds

Arg. a greyhound courant sa. betw. three birds of the second legged gu. within a bordure of the last charged with crosses patty and acorns or alternately. Joinn Williams, Dorehester, $V$.

\section{..... Choughs}

Arg. a greyhound courant sa. betw. three Cornish choughs ppr. within a bordure engr. az. charged with four crosses croslet or and as many bezants alternately. Williams.

Alg. a greyhound courant sa. betw. three Cornish choughs ppr. within a bordure engr. gu. charged with elght crosses formy or and as many be. zants ulternately. Willians,' 'Treverne and Probus, Cornwall. IVilliams, Helton ard Whitelavington, co. Dorset, and Oxford. Wizliams, Herringston, co. Dorset; descended from John Williams, Perry Court, and Herringston, $15 \mathrm{I} 3$; quartering Delalynde, Herring, Syward, Argenton, and Browne. Williams, Rushden Hall, co. Nortbampton; and Wanfield Lodge, co. Berks; derived like Winliams, Bridehead, co. Dorset; through Willians, Charmin ster, from Williams, Herringston.

\section{.....Martlets}

Arg. a greyhound courant betw. three martlets sa. Williams, co. Somer'set.

Arg. a greyhound courant betw. three martlets sa. within a bordure engr. gu. (another adds on the bordure acorns or husked vert.) Wilinams, co. Dorset.

\section{....Parrots}

Arg. a greyhound courant sa. betw, three popinjays ppr. within a bordure engr. gu. charged with bezants and erosses patty or alternately. Willians, descended through Williams, Bridehead, from Williams, Herringston co. Dorset.

Bordure

Ars. a greybound courant sa. in a bordure engr. gir. Ralph BRIDEOKE, Bishop of Chichester, 1675.78 .

Arg. a greyhound courant within a bordure engr. sa. Braddocke, Abbaston, co. Warwick.

Arg. in base on a mount ppr. a pine tree vert a talbot tied thereto $\mathrm{ppr}$. and from one of the branches a buglehorn pendent of the second within a bordure of the third. Loothias, Edinburgh.

Arg. a hound pass. within a bordure sa. Fonneys.

Arg. a talbot sejant within a bordure sa. Furnace or lunese, Sandwich, Kent. Fundess, $V$.
BEAST. DOG betw. or wilhin.... cont.

Bordure cont.

Az. a talbot sejant and a bordure engr. arg. Simon Sudbury, alias Tybold, Bishop of Lolldon, 1362; Archbishop of Canterbury, 1375-81.

Gu. a talbot pass. arg. within a bordure erm. WALWYN.

Or a levrier gu. collared sa. within a bordure of the last bezanty. Sr. Peres Burdeux, $H$.

Per fess arg. and sa. a greyhound and mule within a borclure engr. counterclianged. AsHBerton. Sa. a bloodhound pass. within a bordure engr. arg. Sudbery.

Sa. a hound pass. arg. within a bordure or. SudBury.

Sa. a talbot pass, arg. within a bordure engr. or. SudBerRy, $V *$ *

Sa. a greyhound ramp. within a bordure engr. alg. Pourton, $V$. Powrton, $V^{*}$.

Sa. a hound salient within a bordure engr. arg. Perton.

Sa. a hound sejant within a bordure engr. arg. SUDBURY.

Sa. a talbot statant arg. within a bordure engr. or. Sudbury; $V$.

\section{Buckles}

Az. a talbot pass. betw. three oval buckles or. CAster, Kinmel.

Az. a talbot pass. betw. three round buckles or. Cranfield.

\section{Crescents}

Az. a hound pass. betw. three crescents or Cheyney, co. Berks.

\section{Escallops}

Arg. a greyhound courant betw. three escallops sa. Lomax, Parkhurst, Surrey.

Erm. a greyhound courant sa. betw. three escallops gu. Lonax, co. Hertford; and Westminster; quartering Kaye.

Heads (Beast).... Leopard

Or a greyhound courant sa. betw. three leopard's heads az. a bordure engr. gu. HENEAGE, Hainton, co. Lincoln. John Henege, $V$. Hennidge. And with a crescent on a mullet for diff. HrenEage, Compton Basset, Wilts ; quartering Walker; descended through Michael HENEAGE, Keeper of the Records in the Tower of London, b. 1540, from Heneage, Hainton; the heiress m. Walker.

\section{....Wolf}

Arg. a greyhound courant sa. betw. three wolf's beads erased gu. within a bordure az. charged with eight 5-foils of the tirst. Heneage, Hynton, $V$. Henege, $V *$.

$$
\text { .....(Bird) }
$$

Arg. a greyhound courant ermines betw. three eagle's heads erased sa. J JCKSON, co. Northampton; granted 1689 .

\section{Horns}

Arg. a ratchhound courant betw. three huntinghorns sa. Forrester, Dundee.

Vert a greyhound pass. betw. three hunting. horns arg. stringed gu. CARSTORPHiN or CORSTORPHINE.

Vert a greyhound salient betw. three huntinghorns alg. Corstorphine, Kings Barnes, Scotland.

\section{Pheons}

Gu. a grey hound courant betw. three pheons arg. JACISSON.

Gil. a greybound courant arg. betw. three pheons ol. JAckson, Southgate, Middlesex. 
BEAST. DOG betw, or within.... cont.

Pheons cont.

Gu. a hound pass. betw. three pheons or within a bordure engr. arg. pelletty. Hunt.

ELEPHANT betw, or within...

Arg. an elephant statant and carrying a howdah containing tbree persons with a driver ppr. a bordure or. The Rajah KaLEe KaIshNa Bahadur; granted in India, 3 April 1833. R. Asiatic Society's Journal, 1843, vii. 201.

GOAT betw, or within....

Gu. a goat statant arg. armed and crined or betw. three saltires of the last. BaKER, quartered by Cresswell.

HARE betw. or within...

\section{Bordure}

Az. a hare salient arg. with a bunting-horu round the neek vert garnished gu. within a bordure wavy of the second charged with three crescents and as many roses of the last. Clebland, Barbadoes.

Az. a hare salient guard. arg. with a hunting. born hanging about the neck vert garwished gu. within a hordure countercompony of the second and first. Cletand, Edinburgh.

\section{Mullet}

Az. a hare ramp. betw. three mullets or MARCHANT.

Sun

Az. a hare courant betw. three suns or. WATson, Siratford, co. Gloucester. Thomas Watson, Bisbop of Lincoln, 1557-9.

\section{Bordure}

HORSE betw, or within....

Gu. a mule within a bordure arg. Moyse, Tye, Kent.

Gu. a mule statant within a bordure arg. Sir Thomas Moyce, Kent, $V$.

Per fess arg. and sa.a mule and greyhound within a bordure engr. counterchanged. AshBErton.

Sa. a horse carrying a man armed at all points within a bordure arg. Nevoy, Scotland.

\section{Flowers}

Az. a horse pass. arg. bridled gu. betw. three ma. rigolds or. Morecroft, Churehill, co. Oxford.

Spears

Arg. a horse pass. bay colour betw. two tilting. spears in fess sa. Shekel, Pebworth, co. Worcester.

\section{Wheels}

Az. a horse arg. bridled gu. betw. three wheels or. Morcraft.

LION betw, or within.....

\section{Annulets}

Sa. a lion ramp. arg. crowned or betw. three an. nulets of the second. MatTon. Sir Henry de WaLTON, $V$.

Vert a lion pass. or betw. three annulets arg. Hermon, Hendon.

Vert a lion pass. or armed and langued gu. betw. three anmmlets arg. Herman, Middleton Stoney, co. Oxford ; confirmed 10 Dec. 1630 .

Gu. a lion ramp. arg. gorged with a collar vert and supportung betw. the pars the fasces erect ppr. banded ol betw. four annulets of the last and as many 5 -foils of the second alteruately. SIDDONs; granted 1819.

Sa. a lion ramp. within an olle of eight annulets alg. MaLton or MOLTON.
BEAST. IION betw, or within.... cont.

\section{Annulets cont.}

Az. a lion ramp. arg. crowned or betw. ten annulets of the second. MaLTON.

Sa. a lion pass. betw. ten annulets arg. Fulthorp. Sa. a lion ramp. within an orle of annulets arg. MALTON, $V^{*}$.

Sa. a lion ramp. arg. crowned or within an orle of annulets of the second. MErToN.

Sa. a lion salient within an orle of annulets arg. FulThORPE, $V^{*}$.

\section{Arrows}

Az. a lion ramp. betw. two arrows palewise in fess arg. CANTILON, Ireland.

Az. a lion ramp. betw. two arrows in fess arg. Cantilion, Ireland.

Az. a lion ramp. arg. betw. two arrows or feathered and barbed of the second. Cantilion.

Vert a lion ramp. reguard. betw. three arrows or. YELDART.

Vert a lion ramp. reguard. crowued betw. three arrows or. GrLdart, Liverpool, co. Lancaster; granted 20 Dec. 1759.

Vert a lion ramp. reguard. and ducally crowned betw. three arrows or. GELDART, Cambridge.

\section{Axes}

Sa. a lion ramp. or ducally crowned arg. betw. three battle-axes of the last handles of the se. cond. Shorter, Lordon; granted 14 Oct. 1687.

\section{Bars}

Arg. a lion pass. az. betw. a bar gemel in chief and three mullets in base gu. M'Kellor, Scotland.

Arg. a lion pass. az. betw. two barrulets gu. in chief three crescents sa. and in base as many mullets of the third. M.Keliar, Scotland.

Beasts.... Deer

Arg. a lion ramp. betw. two harts in chief gu. 'Trudale.

$$
\text { ....Lions }
$$

Per saltire or and erm. a linn pass. az. betw. two others rass. reguard. in pale gu. MACHAHON, Baronetcies 6 May, 1815, and 7 Aug. 1817.

Quarterly or and gu. in the centre a lion ramp. az. four lions ramp. counterchanged. VAUGHAN, Dolymelyullyn; derved through Vaughan, Hengwrt, co. Merioneth; from Cadwgan, Lord of Nannau. VaughaN, Chilton Gruve, near Slirewsbury.

\section{Bells}

Az. a lion ramp. guard, within an orle of bells arg. cannoned or. OsNex, Louth, co. Lincoln.

\section{Bends}

Arg. a liou pass. gu. betw. two bendlets az. Marshau, Earl of Romuey.

Arg. a lion pass. gis. betw. two bendlets az. on each three crosses croslet or. Marshant, $V^{*}$.

Arg. a lion pass. gu. betw. two bendlets az. on each three erosses croslet or within a bordure engr. gu. Narsham, $V$.

.... crusily sa. a lion pass. gu. betw. two bendlets .... on each three crosses croslet or. Marsham, iT.

Arg. semy of crosses croslet sa. a lion pass, gu. betw. two bendlets az. on each three crosses croslet or. Marshant.

Arg. erusily fitchy sa. a lion pass. gu, betw. two bendiets az. each cbarged with three crosses croslet or. Marshan, Stratton Strawless, Norfolk. 
BEAST. LION betw. or within.... . cont.

Bends cont.

Arg. a lion pass. betw. two cotises gu. Gawler.

Erm. a lion pass. betw. two cotises gu. Cooke, London.

Gu. a lion ramp. arg. betw. trro cotises or. Playstow.

Or a lion pass. sa. betw, two cotises gu. Sir John Tracy, Barstable, $V$.

Or a lion pass. guard. sa. betw. two bendlets gu. BoLToN.

Or a lion salient sa. betw. two cotises gu. Tracy. Or a lion betw. two cotises sa. Tracr, Cornwall. Or a lion pass. sa. betw. two bends gemels gu. Tracy, Barnstaple, co. Devon.

Sa. a lion lamp. or cotised gu. betw. three crosses patty of the second. AyLiffe, $V^{*}$.

\section{Billets}

Az. a lion ramp. betw, three billets or. Jesson.

Or a lion pass. betw. six billets sa. Smartwood, London.

Arg. a lion ramp. gu. betw. eight billets az. THORPE.

Arg. a lion ramp. betw. eigbt billets sa. Buckminster, co. Leicester.

Gu. a lion ramp. or surrounded by eight batons (or billets) of the same on an escucheon or a cross sa. betw. four spread eagles ppr. Bur.mer.

Arg. a lion ramp. betw. ten billets sa. Gisons.

.... a lion ramp..... betw. ten billets.... within a bordure.... John Gisons, Lord Mayor of London, 1245.

Az. a lion ramp. within an orle of billets or and a bordure engr. arg. Jesone, $V^{*}$. Jesonson, $V$.

Az. a lion ramp. arg. witbin an orle of billets and a bordure engr. or. Gysons, Lord Meyor ot London, 1245, 1246, 1249, 1311, and 1314 .

Az. a lion salient arg. within an orle of billets or. Gessors, $V^{*}$.

Az. a lion ramp. within an orle of billets or. Sr. John Gessors, $V$.

Gir. a lion ramp. within an orle of billets arg. NeIrnurst, co. Buckingham, $V$.

Gu. a lion salient within an orle of billets arg. Neirnest, $V^{*}$.

Gu. a lion ramp. arg, within an orle of billets or. Creping, co. Lincoln. Sr. Jolun Cirepinge, temp. Edw. III, $V$. Sr. William Grammakr, co. Lincoln, $V$.

Gu. a lion salient arg. within an orle of billets or. Creping, $V^{*}$.

$\mathrm{Gu}$. a lion ramp. within an orle of billets or. $\mathrm{Sr}$. Raufe Bulwer, Essex, temp. Edward I, $\vec{V}$.

Gu. a lion salient within an orle of billets or. Buldier, $V^{*}$.

Gu. a lion ramp. per fess or and arg. within an orle of billets of the second. BuLMer, $V^{*}$.

Or a lion ramp. within an orle of billets sa. KychaRd, $V$.

\section{Birds.... Choughs}

Or a lion pass. guard. sa. betw. three Cornish choughs ppr. Drxwoon, Dunton, Essex.

$$
\text { .... Doves }
$$

Az. a lion pass, guard. ducally crowned or betw. three turtle doves rousant arg. each holding in the beals a trefoil slipped gold. Bird, Westminster; descended from co. Salop; granted 16 Sept. 1723.

$$
\text { ..... Eagles }
$$

Or a lion ramp. betw. three demi eagles displ. purp. LACE, Isle of Man; and Ingthorpe Grange, co. York.
BEAST. IION betw. ör within.... cont.

Birds cont. Martlets

Az. (arg. $V^{*}$.) a lion pass. betw. three martlets or. J ACKSON, $W$.

$\mathrm{Gu}$ a lion pass. or within an orle of martlets arg. VALONYS, $V$.

$$
\ldots \text {. Owls }
$$

Vert a lion ramp. betw. three owls arg. Holgrave.

\section{Bordure}

Arg. a demi-lion ramp. gu. within a bordure sa. bezanty. Lynne, co. Cambridge ; and Southwick, co. Northampton.

Gu. a demi-lion ramp. arg. within a bordure sa. bezanty. LYNDE or LYNNE, London; and co. Cambridge. Lynde, co. Cambridge, $\boldsymbol{V}$. LYNn, co. Devon; co. Northampton; and Bassingborne, co. Cambridge. LynN, Westminster; and Clapham, Surrey. Stokes, $V^{*}$.

Gu. a demi-lion issuant arg. armed and langned az. within a bordure sa. bezanty. LyNne, South wicke, co. Northampton, 1716.

Gu. a demi-lion ramp. tail forked arg. within a bordure sa. bezanty. Stokes, Kent, $V$.

Gu. a demi-lion ramp. or within a bordure sa. bezanty. Lynde or Lynne, co. Cambridge; and Jondon. STokes, Watersend, Kent.

.... a lion ramp..... within a bordure engr..... Ponerot.

....a lion ramp..... within a bordure indented .... Humphry Llown, Bishop of Bangor, 1673-89.

.... a lion ramp..... within a bordure indented .... RIDDELL.

Arg. a lion ramp. within a bordure az. Dowetr, co. Stafford.

Arg. a lion ramp. az. within a bordure of the second charged with fleurs-de-lis or. SaUnders or SANDERs, co. Oxford.

Arg. a lion ramp. az. crowned gu. witlin a bor. dure of the second charged with eight fleursde-lis or. Saunder, London, $V$.

Arg. a lion ramp. within a bordure invecked az. Faconbridge.

Arg. a lion rainp. az. armed and langued gu. within a bordure engr. of the second. CRICHTON, Brunston, Seotland.

Ajg. a lion ramp. az. crowned with an antique crown or within a bordure chequy of the first and second. M'Dowarl London; and Scotland.

Arg. semy of crosses croslet fitchy gu. a lion rarnp. az. within a bordure erm. MonTford, Kyluhurst, co. York.

Arg. a lion ramp. az. a bordure gu. Clane or Klane.

Arg. a lion pass. guard. gu. within a bordure engr. az. OGILYY, Ragel, Scotland.

Arg. a lion ramp. gu. within a bordure az. Duthie or Duthill, Scotland.

Arg. a lion ramp. gu. debruised with a bend (plain $V^{*}$ ) engr. compony or aud vert within a bordure az. STEWARD, Norfolk, $V$.

Arg. a lion ramp. gu. within a bordure az. charged with three boar's heads couped or two in chief and one in base. Dundas, Viscount Melville.

Arg. a lion ramp. gu. within a bordure engr. az. Somarne; but webuly or wavy, $V$.

Arg. a lion ramp. gu. ducally crowned or within a bordure engr. az. bezanty. Berington.

Arg. a lion ramp. gu. within a boldure compony gu. and arg. Dundas, Breastmill, Scotland.

Arg. a lion ramp. gu. within a lordure compony of the second and az, Duniend. 
BEAST. LION betw. or within.... cont.

Bordure cont.

Arg. a lion ramp. gu. within a bordure engr. compony of the second and az. Donhead. DONHED, $V$.

Arg. a lion ramp. gu. ducally crowned or within a hordure engr. compony of the second and az. DONHEv, $I^{*}$.

Arg. a lion ramp. gu. within a bordure compony or and vert. Lepla, Isle of Ely, cu. Cambridge.

Arg. a lion pass. guard. gu. crowned with an imperial crown and collared with an open one or within a bordure counter-compony of the second and arg. UGILvY, Inchaven, Scotland.

Arg. a lion ramp. gu. within a hordure erm. Dundas, Arniston, Scotland. Dundas, Beechwood, Mid Lothian; Baronetcy 24 August 1821 .

Arg. a lion pass. guard. gu. crowned with an imperial crown and collared with an open one or within a bordure of the second charged with eight crescents of the field. OGILvY, Logie, scotland.

Arg. a lion pass.guard. gu. crowned with an imperial crown and collared with an open one or within a bordure engr. of the second. OGILvy, Cluny, Scotland. OGilvy, Pitmonies, Scotland.

Arg. a lion pass. guard. gu. crowned with an imperial crown and collared with an open one or within a bordure indented of the second. Ogilsy, Newgrange, Scotland.

Arg. a lion ramp. aud a bordure gu. Blamone. Blomer, Loudon. Dundas, Bandary, Scotland. Russeli, West Ruddam, Norfolk, $V$. Russeli., Badham, Thorpe, and West Burnam, Norfolk.

Arg. a lion ramp. within a bordure gu. charged with eight crosses croslet or. CHepsiow, $V$. St. Cleere, co. Dorset, 1716.

Arg. a lion ramp. within a bordure gu. bezanty. Trinitarian Priory at Graresbonow or KNaresborovgh, co. York.

Arg. a lion ranp. within a bordure engr. gu. Donhead. Dunhed, $V$.

Arg. a lion ramp. gu. within a bordure engr. or. SteWARD, Norfolk.

Arg. a lion ramp. gu. within a bordure sa. Soneler. William Seint Ci,ER, $E$.

Arg. a lion ramp. gu. within a bordure sa. crusily or. Saint Clere, co. Dorset, 1716. William SEINCLER, $E$.

Arg. a lion ramp. gu. within a bordure sa. hezanty. Conte de Conevertue, $E$. Trinitarian priory at KNaresborough or GNaresborow, co. York. William SEincler, $E$.

Arg. a lion ramp. surmounting a crosier in bend dexter gu. within a bordure sa. bezanty. Cistercian Abbey at HaIres or Hales, cu. Gloucester, and at Holir Cultram, Cumberlavd.

Arg. a lion ramp. gu. within a bordure engr. sa. Champnes, Yarvescombe. Champery, Barnstaple, co. Devon. Harper, Essex. Mouthwey.

Arg. a lion ramp. gu. within a bordure engr. sa. bezanty. Cornwall.

Arg. a lion ramp. gu. armed az. within a bordure sa. Lane, Roscommon, Ireland; granted 6 April, 1661.

Arg. a lion ramp. gu. crowned az. a bordure sa. bezanty. Hamerel Leices, A, Harl. MS.6137, fo. 97 .

Arg. a lion ramp. gu. crowned or within a bordure ....crusily.... William de SencLeb, $F$.
BEAST, LION betw, or within.... cont.

Bordure cont.

Arg. a lion ramp. gu. crowned or within a bordure sa. bezanty. Le conte de ConnwaIL, $B$, or Cornewaille, $N, P$. Le contee de Cornewatle, $C, Y$. Richard Plantagenet, Earl of Poitou and Cornwall, $Z, 95$.

Arg. a lion ramp. gu. ducally crowned or within a bordure sa. bezanty. ConNwall, Court in St. Stephen. Brannell, Cornwall. Le Conte de Cornewail, $J$; or Connwaile, $G$. Countee de Cornwall, $D, F$. Conte de Cornualle, $E$. Sr. Edmond de Connwayle, L, Harl. MS. 6137. The Earl of ConNwaLl, founder of S. Robert's at Knarsburg, $V$. KNaresburgh, Knaresborough, co. York. KNARSBURGH, $V^{*}$.

Arg. a lion ramp. gu. crowned or within a bordure engr. sa. OsBert.

Arg. a lion ramp. gu. crowned or within a bordure engr. sa. over all on a bend of the last nine martlets of the second. Cornwail.

Arg. a lion ramp. gu. crowned or within a bordire engr. sa. bezanty. Geoffry de Connwalt, Baron of Burford, $Z, 99$.

Arg. a lion ramp. gu. ducally crowned or within a bordure engr. sa. bezanty. ConNewall, Berrington, co. Hereford, and Diddlebury, co. Salop. Foliott Herbert Walker CoRnewall, Bishop of Bristol, 1797, Worcester, 1803-31; quartering per pale az. and gu. three lions ramp. arg. with gu. a cross raguly betw. three lion's heads crowned arg. ConNewall, Lon. don; and Moceas Court, co. Hereford; Baronetcy 4 Aug. 1761; quartering Amyand.

Arg. a lion sejant gu. within a bordure engr. sa. FARNwELL. (Another, the lion holding in both paws a palm branch vert.)

Arg. a lion ramp. guard. ppr. holding betw. the paws a battleaxe head downwards of the second within a bordure az. Cracknell De Crackneli or Crakeneld, Devonshire House, near Bath, co. Somerset; Cracknell, Isle of Wight; and Burwall St. Mary, co. Cambridge; quartering Phillips.

Arg. a lion ramp. purp. within a bordure compony or and gu. bezanty. LAcY, 1732 .

Arg. a lion ramp. sa. within a bord ure arg. charged with eight torteaux. Sr. Edmond Poynt, $V$.

Arg. a lion ramp. sa. within a bordure az. Blocase, Scotlaud. Brokkas, Scotland. Le Sire BuRneld; quartering or a saltire engr. sa., $Y$.

Arg. a lion ramp. sa. crowned or within a bordure az. Burnell, Holgate, co. Salop. Robert Burnel, Bishop of Bath, etc., 1275-92. Le S. le Bunnel, $S$. Burnell; quartered by Ratcliff, Lord Fitzwalter, $U$. Handey. Hego. Loveli, Lord Lovell.

Arg. a lion ramp. sa. ducally crowned or within a bordule az. Sr. Edward Burweis, $V$.

Arg. a lion ramp. sa. crowned or debruised by a baton ga. within a bordure az. Burnell.

Arg. a lion ramp. sa. ducally crowned or within a bordure az. bezanty. Burnell.

Arg. a lion ramp. sa. crowned or langued and armed gu. within a bordure az. BunNeLL.

Arg. a lion pass. guard. sa. within a bordure engr. gu. Laukin.

Arg. a lion ramp. sa. within a bordure gu. bezanty. Pichering, $V^{*}$. Sire Thomas de Pykeringe, N. Sir Thomas Prkering, Essex, temp. Edward III, $V$.

Arg. a lion ramp. sa. a bordure engr. gu. Dowelt. Pomeroy. Pooley, co. Gloncester. 
BEAST. LION betw, or within.... cont.

\section{Bordure cont.}

Arg. a lion ramp. sa. over all a fess battelly az. within a bordure engr. gu. (another the fess raguly). CRETOW E.

Arg. a lion ramp. sa. over all a fess counter-embattled az. within a bordnre engr.gu. MideleHo.

Arg. a lion ramp. sa. within a bordure invecked gu. Pomeroy, Chalfont St. Giles, co. Buckingham.

Arg. a lion ramp. sa. over all a fess raguly az. within a bordure engr. gu.

CRETOWNE. Cretownes, $V$.

Arg. a lion ramp. within a bordure sa. ST. GEorge. WEST, Ireland.

Arg. a lion ramp. sa. within a bordure of the last charged witb torteaux. Poynton.

Arg. a lion pass within a bordure engr. sa. LaVERING. Lawryn.

Arg. a lion pass. sa. a label of three points gu. a bordure engr. of the second. LAWRYN, $V$.

Arg. a lion ramp. within a bordure engr. sa. Berden, $V$. Berven. Berwen. Bovell. Bovile. Bcwell or Boweids, Rushall, co. Stafford. Bowells, $V$. Champaneys, Orchardly, co. Somerset. CowLEY; quartered by Knightley. Handingside or Handysyde. Hanginside or Hanoreshaw, Scotland. Harper, Essex, $\boldsymbol{V}$. Harper or Harpur, Ca]k, co. Derby ; co. Devon; and co. Stafford.

Arg. a lion ramp. sa. within a bordnre engr. of the last charged with ten nullets as the first. Cowler, London.

Arg. a lion ramp. sa. armed and langued gu. within a bordure of the second. Mowat, Inglistoun, Scotland, Bart.; descended from Balquhollie.

Arg. a lion ranı. sa. armed and crowned or within a bordure of the second. WEsT, Irelaud.

Arg. a lion lamp. sa. crowned or within a bordure of the second. WEST, Ireland, $V$.

Arg. a lion ramp. sa. ducally crowned or within a bordure of the second. Fochford, $V$.

Az. a lion pass. within a bordure arg. charged with eight round buckles of the first. Ochterlony, Kelly, Scotland.

Az. a lion lamp. within a bordure arg. KavenagH, Belian, Ireland.

Az. semy-de-lis and a lion ramp. within a bordure arg. Holland, Ely, in the Isle of Ely.

Az. a lion ramp. within a bordure arg. charged with ten buckles gu. Auchterlony.

Az. a lion ramp. within a bordure arg. charged with eight mullets.... LAmond.

Az. a lion ramp. arg. within a bordure of the last charged with eight torteaux. Roy, Scotland.

Az. a lion ramp. arg. gorged with an antique crown or within a bordure of the second charged with eight sinister hands couped gu. M'1)owaLl, Culgroat, Scotland.

Az. a lion ramp, arm. erowned with an antique crown or armed and langued gn. within a bordure of the second charged with six frasiers of the first. Mac Dougall, Makerston, co. Roxburgh; the heirs m. Hay and Brisbane.

Az. a lion ramp. arg. crowned or within a bordure of the second charged with eight (ogresses, another) torteanx. HeNLey, co. Somerset, 1612 ; and Northington, co. Hants.

Az. a lion ramp, withiu a bordure flory arg. LovelL. Az. a lion ramp. arg. crowned or within a bordure erm. Gerrard, Longhide, co. Somerset.

Az. a lion ramp. arg. within a bordure gu. charged with eight buckles and escallops or alternutely. Ochterlonie, Grind, Scotland.
BEAST. LION betw. or within.... cont.

Bordure cont.

Az. a lion ramp. arg. within a bordure or. Sir Andrew Monhault, Masenden, $Q$. Auger de Mohaut, $Q$.

Az. a lion ramp. arg. within a bordure engr. or Lamont. Tirrell or Tirrol, co. Somerset, I'irrell, co. Hertford. Sir Roger TyrRell, $L$. or T'irpeli, co. Hereford, temp. Edward III, $V$. TyrReIL, $V *$.

Az. a lion ramp. arg. within a bordure indented or. Sire Roger Tyret, $N$.

Az. a lion ramp. arg. armed gu. a bordure or. Sir Andrew Monthaut, $Q$, Harl. MS. 6595.

Az. a lion ramp. guard. arg. within a bordure engr. or. Dalton, co. York.

Az. a lion ramp. arg. crowned or within a bordure per bordure gu. and of the second. Hugh Batllol, Bywell, $P$.

Az. a lion ramp. within a bordure engr. erm. Strytt, $V$. Strytte, $V^{*}$. Stryttle.

Az. a lion pass. guard. or within a bordure arg. Thompson, Cottingham Castle, co. York.

Az. a lion ramp. or withı a bordure arg. charged with eight annulets sa. ReEcE, Usk, co. Monmouth ; Cardiff, co. Glanıorg an ; and Longlown, co. Hereford ; quartering Proger, Corbett, Milo Fitz-walter, Newmarch, De Fortilus, Marshall, Clare, Gifford, Bleddyn Broadspear, Gwerndu, and Lewis.

Az. a lion ramp.or within a bordure erm. LANDREs. Az. a lion ramp. or within a bordure engr. gu. Pikenham, $V^{*}$ Pukenhai. Pyenenham, $V$.

Az. a lion salient or within a bordure engr. gu. Pikenharr.

Az. a lion ramp. within a boldure or. ARUNDELL, $V^{*}$. Balesmore. Belisme, quartered by Talbot, Earl of Shrewsbury, $U$. Koger de Belismo, (de Montgomerico,) Earl of Arundel and Shrewsbury, $V$. Montgomeri, co. Salop. Town of Montgomery, co. Salop. Benedictune Abbey at Shrewsbury, co. Salop. Rogers, Balismo. Talbot, co. Worcester. Sir George TaLbot, Earl of Shrewsbury, for Belesme; quartering Talbot, Nevil Lord Furnival, Furnival, Verdon, and Strange, $U$.

Az. a lion ramp. tail forked within a bordure or. BELISHO.

Az. a lion ramp. ducally crowned or within a bordure of the second charged with eight sinister hands gu. M'Dowall or M'Dougali, Scotland.

Az. a lion ramp. per fess or and arg. within a bordure of the last. Karadoc, Wales.

Az. a lion ramp. per fess or and arg. within a bordure silver semy of annulets sa. Caradoc Vretchvras. Mainerch, Brecon. Byam. Price, Brecon Priory.

Bendy of six gu. and vert a lion ramp. double tailed or within a bordure engr. arg. pelletty. COPINGER.

Erm. a lion ramp. az. crowned or within a bor. dure of the second charged with elght plates. Prckering, Wallford, co. Chester.

Erm. a lion ramp. gu. within a bordure az. charged with eight Heurs-de-lis or. WoorLey or WORLEY.

Erm. a lion ramp. gu. within a bordure sa. Sir William Pritcharn, Lord Mayor 1684.

Erm. a lion ramp. gu. within a bordure sa. fretty or. Hughes, Nuneaton, co. Warwick.

Erm. a lion ramp. gu. witlun a bordure sa. be. zanty. Richard, Earl of Connwall. 
BEAST. LION betw. or within.... cont.

Bordure cont.

Erm. a lion ramp. gu. within a bordure engr. sa. bezanty. Cornwall.

Erm. a lion ramp. gu. crowned or within a bordure sa. Fanhope, Cornwall.

Erm. a lion ramp. gu. crowned or within a bordure sa. bezanty. Bryan. Fanhope, Cornwall.

Erm. a lion ramp. gu. crowned or within a bor. dure engr. sa. bezanty. CoRnwall, Essex, m. Bryan Cornewalle, $S$. Mounsyer John Cornwayle, T. Geoffiy de Cornwall, Baron of Burford, $Z, 99$. Sir John Connwald, Baron of Fanhope and Millbrook, ob. 1443, Z, 258. Cornwail, Fanhop, $V$.

Erm, a lion ramp. reguard. gu. crowned or within a bordure sa. bezanty. Cornwall, co. Salop.

Erm. a lion ramp. sa. a bordure az. Prichard, PRITCHARD.

Err. a lion ramp. sa. armed and langued gu. within a bordure az. Jobu Prichet, Bishop of Gloucester 1672.81.

Erm. a lion ramp. sa. within a bordure gu. semy of mullets arg. Madoc Dantr.

Erm. a lion ramp. within a bordure engr. sa. RushaLl.

Gu. a lion pass. within a bordure engr. arg. Ludlow. Markes, Essex, $T$. Markes, 1732. Gu. a lion ramp. within a bordure arg. DUNBAR, Duru, co. Banff; Baronetcy 1697 ; quartering Randolph, all within a bordure nebuly quarterly az. and of the last. DUNBAR, Eutrick, Scolland. GrandFord. Mowbray, co. York. Aud with a mullet for ditf. LETsLer.

Gu. a lion ramp. arg. within a bordure of the last charged with nine escallops vert. GODARD.

Gu. a lion ramp. arg. withın a bordure of the last charged with three roses and as many cushions as the first alternately. Dunbar, Hillhead, Scotlaud.

Gu. a lion ramp. arg. within a bordure of the last charged with eight roses as the first. Le conte Patrik de Dunbarre, P. Patrik counte de Dunbarre, $Y$. Dunbar, Boath, co. Nairn, Baronetcy 1814. The Earl of LAONOIS, $K$. March. Le counte Patrick, $H$. Dunbar, Westfield, Scotland; quartering Randolph. Dunbar, Cumnock, Scotland; with the same quartering. DUNBAR, Inchbreck, Scotland; with the same quartering, within a bordure gu. charged with eight anuulets .... DuNBAR, Murray, and Grange, Scotland; with the same quartering within a bordure arg. charged with eight frasiers gu. Dunbar, Northfield, co. Elgin, Baronetcy 1698; with the same quarter. in ${ }^{\prime}$, within a bordure (vairy gu. and or with a lion ramp. par surtout, anotber) quarterly a\%. and gu.

$\mathrm{Gu}$. a lion ramp. arg. within a bordure of the second charged with ten roses of the first. Dunbar, Baldoon, Scotland.

$\mathrm{Gu}$. a lion ramp. arg. within a bordure of the second charged with eight 5.foils as the first. Patrick, Durham. Count Patrick de Dunbar, $D, V$. Le counte Patrick, $J$.

Gu. a lion ramp. arg. withın a bordure of the second charged with eight pierced 5 -foils (or frasers) as the first. Patrick, Earl Dunbar, Scotland, $V$.

Gu. a lion ramp. arg. within a bordure of the second charged with eight roses as the field a label az. Patrick de DUNBAr, son of the Earl of Launois, $K$.
BEAST. IION betw, or within.... cont.

Bordure cont.

$\mathrm{G}$ u. a lion ramp. within a bordure dancetty arg. LLoxd, Forest, co. Carmarthen.

Gu. a lion ramp. within a bordure engr. arg. Champney, co. Devon. Newport Charletr, Hanley Court, co. Worcester. Gray, Baron Gray. Gray, Hartsheath Park, co. Flint; quartering erm. two bars vert, with arg. a fess az. betw. in chief an eagle displ. with two beads sa. and in base a lion ramp..... M. Thomas Gray, S. Grey, Earl of Tanquerville and Lord Powis, $Z$, 319. Grey, Earl Grey. William Grey, Bishop of Ely 1454-78. Edward GREY. Bishop of Hereford 1832-7. Sir Edward Grey, Werke, and Chillingham, $V$. Grey, Bart. 'Grey, Mol. wick, Chillingham and Berwick, Northumberland. Grey, Norton, co. Durham. Horton. Powis. Ridell, Middlesex. Sir William Ryoell, $L$. Waldace, Johnstone, Scotland.

Gu. a lion ramp. within a bordure engr. arg. a dexter baton sa. Le bastard Grey, $R$.

Gu. a lion ramp. arg. within a bordure engr. of the second charged with eight thistles .... Gray, Dingwall, Pursuivant.

Gu. a lion ramp. arg. within a bordure engr. of the second pelletty. Henry MúpDac, Archbishop of York 1147-53.

Gu. a lion ramp. crowned arg. within a bordure engr, of the last. Moubray, Cockairny, co. Fife.

$\mathrm{Gu}$. a lion ramp. within a bordure indented arg. Merks. Mert. SirWilliam Rydell, L, Harl.MS. 6137 , or RIDEL, $N$, or Rydei, $O$, or Ridel, $Y$. Gu. a lion ramp. within a bordure indented arg. a baton az. Sir Thomas Gray, $M$.

Gu. a lion ramp. within a bordure 'cersele' arg. Monsire William RIDELL, $Y$.

Gu. a lion ramp. arg. a bordure wavy of the second charged with eight mullets of the first. Wallace, Auchans.

Gu. a lion ramp. arg. within a bordure az. WALLACE, Ireland,

Gn. a lion ramp. arg. within a bordure 'cersele' or. Monsire Thomas de Grey, $Y$.

Gu. a lion ramp. arg. within a bordure compony of the last and az. WALLACE, Eldersly. Wallace, Barnn Wallace. Wallace, Perth, Scotland. WaLIIS. Wessington.

Gu. a lion ramp. arg. within a bordure compony of the secorid and or. CHAMON or CHAMOND.

Ga. a lion ramp. arg. within a bordure compony of the last and sa. NERMONT or NERNEwTE.

Gu. a lion ramp. arg. within a bordure engr. compony of the last and sa. CARRELL.

Gu. a lion ramp. arg. within a bordure compony of the last and sa. bezanty. Gray, Middlesex. Gray, Newcastle-upon-Tyne.

Gu. a lion ramp. arg. within a bordure compony or and az. John Channon, Colthoop, $Y$.

Gu. a lion ramp. arg. within a bordure compony or and sa. Mowbray, co. York.

Gu. flory and a lion ramp. arg. within a bordure engr. erm. Robert Gray, Bishop of Bristol $1827-34$.

Gu. a lion ramp. arg. within a bordure or semy of aunulets sa. Madoc ap MaEnirch.

Gu. a lion ramp. arg. within a bordure or charged with eight 5 -foils of the first. DunBar.

Gu. a lion ramp. arg. within a bordure engr. or. Sir Christopher de Bourne, $R$. 'Thomas Gray, Heton, $Y$. Maris. Joan de Merc, E, Harl. MS. 6137, but Mere, E, Harl. MS. 6589. Menrs, Essex. Merke, $V$. 
BEAST. LION betw. or within.... cont.

Bordure cont.

Gu. a lion ramp. arg. within a bordure flory or. J.ODGE, London and co. Salop.

Gu. a lion ramp. arg. within a bordure indented or. Meene, Essex. Sire Johan de Merk, $N$.

$\mathrm{Gu}$. a lion ramp. arg. crowned or within a bordure engr. of the last. Espene, co. Lancaster. Garnetr, co. Lancaster. Garnett, Nentwich, 1730. Gernett. Grance or Grancey. Sir Henry Grance, alias Garnett, $V$. Green, Samford, Essex.

Gu. a lion ramp. arg. within a bordure quarterly first and fonrth of the second charged with three roses of the first second and third vert. Dunbar, Edinburgh.

Gu. a lion ramp. arg. within a bordure engr. sa. GANFORD, GRANFORD, $V *$. GRANDFORD, $V$. Sir John Merkes, Essex, temp. Edward I, $V$.

Gu. a lion ramp. arg. within a bordure vert. OXENBRIDGE.

Gu. a lion ramp. arg. ducally crowned or within a bordure vert an escallop of the second. Oxenbrig, $Y *$.

Gu. a lion ramp. arg. within a bordure vert charged with eight escallops of the second. OXÉNBRIDீGE, Hampshire; Visitation 1634. Sir Godard OXENBRIGE, $V$.

Gu. a lion ramp. double tailed erm. within a bordure engr. arg. Grey, Thrandeston, Suffolk.

Gu. a lion ramp. within a bordure engr. erm. Ridel, Middlesex.

Gu. a lion pass. guard. or within a bordure arg. THomeson, London.

Gu. a lion ramp. or within a bordure arg. Everard, Bishop of Norwich 1121-45.

$\mathrm{Gu}$. a lion ramp. or on a bend az. three woolpacks of the second within a bordure arg. charged with eight roses of the field. Dunbar, Machremore, Scotland.

Gu. a lion ramp or within a bordure engr. arg. Grex, Scotland.

Gu. a lion ramp. or within a bordure indented arg. RidelL, co. Lancaster and Westmoreland. RYDELL, $V$.

$\mathrm{Gu}$. a lion ramp. or within a bordure invecked arg. GRIFFIN.

Gu. a lion ramp. with one head and two bodies or crowned az. within a bordure arg. KeLLAyt.

Gu. a lion guard. crowned with two bodies ramp. connter-ramp. or within a bordure arg. James KELLA M, $V$.

Gu. a lion pass. (another ramp.) or within a bordure compony az, and arg. Honburg, $Z$, $87 \mathrm{l}$.

Gu. a lion ramp. supporting a pastoral staff or within a bordure compony of twelve pieces of the second and first charged with as many crowns eounterehanged. Louis de LUXe mbURGH, Archbishop of Rouen, Bishop of Ely 1438-43.

Gu. a lion ramp. or within a bordure compony of the last and sa. Nermont or Nernewte.

Gu. a lion ramp. or within a bordure erm. Fakeron, Falcron, or Fallicron.

Gu. a lion ramp. or within a bordure engr. erminois. TALBOT, Baron Talbot de Malahide.

Gu. a lion ramp. or armed and langued az. holding in the dexter paw a scimitar arg. within a bordure gu. SCrymgeor, Kirlitonn, Scotland. And with a martlet for diff., Scryageor, Dundee, Scotland.
BEAST. LION betw, or within....cont.

\section{Bordure}

Gu. a lion ramp. within a bordure or. GREY, Lord of Powys. Montgomery. TALBot, co. Gloncester.

Gu. a lion ramp. supporting a curtel-axe between the paws within a liordure or. Norwey.

Gu. a lion ramp. or within a bordure of the last charged with eight roses of the first. Dunbar, Mochrum, co. Wigton, Baronetcy 1694; quartering Randolph.

Gu. a lion ramp. within a bordure engr. or. Borne. Bowrne. Gwyn. Madoc. The arms of Rhys ap Griffith, Prince of S. Wales, as descended from Rhys ap TewDwr Mawr, and adopted by Richard TALBOT before 1301, in right of his mother Gwenllian, daughter and heiress of that prince. Powis. TaLBOT, co. Gloucester; and co. Hereford. Sir Gilbert TАI BоT, co. Gloucester, temp. Edward III, $V$. TАLвот, Goderich Castle; aud Blackmere, $Z$, 242, 448. Sir Gilbert TALBotT, $L$. Richard le Talвoтt, Steward of the King's House, $Q$. M. Richard TALBOT, quartering arg. two lions pass. in pale gu., $S$; or le $\mathrm{Sr}$. de TALBott, $T$. Le Sire de TaLBOT, $Y$. TaLBot, Castle Talbot; and Talbot Hall; derived from TaLBor, Ballynamony, co. Wexford,1586. Richard TAlBot, Bishop of London 1262. William TaLBOT, Bishop of Oxford 1699-1715. TALBOT, Earl of Shrewsbury. And with due diff., 'ГАLвoт, Stourton Castle, co. Stafford; Bishop of Oxford 1699, Salisbury 1715, Durham 1721-30. And with, a crescent for diff., Chetwynd-TALBoT, Earl Talbot. TaLBoT, Belfast, co. Autrim, Bart. And with a mullet within an annulet gold for diff., Powel., Brandlesome Hall, co. Lancaster; and Stanage Park, co. Radnur; de. rived through Powell, Bricknell, co. Salop, temp. Elizabeth, from Rhys-ap-Tudor, King of South Wales.

Gu. a lion ramp. and a bordure engr. or over all a bendlet az. Sir John TALBotT, $\boldsymbol{R}$.

Gu. a lion ramp. within a bordure indented or. Dee, Mortlake, Surrey. Evans, Tre Castell, Wales. John ap John Grismand. JoNes, Sunningwell, near Abingdon, co. Berks; Chasleton, co. Oxford; and co. Worcester. Thomas ap Llewelyn, last Lord of South Wales; descended through Rees or Rhys ap TewnwR Mawn, or the Great, King of South Wales, from Cadelh, King of South Wales, second son of Rhodri Mawr, King of Wales; the herress n. Griffth Vychan, Lord of Glyndwrdwy. Montlake, Surrey. Sir Gilbert Talbott; $L$, Harl. MS. 6137 , or TALEBOT, $N$.

Gu. a lion ramp. within a bordure indented or a crescent for diff. Francis DEE, Bishop of Peterhorough 1634-8.

Gu. a lion ramp. or holding a rose arg. within a bordure indented of the second pellety. LLOYD, Forest, 1663, in Woking Church.

Gu. a lion ramp. and a bordure 'recercele' or. Monsire TALBOT, $Y$.

Gu. a lion ramp. or within a bordure vair. Scrimshawe Scrimshire Srrimshere Skyrdiester or Skrymsher, co. Nottingham; Norbury and Aqualate, eo. Stafford; originally from Scotland. Skyrmesovre, South Muscham, co. Nottingham, $V$. Skrymshere, $V$.

Gyronny of eight arg. and gu. a lion ramp. or within a bordure az. chargerl with eight crosses patty of the third. Nathew, London, $J$. 
3EAST. LION betw, or within.... cont.

Bordure cont.

Jyronny of eight arg, and sa. a lion ramp. gu. within a bordure of the last crusily or. Matтhew, co. Buckingliam.

Jyronny of eight gu. and sa. a lion ramp. or within a bordure az. charged with eight crosses croslet gold. Mathew, Thornton, co. Bucking. ham; and Braddon, co. Northampton; de. scended fron Sir John Mathew, Lord Mayor of London 1490. Mathew, co. Northampton, $W$.

Jyronny of eight gu. and sa. a lion ramp. or within a bordure az. charged with eight crosses formy of the third. MatTHEw, T'horuborough, co. Buckingham; and Wales.

Jyronny of eight sa. and gu. a lion ramp. arg. within a bordure of the last charged with four crosses croslet and as many crescents of the second alternately. Mathison, Edin. burgh.

Gyronny of eight sa. and gu. a lion ramp. arg. within a bordure of the last charged with eight crosses croslet of the second. MATHEson, Balmacara.

Gyronny of eight sa. and gu. a lion ramp. arg. within a bordure counterchanged of the field. Mathieson.

Gyronny of eight sa. and gu. a lion ramp. arg. within a bordure or charged with eight crosses croslet fitchy of the second. MatTison.

Gyronny of eight sa. and gu. over all a lion ramp. or within a bordure az. semy of crosses croslet or. Matthew, Brandden, co. Northampton.

Gyronny of eight sa. art gu. a lion ramp. or within a bordure az. charged with as many fleurs-de-lis gold. Mathew, Lord Mayor of London 1490.

Gyronny of eight sa. and gu. a lion ramp. within a bordure or charged with eight crosses croslet fitchy of the second. Matthison, Scotland; confirmed 1 October 1639.

Or a lion ramp. and bordure engr. .... DEE.

Or a lion ramp. within a bordure az. Jones, Dol-rn-Edeirnion, co. Merioneth.

Or a lion ramp. within a bordure engr. az. Alingaton, London, CHariet, Master of University College, Oxford. Ollington.

Ora lion ramp. az. armed and langued arg. within a bordure of the second entoury of mitres gold. William of S. MARY's-CHuRch, Bishop of Lon. don 1199.1221 .

Or a lion ramp. az. Within a bordure compony arg. and gu. PERCY, Holderness, co. York.

Or a lion ramp. az. within a bordure gu. Crichton, Cranston, Scotland; descended of Frendraught.

Or a lion ramp. az, a bordure 'recersele' gu. Monsire William de Percr, $Y$.

Or a lion ramp. az. armed and langued gu. in a bordure engr. of the last. Thomas PERcy, Bisbop of Norwich 1356.69.

Or a lion ramp. gu. within a bordure az. entoury of mitres of the first. Henry Marshall, Bishop of Exeter 1191.1206.

Or a lion ramp. gu. couped in all the joints of the first within a bordure az. MAITLAND, Eccles, Scotland; a cadet of Lethington.

Or a lion ramp. gn. couped in all the joints of the first within a bordure wavy az. MAITLAND, Scotland. And with the bordure charged with eight granadoes of the first. MaItLAND, Scotland.
BEAST. LION betw, or within.... cont.

Bordure cont.

Or a lion ramp. ga. couped in all the joints of the first within a bordure chequy arg. and az. Maitland, Giglit; and Pitritchie, Scotland; descended from MatTland of Thirlestane.

Or a lion ramp. gu. within a bordure compony arg. and az. BODIHAr.

Or a lion ramp. gu. within a bordure compony of the second and arg. Grey, Lord of Powis.

Or a lion ramp. gu. within a bordure compony of the first and second charged with eight bezants. Lacx, co. York.

Or a lion ramp. within a bordure gu. Malony. TALBot, ireland, $V$.

Or a liou ramp. gu. within a bordure of the second charged with eight roses arg. Spens, Lathallan, co. Fyfe; quartering Campbell, 1392.

Or a lion ramp. couped in all the joirits of the first within a bordure embattled gu. Martuand, Dundrenuan, co. Kirkcudbright; quartering arg. the ruins of an old abbey on a piece of ground ppr.

Or a lion ramp. within a bordure engr. gu. DUNHEAD or DUNHED. And with a crescent for diff., Pomeroy or Ponery, co. Devon; and St. Columb, Cornwall.

Or a lion ramp. tail forked within a bordure gu. MALORT, London; and co. Cambridge.

Or a lion ramp. tail forked gu. collared gold within a bordure of the second. MALLORY, Lord Mayor of London 1561.

Or a lion ramp. guard. tail forked gu. collared arg. within a bordure of the second. MaLlors, Lord Mayor of London 1564.

Or a lion ramp. gu. within a bordure sa. Bonnett. St. Clere.

Or a lion ramp. gu. within a bordure sa. bezanty. Bachet, $V$. Bashett, $V^{*}$. Bersis. Bersiss or Bestis. Sir John St. Cleere, T. St. Ciene, I'*.

Or a lion ramp. gu. crowned az. a bordure sa. bezanty. Haineris Beices, $A$.

Or a lion ramp. gu. within a bordure embattled sa. Brunet.

Or a lion ramp. gu. within a bordure engr. sa. Frfane, Nene-Sollers, co. Salop ; and the Bower, co. Worcester, temp. Edward III. M. John Pomeray, $S$. Heury de la Pomereye, $Y$. Poderey or Ponderoy. Ponienoy, co. Devon; and co. Worcester. Posreny, Tregny, Cornwall. Pomery, $V$. Pommeroy, $V^{*}$. Spence, Shetland. And with a label of three points arg. Fitz-Pomery.

Or a lion ramp. gu. holding in the dexter paw an apple ppr. within a bordure engr. sa. POMERoY, Ireland. Pomfroy, Viscount Harberton.

Or a lion ramp. gu. within a bordure engr. sa. charged with four buckles ppr. SPENCE, Shet. land; granted 1788 .

Or a lion ramp. gu. within a bordure engr. sa. charged with eight crosses patty arg. PouErox, Epping; granted ....

Or semy of crosses croslet fitchy sa. a lion ramp. gu. within a bordure engr. of the second, ADAlis, Charlton Adam, co. Somerset; and Bowdon, co. Devon.

Or a lion ramp. crowned gu. a bordure indented sa. M. John de Gaure, $D$.

Or a lion ramp. guard. gu. armed and langued az. within a bordure indented sa. Pomerai, Berie. Pomerai, co. Devon, temp. Henry I.

Or a lion ramp. gu. collared or a bordure vert besanty. Richgra Talвot, $C^{\prime}$. 
BEAST. LION betw. or within.... cont.

\section{Bordure cont.}

Or a lion ramp. reguard. pean within a bordure .... bezanty. Bache, Stanton, co. Derby; the heiress $m$. Thornhill.

Or a lion ramp. reguard. sa. within a bordure engr. compony arg. and az. John, great grandson of Griffith $\mathrm{GocH}$ took 1693 the name of Jones, Llanio, co. Cardigan.

Or a lion ramp. sa. within a bordure gu. Gornar, Baldwin de Frandres, A, Harl. MS. 6137, fo. 97. Robert de Gourney, $B$. Sir William de Gornay, temp. Edward I, $V$. TORney or Tourney, Canby, co. Lincoln.

Or a lion ramp. sa. within a bordure gu. bezanty. Pickering.

Or a lion ramp. sa. within a bordure engr. gu. Ftanders. Baldwin de Fiandres, $A$.

Or a lion ramp. within a bordure sa. charged with crosses croslet of the field. St. Cr.ere.

Or a lion ramp. sa. in the dexter forepaw a heart gu. within a bordure of the second charged with a double tressure flory counterfiory of the first. Buchanan; quartering Cross.

Or crusily fitchy a lion ramp. within a bordure sa. ADAMS.

Or a lion ramp. sa. collared and chained of the first within a bordure of the second charged with eight crosses croslet gold. PHWLIPPs, Longworth, co. Hereford; descended like Phillipps, Bryngwyn, co. Hereford, through Phillipps, Huntington; Eaton Bishop and LowerEaton, co. Hereford ; from Owen, younger brother of John Phillipps, Kilgainvain in Dis. serth, co. Radnor, 1595 .

Or a lion ramp. within a bordure vert. Chardet, Hillmore, co. Worcester.

Paly of eight gu. and sa. a lion ramp. within a lordure nebnly or. Ginffith, Bangor, co. Carmarthen.

Per bend arg. and or a liou ramp. sa. within a bordure compony of the first and gu. Philip.

Per bend sinister arg. and sa. a lion ramp. coun. terchanged within a bordure compony gu, and or. Richard HARPER, co. Derby, Justice of the Common Pleas, 1572,W. Harper, Swarleston, co. Derby.

Per beud sinister erm. and ermines a lion ramp. or within a bordure gu. Madoc LLwyd, living 1350.

Per bend erm. and ermines a lion ramp. within a bordure engr. or. EDWARDs, Prestbury, co. Gloucester.

Per bend sinister erm. and ermines a Jion ramp. within a bordure engr. or. EDWARns, co. Bedford; London; and Bristol, co. Somerset. Jones or Johnes, Grothkenan, co. Denligh.

Per bend sinister erm. and ermines a lion ramp. within a bordure invecked or. EDwards, co. Bedford: Bristol, co. Somerset; and London.

Per bend sinister erm. and ermines a lion ramp. or within a bordure engr. per bend sinister arg. and sa. Jones, Archdeacon of Hereford, ob. 1823.

Per bend sinister erm. and erminois a lion ramp. or within a bordure gu. LLord, Leaton Knolls, co. Salop; descended through Madoc Lloyd, Lord of Chirkland, from Tudor Trevor.

Per bend or and arg. a lion ramp. sa. within a bordure compony purp. and of the second. Burnell, $V^{*}$. Philtr. Prizlip. Sir David PHILIIPP, $V$.
BEAST. IION betw, or within.... cont.

Bordure cont.

Per bend sinister sa. and arg. a lion ramp. coun. terchanged within a bordure engr. gu. TANAT, Blodwell, co. Salop.

Per chief az. and arg. over all a lion ramp. gu. within a bordure compony of the second and sa. charged with escallops counterchanged. Aston.

Per fess arg. and gu. a lion ramp. within a bordure counterchanged. Bowels, Berry Court, co. Hants; granted 13 Dec. 1662. Phillipe de Ferne, $A$, but Cerne, $A$, Harl. MS. 6137, fo. 95, and $E$, but Cerue, E, Harl. MIS. 6137. FERNE.

Per fess arg. and gu. a lion ramp. counterchanged within a bordure or. Cerne, Malcombe Horsey. Per fess arg. and or a lion ramp. per fess gu. and az. all within a bordure compony of the second and third. HarPer, Walton, co. Lancaster; confirmed to John HARPER, Alderman of London, by Segar. HaRPer; quartermng Strachey and lioberts; quartered by Shepherd.

l'er fess arg. and sa. a lion ramp. counter'changed within a bordure compony or and gu. HARPER, Loudon.

Per fess gu. and az. a lion ramp. withiu a bor. dure or. Prifips, Tenterden, Kent.

Per fess inderted or and arg. a lion ramp. sa. within a bordure gu. charged with eight plates. Thomas Burneli, London, V. Burnell, Beall chieff Abbey, co. Derby; and Winkbourne Hall, co. Nottingham; quartering Pegge. Burnell, in Rothwell Chnrch, 1718 and 1780 . Phillip.

Per fess or and gu. a lion ramp. within a bordure embattled counterchanged, MIDdLeton, Kill Hill, Scotland.

Per fess or and gn, a lion ramp. within a bordure indented counterchanged. Middeten, Essex.

Per fess ol' and gu. a lion ramp. within a bordure nebuly counterchanged. MIDDLETON, Clerk Hill, Scotland.

Per fess sa. ard arg. a lion ramp. counterchanged within a bordure engr. gu. GreEN, $V$. GRENE, $V^{*}$. GRLEN, Essex.

Per pale arg. and sa. a lion ramp. gu. within a bordure engr. conuterchanged. Chanipneys, Hall Place and Ostenhanger, Kent; descended through Sir John Champness or Champneys, Lord Mayor of London 15:34; from Champneys, Orchardleigh; the heiress in. 1767, Burt or Byrte. Champners, Kent, $V$.

Per pale arg. and sa. a lion ramp. guard. gu. within a bordure engr. counterchanged. CHampneys, Puddle Town, co. Dorset.

Per pale arg. and sa. a lion ramp. within a bordure gu. and or. Champney.

Per pale az. and gu. over all a lion pass. guard. holding a crosier enfiled with a mitre or all within a bordure arg. charged with eight text B's sa. Clunac Priory and Abbey at Bermondasy, Surrey.

Per pale erm. and az. a lion ramp. counterchanged within a bordure sa. bezanty. MARKE.

Per pale erm. and az. a lion pass. gu. within a bordure engr. of the last charged with fleurs. de.lis or. BigGs, Little Langford, and Stockton, co. Wilts.

Per pale erm. and az. a lion pass. gu. crowned or within a bordure engr. of the third charged with eight fleurs-de-lis of the fourth. BIGG, Benendon, Kent; Haines Hill, co. Berks ; and Chilton Follyatt, co. Wilts. BIGGs, London. 
BEAST. IION betw, or within. ... cont.

\section{Bordure cont.}

Per pale gu. and az. a lion pass. guard. holding in his dexter paw a crosier erect enfiled with a mitre or all within a bordure arg. charged with eight B's sa. Cluniac Priory and Abuey at Bermondsey, Surrey.

Per pale or and sa. a lion ramp. gu. within a bor. dure engr. counterchanged. CHAMPNErs, Orchardley, co. Somerset, Bart.

Quarterly gu, and or in the first a lion pass. arg. within a bordure compony of the last and az. (but?) Massy, Alford, co. Chester.

Quarterly gu. and sa. a lion rainp. collared arg. within a bordure of the last charged with sixteen torteaux and ogresses alternately. Ayıorfe, co. Wilts and co. Dorset, $V *$.

Sa, a lion ramp. arg. depressed by a baton com. pony or and gu. within a bordure of the second. Browne, co. Chester, $W$.

Sa. a lion ramp. and a bordure engr. arg. with a crescent.... Wasteneys, Bamborough Church. co. York.

Sa. a lion ramp. arg. armed and langued gu. on a bordure of the secnnd charged with eight 3 -foils slipped of the field. Clifton.

Sa. a lion ramp. arg. crowned or on a bordure of the second eight anuulets of the first. Sir Henry de Malton, $V$.

Sa. a lion salient arg. within a bordure of the second depressed by a baton compony or and gu. Browne, $V^{*}$.

Sa. semy of crosses croslet a lion ramp. arg. within a bordure chequy or and gu. Long.

Sa. a lion ramp. arg. within a bordure compony of the second and first. Lewes, co. Glamorgan. Nerncrote. Nernewt, $V$.

Sa. a lion ramp. arg. ducally crowned or within a bordure compony of the second and first. Nernewt, $V^{*}$.

Sa. a lion salient arg. armed and langued gu. within a bordure compony of the first and second. IcKworth.

Sa. a lion ramp. arg. a beud compony gu. and of the second witlin a hordure of the last. Browne, London.

Sa. a lion ramp. arg. crowned or within a bordure engr. gu. Segrave, co. Leicester.

Sa. a.lion ramp. arg. and a bordure or charged with eight 5-foils az. BEST.

Sa. a lion ramp. arg. within a bordure engr. or. Gethin TeDWDEG; descended from David GocH, Lord of Penmachno. Griffith ap David GocH, living 1284. LLoyd, Esclusham and Dulaseu; derived from David GocH ap David, Lord of Penmachno, said to be a son of David ap Griffirh, the last Prince of North Wales; the heirs $m$. Conway, Owen, and Ravenscroft.

$\mathrm{Sa}$. flory or a lion ramp. arg. ducally crowned and holding in the dexter forepaw a sword erect ppr. all within a bordure wavy of the second. Phillipps, Middle Hill, co. Worcester; Baronetcy 1 September 1821.

Sa. a lion ramp. or within a bordure erm. Landres. Londres. Sr..... de Loundres, $V$. Sa. a lion ramp. or within a bordure engr, erm. LoUNDRES, $V^{*}$.

Sa. a lion ramp, within a bordure engr. or. FuINT. Harper, Kent.

Vert a lion ramp. within a bordure engr. arg. Gray, Bishopwearmouth, co.Durbam. Heyton, $V$. Heton, $V$. Thomas de Heeton, and in margin Grey de Heton, X. Thomas Gray.... I.
BEAST. IION betw, or within.... cont.

Bordure cont.

Vert a lion ramp. arg. armed and langued git. within a bordure engr. of the second. Hume, Kimmerghame, Scotland; quartering Polworth and Sinclair.

Vert a lion ramp. arg. within a bordure compony or and az. Washington, co. York.

Vert a lion lamp. arg. within a bordure erm. HunE, Crossrig, and Lenhouse, Scotland; quartering Blackadder.

Vert a lion ramp. arg. within a bordure or. Home, Ford.

Vert a lion ramp. arg. within a bordure or char'ged with nine fountains or wells $\mathrm{ppr}$. HoME, Whitfield, Scotland; quartering Pepdie and Cairncross; derived like Home or HumE, Ninewells, Berwick; through Номе, Tynninghame, from Home. Dunglass, ob. 1424.

Vert a lion ramp. guard. with two bodies ramp. counter-ramp. or within a bordure engr. arg. Atwaler, $V^{*}$ Atwater, $V$.

Vert a lion ramp. within a bordure or. WICHE or Wythe, Droitwich, co. Worcester.

Vert a lion ramp. within a bordure engr. or. Norton.

\section{Buckles}

Gu. a lion pass. guard. arg. betw. three buckles or. GaYNSFORD or GaYNSFORTH. Castles

Az. a lion ramp. betw. in chief two castles triple towered and in base a scaling ladder arg. a bordure or charged with four roses gu. and as many spear heads sa. alternately. Janies, Prestejgn.

\section{Chess-rooks,}

Arg. a lion pass. guard. gu. royally crowned or betw. two chess-rooks in chief sa. and a cup in base gold jessant a flame ppr. a bordure az. Ogitivie, Ruthven, Scutland.

\section{Chief}

Per fess or and arg. in chief a lion ramp. holding in the paw a cross formy fitchy gu. a chief sa. in base a cross formy fitchy erm. summounted by a fleur-de-lis of the fourth. VAwDkEy, Riddings, co. Chester.

on a Chief

Or a lion pass. gu. on a chief az. three bezants in base three bars wavy sa. Hankuns, Greenhouse, co. Gloucester ; quartering Machen.

Per saltire az. and gyronny of eight or and sa. in chief a wounded lion couchant arg. pierced by a spear behind gu. his head resting on a shield gyronny of eight as above on a chief gu. within a bordure arg. the white horse of Hanover between two eastern gold crowns in base a holly bush or surmounted by a crook and bugle horn saltirewise silver. Burnes; descended from Campbell, Burnhouse.

\section{Combs}

Az. a lion pass. guard. betw. three combs or. Company of Combmakers, London.

\section{Coronets}

Az. a lion pass, or betw. three crowns arg. NonTH.

Sa. a lion ramp. betw. three mural crowns or. WALTHEW, Deptford, Kent; granted 1611.

Sa. a lion ramp. betw. three ducal corouets or and two flaunches erm. KING, Exeter; granted 1691.

Arg. a lion couchant az. hetw. four ducal coronets gil. Butrierworth, co. Lancastel. 
BEAST. LION betw, or within.... . cont.

Crescent

Per chev. embattled az. and sa. a lion ramp. with in chief a crescent and in base a mullet or. DEWPORT. Crescents

Per cliev. engr. gu. and elm. in chief a demi-lion ramp. arg. betw. two crescents or. Dares, Loddlon, Norfolk.

Per chev, engr. gu. and erm. in chief a demi-lion ramp. betw. two crescents or. DarRes.

Arg. a lion pass. guard. betw. in chief two crescents and in base a 5 -foil gu. OGILvy, Banff, Scotland.

Arg. $\Omega$ lion lamp. gu. betw. in chief two crescents enclosed by as many pierced mullets sa. in base three of the last gu. Drson, $V^{*}$.

Arg. a lion ramp. gu, betw. in chief two crescents sa. encloserl by as many mullets pierced of six points in base three of the last as the second over all a fess az. Sr..... Dyson, Ireland, $V$; but Dilon, Harl. MS. 1392, fo. 146.

Arg. a lion pass. betw. three crescents.... Covenaugh.

Arg. a lion ramp. az. betw, three crescents gu. DARE.

Arg. a lion pass. betw. three crescents gu. Dili,on, Ireland. Drllon, Lismullen, co. Neath; Baronetcy 31 July 1801; quartering Dillon.

Arg. a lion ramp. betw. three crescents gu. over all a fess az., iucorrectly a pale, and ascribed to Dillwy or Dilwyn. Dillon.

Arg. a lion ramp. betw. three crescents each of the last enclosing an estolle gu. over all a bar (another a fess) az. Dilion, Earl of Roscom. mon. Dirlon, Chimwell, co. Northampton. DirLon, Proudston and Skreen, co. Meath, Ireland; granted by Francis, Emperor of Ger. many, 22 Aug. 1767.

Arg. a lion ramp. gilard. betw. three crescents each of the last enclosing an estoile gu. over all a bar (another a fess) az. Dillon, lreland.

Arg. a lion salient betw. three crescents each of the last euclosing an estoile gu. over all a bar (another a fess) az. Dillon.

Arg. a lion ramp. betw. three crescents gu. each of the last enclosing an estoile sa. over all a bar (another a fess) az. Dillon, Baron Clonbrock.

Arg. a lion ramp. guard. sa. betw. three crescents gu. Brownrigg.

Arg. a lion ramp. guard. sa. betw. three crescents gu. in the dexter forepaw a sword ppr. hilt and pomel or entwined by a serpent vert. Brownrigg, Baronetcy 9 March 1816.

Az. a lion pass. betw. three crescents arg. Cavanagh.

Gu. a lion ramp. betw. three crescents arg. Letster, $V^{*}$. Salisbury, Manchester and Wales.

G11. a lion salient arg. crowned or betw. three crescents of the second. SALisBury, $V^{*}$.

Gu. a liou ramp. arg. ducally crowned or betw. three crescents of the last. . Salisbury, Barnstaple, co. Devon. Thomas Sarisbury, co. Denbigh, $V$. Johw Salusbury, Lleweny, co. Denbigh, ob.1289: Baronetcy 10 November 1619 , extiuct 23 May 1684; from whom descended the branches at Euloe, co. Flint; Horton; Llanrhaiadr Hall, co. Denbigh, the heiress m. Lloyd; Leadbroke, co. Flint; Denbigh, the heiress m. Williams ; Rûg, co. Merioneth, and Bacbymbid, co. Denbigh, quartering Ievan ap Howel Lold of Fûg-yn-Edeirnion, co. Merioncth, a heiress
BEAST, LION betw. or within.... cont.

\section{Crescents cont.}

m. Bagot; Saethmarchog, co. Merioneth, quartering John ap Rees descended from Rees ap Invan Baron of Kymmer-yn-Edeirnion; Maskadern ; Llanrwst, co. Caernarvon; Bachegraig, co. Denbigh, the heiress m. Thrale and Piozzi; Llanwern, co. Monmouth, Baronetcy 4 May 1795 , descended from Salusbury, Flas y-Ward, co. Denbigh ; and Erbistock, co. Flint. Jobn Salisbury, Suffragan Bishop of Thetford, Bishop of Durbam, 1570.3.

Gu. a lion ramp. double tailed arg. ducally crowned or betw. three crescents of the last. SAIISBURY, Catanger, co. Somerset.

Gu. a lion ramp. or betw. three crescents arg. Salusbury, Barnstaple, co. Devon; Visitation 1620.

Or a lion ramp. betw. three crescents gu. GaLLand.

Or a lion ramp. per fess az. and gu. betw. three crescents of the second. Geoffrey BLythe, Bishop of Lichfield, etc., 1503.31.

Or a lion ramp. (salient $V^{*}$.) per fess az. and gn. betw. three crescents per pale as the last. Blythe, Blythe, co. Lincoln, $V$.

Or a lion ramp. sa. armed and langued gu. betw. three crescents of the last all within a double tressure flory counterflory of the second. WhANNELL, co. Ayr ; granted 4 Aug. $17 \% 8$.

Per pale arg. and gu. a lion ramp. betw. three crescents counterchanged. CAVENAGH.

Sa. a lion ramp. or crowned arg. betw. three crescents of the second. KING.

Arg. a lion ramp. betw. four crescents each enclosing an estoile gu. over all a bar (another a fess) az. Dillon, Newton Farrers, Bratton, Chimwell, Wroughton, and Hart, co. Devon; and Farthingoe, co. Northampton.

Gu. a lion ramp. between five crescents arg. two two and one. Letster, $V$.

Gu. a lion ramp. guard. and an orle of eight crescents alg. BEaumont, $V$.

Arg. a lion ramp. sa. within an orle of crescents gu. SKYNNER, Boston and Thornton, co. Lincoln.

Gu. a lion ramp. and an orle of crescents arg. Sr. Thomas Beamont, $Q$. And with a label of three points or. Sir Thomas Beatjaont the younger, $Q$.

Gu. a lion ramp. arg. langued and armed az. within an orle of crescents of the second. Beaumont, Whitley Beaumont, co. York; de. rived from Sir William de BeLlomonT, 1298; Baronetcy 1628. Beaunont, Oalss in Darton, and Bretton Hall, co. York. Sir Thomas Beaumont, Q, Harl. MS. 6595. And with a label of three points or. Sir Thomas Beaumont the younger, Q, Harl. MS. 0595 .

\section{Crosses}

Arg. a lion ramp. sa. murally crowued or and two crosses croslet fitchy in pale betw. two piles is. suing from the dexter and sinister chief sa. each pile charged with three crosses croslet fitchy of the third. Levetr, Milford, co. Stafford; derived through Sil Richard LeverT, Lord Mayor of London, 1700; from Levett, Savernuke.

Or a lion ramp. sa. ducally gorged and chained gold betw. in chief two crosses croslet fitchy gu. and in base an escallop gu. Phillips.

.... a lion ramp..... betw. in chief tivo crosses moline and in base a fleur-de-lis.... HUdDarT, Bryukir, co. Carnarvon. 
BEAST, LION betw. or within.... cont.

\section{Crosses cont.}

Arg. a lion ramp. betw. three crosses croslet fitchy az. within an orle gu. M'Cleish, Maryfield, Scotland.

Arg. a lion pass. betw. three crosses patty gu. DEIGHTON.

Arg. a lion pass. betw. three crosses formy fitchy gu. Dighton, Hostow, co. Lincoln; London; and Wolcester.

Arg. a lion ramp. betw. three crosses croslet fitchy gu. Bowyer, Kingspersley or Knipersley, co. Stafford, Baronetcy 11 September 1660, extinct 1701 ; the heirs m. Adderley, Gresley, Oldfield, Bellot, and Port.

Arg. a lion ramp. betw, three crosses patty fitchy gu. WaLL.

Arg. a lion ramp. gu. betw. three crosses croslet fitchy sa. Pratr, Ireland.

Arg. a lion ramp. sa. betw. three crosses croslet fitchy gu. Bowyer, Knipersley, co. Stafford.

Arg. a lion ramp. betw. three crosses croslet sa. and as many escallops gu. King, Pyrland Hall, co. Somerset; quarterly with Meade.

Arg. a lion ramp. betw. three crosses croslet fitchy sa. a bordure engr. az. charged with four crosses croslet fitchy and as many fleurs-de-lis or alternately. Levetr, Wichnor Park, co. Stafford.

Az. a lion ramp. or betw. three crosses croslet fitchy arg. Axlewax, Taunton, co. Gloucester.

Az. a lion ramp. betw. three crosses croslet or. JoRDON.

Eim. a lion pass. betw. three crosses formy fitchy gir. Dighton, co. Hertford.

Gu. a lion ramp. betw. three crosses croslet fitchy arg. CAPEL.

Gu. a lion ramp. arg. betw, three crosses croslets fitchy or. CAPEL, Earls of Essex.

$\mathrm{Gu}$. a lion pass. guard. betw. three crosses croslet or. Brins, $V$. Thomson, $V$. 'THomson; quartering or a fess betw. three martlets sa.

$\mathrm{G}$ !l. a lion ramp. betw. three crosses croslet fitchy or. CAPEL or CAPELL, Lord Mayor of London, 1503, 1509. Arthur Lord CAPEL, Hadham, co. Hertford, $Z, 36 t, 539$. Sir Giles Capeld, $V$. Capel Coningsby, Earl of Essex; quartering gu. three conies arg.

Gu. a lion ramp. betw. three crosses patty or. Crosthwaite, Ireland.

$\mathrm{Gu}$. a lion salient betw. three crosses botorıny fitchy or. SAPEL.

Or a lion ramp. betw. three crosses croslet fitchy gu. M'Intosh or Macintosh, England.

Or a lion ramp. betw. three crosses moline (sometimes patonce) gu. Francis Turner, Bishop of Rochester, 1683; of Ely, 1684-!)1.

Or a lion ramp. sa. betw. three crosses formy fitcliy at the foot gu. Fursland, W. Fursland or Furstland, Bickington, co. Devon; Visita. tion 1620.

Or a lion pass. betw. three crosses formy sa. BaLes, Wilby, Suffolk.

Or a lion ramp. sa. betw. three crosses croslet of the second. MATHEw, Trevor, and Llewenny Green, co.Denbigh; descended from Lland aff.

Or a lion ramp. vert betw, three crosses croslet sa. Sutton, London; and co. Stafford.

Per fess dancetty or and arg. a lion ramp. az. in chief an ogress betw. two crosses croslet gu. and in base a cross croslet of the last betw. two peilets. BECKaran, Londor.
BEAST, LION betw. or within.... cont.

Crosses cont.

Quarterly gu. and sa. a lion ramp. betw. three crosses patty or within a bordure arg. charged witlı eight tortegux. AxhIFFe, Skeres, co. Hants.

Quarterly gu. and sa. a lion ramp. betw. three crosses formy fitchy at the foot or. Colswill or Colsell, Kent.

Quarterly gu. and sa. a lion ramp. or collared.... (? az. mane erect) betw. three crosses formy fitchy.... within a bordure arg. charged with sixteen torteaux and ogresses alternately. Thomas Ayloff, Kent, $W$. Ayloffe, Kent; and co. Wilts.

Sa. a lion ramp. arg. collared gu. betw. three crosses patty or. ILIFF, Newington Butts.

Sa. a lion ramp. barry of seven (another ejght) ar'g. and gu. (another of the first) betw, as many crosses croslet as the second. Cistercian Abbey De Varlue-Crucrs, co. Denbigh.

Sa. a lion ramp. erm. betw. three crosses croslet fitchy or. KING.

Sa. a lion ramp. erm. (or erminois) betw. three crosses patty fitchy or. KrNG, Belle-Vue, Kent, Baronetcy 18 July 1792.

Sa. a lion ramp. guurd. erm. betw. three crosses patty fitchy at the foot or. Krivg,Bromley, Kent.

Sa. a lion ramp. betw, three crosses croslet or. King, Umberslade, co. Warwick. KrNG, Hun. grill, co. York. Walker KING, Bishop of Rochester, 1809-27.

Sa. a lion ramp. betw. three crosses patty or. Ayloffe, in Chobbam Church, Surrey, $157(0.90$.

Sa. a lion ramp. betw. three crosses formy fitchy or. KrNG; granted 1611 .

Sa. a lion ramp. or armed and laugued gu. betw, three crosses croslet of the second. John KING, Bishop of London, 16l1-21. Henry KING Bishop of Chichester, 1641.69.

Sa. a lion ramp. or collared gu. betw. three crosses formy of the second. Ayloffe, Braxted Magna, Essex; Framfield, Sussex; and Suffolk. Aylfiff, Bretaines, Essex, $V$. Ayroffe, $V *$.

Sa. a lion ramp. or ducally crowned arg. betw. three crosses croslet of the second. KING, co. Devon; and Towcester, co. Northampton. NAUNTON.

Sa. a lion ramp. or crowned arg. betw. three crosses croslet fitchy of the second. KING.

Sa. a lion ramp. ducally crowned betw. three crosses croslet or. King. Robert KING, Bisbop of Oxford, 1542.57. John KING, Bishop of London, 1611.21.

Sa. a lion ramp. ducally crowned or armed and langued gu. betw. three crosses croslet of the second. KING.

Sa. a lion ramp. guard. or collared gu. betw. three crosses of the second. AxLOFTE.

Gu. a lion ramp. or betw. four crosses patonce vair two and two. RaIson. Reason, $V$.

Gu. a lion ramp. or betw. four crosses patty vair. RESON or REASON.

Gu. a lion salient or betw. four crosses patonce vair. REAsON, $V^{*}$.

Gu. a lion pass. per pale or and arg. betw. four crosses croslet of the last. Astei.L, co. Huntingdon; Everton, co. Bedford; and London; ouartering Thornton and Godin.

Sa. a lion ramp. betw. four crosses croslet arg. and two flaunches of the last charged each with a cross croslet of the field. Loxi. 
BEAST. IION betw. or within.... cont.

\section{Crosses cont.}

Arg. a lion ramp. betw. five crosses croslet fitchy gu. Brett, co. Somerset.

Gu. a lion ramp. betw. five crosses croslet fitchy or. Delaware.

Or a lion ramp. guard. betw. five crosses croslet fitchy gu. Brett, Hent.

Arg. a lion pass. reguard, coward sa. betw. six crosses croslet fitchy gu. HiNgHair.

Arg. a lion ramp. sa. betw. six crosses croslet fitchy gu. Phelps.

Arg. a lion pass. reguard. betw. six crosses patty fitchy sa. Hizam.

Arg. a lion pass. leguard. coward betw. six crosses patty fitchy sa. HIGHAM, Kent; buried at Cauterbury, $V$. Hizham, $V$. Hizam, $V^{*}$.

Arg. a lion ramp. betw. six crosses croslet fitchy sa. Hautevilie; quartered by Groove.

Az. a lion pass. guard. arg. betw, six crosses croslet or. Astrey.

Gu. a lion couchant betw. six crosses croslet arg. three and three. Kemeys Trnte, Halsewell or Hatswell in Goathurst, co. Somerset; quartering Halswell and Wharton.

Gu. a lion ramp. betw. six crosses croslet fitchy arg. Herily W ARE, Bish op of Chichester 1418-20.

Gu. a lion pass. guard. arg. crowned or betw. six crosses croslet of the last. Sr. Gerurd de Lisie, $V$.

Per ben? sinister sa. and arg. a lion ramp. betw. six clisses croslet counterchanged. Longe.

Sa. a lion pass. arg. crowned or betw. six crosses croslet of the second. Chastelon.

Arg. a lion ramp. tail forked and nowed betw. seven crosses croslet gu. Sr. Giles Brews, Essex, temp. Edward III, $V$.

Az, a lion ramp. betw. seven crosses croslet fitchy arg. BREwEs.

Az. a lion pass. guard. arg. betw. seven crosses croslet or. AsTeley, $V$.

Az. a lion pass. guald. betw. seven crosses croslet or. AstLey.

.... (gu. ?) a lion ramp. arg. bctw. seven crosses croslet fitchy .... (? of the second). Sr. John de la I ARRE, temp. Edward I, $V$.

Gu. a lion ramp. coward tail elevated over the back arg. betw. seven crosses croslet fitchy or. Trtemarch, $V$.

Gu. a linn ramp. or betw. seven crosses croslet arg. Sir William de la Warre, $R$.

Gu. a lion ramp. betw. seven crosses croslet fitchy or. Sr. William de Brus, $J$.

Or a lion ramp. betw. seven crosses croslet fitchy gu. Brett, Kent. $V$.

Or a lion ramp. tail forked betw. seven crosses croslet gu. Sr. Robert VEnoun, co. Lincoln, temp. Edward III, $V$.

Or a lion ramp. betw. seven crosses croslet sa. ARdenn, $V$. ARdern, $V$.

Per pale gu. and sa. a lion ramp. arg. betw. seven crosses croslet fitchy or. Bramtot, $r$.

Sa. a lion ramp. betw. seven crosses croslet arg. Sir Geffrey WateviLe or Watervile, $L$.

Sa. a lion ramp. betw. seven crosses croslet fitchy arg. HANTEVILL, $V$.

Arg. a lion ramp. betw. eight crosses croslet titchy az. LAVELL or LovelL, co. Oxford.

Arg. a lion ramp. az. betw. eight crosses croslet fitehy gu. Sr. Thomas MoNTFord, co. York, $V$.

Arg. a lion ramp. az. betw. eight crosses croslet fitchy gu. and a bordure erm. Montevustr, Keluehurst, co. York, $V$.
BEAST. LION betw, or within.... cont.

\section{Crosses cont.}

Arg. a lion ramp. betw. eight crosses botonny gu. Venour, co. Lincoln.

Arg. a lion ramp. tail forked betw. eight crosses croslet gu. Sir John Havering, co. Wilts, V.

Arg. a lion ramp. gu. betw. eight crosses patty fitchy sa. HunTER.

Arg. a lion pass. reguard. coward sa. betw. eight crosses croslet gu. Sr. Henry BawLE, $V$.

Arg. a lion ramp. betw. eight crosses croslet sa. ARDYN ARDEM or ARDERN.

Arg. a lion ramp. betw. eight crosses patty sa. Bodenfietd.

Az. a lion rainp. betw. eight crosses croslet arg. Braytoft, $V$. Sr. Hugh Kinardsly, temp. Edward I, V. Loxley, co. Stafford.

Az. a lion ramp. betw. eight crosses croslet fitchy arg. Deckles or Dekes. Sr. Robert Deknes, $V$.

Az. a lion ramp. guard. betw. eight crosses croslet arg. Sr. Richard Dalton, co. Lancaster, $V$.

Az. a lion ramp. betw. eigbt crosses croslet or. Brewes, Gower, Wales, $V$.

Gu. a lion ramp. betw. eight crosses croslet arg. WARRE.

Gu. a lion ramp. betw. eight crosses croslet fitchy arg. Deiaware. Estercombe, co. Somerset. Hobury, $V$. Laward or Lawarre, Estercombe, co. Somerset; granted 1756.

Gu. a lion ramp. arg. armed and langued az. betw. eight crosses fitchy of the second. Delawarr.

Gu. a lion pass. arg. betw. eight crosses croslet or. WARE.

Gu. a lion pass. arg. betw. eight crosses croslet or. within a bordure of the last charged with ogresses. WARE.

Gu. a lion ramp. guard. arg. betw. eight crosses croslet or. Asteley, $V$.

Gu. a lion ramp. guard. arg. armed and langued az. betw. eight crosses croslet or. Astuey.

Gu. a lion pass. or betw. eight crosses croslet fitchy arg. HoBury.

Gu. a lion ramp. or betw. eight crosses croslet fitcby arg. HoEury, $V$.

Gu. a lion ramp. betw. eight crosses croslet or. Sir John Brewse, $R$. Kned, $\boldsymbol{V}$.

Or a lion ramp. betw. eight crosses croslet az. Bonneli, Norfork. Bonvile, Norfolk.

Or a lion ramp. gu. betw, eigbt crosses patty fitchy sa. Hunter, Lord Mayor of London, and Baronetcy 1812.

Or a lion ramp. betw. eight crosses croslet sa. ARDYN ARDeM or ARdern. Roche.

Or a lion ramp. betw. eight crosses croslet fitchy sa. within a bordure engr. az. ADAus, Brompton Kent; descended from Adams, co. Devon.

Or a lion ramp. tail forked and nowed betw. eight crosses croslet sa. Sir Piers BREws, co. Gloucester, temp. Edward III, $V$.

Per pale az. and gu. a lion ramp. arg. betw. eight croslets or. SyTon, co. Salop.

Per pale gu. and az. a lion ramp. betw. eight crosses croslet arg. Hutchinson, Earl of Donoughmore; quartering Hely and Nixon.

Per pale gu. and az. a lion ramp. arg. betw. eight crosses croslet or. Hutchinson, Bishopswearmouth, co. Durham; descended from Hutcbinson, Cumberland, temp. Charles I. Hutchinson, Ireland. Hutchinson, Essex; and co. York. 
BEAST. LION betw, or within.... cont.

\section{Crosses cont.}

Per pale gu. and az. a lion ramp. betw. eight crosses croslet or. Hutchinson.

Purp. a lion ramp. or betw. eight crosses croslet fitchy arg. Sr.... de Tidemarch, $V$.

Sa. a lion pass. guard. arg. crowned or betw. eight crosses croslet of the second. Sr. Makelon Chatelon, $V$.

Sa. a lion ramp. betw. eight crosses croslet arg. Sir Geoffry Hanteville, Cornwall, temp. Ed. ward II, $V$. Hantvill. Henville.

Sa. a lion ramp. betw. eight crosses patty fitchy arg. Linesley, Linesley, co. Lancaster.

Sa. a lion ramp. erm. betw, eight crosses croslet arg. LoNG, co. Wilts.

Arg. a lion ramp. betw. nine crosses croslet fitchy gu. Bretr, co. Somerset.

Arg. a lion pass. reguard. sa. betw. nine crosses croslet gu. BawLE, $V^{*}$.

Arr. a lion ramp. betw. nine crosses croslet sa. HandField, Ashford, Kent.

$\mathrm{Gu}$. a lion pass. arg. betw. nine crosses croslet or. Pengilli, $V$.

$\mathrm{Gu}$ a lion lamp. betw. nine crosses patty fitchy or. Hopton, Hopton, co. Salop, temp. Stephen. Hopton, Canon Frome, co. Hereford; descended from Sir Richard Hopton, Rockhill, and Cherbury, living 1602 ; quartering Hopton.

Per pale az. and gu. a lion ramp. erm. betw. nine crosses croslet or. Synge-Hutchinson, Castle Sallah, co. Wicklow, Baronetcy 1782 ; quarter. ing Synge, and arg. an eagle displ. with two heads sa.

Arg. a lion ramp. az. betw. ten crosses croslet fitchy gu. within a bordure erm. MOUNTFORD, Kelnhurst, co. York.

Arg. a lion ramp. betw, ten crosses croslet fitchy gu. Bretr, Ocle Court, near Hereford.

Arg. a lion ramp. tail nowed betw. ten crosses croslet gu. Bruse, Norfolk.

Arg. a lion ramp. betw. ten crosses croslet sa. MountFond.

Az. a lion ramp. betw, ten crosses croslet or. Bruse.

Az. a lion ramp. within an orle of ten crosses croslet or a bendlet compony arg. and gu. Sir Henry BEAMOND, $V$. 'The bendlet cbarged with three mullets sa. Beaumont, $V$. The bendlet compony erm. and gu. Beaunont, $V$.

Az. a lion ramp. or crowned gu. betw. ten crosses croslet of the second. Goshald.

Or a lion ramp. betw. ten crosses croslet sa. Adpars, co. Devon. Ardyn Ardem or Ardenn.

Per pale gu. and az. a lion ramp. gnard. arg. betw. ten crosses croslet or. Hutchinson, Owthorp, co. Nottingham.

Per pale gu. and sa. a lion ramp. betw. ten crosses croslet fitchy or. Brametost.

Arg. a lion ramp. betw. twelve crosses croslet gu. VENOR.

Az. a lion ramp. betw. twelve crosses croslet or. De Brewosa.

Per pale gu. and az. a lion ramp. bendwise betw. fourteen crosses croslet fitchy or. Poweld, Bruton, co. Somerset; granted 1581.

Arg. a lion ramp. within an orle of crosses croslet fitchy az. Braytoft.

Arg. a lion ramp. az. within an orle of crosses croslet gu. Montrond, $V^{*}$.

Arg. a lion ramp. az. within an orle of crosses croslet fitchy gu. and a boydure erm. MONTFORD, $V^{*}$.
BEAST. IION betw, or within.... cont.

Crosses cont.

Arg. a lion ramp. tail forked az. within an orle of crosses croslet gu. Mountrond, co. York; granted 18 February ]602.

Arg. a lion ramp. within an orle of crosses croslet fitchy gu. Brett, ob. 1769, in Ash church, Kent.

Arg. a lion ramp. double tailed within an orle of crosses croslet gu. Brewes, $V *$ Havering, $V^{*}$.

Arg. a lion ramp. sa. within an orle of crosses croslet fitchy sa. HigHair.

Az. a lion ramp. within an orle of crosses croslet arg. Braytoft, $V^{*}$. Dekres, $V^{*}$. Kynardesly, co. Salop, temp. Edward I. Krnnersiey, Loxley, co. Stafford; quartering Snejd.

Az. a lion ramp. sans tail within an orle of crosses moline arg. BREToste.

Az. a lion ramp. within an orle of crosses croslet or. William de Brewase, $E$, or Brewose, $E$. RowseT or Rouzet.

Az. a lion ramp. or crowned gu. within an orle of crosses croslet of the second. De Brewes, $V *$.

Az. a lion ramp. or crowned and armed gu. within an orle of crosses croslet as the second. Sir John Bruse, Q, Harl. MS. 6595.

Az. a lion salient within an orle of croslets or. Brewes de Gower, $V^{*}$.

$\mathrm{Gu}$ a lion ramp. guard. within an orle of crosses croslet arg. ASTELL.

$\mathrm{Gu}$. a lion salient arg. within an orle of crosses croslet fitchy or. Tytemarch, $V^{*}$.

Gu. a lion pass. guard. within an orle of crosses croslet or. Astetiey and Astel.

Gu. a lion ramp. within an orle of crosses croslet or. Hopton, Gloucester, temp. Edward I. Opton or Oxton, co. Gloucester.

Gu. a lion ramp. within an orle of crosses croslet and mullets alternately or. Martin, Ripe, Sussex. Wykeham-Martin, Leeds Castle, Kent; and Chacombe Priory, co. Northampton; quartering arg. two chev, sa. betw. three roses gu. seeded or barbed vert.

Gu. a lion ramp. within an orle of crosses croslet fitclyy or. JORDAN; quartered by Wilson.

$\mathrm{Gu}$. a lion salient within an orle of crosses croslet or. KNELL, $V^{*}$.

Or a lion ramp. arg. within an orde of crosses croslet az. Loveli, $V^{*}$.

Or a lion ramp. within an orle of crosses croslet gu. Brett.

Or a lion ramp. within an orle of crosses croslet fitchy gu. Bretr, co. Devon, and Kent.

Or a lion ramp. double tailed within an orle of crosses croslet gu. Venour, $V^{*}$.

Or a lion salient within an orle of crosses croslet fitchy gu. BRETT, $V^{*}$.

Or a lion ramp. gu. within an orle of crosses patty fitchy sa. HUNTER.

Or a lion ramp. double tailed sa. within an orle of crosses croslet gu. BREwEs, $V^{*}$.

Or a lion ranu. within an orle of crosses croslet Sa. ARDEN, $V^{*}$. ARDERN, $V^{*}$.

Purp. a lion salient or witbin an orle of crosses croslet arg. De Tide irarch, $V^{*}$.

Sa. a lion ramp. within an orle of crosses formy fitchy arg. Levesey, co. Lancaster.

Sa. a lion salient within an orle of crosses croslet arg. Hanteville, $V^{*}$.

\section{Cups}

Az. a demi-lion ramp. couped betw. three covered cups or. SHaw, Scotland. 
BEAST. LION betw. or within.... cont. Cushions

Gu. a lion ramp. arg. betw. three cushions or within a kordure of the second charged with eight roses of the first. Dunbar, Lenchit, Scotland.

\section{Escallops}

Gu. a lion pass. guard. betw. two escallops in pale arg. and as many flaunches of the second each charged with a lion ramp. sa. IAw KER.

Arg. a lion ramp. betw, three escallops az. JEANES.

A rg. a lion ramp. az. betw. three escallops gu. Janes, Cornwall; co. Worcester; and co. Glou. cester. JANES or JAMES, Kirtling, co. Cambridge; and Botalock, Cornwall.

Arg. a lion pass. guard. gu. betw. three escallops az. BarNeBY, Hereford.

Arg. a lion pass. guard. betw. three escallops sa. Bernbrey, co. Worcester.

Arg. a lion ramp. betw. three escallops sa. Aldington, that Ilk, Scotland.

Az. a lion pass. betw. three escallops arg. HeND or HiNDE.

Az. a lion ramp. betw. three escallops arg. GiBon.

Az. a lion ramp. guard. betw. three escallops arg. Grabon.

Az. a lion ramp. arg. betw. three escallops or. Ponton.

Az. a lion pass. betw. three escallops or. HENDEN, Serjeant-at-law, $W$. Hendon, Kent.

Gn. a lion pass. guard. betw. three escallops arg. SH1ELD.

Per fess az. and arg. a lion ramp. bet $x$. three escallops counterchanged. WINDOTT.

Per fess gu. and or a lion ramp. per fess arg. and az. betw. three escallops connterchanged of the field. Wimborits.

Per fess vert and sa. a lion ramp. erm. betw. three escallops arg. Claye or Crey, Tells, co. Salop.

Per pale vert and sa. a lion ramp. erm. betw. three escallops arg. Clay, London.

Sa. $\Omega$ lion pass. arg. betw. three escallops of the second each charged with a lozenge az. John HYNDE, $V$.

Sa. a lion pass. guard. betw. three escallops arg. Barneby, Brockhampton, co. Hereford; de. scended from Thomas Barnebr, Ludlow, co. Salop, treasurer to Edw. IV.

Sa. a lion ramp. arg. crowned or betw. three escallops of the second. GrвBon, co. Dorset.

Sa. a lion ramp. guard. (? arg.) crowned or betw. three escallops arg. GiBnoN, co. Dorset.

Sa. a lion ramp. guard. or betw. three escallops arg. GibBon, Bishop's Bourre, Kent.

Tert a lion ramp. arg. betw. three escallops or. Reynolds, Ireland.

Per pale arg. and gn. a lion ramp. betw. four escallops counterchanged. RoBARTs, London.

Az. a lion ranp. arg. betw. six escallops or three two and one. Puller.

Arg. a lion ramp. sa. within an orle of seven escallops gu. Francis MaNBY, Elsam, co. Iincoln, $W$.

Arg. a lion ramp. sa. betw. eight escallops gu. M ANBy, Elsham, co. Lincoln; and London.

Az. a lion ramp. arg. betw, eight escallops or. AsKeBy.

Or a lion ramp. sa. within an orle of eight escallops gu. Sir William MaNse, Sussex, temp. Edward III, $Y$.

Arg. a lion ramp. sa. betw. ten escallops gu. MANBE.
BEAST. LION betw, or within.... cont.

Escallops cont.

Arg. a lion ramp. within an orle of escallops gu. MANSE, Suffolk, temp. Edward III.

Arg. a lion salient sa. within an orle of escallops gu. ManBy, $\mathrm{V}$ *.

Arg. a lion ramp. witlin an orle of escallops sa. Manbye, Essex.

Az. a lion ramp. within an orle of escallops or. Hender, Botreaux Castle, Cornwall.

Or a lion salient sa. within an orle of escallops gu. Manse, $V^{*}$.

Sa. a lion ramp. within an orle of escallops arg. Richard Holand, $Y$, or De Howiand, $Y$. Escrolls

Az. a lion ramp. or betw. three escrolls arg. Gouls.

Estoiles

Arg. a lion ramp. betw. three estoiles eacl enclosed by a crescent gu. over all a har (another a fess) az. Dillon, Chimwell, co. Northamp. ton. Dillon, Proudstone and Screen, co. Meath, Ireland : granted by Francis, Emperor of Germany, 22 August 1767. Dillon, Earl of Roscommon.

Arg. a lion ramp. guard. betw. three estoiles each enclosed by a crescent gu. over all a bar (another a fess) az. Drroon, Ireland.

Arg. a lion salient betw. three estoiles each enclosed by a crescent gu. over all a bar (another a fess) az. Dilion.

Arg. a lion ramp. gu. betw. three estoiles sa. erch enclosed by a crescent of the second over all a bar (another a fess) az. Dillon, Baron Clon. brock.

Arg. a lion ramp. guard. gu. betw. three estoiles vert. LEvesey, Kent; and co. Lancaster.

Az. a lion pass. betw, three estoiles arg. Burard. Neale, late Burrard, Walbampton, co. Hants.

Or a lion pass. betw, three estoiles gu. Butcher. Arg. a lion ramp. hetw. four estoiles each en. closed by a crescent gu. over all a bar (another a fess) az. Dilion, Newton Farrers, Bratton, Chimwell, Wroughton, and Hart, co. Devon; and Farthingoe, co. Northampton.

\section{Fishes}

Arg. a lion pass. paly of six sa. and or betw. three dolphins embowed naiant gn. each fish charged with three bezants a tressure flory counterflory purp. John Caunton, co. Warwick, W. Cawton, Y*.

Arg. a lion pass. sa. betw. three dolphins gu. Canton. Cawnton.

Arg. a lion pass. sa. betw. three dolphins embowed naiant gu. CaUnton, Kent, $W$.

\section{Flaunches}

Arg. a lion pass. gu. betw. two flaunches sa. GARPITTE.

Arg. a lion pass. betw. two flaunches purp. JARRETT.

Arg. a lion pass. betw. two flaunches sa. Garat or Garretr, London. Garritt.

Arg. a lion pass. guard. betw. two flaunches sa. Antonie or Antons, Suffolk.

Gu. a lion ramp. or between two flaunches erm. SELLY.

$\mathrm{Gu}$. a lion ramp. betw. two flaunches or each charged with three billets of the first. Mowbray.

Or a lion ramp. reguard. betw. two flaunches sa. each charged with a mullet arg. Matthews, co. Hereford; quartering per pale az. and gu. 
BEAST. LION betw, or within..... cont.

Flaunches cont.

a chevron or betw. three lions ramp....., with arg. on a chevron sa. five spots of ermine in the dexter chief point a mullet of the second, and gu. three stirrups leathered and buckled or, and or a cross patty fitchy gu., and gu. three lions pass, arg.

Per pale erm. and ermines a lion ramp. or betw. two flaunches arg. each charged with a spear palewise.... Edwards, Llandaff' House, co. Glamorgan; quartering Richards.

Sa. crusily and a lion ramp. arg. betw. two flaunches erm. Lon , Whaddon and Becking. ton; granted 1561 to Thomas LoNGE, Trowbridge, co. Wilts.

Sa. a lion ramp. or betw. two flaunches arg. Cenely, Essex. Prestwood, co. Deron; and co. Worcester.

Sa. a lion ramp. betw. two flaunches or. Prestwood, Boterford, North Huish, co. Devon, temp. Elizabeth. Prestwood, $W$.

Sa. a lion salient betw. two flaunches or. Prestwood, $V^{*}$

\section{Fleurs-de-lis}

Arg. a demi-lion betw. eight fleurs-de-lis gu. MaUNdReLI, co. Wilts.

Arg. a demi-lion within an orle of fleurs-de-lis gu. Mandrey, Essex.

Az. a demi-lion ramp. within an orle of fleurs-delis or a label of five points of the second. Marneit.

Or a lion ramp. sa. betw. two fleurs-de-lis az. Fairclodgh, co. Hertford; co. Bedford; co. Lancaster ; co. Lincoln; and London; granted 2 November 1583.

Per bend sinister engr. or and sa. a lion ramp. betw. two fleurs-de-lis counterchanged. French, Belturbet, co. Cavan, Ireland, granted 26 July 1682.

Per saltire az. and gu. a lion pass. guard, betw. two fleurs-de-lis in pale or. John Young, Bishop of Rochester, 1578.1605; confirmed 1578.

Quarterly or and gu. a lion ramp. betw, in chief two fleurs-de-lis and in base a mascle counterchanged. GoodwIN.

.... a lion pass. guard. .... betw. three fleursde-lis.... William de Corneull, Bishop of Licbfield, etc., 1214-23.

Arg. a lion pass. az. betw. three fleurs-de-lis gu. Bragdon or Bragden, London.

Arg. a lion pass. gu. betw. three fleurs-de-lis az. PrICE.

Arg. a lion pass. betw. three fleurs-de-lis gu. - Bragden.

Arg. a lion ramp. betw. three fleurs-de-lis gu. Month or MURth alias Randall, Talland and Roose, Teneglos, Cornwall; the heiress $m$. Woolcombe.

Arg. a lion pass, gu. betw, three fleurs-de-lis sa. Gwyddno Garan Hir, Vaughan, Caethle, and Penmaen Dovey. Pryce, Gunley. Pughe, Ty Gwyn.

Arg. a lion pass. sa. betw. three fleurs-de-lis gu. Evans, co. Montgomery; and Portsea, co. Southampton. Farne. Griffith, Penpom pren, co. Cardigan. Griffith, Trevalyn Hall, co. Denbigh. Perkins. Perkins, Nuneaton, co. Warwick. Pryce, Gunley, co. Montgomery; derived from Einion ap SitsyLLt, Lord of Mathafarn in C5veiliog, tenth in descent from Gwyddno Garan Hir, Lord of Can.
BEAST. LION betw, or within.... cont.

\section{Flenrs-de-lis cont.}

tref Gwaelod; quartering Ievalı ap Rys, Da. vid Lloyd ap Gritfith ap Kered, and Evan ap Rhys ap Hugh. PugH.

Arg. a lion pass. guard. sa. crowned with an an. tique crown or betw. three fleurs-de-lis gu. PUGH.

Arg. a lion pass. guard. sa. crowned or betw. three fleurs-de-lis gu. PUGH; descended from Cadwallader, Llanerchydol, co. Montgomery; qual. tering sa. three greyhounds courant arg.

Arg. a lion ramp. sa. betw. three fleurs-de-lis gu. Vaughan, Penmaen Dovey, co. Merioneth; descended from Einion ap Sitsyllt.

Arg. a lion ramp. betw. three fleurs-de-lis sa. ARCheBold or ARCHBold, co. Stafford.

Az. a lion pass. betw. three fleurs-de-lis arg. Brodigan, Pilton House, Drogheda. Gullford. NoRTH.

Az. a lion pass. or betw. three fleurs-de-lis arg. North, Earl of Guilford. Lord North, Carthledge, co. Cambridge, $Z, 347$. North, Baron North and Grey, 1716. Brownlow North, Bishop of Lichfield, etc., 1771; Worcester 1774; Winchester 1781-1820.

Gu. a lion ramp. betw. three fleurs-de-lis or. Marks.

Or a lion ramp. sa. betw, three fleurs-de-lis az. Fatrclough, co. Bedford; co. Hertford; co. Lancaster; co. Lincoln; and London; granted 2 November 1583. Fearclough, in Horshil Churcb, Surrey.

Or a lion ramp. betw. three fleurs-de-lis sa. FArLovge, co. Lancaster.

Per pale or and az. a lion pass. guard. betw. three fleurs.de.lis connterchanged. North, co. Cambridge.

Per pale or and gu. a lion ramp. betw. tliree fieurs-de-lis counterchanged. GooDwIN or Goonwys, Upper Winchingdon; descended from Sir John Goodwin, Bishop's Woburn, co. Buclingham; the heiress m. Wharton.

Sa. a lion pass. or betw. three fleurs-de.lis arg. Norte.

Sa. a lion ramp. or betw. three fleurs-de-lis erm. Kelley, Terrington, co. Devon.

Vert a lion ramp. betw. three fleurs-de-lis or. SALVADOR, London.

Per bend gu. and erm. a lion ramp. betw. four fleurs-de-lis in cross and as many roses in square counterchanged. HoLLAND.

Az. a lion salient guard. betw. five fleurs-de-lis arg. Holland, co. Devon.

Arg. a lion ramp. betw. six fleurs-de-lis sa. ARCHEBOLd or ARCHBOLd, co. Stafford.

Az. a lion ramp. guard. betw. six fleurs-de-lis arg. HoLland, Holland, co. Lancaster, temp. King John. Holland, Denton, co. Lancaster. Robert de Holtand, a Baron 1315; and his descendants Earls of Kent.

Sa. a lion ramp. erm. crowned or betw. six fleurs. de-lis of the third. Sir Mathew PHuLIPp, $V$.

Arg. a lion ramp. betw. seven fleurs-de-lis sa. Buckmaster, co. Devon; co. Lincoln ; and co. Northampton. Sr. William Bocmonster, $V$.

Sa. a lion ramp. erm. crowned gold hetw. seven fleurs-de-lis in orle or. PHnIP, Lord Mayor of London, 1563.

Vert a lion ramp. or crowned gu. betw. seven fleursde-lis of the second. Sr..... de Beiston, $V$. Arg. a lion ramp. gu. betw. eight fleurs-de.lis az. Thorpe, Holderness, co. York, $V$. 
BEAST. LION betw, or within.... cont.

Fleurs-de-lis cont.

Az. a lion ramp. gaard. betw. eight flears-cle-lis arg. Holland, Ely, co. Cambridge; Boston, co. Lincoln; and West Angmering, Sussex. Sir Robert de Holland, temp. Edward V.

Az. a lion ramp. guard. betw. eight fleurs-de-lis arg. in orle over all on a bend gu. three keys wards upwards or. Gilbertine Priory at Holland-Brigge, co. Lincoln. Benedictine Priory at Holand or HollaNd in Wigan, co. Lancaster.

Az. a lion ramp. arg. betw. eight fleurs-de-lis or. Sir Thomas Poole, co. Chester, $V$. Poole, Mayfield, co. Cork. Poole, co. Devon; Saperton, co. Gloucester; and Oakley, co. Wilts.

Az. a lion ramp. betw. eight fleurs-de-lis or. Beaunont, Bucliland, Surrey. Beaumond, $V^{*}$. Beaumont, Hackney; descended from Beaumont, Stenghton Grange, co. Leicester. Sr. .... Beaumont, $V$.

Gu. a lion ramp. betw. eight fleurs-de-lis arg. Daniell. Davilie. Sr.John Daywill, temp. Edward I, $V$.

Gu, a lion ramp. betw. eight fleurs-de-lis or. MARKE.

Sa. a lion ramp. crowned or betw, eight fleurs de.lis arg. PHILIP.

Az. a lion ramp. arg. betw. nine fleurs-de-lis or a crescent for diff. PoLE, Aldenham Abbey, co. Hertford ; Baronetcy 1801, extinct 1830 ; the heiress $m$. Stuart; descended through Pole, Stoke Damarel, from PoIE, Shute House, Axminster, co. Devon; Baronetcy 12 September 1628 .

Az. a lion ramp. or armed and langued gu. betw. ten fleurs-de-lis of the second. BEaumont, co. Jeicester; and Beaumont Hall, Suffolk.

Sa. a lion ramp. arg. betw. ten fleurs-de-lis or. Philips, co. Lancaster.

Sa. a lion ramp. erm. betw. ten fleurs-de-lis or. Phiriss, co. Lancaster.

Arg. a lion salient gu. within an orle of fleursde-lis az. THORP, $V$ *

Arg. a lion ramp. within an orle of fleurs-de-lis sa, Bockmonster, $V^{*}$.

Az. a lion salient within an orle of fleurs-de-lis arg. Lovell.

Az. a lion salient arg. within an orle of fleurs-delis or. POOLE, $V^{*}$.

Az. a lion ramp. within an orle of fleurs-de-lis or. LOVELL.

Barry of four or and arg. a lion ramp. guard. gu. within an orle of flears-de-lis az. Thorpe, London.

Sa. a lion ramp. arg. ducally crowned and holding in the dexter forepaw a sword erect ppr. within an orle of fleurs-de-lis and a bordure wavy or. Phillipps, Middle Hill, co. Worcester; Baronetcy 1 September 1821.

Sa. a lion ramp. erm. crowned or within an orle of fleurs-de-lis of the third. PHiLLIP, $V^{*}$.

Flowers (Roses)

Gu. a lion pass. guard. or betw. two roses in pale arg. and as many flannches of the second each charged with a lion ramp. sa. Dawnins, St. James's, Westminster.

Az. a lion pass. guard. betw. two roses one in chief and one in base arg. Prout.

$$
\text { .... (Primroses) }
$$

Arg. a lion pass. guard. gu. regally crowned or betw. three primroses of the secold. OGluvie, Ediubargh.
BEAST. LION betw. or within.... cont.

Flowers cont. (Roses)

Arg. a lion ramp. betw. three roses gu. barbed and seeded ppr. two flaunches of the second. Ricketтs, Redland Hill, co. Gloucester.

Az. a lion couchant betw. three roses arg. Town of Luduow, co. Salop.

Erm. a lion ramp. gu. betw. three roses az. T'udway.

Gu. a lion pass. guard. or betw. three roses arg. Tadowe, Essex and Kent.

Ga. a lion pass. betw. three roses or. Fowle, Chute Lodge, co. Wilts.

Gu. a lion pass. guard. betw. three roses or barbed vert. Fowle, River Hall, Sussex.

$$
\text { ..... (Roses) }
$$

Per bend gu. and erm, a lion ramp. betw, four roses in square and as many fleurs-de-lis in cross counterchanged. HoLLAND.

$$
\text { .....(Lilies) }
$$

Gu. a lion ramp. betw. eight lilies arg. Denvile or Devile.

$$
\text { .....(Pinks) }
$$

Arg, a lion ramp. per fess gu. and vert within an orle of pinks slipped and leaved ppr. EDsin, Surrey.

\section{....(Roses)}

Arg. a lion ramp. sa. within an orle of roses gu. Pierpont. Sire Robert Pirepound, $N$.

Arg. a lion ramp. within an orle of roses sa. Pierpont.

Az. a lion ramp. within an orle of roses or. Bowen, co. Oxford.

\section{3-Foils}

Arg. a lion pass. gu. betw. three 3-foils slipped vert. Lamesey or Lambsex. Levesey, $V$. Leviesey, $V^{*}$.

Arg. a lion ramp. gu. betw. three 3-foils vert. LYNDSEX.

Arg. a lion ramp. gu. betw. three 3.foils slipped vert. Levesey, co. Lancaster, $V$. Livesey, Livesey, co. Lancaster, and Eastchurch, Kent: Baronetcy 11 July 1627 . Livcy.

Arg. a lion ramp. sa. betw, three 3.foils gu. Mullox, Hughstown; and Oak Port, co. Roscommon; derived through Muluoy or O'Mulcox, Standard-bearer to the Crown of England in Treland; from Niall of the Nine Hostages Monarch of all Ireland.

Arg. a lion ramp. sa. betw. three 3-foils (another slipped) gu. MoLloy, Middlesex.

Az. a lion ramp. betw. three 3-foils slipped arg. CAWSON, London. SkıP.

Or a lion ramp. betw, three 3-foils vert. Sheridax.

Per pale gu. and vert a lion salient betw. three 3-foils or. Gaynor, Meath and Langford, Ireland; granted 21 December 1666.

Vert a lion ramp. or betw. three 3.foils slipped of the last. Sheridan, Ireland. Thomas Sheridan, Cavan, Ireland, 1730.

Ga. a lion ramp. betw. six 3-foils slipped arg. Pengelly, Sortridge, Whitchurch, co. Devon.

Ga. a lion ramp, arg. betw, six 3-foils slipped or. Pengelly, $V$.

Gn. a lion ramp. betw, eight 3-foils slipped or. Sr. $\ldots$ de Motintender, $V$.

Sa. a lion ramp. betw. eight 3-foils slipped arg. Plantney, Wolverhampton, co. Stafford ; granted 1583.

Az, a lion ramp. within an orle of 3 -foils arg. Holland, Bognor, Sussex. Pechey, Cornwall. 
BEAST. LION betw, or within.... cont.

\section{3-Foils cont.}

Gu. a lion ramp. within an orle of 3 -foils arg. Pengeley, Cornwall.

$\mathrm{Gu}$. a lion salient arg. within an orle of 3.foils slipped or. Pengeliy, $V^{*}$.

Per pale or and gu. a lion ramp. within an orle of 3 -foils all counterchanged. Roger Rowe, Alport, co. Derby ; granted ....

\section{5-Foils}

Arg. a lion pass. reguard. ermines betw. two 5 -foils in chief vert and an escallop in base gu. JEKEN. JEKIN, Dover; grantcd 16 July 1803.

Arg. a lion ramp. gu. betw. two 5-foils vert. $\mathrm{M}^{6} \mathrm{G}$ own, Scotland.

Arg. \& lion ramp. az. betw. three 5-foils and a double tressure flory counterflory gu. LYoN.

$\mathrm{Gu}$. a lion ramp. betw. three 5 -foils and a bordure engr. arg. Gray, Dalmarnock and Carntyne, co. Lanark; quartering Hamilton.

Gi1. a lion ramp. arg. betw. three 5-foils erm. Hamilton, Cambuskeyth and Grange, co. Ayr.

Gu. a lion ramp. arg. gorged with a collar vert and supporting betw. the paws the fasces erect ppr. banded or betw. four 5 -foils of the second and so many annulets as the third alternately. SidDoNs; granted 1819.

Sa. a lion ramp. betw. five 5-foils arg. Clifton, Laiton Bromswold.

Arg. a lion ramp. sa. betw. six 5-foils gu. Sr.... de Perpound, $V$. Pemeront, $V^{*}$. Pierrepoint, $V^{*}$.

Gu. a lion ramp. the head arg. divided by a line of erasure from the body within an orle of seven 5-foils or. Grace, $V$.

Arg. a lion ramp. sa. betw. eight 5 -foils gu. Pierpornt, Holm-Pieruoint, co. Notts, $Z, 399$.

Arg. a lion ramp. sa. armed gu. within an orle of eight 5-foils of the second. Clifton, co. York.

Az. a lion ramp, guard, or betw, eight 5 -foils .... ANDRowx, $V$.

Az. a lion ramp. betw, eight 5 -foils or. Lovd.

Sa. a lion ramp. betw. eight 5-foils arg. Sr. Gervas Cuffton, $V$.

Sa. a lion ramp. betw, eight 5-foils arg. with a 3 -foil slipped of the last in chief for diff. Clifton, Barrington, co. Somerset.

Az. a lion ramp. guard. or betw. ten 5-foils arg. ANDROWEY Or ANDWEY.

.... a lion ramp..... crowned .... within an orle of 5-foils. . .. Edward LLoYd, Kidwelly, 1660-70.

Arg. a lion ramp. sa. within an orle of 5-foils gu. Monsire de Pierpoint, $Y$, or Pierpount, $Y$. Pierrepoint, in Rawmarsh Church, co. York.

Arg. a lion ramp. witbin an orle of 5 -foils sa. M. John de Clifton, $S$.

Gil. a lion ramp. arg. within an orle of 5 -foils or. GRACE, $V^{*}$.

Gu. a lion ramp, within an orle of 5 -foils or. Grace, co. Huntingdon; co. Somerset; co. Wilts ; and Ellington, co. Durham.

Or a lion ramp. sa. within an orle of 5 -foils az. SidDONs.

Sa. a lion ramp. within an orle of 5 .foils arg. Clifton, $V^{*}$. Clifton. M. Edmond Perpond, $S$.

Sa. a lion ramp. within an orle of pierced 5 -foils arg. Pierpont.

Sa. a lion ramp. within an orle of 5 -foils or EDwardes, Rhyd-y.Gôrs, co. Carmarthen, and Gileston Manor, co. Glamorgan; quartering gu. a cher. or betw. three Bowen's knots ...., with sa. three buck's heads cabossed arg., and chequy or and sa. a fess arg.
BEAST, IION betw, or within.... cont.

6-Foils or 7-Foils

Arg. a lion ramp. sa. within an orle of 'setfoils' or 'seyfoils' gu. Thomas Pierpoint, $Y$. Henry Pierpount, $Y$.

\section{Fruits (Acorrs)}

Arg. a lion pass. gu. betw. two acorns az. in bend cotised erm. RODEs.

Arg. a lion pass. guard. gu. betw. two acorns in bend az. cotised ermines. Rhones, Bellair and Shapwick, co. Devon; quartering Sleech, Andrew, and Cholwich. John Rhones, Horbury, eldest and disinberited son of Sir John Rhodes, Barlborough. Rhodes or Rodes, Great Houghton, co. York; the heiress m. Busk; descended like Rhodes or Rodes, Staveley-Woodthorpe, and Barlborough, co. Derby ; Baronetcy 1641, extinct 1743, the heirs m. Heathcote and Reaston; (through Francis RoDEs, Judge of the Common Pleas, temp. Elizabeth ;) from Gerard de RODEs, Horncastle, co. Lincoln, temp. Henry II. Sir John de Rodes, co. Nottingham, $Y$.

Or a lion pass. sa. betw. three acorns vert. Drywood, Shipston, co. Essex.

$$
\text { .....(Corn) }
$$

Vert a lion ramp. betw. five ears of wheat or two two and one. JoANes, Wales.

$$
\text { ..... Acorns) }
$$

.... a lion salient guard. arg. betw. six acorns or. Chenduit.

Gu. a lion ramp. arg. betw. six acorns slipped or. ATwood, Suffolk.

Gu. a lion ramp. arg. betw. eight acorns or. ATwood, $V$.

Gu. a lion ramp. guard. arg. betw. eight acorns slipped or. ATtwood, co. Gloucester.

Gu. a lion ramp. reguard, arg. betw. eight acorns or. Cheyndute, $V$.

Gu. a lion ramp. arg. within an orle of acorns or. ATTWOOD.

Gu. a lion salient reguard. arg. within an orle of acorns or. Cheyndute, $V^{*}$.

Garb

Sa. a lion ramp. betw. a garb in clief and a writing pen in base arg. EDGar, Kithock, Scotland.

\section{Garbs}

Per bend az. and vert a lion ramp. arg. betw. two garbs or. SHERFIELD.

Sa. a lion ramp. arg. betw. in chief two garbs of the second banded gu. and in base a bezant. EDgar, Pollend, Scotland; descended from Kithock.

Arg. a lion pass. environed with a laurel vert betw. three garbs az. banded or. Grisewood, London.

\section{Gouttes}

Per bend arg. and or a lion ramp. ppr. murally crowned gu. within an orle of gouttes-de-sang. Hall, Mollame, co. Kircudbright.

\section{Hand}

Arg. a lion ramp. gu. betw. in chief a dexter hand apaumy and a cross croslet fitchy of the last and in base a salmon naiant az. DONALD.

\section{Hands}

Arg. a lion ramp. sa. betw. two dexter hands couped at the wrist gu. Crossby, Newcastle. Croseby, co. York.

Arg. a lion ramp. sa. (another armed and langued gu.) betw. in cluief two sinister hands apaumy conped gu. and in base a crescent az. Farquear; Baronetcy 1 March 1796. 
BEAST. LION betw, or within..... cont.

\section{Hands cont.}

Arg. a lion ramp. sa. armed and langued gu. betw. in chief two sinister hands apaumy couped of the last and in base a crescent az. a crescent for diff. Farquhar, Baronetcy 21 August 1821.

Per fess arg. and or a lion ramp. per fess gu. and sa. betw. two dexter hands in chief of the third. DALY, Dunsandle and Benmore, co. Galway.

Arg. a lion ramp. betw. three dexter hands couped at the wrist gu. Mageoghagan, Ireland.

Arg. a lion ramp. sa. armed and langued or betw. three sinister hands couped palewise gu. Farquhar, Gilmilnscroft, Scotland; the heiress m. 1777 Gray.

Arg. a lion ramp. sa. betw. three sinister bands gu. within a bordure az. MAC FARQUHAR, Edinburgh.

Az. a lion pass. guard. paly of ( $\operatorname{six} V^{*}$.) seven arg. and or betw. three dexter gauntlets back part outwards of the second all within a bordure engr. gold. Conway, $V^{*}$. Conwer, $V$.

Frm. a lion ramp. betw. three dexter hands couped gu. Richard Nem or Nerie, Bishop of Rochester, 1608; Lichfield, ete., 1610-14; granted 1612. NEALE, Westminster; granted November 1612 .

$\mathrm{Gu}$. a lion pass. betw. three gauntlets backs outward or. Lusher, London.

Gu. a lion pass. guard. betw. three gauntlets or. LASHAw, London.

\section{Head}

Or a lion ramp. gu. surmounted by a bend sa. in chief a stag's bead cabossed of the second and in base a cross croslet fitchy of the third. SPENCE.

\section{Heads (Beasts) Boar}

Arg. a lion pass. betw. three boar's heads couped sa. Alphe, co. Hants.

Az. a lion ramp. betw, three boar's heads erased arg. Gondon, Beldorny, Scotland; quartering az. three boar's heads within a bordure engr. arg.

Az. a lion pass. guard. arg. betw. three boar's heads erased or. Gondon, 'Terpersy, Scotland.

Or a lion ramp. betw. three boar's beads erased sa. Wood, Brownhills, co. Stafford.

$$
\text { .... Dog }
$$

Per bend erm. and ermines a lion ramp. betw. three talbot's heads erased or. Travers, Wales.

Per pale arg. and az. a lion pass. betw. three greyhound's heads erased counterchanged. NEELD, Grittleton House, co. Wilts.

$$
\text { .... Leopard }
$$

Or a lion ramp. guard. gu. betw. three leopard's heads sa. Keтr, Kellsall, Suffolk, granted 1756.

$$
\ldots .0 \mathrm{x}
$$

Arg. a lion pass. betw. three bull's heads couped gu. Belyn.

Arg. a lion pass. sa. crowned (? or) betw. three bull's heads couped of the second attired gold. Boleine, $V$. Boleyn, $V *$ *

$$
\text { .....Human Figure }
$$

Or a lion pass. betw. three helmets sa. NAPPs or Napp, Needham.

Sa. a lion pass. guard. betw. three helmets arg. CoMpton.

Sa. a lion pass. guard. or betw. three helmets arg. Henry Compton, Bishop of Oxford 1674, Lon-
BEAST. LION betw, or within.... cont.

Heads cont. Human Figure cont.

don 1675-1713. Compton, Marquis and Earl of Nortbampton; Earl Compton of Compton, and Baron Wilmington of Wilmington. Compton, Carham Hall, Northumberland; the co-heir's m. Hinde and Compton.

Sa. a lion pass. guard. or betw. three esquire's helmets arg. Sr. Henry Compron, Lord Compton, $V$. Sir William Compton, $V$.

Sa. a lion pass. guard. or betw. three esquire's helmets ppr. garnished gold. Compton, Lyudhurst, co. Hants.

$$
\text { ..... Monster }
$$

Az. a lion pass. arg. betw. three griffin's beads erased or. Box, Sheriff of London 1570.

Az. a lion pass. guard. arg. betw. three griffin's heads erased or. Box.

Az. a lion pass. betw. three griffin's heads erased or. Box, Oxford.

$$
\text { .... Spears }
$$

Gu. a lion ramp. betw. three spear-beads arg. MaCnamara.

\section{Inkmoline}

Arg. a lion ramp. gu. betw. three inkmolines sa. a bordure az. charged with an annulet or. TURNER.

Knot

Az. a lion ramp. or in a true love knot arg. betw. four fleurs-de-lis their stalks bending towards the centre of the second, HogHe, Penymaes; quartered by Rees or Rhys.

\section{Ladders}

Sa. a lion pass. betw. three scaling ladders arg. Morris.

Sa. a lion pass. or betw. three scaling ladders arg. Morris, Cardigan, Wales.

Sa. a lion ramp. betw. three scaling ladders or. JFFFREY, co. Worcester, $W$. JEFFERYES or Geffreys, Clifton, Homecastle, co. Worcester.

Sa. a lion salient betw. three scaling ladders or. JEFF EREY, $V^{*}$.

\section{Leaves}

Or a lion ramp. sa. armed and langued gu. betw. three bolly leaves slipped ppr. Surman, Treddington House, co. Gloucester.

Or a lion ramp. sa. betw. three holly leaves vert. Sherman, Littlelinton, co. Cambridge; and Croydon, Surrey.

Or a lion ramp. sa. betw. three oak leaves vert. Sterman, Yoxley, Suffolk.

Or a lion ramp. sa. betw. three parsley leaves vert. CLAPpESON.

\section{Ietters}

Arg. a lion pass. guard. az. betw. three Roman text R's .... Pare, Wisbeach, Isle of Ely; granted ....

\section{Lozenges}

Gu. a lion pass. and two lozenges or. Robert Thornham, $X$, i.e. Robert (nephew of Michael de Turnham) founder of Bavham Abbey, Sussex. N.B., as this blason is indecisive, see Lion and in chief.... Lozenges.

\section{Lures}

Gu. a lion pass. erm. betw. three hawk's lures arg. Chester, Amesbury, co. Gloucester.

Mascle

Arg. a lion ramp. in a mascle sa. Pot or Putr, Combe. Gillingham, co. Devon, Baronetcy 21 July 1666 ; extinct 1721 .

Mascles

Gu. a lion pass. or betw. two mascles arg. Turnham, Kent and Surrey, temp. John. 
BEAST. LION betw, or within.... cont. Mascles cont.

Az. a lion pass, or betw. three mascles arg. THorney, London; descended from co. Nottingham; confirmed 10 December 1615.

Az. a lion pass. betw, three mascles or. Caterari, Horton, co. Chester, temp. Edward I.

\section{Mullets}

Or a lion ramp. gu. betw. two mullets in fess az. WaLlace, Arbrothick, Scotland; quartering gu. a fess chequy az. and arg.

Arg. a lion ramp. double-tailed betw. three pierced mullets of six points az. Harter, Broughton Hall, Manchester.

Alg. a lion ramp. sa. betw. three nullets gu. Chessells, Scotland.

Arg. a lion ramp. betw. three mullets sa. HAYs. IVOLNEY.

Az. a lion pass. betw. three mullets or. Prettruan, $V^{*}$.

Gu. a lion pass. guard. betw. three mullets arg. Prettyjohn. George Pretyman afterwards Tomine, Loddington, co. Leicester; Bishop of Lincoln 1787, Winchester 1820-7.

Gu. a lion ramp. betw. three mullets arg. MaLoNe, Ballynahown and Baronstown, Ireland; Baron Sunderlin 1785.

Gu. a lion pass. betw. three mullets or. Prettranan, Norfolk; and Bawton, Suffolk; granted 1599; confirmed 1607. Sir John Prettyman, per Camden, 1607, $W$.

Gu. a lion pass. guard. betw. three mullets or. PretTyMan.

Gu. a lion ramp. betw. three mullets or. Whitbroke, Water Newton, co. Huntingdon. Witнвroke, co. Salop, $V$.

Or a lion lamp. gu. betw, three mullets az. over all a fess chequy arg. and of the third. Steuart, Dalguise, Scotland.

Or a lion ramp. sa. betw. three mullets gu. De WoLVEY; quartered by Holte.

Or a lion ramp. (salient $V^{*}$ ) betw. three mullets sa. WolNey, $V$.

Per bend or and arg. a lion ramp. betw. three mullets counterchanged. SAMSON, Scotland.

Sa. a lion pass. guard. betw. three mullets arg. Crawley, London. Shrawley, London, 1588.

Arg. a lion ramp. gu. betw. five pierced mullets the two in chief enclosing a pair of crescents sa. the others as the second. Drson, $V$.*

Arg. a lion ramp. betw. five pierced mullets of six points gu. the two in chief enclosing a pair of crescents sa. over all a fess az. Sr..... Dyson, Ireland, $V$, but DiLoN, Harl. MS. 1392, fo. 146.

Gu. a lion ramp. or betw. six mullets arg. TopHam.

Gu. a lion ramp. betw. seven mullets arg. three two and two. SALTREN, Treludick, Cornwall.

Or a lion ramp. gu. betw. eight mullets az. MOLFYN or MOLFIN.

Az. a lion ramp. within an orle of mullets arg. Saltren, Petticombe, Cornwall; descended from Saltren, Treludick.

Gu. a lion ramp. within an orle of mullets and crosses croslet or alternately. Martin, Ripe, Sussex. Wykeham-Martin, Leeds Castle, Kent; and Chacombe Priory, co. Northampton; quartering arg. two chev, sa. betw. three roses gu. seeded or barbed vert.

\section{Nails}

Gu. a lion ramp. arg. betw. eight nails or Breedon, Croton, co. Northampton.
BEAST. LION betw. or within.... cont.

\section{Nails cont.}

Gu, a lion ramp. arg. within an orle of eight passion (or calvary) nails or. Breedon, confirmed 1783 to Symonds, Bere Court, Pangbourn, co. Berks.

Orle

Arg. a lion ramp. within an orle gu. Blamore.

$\mathrm{Az}$. a lion ramp. within an orle engr. on the inner side and a bordure arg. Renton, Billie, Scotland.

Gu. a lion salient within an orle or a label of three points compony az. and vert. BLAUMESTER, $V^{*}$.

vert a lion ramp. within an orle arg. HAGGer. LoVELOCK.

\section{Pheons}

Az. a demi-lion ramp. betw. three pheons or. Harrison, Galligreaves House, Blackburn, co. Lancaster.

Arg. a lion pass. guard. gu. betw. three pheons gz. Shearwood.

Arg. a liow ramp. gu, betw. three pheons az. EgERTON.

Arg. a lion ramp. betw. three pheons gu. EgERTON.

Arg. a lion ramp. gu. betw. three pheons sa. Becket. Town of Brackley, co. Northampton; quarterly with Stanley. Edgerton. Egerton, Earl of Bridgewater, $Z$, 542, Viscount Brackley, Baron Ellesmere, afterwards Duke of Bridge. water. Leveson-Gower EGERTON, Earl of Ellesmere and Viscount Brackley. GrosvenorEgerton, Earl of Wilton, Viscount Grey de Wilton. John Egerton, Bishop of Bangor 1756, of Lichfield, etc. 1768, Durham 1771-87. Thomas EgERTon, Viscount Brackley, and Chancellor 1618. Sr. Richard Egerton, $V$. Egerton, Broxton, co. Chester, 1730; descended from EgERToN, now Grey.EGERToN, Egerton and Oulton Park, co. Chester; Baronetcy 5 April 1617; quartering Grey with a label of five points gu. EgERTon, Tatton, co. Chester; derived from EgERTon, Earl of Bridgewater ; the heiress m. 1747, Tatton.

Arg. a lion ramp. gn. betw. three pheons within a bordure engr. sa. Egerton, Essex.

Az. a lion ramp. betw. three pheons arg. Cologan, Ireland. Cologan, Island of Teneriffe.

Az. a lion pass. betw. three pheons or. Wolstenholme, Dransfield, co. Derby ; confirmed 1604. Wolstenholise, Horsley-Gate, Droufield, co. Derby, 1460 ; a younger branch of Wolstenholme of Wolstenholme, co. Lancaster. Wolstenholme, Minsingden, Edmonton, Middlesex, Baronetcy 10 January 1664, extinct ....

Az. a lion pass. guard. betw. three pheons or. Wolstenholir, Nostel, co. York. Worstanholme, Winchenden, Middlesex. Wolstenholme, Loudon; Baronetcy 10 Jan. 1664 , extinct ....

Gu. a lion pass. guard. chequy arg. and az. betw. three pheons of the second. HADDERwick, Pitcullo.

Or a lion ramp. gu. betw. three pheons az. M'NAIR or M'NAYR.

Or a lion ramp. gu. betw. three pheons sa. Macnamara.

Or a lion ramp. gu. betw. three pheons within a bordure engr. sa. EGERToN, co. Stafford.

Arg. a lion ramp. gu. langued and armed az. betw. six pheons sa. EgErTon, Malpas; quartered by Holte. 


\section{BEAST. LION betw, or within.... cont.}

\section{Pheons cont.}

Arg. a lion ramp. per fess gu. and vert betw. seven pheons az. Roope, Horswell, co. Devon; Visitation 1620 ; the heiress m. Ilvert. Roope, Bristol; confirmed to Harris $17 \% 1$.

Arg. a lion ramp. gu. betw. eight pheons sa. Rope, Rope and Staple, co. Chester; and Tunstall, co. Devon.

Or a lion ramp. gu. betw. eight pheons sa. Rope, $V$.

Arg. a lion ramp. betw. twelve pheons az. Roope.

Or a lion ramp. betw. twelve pheons az. Roope, co. Devon.

Or a lion ramp. gu. within an orle of pheons sa. Roppe, $V^{*}$.

Piles

Vert a lion ramp. betw. two piles engr. issuant from the chief arg. a bordure engr. of the last charged with six popinjays as the field beaked and membered gu. Home, Well Manor Farm, co. Hants; Baronetcy 2 January 1813.

\section{Roundles}

Erm. a lion ramp. sa. (another armed and langued gu.) betw. in chief two torteaux and in base a hand grenade exploding ppr. BALL, Blofield, Norfolk, Baronetcy 24 June 1801.

Per bend gu. and arg. a lion salient betw. three roundles counterchanged. Rossie, Scotland.

Az. a lion pass. or betw. three bezants. Bongex, London, I239. John Bungey, Mistold, Kent; granted by Cooke, TW. Bungex, Kent; Dorking, Surrey; and Norfolk, 1588.

Gu. a lion pass. or betw. three bezants. Harborne, Middlesex; Norfolk; and Thackley, co. Oxford; granted 1613.

Gu. a lion pass. guard. or betw. three bezants. John Harborne, Shere Lane, Middlesex; granted by Camden, $W$.

Or a lion ramp.az. betw. three hurts. WAYNFORTH, Roydon, Diss, Norfolk.

Or a lion ramp. double tailed az. betw. three hurts. WaNkFord, Berwick Hall, Essex; granted 18 September 1664.

Or a lion ramp. sa. betw. three ogresses. GibBon, Rolvenden, Kent; granted 6 A pril 1629. Gibons.

Per fess dancetty or and arg. a lion ramp. az. in chief an ogress betw. two crosses croslet gu. and in base a cross croslet of the last betw. two pellets. BEckMan, London.

$\mathrm{Gu}$. a lion ramp. or betw. three plates each charged with a 3-foil shpped vert. Crosweller, co. Hants.

Gu. a lion ramp. guard. per fess or and arg. betw. three plates each charged witl a cross of the first. Trinitarian or Maturin Priory at Hounslow, Middlesex.

Or a lion ramp. sa. betw. three torteaux. LudLow, Wales.

Per pale arg. and or a lion pass. sa. betw. three tortenux. Stanbury.

Gu. a lion ramp. arg. betw. eiglit bezants. Sr. .... de Hewikes, $V$.

Sa. a lion ramp. arg. betw. eight plates. Prenne, $V$.

Gu. a lion ramp. arg. betw. nine plates. HEYWICK.

Az. a lion ramp. guard. arg. betw. ten plates all within a bordure of the second. HoLLAND, Burwarton, Charlecot, and Pickthorne, co. Salop.

Sa. a lion ramp. arg. within an orle of bezants or plates. Prenne, $V^{*}$.
BEAST. LION betw, or within....cont.

Roundles cont.

Gu. a lion ramp. erm. within an orle of plates and bezants alternately. Hincks, Breckenbrough, co. York; and Huntington, co. Chester; descended from Hincks, Chorlton, co. Chester; quartering Callys, Stevenson, Cowper, and Alleyne.

Arg. a lion ramp. sa. within an orle of torteaux. Poynton.

\section{Saltires}

Gu. a lion pass. guard. betw. three saltires or. LANE.

Sa. a lion pass. guard. or. betw, three saltires couped arg. Samuel Tноmpson, Windsor Herald, $W$. Thompson, Streatham, Surrey.

\section{Ships}

Per pale gu. and az. a lion ramp. or betw. three sterns of ships arg. Town of Ipswich, Suffolk.

\section{Spears}

Arg. \& lion ramp. gu. betw. two demi-spears in fess ppr. Macnamara, Scotland.

Arg. a fion ramp. sa. betw. two demi-spears erect in fess ppr. Macnamara.

\section{Sprigs}

Arg. a lion ramp. or and broom slips (? ppr.) SANDdE HARD. Jevan JoRworth, Llanjwlyn. Powell, Holsley.

\section{Staves}

Arg. a lion ramp. sa. betw. three palmer's staves or. Palmer.

Arg. a lion ramp. betw. three palmer's staves sa. heads ends and rests or. Palmer, London, 1634 .

\section{Swords}

Gu. a lion ramp. arg. betw. two swords pomels downwards points to the dexter and sinister chief ppr. DEMSEX.

Vert a lion ramp. betw. two swords wavy in fess or. J)EMPSEY.

\section{Tails}

Arg. a lion ramp. gu. betw. three erm. spots .... O'Dwire, Ireland.

\section{Tussels}

Gu. a lion pass. betw. three tassels arg. Chestor, co. Gloucester.

\section{Tressure}

Or a demi-lion ramp. with an arrow shot in his mouth in a double tressure gu. Augmentation granted 1524 to Thomas How ARD, Duke of Norfolk, for bis victory at Flodden.

Arg. a lion ramp. within a double tressure flory counterflory az. Bowes-Iyon, Earl of Strathmore and Kinghorn; quartering gu. three lions pass. in pale ....

Arg. a lion ramp. az. armed and langued within a double tressure flory counterfiory gu. LxoN, Glamis, co. Forfar, Earl of Strathmore. Lyon, Hetton, co. Durham. Lyon, Auldbar, co. Forfar. Lyon, Jamaica; Woolavington, and Goring, Sussex; and New Lodge, co. Berks; descended through Lxon, Castle Lyon, co. Perth, from Lyon, Auldbar; quartering Ochterlony, Stewart, Read, and Guthrie.

Arg. a lion ramp. gu. within a bordure flory counterflory .... Deans-Dundas, Barton Court, co. Berks ; quartering Whitley, and Deans.

Arg. a lion ramp. within a double tressure flory counterflory gu. Dundas, Earl of Zetland.

Az. a lion ramp. arg. within a double tressure flory counterflory gu. Drumurond, Melfort. 
BEAST. IION betw. or within.... cont.

Tressure cont.

Az. a lion ramp. within a tressure flory counterflory or. LODGE.

Az. a lion ramp. within a double tressure flory counterflory or. LoDGe, Nettlested, Suffolk.

Or a lion ramp. within a double tressure flory counterflory gu. Le roy d'Eschose or Escoce, $E$. M'As.pin, quartering arg. a fir tree growing ont of a mount in bend sinister vert surmounted by a sword in bend ensigned on the point with a royal crown ppr., with gu. three antique crowns or, and az. an eagle displ. with two heads arg. Maitland, co. Gloucester. Attributed to Matulda, Queen to Henry I, $Z, 2$. Scotland, $Z, 87,155,325,326,522$. STEWart, Earl of Murray; quartering or a fess chequy az. and arg., with or three cushions and a double tressure flory counterflory gu. STEWART, Earl of Buchan; quartering Buchan. STENART, Burgh, Scotland; quartering az. a galley sails furled arg. Steuart, Ballechin, co. Perth ; derived from SteUART, Sticks, illegitimate son of James II of Scotland; quartering or a fess chequy az. and arg. within a boraure engr. of the first. Steuakt, Stewartfield, co. Edinburgh; descended from John Steuart, Killichassie, a younger son of Stevart, Ballechin, with the same quariering. STEWART, Lord Ochiltree, Scotland; quartering Stewart in chief a label sa., with arg. a saltire engr. betw. four roses gu. all within a bordure compony az. and arg. Stewart, Ardverlich, Scotland; quartering Stewart in chief a mullet gu., with arg. a saltire engr. betw. four roses gu. all within a bordure compony az. and of the first all quarterly with Scotland. STUART, Earl of Castle Stuart; quartering Stuart in chief a label of three points gu., with arg. a saltire betw. four roses gu., and az. a lion ramp. arg., the whole within a bordure compony of the second and first.

Or a lion ramp. within a double tressure flory counterflory gu. a bordure compony arg. and az. STuart, Earl of Moray, Lord Doune and Abernethy; quartering Stewart and Moray.

Or a lion ramp. within a double tressure flory counterflory gu. a bordure compony az. and arg. Lundin, that Ilk. Stewart, Athenry, co. Tyrone, Baronetcy 21 June 181)3.

Or a lion ramp. within a double tressure flory counterflory gu. a bordure compony gu. and arg. Stuart, Dunenrn, co. Fife; derived from Moray; quartering Stewart and Moray, over all in the centre a crescent sa.

Or a lion ramp. within a double tressure flory counterflory gu. over all a ribbon sa. STEWART, Earl of Orkney; quartering Orkney.

Or a lion ramp. couped in all the joints within a double tressure flory counterflory gu. MATTLAND, Earl of Lauderdale. Gibson-Maitrand, Cliftou Hall, Mid Lothian, Baronetcy 30 November 1818. MaItiand, Hollywich, Sussex.

Or a lion ramp. sa. armed and langued gu. within a double tressure flory counterflory of the second. Buchanan, Auchintorlie and Ardinconnal, co. Dumbarton, and Hillington, co. Renfrew; descended like Buchanan, Drumpellier, co. Lanark; through Buchanan, Mochastel; from Buchanan, Leny, a cadet of Buchanan, Buchanan, Scotland. And with a crescent for diff., Buchanan, Sound, Scotland.
BEAST. LION betw. or within.....cont.

Tressure cont.

Or a lion ramp. sa. armed and langued gu. within a double tressure flory counterflory of the se. cond a bordure of the third charged with eight crescents arg. Buchanan, Miltown, Scotland.

Or a lion ramp. sa. holding in his dexter paw an arrow and in the sinister a bow all ppr. within a double tressure counterflory of the second. Buchanan, Drumhead, Scotland, a cadet of Drumakill.

Or a licn ramp. sa. armed and langued gu. holding in the dexter paw a crown or all within a double tressure flory counterflory of the second. Buchanan, Carbeth, Scotland; descended from Buchanan of that Ilk.

Or a lion ramp. sa. holding in the dexter paw a man's heart ppr, all within a double tressure counterflory of the second. Buchanan, Drumaliill, Scotland, a cadet of that Ilk.

Or a lion ramp. sa. holding in his dexter paw a sabre or crooked sword ppr. all within a double tressure flory counterflory of the second. Mac Causland, Strabane, Ireland.

Or a lion ramp. sa. in the dexter paw a dagger ppr. all within a double tressure flory counterflory of the second a bordure invecked $\mathrm{gu}$. Buchanan, Ardoch, co. Dumbarton, descended from Buchanan, Carbeth.

Per bend or and sa. a lion ramp. within a double tressure all counterchanged. BuchanaN, Stirling, Scotland.

Per fess or and gu. a lion ramp. within a double tressure flory counterflory counterchanged. Middleton, Earl of Middleton. Middleton, Chelsea, Middlesex; and Scotland.

\section{Trees}

Arg. a lion ramp. gu. betw. two laurel branches crossed saltireways in base ppr. DE Silva.

Wreath

Arg. a lion ramp. gu. encircled by a wreath of brambles ppr. Du Silva, Portugal.

oX betw. or within....

\section{Annulets}

Erm. a bull pass. betw. three annulets gu. Bevan, Bury St. Edmunds.

\section{Bordure}

Arg. a bull gu. within a bordure sa. bezanty. Cole, Cornwall. Cores, Parrocks Lodge, near Chard, co. Somerset.

Arg. a bull pass. gu. within a bordure sa. bezanty. Cowley, co. Devon.

Arg. a bull pass. gu. armed or within a bordure sa. bezanty. CoLe, Stoke Lyne, co. Oxford; and Twickenham, Middlesex.

Arg. a bull pass. sa. on a bordure of the second eight bezants. Moorsine; quartering or on a chev, az. betw. three boar's heads erased sa. as many pierced mullets arg.

Arg. a bull pass. sa. within a bordure of the second bezanty. LAMELIN, Lamelin, Cornwall ; the heiress m. Trelawny.

Arg. a bull pass. sa. armed or within a bordure of the second bezanty. Cole, Slade, co. Devon, temp. Henry IV, and London.

Arg. a bull pass. sa. attired or within a bordure of the second bezanty. LYARDE Lyarte or LyHaRte.

Arg. a bull pass. sa. collared and lined or within a bordure of the second bezanty. Cole, Lusse, co. Hants; confirmed.... 
BEAST. OX betw, or within.....cont.

Bordure cont.

Arg. a bull pass. coward sa. within a bordure of the last bezanty. Liard, Norfolk.

Erm. a bull pass. gu. within a bordure compony or and az. DRew or DRewe, Cliff and Higham, alias Norton, co. Devon; Broxbourne, co. Hertford ; and co. Wilts.

Erm. a cow statant gu. within a bordure sa. be. zanty a crescent for diff. Cowell.

Per pale indented arg. and gu. a bull pass. coun. terchanged armed or within a bordure sa. bezanty. Colles.

Per pale indented gu. and arg. a bull courant counterchanged within a bordure sa. bezanty. Colle, $V^{*}$. Coulee, $V^{*}$. Coullee, $V$.

Per pale indented gu. and arg. a bull pass. counterchanged within a bordure sa. bezanty. Cowley. Colliray.

Per pale indented or and gu. a bull pass. counterchanged within a bordure .... bezanty. Callore.

\section{Crosses}

SHEEP betw, or within....

Gu. a ram pass. arg. attired or betw. three crosses croslet fitchy of the last. Cupholme, Boston, co. Lincoln; granted 26 October 1562. TUPHoLmE, co. Lincoln.

Tressure

Az. a goldeu fleece within a double tressure flory counterflory or. $J_{A S O N}$, Broad Somerford, co. Wilts; Baronetcy 5 September 1661, extinct 1738; and Enfield, Middlesex.

SQUIRREL betw. or within....

Arg. a squirrel sejant cracking a nut.... on a bordure az. eight fleurs-de-lis .... Fovtert.

Gu. a squirrel sejant arg. within a bordure sa. bezanty. Srokes, Kent.

TIGER betw. or within....

Arg. a heraldic tiger statant gu. on a bordure sa. eight fleurs-de lis.... Lone, London.

\section{Bordure}

WOLF betw. or within....

Arg. a wolf salient az. within a bordure engr. sa. LOVELL.

Arg. a wolf pass. sa. transfixed with a sword ppr. within a bordure gu. DUMBREck, Edinburgh.

Arg. a wolf salient sa. within a bordure engr. of the second charged with eight bezants. ATwOOD.

Arg. a wolf salient sa. collared of the first within a bordure of the second. ATwood.

Or a wolf salient az. within a bordure engr. sa. Lovel, $V$. Another, the wolf ramp.

Crosses

Per pale or and arg. a wolf salient az. betw. eight crosses croslet fitchy gu. Phelps, London.

$\mathrm{Gn}$. a wolf salient arg. within an orle of crosses croslet or. AstLEY.

Roundles

Ajg. a wolf salient sa. betw. three torteaux within a bordure of the second. ATwOOD.

BOAR betw. or within....

and in chief....

Arg. on a mount a bear standing against a tree all ppr. the bear collared and chained or betw. in fess two escucheons each charged with the arms of France and England quarterly on a chief arg. a ling crowned and habited ppr. holding in his dexter hand a mound and in the sinister a sceptre both or. Town of BERwICK, Northumberland.
BEAST. CAMEL betw. or within....

and in chief....

Or a camel sa. betw. two catherine wheels az. on a chief of the last a catberine-wheel arg. enclosed by two bezants. Wheeler, Stolse, Surrey.

Or a camel sa. statant sa. betw. three half-wheels az. on a chief of the third a wheel arg. enclosed by two bezants. Wheler, $V^{*}$. John WHELLER, Stoke, Surrey, 1543, $V$.

Or a camel betw, three half-wheels sa. on a chief az. a catherine-wheel or enclosed by two bezants. WheELER, in Thames Ditton Church.

\section{DEER betw, or within...}

and in chief....

Or a stag courant betw. three roses gu. on a chief sa. as many escallops of the field. GrAHAM, Bachlavy, Scotland; a cadet of Inchbrakie.

DOG betw. or within....

and in chief....

Sa. a talbot betw. two bars and in cbief two other talbots arg. HaTNAULT or HENAWD (?).

\section{HORSE betw. or within....}

and in chiof....

Gu, a mule pass. within a bordure arg. a chief of the second. MoyLe.

\section{LION betw, or within....}

and in chief....

\section{Beasts}

Arg. a demi.lion issuant gu. betw. two bars wavy az. in chief as many demi.lions also issuant of the second. MILLIGaN or Mulimirine, Scotland.

\section{Buckle}

Or a lion ramp. gu. within a bordure wavy az. in chief a buckle betw. two lozenges sa. SPENCE, Edinburgh.

\section{Canton}

Az. a lion ramp. (salient $V^{*}$ ) or within a bordure engr. gu. a canton of the second. GaYe, co. Devon, $W$.

Az. a lion ramp. within a bordure or a canton of the secoud. Gar.

Az. a lion ramp. (salient $V^{*}$ ) within a bordure engr. or a canton of the second. $J_{A Y}, V^{*}$.

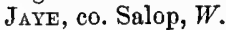

Gu. a lion ramp. or within a bordure engr. erm. a canton of the last. Gray, Dowland, Essex ; granted 1634 .

Gu. a lion ramp. within an orle of eight fleurs-delis or a canton erm. MARKE, Woodhill, Cornwall.

Gu. a lion ramp. within an orle of fleurs-de.lis or a canton erm. Markes, $V$.

Per pale az. and sa. a lion ramp.erminois ducally crowned and holding betw. the paws a mascle or within an orle of fleurs-de-lis arg. a canton erm. Philips, Weston, co. Warwick; and Sedgley, co. Lancaster; Baronetcy 21 February 1828 ; descended like Philips, The Park, Prestwich, co. Lancaster; and Snitterfield Park, co. Warwick, and like Philips, Bayk Hall, co. Lancaster, through PHilips, Heath Honse, co. Stafford, from Francis PhyLYPPE, Neyther Teyne, ob. 1552-3; quartering Whetall, Stubbs, and Burton.

on a Canton

Gu. a lion ramp. arg. ducally crowned gold within a bordure nebuly or on a canton of the last an eagle displ. with two heads sa. GarNerT, Bleasdale Tower, and Lark Hill, co. Lancaster. 
BEAST. IION betw, or within....

and in chief.... cont.

on a Canton cont. Harp

Arg. a lion ramp. gu. within a bordure sa. on a canton az. a harp or crowned ppi. LANE, Tulske, co. Roscommon; Baronetcy 11 Febrnary 1660 ; extinct 2 August 1724 ; created Visc. Laneshorough 1676 ; the heiress m. Fox. ....Garb

Arg. a lion ramp. betw. three crosses croslet gu. on a canton az. a garb or. Bowrer.

$$
\text { .....Head }
$$

Az. a lion ramp. betw. two flaunches arg. on a canton gu. a lion's bead erased of the second. Garmat.

$$
\text { ..... Ship }
$$

Gu. a lion ramp. (another tail forlied) betw. three martlets arg. on a canton or the stern of a ship of the line ppr. Brenton; Baronetcy $24 \mathrm{De}$ cember 1812 .

\section{..... Sword}

Per fess embattled gu. and az. a lion pass. ermi. nois betw. three mullets of six points or on a canton arg. a sword erect ppr. Burrard, Ly. mington, co. Hants; Baronetcy 12 November 1807.

\section{Chief}

Az. a lion ramp. betw. seren billets arg. a chief or. GOLDWELL.

Arg. a lion ramp. gu. within a bordure indented of the second charged with eight bezants a chief erm. Moncrieff, Sauchope, Scotland.

Arg. a lion ramp. gu. within a hordure invecked of the second charged with six crescents of the field a chief erm. Moncrief, Boghall, Scotland.

Arg. a lion ramp..... betw. three buckles gu. a chief chequy az. and of the first. Fergijson, Raith, Scotland.

Arg. a lion ramp. betw. three crescents sa. a chief vair. WiLcocrs, London; and co. Salop, 1634. Wircocks, Brightlingsea, Essex; and Tottenham, Middlesex. Wilcox, Middlesex, $17 \mathrm{I} 6$.

Arg. a lion pass. betw. three crosses patty fitchy gu. a chief az. Sir Francis Jones, Lord Mayor of London, I 620 .

Az. a lion pass. betw. three crosses patty fitchy or a chief of the second. Johnes. Jones, co. Berks; London; and co. Salop; granted Nov. 1610. Sir Francis Jones, Lord Mayor of London, 1620; descended from Jones, Claverley, co. Salop.

Az. a lion pass. guard. betw, three crosses croslet fitchy or a chief of the second. Sir Francis Jones, Lord Mayor of London, 1620.

Az. a lion ramp. betw. three crosses formy fitchy or a chief of the second. JoHnes, London.

Az. a lion ramp. betw. eight crosses croslet fitchy or a chief of the secoud. Jordan, co. Somerset; Chittern and Whistley, co. Wilts; 1604.

Az. a lion ramp. betw. three fleurs-de-lis or a chief vair. HARDisTy, co. York.

Arg. a lion rump. betw. two mullets in fess gu. a chlef erm. Moncriefr, Moncrieff.

Arg. a lion ramp. gu. armed and langued az. betw. two mullets .... a chief erm. MoncriefF, That Ilk, co. Perth; Baronetcy 30 November 1685 .

\section{on a Chief..... Bend}

Erm. a lion ramp. guard. sa. bolding betw. the paws a woolpack ppr. within a bordure of the second charged with eight bezants a chief wavy gil. thereon a bend engr. or betw. two roses arg. barbed and seeled pin. B.sche, Coventry.
BEAST, LION betw. or within....

and in chief.....cont.

on a Chief cont. Castlo

Or a lion ramp. within a bordure embattled gu. on a chief of the last a castle arg. masoned sa. betw. two Moor's heads couped ppr. banded of the third. Siesser, Scotland. ....Escallous

Or a lion ramp. az. betw. three roses gu. on a chief sa. as many escallops of the first. Graham, Grahamshall, Scotland; a cadet of Gorthy.

$$
\text { ..... Estoiles }
$$

Arg. a lion pass. in bend betw. two cotises gu. on a cbief az. as many estoiles or. Coor, London.

Az. a lion ramp. arg. within a bordure gu. on a chief of the second three stars of the first. InaIIs, Scotland.

Az. a lion ramp. arg. armed and langued gu. within a bordure of the second over all on a chief or three estoiles of the field. INGLis, MiltonBryant, co. Bedford: Baronetcy 26 June 1801. .... Fleur-de-lis

Vert a lion ramp. betw. three annulets arg. on a chief or a fleurs de-lis gu. betw. two towers ppr. Playfair, Edinburgh.

$$
\text { ....Gun }
$$

Arg. a lion ramp. ppr. holding in the paws an eastern crown or betw. three battle-axes sa. a chief gu. charged with a fieldyiece mounted on a carriage of the second betw. two towers as the first the dexter superinscribed "Hatrass" and the sinister "Bhurtpore" in letters gold. Battine; granted...

$$
\text { ..... Hand }
$$

Az. a lion pass. arg. betw. two stars in chief and a cross croslet fitchy in base on a chief or a sinister hand couped supported by two lions ramp. combatant gu. Burrakd.

$$
\text { .....Hands }
$$

Erminois a lion ramp. sa. betw. three fleurs-de-lis az. on a chief indented of the last three sinister bands erect and couped or. MunYard, Camden 'lown, Middlesex; granted....

$$
\text { .... Head }
$$

Arg. . a lion ramp. gu. betw. three 5 -foils vert on a cbief az. a Loar's head couped betw. two fleursde-lis or. M'Gouan, Scotland.

$$
\text { .... Mullets }
$$

Az. a lion ramp. within a bordure arg. over allon a chief or three mullets of six points as the field. Ingris, Milton-Bryant, co. Bedford; Baronetcy $26 \mathrm{June} 1801$.

Arg. a lion ramp. betw. four crescents in square or on a chief az. three mullets of the field. Russelu, Longridge.

Az. a lion ramp. betw. three escallops or on a chief arg. as many mullets of the field. Ponton, Edinburgh.

$$
\text { .... Rourdles }
$$

Or a lion ramp. az. betw. three arrows ppr. headed and feathered arg. two and one ou a chief gu. as many bezauts. Hurron, Scotland. Hutros, Notton Lodge, co. Wilts.

Or a lion ramp. gu. betw. three arrows ppr. on a chief of the second as many bezauts. HUTTON.

$$
\text { .... Spear }
$$

Gu. a lion ramp. betw. three crescents arg. on a chief embuttled of the last a tilting-spear in fess head to the sinister the staff encircled by a chaplet of oak ppr. STUDD, Ipswich. 
BEAST.

LION betw. or within....

and in chief.... cont.

on a Chief cont. Sun

Arg. a lion pass. gll. betw. three fleurs-de-lis az, on a chief of the third the sun in splendour or.

Le Poer Trench, Earl of Clancarty ; formerly quartering Power and Gardiner, but now quartering Le Poer, and over all the quarters an escucheon or ensigned with the coronet of a Marquis of the Netherlands, and charged with $a$ wheel of six spokes gu. for Heusden. Trench, Baron Ashtown.

$$
\text { ..... Sword }
$$

G11. a lion ramp. arg. betw. three escallops.... on a chief erm. a sword and branch of oak crossing each other in saltire ppr. CAPE.

Crescent

Per chev. embattled az. and sa. in base a lion ramp. or a bordure gu. in the dexter chief point a crescent arc. in the sinister chief point a mullet gold. Dupor't, Shipshead, co. Leicester. Crescents

Arg. a lion ramp. gu. betw. five pierced mullets two two and one the lower ones of the second the upper ones inclosing two crescents sa. Dyson, $V^{*}$.

Arg. a lion ramp. betw. five pierced mullets gu. in chief two crescents sa. over all a fess az. Sr. .... Drson, Ireland, V. But Dilon, Harl. MS. 1392, fo. 146 .

\section{Cross}

Az. a lion ramp. arg. betw. three lozenges or each charged with an increscent gu. in chief a cross croslet of the third. DARE, Cranhrooke House, near 11 ford, Essex; quartering HALL.

\section{Cup}

Az. a lion ramp. arg. gorged with an antique. crown or within a bordure erm. in the dexter chief point a covered cup of the third. M'Dowall, Scotland.

\section{3-Foil}

Sa. a lion pass. betw. two cotises arg. in the sinister chief a 3 -foil slipped erm. Browne, co. Derby.

Sa. a lion ramp. betw. eight 5 -foils and a 3 -foil in chief slipped arg. Clifton, Barrington, co. Somerset.

Garb

Az. a lion ramp. arg. within a bordure erm. in the dexter chief a garb of the second. M'Dowst, Bankton.

Heads

Arg. a lion pass. gu. betw. two bars sa. charged with three bezants in chief as many buck's hends cabossed of the second. PARker, Hurstmonceaux, Sussex.

Arg. a lion pass. gu. betw. two hars sa. charged with three bezants two and one in chef as many buck's heads of the third. PArker.

Arg. a lion pass. gu. betw. two bars sa. charged with three bezants two and one in chief three (brck's $V^{*}$.) stag's heads cabossed of the third. Sr. Henry Parker, Lord Morley, $V$. Parker, Lord Morley and Monteagle. Parier, Green Park, co. Cork.

Arg. a lion pass. betw. two bars sa. the upper charged with a crescent arg. betw. two plates the lower with a single plate in chief three stag's heads cabossed of the second. Parker, Ratton; quartered by Eliott.

\section{Mullet}

Az. a lion ramp. betw. three boar's beads couped or in chief a mullet arg. Gondon, Cadiz.
BEAST. IION betw. or within.... Minllets

and in chief.... cont.

Arg. a lion pass. betw. two barrulets gu. in chief as many mullets az. M`CANALD, Scotland.

Arg. a lion nass, hetw. two barrulets gu. in chief three mullets az. MAKRAYNALD or M'RAYNALD, Scotland.

OX betw. or within.... and in Chier....

\section{on a Canton.... Harp}

Arg. a bull pass. sa. armed or within a bordure of the second bezanty on a canton sinister az. a harp of Ireland. CoLE.

Arg. a bull pass. sa. armed and unguled or within $a$ bordure of the second bezanty on a canton az. a harp of the third stringed of the first. CoLe, Earl of Enniskillen.

$$
\text { .....Head }
$$

Arg. a bull gu. within a bordure sa. bezanty on a canton erm. a nag's head ppr. over which on a chief or three estoiles gu. CoLE, Brandrum, co. Monaghan; descended from Edward Cole, Twickenham, born 1579 .

Chief

Gu. $\Omega$ bull betw. three roaches haurient arg. a chief chequy or and az. Roche, co. York.

Or a bull pass. gu. betw. three roaches hanrient ppr. a chief chequy az. and of the first. RocHe, Lord Mayor of London, 1540.

Or a bull trippant betw. three dragon's heads erased gu. a chief countercompony az. and arg. Sir William Roche, Lord Mayor of London, 1531.2; the heiress m. Boteler. Roche, Lanier, co. Hertford.

on a Chief.... Roundles

Per pale or and arg. a bull pass. within a bordure sa. on a chief of the last three bezants. CozE, Shenley, co. Herts, 1640 .

\section{Mitre}

Arg. a bull pass. sa. armed and uriguled or within a bordure of the second bezanty in the middle chief point a mitre gold. Walter le HERT, Bishop of Norwich, 1446-72.

\section{Piles}

Vert a lion ramp. within a bordure engr. arg. charged with six popinjays of the field beaked and membered gin, two piles also engr. issuant from the chief of the second. Honte, Well Manor Farm, co. Hants; Baronetcy 2 January 1813.

\section{SHEEP betw, or within....}

and in chief....

Per pale gu. and az. a fleece round the body a collar and ring on each side a fleur-de-lis in chief a lion pass. guard. all or. Town of Tavistock, co. Devon.

BOAR betw. or within....

and in base....

Arg. a boar pass. gu. crined or betw. three long bows charged with arrows and bent pointing in centre one in chief and a sliff with oars sa. within the two in base. O'MALLEY, Rosehill, co. Mayo; Baronetcy 2 July 1804.

\section{HOUND betw. or within....}

and in base...

Per fess arg. and sa. in chief a greybound courant a bordure engr. and in base an owl all counterchanged. Fond, Chagford, Bagtor, and Mutwell, co.Devon. Forde, 15:24, $W$. The greyhound collared counterchanged and the legs of the bird or; John Fond, Ashberton, co. Devon, $V$. 
BEAST. LION betw. or within....

and in base....

\section{Crescents}

Per fess az. and gu. in chief a lion ramp. or betw. two swords ppr. and in base three crescents two and one arg. MAC LogHLIN, Ireland.

Graft or Gusset

Gu. a lion ramp. or betw. two flaunches erm. and a graft in point of the last. CEELY, $V^{*}$.

Gu. a lion ramp. or betw. two flaunches and $n$ gusset in base erm. Cely Ceely or Ceily, Havering, Essex.

\section{Sword}

Gu. a lion pass. in chief betw. two mascles and in base $\mathrm{a}$ sword palewise point downwards betw. two boar's heads couped arg. SLEwMan, Scotland.

\section{On 1 BEAR}

Arg. on a bear salient sa. a 5-foil of the first at the shoulder. APpleton.

\section{Mullet}

\section{On 1 DEER}

Az. on a buck lodged arg. a mullet sa. at the shoulder. Downe or Downes, $V^{*}$.

Az. on a hart lodged arg. a mullet.... (? for diff.). Francis Downe or Downes, Little Hyde, co. Hereford, $W$.

Az. on a stag. lodged arg. upon a mount vert a mullet sa. at the shoulder. Downes.

\section{On $1 \mathrm{DOG}$}

Arg. on a talbot pass. sa. gouttes d'or. SHIRINGton, $V^{*}$.

Arg. on a talbot statant sa. gouttes d'or Sherington, $V$.

\section{On 1 GOAT}

Arg. on a goat sa. standing on a child ppr. in a cradle gu. swaddled or and feeding on an oaktree upon a mount vert gouttes d'ean. Davies, Elmley Park, co. Worcester; quartering Baillie and Pierce; descended like Davies, Woodgate, and Daneluurst, Sussex; from Davies, Marsh.

\section{Annulet}

\section{On 1 LION}

Arg. on a lion ramp. sa. an annulet.... at the shoulder. Brian de Stapuj.ton, $Y$.

\section{Barnacle see Brize.}

\section{Bends}

Sa. on a lion ramp. arg. three bends (another bendlets) gu. HoLme, $V$. Hounes, North Mymes, co. Hertford ; and Hampoll, co. York. Billets

Arg. on a lion ramp. az. billets of the field HaLSBY, co. Leicester.

Arg. on a lion ramp. sa. billets or. Ascheby. Ashiy, co. Leicester. Monsire Robert de Asiebr, $Y$. Roger de Askeby, $Y$. Sire Robert de Asscheby, $N$. 'Tillioll.

Arg. on a lion ramp. vert billets of the field WILLINMS.

Az. on a lion ramp. arg. billets gu. Sr. .... de Bruyn, Cumberland, $V$. Bruín. Jackson, $V$.

Az, on a lion ramp. alg. billets sa. GoLdweLI. Gouldwert, Kent.

Az. on a lion ramp. or billets gu. Browning, Cambridge. Bryne.

Gu. in chief on a lion pass. guard. arg. billets sa. Robert Brids, $E$.

Gu. on a lion ramp. arg. billets sa. Gouldwell, Kent.

Gu. on a lion ramp. arg. billets sa. a label compony az. and vert. BLANNESTER.
BEAST.

On 1 LION.... cont.

Billets cont.

$\mathrm{Gu}$. on a lion ramp. or billets of the first. Bulmer, $V^{*}$. Bullmer, Sheriff Hutton, co. York, temp. Edward I, $V$.

Gu. on a Jion ramp. or billets sa. Ausketill Bulmer, Shireslioton, $Y$.

Or on a lion ramp. sa. billets arg. Ganeth, co. Cambridge.

Per chief or and az. over all on a lion ramp. arg. billets.... GoLDWELL.

Per chief or and az. over all on a lion ramp. arg. billets sa. GouIDWELI, Wisbeach, co. Cam. bridge ; and Bury St. Edmund's, Suffolk. Thomas Goldwell, Bishop of St. Asaph, 1556-8. Geffrey Goldwel, Great Chard, Kent, $V$.

Sa. on a lion ramp. crowned or billets of the first. Delaplanche, co. Buckingham.

\section{Brize}

Or on a lion ramp. az. ' ung brize' (? a barnacle, or ? a gad-fly) arg. Sr. Piers de Breyser or Persey, $L$.

\section{Bird Chaffinch}

Arg. on a lion ramp. sa. a 'pinzon' or at the shoulder.... Sire .... Mounprnzon, $N$. .....Martlet

Arg. on a lion ramp. sa. a martlet of the first at the shoulder. Monrpesson, Bathampton, co. Wilts.

Or on a lion ramp. sn. a martlet arg. at the shoulder. Poltex, co. Cambridge.

Per bend sinister erm. and sa. on a lion ramp. or a martlet gu. at the shoulder. Trevon, Norfolk.

\section{Caltraps}

Vert on a lion ramp. ol caltraps sa. LigHtories, co. Lancaster.

\section{Chess-rook}

Sa, on a lion ramp, arg. a chess rook gu. at the shoulder. Sir Christofer de Verdon, $R$. Monsire Thomas de VERDon, $Y$.

\section{Chevrons}

Or on a lion ramp. gu. three chev. arg. Sr. John BAUDE, $V$. RAND, Norton, Gateshead, and London, 1578-1606. RANDE or RaND, Northampton, and Rowell, co. Northampton. Crescent

Arg. on a lion ramp. az, armed gu. a crescent of the field (another, or) at the shoulder. ATHELL.

Arg. on a lion ramp. double tailed purp. ducally crowned or a crescent at the neck.... Fozliott, Ballyshannon, created Baron Folliot, 1619 ; descended from Folliot of Pyrton; the coheirs m. Foley, Walker, Powell, Jones, and Baugh.

Gu. on a lion ramp. arg. a crescent.... at the shoulder. Mowbray.

Or on a lion ramp. az. armed gu. a crescent of the third at the shoulder. ATHELL.

Or on a lion ramp. sa. a crescent arg. at the shoulder. Poorey, co. Chester, and Snffolk.

Or on a lion ramp. vert a crescent sa. at the shoulder. SutTon.

Per pale erm. and or on a lion ramp. gu. a cres. cent.... at the shonlder. Withie.

Per pale sa. and gu. on a lion ramp. guard. arg. crowned or a crescent.... (of the second, $V^{*}$.) at the shoulder. Edward Bestney, Sume, co. Cambridge, $V$.

Per pale sa. and gu. on a lion ramp. guard. crowned or a crescent of the second at the shoulder Bestney. 
BEAST.

On 1 LION.... cont.

\section{Cross}

Arg. on a lion ramp. tail forlked purp. crowned or a cross patty of the field. STory.

Arg. on a lion ramp. purp. a cross patty or at the shoulder. Story.

Arg. on a lion ramp. tail forked purp. a cross patty or at the shoulder. M. Richard Story, $S$.

Arg. on a lion ramp. sa. a cross patty of the field at the breast. Pownall, Pownall, co. Chester; a lieiress, about 1328, m. Fitton; and its branch Pownall, Barnton, co. Chester; from which desceuded Thomas Pownall, Governor of New Jersey, ob. 1805 ; Sir George Pownall, ob. 1834 ; and Pownall, Liverpool.

Arg. on a lion ramn. sa. a cross patty of the field at the shoulder. Newton, co. Somerset; and Sussex.

Arg. on a lion ramp. tail forked sa. armed gu. a cross patty of the field at the shoulder. Newton, London; co. Somerset; Suffolk; Sonthover, Sussex; and co. IVilts.

Arg. on a lion romp. sa. a cross patty or at the shoulder. Newton, Newton, co. Chester.

Arg. on a lion ramp. tail forked sa. a eross croslet or at the shoulder. NEwron, Suffolk.

Arg. on a lion ramp. vert a cross potent.... at the shoulder. Sheriunne, Stonyhurst, co. Lancaster; Baronetcy 5 February 1685-6 ; extinct 1717.

Az. on a lion ramp. arg. a cross croslet gu. Brun.

Az. flory arg. on a lion ramp. of the last a cross patty gu. at the shoulder. Syr Otes Holland, $Q$.

Az. on a lion ramp. or crowned arg. a cross croslet sa. at the shoulder. DaleLL, co. Wilts, $V$.

Az. semy of crosses eroslet or on a lion ramp. ducally crowned of the last a cross croslet sa. at the shoulder. Brewes.

Gu. on a lion ramp. arg. a cross croslet of the field at tlie shoulder. SALISBunY.

Or on a lion ramp. sa. a cross patty arg. at the shoulder. Thomas Pownall, Wrexliam, co. Salop, 1643; ob. 1695; and his descendants, until 1819 , when a chief wavy az. charged with a dolphin naiant or betw. two crescents arg. was added in memory of John Fish, Kempton Park, Middlesex.

Vert on a lion ramp. arg. a cross patty gu. at the slioulder. Love, co. Oxford; Norton and Goudhurst, co. Hants.

Vert on a lion ramp. guard. or a cross formygu. at the shoulder. Love, Agnow, co. Northampton.

\section{Crosses}

Az. a lion ramp. arg. semy of crosses croslet fitcly gu. Bnowne, $W$.

Per fess gu. and sa. a lion ramp. arg. semy of crosses croslet of the first. LODGE, Leeds, co. York.

Sa, a lion ramp. arg. powdered with crosses croslet of the field. Holmes, co. York.

Escallops

Or on a lion ramp. sa. three escallops arg. Barnaby, co. Salop.

Or a lion ramp. sa. hung about with escallop shells arg. Barnby, Barnby and Midhope, co. York; the coheirs m. Allott and Bowden.

Or a lion ramp. sa. armed and langued gu. powdered with escallops arg. Barnebr, Barneby Hall in Cowthorne, co. York.

Escarbuncle

Per pale az. and gu. on a lion ramp. arg. an escarbuncle of the second at the shoulder. HaLton, Bristol.
BEAST.

\section{Escucheon}

Gu. a lion ramp. erm. gorged with a collar gemel az. therefrom pendent an escucheon of the last charged with a mullet arg. Pownalu, Liverpool; and Pownall, co. Chester; derived from the Barnton branch of Pownall, Pownall.

Or on a lion ramp. sa. an antique escucheon or charged with a cross patty gu. Pownal.

Estoile

Arg. on a lion pass. guard. gu. crowned or a star of the first at the breast. OGILvy, Inchmartine, Scotland.

Arg. crusily fitchy gu. on a lion ramp. of the second armed and langued or an estoile.... at the shoulder. Bretr.

Az. on a lion ramp. arg. crowned or a star of the first at the shoulder. M'DowaLI or M'Dougal, $\mathrm{M}$ 'Kerston, Scotland.

Erm. on a lion ramp. sa. an estoile or at the shoulder. Blaquiere, Baron de Blaquiere.

Fess

Or on a lion ramp. gu. a fess of the field. BArBy, Ireland.

Or on a lion ramp. vair a fess gu. Monsire Richard le JEN, $Y$.

Vert on a lion ramp. or a fess gu. Richard de FEN, $Y$.

\section{Fish}

Arg. on a lion ramp. sa. a dolphin of the field at the shoulder. ELIIs.

Arg. on a lion ramp. sa. a dolphin or at the shoulder. Momitesson, Norfolk.

Arg. on a lion ramp. sa. a dolphin embowed naiant or at the shoulder. Sr. Ellis de Montpinson or Mountpinzon, Norfolk, temp. Edward III, $V$. Mountpinzo, $V *$.

\section{Fleur-de-lis}

Arg. on a demi-lion ramp. sa. a fleur-de-lis or at the shoulder. Menvyn, Trellick Castle, co. Tyrone; descended from Mervyn, Pertwood, and Fonthill Giffard, co. Wilts.

Arg. on a demi-lion ramp. gu. a fleur-de-lis or at the shoulder. Menvyn, $W$.

Arg. on a lion ramp. az. a fieur-de-lis gu. at the shoulder. Geravaise de Clifton, $Y$.

Arg. on a lion ramp. az. a fleur-de-lis or at the shoulder. M. Roger Fauconberge, $S$.

Arg. on a lion ramp. gu. crowned or a fleur-de-lis gold at the shoulder. Bavent, $V$.

Arg. on a lion ramp. sa. crowned or a fleur-de-lis of the first at the shoulder. MorLey.

Arg. on a lion ramp. sa. a fleur-de-lis or at the shoulder. Sir Philip Berington, $L$. Monsire .... Walkfayre, $Y$. Warrington or WARMYNTON.

Arg. on a lion ramp. tail forked sa, a fleur-de-lis or at the shoulder. BERINGTON, co. Leicester. Sir Philip Barrington or de Carrington, $L$, 94. Sire Felip de Baringtone, $N$.

Arg. on a lion ramp. tail forked and nowed sa. a fleur-de-lis or at the shoulder. Sr. Philipp Barington, co. Leicester, temp. Edward III, $V$. Sr: Thomas Barinton, temp. Edward II, $V$.

Arg. on a lion ramp. double tailed sa. a fleur-de. lis or at the shoulder. Barrington, $V^{*}$.

Az. crusily or on a lion ramp. arg. a fleur-de.lis sa. at the breast. JuRDON, Walverton.

Az. crusily or on a lion ramp. of the last a fleurde-lis gu. at the shoulder. Breuse. Sire Giles de Breouse, $N$.

Az. on a lion ramp. arg. a fleur-de.lis gu, at the shoulder. Monsire Jerves de Cliftos, $Y$. 


\section{BEAST. On 1 LION.... cont.}

Fleur-de-lis cont.

Gu. on a lion ramp. arg. a fleur-de-lis az. at the shoulder. Daldeburgh or Dalderbrighe. Sir Hugh Daldeburgh, $V$.

Gu. on a lion ramp. arg. a fleur-de-lis sa. at the shoulder. Dateborovgh.

Or on a lion ramp. az. a fleur-de.lis of the field. EGREMOND.

Or on a lion ramp. az. ducally crowned arg. a fleur-de.lis gold at the shoulder. Sr. .... D'Egremond, $V$.

Or on a lion ramp. with two tails gu. collared arg. a fleur-de-lis of the first at the shoulder. Mallony, Woodford, co. Northampton.

Sa. on a lion ramp. arg. a fleur-de-lis gu. at the shoulder. Sir Stepben de Segrave, $L$. And over all a baton engr. gu. Sir Henry de Segrave, $L$.

Sa. on a lion ramp. arg. crowned or a fleur-de-lis gu. Johan de Segrave, G. Sir Stephen Segrave, $L$. Sir Estevene de Segrave, $N$. And over all a baton engr. gu. Sir Henry de Segrave, $L$.

Fleurs-de-lis

Arg. on a lion ramp. sa. crowned or five fleursde-lis of the last. Sr. .... de Barington, co. Leicester, $V$.

Arg. on a lion ramp. tail forked sa. five fleurs.delis or. Sr. Thomas Barinton, temp. Edward II, $V$. Barantrane, $V$. The lion double tailed. BARYNTON, $V^{*}$.

Arg. on a lion ramp. sa. fleurs-de.lis or. Barrington, co. Somerset.

Arg. on a lion ramp. sa. crowned or fleurs-de-lis gold. Barrington, $V^{*}$.

Arg. on a lion ramp. double tailed sa. fleurs-delis or. Barantine, $V^{*}$.

Gu. on a lion ramp. erm. fleurs-de-lis az. Dalberough or DaIdebrovgh.

Or on a lion ramp. az. fleurs gold. Egremond.

Or on a lion ramp. double tailed sa. fleurs-de-lis gold. Bafantine.

\section{3-Foil}

Arg. on a lion ramp. sa. ducally crowned or a 3-foil slipped vert at the shoulder. Ducane.

Az. on a lion ramp. or ducally crowned arg. a 3.foil slipped sa. at the shoulder. Sr. James Darelt, Calehill, Kent, $V$.

$\mathrm{Gu}$, on a lion ramp. per fess arg. and sa. crowned or a 3-foil slipped vert. Greene, Chester, Harl. MS. 1535 , fo. 15, b.

\section{5-Foil}

Arg. on a lion ramp. gu. a 5-foil of the field at the shoulder. EskLe Estee or Estele, co. Leicester. Sr. Andrew de Esteley, $H$. Sir Nicholas Estreigh or Astreigh, I. Sir Nicholas de Estree, $N$. And with a label of three points az. Sire Giles de Estree, $N$. Sir Giles de Estley, co. Leicester, temp. Edward III, $V$. Esteley, $V^{*}$.

Arg. on a lion ramp. gu. a 5 -foil of the first at the shoulder a label of three points az. Ascley. Esteley or Estley.

Arg. ou a lion ramp. gu. a 5 -foil of the first over all a baton or bendlet az. Estatford. Ethelstan, co. Lincoln. Ethelstan, co. Leicester. Sire Richard de Echebastone, $N$. Sr. Richard Eschelaston, co. Leicester, temp. Edward III, $V$.

Arg. on a lior ramp. gu. \& 5-foil erm, at the shoulder. Thoinas Astelee, $Y$. Monsire Thomas de Astrey, Y. Esteley, co. Leicester.
BEAST.

On 1 IION.....cont.

5-Foil cont

Arg. on a lion ramp. sa. a 5 -foil or at the shoulder. WALKFARE. WAKEFORE, $V^{*}$. Sir Robert WAKEFanE, Norfolk, temp. Edward III, $V$. Fretty

Arg. a lion ramp. az. fretty of the field. Bolton.

Arg. a lion ramp. tail forked (double tailed $V^{*}$ ) az. fretty or. Cokenam, $V$.

Arg. a lion ramp. sa. fretty of the first. Robert de Ashby, temp. Edward I, $V$.

Erm. a lion ramp. per fess az. and gu. fretty or. Forder or Fondore, Surrey.

Gu. a lion ramp. arg. fretty az. Sr. William de Hurton, $\boldsymbol{V}$.

Gu. a lion ramp. erm. fretty sa. Blackborne, $V^{*}$. BLackBounne, $V$.

Gu. a lion ramp. or fretty az. DERnford. Marmion, $V^{*}$. Sr. William Mariryon, co. Gloucester, $V$.

Or a lion ramp. az. fretty arg. Benton. Raphe BoxhIL, $Y$. Monsire .... BoxнII, $Y$. Sr. Allan Boxhull, Surrey, temp. Edward I, $V$. Boxhull or Boxmel, Sussex. Sire Alayn de Bokeshulle, $O$. Sire Alleyn de Boxaulle, $N$. Boxull. Buckhull or Buckshall, Sussex. Bukeyl or BukeleEt. Voxhill.

Or a lion ramp. double tailed az. fretty arg. BucKulL.

Or a lion ramp. az. fretty or. Bexhull or Bexull. Per fess erm. and arg. a lion ramp. az. and gu. fretty of the second in the upper part. Forder, $V^{*}$.

\section{Goutte}

Arg. on a lion ramp. sa. a goutte d'or streaming at the shoulder. Ludow.

Arg. a lion ramp. vert mouth bloody. JoAnes, London, and co. Worcester; granted 1634; quartering gu. a bend or, and over all a label of three points sa. a martlet for diff.

Arg. a lion ramp. vert vulned ppr. at the mouth. Tyrwhitt-Jones, Stanley Hall, co. Salop. Baronetcy 3 October 1808 ; quartering Tyrwhitt.

Arg. a lion ramp. vert. vulned gu. at the breast. Jones, Chilton, and Shrewsbury, co. Salop; granted 16 June 1607.

Arg. a lion ramp. vert. vulned gu. at the shoulder. Jones, co. Denbigh. Jones, co. Salop, $W$.

Az. a lion ramp. arg. crowned or vulned gu. at the shoulder. Darel., Sessay.

Gu. a lion ramp. erm. vulued of the first at the shoulder. GroBHaM, Great Wishford, co. Wilts. Grubham, Bishops' Lediard. Grubbam.

Or a lion ramp. sa. vulned gu. at the breast. Sames Sammes or Sams, Little Totham, and Toulson, Essex.

Per pale gu. and az. a lion ramp. or vulned of the field. Hankey, Overton, co. Chester. Harl. MS. 1535 , fo. 17 .

Vert a lion ramp. arg. vulned gu. at the shoulder. Bolebee, co. Buckingham. Bulbeck, Essex. BULIBECK.

Vert a lion ramp. or vulned gu. at the shoulder. Robsard, $V$. Robsart, $V^{*}$. Robsert, Normaudy, and Warwick, temp. Richard II.

\section{Gouttes}

.... on a lion ramp. with two heads .... gouttes de sang. Mason.

Arg. on a lion ramp. az. crowned or gouttes erm. HaNcloo. Handiow, co. Oxford.

Arg. on a lion ramp. az. gouttes d'or. AsmbX, co. Leicester. Birnele, co. Oxford. Burnell, $V$. 
BEAST.

\section{Gouttes cont.}

Burnill. Sr. de Byrnelu, Hold, co. Oxford. $V$. Hadlow. Hallam, Hallam, co. York. Haldam, West-Hallam, Kirk-Hallam, and Hallam-Parva, co. Derby. Halom, $V$. Sir John de Hadrowe Hanle or Haute, $L$. Sire Johan de Hanlou or Hatlou, $N, Y$. Monsire John de Hanlow or HaLOU, $Y$.

Arg. on a lion ramp. az. crowned or gouttes gold. Sir John Handow, $V$. Handowe, $V^{*}$.

Arg. on a lion ramp. tail forked az. crowned gold gouttes d'or. Sr. .... de Burnell, $V$.

Arg. on a lion ramp. double tailed az. crowned gold gonttes d'or. De Bunneli, $V^{*}$.

Arg. on a lion ramp. gu. gouttes d'or. Asнвy, co. Leicester.

Arg. on a lion ramp. sa. gouttes d'eau. Mortmer, Vamouth, Scotland.

Arg. on a lion ramp. sa. gouttes d'or. Birnelu, co. Oxford. BRonewich or Bromwter, co. Gloucester, co. Hereford, and co. Hertford. Mortimer, Craigyvar, Scotland.

Az. on a lion ramp. arg. crowued or gouttes d'eau. Cosyn, Kient.

Az. on a lion ramp. arg. gouttes de larmes. Foster, Essex.

$\mathrm{Az}$. on a lion ramp. arg. gouttes de sang. Beresford. Browne. Broin. Bryme, Cumberland. Sire Richard le Brun, $N$. Brynne, $V$.

$\mathrm{Az}$. on a lion ramp. arg. tail erect gouttes de sang. Thomas Brune, $Y$.

$\mathrm{Az}$. on a lion ramp. arg. gouttes purp. Foster, Essex, $V$, and Suffolk.

Az. on a lion ramp. arg. armed or gouttes de poix. Coveld.

Az. on a lion ramp. arg. crowned or gouttes de sang. Cosyn, co. Dorset.

Az. on a lion ramp. arg. collared gu. and ducally crowned or gonttes de poix. JARRETt, London; granted 19 th May 1696.

Az. on a hon ramp. arg. langued and collared gu. crowned or gouttes de poix. GARRET.

Az. on a lion ramp. guard. arg. ducally crowned or gouttes de sang. BurnelL.

Az. on a lion ramp. ducally crowned or gouttes de sang. Cossen, Penzance.

Az. on a lion ramp. crowned or gouttes de sang. Cosine, Kent, $W$. Manderne, Penzance, Cornwall.

Az. on a lion ramp. tail forked or gouttes de sang. Cosyn.

Az. on a lion ramp. tail forked and renowed or crowned arg. gouttes de sang. Robert Cosine, co. Dorset, $V$.

Az. on a lion ramp. double-tailed and nowed (or) gouttes de sang. Cosyn, $V^{*}$.

Erm. on a lion ramp. gu. gouttes d'or. Rous.

Erm. on a lion ramp. per fess gu. and az. gouttes d'eau. Fondeor.

$\mathrm{Gu}$. on a lion pass. guard. arg. gouttes de sang. Rrvell.

Gu. on a lion ramp. arg. gouttes purp. Foster, Essex.

Gu. on a lion ramp. arg. gouttes de poix. John Nevilue le Forester, $Y$.

Gu. on a lion pass. guard. or spots or gouttes sa. ArLote or Arlott.

Gu, on a lion ramp. or gouttes de poix. Harmlyy. Hanmalyn, Monsire HaMLYN, $Y$.

Gyronny of eight or and az. on a lion ramp. of the first gouttes de sang. MackLow or Mocklow. co. Worcoster.
BEAST. On 1 LION.... cont.

Gouttes cont.

Or on a lion ramp. az. gouttes de sang. Mortiner, London.

Or on a lion ramp. gu. gouttes gold. Mortmer, Scotland; descended from Alanus de Montimer, Lord, by marriage with the heiress of Vipont, 1126, of Aberdour.

Or on a lion ramp. sa. gouttes d'eau. Granetz, Wales, $V$. Granlesse or Grantz, Wales. Mortimer.

Or on a lion ramp. sa. wounds all over gu. Sr. Thomas Lodelowe, $V$. Ludiow, Morehouse, co. Salop.

Or on a lion ramp. sa. gouttes gold. Sr. .... de Brosrwich, $V$. BRoMfwich or BRomwich, co. Gloucester, co. Hereford, and co. Hertford. Cevert or Court.

Paly of six arg. and az. on a lion ramp. sa. gouttes d'or. Mortinien, Auchenbody, Scotland.

Per chief or and az. over all on a lion ramp. arg. gouttes de poix. James Goldweld, Bishop of Norwich 1472-99.

Per fess alg. and sa. on a lion ramp. the lower part erm. over the upper part gouttes d'eau. KYnNelmatich, $V . *$

Per fess arg. and sa. on a lion ramp. gouttes counterchanged. KYNNELMARCH, $V$.

Per pale gu. and az. over all on a lion ramp. or gouttes de sang. Sir Adolphus Oughton, 1779.

Sa. on a lion ramp. arg. gouttes de sang. Neviul, Essex.
Insect (Gad-fly) see Brize.
Key

Az. on a lion ramp. arg. holding in the dexter paw a trident or a key in pale of the field at the side. OchterLony; certified 1779.

Mascles

Arg. on a lion ramp. (purp.) mascles (lozenges voided) or. Thomas HARTFond, Badesworth, $Y$. Mullet

Arg. on a lion ramp. sa. a pierced mullet gu. at the shoulder. M. Bryan de Stapelton, $S$.

Arg. on a lion ramp. gu. a mullet .... at the shoulder. Duboys, London; granted 1634.

Arg. on a lion ramp. gu. collared of the field with a mullet az. at the shoulder. Aysildey.

Arg. on a lion ramp. sa. a mullet (another the mullet pierced) gu. at the shoulder. STAPLETON, temp. Edward III.

Arg. on a lion ramp. sa. a mullet or at the shoul. der. Sir Thomas Mompesson, Brthhampton, co. Wilts, 1730. Myles Stapilton, S. Sire Robert de Walikefare, $N$.

Az. on a lion ramp. arg. a pierced mullet sa. at the shoulder. Cnewe.

Az. flory arg. on a lion ramp. reguard. of the second a mullet ..... at the shoulder over all a bend gu. BRETT.

Or on a lion ramp. az. a mullet of the field at the shoulder. M. Rauff PERCY, $S$.

Or ou a lion pass. gu. a mullet .... at the shoulder. Games, $V$.

Or on a lion pass. gu. a pierced mullet arg. at the shoulder. Games.

Or on a lion ramp. gu. a pierced mullet arg. at the shoulder. M. George Frubrige, $S$.

Or on a lion ramp. tail forked vert a mullet arg. Sutton, co. Leicester.

Per fess or and sa. on a lion ramp. per fess arg. and of the first a mullet .... at the shoulder. Jolin Wellysand, $V$. 
BEAST. On 1 LION.... cont.

Roundle

Gn. on a lion ramp. or a plate at the breast. Morris.

\section{Roundles}

Erm. on a demi-lion ramp. erased az. collared or three torteaux. CARD.

Arg. on a lion ramp. sa, ducally erowned or eight roundles az. Burwell, $V^{*}$.

Barry of tive arg. and gu. over all on a lion ramp. double-tailed or pellets. Brandon, Chamberlain of London.

Per pale gu. and az. on a lion ramp. arg. pellets. Stocket, Bradstet, Kent.

Sa. on a lion ramp. arg. pellets. Browne, $W$. Spots

Gu. on a lion pass. guard. or spots sa. ArLote or ARLOTT.

Staple

Arg. on a lion ramp. sa. a staple or at the shoulder. Stapleton, co. Lancaster. Tails

Per fess indented sa. and arg. on a lion ramp. counterchanged three erm. spots in chev. at the shoulder. KyfFis, Belmont, co. Denbigh.

Wound see Goutte.

\section{Cross \\ On $10 \mathrm{X}$}

Arg. on a bull statant gu. armed or upon a mount vert a plain cross arg. at the shoulder. RidLey. Estoile

Arg. on a bull pass. gu. upon a mount with rushes ppr. a star at the shoulder. Ryduey, Willimonswight, Northumberland; confirmed 11 July 1581 .

\section{4-Foil}

\section{On 1 WOLF}

Az. on a wolf salient arg. a 4-foil gu. at the breast. DAvis, co. Hereford; quartering Heven.

\section{Fleur-de-lis}

Az. on a wolf ramp. arg. a fleur-de-lis gu. at the shoulder. Dis, Bristol; granted 1558.

\section{Goutte}

Per pale az. and gu. a wolf salient or vulned of the second at the shoulder. HAwise.

Ier pale gu. and az, a wolf salient erminois vulned on the shoulder of the first. Sir Henry HANKEY, Alderman of London, ob. 1736; from his eldest son, Alderman Sir Joseph HaNKey, derived Hankey, East Bergholt, Suffolk; and from his second son, Alderman Sir Thomas Hankey, Hankey, London, and Fetcham Park, Surrey.

$$
\text { Tail }
$$

Az. on a wolf ramp. arg. an erm. spot at the shoulder. Sir Daniel Dus, $W$.

On 1 DEER and in chicf....

Per chev. or and vert in base on a hind trippant arg. a cross tau and in chief a cross tatu betw. two urosses patonce fitchy gu. Ireland, 1725 .

On 1 DOG and in chief....

Arg. on a talbot sa. a 3-foil slipped or at the shoulder on a chief indented az. three crosses croslet of the third. KENE, Norfolk, and Suffolk.

\section{Birds}

Or on a lion ramp. az. a bezant at the shoulder in chief two martlets sa. Jones, London.
BEAST. on 1 LION and in chief....

Canton

Sa. on a lion ramp. or gouttes sa. a canton of the second. EDward, Bermondsey, Surrey, $W$. on a Canton

Per fess or and az. on a lion ramp. gouttes counterchanged a canton of the second charged with a roebuck's head couperl of the first. SADLER, co. Hertford.

Chief

Az. on a lion ramp. arg. billets sa. a chief of the last. Gouldwell, Kent.

Gis. on a lion ramp. arg. billets sa. a chief of the last. GouldwelL, Kent. on a Chief..... Anchor

Az. on a lion ramp. arg. an eagle displ. sa. at the shoulder on a chief wavy erm. an anchor erect of the third the shank surrounded with a naval crown rim az. sterns and sails ppr. LouIs, Chelston, co. Devon, Baronetcy 7 April 1806.

$$
\text { .... Escallops }
$$

Arg. goutty de sang. on a lion ramp. sa. gouttes d'or a chief az. charged with three escallops arg. Patrison, Kelvin Grove, Scotland; quar. tering Robertson, and on an escucheon of pretence Moncrief.

$$
\text { ....Fish }
$$

Or on a lion ramp. sa. a cross patty of the first at the shoulder (Pownal, Wrexhan, co. Salop, $16 \pm 3$; with an augmentation in memory of John Fish, Kenpton Park, Middlesex, of) a chief wavy az. charged with a dolphin embowed as the field betw. two crescents arg.; granted 1819 to the descendants of Thomas Pownall, and now borne by Henry Pownal, Chairman of the Magistrates for Middlesex, impaling Waterhouse.

\section{On 1 BOAR and in base....}

Az. on a boar or a fleur-de-lis gu. in base three 3-foils slipped of the second. Massingbend, Gunby, and Bratoft, co. Lincoln.

$\mathrm{Az}$. on a boar statant or a cross gu. at the shoulder in base three 4-foils of the second. Massingberd, $V$.

\section{On 1 DOG betw. or within....}

Gu. on a greylound courant in fess arg. collared az. betw. three pheons or a torteau at the shoulder. JACKsoN, Bath, co. Somerset.

On 1 HORSE betw, or within....

Gu. on a horse courant or with a plume to the head bridle saddle and trappings of the field betw. three garbs as the second a 5 -foil at the shoulder like the first the hip covered by an escucheon .... charged with a cross .... MALT, $V$.

\section{On 1 LION betw, or within.... \\ Annulets}

Or on a lion pass. betw. three annulets sa. a mart. let.... Thomas Tuder, Hartwell, co. Northampton, $W$.

Bordure.... Crosses

Az. on a lion ramp. within a bordure flory arg. crosses croslet fitchy gu. Sir Thomas LODGE, Lord Mayor of London, 1562.

Az. on a lion ramp. within a bordure arg. charged with eight fleurs.de.lis of the third crosses patty fitchy gu. LoDGe, Bodsilin, co. Carnarvon. ....5-Foil

Arg. on a lion ramp. within a bordure gu. a 5 -foil of the first. ERDington. 
BEAST. on 1 LION betw, or within..... cont. Bordure cont. Gouttes

.... on a lion ramp..... crowned .... within a bordure compony..... and.... gouttes.... Robert WALDBY, Archbishop of Dublin, Bishop of Chichester, 1396, and Archb. of York 1396-8.

$$
\text { ....Head (Beast) Boar }
$$

G11. On a lion ramp. within a bordure engr. arg. a boar's head couped az. at the breast. Horton, Chaderton, co. Lancaster; Baronetcy 19 January 1764 , extinct 2 March 1821, and Howroyde, co. York; descended through Joshua Horton, Sowerby, n. 1619, from William Horton, Barkisland, Halifax; the heiresses m. Rhys and Pollard.

$\mathrm{Gu}$. on a lion ramp. within a bordure engr. arg. a boar's head couped sa. GreEN ; granted 1725 .

$$
\text { ......Key }
$$

Az. on a lion ramp. arg. holding in the paws a trident erect or within a bordure wavy as the second charged with four buckles gu. a key wards upwards of the field at the shoulder. Ochterlony ; Baronetcy 8 December 1823.

$$
\text { .....Mullet }
$$

Gu. on a lion ramp. witlin a bordure engr. arg. a mullet of the first at the shoulder. William Grey, Bishop of London 1426 ; Lincoln 1431-6.

Gu. on a lion ramp. within a bordure engr. or a mullet urg. at the shoulder. John TALBOTT, $Y$.

\section{.... Roundle}

Gn. on a lion ramp. within a bordure indented or pelletty a pellet. MORrice or MorYs, London.

\section{Crescents .....Bar}

Arg. on a lion ramp. betw, four crescents inclosing estoiles gu. a bar az. Dillon, Chimwell, Wroughton, and Hart, in Heanton, co. Devon; Farthingoe, co. Northampton. Dillon, Newton-Farrers and Bratton, co. Devon.

$$
\text { ..... Crescent }
$$

Gu. on a lion ramp. arg. betw. three crescents or a crescent sa. at the shoulder. SAlisbury, Ravenston, Burgland, co. Leicester.

$$
\text { ....Gouttes }
$$

Arg. on a lion ramp. sa. langued and armed gu. betw. three crescents of the last gouttes d'or. Ralph Brownrigg, Bishop of Exeter, 1642-59.

Arg, on a lion ramp. sa, betw. three crescents of the second gouttes d'or. Brownrig or BrownRIGG.

\section{Crosses ....Annnlets}

Sa. on a lion ramp. betw. five crosses croslet arg. within a bordure engr. or an annulet of the first at the shoulder. LoNG, Isle of Wight; granted by Harvey.

\section{....Barrulets}

$\mathrm{Gu}$. on a lion ramp. arg. betw. three crosses croslet fitchy or as many barrulets sa. Cistercian Abbey De VAlie-Crucis, co. Denbigh.

Sa. on a lion ramp. betw. as many crosses croslet arg. three bars (gu, another) of the first. Cistercian Abbey De Value.Crucis, co. Nenbigh.

\section{.....Crescent}

Az. on a lion ramp. or crowned .... within an orle of crosses croslet of the second a crescent .... at the shoulder. Sir John (another, Peter) Brwes, $Q$.
BEAST. On 1 LION betw, or within.... cont.

Crosses cont. Estoile

Arg. on a lion ramp. (salient $V^{*}$.) betw. eight crosses croslet fitchy gu. an estoile at the shoulder or. BretT, $V$.

$$
\text { ....3-Foil }
$$

Arg. on a lion ramp. betw. eight (another, ten) crosses croslet fitchy gu. a 3 -foil slipped or at the shoulder. Bretr.

\section{Escallops}

Arg. on a lion ramp. sa. betw, eight escallops in orle gu. a rose or for diff, at the shoulder. Moffett, Chipping Barnet, co. Hertford; derived from Moffat, Lauder; granted 10 May, 1585.

Per fess gu. and or on a lion ramp. per fess arg. and az. betw. three escallops gouttes counte:changed. Windoute or Windowche, Radiswell, co. Hertford; granted 1515. Bartholomew Wydent, Radiswell, co. Hertford, $V$.

\section{Fleurs-de-lis}

Az. on a lion ramp. arg. within a tressure of demi fleurs de-lis and a bordure of the second crosses croslet gu. LODGE, London.

\section{Hands}

Az. on a lion pass. or betw. three dexter gauntlets the back parts outwards arg. gouttes d'eau. Conway, $W$.

Az. on a lion pass. arg. betw. three dexter gaunt. lets of the second gonttes d'or. Conway or Conwey, Callis.

Az. on a lion pass. guard, betw. three dexter gauntlets back parts outwards arg. all witlin a bordure engr, three pales or. ConWaY, $V^{*}$. Conwey, $V$.

Heads

Az. on a lion pass. arg. betw. three griffin's heads erased or gouttes de sang. William Box, Alderman of London, $V$.

\section{Leaves}

Or on a lion ramp. sa. betw. three oak leaves vert an annulet for diff. at the shoulder. Sherman, London, and co. Devon; descended from Sherman, Yoxley, Suffolk.

\section{Mullets}

Or on a lion ramp. sa. within an orle of mnllets az. three escallons arg. Bariady, co. York.

\section{Or 1 IION betw, or within....} and in chief....

Az. on a lion ramp. betw. eight crosses croslet fitchy or three two two and one a crescent gu. at the shoulder a chief of the second. Desaware. Jordan, co. Somerset; Chittern and Whistley, co. Wilts, 1604.

\section{BEASTS.}

\section{BEARS}

Arg. two bears az. Halton, Halton Craven, co. York; derived from Sir John de Halton, temp. John, a heiress m. Talbot.

\section{BEAVERS}

Vert on a base barry of five ( $\operatorname{six}, V^{*}$.) arg. and az. two beavers ramp. combatant or. Thomas Beveridg, co. Chester, 1595; granted by Lee, W. BeVERIDGE, $V *$.

Vert in point harry wavy of six arg. and az. two beavers ramp. combatant or. Beveridge, Kent, Chichester, and Normandy. 
BEASTS.

\section{BOARS}

Erm. two boars pass. gu. (another langued az. tusks and bristles or). Whiснсоте; Baronetcy 2 April 1660.

Erm. two boars pass. gu. armed or. WhICHCORD, Maidstone, Kent.

Erm. two boars statant gu. John Wнгснсотr, $V$. Erm. two boars statant gi. armed and maned or a crescent in dexter chief for diff. Charles Wніснсоот, London, 1633.4; Harl. MS. 1358, fo. 12 .

\section{CATS}

Arg. two cats pass. gu. CATT.

Arg. two cats pass. sa. CatT.

Gu. two cats pass. guard. arg. Catron, $V$.

\section{DEER}

Arg. two demi bucks courant conjoined gu. Buckwis't.

....two does countersalient.... Dryenurst.

... . semy of roundles .... two stags courant.... Andrew BoferelL, Lord Mayor of London, 1232.9; Harl. MS. $13 \pm 9$.

Sa. two bucks courant arg. Buckside, $V^{*}$.

Sa. bezanty two bucks in full course arg. Buckereli, co. Devon.

Sa. two bucks courant arg. attired or. Robert Bucksyde, $V$.

Sa. bezanty two bucks courant arg. attired or. Bockerell. Bucrwell, London.

Sa. bezanty two bucks pass. arg. Bockenell or Boreretr, Lord Mayor of London, 1232-37. BuCKsIED.

Sa. two bucks pass. arg. attired or. Buckside.

Sa. on a mount vert two stags salient affrontant arg. attired or. John EISHER, Bishop of Exeter, 1803, Salisbury 1807-25.

Sa. two hinds counterpass. the one facing to the sinister surmounting the other in fess arg. Cottingham, co. Chester, $V$.

Sa. two hinds counter-trippant in fess arg. Cottinghair or Cottington, co. Chester; and Middlesex.

Sa. two hinds counter-trippant in pale ar'g. Cotting ham or Cuttington.

Sa. two bucks in full course or. Buckside.

\section{DOGS}

Arg. two greyhounds in full course gu. collared or. DogGetT.

Arg. two talbots pass. (anotber statant) gu. Breton.

Arg. two greyhounds courant sa. Alford, co. Devon.

Arg. two talbots pass. sa. Martyn, Kent.

Az. two greyhounds courant arg. Row, Cornwall.

Az. two dogs arg. pursuing a stag in full course all bendwise and at random or. Yardeer.

Az. two hounds in full speed after a stag courant all in bend or. JARDELAY.

Bendy of seven arg. and gu. two greyhounds courant bendwise sa. Trew.

Erm. two greyhounds courant per pale gu. and sa. Penne or Penny, Peterborough, co. Northampton; granted 1574 .

Erm. two greybounds courant reguardant per pale gu. and sa. Thomas Penne, Doctor of Physic, London, 1574, W; Harl. MS. 1350, fo. $123 \mathrm{~b}$.

Gu. two dogs (sometimes greyhounds) arg. Nicholas de le Ben, Len, or Ven, $A$. Nicole de LEv, A, Harl. MS. 6137 , fo. 96 .

\section{BEASTS. 2 DOGS cont.}

Gu. two greyhounds salient affrontant.... collared sa. DoGGet, Honing-Serbarne and Wronger, Norfolk.

Gu. two greyhounds salient affrontant or. Dogget, Norfolk.

Per bend dancetty or and sa. two talbots pass. counterchanged. Drxon, Wymondham, Norfolk.

Per bend sanguine and vert two greyhounds courant bendwise arg. Clayhills, Innergowrie, Scotland.

Per chev. arg. and sa. two greyhounds in full course counterchanged. BLADLOW.

Per chev. sa. and erm. two greyhounds counterchauged. Bladlow,

Per saltire erminois and erm. two greyhounds courant reguard. gi. PENNY, Higher Nutwell House, co. Devon; granted ...

Sa. two greyhounds endorsed arg. BARNARD, co. Hants.

Sa. two hounds courant arg. Montagee.

Sa. two talbots pass. arg. Montague.

Sa. two greylounds combatant or. DogGetr.

Sa. two she-talbots pass. counterpass. ppr. the one surmounting the other. GotTINGTON.

\section{FOXES}

Arg. two foxes salient countersalient in saltire the sinister surmounting the dexter gu. CADROD HaRD, living 920. KaDRAD. KaDRODHaRd, Wales. Kadrohand, Wales. Williams, Isle of Anglesea. Williams, Wynnstay and Bodelwyddan, co. Flint.

Az. two foxes (another wolves) statant reguard. (pass. $V^{*}$.) coward or. Pavell, $V$.

\section{GOATS}

Az. two goats salient combatant arg. KIDD.

Sa. two goats statant affrontant or. A quartering granted to the CoMPANY of LEATHERSELLERS in London, 7 November 1505, Harl. MS. 1359, fo. 75 .

\section{HORSES}

Sa. two horses pass. arg. Coulthurst.

\section{LEOPARDS}

...two leopards pass..... armed and langued .... AstLey.

Arg. two leopards pass. gu. Sampson.

Arg. two leopards pass. sa. Fletwick. Sampson. Az. two leopards arg. armed and langued gu. BARNEY.

Bendy of six arg. and az. two leopards or. Caronges.

Gu. two leopards arg. HaLden, That Ilk.

Gu. two leopards pass. arg. Deladiare. Mare. Marshall.

Gu. two leopards pass. arg. spotted sa. Mare, Chester.

Gu. two leopards pass. erm. Sorreld, France.

Gu. two leopards pass. or. Marshall.

Gu. two leopards pass. guard. or. LongspeE, Normandy.

Gu. two leopards pass. guard. or over all a baton az. Reginald Fitzroy or de Dunstanvile, ob. $1176, Z, 50$.

Or. two leopards pass. az. Gorney.

Sa. two leopards pass. arg. Roches.

\section{IIONS}

Gu. two demi-lions pass. guard. or. AcHE or Achey, co. Devon. HaCHe, Hache and North Aller, co. Devon. Hatch or Hacche, Hatch, and Saterleigh Park, co. Devon. 


\section{BEASTS. 2 LIONS cont.}

Gu. two demi-lions pass. guard. couped or. John Acche, co. Devon, $V$. HaCH, $V$. Hache, $V^{*}$. Натсн, Sutton, Surrey; quartering Cliffe. Hatch, Windsor, co. Berks.

Sa. two demi lions pass. guard. or. ACHE or ACHEY, co. Devon. Hatch.

....two lions ramp. addorsed.... David ap Buethin, Bishop of St. Asaph, 1314-52. Ithel ap Bledyn's seal.

Arg. two lions pass, az. Dale. Goldington, co. Bedford. Sire Rauf de Goldingtone, $N$. Somery, co. Warwick.

Arg. two lions pass. az. crowned or. Cundy.

Arg. two lions pass. guard. az. Hanner, $Z, 649$. Hanmer, Beachfield, co. Salop. Hanmer, Hanmer, co. Flint, Baronetcy 3 May 1774.

Arg. two lions pass, guard. az. armed and langned gu. Hanmer, Hanmer, co. Flint; Baronetcy 3 May 1774. John HANMER, Bishop of St. Asaph, 1624-9. Hanmer, Bodnod Hall, co. Denbigh; and Haxier, Holbrook Hall, co. Suffolk; branches of HANMER of Hanmer.

Arg. two lions ramp. combatant the first az. the second gu. LUCAs, $V$.

Arg. two lions ramp. addorsed the first az. the second gu. Lucas.

Arg. two lions pass. gu. John Conrngsiy, slain at Chesterfield, 1266. ConingsBy, Coningsby Castle, co. Lincoln; quartering gu. three conies sejant arg. Estranúz, co. Gloucester. Joan l'Estrange, $E$. Sir Fouk le Estrange, $N$. Frandolfe or Frandolph. Geoghegan, Ireland. LTGon, Upton St. Leonard's, co. Glouces. ter; and Madesfield, co. Worcester. Littrebury. LrtTieton. Lygon, Earl Beauchamp. Pigon, co. Warwick. St. Ive. Strang, $V^{*}$. Sir .... de Strange, Corfham, and Frandolfe, $\boldsymbol{V}$. Strange, Norfolk. John le Strange, $A, B$, or le Strang, $D$. Jon de Strange, $F$. Sire Johan le Straunge, J. Sir Foulk le Straunge, L. Strange; quartered by Talbot, Earl of Shrewsbury, $U$. John le Strange, Baron of Knoking, $Y$. Monsire le Strange, Blackmere, $Y, Z, 210$.

Arg. two lions pass. gu. a label az. John, son of John le Strange, $B$.

Arg. two lions pass. gu. crowned of the first. GRANDFORD.

Arg. two lions pass. guard. gu. Clanny, Bishop Wearmontb, co. Durham; quartering Mitchell. Denstone. Saunsuin Foliott, E. Sampson Folrot, $V$. M. John LrTtelibury, $S$. Littlebory, Fillingham, co. Lincoln. Sr. de Littuebury, Kirton in Holland, co. Lincoln, $V$. SAMPSON.

Arg. two lions pass. guard. gu. a label az. Littlebury.

Arg. two lions pass. guard. gu. debruised by a bend vert charged with three eagles displ. or. Brentisie. William Littelbury, $Y$.

Arg. two lions pass. guard. gu. crowned az. Panneli, co. York.

Arg. two lions pass. guard. gu. erowned or. VaUghan, co. Montgomery, $V$.

Alg. two lions ramp. gu. FenRy.

Arg. two lions ramp. addorsed gu. Rogens, $V^{*}$.

Arg. two lions ramp. combatant gu. LовB. Lucas, Suffolk. Sr....de Somenton, $V$.

Arg. two lions ramp. combatant gu. supporting with the forepaws a sword as the first hilt and pomel or. Carrold, Ballynure, co. Wicklow.

\section{BEASTS. 2 LIONS cont.}

Arg. two lions ramp. combatant supporting with the forepaws a sword palewise gu. O'CARnrL, Ireland.

Arg. two lions ramp. guard. gu. Clancy, Clare, Ireland.

Arg. two lions ramp. conjoined with one lead guard. per pale gu. and sa. Hower., Kent; Stratford and Haley, Norfolk; and Sussex.

Arg. two lions ramp. combatant under one head guard. per pale gu. and sa. Davy Howeus, $V$.

Arg. two lions ramp. combatant ppr. O'CuILEAN, Carbry, Ireland.

Arg. two lions pass. sa. Browne, co. Lincoln. Feltweli. De Hervili, $V^{*}$. Ligon. OSWALKYRKE.

Arg. two lions pass. sa. over all two bars of the second charged with as many escallops of the first. Fletwick.

Arg. two lions pass. sa. crowned or. Catesby, Haldmead, co. Bucks. Cramiford or Creniford. $\mathrm{S}$..... de Crawnford, $V$. Graftord, $V^{*}$. Granford, $V$. GraUnFord, $V$. De GrawnFord, $V$ *.

Arg. two lions pass. coward sa. FIItwikes. HERWELL.

Arg. two lions pass. guard. sa. Bruneck. Frtz. David Feltwicke, $Y$. Sir David Fletewiks, co. Bedford, temp.Edward III, $V$. Futetewikes, $V^{*}$. Fletwick, co. Bedford. Sire David de Firttewik, $N$. Flytewikes, $V^{*}$. Flytewykes, $V$. M. William Godertche, $S$. Hanmer. Harewell. Oswaldirieg. Samipson.

Arg, two lions pass, guard. sa. crowned or. Sir William Catesby, $V$. Catesby, Whiston, Althorpe-Hinton, and Ashby-Legers, co. Northampton.

Arg. two lions pass. reguard. sa. Burrh. John Fotheringhay, $Y$. Howell.

Arg. two lions pass. reguard. coward the tails reflexed over the back sa. David Flexwrke, $V$. Sr.... de Hervili, $V$.

Arg. in chief two lions ramp. sa. CauTy.

Arg. two lions ramp. combatant sa. HoYLE. SMERdon, London.

Arg. two lions ramp. addorsed sa. Somerton. Arg. two lions pass. vert. Meryteld, $V$. MiRFIELD.

Arg. two lions pass. guard. vert. Mirfield. Az, two lions pass. arg. Barne, Essex. Barnes. Bourne, London, 1570. Camvile or CampirLe, co. Warwick. Ludlow. Percivall.

Az. two lions pass. arg. crowned or. Bodelsgate, Cornwall. HerwiL, $V$.

Az. two lions pass. guard. arg. BARNE, London. Sr... de BaRne, Normerston, co. Buckingham, $V$. Barnes, London, 1614. Baron, Saffron Walden, Essex ; and London; Harl. MS. 1359 , fo. 38. Bodulgate, Bodulgate, Cornwall, a coheiress m. Roscarrock. LudLow, co. Salop. Normeston, co. Buckingham.

Az. two lions pass. guard. arg. armed and langued gu. Astley (?). Barney.

Az. two lions ramp. combatant arg. GARRARD, London.

Az. two lions ramp. supporting a tower with three fleurs-de-lis out of the battlements arg. Latuly.

Az. two lions ramp. arg. chained or supporting a tower triple turreted of the second. KELLY, Castle Kelly, Ireland.

Az. two lions ramp. guard. arg. Edward Bannes, London, 1614, Harl. MS. 6095, fo. 32 b. 


\section{BEASTS.}

\section{IIONS cont.}

Az. two lions ramp. guard. combatant arg. Jacob GARRARD, Harl. MS. 1358, fo. 28. GARRETT, Gracecburcb Street, London; granted 1632. GarRarD, Langford, Norfolk; Baronetcy 16 August 1662 , extinct $12 \mathrm{March}$ 1728.

Az. two lions pass. or. Ardington, co. Berlss; and co. Leicester. Barry. Berkeley, $V$. Berkely, $V^{*}$. Bodulgate. Eaner, knighted 1794, Lord Mayor of London 1801 and 1802; quartering sa. on a chief arg. three lion's heads erased of the first. EDington. Ener. Sir Thomas Erdington, $V$. Erdington, co. Leicester; quartered by Holte. Mr. Thomas de Ennington, $S$. Gourery. Hemry de Herdinton, $F$. Hertington. Percivali. Percivall de Someri, $E, N$. Somery, co. Warwick.

Az. semy of estoiles and two lions pass. or. Casneto, Coventry. De Castinets or Cheyney. Robert Cheyney (Latine de CASNeto), $Y$.

Az. two lions pass. or armed and langued gu. Brampton.

Az. two lions pass. coward or. Payneid.

Az. two lions pass. giard. or. Sr... BanRY, co. Oxford, $V$. Robert de Banri, $E, F$. Sire Robert Barri, $N$. Denston, Suffolk, $V$. Ekdington, co. Berks. Pipe.

Az. two lions pass. guard. or a label of three points arg. Sr.... De Eineney, $V$. Eskeney.

Az. two lions pass. reguard. or. Paneil. Pavell, $V^{*}$.

Az. two lions pass. reguard. coward the tails reflexed over the back or. PANELL, $V$.

Az. two lions ramp. combatant or. Carpenter. CARTER, St. Columb, Cornwall, $W$; originally from co. Stafford; the co.beirs m. Silly, Tanner, Hoblyn, and Hawkey. Carter, Cold Aston and Sevenhampton, co. Gloucester.

Arg. two lions ramp. combatant or supporting a castle ppr. KeLty.

Arg. two lions ramp. combatant or supporting a sword in pale.... O'MEAGHIR, Ireland.

Az. two lions ramp. guard. addorsed or. GARRAD, London; (? not) granted 18 December 1632. .

Barry dancetty of seven az. and arg. two lions pass. of the last. Denmar, Kenfield, Kent.

Bendy of six arg. and az. two lions pass. guard. or. Caronges.

Erm. in chief two lions ramp. az. ADkins.

Erm. two lions pass. guard. gu. JEFFERY.

Erm. two lions pass. guard. gu. ducally crowned or. ReYnolDs, London.

Erm. two lions ramp. combatant gu. Lucas, Cornwall.

Erm. two lións ramp. combatant gu. and a label of the same for diff. Corselirs, Italy.

Gu. two lions pass. arg. Deladiane, co. Hants. Estrange, co. Gloucenter. Eube le Estrange, $G$. John le Estrange, Knokinge, $K$. Sir Johan le Estrange. $N$. Felton, co. Glouces. ter. John Orey, Y. SPRinghose. Hamund Je Strange, $E$. Mlonsire le Strange, (and in a later hapd Baron of Knocking), $Y$. Strange, Knockyn; quartered by Stauley, Earl of Derby, $U$. Le Sr. de Strange, T. Le S. le Strange, S. Y. Mr. John le Strange, S. Syr Roger le Strange, $Q$. Strange, co. Gloucester; and Hunston, co. Norfolk. Straunge. co. Gloucester, $V$.

Gu. two lions pass. arg. in the dexter chief a fleur-de-lis sa. for diff. Mounsyr John Strange, $T$.
BEASTS.

2 LIONS cont.

Gu. two lions pass. arg. a label az. Roger Spreengenose, $E$. The label of five points. Roger Springhose, $F$.

Gu. two lions pass, arg. a label or. Sire Johan de Freby, $N$. The label of three points. Sir Jobn Oney, co. Chester, $V$. Orreby, $V$.

Gu. two lions pass. and over all a bend arg. HOLLAND.

Gut. two lions pass. arg. over all a bend az. Fitz-PAYNe.

Gu. two lions pass. arg. over all a baton compony of the second and az. FELToN.

Gu. two lious pass. arg. over all a bend compony or and az. FitzPayne, co. Gloucester.

Gu. two lions pass. arg. over all a baton compony or and az. Sire William de Feittone, $N$.

Gu. two lions pass. arg. over all a bend erm. Strange, Cirencester and Broome's Court, co. Gloucester; and Somerford Keynes, co. Wilts. Gu. two lions pass. arg. a bend or. Estrange, co. Gloucester. Strange, Cirencester, and Mounes Court, co. Gloucester; and Somerford Keynes, co. Wilts. Le Strange, $V^{*}$.

Gu. two lions pass. arg. over all a bendlet or. M. John le Straunge, $S$. Hamor le Strange, $V$.

Gu. two lions pass. arg. over all a baton or. Sir Hamond le Strange or Estrange, $L$.

Gu. semy of martlets or two lions pass. arg. Sire Johan le Estrange, $N$.

Gu. crusily fitchy and two lions pass. arg. Robert le Strange, $E$; or de Lestrange, $E$.

Gu. crusily fitchy or two lions pass. arg. Acton.

Gu. two lions pass. arg. armed az. Syr Roger le Strange, $Q$.

Gu. two lions pass. arg. armed and langued az. Grytryth AP Cynan, King of North Wales.

Gn. two lions pass. arg. armed and langued az. a label of three points or. Strange as quartered by Holte.

Gu. two lions pass. arg. collared az. Delamene, co. Dorset.

Gi1. two lions pass. arg. collared sa. De la Mare, $V$.

Gu. two lions pass. combatant arg. Coghlan or COGHLEN.

Gu. two lions pass. arg. crowned or. Bodelsgate, $V$. Bodelsgate, Cornwall. Botesgist or Botsgist. Le Sr. de Folton, T, Harl. MS. 6137. Strange, Walton, co. Warwick, $V$.

Gu. two lions pass. guard. arg. Delamare. HaLden, that Ilk. HaLdon, Haldon, Scotland. Jatiare, co. Hants., temp. Edward III. L'Estrange, Knockyn, co. Salop; quartered by Noel. L'Estrange, Moystown, King's County; descended from L'Estrange, Hunstantov. Littlebury, Stensby and Winsby, co. Lincoln. M. John de la Mare, $S$. Mare or De La MARE. Sir Robert DE LA MARE, co. Hants, temp. Edward III, $V$. Pers de la Mare, $E, F$. Sire Robert de la Mare, I. Marshall.

$\mathrm{Gu}$ two lions pass. guard. arg. over all a bend az. (The ancient arms of) L'Estrange, Hulston or Hunstantor, Norfolk; derived from Hamon L'Estrange, brother of John, sixth Lord Strange of Knockyn; Baronetcy 1 June 1620; extinct 2 September 1700 ; the heirs m. Styleman and Astley.)

Gu. two lions pass. guard, arg. collared sa. Delamare.

Gu. two lions pass. guard. arg. crowned or. Boldisgate. 


\section{BEASTS}

2 IIONS cont.

Gu. two lions ramp. arg. AmBridge.

Gu. two lions ramp. addorsed arg. Rogens, $V$.

$\mathrm{Gu}$. two lions ramp. combatant arg. Winstanton, co. Chester.

Gu.two lions ramp. comb. supporting a tower arg. Keluy, Newtown, co. Galway.

$\mathrm{Gu}$. on a mount vert two lions ramp. supporting a tower arg. KeLLY, Castle Kelly, co. Galway.

Gu. two lions ramp. comb. supporting a dexter hand couped at the wrist and erect arg. KING, Earl of Kingston. And with a crescent for diff. King, Viscount Lorton.

Gu. two lions ramp. combatant conjoined under one head guard. arg. Kellan or Kellum.

Gu. two lions pass, erm. Fellbridge or Felibryage, co. Gloucester. Sir Robert de Felton, co. Gloncester; temp. Edward III, $V$. Sire Robert de Feltone, $N$. Le Sr. de Felton, $T$. William Felton, $Y$. Monsire Felton, $Y$. Folton.

Gu. two lions pass. erm. in chief a mullet or for diff. Sire Roger de Feltone, $O$.

Gu. two lions pass. erm. crowned or. FELTon, co. Gloucester; Felton, Northumberland; and Playford, Suffolk; Baronetcy 20 July 1620, extinct 18 November 1719 ; the heirs $m$. Hervey and Platers. Sir John de Felton, the son, L. Sire Johan de Feltone, N. Sir William Felton, $Q$.

Gu. two liows pass. erm. ducally crowned or a mullet for diff. Nicholas FeLton, Bishop of Bristol 1617. Ely 1619-28.

Gu. two lious pass. erm. crowned or armed az. Sir William FeltoN, $Q$.

Gu. two lions pass, guard. erm. Sorrell, Waltham and Stebbings, Essex; and Ipswich, Suffolk. Sonneli, France.

Gu. two lions pass. or. Broneswike or Bromester. Patwarden. Pedwarden, co. Hereford. Petwarden, co. Lincoln. Sir Walter de Petwardyn, $V$. Wat de Pedwerdin or Pedwordin, E. William de Pedwordon, $F$. M. Waut Pedwardyn, $S$. Thomas Pedwardyn, $Y$. Monsire Pedwardin, $Y$.

Gu. two lions pass, or a label of three points az. M. Robert PEDWARDYN, $S$.

Gu. two lions pass. guard. or. Bars. Brunswick, $Z, 871$. Catzenellenbogen, $Z$, 606,679 ; but this coat is really for Dietz. Catesnelibogen Catsenelbogen Catsznellage or Katznelloofn. Richard de Dovre, $B$. Delamare. Richard fitz le Rey, A, Harl. MS., (i] 37 , fo. $89, \mathrm{~b}$, aud attributed to William I and II, Robert duke of Normandy, Henry I, the Empress Maud, Stephen, Henry II until his marriage 1151 with Eleanor of Aquitaine, and John Plantagenet while Lord of Ireland and Earl of Mortaigne, $Z, 1,-59$; attributed (with the lions to the sinister side) to Ricliard I, Ducarcl, Antiquities, p. 30. Fulke TaIBoIs, Earl of Anjou. Harecourt, $V^{*}$. Longspee, Normandy. Marshall. Duke of Normandy, $V$. Richard Pipe, Yerdington, $m$. the daugliter of Halecourte, $V$. Pype, $V^{*}$. Geoffry Rufus, Bishop of Durham, 1]33-40. ST. Valony, Normandy. Richard de VAREN, $Z, 76$.

Gn. two lions pass. guard. or a baton az. Attributed to Reginald Fitz-Roy, or de Dunstanvile, Earl of Cornwall, ob. $1170, Z, 50$.

$\mathrm{Gu}$ two lions pass. guard. or a bendlet sinister.... Geoffrey Plantagenet, Bishop of Lincoln 1173.82, Archbishop of York 1191.1212, Add. MIS.. 124:33.
BEASTS.

2 IIONS cont.

Gu. two lions pass. guard. or depressed by a sword erect palewise arg. hilted or. William Longespe, Duke of Normandy, $V$. Longespee. $\mathrm{Gu}$. two lions pass. guard. or armed and langued az. BRUnswick, $Z, 575,875$.

Gu. two lious pass. guard, or collared sa. Delamare, co. Hants.

Gn. two lions pass. reguard. or. ACLE, co. Devon. $\mathrm{Gu}$. two lions ramp. iu fess or. ORBY.

$\mathrm{Gu}$. two lions ramp. combatant or. Attributed to Richard I while Earl of Portou, $Z, 73,81$.

$\mathrm{Gu}$. on a mount vert. two lions ramp. or supporting a tower arg. O'KELLY, Ireland.

Gu. two lions ramp. supporting a tower triple towered or. O'KEI.LY, Ireland.

$\mathrm{Gu}$. on a mount vert. two lions ramp. supporting a tower triple towered in the port a portcullis or. Town of NorTHanipton.

Gu. two lions ramp. combatant under one head guard. or crowned az. the tails coward and reflexed over the back. Comberton, $V$. John Nonthampton, Lord Mayor of London, 1381-:2, Harl.MS., 1349, fo. 9.

Gu. two lions sejant under one head guard. or crowned az. Comberton.

Or two lions pass. az. Endinaton, co. Salop. Endington, co. Warwick, temp. Henry VI. Attributed to William Fitz-AnsculpH, Lord of Dudley, temp. William I, who was succeeded by Paganel Paganell or Painel; seal of Gervase Paganell, 1187, Monasticon, v, 204; by marriage with whose heiress John de SomenY bad the manor of Dudley. Robert de Somerye, $A$. Roger de Sumeri, A, Harl. MS., 6137 ; or Somery, $B, C$; or Someri, $E$; or Somerey, $F$. Sir Johan de Sunteri, $J$; or Someri, $N$. Roger Sonery, $Y$. Sir .... de Somery, co. Warwick, temp. Edward I, $V$. John de SutTon, by marriage with the eldest coheir of Somery, obtained, 1332-42, the manor of Dudley, and founded the family of Sutron alias DuduEy barons of Dudley extinct in the male line 1043; the beiress $m$. Ward; the barony feil into abeyance 1757. William DudLey, Bishop of Durham 1470.83 quartering (for Sutton) arg. a cross patonce az.; seal in Surtees, Durhan. Dediex, co. Stafford. Percivall. Sleswick, $Z, 554$.

Or two lions pass. counterpass. az. LEGGE, Legges, Tumbriclge, Kent; quartered by Beebee.

Or two lions pass. az. langued gu. PaganeLu, quartered by Sutton, baron Dudley, $U$.

Or two lions pass. guard. az. DaвYtot. Gomerx, V. Gourey, co. Bedford. Gonorey. Gundry. SoMery, $V$.

Or two lious couchant gu. Bredwardine, co. Brecknock.

Or two lions conchant coward the tails reflexed over the back gu. Sir Walter Bredwarden (?). Or two lions pass. gu. Sir Brian de Brampton, $V$. Brian de Brompton, $Y$. Brian de Bramptone, $E, F$. Brian de Bointon, $E$, Harl. MS., 6137. Frandolph or Frandolfe. St. Peere. St. Walary, co. Oxford, $V$. St. WAIERY, $V^{*}$. Sire Pichard de SEINT WAI, N. Strange, Norfolls.

Or two lions pass. gu. a label of five points az. Wat de Bronton, $F$. The label sa. Wat de BROBTONE, $E$.

Or two lions pass. gu. over all a baton sa. Joan de Brontone, $E$. 


\section{BEASTS}

2 LIONS cont.

Or two lions pass. gu. over all a bendlet sa. John de Brunton, $F$.

Or two lions pass. gu. over all on a bendlet (bend, $V$.) sa. three escallops arg. Bromion, $T$. Brian de Brontone, $E$.

Or two lions pass. gu, on a bendlet sa. three escallops or. Baudwin de Brunton, $F$.

Or two lions pass. gu. armed and langued az. Brampton.

Or two lions pass. gu. crowned arg. Sir Robert Goldingroin, co. Bedford, temp. Edward $1, \mathrm{~V}$. Gouldington, $\mathrm{J}^{\text {** }}$.

Or two lions pass. guard. the one in chief ga. that in base az. DABITOT.

Or two lions pass. guard. gu. Gefrai d'Aветот or Автотт, $E$. Geffrel de Авттот, $F$. Daвсотt. Dabitot, $Y$. Dauce. Ducie. Ducr, Tortworth, co. Gloncester.

FOLIOTT, $\mathrm{V}^{*}$. Littlebury, co. Lincoln. Jon de St. Valery, $F$. St. WALLeY or St. Wallery, Beckeley, co. Oxford, temp. Willian the Contueror. Joan de Scin WaLeri or Sein WaLleri, $E$. SAMSON, $T^{*}$.

Or two lions pass. counterpass. guard. gu. ABcot.

Or tro lions ramp. addorsed gu. Bryan. CORnES.

Or two lions ramp. addorsed in fess gu. Sire de Waderibouxt, $A$, or Wadripun, $D$.

Or two lions ramp. combatant gu. Wincheons. Wy conb. WYcombe, $V$.

Or two lions ramp. combatant gu. langued and armed az. Wyconis. WycomBE.

Or two lions pass. sa. Aruington. O'Rourk, Ireland.

Or two lions pass. sa. a label gu. Sire John de Goldintone, $O$. Monsire de Goldington, $Y$.

Or two lions pass. sa. crowned of the first. Cranfond. Crenford or Crampord. GRANDFORD.

Or two lions pass. guard. sa. Sir John de Godington, $R$. Attributed to Rushout, Bart. 1730 .

Or two lions ramp. sa. ENEMEAD, quartering arg. two lions ramp. gu.

Paly of four erm. and vert two lions pass. gu. Lowthwick. Lowthwike, $Y$.

Pean two lions pass. per pale or and arg. Dotisin, Grenada Hall, in Barbadoes; and Bugle Hall, co. Hants.

Per bend or and az. two lions ramp. counterchanged. VENNOR.

Per cliev. arg. and gu. in chief two lions ramp combatant sa. LEIGH or LEa.

Per chev. indented arg. and purp. two lions ramp. in chief of the second. SIIPToN, 1730.

Per chev. gu. and az. two lions ramp. combatant or. Honour of Clare or ClaRence.

Per chev. or and gu. in chief two lions ramp. combatant of the second, LEE or LEA.

Per chev. or and gu. in chief two lions ramp. combatant sa. armed and langued of the second. LEE or LEA, St. Julian's, and Sopwell, co. Hertford.

Per chev. sa. and erm. in chief two lions ramp. or. Bery, Norfolk.

Per chev. indented sa. and erm. in chief two lions ramp. or. Bures or Bowers, Norfolk and Suffolk.

Per fess sa. and arg. two lions pass. counter. changed armed and langued gu. PAYNe, East Grinstead; and Newick, Sussex; granted 25 Feb. 1661
BEASTS

2 LIONS cont.

Per pale arg. and az. two lions ramp. counterchanged. Braytort, Braytoft, co. Lincoln. Scarlton.

Per pale arg. and az. two lions ramp. addorsed counterchanged. Gregory, High Hurst, co. Lancaster; and Rodington, co. Salop.

Per pale arg. and az. two lions ramp. addorsed counterchanged langued gu. GREGORY, Lord Mayor of London, 1451; Harl. MS. 1349.

Per pale arg. and az. two lions ramp. combatant counterclianged. Scrotвотts, $V$.

Per pale arg. and az. two lions ramp. guard. addorsed counterclianged. GREGory, Lord Mayor of London, 1451.

Per pale arg. and az. two lions ramp. reguard. addorsed counterchanged. Scнотвоттs, $V^{*}$.

Per pale arg. and gu. two lions ramp. combatant connterchanged. Bishton.

Per pale indented arg. and sa. two lions ramp. combatant counterchanged. Shotbolt, co. Hertford. Per pale az. and gu. two lions pass. or. MADock, $V *$. MadoK, $T$.

Per pale az. and gu, two lions pass. or. MADDox, Wormlerbury, co. Herts ; Baronetcy 11 March, 1675-6, extinct 14 December, 1716; descended from MADDOX, Bongiton, Kent; the hers. rr. Rudyerd and Pollen.

Per pale indented az. and or two lions ramp. combatant lolding a crescent counterchanged. Hone, the Spa, co. Gloucester.

Per pale gu. and arg. two lions .... counterchanged. ElLEsworth.

Per pale gu. and az. two lions pass. or. MADox, co. Hertford; London; and Masterley, co. Salop.

Per pale gu. and az. two lions pass. in fess or. Maddocks.

Per pale gu. and vert two lions pass. guard. arg. Geffri de Авiтot, de HyNdelippe in a later hand, $F$.

Per pale or and az. two lions ramp. addorsed counterchanged langued gu. Wm. Gregony, Lord Mayor of London, 1451, Harl. MS. 1:349.

Per pale or and az. two lions ramp. reguard. addorsed connterchanged. Sснотвот, V.

Per pale or and gu. two lions pass. respectant in fess counterchanged. EvarT.

Per pale or and gu. two lions ramp. addorsed counterchanged. BI.AYNEY, co. Montgomery. DEJwood, quartered by Itlell, 1730.

Per pale sa. and arg. two lions ramp. combatant counterchanged. WHAPLOD.

Quarterly arg. and az. in the first and fourth quarters a lion ramp. gu. Pollexfen, co. Devon, $W$. Pollexfen, Kitley, co. Devou, Visitation 1620; the heiress m. Bastard.

Quarterly arg. and sa. in the first (? and fourth quarters) a lion ramp. of the second. Breton. Quarterly arg. and sa. in the second and thrrd quarters a lion ramp. or over all on a bend gu. three annulets of the third. HULEERT, granted 1639. HurLebert.

Quarterly erm. and gu. in the first and fourth quarters a lion ramp. .... over all an arrow in bend sinister point upwards .... Fosretr, Rosebill, Abbott's Langley, co. Hertford.

Quarterly or and gu. in the first (? and fourth quarters) a lion pass. az. Sorrey.

Quarterly sa. and arg. in the first (? and fourth quarters) a lion pass. guard. or. BREToN.

$\mathrm{Sa}$, two lions pass. arg. GLeke. Hoches. Stmagriers. Strangeways. 


\section{BEASTS. 2 LIONS cont.}

Sa. two lions pass. arg. oppressed with as many pales gu. GLEKE.

Sa. crusily fitchy (crusily only $V^{*}$.) or two lions pass. alg. John Wybury, $V$.

Sa. two lions pass. counter-pass. arg. collared gu. GLEG.

Sa. two hons pass. counter-pass. arg. collared gu. the one in chief towards the sinister. GLEGG or Glegge, Grange and Irbie, co. Chester; descended from GiEGG, Gayton, co. Chester ; the hejress m. Baskervyle.

Sa. two lions pass. arg. crowned or. Dymoke, Scrivelsby, co. Lincoln; quartering, among many other coats, Ludlow, Marmyon, Welles, Warterton, 'lalboys, Umfraville, and Kyme; Baronetey 1841. M. John Dymore, $S, Y$. Sir Robert Dymoke, $V$. Dyноке or Dimock. Dymoke, Grebby Hall, co. Lincoln; descended from Dymoke, Scrivelsby; the heiress m. Wells. Hartwell. John de Herunvile, $F, 354$.

Sa. two lions pass. arg. crowned or each holding a fleur-de-lis az. De WynLEy, co. Stafford; granted (1328 ?).

Sa. two lions pass. guard. arg. Sir .... de Brituer, V. Roche. Jolun de Roches, Y. Roches, $V$.

Sa. two lions pass. guard. arg. debruised by as many palets gu. GleGG, $V^{*}$. GLEGGE, Wyrall, co. Chester, $\mathrm{T}^{\prime}$.

Sa. two liuns ramp. addorsed arg. WADERPOND, France.

Sa. two lions ramp. combatant arg. crowned or. Prale or Prall. Pralle, $V$.

Sa. two lions pass. erm. ducally crowned or. Felton, Ipswich, Suffolk.

Sa. two lions pass. or. ARnoud, co. Huntingdon. Exeney. Sir Nicholas Kerkedy, $V$. Kevereld, Keverell, Cornwall. Kirke By.

Sa. two lions pass. or a label of three points gu. ELEnRy.

Sa. two lions pass. or debruised by as many palets gn. GLEKE.

Sa. two lions pass. crowned or. Harewell.

Sa. two lions pass. guard, or. Rushout.

Sa. two lions ramp. combatant or. Nicholas Carter, M.D, Willesborow, Kent; and London ; 1730 .

Sa. two lions pass. paly of six (another, of eight) arg. and gu. (usurped by CuthBert or Cutbert) ; Strangwayes, Alne, and Well, co. York; and Barham Wood, co. Hertford; des. cended, throngh the marriage of James Strangways with a heir of Conyers of Ormsby, co. York, from Sir James Strangwish, Harlesey Castle, co. Yorli, a branch of Strangwayes, Nelbury Sempford, co. Dorset; the herrs m. Horner and Fox. Strangways $V *$. Sir .... Strangwish, co. Dorset, $V$.

Sa. two lions pass. paly of six (another, of eight) arg. and gu. armed or. Strangaysshe, Harlesey, co. York.

Vert two lions pass. arg. Mirfield, Thureroft, co. York.

Vert two lions pass. arg. armed and langued gu. Myrfeld, Tonge.

Vert two lions pass. arg. crowned or. Merefield. MERFELD, $V$.

Vert two lions ramp. arg. crowned or. Merefield.

Vert two lions pass. erm. crowned or. Sr.... de Merfeld, $T$.

Vert two lious pass. or. William de ivarchia, Bishop of Bath, etc., 1293. 1302.

\section{BEASTS. 2 LIONS cont.}

Vert two lions ramp. in fess or. KNiGhton.

Vert two lions ramp. combatant or. MAson, Didlebury and Minton, co. Salop.

Vert two lions ramp. combatant supporting a sinister hand or. RILEy, Forest Hill, co. Berks. O'Reilly, Heath House, Queen's County; Boyne Lodge, co. Neath; Ballykilchrist, Bally. morris, and Anneville, co. Longford.

\section{OXEN}

Arg. two bulls pass. .... each having a bell suspended round the neck.... armed and hoofed or. DEFoIX.

Sa. two bullocks pass. or. STAyuer.

\section{SQUIRRELS}

Arg. two squirrels sejant addorsed cracking nuts gu. William Samuell, co. Northampton, $W$. SAMWELL, Upton and Gayton, co. Northampton; Baronetcy 22 Dec. 1675 , extinct 18 October 1789.

Arg. two squirrels sejant gu. Kocker.

Erm. two squirrels ramp. addorsed gu. George Samuell or Samwell, co. York, $W$.

Erm. two squirrels ramp. (Harl. MS. 1359, fo. $37 \mathrm{~b}$, but another sejant) addorsed gu. Sanueir, alias Samwell, Doncaster, co. York.

Per chev. gu. and paly of six vert and arg. in chief two squirrels sejant respectant eracking nuts or. ADOTr, $V$.

\section{URCHINS}

Gu.two porcupines arg. Mericke, Wigmore Castle, Hereford, I560, and co. Radnor.

\section{WOLVES}

Az. two wolves pass. coward or. PAYNell.

Az. two wolves (another, foxes) statant (pass. $V^{*}$.) reguard. their tails reflexed betw. their legs or. PAVEIL, $V$.

Gu. two wolves pass. arg. Low. Le Lowe, $V^{*}$. Lowe, co.Salop ; Walden, Essex ; and Lowe, co. Worcester.

Gu. two wolves statant arg. Le Low, $V$.

Or two wolves pass. sa. mouths embrued gu. Oliver Peard, Mayor of Barnstaple, co. Devon, 1575; the heiress m. Dickinson.

Sa. two wolves pass. arg. WOLF. WOLFE, $V^{*}$.

Sa. two wolves statant arg. Sir William Wolfe, $V$.

Vert two wolves pass. or. Stanhor.

Axes

Arg. two boars ramp. combatant ppr. in chief two battle-axes in saltire of the last. MAC Swrnie, Ireland.

\section{Canton}

Az. two boars pass. or a canton erm. Sherrard, co. Stafford.

2 DEER and in chief....

Per chev. az. and gu. two harts counter trippant or in chief a fountain ppr. HaRT.

2 DOGS and in chief...

on a Chief.... Estoiles

Arg. two greyhounds courant sa. on a chief az. three estoiles or. Mone, Essex; co. Lincoln; London; and co. Stafford; confirmed 14 July 1593. Moore, Lincoln's Inn; quartering sa. two palets arg. on a fess gu. three fleurs-de-lis or.

Arg. two greyhoun?s courant sa. on a chief az. three estoiles of six points or a crescent for diff. David Moone, 1693, in Chertsey Church, Surrey. 
BEASTS. 2 DOGS and in chief....cont. on a Chief cont. .....Head

Sa. two greyhounds ramp. reguard. addorsed arg. in chief betw. them a fawn's head cabossed or. BarNaRD, co. Hants, $V$.

\section{FOXES and in chief....}

Purp. two foxes ramp. combatant arg. on a chief of the second a dove volant ... O'DONOGHUE of the Glens, in Mucross Abbey.

\section{LEOPARDS and in chief....}

Arg. two leopards pass. sa. on a clief of the second tbree covered cups or. WrraLt, co. York.

2 LIONS and in chief....

\section{Canton}

Gu. two lions ramp. arg. a cauton or fretty sa. BoKeland.

Sa.two lions pass. paly of six arg. and gu. in the dexter chief a canton of the second. Strangwayes, Alne, co. York; quartering Swainston.

on a Canton..... Fret

Gu. two lions ramp. arg. on a canton or a fret sa. Rutr, co. Buckingham.

Gu. two lions ramp. arg, on a cauton sa. a fret or. WROTH.

Or two lions pass. gu. on a canton sa. three plates. Francis Goowin, Bishop of Llandaff 1601 ; Hereford 1017.33 .

Or two lions pass. sa. on a canton of the second three bezants. Godwys, Kent.

Or two lions pass. sa. langued gu. on a can. ton of the second three bezants. Thomas GoDwIn, Bishop of Bath, etc., 1584-90.

Or two lions pass. guard sa. on a canton of the second three bezants. Goodwin.

\section{Chief}

Arg. two lions pass, guard. sa. a chief gu. Weatherali or Weatherell. Wetherall.

Gu. two lions ramp. combatant and a chief arg. OkEs, Oundle, co. Northampton, W. OAKEs or Okes, Oundle; quartering sa. a fess betw. six acorns or.

Gu. two lions ramp. combatant or a chief arg. OKEs, $V^{*}$.

Per pale or and gu. two lions pass. in fess and a chief engr. counterchanged. Jones, Ireland.

on a Chief.... Bird

Az. tro lions pass. guard. in pale or on a chief of the last a dove wings expanded of the first. Rover, Westminster; certified May 1779.

$$
\text { ....Cups }
$$

Arg. two lions pass. sa. on a chief indented of the last three covered cups or. Wetherali, co. Lincoln.

Arg. two lions pass. guard. the first gu. the second sa. on a chief of the last three covered cups or. Hugh Wrrall, co. Iork, $V$.

Arg. two lions pass. guard. sa. on a chief gu. (sa. Harl. MS. 1359 , fo. 8 b.) three covered cups or. Wetherall Wyralil or Wyrrall, Loversall, co. York; confirmed $153 \%$.

Arg. two lions pass. guard. sa. on a chief dancetty of the second three covered cups arg. Sir Charles Wethereli, Attorney-General 1820.

Arg. two lions pass. guard. sa. on a chief of the second three covered cups or. Bew. Worrell. Wyrali, co. York.

Or two lions pass. guard. sa. on a chief az. three covered cups of the field. Worrelc, Londor.
BEASTS. 2 LIONS and in chief....cont.

on a Chief cont......Figure

Gu. two lions pass. guard. or on a chief az. the Virgin Mary a circle of glory over her head sitting on a tombstone issuant from the chief in the dexter arm the infant Saviour head radiant in her sinister hand a sceptre all as the secoud. Bishopric of Lincoun, $U$.

Gu. two lions pass. guard. or on a chief arg. a mitre. . betw. two crosiers az. Benedictine Abley at Malmesbury, co. Wilts.

$$
\text { .... Rock }
$$

Per pale az. and gu. two lions ramp. combatant arg. on a chief of the last a rock issuant from the sea all ppr. Coesvelt.

\section{.... Roundles}

Sa. two lions pass. or on a chief of the second three ogresses. Goodinge, Henley, co. Oxford.

Per pale sa. and arg. two lions ramp. combatant counterchanged on a chief sa. five bezants two one and two. Whaplod. Whaplode, $V$.

\section{Quarter}

Gu. two lions ramp. arg. a quarter sa. fretty or. John BicliLonde, $Y$.

on a Quarter..... Fret

Arg. two lions ramp. gil. on a quarter sa. a fret or. Burell. Bukeshili, Sussex.

G11. two lioncels ramp. guard. or armed and langued az. on a quarter of the second a fret of the first. Jones, Bealanamore and Headford, co. Leitrim; derived from Jones, Dublin, descended from Wales, 1662; quartering Hayward, Coote, and Cuffe.

\section{Swords}

$\mathrm{Gu}$. two lious ramp. combatant holding a garb or in chief three swords two in saltire points upward and one fesswise hilt to the sinister ppr. O'Breanon, Jobh, Ireland.

2 WOLVES and in chief....

Gu. two wolves pass. or on a canton arg. a demi rose of the field. VELLOWES.

2 DEER and in base....

Per chevron crenely vert and arg. in chief two bucks trippant ppr. each gorged with a collar or in base a cross flory of the first. Parkhouse, Eastfield Lodge, Bittern, co. Hants; derived from Parkhouse, co. Devon.

\section{DOGS and in base....}

Az. two talbots in chief and a spur-rowel in base or. Vivian, France.

\section{LIONS and in base....}

\section{Anchor}

Per fess sa. and arg. in chief two lions ramp. guard. in fess and in base an anchor with cable counterchanged. Young, Formosa Place, co. Buckingham; Baronetcy 24 November 1813.

Quarterly indented arg. and az. in the first and second quarters a lion ramp. gu. in the third an anchor cabled or in the fourth a crescent.... Sutton, Middlesex.

\section{Beast (Boar)}

Per chev. or and gu. in chief two lions pass. guard. in base a boar pass. counterchanged. Eason.

Per chev. or and vert in chief two lions pass. guard. gu. in base a boar pass. of the first. M'DoNAGH, Ireland. 
BEASTS. 2 LIONS and in base.... cont. Crescent

Az. in chief two lions .... respectant supporting a garb in the dexter base a crescent or in the sinister an Irish harp gold stringed arg. (The ancient alms of) FogarTy.

\section{Crescents}

Az. two lions ramp. combatant .... supporting a sword in pale.... in base two crescents... MARER.

\section{Fish}

Vert two lions ramp. combatant arg. supporting a sinister hand couped gu. in base a fish of the second. O'NEILL.

\section{Fleur-de-lis}

Per chev. gu. and az. in chief two liors ramp. combatant in bave a fleur-de-lis or. Sir John de Clarence, natural son of Thomas Duke of Clarence, son of Henry IV; Planché, Poursuivant, p. 155. Sir Bartholomew Clarence, $V$.

Per chevron gu. aud az. in chief two lions ramp. guard. combatant in base a fleur-de-lis or. Sir Jobn de Clarence, $Z, 311$.

\section{Key}

Per chev. gu. and az. in chief two demi-lious ramp. couped in base a key in pale or. FunN. Niascles

Per fess sa. and arg. in chief two lions ramp. in base three mascles counterchanged. Ogyston, Scotland.

Iullet

Per chev. .... and .... in chief two deni. lions ramp. .... in base a mullet .... Redington, Kilcornan; descended from Redington, Creganna, co. Galway.

\section{Swords}

Az. two lions ramp. or supporting a tower arg. in base a scimitar pomel and hilt towards the sinister betw. two other scimitars pomels and hilts to the dexter ppr. impaled with gu. on a bend or betw. three fleurs-de-lis arg. six ogresses all within a bordure gold. Guxon, Richmond, Surrcy; granted....

\section{Tree}

Per chev. gu. and arg. in chief two lions ramp. of the second in base an oak-tree fructed or. Timpson, Exeter and Ireland; granted 1767.

\section{SQUIRRELS and in base...}

Per chev, gu. and arg. in chief two squirrels sejant cracking nuts .... in base three piles vert. ADDOTS.

\section{DEER betw. or within....}

Sa. two bucks courant arg. within an orle of bezants. Andrew Bockereli, Lord Mayor of London, $V$.

\section{DOGS betw. or within....}

\section{Bordure}

Per chev. erm. and sa. two greyhounds in full course .... within a bordure az. semy.de-lis or. BADLOWE.

Per chev. sa. and erm, in chief two greyhounds ramp. respectant arg. a bordure az. charged with eight fleurs-de-lis or. BLADLow, $V$.

\section{Cherrons}

Arg. two talbots pass. (counterpassant,' $V^{*}$.) respectant betw, as many chevronels sa. within a bordure engr. gu. Bealbrenger, $V$.

\section{Flaunches}

Or two talbots pass. sa. langued gu. betw. two flaunches of the second. Aldman, Shrimpling, Norfolk.
BEASTS. 2 DOGS betw, or within.... cont.

Heads

Sa. two greyhounds .... addorsed arg. betw. as many buck's heads cabossed or. BARNard.

2 FOXES betw, or within....

Per chev. az. and erm. in chief two foxes pass. arg. within a bordure of the first charged with eiglit fleurs-de-lis or. Bled

\section{LEOPARDS betw, or within....}

Gu. two leopards pass. or over all a bend az. with in a bordure of the last semy-de-lis gold. HOLLAND.

Gu. two leopards pass. or over all a bend az. within a bordure of the last semy of escallops arg. HOLlaNd.

\section{LIONS betw, or within....}

\section{Bends}

Arg. two lions pass. in bend sa. betw. as many cotises gu. Kezewich, co. Lancaster; and Peamore, co. Devoll.

Arg. two lions pass. guard. in bend sa. betw, as many bendlets gu. John KenEwiche, $V$.

Arg. two lions pass. in bend betw. as many cotises sa. KeMISH or KeYMICHE, co. Lancaster.

Arg. two lious ramp. in bend. betw. as many cotises sa. KELWICH.

\section{Birds (Martlets)}

Gu. two lions pass, arg. within an orle of martlets (of the second, another sa., another) or. Sir John Le Straunge, $L$.

$$
\text { ..... (Parrots) }
$$

Or two lions pass. gu. betw. three popinjays ppr. Pedwardyn.

\section{Bordure}

.... two lions pass. guard. .... crowned .... within a bordure .... semy of roundles .... Henry de BloIs, Bp. of Winchester 1129.71. Arg. two lions pass. guard. sa. crowned or within a bordure engr. gu. CATISEy, co. Warwick.

Az. two lions pass. guard. arg. within a bordure gu. William Edendon, Edindon, or Edington, Bishop of Winchester 1346-66; Add. MS. $12 \pm 43$, fo. 130 .

Az. two lions pass. arg. within a bordure engr. or. Seymour.

Az. two lions pass. or within a kordure arg. William Fdendon, EDINDON or EDington, Bishop of Winchester 1346-66, Harl. MS. 6100. $\mathrm{Az}$. two lions pass, or within a bordure gu. William Edendon, Edindon, or Edington, Bishop of Winchester 1346-66; $A d d$. MS. 12443, fo. 130. Edington. Sire Henri do Erdingtone, $N$.

Az. two lions pass, within a bordure or. Edington.

Az. two lions pass guard. within a bordure engr. or. M. William Barre, $S$.

Gu. two lions pass. within a bordure engr. arg. Sire Roger le Lesstrannge, $J$. Strange, London.

Gu. two lions pass. within a bordure eugr. arg. over all a bendlet erm. Estrange.

Gu. two lions pass. within a bordure flory counter. flory arg. Felton, co. Gloucester.

Gu. two lions pass. within a bordure indented arg. over all as many bends az. Estrange.

$\mathrm{Gu}$. two lions pass. guard. within a bordure engr. arg. L'Estrange, Lord of Ellesmere, 1301.

Gu. two lions ramp. combatant under one head arg. crowned az. within a bordure of the second. Kellam or Kirlom, Hickleton, co. York; quartering Preston. 
BEASTS, 2 LIONS betw, or within.... cont.

Bordure cont.

Gn. two lions pass, arg. within a bordure az. Gernon, co. H reford.

Gu. two lions pass, arg. within a bordure engr. or. Estrange. Ringer Le Strange, $E$; or Straunge, G. Talbot.

$\mathrm{Gu}$. two lions pass. arg. within a bordure indented or. Sire Roger Le Estrange, $N$.

$\mathrm{Gu}$. two lions pass. arg. within a bordure indented or over all a baton az. Sire Johan Le Estraunge, $N$.

Gu. two lions pass. guard. arg. within a bordure engr. sa. Ilconbe. Sali, co. Devon, $W$.

Gil. two lions ramp. conjoined with one head or crowned az. within a bordure arg. Keltan.

Gu. two lions ramp. combatant under one head guard. or crowned az. within a bordure urg. James KeLLaM, $V$.

Gu. two lions pass. or within a bordure az. Garnon, Garnons, cn. Hereford; and Harnhill, co. Gloucester; quartering sa. a chev. betw. three fleurs-de-lis arg., with arg. a chev. betw. three dolphins embowed hamrient az. Gannoss, Colommendy, co. Denbigh ; quarterungVaughan, Wyone, and Wynne.

Gu. two lions pass. guard. or oppressed by a bend az. within a boldure of the third semy de lis .... Holland.

Gu. two lions pass. guard. or oppressed by a bend az. within a bordure of the third semy of es. eallops arg. Holland.

Gu. two lious ramp. or crowned az. within a bordure of the second. Keliam.

Or two lions pass. within a vordure az. DUdLex.

Or two lions pass. az. within a bordure of the second charged with escallops of the first. WARE, co. Devon; Leigh, Essex; and Ireland.

Or two lions pass, az. armed and langucd gir. within a bordure of the second charged with twelve escallops of the first. Hibbert-WARE, Edinburgh; quartering Hibbert.

Or two lions pass, within a bordure engr. az. John Dedrey. Serjeant of the Pastry to Queen Elizabeth; granted by Cooke, $W$.

Or two lions pass. az. within a bordure gu. charged with eight martlets of the first. Sir John de VAUs, co. Worcester, temp. Edward I, $V$. Sir Jobn de Wayez or Wayz, $L$.

Or two lions pass. az. within a bordure gir. charged with eight escallops of the first. WARE.

Or two lions pass. guard. az. within a bordure gu. charged with martlets of the first. Sir John WeY, but in the margin WARE or WeRE, $L$.

Or two lions pass. guard. gu. within a bordure az. DETON.

Quarterly or and arg. two lions pass. in pale sa. within a hordure az. and gu. Currs, descended from O'Currie, a branch of the O'Rourkes, lords of I Brien Brefney, now part of co. Cavan.

Sa. two lions pass. guard. within a bordure engr. or. Rushout, Milnst Maylards or Milast Green, Essex; Northwick Park, co. Worcester ; Thurlestane House, co. Gloucester; and Harrow, Middlesex; Baronetcy $17 \mathrm{July} 1661$; cre. ated Baron Northwick 26 Octuber 1797. Cockerell-Rushout, now Rushout-Rushout, Sezincot, co. Gloncester ; quartering Cockerell ; Baronetcy 25 September 1809.

Vert two lions sejant under one head within a bordure engr, arg. Atwater.
BEASTS, 2 LIONS betw, or within.....cont.

\section{Bordare cont.}

Vert two lious ramp. comb. under one head guard. or within a bordure eugr, arg. ATwaler, $V^{*}$. Atwater, $V$.

Castles

Az. in the sinister chief and dexter base points a lion ramp. erm. ducally clowned or in the opposite points a tower arg. Skrine, Warleigh, co. Somerset; and Stubbings, co. Buckingham.

$\mathrm{Gu}$. in the sinister chief and dexter base points a lion ramp. in the opposite points a tower arg. Skearne Skerne Skryne or Skrre.

$\mathrm{Gu}$. in the sinister chief and dexter base points a lion ramp. in the opposite points a tower or. Skearne or Skerne, Bonby, co. Lincoln, and Portington, co. York.

$\mathrm{Gu}$. in the sinister chief and dexter base points a lion ramp. in the opposite roints a tower triple towered or. Castelyon, co. Liucoln. Castillon.

\section{Chevrons}

Sa. two lions pass. respectant enclosed betw. as many chevrons alg. Chipman. Chipnam, $V$. Chypenhal, $V$.

Sa. two lions pass. respectant the first or the second arg. betw. two cherrons as the last. Chipenham or Chipnan, $V^{*}$.

\section{Crosses}

Or two lions pass. and three crosses croslet fitchy sa. GaRTH, Morden, Surrey; granted 1564; the heiress m. Stone. Grart.

Sa. two lions pass. betw. eight crosses croslet arg. SpRINGESTOWE.

Gu. two lions pass, arg. betw. nine crosses croslet fitchy or. Dalberg-Acton, Aldenham Hall, and Round Aston, co. Salop; Baronetcy 17 January 1643-4; derived from William de Acton Burnel, temp. Edward III: and its branches AcToN, Acton Scott, co. Salop (the heiress m. Staclihouse); and Acton, Gatacre Park, co. Salop.

Or two lions pass. betw. ten crosses croslet sa. Goodrich.

\section{Estoiles}

Arg. two lions ramp. comb. supporting a dexter hand gu. in clijef three estoiles.... and in base a salmon naiant.... JoHnson, New York, U.S.; and Twickenbam, Middlesex.

Arg. two lions pass. within an orle of estoiles or. De Casnets, Coventry, and Glentham, co. Warwick.

\section{Flaunches}

Az. two lions pass. guard. or betw. as many flaunches erm. Chibnale or Chibnall, Fil. mersham, co. Bedford; Astwood, co. Bucking. ham; and co. Northampton.

Or two lions pass. guard. between as many flaunches az. over all on a fess gu. three bezants. NoBle, Cornwall; Belson, and Bishops Fenton, co. Deron; and Barming, Maidstone, Keut.

Sa. two lions pass, arg. betw, as many flaunches of the last each charged with a fess az. STEED, $V^{*}$.

Fleur-de-lis

Az. two lions pass. guard. the verge of the escucheon charged with demi-fleurs-de-lis or. An augmentation granted to Catherine Howard, fifth wife of Henry VIII; $Z, 489$.

\section{Flowers}

Gu. two lions pass. enclinsed betw. three roses in pale arg. Hughes, Kinmel Park, co. Denbigh, Baron Dinorlen, 10 September 1831; extinct 6 Octuber 185\%. 
BEASTS. 2 LIONS betw. or within.... cont. Heads

Quarterly per fess wavy az, and or in the first and fourth quarters a lion sejant extending the dexter paw arg. in the second and third a fox's head erased gu. THompson, London.

\section{Mullets}

Arg. two lions ramp. combatant supporting a dexter hand couped at the wrist in chief three mullets gu. on the base in waves a salmon naiant ppr. O'Neale, Ireland.

Arg. two lions ramp. combatant supporting a sinister hand apaumy couped at the wrist in chief three mullets gu. in base a salmon naiant ppr. O'Nrill, Upper Clanaboys, Treland; Baronetcy 13 November 1643 ; extinct (?).

Sa. two lions ramp. supporting a sinister hand betw. three mullets arg. DonnelL, Ireland.

Sa. two lions respectant arg. supporting a sinister band gı. betw. three mullets of the second. DONNELI.

\section{Tressure}

Gu. two lions pass. within a double tressure arg. FELTON.

$\mathrm{Gu}$. two lions pass. within a dauble tressure flory counterflory arg. John Feston, $X$. William Feiton, Y, Felton, co. Gloucester.

Gu. two lions pass. guard. arg. within a double tressure flory counterflory of the second. Sr. John de Ferton; co. Gloucester, $V$.

Gu. two lions pass. arg. withm a double tressure flory counterflory or. M. John de Fetton, $S$.

2 OTTERS betw. or within....

Per pale arg. and sa. two otters enclosed betw. three 5 -foils in pale counterchanged. Horton, Kent.

\section{SQUIRRELS betw. or within....}

\section{Bordure}

Arg. two squirrels sejant addorsed gu. within a bordure sa. Samwell, Cornwall.

\section{Crosses}

Arg. two squirrels ramp. combatant gu. betw. eight crosses croslet three one three and one sa. Wood, $V$.

Arg. two squirrels sejant affrontant gu. betw. nine crosses croslet sa. Wood, $V *$.

2 WOLVES betw, or within....

\section{Bordure}

Arg. two wolves pass. sa. on a bordure gu. eight pair of lion's gambs in saltire or. Ayala.

Arg. two wolves pass. sa. within a bordure or fretty gu. Ayara, Spain.

Arg. two wolves (pass. $V^{*}$.) statant sa. on a bordure or eight saltires couped gu. John AYALA, Spain, $V$.

\section{4-Foils}

Per pale arg. and sa. two wolves pass, enclosed betw. three 4-foils in pale within a boldure counterchanged. HORDEN, Kent.

Per pale arg. and sa. two wolves pass. enclosed betw. three 4 -foils in pale counterchanged witl.in a bordure per pale gu. and or. Horden, Kent, $\boldsymbol{V}$.

\section{5-Foils}

Per pale arg. and sa. two wolves enclosed betw. three 5-foils in pale counterchanged within a bordure per pale gu. and or. Harding, Kent. HORDEN,
BEASTS, 2 DOGS betw, or within....

\section{Head}

and in chief....

Gu. two greyhnunds salient countersalient in sal. tire the dexter surmounted of the sinister arg. collared of the field betw. three fleurs-de-lis two and one in cbief a stag's head couped attired with ten tynes or. UDNEY, That Ilk.

\section{Horn}

Arg. two greybounds courant in pale sa. in chief a buglehorn of the last stringed gu. within a bojdure az. Scougalu, Edinburgh. And with the bordure wavy. Scougall, Scotland.

\section{LIONS betw, or within....}

and in chief....

Or two lions pass. betw. three crosses croslet fitcliy sa. a canton gu. for diff. Lowndes, Mordon, Surrey.

2 SHEEP betw. or within....

and in chief....

Quarterly az. and or in the first and fourth quar. ters a golden fleece in the second and third quarters a castle gu. betw. two flemrs-de-lis in fess of the first a chief erm. PLEwES or PLowes, granted, 20 October 1792, to John Plowes, Leeds, and to the family (of his greatuncle, Matthew Prowes) at Malaga in Spain, descended from Piewes, Masham, co. York.

\section{LIONS betw. or within....}

and in base....

\section{Crosses}

Per chev. arg. and purp. in chief two lions ramp. combatant sa. in base three crosses patty two and one of the first all within a bordure az. charged with eight fleurs-de-lis or. BLEDLow, London.

\section{Sword}

Az. two lions ramp. or supporting a tower arg. in base a scimitar poinel and hilt towards the sinister betw. two others towards the dexter ppr. impaling gu. on a bend or betw. three fleurs-de-lis arg. six pellets all within a bordure gold. GuYon, Richmond, Surrey, granted ....

\section{On 2 LIONS}

\section{Bendlets}

Sa. on two lions pass. in pale arg. three bendlets to each gu. Strangeways.

\section{Chevron}

Sa. on two lions ramp. combataut arg. as many chev. of the field. THLPENHam.

Fleur-de-lis

Gu. on two lions pass. arg. a fleur-de-lis at the shoulder of each sa. Mounsyer John Strange, $T$. Sa. on two lions pass. arg. crowned or a tleur-delis at the shoulder of each az. HeroviuL.

Sa. on two lions pass. arg. ducally crowned or a fleur-de-lis at the shoulder of each az. Herwille.

\section{Roundles}

Gu. on two lions pass. guard. arg. spots sa. MARE, co. Chester.

\section{On 2 CATS and in chief...}

Per fess gu. and az. on two cats pass. guard. arg. ogresses on a canton or a cross croslet fitchy sa. R. R. CATON, F.S.A., descended from CAton, Denham, Suffolk; 'Thorpe-Abbots, Norfolk; Binbrook, co. Lincoln, and Carr House, Howden, co. York; quartering Constable of Swaffham, co. Nolfolk; Bewley, and Good. hand, co. Iincoln; and Hawlismore or Hockmore, co. Nottingham. 


\section{BEASTS.}

\section{BADGERS}

Arg. tiree broclis statant az. BRоскноLе, $V$. Arg. three brocks ppr. BRocK.

Arg. three badgers sa. BrockHOLE or BrockoLe, Brockole, co. Lancaster.

\section{BATS}

Arg. three bats displ. sa. Backсомвe, co. Devon. Colyra, V. William Heiworth, Bishop of Lichfield, etc., 1420.47 .

Or three bats sa. BATE.

\section{BEARS}

Arg. three bears in pale sa. Lowis, $V^{*}$. Travers, $V^{*}$. Worcel, $V^{*}$.

Arg. three bears sa. Ditchfieid, Ditton.

Arg. three bears sa. muzzled or. Венгналr, $V *$. Herbottyl, $V *$.

Arg. three bears couchant sa. armed gu. Pushbrooke.

Arg. three bears pass. in pale sa. De Estrivers, Cumberland. Travers, en. York.

Arg. three bears pass. sa. BRockHole, $V^{*}$.

Arg. three bears pass. sa. armed gu. muzzled or. Berhasi, Kent.

Arg. three bears pass. sa. muzzled or. Barban. Bearcroft. Pichard Berhalgh, $X$, (Trevie?).

Arg. three bears statant in pale sa. Trivens. Lewes Worceli, $V$. And with a mullet in dexter chief for diff. Travers, London, 1633.4; Harl. MS. 1358 , fo. 31 b.

Arg. three bears statant sa. muzzled or. Berehas, Kent, $W$. Herbotyli, $V$.

Az. three bears pass. arg. Travers.

$\mathrm{Az}$. three bears (pass. $V^{*}$.) statant arg. muzzled gu. Traves, $V$.

Gn. three bears arg. Sire Richard de BanLing ham, N. Berlingham, Essex.

Or three bears in pale sa. Berami, $V^{*}$.

Or three bears pass. sa. Berham, Kent, 1730.

Or three bears pass. sa. muzzled gu. Barram, Kent.

Or three bears statant in pale sa. Beran, Kent, $V$.

Per fess indented arg. and sa. three bears muzzled counterchanged. QuYnBorow, Norfolls.

Per fess indented arg. and sa. three bears pasa. counterchanged. QuinBorovgh, Norfolk, 1716.

Per pale sa. and arg. three bears counterchanged. BERE.

Per pale sa. and arg. three bears (pass. $V^{*}$.) statant in pale countercbanged muzzled gu. BERE, $V$.

Per pale sa. and arg. three bears statant counterchanged muzzled gu. BERE, $V$.

Per pale sa. and az. three bear's counterchanged muzzled gu. Berais, $V^{*}$.

Sa. three dancing bears or. BAFFORD. BASFORD, co. Nottingham.

\section{BOARS}

Arg. three boars az. ELwike, $V^{*}$.

Arg. three boars pass. az. ELwick, co. York, and Lancaster. ELWYKE.

Arg. three boars statant az. Elwrie, $V$.

Arg. three boars gu. Heniz.

Arg. three boars sa. Swynne, $V^{*}$.

Arg. three boars barwise sa. Brothall.

Arg. three boars pass. in pale sa. Burler, co. Somerset. Newbold, co. York. Sumpten.

Arg. three boars pass. sa. armed or. SwYNe.

Arg. three boars (? bears) pass. sa. muzzled or.

Trevie, Trevi, Camelford, Cornwall.

Arg. three boars statant in pale sa. Butreler, $V$.

Arg. three boars statant sa. Swynno, $V$.
BEASTS.

3 BOARS cont.

Arg. three boars statant with bones in their mouths sa. GrizzLenurst.

Az, three boars in pale arg. Bacon, $V^{*}$.

Az. three boars arg. Goughe, $V^{*}$.

Az. three boars arg. ears tusks and feet or. Goche Gooche or Goodge, Alvingham, co. Lincoln.

Az. three boars pass. in pale arg. Philip Phichdan.

Az. three boars pass. arg. BACON, co. Hants. Goche, co. Lincoln. Googe. Gouge, Wales. Gough, Wales.

Az. three boars statant in pale arg. Bacon, $V$.

Az. three boars statant arg. Mathew GovgHe, $V$.

Az. three boars pass. or. ABrell. Bacon, Norfolk. M'Geonoe, Scotland.

Az. three boars pass. or a fleur-de-lis in the centre for diff, Bacon, Harlston, Norfolk.

Az. three boars statant or. ABRAHALL, London, 1633-4, Harl. MIS. 1358, fo. 18 b.

Az. three bears in pale sa. Butteler, $V^{*}$.

Gu. three boars pass. arg. Coates.

Or three boars (? urchins) statant az. Heury de Herice, $A$.

Or three boars pass. in pale sa. Heris.

Or three boars pass sa. Swine.

Sa. three hoars arg. Robert SwYNenowe, $X$.

Sa. three boars pass. arg. armed or. Winsington, co. Gloucester.

Sa. three boars pass, or. Swinhor, Calcutta.

\section{CAMELS}

Or three camels sa. Cadielis, $V^{*}$.

Or three camels statant sa. Camells, $V$.

\section{CATS}

Arg. three cats pass. in pale sa. KEAT or Keate, Hoo and Paul's Walden, co. Hertford; Baronetcy 12 June 1660 , extinct 6 March 1757. Keate, Woodford, Essex, and Grovehurst, Kent. Keats, co. Berks and co. Gloucester. Kete, St. Columb, Cornwall.

Arg. three cats pass. guard. in pale sa. CaTT, $V$.

Arg. three cats statant guard. in pale sa. KEATE or Kete, London, 1633.4, impaling Armstrong, Harl. MS. 1358 , fo. 16 b.

Erm. three cats in pale az. ADans, Lord Mayor of London 1648; Baronetcy 13 June 1660; extinct 12 April 1770. ADAns, Charwelton, co. Northampton, 1360 ; the heiress m. Marriott. ADAMs, Welton, co. Northampton, a branch of Adains of Charwelton.

Erm. three cats pass. guard. in pale az. Roger Anans alias TASKER, London, 1584 ; quartering arg. three bars and in chief as many lozenges az., with or a fess betw. three lions ramp. guard sa., and az. a chevron arg. betw. three 3 -foils slipped or; altered 1590, Harl. MS. 1359 , fo. $105 \mathrm{~b}$.

Erm. three cats pass, guard. az. TibBetr.

Erm. three cats pass. guard. in pale az. Roger ADAMS alias TASKER, London, 1590; granted by Cooke, $W$; the cats two and one proper, $V^{*}$.

Erm. three cats statant guard. in pale az. a crescent for diff. ADAns, London, 1633-4, Harl. MS. 1358, fo. $26 \mathrm{~b}$.

Erm. three cats passant in pale sa. ADAMS.

Per fess embattled gu. and sa. three cats pass. arg. Lijppingcote, co. Devon.

Per fess nebuly gu. and sa. three cats pass. arg. Luppingcote, Wybbery, co. Devon.

Sa. three cats arg. LrNCH, Kent. 
BEASTS.

3 CATS cont.

Sa. three cats pass. in pale arg. Schrves, Mureton, Scotland.

Sa. three civet cats pass. in pale arg. Seeves, Murton, Kimbach, and Kilwhiss, Scotland.

Sa. three cats pass. in pale arg. (? spotted .....) ShIVEz, Muirtonn, Scotland; quartering arg. on a cross moline sa. a mullet of the field.

Sa. three cats pass. guard. arg. Jobn CATRIK or Keteriche, Bishop of St. Javid's 1414; Lich. field, etc., 1415: Exeter, 1419.20.

Sa. three cats statant (pass. $F^{*}$.) guard. arg. collared and belled or. CовттоN, Catton, $V$.

Vert three cats pass. arg. Gibbes, Parrott, co. Dorset.

\section{DEER}

Arg. three bucks comrant gu, attired or. WhaLLEY, $V^{*}$.

Arg. three roebucks in full course gu. RoE, Scotland.

Arg. three stags lodged gu. Jor.LY, London.

Arg. three harts pass. gu. attired or. WHALIEY, co. Lancaster; and Sussex.

Arg. three bucks (not trippant but) passant (in grant 20 May 1479.80, Harl. MS. 1359 , fo. 74 b; and repeated when an inpalement was grauted 1505,) reguard. gu. attired and unguled (not sa. but) or. Company of Leathersellers, London.

Arg. three harts springing gu. attired or. Whaliey, Sussex, $V$.

Arg. three roebucks ppr. attired or. Rone, Longford, co. Salop.

Arg. three bucks trippant ppr. Browne, Middlesex. Rone, Samborne Hall, Essex.

Arg. three stags trippant ppr. RoANE.

Arg. three (bucks $V^{*}$.) roebucks courant (springing $V^{*}$.) sa. in chief a crescent for diff. Sir John Rogers, Comptroller of the Household temp. Elizabeth, $\mathrm{V}$.

Az. three bucks pass. arg. Green, Northumberland.

Az. three stags trippant arg. Jesus' College, Oxford, founded 1571, being the arms of Hugh Price, LL.I., a chief contributor to the building.

Az. three bucks or. Goughton. Green, $V^{*}$.

Az. three liarts or. HAMOND,

Az. three buclss cotmant or. Green, Boys' Hall, Essex, and co. Oxford.

Az. three (bucks $V^{*}$.) harts lodged or. ApPuLBY, $V$. APULBY, $V^{*}$.

Az. three hucks pass. or. Grees, co. Northampton. And with a mullet of the last in chief for diff. Sir William GreEN, co. Oxford; confirmed February 1605; Harl. NIS. 6095, fo. 22.

Az. three harts sejant or. ApLenr.

Az. three bucks statant or. M. Thomas Green, $S$.

Az. three stags statant or a slipped 3.foil arg. in chief for diff. John Green, Judge of the Sheriff's' Court, London, 1633-4, Harl. MS. 1358 , fo. 43 .

Az. three bucks trippant or. GREen, Boys' Hall, Essex; and co. Oxford. Sir Thomas Grees, co. Northampton, $V$. John Grees, in Horshill Church, Surrey, 165l. Thomas GreEN, Bishop of Norwich 1721; Ely, 1723-38. Greene, Kilmanahan Castle, Clonmel. Greene, Killranalagh, co. Wicklow. Tregagie.

Az. three bucks trippant or a crescent for diff. Green, Barnet, co. Hertford; and Bristol.
BEASTS.

3 DEER cont.

Az. three stags trippant or. Grees, Buckden. Green, co. York. John Grees, Bishop of Liu coln 1761-79. Greene, Lichfield; quarternng Webb aud Jevon.

Az. three bucks pass.ppr. Gneen, co. Northampton. Erm. three stags (statant only, Harl. MS. 12 143 ) at gaze gu. John Blytri, Bisbop of Salisbury 1493-9.

Erm three (busks $V^{*}$.) roebucks stataut gir. attired or. Thomas Brythe, Querreby and Barnby, co. York, 1566, W.

Erm three bucks trippant gu. attired or. BLrthe. Erm. three roebucks trippant ppr. BLythe, Burchet, co. Derby. BLythe, Norton, co. Derby. William Blythe, father of John Blythe, Bishop of Salisbury, 1493.9; and of Geffrey BLyThe, Bislsop of Lichfield and Coventry 1503.31, had a grant of these arms temp. Hen. VII.

Gu. three bucks arg. Chener or Chever.

Gu. three bucks pass, arg. Gonton Gorton Gouton or GunTon.

Gu. three bucks or. GonTon Gorton Gouton or Gunton, Peterborough, co. Northampton.

Gu. three bucks pass. or. GONTON or GoUgHTON.

Gu. three loebuclis pass. or. Rut THERFAM.

Gu. three stags trippant or. HINDE, Essex; with an inescucheon for Thaver.

Or three bucks pass. az. WATts.

Or three bucks lodged ppr. Br,OoD.

Or three stags trippant ppr. Rogers, as quartered by Harrison.

Or three stags trippant sa. that in base standing under a tree ppr. Eastwood, Castletown Castle, co. Louth ; originally from co. Nottingham.

Per chev, engr. arg. and sa. three hinds tripjant counterchanged. Flow ERdue.

Per chev. az. and gu. three bncks or. Hart, $V^{*}$. Per chev. az. and gu. three bucks in full course or. Green.

Per chev. az. and gu. three harts statant or. Sir Percivall $H_{A R}$, lient, $V$.

Per cluev. az. and gu. three bucks trippant or. Dunscombe.

Per cliev. az. and gu. three harts trippant or. Hart, Westmill, co. Hereford, temp. Edward III ; London; Ware, co. Hertford; and (by marriage with Elizaheth Peche) Lullingrstone Castle, Kent; the heiress m. Bluet and Dyke.

Per chev. gu. and az, three bucks or. HarT.

Per chev. gu. and az. three bucks in full course or. Dunscosibe, London.

Per chev. gu. and az. three harts trippant or. Harte, Kent, $W$.

Per chev. gu. and sa. three hinds or. Brown alias Weare, $V^{*}$.

Per chev. gu. and sa. three hinds pass. or a crescent for diff. Weare alias Brown, Denford, co. Berks; and Boxton, co. Wilts.

Per chev. gu. and sa. three hinds statant or Bnown alias WEARe, Marlborough, co. Wilts, $V$.

Per chev. or aud gu. three bucks counterchanged. Caulx.

Per pale az. and sa. three bucks trippant or. GREENE. Mitcham,Surrey; granted Januaryl lo63. Per pale gu. and az. three bucks trippant or. Sir John Suckling; descended from Suckling, Wooton, Norfolk, the heiress m. Fox.

Sa. three binds counterpass. arg. CotTrngham.

Sa. three bucks pass. or. Rosseley.

Sa. three bucks trippant or. SwIFT, Blandford, co. Dorset. 
BEASTS.

3 DEER cont.

Vert three bucks arg. attired or. TroLlop, $V^{*}$.

Vert three stags courant in pale arg. RAE, Esk Grove, Mid Lothian ; Baronetcy 27 June 1804.

Vert three liarts courant (another salient) arg. Andrew Troliope, $V$.

Vert three (bucks $T^{*}$.) barts lodged arg. Anderson, Newcastle, $1615, \mathrm{~W}$.

Vert three stags lodged argent attired or and langued ( $\mathrm{gu}$. or) gold. ANDERSon, removed from Alnewick to Newcastle, 1615; Vincent's Collect. in College of Arms, 149, fo. 41 .

Vert three bucks pass. arg. Troup, that Ilk.

Vert three bucks pass. arg. armed or. Trollop, City of Durham; confirmed $27 \mathrm{July} 1639$; quartering Harpins aud Hawicks with a cres. cent gu. for diff.

Vert three bucks pass. arg. attired or a crescent for diff. Trollop, Thornley, co. Durham.

Vert three harts salient (another courant) arg. Andrew Trollop, $V$.

Vert three roebuclis trippant arg. attired or. Scotr, Barnes Hall, Ecclesfield, co. York.

Vert three (roebucks statant, Harl. MS. 12443) stags trippant arg. attired or. Thomas Scct alias RotherHam, Bishop of Rochester, 1468; Lincoln, 1471; Archbishop of Yorls 1480.15()0, Cardinal S. Cecilia, and Chancellor of Englaud.

Vert three bucks at gaze or. Rotheran, $V^{*}$.

Vert three roebucks or. RotherhaM, Essex.

Vert three bucks in full course or. Pothenham, co. Redford.

Vert three harts in full course or. Trollop, co. Northumberland.

Vert three bucks lodged or. ANDERson, Coxlodge, co. Northumberland; descended through Anderson, Jesmond House (of which the elder branch settled at least three-quarters of a century ago in St. Petersburgh), from Anderson, North Shields, afterwards of Newcastle-upon'Tyne.

Vert three roebucks statant or. Sir Thomas Rotherai, $V$.

Vert three bucks statant at gaze or. Green, $Z$, 490 .

Vert three bucks trippant or. Rotheram, Dronfield, co. Derby ; co. Bedford ; Essex ; aud co. Somerset. Thomas Green, Bishop of Norwich 1721; Ely 1723-38. Trollor.

Vert three bucks trippant or over all a bend sinister arg. Rotherham, Farley, co. Bedford.

Vert three stags trippant ppr. Scotr, Aldborough, East Riding, co. York.

\section{DOGS}

Sa. three demi-greybounds courant couped and collared in pale dexter and as many pierced mullets in pale sinister arg. Goodran, $V$.

Arg. three talbots pass. az. HAMLEx, Trebletbick, temp. Henry VII, and S. Columb; descended from HaMLEy, Halwyn, co. Cornwall, extinct 1427, the heiress m. Champernowne. Hanley.

Arg. three greybounds gu. Sire William MaUleverer, $N$.

Arg. three greyhounds gu. collared sa. WHELPDALE or. Whelpedale.

Arg. three greyhounds courant in pale gu. Martyn, Kent.

Arg. three greyhounds courant in pale gu. collared (of the field? or) az. WHELPDALE, Skirsgill and Penrith, co. Cumberland. Roger WhelpDale, Bishop of Carlisle, 1419-23.
BEASTS. 38 DOGS cont.

Arg.three greyhounds courant in pale gu. collared or. Whelpiale, $V$.

Arg. three greyhounds pass. gu. WhELPdale.

Arg. three greyhounds .... sa. collared arg. Arglwydd y Bryn.

Arg. three greyhouuds in pale sa. collared or. More, co. Lancaster.

Arg. three greyhounds sa. collared or. John Manchell, $X$.

Arg. three greyhounds couchant sa. IORwerth SA1s.

Arg. three greyhounds courant in pale sa. Brisco, Crofton, co. Cumberland, Baronetcy $11 \mathrm{July}$ 1782. Brisco, Coghurst, Sussex; a branch of Brisco, Crofton Hall. Adam Brisco, Yarwell, co. Northampton, $W$. Cooper. Scourfield, Brecon. And with a martlet in chief for diff. Brisco, co. Hertford, $W$.

Arg. three greyhounds courant in pale sa. collared arg. Wigmore, in Ingham Church, Norfolk, 1315. Gough, Sep. Monts., 1, ii, 121.

Arg. three greyhounds courant in pale sa. collared or. Maliverer, Bemesley, $V$. Moore. More, More Hall and Bank Hall, co. Lancaster; Ba. ronetcy 22 November 1675 , extinct $21 \mathrm{May}$ 1810 ; the herress m., 1795, Browning. Sir Thomas Wignore, $V$.

Arg. three greyhounds courant sa. OGLE.

$\Lambda \mathrm{rg}$. semy of crosses patty fitchy and three greyhounds conrant sa. Smith, Stratford on-Avon, co. Warwick, 1626 .

Arg. three talbots pass. in pale sa. Martyn, Kent.

Arg. three hounds (another, talbots) pass. sa. Chantrela, co. Devon.

Arg. three talbots pass. sa. Chantreic, $V$.* Chaunterfil.

Arg. three greyhounds pass. sa. collared gu. Whelpdale or Whelpedale.

Arg. three greyhoutids pass. sa. collared or. Wigmore, Stamford, co. Lincoln.

Arg. three tulbots statant sa. William Chantreli, Brampton, co. Devon, $V$.

Az. three bloodhounds arg. RAgon.

Az. three greyhounds arg. LANHoRgy, Cornwall.

Az. three greyhounds in full course arg. Barneyes.

Az. three greyhounds arg. pursuing a stag in full course all bendways and at random. YARDLEY or YARDELEY.

Az. three greyhounds courant in pale arg. collared gu. Berington, co. Stafford.

Az. three greyhounds courant in pale arg. collared or. BARNEIS, $V$.

Az. three greyhounds courant arg. ducally gorged or. Sinderton, co. Cambridge.

Az. three greyhounds pass. arg. Lenhorgy, Cornwall.

Az. three greyhounds pass. arg. collared or. BARNEYS.

Az. three talbots or. Pagon.

Az. three talbots pass. or. PEake or PEke, Sandwich, Keut.

Az. three taliots statant or. Edward PEke, Heldchurch Gate, Kent; granted by Cooke, $W$.

Barry of three sa. and erm. as nany talbots pass. or over all a sinister bendlet .... ALLENson.

Erm. three greyhounds courant in pale gu. DEACH, $V$.*

Erm. three talbots pass. sa. Borley, Essex.

Gu. three hounds courant in pale arg. Ps. de KenetTs, $F$. 


\section{BEASTS.}

\section{DOGS cont.}

$\mathrm{Gu}$. three greyhounds cuurant in pale arg. Gerwoys, $V$. William Marevereir, $F$. Joan Mauleverer, $E$. M. William Mauleverere, $S$.

$\mathrm{Gu}$. three greyhounds in full course arg. Gervis.

Gu. three greyhounds courant in pale arg. collared az. Hakding, Houldingfield, co. Durham. Sir John Maleverer, Alderton, $V$. Mauliverer, V.*

$\mathrm{Gu}$. three greyhounds courant in pale arg. collared of the field. Mauleverer, Barovetcy 4 August 1641 , extinct March 1713.

Gu. three greyhounds courant in pale arg. collared or. Harding, co. Dorset. JohNson, London, $W$. M. Olyver Mauleverere, $S$. Mauleverer, Allerton-Mauleverer, co. York; Baronetcy $4 \mathrm{Au}$ gust 1641 , extinct March 1713.

Gu. three greyhounds courant arg. collared sa. studded or. QuIXIsey.

Gu. three hounds pass. arg. RAGoN or RAGAN.

Gu. three greyhounds pass, arg. Gervis. John Mauleverer, $Y$.

Gu. three talbots (pass. $V^{*}$.) statant arg. RAGoN, $V$.

Gu. three greyhounds courant in pale or. HARDING.

Gu. three greyhounds in fnll course in pale or. Gerveis.

$\mathrm{Gu}$. three greyhounds courant in pale or collared az. HARDING, Coaley, co. Gloucester; and Rockfields, co. Monmouth. John Harding, temp. Heary V, $V$. HaRding, Houldingfield, co. Durbam.

Gu. three greyhounds pass. or. Gervas.

Or three talbots pass, az. TaLBoT.

Or three hounds pass. gu. Champayne, Kent.

Or three greyhounds passant sa. Alles, Hoyland, co. York.

Per chev. or and gu. three greyhounds in full course counterchanged. HAST, Wyndham, Norfolk.

Per chev. or and sa. three greyhounds courant counterchanged. Prentice, Northampton, 1716. The greyhounds collared .... Prentys, Wygenhall and Burston, Norfolk.

Per fess embattled gu. and sa. three talbots stataut guard. arg. LIPPINCOTT or LUPPINCOTT, Wibbery, Alverdiscot, co. Devon; extinct 1779. LippincotT, Bristol; Baronetcy 7 September 1778, extınct 23 August 1829; quarternng sa. a chev, arg. betw. three mermaids ppr. crined and combed or.

Per pale arg. and vert three greyhounds counterchanged. Thomlinson, Newcastle-on-Tyne.

Per pale gu. and az. three hounds in full cry arg. Tunner, Lord Mayor of London, 1769, and Tablehurst, Sussex.

Per pale gu. and az. three talbots pass. arg. Torner, Reading, co. Berkshire. 'Torner, Tableheart, Sussex; confirmed 27 June 1579. Turner, Sussex, $W$.

Per pale or and arg. three hounds pass. gu. DANDEZEY.

Per pale vert. and arg. three greyhounds courant iu pale counterchanged collared or. TomLin. son, Birdford, co. York.

Sa. three greyhounds .... arg. Gwion BENARw.

Sa. three greyhounds .... in pale arg. collared gu. MaLyveler, Wodersome, co. York.

Sa. three greybounds courant in pale arg. Langworthy, Bath. Maleverer, Wedersun, $V$. Mauiliverer, $V$.*
BEASTS.

3 DOGS cont.

Sa. three greyhounds courant in pale arg. collared gu. WIGMORE, Norfolk; granted 1586.

Sa. three houuds courant arg. collared gu. VAUGHAN, Wigmore, co. Hereford.

Sa. three greyhounds courant arg. collared gu. Matuory, Wooderson, co. York.

Sa. three greyhounds courant in pale arg. collared or. Machell, Penny Bridge, co. Lancaster; a younger brancli of MachelL, MaUchaEl or Mauchel, Crakenthorpe Hall, co. Westmoreland; and Beverles, co. York. Mauleverer, Allerton-Mauleverer, co. York; Baronetcy 4 August 1641; extinet March 1713. Mauleverer, Arncliffe, co. York; the co-heirs $m$. Lindsey and Gowan. Micheld, $V *$. Mychell, co. Wilts, $W$. Sa. three greyhounds in full course arg. collared or. BenYngton.

Sa. three hounds pass. arg. Bunton. Horner, Coleford, co. Somerset; granted 1584, Harl. MS. 1359, fo. 119.

Sa. three greyhounds pass. arg. Burton.

Sa. three talbots pass. arg. Sir John Horner, Coleford, co. Somerset; granted by Cooke, $W$.

Sa. three greyhounds pass, arg. collared compony or and sa. Robert Mauleverer, $Y$.

Sa. three greyhounds courant or. Bunton.

Vert three talbots pass. arg. HuL, Lewisham, Kent.

\section{FOXES}

Arg. three foxes (courant $V^{*}$.) pass. in pale gu. Tregoos, $V$.

Arg. three foxes pass. gu. Tregos, Cornwall.

Arg. three foxes courant sa. Tregoze, Cornwall. 3 GOATS

Arg. three goats sa. Muli.ING, Cornwall.

Arg. three goats salient sa. APUlstone or Apulton, co. Lancaster.

Az. three goats arg. attired or. HanLEY, co. Devon, and Cornwall.

Az. three goats couchant arg. attired or. HaNBY. HawLeY.

Az. three goats (pass. $V^{*}$.) statant arg. HaNLEY, Cornwall, $V$.

Gu. three goats pass. arg. Gotham, $V^{*}$.

Gu. three goats pass, arg. attired or. Mallyng, Cornwall.

Gu. three goats pass. arg. attired and unguled or. STAMFIELD, Newmills, Scotland.

$\mathrm{Gu}$. three goats salient arg. THarrold.

Gu. three goats statant arg. Richard Gотнам, $V$.

Per chev. sa. and arg. three goats pass, counterchanged. Crosby.

Per fess enbattled arg. and az. three goats pass. counterchanged attired or. $M_{A N}$, Lancashire.

Per fe'ss embattled arg. and gu. three goats pass. counterchanged. Mas, Bullingbrooke, co. Lin. coln.

Per fess embattled gu. and arg. three goats pass. counterchanged. GOATHAM.

Sa. three goats courant in pale arg. MaLLyN, Cornwall, $V$.

Sa. three goats pass, in pale arg. Muliring or Mullinge, Thiugden, co. Northampton, and co. Northumberland.

Sa. three goats pass, arg. HANMer, Elweny Maptis, co. Salop. DYer, $V^{*}$. Gateford. STANSFIELd, Esholt Hall, co. York; quartering Crompton and Rookes.

Sa. three goats pass. arg. armed or. GAYTFoRd. 


\section{BEASTS.}

3 GOATS cont.

Sa. three goats pass. arg. attired or. Dyen, Aldebury, co. Hertford; and Stoughtolı, co. Huntingdon; granted 1575 . Holloway. TownLEY, co. Lincoln.

Sa. three goats ramp. arg. GatFoed, $V^{*}$.

Sa. three goats salient arg. Garford. Gatesford. GAYTFORD, $V$. THoRoLd, Marston, co. Lincoln, Baronetey 24 August 1642. Thorold, The Hangh, co. Lincoln; Baronetcy 14 June 1644, extinet 30 November 1706 . THonoLd, Harm. ston, co. Lincoln, Lord Mayor of London 1720; Baronetcy 9 September 1709 , extinct 2 January 1;37-8. Thorold, Harmston, co. Lincoln; Baronetcy 24 March 1740-41, extinct August 1764. Thomas Thorold, London, 1633-4; quartering Hongh, Marston, and Berehaugh, Harl. MS. 1358, to. 87 b. THoros, Chester. ton, co. Cambridge.

Sa. three goats salient arg. attired or. THonoLD, Marston, co. Lincoln; granted 1574.

Sa. three goats statant arg. Sir James Drer, $V$.

Sa. three goats statant (pass. $V^{*}$.) arg. collared and belled or. Stansfield, Stansfield, co. York, $V$.

Sa. tbree goats trippant arg. STANsFeld, Stansfield, co. York; and its branch, Stansfeld, Bur. ley, co. York, quartering Wolrich.

Vert three goats pass. arg. STANHope.

Vert three goats pass. arg. armed or. STANSFIELD, Lewes, Sussex; confirmed by Segar.

Vert three goats pass. arg. two and one attired or. Stanfield, The Cliff, Lewes, Sussex.

Vert three goats pass. arg. horns tipped sa. STANFORD.

Vert three goats pass. in pale ppr. LLoyd, Clockfaen, co. Montgomery.

Vert three goats trippant arg. STANSFIELD, Esholt, co. York, quartering Crompton.

\section{HARES.}

Arg. three conies (another current) az. ARRowOOD or ARwood, co. Lancaster.

Arg. three (conies, $V^{*}$ ) hares current in pale az. ARWARD. ARWOOD, $V$.

Arg. three conies gu. (The old bearing of) GRAZEBROOK originally de GRESBROKE, and Greysbroke, Greysbrooke Hall, Shenstone, co. Stafford, now of Audnam, Stourbridge, co. Staf ford.

Arg. three hares playing bagpipes gu. This coat has been assigned to Hopwell, co. Devon. Fitz-Ercald, co. Derby ; extinct temp. Richard I ; the co-heirs m. Longford and Sacheverell.

Arg. three conies sa. Srroud, 1730.

Arg. three conies pass. sa. Conyston.

Arg. three conies sejant sa. Strode, co. Somerset, 1716.

Az. three hares in pale arg. Leverington.

Az. three hares arg. Leventon.

Az. three leverets courant in pale arg LEVERINGTON, $V$.

Gu. three hares in pale arg. Leverington.

Gu. three conies sejaut arg. Conrngsby, Hamp ton Court, co. Hereford; co. Worcester; and co. Salop.

Or three conies sa. Coninghan. Conyston.

Or three conies couchant sa. Coningeston, $V$. Coningston, $V$.*

Sa. three conies courant arg. Conycliff, $V$. Conylesh, co. Lancaster. Cunliff, Chisle. hurst, Kent. Conliffe, Liverpool, co. Lan. caster; Saighton, co. Chester; and Acton, co. Denbigh, Baronetcy 26 March 1759.
BEASTS.

3 HARES cont.

Sa. three conies courant or. CunlfF, Chisle. hurst, co. Kent.

Vert three hares courant ppr. WITTs, London; granted 1 February 1769.

\section{HORSES}

Arg. three horses ramp. sa. HICKERINGILL, Lawford, Essex.

Gu. three horses courant arg. FrYe, Yartye, temp. Edward IV, and Deer Parkwood and Dulcis, co. Devon. Kerchinale, Parwell, co. Northampton.

Gu. three colts courant arg. a fleur-de-lis or in the centre for diff. Fry.

Per pale wavy or and gu. three horses courant arg. Fray or Frye, Surrey, and Antigua.

Per pale vert and gu. three horses courant arg. bridled or. FRY.

Vert three horses arg. bridled or a fleur.de-lis of the last in the centre for diff. FrIE.

Vert three horses courant in pale arg. Frr.

Vert three horses courant in pale arg. bridled or. FRr, Brompton.

Vert three horses courant arg. bridled or. Frec, V. Fry, Exeter, co. Devon; and Tarrant, Gunfold, Dorset.

\section{LEOPARDS}

Some of these are probably Lions.

Arg. three leopards in chief gu. YoNGE.

Arg. three leopards gu. armed and langued or. FAWCONBRIDGE.

Az, three leopards pass. arg. Barne, Iondou. Az. three leopards pass. or. BARNe, London.

Az. three leopards segreant or. Hetherfield.

Gu. three leopards pass.arg. HaRriard, co. Hants. Gu. three leopards pass. or. O'BRIEN, J reland. Gu. three leopards ramp. or. Fitz Herbert.

$\mathrm{Gu}$. three leopards pass. guard. per pale or and arg. O'Brien, Shotgrove, Essex.

Per fess embattled gu. and sa. three leopards pass. arg. Lippincott.

Per fess embattled gu, and sa. three leopards pass. arg. spotted of the second. LuPPINGCote, co. Devon.

Per pale arg. and sa. three leopards in pale coun. terchanged. AsHILL.

Sa. three leopards ramp. arg. spotted of the field. LynCH, Groves, Kent: and Rixton Hall, co. Lancaster.

Sa. three leopards in pale erm. WaLker, co. Cambridge.

Sa. three leopards pass. in pale or a crescent for diff. Bourchier, Essex.

Sa. three leopards pass. in pale or spotted of the field. Bovchien, Little Stainbridge, Essex.

Sa. three leopards in pale or spotted of the first. Bourchier, 1610.

\section{LIONS}

Arg. three demi-lions ramp. gil. Bene. Benet, co. Berks. Esturmy. Fisher. Henri le Merville, E, Harl. MS. 6137 ; but le Sturmi (and in the margin) seript le Mervin, sed dubro, $E$, Harl. MS. 658\%. Starmin, $V^{*}$. Stirny, $Z, 488$. Stormyn, co. Somerset. Sturuy, co. Wilts, 1716. Sturiyn, $V$.

Arg. three demi-lions ramp. couped gu. KaHL.

Arg. three lions gut issuant out of two bars wavy az. Mullikine, Scotland.

Arg. three demi-lions gu. issuant out of water ppr. Mulliwen, Scotland. 


\section{BEASTS.}

\section{LIONS cont.}

Az. three demi-lions ramp. arg. Newian.

Az. (but ? sa.) three demi-lions ramp. erased erminois. Grees, Cawthorne, and Thunder. cliffe Grange, Sheffield; granted 6 October 1612.

Az. three demi-lions pass. guard. or. HamoND, Kent.

Az. three demi-lions ramp. or. Harrison, Acaster, Caton, and Flaxby, co. York. Harrison, Greenbank, Ambleside, co. Westmoreland.

Az. three demi-lions ramp. erased or. Thomas HARRISON, Mayor of York; granted 2 August 1592.

Az. three demi-lions ramp. erased or each crowned with an eastern erown arg. Harrison, Hendon, Middlesex; and Westmuster: Bluemantle Parsusvant of Arms, 1767; Windsor Herald, 1774; Norroy King of Arms, 178t; and Clarenceux King of Arms, 1803. Rogers-Harnison, Hendon, Middlesex, quartering Pogers. FogersHarrison, Blanche Lyon Pursuivant of Arms Fxtraordinary, and Bluemantle Pursuivant of Arms, 1831; quartering Rogers, with over all in the centre chuef point on an inescucheon gu. a lion ramp. arg. in allusion to the office.

Gu. three demi-lions pass. in pale arg. crowned or. Bennet.

Gu. three demi-lions ramp. arg. with a mullet or in the centre for diff. BENETT, Norton Bavant, Westbury, and Pyt House, co. Wilts.

Gu. three demi-lions ramp. couped arg. with a bezant in the centre for diff. Sir Thomas BenNet, Lord Mayor of London 1603, Harl. MS. 1349 ; but BennetT, 6095, fo. 23 b.

Gu. three demi-lions couped or. PEPPEn, Ireland. Gu. three demi-lions pass. or. Esche or Eschey. Hamiond, Cheam, Surrey.

Gu. three demi-lions pass, guard. or. $\mathrm{H}_{\mathrm{ACH}}$, co. Devon.

Or three demi-lions pass. guard. gu. KNolles. co. Hants. Knowles, Dowaton and Winches. ter, co. Hants; Visitation 1634.

Or three demi-lions ramp. ga. Bennet, co. Devon.

Per pale indented arg. and vert three demi-lions those in chief the dexter gu. the sinister or and that in base per pale indented gu. and or. Hawkins-Whitshed, Killincarrick, co. Wicklow, and Jobstown, co. Mayo, Baronetey $16 \mathrm{May}$ 1834 ; quartering Hawlins. WhItSheD, Dubliu; certified 7 July 1705.

Per pale az. and or thiee demi-lions pass. guard. in pale arg. Harrond, Kent.

Per pale az. and sa. three demi.lions ramp. erm. each gorged with a collar gemelly gu. Harrison, Ripley, Surrey; granted 31 March 1819.

Per pale gu. and az. three demi-lions ramp. arg. ducally crowned or. WIBERd, Essex.

Per pale gu. and az. three demi-lions pass. or. LENNARD.

Per pale gu. and az. three demi-lions pass.guard. or. HAmond, Windingham, co. Cambridge; co. Hertford; Tuddington, Middlesex; and co. York.

Per pale or and az. three demi-lions pass. counterchanged. Hasnoro, co. Buckingham; and Kent.

Sa. three demi-lions ramp. couped arg. langued gu. Newman, Mamhcad, co. Devon, Baronetcy 17 March $18: 36$.

\section{BEASTS. 3 LIONS cont.}

Sa. three demi.lions ramp. erased without tails (but with tails Harl. MS. 1359, fo. 13, confirmed 1 July 1588) arg. Randall, co. Berks; and Kentesbury, co. Devon, 1583, quartering Woolfe ; the heiress m. Jones.

Sa. three demi-lions ramp. erm. Newman, Crediton, co. Devon.

Sa. (but ? az.) three demi-lions ramp. erased ermuois. Gresne, Cawthorne, and Thundercliffe, Grange, co. York, granted 1012.

.... three lions pass .... Wulstan de Bransfond, Bishop of Wol'cester 1339-49.

.... three lions pass. in pale arg. over all on a bend sa. three aunulets or. Parlar, Westminster.

.... three lions ramp. .... over all a bend of lozenges .... Nicholas Prk's Seal.

.... three lions ramp. guard .... Philip de VACHE's Seal, 1382.

Arg. three lions .... az. over all a bend gu. Elley, co. Hants.

Arg. three lions .... az. crowned or. Josceus de Dinant, Dugdale, Bar. i, 443; Joos of Ludlow ; Leland, Coll. i, 232.

Arg. three lions pass, in pale az. Geffrey de Colvile, $A$, but Camvile, $A$, Harl. MS. 6137.

Arg. three lions pass. guard. in pale az. GREGG. Arg. three lions ramp. az. Mildmar. Mmdnay, Earl of Fitz-Walter, Viscount Harwich, creation 14 May 1730, extinct 1756; Baron Fitz. Walter, creation 10 February 1669 . Mildyay, Moulsham, Essex; Baronetcies 29 June 1611, extinct 13 February 1625-6 ; 5 February 1765, extinct 8 August 1i71. St. John Mildmay, Farley, Dogmersfield Park, and Shawford, co. Hants; Hazelgrove, co. Somerset; Moulsbam Hall, and Marks, Essex; Baronetcy 9 October 1772. Sir .... TALBotr, Bashall, co. Lancas. ter, $R$.

Arg. three lions ramp. az. armed and langned gu. St. John-Mildiay, Moulsham Hall, Essex, quartering St. John; Baronetcy 9 October 1772. Mildmay, The Graces, Essex. Mildmay, Danbury, Essex; and Apthorp, co. Northampton.

Arg, three lions pass. in pale gu. Desnay, co. Lincoln, $V$. Disney, co. Lincoln. Disni, un Norton Disney Charch, co. Lincoln. M. WilJiam Dysney, $S$. Faconberge. Fawconeridge, $V$ *. FaWconbrige, $W$. Kinerby. Kynnerby, $V$. T. Littlebury, $V$. St. Ive. Johan de ST. Yve, $F$.

Arg. three lions pass. gu. Desnay, $V^{*}$. Honsire de Dilny, $Y$. Fawconbridge. Humfines. Gloucester. Kynerby, $V$ *

Arg. three lions pass. gu. armed az. Dynsey.

Arg. three lions pass. tails coward in pale gu. WALLEYS Ol WALLIS.

Arg. goutty de sang three lions pass. gu. crowned or. FAYRFORD.

Arg. goutty de sang three lions pass. tails coward gu. crowned or. FAYrFond.

Arg. three lions pass. guard. in chief gu.x IONGE.

Arg. three lions pass. guard. in pale gu. Brograve, Hamels, co. Hertford; Baronetey $18 \mathrm{March} 1662$; extiuct 8 June 1707 ; co. Lan. caster; and London. Brograve Burgraye or Boroughgrave, Nolfolk, and co. Warwick. Brograve, $V$. Fawconbridge, $V^{*}$. Sir William Fawconbrig, $V$. 
BEASTS.

\section{LIONS cont.}

Arg. three lions pass. guard. gu. Fauconberge, de l' Sonth, $Y$.

Brograve, Hamels, co. Hertford: Baronetcy 18 March 1662; extinct 8 June 1707. OnfLELD, co. Lincoln.

Arg. three lions pass. guard. gu. armed and langued ol. Fawconbridge.

Arg. three lions pass. reguard. in pale (another tails coward and reflexed over the backs) gu. North WALEs, Harl. MS. 4199 , fo. $22 \mathrm{~b}$, and $23 \mathrm{a}$.

Arg. goutty de sang three lions pass. reguard. gu. crowned or. FAIRFORD.

Arg. three lions ramp. in fess gu. Knapman.

Arg. three lions ramp. in pale gu. GIFFord, Claydon, co. Buckıngham.

Arg. three lions ramp. gll. Band. Sir John de Belfous, L. Belhouse, Essex and Devon. Sr Joln Bethouse or de Baylhows, Essex, temp. Edward I, $V$. Sire Johan de Belle. hous, $N$. Sir John de Belious, L, Harl. MS. 6137. Coshalie. Gosholime, $V$. Huliy, Ireland. Kirkham. Iivrham, Devon. Mirrie or MIRRY. TALBOT.

Arg. three lions ramp. gu. and a fess sa. Jolın de la Hese, $Y$.

Arg. semy of crosses croslet sa. three lions ramp. gu. Bellhouse, Essex.

Arg. three lions ramp. gu. crowned or. HarLewyn, V. Hascalerton.

Arg. three lions pass. guard. in pale per pale or and gu. Donough, third son of O'Brien, first Earl of Thomond, quartering arg. three piles in point gu., and az. a pheon arg., Harl. MS. 4039.

Arg. three lions ramp. ppr. Huntingdon, Ashmole MS. T63.

Arg. three lions ramp, purp. Bayons, co. Lin1coln and Essex. Sire Robert de Bayouse, $N$. Huntington. Sire Edmon Taiebot, N. Esmond Talbot, $Y$. Sr.Edmond Talmot, $L$; or TalbotT, L, Harl. MS. 6137. Sir .... TALBOT, Bashall, co. Lancaster, $R$. Sr. John TALBot, Bashall, co. Lancaster, $Y$. TALBOT, Hymsworth, co. York. M. Thonias TaLbott, $S$. Wolton. Wyays.

Arg. three lions ramp. purp. in the centre a fleur-de.lis gu. for diff. TALBoT, London, 1633-4, Harl. MS. 1358, fo. 67 b.

Arg. three lions salient purp. TALBOT, Salesbury, co.York; derived (through William, younger son of Erlmund Talbot of Bashall, 1301; the heiress m. Warren) from TalBot, Bashall, co. York, the senior line of the great house of Talbot, quartering Ferars, Belars, Halton, Arderne, and Bradley; descended from Geoffrey TALBOT, temp. Stephen, and Thomas TALBOT, who acquired, 1254, Bashall and Mitton; the heirs m. Whyte, Ferrers, Walmesley, and Lloyd. TALBOT, Lancaster, 1716.

Arg. three lions salient purp. armed and langued az. Talbot, Basball.

Arg. three lions dormant in pale sa. LLOYD, Welcombe, co. Warwick; London; Acombe and Coatham, co. York; quartering Carte; descended from Gamaliel Ltoyd, Mattersey, co. Notting. ham, ob. 1661.

Arg. three lions pass. in pale sa. Brompies.d. Bromfield. Sir Thomas Cheverell, co. Wilts, V. Malory.

Arg. three lions pass. sa. Cheveret, $V^{*}$. Cheverotle Cheveroll or Cheveryil. Hutchins, Ireland. MALLoRr, co. Lejcester.

Arg. three lions pass. in pale sa. armed and lan. gued gu. CAREW, Surrey; co. Gloucester; Kent.

\section{BEASTS.}

3 LIONS cont.

Arg. three lions pass. guard. in pale sa. Calcrafr. Arg. three lions pass. guard. sa. Huтchings, Sandford Orcas, co. Somerset, and Chester. street, Grosvenor-square, London.

Arg. goutty de sang three lions pass. reguard. sa. crowned or the tails reflexed over the back. FAIRFORD, $V^{*}$. FAYREFORD, $V$.

Arg. three lions ramp, sa. Chevenall or Chevereli, co. Wilts. Chevereil, quartered by Hastings, Earl of Huntingdon. Sr. Alexander Cheverolle, co. Wilts, $V$. Sir Alexander Cheverell Cheverill or Cheveroli, $L$. Sire Alisandre Cheveroyl, $N$. Cheveroyle, $V^{*}$. William Le Genne, $A$. Jove. Vilant.

Arg. three lions ramp. sa. and a chevron gu. Richard Bourne, $Y$.

Arg. three lions ramp. sa. collared and chained or. Tiffin, Wake's Hall, Essex.

Arg. three lions ramp. sa. crowned or. Roger MARMION, $V$.

Arg. three lions salient vert. TаLвот, co. Lan. caster.

Az. three lions pass. in pale arg. Geffray de Camuvile, $F$. Geffrai and Thomas de Camvile, $E$. Robert de Camivile, $A$. Sr.Geoffry Camruth, temp. Edward I, $V$. Caner. William de Kanuvile, $G$. Ludlow, co. Salop. And with a label of five points gu. William de Carivile, $E$.

Az. three lions pass. arg. Sir Geffrey CarrviLe, $I$. Cairvill, $V^{*}$. Hugh Carrville, $Y$. Sire Geffrey de Cantyle, $N$. Monsire de Caumvile, $Y$.

Az. three lions pass. guard. in pale arg. LoDeLow, $V^{*}$. Sr. Thomas Lodrow, co. Salop, temp. Edward I, $V$. Lodlow, $V *$.

Az. three lions pass. gnard. arg. Barne, London. Camintlle, co. Devon. Sire Thomas de Lodelawe, $N$. Monsire de Ludlawe, $Y$. John de LUDLOWE, $Y$.

Az. three lions pass. reguard. arg. Lublow.

Az. three lions ramp. in chief arg. TibBirts.

Az. three lions ramp. arg. Canvile. Chiche, $V$. Say. ThetFord. Warwick, Warwick, Cumberland; descended from Odard, to whom the manor was given by Ranulph de Meschines, temp. Henry I.

Az. crusily or three lions ramp. arg. Lucr.

Az. three lions ramp. arg. crowned or. DHLFord. Sir Richard Fond, I, Harl. MS. 6589. Sir Richard de la Forde, $I$. Forde, $V^{*}$.

Az. three lions ramp. arg. ducally crowned or a mullet for diff. LAwFond, quartering Mauduit with or on a chev, az. betw. three greyhounds courant sa. as many 3-foils slipped arg. Az. three lions ramp. arg. enraged gu. Mildmar. Az. three lions ramp. guard. in pale arg. LuDLow. Az. three lions pass. guard. in pale erm. Thetrond, Batishall, Norfolk.

Az. three lions pass. in pale or. ERdington, co. Leicester. LodLow.

Az. three lions pass. or. Combriel.t. Ludlow.

Az. three lions pass. guard. in pale or. Town of Romney, Kent.

Az. three lions pass. guard. or. BARNe, London. Beauvois. Camville, co. Stafford.

Az. three lions pass. guard. in pale crowned with ducal coronets or. Town of ApPLEBx, Westmoreland; seal in the town chest.

Az. three lions pass. guard. (another segreant) or. Hetherfield.

Az. three lions pass. reguard, in pale or. Town of MALDON, Essex. 


\section{BEASTS.}

\section{LIONS cont.}

Az. three lions ramp. or. CHıche. Roger Fenes (not Fenesport), $Y$. Fenis. Sir James Fenys, Essex, $V$. Fiennes, Kent. Fines, Viscount Say and Sele, 1730. Fyneaux. Fynes, $V^{*}$. Longspee. Sir Roger de Morteyn, J. Say.

Az. three lions ramp. or a label gu. Sire Giles de Fenz, N. The label of three points, Fordayne.

Az. crusily and three lions ramp. or. Lucy.

Az. three lions ramp. or crowned arg. Sr. Adam Ford, K, Harl. MS. 6589.

Az. three lions ramp. crowned or. Fond, co. Devon, co. Derby, Surrey, Sussex, co. Wilts, and Islington. Fond, Ellel Hall, co. Lancaster. Sr. Adam Forde or De la Forde, $K$, Harl. MS. 6137 and 6589. Sr. Adam Forde, co. Wilts, temp. Edward I; and Herting, Sussex, $V$. Sire Adam de la Fonde, $N$. William Ford, Parson at the Charterbouse, 1619.

Az. three lions ramp. guard. or. Hetherfield. Barry of six arg. and az. three lions ramp. gu. WOODBURGH.

Barry of six arg. and gu. three lions ramp. of the first. Estwell.

Barry of six arg. and sa. three lions ramp. gu. Woodburgh.

Barry of eight or and arg. (but? az.) three lions pass. sa. Wilmot-Sitwell, Stainsby, co. Derby, quartering Wilmot.

Barry of eight or and arg. (but ? az.) three lions ramp. sa. Sitwell, co. Derby.

Barry of eight or and vert three lions ramp. sa. Sitweld, Reinshaw, co. Derby; Baronetcy 3 October 1808; Barmoor Castle, Northumber. land; and Furney Hall, co. Salop. Sitwell, Stainsby, co. Derby, quartering Wilmot.

Barry of ten arg. and az. three lions ramp. gu. crowned or. Raffe de WoDEBITH, $A$, or Wodebinch, A, Harl. MS. 6137. WoodbUrGH.

Barry of twelve arg. and az. three lions ramp. gu. Sr. de Woodborne, $V$. Woodburne.

Barry of twelve arg. and az. three lions ramp. purp. Stobart, Picktree, Chester-le-street, co. Durluam, quartering Douglas.

Barry of twelve arg. and gu. three lions ramp. sa. Sr. Nicholas EstoteviL, temp. Edward III, $V$. Estotvile, $V^{*}$.

Barry of thirteen arg. and az. three lions ramp. gu. Rauf de Wodeburh, $E$.

Barry of fourteen arg. and sa.three lions ramp. gu. William Wodebunh, $E$.

Barry of fifteen arg. and az. three lions ramp .gu. crowned or. WoodBurge.

Barry arg. and az. three lions ramp. gu. Rauf de WodBurH, $Y$. Jobn Wood burhe, $Y$. Thomas Woddeburgh, $Y$. Monsire de Woodburgh, $Y$.

Barry arg. and az. three lions ramp. purp. Rafe Stodubynt, $Y$.

Barly arg. and gu. three (cos, i. e.) lions ramp. sa. Walter de Stoteville, $C$. Sire Nicolas de Estotevile, $N$.

Chequy or and gu. three lions ramp. arg. SPARChFord or SPECHTORD.

Chevronelly of seven arg. and gu. three lions ramp. or. Cromwest, co. Huntingdon.

Chevronelly of seven gu. and arg. over all three lions ramp. or. Richard Willuass alias Cronwell, $V$.

Erm. three lions ramp. .... Byard. Gates, Colliton, co. Devon.

Erm. three lions ramp. arg. Pronze, $V^{*}$.
BEASTS.

\section{LIONS cont.}

Erm. three lions pass. in pale gu. Combe, Cludington, co. Buckingham, and co. Hertford. Combe, $V$. Combe, Stratford-on-Avon, Harl. MS. 1359 , fo. 119 b. ENGLISH.

Erm. three lions pass. gu. Richard de Combe, $Y$.

Erm. three lions pass, guard, in pale gu. Richard and Thomas Callcroft, Chesterfield, co. Derby, temp. Henry VI. Robert Calcroft or Colcroft, 1716.

Erm. three lions pass. guard. gu. Richard de Combe, $Y$. Monsire de Faconberge de Sa, $Y$.

Erm. three lions ramp. gu. Bezhouse, Essex. Chidelly, co. Devon. Sr. .... de Chidley, co. Devon, $V$. Chudleigh, Broad Cleft, and (by marriage with Thomasine Prous) Ashton, co. Devon; Baronetcy 1 August 1622; extinct l August 1745; the co-heirs m. Prideaux, Chichester, Oxenden, and Haines. Chudrey, co. Devon, 1730.

Erm. three lions ramp. gu. crowned or. Merney or Mery, Renbuine and Barton, co. Derby.

Erm. three lions pass. sa. ENGLISH.

Ermines three lions pass. in pale arg. ENGLISH.

Ermines three lions ramp. arg. Richard Pronze, Exeter; granted by Cooke, $W$. Proos or Prowze; granted 1589.

Gu. three lious .... arg. BAARE or BARE.

Gu. three lions pass. in pale arg. GEFFry. M. John Gifrard, $D$. John Giffard, $E, F, G$. GifFARD or GIFFord, Brimsfield, co. Gloucester; Midley Claydon, co. Buckingham; Burstall, co. Leicester; St. James's Abbey, co. Northampton; and co. Oxford. Sr. John Gifford, Brymmesfled, co. Gloucester, $V$. Walter (sometimes called William) GIFFard GIFFORDE or GYFFORD, Bishop of Bath, etc., 1265 ; Archbishop of York 1267.79 ; Havl. MSS. 1357, 6100. Godfrey (sometimes called Geoffry, Lord) GIFFARD GIFFoRd or GrFFORDE, Bishop of Worcester 1268-1302; Harl. MSS. 1357, 6100. MA'GRAE or MAGRATh, Ireland; quartering or a dexter band couped ppr. lying fesswise holding a long cross gu. (another az.) with az. a dexter hand couped ppr. holding a battle-axe arg., and arg. a goat trippant (another pass.) sa., Harl. $M S .4039$, fo. 138 .

$\mathrm{Gu}$. three lions pass. arg. BrIMFIELD or Brimrold. Griftith ap Cynan, ob. 1136, father of Owen Gwynedd. Fitz-Payne, co. Gloucester. GIFFARD, Earl of Buckingham. John Giffard, $C$. Sire Johan Giffard, $N$. William Giffard, $Y$. Monsire Gifford, $Y$. Gifford, $V^{*}$. LEBNEFE, co. Buckingham.

Gu. three lions pass. arg. a label az. Sir Johan Giffard le Boef, $N$. Gifford, co. Worcester. Gu. three lions pass. in pale arg. over all a label of five points az. Gifford le BeFF, $A$; or de BeF, A, Harl. MS. 6137. Joan Giffard de Bef, $E$.

$\mathrm{Gu}$. three lions pass. in pale arg. a label of three points sa. Sr. Simon GyFFord, co. Gloucester, $V$.

Gu. three lions pass. arg. a label sa. Sire Esmoun GifFARD, $N$. The label of three points, GIFFORD, $V *$.

Gu. three lions pass. arg. a bend az. Fitz-PAYNE, $V$ *; the name and arms were taken by a younger son of Richard Lord Grey, of Codnor, born about 1321 , on succeeding to the manor of Charleton Grey, co. Somerset, by virtue of a special entail made by Robert Lord Fitz-PAYNE and Ela his wife. Robert le Fitz-Payne, K, Harl. MS. 6589. 


\section{BEASTS.}

\section{LIONS cont.}

Gu. three lions pass. in pale arg. over all a bendlet az. Robert le Fitz-PAYNe, K, Harl. MS. 6137. Sr. Robert Fitz-Payne, co. Gloucester, temp. Edward I, V. Fitz.Payne, co. Dorset and co. York, temp. Henry II, a Barony 1299. Mandeville, co. Dorset.

Gu. three lions pass. in pale arg. a baston az. Roberd Fitz-Paine, $G$. Sire Roberd la Fitz-PAIN, $J$.

Gu. three lions pass. arg. a baston az. Sire Robert le Fiz-Pain, $N$. John le Fitz.PAine, $Y$. Sr. le Fitz-Payn, $H$. Robert le FirzPayne, $K$. Sr. Robert Fitz PAine, K, Harl. MS. 6589. Monsire Rober't Fitz-Payne, $Y$.

Gu. three lions pass. in pale arg. a bendlet (kend $V^{*}$.) compony or and az. Sr. Robert FITZ-PAYNE, co. Gloucester, $V$.

Gu. three lions pass, arg. a baston compony or and az. Sire Robert le FIZ.PAYN, $N$.

Gu. three lions pass. in pale arg. over all on a bend sa. as many buck's heads cabossed or. BeCHE, $V$.

Gu. three lions pass. arg. over all on a bend sa. as many buck's heads cabossed or. BecHe.

Gu. three lions pass. in pale arg. over all on a bend az. as many mullets or. PaLley.

Gu. three lious pass. arg. over all on a bend az. as many mullets or. Sr. Walter Paveley, $R$.

Gu. three lions pass. arg. over all on a baston.... as many mullets or. Monsire Walter de Paveley, $Y$.

Gu. three lions pass. in pale arg. armed and langued az. William GIFFARD GifFord or GYFFORD, Bishop of Winchester 1107-29; Harl. MSS. 1357, 6100.

Gu. three lions pass. in pale arg. armed gu. GRIFFith aP CYNAN, King of North Wales (derived through Anarawd, King of North Wales, from Rhodric Mawr, King of Walcs), from whom descended the Princes of North Wales; David Goch AP David, Lord of Penmachno; and Roderick ap Owfn Gwynedd, Lord of Anglesey.

Gu. three lious pass. arg. incensed az. Griffith ap Conan, King of North Wales, 1078.

$\mathrm{Gu}$. three lions pass. guard. in pale arg. Bronflet or Bronslet, co. Lancaster. Town of Srockeridge, co. Huntingdon.

Gu. three lions pass. guard. arg. Bromfield, co. Lincoln. Harriard, co. Hants. Neale.

Gu. three lions pass. guard. (? arg.) over all a bend (? az.). Isabel (PAgane) Fitz.PAYne; seal 1347; and Maud Fitz-PAYne, seal 1356; Dallaway, Inquiries.

Gu. three lions pass. guard. arg. over all on a bend sa. as many pierced mullets of six points or. PAYLER, co. York, confirmed 20 October 1585.

$\mathrm{Gu}$. three lions pass. guard. arg. incensed az. Griffith ap CoNAN, King of North Wales, 1078.

Gn. three lions ramp. arg. Bare. BARnake, co. York. Bawde. Felton. Fitz-Barnard. Gawer. Goldington. Grymbolde de Pancevot, A. Grynbald Pancefoote, $Y$. Pauncefoote, $V^{*}$, London, 1633.4, Harl. MS. 1358 , fo. 66 b. Sr. Gilbert Pauncefote, co. Gloucester, $V$. Pauncerote, East Stoke, co. Nottingham. Sir Gilbert PaUncevod, N. Grimbaud Paunceyot, E. Grunbaud Paunstefot, $F$. Pauncefoot Dunconse, Great Brickilill, co. Buckingham, descended through PAUnCEFoot, Witham-on-the-Hill, co. Lincoln, like PAUnCEFooT, Hasfield, co. Gloucester, from Geoffrey de T'auncefote, Steward of the Household to Jolnn. Ragtand. Sire Jolian le fitz Reinald, $J$.

\section{BEASTS. 3 IIONS cont.}

Roos ol Roose. (The ancient arms of) Ross, Earl of Ross. Ross, London. Ross, Balnagowan Castle, co. Ross, and Bonnington House, co. Lanark; Baronetcy 28 February 1668. Hugh le Vache, $Y$.

Gu. three lions ramp. arg. a label az. Sr. John le Ros le fitz, $L$.

Gu. three lions ramp. arg. a label of as many points az. Deravache, co. Buckingham. Sir John Roos le filz, L, Harl. MS. 6589. Sr. John le Ros le fitz, L, Harl. MS. 6137.

Gu. three lions ramp. arg. a label of as many points compony or and az. De la $\mathrm{V}_{\mathrm{ACH}}$. Sr. Rice Delavache, $V$. The label chequy or and az. Sire Richard de la VACHA, $N$.

Gu. billetty or three lions ramp. arg. Joan de Bond, E, or Hond, E, Havl. MIS. 6137.

Gu. crusily or three lions ramp. arg. GAY, Elmsted and Peckham, Kent. Gaye, Kent, $V$. Lucy.

Gu. three lions ramp. arg. armed az. Sir Richard de la VACE, Q, Harl. MS. 6595.

Gu. three lions ramp. arg. crowned or. Codening. Delavache. La Rache, $i$. e. Lavache, co. Oxford. Sir Philip de la VACH, K.G., co. Buckingham, $V$. Sir Richard de la VACH, $Q$. M. Philip la VACHE, $S$. VACHELl.

Gu. three lions ramp. all meeting under one head in the fess point guard. arg. armed arid langued az. EDsrond ; (? Edmund Crouchback, Piantagener, Farl of Lancaster, temp.Edw.I.)

$\mathrm{Gu}$. three lions ramp. tails forked arg. Osbern de Avenebury, $F$.

Gu. three lions pass. guard. per pale barry or and arg. a label of three points of the last. Brotherton.

Gu. three lions pass. erm. FELLBRIDGE.

$\mathrm{Gu}$. three lions pass. reguard. erm. Girfond, co. Buckingham.

Gu. three lions ramp. erm. LANDONTHOR.P or LANDORTHORPE. LUNDERTHORP, $V$. ROOS OrROSSE. Gu. three lions pass. or. Fitz-Herbert. Roos or Ross, Scotland.

Gu. three lions pass. or and a bend az. GibBons. $\mathrm{Gu}$. three lions pass. in pale or each holding betw. their forepaws a helmet ppr. Dongan.

Gu. three lions pass. or each holding in the dexter paw a close lielmet arg. garnished of the second. Dungan, Dublin; quartering az, six plates on a chief or a demi-lion ramp. gu.

Gu. three lions pass. or each holding betw. the forepaws a helmet arg. Dungan, Earl of Limerick, Harl. MS. 4010, fo.135. O'DoNOGANe, Harl. MS. 4039, fo. 88.

Gu. three lions pass. in pale or armed and langued sa. Howelz-DHu, North Wales.

Gu. three lions pass. guard. in pale or. FNGLAND, after the marriage 1152 of Henry (Shortmantle, Ptantagenet) II with Eleanor of Aquitaine, $Z, 3,59$. Richard (Lionheart, Plantagenet) $\mathrm{I}, 1189, Z, 73$; Richard le roye d'Angletere, A. John (Lackland, Plantagenet), $1199, Z, 81$. Henry (of Winchester, Plantagenet) III, $1216, Z, 87$; Le roy d'Angleterre, $B$; Le roy d'Engleter, $C$ : and his wife Eleanor daughter of Raymond BERENGAR Earl of Provence and Forcalquier, $Z, 57,89$. Edward (Longshanks, Plantagenet) 1, 1272 , $Z, 127$; $V$; Rey de Augleterre, $D$; Rey d'Angleterre, $E$; Rey d'Fngleterre, $G$; Le roy, $H$; Edward roy d'Angleterre, $J ; K$; Edward roy d'Angletere, fitz du roy Henrye, $K^{*}$, Harl. MS'. 6137 ; Edward (of Carnarvon, Plantagenet, II, 


\section{BEASTS. 3 LIONS cont.}

1307, Z, 145; Le roy de Engletere, $N$. Edward (of Windsor, Plantagenet) III, 1327, until he quartered 1339 and assumed 1341 (Barnes, Edward III, p. 154) the arms of France, $Z, 157$. Le roy d'Angleterre, $Y$. Islands of Guennsex, etc. Cistercian Abbey at Furnes, co. Lancaster (but?). Town of Yanmouth, Norfoll, dimidiating az. three herrings naiant in pale arg. fiuned and tailed or. (Edward I,) dimidiated with az. semy of fleurs-de-lis or by his wife, Margaret CAPET, 1299-1317, daughter of Philip (the Hardy) 1II, King of France, $Z, 133$. (Edward II,) with the same dimidiation by his wife Isabel CAPET, 1307-57, daughter of Philip (the Fair) IV, King of France; $Z, 145$. City of Chester, dimidiating az. three garbs or. Town of Hastings, Sussex, dimidiating az. three hulks of ships in pale arg. Town of Ransgate, Kent, with the same dimidiation. Town of SANDWICH, Kent, with the same dimidiation. Town of Winchelsea, Sussex, with the same dimidiation. Benedictine Abbey at Feversear, Kent, with the same di. midiation and over all a crosier gu. Le Cynqportes, $i$. $e$. Dover, IJastings, Hythe, Romney, Rye, Sandwich, and Winchelsea, dimidiating az. three hulks of ships in pale or, T. Benedictine Abbey at Feversham, Kent, with the same dimidiation and over all a crosier gu. (Edward III,) impaled with or a lion ramp. sa. quarterly with or a lion ramp. gu. by his wife Philippa de Avesnis, 1328-69, daughter of William Count of Hainault, Hollaud, Zeeland, and Friesland. Anne (Stewart or Stuart, afterwards Oldenburg), after the Union 1706, impaling Scotland and quartering France and, in the third quarter, Ireland. George (Louis GuelPH) I, 1714, impaling Scotland and quartering France and in the third quarter Ireland, over all on an escucheon gu. a borse courant arg.; but afterwards impaling Scotland and quartering France, Ireland, and, in the fourth quarter, over Brunswick. Lüneburg-(Lower Saxony or Westphalia, i. e.) Hanover, an escucheon for the Archtreasurership of the Holy Roman Empire. George (Augustus GUelPH) II, 1727, with the same im. palement, quarterings, and escucheon. George (William Frederick GUELPH) III, 17 60 , with the same impalement, quarterings, and escucheon, until (the Union) 1 January 1801. (Edward III,) impaled with or two lions ramp. sa. in bend betw. as many gu. by his wife Philippa de Avesnis, 1328-69, daughter of William Count of Hainault, Holland, Zeeland, and Friesland, $Z, 158$. Town of Stamford, co. Lincoln, impaling chequy or and az. Benedictine Abbey at Fevershar, Kent, impaling az. three bulks of vessels issuant from the sinister in pale (arg. another) or depressed by a crosier gu. (Edward III,) quartered with quarterly or a lion ramp. sa., and or a lion ramp. gu. by his wife Philippa de Avesnıs, 1328.69, danghter of William Count of Hainault, Holland, Zeeland, and Friesland. (James Francis Edward Stewart or STuART, called James III, 1701, quartering Scotland, France and in the fourtb quarter Ireland) impaled with Polaud quartering Lithuania and over all on an escucheon az. an antique shield or by lis wife Maria Clementiua Sobıssi. (Alexandriua) Victoria (GUelph until 1840, afterwards SAXE), 1837, quartering Scotland and, in the third quarter,

\section{BEASTS. 3 LIONS cont.}

Ireland. George (William Frederick GoELPH) III, quartering Scotland and, in the third quarter, Ireland, over all an escucheon ensigned with the electoral cap (until 8 June 181.6, when a crown was assumed) of Hanover, and charged with Brunswick-Lïneburg. (Lower Saxony or Westphalia, i.e.) Hanover, with over all an inescucheon for the Archtreasurership of the Holy Roman Empire. George (Augustus Frederick GuELPH) IV, 1820, with the same quarterings, escucheons, and crown. William (Henry GUel.PH) IV, 1830, with the same quarterings, escuclseons, and crown. (Edward III,) quartered with or two lions ramp. sa. in bend betw. as many gu. by his wife Philippa de Avesnis, 1328.69, daughter of William Count of Hainault, Holland, Zeelaud, and Friesland, $Z, 158$. Henry (Tudor) VIII, $1509-47$, quartering az. three fleurs-de-lis or on weapons in the 'Tower' of London, etc. (Edward II,) quartered with az. semy of fleurs-de-lis or with Navarre and Champagne, by his wife Isabel CAPET, 1307-57, daughter of Philip (the Fair) IV, King of France. (Edward III,) quarterning az. semy of fleurs-de-lis or from 1339 until 1341 , when he assumed the arms of France, (Barnes, Edward III, p. 154). Richard (of Bordeaux, Plantagenet) I1, 1337.99, quartering az. semy of fleurs-de-lis or in some places, $Z, 191$. $\mathrm{Gu}$. three lions pass. guard. in pale or a label.... Attributed to Geoffry (Plantagenet), Juke or Earl of Bretagne and Earl of Richmond, $Z, 67$, and to his son Arthur Plantagener, $Z, 68$. The label of (three, sometimes of) five points. Edward (Longshanks) Plantagenet, $Z, 127$. Edward (of Carnarvon) Plantagenet, $Z, 145$. Edward of Windsor) Plantagenet, $Z, 157$. (Probably)Edward(ofWoodstock)Plañtagenet until 1339. Cistercian Abbey at Combe, co. Warwick.

Gu. three lions pass. guard. in pale or a label of three (sometimes of five) points arg. Le Conte Mareschall, $Y, i$. e. Thomas (of Brotberton) Plantagenet, Earl of Norfolk and Suffolk 1312, Marshal 1315, ob. 1338, fifth son of $\mathrm{Ed}$ ward I, $V ; Z, 205$; and his daughter Margaret (Plantagenet) Marshal, Countess of Norfolk, Lady of Segrave, created Duchess of Norfolk 1397, ob. 1399 ; from her marriage with John Lord Segrave descended Elizabeth Segrave, wife of John Lord Mowbray, whose son, Thomas Mowbray, Earl of Nottingham I382, Earl Marshal 1385, and Dulse of Norfolk 1397, ob. 1400, assumed as Le C. Maryschall Sr. de Mowbrax, $S$, quartering gu. a liou ramp. arg. this coat, which was carried by his second and third successors, Dukes of Norfolk, until his inheritance was divided between the heirs of his daughters, who m. Howard and Berkeley, $Z$, 212, so that this coat as quartered by Howard Duke of Norfolk, $U ; Z, 496$; was borne by Catharine daughter of Sir Edward HOWARD and fifth wife of Henry VIII, $Z, 489$. And from the marriage of the same Margaret, ob. 1399, with Sir Walter Manny, descended Anne Manny, wife of John Lord Hastings, Earl of Pembroke, and her son Joln Hastings, Earl of Pembroke, Lord Hastings, Weshford, and Abergavenny, ob. 1390, who assumed this coat quarterly with Hastings (and in the third quarter Valence in sone places) quartering Valence, $Z, 209$. 


\section{BEASTS.}

\section{LIONS cont.}

Gu. three lions pass. guard. in pale or a label of three (sometimes of five) points az. Sire ANFour, $D$. Edward (Lougsbanks) Plantagenet, $B$, until 1272. Edward (of Carnarvon, Prantagener, Prince of Wales and Earl of Chester 1301-7, Earl of Ponthieu and Monstroile) le fitz le roy, $J$; or le fitz roy, $K$, Harl. MS. 6137 ; or le filz le Roy, $K$, Harl. MS. 6589. (Probably) Edward (of Windsor) Plantagener, until 1327. (Probably) Edward of Woodstock (Plantagenet), son of Edward III, born 1330; created Earl of Chester 1333, Duke of Cornwall 1337; until 1339. Henry (Grismond or Tortcol, Plantagenet), then (1345) Earl (created, 1351, Duke) of Lancaster, ob. $1361, Q$ (but in error). Conte de LANCastr, E, Harl. MS. 6137 (but in error.)

$\mathrm{Gu}$. three lions pass. guard. in pale or a label erm. College of Newark, or St. Mary the Greater, at LEICESTER.

Gu. three lions pass. guard. in pale or a label of three (sometimes of five) points az. charged with fleurs-de-lis of the second. The county of Lancaster. Cnte de Lancastr, $E, i$. $e$., Esmond fitz du roy (Henry III), Conte de Lancastre, $Y$; also called S. Edmund frère le roy (Edward I), $G$; and Edmund frère du roy, Conte de Lancastre, $P$; being Edmund (Crouchback) Plantagenet, Earl of Leicester and Seneschal 1264, Earl of Lancaster 1267, Earl of Derby and Campaigne, Lord of Monmouth, titular King of Sicily, ob. $1296, V ; Z$, 103. And his descendant le Counte de Lancastre, $J ; N ; i$. e. Sr. Thomas le Counte de Lancastre, $H$; Thomas le Conte de Lancaster, $K$, Harl. MS. 6589; Thomas le Countie de Lancaster, $K$, and L, Harl. MS. $613 \pi$; or Thomas Counte de Longcastre, I, Harl. MS. 6589 ; Le Connte de Lancaster, L, Harl. MS. 6589 ; being Thomas Plantagenet, Earl of Leicester, etc., beheaded 1321-2 at Pontefract, $Z, 107$ : and his nephew, Heury (Grismond or Tortcol) Plantagenet, Farl of Derby, 133\%, Leicester and Lancaster and Seneschal 1345, Lincoln 1249, Duke of Lancaster 1351, Lord of Bragerac and $B \in m$ fort, ob. 1361, $Z, 112$ : and his daughter Blanche Plantagenet, $Z, 113$ : and her son Henry IV, while Earl of Derbs, $Z, 266$. An augmentation to Anne Borers or Bullen, second wife of Henry VIII, $Z, 487$, quarterly with Angoulême, Guienne. Butler quartering Rochford, Brotherton, and Warren. Leicester College at NEwart, co. Nottingham; (in error for the College of Newark, or St. Mary the Greater, at LEICESTER).

Gu. three lions pass. guard. in pale or on a label arg. as many eagles displ. of the first. M. Thomas Movbrar, quartering gu. a lion ramp. or and a label of three points az., $S$.

Gu. three lions pass. guard. in pale or a label of three points arg. charged with nine torteaux. (Richard Plantagenet); le Duke de York, $T$, ob. at battle of Wakefield, 1460, son of Richard Earl of Cambridge beheaded at Southampton, 34] 5.

Gu. three lious pass. guard, in pale or impaling Scotland and quartering France, Ireland, and, in the fourth quarter, Brunswick-Lüneburg. (Lower Saxony or Westphalia, i.e.) Hanover, over all a (label with proper difference. Sophia Dorothea, diughter of George I; ob. 13 No. vember 1726. Anne, afterward's Privess of

\section{BEASTS 3 LIONS cont.}

Orange, ob. 12 January 1759 ; Amelia Sophia Elizabeth, ob. 31 October 1786; Elizabeth Caroline, ob. 28 December 1757; Mary, afterwards Landgravine of Hesse Cassel, ob. 14 June 1771; Loussa, afterwards Queen of Denmark, ob. 8 December 1751; daughters of George II. And with the differences described on the next page, the daughters of George III until 1801. The) label of three points arg. Frederick Louis GUELPH, son of George II, ob. 1751 (but in error). 'The label having the centre point charged with a cross gu. William Augustus GuespH, created Duke of Cumberland, Marquis of Berkhampstead, Earl of Kennington, Viscount of Trematon, Baron of Alderney 27 July 1726, ob. 1765; second surviving son of George II. And with the addition of two anchors erect az. to the label. William Henry GUeLPH, created Duke of Clarence and St. Andrews, and Earl of Munster 20 May 1789; third son of George III; until 1801. But with fleurs-de-lis az. instead of the anchors upon the label. Edward GuespH, created Duke of Kent and Strathern, and Earl of Dublin 24 April 1799; fourth son of George III; until 1801. And with the label charged with a fleurs de-lis az. betw. two crosses gur. Ernest Augustus GuelpH, created Duke of Cumberland and Teviotdale, and Earl of Armagh 24 April 1799; fifth son of George IlI ; until 1801. Gu. three lions pass. guard. in pale or impaling Scotland and quartering France, Ireland, and, in the fourth quarter, Brunswick.Lüneburg. (Lower Saxony, or Westphalia, i.e.) Hanover, over all a label of five points arg. charged with a cross and four cantons gu. Edward Augustus Guelph, created Duke of York and Albany and Earl of Ulster 1 April 1760, ob. 1767; younger brother of George III. And with fleurs-de-lis az. instead of the cantons. Henry Frederic GuelPH, created Duke of Cumberland and Strathearn, and Earl of Dublin 22 October 1766 ; ob. 1790 ; youngest brother of George III. And with the label only charged with a fleur-de-lis az. and four crosses gu. William Henry Guesph, created Duke of Gloucester and Edinburgh, and Earl of Connaught 19 November 1764; youngest (but one) brotber of George III; until 1801; and his daughter Sophia Matilda; and his son William Frederick, in $\nabla . p$. with another label of three points.... both until 1801 .

Gu. three lions pass. guard. in pale or impaling Scotland and quartering France, Ireland, and in the fourth quarter, Brunswick-Lüneburg(Lower Saxony, or Westphalia, i. e.) Hanover, with an inescucheon gu. simply over all a label of three points arg. George Augustus GuelpH, Prince of GreatBritain,Electoral Prince of Bruns. wick-Lüneburg, Duke of Cornwall and Rothsay, created Duke and Marquis of Cambridge, Earl of Milford Haven and Carrick, Viscount Nortballerton, Baron of Tewksbury and Penfrew, Lord of the Isles and Steward of Scotland 1706, Prince of Wales aud Earl of Chester 27 September 1714; eventually George II. Frederick Louis GuelPH, Prince of Great Britain, Electoral Priuce of Brunswick-Lüneburg, Duke of Cornwall and Rothsay, created Duke of Edin. burgh, Marquis of the Isle of Ely, Earl of Eltham and Carrick, Viscount of Launceston, Baron of Snowdon and Renfrew 1726, Lord 


\section{BEASTS.}

3 LIONS cont.

of the Isles and Steward of Scotland 1727, Prince of Wales and Earl of Chester 8 January 1729, ob. 1751. George William Frederick GuelpH, Prince of Great Britain, Electoral Prince of Brunswick-Lüneburg, created Duke of Edinburgh, Marquis of the Isle of Ely, Earl of Eltham, Viscount of Launceston, Baron of Snowdon 175l, Prince of Wales and Earl of Chester 20 April 1751; eventually George III. GeorgeAugustus Frederick GUELPH, Prince of Great Britaiu, Electoral Prince of Brunswick-Lüneburg, Duke of Cornwall and Rothsay, Earl of Carrick, Baron of Renfrew, Lora of the Isles, and Hereditary Great Stew. ard of Scotland 1762, Prince of Wales and Earl of Chester 19 August 1762 ; until 1801; eventually George IV. But with the inescucheon arg. a wheel of six spokes gu, and the label charged on the centre point with a cross gu. Frederick GueLrH, Bishop of Osnaburgh 27 February 1764, cleated Duke of York and Albany and Earl of Ulster 29 November 1784; second son of George III; until 1801. But with the label charged with nine torteaux, Ernest Augustus GuELPH, Duke of Brunswick, Bishop of Osnaburgh 1715, created Duke of York and Albany and Earl of Ulster 5 July 1716; ob. 4 August 1728; Add. MS. 6278; brother of George I.

Gu. three lions pass. guard. in pale or quartering Scotland and, in the third quarter, Ireland, over all a label of three points arg. James Francis Edward Stewart or Stuart, son of James II, 1688-1701, eventually called James III. But with the label charged on the centre point with a cross on. Francis Albert Augustus Charles Emanuel Saxe, Duke of Saxony, Prince of Sase-Coburg Gotha, quartering Saxony.

Gu. three lions pass. guard. in pale or quartering Scotland and, in the third quarter, Ireland, over all an escucheon for Brunswick-Lüneburg(Lower Saxony or Westphalia, i.e.) Hanover, and in chief a label (of three points arg.?). Charlotte Caroline Augusta Guelph, Princess of Wales, afterwards Princess of Saxe-CoburgSaalfeld; ob. 6 November 1817 ; daughter of George IV. The label charged with a cross gu. and two anchors erect az. William Henry Gues.PH, created Duke of Clarence and S. Andrews, and Earl of Munster 20 May 1789; third son of George III ; after 1800 ; eventually William IV. But with fleurs-de-lis az. instead of the anchors upon the label. Edward GuevpH, created Duke of Kent and Strathern, and Earl of Dublin 24 April 1799; fourtb son of George III; after 1800; ob. 23 January 1820. And with the label charged with a cross between two roses gu. Elizabeth GUELPH, afterwards Landgravine of Hesse Homburg; third daughter of George III; ob. 10 January 1840. And with the label charged with a cross between four bearts two and two in pale gu. Adolphus Frederick Guelph, created Duke of Cambridge, Earl of Tipperary; and Baron of Culloden 27 November 1801 ; ob. 8 July 1850; seventh son of George III; and his children George William Frederick Charles in v. p. with another label of three points ...., afterwards Duke of Cambridge, etc., Angusta Caroline Elizabeth Mary Sophia Louisa afterwards Duchess of Mecklenburgh-Strelitz, and Mary Adelaide Wilhelmina Elizabetl. And with the label charged

\section{BEASTS.}

3 LIONS cont.

with a fleur-de-lis az. between two crosses gu. Ernest Augustus GuelPH, created Duke of Cumberland and Teviotdale, and Earl of Ar. magh 24 April 1799 : fifth son of George III ; after 1800; eventually King of Hanover, 20 June 1837; and his son George Frederick Alexander Charles Ernest Augustus, with another label of three points .... And with the label charged with a rose betw. two cantons gu. Mary GuenPH, after'wards Duchess of Glouces. ter"; fourth daugbter of George III; ob. 30 April 1857. And with the rose only betw. two crosses gu. Charlotte Augusta Matilda GuelPH, Princess Royal, afterwards Queen of Wurtemberg; eldest daugbter of George III ; ob. 6 Oc. tober 1828. And with the rose only between two hearts gu. Amelia GuelPH ; sixth daughter of George III; ob. 2 November 1810. And with the rose only between two ermine spots. Augusta Sophia GUELPH; second daughter of George III ; ob.22 September 1840. And with the label charged with a heart between two roses gu. Sophia GuEIPH; fifth daughter of George III; ob. 27 May 1848. And with the label charged with two hearts in pale between as many crosses gu. Augustus Frederick Guslph, created Duke of Sussex, Earl of Inverness and Baron of Arklow 27 November 1801; sixth son of George III; ob. 21 April 1843.

$\mathrm{Gu}$. three lions pass. guard. in pale or quartering Scotland and, in the third quarter, Ireland, with an inescucheon for Brunswick-Lüneburg(Lower Saxony or Westphalia, i. e.) Hanover, and over all a label of five points arg. charged with a fleur-de-lis az. between four crosses gu. William Henry GuenPH, created Duke of Gloucester and Edinburgh, and Earl of Connaught 19 November 1764 ; a brother of George III ; after 1800; ob. 1805; and his daughter Sophia Matilda, ob. 29 November 1844 ; and bis son William Frederick GUELPH, in v.p. with another label of three points ....., afterwards Duke of Gloucester, etc.,ob.s. p. 30 November 1834. But with the label only charged with a rose gu. Leopold George Frederick $S_{A x E}$, Prince of Saxe-Coburg Saalfeld, by warrant 7 April 1818, quarterly with Saxony; afterwards King of the Belgians.

$\mathrm{Gu}$. three lions pass. guard. in pale or quartering Scotland and, jn the third quarter, Ireland, over all an escucheon for Brunswick-Lüneburg(Lower Saxony or Westphalia, i. e.) Hanover, with an inescucheon gu. simply, over the whole a label of three points arg. George Augustus Frederick GuelPh, Prince of Great Britain, Electoral Prince of Brunswick.Lüneburg, Dulse of Cornwall and Rothsay, Earl of Carrick, Baron of Renfrew, Lord of the Isles, and Hereditary Great Steward of Scotland, created Prince of Wales and Earl of Chester, $19 \mathrm{Au}$ gust 1762 , after 1800; eventually George IV. But with the inescucheon arg. a wheel of six spolses gu. and the label charged in the centre point with a cross gu. Frederick GueLPH, elected Bishop of Osnaburgh $27 \mathrm{Fe}$ bruary 1764, created Duke of York and Albany, and Earl of Ulster 29 November 1784, secoud son of George III; after 1800; ob. 5 January 1827.

$\mathrm{Gu}$. three lions pass. guard. in pale or quartering Scotland and, in the third quarter, Ireland, with an jnescucheon for Saxony, and over all 


\section{BEASTS. 3 LIONS cont.}

a label of three points arg. Albert Edward Saxe, Prince of the United Kingdom of Great Britain and Ireland, Prince of Saxe Coburg Gotha, Duke of Saxony, Duke of Cornwall and Rothsay, Earl of Carrick, Baron of Renfrew, Lord of the Isles, and Steward of Scotland, created Prince of Wales and Earl of Chester 8 December 1841, Earl of Dublin $17 \mathrm{~J}$ anuary 1850. The label charged with a cross gu. and two anchors erect az. Alfred Ernest Albert, Prince of the United Kingdom of Great Britain and Ireland, Prince of Saxe-Coburg Gotha, Duke of Saxony. But with a rose betw. two crosses gu. Victoria Adelaide Marr Louisa SAxE, Princess Poyal of the United Kingdom of Great Britain and Ireland, afterwards Princess Frederick William of Prussia.

Gu. three lions pass. guard. in pale or quarterly with az. semy of fleurs-de-lis or over all a label .... (Probably) Edward (of Woodstock) Plantagenet, Duke of Cornwall, between 1339 and 1341 : which might account for this mode of marshalling the arms of Fichard II, "as set up in lis time, and now in being in the west window of the abbey of Shrewsbury, and of several princes of the royal house there also depicted, with their distinctions," as noted by Sandford, p. 191.

$\mathrm{Gu}$. three lions pass. gnard. in pale or over all a bend (sometimes a bendlet, sometimes a bas. ton) az. (Attributed to) John (Lackland) Plantagenet (but ? two lions). Sire Henry (Plantagenet) de Lancastre, $H ; J ; K$, Harl. MS. 6317 ; $N$; brother of (Thomas) the Earl of Lancaster, $Y$; le Connt de Darby, $Y$; Henry le filz de Lancaster, or Henry de Longcastre brother of Thomas Counte de Longcastre, $K$, Harl. MS. 6589 ; i. e., Henry, son of Edmund Crouchback, and afterwards Earl of Lancaster and Derby, Lord of Monmouth, created Earl of Leicester, 1323-4, Steward 1327; Earl of Provence $1335, V ;$ ob. $1345 ; Z, 109$.

$\mathrm{Gu}$. three lions pass. guard. in pale or quartering Scotland, and, in the third quarter, Ireland, over all an escucheon of Brunswick-Lüneburg(Lower Saxony or Westphalia, i.e.) Hanover, and over all on a couped sinister baton az. three anchors or. George FitzCLARENCE, created Earl of Munster, Viscount Fitzclarence, and Baron of Tewlisbury 4 June 1831 ; a natural son of William IV; the baton afterwards changed to gu. simply.

Gu. three lions pass. guard. in pale or over all a crosier staff gu. crook sa. Cistercian Abbey at Vale Royal, co. Chester.

$\mathrm{Gu}$. three lions pass. guard. or. Guerssey. O'Brien, Ireland.

$\mathrm{Gu}$. three lions pass. guard. or a label of three points arg. DE Brotherton, $V^{*}$. The label of five points arg. Mowbrax. The label az. flory or. Leicester College at NEwart, co. Nottingham (in error, for the College of Newark, or St. Mary the Greater, at LEICEster).

Gu. three lions pass. guard. or collared with crowns az. Confirmed to Otho de Mandeville, 1393.4, the patent of the grant by Edward III to his father Peter having been lost. Ashmolean MS. 835 , fo. 365 .

$\mathrm{Gu}$. three lions pass. guard. in pale crowned or. Town of APPIEBy, co. Westmoreland, supposed to have been granted by Henry II.
BEASTS. 3 LIONS cont.

$\mathrm{Gu}$. tbree lions pass. reguard. or over all a bend az. Fitz-Roy.

Gu. three lions ramp. or. Barnard. Sir Piers Fitz-HaRBERT, Lord of Blancovenny in Wales, $V$. Fitz-Herbert, Tissington, co. Derby, Baronetcy 10 March 1783. Fitz-Herbert, Norbury, co. Derby, and Begbrook, co. Oxford. Reynald Fitz-Piers, $Y$. Sire Johan le Fitz-Reinald, $J$. Reinauld le Fitz-Piers, $B$. Renaud le Fitz.Ps, E. Fitz-Reignald. Sire John le Fitz-Renaud, $N$. B. Hoderngo, $F$. Roos or Rosse, Essex.

$\mathrm{Gu}$. three lions ramp. or a crescent for diff. Fitz-Herbert, Baron St. Helens.

Gu. three lions ramp. or a label arg. Baudewin de Coneringe, $Y$. The label of five points. Baudwin Coderugge, E. Badwin de Conerugge, E, Harl. MS. 6137.

Gu. billety and three lions ramp. or. Jobn de Herond, $F$.

$\mathrm{Gu}$. three lions ramp. crowned or. $\mathrm{LA}_{\mathrm{A}} \mathrm{R}_{\mathrm{ACH}}$, i.e. Lavache.

Gu. three lions ramp. or with wreatbs on their heads az. KrLLAy.

Gu. three lions ramp. guard. or. Fitz Herbert. Gu. three lions ramp. all meeting under one head in the fess point guard. or armed and langued az. (? badge of) Edmond (Crouchback) Plantagenet, Earl of Lancaster, temp. Edward I, $Z, 103$.

Gu. three lions pass. guard. in pale per pale or and arg. Fevershair, Kent. Mac-Brien Arragh, Arragh, co. Tipperary ; Baronetcy 1623, extinct 1626. O'BrLan, Earl of Tomond, $V$. O'Brien, Earl of Thomond and Baron of Ibracan 1543.4, and 1552 , Viscount Tadcaster, 1714, extinct 1741; quartering arg. three piles meeting in point issuant from the chief gu., and or a pheon az. O'Brien, Baron Inchiquin and Burren 1543-4, Earl of Inchiquin 1654, extinct 1855; Marquess of Thomond 1800, extinct 1855; Baron Thomond of Taplow 1801, extinct 1808; Baron Tadcaster 1826, extinct 1846 ; with the same quarterings. O'Brien, Dromoland and Leaghmenagh, co. Clare; Baronetcy 9 November 1686 ; Baron of Inchiquin (1543) 1855, with the same quarterings. O'BrIEN, Viscount Clare, Harl. MS. 4040, fo. 288.

Gu. three lions pass. guard. in pale per pale or and arg. a label three of points silver. O'Brien, Baron of Inchegwine 1543; Harl. MS. 1362, fo. 37 .

Gu. three lions pass. guard. per pale or and arg. O'Brien, Earl. of Thomond, quartering Bryan with gu. a pheon arg. $Z, 357,371$. O'Brien, Shotgrove, Essex.

Gu. three lions ramp. ppr. Guns, Irstead, Norfolk.

Or three lions .... az. RepLey.

Or two lions pass. in chief and one in base ramp. az. Tappenden, Faversham, Kent.

Or three lions pass. in pale az. Johan de Someri, G. Sir John SoMerye, L, Harl. MS. 6137.

Or three lions pass. az. Sr. John de Sorrery, L, Harl. MS. 6589 .

Or semy of hearts gu. and three lions pass. in pale az. DenMark, $Z, 276$.

Or semy of bearts gu. and three lions pass. az. crowned of the first. Denalark, $Z, 326$.

Or three lions pass. guard. in pale az. LunLow.

Or semy of hearts gu. and three lions pass.guard. in pale az. (another,crowned of the first.) Denmark. 


\section{BEASTS. 3 LIONS cont.}

Or sersy of hearts gu. three lions pass. guard. az. cruwned of the first. Deniark, $Z, 554$.

Or three lions pass. reguard. az. LuDLOw.

Or three lious ramp. az. Sir .... de Risialgh, $R$.

Or three lions ramp. az. ducally crowued gu. Delillers, London; granted 1657.

Or three lions ramp. all meeting under one head in the fess point guard. az. that at base respectart the sinister side. NASHE, $W$.

Or three lions ramp. tails forked az. Montarne, co. Leicester.

Or' three lions couchant gu. Lye, co. Wilts, and co. Hereford.

Or semy of hearts gu. three lions pass. of the second crowned armed and langued az. DenITARK.

Or three lions pass. guard. in pale towards the sinister gu. Motreux, Beechamwell, Norfolk.

Or three lions pass. guard. gu. Kings of WaLES.

Or three lions ramp. gu. Cresacre, co. York, $V$. Creseacre, Barnborough, co. York; the heiress m. More.

Or three lions ramp. gu. over all a bend az. Palley.

Or three lions ramp. gu, over ail a bendlet sa. HAYWARD, co. Hereford.

Or three lions ramp. purp. Cresacre or Cresakre, in Brodsworth Church, co. York.

Or three lions .... sa. Sir Dunkan Matsdonetr d'Escoce, $M$.

Or three lions couchant in pale sa. Llord.

Or three lions pass. in pale sa. Sr. Nicholas CAREw, co. Devon, temp. Edward I, $V$. CAREW, Hackcombe, co. Devon; Baronetcy 2 August 1661. CAREw, Beddington, Surrey; the heiress m. Throckmorton, who assumed the name, and had a Baronetcy 11 January 1715 ; extinct 19 August 1762. Pichard de CAREw, Bishop of St. David's, 1256-80. Nicoll de Carru, $K$, Harl. MS. 6137. Sir John Carwe, Q. Fowkroy. Johan de Kareus, $G$. Adam de Mongomery, $F$, or MUNGoueri, $E$.

Or three lions pass. sa. Monsire de CAREw, $Y$. CAREW, $V^{*}$. CaREW, Buron Carew of Castleborongh, and its brancil CAREw, Ballinamona, co. Waterford; descended from England. Sir Nicholas CAREw, $K$, and Nicholas de CAREw, $K$ : Harl. MS. 6589. Carne. Le Baron de Carret, $Y$. Sire Nicholas $\mathrm{C}_{a r r u}, N$. Nicholas de Karru, $K$. Mallory, co. Leicester.

Or three lions pass. in pale sa. a label of three points gu. Sir John de Carew or Carewe the younger, $Q$.

Or three lions pass. sa. a label gu. Sire Joban de Carro, $N$.

Or three lions pass. in pale sa. armed and langued gu. Sir Nicholas CArew, Carew Castle, co. Pembroke, ob. 1449 (derived through Osborne Fitzgerald, Lord of Ynysymaengwyn, from Walter Fitz-Otho); and his descendants, CAREw, Earl of Totness, Baron of Clopton, 1626-9; Carfw, Haccombe, co. Devon, Baronetcy a August 1661 ; CAREw, East Anthony, Cornwall, Baronetcy 9 August 1640 , extinct 24 March 1748, quartering Pole; and CAREw, Crowcombe, co. Somerset. CAREw, Beddington, Surrey; the heiress $\mathrm{m}$. Throckmorton, who assumed the name, and had a Baronetcy 11 January 1715; extinct 19 Angust 1762. Sir Jolnn CAREwe, Q, Harl. MS. 6595.

\section{BEASTS. 3 LIONS cont.}

Or three lions pass. in pale sa. armed and langued gn. a label of three points of the last. $\mathrm{Sr}$. John Canew the younger, Q, Harl. MS. 6595.

Or three lions pass. guard. in pale sa. MaLoRY, Draughton, co. Northampton. Sr. Piers Maloure, co. Leicester, temp. Edward I, $V$.

Or three lions pass. guard. sa. Sire Peres Maloure, $N$.

Or three lions pass. reguard. sa. LudLow.

Or three lions ramp. sa. Hirlion, Essex: Mallore, $V^{*}$. Sir John Malore, co. Leices. ter, $r$.

Or three lions ramp. sa. langued armed and crowned gu. Gueris, Norton Fitz-IVarren, Taunton; descended from Guerin, Champagne, Isle of France, and Auvergne.

Per chev. arg. and az. three lions ramp. counterchanged. Sir .... Repley, $V$.

Per chev. embattled arg. and az. three lions ramp. counterchanged. Holker. Hulke, $V$.

Per chev. embattled arg. and gu. three lions ramp. counterchanged. HUCKLE. HULKE. WIFOLDE, $V^{*}$.

Per chev. az. and or three lions pass. counterchanged. WARING, Ireland.

Per chev. az. and or three lions pass. guard. in pale counterchanged. William Caturn, Leyborne, Kent; granted 1470, Harl. MS. 1350, fo. 5 .

Per chev. az. and or three lions ramp. counter. changed. Ripley, Cornwall.

Per chev. embattled gu. and or three lions ramp. counterchanged. WIFIELD, London. WYFFOLDE, $V$. Sir Nicholas WIFFoLD, Lord Mayor of London, 1450, Harl.MS. 1349.

Per chev. embattled gu. and or three lions ramp. guard. counterchanged. WILForD, Lord Mayor of London, 1450.

Per chev. or and az. three lions pass. guard. in pale counterchanged. Catuin, Kent.

Per chev. or and az. three lions ramp. counterchanged. Repuex, Chertsey, Surrey. Warington. WARrington, Aigberth, co. Lancaster; and its branches, WARRINGTON, quartering Strudwick; and Warrington-Carew, $\mathrm{Ca}$ rew Castle and Crowcombe.

Per chev. embattled or and az. three lions ramp. counterchanged. HoLKER, London; granted 1 January 1770.

Per chev. or and az. three lions ramp. those in chief combatant all counterchanged. Robert Warmington, of Calais, temp. Edward IV, $V$.

Per chev. or and gu. three lions pass. counterchanged. Lund, co. York, and Parson's Green, Middlesex.

Per chev. flory counterflory or and gu. three lions pass. counterchanged. Lownde, Jekesford, co. Cambridge.

Per chev. dovetailed or and vert three lions ramp. counterchanged. RiPLET, Westminster, Mid. dlesex; granted 1742; London; and Ripley, co. York.

Per chief az. and erm. three lions ramp. or. Monsire Richard Fitz-Henry, $Y$.

Per fess arg. and az. three lions pass. counter. changed. VALE.

Per fess arg. and erm. three lions pass. guard. in pale sa. Calcraft, Kent.

Per fess dancetty (or indented) az. and gu. three lions pass. in pale or. Sir Bryan Tuke, $V$.

Per fess indented az. and gu. three lious pass, or. Tuke, Cressiug Temple, Essex. 


\section{BEASTS.}

3 LIONS cont.

Per fess az. and or on the first three lions ramp. in bar arg. crowned or. Jon de Besenore, A, Harl. NS. 6137.

Per fess erm. and az. three lions ramp. in chief or. Fitz-Henry.

Pel fess embattled gu. and or three lions ramp. counterchanged. Wifield.

Per fess embattled gu. and sa. three lions pass. guard. arg. LiprincotT.

Per fess or and az. in chief three lions ramp. vert. Reynolds, London; granted 1714.

Per fess or and gu. three lions pass. counterchanged. Kenerby.

Per fess sa. and arg. three lions ramp. counterchanged. Young, Clare, Suffolk; the co-heirs $\mathrm{m}$. Cook and M'Lean.

Per fess sa. and arg. three lions ramp. guard. counterchanged. Younge, Buclihorne, and Colbroke, co. Dorset.

Per pale arg. (az. in pencil) and gu. three lions ramp. erm. Jeffray de Rous, $Y$.

Per pale arg. and sa. three lions pass. guard. in pale counterchanged. AsHiLl.

Per pale arg. and sa. three lions ramp. counterchanged. ETHERINGToN, Kingston-uponHull, and Ferriby, co. York. Hetherington. Hetherton. Sir Thomas Pullison, Lord Mayor of London 1584, living 1602, Harl. MS. 1319. Pultison, London.

Per pale az. and gu. three lions pass. guard. arg. Isaac MADDox, Bishop of St. Asaph 1735, Worcester 1745.59 .

Per pale az. and gu. tliree lions ramp. arg. Evans, Hill Court. Gwrn, Ford Abbey, co. Devon; quartering Prideaux and Fraunceis. Fitz-Herbert. Hearbbett. Sir Geolge Herbert, $\boldsymbol{V}$. Herbert, Baron Herbert of Gower and Chepstow, 1461, Earl of Pembroke 1468, (resigned ....) and of Huntingdon 1479, extinct 1491 , the heiress $m$. Somerset, $Z, 337$, 357. Herbert, as borne on an escucheon by Somerset, Earl of Warwick, $U$. William Herbert, Earl of Pembroke, at the Charterhouse 1619. Herbert, Baron Herbert of Cardiff, and Earl of Pembroke 1551, into which title merged, 1630, that of Herbert, Baron Herbert of Shurland and Earl of Montgomery 1605. Herbert, Red (or Powis) Castle, co. Montgomery; Baron Powis 1629, Baronetcy 16 November 1622 ; Earl of Powis 1674 ; Viscount Montgomery and Marquis of Powis 1687; extinct $1748, Z, 362$ (this family had a crescent for diff.). HERBERT, Baron Herbert 1624, Baron Herbert of Chirbury 1629, extinct 1691; renewed 1694; extinct 1738; renowed 1743; Baron Powis, Viscount Ludlow, Earl of Powis 1748; Baron Herbert of Cherbury and Ludlow 1749; extinct 1801. Clive, now Herbert, Baron Clive 1794 ; Baron Powis, Baron Herbert of Cherbury, Viscount Clive and Earl Powis 1804. Herbert, Earl of Torrington, Baron Herbert of Torbay 1689-1716. Hereert, Baron Porchester, 1780; Earl of Carnarvon 1793. Herbert, Tintern, co. Monmouth; Baronetcy 3 July 1660; extinct .... Herbert, Bromfield, co. Salop; Baronetey 1660; extinct 1669. Jones, Slowey, co. Somerset. Jones, Llauarth, and Treowen, co. Monmouth; derived from William ap JENKIN, alias HERBERT of Werndu, near Abergavenny ; quartering Corbet, Fitzwalter, Newmarch, Vivonia surnamed de Fortibus, Mallet, Ferrer's, Marshall, Strong-

\section{BEASTS.}

3 LIONS cont.

bow, Clare, Giffard, Macmorough, Blethin Broadspeare, Gwarinddy, Huntley, Hastings, Wallis, Morgan, Wyborne, and Lee. Morgan, Ashtowne,Wales. Prodgers. Edward Progers, Groom of the Bedchamber temp. Charles II. Progers, Gwarindee, or Werridu, co. Monmout descended from William ap JENKIN, alias HERBEnt, lord of Gwarindee, temp. Edward III. William Thonas, Bishop of St. David's 1678, Worcester 1683-9. VAUGHaN, Bridwarden, co. Hereford; Cleilow, co. Radnor; and Court Field, co. Monmouth.

Per pale az. and gu. three lions ramp. arg. a crescent and a label of five points or. Henry Herbert, Winister, $Z, 348$.

Per pale az. and gu. three lions ramp. arg. armed and langued or. Herbert, St. Julian's and Magor, co. Monmouth (derived from George, third son of William HerBerT first Earl of Pembroke), the heiress $m$. Baron Herbert of Chirbury. Herbert, Baron Herbert of Chirbury; Herbert, Earl of Powis; Herbert, Tintern; and Herbert, co. Kerry; all derived like Herbert, Coldbrook, co. Monmouth (the heiress, 1709, m. Powell), from Richard, third son of William Henbert, Raglan Castle, co. Monmouth, youngest brother of William Herbent, first Earl of Pembroke of the original creation. And with a crescent for diff. Evans, Hill House, co. Hereford.

Per pale az. and gu. three lions ramp. double tailed arg. Morgan.

Per pale az. and gu. three lions ramp. erm. Sir Johan le Rous, $N$. Jeffray de Rous, $Y$. Rous, co. Gloucester. Sir Roger Rouse, co. Gloucester, temp. Edward I, $V$.

Per pale az. and gu. three lions ramp. erm. armed gu. Rous, Lord of Immer.

Per pale az. and gu. three lions pass. or. Delaland.

Per pale az. and gu. three lions ramp. or. Gates, Essex. Herbert le Fitz Manewe, B. Mahu Fitz JOHAN, $G$.

Per pale az. and gu. three lions ramp. guard. or. G Gates, Essex, $V$.

Per pale erm. aud az. three lions ramp. or. Fitz-HenRy.

Per pale gu. and az. three lions ramp. arg. Sir Richard Esteney, $V$. Estudy or Estney. Herbert, Earl of Huntingdon, Lord Herbert of Gower and Chepstow, until 1491, $Z, 337$. Gile le Rous, $E$, or Rus, $F$. Sherman.

Per pale gu. and az. three lions ramp. arg. enraged counterchanged. HERBERT.

Per pale gu. and az. three lions ramp. erm. Philip le Fitz-Maneu, $E$. Le Fitz Manew, $F$. Mathew, $W$.

Per pale gu. and az. three lions pass. guard. in pale or. Henri de la Launde, G. Lawne.

Per pale gu. and az. three lions ramp. or. Fitz JoHn.

Per pale gu. and az. three lions ramp. guard. or. Gates, Essex, and Semer, co. York.

Per pale gu. and or three lions counterchanged. O'Brien, Blatherwycke Park, co. Northampton; descended through Henry O'Brien, Stonhall, co. Clare (who n., 1699, the heiress of Stafford of Blatherwycle), from Sir Donatus O'Brien, Dromoland, co. Clare; quartering arg. three piles gu., and arg. (properly? or) a pheon az. 
BEASTS.

3 LIONS cont.

Per pale gu. and sa. three lions pass. in pale arg. The O'Grady, Kilballyowen, co. Limerick.

Per pale gu. and sa. three lions pass. guard. per pale arg. and or the centre lion charged on the side with a portcullis (az. another) sa. O'GRADY, Viscount Guillamore, 28 Jauuary, $183 \mathrm{l}$.

Per pale or and arg. three lions pass. in pale gu. Lewelis, $V$. Leweliyn. Llewellyn, $V^{*}$.

Per pale or and az. three lions ramp. counterchanged. Rowse.

Per pale or and az. three lions ramp. gu. Sire Roger le Rous, $N$.

Per pale or and gu. three lions ramp. counter. changed. Rous, $V$. Rouse, $V^{*}$.

Per pale or and gu. three lions ramp. erm. Rous or Rowse.

Per pale or and sa. three lions ramp. counterchanged. Bishor, Pocklington, co. York.

Per pale sa. and arg. three lions ramp. counterchanged. Palliser, The Vache, co. Buckingham, and Castletown House, co. Wexford, Baronetcy 6 August 1773. PALliser, Deptford, Kent; granted 8 October 1773.

Per pale sa. and arg. three lions ramp. guard. counterchanged. Young, co. Dorset.

Per pale sa. and gu. three lions pass. arg. SteERE, Jayes, Dorking, Surrey; quarterıng Lee.

Per pale vert and gu. three lions pass. in pale arg. O'Grady, Harl. MS. 40:39, fo. 169 .

Per pale vert and gu. three lions pass. arg. Gradr, Ireland.

Per saltire or and erm. a lion pass. az. betw. two others pass. reguard. in pale gu. MAC MAHON, Baroneteies 6 May 1815, and 7 August 1817.

Purp. three lions ramp. or. Fitz-RaynoLd, co. Lancaster.

Quarterly az. and gu. three lions ramp. arg. Herbent, Earl of Pembroke, after 1661, when the bordure compony or bezanty and gu. was abandoned; (this coat seems false).

Quarterly gu. and az. three lions ramp. arg. Sr. William Morgan, $\boldsymbol{V}$.

Quarterly per fess indented gu. and az. three lions ramp. arg. MEdicotT, Abingdon, co. Berks; London; and co. Salop, 1634, Harl.MS. 1358, fo. 83. MedlycotT, Veu House, Milborne Port, co. Somerset; Baronetcy 3 October 1808.

Quarterly gu. and erm. three lions pass. with tails extended or. Shaxton, Buthell, Norfolk.

Sa. three lious nass. in pale arg. ENGLish, Oving. ton Manor, and Bucking, Essex. ENGLIsh, Kent, co. Lancaster, and co. Stafford. EngLish, $V$. Pylston, $V$. And with a crescent or (? for diff.) Richard BEADON, Bishop of Gloucester 1789, Bath, etc. 1802.24 , Cole, $M S$. xlix, fo. 3 b.

Sa. three lions pass. arg. Aigres, co. Nolth. ampton and Northumberland. Thomas English, Buckland, Maidstone, Kent, 1730. (? Hwyfa ap IorwerTH, heiress eventually to Puleston, thence to Cooke.) Mervyn, Durford, co. Hants. Pelstone.

Sa. three lions pass, guard, in pale arg. AYGLE.

Sa. three lions pass. guard. arg. John KETERICH or CATRICK, Bishop of St. David's 1414, Lichfield, etc. 1415, Exeter 1419-20.

Sa. three lious ramp. arg. AIgles, Northumberland and co. Nortbampton. Bernharr, $V$. Sire Johan le Englers, $N$. Sr. John Engleys, Northumberland and Cumberland, temp. Ed-
BEASTS.

3 LIONS cont.

ward I, V. ENGLish, Stockley English, and Bradninch, co. Devon. William Englishe, $Y$. Engleys or Englys. Englys, Northumberland. Preuz, V. Prous, Chugford, V. Prous or Prowze, Gidley Castle, temp. Henry II, and and Way, in Chagford, co. Devon; the heiress m. Moels or Mules. Younger branches were settled at Withecomb, Barnstaple, Tiverton, Crediton, etc. Prouse, $V^{*}$. Prouse or Precz. SANDFord. STANFORD.

Sa. crusily or three lions ramp. arg. Sire Wil. liam le Preuz, $N$, Sir William Preuz, Cornwall, temp. Edward III, $V$. Predze, $V^{*}$.

Sa. crusily fitchy or three lions ramp. arg. PReUX or Prewxe; quartered by Hastings, Earl of Huntingdon. Wilbury, $V$.

Sa. three lions ramp. arg. ducally crowned or. LAWFORD.

Sa. three lions ramp. arg. enraged gu. Misdmar. Prowse (a younger branch of Prouse or Prowze of Gidley, co. Devon).

Sa. three lions ramp. guard. arg. AlgLes, North. umberland ard co. Northampton.

Sa. three lions pass. guard. in pale erm. WALKER, co. Cambridge.

Sa. three lions pass. in pale or. William D'Arderne, $E$, or Ardern, $F$. Coumbe, $V$. Malefourd, $V$. Malford.

Sa. three lions pass, or. ARDERne. Bouchier, Essex. And with a crescent for diff. Richard BEADON, Bishop of Gloucester 1789, Bath, etc. 1802-24.

Sa. three lions pass. guard. in pale or with a cres. cent for diff. Bourchirr, Essex.

Sa. three lions pass. reguard. the two in chief recontrant or. DALWAY.

Sa. three lions ramp. or. Combe Coombe or Coumbe, Stratford on-Avon, co. Warwick. Duponce. Eyston, Isleworth, co. Middlesex; quartering through Stow of Burford, co. Oxon, De Arcubus of East Hendred, co. Berks. M. Reynaud le Fitz Plers, $D$. Gefrai Turbertile, $E$. Sa. crusily fitchy of seven and three lions ramp. or. WyBBURY, $V$.

Sa. three lions ramp. or armed and langued gu. Erston, East Hendred, co. Berks, 1716.

Sa. three lions pass. guard. per pale arg. aud or. Mervin, Pertwood and Fonthill Giffard, co. Wilts; Visitation 1565. Mervyn, Marwood, co. Devon; the heiress m. Cutcliffe.

Sa. three lions pass. guard. in pale per pale or and arg. Menvyn, Fonthill, co. Wilts.

Vert three lions pass. in pale arg. Magrath, Lambeth; quartering gu. an arm couped ppr. the hand holding a cross croslet fitchy or, with gu. an arm erect the hand holding a battle-axe in bend sinister ...., and vert a buck salient or.

Vert three lions pass. guard. arg. Merefield.

Vert three lions ramp. arg. WanWiCK. Warwick. WARDWICK.

Vert three lions ramp. arg. collared or chains fixed to the collar of the last pendent betw. the legs and over the loins. Tyson, Malton and Alrwick, Northumberland.

Vert three lions ramp. arg. crowned or. LYMraRake, $V$. Sir Jolnn Mardenike, $V$. Mardewike, $V *$. Tison, Northumberland, and co. Wilts. Tyson, impaling Bevers, 1761.

Vert three lions ramp. arg, crowned collared and chained or. Tison or Trson, Woodland Green, co. Gloucester ; granted 24 February 1708. 


\section{BEASTS. 3 LIONS cont.}

Vert three lions ramp. arg. crowned ducally gorged and chained or. Tusos.

Vert three lions ramp. tail forked arg. WaRDwrkE, John WARDWICIE, Y. WARWICK or WARWYIE.

Vert three lions ramp. or. LoNG.

Vert three lions ramp. guard. or. William Chelmick, Ragdon, co. Salop; granted by Cooke, $W$; confirmed 1 June 1582, Harl. MS. 1359, fo. 123 b. Chilnick, Ragdou, co. Salop.

Vert three lions in fess per pale arg. and or. Springham, Dublin.

\section{LYNXES}

Sa. three lynxes pass. guard. arg. LrNCH.

Sa. three lynxes salient arg. Linch.

Sa. three lynxes ppr. LxNcH, Kent.

\section{MOLES}

Arg. three moles sa. Nancothan, Redriff, Corn. wall. Nangathan. Nangarthian. Wighton. Arg. three moles sa. snouts and feet gu. Mangotham, Scotland. Nangothan or Nangothair, Scotland.

\section{OUNCES}

Sa. three ounces statant in pale or spotted of the first. Sir James Bourchen; 1610; Harl. MS. 6095 , fc. 15 b.

\section{OTTERS}

Arg. three otters issuant out of a fess wavy sa. Meldrun, Fyvie, Scotland.

Arg. three otters pass. sa. WoRCELl or Worsell.

Az. three otters in pale or. Prode, Kent; in Canterbury Cathedral.

Az. three otters pass. in pale or each holding in the mouth a fish arg. Pfoude, Egston, Kent.

\section{OXEN}

Arg. three calves (pass. $V^{*}$ ) statant gu. CAIFE, $V$. Arg. three calves sa. Duncalfe, Foxley, co. Chester. Metcalfe.

Arg. three bulls pass. sq. Hamelen Hamelin Hamelyn Hameline and Hanelyng. Hayton. STICKLEWEY, $V^{*}$. Thomas STIKLEWEY, $V$. STRIKLEWEY, $V^{*}$.

Arg. three calves pass. sa. Medcalf, Askrigh, Berepark, and Reddall, co. York. MEdcalfe or Metcalfe, Chelmsford, Essex; and co. York. Metcalre, Hawstead, Suffolk.

Arg. three bulls pass. sa. armed or. AsHLEy, co. Somerset. Cooper, Wimborne St. Giles, co. Dorset.

Arg. three bulls pass. sa. armed and langued gu. Hadielrn or HaMiLing.

Arg. three bulls pass. sa. armed and unguled or. Ashley-Cooper; Baronetcy 4 July 1622; Baron Ashley, 20 April 1661; Baron Cooper and Earl of Shaftsbury, 23 April 1672; quartering Cooper.

Arg. three cows pass. sa. eyes gu. collared or. Benedictine Alien Priory at Cowick Cowike or Cuich, co. Devon.

Arg. three calves statant sa. Sir James Metcalfe, $V$.

Arg. three bulls statant sa. armed or. Hamelyn, $V$.

Erm. three bulls pass. or. Horne.

Or three bulls pass. sa. SQuibB, Reading, co. Berks.

Or three bulls pass. sa. armed gu. Seurbi, co. Dorset.

Tert three bulls salient arg. Rowland LEE, Bishop of Lichfield, etc. 1534-43.

\section{BEASTS.}

3 SEALS

Per chev. sa. and arg. three seabears counter. changed. Flowerdew, Norfolk.

\section{SHEEP}

Arg. three rams pass. sa. Sydenhas, Brimpton, co. Somerset; Baronetcy $28 \mathrm{July} 16 \pm 1$; extinct 10 October 1739; Sydenham, and Kitsford, co. Somerset: with its branches at Coombe, Or. chard, Chelworthy, and Whetston, co. Somerset; and Winford Eagles, co. Dorset. Simon Sydenham, Bishop of Chichester 1431.8.

Az. three holy lambs or. Row, co. Devon, 1716. $\mathrm{Az}$. three paschal lambs pass. or. Lamb.

Gu. three holy lambs staff cross and banners arg. Rowe, Tolesby Hall, co. York. Rowe, Tavistock, co. Devon; a younger branch of Rowe, Lamertou, co. Devon, Visitation 1620.

Gu. three paschal lambs pass, arg. the banners charged with a cross gu. LAMB.

Gu. three paschal lambs or. Rowe or RAwe, Cornwall.

Gu. three rams arg. Ramsey.

\section{SQUIRRELS}

Arg. three squirrels sejant cracking nuts gu. Marthebr.

Or three squirrels gu. AshweEd. SQume.

Vert three squirrels sejant arg. BAxter.

\section{URCHINS}

Arg. three hedgehogs sa. Brramr. Couse. Harries, Mabie, Scotland. Herrz.

Arg. three porcupines sa. Brron, Byron, co. Lancaster.

Az. three hedgehogs arg. Heriz. Herys.

Az. three hedgehogs or. Heriz, co. Leicester. Herrer. Sweliton, $V^{*}$. Swilton. Swinborne or SWYNBORNE.

Az. three hedgehogs (or porcupines) or. AbRAHALL, co. Hereford; quartering Kyrle.

Az. three urchins pass. in pale or. Wood.

Az. three hedgehogs statant or. Sir Roger SWELYTON, $V$.

Or tbree hedgehogs az. Harris, Boreatton, co. Salop; Baronetcy 16 Dec. 1622; extinct 1685.

Or three urchins (? boars) statant az. Henry de Herice, $A$.

Or three hedgehogs pass. in pale gu. Hercy.

Or three porcupines sa. Henrs. Hercy. Henry de Herice, A, Harl. MS., 6137.

\section{WEASELS}

Gu. three weasels courant arg. ScHoppin.

\section{WOLVES}

Arg. three wolves courant in pale az. NANphant. Cornwall. Penpons, Treswithan, Cornwall.

Arg. three wolves (pass $V^{*}$ ) statant in pale az. Nanfant or Ponpons, $V$.

Arg. three wolves pass. gu. Hacker. Lovetr, Derby; a younger branch of Lovett of Stantou, co. Leicester.

Arg. three wolves pass. gu. on the shoulder of the first a mullet or. Roger WHELPDALE, Bishop of Carlisle 1420-3.

Arg. three wolves pass. ppr. Lovetr, Belmont, co. Salop.

Arg. three wolves pass. in pale sa. LoverT, Liscombe, co. Buckingham; Baronetcy 23 Ociober 1781; extinct 30 January 1812. Lovetr, $V^{*}$. Lovet or Lovetr, Codnor, co. Derby; Tavistock, co. Devon; Essex; co. Huntingdon; and Ostwell, co, Nortlampton. Penpons, Penpons, in St. Kew, Cornwail; the heiress $\mathrm{m}$. Arundell. 


\section{BEASTS. 3 WOLVES cont.}

Arg. three wolves pass. sa. Levet, LevetT or Levitr, Ireland. Lovate, Clayton Hall, co. Stafford; descerded from Lovett, Astwell, co. Northampton; the herrs m. Booth and Wise.

Arg. three wolves sa. two in chief (ramp.?) combatant one in base pasa. Clay.

Arg. three wolves statant in pale sa. William Lovet, $V$.

Az. three wolves pass. al'g. Crowas.

Az. three wolves pass. arg. collared or. Crowan.

Az. three wolves (pass. $V^{*}$.) statant in pale arg. collared or. Crowan, $V$.

Az. three wolves pass. or. Mandevire, Essex.

$\mathrm{Gu}$. three wolves pass. arg. LELon or LELow.

Or three wolves statant in pale az. Woor,Fs; confirmed 1 July 1588, Harl. MS. 1359, fol. 13.

Vert three wolves pass. arg. Stanhope, co. York.

Vert three wolves pass. in pale or. Mandevine. Manloveli, $V$.* Mauloveli, $V$. John Stanhop, Tuxford-en-Clay, $V$.

Vert three wolves pass. or. Stanhope, co. York. 3 BEARS and in chief....

\section{Annulets}

Arg. three boars az. in chief as many annulets of the last. KruBy, co. York.

\section{Chief}

Arg. three boars pass. az. a clief of the last. GREGOR.

on a Chief.... (Beast) Lion

Az. three boars pass. in pale arg. on a chief gu. a lion pass, or. Druocke, Erdington, co. Warwick.

Or three boars az. on a chief of the second a lion pass. of the first. GraGor or Gregor.

\section{CATS and in chief....}

Pean three mountain cats pass. in pale arg. on a canton or a fess gu. surmounted by an anchor of the third encircled by a wreath of laurel vert. Keats, Dorrant House, Dover; quartering Goodwin.

\section{Chief}

\section{DEER and in chief...}

Arg. three buclss trippant ppr. a chief az. PAREer, Upton Cheney, co. Gloucester.

Arg. three stags sa. attired or a chief az. Rogers, Bristol and Eastwood, co. Gloncester.

Az.three stags or a chief of the second. Grees, Poulton, co. Chester.

Erm. three bucks pass. gu. a chief az. Buythe, co. York.

Erm. three bucks gu. attired or a chief az. BLythe, co. York.

\section{on a Chief.... Castle}

Or three hinds trippant gu. on a chief of the last a tower tripple-towered betw. two escucheons of the first. SKUT, Stanton-Drew, co. Somerset.

Or three hinds pass. ppr. on a chief $\mathrm{gu}$. a tower of the first betw. two escucheons arg. Scutr, Micklefield, co. Suffolk.

Or three hinds pass. ppr. on a chief gu. a tower betw. two escucheons of the first. Scutre, co. Dorset.

Or three hinds trippant ppr, on a chjef gu. a castle betw. two escucheons of the second. Skutt, co. Somerset.

$$
\text { ..... Crescents }
$$

Az. three bucks trippant erminois on a chief or three crescents sa. GreEn, I'oulton Hall, co. Chester.
BEASTS. 3 DEER and in chief....cont.

on a Chief cont. Cross

Erm. three bucks trippant gu. on a chief indented per pale or and az. a cross patonce counterchanged betw. two roses the dexter gu. the sinister or. Geoffry Buytue, Bishop of Lichfield, etc. 1503.31.

$$
\text { ..... Fruit }
$$

Erm. three bucks trippant sa. on a chief wavy az. as many acorns slipped or. Rogers, Yarlington, co. Somerset; quartering Robinson, Liroyd and Pickering.

\section{Mullet}

Az. three bucks or in chief a mullet....GREEN, co. Oxford 1605.

\section{DOGS and in chief....}

on a Canton (Beast) Deer

Erm. three greyhounds courant sa. collared gu. on a canton of the last a lion pass or. Moore, Appleby-Parva, co. Leicester and co. Derby. ..... Lion

Erm. three greyhounds courant sa. and on a canton gu. a lion of England for augmentation. Moore, Lord Mayor of London 1682. Chief

Arg. three hounds sa. a chief per pale erm. and gu. Barley, co. Derby.

Per pale wavy arg. and vert three greybounds courant counterchanged a chief indented arg. Tominson, Cholmondeley, co. Chester.

Per pale wavy arg. and vert three greyhounds courant counterchanged a chief indented az. Thomlinson, Blencogo, Cumberland.

Per pale wavy arg. and vert three greyhounds counterchanged a chief invecked az. Thombinson, Gateshead, co. Durham ; Visitation 1615.

on a Chief..... (Beast) Deer

Vert three hounds comrant bendwise at random arg. on a chief of the last a stag in full speed ppr. Wudish, quartered by Pie 1716.

$$
\text { .....Fox }
$$

Vert three greyhounds arg. gutty-de-larmes on a chief or a fox pass. gu. WELdisH, Lynton, Kent; granted 14 March, 1542.

$$
\text { .....Crosses }
$$

Arg. three greyhounds courant in pale sa. on a chief engr. az, as many crosses croslet or. ToMLINSQN.

\section{.....Horns}

Vert three greyhounds courant arg. on a chief of the last as many buglehorns sa. stringed gu. Hunter.

Vert three dogs of chase arg. collared or on a chief of the second as many hunting borns of the first stringed gu. Hunter, Kirkland, co. Ayr; descended from Robert second son of Robert Hunter of Hunterston living 1674. Hunter, Croyland, co. Lincoln; descended from James fourth son of Robert HunTER of Hunterston living 1674; quartering Orby, Howard and Gerard. Hunter, Hunterston, co. Ayr.

\section{Roundle}

Gu. three greyhounds courant az. in chief a torteau.... Pentpans.

\section{GOATS and in chief....}

Arg. three goats pass. gu. a chief az. Buythe. Az. three goats pass. and a chief arg. HALEY, London, and Edgware Bury, Middlesex. 
BEASTS. 3 LEOPARDS and in chief....

Arg. three leopards ramp. gu. (on a chief of the second a lion pass. of the first?) YONGE.

Or three leopards pass. ppr. on a chief sa. a demi griffin segreant erm. liolding in the mouth a key as the second betw. two 5-foils of the fourth. GreEN, Milnrow, co. York; Baronetes 5 December 1805 ; extinct 12 July 1831 .

\section{LIONS and in chief....}

\section{Canton}

Az. three demi-lions ramp. arg. a canton.... HARRISON, Orgrave, co. York; quartering Swyft by descent from Swyft, Darnal, through Dicksoll.

.... three lions ramp. .... a canton erm. Henry Forstesisuri.

Arg. three lions ramp. gu. a canton of the second fretty or. Bucriand, Langley, co. Buckingham.

Erm. three lions ramp. gu. crowned or a canton of the second. MERry, Barton, co. Derby; the heiress m. Simpson.

on a Canton.... Fret

$\mathrm{Gu}$. three lions ramp. arg. on a canton sa. a fret or. Buckland or Bucinze, co. Somerset.

$\mathrm{Gu}$. three lions ramp. guard. or on a canton of the second a fret of the first. Jones, Dublin. .... Roundles

Or three lions ramp. sa. on a canton of the last three bezants. GoDwIN, $V^{*}$. Thomas GoDwys, Bishop of Bath and Wells 1581-90, Harl. MS. 1359 , fo. 119 ; (but the lions appear to be pass. and the name GodyN, Harl. MIS. 1069, fo. 60); granted by Cooke, $W$.

Chief

Gu. three demi-lions and a chief or. Fisher.

Gu. three demi.lions ramp. and a chief or. Sir Edward Fisher, London, 1533-4, Harl. MS. 1358 , fo. $85 \mathrm{~b}$.

$\mathrm{Gu}$. three demi-lions ramp. couped and a chief or. Fisher, co. Gloucester, co. Hertfurd and co. Stafford.

Gu. three demi-lions ramp. and a chief indented or. Fisher, Middlesex.

Or three demi-lions ramp. and a chief indented gu. Fishar or Fisher, co. Hertford; London; and co. Stafford; granted July 1614, Harl. MS. 6095 , fo. 32. Sir Thomas Fismer, Loudon, $W$.

Arg. three lions ramp. and a chief az. GRANr, Crundali, co. Hants, 1716.

Arg. three lions ramp. gu. a chief az. Thomas, Yapton Place, co. Sussex, Baronetcy 6 September 1766, and his descendant Freeman, now Thонаs, Ratton, co. Sussex.

Arg. three lions pass. guard. (another salient reguard.) and a chief gu. Yelverton.

Arg. three lions ramp. and a chief gu. Yelverton, Easton-Manduit, co. Northampton. Yelverton, V. Yelverton, Baron Grey de Ruthin, 1329; Viscount Longueville, 21 April 1690, and Earl of Sussex, 26 Sept. 1717, extinct 1799; quartering Grey. Yenverton, Baron Avonmore, 19 June, 1795, Viscount Avonmore, 29 Dec. 1800.

Arg. three lions ramp. guard. and a chief gu. Yelterton, Rougham, co. Norfolk.

Arg. three lions ramp. guard. sa. a chief gu. Yelverton, Norfolk, $V$.

Az. three lions ramp. or a chief arg. Butron, co. Wilts. Grace. Nicholas le Gras, $A$. Grasse. GRANT, alias BUTTELL; quartered by Weld, Harl. MS. 6095, fo. 23 b. Nicholas Le Gros, V. Le Gross, $T^{*}$. Legrosse.
BEASTS. 3 LIONS and in chief....cont.

Chief cont.

Az. three lions ramp. or a chief of the first fretty arg. Grace.

Gu. three lions pass. or a chief indented az. Tuck.

Per chev. az. and or three lions pass. guard. in pale counterchanged a chief arg. CATLIN or Catlyn, co. Bedford; and Rand, co. North. ampton.

Per pale arg. and sa. three lions ramp. counterchanged a chief arg. Etherington, co. York. on a Chief.... (Beast) Lion

Arg. three lions ramp. az. on a chief gu. a demilion ramp. issuant or. De GoRe, $V *$.

Arg. three lions ramp. az. armed and langued gu. on a chief of the last a demi-lion ramp. issuant or. O'GARA; Harl. MS. 4039, fo. 64 .

Az. three lions ramp. arg. on a chief gu. a demilion ramp. issuant or. G $\mathrm{ARE}$, Kent. Sir Simon At Gare, $V$.

Az. three lions ramp. arg. on a chief gu. a demilion ramp. couped or. George De Gore, $V$.

Az. three lions ramp. or on a chief gu. a demilion ramp. of the second. Gore.

Arg. three lions ramp. guard. gu. (on a chief of the second a lion pass. of the first ?) YoNGE.

Az. three lions ramp. arg. on a chief gu. a lion pass. or. GORE.

.... (Beasts) Lions

Arg. three lions ramp. gu. on a chief of the second as many ramp. guard. of the first. YELVERTON, $V$.

Arg. three lions ramp. guard. gu. on a chief of the second as many of the first. Yelverton, $V^{*}$. ..... Crescents

Arg. thlee lions ramp. sa. on a chief indented az. as many crescents or. Harver, Ireland; granted in Ireland, 1665.

..... Crosses

Az. three lions ramp. arg. on a chief of the last as many crosses croslet sa. Mathew, Coggeshall, co. Essex.

\section{.... Escallops}

Arg. three lions ramp. gu. on a chief az. as many escallops of the first. Power.

Erm. three lions ramp. gu. on a chief sa. as many escallops arg. each charged with a cross of the second. Power.

$$
\text { ..... Flower }
$$

Per chev. az. and or three lions pass. guard. counterchanged on a chief arg. a rose gu. barbed vert seeded gold betw. two fleurs-de-lis of the fourth. CatTelen or Catiyn.

Per pale az. and gu. three lions ramp. arg. a chief per pale or and arg. charged on the dexter side with a rose gu. and on the sinister with a thistle vert. Pembroke Corlege, Oxford; founded 1620 .

$$
\text { ......Fret }
$$

Gu. three lions ramp. or on a chief of the second a fret of the first. Jones, Wateringbury Place, co. Kent.

$$
\text { .....Hand }
$$

Arg. three lious ramp. gu. armed and langued az. on a chief of the last a dexter hand fesswise couped at the wrist ppr. holding a dagger arg. hilt or in pale betr. two pheons of the last. O'Kearnea, alias CARNEY, Harl.MS.4039, fo.153. .....Human Figure

Az. three lions pass. guard. in pale or on a chief gu. the Virgin and Child of the second. Augus. tinian Priory at NEwstead, co. Nottingham. 
BEASTS. 3 LIONS and in chief.... cont.

on a Chief....Human Figure cont.

Gu. three lions pass. guard. in pale or on a chief az. the Virgin aud Child of the second. Augustinian Priory at Newstead, co. Not. tingham.

$$
\text { ....Reptiles }
$$

Per chev. az. and or three lions pass. guard. in pale counterchanged on a chief arg. as many adders nowed erect sa. Richard Catlyn, Hatford Hall, co. Norfolk; certified 1 December, 1555; Harl. MS. 1359, fo. $62 \mathrm{~b}$.

\section{Head}

Per saltire or and arg. three lions ramp. az. armed and langued gu. in the chief centre section an open helmet affronty unbarred ppr. on a chief gu. three escallops arg. Power, Roebuck House, co. Dublin; Sampton and Edermine, co. Wexford; Baronetey Aug. 1841. Quarter

Ar. three lions ramp. gu. a quarter sa. fretty or. Sr. .... de Bucnland, $V$.

$\mathrm{Gu}$. three lions ramp. ar. a quarter sa. fretty or. John de Bucklonde, Y. John Wroth, $V$. WROTHE, $V^{*}$.

\section{OXEN and in chief....}

Arg. three calves pass. sa. a canton gu. Metcalfe, London.

Az. three bulls pass. arg. (another, or) a canton erm. Bishopton, co. Warwick.

3 SQUIRRELS and in chief....

Or three squirrels sejant ppr. a chief gu. in the dexter corner a cross patty of the field. Boonne, Battle, Sussex.

\section{GOATS and in base. .}

Az. three goats salient arg. in the dexter base a rising sun or. County of MERIONETH.

\section{LEOPARDS and in base....}

Per chev. arg. and gu. in chief three leopards of the second in base a crescent or. Chapman.

\section{Bars}

\section{LIONS and in base....}

Arg. three demi-lions gu, and two bars wavy az. Milizigan or Mullukine, Scotland.

Arg. three lions gu. issuant out of two bars wavy az. Mullikine, Scotland.

Erm. three lions and in base as many bars gu. KNYLL, Knill, co. Hereford.

Crescent

Per chev. arg. and gu. in chief three demj-lions of the second in base a crescent of the first. Chapdian.

Per chev. arg. and gu. in chief three lions pass. guard. of the second in base a crescent or. Chapman.

\section{Water}

Arg. three demi-lions gu. issuant out of water ppr. Muluiken, Scotland.

3 BEARS betw. or within....

Or three bears pass. within a bordure engr. sa. WIGTON, $V^{*}$.

Sa. three dancing bears or a bordure arg. BAFFORD, co. Nottingham.

3 BOARs betw, or within....

\section{Bordure}

Or three boars pass. within a bordure engr. sa. WigToN.

Vert three boars or on a bordure arg......fleurs de-lis az. Maurice Fitz-Rogen, Whitington.
BEASTS, 3 BOARS betw, or within....cont.

\section{Crosses}

Arg. three boars statant sa. and as many crosses patty in pale gu. Boteler, $V$.

\section{DEER betw, or within....}

Bordure

Az. three bucks trippant within a bordure or. Green, Wylin, co. Warwick; and Rolleston, co. Leicester; quartering Pell, Fortrey, Jocelyn, Bardolf, etc.

Vert three bucks courant arg. attired or within a bordure of the second. Trollope, Casewick, co. Lincoln ; Baronetcy 1611.

Vert three bucks pass. within a bordure or. GrEen.

\section{Crosses}

Vert three stags trippant two and one betw. two crosses croslet in chief and one in base or. Green, Chiddingly, Sussex, quartering Verral.

3 DOGS betw. or within...

\section{Bendlets}

Arg. three greyhounds courant in bend betw. two cotises and three eagles displ. sa. Craye, Wickford, Isle of Ely.

\section{Bordure}

Arg. three greyhounds courant sa. Lovet, co Nortliampton, quarterly with erm. simply, all within a bordure of the second platy.

Az. three greyhounds courant in pale arg.collared gu. within a bordure of the third. Berington, co. Salop.

Sa. three greyhounds courant in pale arg. collared gu. a bordure of the second. Berington, Bradwell and Sandbach.

Sa. three greyhounds courant in pale arg. collared or within a bordure of the second. MACBELL, Wendover, co. Buckingham.

Sa. three greyhounds courant in pale arg. within a bordure compony or and gu. Mychell, $V^{*}$.

Sa. three groyhounds courant in pale arg. collared or within a bordure compony or and $\mathrm{gu}$. MrcheLL, co. York, $W$.

Sa. three greyhounds courant in pale arg. collared gu. within a bordure of the third. BarINGTON or BERINGTON.

Sa. three greyhounds courant (in pale?) arg. collared or within a bordure gu. a crescent for diff. Berington, Wintercott, co. Hereford; and Little Malvern Court, co. Worcester.

Sa. three greyhounds courant in pale arg. collared gu. within a bordure engr. or. MacheIL, Swaley, co. Lincoln.

Crosses

Arg. three greyhounds courant betw. ten crosses formy fitchy sa. Sirth, London; and Crabbett, Sussex.

Arg. three greyhounds courant in pale sa. collared or betw. ten crosses patty fitchy of the second. Sмгтн, temp. Henry VIl, $V$.

\section{GOATS betw, or within....}

Or three goats salient within a bordure sa. Thorold, Boston, co. Lincoln; confirmed 10 November 1631.

Sa. three goats courant arg. within a bordure engr. of the last. CHaMber, $V$.

Sa. three goats pass. arg. within a bordure engr. of the last pellety. Stanfield, co. York.

Sa. three goats pass. arg. within a bordure or pel lety. Stanfield. 


\section{BEASTS. 3 HARES betw, or within....}

Arg. three conies within a bordure sa. Tripconie, Cornwall.

Gu. three conies sejant within a bordure engr. arg. ConingsBy, Norfolk.

Gu. three conies sejant arg. within a bordure engr.sa. Sr. Humfry ConesBy, co. Hereford, $V$. Coningsby, Norfolk, and co. Hereford.

$\mathrm{Gu}$, three rabbits arg. within a bordure engr. sa. LONESBY.

\section{HORSES betw. or within....}

Sa. three nags pass, arg. within a bordure or. Trotter.

\section{LEOPARDS betw, or within ....}

\section{Bendlets}

Arg. three leopards in bend sa. betw. two bendlets gu. Kenewrche, co. Lancaster.

\section{Bordure}

$\mathrm{Gu}$. three leopards pass. in pale within a bordure or. Holland.

\section{LIONS betw, or within....}

\section{Bars}

Az. three lions pass. in pale or and two bars arg. Minterin or Minterne, Batcombe, co. Dorset; and Thorpe, Surrey.

Gu. three lions pass. in pale or and two bars bumetty arg. Gibson, Teede, co. Lancaster. Margaret Gibson, wife of Ascue; granted 5 June 1557-8, Harl. MS. 1359, fo. 80.

Sa. three lions ramp. and two bars dancetty arg. Dandelion Dauntenlion or Dent de Lion, Margate, i. e. Jsle of Thanet, temp. Edward I. The heiress, daughter of John, whose effigy is in the north, or St. James's, chancel of St. John's Church (a brass, 1445), m. Petit of Shalmesford, near Chatham.

Sa. three lions ramp. in fess betw. two bars dancetty arg. Petxt.

Az. three lions pass. guard. in fess betw. two bars gemels arg. PiERS, Tristernagh Abbey, co. Westmeath; Baronetcy 18 February 1660.

Sa. three lions pass. and two bars gemels arg. a crescent or. BROWNE.

\section{Bendlets or Cotises}

Arg. three lions pass. guard. sa. between two bendlets gu. KeкEWICHE. Kекеwich, $V *$. KeKewyche, co. Lancaster.

Arg. three lions pass. in bend betw. two bendlets sa. Hawrrey, Ascott, Middlesex. Kenewyche, co. Lancaster.

Gu. three lions pass. (guard. $V^{*}$.) in bend arg. betw. two bendlets compony az. aud of the last. Moliyne, $V$.

Or three lions pass. in bend sa. betw. two bendlets vair. GAPE, St. Alban's, co. Hertford ; granted 1684.

Sa. three lions in bend betw. two bendlets arg. Brown.

Sa. three lions pass. betw. two bendlets arg. a 3 -foil in chief for diff. Browne, London, 1633 . 4, Harl. MS. 1358, fo. 61 b.

Sa. three lions pass. betw. two bendlets arg. and as many 3-foils slipped erm. Browne, Woodsmore, co. Hertford.

Sa. three lions pass. in bend betw. two bendlets engr. arg. Sr. Mathew Browne, Bechworth, $V$. Browne, lient.

Arg. three lions ramp. in bend betw. four cotises sa. Hawtre, co. Buckingham.
BEASTS, 3 LIONS betw, or within.... cont.

Bendlets or Cotises cont.

Sa. three lions pass. in bend betw. two double cotises arg. Sir Anthony Brown, Viscount Montagu, $V^{Y}$; $Z, 34^{2}, 356$; a beiress $m$. Poyntz. Browne, Bechworth, $V$; or Betchworth Castle, Sirrey. Browne, Baron Monteagle 1760 and 1806, Viscount Westport 1768, Earl of Altamont 1771, Marquis of Sligo 1800. Browne, Caughley, and the Woodlands, co. Salop. Browne, Passage, co. Cork; and Bronwylfa, St. Asaph.

Sa. three lious pass. in bend betw. two double cotises arg. a crescent for diff. Browne, Galston Park, co. Westmeath, and the Neale, co. Mayo; Baronetcy 21 June 1636, Baron Kil. maine 1789. Browne, Ballinvoher, co. Cork, 1647 .

Sa. three lions pass. in bend betw. two double cotises arg. a mullet for diff. Browne, Baronetcy 8 December 1797 ; quartering De Beauvoir.

Sa. three lions pass. in bend arg. crowned or betw. four cotises of the second. HAWTRE, co. Bedford.

Sa. three lions ramp. betw. two double cotises arg. Browne, $V^{*}$.

\section{Birds}

Or three lions pass. gu. betw. three popinjays ppr. PEDWARDYN.

\section{Bordure}

Arg. three demi-Jions ramp. couped gu. within a bordure gu. of the last charged with eight bezants. Fisher, co. Northampton, $W$.

Arg. three lions pass. in pale within a bordure az. Grigg, Bealing Parva, Suffolk.

Arg. three lions pass. in pale gu. armed and langued az. within a bordure of the last. M'Kineriny, Harl. MS. 4039, fo. 139.

Arg. three lions .... gu. within a bordure engr. az. Gloucester, co. Gloucester.

Arg. three lions ramp. gu. within a bordure 'cersele' az. Monsire de Groucestre, $Y$.

Arg. three lions ramp. gu. within a bordure indented az. Sire Walter de Glovcestre, $N ; O$. Arg. three lions ramp. gu. within a bordure sa. William de Kirkham, $E$. Nichol de Kirkeam; F.

Arg. three lions ramp. gu. within a bordure engr. sa. KirkHam, Ashcombe, temp. Henry III and Blackdon, co. Devon, temp. Edward I; the herress m. Blount; a younger branch settled at Pinhoe.

Arg. three lions ramp. gu, within a bordure in. dented sa. Sire William de Bercenous, $N$.

Al'g. three lions pass, in pale sa. armed and lan. gued gu. a bordure chequey (another compony) of the second and or. CAIEw, Kent.

Az. three lions ramp. within a bordure arg. Chich, $V^{*}$. CHiche, $V$. ChickIEs.

Az. three lions ramp. or ducally crowned gu. within a bordure erm. Froun.

Erm. three lions ramp. within a bordure engr. gu. Kincham or KirEHam.

Erm. three lions ramp. gu. within a bordure engr. .... Cuthbert Blakeden, Serjeant of the Confectionery to Henry VIII; in Thames Ditton Church, co. Surrey, $15 \pm 0$.

Erm. three lions ramp. gu. within a bordure engr. sa. Belnouse, Essex. Kirkeham, $V^{*}$. Sr. John Kyrkнam, Blakedon, co. Devon, $\boldsymbol{V}$.

Erm. three lions ramp. within a bordure or. BlackMan, London, and East Indies. 
BEASTS, 3 LIONS betw, or within.... cont.

Bordure cont.

Ermines three lions ramp. or a bordure of the second semy of cresceuts az. Blackman, quartered by Harnage.

Gu. three lions pass. guard. in pale arg. on a bordure az. ten saltires of the second. City of HEREFORD.

Gu. three lions ramp. arg. within a bordure countercompony arg. and gu. Ross, Kindies, Scotland.

Gu. three lions ramp, arg. within a bordure countercompony or and gu. Ross, Pilkerie, Scotland.

Gu.three lions pass. in pale arg. within a bordure or. Elys GiFFARD, $A$.

Gu. three lions ramp. arg. within a bordure or charged with as many leopards' faces of the first. Ross, Belfast.

$\mathrm{Gu}$. three lions ramp. arg. within a bordure in. vecked sa. Ross, Nuik, Scotland.

Gu. three lions ramp. within a bordure erm. Wirlis, Warlis, Essex.

Gu. three lions pass. guard. in pule or within a bordure arg. Edmund de Woopsrock, Earl of Kent, son of Edward II, $V$; Conte de KENT, $Y$; i.e. Edmund (of Woodstock) Plantagenet, Earl of Kent, 1321, ob. 1330 ; sixth son of Edward II, $Z, 215,216$. And his children, Edmund, ob. 1332; and John, ob. 1352, successively Earls of Kent; and Joan the Fair Maid of Kent, who m. Sir Thomas Holand, created Earl of Kent and Baron Wake of Lidel; so that this coat was assumed by le Conte de Kent (Holland), $S$, her son Thomas Holand, Earl of Kent and Baron Wake, 1360, Marshal 1380,ob. s. p. 1397 ; and was the coat as well of his six daughters and co-heirs as of his sons Thomas ob. 1400, and Edmund ob. 140\%, Z, 154, 205, $215.8,311,324,378$.

Gu. three lions pass. guard. in pale or within a bordure engr. arg. OnIel Coliege at Oxford, founded 1323 by Adam de Brome, Confessor of Edward II.

$\mathrm{Gu}$. three lions pass. guard. in pale or within a bordure az. Contee de Chestre, $Y$.

$\mathrm{Gu}$. three lions pass. guard. in pale or within a bordure az. semy of fleurs-de-lis gold. Conte de Cornewaille, $Y$; $i . e$. Johu (of Eltham) Plantagenet, Earl of Cornwall, 1328, ob. 1334, second son of Edward $11 ; Z, 153$. Le C. de Huntyndon (in a later hand Duke of Excester, Holland), $S ; i$. e. John Holrand, Earl of Huntingdon 1388, Duke of Exeter 1398, V, ob. 1400 ; and his son Richard, ob. 1415 ; and another son Joln, Duke of Exeter, Earl of Huntingdon and Ivory, Lord of Sparre, ob. 1446 ; and his son Henry, ob. $1473, Z, 218,219$.

$\mathrm{Gu}$. three lions ramp. or within a bordure engr. arg. Reginald Fitz-Piens, $V$. M. Edmond Fitz-Hugh, $S$. Pevereil, $V$. Fitz-Pyers, $V^{*}$.

Gu. flory or three lions ramp. within a bordure of the second. Wilbury, co. Devon.

$\mathrm{Gu}$. three lions ramp. or within a bordure in. dented arg. Sire Reynald le Fitz-Renald, $O$.

Gu. three lions pass. guard. in pale or over all a crosier the staff gu. crook sa. all within a bordure of the last bezanty. Cistercian Abbey at VALE-Royal, co. Chester.

Gu. three lions pass, guard. per pale or and arg. within a bordure az. charged with eight escallops silver. O'MEARA, (pencil note in) Harl. MIS. 4039 , fo. 44 .
BEASTS. 3 LIONS betw. or within.... cont.

Bordure cont.

Or three lions pass. guard. in pale gu. within a bordure of the last charged with six crescents as the first. O'MEARA, Ireland, Harl. MS. 4039 , fo. 44 .

Or three lions ramp. sa. within a bordure engr. az. MaLLoRy.

Per chev. az. and or three lions pass. guard. in pale counterchanged within a bordure arg. Robert Catelyn, Rondes, co. Northampton, $W$. Catlyn, $V^{*}$. Catlyne.

Per fess arg. and erm. three lions pass. guard. in pale sa. within a bordure wavy az. Calcraft, Ingress, Kent; granted 8 December 1770 .

Per fess gu. and arg. (sometimes per fess gu. and erm.) three lions ramp. counterchanged within a bordure erm. Willis, Fen-Ditton, co. Cambridge; Horingsley, and Bales, co. Hertford. WILL1s, co. Dor'set.

Per pale az. and gu. three lions ramp. arg. within a bordure compony of the second and sa. in every second division of the bordure a bezant. Herbert, Conington, co. Huntingdon. Per pale az, and gu. three lions ramp. arg. within a bordure compony or and of the second. Herbert, Tinterne, co. Monmouth.

Per pale az. and gu. three lions ramp. arg. within a bordure uebuly or. Howent.

Per pale gu. and az. three lions ramp. arg. within a bordure compony of the last and az. Herbert Losinga, Bishop of Norwich 1091. 1119.

Per pale or and gu, three lions pass. in pale within a bordure all counterchanged. WeтhYPoL, $V$. Wythypoli, $V *$ *

Per pale or and gu. three lions pass. guard. within a bordure all counterchanged. Withypoule, Suffolk.

Per pale sa. and arg. three lions ramp. counter. changed within a bordure per pale of the se. cond and az. Palliser, Amersham, co. Buckingham.

Quarterly az. and gu.three lions ramp. arg. with. in a bordure compony or bezanty and gu. Herbert, Earl of Pembroke, temp. Edward VI, but the bordure was abandoned before 1661 ; (this coat seems false).

Sa. three lions ramp. arg. within a bordure or. Prowse, Oldcliffe, co. Somerset.

\section{Crosses}

Arg. three lions ramp. gu. two and one betw. three crosses croslet fitchy of the last one and two. Belnouse, Aveley, Essex.

Per pale gu. and az. three lions ramp. two and one arg. betw. three crosses patty fitchy one and two erminois. Prodgers or Progers, Bromfield, co. Salop; originally from Gwerndee and Gwenvale, South Wales.

Sa. three lions pass. arg. betw. four crosses patty .... (Attributed to) Richard BEadon, Bishop of Gloucester 1789, Bath, etc. 1802-24.

Gu. three lions ramp. guard. betw. eight crosses croslet fitchy or. GAY or GaYE, Kent.

Gu. three lions ramp. arg. betw. nine crosses croslet or. GAYE, $V^{*}$.

Sa. three lions ramp. arg. betw. nine crosses croslet or. PnEUzE, $V^{*}$. The croslets fitchy. WILBURY, $V$.

\section{Fleurs-de-lis}

Az. three demi-lions within an orle of fleurs-delis or. Mornelr. 
BEASTS. 3 MOLES betw, or within....

Arg. three moles pass. in pale within a bordure engr. sa. Wighton.

Or three moles statant within a bordure engr. sa. Thomas Wigton, $V$.

\section{SHEEP betw. or within....}

Or three rams pass. sa. betw. two bendlets az. in chief a lion ramp. and in base a scaling ladder of the second. BRACE.

\section{TIGERS betw. or within....}

Sa. three tigers pass. in bend betw. two double cotises arg. Browne, Canterbury, Kent.

\section{WOLVES betw, or within....}

\section{Bordure}

Arg. three wolves courant in pale within a bordure uz. Keymer.

$\Delta r g$. three wolves courant in pale az. within a bordure .... Keymen, Chelbrough, co. Dorset.

Arg. three wolves pass. in pale az. within a bordure .... bezanty. KYMER, Wastchelborow, co. Dorset.

Or three wolves pass. in pale az. within a bordure per bordure indented gu. and az. Lupus, $V^{*}$. Anthony Wolfe, co. Devon, $V$.

\section{Flaunches}

Az. three wolves statant in pale or betw. two flaunches of the last each charged with an anchor az. Chauncy, Harl. MIS. 1358, fo. 60 b.

$\mathrm{Az}$. three wolves pass. in pale or betw. two flaunches of the last each clrarged with an anchor sa. Chauncey.

\section{CATS betw. or within....}

and in chief....

Sa. three cat-a-mountains.... within a bordure arg. in chief a crescent betw. two mullets az. Chivas, A berdeen.

\section{LIONS betw. or within....}

\section{Bendlets....3. Foil}

and in chief....

Sa. three lions pass. betw. two bendlets arg. in the sinister chief point a 3 -foil of the last. Browne, co. Dorset.

Sa.three lions pass. in bend betw. two cotises arg. in chief a 3 . foil slipped erm. Browne, Snelstop, co. Derby.

$$
\text { .....Head }
$$

Sa. three lions pass. in bend betw. two cotises arg. in chief a griffin's head erased of the second. Browne, Kent.

\section{SHEEP hetw, or within ... and in chief....}

Or three rams pass. sa. within two bendlets az. betw. in chief a lion ramp. and in base a scaling ladder of the second on a chief wavy part of the works defending the town and port of Algiers. Brace.

\section{On 3 CATS}

Sa. on three cats pass. in pale arg. (? spots....) SHIVEZ, Muirtown, Scotland; quartering arg. on a cross moline sa. a mullet of the field.

\section{On 3 DOGS}

Sa. on three greyhounds pass. arg. collared eompony or and of the first an escallop at the shoulder of each as the field. Adam de QUIXIEY, $Y$.
BEASTS.

On 3 LIONS

\section{Billets}

Gu. on three lions pass. arg. billets sa. BECHE. Crosses

Az. on three demi-lions couped arg. crosses croslet sa. Newhan, Dartmouth, Mamhead, and Stokeley, co. Devon; Baronetcy 17 March 1830 .

\section{Fretty}

Arg. three lions pass. (another ramp.) sa. fretty az. Alwyn, co. Devon; quartering per pale or and az. three eagles counterchanged.

Sa. three lions ramp. or fretty az. WI WETON.

\section{Gouttes}

Az. on three demi-lions ranp. arg. as many gouttes-de-sang at the shoulder of each. Newenham, co. Nottingham; and Everdon, co. Northamptor.

Az. on three demi-lions ramp. arg. gouttes-de. sang. Sr. .... Newenham, co. Northampton, $V$. Newran, co. Buckinglam, 1716. Newman, Ludgvan and Gluvias, Cornwall. NowenHadr.

\section{Mallets}

Gu. on three lions ramp. sa. a mallet at the shoulder of each.... Sr. Stukeler, $V$.

Mullets

Or on three demi-lions couped in bend az. a mullet to each arg. Mernot, granted 1835 .

$\mathrm{Gu}$. on three lions ramp. sa. a mullet at the shoulder of each .... Stuineley, $V *$.

Portcullises

Per pale gu. and sa. three lions pass. guard. in pale per pale arg. and or the centre lion charged on the side with a portcullis (az. another) sa. O'Grady, Viscount Guillamore; Baron O'Grady of Rockbarton, 28 January 1831.

\section{Roundles}

Arg. goutty-de-sang on three lions pass. in pale gu. crowned or bezants. FAYREFord, $V$. FAYRFord, I'*

Arg. goutty-de-sang on three lions ramp. gu. crowned or bezants. Fayrford.

Arg. on three lions pass, in pale sa. bezants. Colwell, $V$.

Arg. on three lions pass. sa. bezants. Courile.

Per fess embattled gu. and sa. on three lions pass. guard. arg. spots of the second. LUPPINGcote, co. Devon.

Sa. on three lions ramp. guard. arg. spots of the field. Lynch, Groves, Kent; and Rixton Hall, co. Lancaster (but? if not lynxes ramp. guard. ppr. as in article 3 LYNXes).

Sa. on three lions pass. guard. in pale or spots of the field. Bouchier, Little Stainbridge, Essex. Bourchier, 1610.

\section{On 3 OUNCES}

Sa. on three omuces statant in pale or spots of the first. Sir James BourcHer, Harl. IIS. 6095 , fo. $15 \mathrm{~b}$.

\section{On 3 WOLVES}

Arg. three wolves pass. gu. on the shoulder of the first a mullet or. Roger WheipdaLe, Bishop of Carlisle 1420-3.

On 3 cats and in chief....

Pean on three cat-a-mountains pass. in pale arg. (? spots....) on a canton or a fess gu. surmounted by an anchor of the third encircled by a wreath of laurel vert. Keats, Dorrant House, Dover; quartering Goodwin. 
BEASTS. On 3 DOGS and in chief....

on a Chief.... (Beast) Fox

Vert on three greyhounds .... arg. gouttes-delarmes on a chief or a fox pass. gu. WELDISH, Lynton, Kent; granted 14 March 1542.

$$
\text { ....Gnn }
$$

Arg. on three hounds pass. sa. as many plates to each on a chief gu. a culverine betw. two anchors or. Gonston or Gunston, London.

On 3 CATS betw, or within.... and in chief....

Sa. on three cat-a-mountairs within a bordure arg. (? spots....) in chief a crescent betw. two mullets az. Chrvas, Aberdeen.

\section{DEER}

Quarterly or and az. four roebucks .... counterchanged. LLOYD, Holyroode, and Whitnester, co. Gloucester; and Cheame, Surrey.

Quarterly or and az. four roebucks trippant counterchanged. LLoyd, Bradenham House, near Wycomb, co. Buckingham.

Quarterly or and az. four roebucks pass. counter. changed. RosindaLE, 1441.

\section{IEOPARDS}

Quarterly az. and gu. four leopards pass. arg. Peart.

\section{IIONS}

Az. four lions ramp. two and two or. Lurman, Bentley, co. Hants; and Langley, Sussex; granted 1738.

Or four lions ramp. in quadrangle the first and fourth sa. the secoud and third gu. Philippa de Avesnis, daughter of William Count of Hainault, Holland, Zeeland, and Friesland, wife of Edward III; 1328.69; Lansdowne MS. 874, fo. 105 .

Per pale indented gu. and arg. four lions ramp. counterchanged. Ellesworth, Oxford.

Per saltire urg. and sa. four lions ramp. counterchanged. Payne, co. Lincoln, and co. Stafford.

Per saltire az. and or four lions ramp. counterchanged. GoLD.

Quarterly arg. and gu. four lions ramp. counterchanged over all on a fess sa. three garbs or. Murphy, Ireland.

Quarterly arg. and sa. four lions ramp. counterehanged. Cynvraig SaIs.

Quarterly az. and arg. four lions ramp. counter. changed. Sir William Pipard, $V$.

Quarterly az. and gu. four lions pass. guard. arg. Peart.

Quarterly az. and gu. four lions pass. guard. counterchanged. Principality of WALES.

Quarterly az. and gu. four lions ramp. counterchanged. Pigot.

Quarterly per fess indented az. and or four lions pass. counterchanged. Cromwerl, Putney, Surrey. Cromwerl, $V^{*}$. Crumwell, Lord of Okeham, $V$.

Quarterly gu. and arg. four lions pass. counterchanged. Meredydd Ap Crnan.

Quarterly gu. and arg. four lions ramp. counterchanged over all on a bend sa. thiree garbs or. MurPHy.

Quarterly gu. and az, four lious ramp. or. P'EAR'T.
BEASTS.

4 IrIONS cont.

Quarterly gu. and or four lions pass. counter. changed. Prince de Gales ( $i$. e. Wales), $G$.

Quarterly gu. and or four lions pass. guard. counterchanged. Llewyllyn Ap JoRwerTH, slain 1282. South Wales. Le Prince de Galfs, $Y$. Quarterly gu. and or four lións ramp. counterchanged. Owen Glendwr, seal 1404.

Quarterly or and arg. in the first and fourth two lions ramp. sa.in the second and third as many lions ramp.gu. ENEMEAD.

Quarterly or and az. four lions pass. counter. changed. Llord, co. Denbigh.

Quarterly per fess indented or and az. four lions pass. counterchanged. CRomweLL, Lord of Okton, temp. Charles I.

Quarterly or and az. four lions pass. guard. counterchanged. Ap-GRIFFYN, Wales.

Quarterly or and az. four lions ramp. counterchanged. Lutley, Lawton and Bromscroft, Munslow Hall, co. Salop. Luttelex, Broms. croft, co. Salop, and co. Worcester.

Quarterly or and az. four lions statant guard. counterchanged. David ap GRIFFITH, $E$.

Quarterly or and gu. four lions pass. counterchanged. Guales. Lloyd, Swan Hill, co. Salop.

Quarterly or and gu. four lions pass. guard. counterchanged. EDWARDs, Wales. Anm. (for Thlin, i. e. Llewellyn) ap Griffm, $E$. Prince de Guales, $D$. Assumed, with the title of King of Wales, by Owen ap GrIfFITH-VYcHAN (Owen Glendower), Lord of Glyndwrdwy, co. Merioneth, instead of his own coat, paly of eight arg. and gu. over all a lion ramp sa. Llewellyn aP Griffith, Prince of North Wales, commonly but erroneously termed the last native Prince of that country; derived from Griffith ap Cynan, King of North Wales; slain 10 December 1282. LlewLlyn AP MaDoc, Baron of Cryniarth-yn-Edeirnion, co. Merioneth, Bishop of St. Asaph, 1357-75; derived from Ellis, living 1281, second son of Iorweth, Lord of Half-Edeirnion. NoRTH WALES.

Quarterly sa. and or four lions ramp. couriterchanged. BINGE.

\section{LIONS and in chief....}

Quarterly az. and gu. four leopards pass. or on" a chief of the third an ogress. PEART or Pert.

Quarterly az. and gu. four lions pass. guard. or on a chief dancetty arg. three pellets. Thomas Pert, $V$.

\section{DEER betw. or within....}

Quarterly or and az. four roebucks pass. counterchanged (within a bordure gu. given by Harvey to the antiquary) Humphrey Llovd, properly Rosindale.

Quarterly or and az. four bucks trippant counterchanged within a bordure of the first. LLOYD alias Ressindar, Cheam, Surrey; and Denbigh, co. Denbigh, $Z, 424$.

\section{DOGS betw. or within....}

Arg. four hounds gu. within a bordure sa. charged with eight crescents or. GLover, Oxford.

4 LIONS betw, or within....

Arg. four lions pass. guard. in bend betw. two double cotises sa. Halls. Hawrre, $V$. 


\section{BEASTS.}

\section{LIONS}

Az. five lions ramp. in saltire or. Byntworth.

Ga. five lions ramp. in cross or. Bintworth, $V$. Richard de Brnteworth, Bishop ol Loudon 1338.9. Byntworth. John de la Sale, Bintworth, $V$.

Quarterly or and gu. five lions ramp. in saltire the central one az. the others counterchanged. VAUGHAN, Dolmelynllyn; derived tbrough VAUGHaN, Hengwrt, co. Merioneth; from Cadwgan, Lord of Nannau. VaUghaN, Chilton Grove, near Shrewsbury.

5 LIONS and in chief.... (probably these are 6 Lions)

\section{Canton}

Az. five lions ramp. arg. a canton erm. Lembonne. on a Canton

Az. five lions ramp. or on a canton arg. a mullet gu. Kyrkby or Kyrby, Kent.

\section{Quarter}

Az. five lions ramp. arg. a quarter erm. Sir Ro. bert de SHIRLAND, L, Harl. MS. 6589.

\section{LIONS betw, or within....}

Az. five lions ramp. arg. within a bordure 'cersele' or. Monsire John .... (probably Byntworth), $Y$.

\section{DOGS}

Vert six talbots pass. arg. three two and one. HownHIL, $V$.

\section{GOATS}

Qiarterly arg. and gu. iu each of the second and third quarters three goats statant arg. attired or. Mounsyer Piers Buckton, $T$.

\section{LIONS}

... six lions ramp. .... Woodbridge, Suffolk, 1601.

Arg. six lions ramp. az. Deting. Morteign, $V^{*}$. Sr. Roger Monteigne, Lord of Dunnesby, $V$. Mortein. Morteyn, $V$. Wintringhair, Baronetcy 7 Nov. 1774; extinct 10 January, 1794. Arg. six lions ramp. gu. GreBY or GreYBY. Grevil, $V^{*}$. Sr. Adam Greyvill, $V$. Leybock. Sr. James Leybourne, Consewyke, $V$. Litrle. RaIle. Rayle, $V$. Sr.Payne Vilers, $V$. Vilters, $V^{*}$. VILLIERs. Town of WARrington.

Arg. six lions pass. sa. Datuing.

Arg. six lions ramp. sa. Sire William Leybourne, $J$. Litthe. Rivers. M. Arnold SAvaGE, $S$. Sr. Arnold SAvage, Kent, $V$. Sire Roger Savage, N. Savage, Earl Rivers, Viscount Colchester 1639-1728. SAVAGE, co. Chester; 'I'idbury, co. Gloucester; Bradway, Tidmington, and Powick, co. Worcester. And with an annulet az. for diff. SaVage, Ardchin Castle, co. Down; and Lisanoure Castle, co. Antrim. And with a crescent for diff. SAVAGE, EImley Lovet, co. Worcester; and Highgate, Middlesex. Bar. telmeu de WoT'IGBI', $A$, or de WATREINGBERY, A, Harl. MS. 6137.

Arg. six lions ramp. sa. langued gu. SAvage, Ballymadun, co. Dublin; quartering King, Welstead, Benuet, and Christian; descended through SAvaGE, Lukeslaud House, co. Devon; and Knockadoo, co. Sligo, from SAvaGE, Ballyvarley, co. Devon; a desceudant of SAvaGe, Lord Savage of the Little Ards, ob. at Portaferry, co. Down, 1572 .

Arg. six lions ramp. tails forked sa. Morton.
BEASTS.

6 IIONS cont.

Az. six lions ramp. arg. William LEBonne, $A$, or de Leborne, $D$. William and Roger de Leiborne, A, Harl. MS.6137. Sire William de Leyborne, $N$. Leyborne, Kent; Cunswicke, co. Westmoreland; and Caveswick, co. York. Roger Leybonne, $A$, or de Leyborne, $B$, or de Leyburne, $C$. Sir Henry de Leybourne, $L$, Harl. MS.6137. Sr. William Leybourne, temp. Edward I, $V$. William de Leybounne, $K$; or de Leyburne, $E$; $G$. John Leyburne, Kent, $Y$. Az. six lions ramp. arg. three and three. Cheyney, co. Bedford.

Az. sis lions ramp. arg. a label compony or and gu. Sire Henri de Lexburne, $N$. The label gu. Sir Henry LeybonNe, L, Harl. MS. 6589. The label of four points gu. Roger de Leyburne, $G$. Thomas de Leyburne, $G$.

Az. six lions ramp. arg. armed and langued or. Roger Leyburn, Bishop of Carlisle, 1504-7.

Az. six lions ramp. or. Sire Roger de Morteyn, N. De la Forde, co. Devon. Nicholas Longespe, Bishop of Salisbury, 1291.7. LONGASPEE LONGESPEE or LONGSPARD, $E$. Gul. LONGESPE, C. Longspey, Earl of Salisbury, $V$. Le Conte de Sainsbury, $B$, Longespee, $P$. Le Conte de Sajisbury, $D$. C. de Salisburei, $F$. Cunte de Salesburs, $G$. Cute de Salisbcri, E. Monsire William Longespee, Conte de Salisbury, $Y$. Le Counte de Saliseurs, $N$. William Longespee, Earl of Salisbury, 1196-1256; as having m. Ela beiress of William Fitz-Patrick D'Evereux, Earl of Salisbury; the heiress m. Henry Lacy, Earl of Lincoln, Z, 114-8.

Az. six lions ramp. or a label gu. Estiene Longespee, $B$. The label of (three $V *$.) five points gu. Stephen LoNgspey, $V$; Earl of Ulster, third son of the Earl of Salisbury; his heiress $\mathrm{m}$. De la Zouch, $Z, 114-8$.

Az. six lions ramp. or a file of four points gu. LEIBOURNE.

Az. six lions ramp. or over all a bendlet sinister .... Nicholas Longespe, Bishop of Saliskury 1291-7; fourth son of the Earl of Salisbury.

Az. six lions ramp. or a baston dexter gu. Bicknor, $W$.

Bary arg. and az. six ljons ramp. gu. Marshe.

Erm. six lions ramp. sa. Mabball or Mabbatt.

Gu. six lions pass, arg. crowned or. HASELERToN, co. York.

Gu.six lions ramp.arg. Esharton. Fitz-Raynard or Fitz-Raynolid. Haselierton. Sir .... de Layborne, $R$. Sire Richard de Leyborne, $N$. Sr. James Lerbourne, Consewyke, $V$. M. Thomas Leybourne, $S$. Joan Seint Helene, $E$, or de Seint Helene, $F$. Trlmanston.

Gu. six lions ramp. arg. a label az. Sire Nicholas de Lexburne, $N$.

Gu. six lions ramp. arg, crowned or. Sire Thomas de Haselartone, $N$. Haselerton, Great Grimsby, co. Derby. Wauter de Heslarton, I. Heslerton, Potford, Heslarton, and Waverthorpe, co. York.

Gu. sis lions ramp. arg. ducally erowned or. Sir 'Thomas Haselerton, co. York, temp. Edward $1, V$.

Gn. six lions ramp. erm. Roger cle Temmaston, $A$. Or six lions ramp. az. Detring. Dorcestre, Sussex. Sir Roger Monteyne, $r$. Morton.

Or six lions ramp. tails forked az. Robert (alii Roger) de Mortaigne, $K$, Harl. MS. 6589. Sir Roger Monteynes, $K$, Harl. MS. 6589.

Or six lious ramp. gu. Villiens. 
BEASTS.

6 LIONS cont.

Or six lions ramp. gu. over all a bend arg. Sire Henri de Box, $N$.

Or six lions ramp. sa. Bromwich. Dateling. Doncaster, Dorcet. Sr. Oliver Dorcest, $V$. Dorchester. John de Layburne of the North, $Y$. Leibonne. Sire William de Lerbourne of the North, $N$. Roger de Leiburne or Leyburne, $E$. M. Roger de Leyborne, $D$. Sir William Leybourne, $J$. Thomas MaLuRe, $Y$. Mortaigne. Sir Roger Morteyne, $I$. Robert de Morteygne, $K$, Harl. MS. 6137. WOTINGBURY.

Or six lions ramp. sa. two two and two. Ferrers. Or six lions salient sa. Dateling.

Per bend arg. and sa. six lions ramp. counterchanged. TIChBorough.

Per fess gu. and arg. six lions ramp. counterchanged. Yeiverton.

Per fess or and sa. six lions ramp. counterchanged. VIGoR, quarteriug Stonhouse.

Per pale az. and gu. six lions ramp. or. FITZ-JоHN.

Sa. six lions couchant coward arg. Bateman, Essex. Sa. six lions couchant guard. (dormant $V^{*}$.) coward the tail reflexed over the back arg. Bateman, Essex, $V$.

Sa. six lions pass. arg. Dentry.

Sa. six lions ramp. arg. William de Clinge, $A$, but de Detling, $A$, Harl. MS. 6137. Clings. Deliyne. M. .... de Dething, $D$. Detuing, $V^{*}$. Sir John Detrling, $V$. Eagle, Suffolk. William de Ecligges or Eclingaes, E. Egles. Englis or Englys. Sir Thomas Englis, Ta. rone, $V$. William de Ocuinge, $Y$. Rayle, $V^{*}$. Lawrence Savage, $Y$. Taney. Tawne.

Sa. six lions ramp. gu. William de St. Mantin, $F$. Sa. six lions couchant or. BATEMAN.

Sa. six lions ramp. or. Merefield. Laurence de St. Martin, Bishop of Rochester, 1251-74. John de St. Martyn, $r$. Sr. Regnald ST. Martyn, co. Wilts, temp. Edward I, $V$. Sire Renaud de Srin Martin, $N$. William de Sein Martyn, $E$.

Sa. six lions ramp. or crowned gu. Fonde.

Vert six lions ramp. arg. Litle. Merefield.

Vert six lions ramp. or. Sire Nichol de LANGEFORD, $O$.

\section{LIONS and in chief....}

\section{Canton}

Az. six lions ramp. arg. a canton erm. Sr. Thomas Cheney, Shepey, Kent, $V$. Cheney, Sherland, Isle of Sheppey. Chenex, Higham, Kent; and Warblington, Sussex. Chenex, Yoxall, co. Stafford; and Monyash, co. Derby. (? Leiborne.) Sr. Robert de Scirland, $L$. Sire Robert de Scirtande, N. Roger de Scirland, $D$. Roger de Schirlond, $F$. Sherland, Sheppey, Kent ; and Norfolk. Sr. Robert de Sherland, Kent, $V$. Roger Sirlonde or de Struonde, $E$.

Az. six lions ramp. arg. three and three a canton erm. Chenie or Cheyney, Kent.

Az. six lious ramp. or a canton erm. Cheyner. Mloun (? son) frère, $i$. e. the brother of Gul. LoNGESPE, $C$.

on a Canton.... Fleur-de-lis

Arg. six lions ramp. sa. on a canton az. a fleur-delis of the field. Savage, late Clavering, Elm. ley Castle, co. Worcester.

$$
\text { ..... IIullet }
$$

Az. six lions ramp. arg. on a canton or a mullet gu. KMBY, Kent.
BEASTS. 6 LIONS and in chief.... cont.

on a Canton ...Mullet cont.

Az. six lions ramp. or on a canton arg. a mullet gu. KYrby or KYrRBy, Kent.

Az. six lions ramp. or on a canton of the second a mullet gu. HarNhulL, $\boldsymbol{V}$. Sr..... KYRKEBY, Kent, $V$.

on a Chief. . . .5-Foils

Or six lions ramp. sa. on a chief gu. three pierced 5 -foils of the first. Jobn Martine, London, temp. Henry VIII, $V$.

Or six lions ramp. sa. on a chief of the last three 5-foils of the first. MarTyn, London. Quarter

Az. six lions ramp. arg. a quarter erm. Thomas Layburne, $Y$. Roger de Schireland, $Y$. Roger de Swelande, A, Harl. MS. 6137.

\section{DOGS betw. or within....}

Quarterly arg. and erm. in each of the first and fourth quarters three greybounds courant sa. all within a bordure of the third platy. Lover, co. Northampton.

\section{LIONs betw. or within....}

Az. six lions ramp. arg. within a bordure of the second charged with ten hurts. LightBonNE, co. Lancaster; and Manchester; granted 1662. Az. six lions ramp. arg. within a bordure or. LEIBOURNE.

Az. six lions ramp. arg. within a bordure engl. or. Sir John de Layborne, $R$. Sir Simon Leyborne, Kent, temp. Edward I, $V$. Symon de Leybourne, $G$. Leybourne, $V^{*}$. Lightborne, co. Somerset.

Az. six lions ramp. arg. a bordure indented or. Sire Simon de Leybourne, $N$.

$\mathrm{Gu}$. six lions ramp. or within a bordure engr. arg. Fitz-Henbert.

\section{IroNs betw. or within....}

and in chief....

\section{Canton}

Az. six lions ramp. arg. within a bordure or a canton erm. Bures.

Quarter

Az. six lions ramp. arg. a quarter erm. and a bordure engr. or. .... Layburne du Conte de Salisbury, $Y$.

\section{LIONS betw. or within....}

Az. nine lions pass. guard, or and two bars gu. Bradshaw, co. Buckingham, 1506.

\section{DOGS or WOLVES betw. or within....}

.... ten (hounds or wolves ?) statant .... three three three and one and three bars (? gu.) Maundy, Sandwich, Kent.

\section{LIONS unnumbered}

Arg. semy of annulets within each a lion ramp. and an eagle displ. alternately sa. in the interstices a lesser annulet of the last. Yvarn.

Arg. fretty and in each space a lion pass. gu. MoORLE, $V$.

Az. fretty gu. semy of lious pass. guard. of the second. MoORLE, $\mathbf{J}^{*}$.

\section{BEE see Insect}

\section{BEEHIVE}

Arg. a beehive beset with bees volant ppr. Treweek, Penzance, Cornwall. 


\section{BEEHIVE cont.}

Arg. on a piece of ground in base vert a beehive sa. beset with bees volant ppr. IUnSFord, Tiverton, co. Devon.

Arg. a beehive beset with bees diversely volant sa. RoE, co. Chester, 1716. Rooe, Markelsfield, co. Chester. Rowe, Macclesfield, co. Chester; granted 20 March 1653. Rows, Makesfields, co. Chester, Harl. MS. 1535, fo. $241 \mathrm{~b}$.

\section{BEEHIVE and in chief....}

Arg. a beehive beset with eleven bees rolant sa. on a canton gu. a rose of the first. RoE, Ireland.

\section{On 1 BEEHIVE}

Arg. on a beehive sa. a (buck $V^{*}$.) hart lodged arg. attired or. SADELLAYER, co. Stafford, $V$.

\section{BEEHIVES}

Arg. three beehives vert. ShakerLey.

Sa. three beehives or. Gervis, Suffolk. Jervis, Suffolk. JERvys, Suffolk, $W$.

\section{BEEHIVES and in chief....}

Az. three behives arg. a canton erm. Bishopton, co. Warwick.

Az. three beehives or a canton erm. Bishopton, $V$.

\section{BEEHIVES betw, or within....}

Gu. three beehives betw. nine bees volant or. LEHOOP.

\section{BEETLE see Insect.}

BELI betw, or within....

Gu. a bell or betw. three fleurs-de-lis arg. RINGER, Norfolk.

\section{BELLS}

.... three church bells .... Nicholas BeLLE Boston, co. Lincoln, seal 1322, $V$.

.... three bells with cannons and clappers .... Stephen de Norton, seal.

Arg. three bells az. WORdeswortH. WORDsworth

Arg. three war bells gu. Kedmarston, Suffolk.

Arg. three church bells sa. HaIton. Hartin, $V^{*}$. Hayton, $V$. Haytyn, $V$. Heaton, $V^{*}$.

Arg. three church bells sa. edged or clappers of

the first. Benet, $V$. Bennett, $V^{*}$.

Az. three bells or. BELI, Scotland.

Az. crusily and three bells or. SAMORE.

Gu. three church bells arg. Porter.

$\mathrm{Gu}$. three bells or. Swrmmer.

Gu. three church bells or. Porter, co. Bucking. ham.

Or three church bells gu. Bromle, $V$.

Or three hawh's bells gu. ENGBorise, $V$.

Sa. three church bells arg. Porter, Bishop of Clogher; descended from Porter, The Close, Bolton, supposed to be like Porter, Weary Hall, Bolton, Cumberland, a younger branch of Porter of Allerby. Ponter, Ireland, and Aston, co. Warwick. Sir William Porter, temp. Henry V, $V$. Ponter, Suffolk, 7730.

Sa. three hawk's bells or. BeLlchanders. Bellschamber, $V$.
3 BELLS and in chief....

\section{Canton}

Sa. three church bells arg. a canton erm. Porter, $V$. Ponter, Kent; and co. Lincoln. Porter, Alfarthing, Surrey ; derived through Endymion Porter, Groom of the Bedchamber to Charles I, from Robert brother of Sir William Porter, temp. Henry V; the heirs $\mathrm{m}$. Walsh, Semper, Pieraggi, and Piggot. Porter, Suffolle, 1730. And with a crescent for diff. P'ORTER, Wadhurst, and Seaford, Sussex.

Sa. three church bells .... and a canton erm. Porter, St. Stephen's, Cornwall.

Chief

Sa. three church bells arg. a chief erm. Porter, co. Lincoln ; and St. Margaret's-in-Southernam, Suffolk.

\section{BELLS betw, or within....}

Sa. three church bells arg. two and one betw. three estoiles or one and two. BeLL, co. Berks; and co. Buckingham.

\section{On 3 BELLS}

Per chev. sa. and arg. three church bells .... each charged with an ermine spot.... Porter, London.

\section{BELLS}

Az. four hawk's bells or conjoined in saltire by a double and wreatbed cord alternately arg. and sa. Sir Ralph Josselyne, Alderman of London, $V$. Josselyn, Newhall, Essex, $V$.

\section{BELLS}

Az. five bells in cross or. Mulliss, Ireland.

\section{BELLOWS}

Arg. three pairs of bellows sя. ScIpton, 1716. ShIPton, co. Leicester. SkIPton.

\section{BELT}

(including Dog's Collar and Man's Garter.)

Arg. a demi-belt fired in fess az. buckled edged and garnished or. Beltaraine.

Vairy a garter (but ? bendlet) gu. HeBmines, France.

\section{BELT betw. or within.... \\ Beads}

Pel fess gu. and az. a man's garter fesswise arg. fimbriated and buckled in the centre or betw. in chief a rosary and in base three bells of the last. BeADNELL.

\section{Buckles}

Sa. a man's garter buckled in orle .... betw. three square buckles tongues erect or. Bockiand.

\section{BELTS}

Gu. two half-belts with buckles arg. PelHaM. Gu. two pieces of belts palewise in fess the buckles erect in chief (arg $\mathrm{J}^{*}$.) or. Pelham, $V$.

\section{BELTS}

Arg. three belts the under parts couped in fess az. buckled and garnished or. Narbon.

Gu. three men's garters nowed and buckled arg. Sydemers.

3 BELTS and in chief...

Vert three belts (or dog-collar's or garters) or on a chief arg. three hunting-horns of the first stringed and tipped gu. HUNTEr. 


\section{Per BEND}

Per bend sinister arg. and gu. Zurith, 1716.

Per bend dancetty arg.and gu. Ferne, co. Stafford. Per bend embattled arg. and gu. The Lord Treasurer (of Ireland) Harl. MS. 4040. BoyLE, Baron Boyle of Youghal 6 September 1616; Viscount Dungarvan, Earl of Cork 26 October 1620; Baron of Broguill 28 February 1627; (Baron Cliffird of Lanesborough 9 November 1644; Earl of Burlington 20 March 1664, extinct 1753; Baron Carleton 26 October 1724, extinct 1725;) Earl of Orrery 5 September 1660 ; Baron Boyle of Marston 10 September 1711. Boyle, Baron of Bandon and Viscount Kynalmeaky, extinct 1642. BoYLe, Viscount Shannon, extinct 1740. Boyle, Baron Boyle and Viscount Blessington 23 August 1675, extinct 1732. Boyle, Earl of Shannon, Viscount Boyle of Bandon, Baron Boyle of Castle Martyr 20 March 1756, Baron Carleton 21 August 1786. Borle, Middlesex. Richard Boyle, Archbishop of Tuam, ob. 1644. Michael Boyle, Bishop of Waterford. Michael Borce, Arch. bishop of Armagh, ob. 1702. John Boyle, Bishop of Cork, etc., ob. 1620. BorLe, Earl of Cork, Harl. MS. 4040, fo. 39, with an inescucheon chequy or and az. a fess gu. But with a crescent az. for diff. Borte, Earl of Orrery, Harl. MS. 404n, fo. 97; Boyle, Viscount Shannon, Harl. MS. 4010, fo. 272. The crescent sa. BoYle, Viscount Blessington, Harl. MS. 4040 , fo. 312. With a 5 -foil .... for diff. Boyle, Hay Castle, co. Hereford. With a mullet sa. for diff. Boyle, Viscount Dungarvon, Harl. MS. 4040, fo. 296. Boyle, $V^{*}$.

Per bend sinister embattled arg. and gu. ByLes.

Per bend indented arg. and gu. a crescent for diff. Henry Fenne, Bishop of Chester 1662-8.

Per bend nebuly arg. and gu. Folkstayn.

Per bend arg. and sa. Chaponn.

Per bend sinister arg. and sa. Chapoin, $V$.

Per bend dancetty arg. and sa. Kendall, Ripon, co. York. And with a pierced mullet gu. for diff. Kendall, Thorpinules, co. Durham, 1575.

Per bend embattled arg. and sa. Dangate. Daungate, $V$. Dawngate. Denewgate, $V$. Eleam. Kelle, London. Kell, or Kelue. KENLEY.

Per bend indented arg. and sa. Kendal, Durham. Kenley. Warner, Suffolk.

Per bend az. and gu. Weller. Wheler.

Per bend in point to the sinister az. and or. Bourckland.

Per bend indented az, and or. WhISTLEFORD.

Per bend embattled gu. and arg. Boyse, Kentish Town, Middlesex; granted 24 January 1569.

Boyley, $V$.

Per bend sinister embattled gu. and arg. Boyley, $V$. Boyle, $V$.* John Beauly del South; ('de gu. et d'arg. embelief battaillee') ; $X$.

Per bend nebuly gu. and arg. Folkstayn.

Per bend embattled gu. and erm. Aungate.

Per bend and per pale or and arg. JoHnson, 1730 .

Per bend or and az. Crane.

Per bend dancetty or and az. Markington, $V$. WhISTILFORD, $V$, quartering per fess az. and or three annulets counterchanged. WHISTLE. FORD, $V$.

Per bend embattled or and az. Pottman.

Per bend indented or and az. Gosnold Markington, $V$. Whistilford; quartering per fess az, and or three annulets counterchanged. Whistleford, $V$.
Per BEND cont.

Per bend dancetty or and gu. Fenne.

Per bend indented or and gu. Ferne, Parwich and Snitterton, co. Derby; Temple-Belwood, co. Lincoln; and co. Stafford.

Per bend or and vert. Hawle. Hawley. Lander, St. Ives, Cornwall.

Per bend embattled sn. and arg. Dangats. J)angate. Kenley. $V$.

Per bend engr. sa. and arg. Darsallough, Scotland.

Per bend indented sa. and arg. Markington. WARNER, London; Norfolk; and Peterborough. WARNER; quartering az. a fleur-de-lis or ; $V$.

Per bend (? sinister) indented sa. and arg. Nicholas GuLıotr, Merkington; ('d'arg. a une cheif de sa. endentee embelief: ill port bend endente de sa. et d'arg ?) ; $X$.

Per bend vert and or. HALL, $V$.

\section{BEND}

\section{(including Baston, Bendlet, Cost or Cotise, Garter, Ribbon, and Scarf or Scarp)}

.... a bend gu. over all six barrulets .... John de Horbyre, $D$. (? if this be not barry arg. and az. a bend gu. Sire Johan de Horburi, N,).

Arg. a bend az. Badye. Bendmaine. Buset, $V$. Busts. Buts. Cheuston. Denniston. Hovile. Payne. Sandilands, Scotland. Terell or Terrele, co. Hertford.

Arg. a bend az. and a label of five points gu. Hue d'Hovile, $E$. Hugo de Hovile, $F$.

Arg. crusily fitchy and a bend az. Colwike. Arg. a bend dancetty az. Brampton.

Arg. a bend embattleil counter-embattled a.z. Sandilands, Craibston, Scotland.

Arg. a bend engr. az. Sr. Richard Foreram, $V$. Foxali. Foxсотe. Sr. William Gorney, Normandy, Q, Harl. MS. 6595. Grone, $V$. Grove, 1730. Ratgnit. John RYgate, Howke, $\boldsymbol{Y}$. Monsire Rolgate, $Y$.

Arg. a bend engr. az. fimbriated or. Brescy, $V$. Bressy, $V$.*

Arg. a bend fusily az. Reygate.

Arg. a bend indented az. Branipton, $V$.

Arg. a bend lozengy az. Gasticke.

Arg. a bend wavy az. Sir William Borner (Gronex), Nornandy, Q, as printed by Mores. Swale, London; granted 25 March 1591.

Arg. a bend chequy arg. and gu. Roland VAux, $X$. Arg. a bend chequy or and az. (? BODHAM). Toase, Anlaby House, Hull, co. York.

Arg. fretty sa. over all a bend chequy or and az. Reymes Reynes or Rueynes, co. Durset.

Arg. a bend chequy or and gu. VautK, or Vaus, Wipsnot Hall, co. Bedford. Vaux, Tryermayne, quartered by Brougham.

Arg. fretty cbequy or and gu. over all a bend as the fret. RrNes, co. Devon.

Arg. fretty sa. over all a bend chequy or and gu. Raynes.

Arg. a bend chequy sa. and or. Tipper.

Arg. a bend compony az. and gu. Paris or Parris. Parys, $V$.

Arg. fretty sa. over all a bend compony az and or. REYNES, $V$.

Arg. a bend compony gu. and az. Grassall, $V$. Grasseli. Gressall.

Arg. a bend compony gu. and or. VAuLx, $V$.**

Arg. a bend compony gu. and sa. Leventhorpe, Stringey Hall, co. Herts; Baronetcy 13 May 1622 , extinct 30 August 1680. 


\section{BEND cont.}

Arg. a bend compony sa. and or a cross gu. Bluckborne.

Arg. a bend counter-compony or and gu. Harwedon. Vaulx, co. Northumberland, $V$. VAUX.

Arg. a bend gu. Barnack. Bisset, Scotland. Chenston. Cheverston. Cramond. Dance. Daniell, temp. Edw. II. Depden, $V$. Depton, $V^{*}$. Duval or Duvall. Freton. Graben. Graybow. Hallington. Heyland, Suffolk. Karkettle, Scotland. Stainburgh. Tirington Trrenton or Tyrington. Raf de Tirentone, $F$. Ranf de Trayhampton, $P$. Tranton, $V^{*}$. Treanton, co. Lincoln, $V$. Sire Rauf de Treauntone, $N$. Treantone, co. Lincoln. Rauf de Trehampton, $B$. Trentane, co. Lincoln. Trrenton and Trrington. Vans, Barnbarroch, co. Wigton. VICARIDGE.

Arg. a bendlet gu. Botringhan, $V^{*}$. Bodrugan, $V^{*}$.

Arg. a bend sinister gu. Bisset or Bizzet.

Arg. a bend gu. a label of five points az. Shildingford, Shillingford, co. Devon.

Arg. a bend and label gu. Kendall. co. Bedford. Arg. a bend and a label of three points gu. Kendali, co. Bedford.

Arg. a bend gu. and a label of three points sa. Congalton, Congalton, Scotland; quartering arg. a fess sa. betw. two cotises compony az. and of the second.

Arg. \& bendlet gu. over all a lion ramp. sa. Hue BURNeL, $F$.

Arg. a bend dexter surmounted by two bendlets gu. Bynon.

Arg. a bendlet gu. over all a cross or. GaLLwAY, Ireland.

Arg. a bend gu. over all a cross patriarchal sa. RoRke, Ireland.

Arg. a bend gu. over all three pales sa. BuRgeHIL.

Arg. a bend gu. over all four pales sa. BURGEHILL.

Arg. a bend dancêtty and fess gu. Domell, co. Wilts.

Arg. a bend engr. gu. Chittercrorte or Chitecrofte. Chyttecrost, $V$. Colepeper or Culpeper, Kent. Colepepper, Bay Hall, and Peppenbury, and its branches at Bedgebury, Wakeburst (Baronetcy 29 September 1628, extinct 28 March 174(1), Wigshill, and Colepeper, Baron Colepeper of Thoresway, co. Lincoln, 21 October 1611, extinct 1725, properly with a crescent for diff. CoLPEPPER, $V^{*}$. Colepeper, Preston Hall, and Oxenheath, Kent. Walter Colepeper, Kent, $V$. Colepepper, Harl. MS. 6137, fo. 40. Culpeper, Preston Hall, Aylesford; Baronetcy 17 May 1627, ex. tinct 18 May 1723 . Robert WaLrand, $B$.

Arg. a bend engr. gu. impaling arg. a ship ppr. and on a point per chevron vert a lion ramp. arg. O'LeARy, Harl. MS. 4039.

Arg. a bend engr. gu. a crescent sa. for diff. WALDRON.

Arg. a bend engr. gu. a labe] az. Lancelot de Meiniark (? Seinmark), $C$.

Arg. a bend engr. and voided gu. Honerutan, Scotland. HonYman, Armadale and Græmsay, co. Orkney, Baronetcy 11 May 1804.

Arg. a bend counterflory gu. BRomfietr.

Arg. a bend of four fusils conjoined gu. Bradestone, $V$.

$A r_{c}$. a bend of six fusils conjoined gu. John de GREY, $E$.

\section{BEND cont.}

Arg. a bend indented gu. John Warrant, $Y$.

Arg. a bend of lozenges and roses alternately disposed gu. Alten.

Arg. a bend lozengy of the first and gu. Wynselow, Gozheche, $V$. Gosheche, $V^{*}$. GOSTRECHE, $V^{*}$.

Arg. a bend of five lozenges conjoined gu. Ro. bert WALROND, $F$.

Arg. a bend lozengy gu. Bradeston. Ley, co. Stafford.

Arg. a bend masculy gu. Camperney or CAMPNEY.

Arg. a bend voided gu. Ireton.

Arg. $a$ bend wavy gu. Goldingharr, Barnbam, Norfolk; and Balsted, Suffolk. Goldingham, Suffolk, V; or Essex, V, Harl. MS. 1392, fo. 557.

Arg. a bend purp. Sr. Nicolas Maximians, Mr.

Arg. a bend engr. purp. MaLemanis, Kent. Matemaynes, $Y$. Sir Nicholas Malemeis, $N$. Sir (Michael, L, Harl. MS. 6137) Nicholas Malveroures, $L$ : but Sir Nicholas MaLHeUREUX, L, Harl. MS. 6589. Nicholas MaLdieyns, $Y$. MaLixs or MaLennys, Kent, $v$. MaLynes, Kent.

Arg. a bend sa. Blackborne. Blanton, co. Lancaster. Bredham, Kent. Crewell, $V^{*}$. Chwelu (sic), $V$. Damilston, Crapwond, Scotland. Danielston, Danielston, Scotland. Delapoole. Dennistoun, Dennistoun, co. Renfrew. Hue le Despensier, quartering gu. fretty or, $K$; for Audeley, $Q$. Dirton, co. Lancaster. Dutron, co. Chester; quartering gu. a fret or. Dytton, $V$. ERdeswick, co. Stafford. Ernelle. Erswyke. Gothair. Hardeworth, $V$. Hardworth, $V^{*}$. Hogh. John Hough, Bishop of Oxford 1690, Lichfield etc. 1699, Worcester 1717-43. Hovg H, Layton, co. Chester. Maller. Madlex. Monceux. Walter de Muttans, $A$. William de Mouncels, $A$, Harl. MS. 6137. M. Walran de Muncels, $D$. Paganel. Pannal Pannel or Pannell, co. Lincoln; and Panmall, co. York. Raphe Parne, $Y$. Sire Rauf PAYNel, $N$. Sr. Raphe Payneli, $Y$, in debate with Stopham. PAYNeLL, co. Lincoln. Paxneli, V. Potts. St. Barbe. St. Low. Sr. Urian St. Piere, I. Scopham, Bernake, $V$. Sr. .... de Serntlo, $V$. Spencer. John Stapham, $V$. Stephant. Thomas Stapham or Stopham, $Y$, in debate with Paynell. Sire William de Stopham, $N$. Trenthamr. Vavasour. Watton. Yetton.

Arg. a baston sa. John Stophan, $Y$.

Arg. a bend sa. a label gu. Sr. Peres de MAULer, $M$. Sire Urien de Seinpere, $N$.

Arg. a bend sa. a label of three points gu. Sr. Lo, Chideock. St. LOE, 1730. ST. LOFE, $V^{*}$. Sr .... de Seint Lowe, $V$. St. Pier, co. Worcester. Sir Brian S. Pier or de S. Pier, L. Arg. a bend sa. a label of four points gu. SEYATPER.

Arg. a bend sa. a label of five points gu. Urian de St. Peire or Pere, E. St. Peire St. Pere or St. Pierre, Runsell, Essex. Sent Pier, $V^{*}$. Saynt Pier, $V$. Hurien de SernP', $F$. John de Stopham, $G$.

Arg. a bend and a label of three points sa. ST. Low.

Arg. a bend sa. and a label or. Sire Johan de STOPHAM, $N$.

Arg. a bend sa. surmounted by three bars az. LEGH: LEIGH. 


\section{BEND cont.}

Arg. a bend embattled sa. Monsire Henry de Santon, $Y$ (? in error). Henry de Standon, $Y$. Stanton. Staundon. Henry de Staunton, $X$.

Arg. a bend embattled counter-embattled sa. SabrahaM, Tesemouth, Northumberland. Sabram, $V$. Safferham ol Sayperham. Saperhadr, $V$. Spram, $V$. Henty Steynton, $V$. Arg. a bend dancetty sa. Lis'ron.

Arg. a bend engr. sa. Bradden. Brodden, co. Northampton. Crouch or Crowch. Sire Henry de Glastingburs, $N$. Sir Henry Glastonbury or de Glastonburt, $L$. Jolun Glastonbury, $Y$. Sr. James Radchiff del Tour, co. Lancaster, $V$. Radclyffe, Radelyffe Tower, co. Lancaster; Smithills, Ordshall, Mellor, Foxdenton, etc. RADCLIFFE, Baron Fitzwalter 1432, Viscount Fitzwalter 18 June 1525, Earl of Snssex 8 De. cember 1529, extinct 1641. Radclyffe, Baronetcy 31 Jannary 1620, Baron Tyndale, Viscount Radclyffe and Langley, Earl of Derwentwater $7 \mathrm{March} 1688$, extinet 1716 . RADCLiffe, Chat. tert on, co. Lancaster; Franklin, Hockwortby Court, and Warleigh, co. Devon. Sir Robert Ratclifte alias Kirisland, Lord Fitzwalter; quartering Fitzwalter, Burnell, and Multon of Fgremont, $U$. Sir John Ratclyffe, $Q$, or Ratclife, Q, Harl. MS. 6595. Sidney and Sussex College, Cambridge, impaling Sidney; founded 1595. Stretton.

Arg. a bend engr. sa. a crescent of the first for diff. Radcliffe, Milnesbridge House, co. York; Baronetcy 2 November 1813. The crescent gn. charged with a mullet or for diff. RADCLIFF, Stepney.

Arg. a bend engr. sa. an escallop .... for diff. RatCliff, Chappeil, Essex.

Arg. a bend engr. sa. an escallop ....' en le sou'eigu peice'. William 'Usance, $Y$.

Arg. a bend engr. sa. a fleur-de-lis gu. for diff. William fitz William RadclifF, $1350, V$. The fleur-de-lis sa. Ratcliffe, Todmorden, co. Lancaster, and co. York.

Arg. a beud eng1. sa, a label gn. Walter de Beconus, $Y$. Walter Benuns, $Y$. The label of three points gn. BerINs.

Arg. a bend engr. sa. a mullet .... for diff. Radchiff, co. Chester; Mulgrave and Newton. Durham; Oxford; and Standish, co. Warwick.

Arg. a bend of four fusils conjoined sa. Sir Henry Glastinges, $V$.

Arg. a bend of four fusils conjoined sa. and in the sinjster chief a crescent of the second. LyE, $V$.

Arg. a bend fusily sa. Drgons. Sir Henry Glastingburt, $R$. Richard.

Arg. a bend fusily sa. and a label of five points gu. Sir William Cozans, $R$.

Arg. a bend fusily in the sinister corner a crescent sa. LIE, co. Chester. L'E.

Arg. a bend indented sa. Anston. John Gilastonbury, $Y$. Sir Richard Lyston, $V$.

Arg. a bend lozengy sa. Bainton, London. Beton. Glastendury, co. Dorset. Ketsfond. Kitesfond, co. Somerset. Leigh, Quithiock, Cornwall. Sydenham. Wrume, quartered by Lelgb.

Arg. a bend masculy sa. a label of three points gu. Beton.

Arg. a bend masculy sa. Cosars. Glastenbury.

Arg. a bend mascnly sa. a label of five points gu. CosARs.

Arg. a bend nebuly sa. Coterell Cotterali Cotterell or Cotterill.
BEND cont.

Arg. a bend raguly sa. Saunton, $V$.

Arg. a bend voided sa. Rawleter, Wimondley, co. Herts.

Arg. a bend sa. voided of the field wavy. Wigmur, Wigmur, Scotland.

Arg. a bend wavy sa. Burton, Kynsley, co. York. Sir John de Burton, $S$. Sr. Thomas Burton, Kynesley, $V$. ColHet. Cotterells, co. Devon. WaLLOP, Baron Wallop and Viscount Lymington 11 June 1720, Earl of Portsmouth, 11 April 1743. WaLlop, Farleigh.Wallop, co. Hants, 1730. WaLlOPE, $V^{*}$. WaLloP, Bugbroke; co. Salop. WALLOPP, $V$.

Arg. a bend vairy or and gu. Penceller, $\boldsymbol{V}$. PENCOLER.

Arg. a bend vert. Grey. Kendal, 1730. Kendel. Kendall, co. Devon. O'Malune, harl. MS. 4039 , fo. 118 .

Arg. a bend vert with a label gu. Sire Robert de Kendale, $N$. Richard de Kendale, $Y$. Robert de Kendall, $Y$. Monsire Kendall, $Y$. The label of tluree points. Sr. Edmond Kendall, co. Bedford, $V$. Sir Robert Kendalle, $L$. Kendall, co. Bedford. The label of five points. Sr. Robert de KENDALL, V. Kendali, co. Bedford.

Arg. a bend engr. vert. Hales. Malmeis.

Arg. a bend wavy vert. CoLHeT.

Arg. a bend wreathed az. and or. OARE or ORE, Oare, Sussex.

Az, a bend arg. Benton. Bisset, Scotland. Busts. Bussets or Bustes. Coche't. Lanwall. Sr. Jolin Lavali, $V$. Lawall. Levall. Swathinge, $V$. Swathong or Swathyng, Norfolk.

Az. crusily or a bend arg. Sire Thomas Filz-Eustace, $N$.

Az. a vend arg. impaling arg. a bend az. Zorke, called Yonk, $V$.

Az. a bend arg. impaling the same. Zorke, $V$.

Az. a bend sinister arg. Bisset or Bizzet, Scotland.

Az. a bend arg. on an inescucheon or a bend engr. sa. Sire Johan de Lydevusens of France, $O$.

Az. a bend embattled arg. Wallies, 1716. WALLEYS. WALLIS or WALLES.

Az. a bend connter-embattled arg. Weires, $V$.

Az. a bend double dancetty arg. LORKs.

Az. a bend engr. arg. Beringham. Birningham. $A z$, a bend of three and a half fusils conjoined aig. Sr. Peter Gussau', $V$. Gussaud, $V^{*}$.

Az. a bend lozengy arg. GwYN, co. Derby. Richands, Yarland or Yevelaud, Isle of Wight, from co. Monmonth. Richards, Rahere.

Az. a bend wavy arg. Swale, South Stainley; confirmed 1603-35.

Az. a bend barry indented or and gu. Bracy.

Az. a bend chequy arg. and gu. Steer, England.

Az. semy of fleurs-de-lis or a bendlet (or baston) compony arg. and az. JOAN, daughter of Charles (CAPET) II King of Navarre and Count of Evrens, second wife of Henry IV, quartering Navarre.

Az. semy of 5 -foils or a bendlet compony arg. and gu. RODVILLE.

Az. a bend erm. Dever. Philpot.

Az. billetty arg. (but altered to or) a bend erm. John Suith, Hellsworth, Suffolk, $W$.

Az. a bend lozengy arg. and gu. Gwrnne, Ireland. 


\section{BEND cont.}

Az. a bend or. Carminow, Carminow, Cornwall; as allowed to this family according to the evidence given by John of Gaunt in the cause Scrope $v$. Grosvenor; the colieiresses m. Arundell, Trewarthean, and Petit: the younger branches settled at Boconnoc (the coheirs $m$. Carew and Courtenay), Fentongollan (the coheirs m. Salter and Cole), Resprin in S. Winnow, Yolmawgan, Trenowth, etc. CarrynaLI. Carmynell. Carmynow, $V$. Corwall, Corwall. Grosvenor, until the decision 1390 in the cause Scrope $v$. Grosvenor. Mark, Scotland. Robert de Muntein, A. Harl. MS. 6137. Robert de Mu'tein, $A$. Scroop, $V^{*}$. Scrope, as early as 1203 , according to the evidence given by Chauncy in the cause Scrope $v$. Grosvenor, instituted 1384.5 by Sir Richard Lescrop, first Baron Scrope of Bolton, whose title descended through Emanuel Earl of Sunderland ob. 1630 and now vests in Jones, Caton, co. Lancaster. The coat has been assigned without proper difference to members of younger branches, as to William Scrope, K.G., Lord of the Isle of Man 1693, Earl of Wiltshire 29 September 1397, ob. 1399: Scrope, Cockerington, co. Lincoln, Baronetcy 16 January 1660-7; extinct 1680 ; derived throngh Scrope, Hambledon, co. Buckingham, from SCROOPE or Scrope, Spennithorne and Danby, co. York, a younger son of Henry sixth Lord Scrope of Bolton: and to Scrope, Castlecombe, co. Wilts, the heiress m. Thomson; descended from Stephen Scrope Lord of Bentley, third son of Richard first Lord Scrope of Bolton : as well as to Scrope, Lord of Masham and Upsal, extinct 1517. Richard Scroope, Bishop of Carlisle 1464-8. Dominus Scroope de Bolton, $V$. M. Richard le Skrop, $S$.

Az. a bend or and a label arg. Geffray le Scrope, $Y$. Richard Scrope, Bishop of Lichfield etc. 1386, Archbishop of York 1398.1405. Sir Geoffry LE Scrope, Masham, co. York, ob. 1340 ; a Barony in abeyance since 1517.

Az. a bend or and a label of three points arg. $\mathrm{C}_{A Y}$, Scotland. Scoop (but? Scrop). Scrope, Masham, co. York. Henry le Skrop, $S$.

Az. a bend or charged with an annulet in the centre.... for diff. a label of three points arg. Sir John Lescrop, fifth son of Henry first Lord Scrope of Masham, ob. 1405.

Az. a bend or and a label of three points arg. charged with an annulet sa. M. Thomas le Scrop, $S$.

Az. a tiend or and a label of three points arg. each point charged with as many bars gu. Henry, fourth son of Henry first Lord Scrope of Masbam. M. Henri le Scrop, $S$.

Az. a bend or and a label of five points arg. Sr. Geffry Scroope, Masham and Upsall, $V$.

Az. a bend or and a label compony arg. and gu. Sir William, third son of Sir Geoffry Scrope the first of Masham; ob. 1367; but probably in error as this was the distinction of the eldest son in that family, as borne by Sir Geoffry, eldest son of Henry first Lord Scrope of Masham, oh. 1362.

Az. a bend or and a label erm. Sir William, third son of Sir Geoffry Scrope the first of Masham, ob. $\mathbf{3} 367$.

$\mathrm{Az}$. a bend or and a label of three points erm. M. John le Scrop, $S$.

Az.a bend or and a label gu. Monsire de Carminou, (co. Devon, and Cornwall, added 15(12), $Y$.

\section{BEND cont.}

Az. a bend or and a label of three points gu. Beringham, Worcester. Thomas Carminow, $Y$. Henry, third Lord Scrope of Mashan, during the life of his fatber. William Le Scrope, K.G., Lord of the Isle of Man, 1693; Earl of Wiltshire, 29 September, 1397, ob. 139!); quartering $\mathrm{MAN}_{\mathrm{AN}}$.

Az. a bend or and a label of three points gu. but the centre point arg. Geoffery Scrope, a priest, ob. 1389; fifth son of Sir Geoffery Scrope the first of Masham.

Az. a bend and a label or. Monsire Jefferey Destron (apparently meant for Scrope), $Y$.

Az. a bend or and in chief of the bend a mullet erm. for diff. M. Steven le Scrop, $S$; third son of Ricluard first Itord Scrope of Bolton; from whom descended Scrope, Castlecombe, co. Wilts; the heiress $\mathrm{m}$. Thomson.

Az. a bend or aud a fess arg. Dowson.

Az. a bend and over all a crosier in bend sinister or. Benedictine Priory of S. Martin at Richuond, co. York.

Az. $\Omega$ bend over all a crosier in bend sinister or the staff arg. (Abbey of S. Agatlia at Richmond, co. York, but?).

Az. billety and a bend or. Le Counte de Marre, C. Reguighers, $V^{*}$. Monsire John de Remeghers, $W$.

Az. semy of estoiles and a bend or. Persam.

Az. a bend bretessed or. Brescett.

Az. a bend engrailed or. Beringham. Sr. William BerminghaM, $I$. Bringhall. Sir Thomas Bernyngham, $L$. Sire William de Berminghair, $N$. Sire William Byrmyngham, O. Marlere. Marshalt.

Az. a bend engrailed or and a label gir. Berenghadr. Sire Thomas de Berminghar, $N$.

Az. a bend engrailed or and a label of three points gu. Birninghar.

Az. a bend engrailed or and a label of five points gu. Sr. Thomas Benuryeham, co. Worcester, $V$. Berirynham, $V^{*}$. Bermingham, 1730.

A7. a bend fusily or. Bermingham. Birmingham. FoKeraM.

Az. a bend of five fusils conjoined or. Sire William de Burmichame, $J$.

Az. a bend of six fusils conjoined or. Wat de Birmingham, $E$. Will. de Biring ham, $E$, Harl. MS. 6137.

Az. a bend invecked or. Braddeltr.

Az. a bend lozengy or. Berminghall. Town of Birminghan; quartering per pale indented or and sa. Bringham.

Az. a bend lozengy (or of seven lozenges conjoined) or. IVill. de Birming hadr, $F$.

Az. a bend voided or. Busson, London.

Az. a bend wavy or. AldaM, Suffolk.

Barry of three arg. and az, a bendlet gu. IRDIS or IRISH.

Barry of three arg. and gu. a bend of the last. Polle Tne.

Barry of three arg. and gu. a bendlet of the last. Poleyn. Polin.

Barry of three arg. and gu. a bend sa. Ficher.

Barry dancetty of three arg. and gu. a bend sa. Sire Felip de Nevile, $N$.

Barry of three arg. and gu. a bendlet sa. Poleyne.

Barry of three az. and arg. a bend gu. FErRERs. IrEYs or IrIsH, lreys, co. Dorset. 


\section{BEND cont.}

Barry of three chequy or and az. and gu. a bend of the last. Clifford, Kent.

Barry of three or and az. a bend gu. Eluoway. ELWES, Stoke, Suffolk; Baronetcy 22 June 1660 , extinct 20 November 1778; descended like Eıwes, co. Liucoln, co. Hertford, co. Northampton; and Essex; through Geoffry ELwes, Alderman of London, from Elwes, or HELwish, Askham and Worleby, co. York.

Barry of three or and cheguy arg. and az. a bend of the third. Fleming, Brawchan, Scotland.

Barry dancetty of three or and ermines a bend vert. Quarles.

Barry of three or and gu. a bend sa. Fecher. Fisher.

Barry of three or and gu. a bendlet sa. Poleyne.

Barry dancetty of three or and sa. a bend of the last. Nevili, co. Huntingdon.

Barry of four arg. and sa. a bend gu. Deanfierd. Dronesfield.

Barry of five arg. and az. a bend of the last. Martingdaie or Martindale. Montford, $V$. Mountford, $V^{*}$.

Barry of five arg. and az. a bendlet of the last. Mountrond, co. Warwick.

Barry of five arg. and az. a bend chequy gu. and of the first (another gu. and or). LEGG.

Barry of five arg. and az. a bend compony gu. and .... Lea or Leigh, Bradley, co. Laneaster.

Barry of five arg. and az, a bend compony gu. and or. LeIGH, Ridge, co. Devon. Leigh, Bardon, co. Somerset, 1595 ; descended from Leigh of Ridge.

Barry of five arg. and az, a bend compony or and gu. LEIGH, Ridge in Bishop's Morchard, co. Devon; Visitation 1620.

Barry of five arg. and git. a bend az. Martindale.

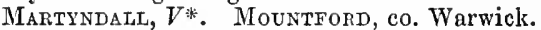

Barry of five arg. and gu. a bendlet az. Martindali, $V$.

Barry wavy of five arg. and gu. a baston of the last. Sir Roger d'Abions, $L$.

Barry of five arg. and gu. a bendlet or. Mainwaring, Croston, co. Chester; derived from an illegitimate son of Mainwaring of Over Peover, 1540.

Barry of five arg. and gu. a luendlet sa. Morton.

Barry of five arg. and sa. a bend erm. Finchan.

Barry of five arg. and sa. a bend gu. Robert Ascheton, seal 1341. Ashton. Lynde, $V$.

Barry of five arg. and sa. a bendlet gu. Sir Ro. bert Ashton.

Barry of five arg. and sa. a baston gu. Sir Robert de Ashton, Constable of Dover Castle, V. LrNDE, $V$.

$B$ arry nebuly of five arg. and sa. a bend gu PoHer, Cornwall.

Barry nebuly of five arg. and sa. a bend or. Power, Bletchington, Surrey; granted 8 June 1601.

Barry of five arg. and vert a bendlet gu. Herthalt.

Barry of five az. and arg. a bend chequy or and gu. William de LeEgH, $X$.

Barry of five az. and arg. a bend compony of the last and gu. LEA or LEE, Cumberland.

Barry of five az. and arg. a bend compony gu. and or. LEGH, Adlington, co. Chester; derived from Legh of Booths.

Barry of five az. and arg. a bend compony or and gu. LEgh or LFIgH, Adlington, co. Chester,
BEND cont

$V^{*}$. LEgH or Leigh, Isell, Cumberland, temp. Edward II.

Barry of five az. and arg. a bendlet compony or and gu. LEGH, Adlington, co. Chester, $V$.

Barry of five az. and arg. a bend countercompony or and gu. LE1GH, 1369. LEGH of the North, $V$. LEGH, Iseil, co. York, $V$.

Barry of five az. and arg. a bend gu. Done. LeE, Plaistow, Essex; and Ratcliffe, co. Leicester. Edmund LEE, 1705, in Egham Church. LEGH, Norbury Booth's Hall, co. Chester; quartering Pennington, Leigh, Corona, Baggileigh, Sandbach, Leche, Grosvenor, Barcroft, Wade, and Dawson; descended from John Legh, temp. Edward I, youngest son of Richard de Lymme, by Agnes de Legh, his first wife. The branches were Legh of Adlington, Annesley, Baggileigh, Isell, Lyme, Ridge, Stockwell, and Stoneleigh. Leigh. Venables, $V^{*}$.

Barry of five az. and arg. a bendlet gu. LEGH, Bothes, co. Chester, $V$. Sir Alexander Venables, temp. Edward 11 and III, $V$.

Barry of five az. and arg. a bend or. Pole.

Barry of five az. and erminois a bend countercompony of the second and gu. LEE, London.

Barry of five az. and or a bend chequy of the last and gu. LEE, Ditton, Moreton, and Hartwell, co. Buckingham, Baronetcy 16 August 1660; extinct 1827.

Barry of five az. and or a bend gu. Burdetr.

Barry of five az. and or a bend of the last. LEIGH, Preston, co. York. Patte. Pott or Potts, London, and Norfolk. Potrs, Mannington, Norfolk; Baronetcy 14 August 1641, extinct 14 January 1731-2; descended from John Pot, who had a grant of arms 1583. Ports, Chester. Potrs, South Shields, co. Durham.

Barry of five az. and or a bendlet of the last. Poтt, Bentham Fill, Kent; quartering gu. three swords erect ppr., with gu. a cross engr. betw. four pheons arg.

Barry of five gu. and arg. a bend of the last. Wallis Welch or Welsh, Wanlip, co. Leicester, 7 Edward $\mathrm{I}$.

Barry of five gu. and erm. a bend of the first. WORKSHALI Or WORSHALI.

Barry of five gu. and erm. a bend engr. sa. Pentolph, co. Salop.

Barry of five or and az. a bend gu. QUAPLED QuAPELADE or QuAPPElad.

Barry of five or and gu. a bend az. WAKE, Kent.

Barry of five or and gu. a bendlet az. WAKE, Kent, $V$.

Barry nebuly of five or and gu. a bend az. LONELI.

Barry of five or and gu. a bend of the last. PALMER.

Barry of five or and gu. a bend of the first. WAKE, Kent.

Barry of $\operatorname{six} . .$. and .... a bend .... Richard de Marisco, Bishop of Durham 1217-26.

Barry of six arg. and az. a bend ccmpony of the the first and gu. Gray.

Barry of six arg. and az. over all a bendlet compony of the first and gu. AvENSLY.

Barry of six arg. and az. a bend compony or and gu. Grey, Wolbediug, Sussex; and Barton, co. York. GREY, Jofard, co. Lincoln; and Bar. ton, co. York. Grey, Northumterland; Leland, Collect. ii, 509, suggests a ladd 3 r. 


\section{BEND cont.}

Barry of six arg, and az. a baton compony or and gu. Sire Nicholas de GreY, $N$. Robert GREY, Barton in Ridale, $Y$.

Barry of six arg. and az. a bend gu. Fitz-PAYNE. Grant. Gray, Essex. Walter de Grey, Bishop of Worcester 1214-16. Le Sr. de Grey, Rotherfeld, $S$. Grey, Rotherfeld, co. Oxford, $V$. M. Richard GreY, S. Quaplod.

Barry of six arg. and az. a bendlet gu. AvensLY or ANstey. Robert de Grer, E, Harl. MS. 6137 ; or de GreY, $E$; or le Grey, $F$. Sir Jolın Grey, Rotherfeld, co. Oxford, $V$.

Barry of six arg. and az, a baston gu. Sire John de (Horbourne? in pencil), $J$.

Barry of six arg. and az. a bend sa. Moncaster. Barry of six arg. and gu. a bend az. Sire de Audenard, A, Harl. MS. 6137. Damoly, Ire. land. Mantinhary. Molcaster or Moncaster, co. York.

Barry nebuly of six arg. and gu. a bend az. Champney. Damorie, co.Somerset. Darmors, $V *$ *

Barry wary of sis arg. and gu. a bend az. Danory or. Daniour.

Barry nebuly of six arg. and gu. a bend engr. az. Damer, Milton Abbey, co. Dorset. Damer, Baron Milton 11 May 1762, Viscount Milton and Earl of Dorchester 18 May 1792, extinct 7 March 1808. Amery D'Ameny or Aumany, Park House, Stourbridge.

Barry of six arg. and gu. a bend (fusily $V^{*}$.) of four and a half fusils conjoined az. John de Roos, Tyd, $V$.

Barry of six arg. and gu. a bend sa. Martingdale, Arcleby, Cumberland. Moncaster or Molcaster, co. York. Roos. Rosse.

Barry of six arg. and gu. a baston sa. William Martynale, $X$.

Barry of six arg. and sa. a bend ermine. FINCHAM, Outwell, Isle of Ely. Fyncham, $V$. Merrets, London; granted $13 \mathrm{July} 1666$.

Barry of six arg. and sa. a bend gu. Finchanr, Outwell, Isle of Ely.

Barry of six az. and arg. a bend compony of the last and gu. LEIGH, co. Chester.

Barly of six az. and arg. a bend compony or and gu. Bоотн.

Barry of six az. and arg. a bend gu. Bournelt. Bowrdiel. Nicholas of Ely, Bishop of Winchester 1268.80.

Barry of six az, and arg. a baston gu. Monsire de Grey, Barton, $Y$.

Barry of six az. and or a bend arg. Stanhold.

Bany of six gu, and arg. a bend engr. sa. Roos or Posse.

Barry wavy of six gu. and vert a bend erm. DANIORY.

Barry nebuly of six or and az. a bend arg. Pewley.

Earry wavy of six or and az. a bend arg. PanelL, K.G., i.e. Sir WaIter PAVELEY, ob. 28 June 1375. Pelley. Penley.

Barry of six or and az. a bendlet erm. Herevi de Stanhowe, $E$.

Barry of six or and az. a bend gu. Gant or Gaunt, Barony extinct 129\%. GAUNT, Highfield, and Leek, co. Stafford. Gilbert de Gaunt, called Earl of Lincoln, ob. 1160; and his nephew, Gilbert, called Earl till 1217. Gilbert de Gaunt, Swaldale, $X$. Gilbert. Knaplod. Lighair. Sir Richard Pembridge, 1375, in Hereford Cathedral. Quaplade, $V^{*}$. Stanhow, Norfolk.
BEND cont.

Barry of six or and az. a bendlet gu. Henri de Pembruge, E; or Penbrugge, E, Harl. $M S$ $6137 ; F$. Edmund Quaplade, $V$.

Barry of six or and az. a baston gu. Sir Henry Penebruge or de Penebruge, $L$; or de Penbrige, L, Harl. MS. 6137.

Barry of six or and az. a bend of five lozenges conjoined gu. Henyngton or HenYngton, co. Chester.

Barry of six or and gu, a bend arg. LANGTON.

Barry nebuly of six or and gu. a baston arg. John Lovel le filz, $D$.

Barry of six or and gu. a bend az. Sire de Dudenan, $A$.

Barry nebuly of six or and gu. a bend az. for diff. Loves, Tickwell.

Barry of six or and gu. a bend erm. Menret, $V^{*}$. Barry of six or and gu. a bend of the last. Sarnt OWEN.

Barry wavy of six or and gu. a baston sa. John LOVELL, $F$.

Barry of six or and gu. a bend vair. GANT, co. Lincoln. GaUNT, Canterbury.

Barry nebuly of six or and sa. a bendlet arg. Paveley, $V$.

Barry of six or and sa. a bend erm. Monsire John Enerike, $Y$. Sire Joban de Meniet the nephew, N. Merits, co. Wilts. Sr. John Meryet, $V$.

Barry of six or and sa. a bend gu. Shouldhar, Norfolk.

Barry of six or and vert a baston compony arg. and gu. Sir Christopher (aliter Thomas) Poynings, $R$.

Barry of six or and vert a bend gu. Poynings, $V^{*}$. Poynings, Baron St. John of Basing 1361 1428 , a cadet of Poynings, Baron Poynings 1204-1446; $Z, 225$. Lucas Poynings, $A$, Harl. MS. 6137; or de Poynge, A. Sir Michael Pornings, L. Sir (Michaell, Harl. MIS. 6595) Nicholas Poynings, $Q$.

Barry of six or and vert a bendlet gu. Le S. de Poinynges, $S$. Sr. Michael Pornings, $V$. Le S. de Poynings, $T$, quartering gu. three lions pass. in pale arg. a bendlet az.

Barry of six or and vert a baston gu. Sir John Poynings, $R$. Thomas Poynings, $Y$.

Barry of seven arg. and az. a bend gu. GAUNT, Lord Lindsey.

Barry of seven arg. and az. a bend masculy gu. GREY.

Barry of seven arg. and gu. a bend sa. Multon, Rosse, $V^{*}$. Thorpe, $V^{*}$.

Barry of seven arg. and gu. a bend engr. sa. Newel. Rosse, $V$. Sire Johan de Ros, $N$. THORPE, $V$.

Barry of seven arg. and sa. a bend erm. Finchan, Cambridge, and Norfolk. FynCHair, Norfolk, $V$.

Barry nebuly of seven arg. and sa. a bend or. Poore, co. Oxford.

Barry of seven az. and or a bend arg. Stanhowe. Barry wavy of seven az. and arg. a bend gu. Halswell, Halswell, and Wells, co. Somerset.

Barry of seven az. and or a bend compony arg. and gu. LEIGH, co. Chester.

Barry of seven erm. and az. a bend gu. Fromantrill, $V^{*}$.

Barry of seven erm. and az, a bendlet gu. Fromantrel, $V$.

Barry of seven or and az. a bend gu. ELrand. Penbrug, $r$. Quapelade Quapled or QUAPPELAD. 


\section{BEND cont.}

Barry of seven or and gu. a bend az. Brandeston. Sir Hugh de Braundeston.

Barry of seven or and vert a bend gu. Puninge.

Barry of seven or and vert a baston gu. Sir Michael Poyninges, L, Harl. MS. $613 \%$.

Bairy of eight arg. and az. a bend fusily gu. HeMington or HeMMington.

Barry of eight arg. and gu. a bend sinister az. MaLcasty.

Barry of eight arg. and sa. a bend erm. Mariot.

Barry of eight az. and or a bend arg. Stannow, Norfolk.

Barry of eight or and az. a bend arg. StanhoE.

Barry of eight or and az. a bend gu. Gaunt, Earl of Lincoln. Gaunt, Highfield, and Leek, co. Stafford ; descended from GAND or GAUNT, Rowley, co. Stafford, claiming descent from the ancient Earls of Lincoln. GaUnT, $V^{*}$.

Barry of eight or and az. a bendlet gu. Giles GAUnT, $V$.

Barry of eight or and sa. a bend flory vert. $\mathrm{S}_{\mathrm{AXE}}$ (" being a chaplet of rue given by Frederick Barbarossa to Bernard of Anhalt, Duke of Saxony"), $Z, 69$.

Barry of nine arg. and gu. a bend az. Mulcaster, Charlwood, Surrey; Visitation 1662; derived through Mulcaster, Carlisle, from Mulcaster, Taperham, temp. William II. Mulcaster, Charlton Place, near Canterbury.

Barry of nine arg. and gu. a bend sa. Chaworth.

Barry of nine gu. and arg. a bend or. SockwELL.

Barry wavy of nine or and sa. a bend arg. Poole, co. Oxford.

Barry of ten arg. and gu. a bend az. Mulcaster, Cumberland.

Barry of ten arg. and gu. a bendlet az. Moncaster, $V$.

Barry of ten arg. and gu. a bend engr. az. Moncaster, $V^{*}$.

Barry of ten arg. and gu. a bend sa. Burton.

Barry of ten arg. and gu. a bend engr. sa. Roos, $V^{*}$. ThORP, $V^{*}$.

Barry of ten arg. and gu. a bendlet engr. sa. Roos, $V$. Thorpe, $V$.

Barry of ten az. and arg. a bend gu. Ely, Essex.

Barry of ten or and sa. a bend gu. BAKER, Monckwith, Essex. Barker, Kent; Middlesex; and Surrey.

Barry of twelve arg. and az. a bend gu. Remington, Lund, co. York. Pemington, Crow Trees, Melling, co. Lancaster.

Barry of twelre arg. and gu. a bendlet az. M. Robert MoNCASTRE, $S$.

Barry of twelve gu. and arg. a bend sa. Sir William Webb Follett, Solicitor-General; derived from Follett, Topsham, Exeter.

Barry of thirteen arg. and az. a bend of the last. Mulchester.

Barry of thirteen arg. and az. a bend gu. GaUnt.

Barry of fourteen arg. and az. a bend gu. Mulcaster, $V$, or Mulchester, $V$. Henri le WaIEIS, $E$.

Barry of fourteen arg. and az. a bendlet gu. Henri le WaLEIS, E, Harl. MS. 6137.

Barry arg. and az. a bend gu. Hugh L'Archeveske, $C$. Sire Johan de Grey, $N$. Sire Johan de Horburi, $N$. Partney.

Barry arg. and az. a baston gu. Le Sire GREY, Rotherfeild, $Y$. Sr. John GRAY, $H$.

Barry arg. and az, a bend engr. gu. Jolın de GRAY, $h$.
BEND cont.

Barry wavy arg. and gu. a baston az. Sir Roger D'Amory, $L$. Sir Roger Damrye, $L$, Harl. MS. 6137.

Barry arg. and gu. a bend sa. Henry de Chaworth, $X$. Henry Chaworthe, $Y$.

Barry wavy arg. and gu. a bend sa. Sire Roger Ammort, $N$.

Barry az. and arg. a baston compony arg. and gu. Sire Nichol de Grey, $O$.

Barry az. and arg. a bend compony or and gu. Sr. Nicol de Gray, $M$.

Barry or and az. a bend gu. Sire Gilbert de Gaunt, $N ; P$. Geffry de Gaunt, $C$. Sire Henri de Penbruge, $N$.

Barry wavy or and gu. a baston az. Sir Thomas Lovel, $L$; or Lovel, $N$.

Barry wavy or and sa. a bend arg. Sire Water le Pavele, $N$.

Barry or and vert a bend gu. Sire Michel de Poninges, $N$.

Barry or and vert a baston ga. Jolon Poynings, $Y$. Barry vair and gu. a bend or. Thomas de Coscy, $C$, or Coucy, Harl. MS. 6589.

Chequy arg. and az. a bend erm. Ward, co. Stafford.

Chequy arg. and gu. a bend az. Barkesworth, $V$. Beckering, co. York. Sire Thomas de Bekeringe, $N$.

Chequy arg. and gu. a baston az. Thomas Beneringe, $Y$. Thomas de Berkeyng, $M$.

Chequy arg. and gu. a bend chequy az. and or. BERING.

Chequy arg. and gu. a bend sa. Banening, $V^{*}$. Beckering, co. York. Sir Christopher de Benering, $R$. Leskesworth, Suffolk. Pickering.

Chequy arg. and gu. a bendlet sa. William Berering, Blunt, $V$. TVilliam Buount, $Y$.

Chequy arg. and sa. a bend gu. Richard le Brut, E. Helinbridge, co. Gloucester. Partridge, Kent. Pertricke.

Chequy arg. and sa. a bendlet gu. John de Helmebrige, co. Gloucester, $V$. Helmebridge, $V^{*}$.

Chequy az. and or a bend erm. Sir Adam Clitfton, Norfolk, $V$. WaRd, Norfolk.

Chequy az. and or a bend gu. Walter de Clifford, $F$.

Chequy gu. and arg. a bend az. Barkesworth, $V^{*}$. Barkyworth.

Chequy gu. and arg. a bend wavy or. Martyre. Chequy gu. and or a bend rair. Bortreaux.

Chequy or and az. a bend erm. Clifton, Norfolk. Cumpon, $V^{*}$. Wand, Bexley and Poswylke, Norfolk. WARD, co. Berks; and Birmingham, co. Warwick; granted 22 Dec. 1575. WARD, Baron Ward of Birmingham 23 Marcl 1644; Viscount Dudley and Ward 21 April 1763, Viscount Ednam and Earl of Dudley 5 October 1827, extinct 6 March 1833 .

Chequy or and az. on a bend erm. a mullet gu. for diff. Joseph Wand, Steward of the Charterhouse 1619.

Chequy or and az. a bend gi. Cltrford, co. Somerset. Reinaud de Clifford, $E$. Sire Johan de Cutrford, $N$. Toger de Clifford, $P$. Gautier de Clifford, $P$. Walter de Clifford, $B$. Chequy or and az. a bendlet gu. Clifford.

Chequy or and gu. a bend arg. Aile or Ayles. CAYley or CAyi.y, Norfolk.

Chequy or and gu. a bend az. Barkworth. Botereulx. 
BEND cont.

Chequy or and gu. a bend erm. Carzer, $V$. Cayley or CAYly, Norfolk. Sire Adam de Cayli, $N$. Sr. Adam Clifton, Norfolk, $V$. Clifton, Bokenham, Norfolk. Adam de Clifton, $X$; or Clifton, Y. Kingston.

Chequy or and gu. a bend erm. charged with a fleur-de-lis sa. for diff. Clirton, Fakenham, Norfolk.

Chequy or and gu. a bend erm. a mullet sa. for ditf. Clifton, Toftrey, Norfolk.

Chequy or and gu. a bend sa. Beckering. Moulton, Rogers, Ireland.

Chequy or and gu. a bend vair. Le Sire Botreaux, $Y$. Monsire de Botereux, $Y$. Botreulx, $V$. Botreux, $V$. Thomas Manduit, $Y$.

Chequy or and vert a bend erm. Sparke, Essex; London; and Plymouth, 157\%. Bowyer Edward Sparke, Bishop of Chester 1810, Ely 1812-36. William Sparke, $V$. Sparkes, Glenham, Suffolk. Sparis, co. Wexford; Byfleet, Suriey.

Chequy or and vert a bend erm. and a label of three points gu. SPARkes, Cornwall; and Ply. month, co. Devon.

Chequy sa. and arg. a bend gu. Brute or Broit. Helmebridge, co. Gloucester. Kendall.

Chevronelly of tbree arg. and gu. a bendlet az. Crontell.

Chevrovelly of three or and sa. a bend. engr. arg. HIGHAM.

Cherronelly of five gir. and arg. a bend sa. PaRneli.

Chevronelly of seven arg. and sa. a bend erm. Enderbie, co. Bedford.

Erm. a beod az. Beavir, $V^{*}$. John de Borne, A. Bourne, $V^{*}$. Bowrne, $V$. Sir Henry Dever, $V$. English, $V^{*}$, co.Lincoln. Englishe, $V$. Felding hair or Fillingham. INgisis.

Erm. a bend. engr. az. English. FillinghaM. Orden.

Erm. a bend chequy arg. and sa. Curson, $V^{*}$.

Erm. a bend chequy sa. and arg. Corson, $Y$. Curzon, $T$.

Eim. a bend compony arg. and sa. Armbatr.

Erm. a bend counter-compony arg. and sa. Curson, Litheringset, Norfolk. Mounsyer John Curson, $T$. And with a martlet in chief gu. for diff. Mounster Cursos, $T$.

Erm. a bend gu. Henry de Apeiderfild, $A$. APLEDORFIELD. APLETRESEND or APPELTRESEND. Applederfield. Henry de Apulderfield, $A$, Harl. MS. 6137. Aype. Barnake. Bathe or Bathon, co. Devon; Pole, 87, 191, 232, 320, 469. Bernake. Bowers. Burie, quartering az. a falcon volant belled or. Dever. Elmested. John Elusted, $V$. Gothair. Isely, Kent. Jenney, Norfolk and Suffolk. Sir John de WaleYs, $L$. Sire Johan le WaLEys, $N$. WALLIS, co. Somerset. Wallis, Drishane Castle, co. Cork. Walles or Walleys, co. Dorset; and Trowbridge, co. Wilts. WaLleys. Sir John Welles, $L$. Quartered by IsLey, $V$.

Erm. a bend gu. charged with a 5 -foil in chief or. Sir Richard Bernake, $V$. Honnere, $V$.

Erm. a bend gu. and three chevrons or. Burler.

Erm. a bend gu. over all a fess or. Pennel or Pennelu.

Erm. a bend engr. gu. Plugenet, Lambourne, co. Berks; and Kilpeck Castle, co. Hereford; temp. Edward I. Sire Aleyn Plokenet, N. Adam Plonienet, $Y$. Monsire Pluknett, $Y$. M. Alayn de Plokentett, $D$.
BEND cont.

Erm. a bend fusily gu. Bainton. Plumileigh or Plumley, Dartmouth, co. Devon. Plonkett or Plonket. Plunketr. Pie. Pre, Hone, co. Derby ; Baronetey 13 January $\mathbf{l} 604.5$, extinct 23 May 1734; descended, like Pye, Wadley, co. Berks, through Pre, Faringdon, co. Berks; and Clifton, co. Stafford, from Pye, the Mynde, co. Hereford; derived from Hugh Pye or Ap Hugh, Lord of Kilpec Castle, temp. Henry I.

Erm. a bend of six fusils conjoined gu. Alain (or Aleyn, $G$;) Plokenett, $E$.

Erm. a bend sinister of six (another eight) fusils gu. Sire Aleyn Plokenet, $J$.

Erm. a bend lozengy gu. PIE, Herald Painter, 1716, quartering Wildish. Plometey, Dart. mouth, co. Devon. Plumley, co. Devon.

Erm. a bend sinister of five lozenges conjoined gu. Alen de Plokenet, $A$; Alain Plokenet, A, Harl. MS. 6137 .

Erm. a bend masculy gu. Chanpaneis, quartered by Fiennes.

Erm. a bend voided gu. Ireton.

Erm. a bend wavy gu. Goldingham.

Erm. a bend sa. Attemore. Gotham. Laville. WALLES, $V^{*}$. Sir John WALLEXs, co. Somerset, $V$. Wallis, co. Somerset.

Erm. a bend engr. sa. Kessall, Bradshaw and Heathside, co. Chester; a younger branch of Kelsall, Kelsall, Tarvin, co. Chester. Kersall, Boston, co. Lincoln, and Middlesex. Adan Plunkenet, $Y$.

Erm. a bend fusily sa. WitnelL, $V^{*}$.

Erm. a bend of four fusils conjoined sa. Sir William Wytnyli, $V$.

Erm. a bend indented sa. West, HamptonPoyle, co. Uxford.

Erm. (but in pencil also crusily ....) a bend vair. Henry de RaLle, A, Harl.MIS. 6137.

Erm. a bend vairy gu. and or. Henry le Firz ApelderfeLd, $A$, or Henry le Fiz Apulderfeild, A, Harl. MS. 6137.

Erm. a bend vert. LANGLY, $V^{*}$. Richard LANGLEY, Sawley, $r$.

Erm. a bend engr. vert. WATNoLL, co. York.

Erminois a bend sa. BADDELEY or BADLEY.

Fusily or and vert a bend gu. YoNG, co. Somerset.

Gu. a bend arg. Belkejore. Collombers. Daveli. Filiet or Filiziot. Folet. Foriot, co. Northampton. Foliot or Folliot, Norfolk. Follot, Staple House, Nantwich, co. Chester; Londonderry; and co.York. Monsire Folisiot, $Y$. Sr. John Folyots, Norfolk, V. Foliot, Baron of Balishannon, Harl. MS. 4040 , fo. 438. FFoliot, $F$. Sire Richard Foliot, $E ; J ; N$. Sir Richard Foliot, $L$. Gilbert Foliot, Bishop of Hereford 1148, London 1163-88. Robert Foliot, Bishop of Hereford 1174.86. FOLIOT, see the claim of Edward de Hastings, Harl. MS. 1178, fo. 39-41. Richard Folioti, $B$. Folyot, Fenwyle, co. York. Sr. Picbard Folliot, $M$. Richard Folyott, $Y$. Hansard. Haward. Herman. Kellobery. Lavall or Lawall. Peter de Lria, Rishop of St. David's 1176-98. Roy, co. Dorset, temp. Charles II; and London. TolitotT.

Gu. a bend arg. a label of five points az. Ror.

Gu. a bend arg. a label or. Sire Edmon Forrot, $N$.

Gu. a bend arg. a mullet .... for diff. Hansand, Westmoreland. 


\section{BEND cont.}

Gu. crusily and a bend arg. Sire John HaUward,

$N$. Sire William HauWard, $O$. Sir .... de Howart, $F$. Cael de Hunting feitid, $A$, Harl. $M S .6137$. Jeer d'Huntingfeld, $E$.

Gu. crusily bottony and a bend arg. William HaWARD, $Y$. John HormesBy (in the margin Ormesby), $Y$.

Gu. crusily fitchy and a bend arg. Cael de HunTINGFYiD, $A$.

Gu. bezanty a bend arg. Sire Amory la Souche, N. Sir Amery la Souche, O. Zouchy.

Gu. a bend arg. over all a cross crosslet fitchy sa. WELSTEAD.

Gu. a bend urg. over all a fess or. Fitz-Osborne, Earl of Hereford 1066-74. OsBern, Bisbop of Exeter 1072-110\%. De Breteville.

Gu. a bend arg. surmounted by a fess vert. Fitz-Osborne.

Gu. a bend embattled arg. Abeinshertes, Suf. folk. Sire Johan de Penzret, $N$. Walleys.

Gu. a bend embatlled counter-embattled arg. Aleynsierls. Penford, co. Cambridge; Sr. John Penserd, Cumberland, $V$. Penzert, $V$. Thomas ScherLIs, $V$.

Gu. a bend engr. arg. Fenton, That Ilk, Scotlaud. GAMACK, Clerkenshalls, Scotland. Gammack or Gamane, Clerkinsheills. Gamiel, Clerkinsheills, Scotland. Raker. Sire Symon de Ralee, $N$. Sr. Simon Radlee, Cornwall, $V$. Raleigh, co. Devon.

Gu. a bend fusily arg. Auncell. Berkedon, $V^{*}$. Denajure Demaure or Deumore, Tournay. Fresford, $V^{*}$. Freshford. Ralegh, $V^{*}$. Riod.

Gı. a bend of three and a half fusils conjoined arg. Sr. .... de Fresford, $V$. Sr. de RALEgh, Cornwall, $V$.

Gu. a bend of four fusils conjoined arg. BERKEDON, $V$.

Gu. a bend of five fusils arg. Les armes del office du Mareschall d'Irland, $X$. Freford, Cornwall.

$\mathrm{Gu}$. a bend fusily arg. in the sinister chief point a martlet or. Freford.

Gu. a beud lozengy arg. Freford. Freson, Cornwall. William de Raleigh, Bishop of Norwich 1239-42, Winchester 1244-50. Rawley or Paleigh, Fardell, co. Devon.

Gu, a bend of five lozenges arg. Freford.

Gu. a bend masculy arg. Ancell. Freford, $V^{*}$. FreEFord.

Gu. a bend of four mascles arg. Freford, $\boldsymbol{V}$.

Gu. a bend of five mascles conjoined arg. FREFORD. And with a martlet or in the sinister chief point for diff. FREFORD.

Gu. a bend raguly arg. Penruddock, Compton, co. Wilts; derived from PENRUDDOck, Arcleby, co. Cumberland, temp. Elizabeth.

Gu. a bend arg. vorded or. Mries.

Gu. a bend chequy arg. and az. KENDALL.

Gu. a bend chequy or and az. Hampsted, Norfolk. Hansted, Northumberland. PaPE.

Gu. crusily arg. a bend chequy or and az. Ormssy, Norfollk. Sire William de ORnisby, $N$. And with a mullet sa. for diff. Sire Johan de ORNESBY, $N$.

Gu. flory or a bend compony arg. and sa. Gargate. Gu. a bend counter-compony or and az. Orniesby. Gu. a bend erm. Habibrt, Rye, Sussex. Rre. Waleys. Sir John Walleys, $R$. Walwen, $V$. WALWEYN. WALWYN or WALWEN. WALWYN WaLWayne or WaLWynne, Walwyn's Rents, co. Brecon; and Longford or Longworth, co. Hereford. WELWYN.
BEND cont.

Gu. a bend erm. a label az. Sr. William de Rre, $M$.

Gu. a bend erm. a label or. RAY, Berwick Pursuivant of Arms, ob. 1565. Refer or Refere, co. Lincoln. Monsire William de Riron, Y. RIsE. Rizer, co. Lincoln. Sire William de Ryzere. $N$. Gu. a bend erm. over all a label of three points or. ReFene, co. Lincoln, $V$. William de Rye, $Y$. Sr Nicholas Rye, co. Lincoln, $V$. Rye, co. Lincoln, 1730.

Gu. a bend erm. a label of five points or. Riy. Sir William Rye or de Rye, L. Rye, co. York.

Gu. bezanty a bend erm. Sr. Amory de la Zouch, L. Harl. MS. 6137.

Gu. a bend fusily erm. Heale, Highfield, co. Herts, descended from Heale, South Heale, co. Devon. Heeley. Hele, Dorset. Rede, $V^{*}$. Ridge or Redege. Ridge or Redege, co. Devoll.

Gu. a bend of four fusils conjoined erm. Nicholas REDE, $V$.

Gu. a bend lozengy erm. HeELey, co. Stafford. Gu. crusily or a bend lozengy erm. Sire Geffrey de Aubemarle, $N$.

Gu. crusily or a bend of mascles erm. Averance. Gu. a bend or. Chalon, $Z, 606,607,679$; M. Roger de Clarendon, $S$. Colemiert. Collomber. John de COlunibers, $V$. Coldmbert, 1730. Folet. Folliot, Norfolk. Hastings. Herman. Kellobeiry. Marshall. Morell. Porteen. Shannon. Welweyn.

Gu. a bend or and a label arg. WaLwern, co. Leicester.

Gu. a bend or and (another charged with) a label of three points arg. Cluniac Priory of St. Mary Magdelen at Barnstable, co. Devon.

Gu. billety and a bend or. Moryan de Sanarsez, $W$.

Gu. crusily and a bend or. William de Preston, A, Harl. MS. 6137. Sir William de Prestone, I.

Gu. crusily and a bendlet or. Hereni de Chaurs, $F$.

Gu. crusily potent fitchy and a bend or. William de Preston, $A$.

$\mathrm{Gu}$. goutty d'or a bend of the last. YaRmouth, co. Devon.

Gu. a bend or and three sinister bendlets arg. the centre one surmounting the bend. AlwrIGHT or Allwhight.

Gu. a bend bevilled or. Bovine.

Gu. a bend engr. or. Manchenhali. Marshal, 1730. William Marshald, Marshal of Ireland. William de Mareschal, $K$. Sir William le Mareschat, $L$. Sire William le Marechal, $N$. Sire Ancel le Mareschat, $O$. William MARESCHALL, $Y$. MarSHall, Norfolk, $V$. Marsharl or Mariscall, Norfolk. Serle.

Gu. a bend engr. or a label arg. BRAYBEefE. Manchinghari. Marchall. Sire Auncel le Mareschal, $N$. Sire Aunsel le Mareschall, $L$. Gu. a bendlet enhanced or. GRELY.

$\mathrm{Gu}$. a bend flory or. Goldinton, $V^{*}$.

Gu. a bend flory counterflory or. GoLdington, $V$.

Gu. a bend fusily or. AnselL, $V^{*}$. Boluetis, $V^{*}$. John Manshal, Earl of Warwick.

Gu. a bend of five fusils conjoined or. BoLletis, $V$. Ansell Mareschall, Rye, Norfolk, $V$. John le Marescal, A, Harl. MS. 6137. Monsire Mareshall, $Y$. Joan le Marischale, $\boldsymbol{E}$. 
BEND cont.

Gu. a bend of six fusils conjoined or. Sir William le Mareschal, $L$.

$\mathrm{Gu}$. a bend of five (another seven) fusils conjoined or. Sire William le Mareschall, $J$.

$\mathrm{Gu}$ a bend of six fusils conjoined or and a label arg. Sir Aunsel le Mareschall, L, Harl. MS. 6137.

Gu. a bend of four and a balf fusils conjoined or and a label of three points arg. Braybec, $V$.

Gu. a bend fusilly or and a label of five points arg. Braybeck, $V^{*}$. Jolin de Brainef, $E$.

Gu. $a$ bend of five fusils conjoined or and a label of as many points arg. CHRACHeth, $F$.

Gu. a bend Jozengy or. Ancell. Mareschall, Hengham, Norfolk, temp. Henry III. William MarshaLl (Marshal of Ireland) seal. Marshall or Mareshall, Norfolk. And with a mullet of the second. Marshali.

$\mathrm{Gu}$. a bend of five lozenges conjoined or. Jon le Marescal, A, Harl. MS. 6137; or John de Marshall, $A$.

Gu. a beud masculy or and a label arg. Marshall.

Gu. a bend vair. Beauchampe, co. Somerset. Sire Robert Beaupeyl, $O$. Beawchamp, $V$. Beawpell. De Bouverie, Brabant, 1396. Gilbert, co. Salop. Knifton, co. Derby. Kniveton, Bradley, co. Derby. Raleigh. Rase, $V$. Windlesore.

Gu. a bend rair in the sinister chief point an annulet arg. for diff. BEAUCHAMP, $V$.

Gu. crusily arg. a bend vair. RaLeigh. John Ralee, $Y$. Monsire de Raley (co. Devon and Cornwall added), in $1562, Y$.

Gn. crusily or a bend vair. RaBr or Rabey. Henry de Raley, $F$. Henry de Ralie, $A$. Raleigh. Henry de Roleie, $E$.

Gu. a fret of six arg. over all a bend vair. Nonton. $\mathrm{Gu}$. fretty arg. over all a bend vair. Norton, co. Bedford; co. Buckingham; and Mark-Atcell, co. Hertford.

Gu. a beud wavy vair. Crowther, London and co. Salop.

Gu. a bend vairy arg. and gu. Penceler, $V$.

Gu. fretty arg. a bend valry of the second and first. Nowell Novelie or Novell, co. Staffurd.

Gn. a bend vairy arg. and sa. Geynes, Yolgrave, co. Derby. GiI.Bert, alias Kniverton, Youlgreve, co. Derby, 1300 ; the heiress $\mathrm{m}$. Barnesly, temp. Charles I. Kinveton, alias Gilbert, co. Derby. Kniveton, alias Gilbert, $V^{*}$. Knyveton, alias Gilbert, Yelgrave, co. Derby, $r$.

Gu. a bend wary vairy arg. and vert. Crowder, Clapham, Surrey.

$\mathrm{Gu}$ a bend wavy vairy or and az. Crowcher.

Gu. a fret of six arg. over all a bend vairy or and of the first. Nevill. Norton, co. Bedford; co. Buckingliam; and Mark-Astell, co. Hertford.

$\mathrm{Gu}$. fretty arg. over all a bend vairy or and of the first. Sr. .... de Norvill, $V$. Norvyle. Nowell Novelle or Novell, co. Stafford.

$\mathrm{Gu}$. a bend vert fimbriated or. O'DuLin, Harl. MS. 4039 , fo. 155 .

Gyronny of six arg. and gu. a baston az. Mousire Giles Bassingbourne, $Y$.

Gyronny of eight or and sa. a bend gu. LAND.

Lozengy.....and....a bend raguly.....John de Prayers, secretum temp. Edward III, $A r$ chaologia, $\mathrm{xxix}, 406$.

Lozengy arg. and gu. a bendletaz. Richard de la ROKELE, $\mathrm{E}$.
BEND cont.

Or a bend az. Badye. Burton, co. Oxford. Busts or Buset. Caltherupe. Calthrop. Carthorp, $V^{*}$. Carthorpe, $V$. Cathrope. Cheuston. Sir William Crop, L, Harl. MS. 6589. Doilly. Donhault, co. Northampton and Oxford; granted 1600. GraY. GREY. Mathew de Irie (not Trie) A. Terrenl or Tereli, co. Hertford. Teye. Vernon.

Or a bend sinister uz. TRYe, originally from France, settled in England in the fourteenth century, at Alkington, and 1449 at Hardwicke and Haresfield, co. Gloucester. 'True, Leckhampton Court, co. Gloucester.

Or a bend engr. az. Clark, 1730. Clarke, co. York. Fetherhant, co. Berks. Fokeram or Fokerhasi, co. Berks. Sire Richard Foteram, N. Grove.

Or a bend engr. az. charged in chief with a mullet arg. for diff. Cranke, co. York, $V^{*}$. But on the mullet a crescent .... Clerke, Itringham, co. York, $V$.

Or a bend az. charged in chief with a plate for diff. Clarke, Baron of the Exchequer, $W$.

Or a bend flory counterflory az. Goldington.

Or a bend fusily az. Fokerand.

Or a bend of five (another six) fusils conjoined az. Richard Fukeram, $E$.

Or a bend indented (aliter lozengy) az. Thomas Foukerhani, $Y$.

Or a beud lozengy az. Fokeram, co. Berks. Fokerhall, co. Berks and Derby. Thomas Foukerham, $Y$.

Or a bend voided az. Boyle, Ireland; quartering arg. a chough ppr.

Or a bend chequy arg. and sa. Gresson, $V^{*}$. Grossome.

Or a bend chequy az, and arg. Menteath, Blackburn; quartering az. three buckles or.

Or a bend chequy erm. and ermines. STYLe, Puddle Town, co. Dorset.

Or a bend chequy erm. and sa. Strise.

Or a bend chequy gu. and arg. Thos, Scotland. WHISHAW.

Or a bend chequy of the first and gu. UFFLEET. Or a bend chequy sa. and arg. Gressonne, $V$. Monteith, Carss, Scotland; quartering or a lymphad with one mast sa. and in chief three buckles az. Monteith, Kerse, Scotland.

Or a bend chequy sa. and arg. quartering or a lymphad with a mast sa. and in chief three buckles az. over all a crescent.... in the centre of the quartering for diff. Monteith, Millhall, Scotland.

Or a bend compony az. and gu. ANsert.

Or a bend compony erm. and sa. Strue, $V^{*}$.

Or a bend compony ermines and erm. Strle.

Or a bend compony sa. and arg. SMallibone, Uplam, co. Berks.

Or a bend counter-componysa. and erm. STrLe, $V$. Or a bend erm. perforating a chev. gu. HADSTOCE, Suffolk. HoDSTOKE, $V$.

Or a bend gu. Auncell. Challon. Chtgastone, Wigton; quartering gu. two bears bendy of six arg. and vert counterchanged. CoNGaLTon, East Lothian, Scotland; quartering gu. a fess or. betw. two cotises compony arg. and az. Cotchere. Sire Elys Cotel, $N$. Thomas Cotell, Y. Cottell, 1730. Cotell, co. Somerset, $V$. Cotrle, Sampford Peverell and North Taunton; granted 8 November 1580. Cuthell. Dancell. Dansell, $V$. M'Gachen, Tulliquhat, Scotland. St. Leger. 


\section{BEND cont.}

Or a bend gu. with a crescent.... for diff. Co TELL

Or billety az, a bend.gu. Gastelyne, co. Han ts Sire Johan Gasceline, $N$. Sir John Gasselyn de la Comune, $L$. Sir John Gasteline, $L$. Harl. MS. 6137.

Or billety and a bend gu. Sir John Gasseryne, $L$., Harl. MS. 6589.

Or crusily and a bend gu. Honmzoore, Suffolk. Sir William HuNTINGFiELD, $I$.

Or crusily sa. a bend gu. John de Nevile le foresticr, $B$.

Or goutty-de-sang a bend gu. Jernouthe, $W$.

Or a bend gu. over all a fess az. Exxowax. Elwas. Exwes, Stoke, Sutfolk; Baronetcy 22 June 1660 ; extinct 20 November 1778; descended like Elwes, co. Lincoln; co. Hertford ; co. Northampton and Essex, through Geoffry Erwes, Alderman of London, from Elwes or Helwish, Askham and Worleby, co. York.

Or a bend gu. surmounted of a fess chequy arg. and az. Stewart, Castlemilk, Scotland, Lyon Register: and with a crescent gu.in the sinister chief point for diff. STEWART, Torrence, Scotland.

Or a bend engr. gu. Wriothsley. Wristeley, Kent. Writley, or Wrytelley. Wryoteslex, $V$. Hugh de Wryottesley, $S$.

Or a bend lozengy gu. Pinckney or Pynkenny, Sutton-Pagnell, co. York.

Or a bend masculy gu. CawPNy.

Or a bend nebuly gu. POLEYNe.

Or a bend lozengy gu. and arg. Winssow.

Or a bend lozengy gu. and or. Winslow.

Or a bend sa. Bonavile or Bonvile. Bongirlon; quartering gu. three bezants. Bonvile. Flening, Coruwall. Fossard, Doncaster, co. York, temp. Richard I. Robert Fossarde, $P$; or Fossard, $X$. Gotham, $V$. Holwell. Mankey. Marley or Marlow. Mautey, Baron of Mulgrave, extinct 1415. Pers de Mauley, G. Mon. sire de Maulait, $Y$. Sire Peres de Maulee, $N$. Sr. Piers (Peres, $H$, ) de Mauley, $J$. Mawley, $V$. Sir Robert Mawlex, $Q$; or Mawlye, $Q$, Harl. MS. 6595. Peter de Molulaco, temp. Edward III, 1716. Le Sr. de Maulye, or Mawlex, $T$. Le Sire de Madley $Y$; quartering Bigote, $X$. Mawley, or Malo Lact, 1328. Monceux. Musgrave. Yeton, or Yeaton. YETTON, $V$.

Or a bend sa. over all a fess gu. Polimexne, King's Weston, co. Gloucester.

Or billety and a beod sa. Harows $V^{*}$. Marows, V. MarRows, $V^{*}$.

Or a bend dancetty sa. DownemaIs or DownHaLI, London; co. Oxford; and Geddington, co. Northampton.

Or a bend engr. sa. Sire Robert Achard, $N$. Achard, co. Berks. Robert Arehard, $V$. Sir Henry Glastenbury, co. Somerset, $V$. Giastinbras, $V$. Monsire de Glastingburi, $I$. ManLY.

Or a bend fusily sa. Glastenbury.

Or a bend of five fusils sa. Acharo.

Or a bend sinister (fusily, $V^{*}$.) of five fusils conjoined sa. Archard, $V$.

Or a bend indented sa. in the sinister chief a pierced mullet gu. (? for diff.) Downhalr, $V$.

Or a bend wayy sa. Burton, co. York. Burton; quartering .... a fleur-de-lis.

Or a bend dancetty vert. Dawbney.
BEND cont.

Paly of three arg. and sa. over all a bend gu. Blake, Essex.

Paly of four or and gu. a bend sa. Buton.

Paly of five gu. and or over all a bend arg. LANGFORD.

Paly of six arg. and nz. a bend compony gu. and or. AnNesuey. Sir Walter Levett, first Mayor of Chester, $V$.

Paly of six arg. and az. a bend gu. Andesley. Annesiex; Baronetcy 1620, Baron Mountnorris ] 628, Baron Altham 1680, Viscount Valentia 11 March 1622; Baron Anvesley of Newport Pagnell and Earl of Anglesey, 20 April 1661, extinct in England 1761; Earl of Mountnorris 20 December 1793. AnNestey, Bletch. ingdon, co. Oxford. Anneslex, Rawmarch Church, co. York. Annesley, $V^{*}$. Borghul, co. Salop. Grandison Grandeson Grandson and Granson. Gurnay.

Paly of six ar. and az. over all a bendlet gn. Thomas Annesley, $V$. M. John de Annesleye, $S$. ANNesLey, Viscount Valentia; quartermg vert three battleaxes in fess or, with or a pile gu.; Harl. MS. 4040 fo. 163.

Paly of six arg. and az. over all a bend or. Strading; quartering Berkerolles. And with a mullet for diff. Stradling; quartering Turbervile.

Paly of six arg. and az. a bend paly of six gu. and or. Levet or Levett.

Paly of six arg. and az. a bend sa. Amosuey. Eveby. Rubert Sanezrson, Bishop of Lincoln, 1660-3; quartering erm. on a canton .... a saltire engr. .... charged with a crescent. .... Saunderson, Blythe, co. Nottingham; Rotherham, Sheffield, Tickhill, Firbeck, etc., co. York.

Paly of six arg. and az. a bend vairy arg. and sa. ANNESLEY.

Paly of six arg. and gu. a bend of the first. LANGFoRD or LONGFORD, co. Leicester.

Paly of six arg. and gu. a bend compony or and sa. WoOdROFFE.

Paly of six arg. and gu. a bend counter. changed. Pocklington or Pollington, co. York.

Paly of six arg. and gu. a bend erm. Breacourt. Draycote, Draycote, co. Stafford. Richard Draycott, $V$.

Paly of six arg. and gu. a bend sa. Enby. Eneby, $V$. Robert Eveby or de Evebt, $A$. Reyden or Reydell, co. Bedford. Ridell, co. Bedford. RYNeLL.

Paly of six arg. and gu. a hend vairy arg. and sa. Monsire de Annescex, $Y$.

Paly of six arg. and gu, a bend vairy or and sa. Nelson, Chaddleworth, co. Berks.

Paly of six arg. and purp. a bend vairy or and sa. Henri le Nelsun, $F$.

Paly of six arg. and sa. a bend erm. Draycote, Losco, co. Derby. Marryatr.

Paly of six arg. and sa. a bend gu. Burghirt, Brecon; and Bungay, Suffolk.

Paly of six arg. and sa. a bend or. Trench.

Paly of six arg. and vert a bend gu. BAUnFIEID, $V^{*}$. Sir Thomas Baunfeld, co. Devon, $V$.

Paly of six erminois and pean a bend engr. counterchanged. Calvert; Baronetcy 3 December 1818 .

Paly of six gu. and arg. a bend compony az. and or. WOODROFFE. 
BEND cunt.

Paly of six gu. and arg. a bend counterchanged. Sir Richard Woodrufe, $V$.

Paly of six gu. and or a bend arg. Sir Nicolas LANGFord, $R$. LongFord, $V^{*}$.

Paly of six or and az. a bend gu. Solers.

Paly of six or and az. a bendlet gu. William de Sherlex, $F$.

Paly of six or and gu. a bend arg. LambFond or LaMiford. LANGFORD, co. Derby; co. Notting. ham; and co. Salop. Sir Nicolas (Thomas, Harl. MS. 6595) Lang Forde, Q. Sr. Nicholas LoNGForD, Longford, co. Derby, $V$; Visitation 1569 ; the coheirs, 1610, m. Hastings and Dethick.

Paly of six or and gu. a bendlet arg. M. Nicolas de Longeford, $S$.

Paly of six or and gu. a baston arg. Monsire Nichell de LANGFord, $Y$.

Paly of six or and gu. a bend az. Langdale.

Paly of six or and gu. a bend erm. Dracot or Draycott, co. Derby; and co. Stafford. Draycotr, $V^{*}$.

Paly of six or and gu. a bend of the first. LANGDALE.

Paly of six or and sa. a bend counterchanged. Calvert, Little Hadham, co. Hertford, and its branches, London; Albury Hall; Hunsdon; Nine Ashes; and Hall Place, Bexley, Kent. Calvert (descended from a family of CaLuwart Calvart or Culviert, seated near Ghent in Flanders) ; Baron Baltimore 20 February 1624, extinct 1773 ; absolute lord and proprietor of Maryland and Avalon in America, quartering quarterly arg. and gu. a cross botonny throughout counterchanged; Harl. MS. 4040, fo. 462 . Viscount BaLtimore, $Z, 651$. HaRFond.

Paly of six or and sa. a bend gu. MORe, co. Salop.

Paly of six or and vert a bend gu. Bamfield or Baunefieid.

Paly of six sa. and arg. a bend gu. More, More Hall, near Sheffield; quartering Brightholmley.

Paly of seven arg. and gu. a bend counterchanged. Polington.

Paly of seven arg. and gu, a bend sa. REDEN or Redon. Southern.

Paly of seven .... and .... a bend .... Nichol de LANGFord, in Norton Disney Church, co. Lincoln, Harl. MS. 6829, fo. 310 .

Paly of eight or and gu. a bend arg. LANGFORD.

Paly of nine or and az. a bendlet (sa. $V^{*}$.) arg. Solas, $V$.

Puly of ten arg. and sa. a bend gu. Burhall.

Paly of ten arg. and sa. a bendlet gu. Roger de Burhhulle, $E$.

Paly of ten or and az. a bendlet gu. Henry de Solers, $E$.

Paly arg. and az, a bend gu. Ansgeley. Grantson.

Paly arg. and az. a baston gu. John Aunseic (in pencil ANstey), $X$.

Paly arg. and gu. a bend sa. Sire Johan RIDEL, $N$.

Paly or and gu. a bend arg. Sire Johan de Langford, $N$. Sire Nichol de Langeford, $O$.

Paly or and gu. a bend sa. Le Conte de Huntingdon, $B ; P$; probably for St. Liz.

Paly or and sa. a bend gu. Burghail.

Per bend arg. and sa. a bend embattled counterchanged. Strangitan.

Per bend sinister or and az. a bend counterchanged. Richard de Bury, alias ANGArviLL, Bishop of Durham, 1333-45.
BEND cont.

Per bend sa. and arg. a bend raguly counterchanged. Genton, Essex, $V$. Strangman, HadleyCastle, Essex, 1730.

As to the following cases of $a$ bend upon a field divided 'per chief,' see also 1 BEND and a Chief.

Per chief arg. and az. a bend sa. Reynand de Ridmer, $P$.

Per chief indented arg. and az. a bend sa. Reynaud de Rioner, $P$.

Per chief arg. and barruly sa. and of the first over all a bend engr. az. Roose.

Per chief arg. and barry gu. and of the first a beud engr. az. John Rous, Tyde, $Y$.

Per chief az. and arg. a bend gu. Payn de Gaymage, $Y$. (? Rauf Cromwell, $Y$.)

Per chief az. and arg. a bendletgu. Sire Rauf de Cronuelle, $J$. Simon de Cronfeli, $E$.

Per chief indented az. and arg. a bend gu. Berhome. Bethum, $V^{*}$.

Per chief indented az. and arg. a bendlet gu. Sir Richard de Betrum, co. Lancaster, $V$.

Per chief az. and arg. a bend engrailed gu. Halden. SirJohn Penbrige, $W$. Penbruge, $V$.

Per chief az. and arg. a bend fusilly gu. Penbria, $V^{*}$. Penbrugg, $V^{*}$.

Per chief az. and arg. a bend of four and a half fusils conjoined gu. Sir John Penbrige, temp. Edward VI, $V$. Penbrugg, $V$.

Per chief az. and arg. a bend of five fusils con. joined gu. a label of five points arg. the label under the bend. Adam de Gammage, $F$.

Per chief az. and arg. a bend of five (another six) fusils conjoined gu. a label of five points or. Nicol de Gamage or Gammage, $E$.

Per chief az. and arg. a bend of seven fusils conjoined gu. Pain de Gamage, E.

Per chief az. and arg. a bend of five lozenges conjoined gu. Pain de Gatheel, $F$. Rauf GaMAGE, $V$.

Per chief az. and arg. a bend engr. or. Sire Johan de Penbruge, $N$.

Per chief dancetty az. and arg. a bend sa. Power, Ireland.

Per chief indented az. and arg. a bend sa. RIDMER.

Per chief indented az. and arg. a baston sa. Reinold de Ryduer, $Y$.

Per chief az, and or a bend gu. Harrington.

Per cbief indented az. and or a bend gu. Betham, co. Lancaster.

Per chief chequy arg. and az. and gu. a bend erm. Hadsted, 1716.

Per chief chequy arg. and az. and or a bend gu. LIGEN LINQ or LiNQUe (from a family of Linque in Hainault), Harlackston, co. Lincoln; granted 20 January 1619.

Per chief chequy or and az. and gu. a bend arg. Sir Robert de Hansted, $L$; or de Haustede, $N$; but de Hanstede, $N$, Harl. MS.6137.

Per chief chequy or and az. and gu. a bend erm. Sire Johan de Haustede, $N$; but de Hanstede, N, Harl. MS. 6137.

Per chief chequy or and az. and gu. a baston erm. Sire John de Haustede, $O$. John Hansted, $Y$.

Per chief chequy or and az. and gu. a bend sa. Jolin Hahsteed, $Y$.

Per chief gu. and arg. a bend az. Le Connwalu. Sr. .... de Cromweld, $V$. CRunweri, harl. MS. 6829 , fo. 59 . Sr. John de Haryngton, $N$, Harl. MS. 0137 .

Per chief gu. and arg. a bendlet az. Sr. .... de Cromweli, $V$. 


\section{BEND cont.}

Per clief gu. and arg. a baston az. Thomas Cromewell, Lamelay, $Y$. Rauf de Cromwelue, G.

Per chief gu. and arg. a bend engr. az. Cromwell. Leake Leke or Leyise, co. Lincoln. Sr. . de LeEke, $V$. M. Andrew de Leyke, $S$. Leyke, $V$. Sr. John Penbrige, $V$.

Per chief gu. and arg. a bend engr. az. in the sinister point an annulet arg. LEEKE, Harl. MS. 6829 , fo. 58 .

Per chief gu. and arg. a bend engr. az. in the sinister point a fleur.de-lis or for diff. LeEke, co. Salop.

Per chief gu. and arg. a bend engr. az. in the sinister chief a pierced mullet or for diff. M. Fobert de Leyie, $S$.

Per chief gu. and arg. a bend compony or and az. Cronwell.

Per chief gu. and arg. a baston compony or and az. Sire Richard de Cronewerl, $O$. John Cromwell, $Y$. Monsire William Granwell, $Y$.

Per chief gu. and arg. a bend engr. sa. Bridi, $V$. Bridge, Essex; and Bosbury, co. Hereford. Bridge, $V^{*}$.

Per chief gu, and az. a bend engr. arg. Sir John de Penebruge, $L$; or de Penbrige, $L$, Harl. MS. 6137.

Per chief gu. and az. a baston engr. arg. Sir John Pentbrige, $L$, Harl. MS. 6589.

Per chief gu. and or a bend az. Sir John Barington, $V$; but in a later hand, Harington. Sire Johan de Haringtone, $N$. Harrington.

Per chief gu. and or a bend sa. Heringdon. John de Harrington, $I$.

Per chief gu. and vair a bend of the first. John Mounteney, $Y$.

Per chief or and gu. a bend compony az. and arg. Sr. Johu Mauleverer, $M ; Y$.

Per chief or and gu. a baston compony az. and arg. Monsire Chalenor, $Y$. John Maleverer, $Y$. Sire Johan Mauleverer, $N$.

Per chief or and vair a bend gu. Sir John de Tycheburne, 1350-80.

Per chief or and vairy arg. and sa. a baston gu. Rauf Mounteney, $Y$.

Per chief sa. and arg. a bend engr. gu. HALDEN, Kent, $V$. Holden, $V^{*}$. But see in Per fess ....und.... a bend...., and in 1 Bend and a Chief.

Per chief vair and arg. a bend engr. sa. Fitz-herbert, co. Leicester.

Per chief vairy or and gu. and arg. a bend az. Fitz-herbert, temp. Heury I.

Per chief vairy or and gu. and arg. a bend sa. Fitz-herbert, $V^{*}$. Fitz-Herbeit, Norbury, co. Derby, 1125, and Swinnerton, co. Stafford. Norberry or Norbury, Norberrey, co. Derby.

Per chef vairy or and gu. and arg. a bendlet sa. Fitz-herbent, Norbery, co. Derby, $V$.

Per chief vairy or and gu. and arg. a beud engr. sa. Fitz-herbert, co. Leicester.

Per chief indented vert and arg. over all a bend gu. Nevrul, $V^{*}$. Sr. Thomas de Nevile, $N$, Harl. MS. 6137 .

Per ehief indented vert and arg. a bendlet gu. Sr. Thomas Nevist, co. Lincoln, $V$.

Per chief indented vert and or a bend gu. Sire Thomas de Nevile, $N$. Nevill, Falding. worth, co. Lincoln. Nevill, $V$.

Per chief iudented vert and or a bendlet ga. Sandwich.
BEND cont.

Per fess gu. and arg. a beid wavy per fess or and of the first. WELNBorn, $V^{*}$.

Per fess gu. and arg. a bend wavy per fess or and sa. WeLniorn, $V^{*}$. Weldborn, $V$.

Per fess or and gu, a bend erm. KrnkE. Pentfather, London. Pennefather, Ballyowen and New Park co. Tipperary; heiresses m. Palliser, Williams, Mac Donnell, and Moore.

Per fess sa. and arg. a bend engr. gu. Horden; but see in Per chief.... and.... a bend...., and in 1 Bend and a Chief.

Per pale arg. and az. on the dexter side two palets sa. over all a bend or. French, quartered by Chiswell.

Per pale arg. and gu. a bend az. Bedford.

Per pale arg. and gu. a bend counterchanged. Champer. Sr. Thomas Chaucer, $V$.

Per pale arg. and gu. a bend engr. counterchanged. RoBinson, Cornwall, 1716.

Per pale arg. and gu. a bend engr. sa. RoBinson, Helstones and Sythney, Cornwall.

Per pale az. and gu. a bend or. BEDFond. Stephen Langton, Archbishop of Canterbury 1207-28.

Perpaleaz. and sa. a bend or. BEDFond, Durham. Per pale gu. and arg. a bend counterchanged. Chaucer.

Por pale gu. and sa. a bend arg. John WeLl, $V$. Per pale or and arg. a bend wavy gu. ANTESHYe. Per pale or and gu. a bend counterchanged. Pollington.

Per pale or and sa. a bend counterchanged. WRIGHT, Kent; granted 1603.33.

Per pale sa. and az. a bend chequy arg. and gu. Welston.

Per pale sa. and az. a bend chequy gu. and arg. WOLSTON or WOLSTONE.

Per pale sa. and az. a bend chequy gu. and or. Wodstone.

Per pale sa. and az. over all a bend compony arg. and gu. Velston. Welston. Welstone, $V *$ *

Per pale sa. and az, a bend compony or and gu. Worston.

Per pale sa. and az. a bend counter.compony arg. and gu. Velston, $V$. Welstone, $V$.

Perpale vert and gu. a bend erm. CARPEnTER; Kent.

Pean a bend lozengy arg. Barnton, quartered by Sandys.

Potent counter-potent arg. and sa. a bend gu. Manchester, co. Stafford.

Purpure a bend (archy or) champaine arg. ARciny.

Quarterly arg. and az. a bend gu. Bray, $V^{*}$. Haliers. Hellers. Helers, $V^{*}$. Ray.

Quarterly arg. and az. a bendlet gu. Bray, V. Helers, Pokelay, $V$.

Quarterly per fess indented arg. and az. a bend gu. Buomriesd, Suffolk. Charles James Blomfield, Bishop of Chester 1824, of London 1828-56. BLUNDEvill.

Quarterly indented arg. and az. a bend gu. Barkeley.

Quarterly arg. and az. a bend sa. Witherington, co. York.

Quarterly arg. and erm. a bend az. over all a closs gu. a crescent for diff. Beckswell or Benyswell alias Shordich, Bekyswell, Norfolk. Quarterly arg. and erm. a bend gu. CARDIGAN or CARDICAN, IVales. CARDYCAN, $V$ *

Quarterly arg. and erm. a bendlet gu. CARDycan, $V$. Quarterly arg. and erm. a bend sa. over all a cross gu. Suondicn, Bekyswell, Norfolk. 
BEND cont.

Quarterly arg. and gu. a bend az. Henlens. Massey. Massy, Timperley, Harl. MS. 1424. Rockley. Timpliey, TyMperley or Tymply. Witherington, co. York.

Quarterly arg. and gu. a bend of the last. Beauchampe. Sr. Neel Lorynge, K.G., $V$. Sire Peres Loring, $N$. Mascr, $V^{*}$. Wranston (sic) $V^{*}$.

Quarterly arg. and gu. a bendlet of the last. Sr. William Loring, $T$. Mascy, Timperley, co. Chester, $V$.

Quarterly arg. and gu. a bendlet of the second charged with a pierced mullet or (? for diff.) Everinghadi, $V^{*}$.

Quarterly arg. and gu. a bend engr. of the second. BedFord. LoRING, $V^{*}$. LORINGE, Suffoll. Neel Lorryng, $S$.

Quarterly arg. and gu. a bendlet engr. of the second. Roger Loning, $V$.

Quarterly arg. and gu. a bend lozengy of the second. Loringe, co. Bedford.

Quarterly arg. and gu. a bend or. Sire Richard de WALEys, $N$.

Quarterly arg. and gu. a baston or in the second. Monsire WALEYS, $Y$.

Quarterly arg. and gu. a bend sa. Ascheler. Ashley or Astley, co. Devon. Beckering or Berering. Dutton, co. Chester. Pomfret, Butbery, Essex. Somierford. Widdrington, Northumberland; Baronetcy, 9 July 1042. Baron Widdrington, 10 November 1643; attainder 1716. Widrington, Fenham, Northumberland 1730. Witherington, $V^{*}$. Wodrington, $V^{*}$. Quarterly arg. and gu. a bend sa. with due diff. Widrington, Monkwearmouth, Durbam.

Quarterly arg. and gu. a bendlet sa. Witherington, $W$. Sr. John Wodrington, $v$. Wodrington, Wodrington, Northumberland, $V$. M. Gerrard de Wytunyngton, $S$.

Quarterly arg. and gu. a baston sa. Johu de WYdERINGTON, $Y$.

Quarterly arg. with gu. a fret or over all a bend sa. (this is probably arg. a baston sa. quartering Audeley). LE Despenser (i.e. Steward to Henry I, 1105), $Z$; 332, as an inescucheon to Beauchamp, Earl of Warwick; and 442, 445, as a quartering to Pole. Sir Hugh le de Spencer, $V$. Hugh le Spencer, (lord of Glamorgan), Q, Harl. MS. 6589.

Quarterly arg. with gu. a fret or over all a bendlet sa. (Thomas) DesPencer (Earl of Gloucester, 29 September 1397, beheaded 1400); quartered by Neville,Lord Abergavenny, $U$. LeSr.de Spencer sed quære Spenscer, $T$. Le Sr. (Thomas) le Spenser, $S$. Hugh le Despenser, $Z, 140$.

Quarterly arg. with gu. fretty of six or over all a bendlet sa. Hugo le Dispencer, A, Harl. MS. 6137. Hue le Despenser, $E$. Sire Hugue le Despenser, $J$. Hughe de Spencer, $A$.

Quarterly arg. with gu. fretty of six or over all a baston sa. Hue le Despenser, G. M. Hue le de Spenser, $D$. Pobert de Staunrone, corrected in a later hand to Stanhoue, $F$.

Quarterly arg. with gu. fretty or over all a bend sa. Hue le Despencer, $K$, Harl. MS. 6137; (Earl of Winchester 10 May 1322, hanged 9 October 1326); $N$. Hugh le Despenser; (lord of Glamorgan); $P$. Hue le De Spenser, $B$.

Quarterly arg. with gu. fretty or over all a bend sa. and a label az. Sire Hue le Despenser le filz; Earl of Gloucester 1313, hanged 29 November 1326$) ; N$. The label of five points. Phillip or Philly pe Stencer, $Q$; Barony 1387, ob. 1423.
BEND cont.

Quarterly arg. with gu. fretty or over all a bendlet sa. Hugh Spencer (Audeley; Harl. MS. $6595)$, Earl of Gloucester, $Q$.

Quarterly arg. with gu. fretty or over all a bendlet sa. in chief of the first quarter a martlet of the last. M. Hugh le Spencer, $S$.

Quarterly arg. with gu. fretty or over all a baston sa. Monsire le Despencer, $Y$. Hugh le De Spenser, $Y$. Sr. Hugh de Spenser, $H$.

Quarterly arg. with gu. fretty or over all $a$ baston and a label sa. Sir Hugh le Despenser, $L$.

Quarterly arg. diapered masculy the spaces filled by 4 -foils with gu. fretty of six or over all a bend sa. Hugh le de SPENser, lord of Glamorgan and Mortaigne; seal in Dallaway.

Quarterly arg. and gu.a bend engr. sa. LORINGE, K.G. 1348 .

Quarterly arg. and sa. a bend wavy erm. Spencer. Quarterly arg. and sa. a bend gu. Burston, Norfolk. Conquest. Ducket. Engham. Everingham, co. Lincoln. Sr. Robert de Hoo, N, Harl.MS.6137. Preston. Spencer, Ireland. Quarterly arg. and sa. a bendlet gu. BRESTON, Norfolk, $V$. Preston, co. Lincoln, 1716. M. William $\mathrm{S}_{A \mathrm{~L} Y}, \mathrm{~S}$.

Quarterly arg. and sa. a bendlet gu. charged with a pierced mullet or (for diff.) EVERINGHAM, Rokkle, $V$.

Quarterly arg. ard sa, a baston in bend gu. Burston, Norfolk.

Quarterly arg. and sa. a baston gu. John Everingham, Rolilay, $Y$. Monsire de Everingham, Rokeley, $Y$.

Quarterly arg. and sa. a bend lozengy gu. Cheney, $V^{*}$. Cheyney, co. Cambridge.

Quarterly arg. and sa. a beud of five lozenges conjoined gu. Sr..... de Cheney, co. Cambridge, $V$.

Quarterly arg. and sa. a bend or. Sire Robert de Hoo, $N$. Rous or Rowse.

Quarterly arg. and sa. a bend of the last. LERowse. Sire Richard le Rous, $N ; V$. Rous or Rowse, co. Bedford.

Quarterly arg. and sa. a bendlet of the last. Everinghajr. M. Lawrens Evingham, $S$.

Quarterly arg. and sa, a baston of the last. Sire Richard le Rous, $Y$.

Quarterly arg. and sa. a bend vair. FANWYKE.

Quarterly az. and arg. a bend or. LANGSTONE, $V^{*}$.

Quarterly az, and arg. a bendlet or. Robert LANGSTONE, $\boldsymbol{V}$.

Quarterly per fess indented az. and gu. a bend arg. WEston, $V^{*}$.

Quarterly per fess indented az, and gu. a bendlet arg. WEston, $V$.

Quarterly indented az. and gu. a bend arg. WEst. WESTON.

Quarterly az, and or over all a bend gu. BuRGG, $V^{*}$.

Quarterly az. and or over all a bendlet gu. BuRgGs, $V$.

Quarterly az and or over all a baston gu. Sir John Sumerx, Kent, $J$. Sir John de Sumereye, Kent, L, Harl. MS., 6137 .

Quarterly gu. and arg. a bend of the second. WALLEYS.

Quarterly gu, and arg. a bend or. WaLis, BurghWallis, co. Yort. WaLLEYs.

Quarterly gu. und arg. a bendlet or. WARD.

Quarterly gu. and arg. a baston or. Steven or Stevene le WaLeise or WaLeis $E$. Richard WALLAYS, $Y$. 


\section{BEND cont.}

Quarterly gu. and arg. a baston engr. or. Richard WalLAYS, $Y$.

Quarterly gu, and arg, a bend sa. Spencer, co. Chester.

Quarterly gu. and erm. a bend or. Bunford.

Quarterly gu. and or a bend arg. Frtz-NicolL, $V^{*}$. Stephen Langton, Archbishop of Canterbury, 1207.28. TREACEY.

Quarterly gu. and or a bendlet arg. Frtz-NicoL, $V$. M. Thomas Fitz-Nicol, $S$.

Quarterly gu. and or a baston arg. Nicolas Fitz-Harding, temp. Henry II., Cotton. MS Julius C. vii., fo. 113 .

Quarterly gu. and or a bend sa. Langley.

Quarterly gu. and or a sinister baton sa. and a label of five points arg. Sire.... Fonur, $J$.

Quarterly gu. and or a bend vair. M. Thomas Sakevilie, $S$, Geffrey Sakevill, Sussek, $X$.

Quarterly gu. and vair a baston arg. Monsire le Constabie, Seigneur de Flamburgh, $Y$.

Quarterly gu. and vair over all a bend or. Constable, Everingham, co. York; descended like (Constable, Wassand, and) Sr. Robert Constable, Flamborough, co. York, $V$; from Robert, second son of John de Lacy, Baron of Halton and Constable of Chester. Constable, Oak House, Battersea, co. Surrey. Sir John de Constabie, I, Harl. MS. 6589. Govis.

Quarterly gu. and vair a bendlet or. M. Richard Constable, $S$.

Quarterly gu. and vair a baston or. Robert Constaein, $Y$.

Quarterly or and arg. a bend sa. Robert le Fitz-Rogier, $K$. And with a label vert, his son John Clayering, $K$.

Quarterly or and az. a bend gu. Borough. Burges. Savery. Sire Johan de Someri, $N$. Somerey, $V^{*}$. Somery, co. Bedford. Ulterton, $V^{*}$. Wollerton, or Wolterton.

Quarterly or and az. over all a bendlet gu. Soderex, co. Bedford and co. Hertford, $\boldsymbol{V}$. Ulterton, Norfolk, $V$.

Quarterly or and az. a baston gu. Gile de Berkeley, $F$. Sir John Somery, $L$.

Quarterly per fess indented or and az. a bend gu. Blundell. Blundevill.

Quarterly indented or and az. a bend gu. BARELIE:

Quarterly or and az. a bendlet purp. Giles de Berklaie, $E$.

Quarterly or and az, a bend vair. SAveli, Kent. Quarterly or and gu. a bend az. FELL. Fitz-Walter. M'Iver, Liverpool.

Quarterly or and gu. a bendlet az. CLavering.

Quarterly per fess wavy or and gu. a bend counterchanged. ANNCEY.

Quarterly or and gu. a bend of the last. Beauchampe. William Beauchamp, $B$; de Bedford, $P$. Beauchamp, $V^{*}$. Walter Belchaunt, $C$. Bedford. Brskell. Sr. Neall (aliter Nigell) Loringe, $Q$.

Quarterly or and gu. a bendlet of the last. Beauchamp, Baron of Bedford, $V$.

Quarterly or and gu. a baston of the last. Joan de Beachamp de Bedford, $E$.

Quarterly per fess indented or and gu. a bend of the last. BeauchampF.

Quarterly or and gu. a bend sa. Beauchampe, Baron of Bedford. Becking. Robert Clanering, Bishop of Llandaff, 1725, Peterborougl, 1729.47 Clavering, Axwell Park, co. Durham; Baronetcy 5 June 1661; a

\section{BEND cont.}

branch of Claterrng, Callaly, Northumberland, derived through Robert Frtz-Roger, Baron 1295, (Lord of Clavering, Essex, whose descendants adopted that name), from Richard Fitz-Eustace, son of Eustace Fitz-Jobn, nephew and heir of Serlo de Burgh; and from this Fitz.John descend Clavering, Warkworth, Learchild, \&c.; EURE; Barony 1300; EURE, Axbolm; and LACY, Baron of Halton. Roger le Fitz-John, Eure, B. Euery. Evers. Fitz-Richard. Robert le Frtz-Rogier (Clavering), $K$. Fitz-Roger, $V^{*}$. Sire Robert le Fitz-Roger, $N$. Robert Frtz-Roger, Clavering, $P, Y$. Garshall. Lacy. Ianglet. Langton, Langtonwick, co. Berks. (The ancient arms of) M'Iver, Ashnish Cave. Malbone. Roger. Widdrington, co, Lincoln; and Swinburne and Widdrington, Northumberland; quartering gu. a fess betw. three hedgehogs arg.

Quarterly or aud gu. a bendlet sa. M. Robert Clav'YNGE, $S$. Henry de Evers, $F$. Robert le Frtz-roger, $E ; F$; Lord of Clavering, $V$. Madbanc, Wick; Malbane; and Nautwich, co. Chester.

Quarterly or and gu. a baston sa. M. Robert le Fitz-roger, $D$. Sir Robert Fitz-Roger, $H$.

Quarterly or and gu. a bend sa. and a label arg. Le Conte de Nichole, $B$.

Quarterly or and gu. a bend sa. and a label of three points arg. Fitz-Roger, co. Lincoln. LACY, Normandy. LANGLEY.

Quarterly or and gu. a beudlet sa. and a label of three points arg. M. John Clav'ING, S. Conte de Nichol.e, $E$.

Quarterly or and gu. a bend sa. and a label of five points arg. Clavering. Lacy, $V^{*}$. Cluniac Alien Priory at Pontefract, co. York. Quarterly or and gu. a bendlet sa. and a label of five points arg. John de LACY, Earl of Lincoln and Lord of Pontefract, $V$. C. de Lincole, $F$. Quarterls or and ga. a baston sa. and a label of five points arg. Le veyl escu de Nicole, $G$. Conte de Nicold, $D$.

Quarterly or and gu. a bend sa. and a label of six points arg. Nicholls or Nycolls.

Quarterly or and gu. a vend sa. and a label of three points az. Roger de Trompington, $V$.

Quarteriy or and gu. a bend sa. and a label of five points of the last. Pomfretr, Duelish, co. Devon.

Quarterly or and gu. a bend sa. and a label vert. Sire Johan de Claveringe, $N$. John le filz-Roger le filz de Clavering, $K$, Harl. $M S$. 6137.

Quarterly or and gu. a bend (another a bendlet) sa. over all a crosier (sometimes on the sinister side) in pale (sometimes by error in bend sinister) the head sometimes turned to the sinister side or. Cistercian Abbey at Comberarere, co. Chester.

Quarterly or and gu. a bend engr. sa. Claver.

Quarterly or and gu. a bend vair. FAGEviLE or Fagenill, Suffolls. Sire Andreu de Sageville, N. Sacrvile, Selscombe, Sussex, 1730. SACIVILL. SACKVILLE, Baron Buckhurst and Earl of Dorset, 13 March 1603; Duke of Dorset, 17 Jnne 1720; Baron Cranfield, Earl of Middlesex, 4 April 1675; Baron Bolebrooke, Viscount Sackville 11 February 1782; extinct 29 July $1843 ; Z, 372$ c. Sajervyle, co. Buckingham. Adam de Samevile, $A$. Andreu de 


\section{BEND cont.}

SAkEvile, A, Harl. MS. 6137. Sir Richard SAckvill, Withiam, Sussex, $V$.

Quarterly or and gu. a bendlet vair. Siccavilu, $V$. Sekevili, $V$.

Quarterly or and gu. a baston vair. John Sackvile, $Y$. Monsire de Sakevile, $Y$.

Quarterly or and gu. a bend vert. FAGevile or Fagenill, Suffolk. Sacizvile, Suffolk.

Quarterly or and gu. a bend engr. vert. Constable.

Quarterly or and sa. a bend dexter arg. Langton, co. Lincoln, 1716.

Quarterly or and sa. a bend gu. Besley. Sr.... de Biskele, $V$. Whunston (sic for Wolunston), $V$. Byfcelex. Fastolfe (probably), in Ingbam Church, Norfolk, impaling Gimming. ham.

Quarterly or and sa. a bend of the first. Rous, or Rowse.

Quarterly or and sa. a beud of the second. John Langton, Bishop of S. David's 1447, Cole MS. Add. MS. 5798 .

Quarterly or and sa. a bendlet of the last and a label arg. Fitz-Eustace.

Quarterly sa. and arg. over all a bend of the second. LANGTON, York, $i$.

Quarterly sa. and arg. a bendlet sinister gu. EveringHaMr.

Quarterly sa. and ar. a bend or. Hoe, co. Bed. ford. Prouse or Prouze. Provze, Foscot, co. Somerset. Prowze.

Quarterly sa. and arg. a bendlet or. Robert de Ho, $F$.

Quarterly sa. and arg. a baston or. Robert d'Hoo, $E$.

Quarterly sa. and arg. a bend lozengy or. Cherney.

Quarterly sa. and or a bend arg. Langton, Langton, co. Lincoln, 1730. LANGTON, $V^{*}$.

Quarterly vair and gu. a bend or. Sir Johu de Constable, $I$.

Quarterly vair and gu. a bend engr. or. Sir Robert le Conestable, $M$.

Quarterly vair and gu. a baston engr. a. Sr. Robert le Conestable, $N$.

Quarterly vert and or a bend arg. Peveretl.

Quarterly vert and or a bend of the second. Espayne, $V^{*}$. Espaine.

Quarterly vert and or a bendlet of the second. Espayne, $V$.

Quarterly vert and or a couped baston of the second. De Hispania, Spains Hall, Finching. field, Essex.

Sa. a bend arg. Adington. Ansingham. Anting BaM, $V$. ANThinghaM AUtinghaM or Anting Hair, co. Lancaster and Norfolk. Attringham. Benton. Monceup. Riviere, 1390.

Sa. a bend arg. over all a file of three points or. KAY, co. York.

Sa. a bend sinister surmounted of another dexter arg. Newton, Essex.

Sa. billety and a bend arg. Baudwin Boliers, A, Harl. MIS. 6137. Baldwyn de Bourere, $A$. Baudwin de Boulers, $F$.

Sa. billety and a baston arg. Baudwin de Boulers, $E$.

Sa. crusily and a bend arg. Sire Thomas de Longevulers, $O$.

Sa. a bend embattled arg. Maxston.

Sa, a bend embattled counter-embattled arg. Manston, $V^{*}$. Maston, $V$.

\section{BEND cont.}

Sa. a bend engr. arg. Bradden, $V^{*}$. Braddene Braden and Bradens, co. Rutland. Bradnen or Braden, Northumberland. Sire Geffrey de Braddene, $N$. William Braddene, $X$. Sr. Geffry Braddern, co. Northampton, V. Braden, co. Northampton, $V$.

Sa. a bend engr. arg. voided or. CromwerL.

Sa. a bend fiory arg. Hellard, Cornwall; and Mitcham, Surrey. Heltard alias Highlord, London; granted 26 May 1630. HyGHLORD alias Hertard, co. Devon; and Mitcham, Surrey. SPENaR.

Sa. a bend flory counterflory arg. HELLond or Highlord, Woodbury, co. Devon.

Sa. a bend fusily arg. Sir Robert Baynton, $R$. Bodieon. Braddon. Cusanor, $V^{*}$. Cusant. Hertford, $V^{*}$. Lenthall, $V^{*}$. Lenthall, co. Dorset. Raleigh. Sir William de Watenald, $R$.

Sa. a bend of four fusils conjoined arg. Cusamor, $V$. Hertford, $V$. Sir Rowland Lenthali, $V$. Sa. a bend of five fusils conjoined arg. William de Braddone, $G$.

Sa. crusily and a bend of five lozenges conjoined arg. Robert de WerfeILd, A, Harl. MS. 6137, fo. 93 .

Sa. a bend indented arg. Manston.

Sa. a bend lozengy arg. Bayston, co. Wilts. Bayntun, Bromham, co. Wilts; Baronetcy 9 July 1762 , extinct 12 August 1816 ; the coheirs m. Caswell, Sacombe, and Starky. Hartrord Lenthal, co. Oxford, 1730.

Sa. a bend masculy arg. BERFord.

Sa. a bend (? of nine) mascles arg. Thomas Malemaynes, $X$.

Sa. a bend raguly arg. Genton. Maston.

Sa. a bend compony arg. and az. Cisterciar Abbey, at Funnes or Furness, co. Lancaster.

Sa, a bend erm. Рнilipot, Tonbridge, Kent. Philips. Philpot, co. Hertford, 1716. Sir John Philpoti, $V$. Phinlpots, $V$. Рнillot, Compton, Thaxton, and Wood Hall, co. Hants. Sir John Pнilpot, Lord Mayor of London 1378. Rive.

Sa. a bend lozengy arg. and gu. Wonsycke.

Sa. a bend or. Celny. Celuy, Warley, V. Ge. rerd HoRE, $V$. Hore, co. Devon and Norfolk. Sa. a bend or and a label of five points arg. Carswell, Hach Arundell, co. Devon; the heiress m. Langworthy. Karswill.

Sa. a bend sinister surmounted by another dexter or. Newton, Essex.

Sa. a bend or over all a crosier in bend sinister staff arg. crook or. Premonstratensian Abbey of St. Agatha at EASBY, co. York.

Sa. crusily fitchy and a bend or. Henri de Haninvile, E, Harl. MS. 6137; or Hamuvile, $E$.

Sa. a bend engr. or. Sire William de Wrtfeld, $O$. Sa. semy of crosses croslet and a bend engr. or. WhitField.

Sa. a bend flory counterflory or. Bromfreet. Sir Henry Bromflete, $V$. Hightord, Surrey. Bromifett. Vescy, Bromfleet.

Sa. a bend fusily or. EREFord, $V *$. HEREFord" Sir William de Watenald, $R$. Witevelde, $V^{*}$. Sa. a bend of four-and-a-half fusils conjoined or. Sr. Thomas Ereford, $V$. Sr. William de Witevelde, $V$.

Sa. a bend of five lozenges conjoined or. Robart de Witefelde, $A$. Richard de Wittefeld, F. 


\section{BEND cont.}

Sa. crusily and a bend of seven fusils conjoined or. Robert de WiteFeid, $E$.

Sa. a bend masculy or. Wilteneld. Wintnald.

Sa. a bend vair. Standon, co. Lancaster.

Vair a bend gu. BrolHole. Delamotte. Heilam. Mancester. Manchestre. Mansuen or Mansuen, Norfolk; and Mansuer, co. Westmoreland.

Vair a baston gu. Sir Guy de Mancestre, $O$.

Vair a bend gu. and a label arg. William del Mote, $Y$. OpLe.

Vair a bend gu. and a label of four points arg. Lamote.

Vair a garter gu. Hebuines.

Vair a bend engr. gu. Brian de Gouvis, $E$.

Vair a bend indented gu. Brian de GonUa, $E$, Harl. MS. 6137.

Vair a bend lozengy gu. Delantote. Govis.

Vairy arg. and gu. a bend of the second. MANCESTER, $V^{*}$.

Vairy arg. and gn. a bendlet of the second. $\mathrm{Sr}$. William Booth, $R$. Richard de Mancester, $V$.

Vairy arg. and gu, a bend sa. BEсHE.

Vairy arg. and sa. a bend gu. Bracebridge. Mancester. Manchester or Maunchester, $V^{*}$. Mansuer or Mansuen, Norfolk; and Mansuer, Westmoleland. MonTJoY.

Vairy arg. and sa. a bendlet gu. Joan de Maincestre, E, Harl. MS. 6137. Richard de Manchester or Mancester, $V$. Sr. Symon Manchester, co. Warwick, $V$.

Vairy arg. and sa. a baston gu. Monsire Rauf de MontJoy (apparently meant for Mounteney), $Y$. Joan de Mamcestre, $E$.

Vairy arg. and sa. a baston or. Sir John de Grandon, $L$, or de Grandone, $N$.

Vairy or and az. a bend arg. Penerell or Penreli.

Vairy or and az. a bend gu. Brian de Gouvis, Y. Grand.

Vairy or and az. a bend gu. and a label arg. Monsire William DeLaours, $Y$.

Vairy or and gu. a bend az. Fenrers, Walton, co. Derby.

Vairy or and gu. a baston az. Sire Thomas de Ferers, $N$.

Vairy or and vert a bend arg. Penerell or Penreli.

Vairy or and vert a bend erm. Cocke, $V^{*}$. Henry KOOKE, $V$.

Vert a bend arg. HAXTON, Essex. Hinton, Essex.

Vert a bend arg. charged with a cross patty fitchy in the chief point gu. (? for diff.) AlBoN, $V$.

Vert a bend embattled arg. Penford, Cumberland.

Vert a bend erm. Wetnali. (The ancient arms of) Wettenhall, Wettenhall and Hankelow, co. Chester. Wettenhali, Kent ; and Hemyngs, co. York. Sr. Thomas Whetenhal, Kent, $V$. Whetnall, Hestall Court, Kent. Whitenhali, $V *$. Thitenhall or Whitnall, Kent.

Vert a bend erm. in chief a crescent of the last. WhetonhalL, Richmond, co. York.

Vert a bend dancetty erm. Somery.

Vert a bend indented erm. Sommer, London.

Vert a bend or. Dicton, called Toupysfeid, $V$. Heanton, old Port, co. Devon; the heiress m. Somaster. Hinton, co. Derby; and Deverel Langbridge, co. Dorset. Topsfield. TOUPEFIELD, $V *$ *

Vert a bend fusily or. KNight, $V^{*}$.
BEND cont.

Vert a bend of five fusils conjoined or. KNIGHT,

Vert a bend of fusils or and a crescent .... diff. KNIGHT, London; and Kent.

Vert a bend lozengy or. KNIGHT, Middlese quartering per chev, arg. and sa. three 5-fo counterchanged, over all as an augmentati an escucheon arg. charged with a cross of : George. KNIGHT, Norroy King of Arms, c 1593. KnIGHT, co. Hants. And with a cresce for diff. KNIGHT, Chester Herald, ob. 1618.

\section{BEND and in chief....}

\section{Annulet}

Arg. a bend and in chief an annulet $\theta$ ALLESLEY.

Arg. a bead and in the sinister chief an annu az. Cooke, London; and Harefield, Middlest Core.

Arg. a bend compony az. and gu. an annulet the second. Coore.

Gu. a bend and in the sinister chief an annu] arg. Beauchamp.

Gu. a bend vair in the sinister chief an annul arg. for diff. BEAUCHAMIP, $V$.

Per chief gu. and arg. a bend engr. az. in t] sinister chief an annulet arg. Leeke, $H a$ i MS. 6829 , fo. 58.

\section{Arrows}

Arg. a bend gu. in chief two broad arrows sho conjoined by an annulet palewise az. Comriz Scotland.

\section{Bars}

Gu. a bend and in chief a bar gemel or. GneLI Grely and Grisley.

Beast ( $\mathrm{Dog})$

Or a bend chequy gu. and arg. in chief a talb pass. sa. AITEIN or ATEIN.

$$
\text { …(Lion) }
$$

Arg. a bend gu. in chief a demi-lion s Cresset, Essex.

Arg. a bend and in chief a lion ramp. sa. Osson Ireland.

\section{Bendlets}

Arg. a bend and two cotises on the chief side $g$ BERON.

Gu. a bend and two cotises on the chief side o GRISLEY, Manchester.

Or a bend and two bendlets on the chief side ver BONDY.

Sa. a bend and two cotises on the chief side o HerLand.

Bird (Cock)

Arg. a bend and a cock in chief gu. LaW, Lar bridge, Scotland.

$$
\text { .... (Crows and Choughs) }
$$

Or a bend gu. in the sinister chief a Cornis chough ppr. MaRDEN, London.

Or a bend engr. sa. in the sinister chief a Cornis chough ppr. FRANCKE.

$$
\text { .....(Eagle) }
$$

Sa. a bend engr. arg. in the sinister chief a eagle displ. or. BRADDOCK.

$$
\text { .....(Faicon) }
$$

Gu. a bend wavy arg. and in the sinister chief falcon standing on a perch or. HAWKERIDGI Hawkworthy, co. Devon.

$$
\text { .....(Martlet) }
$$

Arg. a bend sa. in chief a martlet of the las Zenham or Zennam. Peter Zeraran, $V$.

Gu. a bend fusily arg. in the sinister chief martlet or. Browne, co. Leicester. FREFORD Or a bend sa. iu clief a maitlet vert. Porman. 


\section{BEND and in chief....cont. \\ Canton}

N.B.-For all varieties of ' $a$ Chevron Bend and Canton,' see 2 CHevrons and in chief a Quarter....

Arg. a bend and canton gu. KenYelu.

Arg. a bend gu. a canton sa. Kerrisl.

Arg. a bend engr. and a canton sa. DALBr, $V$.

Barry of five arg. and gu. a bend sa. over all a canton of the second. Copeland, London; and Bootle, Cumberland.

Barry of ten or and sa. a bend erminois a canton gu. Mulcaster, Barham, Kent.

Erm. a bend gu. a canton sa. GaLtoN.

Lozengy or and sa. a bend compony of the first and az. a canton erm. Buck.

Or a bend gu. a canton sa. Wirale.

Sa. a bend or on a chev. arg. three mullets of the first a canton of the second charged with a lion ramp. gu. GILL or GyLL, co. Hertford.

\section{on a Canton (Beast) Sheep}

Az. a bend or on a canton arg. a holy lamb gu. carrying a banner of the second. EYNELL or EYTeil.

\section{....Fleur-de-lis}

Arg. a bend sa. on a canton az. a fleur-de-lis of the field. Browne, Canterbury, Kent.

$$
\text { .... Heads (Leopards) }
$$

Or a bend gu. on a canton of the second a leopard's face of the first. Ronynali.

Sa. a bend or on a canton arg. a leopard's face gu. IsaAC (Buriatt, in Atherington, co. Devon, temp. Henry III.)

Sa. a bend or on a sinister canton arg. a leopard's head of the second. ILSAKE, $V^{*}$. IsAac, $A d d$. MS. 5480 , fo. 205 . Issake, Kent, $V$.

Sa. a bend or on a canton arg. a leopard's head of the field a label for diff. Izacke, co. Exeter.

Sa. a bend or on a sinister canton of the last a leopard's face sa. IsAAC, Boughton, co. Worcester.

$$
\text { .....(Lions) }
$$

Gu. a bend erm. on a canton or a lion's head erased of the first. Milbanise, Halnaby, co. York, Baronetcy.... MILbank, Thorpe Perrow and Barningham Park, co. Yolk.

Gu. a bend erm. on a canton or a lion's head erased sa. Millibank.

Or a bend chequy sa. and arg. on a canton of the second a lion's head erased of the first. Monteith, Auldeathie, Scotland.

Paly of six arg. and gu. a bend erm. on a canton or a lion's head erased of the second. Malbanike, co. Lancaster.

$$
\text { .....Horn }
$$

Paly of six or and gu. a bend counterchanged on a canton sinister sa. a bugle horn strínged or. Tizard, Winterbolne St. Martin, co. Dorset, quartering Harrlins.

$$
\text { ....Mullet }
$$

.... a bend wavy .... on a sinister canton .... a mullet.... WeBster.

$$
\text { ......Mullets }
$$

Arg. a bend gu. on a canton of the second tro mullets of the first. Stanlow, co. Devon and Norfolk.

$$
\text { .... Ship }
$$

Or a bend gu. on a canton arg. a galley oars in action of the secoud. KeEP.

$$
\text { .....staff }
$$

Arg. a bend lozengy sinister gu. on a canton of the last a crosier.... Cistercian Abbey at BoxLEY, Kent.

\section{BEND and in chief.... cont.}

\section{Castle}

Sa. a bend arg. in the sinister chief a tower of the last. Plunket, Baron of Killeen, 1403, Earl of Fingal, 26 September 1628, Harl. MS. 4010 , fo. 75 . And with a crescent az. for diff. Prunket, Baron Lowth, 15 June 1541, Harl. MS. 4040, fo. 418. And with the crescent gu. Pluniet, Baron Dunsany, Harl. MS. 4040, fo. 406.

Sa. a bend arg. in the sinister chief a tower triple-towered of the last. PLunietr, Ireland.

Sa. a bend arg. in the sinister chief a castle of the second. Plunketr, Baron Dunsany.

Sa. a bend arg. in the sinister chief a tower triple-towered of the second on a canton gu. a naval coronet or. Plunketr, Lowth, Ireland.

Sa. a bend arg. in chief a tower triple towered or. Plonckneti or Plonkett.

Chief (see also Per chief.. and.. a bend...) Arg. a bend gu. a chief az. Rauf Crowwell, $Y$.

Arg. a bend engr. gn. a chief az. Holden. Penibridge, co. Chester; and see Per fess.... and ..... a bend....

Arg. a bend lozengy gu. a chief az. GaMnGE, $V^{*}$. Arg. a bend of four lozenges conjoined gu. a chief az. Raufe Gamage, $V$.

Arg. a bend engr. gu. a chief sa. HALDANE.

Arg. a bend sa. a clief gu. Bridge, co. Lancaster.

Arg. a bend engr. sa. a chief gu. LEATE or LEKT.

Arg. a bend and a chief sa. Bridge, co.Lancaster.

Arg. a bend sa. a chief vair. Michael de Northburg, Dishop of London 1354-61.

Arg. a bend sa. a chief vairy or and gu. Norbery Norberry or Norbery.

Az. fretty arg. a bend and a chief of the second. ELLERKET.

Az. a beud and a chief or. Carminow, $V^{*}$. Carmynow, $V$. Carminaw, Cornwall.

Az. a bendlet and a chief or. Carmynow, $V$.

Az. a bend and a chief indented or. Clare.

Barry of ten ar. and az. a bend and a chief gu. FALLENY.

Erm. a bend az. a cbief gu. Champaigne Chanipain or Champigne.

Erm. a bend wavy gu. a chief az. Netherconts, co. Lincoln.

Gu. a bend and a chief arg. Heliss.

Gu. a bend lozengy and a chief arg. Rochewell. And in the sinister chief a martlet of the first. ReCheweLL. $V^{*}$.

Gu, a bend of five lozenges conjoined and a chief arg. on the sinister side a martlet of the last. Sir Johu RechewetL, $V$.

Gu. a bend or a chief arg. Bourgeors.

Or a bend az. a chief gu. Harington.

Or a bend gu. a chief chequy arg. and az. De LIIGNE.

Or a bend and a chief gu. Anaf or Chacombe, co. Leicester.

Or a bend indented gu. a chief vert. Nevill, co. Lincoln.

Sa. a bend and a chief arg. Helles. Hellis.

Vair a bend and a chief gu. John Mounteney, $Y$.

Vairy arg. and sa. a baston gu. a chief or. Rauf Mounteney, $Y$.

Vairy or and az. a bend gu. a chief of the first. UGESBORNE.

on a Chief.... Bar

Arg. a bend sa. on a chief gu. a barrulet wavy or. Nonbery, co. Derby. 
1 BEND and in chief....cont.

on a Chief cont. Bars

Alg. a bend sa. or a chief gu. two barrulets of the first. NERBERYE.

Arg. a bend sa. on a chief gu. two barrulets or. Nerberye or Nerbury. Nerbury, co. Devon.

$$
\text { .....Beasts }
$$

Arg. a bend compony az. and or on a chief gu. two lions pass. guard. in pale of the third. John Curzox, Bellingford, Norfolk, $V$.

Az. a bend chequy or and az. on a chief gu. two lions ramp. of the second. Curson, Norfolk.

$$
\text { ..... Bird }
$$

Gu. a bend lozengy arg. on a chief of the second a martlet sa. RochewerL, Wales.

$$
\text { .... Birds (Crows and Choughs) }
$$

Az. a bend or on a chief arg. two Cornish choughs ppr. VYNER.

Az. a bend or on a chief of the last two Cornish choughs ppr. Viner. Vyner, Gautby, co. Lincoln.

$$
\text { .... (Martlets) }
$$

Arg. a bend az. on a chief gu. three martlets of the field. Hague, Stanley Hall, Wakefield.

$$
\text { ..... Escallops }
$$

Arg. a bend fusily gu. on a chief az. three escallops of the first. Gamadge, $V^{*}$. Gamage, $V^{*}$.

Arg. a bend of four fusils conjoined gu. on a chief az. three escallops of the first. Sr..... de Gamage, $V$.

Arg. a bend lozengy gu. on a chief az. three escalJops of the first. Gamach, $V^{*}$. Gamage, $V^{*}$. Gamage, Wales.

Arg. a bend of five lozenges conjoined gu. on a chief az. three escallops of the first. Sr. .... de Gamach, $V$. Sr. William Gamage, Coyte, $V$.

Arg. a bend engr. gu. on a chief of the last three escallops of the first. Power, Coreen, co. Galway.

Sa. a bend or on a chief arg. three escallops gu. MODERBY, $V$.

\section{.....Hand}

Az. a bend or on a chief arg. a sinister hand betw. two Cornish choughs ppr. VYNER or VINer, London.

$$
\text { .... Head (Beast) Leopard }
$$

Arg. a bend sa. on a chief of the secoud a leopard's head or. Jencote JeniCOT or JenYCOTE, Gascoygne.

\section{.....(Monster) Dragon}

Barry of eight per pale az. and or (another arg.) counterchanged a bend erminois on a chief gu. a dragon's head erased betw. two annulets of the second. Knighton, Carlston, co. Dorset; and Blendworth Lodge, co. Hants; Baronetcy 1 January 1813.

$$
\text { .... Heads (Beasts) Leopards }
$$

Arg. a bend sa. on a chief gu. three leopard's heads or. Jenicor, Gascoigne, $V$.

Barry of five (seven $V^{*}$ ) nebuly arg. and sa. a bend of the last on a chief gu. three leopard's heads or. Clement, Kent, $W$.

$$
\text { .... (Monsters) Griffins }
$$

Or a bend sa. on a chief gu. three griffin's heads erased of the field. Percival.

$$
\text { .....Mullets }
$$

Arg. a bend gu. on a chief of the last two mullets or. Sr. John St. Jorn, Bletso, $V$.

Arg. a bend engr. gu. on a chief sa. two mullets or pierced of the second. SALway.
1 BEND and in chief.....cont.

on a Chief cont. Ir pllets cont.

Or a bend az. on a chief gu. two mullets arg. pierced of the first. Gorges.

Arg. a bend gu. on a chief of the last three pierced mullets of the first. WhitrielD or WhITEFIELD.

Arg. a bend gu. on a chief of the last three mullets or. Sr. JoHs, Treland.

$$
\text { .... (Roundles) Bezants }
$$

Arg. a bend gu. on a chief of the last three bezants. Sterreli, co. Lincoln.

$$
\text { .... Torteaux }
$$

Gu. a bend erm. on a chief arg. three torteaux. Broun, $V^{*}$.

Sa. a bend erm. on a chief arg. three torteaux. Broun, $V$. Browne, Essex.

$$
\text { .... Packs }
$$

Arg. a bend sa. on a chief gu. three woolpacks or JoHnson, Long Melford, Suffolk; granted 1663.

Arg. a bend sa. on a chief of the second three woolpacks of the first. James JoHnson, Bishop of Gloucester 1725, Worcester 1759.74.

$$
\text { ..... Saltire }
$$

Az. a bend or on a chief arg. a saltire engr. gu. betw. two Cornish choughs ppr. Vyner, Lord Mayor of London 1654 and 1675. VYNER, Gautbv, co. Lincoln; anciently Le Veneur, co. Gloucester, co. Warwick, ana co. Lincoln. VYNER, Corndover, co. Salop.

$\mathrm{Gu}$, a bend or on a chief of the last a saltire engr. of the first betw. two Cornish choughs sa. VYNOR or VYNORS, co. Wilts.

\section{Coronet}

Az. a bend raguly .... in the sinister chief a ducal coronet or. Merlin, Portcullis Pursuivant at Arms 1559.

Az. a bend raguly arg. in the sinister chief a ducal crown or a crescent az. on the bend for diff. Merland, co. Lancaster, $\boldsymbol{I}$.

\section{Crescent}

Arg. a bend of four fusils conjoined sa. in the sinister chief a crescent arg. LYE, $V$.

Vert a bend erm. in chief a crescent of the last. Whetonhall, Richmond, co. York.

\section{Cross}

Az. a bend wavy .... in the sinister chief a cross coupy arg. William de Curbellio, Archbishop of Canterbury 1123-36.

\section{Escallop}

Arg. a bend eugr. sa. an escallop ....' en le sou'eign peice'. William CUSANCE, $Y$.

Arg. a bend engr. sa. an escallop .... for diff. Ratcliff, Chappell, Essex.

Arg. a bend engr. sa. in the sinister chief an escallop gu. Sir Richard RadcltFF, $V$.

Arg. a bend engr. and an escallop in the sinister chief sa. Cusance.

\section{Estoile}

Az. a bend and in chief an estoile or. Falmaner, Ireland.

\section{Fleur-de-lis}

Arg. a bend engr. sa. a fleur-de-lis gu. for diff. William fitz William Radcurf, 1350, $V$. The fleur-de-lis sa. RATCLIFFE, Todmorden, co. Lancaster; and co. York.

Az. a bend nebuly and in the sinister chief a fleur-de-lis arg. SwaIl.

Per chief gu. and arg. a bend engr. az. in the sinister chief a fleur-de-lis or for diff. LEEkE, co. Salop. 
1 BEND and in chief.... cont.

Flower.... Rose

Barry of three or with chequy az. and arg, a bend and in chief a rose gu. STewart.

Barry of three or with chequy az. and arg. a bend engr. and in chief a rose gu. Stewart, Minto, Scotland. Stewart, Baron Blantyre, 10 July 1606.

$$
\text { .... Thistle }
$$

Az. a bend ermirois in chief a thistle arg. KeMPSTER.

Gu. a bend engr. arg. in chief a thistle leaved or. GemmiL, Scotland.

5-Foil

Gu. a bend or and in the sinister chief a 5 -foil arg. Delafountaine, Essex. Fountain, Belchamp St. Paul; granted 22 February 1619.

Gu. a bend or and in the sinister clief a 5.foil erm. Fountain, Belchamp St. Paul, Essex; granted 22 February 1619. Fontaine, London. 6-Foil

Gu. a bend and in the sinister chief a 6-foil arg. De la Fountain, Belchamp St. Paul, Essex; granted by Camden. Garb

Arg. a bend sa. and in the sinister chief point a garbgu. Whiтwortн, Adbaston, co. Stafford. Grn

Arg. a bend engr. and in chief a matcblock sa. Cosance, Higham Barrow.

Hand

Arg. a bend wavy sa. an arm issuing from the sinister of the last on a glove of the first a hawk or. Hawkeridge, co. Devon.

Head (Beast) Bear

Arg. a bend engr. gu. and in chief a bear's head erased az. muzzled of the second. LETHINGTON, Saltcoats. LIVINGTON. .... Leopard

Sa. a bend and in the sinister chief a leopard's head or. Isack, Brakesborne, Kent. .....Lion

Sa. a bend erm. and in chief a lion's head erased arg. Pніцет, London; and Feversham, Kent.

\section{.... (Monster) Griffin}

Gu. a bend and in chief a griffin's head arg. AsHwooD.

\section{.... Unicorn}

Arg. a bend and in chief a unicorn's head erased sa. DenNistoun.

\section{Label}

Arg. a bend sa. a label of three points gu. ST. Lo, Chideock. St. Loe, 1730, St. Lowe, $V^{*}$. Sr..... de Seint Lowe, $V$. St. Pier, co. Worcester. Sir Brian St. Pier or de ST. Pier, $L$, co. Devon; Sture, Hewish and Marridge, co. Devon; Visitation 1620 .

\section{Maunch}

Vert a bend or and in chief a maunch sa. TyNMORE.

Leaf

Arg. a bend and in the sinister chief an oak leaf az. Соск. Cox, co. Salop.

Arg. a bend sa. in the sinister chicf an oak leaf az. Cox, London; and co. Gloucester. Mullet

Chequy or and gu. a bend erm. and a mullet sa. (for diff.). CiIfton, Toftrey, Norfolk.

Gu. a bend arg. and a mullet .... (for diff.). Haward, Westmoreland.

Gu. a bend arg, and a mullet or. Donsels, co. Devon.

\section{BEND and in chief....cont.}

\section{Mnllet cont}

Or a bend indented sa. in the sinister chief a pierced mullet gu. (? for diff.). Downham, $V$.

Per chief gu. and arg. a bend engr. az. in the sinister chief a pierced mullet or for diff. M. Robert de LeYke, $S$.

\section{Roundle}

Arg. a bend lozengy sa. in the sinister chief point a bezant. Tavenor, Uxminster, Essex.

Arg. a bend lozengy sa. in the sinister chief a torteau. Taverner, Essex; Hoxton, co. Hertford; and Kent; granted 1575 ; and by patent 1604.

Az. a bend erm. in chief three bezants fesswise. PlaskftT.

Staff

Quarterly or and gu. a bend sa. in the sinister chief quarter a crosier of the first. Cistercian Abbey at Comerrmere, co. Chester.

\section{BEND and in base....}

Bird

Or a bend raguls sa. in base a martlet gu. beaked of the second. ELDRED or ELDRIGE. Cross

Or a bend and in base a cross croslet gu. MurRILL. 5-Foil

Vert a bend lozengy or in base a 5 -foil arg. KNIGHT, Chawton, co. Hants ; granted 1738. Mullet

Or a bend raguly sa. in base a mullet gu. ELDRED.

1 BEND betw, or within....

\section{Anchor}

Az. a bend sinister or in base the end and stock of an anchor gold issuant from waves of the sea ppr. in chief two estoiles in like bend as the second. Shiffner, Combe Place, Sussex; Baronetcy 16 December 1818.

Anchors

Vert a bend or betw. two anchors arg. Gromuey, Ireland.

\section{Annulet}

Arg. a bend sinister sa. in chief an annulet gu. in base a griffin's head erased of the second holding in his beak a key az. $\mathrm{C}_{A Y}$, Bishopwear. mouth, co. Durbam. Kay, Sunderlard, co. Durham; and North Shields, Northumberland. CAY KAY or KEAY, Scotland.

\section{Annulets}

Quarterly or and gu. over all a bend sa. betw. two annulets one in each of the second and third quarters (arg. Sr. Robert Bourgilons, $N$, Harl. MS. 6137), as the first. BorgilloN. Boungyton, $V$.

Arg. a bend engr. sa. betw. three annulets gu. DoDsworth, co. York.

Arg. a bend betw. three annulets sa. DoDsworth, formerly Smith, Newland Park, co. York; quar. tering Smith; Baronetcy 22 January 1784.

Az. a bend betw, three annulets or. Nоск.

$\mathrm{Gu}$. a bend or betw, three annulets arg. Brasier or BRAZIER.

Sa. a bend betw. three annulets or. (? LEEK.)

Alg. a bend az. betw. six annulets gu. Sir Ed. mond de Plescy, $L$. Sir Edmond de Pleice, L, Harl. MS. 6137.

Gu. a bend or betw. six annulets arg. Lealle. Gu. a bend betw. six annulets or. Stockiey or STOCKELEY.

Or a bend az. betw. six annulets gu. Bure. 
1 BEND, betw, or within.... cont.

Annulets cont.

Quarterly or and gu. over all a bend sa. betw. six annulets three in each of the second and third quarters two and one arg. Bongulion. Sire Pobert Borgyloun, N. Burgonyon or Bungulion. The annulets gold (but this coat is Or a bend sa. quarterly with gu. three annulets or, Cotton $M S$. Tiberius $D, 10$. Bourgyloun, co. Worcester, $V$.

Sa. a bend arg. betw. six annulets or. Lerie, $V$. Sa. a bend betw. six annulets or. Laxe, $V^{*}$. Sr. .... de Lere, co. Lincolu, $V$. Leake.

\section{Arrows}

Vert a bend betw. two hirdbolts bendways or point downwards. BoLter.

Arg. a bend raguly betw. three arrows gu. feathered and barbed or. Massergh, Berwick Hall, Westmoreland.

\section{Axes}

Arg. a bend betw. three pick-axes and five ( $\operatorname{six} V^{*}$.) lozenges sa. Bolron, $V$.

Arg. a bend betw, six pick-axes sa. Pigotr, $V^{*}$. Pigotx, co. Bedford. Sr. Randolfe Pygott. $V$. Gu. $\Omega$ bend betw. six pick-axes arg. Pickeworth. Sr. Phillip Pickworth, $V$. Monsire de Pickworth, $Y$. John Pikeworthe, $Y$.

Gu. a bend betw. six pick-axes or. Thomas Pikeworth, $X$.

\section{Barrels see Tuns \\ Baskets}

Sa. a bend or betw. three hand-baskets arg. Woolston, Tor Newton, co. Devon, 1716.

Sa. a bend or betw. six dorcers $i$. $e$. wicker baskets with handles arg. WoLston, $V$.

Beast....Fox

$A z$, a lend betw. in chief a fox courant and in base two mullets arg. Wyure, Beverley. WyLite, Edinburgh, Lyon Register.

$$
\text { .....Lion }
$$

Per bend or and az. a bend compony of three di. visions gu. arg. and gu. in chief a demi-lion ramp. couble tailed of the second in base a sun in splendour ppr. Horrmax.

Az. a bend or betw. in chief a lion ramp. and in base a bugle arg. stringed sa. Smellet, Scotland. Shenlie, London, and Scotland. Shollet, Bonbill, Scotland. And with a bordure arg. SHollet, Kirktown, Scotland.

\section{Beasts ..... Badgers}

Az. a bend wavy betw. two badgers (? moles) sta tant arg. Qwick, quartered by Molton, Harl. MS. 10 s0, fo. $104 \mathrm{~b}$.

$$
\text { ..... Bears }
$$

Arg. a bend sa. betw. two bears salient of the second chainerl and muzzled or. WHEatLey or Whetrey, Fakenbam, Norfolk.

Arg. a bend sa. betw, two bears ramp. of the second muzzled lined and ringed or. WHETLEY, Southbreak, Norfolk.

$$
\text { .....Deer }
$$

Vert a hend betw. two bucks trippant erm. Bucke, co. Cambridge. Bucke, $V^{*}$.

$$
\text { .... Dogs }
$$

Arg. a bendlet gu. betw. two greybounds courant in bend sa. enclosed by as many bendlets of the first. Triew.

Gu. a bend betw. two talbots pass. arg. KrLeman. Sa. $a$ beod betw, two talbots pass. arg. HoLlis, Erebs, co. Lincoln; and Nottingham; granted 24 May 1550. Holirs, Shire Newton House, co. Monmouth.

\section{BEND betw. or within.... cont. \\ Beasts cont. Lions}

Arg. a bend betw. two demi-lions ramp. sa. Cossart.

Arg. a bend betw. two lions ramp. az. FOUNDER or Foundaure. Foundowre, $V^{*}$. Fowndowre, $V$.

Arg. a bend engr. az. betw. two lions ramp..... Dickenson, co. Wilts.

Arg. a bend ermines betw. two lions ramp. sa. Osborne. London.

Arg. a bend engr. betw. in clief a lion pass. and in base a lion counterpassant gu. GLeig, Scotland.

Arg. a bend (masculy?) betw. two lions pass. guard. gu. BRADGate, Leicester.

Arg. a bend sa. betw. two lions ramp. gu. Hepworth, Armley Heights, and Pontefract, co. York. Osborne, Osborne House, Spondon, co. Derby.

Arg. a bend betw. two lions ramp. sa. OsBorn, Chicksand Priory, co. Bedford; Baronetcy 11 February 1661.

Az, a bend betw. two lions ramp. arg. BREnT. DODIER.

Az. a bend betw. two lions ramp. or. ATYE or Atrre, Newington, Middlesex; granted 1583. But langued gu. Atx, Middlesex.

Frm. a bend betw. two lions pass, reguard. gu. LybB, co. Oxford. Lybie.

Ernı. a bend betw. two lions ramp. gu. LrBBE, Hardwich, co. Oxford. LybBe, co. Oxford, and Devon, $W$.

Gu. a bend lozengy betw. two lions pass. arg. WHISTLER

$\mathrm{Gu}$. a bend betw. two lions ramp. or. KIBrow.

Gu. a bend or betw. two lions ramp. sa. STRANGE, Norfolk.

Or a bend compony (another countercompony) az. and arg. betw. two lions ramp.gu. Stewart, quartered by Vane.

Or a bend engr. betw. two lions ramp. gu. Dicinson.

$$
\text { .....Moles }
$$

Az. a bend wavy betw. two moles (? badgers) statant arg. Qwick, quartered by Molton, Harl. MIS. 1080 , fo. $164 \mathrm{~b}$.

$$
\text { .....Tigers }
$$

Arg. a bend betw. two tigers .... sa. Osborne, Norfolk.

$$
\text { .....Bats }
$$

Or a bend gu. betw. three bats sa. Lorayne.

$$
\text { .....Goats }
$$

Sa. a bend betw, three goats pass. arg. GarfortH. .... Lions

Arg. a bend betw. three lions ramp. sa. OsBORN, $V^{*}$.

\section{....Moles}

Az. a bend wary betw, three moles arg. Quтcк, co. Devon.

$$
\text { ..... Sheep }
$$

Per fess arg. and sa. a bend lozengy betw. three rams counterchanged. Sydenham.

$$
\text { .....Goats }
$$

Sa. a bend betw. six goats .... arg. Gatesford, co. Chester.

Sa. a bend betw. six goats pass. arg. GaRForTH, co. York.

Sa. a bend betw. six goats ramp. arg. Gayterord, $V$ *. GaYtFond, $V$.

Sa. 凡 bend betw. six gouts salient arg. GATEFord, co. Salop. But attired or. GARFoote, Hyde, Essex; and Farnham, Suffolk, 1034. 


\section{BEND betw, or within.... cont.}

Beasts cont. Lions

Arg. a bend betw. six lions ramp. gu. SAwrey.

Arg. a bend lozengy or betw. six lions ramp. sa. Bawdewyn, $V^{*}$. Bawdwen. Bawdwine Tistesborough or Titesbury, $V$. Tyttesbury, $V^{*}$.

Arg. a bend betw. six lions ramp. sa. Franks, Teddington, Middlesex.

Az. a bend arg. betw. six lions ramp. or. Sire Edmond de Boun, $O$.

Az. a bend gu. betw. six lions ramp. or. Bicknor, $V^{*}$.

Gu. a bend betw. sis lions ramp. arg. MarthaM, $V$.

Gu. a bend arg. betw. six lions ramp. or. Box.

Gu. a bend erm. betw. six lions ramp. or. Cowper, Bolton-upon-Swale, co. York.

Gu. a bend engr. or betw. six lions ramp. arg. Asbs, Cleadon, co. Durham.

Gu. a bend engr. betw. six lions ramp. or. Cooper, Earl of Shaftesbury, quarterly with Asbley. Cowper.

$\mathrm{Gu}$. a bend vair betw. sis lions ramp. or. CowPER, co. York.

Or a bend az. betw. six lions ramp. gu. Box, Sussex. Sr. Henry Box, Essex, temp. Edward $\mathrm{I}, V$.

\section{Bendlets or Cotises.}

.... a bend betw. two cotises .... Richard HARBELL or rather HARDELL, Lord Mayor of London, 1253; Stow.

Arg. a bend az. betw. two cotises gu. Thomas Barwis, $Y$. Berroys or Berrois, Berwis, $V^{*}$. BERWYS, $V$.

Arg. a bend az. betw. two cotises engr. gu. SEATCHARD.

Arg. a bend az. betw. two cotises wayy gu. Grey, Essex.

Arg. a bend az. betw. two cotises sa. CHyrfold.

Arg. a bend of five lozenges conjoined az. betw. two cotises vert and as many scorpions sa. O'Sinan, Ireland, Harl. MIS. 4039, fo. 235.

Arg. a bend compony gu. and az. betw. two cotises of the second. Lenthorpe, Essex.

Arg. a bend compony gu. and sa. betw. two cotises of the second. Sr. .. de Lenthors, $V$. Lenthorp Lenthrop or Leventhorp, Essex; and Shingley Hall, co. Herts. Levethrope.

Arg. a bend betw. two cotises gu. Frampton, co. Dorset. Kingston. Walter de Stokes, $V$.

Arg. a bend betw. two cotises gu. and six Cornish choughs ppr. Gostwick.

Arg. $a$ bend betw. two cotises and three eagles gu. EarnLer, lient.

Arg. a bend betw. two cotises and six crosses croslet gu. BUDNELL.

Arg. a bend betw. two cotises gu. and six crosses croslet sa. Brudenell.

Alg. a bend betw. two cotises gu. and six crosses croslet fitchy sa. Brudenell or Bruddenell. BREWDNELL.

Arg. a bend betw. two cotises gu. and six crosses pomelly fitchy sa. BRUdDenell, $V^{*}$. Brudenell, $V$.

Arg. a bend betw. two cotises and three boar's heads gu. WALter, co. Warwick.

Arg. a bend betw. two cotises dancetty gu. COKERFIELD.

Arg. a bend betw. two cotises dancetty and three mullets gu. HacKLET.

Arg. a bend betw. two cotises indented gu. Colemited, $V$. Cokerfield.

\section{BEND betw. or within.....cont.}

Bendlets or Cotises cont.

Arg. a lend dancetty betw. two cotises gu. and six mullets sa. Skarcliff or Skarclis.

Arg. a bend engr. betw. two cotises gu. LAYFond or LAYFoRTH.

Arg. a bend nebuly betw. two bendlets gu. Knighton. Chellonx called Kingston, $V$.

Arg. a bend nebuly betw. two cotises gu. Chelley. Arg. a bend wavy betw. two bendlets gu. Chellory, $V^{*}$. Kingston, $V^{*}$.

Arg. a bend wavy betw. two cotises gu. KINGSTon, co. York. KYneston or KYngeston.

Arg. a bend gu. betw. two cotises sa. Frampton, Moreton, temp. Edward III ; and Buckland; co. Dorset. Layland. LELand.

Arg. a bend gu. betw. two cotises and three boar's lieads erect and erased sa. a labei of the second. CAMDOY.

Al'g. a bend gu. betw. two cotises and six billets sa. BAXten, co. Hereford; quartered by Lenthall.

Arg. a bend gu. betw. two cotises engr. on their outer edge sa. Surnden or Surrendes, Kent.

Arg. a bend gu. betw. two cotises indented sa. Aleyn Plonket, $V$.

Alg. a bend gu. betw. two cotises nebuly sa. Surnenden, $V^{*}$. But the cotises nebuly on their outer edge. Surrenden, Kent, $V$.

Arg. a bend engr. gu. betw. two cotises sa. Sr. Robert Mone, $V$. Roger Mone, $V$. Mure, Norfolk.

Arg. a bend engr. sa. betw. two cotises az. and six martlets of the second. Strethe, $V$.

Arg. a bend sa. betw. two cotises gu. ALspach or Alspath. Sr. Gerard alspathe, $V$. Macnot or Maconnant, co. Lincoln. Sr. Giles Maconant, co. Lincoln, $V$. Sire Geffrey Maucovaunt, $N$. Sr. Geffrey Madconant, co. Lincoln, temp. Edward $I, V$. Gettra Mauconvenant, $Y$.

Arg. a bend sa. betw. two cotises within a bordure gu. Alspathe.

Arg. a bend sa. betw. two cotises gu. and three covered cups of the second. ButLer, Suffolk. Arg. a bend sa. betw. two cotises engr. gu. and as many eagles displ. vert. Sivedale, Liverpool, co. Lancaster.

Arg. a bend engr. sa. betw. two cotises gu. Stretton, Lenton Priory, co. Nottingliam. Sr. Oliver Stretton, $V$. Tetlow, Olingham, co. Lancaster.

Arg. a bend betw. two cotises sa. Ellys de KNolle, $Y$. Stane, Forest Hall, Essex; quartering Bramston. Stanye, $V$.

Arg. a bend betw. two cotises and three lions ramp. sa. SANDERBY.

Arg. a bend betw. two cotises and six lions ramp. sa. Bohun, Essex, $V$. Scarby or Scardby. Seveley. SNardby or SNarley; M. Joln Soardebr, $S$. Suardby, $V^{*}$. Monsire de SWardiy, $Y$. Joln SYWardiy or SyWardiye, $Y$.

Arg. a bend betw. two cotises sa. within a bordure engr. gu. bezanty. Littleton. co. Leicester. Wescot or Westcott, Raddon, co. Devon; and co. Warwick. Westcote.

Arg. a bend betw. two cotises sa. within a bordure of the last bezanty. Weston, co. Bedford.

Arg. a beud betw. two cotises within a bordure engr. sa. Dowrish, co. Devon.

Arg. a bend betw. two cotises within a bordure engr. sa. a label of three points az. Downiche, Dowriche, co. Deron. 
1 BEND betw, or within.... cont.

Bendlets or Cotises cont.

Arg. a bend betw. two cotises within a bordure engr. and in the sinister chief a mullet sa. for diff. AIsPach.

Arg. a bend betw. two cotises sa. and as many garbs gu. WHITEFond. WHITFORD.

Arg. a bend betw. two cotises engr. sa. Whitfelld, $W$. Whitfieid, co. Northamp. ton; Sussex; and Whitfield Hall, co. Northumberland; derived from WHITFIEID, Tenterden, 1548, second son of WhitFiELD, Wadhurst, Sussex. Whitrield, Mortlake, Surrey ; granted 1606.

Arg. a bend engr. betw. two cotises sa. Clobery, Bradstone, quartered by Holte. Clowbery, $W$. Hodisham, Suffolk. Waller, Suffolk, V. Walier, Boklesham, Suffolk. Wortham, Wortham, Suffolk.

Ar. a bend betw. two cotises engr. and six martlets sa. Thomas Fitz-Hariert, $X$.

Arg. a bend of five lozenges conjoined betw. two beudlets sa. Tonke, $V$.

Arg. a bend nebuly betw. two cotises sa. WhITING.

Arg. a bend wavy betw. two cotises sa. Neffeile. Whrting, Wood, co. Devon.

Arg. a beud vairy or and gu. hetw. two bendlets vert. Plum, Maldon, Essex. Plum or Plume.

Arg. a bend vert betw. two cotises gu. Gray. Hendey. Hendrs. Hendys, $V$. Hendy, $V^{*}$.

Arg. a bend vert betw. two cotises dancetty gu. Grey or Gray, Segenhoe, co. Bedford; Essex; and Pellham, co. Hertford.

Arg. a bend vert betw. two cotises indented gu. Gray, $V^{*}$. Gray, Essex. Sr. Roger Grey, $V$. KenDALI, co. Hertford.

Arg. a bend dancetty vert betw. two cotises gu. Kendali, co. Hertford.

Arg. a bend dancetty vert betw. two cotises of thesame gu. Sile Edmon de Kendale, $N$.

Arg. a bend indented vert betw. two cotises gu. Kendari, co. Northumberland, $V$.

Arg. a bend betw. two cotises (? all) dancetty vert. Edmond de Kendale, $B$.

Arg. a lend betw. two cotises and six lions ramp. vert. SNardBy or SNarLEY.

Az. a bend betw. two cotises arg. Fortescue. HIGHAM.

Az. a bend betw. two cotises arg. and six lions ramp. or. BoHun, $V^{*}$. Joan de Boun, $E$. Sire Henri de Boun, $N$. HaRford.

$A z$. a bend betw. two cotises and four birds volant arg. CREwse.

Az. a bend betw. two cotises arg. and six martlets or. Tonge, Thickley, Durham ; Visitation 1615. M. Reynard de la BEER, $S$.

Az. a bend betw. two cotises arg. and six crosses patty or within a bordure engr. gu. platy. Hopton, $V^{*}$.

Az. a bend betw. two cotises and as many garbs arg. Tillotson, co. York. John Tillotson, Archbishop of Canterbury 1691-4.

Az. a bend betw. two cotises and six lroar's heads arg. Estinng. Esing, $V^{*}$. The heads fess. wise and couped. Rafe Esings, $V$.

Az. a bend betw. two cotises arg. and sis boar's heads or. EsIINGE.

Az. a bend wavy betw. two cotises arg. CAines or Kaynes, Tarent Kaynston. Keines, co. Somerset. Keynes, $\boldsymbol{V}$. Keynes or Kieignes, Winkley Keynes, co. Devon, temp. Henry II, and co. Somerset. KYYNe or Kines.
1 BEND betw. or within.....cont.

Bendlets or Cotises cont.

Az. a bend (sometimes a bendlet) wavy betw. two (beudlets $V^{*}$.) cotises arg. KeInes. Keynes, $V^{*}$. Az. a bend arg. betw. two cotises gu. and six lions ramp. or. Henry de Boun, $B$.

Az. a bend arg. betw. two cotises or. BAHON. BanHaM. Humphrey BoHun, Earl of Hereford, $K$; Harl. MS. 6137.

Az. crusily or a bend betw. two cotises arg. Sire Richard de As'tone, $N$.

Az. a bend arg. betw. two cotises indented or. Clopton.

Az. a bend arg. betw. two cotises potent on the upper side or. ChaMragne; quartered with France and Navarre by Isabel CAPET, daughter of Philip (the Fair) IV, king of France, and wife of Edward II, 1307.57.

Az. a lend arg. betw. two cotises and six lions ramp. or. Humfrey de BoHठN, Earl of Hereford, Essex, and Northampton; seal to will 1319: and on the tomb in Westminstor Abbey of Eleanor BoHuN, duchess of Gloucester, ob. 1399. BoHUN, $Z, 143,229,233$, 266. BoHun, quartered by Stafford, Earl of Wiltshire, $U$. Humfrey de BoHun, Earl of Hereford, $V$. Hum. fray de Boun, Counte de Herford, Conestable de Engletre, $H$. Mousire Umfray de Boune, Counte de Hereford, $Y$. Le Conte de Hereford, $B ; D ; E ; J ; L ; N ; P$; but the lions "embelis" in $P$. Humfrey, Earl of Hereford, $K$. Le Counte de Herford, $C$. And with a label gu. Humpliry de Boun, $B$ : Henry de Boun, son of the Constable, $H$. And with a crescent gu. in chief of the bend. BонUn, quartered by Bourchier, Earl of Essex, $U$.

Az. a bend arg. betw. two cotises and six martlets or. Delaber, Southam, co. Gloucester. Simon de Labere, E. Delabere or Dollabe. Pemse. Henry de Pyens, $G$. Tonge, $V$.

Az. a bend arg. betw. two cotises and six crosses croslet or. Aston, co. Wilts, V. Richard Astone, $V$.

Az. a bend arg. betw. two cotises and six crosses croslet fitchy or. Aston, co. Wilts.

Az. a bend arg. betw. two cotises and six crosses patty or within a bordure engr. gu. aud charged with eight plates. Horron, Suffolk, $V$.

Az. a bend arg. betw. two cotises and eight 3.foils or. AsToN.

Az. a bend eugr. arg. betw. two cotises or. AlunD, Ireland. Fortescue, Winston, Preston, and Fallapit, co. Devon : the beiresses m. Fortescue and Bury. Fortescue, Baron Fortescue, $5 \mathrm{July}$ 1746, Viscount Elurington and Earl Fortescue, 1 September 1789. Fontescue, Dromisken and Ravensdale, co. Louth; derived from ForTEscue, Buckland Filleigh, co. Wevon. Fortescue, Knoll's Hill, Stapleford Abbots, Essex. Fontescue; Barony 26 May 1770 , Viscounty 23 July 1776, Earldom 10 February 3777, extinct .... B Baron Clermont 1852. And with a mullet or in cliief of the bend for ditf. Sir John Fortescue, $V$.

Az. a bend engr. arg. betw. two cotises or within a bordure of the second. Fontescue.

Az. a bend engr. arg: betw. two cotises or within a bordure compony of the second and first. Fontescue.

Az. a bend eugr. arg. betw. two cotises or within a bordure gu. Forteseue.

Az. a beud nebuly arg. bctw. two cotises or. Clencues. 
1 BEND betw. or within.... cont.

Bendlets or Cotises cont.

Az. a bend compony or and gu. betw. two cotises of the second. Rowbache, Lytton, co. Hertford; confirmed 1604.

Az. a bend erm. betw. two cotises arg. and six lions ramp. or. Sr. Humfrey de BониN, $N$; Harl MS. 6137. Sire Ounfrei de Boun, $N$.

Az. a bend erm. betw. two cotises arg. and as many eagles rising or. VASHEN.

Az. a bend erm. betw. two cotises arg. and three goat's beads erased of the second armed or. $\mathrm{G}_{\mathrm{ASON}}, V^{*}$.

Az. a bend erm. betw. two cotises or and as many falcons volant of the third. Justice.

Az. a bend betw. two cotises gu. and six boar's heads arg. EsTLING.

Az. a bend gu. betw. two cotises and six lions ramp. or. Henri de Boun, $E$.

Az. a bend gu. betw. two cotises and six boar's heads couped or. Raffe de Esiynge, $A$. The heads bendwise, Rauf de Esinnge, A. Harl. MS. 6137.

Az. a bend indented or and erm. betw. two cotises counterchanged. Christonson, co. Devon.

Az. a bend or betw. two cotises arg. Poynes.

$\mathrm{Az}$. a bend or betw. two cotises arg. and six dorcers i. e. wicker haskets bendwise of the second. Eastland, $V^{*}$. Estrand, $V$.

Az. a bend or betw. two cotises arg. and six lions ramp. of the second. Comte de Hereford, $G$.

$A z$, a bend or betw. two cotises arg. and six mart. lets of the second. Sr. Kinard de la Bere, $V$.

Az. a bend or betw. two cotises arg. and tbree stag's heads couped of the second. HawORTH, Thurcroft, co. Lancaster.

Az. a bend or betw. two cotises arg. and six horseshoes of the second. EASTIAAND or ESTLAND.

Az. a bend or betw. two cotises arg. and six mullets of the second. OLDisife.

Az. a bend or betw. two cotises indented arg. PoIERd.

Az. a bend betw. two cotises or. Bownas.

Az. a bend betw. two cotises and six lions ramp. or. RichMOND. VIAN.

Az. a bend betw. two cotises and six martlets or. Tong, Tunstall, Kent.

Az. a bend betw, two cotises and six covered cups or. Butler.

Az, a bend betw. two cotises and four crosses patty or. Ringham, Baron Clanmorris, $30 \mathrm{July} 1800$.

Az. a bend betw. two cotises and six crosses cros. let or. Aston, Suffolk. Aston, $V^{*}$. Astone, $V^{*}$. Astone or Astonne.

Az. a bend betw. two cotises and six crosses cros. let fitchy or. BLAKET, co. Gloucester; and co. Hereford. Sir John BLaket, $V$.

Az. a bend betw. two cotises and six crosses patty or. Bingham, Earl of Lucan; Baronetcy 1632; Barony 24 July 1770 ; Earldom 6 October 1795 quartering Turbervill, and Lucan; descended through BingHam, Binghams-Melcombe, co. Dorset, originally of Sutton Bingham, co. So. merset, from Sir John de Bingham, temp. Henry I; quartering Tubervill, Chaldecott, and Potenger. Robert de BrNg Harr, Bishop of Salisbury 1228-46. Bingham, The Vines, Rochester, Kent. Robert Brngham, co. Dorset, $V$. Bingham, Baron Clanmorris, 30 July 1800.

Az. a bend betw. two cotises and as many garbs or. Telstone or Tilstone, co. Chester. John Tiliotson, Archbishop of Canterbury 1691-4. Tilston or Tilson, Huxleigh, co. Chester; confirmed 28 August 1580.
1 BEND betw. or within.....cont.

Bendlets or Cotises cont.

Az. a bend betw. two cotises and six mullets or. John de la Bere, Bishop of St. David's 1447.60

Az. a bend betw. two cotises indented or. Power, co. Devon, $V$. Poyer, $V$.

Az. a bend per bend iudented arg. and gu. (gu. and arg. Harl. MS. 6137, N.) betw. two cotises of the second and six lions ramp. or. Emoun de Beun, $N$. Sr. Edmond de Bohun, $N$.

$A z$. a bend per bend or and arg. betw. two cotises and six martlets those in chief as the second those in base of the third. Richard Tonoe, London, $V$.

Az. a bend per bend or and arg. betw. two cotises of the third and six martlets of the second. TONGE, $V^{*}$.

Az. a bend vairy gu. and arg. betw. two cotises of the third and as many eagles displ.or. EDWARDs, London.

Erm. a bend betw. two cotises gu. JenNey, Frisby Hall, co. Derby ; descended from Jenny or Gyney circa 1563. JenneY, Great Cressingham, Norfolls.

Erm. a bend betw, two cotises and in chief a unicorn's head couped in base a cross croslet fitchy gu. Edmund Denrson, Bishop of Salisbury $1837-54$.

Erm. a bend gu. betw, two cotises or. GRIFFIN, co. York. Griffithe, co. York, $V$. Griffith, co. York. Gryffithe, $V^{*}$. Jennex, Norfolk, $V$. Jenney or JennY, co. Lincoln; Tottenham, Middlesex; and Fenuerton, Suffolk. JENNEY, Knodishall; and Bredfield House, Suffolk; quartering Bokill, Leiston, Gerard, Bois, Wichingham, Illey, Plumstead, Falstoff, Holbrooke, Rede, Toley, Marryott, and Bloomfield.

Erm. a bend betw. two cotises or. EWEN.

Erm. a bend betw. two cotises sa. John Jene, $V$. Jenney, Great Cressingham, Norfolk. JENNY, $V^{*}$.

Erm. a bend vair betw. two cotises sa. Plumbe, Aughton; and Prescott, co. Lancaster; descended from Plumbe, Kent; Marston, co. Leicester; and Norfolk; granted 10 June 1563. Plunibe, $V^{*}$. Pluminer, co. Hertford, 1716.

Gu. a bend betw. two cotises arg. Sr. .... de Cowe, $V$. Cow, Kent; and Norfolls. Dantrex or Dantree, Norfolk. Dawtrey, Norfolk. Englebert. London; Middlesex; and co. Pembroke. Pendergast, Ireland. Robert Pendergest, $Y$.

Gu. a bend betw. two cotises and as many birds (? pheasants) arg. Mons. Rusten Valenan, $T$.

Gu. a bend betw. two cotises and six crosses croslet fitchy arg. Manswield.

Gu. a bend betw. two cotises arg. and six crosses croslets or. MANFEID, Skirpenbeck, co. York; confirmed 20 September 1563. MANFELD, Hutton-on-Derwent, co. York. The croslets fitchy or. Manfeld, $V$. Manfled, $V$. Mansfield.

Gu. a beud wavy betw. two bendlets arg. ETTon, $V$.

Gu. a bend wavy betw. two cotises arg. ETon or Eтton, Ireland. ЕттоN.

Gu. a bend arg. betw. two cotises or. Sire Johan de Coue, N. Cove, co. Hereford. Sir John Coue, L; but Tonex, L, Harl. MS. 6137 . Johu de Cowe, $Y$. Monsire la Cowe, $Y$. Sr. Laurence Dautre, Norfolk, $V$. DAwTis, $V^{*}$. Dawtree. Felbich. Prasers, Essex. 
1 BEND betw. or within.... cont.

Bendlets or Cotises cont.

Gu. a bend arg. betw. two cotises dancetty or. Dauntre, $V$.

Gu. a bend arg. betw. two cotises engr. or Dawtrey. Lyon Dautix, $Y$.

Gu. a bend arg. betw. two cotises indented or. Dauntre, $V^{*}$. Lawndaur, $V^{*}$. Lawndawre, $V$.

Gu. a bend dancetty arg. betw. two cotises or. HACKLET, co. Salop.

Gu. a bend nebuly arg. betw. two cotises or. Clenche.

Gu. a bend erm. betw. two cotises dancetty arg. WICKE.

Gu. a bend erm. betw. two cotises or. WiKEs.

Gu. a bend erm. betw. two cotises dancetty or. Wikes.

Gu. a bend erm. betw. two cotises indented or. Wykes, co. Gloucester. Wykes, $V$.

Gu. a bend indented point in point arg. and sa. betw. two cotises or. Clench.

Gu. a bend or betw. two cotises arg. ArFane. Arsacke. ARsake, $V$. Englebert, Sherborne, co. Dorset. Ingllbert, $V$. Inglebert or INGIEBERE.

Gu. a bend betw. two cotises or. AISACKE. INGLEBERT.

Gu. a bend betw. two cotises and six martlets or. Mortrmer. Thomas Mounteney, $Y$. Sire Johau de Mountenx, $N$, or de Mouncenex, $O$. Mountney, Essex.

Gu. a bend betw. two cotises and four crosses patty or. BINGHAM; quartered by Michel, 1716.

$\mathrm{Gu}$. a bend betw. two cotises and tive mullets or. Mountney.

Gu. a hend betw. two cotises and six mullets or. Sr. Joln de Montenex, Essex, temp. Edward I, $V$. Mountney, $V^{*}$.

Gu. a bend betw. two cotises indented or. LANDAWRE LANDAWREY or LANDWREY.

Gu. a bend wavy betw. two cotises or. Eaton.

Gn. a bend sa. betw. two cotises or and as many mullets and as many swans arg. Russeis.

Gu. a bend vair betw. two cotises arg. John Beaupell, $Y$. Beawpell. Monsire Bewpell, (co. Devon and Cornwall added in a later hand,) $Y$.

Gu. a bend vair betw. two cotises arg. and six escallops of the second. BEwPEL, Cornwall.

Gu. a bend vair betw. two cotises or. Sr. .... BEAUPLe, $V$.

Gu. a bend vair betw. two cotises sa. and six escallops arg. BEAUPELL.

Or. a bend wavy betw. two cotises az. Fishpool.s, Great Bunstead, Essex.

Or a bend az. betw. two cotises gu. HARDELC.

Or a bend engr. az. betw. two cotises sa. Hanbury, Holfield Grange, Great Coggeshall, Essex. (? Robert Hanburx, citizen and goldsmith, London, 1593.)

Or a bend chequy gu. and arg. betw. two cotises of the second. Fosketr.

Or a bend erm. betw. two cotises indented az. Shakeby, $V^{*}$. Shekeby, $V$.

Or a bend ermines betw. two cotises dancetty az. SKEGBY.

Or a bend wavy betw. two cotises ermines. Fisher.

Or a bend betw. two cotises gu. Gaimes.

Or a bend betw. two cotises gu. a label az. Sire Eble de Mounz, $N$

Or a bend betw. two cotises in chief a lion ramp. and in base two lions combatant gu. WAshetr,
1 BEND betw. or within.... cont.

Bendlets or Cotises cont.

London; and Pentlow Hall, Essex; confirmed 20 January 1818.

Or a bend betw. two cotises and three boar's heads gu. WaLter.

Or a bend wavy betw. two cotises gu. Fishold.

Or a bend gu. betw. two cotises and six martlets vert. WALDEN.

Or a bend sa. betw. two cotises arg. and two boar's heads couped of the second. CaMnery.

Or a bend betw. two cotises sa. Hardes, Lord Mayor of London 1254-58. Sire Richard de Harlee, $N$. Sr. Richard Harleor or Harlex, co. Salop, $V$. HaRrey, Earl of Oxford. Harteey. Herthey or Hertiey. And with a crescent .... on the bend for diff. John HARLIEY, Bishop of Hereford 1787-8.

Or a bend betw. two cotises sa. within a bordure engr.gu. on the bend a fleur-de-lis of the field for diff. John HARLEY, Bishop of Hereford 1553.4, Harl. MS. 1359.

Or a bend betw. two cotises and six lions ramp. sa. WARTER or Wartur.

Or a bend betw. two cotises sa. and three boar's heads couped within a bordure gu. WaLter, Crawdon, co. Cambridge; and Bradrell, co. Hereford.

Or a bend betw. two cotises engr. sa. GAYTHOLD. GWYTHOLD, $V$.

Or a bend engr, betw. two cotjses sa. GuYTHold.

Or a bend wavy betw. two cotises sa. NIFFIELd, co. York.

Or a bend vair betw. two cotises gu. Bowyer, Lincoln, 1576. Bowyer, London. Bowyer, Camberwell, and Charlwood, Surrey; and London. Bowyer, Denham Court, co. Buckingham; and Radley, co. Berks; quartering Knypersley, Grosvenor, Venables, Stonhouse, Brett, etc.; Baronetcies 1660 and 1794.

Or a bend vair betw. two cotises sa. Bowyer, Camberwell, and Charlwood, Surrey. Bowyer, London, $V$. Bower.

or a bend vair betw. two cotises indented sa. Нгтсн, co. Worcester; co. Berlis; and co. Gloucester; quartering per fess or and sa. three estoiles counterchanged. HITcH or Hithe, Kempston, co. Bedford; and Wendlebury, co. Oxford.

Or a bend vairy of the first and purp. betw. two cotises gu. Bouvier.

$\mathrm{Or}$ a bend vert betw. two cotises sa. HANBURY.

Or a bend engr. vert betw. two cotises sa. Williams.

Or a bend engr. vert betw. two cotises sa. Hanbury, Colebrooke, co. Monmouth ; a branch of HANBUnY, Pont-y-pool, co. Monmonth; derived from Richard Hanbury, third son of Hanbury, Hanbury, co: Worcester.

Or a bend engr. vert betw. two cotises sa. in chief a crescent .... on a crescent .... fur diff. Hanbury, Kelmarsh, co. Northampton; descended from HANBURY of Hanbury; quartering Bateman; Baron Bateman, 30 January 1837.

Per pale gu. and arg. a bend wavy sa. betw. two cotises wavy or. WYLBORNE.

Quarterly sa. and or over all a bend erm. betw. two cotises engr. of the first. DaIntry, Rhode $\mathrm{H}$ all, co. Chester.

Sa. a bend betw. two cotises and as nuny griffius arg. Pinker, Diuder, co. Somerset. 
1 BEND betw. or within.... cont.

Bendlets or Cotises cont.

Sa. $\Omega$ bend betw. two cotises arg. and three fleursde-lis .... Herand, $V$; co. York, $W$. Peter Hellatd, Prior of the Commons of Bridlington; granted temp. Edward III, $W$.

Sa. a bend betw. two cotises and six fleurs-de-lis arg. HeLLerd, Bridlington, co. York; granted 1470 .

Sa. a bend betw, two cotises dancetty arg. Devali.

Sa, a bend arg. betw. two cotises or. Mons. Walter Clopton, $T$, Harl. MS. 6137.

Sa. a bend arg. betw. two cotises dancetty or. Clopton.

Sa. a bend arg. betw. two cotises engr. on the out. sides or. Daintri.

Sa. a bend betw. two cotises flory on the outer side arg. Hellard, $V$.

Sa. a bend betw. two cotises flory counterflory arg. Helard. Hellard, $V^{*}$.

Sa. a bend arg. betw. two cotises indented or. Clopton, Kentwell, Suffolls; 1730. And with an annulet .... on the bend for diff. Mons. Walter Clopton, $T$.

Se. a bend betw. two cotises wary arg. Bennall.

Sa. a bend of lozenges betw. two bendlets arg. Puckerrag, Flamborough, co. York; confirmed 26 June 1579.

Sa. a bend engr. betw. two cotises arg. VELLINGTON. WeLINGTON, $V$. WILLINGHair. WILLINGTON, 1730.

Sa. a bend engr. arg. betw. two cotises or. WILLINGTON.

Sa. a bend fusily betw. two cotises arg. Puckering, Weston, co. Hertford; and co. Warwick.

Sa. a bend of five lozenges conjoined and con. fined betw. two cotises arg. Sir Thomas Pucrering, co. Warwick, $W$; Baronetcy ....

Sa. a bend erm. betw. two cotises arg. and six martlets or. MERLAY.

Sa. a bend betw. two cotises erm. DoDenhay or DOWDNAY.

Sa. a bend erm. betw. two cotises or. Clorton, Suffolk.

Sa. a bend erm. betw. two cotises and six martlets or. Wingate or Wyngate, Harlington, and Sharpenhoe, co. Bedford. Wyigate, Barnend, and Harlington, co. Bedford.

Sa. a bend erm. betw. two cotises dancetty or. Clopton, Clopton, Suffolk, 1586.

Sa. a bend erm. betw. two cotises flory counter. flory or. KECK, Staughton Grange, co. Leicester; and Bank Hall, co. Lancaster.

Sa. a bend erm. betw. two cotises inclented or. Sr. William Clopton, $V$.

Sa. a bend betw. two cotises and as many griffins segreant or. MarchaNn, co. Buckingham; granted 1582. Merchand or Merchant, co. Buckingham.

Sa. a bend betw, two cotises or and six crosses croslet fitchy .... Reston.

Sa. a bend betw. two cotises flory or. KeLk or Kelke. Kelke, Kelke, co. Lincoln.

Sa. a bendlet betw. two bendlets flory counterflory or. KELKE, $V$.

Sa. a bend betw. two cotises or on each cotise fourfleurs-de-lis sa. Cutr, Dartmouth, co.Devon.

Sa. a bend engr. betw. two cotises or a label of three points arg. CARELEE, London; granted 10 December 1530 .

Sa. a bend invected betw. two cotises or a label of three points .... Carkile, London.
1 BEND betw. or within.... cont.

Bendlets or Cotises cont.

Vert a bend betw. two cotises arg. Pearse, Suffolk.

Vert a bend arg. betw. two cotises or. PeErers, $V^{*}$. Peeres, Essex. Peers. Sir Tomas de Peres, $N$. Sr. Thomas Pienes or Perers, $V$. Prior, Essex.

Vert a bend erm. betw. two cotises and three fal. ccns volant or. Justice, co. Stafford.

Vert a bend betw. two cotises or. Pearse, Middlesex; and Norfolls. Prior, Essex.

Vert a bend betw. two cotises dancetty or. Power, Cornwall.

Arg. a bend betw. three fizures wavy sa. Sir Ro. bert de Barchatle, alii Debenhale, $R$.

Arg. a bend engr. betw. four cotises gu. LAYFORTH, $V$.

Arg. a bend betw. four cotises sa. Barton, Didlestone, co. Salop. Clued or Clud, co. Salop; and co. Nottingham. And with a martlet in chief sa. Orleton, Orlton, co. Salop.

$\mathrm{Az}$. a bend betw. four cotises arg. and six martlets or. Bellaber.

Az. a bend betw. four cotises dancetty arg. Zorrs.

Az. a hend arg. betw. four cotises potent or. SANXER.

Az. a bend arg. betw. four cotises each of the last potent on the inner side or. Henry de BLoIs, Bishop of Winchester 1129-71.

Az, a bend betw, four cotises and six martlets or. DelLabere.

Az. a bend vair betw. four cotises or. CLENCH.

Gu. a bend vair betw. four cotises or. GARDNER.

\section{Billets}

Arg. a bend betw. three billets gu. Dupont.

Arg. a bend betw. six billets gu. Lavenses, $V^{*}$. Le Sr. de Savenses, $W$.

Az. a bend arg. betw. six billets or. Sмrтt, Tudenham, and Edmondsbury, Suffolk. Sмiтн, Middlesex; confirmed 5 May 1561. Sirtн, $V$. Jenkin Smiтh, London, $W$.

Az. a bend erm. betw. six billets or. Sмгтн, Gunton, Norfolk.

Gu. a bend betw. six billets arg. Le Sr. de Cartheze, $W$. Carthuze, $W$.

Or a bend betw. six billets az. Hordentrn, $V$.

Or a bend betw. six billets sa. Barker, Suffolk.

Sa. a bend betw, six billets arg. BAWDWIN, $V^{*}$.

Sa, a bend engr. betw. six billets arg. Alington, Lord Alingtoll, $Z, 540$ : Baron Alington of Wimonley 5 December 1682 ; extinct 18 September 1691 ; Baron Allington of Killard $28 \mathrm{July}$ 1642; extinct 1722: Harl. MS. 4040, fo. 490 . Allington, Horsheath, Kent.

Sa. a bend arg. betw. six billets or. Sагтн, London.

Sa. a bend chequy arg. and gu. betw. six billets of the second. CaLlender, Kincardine.

Sa. a bend chequy or and gu. betw. six billets of the second. CaLLender, Ireland.

Sa. a bend betw. six billets or. Callendar, May. ners. Hardenton, $V *$. Hardentun, $V$.

$A z$, a bend arg. betw. seven billets or four and three. Jenkin Smrit, Bury, $V$.

Sa. a bend betw. seven billets arg. four and three. Sнттн, co. Buckingham.

Sa. a bend arg. betw. seven billets or four and three. Smrth, $V^{*}$. Smithe, $V$. 
1 BEND betw. or within.... cont.

Billets cont.

Sa. a bend betw. seven billets or four and three. Smyтh, co. Buckingham.

Arg. a bend betw. eight billets sa. Bomvilers, $V^{*}$. BonvyLERs, $V^{*}$.

Az. a bend betw. eight billets or. Le Sr. de Remauiles, $V$. Rejiulles, $V^{*}$.

Sa. a bend engr. betw, eight billets arg. ALINGTON or Alinnoton, Wymondley, co. Hertford; and Horsheath, co. Cambridge; Barony in Ireland 1642 ; extinct 1722 ; and in England 1682 ; extinct 1691. Sr. Giles Alington, $V$. Alington, Swinhope, co. Lincoln; descended from Sir Giles Ainnaton, Horseheath.

Sa. a bend betw. nine billets arg. four aud five. Bomviliers, $V$. Bawdwyn de Bonvylers, $V$.

Or a bend betw. ten billets sa. HaRows, $V^{*}$. Marrows, $V *$. Marows, $V$.

Gu. a bend betw. twelve billets or. Moryan, $V^{*}$. Mons. Moryan de Sanansez, $W$.

Arg. a bend betw. fourteen billets gu. Bulteel, Fleet; and Lyneham, co. Devou; quartering Crocker or Croker.

Az. billety arg. (but altered to $n r$ ) a bend erm. John SirTH, Hellsworth, Suffolk, $W$.

Az. billety and a bend or. Le Counte de Marre, C. Regmighers, $V^{*}$. Monsire John de Remeghers, $W$.

Or billety az. a bend gu. Gastelrne, co. Hants. Sire Johan Gasceline, $N$. Sir John Gasselyn de la Commune, $L$. Sir John Gastelyne, $L$, Harl. MS. 6137.

Or billety and a bend gu. Sir John Gasselyne, L, Harl. MS. 6589.

Sa. billety and a bend arg. Baudwin Boliers, $A$, Harl. MS. 6137. Baldwyn de Boliere, $A$. Baudwin de Boulers, $F$.

Sa. billety and a baston arg. Baudwin de Boolers, $E$.

Bird ..... Cock

Erm. a bend betw. in chief a cock and in base two mullets gu. LAw, Anstruther, Scotland. .... Eagle

.... a bend .... betw. in clief an eagle displ. ... . and in base a croslet sa. HuLlONADGE.

Arg. a bend .... betw. in chief an eagle displ. vert and in base two ogresses. Rushworth.

Arg. a bend sa. betw. in chief an eagle displ. sa. armed gu. and in base a cross croslet of the second. RYsHwORTH.

Arg. a bendlet (or baston) sa. betw. in chief an eagle rising overt vert and in base a cross cros. let of the second. Ricswonth, $V$. Riesworth, $V^{*}$.

\section{Birds}

Arg. a bend voided between two birds sa. Bradeshaw, $V^{*}$. Bradshaw, $V$.

$$
\text { ..... Cocks }
$$

Arg. a bend between two cocks sa. Hononigg, co. York.

Erm. a bend between two cocks gu. LAw, Burntoun, Burntwood, Lauristoun, and Pittilock, Scotland.

Erm. a bend between two cocks within a boraure gu. Law, Easter Kinevie, Scotland.

Erm. a bend between two cocks within a bordure engr. gu. Law, Cameron, Scotland.

Erm. a bend raguly between two cocks gu. Law, Newton, Scotland.

$$
\text { .... Crows and Choughs }
$$

Arg. a bend engr. az. between two Cornish choughs ppr. Dotson, Heye, Cornwall.
1 BEND betw. or within.....cont.

Birds cont. Crows and Choughs

Arg. a bend dancetty sa. between two Cornish choughs ppr. Franke.

Arg. a bend engr. sa. between two Cornish choughs ppr. Francke, Grimsby, co. Lincoln, temp. Richard II; Essex and Sussex. Thomas Franke, Essex, $V$.

$$
\text { ....Ducks and Shovellers }
$$

Gu. a bend nebuly between two shovellers arg. READE or READ, co. Oxford.

$$
\text { ..... Eagles }
$$

Arg. a bendlet between two eagles displ. az. Bowker.

Arg. a bend gu. between two eagles displ. sa. VEZAY or VEZEY.

Arg. a bend between two eagles displ. sa. Saltonstall, co. York.

Arg. a bend sa. fimbriated the outer edge being engr. gu. between two eagles disp. vert. Squedali, $W$.

Az. a bend between two eagles displ. and doubleheaded or. Krnge, London.

$\mathrm{Gu}$. a bend between two eagles displ. arg. Used by TrNEER, co. Wilts.

Gu. a bend engr. erm. between two eagles displ. or. KInGE.

Gu. a bend between two eagles displ. or. Sir Thomas Travel, Westminster 1730. Traveli.

Or a bend between two eagles displ. sa. Saltonstali, $V^{*}$. Saltonston, co. York ; and Lord Mayor of London 1597. Salitenstall, London; granted by Cooke, $V$.

Sa. a bend between two eagles displ. arg. Wadnester. Wodnester, Bromyard, co. Hereford; granted by Cooke, $V$.

Sa. a bend arg. between two eagles displ. or. Woodnester, Bromyard, co. Hereford. WEDNESTER, Bromyard, co. Hereford; granted 30 November 1588.

Sa. a bend erm. between two eagles displ. and double-headed or. Newcourt, Halesworthy, and Pickwell, co. Devon; a beiress m. Chichester.

\section{.....Falcons}

Arg. a bend wary az. between two falcons close ppr. heaked legged and belled or. НовBs, Tooting, Surrey. HoBs, Quedgley, co. Gloucester.

\section{.....Herons and Cranes}

Az. a bendlet (bend $V^{*}$.) between two herons (or cranes) arg. HygHAM, $V^{*}$. HYHAM, $V$.

$$
\text { .....Martlets }
$$

Arg. a bend engr. between two martlets az. STAFFERTON.

Arg. a bend engr. between two martlets gu. Stafferton. Standon. Staverdon, $V$.

Gu. a bend erm. between two martlets or. FENELL.

Gu. a bend erm. between two martlets or. Wright, co. Hants and London, 1587.

Gu. a bend between two martlets or. John Slaney, London, and co. Worcester, 1716.

Per bend dancetty arg. and sa. a bend between two martlets counterchanged. BENNET, co. Devon, and co. Salop.

Per bend arg. and sa. a bend raguly between two martlets connterchanged. Brokeman, Kent.

$$
\text { .... Swans }
$$

Az. a bend betw. two swans arg. JENIson, Yokeflete, co. York: and branches at Newcastle, Walworth, Elswick, Nesham, and Husworth. 
1 BEND betw, or within.....cont.

Birds cont. Swans cont.

Az. a bendlet (bend $V^{*}$.) betw. two swans arg. ducally gorged and lined or. Petrine, $V^{*}$. Petfyne, $V$.

Az. a bend engr. betw. two cygnets arg. gorged with ducal crowns with strings reflexed over their backs or. Pitfield, Seymonsbury, co. Dorset; and Hoxton, Middlesex.

Az. a bend engr. arg. betw. two swans ppr. (sometimes crowned and) chained or. Pitfield, 1716.

Az. a bend or betw. two swans arg. JENIson, Northumberland.

Az. a bend wavy or betw. two swans arg. mem. bered of the second. JENISON, co. Lincoln; co. Nottingham; Itheston, co. Nortbampton; co. York; and Wales.

Az. a bend or betw. two swans ppr. JENEson, quartered by Gordon.

$$
\text { .....Buntings }
$$

Arg. a bend gu. betw. three bunten birds ppr. Bunten or Bunting, Ardoch, Scotland.

Arg. a bend engr. gu. betw. three bunting birds ppr. Bonteine, Mildovan.

$$
\text { .... Choughs, Pies, \& Ravens }
$$

Arg. a bend az. betw. three choughs ppr. Carigs.

Arg. a bend gu. betw. three Cornish choughs ppr. Gosfright.

Arg. a bend gu, betw. three magpies ppr. Carigs. Carygoes.

Arg. a bend engr. gu. betw. three Cornish choughs ppr. Bontien.

Arg. a bend sa. betw. three Cornish choughs ppr. Quilter, Staple, Kent; granted 12 June 1551.

Or a bend gu. betw. three ravens ppr. WITHAM or Wythani, Goldesborough, co. York; Baronetcy 13 December 1683 ; extinct 15 November 1689. ..... Cocks

Az. a bend or betw, three cocks arg. LANGSTAFF. .... Eagles

Arg. a bend betw. three eagles displ, sa. PAGE or Paige, co. Deron. Popelley. Popley.

Az. a bend яrg. betw. three eagles displ. or. Halanton, $V^{*}$. Halengton. Hallington.

Az. a bendlet arg. betw, three eagles displ, or. Halanton, $V$.

Az. a bend engr. erm. betw. three eagles displ. or. Krnge, Essex.

Gu. a bend vair betw. three eagles displ. arg. Bewpell.

Or a bend gu. betw. three eagles sa. Wiтнам, Cliffe, co. York; quartering Wauton, Wycliffe, and Meaburn.

Or a bendlet (or baston) gu. betw. three eagles close sa. Withean, co. York, $V$. Witham, $V$.

Or a bendlet (or baston)gu. betw. three eagles close in trian aspect sa. Robert W ITHan, co. York, $V$. .....Falcons

Or a bend gu. betw. three falcons sa. Whiтнам. .... Hawks

$\mathrm{Gu}$. a bend betw. in chief two hawls and in base another or. SLANEY, co. Worcester. .... Lapwings

$A z$, a bend betw. three lapwings arg. HrHam, $V^{*}$. .... Magpies see Crows .....Martlets

.... a bend .... betw. three martlets .... TILII; seal 1345.

Arg. a bend betw, three martlets gu. Staverdon.

Arg. a bend engr. sa. betw. three martlets or. Straits or Stretch, co. Devon.

Az. a bend engr. betw. three martlets arg. Scurfield, Offerton, and Elstob, co. Durham.
1 BEND betw, or within.....cont.

Birds cont. Martlets cont.

Az. a bend arg. betw. three martlets or. . Mountney, Newlaud-Verdon, co. Ieicester.

Gu. a bend betw, three martlets or. Lynad, Ireland. Slaney or Slany, Milton, co. Stafford; and Lord Mayor of London, 1595; granted 1595.

Sa. a bend betw. three martlets or. Slaney, Hat. ton Grange, co. Salop.

$$
\text { ....0wls }
$$

Az. a bend engr. or betw. three owls arg. each on a tun lying fesswise of the second. Caston, Babram, co. Cambridge; granted 25 June 1567. Catton.

Sa. a bend or betw. three owls arg. Caton.

Sa. a bend engr. or betw. three owls arg. Catron, $V^{*}$. Cotton, $V$.

Sa. a bend or betw. three owls arg. membered of the second. CatTon.

$$
\text { .....Pelicans }
$$

Az. a bend or betw. three pelicans feeding their young arg. CRAMTOND or CRAWMOND, Auldbar, Scotland.

$$
\text { .....Pewits }
$$

Or a bend gu. betw. three pewits sa. WithaM, Cliffe, co.York; originally of co. Jin coln; quartering Wauton, Wycliffe, and Meaburn. Withasi, Headlam and Lartington Hall, co. York.

$$
\text { .... Pies see Choughs }
$$

Az. a bend arg. betw. three swans of the second crowned (another collared and chained) or. Petexn.

$$
\text { ....Eagles }
$$

Or a bend gu. betw. four eagles displ. sa. Tezer.

$$
\text { .... Baldcoots see Pigeons }
$$

Arg. a bend wavy betw. six cocks gu. Coxwer., Ablington, co. Gloucester; quartering Roger's.

$$
\text { ..... Eagles }
$$

Or a bend gu. betw. six eagles displ. sa. Sire Felip de VerLey, $N$.

Or a bend gu. betw. six eagles displ. sa. armed arg. VALE.

\section{....Herons and Storks}

Arg. a bend sa. betw. six storlss ppr. STAREY, Bromham, co. Wilts; quartering Bayntun. Starkte, Frenchwood, co. Lancaster; and Ridd]esden Hall, co. York; descended through Starkie,Huntroyd,co.Lancaster; from StaRkIE, Stretton, co. Chester.

Arg. a bend betw. six storks sa. StarkiE, co. Lancaster.

\section{.....Martlets}

.... a bend .... betw. six martlets .... Sir Richard de la Mane, co. Hereford.

Arg. a bend betw. six martlets gu. Sire Thomas de Forneval, $N$. Thomas de Fourneval, $K^{*}$. Sr. Thomas Fournivall, $H$, or Furnivali, $J$. Furneval. Monsire de Furnevatis, $Y$. Furnival, quartered by Talbot Earl of Shrewsbury, $U$. Gerard de FurNivaII, $E$. Sr. Thomas FurNrvall, V. Furnivali, co. Hertford, temp. Henry III. Le Sire de Furnivalie, $Y$. Walter de Furnivalie, $C$. Thomas Furnyvall, $B$. Hulgrave, co. Chester. Hulgreve, Beverton, co. Chester, $V$. Tempest. Thaworth. And with a label az. William Furnivalu, $B$. The label of three points. Furntyall, co. Hertford, temp. Henry III.

Arg. a bend betw. six martlets gu. over all a crosier or. Priory of Austin Canons at RADFond or Winkesop, co. Nottingham. 
1 BEND betw, or within.... cont.

Birds cont. Martlets cont.

Arg. a bend betw. six martlets gu. within a bor. dure az. Furnival's InN, London.

Arg. a bend gu. betw. six martlets sa. Fournivalu, V. PYNE.

Arg. a bend betw. six martlets sa. ARDEs. Cheyney. M. Richard Tenpest, $S$. Sr. Richard Tempest, $V$. William Tempest, $Y$. Tempest, Rayne, Yellison, Holmeside, Brancepeth, Wynyward,etc. Tenpest, Bracewell, and Waddington, oc. York; quartering Waddington, Leygard, Heb. den, Rye, Bolling, and Bradford. Tenpest, Rayne, co. York; derived like 'Tempest, Yellison, co. York, from Tempest, Broughton Hall, co. York; and Coleby Hall, co. Lincoln; Baronetcy $18 \pm 1$; quartering Waddington, Leygard, Gilliot, Oglethorpe, Scrope, and Meynell. Tempest, Tong Hall, co. York; Baronetcy 25 May 1664; extinct 29 January 1819 ; quartering Plumbe, with Hebden, Rie, Bolling, Mirfield, Tong, Savile. Cholmley, and Frank. Tempest, Holmeside, Stella (Baronetcy 23 December, 1622; extinct 31 May 1742;) Brancepeth, Wynyard, etc., co. Durbam; delived from Rowland, second son of Sir William Tempest of Studley; quartering Elmdom.

Arg. a bendlet betw. six martlets within a bordure engr. sa. Monsyer Hewgh Lutterelu, $T$.

Arg. a bend engr. betw. six martlets sa. TEnpest, Stella; Baronetcy 23 December 1022 ; extinct 31 May 1742; and Stanley, co. Durham. Tempest, $W$. Tenpest, Braswell, Broughton, and Tong, co. York.

Arg. a bend indented betw. six martlets sa. Richard Tempest, $Y$.

Az. a bend betw. six martlets arg. Thomas Loterel or LoterelL, $\boldsymbol{E}$. Monsire Lotereit, $Y$. Sr. Hugh Lotereli, $V$. M. Andrew Lot'ReI, $S$. LotTerell, $V^{*}$. Sire Gefferay Luterell, $J ; M$. Robert Lutrel, $I$. LutTerell, co. Somerset.

Az. a bend fusily betw. six martlets arg. PERrot or Perrott.

Az, a bend arg. betw. six martlets or. Eustace. Luttereld, co. Somerset. Sr. Thomas de Mountaneye, temp. Edward I, $\boldsymbol{V}$. Robert de Munteney, $D$, or de Munteny, $D$. And with a label gu. Mountney.

Az. a bend betw. six martlets or. BRETon. Sire Geffrey Loterel, $N$. Robert de Mo'Ton, $F$. M. Robert Mouncenfie, $S$. Sire Emanf de Mounteney, $N$. Frnand de Mounteney, $B$, or de Mountney, $J$. Mountney, $V$ *. Mountney, Essex; co. Leicester ; and Gestwick, Norfolk. Robert de Modntney, $E$. Sir Evans de Mountney, $N$, Harl. MS. 6137. Seaton. And with a label of five points gu. Ernaud de Mountaey, $E$.

$\mathrm{Az}$. a bend or charged with a mullet gu. for diff. betw. six martlets of the second. Sire Johan Montenx, $N$. Sir John Modntney, N, Harl. MS. 6137, L.

Az. a bend engr. betw. six martlets or. Perys Pigot, $C$. Per's Pigod, $E$. Piers Pigott, $X$. Sire Peres Рyсот, $N$.

Az. a bend fusily betw. six martlets or. PIGot.

Az. a bend indented betw. six martlets or. Pers Picot, $F$. Piers Pigoti, $Y$.

Az. a bend lozengy betw. six martlets or. PERot. Perrott. Pycott, $V^{*}$.

Az. a bend of six lozenges conjoined betw. as many martlets or. Sr. John PycotT, $r$.
1 BEND betw, or within.... cont.

Birds cont. Martlets cont.

$\mathrm{Gu}$. a bend betw. six martlets arg. BRETT, Ireland. Mountney. Seyton. Maydwell, and Wyckdym, co. Northampton. St. Lyz.

Gu. a bend dancetty betw. six martlets arg. Scrutevilise, now spelt Scurfield, Kibblesworth, co. Durham; Visitation 1615.

Gu. a bend arg. betw. six nartlets or. SAyton or Seaton. Seton, $V$. John de Seton, $Y$. M. John de SEyton, $S$, ob. 1396. Sr. John de Seyton, $V$. Sir John Sutton, $V$.

Gu. a bend betw. six martlets or. Brett, $V$. Sir Robert de Ekeleshall, N, Harl. MS. 6137. Malieu de Furneus, $G$. Furneux. Sr. .... de Heland, $V$. Heland, co. York. Heyland, co. York. Monsire Montney, $Y$. Sire Thomas de Mounceney, $O$. M. Jobn Mounceneye, $S$. Thomas Mountenay, $Y$, or de Mountney, $N$, Harl. MS. 6137. Mounteney, Shierclife, Cowley, etc., co. York. Mountney. Seyton, Maydwell, and Wickdym, co. Northampton. Sutton, Essex. And with a mullet for diff. Sire Tobam de Mounteny, $N$.

Gu. a bend fusily betw. six martlets or. PIGor, co. Derby.

Or a bend betw. six martlets gu. George Furnival, $B$. Thomas Furnival or Furnivall, $E$. Gerard Furnival, Munden ; his heiress m. John Vufflete or Ufflete, $V$. GoBand or GoBaRd, co. Warwick. Luteral, co. Derby; and co. Nottingham. Mounterey, Cowley, co. York. UfFleEt. M. Gerard UFFLeT; quartering arg. on a fess az. three fleurs-de-lis or, $S$.

Or a bend betw. six martlets sa. Bearslery. Cistercian Priory at Crokesnen Croxden or Croxton, co. Stafford. Sire Andrew Lotenel, $N$, or Loterell, co. Lincoln, $V$. Lottereid, $V^{*}$. Luttrel., Hartland, co. Devón; a branch of Luttrell, co. Somerset. LutTrell or Loterel, Hooton Pagnel, York, a Baron 1295. LutTrelu, Luttrellstown, co. Dublin; Hartland, Honnebere. Sandon Court, and Chelsea; derived through Lutraeli, Dunster Castle, co. Somerset (the heiress $m$. Fownes), from John, joungest son of Andrew LutTrell of East Quantockshead, temp. Edward I.

Or a bend betw. six martlets within a bordure sa. Monsyer Hewgh Lu'terelel, T, Harl. MS. 6137.

Or a bend betw. six martlets within a bordure engr. sa. M. Hue Lutrel, $S$.

Sa. a bend betw. six martlets arg. Sr. John Goband, $V$. Goband or Gobbard. Smyth, Morvell, Bridgenorth, co. Salop. Smrthe, Hilton, Bridgenorth, co. Salop. Henri de (Som'RI, in a later hand), $F$. Tongue.

Sa. a baston betw. six martlets arg. Herry de SoMeri, $F$.

Sa. a bend arg. betw. six martlets or. INCKELL. INKELL, $V$. JUGGELL.

Sa. a bend or betw. six martlets arg. LE BotiLeR, Wemering, co. Hants; and Long Blandford, co. Dorset.

Sa. a bend betw. six martlets or. Eccleshall, co. Worcester. Eckersali, Bury, co. Lancaster. Sr. Robert Eckleshall, temp. Edward I, $V$. Egleshall. Sire Robert de Exeleshate, $N$. Solers. Williscot, co. Salop, $W$. Wollascot, Wollascot, co. Berks.

$$
\text { ..... Pigeons }
$$

Sa. a bend betw. six bald coots or. BoulcotT, co. Hereford; and co. Brecon, quartered by Hughes. 


\section{BEND betw. or within..... cont.}

\section{Bordure}

.... \& bend within a bordure engr. .... Bilkemore, co. Bedford.

Arg. a bend chequy or and sa. within a bordure engr. gu. BoDHam.

Arg. a bend gu. within a bordure erm. FANNeLL. HANNELL.

Arg. a bend gu. within a bordure of the last bezanty. FanNell or Fauneli, co. Northampton. Favel, co. Northumberland.

Arg. a bend within a bordure engr. gu. Musand, London. Sir John Musters, Hirklington, co. York, $1356, V$.

Arg. a bend gu. within a bordure sa. Fannell, co. Northumberland. Sr. William FanNeLL, co. Northampton, $V$. JAMEs.

Arg. a bend gu. within a bordure sa. bezanty. Roger Fanneld, $Y$. Sire IVilliam Fauvel, $N$. Monsire Fauvelu, $Y$.

Arg. a bend sa. within a bordure engr.az. KNEvETT, Norfolk.

Arg. a bend lozengy sa. within a bordure or an annulet for diff. Taverner, Heaton, co. Hertford.

Arg. a bend within a bordure engr. sa. KENNET. KNEVET,Norfolk and Escrick, co.York. KNEvETT or Knevit, Rosemaryn, Cornwall; Norfolk; and Suffolk. KNives, Charlton, co. Wilts, $Z$, 398. Knyvetr, Norfolk, $V$. Knyvet , Buckenham, Norfolk; Baronetcy 22 May 1611, extinct about 1699; the heiress of KNYTETT of Ash. wellthorpe m. Wilson.

Arg. a bend engr. within a bordure sa. KnevetT.

Az. a bend wjthin a bordure engr. arg. WADE. WARDE.

Az. a bend arg. within a bordure engr.gu. Bisset, Darlington, co. Durham.

Az. a bend arg. within a bordure engr. or. WADE.

Az. a bend of three lozenges conjoined within a bordure erminois. Sarnsbury, Froyle, co. Hants.

Az. a bend of three lozenges conjoined within a bordure engr. erminois a mullet for diff. Thomas Sainsbury, Lord Mayor of London 1787.

Az. a bend or within a bordure arg. Overton, Westmoreland. Quenton, Westmoreland, $V$.

Az. a bend or within a bordure engr. arg. WARD.

Az. a bend or within a bordure gu. charged with eight mitres or a label arg. Richard Scrope, Bishop of Lichfield, etc., 1386, Archbishop of York 1398-1405.

Az. a bend within a bordure or. Oventon.

Az. a bend within a bordure or charged with eigbt mitres of the first a label arg. Richard SCrope, Bishop of Lichfield, etc., 1386, Archbisbop of York 1398-1405.

Az. a bend per pale gu. and or a bordure counter. changed. HEaTH, co. Hertford.

Barry of three or with chequy az. and arg. over all a bend within a bordure gu. STEWARD, Nottington House, co. Dorset.

Barry of three or with chequy az. and arg. over all a bend engr. within a bordure indented gu. Stewart, Burray, or Borrow, Scotland.

Barry of five az, and arg. a bend gu. within a bordure compony of the second and third. LEE.

Barry of five az. and arg. a bend gu. within a bordure engr. compony of the second and third. LEY, co. Buckingham. Isalt.

Barry of five or and gu. a bend sa. within a bordure az. Fauliner.

Barry of six or and vert a bendlet gu. within a bordure engr. erm. Poynings.

\section{BEND betw. or within.....cont.}

\section{Bordure cont.}

Chevronelly of five gu. and arg. a bend sa. within a bordure of the second. PARNELL.

Chevronelly of five gu. and arg. a bend sa. within a bordure or. PAnNeli.

Gu. a bend within a bordure engr. arg. Belrmoke. John Beliemore, $Y$.

Gu. a bend and a bordure "recercele" arg. Monsire de Brikemone, $Y$.

Gu. a bend arg. a bordure engr. or. DAvell.

Gu. a bend arg. within a bordure sa. bezanty. FANNELL.

$\mathrm{Gu}$ a bend or within a bordure erm. Grosvenor, co. Stafford.

Gu. a bend and bordure engr. or. Daniell, Durham.

Gu. a bend and bordure engr. and in chief a martlet for diff. or. DANIELL.

Gu. a bend fusily within a borảure engr. or. Marshall, Shipston on Stour. Marshall, Norfolk; co. Salop; and co. Stafford.

Gu. a bend within a bordure vair. HoDENGE, $V^{*}$. Sr. J. Hoding, Burnham and Beckonsfeld, co. Buckingham, temp. Edward I, $V$.

$\mathrm{Gu}$. a bend vairy .... and .... within a bordure vair. WARDE, $V$.

Or a bendlet arg. (? az.) within a bordure engr.gu. NewBorough.

Or a bend gu. surmounted of a fess within a bordure chequy az. and arg. Stewart, London, descended from Steuart, Allanton.

Or a bend gu. within a bordure of the last bezanty. FanNeli or Fauneli, co. Northampton. Fannel, $V^{*}$. Sr. William Fanneld, $V$. Favelu, co. Northampton. LEDET, WestWardon, co. Northampton. Per pale gu. and or a bend and bordure counterchanged. Clarke, co. Northampton. Heete, co. Hertford.

Quarterly arg. with gu. fretty or over all a bend sa. within a bordure az. charged with eight mitres of the third. Henry Despenser, Bishop of Norwich 1370.1406.

Quarterly gu. and vair over all a bend engr. or within a bordure az. charged with eight plates. Constable, Edinburgh.

Quarterly per fess indented or and az. a bend gu. within a bordure of the second charged with eight mitres of the first. Thomas de BLUNDEviLE, Bishop of Norwich 1226-36.

Quarterly or and gu. a bend sa. within a bordure az. De Pontefract, the heiress cc. 131$) 0 \mathrm{~m}$. Hilton. Quarterly or and gu. a bend vair within a bordure compony arg. and az. SAckriLE.

Sa. a bend within a bordure indented arg. Musters.

Vert. a bend erm. within a bordure engr. gu. charged with eight bezants. Whettenhalt.

\section{Bougets}

Arg. a bend betw. two water bougets sa. Locker, Essex; co. Hereford; Homes, co. Hertford; and co. York.

\section{Buckles}

Arg. a beud az. betw. three square buckles gu. BARRetT, Suffolk.

Arg. a bend az. betw. three lozenge buckles tongues in fess gu. an annulet on the bend for diff. BaretT.

Or a bend chequy sa. and arg. betw. three buckles .... Dalyell, Binns, co. Linlithgow; Baro. netcy 7 November 1685 , quartering sa. a naked man ppr. a canton arg. charged with a sword and pistol saltirewise gu. 
1 BEND betw, or within.... cont.

Buckles cont.

Arg. a bend betw. six buckles az. Thomas HADDAM, $Y$. HADHAM.

\section{Canton}

Vert a bend fusily or and a canton gu. in base a 5-foil arg. KNIGHT, Godmersham, Kent; and Chawton, co. Hants, quartering Austen.

\section{Castle}

Az. a bend lozengy or betw. in chief a tower arg. and in base a ship with three masts sails furled of the second. Town of St. Mawes, Cornwall.

Sa. a bend betw. in chief a castle and in base a portcullis (arg. another) or. Plunket, Baron Plunket, 1 June 1827.

\section{Coronets}

.... a bend .... betw. three crowns .... impaling quarterly .... three crowns .... with .... a cross.... Benedictine Abbey at Athelney, co. Somerset.

\section{Crescent}

Arg. a bend betw. in chief a crescent gu. and in base a fleur-de-lis az. Homyzu, Scotland.

Arg. a bend indented betw. a crescent and mullet gu. Allen, London.

\section{Crescents}

Arg. a bend betw. two crescents gu. Homil or Humirell, Scotland.

Arg. a bend engr. betw. two crescents sa. Hedisham. Heisham. Hodisham. Hodysham, $V$.

Arg. a bend raguly vert betw. two crescents gu. Marshall.

Az. a bend engr. erminois betw. two crescents or. WATTS.

Az. a bend betw. two crescents or. Debenham, Suffolk.

Gu. a bend engr. betw. two crescents arg. Fenton, Millearn.

Sa. a bend betw. two crescents arg. Debenali, $V$ *.

Sa. a bend betw. two crescents or. Debenham, Suffolk. Debynhari, $V$.

Sa. a bendlet betw. two crescents or. Demenam, r. DEBNAM.

Arg. a bend betw. three crescents az. TIGHE, Ireland.

Arg. a bend engr. gu. betw. three crescents sa. WALDRON, Ireland.

Arg. a bend engr. betw. three crescents sa. CaNt. Hodisham.

Arg. a bend betw. three crescents sa. flammant ppr. PADDoN, Henton Deweney, Hants; granted 1590.

Or a bend betw. three crescents az. within a bordure engr. quarterly gu. and arg. Sсот, Balmouth, Scotland.

Per chev. embattled erm. and gu. a bend or betw. three crescents counterchanged. Surtr, co. Somerset.

Per fess embattled erm. and gu. a bend or betw. three crescents counterchanged. Sнттн, co. Somerset.

Arg. a bend fusily sa. betw. six crescents gu. Lxe.

Arg. a bend betw. six crescents sa. Tregos. Troys, $V$.

Gu. a bend betw. six crescents arg. Sir Edmund Folyot, $M$. Esmond Folloto, $Y$.

Gu. a bend arg. betw. six crescents or. LiLL, Ireland.
1 BEND betw. or within.... cont.

Crescents cont.

Gu. a bend urg. betw. six crescents 'pendent' or Esmond Follyot', $Y$.

Gu. a berid compony or and az. betw. six crescents arg. Liril or Liold, Kent. WELby, Kent.

Gu. a (bend $V^{*}$.) bendlet compony or and az. betw. sir crescents arg. Sir John de WeLLe, Kent, $V$.

$\mathrm{Gu}$ a bend or betw. six crescents arg. LEALLE or Lealu, Kent. Leall, $V^{*}$. Levall.

Gu. a bendlet or betw. six crescents arg. LraLL, $V$. Sa. a bend or betw. six crescents arg. WeLly. Crosses

Arg. a bend lozengy sa. betw. two crosses croslet fitchy gu. EEnings or Exins, Raundes, co. Northampton. Eurins.

Arg. a bend betw. two crosses croslet sa. Burnam.

Arg. a bend lozengy betw. two crosses croslet fitchy sa. Ligh. SYDenham.

$\mathrm{Gu}$. a bend raguly betw. two crosses croslet arg. Pelsett, Milton, co. Cambridge; and Ithain, Kent. Plessetr, Milton, co. Cambridge.

Or a bend betw. two crosses croslet sa. Bornam. Burnam, $V$.

Or a bend vair betw. two crosses verdy voided sa. Mangle or Mangles. Mangles, Woodbridge, Surrey.

Sa. a bend or betw. two crosses flory arg. SHeldon, Arden, co. Warwick; granted 8 February 1475.

Arg. a bend betw. thlee crosses gu. Royle, Canterbury.

Arg. a bend engr. betw. three crosses croslet fitchy ga. BorkNOGE.

Arg. a bend lozengy sa. betw. three crosses croslet fitchy gu. Twinele, Peterborougb.

$A z$. a bend betw. three crosses crosslet fitchy or. Blaceet, $V^{*}$. Sir Edmond Blaket, co. Gloucester, $V$.

Gu. a bend betw. three crosses patoncy arg. Rereresby. Reresby, $V$.

Or a bend (another engr). gu. betw. three crosses formy fitchy az. Maxton, Cultequhay, Scotland.

Sa. a bend betw. three crosses botonny fitchy arg. LEAKE.

Sa. a bend arg. betw. three crosses croslet fitchy gu. BRIghtwalton.

Arg. a bend wavy betw. six crosses croslet fitcly az. Were, co. Devon, 1620 .

Arg. a bend az. betw. six crosses croslet vert. WOODTHORPE.

Arg. a bend az. betw. six crosses croslet fitchy vert. WODTHORP, $V$. WOODTHORPE.

Arg. a bend betw. six crosses croslet gu. Monsire de Bobking, Y. Bocking or Bockkinge.

Arg. a bend engr. betw. six crosses croslet gu. Bocininge, $V$. Boring, Suffolk.

Arg. a bend nebuly betw. six crosses croslet gu. Bocking, $V^{*}$. Bockyng, Suffolk, $V$.

Arg. a bend nebuly counter-nebuly betw. six crosses croslet gu. FodringaY.

Arg. a bend sa. betw. six crosses croslet gu. Durvassall, co. Warwick. Watton, Watton, co. Nottingham.

Arg. a bend betw. six crosses crosletsa. CaUston, $V^{*}$. Si. Richard Kawston, $V$. Languilles or LANGViLLES.

Arg. a bend of three fusils conjoined betw. six crosses croslet sa. Connewallu, $V$.

Arg. a bend fusily betw. six crosses croslet sa. Cornewayle, $V$ *. 


\section{BEND betw. or within.... c snt.}

Crosses cont.

Arg, a bend of three lozenges conjoined betw. six crosses croslet sa. Sr. John Connwall, $V$.

Arg. a bend betw. six crosses croslet fitchy sa. Tye, Clopton, Suffolk.

Arg. a bend of three fusils conjoined betw. six crosses croslet fitchy sa. M. John de Cornewaile, $S$.

Arg. five fusils in bend betw. six crosses croslet fitchy sa. Cornwall.

Az. a bend betw. six crosses croslet arg. How ARD.

Az. a bend betw. six crosses croslet fitchy arg. Chein, Esselmount, Scotland. Hewstas, $V$.

Az. a bend betw. six crosses patty fitchy arg. Chein or Chryne, Scotland.

Az. a bend arg. betw. six crosses croslet or. Eustass, $V$. Fitz-Eustace, co. Leicester.

Az. a bend betw. six crosses croslet or. BEDULEY, co. Stafford. Marn.

Az. a bend betw. six crosses croslet fitchy or. Areskine, Scotland. Blaket, co. Gloucester. Drayton, co. Wilts. Sr. John Drayton, $V$. ERskine, Tinwall; quartering arg. a pale sa. in the dexter chief point a lion's head erased gu., and gu. on a fess betw. three cusbions arg. a mullet of the first. Erskine, Balquhan and Balgounie; quartering arg. a pale within a bordure sa. Erskine, Bygone; quartering arg. a pale sa. over the quarters a crescent arg. LIALL. LYALL. MAR; quartering gu. fretty or for de Lyle, Baron Lyle. Marr; quartcred by Douglas. Ormesbr, co. York. Sir Symon de Sennyle, $R$.

Gu. a bend betw. six crosses croslet arg. Forneaux or Forneaulx. Hornsey. Hornsley. Poyly.

Gu. a bend betw. six crosses crosslet fitchy arg. Cheyne, Straloch, Scotland. Chein or Cheyne, Scotland. Sir John HaWARDE, but Howard, Harl. MSS. 6589, 6595, Admiral of the North Fleet, $Q$. John Haward, $S, X, Y$. Monsire HaWARd, $Y$. HoRnsley. HowaRd, $Z, 212$. Sr. de Howard, Norfolk, $V$. Howard, Earl of Northampton and Baron Howard 33 Mareh 1604, extinct 1614. Howard, Bushy Park, co. Wicklow, Baronetey 1838. Howard, Earl of Wicklow, 20 December 1793 ; Viscount Wicklow, $23 \mathrm{~J}$ une 1785 ; Baron Clonmore, $21 \mathrm{July} 1778$; quartering arg. a lion ramp. gu. OrmesBy, None Ormesby, and Louth, co. Liucoln.

$\mathrm{Gu}$. a bend betw. six crosses fitchy arg. within a bordure erm. CheIN or CHEYNe, Scotland.

$\mathrm{Gu}$. a bend betw. six crosses formy fitchy arg. HUNTINGFIELD.

Gu. a bend chequy or and az. betw. six crosses croslet arg. Ormser, $V$.

Gu. a bendlet (bend $V^{*}$.) compony or and az. betw. six crosses croslet of the second. ORNESBY, $V$.

Gu, a bend of five lozenges conjoined erm. betw. six crosses croslet or. Aubeniarle, co. Dorset, $V$.

Gu. a bend betw. six crosses botony or. Lenysis.

$\mathrm{Gu}$. a bend betw. six crosses croslet or. Sr. Simon de Forneux, $V$. Fornesulx, $V$. Furneaulx. Furneaux, quartered by St. Barbe. Furnivall. Hornsby or Hornesby. Orisby, Cloghan, co. Mayo, Baronetcy 1812 , extinct 9 August 1833. OrmesBY, co. Lincoln, 1716. OrMSBY, quartering its augmentation with Owen, Maurice, Lacon, and Godolphin. Sir William Preston, I, Harl. MIS. 6589. Piers de Preston joust Wendeslawe, $P$.
1 BEND betw. or within.....cont.

Crosses cont.

$\mathrm{Gu}$ a bend Jozengy betw. six crosses croslet or. AUBEMARLE.

Gu. a bend betw. six crosses croslet fitchy or. Ormesby, None Ormesby and Louth, co. Lincoln ; Rathlec; Tobbervaddy; Cloghan ; Mory villa; Anuagh; Comya ; and Willowbrook, lreland. PREston.

Gu. a bend betw. six crosses patty or. Preston. Gu. a bend betw. six crosses patty fitchy or. Chein, Scotland. Preston.

Gil. a bend vair betw. six crosses croslet arg. Hall, co. Devon. Paley, Langcliffe Craven, Harrowgate, and Bowling $\mathrm{Hall}$, co. York. Palye. Sir John Ralegh, Cornwall ; or Ralex, $V$. Raleigh, Cornwall.

Gu. a bend vair betw. six crosses patty arg. Palye. Rafie.

Gu. a bend vair betw. sis crosses croslet or. RaIEY, co. Warwick.

Gu. a bend vair betw. six crosses formy or. Kniveton, Bradley, co. Derby.

Gu. a bend vairy or and arg. betw. six crosses croslet fitchy of the third. Howand.

Gu. a bend vair betw. six crosses potent or. Sir John de Palie, $R$.

Or a bend betw. six crosses croslet sa. Kawson. Or a bend betw. six crosses croslet fitchy sa. Sr. John Longevillers, $V$. Longrillers, $V^{*}$.

Or a bend vair betw. six crosses crosslet .... BANCROF'T.

Sa. a bend betw. six crosses croslet arg. Forneaux. LAKE, Edmonton, Middlesex; and London; Baronetcy 1711; borne in second quarter with a mullet for diff. on the bend. Longlevers, Longvillers, or Longwers, co. York. Longvillers, co. Northampton, temp. Edw. I. Thomas Longvillers, Y. Monsire de Lungevilers, $Y$. Stanhop. Stanhore, alias Longviliers. Sr. Fdward Stanhope, Harl. MS. $613 \%$, fo. 44 .

Sa. a bend betw. six crosses croslet arg. Putnam. Longvillers, $V$. Sr. Edward Stanhop, $V$.

Sa. a bend betw. six crosses croslet fitchy arg. Laske quartered by Hussey. Lake, $W$. Arthur LATE, Bishop of Bath, etc., I616.26. John LaKe, Bishop of Sodor, etc., 1682, Bristol 1684, Chichester 1685-9.

Sa. a bend betw. six croses formy arg. VIUIIERS. Sa. a bend betw. six crosses croslet or Forneaulx, $V$. Forneaux. Longvillers, co. Nortbampton.

Sa. a bend betw. six crosses croslet fitchy or. Befeston or Beston co. York. Blacket. BLessone.

Arg. a bend wary betw. eight crosses croslet gu. BoCKING.

Az. a bend of four mascles arg. betw. eight crosses croslet or. AmERANCE.

Az. a bend arg. betw. eight crosses crosslet or. Fitz-Eustace, $V^{*}$.

Az. a bend arg. betw. nine crosses croslet or. $\mathrm{Sr}$. Thomas Fitz-Eustace, co. Lincoln, $V$.

Az. a bend betw. nine crosses croslet or. Fitz-Eustace, co. Lincoln.

Or a bend varr betw. nine crosses croslet gu. RaLey. Arg. a bend nebuly betw. ten crosses croslet gu. BoBKING.

Az. a bend arg. betw. ten crosses croslet fitchy or. Eustace.

Arg. crusily and a bend wavy gu. John do BaCKING, $\boldsymbol{Y}$. 
1 BEND betw, or within.... cont.

Crosses cont.

Arg. crusily fitchy and a bend az. Corwike.

Az. crusily or a bend arg. Sire Thomas Fitz-Eustace, $N$.

Erm. (but in pencil also crusily ....) a bend vair. Henry de Ralle, A, Harl. MS. 6137.

Gu. crusily and a bend arg. Sire John HaUWARD, $N$. Sire William Hauward, $O$. Sire .... de Howart, $F$. Cael de Huntingfeild, $A$, Harl. $M S .6137$. Jeer d'Huntingreld, $E$.

Gu. crusily bottony and a bend arg. William Haward, $Y$. John Horaresby (in the margin ORMEsBY ), $Y$.

Gu. crusily fitchy and a bend arg. Cael de HuNTINGFYLD, $A$.

Gu. crusily arg. a bend chequy or and az. Ornisby, Norfolk. Sire William de Onnesbr, $N$. And with a mullet sa. for diff. Sire Jolsan de ORNESBY, $N$.

Gu. crusily or a bend lozengy erm. Sire Geffrey de aubemarle, $N$.

Gu. crusily or a bend of mascles erm. Averance.

Gu. crusily and a bend or. William de Preston, $A$, Harl. MS.6137. Sir William de Prestone, I.

Gu. crusily and a bendlet or. Hereni de CHaUrs, $F$.

Gu. crusily potent fitchy and a bend or. William de Preston, $A$.

Gu. crusily arg. a bend vair. Raleigh. John Ralee, $Y$. Monsire de Raisey (co. Devon and Cornwall added), in $1562, \mathrm{Y}$.

Gu. crusily or a bend vair. RABEY or RABY. Henry de Raley, $F$. Heury de Ralle, $A$. Raleigh. Henry de Roleie, $E$.

Or crusily and a bend gu. HoLBrooke, Suffolk. Sir William Huntingfield, $I$.

Or crusily sa. a bend gu. John de Neviue le forostier, $B$.

Sa, crusily and a bend arg. Sire Thomas de LONGEVilers, $O$.

Sa. crusily and a bend of five lozenges conjoined arg. Robert de Werfeild, A, Harl. MS. 6137, fo. 93 .

Sa. crusily fitchy and a bend or. Henri de Haninvile, E, Harl. MS. 6137 ; or Hanuvile, $E$.

Sa. crusily and a bend engr.or. WhitField.

Sa. crusily and a bend of seven fusils conjoined or. Robert de Witefeld, $E$.

\section{Cups}

Arg. a bend sinister betw. in chief three co. vered cups and in base as many falcons sa. Scarborough, Glusburn, co. York.

Az. a bend betw. three covered cups or. Butler, Harl. MS. 6137, fo. 44.

$\mathrm{Gu}$. a bend betw. three covered cups or. Boteler, co. Lancaster. John Butler, Bishop of Oxford 1777; Hereford 1788-1802.

Sa. a bend arg. betw. three covered salts or. Flilingham. Follinghaim.

Arg. a beud betw. six covered cups sa. Botteliner, Wildeche, $V$. Boteller, $V^{*}$.

Arg. a bend engr. betw. six ewers sa. Wood, $V^{*}$. Az. a bend arg. betw. six covered cups or. $M$. John BOteler, $S$.

Az. a bend betw. six cups or. Sire William le Botiler, Wemme, $N$.

Az. a bend betw. six covered cups or. Butrer, Beautfey, co. Lancaster. Boteler or Butler, co. Lancaster. Botelder, Borde Warington, co. Lancaster, $V$.
1 EEND betw, or within..... cont.

Escallops

Gu. a bend or betw. two escallops arg. Peter. Petre, Baron Petre of Writtle, Essex, 21 July 1603, $Z$, 351. Petre, Fidlers, Essex; the herress $\mathrm{m}$. Canning.

Arg. a bend betw. three escallops sa. Sir Clement Cotterell, Groom Porter to James I. Cottereil, Hadley, Middlesex. Coterell, $V$. Cotterell, South Repps, Norfolk.

Az. a bend betw, three escallops arg. DANIEL, Ireland. Garraway.

Erm. a bend betw. three escallops sa. Cotterelt. Gu. a bend betw. three escallops arg. WrgNall. Gu. a bend or betw. three escallops arg. Wignale, $V$. Wignall, $V^{*}$.

Gu. a bend betw. three escallops or. John le Channosley, $V$. Channesley, $V$ *

Gu. a bend vair betw, three escallops arg. Kemp, co. Devon.

Vert a bend erm. betw. three escallops arg. HuRD. Arg. a bend engr. gu. betw. six escallops az. Eschalard de Mont Tyrelie (? Monsyrole) $C$. Arg. a bend betw. six escallops sa. Cockerel. CotTerell. Waltham. WaLton, $V$.

Az. a bend betw. six escallops arg. Monsire de Frechevile, $Y$. Frechevill, Staveley, co.Derby, $V$. John Freschevile, $Y$. Freschevilue, Staveley, co. Derby; co. Devon; and co. Nottingham, temp. Henry III; Barony 29 Edward I; Baron Frescheville of Staveley 16i4; the co-heirs $\mathrm{m}$. Pawlet, Warwick, D'Arcy, and Colepeper. Freshfield, co. Derby. Freshfield, Moor Place, Betchworth, Surrey. Freshvml. Freshwell. And with a pierced mullet gu. in chief of the bend for diff. M. Rauf Freschevins, $S$.

Az. a bend arg. betw. six escallops or. Cruse, Cruse Morchard.

Az. a bend compony or and sa. betw. six escallops arg. Treveyston, $V$. Treveson Trevison or TREVysen.

$A z$. a bendindented point in point or and gu. betw. six escallops of the second. Cruse, co. Devon. Az. a bend or betw. six escallops arg. Breton.

Az. a bend betw. six escallops or. Daniele, $V^{*}$; Tideswell, co. Derby ; a co-heiress m. Meverell. Danyell, Tyddeswall, co. Derby, $V$. Davield, Folijames, Hasfield Court, co. Gloucester; descended from Fuljambe or Foljambe, Walton, co. Derby. Tydoeswall, $V^{*}$.

Az. a bendlet betw. six escallops or. John Daniel or Danieli, $E$.

Az. a bend per bend indented arg. and gu. betw. six escallops or. Cruwys, Morchard and Ne. therep, co. Devon; the co-heirs $\mathrm{m}$. Sharland and Melhuish. Crews, Fotberingham, co. Northampton, and Cruse Morchard, co. Devon. Gu. a bend betw. six escallops arg. WYGNaLL. Gu. a bend betw. six escallops or. Chamersley. Gu. a bend vair betw. six escallops arg. Barné or Barres. Beaupel, $V^{*}$. Sire Robert Beaupej, N. Beopeli or Berpeli, Cornwall. Sr. Robert KenPE, co. Devon; and Cornwall, $V$. KEMP, $V^{*}$.

Gu. a bend vair betw. six escallops or. BEAWPELL. Saxilby, $V$.

Sa. a bend betw. six escallops arg. Folkingham. Foulchampe. Fowlchampe.

Sa. a bend arg. betw. six escallops or. INGIETT, Allington, co. Devon.

Sa. a bend or betw. six escallops arg. FolJambe, Wakefield, co. York. M. Godfry FoJJAMLE, S. 
1 BEND betw, or within.....

Escallops cont.

Sa. a bend betw, six escallops or. Thomas Foleganibe, $E$. Foliamir, $V^{*}$. Sr. Godfrey Folianibe, Walton, co. Derby, $V$. Foljambe, Walton, and Linacre Hall, co. Derby; Os. berton, co. Nottingham; and Aldwarke, co. York. Foulion, co. Derby. Foulchampe or Foulgeham, co. Lincoln.

Sa. a bend betw. six escallops or within a bordure engr. gu. Foliambe, Croxdon, cu. Stafford.

\section{Escucheons}

Az. a bend per bend dancetty gu. and arg. betw. two escucheous or. CREwse, co. Devon.

Arg. a bend vair betw, three escucheons sa. each charged with a pheon of the field a bordure engr. gu. bezanty. Briggs, Halifax; and Birstwith Hall, Ripley, co. York.

Arg. a bend vert betw. three inescucheons gu. Patmer, co. York.

\section{Estoiles}

Az. a sinister bend arg. betw. two stars of the last. Barr, France.

Az. a bend sinister in chief two estoiles in like bend or in base the end and stock of an anchor gold issuant from waves of the sea ppr. Shiffner, Combe Place, Sussex; Baronetcy 16 December 1818 .

Sa. a bend betw. three estoiles or. AstrerLey or Asterly. Asterley or Esterley, East Newton, and Willingham, co. Lincoln.

Arg. a bend betw. six estoiles gu. Chipman, Bristol.

Az. a bend raguly betw. six estoiles or. Payne, Midlow, St. Neot's, co. Huntington.

Gu. a bend betw. six estoiles arg. Hanford.

$\mathrm{Gu}$. a bend arg. betw, six stars with as many points of the second. KENELwORTH.

Or a bend betw. six estoiles az. Skeqnes, Skegnes, co. Lincoln.

Sa. a bend betw. six estoiles or. Astroby. Estbr, co. Lincoln. Estebr, co. Lineoln, $V$.

Az. semy of estoiles and a bend or. Pensam. Feathers

Or a bend sa. betw, three pens gu. Rinel. Fire-balls

Arg. a bend engr. az. betw. two fire-balls ppr. Symonds, Pilsdon, co. Dorset; quartering per fess sa. and arg. a pale counterchanged on each piece of the first a 3 -foil slipped of the second, being an augmentation granted 1587 .

Arg. a bend engr. az. betw. two fire-balls sa. Srmonds, co. Gloucester.

Az. a bend raguly arg. betw. six fire-balls or flamed in cross .... Symon, Cambridge, $W$.

Fish

Gu. a bend betw. two fishes embowed bendwise arg. Marthair, $V$.

Gu. a bend wavy betw. two fishes bendwise arg. Martham.

$$
\text { .... Barbels }
$$

Sa. a bend betw. two barbels arg. French.

$$
\text { ....Dolphins }
$$

.... a bend or betw. two dolphins embowed arg. French, Cranfield, Essex.

Az. a bend engr. betw. two dolphius naiant arg. Trench.

Az. a bend erm. betw. two dolphins embowed bendwise or. LENTON, co. Buckingham; and Aldwinkle, co. Northampton; granted $21 \mathrm{March}$ 1584.

Az. a bend betw. two dolphins or. FrankLand, co. York.
1 BEND betw. or within.... cont.

Fish cont. Dolphins cont.

Az. a bend betw. two dolphins haurient embowed or. Franckin, co. Wevon.

Az. a bend betw. two dolphins embowed bendwise or. Franklyn, Buckfaster, co. Devon, $W$.

Gu. a bend betw. two dolphins embowed bend. wise arg. French, Sussex, $W$. French, Stream, Sussex; sometimes with a label of three points az.

Gu. a bend nebuly betw. two dolphins embowed bendwise arg. Seriant or SerJant, Kent, $V$.

Gu. a bend nebuly betw. two dolphins haurient arg. Sariant, $V^{*}$.

Gu. a bend wavy betw. two dolphins embowed bendwise arg. Martham, $V$.

Gu. a bend nebuly arg. betw, two dolphins em. bowed or. Sargant or Sergeant, Dynton, co. Buckingham.

Gu. a bend nebuly or betw. two dolphins arg. Sargant Sargeaunt or Sergeant, Northum. berland.

Sa. a bend betw. two dolphins embowed bendwise arg. Frenche, $V$.

Sa. a bend betw. two dolphins embowed haurient arg. French, co. Devon.

Sa. a bend wavy betw. two dolphins embowed naiant arg. TULSE, Lord Mayor of London 1681.

Sa. a bend arg. betw. two dolphins embowed bendwise or. French, Kent. French, $W$.

Sa. a bend arg. betw. two dolphins haurient embowed arg. Frfnch, $V^{*}$.

Sa. a bend arg. betw. two dolphins naiant or. FRENCH, 1730.

Az. a bend or betw. three fishes naiant arg. Gornay, Calais. Gornaye.

Sa. a bendlet betw. three fishes haurient arg. French, $W$.

\section{....Dolphins}

Gu. a bend betw. three dolphins naiant or. Frankland, co. York.

Gu. a bend wavy betw. three dolphins arg. Martham.

$\mathrm{Gu}$ a bend betw. three dolphins or. Osborne.

Az. a bend engr. betw. six fishes haurient arg. Coupir.

\section{Fleurs-de-lis}

Az, a bend wavy arg. betw. two fleurs-de-lis erm. Borovgr, Norham, co. Devon; and Kent. Burrowes, Kent, $W$.

Az. a bend wavy arg. betw. two fleurs.de.lis or. Borough, Norham, co. Devon; and Kent.

Az. a bend or betw. two fleurs-de-lis arg. WRAGG.

Gu. a bend vair betw. two fleurs-de-lis arg. Buors, Grundisburgh Hall, and Cockfield Hall, Suffolk; Baronetcy 15 April 1686.

$\mathrm{Gu}$ a bend vajr betw. two fleurs-de-lis or. BuIss. IsLEY.

Per fess arg. and gu. a bend betw. two fleurs.delis countercbanged. Smith, Dorchester.

Quarterly gu. and sa. over all a bend betw. two fleurs de-lis arg. Hexstall, co. Stafford, $V$.; and Hexstall, co. Warwick. Hextall, $V$.**

Quarterly gu. and sa. a bend .... betw. two fleurs. de-lis or. HEPSTALL.

Sa. a bend vair betw. two fleurs-de-lis or. BLors, Ipswich, Suffolk.

Az. a bend wary betw. three fleurs.de.lis erm. Burrowes, $V^{*}$.

Gu. a bend betw, three fleurs-de-lis arg. Cantelow or Cantelo, co. Salop. Cantelo, co. Salop, $V$. Cantelupe or Cantelow. Hart, co. Devon; 
1 BEND betw, or within.... cont.

Fleurs-de-lis cont.

and Highgate, Middlesex. H.sт, Yarnacombe, co. Devon; quartering Prowse. Hart, Scotland.

Gu. a bend arg. betw, three fleurs-de-lis or. Cantelow, co. Salop.

Sa. a bend betw. three fleurs.de-lis arg. Hert, Bony-Tracy, co. Devon.

Sa. a bend arg. betw, three fleurs-de-lis or. Redmene, $V *$.

Sa. a bend betw. three fleurs-de-lis or. Scarbar or Scarber, Ireland. Scarber, $V$.

Sa a bend engr. betw. three fleurs-de-lis or. Hart, Hampton-Wick, Middlesex. Harte, Melton Mowbray, co Leicester.

Arg. a bend lozengy gu. betw. six fleurs.de-lis az. Flote, France.

Arg. a bend betw. six fleurs-de-lis gu. Sr. Richard Fitz-Ellis, $V$.

Arg. a bend gu. betw. six fleurs-de-lis vert. Beston. Pointington or Pontington, Pennycott, co. Devon, temp. Edward III. Poyntington, $W$.

Arg. a bend fusily purp. betw. six fleurs-de-lis az. BARNARD, co. Lincoln.

Arg. a bend of eight and a half lozenges purp. betw. six fleurs-de-lis vert. Archinbald Barnard or Barnarde, a Grscoigne, born in England, lord of Halnaby, co. Lincoln; granted 24 Nov. 1580 ; Harl. MS. 6169 , fo. 1 .

Arg. a bend betw. six fleurs-de-lis (or bees) sa. Beston, Kyrke Beston, co. York.

Az. a (bend $V^{*}$ ) bendlet arg. betw. six fleurs-delis or. Coove, $W$.

Az. a bend or betw. six fleurs-de lis arg. Crooks. Crowke, $V^{*}$.

Az. a bendlet or betw. six fleurs-de-lis arg. Crowke, $V$.

Az. a bend nebuly or betw. six fleurs-de lis arg. Billclifre, Turganby, Kent.

Giı. a bend betw. six fleurs-de-lis arg. FitzEists.

Per bend arg. and sa. a bend of forr lozenges betw. six fleurs-de-lis all counterchanged. Potenger, quartered by Bingham.

Sa. a bend arg. betw. six fleurs-de.lis or. REDHERE, $V$. REDMORE.

Az. flory or and a bendlet (or baston) compony arg. and az. Joan, daughter of Charles (CAPET) II, King of Navarre and Count of Evreux, second wife of Henry IV; quartering $\mathrm{Na}$ varre.

Gu. flory or a beud compony arg. and sa. Galigate.

Flower.... Rose

Arg. a beud az. betw. in chief a rose and in base a fleur-de.lis gu. Overion, Lea, co. Leicester.

Arg. a bend sa. betw. in chief a rose and in base a Heur-de-lis gu. Orton or Ortun, Lea, co. Leicester. Oventon, co. Stafford, $V$.

$$
\text { .....Roses }
$$

Arg. a bend engr. sa. betw. two roses gu. seeded arg. barbed vert. MAC Brouden, Ireland; Harl. MS. 4039 , fo. 145 .

$$
\text { ....Columbines }
$$

Sa. a bend. arg. betw. three columbines of the second. WaLshe, Colbye, Norfolk.

$$
\text { .....Roses }
$$

Arg. a bend az. betw. three roses gu. Penrose, Ireland. Giles de Bridpont, Bishop of Salis. bury 1256-62.
1 BEND betw. or within..... cont.

Flowers cont. Roses cont.

Az. a bend arg. betw. three roses or stalked and leaved.vert. GaLiard or GaLIAard.

Az. a bend betw. three roses or. GaLliard, London.

Gu. a bend betw. three roses arg. seeded sa. Berondowne, Cumberland.

Arg. a bend betw. six roses gu. Brideport, co. Somerset. Burport, co. Somerset.

Arg. a bend engr. betw. six roses gu. WARNER.

Arg. a bend betw. six roses gu. seeded of the field barbed vert. WARNER, London.

Gu. $a$ bend. betw. six roses arg. seeded or. Musis or LE Musis.

Gu. a bend or betw. six roses arg. Lemuses or LenNuses, Tournay.

Or a bend engr. betw. six roses gu. WArner, Essex, $V$. WARner, Warnerhall, Essex; and Brokenthwait, Kerbyoverbow, co. York, 1730.

Or a bend engr. betw, six róses gu. barbed vert. Warnen, Warner Hall, Brakenthwaite; and Knaresborough, co. York. W ARNER, Waltham, Essex; and Sussex; 1609.

\section{3-Foils}

Or a bend counter-embattled betw. two 3-foils slipped sa. Lewin, $V^{*}$. Lewins.

Or a bend raguly sa. betw. two 3 -foils slipped vert. LEWEN, Siston, co. Leicester.

Arg. a bend betw. three 3.foils within a bordure engr. sa. KNEVET.

Az. a bend erm. betw. three 3-foils slipped arg. Lawson, Ireland.

Gu. a bend betw, three 3-foils arg. Harnge.

Gu. a bend betw. three 3 -foils slipped or. HARVEY, Ireland.

Or a bend az. betw. three 3.foils slipped vert. Smithe, $V$. Smythe, $V$.

Sa. a bend betw. three 3-foils arg. INBELL or JubeLL. IRERILL.

Sa. a berd betw. three 3-foils slipped arg. IRBILL.

Or a bend betw. six 3-foils slipped purp. HaCkWeli, $W$. HaCkwell or Hakewill, Totness, co. Devon; and co. Lincoln. Huckvile, co. Devon.

\section{5-Foil}

Arg. a bend sa. betw. in chief a 5 -foil gu. and in base a sword in pale az. bladed or. BenNiE Benny Benzie or Binney, Scotland.

Arg. a bend betw. two 5-foils sa. William Bentham, Bentham, co. Gloucester, $V$. Thomas Bentham, Bishop of Lichfield, \&c. 1560-79.

Arg. a bend erm. betw. three 5 -foils pierced sa. Ranson.

Az. a bend engr. betw. three 5-foils arg. Fraser, Farralane; quartering arg. three antique crowns gu.

Or a bend engr. betw. six 5.foils gu. WARner, Essex, $V$.

Quarterly arg. and az. on the second three 5-foils of the first over all a bend compony of the second and gu. Greshali.

Sa. a bend engr. betw. six 5-foils or. Pover; confirmed 12 May 1588. Thomas Povey, Master of Requests temp. Charles II.

Sa. a bend engr. vert betw. six 5-foils or. Pover.

Az. semy of 5 -foils or a bendlet compony arg. and gu. Rodvilie.

\section{Fruits.....Acorns}

Sa. a bend betw. three acorns or. Acrens or AKERS. 


\section{BEND betw, or within.... cont.}

\section{Fruits cont. Pears}

Gu. a bend betw. three pears (another slipped) or. Abbey of Austin Canons at Hartiland or Hertland, co. Devoll.

Gu. a bend betw. six pears erect or leaved vert. Clopton.

\section{Garbs}

Az. a bend voided betw. two garbs arg. Tillotson, co. York.

Gu. a bend engr. betw. two garbs arg. WalwortH, London; and Suffolk.

Gu. a bend ragnly arg. betw. two garbs the upper one or the lower of the second. Sir William de WALWorth. Lord Mayor of London 1374 and 1380, ob. 1383, Harl. MS. 1349.

Gu. \& bend raguly arg. betw. two garbs or. Krliningall, Cumberland. Walworth, $V$. Walworth, Lord Mayor of London 1374 and 1380.

Gu. a bend betw. two garbs or. Roo, Lon. don.

Gu. a bend vair betw. two garbs or. Richards.

Gu. a bend vair betw. two garbs placed bendwise or. Riccard, Hatfield, co. York.

Sa. a bend raguly arg. betw. two garbs or. Whetcrofte, Suffolk.

Az. a bend gu. (old glass shows it or) betw. three garbs or. Sandbache, co. Chester, Harl. MS. 1535 , fo. 26 .

Az. $a$ bend engr. betw. three garbs or. KEnPE, Norfolk.

Az. a bend vert betw. three garbs arg. HOLDSHEFFE.

Gu. a bend raguly betw. three garbs arg. Kulinghale, $V^{*}$.

Gu. a bend engr. arg. betw. three garbs or. Walwarne, London.

Gu. a bend raguly arg. betw, three garbs or. Filimghali, Middleton St. George, co. Durbam, 1390 . Killinghaulie, $\boldsymbol{V}$.

Gu. a bend eugr. betw. three garbs or. KEMPE, Kent; Norfolk; and Suffolk.

Sa. a bend rairy or and gu. betw. eight garbs of the second. Bures.

\section{Gouttes}

Arg. a bend gu. betw. eight gouttes-de-sang four and four. Loxam.

Gu. goutty-d'or a bend of the last. Yardouth, co. Devon.

Or goutty-de-sang. a bend gu. Jernouthe, $W$.

\section{Hammers}

Arg. a bend betw. three bammers and five lozenges sa. Bolron.

Arg. a bend fusily betw, three hammers sa. Bolron, co. Chester.

Arg. a bend of six lozenges conjoined betw. as mauy hammers with the clawed ends to the dexter sa. Bolron, co. Chester, $V$.

\section{Hands}

Sa. a bend betw. two dexter hands arg. Bracer or Brassy.

Sa. a bend betw. two hands and arms couped at the elbows arg. habited in mail ppr. BrACE, co. Worcester.

Gu. a bend betw. three dexter hands couped arg. LOVEDON.

Sa. a bend arg. betw. three dexter hands couped ppr. Brace.

Gu. a bend betw. four sinister hands apaumy couped arg. Loveden, Fyfield and Buscot, co. Berks; granted 1589. LOVEDON, $V$.
1 BEND betw, or within.... cont.

Head.... Beast

Az. a bend betw. in chief a buck's head erased and in base three crosses croslet fitchy arg. Garnow, Bolnore, Cuckfield, Sussex.

Az. a bend betw. in chief a deer's head erased and in base three crosses croslet fitchy arg. PérReE.

Az. a bend betw. in chief a stag's head couped (?arg.) attired or and in base three crosses croslet fitchy of the second. GArRIOcH, Kinstair, Scotland.

Gu. a bend chequy arg. and az. betw, in chief a buck's head erased and in base a cross couped and pierced or. Bork, Scotland.

Or a bendlot betw. in chief a stag's head erased and in base a hunting-horn sa. garnished gu. Porterfield, That llk.

\section{.... (Monster) Unicorn}

Arg. a bend betw. in chief a unicorn's head erased and in base a cross croslet fitchy gu. Denison, Kilnwick Percy, co. York. Dennison.

Arg. a bend sa. betw. in chief a unicorn's head erased ppr. and in base a cross croslet gu. Denison, Rusholme Park, co. Lancaster; and Stockgrove, co. Buckingham.

.... a bend or betw. in chief a unicorn's head erased .... and in base four crosses croslet flory (? fitchy) .... Foster, Wadsworth Banks, and Heptonstall Slack, near Halifax.

\section{Heads..... (Beasts) Boars}

Gu. a bend betw. two boar's heads erased bendwise arg. HAKE, Peterborough, co. North. ampton.

\section{..... Deer}

.... a bend betw. two buck's heads cabossed .... More, Morehouse, co. Sussex.

Arg. a bend az. betw. two buck's heads cabossed sa. Cranagr, Pixley, co. Chester.

Arg. a" bend engr. az. betw. two buck's beads cabossed (sa?) and attired gu. NedHas, Sharington, co. Salop, $Z, 320$.

Arg. a bend az. betw. two bucli's heads cabossed sa. Needearr, Viscount Newry and Morne 18 April 1625, Earl aud Viscount Kilmorey 12 January 1822.

Arg. a bend. engr. az. betw. two buck's heads cabossed sa. Sr. Robert Ne EDHAM, co. Chester, $V$.

Arg. a bend engr. az. betw. two stug's heads cabossed sa. Needfarr, quartering arg. on a chief vert a cross tau betw. two mullets arg.; Harl. MS. 4040, fo. 187; Viscount Newry and Morne 18 April 1625; Earl and Viscount Kil. murrey or Kilmorey 12 January 1822.

Arg. a bend engr. az. betw. two bucks' heads cabossed sa. attired or. NeEDHaM or NeDHam, Nedham in the Peak, co. Derby, 1154; ancestor of NeEdhair, Cranage, co. Chester; and Thornsett (by marriage with Mellure), as well as of its branches at Snitterton and (by marriage with Cadman) Cowley, co. Devon; as well as of Nemdham, co. Hertford, co. Leicester; and Suffolk.

Az. a bend betw. two stag's heads couped or. HAworth, Haworth, co. Lancaster. Haworth, Hull Bank House, Hull; Rowlston Hall, Hornsea, co. York; Barham Wood, co. Herts. Howorth, Howorth, co. Lancaster.

Az. a bend betw, two buck's heads erased or. KeTtue, London.

Az. a bend wavy betw. two buck's heads erased or. HAREWARE, co. Warwick. 
1 BEND betw, or within.....cont.

Heads cont. (Beasts) Deer cont.

Gu. a bend embattled or betw. two buck's heads cabossed arg. attired of the second. Crofts; granted 25 July 1709.

Quarterly arg. and sa. over all a bendlet gu. betw. two stag's heads cabossed or. HenHurl.

$$
\text { .....Foxes }
$$

Or a bend az. betw. two fox's heads erased gu. TIDcomse, Estcot, co. Wilts; granted 1693-4.

$$
\text { .... Leopards }
$$

Gu. a bend engr. az. betw. two leopard's heads jessant-de-lis or. Dennis, Pucklechurch, co. Gloucester.

$$
\text { .... Lions }
$$

Arg. a bend betw. two lion's heads erased sa. Mello. Melus, $V^{*}$. Mevies or Mulds. Moles.

Arg. a beudlet betw. two lion's heads erased sa. Melus, Mells, co. Chester, $W$.

Arg. a bend sa. betw. two lion's heads sa. langued gu. Meoles, co. Chester.

Or a bend az. betw. two lion's heads erased gu. Cooper, Hackesworth, co. Nottingham.

Or a fess chequy az. and arg. surmounted by a bend. engr. gu. betw. two lion's beads erased of the last all within the royal treasure of the fourth. Stuart, Mains, Scotland.

Or a bend sa. betw. two lion's heads erased gu. GRITTON.

Or a bend betw. two lion's heads erased sa. Fassett.

$$
\text { ..... Otters }
$$

Arg. a bend betw. two otter's heads couped gu. Leithingtown or Livington, Saltcoats, Scotland.

Arg. a bend engr. gu. betw. two otter's beads couped sa. LETHINGTON.

$$
\text { ....0xen }
$$

Arg. a bend engr. az. betw. two bull's heads cabossed or. NEDEHAII.

Barry of four arg. and gu. a bend or betw. two bull's heads sa. Halgate or Holgate, Hels. worth, co. York.

Gu. a bend engr. betw. two bull's heads couped or. Thomas Secker, Bishop of Bristol 1735, Oxford 1737, Archbishop of Canterbury 1758.68.

$\mathrm{Gu}$. a bend counter engr. betw. two bull's heads erased or. SAKER or SACKER, Feversham, Kent; confirmed 1615. Thomas SEcker, Bishop of Bristol 1735, Oxford 1737, Archbishop of Canterbury 1758.68, portrait. Secker. $V^{*}$. SACRE, $V^{*}$.

Or a bend betw. two bull's heads couped sa. Holgate, Walden, Essex.

Vert a bend embattled betw. two bull's heads erased arg. Strasacker.

Vert a bend engr. betw. two bull's heads erased arg. Strasacer, $V$. Strasacker. Strasacre, $V^{*}$.

\section{Heads.... (Birds) Eagles}

Gu. a bend vairy or and az. betw. two eagle's heads couped arg. KeLterton.

$$
\text { .....Herons and Storks }
$$

Az. a bend vairy or and gu. betw. two stork's heads erased arg. Stalebroke, London.

$$
\text { .... Lapwings }
$$

Az. a bend vairy of two rows or and gu. betw. as many lapwing's heads erased arg. STALPRock, London, $V$.

\section{.....Pelicans}

Az. a bend arg. between two pelican's heads erased or. HORMaN.
1 BEND betw. or within.... cont.

Heads cont. (Monsters) Griffins

Az. a bend wavy betw. two griffin's beads erased or. West, Cliff, Sussex.

\section{....Unicorns}

Arg. a bend betw. two unicorn's beads erased az. Sirth, Milford, Surrey ; confirmed 29 June 1667.

Az. a bend wavy or betw. two unicorn's heads erased arg. maned gold. Pience, Canterbury, Kent.

Gu. a bend embattled betw. two unicorn's heads erased or. Pearse, Bradninch, co. Devon.

Sa. a bend wavy arg. betw. two unicorn's heads erased or. Peeres or Perse, Westdown, Kent. Piers, West Downe, Kent, $W$.

Sa. a bend raguly betw. two unicorn's heads erased or. PeIrce. Piers.

\section{..... (Beasts) Bears}

Az. a bend betw. three bear's heads erased or. IVESTDEN, co. Lincoln.

\section{.....Boars}

Alg. a bend gu. betw. three boar's heads couped sa. Wall, Preston, and Wallrush, co. Lancaster.

Az. a bend betw. three boar's heads couped arg. Gordon, Stichel, and Lochinvar, Scotland. Gordon, Cardiness, Scotland. Peters, Aboyne Castle, co. Aberdeen.

Az. a bend betw. three boar's heads couped or a label of as many points arg. Gordon, Craighlaw, Scotland.

Az. a bend betw. three boar's heads couped or within a bordure of the last. Gordon, Troquban, Scotland; a cadet of Lochinvar.

Az. a bend betw. three boar's heads erased or. Gordon, Sherm, Scotland; a cadet of Lochinvar.

Az. a bend engr. betw. three boar's heads erased or. Gordon, Dengeuch, Scotland; a cadet of Lochinvar.

Or a bend sa. betw. three boar's heads gu. Camidoy.

Or a bend betw. three boar's heads fesswise couped sa. Camery, $V$.

Or a bend betw. three boar's heads couped sa. armed of the field. CaNIEREY or Camenx.

Vert a bend betw. three boar's heads couped arg. Peters Peterson Peiters Petres and Petrus, Scotland.

Vert a bend betw. three boar's heads couped or armed and langued gu. Peters, Scotland.

$$
\text { ....Deer }
$$

Arg. a bend engr. az. between three stag's heads cabossed sa. NeEdHayr, Lenton, co. Nottingham; and The Varteg, co. Monmouth; quar. tering Lee, Manning, Allison, and Coulson. NeEDHAM, co. Hertford ; granted 1586.

Az. a bend or betw. three buck's heads couped arg. Haworth, Manchester.

$$
\text { ..... Dogs }
$$

Arg. a bend betw. three greyhounds beads erased sa. WALDRON.

\section{.... Leopards}

.... a bend engr. betw. three leopard's beads jessant-de-lis.... Wrotr, Gunton, co. Suffolk.

Arg. a bend engr. betw. three leopard's beads az. jessant-de-lis or on the bend a martlet of the field for diff. Dennis, co. Gloucester.

Az. a bend erm. betw. three leopard's heads or jessant fleurs-de-lis gu. Cantelow or Cantelupe.

Az. a bend betw. three leopard's heads or. Notr or Notte, London; and Sheldesley, co. Worcester. 
1 BEND betw. or within.... cont.

Heads cont. (Beasts) Leopards cont.

Gu. a bend betw. three leopard's faces arg. Peter, Ireland.

Gu. a bend. engr. az. betw. three leopard's heads or jessant-de-lis of the second. DENNrs.

Or a bend betw. three leopard's faces az. WALDIE, Hendersyde, Kelso, co. Rox burgh.

Or a bend betw. three leopard's faces az. on the bend a crescent .... for diff. WALDY, co. York and co. Durham; descended from Waldie, Kelso.

Or a bend az. betw. three leopard's faces gu. WALDO, quartered by Sibthorp.

$$
\text { ....tions }
$$

Arg. a bend gu. betw. three lion's heads erased sa. crowned (of the second another) or. PEDErToN, Cornwall; and co. Somerset.

Arg. a (bend $V^{*}$.) bendlet gu. betw. three lion's heads erased sa. crowned or. PEDErTon, Cornwall, $V$.

\section{....Wolves}

Or a bend gu. betw. three wolf's heads erased sa. Massy.

$$
\text { ..... (Birds) Crows }
$$

Az. a bend betw. three crow's heads erased arg. CASSIE.

Arg. a bend gu. betw. three falcon's heads erased sa. Gelouer, $V$.

Az. a bend betw, three falcon's heads erased arg. beaked or. Chapresey alias Chersey, Kent, $V$. Chartsey, $V^{*}$.

\section{....Hawks}

Az. a bend betw. three hawk's heads erased arg. Chartsey, Kent.

$$
\text { .....Herons }
$$

Sa. a bend arg. betw. three heron's heads erased of the second. Glover.

$$
\text { .....Pigeons }
$$

Az. a bend engr. or betw. three dove's heads erased ppr. TAYLOR, Heston, Middlesex.

$$
\text { ....Peacocks }
$$

Sa. a bend betw. three peacock's heads and necks erased arg. GElouer, $V$.

\section{....Human figure}

Az. a bend or in chief three boy's heads couped at the shoulders arg. each enwrapped about the neck with a snake ppr. in base as many griffin's beads erased of the third. MADOCK, Hartbury, co. Gloucester.

\section{.....(IIfonsters) Dragons}

Arg. a bend gu. betw. three dragon's heads couped sa. Massy, $V$.

Arg. a bend sa. betw. three dragon's heads erased gu. Corson, Suffolk.

\section{....Griffins}

Arg. a bend gu. betw. three griffin's heads erased sa. Golever or Golloner.

Arg. a bend sa. betw. three griffin's heads erased gu. Curson, Suffoll.

Arg. a bend betw. three griffin's beads erased sa. Sr. William WaLdERN, Lord Mayor of London, $V$. WALDREN, Lord Mayor of London 1412 and 1422. WALDRoN, Lord Mayor of London 1412 and 1422, Harl. MS. 1349.

Sa. a bend betw. three griffin's heads erased arg. Golever or Goloner.

\section{.... Unicorns}

Arg. a bend betw. three unicorn's heads erased gu. WOMBWELL, co. York.

\section{BEND betw. or within.... cont.}

Heads cont. (Monsters) Wiverns

Arg. a bend gu. betw. three wivern's heads erased sa. Massy.

Arg. a bend sa. betw. three wivern's heads erased gu. Corson, Suffolk.

$$
\text { ..... Spears }
$$

Arg. a bend betw. three cronels sa. Cornall, $V^{*}$. Cronall.

Gu. a bend betw. three spear's heads arg. AP. DULFYN, $V^{*}$. Kynvillem ap-Dulfyn APVAUGHaN, $V$. KYNvillewr, $V^{*}$.

Sa. a bend betw. three spear's heads.... CARRIER, Wirksworth, co. Derby.

$$
\text { ..... (Beasts) Leopards }
$$

Arg. a bend and pile betw. four leopard's faces gu. GaRWAY.

\section{.....(Monsters) Unicorns}

Arg. a bend between four unicorn's heads couped gu. WOMBWELL.

\section{.... Human figure}

Az. a bend or in chief three boy's heads couped at the shoulders arg. each enwrapped about the neck with a snake ppr.in base as many griffin's heads erased of the third. MADOCK, Hartbury, co. Gloucester.

$$
\text { .... (Beasts) Leopards }
$$

Az. a bend arg. betw. six leopard's heads or. Finchinfield, Suffolk. Finchingaeld, $V$. FynchingFeild, $W$.

Az. a bend betw. six leopard's heads or. Hunt, Lynden and Hindon, co. Rutland; and Gayton, co. Stafford. And with a mullet on the bend as if for diff. Hont, not of this family.

Az. a bendlet betw. six leopard's heads or. Hunr, $V$. John Hunt, Lyndon, co. Rutland, $W$.

Gu. a bend betw. six leopard's heads and recks erased or. Skold, co. Brecknock, and co. Hereford.

\section{.... Lions}

Gu. a bend betw. six lion's heads erased arg. Skoll, Much Cowarne, co. Hereford. And with a mullet on the bend for diff. Sr. Walter Skull: co. Hereford, $V$.

Gu. a bend arg. betw. six lion's heads erased or. SEULL.

Gu. a bend betw. six lion's beads guard. erased or. SizuL, co. Brecknock; and co. Hereford.

Gu. a bend voided betw. six liou's heads erased or. Sculi, co. Worcester.

$$
\text { ..... (Monsters) Unicorns }
$$

Gu. a bend betw. six unicorn's heads couped arg. WorbwrL, Wombwell, co. York, 1585, W. WoMrbwell, Wombwell and Silvercliff, co. York.

Gu. a bend betw. six unicorn's beads erased arg. WoMbwel, Wombwell, co. York, Baronetcy 26 August 1778.

Gu. a bend erm. betw. six unicorn's heads erased arg. WombweLl, Northfeld, Kent, $W$; granted 10 September 1574.

$$
\text { ..... Spears }
$$

Arg. a bend betw. six cronels sa. Cornall, $V$.

\section{Horn}

Arg. a bend betw. in chief a buglehorn sa. stringed and garnished or and in base a stag's head couped ppr. attired of the third. SHARD, Horsleydown, Surrey.

\section{Horns}

Arg. a bend az. betw. three hunting-horns sa. stringed gu. PENNYCOK, That Ilk. 


\section{BEND betw. or within.... cont. Horseshoes}

Arg. a bend wavy gu. betw. two horseshoes of the field (but? az.) HoDsDon.

Arg. a bend wavy gu. betw. two horseshoes az. Hodson, $W$.

Insects.... (Emmets)

Arg. a bend az. betw. three emmets sa. MASsY. ....(Gadties)

Arg. a bend betw. three gadflies volant sa. Bestow.

$$
\text { .....(Bees) }
$$

Arg. a bend betw. six bees sa. Benston, Beeston Castle, co. Chester, extinct about 1626. BeEsTon, Okebam,co. Rutland and Possbrook, co. Hants; a heiress m. Modyford and Long.

Arg. a bend betw. six bees volant en arriere sa. Beston, Kyrke Beston, co. York. Biston.

Sa. a bend betw. six bees volant en arriere arg. a crescent....for diff. Wm. BeEstone, 1639; tomb in St. Mary's Church, Lambetb, Surrey. .....(Butterflies)

Arg. a bend betw. six butterflies volant sa. Beeston, $V^{*}$.

$$
\text { .....(Gadflies) }
$$

Arg. a bendlet betw. six gadtlies sa. Beeston, co. Chester, $V$.

\section{Keys}

Arg. a bend engr. betw. six keys four in chief and two in base interwoven and endorsed sa. Ridge, co. Lancaster.

\section{Leaves}

Arg. a bend betw. three oak leaves vert. SHone, co. Derby.

\section{Locks}

Per fess or and sa. a bend wavy betw. two padlocks counterchanged. WHitLock, co. Devon, granted ....

\section{Lozenges}

Arg. a bend az. betw. three lozenges of the last each charged with a fleur-de-lis or. Musgrove, Lord Mayor of London 1850, Baronetcy 2 Augnst 1851 ; seal.

Arg, a bend betw. three lozenges in chief and as many mattocks in base sa. Borron.

Arg. a bend betw. five lozenges and tbree pickaxes sa. Bolron, $V$.

Arg. a bend betw. five lozenges and three bam. mers sa. Bolron.

Arg. a bend betw. six lozenges and three pickaxes sa. Bolron, V*

Arg. a bend betw. six lozenges sa. Wenington, Lincoln. Wenington, co. Laucaster, $V$. Wigington. Winnington. Wynington, co. Devon; and Birches, co. Lancaster.

Az. a bend betw. six lozenges or. Plompton or Plumpton, co. Lancaster. Plomton, co. Lan. caster, $V$.

Az. a bend betw. six lozenges or within a bordure arg. Plompton, co. Lincoln.

$\mathrm{Az}$. a bend betw. six lozenges or each charged with an escallop sa. PoLLen.

$\mathrm{Gu}$. a bend or betw. six lozenges .... JuDs.

Gi. a bond betw. six lozenges ol. Fitz-Ives, $V$. Fitz-Jues, $V$ *

\section{Lures}

Az, a bend betw. three lures or. Chariery or Chatringy. Wade.

Az. a bend betw. three lures or within a bordure gu. bezanty. WADE, London. Mascles

Gu. a bend betw. six mascles arg. John de Freford, $Y$.

\section{BEND betw. or within.... cont.}

\section{Monsters}

Az. a bend chequy gu. and or betw. two unicorns pass, arg. CHARPENTIER.

Mullet

Arg. a bend az. betw. in chief a pierced mullet and in base an annulet gu. SAMon, co. Nottingham.

Az. a bend in chief a mullet of six points in base three piles wavy or. FURY, Westminster.

Gu. a bend engr. or in chief a mullet in base a stag's head cabossed arg. STABIE, granted 1767.

\section{Mullets}

... . a bend .... betw. two mullets .... W พттнam, Wytham, co. Berks.

Arg. a bend raguly betw. two mullets az. BIGGER. Arg. a bend az. betw. two mullets gu. AYre.

Arg. a bend counterembattled az, betw. two mullets gu. BigGer, Edinburgh.

Arg. a bend wavy az. betw. in chief two mullets and in base a fleur-de-lis (gu. ?). MASON, Ayr, and Rosebank, Scotland. MAISON, Scotland.

Arg. a bend wavy az. betw. in cbief two mullets and in base a fleur-de-lis gu. within a bordure engr. of the second. Masson, Inveresk.

Arg. a bend erm. betw. two mullets sa. PEele or Pris, co. Devon.

Arg. a bend betw. two mullets gu. Twrss.

Arg. a bend engr. betw. two spur-rowels gu. Glasford, Douglaston. Glassford.

Arg. a bend engr. betw. in chicf two spur-rowels gu. and in base a hunting born of the second garnished sa. GLASSFord, Borrostounness, Scotland.

Arg. a bend betw, two mullets sa. Delapilue. Pell. Pyell.

Arg. a bend betw. two pierced mullets sa. PeELE, co. Chester. Peeld, V. Piel, $V^{*}$. Sir Albert Pell, Serjeant-at-law.

Gu. a beud sinister arg. betw. two spur-rowels or. AsLoum, Scotland.

Gu. a bend betw. two mullets erm. Downton.

Or a bend az. betw. two mullets gu. Mennicone, Paris; and Sunbury, Middlesex.

Or a bend betw. two pierced mullets of six points sa. Weoley, Camden, co. Gloucester; confirmed 25 April 1580.

Per pale az. and gu. a bend betw. two mullets arg. Bright, $V^{*}$. Briget, Claybroke, co. Nortbumberland.

Per pale az. and gu. a bend or betw. two mullets arg. BRIGHT, quartered by Dalton, 1765 , in Sheffield Church.

Per pale az. and or a bend betw. mullets counterchanged. BRIGHT, Ireland.

Per pale gu. and az. a bend betw. two mullets in pale arg. Bright, Carbrook, and Badsworth, co. York; Baronetcy 16 July 1660 , extinct 13 September 1688 ; the beiress m. Liddell.

Per pale gu. and az. a bend or betw. two mullets arg. Briget, Bannercross, Ecclesall, co. York.

Ar'g, a bend az. betw. three mullets gu. Biggar, Wolmet, Scotland. Dalias. Langlex, Essex, $V$. LARGE.

Arg. a bend az. betw, three pierced mullets gu. Robert LaRge, Lord Mayor of London 1439, Harl. MS. 1349.

Arg. a bend az. betw. three mullets sa. Dallas, Petsall, co. Stafford; Baronetcy 21 July 1798.

Arg. a bend sa. betw. three mullets gu. Clayton. Grosvenour, co. Stafford. 
1 BEND betw, or within.... cont.

Mullets cont.

Arg. a bend betw, three pierced mullets sa. John PIEL, Lord Mayor of London 1372, Harl. MS. 1349.

Arg. a bend vert betw. three mullets gu. Ivony. Az. a bend betw. three mullets arg. WYLIE.

Az. a bend betw. three mullets or. Benweis. HOOLEY.

Or a bend betw. three mullets gu. within a bordure countercompony arg. and az. Le Grande, 1730.

Arg. a bend betw. four mullets gu. within a bordure compony of the first and az. LEGRAND.

Arg. a bend betw. six mullets.... Murne.

Arg. a bend az. betw. six mullets gu. LARGE or Longe.

Arg. a bend betw. six mullets gu. Peirs Breton, $Y$. John Moxine, $X$. Pyne, Cornwall. 'Гhaworth. Wheliting, Ireland.

Arg. a bend gu. betw. six mullets sa. Prne, Cornwall. Pyne, Cornwall, V. Pyme or Pyne, Cornwall.

Arg. a bend per bend az. and gu. betw. six mullets of the third. Werlings.

Arg. a bend per bend az. and gu. in chief three mullets of the third in base as many mullets of the second. Wheiring, $V^{*}$. Whelyng, $V$.

Arg. a bend per bend gu. and az. in chief three mullets of the second in hase as many mullets of the third. Whending. Whelyng, V, Cotton $M S$, Tiberius, $\mathbf{D}, 10$.

Arg. a bend betw. six mullets sa. ARDEs, $V^{*}$. ARDES, Sharington, co. Buckingham. Ardis, $V$. ARDYs. DEards, co. Hertford; and London.

Az, a bend betw. six mullets arg. Breton, co. Lincoln; and Norfolk. Fodringham, co. York. Forthinghan, Soutbampton. Hanby. Holbert. Hodby, Hoby, co. Leicester. Sayton or Seaton. Seton. Sayeton, $V$. Sayton, $V^{*}$.

Az. a bend betw. six pierced mullets arg. HоLBE, $V$.

Az. a bend arg. betw. six mullets or. FrodingHart, co. York. Frothingham, Holderness, co. York, $V$. Frothingham, South Frothingham, co. York. JENKYN.

Az. a bend erm. betw. six mullets arg. HULBERT. Az. a bend betw. six mullets or. Breton, co. Lincoln; and Norfolk. Robert BretoN, $Y$. Monsire John Breton, $Y$. Sire William Bretoun, $N$. Sire Robert Bretoun, $O$. Fordringham, co. York. Froddingham, Holderness. HoBY, co. Leicester.

Az. a bend betw. six pierced mullets or. Breton, co. Leicester; London; Island of Jersey ; and co. Stafford. M. Robert Breton, S. John fitz Robert Breton, 25 Edward III, $V$. Sr. Robert Bretion, $V$. Sr. William Bretton, co. Lincoln, temp. Edward I, $V$.

Az. a bend betw. six mullets or pierced gu. Beton. Breton, co. Lincoln.

Gu. a bend betw. six mullets arg. Hamford, co. Lincoln. HaNFord, co. Lincoln. Hansard. Sr. John HaNSARD, co. Lincoln, temp. Edward I, $V$. Sire Johan Haunsard, $N$.

Sa. a bend arg. betw. six mullets or. INckell. Nails

Arg. a bend gu. betw. six nails sa. TrLer. John Tyler, Bishop of Llandaff 1706.24.

Arg. a bend betw. six nails or. TyLER, $V^{*}$.

Vert a bend arg. betw. six nails or. Tylen, $V$.
1 BEND botw. or within.....cont.

\section{Purses}

Arg. a bend betw. six pouches sa. WoLston, Cornwall.

Sa. a bend betw. six pouches arg. WoLston, co. Devon.

Roundles.... Fountains

.... a bend sa. betw. two fountains. Srkes, co. York.

\section{.... Iurts}

Arg. a bend compony gu. and of the first betw. two hurts. GAUGHTON.

\section{.....0gresses}

Arg. a bend compony gu. and of the first betw. two ogresses. Govghton or Gowtheton.

Or a bend compony gu. and arg. betw. two ogresses. Gewthon or Gowtheton, $V$. Goughton.

Or a bend compony gu. and of the first betw. two ogresses. JAQUEMAN.

\section{.....Plates}

Quarterly or and gu. a bend sa. in the second and third quarters a pierced plate. Borgituone, Norfolk.

....Torteaux

Arg. a bend gu. betw. two torteaux. Strutton, quartered by Pie 17L3.

$$
\text { .....Bezants }
$$

Gu, a bend arg. betw, three bezants. Carsist. Sa. a bend .... betw. three bezants. CaNE. Sa. a bend raguly arg. betw. three bezants. WALWORTH.

\section{..... Fountains}

Sa. a bend or betw. three fountains ppr. STurron, co. Somerset. The lord of Stounton, $V$. ..... Hurts

Or a bend vair betw. three hurts. Prtr, Goldball, co. York ; quartered by Lysley.

$$
\text { .... Ogresses }
$$

Arg. a bend sa. betw. three ogresses. Benvil. Cotтon, Laughton, co. Leicester, and co. Stafford. CoTTON, Wittington, co. Gloucester. Cotтon, Bellaport, co. Stafford ; and Etwall, co. Derby ; descended, like Cotтon, Connington, co. Huntingdon, from CоттоN, Redware, co. Stafford; originally from co. Chester. William CoTTon, Bishop of Exeter 1598-1621.

\section{....Torteaux}

Arg. a bend. sa. betw. three torteaux. Охтову. Or a bend gu. betw. three torteaux. Countnex, co. Somerset.

\section{....Bezants}

Az. a bend erm. betw. six bezants. Armony. Az. a bend or betw. six bezants. Lolde, $V$.

Gu. a bend arg. betw. six bezants. CARYFIt. Caryset, co. Cornwall, $V$. Armony. Fitz. Warren, co. York. Monsire la Zodch, $Y$. (? Aymer la Zouche, $Y$.)

Gu. a bend engr. arg. betw. six bezants. Cansey, Dykelborough, Norfolk.

Gu. a bend elm. betw. six bezants. Armonx. Covght, $V$. Cowght. Sr. Armony Cowgthe, $V$.

Gu. a bend or betw. six bezants. Carset or Canerset, co. Devon.

Sa. a bend raguly arg. betw. six bezants. WALWORTH, $V$.

\section{.... Fountains}

Sa. a bend or betw. six fountains ppr. Stounton, Baron Stourton. Sturton, Sturton, co. Not. tingham. Sr. John Sturton, $T$.

$$
\text { ....0gresses }
$$

Arg. a bend embattled sa. betw. six ogresses. Burnell. 
1 BEND betw, or within.... cont.

Roundles cont. Plates

Sa. a bend or betw. six plates. Attributed to Nicholas BubBewrtH, Bishop of London 1106, Salisbury 1407, Bath \&c. 1408-24.

Gu. a bend arg. betw. six plates. (? Aymer la Zouche, $Y_{\text {.) }}$

\section{Bezants}

Gu. a bend arg. betw. eight bezants. Sir Amory de la Zodch, $L$.

Gu. a bend. arg. betw. ten bezants. Sr. Amory la Zouch, co. Leicester, $V$.

Gu. a bend erm. betw. ten bezants. ZoucH, co. Leicester. Sir Amery de la ZoucH, $L$.

Gu. a bend engr. erm. betw. ten bezants. Zоuch.

Gu. bezanty and a bend arg. Sir Amory la Souche, $N$. Sir Amery la Souche, $O$. Zouch.

Gu. bezanty and a bend erm. Sr. Amory de la ZoठcH, L, Harl. MS. 6137.

Saltires

Az. a bend erm. betw. six saltires arg. within a bordure of the second. Barchay.

\section{Spur-rowels}

Arg. a bend engr. betw. two spur-rowels gu. GLASFORD, Douglastoun. GLASSFORD.

Arg. a bend engr. betw. in chief two spur-rowels and in base a hunting horn gu. garnished sa. Giassford, Borrowstounness, Scotland.

Gu. a bend sinister arg. betw. two spur-rowels or. Ascoum, Scotland.

Staves

Arg. $a$ bend betw. three crosiers gu. DensmL.

Gu. a bend arg. betw. three crosiers or. Donseul.

Gu. a bend arg. betw. four crosiers (or crooks) or. Donselu, co Devon, $V$. Swords

Quarterly gu. and az. a bend wavy vairy or and erm. in the second quarter two swords in saltire surmounted by the fasces erect ppr. within a chaplet of oak vert in the third quarter a sword erect within a chaplet of oak all ppr. John Crowden, Lord Mayor of London 1830. Trees

Arg. a bend sa. betw. threeivy branches ppr. Ivetr. Tressure

Barry of three or and chequy arg. and az. a bend engr. within a double tressure flory counter. flory gu. Stewart, Baron of Garlies $19 \mathrm{July}$ 1607, Earl of Galloway 9 September 1623, Baron Stewart of Garlies 6 June 1796.

Barry of three or and chequy az. and arg. a bend engr. within a double tressure flory counterflory gu. Stewart, Glassermont, Scotland.

Barry of three or and cliequy az. and arg. a bend engr. within a double tressure flory countertlory within a bordure gu. STEWART, Sorbie, Scotland.

Tuns

Az. a bend engr. betw. three tuns lying fesswise or on each an owl arg. CaltoN, Babram, co. Cambridge; granted 25 June 1567. Catton. Wheels

Vert a bend betw, three wheels or. Deniy. Wings

Arg. a bend betw. three wings az. Batchelor, Easingwold, co. York. Bacheler, $V$.

Arg. a bend betw. three wings sa. BAcHeler.

1 BEND betw, or within... and in chief....

Beast.... Dog

Gu. a bend within a bordure erm. in chief a talbot pass. or. WALWYN, V*.
1 BEND betw, or within....

and in chief.....cont.

Beast cont: Dog cont.

$\mathrm{Gu}$. a bend sinister within a bordure erm. in chief a talbot pass. or. WALWyn, the Hay, co. Bre. con ; and Longworth, co. Hereford.

$\mathrm{Gu}$. a bend within a bordure erm. in chief a talbot statant arg. armed and langued az. WALWYN, Witham, Sussex.

$\mathrm{Gu}$. a bend within a bordure engr. erm. in chief a talbot pass. or. WALWYN.

Bird.... Martlet

Arg. a bend betw. four cotises sa. in chief a mart let of the last. OrLeton, Orlton, co. Salop.

Canton

Gu. a bend erm. betw. two lions ramp. or a canton of the last. Dumberton.

Arg. a bend wavy sa. betw. three cocks gu. a can. ton barry wavy of six or and az. Cocke.

Az. a bend engr. erminois betw. two crescents or a canton gu. WaTTS.

Az. a bend engr. betw. three 5.foils (or frasiers) arg. a canton gyronny of eight or and sa. Fraser, Leadclune, co. Inverness; Baronetcy 27 November 1806, quartering arg. three an. tique crowns gu.

Arg. a bend engr. az. betw. two stag's heads cabossed sa. a canton or. NEEDHAM, Kynoleton, co. Derby.

on a Canton.... Anchor

Or a bend vairy arg. and gu. betw. two cotises and as many towers az. on a canton of the same an anchor in bend sinister of the first surmounted of a sword in saltire ppr. Boger.

$$
\text { .....Beast }
$$

Sa. a bend or on a chev. arg. three mullets of the first on a canton of the second a lion ramp. gu. GuL, co. Hertford.

$$
\text { .....Bird }
$$

Arg. a bend wavy sa. betw. three cocks az. (another gu.) on a canton barry wavy of six or and az. a swan ppr. Cocke or Colie, co. Hants. .... Castle

Arg. a bend sinister betw. two cotises sa. on a canton of the last a castle of the second. Carnerd, Kent.

\section{.....Flower}

Gu. a bend betw. six crosses croslet fitcby or on a canton arg. a rose of the field. OrmsBy, quar. tered by Gore.

$$
\text { ....Head }
$$

Gu. a bend or betw. six crosses flory fitchy arg. on a canton of the second a hind's head erased ppr. Howard, Hackuey, Middlesex.

$$
\text { .....Saltire }
$$

Sa. a bend engr. or betw. two cotises arg. on a cantou of the last a saltire gu. REDHEAD.

\section{Chief}

Arg. a bend az. betw. three escucheons gu. each charged with a fess of the first a chief of the second. Aluestrey.

Arg. a bend chequy sa. and erm. betw. two lion's heads erased gu. a chief az. STEel or STEELE.

on a Chief.... Bars

Or a bend betw, two bull's heads couped sa. on a chief arg. two bars gu. surmounted by a crutched staff in bend az. Robert Holgate, Bishop of Llandaff 1537, Archbishop of York 1545 ; granted 1541.

Arg. a bend sa. within a bordure vairy or and gu. on a chief gu. two bars or. Nerbury, co. Derby. 
1 BEND betw, or within....

and in chief.... cont.

on a Chief cont. Billets

Arg. a bend chequy sa. and erm. betw. two lion's heads erased gu. a chief az. as many billets or. Steele, Scotland.

Arg. a bend ehequy erm. and ermines betw. two lion's heads erased gu. on a chief az. three billets of the field. StuedL or Stxle, Kent.

Arg. a bend chequy erm. and sa. betw. two lion's heads erased gu. on a chief az. three billets or. SteELE.

Arg, a bend compony erm. and ermines betw. two lion's heads erased gu. on a chief az. three billets of the first. Strex, $V^{*}$.

Arg. a bend compony erm. and ermines betw. two lion's heads erased gu. on a chief az. three billets or. Styelis.

Arg. a bend compony erm. and (erminois $V^{*}$.) pean betw. two lion's heads erased gu. on a chief az. three billets or. Sir John STYELL, $V$.

Arg. a bend countercompony ermines and erm. betw. two lion's heads erased gu. on a chief az. three billets arg. Sr. John Styeli, $V$.

Arg. a bend countercompony or and sa. betw. two lion's heads erased gu. on a chief az. three billets or. Steele, Ireland.

Arg. a bend countercompony sa. and or betw. two lion's heads erased gu. on a chief az. three billets of the third. STEELE, Hampstead, co. Dublin, Baronetcy 1788.

$$
\text { ..... Bird }
$$

Az. a bend arg. betw. in chief a fox pass. and in base two mullets of the second on a chief of aug. mentation or the imperial eagle of Russia. WyuE. .....Chessrook

Gu. a bend vair betw. three garbs or on a chief arg. a chessrook sa. RiccArde, co. York.

$\mathrm{Gu}$. $\mathrm{a}$ bend vairy arg. and vert betw. three garbs or on a chief erm. a chessrook sa. betw. two be. zants. Ricardo, Gatcombe Park, co. Gloucester. .... Chessronks

$\mathrm{Gu}$. a bend vair betw. two garbs or on a chief arg. three chessrooks sa. Thomas RyCARD, Heyttesfeld, co. York, $V$.

$$
\text { .... Coronet }
$$

Or a bend chequy az. and arg. within a bordure gu. a chief embattled of the last thereon an eastern crown of the third the rim inscribed "Ghuznee" in letters sa. betw. on the dexter pendent by a riband per pale vert and of the fourth a representation of the badge of the third class of the Order of the Dooranee empire and on the sinister pendent from the like riband a represen. tation of the gold medal presented for the capture of Ghuznee. Monteath.

$$
\text { ....Escallops }
$$

Az. a bend betw. two cotises and three escallops or on a chief of the last as many escallops of the first. Sir Christopher Pulter, Lord Chief Justice of Bengal ; ob. 1824.

Az. a bend betw. in chief a buck's head couped and in base a cross croslet arg. on a chief of the secoud three escallops gu. Petrie, Lewisham, Kent.

Az. a bend betw. in chief a stag's head couped and in base three crosses croslet fitchy arg. on a chief of the last three cscallops gu. Petrie, Portletham, co. Aberdeen.

Arg. a beud eugr. gu. betw. two fox's (another wolf's) heads erased ppr. on a chief of the second three escallops of the field. Power, Kil. fane; Baronetcy 15 July 1836.
1 BEND betw. or within....

and in chief....cont.

on a Chief cont. Estoiles

Arg. a lion pass. in bend betw. two cotises gu. on a chief az. as many estoiles or. Coor, London.

$$
\text { ....Fish }
$$

Sa. a bend betw. six crosses croslet fitchy arg. on a chief of augmentation of the last a representation of the fisl of Mogul barwise per pale or and vert banded vert and gu. pierced with a shaft erect headed with a crescent and by other shafts in saltire headed variously with golden balls an annulet etc. Lake, Baron Lake 13 September 1804, Viscount Lake 4 November 1807, extinct 24 June 1848.

$$
\text { ..... Fleurs-de-lis }
$$

Or a bend chequy or and sa. betw. three lion's heads erased gu. on a chief az. as many fleurs. de-lis of the field. Strue.

$$
\text { ..... Flowers }
$$

Az. a bend betw. three talbot's heads erased arg. on a chief or as many roses gu. barbed and seeded ppr. HaLL, Whatton Manor, co. Nottingbam.

$$
\text { ....5-Foil }
$$

Gu. a bend arg. betw, two escallops or on a chief of the last a 5-foil betw. two fleurs-de-lis az. Peters, London.

$$
\ldots \text { 5-Eoils }
$$

Sa. a bend vair betw. two swans or on a chief of the last three 5-foils gu. Rexmond, $W$.

$$
\text { .... Heads (Beasts) Horses }
$$

Arg. a bend gu. betw. six Cornish choughs sa. on a chief az. three horse's heads couped of the first bridled or. Gostwick, co. Bedford.

Arg. a bend gu. betw. six birds sa. on a chief or three horse's heads couped erect az. bridled of the first. Gostrke, $V^{*}$. Gostwrke, $V^{*}$. Sir John Gostrke, co. Bedford, $V$.

$$
\text { ..... Leopards }
$$

Sa. a bend erm. betw. two snakes nowed or on a chief arg. three leopard's faces gu. ADDison, Nework House, Maidstone, Kent; quartering Greenstreet.

$$
\text { .....Mullets }
$$

Arg. a bend gu. betw. three Cornish choughs ppr. on a chief of the second as many mullets of the field. Goskar.

Arg. a bend betw. two cotises gu. and six martlets sa. on a chief or three mullets of six points vert. Gostwick, Cornwall.

Arg. a bend gu. betw. two cotises sa. and six Cor. nish choughs ppr. on a chief az. three mullets or. Gostwick, Willington, co. Bedford.

Arg, a bend gu. betw. two cotises and six ravens sa. on a chief or three mullets vert. Gostwick, $V^{*}$. Gostwak, Cornwall, $V$.

Arg. a bend betw. two cotises sa. on a chief gu. three mullets of the first. ST. JoHN, Cornwall. ....Roundle

Or a bend sa. fimbriated arg. betw. three pheons of the second on a chief gu. a bezant betw. three fleurs-de-lis of the field. Longstairf. ..... Spears

Az. a bend arg. betw. three annulets or on a chief of the second as many spears of the field. Ruddiman, Scotland.

\section{Fish}

Az. a bend betw. two cotises or in chief a dolphin naiant arg. TATLOCK.

Az. a bend engr. betw. two cotises or in the sinister chief a dolphin arg. TatLock, Ewell Surrey. 
1 BEND betw. or within.... and in chief....cont.

Garb

Arg. a bend betw. two cotises sa. in chief a garb gu. Whitford, Scotland,

Arg. a bend between two cotises sa. in chief a garb of the last. Whitefoord, Blairquhau, Scotland.

Head

Az. a bend betw. two cotises and in chief an eagle's head erased or. BILLesDon, Lord Mayor of London 1483 .

Mullet

Arg. a bend betw. two cotises within a bordure engr. and in the sinister corner a mullet pierced sa. AlsPaCH.

\section{On 1 BEND}

\section{Anchor}

Sa. on a bend or an anchor of the first. Dilkes. Anchors

Or on a bend gu. six anchors in cross arg. BelListon.

Annulet

Arg. on a bend az. an annulet in the chief point or. Geffery Stukeley, $V$.

Arg. on a bend gu. an annulet or. AvaN, Wales.

Arg. on a bend sa. an annulet in chief or. Saintlo. St. Lowe, $V^{*}$. Sayntlo, $V$.

Arg. on a bend engr. sa. an annulet or. RADCLIFF, co. Leicester.

Az. on a bend or an annulet in the centre... . for diff. a label of three points arg. Sir John LEscrop, fifth son of Henry first Lord Scrope of Masham, ob. 1405 .

Az. on a bend or an annulet gu. Deane.

Lozengy arg. and vert on a bend az. an annulet in chief of two heraldic ibex heads or. Sir John YoNG, Lord Mayor of London 1466, Harl. MS. 1349.

Or on a bend az. an annulet betw. two pheons issuing out of the same as the first. Comry.

Per chief gu. and or on a bend az. an annulet or. Harington, co. Derby.

Quarterly gu. and vair on a bend or an annulet .... Constable, Dromonby, Cleveland.

Quarterly gu. and vair on a bend or an annulet and below it a crescent in chief. Consteble, Swaffham, Norfolk; quartered by Caton.

\section{Annulets}

Lozengy arg. and gu. on a bend az. two annulets interlaced in the chief point of the first. Rowys, $V$.

Arg. on a bend az. three annulets or. Bendtelly. Benteley, $V^{*}$. Bentley, $V$. John Westemore, $V$. Westremore.

Arg. on a bend gu. three annulets or. Avan, Wales. BECHaMpe, $\boldsymbol{V}$.

Arg. on a bend sa. three annulets of the field. ST. Low.

Arg. on a bend sa. three annulets or gem-rings conjoined or. HAWBERKE, co. Leicester.

Arg. on a bend sa. three anuulets or. St. LoE, $V^{*}$. St. Low. And with a label of three points gu. Sr.John Seyntroe, $\boldsymbol{V}$.

Arg. on a bend sa. fimbriated of the first three aunulets of the field. Dagnia, Sonth Shields, co. Durham; and Newcastle-on-Tyne.

Arg. on a bend engr. sa. three annulets of the field. Loadsman.

Arg. on a bend engr. sa. three annulets or. Clarkson, Kirton, co. Nottingham.
On 1 BEND..... cont.

Annulets cont.

Paly of six arg. and az. over all on a bend sa. three annulets or. Sanderson, Baron Saun. derson 19 October 17l4, Viscount Castleton 2 July 1716, Earl of Castleton 18 June 1720 , Viscount Castleton, Harl. MS. 4040, fol. 199. Saunderson, Saxby, Gainsborough, and Alford, co. Lincoln; descended from Alexander de Biddic, co. Durham 1330. Saunderson, Rous, co. Lancaster, and Addington, co. Northampton. Per fess or and sa. on a bend three annulets counterchanged. Abraham.

Quarterly or and gu. on a bend sa. three annulets of the first. Booguylon (a mistake for Bourguylon), co. Worcester. Borgilon or Bourgilon, co. Worcester.

Érm. on a bend sa. five annulets or. Keanns, Ireland.

Arg. on a bend az. six annulets or. Stockley or Storelley.

Arg. on a bend sa. nine annulets or interlaced in threes. HAWBEREE.

\section{Arrows}

Or on a bend sa. two arrows arg. WeYmouth.

Arg. on a bend az. three arrows or feathered and headed of the first their heads toward the chief. Cholwlul or Cholvile, co. Devon; granted 1613.

Arg. on a bend sa. three arrows of the field. Dawne or Dawn, co. Chester.

Arg. on a bend sa. three arrows or feathered of the first points downwards in pale of the bend. Cholwell, granted 1613, W. Cholwill, Lodesford, co. Devon; confirmed 28 November 1613.

Barry of four az. and arg. on a bend of the first three arrows of the second. Dawner, co. Chester.

Barry of tive arg. and az. on a bend gu. three arrows of the field. DAwne, co. Chester. Venables, co. Lancaster. M. Richard de Venables, $S$.

Barry of five az. and arg. on a bend gu. three arrows of the second. Done, Utkinton, Flaxyards, Duddon, aud Oulton, co. Chester.

Barry of five az. and arg. on a bend gu. three arrows or. DAwney. Donne or Doan, co. Chester.

Barry of five az. and arg. on a bend gu. three arrows or in pale with the bend feathered and headed of the second. Dawne, co. Chester, $V$. Sir John Done, Utkinton, co. Chester, $W$.

Barry of six arg. and az. on a bend gu. three broad arrows of the second. Doue.

Barry of seven az. and arg. on a bend gu. three arrows of the second. Wone, Utkinton.

Barry of nine az. and arg. on a bend gu. three arrows of the second. Done, Utkinton.

Axe

.... on a bend a battle-axe betw. a boar's head couped.... and a leopard's face.... JEDDoN. Bar

Arg. on a bend az. a bar betw. two crosses patty or. BeAupere.

\section{Bars}

Arg. on a bend gu. two bars and in chief a lion ramp. or. Richard Palinghair, $V$.

Arg. on a bend gu. three bars dancetty (indented $V^{*}$.) or. HatTon, $V$.

Arg. on a bend sa. three bars (aliter gobbons) of the first each charged with a saltorel gu. WORSYCKE.

Barry of six az. and or on a bend arg. three bars of the first. John de Routhe, $Y$. 
On 1 BEND....cont.

\section{Bars cont.}

Erm. on a bend gu. three barrulets wavy or. Getham, $V$. Gotham.

Paly of six arg. and az. on a bend gu. three bars or. Levet or LevetT.

Gu. on a bend arg. tivo bars gemel of the first. Schorcher, $V^{*}$.

Baston see Instruments (Flute)

Gu. on a bend engr. or a baston az. Euiot Eirott or Ellioti, Stobbs, co. Roxburgh, Baronetcy 3 September 1666.

Beast.... Dog

Az. on a bend embattled arg. a greyhound courant betw. two escallops sa. HoRnYold or Honniold, Hanley Castle, and Blackmore Park, co. Worcester.

$$
\text { .... Lion }
$$

Arg. (another or) on a bend sa. a demi-lion of the first hetw, tro ogresses. Allotr, co. Lancaster; and co. Lincoln.

Arg. on a bend of the first fimbriated erm. a lion pass. gu. betw. two acorns az. RoDes.

Arg. on a bend of the first fimbriated ermines a lion pass. guard. gu. betw. two acorns az. Phodes, Bellair and Shapwick, co. Devon; quarterıng Sleech, Andrew, and Cholwich. John RHoDEs, Horbury, eldest and disinherited son of Sir John RHodes, Barlborough. RHODEs or RoDes, Great Houghton, co. York; the heiress m. Busk; descended like Phodes or Rodes, Stareley. Woodthorpe, and Barlborough, co. Derby ; Baronetcy 1641, extinct 1743, the heirs m. Heathcote and Reaston; (through Francis Rodes, Judge of the Common Pleas, temp. Elizabeth ); from Gerard de Rodes, Horncastle, co. Lincoln, temp. Henry II. Sir John de Rodes, co. Nottingham, $V$.

Arg. on a bend az, a lion ramp. or. Pallingham.

Arg. on a bend compony gu. and or in the chief point a lion pass. of the last. Palingham, $\checkmark *$.

Arg. on a bend raguly gu. a lion pass. of the first. Comes, London. Goodwis, Rawmarsh. co. York; descended from GoodwIN of East Grimstead, Sussex; the heirs in. Oates and Crowder.

Arg. on a bend gu. a lion pass. or. Gallop.

Arg. on a bend gu. a lion ramp. or. PaliLingham.

Arg. on a bend sa. a lion pass. or. Duller, Duller.

Az. on a bend or a lion pass. purp. Sire Henri de Skrop, $N$.

Az. on a bend or a lion pass. in chief purp. Sir Henry Scroope, Essex, temp. Edward III, $V$.

Az. on a bend or a lion ramp. purp. Sir Henry le Scrope, $M$. Henry le Scroop, Boltun, $Y$. Monsire William le Scroope, $Y$.

Az. on a bend or a lion ramp. in clief purp. Sir Henry Scrope, Chief Justice, first Lord Scrope of Bolton, ob. 7 September 1336.

Az. on a bend or a lion pass. sa. Henry Scrope, third Lord Scrope of Masham, beheaded $5 \mathrm{Au}$ gust 1415 .

Barry nebuly (or wavy, Cotton MS. Tiberius, D, 10, fo. 887) of six arg. and az. on a bend gu. a lion pass.guard. or. Company of Haperdashers anciently called Hurrers and Milleners, London; incorporated 1447. COMPANY OF HaBerdashers, Exeter.

Barry of six or and az. on a bend gu. a lion pass. betw. two roses (arg. another) all of the first. LYNGARD or LiNGHARDE, Willingburgh, co. Northampton.
On 1 BEND..... cont.

Beast cont Lion cont.

Barry of six vert and gu. on a bend or a lion pass. betw. two 5-foils purp. Magnes.

Chequy or and az. on a bend gu. a lion pass. of the first. Brooks, Whitchurch, co. Hants.

Gu. on a bend arg. a lion pass. sa. Cynric EFEIL, Lord of Eglwys Egle, son of Madoc, last Prince of Powys-Fadog; and his descendants, Broughton, Wrexham: Davies, Eton House, Kent; and Trefynant, co. Denbigh derived (like Davies, Marrington Hall, co. Salop) from Devies, Gwysanney and Llanerch, co. Flint, a heiress m. Puleston : Eyton, Leeswood, co. Flint: Lewis, Hendrebiffa: Parry, Plas Newydd: Roberts, Nerquis: Williams, Arddynwent: Wrnne, Hartsheath, and Tower, co. Flint. DAvid, North Wales; confirmed 20 April 1581. Davies, Hanwell, Middlesex. Richard Parry, Bishop of St. Asaph 1604-23. Williams, Aswarby, co. Lincoln.

Gu. on a bend arg. a lion ramp. sa. Parry.

Gu, on a bend erm. a lion pass. sa. Davis.

Gu, on a bend or a lion pass. sa. DE Doway.

Gu. on a bend or a lion pass. guard. sa. GoLlop, North Bowood, Temple, and Strode House, co. Dorset.

Per pale arg. and az, on a bend gu. a lion pass. guard. or. BEANFORD or BEAUFORD, co. Lancaster.

\section{Beasts.... Dogs}

Gu. on a bend arg. two greybounds pass. sa. Whitehouse.

\section{....Antelopes}

Arg. on a bend gu. three antelopes pass. of the first attired or. Halliwell, Pike House, co. Lancaster; a beiress m. 1720 Beswicke.

$$
\text { ..... Bears }
$$

Gu. on a bend arg. three bears sa. Lettenington. LetTRINGTON, $V^{*}$.

$\mathrm{Gu}$. on a bend arg. three bears bendwise statant sa. inuzzled .... LetTrington, $V$.

Gu. on a bend or three bears statant sa. LutTrington.

$$
\text { .....Boars }
$$

Arg. on a bend sa. three grices pass. of the first. GrICE, Iver, co. Buckingham; and Littleton, Middlesex.

Paly of six or and gu. on a bend sa. three boars pass, arg. BurTon or BYrTon.

Paly of six or and gu. on a bend sa. three boars bendwise statant arg. Byrton, $V$.

Quarterly az. and or on a bend arg. three boars sa. Legrye, Brockdish, Norfolk.

Quarterly gu. and az. on a bend arg. three boars sa. Grrse, Norfolk. Legryde, Brockdish, Norfolk. Le Grice, Treriefe, Cornwall.

Quarterly gu. and az. on a bend arg. three boars pass. sa. armed or. GrICE, Broliedish, Norfolk. GRYs.

Quarterly gu. and az. on a bend arg. three boars bendwise statant sa. Gryse, Norfolk, $V$.

Quarterly or and az. on a bend sa. three boars pass. ol. GrYce, Norfolk.

$$
\text { ..... Cats }
$$

Arg. on a bend sa. three cats a-mountain coward tails reflexed of the first. GaWTREe, Boston, co. Lincoln.

$$
\text { .....Deer }
$$

Arg. on a bend sa. three hinds pass. .... Date, Surrey.

Sa. on a bend or three bucks trippant gu. Chevercot. 


\section{On 1 BEND..... cont.}

Beasts cont. Dogs

Arg. on a bend sa. three greyhounds courant of the first. Neale or Nelt.

Arg. on a bend sa. three talbots of the first. DALE.

Arg. on a bend sa. three greyhounds courant or. Neale.

Or on a bend az. three spotted dogs of the first. Firmiage or Fixmage, Ashfield, Suffolk.

\section{....Goats}

Or on a bend gu. three goats arg. John de Chevereston, $Y$. Chynston or Chyneryston.

Or on a bend gu. three goats pass. arg. HOLLOWELL.

Or on a bend gu. three goats pass. arg. armed of the first. Cheriston, $V^{*}$. Haleighwell, $V^{*}$.

Or on a bend gu. three goats arg. attired of the first. Chemorton. Halligwell, Holwell; quartering Norbury and Boteler, the heiress m. Braye. Haswell.

Or on a bend gu. three goats pass. arg. attired of the first. Cheritson. Halwell or Halywell.

Or on a bend gu. three goats bendwise statant arg. armed or. Cheristone alias Haleighweli, $V$.

Or on a bend gu. three goats trippant arg. attired of the first. Halliwell.

$\mathrm{Or}$ on a bend sa. three goats pass. arg. armed of the first. Atwyne, $V^{*}$. Halyweld, $V^{*}$.

Or on a bend sa. three goats pass. arg. attired of the first. Haluwell Halwell or HaLywell.

Or on a bend sa. three goats bendwise statant arg. armed of the first. ALWYN alias HALYwEL, V.

\section{.... Leopards}

Chequy or and az. on a bend gu. three leopards ramp. of the first. WARREN, co York.

Or on a bend az. three leopards nass. of the first. Firitage or Ffirmage, Awfield, Suffolls.

$$
\text { ..... Lions }
$$

Az. on a bend or three demi-lions of the first. HАMME.

Arg. on a bend az. three lions pass. in bend or Mounsyer Nicholas Hawe, $T$; but Hawte, $T$; Harl. MS. 6137.

Arg. on a bend az. three lions ramp. or. Bounne, $V^{*}$. Hacote, $V^{*}$. Hawe. Hawte, $V *$.

Arg. on a bend az. three lions ramp. palewise or. Bourne, Kent, $V$. Sr. Nicholas Hawte, $V$.

Arg. on a bend engr. gu. three lions pass. of the first. Besny or Besyn.

Arg. on a bend engr. gu. three lions ramp. of the first. John de Brentislee, $Y$. Brentisley, $V$. Brentisle Brentisley or Brentsley.

Arg. on a bend gu, three lions pass. or. LEM.

Arg. on a bend engr. gu. three lions pass. guard. or. WynisBuRY.

Arg. on a bend gu. three lions ramp. or. Rrvens.

Arg. on a bend gu. three lions ramp. palewise or. Sr. Laurence JenI, $V$. TURroplere, $V$.

Arg. on a bend engr. gu. three lions ramp. or. Brantesley or Brantsley.

Arg. on a bend sa. three lions pass. of the first. Borne. Haggar, Bourne, co. Cambridge ; and Essex.

Arg. on a bend sa. three lions ramp. of the first. Blanton, $V^{*}$. Esingold.

Arg. on a bend sa. three lions ramp. palewise of the first. Bianton, co. Lancaster, $V$.

Arg. on a bend sa. three lions ramp. guard. of the first. Blanton, co. Lancaster.

Az. on a bend sa. thrue lions pass. or. Thornton.
On 1 BEND.....cont.

\section{Beasts cont. Lions cont.}

Arg. on a bend sa. three lions pass. guard. or. Gerard, Fisherton, co. Lincoln.

Arg. on a bend sa. three lions ramp. palewise or. Sr. Nicholas Hawte, $V$.

Chequy arg. and gu. on a bend az. three lions ramp. of the first. Sire Robert de BarKesworthe, $N$. LEREsworth, Suffolk.

Chequy arg. and gu. on a bend az. three lions ramp. palewise arg. Sr. Robert LEREESWORTH, Suftolk, temp. Edward I, $\boldsymbol{V}$.

Chequy arg. and gu. on a berid sa. three lions pass, or. Chandler, London.

Chequy arg. and gu. on a hend engr. sa. three lions pass. or. CHAUndler.

Chequy az. and or on a bend gu. three lions pass. bendwise arg. Chifford, Frampton, co. Gloucester, $\boldsymbol{V}$.

Chequy az. and or on a bend gu. three lions pass. guard. arg. WARREN, $V^{*}$.

Chequy az. and or on a bend gu. three lions pass. guurd. of the second. Warren, co. York, $V$.

Chequy or and az. on a bend gu. three lions pass. arg. CLIFFORD, $V^{*}$.

Chequy or and az. on a bend gu. three lions ramp. arg. WARREN, co. York, $V$.

Chequy gu. and arg. on a bend az. three lions ramp. of the second. Barkworse.

Chequy gu. and arg. on a bend engr. sa. three lions pass. of the second. Edward Chandler, Bishop of Lichfield, \&c. 1717, Durham 1730-50.

Chequy or and az. on a bend arg. three lions pass. gu. WaRren.

Chequy or and az. on a bend gu. three lions ramp. arg. Jaan de Clifford, $E$.

Chequy or and az. on a bend gu. three lions pass. of the first. ClIFFORD.

Chequy or and az. on a bendlet gu. three lions pass. of the first. Clifford, Frampton, co. Gloucester.

Chequy or and az. on a bend gu. three lions pass. guard. of the first. WARREN, $V^{*}$.

Chequy or and az. on a bend gu. three lions ramp. of the first. Clifton, Frampton, co. Gloucester.

Chequy or and az. on a berd gu. three lions ramp. guard. of the first. WARRFin, co. York.

Chequy or and gu. on a bend az. three lions ramp. arg. Barisworth, Wyton, co. York.

Chequy or and gu. on a bend engr. sa. three lions pass. guard. of the first. Candeler, co. Hants.

Erm. on a bend az. three lions pass. guard. or. Borne, Kent.

Erm. on a bend az. three lions rainp. or. John de Borne, A; Harl. MS. 6137. Bourne, Kent, $V$.

Erm. on a bend gu. three lions .... reguard. or. Borne, Kent.

Erm. on a bend gu. three lions ramp. or. Browne.

Erm. on a bend gu. three lions ramp. guard. or. Barney, Kent.

Gir. on a bend arg. three lions ramp. sa. Sr.John Huntingfeld, Norfolk; temp. Edward I, $V$. Sire Wauter de Hontingfeld, $N$. John de Huntingfeild, $X, Y$. Midleton, co. Chester; the heiress m. Massey, Harl. MS. 1424.

Gu. on a bend or three lions pass. sa. HaGAR.

$\mathrm{Gu}$. on a bend or three lions ramp. palewise sa. Mongomery, $V$.

Or on a bend az. three lions pass. arg. EmMErson. Or on a bend az. three lions pass. guard. of the first. Finhage, Awfield, Suffolk. 


\section{On 1 BEND.... cont.}

Beasts cont. Lions cont.

Or on a bend az. three lions ramp. of the first. Viens.

Or on a bend sa. three lions pass, arg. HaGAR, Bourne, Essex; grantcd 1615.

Or on a bend sa. three lions pass. guard. of the first. Brantwayte.

Paly of six arg. and az. on a bend or three lions pass. gu. Solers, co. Brecknock.

Per fess indented or and vert on a bend engr. az. three lious pass, arg. Eurerson, Foxton, co. Durham; granted 1535. Emersun, Tempo, co. Fermanagh.

Per pale arg. and az. on a bend gu. three lions pass. guard. or. BEANFORD or BEAUFORD, co. Lancaster.

Per pale arg. and az. on a bend gu. three lions pass. guard. in pale or in the upper part of the bend a label of three points as the second charged with nine fleurs-de.lis or. M. John Beaufort, $S$; $i$. e. Jolun de Beaufort eldest son of John of Gaunt betore legitimation. BEAUford, $V$.

Per pale arg. and az. on a bend gu. three lions pass. guard. or a label of three points az. bezanty. Beaufond.

Quarterly arg. and sa. on a bend gu. three lions pass. cr. Hubart HUbert or HubBend, Birchanger, Essex; granted May 1578.

Quarterly arg. and sa. on a bend gu. three lions ramp. or. HUBERT, $V^{*}$.

Quarterly arg. and sa. on a bend gu. three lions ramp. palewise or. HuBbard, $V$.

Quarterly gu. and or on a bend arg. three lions pass, az. Perry or Pery, Walter, co. Devon.

Quarterly gu. and or on a bend arg. three lions ramp. of the first. HoNTINGFIELD.

Quarterly gu. and or on a bend arg. three lions pass. ppr. PERRY; quartering Watlington.

Quarterly gu. and or on a bend arg. three lions pass. sa. Pery, Baron Glentworth 21 May 1790, Viscount and Earl of Limerick 11 February 1803, Baron Foxford 11 August 1815.

Quarterly gu. and or on a bend of the first three lions pass. az. PERY, West Waters, co. Devon. Quarterly or and gu. on a bend sa. three lions pass. arg. Percy.

Quarterly or and sa. on a bend gu. three lions ramp. of the first. Hubert, Sunbury, Mid. dlesex.

\section{..... Ounces}

Arg. on a bend sa. three ounces pass. or. WATONE. ....0xen

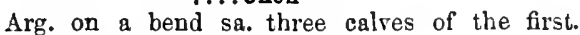
VEALE, co. Chester, 1716.

Arg. on a bend sa. three calves pass. of the first. Veale, quartered by Lane.

Arg. on a bend sa. three calves statant of the first. Robert le VEL, $A$; or le VeLE, $A, H a r l$. MS. 6137.

Arg. on a bend sa. three calves or. VeLE, $V^{*}$.

Arg. on a bend sa. three calves pass. or. TEALE, Over, co. Gloucester. WELKE.

Arg. on a bend sa. three calves bendwise passant or. Sr. Peirse Vele, $V$.

$$
\text { ..... Sheep }
$$

Or on a bend gu. three rams reguard arg. RAMry.

Or on a bend sinister gu. three rams arg. Haleighweld, glassin Stoke Dabernon Church. .... Orchins

Erm. on a bend az. thr'ee hedgehogs or. Harris, Windsor, co. Berks.
On 1 BEND.... cont.

Beasts cont. Wolves

Arg. on a bend sa. three wolves of the first. DaLE. Arg. on a bend sa. three wolves pass. of the first. Jolin Dale, D.C.L., $V$. Deale, $V$.

Arg. on a bend sa. three wolves pass. or. Bentley, Brentwood, Essex. Bentley, Birch House, Bolton, descended through BEnTLEy, Bentley Hall, Bury, from BentLEY, co. Lancaster. Bells

Arg. on a bend sa. three hawk's-bells or. Belton, $V^{*}$. Bend

Arg. on a beud indented az, a bendlet or. BoDyHa

Arg. on a bend engr. az. another or. Brescy, V. Br.zssy, $V^{*}$.

Az. crusily arg. on a bend or another gu. Richard de Estone, $E$.

Az. crusily or on a bend of the last another gu. Richard de Stone, E, Harl. MS. 6137.

Gu. on a bend engr. or a baston az. Eliot Eliott or Elliots, Stobbs, co. Roxburgb; Baronetcy 3 September 1606.

Gu. on a bend indented arg. another of the same az. Sire Huge de Fnenes, $N$, but see Saltire.

Gu. on a bend indented or another of the same az. Sire Walter de Frenes, $N$, but see Saltire. Gu. on a bend or another sa. charged with two mullets of the second pierced as the first alteruately with as many swans arg. M. Robert Russelt, $S$.

Gu. on a bend vert another or. O'Dunis, Harl. MS. 4039 , fo. 155 .

Or on a bend gu. another az. (? Pitchen.)

Quarterly erm. and or on a bend engrailed gu. another plain arg. charged with three 3-foils sable. Benson. Benson, Baysbrown, 1546, Hawkshead, and Lodge Lane, co. Lancaster; and Parkside, co. Westmoreland.

\section{Bends}

Sa. on a bend wavy arg. three bendlets wavy az. Standen, $V$.

Billets

Chequy arg. and gu. on a bend az. three billets or. Brakelery, $V$. Brakentey, $V$.

Chequy erm. and gu. on a bend az. three billets or. Brackley, $V^{*}$. Brakeley. Brakley, $V$.

Chequy gu. and arg. on a tend az. three billets or. Brackley, $V^{*}$. Parkeley.

Chequy gu. and erm. on a bend az. three billets or. BarkLEY.

Erm. on a bend az. three billets palewise each charged with a torteau. LAFFEr.

Lozengy erminois and sa. on a bend wavy gu. three billets arg. BuundeLL, Deysbrook, West Derby, co. Lancaster; quartering Hollinshead. Sa. on a bend or three billets of the first. SнIт, $W$; quartered by Viell.

Arg. on a bend gu. six billets palewise of the shield as the first. Brette: $V$.

Gu. on a bend arg. seven billets sa. M. Thomas Morrewes, $S$.

Gu. on a bend arg. seven billets one two one two and one sa. Moreyns, $T^{*}$.

Gu. on a bend arg. seven billets palewise of the bend sa. Sr. de Moryens, $V$.

Arg. on a bend gu. nine billets five and four of the first. BRETT.

Arg. on a bend gu. billets of the first. Bretr.

Az. on a bend arg. billets sa. Morieux, Suffolk.

Gu. on a bend arg. billets of the first. Mrrenouse, Brownslade, co. Pembroke; descended from Minehouse, Miresike, co. Cumberland. 
On 1 BEND.... cont.

Billets cont.

Gu. on a bend arg. billets sa. Morow.

Per chief or and az. on a baston urg. billets sa. GOLDWELL, $V *$.

Bird ..... Chough

Gu. on a bend arg. a Cornish chough in the dexter chief point ppr. MARDEN, Marden, co. Hereford; and London.

$$
\text { .... Eagle }
$$

Az. on a bend arg. an eagle displ. sa. London; and Sussex; granted 1591.

Vaury arg. and sa. on a bend gu. an eagle or. Mancester or Manceester, co. Warwick. ..... Martlet

Gu. on a bend erg. a martlet sa. FoLIot.

Gu. on a bend arg. a maltlet in the dexter point sa. Foliot, Bromyard, co. Worerster.

Gu. on a bend or a martlet sa. J'ugin.

Paly of eight or and gu. on a bend sinister az. a martlet betw, two mullets arg. HAck, Scotland.

Quarterly gu. and or on a bend arg. a martlet betw. two 5 -foils of the first. SouthaLL. Birds

Gu. on a bend sa. fimbriated or two pierced mullets and as many ducks arg. membered of the first alternately. Sr. Robert Russer., $V$.

Arg. on a bend sa. three birds of the first. Cariges, $V^{*}$. Danby, co. York.

Erm. on a bend gu, three brrds vert. Danvers, co. Nortbampton; and co. Oxford.

Gu. on a henù arg. three burds az. Steplien Jatrington, Bishop of St. Davids 1415, Cuichester 1417.8.

Gu. on a bend or three birds sa. DYNe, Northumberland.

Paly of six arg. and sa. on a bend gu. three hirds or. Bunner, Birthwaite, c'o. York.

Per bend gu, and vert on a bend indented arg. three birds sa. Dickinson.

Sa. on a bend sinister arg. three birds of the first. JIVE, $V^{*}$.

\section{....Canaries}

Sa. on a bend or tluree canary birds ppr. KinneIr, that Ilk.

\section{.... Choughs, Daws, and Ravens}

Arg. on a bend gu. three ravens in pale of the field as the first. Cariges, $V$.

Arg. on a bend gu. three magpies ppr. Canhey.

Az. on a bend engr. arg. three daws ppr. Dawson, Newcastle.

Az. on a hend engr. arg. three ravens ppr. DAwson, Newcastle.

Az. on a bend engr. arg. three daws sa. Dawson, $V *$.

Az. on a bend engr. arg. three ravens close sa. Dawson, $V$.

Gu. on a bend arg. three ravens ppr. Dive, co. Northampton.

Gu. on a bend arg. three Cornish choughs ppr. Pontington, Baruby-Dun, co. York.

Gu. on a bend arg. three ravens sa. beaked and membered gu. Portington, Barnby of the Dean, co. Yurk.

Gu. on a bend arg. tluree Cornish chougbs sa. I'ANS, Whitstone; descended from Robert I'ANs, Master of the Ordnance to Queen Elizabeth.

Gu. on a bend or three Cornish choughs ppr. Brabasson or Brabazon.

Per bend gu. and vert on a bend dancetty arg. three ravens sa. Craycroft, co. Lincoln, $r$.

Per bend vert and gu. on a bend dancetty or three ravens ppr. Craycroft, co. Liucoln.
On 1 BEND.... cont.

Birds cont. Choughs, Daws, \& Ravens, cont. Per pale (vert and) gu. on a bend indented arg. three crows sa. Craycroft, $V^{*}$.

Sa. on a bend three Cornish chouglis ppr. Portyngton, Portyngton in Howden, co. York.

Sa. on a bend arg. three ravens ppr. Dive.

Sa. on a bend sinister arg. tbree ravens of the first looking to the sinister. Drve, $V$.

$$
\text { .... Cocks }
$$

Arg. on a bend of the first fimbriated sa. three eocks looking behind of the secoud. HoughBrig, $V^{*}$. Hovghbrige, co. York, $V$.

Quarterly sa. and arg. on a hend of the last three cocks gu. Hoov, Honridge, Scotland.

$$
\text { .....Cormorants }
$$

Gu. on a bend wavy arg. three cormorants sa. beaked and membered or. Sr. Robert READE, (? co. Lincoln) , $V$; Puisne Justice of the King's Bench 1496, Chief Justice of the Common Pleas 26 April 1507.

$$
\begin{aligned}
& \text {... Crows see Choughs } \\
& \text {... Daws see Choughs } \\
& \text {... Doves see Pigeons } \\
& \text {....Ducks, Drakes, etc. }
\end{aligned}
$$

Arg. on a bend gu. three slieldrakes of the first. Dr. Gilbert Sheldon, Ashmol. MS., Wood, F, 33, fo. 93 , co. Stafford. Sheldon, $V^{\prime}$.

$\mathrm{Gu}$. on a bend arg. three shovelers sa. READE, co. Lincoln. But three teals sa. Pontington. $\mathrm{Gu}$. on a bend nebuly arg. three shovelers sa. membered of the first. REEDE, Wembary, co. Devon; Visitation 1620.

Gu. on a bend wavy arg. three shovelers sa. Rede, Keut. But beaked or. REad, $V^{*}$.

Gu. on a bend or three shovelers sa. membered of the first. ReEde.

$\mathrm{Gu}$. on a bend sa. three ducks arg. (a mistake for) Russeil.

Or on a bend sa. three ducks arg. Russell, $V *$.

$$
\text { ..... Eagles }
$$

Arg. on a bend az. three eagles displ. or. Dallamer. Sr. Hugh de la Mare, temp. Edward III, $V$. Delamaite or Delaneere, Essex. Sire Jolian de la Mane, $N$. Si. Thonias de la Mare, Essex, $V$. Delaware. Guising. Gymisying Gyslyng or Grssinge. Heydon.

Arg. on a bend az. three eagles displ. the bodies bendwise sinister or. Gissing. Gissinge, $V$. Arg. on a bend az. three eagles displ. or armed az. M. Thomas Gissyng, $S$.

Arg. on a bend gu. three eagles of the first. Gossinge or Gosson.

Arg. on a bend gu. three eagles displ. of the first. Hallington, co. Cambridge. Kilwarby. Pave, $V$. Paven, $V$. Pavent, $V$.

Arg. on a bend gu. three eagles displ. or. Phillip de Abrington, $A$. Robert Abington, co. Cambridge, tenm. Edward J, $V$. ABbington, Dowdeswell, co.Gloucester. Babington, $V$. Sr. Richard de Habington, $V$. Habington, Henley, co. Worcester. Halampton. Sire Robert de Halontone, $N$. Robert de Halwetun, $G$. Harrington. John Panent, $Y$. John Pavent, $X$. Monsire de Pavent, $Y$.

Arg. on a bend gu. three eagles displ, or an annu. let of the second. ABINGDon or ABINGton, Dowdeswell, co. Gloucester; granted 1595 . Anthony Babington, Gentleman Usher to Queen Elizubetlı; granted by Cooke; $V$. 


\section{On 1 BEND.... cont.}

Birds cont. Eagles cont.

Arg. on a bend gu. three eagles displ. or in chief a crescent of the second. HABINGDON, co. Hertford.

Arg. on a bend gu. three eagles displ. in pale of the shield or. William de Gabon, $F$.

Arg. on a bend gu. three eagles displ. or beaked and legged az. ABINGDON, Abingdon, co. Cam. bridge; Wichenford, Brokhampton, and Hindlip, co. Worcester; the lieiresses m. Compton, Branthwaite, and Fountain.

Arg. on a bend sa. three eagles displ. of the first. Erneley, co. Wilts. Evell. Mawley, co. York. Porellex, $V$.

Arg. on a bend sa. three eagles displ. or. John de Boltune, G. Earnley, Sussex. Ernle, Conock, and Brimslade Park, co.Wilts; branches, through ErnLe, Etchillampton, co. Wilts; Brronetcy 2 February 1661 , extinct 20 December 1787 (the herress m. Drax); from Ennle, Frnle, Sussex ; and Whetham, co. Wilts; temp. Henry III; quartering Finnamore and Kyrle. Erniey (not Enveley), co. Wilts. Houghton, Gunthorp, Norfolk. Howghton, $V$. Mancourt. Warrington. Tearly, co. Devon.

Arg. on a bend sa. three eagles displ. the bodies bendwise sinister or. Emesiex, $V$. Ernele, $V^{*}$. Evell, $V$. Erneley, $W$.

Arg. on a bend sa. three eagles displ. with two necks or. Creneley. Ernell, $W$. Frnell (sic), $V$.

Arg. on a bend rert three eagles displ. or. Sir John de Hansted, $L$.

Az. on a bend or three eagles displ. gu. Amory. Ammory, co. Oxford. Holton, $V$.

Az. on a bend or three eagles displ. sa. WoLSEY, curate of Hornsey 1664.

Az. on a bend or three eagles displ, sa. armed gu. Ajiony, co. Oxford. AMdaRY, $V$.

Az. on a bend or three eagles sa. armed gu. Axvony.

Barry of six arg. and sa. on a bend gu. three eagles displ. ol. Papenham, $V *$ Pappenham, $V$.

Barry of six or and sa. on a bend gu. three eagles displ. or. Pakenharr.

Barry neibuly of seven arg. and sa. on a bend gu. three eagles displ. of the first. Grandon, $V^{*}$.

Chequy or and az. on a bend gu. three eagles displ. arg. HAWARD, Cornwall. Sire Robert Hereward, $N$. Sr. Robert Herwarde, co. Cambridge, temp. Edward I, $V$. Harwood, HERWARD, HORWODE, and WHORWOOD.

Chequy or and az. on a bend gu. three eagles displ. with two heads arg. Herward, co. Sulop; and Odiam, co. Hants.

Chequy or and az. on a bend gu. three eagles displ. of the first. Harward, Cornwall; and co. Worcester. Herward.

Erm. on a bend gu. three eagles displ. arg. Bagshote.

Erm. on a bend gu. three eagles or. BaDger or BagehotT, co. Cambridge, co. Gloucester, and co. Leicester.

Erm. on a bend gu. three eagles displ. or. BAcks, Trumpington, co. Cambridge. Badger, Hall Place, Prestbury, co. Gloucester. Monsire Bagot, $Y$. John BagotT, $Y$. Sir William Bagotr, $L$. or Bagehot, N. Bacot or Bagor.

Erm. on a bend gu. fimbriated engr. or thi ec eagles displ. arg. SELMian; granted 1789.

Erm. on a bend sa. three eagles displ. arg. Sr. William BaGHoTt, co. Canbridge, $V$.
On 1 BEND..... cont.

Birds cont. Eagles cont.

Erm. on a bend sa. three eagles displ. or. SELMAN, Middlesex; and Harrington Ludlow, co. Salop. Erm. on a bend flory counter-flory sa. three eagles displ. or. Baddiford, Dartmouth, co. Devon.

Gu. on a bend arg. three eagles displ. az. STROTHER.

Gu. on a bend arg. three eagles displ. sa. Southenne, Fitts, co. Salop; granted or con. firmed 1929.

$\mathrm{Gu}$. on a bend arg. three eagles displ. pointirg to the sinister sa. Sotheron, $V^{*}$. Sotherton, $J^{*}$.

Gu. on a bend engr. arg. three eagles displ. the bodies bendwise sinister sa. SOTHERON, $W$. Sotherton, $\boldsymbol{V}$.

Gu. on a bend arg. three eagles displ. vert. Stroder, $V$. Thomas Strother, $V$. Strodet.

Gu. on a bend arg. three eagles displ. vert armed gu. M. Thomas de Strothere, $S$. Thomas STrother, $X$.

Gu. crusily arg. on a bend erm. three eagles displ. of the first. Brown or Browne, London; and Norwich.

Or on a bend gu. three eagles displ. arg. LoRRaIne, $Z, 299,524$.

Or on a bend engr. gu. three eagles displ. of the first. BACHECOT.

Or on a bend sa. three eagles displ. arg. ManLey. Robert de Maulei, $G$, or Maulee, $N$. Mauley. Sr. Robert Mawley, co. York, temp. Edward I, Y.

Paly of six arg. and az. on a bend gu. three eagles displ. of the first. Sr. William GraUntson, $Q$.

Pyly of six arg. and az. on a bend gu. three eagles displ. or. Grandison or GraNDSON, co. I ancaster. Sr. William Grandeson, temp. Edward I, boin in Burgundy, $V$. Grandison, $V^{*}$. Grannson. Sir William Grauntson, $I$; or Grantson, Q. Harl. MS. 6595.

Paly of six arg. and gu, over all on a bend of the first three eagles displ. of the second. LAANGFORD, Bedford, 1607.

Paly of six arg. and sa. on a bend gu, three eagles displ. or. Papenhan, $V$.

Paly of six arg. and vert on a bend gu. three eagles displ. or. Grandison, temp. Henry III.

Paly of six gu. and or on a bend sa. three eagles displ. arg. LANGFORD, Selford, co. Bedford; granted March 1607.

Paly of six or and sa. on a bend gu. three eagles displ. of the first. PAPENHAd, $V^{*}$.

Paly arg. and az. on a bend gu. three eagles displ. or. Sr. William G'ntson, $H$; or de Grantson, $K$; or de Graunson, $N$. Sire Piers de Graunsori, 0 .

Quarterly arg. and az. on a bend sa. three eagles displ. and armed of the first. Blonre or Blunts.

Quarterly arg. and gu. on a bend sa. three eagles displ. or. Baxted, Essex. M. Thomas Blount, $S$. Sr. William Blount, Essex, $V$. Sr. Hugh Blounr, temp. Edward I, V. Sire Huge le Blount, N. Hue le Blunt, $E$. Blount or Blunt, Essex. Boxsted, Essex.

Quarterly arg. (az. in $V^{*}$.) and arg. in the second and third a chev. sa. charged with three mullets of the first orer all on a bend sa. as many eagles displ. arg. Houghton, $V$. How H TON, $V^{*}$. Quarterly or and az. on a bend of the second three eagles displ. of the first. HonsenIIVDEN, $W$. Horsedyden, $I^{*}$. 
On 1 BEND.....cont.

Birds cont. Eagles cont.

Quarterly or and gu. on a bend sa. three eagles displ. arg. BLOUNT.

Sa. semy of crosses croslet or on a bend gu. tliree eagles displ. of the second. Beston.

Vair on a bend gu. three eagles displ. or. Grandon.

Vairy arg. and sa. on a bend gu. three eagles or. Sire Symou de Maincestre, $N$. Mancesten or Manchester, co. Warwick. Sir Symon de Manchester or Mauncester, $L$.

Vairy arg. and sa. ou a bend gu. three eagles displ. of the first. Sr. Johu Grandon, co. Warwick, temp. Edward I, $V$.

Valry arg. and sa. on a bend of the second three eagles displ. or. Grandon, co. Warwick.

Vairy or and sa. on a bend gu. three eagles displ. of the first. MANEster.

$$
\text { .....Falcons }
$$

Or on a bend az. three falcons mounting arg. jessed and belled of the first. DEGGE, co. Derby ; and Callow Hill, co. Stafford.

Or on a bend az. three falcons volaut of the first with a crescent for diff. Simon DEgG, co. Derby, 1716.

\section{....Magpies see Choughs .....Martlets}

Arg. on a bend az. three martlets of the first. NewaLd, Cargow, Scotland.

Arg. on a bead az. three martlets or. HARDING, Upcot, co. Devon. HARDING, London, $V$. Harding, Newtowne, co. Wilts.

Arg. on a bend gu. three murtlets of the field. Burdett, Rowell. Handing, Ireland.

Arg. on a beud gu. three martlets or. Bracester. Bronton. (?) Clyuerowe. Danvers, co. Wilts. Danvers, $V^{*}$. Davers, co. Wilts.

Arg. on a bend gu. tbree martlets or winged vert. Sr. Thomas Danvers, $V$.

Arg. on a bend sa. three martlets of the first. Bileston. Bongheron. Boughton, co. York. Ditton. Hinton, co. Salop.

Arg. on a bend sa. three martlets of the first in chief a crescent of the second (? for diff.). Anne, Exeter, $V$. Anne, co. Northampton; co. Oxford.

Arg. on a bend sa. three martlets or. AnNe, co. Nortbampton. Boaton. Broughtor, Kent, $V$. Curson, Suffolk. Davers, Rougham, Suffolk. Entwistle, co. Leicester. Harding, London. Sire Johan de Hasthorpe, $O$. Helion, Asseriston, co. Devon; extinct temp. Edward I. Maleysell, $V^{*}$. Sr. .... Maloysell, $V$. Northage, London.

Arg. on a bend vert three martlets or. DAvers, co. Warwick.

Az. on a bend arg. three martlets gu. Boteler. Boteller, $V$.

Az. on a bend engr. or three martlets gu. DAwson, Ireland; London; and Allan Bank, Grasmere, Westruoreland. Dawson, Baron Dartrey 28 May 1770, Viscount Cremorne 9 June 1785, extinct 1 March 1813; Baron Cremorne 7 No. vember 1797; Barou Dartrey 1847; quartering az. three torches erect ppr.

Az. on a bend or three martlets sa. Daniell. Farrington.

Az. on a bend dancetty or three martlets sa. Crecroft, Crecoft.

Barry of six arg. and az. on a bend gu. three martlets of the first. RoTHERHELD.
On 1 BEND.... cont.

Birds cont. Martlets cont.

Barry of six arg. and az. on a bend gu. three martlets or. GREY, $V$.

Barry of six or aud vert on a bend gu. three martlets of the first. Poynes, Sussex.

Chequy arg. and sa. on a bend gu. three martlets or. Partridge.

Erm. on a bend az. three martlets or. CHEyney, Tuddington, co. Bedford; Kent; and Woodley, co. Berks.

Erm. on a bend gu. three martlets or. Cheynex.

Erm. on a bend sa. three martlets arg. Curson. Gravesend, $V *$. Graveshend, $V$.

Erm. on a bend sa. three martlets or. The original coat of Cheney, Sherland, Sbeppey, Kent. Cheney, Sussex, $V$. Sir Roger Cheney, West Woodhays. Cheney, Tuddington, co. Bedford ; Kent; and Woodley, co. Berks. Gravesend or Grayeshend, Kent.

Gu. on a bend arg. three martlets sa. AuDBY. Brabson, Harl. MS. 160)3. Eudeby. Williem Guyngton, $Y$. Ovington, $V$. Portington, co. York, $V$. Portington, co. Lincoln and co. York. Quinton, $V$. Quyntin, $V^{*}$. Quyntine, Nortl ampton, $V$. Quinton or Quintin. WYNN.

Gu. on a bend or three martlets sa. ANDBY ANDELBY or ANDERBy. AUDBY, $V$. AUdeby. Brabason, $V^{*}$. Sir Roger BrabazoN, $N$. Sr. Roger Brabazon, co. Leicester, temp. Edward I, $V$. Brabazon, Rath House, co. Louth; descended through Brabazon, Callistown, from the first Lord Brabazon. Brabazon, Baron of Ardee 1618, Earl of Meath 1627, Harl. MS. 4040 , fo. 63, Baron Chaworth 1831. Collens, $V$. Coulins. ODEBY, $V$.

Gu. on a bend engr. or three martlets .... Dawson, London.

Or on a bend az. three martlets of the first. Childroy. Clyderoyce.

Or on a bend gu. three martlets arg. Chesildon.

Or on a bend sa. three martlets arg. Cunson. ONscotT or ONSLeTt.

Paly of three gu. and sa. on a bend or as many martlets of the second. BLAKE, Suffolk, $V$.

Paly of six arg. and az. on a bend gu. three martlets or. BURdTE, $V$. Rotherfieds, $V$.

Paly of six arg. and az. on a bend or three martlets gu. CHernell.

Paly of six arg. and sa. on a bend gu. three martlets or. Burdet, Burthwaite, co. York; and Acomb, near York; Baronetcy 1665. PrICHARD, Osgodby, assumed $31 \mathrm{July} 1781$ the name and arms of Burdet. BURDEITE. Harl. MS. 1392. (? Draunsfaeld, Stubbs Waldyng).

Paly of six or and az. on a bend gu. three martlets arg. Rotherfiet.D.

Paly of six or and az. on a bend gu. three martlets of the first. Sir Richard Martin, Lord Mayor of London 1589.

Paly of six or and gu. on a bend sa. three martlets of the first. Elton, Ledbury, co. Hereford. Quarterly arg. and az. on a bend gu. three martlcts or. LE Gros.

Quarterly arg. and az. on a bend sa. three mart. lets or. Legoos, Crostwight, Norfolk. Gros, $V$. Sire Renaud le Gros, $N$. Grosse, Cam. borne, Corrwall; the heiress m. Buller.

Quarterly arg. and sa. on a bend gu. three martlets of the first. Carnus, Astwitt, Westmore. land. LACY. 
On 1 BEND.... cont.

Birds cont. Martlets cont.

Quarterly arg. and sa. on a bend gu. three martlets or over all a label of as many points .... Lacr, $V$. The label of the fourth, Lacr. The label of five points of the last each charged with an ermine spot of the second. Lacy, Walshanin-the-Willows, Norfolk; and Suffolk.

Quarterly or and az. on a bend sa. three martlets of the first. Grosse, Camborne, Cornwall ; the heiress $\mathrm{m}$. Buller.

Quarterly or and az. on a bend vert three martlets of the first. Eardery. PetTie Petty or Petre, Tetsworth, and Henley, co. Oxford: and Huntingdon, co. Warwick. YaRdLy. YARDELEY, co. Warwick. And in chief a 3-foil slipped of the second. Nicholas PETTY, Warwick, $V$.

Quarterly or and sa. on a bend ga. three martlets of the first in chief a label of five points erm. RACY, Suffolk; but ? LACY.

Sa. cn a bend arg. three martlets of the first. (Nornel, a mistake for) Norver, that Ilk.

Vert on a bend dancetty arg. three martlets sa. Cracroft, Hackthorn, co. Lincoln. Craycroft, co. Cambridge; and co. Lincoln.

$$
\ldots .0 \text { wls }
$$

Arg. on a bend gu. three owls of the first. Tillington. Trllington, $V$.

Arg. on a bend gu. tbree owls or. Tenterden, Kent.

Arg. on a bend sa. three owls of the first. Flemyng. Sir John Savile, Savile Hall, Methles, Thribers, and Darrington; herresses $m$. Finch, Leech and Sotheron. Savile, co. Lin. coln; and Darton Grange, co. Nottingham. Savile, Baron Pollington 1753; Viscount Pollington and Earl of Mexborough 1760. SariLL, $V^{*}$. Savill, Rufford, co. Nottingham; and Thornbill, co. York; Baronetcy 24 June 1611 , Baron Saville of Eland and Viscount Halifax 13 January 1688, Earl of Halifax $16 \mathrm{July} 1679$ Marquis of Halifax 22 August 1682 ; extinct 1700. Savile, Copley, co. York, $Z, 362$. Sr. John Sayveli, $V$. M. John Sayvild, $S$. And with a martlet for diff. SAviris, Humby, co. Lincoln. But with a crescent for diff. SariLe, Copley, co. York. Savile, alias Barkston, Howley, co. York; Baron Savile of Pontefract 21 July 1628, Viscount Savile 11 July 1628 , Earl of Sussex 25 May 1614; extinct 1671. But with a 3 -foil slipped sa. for diff. SAvmE, Blaby, co. Leicester. But with a label of three points gu. M. John SAYviLL, S. But with a mullet for diff. SAvELL, Barraby, co. Lincoln. Savil, , Wath, co. York, quartering Fleming.

Arg. on a bend sa. three owls of the first a baton in bend sinister gu. SAFELI, York.

Arg. on a bend sa. three owls ppr. Savrue, Savile in Dodsworth, co. York.

Or on a bend sa. three owls of the first. Stradley, $V$.

$$
\text { ..... Pheasants }
$$

Arg. on a bend az. three pheasants or in chief a crescent (? for diff.) of the second. OGILL, Poppill, Scotland.

$$
\begin{aligned}
& \text {.... Pies see Chonghs } \\
& \text {.... Pigeons }
\end{aligned}
$$

Arg. on a bend az. three doves of the first with olive branches in their mouths ppr. THOMASON, co. Chester.

Arg. on a bend sa. three doves close of the first. Pigeon, Deptford, Kent.
On 1 BEND.... cont.

Birds cont. Pigeons cont.

Arg. on a bend sa. three doves of the first col. lared and membered gn. Curson, Norfolk.

Arg. on a bend sa. three doves of the first mem. bered gu. PAGE, Kent.

\section{....Popinjays}

Arg. on a benà sa. three popinjays or. Cunzon.

Arg. on a bend sa. three popinjays or beaked and legged gi. Sr. Robert Corson, Kedleston, co. Derby, $V$.

Arg. on a bend sa. three popinjays or collared gu. Roper-Curzon, Baron Teynham 1616; quartering Roper. Cursham or Curson. Curzon, Baronetcy 1611; Baron Scarsdale 1761.

Arg. on a bend sa. three popinjays or collared and membered gu. Curson, Kedleston, co. Derby. And in the sinister chief a crescent of the last for diff. M. Roger Curson, $S$.

$\mathrm{Az}$. on a bend arg. three popinjays vert beaked and legged gu. Curson.

Gu. on a bend arg. three popinjays vert. Mon. sire de Dune, $Y$.

$$
\begin{aligned}
& \text {... Ravens see Chonghs } \\
& \text {.... Sheldrakes see Ducks } \\
& \text {.... Shovelers see Ducks } \\
& \text {.... Swans }
\end{aligned}
$$

Arg. on a bend wavy az. three swans of the first. Dawes, London; and Norfolk.

Arg. on a bend gu. three swans of the first. Sheldon, $V$.

Arg. on a bend gu. three swans or. Sheidon.

Arg. on a bend engr. gu. three swans ppr. Clark, Bishop-Wearmouth, co. Durham.

Arg. on a bend sa. three swans close of the first. Hester. Russeld, co. Wilts.

Arg. on a bend sa. three swans ppr. Russell.

Arg. on a bend sa. three swans ppr. membered and armed gu. Rossen, Kentchurch, co. Hereford.

Or on a bend sa. three swans arg. Russell, $V$.

$$
\text { .... Teals see Ducks }
$$

Gu. on a bend arg. four eagles displ. vert. Baxter, Northumberland.

$$
\text { ..... Bougets }
$$

Arg. on a bend az. three water bougets or. Sr. Robert Joce, $V$. JoRCEy or JoRcie. Monsire Robert JoRCE, $Y$. Robert JoRce E, $Y$.

Arg. on a bend az. three water bougets or a crescent of the second. Dryton, $V^{*}$. Drytun, $V$. Arg. on $a$ bend gu. three water bougets or. JOCE. John Joos, $V$.

Arg. on a bend sa. tbree water bougets of the first. Boterford, co. Devon. Sr. Richard le Roos, $V$.

Arg. on a bend vert three water bougets of the first. Boterwike.

$\mathrm{Gu}$. on a bend wavy arg. three water bougets sa. Faueis, Cornwall.

Or on a bend gu. three water bougets arg. Cheverston. Chimston, $V^{*}$. Chinston. Chymerstone, $V^{*}$. Sr. John Chym'sron, $V$. Paly of six arg. and gu. (but $V^{*}$ gu. and arg.) on a bend sa. three water bougets of the second. Sr. .... de Birton, $V$. Byrton, $V^{*}$.

Paly of six or and gu. on a bend sa. three water bougets arg. M. John de Brrton, $S$. Monsire de Brrton, Y. Bytron.

Paly or and gu. on a bend sa. three water-bougets arg. John de Birton, $Y$. 


\section{Buckles}

On 1 BEND.... cont.

Arg. on a bend az. three buckles of the field. Simrling, Craig, Scotland.

Arg. on a bend az. three buckles or. LEsLIE, Scotland. Leshie, Baron Leslie and Ballen. breich before 1458, Earl of Rothes 1458; quartering Abernethy. LESLIE, Ballybay, co. Monaghan, and Leslie House, co. Antrim; with the same quarteriug; removed from Scotland to Ireland 1614. LesLy, Lord Lindores 25 December 1600 , extinct ....; with the same quartering: over all an escucheon gu. charged with a castle triple-towered arg. masoned sa. for the title of Lindores. Walter LESLIE, Lord of Ros 1867 , quarterly with .... three lions ramp..... for Ros, Seal, being the earliest instance known of quartering in Scotland. Stiring, Keir, Scotland.

Arg. on a bend az. three buckles or; quarterly with arg. a lion ramp. gu. debruised by a ribbon sa.; all within a bordure of the first. Lescie, Meadowsall, Glasgow ; and Endordivit, Scotland.

Arg. on a bend az. three buckles or; quarterly with or a lion ramp. gu. debruised by a ribbon sa.; all within a bordure chequy vert and arg. Leslie, Wardis and Findrassie, co. Moray; Baronetcy 1625. And with the same quartering all within a bordure indented and parted per pale az. and arg. Lescy, Torry, Scotland. And with the same quartering all within a bordure parted per pale chequy and counter-compony gu. and or. LEsLy, Burds. bank, Scotland.

Arg. on a bend az. three square buckles or. Strarling, Stopposley, co. Bedford ; Lord Mayor of London, 1670 ; granted 15 Sept. 1601.

Arg. on a bend embattled az. three buckles or. LesLy, Aberdeen, Scotland.

Arg. on a bend engr.az.three buckles or. Stiruing, Ardoch, Scotland, Baronetcy ....; quartering arg. a cross engr. az.

Arg. on a bend gu. three square buckles of the first. Rosceliys, $V^{*}$.

Arg. on a bend gu. three buckles or. Casye, co. Warwick. WETSHALL.

Arg. on a bend gu. three round buckles tongues pendent in bend or. Thomas CAssy, $V$. Rosceniyn, $V$. But the tongues fesswise to the sinister. RocelLYN, Cotton MS. Tiberius D 10 .

Arg. on a bend sa. three buckles of the first. Beawlot. Stirling, Kippendavie, Scotland.

Arg. on a bend sa. three buckles tongues in chief of the first. Strirling, Scotland.

Arg. on a bend sa. three buckles or. BowHie. Bunekill Bunell or Bunkell, Scotland. Burn. Strmling, Keir, Scotland.

Arg. on a bend sa. three round buckles tongues in chief or. Joan de Wantone, $E$. The tongues in fess. Johan de Wanton, $F$.

Arg. on a bend vert three buckles or. Stirling, Keir, Scotland.

Az. on a bend arg. three fermails of the first. (Another gu.) KINGE.

Barry of three or with chequy az. and arg. over all on a bend .... three buckles .... Ste. Start, Baron Darnley and Earl of Lennox, Duke of Lennox 1581; Earl of Newcastle and Duke of Richmond 1603.4, Baron Stewart of Newbury and Earl of Lichfield 1645; extinct 1672.
On 1 BEND.... cont.

\section{Buckles cont.}

Barry of three or with chequy az, and arg. or a beud gu. (another sa.) three buckles of the first. Strewart, Bonkhill, Scotland. Alan Stuart, Ocliltree, 1377, Seal.

Barry of three or with chequy az. and arg. over all oll a bend sa. three buckles or. STEWART, Earl of Angus; quartering Abernethy.

Paly of six arg. and az. on a bend gu. three round buckles or. Gransum. Guson, London.

Paly of six arg. and az. on a bend gu. three round buckles points upward or. Sir Othes de GraUndisson, R. Mounsyer William Grantsonn, $T$.

Paly of six arg. and az. on a bend gu. three round buckles points to the sinister or. Sr. William Grandeson, $V$. Grandison, see the glass in the church, at Seale, Kent. Sr. Williain Graneson or Granutson, Cotton MS. Tiberuus D 11).

Paly of six arg. and az. on a bend sa. three round buckles or. Grewiston.

Paly of six az. and arg. on a bend gu. three square buckles or. Grandeson, $V *$.

\section{Caltraps}

Gu. on a bend arg. three caltraps sa. GawLER. Castles

Quarterly arg. and sa. on a bend gu. two castles of the first. Ploncknett or Plunkett, Ireland.

Quarterly arg. and sa. on a bend engr. gu. two castles or. Plonckett or Plonkett, Ireland.

Arg. on a bend embattled counter-embattled gu. three tuwers triple-towered of the field. CHESLIN, London.

Arg. on a bend embattled counter-embattled gu. three castles of the first. CHEstLIN.

Arg. on a bend sa. three towers triplo-towered of the first. AsHborne or Ashburne, Ireland.

Az. on a bend arg. three castles sa. Castel. Castle, Lundon.

Az. on a bend arg. three towers triple-towered sa. purtled or. Castell, East Hatley, co. Cam. bridge.

Az. on a bend or three castles sa. Castuyn.

Gu. on a bend arg. three castles of the first. Castlyn.

Gu. on a bend arg. three castles sa. Caslyworth or CASTELLyN.

Gu. on a bend arg. three towers sa. Castrworth, $V$.

Gu. on a bend arg. three towers triple towered sa. BennetT, Boston, co. Lincoln.

Gu. on a bend embattled arg. three towers triple. towered sa. CHESLIN, London.

$\mathrm{Gu}$. on a bend or three castles of the field. Castlyn.

Gu. on a bend or three castles sa. Castelline.

Gu. on a bend or three towers sa. Castrwonth.

$\mathrm{Gu}$. on a bend or three towers sa. each with another on the top. Castryy or Chastelyn, $V$. Or on a bend az. (? three) castles arg. Robert Dancastre, $Y$.

Paly of six arg. and az. on a bend gu. three towers triple-towered ol. EsterLing.

Quarterly arg, and gu. on a bend vert three castles or. REMPSTON.

\section{Chevronels}

.... on a bend .... three chevronels .... in the sinister chief a pierced mullet .... Thomas Seguinton, seal 5 ilenry $1 \mathrm{~V}$.

Arg. on a bend az, three chev. or. Bencher. Fitton. Sir Richard Fytton, $V$. 
On 1 BEND.... cont.

Cherronels cont.

Arg. on a bend gu. three chev. erm. Boteler, $V^{*}$. Boteller, Bardfeld, Essex, $V$. Botoler or Butler, Essex.

Arg. on a bend gu. three chev. or. Botelen.

Erm. on a bend gu. three chev. or. Brayire or Brulye. Brinley. Bruley Brulye or Bruly. Hercy (Roger, Harl. MS. 6137) de Bruili, E. William Brucex, Waterstoke, co. Oxford, $V$. KixNDALL, $V$.

Gu. on a bend erm. three chev. of the first. Hodiam, $V$. Prior, Essex, $V$.

Gir. on a bend .... three chev. sa. ExGLxsvirt, co. Devon.

Sa. on a bend erm. three chev. gu. Hodianr. Prior, Roding, Essex.

Sa. on a bend erm. three cher. gu. betw. four stars of eight points wavy or. Prior, Essex, temp. Henry III ; co Oxford ; co. Lancaster; co. Cambridge; and also Rathdowney, etc. in Queen's County; the heiress m. Murray.

\section{Chessrooks}

Arg. on a hend sa. three chessrooks of the first. Bunbury, Bunbury and Stanney, co. Chester; and Great Barton, Suffolk, Baronetcy 1681. Richard Bunbery, $V$. Bunbert, $V^{*}$.

Az. on a bend or three chessrooks gu. Boull. Combs

Arg. on a bend gu. three combs or. Comrbe.

Erm. on a bend gu. three combs bendwise or. COMBE, $V$.

Coronet

Paly of six arg. and sa. on a bend gu. a Saxon crown or. BURGHILL. Coronets

Arg. on a bend az, three mural crowns or. STANLET, $V *$ *

Crescent

Arg. on a bend az. a crescent or. Stutheley.

Arg. on a bend az. a crescent betw. two acoms or. ij tirRHEAd, Bredisholm, Scotland.

Arg. on a bend engr. sa. a crescent of the first for diff. Radcliffe, Milnesbridge House, co. York; Baronetcy 2 November 1813.

Arg. on a bend engr. sa. a crescent in chief or. Sr. John Radcliff de la Tour, co. Lancaster, $V$.

Or on a bend az. a crescent betw. two spur. rowels of the first. NAPIER, Wright's Houses, Scotland.

Paly of eight or and gu. on a bend sinister az. a crescent arg. betw. two stars of the first. MACKY, Scotland. But the crescent arg. betw. two spur-rowels of the first. M MCK or MAKE, Scotland.

Sa. on a bend arg. a crescent az. Anthinghasr. Crescents

Or on a bend engr. erm. two crescents gu. BROADOKE, Suffolk.

Arg. on a bend az. three crescents or. RIDER, co. York. Sr. John Ryder, $V$. Monsire John de Rither, $X$; or de Pitteer, $Y$. Monsire de Piyther, $Y$.

Arg. on a bend gu. three crescents of the first. Ring.

Arg. on a bend gu. three crescents or. Godeston, Essex.

Arg. on a bend sa. three crescents of the first. Aynesworth, $V$. Elimeden, $V$. Elmedon, $V *$. William Elmmedon, $X$. Elyndon, co. York.

$\mathrm{Az}$. on a bend or three crescents of the first a label arg. Sir Thomas second son of Sir Geoffrey Scrope of Masham.
On 1 BEND.....cont.

\section{Crescents cont.}

Az. on a bend or three crescents gu. Hines, Ireland.

Barry of five az. and or on a bend sa. three crescents of the second. Twitham.

Erm. on a bend sa. three crescents arg. HrBbert, London. Hibbert, Birtles Hall, co. Chester.

Erm. on a hend engr. sa. three crescents or. Аввот.

Gu. on a hend .... three crescents of the first. DUFFY, Treland.

Gu. on a bend sinister arg. three crescents sa. WASTON, Scotland.

Gu. on a bend or three crescents az. Denovan, Scotland.

Lozengy arg. and sa. on a bend of the first three crescents of the second. Gargrave, Nostel, and Kinsley, co. York.

Lozengy arg. and sa. on a bend gu. three crescents or. Gargrave, Snapthorpe, and Kynesley, co. York.

Lozengy arg. and sa. on a bend of the second three crescents of the first. Sr. William Gardegrave, $V$. Gargrave, $V^{*}$. Sir John GarGrave, Master of the Ordnance to Henry $V$ in France; and Nostel, co. York.

Lozengy or and az. on a bend gu. three crescents arg. DUBBER, Beackworth, Surrey; granted 1623.

Lozengy or and sa. on a bend of the second three crescents of the first. Gatrgrave.

Or on a bend gu. three crescents' arg. William OTter, Bishop of Chichester 18:36-40.

Or on a bend gu. three crescents of the first. OtTER, co. Huntingdon.

Or on a bend sa. three crescents arg. Chyndon.

Or on a bend sa. three crescents of the first. Clinnan. Gogrri, Semington, Norfolk.

Sa. on a bend arg. three crescents gu. in the sinister chief a crescent of the second for diff. M. Nycol de Clyfton, $S$.

Sa. on a bend arg. three crescents of the field. Axnsworth. Charnock, co. Chester. Chernocke, $V$. Chernoke, co. Chester. CHERNOKE, $V^{*}$.

Vert on a bend arg. three crescents sa. Maldard. Vert on a bend arg. three crescents sa. in the sinister chief point a mullet of the second. ALDERTON, Ipswich.

\section{Cross}

Arg. on a bend engr. az. a cross croslet or. ClaRke, co. York.

Arg. on a bend engr. az. a cross croslet fitchy or. Clarke, London.

Arg. on a bend of the first fimbriated engr. sa. a cross croslet gu. RadciIfF.

Arg. on a bend dancetty (or indented) sa. a cross patty fitchy or. Lxston, Essex, $V$.

Chequy or and gu. on a bend erm. a croslet of the second. Clifton, Norfolk.

Gu. on a bend az. a cross formy arg. Nelson, Lord Mayor of London 1766.

Vert on a bend arg. a cross patty fitchy in the chief point gu. Albon, $V$.

\section{Crosses}

Arg. on a bend compony of three az. and or two crosses croslet of the last. BeattPreE.

Arg. on a bend compony of three az. and or two crosses patty of the last. BeaUpere, $V$.

Arg. on a bend gu. two crosses couped of the first. LAUDERHONIE, Scotland. 
On 1 BEND.....cont.

Crosses cont.

.... on a bend engr. .... three crosses croslet fitchy .... Richard de Richnond, Seal, $W^{r}$.

Arg. on a bend az. tbreo crosses croslet fitchy of the first. Robert Causton, $X$. Wonwell.

Arg. on a bend az. three crosses croslet or. Kirngeston, $V$ *. Krngiston, $V$. Loudhad, $V$. Lowdham, co. Derby. Ludham.

Arg. on a bend az. three crosses formy or. Sibser, Westbarssam, Norfolk.

Arg. on a bend gu. three crosses formy of the first. BAYNBRIDGE.

Arg. on a bend gu. three crosses patty fitchy of the first. OLdField, Oldfield, co. Chester.

Arg. on a bend gu, three crosses croslet or. John Loudhasi, $V$. Thomas Polhill, 1716. Poley, $V$. Poley (removed from Poley, co. Hertford, to Boxted and Badley, Suffolk, temp. Edward III or Richard II, as borne by Sir Humphrey Poley, 1107. Polley, $V$. Pooley. Potey, $V^{*}$. Arg. on a bend gu. three crosses croslet fitchy or. ENARD.

Arg. on a bend gu. three crosses formy or. M'FAdYen, Scotland. M. Rauff Poley, $S$.

Arg. on a bend sa. three crosses bottony of the first in the centre chief a mullet for diff. Charnock, Leyland, co. Lancaster, Harl. MS. $14: 37$, fo. 272 .

Arg. on a bend sa. three crosses croslet of the first. Channocke or Chernocke, Hulcot, co. Bedford; quartering arg. a cross engr. gu. 1566, with a crescent in centre over all for diff. Harl. MS. 2109, fo. 39; Baronetcy 21 May 1661, extinct 1779 ; an beiress $m$. Smith ; derived from Charnocke, Charnocke, co. Lancaster; temp. John; quartering az. a cross moline and in chief a ducal coronet or for Molyneux, Harl. MS. 1437, fo. 17; the heirs m. Brooke, Parker, and Hoghton. And with a mullet in chief of the second. Charnock. Charnoke, co. Lancaster, $V$.

Arg. on a beud sa. three crosses croslet fitchy of the first. Canston. Caston, co. Cambridge; and Suffolk. Robert CAUSTON, Y.

Arg. on a bend engr. sa. three crosses croslet fitchy of the first. Sr. de Cressenor, Suffolk, $V$. Cressenor Cresnor or Cresnall, Morley, Norfolk; and Suffolk.

Arg. on a bend sa. three crosses formy flory of the first. Charnock.

Arg. on a band sa. three crosses patonce of the first. Golborne.

Arg. on a bend sa. three crosses patty of the first. Charnock, $V$.

Arg. on a bend sa. three crosses tau of the field. BERD.

Arg. on a bend sa. three crosses croslet or. Oventon.

Arg. on a bend sa. three crosses croslet fitchy or. Canston.

Arg. on a bend engr. sa. three crosses croslet fitchy or. Cressenor Cresnor or Cresnalt, Morley, Norfolk; and Suffolk. Cressener, Essex; and London. Crestnox, Attleburgh.

Arg. on a bend sa. three crosses patonce or. Sr. Thomas GolBorne, $V$.

$\mathrm{Az}$. on a bend arg. three crosses croslet fitchy gu. Evard, $V$, or EVERARD, $V$.

$\mathrm{Az}$. on a bend arg. three crosses formy $\mathrm{gu}$. Bleton.

Az. on a bend arg. three crosses moline gu. John de Bleton, $V$.
On 1 BEND.... cont.

Crosses cont.

Barry wavy of six arg. and az. on a bend or three crosses patty fitchy gu. CrocchaRd, $V^{*}$. Crowchand, $V$.

Gu. on a bend arg. three crosses sa. RFREsBy, $V^{*}$. Gu. on a bend arg. three crosses croslet sa. RERESBY.

Gu. on a bend arg. three crosses croslet fitchy sa. Reresby or Repesbury.

Gu. on a bend arg. three crosses flory sa. Grisley. Reresby, Thribergh, co. York.

$\mathrm{Gu}$. on a bend (another, bendlet) arg. three crosses patonce sa. Renesby, Thriberg, co. York, $V$; Baronetcy 16 May 1612, extinct 11 August 1748.

Gu. on a bend engr. arg. three crosses patonce sa. an anvulet for diff. Keversby.

Gu. on a bend arg. three crosses patty sa. Bershabr. Beston. Reresby, Thriburgh, co. York. Sire Adam de Reresby, $O$. John de Reresby, $X$. William Ryresbye, $Y$. Monsire de Rolosby, $Y$.

Gu. on a bend arg. three crosses patty sa. a label or. Thomas Reresby, the son, $Y$. William de Reresby, the son, $X$.

$\mathrm{Gu}$. on a bend az. fimbriated wavy arg. three crosses formy fitchy or. John de KIRKEBY, Bishop of Carlisle 1332-53.

Or on a hend az. three crosses croslet fitchy of the first. Wonwell. WONWELL, $V$.

Or on a bend az. three crosses patty fitchy of the first. Wonvill, co. Devon. Pruteston, Pruteston, now Preston, co. Deron; the heiress m. Fortescue.

Or on a bend gu. three crosses formy arg. BENson. Or on a bend gu. three crosses moline arg. Belliston, co. Chester; and co. Devou. Bellyston, $V$. Bettyston. Betyston, $V^{*}$.

Or on a bend gu. three crosses patty fitchy arg. OLDFIELD, Bradield, co. Chester ; confirmed 7 February 1578 .

Or on a bend engr. gu. three crosses botonny fitcluy of the first. WoODCock, Essex.

Or on a bend gu. three crosses croslet of the first. PolHmu alias Polley, Detling, Hollingbourne, Kent; Sussex; and Howbury Yark, co. Bed. ford; quartering Buckland.

Or on a bend gu. three crosses croslet fitchy of the first. Everard, Suffolk. Woodcock.

Or on a bend gu. three crosses pometty fitchy of the first. Sr. Jobn Woopcock, Lord Mayor of London 1405, Harl. MS. 1349.

Or on a bend sa. three croslets .... Mauley.

Or on a bend sa. three crosses croslet arg. Carston. Coston. And with a crescent gu. for diff. Hawicks.

Or on a bend sa. three crosses croslet fitchy arg. Carston, $V^{*}$. Robert Caston or Causton, $V$. Marner.

Per fess indented arg. and gu. on a bend az. three crosses croslet fitchy or. Acton, Harl. MS. 6137 , fo. 44.

Quarterly arg. and gu. on a bend az. three crosses patty of the first in chief an annulet counterchanged. Acton.

Quarterly arg. and gu. on a bend az. three crosses patty fitchy or in chief an annulet counterchanged. Hugh Acton, London, $V$.

Quarterly per fess indented arg. 'and gu. on a bend az. three crosses patty fitchy or. AcToN. But with in chief an annulet counterchanged. Hugh Acton, Loudon, $V$. 
On 1 BEND

Crosses cont.

Quarterly arg. and gu. on a bend sa. three crosses croslet fitchy or. Thomas Blount, $X$.

Quarterly per fess indented gu. and arg. on a bend az. three crosses patty fitchy or in chief an amnulet counterchanged. AcToN, $V^{*}$.

Quarterly gu. and or on a bend sa. three crosses patty arg. O'HANNAN, Harl. MS. 4039, fo. 221 .

Quarterly or and az. on a bend gu. three crosses croslet arg. FAStoLfe, Suffolk.

Quarterly or and az. on a bend gu. three crosses croslet of the first. Falstolfe, Suffolk. Sir John Fastolfe (K.G.), V; Druery, Yarmouth, p. 110 .

Quarterly or and gu. on a bend sa. three crosses formy fitchy arg. HanNaM.

Quarterly or and gu. on a bend sa. three crosses patty ar. HaNAM, $V$. HaNHaM, $V$. HanNam, $V$.

Quarterly or and gu. on a bend sa. three crosses formy fitchy of the first. HARMAN, co Dorset.

Quarterly or and gu. on a beud engr. sa. three crosses patty fitchy of the first. HANHAM, Dean's Court, Wimbourne, co. Dorset; and Newston Park, co. Wilts; Baronetcy 24 May 1667.

Sa. on a bend arg. three crosses croslet gu. TEr, Northumberland. Peter TEx, $V$.

Sa. on a bend arg. three crosses croslet of the first in the sinister chief a pierced mullet of the second. Brightwalton. $V$.

Vert on a bend arg. three crosses formy fitchy az. Albon. Allibone.

Vert on a bend arg. three crosses patonce sa. WYNFIELD.

Arg. on a bend az. five crosses croslet or. Sr. John Loudhan, $V$.

Arg, on a bend az. five crosses formy or. SYBSEY, Westbarssam, Norfolk.

Arg. on a bend az. seven crosses croslet or. LODHAII.

Arg. on a beud az. crosses croslet or. Sire Johan de Loudhan, $N$. LondHan or Lowdham, Norfolk; and Suffolk. Loudhan, Essex; co. Nottingham; co. Derby; and co. Lincoln.

Cups

Arg. on a bend sa. three covered cups of the first. Bixton, $V^{*}$. Ciaphan. Massy, co. Lancaster, Naylour, Kent. Rixton, Warrington, co. Lancaster. Rrxton, Rixton, co. Chester. Rixton, $V^{*}$. Thonnton, $V$. And with a 4 -foil in chief for diff. Robert de ClapeHar, $X$.

Arg. on a bend sa. three covered cups crowned of the first. John Rriton, $V$.

Arg. on a bend sa. three cups or. Thonnton, Willoughby, co. Lincoln.

Arg. on a bend sa. three covered cups or. Marche. Naller. Rixton, Warrington, co. Lancaster.

Alg. on a bend sa. three ewers of the first. LEWER.

Gu. on a bend arg. three covered cups sa. Butler, co. Lancaster. Botelier, $\boldsymbol{V}$.

Gu. on a bend sa. three covered cups arg. Pincerna alias Lanherne, Cornwall. Cushions

Paly of six arg. and gu. on a bend az. three cushions or. LUNDIE or Lundy, Scotland.

Paly of ten arg. and gu. ou a bend az. three cushions of the first. Lunden, Balgony, Scotland; quartering arg. a cross moline square pierced gu.

\section{Escallop}

On 1 BEND.....cont.

Arg. ou a bend engr. sa. an escallop gu. Radcliff, $V^{*}$. And with a label of the last. RADClifF.

Arg. on a bend engr. sa. an eseallop gu. over all a fess of the last. Radcliff.

Gu. on a bend arg. an escallop betw. two mullets sa. Dishington, Scotland.

Or on a bend az. an escallop arg. Gernon.

Or on a beud az. an escallop in the chief point arg. GERNON, $V$.

Or on a bend engr. az. an escallop of the first. Clarie, Westminster, Middlesex; and co. York.

\section{Escallops}

Arg. on a bend az, three escallops of the first. Barnard, London. Bernard, Baron Bandon 30 November 1793, Viscount 6 October 1795 , Viscount and Earl 6 August 1800. Bernard, Palace Anne, co. Corl. Birnand, $V *$. Birnard. Burnand, Essex, $V$. Byrnande, co. York. Sir Hugh Eland, Essex, temp. Edward I, $V$. Garman Garion and Grraon. Westey, co. York. And with in the sinister corner a mullet .... enclosed by an annulet .... B Brnard, co. York; and Norfolk.

Arg. on a bend az. three escallops erminois. Leving or Living, Woolwich, and Bridgen, Kent.

Arg. on a bend az, three escallops or. Barnard. Browne. Dyncaster. Rem, The Carse, Scot. land.

Arg. on a bend gu. three escallops of the first. Ashborne, Harl. MS. 1603. Eland. William de Laton, $X$. Layton.

Arg. on a bend gu. three escallops or. AstoreLL, co. Huntingdon. Cland or Clande, Éssex. Elane. Sire Huge de Elaunde, N. Eruand, co. York. Robert KILWARBY, Archbishop of Canterbury 1272.8. Parott Perott or Perrott. Taniesley and Tankisle. Tankersley, $V^{*}$. Tankersley, Tankersley, co. York. Tankmsini, Terington, $V$. Terington.

Arg. on a bend sa. three escallops of the first. Danyeli, $V$. Erley. Hawkwood. Kenley, Irelaud, $V$. Krnley. Baptist Levinz, Bishop of Sodor, etc. 1655-93. Pring, Scotland.

Arg. on a beud sa. three escallops erm. Levinz. Arg. on a bend sa. three escallops or. Pringle, Torsonce, Teviotdale; and Buruhouse, Scotland. Tirington. Tyrington, $V$. Tyryngton, $V^{*}$.

Az. ou a bend arg. three escallops of the first. Byrnand, Kuaresborough; the heiress m. Trappes, Blount, and Egerton.

Az. on a bend arg. three escallops gu. Monsire de Granson, $Y$.

Az. on a bend or three escallops gu. BIsset. Byssett, $V$ *

Barry of five sa. and or on a bend arg. three escallops gu. Layton. LeightoN.

Barry of six arg. and az. on a bend gu. three escallops or. Gray.

Barry of six arg. and erm. on a bend gu. three escallops or. Burton, $V$.

Barry nebuly of six arg. and gu. on a bend sa. three escallops or. CLISALD.

Barry wavy of six arg. and gu. on a bend sa. three escallops or. CHESULL.

Barry of six or and az. on a bend arg. three escallops gu. BrNGESIIEAD. Sr. Walter IingesHeMEDE, co. Salop, temp. Edward I, $V$. Kingesuede, $V^{*}$. Kingsiead. 


\section{On 1 BEND.... cont.}

Escallops cont.

Barry of six or and az. on a bend gu. three escallops arg. Rauf de Lingaine, $E$.

Barry of six or and az. on a bendlet gu. three escallops arg. Raf de Lingeyne, $F$.

Barry of six or and az. on a bend gu. three escallops of the first. Porter, co. Lancaster.

Barry of six or and az. on a bend sa. three escallops arg. Lingard. Linger, co. Lancaster. Lyngarde, Crudworth, co. Warwick; and co. Lancaster.

Barry of six or and gu. on a bend sa. three escal. lops arg. Lighтғоот, Ashford, Kent.

Barry of six or and gu. on a bend sa. three escallops of the first. LightFoot, Loudon.

Barry of seven arg. and gu. on a bend of the last tbree escallops or. Mencaster.

Barry of seven arg. and gu. on a bend sa. threo escallops or. Mencaster, Essex. Sir Walter Moncaster, Essex, temp. Edward I, $V$.

Barry of seven arg. and sa. over all on a bend gu. three escallops or. Spruse or Spreder, $V$. Spreuse, $V^{*}$.

Barry of seven or and az. on a bend engrailed of the first three escallops sa. SAXDY, Norfolk.

Earry of seven or and on a beud sa. three escallops of the first. LightFoor.

Barry of eight arg. and gu. on a bend sa. three escallops or. Gibion. Goyion. Gonyon, $V$. Gobyns, co. York.

Barry of eight or and az. on a bend arg. three escallops gu. Kingshamed.

Barry of ten arg. and gu. on a bend sa. three three escallops or. Gobrns, co. York.

Barry of ten or and gu. on a bend sa. three escallops of the first. Moncaster.

Barry of twelve arg. and gu. on a bend az. three escallops or. Wat de Molecastre, $E$.

Barry of twelve arg. and gu. on the last ten martlets sa. three three three and one over all on a bend sa. three escallops or. STocke, co. Wilts.

Barry arg. and gu. on a bend sa. three escallops or. Sire Walter de Kyngeshenede, $N$.

Bendy sivister of six arg. and gu. on a bend sa. three escallops of the first. Gibions.

Chequy arg. and sa. on a bend gu. three escallops or. Partridge, Cirencester, and Wishanger, co. Gloucester; and Fiubarrow, Suffolk. Patreche Patriche or Partriche, co. Gloucester, from Kendall, Westmoreland; confirmed 1561 and 1566, Harl. MIS. 1011, fo. 13 b. Portridge, Suffolk; and co. Salop.

Chequy arg. and sa. on a bend or three escallops of the secoud. Pertricke, Suffoll.

Chequy or and a\% on a bend gu. three escallops arg. Lawrence, co. Devon.

Erm. on a beud engr. az. three escallops or. Fisher.

Erm. on a bend engr. gu. three escallops arg. Gumley.

Erm. on a bend gu. three escallops or. BaGaret. Lewne. Richard Lewyne, $X$. Perott, Wales. WANSEY, Milford, co. Hants: and in Warminster Church, co. Wilts. Wendessey, $V^{*}$. Sr. Thomas Wendisley, Wendisley, co. Derby, $V$. Sire William Wene, $O$. M. 'Thomas de Wennesley, $S$. Wensley or Wendesley, Wendesley, co. Derby; extinct 1591 ; the heiress m. Blackwall.

Erm. on a bend sinister gu. three escallops or. Parote, Wales, $\boldsymbol{V}$.
On 1 BEND......cont.

\section{Escallops cont.}

Gu. on a bend arg. three escallops az. Sr. Roger Wentworth, Harl. MS. 6137, fo. 41. Byssetr, quartered by Sr. Roger Wentworth, $V$.

Gu. on a bend arg. three escallops of the first. LAYToN or Leighton. Nottinghan, Ireland.

Gu. on a bend arg. three escallops sa. BASSETT. Bisett. Bissell. Bisset, $V^{*}$. Brssett, $V$. Dawtree. Roye, France. Knoell or Knowles, Samford Orcas, co. Dorset; and co. Somerset. Sr..... KNoyle, $V$. Joln Warryn, $V$. And with a label of as many points az. Fitz. Byset. But the label per pale az, and or. Sr. William Byset, $V$.

$\mathrm{Gu}$. on a bend arg. three escallops vert. Thomas de Seinmartin, $F$.

Gu. on a bend or three escallops arg. NottingHan, Ireland.

Gu. on a bend or three escallops sa. Dantree. DanTY.

Gu. billety and on a bend or three escallops sa. CURSON.

Or on a bend az. three escallops arg. Garnonne. Or on a bend az. three escallops of the first. Wat de Everleie, $E$; or de Everley, $F$. Garnon. Sir Nicholas Gernon, $V$. Wautier de Heverley, $Y$.

Or on a bend gu. three escallops arg. Dodgin. Polhey, Essex.

Or on a bend sa. three escallops of the first. Dishing'ron, Ardross, Scotland.

Paly of five gu. and arg. on a bend sa. three escallops of the second. GIBBON.

Paly of six arg. and az. on a bend gu. three escallops or. Sr. de Ga'nson, F. Grandson, $V^{*}$. Otes de Grantson, A, Harl. MS. 6137; but de G'uton aliter Graunson, $A$. M. Othes de Grandzon, $D$. Graundson, $V$. Hoste de Graunson, E. Sr. Otho Grandsone, Bishop of Oxford. $V$, but Sir Oto de Grauntson, Bishop of Exeter 1327.70, Cotton MS. Tiberius, D 10, called Johu Grandison, Add. MS. 12443. Grandison, co. Lancaster. Grannson, Exeter. Paly of six arg. and gu. on a bend sa. three escallops of the first. GrBbons, Shrewsbury. Gibeon, Essex. Gibson, co. York.

Paly of six arg. and sa. on a bend gu. three escallops of the first. BourgноPE, Ireland. Burghill, Harl. MS. 1603. Burghul, Ireland.

Paly of sis arg. and sa. on a bend gu. three escallops or. Borghull, Ireland. Broughali or Browghill, Ireland. BurghidL, Ireland, $V$

Paly of six az. and arg. on a bend gu. three escallops or. Grandson, $V^{*}$.

Paly of six or and gu. on a bend sa. three escal. lops of the first. John ANSLEY, Lord Mayor of London, 1808.

Paly of six vert and erm. on a bend gu. three escallops arg. Burton, Wemby, $W$.

Paly of seven az. and arg. on a bend gu. three escallops or. Sire Otes de Graunçoun, $J$.

Paly of eight arg. and gu. on a berd sa. three escallops of the first. Gobyon, $V^{*}$.

Paly of ejght arg. and gu. on a bend sa. three escallops or. Gibion. Gobyan or Gubyon. Sr. Hugh Gobyon, $V$.

Paly az. and arg. on a bend gu. three escallops of the second. William Graunson, $Y$.

Paly az, and arg. on a bend gu. three escallops or. Otes Graunson, $X$. 


\section{On 1 BEND.....cont.}

Escallops cont.

Per chief indented az. and arg. on a bend gu. three escallops of the second. Butler, $V^{*}$.

Per chief indented az. and or on a bend of the first three escallops or. Buti.er, Baron Dan. boyne; quartering gu. three covered cups or, with or a fess sa., Harl. MS.4040, fo. 410 .

Per chief indented az. and or on a bend gu. three escallops arg. Butler, Baron of Dunbeyne, Harl. MS. 1603; Baron of Durboyn, $W ; \mathrm{Ba}$ rony 11 June $15 \pm 1$.

Per chief indented az. and or on a bend sa. three eseallops arg. Boteler, Lord Dunblaine. Mac Pheris.

Per chief indented sa. and arg. on a bend az. three escallops or. Power, Earl of Tyrone, Harl. MS. 4010, fo. 123; Viscount Decies aud Earl of Tyrone 9 October 1673 ; extinct 19 August 1704.

Quarterly arg. with gu. a fret or over all on a bend sa. three escallops of the first. Spencer, Althorp, co. Nottingham, $Z, 542$.

Quarterly arg. and sa. on a bend gu. three escal. lops betw. five buck's heads cabossed of the first. Eland or EyLAND, co. York.

Quarterly az. and or on a bend gu. three escallops arg. Falstofe, $V *$. Falstuffe.

Quarterly gu. and or on a bend sa. three escallops arg. Eure, $V *$ *

Quarterly or and az. on a bend gu. three escal. lops arg. Falstof. Sr. John Falstofe, $V$. Thomas Falstoffe or FASTOLF, Bishop of St. David's 1353-61. M. John Fastolf, S. Ascribed to Sir Joln F AstoLfe, K.G., by Ashmole incorrectly, Druery, Yarmouth, p. 110.

Quarterly or and gu. on a bend of the second three escallops of the first. Evers.

Quarterly or and gu. on a bend sa. three escallops arg. MI. Rauf de Euar, S. Sir John de Euer, M. Sr. Ranfe Euere, co. York, V. Eure, co. Buclingham, temp. Henry III. Eure, Bishop's Middleham, co. Durham. Eure or Evre, Northumberland; Baron Wilton, co. Durham, 24 February 1544; extinct 1698. EurE Eurr. Etre Evers Ewere Ivre or Yver, co. Lincoln; and co. York. Sire Johan de Oevre, $N$. YeVERs.

Quarterly or and gu. on a bendlet sa. three escal. lops arg. Henri de Euere, $E$; but D'Evere, E, Harl. MS. 6137.

Qnarterly qr and sa. on a bend gu. three escallops arg. FAstulfe.

Quarterly or and sa. on a bend of the last three escallops-arg. Evers.

Sa. on a bend arg. three escallops of the first. Burneli, London.

Sa. on a bend arg. three escallops gu. Hambrois, $V$. Latin or Laxton. Sr. de Latton, $V$. Layton, Dalemain, Cumberland. Leighton. Lutros.

Vairy arg. and gn. on a bend sa. tliree escallops of the first. Cheshull, Essex, $W$.

Vairy arg. and gu. on a bend sa. three escallops or. Cheshuti, Essex, $V$.

Vert on a bend arg. three escallops gu. de Houn in a later band), $F$.

Quarterly or and gu. on a bend sa. fonr escallops arg. John de EoEre, $Y$.

Az. on a bend arg. five escallops gu. CRikrofr.

Gu. on a bend or five escallops sa. three and two. VENOR, London, 1480.

Gu. on a bend sa. five escallops arg. (? VEnE).

\section{Escarbuncles}

On 1 BEND.... cont.

Arg. on a bend gu. three escarbuncles or. Thornton, Newnham aud Brockhall, co. Northampton; quartering Newnham. Aud with a 5 -foil az. for diff. 'T'Honnton, Lingall, co. York. But with a mullet .... for diff. Thonnton, Greenford, co. Hertford.

Arg. on a bend gu. three escarbuncles of eight points or. Sr. Peirse 'Ihorneton, co. Cbester, $V$.

Arg. on a bend gu. three escarbuncles of eight points flory at the ends or. Sir Piers de Thornton, $R$.

Arg. on a bend gu. three escarbuncles or a fleurde-lis sa. for diff. Thornton, Middlesex; granted 12 March 1575.

\section{Escucheons}

Arg. on a bend sa. an escucheon of the first charged with a lion ramp. purp. Sr. William Scopham, $V$.

Arg. on a bend sa. an escucheon or charged with a lion ramp. purp. Scopham.

Arg. on a bend sa. an escucheon purp. cliarged witl: a lion ramp, of the first. ScopHAM, $V^{*}$.

Gu. on a bend arg. three shields sa. Caink or Croke, Scotland. Crook. Crooks or Crucks. $\mathrm{Gu}$. on a bend or three shiclds of the first. Crooks. SHiElos or SHIElis, Scotland.

Gu. on a bend engr. or three shields az. SHIELs, Scotland.

Gu. on a bend engr. or three shields sa. SHEmD, That Ilk.

Per chief az. and arg. on a bend gu. three escu. cheons per fess vert and of the second. Allestry.

Per chief gu. and arg. on a bend az. three shields or. Athestrey, Turndich, Alvaston, and Waiton, co. Derby.

Per chief gu. and arg. on a bend az. three shields also per chief gu, and arg. Alestry, $V$.

Estoile also see Mullet and Rowel

Erm. on a bend az. a magnetic needle pointing at a polar star or. Perry, Baron Shelburue 31 December 1688.1708, 26 October 1699; Viscount Dunkerron and Earl of Shelburne 29 April 1719, extinct 1751. Fitzmanrice-Pertr, Baron Dunkerron and Viscount Fitzmaurice 7 October 1751, Earl of Shelburne 26 June 1753, Baron Wycombe 17 May 1760 , Viscount Calne and Calstone, Earl of Wycombe and Marquis of Lansdowne 30 November 1781; quartering Fitzmaurice.

Or on a bend az. an estoile betw. two crescents arg. Scort, Ireland. The patriarchal coat of Scot or Scotr. Scotr, Baron Earlsfort 10 May 1784, Viscount Clonmel 18 August 1789, Earl of Clonmel 20 December 1793.

Or on a bend az. an estoile betw. an increscent and decrescent .... Scotr.

$\mathrm{Or}$ on a bend az. an estoile (or mullet) betw. two crescents of the first. Scot, Buccleuch, as borne on an inescucheon by James Crofts afterwards Scor, Duke of Monmouth after 22 April 1667, as Duke of Buccleuch, Earl of Dalkeith, Baron Whitchester and Ashdale 20 April 1673, Z, (639; and after his attainder, 1685 , by his son James Scot (Earl of Ioncaster afterwards) Earl of Dalkeith, $Z, 614$; and by his son Francis Scor, Baron Tyndale and Earl of Doncaster 23 March 1743, Duke of Bucclench 1732 ; and by his uncle Henry Scot, Baron Goldylinds, Viscount Hermitage, and Earl of Delorain 29 March 1706, extinct 1807 ; $Z, 644$. 


\section{Estoiles}

On 1 BEND.....cont.

Arg. on a bend az. three stars of the first. Bacster, $V$. Baxter, co. York. Dennam.

Arg. on a bend az. three estoiles or. Baxter, co. York. Baxter, $V^{*}$. Hemy, Hooton.

Arg. on a bend sa. three estoiles of the first. Fitz-Wilisam, $V$.

Erm. on a bend az. three estoiles or. ExaLL, St. Ires, co. Huntingdon.

Gu. on a bend or three estoiles sa. Dastin, co. Worcester.

Sa. on a bend chevronelly of seven erm. and gu. four estoiles of eight points wavy or. PRIOR, Essex, temp. Henry III ; co. Oxford; co. Lancaster; co. Cambridge; and also Rathdowney, etc. in Queen's County; the heiress m. Murray.

\section{Gouttes}

Paly of six or and gu. an a bend sa. three gouttes arg. Binton.

\section{Feathers}

Or on a bend sa. three ostrich feathers arg. passing through as many serolls (of the last, another) of the first. Sir Roger de Clarendon, beheaded 1402, natural son of the Black Prince, supposed to be the ancestor of Smin, Essex, $Z, 189$.

Or on a bend sa. three ostrich feathers palewise arg. Sr. Roger Clarendon, $V$.

\section{Fess}

Gu. on a bend arg. a fess betw. two bars gemel of the first. Schorcher, $V$.

Arg. on a bend az. a fess betw. two crosses croslet or. Beaupree.

Arg. on a bend az. a fess betw. two crosses patty or. Beaupere, $V$.

\section{Fishes}

Arg. on a bend sa. three fishes of the first. SANkey, co. Bedford; Edesborough, co. Bucks; and Sankey and Southall, co. Lancaster.

Arg. on a bend sa. three fishes bendwise of the first. Saniey, Ireland. Sankers, $V$.

$$
\text { ....Dolphins }
$$

Arg. on a bend az, three dolphins of the first. Franklyn, Moore, co. Hertford, and Middlesex. Franklin, Baglan House and Clemenstone, co. Glamorgan.

Arg. on a bend az. three dolphins embowed bendwise of the first. FrankLYN, Willesden, Middlesex, granted by Camden, $W$.

Arg. on a bend gu. three dolphins embowed or. Edward Fox, Bishop of Hereford 1535-8, quartering or a chev. betw. three fox's heads erased gu. (but this seems in error).

Arg. on a bend sa. three dolphins of the first. SYMEON.

Arg. on a bend sa. three dolphins embowed of the first. Rout, Sacombe Park, co. Herts; and Spye Park, co. Wilts; quartering Bayntun; an heiress m. Caswall.

Arg. on a bend sa.three dolphins haurient of the first. Roult, Mylton, co. Bedford.

Arg. on a bend sa. three dolphins naiant of the first. Simpkin.

Arg. on a bend sa. three dolphins of the first crowned or. Polte, Kent.

Arg. on a bend sa. three dolphins or. STocks or Stores, co. Cambridge.

Arg. on a bend sa. three dolphins embowed or in chief a crescent (? for diff.) gu. MAwLE, Suffolk.

Arg. on a bend sa. three dolphins embowed bend. wise naiant or. Edward Fox, Bishop of Here.
On 1 BEND.....cont.

Fishes cont. Dolphins cont.

ford 1535-8, quartering arg. a plaiu inescucheon and a side indented sa., Cotton MS. Tiberius, $D, 10$, p. 865 . Stmeon, $V$. SymкY, V.

Arg. on a bend sa. three dolphins naiant or. Bures, $V^{*}$. Simion, $V^{*}$. Symikin, $V^{*}$.

Arg. on a bend engr. sa. three dolphins naiant embowed or. STokys, co. Cambridge.

Az. on a bend arg. three dolphins .... Simeon, Chittworth.

Az. on a bend gu. three dolphins arg. Robert Edenhan, Swaldale, $X$.

Gu. on a bend wavy arg. three dolphins sa. Martham.

$\mathrm{Gu}$. on a bend arg. three dolphins embowed vert. Flambert.

Or on a bend gu. three dolphins arg. EDNor EDENHalr or EDNower.

Or on. a bend gu.three dolphins arg. finned gold. Richard EDENHAM, Bishop of Bangor 1464-96.

Or on a bend sa. three dolphins arg. MANLEY. Sire Johan de Maulee, $N$. Mawley, co. York.

Or on a bend sa. three dolphins embowed naiant arg. Marley. Mauley, $V^{*}$.

Or on a bend sa. three dolphins embowed bendwise naiant arg. Mauley, $V$.

$$
\text { ..... Eels }
$$

Az. on a bend or three (eels ?) coiled palewise of the first. Castelton, $V$.

$$
\text { ....Lampreys }
$$

Az. on a bend or three lampreys of the first. Castleton or Castleton, Suffolk.

$$
\text { .... Pikes }
$$

Arg. on a bend sa. three piles haurient of the first. HewisII, co. Devon.

$$
\text { ....Roaches }
$$

Arg. on a bend az. three roaches (arg. alias arg. finned and tailed or, i.e.) ppr. taken by Oliver Hrwish, temp. Edward III on marriage with De la Roche. Hewish Hiwis Huish Huyshe or Hywis, Lod Hiwis, Lynch, Doniford, Aller, and Taunton, co. Somerset; Sand and Clisthydon, co. Devon; co. Derby; aud co. Nottingham. Hewes or Hewise, Donyford, co. Somerset, 1623; quartering barry of eight or and az. on a bend engr. gu. three heads of spears or, with arg. a fess of five lozenges conj. gu. plain cotised sa., Harl. MS. 1445, fo. 230 and 20. And with a mullet in chef for diff. Huist, Sand, Sudbury, co. Devon. Harl. MS. 1415, to. $325 \mathrm{~b}$.

\section{....Trouts}

Arg. on a bend sa. three trouts or. OsBorne, London.

\section{....Whitings}

Arg. on a bend sa. three whitings ppr. Whiting. Fleur-de-lis

Arg. on a bend az. a fleur-de-lis or. Goldington. Arg. on a bend sa.two 5 -foils and a fleur-de-lis of the first. Morgan.

Chequy or and gu. on a bend erm. a fleur-de-lis for diff. sa. Clifton, Fukenham, Norfolk.

Lozengy arg. and gu. on a bend az. a fleur-de-lis betw. two pair of annulets interlaced of the first. GEBEs.

\section{Fleurs-de-lis}

Masculy arg. and gu. on a bend sa. two fleurs-delis or in chief an annulet for diff. of the first. Gibons.

Paly bendy arg. and gu. on a bend az. two fleurs. de-lis of the first. Gibies. 
On 1 BEND.....cont.

Fleurs-de-lis cont.

Paly bendy sinister arg. and gu. on a bend az. two fleurs-de-lis or. GrbBes, $V$.

Arg. on a bend az. three fleurs-de-lis of the first. Eyters. Juers. Gruffyd Lloyd. Powtrell.

Arg. on a bend az. three fleurs-de-lis or. Bowe, $V$. Bone or Boun. Bonney. Bradfiej,d. Delamare or Delameere, Essex. Everers. Ervers. Iners, Ireland. Ivers, $V^{*}$. Jevers, $V *$ UFFLEET.

Arg. on a bend engr. az. three fleurs-de-lis or. Holt or Holte, Suffolk.

Arg. on a bend gu. three fleurs-de-lis of the first. Coulson, Jesmond, and Blenkinsopp Castle, co. Northumberland.

Arg. on a bend per bend az. and gu. three fleursde-lis of the first. PENDER, Cornwall.

Arg. on a bend sa. three tleurs-de-lis of the first. HoLt, Swaston, co. Cambridge. Melnehouse, $V$.

Arg. on a bend sa. three fleurs-de-lis of the first in the sinister chief a crescent for diff. or on a crescent gu. Thomas Wood, Kelnwike, co. York, granted by Flower, $W$.

Arg. on a bend dancetty sa. three fleurs-de-lis of the first. Cuffe, co. Somerset. Custe, co. Somerset.

Arg. on a bend engr. sa. three fleurs-de.lis of the first. HoLT, co. Lancaster; and London; granted 18 June, 1582. HoLT, Lord Chief Justice 1689. HoLT, Grestelberst, co. Lan. caster, $V$. HoLt, Twyford and Portsmouth, co. Hants; a younger branch of Holt of Lan. cashire; Visitation 1634. HoLT, Stubbylce, co. Lancaster. Melhursh, co. Devon; and Taunton, co. Somerset. Melvehouse. Mennehouse, $V^{*}$. Milnehouse, $V$. Sale, Barrow, co. Derby ; Visitation 1662; an heiress m. Dalrymple.

Arg. on a bend sa. three fleurs-de-lis or. Sr. Rauf Shelton, $\boldsymbol{V}$. Robert Stretton, Bishop of Lichtield, etc., 1360.85. Spencer. Yvens, Ireland.

Arg. on a bend sa. three fleurs-de-lis or a label gu. Skelton, co. Leicester.

Arg. on a bend engr. sa. three fleurs-de-lis or. Holt or Holte, Suffolk.

Az. on a bend arg. three fleurs-de-lis sa. each charged with as many bezants. Wood.

Az. on a bend or three fleurs-de-lis of the first. By, Shernfold Park, Sussex.

Barry of six arg. and az. on a bend gu. three fleurs-de-lis or. Gray.

Erm. on a bend az. three fleurs-de-lis or. BERY, Colton, co. Devon. Berx, $V^{*}$. Berry, $V$. Bury, Collerton, $V$. Bury, Coleton aud Doniton, co. Devon; quartering Cole.

Erm. on a bend engr. az. three fleurs-de-lis or. Bery, $V *$ * Bery, Colleton, co. Devon. Bewrye, Collaton, co. Devon. Burye, co. Devon.

Erm. on a bend engr. az. three fleurs-de-lis or each charged with an annulet sa. BERY, Worlingham, Suffolk.

Erm. on a bend engr. gu. three fleurs-de-lis or. Bery, Essex, $V$, and Cotton MS. Tiberius, $D, 10$.

Erm. on a bend engr. gu. three fleurs-de-lis or each charged with as many pellets. Burye, Suffolk.

Erm. on a bend engr. sa. three fleurs-de-lis or. Berry, Burly, co. Devon.

Gu. on a bend az. three fleurs-de-lis arg. FitzWALTER, $V$.
On 1 BEND.....cont.

Fleurs-de-lis cont.

Lozengy arg. and sa. on a bend of the second three fleurs-de-lis or. Gargrave.

Or on a bend az. three fleurs-de-lis arg. Sire Robert Pontrel, $N$. Roger Pontrell, $Y$. Monsire Poutrell vel Peverell, $Y$. Powdrell, $V$. Powntrell. Sr. Robert Powtrell, $V$. Robert Powtredi, $Y$.

Or on a bend az. three fleurs-de-lis of the first. Bone. Poundrell or Powtrell, co. Derby.

Or on a bend engr. az. three fleurs-de-lis of the first. Powderell Powndrell or Powtrell.

Or on a bend dancetty sa. three fleurs-de-lis of the first. VAvasour, co. York.

Or on a bend engr. sa. three fleurs-de-lis of the first. SALL, Shardlow, co. Derby.

Paly of six arg. and az. on a bend gu. three fleurs-de-lis or. John de Esterling, $G$.

Quarterly arg. and az. on a bend gu. three fleurs de-lis of the first. Garshati, co. Warwick. RAE.

Quarterly arg. and az. on a bend gu. three fleurs. de-lis or. Bray, co. Oxford. Bray, $V^{*}$. Monsire de Bray, $Y$. Garshall, co. Leicester. John de Ray, $Y$.

Quarterly arg. and az. on a bendlet gu. three fleurs-de-lis or. Brax, co.. Oxford, $V$.

Quarterly arg. and gu. on a bend sa. three fleursde.lis or. Puxtx, ca. York.

Quarterly arg. and sa. on a bend gu. three fleurs. de-lis of the first. Sire Thomas de Garshale, $N$. Sr. Thomas Garshall, co. Warwick. GoDweston.

Quarterly arg. and sa. on a bend gu. three fleursde-lis or. GaRSHALL, co. Warwick.

Quarterly or and az. on a bend of the second three fleurs-de.lis of the first. BaY. BYE.

Quarterly or and az. on a bend gu. three fleursde-lis .... BerENGER.

Quarterly or and gu. on a bend az. three fleurs. de-lis arg. Fitz-IVAter, $V^{*}$.

Quarterly or and gu. on a bend az. three fleursde.lis in pale arg. Fitz-Walter, Dcrney, co. Buckingham, $\boldsymbol{V}$.

Quarterly or and gu. on a bend az. three fleurs. de.lis of the first. FITZ-WALKER or Fitz-Walter, co. Buckingham.

Quarterly or and gu. on a bend sa. three fleursde-lis arg. BeE, Horslow, co. Lincolu. Eure or Evers, co. Lincoln; and co. York.

Sa. on a bend arg. three fleurs-de-lis of the first. WooD, co. Stafford; and West Cutton and Thorp, co. York; granted 6 May 1578.

Or on a bend az. five fleurs-de-lis palewise of the field as the first. Goldington, $V$.

Arg. on a bend az. six fleurs-de-lis two two and two of the first. DENviLE or DEwILE.

Arg. on a bend az. six fleurs-de-lis two two and two or. Claphan, Barnstaple, co. Devon. Clapham or Champham, co. York; Cotton MS., Tiberius $D, 10$. CrapHam. Burley Grange, co. York. Claphadr, co. York, V; Beamsley, co. York; Cotton MS., Tiberius, D, 10. Mounger, $V^{*}$. Moungre, $V^{*}$. Moungres, $V$. Mowgre.

Arg. on a bend sa. six fleurs-de-lis two two and two or. ClapHasr, co. Warwick; and co. York.

Or on a bend az. six fleurs-de-lis of the first. MowGreY.

Arg. on a bend az. eight fleurs-de-lis or. Dexverr, co. York. 


\section{On 1 BEND.....cont}

Fleurs-de-lis cont.

Arg. on a bend az. fleurs-de-lis or. Sr. Noel Carrone, $W$; i. e. Noel de Caron, Ambassador from Holland 1589, Aubrey, Surrey, i, 9. Goldington.

Arg. on a sinister bend az. fleurs-de-lis in dexter bendwise or. Caroone, Surrey.

Flower.... Rose

Arg. on a bend az. a rose betw. two griftin's heads erased or. ToRRELI.

Arg. on a bend sa. a rose betw. two griffin's heads erased or. CARRELl.

Barry nebuly of five arg. and gu. on a bend engr. sa. a rose betw. as many mullets or. Chiswel, London; granted 13 Ápril 1714. ChiswelL, quartering French; granted 10 December 1773 to Mullman, Debben Hall, Essex.

Erm. on a bend sinister .... a rose arg. betw. two bezants. Cosway.

$\mathrm{Gu}$. on a bend arg. a rose betw. two lions pass. of the first. Herren, Sylington, Scotland.

Gu. on a bend arg. a rose betw. two lions ramp. of the first. Herin, That Ilk. Herring, Le. thendy, Scotland; quartering az. a chev. or. Herring ol Herin, Scotland. Heron, That Ilk.

\section{Flowers.... Roses}

Az. on a bend or two roses gu. stalked and leaved vert. WAYD, $V^{*}$.

$$
\text { ....Gilly-flowers }
$$

Az. on a bend arg. three gilly-flowers ppr. WADE, Chapel Allerton, co. York; and Monkton Farleigh, co. Wilts.

\section{....Pansies}

Gu. on a bend or three pansy-flowers ppr. stalled and leaved vert. Paskin.

$$
\text { .... Roses }
$$

Arg. on a bend az. three roses of the first. CAlEEY, Aston, co. Oxford.

Arg. on a bend gu. three roses of the first. DEPDEN or Deptun, co. Hereford.

Arg. on a bend gu. three roses or. Cassy. Cockser, Ireland. DebDen, Branston, Suffolk. Rossels, Ratcliffe-upon-Trent, co. Nottingham.

Arg. on a bend sa. three roses of the first. CAREy, Guernsey, descended through CAREy or Carey, co. Devon; from Adam de Karry, Lord of Castle Karry, co. Somerset, 119১; like CARY, Cockington, Clovelly, Marldon, Torr Abbey, Follaton, and Chilton Foliot. Sr. Oswald CARY, $V$. CARY, Chilton-Foliot, $Z$, 334. CARX, Adenham, co. Hertford, $Z, 399$. $\mathrm{C}_{\mathrm{ARY}}$, Follaton, co. Devon; quartering Flemirg. Curry. Gillbande. And with a mullet of the second for diff. Valontine CAREx, Bishop of Fxeter, 1621.6.

Arg. on a bend sa. three roses of the first seeded or. TEMPEST.

Arg. on a bend sa. three roses of the first barbed and seeded ppr. CARY, Viscount Falkland 10 November 1620 ; Baron Hursdon 15 May 1832: quartering Spencer (but in some books Lucas) and Beaufort. And with the same quarterings with a crescent .... for diff. CARY, Baron Hunsdon $13 \mathrm{~J}$ anuary $1558-9$, extinct 1765 ; Viscount Rochford 6 June 162I ; Earl of Dover 8 March 1628, extinct 1677. And with also $a$ martlet .... for diff. CAREX, Baron Carey of Leppington 6 February 1622, Earl of Monmouth 7 February 1626 ; extinct 1661 .

Arg. on a bend sa. three roses or. Clayton, $V^{*}$. HanesLyn, $V$. Haselin. And with a crescent. in the sinister chief gu. CLAYTuN, $V$.
On 1 BEND.....cont.

Flowers cont. Roses cont.

Arg. on a bend vert. three roses or. DANCY. Dauncy, $V *$. Dauney, $W$. Dawnex, London.

Barry of six arg. and az. on a bend gu. three roses of the first. Gray, York.

Barry of six or and az. on a bend of the last three roses arg. Lingen or Lingayne, co. Derby; co. Gloncester; co. Salop ; co. Northampton; and co. Worcester. Lingen, Lingen Castle, near Wigmore, temp. Henry III; Dutton Court, co. Hereford; and Penlanole, co. Radnor.

Barry of six or and az. on a bend gu. three roses arg. Lingaine, $V^{*}$. Lingen or Lingayne, co. Derby ; co. Gloucester; co. Northampton; co. Salop; and co. Worcester. LINGen, Lingen Castle, near Wigmore, temp. Henry III ; Sutton Court, co. Hereford ; and Penlanole, co. Radnor. LyNGAYN, $V$.

Chequy or and gu. on a bend az. three roses arg. Vaux, Tryermayne, Cumberland; an heiress $1553 \mathrm{~m}$. Brougliam.

Erm. on a bend az. three roses or. Fatshed. (The ancient arms of) Penrose, Penrose in Sithney, Cornwall; an heiress m. Pearce. Penrose, Cornwall, $r$.

Erm. on a bend gu. three roses arg. WaDmaN, London.

Erm. on a bend vert tliree roses arg. barbed and seeded or. Vidion, Half Yowke, Maidstone, Kent; grantcd :3 December 1664.

Gu. on a bend arg. three roses of the first. $J_{A Y}$. Sr. Peter Russeli, Russell, co. Salop, $V$. And in chief a crescent of the second. Clayton, $V$.

$\mathrm{Gu}$. on a bend engr. arg. three roses of the first. $\mathrm{J}_{\mathrm{AY}}, \boldsymbol{V}$. KenWICK.

Gu. on a bend engr. arg. three roses of the first seeded or. JAYE, London; and Norfolk, 1601.

Gi. on a bend arg. three roses sa. Berenden. Beronden, $V^{*}$. Berondon, $W$. Sire Gilberd de Borondone, $N$.

Or on a bend sa. three roses pierced of the field. Tenipest.

Quarterly arg. and az. on a bend gu. three roses of the first. Watkinson, co. York.

Quarterly arg. and gu. on a bend az. three roses of the first. Harian, Harman Hall, Sussex.

Quarterly arg. and sa. on a bend gu. three roses of the first. Garshall.

Sa. on a bend arg. three roses gu. Roos or Rosse. Roos, $V^{*}$ Roose, $V$. Rose. Edward Smallweli, Bishop of St. David's I783. Oxford 1788.99.

\section{Flute see Instrument}

\section{3-Foils}

Arg. on a bend az. three 3-foils slipped or. Lewis ADAM, co. Devon, $V$. ADaMs, Middlesex. Rokesborodgh. And with a mullet gu. pierced or. Rokesbourough, Cotton MS. Tiberius D. 10. But the mullet charged with a crescent of the third for diff. Ronesborough, $V$. Pokeseurgh, $V *$.

Arg. on a bend gu. three 3-foils slipped of the first. SEgrove.

Arg. on a bend sa. three 3-foils slipped of the first. Sir John Chadworth or SHadworth, Lord Mayor of London 1401, Harl. MS. 1349. Chadworth, $V^{*}$.

Arg. on a bend sa. three 3-foils slipped or. Thomas Gausill, $X$. Harvey, co. Stafford.

Az. on a bend or three 3-foils vert. Harvie, Broadley, Scotland. 


\section{On BEND....cont.}

3-Foils cont.

Barry of five arg. and gu. on a bend of the second three 3-foils slipped of the first. PaLdier. But slipped or. PaLMER, $V$.

Barry of ten arg. and sa. on a bend az. three 3.foils slipped or. Potr, co. Chester; and Stancliff, co. Derby.

Erm. on a bend.... three 3 -foils slipped. Covener, Hinxhill, co. Kent.

$\mathrm{Gu}$. on a bend arg. three 3-foils vert. Capt. George HaRver; quarterng sa. a lion ramp. arg. within a bordure compony of the second and first, with Drewry and Wiltshre.

Gu. on a bend arg. three 3-foils slipped vert. Harvey, co. Devon; and Sutfolk. Harvey, Thuley, co. Bedford. Hervey, Kidbrook, Kent; Baronetcy 31 May 1619, Baron Hervey 1020 and 7 February 1627.8 ; extinct 1642 ; descended like Henvey, Baron Hervey 23 March 1703, Earl of Bristol 19 October 1714, Earl Jermyn and Marquis of Bristol 30 June 1826, through Hervey, Ickworth, Suffolls, from Hervey, Thurley, co. Bedford (quartering Hammon or Harman) the name and arms of which last family were taken by Gerard son of Margaret SirART to wliom the estate at Thurley was bequeathed temp. Henry VIII by (Sr. George Hervy, $V$ ). John Hervy, from whom this coat was claimed 1408.9 as a variation of FoLIOT by Edward Sieur de Hastings; Harl. MS. 1178, p. 40. Hervey, Killiane Castle, co. Wexford; descended from Harver, Mayor of Lyme Regis, co. Dorset, 1614. Henvey quartered by HerveyBathurst, Bart.

Or on a bend sa.three 3 -foils slipped arg. Coner or Coyney, $V^{*}$. Coyne, co. Stafford. Coyney, Weston Coyney, co. Stafford, temp. Henry III. Cune, Wesen-Cune, co. Stafford. Cuney, Weston-Coyvey, co. Stafford, $Y$. Cwney; Cotton MS. Tiberius, D, 10. QUINey, co. Stafford.

Paly of six arg. and az. on a bend gu. three 3.foils slipped or. Fautener, V. Fawconer ol Fawhoner. Fawkenor, $V^{*}$. Fawhoner, co. Buckingham and co. Hants.

Paly of six arg. and sa. on a bend vert three 3 -foils slipped arg. Sr. Thomas FALCONER, Lord Mayor of Loudon 1414, Harl. MS. 1319. FAULCONER, co. Hants.

Paly of six arg. and sa. on a bend vert three 3.foils slipped or. FALCONER, Lord Mayor of London, 1414. Falikener. Fawherer.

Paly of six or and gu. on a bend sa. three 3-foils arg. Burton.

Paly of seven sa. and arg. on a bend vert three 3 .foils slipped arg. FAUKENNER. $V$.

Paly of eight az. and arg. on a bend gu. three 3.foils or. FAUKENNER.

Quarterly erm. and or on a bend plain arg. fim. briated engrailed gu. three 3-foils sa. Benson, Baysbrown, 1546, Hawkshead, and Lodge Lane, co. Lancaster; and Parkside, co. Westmoreland.

Sa. on a bend arg. three 3-foils slipped vert in chief a fleur-de-lis erm. HARver, Suffolk.

$\mathrm{Gu}$. on a bend arg. five 3.foils slipped vert. Drayton, $V$.

\section{4-Foil}

Arg. on a bend sa. a 4-foil or between two escal. lops of the first. Crofts, co. York.

\section{4-Foils}

.... on a bend....three 4 -foils .... Henworth.

Arg. on a beud sa. three 4-foils of the first. EYER. Payderday, $V^{*}$.
On 1 BEND..... cont.

4-Foils cont.

Arg. on a bend sa. three 4-foils slipped of the first. PADERDAY, $V$.

Arg. on a bend sa. three 4 -foils slipped and leaved of the first. Paderday.

Quarterly arg. and az. on a bend gu. three 4-foils. of the first. Chittinge. Chitting, Chester. 5-Foil

Erm. on a bend gu. a 5 -foil or. Barnake, $V^{*}$. Honnere, $V *$ *

Erm. on a bend gu. a 5-foil in chief or. . Sir Richard Bernake, $V$. Honner. Honnere, $V$. Gu. on a bend arg. a 5 -foil betw. two lions pass. of the first. HERING.

Or on a bend engr. az. a 5-foil of the first. Clarke, Ford, lient; and Essex.

Quarterly per fess indented gu. and or on a bend of the second a 5.foil betw. two ducks az. BINDLosse.

Quarterly per fess indented gil. and or on a bend of the second a 5 -foil betw, two martlets az. Bendlowes, Essex.

Quarterly per fess indented or and gu. on a bend az. a 5 -foil betw. two martlets of the first. BINdLosse, Borwick, co. Lancaster; and West. moreland; Baronetcy 1641 ; extinct 1688; the heiress $m$. Standish.

Vert on a bend arg. a 5 -foil betw. two lions pass. guard. gu. Hering, lsland of Jamaica. Hering, Owsley-Minor, co. Warwick, temp. Henry VII.

\section{5-Foils}

Gu. on a bend or two 5-foils az. and in the sinis. ter chief point a crescent surmounted of a cross croslet of the second. Cook, Pittenweem, Scot. land.

Arg. on a bend az. three 5-foils of the first. Cokesey.

Arg. on a bend az. three 5-foils or. Sir John Cokesay, $V$. M.lWauter Cokesere, $S$. Coorsey. Magnus, Archbishop of Canterbury. St. Petro. Arg. on a bend gu. three 5 -foils of the first. Rosseter, co. Lincoln. Trehampton.

Arg. on a bend gu. three 5-foils or. Crehington. Crekhaditon, $V$. Crekington. Ekington or Ekinton. Frehamton. John Trehampton, $Y$. Monsire de Trehampton, $Y$. Trehauton, $V$. Tremington, $V^{*}$.

Alg. on a bend sa. three 5-foils of the first. Amatrst. Beawford, co. Warwick. Cociser. Manington. Nicolets.

Arg. on a bend sa. three 5 -foils slipped of the first. COYNY or CoYney.

Arg. on a bend engr. sa. three 5.foils of the first. Harris, London; granted 10 April 16\%1.

Arg. on a bend sa. three 5-foils or. Boyce. Boyesse, $V$. Boyse, $V^{*}$. Braylesford, $V$. Calis. Carlesse. Charles or Chareles. Churles, $V$. M. John Hauberi, $S$. Martyn, Okingham, co. Berks.

Arg. on a bend sa. three blind 5 foils or. Braylesford; Cotton MS. 'Tiberius, D, 10.

Az. on a bend or three 5-foils of the first. Challenge, co. Gloucester.

Barry of six ol and az. on a bend gu. three 5-foils arg. Langhar. Sr. Rauf Lixgaine, $V$. LYNGAINE, $V *$.

Barry of six or and az. on a bend gu. tliree 5 -foils of the first. LONGAYNE. LYNGAYNE.

Chequy or and az. on a bend gu. three 5-foils arg. Wicherley or Witcheriey, Wicherley, co. Salop. 


\section{On 1 BEND.....cont.}

5-Foils cont.

Erm. on a bend az. three 5-foils arg. Beaufox, Edmondscott, co. Warwick; quartered by Wilder.

Erm. on a bend az. three 5-foils or. Sr. Thomas Beaufo, co. Warwick, 1619, W. Beawfoy. Beufo, $V^{*}$. Enolph, Kent. Low.

Erm. on a bend engr. az. three 5-foils or. Fifield alias Lowe, Bromley, Kent. Fishead. Fishide or Hyshid, $V$. Herris, Sandon, Essex. Low, $V^{*}$. Lowe, Bromley, co. Kent; and Lord Mayor of London 1604. Lowrde, London.

Erm. on a bend gu. three 5.foils arg. Barnake, $V$. Erm. on a bend gu. three 5.foils or. Barnand, co. Somerset and co. Gloucester. Barnake. Cremington, $V$. Crekington. Trehington.

Erm. on a bend sa. three 5 -foils arg. EDolfe, Kent, $V$. EDorphe, Hinxell, co. Kent.

Erm. on a bend engr. sa. three 5-foils or. Lowe, Bromley, co. Kent; and Lord Mayor of London 1604.

Gu. on a bend arg. three 5-foils of the first GlagG, $V$. MaIN, England.

Gu. on a bend arg. three 5-foils of the first over all a fess enhanced or. BRoAdHEAD.

Gu. on a bend arg. three 5-foils sa. BERONDON, co. Stafford.

Gu. on a bend erm. three 5-foils sa. Roddar, Roddam, Northumberland. RodDad, Colches. ter, Essex.

Gil. on a beud or three 5.foils of the first. Glagge.

Or on a bend az. three 5-foils of the first Bludder or Bluther, London. Harris, Maldon, Essex. Arthur Herris, co. Hertford, $W$. Heris, Herys, $r$. And with a mullet .... for diff. Herrys, Cryzsey, Essex; confirmed 19 Nov. 1578.

Or on a bend engr. az. three 5-foils of the first. Harris, Criclisey, Essex.

Or on a bend gu. three 5 -foils of the first. HerRis, Woodham Mortimer, Essex.

Or on a bend engr. gu. three 5.foils of the first. Cooke.

Or on a bend sa. three 5-foils arg. Thomas Menvile, $V$. Meverell and Mevill.

Paly of four arg. and az. on a bend gu. three 5 . foils of the first. Easterling.

Paly of six arg. and az. on a bend gu. three 5 -foils or. Easterling or Stradling. Stradling, St. Donat's Castle, co. Glamorgan ; Baronetcy 21 May 1611; extinct 27 September 1738 one heiress m. Turberville.

Paly of six az, and arg. on a bend gu. three 5-foils or. Esterling or Stradiling, Wales, 1732. Estreling, V. Sir Edward Stradling, Wales, $V$. Stradlyng, $T$.

Paly of six az. and or on a bend gu. three 5 foils of the second. Stardeling, Wales.

Paly of six sa. and arg. on a bend gu. three 5 -foils or. Dransfield.

Paly of eight arg. and sa. on a bend of the last three 5.foils or. Faukenner, Surrey.

Per fess gu. and az. on a bend engr. arg. three 5 -foils of the second. Gyues.

Quarterly or and gu. on a bend sa. three 5-foils arg. Eure.

Sa. on a bend. arg. three 5-foils gu. Berts. Dintres. Dyntees, $V$.* Sr. de Dyntrees, $V$. DYNTREY.

Sa. on a bend arg. three 5-foils of the first. Berendon, $V^{*}$. Sr. John Berondon, $V$.
On 1 BEND.... cont.

5.Foils cont

Quarterly arg. and az. on a bend compony gu. and of the second six 5-foils (? of the first). Greshati or Grasselil. Gressall, $\boldsymbol{V}$.

Fret

Or on $a$ bend az. a fret of the first. Over. Frets

Arg. on a bend sa. three frets the maseles of the first the batons gu. Pobert Worswike (UnswIK in pencil), $Y$.

Sa. on a bend wavy arg. three frets az. STANDEN.

\section{Fretty}

Arg. on a bend gu. fretty az. Bnedgar, Bredgar, Kent.

Arg. on a bend gu. fretty or. Ratwell or Rattellwell. Rockelwell or Rottlewell. William Rotelwell, $V$.

Chequy or and az. on a bend git. fretty erm. Cheynex, Drayton, co. Buckingbam.

Gu. on a bend arg. fretty az. ORRE.

Lozengy arg. and az. on a bend gu. fretty or. Cheyner, co. Chester.

Lozengy or and az. on a bend gu. fretty of the first. Cheyney, co. Chester.

\section{Fruits ....Acorns}

Arg. on a bend az. three acorns of the first in chief a mullet sa. Morehead, Scotland.

Arg. on a bend az. three acol'ns or. MuIrheAD, Lauchop, Scotland. Rarlton, Fakenham, Norfolk.

Arg. on a bend az. three acorns in the seed or. Ralston, Auchentorlie, near Paisley; a younger branch of RaLston, Ralston, co. Renfrew, the heirs $m$. Crawfurd and Studdert. John de Ralstoune or Ralphstown, Lord High Treasurer, Bishop of Dunkeld 1448.52.

Arg. on a Lend az. three acorns slipped ppr. Mulrhead; qualtering Grosett.

Arg. on a bend sa. three acorns or. AckHURs'r. Akaris 1732. AKanYs, $V^{*}$.

Arg. on a bend sa. three acorns slipped or. Akarys, $W$. Akyris, Cot. MS. Tiberus, $\mathrm{D}, 10$. Arg. on a bend sa. three acorns or husked vert. Ackers, Bankhouse, Manchester ; and Moreton Hall, co. Chester. Ackers, The Heath, Leintwardine, co. Salop. AkArys AkErs AkerIs, or AKYRIS.

Arg. on a bend vert three acorns or. CAwood, Cawoodhall, co. Lincoln.

Erm. on a bend or three acorns ppr. DaliIng, Burwood Park, Surrey; Baronetcy 11 March 1783.

Erin. on a bend sa. three acorns or. AmRas, Norfolk; originally Kent. DaliIng, $V^{*}$. Dallinge. John Dauling or Dawling, in Christ Church, Southwark, 1715. Rev. John Daulinge 1710. Dolling.

Erm. on a bend sa. three acorns slipped or. Dalling, $V$. Dallyng and Dallyngs, Cotton $M S$. Tiberius, D. 10 .

Erm. on a bend sa. three acorns or slipped vert. DALIING.

Erm. on a bend sa. three acorns ppr. DaLIING, Burwood Park, Surrey; Baronetcy 1783.

$$
\text { .....Apples }
$$

Arg. on a bend sa. three apples or. Apelton. APLEBy. APOLBY, $V *$.

Arg. on a bend sa. three apples slipped or. APULBY, $V$.

Arg. on a bend sa. three apples.... stalked and leaved or. ApPuLBX. 
On 1 BEND... cont.

Fruits cont. Grapes

Or on a bend sa. three clusters of grapes arg. MARoley, co. York, temp. Edward I.

$$
\text { .....Pears }
$$

Arg. on a bend sa. three pears or. Penire. Perry, co. Worcester. Pery, $V^{*}$. Piry, co. Worcester.

Arg. on a bend sa. three pears slipped erect bend. wise of the shield or. PERY, $V$. PERYe; Cotton MIS. Tiberius, D, 10.

Arg. on a bend sa. three pears ppr. Pennoyne, co. Brecknock.

$$
\text { .....Rye }
$$

Gu. on a bend arg. three rye-stalks sa. Rey or RY. Rye, Suffolk, 1716.

Gil. on a bend arg. three rye-stalks and ears sa. Rye or REYE.

Gu. on a bend erm. three rye-stalks sa. ReYe.

Gu. on a bend erm. three rye.stalls and ears sa. Rye or REYe, Whitwell, co. Derby; Harl. LSS. 1093 , fo. $81 ; 1537$, fo. 16 .

$$
\text { .....Wheat }
$$

Arg. on a bend erm. three ears of wheat sa. Rive, $V^{*}$.

(Gu.) on a bend erm. three ears of wheat sa. RYE, Whitwell, co. Derby; granted 1575, W.

$$
\text { .... Rye }
$$

Arg. on a bend az. six ears of rye two two and two or. Ryan, Ireland.

$$
\text { ..... Wheat }
$$

Arg. on a bend gu. six eal's of whegt two two and two or. O'Rran, Ireland; quartering az. a chev, hetw, three griffin's heads arg.; Hart. MS. 4039 , fo. 47 .

\section{Fusils}

Arg. on a bend sa. three fusils of the first. WARINGS.

Arg. on a bend sa. three fusils erm. Dent, London.

Az. on a bend or three fusils gu. Mete, Kent.

Or on a bend per bend gu. and sa. three fusils conjoined of the first. DENT, Shortflatt Tower, Belsay, Newcastle-on-Tyne; quartering Hedley.

\section{Garbs \&c.}

Arg.on a bend az. three oat-sheaves or. OTELEY, Yitchford, co. Salop, W. Adam OtLer, Bishop of S. David's, 1713-23. Ortuey, Ottley, co. Salop; the heiress m. Kynaston.

Arg. on a bend az. three garbs or. Feton. Finton. Firton, Gawsworth, co. Chester; a younger branch of Fitton, Pownall, co. Chester, the co.beirs $\mathrm{m}$. Newton and Minshull, a younger branch of Fitton, Bolyn, co. Chester, temp. Henry III ; extinct about 1370 ; the heiress m. Venables. Fytton, $V$. Hesketh, Lancaster. Peverell, co. Worcester. William Proid, $V$. Proyd, $V^{*}$. And in chief a crescent of the second for diff. M. Pichard Fytron, $S$.

Arg. on a bend engrailed az. three garbs or. RICKARDS.

Arg. on a bend gu. three garbs or. BARLEY, co. Derby. Fiton. Maltby, $V$. Maltby, Maltby, Cleveland, co. York. MaLBy or MaLTBy.

Arg. on a beud sa. three garbs or. HesEetH, Rufford, co. Lancaster. Hesketh, $V^{*}$. Sir Thomas Hesketr, co. Lancaster, $V$.

Arg. on a bend engr. vert three garbs or. Richards, co. York; granted 1505. Ricrards, Evenjobb, co. Radnor; Llantrissant, co. Glamorgan : co. Hereford and co. Somerset; quartering Taylor and Boulcott.
On 1 BEND.....cont.

Garbs cont.

Erm. on a bend vert three garbs or. Richardson, Suffolk, 1716.

Or on a bend az. three oat-sheaves of the field. OTLEy.

Or on a bend sa. three garbs of the first. HaskftT. Sa. on a bend arg. three garbs gu. PAckington, Edgeworth, co. Middlesex; and Surrey. Parington, $V$.

\section{Gouttes}

Or on a bend gu. three gouttes arg. Chinston.

Paly of six or and gu. on a bend sa. three goutles arg. Bmton, $V$.

Gu. on a bend arg. eight gouttes-de-poix in pairs. Morrions; Cotton MS. Tiberius, D. 10.

Barry of three sa. and erm. on a bend gu. gouttes d'or. Speliman or Spillitan.

Barry of three sa. and erm. on a bend or gouttes de-sang. Spelitan or Spilman.

Gu. on a bend arg. gouttes-de-poix. Morcomes or' Morconds, Sutiolk. Morion, Norfolk.

Or on a bend (? az.) gouttes d'eau. Chyusvon.

Paly of six or and gu. on a bend sa. gouttes arg. Briton Britain or Britton. Brrton.

\section{Hammers}

Gu. on a bend arg. three mallets sa. OnIngton.

\section{Handcuffs sec Swivels}

\section{Hands}

Erm. on a bend sa. two hands and arms arg. rending a horseshoe gold issuing at the elbows from the dexter and sinister sides out of clouds az. radiated or. Borlace, $V^{*}$. Borlas, St. Newlyne, Cornwall, $V$. Borlase, Pendeen in St. Just, Cornwall; descended like BorLase, Buckmer, co. Buckingham, Baronetcy 6 May 1642, extinct 1688, through BorLase, Trelud. dra, from Borlase, Borlase, St. Wenn, Colnwall ; extinct temp. Elizabeth; the co-heirs m. Toukin and Bray.

Arg. on a bend sa. three dexter hands apaumy couned of the first. EsIngold. MAYN, $V$. MaYNe, co. Warwick; and Rowston, co. York.

Arg. on a bend sa. three sinister hands couped at the wrist of the first. MAYNe, Bornington, co. Hertford.

Arg. on a bend engr. sa. three dexter hands couped at the wrist of the first. Mayne, Teffont Ewyas, co. Wilts, 1679 .

Erm. on a bend sa. three dexter hands couped arg. MAYNE, Crestow, co.Buclingham; granted June 1604.

Erm. on a bend sa. three dexter hands or. MAIN, co. Buckingham.

Or on a bend az. three dexter hands couped at the wrist clenched arg. Esingold, $r$.

Or on a bend az. three hands clenched and couped at the wrist of the first. ARMes.

Or on a bend az. three hauds (clasped or) clenched of the first. EsINGoLd.

Or on a bend az. three pair of hands clasped of the first. EsINGOLD.

Head..... (Beast) Boar

Az. on a bend arg. a boar's head betw. two mullets gu. HONCHACH or HONYCHURCH.

Az. on a bend or a boar's head betw. two mullets gu. Honchach or HonychuROH.

Gu. on a bend arg. a boar's head betw. two mul. lets gu. HONYCHURCH. ....Deer

On a bend vert fimbriated or a stag's head cabossed or. O'Doule e, Harl. MS. 4039 , fo. 105 . 


\section{On I BEND.... cont.}

Head cont. (Beast) Dog

Paly of six arg. and az. on a bend gn. a grey. hound's bead erased betw. two dexter hands couped at the wrist arg. NEAL, Yeovil, co. Sumerset.

$$
\ldots \text {...Ibex }
$$

Lozengy arg. and vert on a bend az. an ibex bead erased of the first attired or. YoNGE, co. Wilts.

$$
\text { .... Leopard }
$$

Chequy or and gu. on a bend vert a leopard's head betw. two annulets of the first. Reynes, Stapleford, co. Nottingham.

$$
\text { .... (Bird) Duck }
$$

Paly of six arg. and sa. on a bend or a teal's head erased az. Burwet..

$$
\text { ....Swan }
$$

Paly of six arg. and sa. on a bend or a swan's head and neck erased az. beaked gu. in chief of the bend. Burwell, $V$.

$$
\text { .... (Human Figure) }
$$

Arg. on a bend gu. an esquire's helmet or. Tritten or Trayton.

Arg. on a bend gu. a belmet in the dexter chief point or. TRAYTON.

Arg. on a bend sa. a helmet of the first. Trayton, Lewes, Sussex, $W$.

Arg. on a beud gu. a belmet or. Trarton, Suffolk, 1716 .

Arg. on a bend gu. a close helmet ppr. Trayton; quartered by Fuller.

$$
\text { ..... (Monster) Dragon }
$$

Az.on a bend arg. a dragon's head fesswise erased close to the ears hetw. two mullets gu. Sr... de Honychunch, $V$. Hoxychurch, Honychurch (temp. Henry III), and Aveton Giffard, co. Devou.

$$
\text { .....Griffin }
$$

Erm. on a bend az. a griffin's head erased betw. two spear-heads or. Hordip, London and Southampton; granted 5 June 1725.

\section{Heads.... (Beasts) Ibex}

Lozengy arg. and vert on a bend az. two jbex heads erased of the first attured or. Yonge, co. Wilts. And with a crescent in chief of the bend. Sr. John Yong, Lord Mayor of London $1 \pm 66$; Harl. MS. $13 \pm 9$.

\section{.... Lions}

Gu. on a bend arg. two lion's heads erased of the first. PENDER, Scotland.

\section{..... (Monsters) Unicorns}

Paly bendy of six arg. and vert on a bend az. two unicorv's heads bendwise erased of the first. YoNGE, $V$.

\section{..... Beasts)}

Fusily arg. and vert on a bend az. three (? ibex or uuicorn's) heads erased or. Yong; Bristow.

$$
\text { ..... Bear's }
$$

Arg. on a bend gu. three bear's heads erased of the first. Gemiel Gemel or Genill, Scotland.

Arg. on a bend sa. three bear's heads elased of the first muzzled of the second. Fitz Ounse, co. Somerset.

Or on a bend sa. three bear's heads arg. muzzled of the first. FESARD.

Or on a bend sa. three bear's heads erect conped arg. muzzled gold. Fitz. Urse, co. Somerset, $V$. .... Boar's

Arg. on a bend az. three boar's heads erased of the first. HartLEY, Meler'starmes, Scotland.

Arg. on a bend az. three boar's heads couped or. PidDLEDON. 0n 1 BEND.....cont.

Heads cont. (Beasts) Boars cont.

Arg. on a bend sa. three boar's beads couped or. ReKedon or RyKesdon. Ridlesdon.

Arg. on a beud sa. three boar's heads bendwise couped or. Rikdon, $V$. RyKdon, $V^{*}$. Rirkesdon, $V$.

Barry wavy of six arg. and az. on a bend sa. three boar's heads couped of the first. Purcell, co. Salop.

Barry wavy of six arg. and az. on a bend sa. three boar's heads erased or. Purcell, Westminster.

Barry nebuly of six arg. and gu. on a bend sa. three boar's heads of the first. Pijncell, Ouneslow, co. Salop; granted April 1597.

Barry wavy of six arg. and gu, on a bend sa. three boar's beads of the first. Purcell, Temple Mary, Burton Honse and Highfort, Altamira, and Annabella, co. Cork; descended through Purceld, Croagh Purcell, co. Limerick, from Purcell, Loughmoe.

Barry wavy of six arg. and gu. on a bend sa. three boar's heads fesswise couped or. Pursell, $V$.

Barry nebuly of seven (eight $V^{*}$ ) arg. and gu. on a bend sa. three boar's beads fesswise couped or. Punselt, $V$.

Erm. on a bend sa. three boar's heads erased arg. GeLiIAT or GeLIYot, co. York.

$\mathrm{Gu}$. on a bend arg. three boar's heads bendwise couped sa. BewYזE, $V$.

Or on a bend az. three boar's heads erased of the first. Haitise, Mellarstonn, Scotland.

Or on a bend gu. three boar's heads conped erect of the first. Tuning, Foveran, co. Aberdeen; Baronetcy 1638.

Or on a bend vert three boar's heads erased sa. HEATLEY.

Paly of six or and gu. on a bend sa. three boar's beads arg. Brrton.

Per bend gn. and or on a bend arg. three boar's heads couped sa. Bewixe.

Quarterly gu. and arg. on a bend of the first three boar's heads erased of the second. Burston, Kent.

Vairy arg. and gu. on a bend sa. three boar's heads cnuped or. Purcell. The heads fess. wise. Punseli, $V$.

$$
\text { ....Deer }
$$

Arg. on a bend az. three buck's heads cabossed of the first. FAwCETT, Ireland.

Arg. on a bend az. three bnck's heads cabossed or. Stanley, $V^{*}$. Elizabeth, coheir of Ferdinand, Stanlex, $Z, 442,542$.

Arg. on a bend az. three buck's (another stag's) heads cabossed or. Thomas Stanley, Bishop of Sodor, \&c., 1510-1545 and 1556.58. 'Thomas STANLEY; quartering Lathom (the chief not indented), $X$. Assumed on marriage with Joan de Bamvile by Williain Stanley, Stoneley; from whose sons, who might thereby quarter Bam. vile, Stourton, and Silvester, descend witb due diff., St tanler, Ponsonby Hall, Cumberland, and (the senior branch of all these families) STANLEY, quartering Hooton and by one match Parry, a branch $m$. an heiress of Massey, and this family became for a short period StanleyMassey, bint since 1792 Massey-Stanley; Baronetcy 17 June 1602. And without the quartel'mgs of Hooton, \&c. with due diff. (the diff. now omitted) John Stanley, K.G., who m. an heiress of Lathom, and became 1405.6 Lord of the Isle of Man, from whom descended STantey, Elford (with a crescent gu. for diff.), Pipe 
On 1 BEND.....cont.

Heads cont. (Beasts) Deer cont.

(with due diff.), \&c.; and through a marriage with an herress of Harrington, Thomas Stanley Baron Stanley 20 January 1456, from whose marrage with a cohtiress of Goushill, representing Fitz Alan, Albıni, and Warren, descended Stanley Earl of Derby 27 October 1485; James Stanley Bishop of Ely 1506.15, quartering Lathom quartering Man over all an inescucheon for Montaut; and (with a crescent for diff.) Stanlex, Baronetcy 25 June -1660, Baron Stanley of Alderley 9 May 1839, Baron Eddisbury 12 May 1848; which last family bas $m$. heirs of Weever and Warburtou, (and a second son $\mathrm{m}$. Byron, his coheiresses $\mathrm{m}$. Leigh, Venables, Wilbraham, and Swettenbam) and Owen, from whom descended Edward STanley Bishop of Norwich 1837.49 . Thomas S'TANLEY, second Baron Stanley, who quartered Stanley with Lathom and Warren, with in the second and third grand quarters Man and over all an inescucheon for Montaut, $Z, 329$, became Earl of Derby 27 October 1485; his sons were George Stanley Lord Strange jure ux. Joan Strange who brought the guarterings of Mohun with Widvile; and Edward STANLEY, Hornby Castle, Baron Monteagle 1514, quartering Lathom and Warlen with in the second and third quarters $\mathrm{Man}$ over all in the centre a crescent or, $U$, extinct 1581 ; the heiress m. Parker. The elder son had two sons; the younger, settled at Crosshall, had a son Henry who m. an heiress of Stanley (of Bickerstaff) a branch of Stanley of Hooton, and from him descend through Stanter, 13icker'staff, and Crossball, co. Lancaster, Baronetcy 26 January 1627, STANLEX eleventh Earl of Derby; Stanler, Ormskirk; and (by $\mathrm{m}$. with an heiress of Shawe) STANLEY, Crosshall, co. Lancaster : the elder son Thoraas, second Earl of Derby, Viscount Kynton, Baron Stanley and Strange, Lord of Knokyn, Mohun Basset, Burnel, and Lacy, Lord of Man and the Isles, quartered Stanley, Lathom, and Warren, with in the second and third grand quar. ters Man, and in the fourth Strange quartering Wydvile, over the whole an inescucheon for Montaut, $U$. A grandson, Thomas Stanley, Winwek, m. an berress of Vernon; his co-herrs $m$. Fortescue and Digby. The co-heirs of the fifth Earl of Derby m. Brydges, Egerton, and Hastungs $(Z, 442)$, when the Baronies of Stanley and Strange fell into abeyance. James Stanler, seventh Earl Derby, Baron Strange 1627 , and his descendants to James tenth Ear Derby ob. 1735.6 ; the eventual heiress had $\mathrm{m}$. Murray, Baron Strange of that creation and Lord of the Isle of Man, jure uxoris. Edward STANLEx, eleventh Earl Derby, $m$. an heiress of Hesketh, and had a son James, from whom by m. with an heiress of Smith descends Smith. Stanley, Bart., Baron Stanley 22 December 1832 and Earl of Derby, Knowsley, co. Lancaster.

Arg. on a bend az.three stag's heads cabossed or. Stanley, Skottoe, Nolfolk.

Arg. on a bend az. three stag's heads cabossed bendwise or. Stanley, co. Lancaster, $V$.

Arg. on a bend az. three buck's heads couped or. LAMBPOR'T.

Arg. on a bend gu. three buck's heads cabossed of the first. Norman.

Arg. on a bend gu. three buck's heads or. BICHe, Berlishire. (? Trethelifie, Cornwall.)
On 1 BEND....cont.

Heads cont. (Beasts) Deer cont.

Arg. on a bend gu. three buek's heads cabossed or. Beche, Berkshure. Nornan, $V^{*}$. And with a label of five points az. BIECH, $V *$.

Arg. on a bend gu. three luart's heads cabossed or. NorMtan.

Arg. on a bend gu. three stag's heads bendwise cabossed or. Sire Johan de Becene, $N$. Norman, $V$. And with a label of five points az. Sr. Willian Byech, $V$.

Arg. on a bend gu. three stag's heads couped or. Busirn. And with a martlet in chief sa. Sir John de la BEcHe, $L$. But with hind's heads, Sir Jolun de la VAche, L, Harl. MS. 6137. But the stag's beads erased or in chief a martlet sa. Sir John de la Beacee, L, Harl. MS. 6589.

Arg. on a bend sa. three buck's bearls cabossed of the first. Fassetr or Faussett, co. Lincoln. Forset, Bellingsby, co. Lincoln. Hayton.

Arg. on a bend engr. sa.three buck's heads of the first. Hleaton, Plas Heaton, co. Denbigb.

Arg. on a bend engr. sa. three bucli's heads ca. bossed of the first. EATON.

Arg. on a bend sa. three hart's heads or. Hertfand, co. Devon. WEdLand.

Arg. on a bend sa. three buck's heads cabossed or. Foster, $V^{*}$. Woodland, $V *$.

Arg. on a tend sa. three huck's heads cabossed or armed of the first. Fosset.

Arg. on a bend sa. three stag's heads cabossed or. STANLEY.

Arg. on a bend sa. three stag's heads bendwise cabossed or. Sr. Waltel Woodland, $V$.

Arg. on a bend engr. sa. tluree buck's heads ca. bossed or. Forster, Battle, Sussex.

Arg. on a bend engr. sa. three stag's heads bend. wise cabossed or a crescent in chief for diff. Foster, Iden, Sussex, $W$.

Arg. on a bend wavy sa. three bucli's heads cabossed or. Foster, Essex.

Arg. on a bend vert three buck's heads of the first. Ferniley.

Arg. on a bend vert three buck's heads cabossed of the first. Fawset, Bellingsby, co. Lincoln.

Az. on a bend gu. three buck's heads or. (?) Tretheriffe, Coruwall.

Erm. on a bend sa. three stag's heads cabossed arg. Servington.

Gu. on a bend or three buck's heads of the first. HeLIGaN, Cornwall.

Gu. on a bend or three buck's heads cabossed sa. TrFDeneck, Tredeneck, co. Cornwall. TiredenNick.

Or on a bend gu. three bucls's heads cabossed of the first. BECHe.

Or on a bend sa. three buck's heads cabossed arg. 'I'IEDENNICK, Tredennick, co. Cornwall.

Or on a bend sa. three buck's heads erased.... BilliNg or BILLINGE.

Or on a bend vert three buck's heads arg. Ferwley, co. Lapcaster.

Or un a bend ver't three buck's heads cabossed arg. FERNLEY, $V^{*}$.

Or on a bend vert three stag's heads bendwise cubossed arg. FERnLey, co. Lancaster, $V$.

Or un a bend vert three buck's heads cabossed a' $r$ attired of the field. Flrneley or FE RNLEY, eo. Chester ; co. Lancaster ; and Sutton, Suffolk.

Or on a bend vert three buck's heads cabossed of the first. FennLer, Suffolk.

Firt on a bend or three stag's heads cabossed sa. TAlLEY, Loudon; and cu. York. 


\section{On 1 BEND.... cont.}

Heads cont. (Beasts) Dogs

Barry of five gu. and or on a bend arg. three talbot's heads erased sa. GoDDEs, Leyborn Castle, 1574 ; and Finchden, Tenterden, Kent.

Erm. on a bend sa. three taluot's heads erased arg. Doget, Kent. Dogetts, $V$. Doggett, $Y *$.

Erm. on a bend sa. three talbot's heads erased or. Doget, Kent.

Or on a bend az. three greyhound's heads erased of the first collared arg. LAToN.

Or on a bend gu. three greyhound's heads erased of the first collared and ringed of the second. Laton, $V$.

Per fess arg. and git. on a bend sa. three hound's heads erased of the first. Reynolds.

$$
\text { .... Foxes }
$$

Arg. on a bend sa. three fox's heads erased or. W'ALKLLX, co. York.

Lozengy arg. and vert on a bend az. three fox's heads erased of the first. Yonge, co. Wilts.

$$
\text { .....Goats }
$$

Arg. on a bend sa. three goat's heads (palewise, $V$.) erased of the first horned or. MuLsho, $V^{*}$. Mulso, $V$.

Arg. on a bend engr. sa. three goat's beads couped of the first. Lampet, Suffoll. Lampet or LaMipeth.

Arg. on a beud engr. sa. three goat's heads couped of the first attired or. BREDwELL, Siffolk.

Erm. on a bend sa. three guat's heals erased arg. Mulsho or Mulshoe, Goldiugton co. Buckingham; Thingdon, Suffolk ; Goathurst, co. Hereford, de; Add. MIS. 19142, fo. 373; granted 10 December 1587 .

Erm. on a beud sa. three goat's beads erased arg. attired or. Marshe. Mulsho, $V^{*}$. Sir Edmund Mulso, $V$. 'l'homas Mulso, co. Northampton, $W$.

\section{....Leopards}

Arg. on a bend az. three leopard's faces or. ADEY, Woddington, lient; Combe, co. Gloacester; and Merlsyate Cell or Priory, co. Hertfurd. Bury. Burys, $W$.

Arg. on a beud az. three lenpard's heads or. Buris. Burys, $V^{*}$. Coker. Hedley, co. Salop.

Arg. on a bend az. three leopard's faces (heads $V^{*}$.) erased or. Sr. John Bunys, $V$.

Arg. on a bend gu. three leopard's faces (heads $V^{*}$.) of the first. Kimbeis, $W$. Krmble, $V$.

Arg. on a bend engr. gu. three leopard's faces (heads $V^{*}$.) of the first. BoLTon, co. York, $V$. Boulton, Norfulk; and co. York.

Arg. on a bend gn. three leopard's faces or. Bolton. Cesir, $V$. William Coker, $V$. And with a martlet in chief sa. Coker.

Arg. on a bend gu. three leopard's heads or. Cesir, $V^{*}$. Coker as quartered by Jane Seymour third wife of Henry VIII, Z, 488 . Corer, Mopowder, co. Dorset. Coker, $V^{*}$. Cokerey. Arg. on a bend engr, gu. three leopard's faces or. Nicholas Barbon, M.D., London, 1730.

Arg. on a beod purp. three leopard's heads or. CEsrr.

Arg. on a bend sa. three leopard's faces of the first. Sr. John Kokyrhan, $V$. GWEIRYd AP Ruys Goch, Lord of Tal Ebolion in Anglesey. Henluys, Anglesea, 1743 .

Arg. on a bend sa. three leopard's heals of the first. Cokerharr, co. Derby. Hokyran, $V^{*}$. Morris, Ystradmeuric, co. Cardigan.

Arg. on a bend sa, three leopard's faces gu. (?) CUKER.
On 1 BEND.... cont.

Heads cont. (Beasts) Leopards cont.

Arg. on a bend sa. three leopard's faces or. Sr. John Cokerham, $V$.

Arg. on a bend sa. three leopard's heads or. Cockeram or Cockerham, Hillersdon, co. Devon, and Purbeck, co. Dorset. Corerham, $V^{*}$. Cokerham, co. Derby. Kokyrham, $V^{*}$.

Az. on a bend arg. three leopard's hearls of the first crowned or. Gomney or Gononey, Essex.

Barry of five gu. and arg. on a bend or three leopard's faces sa. Higgat.

Barry of five gu. and arg. on a bend or three leopard's heads sa. HIGGat, Suffolk.

Barry of six arg. and az. on a bend gut three leopard's faces (heads $V^{*}$.) or. Grey, $V$.

Barry of six arg. and az. on a bend gu. three leopard's faces jessant-de-lis or. Grex, Lanfrid, $W$.

Barry of seven arg. and az. on a bend gu. three leopard's heads or. Gray.

Cbequy az. and or on a beud arg. thlee leopard's faces gu. WORDEN.

Chequy or and az. on a bend gu. three leopard's faces (beads $V^{*}$.) arg. ChIFFord, co. Somerset, $W$.

Chequy or and az. on a bend gu. three leopard's faces of the first. ClifFord.

Erm. on a bend az. three leopard's faces or. Cambride, $W$.

Erm. on a bend az. three leopard's heads or. Cambird, $V^{*}$. Langley, co. Lincoln.

Erm. on a bend gu. three leopard's faces or. Stinte, $V$.

Erm. on a bend gu. three leopard's heads or. Stinte, $V^{*}$. Stynte or Styner, co. Devon.

Erm. on a bend sa. three leopard's faces (heads, $V^{*}$.) arg. Dogate, $V$.

Erm. on a bend vert three leopard's faces (heads, $V^{*}$.) or. Sr. John Langley, Lord Mayor of London $1576, \mathrm{~W}$.

Gu. on a bend arg. three leopard's faces (beads) of the first. WERDEN, Leyland, co. Lancaster; and Cholmeaton, co. Chester; Paronetcy 28 November 1672; extinct 16 February 1758; the coheirs m. Fitzroy and Bayntun. WYorden, co. Lancaster; and London.

Gu, on a bend engr. arg. three leopard's faces of the first. Boulton, Burston, co. Norfolk.

Gu. on a bend arg. three leopard's faces or. Hadey. Stevenson, Boston, co. Lincoln. (These are errors in $W$.)

Gu. on a bend arg. three leopard's heads ppr. Stevenson or Stevinson, Weston, co. Derby; aud co. Lincoln.

Gu. on a bend arg. three leopard's faces sa. ADY or Adry. Burgh, $W$. Stephenson.

Gu. on a bend arg. three leopard's heads sa. BurgH, $\mathrm{J}^{*}$.

Gu. on a bend arg. three leopard's faces vert. Haddey and Hadley, $W$. Hadey, $V$, Cotton MS. Tiberius, D, 10. Stevenson, Boston, co. Lineoln, MS. Tiberius, D, I0. Stevenson, Onnston or Unston, co. Derby; Visitation 1662. Gu. on a bend arg. three leopard's beads vert. HADEY, $V^{*}$. HADLEY, $V^{*}$. Hayduy, London. Stephrnson, Doiley, co. Middlesex; CumberJand ; co. Derby ; co. Lincoln ; London; and co. Yorls. Stevenson, $V^{*}$. Stevenson or Stevynson, Weston, co. Derby; and co. Lincoln.

$\mathrm{Gu}$. on a bend arg. three leopard's faces vert langned of the field. ADY ADEY or ADDEY, Kent; London; and co. Hereford. 
On 1 BEND..... cont.

Heads cont. (Beasts) Leopards cont.

$\mathrm{Gu}$. on a bend erminois three leopard's faces vert. Stevenson, Cumberland; granted to Sir William Sterenson, Lord Mayor of Lonion 1764.

Gu. on a bend or three leopard's faces az. Stephenson, Knaresdale Hall ; and Newcastle.

Gu. on a bend or three leopard's faces vert. Stephenson, Farleigh Hill, co. Berlis. But leopard's heads vert. HAYDAY, Weston,co.Hereford.

$\mathrm{Or}$ on a bend az. three leopard's heads (arg. another) or. Mingay or Minger, Gimmingham, Norfolk.

Or on $a$ bend sa. three leopard's heads arg. KATHERAM.

Sa. on a bend erm. three leopard's faces of the first. Kenble, Wydell, co. Wilts; and Lamborne, co. Berks.

\section{....Lions}

Arg. on a bend az. three lion's lieads erased of the first. Stephen, Barton-on-the Hill, co. Gloucester ; granted $15 ! 1$.

Arg. on a bend az. three lion's heads erased or. BERY.

Arg. on a bend gu. three lion's heads or. Cooker, co. Devon.

Arg. on a bend gu. three lion's lieads couped or in chief a martlet sa. BEche.

Arg. on a bend gu. three lion's heads erased or. CARDEN or CARDIN.

Arg. on a bend sa. three lion's beads erased of the first urowned or. Sir Thomas Wrathe. Wroth, Essex; Woodbery and Youngs, co. Hertford; Blendenhall, co. Kent; and Hempneyshall, co. Suffulk. Wroth, Durants, Enfield, co. Middle. sex. Sr. Robert Wrothe, Middlesex, $V$.

Chequy arg. and sa. on a bend gu. three lion's heads erased or. Churchar, Slingfield, Sus. sex. Hoveden, Lelban, Ireland, granted 1585 ; Harl. MS. 1359, fo. 90 b.

Chequy sa. and arg. on a bend gu. three lion's beads erased or. Hoveden.

Erm. on a bend az. three lion's heads erased.... Westonstone.

Erm. on a bend az. three lion's heads erased or. Weston or Wiston, Sussex, $11 \tau 6$.

Erm. on a bend gu. three lion's heads erased or. WEston, $V$.

Gu. on a bend arg. three lion's heads erased of the first. TurPIN, Knaptoft, co. Leicester.

$\mathrm{Gu}$. on a bend arg. three lion's heads erased sa. Turpen, $V^{*}$. Turpin, co. Cambridge; and co. Leicester. TURPyN, $V$

Or on a bend az. three lion's heads erased of the first. Corders or Cordrey.

Quarterly arg. and gu. on a bend az. three lion's heads erased or. Borsting.

Quarterly arg. and sa. on a bend gu. three lion's Jjeads erased of the first (langued or, Add. MS. 14307, fo. 8 b). Bukston, lient; Harl. MS. 4108, fo. 66 .

\section{..... Oxen}

Arg. on a bend sa. three bull's heads couped of the first. Martin Heton, Bishop of Ely 1599. 1010, quartering arg. a negro's head couped betw. three fleurs.de-lis sa.

Arg. on a bend engr. sa. three bull's Leads cabossed of the first. Herton, Heiton, co. Lancaster. Helton. Heton, co. Lancaster. James HeTon, $V$.

Arg. on a bend engr. sa. three bull's beads erased of the first. Eton, co. Chester; and co. Lan. caster. Hertox, Heaton.
On 1 BEND.....cont.

Heads cont. (Beasts) Sheep

Arg. on a bend sa. three rain's beads cabossed of the first. Creswell. Creswyll, $V$.

Arg. on a bend engr. sa. three ram's heads ca. bossed of the first attired or. LanIPEN, $\mathrm{Pa}$ derda in Jinkinhorne, Cornwall.

Arg. on a bend engr. sa. thrce ram's heads couped of the first. LAMPETH, $V^{*}$.

Arg. on a bend engr. sa. three ram's heads of the first attired or. LAMPET or LAIIPETH, Suffolk.

Arg. on a bend sa. three ram's heads cabossed or. Creswell or Creswyll.

Arg. on a bend engr. sa. three ram's heads couped or. LaMpeth, $\boldsymbol{V}$.

Or on a bend az. three ram's heads couped arg. Benedictine Abbey at RAnsey, co. Huntirgdon, $U$; (another, attired of the first).

$\mathrm{Or}^{*}$ on a bend sa. tbree ram's heads couped arg. Frtz-Vrith.

\section{....Wolves}

.... on a bend .... three wolf's heads erased .... John Lowe, Bishop of S. Asaph 1433; Rochester 1444.67.

Arg. on a bend az. three wolf's heads erased of the field. Lowe, Southmills, co. Bedford. Lowe, Clifton-Reynes, co. Buckingham.

Arg. on a bend 'sa. three wolf's heads erased or. Lamburne.

Arg. on a bend vert three wolf's heads erased of the first. Middleton, Stansted Mountfichet, Essex, 1732; descended like Myddeton, Chirls Castle, Baronetcy 1600, extinct 1718, the heirs m. Biddulph and West; throngh MydDeLtoN, Lord Mayor of London 1613, brother of Myddelton, Ruthyn, Barouetcy 22 August 1622, from MrdDeliton, Gwaynynog, co. Den. bigh, and Riride Pothan, alias VLAIDd, co. Denbigb; Harl. MS. 1507, fo. 383.

Heads.... (Birds) Choughs

Az. on a bend wavy .... three chough's heads erased sa. Trebartha, Trebartha, in Nortbill, Cornwall; the beiress $m$. Spoure.

$$
\text { .... Cocks }
$$

Arg. on a bend az. three cock's heads erased or combed and wattled gu. WorshIpp, $V$. WorshIP, $V^{*}$. ..... Swans

Arg. on a bend wavy az. three swan's heads erased of the first. SWAN.

$$
\text { ..... (Human Figures) }
$$

Arg. on a bend sa. three satyr's heads couped at the (neck, $V^{*}$.) shoulders of the first horned or. WHEYWELL, $V$.

Az. on a bend or three Moor's heads sidefaced couped sa. Eveshair, co. Hereford.

Erm. on a bend sa. three close helmets or. Compton, Piersilen, Hants, 1534 ; and Surrey.

Or on a bend sa. three helmets .... Mauley.

$$
\text { Heads.... (Fish) }
$$

Erm. on a bend sa. three fish's heads erased arg. Gelliat or Gellot. Giliett.

$$
\text { .....Eels }
$$

Erm. on a bend engr. sa. three conger-eel's heads erased arg. collared with a bar gemel gu. Clarke, lpswich, Suffolk.

$$
\text { .... Lucies }
$$

Erm. on a bend engr. sa. three lucy's heads erased or collared with a bar gemel gu. GILLET or Gillot, Broadfield, Norfolk. Giniet alias Chandier, Ipswich, Suffolk.

$$
\text { .... Whales }
$$

Erm. on a bend sa. three whale's heads erased or. WHAILEY. 
On 1 BEND.... cont.

Heads cont. (Monsters) Dragons

Erm. on a bend sa. three dragon's heads erased close to the ears arg. Gellyate, $V^{*}$. Geluyote, $V$.

\section{....Griffins}

Arg. on a bend az. three griffin's heads erased of the first. Astley, co. Warwick. Bowes.

Arg. on a bend sa. three griffin's heads erased of the first. White, St. Stephen's, Cornwall.

Arg. on a bend sa. thrce griffin's heads erased or. YonGE, co. Devon; and Crome-Dabitot, co. Worcester.

Arg. on a bend sa. three griffin's heads erased palewise or. John YongE, co. Worcester, $V$.

Arg. on a bend sa. three griffin's heads or vulned gu. Thomas Youxa, Bishop of St. David's 1560; Arehbishop of York, 1561-70.

Arg. on a bend vert three griffin's heads erased of the first. Middeton, Lord Mayor of Lon. don 1613 .

\section{....Unicorns}

Arg. on a bend vert three unicorn's heads erased of the first armed or. SmirH, Houghton Castle, Northumberland.

Gyronny of eight or and az. on a bend embattled counterembattled erm. three unicorn's heads couped sa. William Horne, co. Lincoln, $V$.

Lozengy arg. and vert ou a bend az. three unicorn's beads erased or. Young, London, 1716.

Per pale or and erm.on a bend gu. three unicorn's heads erased arg. crined and attired of the first. Bubb, Carlisle.

\section{....Wiverns}

Erm. on a bend sa. three wivern's beads erased arg. Gelliat or Gellyot. .....(Spears)

Arg. on a bend az. three spearheads bendwise of the first. Sharper or Sharpeigh. Robert SharPey, Sherpey, Kent; granted $1595, W$.

Arg. on a bend az. three coronels rever.ed or. Cheynduit,$V^{*}$. Sr. John Chendurt, $V$. Foxсотт, $V$.

Barry of six or and az. on a bend engr. gu. three spearbeads arg. BALCH, Virginia and Philadelphia, U. S. of N. America; descended from Balch or Balche, Highham and Horton, co. Somerset; and Tavistock, co. Devon, Harl. MIS. 1445 , fo. 168 , but the spearheads or, as quartered by Hewes or Hewisb, Harl. MIS. 1445 , fo. 20 .

\section{.....(Beasts) Deer}

Quarterly arg. and sa. on a bend gu. five buck's heads cabossed inclosing three escallops of the first. Erand or Eyland, co. York.

\section{Hearts}

Gu. on a bend arg. three hearts of the first. Crarli, Scotland.

Paly of four or and az. on a bend arg. three human hearts ppr. each pierced with two arrows saltirewise of the first. HaLL, Moundesmere, co. Hants; granted 1767 .

Sa. on a bend erm. three hearts gu. Ellard,

Vert on a bend arg. three beasts gu. Tooker, $W$.

Vert on a bend engr. arg. three bearts gu. Tooker, Maddington, co. Wilts, temp. Elizabeth. 'Cooker, quartering Biggs.

\section{Hives}

Eim. on a bend sa. three beehives or. Frax. Horns

Arg. on a bend engr. az. three buglehorns of the tirst. Greenough, London, quartering Bellas.

\section{On 1 BEND.....cont.}

\section{Horns cont.}

Arg. on a bend sa. three buglehorns stringed of the first. Greenhaugh or Greenhow, Bradleshain and Greenhaugh, co. Lancaster.

Arg. on a bend $\mathrm{SH}$. three hunting-horns stringed of the first. GREENALGH or GreENSUGH.

Arg. on a bend engr. sa. three buglehorns of the first. GERNaLD, $V$. GrenaLd or GreynaLD.

Arg. on a bend engr. sa. three buglehorns stringed of the first. Gernald, $V$. Greanhali. GREENOUGH.

Arg. on a bend engr. sa. three buglehorns of the first stringed vert. LYNakER.

\section{Horseshoe}

Erm. on a bend sa. a horseshoe or being rent by two hands and arms arg. issumg at the elbows from the dexter and sinister sides out of clouds az. radiated gold. Borlace, $V^{*}$. Borlas, St. Newline, Cornwall, $V$. Borlase, Pendeen in St. Just, Cornwall ; descended like BorLase, Bockmer, co. Buckingham; Baronetcy 6 May 1642, extinet 1688, through Boplase, Trelud. dra, from Borlase, Borlase, St. Wenn, Cornwall; extinct temp. Flizabeth; the coheirs m. Tonkin and Bray.

\section{Horseshoes}

Arg. on a bend az. three horseshoes or. Farrer.

Arg. on a bend engr. gu. three horseshoes of the first. Farier, Cole Brayfield, near Olney, co. Buckingham. Farrer, Harrold, co. Bedford; Great Arnwell, co. Hertford; and co. Somerset; granted 1609.

Arg. on a bend sa. three horseshoes of the field. Crispe, Kent. Farrow. Ferrers, Bere Ferrers, co. Devon; the heiresses in. Champernowne, Poynings, and Fleming. Ferrers, Churston, co. Devon; the heirs $m$. Ashford and Yarde.

Arg. on a bend engr. sa. three horseshoes of the first. Farrar, Hull, co. York. Farrer or Farror, co. Hertford; London; and Ewoot, co. York; granted 1609.

Chequy arg. and gu. on a bend of the first three horseshoes sa. Trethevey, Egloshayle, Cornwall.

Chequy or and gu. on a bend arg. three horseshoes az. HARDFEILD.

Gu. on a bend az. three horseshoes arg. DEтHICK, Lord of Bredsall, co. Derby.

Or on a bend az. three horseshoes arg. FERRIER, Belleside.

Or on a bend gu. three horseshoes of the first. Ferrers, London; and Teddington, co. Glou. cester, 1625 .

Or on a bend sa. three horseshoes arg. FErRers, Boswithgy and Trelowarren; the heiress m. Vyvyan. Sir John Ferrers, Gornwall, $V$. William Ferrers, Cornwall, $Y$. Monsire William de Ferrers (added about 1562), $Y$. Ferrers, Churston, to. Devon; extinct tenip. Henry VI; the coheirs m. Ashford and Yarde. Ferrers, Bere Ferrer's, co. Devon; the coheirs m. Champernowne, Poynings, and Fleming. Priske, Helston, Cornwall; the coheirs $m$. Trewren, Pemrose, and Penneck. Shoyswel, Shoyswell, Sussex.

Or on a bend engr. sa, three borseshoes arg. Farrer, Robert Ferrer, Bishop of St. David's 1548.54 .

Paly of six arg. and gu. on a bend az. three borseshoes or. Meigneli, co. Leicester, temp. Edward I. 
On 1 BEND......cont.

Horse-shoes cont.

Paly of six arg. and gu. on a bend sa. three lorse. shoes or. Monsire Gilbert de Menell, $Y$.

Paly of six gu. and or on a bend sa. three horseshoes arg. Menneld. Sir William Meneli or MeNYLL, Harl. MS. 1392.

Paly of six gu. and or on a bend sa. three horse. shoes of the second. Sir William MenrLL, $V$. Mennell or Meynell.

Paly of six or and gu. on a bend sa. three horse. shoes arg. Sr. William MENeLL, $V$.

Paly of eight arg. and gu. on a bend az. three horse-shoes or. William MENyLL, $Y$. Monsire William de Menill, $Y$.

Paly of twelve arg. and gu. on a bend az.three horse-shoes or. Henry Menye, Y. Monsire Hugh Menilt, $Y$.

\section{Ink-molines}

Arg. on a bend gu. three ink-molines of the first. Speccott, co. Devon.

Erm. on a bend .... three ink-molines .... Echard, Bersham, Suffolk.

Erm. on a bend az. three ink.molines or. EChard.

Or on a bend gu. three ink-molines arg. Berston, $V$. Speccot, Merton, co. Devon; the coheirs m. Hals, Hele, and Reynell. Speccotr, An. derdon, Cornwall; the beiress m. Spoure.

Insect

Gu. on a bend engr. arg. a grasshopper sa. LouIs, Colyton House, co. Devon.

Insects.... Bees

Or on a bend az. three bees volant arg. Butterfield.

\section{.....Butterflies}

Arg. on a bend az. three butterflies or. Boterwike. Butterwike.

Arg. on a bend sa. three butterflies of the first. Boterford, co. Devou.

Arg. on a bend sa. three butterflies or. BoterWIKE.

Arg. on a bend vert three butterflies of the first. Boterwike.

Arg. on a bend vert three butterflies volant or. Butterwik, $V^{*}$. Butterwike.

Or on a bend sa. three butterflies (volant $V^{*}$.) arg. Boterford, co. Devon. Butterford, $V$.

Or on a bend sa. three butterflies arg. Somersald or Somershall, co. Derby.

$$
\text { ....Gadbees }
$$

Arg. on a bend vert three gadbees volant or. Butterwike, $V$.

Instrument (Flute) but see On 1 Bend .. Baston

Gu. on a bend or a pipe (or flute) of the first. EliotT or Elliot, Redheugh now called Lauriston, Scotland.

Gu. on a bend indented or a flute of the first. Elilot, Eskelton, Scotland; descended through Eliotr, Unthank, from Lauriston.

\section{Keys}

Arg. on a bend az. two pairs of keys endorsed handles fretty or. Spencer, Crediton, co. Devon.

Arg. on a bend sa.four keys endorsed two and two and interlaced at the bows of the first. Spencer, $V^{*}$.

Arg. on a bend sa. two pairs of keys endorsed and fretty or. Spencer, co. Devou.

Arg. on a bend sa. two pairs of keys endorsed wards arg. and interlaced at the bows or. SPENCER, $V$.

\section{Label}

On 1 BEND..... cont.

Gu. on a bend or a label of three points arg. Cluniac Priory of St. Mary Magdalen at Barnstable, co. Devon.

Quarterly or and gu. on a bend sa. a label of three (another five) points arg. LACY.

Leaves.... Elm

$\mathrm{Gu}$. on a beud arg. three elm.leaves of the first. Woop, $V$.

..... Holly

.... on a beud arg. three holly leaves ppr. Cobrold, Ipswich.

Az. ou a bend arg. three holly leaves vert. HoLlingsworth HoLlinsworth or Hollywworthe, Hollingworth, co. Chester.

Sa. on a bend arg. three holly leaves vert. Holitngworth, co. Cbester, $V$. .... Ivy

Arg. on a bend $\mathrm{gu}$. three ivy leaves of the first. YENERY.

\section{$\ldots$... Oak}

Arg. on a bend gu. three oak leaves of the first. Ivery, Dungate, co. Somerset. Yevenex. .....Walnut

Arg. on a bend gu. three walnut leaves of the first. Uverey, $V^{*}$. Teverey, $V^{*}$.

\section{.... Woodbine}

Arg. on a bend gu. three leaves (woodbine?) of the first. Yeverey, $V$.

$\mathrm{Gu}$. on a bend arg. three leaves (woodbine?) of the first. WoD, $V$, Cotton MS. Tiberius $\mathrm{D}, 10$.

\section{....Holly}

Gu. on a bend arg. six holly leaves two two and two bendwise in fess sa. RYoN.

Legs ..... (Beasts)

Gu. on a bend arg. three lion's paws erased az. Sparman, Suffolk.

$$
\text { …(Birds) }
$$

Gu. on a bend arg. three eagle's legs couped (at the thigh, $V^{*}$.) above the foot sa. SchirLey, $V$.

Gu. on a bend or three eagle's legs sa. Sheruer. .....(Human figure)

Az. on a bend erm. three legs couped at the thigh or. Custace.

Az. on a bend or three shambrogues gu. PEDE, Bury, Suffolk.

Or on a bend sa. three shambroughs arg. Blagraye.

Or on a bend sa. three legs in armour couped at the thigh and erased at the ancle ppr. Bragrave, Highworth, Calcot, and Watchfield, Berks.; quartering Blagrave, Uttoseter, co. Stafford; and Bulmarsh Court, Berks.

\section{Letters}

Arg. on a bend sa. three taus of the first. BrRD. Lozenge

Arg. on a bend gu. a lozenge or. Harwedon.

Az. on a bend or a lozenge in chief erm. M..... le Scrop, $S$.

Bendy of six az. and gu. on a bend or a lozenge of the second. Moret.

\section{Lozenges}

Arg. on a bend az. three lozenges of the first each charged with a pheon gu. AtHerley, co. Derby.

Arg. on a bend az. three lozenges of the first each charged with a pheon sa. Ridgley or RigelEy.

Arg. on a bend az. three lozenges erm. DENT, Dent, Newcastle-on-Tyne.

Arg. on a bend az. three lozenges or. FELding, London. 


\section{On 1 BEND.....cont. \\ Lozenges cont.}

Arg. on a bend gu. three lozenges of the first. Mercy, $V$. Merey, $V^{*}$. Mereys, $V *$. Merrey. Mort, Astley, co. Lancaster.

Arg. on a bend gu. three lozenges erm. Boteler, Essex.

Arg. on a bend gu. three lozenges or. Peart, co. Lincoln. Woolfall. Wotshall, $V$.

Arg. on a bend gu. three pierced lozenges or. William de Perc, $X$.

Arg. on a bend sa. three lozenges of the first. Carrington, co. Chester.

Arg. on a bend sa. three lozenges of the first on each a saltire gir. Unswick, Cumberland; co. Lancaster; and co. York. Unswicke. M. Robert de Urswike, $S$. Sr. William Unswick, $V$. And in the sinister chief a crescent of the second for diff. M. Wanter URsewrcre, $S$.

Arg. on a bend sa. three lozenges erm. Sr. Peter Angerton, $V$. Dent, Surrey.

Arg. on a bend sa. three lozenges or each charged with a cross gu. URSWEEKE or URSWYCKE, co. Lincoln.

Az. on a berd or three lozenges (gu. another) sa. Meie, Kent.

Barry of six arg. and az. on a bend gu, three lo. zenges of the first. Penbrigg, $V$ *.

Barly of six or and az. on a bend gu. three lozenges arg. Penbriga, $V$.

Gil. on a bend engr. arg. three lozenges of the first. Scarbridge, co. Lancaster. Scarsberg, $V *$. Scharsbrige, co. Lancaster, $V$.

Gu, on a bend or three lozenges az. Mete.

$\mathrm{Or}$ on a bend wavy az. three lozeriges of the first. Halyburton, Egliscairnie, Scotland.

Or on a bend the upper side waved and the under side engr. az. three lozenges of the first. Haliburton, Scotland.

Or on a bend gu. three lozenges vair. Chamberlayn. Sr. ... de Chambleleyn, $V$. CHAMBLEYN.

Quarterly arg. and sa. on a bend gu. three lozenges (of the first another) or. Cheyney.

Quarterly per fess indented or and sa. on a bend of the last three lozenges of the first. HaRMor, co. Gloucester ; granted 1615.

Sa. on a bend arg. three lozenges az. each charged with a sun in glory. SHippendson, Bishop Wearmouth; Piddinghall Garth and Murton, co. Durbam; quartering Musgrave, Kirshaw, and Sykes.

Sa. on a bend arg. three lozenges of the first. Rauf Carington, co. Chester, $V$. Carrington, Carlington, co. Chester; extinct Elizabeth; the heiress m. Booth. Carrington, co. Devon. Carrington, Missenden Abbey, co. Bucks. Carrington or Carrynton. Carrington, Ogbourne St. George, co. Wilts. Carryngton, $V^{*}$. Sr. John Ċaryajgton, $V$. Shyth, Rivenball, Essex.

Sa. on a bend engr. arg. three lozenges of the first. Clarke, London.

Arg. on a bend gu. four lozenges of the first. Grefield. Grefylde, $V$. Grenfylde, $V *$. Greyfield. Mort, Astley, co. Lancaster.

Arg. on a bend gu. five lozenges of the first. HAREWEDON.

Arg. on a bend gu. five lozenges or. Harowdon. Harrowdon. Harvedon. Harwedon.

Arg. on a bend gu. five lozenges conjoined or. John Harowdon or Harwedon, co. Lancas. ter, $V$.
On 1 BEND.....cont.

Lozenges cont.

Or on a bend gu. five lozenges vair. Berhus, $V$. Arg. on a bend sa. six lozenges or. PAsture, France: granted 1457.

\section{Lure}

Arg. on a bend sa. a lure or. Brock, Saltwood, Kent. Broore, London.

Arg. on a bend sa. a lure the line wavy in bend or. Broke, $V$. Brooke.

Erm. on a bend sa. a lure or lined and ringed arg. a crescent for diff. Brooke, Somerset Herald, 1790. Mascle

$\mathrm{Gu}$. crusily or on a bend of the second a mascle ermines. ANGemarle or ANDEMarle, co. Dorset. Mascles

Arg. on a bend az. three mascles of the first. Audsrley, Blake Hall, and Coton, co. Stafford; Weddington, and Hams Hall, co. Warwick.

Arg. on a bend gu. three mascles of the first. Peart or Pert, Essex; Middlesex; and Nor. folk. PERT, quartered by Slaughter, iu church at Tewksbury, 1640.

Arg. on a bend gu. three mascles or. Pert, Arnold, Essex; and Fryarne, Middlesex. Peart or Pert, Essex; Middlesex; and Norfolk. Sr. Willian Pert, $V$. And with a label of three points sa. PERT, Essex.

Arg. on a bend sa. three mascles of the first. Blatr, The Caiss. Sr. Willam Carington, $V$. Carleton, $V$. Carleton, Sulrey; co. Bedford; Linton, co. Cambridge; Ampthill, co. Bedford, 1752 ; and London. CARLETON, Baron Carlton, 22 May 1626; Viscount Dorchester, 25 July 1628; extinct 1631. (Attribnted in error to Carleton, Baron Carleton 1789 ; Viscount Carleton 1797 ; extinct 1826). CarLton, $V$. Warings, $V$. Warnings. Warren, London.

Arg. on a bend sa. three mascles of the first interlaced with saltires gu. Worswike (in pencil URSWIK), $Y$.

Az. on a bend arg. three mascles gu. Randes, Clavesley, co. Northampton.

Az. on a bend or three mascles gu. Mete. Metz. Myte, Gunthorpe. And in the sinistex chief a fleur-de-lis of the second. Mentez, $V$. Mete, Kent, $V$.

G11. on a bend arg. three mascles of the first. PERT, Essex.

Or on a bend az. three mascles of the first. Halyburton, That Ilk, co. Berwick.

\section{Maunches}

Arg. on a bend sa. three maunches of the first. THorpe, Boston, co. Lincoln.

\section{Mitre}

Paly of six arg. and sa. on a bend gu. a mitre or. John BourghILL, Bishop of Llandaff 1396 ; Lichfield, etc. 1398.1414. BurghiLL, Lichfield. Paly of six arg. and az. on a bend gu. a mitre betw. two eagles or. John de Grandison, Bishop of Exeter 1328-69.

\section{Mitres}

Barry of six arg. and az. on a bend of the second three mitres or. John Grey, Bishop of Norwich 1200.14.

Monster

Az. on a bend arg. a pegasus in full speed sa. MrLDiAs, Essex; granted 20 May 1552.

\section{Monsters (Unicorns)}

Arg. on a bend sa. three unicorns pass. of the first. VEALE. 
On 1 BEND.... cont.

Monsters (Wiverns)

Or on a bend sa. three wiverns arg. Sire Edmon de Maulee, $N$. Mullet

Arg. on a bend az. a mullet betw. two acorns or. Muirhead, Stanhope, Scotland.

Arg. on a bend az. a pierced mullet of six points or betw. two garlss of the first. Spunway, Spurway, and Oaliford, co. Devon.

Arg. on a hend sa. a mullet betw. two garbs of the first. Spurway, Spurway, co. Devon, $W$. Spurware, Dartmouth, co. Devon.

Arg. on a bend engr. sa. a mullet of the first. Binning, That llk, Scotland. Crathorne, co. York. Ratcliffe, Mowgrave, co. York.

Arg. on a bend engr. sa. a mullet and a waggon of the first. Binning, Easter Biuning.

Az. on a beud or a mullet in chief erm. Steven le Scrop, $S$; Lord of Bentley, third son of Pichard first Lord Scrope of Bolton; from whom descended Scrope, Castlecombe, co. Wilts; the heiress $\mathrm{m}$. Thomson.

Erm. on a bend az. a mullet arg. betw. two garbs or. Modyford, London; Baronetcy $18 \mathrm{Fe}$ bruary $166 \mathrm{I}$; extinct 1673 ; Baronetcy $1 \mathrm{March}$ 1663 ; extinct 1703 .

Erm. on a bend engr. vert a mullet or. WATNOLL, co. Yorls.

Gu. on a bend sinister arg. a mullet sa. LIDDEs, Halkertoun, Scotland.

Gu. crusily arg. on a bend of the second a nullet sa. Onsley, Courtenhall, co. Northampton; and Onslow, co. Salop.

$\mathrm{Gu}$. on a bend sinister arg. a mullet betw. a cross conped in chief and two crescents in base sinister bendwise sa. VASTON, Scotland.

Or on a bend az. a mullet (or estoile) betw. an increscent and decrescent .... Scotr.

Or on a bend az. a mullet (or estoile) betw. two crescents arg. Scotr, Ireland. The patriarchal coat of Scot or Scort. Scotr, Baron Earlsfort 10 May 1784, Viscount Clonmel I8 August 1789, Earl of Clonmel 20 December 1793.

Or on a bend az. a mullet arg. betw. two crescents of the first. Scor, Whitebaugh, Scotland.

Or on a bend engr. az. a mullet arg. ClaRkE, Snailwell, co. Cambridge; Baronetcy $25 \mathrm{July}$ 1098; extinct 23 May 1806. Clarke, Norfolk. ClaAREe, $V^{*}$.

Or on a bend engr. az. a mullet in chief arg. Sr..... de Clarke, co. York, $V$. But on the mullet a crescent sa. Clerie, Itringham, co. York, $V$.

Or on a bend engr. az. a pierced mullet arg. Clenke, $T^{*}$.

Or on a bend sinister az. a mullet of the first. BARBER.

Or cn a bend az. a mullet or estoile betw. two crescents of the first. Scor, Buccleuch, as borne on an inescucheon by James Crofts afterwards Scot, Duke of Monmouth after 22 April 1667, as Dulse of Buccleuch, Earl of Dal. keith, Baron Whitchester and Ashdale 20 April $1673, Z, 639$; and after his attainder, 1685 , by lis son James Scot (Earl of Doncaster afterwards) Earl of Dalkeith, $Z, 6 \pm t$; and by his son Francis Scor, Baron Tyndale and Earl of Doncaster 23 March 174:, Duke of Buccleuch $17: 32$; and by bis uncle Henry Scot, Barou Goldylinds, Viscount Hermitage, and Earl of Delorain 29 March 1706 ; extinct $180 \%$; Z, 644.
On 1 BEND.... cont.

Mullet cont.

Or on a bend gu. a mullet in chief of the first. over all a fess chequy az, and arg. Stewart, Birnie, Scotland.

Or on a bend sa. a mullet of six points (arg. anotber) or. BonviLe.

Quarterly arg. and gu. on a bend of the second a pierced mullet or. Everinghalt.

Quarterly arg. and gu. on a bend of the second a pierced mullet or. Everinghar, $V^{*}$.

Quarterly arg. and sa. on a bendlet gu. a pierced mullet or. Everinghad, Roklile, $V$.

Quarterly or and gu. on a bend sa. a mullet arg. BURGONYON.

Quarterly or and gu. ov a bend sa. a pierced mullet or. Borgiron.

\section{Mullets}

Arg. on a bend gu. two mullets of the first. ST. JoHN.

Gu. on a bend sa. fimbriated or two pierced mul. lets alternately with as many ducks arg. mem. bered of the first. Sr. Robert Russell, $V$.

Gu. on a bend sa. fimbriated or two mullets of the third prerced as the first alternately with as many swans arg. M. Robert Russell, $S$.

.... on a bend .... three pjerced mullets of six points .... Roger de MARCH, seal.

Arg. on a bend az. three mullets of the first. M'Kechnie, Scotland. Touns, Innerleith, Scotland. WAynaru or WynARD, co. Devon.

Arg. on a bend az. three pierced mullets of the first. Wenard, co. Devon. Wenard, Cornwall, $V$. Wynard, Haccombe, co. Devou.

Arg. on a bend az. three mullets or. Bosuile or Bosvile. Simon Bosvill, $V$. Richer.

Arg. on a bend az. three mullets or over all a file of four points gu. KEDale.

Arg. on a bend az. three mullets of six points or. Bosuile or Bosville.

Arg. on a bend az. three pierced mullets or. M. Robert Kíndale, $S$. Morby. Morley.

Arg. on a bend az. three pierced mullets of six points or. MORBY.

Arg. on a bend az. three pierced mullets of six points or over all a label of five points gu. Sr. Robert de Morby, $V$.

Arg. on a bend engr. az. three mullets or. Towrns, Scotland.

Arg. on a bend gu. three mullets of the first. CABER. WANKER.

Arg. on a bend gu. three mullets or. (A mistake for Bampfilde.) Sr.HumfryBradBonne, TheHogh, co. Derby, $V$; quartered by Holte. Bradburne, Bradburne; and London. Danett, London.

Arg. on a bend gu. tbree pierced mullets or. Monsire de Bradbourne, $Y$.

Arg. on a bend gu. three mullets or pierced vert. John de Bradburne, $Y$.

Arg. on a bend.gu. three mullets per pale or and of the first. Mark Waulkerne, $V$.

Arg. on a bend sa. thuee mullets of the first. Anne, co. Oxford. Biliston. Bunerile. Clifton, co. Lancaster, and co. York. Davies. Sr. John Denam, $V$. Denham, $V^{*}$. Entwisell or Entwistle, Manchester. Manington. Pulesden or Pulesdon. John Puleston, Havod-y-wern. PUusdon or Pulston. SPEncer, Norwich; quartering gu. a fret ol. And with a crescent gu. for diff. Davis, Erdlisham.

Arg. on a bend sa. three pierced mullets of the first. Manaton or Mannington, Manaton in Southill, Cornwall. 


\section{Mullets cont.}

Arg. on a bend sa. three nullets of six points as the first. Manyngton, $V$. Monington, Cornwall. Arg. on a bend engr, sa. three mullets of the first. Andrews, Suffolk. Enswell or Entwysseid, Enswell, co. Lancaster. EnTwiseli, $V$. Entwisle, Foxholes, Rochdale, co. Lancaster.

Arg. ou a bend engr. sa. tbree plerced mullets of the first. Entweseli, $V$. Eirnfield.

Arg. on a bend flory counterflory sa. three mullets of the first. THonte, $V$.

Arg. on a bend flory sa. three pierced mullets of the first. THORLEY.

Arg. on a bend flory counterffory sa. three pierced mullets of the first. William ThorLe, $V$. THORLEY, $V^{*}$.

Arg. on a bend sa. three mullets gu. Thomas de SPENETHORNe, $X$.

Arg. on a bend sa. three mullets or. Denham. Hooton. Hothami. Latjghton. Manington, co. Devon. Mannington. Moglynton, $V$, Cotton MS. Tiberius D, 10. Molington or Monymon, $V$. Molyngton or Monyngton, $V^{*}$. SPENYTHORNE.

Arg. on a bend sa. three mullets of six points or. Estmerton.

Arg. on a bend flory sa. three pierced mullets or. William Thorle, $V$.

Arg. on a bend vert three mullets or. Hoton, $V$. Hоoтon, co. Chester. Sr. William Hooton, $V$.

Az. on a bend arg. three mullets gu. Bisset. Gay or Gayes. Gays, $V$. Ousefoot.

Az. on a bend arg. three pierced mullets gu. Bonn or Boun, co. Northampton. CuIfron, co. Chester.

Az. on a bend arg. three mullets sa. RoBerts, Kent; and Boresell, Sussex.

Az. on a bend erm. three mullets sa. GAY.

$\mathrm{Az}$. on a bend or three mullets of the first. Berweli, $V$.

$\mathrm{Az}$. on a bend or three mullets gu. Berwell, $V^{*}$. Dawson, Castle Dawson, co. Londonderry, descended from Westmoreland.

Az. on a bend or three pierced mullets gu. Baunfeld, Cornwall, $V$.

Az. on a bend or fimbriated gu. three mullets of the second. Blanchanster.

Az. on a bend or three pierced mullets sa. TIGG, Winslow, co. Buckingham.

Barry of four arg. and gu. on a bend sa. three puerced mullets of the first. Deanfierd.

Barry of five arg. and gu. on a bend az. three mullets of the first. Welchinan, Brackley, co. Northampton; and Kineton, co. Warwick.

Barry of five arg. and sa. on a beud gu. three mullets or. Dransfield.

Barry of six arg. and az. on a bend gu. three mullets of the first. Pabenherr.

Barry of six arg. and az. on a bend gu. three pierced mullets of the first. Pabenham, $V^{*}$. P'OPENHAM.

Barry of six arg. and az, on a bend gu. three mullets of the first pierced of the second. Sir John Pabenham, co. Bedford, temp. Edward I, $V$. Pabenhei.

Barry of six arg. and $\mathrm{az}$. on a bend gu. three mullets or. Grey, $V$. The mullets pierced of the second. M. Laurens de Papenham, $S$.

Barry of six az. and arg. on a bend gu. three mullets ol. PaIrEnHadr, co. Bedford. Sire Johan de Pabenhan, $N$. And with the mullets pierced. Sir Johan de l'ABEnhan, the sull, $N$.

\section{On 1 BEND.....cont.}

Mullets cont.

Barry of six or and az. on a bend gu. three mullets arg. Pembridge, Mansellgamel, Wales.

Barry of six or and sa. on a bend gu. three mullets arg. Pembridge, Mansell Gamage, co. Hereford.

Barry of six or and vert on a bend gu. three mullets arg. Sir Thomas (Frene a mistake for 'brother of ' Micliael) Poynings, $L$.

Barry of six or and vert on a bend gu. three mullets of the first. Poyninges, $V^{*}$. Sr. Thomas Poynings, Essex, temp. Edward I, $V$.

Barry of six sa. and or on a bend gu. three mullets or. Pakenham, co. Bedford.

Barry nebuly of seven arg. and gu. on a bend sa. three mullets or. Chissers or Chussere.

Barry wavy of eight arg. and az. on a bend gu. three mullets or. Alport, Cannock, co. Stafford; quartered by Flctcher.

Barry wavy of eight arg. and az. on a bend or three mullets gu. ALLPorT, Cannock, co. Stafford. AlPonT, $V^{*}$.

Barry of fourteen arg. and az. on a bend gu, three mullets of six points or. Richard de Valoines, $E$.

Barry or and az. on a bend gu. three mullets arg. Byrgaine. Sire Johan de Penbluge, $N$.

Barry or and vert on a bend gu. three mullets arg. Sire 'Thomas de Poninge, $N$.

Chequy erm. and gu. on a bend az. three mullets or. Brackley or Blakley.

Chequy gu. and arg. on a bend az. three mullets or. Haffenden, Kent.

Chequy sa. and arg. on a bend az. tbree mullets or. Hafrenden, Homewood, Kent; and Clear. well Court, co. Gloucester ; descended from HaFrenden, Bugglesden, 1483.

Erm. on a bend .... three mullets .... Durbin. Erm. on a bend az. three pierced mullets arg. Wenard ol Wenward.

Erm. on a bend az. three mullets or. Spencer, Newcastle-on-Tyne.

Erm. on a bend az. three pierced mullets or. Richard Weathershed, Archbishop of Canterbury 1229-31.

Erm. on a bend gu. three mullets or. Davenets. Sr. Vincent Davent, $V$. Hancott.

Erm. on a bend sa. three mullets arg. Ressant. Erm. on a bend sa. three mullets or. DEN, Eversfield, Sussex. Ersefieid, Denny, Hors. ham, Sussex. Everfield, Surrey. Eversfield or Ersfield, Charlion Court, Steyning, Sussex.

Erm. on a bend sa. three mullets or pierced arg. Kissun, $V$.

Erm. on a bend sa. three pierced mullets or. Eyensfield, Catsfield, and Denne Park, Sussex. Erminois on a bend gu. three inullets arg. Durbin, Bristol.

Gu. on a bend arg. three mullets az. Brabazon. Shaftow, $V^{*}$. Shastow, $V$. Robert de Shastowe, B. Slack.

Gu. on a bend arg. three mullets az. in the sinister chief a martlet or. Clydenow, $V^{*}$. Clydrowe, $V$.

Gu. on a bend arg. three mullets of the first a martlet or. CIIDERowe.

Gu. on a bend arg. three mullets sa. Brabazon. Delayali. Dishington, Scotland. Liddel, Halkertom, Scotland. Ovington. Reresby, $V$. Reslye, Suffull. Rorsuy, co. Yurls. 
On 1 BEND.... cont.

Mullets cont.

Gu. on a bend arg. three pierced mullets sa. M. Thomas Rersby, $S$.

Gu. on a bend or three mullets az. Brabazon. Clenerow.

Gu. on a bend or three mullets of the first. Colisins.

Gu. on a bend or three mullets sa. Brabazon. Portington, $V$.

Or on a bend az. three mullets arg. Wenard, co. Devon.

Or on a bend az. three pierced mullets arg. WYMARD, $V$.

Or on a bend az. three mullets of the first. Grni, Exeter.

Or on a bend gu. three mullets arg. Bamrield, $W$. Baynfield, co. Devon. Brantilo, Essex. Bronifield. Brunfield. And with an annulet sa. for diff. BarNFIELd, co. Devon; and Newport; co. Salop. But with a label of three points .... Bampryide; Baronetcy 14 July l64l, Baron Poltimore 10 September 1831; quartering arg. two chev. gu., with or a maunch gu., and arg. a lion ramp. gu.

Or on a bend sa. three mullets arg. Sire Nicholas Boneville, O. Bonvile, co. Devon. Bothnell. Hathorne. M. John de Holgont, $S$; Monsire John de Нотном, $Y$. John de Нотним, $Y$. Howden. Huthorne. Russell, co. Wilts. And with a martlet gu. for diff. Sire John Hothon, $O$.

Or on a bend sa. three mullets and as many swans arg. Russell, co. Wilts.

Or on a bend sa. three pierced mullets arg. Hothans. Ocfleet, $V^{*}$. Gerard Ousflete, $V$. Or on a bend sa. three mullets arg. pierced gu. Holdialr. John de Hothan, $Y$. Hotham, $V^{*}$. Hothans, co. York. Nlonsire John de Нотнов, $Y$. Sr. Jolm HorHont, Scarborough in Holder. ness, $V$. Hutham, co. York.

Or on a bend sa. three mullets arg. pierced of the first. Joha Benvile, $Y$. Monsire de Bonville, (added about 1562 to) $Y$. Hollitar.

Or on a bend sa. three mullets of six points arg. Bunvite, $V^{r}$.

Or on a bend sa. three pierced mullets of six points arg. Sr. Nicholas de Bonvile, $V$.

Or on a bend sa. three mullets of the first. Compton, co. Warwick, $V$. Bonvile, co. Deron. Huthorne. Matran, co. Devon. Meteau, co. Devon. Monington, Sarnesfield, co. Hereford. Owsints.

Or on a bend sa. three pierced mullets of the first. Seagar or Seager. Sigare.

Or on a bend vert three mullets of the first. Somersetr, South Brentin, co. Somerset.

Paly of three gu. and sa. on a bend or three mullets of the second. Blacke, Suffolk; and Essex.

Paly of six arg. and az. on a bend gu. three mullets of the first. Alexander. Sanderson, 1716 .

Paly of sis arg. and az. on a bend gu. three mul. lets or. Grandison.

Paly of six arg. and gu. on a bend of the second three mullets or. Neale or Nele, co. Buckingham.

Paly of six arg. and gu. on a bend sa. three mullets or. Elton, $V_{\text {.; }}$ quartered by pilkington. Pillington, $V$. Pylisenton, $V$.

Paly of six gu. and arg. on a bend sa. three mul. lets or. ELton, $V^{*}$.
On 1 BEND.... cont.

Mullets cont.

Paly of six gu. and or on a bend sa. three mullets of the second. Elton, co. Berks; and London. Elton, Clevedon Court, near Bristol; Baronetey 31 October 1717. Marwood-Elton, Wid. worthy Court, co. Devon; Baronetcy 1 August 1838.

Paly of six or and az. on a bend sa. three nullets of the first. Eltion, Elton, co. Chester.

Paly of six or and gu. on a bend sa. three mullets of the first. Elton, Ledbury, and Redland, co. Hereford; Tetbury, and Newent, co. Glou. cester.

Paly of six sa. and arg. on a bend gu. three mullets or. Dransfeld, $V$. Draunfield, co. Stafford. Dransfield, Essex'; and Stobbed Walding, co. York.

Paly of six sa. and arg. on a bend of the first three mullets or. Christopher Dransfeld, $V$. Dransfieid.

Paly of eight or and vert on a bend gu. three mullets arg. Banpfield, co. Devon.

Yaly or and az. on a bend gu. three mullets arg. Sire Ontuel Pouvel, $O$.

Per bend gu. and vert on a bend dancetty arg. three mullets sa. Craycroft, co. Lincoln.

Per chief or and vair over all on a bend gu. three mullets arg. Shenbroore, quartering arg. a chevron embattled counterembattled sa. betw. three roses ..... stalked and leaved ....

Per chief or and vair over all on a bendlet gu. three mullets .... Hoggeshawe sive Hoggesb $\ldots, E$. Rohert de ShIREbrok, $E$.

Per chief or and vair over all on a bend gu. three pierced mullets arg. Sherbrooke, Oxton, co. Nottingham.

Quarterly arg. and az. on a bend sa. three mullets or. Greys. Grosse. Sr. Regenold Le Gros, temp. Edward I, $V$. Legrosse, Suffolk.

Quarterly arg. and gu. on a bend sa. three mullets of the first. Ashley, co. Chester, $V$. Syr Alayn Calveringe, Q, Harl. MS 6595.

Quarterly arg. with gu. a fret or over all on a bend sa. three mullets of the first. Sr. (Hewgl, Harl. MS. 6595$)$ Hugh Spencer, Q; but Gil. bert le Despencer, Q, Harl. MS. 6589.

Quarterly arg. and gu. on a bend sa. three mullets or. Renest. Renost Revest or Revost. Rymost. Renofte, $V^{*}$. Ricroft. Rycroft, $\checkmark *$.

Quarterly arg. and gu. on a bend sa. three pierced mullets or. Remoste, $V$. Renoste, $V$. Riycroste, $V$.

Quarterly arg. with gu. fretty of six or over all on a bendlet sa. three mullets of six points of the third. Alayn de Eldesfeld, $G$.

Quarterly arg. and sa. on a bend gu. three mullets of the first. CALY, co. Wilts. CaLLeY Caley or Caylley, Burderop Park, and Blunsdon St. Andrew, co. Wilts; descended through Calley, Loudon, from Norfolk. Sr. John CAYLE, $V$. CAYLEY, Wydale House, co. York. CAYLEY, Brompton, eo. York; Baronetey 1661. John Curpesbye, ob. 1594, brass in Clippesby church, co. Norfolls; quartering tbree martlets within a bordure; an eagle displ. and over all a bendlet; a chevron betw. three herons; a fish haurient; crusily of twenty-four a saltire; Clipesbye (or Caly ?); on a chief three roundles; a lion ramp.; a chev. betw. three lions ramp.; and barry of eight. ChupLesey or Clypsey, Norfolk. Everinghatr. 
Ou 1 BEND.... cont.

\section{Mullets cont.}

Quarterly arg. and sa. on a bend gu. three pierced mullets of the first. Clespesby, Clespesby.

Quarterly arg. and sa. on a bend gu. three pierced mullets or. Clypsey or Clypsiey, Norfolk.

Quarterly or and gu. on a bend sa. three mullets arg. Sr. Alexander de Cravering, Essex, temp. Edward I. $V$. Sire Alisaundre de Claveringe, N. M'Iver, England.

Quarterly or and gu. on a bend sa. three mullets of the first. Syr Alajn Claveringe, $Q$.

Sa. on a bend arg. three mullets gu. Clifton, Clifton, and Lytham Hall, co. Lancaster; and Kent. Clifton, $V$ *⿻ Monsire de Clifton, $Y$. John Clyfton, $Y$. M. Robert de Clyfton, $S$. Sr. Robert Cirfton, $V$. Francis Glisson, M.D., 1732. And with a fleur-de-lis in the sinister chief or. Cusfon, London,

Sa. on a bend arg. three pierced mullets gu. Cinnton. Glisson, Ramplsham, co. Dorset. GLysson. And with a crescent .... within an annulet .... for diff. Cliston or Guisson, co. Somer'set.

Vert on a bend arg. three mullets gu. VaLLetort, North 'Tawton, co. Devon.

Vert on a hend or three mullets gu. Bamfield or BaUmfieis, Cornwall; and co. Devon.

Vert on a bend or three pierced mullets gu. Baunfeld, Cornwall, $V$.

Arg. on a bend az. five mullets or in the sinister chief a fleur-de-lis erm. Skiger.

Arg. on a beud sa. six mullets of the first. BONVILI.

Gu. on a bend arg. six mullets of the first. Brote,

Palets

Barry of six az. and or on a bend arg. three palets az. Johu de Routhe, $Y$.

\section{Pheon}

Erm. on a bend gu. a pheon in canton or. LOFT, Healing, co. Lincoln.

Erminois on a bend gu. a pheon in canton or. WaLLIS, Healing, near Grimsby, co. Lincoln; derived through Wallis, Trowbridge and Grovely, co. Wilts, from Henry Wallis, Lord Mayor of London; an heiress m. Farr.

\section{Pheons}

Arg. on a bend sa. three pheons of the first. Abland. Adan, Gwent. Bland, Blands Gill, and Kippax Park, co. York; Baronetcy $80 \mathrm{Au}$ gust 1642 ; extinct 16 October 1756 . Dawney, co. Chester. Dawtrey. Egerton. Helme, co. Worcester. MaDWonth, co. Lincoln. Welanse, $V$. Welarge, $V *$.

Arg. on a bend sa. three broad arrow beads of the field. DAWNEY, co. Chester.

Arg. on a bend sa. three pheons of the first points embrued. Breaver, St. Breavel, and Gold. cliffe, co. Monmouth.

Arg. on a bend engr. sa. three pheons of the first. MADEWORTH, $V$. MOLDEWORTH, $V$. Moldworth, $V^{*}$. Mudeworth, $V^{*}$.

Arg. on a bend sa. three pheons or. Neel ABLand, $V$. Bland, $V^{*}$. NeEL, $V^{*}$.

Arg. on a bend sa. three plienns pointing to the dexter chief or. Becimore, $V^{*}$. Bekemore, $V$.

Barry of five az. and arg. on a bend gu. three pheons of the second. Peter Leigh, Berthing. ton, Harl. MS. 1424, fo. 85 .

Barry of five az. and arg. on a bend or three plicons gu. Legh, $V$. Leigh, $V^{*}$.
On 1 BEND.....cont.

Pheons cont.

Erm. on a bend sa, three pheons arg. Carleton, Carleton, Penrith; (of this family was George. Carieton, Bishop of Llandaff 1618, Chichester 1619-28;) and Carleton, Brampton Fort, Cumberland, from whom descended Carieton, Market Hill, co. Fermanagh (the heiress $\mathrm{m}$. L'Estrange), through CarLeton, Rossfad, co. Enniskillen, from whom descended Guy Carleton, Bishop of Bristol 1672, Chichester 1679.85; and Carieton, Baron Dorchester, 21 August 1786. Charleton, Guissons, Sussex. Stockall or Stockdale. Stockdale, Loclin. ton, co. York; confirmed 1582. StockdaLL, $V$.

Erm. on a bend sa. three pheons or. BLand, London; and co. York. BLAND, Derriquin, co. Kerry. Guy Carleton, Bishop of Bristol 1672-9, Chichester 1679-85. STOcKLEY or STOKELLEY.

Or on a bend az. three pheons of the field. Thistiethwarte, Winterslow, co. Wilts; Whiteway, co. Dorset; and Southwick, co. Hants; the heirs m. Childecot and Frederick.

Or on a bend engr. az. (sometimes vert?) three pheous of the first. 'Tipring, Draycott, co. Oxford.

Or on a bend engr. vert three pheons of the field. Tipping, Wheatfield, co. Oxford ; granted 1574. Paly of six arg. and sa. on a bend or three pheons of the second. HATHEWAY.

Kakes

Arg. on a bend sa. three rakes of the first Brambert. Brunibert.

\section{Reptiles}

Az. on a bend arg. three snakes coiled of the first. Castelton, $V^{*}$; these are eels.

Az. on a bend arg. three adders embowed of the first. Castleton, Surrey.

$\mathrm{Az}$. on a bend or tbree adders nowed vert. Castieton, Suffolk; Surrey; aud co. Lincoln.

Roundle.... Bezant

Arg. on a bend engr. gu. a bezant betw. two swans ppr. Clarke, Dublin ; granted 26 January 1688.

Arg. on a bend sa. a bezant. PINchbecr, Pinchbeck, co. Lincoln. Pinchebecis, Pinchbeake, $V$.

Barry of five arg. and az. on a bend gu. a bezant. Grey, Horton, Northumberland.

Barry of sis arg. and az. on a bend gu. a bezant. Grey, Chillingham.

Barry of six arg. and az. on a bendlet gu. a bezant in chief. Sr. Thomas Grey, Norton, Northumberland, $V$.

Erm. on a bend az. a bezant betw. two fleurs-delis or. BuRY.

$$
\text { ....Plate }
$$

Or on a bend engr. az. a plate in chief. Clarke, Baron of the Exchequer, $W$.

$$
\text { .....Torteau }
$$

Barry of five gu. and arg. on a bend or a torteau betw. two leopards faces az. HIGHGate, Hayes, Middlesex; and Rendlesham, Suffolk. Heygate, Southend, Essex; Baronetcy 30 September 1831. Hygate, $W$.

\section{Roundles....Plates}

Quarterly or and gu. on a bend sa. two plates. Burgilton, Norfolk. Burleton or Burlton, Wyken $\mathrm{Hall}$, co. Leicester; descended from Burleton, Knoyle, co. Wilts, temp. Eljzabetb, quartering Trotman.

$$
\text { .... Roundles }
$$

. on a bend .... three roundles .... Rich. ard Punchardon, seal, 1441. 


\section{On 1 BEND.... cont.}

Roundles cont.

Chequy .... and erm. on a bend .... three roundles .... Pantryche, $V$.

\section{.....Bezants}

Arg. on a bend az. three bezants. Colwike, quartering arg. a cross croslet fitchy .... Whitiey orWhiri.eigh, Cornwall; and co.Devon. Arg. on a bend gu. three bezants. Curson, Nor. folk. SAPY.

Arg. on a bend sa. three bezants. Apleby or Appulby. Burden. Burdens, co. Wilts, $V$. Burdett. SirPichard Cornwall, R. Halteweli, co. Devon. JaQues or JAcQues. Majingfield, co. York. Markenfeld, attainted 1537. Markenfield, co. York. Markingfield, co. York. Andrew Merheingefeillde, $Y$. SkYGgILL, co. Devon.

Arg. on a bend engr. sa. three bezants. Bianeway, Shrewsbury.

Barry of six arg. and az. on a bend gu. three bezants. Grey, V. Grey, the Oaks, Surrey; descended from Grey, Backworth, Northum. berland.

Barry nebuly of six arg. and gu. on a bend sa. three bezants. M. John Golaffre, $S$. Golofer, $V$. Golston, $V^{*}$. And with a label of as many points of the second. Golorer.

Barry wavy of six arg. and gu. on a bend sa. three bezants. Golorrey.

Barry of seven arg. and az. on a bend gu. three bezants. Green. Grey.

Barry wavy of seven gu. and arg. on a bend sa. three bezants. Golofer or Golofrs.

Barry wavy of nine arg. and gu. on a bend sa. three bezants. Sir John Golafre, ob. 1442, tomb in church at Fyfield, co. Berks. Golofer, co. Oxford.

Barry nebuly arg. and gu. on a bend sa. three bezants. Golnofre, Ashmole MS. Hood F, 33 , fo. 91 . GOLONER.

Barry wavy arg. and gu. on a bend sa. three be. zants. GcDFrey.

Barry wavy gu. and arg. on a bend sa.three be. zants. Jobn GoLOFRE, $X$.

Erm. on a bend gu. three bezants. Dagworth. Folcher, co. Derby, $V$.

Erm. on a bend sa. three bezants. St. Albyn, Paracombe, co. Devon; and Alfoxton, co. So. merset; quartering Popbam. St. Aubrn, Alfoxton, co. Somerset.

Fusily or and vert on a bend az. three bezants. YONG, co. Berks.

Or on a bend sa. three bezants. JAQUEs.

Or on a bend engr. sa. three bezants each charged with a mullet sa. Cutrs.

Or on a bend raguly sa. tbree bezants. ELDRED, Saxbam Magna, Suffolk; Baronetcy 29 Janu. ary 1641-2 ; extinct about 1653 . Eldred, Norfolk; Suffolk; aud London, 1592.

Per chief engrailed sa. and or on a bend engr. gu. three bezants. HaLLet, Higham, Canterbury. Hallet, Cannons, Middlesex. Hallet, Stedcombe, in Axmouth, co. Devon; originally from Barbadoes, 1691; quartering Southcote. Hallett. And with a erescent for diff. HaLLET, Whitchurch, Middlesex; certified May 1799.

Quarterly arg. and gu. on a bend sa. three bezants. Bostrey.

Vairy arg. and gu. on a bend sa. three bezants. GOLEVER. GOLLOFre.

Vairy gu. and arg. on a bend sa. three bezants. Thomas Golorre, $Y$.
On 1 BEND.... cont.

Roundles cont. Hurts

Az. on a bend arg. three hurts. Schoor.sy, Cad. well, co. Bedford; confirmed 6 June 1582.

Sa. on a bend flory counterflory or three hurts. Bromfleete, $V^{*}$. Nicholas Bronflete, $V$. ..... Ogresses

(Az.?) on a bend (arg.?) three ogresses. DRYTON.

\section{....Plates}

Arg. on a bend gu. three plates. William Beauchasip, Cumberland, $X$.

Arg. on a bend sa. three plates. Burges. Sir Richard Connwall, $R$. M. Thomas Blyg'Feld, $S$. Lacy, $V$. Lynney. Silvelney or Silveney, Ireland. Sylvelney, Ireland, $V$.

Arg. on a bend engr. sa. three plates. Sir Johu Curss, Thaxted, Essex; and Childerley, co. Cambridge; Baronetcy 1600 ; extinct 1670 . Cutrs, Woodhall, Essex ; Baron Cutts, of Gow. ran, 1690 ; extinct 1706-7.

Barry nebuly of five arg. and gu. on a bend sa. three plates. Goulstone. Gulston, co. Hertford ; co. Leicester; and London.

Barry nebuly of six arg. and gu. on a bend sa. three plates. Gulston, $Z, 383$. Gulston, West Clandon, Surrey; quartering Bigg.

Barry of six or and az. on a bend gu. three plates. Sir John Lyngaine, $V$. Lyngayne, $V *$.

Erm. on a bend gu. three plates. Folcher. Forcher. Fother or Folcher, co. Derby. Fulcher, co. Derby.

El"n. on a bend engr. sa. three plates. Coтtes. Cutrs.

Or on a bend gu. three plates. Cuneverston. HUNTINGFIELD.

Or on a bend engr. sa. three plates each charged with a martlet of the second. Cutrs, Kent.

Quarterly or and gu. on a bend az. three plates. Storimyns, Suffolk. Sturiryn, Suffolk, $V$. ....Torteaux

Az. on a bend arg. three torteaux. Enersos, Nercastle.on.Tyue. Emerson, co.Lincoln; and Norfolk. Hone or Honew, Trenowth, Cornwall. $\mathrm{Az}$. on a bend or three torteaux. Edmerston. Holzis. Whitteley or Witley, co. York.

Az. on a bend or three torteaux and in the sinister chief a crescent of the second. Whitteley, co. York, $V$.

Barry nebuly of seven arg. and vert on a bend of the first as many torteaux. Goulston, co. Hertford.

Per pale wavy or and gu. on a hend arg. three torteaux. Mavdit, Great Stretton, co. Lincoln. .... Bezants

Arg. on a bend gu. four bezants. Cursons, $V^{*}$. Cursonne called Markeail, $V$.

Quarterly arg. and gu. on a bend sa. four bezants. Borpsted, Essex. Boxsted, Essex, $V$.

Quarterly gu. and arg. on a bend sa. four bezants. Boxsten. Boxted, $V^{*}$.

Arg. on a bend sa. five bezants. Burden. PaLmer, co. Leicester, $V$.

Barry of six arg. and az. on a bend gu. five bezants. Richard de Ore, $A$.

Paly of four arg. and sa. on a bend gu. five be. zants. Newdich or NewDick, co. Worcester; granted 1 December 1580. Thomas Newdros, $V$. NEWDYKE, $V^{*}$.

Quarterly arg. and gu. on a bend sa. five bezants. BOXSTED.

Quarterly or and gu. on a bend sa. five bezants. Sterbing, London; and Wisset, Suffolk. 


\section{On 1 BEND.... cont.}

Roundles cont. Bezants cont.

Arg. on a bend sa. twelve bezants four four and four in cross of the bend. Boyes, $V$. Boyse, $V$.

Arg. on a bend gu, bezants. Curson, Norfolk. Sire Johan Cursoun, $N$. OURsonne or Ourston, Norfolk.

Barry wavy arg. and gu. on a baston sa. bezants. John GolorRe, $Y$.

Gyronny of eight arg. and gu, on a bend sa. bezants. Boxsted.

Lozengy or and az. on a berd gu. bezants. WALDRON.

Quarterly arg. and gu. on a bend sa. bezants. Sire Rauf de Boxstede, $N$.

Quarterly or and gu. on a bend az. plates. Sire Roger Normyn, $N$. Stormyn.

\section{Rowel}

Arg. on a bend az. a spur-rowel or betw. two garbs of the first. Spurway, Spurway, and Oakford, co. Devon.

Rowels

Arg. on a bend az. three rowels or. Morby. Saltires

Arg. on a bend compony of seven sa. and of the first three saltires gu. Worsycke.

Shackles

Arg. on a bend sa. three fetterlocks or. Lockhant, Barr, Scotland.

Quarterly or and az. on a bend gu. three handcuffs of the first. Bryan, $V^{*}$.

Quarterly or and gu. on a bend of the last three swivels of the first. Bryan, $V$.

Spades and Shovels

Arg. on a bend vert three half-spades of the first palewise of the shield. Swettenhan, $V$.

Paly of six arg. and gu. on a bend vert three half-spades of the first. Swetenham, Somerford Booths, co. Chester, temp. Edward I; quartering Comberbach.

Arg. on a bend az. three spades of the first. Sweetnam or Swetenham.

Arg. on a bend sa. three spades of the first. Swettenham, Swettenham, co. Chester.

Arg. on a bend vert three shovels bendwise in bend of the first. Swetenfiar or Swetnam, co. Chester, $V$.

Arg. on a bend vert three spades of the first. Swetenhali, Somerford, co. Chester, Harl. MS. 1535 , fo. 251 .

Arg. on a bend vert three spades or. SWEETINGTON.

Spear

Or on a bend sa. a spear of the first. SHAKspeare, granted 1546 .

Staples

Sa. on a bend arg. three staples of the first. StAPLEHILL, $V$.

\section{Swivels see Shackles}

Sword

Paly of six arg. and az. on a bend sa. a sword of the first. Alexander or Sanderson, Durham.

Paly of six arg. and az. on a bend sa. a sword ppr. hilt and pomel or. SaUnderson, Brancepeth, Headley Hope, Newcastle-on-Tyne, Eiggleston, etc. The sword granted to H. Saunderson, Constable of Brancepeth, as an augmentation, 27 February, 1603.

Per cbief az. and erm. over all on a bend gu. a sword arg. hilt and pomel or. GLADwIN, Coldaston, temp. James I ; Edelston, Tupton, and Stubbing, co. Derby ; granted 1686.

\section{Swords}

On 1 BEND.....cont.

Arg. on a bend vert six daggers saltirewise of the first pommelled or. Sмyтн.

Arg. on a bend vert six falchions saltirewise of the first hilted or. Curington.

Tails

Arg. on a bend sa, three ermine spots of the first. JoHnson, Gainsborough, co. Lincoln; granted 7 May 1579.

Trees

Arg. on a bend engr. az. three stumps of trees couped and eradicated as the first. Foscot Foscott Foxcot or Foxcott, co. Berks, temp. Henry VI.

Az. on $a$ bend engr. arg. three trees eradicated vert. Hugo, co. Devon.

Quarterly az. and erm. on a bend or three cocoa. nut trees eradicated ppr. BraE, Bengal.

\section{Waggon}

Arg. on a bend engr. sa. a waggon of the first. Binning, Carloury Hall, Scotland. And with a mullet of the first. Binning, Easter Binning. Wheels

Arg. on a bend gu. three catharine wheels of the first. THORNTON.

Arg. on a bend gu. three catharine wheels or. Bonefat. Bonifant or Butteyant.

Arg. on a bend sa. three catharine wheels of the first. RIDDALL.

Gu. on a bend or three catharine wheels vert. Stevens.

Or on a bend az. three catharine wheels arg. Riddall, co. Hertford. Rudali or Ruddall. Rudhall, Rudhall, and Ross, co. Hereford. Piydali, co. Hereford, $V$.

Or on a bend az. three catharine wheels of the first. RudDall.

Or on a bend sa. three catharine wheels arg. Ridalu or Ridnuli, co. Hertford. Ruddall.

Wings

Alg. on a bend gu. three pairs of wings of the first. WingFieLd, Norfolk.

\section{Wreath}

Arg. on a bend engr. sa. a chaplet at the dexter point or. Bridge or Brigge, Bosbury.

Per chief gu. and az. (? arg.) over all on a bend engr. sa. a chaplet in the dexter point or. Bridge, Bosbury, co. Hereford.

\section{Wreaths}

Arg. on a bend gu. three chaplets of roses ppr. WOODBRIDGE.

Arg. on a bend sa. three chaplets of the first. Rositur, $V^{*}$. Rossetre. Richard Rossetur, Somerby, co. Lincoln; granted 1592, $W$.

$\mathrm{Az}$. on a bend arg. three chaplets of roses gu. Buencowe, Little Blencowe, Cumberland; and Thoby Priory, Essex; quartering gu. a canton arg.

Az. on a bend arg. three chaplets vert. BLencko, Sussex. Blencow.

Barry of five arg. and az. on a bend gu. three chaplets or. GREY, co. Hereford.

Barry of six arg. and az. on a bend gu. three chaplets or. GRAY, London; granted April 1635.

Erm. on a bend gu. three chaplets or. ILLINGWORTH, co. Leicester.

Gu. on a bend or three chaplets of the first. Stephens, Waterford, Ireland. Williams, co. Devon.

Gu. on a bend or three garlands vert. Sterens, Smethwick, co. Stafford. 
On 1 BEND.... cont.

Wreaths cont.

Or on a bend gu. three chaplets of the first. Wood, $V^{*}$.

Or on a bend gu. three chaplets of the first a crescent for diff. Woon, Stapleford, Essex, W.

Paly of six or and az. on a bend gu. three chap. lets arg. Lingen, Northumberland.

Quarterly urg. and gu. on a bend sa. three chaplets or. Hatт, co. Berks; Orsett, Essex; and London.

Sa. on a bend arg, three chaplets gu. Blenco.

Sa. on a bend compony arg. and az. three chap. lets $\mathrm{gu}_{\text {. (The ancient arms of) Br.encowe, }}$ Little Blencowe, Cumberland; and Thoby Priory, Essex.

On 1 BEND.... and in chief....

\section{Anchor}

Arg. on a bend engr. sa. three roses of the first in the sinister chief an anchor of the second. CARY, London.

Annulet

Masculy arg. and gu. on a bend sa. two fleurs-delis or in chief an annulet of the first. GiBons.

\section{Beast..... Iion}

Gu. on a bend arg. three fleurs-de.lis .... in chief a demi lion ramp. .... Hughes, Maidstone, Kent.

Sa. on a bend erm. an annulet gu. in chief a lion pass. guard. arg. Philpot.

Gu. on a bend or three eagles displ. vert in chief a lion ramp. arg. RaMregg.

Gu. on a bend invecked arg. a shepherd's flute az. in chief a lion pass. guard. of the second royally crowned or. Elliot, Woolie.

Barry of three or with chequy az. and arg. on a bend gu. a bezant betw. two buckles gold in chief a lion pass. guard. of the fourth. STUART, Allan Bank, co. Berwick; Baronetcy 15 August 1687.

Bird.... Chough and Raven

Arg. on a bend engr, az. three buckles or in chief a raven ppr. sitting upon an oak-tree slipped vert. Stirling, Law, Scotland.

Arg. on a bend gu. three mullets of the first in the sinister chief a Cornish chough ppr. Sr. Robert SHoLE. $V$.

$$
\text { ....Hawk }
$$

Erm. on a bend gu. three crosses croslet fitchy arg. in the sinister chief a hawk wings endorsed or. TADDY.

Buckle

Or on a bend az. three mascles of the first in the sinister chief an oval buckle erect of the second. HALIBURTON.

Or on a bend az. three mascles of the first in the sinister chief a buckle as the second. Halyburton, Newmains, Scotland. Canton

Or on a bend az. an estoile betw. two crescents of the first a canton erm. and in the centre chief point a sword erect ppr. Scotr, quartered by Douglas.

Eim. on a bend sa. three martlets or a canton of the third. Wilkins, Kent.

Arg. on a bend gu. three pheons or a canton erm. Jo Hnson, Withcot, co. Leicester; granted 1727 . on a Canton.....Anchor

Arg. on a bend sa. three roses of the first a can. ton or charged with an anchor as the second. Carey, London. Cary, London; and Bristol.
On 1 BEND.... and in chief.... cont.

on a Canton cont. (Beast) Cat

Paly of six arg. and gu. on a bend sinister az. a martlet betw. two mullets of the first a can. ton as the last charged with a cat ramp. sa. Mack, Edinburgh.

$$
\text { .....Lion }
$$

Arg. on a bend gu. three crosses croslet or a canton of the third charged with a lion ramp. sa. Poley, Poley, co. Hertford; and Boxted and Badby, Suffolk.

Arg. on a bend sa.three pierced mullets of the first a canton az. charged with a lion pass. arg. Gir., London; granted about I 506.

Sa. on a bend or three mullets of the first a canton az. charged with a lion pass. as the second. GIIL.

\section{....Bendlets}

Arg. on a bend sa. three martlets of the first a sinister canton gu. charged with two bendlets the uppermost engr. or. LaNCASHIRE.

Erm. on a bend sa. three mullets arg. a sinister canton gu. charged with two bends or. LANCASHIRE.

\section{.....Fleur-de-lis}

Arg. on a bend sa. three owls of the first a canton or charged with a fleur-de-lis gu. SAvILL, Nottingham.

\section{.... Flower (Rose)}

Erm. on a bend sa. three sea-pies ppr. a canton or charged with a rose gu. Wilkins, Kent.

Arg. on a bend sa. three martlets or a canton of the last charged with a rose gu. Wilisins, London.

Erm. on a bend sa. three martlets arg. a canton or charged with a rose gu. Wuxins, Thong, Kent.

Or on a bend az. three martlets arg. a sinister canton of the second charged with a rose as the first betw. two fleurs-de-lis of the third. HARDING, London; granted 30 August 1568.

$$
\text { .....Head }
$$

Or on a bend gu. three goats pass. arg. attired and unguled of the first a sinister canton sa. charged with a buman skull ppr. ZePHani, Walton-upon-Thames, Surrey; granted 1762.

Gu. on a bend arg. three 3-foils slipped vert a canton or charged with a leopard's head of the first. HaRver, Essex; London; Norfolk; Coates, and Westfavell, co. Northampton; and Ickworth, Sussex.

$$
\text { .....Mullet }
$$

Arg. on a bend sa. three owls of the first a canton or charged with a mullet gu. Savile, Oxton, co. Nottingham.

Arg. on a bend gu. three mullets or a canton of the second charged with a mullet of the third. STANLEY, Strickland, co. Lincoln.

Or on a bend gu. three mullets arg. a canton of the second charged with a mullet of the first. Stanlowe, $V$.

$$
\text { .....Mrullets }
$$

Arg. on a bend gu. three mullets of the first a canton of the second charged with two mullets as the field. Staniaw or Stanlow, Stickford, co. Lincoln.

\section{....Roundle}

Erm. on a bend az. a dove betw. two plieons arg. a canton gu. charged with a bezant. Coyne, Dublin; granted 1663. 
On 1 BEND.... and in chief.... cont.

on a Canton cont. Ship

Paly of eight arg. and gu. on a bend sinister az. a martiet betw. two mullets of the first a canton of the third charged with a galley arg. MACK, Glasgow.

\section{Chessrook}

Sa. on a bend arg. three roses gu. barbed vert in the sinister chief a chessrook as the second. SMALL.

Sa. on a bend arg. three roses gu. barbed vert seeded or in the sinister chief a chessrook as the second. Siralder, Thorpe Arnold, and Stonesby, co. Leicester.

$\mathrm{Sa}$. on a bend arg. three roses of the first in the sinister chief a chessrook as the second. Smali, co. Hertford.

Chief

Az. on a bend .... frets arg. a chief of the last. Ellerker.

Arg. on a bend az. three buck's heads cabossed or a chief gu. Stanley, Willington, Kent.

Az. on a bend arg. three mullets gu. a chief or. JeLLICOE.

Arg. on a bend sa. a lure lined and ringed of the first a chief of the second. Brook or Brooke, co. Buckingham; confirmed 1605.

on a Chief.... Anchor

Erm. on a bend sa. three 3-foils .... a chief gu. charged with au anchor betw. two martlets az. DaLiming.

\section{..... (Beast) Lion}

Az. on a bend or two fleurs-de-lis of the first a chief as the second clarged with a lion pass. gi. Overian, Norfolk.

Arg. on a bend az. three fleurs-de-lis (or ?) a chief gu. charged with a lion pass. gold. BuDD.

Arg. on a bend sa. three fleurs.de-lis or a chief of the second charged with a lion pass. as the third. Hayward, Quedgeley House, Gloucester.

Barry wavy of eight arg. and az. on a bend or a dragon pass. with wings indorsed and tail ex. tended vert a chief gu. charged with a lion pass. guard. of the third betw. two bezants. Society of Merchants Adventurers at Bristol.

\section{....Bells}

Arg. on a bend az. surmounted by a buglehorn sa. three buckles or a chief charged with as many bells of the fourth enclosed by two saltires engr. of the third each betw. four mullets gu. Luke, Glasgow, and Greenfield, Scotland; granted 1749 .

$$
\text { ....(Birds) Eagles }
$$

Az. on a bend or three fleurs-de-]is of the first a chief of the second charged with two eagles displ. as the field. Martain or Martin, Bowton, co. Cambridge, 1604 .

$$
\text { ..... Martlets }
$$

Az. on a bend arg. three human hearts gu. a chief of the second charged with as many martlets sa. IEGGET, Scotlaud.

$$
\text { .....Bridge }
$$

Or on a bend engr. sa. a chaplet of oak as the first a chief az charged with a bridge baving three arches embattled and at each end a tower ppr. Bridge, co. Dorset.

$$
\text { ..... Castlo }
$$

Gu. on a bend or a baton humetty az. a chief of the last charged with a castle (Gibraltar) betw. two pillars arg. on the gates a key and under them Plus uitra gold. ELIotr, Baron Heathfield, $6 \mathrm{July} 1787$; extinet 26 January 1813.
On 1 BEND.... and in chief.... cont. on a Chief cont. Crescent

Arg. on a bend gu. three catharino: wheels or a chief of the second charged with a crescent hetw. two leopard's faces as the first. Hardy, Ireland.

Az. on a bend or a martlet gu. a chief arg. charged with a crescent sa. betw. two stag's heads couped of the second. Dix.

$$
\text { .....Cross }
$$

Arg. on a bend sa. three 5-foils of the first a chief az. charged with a cross croslet betw. two fleurs. de-lis or. Morgan, Kent.

Arg. on a bend engr, sa. three 5-foils of the first. a chief az. charged with a cross flory betw. two fleurs-de-lis or. MORGAN, co. Lincoln; and London.

Az. on a bend gu. two garbs or a chief sa. charged with a cross tru arg. Thavies InN, London.

Or on a bend gu. a harp of the first a chief as the second charged with a cross arg. Nevilu, Ireland.

\section{....Crosses}

Arg. on a bend sa. three roses of the first a chief gir. charged with as many crosses patty or. William Caner, Bishop of Exeter 1820, St. Asaph 1830-46.

$$
\text { .... Escallops }
$$

Arg. on a bend az. three mascles of the first a clijef as the second charged with so many es. callops or. Gamage.

$$
\text { ..... Estoiles }
$$

Erm. on a bend gu. three annulets arg. a chief az. charged with three estoiles of the third. ADDrson, Sudbury; and Chilton.

$$
\text { .... Flower }
$$

Gu. on a bend or a martlet sa. a chief of the second charged with a rose betw. two 5-foils az. Peter.

$$
\text { ..... Flowers }
$$

Az. on a bend arg. a bear sa. a chief of the second charged with three roses gu. barbed or. SANDES. .....Heads

Erm. on a bend engr. gu. gouttes arg. a chief az. charged with a (buck's $Y^{*}$.) stag's head couped or. William Hedingham, $V$.

$\mathrm{Az}$. on a bend or three martlets gu. a chief arg. charged with two reindeer's heads couped of the third. Dickes, Norfolk. Dyx, Wykmer, Norfolk.

Sa. on a bend arg. three birds gu. a chief or charged with three reindeer's heads cabossed sa. AYLEWORTH:

Erin. on a bend gu. three annulets or a chief az. charged with three leopard's heads of the third. Joseph ADdison, temp. Anne; descended from Westmoreland. ADDIson, Preston, co. Lancast. Erm. on a bend gu. three annulets .... a chief vert charged with as many leopard's faces .... ADDISON.

$$
\text { ..... Landscapes }
$$

Barry of seven gu. and or on a bend erm. a sphinx betw. two wreaths of laurel ppr. a chief embattled charged with a view of a fortified town and under it Acre. Cameron, Fassifern, and Callart, co. Argyle, and Arthurstone, co. Angus; Baronetcy $8 \mathrm{M}$ arch 1817.

$$
\text { ..... Letter }
$$

Az. on a bend gu. two garbs or a chief sa. charged with the letter T arg. Thavies InN, London.

$$
\text { ..... Mullets }
$$

Az. on a bend or three escallops .... a chief .... charged with two mullets .... HoGa, co. Devoll. 
0n 1 BEND.... and in chief.... cont. on.a Chief cont. Mullets cont.

Az. on a bend arg. three buckles of the first a chief as the second charged with so many mul. lets of six points like the field. M'INNEs Edinburgh.

\section{....Rowels}

Arg. on a bend sa. three mascles of the first a chief as the second charged with so many spur rowels or. Brand, Braberton, Scotland.

$$
\text { .....Saltire }
$$

Or on a bend gu. a harp of the first a chief of the second charged with a saltire arg. NEVILL, Ireland.

Per bend az. and gu. on a bend or a vine branch ppr. $u$ chief erm. charged with a saltire engr. of the second betw. two Cornish choughs ppr. VINER, Badgeworth, co. Gloucester, quartering Ellis.

\section{.... Wheels}

Arg. on a bend engr. gu. a crescent betw. two leopard's heads of the first a chief (az. $W^{r}$ ) charged with three catharine wheels (or W.). John Hardy, Alderman of London, $V$. Hardy or HaRDYE.

Arg. on a bend gu. a leopard's face betw. two crescents of the field a chief as the second charged with three catharine wheels like the first. HARDY.

\section{Coronet}

Az. on a bend raguly arg. a crescent of the first at the dexter point in the sinister chief a ducal crown or. Merland, co. Lancaster, $V$.

Crescent

Sa. on a bend arg. three crescents gu. in the sinister chief a crescent of the second. M. Nycol de Clyfton, $S$.

Arg. on a bend sa. three fleurs-de-lis of the first in the sinister chief on a crescent gu, a crescent or. Thomas Wood, Kelnwike, co. York; granted by Flower, $W$.

Arg. on a bend sa. three roses or a crescent in the sinister clief gu. Claytun, $V$.

$\mathrm{Gu}$. on a bend arg. three roses of the first in chief a crescent as the second. Clarton, $V$.

$\mathrm{Gu}$. on a bend or two 5-foils az. and in the sinister chief point a crescent surmounted of a cross croslet of the second. Cook, Pittenweem, Scotland.

\section{Cross}

Arg. on a bend az. three annulets or in chief a cross croslet of the second. Clayton, co. Stafford.

Arg. on a bend az. three annulets or in the sinister chief a cross formy fitchy of the second. Coleugh.

Arg. on a bend quarterly gu. and az. three annulets of the first in the sinister chief a cross patty per pale of the third and second. EsGaston, $V$.

Sa. on a bend arg. another nebuly of the first in the sinister chief a cross croslet fitchy of the second. Writle, $V$. Writteli, $V$. Wrytitle, $V^{*}$.

Sa. on a bend arg. another wavy of the first in chief a cross croslet fitchy as the second. IVRITLE, $V^{*}$.

Arg. on a bend az. three pierced bezants in chief a cross croslet or. CoLwike.

Arg. on a bend az. three bezants in the sinister chief a cross croslet fitchy of the second. Colwyke, $V$. Fitzwarin.

Arg. on a bend engr. az. a sun in chief or and an eagle wiugs elevated of the field in base in the sinister chief a cross flory gu. AYERst.
On 1 BEND.... and in chief.... cont.

Cross cont.

Arg. on a bend indented sa. in chief a sun or and in base an eagle wings elevated gazing ppr. in the sinister chief a cross croslet gu. AyEnst, Canterbury.

Escallops

Erm, on a bend sa. three plueons arg. in the sinister chief an escallop gu. STACKDall or Stockdale, Bilton Park, co. York.

Quarterly arg. and sa. on a bend gu. three mullets or in the sinister chief an escallop of the first. Evryng, quartered by Lyenys, V; Cotton MS. Tiberius D, 10 .

\section{Fetterlock see Shackle}

\section{Fleur-de-lis}

Arg. on a bend gu. three escarbuncles or in chief a fleur-de-lis sa. Thonnton, Middlesex; granted 12 March 1575.

Sa. on a bend arg. three 3 -foils slipped vert in chief a fleur-de-lis erm. Harver, Suffolk.

Flower.... Columbine

Or on a bend az. three buckles of the first in chief a columbian flower slipped ppr. StrrLing, Dundee, Scotland.

$$
\text { ....Rose }
$$

Or on a bend az. an estoile of six points betw. two cresceuts of the first in the sinister chief a rose gu. stalked and leaved vert. SCOT or Scotr, Harden, Scotland. And its descendants, Scot', Gala House, co. Selkirk; quartering Pringle; and ScoтT, Raeburn, co. Selkirk. And with the rose surmounted by a crescent .... Scot, Highchester, Scotland.

Gu. on a bend arg. a rose betw. two lions ramp. of the first in chief a rose as the second. Herring, Scotland.

Or on a bend az. a mullet betw. two crescents of the first in chief a rose gu. stalked and leaved vert. ScoTt, Broadmeadows, Scotland.

\section{Flowers}

Or on a bend sa. a lion pass. arg. in chief three roses gu. Leyland, Morley, co. Lancaster; quartering arg. two swords in saltire sa.

\section{3-Foil}

Arg. on a bend sa. three annulets of the first in the sinister chief a 3 -foil slipped as the second. LABORER. Leybors, $V^{*}$, but really a quartering of Layborne, $V$ : but it seems to belong to Labourn, Cotton MS. Tiberius D, 10.

Or on a bend engr. vert three martlets arg. in clief a 3 -foil of the second. Pelley.

Arg. on a bend sa. three covered cups of the first in the sinister chief a 3.foil slipped as the second. Clapham.

Arg. on a bend gu. three lozenges of the first in chief a 3-foil slipped as the second. Marsh, London; and Darks, Middlesex.

Arg. on a bend gu. three lozeuges or in the sinister chief a 3 .foil slipped gu. VIALLS, Twick. enham, Middlesex.

Head.... (Beast) Deer

Sa. on $a$ bend or three birds vert in chief a stag's head cabossed of the second armed gu. KInNear, Scotland.

$\mathrm{Gu}$. on a bend arg. three caltraps ppr. in the sinister cbief a buck's head couped or. GAwLER.

$$
\text { .....Lion }
$$

Arg. on a bend engr. az. three buckles or in chief a lion's head erased gu. Stirling,Bankell,Scotland. Arg. on a bend engr. az. three round buckles or in clijef a lion's head erasedgu. Sterling,co. Herts. 
On 1 BEND.... and in chief.... cont.

Head cont. (Monster) Unicorn

$\mathrm{Gu}$. on a bend arg. three bald-coots sa. beaked and legged of the first in the sinister chief a unicorn's head erased as the secoud. Marsden, Manchester; aranted 1733.

Gu. on a bend or three bald-coots sa. beaked and legged of the first in the siuister cbief a nnicorn's bead erased of the second. Marsien, Manchester ; granted 1753. Marsden, Chelmorton, co. Derby.

$\mathrm{Gu}$. on a bend or three bald-coots sa. beaked and legged of the first in the dexter chief a key with a sprig of sbamrock in the sinister chief a unicorn's head erased gold holding a sprig of shamrock in the mouth ppr. William Marsies, Secretary to the Admiralty temp. George III: and Alexander MARsDEN, Under-Secretary of Ireland.

Horn

Arg. on a bend sa. a rose of the first in the sinister canton a bugleborn strung as the second. Shrrd, Disley, co. Chester.

\section{Leaf}

Arg. on a bend sa, a spear's head or in the sinister chief an oakleaf as the second. Coxe, London.

\section{Mullet}

Gu. on a bend arg. three crescents az. in the sinister chief a prerced mullet of the second. Napien, Kilmacheugh, Scotland.

Vert on a bend arg. three crescents sa. in the sinister chief a mullet of the second. ALderton, Ipswich.

Arg. on a bend sa. three crosses bottony of the first in the centre chief a mullet .... Charnock, Leyland, co. Lancaster, Harl. MS. 1437, fo. 272.

Arg. on a bend az. three roaches (arg. alias arg. finned and tailed or $i . e$.) ppr. a nullet in chief .... Huisr, Sand, Sudbury, co. Devon, Harl. MS.. 1445, fo, 325 b.

Arg. on a bend az. three 3 -foils slipped or in the sinister chief a mullet gu. charged with a cres. cent of the third. Romesburgh, $V^{*}$.

Arg. on a bend az. three 3-foils slipped or in the sinister chief a mullet gu. pierced or. Ronesborough, $V$.

\section{Quiver}

Or on a bend az. an annulet and two pheons conjoined in bend as the first in chief a quiver full of arrows ppr. Comrie, Scotland.

\section{Roundle .....Bezant}

$\mathrm{Gu}$. on a bend arg. three mullets az. in chief a bezant. Willans, co. York.

Gu, on a bend arg. thiree prerced mullets of six points sa. in chief a bezant. WILLIAM or WILLAN, Loudon; granted 1617. WILLAN, London. WiliaN, Kingston-upon-Hull, co. York; confirmed 1 May 1617.

$$
\text { .... Plate }
$$

Sa. on a bend arg. three fleurs-de-lis az. in chief a plate. Borodalle.

\section{Roundles.... Bezants}

Gu. on a bend arg. three mullets az. in chief two bezants. LIDDELl or Lidell, Scotland. Rowel

Gu. on a bend arg. three crescents az. in the sinister chief a spur-rowel of the second. NAPIER, Kilmacheugh, Scotland.

\section{Shackle}

Arg. on a bend az. three acorns or husks vert in clief a fetterlock az. MUIRHEAD.
On 1 BEND.... and in chief.... cont.

\section{Spear}

Or on a bend az. a star betw, two crescents of the first in chief a broken lance gu. Scot, Whitislaid, Scotland. And with a crescent for diff. Scot, Toderuck, Scotland.

\section{Sword}

Or on a bend az. a mullet betw. two crescents of the first in chief a sword palewise ppr. Scotr, Horslehill, Scotland.

\section{Swords}

Erm. on a bend az. a rose betw. two annulets or in chief a sword in pale ppr. lilt and pomel gold crossed by another the hilt towards the dexter side of the escucheon. Jones, Marshal of the King's Bench, London.

\section{Tree}

Arg. on a bend engr. az. three buckles or in chief an oak-tree slipped vert surmounted by a raven ppr. S'tirling, Law, Scotland.

\section{On 1 BEND.... and in base....}

\section{Arrow}

Or ou a bend az. an estoile betw. two crescents of the first in base an arrow bendwise ppr. feathered and barbed gold. Scotт, Clerkington, and Malleny, Scotland; a scion of Buccleucb.

Or on a bend az. an estorle betw. two crescents arg. in base ars arrow and bow of the second. Scot, Hassindene, Scotland.

\section{Bird}

Arg. on a bend sa. three boar's heads erased or in base a Cornish chough ppr. CARR.

Cross

Or a bend gu. a crescent arg. in base a cross croslet of the second. MERILL.

Gamb

Per fess or and gu. in chief on a bend az. an es. toile betw. two crescents of the first in base an eagle's leg couped at the thigh in pale or. Scot, Holland.

\section{On 1 BEND betw, or within....}

\section{Arrows}

Az, on a bend betw. two arrows arg. three fusils gu. Cheshire, Dublin; granted 1618.

\section{Axes}

Or on a bend engr. betw. six battle-axes erect az. three swans with wings elevated arg. bealied and membered sa. DAwEs, Westbrooke, Bolton; quartering Corr, Alleyne,De Hedesa or Hede, etc.

Beast..... Dog

Sa. on a bend betw. in chief a greyhound comrant and in base a dolphin embowed arg. tbree roses gu. Holles.

Az. on a bend or betw. in chief a talbot courant and in base a dolphin embowed arg. three torteaux. Hollueis or Holles.

Sa. on a bend betw. in chref a hound pass. and in base a dolphin embowed arg. three torteaux. Hollis, co. Devon; and co. Nottingham.

Sa. on a bend betw. in chief a talbot courant (sa. lient, V.) and in base a dolphin haurient em. bowed arg.three torteaux. Sr. William HolleIs, London, $V$. Holleys, Lord Mayor of London, 1539. Hollis, $V *$ *

$$
\text { .... Lion }
$$

Gri. on a bend or betw. in chief a lion ramp. and in base a ram conrant arg. attired or three eagles displ. vert. Ramrige, $V^{*}$. The eagles armed of the first. 'Thomas Rameas, Abbot of St. Alhans, $U$. 
On 1 BEND betw. or within.... cont.

Beast cont. Lion cont.

$\mathrm{Gu}$. on a bend or beiw. in chief a lion ramp. and in base a ram salient arg. three eagles displ. vert. RAMRIGE, $V$.

Or on a bend az. betw. in chief a lion ramp. sa. and in base three oak-leaves vert as many es. callops of the first. Shiers, Slyfield House, Surrey. Skeres, co. York: granted 16i2.

Arg. on a bend vert betw, in chief a lion ramp. sa. and in liase three pomeis as many escallops of the first a crescent for diff. Skyres, skyers Hall, Alderthwayt, co. Tork.

Arg. on a bend betw. in chief a lion ramp. and in base a cross patty gu. three garbs or. Edmund Maltby, Bishop of Chichester 1831; Durbam 1836.56; ob. 3 July 1859.

$\mathrm{Gu}$. on a bend betw. in clief a lion ramp. and in base three iozenges or as many 3 -foils vert. ACland, co. Devon.

Sa. on a bend betw. in chief a lion salient and in base a dolphin arg. three torteaux. Horis, Fincham, Norfolk.

Beasts.... Cats

Arg. on a bend betw. two cats pass. guard. sa. three fishes haurlent in pale of the bend or. OsBarne, $Y$.

\section{..... Dogs}

Sa. on a bend betw. two talbots pass. and a dolphin embowed arg. three annulets gu. Holles or Hollys, Norfolk.

Arg. on a bend az. betw. two greyhounds salient sa. three birds or. Crugg, $V^{*}$. Crugge, temp. Henry III, $V$.

Arg. on a bend az. betw. two grevhounds courant bendwise sa. three Cornish choughs or. Scrogas or Scrugges, Reynold, co. Bedford.

Arg. on a bend az. betw. two greyhounds courant sa. three martlets or. Crugg or Crugge.

Arg. on a bend az. betw. two talbuts pass. sa. three martlets or. Cragg, co. Devon.

Arg. on a bend engr. az. betw. two demi-grey houuds ramp. sa. platy and collared arg. three marigolds gu, stalked and leaved vert. SHerT, $V^{*}$.

Arg. on a bend engr. az. betw. two demi.greyhounds courant bendwise sa. each charged on the body with four plates three thistles or. William SMerT, London, $V$.

Az. on a bend engr. arg. betw, two talbots pass. or three bunches of grapes ppr. RoydHouse, London; granted 1714.

Arg. on a bend sa. between two greyhounds gu. a wolf's head erased.... LARDINAR.

$$
\text { ..... Lions }
$$

Gu. on a bend betw. two demi-lions ranp. arg. as many fleurs.de-lis az. Hughes, Middleton Stony, co. Oxford.

Arg. on a bend gu. betr. two demi.lions ramp. couped ppr. three fleurs.de-lis or. Hughes, co. Northampion.

Az. on a beud engr. betw. two demi-lions ramp. arg. a rose gu. seeded or barbed vert enclosed by as many boar's heads couped sa. Webster, Essex.

Arg. on a bend gu. betw. two demi-lions ramp. couped sa. (anotber, armed and langued of the second) three lozenges vair. Bishop.

Az. on a bend betw. two demi.lions ramp. erased or three lozenges vairy arg. and gu. GOODDEN. Bower Hinton, and Martock, co. Somerset; and Over Coinpton, co. Dorset; quartering Bisbop.
On 1 BEND betw. or within..... cont.

Beasts cont. Lions cont.

Arg. on a bend gu. betw, two demi-lions ramp. sa. three mascles vair. Goonwis, Pleintree, Herts. Arg. on a bend engr. az. betw. two demi.lions ramp. gu, three mullets or. WREY, Sussex.

Arg. on a bend engr. az. betw. two demi-lions ramp. gu. bezanty three pierced mullets of six points or. John de Wrey, Sussex, $V$.

$\mathrm{Gu}$. on a bend or betw. in chief a lion ramp. and in base a ram salient arg. three eagles displ. vert. RAMRIGE, $V$.

Gu. on a bend or betw. in chief a lion ramp. and in base a ram courant arg. attired or three eagles displ, vert. Rarrige, $V^{*}$. The eagles armed of the first. Thomas RAMrege, abbot of St. Alban's, $U$.

Arg. on a bend engr. betw. two lions ramp.sa. three annulets or. Lambent, Kirton, co. Lincoln; and Boyton, co. Wilts, 1572.

$A z$. on a bend engr. .... betw. two lions ramp. .... three annulets .... Cooper, Northumberland.

Quarterly arg. and sa. on a bend gu. betw. two lions ramp. three annulets or. HULBERT, granted 1639. HuRLEBERT.

Alg. on a bend vert betw. two lions pass. gu. threo eagles displ. or. Littlebury.

Arg. on a bend vert betw. two lions pass. guard. gu. tliree eagles or. Monsire de Littuebery, $Y$.

$\mathrm{Az}$. on a bend or betw. two lions ramp. arg. three nortlets of the first. Cosens, Yetwinster, co. Dorset.

Or on a bend betw. two lions ramp. az. three martlets arg. Dowes, Essex.

Or on a bend betw. two lions ramp. sa. three martlets arg. Downes.

Az. on a bend betw. two lions ramp. arg. three popinjays vert heaked and membered (another, collared) gu. Cunson, Croxhall, co. Derby, $V$.

Az. on a bend betw. two lions ramp. arg. tbree popinjays vert membered gu. collared or. Curson, Cropton, co. Derby.

$\mathrm{Gu}$. on a bend arg. betw. two lions ramp. or three parrots vert. PARTRICH or PARTRIDGE.

Az. on a bend betw. two lions ramp. or three doves of the first membered gu. Curson.

Or on a bend betw. two lions ramp. az. three doves arg. Dowes, Essex.

Or on a bend betw. two lions ramp. sa. three doves palewise arg. beaked and legged gu. Dowes, Essex, $\boldsymbol{V}$.

Or on a bend betw. two lions ramp. sa. three chevrouels of the first. HaLl.

Arg. on a beud betw. two lions ramp. sa. three es. callops of the first. Norton, King's Norton, co. Worcester; Sherington, co. Buckingbam; Hinxton, co. Cambridge; and Albbots Leigh, co. Somerset.

Or on a bend sa. betw. two lions pass. gu. three escallops arg. Brompton.

Arg. on a bend az. betw. two lions ramp. gu. a fleur-de-lis enclosed by two griffin's heads erased or. Lynes, Tooley Park, co. Leicester; Hatton, co. Warwick; and Corley and Kirkby Mallory.

Arg. on a bend az. betw. two lions pass. guard. gu. fretty of the first. BREDGATE or BREDGATT, Kent.

Alg. on a bend betw. two lions ramp. sa. three boar's heads couped or. Specrard, London; granted November 1611.

Arg. on a bend betw. two lions pass. az. three fox's heads erased or. Fox. 
On 1 BEND betw. or within.... cont.

Beasts cont. Lions cont.

Az. on a bend arg. betw. two lions pass, or three leopard's faces gu. Stevenson, Stanton, Rowsley, and Elton-on-the-Peak, co. Derby; the heirs m. Holden and Joliffe; granted 1688.

$\mathrm{Gu}$. on a bend engr. betw. two lions ramp. or three scaling-ladders of the first. KEELINGE, Bewarsley, and Sedgley Park, co. Stafford. Sir John Keelinge, Chief Justice of the King's Bench; a heiress m. Fletcher.

Ern. on a bend betw. two lions ramp. az. three pierced mullets of six points or. WARMOUTH, Newcastle-on.Tyne.

Or on a bend betw. two lions ramp. sa. a dragon pass. wings elevated of the first. Pembroke, St.Alban's, co. Herts; granted 1771. Pembroke, certified June, 1772 ; quartering arg. a wolf statant gu. on a chief indented of the last three fleurs-de-lis as the first.

Arg. on a bend betw, two licns .... sa. a wivern extended of the first. Newport, $V$. Ruding, $W$.

Arg. on a bend betw. two lions ramp. sa. a wivern of the first. Pembrooks.

Arg. on a bend betw. two lions ramp. sa. a wivern with wings overt of the first. Rudinge or Rudings, Westcot, co. Leicester; and MartynHosontide, co. Worcester.

Arg. on a bend az. betw. two lions ramp. gu. three bezants. M. Robert Turk, $S$. TURKe, $V$. TURke, London, temp. Edward III.

Arg. on a bend engr. betw. two lions ramp. sa. three bezants. MaLcher.

Erm. on a bend wavy az. betw. two lions ramp. gu. three bezants. Buckinghair, London; granted 15 December 1708.

Or on a bend engr. sa. betw. two lions salient az. three bezants. HoLstock, Orsett, Essex.

Arg. on a bend engr. sa. betw. two lions pass. az. three plates. Howlestock, Essex.

Arg. on a bend engr. betw. two lions ramp. sa. three plates. LAMrPARD.

Arg. on a bend engr. betw. two lions ramp. sa. langued and armed gu. three plates. Cooper, co. Warwick.

Gu. on a bend betw. two lions ramp. arg. as many pellets. Beverenam, Ireland.

$$
\text { ....Tigers }
$$

Arg. on a bend betw. two tigers salient sa. three dolphins or. Osbonne, Cleby, Essex; and Kirkby Bydon, Norfolk.

Arg. on a bend betw. two tigers .... sa. armed and langued gu. three dolphins or. OsBonne.

$$
\text { .....Cats }
$$

Arg. on a bend betw. three cats salient sa. as many bnckles or. OsBer.

$$
\text { ..... Foxes }
$$

Arg. on a bend az. betw. three foxes sa. as many martlets of the field. Crudge, co. Devon.

$$
\text { .... Lions }
$$

Az. on a bend engr. arg. betw. three lions pass.guard. or as many crosses patty sa. FAwLer, co. Salop.

Arg. on a bend betw. three lions ramp. sa. as many boar's heads couped or. SPORKant, London, 1611.

Az. on a bend arg. betw. three lions .... or a lozenge gu. Bowran.

Gu. on a bend or betw. three lions ramp. arg. as many mullets az. Palley. Pally, $V$.

$\mathrm{Gu}$. on a bend or betw. three lions pass. guard. arg. as many pierced mullets of six points sa. Payler, Thoralby, eo. York; Baronetcy 28 June 1642; extinct 1706.
On 1 BEND betw, or within.... cont.

Beasts cont. Lions cont.

Arg. on a bend betw. six lions ramp. sa. three lions pass. of the first. WATSON.

Az. on a bend betw. six lions ramp. or a bendlet arg. C. de Hereford, $F$.

Az. on a bend gu. fimbriated arg. betw. six lions ramp. .... three escallops .... Boone.

Arg. on a bend gu. voided of the field betw. six lioncels az. three estoiles sa. BoHUN.

Arg. on a bend engr. betw. six lioncels gu. a rose of the first betw. two arrows ppr. SAwREY, Broughton Tower, co. Lancaster.

\section{Bendlets or Cotises}

Quarterly gu. and erminois on a bend wavy betw. two cotises arg. an anchor enclosed by as many estoiles of the fir'st. LAWFORD.

Arg. on a bend betw. two cotises sa. an annulet of the first. Dawney.

$\mathrm{Gu}$. on a bend betw. two cotises or an annulet sa. Pearce.

Vert on a bend betw. two cotises or an annulet sa. Pearce, Middlesex; and Withingham, co. Norfolk; granted 20 October 1715.

Arg. on a bend betw. two cotises gu. three anniz. lets or a bordure engr. sa. Selwrn, Sussex, 1716.

Arg. on a bend betw. two cotises sa. three annulets of the first. DawnaY, Baronetcy 19 May 1642, Viscount Down, 19 February 1680. DAwney, Cowick, and Eskyrke, co. York.

Arg. on a bend betw. two cotises sa. three annulets or. DAwney, co. Chester; and Sesay, co. York. William Dawney, $V$. Selwyn, Stonehouse, co. Gloucester.

Arg. on a bend betw. two cotises sa. three annulets or a bordure gu. SELwYN.

Arg. on a bend betw. two catises sa. tbree annulets or a bordure engr. gu. Selwin, Friston, Sus. sex; quartering Sberington. John SELWYN, Sussex, $V$. Selwyn, Essex; and Freston, Bechington, Sussex ; granted May 1611.

Or on a bend betw. two cotises sa. three annulets of the first a bordure engr. gu. Selwin, Suffolk.

$\mathrm{Gu}$. on a bend betw. two cotises and as many pheons or a (baston or) flute of the first. Eluiot, Scotland.

Arg. on a bend betw. two cotises sa. a lion pass. guard. of the first. Tотнu, quartered by Lane.

Arg. on a bend betw. two cotises sa. a lion pass. guard. of the first crowned or. KNowLER, Stroud, Kent. Master, Bapchild, Kent.

Az. on a bend betw. two cotises arg. a lion pass. sa. Toтнпl, Plymouth, co. Devon; and Exeter.

Az. on a bend arg. betw. two cotises or a lion pass. sa. TотнiLl, quartered by Harvey, $V$, (granted $1561, W$ )

$\mathrm{Az}$, on a bend arg. betw. two cotises or a lion pass. guard. sa. langued and armed gu. in chief a label of three points with a crescent for diff Tothill, Peamore, co. Devon; the coheiresses m. Northleigh and Tothill.

Az. on a bend betw. two cotises or a lion pass. sa. Tothill. London.

$\mathrm{Gu}$. on a bend betw. two cotises arg. a lion pass. az. GibBard.

Arg. on a bend hetw. two cotises sa. three cats or. Coke, Tregasa, Cornwall.

Erm. on a bend betw. two cotises gu, three cat-a. mountains arg. Coore, Thorne, co. Devon; the heiress m. Misson. 
On 1 BEND betw, or within.... cont.

Bendlets or Cotises cont.

Erm. on a bend betw. two cotises sa. three cats pass. guard. or. Cooze, co. Devon; and Traise, Cornwall.

Erm. on a bend betw, two cotises .... three leo. pards (? lions pass. guard.) or in the sinister chief a label of as many points over a crescent arg. CoKe.

Alg. on a bend sa. betw. two cotises az. and as many six.pointed pierced mullets sa. three liuns ramp. of the first. Brown, Harebill's Grove, co. York; and Chapel Allerton, Leeds; quartering Williams.

Arg. on a bend betw. two cotises sa. three lions ramp. of the first. Browne, co. York.

Arg. on a bend vert betw. two cotises gu. three lions pass. of the first. WALPOLE or WALLPOOL, Pinchbach, co. Lincoln.

Erm. on a bend az. betw. two cotises .... three lions pass. or. ARNewood, co. Hents.

Erm. on a bend betw, two cotises sa. three lions pass. or. Coore.

Quarterly or and sa. on a bend gu. betw. two cotises erm. three lions pass, arg. PARry, Lord Mayor of London 1739.

Quarterly or and sa. on a bend gu. betw. tro co. tises erm. three lions pass. guard. arg. Perry, London ; granted 8 March 1700.

Arg. on a bend betw. two cotises az. three wolves pass. or. Dawney, $V$.

Arg. on a bend betw. two cotises sa. four lions pass. guard. of the first. Hawtre. Hawtree, $V^{*}$.

Erm. on a bend betw. two cotises sa. three church bells arg. Bunworth.

Arg. on a bend betw. two cotises gu. a bendlet of the first. Chelley.

Gu. on a bend betw. two cotises arg. a bendlet wavy az. LugG, co. Gloucester.

Arg. on a bend betw. two cotises gu. three billets sa. Miliot, Whitehill, co. Durham, 1615.

Az. on a bend betw. two cotises arg. three billets sa. HAGGerston, Nortbumberland, $V$; Baronetcy 15 August 1643 .

Arg. on a bend betw. two cotises sa. as many double headed eagles displ. or. FarnLey, Cornwall.

Gu. on a bend betw. two cotises arg. three birds vert. DANE.

Az. on a bend or betw. two cotises arg. tluree Cornish choughs ppr. Darlston, co. Worcester.

Arg. on a bend az. betw. two cotises gu. and six battle-axes sa. as many shovelers or. Daws, Putney, Middlesex.

Arg. on a bend betw. two cotises az, three eagles displ. or. SAPIE. SAPYE.

Arg. on a bend az. betw. two cotises gu. three eagles displ. or. Sr. Richard SApy, $V$.

Arg. on a bend engr. betw. two plain cotises gu. three eagles displ. of the second. EarnIng, London; aranted 6 December 1662 .

Arg. on a bend sa. betw. two bendlets dancetty gu. three eagles displ. of the first. Peple, co. Devon, Popise, co. Wilts; and co. York.

Arg. on a bend betw. two cotises sa. three eagles .... of the first. BADEWE.

Arg. on a bend betw. two cotises sa. three eagles displ. of the first. Popeley, Wolby Moorhouse, co. York; allowed ty Glover 1585. Poprey, Morehouse, co. York.

Arg. on a bend betw. two cotises sa. three eagles .... or. BADEWE.
On 1 BEND betw. or within.....cont.

Bendlets or Cotises

Arg. on a bend betw. two cotises sa. three eagles displ. or. Baw or Bawood. EMLLeE or Ernelee, $V$. Ernelie, Kent. Erneley, $W$. Ernley. (ERveley in error.)

Arg. on a bend betw. two cotises sa. three double headed eagles displ. or. Farnuey, Corrwall.

Arg. on a bend betw. two bendlets dancetty sa. three eagles displ. or. Popley, Salisbury.

Arg. on a bend vert betw. two cotises gu. three eagles displ. of the first. SAPYE.

Arg. on a bend vert betw. two cotises gu. three eagles or. Robert SAPY, $Y$.

Az. on a bend betw. two cotises arg. three eagles displ. gu. Badifforde, $V^{*}$. Badisforde, $V$.

Gu. on a bend betw. two cotises arg. three eagles displ. vert. Sr. John DownFrIst, $V$.

Or on a bend sa. betw. two cotises dancetty gu. three eagles displ. of the first. Poplex, Bris. tol; granted 1672 .

Or on a plain bend betw. two cotises dancetty sa. three eagles displ. arg. RAMEY, in Ormesby St. Margaret Church, Norfolk.

Arg. on a bend engr. betw. two cotises az. three martlets of the first. Truston.

Arg. on a bend engr. az. betw. two cotises gu. three martlets or. WACKETT.

Arg. on a bend az. betw. two cotises wavy sa. three martlets or. Bucise, Kent.

Arg. on a bend betw. two cotises gu. three martlets or. AkELAND or AkElout, co. Gloncester. Akeiont, co. Gloucester.

Arg, on a bend betw. two cotises sa. three mart. lets of the first. Monsire Dinacid de Rus, $Y$.

Arg. on a bend betw. two cotises sa. three martlets of the first a bordure engr. az. WOODARD, Essex. Arg. on a bend betw. two cotises sa. three martlets or. DAWNEY, co. Chester; and Sesay, co. York. GoLDSWORTHY.

Az. on a bend betw. two cotises and three escal. lops arg. as many martlets of the first. Punien. Az. on a bend betw. two cotises arg. three martlets gu. Edwards, London. Southouse.

Gu. on a bend betw. two cotises arg. three mart lets vert. Fitz-Williams, Baron of Lisford, Harl. MS. 4040, fo. 454 .

Gu. on a bend arg. betw. two cotises or three martlets sa. Hilton, Dyons, co. Durham. Hinton. John de Hynton, $Y$. Sr. William de Hriton, $V$.

Or un a bend betw. two cotises sa. tbree martlets arg. a bordure engr. az. WoodWARD, St. Ed. mundsbury, Suffolk.

Sa. on a bend betw. two cotises arg. three martlets of the first. Norvel.

Sa. on a bend betw. two cotises or three martlets of the first. Norviu, Boghall, Scotland.

Arg. on a bend betw. two cotises gu. three owls or. Sr. John Frauncis, $V$.

Arg. on a bend sa. betw. two cotises gu. three owls of the first. SAVIrL, Bakewell, co. Derby.

Arg. on a bend betw. two cotises sa. three owls of the first. Savine, Hill-top, co. Derby, 1600; the beiress m. Gilbert.

Sa. on a bend betw. two cotises gu. three owls or. Francis, $V^{*}$.

Gu. on a bend arg. betw. two cotises or three popinjays vert. William de ANNe, $Y$.

Gu. on a bend betw. two cotises or three popin. jays vert. AnNs.

Arg. on a bend az. betw. two cotises gu. three doves or. Davis. 
On 1 BEND betw, or within.....cont.

Bendlets or Cotises cont.

Arg. on a bend az. betw. two cotises gu. and six battle-axes sa. three swans or. DAWEs, Stapleton, co. Leicester; Stow market, Suffolk; and co. Stafford. John Dawes, Alderman of Lon. don, $V$. DAwes, Baronetcy 1 June 1663 ; extinct 28 May 1741. Sir William Dawes, Bart., Bishop of Chester 1707; Archbishop of York 1714.24.

Arg. on a bend sa. betw. two cotises gu. and six halberds of the second three swans of the first. Dawes, London; and co. Salop.

Erm. on a bend betw. two cotises gu. and three annulets sa. as many swans close arg. Clarke, Dunham Lodge, Norfolk, Baronetcy 30 Sep. tember 1831 .

Gu. on a bend sa. betw, two cotises or three swans arg. Charington.

Arg. on a bend betw. two cotises az. three water bougets or. Browne, co. Warwick.

Arg. on a bend betw. two cotises arg. three water bougets of the first a mullet in chief of the second for diff. Sr. William Brom or Broun, $V$. Brome, $V^{*}$.

Or on a bend betw. two cotises az. three water bougets arg. Browne, Midlewich, co. Chester, $W$.

Arg. on "a bend engr. gu. betw. two cotises sa. three round buckles or. CASE, Thingwall Hall, near Liverpool; and Red Hazels, co. Lancaster. CAsy, co. Chester.

Gu. on a bend betw. two cotises arg. three castles sa. Roushby.

Quarterly arg. and gu. on a bend vert betw. two cotises or three towers of the first. KEMPsToN or Kempton, $V^{*}$. ReMpston or Rempton, $V$.

Sa. on a bend betw. two cotises arg. three cbev. gu. GyMBER, London, 1520.

Arg. on a bend betw. two cotises gu. an eastern crown or enclosed by as many swans ppr. a bordure vert. ClaRke, Crosses Green House; and Rossmore, co. Cork, Baronetcy $23 \mathrm{~J}$ une 1824.

Or on a bend az. betw. two cotises gu. and so many escallops as the second a crescent arg. enclosed by a pair of suns in splendour. Bright.

Arg. on a bend az. betw. two cotises gu. three cres.cents or. John REVER (in pencil RIDER), $X$.

Arg. on a bend betw. two cotises sa. three crescents of the first. Cresse or Cressy, Ouldcotts, co. Nottingham. Crosse.

Arg. on a bend betw. two cotises sa. three crescents or. Cressey, $V *$ Cressy, $V$. Rowley, Lawton, co. Chester, 1663.

Az. on a bend betw. two cotises or three crescents gu. Bellamy, Middlesex. Williams, Lord Mayor of London 1736.

Erm. on a bend betw, two cotises gu. three cres. cents arg. Howxley, co. Chester. Huxley, Edmonton, Middlesex.

Erm. on a bend betw. two cotises gu. three crescents or. Huxley, Huxley, co. Chester. Huxley, $W$.

Or on a bend betw. two cotises sa. three crescents arg. Rowley.

Vert on a bend betw. two cotises or three crescents gu. Belladry, Middlesex.

Gu. on a bend dancetty betw. two cotises arg. a cross bottony fitcliy az. EToN, Ireland.

Sa. on a bend betw. two cotises indented arg. a cross croslet fitchy in the dexter chief gu. Richard Devali, $V$; but Denali, Cotton $M S$. Tiberius D, 10.
On 1 BEND betw. or within.... cont.

\section{Bendlets or Cotises}

Sa. on a bend arg. betw. two cotises indented or a cross croslet (fitchy $V^{*}$.) gu. Sr. Richard de DANELL, $V$.

Arg. on a bend betw. two cotises sa. and as many garbs gu. three crosses patty of the first. Walter WHITEFOORD WHITFORD or WHITWORTH, Bishop of Brechin, 1634.8.

Gu. on a bend arg. betw. two cotises or three crosses croslet sa. Rousby, $V$.

Gu. on a bend arg. betw. two cotises or three crosses patonce sa. Reresby, $V$; but Rosby, Cotton MS. Tiberius $\mathrm{D}, 10$.

Gu. on a bend arg. betw. two cotises or three crosses patty sa. Reresby.

Or on a bend betw. two cotises sa. three crosses moline of the first. Jesson, co. Lincoln.

Per pale wavy az. and gu. on a bend betw. two cotises or three crosses croslet vert. BEYNoN, Carshalton, Surrey; quartering Batley.

Quarterly arg. and sa. on a bend betw. two cotises gu. three crosses formy or. Beraston, Alden. ham, co. Hertford; granted 1606.

Quarterly arg. and sa. on a bend betw. two cotises gu. three crosses formy fitchy or. Boraston, co. Worcester ; and co. Hertford, 1606. Boreston or BorReston.

Or on a bend betw. two cotises sa. three covered cups of the first. NAYLER, London, $W$. Naylor, Newland, co. Gloucester.

Arg. on a bend betw. two cotises az. and as many martlets sa. three escallops or. François de la Barre, $V$. Gronlu, France, $V$.

Arg. on a bend gu. cotised sa. two escallops or. Sir Walter Beringham, $L$.

Arg. on a bend gu. betw. two cotises az. three es. callops of the first. BaWINGHAM or BAWNINGHAM, Norfolk.

Alg. on a bend gu. betw. two cotises az. three es. callops or. Sir Wauter de Bernyngham, $N$. Sr. Walter Bernyngham, Norfolk, temp. Edward $\mathrm{I}, V$.

Arg. on a bend betw. two cotises gu. three escallops or. Bermingham, Norfolk. Nabis, co. Stafford, 1716.

Arg. on a bend gu. betw. two cotises sa. three escallops or. Sir Walter Beringhan, L. Monsire de Bermingham, Norfolk, $Y$. Walter Berningham, Norfolk, $Y$. Birmingham, Norfolk. Darmin, $V^{*}$. Darmine. Sr. Guy Darmyne, $V$. Dermine, $V$.

Arg. on a bend gu. betw. two cotises vert three escallops or. DARW1N, Cleatham, co. Lincoln; and Middlesex. Darwin, Trulston Grange, co. Derby.

Arg. on a bend betw. two cotises and as many lions ramp. sa. three escallops of the first. Norton, co. Somerset, $V$.

Arg. on a bend betw. two cotises sa. three escallops ol. Sir Walter de BeringHam, $L$, Harl. MS. 6137.

Arg. on a bend betw. two cotises and as many lions ramp. sa. three escallops or. Nonton, Canterbury, Kent.

Arg. on a bend betw. two cotises and three lions ramp. sa. as many escallops or. Norton, co. Somerset.

Arg. on a bend betw. two cotises and six lions ramp. sa. three escallops of the first. Norton, co. Somerset.

Arg. on a bend sa. betw. two cotises vert three escallops or. Sr..... DE LA H $H_{A Y}$, Spaldington, $V$. 
On 1 BEND betw. or within..... cont.

Bendlets or Cotises cont.

Az. on a bend betw. two cotises arg. three escal. lops gu. William RoMnex, London; granted (16 December) 1593,W. Rumney, Sheriff of London, 1603.

Az. on a bend arg. betw. two cotises or and as many lions ramp. of the second three escallops gu. Boon or Boone.

Az. on a bend arg. betw. two cotises and six lions ramp. or three escallops gu. BoHUN or Boone, co. Lincoln. Pbilibert Bonun, $V$. Sire Gilberd de Boun, $N$. Gilbert de Boun, $E$. De Bonun.

Az. on a bend arg. betw. two cotises and as many mullets or three escallops gu. Benedictine Abbey at WaLden, Essex ; Reyner, i, 215.

Az. on a bend gu. betw. two cotises and as many mullets or three escallops arg. Benedictine Abbey at WALDEN, Essex (in error).

Az. on a bend betw. two cotises or three escallops of the first. Byssetr, $W$.

Az. on a bend betw. two cotises or three escallops sa. Kinge, Essex.

Barry of six or and az. on a bend engr. sa. betw. two cotises gu. three escallops of the first. Cave. Thomas SAXBY, Nortbumberland, $V$.

Barry of eight or and az. on a bend engr. sa. betw. two cotises gu. three escallops of the first. SEXBYE.

Erm. on a bend gu. betw. two cotises az. three escallops arg. Kensey, co. Hertford.

Erm. on a bend betw. two cotises gu. three escal. lops or. Perrot or Perrott, co. Devon.

Erm. on a bend betw. two cotises and as many crosses patty gu. three escallops .... KILDERBEe, Suffolk.

$\mathrm{Gu}$. on a bend betw. two cotises arg. and as many fleeces or tbree escallops of the first. IBEETSON, Leeds, and Denton Park, co. York; Baronetcy 12 May 1748.

$\mathrm{Gu}$. on a bend arg. betw. two cotises or three escallops sa. Dantree. Dawtuarsh. Sir James Dawtre. $V$. Dawtree, $V$. Saltmarsh.

Or on a bend betw. two cotises az. and six 3.foils slipped vert three escallops of the first. Rowe, Windle Hill, co. Derby; and London; granted 1612. Rowe, Biistol.

Per pale or and sa. on a bend betw. two cotises erm. three escallops gu. Lonax, Clayton Hall, co. Lancaster; quartering Grimshaw andClayton.

Sa. on a bend betw. two cotises arg. three escal. lops gu. Godfrey de KINTON or LUDHAM, Archbishop of York 1258-65.

Sa. on a bend arg. betw. two cotises erm. three escallops gu. Bulmer, Norfolk. Lodiener LoMneir or Loynyer, Norfolk. LoMner, Ma. nyngton, Norfolk.

Sa. on a bend arg. betw. two cotises erm. three escallops of the first. Bulmer, Norfolk.

Sa. on a bend arg. betw. two cotises or three escallops gin. Ludhair, $V$.

Sa. on a bend engr. betw. two cotises erm. three escallops gu. Lowier, Norfolk.

Or on a bend engr. betw. two cotises engr. az. and six torteaux five escallops arg. PARBURx, London.

Az. on a bend betw. two cotises or and sis lozenges arg. each charged with an escallop sa. (five, another) six escallops vert. Boileau. Polien, Little Bookham, Surrey; quartering Boileau. Pollen, Redenham, co. Hants; Ba. ronetey 11 April 1795.

Arg. on a bend betw. two bendlets gu. an estoile or. HECTOR.
On 1 BEND betw. or within.....cont.

\section{Bendlets or Cotises cont.}

Arg. on a bend wavy betw. two cotises and as many lions ramp. sa. crowned or three estoiles of the first. Anderews, Kimpton Park, co. Middlesex; granted 2 September 1704.

Or on a bend betw. two cotises gu. three estoiles of $\operatorname{six}$ points as the first. Vowe, Hallaton, co. Leicester, 1401; quartering Deixter.

Arg. on a bend betw. two cotises sa. three fishes of the first. OsBorne.

Arg. cn a bend betw. two cotises sa. three fishes or. Osborne, London, temp. Henry VI.

Or on a bend betw. two cotises sa. within a bordure engr. gu. a fleur-de-lis of the first. Jobn HARLEy, Bishop of Hereford 1553.4.

Arg. on a bend betw. two cotises sa. a fleur-de-lis enclosed by two 5-foils of the first. John Morgan, Morganshays, co. Devon, $W$. Morgan, co. Devon; Mapton, co. Dorset; and Hambury, co. Worcester.

Arg. on a bend betw. two cotises sa. a fleur-de-lis enclosed by two 5 -foils or. Morgan, co. Devon; co. Dorset; and co. Worcester.

Arg. on a bend betw. two cotises az. three fleursde-lis of the first. GyrLYN.

Arg. on a bend betw. two cotises gu. three fleursde-lis of the first. John Thowlng, $V$. Twinge.

Arg. on a bend betw. two cotises gu. three fleursde.lis or. HackLUYT, co. Salop. Sir Richard Hakeidit, $N$.

Arg. on a bend betw. two cotises gu. three fleursde.lis or a bordure of the second. Sire Richard Archat, $M$.

Arg. on a bend gu. betw. two cotises sa. three fleurs-de-lis or. Gerlinge, Outwell, Norfolk; and co. York. Sir Richard HacheT (and in the margin? Hakelett or HakLute, L, Harl. IIS. 6137), L.

Arg. on a bend per bend gu. and az. betw. two cotises connterchanged three fleurs-de-lis .... Gurlyn, $V$. The fleurs-de-lis of the first. GURLis.

Arg. on a bend per bend az. and gu. betw. two cotises engr. on the outside sa. three fleurs-delis or. GYrLyn, Wellingham, Norfolk.

Arg. on a bend per bend gu. and az. betw. two cotises engr. sa. three fleurs-de-lis or. GinLING, Stradbroke, Suffolk; East Dereham, Twyford, Yaxham, Foulsham, Bintry, Foxley, Scarning, Gressenhall, Bradenham, and Holt, Norfolk.

Arg. on a bend indented sa. betw. two cotises az. each charged with three bezants as many fleursde-lis of the first. Cuffe, Baron Desart, 10 November 1733, Viscount Castle Cuffe 6 January 1781, Earl of Desart 20 December 1793. Cuffe, Leyrath, co. Kilkenny, Baronetcy 1 October 1799 .

Arg. on a bend indented sa. betw. two bendlets az. each charged with four bezants three fleursde-lis of the first. Jobn CuFf, Ilcester, co. Somerset, $V$. CuFfe, $V *$.

Arg. on a bend dancetty sa. betw. two cotises az. bezanty three fleurs-de-lis of the first. Coffe, Ilchester, co. Somerset.

Arg. on a bend indented sa. betw. two cotises az. each charged with three bezants as many fleursde-lis or. Cuff, Baron Tyrawley, 7 November 1797 ; extinct 1821 .

Arg. on a bend sa. betw. two cotises gu. three fleurs-de-lis or. HacHeT.

Arg. on a bend betw. two cotises sa. three fleursde-lis of the first. MIORgaN. 
On 1 BEND betw, or within.... cont.

Bendlets or Cotises cont.

Erm. on a bend engr. az. betw. two cotises gu. three fleurs-de-lis or. Buny, Linwood Grange, co. Lincoln; and Bath, co. Somerset.

Arg. on a bend az. betw. two cotises gu. six fleursde.lis two two and two or. Clapham, London, and Northampton.

Arg. on a bend betw. two cotises sa. a rose en. closed by as many annulets gu. Conway alias Williams, co. Brecon (? an error).

Az. on a bend arg. betw. two cotises or and so many demi-lions ramp. erm. a rose gu. seeded and leaved ppr. enclosed by a pair of boar's heads couped sa. langued as the fifth. WEBSTER, Battle Abbey, Sussex, Baronetcy 21 May 1703.

Az. on a bend or betw. two cotises arg. a rose gu. enclosed by a pair of leopard's faces sa. KEMBLE.

Sa. on a bend betw. two cotises arg. a rose enclosed by as many annulets gu. CoNway, co. Buckingham; co. Gloucester; and co. Warwick Conway, Bodtryddau, Soughton, etc., North Wales; (descended from the same commou ancestor as Conway, Barons Conway 24 Marcb 1624, Viscount Killutagh 15 March 1626, Viscount Conway 26 June 1627, Earl of Conway 3 December $16 \% 9$; extinct 1683 ;) the beirs m. Longueville and Potter. Conway, Hendre, co. Flint; the heiress m. Egerton. SeymourConway, Baron Conway 17 March 1702-3, Baron Conway and Killutagh 16 October 1712, Viscount Beaucliamp and Farl of Hertford $3 \mathrm{Au}$ gust 1750, Earl of Yarmouth and Marquis of Hertford 5 July 1793.

Sa, on a bend betw. two cotises arg. a rose gu. enclosed by as many anuulets or. Sir John Conway, temp. Elizabeth.

Sa. on a hend betw. two cotises arg. a rose gu. enclosed by as many annulets of the first. Seymour-Conwar, Baron Conway .17 March 1702-8, Baron Conway and Killutagh 16 October 1712, Viscount Beauchamp and Earl of Hertford 3 August 1750, Earl of Yarmouth and Marquess of Hertford $5 \mathrm{July} 1793$; quartering quarterly or on a pile gu. betw. six fleurs-de-lis az. three lions pass. guard. of the first, with gu. two wings conjoined in lure or.

Sa. on a bend arg. betw. two cotises erm. a rose enclosed by as many annulets gu. Sr. Hugh Conway, $V$. Conwey.

Sa. on a bend arg. betw. two cotises erm. a rose gu. enclosed by as many annulets or. M. Henry Coneway, $S$.

Sa. on a bend arg. betw. two cotises erm. a rose ppr. enclosed by as many annulets of the first. Ginly, Hawkdon, Suffolk.

Sa. on a bend or betw. two cotises erm. a rose enclosed by as many annulets .... GILLY, Wanstead.

Arg. on a bend betw. two cotises az. three roses of the first. Dawnex, co. Chester.

Arg. on a bend betw. two cotises az. three roses or. Aundy, $V$. Awdrey, co. Oxford. Awndye, co. Devon. Dawney, co. Devon. Dawny, $V^{*}$. Fonsan, $V^{*}$. Forson (this is forsan 'perbaps', i. e. AUNDY forsan) DAUNY, W.

Arg. on a bend betw. two cotises az. three roses or barbed vert. ANDEY ANDY or ANDEY, co. Devon.

Arg. on a bend az. betw. two cotises gu. three roses (another, 5-foils) or. DAUneY, $V$, Cotton $M S$. Tiberius $\mathrm{D}, 10$.
On 1 BEND betw. or within.... cont.

Bendlets or Cotises cont.

Arg. on a bend betw. two cotises sa. three roses of the first. Amyas, Netherton, Wakefield, co. York. Arg. on a bend betw. two cotises sa. three roses of the first seeded or barbed vert. Ames, Clifton, and Bristol.

Arg. on a bend vert betw. two cotises az. three roses of the first. DaWney.

Erm. on a bend betw. two cotises gu. three roses arg. WADMAN, Imber, co. Wilts.

$\mathrm{Gu}$. on a bend betw. two cotises or three roses of the first seeded as the second barbed vert. Hirlmian.

Or on a bend engr. betw. two cotises sa. three roses of the first. PAYNE, Wallingford, co. Berks; confirmed 12 January 1586 ; and London.

Sa. on a bend arg. betw. two cotises erm. three roses gu. Conway, $V^{*}$. Sr. Hugh Conwey, co. Worcester, $V$. Sr. Hugh Conyway, V, Cotton MS. Tiberius D, 10. ConwaY, Baron Conway, Harl. MS. 1966, fo. 139.

$\mathrm{Sa}$. on a bend betw. two cotises or three roses gu. stalked and leaved vert. Simperton.

Arg. on a bend betw. two cotises sa. three 4-foils of the first. DANDY, Trewen, Cornwall.

Sa. on a bend betw. two cotises or tbree blind 4-foils slipped gu. Symprington, $V$.

Sa. on a bend betw. two cotises or three 4-foils slipped gu. Simpington. Symprington, $V$.

Sa. on a bend arg. betw. two cotises erm. a 5 -foil enclosed by as many annulets gu. Conway. Sr. Hugb Conwer, co. Warwick, $V$.

Arg. on a bend az. betw. two cotises .... three 5 -foils $\ldots$ John DanNaY, $Y$.

Arg. on a bend betw. two cotises az. three 5-foils of the first. AUDRY, co. Wilts.

Arg. on a bend betw. two cotises az. three 5 -foils or. AwDrx, Seend, and Notton, co. Wilts.

Arg. on a bend betw. two cotises az. three pierced 5 -foils or. DANREY.

Arg. on a bend az. betw. two cotises gu. three 5.foils or. Dauncy, $V$. Dauney, $V$, Cotton $M S$. Tiberius $\mathrm{D}, 10$. Dawney, $V^{*}$. Dawtrey. EKINGTON.

Arg. on a bend az. betw. two cotises dancetty gu. three 5.foils or. Cocksey Cookesey or Cooksey.

Arg. on a bend betw. two cotises gu. three 5-foils of the first. Swain or Swaine.

Arg. on a bend betw. two cotises gu. three 5-foils or. Dawnay. Echington. Lecpon, Wilborne, co. Lincoln. LectoN.

Arg. on a bend gu. betw. two cotises or three pierced 5-foils of the last. ERINGTON.

Arg. on a bend sa. betw. two cotises az. three pierced 5 -foils or. Danrex or DaUdie, Laureth, Cornwall.

Arg. on a bend betw. two cotises sa. three 5-foils or. Sr. Hugh Dawney, co. York, $V$.

Arg. on a bend vert betw. two cotises az. three 5.foils or. Nicholas DannaY, $Y$. Monsire Nichol Dauny, $Y$.

Or on a bend betw. two cotises sa. three 5-foils of the first. Gayer. Sayer, Michael-Penkevell, Cornwall.

Quarterly arg. and az. on a bend invecked betw. two cotises sa. and as many mullets erm. three 5-foils or. DENDY, Griggs or Gulshaw, Towerbill in Horsham, Sussex; granted September 1793.

Sa. on a bend betw. two cotises arg. three 5 -foils gis. Bettes, Norfolk. 
On I BEND betw, or within.... cont.

Bendlets or Cotises cont.

Sa. on a bend arg. betw. two cotises or three pierced 5.toils gu. Betres, Norfoll.

Sa. on a bend or betw. two cotises arg. tbree 5 -foils sa. Bettes, co. Hants.

Arg. on a bend sa. betw. two cotises gu. three pears pendent or. Perry.

Arg. on a bend betw. two cotises az. three garbs or. Blice, V. Buiss or Bissse, Market Harborough, co. Leicester. Richard BLISSE, 1703, in St. Saviour's Church, Southwark.

Arg. on a bend gn. betw, two cotises sa. three garbs or. SANDFond, Crowcorne, co. Hertford.

Arg. on a bend betw. two cotises sa. three garbs or. Whitford, England.

Az. on a bend betw. two cotises arg. three garbs of the first. HAGgerstone, Northumberland.

Erm. on a plain bend betw. two cotises engr. gu. three garbs or. Mantebey. Mautby or MAUTEBy ; granted May 1612, Harl. MS. 6095, fo. 20 .

Erm. on a plain bend gu. betw. two cotises engr. or three garbs of the last. MAUTBY (in error).

Or on a bend betw. two cotises az. three garbs .... TILson.

Arg. on a bend gu. betw. two cotises sa. as many dexter hands couped ppr. Waller.

$\mathrm{Gu}$. on a bend betw. two cotises or a leopard's head betw. two fleurs-de-lis of the first. GARDNER, London.

Quarterly gu. and az. on a bend betw. two cotises or and as many griffins segreaut holding in the dexter claw a round buckle gold a leopard's face of the first having in the mouth a round buckle of the second enclosed by a pair of fleurs-de-lis sa. GARDENOR.

Or on a bend betw. two cotises sa. a lion's face enclosed by so many chaplets of oak as the first. Bentley, Middlesex; Hersey, Hadleigh, and Boxford, Snffolk; and Scarborough, co. York.

Erm. on a bend betw. two cotises sa. three boar's heads couped arg. Burnman, co. Devon.

Erm. on a bend betw. two cotises sa. three boar's heads bendwise couped or. Boriras, co. Devon; and co. Somerset. Bowerman, $V^{*}$. James Bowreman, Hemyoke, co. Devon, $W$.

Gu. on a bend arg. betw. two cotises or three boar's heads sa. EDgecumbe.

Gu. on a bend erm. betw. two cotises three boar's heads couped or. EgEcombe.

Gu. on a beud ermines betw. two cotises or three boar's heads couped arg. EDGECUMBE, origin. ally Eggescombe, co. Devon. Edgcumbe, Baron Edgcumbe 20 April 1742, Viscount Mount Edgcumbe and Valletort 5 March 1781, Earl of Mount Edgcumbe 3! August 1789. Egecombe, $V^{*}$. The heads fesswise. Sr. Richard Eggcombe or Eggecombe, $V$.

$\mathrm{Gu}$. on a bend sa. betw. two cotises or three boar's heads fesswise couped arg. EDGEcombe, co. Devon. Sr. Pierse Egecome or Egrcombe, $V$.

Or on a bend az. betw. two cotises gu. three boar's heads erased of the first. HATEIEY, Scotland.

Or on a bend betw. two catises gu. three boar's heads of the first. WaLter, Cornwall; and co. Devon.

Or on a bend sa. betw. two cotises gu. three boar's heads bendwise couped arg. a bordure engr. sa. WALTER, $V$.

Arg. on a bend betw. two cotises az. three buck's beads bendwise cabossed or. Stanley, $W$.
On 1 BEND betw, or within.... cont.

\section{Bendlets or Cotises cont.}

Arg. on a bend az. betw. two cotises gu. three stag's heads cabossed or. Stanley, Moore Hall, co. Lancaster; and Lee House, Sussex.

Arg. on a bend az. betw. two cotises vert three stag's heads cabossed or. Stanlex, Dalegarth, and Ponsonby Hall, Cumberland.

Sa, on a bend betw. two cotises or three stag's heads cabossed gu. Hellenes, co. Hereford; and co. Salop.

Or on a bend per bend gu. and az. betw. two cotises sa. and as many roundles per pale of the third and second three fox's heads couped of the first. ToDD, Hampstead; granted ....

Arg. on a bend engr. sa. betw. two cotises and as many estoiles az. three fox's beads erased or. Tond, Molesey, Surrey; granted 12 December 1823.

Arg. on a bend az. betw. two cotises duncetty gu. three leopard's heads erased or. Nicholas GraYe, Schoolmaster at the Charterhouse, 1619. Az. on a bend betw. two cotises arg. three leopard's heads .... (another crowned gu.) Gournay.

Az. on a bend betw. two cotises arg. three leopard's heads gu. ducally crowned or. GorNaY, Essex, V. Gorney, Essex.

Az. on a bend erm. betw. two cotises or three leopard's faces ppr. Foot, Brentford, Middlesex; granted 14 December 1769.

Arg. on a bend betw. two cotises az. three lion's heads erased of the first. LowE, co. Stafford; granted 1592 .

Arg. on a bend betw. two cotises gu. three lion's beads erased or. LAMBORNE.

Arg. on a bend sa. betw. two cotises gu. three lion's heads erased of the first. M. William LAMBRUN, $S$.

Arg. on a bend sa. betw. two cotises gu. three lion's heads erased or. Lamborne, $V$. M.William Laniburn, $S$.

Arg. on a bend betw. two cotises sa. three lion's beads erased or. Burton, Rutland; in Bristol Cathedral.

Erm. on a bend betw. two cotises sa. three lion's beads erased or. LambonNe, temp. Henry VI. Or on a bend betw. two cotises sa. three lion's heads erased of the first. Lowe, co. Worcester.

Vert on a bend arg. betw. two cotises or three tiger's heads ppr. BoDicote or BoDycoAt, London.

Arg. on a bend sa. betw. two cotises gu. three wolf's heads erased or. LambUrne, $V$.

Or on a bend betw. two cotises sa. three wolf's heads erased of the first. Lowe, Bromsgrove, co. Worcester; quartering Furye and Hill.

Arg. on a bend sa. betw. two cotises gu. three dragon's heads erased or. LANBRUN, $V^{*}$.

Arg. on a bend sa. betw. two cotises gu. three dragon's heads erased close to the ears or. Lanbrun', $V$. Lambrand or Lambrund.

Arg. on a bend betw. two cotises sa. three griffin's heads erased of the first. SAIE, co. Lincoln; and co. Yorls. Sall SaLLE or SALLET, co. Lincoln. SAWLEY, $V$. The heads or. SAwLex, $V^{*}$.

Erm. on a bend betw. two cotises sa. three griffin's heads erased or. YoNGE, Bassingbourne, co. Berks; and Culliton, Axminster, and Heltons, co. Devon.

Erm. on a bend engr. betw. two cotises sa. three griffin's beads erased or. Yoong; granted I583, $W$. 
On 1 BEND betw. or within.... cont.

Bendlets or Cotises cont.

Per pale vert and or on a bend engr. erm. betw. two cotises and as many escallops arg. three griftin's heads erased .... Young, Hawkhurst, Kent.

Tert on a bend engr', arg. betw, two cotises or three hearts gu. Toker, the Oaks Ospringe, Kent.

Arg. on a bend gu. betw. two cotises sa. three horseshoes of the first. Ferners, Skillingthorpe, co. Lincoln, 1730.

Erm. on a bend betw. two cotises gu. in chief a cross moline az. and in base an anchor erect sa. three horseshoes or. FERRIs, Hawkhurst, Kent; and Thackham, Sussex.

Or on a bend gu. betw. two cotises az. three horseshoes of the first. Ferrers, Fiddington, co. Gloucester.

Or on a bend betw. two cotises sa. three horse. shoes of the first. Farrar, London.

Gu. on a bend betw. two cotises and as many pheons or a flute (or baston) of the first. ElLiot, Scotland.

Arg. on a bend per bend az. and gu. betw. two cotises three lozenges each charged with a fleurde-lis counterchanged. GorLAND.

Arg. on a bend betw. two cotises sa. three lozenges erm. Reeves. Fernes, Dandey Court, co. Dorset. Rivers, co. Dorset. Ryves, co. Dorset, 1716.

Az. on a bend arg. betw. two cotises and six lions ramp. or a mascle gu. Bowne, co. Hertford.

Arg. on a bend betw. two cotises sa. three mascles erm. Rives, Damory Court, co. Dorset.

Sa. on a bend betw. two cotises arg, three mascles of the first. Bourdman.

Or on a bend betw. two cotises and as many garbs az. a mitre of the first. Tylson. The mitre stringed. Tulson, $V^{*}$.

Arg. on a bend betw. two cotises az. three griffins pass. or: GraA or Grey.

Arg. on a bend betw. two cotises sa. a mullet of the first. Andrews.

Arg. on a bend betw. two cotises engr. sa. a mullet .... Elusted, Dovor.

$\mathrm{Az}$. on a bend engr. arg. betw. two cotises or a mullet in chief sa. Sr. John Fortescue, $V$.

Or on a bend sa. betw. two cotises az. a mullet arg. euclosed by as many bezants. Robert StrCHeld, Bishop of Durham 1200-74.

Arg. on a bend betw. two cotises .... three mullets or. Leather or Leatherland.

Arg. on a bend betw. two cotises az. three mullets or. Jues.

Arg. on a bend az. betw. two cotises gu. three mullets or. Daneray.

Arg. on a plain bend az. betw. two cotises wavy sa. three mullets or. Bucke, Kent.

Arg. on a bend betw. two cotises gu. three mullets of the first. HaKELUYT, co. Gloucester.

Arg. on a bend betw. two cotises gu. three mullets or. AkELAND or Aiselout, co. Gloncester. Hacclut or Haiseluyt, co. Gloucester. Sire Edmon Hakelut, $N$. Sr. John Hakeluyt, co. Gloucester, $V$. Rowley, Baron Langford, 30 July 1800.

Arg. on a plain bend betw. two cotises indented gu. three mullets or. Sr. Edmond HakELUTE, co. Salop, temp. Edward I, $V$.

Arg. on a bend betw. two cotises wavy gu. three mullets or. Hacklet or Haciluit, co. Salop.

Arg. on a bend betw. two cotises gu. three mullets or pierced az. M. Leynard HAEELUYT, $S$.
On 1 BEND betw. or within.....cont.

\section{Bendlets or Cotises cont.}

Arg. on a bend betw.two cotises gu. three pierced mullets or. Hacklet Hacklute or HackluY', co. Gloucester and co. Salop.

Arg. on a bend gu. betw. two cotises sa. three pierced mullets or. Bradbourne, co. Derby. Roure or Rowry.

Arg. on a beud engr. sa. betw. two beudlets engr. gu. tbree mullets of the first. Sr. de Prgotr, Norfolk, $V$.

Arg. on a bend betw. two cotises sa. three mullets of the first. Lancelot Andrews, Bisbop of Winchester (at the Charterhouse), 1619. Andrews, Lath bury, co. Buckingham; Norfolk; and Suflolk. ARderes, Meriden, co. Warwick. Sr. .... de Estmarton, $V$. Esmerten or Estmerton. Rece. Rew or Rue. John Roney, $V$. Rony. M. John de Rouche or de Routh, $S$. Routhe, $V$. M. Oldam de Rue, $Y$. Arg. on a bend betw. two cotises sa. three mullets of the first pierced gu. ANDREwes.

Arg. on a bend betw. two cotises engr. sa. three mullets of the first. Pigot, Norfoll.

Arg. on a bend engr. betw. two cotises sa. three mullets of the first. ANDREw, Suffolk, $\boldsymbol{V}$. Andrews, $V *$. Thorgry or Thourghgram.

Arg. on a bend engr. betw. two cotises and as many lions ramp. sa. three mullets of the first. ANDREwes or ANDrews, Suffolk.

Arg. on a bend engr. betw. two cotises sa. three pierced mullets of the first. Thungryn, $V$.

Arg. on a bend betw. two cotises sa. three mullets or. Eshenten or Estmerton. Lenthall, Hampton Court, Leynthall Earls, and Leynthall Starks, co. Hereford ; Latchford, Great Haseley, Burford Priory, and Yelford Hastings, co. Oxford; and Besselsleigh, co. Berlss. Lenther.

Arg. on a bend betw. two cotises and three martlets sa. as many mullets or. Pury or Pyry, co. Wilts.

Arg. on a bend betw. two cotises sa. three mullets or pierced az. M. Leonard HaKerytT, $S$.

Arg. on a bend betw. two cotises sa. three mullets or pierced gu. Sir Rowland Lenteall, temp. Henty VI, $V$. LeThadL, $V^{*}$.

Arg. on a bend engr. betw. two cotises sa. three mullets or. Lancelot ANDREwES, Bishop of Chichester 1605, Ely 1609, Winchester 1619-26. ANDREws, Suffolk.

Arg. on a bend wavy betw. two cotises sa. three puerced mullets or. White, $V^{*}$. White, Exeter; granted 24 March 1541. White, Linley Hall, Bishop's Castle, co. Salop.

Az. on a bend betw. two cotises arg. and six lions ramp. or three mullets gu. BонuN.

Az. on a bend betw. two cotises arg. and six lions or three pierced mullets gu. Nottingham.

$\mathrm{Az}$. on a bend arg. betw. two cotises and six lions ramp. or three mullets gu. William BoHun, Earl of Northampton, $Q$; quartered by Stafford Earl of Wiltshire, $U$. The mullets pierced. William de BoHun, Earl of Northampton, $V$.

Az. on a bend arg. betw. two cotises and six lions ramp. or three mullets sa. BoHun.

$\mathrm{Gu}$. on a bend betw. two cotises arg. three mullets sa. HaCcLuYT.

Gu. on a plam bend betw. two cotises indented or three mullets of the first. Marmabeld, Gernock. Or on a beud engr. gu. betw. two cotises sa. turee mullets arg. Andrewes, St. Edmuud's Bury, Suffolk; and co. Wilts. 
On 1 BEND betw, or within.....cont.

Beudlets or Cotises cont.

Az. on a bend betw. two cotises arg. three palets gu. VIDALl.

Erm. on a bend sa. betw. two cotises gu. three pheous or. Brand, Randall's Park, Leather. head, Surrey.

Sa. on a plum bend erm. betw. two cotises engr. and as many 5-foils or a hurt enclosed by a pair of escallops az. Peters, Newcastle-onTyne.

Arg. on a bend betw, two cotises az. three bezants Cars. Felton, Suffolk.

Arg. on a beud betw. two cotises gu. three bezants. Bishop, co. Dorset; and co. Somerset. Bishop, Norfolk, $W$. Bisshopp, Baronetcy 23 July 1620, Baron Zouche of Harringworth $27 \mathrm{Au}$ gust 1815 , abeyance 11 November 1828 , revived to Cunzon, Baroness Zouche January 1829; quartering Hedges, Tate, and Zouche. (? Tho. mas Brsshop, Henfield, Sussex, 1559.)

Arg. on a bend gu. betw. two cotises sa. three be zants. Bishop, Evesham, co. Worcester.

Erm. on a bend gu. betw. two cotises .... three bezants. Bishopp, co. Salop, $W$.

Erm. on a bend betw. two cotises gu. three bezants. Bishop, $V^{*}$. Bishoppe, Bristol, co. Somerset.

$\mathrm{Or}^{\circ}$ on a bend engr. gu. betw. two cotises sa. thrce bezants. HANBURY, co. Stafford.

Sa. on a bend betw. two cotises or three ogresses. Capell. Caps, Cornwall, $V$.

Arg. on a bend betw. two cotises az. three plates. FeLton, Suffolk.

Arg. on a bend betw. two cotises gu. three plates. Sr. Thomas Bishop, Parham, Sussex, $W$. HAYwood, co. Stafford.

Or on a bend az. betw. two cotises gu. three plates. Ficton, Suffolk, $V$.

Az. on a bend arg. Letw. two cotises or three torteaux. Boughan, co. Lincoln.

Az. on a bend arg. betw, two cotises and six lions ramp. or three torteaux. Batian.

Or on a hend betw. two cotises gu. five bezants. Rous or Rowse, London.

Sa. on a bend arg. betw. two cotises or three sal. tires gu. Sr. Nicholas Lovayne, Pencherst, Kent, $V$.

Arg. on a plain bend betw. two cotises potence on the outer edge sa. a tilting spear of the first. Carmichael, Carsepherne; which coat passed by an heiress, 1504, to Coulthart, Coulthart, co. Wigton.

Arg. on a bend az. betw. two cotises and six hal. berds sa. three swords or. DANEs, London.

Sa. on a plain bend (arg. in Withe) betw. two cotises indented or an elmine spot bendwse at tbe top. Clopton, $V$.

Arg. on a bend gu. betw. two cotises az. and six martlets of the second three wings of the first. W $\triangle$ IIDEN.

Or on a bend gu. betw. two cotises az. and six martlets of the second three dexter wings elevated arg. Sr. Richard W WLDEN, $V$. W Buckworth, co. Huntingdon; and Norfoll.

Or on a bend gu. betw. tro cotises sa. and six martlets of the second three wings arg. WALDEN.

Arg. on a bend gu. betw. two cotises sa. three pair of wings conjoined and levated as the first. WingField, Baron Wingfield and Visconnt 1wwerscourt 4 February 1713, Harl. MS. 4040, fo. 308 .
On 1 BEND betw, or within.... cont.

\section{Bendlets or Cotises cont.}

Arg. on a bend gu. betw. two cotises sa. three pairs of wings conjouned in lure of the first. WINGFIELD, Onslow, co. Salop; The Gro, and Rhysnant, co. Montgomery; descended through Wingfield, Glossop, like Wingfield, Dunham Magna, Norfulk, and WingField, Kimbolton, co. Huntingdon, from WingFielD, Letherungham, Suffolk; a beiress $m$. Dillon. WingField, Tickeucote, co. Rutland. Sr. Thomas WingFeind, $V$. Wingfield, $V^{*}$. WingField, Baron Wingfield and Viscount Powerscourt 4 February 1743 .

Arg. on a bend .... betw. two cotises sa. three chaplets gu. Saxton, co. York ( $V$. in error).

Or on a bend gu. betw. two cotises sa. three chaplets of the first. Saxton, co. York.

Sa. on a bend betw. two cotises arg. three chaplets gu. SAXTON, $V^{*}$.

Sa. on a bend betw. three cotises arg. as many martlets gu. William Suthes, 1625, S. Mary's Lambeth; Aubrey, Surrey, v, 248, and so given in other descriptions of the church : but two cotises only; Add. MS. 6409 , fo. $40,47$.

Arg. on a bend betw. three (probably a mistake as the above) cotises sa. four mullets or on an inescucheon the arms of Mortimer. Sire Hugh de 'I'urpinton, $O$.

Per pale sa. and gu. on a bend engr. betw. double cotises and two escallops arg. three lions pass. guard. of the first. Brown.

Per bend sinister or and gu. on a bend betw. doulle cotises tbree lions pass. bendwise countercbanged. Smart, $V$. Simarte, $V^{*}$.

Arg. on a bend betw. double cotises sa. three spread eagles of the tirst. Browne, co. Lan. caster.

Arg. on a bend betw. double cotises sa. three eagles displ. in pale of the bend or. BADEN. Sir Hugh BaDEw, $V$.

Or on a bend engr. betw. double cotises sa. three hor'sesboes arg. Ferrior, Pearston, and Hasguard $\mathrm{Hall}$, co. Pembroke.

$\mathrm{Gu}$. on a bend al'g. betw. double cotises or an ogress. CAnnon, co. Pembroke; granted February 1614.

$\mathrm{Gu}$. on a bend betw. double cotises or three torteaux. Conx, Basingthorp, Cumberland, 1612. Billets

Arg. on a bend betw. three billets sa. as many men's heads couped at the shoulders of the first. WEDINSON.

$\mathrm{Gu}$. on a bend arg. betw. six billets or three es. callops sa. Robert Cunson, $T$.

Gu. on a bend betw. six billets or three escallops sa. Robert Cunson, T, Harl. MS. 6137.

Arg. on a bend betw. six billets gu. three veiled nun's heads couped bendwise of the first. WEDNISSON, $V$.

Gu. on a bend betw. ten billets or three escallops sa. Robert Corson, $V$. Curson.

\section{Bird}

Arg. on a bend betw. a martlet in chief az. and a bugle in base sa. stringed of the second two crescents as the first. Piliuire, Cupar of Augus. Birds

Arg. on a bend sa. betw. two birds volant vert as many roses gu. Ringworth.

Quarterly gu. and sa. in the second and third quarters a bud the former holding in its leak a cross patty fitchy the latter a cross croslet fitchy arg. over all on a bend engr. or three burts. CoBLEIGH. 
On 1 BEND betw. or within.... cont.

Birds cont. Cocks

Arg. on a bend betw. two cocks gu. three mullets of the first. Edmund Law, Bishop of Carlisle, 1709.87

Arg. on a bend engr. betw. two cocks gu. three pierced mullets of the first. George Henry IAw, Bishop of Chester 1812, Bath, etc., $1824-45$.

Erm. on a bend engr. betw. two cocks gu. three mullets arg. LAws, Scotland.

Erm. on a bend engr. betw. two cocks gu. three mullets or. L $\Lambda$, Cannon Hill, Maidenhead, co. Berks.

Erm. on a bend engr. betw. two cocks gu. three pierced mullets or. Edmund LAw, Bishop of Carlisle 1769-87; and his descendant, LAw, Baron Ellenborongh 19 April 1802, Viscount Southam and Earl of Ellenborough 22 October 1844.

Az. on a bend embattled arg. betw. two cocks of the second crested and jelloped or a snake vert. JOHNSON.

Az. on a bend raguly arg. betw. two cocks of the second crested and jelloped or a snake vert. JoHNSON, co. Northampton.

\section{.....Crows and Choughs}

Arg. on a bend engr. sa. betw. two Cornish choughs ppr. three escallops of the first. Rowlex, Tend. ring Hall, Suffulk; Baronetcy $10 \mathrm{June} 1786$. Rowler, Hill House, co. Berks; Baronetcy 22 February 1836.

Arg. on a bend betw. two crows sa. three escallops of the first. Rowley, Wykin, and Rowley, co. Salop.

Arg. on a bend az. betw. two crows sa. three garbs or. WICKSTEAD.

$$
\text { .... Ducks }
$$

Gyronny of eight gu. and sa. on a bend engr. .... betw. two ducks arg. each holding in the beak a cross croslet or three roundles .... COSELEGH, $V^{*}$. COBLEgh, $V^{*}$.

$$
\text { .... Eagles }
$$

Arg. on a bend engr. gu. betw. two eagles displ. vert another bend sa. Squedal, $W$.

Erm. on a bend engr. az. betw. two eagles displ. another bend plain or charged with three lions pass. ppr. MAzE, co. Somerset; granted ....

Or on a bend betw. two eagles displ. sa. three crosses croslet of the first. PaYnes, Kent.

Gu. on a bend rayouated betw. two eagles displ. or three roses of the first. BoDEn, Middlesex.

Quarterly per fess indented arg. and gu. on a bend engr. az. betw. two eagles displ. or a fret of the last enclosed by two doves ppr. AnDLEY, London.

Quarterly per pale indented or and az. on a bend of the second betw. two eagles displ. gold a fret enclosed by two martlets as the last. AudLey, Waldon, Essex. MagdalenColuege, Cambridge.

Per pale gu. and az. on a bend betw. two eagles displ. arg. three garbs vert. GoYLING.

Erm. on a bend betw. two eagles displ. sa. three griffin's heads erased arg. Young, Lambeth, Surrey, 1826.

Az. on a bend arg. betw, two eagles displ. or three mascles of the first. Maund, co. Oxford, 1660.

Or on a bend az. betw. two eagles displ. sa. three mullets of the first. Renous. Renouse, Stanmore, Middlesex; granted 1758.

Sa. on a bend betw. two eagles displ. arg. a wreath enclosed by as many escallops gu. John Malyn, Abbot of Waltbam, $U$.
On 1 BEND betw, or within.... cont.

\section{Birds cont. Martlets}

Arg. on a bend betw. two martlets gu. three escallops or. Sr. Robert WADEsLe, co. York, temp. Edward I, $V$. WADESLEY or WADISLEY, co. York.

Arg. on a bend betw. two martlets sa. three escallops of the first. WADESLEY or WADISLEY.

$$
\text { ....Pelicans }
$$

Az. on a bend arg. betw. two pelicans or three ogresses. Cowper, London.

$$
\text { ..... Swans }
$$

Az. on a bend wavy or hetw. two swans arg. three roses gu. Jenysonn, Burnham West Gate, Norfolk.

Gyronny of eight gu. and sa. on a bend engr. or betw. two swans close holding in their beaks a cross croslet fitchy arg. three hurts. CoBLIGH or CoRoleche.

Gyronny of eight gu. and sa. on a bend engr. or betw. two swans arg. each holding in the beak a cross bottony fitchy gold three hurts. Cobelegh, $V$.

Gyronny of eight sa. and gu. on a bend engr. or betw. two swaus arg. three ogresses. CoBleigH, co. Devon. Cobleigh Cobley and Colegh.

$$
\text { ..... Crows and Choughs }
$$

Arg. on a bend az. betw. three Cornish choughs jpr. as many garbs or. Wicksted, Nantwich, co. Chester.

Arg. on a bend engr. gu. betw. three Cornish choughs ppr. as many leopard's heads or. Wightman, Harrow, Middlesex; granted 14 July 1562 .

Arg. on a bend betw. three crows sa. as many leopard's heads of the first. CARR, T'ewksbury, co. Gloucester.

Or on a bend betw. three crows sa. as many pard's heads erased of the first. CARR, Newcastle, and Cocken Hall, Durham. CARR, Bishopwearmoutb, quartering Dale.

$$
\text { .....Martlets }
$$

Az. on a bend betw. three martlets or so many of the same as the first. Clederow.

Arg. on a bend betw. three martlets gu. as many escallops of the first. WADESLEY.

Quarterly indented arg. and sa. on a bend of the second betw. three martlets so many fleursde-lis as the first. Herman, co. Buckingham.

Arg. on a bend gu. betw. three martlets sa. as many mullets of the first. SHelly.

Erm. on a bend betw. three martlets sa. as many mullets or. Eversfield, Sussex.

Arg. on a bend betw. three martlets gu. as many plates. BaLIfFFe.

Arg. on a bend sa. betw. three martlets gu. as many bezants. WortLEY.

$$
\text { .... Owls }
$$

Az. on a bend wavy betw. three owls or as many fleurs-de-lis of the first. Stacre, co. Nottingham.

\section{.....Pigeons}

Vert on a bend ernbattled counterembattled or betw. three doves arg. as many crosses croslet sa. Stones, Cartmell, co. Lancaster; and Middlesex; granted 1771.

$$
\text { ..... Martlets }
$$

Arg. on a bend betw. six martlets gu. three of the same or. WARD or WARE. Sr. de W $\triangle \mathrm{RDE}, V$.

Arg. on a bend betw. six martlets gu. three cres. cents or. Wortery, co. York. 
On 1 BEND betw. or within.... cont.

Birds cont. Martlets cont.

Arg. on a bend betw. six martlets gu. three escallops or. Sire Robert de WADEsLe, $N$.

Sa. on a bend betw. six martlets arg. (or $V^{*}$.) three roses gu. Rossham, $V$.

Arg. on a bend betw. six martlets gu. three lozenges of the first each charged with a saltire of the second. Eckersall, Middlesex; granted 1761.

Az. on a bend betw. six martlets or a mullet gu. Sire Johan Mon'eny, $N$. Sir John Mountney, $N$, Harl. MS. 6137, L.

Arg. on a bend betw. six martlets gu. three mul. lets or. Wrotfilex, co. York.

Arg. on a bend gu. betw. six martlets sa. three pierced mullets of the first. SHeller.

Arg. on a bend betw. six martlets gu. three bezants. Robert de Morcelye, $Y$ (a mistake for Wortelye). W ARdell, $V$. WardLe. Wickler. Wombwell. Thomas Wombeli, $X$. Monsire de Worseley, $Y$. Sr. Nicolas Wortelley, co. York, $V$. Wortuer, Wortley, co. York; Baronetcy 29 June 1611; extinct 14 March 1665. Sire Nicholas de Wortele, $N$.

Gu. on a bend or betw. six martlets arg. three torteaux. WARDELL, London; granted 26 June 1773 .

Or on a bend betw. six martlets gu. three wings arg. WARDE, $V^{*}$.

$$
\text { ..... Pigeons }
$$

Vert on a bend counterembattled or betw. six doves arg. three crosses humetty sa. SToNes, Mosborough, co. Derby; granted 1693.

Sa. on a beud betw. six doves arg. legged gu. three pheons of the first. Alsoppe, London, 1797.

\section{Bordure}

Or on a bend gu. within a bordure of the second bezanty three annulets of the first. FarNall, quartering Elliott.

Arg. on a plain bend gu. within a bordure engr. of the second a lion pass. of the first. Mosters.

Arg. on a plain bend gu. within a bordure engr. of the second a lion pass. guard. or. Musters, co. Nottingham. Sir John Musters, 1730.

Quarterly gu. and az, on a bend arg. within a bordure sa. three boars pass. of the last armed or. Grys, Wakefield, co. York.

Arg. on a bend sa. within a bordure compony of the first and az. three calves pass. or. VEELE, Langford, co. Gloucester. Veluer, Essex.

Arg. on a bend indented az. within a bordure gu. a bendlet or. BoDyhan.

Arg. on a plain bend within a bordure engr. sa. another bend of the first. Dowrish, $W$.

$\mathrm{Gu}$. on a bend engr. or within a bordure of the second surmounted by another az. charged with four crescents and so many mullets arg. a baton as the tbird. EluIot, Bortbwickbrae, Scotland.

$\mathrm{Gu}$. on a bend or within a bordure of the second charged with six garbs a baton az. ELLIOT, Binksnow, Scotland, descended from Lariston.

$\mathrm{Gu}$. on a bend or within a bordure of the second charged with eight bearded garbs a baton az. Elliot, Harwood, Scotland.

Gu. on a bend engr. or within a hordure vair a baton az. Elirot, Miuto, Scotland. Elliot, co. Poxburgh.

Az. on a bend or within a bordure arg. three bitterns sa. membered gu. READE.
On 1 BEND betw, or within.....cont.

Bordure cont.

Az. on a bend wavy or within a bordure engr. arg. pelletty three bitterns sa. membered gu. REDE.

Az. on a bend wavy or within a bordure engr. arg. charged with torteanx and hurts alternately three Cornish choughs ppr. ReDE, Ashmans, Suffolk. Rede, Norwich; and Beccles, Suffolk.

$\mathrm{Gu}$. on a bend wavy or within a bordure engr. of the last charged with eight torteaux three Cornish choughs ppr. READ, Hitchin, co. Hertford.

Az. on a bend wavy or within a bordure engr. arg. charged with torteaux three shovellers .... Reade, Massingbam Magna, Norfolk.

Arg. on a bend within a bordure gu. three martlets or. Burghwell. Hobilder or HoBildod. Arg. on a plain bend within a bordure engr. gu. three martlets or. HOBILDOD, $V^{*}$. HOBYLDOD, $V$.

Arg. on a bend gu. within a bordure engr. sa. three martlets or. LACY.

$A z$. on a bend wavy or within a bordure arg. charged with ogresses and torteaus alternately three martlets sa. Reade, Suffolk.

Az. on a bend wavy or within a bordure engr. arg. charged with eight torteaux three martlets sa. READE, Suffolk.

Gu. on a bend arg. within a bordure compony of the second and sa. three martlets as the last. QUINTON.

$\mathrm{Gu}$. on a bend within a bordure arg. three mart. lets sa. Bookey.

Gu. on a bend or within a bordure erm. three martlets az. CoLliNs, Sittingbourne, Kent; London; and Sussex. Collins, Kirkman Bank, Knaresborough.

Or on a bend within a bordure az. three martlets arg. O'Calane sive CuIlean alias Collins, co. Limerick.

Sa. on a bend within a bordure or three martlets vert. Kinnear, Edinburgh.

Az. on a bend wavy or within a bordure arg. charged with ogresses and torteaux alternately three swans sa. Keade, Suffolk.

Az. on a bend wavy or within a bordure engr. arg. charged with eight torteaux three swans sa. ReADE, Suffolls.

Arg. on a plain bend within a bordure indented az. three buckles or. LEsLy, Kinivie, Scotland.

Arg. on a plain bend az. witbin a bordure invecked of the second charged with eight crescents of the first three buckles or. LEsLy, Colpnay Shiels, Scotland.

Arg. on a bend az. within a bordure chequy gu. and or three buckles of the last. LEsLx, Finrassie, Scotland, quartering Abernethy.

Arg. on a bend az. within a bordure gu. three buckles or. Leslie, Powis, Scotland ; quartering az. three frases arg. within a bordure quartered or and of the second the first charged with antique crowns gu. the last with as many 5 -foils silver.

Erm. on a bend within a bordure gu. three buckles arg. Nuttebury or Muttlebur.

Erm. on a bend within a bordure gu. three round buckles or. Muttlebury, Jordaine, co. Somerset.

Paly of six arg. and gu. on a plain bend within a bordure indented az. three cushions or of the third. Lunden, Auchtermerny, Scotland. 
On 1 BEND betw. or within.... cont.

\section{Bordure cont.}

Paly of seven arg. and gu. on a plain bend within a bordure engr. az. three cushions or. Lundin, Scotland.

Arg. on a bend within a bordure az. three escallops or. Prinole, Blindlee, Scotland.

Arg. on a plain bend within a bordure engr. sa. three escallops or. Tirington.

Quarterly arg. with gu. fretty or on a bend sa. within a bordure az. charged with eight mitres of the third three escallops .... Henry Despenser, Bishop of Norwich 1370-1406.

Or on a bend withun a bordure az, an estoile betw. two crescents of the first. Scotr, Burn. head, Scotland.

Or on a bend az. within a bordure compony of the second and first an estoile betw. two erescents as the field. Scotr, Mangerton, Scotland.

Or on a bend az. within a bordure compony gu. and arg. an estoile betw. two crescents of the first. Scot, Gornberry, Scotland.

Or on a bend az. within a bordure counter. compony of the second and first an estoile betw. two crescents as the field. Scotr.

Or on a bend az. within a bordure gu. charged with eight bezants an estoile betw. two crescents of the first. Scor, Edinburgh. Scot, Elie, Scotland.

Or on a plain bend az. within a bordure engr. gu. an estoile betw. two crescents of the first. Scot, Scotstarvit, Scotland. Scot, Orkney, Scotlaud; quartering Gordon. And with a mullet for diff. Scot, Pitlochie, Scotland. Scot, Lethum, Scotland.

Or on a bend az. within a bordure per pale gu. and of the second the dexter side engr. and the sinister indented an estoile betw. two crescents as the first. Scor, Vogry, Scotland.

Or on a bend az. within a bordure quarterly of the first and second an estoile betw. two crescents gold. Scotr, Hadshaw, Scotland.

Or on a plain bend az. within a bordure engr. sa. charged with eight escallops or an estoile betw. two crescents of the first. ScotT, quartered by Murray.

Arg. on a bend az. within a bordure erm. three fleurs-de.lis or. BARDFEILD, $V$. BARDFIELD, $V^{*}$.

Or on a bend engr. az. within a bordure gu. three fleurs-de-lis arg. Powntrell or Powtreli.

Per bend arg. and sa. on a bend within a bordure threefleurs-de-lis all counterchanged. Cocket'r, Hampton, Suffolk.

Quarterly arg. with gu. fretty or over all on a bend sa. charged with eight mitres of the third tbree fleurs-de-lis .... Henry Despenser, Bishop of Norwich 1370.1406.

Arg. on a plain beud within a bordure engr. az. a rose betw. iwo griffin's heads erased or. TORRELL.

Arg. on a plain bend sa. within a bordure engr. az. a rose of the first betw. two griftin's heads erased or. CARRELI, Warnham, Sussex, $V$.

Arg. on a plain bend sa. within a bordure engr. az. a rose betw. two griffin's heads erased or Carrell or Carril, Sussex; and Kent.

Arg. on a plain bend sa. within a bordure engr. az. a rose betw. four grifin's heads erased or. Carreli, $V^{*}$.

Az. on a plain bend within a bordure engr. or two gillyflower's gu. WADE, Warwick.

$\mathrm{Az}$. on a bend or within a bordure arg. two pinks slipped ppr. WADE.
On 1 BEND betw, or within.... cont.

Bordure cont.

Az. on a bend or within a bordure engr. arg: two roses gu. stalked with as many leaves to each vert. WAYD $V$.

Arg. on a plain bend within a bordure engr. sa. three 3 -foils of the first. KNEvET, $V$.

Arg. on a bend within a bordure both engr. sa. three 3-foils slipped of the first. KNYvet.

Gu. on a bend within a bordure arg. three 3.foils slipped vert. CoLlege of the Professors of Civil and Canon Law, at Doctors' Commons. Az. on a plain bend or within a bordure engr. ar'g. two 5-foils gu. WARD, Coventry, co. Warwicl. Az. on a plain bend or within a bordure engr. arg. two pierced 5-foils gu. WADE, Coventry, co. Warwick.

Az. on a plain bend or within a bordure engr. .... two 5 -foils gu. Thickness, co. Stafford.

Sa. on a plain bend within a bordure engr. arg. three 5.foils gu. BETTs, Wortham, Suffolk.

Sa. on a plain bend arg. within a bordure engr. or three 5-foils gu. BETtes.

Arg. on a bend within a bordure az. three garbs or. Felton.

Az. on a bend within a bordure gu, three garbs or. Chester or Stroud InN, London.

Arg. on a bend sa. within a bordure gu. three garbs or. HesketH.

Arg. on a plain bend gu. within a bordure engr. sa. three leopard's beads or. Coker, Mawpowder, (co. Dorset) $W$.

Arg. on a bend within a bordure both engr. az. three wolf's heads erased of the first. Lowe, $V$.

Arg. on a plain bend sa. within a bordure engr. of the second bezanty three griffin's heads erased as the first. Younge, Raxwell, and Poxhall, Essex.

Arg. on a plain bend sa. within a bordure engr. of the second charged with eight bezants three griffin's heads erased or a crescent for diff. Younge, Reading.

Gu. on a bend engr. or within a bordure engr. of the second and charged with eight mullets a flute az. Elliot, Scotland.

Gu. on a hend within a bordure both engr. or a shepherd's flute of the first. ELIIOT, Levington, Scotland.

Arg. on a bend sa. within a bordure of the second bezanty three elm leaves or. WALLER, co. Devon.

Az. on a bend or within a bordure gu. bezanty three lures of the first. WADE, $V^{*}$.

Az. on a bend or within a bordure gu. bezanty three lures palewise of the first wings of the third. WADE, London, $V$.

Az. on a bend or within a bordure engr. gu. be. zanty three lures of the first. WADE, $V^{*}$.

Az. on a (? plain) bend within a bordure embattled arg. a mascle gu. in (?) the dexter chief a martlet of the second. Bissetr.

Arg. on a bend az. within a bordure gu. charged with eight bezants a mullet between two crescents of the first. RALPH.

Or on a bend witbin a bordure az. a pierced mul. let betw. two crescents of the first. SCOT, Hnudilshope, Scotland.

Or on a bend az. within a bordure gu. charged with eight bezants a mullet betw. two crescents arg. Scotr, Ardross, Scotland; and Ely.

Or on a plain bend az. Within a bordure engr. gu. charged with eight bezants a mullet betw. two crescents arg. Scotr, Edinburgh. 
On 1 BEND betw, or within.... cont.

Bordure cont.

Or on a bend az. within a bordure gu. charged with eight bezants a.mullet betw. two crescents arg. Scotr, Ardross, Scotland; and Ely.

Or on a bend az. within a bordure engr. gu. charged with eight bezents a mullet betw. two crescents arg. Scotr, Edinburgh.

Or on a bend az. within a bordure gu. a mullet betw. two crescents of the first. Scotr, Gibleston, Scotland; quartering az. three boar's heads couped or each having in the mouth four arrows gu.

Arg. on a bend sa. within a bordure gu. three mullets of the first. SPENCER, Norfolk.

Barry of six arg. and az. on a bend gu. within a bordure or three mullets of the first. OFFORD, $V$.

Barry of eight arg. and az. on a bend gu. within a bordure vert three mullets of the first. OFFORD.

Paly of six arg. and az. on a bend gu. witbin a bordure or three mullets of the first. OxFORD, co. Oxford.

Quarterly or and gu. on a plain bend within a bordure indented sa. three mullets airg. WatviLE, Essex.

Arg. on a bend engr. sa. within a bordure compony or and gu. three bezants. Cotrs.

Arg. on a bend sa. within a bordure gu. three hurts. Bateman.

Arg. on a bend engr. within a bordure gu. three plates. HaywOOD.

Arg. on a bend engr. sa. within a bordure com. pony or and gu. three plates each charged with a martlet of the second. Cotres, Essex.

Arg. on a bend sa. within a bordure gu. three plates. Batedian, $V$.

Gu. on a plain bend within a bordure engr. arg. five ermine spots sa. ROADLEy, Searby, co. Lin colu.

Arg. on a bend engr. az. within a bordure erm. a waggon of the first. Binning, Pilmuir, Scotland.

Al.g. on a bend engr. within a bordure sa. a wag gon or. Binning, Wallifoord, Scotland.

\section{Bougets}

Az. on a bend betw. two water-bougets or three leopard's faces gu. Hunt (Exeter, and Chudleigh), co. Devon; granted 1580, W.

$\mathrm{Az}$. on a bend betw. three water-bougets or as many leopard's faces gu. HuNr.

\section{Buckle}

Barry of three or with chequy az. and arg. on a bend engr. gu. betw. a buckle in chief as the fourth and an escallop in base sa. three buckles of the first. Stewart, Edinburgh.

\section{Buckles}

Arg. on a bend az. betw. three lozenge buckles the tongues in fess (with points to the sinister $V$.$) gn. an annulet in the centre .... BarET,$ Suffolk, $V$. The annulet for diff. Baretr, $V^{*}$. The annulet or. Barrets, Suffolk.

\section{Caltraps}

Arg. on a bend gu. betw. two caltraps sa. three 5 -foils or. Davies, Killenny; granted $23 \mathrm{Fe}$. bruary 1566 .

\section{Castles}

Sa. on a bend or betw. two turrets arg, three pheons gu. JoHnson, Troyzell, Durham.
On 1 BEND betw, or within..... cont.

\section{Canton}

Barry of three or with chequy az. and arg. on a bend gu. betw. On a sinister canton of the fourth a lion pass. guard. as the first pierced with a dart and in base a broken spear surmounted by a helmet all ppr. three buckles gold. Seton-Steuart, Allanton, co. Lanark, Baronetcy 22 May 1815.

\section{Chevrons}

Quarterly arg. and sa. on a bend of the last betw. two (another, four) chev. three eagles displ. or. Holland.

Quarterly az. and arg. on a bend betw. two chev. sa. charged with six mullets three eagles displ. of the second. Howgrton.

\section{Cogs}

Sa. on a bend betw. three cogs of a millwheel or as many elm leaves vert. CogGs, London.

\section{Cotises see Bendlets}

\section{Crescents}

.... on a bend .... betw, two crescents .... an estoile .... Murdiston.

$\mathrm{Az}$. on a bend sa. betw. two crescents gu. three annulets or. IEvan AP RYs.

Arg. on a bend sa. betw. three crescents gu. as many annulets or. Rees GocH, Lord of Marton, Wrales.

Az. on a bend invected arg. betw. three crescents each surmounted by a mullet of eight points or as many chaffinches ppr. CHaffers, Liverpool ; granted ....

\section{Cross}

Az. on a bend betw. in chief a cross croslet and in base a 3-foil slipped or a talbot's head erased sa. a bordure of the second. HeuscH, London.

Gu. on a bend betw. in chief a cross croslet fitchy and in base a fleur-de-lis arg. three spur-rowels of the first. LIDDEL, Edinburgh.

Crosses

.... on a bend .... betw. two crosses croslet fitcby .... an escallop .... enclosed by as many crescents .... Jolun HrLL, Glasgow, Laing, Ancient Seals, p. 95, by misprint LyeL.

Erm. on a bend betw. two crosses sa. three lozenges arg. ARPE.

Or on a bend betw. two crosses patty az. three mascles of the first. Coress, Balmano, Scotland.

Arg. on a bend betw. two crosses formy fitchy gu. three mullets of the first. BRUMSTED. Bumsted, Suffolk.

Arg. on a bend betw. two crosses patty fitchy gu. three pierced mullets of the first. Bumsted, Suffolk, $V$.

Arg. on a bend quarterly az. and gu. betw. three crosses formy of the last as many anuulets of the first. Estgaston.

Sa. on a bend betw. three crosses croslet fitchy arg. a hound of the first. WREkHILI or WRITEL.

Arg. on a bend betw. three crosses formy gu. a lion pass. or. Marsham.

Sa. on a bend erminois betw. three crosses patty fitchy or four crescents gu. Unsworth, Mogul Hall, near Liverpool.

Arg. on a bend betw. three crosses croslet fitclyy gu. an escallop of the first. Cray.

$A z$, on a bend or betw. as many crosses croslet fitchy arg. three roses gu. KENwARD, Yalding, Kent. 
On 1 BEND betw. or within.....cont.

\section{Crosses cont.}

Arg. (aliter or) on a bend gu. betw. three crosses patty fitchy at the foot az. (aliter sa.) as many pierced 5 -foils silver. Nicholas Kentwod, $V$, Cotton MS. Tiberius D, 10.

Arg. on a bend betw. three crosses croslet fitchy sa. as many 5-foils or. Kentwoon, co. Berks.

Erm. on a bend az. betw. three crosses croslet gu. as many 5 . foils or a bordure engr. of the second. Soothwel., granted ....

Or (aliter arg.) on a bend gu. betw. three crosses patty fitchy at the foot az. (aliter sa.) as many pierced 5-foils silver. Nicholas KENTwod, $\vec{V}$, Cotton MS. Tiberius D, 10.

Or on a bend betw. three crosses croslet fitchy sa. as many pierced 5 -foils of the first. Nicholas Kentwood, co. Berks, $W$.

Or on a bend betw. three crosses patty fitchy at the foot sa. as many 5-foils of the first. Kentwood, $V^{*}$.

.... on a bend .... betw. three crosses croslet .... as many mascles .... Coless, Scotland.

Gu. on a bend betw. six crosses croslet arg. an annulet .... Howard, co. Lancaster.

Arg. on a bend betw. six crosses croslet sa. three annulets of the first. WATTON.

$A z$. on a bend betw. six crosses croslet or another bend gu. Ricard de Astone (in a later band Estone), $F$.

Gu. on a bend indented betw. six crosses croslet arg. three eagles displ. sa. Sotheron, co. York; Darrington, and Kirklington, co. Nottingham; the heiress m. Estcourt.

Sa. on a bend arg. betw. six crosses croslet or three eagles displ. gu. Beston.

$\mathrm{Gu}$. on a bend engr. betw. six crosses botonny fitchy or three crescents of the first. HowARD, London ; granted 1756 .

$\mathrm{Gu}$. on a bend betw. six crosses croslet fitcluy arg. an escucheon or charged with a demi-lion ramp. pierced through the mouth with an arrow within a tressure flory counterflory gu. Howard, Baron Howard (in abeyance 1777) and Earl of Surrey; Duke of Norfolk and Earl Marshal 1 February 1514, attainted 1546-7, restored Earl of Surrey and Duke of Norfolk 1553, attainted 1572. Howand, Earl of Arundel, by possession, and by summons 16 January 1580, attainted 1589, restored as Baron Mowbray, Fitz-Alan, Clun, Oswestry, and Maltravers, Earl of Arundel and Surrey 1604, Earl Marshal 1621, Earl of Norfolk 6 June 1614, restored Duke of Norfolk 29 December 1664 (Baron Howard of Castle-Rising $27 \mathrm{M}$ arch 1669 , Earl of Norwich 19 October 1672, extinct 1777), Earl Marshal and Hereditary Marshal 19 October 1672: being the augmentation granted for the victory at Flodden 9 September 1513 to Sir Thomas Howard, Duke of Norfolk and Earl of Surrey, $Z, 358,3 i 2,489$; quartering Brotherton, Mowbray, and Warren, $Z, 496$; but quartering Brotherton, Warren, and Mowbray, $U$. And with the same quarterings but with a label of three poirits or. Sir Thomas Howard, his eldest son, Earl of Surrey, $U$. (? But with an annulet (? mullet) ....) William Howarn, his fifth son, ancestor of HowARD, Baron Howard of Effingham 11 March 1553-4 (Earl of Nottingham 22 October 1596, extinct 26 April 1681; Earl of Effingham 8 December 1731, extinct 11 December 1816); Earl of Effingham July 1838. (? But with a martlet
On 1 BEND betw, or within.... cont.

Crosses cont.

....) Howard, Greystoke, (? But with a crescent ....) Thomas Howard, Viscount Howard of Bindon 13 January 1559 , extinct 1610 . Thomas Howard (Baron Howard de Walden 24 October 1597, in abeyance 1689), Earl of Suffolk 21 July 1603; Baron Howard of Charleton and Viscount Andover 23 January 1621.2, Earl of Berkshire 6 February 1625.6 (Baron Cbesterford and Earl of Bindon 30 December 17(16, extinct 1722) : (And with a rose on the crescent his descendant Howard, Baron Howard of Escrick 12 April 1628, extinct 1715.) Henry Howard, Baron Howard of Marnhull and Earl of Northampton 13 March 1604, extinct 1614 . (? But with a martlet on the crescent.) Howard, Castle Rising, the heiress m. Upton. (? But with a cross moline charged with acrescent.) Howard, Greystoke. (? But with a mullet ....) Edmund HowARD, father of Catherine fifth wife of Henry VIII. William Howard, Naworth, and his descendants, Howard, Baron Dacre, Viscount Howard and Earl of Carlisle 30 April 1661. And with a crescent on the mullet. Howard, Corby Castle, Cumberland. But with a mullet (? annulet) sa. charged with a crescent or. HowARD (descended from Howard of Effingham), quartered by Vyse, Boughton House, co. Northampton.

Arg. (aliter or) on a bend betw. six crosses croslet fitchy sa. three 5 -foils gold. KeNTwOod, co. Berks.

Or on a bend betw. six crosses croslet az. three garbs of the first. Richard BANCROFT, Bisbop of London, 1597; Archbishop of Canterbury ] 604-10. John BANCROFT, Bishop of Oxford 1632.41 .

Arg. on a bend az. betw. six crosses patty gu. an armed dexter index hand of the first enclosed by two mullets or. O'HurLey, Harl. MS. 1039 , fo. 165 .

Sa. on a bend .... betw. six crosses formy .... three buglehorns .... HoRnER, co. Dorset.

Sa. on a bend arg. hetw. six crosses patty fitchy .... three buglehorns of the first stringed or. Horner, $V^{*}$.

Sa. on a bend betw, six crosses patty fitchy arg. three buglehorns of the first stringed or. HORNNER, $V$.

Sa. on a bend betw. six crosses patty fitchy arg. three buglehorns stringed of the first. HORNER.

Arg. on a bend betw. six crosses croslet gu. three lozenges of the first. Buraes, co. Leicester.

Sa. on a bend betw. six crosses croslet arg. a mullet in chief .... LAKE, Edmonton, Middlesex; and London; Baronetcy 17 October 1711. Gu. on a bend arg. betw. six crosses eroslet fitchy or a mullet betw. two 5-foils of the first. Howard, London.

Gu. on a bend betw. six crosses formy fitchy arg. three mullets sa. Ayre, Walton, co. Deron. Eare, Wotton, Norfolk.

Arg. on a bend sa. betw. six crosses croslet gu. three bezants. WaLtoN. WatTon. WhatTon, Osmaston Cottage, co. Derby. Whatton, Loughborough Parks, co. Leicester; quartering Biset, Basset, De Malbanc, De Dunstanville, Fitzhenry, Lovetot, Palmer, Staple. ford, Beler, Ryvers, Heriz, Blount, and Watkinson. 


\section{On 1 BEND betw. or within.... cont.}

Crosses cont.

Arg. on a bend sa. hetw. six crosses croslet fitchy gu. three bezants. Preston, co. Leicester.

Arg. on a bend vert betw. six crosses croslet fitchy gu. three crosiers or. WEAR WEARE or Were, Wear Gifford, Rumington Maror, near Wellington; Poole; and Sampford Arundell, co. Devon; and Hampton Bishop, Giddes Court, and Mannox, co. Hereford.

Az. on a bend or betw. crosses croslet arg. another bend gu. Richard de Estone, $E$.

Az. on a bend betw. crosses croslet or another bend gu. Richard de Stone, E, Harl. MS. 6137.

Sa. on a bend gu. betw. crosses croslet or three eagles displ. of the second. Beston.

$\mathrm{Gu}$. on $\mathrm{\Omega}$ bend erm. betw. crosses croslet arg. three eagles displ. of the first. Brown or Browne, London; and Norwich.

Gu. on a bend betw. crosses croslet or a mascle ermines. Anbentarle or Andemarle, co. Dorset.

Gu. on a bend betw. crosses botonny arg. a mullet 'in the point of the bend'sa. Monsire de Ormesby, $Y$.

Cups

Az. on a bend betw. three covered cups or as many boar's heads erased gu. Carketrue, Scotland.

\section{Escallops}

$\mathrm{Gu}$. on a bend arg. betw. two escallops or a grey. hound courant sa. a bordure engr. of the third. LUTTERFORD, Lutterford, co. Stafford.

Quarterly sa. and gu. on a bend betw. two escal. lops or a greyhound courant enclosed by two 4-foils of the second. PEDDER, Ashton Lodge, co. Lancaster, quartering Wilson.

Az. on a bend betw, two escallops or a crow sa. en. closed by as many 5.foils gu. Petre, Baron Petre, 21 July 1603.

Gu. on a bend or betw. two escallops arg. a Cornish chough ppr. enclosed by as many 5 -foils az. Peter, Harlyn, Cornwall; quartering Michell, Coryton, Ferrars, and Bodulgate. Peter, Bowhay, co. Devon; derived from Peter, Torr Newton, ancestor of the Lords Petres of Writtle; the heiress m. Apsley. Peters, London.

Arg. on a bend sa. betw. two escallops az. enclosed by as many bars gu. three martlets or. Martindale.

Arg. on a bend engr. gu. betw, two escallops az. three mascles or. PEAT, Sevenoaks, Kent.

Gu. on a bend or betw. three escallops sa. ten billets of the second. Conzon, $V^{*}$.

Or on a bend sa. betw. three escallops az. as many garbs of the first a bordure gu. BLersho, Winington, co. Bedford.

Az. on a bend betw. three escallops arg. a (bezant $V^{*}$.) roundle in the dexter chief .... James Platt, Playster, Essex; granted 6 kebruary, $1578, \mathrm{~W}$.

Az. on a bend betw. six escallops arg. a pierced mullet gu. in chief of the bend. M. Rauf Freschevisi, $S$.

Arg. on a bend betw. six escallops sa. a mullet or. WALTON.

\section{Estoiles}

Per bend az. and or on a bend sa. betw. two es toiles of sixteen points counterchanged a lion pass, arg. enclosed by as many crosses moline of the second. HAGArT, Bantascan; granted 1814.

Az. on a bend arg. betw. two estoiles of six points or three rudders sa. Putland, Ireland.
On 1 BEND betw, or within.... cont.

Estoiles cont.

Arg. on a bend betw. three estoiles gu. (sometimes az.) as many crescents of the first a bordure eugr. sa. ARchibaLd, Scotland. Anchibald, Rusland Hall, co. Lancaster; Gresford, North Wales, and Coleraine, co. Londonderry; from Scotland.

$\mathrm{Gu}$. on a bend arg. betw. six estoiles or three ogresses. Shipman, Sarington, co. Nottingham, granted by Dugdale.

\section{Fetterlocks sce Shackles}

\section{Fish}

Erm. on a bend engr. az. betw. in chief a dolplin .... and in base an anchor .... cabled .... three crosses flory or. GRIESDALE, London.

Fishes .... Crabs

Arg. on a bend sa. betw. two crabs of the second a cross croslet of the first. Crosse.

Or on a bend betw. two sea-crabs sa. three crosses croslet of the first. Crosse.

$$
\text { .... Dolphins }
$$

Arg. on a bend betw. two dolphins naiant sa. three eagles displ. of the first. Youngen, Harl. MS. 6829 , fo. 47 .

Arg. on a bend betw. two dolphins haurient embowed sa. three eagles displ. of the first. Younger.

Az. on a bend wavy or hetw. two dolphins em. bowed arg. three escallops gu. FleEt, Kent. FleEte, Iondon ; granted 13 May 1691.

Arg. on a bend betw, two dolphins embowed bendwise gu. three lion's beads erased bendwise or. Franisis, Kent, $T$.

Az. on a bend betw. two dolphins embowed or three lion's heads erased gu. Franisin.

Gu. on a bend betw. two dolphins .... or three lion's heads erased of the first. FrankLyn, Kent.

Arg. on a bend betw. three dolphins sa. as many eagles displ. of the first. Younger, alias Youngrave, co. Hereford; and Daventry, co. Nortbampton.

\section{Fleurs-de-lis}

Arg. on a bend betw, two fleurs-de-lis gu. a lion pass. or. LANY, co. Leicester; London; and Cratfield, Suffolk.

Az. on a bend or betw. two fleurs-de-lis arg. a lion ramp. guard. gu. NowL $\Lambda$ ND, Ireland.

Az. on a bend betw. two fleurs-de-lis or a lion pass. guard. gu. holding in the forepaw a fleurde-lis of the first. NoLAN, London.

Or on a bend betw. two fleurs-de-lis gu. a lion pass. of the first. Benjamin LANEY or LANY, Bishop of Peterborough 1660, Lincoln 1663, Ely 1667-75. LaNy, Newick, co. Leicester; and Ipswich, Suffolk.

Az. on a bend engr. or betw. two fleurs-de-lis arg. an eagle with two heads displ. sa. KaTER, from Lippy, Germany.

Arg. on a bend betw. two fleurs-de.lis sa. three standing cups (with covers ?) of the first. Rigston.

Az. on a bend betw. two fleurs-de-lis or a fleur-delis of the first held in the forepaw of a lion pass. guard. gu. Nolas, London.

Arg. on a bend betw. two fleurs-de-lis sa. three boar's heads couped or. Bestroe or Bestrow.

Arg. on a bend sa. betw. two fleurs-de.lis az. three leopard's heads or. Cockrajr.

Arg. on a bend betw. two fleurs-de-lis sa. three leopard's heads or. DARnel or Darnol, London. 
On 1 BEND betw. or within.... cont.

Fleurs-de-lis cont.

Az. on a bend betw. three fleurs-de-lis or a lion pass. guard. bendwise gu. John Srmngs, London, M.D.; granted 15\%4, $W$. Syminges. SFMIRGEs, $V$ *.

Az. on a bend arg. betw. three fleurs-de-lis or another bend of the last charged with as many escallops of the first. HAMSTED.

Az. on a bend arg. betw. three fleurs-de.lis or as many escallops gu. Hanpsted. Hamsted, $V$.

Az. on a bend or fimbriated arg. betw. three fleursde-lis of the second so many escallops as the first. Hamsted, $V^{*}$.

Erm. on a bend engr. gu. betw. three fleurs-de.lis az. as many escallops or. Gurrex, Isleworth, Middlesex.

Arg. on a bend betw. three fleurs-de-lis sa. as many boar's heads couped or. BASTARD, Aslington, Norfolk.

Arg. on a bend sa. betw. three fleurs-de.lis az. as many leopard's heads of the first. Cokerham, Columbton, co. Devon.

Arg. on a bend betw. three fleurs-de.lis az. as many mullets or a hordure wavy gu. LeEth.

Az. on a bend betw. three fleurs-de-lis or as many pierced mullets gu. LEATHEs, Herringfleet Hall, Suffoll. Leathes, Leathes, and Dalehead, Cumberland.

Erminois on a bend gu. betw. six fleurs-de-lis az. three escallops arg. VEN , Ipswich.

$\mathrm{Gu}$, on a bend arg. betw. six fleurs-de-lis or a rose of the first. Charles Alemant, $V$. Alement. Flower

Arg. on a bend engr. az. betw. in chief a rose and in base an annulet gu. three buckles or. Stirling, Achoyle, Scotland.

Arg. on a bend engr. az. betw. in chief a rose and in base a boar's head cabossed gu. ensigned on the head with a cross ppr. three buckles or. Stralrag, Craigburnet, Scotland.

Arg. on a bend engr. az. betw. in chief a rose gu. and in base a trephine ppr. three buckles or. Stirling, Edinburgh.

Flowers .... Roses

Arg. on a bend engr. az. betw. two roses gu. three buckles or. StrRLing, Deuchray, Scotland; granted 1803; quartering or in fess a broken wall az. masoned sa. in base a rose gu. on a chief engr. of the third three escallops or in the collar point a crescent as the fourth for diff., with arg. a saltire engr. az. a chief of the last charged with three mullets of the first. Strrima, co. Hertford.

Arg. on a bend engr, az. betw. two roses gu. seeded or barbed vert three buckles of the fourth a bordure as the fifth. Stiring, Faskine, co. Lanark, Baronetcy 15 December 1800.

Az. on a bend or betw. two roses arg. three crescents sa. Firenrace, West Indies; descended from Firfarace or Firebrass, Stoke Golding, co. Leicester, 1682; and London.

Arg. on a bend betw. two roses gu. a thistle betw. two fleurs-de-lis or. Rome, descended from Clowdon.

Arg. on a bers gu. betw. three gilliflowers slipped (gu.) ppr. an anchor of the first a tressure flory counterflory vert. LEvingstone (Baronetcy 1027; Viscount Newburgh 13 September 1647, extinct 1694), Baron Levingstone, Viscount Kynnaird and Earl of Newburgh 31 December 1660; the heirs m. Clifford, Radcliffe, Mabony, and Giustiniani.
On 1 BEND bẹtw, or within.....cont.

Flowers cont. Roses cont.

Arg. on a bend sa. betw. three roses gu. as many birds volant of the first. RINGWORTH.

Arg. on a bend sa. betw. five roses gu. three mullets or. WerLs.

Arg, on a bend az. betw. two sprigs vert each of three roses gu. a crescent enclosed by a pair of mullets as the first. MIRrIE.

Arg. on a bend sa. betw. six roses gu. three pierced mullets or. Welles. WELles or Wyiles, $V$. Wyidis, $V^{*}$.

Arg. on a bend wavy betw. six roses gu. three plates. Warrender, Lochend, East Lothian, Baronetcy 2 June 1715.

\section{3-Foils}

Or on a bend engr. az. betw. two 3-foils slipped .... three martlets .... Pelly, Upton, Essex, Baronetcy 6 July 1840.

Arg. on a bend betw. two 3.foils sa. three lozenges of the first. Clarkesons.

Arg. on a bend betw. two 3-foils slipped sa. three mascles or. LAwson or LEwSON.

Arg. on a bend betw. three 3-foils slipped gu. as many annulets of the first. LABORNe.

Arg. on a bend .... betw. three 3-foils slipped $\ldots$. as many cups of the first. THornton, co. York.

\section{4-Foils}

Gu. on a bend erm. betw. two 4-foils or three mullets of six points az. Axsscer, Little Harle Tower, Northumberland ; quartering Murray.

5-Foil

Gu. on a bend arg. betw. in chief a 5-foil of the second and in base a hawk's leg jessed and belled or a hawk's lure as the first. SAUCHY, That Ilk.

\section{5-Foils}

Arg. on a bend engr. az. betw. two 5 -foils gu. three buckles or a bordure vert. Stiring, Drumpellier, Scotland.

Sa. on a bend betw. two 5 -foils or three bear's heads erased of the first muzziled arg. a cres. cent for diff. Brightridge, co. Oxford.

Sa. on a bend arg. betw. two 5-foils .... three boar's heads erased of the first. Britraidge, Harrow-on-the Hill, Middlesex; and Sutton Hall, Essex.

Sa. on a bend or betw. two 5-foils arg. three boar's heads erased of the first muzzled of the second. BrIghtBRidge, co. Buckingham.

Gu. on a bend engr. betw. two 5-foils arg. three leopard's faces vert. ALDERSEy, London; and Kent.

Gu. on a bend engr. arg. betw. two 5-foils or three leopard's faces vert. ALDERSEY, Aldersey, and Spurstow, co. Chester.

Gu. on a bend betw. two 5-foils or three leopard's faces az. Alderser, co. Chester.

Sa. on a bend engr. betw. six 5-foils or an annulet of the first. Pover, London; granted November 1614.

\section{Frets}

Quarterly arg. and gu. on a bend sa. betw. two frets or three escallops arg. SPEncer, Yarnton, co. Oxford; Baronetcy 29 June 1611; extinct 1771. Spencer, Baron Spencer und Viscount Spencer 3 April 1761, Viscount Althorp and Earl Spencer 1 November 1765. SPEncer, Baron Churchill, 11 August 1815. And with a bordure az. charged with enght mitres gold. Henry Despenser, Bishop of Norwich 1370 . 1406. Spencer, Duke of Marlborough till 1807. 
On 1 BEND betw. or within.... cont.

Frets cont.

Quarterly arg. and gu. on a bend az. betw. two frets or three fleurs-de-lis of the first. Lituington, London.

Quarterly arg, and gu. on a bend sa. betw. two frets or tbree fleurs-de-lis of the first. Spencer, Oftley, and St. Alban's, co. Hertford. And with a bordure az. charged with eight mitres silver. Henry Despenser, Bishop of Norwich 1370 . 1406, Harl. MS. 12443, fo. 101.

Quarterly or (? arg.) and gu. on a bend sa. betw. two frets or three fleurs-de-lis arg. Spencer, London; and co. Bedford.

Quarterly arg. and gu. on a bend sa. betw. two frets or three mullets of the first. ELFord.

Quarterly arg. and gu. on a bend sa. betw. two frets or five mullets of the first a bordure counterchanged as the second and the field. Spencer, Bradfield, Norfolk; and Suffolk. Spencer, Worsted, Norfolk.

Az. on a bend betw. three frets or as many bugle. horns of the first. NEwPORT.

\section{Fruits.... Acorns}

Arg. on a bend betw, two acorns slipped gu. an anchor in chief of the first a dooble tressure counterflory vert. RADcliffe, as Baron Levingstone, Viscount Kinnaird and Earl of New. burgh, $1755 \cdot 1814$.

Arg. on a bend engr. sa. betw. two acorns slipped vert three fleurs-de-lis or. WARD, Walcot, and Salhouse, Norfolk, 1639 .

Fusils

$\mathrm{Gu}$. on a bend engr. betw. six fusils or three escucheons az. Leitch, Scotland.

\section{Garbs}

Vert on a bend betw. two garbs or a swan sa. enclosed by as many hurts. George Scholer, Lord Mayor of London 1812-13. Scholey, Gorber Hall, Barnsley, co. York.

Gu. on a bend betw. two garbs or three crosses croslet fitchy sa. William Roo, Mercer, Lon. don, $V$.

Vert on a bend betw. two garbs or three vine leaves of the first. Feaulitead,Clapham,Surrey.

Erm. on a bend az. betw. two garbs or a mullet arg. MuddFond.

Gu. on a bend betw. three garbs or as many crosses patty fitchy of the first. Rowe, Alport, co. Derby. Rowe, in Youlgrave Church, 1613.

\section{Head .... Beast}

Arg. on a bend gu. betw. in chief a lion's head cabossed and in base an eagle's leg conped at the thigh holding a torteau three arrows ppr. PAYNE.

\section{....Human Figure}

Arg. on a bend az. betw. in chief a Moor's head in profile couped sa. wreathed about the temples or and in base a garb of the secoud three arming buckles gold. Stiri.ing, Uppal, Edinburgh, Baronetcy $19 \mathrm{July} 1792$, extinct ... But with the bend engr. Strrurng, Old Montrose, Scotland.

\section{.....Monster}

Az. on a bend erm. betw. in chief a unicorn's head erased and in base a lion ramp. erminois an open book ppr. enclosed by two roses gu. barbed and seeded vert. FARDELL, co. Lincoln.

Arg. on a bend betw. in chief a unicorn's head erased and in base a cross croslet fitchy sa. three bezants. DENISON; quartering Beckett, diff. by an annulet.

\section{On I BEND betw. or within.... cont.}

Heads ..... (Beasts) Deer

Arg. on a bend gu. betw. two stag's heads cabossed sa. a greyhound courant of the first. Bighton, co. Derby.

Sa. on a bend betw. two stag's heads cabossed arg. a greybound courant of the first. BEIGHTON, Wirksworth, co. Derby.

Sa. on a bend or betw. two stag's heads cabossed arg. armed of the second three martlets of the fir'st. Kinnear.

Arg. on a bend engr. az. betw, tro buck's heads cabossed sa. an escallop or. Nedhanr, Wymondesley, co. Hertford; confirmed 18 February 1586.

Arg. on a bend vert betw. two buck's heads cabossed sa. three roses of the first. MAY, co. Wilts.

Gu. on a bend engr. arg. betw. two stag's heads erased erminois three 3-foils slipped vert. Jones, Sugwas Court, co. Hereford.

$$
\text { .... Dog }
$$

Or on a bend gu. betw. two talbot's heads erased sa. three fleurs-de-lis arg. Ashman, Lymmington, co. Wilts.

Quarterly arg. and az. on a bend gu. betw. two talbot's heads erased three 4-foils of the first. Chittinge, Suffolk.

Quarterly per pale indented gu. and az. on a bend betw. two greyhound's heads erased or collared of the first three escallops sa. Sмттн or Sarthe, Suffolk.

$$
\text { ..... Elephant }
$$

Gu. on a bend arg. betw. two elephant's heads erased or three ogresses. QueLcR, Wallingford, co. Berks.

\section{..... Horse}

Gu. on a bend engr. or betw. two nag's heads erased arg. three fleurs-de-lis of the first a mullet in chief .... for diff. Henry Perys, Bishop of Sodor, etc., 1840, Worcester 1841.

Sa. on a bend betw. two nag's heads erased arg. three fleurs-de-lis az. Pepys, co. Cambridge, 1716.

Sa. on a bend or betw. two nag's heads erased arg. three fleurs-de-lis of the first. LESLIE, Juniper Hill, Surrey, Bart. Perys, London; and Ridley Hall, co. Chester, Baronetcy 23 1801, Baron Cottenham 1836, Viscount Crow. hurst and Earl of Cottenbam 11 June 1850. Peprs, Ashop, Éssex ; and Southcreak, Norfolk. Pepys or Pipis, Cottenliam, co. Canıbridge; and Brampton, co. Huntingdon. PlPE, Cotten. ham, co. Cambridge.

$$
\text { .... Leopard }
$$

Az. on a bend arg. betw. two leopard's faces or a mural crown gu. enclosed by as many fleurs-delis sa. Bromhead, Thurlby Hall, co. Lincoln, Baronetcy 31 October 1757.

$$
\text { ....Lion }
$$

Erm. on a bend betw. two lion's heads erased gu. three chev. or. Brewley.

Arg. on a bend gu. betw. two lion's heads erased sa. three crosses croslet of the first. HADDERLEY, Essex.

Arg. on a bend gu. betw. two lion's heads erased sa. three crosses patty of the first. ADDERLEx, co. Stafford. HADERLEY, $V$.

Arg. on a bend gu. betw. two lion's heads erased sa. three crosses croslet or. ARDERLEY, $V^{*}$. Atherley, $V$. Haderly or Hadderley. Sr. John Hardderly .Alderman of London, $V$. HaRderLy, $V *$. 
On 1 BEND betw. or within.... cont.

Heads cont. (Beasts) Lion cont.

Arg. on a bend betw. two lion's heads erased sa. three crosses formy or. ATHERLEY.

Arg. on a bend betw. two lion's heads erased sa. three crosses croslet or. HARDELEY.

Per fess gu. and az. on a bend engr. betw. two lion's heads erased arg. as many crosses croslet fitchy or a 5-foil pierced of the second for diff. GRILES.

Sa. on a bend betw. two lion's heads erased arg. three escallops .... SHLELD, Northumberland.

Arg. on a bend betw. two lion's heads erased gu. a dolphin of the first. FrankIIN, Ireland.

Arg. on a bend betw. two lion's heads erased gu. a dolphin embowed of the first enclosed by as many birds close or collared az. FrankLin, $V *$.

Arg. on a bend betw. two lion's heads erased gu. a dolphin embowed enclosed by as many mart. lets or. Frankin.

Arg. on a bend engr. betw. two lion's heads erased gu. a dolphin naiant betw. as many birỏs or. FrankLYN.

Arg. on a bend betw. two lion's heads erased gu. a dolphin embowed bendwise or betw. as many birds close of the last collared az. Oliver Franklin, co. Devon, ob. s. p., buried at Ware, $V$.

Az. on a bend engr. betw. two lion's heads erased or three 5.foils gu. GeLL.

Per fess gu. and az. on a bend arg. betw. two lion's beads erased and three crosses croslet fitchy one and two or as many 5 -foils of the first. Giles or Ginle. GLLLES, Norfolk, $V$.

$\mathrm{Gu}$. on a bend compony arg. and az. betw. a pair of lion's beads erased as the second three lco. pard's faces or a bordure like the bend. Ferby. GUNTHORPE.

Gu. on a bend compony arg. and az. betw. two lion's heads erased as the second three leopard's faces or a bordure compony or and of the third. Feneby.

\section{....Wolf}

Or on a bend az. betw. two wolf's heads couped at the neck ppr. three buckles of the first. Lashley, Scotland.

Az. on a bend engr. or betw. two wolf's beads arg. three crosses croslet gu. Cowper, Overleigh, co. Chester; granted 1642.

Or on a bend betw. two wolf's heads erased sa. three dolphins of the first. OsBonNe, co. Derby.

\section{..... (INonster) Dragon}

Arg. on a bend betw. two dragon's heads couped gu. three doves of the first. Cosens.

$$
\text { .....Griffin }
$$

Arg. on a bend engr. az. betw. two griffin's heads erased gu. an annulet enclosed by as many crescents or. Kay, East Sheen, Surrey, Baro. netcy 5 December 1803.

\section{.... Unicorn}

Arg. on a bend gnl. betw. two unicorn's beads erased az. armed maned and crined or three crosses croslet of the last. Sirth, Stoclitonupon-Trent; granted....

Arg. on a bend engr. az. betw. two unicorn's heads erased gu. three fleurs-de-lis or. SirtH, co. York; and Dunston, co. Derby.

Arg. on a bend betw. two unicotn's heads erased az. three fusils of the first. BeverLey, co. York.
On 1 BEND betw. or within.... cont.

Heads cont. (Monsters) Unicorn cont.

Arg. on a bend az. betw. two unicorn's heads erased of the second armed and maned or three lozenges erminois. Smrth, co. Durham, 1615. Smrth, West Harrington, co. Durham.

Arg. on a bend betw. two unicorn's heads couped az. three lozenges or. SMYTH, Ballynatray, co. Waterford; quartering Grice, Rogers, and Mitchell. SмгтH, Gaybrook, co. Westmeath, originally from Yorkshire. SнттH, Heath Hall, co. York; derived from Smyth of Myreshaw, Bradford, 1594. Siryth, Drumcree, co. West. meath; quartering King. Sмгтн or Sмyтне, Gaybrook and Barbavilla, co. Westmeath; derived through William Sмхтн, Bishop of Kilmore, like Edward इігтн, Bishop of Down 1699 ; and Thomas SMYTH, Bishop of Limerick 1696 ; from Siyte, Dundrum, co. Down, and Rossdale Abbey, co. York.

Arg. on a bend betw. two unicorn's heads erased az. three lozenges bendwise or. BeverLey, co. Chester, $\boldsymbol{V}$.

Arg. on a bend az. betw. two unicorn's heads erased of the second armed or three lozenges of the last. Cusac-Smith, Newtown, King's County, Baronetcy 28 August 1799, quartering Cusac.

Arg. on a bend betw. two unicorn's heads couped gu. three lozenges of the first. Snitn, Dringhouses, co. York.

Arg. on a bend az. betw. two unicorn's heads erased sa, three mascles or. Sџгттн, Beverley, co. York; granted 18 March 1576.

$$
\text { ..... (Beasts) Deer }
$$

Az. on a bend betw. three hart's heads erased arg. attired or as many crosses croslet fitchy of the second. Mar and Garioch of Caskieben, composed in one coat, as quartered by Johnston.

Az. on a bend engr. arg. betw. three roebuck's beads couped or collared gu. a torteau enclosed by two mascles sa. pierced of the third. Gason, Kent.

$$
\text { .....Boar }
$$

Vert on a bend betw. three boar's heads arg. as many mascle-shaped buckles az. tongues gu. Peters, Scotland.

Arg. on a bend betw. three boar's heads erased az. a man's heart ppr. within a fetterlock or. LockHart, Birkhill, Scotland.

Or on a bend $a z$. betw. three boar's beads erased sa. as many mascles of the first. Halyburton, Pitcur, co. Forfar.

$$
\text { ..... Leopard }
$$

Az. on a bend arg. betw. three leopárd's heads couped gu. two lions pass. or. Steavenson, Fortiose, Scotland. Steavenson or Stevenson, Newcastle-on-Tyne; descended from Stanton and Elton, in the Peak of Derby ; granted 14 June 1688.

Arg. on a bend engr. betw. three leopard's heads az. jessant-de-lis or a martlet of the first. DENNis, co. Gloncester.

$\mathrm{Az}$. on a bend betw. three leopard's faces or as many martlets gu. Motre.

Az. on a bend betw. three leopard's faces one and two or as many martlets gu. Sr. John NorT, Alderman of London, $V$; (the heads two and one) Lord Mayor 1363, Harl. MS. 1349. Notte, in Thames Ditton Church. Notr, Kent; and London: granted 1587.

Arg. on a bend betw. three leopard's heads gn. as many dexter hands clenched of the first. Walier, $V^{*}$. Walter, temp. Edward IV, $V$. 
On 1 BEND betw, or within.... cont.

Heads cont. (Beasts) Leopard cont.

Or on a bend betw. three leopard's heads gu. as many dexter hands clenched arg. WaTUn, $V$. ....Lion

Arg. on a bend gu. betw. thrce lion's heads erased sa. as many crosses patty of the first. Sir John Hatberley, Lord Mayor of London 1442, Harl. MS. 1349.

Per fess gu. and or on a bend engr. arg. betw. three lion's heads erased two and one .... and crosses croslets one and two .... so many 5 -foils of the first. Gmies, $V^{*}$.

Arg. on a bend engr. betw. three lion's heads erased gu. a dolphin enclosed by two birds or. Franklyn, co. York.

Arg. on a bend betw. three lion's heads erased gu. two dolphins or. FrankLYN.

$$
\text { .... (Birds) Hawk }
$$

Or on a bend az. betw. as many hawk's heads erased sa. three 5-foils of the first. Honners.

$$
\text { .... (Monsters) Dragon }
$$

Arg. on a bend sa. betw. three dragon's heads erased gu, as many popinjays of the first. Curzon.

$$
\text { .... Griffin }
$$

Arg. on a bend sa. betw. three griffin's heads erased gu. as many martlets of the first. Curson.

\section{.... Wivern}

Arg. on a bend sa. betw. three wivern's heads erased gu. as many martlets of the first. Curson.

Arg. on a bend sa. betw. three wivern's heads couped gu. langued az. so many popinjays of the first collared and membered as the third. Curson.

\section{..... (Beasts) Lion}

Arg. on a bend sa. betw. four lion's heads erased gu. three estoiles or. Piliesden, $V$. Pitesdon, Wales.

\section{....Boar}

Or on a bend betw. six boar's heads az a demilion betw. two fleurs-de-lis of the first. BENNET, co. Leicester.

$$
\text { ..... Leopard }
$$

Az. on a (bend $V^{*}$.) bendlet betw. six leopard's faces or three water bougets sa. Hunt, Stoke Danby, co. Rutland, $W$. Hunte, $V$.

Az. on a bend betw. six leopard's heads or as many water bougets sa. HunT, $V^{*}$.

Az. on a bend betw. sis leopard's heads or a mullet .... Hunt.

Gu. on a bend betw. six lion's beads erased arg. three mullets az. Sculd.

Gu. on a bend arg. betw. six lion's heads erased or as many mullets sa. SruLL.

\section{Horns}

Or on a bend az. betw. two buglehorns stringed sa. a buckle enclosed by two estoiles of the first. Burn, London; granted ....

Gu. on a bend engr. betw. two buglehorns arg. three ogresses. Repington, co. Warwick.

Gu. on a bend engr. or betw. two hunting-horns stringed arg. three ogresses. Repington.

Quarterly vert and arg. on a bend engr. or betw. two buglehorns .... stringed .... three an. nulets .... Lonsdale, co. York. John LONSDALE, Bishop of Lichfield 1843; quarter. ing az. a bend wavy betw. three estoiles arg., with lozengy arg. and gu., and gu. six martlets in pile arg.
On 1 BEND betw, or within.... cont

Horns cont.

$\mathrm{Gu}$. on a bend engr. or betw. three buglehorns arg. as many ogresses. RYMrringden, $V^{*}$.

Gu. on a bend engr. or betw. three stringed buglehorns arg. as many ogresses. John Rydipingden, $\boldsymbol{V}$. Rimpingdon.

Ink-molines

Arg. on a bend engr. betw. two inkmolines in bend sa. three fleurs-de-lis of the first. HoLt, Bishham Hall, Billinge Higher End, co. Lancaster; granted ....

\section{Leaves}

Arg. on a bend az. betw. two holly-leaves vert three buckles or. LesLy, Wardis, Scotland.

Letter

.... on a bend betw. a Roman letter $W$.... and an annulet .... three hearts .... Walter de Wele, ob. 1388, Great Grimsby Church, Harl. MIS. 6829 , fo. 3 .

\section{Lozenges}

Az. on a bend or betw. six lozenges of the second each charged with an escallop sa. four escallops of the last. PaULIN.

$\mathrm{Az}$. on a bend or betw. six lozenges of the second each charged with an escallop sa. five escallops of the last. Sr. Raufe Pulleyn, Scotton, co. York, $V$. Pullen or Pulleyn, co. York.

Arg. on a bend betw. sis lozenges sa. three 5-foils or. Gargrave.

\section{Mascles}

Sa. on a bend arg. betw. six mascles or three cushions of the last. St. Michaes, Blackwater, Scotland.

\section{Mionsters..... Sea-Lions}

Or on a bend betw. two sea-lions erect on their tails az. three stag's heads cabossed of the first. HaRLand.

Or on a bend wavy betw. two sea-lions ramp az. three buck's heads cabossed or. HERLAND.

Or on a bend wavy betw. two sea-lions sa. three buck's heads cabossed arg. HARLAND, Sproughton, Suffolk, Baronetcy 13 March 1771 .

\section{Mullets}

Arg. on a bend nebuly betw. two mullets of six points sa. three lions pass. of the first. Bnown, Woodplumpton, St. Michael, co. Lancaster.

Arg. on a bend az. betw. two mullets gu. three buckles or. Lesty, Pitcaple, Scotland.

Arg. on a bend az. betw. two mullets of the second a crescent of the first. ARCHIBALD, Blackhall.

Arg. on a bend engr. az. betw. two pierced mullets sa. three crescents or. WAREING or WARINGE, Walmesley, co. Lancaster.

Arg. on a bend betw, two mullets gu. three crescents of the first. Carketrle, Scotland.

$A z$. on a bend betw. two nullets or three escallops enclosed by a pair of cotises gu. Benedictine Abbey at LitTLE WALDEN or SAFFroN WaLden, Essex, Hart. MS. 1042, fo. 32 .

Az. on a bend betw. in chief two mullets and in base a mascle arg. three 3 -foils slipped vert. HARVEY.

Quarterly arg. and az. on a bend barry of six as the second and gu. betw. two pierced six-pointed muilets three 5.foils or. KING, Staunton Park, co. Hereford.

Arg. on a bend betw. two mullets sa. three 5.foils or a bordure gu. bezanty. John Cocrser, Evesham, $V$, co. Worcester, $W$. 
On 1 BEND betw. or within..... cont.

Mullets cont.

Or on a bend engr. betw. two pierced mullets of six points az. three mascles as the first. Sterndale, Ottar, Hindostan ; granted ....

Or on a bend az. betw. two pierced mullets gu. three crescents of the first. Scot, Spencerfield, Scotland.

Gu. on a bend betw. two mullets arg. gouttes az. Bishopric of BANGor.

$\mathrm{Gu}$. on a bend betw. two pierced mullets arg. gouttes-de-larmes. Bishopric of Banaor, Cole MS. xxx.

Gu. on a bend betw. two pierced mullets arg. gouttes-de-poix. Bishopric of Bangor, $U$. Skevington, $V$.

Gu. on a bend or betw. two pierced mullets arg. gouttes de poix. Bishopric of Bangor.

Arg. on a bend az. betw. three mullets sa. as many 5-foils or a bordure gu. bezanty. Cookesey, Little Wolverton, and Engham, co. Worcester.

Arg. on a bend betw. six mullets gu. a cross patty of the first. HoLDernes. Liegard, co. Leicester; and co. York. The mullets pierced. LEGARD, Anlaby co. York.

Arg. on a bend betw. six mullets gu. a cross patty or. LEguARD.

Az. on a bend arg. betw. six mullets or frets gu. Breton. Richard Bretton, $V$.

Az. on a bend arg. betw. six mullets of as many points or frets gu. Breton.

$\mathrm{Az}$. on a bend betw. six mullets or a bear's gamb couped at the knee sa. Bretoron.

Nails

Vert on a bend arg. betw. six passion-nails or three crescents gu. Tyuer, Monmouth.

\section{Pheons}

Sa. on a bend betw. two pheons arg. three buckles of the first. StuBbs, Stanford, co. Lincoln. Stubss, Water-eaton, and Bloxwich, co. Stafford; the heirs m. Rann, Slany, Brearley, and Wightwick.

Sa. on a bend or betw. two pheons arg. three buckles of the first. Sturbs, Durbam.

Sa. on a bend or betw. three pheons arg. as many round buckles gu. StubBs, London.

Sa. on a bend or betw. three pheons arg. as many fermaulx gu. StubBe, Norfolk, 1716. Stubs, Archdeacon of St. Alban's.

Sa. on a bend betw. three pheons arg. as many round buckles of the first. STUBBE, Laxfield, Suffolk.

Sa. on a bend betw. three pheons or as many buckles gu. StuBBs, co. Hertford.

\section{Roundles}

Sa. on a bend arg. betw. two roundles erm. three pierced 5-foils gu. Conway, Callis.

$$
\text { .....Bezants }
$$

Sa. on a bend .... betw. two bezants three mart. lets of the first. JaMEs, co. Worcester.

$\mathrm{Sa}$ on a bend or betw. two bezants three martlets of the first. ADAMr, $V^{*}$. ADAMs, London, 1639.

$\mathrm{Gu}$. on a bend or betw. two bezants three lion's heads erased ppr. Grant-Francrs, Cae Bailey, Swansea; quartering Atwell and Grant.

$$
\text { ..... Ogresses }
$$

Arg. on a bend gu. betw. two ogresses as many swans ppr. Clarke, Northumberland; descended from Clerke, Launde Abbey.

$$
\text { .....Plates }
$$

Gu. on a bend ern. betw. two plates three 3-foils arg. Blackshaw.
On 1 BEND betw. or within.... cont.

Roundles cont. Plates cont.

Gu. on a bend erm. betw. two plates three 3 -foils slipped vert. BLacishane.

Sa. on a bend arg. betw. two plates three pierced 5-foils gu. Conwax, Callis.

$$
\text { .... Pomeis }
$$

Arg. on a bend .... betw. two pomeis three mullets or. Welman, Poundsford Park, co. Somerset; derived from Welman, Taunton, i650; quartering arg. three torteaux a chief gu. a label of three points az.

\section{.....Torteaux}

Or on a bend sa. betw. two torteaux three garbs of the first. HesкeтH, Gwyrch Castle, co. Denbigh; quartering Bamford and Lloyd.

$$
\text { ....0gresses }
$$

Arg. on a bend gu. betw. three ogresses as many swans ppr. Clarke, London. Clarke, co. Northampton. ClaRk, Bridwell, Halberton, co. Devon.

Arg. on a bend sa. betw. three ogresses as many swans of the first. Clark, quartered by Robinson.

$$
\text { ....Torteaux }
$$

Arg. on a bend gu. betw. three torteaux as many swans arg. Clarke, Welton Place, co. Northampton. Clarke, Duke's Bridge House, Bungay Boyscott, Suffolk.

$$
\text { .....Bezants }
$$

$\mathrm{Gu}$. on a bend arg. betw. six bezants three fleurs. de-lis az. BusBy.

$$
\text { .... Fountains }
$$

Sa. on a bend engr. or betw. six fountains a mullet for diff. gu. Stunton, co. Leicester.

\section{Rowel}

Gu. on a bend betw, in chief a rowel and in base an annulet arg. three crescents az. NApien, Glasgow.

\section{Rowels}

Or on a bend az. betw. two spur-rowels gu. three crescents of the first. Scot, Spencerfield, Scotland.

\section{Shackles}

Sa. on a bend or betw. two shacklebolts arg. three pheons gu. Jomnson, Twyzell, co. Durham; a coheir m. Brockboles and Jones.

Arg. on a bend gu. betw. three fetterlocks az. a shepherd's flute or. ElLiot, Leith, Scotlend.

\section{Trees}

Arg. on a bend az. betw. three oak-branches slipped vert acorned ppr. as many buckles or. LEsLy, Oustons, Scotland.

Quarterly erm. and az. on a bend gu. betw. two vine-branches and bunches of grapes ppr. three stag's heads cabossed arg. IGGULDEN,Deal, Kent. Arg. on a bend engr. gu. betw. two hop-vines with poles ppr. growing out of mounts vert three stag's heads cabossed or. Boorman, East Peckham, Kent.

\section{Tressure}

Arg. on a bend az. within a double tressure flory counterflory gu. three buckles or. LESLY, That Ilk.

Or on a bend within a double tressure flory counterflory az. a pierced mullet betw. two crescents of the first. Scot, Thirlestane. Wings

Per bend arg. and or on a bend engr. sa. betw. two sinister wings elevated gu. another bend plain counterchanged of the field charged with three garlands of red roses leaved vert. SAxToN, Circourt, co. Berlss; Baronetcy 1794. 
On 1 BEND betw, or within....

and in chief..... cont.

\section{Beast}

Barry of three arg. with chequy of the first and az. on $\mathbf{s}$ bend engr. counterengrailed as the last betw. a Moor's head couped in profile ppr. and a garb like the bend three oval bucliles points upwards bendwise or in chief a lion ramp. gu. Sririso, Upral, and Mansfield, co. Ayr; Baronetcy $19 \mathrm{July} 1792$.

\section{Canton}

Arg. on a bend engr, vert betw. two stag's heads cabossed sa. atured or three bezants a canton erminois. NEEDs, co. Devon, quartered by Grazebrook.

on a Canton.... (Beast) Lion

Arg. on a bend gu. betw. three ogresses as many swans of the first for an augmentation a sinister canton gu. charged with a lion pass. guard. or betw. two flasks erm. Clanke, Ireland; descended from Clarke, co. Warwick; granted 25 April 1667.

$$
\text { .... Sheep }
$$

Arg. on a bend gu. betw. three ogresses as many swans of the first a sinister canton az. charged witl a demi-ram salient arg. and two flenrs-delis in chief or being the arms of Lonis d'Orleans, Duc de Longueville, taken prisoner at Borny, near Terouenne, 14 August, 5 Henry VIII (see Baronetage). Sr. John Clarke, $V$. But with a dexter bendlet (or baston) silver over the canton. Clarke. $V^{*}$. But the baston gold. Cleree, Hitcham, co. Buckingham; Baronetcy $13 \mathrm{July} 1660$. But with the canton az. charged with a demi-ram mounting arg. armed or betw. two fleurs-de-lis of the last and a baston gu. Clarke, co. Oxford. But with the demi-ram mounting arg. armed or hetw. two fleurs-de lis in chief of the last and the baston silver. Clarke, Enfield; a coheir m. Meymott.

$$
\text { ..... Crescent }
$$

Arg. on a bend az. within a bordure engr. gu. three stag's heads cabossed or a sinister canton of the last charged with a crescent .... STANLEY.

$$
\text { .... Cross }
$$

$\mathrm{Sa}$, on a bend betw. three leopard's faces or as many elm-leaves vert a canton arg. charged with a cross moline gu. ETTON.

Sa. on a bend betw. three leopard's heads or as many oak-leaves vert a canton arg. charged with a cross formy gu. FreEKBY or Freshby.

Sa. on a bend betw. three leopard's heads or as many (woodbine?) leaves vert a canton arg. charged with a cross patty gu. ETron, Fresby, $V$.

\section{....Fess}

Arg. on a bend betw. six martlets gu. three bezants a canton or charged with a fess chequy az. and of the first within a double tressure flory counterflory gu. WorTLEY, quartered by Mackenzie, Baron Wharncliffe.

$$
\text { .... Flower }
$$

Erminois on a bend az. betw. two cotises sa. three martlets arg. a canton or charged with a rose gu. Wruss, Frocester, co. Gloucester; granted 1759.

Or on a bend letw. two cotises and as many garbs az. a mitre of the first a canton gu. charged with a rose arg. TILson, quartered by Chowne.

Arg. on a bend betw. two cannons sa. three eagles displ. of the first a canton or charged with a rose gu. Younges.
On I BEND betw. or within....

and in chief.... cont.

on a Canton cont. Garb

.... on a bend betw. two cotises .... three escal. lops .... a canton .... charged with a garb .... KING, Tilney All Saints'Chureh, Norfolls. .... Sword

Arg. on a bend betw. two cotises and as many unicorn's heads erased az. three lozenges or a canton gu. charged with a sword ppr. pomel and bilt gold, the blade encircled by an eastern crown of the last. Snritu.

\section{Chief}

Arg. on a bend betw. two birds gu. five gouttes of the first a chief chequy sa. and or. Thomas Plaidell, Colsbull, co. Berks, 21 Henry VII, $V$. Pleydeis, $V *$.

Arg. on a bend gu. betw. two Cornish choughs (aliter martlets aliter plovers gu.) ppr. (six) gouttes d'eau a chief chequy sa. and or. Pleydell, Amnes-Crucis, co. Gloncester; and Westcot and Isley, co. Berks; the heiress $m$. Dawney; descended (like Pleydell, Midghill, quartering Morton) from Pleydell, Colshull, co. Berks, ancestor of PLEYdelt, Shrivenhar, co. Berks; Crickdale, co. Wilts ; and Coleshill, quartering Pratt, Baronetcy I5 June 1732, extinct 14 October 1768 ; the heiress $\mathrm{m}$. Beuverie.

Arg. on a bend gu. betw. two martlets sa. gouttes d'eau a chief countercompony sa. and or. Plaudeli, Norfolk.

Gu. on a bend or betw. six plates three torteaux a chief erm. Drxon, Ramshaw, co. Durham; confirmed 14 September 1615.

Gu. on a bend or betw. six plates three torteaux a chief erminois. Duxon, Rainsham, co. Durham.

on a Chief.... Arrow

Quarterly erm. and or on a bend az. betw. two palm.trees ppr. each rising from a mount vert three mullets of the second a chief gu. charged with an arrow barbed and flighted.ppr. beld in the dexter paw of a griffin pass. gold. Connfoor, Ryde, Isle of Wight; and Petersham, Surrey.

\section{....Arrows}

Arg. on a bend betw. two cotises sa. three 5.foils or a chief gu. charged with as many arrows points downward ppr. Littrehales, Ranston, co. Dorset; and Ashcornbe, Sussex.

$$
\text { ..... (Beast) Hors } \theta
$$

Arg. on a bend betw. two birds az. three garbs or a chief quarterly sa. with gu. goutty or charged with over all a horse courant arg. bridled gold. John WAsteL, prior of Dunstable; and his brother 'Thomas WASTELL, $V$.

Arg. on a bend az. betw. two doves of the second collared as the first three garbs or a chief quarterly sa. with gu. goutty or charged with over all a horse at full speed arg. bridled purp. bezanty. WASTELL, co. Northampton; and Wastell Head, Westmorelınd. Wastell, Newborough, Northumberland, quartering Bacon; descended from WASTEL, Scorton, co. York, 1659. Arg. on a bend gu. betw. ttwo fulcons ppr. three garbs or a chief quarterly sa. with gu. goutty or charged with over all a borse courant arg. Westell, Pinkney Green, Maidenbead.

$$
\text { .... Lion }
$$

Sa. on a bend betw. two pair of manacles arg. three plueons bendwise in bend gu. a chief or charged with a demi.lion ramp. issuant enclosed by a pair of lozenges az. Thomas JoHsson, Lothelay, co. York, $Y$. 
On 1 BEND betw. or within....

and in chief.....cont.

on a Chief cont. (Beast) Lion cont.

Sa. on a bend betw. two turrets arg. three pheors gu. a chief or charged with a lion pass. betw. a pair of lozenges az. Jounson, Northumberland.

Arg. on a bend betw. two roses gu. barbed and seeded ppr. a rose enclosed by so many Heurs. de-lis or a chief of the second charged with a lion pass. as the fourth. Hayward, Dewes Grove, Sandhurst, co. Gloucester; granted 1750.

$$
\text { ..... (Bird) Eagle }
$$

Arg. on a bend betw. two mullets gu. three 3-foils slipped of the first a chief az. charged with an eagle wings expanded enclosed by a pair of 5-foils stalked and leaved or. Parshed or Polshed, $V$ *.

Arg. on a bend sa. within a bordure erm. three garbs or a chief az. charged with a double. headed eagle displayed ppr. Hesketh, quartered by Fleetwood.

$$
\text { ....Pelican }
$$

Arg. on a bend betw. two mullets gu. three 3.foils as the first a chief az. charged with a pelican enclosed by a pair of 3 -foils or. POLSHED. Polsted, Thames Ditton Church.

Arg. on a bend betw. two mullets gu. three 3.foils slipped as the first a chief az. charged with a pelican rising wings overt inverted vulning itself and enclosed by a pair of 5 -foils stalked and leaved or. Richard PALshep or Polshid, Southampton, $V$.

$$
\text { .....(Birds) Martlets }
$$

Az. on a bend betw, two cotises arg. three escallops (az. $V^{*}$.) gu. a chief or charged with as many martlets of the first. PULLEYNe, $V$.

Az. on a bend betw. two cotises arg. three escallops gu. a chief or charged with as many mart. lets sa. Pulleine, Killinghall, Carleton Hall, and Crake Hall, co. York; the heiress m. Stanhope. Puilen, co. York.

$$
\text { .... Castle }
$$

$\mathrm{Az}$. on $\mathfrak{a}$ bend betw, two water bougets or three leopards faces gu. a chief as the last charged with a castle triple.towered arg. having from the centre tower of a pyramidical shape a banner displ. like the first. HonT, Limerick.

$$
\text { ..... Coronet }
$$

Arg. on a bend engr. az. within a double tressure flory counterflory with thistles vert three buckles or a chief gu. charged with an imperial crown placed on the dexter side and guarded of a sword in pale held by a naked hand and arm issuing out of a cloud from the sinister ppr. Stirling, Glorat, co. Stirling; Baronetcy 1666.

\section{.... Cross}

Gu. on a bend or betw. two escallops arg. a Cornish chough ppr. enclosed by as many 5 -foils az. a chief of the second cliarged with a cross betw. two demi fleurs-de-lis lilke the first. Peter, Ingatestone, Essex.

Arg. on a bend betw. two cotises sa. a fleur-de-lis enclosed by as many 5 -foils like the first a chief az. charged with a cross patonce within a pair of arrows or. Morgan, South Maplerton, co. Dorset.

$$
\text { .... Escallops }
$$

Sa. on a bend betw. two leopard's heads arg. three crosses patty az. a chief or charged with as many escallops gu. Sr. John Mylborne, Alderman of London, $V$. Myleourne, $V^{*}$.
On 1 BEND betw. or within...

and in chief.... cont.

on a Chief cont. Escallops cont.

Sa. on a bend betw. two leopard's heads or three crosses patty as the field a chief arg. charged with so many escallops of the first. Murborne, Alderman of London 1535. Milbonne, Suffolk.

Sa. on a bend betw. two leopard's heads or three crosses formy as the field a chief of the second charged with so many escallops like the first. MilboRne, Lord Mayor of London 1521.

$$
\text { .....Estaile }
$$

Arg. on a bend az. betw. two pheons sa, a leopard's face enclosed by as many escallops or a chief engr. gu. charged with an estoile within a pair of fleurs-de-lisgold. Langstarf, Newcastle.

$$
\text { .... Flower }
$$

Az, on a bend betw. two escallops or a Cornish chough ppr. enclosed by so many 5 -foils gu. a chief of the second charged with a rose within a pair of dimidiated fleurs-de-lis as the fourth. Sir .... Petre, ob. 1572.

$\mathrm{Gu}$. on a bend or betw. two escallops arg. a Cornish chough ppr. enclosed by so many 5 -foils az. a chief as the second charged with a rose within a pair of fleurs-de-lis like the first seeded gold barbed and leaved vert. Peter or Petre, co. Devon; and Essex.

$$
\text { .....Flowers }
$$

Az. on a bend arg. betw. two estoiles or a naked boy (another a child another a man) frontfaced holding in both hands (ppr. another) sa. the tongue of a bear (pass. another) statant of the last estoiled gold a chief as the secoud charged with three roses gu. radiated like the third. Richard Barnes, Bishop of Carlisle 15\%0, Durham 1577.87, confirmed 23 April 1571, Harl. MSS. 5847 , fo. 20 .

$$
\text { .... Garbs }
$$

Per pale az. and gu. on a bend or betw. two eagles displ. arg. three (another pierced) mullets sa. a chief of the fourth charged with as many garbs vert. John TravelL, London; descended from Travelt, Wenlock, co. Salop, 1633-4, Harl. MS. 1558, fo. 75. TravelL, Northampton; and Coventry, co. Warwick.

$$
\text { .... Heads (Beast) Deer }
$$

Arg. on a bend counterembattled az. betw. three stirrups sa. so many roses of the first a chief as the second charged with buck's heads in like number cabossed or. BENE.

$$
\text { ..... Leopard }
$$

Or on a bend sa. betw. two water bougets az. a chev. and three pheons of the first a chief gu. charged with three leopard's faces gold. Hunr.

$$
\text { .....Monster (Griffin) }
$$

Quarterly erm. and or on a bend az. betw. two palm-trees ppr. each growing out of a mount vert three mullets of the second a chief gu. charged with a griffin pass. gold the dexter claw grasping an arrow barbed and flighted ppr. Connfoor, Ryde, Isle of Wight; and Peters. ham, Surrey.

\section{.... Millets}

Az, on a bend betw. two eagles displ. arg. three garbs vert a chief or charged with as many mullets sa. GEYLIN, $V$. GoYLIN, $V^{*}$.

Per pale gu. and az. on a bend betw. two eagles displ. arg. three garbs vert a chief or charged with as many pierced mullets sa. Goyms, $V^{*}$. GOYLYN, $T$. 
On 1 BEND betw, or within....

and in chief.....cont.

on a Chief cont. Pheons

Vert on bend arg. betw. four cotises erm. and two covered cups or a lion pass. gu. a chief az. charged with three plieons of the fourth. Cronpton, Breightmet, co. Lancaster; Woodend, co. York, Baronetey 21 July 1838; Milford House; Durant Hall, Chesterfield; and The Lilies, co. Derby.

$$
\text { ....Roundle }
$$

Or on a bend .... betw. three pheons .... another bend .... a chief gu. charged with a bezant enclosed by two fleurs-de-lis of the first. LONGSTAFF.

$$
\text { .....ship }
$$

Quarterly arg. and gu. on a bend engr. or betw. in the sinister point a horse's head erased and in the dexter base a right hand erect couped arg. an arrow point upwards sa. a chief of the second charged with an East India merchantman in full sail with English colours on wares of the sea ppr. Ali MoHomad Khan, J.P., Bombay; granted 28 March 1854.

$$
\text { ..... Sprigs }
$$

Sa. on a bend betw. in chief a greyhound courant bendwise and in base a dolphin haurient arg. three torteaux a chief of the second charged with three sprigs of strawberry fructed ppr. Houmst, Midhurst, and Isodsworth, Sussex.

$$
\text { .....suns }
$$

.... on a bend .... betw. two estoiles .... a bear statant .... a chief .... charged with three suns .... Richard Barnes, as Bishop of Carlisle 1570-77, Add. MS. 12443, fo. 64 .

\section{Escallop}

Arg. on a bend betw. two cotises sa. three eagles displ. of the first in the sinister chief an escal. lop as the second. ABIngton, co. Dorset.

Arg. on a bend sa. betw. two cotises az. three buck's heads cabossed or in the sinister chief an escallop gu. HarLand, Sutton Hall, near York; quaitering Hoare.

$$
\text { Head }
$$

Or on a bend az. within a bordure gu. a six pointed mullet betw. two crescents arg. in cbief a boar's head couped of the third. Scotr, Scottshall, Scotland.

\section{on a Quarter}

Az. on a bend wary arg. within a bordure engr. of the second pelletty three birds sa. their breasts gu. a sinister quarter arg. divided by a lion in pale the dexter side charged with two staves couped and raguly in saltire gu. enfiled with a Saxon coronet gold on the sinister a man ppr. habited or in the right hand a sword held over his bead in the left a man's head couped ppr. READE, Symington, Norfolk.

Arg. on a bend gu. betw. three ogresses as many swans (arg. $V^{*}$.) or a sinister quarter az. charged with a demi-ram springing couped arg. (armed or $V^{*}$.) in chief two fleurs-de-lis or and a baston $\left(\arg . V^{*}\right.$.) .... Clarke, Quarendon, $V$.

\section{$1 \frac{1}{2}$ BEND}

(see 2 Bendlets and in chief.... a Quarter.)

Gu. a bend and a half arg. a quarter erm. John de Creseby, Merst, $X$.

\section{BENDLETS}

Arg. two bendlets az. Taf le Botiler, $F$. Martén or Marton.

\section{BENDLETS cont.}

Arg. two bendlets one enhanced the other in base az. over all a saltire gu. DorIEN or DorrIEN.

Arg. two bendlets engr. az. IEver, co. Lancaster.

Arg. (? az.) two bendlets erm. LAcy.

Arg. two bendlets gu. Aket, co. Derby. Sire Iauf le Botillen, $O$. Sr. Walter Hache, Kent, L, Harl. MS. 6589. HaCKet or HaCkETT. Hacky. John Hagget (in pencil Hacket), Y. Haggatt or Haget, co. Somerset, temp. Henry VI. Sr. Walter Hased, $L$. Walter Haket, co. Derby, $V$. Sire Walter Haket, $N$. Sr. Walter HakeTt, L, Harl.MS.6137. Hoog. John Ineton, Lord Mayor of London 1659. Irton. Rothery. Ascribed to Siward, the Saxon, Earl of Southampton, temp. William I, impaling gu. simply. WOOLFALL, co. Laucaster. And with a label of three points az. Sr. William de Hoytren (? Koyken), I, Harl. MS. 6589.

Arg. two bendlets the outer edges engr. gu. Honeyman, Scotland. Honrman, Armadale and Græmsay, co. Orkney; Baronetcy 1804.

Arg. two bendlets engr.gu. Blage, Baron of the Exchequer, $V ; i$. $e$. Pobert Blagge, 1512. Buague, Hollinger, Suffolk, from Kent; the cohells $\mathrm{m}$. Yarburgh and Godolphin. Blaye, $V^{*}$. Glatingbras. Leaver or Lever. Pigott, Norfolk.

Alg. two bendlets the one at the top and the other at the bottom splintered $\mathrm{gu}$. Brokenstaffe.

Arg. two bendlets indented gu. RuyalL.

Arg. two bendlets wavy gu. William Brewer, Bishop of Exeter 1224-44. HANKFORD.

Arg. two bendlets humetty purp. KeYE, Milcomb, co. Oxford; granted 1688 .

Arg. trio bendlets sa. M. William Bradsaw, $S$. Thomas Bradschawe, $X$. Bradshaw, co. Lancaster, $V$. William Bradshaw, Bishop of Bristol 1724.32. Bradshaw, Darey-Lever, co. Lancaster. Bredham, Kent. Empson. Kay, EdithWeston, Rutland: and Woodsome, co. York. John Kaye, Bishop of Bristol 1820, Lincoln 1827.53. KEY, Woodstone, co. York. KEY. Poulter, Essex. Rawleter, Wimondley, co. Herts. And with a martlet in the dexter chief point sa. KAY, Milshaw, Dalton; and the Heath, co. York. The martlet in the sinister chief point. KAY, Newhall, co. York. But with a crescent in the dexter chief gu. Bradshaw, Kent; and co. Lancaster. But with a mullet for diff. $\mathrm{KAY}$, Glatton, co. Hunt. ingdon.

Arg. two bendlets sa. quartering Lister; the whole within a bordure wavy az. Lister-KAY, Denby Grange, co. York; Baronetcy 28 December 1812.

Arg. two bendlets one plain the other engr. sa. a crescent gu. Lever, Lever, co. Lancaster.

Arg. two bendlets the under one engr. sa. LEver, Arlington, co. Lancaster.

Arg. two bendlets the upper one engr. sa. LEATER, co. Lancaster, quartering Cunliffe aliter Bavoyr, with Ratcliffe and Aylworth, Harl. MS. 6159, fo. 51, b. Lever, $V$.

Arg. two bendlets engr. sa. Eirsom, $V$. Lever. Sr. Richard Radclif , Smethirle, $Y$. Ratcliffe, co. Derby ; and co. Lancaster. Stanes. And with a cross croslet in the lexter chief point sa. Padchifr. But witb a label gu. Sr.John Padchif, Wodeshall, $F$. 


\section{BENDLETS cont.}

Arg. two bendlets engr. sa. a label of three points gu. RadclyfFe, Ordshall, and Foxdenton, co. Lancaster; derived from Radelyffe, of Rad. clyffe 'Tower: quartering Radclyffe, Legh, Venables, Lege, Leigh, Baguley, Corona, Ardern, Sandbach, Ashaw, Elstor, Aughtor, Hulton, Bowden, Harrington, Cansfield, Flemyng, English, Urswick, Bradshaw, Verdon, Pilkington, Eyre, Padley, Blakewell, Stafford, Nuttall, and Bagshaw. Ratcliffe, Malory, co. Derby ; and Ordeshall, co. Lancaster. And with also a crescent gu. Radchiffe, Mellor, co. Derby; Visitation 1611 .

Arg. two bendlets engr. sa, a baston gu. BLAGGE, Kent.

Arg. two bendlets engr. sa. a fess gu. John Radclif, Chedyrton, $V$. Radcliff, $V^{*}$. RATCLIFFE.

Arg. two bendlets invecked sa. a mullet in the sinister chief point for diff. ... RADCLIFFE, Somerset Herald, 35.37 Henry VIII.

Arg. two bendlets neluly sa. Hackfond. HANKFORD, $v$. HAWKEWOOD. HOUGHFORD. Isburye. Stapledonne, Exeter, Harl. MS. 5827, fo. 158 . Sr. Richard Stapleton, $V$.

Arg. two beudlets raguly sa. WAGSTAFF, co. Derby.

Arg. two bendlets raguly the lower one couped at the top sa. Wagstaffe, Haseland. co. Derby ; granted 1611.

Arg. two bendlets wavy sa. Hackworthy, co. Devon. Hallesfield, HANDFord, co.Somerset. HANFORD, co. Somerset. Sr. John Hankford, $\boldsymbol{V}$. William de Hellifield, $\boldsymbol{Y}$. Walter Stapledon, Bishop of Exeter 1308-26, Harl. MS. 5827, fo. 61. Stapledon, Stapledon, co. Devon; the beiress m. Hankford. Stapleton, $V^{*}$. Richard de Stipilton, $Y$.

Arg. two bendlets the inuer sides ravy sa. Wigmur, Wigmur, Scotland.

Az. a bend arg. impaling arg. a bend az. ZOREE, called Yonke, $V$.

Az. a bend arg. impaling the same. Zorke, $V$. Zorke, Harl. MS. 1392 .

Az. two bendlets arg. Hancre. Lichfield. 'Tancey or Tancre. Bartram de Tancre, $A$, or TANCRE, Harl. MS. 6137.

Az. two bendlets enhanced arg. SherLe.

Az. two bendlets engr. arg. Frenes.

(? Az.) two bendlets erm. IAdCx.

Az. two bendlets or. Bylfspon, London. Doyly, $V$; i. e. D'OyLr, Turville, in Hambleden, co. Buckingham; the heiress m. Pococke; descended through D'Oysy, Palmoor or Parmoor, in Hambleden ; and Hulcomb, and Stadham or Stodbam, co. Oxford; the heiresses m. Ramsey, Gronlett, and Stephenson; from Dorler, Hocknaton, founder of Oseney Abbey; reversing the tinctures as in Turville Church. VILIEY.

Az. two bendlets sinister or. STOPEForD.

Erm. two bendlets gu. Ireton, Ireton, $V$. Ireton, Little Ireton, co. Derby; and Attenton, co. Nottingham; the heiresses $m$. Polhill, Lloyd, Bendysh, and Carter. Irton.

Gu. two bendlets arg. Grely. Talbot.

Gu. two bendlets wavy arg. Bruninge, co. Derby.

Gu. two bendlets wavy one arg. the other or. Braveing, co. Wilts, Bruer or Brewer, co. Devon. Bruen. Brunna, $V^{*}$. Richard Bruning, Segre, co. Wilts, $W$. Cistercian Abbey at Dunkestell, co. Devon.

\section{BENDLETS cont.}

Gu. two bendlets erm. Boteller, Bedmanton, $V$. Kingfieid Kingsfield and Kingsford. Kyngesfeld, $\boldsymbol{V}$. KYngsfeld, $V^{*}$.

Gu. two bendlets wavy erm. LACY, London.

Gu. two bendlets one or and the other arg. Bacher. Milo Fitz-Walter, Earl of Here. ford; the heiresses m. Bohun, Braose, and Fitzherbert.

$\mathrm{Gu}$. two bendlets the upper or the lower arg. FITZ-W

Ga. two bendlets or. Fitz-With. Fitz-Wythe, $V$. Alun Frene (? brother of $\mathrm{Sr} . . .$. de Dinawesbran ), $E$, in a later hand. Gloucester. Miles. Sudley.

$\mathrm{Gu}$. two bastons couped in guise of a ehevron or. Christopher Drownsfeld, $X$.

Gu. two bendlets engr. or. FItz-WIGHr.

Gu. two bendlets indented or. Frenes, co. Hereford.

Gu. two bendlets wavy or. Bnewer, co. Devon; Pole, ii, 473. Briwere, temp. Henry II. Cis. tercian Abbey at Dunkeswell, co. Devon.

Gu. two bendlets vair. FAGGE, $V^{*}$. FAGG, Wiston, Sussex; and Mystole, Kent; Baronetcy 11 December 1660. Frene.

Or two bendlets az. BoyLe, Ireland; quartering arg. a Cornish chough ppr. Dowlexy, founder of Osney Abbey, co. Oxford, who entered England with William I, Cotton MS. Tiberius $\mathrm{D}$, 10. Dolley, $V$. DoYley, $V *$. De Oiglif De Orlly De Oyly D'Orley or D'Oyly, Baron of Hocknorton, co. Oxford, quartered by Newburgh. Doycey or D'Oysy, Wremharn and Pushall, from whom descended DoYLY, Raunton. Doyley or D'Oyly, Pushall, and Jurlen, quartered by Wickham. Doyley or D'Orcx, Jurden, and Greenland or Southland, from wbom descended D'OyLEy, Marton, Mereton, Merton, or Moreton, co. Oxford (and its branch D'OyLy, Adderbury); the heiresses $m$. Harrington, Dyer, and Gower. Doysey or D'Oycy, Palmoor or Parmoor, co. Buckingham; Hulcomb, and Stadham or Studham, co. Ox. ford; the beiresses m. Ramsey, Groulett, and Stephenson ; descended from DoYLEY or D'OYLY, Greenland or Southland; Marlow, co. Buckingham; and Chislehampton, co. Oxford; quartering Moore, Brocas, Roches, and Banbury; Coulston; Edmunds, Fray, Bledlow, Frowike, Adrian, Pounz, Derham, Cornwall, Gloucester, Sturgeon, Starke, Oulton, Wrembury, and Boyton, Harl. MS. 1095, fo. 108; Baronetcy 7 July 1666 , and also quartering Cholmeley and Carter: Christopher D'OyLEy, Alderbury, co. Oxford, 17:30 ; Laud D'Oyley, London, 1730. Robert Doysey, Turville, quartering Moore, 1564, Harl. MS. 1095. D'Oyley, Norfolk, and co. Oxford. Duduey. The Abbey of Augustinian Canons at Oseney, co. Oxford. The early arms of the bishopric of OXFORD.

Or two bendlets dancetty az. SyNepley or Srnopoly, quartering arg. an eagle displ. or.

Or two bendlets compony gu. and arg. MaIBone. Or a bend dexter gu. and another sinister az. (? Pitcher.)

Or a bend sinister gu. and another dexter az. Bendali. (? Pitcher.)

Or two bendlets gu. Demaunt. John Doycey, $Y$. D'Oyly, Marton, Mereton, Merton, or Moreton, co. Oxford; descended from D'Oyly, Greenland; the heirs $m$. Harrington, Dyer, and Gower. Harold. Prchard. St, Low, co. Worcester. 


\section{BENDLETS cont.}

Selier, co. Worcester. Sudiey, $V$. Sudejey or Sudley, Sudley Castle, co. Gloucester; and co. Warwick. Sr. Johan de Sulfe, J. Sr.Jobn Suley, $I$. Sire Johan de Suleye, $N$. Joan de Suley or Sulleye, $E$. Baltholmewe de Suldy, $A$. Johan de Suthleye, $G$. Ralph Tracy, co. Worcester, $V$.

Or two beudlets gu, a label of three points az. Sudeley, $r$. Sr. .... de Sully, co. Worcester, I. SULLY, $V^{*}$.

Or two bendlets gu. a label az. Penrey. Sudley, co. Worcester. Sire Bertelnehu de Suleye, N. Sully.

Or two bendlets gu, a label of fire points az. Tracy.

Or two bendlets gu. a label barruly arg. and az. M. William de Sulexe, $L$. Sire William de Suleye, $N$.

Or two bendlets gu. a label compony az. and arg. M. William Suley, L, Harl. MS. 6589.

Or two bendlets gu. a label vair. SUdLey.

Or two bendlets (? four) gemels gu. Fundin.

Or two bendlets sa. HaLjer, Coruwall.

Or two bendlets engr. sa. BlatewaIte, co. De. von; inpuling az. a lion arg., Pole, i, 132. Brainthwaite or Brantewaite, Norfolk, 1730. Braintewrt, Ringwood, co. Hants. Braithwaite or Branterwatte, London, 1582. Branthwayt, quartered by Weston. Empson, quartering sa. a chev. betw. three escallops or.

Per bend az. and arg. two bendlets engr. counterehanged. Sr. Hugh de Frenes, $V$. Frenes, 1730. Frennes.

Per bend or and arg. two bendlets ermines. KIng.

Per pale arg. and gu. two bendlets counterchanged. Dallington, co. Lincoln.

Per pale az. and arg. on each side a bend coun. terchanged. Zorke, called Yorke, $V$.

Sa. two bendlets arg. Hareford, $V$. HAREFord, Bosbury, co. Hereford. HartFord.

Sa. a bend sinister surmounted of another dexter arg. Newton, Essex.

Sa. two bendlets chequy or and arg. Scarton, Middlesex.

Sa. two bendlets compony or and arg. Sharieton, $V *$.

Sa. two benflets countercompony or and arg. Sharlton, $V$.

Sa. a bend sinisier surmounted by another dexter or. Newton, Essex.

Sa. two bendlets dancetty or. Delariver.

Si. two bendlets vair. STANDON.

\section{BENDLETS and in chief....}

\section{Bird..... Cock}

Arg. two bendlets gu. in chief a cock sa. FADEN. ..... Crow

Arg. two bevdlets sa. in the sinister chief point a Cornish chough ppr. Powlees. Pulter, Bradfield.Wimondley, co. Hertford.

\section{Canton}

Arg. two bendlets gu. a canton erm. CHesBy, co. York.

Arg. two bendlets engr. and a cantonsa. Percey, Filson, Kent.

Gu. two bendlets arg. a canton erm. Sr. Robert Clesby, co. York, $Y$. Creseby, Merst.

$\mathrm{Gu}$. two bendlets wavy or a canton vair. Brewer or Bruer, Kent. Darrelu, Rye, Sussex.

Gu. two bendlets vair a canton or. Ford.
2 BENDLETS and in chief..... cont.

on a Canton..... Anchor

$\mathrm{Gu}$. two bendlets vair on a canton or an anchor sa. Ford, London.

$\mathrm{Gu}$. two bendlets vairy or and az. on a canton of the second an anchor sa. Ford, co. Gloucester; Bexley, and Canterbury, Kent; London; and Suffolk.

\section{..... (Beast) Hound}

Gu. two bendlets vair on a canton or a demigreyliound sa. Foril.

Gu. two bendlets vairy arg. and sa. on a canton or a demi-greyhound courant of the third. Forth, Butley, Suffolk.

Gu. two bendlets vairy or and sa. on a canton of the second a demi-greybound couped courant of the third. Forth, Butley Abbey, and Had. leigh, Suffolk.

Gu. two bendlets arg. on a canton or a greyhound issuant sa. Ford or ForTH.

Gu. two bendlets vair on a canton or a greyhound courant sa. William Ford, Hadley, Suffolk, $V$.

Per pale gu. and or two bendlets vair on a canton of the second a greyhound courant sa. ForD, Ember Court, Surrey; Baronetcy 22 Feb. 1793. .....Lion

Sa. two bendlets erm. on a canton arg. a lion ramp. of the first. AdLER, Haverstoke, Essex. .....Bend

Sa. two bendlets arg. on a canton az. a bend or. HARFORD, Sirboury House, Ebbw Vale, co. Monmouth; descended like Harford, Blaise Castle, co. Gloucester, from HARFORD, Bosbury, co. Hereford.

.... Chessrook

Arg. two bendlets az. on a canton sa. a chessrook or. BRAYlford, $V$.

$$
\text { .... Escallops }
$$

Or two bendlets gu. on a canton arg. five escallops sa. Tracy.

$$
\text { ....Roundle }
$$

Sa. two bendlets or on a canton az. a bezant. Stolyon or Stalion, Warbleton, Sussex.

$$
\text { .... Roundles }
$$

$\mathrm{Gu}$. two bendlets vair on a canton or three ogresses. Ford.

\section{Chief}

Arg. two bendlets gu. a chief sa. Bowler.

Az. two bendlets and a chief arg. Newbald, $V$. Newbald or Newbold, co. Derby ; and London.

Gu. two bendlets wavy or a chief vair. Brewer, Bermondsey; and Norfolk. And with a mullet for diff.... B Brewen, London; and co. Somerset.

Or two bendlets az. a chief gu. Harnington.

Or two bendlets gu. a chief sa. Sr. Henry le Boteller, $J$.

on a Chief ..... (Beast) Fox

Or two hendlets az. on a chief of the last a fox courant as the first. Fox, co. Lincoln.

$$
\text { ..... Bird }
$$

Sa. two bendlets or on a chief of the last an eagle displ. as the first. Mayern, London.

$$
\text { .... Birds }
$$

Or two bendlets az. on a chief of the last two martlets as the first. BronHIL.

$$
\text { .... Heads }
$$

Arg. two bendlets wavy sa. on a chief gu. three leopard's faces or. Clement, Kent.

$$
\text { ..... Mullets }
$$

.... tro bendlets .... on a chief .... three mullets .... Henry le Boteler, Laton, co. Lancaster; scal, Cott. $M S$. Tiberius D, 10, fo. 771 . 
2 BENDLETS and in chief.....cont.

on a Chief cont. Roundles

Arg. two bendlets wavy sa. on a chief gu. three bezants. Cusments, Baron Leitrim, 11 October 1783, Viscount Leitrim 20 December 1793, Earl of Leitrim 6 October 1795, Baron Clements 1831 .

\section{Crescent}

.... two bendlets .... in the sinister chief a crescent .... Nicholas de CuIfton, seal 1466, Harl. $M I S .6829$, fo. 25 .

\section{Cross}

Arg. two bendlets and in the sinister chief point a cross croslet sa. Bonde. Bond, Ireland. John BoNd, ob. 1578.

Arg. two bendlets and in the sinister chief a cross croslet fitchy sa. William Bonde, $V$. Bonde, Clerk of the Green Cloth, $V$.

Arg. two bendlets sa. in chief a cross patonce. Anthony BoND, $15 \pi 6$.

\section{Escallop}

Arg. two bendlets engr. the under one couped at top in chief an escallop sa. WAGSTAFF, co. Warwick.

Or two bendlets az. in the dexter chief an escal. lop gu. Tracy.

Or two bendlets gu. in the dexter chief an escallop sa. Sr. William Tracy, $L$.

Or two bendlets gu. in the sinister chief an escallop sa. Sr. William Tracy, L, Harl. MS. 6137.

Or two bendlets gu. in chief an escallop sa. Sire William de Tracy, $N$.

Or two bendlets gu. an escallop sa. betw. the bends and a label of five points az. Sir John TraCY, $R$.

Head

Az. two bendlets and in the sinister chief a griffin's head erased or. Billeston, $V^{*}$. Sr. Robert Billesdon or Bylesdon, Haberdasher, Lord Mayor of London, $V$.

Quarter

Gu. two bendlets arg. a quarter erm. John de Creseby, Merst, $X$.

\section{Roundle}

Arg. two bendlets sa. separated by an ogress in the dexter chief point. Browne, co. Bedford, $W$.

\section{Roundles}

Or two bendlets gu. in chief three torteaux. BLUMWORTH.

\section{BENDLETS and in base....}

Arg. two bendlets sa. in base an ogress. Browne, Brynsop, co. Lancaster.

\section{BENDLETS betw, or within.... \\ Bells}

Sa. two bendlets betw. three hawl's bells arg. BRADSHAW.

\section{Birds}

Arg. two bastons betw. as many birds sa. Bradeshaw, $V$. Bradshaw, $V^{*}$.

$$
\text { .....Choughs }
$$

Arg. two bendlets sa. betw. as many Cornish choughs ppr. Poulter.

$$
\text { .....Martlets }
$$

Arg. two bendlets betw. as many martlets sa. BraDshaw, Belper, Holbrook, and Barton Hall, co. Derby; descęnded from Bradshaw, Windley. And with an annulet gu. for diff. Bradshaw, Marple. co. Chester; and Bradshaw Hall, co. Lincaster.

\section{BENDLETS betw, or within.....cont. Birds cont. Cocks}

Arg. two bendlets betw. three cocks sa. HeUdright. Howbridge or Howghbrige, co. York.

\section{Martlets}

Arg. two bendlets betw. three martlets sa. BradshaW, Windley, co. Derby ; derived from Bradshaigh or Bradshaw, Haigh, co. Lancaster, descended from Sir John Bradshaw, Bradshaw; Baronetcy 17 November 1679 ; extinct....

Per fess or and gu. two bends invecked betw. six birds counterchanged. WELFITT.

\section{Bordure}

Arg. two bendlets az. within a bordure engr. sa. Harron, Kent, $V$.

Arg. two bendlets and a bordure gu. HAWARD, confirmed 1616. HaYWoOD.

Arg. two bendlets nebuly (or wavy sa.) within a bordure az. (another gu.) charged with eight pair of keys endorsed and interlaced in the rings or. Exeter College, Oxford, 1316.

Arg. two bendlets within a bordure sa. M. William de Acherton, $S$. Atherton, co. Lancaster. Atherton, $V$.

Arg. two bendlets with a bordure and label sa. DowrisH.

Arg. two plain bendlets and a bordure engr. sa. a label of three points az. DowrisH, $W$.

Arg. two bendlets wavy sa. within a bordure .... charged with eight pair of keys in saltire .... Walter Stapiedon, Bishop of Exeter 1308.26, Add. MS. 12443, fo. 132 .

Arg. two cotises wavy within a bordure sa. charged with eight keys or. STaPLETon.

Gu. two bendlets within a bordure arg. BALDWIN, Bishop of Worcester 1180, Archbishop of Canterbury 1184-90.

Sa. two bendlets within a bordure or. Duhurst, Cheshunt, co. Hertford.

$$
\text { Cups }
$$

Arg. two bendlets betw. six covered cups sa Mons. Andrewe Butlen, quartering (gu.) a cross (this ought to be a cross moline arg.) and a bordure engr. (or), T, Ashmol. MS. 1120. Escallops

Az. two bendlets betw. six escallops arg. Crotse or Crijse. Croisse, Ireland.

Az. two bendlets and six escallops one two and three arg. Cruse, Baron Cruse, Harl. MS. 1603.

Az. two bendlets and six escallops two two and two arg. Cruse, lreland, $V$.

Az. two bendlets betw. six escallops three and three arg. CruYs.

Arg. two bendlets betw. nine escallops gu. Crasp. Tracy or 'T'resse, Newington, Malling, and Hoo, Kent.

Or two bendlets betw. nine escallops three three and three gu. Crasy. Tracy, V. William Trasi, $E$. 'I'resse, $V *$ *

\section{Fishes}

Arg. two bendlets betw. as many dolphins sa. FRENCH.

\section{Fleurs-de-lis}

Per bend az. and gu. two bendlets betw. three fleurs-de lis counterchanged. Gururn, Cornwall. Garbs

Az. two bendlets betw. as many garbs arg. THLOTSON, co. York, 1716.

Az. two cotises betw. as many garbs or. 'TILLOTSON.

Gu. two bendlets vair betr. as many garbs or. 'I'OLEson, Lonclun. 
2 BENDLETS betw, or within.... cont.

Heads (Beast) Boar

Or two bendlets engr. az. betw. as many boar's heads erased sa. EAsthope, Fir Grove, Surrey; Baronetcy 1811.

$$
\text { .... Leopard }
$$

Az. two bendlets arg. and three leopard's heads or one in the dexter chief point. Cromy, $V^{*}$. Crons, $V$.

Arg. two bendlets wavy sa. betw. as many leopard's faces within a bordure gu. Cienent.

\section{Mullets}

Arg. two bendlets betw. as many mullets sa. Bromne, Nether.Legh, co. Chester.

Arg. two bendlets engr. gu. betw. three mullets sa. Brissinghair. Bugod.

\section{Roundles}

Arg. two bendlets lozengy sa. betw. as many torteaux. Richard de Bynteworth, Bishop of London 1338-9.

Arg. two cotises gu. betw. three torteanx. HAYWOOD.

Arg. two bendlets sa. betw. five ogresses in saltire. ChaNDLER, London. ChANDLER, impaling Currie, in Witley Church, Surrey.

\section{BENDLETS betw, or within ....} and in chief....

\section{on a Chief..... Heads}

Arg. two bendlets wavy sa. a chief gu. charged with three leopard's faces or all within a bordure compony of the first and az. CLEMENT.

$$
\text { ....Pale }
$$

Sa. two bendlets raguly betw. as many bawk's arg. belled of the second a chief of the last charged with a pale az. betw. two fleurs.de.lis as the first on the pale a cross patonce silver. BRADSHAW.

Head

Az. two bendlets arg. betw. as' many leopard's heads or and anotlier in the dexter chief point. Cromy, $V^{*}$. Crony, $V$.

\section{On 2 BENDLETS}

Arg. on two plain bendlets gu. as many cotises indented or. LANDor, Rugely, co. Stafford; Ipsley, Court, co. Warwick; and Llanthony Abbes, co. Monmoutb; granted 8 June 1687.

\section{Crosses}

Arg. on two bendlets gu. six crosses croslet or. WyLde, $V^{*}$. But the croslets fitchy in bend sinister. WYLDE, $V$.

\section{Fleurs-de-lis}

$\mathrm{Gu}$. on two berdlets or six fleurs-de-lis vert. Draper, $V *$.

\section{Flowers}

Arg. on two bendlets az. three roses in the upper one or and as many acorns in the other of the first. Lickie, Scotland.

\section{Lozenges}

Gu. on two bendlets arg. four lozenges az. Roche.

\section{Mullets}

Az. on two bendlets arg. (another or) six mullets gu. Horshair.

\section{Roundles (Bezants)}

Arg. on two bastons gu. bezants or. Robert de WeLIE, $B$.

$$
\text { .... (Plates) }
$$

Arg. on two bendlets sa. six plates. PAGE.

\section{BENDLETS}

Arg. three bendlets az. Annors. Malton, Ire. land. Sr. Richard de Marton, $V$. Martyn, co. Devon. Richard Merton, $Y$. Monsire Richard de Merton, $Y$. Morton or Martyn. Stroche, $V$.

Arg. three bendlets wavy az. Pater. Playter, co. Suffolk, $V$. Playtor. Wilibornham, co. Norfolk, $V$. Wilbraham, Woodhay, co. Chester, $W$. Bootle-WilBraHaM, Baron Skelmersdule 13 January 1828; quartering Bootle; descended through Wilbraham, Rode, like Winbraham, Nantwich (quartering Clive), and Delamere House; and lilie Wilbraham, Radnor and Woodbey, Baronetcy 5 March 1620-1, extinct 1692, the coheirs m. Middleton, Tollemache, and Newport; from Wilburghan, Wymincham, all quartering Venables, Crosby, and Golborne.

Arg. three bendlets compony gu. and of the first. FAUGAM.

Arg. a bend double cotised on the upper side gu. Byron.

Arg. three bendlets gu. Albing. Beron and Berrn, co. Lincoln, BoDEINGHAM or Bodrington. Bodrigan or Bodrugan, Bod. rigan in Gorrans, Cornwall; extinct about 1331; the heiress m. Trevartbian. Otes de Bodringham, $Y$. Sr. Henry de Bodrugan, $V$. Monsire Otes de Bodygan, $Y$. Sire Henry de Bot'ingham, N. Botingham, Cornwall. Sire Otes de Botringh'm, $O$. Botringham, co. Devon. Botringham, $V^{*}$. Sr. .... de Botringham, Cornwall, $\boldsymbol{V}$. Sire John de Brackworth, O. Byrone. M. Richard Byron, $S$. Sr. John Brron, co. Nottingham, $V$. Sire James Byroun, $N$. Cliffon. Dodrugan, $V^{*}$. Lancelot, co. Leicester. Sanderson, Nisbet, i, 92. WALLISBorough or WALSBorough.

Arg. three bendlets gu. a label az. Richard Buroun, $M$. The label of three points. Sir John Brron le fils, $P$. John Brron, $Y$. Monsire Byron, $Y$. Sr. William de Koyken, $I$.

Arg. three bendlets gu. a label of five points az. James de Birune, $F$.

Arg. tbree bendlets gu. a label sa. Heiras.

Arg. three bendlets gu. a label of five points sa. James de Brroune, E, Harl. MS. 6137.

Arg. three bendlets gu. over all a lion ramp. sa. Younge.

Arg. three bendlets gu. over all an estoile az. Hector. Sire Hectore de Mares of the Table Round, Cott. MS. Tiberius D, 10, fo. 702 .

Arg. three bendlets gu. in the centre the sun or. Hector.

Arg. three bendlets enhanced gu. BERUN. Bockinghay. Byron, $V^{*}$. Byron, Ayton, North Riding, co. York; quartering Standish or Standidge. BYron, Baron Byron 24 October $16 \pm 3$.

Arg. three bendlets enhanced gu. a label of five points sa. James de Bıroune, $E$.

Arg. three bendlets sinister gu. Burun.

Arg. three bendlets eng. gu. Glatingrras.

Arg. three bendlets wavy gu. Luton, co. York. Pater.

Arg. three bendlets sa. Bentley, Butringham. Canston. Cawood. Cow Cowe or Cowy. Hacconise, Haccombe, co. Devon, temp. Henry III ; the heiress m. Ercedekne. Sire Estevene de Haccombe, $N$. John de Hacconbe, $Y$. Monsire .... de HaUtconibe, $Y$. HaLleep, Cornwall. Hanconbe or Hantonbe, Cornwall. 


\section{BENDLETS cont.}

Restwold, co. Berks, 1716. Resitwould, co. Leicester, quartered by Waterton. SANDERSON, Scotland. 'Travers, co. Devon. 'Trevery, co. Devon. Trevory, co. Devon, $V$.

Arg. three bendlets sa. over all a lion ramp. gu. Cutler, Ipswieh, Suffolk; confirmed $21 \mathrm{July}$ 1612.

Arg. three bendlets sa. over all a chev. erm. Blanchuinster, Cornwall.

Arg. three bendlets embattled sa. Hadrian DE Castello, Bishop of Hereford 1502, Bath. etc. 1504-18.

Arg. three bendlets engr. sa. Whitfield, Kent; descended from Nortbumberland. Trevalder.

Arg. three bendlets engr. sa. over all a scarpe gu. Blage, Kent.

Arg. three bendlets wavy sa. Estbery IsBery or Isbury. EstBeny or Isbury, $V$.

Arg. three bendlets vert. NuN, Ireland.

Az. three bendlets arg. Merton, Merton, co. Devon; and Mellings, co. Lancaster. Merton, $V$. Solden or Soldon. Stephen Sodan, $A$, Harl. MS. 6137.

Az. three bendlets and an inescutcheon arg. Fountavill.

Az. three bendlets wavy arg. GodschaLI, Lord Mayor of London 1742 .

Az. three bendlets chequy or and gu. Solers.

Az. three bendlets compony or and gu. SoI.EnI or Solere, $V *$.

Az. three bendlets counter compony or and gu. SOLERE, $V$.

Az. three bendlets erm. Iacey. Facheli, $V$. VACHELL, co. Berks.

Az. three bendlets or. Fitz-WILLIAM, Cornwall, $V$. Fitzwilliars, Cornwall. Mantaby, $V^{*}$. Manteby, $V$. Simon de Mepham, Arch. bishop of Canterbury 1328.33. Sire John de Mounford, $J$. John Tresley, $V$. Villey.

Az. three bendlets embattled counter-embattled or. Freynes.

Erm. three bendlets .... Gunthwaite.

Erm. three bendlets az. John VACHELL, co. Berks, $V$. WiLLington, $V$.

Erm. three bendlets gu. Boors. GuLes. KNowling or KNolling, Exeter, Harburton, and Lower Washbourne, co. Devon; quartering Kirkham; the coheir m. Fowell. Quenryn. SMIRKE. VAChEIL.

Erm. three bendlets gu. over all a label of as many points arg. Barron. The label az. Baron.

Erm. three bendlets enhanced gu. Brron, co. Herts; and Coulsden, co. Stafford.

Gu. three bendlets arg. ALBALANDA, Nansavallon or Blanchland in Kea, Cornwall; the heiress m. Boscawen. Biron. Borvill. Butler. John Greley, $Y$. Malveysin, co. Stafford and co. Lancaster; heiresses m. Cawarden, Stanley, Langton, Chadwicke, and Sewal. Henry de Manniesin (in pencil Malvorsin), A. Henry MauUtsin, $A$, Harl. MS. 6137. M. Robert MawresYN, S. John Manveyson, $Y$. Monsire Mauveysin, $Y$. MuRdahes, $T$.

Gu. three bendlets arg. a label of five points az. James Brrun, $A$, or de Byrun, Harl. MS. 6137.

Gu. three bendlets arg. a label. az. Biron.

Gu. three bendlets arg. over all a pale or. Burgaw.

\section{BENDLETS cont.}

Gu. three bendlets eribanced arg. Mawnrse, $V$. Mawnyss, $V^{*}$. Mauissyn, $V$. Mavissyn, $V^{*}$. Gu. three bendlets erm. Richard Chesnutr, $Q$, Harl. MS. 6595. Sr. Reynald Chesenunt, $Q$. Sr. Menald de Chesthannt, $Q$, Harl. MS. 6589. Sr. Rowland Coykyng, $V$.

Gu. three bendlets or. Criejul or Gryll. Crynes. Robert de Greleie, $E$. Sir Thomas de Greley, N. Sr. Thomas Greyley, I, Harl. MS. 6589. Sr. Thomas de GreyLy, J. GriLL, Tavistock. Gryll. Hamlynn. Maltesme. MARDAKES or MURDAKES.

Gu. three bendlets or on a fess vert as many plates. Copinger, $V^{*}$. Copingere, $V$.

Gu. three bendlets or a label of five points arg. Hamund Hancett, $E$.

Gu. three bendlets 'embelief' or. William Gremer, $B$.

Gu. three bendlets enhanced or. Johan de Grelli, G. Grelley or Grayley, co. Lancaster. Sr. .... de Greyley, lord of Manchester, co. Lancaster, $V$. GRELLEY or GRESLET, lord of Manchester, Memoirs of Lit. and Phil. Soc. of Manchester, 2 series, iv, 473. Borough of IANCHESTER. $_{\text {AN }}$

Gu. three bendlets dancetty or. MandatT.

Gu.three bendlets engr. or. CAWLEY, co. Stafford.

$\mathrm{Gu}$. three bendlets (perhaps enhanced) the chief part of the two adjacent sides of the lower bendlets indented (as if overlaid by three fusels or lozenges of the first) or. Hamo HAUTEYN, $F$.

Gu. three bendlets vair. Bkay, Northumberland and London, 1787. John Longvale, $X$. Landwath. Longvalle, $V *$.

Or three bendlets az. Morton or MARTyN. Ponthieu, France.

Or three bendlets az. an escucheon chequy or and gu. LYFord.

Or three bendlets wavy az. on an escucheon .... as many fusils .... Simon Montacute, Bishop of Worester 1334, Ely 1337.45.

Or three bendlets compony az. and arg. FaGAN, Ireland.

Or three bendlets compony gu. and arg. FaGAN, Ireland. FAwGCAN, Ireland, $V$.

Or three bendlets countercompony gu. and or. FANGEANE, Harl. MS. 1441 .

Or three bendlets erm. Govery, Stangod, co. Lincoln. GUEVERA, Lincoln; granted 1617 ; quartering gu. five watercress leaves in saltire arg. Guevera, co. Lincoln; quartering gu. five watercress leaves pendent in saltire arg. all with in a bordure inscribed La mayor victoria de ellas es el bien merecellas.

Or tbree bendlots gu. Jarman. Muschampe. Sisson.

Or three bendlets gu. a label of five points az. Henry HaReTt, $F$.

Or three bendlets and a fess gu. Copenger, Norfolk.

Or three bendlets gu. a fess sa. Coppinger or Copinger, Ireland.

Or three bendlets gu. a fess vert. Copenger, Norfolk.

Or three bendlets enbanced gu. GrrLLs, Helston, Cornwall; quartering Beere, Gerveys, Bonathlack, Treveylos, Trevanion, Glynn, Polkinghorve, etc.

Or three bendlets sa. BEntLey, co. Derby, and co. Stafford. Boyvili, $V$. Thomas Colke, Y. Ferrer. Halep, Lamorran, Cornwall. 


\section{BENDLETS cont.}

Or three bendlets sa. over all a lion ramp. gu. Cutuer, Chantry, Suffolls.

Paly of three arg. and gu. three bendlets of the last. LANCEJ,OT.

Per pale gu. and az. three bendlets sinister counterchanged over all a pale or. BUrgau.

Per pale or and gu. three bendlets sa. Benflet. Bentiet. Beuflet.

Quarterly az, and or three bendlets dexter gu. MaRLOW. MaRLowe, $V$.

Quarterly or and az. over all tbree bendlets gu. MARLOWE, $V^{*}$. M ARLOW, quartering Kent.

Sa. three bendlets arg. Benteey. Sr..... de Cawston, $V$. Cecill, $V^{*}$. Cecyll, $V$. Cocke, Sandbridge, Essex. Cooke or Cook, Little Staybridge,Essex. Coore, Middlesex. Kones, $Y$.

Sa. three bendlets (these are piles in bend) the upper ends flory arg. Robert de Nonton, $X$.

Sa. three bendlets erm. Gomblewhat, co. York.

Sa. three bendlets or. Cooke. Jnnys.

Sa. a plain bendlet betw, two bendlets flory coun. terflory or. İELKE.

Vair three bendlets gu. Sr. Pobert Braye, co. Northampton, $V$. Bray, $V^{*}$. Bray, Northumberland. Sire Robert de Bray, $N$.

Vert three bendlets arg. Braye.

\section{BENDLETS and in chief....}

\section{Centon}

Arg. three bendlets az, a canton gu. Regan, Ireland.

Arg. three hendlets gu. a canton crm. CLESBY, co. York.

Arg. three bendlets engr. gu. a canton erm. Clesby, Clesby, co. Yorl.

Arg. three bendlets engr. and a canton gu. HerToN.

Arg. three bendlets engr. gu. a canton or. Honton, Wales. Sr. Philip Honton, co. Pem. broke, $V$.

Az. tbree bendlets or a canton erm. Bishopton or Bishopstone, co. Warwick. Frtz-Otes.

Or three bendlets az. a canton arg. Botatort or Botetourt. Bottescourt, $V^{*}$. Bottetourt, $V$. Rowton, $V$.

Or. three bendlets az. a canton erm. Fitz-Otes, $V *$.

Sa. three bendlets engr. .... a canton or. Horton, Wales.

on a Canton.... Beast

Arg. three bendlets az. on a canton sa. a lion pass. guard. of the first. Shershald.

Arg. three bendlets az. on a canton sa. a lion pass. or. Sharshatr, co. Salop.

Arg. three bendlets az on a canton sa. a lion pass. guard. or. GuYan, Danes Hall, Essex.

Arg. three bendlets gu. on a canton of the second a lion pass. as the first. Burnshed or Burnishide.

Arg. three bendlets gu. on a canton of the second a lion ramp. as the first. BeLlingham. Burnshed or Burnishide.

Gu. three bendlets arg. on a canton of the first a lion ramp. arg. BELIINGHANI, $V^{*}$.

$$
\text { .... Castle }
$$

Arg. three bendlets sa. on a canton of the second a castle as the first. CARnelu.

Arg. three bendlets sa. on a canton of the second a tower triple-towered as the first. Carneli, Cott. $M S$. Tiberius $\mathrm{D}, 10$. Caruel, $V$. CARVELL, $V^{*}$.
3 BENDLETS and in chief.... cont.

on a Canton cont. Castle cont.

Arg. tbree bendlets wavy sa. on a canton of the second a tower triple-towered as the first. Carneli, co. York.

Arg. three bendlets sa. (and for services in Scotland) on a canton vert a castle arg. fired ppr. Carvire, Berwick-upon-Tweed.

\section{.....Cross}

Arg. three bendlets sa. on a canton of the second a cross as the first. Noy or Noye.

Arg. three bendlets sa. on a canton of the second a cross or. Noye.

\section{.....spur}

Arg. three bendlets gu. on a canton az. a spur with buckle and leathers or. KNIGHT, co. Northampton, 1613. KNight, Sheffield, 1841.

Arg. three bendlets gu. on a canton of the second a spur leatbered the rowel downwards or. KNight, Cbarwetton, and Rowington, co. Nortb. ampton; granted 1613.

$$
\text { Castle }
$$

Sa. three bendlets and in chief a castle arg. CARELL.

Chief

Arg. three bendlets and a chief gu. Bermy, co. Lincoln.

Arg. three bendlets sa. a chief or. FAGE.

Az. three bendlets arg. a chief erm. Martin, London; granted August 1615. MARTYN, Woodford, Essex ; co. Lancaster ; und London.

Az. three bendlets or a chief erm. Hawkes, co. Stafford.

Gu. three bendlets or a chief per fess erm. and arg. Venner, Hundeseot, and Knolle, co. Devon, 1620. Vennor, Chitelhampton.

on a Chief .... Bar

Az. three bendlets or on a chief arg. a bar dancetty gu. Twigg or Twigae.

Arg. three bendlets gu. on a chief sa. a bar dancetty or. Witrewronge, Rothamsted. co. Hertford, quartered by Lawes through Bennet.

$$
\text { .... Beast }
$$

Arg. three bendlets sa. on a chief gu. a demibuck salient issuant arg. attired and unguled or. Lieubenrood, Prospect Hill, Reading, co. Berks.

$$
\text { .....Bird }
$$

Arg. three bendlets az. on a chief gu. three cocks of the first. TAYLEUR.

$$
\text { .....Birds }
$$

Erm. three bendlets az. on a chief or as many martlets sa. Pocklington; granted 22 June 1761. Pocklington, Muskham House, co. Nottingham; and Barrow House, co. Cumberland.

\section{.....Coronet}

Sa. three bendlets raguly arg. on a chief of the second as many Saxon crowns of the first. Camber, Tilbury, Essex.

$$
\text { ....Crosses }
$$

Or three bendlets az. on a chief erm. two crosses patty gu. Hawkes, Marlborough. Hawkes, Ogbourne St. Andrew, co. Wilts; quartered by Ward.

.....Fleurs-de-lis

Gu. three bendiets or on a chief per fess erm. and arg. three fleurs.de.lis in the upper part sa. Draper, Great Marlow, co. Buckingham. 
3 BENDLETS and in chief.... cont.

on a Chief cont. Fleurs de-lis cont.

Or three bendlets az. on a chief of the second fleurs-de-lis as the first. $\mathrm{DE}$ VISnE, co. Devon; and co. Gloucester; quartering az. fretty or and semy of fleurs-de-lis ...., with arg. a chev. betw. in chief two estoiles and in base a crescent gil.

$$
\text { ..... Flower }
$$

Gu. three bendlets arg. on a chief per fess arg. and or a rose in the upper part gu. Comte des URsins, $Z, 407$; and Glover.

$$
\text { .....Foils }
$$

Gu. three bendlets arg. on a chief or as many 5-foils az. Connoy or Conny, Ireland. .....Mullets

Or three bendlets gu. on a cbief az. as many mullets of the first. Monpesare, France. Mountrinson.

Gu. three bendlets or on a chief per fess erm. and arg. in the upper part as many mullets sa. Draper, Collinson, Somerset, ii, 333.

$$
\text { ....Palets }
$$

Az. three bendlets or on a chief of the first two palets betw. so many squires based as the second an inescucheon arg. Sr. Reinold Presmarch, I, Harl. MS. 6589 .

$$
\text { .... Roundle }
$$

Or three bendlets gu. on a chief of the last a plate betw. two lions combatant as the first. Hospital, afterward Augustinian Priory, of ST. Gregory at Canterbury.

$$
\text { .....Sbip }
$$

Gu. three bendlets enhanced or on a clief arg. a ship under sail in waves of the sea ppr. Ne1Ld, Manchester; granted ....

Crescent

Arg. three bendlets engr. and in the sinister chief a crescent gu. ANson, Baron Anson 13 June 1747 ; extinct 14 June 1702, quartering Carrier; Anson, Baron Soberton and Viscount Anson 17 February 1806, Earl of Lichfield 15 September 1831, quartering Adams, Sambrooke, and Carrier.

\section{Cross}

Or three bendlets and (in chief?) a cross croslet sa. Bentley, Horsley, co. Derby.

\section{Estoile}

Az. three bendlets gu. (in chief ?) an estoile az. Hector.

Mullets

Sa. three bendlets arg. in chief a mullet of six points or. LEODEPART.

Quarter

Or three bendlets az. a quarter erm. Hugh le Fitz-Otes, $V$.

on a Quarter

Gı. three bendlets arg. on a quarter gu. a lion ramp. of the second. BeLirngham, $V$.

\section{BENDLETS betw, or within....}

\section{Beasts}

Az. three bendlets gu. and two greyhounds courant bendwise sa. TREw.

\section{Bendlets or Cotises}

Arg. three bendlets each betw. two cotises engr. on the outer side gu. HonEyman or Honyman, Scotland, Nisbet, i, 92.

Birds

Sa. three bendlets and as many birds arg. Bradshaw, co. Chester.

\section{BENDLETS betw. or within.... cont.}

\section{Bordure}

Arg. three bendlets and a bordure az. Ponthiev, France, but in error.

Arg. three bendlets az. a bordure gu. HeLnian, $V^{*}$. Arg. three bendlets az. a bordure gu. bezanty. Perient.

Arg. three bendlets az. a bordure engr. gu. HeLitan, $W$.

Arg. three bendlets gu. a bordure of the second bezanty. Whalisburgh.

Arg. three bendlets gu. a bordure sa. bezanty. WaIesborough or Walisbonough. WaILIS. Borovgh or WatsBorovgh. WhalesBuRgh or Whalisworth, Whalisborough, Cornwall. Whalisborough, Cornwall, V; Collinson, Somerset, ii, 333. WhaLISBURGH, $V^{*}$.

Arg. three bendlets gu. a bordure engr. sa. Boderinghail or Bodrington, Cornwall.

Az. three bendlets arg. a bordure .... entoury of fleurs-de-lis .... Fenter, $V$.

Az. three bendlets or a bordure gu. Gwy de la Roc:e, $A$.

Gu. three bendlets or over all a fess vert charged with three plates a bordure purp. Copinaen, $V$.

Or three bendlets az. a bordure engr. .... (?'Thomas TrILIEK, Bishop of Rocbester 1365-72.)

Or three bendlets az. a bordure gu. NERBorodgh or Newborough, co. Wilts. Ponthieu, $Z, 129$; and Glover; and Gough, i, 70; tomb of Eleanor of Castile in Westminster Abbey. Otes Traisene, A, Harl. MS. 6137.

Or three bendlets az. a bordure gu. entoury of fleurs-de-lis arg. Guy de la Roce, $A$, Harl. MS. 6137.

Or three bendlets az. a bordure engr. gu. NEBorgy. Newbonough, Berkeley, co. Somerset; and co. Wilts ; Collinson, Somerset, ii, 203; iii, 562, 585. Sr. Roger Nmwborough, $V$.

\section{Heads}

Az. three bendlets betw. six boar's heads couped arg. Elyng. EstLing.

Az. three bendlets betw. six boar's heads fesswise three and three couped or. EsIINGE, $V$.

Orle

Arg. three bendlets within an orle az. Trustake, co. Devon.

\section{BENDLETS betw. or within....} and in chief....

\section{on a Canton}

Arg. three bendlets within a bordure gu. on a canton az. a spur with the rowel downwards leathered or. KNIGHT, Banbury, co. Oxford. KNIGHT, $V^{*}$.

\section{On 3 BEHDLETS}

\section{Bendlets or Cotises}

Arg. on three bendlets engr. gu. a pair of cotises to each of the first. Honevinan or Honyman, Scotland.

\section{Flowers}

Arg. on three bendlets sa. as many roses to each of the first. Penrose, Tregetbow in Manaccan, Cornwall. The modern arms of Penrose, Penrose in Sithney, Cornwall, after 1531.

\section{Heads}

Sa. on three bendlets arg. as many lion's beads erased of the first. Piddershall.

Arg. on three bendlets sa. as many griffin's heads elased of the first. Ridesdale or Ridlesdale, co. York. 


\section{On 3 BENDLETS cont.}

\section{Mullets}

Az. three bendlets or on the middle ono as many pierced mullets gu. Horshar.

$\mathrm{Az}$. on three bendlets or a mullet in the centre of each gu. Horsham.

Az. on three bendlets or as many mullets to each gu. Honsham, $r$.

Roundles

Arg. on three bendlets az. as many bezants to each. Marton, Craven, co. York.

\section{On 3 BENDLETS and in chief....}

Or on three bendlets sa. a lion's head erased to each .... on a chief indented az. as many crosses patty fitchy .... RidSDAIE, Old Hall, Wakefield, co. York.

\section{BENDLETS}

Arg. four bendlets gu. Copinger, Kent. Sr. .... de Taliot, $V$. 'Гalbott, $V *$.

Arg. three bendlets engr. sa. over all a scarp gu. Blage, Kent.

Az. four bendlets or. BILsdon. Bydelesdon or Bydesdon, $V^{*}$. Montford, $V^{*}$.

Az. four cotises gemelled or. BYDELEsDon or ByDEsDon, $T$.

$\mathrm{Gu}$. four bendlets arg. Boynele or Boytulie. Boyvilu, $V$. Cayly. Talbot.

Gu. a bend or and three sinister bendlets arg. the centre one surmounting the bend. AliwRIght or ALWRIght.

Or four bendlets az. Forde, Hadley, Suffolk. Sr. William Montford, $V$. Mountford, Sussex. And with a label of five points gu. Mounford, $F$.

Or four beudlets gemelled az. Fundis, quartered by Purefey and by Harecourt.

Or four bendlets sinisteraz. Piers de Mountrorth, A, Harl. MS. 6137 .

Or four bendlets gu. TALBOT, $V^{*}$.

Or four bendlets gemelled gu. (? Fundis.)

Or four bendlets sa. Bornel.

Sa. four bendlets arg. Walwardington, $V^{*}$.

\section{BENDLETS and in chief...}

\section{Canton}

Az. four beudlets arg. a canton erm. Fiтz. OTES.

Or four bendlets az. a canton erm. BISHOPSDON, $V^{*}$. BEsHe.

on a Chief

Gu. four bendlets or on a chief per fess arg. and erm. three fleurs.de lis in the upper part sa. Draper, London; granted 1618.

\section{Head}

Az. four bendlets gemelled and in the sinister chief an eagle's (or griffin's) head erased or. Sir Robert (BILISDen, Harl. MS. 1349), but Sir Nicholas Billesdon or rather Bildoon, Lord Mayor of London 1483, Cotton MS. Claudius C III, fo. 6 b. Sir Nicholas BILsDon, temp. Edward IV, Harl. MS. 6137, fo. 44.

$$
\text { Quarter }
$$

Or four bendlets az. a quarter erm. Monsire de Bishopesdon, $Y$. Sr. John Bishopsdon, $V$. John de Bisshopsdonne, $Y$.

\section{BENDIETS betw, or within....}

Or four bendlets az. a bordure gu. (The old arms of ) Burgundr.

\section{BENDIETS}

Arg. five bendlets gu. TALBOT.

$\mathrm{Gu}$. five bendlets arg. Clifton.

Or five bendlets gu. Richard Tагвотт or Thalebott. $E$; but Talebot or Chalebot, $E$, Harl. MS. 6137.

Or five bendlets enbanced gu. Sr. Gilbert TаLBOT, $V$.

Sa. five bendlets arg. over all a chev. gu. LONGHURST.

\section{BENDLETS and in chief....}

Or five bendlets az. on a canton arg. a lion pass. guard. gu. Passelon, Essex.

\section{BENDLETS}

Arg. six osjer wands (or bastons) interlaced in saltirewise in true love (sometimes in cross) ppr. $i$. e. sa. Walter SirIRLAWE, Bishop of Lich field, etc. 1386, Bath, etc. 1386, Durbam 1388-1406.

Az. six bendlets or. Pers de Montfort, $G$.

$\mathrm{Gu}$. six bendlets three sinister and as many dexter vair. Robert de Lathun, $E$; but de LA TuN, E, Harl. MS. 6137.

Or six beridlets az. Mountford.

\section{BENDY of 6}

Bendy of six arg. and az. Sire Johan de SEIN Fylebird, N. St. Philbert, co. Osford, $V$. St. Philibert, co. Oxford. Phillebert, co. Oxford. St. Philitert, Barons St. Philibert 1299-1359. Monsire de St. Phillibert, $Y$. Steven de Sodan, $A$. Synsyward, $V$. And with a crescent for diff. St. Philibert, Norfolk. Bendy wavy of six arg. and az. Plater or Playters, Thornden and Sotterley, Suffolk; Baronetcy 13 August 1623; extinct 23 Septem. ber 1832. Playter, Saterby, Suffolk, $W$.

Bendy of six arg. and gu. Avesness. Byrour. VALETORT, Cornwall. And with a label of as many points az. Byroy.

Bendy of six arg. and sa. Causton. Cawston, $V^{*}$. Haccomb. Oxon, $V^{*}$. Tonckes, co. Cambridge. Tonkes, co. Cambridge, $V$. And with a mullet gu. for diff. Tongue, Dublin.

Bendy wavy of six arg. and sa. Estbury, $V$. IsBERY, $V$.

Bendy of six az. and arg. Frene, co. Hertford. St. Phumbert, Norfolk, temp. Edward III. Roger Sastywand (sic), $X$.

Bendy of six az. and erm. Fachell or VACHELL, co. Berks, $V$. John Farnehile, $X$. 'Tonies, $V *$. Bendy of six az. witb fusily or and gu. Moret.

Bendy of six az. and or. Frenes, co. Herford, $V$. Bendy of six erm. and gu. ABrey. Sr. Roland Coykyn, L; but Rokin, L, Harl. MS. 6589. Dickins, $V^{*}$. Dickens or Dikens. Sr. Reginald Dikings, co. Devon, $V$. Roo.

Bendy of six gu. and arg. Avesnes, $V$. Thomas CokYn, $X$.

Bendy of six gu. and erm. Cockayne, co. Dorset. Cokeyne, co. Dorset. Sire Renaud de Coysin, $N$. Roland Q'RKIN, $G$.

Bendy of six gu. and or. Midnand. (? Milo de GLovcester.)

Bendy of six or and az. Mountford. Sysung, $V$. Srsun, $V$ *⿻.

Bendy of six or and gu. Sr. Walter Frenes, co. Hereford, $V$. (? Milo de Gloucester.)

Bendy of six champaine purp. and arg. BowBrIDgE. 
BENDY of 6 cont.

Bendy of six sa. and arg. Cawston, $V$. Walrington or Wolwardington, co. Warwick.

Bendy of six vair and gu. Le Sieur de Longevalue, $W$.

\section{BENDY of 8}

Bendy of eight arg. and az. MOUNTFORD, co. Warwick.

Bendy of eight arg. and gu. Minshaw.

Bendy of eight az. and or. Mountfort.

Bendy of eight erm. and gu. Awbrey, Chaldenwich, and Burton, co. Wilts. Hendrie or HENDRY.

Bendy barry of eight gu. and or. Holland, co. Lincoln.

Bendy of eight gu. and or. Sr. Thomas Greyley, $I$.

Bendy of eight or and az. a label of five points gu. Robert de Montfont, A, Harl. MS.6l37.

Bendy lozengy (? paly) of eight or and az. Bucr, Hamby Grange, co. Lincoln.

Bendy of eight or and gu. CopInger, Suffolk.

\section{BENDY of 10}

Bendy of ten arg. and az. Mountford.

Bendy of ten arg. and gu. Beteler. Talbot, Cornwall. TALBOT, Salwarp, co. Worcester.

Bendy of ten arg. and sa. Isabel daughter of Aymer Earl of Angoulême, and wife of King John. Sire Peres de Wolwardingtone, $N$.

Bendy of ten az. and or a label of five points gu. Robert Munfont, A.

Bendy sinister of ten az. and or. Piers de Mountforth, $A$.

Bendy of ten gu. and or. Berningham, Harl. MS. 1603.

Bendy of ten or and az. Pers de Monfort, $F$. Piers Montford, Lord of Beaudsert, $V$. Sire Johan de Montford, $N$. Montfort, Brecon, and Beldesert Castle, co. Warwick, temp. Henry II. Monsire de Montfort, $Y$. John de Mounford, $Y$. Modntford, Radwinter, co. Stafford; and co. Warwick. Piers de Munford, E.

Bendy of ten or and az. a label of five points gu. $M$. Robert de MoundFord, $D$, or Munpord, $E$, or MONIFORD, E, Harl. MS. 6137. Sr. William Mounford, $J$. Mountford.

Bendy of ten or and sa. Bishopton. William Bisshoresdonne, $F$. William de Bissopeston, $E$.

Bendy of ten sa. and arg. Wolwardington or Walrington, co. Warwick. Sr. Piers WOLWARDINGTON, co. Warwick, $V$. WoOD. WARDINGTON.

\section{BENDY of 12}

Bendy of twelve or andaz. Peres de Mountfort, $D$.

\section{BENDY unnumbered}

Bendy arg. and az. Sire John de Seint Fulbert, $O$.

Bendy lozengy (? paly $Z, 113,276,316$, ) arg. and az. Bavaria, $Z, 564,569$, sil.

Bendy arg. and gu. BonrugaN, Harl. MS. 1074, fo. 322 .

Bendy barry arg. and gu. Crispin.

Bendy lozengy barry arg. and gu. Quarm, Dart. mouth, co. Devon; Nancor, Cornwall. Wenhay or Winemari, co. Chester.

Bendy paly arg. and gu. Sydenham, $V^{*}$.

Bendy lozengy arg. and sa. Crorts, Ialton, co. Lancaster.
BENDY unnumbered cont.

Bendy lozengy barry arg. and sa. Crispin or Crispine.

Bendy sinister and barry gu. and arg. WyER.

Bendy or and az. Mountfort, Beaudesert. Piers de Montfond, $B$. Mountfort, Beamburst Hall, co. Stafford.

Bendy or and az. a label gu. Sire William de Montfort, $N$.

Bendy or and az. a label of three points arg. Mountfort.

Bendy or and az. a label of three points gu. MountFont.

Bendy paly or and az. Bucr, Agecroft Hall, Manchester.

Bendy barry or and gu. Berminghair.

Bendy lozengy or and gu. Isabel, daughter of Aymer Earl of Angoulême and wife of King John.

Bendy lozengy barry or and sa. CANCELLOR or CanCELOR.

Bendy sa. and or. LeIcester.

Bendy lozengy barry sa. and or. InRe.

\section{BESOM see BROOM BILL see AXE}

1 BILLET betw. or within....

\section{Heads}

Az. a billet arg. betw. three boar's hends couped or. Gordon, New-Wark, Scotland.

\section{Leaves}

Arg. a billet betw. in chief three bolly leaves ppr. and in base a hunting horn sa. garnished gu. Burnet, Aberdeen.

\section{BILLETS}

Arg. two billets raguled and trunked placed saltirewise, the sinister surmounted of the dexter az. their tops flaming ppr. Shunstabb.

Arg. two billets one in bend dexter (aliter in pale) az. surmounted by the other sinister (aliter in fess) gu. Benedictine Priory at Castle Hedingham, Hegford, Hegham, Heninghair, or Heveningham, Essex.

\section{BILLETS betw, or within....}

Or two billets raguled and trunked in saltire gu. betw. four escallops az. MUDEN.

\section{BILIETS}

Arg. three stone billets carved gu. Billerierg.

Arg. three billets sa. GADDY or GADDEZ, London.

Arg. three billets (or delves or gads) sa. Richard GADDES, $V_{.}$; and Cotton MS. Tiberius, D. 10.

Or three billets gu. Menuing, $V^{*}$. MerLyng, quartering per bend wavy gu. and arg. $W$.

Or three billets (or delves or gads) gu. MerLing, $V^{*}$. Menlynge, $V$.

\section{BILLETS and in chief....}

Az. three billets two and one or a chief of the last. Dromer.

\section{BILLETS betw, or within....}

Az. three billets in fess betw. four cotises arg. Mullot, Cheshire.

\section{On 3 BILLETS}

Annulets

Arg. on three billets (or blocks or delves or dice) sa. an annulet to each or. Amprose, co. Lan. caster. 


\section{On 3 BILLETS cont.}

Annulets cont.

Az. on three billets (or blocks or delves or dice) arg. an annulet to each sa. Paynter, Boskenna, Cornwall. Paynter, Denmark Hill, and Richmond, Surrey.

Mullet

Arg. on three billets (or blocks or delves or dice) sa. a mullet to each of the first. Aubrose, co. Lancaster. TRENT.

\section{BILLETS betw, or within....}

Sa. four billets or betw. five bezants. Grevile, co. Warwick.

\section{BILLETS}

Or five billets (or delves or gads) tbree and two sa. a label of three points gu. Gefrenx, Cott. MS. Tiberius D. 10. Gerfrey, $V$.

Or five billets in saltire sa. a label gu. Jerrerer. Or five billets in saltire sa. a label of three points gu. GeFfry, Cornwall.

Or fire billets (or delves or gads) in saltire sa. a label of five points gu. GeFrRI, $V^{*}$. GefFrey, $V$.

\section{BILLETS betw. or within....}

Arg. five billets in fess sa. betw, three pheons gu. Arrowsmyth, co. Lancaster.

\section{BILLETS}

Arg. six billets az. fretty three in fess and as many in pale. Hurst, co. Salop.

Arg. six billets three two arid one.... a label gu. JEFFREY.

Arg. six billets three two and onesa. Langriche or LANGRithe, London, quartering gu. a lion ramp. or preying on a dragon reversed of the last. Langrige, $V^{*}$. Langrich, Draper, London, $V$. Langrith. Largriph, London.

Gu. six billets erm. Elvet.

$\mathrm{Gu}$. six billets or. William Couderay, $X$. Monsire COWDREY, $Y$.

Or six billets az. a label of five points gu. CASTIIY,$V^{*}$.

Or six billets three two and one az. a label of three points gu. Fdmund Caselyn, $V$. T'he label of four points. Edmond CASELYN, V., Cott. MS. Tiberius D. 10. The label of five points. Sire Simond GaCeIINE, $J$.

Or six hillets gu. Colenley.

Or six billets three two and one gu. Sr.... de Colvill, $V$. Colevile, $V^{*}$.

Or six billets sa. M'GAvin, Scotland. Monsire Bartholomew Gabrieli, $Y$.

\section{BILLETS and in chief}

\section{Chief}

Arg. six billets three two and one sa. a chief of the last. Coringhair or CoRningham.

on a Chief.... Beast

Arg. six billets three two and one sa. on a chief of the second a lion pass. or armed and langued gu. JEFTERY, London.

Arg. six billets three two and one sa. on a chjef of the second a lion pass. guard or. JEFrRYEs, London.

Arg. six billets sa. on a chief of the second a lion pass. guard. or armed and langued gu. JEFrenEY, Lord Mayor of London 1686 .

Az. six billets or on a chief arg. a lion ramp. gu. billety of the second. Fayreweariser, Suflolk.
6 BILLETS and in chief.....cont.

on a Chief cont. Beast cont.

Gu. six billets three two and one or on a chief of the second a lion pass. vert. Fayreweather or FAwether, Brisset, Suffolk.

$$
\text { ..... Birds }
$$

Az. six billets three two and one or on a chief of the last three birds sa. Donmer, West Wycomb.

\section{BILLETS and in chief....}

\section{Canton}

Az. nine billets three three two and one or a canton erm. Gerard de Fanecurt, $E$.; but Faueconer, E, Harl. MS. 6137.

Gu. nine billets or a canton erm. - $E$.

Sa. nine billets three three two and one or a can. ton erm. Joan de S- $E$.

\section{on a Canton}

Az. nine billets three three two and one or on a canton of the last a bird sa. Robert BLUNDELL, $E . ;$ but Blundel, E, Harl. MS. 6137.

\section{BILLETS betw. or within....}

Az. nine billets arg. four three and two within a bordure gu. BEss.

\section{BILLETS}

Arg. ten billets four three two and one az. Gasselyne, co. Wilts.

Arg. ten billets four three two and one gu. LoFTose, 7 .

Arg. ten billets four three two and one sa. Blunden, Castle Blunden, Kilkenny, Baronetcy 12 March 1760; quartering or a lion passant guard. per pale gu. and sa. LeVALL.

Gu. ten billets erm. WILTHORP.

Gu. ten billets or. WILTHORP.

Gu. ten billets four three two and one ol. CANDREY. Caundrey. Cawdrey, Peres (or Perse) de Couderai, $E$. Conant. Sr. Thomas Cowdray, $V$. Cowdrey, co. Berks; and co. Hants. Denouac.

Or ten billets four three two and one az. GaseleE. Sr. Edmond de Gascelyn, co Hants, $V$. Gasselyn or Gasselyne.

Or ten billets four three two and one gu. William de Colevill, 6 Edward $I, V$. William de Colvile, $E$. Sr de Peye, of France, $W$. Peyce, London.

Or ten billets sa. Gerrny.

Or ten billets sa, a label of five points gu. GeFFEY.

Or ten billets four three and three sa. Gabryeld, $V$, Cott. MS. Tiberius D 10.

Or ten billets four three two and one sa. John Belvalle, $V$. Gabell, Winchester. Gabriet or GABRYELI.

Or ten billets four three two and one sa. a label of five points gu. Edmund GaCeLIN, E. The label gu. fretty sa. Edmund Gasselin, $F$.

Sa. ten billets arg. Blundeli, Crosby, co. Lan. caster.

Sa. ten billets four three two and one or. Cowdrey, Herriard, co. Hants.

10 BILLETs and in chief....

\section{Canton}

Or ten billets four three two and one sa. a canton erm. Sr. Walter Tonke, co. Nottingham, temp. Edward I, $V$. Touke, $V *$.

Sa ten billets or a canton el'm. Towre, Notting. ham. 
10 BILLETS and in chief.... cont.

\section{on a Canton}

Az. ten billets four three two and one or on a canton of the last a raven ppr. BLundell, Ince Blundell, co. Lancaster. Blundell, Carding. ton, co. Bedford; Baronetcy 13 October 1620, Baron Edenderry and Viscount Blundell $2 \mathscr{2}$ November 1720 ; extinct 1756.

\section{Chief}

Az, ten billets four three two and one or a chief of the last. Droner.

$\mathrm{Gu}$, ten billets four three two and one or a chief indented of the last. Sr. Thomas GERTON or Gorton, $V$.

on a Chief.... Beast

Az. ten billets four three two and one arg. on a chief or a demi-lion rampt. issuant sa. Sr. Robert Dormore, $V$. Dormer, $V^{*}$.

Az. ten billets four three two and one or on a chief of the second a demi-lion ramp. issuant sa. Sr. Robert Dormen, Eythorpe, co. Oxford, $V$. Dormer, Ascot, co. Buckingham. Dormer, $Z, 357$, (the lion sometimes incensed gu.) Baron Dormer 9 June 1615 (Viscount Ascott and Earl of Carnarvon 2 August 1621; extinct 1709). Dormor, $V^{*}$. William Dorrore, West Wycomb, $V$. Michell Dorrone, Thumley, $W$. And with a crescent for diff. Donker, Lord Major of London 1541.

$$
\text { ....Birds }
$$

Az. ten billets four three two and one or on a chief of the second three birds of the first. Dormer, Wing, co. Rutland.

Az. ten billets or on a chief of the second three birds sa. Dormer, $V^{*}$. .....Martlets

Az. ten billets or on a chief of the second three martlets sa. Dorner.

\section{BILLETS betw, or within}

Gu. ten billets or within a border engr. arg. charged with eight hurts. Salter, Oswestre, $V$.

Gu. ten billets four three two and one or within a bordure engr. arg. charged with fifteen burts and torteaux alternately. SALTER, Rich Kings, co. Buckingham; Daventry, co. Northampton; and Battisford, co. Suffolk.

$\mathrm{Gu}$. ten billets four three two and one or witlin a bordure engrailed az. bezanty. SALTER, Lord Mayor of London 1740; in Willinghale Dou church.

Gu. ten billets four three two and one or within a bordure invecked az. bezanty. SaltiRe, Oswaldstrey, co. Salop.

\section{BILLETS}

Arg. eleven billets four three three and one sa. LENALI.

Or eleven billets four three three and one sa. John Belvalle, $Y$, Cott. MS. Tiberius D 10.

\section{BILIETS}

Gu. twelve billets three four three and two or. Ps. de Cowdray, $F$.

\section{BILLETS and in chief....}

a Chief

Gu. twelve billets four five two and one.... a chief indented or. GerTon.

\section{BILLETS}

Arg. thirteen billets four three three two and one sa. Belvale.
13 BILLETS cont.

$\mathrm{Gu}$. thirteen billets four four three and two or. Sir Jolin (Thomas, L, Harl. MS. 6137) Couderey, $L$. Cowdrey, co. Berks.

Or thirteen billets four three three two and one sa. GABRYELL, $V$.

\section{BILLETS}

Arg. fifteen billets five four three two and one sa. Belvale.

Or fifteen billets six five three and one sa. BELVALE.

\section{BILLETS and in chief....}

\section{Canton}

Az. fifteen billets five four three two and one or a canton erm. Fanacourt.

on a Chief

Az. fifteen billets five four three two and one or on a chief of the second three birds sa. Sr. Robert Dormore, Wyng, $V$.

\section{BILLETS}

Gu. eighteen billets four five four three and two or. William de Colevile, $F$.

\section{BILLETS}

Per saltire az. and gu. twenty billets or. Conant.

\section{BILLETY}

Arg. billety gu. Sir William Wantrn, $L$, (error). Az. billety and crescents or. Donmare. Billety counter-billety gu. and arg. BILLINGER.

Gu. billety or. Sir John Cowdrey, L, Harl. MS. 6589. Sire Thomas de Coudrey, N. Sire Thomas Coudray, $O$.

Or billety az. Sire Edmon Gasceline, $N$.

Or billety az. a label gu. Sir Walter GASSELYN, $L$. Sire Walter Gasceline, $N$.

Or billety and a label gu. Sir Walter GASSELyN, L, Harl. MS. 6589 .

Or billety sa. Sire Edmond GASELYN, $O$.

Or billety sa. a label gu. Geffrey GACELYN, $B$.

Per chev. arg. and gu. billety counter-changed. Beirald, $V^{*}$.

Per saltire gu. and az. billety or. Conant.

Quarterly arg. and sa. billety counter-changed. KAYLE.

\section{BIRD,}

So many birds are not clearly distinguishable that it will often be requisite to consult several of the following subdivisions, especially the first.

\section{BIRD}

\section{not specially named or distinguished.}

.... a bird .... perched on the stump of a tree.... shooting forth new leaves and growing out of a mount in base... . DEsBrisay.

Az. a bird....feeding on the top of a garb or banded gu. Shear, Cornwall.

Gu. a bird arg.standing upon an apple or. ConHArr, co. Wilts.

Gu. a bird on a rock ppr. Rock.

Per fess arg. and gu. a bird standing .... upon the top of a tree vert with a bell hanging from a sinister bough and over all in base a fish on its back with a ring in the mouth .... City of GLASGOW.

Quarterly per fess indented sa. and arg. in the first quarter a bird (sec DUCK) of the second beaked and legged gu. Brasy, $V$. 
BIRD.

\section{BITTERN see Heron etc. BLACKBIRD}

Arg. a blackbird singing perched upon a vine vert thereon a bat or. Ronayne, D'laughtane, co. Waterford.

Or a blackibird (another a raven ppr.) sa. BECK, London; Baronetcy 1 Nov. 1714 ; extinct 1764: quartering sa. a mullet (another of six points) or, with az. a dolphin haurient (arg. or) or.

\section{CHOUGH see Crow etc.}

\section{COCK}

Arg. a cock gu. Bronhan, Brouchan, Brougham, and Broughan, Wales. Charlesworth. Cheke, Bludball, Suffolk, $W^{\text {}}$.

Arg. a cock gu. armed crested and jelloped or. Broncham, 1730. Brougham, Wales, $V$. Broughard. Cock or Cociss. More, Barking, Essex.

Arg. a cock gu. beaked and legged or. Broughton, $V^{*}$.

Arg. a cock gu. crested and jelloped or. Bronchan or Broughan, co. Cambridge.

Arg. a cock gu. armed crested and jelloped sa. CHEIKE, Essex.

Arg. a cock standing upon the hand ppr. of an arm issuing in fess from the sinister side vested az. HaNCOKE, Ireland.

Arg. a cock ppr. upon a mount vert. TREDCROFT, Horsham, co. Sussex; quartering Scrase and Michel.

Arg. a cock sa. Price, London.

Az. a cock arg. Lospital.

Az. a cock or. Tanand or Tanane, France.

Az. a cock or armed and crested .... Boucherett, Willingham, co. Lincoln ; quartering Ayscoughe.

Az. a dunghill cock perched upon an escallop or. OtTerbury.

Barry of twelve (arg. and gu. $V^{*}$ ) gu. and arg. a cock or. ClYNKE, $V$.

Barry of twelve gu. and az. a cock or crested and jelloped of the first. Clynke or Clurke.

Gu. a cock arg. Chente. Chenvely. Chiefly. Lospital.

Gu. a cock or. HAIrER.

Or a cock standing upon a horn .... HoldiNG, Middlesex.

Or a cock gu. armed crested and jelloped sa. Chere, Debenham, Suffolk, $W$.

Or a cock gu. beaked sa. CheEeE or CHenE, Suffolk. Cheire, $Y *$.

Quarterly or and gu. a cock in the first quarter ppr. Craster.

\section{CORMORANT}

\section{including Lever and Sea Crow}

Arg. a cormorant sa. beaked and legged gu. hold. ing in the beak a branch of sea-weed called laver inverted vert. Town of LIVERPOoL.

Sa. a cormorant arg. Popelier, $V$.

CORNISH CHOOGH see Crow etc. CRANE see Heron etc.

\section{CROW}

including Cornish Chough, Raven, Rook, etc.

Arg. a Cornish chough ppr. Trenothen, Corn. wall. Trenethyn, 1730. Trevethin, $V$.

Arg. a raven ppr. Corbet. Morton, 1730.
BIRD.

CROW, etc. cont.

Arg. a raven croaling ppr. (The ancient arms of) Hampden, Great Hampden, co. Buckingham. Arg. a raven ppr. perched on a torteau. Raves, Creting St. Mary's Suffolk, temp. Henry VIII.

Arg. a rook ppr. (" M $а т т н г W$, quartering sa. a lozenge arg.)

Arg. a raven sa. CoRnet, Hardgray, Scotland. Corber, Morton, Thomas, Worcester, p. 20. Sir Thomas Ernton, $V$. Morton, $V$. Raventhorp, $V$. Raventhorpe. Rolfe.

Arg. a raven sa. membered gu. Trenethin, $V^{*}$. Arg. a raven volant sa. Ernes. WhITHERING or Withering, Overton, co. Stafford.

Gu. a raven ppr. in a garb arg. Watkin ap John Hir.

Or. a raven ppr. Beck, London; Baronetcy 1 November 1714; extinct 12 January 1764; quartering sa. a mullet (another of six points) or, with az. a dolphin haurient (arg. another) or. Corbet, Wattlesburgh, from whom descended Conbet, Leigh and Sundorne Castle; a branch of ConBeT, extinct Barons of Caus, co. Salop: Corber, Hadley and King's Bromley, the heiress m. Grevile: CoRBEt, Stoke and Adderley, quartering Thoret, Erdington, Hopton, Gratewood, and Hill, Baronetcy 19 September 1627 extinct 7 May 1750, from whom descended (Davenant) CoRBET, Baronetcy 27 June 1786 extinct 31 March 1823: Corbet, Moreton Corbet, quartering Thoret, Erdington, and Hopton, from whom descended (besıdes Corbet, Elsham, and Darnhall,) quartering Humfreston, CorBer, Moreton Corbet, Baronetcy 29 January 1642 extinct 6 August 1688 , a widow created Viscountess Corbet 1679 ob. 1682 the heiress m. Kynaston, and its branches CoRBET, Shawbury, Moreton Corbet, and Acton Reynald Hall, Baronetcy 3 October 1808, quartering Prynce and Wicksted: as well as Cor.Ber, Humfreston, quartering Pryse; and its branches, Corbet, Ynysmaengwyn; and Corbett, Nash, quartering Jones, from whom descends Corbetr, Darnhall, Elsham, and Ryther quartering Edwin and Thompson. Cornet, Sprowston; Baronetcy 4 July 1623 extinct 1661. Corbet, Corbet Hill, co. Wexford. ConBet, co. Hereford: Norfolk; and Suffolk. Richard Corbet, Bishop of Oxford 1628, Norwich 1632.5. IAAROCHE, Over, co. Gloucester; quartering arg. on a mount vert an eagle close looking at a sun in glory; $\mathrm{Ba}$ ronetcy 17 August 1775; extinct 1805 .

Or a raven ppr. sitting upon an orb gu. RAvEN, Richmond Herald, ob. 1615 . Raven, Hadley, Suffolk.

Or a raven ppr. collared arg. Corbet.

Or a l'aven rising ppr. RAVEN, London.

Or a raven sa. Sire Peres Conbet, $N$. Sr. Piers Corbet, Walelsborough, co. Gloucester, temp. Edwarl III, $V$. Corbet, Cans; and its rela. tions, Corber, Shawbury, Moreton Corbet, and Acton Reynald Hall; Baronetcy 3 October 1808; and CORBet, Adderley Hall and Child's Ercoll, co. Salop. Conbet, Humfreston, and its descendants as above. CorbeT, Stolie-uponTern, and Adderley; Baronetey 27 June 1786; ex. tinct 31 March 1823. Richard Corbet, Bishop of Oxford 1628, Norwich 1632.5. Morton.

Or a raven feeding on the back of a hog lying fesswise sa. Dansinine, Scotland.

Or a raven sa. standing upon the top of a torteau. PATEN, $V$. 
BIRD.

CROW etc. cont.

Per fess or and arg. in chief a Cornish chough (ppr. another a raven, another) sa. HoARD.

Quarterly per fess indented arg. and gu. in the first quarter a Cornish chough (ppr. another a raven, another) sa. ACTON, London.

Quarterly arg. and sa. in the first a rook pr. on the second a lozenge of the first (? MatThew.)

Quarterly or and gu. in the first quarter a raven ppr. Crastor, Crastor, Alnwick, co. Noitluum. berland; quartering Wood.

Quarterly or and gu. in the first quarter a rook ppr. Craister or Craster, Northumberland.

Quarterly or and gu. in the first quarter a Cornish chough (ppr., another a raven, another) sa. Wristo.

\section{DOVE including Pigeon}

Arg. a dove .... with an olive-branch in the beak vert on the top of an ark in water ppr. GeLite, Blackford.

Arg. a dove rising ppr. out of a tree growing from a mount in base vert. CHaUran.

Az. on a mount in base vert a pigeon arg. Crop. Or a dove rising on the top of a tree ppr. growing out of a mount vert. DDPRatr, Middlesex.

\section{DUCK}

including Mallard, Seateal, Sheldrake, Shoveller, Smew, Teal, and White Nun.

(? Arg.) a sea-teal gu, winged or. Elchar. Az. a sheldrake arg. LonGFond.

Az. a smew or white nun ppr. Aвnотт, Holme, Academy.

Gu. a sheldrake arg. LANGFond.

Gu. a shoveller wings close arg. a crescent.... for diff. LANGFORD or LANGEFORD, London and Middlesex.

Quarterly sa. and arg. in the first quarter a teal of the last. Brezzy.

Quarterly per fess dancetty sa. and arg. in the first quarter a teal of the last. Bressey.

Quarterly per fess indented sa. and arg. in the first quarter a mallard of the last. Brescy or Bressy, Wistaston, co. Chester.

Sa. a shoveller arg. Popler. Popeller, $V^{*}$.

\section{EAGIE}

Arg. a demi-eagle displ. parted per pale issuing from the sinister.... Blomberg, co. Somerset; quartering arg. on a fess sa. a billet fesswise voided betw. .... of the same counterclanged, and arg. a demi-eagle issuing from the dexter ....

Arg. a demi-eagle wings displ. over a castle upon a hill all ppr. Town of BEDFORD.

Arg. a demi-eagle displ. parted per pale issuing from the sinister sa. Laurence Campegrus, Bishop of Salisbury 1525.34, impaling arg. a wolf salient sa.

Alg. a demi-eagle displ. parted per pale issuing from the sinister sa. BounTEYN, quartering sa. a goat salient arg. over all on an escucheon .... a rose ...., $r$.

Gu. a demi-eagle displ. parted per pale issuing from the sinister gu. Swetran, Castleleiffe, Kilkenny, impaling chequy arg. and az.; descended from Sir Robert Swetrian, co. Waterford, Baron by writ to the Irish Parliament 1374.
BIRD.

EAGIE cont.

Or a demi-eagle donble beaded sa. LombarD, Danesfort, near Mallow, co. Cork; impaling fusily or and sa.

.... an eagle displ, reguard .... Town of SEAFond, Essex; seal ....

.... an eagle displ. double headed .... Longsdon, Little Longsdon, co. Derby, temp. Edward I.

.... an eagle displ. ... looking at the sun .... Hewson, Ennismore, Kerry.

.... on a mount.... an eagle rising wings ex. panded and inverted looking upwards ... Sercon. Arg. an eagle displ. double headed .... Lr,WYD, Llwyn-y.Maen, co. Salop.

Arg. an eagle displ.az. Godmonton. Goodranston. Hore, Shandon, co. Waterford; the co-beirs $m$. Donellan, Bellew, and Aylmer. Hore, Pole Hore, co. Wexford; quartering Loundres, Fitzgerald, Misset, Botiler, Geynville, Lacy, Bygod, Marshall, Clare, Giffard, MacMurrough, FitzLeons, Sutton, Curling, Northope, and Clerke. Hore, Harperstown, co. Wexford; temp. Edward III; quartering Harper, St. John, Isham, Russell, Bradstreet, \&c. W WaBY or WAYGBY.

Arg. an eagle az. armed gu. Walter Berdene, $Y$. Arg. an eagle displ. az. armed gu. Bardney. Berden. Bylney, Norfolk. Montgomarere, co. Derby. William Vauncy, $Y$.

Arg. an eagle displ. az. armed or. VANCEY or VANCY, VaUncy. Monsire de Wanty, $Y$.

Arg. an eagle displ, double headed az. armed or. Mitron.

Arg. an eagle displ. barruly gu. and of the first. Thomas de Castre, $Y$.

Arg. an eagle displ. gu. Blunder.. Brun, co. Chester. Chamiberlayn. De Godemantone, $F$. HaLL, South Newington, andBanbury, co.Oxford; and co. Warwick. LANFRET or LANDFRET. Iswis, Harpton Court, co. Radnor; quartering a lion ramp. sa. crowned or. Henry MarTyN, Steple Mordyn, co. Cambridge, 1619, W. KeID, Scotland.

Arg. an eagle displ. gu. armed or. Chamberrin. Chambleyn, $V$.* Sr..de Chamblin, $V$. Goodmanston. Sodthweli, co. York.

Arg. an eagle displ. gu. armed sa. Bickerton, 'That Ilk; and Luffuess; Scotland.

Arg. an eagle wings expanded gu. FergusHill. Arg. an eagle wings expanded gu. standing on the trunk of a tree raguly vert. PORTer, $V^{*}$.

Arg. an eagle rising wings overt inverted gu. standing on a baston raguly in bend vert. William Porter, $V$.

Arg. an eagle displ. double headed gu. Aisencourt, $V$. Aynscourt. Aysingcourt. Dunlor, Dunlop, co. Ayr ; Baronetcy 1838; quartering quarterly gu. a lion ramp. arg.; witb gu. a fess chequy arg. and az. William de GRENEFELD, Archbishop of York, 1306-15. Mitson or Mrlton, co. Oxford. And with a mullet for diff. Duntop, Garnkirk, Scotland.

Arg. an eagle displ. double headed gu. armed az. Milton.

Arg. an eagle displ. double headed gu. armed sa. Milton, Milton, near Thame, co. Oxford.

Arg. an eagle displ. double headed gu. armed vert. Bungh, co. Devon.

Arg. an eagle displ. double headed gu. ducally gorged or. LANG, Ireland.

Arg. an eagle displ. double lieaded per fess gu. and sa. Petricin, Scotland. Peterkyn, $V$. Peterinin, $I^{*}$. 
BIRD.

EAGLE cont.

Arg. an eagle displ. ppr. Enery. Hore.

Arg. an eagle displ. double headed ppr. and a mullet for diff. .... Hesketh, attributed to Huan Blackleach alias Hesketr, Bishop of Sodor, \&c., 1487-1510.

Arg. an eagle displ. purp. Sire John Wauncy, $O$. Arg. an eagle close sa. EnNton, $V$.

Arg. an eagle sa. armed gu. standing on a child ppr. swathed or lying in a cradle vert. Covlchiefe.

Arg. an eagle sa. taking up a child gu. face ppr. KrLCHECE, Kilchech, co. Lancaster; quartering arg. a griffin segreant sa.

Arg. an eagle displ. sa. Anne of Boyemia, wife of Richard II. Bidulpe, East Greenwich, Kent. Brewn. Browne, co. Chester. Broyne. Bruen, Stapleford, co. Chester. Bruen, Bruen Stapleford, co. Chester, $V$. Bruin, $V^{*}$. Bryn. Byrde. Detap. Godmanston. Greenlaw, Scotland. Hulford, co, Gloucester. Lrndsey. Sir Thomas MILLINGton, M.D., 1730. Moniarty, Ireland. Ramsay, quartered by Pitcairn. ST. PAOL, Ewart Park, co. Northumberland; Baronetcy 17 November 1813; quartering az. on a pile issuant from the base throughout gu. betw. on the dexter side three lions ramp. or and on the sinister another of the same arg. a cross as the last charged with nine billets sa., with per pale or and sa. a bend engr. counterchanged, and the same quarterings reversed in order; over all an escucheon of pretence for St. Paul. Fane DE SALIS, quartering az. a griffin segreant or; all quarterly, with paly of six arg. and az. on a chief or a willow or salix ppr., az. three gauntlets or, gu. on a saltire arg. a rose of the first, gu. a fess or betw. six mullets arg., and arg. quarterly with az. fretty silver over all a bend sa. Amys, and Henry, de SAwney, D. Scharlton. Scotez. Sire Johan de Strutheleye, $O$. Sire Johan de StyrchesLegr, $N$. Shelly. Stabley. Stapleford, co. Chester. URWYN. WEsTon, co. Stafford.

Arg. an eagle displ. sa. with a crescent for diff. .... Sir John Ramsay, Scotland, temp. James VI. impaling az. a dexter hand holding a sword in pale arg. hilted and pomelled or piercing a man's heart and supporting on the point an imperial crown ppr.

Arg. an eagle displ. sa. a bend az. Jocors.

Arg. an eagle displ. sa. a (baston Sr. Jobn Joce or JoRCY, $L$, ) bend compony gr. and or. Rose.

Arg. an eagle displ. sa. a (baston Sire Johan JoCE, $N$,) bend gu. JoceYs.

Arg. an eagle displ. sa. on a bend gu. three crescents of the field. Ramsar, Drum.

Arg. an eagle displ. sa. resting each claw on a column with capital and base az. BarTolozzI.

Arg. an eagle displ. sa. standing on a staff raguly fesswise in base vert. SELWARD, co. Warwick; and co. Wilts.

Arg. an eagle displ. sa. armed az. Mulingtron, $V$. Arg. an eagle displ. sa. armed gu. Bocklande or Boteland, Scotland. Boyland, Suffolk. Browne, Ireland. Bruen or Bruin. Harpins. Ransay, Baron Dalbousie 25 August 1618, Earl of Dalhousie Baron Ramsay 29 January 1633 , Baron Dalhousie 11 Angust 1815, Marquis of Dalhousie 25 Angust 1849, quartering Broun. Ransay, Bamff House, co. Perth; Baronetcy 1666. RarrsaY, Russel, Scotland; quartering
BIRD.

EAGLE cont.

Russel. Struutheler, $V$. Monsire de Stirchesly, $Y$. Strecheley, $V *$. Stutheley, $V$. Styrchlegh, co. Derby. Wilberfosse, $V^{*}$.' Arg. an eagle displ. sa. armed gu. over all on an escucheon of the first a saltire of the second charged with an urchin (hedgehog) or. Maxwell, Everingham Park, co. York; and Carlaverock, co. Dumfries; quartering Constable and Haggerston. Maxwell, Earl of Nithsdale 1696-1716.

Arg. an eagle displ. sa. armed and langued gu. Bruyne, Harl. MS. 1603.

Arg. an eagle displ. sa. armed or. Alman. Bockland or Bokeland, Scotland. Bocland, Buckland, co. Hertford. Bokeland, Scots, $V$. Polland. Rockland.

Arg. an eagle displ. sa. armed ppr. WHLERForce, Markington, co. York; a branch of WiLberfos or WLLERForce, Wilberfos, co. York.

Arg. an eagle displ. sa. armed purp. EAgLESTON. Arg. an eagle displ. sa. beaked gu. Sr. John de Sterchilegh, co. Nottingham, $V$.

Arg. an eagle displ. sa. collared ducally of the tirst. HULKEFORD, co. Gloucester.

Arg. an eagle displ. sa. crowned or. Este.

Arg. an eagle displ. and crowned sa. The Trroc. Arg. an eagle displ. double beaded sa. ATHEson, Scotland. Bowcegault. Brin, co. Chester. Browne, Ireland. Browne, Baron Oranmore and Browne, 1838. Este, $Z, 681$. Evans, Marsh-Gibon, co. Buckingham. (? John Evans, Bishop of Bangor 1702, Meath 1715, quartering arg. three ragged staves sa., an escucheon arg. a human leg couped at the thigh sa.) GLYN or Glyne, W. GLYN, Glyn Llhivon, co. Carnarvon; quartering arg, three brands raguly sa. fired ppr., an escucheon arg. a human leg couped at the thigh sa.; and his de. scendants Guynne, Bisseter, co. Oxford; and Hawarden Castle, co. Flint; Baronetcy 20 May 1661 ; quartering arg. three brands raguly sa. fired ppr.; and Glys, Gants, co. Dorset; Baronetcy 22 Norember 1800; descended from GLyN, Ewell, Surrey; Baronetcy 25 September 1759 ; quartering Lewen and Powell. Hoare, Ireland. Hughes, Wales. Hugres, Bodwryn, co. Anglesey. Minlington, Millingtor, co. Chester ; and Essex. Morris, The Hurst, co. Salop. Sicheston. Worte, Luckham, co. Somerset. Anne of BoHemia, wife of Richard II, quartering az. a lion ramp. arg.

Arg. an eagle displ. double headed sa. over all on a chev. gu. three roses or. HuMfreston, co. Hants.

Arg. an eagle displ. double headed sa. standing on a billet traverse the escucheon raguled and trunked vert. SELWOOD.

Arg. an eagle displ. double headed sa. perched upon a staff fesswise raguly vert. DELLWoOD or DELwOOD.

Arg. an eagle displ. double headed sa. standing on a piece of a tree raguly vert. DELWARD or Delwood, $V^{*}$. But with a crescent .... for diff. Henry Deswood, $V$.

Arg. an eagle displ. double headed sa. armed az. Segheston. Sikeston.

Arg. an eagle displ. double beaded sa. armed gu. LLOyd, Havering, co. Essex. Ransey. Siggeston Segheston or Siggeston. Sigheston, $V$. John de Siggston, $V$. Sigastone, $V^{*}$. John de Siggeston, $Y$. Monsire de Sigeston, $Y$. 
BIRD.

EAGLE cont.

Arg. an eagle displ. double headed sa. armed or. Morris. Worth, Coruwall.

Arg. an eagle displ. double headed sa. beaked gu. LoYD, Wales.

Arg. an eagle displ. double beaded sa. beaked or over all a fess gu. Worth, Barnstaple, co. Devon. Wonth or Wrothe.

Arg. an eagle displ. sa. legged gu. Thomas StrichelaY, $Y$.

Arg. an eagle displ. sa. legged or. Bucktand.

Arg. an eagle displ. reguard. sa. armed or. Bokeland, $V$.

Arg. an eagle recursant wings overture sa. BACK.

Arg. an eagle rising sa. armed or. Hutoft or HiLTOFTE.

Arg. an eagle rising wings overt inverted $\mathbf{8 8}$. armed or. Hiltofte, $V$.

Arg. an eagle preyant sa. upon a child swaddled gu. Culchetr, $V^{*}$. The child ppr. swathed gu. banded or. Culcheth or Kolcheth, Culcheth, co. Lancaster.

Arg. an eagle wings expanded sa. preyant upon a child ppr. swathed gu. banded or. HyndLex. KuCHECHE.

Arg. an eagle wings expansed sa. standing upon a child swathed gu. banded or. Сuцснетн, $V$.

Arg. an eagle wings expanded sa. armed or. Hiltofte, $V^{*}$.

Arg. an eagle volant sa. seizing upon a child ppr. swathed gu. in a nest of the first on a tree eradicated as the second. Risley.

Arg. an eagle vert armed gu. Monsire de Bilney, $Y$.

Arg. an eagle displ. vert. Sire Roger de BILNEye, $N$. Sir Roger Billey or Bylney, $L$; but Burlney, L, Harl. MS. 6137. Buney, Norfolk. Mac Eniery, Ireland. Sirthers.

Arg. an eugle displ. vert a baston compony gu. and of the first. Sir John Silton, L, Harl. MS. 6589.

Arg. an eagle displ. vert on a chev. gu. three roses of the field. Humfreston, Humfreston, co. Salop.

Arg. an eagle displ. vert armed gu. Sr. Roger BILNEY, temp. Edward I, $V$. William Byiney, $Y$.

Arg. an eagle displ. vert armed gu. crowned or. Botringhair.

Arg. an eagle displ. double headed vert. Low, $V^{*}$. Low, co. Lancaster. Lowe, co. Lancaster, $W$.

Arg. an eagle displ. double headed in bend vert. DELLWOOD.

Arg. an eagle displ, double headed vert armed gu. LAw, Archdeacon of Rochester.

Az. an eagle displ. arg. CAYNE. Sir Robert Cotton de Bruce, Hatley St. George, co. Cambridge, 1730. Cotтon, Connington, co. Huntingdou, usurped by Cayne. CотTоN, Gidding Abhots, co. Huntingdon; the heiress m. Fitzherbert. Cotron, Ridware, co. Stafford; from co. Chester; adopted, instead of his own coat, arg. a bend sa. betw. two ogresses, by William Cotton (on marriage with Agnes, heiress of Walter de Ridware of Hempstall Ridware, co. Stafford, temp. Edward III), from whom de. scended CotTon, Ridware, Bould, and Crackmarsh, co. Stafford; and CоттоN, Connington, co. Huntingdon; Baronetcy 29 June 1611; extinct 27 March 1752. Este, as borne by Mary Beatrix Eleanor, daughter of Alfonso II Duke of Modena, wife of James II; quarterly with az. three fleurs-de-lis or a bordure in.
BIRD.

EAGLE cont.

dented point in point or and gu. for Ferrara. Hill. Hujlers. Joan de Hulle, $\boldsymbol{E}, \boldsymbol{F}$. Redward or Ridward, Netherseil, co. Leicester, temp. Henry III. Sire Thomas de RIDEWARE, $N$. Sr. Thomas de Ridware, temp. Edward I, V. Rydware or Rydeware, co. Cambridge; and Canterbury, Kent. ShUldhaM, Dunmanway, co. Cork; descended from Schuldam or Shouldham, Shouldham's Manor, Norfolk; Admiral Molyneux SнपLDHAM, Baron Shuldham, 1776 ; and Shuldharr, co. Longford. Sparke. Tovy, Scotland. Vampage. Wilcotrs, $V$. And with a 3 -foil of the second for diff. VAMPAGE.

Az. an eagle displ. arg. on a bar sa. two mullets of the second. BARR or BARRY, Scotland.

Az. an eagle displ. arg. a bend gu. Hill alias Hude, Parva Drayton, co. Salop.

Az. an eagle displ. arg. a bendlet gu. Humires, $V^{*}$. Sr. Richard Hullys, co. Cambridge, temp. Edward I, $V$.

$\mathrm{Az}$, an eagle displ. arg. a baton in bend gu. Hulley Hullies and Hullys. Hulleys or Hullers, co. Cambridge. Sire Richard de Hulles, $N$.

Az. an eagle displ. arg. on a fess sa. two mullets of the second. BARr or BARRY, Scotland. Bettie, Scotland.

Az. an eagle displ. arg. armed or. Sr. Thomas Cotton, Ridware, $V$. Hill. Hulles. Parke, Sr. Thomas de Ridware, temp. Edward I, $V$. Sparke. WIfocks. Wilcotts aligs Sparke, $V$.

Az. an eagle displ. arg. armed or collared witli a ducal coronet gu. Wilcocks.

Az. an eagle displ. arg. armed and collared with a ducal coronet or. Wilcots. Wircotts, $V$.

Az. an eagle displ. arg. armed and crowned (another also holding a scentre and orb) or. EsTE, as borne quarterly with Ferrara by Mary Beatrix Eleanor, daughter of Alfonso II Duke of Modena, wife of James II.

Az. an eagle displ. arg. collared ducally or. Raineford, Cumberland.

Az. an eagle displ. arg. crowned or. Sharnesfeld, K.G., $V$. Sharnesfietid.

Az. an eagle displ. double headed arg. CADMER. MatThEW or MathYN.

Az. an eagle displ. double headed arg. over all a bendlet sa. LANGTON, co. Leicester.

Az. an eagle displ. double headed arg. over all on a fess sa. two mullets of the second. Barrie, Scotland.

Az. an eagle displ. double headed arg. armed gu. Machin. Mathyn, $V$.

Az. an eagle displ. double headed arg. armed or. VAMPAGE.

Az. an eagle with wings elevated arg. Coton, Ashill, Norfolk.

Az. an eagle displ. wings downward arg. crowned or. (Part of the arms of) Diepholz, $Z, 871$.

Az. an eagle barry of six arg. and gu. Monsire John Chanscyre, $Y$.

Az. an eagle displ. barry of six arg. and gu. Chanserie, $V$.

Az. an eagle displ. barry of eight arg. and gu. Cansure. Sr. John Castre or de Castre, $L$. Chanserine, $V^{*}$.

Az. an eagle displ. barruly arg. and gu. Morvild, Cumberland, temp. Henry II.

Az. an eagle displ. chequy arg. and gu. Moravia, quartered by Bohemia. 


\section{BIRD.}

EAGLE cont.

Az. an eagle displ. double beaded erminois. LYDE, Stanton Wick, co. Somerset, 1641 ; and Ayot St. Lawrence, co. Hertford; Baronetcy $13 \mathrm{Oc}$ tober 1772, extinct 22 July 1791, quartering Sage, Payne, and Mortimer.

Az. an eagle displ. or. Bartrair. Beckberie, Hill Wotton, co. Warwick. BIgbery, Essex. Bigbery, $V$. Dunne, Brittas, Queen's County. Godianston, $V$. Goodianston, $V$. Grandison or Granson. Hall or Hull, co. Cambridge. Philip ap Ivos, Lord of Iscoed. J Jeane. Matthew. Raynsford. Wat de Sarnesfeld, $E$. M. Nycoll Sarnesfeld, $S$. SholdhaM or Schouldair, Norfolk. Hugo de Schuldhair, roll of Manor of Marham, Norfolk circa 1275. Spencer. SteEnested, $V^{*}$. Sr. Guy Stenesclode, Essex, temp. Edward I, V. Stensclod. And with a crescent for diff. .... Charles Doyne, D.C.I.., ob. 1617.

Az. an eagle displ. or a baton gu. Sire Johan de Wolvertone, $N$.

Az. an eagle displ. or a bend gu. Wolverton, Wolverton, co. Buckingham, temp. Henry III.

Az, an eagle displ. or a bendlet gu. Sr. John Wolverton, co. Buckingham, temp. Edward $\mathrm{I}, V$.

Az. an eagle displ. or a ribbon gu. Gueriet.

Az. an eagle displ. or on a fess arg. three ermine spots sa. Berger.

Az. an eagle displ. holding in the beak a penner and inkhorn standing on a book fesswise closed the clasps downwards or. Company of Scriveners, London.

Az. an eagle displ. or armed arg. Cestrani or Cestrin.

Az. an eagle displ. or armed gu. Bigburr, Bigbury, co. Devon; the heiresses m. Champer. nowne and Durnford. BIGgorge. HaLL. Sr. $\ldots$... de Hule, co. Cambridge, $V$. Scholdham, $V$. John Sharnesfelde, $Y$. Sharnfielo. Shouldhair, Norfolk. Shuldhair, Marlesford Hall, Suffolk. Speak. John de Wolverton, $Y$. Monsire de Wolverton, $Y$.

Az. an eagle displ. or armed sa. crowned gu. Charnfield, $V^{*}$. Sharnefield, $V^{*}$. SHARNFIELD.

Az. an eagle displ. or ducally gorged arg. HALI. Harrison, London, descended from Durham.

Az. an eagle displ. or crowned arg. SARnefield. Az. an eagle displ. or crowned gu. Sr..... de Charnfelde, $V$.

Az. an eagle displ. and cromned or. Cranfield.

Az. an eagle displ. double headed or. De Borville. Lотн or Lотнe. LYde, Collinson, Somerset, ii, 436. Mitton. Pynell. Speake, $V^{*}$. Speke, co. Somerset, $V$. Sweetman.

Az. au eagle displ. double headed or a bend sa. LANGTON, Church Langton, co. Leicester.

Az. an eagle pouncing on a hare courant or. Denskine, Scotland.

Az. an eagle reguard. to the sinister rising wings overt and inverted or beaked gu. Richard Canvill, $V$.

Az. an eagle ayrant or armed gu. BygBery, co. Devon.

Az. an eagle wings endorsed or. EDMonds, Lyndhurst, near Southampton.

Az. an eagle with wings endorsed standing on a branch of laurel all or. Priory of Austin Canons at Caermarthen, Wales.

Az. an eagle reguard. wings expanded or armed gu. Canvul, $V^{*}$.
BIRD.

EAGLE cont.

Az. an eagle volant or. Enmonos, Winslow, co. Buckinghan ; and Cornwall.

Az. an eagle displ. per pale or and arg. beuked (and legged, Harl. MS. 1392) gu. standing on a piece of a tree raguly (per pale of the third and second, Harl. MS. 1392) .... PYNYLL, co. Devon, $W$. Pyngill, Harl. MS. 1392.

Az. an eagle displ. donble headed per pale or and arg. holding in each claw a baston (erect $V^{*}$.) sloped pilewise of the opposite metals. Pyvell, $V$.

Az. an eagle displ. ppr. Sparkes, in Bramley Church.

Barry of five arg. and az. an eagle displ. double headed gu. Speake, $V^{*}$. Sr.Jolnn Speke, $V$.

Barry of five or and az, an eagle displ. gu. GaRnegotT.

Barry of six or and az. an eagle displ. gu. Sr. John WaLrond, co. Wilts, $V$.

Barry of six or and az. an eagle displ. double headed gu. WALDRoN or WaLroN, co. Devon; Pucklecluurch, co. Gloucester ; and Alborne, co. Wilts.

Barry of seven arg. and az. an eagle displ. double headed gu. armed or. SPEкE, Cornwall.

Barry of seven or and az. an eagle displ. gu. armed or. Jernegan Fitz Hugh, Tanfelde, $P$.

Barry of seven or and az. an eagle double headed expanded gu. WALROND, Alborne, co. Wilts.

Barry of seven or and vert an eaglo displ. gu. Prannelu, Rudsmill, co. Hertford.

Barry of seven or and vert an eagle displ. sa. Prannell or Pranell, Martin Wothy, co. Hants; and London; granted 1584. Henry Prannell, Alderman of London 1584, $W$.

Barry of eight az. and arg. an eagle displ. double headed gu. Le EspeK, co. Devon; SpEke, Whitelackington, co. Somerset; the heiress $\mathrm{m}$. North ; and Spere, Jordans, Ilminster.

Barry of nine or and az. an eagle displ. gu. GarNegan, temp. William I, $V$. Jernegan, $V^{*}$. Barry of ten or and az. an eagle displ. gu. Gernegan, Tanfield, Richmond.

Barry arg. and az. an eagle displ. gu. Waleran, Sutton Walrond, co. Dorset, temp. Henry 1I.

Barruly arg. and az. an eagle displ.gu. GarneaAN or GARNEGOTT.

Barruly or and az. an eagle displ. gu. GarsagaN or GARNEGOTT.

Barruly or and az. an eagle displ. gu. armed of the second. Gernagon Fitz-Gernagon, Tanfeild, $Y$.

Barruly or and az, an eagle displ. of the first. Gernegan.

Chequy az. and or an eagle displ. arg. Barrow.

Erm. an eagle displ. ermines on a chev. engr. or three lozenges az. HyDE, Whetstone, Middlesex; granted 1691.

Erm. an eagle displ. gu. Sr. Thomas Bedingfelde, Norfolk, $V$. Bedingfeld, co. Gloucester; Bedingfield, Suffolk; and Ditchingham, (established there, 1350, by a younger son) Norfolk. Bedingfield, $V^{*}$. Sir Henry Bedingfeld, Oxborough, and Beckhall, Norfolk; and Brailes, co. Warwick; Baronetcy 2 January 1660. Sir Robert BedingField, Alderman of London 1703. Browne, Collinson, Somerset, i, 105. Martyn, Staplemorden, co. Cambridge.

Erm. an eagle displ. gu. armed az. Sr. Nicholas CoDHaM, $V$. 


\section{BIRD.}

EAGLE cont.

Erm. an eagle displ. double headed gu. Woodes, Suffolk.

Erm. an eagle rising holding in the dexter claw a stone gu. John Siminges, M.D., $V$.

Erm. an eagle displ. sa. READ, Cairney, quartered by Lyon.

Erm. an eagle displ. sa. armed gu. a bendlet compony or and az. Rose, Easter Gate, Sussex; granted 16 February 1681 .

Erm, an eagle displ. sa. a fess chequy or and az. Chambers.

Erm. an eagle displ. double headed sa. armed gu. Sr. .... de Worthe, Devon, $V$. Worte or De Worthe, Worth, Devon, temp. Henry II.

Gu. an eagle displ. alg. Chambertayn. Cosyn, Norfolk. Geney. Joan de Godemonestone, E. Godenenonestone, E, Harl. MS. 6137. LYMESEY LyMSEy LyNDSEy or LyNSEY. Priaulx, Guernsey. Sire Henry de SodHuld, $O$. Soormill, Soothill, near Wakefield. Sr. Henry Sothшl, $V$. Sire Johan Sotholde, $N$. Sodthill, co. Leicester. Southwell, Essex; and co. Lincoln. Suthill, Redburn, co. Liv. coln. WAYNY.

Gu, an eagle displ. arg. a bend compony or and sa. Deane.

$\mathrm{Gu}$. semy of fleurs-de-lis and an eagle displ. arg. Goodsinging.

Gu. an eagle displ. arg. beaked or a (fess or rather) bar az. William de Sothilse, $G$.

$\mathrm{Gu}$. an eagle arg. membered or. Johan de Sothute, $G$.

Gu. an eagle displ. arg. armed or. Brgberie. Sothil, , $V^{*}$. Sr. John Sothille, Essex, temp. Edward III, Harl. MS. 1392. Henry SotrHiLL, Y. Sr. John Tothil, Essex, temp. Edward I, $V$. WANEY, $V^{*}$. WAYNEY WAYNY or WaNCY, Harl. MS. 1392.

Gu. an eagle displ. arg. crowned or. Marcrner.

Gll. an eagle displ. double headed arg. MACEIDON, $V$. Malcedon. Fitz-Stephen, Norton, co. Devon.

Gu. an eagle displ. barry of six erm. and az. BARNeTr, quartered by Rolls.

$\mathrm{Gu}$. an eagle displ. barry of six or and vert. Coche or Cocher.

Gu. an eagle displ. barry of eight or and vert. Coche, $V^{*}$.

Gu. an eagle displ. barry of ten or and vert. Sr. .... de Coche, $V$.

$\mathrm{Gu}$. an eagle displ. barry of twelve or and az. Coche, $V^{*}$.

Gu. an eagle displ. barry of twenty-three or and az. CoCHe, $V$.

$\mathrm{Gu}$. an eagle displ. bendy of three or and of the first. ILLEY, co. Lincoln.

Gu. an eagle displ. erm. WANEY, 1730. WAYNEY, $V$.

Gu. an eagle displ. erm. armed or. Madreston. Gu, an eagle displ. or. Genex. Godard, $V$. Godard, Walpole, Norfolk. Goddard, Standen, Swinden, Catford, and Ogbourn, co. Wilts, 1730. Gothard, Newcastle. Keveriond. Sire Peres de Lemesi, $N$. Richar de Limesky, $G$. Lisley. Lyiesey or LyNdsey, co. Warwick. Sire Piers de Lymesy, 0 . Priaulx, Guernsey. M. Raffe RochEFORD, quartering quarterly gu. and or (another or and gu.) a bordure sa. bezanty, S. Storange or Storinge. Strong, Ross, co. Hereford. Strnong, Ireland.

Gu. an eagle displ. or a baston az. Sire Felip de ILLEYE, $N$.
BIRD.

EAGLE cont.

Gu. an eagle displ. or a baston of the arms of Mounford. Sire Richard de Lemesi, $N$.

Gu. an eagle displ. or a bend az. ILLEY, Suffolk.

Gu. an eagle displ. or a bendlet az. Sr. Philip ILLEY, co. Lincoln, temp. Edward I, $V$.

Gu. an eagle displ. or armed and ducally crowned arg. Grabye, $V^{*}$. Granted 1592 to Graves, co. Northampton; James Grayve, co. York; and John Grave, London, W. Grave, Thanks, Cornwall; Westfirle, Sussex ; and Herton, co. York.

Gu. an eagle displ. or armed az. Lemesey, co. Warwick. Monsire de Linsie, $Y$. John LyMesey or Lymesy, $Y$.

Gu. an eagle displ. or armed sa. Lemosy or Lymusey, co. Warwick. Linsey, Arley, co. Warwick: temp. Henry III. LinDser, $V^{*}$. Sr. Piers Lissey, co. Warwick, temp. Edward I, $V$. Pevensey, $V$.

Gu. an eagle displ. or collared ducally az. Stone, London.

Gu. an eagle displ. or crowned arg. Greaves, Fent; and St. Leonard's Forest, Sussex.

Gu. an eagle displ. double beaded or. BLEwETT or Bluetr. Sr. John Ferit or De la Ferit, $I$. Frtz-Stephen, Norton, co. Devon.

$\mathrm{Gu}$. an eagle displ. double-hended or dimidiated with chequy arg. and az. Swe etman, co. Kilkenny; and Swetman, Castleleiffe, co. Kilkenny, as descended from Sir Robert SwetmaN Barony by writ to the Irish Parliament 1734 presumed to be in abeyance.

Gu. an eagle displ. double headed or a baston arg. LENOSBY.

Gu. an eagle ayrant or. BARDOLPH, Norfolk.

$\mathrm{Gu}$. an eagle wings elevated or. HEald, Par's Wood, Didsbury, Manchester; quartering az. a fret or over all on a fess arg. a rose betw. two crosses patty gu. barbed and seeded ppr.

Gu. an eagle wings expanded and ducally gorged or. GRAVE, London; and York; granted 12 June 1591.

$\mathrm{Gu}$. an eagle volant recursant in bend wings overture or. BEes.

Gyronny of eight arg. and gu. in chief an eagle displ. sa. Nicholas, France.

Gyronny of eight arg. and sa. an eagle displ. double beaded or. GooDMan.

Gyronny of eight erm. and sa. an eagle displ. double headed or. GOODMAN, Golborn, co. Chester; co. Hertford; and London. Gorman.

Gyronny of eight or and sa. an eagle displ. arg. LENTHORNE.

Gyronny of eight or and sa. an eagle volant gu. LeVERETT.

Lozengy or and az. an eagle displ. erm. armed of the first. Chinton.

Or an eagle displ. az. Carnegie, Carnegie, Scotland. Sr. Walter Fishide, $V$. Frisheal, co. Dorset. Lucton or Lugrown, That Ilk. Sire William de Mongomeri, $N$, or Montgomery, $O$. Sir John Montgomery, $Q$. Montgomery, Captain of Calais and Admiral of the Fleet 1347. Peverel, Ermington, co. Devon ; the heiress m. Carew. Rouse or Rous, Modbury, co. Devon; the senior descendants of Radulphus le Rufus. Shordham, Norfolk.

Or an eagle displ. az. quarterly with arg. three bars wavy az. on a chlef of the last a castorbeaver with his head turned biting off the castor or. Town of BeverLer, co. York. 
BIRD.

EAGLE cont.

Or an eagle displ. .... on a fess engr. az. a be. zant betw. two buckles. LAPSIEY, Sootland.

Or an eagle displ. az. holding in the dexter talon a rose slipped in pale ppr. Carnegie.

Or an eagle displ. az. armed gu. Carnegie, Southesk, co. Forfar; and Kinnard, Scotland. M. Nicol Mongomeri, $S$. Montgonery, Cub. ley, co. Derby. Sr. Jobn Montgonery, $Q$, Harl. MS. 6595. Sr. IVilliam Montgomery, Derby, temp. Edward I, $V$.

Or an eagle displ. az. armed gu. beaked of the first. Montgomery, Sherington, co. Buckingham; Cubley, co. Derby; and co. Stafford.

Or an eagle displ. az. armed and vulning itself on the dexter wing gu. Pouse, co. Devon, $V$.

Or an eagle displ. pruning its wings az. armed gu. Rous, Edmerstone, co. Devon; and Halton, Cornwall, quartering Ednerstone. Rous, Piercefield, co. Monmouth; and Courtyrala, co. Glamorgan; derived through Rous, Wotton. under-Edge, from Rous, Edmerstone, and Halton, quartering Rous.

Or an eagle displ. az. crowned gu. Sr. John Montgomerx, $Q$.

Or an eagle displ. double headed az. armed arg. Bluett, co. Hants.

Or an eagle close gu. Aquila.

Or an eagle in full aspect gu. standing on a perch issuiug out of the sinister side arg. Body.

Or an eagle displ. gu. John Bluet, G. Sir John BLuetT, L. Dernford. Life; quartering tz. an eagle displ. or. LYFF, $W$. quartering az. an eagle displ. or. LYNDSEy, Colby, co. Norfolk. M'IntiRe, England; quartering arg. a galley sails furled sa. flags gu. Montcomery, Cubley, co. Derby ; extinct temp. Henry VIII, the coheiresses $m$. Vernon and Giffard. Pumise or Purnse.

Or an eagle displ. gu. armed az. Pevensey, $V$. Or an eagle displ. gu. (another purp.) armed az. Sr. .... de Ethelston, co. Chester, $V$. Lindsey, $V^{*}$. Sr. Philip Linsey, co. North. ampton temp. Edward I, $V$. SETHELs'on, $V^{*}$.

Or an eagle displ. double headed gu. Sir John Blewet', L, Harl. MS. 6589. Blewett, co. Hants. Blokt, temp. Edward I, $V$. Sir John Bluetr, co. Hants, temp. Edward I, $V$. Blower. An augmentation to Boyle, Baron Boyle, 31 January 1699, Baron Boyle Viscount Kelburne and Earl of Glasgow 12 April 1703, Baron Ross 11 August 1815 ; quartering Boyle, and with an escucheon for Boyle of Kelburne. Peterkin, Scotland. Sire Johan Pluet, $N$. Rougenont, $V *$. Rougenoun', $V$.

Or an eagle displ. double headed gu. armed arg. Bluet, co. Hants.

Or an eagle displ. gu. armed and langued sa. M'INTYRe, Glenoe, Scotland; quartering arg. a galley sails furled sa. flags gu., with arg. a sinister band couped fesswise gu. holding a cross croslet fitchy sa.

Or an eagle displ. purp. LrNDser, Kent. Sire Felix de Lyndesheye, $N$.

Or an eagle displ. purp. a baston compony az. and arg. Sire Simon de Lindesheye, $N$.

Or an eagle displ. purp. armed gu. ETHELSTAN. Lindsey, Cumberland. John Lrndesey, Y.

Or an eagle displ. purp. (anotber gu.) armed az. Sr. .... de Ethalston, co. Chester, $V^{*}$. Lindsey, $V^{*}$. Sr. Philip Iinsfy, co. Northumberland, temp. Edward I, $V$. Sethelston, $V^{*}$. Or an eagle displ. double headed purp. Lotнe.
BIRD.

\section{EAGLE cont.}

Or an eagle displ. sa. Browne, Ireland. Buggin or Buggens. Carpenter. Benedictine Priory of St. Mary at Coventry, co. Warwick; Mo. nasticon. EDwyn. Ascribed to EDwIN the Saxon Earl of Coventry temp. of William I. Cobhail. Hugfond Hugfonde or Hukeford, co. Gloucester, temp. Edward I. The KIng of the Romans, V. Kirhlle or Krahm, co. De. von. Kirhilu, co. Devon, V. Kirkhill, co. Devon. Panther, Pitmedden, Scotland. John RaMSEY, in S. Olave, Southwark, 1669. Leofric, Earl of Mercia, as borne by Temple, Stowe, co. Buckingham, Baronetcy 29 June, 1611 (Baron Cobbam 19 October 1714; Viscount Cobbam 23 May 1718 till 1749); quartering Sheppey, Everton, Heritage, Spencer, Spencer, Deverell, Lincoln, Warsted, Heritage, and Lee; and by Temple, Baron Temple and Viscount Palmerston 12 March 1772. Weston, Collinson, Somerset, ii 368. Weston, Lichfield; and Preston Hall, Essex; quartering erm. on a chief az. five bezants. Weston, co. Norfolk; quartering Branthwayt.

Or an eagle displ. sa. a bend arg. HAKEFORD.

Or an eagle displ. sa. a beud compony gu. and arg. Seperton, co. Herefurd.

Or an eagle displ. sa. armed az. Porssy.

Or an eagle displ. sa. armed gu. Algar or Alger. Aldiaye. Carnegie. Cullen, East Sheen, Surrey.

Or an eagle displ. sa. beaked gu. Symon de Lindeseie, $G$.

Or an eagle displ. sa. beaked gu. a baston compony az. and gu. Felipe de Lindeseie, $G$.

Or an eagle displ. sa. collared arg. HAKEFORD, co. Gloucester. Huckford, $V$. Sire Wauter de HukEFond, $N$. Sr. Walter Hukford, co. Gloucester, temp. Edward I, $V$. HulkFord, co. Gloucester.

Or an eagle displ. sa. crowned ducally gu. WoLfF, Cams Hall, co. Hants; Balonetcy 18 October 1766 ; extinct 3 February 1837 ; quartering az. an armed arm issuing out of the clouds from the sinister grasping a sword in the attitude of striking ppr., with arg. a naked arm issuing out of clouds from the sinister holding a palm branch ppr., and or a triangle sa. ; over all vert a wolf pass ppr. in chief three fleurs-de-lis arg. Or an eagle displ. double headed sa. Austria. The Emperor of Germany, $V$. Montrerant. Baron De RothschILD; quarterly with az. an arm embowed holding eight arrows counter. crossing each other ppr., and or a lion ramp gu., over all on an inescucheon gu. a round pointed target in bend sinister ....

Or an eagle displ. double headed sa. armed az. RoME.

Or an eagle displ. double beaded sa. armed gu. The Emperor of Almayne, $Y$.

Or an eagle displ. double beaded sa. armed gu. crowned gold. The Empine, as quartered by Modena.

Or an eagle preyant sa. upon an infant swaddled of the first. Culchech or Culanech.

Or an eagle displ. reguard. sa. Weston, Baron Weston 13 April 1628; Earl of Portland 17 February 163:3; extinct 1688. WEston, Rugely, co. Stafford; granted by Segar.

Or an eagle displ. wings downward sa. Frederick II, Emperor of Germany, $Z, 87$. Edmund Earl of Connwaly, son of Richard the King of the Rorrans, $Z, 95$. 


\section{BIRD.}

EAGLE cont.

Or an eagle displ. vert. LyNDSEY, Northum. berland. Sire Pauf de Monhermer, $N$. Sr. Rauff de Monthermer, $H$. Montgonery. Ralph Lord Monthender, impaling or three chev. gu. for his wife Joan (Plantagenet) of Acre, daughter of Edward I, in whose right he was Earl of Gloucester and Hertford. $K$, Harl. MS. $6137 ; Z, 142,441-5$. Mounthermer, Essex. Salisbury, Montgomery.

Or an eagle displ. vert a bend compony arg. (? az.) and or. Sexton.

Or an eagle displ. vert a baston compony gu. and arg. Sir John de Silton Sylhton or Sylton, $L$. Sire Johan de Sibbetone, $N$.

Or an eagle displ. vert a bendlet compony gu. and arg. Sr. John SAPERTON or SAPTON, co. Hereford, $V$. Septon. Sybton or Sybleton.

Or an eagle displ. vert armed $a z$. a bend counterchanged. Sexton.

Or an eagle displ, vert armed gu. Raufe de Monhermer, $F$. Sr. Raufe de Monthermer, $V$. Monsire Edward Mounteermer or de Monthermer, $Y$.

Or an eagle displ. vert armed gu. a baston com. pony of six pieces as the second and arg. Joun de Seperton, $Y$. Monsire de Sepenton, $Y$.

Or an eagle displ. vert armed sa. Monthermer.

Or an eagle displ. vert armed of the last. (? Chamberlayn.)

Paly of six arg. and az. an eagle displ. sa. a bendlet gu. Sr. John Babbwelt, Middlesex, temp. Edward I, $V$.

Paly of six arg. and az. an eagle displ. sa. armed or. BABWELL or BabBWell, Middlesex.

Paly of six arg. and az. an eagle displ. sa. armed or a bend gu. BABBWELL or BABWELL, Middlesex.

Paly of six or and gu. an eagle displ. sa. Stone.

Per bend arg. and a\%. an eagle displ. counter. changed. BlackNeli, co. Warwick; and co. Berks.

Per bend az. and or an eagle displ. counterchanged. Bracknoli.

Per bend gu. and vert an eagle displ. arg. armed or. Eutston, Cogshall, Essex.

Per bend gu. and vert an eagle displ. or. Sr ... de Grave or Grane, $V$. Grave, 1730. Grayne.

Per bend or and az. an eagle displ. counterchanged. Blacirnell, co. Warwick; and co. Berks. BlackNoll, $V^{*}$. Sr. John de Blackwall or Blakenhall, $c o$. Warwick, $V$.

Per bend sa. and arg. an eagle displ. counterchanged armed and erowned gu. Pessemarche or Pessmarche, Essex.

Per bend sa. and arg. an eagle displ. counter. changed crowned or. Pesemarch, $V^{*}$. Sr.... de Pesemarche, Éssex, $V$. Pesemarsh. Peshenche, $V$.

Per bend vert and gu. an eagle displ. or. Grane. Grave, $V$. Greaves, Greaves, temp. Henry III, Ingleby Hill, and Burton-on-Trent; Beeley, and Stanton, co. Derby ; and Mayfield, co. Sta. ford. Grove.

Per chev. engr. or and az. in chief an eagle displ. Sa. Hontbark.

Per chief az. and arg. over all an eagle displ. gu. Euson, Barham, Sussex.

Per chief erm. and or over all an eagle displ. sa. Mewess Mewsse or Mowse, Woburn, Bedford.

Per fess arg. and gu. an eagle displ. double headed counterchanged. NewBottuE. Newbottell, $V$. Newbottel. Newhottell, $V *$.
BIRD.

EAGLE cont.

Per fess az. with paly of six of the first and arg. in chief an eagle displ. as the last. A'Count.

Per fess wavy gu and erm. in chief an eagle displ. or. Southmead, Wrey, Chagford, Devon.

Per fess or and arg. an eagle displ. double headed sa. Des Bouverie.

Per fess dancetty or and arg. an eagle displ. az. UNDERHILI.

Per fess or and gu. an eagle displ. double headed as the second issuant from the top of a demirose and sun conjoined per fess counterchanged. William KNIGHT, Bishop of Bath, etc., 1541-7; Collinson, Somerset, iii, 399.

Per fess sa, and erm. in chief an eagle double headed or. GrefFy or GrefrRy, co. Warwick.

Per fess sa. and gu. an eagle displ. arg. EDGE, London; and co. Stafford. Edge, $W$. Fishide, $V^{*}$. Pilforough, Essex. Pillesburgh or Pullesburgh, $V$. Pullsburgh, $V *$ * Pulesborough or Pullegrough, London.

Per fess sa. and gu. an eaglo displ. erm. ducally gorged or. John CATchER, sheriff of London 1587 ; granted by Cooke, $W$. Сhatcher or Catcher, London.

Per pale arg. and gu. an eagle displ. counterchanged. Wincriey, Brockboles and Collerall Hall, co. Lancaster; assigned to WiNKLEY, Preston, co. Lancaster by Dugdale on account of a scal of WinELEY, Winckley, co. Lancaster, as in Harl. MS. 1437 fo. 93.

Per pale arg. and or an eagle displ. standing on a billet raguly az. Pineli.

Per pale arg. and or an eagle displ. gu. armed sa. THonipson, Boughton, Kent.

Per pale arg. and or an eagle displ. double headed giv. Pite.

Per pale arg. and or an eagle displ. gu. Bennetr, Pyt House, co. Wilts, as lately represented in the thirteenth descent by the Rev. W. C. BENNETT, vicar of Corsham; and his brother James BenNeTt, Esq., of Salisbury; both quartering Ashlock.

Per pale arg. and sa. an eagle displ. counter. changed. Penny.

Per pale arg. and sa, an eagle displ. double headed counterchanged gorged with a ducal coronet or. Loveday, Norfolk ; and Cheston, Suffolk. Lovedaye, Norfolk, $V$.

Per pale arg. and sa. an eagle displ. double headed counterchanged crowned or. LovedAY, Norfolk ; and Cheston, Suffolk.

Per pale az. and gu. an eagle displ. arg. Jersey or Jercy.

Per pale az. and gu. an eagle displ. donble headed arg. Mitton, co. Stafford.

Per pale az. and gu. an eagle displ. arg. armed or. Sr. .... de Jorcy. $V$. Monsire Jorce, $Y$. John Jorce, $Y$. JoYe Or JOYer.

Per pale az. and gu. an eagle displ. or. Joncy, $V$.

Per pale az. and gu. an eagle displ. double headed or. Mitton.

Per pale az. and purp. an eagle displ. double headed arg. Mitron, Weston, $V$.

Per pale az. and purp. an eagle displ. double headed arg. beaked and membered gu. Miтton, co. Stafford.

Per pale erm. and ermines an eagle displ. double headed per pale arg. and sa. Goodman, $r$.

Per pale erm. and or an eagle displ. double headed sa. Goodman.

Per pale gu. and az. an eagle displ. or. Minton, co. Salop. Munors, $V *$. Sr. .... de Mynors, $V$. 
BIRD.

EAGLE cont.

Per pale gu. with chequy arg. and az. over all an eagle displ. double lueaded or armed sa. Swataran, King's Lynn, and Beales, Norfolk.

Per pale gu. and erm. an eagle disul. arg. armed or. Egleston, $V^{*}$. MIalg. de Erliston, $V$.

Per pale gu. and erm. an eagle displ. or. BoRDAM, 1730.

Per pale gu. and vert an eagle displ. arg. Elaston, co. Chester. Harl. MS. 1535, fo. $13 \mathrm{~b}$.

Per pale gu. and vert an eagle displ. arg. armed or. EGLEsTon.

Per pale gu. and vert an eagle displ. or. ErLison. Elitston, London.

Per pale or and arg. an eagle displ. az. armed gu. Cannegie, Pitarrow, Scotland.

Per pale or and arg. an eagle displ. gu. Thompson, 1730.

Per pale or and arg. an eagle displ. double headed gu. armed (az. another) sa. Monsterberge.

Per pale or and arg. an eagle displ. sa. Brrde.

Per pale or and arg. an eagle displ. perched on a ragged staff sa. Pynel.L.

Per pale or and az. an eagle displ. counterchauged. Carpenter.

Per pale or and az. an eagle displ. double beaded counterchanged. Stone, $V$.

Per pale indented or and az. an eagle displ. (? connterchanged). Janvis, London; and Benson, co. Oxford.

Per pale or and az. an eagle displ. per pale sa. and of the first. Opall or Opull.

Per pale or and gu. an eagle displ. double headed az. armed (gu. $V^{*}$.) counterchanged. STone, Survey, $V$.

Per pale or and gu. an eagle displ. counterchanged. Stone, Essex.

Per pale or and gu. an eagle displ. double headed counterchanged. Stone, Dorset; and Somerset.

Per pale or and gu. an eagle displ. double headed per pale az. and or. Stone, Wedmore, Kent; and Soinerset.

Per pale or and sa. an eagle displ. double headed counterchanged collared ducally of the first. Loveday, $V^{*}$.

Per pale sa. and arg. an eagle displ. counterchanged crowned gu. Pesuarsh or Pesurersh, Essex.

Per pale sa. and erm. an eagle displ. double headed arg. Goodran, Chester ; and Blazon, co. Leicester, 1619.

Per pale sa. and erm. an eagle displ. or. Boodant. Goodman ; Collinson, Somerset, ii, 90.

Per pale vert and erm. an eagle displ. or. Goodlad, London.

Per pale vert and gu. an eagle displ. arg. BaLe, Carleton-Curlew, co. Leicester; Laronetcy 1643 ; extinct 1653.

Per saltire arg. and gu. an eagle displ. doubleheaded .... Tatler.

Pel saltire vert and gu. an engle displ. or holding in its beak a cross crosslet fitchy arg. Greaves, Irlam Hall, co. Lancaster; descended from Greaves, Beeley ; quartering Lancashire.

Per saltire erminois and erm. an eagle displ. sa. REID, Ewell Grove, Surrey; Baronetcy 10 November 1823 ; quartering Goodfellow.

Quarterly arg. and or an eagle displ. double headed gu. Prtuan, Dunchideock, Devon.

Quarterly arg. and sa. an eagle displ.gu. Banston, Norfolk.
BIRD.

EAGLE cont.

Quarterly arg. and sa. in the first quarter an eagle displ. of the second. Sir William BIRD, Dean of the Arches, 1619. Byrde, $V$.

Quarterly erm. and or an eagle displ. double headed vert. Lowe, Westminster; granted 1604.

Quarterly gu. and arg. in the first quarter an eagle displ. or armed as the field. PHILIP or Philips, London; and Suffolk ; late of Jamaica. Quarterly gu. and erm. an eagle displ. or. Huson, Tenterden, Kent.

Quarterly gu. and erm. an eagle displ. sa. Huson. Quarterly gu. and vert au eagle displ. bolding in the beak a slip of oak ppr. Greaves.

Quarterly or and arg. an engle displ. gu. Bennett, Surrey; and co. Berks.

Quarterly per fess indented or and az. in the first quarter an eagle with wings expended sa. JoHnson, co. Chester.

Quarterly or and gu. an eagle displ. counterchanged. Alkington, co. Salop.

Quarterly gu. and arg. in the first quarter an eagle displ. or. Sir William Phillis, $V$. Bardolph, Devon; with on en escucheon of pretence az. three pierced 5-foils or.

Quarterly embattled or and erm. over all an eagle displ. sa. Piper, Culliton, Devon, derived from Magnus Piper of Nieustadt in Holstein; quartering Airault.

Quarterly or and gu. in the first quarter an eagle dispi. az. Packenhair, co. Hants.

Quarterly or and gu. in the first quarter an eagle displ. of the second. Pakenhasr, Ireland; and Suffolk.

Quarterly or and gu. in the first quarter an eagle displ. vert. Paganham, $V$. Pageneal, $V$. PaKenhaM, Barou Longford 7 May 1756 , Harl of Longford 5 July 1785, Baron Silchester 17 July 1821; quartering Cuffe, Aungier, and Boyle. Sire Edmon de de Pagenhair, $N$. John de Pagenham, $Y$. Monsirede Pagenhast, $Y$. Sa. an eagle displ. arg. Bryan, Torven, co. Chester. Dennested, $V$. Dernestode. Dernford. William de Dernford, $F$. William Dernsford, $E$. Grandetoft, co. Lincoln. Plllond, Pillond, Devon; the heiress m. Brett. Southele. Robert Stalton, $V$. Streichleigh or Streichlex, co. Nottingham. William Wilcote, Wilcote, co. Oxford, ob. 1411 ; monument. IVILcotTs.

Sa. an eagle displ. wings iuverted arg. Plumstead, Norfolk.

Sa. an eagle displ. arg. armed gu. Bowrand, Essex; and Loudon. Sr. Richard Borland, $V$. Dernford, $V^{*}$. Sr. William Darneford, $V$. Gourray, Kincraig, Scotland. Kunnore, $V$.

Sa. an eagle displ. arg. armed or. Joln de Beauchant, B.

Sa. an eagle displ. arg. armed and standing upon a ragged staff or. Banlaunche Barlew or Barlow, co. Lancaster.

Sa. an eagle displ. arg. armed or standing on the limb of a tree raguled and trunked of the second. Barlow, Burlow.

Sa. an eagle displ. arg. armed and crowned or. Peche or Pechiz.

Sa. an eagle displ. donble healed arg. GodolphIN. Sa. an eagle displ. double beakled arg. armed or. Barloughe or Barlowe, co. Lancaster.

Sa. an eagle displ. double beaded arg. beaked or standing on a piece of a tree raguly of the sccond. Sr. ... de Barraugh, $V$. Barlowe, 


\section{BIRD.}

EAGLE cont.

$V$. And with the eagle armed and a fleur-de-lis in chief of the third. William BARLow, Bishop of Rochester 1605, Lincoln 1698.13; granted 1607.

Sa. an eagle volant arg. Staylton or Stalton.

Sa. an eagle displ. barry of six arg. and gu. Caster, Norfolk.

Sa. an eagle displ. barry of (ten $V^{*}$.) eleven arg. and gu. Castor, $V^{*}$. Sr. John Caster, Norfolk, temp. Edward I, V. Castre, Norfolk.

Sa. an eagle displ. barry arg. and gu. Sire Joban de Castre, $N$.

Sa. an eagle close or. Artus. Roper, Turnditch, and Heanor, co. Derby.

Sa. an eagle displ. or. Gayton. Leofric, Earl of Chester, $X$. Kilmore. Linsey. Sr. Roger de Manwike, $V$. Mercia. Sr. Raufe Monwtke, $V$. NEwIKe or NowIKe. Richard (in the margin Roger) de Nomwicke, Y. Nonwike, $V^{*}$. Norwich. Nunwicke. Tonkin, Plymonth.

Sa. an eagle displ, or armed gu. EDwin. Monsire Roger de Nodnewyke, $Y$. Tonkin Tonkyn and Tonkeyn, Trevannance and Hendra, co. Cornwall ; ascribed to ALFGar or ALGAR, Earldorman, Mercia, ob. 1063; quartered by Manwaringe.

Sa. an eagle displ. double headed or. $M 1^{\prime}$ Causland, Ireland.

Vair an eagle displ. arg. Sherborn, co. Lancaster.

Vert an eagle displ. arg. Anthony Biddulph, 1716. Bidulph, East Greenwich, Kent. Eusley or Emslie, Scotland. Sherborne, Sherborne, co. Lancaster, $W$. Sherborne, Tower of London; quartering arg. a lion ramp. guard. vert. SoNNEFIELD.

Vert an eagle displ. arg. armed gu. Bidpulpr, Amroth Castle, quartering Lygon; derived through Biddulph, Ledbury; like Biddulph, Burghill, and Chirk Castle, co. Denbigh; through Biddulph, Elmhurst, co. Stafford. Westcombe, co. Kent; and Birbury, co. Warwick; from BIDDulpH, Biddulph, co. Stafford. Chawning or Chevening, Cheveuing, Kent. Chevenisg, $V^{*}$.

Vert an eagle displ. arg. armed or. Sherborne, but properly BaILEy, Stonyburst, quartered by Sherborne; Harl. MS. 1549, fo. 12.

Vert an eagle displ, arg. armed sa. Hutron.

Vert an eagle displ. double headed arg. Ноокнам.

Vert an eagle displ. double headed arg. ducally gorged gu. Gunaran, Dover.

Vert an eagle displ. erm. Spark or Sparke.

Vert an eagle displ. or. Eluesiy. Euesiy or Elmesley. Camirle, $V^{*}$. Camvyle, $V$. Eneli. Sonfield, Essex. Sire Guy de Stenefeld, $N$.

Vert. an eagle displ. or in the dexter paw a thistle and in the sinister an arrow .... Eurstey, Scotland.

Vert an eagle displ. or armed sa. Hutton, Hemwick, co. Durham. Huton or Hutton, $\boldsymbol{V}$. Nevesfeld or Nevestreld.

Vert an eagle displ. ducally crowned or. Graves.

Vert an eagle displ. double headed or. CaarviLE. Lutron, Mowlish, and Cofford in Canton, Devon, temp. Henry $V$. Lucos.

Vert semy of 3-foils slipped and an eagle displ. double headed or. Lutron, seal temp. Henry $\mathrm{V}, W$.

Vert an eagle displ. double headed or armed gu. Sr. .... De Luton, $V^{*}$. Luton or LuCoN.
BIRD.

\section{FALCON.}

including Goshawk and Hawk.

Arg. a falcon volaut sa. Ernes. Williams.

Arg. a bawk ppr. armed or, standing on a staff couped and raguly vert. EDGE alias Hawrins, co. Salop.

Arg. a hawk ppr. armed or standing on a trunk of a tree vert. Hawrisigs, co. Salop; and Rushall, co. Stafford.

Az. on a mount vert a falcon holding in the dexter claw a fleur de-lis arg. Rowland Meryck, Bishop of Bangor, 1559-66.

Az. a goshawk arg. Michelgrove.

Az. a hawk volant arg. seizing a heron also volant or. Fournier.

Az. on a mount ppr. a falcon with wings expanded looking at an estoile arg. Alexander.

Az. a falcon volant or. Binns. Byes or Bynes. Camel or Cannyl.

Gu. a falcon rising arg. holding in the dexter claw an oak branch ppr. acorned or. Martin Fotherby, Bishop of Salisbury 1618-20.

$\mathrm{Gu}$. a falcon rising wings expanded arg. Thomus Howele, Bishop of Bristol, 16t4.6.

Gu. a hawk arg. Harbron, co. Chester.

Gu. a liawk reguard. trussing a bird all arg. Goodwing.

Gu. a goshawk or standing on the back of a hare urg. Densiryn, Scotland.

Or a falcon rising az. Price, Plas Cadrant, co Anglesey; quartering gu. threc lions pass. guard...., with sa. an oak tree ppr. fructed or the stem surmounted by two arrows saltirewise..... and sa. a chev. erm. betw. three bull's heads erased al'g.

Or a falcon surgerant az. beaked or. CARwed, Llwy diarth.

Or a falcon volant az. Willians, co. Cambridge. Or a falcon volant sa. Williajs.

Per fess az. and purp. in chief a hawk holding a fleur-de-lis sa. Rowland Meryck, Bishop of Bangor 1559.66.

Quarterly or and az. a falcon arg. MICHELGrove, Essex, $V$.

Quarterly or and az. a falcon volant arg. Michelgrove, Sussex.

Sa. a hawk arg. BoLton, Lord Mayor of London, 1667. Bolton, Bolton, co. Lancaster.

Sa. a falcou arg. armed or. Yelding or YEDLING.

Sa. a falcon arg. armed and billed or. Yeadirng, $V$.

Sa. a gosbawk arg. armed jessed and belled or. Bolton, London.

Sa. a falcon arg. beaked and belled or. BoLton, Suffolk, 161う; quartering gu. three wolf's heads erased or a 3 -foil slipped in the centre.

Sa. a falcon arg. jessed and belled or. Yrading, Kent.

Sa. a hawk arg. belled or. Bolton.

Sa. a hawk standing on a perch arg. beaked and legged or. Hawker, co. Wilts. Hawker, Long Parish House, co. Hants; quartering Ryves and Raneston.

Sa. a hawk arg. belled or standing on a trestle of the second. HawkER, Essex.

Sa. a goshawk perched on a stock (another 1716 fixed in the base point) arg. armed belled and jessed or. WeELE.

Sa. a goshawk ( 1730 ; another a hawk) arg. perched upon a stock (another 1730 standing on a perch) fixed to the base point of the second armed 


\section{BIRD. FALCON cont.}

belled and jessed or. WeEle or Welis, Staverton, co. Devon. WeEle, 1730.

Sa. on a mount vert a falcon erm. beaked and belled or in the mouth a 3 -foil slipped of the second. Bolton, Cranwich, co. Norfolk; granted 1803.

Sa. a falcon volant erm. Stalton.

Sa. a falcon rising or. Peach or Pech.

Sa. a falcon rising overt or. Sr. Nicholas PeChe, $V$.

Sa. a falcon wings expanded or. Peche, $V^{*}$.

Vert a falcon rising holding in the dexter claw a pastoral staff or. Richard de Gratesend, Bishop of Liucoln 1258-80.

\section{FENCOCK see Heron}

\section{GOOSE}

Gu. a barnacle goose arg. BarNer.

Gu. a wild goose close arg. a crescent for diff. LANGFORD, Alington, confirmed by Segar.

Or on a mount vert a Magellan goose sa. head arg. AsHFiEID.

Quarterly indented gu. and vert a goose rising arg. Lovenham or Lovingham.

\section{HAWR see FALCON HEATHCOCK see MOORCOCK HERON}

including Bittern, Crane, Fencock, and Stork

(? Vert) a heron arg. drinking from a well (? or or ppr. or) tenne. HणGн (St. Hugh) Bishop of Lincoln 1] 86-1200.

.... a stork close .... John Eglescliffe, Bishop of Connor 1322, Llandaff 1323-47; seal 1329. Dallaway, Inquiries.

Arg. a heron volant in fess az. membered or. HERONDON.

Arg. a stork ppr. StaRkEY, Tong, co. Leicester.

Arg. a stork ppr. holding in the dexter foot an ancient battle-axe handle gu. top az. BIIL.

Arg. a heron sa.. ERnton. Henon.

Arg. a stork sa. Starkey, Norfolk.

Arg. a crane sa.standing on a staff raguly in base vert. Crane, Camborne, Cornwall.

Arg. crusily fitchy and a stork sa. Puttenham, Sherfield, co. Hants, 1034; the heiress $\mathrm{m}$. Morris.

Arg. a stork sa. beaked or. Everton.

Arg. a bittern sa. membered gu. Matthew.

Arg. a crane sa. membered gu. on the breast a crescent for diff. STAREEY, Olton, co. Chester, $V$.

Arg. a fencock sa. membered gu. Matthew.

Arg. a heron sa. membered gu. STARKY, $V^{*}$. STORY.

Arg. a stork sa. membered gu. Starkey or STARKIE, Lower Hall and Over Hall, Stretton, co. Chester. And with a crescent .... Starkey or Starkie, Oulton, co. Chester; quartering Oul. ton; from whom descended Sir Humphrey Starkey, Chief Baron of the Exchequer, and Starkey, Darley. But with a mullet .... StaRkey or StARKIE, Wrenbury; quartering Oulton.

Arg. a stork sa. membered or. Starke, quartered by Doyley.

Az. a crane arg. Fithie, Scotland. Fythie, Bysack, Scotland.

Az. a crane thrust through with a sword arg. Fithie.
BIRD, HERON cont.

Barry of ten arg. and gu. a stork sa. Starrey, London.

Gu. a heron arg. Heron.

Gu. a stork arg. WAILES.

Gu. on a mount vert a stork in trian aspect to the sinister arg. Arnalt.

(? Gu.) crusily or a heron arg. William Herun, $E$.

Gu. crusily or a heron .... William Herne, (sic) $H^{\prime}$.

Gu. a crane without the head arg. Fin, Scotland. Finnie, Scotland; quartering gu. three skeens fesswise arg. hilted or on the point of each a boar's head couped of the last. And with a mullet in chief (? for diff.) arg. FinN, That Ilk.

Gu. a stork without the head arg. Fyvie, Scotland.

Or a stork ppr. Serjeant's InN, London.

Quarterly per fess indented sa. and arg. in the first quarter a stork or. Brasett.

Sa. a bittern arg. Asbitter.

Sa. a heron arg. Dodbrook, $V^{*}$. Heron, Northumberland; and Scotland. Herun, $V$. Matthew, Dodbrook, Devon, $W$.

Sa. a stork arg. MatThew, Mitton, Cornwall; Dodbroke, co. Devon; and Surrey.

Sa. crusily fitchy and a stork arg. Puttenham or Putnam, co. Bedford; and Penn, co. Bucks.

Sa. a stork or. Roper, co. Derby.

Sa. a stork ppr. Stankey, as borne by Mathew, Dodbrooke, co. Devon; and Milton, Cornwall.

\section{KINGFISHER}

Or a kingfisher close gu. Fyshen, co. Bedford.

Or a kingfisher ppr. FISHER, London; and co. Stafford ; granted 4 February 1607. And with a mullet gu. for diff. Fysher, London, 1607.

\section{LEVER SEe CORMORANT}

\section{MARTLET}

Arg. a martlet sa. Cunson; quartering erm. a bend chequy sa. and arg. Curson, co. Derby quartering or a bend chequy sa. and gold betw. two cotises of the second.

Erm. a martlet gu. Greathead.

Or a martlet vert. Brumhani, co. Leicester.

Per bend sinister arg. and gu. a martlet coun. terchanged. Burwicie.

Per fess arg. and gu. a martlet sa. Renys, $V$.

Per fess arg. and sa. a martlet counterchanged. Reniss, 1730.

Quarterly per fess indented arg. and gu. in the first quarter a martlet (sometimes a mullet) sa. Sir Fowk Fitzwarren, $L$.

Quarterly gu. and or a martlet sa. TunNadine, Ireland.

Quarterly or and gu. a martlet sa. (In error for) ROCHEFORD.

Quarterly or and gu. in the first quarter a martlet sa. Crawcester. John Crawcestree, $X$.

Quarterly or and sa. a martlet gu. (In error for) Bovile.

Quarterly or and sa. in the first quarter a martlet gu. Sir Jolnn Bonvyle, $L$, but Hovine, $L$, Harl. MS. 6137. Sire Johan de BoviLe, N.

Sa. a martlet arg. ADAMr, 1730. AdANIS, Holy. land, co. Pembroke. Mathew, co. Monmouth, T. MIONnY, $V^{*}$.

Vairy arg. and gu. in the dexter chief a martlet sa. Monsire Nichol de Beche, $Y$. 


\section{BIRD. MOORCOCK including Heathcock}

Arg. a beathcock ppr. (i.e. sa.) combs and gill gu. Sir Francis More, Serjeant-at-law, 1619.

Arg. a moorcock ppr. Moor or Moone, Famley, co. Berks; Baronetcy 21 May 1627 ; extinct 10 April 1807. Moore, Inner Temple, London; granted 28 April 1569.

\section{OSTRICH}

Arg. an ostrich sa. holding in the beak a horseshoe (gu. another) or. MackMaHEN, $V^{*}$. MaCMaHEN (Hibernicus sylvestris), $V$. MAC MAHON, Ireland. Marnham.

Gu. an ostrich holding a horseshoe in the beak arg. M $\triangle$ CMAHON, England.

Per fess sa. and arg. an ostrich counterchanged. MAHon, Castlegar, co. Galway; Baronetcy 7 December 1818.

Sa. an ostrich arg. Matrhews, Cornwall.

\section{OWL}

Arg. an owl gu. Herwart, 1730.

\section{PARROT see Popinjay PELICAN}

Arg. a pelican in piety sa. Cantreld, Monsall, co. Lancaster ; and Bury, Suffolk.

Arg. a pelican in piety sa. the nest or. Chantrele, Ockingham.

Arg. a pelican in piety vert. Robert Shenborn, Bishop of St. David's 1505, Chichester, 150836 ; quartering arg. a lion ramp. vert with arg. an eagle displ. vert.

Az. a pelican in piety arg. Chantreli or Chauntrele, Woodley, co. Berks.

Az. a pelican or vulned ppr. BAwdrIFFe. Richard Fox, Bishop of Exeter 1487, Bath 1492, Durbam 149t, Winchester 1501.28, founder of Corpus Christi College, Oxford. Hoadley, granted 1715. Shenman, Inswich, Suffolk. Wakering, Essex.

$A z$. a pelican or vulned ppr. standing on a globe arg. John Pierse, Bishop of Rochester 1576, Salisbury 1577, Archbishop of York 1588.94.

Az. a pelican or vulned ppr. crowned gold. Peins.

(? Az.) a pelican in piety or. AlLAN.

Az. a pelican in piety or. John PIerse, Bishop of Rochester 1576, Salisbury 1577; Archbishop of York, 1588-94. William Pience or Piers, Bishop of Peterborough 1630, Bath 1632-70.

$\mathrm{Az}$. a pelican in piety crowned or the nest vert. Peeres.

Az. a pelican in piety or vulned ppr. Richard Fox, Bishop of Exeter 1487, Bath 1492, Durham 1494, Winchester 1501-28, founder of Corpus Christi College, Oxford.

Az. a pelican in piety ppr. Fox.

Gu. a pelican in piety arg. CAIRNe, Scotland.

Gu. a pelican in piety arg. vulued ppr. ELMIE or Ellem, Elmside, co. Berwick. Elnie, Elme. foord, quartered by Home or Hume.

Gu. a pelican in piety wings displ. or. Tresilian, Tresilian in Newlyn, Cornwall; the heiress m. Carne.

Gu. a pelican in piety or. Morgan, Mellhouse, co. Durham. Tregrilta.

Gu. a pelican in piety or vulned ppr. (The mo. dern arms of) CARNe or LE CARNE, Nash, co. Glamorgan; heiresses m. Markham and Nicholl. CARNE, Ewenny, co. Glamorgan, the heiress $\mathrm{m}$. Turberville.

Or a pelican az. CoIn.
BIRD.

PELICAN cont.

Or a pelican in piety ppr. Rerohedar, Cultebragan.

Per chev. vert and erm. in chief a pelican or vulned ppr. JOYNER.

Quarterly az. and or in the first quarter a pelican in piety arg. Benjamin HOADLX, Bishop of Bangor 1716, Hereford 1721, Salisbury 1724, Winchester 1734-61.

Quarterly per fess dancetty sa. and or in the first quarter a pelican of the second. JACOBS, Ripple, Kent; Hasted, Kent, ir, 132.

Quarterly per fess indented sa. and or in the first quarter a pelican of the second vulning itself ppr. Johnson, Nethercourt, and Margate, Kent, Add. MS. 5507, fo. 200.

Sa. a pelican in piety arg. HINDE or HYNDE. LyNDEY or Lynd, co. Dorset.

Sa. a pelican in piety wings displ, inverted arg. vulned gu. nest or. LXNDE, $V$.

Vert a pelican in piety or. SULERs.

\section{PIGEON see Dove \\ POPINJAY}

\section{including Jay, and Parrot}

Or a parrot ppr. Richard Senhouse, Bishop of Carlisle 1624-6.

Or a popinjay ppr. Senhouse, Calder Abbey, Cumberland; the heiress $\mathrm{m}$. Irwin; a branch like SENHOUSE, Alneburgh or Ellenborough; quartering Ponsonby, Lucy, Copeland, Eglesfield, and Fleming; of Senhouse or Sewynhouse, Seascale, Cumberland.

Or a parrot close vert legged gu. Poyner, Beslow and Shrewsbury, co. Salop.

Per pale arg. and gu. in the dexter fess point a parrot russet beaked and legged or. Richard Senhouse, Bish op of Carlisle 1624.6. Senhouse, Cumberland.

Per pale arg. and gu. in the first a popinjay vert. Senhouse, Calder Abbey, Cumberland; the beiress m. Irwin; a branch like Senhouse, Alneburgh or Ellenborough; quartering Ponsonby, Lucy, Copeland, Eglesfield, and Fleming; of Senhouse or Sewrnhouse, Seascale, Cumberland:

Vert a parrot wings disclosed holding up the left foot or. ANTICK.

\section{RAVEN see Crow}

SEA-TEAL, SHELDRAKE, and SHOVELLER see Duck

\section{SNIPE}

Gu. a snipe arg. gorged with a crown or. SnitTerton, Snitterton, co. Derby; the heiress m. Sacheverell.

\section{ST' RK see Heron SWALLOW}

Arg. a swallow rolant in bend sinister sa. Town of ARUNDEL, Sussex.

\section{SWAN}

Gu. out of a coronet or a demi-swan sans wings arg. from the mouth a scroll compassing the mouth in form of a rein sa. BuckHILL.

Az. a swan ppr. SwaN, Kent.

Gu. a cygnet arg. Thomas AsDale, $X$.

Gu. a swan arg. DALE, co. York. DaLes, Alderman of York. LEIGHAM. RANDOLPH. Stormer (but Storman in Gelbke). 


\section{BIRD.}

SWAN cont.

Gu. a swan close arg. Leighair, 1730 .

Gu. a swan close arg. membered or. Leghasr or Leigham. Leyham, $V$.

Gu. on a mount vert a swan arg. membered col. lared and chained or. DALE, London and co. Northampton, 1613. DALE, Ryhope, quartered by Carr.

Gu. a swan pass. ppr. Frs.

Gu. a swan close arg. membered sa. M. Thomas DaLe, $S$.

Gu. a swan reguard. and standing on a mount in base vert. DAILE, Scotland, J681.

Gu. a swan arg. beaked sa. collared with a coro. net or. Storner (but Storman in Gelble), $Z, 554$.

Gu. on a mound of grass a swan close ppr. ducally gorged and chained or. DaLE, Dalton le Dale.

Gu. on a base vert a swan arg. collared sa. DaLE, Winkell, co. Chester, Harl. MS. 1535, fo. 123.

Gu. a swan wings expansed arg. DALE, Northumberland. RANDOLPH.

Or a swan close gu. Starnforth.

Per fess sa. with bendy (? barry) of six arg. and az. a swan swimming in the waves ppr. Weysouth, co. Devon; and co. Dorset.

Per pale gu. and sa. a swan wings expanded arg. ducally gorged and chained or. Town of BuCKINGHAMr.

Quarterly indented arg. and sa. in the second quarter a swan ppr. BrAcY.

Quarterly per fess indented gu. and vert a swan wings dispi. arg. LOVENHAII.

Sa. a swan close arg. ducally gorged and chained or. Town of Chipping. Wicombe, co. Bucking. ham.

Vert a swan wings expansed arg. Hoppe.

Vert a swan arg. drinking from a well or. Hugh (St.Hugh), Bishop of Lincoln 1186-1200.

Vert in water a swan naiant ppr. VAN JUCHEN.

Vert in water in base ppr. a swan wings expansed naiant arg. JUCHEN or TAN JUCHEN.

\section{TEAL see Duck}

\section{VULTURE}

Erm. a vulture seizing her prey gu. SinnNGes.

\section{COCK and in chief...}

on a Chief.... Crescent

Arg. a cock gu. on a chief az. a crescent betw. two stars of the first. Cock, Scotland.

$$
\text { .....Flowers }
$$

Arg. goutty-de-sang a cock gu. on a chief of the last three roses or. Priory of Austin Canons at Launceston, Cornwall, $A^{-r}$ mol. MS. 763.

Mullets

Per chev. sa. and arg. in base wock in chief two mullets counterchanged. Nicholas Heatr, Bishop of Rochester 1540, Worcester 1543.

$$
\text { CROW and in chief.... }
$$

\section{Lozenge}

Quarterly arg. and sa. in the first quarter a rook ppr. in the second a lozenge of the first. (? Matthew.)

\section{Mullets}

Per chev. sa. and arg. in base a Cornish chough ppr. in chief two pierced mullets of the second. Hospital, afterward Augustinian Priory, of St. Gregony at Canterbury.
BIRD. DOVE and in chief....

on a Chief.... Annulet

Az. a dove ppr. on a chief erm. three annulets or each enriched with a ruby. Bevan, Carmartben; and Ashted, Surrey; granted 1774.

$$
\text { .....Beast }
$$

Per pale az. and gu. a dove arg. beaked and membered or on a chief of the second two lions pass sa. Bowers, Chichester.

Per pale vert and gu. a dove arg. on a chief of the second two lions pass sa. Thomas Bowers, Bishop of Chichester 1722-4.

$$
\text { ....Crosses }
$$

Sa. a dove arg. on a chief of the second three crosses patty gu. Thomas WhIte, Bishop of Peterborough 1685.91 ; granted 1685 .

\section{Crosses}

Per chev. or and az. in base a dove as the first wings expanded beaked and legged gu. in chief three crosses patty as the last. Gleadowe, Hull; and Frodeslay, co. Salop.

\section{Flowers}

Arg. on ground in base vert a dove statant $\mathrm{ppr}$. in chief two roses gu. GoLtshed.

Mullet

Az. a dove rising holding in the beak an olive branch ppr. in chief a mullet betw. two crosses formy or. John Leng, Bishop of Norwich 1723.7 .

\section{DUCK and in chief....}

Arg. a duck ppr. on a chief dancetty gu. a boar's head couped betw. two crescents or. MeIr, Leidcassie, Scotland. Milmirson, Hill, Scotland.

\section{EAGLE and in chief....}

\section{Barrulets}

Or an eagle displ.gu. in chief two barrulets az. Cussans, Jamaica; granted 1767 . Cussans or De Cusance.

Beast

Quarterly gu. and erm. an eagle displ. or in the dexter chief a lion pass. arg. Hewson.

Quarterly gu. and erm. an eagle displ. or in the dexter chief a lion pass. guard. arg. Hewson, London.

Quarterly gu. and erm. an eagle displ. and in the dexter chief a lion ramp. or. HUGHSON.

\section{Book}

Per chev. arg. and az. in base an eagle rising or in chief on a book gu. edges and ornaments of the third betw. a slip of oak fructed and a rose as the fourth stalked and leaved vert a fret in the centre of the cover gold. Evans, Norwich, granted 1772.

\section{Buckle}

Or an eagle displ. and in chief a buckle betr. two annulets az. Carnegre, Newgate, Scotland.

\section{Canton}

Az. an eagle displ, or a canton erm. Frtz.Srmon, co. Hertford.

on a Canton.....Anchor

Gu. an eagle displ. ducally crowned or on a can. ton arg. an anchor (? in bend) ppr. Graves, Baron Graves, July 1794.

$$
\text { .... Billets }
$$

Arg. an eagle displ. sa. on a canton or seven bil. lets ermines. Parkrns, Baronetcy 13 May 1681, Baron Rancliffe 1 October 1795. 
BIRD. EAGLE and in chief.... cont.

on a Canton cont. Birds

Per pale erm. and az. an eagle displ. double headed or on a canton of the second a martlet of the third. Goodman, Ruthin, co. Denbigh; granted 1593, and borne by Gabriel Goonman, Dean of Westminster, ob. 1601, and by his nephew Godfrey Goodman, Bishop of Gloucester 1024-56.

Per pale erm. and sa. an eagle displ. double headed or on a canton az. a martlet of the third. Goodman, Ruthyn, co. Denbigh ; granted 1572. Gawen Goodran, granted 20 Nov. 1573.

$$
\text { .....Fess }
$$

Sa. an eagle displ.ppr. on a canton arg. a fess dancetty of the first. Perkins, Orton Hall, co. Leicester; and Sutton Coldficld, co. Warwick; quartering Steel, Farmer, Beardsley, Shirley, Duncumb, Kirkpatricke, and Sharpe.

Arg. an eagle displ. sa. on a canton or a fess dan. cetty betw. six billets ermines. Pernins, Bun. ney, co. Nottingham.

Arg. an eagle displ. sa. on a canton of the last a fess dancetty or. Penken, co. Worcester.

Arg. an eagle displ. sa. on a canton of the second a fess indented or. Perkins, Ireland.

Arg. an eagle displ. sa. on a canton or a fess dancetty of the second betw. seven billets ermines. Parkins, Baronetcy 18 May 1681, Baron Rancliffe 1 October 1795 ; extinct ....

$$
\text { .....Wreath }
$$

Gu. an eagle displ. arg. armed or on a canton of the second a chaplet graminy vert. GoodALL, Earlstonham, Suffolk; granted 1 March 1612. Chief

Arg. an eagle displ. az. a chief or. Byfforo, co. Hereford.

Arg. an eagle displ. sa. a chief gu. Ramsay, Wauchtown, Scotland; quartering Hepburn.

Arg. an eagle displ. sa. a chief invecked gu. Ramsay, Braxmouth, Scotland.

Arg. an eagle displ. sa. a chief paly of six gu. and of the first. Staynings.

Az. an eagle displ. arg. a chief vairy or and gu. REDward, as borne by Walter de Ridware (Nether Seil, co. Leicester), temp. Henry III; his son omitted the chief, as may be seen by their seals ; Burton, Leicestershire, p. 231.

Az. an eagle displ. or a chief arg. Mynons, co. Hereford.

Az. an eagle displ. double headed or a chief arg. Nordet.

Az. an eagle displ. or a chief erm. Harrison, London.

Az. an eagle displ. gorged with a ducal coronet or' a chief erm. Harrison, London.

Gu. an eagle displ, and a chief arg. Ford.

Gu. an eagle displ. arg. a chief or. Harrison, Newcastle.

Gu. an eagle displ. erm. a chief chequy arg. and az. Halsted, London.

Gu. an eagle displ. erm. beaked and legged or a chief chequy of the last and az. HaLSTED, Sunning, co. Berks; and London; granted 10 May 1687.

Gu. an eagle displ. and a chief or. Harrison, London. Harryson, co. Northampton, $W$.

Or an eagle displ. with two heads purp. beaked and membered gu. a chief nebuly az. LINSKILL.

Or an eagle displ. sa. a chief vair. London. LyNSEy, London.
BIRD. EAGLE and in chief.... cont.

\section{Chief cont.}

Or an eagle displ. sa. armed az. a chicf vair. Lindsey, London; and Bucksted, Sussex ; confirmed 20 June 1608. LYNDsEy.

Purp. an eagle displ. double headed or. a chief arg. Merdred, $V^{*}$. Mordant. Sr. Mordred of the Round Table, $W$.

Sa, an eagle displ. and a chief arg. Bridgewater. on a Chief.... Banner

Gyronny of eight arg. and az. an eagle displ. er. minois on a chief wavy erm. a trident or surmounting in saltire a flagstaff ppr. thereon hoisted a pennant gu. both passing through a chaplet of laurel vert. NicoLas, East Looe, Cornwall; granted 1816.

$$
\text { ..... Beast }
$$

Az. an eagle displ. arg. on a chief or a lion pass. gu. Deypholl, $V$.

Az. an eagle displ. arg. on a chief or a lion pass. guard.gu. DEAPHOLE DEYPHOLl or Deypole.

Sa. an eagle displ. double beaded arg. on a chief gu. a lion pass. or. JollyfFE.

....Book

Arg. an eagle displ. double headed sa. armed gu. on a chief az. a book of the Holy Scriptures open ppr. stringed or. William MorGAN, Bishop of Ilandaff 1594, St. Asaph 1601-4.

$$
\text { .....Chevron }
$$

Sa. an eagle displ. or on a chief az. bordured arg. a chev. betw. in chief two crescents and in base a rose of the second. Mynons, Treago, co. Hereford; and Evenjobb House, co. Radnor. Minors, London.

Sa. an eagle displ. or on a chief az. within a bordure a chev. betw. in chief two crescents and in base a rose of the second. Minons, $V^{*}$. Sr. .... de Mynors, $V$. (? But with a 3-foil instead of the rose. WAynBURST, Norfolk.)

$$
\text { .....Coronet }
$$

Erm. an eagle displ. sa. on a chief gu. a ducal crown or betw. two crosses patty arg. VAN Sittart, London; descended from Prussia. Vansittart, Baron Bexley 1 March 1823; extinct 8 February 1851. Vansittart, Pinckney House, Maidenhead, co. Berks.

$$
\text { .....Crescents }
$$

Arg. an eagle displ. sa. armed or on a chief of the second three crescents erm. Moone, Ash, co. Devon.

\section{.... Cross or Cross-staff see Implement}

$$
\text { .....Crosses }
$$

Arg, an eagle displ. double headed .... on a chief az. three crosses formy fitchy or. WEBB, Kim. bolton, co. Huntingdon.

Arg. an eagle displ. sa. on a chief az, three crosses patty fitchy or. HARRISON, Norfolk. HARRISON, Great Yarmouth; quartering Hargrave, Flight, and the same for Harrison, Great Plumstead.

$A z$. an eagle displ. arg. on a chief or three crosses crosletgu. BuILINGHAM, Harl. MS. 6829, fo. 60 .

$$
\text { .... Escallops }
$$

Az. an eagle displ, erm. on a chief gu. three es. callops or. Middlecot, co. Lincoln.

Per pale az. and or an eagle displ. counterchanged on a chief gu. three escallops arg. JoBson, $W$.

Quarterly erminois and erm. an eagle displ. double headed sa. on a chief engr. az. three escallops or. Baldock, Petham, Kent.

$$
\text { .... Estoiles }
$$

Lindsex, Arg. an eagle displ. double headed sa. on a chief vert two estoiles or. Aitchinson. Atcheson. 
BIRD. EAGLE and in chief.... cont.

on a Chief cont. Estoiles cont.

Gu. an eagle displ. double headed arg. on a chief of the last three estoiles as the first. Atrinson, $V^{*}$.

$$
\text { ....Flears-de-lis }
$$

Arg. an eagle displ.sa. on a chief az. three fleursde lis or. Bridgewater.

$$
\text { .... Flower }
$$

Arg. an eagle displ. double headed sa. on a chief or a rose betw. two martlets gu. ATkinson, Newcastle.

Az. an eagle displ. arg. holding in the beak a sprig of beech or on a chief of the last a rose betw. two crosses botony gu. Nicholas Bulinghan, Bishop of Liucoln 1560, Worcester 1571-7. John Bullingham (sometimes with the crosses croslet fitchy), Bishop of Gloucester 1581-98, Bristol 1581-9.

Az. an eagle displ. arg. holding in the beak a sprig vert on a chief or a rose betw. two crosses croslet gu. Bullinghair, co. Lincoln.

Gu. an eagle displ, arg. on a chief or a rose betw. two martlets az. Atrinson, London; and New. castle.

Gu. an eagle displ. double headed arg. on a chief or a rose of the first betw. two martlets sa. Aitkinson, Scotland.

Per fess sa. and gu. an eagle displ. arg. on a chief or a rose betw. two annulets of the second. EDGE, Strelley, co. Nottingham; granted 9 May 1709.

$$
\text { .... Flowers }
$$

Arg. an eagle displ. double headed sa. on a chief of the second three roses as the first. HILL, London. HILL, $V^{*}$.

Arg. an eagle displ. double headed sa. armed gu. on a chief of the second three roses as the first. Hrrs, London, $V$.

$\Lambda$ rg. an eagle displ. sa. on a chief vert three roses of the first. BYNTONE.

Gu. an eagle displ. arg. on a chief of the last three roses as the first. Linton, Scotland.

$\mathrm{Gu}$. an eagle displ. arg. on a chief az. three roses of the first. Lighton, Scotland.

$$
\text { ....5-Foil }
$$

Arg. an eagle displ. sa. on a chief az. a 5-foil betw. two martlets or. Atkinson, Mayor of Norwich, 1702.

\section{.... Fore-staff see Implement$$
\text { .... Head }
$$

Sa. an eagle displ. arg. on a chief or three pheons of the first. GAvELL, Cobham, Surrey; granted 12 August 1572.

\section{.....Implement}

Or an eagle displ. double beaded sa. on a chief vert a cross staff betw. two spur.rowels or. AcHIEson.

\section{.....Mullets}

Arg. an eagle displ. double headed sa. on a chief az. two mullets or. AITCHEson, North Britain.

Arg. an eagle displ. double headed sa. armed or on a chief vert two mullets of the third. Acheson, Baronetcy September 1628; Baron Gosford 20 July 1776, Viscount 20 June 1785, Earl 1806, Baron Worlingham 1835.

Arg. an eagle displ. double headed sa. on a chief vert three mullets of the first. AcHeson.

$$
\text { .... Roundles }
$$

Arg. an eagle displ. gu. armed az. on a chief of the last three bezants. Arkissos, co. Nottingham, 1614, W.

Arg. an eagle displ. gu. armed or on a chief sa.
BIRD. EAGLE and in chief.....cont.

on a Chief cont. Roundles cont.

three beznnts each charged with a fleur-do-lis az. (Assumed in the present century by GlazEBRook, Oxford Lodge, Warrington, co. Lancaster.) Grazerrook, Stourton Castle, co. Stafford ; and Dallicott House, co. Salop ; quartering (arg. three conies feeding gu. for the ancient arms of) Greysbroke, Wilkes, etc. GrazeBrooK, originally de Gresbroke and Greysbroke, Greysbrooke Hall, Shenstone; and Audnam, Stourbridge, co. Stafford; quar. tering the ancient arms as above, with de Hes. den, Bryndley for Worrall of Stourton co. Stafford, Needs co. Devon, etc. Grazebrook, sometimes quartering Greysbroke, Needs, Bryndley for Worrall, etc.

Az. an eagle displ. erm. on a chief embattled arg. three ogresses. RaynoND, London; granted 11 April 1687. Sir Jonathan Raymond, Alderman of London 1730.

Or an eagle displ. gu. on a chief az. three be. zants. Atkinson, co. Nottingham.

Sa. an eagle displ. or on a chief gu. three bezants. BeLE'TT.

\section{....Rowels}

Arg. an eagle displ. double headed sa. on a chief vert two spur-rowels or. ATchison, Scotland. .....Trees

Gu. an eagle displ. or over the head a plate on a chief arg. a pear-tree vert fructed of the second. De Aguilar, London.

Gu. an eagle displ. or on a chief arg. three pear-trees ppr. fructed as the second glowing out of a mount vert. AQUITAR, London.

\section{Coronets}

Arg. an eagle displ. or in chief a naval crown betw. two bombs of the last fired ppr. Graves, quartered by Sawle.

\section{Crescents}

Arg. an eagle displ. sa. in chief three crescents gu. SpIttue, Leuchat, Scotland.

\section{Crosses}

Or an eagle displ. gu. in the dexter chief a cross croslet fitchy sa. and in the sinister a right luand couped fesswise holding a dagger in pale ppr. M'EnTIRE, Scotland.

\section{Fleur-de-lis}

Erm. an eagle displ. gu. armed az. in chief a fleur.de-lis for diff. or. CoDEnHAM.

\section{Flower}

Or an eagle displ. sa. in chief a rose gu. betw. two mullets of the second. Panton, Blackhouse, Scotland.

Arg. an eagle displ. ppr. surmounted by a galley sa. flags gu. in chief two roses of the last. Donaldson, London.

\section{Hand}

Arg. an eagle displ. double headed sa. surmounted by a galley of the last flags gu. in the dexter chief a sinister hand couped of the second. Donaldon, Kinnardie, Scotland.

Or an eagle displ. gu. surmounted by a lymphad sa. in the dexter chief a right hand couped gu. MACDONAID.

Or an eagle displ. gu. surmounted by a lymphad sa. sails furled and rigged $\mathrm{ppr}$. in the dexter chief a right hand couped as the second in the sinister a cross croslet fitchy of the third. MACDONELi, Glengary.

Or an eagle displ. double headed gu. surmounted by a lymphad sa. in the dexter chief a right hand couped gu. MacDonaid. 


\section{BIRD. EAGLE and in chief.... cont.}

\section{Hand cont.}

Or an eagle displ. double headed gu. surmounted by a galley sa. in the dexter chief a right hand apaumy couped of the second. M'DoNaID, That Ilk; Baronetcy 1625.

Or an eagle displ. double headed sa. surmounted by a lymphad of the second flagged gu. in the dexter chief a left hand couped as the last quartering gu. two arrows saltirewise arg. sur mounted by a fess chequy of the second and first for M'AULAY of Ardincuple about 1720, all within a bordure indented az. charged with eight buckles points in chief gold, in memory of a marriage with Stirling of Caldoch 1684. Donatoson, London; and Williamshaw in Stewarton, co. Ayr (Lion Register, 1766).

Or an eagle displ. double headed sa. armed of the first langued gu. surmounted by a galley as the second in the dexter chief a sinister hand couped like the fourth a mullet for diff. Donaldson, Hiltoun.

\section{Insects}

Gu. an eagle displ. .... in chief three bees or. Humsx, Middlesex; granted.... Mullets

Az. an eagle displ. or in clief three pierced mullets of six points as the last. Tovey, Pynacles, Great Staumore, Middlesex; granted ....

\section{Roundles}

Sa. an eagle displ. or in chief two bezants. Manwike.

Arg. an eagle displ. sa. in chief three pellets. Ramsay, Ireland.

Sun

.... an eagle displ. .... looking at the sun .... Hewson, Ennismore, Kerry.

$\mathrm{Gu}$. an eagle displ. or looking against the sun in its splendour placed toward the dexter chief. (The feudal coat of the lordship of ) Cardross, borne as a surtout by Erskine Earl of Buchan.

\section{FALCON and in chief....}

on a Canton.....Garb

Sa. a hawk arg. on a canton or a garb gu. Boulton, Gibbon Grove, Surrey; quartering az. a chev. betw. two fleurs-de-lis in chief and a crab in base or.

on a Chief..... Arrows

Az. a hawk seizing a partridge arg. on a chief of the last three bolts of the first. KNowLEs.

Or a falcon sa. preying on a moorcock ppr. on a chief of the second three birdbolts arg. Knolles, Little Hampston, co. Devon.

\section{Cross}

Sa. a falcon (another a hawk) or preying on a duck arg. on a chief of the second a cross bo. tonny gu. Spencer MADAN. Bishop of Bristol 1792, Peterborough 1794-1813. MADAN or MadDen, Castle Waterhouse, co. Fermanagh, Ireland.

Sa. a falcon or belled gu. preying on a mallard arg. on a chief of the second a cross botonuy (sometimes a cross croslet) as the third. MADDEN, Monaghan, and Kilkenny ; descended from Hugh MaDDEN, Bloxham Beauchamp, co. Oxford.

Sa. a falcon or belled gu. preying on a mallard arg. on a chief indented of the second a cross botonny as the third. Sir Frederick MADDEN, K.H.F.R.S. F.S.A., descended from the ancient sept of O'Madden, co. Galway, Ireland.
BIRD. FALCON and in chief..... cont.

on a Chief cont. Cross cont.

Sa. a hawk or preying on a duck ppr. on a chief of the second a cross moliue gu. MADDEN. Mullets

Gu. a falcon hooded and perched on a hand issuing out of the sinister side or on a chief arg. three mullets az. BlackHal, Scotland.

Gu. a falcon hooded and perched on a dexter hand in fess couped or on a chief arg. three mullets of the first. BLackHaLI.

$$
\text { .....Rotundle }
$$

Arg. a falcon rising ppr. armed jessed and belled or on a chief az. a bezant betw. two estoiles gold. WALKER, Suffolk; and Redland, co. Gloucester.

Estoile

Az. on a mount ppr. a falcon with wings expanded looking at an estoile arg. ALEXANDER.

Az. a falcon with wings expanded ppr. on a rock or in the dexter canton an estoile of the last. ZinZan, Tylehurst, co. Berks.

$$
\text { Letter }
$$

Per chev. or and vert in base a falcon of the first in chief the letter M. sa. John Marshalt, Bisliop of Llandaff 1478-96.

\section{HERON and in chief....}

\section{Canton}

Arg. a stork sa. bealsed and legged gu. a canton of the second. STARKEY, Wrenbury Hall, co. Chester, quartering Cross.

on a Canton.... Fleur-de-lis

Barry of ten arg. and gu. a stork sa. beaked and legged of the second on a canton as the third a fleur-de-lis like the first. Starkey, London; granted 27 Juue 1513.

Chief

Vert a crane arg. a chief erm. Coustos, Scot. land.

\section{on a Chief..... Annulets}

Or a beron sa. on a chief of the last three annu. lets as the first. Earnshaw, Cayground, co. York; quartered by Marshall.

$$
\text { ..... Crescents }
$$

Arg. a crane holding a stone in the dexter foot gu. on a chief vert three crescents of the first. Sinrson, Tiviotbank, Scotland.

$$
\text { .....Escallops }
$$

Or a heron volant ppr. on a chief sa. three escal. lops of the first. Graham, Douglastoun, Scotland.

\section{....Estoiles}

Arg. a heron rising az. on a chief indented of the second three estoiles or. Crooke, Alderford, Norfolk.

Arg. on a mount vert a heron close erm. a chief gu. charged with three estoiles of the first. Luввоск, Lamas, Norfolk, Baronetcy 9 April 1806.

$$
\text { ....5-Foils }
$$

Per chev. or and gu. in base a crane arg. holding in the dexter foot a stone sa. in chief two 5 -foils of the second stalked and leaved vert. Dearman.

\section{Mullet}

Gu. a crane without the head arg. in chief a mullet (? for diff.) of the last. Fin,, That Ilk, Scotland.

\section{Mullets}

Gu. a crane without the head arg. in chief two mullets of the last. Find, That Ilk, Scotland. Phine, Whitehill, Scotland. 
BIRD. MAGPIE and in chief....

Per fess sa. and arg. in base a magpie ppr. in chief two mullets of the second. Plumesdon or Plurendon.

MARTLET and in chief....

\section{Chief}

Arg. a martlet sa. a chief gu. Paul, Scotland. on a Chief.... Birds

Arg. a martlet sa. on a chief az. three swans wings oudorsed of the first. Swanston, Scotland. Fleurs-de-lis

Or a martlet sa. in chief two fleurs-de-lis gu. FARBridge, Ireland. Sword

Arg. a martlet sa. in the middle chief point a dagger palewise az. hilted or. Melnuish.

MOORCOCK and in chief....

\section{Estoiles}

Per chev. embattled sa. and arg. in base a heathcock of the first combed and wattled gu. in chief two estoiles as the second. HEath. Mullets

Per chev. or and sa. in base a heathcock of the first combed and wattled gu. in chief two mul. lets as the second. Heath, Kepyer, co. Durham; granted 4 August 1558; derived through Heath, London, Warden of the Fleet in 1591 ; and Heath, Twickenham ; from Heatr, Heath, Middlesex; the heiress of Heath, Old Durham, m. Tempest. Heatr, Little Eden, Durbam; Lynn, Norfolk ; and Twickenham, Middlesex.

Per chev. embattled sa. and arg. in base a heath. cock of the first combed and wattled ppr. in clief two six-pointed mullets or pierced gu. Heatн, Mile End, Middlesex; granted 21 June 1707.

\section{Reaping-hooks}

Per cher. sa. and or in base a mooreock of the first combed and wattled gu. in chief two pair of reaping-hooks endorsed and entwined the blades arg. the handles gold. Hockmore, Buckyate, co. Deron.

\section{Scythes}

Per chev. sa. and or in base a moorcock of the first in chief four scythes conjoined two and two arg. the handles of the second. HuckMORE or Hugirore, Buckland Baron, co. Devon; the heiress m. Gould.

\section{OWL and in chief....}

Arg. an owl upon the top of a tree growing out of a mount ppr. in chief two mullets gu. Bouchier, Loudon; from Holland.

\section{PELICAN and in chief....}

\section{Canton}

Az. a pelican (sometimes in piety) or vulned ppr. a canton erm. Richard Fox, Bishop of Exeter 1437, Bath 1492, Durham 1494, Winchester 1501.28, founder of Corpus Christr College, Oxford.

\section{Chief}

Arg. a pelican in piety wings expanded ppr, a chief dovetailed gu. VogUal, London.

Mullets

Or a pelican in piety gu. in chief two mullets az. RrDdock, Scotland.

POPINJAY and in chief....

Or a parrot ppr. a canton sa. Richard SENHOUSE, Bishop of Carlisle 1624.6
BIRD. SWAN and in chief....

Az. a swan arg. a chief erm. PICKerelu, London. Sa. a swan arg. a chief erm. Prkarel, in Burgate Church, Suffolk; and Harl. MS. 1177, fo. I21.

\section{BIRD and in base....}

\section{Fish}

Per fess arg. and gu. a bird standing .... on the top of a tree vert with a silver bell hanging from a sinister bough and over all in base a fish of the first back downwards having a ring in its mouth or. City of GLASGOW.

\section{Fleurs-de-lis}

Per fess embattled az, and arg. on the embattle. ment a lird wings expanded of the second beaked and legged gu, in base three fleurs.delis two and one as the last. Mason, co. Warwick.

\section{Fruit}

Gu. a bird arg. standing upon an apple or. Coneram, co. Wilts.

\section{Garb}

Az. a bird .... feeding on the top of a garb or banded gu. Shear, Cornwall.

Rock

Gu. a bird on a rock ppr. Rоск.

Tree

.... a bird .... perched on the stump of a tree shooting forth new leaves and growing out of a mount in base .... DEsBrisay.

\section{COCK and in base....}

\section{Hand}

Arg. a cock standing upon the hand ppr. of an arm issuing in fess from the sinister side vested az. HANCOKE, Ireland.

Horn

Or a cock standing upon a horn .... HoLDING, Middlesex.

\section{CROW and in base....}

Beast

Or a raven feeding on the back of a hog lying fesswise sa. DAnskine, Scotland.

\section{Mound}

Or a raven ppr. sitting upon an orb gu. Raven, Richmond Herald, ob. 1015. Raven, Hadley, Suffolk.

\section{Roundle}

Arg. a raven ppr. perched upon a torteau. RAvEN, Creting St. Mary's, Suffolk, temp. Henry VIII.

Or a raven sa. perched upon the top of a torteau. Raven, $V$.

\section{DovE and in base....}

\section{Arrow}

Quarterly az. and erm. in the first quarter a dove ppr. in the fourth an arrow or. Hugh Boulter, Bishop of Bristol 1719, Archbishop of Armagh 1723-42; granted 1720 .

Fleurs-de-lis

Az. a point with three battlements arg. on the middle battlement a dove wings displ. ppr. in base three fleurs-de-lis gu. Mason, London; and Stratford-upon-Avon, co. Warwick.

Reptiles

Or a dove volant arg. with an olive branch vert in the mouth in base two snakes entwined chain. wise and in chevron ppr. SLoper, West Woodhay, co. Berks. Sloper, Kent, 1628. 


\section{BIRD. DOVE and in base.... cont.}

\section{Ship}

Arg. a dove .... with an olive branch in the beak vert upon an ark in water ppr. GELLIE, Blackford.

Arg. in chief a dove volant with an olive branch in the beak in base an ark on the sea ppr. GaLliez, co. Galloway.

\section{Tree}

Arg. a dove rising ppr. out of a tree growing from a mount in base vert. Chauran.

Or a dove rising on the top of a tree ppr. growing out of a mount vert. Dupratt, Middlesex.

\section{EAGLE and in base....}

\section{Beast}

Az. an eagle pouncing on a hare courant or. Denskine, Scotland.

\section{Billet}

Arg. an eagle displ. double headed sa. standing on a billet traverse the escucheon raguled and trunked vert. SELWOOD.

Per pale arg. and or an eagle displ. standing on a billet raguly az. Pinel. Bird

Quarterly erm. and az. in the second quarter an eagle rising wings overt inverted and in the third another rising displ. or. Sr. Adam de BERRY, $V$.

Book

Az. an eagle displ. holding in the beak a penner and inkborn standing on a book fesswise closed the clasps downwards or. Company of Scriveners, London. Castle

Per fess or with per pale gu. and vert in chief a demi-eagle double headed displ. issuing sa. the dexter base charged with a tower the sinister with five towers in saltire of the first gate and portcullis to each ppr. VandenBEMPDE.

Per fess or and gu. in chief an eagle displ. double headed of the last in base a castle arg. PayneGallway, Baronetcy 8 December 1812 , quartering Payne. Escallops

Arg. an eagle displ. double headed and in base three escallops two and one sa. William POPE, $V$.

\section{Flower}

Per fess or and gu. an eagle displ. double headed of the second issuant from the top of a demirose and sun conjoined per fess counter. changed. William KNIGHT, Bishop of Bath, etc. 1541-7, Collinson, Somerset, iii, 399.

\section{Human Figure}

Arg. an eagle preyant sa. on a child or swaddled gu. Culcheth, $V^{*}$.

Arg. an eagle sa. taking up a child gu. face ppr. KILCHECH, Kilchech, co. Lancaster; quartering arg. a griffin segreant sa.

Arg. an eagle preyant sa. on a child ppr. swathed gu. banded or. Colcheth or Kulcheth, Culcheth, co. Lancaster.

Arg. an eagle wings expanded sa. preyant upon a child ppr. swathed gu. banded or. Hyndeey. KILCHECHE.

Arg. an eagle wings expansed sa. standing on a child swathed gu. banded or. CuLcheth, $V$.

Arg. an eagle sa. armed gu. standing on a child ppr. swathed or lying in a cradle vert. CoUlChiefe.
BIRD. EAGLE and in base.....cont.

Human Figure cont.

Arg. an eagle volant sa. seizing on a child ppr. swathed gu. in a nest of the first on a tree eradicated as the second. RisLey.

Or an eagle sa. preying on an infant gu. swaddled and apparelled of the first. CuLCHECH or CULEHEOH.

Perch

Or an eagle in full aspect gu. standing on a perch issuing out of the sinister side arg. BODY.

\section{Pillars}

Arg. an eagle displ. sa. resting each claw on a column with capitals and bases az. Bartolozzi.

Sprig

Az. an eagle with wings endorsed standing on a branch of laurel all or. Priory of Austin Canons at Caermarthen, South Wales.

Staff

Arg. an eagle displ. sa. standing on a staff raguly fesswise in base vert. SELWARD, co. Warwick; and co. Wilts.

Arg. an eagle displ. double beaded sa. perched upon a staff fesswise raguly vert. DELLwOod or DELWOOD.

Per pale or and arg. an eagle displ. perched on a ragged staff sa. PyNell.

Sa. an eagle displ. arg. armed and standing upon a ragged staff or. BARLAUNCHE BARLEW or BARLOW, co. Lancaster.

\section{Staves}

$A z$. an eagle displ. double headed per pale or and arg. holding in each claw a baston (erect $V^{*}$.) sloped pilewise of the opposite metals Pyvele, $V$.

Treo

Arg. an eagle displ. double headed sa. standing on a piece of a tree raguly vert. DELWARD or DeLWOOD, $V^{*}$. But with a crescent .... for diff. Henry Deswood, $V$.

Az. an eagle displ. per pale or and arg. beaked (and legged, Harl. MS. 1392) gu. standing on a piece of a tree raguly (per pale of the third and second, Harl. MIS. 1392) ..... PrNyLL, co. Devon, $W$. Pynglul, Harl. MS. 1392.

Sa. an eagle displ. arg. armed or standing on the limb of a tree raguled and trunked of the second. BaRLOW, Barlow.

Sa. an eagle displ. double headed arg. beaked or standing on a piece of a tree raguly of the se. coud. Sr. .... de BARLAdG,$V$. Barlowe, $V$. And with the eagle armed and a fleur.de-lis in chief of the third. William BARLOW, Bishop of Rochester 1605, Lincoln 1698-13; granted 1607. Sa. an eagle displ. double headed standing on a piece of a tree raguly arg. BARLOWE, $V^{*}$.

\section{FALCON and in base....}

\section{Beast}

Gu. a goshawk or standing on the back of a hare arg. Densiry, Scotland. Bird

Gu. a hawk reguard. trussing a bird arg. GOODWING.

$$
\text { .....Heron }
$$

Az. a hawk volant arg. seizing a heron also vo. lant or. Fotrnier.

$$
\text { Castle }
$$

$\mathrm{Gu}$ a falcon rising ppr. from a mount vert within a circular embattled wall (or castle) another a quadrangular castle or. LANION, Lanion, Cornwall, Visitation, Cornwall. 
BIRD. FALCON and in base.....cont.

Castle cont.

Sa. a falcon hovering with bells or over a castle arg. standing on the waves ppr. Lanine, Cornwall, Harl. MS. 4031, fo. 89 b.

Sa. a falcon hovering with bells ppr. over a castle with four towers arg. LANYoN, Lanyon in Madron and Lanyon in Gwinnear, Cornwall. Letter

Per chev. or and az. in chief a falcon sa. in base a letter $M$ arg. John Marshall, Bishop of Llandaff 1478.96.

Luro

Quarterly vert and or in the first quarter a falcon close arg. belled of the second in the fourth a hawk's lure as the third. JEBR. Perch

Sa. a hawk standing on a perch arg. beaked and legged or. Hawker, co. Wilts. Hawker, Long Parish House, co. Hants: quartering Ryves and Raneston. Sprig

Gu, a falcon rising arg. holding in the dexter claw an oak branch ppr. acorned or. Martin Fotherby, Bishop of Salisbury 1618-20. Staff

Arg. a bawk ppr. armed or standing on a staff couped and raguly rert. EDGE alias Hawlins, co. Salop.

Stock

Sa, a goshawk perched on a stock (another, 1716 fixed in the base point) arg. armed belled and jessed or. WEELE.

Sa. a goshawk (1730; another a hawk) arg. perched upon a stock (another 1730 standing on a perch) fixed to the base point of the second armed belled and jessed or. WeEne or Welts, Staverton, co. Devon. Weete, 1730. Tree

Arg. a hawk ppr. armed or standing on a trunk of a tree vert. Hawrings, co. Salop, and Rushall, co. Stafford. HawkINGs.

Trestlo

Sa. a hawk arg. belled or standing on a trestle of the second. Hawker, Essex.

\section{HERON and in basa....}

\section{Castle}

.... a stork ppr. upon a tower triple-towered.... Denton.

Gu. a stork arg. upon a tower or. Sutron, Elton, co. Durham; derived from Sutron, Thorn. borongh, co. York, 1640; the heirs m. Sleigh and Hutchinson; quartering Sleigh and Bathurst.

Gu. a stork ppr. upon a castle or. Sutron, Kit. tismore, co. York.

\section{Staff}

Arg. a crane sa. standing on a staff raguly in base vert. Crane, Camborne, Cornwall. Well

(? Vert) a heron arg. drinking from a well (? or or ppr. or) tenne. HugH (St. Hugh) Bishop of Lincoln 1186-1200.

PELICAN and in base....

Az. a pelican standing on a globe or. John Pierse, Bishop of Rochester 1576, Salisbury, 1577, Archbishop of York 1588-94.

\section{SWAN and in base...}

Vert a swan arg. drinling from a well or. HugH (St. Hugh), Bishop of Lincoln 1186-1200.
BIRD. VULTURE and in base....

Erun. a vulture seizing her prey gu. Siminges.

BIRD betw. or within....

\section{Bones}

Sa. a bird vert membered and collared gu. hetw. three pairs of shinbones in saltire arg. NEwTON. Bordure

Gu. a bird (see CROW) arg. beaked and membered of the first holding in the beak an ermine spot standing upon a garb .... a bordure compony or and az. VAughan, Tyle Glâs, co. Brecon. Mullets

.... a bird (eagle or falcon) .... betw. three mullets .... Jehan de SaLIE, seal (xiv century).

coCK betw. or within....

\section{Barrulets}

Sa. a cock arg. combed legged and wattled gu. betw. two bars humetty or enclosed by so many swans of the second beaked and legged as the third. Edmund Cox alias Cokrs, London : granted 25 January 1554, Harl. MS. 6169 , fo. $26 \mathrm{~b}$.

\section{Birds}

Gu. a cock or betw. three martlets arg. Delaite. CROW betw. or within....

\section{Bordure}

Arg. a raven ppr. a bordure sa. bezanty. Conbet. Gu. a Cornish chough ( see BIRD) .... beaked and membered of the first holding in the beak an ermine spot standing upon a garb gold a bordure compony or and az. WATkINS, Langorse, co. Brecon.

Or a Cornish chough ppr. a bordure arg. charged with eight fleurs-de.lis az. ARRELJ.

Or a raven ppr. a bordure engr. gu. CoRBer, Chadesley Corbet.

Or a raven ppr. a bordure engr. gu. bezanty. Corbet.

Or a raven within a bordure engr. sa. Conber, $V$. Crosses

Arg. a Cornish chough ppr. betw. three crosses patty sa. John Winciars, Bishop of Chiches. ter 1696-1709.

\section{Fleurs-de-lis}

Or a Cornish chough sa. an orle of eight fleursde-lis az. Ariel or ArierL.

IIullets

Arg. a raven sR. betw. three mullets gu. CoRBET, Tow cross, Scotland.

Roundles.... Fountains

Arg. a crow sa. betw. three fountains. Craigdainlie, Aberdeen.

$$
\text { ..... Ogresses }
$$

Arg. a raven volant sa. beaked of the first betw. three ogresses. Withering, Nelmes, Essex; descended from co. Stafford.

\section{Annulets}

\section{DOVE betw, or within....}

Az. a dove arg. betw. three annulets or. William Brvan, Pen-y-coed, co. Carmarthen, granted 1695.

Az. a dove arg. beaked and legged gu. betw. three gem rings or in chief a mullet charged with a mullet. BEAvaN.

\section{Bars}

Arg. upon a mount vert a dore rising ..... nimbed gold all betw. two bars wavy az. charged with three fishes naiant two and one or. John HIIsEy, Bishop of Rochester 1535.8. 
BIRD. DOVE betw. or within.... cont. Buckles

Quarterly gu. and vert a dove rising wings overt inverted (volant $V^{*}$.) betw. three round buckles or. Bramiston, $V$.

\section{Coronets}

Gu. a dove urg. holding in the beak an olivebranch vert betw. three antique crowns arg. Grant, Carron, Scotland.

\section{Crosses}

Az. a dove ppr. betw. three crosses patty fitchy or. WILJirans, Lincoln's Inn.

Sa. a dove (arg. another) ppr. betw. three crosses patty or. John Wirliams, Bishop of Chiches. ter, Sussex, 1696-I709.

\section{Fishes}

Barry wavy of five arg. and az. on a mount vert in the centre a dove rising .... nimbed gold betw. three fishes naiant or. John Hilser, Bisbop of Rochester 1535-8.

\section{Flowers}

Arg. a dove sa. holding in the beak an olivebranch vert standing upon an ark in water ppr. betw. three gilliflowers gu. stalked and leaved of the fourth. JoLLy, Scotland.

\section{DUCK betw. or within....}

Sa. a duck arg. beaked or within a bordure engr. of the last. More, $V^{*}$.

\section{EAGLE betw. or within....}

\section{Axes}

Az. an eagle displ. betw. three poleaxes or. Orme, co. Stafford.

\section{Birds}

Arg. an eagle displ. sa. beaked and membered gis. within an orle of eight martlets az. Ramsay, Methven, Scotland.

Barry of eight or and az. an eagle displ. double beaded sa. within an orle of martlets gu. Browne, Baron Oranmore and Browne 1838, quartering Monck and Prendergast.

Bordure

Arg. an eagle double headed .... within a bordure gu. Lloyd, Hardwicke, co. Salop.

Arg. an eagle displ. sa. armed gu. a bordure of the third. Rarisay, Idington, Scotland.

Arg. an eagle displ. sa. armed gu. a bordure nebuly .... Ramsay, Cockpin, Scotland.

Arg. an eagle displ. sa. armed gu. a bordure of the second cbarged with eight roses of the first. Ramsay, Whitehill, Scotland.

Arg. an eagle displ. sa. a bordure of the second bezanty. Kilisgrew, Killegrew and Arwenick, Cornwall, temp. Richard II; the beiress $\mathrm{m}$. Erisey.

Arg. an eagle displ. double headed sa. a bordure of the last bezanty. GLYN, Cornwall, $V$. Killegrew, $V^{*}$. Kyllegrew, $V$.

Arg. an eagle displ. sa. armed gu. a bordure (sa. Harl. MS. 139\%) bezanty. TREgIAN, $V$.

Arg. an eagle displ. sa, crowned or holding in the dexter claw a sword of the first a bordure of the second bezanty. TREGYAN.

Arg. an eagle displ. double headed and a bordure engr. sa. HOAR or HOARE, Middlesex.

Arg. an eagle close in trian aspect sa. armed or a bordure engr. of the last. Standen, $V$.

Arg. an eagle close sa. armed or a bordure engr. of the second. Standen.

Arg. an eagle wings expanded sa. armed or a bordure eligr. of the second. STANDEN, $V^{*}$.
BIRD. EAGLE betw, or within.... cont.

\section{Bordure cont.}

Arg. an eagle rising wings overt inverted sa armed or a bordure engr. of the second. Standen, $V$.

Az. an eagle displ. and a bordure arg. PoDEnHanr.

Az. an eagle displ. double headed arg. holding in the dexter claw a sceptre and in the sinister a rose ppr. a bordure of the second charged with 5-foils and mullets alternately as the first. Dunlop, Scotland.

Az. an eagle displ. or crowned arg. a bordure of the last. SHERFELD, co. Wilts.

Az. an eagle displ. and a bordure engr. or. Pevelesdon.

Gu. an eagle displ. and a bordure arg. Albany or Daubigny. Southwell. Todney. T'onny.

Gu. an eagle displ, arg. a bordure or. STORINGE.

Gu. au eagle displ. arg. a bordure engr. or. Storange, Ampton, Suffolk, $V$. Straunge, $V^{*}$. Strong. Walsam or Walsham.

Gu. an eagle displ. arg. beaked az. a bordure engr. or. WaLsham, $V$.

Gu. an eagle displ. erm. a bordure engr. erminois. ClaCK, co. Hereford; and Wallingford, co. Berks; granted 13 November 1768.

Gu. an eagle wings endorsed or a bordure erm. FAIRBAIRN.

Gu. an eagle displ. within a bordure engr. or. Strong.

Gu. an eagle displ. or armed az. a bordure engr. of the second. WaLshaM, $V^{*}$.

Or an eagle displ. az. armed sa. a bordure gu. Carnegie, Northesk, Scotlaud.

Or an eagle displ. az. armed gu. a bordure per pale gu. and arg. charged with eight escallops counterchanged. Carnegie, Scotland.

Or an eagle displ. az. a bordure engr. gu. Carnegie, Lour.

Or an eagle displ. gu. a bordure of the second charged with eight 5-foils arg. Limsey. Lymsey, $V^{*}$. Lyvisey, Ifclde, Kent, $V$.

Or an eagle displ. within a bordure gu. charged with ten 5-foils arg. LyNDsey, Gunton, Norfolk.

Or an eagle displ. gu. a bordure sa. charged with escallops .... Lemosy or Lymesey, co. Warwick.

Or an eagle displ. double headed ppr. a bordure invecked erm. Troyte, Chidderleigh, co. Devon; granted 1739.

Or an eagle displ. sa. crowned gu. a bordure az. charged with three fleurs-de-lis in chief gold. Cipriant, London.

Or an eagle displ. vert armed az. a bordure of the third charged with eight lions pass. guard. as the first. Mounthermer.

Or an eagle displ, vert ducally crowned of the first armed gu. a bordure az. charged with three fleurs-de-lis gold. Booker, London; from Woodbouse, co. Nottingham. But with eight fleurs-de-lis. Boocher or Booker, Iondon.

Or an eagle displ. vert a bordure gu. charged with eight lions pass. of the first. Sir Edward Monthermer, $R$.

Or an eagle displ. vert a bordure gu. charged with eight lions pass. guard. of the first. Monthermer, $\boldsymbol{V}$.

Per bend sinister erm. and arg. an eagle displ. double lieaded sa. a bordure of the last bezanty. Loyd, Over'stone Park, co. Nortbampton. 
BIRD. EAGLE betw, or within.... cont.

Bordure cont.

Per pale az. and gu. an eagle displ. double headed and a bordure eng1. or. MYtToN, Shrewsbury. Sir Everard de Motron, and his descendants ; Mrtton, Halston, co. Salop, quartering arg. a 5 -foil az.; Mrtton, by change of name Thorvycroft, Thornycroft; MytToN, Garth, and Pen. y-lan, originally of Pont-ys-cowryd, co. Mont. gomery; Mutron, Llanerch Park, co. Denbigh; quartering Vaughan, Burley, and $\mathrm{De}$ Burgh; the coheirs m. Davies and Eyton: and Mrtion, Weston-under-Lizard, co. Salop; the coheirs m. Phillips and Harpsfield. Myтton, Cleobury North, co. Salop, quartering arg. a chev. sa. betw. three birds ppr.

Per pale gu. and az. an eagle displ. arg. a bordure counterchanged. Mition.

Per pale gu. and az. an eagle displ. double headed or within a bordure counterchanged. Mrtion, co. Salop.

Per pale gu. and az. an eagle displ. double headed and a bordure sa. Killegrew.

Quarterly sa. and gu. an eagle displ. double headed arg. a bordure invecked counterchanged. HoAR, Twyford, co. Hants.

Sa, an eagle displ. and a bordure arg. PARKe.

Sa. an eagle displ. arg. and a bordure az. Richard del PAREe, $Y$.

Sa. an eagle displ. within a bordure engr. arg. HOARE or HORE, co. Gloucester. HOAR.

Sa. an eagle displ. double headed and a bordure engr. arg. Hosre, $V^{*}$. Hore, Chartley, co. Stafford, $V$. Hoare, co. Devon; Middlesex; and co. Cork, 1649; from whom descended Hodre, Audley Place, Cork, quartering Barry, Lyons, and Phillips; and Edward Hoane, Fac. tory Hill, co. Cork, quartering Woodcock, Burnell, Barry, Lyons, Phillipps, Lumm, Purefoy, and Lombard; a cousin of HOARE, Annabelle, Cork ; Baronetcy 10 December 1784; quartering Wallis. HoaRe, Lord Mayor of London 1713. HOARE, Mayor of Cork, 1686, 1710.

Sa. an eagle displ. arg. armed or a bordure engr. of the second. PaLK, Haldon House, co. Devon; Baronetcy 19 June 1782.

Sa. an eagle displ. double headed arg. a bordure or. DUNE.

Sa. an eagle displ. arg. armed gu. a bordure engr. or. Guthrie, Dantzic.

Sa. an eagle displ. erm. a bordure arg. Tufton, Earl of Thavet, $Z, 541$; Baronetcy 29 June 1611; Baron Tufton ] November 1626, Earl of Thanet 5 August If28, quartering Sackvill and Clifford. Robert Tuluy, Bishop of St. David's 1460-81.

Sa. an eagle displ. or a bordure arg. charged with eight leopard's heads gu. Venables, co. Lancaster.

Sa. an eagle displ. or within a bordure compony gu. and az. James Dunne, Merchant, Dublin, ob. 1600 .

Vert an eagle displ, or a bordure gu. Montymer. Crescents

Arg. an eagle wings displ. sa. betw. three crescents gu. Spittal, Scotland.

Arg. an eagle displ. sa. armed gu. betw. three crescents of the last. SpItTLE, Scotland.

Az. an eagle displ. betw. in chief four crescents and in base two bugle horns or dimidiated with lozengy sa. and arg. LOMBARD, Whitechurch, co. Cork, $V$, but in a later hand.
BIRD. EAGLE betw, or within.... cont. Crosses

Gu. an eagle displ. or membered and ducally crowned arg. betw. eight crosses croslet of the second. Graves, Mickleton, co. Gloucester.

Arg. an eagle displ. within an orle of crosses flory gu. MaRTYN.

Escallops

Per pale or and vert an eagle displ. betw. three escallops counterchanged the eagle charged with a 3-foil for diff. LYNECAR, Dublin.

Flaunches

Sa. an eagle displ. betw. two flaunches or each charged with an eagle displ, of the first. Bowland, London.

Sa. an eagle displ. betw. two flaunches arg. each charged with an eagle displ. of the first betw. two ogresses (or torteaux) each charged with a cross patty fitchy or. BOwLAND, London.

\section{Fleurs-de-lis}

Az. an eagle displ. betw. three fleurs-de-lis or. Peake, Foxton, Middlesex.

Gu. an eagle displ. betw. three fleurs-de-lis arg. GodolpHIN, Collinson, Somerset, i, 216.

Gu. an eagle displ. double headed betw. three fleur's-de-lis arg. GodoLphis, Cornwall, $V$. Lord High Treasurer of England, Baron 1664, Earl 1706. GodolpHIN, Trewarvenetb, Cornwall, temp. Henry VIII; the coheirs m. Nicholls and Keigwin.

Arg. an eagle displ. az. armed or within an orle of fleurs-de.lis sa. MaRTyN.

Arg. an eagle displ. gu. within an orle of fleursde-lis sa. Martyn.

Gu. an eagle displ. within an orle of fleurs-delis arg. Goodsinging.

\section{Flower}

Vert an eagle displ. or in the dexter paw a thistle and in the sinister an arrow .... EnsLey, Scotland.

\section{Flowers}

Gu. an eagle displ, betw. three lilies arg. Godolphin, Cornwall.

Gu. an eagle displ. arg. betw. three lilies az. GodolphIN, Cornwall.

Gu. an eagle displ, betw. three lilies or. GODOLPHIN.

\section{3-Foils}

Arg. an eagle displ. double headed within an orle of 3-foils slipped sa. SEEDGREw.

Arg. an eagle displ. double headed betw. five 3-foils slipped three and two sa. SEDEGREW, Ireland, $V$.

Vert an eagle displ. double headed or within an orle of 3.foils or. Lutron, Mowlish, and Cofford in Canton, co. Devon, temp. Henry V.

Vert an eagle displ, double headed betw. 3-foils slipped or. Lutron, temp. Henry $V, W$.

\section{Mullets}

.... an eagle (or falcon) .... betw. three mullets .... Jehan de SaLLE; seal (xiv century).

\section{Orle}

Gu. an eagle displ. or within an orle engr. counterengr. arg. Captain Robert KNox, 1695 , portrait.

Quarterly gu. and arg. an eagle volant sa. within an orle counterchanged. KNox.

\section{Pheons}

Gu. an eagle displ. betw. three pheons arg. ABNET, co. Stafford. 
BIRD. EAGLE betw, or within.... cont.

Roundles.... Bezants

Sa. an eagle displ. arg. within four bezants two and two each charged with a cross croslet fitchy of the first all betw. two flaunches as the second each charged with an eagle displ. like the field armed gu. Humfrey BowLAND, Kinfare, co. Stafford, $V$.

\section{....Torteaux}

Or an eagle displ. gu. within an orle of eight tor. teaux. Busrard, Suffolk. Busserarde. Bussemard, Norfolk, $V$.

\section{Tressure}

.... an eagle displ. arg. membered or within a single tressure flory .... V V cester.

Arg. an eagle displ. az. within a double tressure flory sa. Martyen.

Arg. an eagle displ. gu. within a double tressure sa. Martyn, London.

Arg. an eagle displ. gu. within a double tressure flory counterflory sa. Marten, $V$.

Az. an eagle displ. within a double tressure arg. Wampage, co. Devon.

Az. an eagle displ, within a double tressure flory counterflory arg. Sr. John Vampage, $V$.

Az. an eagle displ. double headed within a double tressure flory counterflory arg. VAMPAGE.

\section{FALCON betw, or within....}

\section{Bordure}

Arg. a falcon ppr. wings elevated belled beaked and legged or holding in its dexter talon a martlet of the last all within a bordure engr. or. Enwards, Pentre, co. Montgomery, and Cilcen, co. Flint; descended from William Lord D'Elbœuf, Normandy.

Az. a falcon volant arg. within a bordure erm. Sir Palmer Fatroonne, Commandant at Tangier, and his son Admiral Fairborne, 1730.

Az. a falcon volant arg. armed jessed and belled or within a bordure erm. FAIrBorne, Newark, co. Nottingham. FaIREBORNE.

\section{Castle}

Gu. on a mount vert within a circular embattled wall (or castle another a quadrangular castle) or a falcon rising ppr. Lanion, Lanion, Corn. wall.

\section{Flowers}

Or a falcon sa. belled gu. betw, three roses of the last leaved vert. HamLYN; now Williams, Clovelly Court, co. Devou; Bartcy. 7 July 1795. Leaves

Arg. a falcon volant ppr. betw. in chief three holly leaves vert and in base a huntinghorn sa. garnished gu. Burnet, Shetchoksly, Scotland; descended from a third son of Leys.

\section{Mullets}

.... a falcon (or eagle) .... betw. three mullets .... Jehan de Salle; seal (xiv century).

$\mathrm{Gu}$. a falcon hooded and perched on a hand issuing out of the sinister side or on a chief arg. three mullets az. BlackHaLl, Scotland.

Gu. a falcon hooded and perched on a dexter hand in fess couped or on a chief arg. three mullets of the first. BLackHaLl.

Sa. a falcon betw. three mullets or. Pendarves, Pendarves, Cornwall; quartering Wynne, Williams, Courtenay, Abrincis, Avenel, St. Attbyn, Carminow, etc. Orle

Gu. a falcon volant or within an orle invecked on the outer side arg. KNox, That Ilk.
BIRD. FALCON betw. or within.... cont.

Orle cont.

Gu. a falcon volant or within an orle wavy arg. KNox, Earl of Ranfurly.

\section{HERON betw, or within....}

\section{Bordure}

Az. a stork close arg. a bordure engr. erm. StaRkey, co. Warwick.

Sa. a stork ppr. within a bordure arg. Mathew, Clanville, co. Hants; quartering Bertie, Willoughby, and De Vere; a younger brother of Mathew, Felix Hall, Essex, quartering Van Lumputt; Sparrow, Mathew, Clare, Smith, and Williams; descended from Mathew, St. Kew, Pennetenny, Tresungher, and Endellyon, Cornwall. Mathew, The Lyth, co. Salop.

\section{Crescents}

Gu. a stork betw. three crescents arg. beaked and membered or. Gibson, Stavely, York; confirmed 16 January 1655, afterwards declared void.

\section{Crosses}

Az. a stork betw. three crosses croslet fitchy or. Oglander, Nunwell, Isle of Wight; and Parn. bam, co. Dorset; Baronetcy 12 December 1665 .

Sa. a stork arg. within an orle of eight crosses croslet fitchy of the last. Patnam.

Arg. a stork betw. crosses croslet fitchy sa. Putrenham, Sherfield, co. Hants, 1634; the heiress $\mathrm{m}$. Morris.

(? Gu.) a beron arg. betw. crosses croslet or William Herun, $E$.

Gu. a heron .... betw. crosses croslet or. Wil. liam Hern, (sic) $F$.

Sa. a stork betw. crosses croslet fitchy arg. Puttenhair or Putnam, co. Bedford ; and Penn, co. Buckingham.

Sa. a heron arg. beaked and legged gu. in an orle of croslets as the second. PUTtenham or Putnam, $V^{*}$.

Sa. a crane (or heron) arg. legged gu.jn an orle of crosses croslet fitchy as the second. Sr. George Puttenham, $V$. Putnair, $V$.

Escallops

Arg. a heron volant az. membered or betw. three escallops gu. Creck.

Arg. a heron volant in fess az. membered or betw. three escallops sa. Herondon.

Arg. a heron volant betw. three escallops sa. Heronden. Horndon.

\section{MARTLET betw, or within....}

\section{Bordure}

Arg. a martlet or held in the dexter talon of a falcon wings elevated ppr. belled beaked and legged gold within a bordure engr. of the last. EDwards, Peutre, co. Montgomery; and Cilcen, co. Flint.

Arg. a martlet and a bordure engr. sa. Standon. Coronets

Sa. a martlet arg. betw. three ducal crowns or. Tolman.

\section{Crosses}

Sa. a martlet betw. six crosses croslet arg. Putman or Putnam, Sussex.

\section{Estoiles}

Sa. a martlet betw. three estoiles arg. (or $V^{*}$.) within a bordure engr. or. Baron, $W$.

Mullets

Az. a martlet hetw. three mullets or a bordure invecked compony arg. and gu. Yousg. 
BIRD. OWL betw, or within....

Arg. an owl ppr. betw. in chief two mullets gu. and in base a tree growing out of a mount as the second. Bouchier, London, from Holland.

\section{PELICAN betw. or within....}

\section{Bordure}

Az. a pelican or vulned ppr. within a bordure of the second. Richard Fox, Bishop of Exeter 1487, Bath, etc. 1492, Durham 1494, Winchester 1501-28, $U$; founder of Corpus Christi College, Oxford, Add. MS. 12443.

Vert a pelican in piety arg. within a bordure in. dented of the first and second. Sherbonne, Bishop of Winchester; but Robert SHERBonN or Sherbourn, Bishop of St. David's 1505, Chichester 1508-36.

\section{Fleurs-de-lis}

Az. a pelican betw. three fleurs-de-lis or. Krmpton, Weston, co. Hertford.

Az. a pelican rising overt inverted betw. three fleurs-de-lis or. Kempton, $W$.

Az. a pelican wings elevated or vulning her breast gu. betw. three fleurs-de-lis of the second. Kempton, Morden, co. Cambridge; and London; granted 1577 .

Az. a pelican arg. vulning herself gu. betw. eight fleurs-de-lis of the second. CARYER, Canterbury; granted 29 June 10 James I.

\section{SWAN betw. or within....}

\section{Bordure}

Az. a swan arg. membered gu. within a bordure engr. or. More.

Sa. a swan arg. membered gu. a bordure engr. of the second. More, co. Devon.

Sa. a swan wings expanded and a bordure engr. arg. Mone, quartering arg. three bars gu. a canton erm.

Sa. a swan wings expanded arg. membered or a bordure engu. of the second. More, 1730.

Sa. a swan arg. a bordure engr. or. Moore.

Sa. a swan close arg. a bordure engr. or. MORE, Linley, co. Salop; a younger branch of More, Larden, co. Salop; desceuded from Mone, More. Moore, co. Devon; co. Hants ; and Surrey.

Sa. a swan wings expanded arg. a bordure engr. or. Moore, co. Hants.

Sa. a swan wings expanded arg. membered gu. a bordure engr. or. Mone, Millichope, co. Salop; ob. 1689 .

Sa. a swan arg. membered and beaked or a bordure engr. of the last. Moore, Earl of Mountcashell, quartering Colvile and Lindsay'. Moore, Barn, co. Tipperary.

Sa. a swan close arg. membered or within a bordure engr. of the last. Mone, $\boldsymbol{V}$.

Sa. a swar wings expanded arg. membered or within a bordure engr. of the third. Moore, Cockham, co. Berks; and Corbet, co. Salop. Moore, Aspley Guise, co. Bedford, quartering Howell.

$$
\text { BIRD betw, or within.... }
$$

Gu. a bird betw. three crescents arg. on a chief or as many ogresses. Thomas VoweLL, $V$.

COCK betw, or within....

and in chief...

Arg. a cock betw. two mullets of six points sa. on a chief gu. three cushions or. STотнаRт.
BIRD. CROW betw, or within....

and in chief....

Arg. a Cornish chough ppr. betw. two arrows in base gu. and in chief an arrow of the second betw. two Cornish choughs of the first. Crastein. Scrace.

\section{EAGLE betw, or within... and in chief....}

\section{Canton}

Sa. an eagle displ. in bend betw. two cotises arg. a canton sinister or. JORDAN, Kent; and Sussex, quartering Woodgate.

on a Canton.... Wreath

Az. on a rock ppr. an eagle rising or betw. in chief the arctic and in base antarctic polar stars on a canton of the third a wreath of laurel vert fructed of the second. Somenset, London; granted 1771 .

Chief

Sa. an eagle displ. in bend betw. two cotises arg. a chief or. JoRDAN, Catwick, and Charlewood, Surrey; granted 2 June 1631.

Arg. an eagle displ. betw. two palets gu. a chief of the last. Dyas.

on a Chief.....Chevron

Sa. an eagle displ, or on a chief az. a chev, betw. two crescents and a 5-foil of the second all (? the chief only) within a bordure of the same. Waynburst, Norfolk.

.... Cross or Cross-staff see Implement .....Escallops

Sa, an eagle in bend betw. two cotises arg, on a chief of the second three escallops vert. JORDAYNE. .....Flower

Arg. an eagle displ. within a double tressure flory counterflory gu. on a chief quarterly or and of the second a rose betw. two lions ramp, in fess counterchanged. Martrr. ....4-Foils

Arg. an eagle volant betw. three 4-foils sa. on a chief of the last so many 4-foils as the first. White, Markle, Scotland.

Arg. an eagle displ. betw. three 4.foils sa. on a chief engr. of the last so many 4-foils as the first. White, Burnedshields, Scotland.

\section{.... Forestaff see Implement \\ ....Implement}

Arg. an eagle displ. double beaded and a bordure invecked sa. on a chief vert a cross-staff betw. two spur-rowels or. ATCHESON.

\section{....Leaves}

Sa. an eagle displ. betw. two bendlets arg. on a chief or three almond (? woodbine) leaves vert. JoRdan, Calais ; and Surrey, $V$. JoRDAN, Calwick, and Charlwood, Surrey.

Sa. an eagle displ. betw, two bendlets arg. on a chief or three oak leaves vert. JorDin or JORDAN, $V^{*}$.

Sa. an eagle displ. in bend betw. two cotises arg. on a chief or three oak leaves vert. JonDAYNE, co. Somerset.

$$
\text { ..... Mullet }
$$

Arg. an eagle displ. within a bordure sa. charged with eight bezants on a chief gu. a mullet betw. two 5 -foils of the first. RAMSAY, Edinburgb. Hand

Or an eagle displ. double headed ppr. beaked and membered gu. surmounted by a galley sa. flag of the third a bordure engr. az. in the dexter chief a sinister hand couped and erect of the second. Donaldson. 
BIRD. EAGLE betw. or within....

and in chief.... cont.

Spur-rowels

Arg. an eagle displ. double headed and a bordure invecked sa. on a chief vert two spur-rowels or. ATCHESON.

FALCON betw. or within.... and in chief....

\section{Birds}

Sa. a falcon close in fess betw. two cotises arg. in chief two falcons close or. Mitchel., Bodmin, Coruwall.

on a Canton.... Fess

Gu. a falcon wings expanded within a bordure engr. or on a canton of the same a fess chequy arg. and az. KNox, Belleck Abbey, Broadlands Park, and Netley Park, co. Mayo; derived from Knox, Moyne and Rappa Castle, co. Mayo, quartering Gore. KNox, Castlerea, and Mount Falcon, co. Mayo; and Woodstock, co. Wicklow.

\section{.....Flower}

Az. a falcon volant within a double tressure flory counterflory or on a canton arg. a rose gu. Rose, London.

\section{MARTLET betw. or within.... and in chief....}

\section{Birds}

Arg. a niartlet within an orle gu. in chief two martlets of the second. RUTHERFord, Eng. land.

\section{on a Chief....4-Foils}

Arg. a martlet betw. three 4-foils sa. on a chief gu. as many 4-foils or. WhrTe, Bankbead, Scotland.

Arg. a martlet betw. three 4-foils sa. on a chief of the last so many 4 -foils as the first. White, Scotland. WhYT, Scotland.

Arg. a martlet displ. betw. three 4-foils sa. on a chief of the last so many 4-foils as the first. Melville - White, Bennochy, and Strathkinness, co. Fife; quartering Melville; descended through Wryte, Kirkcaldy, from Whyte, Maw, and Lumbenny.

\section{.... Roundle}

Gu. a martlet betw. three crescents arg. on a chief or as many ogresses. Voweli, Essex.

\section{Estoiles}

Sa. in base a martlet arg. a bordure engr. or in chief two estoiles of the secund. Baron, Essex; and London.

\section{OWL betw. or within.... and in chief....}

Per fess arg. and sa. in base an owl within a bordure engr. and in chief a greyhound courant all counterchanged. Ford, Chagford, Bagtor and Mutwell, co. Devon. Forde, 1524, $W$. The greyhound collared counterchanged and the legs of the bird or. John Ford, Ashberton, co. Devon, $V$.

\section{PELICAN betw. or within.... and in chief....}

Az. a pelican in piety or vulned ppr. a bordure of the second and a canton erm. Richard Fox, Bishop of Exeter 1487, Bath etc. 1492, Durham 1494; Winchester 1501-28, founder of Corpus Christi College, Oxford.
BIRD, SWAN betw. or within....

and in chief....

Az. a swan wings expanded arg. within a double tressure flory counterflory or a chief gu. charged with on a pale betw. two lions pass. guard. of the third thereon a rose of the fourth seeded gold barbed vert. Society of Musicians, London; incorporated 1604.

\section{EAGLE betw, or within....}

and in base....

Per fess vert and arg. in chief an eagle displ. or a bordure engr. gu. in base three hurts each charged with a bird (? martlet) of the first. Thomas Hutron, Dry Drayton, co. Cambridge, Harl. MS. 1392.

\section{On 1 EAGLE}

\section{Annulet}

Gu. on an eagle displ. or an annulet for diff. (az. another) sa. GoDARD, Norfolk.

Bars

Sa. on an eagle displ, arg. three bars gemelles gu. Caster.

Arg. on an eagle displ. gu. bars of the first. Thomas de Castre, $Y$.

Az. on an eagle displ. arg. bars gu. CANSURE. Sr. John Castre or de Castre, L. Monsire JohnChanscyre, $Y$. Chanserie, $V$. Chanserire, $V^{*}$. Morvilu, Cumberland, temp. Henry II.

Gu. on an eagle displ. erm. bars az. BARNeTt, quartered by Rolls.

Gu. on an eagle displ. or bars az. Cocee, $V$.

Gu. on an eagle displ. or bars vert. Sr..... de Coche, $V$. Cocher.

Sa. on an eagle displ. arg. bars gu. CAster, Norfolk.

\section{Bendlet}

Gu. on an eagle displ. or a bendlet of the first. ILLEY, co. Lincoln.

$$
\text { Castle }
$$

.... on an eagle displ. looking to the sinister wings inverted gu. ducally crowned or a large castle surmounted by two more one above the other arg. TOwn of BEDFORD.

Chevrons

Per fess or and paly of six erminois and az. in chief on an eagle displ. sa. two chevronels arg. A'Court, Baronetcy 4 July 1795; Baron Heytesbury, 1828.

\section{Cross}

Az. on au eagle displ. erm. a cross patonce of the first. William Howley, Bishop of London 1813, Archbishop of Canterbury 1828-48.

Or on an eagle displ. sa. a cross formy fitchy arg. SLESBY.

Sa. on an eagle displ. double headed arg.standing on the limb of a tree raguly and trunked fesswise or a cross fitchy patty gu. BARLOW, Bath.

\section{Crosses}

Or on an eagle displ. sa. five crosses formy fitchy arg. Slesby.

$$
\text { Cup }
$$

Or on an eagle displ. az. armed gu. a cup of the first. Carnegie, Craigie, Scotland.

\section{Escucheon}

Arg. on an eagle displ. sa. an escucheon of the first. MaXwELL.

Arg. on an eagle displ. sa. an escucheon of the first charged with a bordure engr. gu. REw, London, and Lionsdown, co. Hertford. 
BIRD. On 1 EAGLE cont.

Escucheon cont.

Arg. on an eagle displ. double headed sa. an escucheon gu. ReIDE, Collister, Scotland.

Arg. on an eagle displ. sa. armed gu. an escucheon of the first charged with a saltire of the second. MaxwerL, Kirkonnell, Scotland; quartering Kirkonnell.

Arg. on an eagle displ. sa. armed gu. an escucheon of the first charged with on a saltire as the se. cond a hedgehog or. Maxwell, Earl of Niths. dale. Maxwelr, Everingham Park, co. York; and Carlavarock, co. Dumfries; quartering Constable and Haggerston.

Arg. on an eagle displ. sa. armed or an escucheon arg. charged with on a fess az. three lozenges or. Feilding, Baron and Viscount Feilding 30 December 1620, Earl of Denbigh, 14 September 1622 .

Arg. on an eagle displ. sa. armed or an escucheon gu. ReId, Collistoun, Scotland.

Az. on an eagle displ. arg. an escucheon gu. charged with a leopard's head of the second. Cotisuore.

Az. on an eagle displ. arg. an escucheon gu. charged with a leopard's face or. Caster.

Az. on an eagle displ. double headed arg. an es. cucheon gu. CotTesmore.

Az. on an eagle displ. double headed arg. an escucheon gu. charged with a leopard's face or. Sr. John de Cotesmore, $V$. Cottesmore, $V^{*}$.

Az. On an eagle displ. double headed arg. an escucheon gu. charged with a bezant. Cotis MIORE.

Per fess or and arg. on an eagle displ. double headed sa. an escucheon gu. charged with a bend vair. Bouverie, Delapie Abbey, co. Northamptou, a younger branch of Bouverie, Earl of Radnor.

Estoiles

$\mathrm{Ol}^{\circ}$ on an eagle displ. gu. a star of six points as the first. Custance, Weston House, Norwich, quartering Hambleton.

Fleur-de-lis

Arg. on an eagle displ. sa. a fleur-de-lis or. Bruyn, co. Salop.

Er'm. on an eagle displ. az. ducally gorged or a fleur-de-lis of the last. Cookman.

Erm.on an eagle displ.gu. a fleur-de-lis or. Codnam.

\section{Flower ... Rose}

Per fess or and gu. on an eagle displ. double headed sa a demi.rose and a demi-sun conjoined counterchanged of the first. William KNIGHT, Bishop of Bath 1541.7 ; granted 14 July 1514.

Arg. on an eagle displ. sa. a rose as the first. Ramsay, Balmaine, co. Kincardine, Baronetcy 3 September 1685, 13 May 1806. Ramsey, Spanish Town, Jamaica.

Arg. on an eagle displ. sa. armed gu. a rose of the first. Ravsis, Bamff House, co. Pertb; Baronetcy 3 December 1666 .

$$
\text { ....Thistle }
$$

Arg. on an eagle displ. sa. a thistle .... Raysay, France, from Scotland.

\section{3-Foil}

Arg. on an eagle displ. double headed sa. a 3-foil vert. Stuckely, co. Lincoln.

\section{Gouttes}

Arg. on an eagle displ. sa. gouttes of the first. Sr. de LufFincote, $V$.

Arg. on an eagle displ. sa. gouttes de-sang. LUIFYNGCOTTE.

\section{BIRD. On 1 EAGLE cont.}

Gouttes cont.

Arg. on an eagle displ. double headed sa. gouttes d'or. Gryn, Dursington House, Sheering, Es. sex. Glyn, London; and Ewell, Surrey; Baronetcy 1759 , quartering Lewen. And with a crescent for diff. GLYN, London ; and Gaunt's House, co. Dor'set; Baronetcy 1800, quartering Carr.

\section{Head..... (Beast) Leopard}

Arg. on an eagle displ. double hended sa. a leopard's bead or. Salman, Surrey, $W$. Saltman or SALiHoN.

$$
\text { ....Tiger }
$$

Arg. on an eagle displ. sa. armed or a tiger's face of the last. M. Thomas Salman, $S$.

\section{Heads..... (Monster)}

Per fess sa. and az. on an eagle displ. arg. three griffin's heads erased of the second. PILEsBurgh or Pilesborough, Essex.

\section{Maunch}

$\mathrm{Az}$, on an eagle displ, arg. a maunch gu. PECHE or Pechey, co. Oxford.

Az. on an eagle displ. arg. a maunch at the shoul. der gu. Sire Johan Peche, $N$.

Az. on an eagle displ. arg. a maunch at the dexter wing gu. Sr. Thomas Peche, $V$.

Az. on an eagle displ. or crowned gu. a maunch of the third. Pecre or Pecry, co. Cambridge. Mullet

Arg. on an eagle displ. ppr. a mullet of the first. Samuel WILberforce, Bishop of Oxford 1846. Roundle

Arg. on an eagle displ. sa. a bezant. Nicholas Browne, Uxbridge, 1716.

Roundles.... Plates

Arg. on an eagle displ. sa. five plates. Lyndser.

Or on an eagle displ. sa. seven plates in pale. LINSEY.

Or on an eagle displ. sa. nine plates in cross. Sr. de Linsey, $V$. Lyndsex.

Or on an eagle displ. sa. ten plates in cross. LiNDSEY, $V *$.

Or on an eagle displ. sa. armed gu. bezants. Browne, Harl. MS. 1603.

\section{On 1 FAICON.}

Sa. on a falcon arg. membered jessed and belled or a 3 -foil slipped ppr. BoLToN, Woodbridge, Suffolk; granted 26 August 1615.

\section{On 1 HERON}

Arg. on a crane sa. membered gu. a crescent for diff. .... Starket, Olton, co. Chester, $\nabla$.

\section{On 1 EAGLE and in chief....}

on a Chief.... Cross

Erminois on an eagle displ. double headed gu. an eastern clown or a chief vert charged with pendent from a chajn a cross croslet fitchy of the third. Rev. Thomas Raffles, Liverpool.

$$
\text { .... Roundles }
$$

Erminois on an eagle displ. double headed gu. an eastern crown or a chief vert charged with pendant from a chain two oval medallions in pale the one bearing Arabic characters and the other a dagger in fess blade wavy point towards the dexter in relief gold. Sir Thomas Stam. ford RafFLes, Lieut.-Governor of Java, and of Fort Marlborough, Sumatra.

Az. on an eagle displ. arg. three torteaux in pale a chief embattled of the second charged with the like number of tortean. RAYMOND. 
BIRD, On 1 EAGLE and in chief.... cont. Letters

Or on an eagle displ. sa. armed gu. a naval crown gold in ehief the word Trafalgar. Carnegie, Baron Rosehill 1639 ; Earl of Northesk 1647.

On 1 CROW betw, or within....

Arg. on a raven wings endorsed $p p x$. betw. four crosses croslet fitchy one two and one another gu. Cross.

\section{On 1 EAGLE betw. or within....}

\section{Bordure}

.... on an eagle displ..... within a bordure .... entoury of lions ramp. .... three bars .... John Fisher, Bishop of Rochester 1504.35.

Arg. on an eagle displ. sa. within a bordure gu. an escucheon of the last. ReID, Seabank, Scotland.

Sa. on an eagle displ. double headed arg. within a bordure or an escucheon gu. charged with a leopard's head gold. Dune or Dunne, $V$.

Arg. on an eagle displ. double beaded sa. armed within a bordure gu. an escucheon of the first charged with on a saltire as the second a hedgehog or. MAXwELL, Monreith, co. Wigtoun; Baronetcy 8 January 1681.

Arg. on an eagle displ. double beaded sa. armed within a bordure gu. an escucheon or charged with a saltire of the second thereon a hedgehog of the fourth. MAXWELL.

Or on an eagle displ. sa. within a bordure gu. charged with eight 5-foils arg. a mullet of the second. Lyndsey, Kent.

Sa. on an eagle displ. double beaded within a bordure arg. an ermine spot as the first. HosRe, Stourhead; Baronetcy 10 Jun $\theta 1786$.

Sa. on an eagle displ. double headed within a bordure engr. arg. an ermine spot of the first. HoARE, Stourhead, co. Wilts; Baronetcy 10 June 1786; descended from HOARE, Lord Mayor of London 1713 and 1745.

\section{Crescents}

Arg. on an eagle sa. within an orle of eight crescents gu. a mullet of the first. RAISAY, Boghouse, Scotland.

\section{Crosses}

Or on an eagle displ. betw. two crosses croslet fitchy in chief and a crescent in base sa. a mullet arg. all within a bordure arg. Donald, Conheath.

Arg. on an eagle wings endorsed sa. betw. four crosses croslet fitchy one two and one another gu. CRoss.

\section{Escallops}

Per pale or and vert on an eagle displ. betw. three escallops counterchanged a 3-foil for diff. .... Lynecar, Dublin.

\section{Heads}

Arg. on an eagle displ. sa. betw. two boar's heads couped in fess .... an escucheon gu. REID, Edinburgh.

\section{On 1 FALCON betw, or within....}

$A z$. on a falcon displ. betw. three stars arg. a man's heart gu. FALCONER, Halkerton, Scotland.

\section{BIRDS.}

Arg. two birds sa. Ridge.

Per bend (double dancetty $V^{*}$.) fracted or and gu. two birds in bend sinister counterchanged. RAUFF, $V$.
BIRDS.

2 BIRDS cont.

Quarterly .... and .... in the first and fourth quarters a bird close.... William Sever Seveyer Sevier Sewer or Sinows, Bishop of Carlisle 1496, Durham, 1502-5; seal in Surtees, History of Durham.

Quarterly gu. and sa. in the second and third quarters a bird the former holding in its beak a cross patty fitchy the latter a cross croslet fitchy arg. over all on a bend engr. or three hurts. Cobleigh.

\section{BUSTARDS}

Arg. two sea-pies incontrant sa. Trelawny, Cornwall.

\section{COCKS}

Per fess embattled arg. and gu. two cocks counterchanged. MAYCOCK.

\section{CROWS}

Arg. two Cornish cboughs in pale ppr. BonduER Bowler, Bowler, co. Wilts.

Arg. two ravens in pale sa. Bowdess, co. Salop. Arg. two ravens hanging palewise sa. with an arrow through both their heads fesswise ppr. Mundoch, Cumlodden, Scotland.

Barry of three arg. with chequy az. and of the first two crows sa. pendant by the heads on an arrow fesswise as the second. MAc MurdocH, Rosehill. MAcMoRdocH, Cardonald, Scotland.

Or two ravens ppr. Corbet, Leigh; and Sundorne Castle, co. Salop; a branch of Corbet of Caus. .

Or two ravens in fess ppr. Conbet.

Or two crows sa. Conbert, quartered by Holte. Or two crows in pale sa. CaUS. CoRbeht, $K$.

Or two ravens sa. Thomas Corbett, $B$.

Or two ravens in pale sa. Robert Corbet, $A$. Sr. Piers Conbet, Caus, temp. Edward I, $V$. M. Peris Conbett, $D$. Pers Conbet, $E ; G$. P. Corbet, $F$. Sr. Peres Corbett, $H$. Sire Thomas Corbetr, $J$. Sr. Peres Conbett, $N$. Thomas Corbet or Corbetr, Caux, $P ; X$.

Per chev. arg. and sa. in chief two Cornish choughs ppr. MiDLEMORE, $V$.

Sa. two ravens or. CoRbet.

\section{DOVES}

Per chev. arg. and az. in chief two doves of the second. Sherington.

Quarterly gu. and arg. in the first and fourth quarters a dove close of the second. William Sever Seveyer Setier Sewer or Sinows, Bishop of Carlisle 1496, Durham 1502.5.

\section{EAGLES}

.... two eagles wings endorsed respecting each other their two inward feet conjoined .... Town of EAST REDFord, co. Nottingham. Arg. two eagles displ. in fess vert. ZyMon.

Or in chief two eagles displ. vert. RodNer.

Per chev. az. and erm. in chief two eagles displ. or. John Stephens, Colchester, $W$; and Arden, Essex; granted 1592.

Per chev. gu. and erm. in chief two eagles displ. or. JAKEMAN.

Per chev. sa. and arg. in chief two eagles displ. of the last. Shute.

Per chev. sa. and erm. in chief two eagles displ. or. Stringer, Whiston, co. York. 


\section{BIRDS.}

2 EAGLES cont.

Per chev. sa. and or in chief two eagles displ. of the last. Shute, Hollington, co. Cambridge; and Craven, co. York. But with a crescent .... for diff. Shute, Burton House, co. Hants.

Per pale or and sa. two eagles displ. in pale counterchanged. Thomas Wood, M.D., Suffolk, granted $1592 ; W$.

Per saltire arg. and sa two eagles displ. in pale of the second. JACEMAN, co. Buckingham; co. Durbam; Hornchurch, Essex; co. Hereford; and co. Huntingdon; granted 1561. Edward

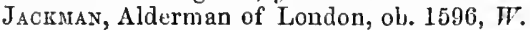

Per saltire gu. and or two eagles displ. in pale of the last. Coppoll alias OGNeLL, Ognell Hall, co. Lancaster.

Per saltire or and gu. two eagles displ. in pale of the first. OGNaL, $V^{*}$. Ognell, Ognell Hall, co. Lancaster; and co. Warwick.

Quarterly erm. and az. in the second and third quarters an eagle rising or. ADAms.

Quarterly erm. and az. in the second quarter an eagle rising wings overt inverted and in the thurd quarter another rising wings displ. or. Sr. Adam de Berny, $V$.

Quarterly erm. and az. in the second and third quarters an eagle volant or. BERry, $J^{*}$.

Quarterly gu. and arg. in the second and third quarters an eagle displ. sa. GODARD.

Quarterly gu. and arg. in the second and third quarters an eagle displ. sa. armed or. John GODDARD, $Y$.

Quarterly or and gu. in the first and fourth quarters an eagle displ. vert. Sr. Edmond Pagexhan, Suffolk, temp. Edward I, $V$.

\section{FALCONS}

Per chev, arg. and gu. in chief two falcons rising ppr. belled or. Stevens, Vielstone, Cross, and Winscot, co. Devon.

Per chev. az. and arg. in chief two falcons rising or. Stephens.

Per chev, az. and arg. in chief two falcons volant or. Stephens, Little Sodbury, and Estington, co. Gloucester, 1730. STePHeNs, Tregony, Cornwall; and Ministerley, co. Salop.

Per chev. az. and arg. in chief two falcons wings expanded or. StEvens, co. Gloucester, 1606 .

Per chev. vert and arg. in chief two falcons or jessed and belled of the second. Stevens, Cullum, co. Berks; granted 3 December 1694. Stevens, Bradfield, co. Berks ; granted 1762.

Quarterly erm. and az. in the sinister chief and dexter base two falcons volant or. Bery.

\section{GEESE}

Sa. two geese incontrant in fess reguard. arg. Tregos.

\section{MARTLETS}

Barry dancetty of three arg. and gu. in chief two martlets sa. Norton, co. Devon.

Per cher. indented az. and or in chief two martlets of the second. Belcher, co. Northampton.

Per fess az. and erm. in chief two martlets or. MEDFORD.

Quarterly arg. and gu. in the first and fourth quarters a martlet of the last. MABERLEY or MABERLY.

Quarterly arg. and sa. in the first and fourth quarters a martlet of the last. M'KIRDY.

\section{BIRDS. 2 MARTLETS cont.}

Quarterly az. and arg. in the first and fourth quarters a martlet or. Kathrens or Kathrins, Ireland.

Quarterly gu. and arg. on the second and third a martlet sa. Critchley. Critchlow.

Sa. two martlets arg. MarshaLL; quartering arg. two mullets sa.

\section{NiOORCOCKS}

Per clev. arg. and sa. in chief two moorcocks ppr. Muddemore, Edgbaston, co. Warwick; the heiress m. Gage; Hawkesby House, co. Worcester; and Enfield, Middlesex.

Per chev, arg. and sa. in chief two moorhens of the second beaked and legged gu. MidLemore, $V^{*}$.

\section{POPINJAYS}

Per saltire vert and arg. two parrots in fess of the first. Stocker. But popinjays, Stoker, $V$.

\section{SWANS}

Sa. two swans reguard. one to the dexter the other to the sinister side arg. TREgosse, $V^{*}$. But membered gu. Tregosse, $V$.

\section{BIRDS and in chief....}

on a Chief.... Arrows

Az. a hawk seizing a partridge arg. on a chief of the last three bolts of the first. KNowles.

Or a falcon sa. preyung on a moorcock ppr. on a chief of the second three birdbolts arg. KNoLles, Little Hampston, co. Devon.

$$
\text { ....Cross }
$$

Sa. a fulcon (another a hawk) or preying on a duck arg. on a chief of the second a cross botonny gu. Spencer M MDAN, Bishop of Bristol 1792, Peterborough 1794. Madan or Madden, Castle Waterhouse, co. Fermanagh, Ireland.

Sa. a falcon or belled gu. preying on a mallard arg. on a chief of the second a cross botonny (sometimes a cross croslet) as the third. MADDEN, Monaghan and Kilkenny; descended from Hugh MadDen, Bloxham Beauchamp, co. Oxford.

Sa. a falcon or belled gu.preying on a mallard arg. on a chief indented of the second a cross botonny of the third. Sir Frederick M $\triangle D D E N$, K.H.,F.R.S.,F.S.A., descended from the ancient sept of O'Madden, co. Galway, Ireland.

Sa. a hawk or preying on a duck ppr. on a chief of the second a cross moline gu. MADDEN.

\section{2 cROWs and in chief....}

Arg. in base two ravens pendent from an arrow fesswise sa. in chief a lion pass, az. MackIE, Bargally, Scotland.

Arg. two crows pendent from an arrow fesswise in chief a lion pass. guard. sa. MACKLE, England.

\section{FALCONS and in chief....}

Per fess arg. and az. in base two hawks belled in fess in chief as many spears in saltire or. VAN Cuelien, London.

\section{MARTLETS and in chief....}

Pily counterpily of four traits the points ending in crosses patty two in chief and one in base sa. and or in base two martlets of the first in chief a tower arg. Poynder and Poynter, London. 
BIRDS. 2 BIRDS and in base....

.... in chief two birds . . . in base a fleur-de-lis .... Odo le Chareter; seal.

\section{CANNETS and in base.... See Ducks}

2 DovEs and in base....

Per chev. engr. az. and erm. in chief two doves arg. beaked and legged gu. jn base three 5.foils two and one of the last. JELF, Oaklands Park, co. Gloucester, from co. Somerset.

\section{DUCKs and in base....}

\section{Annulet}

Arg. in chief two cannets and in base an annulet gu. Kennoway, Scotland. Fish

Per chev. gu. and sa. in chief two shovellers and in base a fish naiant arg. СовB, co. Oxford.

Per chev. gu. and sa. in chief two teals arg. in base a fish or. CoBB or CoBBIs, Norfolk.

\section{EAGLES and in base....}

\section{Castlo}

Per fess az. and arg. in chief two eagles rising or in base on a rock a castle breached the Indian colours struck and flagstatf ppr. STIBBERT, London; granted 12 October 1768.

\section{Cross}

Per chev. or and sa. in chief two eagles displ. of the last in base a cross croslet arg. TownSEND, Thornbury; granted .... Fleurs-de-lis

Per chev. or and az. in chief two eagles displ. in base a fleur-de-lis counterchanged. Broadrip, Dover, Kent.

Per chev. sa. and arg. in chief two eagles displ. or in base a fleur-de-lis of the second. STRINGER, co. Chester.

Mullet

Az.in chief two eagles displ. and in base a mullet arg. Fones, $W$. Fownes or Fones, Cornwall. Fownes, Saxby Saphy, co. Worcester; and co. Devon. Jones.

\section{MARTLETS and in base....}

\section{Beast}

Or in chief two martlets sa. in base a lion ramp. az. charged with a bezant at the shoulder. JoNes, London.

Cross

Per chev. or and gu. in chief two martlets and in base a cross counterchanged. BAsHe, co. Hereford.

Rock

Arg. in chief two martlets gu. in base a rock issuing sa. Cairnie, Scotland.

\section{MO0RCOCKs and in base....}

Per ehev. arg. and gu. in chief two moorhens sa. combed and legged gu. in base a saltire arg. Pashe, co. Hertford.

\section{2 sWANS and in base....}

Per chev. gu. and sa. in chief two swans in base a fish or. Coвb, Peterbridge, Norfolk.

Per cbev. gu. and sa. in chief two swans respectant in base a herring ppr. Coвbe, co. Oxford; Baronetcy 9 December 1662, extinct 7 March 1762 ; co. Bedford ; co. York; Middlesex; and Norfolk; granted by Ballard.
BIRDS. 2 sWANS and in base.... cont.

$\mathrm{Sa}$. in chief two swans respectant ppr. in base a herring or. Совв, Norfolk.

2 BIRDS betw. or within....

Arg. a falcon ppr. wings elevated belled beaked and legged or holding in its dexter talon a martlet of the last all within a bordure engr. or. EDwards, Pentre, co. Montgomery, and Cilcen, co. Flint; descended from William Lord D'Elbouf, Normandy.

2 cRows betw. or within....

Arg. two ravens in pale ppr. within a bordure gu. CORBET.

Or two ravens in pale ppr. within a bordure gu. CORBET.

Or two ravens ppr. within a bordure engr. gu. CoRBet, Corbet, Scotland.

Or two ravens in pale ppr. within a bordure engr. gu. (another sa.) bezanty. Corret, Elton; descended through Corber, Longnor, co. Salop; and Leighton, co. Montgomery; Baronetcy 20 June 1642, extinct....., quartering Uvedale; from Corbet or Corbetr, co. Salop, and the Marches of Wales.

Or two ravens in pale sa. within a bordure engr. gu. Roger CoRset, Lye, $V$.

Or two ravens in pale sa. within a bordure engr. gu. bezanty. Sr. Peter Conber, Hope, $V$.

\section{DUCKS betw. or within....}

Az. two ducks in pale arg. betw. as many flasks erm. Milles, $V^{*}$.

\section{MARTLETS betw. or within....}

Per saltire or and az. on the first two martlets betw. on the second as many 5 -foils counterchanged. HARLOW.

\section{MOORCOCKS betw. or within....}

Per saltire or and arg. two moorcocks in pale betw. as many escallops in fess sa. More, co. Bedford.

\section{PELICANS betw, or within....}

Per bend dancetty or and az. two pelicans vulning themselves wings expanded betw. four flemrsde-lis counterchanged. PoNET.

Per bend indented or and az.in the sinister chief and dexter base a pelican in piety each betw. two fleurs-de-lis counterchanged. John Poynet, Bishop of Rochester 1550, Winchester 1551-3.

2 SWANS betw. or within....

Az. two swans close in pale arg. betw. as many flaunches erm. Meifishe, $V *$. John Melilsh, London, 1634, quartering gu. a lion ramp. or betw. four crosses patonce vair; Harl. MS. 1358 , fo. 54 b. But beaked and membered gu. Milles, $V$.

Az. two swans in pale arg. betw. as many flaunches erm. Meluise, Blythe, co. Nottingham; and Bush Hill Park, Edmonton, quartering Gore. Melirsh, Hamels, co. Hertford; quartering Gore. Melish or Mellish, London; Ragnold, co. Nottingham; and Sandersted, Surrey.

Sa. two swans in pale arg. betw. as many flaunches or. FatToR, Higham, Norfolk.

Sa. two swans in pale arg. membered or betw. as many flaunches of the last. FITTER.

Sa. two swans in pale ppr. membered or betw. as many flaunches of the last. Futrer, Norfolk; and Stainton, Suffolk. 
BIRDS, 2 cocks betw. or within....

and in chief....

Per saltire gu. and az. in fess two cocks (capons) arg. in chief a bull pass. as the third armed gold in base three greyhounds courant in pale silver a chief or charged with on a pale betw. two roses of the first a tower triple-towered like the fourth. Town of Mariborough, co. Wilts.

\section{2 cROWS betw. or within....}

and in chief....

Arg. two crows palewise endorsed sa. with an arrow thrust through their necks ppr, within a bordure engr. and in chief a lion pass. az. M'KIE or MACEIE, Dowlock, Scotland.

Arg. two crows palewise pendent thrust through with an arrow in bend sa. within a bordure engr. az. in chief a lion pass. gu. M'KIE, Balgowan, Scotland.

\section{PELICANS betw, or within....}

and in chief....

Per saltire gu. and or two pelicans in pale betw. so many leopard's heads counterchanged on a chief of the second three chaplets as the first. Morison, London.

\section{2 sWANS betw, or within....}

and in chief....

Sa. two swans wings addorsed in pale arg. betw. as many flannches or on a chief gu. a garb betw. two fleurs-de-lis of the third. Fituer or Fitter.

\section{On 2 BIRDS}

Per chev. gu. and arg. in chief on each of two eagles wings displ. (? of the second) an ermine spot .... STEPHEN.

\section{BIRDS}

(? Gu.) three birds (? arg.). Ayer, $V$.

Arg. three birds sa. Roreston. Warberton, $T$.

Az. three birds arg. armed gu. HODEBY, $V^{*}$.

Az. three birds (probably doves or sea-mews or swallows) arg. beaked and legged gu. AsHe, of the North, $V$. Hodery, $V$. Hodby.

Gu. three birds (probably doves or swallows) arg. AYER, Harl. MS. 1392. LYMinge, co. Leicester.

Gu. three birds or. AREX (but? A YER).

Gyronny of (? six) eight arg. and az. three birds (probably popinjays) vert. Stocke (? STоскеR).

Per bend or and gu. three birds counterchanged. Ranisex.

Purp. three birds (perhaps eagles) displ. arg. Walter Tattesconbe, co. Devon, $V$.

Quarterly or and gu. three birds (perhaps buntings) counterchanged. Bunting.

Sa. three birds (probably doves) arg. Collonibeli, $V^{*}$. Columbels, Darley, co. Derby, $V$. And with a crescent (? for diff.) in chief arg. Bartholomew Naunton, Suffolk, $V$.

Sa. semy of crosses croslet three birds (perliaps swallows) arg. Goodnestone, Kent.

Sa. three birds arg. beaked and legged gu. Hatheway, co. Devon. Hathey, $V^{*}$. Hathey, co. Devon. Heath, co. Devon, $V$. Неath or Hathey. Penniston Pennistone Pennystone or PENyston.

Sa. three birds (perbaps swallows) volant arg. beaked and legged or. MURE, $V^{*}$.

Sa. three birds (perhaps swallows) volant recursant arg. beaked or. MURE, $V$.

Vert three burds arg. Filbert or Filbutt. Filbut, $V^{*}$. Tilbet, $V$. But Filibot is pro. bably right, Cotton MS. Tiberius D 10.
BIRDS. 3 BITTERNS SE HERONS

\section{BLACKBIRDS see THRUSHES \\ 3 BUNTINGS see FINCHES \\ 3 BUSTARDS}

Arg. three seapies ppr. WALDEN.

Az. three bustards rising arg. Nevill.

Az. three bustards volant arg. Neville, $V^{*}$.

Az. three bustards rising or. Nevilu, co. Not. tingham.

Sa. three seapies ppr. Atchiff or Atcliffer.

\section{COCKS}

.... three cocks.... Cistercian Abbey at Coggeshall, Essex.

Arg. three cocks gu. Cock. CockaIn, Lord Mayor of London 1619. Cockaine, co. IHertford. Cockborne, $V^{*}$. Cockbryer. Cockburn or Cockborne, Cockburn, Scotland. Sr. Robert Cockiborne, Scotland, V. Cokaine, co. Stafford. M. John Cokayn, $S$. Thomas de Cokfelde, $X$. Coliborn, 1730. Gam, Wales. Williams, Brecknock, 1716. And with an annulet for diff. sa. Cockaine, co. Leicester; and London. But with a crescent for diff. az. CockBURN, Clarkingtoun, Scotland. But with a mullet for diff. az. CockBurn, Henderland, Scotland.

Arg. three cocks gu. CocisBunN, Langton, co. Berwick; and Kingswood Lodge, Croydon, Surrey ; Baronetcy 1627; quartering Vipont. And with the same quartering but over all a cross erm. surmounted of another of the second charged with a naval crown gold betw. in chief a ship sails furled in fess two towers triple towered and in base a lymphad all ppr. Admiral Sir George Cockburn. And with the same quartering but over all a heart gu. CосквDRN, Cockburn and Ryslaw, co. Berwick; Baronetcy 1628.

Arg. three cocks gu. armed crested and jelloped az. Coraine, Ashborne, co. Derby, temp. Henry III., the coheiresses m. Henslow and Turvile; from whom descended Cozarne or CockaINE, Viscount Cullen 11 August 1642 extinct 11 July 1810.

Arg. three cocks gu. armed crested and jelloped or. Ganme. Price, Wales.

Arg. three cocks gu. beaked and legged or. FondE. Arg. three cocks gu. combed and legged or. Einion SaIs, Wales.

Arg. three cocks gu. crested and jelloped or. Game, Wales. Jenkins, Wales. Joanes, Taplow, co. Buckingham. Morgan, Penderin, co. Brecon. Anian Seys, Bishop of Bangor 1309.28 .

Arg. three cocks gu. armed crested and jelloped sa. Cocrayne, Ashbourne, co. Derby, $V$.

Arg. three cocls gu, armed crested and jelloped sa. Cockaine or Cokaine, Viscount Cullen 11 August 1642 extinct 11 July 1810; descended from Cokaine, A shborne, co. Derby.

Arg. three cocks gu. crested sa. CocKayne, Viscount Cullen 11 August 1642 extinct 11 July 1810.

Arg. three game cocks gu. crested and wattled sa. CockMan.

Arg. three cocks ppr. SALCOCKE.

Arg. three capons sa. Capenhorst.

Arg. three cocks sa. crested and wattled gu. (Ponfret?) $S$.

Arg. three cocks sa. armed crested and jelloped or. Ponfret, $V$. 


\section{BIRDS. 3 cocks cont.}

Arg. three capons sa. armed crested and jelloped or. Capenhurst.

Arg. three cocks sa. armed crested and wattled or. Ponfret, 1730.

Az. three cocks arg. Chanticler, Cornwall.

Az. three cocks arg. armed gu. KoKE, $V^{*}$.

Az. three cocks arg. armed crested and jelloped gu. KoKe. Roke, $V$. Philip ap UCHDRYD.

$\mathrm{Az}$. three cocks arg. armed crested and jelloped ppr. Coxayne, Kerston, co. Northampton.

Az. three cocks arg. crested or. Cocke. Coke.

Az. three cocks or. Chanticler.

Barry of four arg. and gu. in chief three cocks of the second. BLackston.

Barry of five arg. and gu. in chief three cocks of the second. Blackstone or Blakestone, $V^{*}$. Plackeston, Newcastle-upon-Tine, $V$.

Bary of twelve (fourteen $V^{*}$.) arg. and gu. three cocks sa. William STUTVILL, temp. Henry III, $V$.

Barruly arg. and gu. three cocks sa. William de Estotevile de la Marche, $B$.

Erm. three cocks gu. Cockayne, Lord Mayor of London 1751.

$\mathrm{Gu}$. three cocks arg. Bokenton or Bonington. Cockie, Scotland. Kokington. Henry de KoKINTON, $F$.

Gu. crusily and three cocks arg. . . KoKERELI, $E$.

Gu. three cocks arg. armed crested and jelloped or. Cock or Cocis.

Gu. three cocks arg. crested or. Cocke.

Or three coclss sa. Compigne.

Sa. three cocks or membered gu. Ovington, Kent.

\section{3 coots}

Arg. three coots ppr. Coote, co. Lincoln; and Suffolk.

Arg. three coots sa. Coote, Suffolk, $V$.

\section{CORMORANTS}

Az. three cormorants or. SEnens or Sevens, $V^{*}$. Sevens or Sevans, Kent.

\section{CRANES SE HERONS}

\section{CROWS}

Arg, three Cornish choughs ppr. Becketr. Thomas Becret, Archbishop of Canterbury 1162.70. Hare. Peneston, $V^{*}$. Peniston, Cornwall, $V$. Penneston, Halsted, Kent. Penyston, Cornwell, co. Oxford. Penyston, co. Buckıngham; and Leigh, Sussex; granted 12 May 1564. Price, Westbury, co. Bucking. ham. Henry Thomas, M.A., University College, Oxford, ob. 5 May 1673. Priory (or ratber Eastbridge Hospital) of St. Thomas at Canterbury.

Arg. three Cornish choughs sa. Cornwallis, Ireland. Jenney. Johns, Trewince, Corn. wall. OTEWELL, Ireland.

Arg. three ravens sa. Clarke. Nansegles. Rolfe, Sarum, co. Wilts. And with - a 3 -foil for diff. vert. Rolfe, Deptford; Kent; and Hackney, Middlesex. But with a 5 -foil in chief for diff. vert. RoLre, Chisiehurst, Kent; and London.

Arg. on each of three mounts vert a raven sa. Ravenhili, co. Hereford; and Tooting, Surrey.

Erm. three rooks (? chess rooks) gu. Rauf HONDESACRE, $X$.

Or three ravens ppr. a martlet for diff.... Corbet, London.

Or three raveus volant ppr. WoRceley, co. Hants.
BIRDS.

3 CROWs cont.

Or three ravens in pale sa. ADELey, $V^{*}$. Addeley, $V$. CorbetT, $V$.

Or three crows sa. Connellue, Moynalty and Killbeggs, co. Meath.

Or three ravens sa. BARRoN, Gurre, $V$. William Conbet, $F$. Roger Conbet, $G$. Sire Thomas Conbet, $N$. Roger Conbett, $E$; temp. Edward $1, V$. Sr. Thomas Conpetr, $L ; X$, co. Gloucester, temp. Edward I, $V$.

Per chev. vert and gu. three crows arg. CRaw, Auchencraw, Scotland.

Per chev. embattled vert and gu. three crows arg. Craw, East Reston, Scotland.

Per chev. engr. vert and gu. three crows arg. Craw, Heugh.Head, Scotland.

Per fess indented arg. and sa. three ravens counterchanged. S'rory, Knaveton, co. Nottingham ; and Lockington, co. Leicester.

Per fess or and arg. three ravens in chief ppr. CORBYN.

\section{DOVES}

Arg. three doves az. Magill. Rathbone.

Az. three doves arg. Crule.

Az. three pigeons (or doves) arg. beaked and membered gu. (? AsHe.) Asche.

Az. three doves rising arg. legged gu. and crowned with ducal coronets or. BAYLIE.

$\mathrm{Az}$. three doves arg. membered or each holding in the beak an olive branch ppr. NASH, Kil. kenny, Ireland.

Az. three doves or. Crule.

Az. three doves ppr. HоDвY.

Barry of five az. and or three doves ppr. BaRRETT, London; granted 1773.

Gu. three doves close arg. beaked and membered or. Ayer or Ayre, co. Nottingham. (? Ayer, $V$.)

Gu. three doves ppr. HoDBY; 1730.

Gu. three doves close ppr. Ayer, $V^{*}$.

Gu. three doves with leaves in the beaks ppr. Asr. Gyronny of six az. and arg. three doves of the first. Tatham.

Per chev. az. and vert three doves volant arg. Dove or Dowe, Camberwell, Surrey.

Per chev, az. and vert three doves arg. beaked and legged gu. Dove, Camberwell, Surrey; granted 23 January 1572.

Per chev, az. and vert three doves volant or. SPARChFord.

Per fess indented sa. and arg. three doves rising counterchanged. John WAKEMAN, Bishop of Gloucester 1541.2.

Sa. three doves arg. Collumberi, Blyton, co. Lincoln. (? Collumbeli, $V^{*}$.) (? Columbel, Darley, co. Derby, V.) 'Tunsted, Tunsted, co. Derby, temp. Henry VI.

Sa. on the top of each of three garbs or a dove arg. Sharniteld.

Sa. three doves arg. each holding in the beak an ear of wheat (another, laurel) or. Collumbell, co. Derby.

Sa. three doves rising arg. beaked and legged gu. Alsop, Alsop, co. Derby.

Sa. three doves arg. legged gu. in their bills an olive branch vert. Columber, Darley, co. Derby, temp. Richard II; the heiress $\mathrm{m}$. Marbury.

Vert three doves arg. membered or each holding in the beak an olive branch ppr. NASH, Nash. ville, co. Cork; brother of Nash, Brinny, co. Cork; the co-heiresses m. Leader and Evans. Vert three doves volaut arg. BaLAIRE. 


\section{BIRDS. $\quad 3$ DUCKS}

Arg. three mallards gu. Yartie, Yartie, co.Devon. Az. three shovellers arg. Atcliff, $V$. Atclyfee. Az. three shovellers or. Sevens, $V$.

Az. three shovellers or membered gu. Becine. Gu. crusily and three ducks arg. Elkington, $V^{*}$. Gu. three shovellers arg. HerLe. LangForde. Per fess wavy arg. and sa. three ducks (seapies) counterchanged collared or. DEvenisH.

Per fess indented gu. and vert three ducks arg. BiLdrie, Suffolk,

Per fess each puece arg. with in its base barry wavy arg. and az. three ducks swimming their bills in the water or waves of the second over all on a fess engr. gu. so many roses silver. Revers, $V^{*}$.

Sa. three shovellers in pale arg. Poplesham, $V$.

Sa. three ducks arg. Pepplesham, Sussex, temp. Edward IlI.

Sa. three shovellers arg. Pelasham.

\section{EAGLES}

Per fess indented sa. and arg. three demi-eagles displ. couped counterchanged. Batedran.

.... three eagles displ. in fess .... Town of Carnarvon.

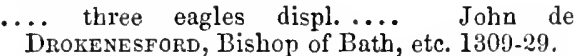

Arg. three eagles displ. az. Billesworth, co. Hereford. Newton, co. Chester.

Arg. three eagles displ.gu. Blundell. Brereton. Clisdon. Devonshire. Doddescombe, Doddescombe.Legh, co. Devon; extinct temp. Edward IlI; heiresses m. Bigbury, Newenham, Prall, and Branscomb. Eaglesfield, 1730. Eglesfield, Alneburgb Hall, co. Cumberland, temp. Henry VIII. Edward LisLe, Yarwell, co. Northampton, $W$. Lisle, co. Warwick. Newenhad, $V^{*}$. Newnam. Rintoul, Scotland. Strode, co. Devon, $V$. Vatrote. And with a cresceut for diff. az. EAGLESFIELD or Eglesfiety, Alwarby, Cumberland.

Arg. three eagles displ. gu. armed az. Bruton. Clifford. Eaglesfield or Eglesfield, Kent. Count de Meghen, Burgundy, $W$.

Arg. three eagles displ. gu. armed sa. EAGLESFIELD or EgLESFIELd, lient.

Arg. three eagles displ. gu. crowned or. Courci, Stoke Courci, co. Somerset. Courcy, Baron Courcy, Harl. MS. I603. Courcy, Earl of Ulster, temp. John. DE Courcy, Baron Kingsale, 1181. De Courcx, Stocliton, Cornwall. Newenham, Newenham, co. Devon, $W$. Newdan, Devon.

Arg. three eagles displ. double headed gu. LIsıE, co. Warwick; and Yarwell, co. Northamptor.

Arg. three eagles displ. purp. RoDner, co.Warwick.

Arg. three eagles displ. sa. Beckweil. Rauf de Iírketon, $E$; but Kirkerone, $E$, Harl. MS. 6137. Thomas KinkTON, $Y$. KIRETON or línton. Rodney.

Alg. three eagles displ. double headed sa. armed gil. Thomas ..., $Y$.

Arg. three eagles vert. Fitz.

Arg. three eagles displ.vert. Sr. .... FItz-Srmon, Essex; $V$.

Az. three eagles displ. arg. Barantyne Barfentine or Barentree, co. Buckinglam and Oxford. Fownes. Hail or Hull. $\Lambda$ dam deNeufventon, $F$. Adam de Newentone, $E$; but Newcourt, $E$, Harl. MS.613T; aud NEwENTON, $Y$. NeWinton. Newton. Pakeiworthe. Waffyer, Ireland.

\section{BIRDS. 3 EAGLES cont.}

Az. three eagles displ. arg. armed gu. Sr. de .... W Earl of Cornwall, $X$.

Az. three eagles displ. arg. armed or. Brentrne. Piers de Gataston, $Y$. Lavenham, Essex, $V$. Lavenhadi or Lavingham, Essex.

Az. three eagles or. Devonshire, Cornwall.

Az. three eagles displ. or. ALFRAMr, co. Chester. Beeby. Bibelues or Bibles and Bibbesworth, co. Hertford. Walter Biblestorith, Y. Wat de Biblesworthin, $E$. Sire Huge de Bilbesworthe, $N$. Sr Walter Billesworth, co. Hereford, temp. Edward I, V. Griffin. Rakelworthe. Walter de Rakelword, $\boldsymbol{F}^{\prime}$. Rimites. Water, Ireland.

Az. three eagles displ. or over all a bend engr. gu. Huleys. Hulleys.

Az. crusily and three eagles displ. or. Alfram. Az. crusily fitchy aud three eagles displ. or. Somervile or Sodiervilde, Whichnovre, co. Statiord, temp. William I. Somervilde, $V$.

Az. three eagles displ. double headed or. Davenhier. Pedocrew, Cornwall, $V$. PEDOGREW, $W$.

Gu. three eagles displ. .... Richard de Newport, Bishop of London, 1317-8 (an error).

Gu. three eagles displ. arg. Caston. Chassens. Thomas de Chanseus, $E$. John de Chanseus, F. Hartford, $V^{*}$. Hereford, Sufton Court, co. Hereford. Henefond (Hereford and Moore, co. Worcester.) Sir Henry Hertford, co. Hert. ford, $V$. Horrord. And with a label of five points az. Henri d'Hereford, $\boldsymbol{E}$.

Gu. three eagles displ. erm. Hereford, Hereford and Moore, co. Worcester. HERTFORD. Gu. three eagles or. BAND, Essex.

Gu. three eagles displ. in bend or. RINGston.

Gu. three engles displ. or. BAND, $V$. BAWDE, Essex. Hartford. Hertford, co. Hertford. Lemiprier. Limesey, Long Iching, co. Warwick. Raf' de Limesi, $F$. Rauf de Lindsex, $E$. LINDESCI or LINDSEY, co. Warwick, temp. Henry IlI.

Gu. three allerions displ. or. Liusey.

Gu. three eagles displ. or armed arg. RACELEWORTH.

Gu. three eagles displ. or ducally crowned and armed arg. Cheales.

Gu. three eagles displ. or armed az. Band. But membered az. LINDSEY, co. Warwick.

Gu. three eagles displ. ppr. crowned or. THEALES.

Or tbree eagles displ. .... Richard de NewPort, Bishop of London 1317.8; Add. MS. 12443.

Or three eagles displ. az. Peche. Pouley, Essex. Poulex, $V^{*}$. Puller, Leigh, Essex. RODNEY.

Or tbree eagles displ. gu. Brunton. Clitrorde, $V$. EAGLESFIEID. EGLESFIELD, $V^{*}$. EGLEFIEI,D EGIESFEILDE, Ambrogg, Cumberland, $V$. EGIESFIEID, Eastham, Kent; and co. York. EGLESFELD, Lekenfeld (Leckonfield), co. York. EGLESFORD, Ambrogg, Cumberiand. Richard de Gravesend, Bishop of Lincoln 1258, London 1280-1303. KILTON. QUEEN'S COLLEGE, Oxford; founded in 1310 by Robert Eglesfuld, confessor to Queen Philippa, wife of Edward III. M. John de RoDNEYE, S. RODNEY, Stoke Rodney, co. Somersel. Rodnex, Collinson, Somerset ii, 407 ; iii, 165, 576.

Or three eagles displ. gu. armed az. Bruton. Clifford. Sr. de Dawes, $W$. 


\section{BIRDS. 3 EAGLES cont.}

Or three eagles displ. ppr. Rodney, co. Hunts; and co. Somerset.

Or three eagles displ. purp. Gedney. Rodner, $V$. RoDNEY; Baronetcy 22 January 1764, Barony 19 June 1782. Rodney, Rodney, Devon.

Or three eagles displ. sa. GEDNEY, Suffolk. Gedney, $V$. Henry Hese, $F$. Hickton, $V^{*}$. Sir Rauf Kicrton, $V$. Kirketon. Radney. Sr. Walter Ronney, $V$. Richard TANe, $Y$.

Or three eagles displ. vert. RoDNEy.

Paly of four arg. and sa. over all three eagles connterchanged. Pewterer or Pewterwre. Powterew, V. Peuterewre, Harl. MS. 1392. Whitcom, Harl. MS. 1392. WhItcomb (in a later band than) $V$. Whiтom, $V$. Whitтom, $V^{*}$. WHITTON.

Paly of six arg. and sa. three eagles counterchanged. Whetrome.

Paly of six gu. and sa. three eagles displ. arg. Coose, London; and Harefield, Uxbridge, Middlesex; and John Cooke, and bis son George, and grandson George, Clief Prothono. taries of the Cormmon Pleas.

Paly of six or and sa. three eagles displ. counterchanged. Whitcomize, Wydecombe, co. Somerset; temp. Henry III.; Berwick Mavesyn, temp. Henry IV.; the Morey, co. Salop; Cleobury Mortimer, and Braxted, co. Essex; quartered by Paget and Niblett. Wycombe, Berwick, and Wycombe, co. Salop.

Per bend sa. and arg. three eagles displ. counterchanged. Brooke, Suffolls.

Per chev. az. and gu. three eagles arg. armed of the second. Cruelis or Crull.

Per chev. embattled az. and or three eagles displ. counterchanged. DERBY.

Per chev. embattled or and az. three eagles counterchanged. Derby.

Per chev. embattled or and az. three eagles displ. counterchanged. DARBY, co. Dorset; and London. John Derbr, Alderman of London, $W$.

Per chev. embattled or and vert three eagles displ. counterchanged. FosTer, Wells.

Per chev. sa. and or three eagles displ. counterchanged. Stringer, Sutton-upon-Lound, and Eaton, co. Nottingham ; and co. Salop.

Per fess indented sa. and arg. three eagles volant counterchanged. WaKEMAN.

Per pale arg. and sa. three eagles displ. counterchanged. WycherLey, Wicherley, co. Salop.

Per pale az. and gu. three eagles displ, arg. Cooke, Broomyard, co. Hereford. Sir Edward Coore, Lord Chief Justice, $W$.

Per pale az. ( ? arg.) and gu. three eagles displ. connterchangcd. Cooke, Mildham, Suffolk.

Per pale az. and gu. tbree eagles displ. or. Aveline, Windsor, and Frogmore, co. Berks.

Per pale az. and sa. three eagles displ. arg. Cooke, co. Lancaster. Cooke, Burstow, co. Surrey ; granted 20 Angust 1662.

Per pale indented az. and sa. three eagles displ. or. Carpenter.

Per pale gu. and arg. three eagles counterchanged. GERGawd or Gerwood.

Per pale gu. and az. three eagles displ. arg. Coke, Holkham, Norfolk; Baron Lovel 28 May 1228, Visconnt Coke and Earl of Leicester 9 May 1744, extinct 20 April 1759; Viscount Coke and Earl of Leicester 12 August 1837 ; Sir Edward Coke, Privy Councillor, 1619. Cooke, Norfolk. Jorcey, M ARTYN.

\section{BIRDS, 3 EAGLES cont.}

Per pale gu. and vert three eagles displ. or. Newman, Kent, $W$.

Per pale or and az. three eagles displ. double headed counterchanged. Mogridge.

Per pale or aud sa. three eagles displ. counterchanged. Stannard, Ireland. Wood, Suffolk.

Purp. three eagles displ. arg. Dodscombe, co. Devon. Gattiscombe, $V^{*}$. Totscombe, co. Devon. (? Walter Tattescombe, co. Devon, V.) Sa. three eagles displ. in fess arg. Withers.

Sa. three eagles displ. arg. Barantyne Barentine or Barentyne. co. Buckinglam, and co. Oxford. William Barantin, or Barentin, $E$. William de Barantine, $F$. Dru Barntin, $G$. And with an annulet in the centre for difference or. Sir Drew Barentine, Lord Mayor of London, 1398, $W$; and 1408. Chanseul, $V$. Peche.

Sa. three eagles displ. arg. armed gu. Barentine, $V^{*}$. Sr. William Barrantine, $\boldsymbol{V}$.

Sa. three eagles, displ. double headed arg. Eliran, Suffolk. Sir Richard Elman, V. Elynam.

Sa. three eagles displ, erm. WAKEFIELD.

Sa. three eagles displ. erminois. Thomas Stringer, Sharlton, $W$. Stringer, Whiston Sharleston, co. York. Stringer, Norton, co. Derby.

Sa. three eggles or. Chausvile.

Sa. three eagles displ. or. Dru de Barantine, $B$. Buckbond. Chassens or Chansens. Emeri di Chanseus, $E$. Emari de Chanseul, $E$. Harl, MS. 6137. Emeri de Chaseus, $F$.

Sa. three eagles volant or. LAURENCE, Kent; and Essex.

Vert three eagles displ. arg. Cremer. Gremer. Vert tbree eagles statant wings displ. arg. collared or. SiItherman.

Vert three eagles displ. or. Sr. de Grymer, $V$.

Vert three eagles displ. in fess or. Owen Gwynedd, Prince of North Wales, ob. 1lif, (son of Griffith ap Cynan, Prince of North Wales, derived from Anarawd, King of North Wales, eldest son of Rhodri Mawr, King of Wales ), and his descendants, LLoyd, Rhiwaedog, co. Merioneth; the heiress, $m$. Dolben; and Lloxd, Plas-yn-dre, co. Merioneth: Morice or Morise, Clenenneu, co. Caernarvon; quartering Lacon; the heiress m. Owen: ANwyL, Park, Bala, etc., co. Merioneth; the heiress $\mathrm{m}$. Williams: Brynker, Brynker, co. Caernarvon, 1775: WrnN, Gwydyr, co. Caernarvon; Baro. netcy 1611, extinct $\tilde{\tau}$ January 1719 ; the heirs m. Bertie and Williams: Wyns, Llwyn, co. Denbigh; and its branch Wynne, Pengwern, co. Merioneth, quartering gu. three lions pass. in pale arg., with per bend sinister erm. and ermines a lion ramp. sa., and erm. a saltire gu. a crescent or: WYNN, Berthdu and Bodysgallen, co. Caernarvon; the heiress m. Mostyn: and Williams-Wyns, Wynnstay, co. Denbigh; Baronetcy 6 July 1688; quartering Cadrod Hardd for Williams. LacoN, Llanddyn and Porkington, co. Salop. Pritchard, Tresgawen, anglesey. Wuliars, Minster, Isle of Thanet, Kent. John Wynne, Bishop of St. Asaph 1715, Bath, etc. 1727.43.

\section{FALCONS}

Arg. three falcons gu. FAULConer, Thurcaston, co. Leicester. Faulinar. Sire Johan le FaUCONER, N. Fawcon or Falcon.

Arg. three falcons close gu. Falconer, co. Leicester. 
BIRDS.

\section{FALCONS cont.}

Arg. three sparrow-hawks close gu. Haydoc or HerDock, co. Lancaster and co. Oxford.

Arg. three falcons rising gu. belled az. NEwELL or Newall, Scotland.

Arg. three falcons close and belled ppr. HoLmoon, Tartoine, Harl. MS. 1441.

Arg. three falcons close sa. O'TwoHmL, Poors, co. Dublin, Harl. MS. 1441.

Az. three falcons wings expanded arg. Nevile, $V$. Az. three falcons wings expanded each standing on a staff couped and raguled arg. Sparnon, Sparnou, Cornwall; and Oston, and Wickham. brook, Suffolk.

Az. three falcons close arg. belled beaked and legged or. Pennington, $V^{*}$. Pennyngton, $V$.

Az. three falcons or. Pennington, co. Lancaster.

$\mathrm{Gu}$. three falcons close arg. Bristow, Surrey. Burstowe, Surrey, $W$.

Gu. three falcons close arg. belled or. Acherton.

Gu. three hawks close arg. beaked and legged or. Atherton, Atherton, co. Lancaster; quartering Lostock, Ashton, Catherall, Gousnor, and Mytton; Harl. MS. 1549 fo. 151.

Gu. three sparrow.hawks arg. beaked belled and jessed or. Atuenton or Atterton, co. Lancaster. Atherton, Atherton, co. York.

$\mathrm{Gu}$. three falcons in fess arg. membered or. John BRDGGEFord; granted 29 August 14l5; Ashmol. MS. 833 , fo. 47 .

Gu. three falcons close arg. membered and belled or. ADDURTON, $V^{*}$. Sr. William Adyrton, co. Lancaster, $V$. Athenton, $V *$.

$\mathrm{Gu}$. three hawks close arg. beaked and belled or. Francke, Kinighton, co. York.

Gu. three falcons or. FAw CON or FALCON, co.Derby.

$\mathrm{Gu}$. three sparrow-hawks or. AtHenton, Atherton, co. Lancaster.

Gu. three hawks belled and jessed or. Atherton. Or three falcons ppr. ABARLE; granted 1572.

Or three hawks ppr. perched arg. DLLington, Dillington, co. Norfolk.

Or three falcons close ppr. belled gu. FALKENER, Ireland. And with a mullet for diff. Falkiner, Anne Mount, co.Cork; Baronetcy 24 Augustl 777.

Or three falcons sa. Whiтнал.

Paly of six az. and or three falcons of the last. Locke; Ashmol. MS. 836 .

Per fess az. and or in chief three falcons volant of the second. Lock, London,

Quarterly indented arg. and sa. three falcons counterchanged. STorey, Ham, Surrey; quartering Shum.

Sa. three falcons arg. HAwKESworfH, Hawkes. worth, co. York; Baronetcy 1678, extinct 1735 ; the beiress m. Ramsden. Hawksworth.

Sa. three falcons close arg. Thorsted, Thursted, co. Derby.

Sa. three liawks each perched on a staff raguly fesswise couped arg. Trenawke, Trebawke, and Rosilian, Cornwall.

Sa. three falcons close arg. beaked and belled or. Haw KSworth, co. Gloucester and co. York.

Sa. three falcons arg. beaked and legged or. FALCONER, co. Hants; and Cogenhoe, co. North. ampton.

Sa. three sparrow-hawks arg. membered or. HoLYworTH.

Sa. three falcons volant arg. membered or. FAULCONER.

Sa. three falcons arg. armed jessed and belled or. HoLYworTH.

Vert three falcons or. LAYSTON.

\section{BIRDS. 3 FINCHES}

.... three sparrows .... PHL PHLip, Brignell, co. York.

Quarterly or and gu. three birds (perhaps buntings) counterchanged. BunTING.

\section{GEESE}

... three geese (another, swans) close .... (assumed by) Brian WaLTon, Bishop of Chester 1660-1.

\section{GULLS}

Az. three seagulls arg. David LLwCH.

Az. three mews arg. beaked and membered gu. Ashe. (? Ashe, of the North, V.)

Barry wavy arg. and az, in fess three seagulls. .... Yswittan WYDDEL.

Gu. three seamews arg. beaked and legged or. Mewy, Merry, co. Devon.

Sa. three seamews arg. Poplesham, $V$. Poppleshadi, $V^{*}$.

\section{HAWKS see FALCONS \\ 3 HEATHCOCKS BEO MOORCOCKS 3 HERONS}

Arg. three herons az. Heron, Essex; and co. Stafford. Sire Odinel Heron, $N$. Heron, Ayplyndon, co. Durham.

Arg. three bitterns gu. ANTrobus.

Arg. three storks ppr. Starkey, Achton, co. Lancaster.

Az. three herons arg. Odinel Heron, B. Joan Herun, $E$. Sire Johan Heroun, $N$. Sr. John Heron, $V$. Heron, Ford Castle; quarteling barry of six arg. and az. a bend gu. charged with a plate.

Az. tbree herons close arg. Heror, Essex; Northumberland; and Ipswich, Suffolk. Thomas Heronvyle, $X$.

Az. three storks rising arg. Edmund GiBson, Bishop of Lincoln 1716, London 1723-48.

Az. three herons arg. heaked and legged or. Odinell HERON, $X$.

Az. three herons arg. 'petiz beestez' (sic in orig.) or. Sir Godard and Sir Roger Heron, $M$.

Az. three storks rising ppr. Gibson, Yelland, co. Lancaster, temp. James I; a heiress m. Wickham. Gibson, Cumberland; Essex; London; and Northumberland. Gibson, Barfield, Cumberland; a branch of GiBson, Myerscough, and Quernmore Park, co. Lancaster.

Gu. three bitterns arg. Bittenneck or BitTeren. Gu. three cranes arg. CRanstoun; Barony 1609. Gu. three cranes close arg. Cranwell, Cranwell, co. Lincoln.

Gu. three herous arg. Heron, Bokenfield and Ford Castle, Northumberland, temp. Edward I. Heron, Chipchase, Northumberland. Heron, Moor, co. Chester. Sir Roger Henon, $N ; X$. Henon, co. Stafford, Hon, Bishopwearmouth, Durham.

Gu. three herons arg. a bend engr. or. Henon, in Canterbury Catbedral.

Gu. three herons arg. beaked and legged or. M. .... HERoN, $S$. And with an annulet in chief of the last. M. Gerard Heron, $S$. But with a cross croslet in chief of the last. M. Wauter HERoN, $S$.

Gu. three heronshaws (or storks) or. TYRwhIT, co. Lincoln, $V$.

Sa. three cranes or. Popleshadi, co. Worcester. 3 KINGFISHERS

Or three kingfishers ppr. FisHen, London. 


\section{BIRDS.}

\section{LAPWINGS}

\section{including Pewits and Tirwhitts}

Az. three lapwings arg. Crule, Cambray, Spain; granted $8 \mathrm{M}$ arch 1631.

Gu. three lapwings or. Durren. Richard TERRICK, Bishop of Peterborough 1757, London 1764.77. Tirwhiт, co. Lincoln, Harl. MS. 1392. TyRwhitt, $V^{*}$.

Gu. three pewits or. Trrwhitт; Baronetcy 3 October 1808; quartering Jones.

Gu. three tirwhitts or lapwings or. TYнwhitт, Baronetcy 30 October 1808, and Tyrwhitt, Nantyr, co. Denbigh; descended through Tyrwhitt, Netherclay House, co. Somerset; from Tyrwhitt, Cameringham, co. Lincoln; a branch like Tyrwhitr, Stainfield, co. Lincoln, Baronetcy 29 June 1611, extinct 22 August 1760, de. rived through Trnwhits, Barton-on-Humber, of TyRwhitT, lietilby, co. Lincoln, and Tyrwhitt, Northumberland; a heiress m. Hunloke.

\section{LARKS}

Arg. three larks ppr. Barier.

Az. three larks or. A YER, 1730.

Or three larks ppr. Barke.

\section{MAGPIES}

Arg. three magpies ppr. OTHWEI.I, or Otteweli. Peyton, co. Lancaster. Waters, Ireland.

Or three magpies ppr. Waters, Ireland.

\section{MALLARDS see DUCKS 3 MARTLETS}

Arg. three martlets gu. CAIRNES, Ireland. Clayte. Fornivale, $V^{*}$. Fornivali, $V$. Furnival. Furnivall, co. York. Muciele, Scotland. Payeur (in a later hand to) $F$. Parent. Arg. three martlets sa. ARMine. Cainnes. Furnivali, co. York. Glen, That Ilk. Jalmes. Street.

Arg. three martlets and four crosses croslet one two and one sa. Goonneston, $V$.

Az. three martlets arg. Hodby. Kirketon, 1730. Henry Kirkton, $V$. Wotton, $V$.

Barry of four or and gu. in chief three martlets vert. Grenway.

Barry of five or and gu. three martlets in pale sa. ANKYrSLEY.

Barry of six arg. and gu. in chief three mart. lets of the second. ANstaboth.

Barry of six arg. and gu. three martlets sa. Chaworth.

Barry of six gu. and arg. in chief three martlets of the second. WARD.

Barry wavy of seven arg. and az. three martlets in fess of the first. Yswithan WYDDELL.

Barry of seven arg. and az. in chief three martlets gu. Sir William Payneld, $I$.

Barry of seven arg. and gu."in chief three martlets az. Molton, Norfolk.

Barry of seven arg. and sa. in chief three martlets of the last. CACEIL. CARRIL, Tangley Park, Surrey. Carrill, Bentons, Sussex; the coheirs m. Viscount Molyneux and Lord Morley. $\mathrm{C}_{A R R I L L}$ or CARRell, Harting, Sussex. Richard CARrYLI, created Baron Carryll by King James II at St. Germains: all descended from Sir John Carylu, Warnham, Serjeant at Law to Henry VIII; Barony and Viscounty 1627, extinct 15 February 1699.

Barry of eight arg. and az. in chief three martlets gu. Payneli.

\section{BIRDS. 3 MARTLETS cont.}

Barry of twelve arg. and gu. three martlets sa. Chóare, co. Lincoln.

Erm. three martlets gu. GoRLEy Gorely or Gnortay, Kent. Goverley, Kent, $V$.

Gu. three martlets arg. Carnsize, Scotland, quartering az. three 5-foils arg. HANSARD, co. Lancaster. M'Gili, Rankeillor, Scotld. Tenterden, Kent. Mathew de Thornetonsteward, $X$. WоттоN, co. Stafford. And with a fleur-de-lis in the centre. CaIrns, Pilmor, Scotland.

Gu. three martlets arg. membered or. AYrE, co. Nottingham.

Gu. three martlets or. CaIRNs, Cairns, Scotland. MacGeE. M'Gill, Viscount Oxenford, 19 April 1651. Terrick, in York Minster. (Probably Rauf fitz Stephen de Thornetonrust, $X$, but Elys de Thorntonrnst bears sa. trois haches battants d'argent, $P$.)

Gyromny of six arg. and az. three martlets sa. TATUM.

Or three martlets az. Oviry.

Or three martlets gu. NELIington, $V$. Merlington. Miliington.

Or three martlets sa. CALvert, Warwickoe, and Lord of Zeveren in Flanders, Harl. MS. 4040 , fo. 462. Manston, Manston, co. Dorset.

Or three martlets in bend sa. Denham, $V$; quartering gu. three martlets in bend arg.

Paly of six arg. and az. three martlets or. Mis.Ls.

Per chev. flory counterflory arg. and gu. three martlets counterchanged. Plomer, Mayfield, and Pettingho, Sussex.

Per chev. embattled arg. and sa. three martlets counterchanged. DoLBIN.

Per chev. flory counterflory arc. and sa. three martlets counterchanged. PLomer, Ireland. Plojier; Baronetcy 1660-1, extinct 1697.

Per chev. az. and arg. three martlets counterchanged. HoDson, Ireland.

Per chev. embattled erm. and az. three martlets counterchanged. HuDson, quartered by Palmer (an error).

Per chev. flory counterflory gu. and arg. three martlets counterchanged. PLUMER, Gilston Park, co. Hertford.

Per chev. gn. and or three martlets counterchanged. Edgeworth, Kilshrewley, co. Long. ford: descended from EDGEwORTH, Edgeworths. town, co. Longford ; quarterung Shuckborougb, Bridgeman, and Lovell.

Per chev, gu. and sa. three martlets or. СовB or COBBE, Ireland.

Per chev. embattled gu. and sa. three martlets or. EDmonds, $V^{*}$. Eunonds, London. EDmons, London; granted 12 June 1610. Simons, $V^{*}$.

Per chev. or and az. three martlets counter. changed. EdGeworth, co. York. EdGworth, 1730. HODGSON, Ireland.

Per chev. embattled or and az. three martlets counterchanged. HoDGson, Filswick House, Northumberland. Hodgson, Penrith, Cumberland; and now of Ludford, near Ludlow. Hodgson, Manor House, Lanchester, co. Dur. ham. Hodgson, Hebborne, co. Durham; derived from Hodson, Mayor of Newcastle 1555, 1596 , and 1580 . Hodsham (Berry). Hudoson, $V *$. Hudson, quartered by Palmer (an error).

Per chev. engr. or and az. three martlets counterchanged. Hodgson, Essex; granted 16:31. HoDGson, Liverpool, or co. Chester, about 1812. Hodgson, Bascodyke, Cumberland; and Middiesex. 


\section{BIRDS.}

3 MARTLETS cont.

Per chev. embattled or and vert three martlets counterchanged. Hudson, London.

Per fess arg. and az. three martlets counterchanged. CLEGHORN, Scotland; and Spain.

Per fess nebuly gu. and arg. three martlets counterchanged. DeEdes, Kent; and London. HIPKISS.

Per fess indented or and az. three martlets counterchanged. Brockman.

Per fess nebuly or and az. three martlets coun. terchanged. Baker, Sussex. Barker, Hambleton, Rutland; Baronetcy 1665 extinct 1708.

Per fess indented or and sa. three martlets coun. terchanged. MiDwinter, co. Devon.

Per fess indented sa. and gu. in chief three mart. lets arg. LOVELACE.

Per fess nebuly sa. and or three martlets counterchanged. BARKER, Hambleton, and Lyndon, Rutland; Baronetcy 1665 extinct 1708.

Per pale and per chev. .... and .... three martlets counterchanged. Renshaw.

Per pale arg. and sa. three martlets in pale counterchanged. SANKIE. SANKEY, Dublin.

Quarterly per fess embattled or and sa. three martlets counterchanged. Hudson, Loudon.

Sa. three martlets in fess arg. Drybung.

Sa. three marlions sinister wings displ. arg. Aтсомв, co. Devon.

Sa. three martlets arg. Marteld. Nanton, Suffolk. NAUGHton, 1730. NAUnton, Suffolk, $V$. Newnton. RaYnham.

Sa. three martlets or. DARCY.

Vert three martlets arg. Brendon.

\section{HEWS see Gulls}

\section{MOORCOCKS}

Arg. three heatheocks sa. beaked and legged gu. Merton.

Sa. three heathcocks arg. membered gu. Heath.

\section{OWLS}

Arg. three owls sa. Bridge, 1730. Brigg or BRIGgs.

Arg. three owls sa. beaked and legged or. BRIGE, $V^{*}$. BRIGge, Norfolk, $V$.

Az. three owls arg. Skepper, co. Lincoln.

Gu. three huits (owles in margin) arg. Sir Richard BER'INGHAM, $L$; the birds without feet, $L$, Harl. MS. 6589 .

Or three owls in fess sa. OuLry.

Sa. three owls arg. Broughton, co. Salop. Burton, Kensley, co. York. Rowton. TrEwOLA.

Sa. three horned owls arg. Festing.

Sa. three owls arg. beaked and legged or. Bodghton, $V$. Trewola, Cornwall.

Sa. three owls or. Thuncaston.

\section{PEAFOWLS}

Arg. three peacocks in pride ppr. Munt. Pawne, 3716. Peacock, Bridge End, Scotland.

Arg. three peahens close ppr. HEAPY.

Az. three peacocks in pride or. TIRWHIT.

Sa. three peacocks arg. RiDgeway alias PEYcock. Sa. three peacocks close arg. Pracock, Finchley, Middlesex. Peacock, $W$.

\section{BIRDS.}

\section{PELICANS}

Arg. three pelicans vulning themselves gu. Honmiston, Hormiston, Scotland.

Arg. three pelicans in piety gu. ORMISTON, Scotiand. Arg. three pelicans in piety or nests vert. Patrison. And vulning themselves ppr. Patrerson or Paterson, Scotland. But with a crescent for diff. Paterson, Scotland.

Az. three pelicans arg. Cricketr, Smyth's Hall, Blackmore, Essex.

Az. three pelicans arg. vulned ppr. PEGGE, Yel. dersley and Beauchieff Abbey, co. Derby; and Laughton, Sussex. Mounsyer PelHaM, $T$. Sr. John Pelham, $V$. Pelham, Baronetcy 1611 , Barony 1706, Viscount Haughton and Farl of Clare 1714, Marquis of Clare and Duke of Newcastle 1715, extinct 1768, Baron Pelham 1762; Earl of Chichester 1801; quartering gu. two demi-belts palewise in fess buckles in chief arg. And with the same quartering Anderson Pelham, Baron Yarborough 1794, Baron Worsley and Earl of Yarborough 1837. And with the same quartering. George Pelhari, Bishop of Bristol 1803, Exeter 1807, Lincoln 1820.7; and John Thomas Pelean, Bishop of Norwich 1857 .

Az. three pelicans in piety or nests vert. Reidieugh, Scotland.

Gu. three pelicans arg. Leechman or LeEshman, Scotland.

Per chev. or and az. three pelicans counterchanged rulned ppr. CaRtwright, Derby.

\section{PHEASANTS}

Arg. three pheasant cocks ppr. O'Cowick, Harl. IIS. 1441, fo. 40 .

Az. three pheasants or. Phesant.

Az. three pheasant cocks or. READ, 1730. Edmund Reade, $V$. Reade, co. Oxford, and co. Somerset.

Az. three pheasants or membered and beaked gu. Fesiant.

Or three pheasants close .... Phesant.

Per pale az. and gu. three pheasants close or. North, co. Hants.

\section{PIGEONS see Doves}

\section{POPINJAYS}

Arg. three popinjays ppr. Penketh, Penketh, co. Lancaster.

Arg. three popinjays vert. Cliffe, co. De. von; and Essex. John Clyfre, of the Wolde, $X$. Pepdie.

Arg. three popinjays vert beaked and mombered gu. PEPdie, Dunglass, Scotland; quartered by Home or Hume.

Gu. three parrots reguard. wings disclosed arg. Brrchelils or Brrtues.

Gyronny of six az. and arg. three parrots vert. STOCKER, Lord Mayor of London 1484.

Gyronny of (? six) eight arg. and az. three birds (perhaps popinjays) vert. STоскE.

Or three parroquets vert. Chauncelen, Brafferton, co. Durham.

\section{RAVENS see Crows}

3 SEAGULLS and 3 SEAMEWS see Gulls

3 SEAPIES see Bustards

3 SHOVELLERS see Ducks

3 SPARROWHAWKS see Falcons

3 SPARROWS see Finches 3 STORIS see Herons 


\section{BIRDS.}

\section{SWALIOWS}

Az. three birds (perhaps swallows) arg. membered gu. Hodby. Hodeby, $V$.

Barry of fonr gu. and arg. on the last three swallows volant sa. Swattow.

Or three swallows close ppr. Watron, co. Leicester 1716.

Sa. three birds (probably swallows) and in chief a crescent (? for diff.) arg. NAUNTON, Suf. folk, $V$.

Sa. semy of crosses croslet three birds (perhaps swallows) arg. Goodnestone, Kent.

Sa. three birds (perhaps swallows) volant arg. beaked and legged or. Mure, $V^{*}$.

Sa. three birds (perbaps swallows) volant recursant arg. beaked or. Mure, $V$.

\section{SWANS}

.... three swans (another geese) close .... (Assumed by) Brian Walton, Bishop of Ches. ter 1600-1.

Arg. three hirds (? swans) sa. WARBERToN, $T$.

Arg. three swans in pale sa. beaked gu. Cressingham.

Arg. three swans close sa. ducally gorged or. Synnot, Ballybrennan, Farrelstown, Ballyhorau, Rossgarland, and Ballytrant, co. Wexford; and city of Waterford.

Arg. three swans disclosed sa. Folgnandiy, 1730.

Arg. three swans rising sa. FolgNar.DBY, $V$.

Alg. three swans volant sa. Folgnarbi or Folnarby.

Az. three swans arg. Carer, Gothele; Collinson, Somerset, i, 256. Charleton, $V^{*}$. Charlton, 1730. Scholar. Scoter or Scotez.

Az. three swans close arg. Sr. Johu Charleton, $V$.

Az. three swans wings endorsed arg. ReDdie.

Gu. three swans arg. Bawdrip, $V^{*}$. LigHT, $V^{*}$. Swanland, Lord Mayor of London, 1329.

Gu. three swans close alg. Bawdripe, $\boldsymbol{V}$. Broderip Brodrepp or Brodribi. Leight. LigHT, $V$.

Gu. three swans close in pale arg. Synnot, Ballymoyer, and Ballywalter, co. Armagh, descended through Synnot, Drumcondra, co. Dublin; from Synnot, Ballytramon, co. Wexford.

Gu. crusily and three swans arg. Eikington, co. Lincoln, $V$.

Per chev. sa. and gu. three swans arg. Mrchell. Per fess dancetty gu. and vert three swans or. BoLDen, Liverpool, quartered by Leonard.

Per fess indented gu. and vert three swans close arg. beaked or. BaLden, Elsington, Norfolls.

Per fess each piece being sa. with in its base barry wavy arg. and az. three swans swimming their bills in the water or waves of the second over all on a fess engr. gu. so many roses silver. Revers, $V$.

Sa. three swans arg. FazakerLer, co. Lancaster. Killesson or Krilmessane. Walton, co. Lancaster. Benedictine Abbey at SeLby, co. York, Cole MS. xxx, 5. But beaked and membered or, Reyner, Apostolatus, i, 216.

\section{THR USHES}

Az. three blackbirds ppr. MeLLor, co. Derby.

3 TIRWHITTS see Lapwings
BIRDS. 3 BIRDS and in chief....

Chief

Arg. three birds (probably blackbirds) sa. beaked or a chief dancetty of the second. MelLer, Middle Temple, London; granted 1719.

on a Chief .... Crosses

Gu. three birds (probably lapwings) or on a chief of the second three croslets as the first. Brokelsbey, co. Lincoln.

$$
\text { .....Fruit }
$$

Or three birds (perhaps martlets) az. on a chief gu. an acorn betw. two mullets of the first. KaIRnie, Scotland.

\section{BLACKBIRDS see Thrushes \\ 3 BUNTINGs see Finches}

3 cocks and in chief....

\section{Chief}

Sa. three cocks and a chief arg. Arthur, Wales. Sa. three cocks arg. a chief ol. ARTHur, $V$. on a Chief.... Palo

Arg. three cocks gu. crested or a chief az. charged with on a pale betw. two ostrich featbers of the first a rose as the second. Richard Cox, Bishop of Norwich 1559, Ely 1560-81.

Arg. three cocks gu. crowned or a chicf az. charged with on a pale betw. two ostrich feathers of the first a rose as the second. Cox, London; granted 1761.

\section{3 cRows and in chief....}

\section{Beast}

Arg. three Cornish choughs ppr. on a chief gu. a lion pass. guard. or. City of Canterbury. on a Chief..... Mullet

Arg. three Cornish choughs ppr. on a chief of the second so many mullets as the first. KrmBEr. .... Roundles

Az. three Cornish chonghs in fess arg. on a chief or as many torteaux. KNIGHT.

\section{DOVES and in chief....}

Az. three doves or on a canton arg. a key in pale gu. Alsop, Lord Mayor of London 1752.

Az. three doves ppr. on a canton or a key erect sa. Arsop, London; granted 1738.

\section{DUCKS and in chief....}

Az. three sheldrakes close arg. a chief erm. HaNs or HansBY, St. Giles, Beverley; and New Malton, co. York; granted $10 \mathrm{Oc}$ tober 1582. HansBY, Tickhill Castle, co. York.

\section{EAGLES and in chief....}

\section{Canton}

Az. three eagles displ. or a canton erm. Fitz-Simon, $V^{*}$.

Or three eagles displ, and a canton erm. Graveshend, Kent.

Or three eagles displ. gu. a canton erm. Richard de Gravesend, Bishop of Lincoln 1258, London 1280-1303. Stephen de Gravesend, Bishop of London 1319-38.

Or three eagles displ. sa. a, canton erm. Stephen de Gravesend, N; Harl. MS. 6589. on a Canton

Erm. tbree eagles displ. gu. on a canton of the second a pierced mullet or. STrode, $V^{*}$. 
BIRDS. 3 EAGLES and in chief.... cont. Chief

Arg. three eagles displ. .... a chief embattled gu. WAFFrE, Ireland.

Az. three eagles displ. arg. a chief embattled or. WAFFYER.

Sa. three eagles displ, and a chief dancetty (indented $\left.V^{*}.\right)$ arg. Stokes, Essex, $W$.

on a Chief.... Escallops

Arg. three eagles displ. gu. on a chief az. as many escallops or. Northcote, Norcote, Devon. .....Fleurs-de-lis

Or three eagles displ. gu. on a chief wavy az. three fleurs-de-lis arg. Pullina.

$$
\text { ..... Head }
$$

Per chev. az. and arg. three eagles displ. counterchanged in chief a leopard's face or. ClaRKE, Dundon, co. Buckingham.

$$
\text { .....Heads }
$$

Gu. three eagles displ. or on a chief .... three leopard's heads .... Band, Wookey House, co. Somerset.

\section{Quarter}

Az. three eagles displ. or a quarter erm. Fitz-Simon, co. Hertford, temp. Edward I, $V$. Sir John Fitz Symon, N ; Harl. MS. 4033 and 5803.

Or three eagles displ. sa. a quarter erm. Grapesend, Kent, $V$.

on a Quarter

Erm. three eagles displ. gu. on a quarter of the second a pierced mullet or. STrode, $V$.

\section{FALCONS and in chief....}

\section{Canton}

Per fess embattled arg. and sa. three falcons belled counterchanged a canton gu. Thompson, co. York.

\section{Roundles}

Arg. three falcons gu. in chief as many pellets. Falkner, co. Lancaster. Sr. Jobn Faukenor, co. Derby, temp. Edward I, $V$.

\section{FINCHES and in chief....}

Arg. three bunten birds az. on a chief of the last a sword fesswise as the first hilt and pomel or. Bunten, Kilbride, Scotland. The birds ppr. Bounton, Scotland.

\section{HERONS and in chief....}

\section{Chief}

Az. three storks arg. a chief erm. HAYEBY. Cross

Gu. three herons arg. beaked and legged or in chief a cross croslet of the last. M. Wauter HERON, $S$.

3 LAPWINGS and in chief....

$\mathrm{Gu}$. three lapwings or on a chief of the last three crosses croslet of the first. Brocirlesby.

\section{MARTLETS and in chief....}

\section{Beast}

Per fess"... and .... in base three birds (? martlets) .... in chief a lion couchant .... Peter Walles; seal 1655.

\section{Canton}

Per fess nebuly az. and sa. three martlets or a canton erm. Barker, Ipswich. Bariker, Bocking Hall, Essex; Bartcy. 1070 extinct 1818; and Kilcooley Abbey, co. Tipperary, descended from Barker, Grimston Hall, Suffolk, Bartcy. 1621 extinct 1766 , the heiress $1 n$. Ponsonby.
BIRDS. 3 MARTLETS and in chief.... cont.

\section{Canton cont.}

Per fess nebuly vert and sa. three martlets or a canton erm. BARKER, Grimston Hall, Suffolk; Baronetcy 1621, extinct 1766 . Chief

Arg. three martlets sa. a chief az. Rednead.

Gu. three martlets arg. a chief erm. M'GELL, Scotland.

Sa. three martlets or a clief arg. DARSETt, $V$. on a Chief..... Annulets

Arg. three martlets gu. on a chief of the second as mayy annulets or. COOPER, co. Salop.

Arg. three martlets gu. on a chief engr. of the second as many annulets or. Cooper, Colne Green, co. Hereford ; Ratling Court, Kent; and Stroud, Sussex. Cowper, Bartcy. 1642, Barony 1706, Viscount Ford wich and Earl Cowper 17 17-8.

$$
\text { .....Axes }
$$

Arg. three martlets sa. on a chief wavy az. as many Danish hatclets or. Enson, Burton-onTrent, co. Stafford, 1395.

$$
\text { .... Beasts }
$$

Gu. three martlets or on a chief arg. a lion pass. guard. of the second. City of CANTERBURY.

$$
\text { ..... Birds }
$$

Arg. three martlets gu. on a chief of the last so many martlets as the first. Fenwicr, $V$. FenwyKe. KeNWICK.

$$
\text { ....Escallops }
$$

Arg. three martlets sa. on a chief of the second so many escallops as the first a crescent sa. for diff. in the centre point. Martyn, $V$.

$$
\text { ..... Fruit }
$$

Arg. three murtlets az. on a chief gu. an acorn betw. two mullets or. CaIrNs.

$$
\text { .....Mullets }
$$

Arg. three martlets vert on a chief indented gu. as many mullets or. MaWER.

Arg. three martlets vert beaked gu. on a chief in: dented (or Hart. MS. 1392) of the first so many mullets sa. Mawer, Hallyng, $V$.

Arg. three martlets vert beaked gu. on a chief indented sa. as many mullets of the first. MAWER.

Gu. three martlets or on a chief of the second as many mullets az. Lusher, Loudon; Putney, Slioland, and Starland, Surrey. ..... Sun

Or three martlets sa. on a chief az. a sun in splendourppr. Merewether, Castiefield, Calue, co. Wilts; and London; quartering Allworth.

$$
\text { .....Roundles }
$$

Arg. three martlets gu. in chief as many ogresses. FALCONER or FAWLCONER, co. Derby.

\section{3 owLS and in chief....}

Arg. three owls gu. a quarter az. GossET orGossett. 3 PEACOCKS and in chief....

Sa. three peacocks arg. a chief embattled or. Peacock, Burnhall, co. Durham; granted 1688.

$$
3 \text { PELICANS and in chief.... }
$$

on a Chief.... Mitre

Arg. three pelicans in piety or nests vert on a chief az. a mitre of the second betw. two mullets of the first. Paterson, Seafield, Scotland.

$$
\text { .... Muliets }
$$

Arg. tluree pelicans in piety or nests vert on a chief az. as many muliets of the first. Paterson, Dalkeith, Scotland.

Arg. three pelicans .... vulned gu. on a cliief embattled az. as many mullets of the first. Paterson, Baunockburn, Scotlrud. 
BIRDS. 3 sWANS and in chief....

Az. three swans arg. a chief or. Swan.

\section{THRUSHES and in chief....}

Arg. three blackbirds ppr. a chief dancetty sa. MeLlor, Ideridgehay ; and Derby.

\section{BIRDS and in base....}

Per fess gu. and az. in chief three birds and in base a fleur-de-lis or. Humphrey Hodgetts, High-Sheriff of Stafford 1720, Shaw, Stafford.

\section{DOVES and in base....}

Per fess wavy az. and arg. in chief three doves ppr. in base on a mount vert a ram couchant sa. armed and unguled or. Pujolas, Middlesex; granted 1762.

\section{FALCONS and in base....}

Arg. in chief three falcons ppr. in base a lion ramp. tail nowed gu. gorged with an eastern coronet or. Bewes, St. Neots, Cornwall.

\section{MARTLETS and in base....}

Per chev, engr. erm. and az. in chief three martlets of the last in base an escallop arg. within an annulet or. Wintre, co. Gloucester.

Arg. in chief three martlets .... in base a lion ramp. gorged with a ducal coronet or. BEWEs.

\section{3 sWANS and in base...}

Per chev. sa. and gu. in chief three swans respect. and in base a herring-cobb naiant ppr. COBBE.

\section{BIRDS betw. or within....}

\section{Bendlets}

Gu. three birds (? crows hawks or pheasants) close in bend betw. two cotises arg. Monsyer Ratie Valenan, T, or Velemane, T, Harl. MS. $613 \pi$.

\section{Bordure}

Or three birds (probably lapwings) surgerant .... a bordure vert. Sir Rhys Hen, co. Caernarvon.

Gu. three birds (probably lapwings) or a bordure arg. Terrick.

\section{COCKS betw. or within....}

Arg. three cocks in bend cotised sa. Herbright. HoNGBIIGG, co. York.

Arg. three cocks reguard. betw. two cotises sa. Houghbrig, $V^{*}$. Houghbrige, York, $V$.

Arg. three cocks in bend reguard. cotised sa. Wyrrall, co. Chester.

Gu. three cocks two and one betw. (nine another) ten crosses croslet arg. KoKerell, $E$.

Or three cocks in bend reguard. betw. two cotises sa. WyrRali.

\section{CROWS betw, or within....}

\section{Arrows}

Arg. three Cornish choughs pyr. two and one betw. as many arrows one and two gu. Crastein. Scrace.

Bordure

Per chev. (another enibattled) vert and gu. tbree crows arg. within a bordure counterchanged. Craw, Nether Byer, Scotland.

3 DOVES betw. or within....
BIRDS. 3 DUCKS betw. or within....

$\mathrm{Gu}$. three ducks betw. nine crosses croslet arg. ElKINGTON, $V^{*}$.

\section{EAGLES betw, or within....}

\section{Bendlets}

Az. three eagles displ. betw. two bendlets arg. BADISFORD, $V^{*}$. BASFORD, Grange, co. Derby.

Az. three eagles displ. in bend betw. two bendlets arg. Belking. Belknappe, co. Warwick.

$\mathrm{Az}$. three eagles displ. bendwise in bend betw. two cotises arg. BADISFORD, $V$. Sr. de Belknap, co. Warwick, $V$.

Az. three eagles displ. in bend betw. two cotises arg. Badford or Badishford, Kent. Belew, co. Warwick.

Az. three eagles displ. in bend betw. two cotises engr. and crosses croslet fitchy or. NICHOLLs, Islip Willen, co. Buckingham.

Gu. three eagles displ. or betw. two bendlets arg. Kingestone, $V^{*}$.

Gu. three eagles displ. bendwise in bend or betw. two cotises arg. Kingestone, $V$.

\section{Bordure}

Arg. three eagles displ. gu. a bordure az. charged with eight bezants. De Lymersi De Lyarerston or De Lymreston alias Levintune.

Gu. three eagles displ. or within a bordure compony arg. and (az. another) sa. TenNars.

Vert tbree eagles displ. in fess within a bordure or. Williams, London.

\section{Crosses}

Az. three eagles displ. or betw. nine crosses cros. let fitchy arg. BIJLinghurst, Newport, Isle of Wight.

Az. three eagles displ. betw. nine crosses croslet or. Alphraham. Somervile. .Somervilde, $V *$.

Az. three eagles displ. betw. ten crosses croslet or. Somervinl, co. Stafford.

Az. three eagles displ. betw. crosses croslet fitchy or. SOMervilde, $V$.

\section{FALCONS betw. or within....}

Arg. three falcons within a bordure gu. FAULCONER, co. Nortlampton.

Arg. three falcons gu. within a bordure sa. Fawcon, co. Northampton.

3 HERONS betw, or within....

Gu. three cranes within a bordure invecked arg. Cranston, Mockrie, Scotland.

\section{LAPWINGS betw, or within....}

Gu. three lapwings within a bordure arg. Terrick, co. Stafford.

Or three lapwings volant (tricked as rising overt inverted) vert membered gu. in a bordure engr. of the second. Sir Rys Hen, Harl. MS. 1441.

\section{MARTLETS betw, or within....}

Bars

Arg. three martlets sa. betw. two bars gu. BARWELT.

Gu. three martlets betw. two bars gu. BRIGFORD, $V^{*}$. BRUGFORD.

Gu. three martlets in fess betw. two bars arg. BRYGFord, $V$.

Or three martlets in pale sa. betw. two bars gu. Ankyrslex. South Wotton, Norfolk. 
BIRDS. 3 MARTLETS betw, or within.... cont. Bars cont.

Or three martlets sa. betw. two bars wavy gu. in chief three crescents in base a portcullis of the second. Workman; quartered by Macnaghten. Bendlets

Arg. three martlets in bend sa. betw. two bendlets engr. gu. PIgot.

Arg. three martlets in bend betw. two cotises sa. Norvel, Gargunnock, N.B. NorvilL, Scotland.

Gu. three martlets in bend betw. two cotises arg. Skarsby or Sharsley.

Sa. three martlets in bend betw. two bendlets arg. Derhaugh, Coulston Hall, Suffolk.

Arg. three martlets betw. four cotises ( ? sa.). Nonmanver., Gargunnock, Scotland.

\section{Bordure}

Arg. three martlets gu. within a bordure or. Catrnes, Monaghan, Ireland; Beronetcy 1708 extinct 1743; descended from CaIrnes, Ordchartown, N. B. -

Az. three martlets within a bordure engr. arg. ADERston or ADDreston. AdDerstone, $V$. ANDERSON, $W$.

Az. thrce martlets or within a bordure engr. arg. Etherton.

Bary of four or and gu. on the upper piece three martlets vert a bordure compony arg. and az. GreENWAY.

Gu. three martlets within a bordure arg. $M^{\prime} G \Pi L$, Ballynester, 1reland.

Gu. three martlets within a bordure engr. arg. M'Gill, Ramgally, Scotland. The bordure indented. M'GILL.

Gu. three martlets arg. within a bordure or. Carreus, Scotland.

$\mathrm{Gu}$. three martlets within a bordure or. CaInNes, Etterton. CARGiLl, Orchyardtoun, Scotland. Carnes, Scotland.

Sa, three martlets within a bordure engr. arg. RIDELI, Norfolk.

\section{Chevrons}

Gu. three martlets betw. two chev. arg. PEAcH, Rooksmore, co. Gloucester; granted 8 Novem. ber 1769 .

\section{Crosses}

Arg. three martlets in fess betw. four crosses croslet fitchy sa. Godstone.

Arg. three martlets two and one betw. four crosses croslet one two and one sa. GoDDIsToN, Essex. Goodiranston, Kent. Goodneston, $V$. Flaunches

Arg. three martlets in pale betw. two flaunches sa. each charged with a lion pass. of the first. Browne, Totteriage, co. Heltford. Browne, Baronetcy 1622, Baron and Viscount Castlerosse 1798, Earl of Kenmare 1800, Baron Kenmare 1856. Browne, Croft, co. Lincoln. JEnkins. The lion pass. guard. of the first (another armed and langued gu.). Browne Baronetcy 1622, Baron and Viscount Castle. rosse 1798, Earl of Kenmare 1800, Baron Ken. mare 1856.

Arg. three martlets in pale betw. two flaunches sa. each charged with a lion pass. or. Browne, Orthwaite Hall, Woodhall, and Tallantire Hall, Cumberland.

Arg. three martlets in pale betw. two flaunches sa. each charged with three lions pass. as the first. Thomas Brown, Bishop of Rochester 1435, Norwich 1436.45, Blomefield, Norfolk, iii, 535.
BIRDS. 3 MARTLETS betw, or within..... cont. Orle

Gu. eight martlets in (? an) orle arg. Fonest, Collinson, Somerset, iii, 402 .

\section{OWLS betw. or within....}

three owls within a (bordure another a) tressure flory counterflory .... John BR1DGEs, Bishop of Oxford 1604-18.

3 PEACOCKS betw. or within....

\section{Bordure}

Arg. three peacocks in pride az. within a bordure engr. gu. William Pawne, $V$.

\section{Estoiles}

Arg. three peacocks in pride ppr. betw. as many stars gu. PEACOCK, Scotland.

\section{PELICANS betw. or within....}

Arg. three pelicans gu. within a bordure wavy vert. Ormiston, Kelso, Scotland.

\section{POPINJAYS betw. or within....}

Arg. three parrots ppr. within a bordure gu. FAIRFOWL, Wester.Lathal, Scotland.

\section{3 sWANs betw. or within....}

Gu. three swans betw. nine crosses croslet arg. ELIIINGTON, co. Lincoln, $V$.

Sa. three swans betw. nine crosses croslet fitchy arg. EsLington.

\section{CRows betw, or within.... and in chief....}

Arg. three ravens sa. betw. two bars dancetty gu. in chief a griffin segreant betw. two grasshoppers of the second. Griffiths.

3 MARTLETS betw. or within.... and in chief....

Arg. three martlets in pale betw. two palets sa. a chief erm. SNodgrass, Scotland.

Sa. three martlets or within a bordure engr. gu. a chief arg. Dassetr, Ricel, co. York.

\section{THRUSHES betw, or within.... and in chief....}

Arg. three blackbirds ppr. betw. two bars dancetty gu. in chief a griffin segreant betw. two crickets of the second. Griffriths, co Hereford.

\section{On 3 cOCKS}

Per fess indented arg. and sa. on the necks of three cocks two bars to each counterchanged. Francis or Fraunces.

\section{On 3 EAGLES}

\section{Escallop}

Per chev, embattled az. and erminois on each of three eagles displ. an escallop at the breast counterchanged. DarBY, Sunniside House, Colebrookdale, co. Salop.

\section{3-Foils}

Per chev. embattled erminois and az. on each of three martlets counterchanged a 3-foil slipped those in chief arg. the third vert. HuDson, Boutherbeck, Cumberland; Baronetcy 28 July 1791, now (1813), Palmer.

\section{BIRDS}

Quarterly nebuly arg. and az. four birds counterchanged. Robins or Robyns, Glassney, St. Winnow, and Troneere, Cornwall. 
BIRDS.

4 CROWS

Ar. four (ravens sa. membered gu. $V^{*}$ ) Cornish choughs two and two respecting each other ppr. Trelamer, $V$.

\section{EAGLES}

Arg. fretty aud four eagles displ. in cross gu. Priory of Austin Canons at Marton, co. York.

Per saltire arg. and or four eagles displ. sa. Barnesdale, 1604.

Per saltire or and arg. four eagles displ, az. Baronsdale, London.

Per saltire or and az. four eagles displ. counterchanged. Cookt.

Quarterly arg. and or four eagles displ. double headed vert. MANSBRIDGE, London.

\section{FALCONS}

Sa. four hawks volant or. Mure, co. Lincoln.

\section{MARTLETS}

.... four martlets .... Luttrell; Collinson, Somerset, iii, 498.

Gyronny of six or and az. four martlets counterchanged. Moditon, Wicklewood, Norfolk.

Gyronny of eight az. and or four martlets counterchanged. Sybelles, Kent.

Gyronny of eight or and az. over all four martlets one two and one counterchanged. SybelLs, Kent, $V$.

Gyronny of eight or and az. over all four martlets two and two counterchanged. Sibbilites, Kent, $V$. Sibbills, $V^{*}$.

Quarterly arg. and gu. four martlets counterchanged. Vannarr, London.

Quarterly wavy or and az. four martlets counterchanged. Slensly, $V^{*}$. Spendeler.

Quarterly nebuly or and sa. four martlets counterchanged. MARKER.

Quarterly or and vert four martlets counterchanged. SPEndLTFF, Falsethorpe, co. Lin. coln.

Sa. four martlets arg. Monnter. Mount.

Sa. four martlets arg. two and two. MEUTER, $V$. Monster, 1730. Monter. Mouter, $V$.

Sa. four martlets (auother volant) arg. one two and one. Mure.

\section{4 sWANS}

Gu. four swans wings erect arg. Roose, Whetstone, Cornwall.

\section{EAGLES and in chief....}

$\mathrm{Az}$. four eagles displ. or a canton erm. Fitz.Syirond, co. Hertford.

Az. four eagles displ. two and two or a canton erm. Sire John Fitz Symon, N; Harl. MS. 6137.

Or four eagles displ. two and two sa. a canton erm. Sire Esteven de Gravesend, $N$; Harl. MS. 6137.

\section{EAGLES betw, or within....}

Arg. four eagles displ. withiu a fret gu. Priory of Austin Cauons at MARTON, co. York.

\section{BIRDS}

Vert five birds (perhaps martlets) two two and one arg. Arvas, Cornwall.
BIRDS,

5 CROWS

Or five ravens two two and one ppr. ConBet or Corbett.

Or five ravens two two and one sa. Corbett, $V$.

\section{EAGLES}

Arg. five eagles displ. in cross sa. Sir Anthony Colclovgr. Blorton, co. Stafford, founded the family of Colclovgh, Tintern Abbey; Ballyteigue, co. Wexford; Queen's County; and New Ross. Colclovghe, co. Stafford, $W$.

Sa. five eagles displ. in cross arg. Duncan or Duncum.

Sa. tive eagles displ. in saltire arg. Roger, of BISHOPSBRIDGE, Archbishop of York 1154-81.

Vert five eagles displ. in saltire arg. Roger, Bishop of Salisbury 1107.39.

Vert five eagles displ. in saltire or. Alexander, Bishop of Lincoln 1123-47.

\section{MARTLETS}

Arg. five martlets three and two gu. DowDaL, 1730. Dowdall, $V^{*}$. But in saltire. Dowdall, Ireland.

Arg. five martlets in cross sa. Brakrn, Chesterton, co. Cambridge.

Arg. five martlets in saltire sa. BodLex.

Az. five martlets in saltire or. GoLdING, Ireland.

Gu. five martlets arg. Cuarelt.

Sa. five martlets arg. ARUNDEL, Somerset.

Vert five martlets arg. two two and one. ARNes, Cornwall.

\section{CROWS and in chief....}

Or five ravens ppr. two two and one on a canton gu. two lions pass. arg. Corbet or Corbetr.

\section{EAGLES and in chief....}

\section{Canton}

Az. five eagles displ: arg. a canton erm. Fitz-Thomas, Lord Mayor of London 1262 to 1265 and 1269.

Az. five eagles displ. or a canton erm. Fitz-Thomas, Essex.

Or five eagles displ. sa. armed gu. a canton erm. Basing.

\section{Quarter}

Or five eagles displ. two two and one sa. a quar. ter erm. Sire Esteven Gravesend, $N$; Harl. MS. 4033 .

\section{MARTLETS and in chief....}

\section{Chief}

Arg. five martlets two two and one sa. a chief az. BODLEY.

on a Chief.... Coronets

Arg. five martlets in saltire sa. on a chief az. three ducal crowns or. Sir Thomas BodLey, founder of the New Library at Oxford, $V$; a descendant of BODLEGH or Bodlex, Dunscombe, in Crediton, co. Devou.

$\mathrm{Gu}$. five martlets arg. on a chief indented or three crowns az. BODLEY.

\section{BIRDS betw, or within....}

Barry of four or and gu. in chief five birds vert membered of the second within a bordure compony arg. and sa. Greenwax.

\section{MARTLETS betw, or within....}

Per chief gu. and az. over all five martlets betw. three garbs or. Strangebow or Strongbow. 
BIRDS. 5 SWANS betw, or within....

Az. five swans close in cross arg. betw. four annulets or. WeBster, co. Cambridge; Essex; co. Huntingdon; and Penns, co. Warwick.

\section{BIRDS}

Arg. six birds (perhaps martlets or swallows) sa. Sr. John ARUndell, Trerese, co. Devon, $V$.

Barry of five or and sa. six birds (perhaps martlets) three two and one gu. William Payneli, $A$.

Gu. six birds (probably popinjays) three two and one arg. MaRMadUKE.

\section{COCKS}

Arg. six cocks three two and one gu. Fitz-Morris.

Arg. six cocks three two and one sa. FITz-Morris.

Arg. six cocks three two and one sa. crested and jelloped gu. Morris, co. Hereford.

Gu. six cocks arg. Nuttali.

Gu. six cocks three two and one or. Sothrul.

\section{CROWS}

Arg. six Cornish choughs three two and one ppr. Dandale.

\section{DOVES}

Az. six doves three two and one arg. LUMLEY. Gu. six ringdoves arg. LUMLEY, $V^{*}$.

Sa. six doves three two and one arg. LEwkNor. Vert six doves three two and one arg. Kerne.

\section{EAGLES}

Arg. six eagles displ. three two and one sa. Richard CAM, A, Harl. MIS. 6137. KIRTON. Raffe de Kyrketon, $A$.

Arg. six eagles displ. vert. Ganeston, Cornwall.

Az. six eagles displ. three two and one arg. Newenton Newerton or Newington, Essex; and Kingston Bousey, Sussex. Sire Adam de Nementone, $N$. Sr. Adam de Newington, temp. Edward I, $V$.

Az. six eagles displ, arg. membered or. MEwYs.

Az. six eagles displ. or. Bieisworth, $V *$ * Mewtis.

Az. six eagles displ. three two and one or. Bibisworth, $V$. Newenton, Essex.

Az. six eagles three two and one or. PECHAND.

Gu. six eagles displ. three two and one arg. BROKESHORNE.

Gu. six eagles displ. three two and one or. Raffe de LynNessey, $A$; or Limsey, $A$, Harl. MS . (i137. Sr. Raffe de Lymsey or Lynsey, $I$; but Linsey, I, Harl. MS. 6589. And with a label of three points (in the margin) az. Sr. Richard de LyMSEY, $I$.

Gu. six eagles displ. double headed three two and one or. Broxborne, $V$.

Gu. six eagles displ. double headed three two and one or armed arg. BRoxBORNE.

Or six eagles displ. gu. Blewet.

Or six eaglets displ. three two and one ppr. BAXTer.

Or six eagles displ. sa. Richard Сена sive Tham, E, Harl. MIS. 6137. Richard TaME, A. TANEY or TANY, Essex. Pichard de TANY, Essex, $V$. Sire Richard de TANY, $J$. Sire Richard T'any, $N$. Richard Thani, $E$. Thany, Stapleford, Essex. Thany or Tany. Sr. Hichard Troney, I, but Tanney, I, Harl. MS.
BIRDS. 6 EAGLES cont.

6589. Drokensford, Essex; quartered by D'Oyly through Legat and Mandeville. TARry (a mistake for T'ANNY?) whose heiress $\mathrm{m}$. Drokensford.

Or fretty az. six eagles two one two and one on the joints .... Priory of Austin Canons at Merton, Surrey.

Or six eagles displ. vert. Piers Gaveston, Earl of Cornwall, 6 August 1:307, beheaded 1314.

Sa. six eagles displ. arg. Sire Dru de Barantin, $N$. Barantine, 1730 . Barrantine, $V^{*}$. Barrantyoe, co. Buckingham, $V$. Biblesworth. Sa. six eaglets displ. three two and one arg. Barantine. Barringston.

Sa. six eagles displ. or. Chanseill, $V$.

Vert six eagles displ. or. Le Counte de Cornewaile, $N$. Piers Gaveston, Earl of Cornwall, temp. Edward II, $V ; Z, j 41$. Ormer or Orisers. Piers.

Vert six eagles displ, three two and one or armed gu. Gaveston, Earl of Cornwall, 1307-14.

\section{GULLS}

Az. six seagulls three two and one arg. the dexter wing displ. the sinister close. APELDY, co. Salop.

\section{HEATHCOCKS see Mioorcocks}

\section{MARTLETS}

Arg. six martlets gu. Clayle or Clarryl. Dowdall, Ireland.

Arg. six martlets three two and one gu. ClaryLL, $V$. Clayli, V. Frome, Kennet, co. Wilts.

Arg. six martlets three two and one sa. Delairare or Delamore. Delamore alias Moreing, Moreton, co. Devon, 1620. De la More or Moring. Moneing, quartering Maltravers.

Arg. six martlets in orle sa. De la Monre or Monrey.

Az. six martlets three two and one arg. ApEIBY or Apleby, co. Salop; and co. Stafford. Grandon.

Az. six martlets two two and two or. AppelBy, co. Stafford.

Az. six martlets three two and one or. Henri de Apebi, $G$. Apelby, co. Leicester. Appleby, co. Leicester. Henri d'APpelbi, $E$. Henry Appleby (in a later hand to) $F$. Sir Henry de Appelis, $L ; N$. M. Emond Appelby, $S$. Monsire de Appleby, $Y$. Sr. Henry Appieby, co. Stafford, temp. Edward I, $V$. Jon le Moine, $F$. Walshe Walsh or Welse.

Barry of five arg. and az. six martlets in orle gu. Sir William PaYneld, L, Harl. MS. 6589 .

Barry of five arg. and gu. six martlets three two and one of the last. Roringe. Roringe, $V^{*}$. RoRynge, $V$.

Barry of five arg. and sa. six martlets in orle gu. Paynell, co. Hants ; and Sussex.

Barry of five arg. and sa. six martlets three two and one of the last. $\mathrm{M}^{6} \mathrm{CoY}$, Scotland.

Barry of five arg. and vert six martlets three two and one gu. ATHORE.

Barry of five az. and erm. six martlets three two and one or. MAw, co. Lancaster; and Suffolk. Leonard MAWE, Bishop of Bath, etc. 1628-9.

Barry of five gu. and arg. six martlets two two and two of the last. EgLand or Eydand, co. Lincoln. 


\section{BIRDS. 6 MARTLETS cont.}

Barry of five gu. and arg. six martlets three two and one of the last. Chalons, co. Devon. Eiseldon. Sr. John Eland, co. York, $V$. Eland or ExLAND, co. York. Elland. YSELDON.

Barry of five gu. and or six martlets .... LEEKS.

Barry of five or and az. six martlets three two and one gu. Thomas Paynell, $A$.

Barry of five or and gu. six martlets three two and one as the last. Marley.

Barry of five or and sa. six martlets three two and one az. CREICH or Creigh, Scotland.

Barry of ten arg. and az. six martlets in orle gu. VaLEnce, Earl of Pembroke, temp. Henry III.

Chevronelly of five arg. and gu. six martlets three two and one sa. Jeners, $V$. Jennets, $V *$.

Gu. six martlets arg. Lumuer, Lumley Castle, co. Durham.

Gu. six martlets three two and one arg. Arthekrli. Carrell, London. Sr. John Clareli, $V$. Clarell, co. York. Clarreli, Clarrell Hall in Tickhill.

Gu. six martlets ol. ClaReL. Sr.William Tochert, $I$. William TovcheTt, $K$, Harl. $M I S .6589$.

Or six martlets three two and one gu. LEwis.

Or six martlets three and three gu. REDFERN.

Or six martlets three two and one sa. Latrent. LUTTERELL.

Per bend embattled arg. and gu. six martlets counterchanged. ELMER.

Per bend sinister double dancetty arg. and sa. six martlets counterchanged. Almeyne, $V *$.

Per bend sinister fracted arg. and sa. six martlets counterchanged. John ALEYNE, Suffolk, $V$.

Per bend rompu arg. and sa. six martlets counterchanged. AlLen, Cresselly, co. Pembroke, a younger branch of ALLEN, Dale Castle, co. Pembroke; the heirs $m$. Lloyd and Philipps. Allen, Bath.

Per bend rompu arg. and sa. six martlets and an annulet in the dexter chief point counterchanged. Allyn, Bampton, co. Devon.

Per bend sinister rompu arg. and sa. six martlets counterchanged. ALEEN or ALLEYN, co. Chester ; Suffolk; and Wilts.

Per bend sinister or and sa. six martlets counter. changed. Joseph Alues, Bishop of Bristol 1834 , Ely 1836.45 .

Per chev. arg. and sa. six martlets counterchanged. ALleN.

Per chev. or and az. six martlets counterchanged. EDGEworTH, co. York.

Per chief gu. and arg. six martlets counter. changed. John de Fenwik, $Y$. Monsire de FENWIKE, $Y$.

Per fess gu. and arg. six martlets three and three counterchanged. FENWICK, Fenwick, and Wallington, Northumberland; Baronetcy 1628; extinct 1697. FENwICK, Bishop Wearmouth, co. Durham. Fenwicke, Iongwitton Hall, Northumberland. Fenwick, Edmonton, Middlesex. FENwICK, Hallaton, co. Leicester.

Per fess gu. and arg. six martlets three two and one counterchanged. M. John Fenwik, $S$. Fenwike, $V^{*}$. Fenwyze, Northumberland, $V$.

Per pale indented .... six martlets two two and two counterchanged. Fanshair.

\section{BIRDS. 6 MARTLETS cont.}

Per pale indented arg. and az. six martlets coun. terchanged. Francham or Franshan.

Per pale indented arg. and sa. six martiets two two and two counterchanged. WREN, $V$.

Per pale arg. and sa. six martlets in pale three and three counterchanged. Fenwicke.

Per pale nebuly az. and or six martlets two two and two counterchanged. James FLEETwOOD, Bishop of Worcester 1675-83. FLEeTwood, Hesketh, Penwortham, Rossall Hall, etc., co. Lancaster; The Vache, in Chalfont St. Giles', and Missenden, co. Buckingham; Cranford, Middlesex; and Calwich co. Stafford; descended from Henry, son of John Fleetwood, lord of Plumpton Parva. And with a crescent for diff..... William FleEtwood, Bishop of S. Asaph 1708, EIy 1714-23.

Per pale wavy az. and or six martlets counter. changed. FleETWOOD.

Per pale indented or and az. six martlets two two and two counterchanged. Fransham, $V$.

Per pale nebuly or and az. six martlets two two and two counterchanged. Fleetwood, $V$.

Per pale nebuly or and az. six martlets three and three counterchanged. FleEtwoon, London.

Per pale wavy or and az. six martlets counter. changed. FleETWOOD.

Per pale indented or and gu. six martlets respectant each other two two and two counterchanged. SaYMeLL, $V$.

Per pale nebuly or and gu. six martlets respectant each other two two and two counterchanged. SaYirell, $V$.

Per pale wavy or and gu. six martlets counterchanged. SAMELL or SAMNELL.

Per pale wavy or and gu. six martlets respecting each other two two and two counterchanged. Nicholson. Saymele, $V^{*}$.

Quarterly gu. and or in the first and fourth quarters three martlets of the secoud. Massy.

Quarterly gu. and or six martlets of the last. Massy.

Quarterly or and gu. six martlets in bend the upper three sa. the lower arg. DenHas, $V$.

Sa. six martlets three two and one .... AppLEBX, 1730.

Sa. six martlets arg. ARUNDEL, Collinson, Somerset, ii, 39 .

Sa. six martlets two two and two arg. Catherine ARONDEL, 1526, seal in Dallaway, Inquiries.

Sa. six martlets three two and one arg. AnUNDELL. BEYFrand.

Sa. six martlets or. Beriston. Breyston.

Sa. six martlets three two and one or. BEYFEard. Beyfrand, $V$.

\section{MOORCOCKS}

Arg. six heathcocks sa. Firz-Moores, $V$.

Arg. six moorcocks sa. FITZ-Mores, $V^{*}$. Fitz-Moores, $V^{*}$.

Arg. six moorcocks three two and one sa. Monwen.

Arg. six moorcocks sa.membered gu. Fitz.Mores, I 730 .

\section{POPINJAYS}

Gu. six popinjays three two and one arg. Mar. maduke de LUMLEY, $V$.

Gu. six popinjays or. Lumaey. 


\section{BIRDS. 6 SWALLOWS}

Sa. six swallows three two and one arg. AnUNDEL, Baron Arundel of Wardour, 1005, $Z, 353,355$ ARUNDEL, Baron Arundel of Trerice, 1664. ARUNDEL, Baron Killard and Viscount Galway, 1727 ; quartering Monckton. Arundel, Menedarva, Trengwainton, and Lifton Park, Devon; quartering Harrss. Hunter-Anundel, Abbotshill, co. Ayr ; and Barjarg Tower, co. Dumfries; quartering Hunter. John Anunde L, Bishop of Chichester 1452-77. John AnUndeL, Bishop of Lichfield, etc., 1496, Exeter 1502-4.

6 CROWs and in chief....

\section{Canton}

Or six ravens three two and one ppr. a canton gir. Conbet. on a Canton....

Or six ravens sa. on a canton gu, two (three Harl. MS. 6137) lions pass. in pale arg. Thomas Corbett, $E$, or Corbet, $F$.

Or six ravens sa. on a canton gu. two lions pass. guard. in pale arg. Thomas Corbet, Al. brighton, co. Salop, temp. Edward 1; married the heiress to Strange of Knocking, $V$.

\section{EAGLES and in chief....}

\section{Canton}

Az. six eagles displ. or a canton erm. John Fitz-Symon, N, Harl. MS. 6589.

Or six eagles displ. three two and one sa. a can. ton erm. Basing, London, 1214.

Chief

Arg. six eagles displ. three two and one sa. a chief nebuly az. EgGinton, Kingston-uponHull; granted .... EgGINToN, Kirk Ella, near Hull, quartering Smyth.

\section{FINCHES and in chief....}

Arg. six sparrows three two and one sa. on a chief indented gu. two swords in saltire betw. as many wolf's heads erased or. Sparow, London; granted 1516 .

\section{MARTLETS and in chief....}

\section{Canton}

Erm. six martlets three two and one gu. a can. ton of the last. RUDDE, London, Harl. MS. 1444.

Per pale nebuly az. and or six nuartlets two two and two counterchanged a canton arg. Hesketh. Fleetwood, Rossall Hall, co. Lancaster; Ba. ronetcy 1838, quartering Hesketh.

Sa. six martlets three two and one or a canton of the second. CheYney, co. Bedford.

on a Canton.... Mullet

Az. (or else sa.) six inartlets three two and one or on a canton arg. a mullet gu. STockHeY, quartered by Sr. W. Raleigh.

on a Chief.... Head

Az. six martlets three two and one or on a chief arg. three buck's heads cabossed .... UPPLEBY, Wootton, co. Lincoln.

\section{BIRDS betw, or within....}

Or six starlings betw. three mullets sa. each of the last charged with a bezant. PeLton.

\section{DUCKS}

Arg. seven cannets three three and one sa. CANNETON.

Gu. seven sheldrakes or. Tuchet. Tucketr, co. Devon.
BIRDS.

7 EAGLES

Or seven eagles displ. three three and one sa. TANEY.

\section{MARTLETS}

Arg. seven martlets three three and one sa. Delamore. Trevilian.

\section{MARTLETS and in chief....}

Barry nebuly of six gu. and arg. seven martlets three three and one sa. on a chief or three ogresses. MarLand, $V$.

\section{MARTLETS}

Arg. eight martlets in orle enclosing a fleurde-lis (? for diff.) sa. Briggam, $V^{*}$. BrighaM, V. Rochdale, 1730.

Barry of five arg. and sa. eight martlets three two and three gu. Panell, $V^{*}$. Sir William Poweld, $V$.

Barry of five arg. and sa. eight martlets as the last. Furlona.

Barry of five gu. and arg. eight martlets three two and three as the last. Chali.ons, co. De. von. DankYRsley, co. York. Sir Thomas de Elande, $S$. Eytend. Siletheley, $V$.

Barry of five gu. and arg. eight martlets four three and one as the last. Eland, in Tankersley Church, co. York.

Barry of five gu, and or eight martlets in orle as the last. Chalons, Devon. Eland.

Barry of five or and az. eight martlets in orle gu. Paynell, co. Hants.

Barry of five or and az. betw. eight martlets three two two and one gu. Thomas Paynell, $G ; Q$. Sir Thomas Paynnell, co. Hants, $V$.

Barry of seven arg. and gu. eight martlets in orle as the last. RYNGE, Norfolk, Harl. MS. 5803. Barry of eight arg. and gu. so many martlets in orle sa. Chaworth, co. Oxford.

Barry of eight or and sa. so many martlets three two two and one as the first. Broker, $W$. BrowkER, London; and Southwark.

Barry of nine arg. and gu. eight martlets in orle sa. Patricke de Chantorth, N, Harl. MS. 6137.

Barry of nine arg. and sa. eight martlets in orle gu. Sr. William PaIsell, L, Harl. MS. 6137.

Barry of ten arg. and az. eight majtlets in orle gu. Countye de Penbroore, Adamarius de Valentia (1296-1303), N, Harl. MS. 6137. Valence, $Z$, 448. Aimer de Valence, $K$, Harl. MS. 6137.

Barry of ten arg. and gu. eight martlets in orle sa. Brecknock. Breknor or Bretnor. Chaucombe.

Barry of twelve arg. and az. eight martlets in orle gu. Valence, $Z, 180$. But enclosing a fleurde-lis (? for diff.) gu. Penbrok, $V$. Valence, $V$.

Barry of thirteen arg. and gu. eight martlets in orle vert. Pairs or Patrick de Chaurs, $F$.

Barry of fourteen arg. and gu. eight martlets in orle sa. Patrick de Chaworth, Harl. MS. 4033.

Barry of sixteen arg. and az. eight martlets in orle gu. Le Counte de Penbrock, $N$; $\mathrm{Harl}$. MSS. 4033. Le Counti de Penbruge, J, Harl. MS. 6589. But barry of twenty. Le Conti de Penbruge, $J$, Harl. MIS. 6137.

Fusily az. and gu. eight martlets three two two and one or. Hencex, Kent; and Rotherhithe, Surrey. 


\section{BIRDS. 8 MARTLETS cont.}

Gu. eight martlets in orle arg. Forest, France. And with a (crescent, another a) 5-foil (? for diff.) erm. Boun. Bowne.

Gu, eight martlets in orle or and a crescent (? for diff.) erm. Sr. ... de BoHuN, $V$.

Iozengy gu. and az. eight martlets in orle or. Herile, Kent.

Paly bendy az. and gu. eight martlets in orle three two and three or. Richard Hendu, Kent, $V$. Henley or Hendeey, Forshorne, Kent (but gu, and az, for HENDLEY, $V^{*}$.).

Quarterly sa. and gu. eight martlets in orle or. Sr. Richard MarLOWE, Alderman of London, $V$. MerLowe.

Sa. eight martlets in orle arg. Bollinge.

Sa. eight martlets three tro two and one arg. Stanton, 1730.

\section{MARTLETS betw. or within....}

Barry of seven arg. and gu. eight martlets or a bordure az. SoMERvill (? in error).

\section{9 cocrs}

Gu. nine cocks three three two and one arg. Henry de Cokyntone, $A$, or Cockington, $A$, Harl. MSS. 6137.

\section{MARTLETS}

Az. nine martlets three three two and one arg. Sr. Jobn de Bellenden, N, Harl. MS. 4033.

Barry of five arg. and gu. nine martlets as the last. More, co. Bedford.

Barry of five arg. and vert nine martlets as the last. Amard. More.

Barry of five gu. and arg. nine martlets .... ETwALL.

Barry of five gu. and arg. nine martlets as the last. Challows.

Barry of fourteen arg. and az. nine martlets four two two and one in orle gu. Cnte de Penbrok, $E ; F$.

Barry of fourteen arg. and gu. nine martlets in orle sa. Pateric de Chaurs, E, Harl. MS. (6137.

Barry of sixteen arg. and gu. nine martlets in orle sa. Pain de Chatrs, $F$.

Gu. nine martlets three three two and one or. ADLYN, London, 1590 .

Sa. nine martlets in orle arg. Godfrey de Beunund, $F$.

\section{POPINJAYS}

Gu. nine popinjays or. Lumley. Thmenae, Hewarth, co. York; descended from THWENGE, Over Helmesley, co. York; the heiress m. Wilmer. Thweng. Tweng.

\section{MARTLETS}

Arg. ten martlets sa. MOORE.

Az. ten martlets four three two and one arg. Ratendeen or Ratenden. Ratendene, $V^{*}$.

Barry of five or and az. ten martlets in orle gu. Paynele, co. Derby, temp. Edward I, Harl. MS. 5803.

Barry of eight arg. and gu, ten martlets sa. Chaworth.

Barry of ten arg. and az. as many martlets in orle gu. Pembroke HaJL, Cambridge; founded 1343 by Mary, daughter of Guy de Chastillion, Comte de St. Paul, in France, and wife of Aymer de Valence, Earl of Pembroke 1296-1323, im. paling Chastillon. William de VALENCE, Earl of Pembroke 1264-96, as quartered by Grey, Earl of Dorset, $U$. Thomas WaLlensis, Bishop of St. David's 1248-55.
BIRDS. 10 MARTLETS cont.

Barry of twelve arg. and gu. ten martlets in orle sa. BreckNock, Wales.

Barry of twelve arg. and gu. ten martlets three three three and one sa. over all on a bend sa. three escallops or. Stocke, co. Wilts.

Barry of fourteen arg. and az. ten martlets in orle gu. M. William VaLENCE, $D$.

Barry of sixteen arg. and az. ten martlets in orle gi. VALENCE, as quartered by Grey, Marquis of Dorset, $U$.

Barry of twenty.one arg. and az. ten martlets in orle gu. William de VaLence, Earl of Pem. broke 1264-96.

Barruly arg. and az. ten martlets gu. Aymer de VALENCE, K, Harl. MIS. 6589.

$\mathrm{Gu}$. ten martlets four three two and one .... DONKET.

Gu. ten martlets four three two and one arg. TOcheTt, $V^{*}$.

Gu. ten martlets four three two and one or Duche or Duchet. Sr. William ThоснeTt, N, Harl. MS. 6137. Guillam de Tochelles, $K$, Harl. MS. 6137. Sir William TOUCHET, N, Harl. MS. 4033.

Gu. ten martlets or. Sr. William Tuchet (Covches in margin), $K$, Harl. MS. 6589.

Paly wavy of eight arg. and az. over all ten martlets four three two and one or. WaLLACE.

\section{MARTLETS}

Az. eleven martlets three two three two and one arg. Sr. John de Beltendene, N, Harl. MS. 6137.

Barry of ten arg. and az. eleven martlets in orle gu. De Valance.

\section{DOVES}

Arg. twelve pigeons az. MoMrpesson.

Arg. twelve birds (pigeons) three three three two and one az. beaked and legged gu. Giles de Monpesin, $G$.

Az. twelve pigeons arg. Mompesson.

\section{MARTLETS}

Az. twelve martlets arg. Ratendon, co. Glou. cester.

Barry of eleven az. and arg. twelve martlets in orle gu. Conte de Pembrok, $G$.

Quarterly gu. and or in each quarter three martlets in bend counterchanged. Denharr.

Quarterly or and gu. in each quarter three martlets in bend counterchanged. VENHAM.

Quarterly or and gu. in the first and fourth quarters three martlets in bend sa. in the third and fourth the like arg. Denhani, $V$.

Quarterly or and gu. in each quarter three martlets in bend sa. Denham, $V^{*}$.

Quarterly or and sa. in each quarter three martlets counterchanged. Denham.

12 MARTLETS and in chief....

Arg. twelve martlets .... separated by three piles from the chief in point gu. Cooe, Harl. MS. 1113, fo. 24

\section{MARTLETS}

Barry of twelve arg. and gu. thirteen martlets in orle sa. M. Patrick Chaworth, $D$.

Barry of fourteen arg. and gu. thirteen martlets in orle sa. Pateric de Chaurs, $E$.

\section{EAGLES unnumbered}

Arg. semy of annulets within each an eagle displ. and. a lion ramp. alternately sa. in the interstices a lesser annulet of the last. Yvain. 


\section{BIRDS. EAGLES unnumbered cont.}

Az. semy of eagles displ. or. Fitz-Symon, co. Hertford.

Or fretty az, the points charged with an eagle displ. arg. Priory of Austin Canons at Merton, Snrrey.

\section{MARTLETS unnumbered}

Per pale indented .... and .... balf an orle of martlets on the dexter side .... Clodshall, Saltley, temp. Edward III.

Arg. fretty gu. semy of martlets sa. Overend, Ireland.

Az. serny of martlets arg. John de Bertendene, $N$, Harl. MS. 6589. Sr. Joln de Ratendene, $N$, Cotton $M S$. Caligula A xviij, and Lansdown MS. 855. Sr. John de RATENDEN, N, Harl. MS. 5803.

Az. martlets in orle or. Sire Robert de Appelby, $O$.

Barry of five arg. and az. martlets in orle gu. William PanNell, $F$. William Paynell, $E, Y$.

Barry of five arg. and sa. martlets in orle gu. Sire William PaynelL, $N$.

Barry of five az. and or martlets in orle gu. Monsire Roger Burdet, $Y$.

Barry of five gu. and or martlets in orle arg. Sire John de Holand, $O$.

Barry of five gu. and or martlets in orle as the last. John BLANDE, $Y$.

Barry of five or and az. martlets in orle gu. Thomas Painel, $E$. Sire Thomas Paynell, $Q, X$.

Barry of five or and gu. martlets in orle as the lust. Merley or Morley, France.

Barry wavy of six arg. and az. martlets in orle sa. Browning.

Barry of six arg. and sa. martlets in orle gu. Sr. William PAYNeLl, L, Harl. MS. 6589, fo. 29.

Barry of seven arg. and gu. martlets in orle as the last. Sire Rauf de Royinge, N. Royniger or RoYiger, Norfolk.

Barry of seven or and gu. martlets in orle as the last. Ronyng.

Barry of eight arg. and gu. martlets in orle vert. Chaworth.

Barry of eight or and az, martlets in orle as the first. Bronker, Kent; and Middlesex.

Barry of ten arg. and az. martlets in orle gu. Le Counte de PEIrBRore, quartering or a maunch gu., $T$. Thomas WaLlensis, Bishop of St. Davids, 1248-55.

Barry of ten arg. and gu. martlets in orle sa. Sir Patrick de Cadurcis or Chaworth, Z, 109. Chaures.

Barry of fourteen arg. and gu. martlets in orle sa. Chaworth. Pevensey.

Barry of sixteen arg, and gu. martlets in orle sa. Chaworth, Annesley, co. Nottingham. Chaures.

Barruly arg. and az. martlets in orle gu. Peشвrook, co. Lancaster. Sr. Aymer de Valence, $K ;$ Harl. MS. 6589. Aymars de VAIENCE, $K$; Cotton MS. Caligula A xvijj. William de Valens, $B$. Le Counte de Valence, $C$. Le Conte de Penbroc, $N$, Cotton $M S$. Caligula A xviij; or PenBBook, $N$, Harl. MS. 5803. William VaLANCE, Conte de Pembroke, $1204-96, P$. VAlence, $Z, 209$.

Barruly arg. and gu. martlets in orle sa. Patrick de Chaforth, N, Harl. MS. 6589. Sr. Patrik de Chauworthe, $N$, Cotton MS. Caligula A xviij. Patrick Craworth, N, Harl. MS. 5803. Thomas Chaworth, $Y$. Monsire de Chaucombe, $Y$.
BIRDS. MARTLETS nnnumbered cont.

Barruly arg. and gu. martlets in orle vert. Patrick Chaworte, $Y$.

Barruly az. and arg, martlets in orle gu. $\mathrm{L}_{\theta}$ Counte de PENBROKE, $Y$.

Barruly az. and or martlets in orle sa. Scatrerset, or SCHATERSET.

Bendy of three arg. and sa. martlets in orle counterchanged. $\mathrm{H}_{\Delta \mathrm{Y}}$.

Gu. semy of martlets arg. Fornest. Touchet.

Gu. semy of murtlets or. Ducketr, Devon. Tuchet. Sire William Thоснет, $N$, Cotton $M S$. Caligula A xviij. Emlam Touches, $K$, Nicolas, 4to. 1828. Emlam and Touches, $K$, Grose. Eulami and Thouchez, $K$, Cotton MS. Caligula A xviij.

Paly of six arg. and az. martlets in orle or. Jenny.

Paly bendy gu. and az. martlets in orle or. HENDLEY.

Quarterly arg. and sa. martlets in orle gu. MARLOW.

Quarterly gu. and az. martlets in orle or. MARLOWE, Lord Mayor of London, 1409 and 1417.

Quarterly sa. and gu. martlets in orle or. MARLOW.

Sa. martlets in orle arg. Stanton.

Sa. martlets in orle or. Ducket, Steeple-Morden, co. Cambridge.

Sa. semy of martlets or. Duckett, co. Devon.

\section{EAGLES and in chief....}

Az, eagles or a quarter erm. Sr. John Fitz Symon, $N$, Cotton $M S$. Caligula A xviij, and Lansdown MS. 855 .

Or eagles sa. a quarter erm. Sr. Estevene de Gravesende, $N$, Cotton MS. Caligula A xviij and Lansdown MS.855. Estion de GraveSEND, $N$, Harl MS. 5803.

\section{MARTLETS and in chief....}

Gu. martlets in orle or on a canton arg, an inescucheon as the first. CHADWICE, Cornwall.

\section{BIRD-BOLT see Arrow \\ BILL-HEAD see Blade}

\section{BITS}

Sa. three snaflle-bits or. Milner, Pudsey, co. York. Milner, London, 1033.4; Harl MS. 1358 , fo. 52 b.

\section{BLACKAMOOR see Human-figure BLACKBIRD see Thrash BLADE}

Arg. the upper half of a sickle blade serrated on the inner (dexter) edge, erect sa. Z $\triangle \mathrm{KEESLY}, V$.

Gu. a hlade of a sword-fish arg. crowned or. Lessieure, Middlesex.

\section{BLADES}

Gu. two scythe-blades the edges inward and points upward in saltire the dexter surmounted of the sinister arg. VAN-MILDERT, Bishop of Llandaff 1819, Durham 1826-36.

\section{BLADES}

....three heads of halberts turned to the sinister (another reversed) arg. HALt, co. Wilts.

Az. three blades of spades or. BEcketon, $V$. Beckton, $V^{*}$.

Sa. three heads of bills arg. LEversegE. 


\section{Annulets}

\section{On 3 BLOCKS}

Arg. on three blocks (or billets or delves or dice) sa. an annulet to each or. Ambrose, co. Lancaster.

Az. on three blocks (or billets or delves or dice) arg. an annulet to each sa. PAynter, Boskeuna, Cornwall. PaYnter, Deumark Hill, and Richmond. Surrey.

\section{Mullets}

Arg. on three blocks (or billets or delves or dice) sa. a mullet to each of the first. AmBrose, co. Lancaster. TRENT.

\section{BLOODHOUND see Dog. \\ BOAR see Beast \\ 3 BOARDS}

Az. three pair of backgammon tables open ppr. edged or. Pegriz, $V^{*}$.

Az. three pair of backgammon tables open of the first poiuted arg. edged or. John Pegrez, $V$.

\section{BODKINS.}

Az. three tailor's bodkins arg. handles or. BODKINES.

\section{BOLT see Bird-bolt and Shackle 3 BOLTS}

Arg. three door bolts gu. Boxton, co. York.

Arg. three bolts (but ? bird-bolts) in pale gu. Boltsham, co. Devon.

Sa. three bolts (but? butterflies) arg. PenheI.LEGE, Cornwall.

\section{BOMB-SHELL see Fireball BONE}

Paly of six or and gu. a jaw-bone in pale az. DAmBoYs.

Vert a shin-bone beld in the mouth of a boar's head couped arg. Mackinnon.

\section{BONES}

Az. two shin-bones in saltire the dexter sur. mounted of the sinister arg. Milbonne. Mulluborn, $V$. Milluboras, $V^{*}$.

Sa. two leg-bones in cross arg. BANE.

Sa. two shank-bones in cross that in pale surmounting the one in fess arg. Baines, Bell Hall, co. Fork.

Sa. two shin-bones in cross that in fess surmounting the one in pale arg. Baynes, Cumberland; Essex; and London. Baxns, 1730.

Sa. two shin-bones in saltire the dexter surmounted of the sinister arg. Newron, co. Cam. bridge. Newton, Essex, $V$.

Sa. two shin-bones in saltire the sinister surmounted of the dexter arg. NEwTon, co. Somerset; co. Gloucester; Duffield; co. Derby, a heiress, m. Hancock; Hader, co. Lincoln; Thorp, co. York; and Horsley and Mickleover, co. Derby ; derived from Newton, Newton co. Chester. Newron, Barr's Court, and Bitton, co. Gloucester ; Gunwarby, co. Lincoln; and co. Somerset; quartering Cradock; Baronetcy, 1660, extinct 1743 . And with a crescent for diff. Newton, Newcastle-on-Tyne.

Vert two shin-bones in saltire the sinister surmounted of the dexter arg. NEwton, Crabaton Court, co. Devon, 1618, descended from Newton, co. Somerset; the heiress, m. Fowell.
2 BONES and in chief....

on a Canton.... Bird

Sa. two shin-bones in cross that in pale surmounting the one in fess arg. on a canton of the last a vulture ppr. Baynes, Harefield Place, Middlesex; Baronetcy, 29 June, 1801.

\section{Roundle}

Sa. two thigh-bones in cross.... in the dexter chief a bezant. Ralph Baines or Bayne, Bishop of Lichfield etc. 1554-9.

\section{BONES betw, or within....}

Arg. two bones (another glazier's nippers, another spokeshaves) in saltire sa. betw. four pears pendent or within a bordure engr. of the second. KELWAY.

\section{BONES}

Or three broken shank-bones fesswise in pale gu. DE Costa.

\section{BONES}

Or six broken bones two two and two barwise the joints almost meeting in pale gu. DE Costa, London.

\section{BONES and in chief....}

Gu. six broken shin-bones two two and two barwise the joints almost meeting in pale arg. a canton erm. MENDEz, London.

\section{BOOK}

... an open book.... Dean and Chapter of RAPHOE; seal.

Az. a book gu. with gilt edged leaves supporting a lamb couchant arg. with nimbus and staff or and banner arg. a cross gu. Company of Stationers, London.

\section{Bird}

BOOK and in chief....

Az. an eagle displ. (another wings expanded) or holding in the beak a penner and inkhorn sa. stringed gu. standing on a book fesswise of the last closed the clasps downwards gold. Company of Scriveners, London.

\section{Candlestick}

.... a book expanded having a candlestick with a lighted calidle in it above the book on the leaves the words Lucerna pedibus meis verbum tuum et lumen semitis meis. Psal. cxix. College of St. MaRY at Manchester in Lancaster.

Chief

Az. an ancient book open indexed edged or a chief embattled of the last. Conroy, lulanbrynmair, co. Montgomery; Buronetcy 26 Juue 1837.

BOOK and in base....

Vert. in chief the holy bible expanded ppr. in base a sand glass running arg. JoAss, Collinwort, Scotland.

B00K betw. or within....

\section{Coronets}

Az.a book expanded arg. garnished and having on the dexter side seven seals betw. three oper crowns or on the leaves the words Sapientia, felicitas (or Sapientiâ et felicitate 1716) latterly these words have been changed for Dominus illumiagtio mea. UNIVERSITY OF OXFORD.

Gu. a book closed richly ornamented ppr. betw. three antique crowns or. Grant.

\section{Flames}

Az. a book open betw. three flames of fire ppr. within a bordure arg. charged with four mullets and so many crosses croslet as the first. Sмrth, Fulinburgh. 
BOOK betw. or within ..... cont.

Heads

Gu a clusped book open betw, three buck's heads erased or. Jobn Buckner, Bishop of Chiches. ter $1798-18 \% 4$.

Mullets

Az. a book or betw. two mullets in chief and a saltire in base arg. Beilby Ponteous, Bishop of Chester 177\%, London 1787-1809.

On 1 BOOK betw. and in base....

Per chev. arg. and az. in chief a book gu. edged and ornamented gold with a fret of the last on the cover between a slip of oak fructed and a rose gu. stalked aud leaved vert. in base an eagle rising or. Evass, Norwich; granted 1772.

\section{BOOKS}

Arg. three books close gu. leaved clasped and garnished or. Paynter, Sprole, Norfolk.

\section{B00TS see Legs \\ BORDORE}

see also Escucheon and Orle

(some coats, placed here in strict compliance with the method of blason, will also be found in the divisions to which they properly belong.)

For a Bordure and a Canton, or and a Chief, or and a Quarter, see those divisions.

Or a demi bordure purp. and a saltire az. BOLDERSALT.

.... fretty .... a bordure .... Jobn Cosin, Bishop of Durbam 1660-72.

Arg. a bordure az. Eltham, Cornwall. Harleston. Walter de Tupigni, $A$. Le Chastelin de Gaunt, $Y$.

Arg. a bordure az. a label of five points gu. Robert de WAVEREY $W$.

Arg. a bordurs az. over all a bend engr. gu. Le Constable de Flaunders, $W$.

Arg. fretty az. a bordure of the last. Harcote, $V$.

Arg. a bordure gu. over all a bend sa. QuixLey or QUYXILEY.

Arg. semy of crosses croslet a bordure gu. Bertram.

Arg. fretty gu. on each joint a bezant a bordure az. Roger Trussell, $V$.

Arg. fretty az. a bordure engr. or. SANBY.

Arg. a bordure engr. sa. a martlet (? for diff.) in the centre of the last. STANDON.

Az. semy of fleurs-de-lis or a bordure gu. Anjou.

Az. a bordure or over all a bend compony arg. and gu. Le Sr. DaNsert, $H^{\prime}$.

Az. fretty arg. a bordure or. LONDEY, Northumberland. Lounde, $V$. Londe, Harl. MS. 5803. LowndE, co. Lincoln; granted 1596.

$\mathrm{Az}$. fretty arg. a bordure engr, or. Monsire de EchINGHAd, $Y$. EcEINGHAM. Sr. Robert Echingham, $V$. Sir Rafe Hethian, $L$, Harl. MS. 6589 , fo. 38 .

Az. fretty and a bordure engr. or. Belscot. Sir Rafe Hithdan, L, Harl. MS. 6589, fo. 44.

Az. fretty arg. a bordule indented or. Sire Robert de Echinghair, N. Echingham, Kent., temp. Edward I, Harl. MS. 5803. Sir Roos de Hetheuan, L, Harl. MS. 0137.

Az. fretty arg. a bordure recercele or. Le Sire FCHINGHAJI, $Y$.
BORDURE cont.

Barry of five arg. and az. a bordure engr. sa. PAER, as quartered by Catherine sixth wife of Henry VIII.

Barry of six arg. and az. a bordure gu. Pomys, $V$.

Barry of six arg. and az. a bordure engr. gu. Sir John Olney, co. Buckingham, $V$.

Barry of six arg. and az. a bordure indented gu. Sire Johan de Olneye, $N$. Olney, co. Buckingham, temp. Elward II, Harl. MS. 5803.

Barry of six arg. and sa. a bordure gu. WATT.

Barry wavy of six gu. and arg. a bordure as the second. Choke, $V$.

Barry of six gu, and arg. a bordure sa. MocLton. Balry of six gu. and erm. a bordure as the first. Dabridgcourt.

Barry of six or and az. a bordure gu. C. AIISANDER, $F$.

Barry of six or and gu. a bordure arg. ST. Lrze. Burry nebuly of six or and sa. a bordure compony arg. and az. Blount, co. Stafford.

Barry nebuly of six with a boldure compony or and sa. Blount, co. Stafford.

Barry of six or and vert a bordure erm. Hoskins, co. Monmouth; granted by Segar.

Barry of six or and velt a bordure gu. Hoskins. Barry wavy of six sa. and arg. (another or) a bordure of the first. CHore.

Barry of eight arg. and gu. a bordure engr. sa. Crisprn, Wallingford, co. Berks, temp. Henry I.

Barry of eight gu. and erm. a bordure compony sa, and or. BURLEy, Harl. MS. 1603.

Barry of eight or and az, a bordure gu. Arden.

Barry of ten arg. and gu. a bordure engr. sa. Crispin, Salisbury.

Barry of ten or and gu. a bordure az. Ferers.

Barry of twelve az. and or (or and az. $V^{*}$ ) a bordure erm. ARNEFORD, $V$.

Barruly arg. and az. a bordure gu. Grinbald, co. Leicester.

Bendy of six az, and or a bordure gu. (The ancient arms of) Burgundx, $Z, 3 \mathrm{I} 2,402$. Merbroke.

Bendy of six or and az. a bordure gu. MARBrore, $V$. Mountford, co. Warwick. Newborough. Bendy of six or and az. a bordure engr. gu. NFborgy. Sr. Robert de Nevo, in margin Newerough, $R$. Otes de Traseye, $A$.

Bendy of seven or and az. a bordure gu. Borgoner, Harl. MS. 5803.

Benrly of seven or and az. a bordure engr. gu. Newborough, Harl. MS. 5803. Otes TraIsene, A, Harl. MS. 6137.

Bendy of eight arg. and az. a bordure engr. gu. NEwBuRgH, co. Dorset.

Bendy of eight erm. and az. a bordure engr. gu. Washer, co. Deven.

Bendy or and az. a hordure gu. Mountfort, Sapworth. NewbURGH, Earl of Warwick until $12 \pm 2$.

Chequy arg. and sa. a bordure of the first. (The ancient alms of ) CATTERICH.

Chequy or and arg. a bordure gu. Green.

Chequy or and az, a bordure erm. WARREN.

Chequy or and az. a bordure gu. Robert of France, Earl of Dretux, $Z, 93,95$. John de Dreux, Earl of Richmond, ob. 1305, Z, 93, 94. Green. John Greene, $X$. Manditt or Manduyt. Thomas Mandut, $E$; or Manduitt, $X$ Thomas Manduyt, $Y$. Thomas Mandyt, Warminster, $V$. 
BORDURE cont.

Chequy or and az. a bordure engr. gu. Drew Druce, Fulham, Middlesex; 1616. Warren. Wirmgay, Norfolk.

Chevronelly of five gu. and arg. a bordure of the last over all a bend sa. PAyneli.

Erm. a bordure compony or and sa. Rondels, Harl. MS. 1441.

Erm. a bordure gu. Hundscot or Hundescot. Sire de Hundiscote, $D$.

Erm. a bordure engr. gu. Barnewer, Crickstown Castle, co. Meath ; Baronetey 16 February 1622, from which descended Barnewall, Baron Trimlestown 4 March If6I; with a crescent for diff. az. Harl. MS. 4010: anả Barnewal., Meadstowu, co. Meath, a younger branch of the Trimlestown family: and Barnewall, Viscount Kingsland; with a crescent for diff. sa. Harl. MS. 4040 . Barnewall, Baron Turvey and Viscount Barnewall 29 June 1646, extinct 1833. BERNEweLL or Bernwell, Ireland. Hepell, Northumberland.

Erm. fretty and a bordure indented gu. $\mathrm{M}^{6} \mathrm{CoL} L O C H$, Muill, Scotland.

Erm. a bordure sa. Basing.

Gu. a bordure arg. Conestable de Franders, $A$, Harl. MS. 6137.

Gu. a bordure arg. over all a baston sa. Sir Robert Crey or de la Crey, $L$.

Gu. a bordure arg. over all a bendlet sa. Sr. Robert de Lacr, co. Cambridge, temp. Edward I, $V$.

Gu. a bordure arg, over all a bend sa. Sire Robert de LACY, $N$.

Gu. a bordure arg. over all an escarbuncle of eigliteen points pometty and flory or. Cleve, as borne by Anne, fourth wife of Henry VIII, quartering Juliers or Gulich, Schwarzenberg, Berg or Mons, La Marck, ...., and Ravensberg.

Gu. a bordure engr. arg. over all a bend of the last. BeLKMore.

Gu. a bordure indented arg. Sir Perducas Darereth, temp. Edward III; Kent, Grammar.

Gu. fretty or a bordure arg. Hewgh AwDLey, Earl of Gloucester, Q, Harl. MS. 6595; 1337 . 47, Harl. MS. 5s03. Jobn de AudLey Y. Monsire Hugh de Audeley, $Y$. Hugo.

$\mathrm{Gu}$. flory or a bordure compony arg. and sa. Gargat.

Gu. a bordure erm. over all a bend sa. William Bennet, $V$.

Gu. a bordure erm. over all a bend engr. sa. Bennet, Norfolk.

Gu. a bordure engr. erm. Acton.

Gu. a bordure or. Constantine de Flanderis, $A$.

Gu. fretty arg. a bordure or. HUdelston.

Gu. fretty and a bordure or. HudLeston, co. York; Harl. MS. 5803.

Gu. fretty arg. a bordure engr. or. Sr. Robert Echingati, $V$.

Gil. a bordure quarterly erm. with countercom. pony or and az. (An error for) Henry Fitzroy, Duke of Pichmond, temp. Henry VIII; Kent, Grammar.

$\mathrm{Gu}$. fretty arg. and a bordure indented or. Sire Adam de Hodlestune, $N$. Hudlestowe, co. York, temp. Edward I, Harl. MS. 5803.

Gu. a bordure engr. sa. an annulet (? for ditf.) in the centre or. Blankensop, Cumberland.

Gyronny of eight arg. and az. a bordure of the list. M'Tavish, Scotland.
BORDURE cont.

Gyronny of eight erm. and az. a bordure engr. .... Le Merchant.

Gyronny of eight erm. and gu. a bordure wavy vert. CAMPBELL.

Grronny of eight or and sa. a bordure compony purp. and erm. Campbell, Scotland.

Gyronny of eight or and sa. a bordure of the first. Campielu, Ardkinglass, a scion of Lorn. Gyronny of eight sa. and or a bordure vair. Campbell, Clothick. Campbell, Lawres.

Lozengy arg. and gu. a bordure az. HoLcotr.

Lozengy arg. and or a bordure gu. ELLACotT or Elurcot, co. Devon.

Lozengy arg. and sa. a bordure of the last. Shiplex, Twyford, co. Hants; quartering Crevecour, Yonge, Mordaunt, Stapleton, and Conway. Jowathan Shipley, Bisbop of Llandaff 1769, St. Asaph 1769.88.

Lozengy az. and or a bordure gu. Elicotr, $V *$.

Lozengy or and az. a bordure arg. Ellicot.

Lozengy or and az. a bordure gu. EuIcotT, $W$. Ellacott, Exeter, Newburgh, Earl of Warwick, ob. 1123.

Lozengy or and gu. a bordure az. HoLcotr or HuLCotT.

Or a burdure engr. sa. KNIGHT.

Or a bordure vair. GwINe. Gwyn. Robert Gynes, $\boldsymbol{V}$.

Per chief chequy or and az. with arg. a bordure erm. HANSTED, co. Northampton, temp. Edward I, Harl. MS. 5803.

Paly of six arg. and gu. a bordure of the last. Ruthien, Baron Ruthven, Freeland, co. Perth, 1657.

Paly of six or and az. a bordure arg. ST. Lrz, Earl of Huntingdon and Northampton, 1075. 1184; Harl, MS. 5803.

Paly of six or and gu. a bordure arg. LAGFonD or LANGFord, Northumberland. Simon de S. LIz, second Earl of Huntingdon; Nisbet, System, i, 38.

Paly of six or and gu. a bordure az. Langsdale. Paly of six or and gu. a bordure erm. LANGFond. Paly wavy of six or and gu. a bordure erm. Valange, $V^{*}$. Valeignes, $V^{*}$. Raph de VALOYNS, $X$.

Paly of ten or and az. a bordure erm. Persall. Paly of ten or and gu. a bordure arg. MaLOQUES. Per chev. arg. and az. a bordnre engrailed gu. Altaribus or EldDers: Harl. MS. 1535 fo. 13 b.

Per chev. arg. and az. a bordure engr. or. Eispres or Elenis.

Per chev, az. and arg, a bordure engr. gu. Eldres. Fldrys, $V$. Elris, $V$.

Per chev. sa. and arg. a bordure counterchanged. WYTTE, $V^{*}$.

(As to cases of a bordure with a field divided 'per chief' or even 'per fess,' see also CHIEF and Bordure.)

Per fess indented arg. and gu. a bordure az. BARRetT.

Per pale arg. and gr. within a bordure engr. sa. Waldegrave, Suffolk.

Per pale az. and gu. a bordure arg. Cluniac Priory at Bermondsey, Surrey ; Tanner.

Per pale gu. and az. a bordure arg. Cluniac Priory or Abbey at BERMONDSEx, Surrey.

Per pale indented gu. and or a bordure az. Bermingham or BiRmingham, Ireland.

Per pale indented gn. and or a bordure vert. Berminghym or Birminghair, Ireland. Mac YARIS. 


\section{BORDURE cont.}

Per pale indented or and gu. a bordure az. Foulke, $V^{*}$. Foulke Bermingham, $V$.

Per pale indented or and gu. a bordure and in the dexter chief a 3 -foil slipped for diff. sa. BenMingham.

Per saltire arg. and sa. a bordure counterchanged. Gotr, Battell, Sussex; and London.

Per saltire or and sa. a bordure countercbanged. SHORTER.

Quarterly arg. and az. a bordure vairy of the first and gu. MaNdeviLe.

Quarterly arg. and gu. a bordure erm. REDForD. Qıarterly arg. and gu. a bordure recercele sa. John de Retford, $Y$. Monsire de Tetford, $Y$.

Quarterly per fess indented arg. aud gu. in the first a bordure sa. AcTon, co. Salop.

Quarterly erm. with paly of six or and gu. all witbin a bordure az. $\mathrm{Sr}$... de KNIGHTI.EY, $V$.

Quarterly gu. and arg. a bordure engr. sa. Retford. Le Conte de Hertford, $X$.

Quarterly gu. and or a bordure az. Power, Norfolk.

Quarterly gu. and or a bordure engr. az. BRUTON, $\mathscr{V}$.

Quarterly gu. and or a bordure counterchanged over all a chev. vair. Fenwrke.

Quarterly gu. and or a bordure vair. FIтz-JонN. Quarterly gu. and vair a bordure or. ConstaBLE. Quarterly or and az. a bordure vair. MaNDEviLIe. Quarterly or and gu. a bordure engr. (indented Harl. MS. 6137) arg. Sir Roger RochFORD, $L$. Quarterly or and gu. a bordure az. John Breton, A. Breton, Essex; and Suffolk. Sr. Jobn Breton, $V$. Bretton, $V$ *. Britten, Essex, Harl. MS. 5803. M. John de Bretun, $D$. Sir Johan Bretoun, $N$. Greton. Grattan.

Quarterly or and gu. a bordure engr.az. BRETON. John le Bruton, $E$.

Quarterly or and gu. a bordure indented arg. and az. John le Fitz Jorn, $C$.

Quarterly or and gu. a bordure sa. HunTINGFIFLD, Kent. Sire Peres de Hontingfield, $N$. Sr. Piers Huntingfeid, $V$. Hottungfieid, Kent, temp. Edward I, Harl. MS. 5803.

Quarterly or and gu. a bordure engr. sa. ENGHAM. Sir Robert de Rochford, $L$. Huntingfiesd, Kent. Sr. Piers Huntranfed, temp. Edward I, $V$.

Quarterly or and gu. a bordure indented sa. Sir Robert de Rochford, L, Harl. MS. 6137, or Rocheford, $N$.

Quarterly or and gu. a bordure indented and in the first quarter a martlet (? for diff.) sa. Sire Johan de Rochefford, $N$.

Quarterly or and gu.a bordure vair. Fitz-GEFFrEY, co. Bedford. John le fitz GefFrey, $B, Y$. John Fitz-GEFfray, $P$. Sir John le Fitz-JefFry, $V$. Jobn Fitz-GeFfrey, Y. M. Richard le Fitz $J_{O H N} D ; E ; N$. Fitz-JEFFrey. Richard Fitz-Joнn, $A ; G$. John le Fitz JoHN, $F$. Mandevilie, Earl of Essex till 1199. Fitz.Piers, Earl of Essex 1199-1227. Sr. Richard de VERE, $R$. VESCY.

Quarterly paly of six arg. and gu. with erm. all within a bordure az. KNIGHTLEY.

Quarterly paly of six or and gu. with erm. all within a bordure az. Persall, $V^{*}$.

Quarterly paly of seven or and gu. with erm. all within a bordure az. Sr. Hugh Persall, $V$. The bordure sa. Perseall.

Quarterly sa. and arg. a bordure erminois. John Hoo, Serjeant at Law, 1716.

\section{BORDURE cont.}

Quarterly vair and ga. a bordure engr. or. Astable. Sr. John Constable, $R$.

Sa. a bordure arg. Bass. Barinoton or Berington, Moresborough, co. Chester, Harl. MS. 1535 , fo. 8 .

Sa, a hordure arg. a label of five points gn. Sire de Corance or Corane, A, Harl. MS.6137.

Sa. a bordure engr. arg. Holland.

Sa. a bordure engr. arg. and a crescent (? for diff.) erm. Batedran, Norfolk. William Bateman, Bishop of Norwich 1344-55.

Sa. seiny of crosses croslet and a bordure or. WitFieid.

Sa. fretty arg. a bordure compony of the second and vert. HARINGTON.

Sa. a bordure or and a label of five points gu. Sire de Corance or Corane, $A$.

Vair a bordure and a label of three points gu. BeauchaAtP, co. Buckingham.

Vairy arg. and gu, a bordure az. Sharshall.

Vairy arg. and gu. a bordure sa. HOGHAHAD or Hoghahed. Thomas Hogsha, $V$. Marley.

Vairy gu. and or a bordure az. Gilbert TALEBot, $F$. Vairy or and gu. a bordure az. Ferrers or Ferreis, co. Hertford. William de Ferres, $F$. Vert a bordure or over all a bend compony arg. and gu. WaLCHANGe or WaLHANG.

\section{On 1 BORDURE}

\section{see also a Chief and bordure \\ Annulets}

Per saltire erm. and az. on a bordure gu. eight annulets or, Barker.

\section{Beasts}

Az. on a bordure of quarterly gu. and the first lions pass. guard. and fleurs-de-lis or. Courtney (in error ?).

Az. semy-de-lis or on a bordure gu. lions pass. guard. of the second. Hameline Plantagenet. Birds .... Martlets

Arg. on a bordure az. eight martlets of the first. M. Thomas de Herpinghadr, $S$.

Arg. on a bordure az. eight martlets or. J JSPER. Arg. on a bordure vert eight martlets or. Empringhas, Grimsby Magna, co. Derby. Barry of eight arg. and gu. on a bordure as the first so many martlets sa. MarLEY, Ireland.

Barry of ten arg. and gu. on a bordure az. eight martlets or. MerLey, Newminster, and Morpeth, Northumberland, temp. Henry III.

Or on a bordure az, ejght martlets of the first. Geney. M. Thomas Enpingham, $S$.

Arg. on a bordure gu. nine martlets of the first. William de ReDHair, $F$.

Arg. on a bordure vert ten martlets or. Entringhait, Harl. MS. 6829 , fo. 6 .

Barry of ten arg. and gu. on a bordure sa. so many martlets as the first. CHANWRIT.

Barry of eleven arg. and gu. on a bordure az. ten martlets or. MERLEY.

Arg. on a bordure az. martlets of the first. Walter WALCOTS, $Y$.

Arg. on a bordure gu. martlets of the first. John CHIDEOK, $Y$.

Arg. on a bordure gu. martlets or. Monsire Henry de Enefele, $Y$.

Arg. on a bordure sa. martlets of the first. Mon. sire de EMPINGHAM, $Y$.

Arg. on a bordure vert martlets of the first. Sir John de Emprngh'M, $O$. Mounsyer Thomas Erpingham, $T$. Walter de Herpingham, $Y$. 


\section{On a BORDURE cont.}

Birds cont. Martlets cont.

Barry (of seven or eight, Somervill, co. Warwick) arg. and gu. on a bordure az. martlets or. Roger de Merley, $B$. Monsire de Somervile, $Y$. Roger Sodivyle, $Y$.

Gu. on a bordure arg. martlets of the first. Sir William Vaux or de Vaux, L. Monsire de VAUX, $Y$. William Wassee, $Y$.

Or on a bordure arg. martlets gu. James VAux, $Y$.

Or on a bordure gu. martlets of the first. Hugh de ENField, $Y$.

\section{....Popinjays}

Vairy or and gu. on a bordure sa. eight popinjays arg. Cunzon, Loking, co. Berks. John Corzon, Falde, co. Stafford, 1350.

\section{Bordure}

Vert on $\boldsymbol{u}$ bordure arg. with ogresses another bordure engr. gu. Binkenhead or Birket.

Buckles

Gyronny of eight or and sa. on a bordure engr. quarterly as the first and az. so many buckles counterchanged. CaMpdell, Lord Campbell of St. Andrew's, 30 June 1841 .

Crescents

Gyronny of eight erm. and gu. on a bordure engr. as the second so many crescents arg. CAMPBELI, Balgairshaw; descended from Campbell, Loudon.

Gyronny of eight or and sa. on a bordure as the first so many crescents like the second. CAMPBELL, Ardintenny. Caupbel. Ar, Ardchattan Priory, co. Argyll. Campelu, Auchawilling. CampBels, Exton Cottage, co. Hants ; and Dunoon, Scot. land. CanpBeli, Islay, and Shawfield.

Gyronny of eight or and sa. on a bordure engr. as the first so many crescents like the second. CaMipbell, Innellan.

Gyronny of eight or and sa. on a bordure in. dented as the first so many crescents like the second. Canrpbel, Skipness, a cadet of Ardintenny.

Vairy gu. and or on a bordure az, crescents gold. (? William Ferrers, $Y$ ).

Vairy or and gu. on a bordure az. crescents gold. FERRERS.

\section{Crosses}

Chequy (or) and (az.) on a bordure (sa.) eight crosses croslet .... Borough of GranthaM, co. Lincoln; seal.

Vair on a bordure gu. eight crosses croslet or. MoLesworth, Viscount Molesworth $16 \mathrm{July} 1716$. Escallops

Gyronny of eight or and sa. on a bordure arg. so many escallops gu. CAMPBELL, Skerrington.

Per pale wavy (? arg.) and (? gu.) on a bordure eight escallops all counterchanged. MAULE, Scotland.

Per pale arg. and gu. on a bordure eight escal. lops all counterchanged. Maule, Earl of Pan. mure 3 August 1646, under attainder: Baron Panmure 9 September 1831, quartering de Valoniis, all quarterly with Barclay quartering Wishart. And with a crescent for diff. in the middle fess point. MAULE, Ballumbie, Scotland.

Per saltire or and gu. on a bordure engr. sa. eight escallops arg. Heveninghadr, $V^{*}$.

Arg. on a bordure az. nine escallops of the first. Walter de TORPIGNI, A, Harl. MS, 6137.

Quarterly or and gu. on a bordure sa. eight escallops arg. Heningham or Heveningham, Norfolk; co. Stafford; and Suffolk. HENNINGHAMr. Heveningham, Suffolk, 1730.
On a BORDURE cont.

Escallops cont.

Quarterly or and gu. on a bordure engr. sa. eight escallops arg. Heveninghair, Suffolk, $V$. HINGHAII, Suffolk.

Estoiles

Erm. on a tordure engr. gu. an orle of estoiles or. William Wicrham, Bishop of Lincoln 1584, Winchester 1595, Harl. MS. 5815, fo. 77-8. Fish

Gyronny of eight or and sa. on a bordure wavy az. as many salmons naiant arg. in the centre a mullet for diff. of the last. CAMPBELL, Shirven.

Quarterly or with barry of six arg. and az. on a bordure sa. eight fish arg. Gobion, Gobion, co. Bedford; an heiress m. Boteler.

Fleurs-de-lis

Quarterly arg. aud gu. on a bordure of the second three fleurs-de-lis as the first. Garshall.

Lozengy arg. and gu. on a bordure az. six fleursde-lis and as many bezants or alternately. Fitzwillitaris, Essex.

$\mathrm{Gu}$. fretty or on a bordure arg. eight fleurs-de-lis Sa. AUDELEY, $V$.

Az. on a bordure quarterly of the first and gu. fleurs-de-lis and lions pass. guard. or. COURTNEY (in error).

Fusily arg. and gu. on a bordure az. flenrs-de-lis or. Fitz-Wilirams.

\section{Flowers}

Arg. on a bordure sa. roses in orle or over all a bend erm. Tanerett.

\section{3-Foils}

Chequy or and az. on a bordure sa. eight 3-foils slipped arg. Town of Grantham, co. Lincoln.

Barry nebuly of six or and gu. on a bordure az. ten 3-foils slipped arg. Loveli, Lasfield, Suffolk; granted 25 June, 1579. LoveL, $V^{*}$.

\section{5-Foils}

Sa. on a bordure arg. three 5.foils gu. Sir John DARCy, $L$.

Arg. on a bordure gu. eight pierced 5-foils or. Godfraye de Basemes, $A$.

Or on a bordure gil. eight pierced 5-foils of the first. God frave de BASEvUE, A, Harl. MS. 6137.

Sa. on a bordure arg. eight 5 -foils gu. Mousire Darcy le frere, $Y$. Sr. Jobn DaRCY, and Sr. John Lyneurye, $R$.

\section{6-Foils.}

Sa. on a bordure arg. ' siste-foils' gu. Sire John Darsy, $O$.

\section{7-Foils}

Sa. on a bordure arg. three ' sit-foils' gu. D'ARcY, Parke, $Y$.

Sa. on a bordure arg. six 'sit-foils' gu. John DARCY, $Y$.

Fruit

Barry of six arg. and az. on a bordure gu. eight apples or. Pomeris or Pomise.

\section{Heads}

Quarterly gu. and or on a bordure sa. eight bull's heads couped arg. ARsICK.

Quarterly or and gu. on a bordure sa. ten bull's heads couped arg. Manasseh Arsic, Cotton $M$ S. Julius C 7, fo. 119 .

\section{Horse-shoes}

Erro. on a bordure gu. eight horse-shoes or. Mogunchery, 1730. Mogunclay, 1730. Montgomery, $V$. 


\section{On a BORDURE cont.}

Horseshoes cont.

Vairy or and gu. on a bordure az. eight horseshoes arg. Feraris, $V^{*}$. William Earl of Ferrers, $V$. Le conte de Ferers, i. $e$., De Ferraris, $V$, Cotton MS. Tiberius D 10 . Ferrers, Earl of Derby, 1138 till 1266 or 1278.

Vairy or and gu. on a bordure sa. eight horse. shoes arg. Ferrers, Newton-Ferrers; Harl. MS. 5803. M. William de Ferrers, $D$. Richard Ferrers, $Y$.

Vairy or and gu. on a bordure az. eleven horseshoes arg. William de Ferrers, $E$; or Ferres, E, Harl. MS. 6137.

Arg. on a bordure gu. twelve borse-shoes or. William de Mongomerr, $F$.

Erm. on a bordure gu. horse-shoes .... William de Mongoureri, $B$.

Erm. on a bordure gu, horse-shoes arg. John Mountgomere, $Y$.

Vairy gu. and or on a bordure az. borseshoes gold. William Ferrers, $Y$.

Vairy or and gu. on a bordure az. horse-shoes arg. Richard Ferrers $Y$.

\section{Mullets}

Erm. on a bordure gu. eight mullets or. WiскнAir, $V^{*}$. Wrckham, Swacliffe, co. Oxford, $V$.

Erm. on a bordure engr. gu. eight mullets or. William Wrскнам or WyкEнaM, Bishop of Lincoln 15\$4, Winchester 1595.

Arg. fretty sa. the field semy of leaves of laurel ppr. on a bordure az. nine six-pointed mullets or. Beloe.

Arg. on a bordure gu. mullets of the first. Sire John de Cramevile, $O$.

\section{Roundles .... Bezants}

Arg. on a bordure gu. bezants. Honte. Humet, Sandford, co. Lincoln, Constable of Normandy, temp. Henry II. John Hunt, $V$. And with a label erm. Hunte, 1730.

Arg. on a bordure sa. bezants. William de Bodiham, $A$; but Lodiham, A, Harl. MS. 6137.

Barry of six erg. and gu. on a bordure sa. bezants. Valletourt, Coruwall, temp. John. Whatesborodgh, Corrwall; and co. Devon.

Barry wary arg. and gu. on a bordure sa. bezants. Shaneshull, co. Leicester.

Bendy of six arg. and gu. un a bordure sa. bezants. Valetort.

Bendy of seven or and gu. on a bordure sa. bezants. WHaLESBOROW, Harl. MS. 5803.

Erm. on a bordure sa. bezants. Turville.

$\mathrm{Gu}$. on a bordure az. bezants in the centre a 5 -foil (? for diff.) erm. DANGERFIELD.

Gu. on a bordure sa. bezants. Barret or Banet.

$\mathrm{Gu}$. on a bordure sa bezants in the centre a 5 foil (? for diff.) erm. Richard de Buny alias De ANGarvill, Bishop of Durham 1333-15.

Gyronny of eight arg. and gu. on a bordure sa. bezants. Peverell, $V$.

Gyronny of twelve arg. and gu. on a bordure sa. bezants. Peperell. Thomas Peverell, $A$, Harl. MS. 6137. Pevered, co. Hants.

Gyronny of sixteen gu. and arg. on a bordure sa. bezants. Thomas Peverell, $A$.

Lozengy arg. and gu. on a bordure az. six be. zants and as many fleurs-de-lis alternately gold. Frtzwilliams, Essex.

Lozengy arg. and gu. on a bordure az. bezants. Fitz-Wilimani, Essex.

Lozengy arg. and gu. on a bordure sa. bezants in the centre a fleur-de-lis for diff. of the second. Frtz. Willian, Mablethorpe, co. Lincoln.
On a BORDURE cont.

Roundles cont. Bezants cont.

Lozengy gu. and vair on a bordure az bezants. Delariver, Harl. MS. 5803.

Lozengy or and az. on a bordure gu. bezants. Newborodgh, co. Warwick.

Lozengy or and gu. on a bordure of the second bezants. Troulor, co. York.

Paly of six gu. and or on a bordure sa. bezants. Sir Richard Bassett, L, Harl. MS. 6589, fo. $29 \mathrm{~b}$.

Paly of six or and gu. on a bordure az. bezants. Bassett.

Paly of seven or and gu. on a bordure az. bezants. Augustinian Priory at Launda, co. Leicester, as founded by Basset of Weldon.

Paly of six or and gu. on a bordure sa. bezants. Sir Richard Bassetr, L, Harl. MS. 6137, fo. $35 ; 6589$, fo. 44 b.

Paly or and gu. on a bordure az. bezants. Sire Richard Basset, $N$.

Per pale iudented (sometimes gu. and or) or and gu. on a bordure az. (sometimes vert) bezants. BermingHAM, seal. BERMINGHAM, Earl of Louth. Bermingham, Baron of Carluine.

Quarterly or and gu. on a bordure sa. bezants. Rocheford, $V$. Sr. Rauf de Rocheford, $N$. M. John Rocheford, $S$. Rochefort. Rochrord. And with an annulet in the sinister chief for diff. arg. M. Rauf Rocheford, $S$. But with a fleur-de-lis in the first quarter (? for diff.) sa. RochFoRD, $V$.

Vair on a bordure gu. bezants. Delaryveu.

Vairy arg. and gu. on a bordure az. bezants. Daltender, Poynings, Sussex; and Buckland, Surrey. Delariver, co. York. Marlay, $V^{*}$. Marley, Branceby, $V$. Marmaduke, $V^{*}$. Rimer. Sire Nicolas De la Rivere, $N$. Mar. maduke de la Rrver, co. York, $V$. Thomas de la Ryver, $V$. Scarshall or ScHarshall. Sharshall, co. York.

Vairy arg. and gu. on a bordure sa. bezants. Greyley. Sr. Thomas Hoggeshage, $Q$. HogshagG or Hogshead.

\section{....0gresses}

Paly of eight or and gu. on a bordure of the first ogresses. Llord, Bodidris, Hopedale, and Gloucester. Lloyd, Eastham, Essex. YNGAR, Yâl, living 1165.

Vert on $a$ bordure arg. surmounted of another engr. gu. ogresses. Birkenhead or Birket.

$$
\text { .... Plates }
$$

Gyronny of eight arg. and az. on a bordure engr. sa. plates. Lund, Sbelford, co. Cambridge; and co. York.

Lozengy or and az. on a bordure gu. plates. Beaumont. Henry, and Waleran, de Newburgh, Earls of Warwick till 1212.

Per pale indented or and gu. on a bordure vert plates. Bernincham, Earl of Louth, Harl. MS. 1603. Bermingham. Preston.

Quarterly or and gu. on a bordure az. plates. ROCHFORD.

\section{....Torteanx}

Sa. on a bordure arg. torteaux. Sr.... de WindHuLL, $V$. WYNDHULL, $V^{*}$.

\section{Tails}

Gyronny of eight or and sa. on a bordure compony vert and arg. eight erm spots as the second. CAMPEELL, Auchinbreck; Baronetcy 21 March 1628. 


\section{Tressure}

Paly of six arg. and gu. on a bordure of the last another charged with a double tressure flory counterflory of the second. Ruthven, Baron Ruthven, Freeland, co. Perth, 1657.

\section{BORDURES}

Gu. three bordures (but? burdon-staves, or ? two orles or tressures and a bordure, or ? three orles) arg. BuRdon.

\section{BOTEROLI see Blade Crampet and Spade-iron}

\section{BOUGET including Bucket and Dosser}

Arg. a water-bouget sa. Heming or Hemming.

Arg. a water bucket sa. hoops and handle or. Pemberton.

Az. a water bouget or. FIFEHEAD, quartering or an eagle displ. az.

Gu. a water bouget arg. Delamore, $V$. GlubB.

Or a water bouget az. Filfed. Filshed, quartering az. an eagle displ. or.

Or a water bouget sa. Johnson, Norfolk, $W$.

Per pale and per saltire erm. and or a water bouget sa. NetTLEFoLd.

Sa. a water bouget arg. WIIton, co. Somerset, College of Heralds. WITON or WITXN, co. Somerset. Sr. de.... Wytton, $V$.

\section{BOUGET and in chief....}

on a Chief.... Annnlets

Or a water bouget sa. on a chief as the second three annulets in fess of the first. Maurice JoHnson, Spalding, co. Lincoln; descended from FiтzJoHN; quartering Downes of Debnam, Suffolk.

\section{....Bendlets}

Az. a water bouget or on a chief arg. three bendlets sa. LightbURne, Ireland.

\section{....Roundles (Bezants)}

Or a water bouget sa, on a chief of the second three bezants. JoHnson, Thwate, co. Lincoln; Blackwall, Middlesex ; and Norfolk. JoHnson, Wildon, co. Lincoln, $W$.

$$
\text { .....(Ogresses) }
$$

Or a water bouget sa. on a chief three ogresses. MaNingham.

Roundles (Bezants)

Sa. a water bouget arg. in chief three bezants. WOTONE.

$$
\text { .....(Plates) }
$$

Sa. a water bouget arg. in chief three plates. WitTon, co. York.

\section{BOUGET betw, or within....}

\section{Bordure}

Or a water bouget sa. within a bordure of the second bezanty. LaNway, $V *$.

Or a water bouget within a bordure engr. sa. CoMpion, $V$.

Fleurs-de-lis

Arg. a water bouget betw. four fleurs-de-lis two and two sa. (The old arms of BANESTER, Darwyn, co. Lancaster, Harl. MS. 6159, fo. 17.

\section{BOUGET betw. or within.... and in chief....}

Gu. a water bouget betw. eight annulets in orle arg. on a chief of the second a fess per fess indented vert and sa. betw. two barrulets the upper as the last and the lower like the third. JAmes, The Close, Exeter.

\section{BOUGETS and in chief....}

on a Chief.... Fleurs-de-lis

Sa. two dossers suspended by an annulet arg. on a chief gu. three fleurs-de-lis or. (The modern arms of) Banester, Darwyn, co. Lancaster, Harl.MS.1549,fo. $30 ; 2086$, fo. $36 ; 6159$,fo.17. Fleurs-de-lis.

Sa. two dossers suspended by an annulet arg. in chief three fleurs-de-lis or. Banesten, Derwyne, co. Lancaster, Harl. MS. 1468, fo. 28.

\section{BOUGEIS betw, or within....}

Arg. two buckets suspended by an annulet saltirewise sa. betw, three fleurs-de-lis gu. BANISTER. Arg. two dossers joinant in fess betw. four fleursde-lis sa. Banester, co. York.

\section{BOUGETS}

.... three pails .... F F FAGE, $V$.

.... three water bougets .... quarterly with .... three bars .... within a bordure engr. ...., .... three braces .... in chief a bar ..... and vair \& fess gu. Cistercian Abbey at Genvis JeRvaulx or JoREVAL, co. York.

Arg. three possenets gu. Rauf Monboucher, $X$. Arg, three water bougets gu. IrDERToN, Northuniberland. Passmore. Roos or Rosse, Essex. Trusbut; Rosa, the heiress of Troisboutz, Baron of Watre in Holderness, $m$. Everard de Roos. R. Trussebuz, in a later hand Trusbot, $F$. Robert Le UsseboT, E, Harl. MS. 6137 ; but Trussebutt, $E$. Wimpey.

Arg. three water bougets sa. ANDERTon, Elderton. ERrington. ElRington, Suffolk. ILDERTON, $Y$. ILDERTON, Nortbumberland. Lilborne or Lilburne, Thickley, Pincherdon, co. Durham. Lilburne, $V^{*}$. Sr. de Lyllburne, $V$. Littleborne. Olderdon, co. York. Rous or Rosse. Sire Johan de Ros, $N$. Sr. George De Ros, $O ; V$.

Arg. three buckets sa. Fallage. Pemberton, St. Alban's, co. Hertford.

Arg.three water bougets sa.hooped or. Fisz-HuGH. Arg. three buckets sa. hoops and handles or. Pemberton, co. York.

Az. three water bougets arg. Rauf de Kmneton, $Y$. KIRTON. Roos or Rosse. Roos, $V$. And with a label or. Sire William de Ros, Zolton, $N$.

Az. three water bougets or. BowcHer. BugG. Kirkton. ROLFE, Inglethorpe, co. York. M. Robert le Roos, $S$. Roose or Roos, co. Gloucester; co. Nottingham; and Swinshead, co. Stafford. Robert Roos de Ingmanthorp, $Y$. Roos, Ingmantborp, $V$, Kirk Dighton, co. York. Monsire de Ros, Ingmanthorp, $Y$. William de Ros, $C$; $J$. Sire William de Ros, Yngmanthorp, $N$. VALANGe, Lochend, Scotland. And with a clescent for diff. Valange, Possel, Scotlaud.

Barry of four gu. and arg. three water bougets of the second. WwLoUgHBy, co. Nottingham.

Barry of six arg. and az. in chief three water bougets gu. Fleming, co. York.

Erm. three water bougets gu. Plompton. M. Jobn le Roos, $S$.

Erm. three water bougets sa. Sr. James Roos, Godney, $V$. Sr. James le Roos, $S$.

Gu. three water bougets arg. ELLERKER. Furfar. Ross. Lewin, Fortfergus, co. Clare, in Clondegad church, 1700. De Ros, Barony 24 December 1264, quartering Fitzgerald. Roos, temp. Ed. ward I. Roos or Rosse. Robert de Roos, $A$. William de Roos, $B$. Robert do Ross, $C$. Ro. 


\section{BOUGETS cont.}

bert de Ros, $D ; E$. William de Ros, $G$; J ; $K ; N$. Le Sire le Roos et de Badlismere, $S$. Le Sire de Roos (or Rosse), T. Le Sire Roos, Hamlake, $Y$, before 1157 till 1508, quartered by Manners. Lord Roos of Beauvoire and Ham. lake, $V$, and his son John de Rosse, Bishop of Carlisle 1325-32. John Ross, Bishop of Exeter 1778-92. Monsire de Ros, Seigneur de Din. lake, $Y$. Ross, Dalton, co. Dumfries; now represented by Ross, Newport, co. Salop. And with a crescent for diff. Ross-LewIN, Ross Hill, quartering Lewin. But with a label for diff. az. Robert son of William de Roos, $B$. Robert de Ros, $E$. With one bouget charged with a crescent. M. William le Roos, $S$.

$\mathrm{Gu}$. three water bougets arg. over all a pastoral staff in pale or. Augustinian Priory at KIRKhaM ; and at WaRTRE, co. York.

Gu. three water bougets in pale arg. over all a cross or. Augustinian Priory at Wartre, co. York.

$\mathrm{Gu}$. three water bougets arg. over all a crosier in pale or. Cistercian Abbey at Revess, Rievali, River, or Rivaulx, co. York.

Gu. three water bougets erm. Thomas KNovile, $Y$. Sr. William Roos, Gedney, co. Notting. ham, $V$. James Roos, $Y$. Roose or Roos, co. Derby ; Boston, co. Lincoln; Laxton, co. Not. tingham; and Brighton, Sussex. William de Ros, $E$. Robert de Ros, $N$. Monsire James Ros, Brighton, $Y$.

$\mathrm{Gu}$. three water bougets or. ELLERKER or Elricar. Sir William Roos, Yolton, $V$. John Roos, Fholton, $Y$. Rosse, Yolton. Monsire de Ros, Yolton, $Y$.

Gu. three water bougets and over all a pastoral staff or. Augustinian Priory at KInKHAM; and at WARTRE, co. York.

Or three water bougets az. Hughe de Boues, $A$, or Bouts, $A$, Harl. MS.6137. Bucey. Sr. Hugh de Bucy, Filfelde, $V$. Bussy. Fifehead. William Fisheade, $Y$. Roos or Rose, Kil. ravock, co. Nairn. Rose.

Or three water bougets gu. Roos, $V$. Surter. Scotland.

Or three water bougets sa. ILDERToN, co. York. PARR. Rolfe, co. York. Thomas Roos, Ken. dalle, $Y$. Roos or Rosse, co. Devon; and Kendal, Westmoreland. Robert de Roos, Werke, $B$. M. Thomas le Roos, $S$. Ross. Ross, Kiendal, $V$, as quartered by Catherine sixth wife of Henry VIII, $Z, 490$. And with a crescent for diff. Roos or Ros.

Per chev. arg. and sa. three water bougets counterchanged. KITchen.

Per chev. engr. arg. and sa. three water bougets counterchanged. Flowerdew or Flowerdue.

Or three water bougets and a crescent sa. John de Roos, $Y$.

Sa. three dossers arg. LILBORNE.

Sa. three dossers (wicker baskets, $V^{*}$.) with handles arg. Sr. John Littleborne, $\dot{V}$.

Sa. three water bougets arg. Sr .... de ELDERTon, Nortbumberland, $T$. Elrington, North. umberland. ERDington, Northumberiand. Ilderton, $V$. Lillborne or Lilburne. M. John Lilbourne, $S$. John de Lyieburne, $Y$. Wilton, Somerset, College of Heralds.

3 BOUGETS and in chief....

\section{Chief}

Arg. three water bougets sa. a chief of the last.
3 BOUGETS and in chief..... cont.

on a Chief

Barry of four arg. and sa. three water bougets vert on a chief gu. three cups of the first. TOPE. Roundle

$\mathrm{Gu}$. three water bougets or in chief a bezant. WALBORNe, quartered by Lassells of Brakenborough, co. Xork, $W$.

\section{BOUGETS and in base....}

Arg. in chief three water bougets sa. and in base a crescent gu. STOckoE.

\section{BOUGETS betw, or within.... \\ Bendlets}

Erm, three water bougets in bend sa. betw. two cotises gu. Huntington, co. Devon.

Bordure

Arg. three waterpots covered gu. within a bordure sa. bezanty. Monboucher.

Az. three water bougets or within a bordure arg. goutty de poix. Bugge. Buga, $V$.

Az. three water bougets or within a bordure erm. Bridges, Goodnestone, Kent; Baronetcy 19 April 1718, quartering Fowler, Mildmay, and Fitzwalter. BuGGE, Harlow, Essex.

Or three water bougets within a bordure engr. sa. Roos or Rosse, Cawton, co. York.

\section{BOUGETS betw. or within....}

and in chief....

Or three water bougets in pale sa. betw. two roundles gu. a chief vert. BOliADAILE Borradatle or Borrodatle.

\section{BOUGETS}

Per saltire or and gu. four water bougets coun. terchanged. ChappelleN.

Gu. four water bougets arg. Sr. William de Bryane, $H$.

\section{BOW}

Arg. a rainbow ppr. Pont.

Az. a bow strung in fess fretted with eight arrows interlaced in bend dexter and sinister arg. headed and feathered or strung. Town of SHEFFIELD.

Az. a bow and arrow partly downwards arg. Madog HYDDGARU.

Az. an antique bow in fess and arrow in pale arg. MULLER.

Az. on the sinister a bow erect on the dexter a quiver erect holding three arrows or. MoLony, Kiltanon, Grandban, and Six Mile Bridge House, co. Clare; quartering gu. two griffins segreant respecting each other, and grasping a staff erect, all arg.

Erm. a cross-bow bent in pale gu. Albaster Allebaster or Arblaster, co. Stafford; and Essex. Arbalester, $V$. Arblaster, 1730.

\section{Arrows}

BOW betw, or within....

Gu. (or sa.) a sling or hand-bow betw. two broad arrows arg. Cawarden, Cawarden, co. Chester; and Ridware, co. Stafford.

$$
\text { Birds .... Cocks }
$$

Arg. a crossbow unbent in pale sa. betw. three cocks .... crested and jelloped gu. Benjamin HyMners, 1716.

$$
\text { ..... Moorcocks }
$$

Erm. a crossbow bent point downwards betw. three moorcocks sa. Highmone, Armathwaite, Cumberland, temp. Henry IV. 
BOW betw, or within....cont.

Birds cont. Moorcocks cont.

Erm. a crossbow bent betw. three moorcocks sa. Hrghmore, Femethwayt, Cumberland. .....Martlets

Arg. a crossbow betw. three martlets sa. Frelket. .... Cocks

Arg. a crossbow unbent in pale sa. betw. four cocks gu. Homer, $V$.

Or a crossbow sa. betw. four cocks gu. Hrmor, Northumberland.

\section{.....Moorcocks}

Arg. a crossbow pointed upwards betw. four moorcocks sa. beaked and membered gu. Highiore, Harby-brow, Cumberland, temp. Edward IV; and Strickland, co. Dorset.

\section{Estoiles}

Az. a rainbow in fess ppr. betw. two estoiles in chief and the sun in base or. Claret.

Head

Sa. a crossbow in bend betw. two pheons arg. Cardon.

Sa. a handbow in bend betw. two pheons arg. Carwardine, Carwardine, co. Hertford.

\section{BOWs}

Arg. two bows one within the other in saltire gu. strung or. Bowman, $V^{*}$.

Az. two bows strung in saltire or. GoDbord, Hatfield, Essex ; and Westhall, Suffolk.

Az. two bows bent one within the other in saltire strung outward the dexter surmounted of the sinister or. GoDBow, $V$.

Az. two bows bent and interlaced in saltire or. GoopBow and GoodBowe.

Az. two bows in saltire or stringed sa. GooDBow.

\section{Bows betw, or within.... \\ Arrows}

Sa. two string-bows endorsed in pale or garnished gu. betw. two bundles of arrows in fess three in each gold barbed and headed arg. tied as the third. Benbow, Newport, co. Salop.

Vert two bows in full bend palewise ppr. stringed arg. betw. three sheaves of arrows two in chief and one in base as the second. Bower, Scotland.

\section{Chief}

Vert two bows bent palewise in fess and three arrows conjoined in base one in pale and two in saltire and a chief embattled all arg. Bover, Wordon Abbey, co. Bedford; and Stow, co. Cambridge; granted 1712.

\section{Roundles}

$\mathrm{Gu}$. two longbows bent and interlaced in saltire or stringed arg. betw. four bezants each charged with a fleur-de-lis az. ReBow, Colchester, Essex; granted 10 April, 1685; quartering Slater.

\section{Bows betw, or within....}

and in chief...

\section{Canton}

Gu. two longbows bent and interlaced in saltire or stringed arg. betw. four bezants each charged with a fleur-de-lis az. a canton of the second. ReBow.

\section{BOWS}

Arg. three crossbows .... Robarts, London.

Arg. three crossbows gu. the iron-work sa. ReADE, co. Gloucester.

Az. three crossbows bent in each an arrow arg. SaCheville.

\section{BoWS cont.}

Az. three crossbows bent or with five arrows diverse to each arg. Sachevrle, $V$. Sachevire, $V^{*}$. Sychevile, $V^{*}$.

Erm. three bows bent gu. Robert de Bowes, $X$.

Erm. three bows strung palewise in fess gu. Bowes, Bradley Hall, Durham; quartering 'Irayne, $\mathrm{De}$ la Hay, Dawden, Conyers, Fitz Hugh, Grey, Conyers, and Aske; and its descendant Bowes, Streatlam, Durham, the heiress m. Lyon.

Erm. three crossbows gu. SICHEvile or SyHeVIle.

Erm. three crossbows unbent gu. Sychevile, $V^{*}$. SAchevile, $V^{*}$.

Erm. three longbows erect gu. M. William de le Bowes, $S$.

Erm. three longbows palewise in fess gu. Bows. Erm. three longbows bent palewise in fess gu. Bowes, Durham, 1716.

Erm. three longbows bent palewise in fess gu. stringed to the sinister sa. Sr. William BowEs, $V$.

Erm. three longbows bent in pale gu. Bowes.

Erm. three longbows bent in pale gu. stringed or. Bowes, Durham ; and co. York.

Erm. three crossbows unbent or. Sychevyle, $V$. Erm. three bows ppr. Bonys.

$\mathrm{Gu}$. three crossbows unbent arg. the triggers or. Sнттн, Codenham, Kent, $W$.

Gu. three crossbows unbent arg. the stocks or. SkYNner, $V$.

Gu. three crossbows unbent or. Skrnner, $V^{*}$.

Gu. three bows ppr. Biwlam; descended from John de Byllam, Billam and Wales, co. York.

Vert three bows strung arg. Bovy, co. Warwick.

\section{Bows and in chief....}

Arg. three crossbows bent each loaded with a three headed bird-bolt sa. a chief vert. Rowland SeARChField, Bishop of Bristol 1619.22.

Az. three crossbows stringed arg. a chief or. Rowland SearchField, Bishop of Bristol 161922.

on a Chief..... Bird

Erm. three bows bent in fess gu. stringed sa. on a chief az. a swan ppr. betw. two leopard's beads or. Bowes or Bows, London.

Erm. three bows palewise in fess gu. stringed to the sinister sa. on a chief (or $V^{*}$.) az. a swan arg. bolding a gem ring in the beals betw. $t$ wo leopard's heads or. Sr.Martin Bowes, Alderman of London, $V$.

Erm. three bows in pale gu. on a chief az. a swan arg. holding in the beak a dish with a covered cup in it betw. two leopard's heads or. Bowes, Lord Mayor of London 1545.

\section{Bows betw, or within....}

Arg. three rainbows ppr. betw. in chief two stars gu. and in base a galley sa. Pont, Shyr's Mill, Scotland.

\section{BOWSTRING}

Az. a bowstring in fess fretted with eight arrows interlaced in bend dexter and sinister arg. headed and feathered or. Town of SHeFrueld.

\section{BOY see Human figure.}

\section{BRACKETS}

Arg. three double brackets sa. Biddell Biddelle or BIDDLE. 
BREAK see Hempbreak

BRANCH see Sprig BRAND see Torch

BRAY see Barnacle BREAM see Fish

BRICK-AXE see Implements

BRICK-KILN see Kiln BRIDGE see Building BRIDLE

Arg. a bridle or. Bridled, co. Devon.

2 BROACHES betw. or within....

and in chief....

Gu. two broaches in saltire arg. betw. as many trundles or on a chief of the second a lion pass. gu. Company of Embroiderers at Bristol and at Chester.

BROAD-ARROW see Arrow and Pheon BROAD.AXE see Axe BROCK see Badger BROCKET see Deer

\section{BROOMS}

Az. two besoms in saltire or. Bonston.

\section{BUBBLES}

Az. three water-bubbles ppr. ArRe.

BUCK see Deer BUCKET see BOUGET \& Tub

\section{BUCKLE}

Arg. a round buckle gu. NAIL.

Arg. a buckle lozengewise sa. HaNLEY, co. Devon.

Arg. a lozenge buckle tongue in fess sa. HоскіN. Gu. a fermail or. Newmarcee.

\section{BUCKLE betw. or within....}

\section{Garbs}

Az. an oval buckle betw. three garbs within a bordure or. Commrng.

\section{Heads}

Az. a buckle or betw, in chief two wolf's heads and in base nn escallop arg. LUMSDEN or Lumsdon. Cushnie, Scotland.

Az. a buckle betw. three boar's heads couped within a bordure embattled arg. FERGUson.

Az. an arming buckle arg. betw. three boar's heads or. Fenguson, Killkerran, co. Ayr, Baronetcy 1703 ; quartering Dalrymple. FERGUSON, Londonderry, Baronetcy 7 October 1801. Ferguson, Bishop Wearmouth, co. Durham.

$\Delta z$. a buclile arg. betw. three boar's heads couped or within a bordure of the second. FERGUSON, Pitfour, Scotland.

Az. a buckle arg. betw. three boar's heads erased or within a bordure .... charged with four crosses croslet fitchy gu. Ferguson, London.

Az. a buckle betw. three boar's heads couped or. Gordon, Banfi, Scotland.

BUCKLE betw. or within....

$$
\text { and in chief.... }
$$

Or a buckle az. betw. three roses gu. on a chief engr. sa. as many escallops of the first. GrAHAM, Limekilns, Scotland.

BUCKLE betw. or within....

and in base....

Or in chief a buckle betw. two annulets in base an eagle displ. az. Carnegie, Newgate, Scot.
2 BUCKLES and in chief....

Sa. two round buckles or on a chief of the last a demi lion gu. Provost.

\section{BUCKLES}

Arg. three lozenge buckles tongues in fess az. FIRTH.

Arg. three lozenge buckles (mascle buckles properly) gu. Germingham, Suffolk. Jerningham, $V^{*}$. Jernegan or Jerninghadr, Cossey, Norfolk; and Somerleton, Suffoll.

Arg. three lozenge buckles tongues fesswise. gu. Stafford-Jerninghait, Baron Stafford 17 June 1824; quartering Stafford.

Arg. three lozenge buckles tongues fesswise to the sinister gu. JERnYnghalt, $V$.

Arg. three lozenge buckles in bend gu. Barratr, Arg, three belt-buckles sa. SAPCOTT, $V^{*}$.

Arg. three belt-buckles tongues in chief sa. SAPCOT; quartered with Sir John Sapcott, $V$, Cotton $M I S$. Tiberius D. 10, fo. 436 .

Arg. three round buckles tongues to the dexter sa. Robert MaLeT, $E$.

Arg. three round buckles tongues pendent sa. JAWDERILL, Cambridge; Sutton, Isle of Ely; and Stoughton, co. Huntingdon; granted 2 July 1597.

Az. three gard-buckles arg. StUKELEY.

Az. three buckles or. Steriing or Stiriing.

Az. three fermails or. Walter de MEINJOHN (? St. JoHN), C. Rede. Rossetyne, Norfolk. Sire William Rosselyn, $N$.

Az. three buckles tongues in chief or. StirLing.

Az. three lozenge buckles tongues in fess or. CoMryns.

Az.three round buckles or. Brampton. Ramiville. Az. three round buckles tongues to the dexter or. Graville, $V$.

Az. three round (square, Brampton, $V^{*}$. RenevinLe, $V^{*}$.) buckles tongues to the sinister or. Bramton, $V$. Renievyle, $V$.

Barry of six arg. and az. three buckles in chief gu. Ralf de Cotone, $Y$.

Barry of six arg. and az. three round buckles tongues to the dexter gu. Raf de Cotun. Raph Coton, $X$.

Barry of six (another of nine) arg. and az. three round buckles tongues to the dexter gu. Sr. Robert fitz RAFE, $L$.

Barry of six arg. and gu. in chief three buckles of the second. Fitz-Ratph.

Barry of fourteen arg. and az. over all three round buckles tongues to the dexter gu. William le fitz $\mathrm{R}_{\triangle F}, F$.

Erm. three lozenge buckles tongues in fess az. BRUMKERD.

Ermines three round buckles tongues pendent arg. JAUDRILL. And with a 3-foil slipped for diff. or. JODRELI, Duffield, co. Derby ; granted 10 July 1707.

Gu. three buckles arg. HaDDELEY, Ireland. Monsire Rocelyn, $Y$. Thomas Rosseline, $Y$. Sire Peres RosseLrn, $N$.

Gu. three buckles lozengy arg. Rocheline.

$\mathrm{Gu}$. three round buckles arg. HADLEY, $V^{*}$, Ireland; and co. Somerset.

$\mathrm{Gu}$. three round buckles tongues to the chief arg. Hadley, Irelaud, $V$. Rosseline or Rosseline, Norfolk.

$\mathrm{Gu}$. three round buckles tongues to the dexter arg. Sr. Thomas Rosselyn, Norfolk, temp. Edward I, $V$. Thomas RoceIIN or Roceline, E. 


\section{BOCKLES cont.}

Gu. three zound buckles tongues to the sinister side arg. HADLEY, Ireland, $V$.

Gu. three square buckles arg. Rosselyn, $V^{*}$.

Gu. three square buckles arg. tongues to the dexter or. HadLEy, Harl. IISS. 1441.

Gu. three buckles or. CroE, Croestoun, Scotland. Gravell or Gravill. Malet, 1355. John SAPY, $X, Y$.

Gu. three round buckles or. Grenill. Gunton, co. Northampton. Mallet.

$\mathrm{Gu}$. three round buckles tongues to the dexter or. Sr. John SAPY, temp. Edward I, V. Graville, France, $V$. John Males, $A$.

Gu. three round buckles tongues to the sinister or. GoNToN, $V$.

Gu. three round buckles tongues in pale or. SAPY or SAPYE.

Gu. crusily and three round buckles or. Roseline. Gu. semy of 3.foils and three round buckles or. WeTtYN or WetTYNG.

Gu. three square buckles or. SAPX, $V^{*}$.

Or three lozenge buckles az. Alling Hair.

Or three buckles gu. WETtYN.

Quarterly or and az. three buckles gu. Bradier. Sa, three buckles arg. JAUDERELL. JODRELL, Yeardsley, and 'Taxal, co Chester.

Sa. three oval buckles fesswise two and one arg. Marten, Marshals Wick, co. Hertford; and London; descended from Marten, Rowsham, 1550 .

Sa. three round buckles tongues pendent arg. JANDRELL. JAODRELL, $V^{*}$. J AUDRELL, $V$. And with a 3-foil slipped or. Jodrell, Duffeld, co. Derby.

Sa. three round buckles tongues to the dexter arg. Robert MALET, $A$.

Sa. three buckles arg. garnished or. Martyn, co. Berks.

Sa. three buckles or. Bunckill.

Sa, three round buckles or. MaLLET.

\section{BUCKLES and in chief ....}

Sa. three round buckles or on a chief of the second a demi lion ramp. gu. Provost.

3 BUCKLES and in base....

Sa. in chief three round buckles arg. in base a talbot pass or. Carter, co. York.

\section{BUCKLES between or within....}

\section{Bordure}

Gu. semy of 3-foils slipped or three buckles of the last within a bordure compony gold and az. WETTYN or WETTYNG.

\section{Crosses}

Gu. three round (square, $V^{*}$ ) buckles betw. nine crosses croslet three three two and one arg. Roscelyn, $V$. Rosselyn, $V$ *.

$\mathrm{Gu}$. three buckles lozengewise betw, nine crosses croslet fitchy or. Rosselyne or Roscelyne.

3-Foils

Gu. three buckles in fess betw. nine 3-foils slipped or. Wetryn, Tournay.

\section{BUCKLES}

Quarterly gu. and vert four buckles or. Branston.

BUCKLER see Target BUFFALO seo $\mathrm{Ox}$

\section{BUILDING}

(except Castle including Tower)

.... a bridge consisting of one large arch and two demi arches thrown over a river on the river a siugle-masted vessel one half of which appears to have passed through the bridge but with the mast and round top on the other side .... TOWn of BIDEFORD.

.... from the door of a church a stag issuant towards a grove of trees ppr. Rey d'IrLANDE.

... a windmill .... Mne M.

$\ddot{A r g}$. on a mount in base vert a brick-kiln of four stories gu. flamant and fumant on the second and top stories ppr. Brickill.

Arg. a bridge of three arches masonry gu. water az. on the bridge a flag or. TrowbrLGE, $V^{*}$. Trowbrige, co. Devon, $V$.

Arg. a bridge of three arches in fess gu. masoned sa. the streams transfluent ppr. a fane of the first. Trowbringe, quartered by Halliday. Arg. an arch of a bridge extended and tripletowered gu. in base water with three ships therein all ppr. BRIDGEWATER.

Arg. on a mount in base vert an antique temple of three stories each embattled from the second battlement two steeples and from the top one each ending in a cross sa. TeMPLAR or TEMPLER. Arg. out of a well gu. an oak-tree vert. WeLLWOod, Garvock, co. Fife.

Az. a bridge of two arches arg. Pouns or PoInt, $V^{*}$.

Az. a covered bridge of three arches throughout arg. James Poynt, $V$.

Az. in base water vert. thereon a bridge of three arches arg. on the centre a turret of the last flagged gu. VINICOMBE.

Az. a church arg. St. Giles standing in the porch in a pastoral habit ppr. mitred and in bis dexter hand holding a passion cross the sinister hand holding a book ppr. See of MurRaY.

Az. a temple arg. St. Michael standing in the porch vested and mitred ppr. his dexter hand elevated to heaven praying over three children in a boiling cauldron of the first in his sinister hand a crosier or. See of ABERDEEN.

Az. a temple or. Temple, Revelrig, Scotland.

$G$ u. a wall extended in fess arched inarched on the top a tower embattled with a round roof betw. two other turrets of the same. BRIDG MORE.

Gu. a bridge of one arch arg. masoned sa. with streams transfluent ppr. BrIDGE, Scotland.

Or on a bridge of three arches in fess gu. masoned sa. as many streams transfluent ppr. a tower of the second thereon a fane arg. Trowhridge, Modbury, co. Devon.

or on a mount vert a windmill sa. William SAMPSON, $V$.

Per pale sa. and az. a windmill or. Walter LEPUL, Gillingham Church, co. Dorset (in a later hand than), $V$.

Sa. a gateway betw. two towers arg. standing on the upper part of a base barry of four as the second and az. Richard Rawson, Alderman of London $3746, W$.

BUILDING and in chief....

\section{Beast}

.... a gateway embattled and wall flanked by two towers issuing from the base and out of the top of the embattled gate a demi-lion holding in the dexter paw a sword point downwards .... M'Lean, Dundee. 
BUILDING and in chief..... cont.

Bird

Quarterly az. and gu. the perspective of an an. tique temple arg. on the pinnacle and exterior battlements a cross or in the first quarter an eagle displ. in the second a stag trippant reguard. of the last. TEMPLER, Stover Lodge, co. Devon.

Arg. over water ppr. a bridge of five arches turreted gu. in chief an eagle displ. sa. LETHBRIDGE, Sandhill Park, co. Somerset; Baronetcy 15 June 1804, quartering Periam, Buckler, and Giffard.

on a Canton

Or over water in base on a bridge of three arches in fesis embattled a tower ppr. thereon hoisted a broad pendent flying towards the sinister a canton az. charged with two keys in saltire wards upwards gold. Trowbridge, Ply. mouth, co. Devon; Baronetcy 30 November 1799.

on a Chief

Or a (dyke or) wall fesswise broken down in some places gu. on a chief sa. three escallops of the first in base a rose as the second. GraHam, Inchbrakie, Scotland.

Or a wall fesswise masoned ppr. the top broken on a chief sa. three escallops of the first in base a rose gu. Græme, Aldbury Court House, Stapleton ; quartering Jones.

\section{Escucheon}

Az. a bridge of three arches double embattled arg. standing in the sea ppr. in chief an escucheon per fess or and gu. on the first three chev. gu. on the second three lions pass. guard. in pale of the first. United Towns of Weymouth and Melcombe Regis.

\section{Estoiles}

Gu. on a bridge of Gothic work in base over a river ppr. a castle surmounted by two others placed pyramidically and embattled on each side a domed tower surmounted with a ball the grand entrance portcullised at the top and against the door a man's head couped close .... in chief on the dexter side an estoile on the sinister a fleur-de-lis .... Town of Bridgewater, co. Somerset; seal.

\section{Human figure}

.... a shrine of Gothic work over it an angel holding an escucheon gu. three lions pass. guard, in pale or. Borough of Winto , co. Wilts; seal.

\section{Ships}

Az. on a mount vert the Royal Exchange ppr. adorned and embellisbed or in chief two ships the dexter under sail hulk of the last mast sail and rigging as the third the sinister ship riding at anchor sails furled blazoned like the dexter all ppr. Royal Exchange Assurance Conrpany.

Sun

Vert a college (or edifice) arg. masoned ppr. in chief the rising sun or the hemisphere of the third. Virginia CoLlege.

\section{BUILDING and in base....}

\section{Trench}

Tert a portcullised gate in the curtain betw. two spired towers and part of a town wall in base a winding trench arg. Richard Hensiey, Captain of Pioneers at the siege of Kinsale; granted 26 April 1602; Harl. MS. 1441.
BUILDING and in base.... cont.

\section{Woolpack}

the castle churcl and town of Tiverton with Lowman's and Exe bridges beneath them a woolpack .... Town of Trverton; seal.

BUILDING betw, or within....

\section{Escallops}

Per fess arg. and vert a chapel of the first roofed gu. betw. four escallop shells counterchanged. Chapelil or Chappell, co. Cambridge; and Gamlingay, co. Huntingdon; Cott. MS. Julius $\mathrm{F}$ viii, fo.

IIonsters

Az. a bridge of three arches embattled at top in fess arg. masoned sa. betw. three sea lions pass. or. Bripgen, Lord Mayor of London 1764. Wings

Az. a pillar (or column) erect betw. two angel's wings elevated or. AwBonN.

\section{BOILDING betw. or within.... and in chief....}

\section{on a Chief}

Or a (dyke or) wall fesswise broken in some places az, a bordure and in base a rose gu. on a chief sa. three escallops of the first. GraHAM, Drynie, Scotland.

\section{Sun}

.... a church with a spire at the dexter end of the church three ears of corn on one stalk at the sinister end a saltire.... on the dexter chief the sun in splendour on the sinister a crescent. Town of AsHburton, co. Devon.

\section{On I BUILDING}

.... on the centre of a bridge of two arches the dexter end in perspective showing the passage over a river at the sinister end a tree issuing from the base against the bridge .... an escucheon arg. a lion ramp. gu. within a bordure sa. bezanty. Town of Grampound, Cornwall.

\section{BUILDINGS}

Az. three wells arg. HoDsoLL.

Gu. three bridges of as many arches .... Cralg, Ireland.

Gu. three porches of churches with double doors expanded (some say three ports) arg. Lesington, $V$. Lessington, $V^{*}$.

Gu. three pair of arches two and one arg. Monsyer William ARches, T, Harl. MS. 6137.

$\mathrm{Gu}$. three arches two in chief and one double in base arg. the imposts or. ArCHEs, $V$.

Gu. three arches conjoined in fess arg. caps and bases or. M. William ARches, $T$, Ashmol. MS. 1120 , fo. 175 .

Gu. three door-arches arg. capitals and pedestals or (another, the arches or). ARCHEs, co. Devon.

Gu. three arches arg. masoned two and one sa. Arches.

Gu. three spires arg. Dacisun.

$\mathrm{Gu}$. three church spires arg. on each a ball and cross croslet fitchy or. DAKEHAM, $V$.

Gu. three square wells arg. water az. HodrsweLL, $V$.

Gu. three wells arg. masoned sa. Hadiswell.

Gu. three door-arches or. ARches, co. Devon.

Gu. three single arches or. ARcher. ARches, Cotton MS. Julius F viii, fo. 7 .

Gu. three arches two single and one double in base or. Arches, $V^{*}$. 


\section{BUILDINGS cont.}

Sa. three dove houses arg. Sr. John Sapcotr, co. Northampton, $\boldsymbol{V}$. SAPCOTES, Cornwall; co. Hertford ; and co. Lincoln. SAPcote, Elton, co. Huntingdon, Cotton MS. Julius F viii, fo. 7 .

Sa. three round wells arg. William Boxton, $V$.

3 BUILDINGS and in chief....

Per fess arg. and vert in base three wells two and one masoned in chief a tree issuant from the fess line ppr. City of WELLS, co. Somerset.

3 BUILDINGS and in base....

Per pale az. and sa. in chicf three cold wells or fountains ppr. in base a hart's head couped or. Caldwell, Glasgow.

Per pale sa. and vert in chief three cold wells or fountains ppr. in base a stag's head couped arg. CALDWELI, Linley Wood, co. Stafford, quartering Stamford.

\section{BULL see $0 x$ \\ 2 BUNDLES OF REEDS}

Arg. two bundles of reeds in fess vert. JANSSEN de HeEz, Wimbledon, Surrey; Baronetey 11 March 1714, extinct 8 April 1777; quartering per fess or and az. two swans close on the fess line ppr., with per fess or and az. a swan on the fess line ppr., and arg. a bundle of reeds vert.

Arg. two bundles of reeds in fess palewise vert. JANSON.

BUNDLE of SILR see Hank and Knot

\section{BURIING IRONS}

Gu. three burling irons arg. BURLER. BurLinger.

\section{BUSH see Tree BUTTERFLY see Insect}

\section{BUTTRICES}

Arg. three buttrices or (? paring knives) farriers' implements in fess sa. BRUTTRIs.

Az. three buttrices handics erect in fess arg. Bettrisch.

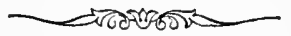

\section{CADUCEUS see Staff 3 CAKES}

Erm. three cakes of copper ppr. on a chief gu. a chamber or. ChameErs, London; granted 1723.

\section{CALF see 0x}

\section{CALTRAPS}

Arg. three caltraps .... Toogood, Sherborne, co. Dorset.

Arg. three caltraps sa. Trap, co. Gloucester, 1716. Trapps, London. Trogood, Sherborne, co. Dorset.

Gu. three (? caltraps) arg. Heury BeLwood, $V$.

Or three caltraps gu. Horseman; granted 1590 .

3 CALTRAPS and in chief....

Or three caltraps sa. a chief of the second. Devie, Guernsey, 1612. De Vic, Guernsey, 1730.
CAMEL see Beast CAMELION see Reptile

2 CANDLESTICKS

Az. two candlesticks (called chalices in $W$. ) in fess or. EMerle.

\section{CANDLESTICKS and in base....}

Arg. in chief two candlesticks sa. in base a mullet gu. KyLE, Scotland.

\section{CANDLESTICKS}

Or three candlesticks sa. KyLE, Scotland.

3 CANDLESTICKS and in chief....

Erm. three candlesticks each enfiled with a wreath of laurel or in chief a mural crown gu. therefrom pendent by a blue ribbon a representation of a medal. TORrens.

3 CANDLESTICKS betw. or within....

Or three candlesticks sa. within a bordure arg. KYLE.

\section{CANNON see Gun \\ CANTON see also Quarter}

Arg. fretty gu. a canton of the first. HanLey, co. Devon.

Arg. fretty gu. a canton az. InEBY, Ireby, Cumberland.

Arg. fretty sa. a canton az. MIDDLETon, impaling arg. a chev. az. betw. three boar's heads ....

Arg. fretty gu. a canton erm. Heway. Hughes.

Arg. fretty sa. a canton erm. Marchington, $V$. Noel, Newbold. Vernon.

Arg. a canton gu. Clare, $V$; attributed to Clare, $Z$, 222. John Moyre, $V$. Polncey, Chester, Harl. MS. 1078, fo. 24.

Arg. a canton and bend gu. KerYell.

Arg. a canton gu. over all a bend sa. Do Bors.

Arg. fretty and a canton gu. HEWAY, co. Devon. Sr. de Hewra, $V$. Sr. Thomas Quitrige, $V$.

Arg. fretty sa. a canton gu. Delariver, $V^{*}$ Delaryver, $V$. Markadnt, $V$. M. Richard Vernon, $S$. Vernon, London. Vernoyte.

Arg. a canton sa. AVERAIr, Harl. MS. 1078, fo 24. Sr. Thomas Sutton, Averam, co. Nottingham, $V$. Sutron, Baron Lexington of Aram 21 November 1645 , extinct 1723. Sutron. Sutron, Norwood Park, co. Nottingham; Baronetcy 25 September 1772, quartering Lexington. Oliver Surton, Bishop of Lincoln 128099. Sutton, co. Wilts; and Ross Way, near Great Berkhamsted, co. Hertford; doscended from Sutton, Lexington. SuTton, Kelham Hall, near Newark, co. Nottingham. quartering Manners. Charles Manners Sutton, Bishop of Norwich 1792, Archbishop of Cauterbury 1805-28, quartering Manners. SuTton, Baron Bottesford and Viscount Canterbury, 1835, quartering Manners.

Arg. fretty gu. a canton sa. InEBY.

Arg. fretty and a canton sa. EARBy. ErLy. Mrddleton, $V^{*}$. Middleton, co. Cambridge; and Stockeld, co. York. MIDELToN, Stokeld, co. York; the heiress m. Haggerston. Midelton, $V$. Natovillet or Natvillet. RADFORD, Irby.

Arg. a canton in base vert. Brucherley.

Az. fretty or a canton arg. WILLELEY.

Az. a canton erm. Symonds.

Az. fretty or a canton erm. Willeley, co. Salop.

Az. fretty arg. a canton gu. St. Leger, $V^{*}$.

Az. fretty arg. a canton or. ST. LEGER, $V^{*}$. 


\section{CANTON cont.}

Az. fretty and a canton or. WILLELEY.

Barry of five arg. and gu. a canton as the last over all a bend az. Copland. Sir John Coupland, $V$.

Barry of five arg. and gu. a canton as the last over all a bend sa. Cortand, Boston, co. Lincoln. Sire Johan du Boys, $N$. Boys, Hoston, Norfolk.

Barry of five arg. and gu. a canton as the last over all a bendlet sa. M. Roger le Boys, $S$.

Barry of five or and gu. a cantor as the last over all a bend sa. Coupland.

Barry nebuly of six arg. and az. a canton as the first. KEBEIL or KEBLE, Suffolk.

Barry of six arg. and gu. a canton erm. Apester Apsley or Aspele, Apesly, Suffolk. Apseley $V^{*}$. Apseiley, $V$. Apsiey, $V$. Aspele, $V$. Asplex, $V^{*}$. Gosell or Goushill, Suffolk. Goushill, Norfolk, $V$. Marshall.

Barry of six arg. and gu. a canton as the second over all a bend sa. Boys, Coningsby, co. York; and Rollesby, Norfolk.

Barry engrailed of six arg. and gu. a canton as the last. MaIDENHaCH ; quartered by Holte.

Barry wavy of six arg. and yu. a canton as the second. Bassetr, co. Leicester.

Barry of six arg. and sa. a canton erm. Marshall, co. Nottingham; and Picking, co. York. WaLdesheFF or WAIDSHEFF.

Barry nebuly of six arg. and sa. a canton erm. KEYBELL.

Barry wavy of six arg. and sa. a canton erm. KEBELL, $V$.

Barry of six arg. and sa. a canton gu. WOODWARD.

Barry nebuly of six arg. and sa. a canton gu. Brockesby or Brokissy, Melton Mowbray, co. Leicester. H. Bassett (but?) $E$. Folville, Kersby, co. Durham.

Barry wavy of six arg. and sa. a canton gu. Brooksby. H. Basset (but?) $E$. Filioll. KeBLe or FeBYLL. KeYBell.

Barry of six arg. and sa. a canton per pale (or and arg. another) or and sa. BELSTED.

Barry of six arg. and sa. a canton quarterly or and arg. BeLsted, Norfolk, $V$.

Barry of six erm. and gu. a canton arg. Husey. Barry of six gu. and arg. a canton erm. WALSHE.

Barry of six or and az. a canton arg. HoLJie, co. Lancaster.

Barry of six or and az. a canton erm. GAwSEL, Wallington, and Wiggenhall St. Mary's, Norfolk. Gosell or Goushili, Wallington, Nor. folk. Gousell or Goussell. Goushill, $V$. M. Philip Spencer, $S$, Sir Philip Spenser, $V$. Spencer or Despencer, co. York; and co. Nottingham.

Barry of six or and gu. a canton erm. GousHnL $V$. M. Nicoll GoushulL, $S$. And with a label of three points az. M. Nicoll his son, $S$.

Barry nebuly of six or and gu. a canton erm LOVELt, co. Buckingham, $V$.

Barry of six or and sa. a canton erm. Marshali.

Barry nebuly of six or and sa. a canton erm Kebell, $V$.

Barry of six or and sa. a canton gu. WOODWARD.

Barry of seven arg. and gu. a canton erm. Apeele. Apesley, Surrey; and Sussex. John A spelie, $V$. Molton. Motton.

Barry of seven arg. and gu. a canton sa. ETone.

Barry of seven arg. and sa. a canton erm. Marshali, Fiskerton, co. Lincoln.
CANTON cont.

Barry nebuly of seven arg. and sa. a canton gu. Keble, West Creting, Old Newton; and Stowmarket, Suffolk.

Barry wavy of seven arg. and sa. a canton erm. KEBYLL.

Barry of seven gu. and arg. a canton erm. WALSHE, $V$.

Barry of seven gu. and arg. a canton or Marshall, Abbot's Anne, co. Hants.

Barry nebuly of seven or and gu. a canton erm. LOVEIL, $V^{*}$.

Barry nebuly of seven or and sa. a canton gu. Folville, co. Leicester.

Barry of seven sa. and arg. a canton as the last. Burton, Lindley, co. Leicester. Havghton. Marshall, co. Hants. Rothington, $V$.

Barry of seven sa. and arg. a canton or. Marshall, Tidesmarch, co. Lincoln; and Abbot's Anne, co. Hants, Harl. MS. 1544, fo. 94 .

Barry of seven vairy arg. and sa. with gu. a can. ton erm. AspLEY.

Barry of eight arg. and gu. a canton sa. Ecron.

Barry of eight arg. and sa. a canton as the first. BELSIDE.

Barry of eigbt arg. and sa. a canton per pale or and as the first. Belstede, $V$. Beicstide, $V^{*}$.

Barry of eight or and az. a canton arg. Holme.

Barry nebuly of eight or and gu. a canton erm. LOVELL, $V^{*}$.

Barry of eight (another, nine) or and sa. a canton arg. Tallant.

Barry of ten arg. and gu. a canton as the same. Paunton, $V^{*}$.

Barry of ten arg. and gu. a canton as the second. Panton. Paunton, $V$.

Barry of ten arg. and sa. a canton erm. MARshaid, co. Derby.

Barry of ten arg. and sa. a canton gir. Tenby.

Barry of ten arg. and sa. a canton per pale or and as the first. Belsted, $V$.

Barry of ten gu. and arg. a canton as the second. Fitz Osborne.

Barry of eleven gu. and sa. a canton erm. Fitz Osborne.

Barry of twelve arg. and gu. a canton as the last. CowfFold, $V$.

Barry of thirteen arg. and gu. a canton as the last. James de Pantone, $F$.

Barry of fourteen arg. and gu. a canton as the last. Cowfold. CowfFold, $V^{*}$.

Bendy of six arg. and az. a canton erm. Fitz-OTES. Bendy of six arg. and sa. a canton erm. Bishopton, co. Warwick.

Bendy of six az. and or a canton arg. Fitz-Otes. Bendy of six or and az. a canton erm. SPENCER. Fitz-Otes. M. Hue le Fitz-Othes, $D$. Hue le Fitz-Hostes, $E$, or Hothes, $E$, Harl. MS.6137.

Bendy of ten or and az. a canton erm. BISchopsden, Ashmol. MS. Wood, F, 33, fo. 91 .

Bendy of ten or and az. a canton gu. Henry de Estoires, $F$. Henry de Stoke, $E$.

Bendy paly arg. and az, a canton erm. SHIRLey or Shurlex, Isfield, Sussex.

Bendy paly az. and or a canton erm. Buck, Rochester.

Bendy gu. and or a canton erm. Bassetr.

Bendy or and az. a canton erm. Sire Johan de Bysscoptone, $N$.

Bendy paly or and az. a canton erm. Buck, Hamby Grange, co. Lincoln; Baronetcy 22 December 1660 extinct 7 June 1782 ; the coheirs m. Isted and Englefield. 
CANTON cont.

Bendy paly or and gu. a canton az.

Chequy arg. and gu. a canton erm. Buckingham.

Chequy .... and .... a canton erm. Thomas and John Rernes, Upton Escudamore, seal, 1416.

Chequy arg. and sa. a canton erm. Caymesie, $V$. Caymesley.

Chequy gu. and or a canton erm. Reyres, $V^{*}$.

Chequy or and az. a canton erm. De Dreux. RICHMOND, Scotland.

Chequy or and gu. a canton arg. Fleet, Kent.

Chequy or and gu. a sinister canton arg. Flete, $V$. Sleech, Sussex. Slefch, Windsor.

Chequy or and gu. a canton erm. Reynes, co. Buckingham; and Kent. M. John Reynes, $S$. M. Thomas Reynes, $S$.

Chequy or and gu. a canton erm. over all a bend az. Reynes, Kent; and co. Huntingdon.

Chequy or and gu. a canton erm. over all a bend of the second. Reynes, Kent; and co. Hunts.

Chequy or and gu. a canton erm. over all on a bend az. a griffin's head erased betw. two falcons arg. HaYnes or Heynes, Surrey.

Chequy or and gu. a canton erm: over all on a bend az. a griffin's head erased of the first betw. two engles close arg. Raynes, Marwood, Kent; Hampstead, Middlesex; and Conyborough, Sussex.

Chequy or and gu. a canton erm. over all on a bend az. a griftin's head crased betw. two birds of the first. Reynes, Lewes, Sussex.

Chequy or and gu. a canton of the second. GIFFord.

Chequy or and gu. a canton sa. Hoode.

Erm.a canton gu. Bassetr, co. Somerset. Sutron.

Erm. a canton sa. .... de SuTon, $F$. Jamis or Janus de Sutron, the son, $E$. Sutron, Ireland.

Ermines a canton erm. DannetT, London.

Fusily erm. and sa. a canton gu. Patren, Bank Hall, co. Lancaster, quartering Peake and Bold; descended through PaTten, Patten Lane, Warrington, quartering Drinkwater; from Richard Patten, Boston, co. Derby, a brother with John Patten, Dean of Chichester, of William Patten, alias Waynflete, Bishop of Winchester, descendants of PATten, Waynflete, co. Lincoln, 1376, quartering Westingcroft; directly descended from Patten, Patine, near Chelmsford, quartering Dagenham, a heiress m. Churchstyle.

Fusily erm. and sa. a canton or. WaynFlete.

Gu. a canton arg. BLencowe, Majston St. Law. rence, co. Northampton, temp. Henry VI, quar. tering Waleston. Bunco, co. Warwick, $W$. Buoys.

Gu. fretty arg. a canton of the second. Harris, 'Cornwall. Hewes, $V^{*}$. Hewis or Hrwis, Stowford, co. Devon; the heiress m. Hawley. Hewrse, Cornwall. Sire Richard Hewys, $N$. Sr. .... de Hewys, Cornwall, $V$.

Gu. fretty or a canton arg. Novelie or Nowell, Gu. fretty arg. a canton az. ANstavill.

Gu. bezanty a canton erm. Davers. Sire Wil liam La Souche, $N$. Monsire John Souche, quartering arg. on a fess dancetty sa. three (anotber seven) bezants, T. Zouch, Collinson, Somerset, ii, 437 ; ii, 34 . Baron Zоuсн, $U$. Le Sr. de Zouch, $T$. Sr. Roger La Zovche, co. Leicester, $V$.

$\mathrm{Gu}$. bezanty and a canton indented in the bottom erm. Sr. Williarn la Zouche, $R$.
CANTON cont.

Gu. a canton or over all a bend erm. betw. two lions ramp. of the second. Dumbleton, London; granted 1759 .

Gu. fretty or a canton of the second. WynaLL.

Gu. bezanty a canton or. ZoucH.

Gyronny of eight az. and or a canton erm. OKeton. OKTON, $V$.

Gyronny of eight or and az. a canton erm. Orenton. Oreton. OKton, $V^{*}$.

Lozengy gu. and vair a canton or. Auncell de Gise, $E$.

Lozerigy or and az. a canton erm. Buck, quar. tering Squire, and impaling Ellison, in Rother. ham Church. Bucks, co. Lincoln. GisBY, co. York.

Lozengy or and gu. a canton erm. Neviule or Nevill.

Lozengy vair and gu. a canton of the last. Auncell de Gise, $A$.

Or fretty gu. a canton arg. NoEL, co. Stafford, temp. Henry II, quartered through De Dunston, by D'Oyley.

Or a canton erm. Symonds.

Or a canton indented in the bottom gu. BESYNRURGH.

Or billety sa. a canton erm. Sr. Walter Tonke, co. Nottingham, temp. Edward I, (an error in) $W$. Tonke or Touke, $V^{*}$.

Or fretty gu. a canton erm. Nevilu. Noer, Luffenham, Rutland, 1730, a descendant of NoEl, Baronetcy 29 June 1611 extinct 1629, Barony 23 March 1616-17. Baron Hicks and Viscount Campden 5 May 1628, Baron Noel 3 February 1681, Earl of Gainsborough 1 December $1682, Z, 372$ c, extinct 1798 , Baronetcy 1781 , Baron Barham 1 May 1805, Baron Noel Viscount Campden and Earl of Gainsborough $16 \mathrm{Au}$ gust 1841, quartering Middleton. NoEL, for. merly NeviLL, Wellingore, co. Lincoln. Noveld, London, 1652.

Or fretty gu. a canton of the second. Novembe.

$\mathrm{O}^{2}$ fretty of six and a canton gu. a label of five points az. ZenviliL.

Or fretty sa. a canton gu. VERNON.

Or fretty gu. a canton per pale erm. and arg. Neviril.

Or a canton sa. Geoffrey RideL, Bishop of Ely 1174-89.

Or fretty gu. a canton sa. OdDESTEN, co. Leicester.

Paly of six arg. and az. a canton erm. a crescent for diff. ..... SHorLEy, Enfield.

Paly of six arg, and az. a canton gu. Brabley. Sr. Sampson de Straunley, $V$. Straunly, $V *$.

Paly of six arg. and az. a canton gu. a martlet for diff..... Mencroft.

Paly of six arg. and gu. a canton erm. Shurley, Whiston Place, Sussex.

Paly of six or and az. a canton arg. Holmes.

Paly of six or and az. a canton erm. Joan de Clinton, $E$. Churlex, Kent. Sr. Raufo Sheriey, $V$. Walter Augustus Shirley, Bishop of Sodor, etc. 1846-7. SHIRLEY, $V^{*}$. M. Hugh de Shirleye, $S$. Shirley, Baronetcy 22 May 1611, Baron Ferrers 14 December 1677-171\%, Viscount Tamworth and Farl Ferrers 3 September 1711. SHirisy, Astwell, co. Northampton; and Stanton Harold, co. Lancaster, $Z, 237$.

Paly of six or and az. a canton gu. BLabey. Blaby, $V^{*}$. 


\section{CANTON cont.}

Paly of six or and gu. a canton erm. Raffe Basset, A. Gowshele, Norfolk. KNIGHT, Brockbole, co. Northampton.

Paly of six vair and gu. a canton or. M. Aunsell de Gayes, $D$.

Paly of eight arg. and az. a canton gu. RoBB, Scotland.

Paly of eight or and gu. a canton vair. Bassetr, co. Devon.

Paly of eight or and gu. a canton vert. Bassett. Paly or and gu. a canton erm. Sr. Rauff BaSSET, $H$.

Per chief erm. with barry of six arg. and az. a canton (of the first, another) or. Hotray.

Per chief indented erm. with barry of six arg. and az. a canton or. Hotham, $V$.

Per chief gu. with barry wavy of six arg. and sa. a canton erm. Barlow, co. Derby, $V$.

Per fess indented the chief per pale arg. and az. the base or a canton gu. Candier, Norfolk; Suffolk; Acomb, co. York; and Callan, co. Kilkenny; quartering Ayscough.

Per pale arg. and gu. a canton sa. Sparshotr.

Per saltire gu. and az. billety or a canton ermine. CONANT ; quartering Stainsby.

Quarterly or and gu. a canton sa. Briggs.

Sa. fretty and a canton arg. HALES. HAULEY, co. Devor, $V$.

Sa. goutty and a canton arg. Dannant or Dannat, co. Salop; and co. Warwick. Sr. de Dannet, $V$, Cotton MS. Tiberius D 10. Sir John DANET, $V$.

Sa. billetty or a canton erm. SeymantFor. Sir Walter THONKE, $I$, but Tonke, I, Harl. MS. 6589 . Toncks or Tonkes, co. Nottingham. Sr. Walter ToNkE, co. Nottingham, temp. Edward I, V, Cotton MS. 'Tiberius D 10. Sire Walter Touk, $N$. Towne, co. Nottingham.

Sa. goutty arg. a canton erm. DANNETT, Watsthorpe, co. Leicester. Dennet, London.

Sa. goutty erm. a canton of the second. DanNeTt, London.

Sa. goutty or a cantou erm. DaNNET or D $D_{\text {ANNETT, }}$ London.

Sa. platy and a canton erm. Henry Mustel, $F$. SOlBURNe, $V$.

Vair a canton gu. John Files, $F$. Filiolu, Woodlands, co. Dorset; and Owldhall, Essex. FILLIOL, $V^{*}$. Sire Johan FILOL, $N$. Joan FILOLL, E, or FILEI, E, Harl. MS. 6137. Sr. William Frlloll, $V$. Walter Marmyon, $V$. Mermiton, $V^{*}$. Mirnor.

Vairy arg. and ermines a canton gu. Stanton, co. Bedford; and co. Leicester.

Vairy arg. and sa. a canton gu. Estanton. Sire William de Estauntone, $N$. Elias de Stanton, $V$. Helias de Stauntone, $E$. Staunton, Staunton, co. Leicester.

Vsiry erm. and ermines a canton gu. Stanton, co. Stafford.

Vairy or and sa. a canton gu. Stanton or Staunton, co. Somerset.

Vert a canton az. Follyold, co. Dorset.

Vert a canton gu. Woodburne.

Vert fretty arg. a canton gu. SALKELD, Whitehall, Cumberland.

CANTON and in chief.... see also on a Chief a Canton
Chief

Barry of six arg. and az. a chief erm. and a canton (of the first, another) or. Hothasr.
CANTON and in chief.... cont.

Chief cont.

Barry of six arg. and az. a chief indented erm. and a cantun or. Hotham, $V$.

Barry wavy of six arg. and sa. a chief gu. and a canton erm. BarLow, co. Derby, $V$.

Coronet

Barry of six or and az. a canton erm. in chief a ducal coronet sa. GOWCELL.

\section{CANTON and BORDURE}

see ulso a Quarter and Bordure

Az. a canton or within a bordure gu. DAwndeey.

Az. a canton or within a bordure gu. bezanty. Dandelieigh. DaNDeleey, $V *$.

Bendy paly or and az. a canton erm. and bordure gu. Buck, co. Lincoln.

Chequy or and az. a bordure gu. over all a canton erm. Dreux-Bretagne. Peter Capet de Dreux, Duke of Bretagne, Earl of Richmond 1219.36; and his son John, Earl 1268; and his son John, Earl 1268, husband of Beatrice second daughter of Henry III; and his son Arthur, Duke of Bretagne; $Z, 93$. Countee de Richiond, $D$.

Chequy or and az. a canton erm. within a bordure gu. Richmond, $V^{*}$.

Chequy or and az. a canton erm. a bordure gu. charged with eight lions pass. of the first. Brittaine, $V^{*}$. The canton orer the bordure. Britton, Harl. MS. 5803.

Chequy or and az. a bordure gu. charged with eight lions pass. guard. of the first a canton erm. S:. John de Bretaigne, younger son of Beatrice second daughter of Henry III, $H$; and $N$, Harl. MS. 4033. The canton within the bordure. Britayne. Brytayne.

Chequy or and az. a bordure gu. charged with eight lions pass. guard. of the first a canton erm. John de Bretaigne, $K ; i$. e. John de Dreux, younger son of Beatrice second daugh. ter of Henry III; and his nephew John, 1334; whose half-brother John was Earl 1341-2; and his son John de Montfort was Earl 1372.83 or $1390, Z, 94$. Le countye de RUGeMounde, John de Brytaine, 1306, Earl of Richemond, $N$, Harl. MS. 6137. The canton within the bordure. Bretaigne.

Erm. a cauton chequy or and az. within a bordure gu. charged with eight lions pass. guard. of the second. Bretayne.

Gyronny of eight or and sa. on a bordure gu. as many escallops of the first a canton also gyronny of eight erm. and gu. CAMPBELL, Sorn. beg, and Barquharrie, descended like CAMFPBELL, Fairfield, from CAMPBELL, Cessnock, co. Ayr; and Treesbank, co. Arggll.

Per fess gu. and arg. a bordure or charged with eight torteaux over all a canton erm. WOODFIELD.

.... or and gu. a canton erm. and a bordure sa. bezanty. Sr. Captan de Bucher, $H$.

On 1 CANTON see also on a Quarter

\section{Annulet}

Barry nebuly of six arg. and sa. on a canton gu. an annulet or. Brockesby, co. Leicester.

Lozengy sa. and arg. on a sinister canton of the first an annulet or. Scholes.

Sa. goutty erm. on a canton of the second an annulei gu. Danet, $V$. 


\section{Annulets \\ On 1 CANTON cont.}

Cantavilla or Cantwell.

Gu. on a canton erm. six annulets or. CaNTwELI, Ireland.

Bars

Arg. fretty gu. on a canton of the first two bars betw. nine martlets three three and three sa. Quatred, lreland. Quaytrell or Quaytrod.

Beast .... Badger

Chequy arg. and sa. on a canton vert a brock pass. ppr. Broоке, Haughton, Shiffnal, co. Salop; quartering Townsend.

$$
\text { .....Bear }
$$

Paly of six or and gu. on a canton arg. a bear salient sa. Trotr, London; granted 1574. Trotr, Cony Hatch, Middlesex. (But? ramp.) Persent'Trot, civca 1660, inBlechingleyChurch. .....Boar

Barry of six or and sa. on a canton az. a boar pass. or. Marriott.

$$
\text { .... Deer }
$$

Arg. fretty sa. on a canton az. a (buck, $V^{*}$.) hart courant or. Greene, $V^{*}$. Grene, $V$.

Arg. fretty sa. on a canton of the second a buck pass. or. Grees.

Erm. on a canton az. a (buck, $V^{*}$.) hart lodged or. Dawson, Bishopric of Durham, $W$.

Erm. on a canton az. a stag lodged or. Dawson, co. York. Dawson, Chelmsford.

Erm. on a canton gu. a buck pais. or. Maycote alias MAcKwith, Reculver, Kent; confirmed November 1604 .

Erm. on a canton gu. a (buck, $V^{*}$.) hart trippant or. Sr. Cavalere Maycotr, Kent, $W$.

Erm. on a cantongu. a stag pass. or. MAcked, Kent. ..... Iion

Arg. on a canton gu. a lion pass. arg. Lile, $V^{*}$. Si. John LyLe, of the North, $W$.

Az. fretty gu. on a canton of the second a lion ramp. as the first. Bellinghair, $V^{*}$.

Arg. on a canton gu. a lion pass. or. Dunstavile.

Ary. fretty gu. on a canton of the second a lion pass. or. Waiter de Dota'vile, $A$. Sr. Walter Dunstavill, Baron of Castelcombe and lord of Colerne and Heytesbury, $V$. But the lion pass. guard. Waiter de Donstanvile, $A$, Harl. MS. 6137.

Arg. on a canton gu. a lion pass. guard. or. Fitz-Roy, natural son of Henry I.

Arg. fretty az. on a canton or a lion ramp. sa. George Cotes Cottes or CotTs, Bishop of Chester 1554.5.

Arg. fretty az. on a canton sa. a lion ramp. or. Cotes, co. Buckingham. Cotes, Elson, co. Leicester.

Arg. on a canton vert a lion ramp. or. Monser Thomas Norton, $W$.

$A z$. on a cauton arg. a lion pass. guard. gu. Bulcosk.

Barry of five arg. and gu. on a canton of the first a lion pass. .... Bellingham.

Barry of five az. and arg. on a canton as the second a lion ramp. gu. Grey.

Barry of six arg. and az. on a canton or a lion ramp. sa. GreY, $V$.

Barry of six arg. and gu. on a canton as the first a lion pass. like the second. BellingHari, Cranche Hall, co. Durham.

Barry of six arg. and gu. on a canton as the second a lion pass. like the (second, $V^{*}$.) first. BeLlinghaM, $V$.

\section{On 1 CANTON cont.}

Beast cont. Lion cont.

Barry wavy of six or and az. on a canton gu. a lion pass. of the first. Holnes, Rampton, aud Retford, co. Nottingham.

Barry wavy of six or and az. on a carton gu. a lion pass. guard. of the first. HoLmes, Kilmallock, Baron Holmes 1760 and 1797! the coheirs m. Worsley, Holmes, and Pushworth. Holnes, Pidford Huuse, and Newport, co. Hants; quartering Worsley. HoLmes, quartering A'Court.

Barry wavy of seven arg. and az. on a canton gu. a lion pass. or. Holmes.

Barry of eight az. and arg. on a canton gu. a lion pass. or. Hares. The lion ramp. or. HADYS.

Barry of ten arg. and az. on a canton gu. a lion pass. guard. or. HALYs, Harwich, $Z, 206$.

Barry of ten arg. and gu. on a canton as the second a lion pass. guard. or. CaUtafeld, Benown, co. Roscommon. CaUlfield, Raheeuduff, Queen's County ; and Clone, co. Kilkenny ; descended like CaULfierd, Mulliutain, co. Tyrone; from CaUlF1ELD, Baron Caulfield 22 December 1620, Viscount Caulfield 8 October 1665, Earl of Charlemont 23 December 1763.

Barry of fourteen arg. and az. on a canton or a lion pass. gu. HALYs, $V^{*}$.

Bendy of six arg. and gu. on a canton as the first a lion pass..... BELLing HaMr.

Bendy of six arg. and gu. on a canton as the first a lion pass. sa. THompson, Lord Mayor of London 1737.

Bendy of ten az. and or on a canton arg. a lion pass. guard. gu. Posselou, $V^{*}$. Posselow.

Bendy of ten or and az. on a canton arg. a lion pass. guard. gu. Passelton, Essex.

Bendy or and az. on a canton arg. a lion pass. guard. gu. Sire Johan Passelev, $N$.

Chequy arg. and az. on a sinister canton of the first a lion ramp. as the second betw. eight crosses croslet sa. Town of Lewes, Sussex.

Chequy az. and or on a canton erm. a lion ramp. gu. Fincher.

Chequy az. and or on a canton gu. a lion ramp. arg. WalLER, Ireland. Sir William W Chequy or and az. on a canton arg. a lion ramp. gu. Warren.

Chequy or and az. on a canton gu. a lion ramp. urg. Poynton, co. Chester. Warren, Burgh Castle, Suffolk. Warren, Aldenham, co. Hertford. Warren, Poynton, co. Chester; derived from Warren Earl of Surrey, quartering Eton. Warren, Baron de Tabley. Warren, Little Marlow, co. Buckingham ; Baronetcy 20 May 1775, extinct 1822. Sir George Warren, K.B. 26 May 1761; quartering Eton, Stokeport,

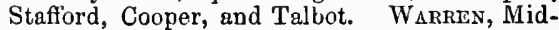
dlesex. And with a mullet enclosed by an annulet in the centre for diff.... W W Harrow, Middlesex; and Aldenham, and Colmye, co. Hertford; a branch of WARnen, Poynton, Harl. MS. 123t, fo. 136 ; 1501, fo. 159 ; 1547 , fo. $95 \mathrm{~b}$.

Chequy or and az. on a canton gu. a lion ramp. arg. gorged with a collar dancetty of the se. cond. Warren, Baron Vernon.

Chequy or and az. on a canton gu. a lion ramp. of the second. WARREYN, $V *$.

Chequy or and az. on a canton gu. a lion ramp. erm. Sir William Warres, $Q$, Harl. $M S$. 6595 . 


\section{On 1 CANTON cont.}

Beast cont. Lion cont.

Chequy or and az. on a canton gu. a lion ramp. double tailed within a bordure erm. Warren, Poynton, co. Chester; St. Alban's and Harden, co. Hertford; and London, Harl. MS. 1546, fo. 54 .

Chequy or and az. on a canton gu. a lion ramp. donble tailed of the first. WALLER, Lisbrian, co. Tipperary.

Chequy or and az. on a canton gu. a lion ramp. of the first within a bordure erm. WARREN, Poynton, co. Chester ; St. Alban's and Harden, co. Hertford; and London, Harl. MS. 1501, fo. 62 .

Chevronelly of six gu. and erm. on a canton gu. a lion pass. or. OrReBy, quartered by Holte.

Chevronelly of seven erm. and gu. on a canton of the last a lion pass. or. Oreby. Orreby, $V^{*}$.

Chevronelly of nine erm. and gu. on a canton of the last a lion statant or. Sr. Phillip OrREBY, Justiciary of Chester, temp. Henry III, $V$.

Gu. fretty arg. on a canton of the first a lion ramp. as the second. Beling giali, $V$.

Gu. fretty or on a canton of the second a lion pass. sa. Rebehont or Rebiront. Relement.

Paly of (six, $I^{*}$.) seven arg. and gu. on a canton as the last a lion pass. guard. like the first. LongCaster, $V$.

Per pale az. and or on a canton arg. a lion ramp. gu. Iles.

Vairy arg. and sa. on a canton gu. a lion pass. guard. or. Stanton, London.

$$
\ldots .0 x
$$

Barry of six gu. and arg. on a canton as the second a calf sa. DEANE.

Barry of seven gu. and arg. on a canton as the second a bull pass. like the first. DEane. ....Rat

Paly of sis or and gu. on a canton arg. a rat salient sa. Tkat, Cornwall.

$$
\text { ..... Sheep }
$$

Per fess embattled arg. and gu. on a canton vert a golden fleece ppr. VANDERPLANK, London. Beasts

Sa. fretty erm. on a canton gu. three (leopards or) lions pass. guard. arg. Matrevers.

$\mathrm{Sa}$. fretty or on a canton gu. three lions .... arg. Walter de Maltrevers, $A$. The lions pass, in pale. William Mautraveres, $E$, or Matreverse, E, Harl. MS. 6137.

Sa. fretty or on a canton gu. three lions pass. in pale of the second. William (Mautravers in a later band), $F$.

\section{Bend}

Gu. on a canton or a bend of the first. Godfrey, Wilmington, Kent.

Vairy or and gu. on a canton az. a bend arg. betw. two cotises and six lions ramp. of the first. Sir Thomas de Ferrers, $L$.

Gyronny of eight or and sa. on a canton alg. a bend sa. betw. in chief an unicorn's head erased and in base a cross croslet fitchy gu. CAmprelt, Barcaldine and Gienure, co. Aigyll; Baronetcy 1831, quartering or a fess chequy arg. and az., with arg. a lymphad sa., and gyronny of eight or and sa. a canton gu. charged with two bars or the whole within a boldure quarterly or and sa.

Gu. on a canton .... a bend sa. charged with three eagles displ. or. Conling.

\section{Billets}

On 1 CANTON cont.

Az. billety or on a canton arg. five billets in saltire sa. Gerard de Ffanecurt, $Y$.

Barry of five or and az. on a canton arg. five billets sa. Jugler, Ryegate, Surrey.

Barry of six or and az. on a canton arg. five billets in saltire sa. Inglos, $V$. YNGioYs.

Barry of seven or and az. on a canton arg. five billets sa. INGLos.

Bird

Az. billety or on a canton of the second a bird (? raven) close sa. Robert Blundell, $F$.

Chequy az, and or on a canton sa. a bird arg. HODDY or HoDY.

Gu. on a cantou arg. a bird wings expanded and inverted sa. HuTTON.

Or fretty sa. on a canton gu. a bird of the first. Brakenbury, Kent.

Paly of sis arg. and az. on a canton or a bird gu. Meduerst, $V^{*}$.

$$
\text { ....Crow }
$$

Az. billety or on a canton of the last a raven ppr. BLUNDEL, Cardington, co. Bedford; Baronetcy 13 October 1620 Baron Edenderry and Vis. count Blundel 22 November 1720 ; extinct 1756 . (? Robert Blundeli, F.)

$$
\text { .... Eagle }
$$

Barry of ten arg. and az. on a canton or a Cornish chough ppr. Нотнам, Baronetcy 14 June 1621, Baron Hotham 7 March 1797.

Az. on a canton arg. an eagle displ. gu. WAY.

Barry of eight arg. and az. on a canton of the second an eagle displ. double-headed or. Greenstreet, co. Hants; and Ospring, Kent ; granted 23 June 1642; quartered by Addi. son.

Or on a canton gu. an eagle displ. of the first. $\mathrm{J}_{\triangle \mathrm{COB}}, 4 d d$. $M S .5480$, fo. 232.

Vert on a canton gu. an eagle displ. or. JACOB, co. Kildare.

$$
\text { .... Falcon }
$$

Erm. on a canton az. a falcon volant or. BREREs, Chorley, co. Lancaster.

Or on a cauton az. a falcon volant of the first. Thurston, Wenman, Suffolk, 1716.

Or on a canton az. a falcon volant jessed and belled of the first Thurstone, Elston, co. Hurtingdon.

Or on a canton az. a hawk rising of the first. (Attributed to) Thurstan, Archbishop of York, 1119.40 .

$$
\text { .....Martlet }
$$

Arg. fretty sa. on a canton gu. a martlet of the first. Marchington, $V$. Vernon.

Barry of five arg. and az. on a canton as the last a martlet (sometimes arg. but) or. LAtHBURY, $V^{*}$; and Holme, co. Derby; Visitation 1611. LATHEBURY, $V$.

Barly of six arg. and az. on a canton as the second a martlet or. LATHBURY, co. Lancaster, and co. Leicester.

Barry of six sa. and arg. on a canton like the first a martlet as the second. THorow.

Barry of seven arg. and az. on a canton of the second a martlet or. Lathebury, $V$.

Bairy of eight arg. and az. on a canton sa. a martlet or. Hотнам.

Barry of eight az. and arg. on a canton or a martlet sa. John de Hothum, Bishop of Ely, 1316.37.

Barly of eight sa. and gu. on a canton as the first a martlet arg. THOROLD. 
On 1 CANTON cont.

Bird cont. Martlet cont.

Barry of fourteen arg. and az. on a canton or a martlet sa. Sir John Hothanr, co. York, $V$. Hotham, Bendby, co. York, $V$.

Erm. on a canton gu. a martlet or. Barton.

Gu. on a canton arg. a martlet sa. Hotтon, Cumberland. Espinasse or Esspinassf.

Paly of six arg. and az. on a canton like the second a martlet as the first. Mednerst.

Paly of six arg. and az. on a canton gu. a martlet as the first. Stranlay.

Paly of six az. and arg. on a canton gu. a martlet as the second. Stranley, $V^{*}$.

Per fess embattled arg. and az. on a canton or a martlet sa. Hотнам.

Vairy arg. and gu. on a canton of the first a martlet sa. Beche. BEEcH.

$$
\text { ... O Owl }
$$

Erm. on a canton gu. an owl arg. Barton, $V^{*}$.

Erm. on a canton gu. an owl or. BARToN.

Erm. on a canton sa. an owl arg. Barton. Forster, $V^{*}$.

Per chief erm. and arg. on a canton gu. an owl of the second. Barton.

Per fess erm. and arg. on a canton gu. an owl or. Barton.

\section{... Pelican}

Erm. on a canton az. a pelican or. Pelt, Norfolls.

Erm. on a canton az. a pelican or vulued gu. PeLL, Dimblesby, co. Lincoln; and Dersingham, Norfolk; granted 19 October 1594.

Erm. on a canton or a pelican vulning herself gu. PeLL, Norfolk; and co. Lincoln.

$$
\text { .... Popinjay }
$$

Paly of six arg. and az. on a canton or a popinjay gu. Meduerst, $V^{*}$.

\section{Birds}

Arg. on a canton az. six martlets or. RuDD or Rudde, Essex; and co. Lincoln.

$\mathrm{Gu}$. fretty arg. on a canton (i.e. for BRecknoke, Cotton MS. 'Tiberius D 10) barry of six arg. and az. martlets in orle as the first. BaptHonp, $V^{*}$. BAPTHORPE, $V$. BRECKNOKE, (an error in) $W$. Buckle

Arg. on a canton gu. a round buckle of the first. MAGGot, Kent.

Building

Barry of six arg. and gu. on a canton as the first a column sa. Deale.

Castle

Barry of six gu. and arg. on a canton of the last a tower triple-towered .... DENE.

Barry of seven gu. and arg. on a canton of the last a tower triple-towered sa. DEALE, Fevers. ham, Kent.

Bendy arg. and sa. on a canton of the second a castle as the first. CARREI.I.

Chessrook

Chequy arg. and vert on a canton gu. a chessrook of the first or. Chesham, $V$. The chessrook or. Chesham, $V$.

\section{Cherron}

Erm. on a canton arg. a chev. gu. William de Miodleton, Bishop of Norwich 1278-88.

Erm. on a canton gu. a chev. or. MidLeton.

Erm. on a canton or a chev. gu. Medilton, $V^{*}$. MELDILTON, $V$.

Coronet

Arg. on a canton gu. a ducal coronet or. Lucas, 1730.

Arg. on a canton sa. a ducal crown or. Lucas, Cornwall. Lucas, $V^{*}$.

\section{On 1 CANTON cont.}

\section{Coronets}

Arg. on a cauton sa. three ducal coronets in bend or. Hillon. Hulson, $V^{*}$.

Crescent

Arg. on a canton gu. a crescent of the first. TutTe, co. Hants; and Chichester, Sussex.

Arg. fretty sa. on a canton gu. a crescent of the first. Rudyend, Hartley, co. Hants, quartering Kidwelly and Maddox, a heiress m. Shipley; descended from Rudyerd, Rudjerd, co. Stafford.

Az. on a canton arg. a crescent gu. CHEYne, Sheppey, Kent, Add. MS. 14307, fo. $11 \mathrm{~b}$.

Barry nebuly of six arg. and sa. on a canton gu. a crescent as the first. KEBLE, Homerston, co. Leicester.

Barry nebuly of six arg. and sa. on a canton gu. a crescent or. KEBLE, co. Leicester.

Erm. on a canton sa. a crescent arg. STRode, Parnham, co. Dorset; the heiress m. Oglander. Strode, Shepton Mallet, co. Somerset, quartering Chetham; descended from Strode, Parnham, quartering Ledred. Stroud, Parnam, co. Dorset, $W$. Stroude, $V^{*}$.

Gu. bezanty on a canton erm. a crescent for diff. az. Sr. John Zouct, Codnor, co. Derby, $V$. Sr. Yvan de la Zouch, $I$; but Eudes, $I$, Har'. $M S .6589$; or Ymes, I, Harl. $M S .6589$ fo. 50 b. Le S. la Zowche, $S$.

Gu. bezanty on a canton erm. a crescent of the first. Zouch, Gosberikirke, co. Lincoln.

Or on a canton gu. a crescent arg. Howly.

Paly of six arg. and az. on a canton or a crescent sa. Lathbury, co. Derby.

\section{Crescents}

Arg. on a canton of the first two crescents gu. SтоpHaM.

\section{Cross}

Arg. fretty gu. on a canton az. a cross patty or. Maleanke, co. Stafford.

Arg. fretty gu. on a canton barry of eight arg. and az. (gu. and or, BABTHORP, $V^{*}$ ) a cross patty gold. Bapthorpe, Sussex, $V$.

Arg. on a canton gu. a cross or. Bradeston. Thomas Bradstone, Norfolk, $V$.

Az. fretty or on a canton gu. a cross moline arg. Momby, Momby, co. Lincoln, $V$. WILLOUGHBX.

Barry of five or and az. on a canton gu. a cross flory arg. ATton.

Barry of six arg. and gu. on a canton sa. a cross fiory as the first. ЕTON or ЕтTON.

Barry of six az. and or on a canton gu. a cross archy (another patonce) arg. AtTon.

Barry of six erm. and gu. on a canton as the last a cross or. Hussey, Baron of Galtrim 1374. Hussey, Earl of Beaulieu ; Hussey, Westown, co. Dublin.

Barry of six or and az. on a canton arg. a cross gu. Cox.

Barry of six or and az. on a canton gu. a cross flory arg. Vescy.

Barry of six or and $\mathrm{az}$. on a canton gu. a cross patty arg. AxToN.

Barry of six or and gu. on a canton erm. a cross as the second. Gatfield.

Barry of seven arg. and gu. on a canton sa. a cross formy or. Ecton.

Barry of seven az. and or on a canton gu. a cross patonce arg. Atton, $V$.

Barry of seven or and az. on a canton gu. a cross patonce arg. DE Aton, 1324. 
On 1 CANTON cont.

Cross cont.

Barry of eight arg. and gu. on a canton sa. a cross or. Eтry. ETy, co. York.

Barry of eight arg. and gu. on a canton sa. a cross patonce for diff. or. Sr. John de EтTon, 1425, V. Ecton.

Barry of eight or and az. on a canton sa. a cross patonce for diff. as the first. Sr..... de EтTon, $V$.

Barry of ten arg. and gu. on a canton sa. a cross patonce or. ETON or ETTON, Gilling, co. York.

Bariy of twelve arg. and gu. on a canton sa. a cross patonce or. M. de ETton, $S$.

Barry of fourteen arg. and gu. (gu. and arg. $V^{*}$.) on a canton sa. a cross patonce for diff. or. Sr. John EtTon, $V$.

Erm. on a canton .... a cross lozengy .... John Arunder, Harl. MS. 380, fo. $123 \mathrm{~b}$.

Erm. on a canton gu. a cross moline or. LewLo, co. Hereford.

Ern. on a canton vert a cross calvary on three grieces or. Quamis.

Gu. fretty or on a canton .... a cross patty .... Henry de Aiditeleley or A UdLey, Baron Aud. ley of Heleigh, temp. Henry III.

Gu. on a canton arg. a cross flory az. Aguilium or Agullun, co. York, $V$. Ripers.

Gu. on a canton arg. a cross flory sa. Agorion or AgulLuN, co. York.

$\mathrm{Gu}$. bezanty on a canton or a cross sa. WASHBORNE.

Lozengy erm. and gu. on a canton az. a cross moline or. Monbernay, $V^{*}$.

Lozengy gu. and erm. on a canton az. a cross moline or. Monbernay, $V$. Monburnay, $V^{*}$. The cross sarcelly or. Montbernay.

Or fretty gn. on a canton arg. a cross patonce az. Draycott, co. Stafford.

Or fretty gu. on a canton az, a cross patonce arg. Maldbanke, co. Stafford.

Or fretty az. ou a canton gu. a cross moline arg. William fitz Robert de WILUGHBY, $V$. WILLOUGHBY, $V^{*}$.

Or fretty az. on a canton gu. a cross patty arg. Mumby, co. Lincoln.

Or fretty az. on a canton gu. a cross moline of the first. Momby, $V^{*}$.

Paly or and gu. on a canton arg. a cross patty sa. Rafe Basset, $C$.

Sa. fretty arg. on a canton gu. a cross patonce or. Henry WAKEFELD, Bishop of Worcester ]375$95, V$.

Vairy arg. and sa. on a canton gu. a cross formy fitchy or. Staunton, co. Lincoln; granted 1610.

\section{Crosses}

Arg. on a canton sa. three crosses croslet fitchy of the first. SHORTHOSE.

\section{Cup}

Arg. on a canton sa. a covered standing cup of the first. Chichester, $V^{*}$; co. Devon.

Erm. on a canton sa. a covered cup arg. John Chichester, Lord Mayor of London 1369, W. Chichester, co. Devon.

Gyronny of eight or and sa. on a canton gu. a covered cup as the first. STretley, Stripton, co. Northampton; and co. Oxford.

Gyronny of twelve or and az. on a canton gu. a covered cup as the first. KirTon, co. Lancaster.

\section{Cup cont.}

On I CANTON cont.

Gyronny of twelve or and sa. on a canton gu. a covered cup as the first. KIRKsLow Kirkstowe ol Kinstow, co. Lancaster. Krrslow, $V^{*}$. ROAN, $V^{*}$.

Vairy arg. and gu. on a canton of the second a covered cup or. BEcHEE.

Escallop

Barry of six or and az. on a canton arg. an escallop gu. HoLmes.

Barry of six or and sa. on a canton as the first an escallop gu. Hormes.

Escucheon

Barry of six arg. and sa. on a canton erm. art escucheon as the second. Marshall, Michelham, and Lewes, Sussex.

Erm. on a canton gu. an escucheon arg. Surkas or SuRteis, Durham.

Erm. on a canton gu. an escucheon voided arg. Beulex. Coortors or Courtoys. Courtors. Surtees. Surteyes, $V *$. Surteys, $V$.

Erm, on a canton gu. an escucheon of the first. Surkas or Surteis, Durham.

Erm. on a canton gu. an escucheon voided or. Surtees or Surteys.

Estoile

Bendy wavy of six erm. and az. on a canton gu. an estoile or. Bendall, Middlesex; granted 1692.

Erm. on a canton sя. a five-pointed estoile arg. Sir William de Strode; Collinson, Somerset, ii, 209,210 , iii, 35 .

$\mathrm{Gu}$. fretty or on a canton of the first a six-pointed estoile as the second. Pors, $V^{*}$. Eye

Vert on a canton arg. an eye ppr. Walker, Barbadoes.

\section{Flear-de-lis}

Arg. on a canton az. a fleur-de-lis or. Sтrch, co. Chester.

Arg. on a canton sa. a fleur-de-lis or. Agmondesham, $V^{*}$. Agmondesham, co. Buckingham, 1730. Aunshasr, $V^{*}$. Awnsam.

Az. fretty arg. on a canton or a flemr-de-lis gu. SoMdry. SoMery, A, Harl. MS. 6137.

Az. fretty erm. on a canton or a fleur-de-lis gu. Campion, London.

Az. fretty or on a canton of the last a fleur-de-lis gi. Symone de Somery, $A$.

Barry of six erm. and sa. on a canton az. a fleur. de-lis or. Comberbach.

Barry of six erm. and sa. on a canton or a fleur. de-lis gu. Cumberledge, co. Stafford.

Barry of six or and sa. on a canton like the first a fleur-de-lis as the last. Marryatr, London.

Barry of six or and sa. on a canton like the last a fleur-de-lis as the first. MANiot.

Barry of seven arg. and az. on a canton gu. a fleur-de-lis or. Marriot.

Barry of seven arg. and sa. on a canton as the second a fleur-de-lis or. Meryett.

Erm. on a canton sa. a fleur-de-lis or. Agmondesham, $V^{*}$. Ansait, $V^{*}$. Anselme, Middlesex. Aunsam. Ensam, $V^{*}$.

Gu. on a canton arg. a fleur-de-lis sa. NEwport, co. Stafford. NEWPORT, $V^{*}$.

Gu. on a canton erm. a fleur-de-lis sa. Newport.

Gu. on a canton sa. a fleur-de-lis arg. NEwPort, $V$ *.

Gyronny of eight arg. and az. on a canton gu. a fleur-de-lis or. PIckarn 


\section{On 1 CANTON cont.}

Fleur-de-lis cont.

Gyronny of eight az. and arg. on a canton gu. a fleur-de-lis or. PICARd or PICkand, Lord Mayor of London 1356.

\section{Fleurs-de-lis}

Arg. on a canton az. two fleurs-de-lis in chief and a rose in base of the first. HARDING.

\section{Flower}

Arg. on a canton gu. a rose of the first. Broadstone.

Arg. fretty sa. on a canton gu. a rose of the first. RuDYard or RudYer.

Arg. on a canton gu. a rose or. Sr. Thomas Bradstone, $Q$. Sr. .... de Bradstone, $V$. INGLETHORPE.

Arg. on a canton gu. a rose or barbed ppr. Bradeston or Bradston, Bradeston, Stinchcombe, and Winterborne, co. Gloucester.

Arg. fretiy sa. on a canton gu. a rose or barbed vert. RUDGer.

Barry of five or and az. on a canton erm. a rose gu. Holmede, co. Chester.

Barry of (five, Harl. MS. 6595) six arg. and gu. on a canton as the second a rose or. Sr. Thomas Lancaster, $Q$, but in the margin Gu. a lion ramp. guard. or collared az.

Barry of six az. and or on a canton arg. a rose gu. HoLmes.

Barry of six or and az. on a canton arg. a rose for diff. gu. Sr. de Holmes, $V$.

Barry of six or and az. on a canton erm. a rose gu. seeded or barbed vert. HoLme, Tranmere, co. Chester.

Barry of six or and sa. on a canton arg. a rose gu. Holmes.

Gu. on a canton arg. a rose of the first. CoAPE. Flowers

Barry of six or and az. on a canton arg. three roses gu. Holmes, co. Lancaster.

\section{3-Foil}

Barry of four or and gu. on a canton as the second a 3-foil slipped like the first. VINCENT, co. York.

Barry of five arg. and gu. on a canton as the second a 3-foil slipped or. VINCENT, Barnborough Grange, and Braithwell, co. York.

\section{5-Foil}

Arg. fretty sa. on a canton gu. a 5-foil for diff. or. Sire Thomas de ErebY, N. Sr. Thomas IREBY, Cumberland, $V$.

Arg. on a canton gn. a pierced 5 -foil or. Bradston.

Barry of five arg. and gu. on a canton like the second a 5-foil as the first. BECKINGHAM, Essex; and co. Berks. Preston, $V^{*}$. The 5-foil or. Preston, $V^{*}$.

Barry of five arg. and sa. on a canton as the second a 5-foil or. TwYFord, $V^{*}$.

Barry of five erm. and gu. on a canton as the second a pierced 5-foil or. Sr. Richard Preston, co. Westmoreland, $V$.

Barry of six or and az. on a canton arg. a 5-foil for diff. gu. in chief a mullet as the second. Holdies.

Barry of eight gu. and arg. on a canton like the first a 5 -foil as the second. Beckingham, $V^{*}$.

Barry of nine arg. and gu. on a canton like the first a pierced 5 -foil as the second. Beckingham, $V$. Bekingham, $V^{*}$.

Erm. ou a canton sa. a 5-foil or. Berford, $V^{*}$. BoRFORD, $V^{*}$.

Gu. on a canton arg. a 5 -foil of the first. RIKY, Ireland.

\section{5-Foil cont.}

On 1 CANTON cont.

Gu. bezanty on a canton arg. a 5-foil sa. Thomas Boterel, $F ; V$. Botterell, $V^{*}$.

Paly of six arg. and az. on a canton gu. a 5-foil or. Stadlega. Stradley. Straley. Strelley. Stretlega.

Vert fretty or on a canton of the second a pierced 5 -foil az. Whitaore, London. 5-Foils

Gu. three 5-foils arg. Farington or FARRIngton, London. Fruit

Gu. fretty or on a canton az. two enrs of wheat slipped without blades of the second. WHYsiaw, Lees, co. Chester. Garb

Barry nebuly of seven (nine $V^{*}$.) arg. and gu. on a canton of the second a garb like the first. Beche, $V$.

Vairy arg. and gu. on a canton of the second a garb as the first. Sr. John Beche, $V$.

Vairy arg. and gu. on a canton of the second a garb or. ВеEсH. ВесHE, $V^{*}$. BrCHe.

\section{Hand}

Arg. on a canton gu. a (dexter) gauntlet (another clasped) or. Topp, Stockton, co. Wilts, 1450; the heiresses m. Everard and Balch. Toppe; Tormarton, co. Gloucester; Baronetcy 25 July 1668 ; extinct .... ; the heiress $m$. Hungerford and Peach.

Arg. fretty sa. on a canton of the last a dexter gauntlet or. MARR, Colchester, Essex.

Harp

Erm. on a canton sa. a harp arg. Francers, $V^{*}$. John Francis, Lord Mayor of London 1400 , $W$. Francis, co. Derby, $W$.

Erm. on a canton sa. a harp arg. stringed or. Frances.

Erm, on a canton sa. a harp or. Francis, $V^{*}$.

Per pale arg. and sa. on a canton gu. a harp or. FARRel or Farrell, Ireland.

Per pale or and sa. on a canton az. a harp of the first. FARrell, Ireland.

Vairy gu. and arg. on a canton or a harp. az. BEAcH, in Netheravon Church, co. Wilts.

$$
\text { Head.... (Beast) Bear }
$$

Gyronny of eight or and sa. on a canton az. a bear's head arg. muzzled gu. CasIPBELL, Carrick Bury, co. Donegal; Baronetcy 1831; quartering arg. a lymphad sa.

$$
\text { .....Boar }
$$

Arg. fretty az. on a canton of the second a boar's head erased as the first langued or. STоKE, $V$.

Arg. fretty az. on a canton of the second a boar's head erased or. STOKE.

Az. fretty or on a canton of the first a boar's head arg. Stoke.

Az. fretty arg. on a canton of the first a boar's head erased as the second langued or. STOKE, $V$.

$$
\text { ....Deer }
$$

Erm. on a canton or a buck's head sa. WeILs, co. Derby.

Vair on a canton or a buck's head cabossed sa. Becher, Kent. Becher, $V^{*}$.

Vairy arg. and gu. on a canton or a buck's head cabossed .... Sir Edward BEAcHer or BECHER, Lord Mayor of London 1728; quartering az. a chev. betw. three lions pass. arg.

Vairy arg. and gu. on a canton or a buck's head cabossed of the second. BEcHER, Chancellor House, Tunbridge Wells, Kent. 


\section{On 1 CANTON cont.}

Head cont. (Beast) Deer cont.

Vairy arg. and gu. on a canton or a (bucls's, $V^{*}$.) stag's head cabossed sa. BEAcH or Becher, Kent; and co. Bedford. Henry Becher, Alderman of Lotidon, $V$. Bisher.

Vairy arg. and gu. on a canton or a stag's head couped sa. Becher, Hollybrook, co. Cork; quartered by Wrixon.

Vairy arg. and gu. on a cantou or a stag's head cabossed vert. BEECHER, granted 6 Oct. 1574.

$$
\text { .....Horse }
$$

Erm. on a canton sa. a horse's head couped arg. with bit and reins gu. Brixton, co. Devon; and Cornwall. Brixton, $V^{*}$.

\section{.... Leopard}

Arg. fretty az. the interlacings each charged with a bezant on a cauton gu. a leopard's head erased at the neck or. LowndEs, from co. Chester, Winslow, Chesham, Whaddon Hall, and Astwood, co. Buckinghan ; Brightwell, co. Oxford; and Rose Hill, Dorking, Surrey.

Barry of six arg. and sa. on a canton as the last a leopard's face or. BABB or BABE. RAvenLech, Essex.

Barry of six arg. and sa. on a canton as the second a leopard's head or. RAVANCE or Reventidge, Essex.

Barry wavy of six arg. and sa. on a canton of the secoud a leopard's head or. BEake, co. Dorset.

Or on a canton sa. a leopard's head of the first. Mingey, Armingale, Norfolk.

$$
\text { ....Lion }
$$

Arg. on a canton gu. a lion's head erased or. MeEcH.

Arg. 'fretty az. on a canton gu. a lion's head erased or. Lowndes, Sandbach, and Hassall Hall, co. Chester; quartering Berington, Kirkby, and Sydebothom. Lowndes, Palterton, co. Derhy; quartering Gorst. Lowndes, Lostock Hall, co. Lancaster, quartering Clayton. Lowndes, Brightwell Park, co. Oxforả, quartering Stone.

Arg. on a canton sa. a lion's head erased or. Bull, London.

Erm. on a canton az. a lion's head erased arg. SEALY.

G11. on a canton arg. a lion's head erased az. DUNNE.

\section{.... Sheep}

Barry of ten arg. and az. on a canton sa. a lam's head couped of the first having two straight and two bent horns or. Clarge. Clarges, Middlesex; Aston, co. Hertford; and Bitch. field Hall, co. Lincoln. The ram's head erased. Clarges, Middlesex.

$$
\text { ....Tiger }
$$

Or on a canton sa. a tigel's head erased of the first langued gu. J J Bassett, co. Wilts.

\section{.... (Monster) Unicorn}

Arg. fretty sa. on a canton per chev, of the second and or an unicorn's head per chev. gu. and gold the horn as the last and sa. Middieton, Crowfield Hall, and Shrubland Hall, Suffolk; Baronetcy 12 May 1804.

\section{Human Figure}

Barry of six or and sa. on a canton gu. a demiwoodman arg. WOODWARD.

Barry of six or and sa. on a canton gu. a demiwoodman with a club on his shoulder as the first. WOODWARD.

\section{On 1 CANTON cont.}

\section{Inkmoline}

Chequy arg. and sa. on a canton of the last an inkmoline as the first. SMallwood.

Chequy arg. and vert on a canton gu. an inkmoline of the first. CHesham.

Leg

Arg. on a canton sa. a lion's gamb erased in bend of the first. Bowtнвy.

Arg. on a canton sa. a lion's gamb erased in bend or. Bowtheny.

Arg. on a canton sa. a lion's paw erased in bend or. BoотнвY, Baronetcy 5 November 1644.

Az. fretty .... on a canton or a lion's gamb erased of the first. Fontechayne. Lure

Arg. fretty engr. sa. on a canton of the last a lure as the first. CaMFIELD.

\section{Maunch}

Arg. fretty sa. on a canton of the last a maunch or. Vernon, Little Beligh, Essex; and co. Nottingham.

\section{Monster}

Paly of eight or and sa. on a canton arg. a griffin ramp. gu. TALAUNT, $V *$. Tallant, $V$. The griffin salient. Talaunt, $V$. Tallant. Mullet

Arg. on a canton gu. a mullet or. ENDFieLD. Enestfield. Enfield, Middlesex.

Arg. on a canton gu. bezanty a mullet or. Sire Bartelmeu de EnEFELD, $N$.

Arg. on a canton sa. a mullet of the first. ENFIELD, Middlesex.

Arg. on a canton sa. a mullet or. Sir Bartholomew de ENFIELD, L, Harl. MS. 6137.

Arg. on a canton sa. a mullet or pierced gu. ENFELD, $V$. ENFIELD, $V^{*}$.

Arg. fretty sa. on a canton of the last a mullet (? for diff.) of the first. InEBY, $V$. The mullet or. IwarbY.

Barry nebuly of five arg. and sa. on a canton gu. a mullet or. BrosesBr. The mullet pierced. Brackesby.

Barry nebuly of five sa. and arg. on a canton gu. a mullet or. Sr. John BrokesBy, co.Leicester, $V$.

Barry of six arg. and gu. on a canton as the second a mullet like the first. Wass, $V^{*}$. Sire William Wasse, $N$. Wasse, $V$. Wash Washe or WASSE, co. Buckingham.

Barry nebuly of six arg, and gu. on a canton as the second a mullet or. Brookesby, brass, 1633, in Stoke Golding Church.

Barry of six arg. and sa. on a canton gu. a mullet or. WOODWARD.

Barry nebuly of six sa. and arg. on a canton gu. a mullet as the second. RokesBy.

Barry nebuly of six sa. and arg. on a canton gu. a pierced mullet for diff. or. Brokesbr, $V^{*}$.

Barry nebuly of seven arg. and sa. on a canton gu. a pierced mullet for diff. or. BrokesBY, co. Leicester, $V$.

Barry of ten arg. and gu. on a canton like the second a mullet as the first. INGLEFIELD.

Barry of fourteen arg. and gu. on a canton like the second a mullet as the first. YNGEFELD, $V$.

Barry of fourteen gu. and arg. on a canton like the first a mullet as the second. INGEFELD, $V^{*}$. INGEFIELD.

Erm. on a canton gu. a mullet for diff. or. Basse r, Collinson, Somerset, i, 148; and Basset, circa $10: 8$, impaling per fess embattled sa. and az. six mullets or, in Claverton Church. Basset, Yetton, $V$. 


\section{On 1 CANTON cont.}

Mullet cont.

Erm. on a canton or a mullet gu. BASSEx, Uliegh, co. Gloucester.

Gu. bezanty on a canton arg. a mullet sa. Sire Thomas la Souche, $N$. Sr. Thomas Zouche, co. Leicester, $V$.

$\mathrm{Gu}$. fretty or on a canton of the first a six-pointed mullet as the second. James de Pors, temp. Edward I, $V$.

Gu. bezanty on a canton or a mullet for diff. sa. ZovсhE, co. Leicester.

Gyronny of eight or and sa. on a canton az. a mullet as the first. BLACKERBY, London; and Shakerland Hall, Suffolk; granted 10 June 1664.

Lozengy gu. and vair on a canton or a mullet for diff. Sa. Sr. John Gise, co. Buckingham, temp. Edward I, $V$. The mullet pierced. GIsE.

Lozengy gu, and vair on a canton or a six-pointed mullet sa. Guise or Gwyse, co. Gloucester. The mullet pierced. Auncel de Grse, $F$.

Or fretty gu. on a canton arg. a mullet sa. Noes, Persall, co. Stafford.

Paly of six az. and arg, on a canton gu. a mullet as the second. Stranley, $V^{*}$. Stanley.

Paly of six az. and arg. on a canton gu. a mullet or. Stanley.

Paly of six gu. and or on a canton arg. a mullet sa. Wells. The mullet pierced. Weries.

Paly of six or and gu. on a canton arg. a mullet sa. WELLES, $V^{*}$.

Paly of seven arg. and gu. on a canton as the first a mullet sa. WeLIs or WerLes, co. Hereford.

Paly of nine gu. and or on a canton arg. a six pointed mullet sa. WeLLes.

Sa. on a canton or a mullet of the first. BuckneL or Brickneli.

Vair on a canton gu. a mullet or. Sr. John Filloll, L; or de Filiold, Harl. MS. 6137. Sire Johan Filou the son, $N$.

Vairy arg. and gu. on a canton az. a mullet .... BEACH or DELABECHE.

Vairy or and gu. on a canton of the second a mullet erm. ANFRONS. Orle

Erm. on a canton gu. an orle arg. Beuley. Coortors Courtors or Courtoys. Scurtors. Surtees. Surteyes, $V^{*}$. Surteys, $T$.

Frm. on a canton gu. an orle or. Suntees or Surteys. Surtees, co. Durham; and North. nmberland. Sortees, Hedley, quartering Aubone or Albany. Surters, Redworth, and Ma. nisforth, quartering Lambton.

Pale

Or on a canton az. a pale engr. erm. betw. six bezants two two and two. WOLD, $V$. Pheon

Erm. on a cauton sa. a pheon arg. Midremone, $V^{*}$.

Gu. fretty arg. on a canton or a pheon of the first. Hugres.

Paly of six arg. and vert on a canton gu. a pheon or. Langlser, Brokley, co. Salop. Pile

Vairy arg. and gu. on a canton az. a pile or, Beach, Nether Avon, co. Wilts.

\section{Pillar see Building}

\section{Rowel}

Paly or and gu. on a cauton az. a rowel arg. Gauter Bertant (Bertran, Harl. MS. 6589), C.

\section{Saltire}

On 1 CANTON cont.

Arg. on a canton sa. a saltire of the first. Chancellour.

Chequy or and gu. on a canton az. a saltire or. Sir William WARREN.

Erm. on a canton arg. a saltire engr. sa. GEFFE or GefFy. Geoffery.

Erm. on a canton gu. a saltire or. JEFFs.

Erm. on a canton sa. a saltire engr. arg. GEFFY, V. JEFFREY.

Erm. on a canton sa. a saltire or a martlet for diff. GEFF, Huborne, co. Berlss ; granted 1 April 1579. Ship

Or fretty gu. on a canton arg. a ship sa. NeviLL. Or fretty gu. on a canton per pale erm. and of the first a ship sails furled sa. Sr. Gilbert Nevill, temp. William I, $V$. Nevics, Bulmer; quartered by Nevill Lord Abergavenny. Spur

Paly of six arg. and az. on a canton as the last a spur or. KNIGHT.

Paly of eight gu. and arg. on a canton as the first a spur or. KNIGHT.

Sword

Chequy arg. and sa. on a canton of the second a sword bendwise as the first. Smallwood, co. Stafford.

\section{Tun}

Barry of five arg. and az. on a canton of the se. cond a tun or. KnIGHToN, co. Hertford.

Barry of eight arg. and az. on a canton or a tun palewise gu. KNIGHTON, Suffolk.

Barry of eight or and az. on a canton gu. a tun or. KNIGHTON, $V$.

\section{Wreath}

Arg. fretty sa. on a canton gu. a chaplet of the first. EARBY, Whaplod, co. Lancaster.

Arg. fretty sa. on a canton gu. a chaplet or. IRBX, Baronetcy 13 April 1704, Baron Bostou 16 April 1761. IREBY, $V^{*}$. URBY.

Arg. fretty sa. on a canton gu. a chaplet of the last. URBY.

Barry of five or and az. on a canton arg. a chaplet of laurel ppr. HoLme.

Barry of five or and az. on a canton gu. a chaplet arg. in the sinister point a lion ramp. sa. HoLMES.

Barry of 'six arg. and az. on a canton as the first a chaplet gu. Horme, Paul-Holme, co. York. Hocmes, co. York.

Barry of six or and az. on a canton arg. a chaplet gu. HoLme, Paull-Holme, co. York; the heiress $m$. Torre.

Barry of six or and az. on a canton erm. a chaplet gu. Holme or Hulme, Overhulme, co. Stafford.

Barry of six or and gu. on a canton like the second a chaplet as the first. Houmes, Berowe: co. Cambridge.

Barry of seven or and az, on a canton arg. a chaplet gu. Hormes, Gawdy Hall, Norfolk.

Barry of eight az. and or on a canton arg. a chaplet gu. Howme, co. Lancaster, V, Cott. MS. Tiberius D 10. Holdies, Coddington, co. Chester. Barry of eight az. and or on a canton arg. a chaplet sa. Hounes, Coddington, co. Chester.

Barry of eight or and az. on a canton arg. a chaplet gu. HoLme, Up-Holland House, co. Lancaster; quartering Bankes; descended from Holme or Huime, Hulme, co. Lancaster ; the heiress m. Hope. Holme, co. Lancas. ter, $V$. 


\section{On 1 CANTON cont.}

Wreath cont.

Barry of seventeen or and az. on a canton arg. a laurel crown gu. Holmede, Coddington, co. Chester.

Wreaths

Barry of eight or and az. on a canton arg. three chaplets gu. Holmes.

\section{On 1 CANTON.... and in Chief....}

\section{Chief}

Arg. a chief erm. on a canton gu. an owl of the first. Barton, co. Buclingham.

Barry of four arg. and sa. a chief of the second on a canton of the last a garb or. Wearer. on a Chief

Gyronny of twelve or and az. on a canton sa. a covered cup of the first on a clief gu. three covered cups gold. Kinstowe, co. Lancaster.

\section{On I CANTON with a Bordure}

\section{Beast}

Barry of six arg. and az. a bordure compony as the second and first on a canton quarterly or and gu. a bear statant arg. within a bordure sa. bezanty. Thomas Grey, Donyngton Park, co. Leicester, $V$. But a boar pass. GRex, $V^{*}$. Grey, Langley, and Donnington, co. Leicester.

$$
\text { .... Lion }
$$

Arg. fretty gu. a bordure engr. sa. over all on a canton of the second a lion (pass. $V^{*}$.) statant or. Dunstanvili, Castlecomb, $V$. Dunstavile, $V *$.

Chequy or and az. on a canton gu. a lion ramp. arg. all within a bordure erm. WARREN, St. Alban's, co. Hertford.

Chequy or and az. within a bordure engr. gu. on a canton of the last a lion ramp. double tailed arg. a fleur-de-lis for diff. Warren, Ashwell, co. Hertford.

Chequy or and az. a bordure engr. sa. over all on a canton gu. a lion ramp. double tailed and nowed arg. WALLER alias WARREN, Bassing. bourne, co. Cambridge; and Asbwell, co. Hertford; a branch of WARREN, Poynton, Harl. MIS. 1546 , fo. 114. And with a fleur-de-lis in the centre for diff. arg. WALLER alias WARREN, Ashwell, co. Hertford ; 1234, fo. $142 ; 1504$, fo. $143 \mathrm{~b} ; 1547$, fo. 20 .

Gu. on a canton arg. a lion ramp. of the first a bordure sa. charged with ejght estoiles as the second. Whine, Doncaster, co. York.

$\mathrm{Gu}$. on a canton arg. a lion pass, sa. crowned or a bordure of the third charged with estoiles as the fourth. WHITE, co. Hants.

Gu. on a canton arg. a lion ramp. sa, a bordnre of the last charged with eight estoiles or. WhITE, $V$.*

Gu. a bordure sa. charged with eight mullets or on a canton erm. a lion ramp. of the first. WHITe, $V *$.

Gu. a bordure sa. charged with estoiles or on a canton erm. a lion ramp. of the second. White, Fyfield, co. Berks; and co. Hants. And with an annulet in the centre for diff. (arg. sometimes) or. White, Baron and Viscount Bantry 31 March 1797, Viscount Bearhaven $29 \mathrm{De}$ cember 1800, Earl of Bantry 22 January 1816. But the annulet in the centre or. ST. Jorin Baptist Coldege, Oxford; founded $\mathbf{1 5 5 7}$ by Sir Thomas White, Alderman of London.
On 1 CANTON with a Bordure cont.

Beast cont. Lion cont.

Gu. on a canton erm. a lion ramp. sa. a bordure of the third charged with estoiles as the se. cond an annulet in chief or. Whiтe, Lord Mayor of London 1553.

Gu. a bordure sa. charged with mullets or on a canton erm. a lion ramp. sa. an annulet for diff. White, London.

Per bend arg. and sa. on a canton gu. a lion ramp. guard. or a bordure counterchanged. Carrell.

Fleur-de-lis

Arg. a bordure sa. on a canton gu, a fleur-de-lis of the first. Grantiridge.

Hand

Arg. a bordure engr. az. on a canton gu. a gaunt. lot clasped or. Topp, Stocliton, and Fisherton, co. Wilts, quartering Lingen.

Spur

Arg. on a canton gu. a spur or a hordure (of the third, another) sa. KNIGHT.

Arg. a bordure sa. on a canton gu. a spur the rowel downwards or. KNrGHT, $V^{*}$.

Arg. a bordure sa. on a canton gu, a spur without leathers rowel downwards or. KNIGHT, 1730. Arg. on a canton gir. a leathered spur rowel downwards or a bordure sa. INIGHT, Norfolk. Paly arg. and gu. a bordure az. on a canton of the second a spur or. KNIGHT, Baschurch, co. Salop; quartered by Holte.

\section{Swords}

Arg. a bordure az. bezanty on a canton gu. three swords barwise the points to the dexter side in pale as the first hilt and pomels or. Ardnidge, Kingsclere, co. Hants; granted 1772.

Wreath

Barry of eight or and az, a bordure nebuly erm. on a canton as the first a chaplet of roses ppr. Holmes, Brook Hall, Norfolk; granted ....

\section{CANTONS}

Per fess the chief part quarterly per fess indented or and erm. the base arg. charged with squires (cantons voided) sa. BARLAY.

Sa. in chief a canton and in base another both on the dexter side arg. Cambridge, Lord Mayor of London 1420.

\section{CANTONS with a Bordure....}

and in base...

Quarterly or and az. in chief two cantors in base (two piles from the point sometimes called) a chev. counterchanged over all an escucheon arg. all within a bordure of the last. Londons.

\section{On 2 CANTONS}

Az. two cantons arg. on the dexter a rose gu. on the sinister a thistle vert. Nowlan, Ireland.

\section{CAP}

including Bonnet, Chapeau, Infula, Hat, Morion, and Steel Cap

Arg. a (chapeau or) hat az. with a plume of ostrich feather in front gu. John Kingeston, 1390 , Harl. MS. 1178 , fo. 42 .

Arg. an infula embowed at the end gu. turned up in form of a hat and engr. with a button and tassel on the top or. Brunt.

Arg. a steel cap ppr. with a feather in front gu. Kingsron, temp. Ricbard 11. 


\section{CAP cont.}

Or a morion gu. KuLHair.

Or a morion sa. garnished and studded or and az. Robinson, Cheshunt, co. Hertford; granted 1402 : London; and Little Baxton, co. Westmoreland.

1 CAP and in base....

Sa. in chief a doctor's cap .... in base three sugarloaves arg. Sugar; Collinson, Somerset, iii, 401 .

\section{CAP betw, or within....}

Quarterly erm. and az. a chapeau gu. turned up of the first betw. two greyhounds courant in pale or. Cope, Osbaston Hall, co. Leicester.

\section{CAPS}

Arg. three (caps or) morions sa. DE LA ReUn, $V^{*}$.

Arg. three (chapeaus or) caps of maintenance sa. Halworth, $V^{*}$. Hatworth, $V$.

Arg. three (caps or) bats without brims sa Delarenor or Delarour, Kent. Delareur, $V$. Hatworth.

Arg. three caps sa. banded or. CAPPER.

Az. three Albanian bonnets or. Vaux, France.

\section{CAPS}

Quarterly az. and or four caps (called pilia pas. toralia, in form of a doge's cap) counterchanged. DRokensford, $V$.

Quarterly or and az. four caps (in form of a doge's cap) counterchanged. MAUNDEFEID, $V *$. MAUNDEFELD, $V$.

\section{CARD see Working-Card \\ CARPENTER'S AXE see AXe}

\section{CASTLE including Tower}

.... a castle .... Town of Knaresborodgh, co. York; with the letters ERQR beneath.

.... a castle domed .... Town of BisHop's Castue, co. Salop; seal.

.... a castle embattled .... Town of Trwhesbory, co. Gloucester.

.... a castle triple-towered .... Town of Tadnton, Collinson, Somerset, iii, 227.

.... on a mount a castle with three domed tow. ers on each a pennon .... Town of NEWBORY, co. Berks; seal.

.... on a mount rising out of water a castle with three towers embattled and domed and joined to each other by a circular wall .... Town of Bosnex, Cornwall; seal.

.... a castle embattled aud towered in the middle the exterior towers domed and on each a flag. Town of PeMbroke; seal.

.... a castle with five towers over the port an escucheon arg. on a cross gu. a fleur-de-lis or. City of Lincoln; seal.

.... on a mount vert a castle with five spires arg.

Town of Queenborough, Kent; Halsted, Kent, ii, 658 .

Arg. a tower with a steeple az. port gu. Delatoure, co. Dorset.

Arg. a tower gu. Kinsey.

Arg. a tower embattled gu. MacNaughten, That Ilk.

Arg. a tower flanked by a wall and two turrets gu. Damian.

\section{CASTLE cont.}

Arg. a square tower issuant out of the base sur. mounted by an open port (or arch) joined to two towers gu. the roof quadrangular or divided into four gable ends az. BrIDGHouse.

Arg. a tower sa. having a scaling ladder raised against it in bend sinister or. MAUNSELL.

Alg. on a mount vert a castle sa. BURGower.

Arg. a tower triple.toweredsa. Castue. Olddastle, lord of Cobham, $V$. Sampson, Kent.

Arg. semy of crosses flory and a tower triple. towered sa. SomaIster, Cornwall, $V$.

Arg. a tower triple-towered sa. chained transverse the port or. Oldcastle, Kent.

Arg. on a mount in base vert a castle triple-towered and portcullis sa. CHenerton or Chinerton, Cornwall. Cheverton.

Arg. on a mount in base vert a tower triple-tow ered sa. Chiverton, Kerris, in St. Paul, Cornwall; the beiress $\mathrm{m}$. Trewren. Richard Chrverton, Lord Mayor of London 1658; descended from CHIvErTon, Trehunsey in Quithiock. Chiverton, Pawle, Cornwall, $W$.

Arg. on a rock ppr. a castle triple-towered and embattled sa. masoned of the first and topped with three ranes gu. wiudows and portcullis sbut of the last. City of Edinborgh.

Az. a castle .... Town of Luggershall, co. Wilts.

Az. a castle arg. Town of Bridgnorth, co. Salop; seal. M'Calloun, Rossie, Scotland. M'Galeon, Ross-sbire.

Az. a tower arg. Delatowre or Delatour. Modat, England. Sampson.

Az. a tower domed arg. Town of GREAT BeDwin, co. Wilts.

Az. a tower (embattled $V^{*}$.) with a cupola arg. door gu. Gilbert DE IA Tour, Barwike, co. Dorset, $\boldsymbol{V}$.

Az. in base water vert on the centre of a bridge with three arches a turret arg. Hagged gu. VINICOMBE.

Az. a castle triple-towered arg. MAC GILLEOUN, Scotland. Town of MARLBOROUGH, co. Wilts.

Az. a tower triple towered arg. Delatowre.

Az. a tower triple-towered and domed arg. Towry, Croglin Hall, Cumberland; the heiress $\mathrm{m}$. Negus ; a branch of Towny, co. York.

Az. a castle triple-towered arg. portholes and gate gu. M'LeOD.

Az. a castle triple-towered and embattled arg. masoned sa. port gu. MACLEOD, Muravenside, Scotland; descended from MACLEOD, That Ilk, quartering $\mathrm{Man}$.

Az. on a mount ppr. couped a castle triple-towered arg. the middle tower cupolaed and flagged. Nielson, Bothwellshiels; quartering arg. a stag's head cabossed ...., and arg. a lion rampant gu.

Az. a castle or. Cassat. Mons. Thomas KaRdeLECKe, $T$.

Az. a tower or. Towers, Northampton; and Little Berkhampstead.

Az. on a mount vert a castle embattled with three towers domed on each a pennon all or. Town of Cuithenow, co. Lancaster.

Az. a tower triple-towered or. Towers, the Manor of Hinton, Isle of Ely.

$\mathrm{Az}$. on a mount in base vert a tower tripletowered or. Casturian, Coberley, co. Gloucester. 
CASTLE cont.

Gu. a castle arg. Barnstable. Lindores. M'LEOD; quartering gyronny of eight or and sa., with or a fess chequy az. and arg., and arg. a bull's head cabossed sa.

$\mathrm{Gu}$. out of a castle arg. a hart issuant ppr. attired or. King of IrELAND, Harl. MS. 304.

Gu. a castle arg. crowned or in the port a cross formy of the second. ATford, co. Devon. The cross formy of the third. FORD or ALFORD, Fordmore, co. Devon, temp. Edward I.

Gu. crusily or a castle arg. Castelock, Feversham, Kent; granted 10 August $\mathbf{1} 614$.

Gu. crusily or a castle arg. masoned sa. Castielock. Feversham, Kent.

Gu. a castle towered arg. City of Duburn.

$\mathrm{Gu}$. on a mount in the sinister base vert on the sinister side a castle with two towers domed on each a pennon all arg. the dexter base barry wavy of six arg. and az. thereon a ship with three masts sailing from bebind the castle or the fore and main masts in sight sa. on each two sails of the second. City of Bristol.

$\mathrm{Gu}$. the barbican of a castle having loopholes gate and portcullis with two pointed side towers on each of the latter a pennon waving arg. and ensigned on the centre of the battlement by a royal coronet or. Borough of DonCASTER, York.

Gu. a tower triple-towered arg. DCNCAster, $V$. MAUDE, Ireland.

Gu. a castle triple-towered arg. masoned sa. Lindores (Title of Lord Lindsay).

Gu. on a rock ppr. a castle triple-towered arg. masoned sa. surmounted by an escucheon gu. three lions pass. guard. in pale or. DoRCHEster, co. Dorset.

Gu. a four-square castle in perspective with as many towers and cupolas one at each angle arg. standing in water az. RAwson, Castleford, co. York, $V$.

Gu. a castle four-square in perspective with a tower at each angle arg. enclosing a falcon volant ppr. standing on a mount vert in the courtyard as the first, Lanxon, Cornwall, $W$.

Gu. a castle surmounted by two others placed pyra. midically and embattled standing on a Gothic bridge with water underneatl on each side the first castle a domed tower surmounted with a bull and the gate in the centre portcullised. Town of Bridgewater; Collinson, Somerset, iii, 76 .

Gu. a tower embattled with a round roof betw. two other turrets standing upon a wall extended in fess arched in arched .... BRIDGMORE.

Gu. a castle or. CASTILE, $Z$, 70. Catherine of Arragon, daughter of Ferdinand II of Spain, first wife of Henry VIII. Philip of Spain, husband of Mary I. Castile, quartering Leon, $Z$, $129,179,250,260,378,499$. CASTILE, quartering Leon, Arragon, Sicily, and Granada, $Z, 475$. Sire de Castilton, $H$. Roy d'Espaigne, quarterly with arg. a lion ramp. purp. $Y$. Doncaster, co. Berlis.

Gu. a tower or. SoLE, London; granted 1591.

Gu.goutty d'eau a castle or. HAwBorgH.

Gu. on a mount vert within a (circular embattled wall or castle another a quadrangular) castle or a falcon rising ppr. LaNion, Lanion, Cornwall.

Gu. a tower embattled or. Hutchings, co. Somerset.

Gu. a castle with two towers or embattled and masoned sa. Casley (originally Chastelai of France), Loudon.

\section{CASTLE cont.}

Gu. a castle witb two towers or embattled and masoned sa. adorned with four vanes arg. Chasteliai, France.

Gu. a tower triple-towered or. CAstrLe, quarterly with arg. a lion ramp. gu. as borne by Eleanor, first wife of Edward I (ob. 1296); and as borne impaled dexter with az. flory or quartering gu. three lions pass. guard. or over all a label of three points erm. by John (Plantagenet) of Gaunt, Earl of Richmond, Duke of Lancaster and Aquitaine, ob. 1398.9; and as borne quarterly with Arragon impaling Sicily in the base point Granada, by Catherine first wife of Henry VIII; and as borne for a third quarter quarterly with Arragon impaling Sicily by Mary I; and as borne quarterly with Arragon impaling Sicily all quarterly with Austria Burgundy Burgundy and Brabant over all Flanders impaling the Tyrol and on a base Granada by Philip Il of Spain her husband.

Gyronny of eight erm. and az. over all a castle arg. Hooper, Hendford, co. Somerset.

Gyronny of eight erm. and arg. over all a castle sa. Hooper, co. Worcester.

Grronny of eight or and erm. over all a tower triple-towered arg. Hopper, co. Devon.

Gyronny of eight or and erm. over all a tower triple-towered sa. HowPER or HoOPER, co. Devou ; Collinson, Somerset, iii, 562. George Hooper, Bishop of St. Asaph 1703, Bath, etc., 1704.27 .

Gyronny of eight sa. and erm. over all a tower triple-towered arg.masoned of the first. Hopper, Shincliffe, and Silksworth, Durbam.

Gyronny of eight sa. and erm. a tower or. Hopper, Durham; quartering Carlos.

Or a tower triple towered az. Blount or Blunt. SANCHETT, $V$.

Or on a bridge of three arches in fess gu. masoned sa. over as many streams transfluent ppr. a tower of the second thereon a fane arg. Trowbridge, Modbury, co. Devon.

Or a castle sa. Mountjoy.

Per fess arg. with chequy or and gu. in chief a castle issuant triple-towered az. City of Chichester.

Per fess arg. and gu. a tower triple-towered or. Rawstonne, London.

Per fess az. and gu. a tower triple-towered or. Rawston, Manchester.

Per fess az. and sa. a castle of four towers arg. Rawson, Stonyroyd, and Halifax, co. York; descended from Rawson, Ingrow.

Per fess gu. and az. a domed tower arg. RAwson. Per fess wavy gu. and az. a castle arg. RAwson, co. York.

Per fess sa. and az. a castle (another, seen obliquely) with four towers arg. Rawson, Darley Hall, co. Lancaster; Bradford, and Nidd, co. York; descended through Rawson, Bolling, quartering Brooke; from RAwson, Bradford, a branch of Ravenson or Rawson, Fryston, co. York, temp. Richard II. Rawson, Besșacarr Grange, Canbley, co. York.

Per fess sa. and az, a castle with four towers the gate displ, arg. on each tower a vane or. Rawson.

Per fess wavy sa. and az. a castle with four towers arg. Rawson, Frystone, co. York.

Per fess sa. and barry wavy of (six, another of) eight arg. and az, over all a square castle ton:ered at each corner (of the second, another) 
CASTLE cont.

ppr. Roger Castueford, Wisperdale, co. York, $1585 ; W$. CASTIEFORD, Worsborough and Wypershall, eo. York.

Per pale arg. and az. a castle gu. CHiscoti, Kent.

Per pale gu. aud sa. a triangular castle with three towers or. City of ExETER.

Quarterly gu. and vert a castle or. SoL̄as, Brabant.

Sa. a castle arg. Hitchins, co. Oxford. Hitchens or Hitchins.

Sa. a castle ( $i$. e. castellated portal betw. two towers) arg. standing on the upper part of a base barry of six as the second and az. Richard Rawson, Alderman of London 1746, W.

Sa. a tower arg. Delatowre. Hutchens.

Sa. a castle triple-towered arg. Hichins, London.

Sa. a tower towered arg. Mowatr.

$\mathrm{Sa}$. a castle with towers turreted in perspective arg. standing in water wavy az. and arg. CASTLEFord, $V^{*}$.

Sa. a quadrangular tower with four towers in perspective arg. masoned and standing in water ppr. Town of Pontefract.

Sa. a castle or. Somers.

Sa. a castle triple-towered or. John Towers, Bishop of I'eterborough, 1639.49.

Sa. a tower or. Thomas Towers, 1352, quartered by Topeliff; $W$.

\section{CASTLE and in chief....}

\section{Axes}

Arg. a tower sa. issuing from the top thereof four battle-axes two to the dexter and two to the sinister az. HICKs, lreland.

\section{Beast}

.... a gateway embattled and wall flanked by two towers issuing from the base and out of the top of the embattled gate a demi-lion holding in the dexter paw a sword point down. wards .... M'LEAN, Dundee.

Gu. out of a tower arg. a demi-lion ramp. or a canton of the second. Castilion, Italy.

$\mathrm{Gu}$. in base a castle arg. in chief a lion pass. or. Castilla, Spain.

$\mathrm{Gu}$. on a basse barry wavy of eight arg. and az. a castle with two towers of the second in chief a lion passant guard. crowned betw. two fleurs. de-lis or. Town of Bridport, co. Dorset.

Quarterly embattied gu. and or in the first quar. ter above a tower arg. a lion pass. guard. gold. A coat of augmentation granted, 1633 , to Robinson, London: Cranford, co. Northampton; Stretton Hall, co. Leicester; Baronetcy 22 June 1608.

\section{Bird .... Eagle}

Arg. over a castle upon a hill a demi-eagle displ. ppr. Town of BEDFord.

Per fess or and gu. in base a castle arg. in clijef an eagle displ. double-headed of the second. Payne-Gallway, Baronetcy 8 December 1812, quartering Payne.

\section{.... Falcon}

Gu. a castle four-square in perspective with a tower at each angle on the top a falcon volant ppr. Lanyon, $V^{*}$.

Sa. in waves ppr. a castle arg. on the top a falcon hovering with bells or. LANINE, Cornwall, Harl. MS. 4031 , fo. 89 b.
CASTLE and in chief.... cont.

Bird cont. Falcon cont.

Sa. a castle with four towers arg. on the top a falcon hovering with bells ppr. Lanyon, Camborne, and Lanyon in Madron and Lanyon in Gwinnear, Cornwall.

$$
\text { .....Herou }
$$

.... a tower triple-towered .... and a stork ppr. DENTON.

Gu. a tower or on the top a stork arg. Sutron, Elton, Durham; derived from Sutron, Thornborough, co. York, 1640; the heirs m. Sleigh and Hutchinson; quartering Sleigh \& Bathurst. Gu. a castle or on the top a stork ppr. SUTton, Kittismore, co. York.

\section{Birds}

.... a castle with a tower at each end the middle of the castle surmounted with another tower the castle arched in base from the dexter tower to the sinister within the arch a lion conchant guard. on the two outside towers a Cornish chough .... Town of Carmarthen.

Per fess az. and arg. in base on a rock a castle breached the Indian colours struck and flagstaff ppr. in chief two eagles rising or. StIBbert, London; granted 12 October 1768.

Az. a castle of three towers arg. masoned sa. standing on a rock ppr. doors and windows gu. on the top of the middle tower a cock and on each of the others an eagle or. CaMPBELL, Dunstaffnage, co. Argyll; Baronetcy $11 \mathrm{March}$ 1836; quartering gyronny of eight or and sa., with or a fess chequy az. and arg., and gu. a boar's head cabossed or betw. a crescent and spur rowel in fess arg.

\section{Canton}

Az. a castle and a canton arg. Town of Bripgnorth, co. Salop.

on a Canton.....Cross

Az. on a base wavy of six az. and arg. a castle with tower and spire near the centre of the field all on the dexter side on the sinister a ship with one mast as if passing by the castle sail furled of the first the mast round tops and rigging or on the stern a man blowing a horn of the last on a canton gold a cross betw. four lions ramp. gu. Town of Lrpd, Kent.

Per fess sa. and az. out of a base barry wavy of four as the second and arg. a castle with four towers in perspective of the last a canton erm. Rawson.

$$
\text { ..... Eruit }
$$

Quarterly gu. and sa. over all a castle triple-tow. ered arg. on a canton of the last three pears in fess sa. City of Worcester.

$$
\text { ...... Keys }
$$

Or over water in base on a bridge of three arches in fess embattled a tower ppr. thereon hoisted a broad pendent flying towards the sinister a canton az. charged with two keys in saltire wards upwards gold. Trowbridge, Plymouth, co. Devon; Baronetcy 30 November 1799.

$$
\text { ..... Legs }
$$

Az. a tower arg. on a canton gu. the three legs of man conjoined and armed ppr. spurs or. M'Leod, Colbeck.

\section{Chief}

Or a tower triple-towered and a chief gu. NetTer.

on a Chief.... Bird

Gu. a tower ppr. on a chief or an eagle displ. sa. Giustinian, Baron Livingstone, Viscount Kynnaird, Earl of Newburgh, 31 December 1660. 
CASTLE and in chief.....cont.

on a Chief cont. Crescent cont.

Arg. a castle gu. on a chief az. a crescent betw. two mullets of the first. Portal, Ash Park, Overton, co. Hants.

Per saltire az. and gu. a castle (i.e. castellated portal flanked by two towers) arg. on a chief erm. a crescent of the first betw. two mullets of the second. Pontal, Freefolk House, co. Hants. .....Fleurs-de-lis

Erm. a tower sa. on a chef gu. three fleurs-de-lis or. Bullivant. .....Heads (Beasts)

Quarterly sa. and az. a quadrangular castle arg. on a chief erm. three bull's heads cabossed gu. Rawson, Brookside, and Wardsend, co. York; temp. Edward IV.

$$
\text { .... (Birds) }
$$

Az. a castle arg. on a chief or three stork's heads erased gu. Surth, Amble, and Togston, Northumberland.

Az. on a mount in base vert a castle arg. on a chief or three stork's heads erased gu. Sniтh, Durham. -...Insect

Quarterly az. and gu. over all a castle or on a chief arg. a bee volant ppr. betw. two martlets sa. Fort, Read Hall, co. Lancaster.

$$
\text { .....Key }
$$

Arg. a castle triple-towered gu. on a chief az. a key erect or betw. two fleurs-de-lis of the first. Dartiquenave, London. .....Mullets

Per pale or and az. on the dexter compartment a tower gu. and on the sinister on a mount vert a seahorse arg. mane fins and tail of the first on a chief gold three mullets of the second. Garrick, Hampton, Middlesex.

$$
\text { .....ship }
$$

Az. a castle triple-towered arg. on a chief or a galley sails furled and oars in actiou sa. flags gu. M'Leod, St. Kilda.

$$
\text { ..... Sun }
$$

Arg. on a mount vert standing on four bars wavy in base of the first and az. a tower triple-towered gu. on a chief of the fourth a sun betw. two estoiles or. Bourne, Chesterton, co. Oxford.

\section{Coronets}

Az. a tower triple-towered or standing on waves in base ppr. in chief two ducal coronets of the second. Company of Merchants, Exeter; 1556.

\section{Estoile}

Gu. on a bridge of Gothic work in base over a river ppr. a castle surmounted by two others placed pyramidically and embattled on each side a domed tower surmounted with a ball the grand entrance portcullised at the top and agaiust the door a man's head couped close .... in chief on the dexter side an estoile on thesinis. ter a fleur-de-lis .... Town of Bridgwater, co. Somerset; seal.

\section{Feathers}

.... semy of martlets and fleurs-de-lis .... a castle with two towers surmounted with a tower in the centre over each tower an ostrich feather .... Town of Corfe Castle, co. Dorset; seal. Fleurs-de-lis

Per chev. arg. and sa. in base a castle or in chief two fleurs-de-lis az. Sorocold, London; 3614. But a tower. Serocold; Cherry Hinton, co. Cambridge; quarterng Pearce.

Per chev, arg. and sa. in base a tower triple-towered or in chief two fleurs.de-lis of the second. LYTTIIL, $W$.
CASTLE and in chief....cont.

Fleurs-de-lis cont.

Per chev. arg. and sa. in base a tower of the first in chief three fleurs-de-lis as the last. Litrel or Little, Bray, co. Berks.

\section{Head}

.... a quadrangular castle surmounted with another over the battlements the bust of a woman her hair dishevelled and ducally crowned .... Corporation of QUeEnBorough, Kent; seal.

\section{Human-figures}

.... a quadrangular castle embattled domed and surmounted with a tower triple-towered on the middle tower a flag gu. out of each of the front towers a man in armour the dexter holding a sword erect the sinister blowing a horn all ppr. Town of THETFORD.

(? gu.) out of water in base an embattled wall enclosing a castle with three gables from the embattled parapet a piece of tapestry hung along the front betw. the bartizans and displ. three shields, viz. .... a lion ramp..... with gu. three lions pass. guard. in pale or, and .... three dexter hands .... on the top on each side of a flag the upper part of a man turned to the sinister one holding a battle-axe the other blowing a horn .... Town of NewCAstieUNDER-LYNE.

\section{Roundles}

Per chev. sa. and or in base a castle triple-towered of the first in chief two bezants. MunN:

Per chev. flory counterflory sa. and arg. in base a tower triple-towered of the first in chief three bezants. Mouns Munds or Muns, Cumbridge; Essex; Middlesex; and Maidstone, Kent. Per chev. sa. and or in base a castle triple. towered of the first in chief three bezants. MUNN. Per chev. flory counterflory sa. and or in base a tower of the first in chief three bezants. Mun, Finchley, andHackney, Middlesex. Mus, Mount Hall, Essex ; Harl. MS. 1551, fo. 102. Mouns Munds or Muns, Cambridge; Essex; Middlesex; and Maidstone, Kent.

\section{CASTLE and in base....}

\section{Beast .... Boar}

Az. in chief a castle with two towers arg. in base a boar pass. or. CAZALET.

$$
\text { ..... Lion }
$$

Gu. a castle surmounted with a tower arg. in base a lion pass. guard. or. City of Norwich.

Per bend az. and arg. in base a tower sa. in chief a lion pass. of the second. Wallis, Ireland.

Per fess vert and gu. in chief a quadrangle of castles walled arg. in base a lion pass. guard. gu. Town of Lincaster.

\section{Birds}

Pily counterpily of four traits the points ending in crosses patty two in chief and one in base sa. and or in chief a tower arg. in base two martlets as the first. Poynder and Poynter, London.

\section{Crescent}

Az. a castle triple towered and in base a crescent or. Bowleau, Norfolk; formerly Baron of Castlenau and St. Croix, Languedoc; Baronetcy July 1838.

\section{Trench}

Vert a castle (i.e. castellated portal flanked by two spired towers) throughout with portcullis let down and in base a winding trench arg. Pichard Hensler, Captain of Pioneers at the siege of Kinsale; granted 26 April 1602. 
CASTLE and in base.....cont.

Woolsack

.... the castle town and church of Tiverton with Lowman's and Exe bridges beneath them a woolpack .... Town of TiverTon; seal.

CASTLE betw, or within....

\section{Axes}

Arg. a tower triple-towered betw. three battleaxes sa. Hickes, Luxillian, Cornwall, $W$.

Arg. a tower triple-towered betw. three poleaxes sa. Hicks, 'Trevitick, and Luxilian, Cornwall.

Or a tower (another, triple-towered) betw. three battle-axes sa. Hext, Kingston, co. Dorset; and Trenarven, Cornwall ; quartering Hawkins and Taylder. Sir Edward HExT; Collinson, Somerset, iii, 182, 185, 445 ; ob. 1624 .

\section{Beasts}

.... on a mount a tower supported by two lions ramp .... Town of ORFORD, Suffolk; seal.

Arg. a castle triple-towered sa. betw. two lions ramp. comb. gu. O'CHALLEY or O'KELLY.

Az. a castle triple-towered betw. two lions ramp. comb. arg. William Kelcey, Dublin, ob. 1597.

Az. a tower triple-turretted arg. supported by two lions of the second chained or. Kerury, Castle Kelly, Ireland.

Az. a castle triple-towered or betw. two lions ramp. comb. arg. William KeLreY, Dublin, ob. 1597.

Az. a castle ppr. supported by two lions ramp. or. KELLY.

Gu. a tower supported by two lions ramp. arg. Kelly, Newtown, co. Gulway.

$\mathrm{Gu}$, a tower supported by two lions ramp. arg. on a mount vert. Kelly, Castle Kelly, co. Galway.

Gu. on a mount ver't a tower arg. supported on each side by a lion ramp. or. Keury, Castle Kelly, Ireland. O'KeILY, Ireland.

Gu. a tower triple-towered supported by a lion on each side or. O'KenLy, Ireland.

Gu. on a mount vert a tower triple-towered in the port a portcullis supported by two lions ramp. guard. or. Town of Northanpton.

\section{Beasts}

Vert a castle triple-towered ppr. betw. five lions pass. guard. or. 'Town of StAFForD.

\section{Birds}

Arg. a tower betw. three martlets BURDENBRoKe.

\section{Bordure}

Az. a castle triple-towered arg. masoned sa. portcullis gu. and a bordure of the second. Macleod, Talisker, Skye.

Barry of seven arg. and gu. over all a tower triple-towered arg. on a bordure az. eight doves or. Town of Morpeth, co. Northumberland.

Sa. a tower or and a bordure vair. TORRe originally DE TurRI, co. Warwick; temp. Henry II; co. Lincoln, 1699; and Snydall, co. York; quartering Mann, Kirkby, Holme, Wasney, and Pockley.

Chequy or and az. a tower triple-towered erm. port displ. sa. within a bordure gu. charged with eight leopards pass. of the first. Britayne.

Gu. a triple circular tower in a pyramidical form the first battlements mounted with cannon or a bordure az. cliarged with eight towers domed arg. Town of LaUnCESTON or DunHeved.

Or a castle .... within a bordure sa, bezanty. Gidley, Honiton, co. Devon
CASTLE betw, or within....cont.

Bordure cont.

Or a triple-towered castle az. and a bordure sa. bezanty. BerkHampsted, Burgh.

Or a castle triple-towered embattled and domed az. on each dome a banner arg. charged with a cross gu. all within a bordure sa. bezanty. Town of Berkhampstead, co. Hertford.

Or a castle sa. and a boraure of the second be. zanty. GidLex, Gidley, co. Devon; exemplified 1671 .

\section{Buildings, etc.}

Az. betw. two pillars a castle arg. with a golden key pendent on the gates. Fortress of GibRaLtaR.

\section{Crosses}

Arg. a tower sa. within an orle of crosses croslet as the last and gouttes de sang alternately. HAMBOROUGH.

Gu. a tower arg. within an orle of crosses croslet and gouttes d'or alternately. Hamborough.

\section{Cups}

Arg. a tower betw. three covered cups az Amcotes, Astrop, co. Lincoln; granted 1548. And with a crescent for diff. Amcotes, Writenby, co. Lincoln.

Arg. a tower triple-towered betw. three covered cups az. Amcots, Essex.

Arg. a tower triple-towered az. betw. three covered cups sa. Alexander AмcotTs, Stropp, co. Lincoln, $1548, W$. AyncotTs, $V$.

Arg. a tower triple-towered az. betw. three cups covered, the lower part sa. the upper of the second. Ayncots Aynescourt or Amcotts, $V^{*}$.

Az. a castle betw. three covered cups arg. Ancotes, co. Lincoln.

\section{Escallops}

Per fess arg. and az. a tower betw. four escallops counterchanged. CHEstLet, $V^{*}$.

Per fess arg. and az. a tower gu. betw. four escallops two and two counterchanged. Chesterl. Chestlet, $V$.

\section{Escucheons}

.... on a mount a castle triple-towered witl spires and fanes on each on the mount before the castle a greyhound couchant .... on each side the castle an escucheon on the dexter France and England on the sinister .... a lion ramp.... over each escucheon a plunie of ostrich feathers. Town of DENBIGH.

\section{Estoiles}

Arg. a castle or betw. two estoiles arg. Str. Awbyne, Cornwall.

Per pale gu. and az. a castle in perspective embattled all round the front triple-towered the whole forming a hexagon or masoned .... the two outside towers domed on each side of the middle tower an estoile sa. Town of Devizes, co. Wilts.

\section{Feathers}

Sa. a tower towered and domed arg. betw. two feathers of the last each in an escroll or. Borough of CALNE or CAWNE, co. Wilts.

\section{Fleurs-de-lis}

Vert a castle arg. betw. two fleurs-de-lis in chief and a cross croslet fitchy in base or. HAVELOCK, Sunderland, co. Durham; granted 1815. The castle with two towers. Havelock, Izon House, Henbury, co. Gloucester, granted 10 July, 1817. 
CASTLE between or within.....cont.

Fleurs-de-lis cont.

Arg. a castle triple-towered and an orle of fleursde-lis sa. Somaster or Sumester anciently Summaster and Sumaister, Cornwall; a heiress m. Colshull; Old Port and Nether Ex, quartering De Heanton and Delaport, a heiress m. Lympenny.

Arg. a castle triple-towered within an orle of fleurs-de-lis and a bordure or. Somaster, old Port, Wydecombe, and Painsford, co. Devon.

Az. a castle arg. within an orle of fleurs-de-lis or. ToRAYNe cr Tourayne.

\section{5-Foils}

Gn. a tower betw. three 5-foils arg. within a bordure potent erm. HamitoN.

Gouttes

Gu. a castle or betw. eight gouttes d'eau. Hamborotgh. Hanburgh.

\section{Heads}

Arg. a (castle or) tower az. betw. three (eagle's another) falcon's heads erased sa. Rawson, Pickborne, co. York.

\section{Keys}

Sa. a tower triple-towered arg. masoned ppr. betw. two keys erect of the second. Town of Totness, co. Devon.

Arg. a tower betw. three keys az. Baner, $V^{*}$.

Arg. a tower betw. three keys erect az. BAKER, Kent; and Sussex. Sennicots.

Arg. a tower triple-towered betw. three keys az. Thomas Baker, Battell, Sussex, $W$.

Alg. a tower betw. three keys erect sa. BAner, Battel, Sussex.

\section{Ladders}

Gu. on a mount in fess vert three towers tripletowered arg. betw. three scaling-ladders or. LEWIS, Llanarchayron, co. Cardigan.

\section{Pheons}

Arg. a tower triple-towered gu. betw. three pheons sa. Joweles, Kent; and Surrey. Jowles, Alkham, Surrey; granted 1620.

$$
\text { Roundles }
$$

Arg. a castle sa. betw. eight torteaux. Worster. Woolsacks

Gu. a castle representing Redmond's Hall betw. three woolpacks ppr. REDiIOND, Rockville, co. Wexford. ReDiond, Killoughter House, co. Wicklow; derived from RAYMOND or REDMOND, The Hall, Killygowan, and Newtown, co. Wexford ; quartering Cooke.

$$
\text { Suns }
$$

Az. a castle or betw. two suns arg. ST. Awbyne, Cornwall.

\section{CASTLE betw, or within....} and in chief....

\section{on a Chief.... Beast (Lion)}

Vert on a base wavy of six arg. and az. a castle betw. two roses or on a chief gu. a lion pass. guard. as the fourth. City of Carusie, Cumberland.

$$
\text { ..... Keyg }
$$

Arg. a castle betw. in chief two crosses patty and in base a ley erect sa. on a chief az. two keys also erect or. BAEER, Ranston, co. Dorset, and Ashcombe, Sussex; Baronetcy 2 September 1802, quartering Littlehales.

$$
\text { .....sun }
$$

Arg. out of a base barry way of four of the field and az. on a mount vert a eastle triple-towered betw. two flaunches gu. on a chief nebuly as
CASTLE betw. or within....

and in chief.... cont

on a Chief cont. Sun cont.

the third the sun in splendour betw. two es. toiles like the first. Bourne, Hilderstone Hall, co. Stafford.

\section{Fleurs-de-lis}

Az. a tower supported by two lions ramp. with three fleurs-de-lis out of the battlements arg. LaLLy.

\section{Human Figure}

.... on a mount a castle triple-towered supported by two beraldic tigers on the outer towers a flag to each from the centre tower a man blowing a horn .... Town of HAVERFoRDWEST, co. Pembroke; scal.

\section{Human Figures}

.... a castle triple-towered on the dexter side the sun in its glory on the sinister a crescent on the top of the two front towers a watchman. Town of Warwick.

\section{Mullet}

.... out of water in base a castle with an em. battled tower at each end on the centre a tower domed thereon a pennon on each side of the castle three ears of wheat on one stalk in chief on the dexter side a six-pointed mullet and on the sinister an increscent again on the sinister side three balls one near the dome of the upper tower and the other two near the battlements of the sinister tower. Town of Malinesnuny; scal.

\section{CASTLE betw. or within...}

\section{Fish} and in base....

.... a castle triple-towered gates open and portcullis raised .... betw. two lions pass. guard..... and in base a fish naiant .... Town of STAFFord. Swords

Per pale az. and gu. on the dexter side a tower arg. supported by two lions ramp. or in base a scimitar hilt and pomel towards the sinister betw. two others hilts and pomels to the dexter ppr. and on the sinister side on a bend of the fourth betw. three fleurs-de-lis as the third six ogresses all within a bordure gold. Goron, Richmond, Surrey; granted ....

\section{On 1 CASTLE betw. or within.... \\ Escucheons}

Arg. on the front of a tower embattled ppr. within a bordure vair an escucheon arg. a chev. betw. three padlocks .... Torn.

\section{Woolsacks}

Sa. on a mount rert out of water ppr, a castle with two towers embattled on each tower a spire surmounted with a ball from the battlements betw. the towers a tower triple-towered all arg. and charged with an escucheon quarterly of France and England under the hattlements of the castle two ruses in fess gold the port ppr. charged on the centre with a key or porteullised of the last on the mount before the port a lion couchant guard. of the fourth on each side the castle in fess a woolpack of the third palewise. Town of GullFord or GuldEFond, Surrey.

\section{CASTIES}

Quarterly arg. and sa. in the second and third quarters a tower triple-towered of the first. Barterowe.

Quarterly gu. and arg. in the first a tower of the second. CASTEL. 


\section{CASTLES cont.}

Quarterly gu. and or in the first and fourth quarters a tower of the second. SALE, London.

Quarterly gu. and vert in the first and fourth quarters a tower or. Solas, $V$.

Quarterly or and vert in the first and fourth quarters a tower triple-towered sa. Carvell.

\section{CAsTLES and in base....}

\section{Beast}

Per chev, gu. and or in chief two towers (but castles, Penton) arg. in base a lion ramp. az. Panton.

\section{Escallop}

Per chev. flory counterflory arg. and sa. in chief two towers (but castles, WHITORNE) and in base an escallop counterchanged. WHITEHORN. Ship

Per chev. or and sa. in chief two triple towers of the second in base a ship in full sail as the first. Howletw, Sydenham, Kent; granted 1559.

\section{CASTLES betw. or within....}

Az. in the dexter chief and sinister base a tower arg. in the opposite points a lion ramp. erm. ducally crowned or. Skrine, Warleigh, co. Somerset; and Stubbings, co. Buckingham; quartering Weston and Tryon.

$\mathrm{Gu}$. in the dexter chief and sinister base a tower and in the opposite points a lion ramp. arg. Skearne or Skmrne. Skrine, Collinson, Somerset, i, 149. Smryne or Skyre.

$\mathrm{Gu}$. in the dexter chief and sinister base a tower (triple-towered Castelyon, co. Lincoln, and CASTILLON) and in the opposite points a lion ramp. or. Skranne or Skerne, Bonby, co. Lincoln; and Portington, co. York.

\section{CASTLES}

Arg. three towers triple-towered az. BotHeLL Haveland, Tewlesbury, co. Gloucester.

Arg. three castles gu. ARFECE ARFoIs or ARForce. CASTELl, Cumberland; and co. Devon. Castell, 1681, Add. MS. 6409.

Arg. three towers gu. ARFECE or AnFoIs, $V$. Le Blond, Ireland. Casteis, Ravington, Norfolk. John Castle, Paveningham, Norfolk, 1614. Terett. Tours, $V$.

Arg. three towers triple-towered gu. Casters, co. Cambridge. Rawson, in Brodsworth Church, co. York. Towers, Crollinghall, Cumberland.

Arg. three towers sa. portcullised gu. HAVELLANDE, Guernsey, Harl. MS. 1465, fo. 167.

Arg. three towers triple-towered sa. Haveland.

Az. three towers arg. inflamed ppr. City of Dublin, Harl. MS. 1441.

Az. three towers domed or gates sa. LE Porte, $V$. Lepont. Le Ports, $V *$. Ponts.

Barry of seven arg. and gu. over all as many castles of the last. ALyne, $V$.

Barry of seven arg. and gu. as many towers of the last. Alyne, $V^{*}$.

Barry of seven arg. and gu. over all as many towers triple-towered or two and one. AlLEN.

Gu. three castles arg. Castell. Morgan.

Gu. three towers arg. Morgan, $V$.

$\mathrm{Gu}$. three towers triple-towered arg. Howell Caerleon. Gaywood, London. Howell, Prince of Caerleon-upon-Uske, co. Monmouth. Town of Newcastle-Upon-Tyne.

Gu. three castles or. Castell, co. Warwick. Casteils or Castiss, quartered by Holte. Townes, Harl. MS. 1386, fo. 66. The gates sa. Casteli, Harl. MS. 1386, fo. 65.
3 CASTLES cont.

Gu. three castles (i.e. castellated portals flanked by by two towers) or. Portnewe (Germany), Harl. MSS. 1401, 1465.

Gu. three towers or. Sir Nicolas Casteli, $V$. Gu. three turrets or. TERRETz.

Gu. three towers with cupolas or. TEReTt, $V$. Gu. three towers triple-turreted or. TolkRE.

Or three castles gu. KesteLL, Kestell in Manaccan, Cornwall; the heiresses $m$. Langford and Penrose.

Or three towers triple-towered gu. CaIffield.

Or three castles triple-towered sa. Castelernt, $V^{*}$. Casteleyut. Le Chasteleyne, $V^{*}$. Le Chesteleyne.

Or three towers triple-towered sa. Castelfynt, $V$. Alan le Chastrleine, son of Lord Gilbert le Chasteleyne, $1310, V$.

Per chev, arg. and sa. three tower's triple-towered counterchanged. Basee, $V^{*}$. Basshe, $V$.

Per pale arg. and gu. three castles counter. changed. Gergond. Prydeux, Cornwall. Treverbyn, Treverbyn, in St. Austell, Cornwall; the coheiresses $\mathrm{m}$. Courtenay and Trevannion.

Per pale arg. and gu. three towers counterchanged. Predieux, $V$.

Per pale gu. and arg. three castles counterchanged. Gergan Gergand or Geerewood. Gergond or Gerwood, $V^{*}$.

Per pale gu. and arg. three triangular castles counterchanged. GERGoNd, Cornwall, $V$. Gerwood, $V$.

Sa. three castles arg. Casteline, co. Dorset.

Vert three towers arg. M'GuIRe. MacQuine or M'Quire, Ireland.

Vert three towers embattled in chief arg. MAC GUARIE, That Ilk; quartering arg. three crosses croslet fitchy .... M McQUIRE, Ire. land, Earl of Enniskillen. And with a crescent in the centre .... McGuarte, Ormaig.

\section{CASTLES ...}

and in base...

\section{Chevron}

Arg. in chief three towers triple-towered and in base a chev. engr. betw. three martlets sa. Webrer ; Collinson, Somerset, iii, 20.

Cross

Per chey. az. and erminois in chief three towers or in base on a mount vert a cross patty fitchy of the third. NogueIRA.

\section{CASTLES and in chief....}

$\mathrm{Gu}$. three towers arg. on each a demi-lion ramp. or. Callis.

\section{CASTLES betw, or within....}

\section{Bendlets}

Per pale gu. and sa. three castles in bend or cotised within a bordure engr. erm. (The ancient arms of ) Spicer, Exeter, co. Devun.

Tressure

Gu. three towers triple-towered within a double tressure flory and counterflory arg. Town of ABERDEEN.

\section{CASTLES}

Arg. five towers two two and one gu. Corneld, $T$. Arg. five castles in cross sa. CoRnell.

Ol five towers triple-towered in saltire gu. CoRNel. Or five castles in cross sa. CoRnwali. Or five towers in cross sa. Conneld, $V$. Or five castles in saltire sa. Conwwall. 
5 CASTLES betw, or within....

$\mathrm{Gu}$. five castles in saltire arg. masoned ppr. betw. two lions counterpassant guard. or. City of WINCHESTER.

\section{CASTLES}

Quarterly arg. and gu. in the second and third three castles in bend or. Rempston.

\section{CASTELLY}

Arg. fretty and semy of castles gu. Nechur, 1730. Tourney, Harl. MIS. 1407, fo. 15 b.

Arg. fretty gu. the field replenished with towers triple-towered sa. NEchuRE.

\section{CAT and CAT-A-MOUNTAIN see Beast CATHERINE WHEEL see Wheel \\ CAVE}

Gu. a cave ppr. therefrom issuant a wolf at full speed reguard. arg. WhLIalss.

\section{CHAIN see also Annulets}

Arg. a chain of nine links in saltire five gu. and four az. Hatchet or HatchetT.

Az. a chain couped in chev. betw. three mitres all arg. at the dexter end of the chain a padlock of the last. Benedictine Abbey at EVEshadr, co. Worcester.

Gu. a chain of seven links in pale arg. KENDALL. Gu. a double orle saltire and cross of chain from an annulet in the centre point or. Navarne, after the battle of Tolosa, 1212. A quartering of IsABEL of France, wife of Edward II. JoAN, daughter of Charles II, King of Navarre and Earl of Evreux, second wife of Henry IV, quar. tered with az. flory or a bendlet compony arg. and gu.

\section{CHAINS}

Arg. three circles of chains (or wreaths ? torces) sa. Sr. Richard de Hoo, Kent, $V$.

Sa. three chains arg. Anderton, co. Lancaster.

Sa. three chains each of four links palewise arg. Anderton, Claiton, co. Lancaster, Harl. MS. 1468 , fo. 96 .

\section{CHAIR}

Or out of a chair resembling a mural coronet reversed arg. a demi-lion ramp. az. Talstock, $V$.

CHART betw, or within....

Per chev. wavy az. and erminois a chart of Chesterfield's Inlet betw. in chief two estoiles arg. and in base on a mount vert a beaver pass. ppr. Christopher, London.

\section{CHALICE see Candlestick and Cup CHAMBER see Gun CHAMELION see Reptile CHAPE see Boteroll}

\section{CHEQUY}

Chequy arg. and az. Sr. de Bretry, $V$. Bretry. Chequer, $V^{*}$. Sr. Laurence de la Chequer (aliter Cheter), I. Sr. Laurence de la Chequre, temp. Edward I, $\boldsymbol{V}$. Dalyoy. Garton, Kent. Gaton. Gatton, Throwly, Kent, Add. MS. 14307, fo. 21. Hamon de Gatton, $A ; D ; V$. Hadelyn.

\section{CHEQUY cont.}

Chequy arg. and gu. Altares. Brokering. Fitz-John. Money Moneye and Morney. Walter de MoncI, $K$. Sr. Wauter de Mon'cx, $H$. Sr. Wauter de Mouncey, J, Harl. MS. 6589. Mouncr. Wauter Mouncy, $Y$. Walter de Redesham, D. Roos or Rosse. Stanecourt. Stavecourt. Vane. Sr.John de Valitibus or VAUx, $A$; founder of Thetford Monastery, $V$. M. John de Vauls, $D$. Joan de Vaus, $E$. Robert de Vausse, $C$. Johan de Vaux, $P, Y$. John de WAREN (corrected WAUS in a later hand), $F$. And with a label az. Sire Johan de VAUS, $N$.

Chequy arg. and gu. 'ove vii quartree d'azure.' Fouk de VAUX, $X$.

Chequy arg. and sa. Brock. Broke, V. Brooke or Brook, co. Salop. Brooke, co. Stafford. 'Town of Drortwich, co. Worcester, impaling gu. two barrows or. ElLINGBridge. Roger Elmbrige, $V$. Hamelyn. Sr. de Hameyn, $V$. HaNNoN. HELMEBRIDGe, $V^{*}$. INKPENNE, Leland, ltinerary, 8vo, Oxford, 1744, iii, 84. Olmebrigr or Ellimbridge. Purley. St. BARBE, Lymington, co. Hants; derived from St. Barbe, South Brent, and Ashington, co. Somerset; and Broadlands, co. Hants; Baronetcy 1663; extinct 1723. ST. BARBE, quartering Furneaux. St. Barbe, $V^{*}$. Symbanbe, co. Somerset. WARREN, Ightfield, co. Salop.

Chequy in perspective arg. and sa. Prospect.

Chequy arg. and vert. Lillington, co. Dorset.

Chequy az. and arg. Mortier. Schultz or Schultze.

Chequy az. and or. Le Counti de Garenne, $J$, Harl. MS. 6137. Glenton. Henry Glynton, founder of Kenilworth Priory, $V$. Green, Ireland. (? Cistercian Nunnery of the Virgin at Marhadt, Norfolk.) C. de Waren, $F$. W ARREN.

Chequy erm. and or. GARTER.

Chequy gu. and arg. Bunchetr. Sire Wauter de Mouncey, J, Harl. MS. 6137. John de Roos, $Y$.

Chequy gu. and or. John Ros, $V$.

Chequy of lines palewise and chevronwise gu. and or. SPotworth.

Chequy or and arg. Gosewyn or Goswrs. Goswin, Harl. MS. ]404, fo. 59. Mortier.

Chequy of nine pieces or and az. Geneva, $Z, 679$. Chequy or and az. Benton. Dantry. Dreux. Fitz-Warren. Sr. John Counte de Garein, $H$. Le Counte de Garene, $N$. Comte de Garenne, $G$. Le Counte de Garenne, $B ; J$, Harl. MS. 6589. Garrene. Canons of the Holy Sepulchre at ThetFord, Norfolk. Hugh Earl of Vermandors, $Z, 95$. Conte de WAREN, $E$. Le Counte de Warenne, $P$. Le Counte de Wareyne, $Y$. Countee de Warren, $D$. Warren, $Z, 399,358,487,496$; quartered by Howard Duke of Norfolk; by Nevill Earl of Abergavenny; and by Stanley Earl of Derby, $U$. John (Plantagenet) Counte de Warren, $K$, in Normandy, and of Surrey and Sussex, ob. 1304. WARREN, Earl Warren, $L$, and Surrey, $V$. Chequy or and az. a label of three points gu. GLinton.

Chequy or and gu. Fitz-Warren. Geylstane. Gilitand or Gitilan. Gili.and Gilleslland or Gilsland, Northumberland. Gilleslland, co. Lincoln. Sr. de Gillesland, $V$. Sr. Robert le fitz John, $I$. Hubert de Maltone, $F$. Huberd de Moleton, $E$. Sire Thomas de 


\section{CHEQUY cont.}

Mortone, N. Sr. Hugh MoLton, co. Lincoln, temp. Edward I, $V$. Walter de Moulton, $K$, Harl. MS. 6137. Turbervirie (but ? a fess erm.) Collinson, Somerset, iii, 125. VaUx, Gillesland, Cumberland, before 1252; the heiress m. Multon. WaRREN.

Ghequy or and gu. ( $a$ bend) vair. Ботreux, $V^{*}$.

Chequy or and sa. Hamerin. Sire James de Moltone, $N$. Molton, Pinho, co. Devon; the heiress m. Streeche. Molton, co. Lincoln. James de Moltune, $G$. Moulton, $\boldsymbol{V}$. OLMBRIDGE.

Chequy or and vert. H HCKFORD, $V$. William de HAKEFORD, temp. Henry III, and his son Thomas, $V$. HaKFoId, $V^{*}$. Hanisord. Pleckford. Sharpe.

Chequy sa. and arg. ST. BARBE, South Brent, co. Somerset; and Astington, near Shirbourn, co. Somerset; Baronetcy 1663, extinct 1723; quartering Leyland and Furnelles or Furneux.

Chequy of twelve sa. and arg. ST. BArbE, co. Somerset, $V$.

Chequy vert and arg. VAIRE.

\section{CHERRY see Fruit \\ CHERUB see Head}

CHESSR00K betw, or within....

Arg. a chessrools (others a castle) betw. three battleaxes sa. HEXT.

\section{CHESSR0OKS}

Arg. three chessrooks gu. WaLsInginad, $V^{*}$.

Arg. three chessrooks in chief sa. Ameline. Rookwood, Rookwood, Suffolk.

Arg. three chessrooks sa. AbELyn Abrueyne or Aylin. Abelyne, $V$. Eltoft or Eltofts, Farnley, co. York.

Erm. three chessroolis gu. Hondesacre, $V$. (? Ruuf Hondesacre, $X_{\text {.) }}$ Hondisacre Hondsacre or Hontsacre. Hondishacre, $E$. Siart. Suert, $V$.

Gu. three chessroolss arg. WALSINGHair, co. Bedford; and Norfolls. Sr. Richard de Walsinghair, $N$, Norfolk, temp. Edward I, $V$.

Gu. three (zules or) chessrooks and a label of three points arg. ZULEISTEIN.

Gu. three chessrooks erm. Simon le Frrz Symon, $E$.

Or three chessrooks gu. Corvin.

Per chev. gu. and erm. three chessrooks in clief of the last. HorwerL, $V$.

Per chev. gu. and erm. three chessrooks counterchanged. HoLLOWELL or HoLWELI.

Sa. three chessrooks arg. ElLERECK. Elleriser. Rooke. WeIDON, $V$.

3 CHESSROOKS and in chief....

Arg. three chessrooks and a chief sa. Rockwood, Ewston, and Weston, Norfolk. Rokewood, $V^{*}$. Rookwood, Eveston, Suffolk.

Or three chessrooks and a chief sa. Rock Rook or Rooke.

Or three chessrooks and a chief embattled sa. Rocke, Abbey Foregate, co. Salop. Rocke, $V^{*}$. Rock, co. Salop, $W$.

Sa. three chessrooks and a chief arg. ARTHUr.

Sa. three chessrooks arg. a chief or. ARTHur, $V$. (An augmentation to) Ornisby.

Sa. three chessrooks and a clief or. Ormesby, co. Lincoln; quartering gu. a bendlet betw. six crosses croslet fitchy ....
3 CHESSR00KS betw, or within....

Gu. three chessrooks erm. betw. two bendlets dancetty (or indented) arg. Hewe, $V$.

\section{CHESSROOKS}

Arg. six chessrooks sa. Rorewood.

Arg. six chessrooks three two and one sa. Rockwood, Kirkby, Suffolk. Rockwood, $V$. Rocold. RoKewode, Acton, Stokenayland, and Stanningfield, Suffolk; quartering Clerbeck, Burgate with Swynford, and Cadwell, the heiress m. Gage.

\section{PER CHEVRON}

Per chev, indented arg, and gu. Brighuen.

Per chev, arg. and or (tricked arg. and gu.). Catilines, co. Northampton, 1716, in error.

Per chev. arg. and sa. Aston, co. Devon; Harl. IIS. 1465 , fo. 27.

Per chev. gu. and arg. AndotT.

Per chev. nebuly gu. and arg. Coverdale.

Per chev. gu. and sa. COBB or CoBus.

Per chev. or and gu. Ley. Molton.

Pel chev. or and sa. Molton.

Per chev. sa. and arg. Ashton or Aston, Ashton, co. Chester. Aston, co. Chester, $V$. Aston, Aston, co. Chester, Harl. MIS. 1535, fo. 7 ; Baronetcy 1028 extinct 1815; a heiress m. Hervey. Aston, Aston, co. Lancaster. Aston, co. Stafford.

Per chev. engr. (but invected, meaning the same, Loner, 1730) sa. and erm. CleneHond, $V$, Cotton. $M S$. Tiberius D 10. CrevenoND, but Creveland in index, $V$. John Lonye, $V$.

Per chev. sa. fretty or and erm. Aston, co. Chester, Harl. MS. 1535, fo. 7 .

\section{CHEVRON}

.... a chev. .... Richard Bedewynd, Reading, seal, 1397.

.... a chev. .... William Linwood, Bishop of St. David's 1422-46.

Arg. a chev, az. Burghepe, $V$. Edmond. Hopton. Lockton, Swinsted, co. Lincoln. Scales, co. York. Swellington, co. Leicester, $V$. Adam Swilington, $Y$. SwHIINGton. Toty or TotTye.

Arg. a chev. az. a label erm. Hopton. Staveley. Swillington.

Arg. a chev. az, a label of three points erm. Swulington, $V$. M. Robert de SwYlington, $S$. Al'g. a chev, az, a label gu. CIrcester, co. Warwick. Sire Thomas de Circestre, $N$. Sisenton or Sysington. Sire Huge de Somingtone, $N$. Swenington, co. York, temp. Edward I. Swilington, Swillington, West Riding, co. York, temp. Edward III. Sr. Adam de Swymelyngton, $M$. The label of three points gu. Arcester, co. Gloucester, $V$. Archest. Thomas Arcester, N, Harl. MS. 1386. Sr. Thomas de Circester, co. Gloucester, $N$, Harl. MS.6137. Sr. Adam de Swerington, co. York; Harl. MS. 6137.

Arg. a chev. engr. az. AskBy, $V^{*}$. Askebr, $V$. Askedy, co. Chester. Askeley Askiey and Skaley. Stapley. Stayley, $V$.

Arg. a chev. compony az. and or. BRITTE.

Arg. a chev. ermines. Wolley, Surrey.

Arg. a chev. gu. ACTON, co. Chester. Thomas Barlow, Bishop of Lincoln 1675-91. BENN. Bolton. Bradie, Scotland. Chelton, $V$. Henry Chilton, Fokeston, $\boldsymbol{V}$. Foriston. Jacor. Marler alias Merler, Kent. John 


\section{CHEVRON cont.}

de Scorenci, A, Harl. MS. 6137. Shelton, $V$. Stocket. Dominus Teres, $V$. Thelton. Tias. John TIES, $Y$. Monsire Henry Ties, Y. Treys. Trye, 1730. Tyas. Tres, Cumberland; and Northumberland, temp. Henry I. Teineis, Lord of Chilton 1301. Sr. Henry Tyes, $H$; $L$, or Teyes, $J$; $Q$; or Tyeis, $L ; N$, or Tyeys, $O$. Henry le Tyors Tieis or Tres, $K$. William de Wanton or WaUton, $A$. White, Ireland. Whizt, Ireland, $V$. Widwill, Earl Rivers.

Arg. crusily sa. a chev. gu. William de M'wire, $A$. John Mereworth, $Y$. The croslets potent. William de Merwre, A, Harl. MS. 6137. Arg. a chev. gu. over all a bend az. Bervilt.

Arg. a chev. gu. over all a bendlet az. Cromweru. CRUTWELL, $V$.

Arg. a chev. gu. over all a bend engr. sa. Lere or LEIKE.

Arg. a chev. gu. on a bend az. three escucheons .... Allestri.

Arg. a chev. enarched gu. Honbearie.

Arg. a chev. engr. gu. Cardinis, Scotland. Chiner, co. Worcester. Chyner, $V$. Chyver.

Flegg. Rat. Royneforth, Essex. Staveley, Staveley, co. Chester.

Arg. a chev. indented gu. Brighteley, co. Devon. Arg. a chev, reversed gu. Grendon.

Arg. a chev, voided gu. STEER, Ireland.

Arg. a chev. per pale or and gu. Weston.

Arg. a chev.purp. MarLer, London; granted 1583.

Arg. a chev.quarterly sa. and gu. Honywood, Kent.

Arg. a chev, sa. Archdeacon, Cornwall. Ares.

Bradley. Denssen. Flockart. Ivis Iwis or Iwrs. Jues orJuis. Lamionne, Polsted. Landon. Lemebonne. Mordant. Prideaux, Prideaux Castle, Cornwall ; extinct temp. Henry VI; a heiress m. Herle. Prideaux, Orcharton, co. Devon, temp. Henry III ; extinct temp. Eliza. beth. Prodney. Stapleherst. Thornton, Thornton, and Tyresale, co. York. Sr. Jonathan Trfinawner, Bishop of Bristol 1685, Exeter 1689, Winchester 1707-21; descended like Trelawny, Coldrinick, from Tre lawny, Trelawny, Cornwall; Baronetcy 1628. Trelawny, Ham, co. Deron; the beiress m. Collins. William de Wantone, $A$, Harı. MS. 6137, William Wanton, Essex, $V$. Wadton, $V^{*}$. William de Wautone, $N$; but Wawton, $S$. Wiley. Robert de Wilebe, $F$; or de Wilebi, $G$; or de Wileby, $E$.

Arg. a chev. sa. an aunulet for diff. gu. WANTON alias WaUton, 1600-20, Harl. MS.1535, fo. 30.

Arg. a chev. and in the dexter chief an annulet sa. Wanton, co. Huntingdon. Waulton or WAUTON. Sir George WAUTON, quartering gu. a lion ramp. arg. crowned or, with Creting, and sa. on a bend or three goats pass. gu. in Great Staughton Church, co. Huntingdon. M. Thomas Wawton, $S$.

Arg. a chev. sa. in the dexter chief a martlet gu. Thomas de WANTON, $Y$. Sir William Wanton, R. WAULTON Or WAOTON.

Arg. a chev. and in the dexter chief a pierced 5 -foil for diff. sa. Kempstone, $V^{*}$. M. Thomas de Rameston, $S$. Sr. Thomas Renipstone, I..G., $V$; temp. Henry IV.

Arg. a chev. sa. a label gu. Orcharton.

Arg. a chev. sa. a label of three points gu. Leigh. iI. Thomas Predias, $S$. Predieux, $V$. Prideaux, Collinson, Somerset, ii, 307; iii, 581. Prideaux, Netherton, co. Devon, Baronetcy $162 \%$.

\section{CHEVRON cont.}

Prideaux, Soldon, Devon; and Place, Corn. wall; derived through Prideaux, Adeston and Thuborough, like Prideaux, Kingsbridge, and Luson, Devon, from Prideaux, Orcharton. John PrIdeux, Bishop of Worcester 164l.50.

Arg. a chev. sa. in the dexter chief a mullet gu. Monsire de WaUton, $Y$.

Arg. a chev. and mullet sa. WAUTon, Shepreth, co. Cambridge.

Arg. crusily and a chev. sa. Sir Henry de Lekburne, $M$; or de Lekebourne, $N$. Mon. sire de Lemeborne, $Y$. Hugh Lekeburne, $Y$. Leiyborne. Sir John de Mereworth, $R$.

Arg. a chev. sa. over all a bend engr. of the first. Highiali or Highair, Branches in Cowling, Suffolk; Harl. MS. 1407, fo. 71 .

Arg. a chev. sa. and a pale erm. Enderbr.

Arg. a chev. sa. and a pile counterchanged. ALWELL, co. Gloucester. ATwILI, co. York, Harl. MS. 1465. A TwILl, co. Devon, Harl. MS. 1465. ATwYLL, $V$. BeringhaM, $V$. Brighani, co. York, Harl. MS. 1465 . Bringham, co. Devon. Chesterton, $V$. Noseworth, $V *$ Otway, Castle Otway, co. Tipperary; descended from OTWAY, Ingmire, co. York; granted 1663.

Arg. a chev. sa. and a pile in point counter. changed. ATWELL, co. Devon; patent 1614.

Arg. a chev. the top ending with a cross patty sa. Findon, Harl. MIS. 1386, fo. 34. GopHili, Surrey.

Arg. a chev. supporting on its point a cross patty sa. Trenereer.

Arg. a chev. enarched sa. Holbane, co. Devon. Holbeane, Holbeame, and Coffinswell, co. Deron; the heiress m. Marwood. Holbeame, co. Devon, $V$.

Arg. a plain chev. sa. fimbriated and engr. az. Stalee. Staley, $V$ *

Arg. a cher. engr. sa. ALAnby, Holbeach, Collinson, Somerset, ii, 443. HOLBEACH or Holigh. Holbeche, $V$. Holdiche. Holliche. Peebles, Dewsbury, co. York. Wooton or Wootton. Wotton, Kent.

Arg. a chev. voided sa. Hughasr.

Arg. goutty de larmes a chev. voíded sa St. MAURE.

Arg. a chev. vert. Chilton. Compton, co. Ches. ter, Harl. MS. 1535 , fo. 11 b. FIELD.

Az. a chev. arg. Allenson. Erteli. Gonwood or GURwOod, from Sayoy. GURWOOD. LAdBrooK or LADBROOKE. LATHEROKE. Sir Johu LODBROKE or LOTHBROEE, co. Warwick, $V$. Lodbrook or Lodbrooke. Prow. Stangate. Az. a chev. arg. a label of three points gu. Clynduie.

Az. a chev. embattled arg. HaLes.

Az. a cbev. of the first fimbriated engr. or. Duley, co. Buckingham, Harl. MS. 1386, fo. 34 . Az. a chev. erm. LADBRokE, Lord Mayor of London 1748. LADBROIE, $V *$. LETEBROOKE. Lidderdate, St. MaryIsle, Scotland. Lodbroke, $V$. John de Lodebroke, S, Harl. MS. 6137 . John LODERRok, $X$. LODBRoke, Lodbrooke, co. Warwick. Sire Johan de Lotebrok, $N$. John de Lowbrose, $E$.

Az. a chev. embattled erm. Rexnolds, co. Leicester.

Az. a chev. engr. erm. Thomas Garrard, Lam. bourne, co. Berks, 1610. Gerard, co. Berks. PUDLEY.

Az. fretty arg. a chev. gu. Faning. 


\section{CHEVRON cont.}

Az. a chev, or. ABborne. Abernie or Aberton. John de Abrnon, $E$. Aspul. Aubermin. Austen, Norfolk. Jolin de Chambernoun, $A$. Chaworth, Suffolk. Chenydoyt or Cheyndutt, co. Buckingham. DabernoN, co. Hants; and Surrey. Dabernon, Bradford, co. Devon; extinct temp. Edward I; the heiress $m$. Deunis. D'ABernon or D'Aubernoun, temp. Edward II, tomb; and Sir John DabernoN, (glass; in church at) Stoke Dabernon, Surrey, $V$. John D'A bernoun, $X$; but Dabernun, $E$, Harl. $M S$. 6137. Sire Johan Daberoun, $N$. Daufernon, Surrey. Dawberon, temp. Edward I. Ispal, Surrey, temp. Edward I. LaDbroke or Lathbroke. Latham. Ledbrooke. Prowst.

Az. a chev. or and a label arg. Sir John D'Abernon, $L$; but de Abestne or Absnor, $L$, Harl. MS. 6137. Sire John Dabernoun, $O$. Sire Johan Dabernoun, the son, $N$.

Az. a chev. or and a label gu. Chenduit, co. Buck. ingham. SHerient, co. Buckingham, temp. Edward T. The label of three points gu. Chendut, $V^{*}$. Sr. Rauf Clyndut, $V$.

Az. crusily and a chev. or. Rauf de Bakepuz, $E$. Simon de Kymbe, $G$; or de Kyme, $N$.

Az. a chev. or over all a lion ramp. of the second. HASTANG.

Az. a chev. dancetty or. Hamerr, co. Buckingham. Hanilton, co. Gloucester.

Az. a chev. disjoint (or broken in the head) or. BroKMALE.

Az. a chev. embattled or. Bayne. Hales. Hall.

Az. a chev. embattled counterembattled or. HALE, Codicote, and King's Walden, co. Hertford, temp. Elizabeth. Hale, $V^{*}$. Halle, $V$.

Az. a chev. engr. or. DudLey, $V$.

Az. a chev. engr. voided or. DuDLEx, co. Berks; and co. Buckingham. DuLy.

Barry of three arg. and sa. a chev. of the last. HONYNGTON.

Barry of three gu, and arg. billety and a chev. of the last. Hardey.

Barry of three gu. and arg. a chev. az. BroadHurst.

Barry of four gu. and arg. a chev. of the last. Kirton, Westmoreland.

Barry of six or and az, a chev. erm. TALwORTH.

Barry of six or and az. a chev. gu. Sr. Peirs TAlworth, $V$.

Barry of six or and az. per pale counterchanged a chev. gu. Simon de Stodham, $E$.

Barry of seven arg. and gu. a chev. az. Gilbert de Sancto Leonardo, Bishop of Chichester 1288-1305.

Barry nebuly of seven gu, and vert a chev. erm. RoLston.

Barry of eight per pale arg. and az. counterchanged a chev. or. Stetham, $V$.

Barry of eight per pale or and gu. a chev. counterchanged. Stellam or Stellhadr.

Barry of ten arg. and gu. a chev. or. Sroke, $V$ De Stoke, Stoke, co. Northampton; quartered by D'Oyly.

Barry of ten vert and arg. a chev. gu. Butrer.

Barry of (fourteen another) fifteen arg. and az. a chevron gu. Bartholomew de la More, $F$; or MARE, $E$.

Bendy of six gu. and vert a chev. erm. BLANCHMINSTER.

Bendy sinister of six gu. and vert a chev, erm. WESTERDALE, $V$.

Bendy of six vert and gu. a chev. erm. Rondston or Rolston. Rolstone, $V^{*}$. Rolston, $V$.

\section{CHEVRON cont.}

Bendy of six vert and gu. a chev. engr. erm. RoIsTONE, $V$.

Bendy sinister of six vert and gu. a chev. erm. Westerdale, $V^{*}$.

Bendy of seven arg. and: sa. a chev, erm. Blanchminster, Cornwall.

Bendy of eight or and vert a chev. erm. INGLEBERT. Bendy of eleven sa. and arg. a chev.gu. LONG HURST. Chequy az. and or a chev. gu. .... de Erdern, $F$. Chequy or and az. a chev. erm. GuY Earl of Warwick, $V$. Gurennon. Ethelswytha de HEsDen, as quartered by Grazebrook. HESDING. Anne Neville, wife of Richard III, quartering Beauchamp, Montagu, Monthermer, Neville, Clare, and Despenser. Henry de Newburgh, Earl of Warwick ob. 1123, and his desceudants till 1243; the heiresses $\mathrm{m}$. de Plessetis, Mauduit, and Beauchamp. Le Conte de Warrewik, $B, P$; or Warwick, $E$; or WARWIK, $C ; Y$. WARWICK, $Z, 331,332,441$. Le viel escu de Warw: $G$.

Chequy or and az. a chev. gu. Emeri de Manes, $E$. Aumeri de Maurss, E, Harl. MS. 6137. MAYroll. REDBORNE.

Chequy or and gu. a chev. az. Baterell. Boterelis, co. Devon. Sire William de Boterels, N. Bottereli, Essex, $V$. Bottrell, Essex.

Erm. a chev, az. Servinton.

Erm. a chev. engr. az. Askeley AsKLey and SKALEX.

Erm. a chev. compony gu. and arg. HiLI.

Erm. a chev. chequy sa. and or. HiLL, Middlesex; and Bromsgrove, co. Worcester. HILLE, Middlesex, Harl. MS. 1386, fo. $34 b$.

Erm. a chev. ermines. WELLINGHAIr. WILLINGHAIr. Erm. a chev, engr, ermines, WyssLowe, $V^{*}$. Wrnslow, $V$.

Erm. a chev. gu. Arras. Cantelow. French. Kinaston. Kynaston, Hardwick, co. Salop; Baronetey ....; quartering Meredith ap Bleddyn. Krnaston, Hordley, co. Salop; granted 1461. Rxneli. Sachevile. Sorett. TaIlefer, Harecleugh. Tichets, $S$. Robert Tichets, $Y$. Sire Thomas Thochet, $N$. Touchet, Essex; and Ireland. Touchet, Lord Audley, quartered with Audley, $U$. Monsire Touchet, co. Derby, $Y$. Sr. William TouchetT, co. Northampton, $V$. Touchets (1301). Roger Tuchet, $Y$. Robert Tuchett, $X$.

Erm. a chev, gu. and a label az. Sire Robert Thochet, the son, $N$.

Erm. a chev. couped gu. Amock.

Erm. a chev. engr. gu. Morton. Stallery. Tunstall, Scargil, co. York. Upton.

Erm. a chev. lozengy az. and or. SmedLey.

Erm. a chev. lozengy gu. aud or. Hri..

Erm. a chev, per pale gu. and or. Cosins or Cosyns, Chorley Hall, co. Leicester; confirmed 13 March 1651.

Erm. a chev. per pale or and sa. Cosxn, London. Cosyn, $V^{*}$. Edwardos, Bristol.

Erm. a chev. engr. per pale or and sa. Cosyn, London; and Newcastle-on-Tyne; granted 12 May 1647. Cosxn, $V$.

Erm. a chev. sa. Arras, $V$. Ffrench, Baron French. French, Baron de Frene. Hatfeld, $V$. Thomas HatField, Bishop of Durham 1345-81, $Q$. Illey Iley and Ilney. Jelley or Jelly. Landstroder. Plomisted, Hatfield, co. Lancaster. Plumsted. Wellingham. WILLINGHAM. 


\section{CHEVRON cont.}

Erm. a chev. couped sa. Jones or Johnes, Caton, co. Lancaster; quartering Johnson, Eure or Eures, and Sirope.

Erm. a ehev, couped sa. Huntcey. Jones, 1730. Erm. a chev, engr. sa. Houghton. Weaslowe. WENsLow, $V$. The chev. counterengr. Hoghton, Harl. MS. 1386, fo. $34 b$.

Gu. a chev. arg. Avene. Barkele, A. Moris de Barkele, $B$. Barjeley. Mauriz de Berkele, $A$, Harl. MIS. 6137. Thomas de Berkeleie, $E$; or de Berkeley, E, Harl. MS. 6137 ; or de Beriflex, F. M. Morris de Berkley, D. Burnebury, Corntwall. Dolseley, $V$. Fittyplace. Fitzhanding, made lord of Berkeley, 1155, took the name of Berkenex, 1170-1189. Folrsand, Scotland. Fulforde, $V$. Fulford, Great Fulford, co. Devon ; quartering Fitzurse, Moreton, Bilston, Bozom, St. George. Cantilupe, St. Albyn, and Challons. Hersey. Kinne. Henry Tres, $V$.

Gu. crusily and a cher. arg. Sir Thomas de Berkeley, $G$; or de Barieley, $H$. Thomas BERTLEY, $Y$.

Gu. crusily and a chev. arg. with a label az. (as Thomas was alive.) Sr. Thomas (? Maurice) BARKeley, the son, $H$.

Gu. crusily patty and a chev. arg. Sir Thomas de Barketer, L, Harl. MS. 0137. Sire Moris Barkley, $Q$. Morice de Barkley, $K$, Harl. MS. 6137, 6589; $Y$. Le Sr. de BarkIJEY, $T$. Sire Moris de Berkeleye, $N$; and his descendants, Earls of Berkeley. Berkeleye. Berreley, $V^{*}$. Sire Morice de Berkeley, $J$. Sr. de Berkely, $V$.

Gu. crusily patty and a chev. arg. with a label az. Moris de Barkier, $K$; the label some. times sa., $K, \mathrm{Harl}$. MS. 6589 .

Gu. semy of roses and a chev. arg. Sire Thomas Barcley, L, Harl. MS. 6589 ; or de Berkeleye, $N$ (? of Wymondham).

Gu. semy of 5-foils and a chev. arg. Sire John Barkeley, $Q$. Berkeley, Wymondham; Baronetcy 1611 .

Gu. a chev. embattled arg. Bird, co. Derby.

Gu. a chev. engr. arg. Hrnkeler, co. Chester, Harl.MS.1386, fo. 34 b. KinkLey. Themilby. Gu. a chev, enhanced arg. CARLYON.

Gu. a chev. raguly of two bastons couped at the top arg. Christopher DRaIEsField, Harl. MS. 1386. Gu. a chev. barry nebuly of six arg. \& sa. HANKFORD.

Gu. a chev. chequy arg. and az. Dance.

Gu. a chev. chequy or and az. Fitz-Piers. Herey or Hery.

Gu. a chev. chequy or and az. surmounted by a bend erm. HANSTED.

Gu. a chev. erm. Roger Berkley, $V$. Boxall or Boxell. Gaultier de Gistelle, $C$. Monsire de Gonneys or Gouneys, $X$. Gwrs, Wis. ton, co. Brecknock. Krrkby. Kirkley. Iundroor, $Y$. Wallis, Surrey; and Sussex. Willians, co. Brecknock. Wolley. Wrmanson. Gu. a chev.erm. a label of five points az. Wruanson. Gu. crusily arg. a chev. erm. Maurice Berkeley, Stolse Gifford and Brimpsfield, ob. 1347, and his descendants, Barons Berkeley of Stratton, Baron Botetourt, Barons Berkely of Rathdown, Viscounts Fitzharding and Earl of Falmouth; Collinson, Somerset, iii, 275; Baronetcy 1660; all extinct.

Gu. bezanty a chev. erm. Sire Oliver la Souche, N. ZOUCH.

Gir. a chev. lozengy or and az. Heire.

\section{CHEVRON cont.}

Gu. a chev. or. Jon Chambernoun, A, Harl. MS. 6137. John de Cobham, $A$; or Coberam, $A, H a r l$. MS. 0137, which seems to suggest three lions ramp. on the chev. Downer. Dulford or Tulford, co. Devon. Gathwite. Gouneris or Gounery. Hadley. Kirkley. Redley. Whitley, co. Warwick. Whitley or Whitlue.

Gu. crusily and a chev. or. Krare, $V$. Phillipe de Kyse, $A$; or de Krne, $E$; or de Күмве, $G$; or de Kene or KrMe, $J$. Philippe, Sieur de Kistes, $K$. Sire William de Krne, N. William KYME, $Y$.

Gu. crusily and a chev. or a label arg. Sir Wi]liam de Kyne, $L ; O$.

Gu. crusily and a chev. or a label az. Sr. William de Kyse, $M$.

Gu. a chev. or and a pile counterchanged. NosEWORTHY.

Gu. a chev. vair. Sr. John BLAKet, co. Buckingham, $V$. Kingston or Kynston. Kniveton. Gu. a chev. vairy arg. and sa. KnIveton or Knyfton, Uphill Lodge, co. Somerset; descended from Kniveton, Mercaston, co. Derby; Baronetcy 1611. Knyveton, co. Derby, $V$.

Gu. a chev. raguly of two bastons couped at the top or. Christofer Drownsfend, $X$.

Gu. a chev, vert. Sire Johan Blaked, $N$. Blaket, co. Buckingham. KYMe.

Lozengy arg, and gu. a chev, az. Busteed. Lozengy or and az. a chev. gu. Georges or Gorge, Westminster ; and Hayes, Middlesex. (The ancient arms of ) Gorges, Collinson, Somerset, iii, 156-8. GoRges, Wraxall, Langford, etc.; granted 1328. GEorge, Baron of Dundalk; quartering arg. a serpent's tail az., with arg. a fess gu. betw. three eagles displ. az., Harl. MS. 4040 , fo. 416 . LEGEARD, co. Yorls.

Lozengy or and vert a chev.az. Younge, co. Hants. Masculy arg.and az. a chev.gu. John LE Gorge, $X$. Or a chev. az. BAstaRD, Efford, Garston, and Kitley, co. Devon. Batstard or Basterd, co. Devon. Batered. Clopton. EDiond. Marler, Kent. Pinierton, London.

Or a chev, az. a label gu. KrRke, co. York. The label of three points KIRKE, $V$. KYrke, $V^{*}$. Or a chev. couched az. DoubLet.

Or a chev. engr. az. Starley.

Or a chev, barry gu. and sa. Lewis Proude, at the Charterhouse, 1619.

Or a chev, engr. barry wavy of six arg. and az. Browne.

Or a chev. chequy az. and of the first $\&$ crescent for diff. LEE, Fishburn, co. Durham.

Or a chev. erm. Souche.

Or a chev. gu. Carrick. Sr. .... de Estafford, J. Le Baroun de Estaffonde, $N$. Ile. StafFord, Grafton, co. Hertford. Le Baron Stafford, $I$. Ralph Baron Stafforde, $Q$. Sr .... de Stafford, $V$. Stafford, Baron Stafford 1299, Earl of Stafford and Duke of Buckingham, $Z, 234,334,446$. Sir Ranf de StAFFord, $R$. Le C. de StAFFORd, $S ; T ; Y$. Le Baron de Stafford, $Y$. Thomas Starford, $S$. A quartering of STAFFoRD, Earl of Wiltshire, $U$. Benedictine Priory at Wotton Wawen or WaLwaynes, co. Warwick, quartering or a hand ppr. issuing from a maunch gu. holding a rose of the last stalked and leaved vert.

Or crusily and a chev. gu. Thomas de Brokehole, $E$. Richard de Holestoc, $F$. Sire .... de Holebrok, $N$. 
CHEVRON cont.

Or a chev. and over all a lion ramp. gu. HASHLARD, $V^{*}$.

Or a chev. gu. surmounted by a bendlet az. M. Robert de StafFord, $S$.

Or a chev. gu. pierced by a bend erm. HaDsтоск, Suffoll. Haystacke. Hodstoke, $V$.

Or a chev. gu. and a bend erm. HaDstock.

Or a chev. gu. pierced by a bendlet sa. LE Hunt, Ireland.

Or a chev. surmounted with a cross formy fitchy gu. Hozbrooke, Suffolk.

Or a chev. gu. the point ending with a cross patty of the last. Holobroke, Suffolk, $V$.

Or a chev. gu. surmounted by a pale sa. HoDGe.

Or a chev. embattled at the top gu. Asty, Harl. MS. 1386 , fo. $34 \mathrm{~b}$.

Or a chev, engr. gu. Chameny Chancey or Chauncey, Northumberland.

Or a chev. paly of eight gu. and arg. per chev. counterchanged. SURrIDGE.

Or a chev. sa. Berton. Donwike. Hameietd or Hanfield, Essex. Hangefeeld, Essex. HaNiNGFiEld. HaNNINGField or HaviNgField, Cornwall. Sire William Hanyngfeld, $N$. Haveringfeld, Essex, $V$. Havingfeld, $V$. Heningrield, Essex, temp. Edward I. Henningfield, Suffolk. John de Scoveney, $A$. YER. And with a mullet for diff. MerFy Morfin or Morfyn, Essex; and Kent.

Or a chev. sa. in the dexter point a pierced muljet of the second. Danwires. Roger Danwykes, $V$. Sr. Thomas de Dauncourte, $V$. Daunecourt, $V^{*}$. Morfyn, Kent, $V$. Murfyn, $V^{*}$. Sr. Thomas Myrfin, London, $V$.

Or a chev. sa. over all a bend engr. arg. Highar, Essex; and Goldhanger, and Branches in Cowling, Suffolk ; Harl. MISS. 1449, 1560.

Or a chev. vair. Sugge, $V$.

Or a chev, vairy or and vert. Sugg or Sugge.

Or a chev, vert. Sr. William INGE, co. Bedford, $V$. INGE, temp. Edward I. INGE or INGHAM, co. Stafford. JuDE, co. Bedford. JUDGE. Ouge. Ynge. Sire William Yngee, $N$.

Paly of three arg. and gu. a chev. counterchanged a 5-foil of the second. Allen, Chelsea, 1563.

Paly of three per chev. sa. and arg. counter. changed a chev. gu. DEare or DEar.

Paly of six arg. and gu. a chev. or. Barkeman, London. Barkihasi, Lord Mayor of London. 1621. BarkHaM, Wayntlete, co. Jincoln; and South Acre, Norfolk.

Paly of six arg. and sa. a chev. gu. Cressen or Cresson.

Paly of six or and gu. a chev.arg. Patissolle, Devon.

Paly of seven arg. and gu. a chev. or. BAREEHAM, London; granted 1611. Barkhan, London.

Per chev. arg. and gu. a chev. per chev. counterchanged. Sr. .... de Whithonse, $V$.

Per chev. sa. and erm. a chev, engr. counter. changed. Cleveland.

Per chev. vert and erm. a chev. engr. counter. changed. Praers, Stoke, co. Chester.

Per fess arg. and sa. a chev. counterchanged. Balnaves, Hallhill. William de Llllebon, $F$.

Per fess az. and or a chev. gu. Hammon. Hamond, co. York.

Per fess gu. and sa. a chev. rompu counterchanged. ALLEN, London.

Per pale arg. and gu. a cliev. per pale purp. and (? arg.) or. Hospital of St.Bantholonew,London.

Per pale arg. and sa. a chev. counterchanged. Ashconer, Scotland. Lawson, Brayton and

\section{CHEVRON cont.}

Isell, Cumberland; Baronetcy 1688, extinct 1806. LAwson, Little Osworth, co Durham ; confirmed 28 February 1558. LAwson, Nesham Abbey, co. Durbam; quartering Cramlington. David Lilleborne, $\boldsymbol{E}$. Londres. Hospital of ST. Bartholomew, London.

Per pale arg. and sa. a chev. gu. Londres. Ryveis, $V^{*}$.

Per pale indented arg. and sa. a chev. gu. Ravell or Ryvell. Raynwell, Lord Mayor of London 1426. Rynell. Ryvelt, $V$.

Per pale az. and arg. a chev. counterchanged. Daspach or Daspatch.

Per pale az. and or a chev. gu. Hamon.

Per pale erm. and ermines a chev. counterchanged. ADDINGToN or ADINGTON, London.

Per pale erm. and sa. a chev. counterchanged. Blondelu, London. Blundell, $V$. Cistercian Abbey called Eastuinster, St. Mary DE Gratirs, or New Abbey at Tower Hill, London. Per pale erm. and sa. a chev. engr. counter. changed. Blunder.

Per pale erm. and sa. a chev. gu. Rrnell.

Por pale indented erm. and sa. a chev. gu. MACKWORTHE, Harl.MS.1386.fo.34 b. RYNELI. Ryveld, $V^{*}$. The indent sinister. Reyveld, $V$. Per pale gu. and az. a chev. engr. or a mullet for diff. Sir Edmond Hoskrns, Oxted, Surrey, 1664, in Carshalton Church.

Per pale gu. and or a chev. ending in a pale counterchanged. Nosworthy, Ince Castle, Cornwall. Per pale indented gu. aud vert a chev. or. Heytesbury, co. Wilts. Heytesbury, Collinson, Somerset, iii, 358. HungenFond, Hungerford, co. Berks. Hungerford, Heytesbury, quartered by Hungerford, Calne, co. Wilts. Sr. .... de HungerFond, $V$.

Per pale indented or and arg. a chev. gu. Cobbile. Codylle, $V$.

Per pale or and az. a chev. erm. Drayton. Lions. WyKe, co. Oxford.

Per pale or and az. a chev. gu. Caldecot.

Per pale or and gu. a chev. counterchanged. WEs'ron, Ireland.

Per pale indented or and gu. a chev. .... Heytesdury, quartered by Hungerford, 1398, at Farleigh Castle Chapel.

Per pale indented or and sa. a chev. chequy or and gu. MAcKWORTH.

Per pale or and sa. a chev. counterchanged. FLEGG, Bray, co. Berks.

Per pale indented or and vert a chev. gu. HUNGERFORD.

Per pale sa. and arg. a chev. counterchanged. STokes, Ireland.

Per pale sa. and arg. a chev. per pale or and gu. LENDRES or LONDRES. LOUNDERS, $V^{*}$. Robert Loundres, $V$. LONDINES or LONDRES, Harl. MS. 1465, fo. 6 .

Per palesa. and or a chev. per pale of the second and gu. LoNDinms or LoNdres, Harl. MS. 1465 , fo. 6 . Per pale vert and arg. a cliev. counterchanged. STOKEs, Ireland, $V$.

Per pile arg. and sa. a chev. counterchanged. Dynton, co. York.

Per pile sa. and arg. a chev. counterchanged. Nosw ORTH, $V$.

Potent counterpotent gu. and arg. a chev. or. Amos or Ames.

Purp. a chev. enarched arg. Anchever, Scotland. Purp. a chev, couched sinister or. Bightine. Purp. a chov. engr. or. Piense. 


\section{CHEVRON cont.}

Quarterly arg. and az. a chev. counterchanged. Chamber. Chambir, $V^{*}$. Chambyr or Chaumbe, $V$.

Quarterly arg. and az. a ebev. engr. counterengr. counterchanged. Chamber, $V$.

Quarterly gu. and or a bordure counterchanged over all a chev, vair. Fenwyke.

Quarterly or and az. a chev. counterchanged. CHAMBER.

Sa. a chev, arg. Cornar, Low Hall, co. York. Thomas Cornay, $V$. Kayre. Keyrs. Pallis or Palys. Penley. Preacher.

Sa. a chev. arg. in chief a fleur-de-lis per pale or and az. KEy, co. York.

Sa. crusily and a chev. arg. Sire William de Paris, $N$; or de Parys, $O$. Monsire de Paris, $Y$. William Parys, $Y$.

Sa. a chev. arg. and a pile counterchanged. Atwyll, $V^{*}$. Beringham, $V^{*}$. Chesterton, 1716. Dirton, co. York, Harl. MS. 1465. Dixton, $V^{*}$. Dyrton, $V$. Dyrton, co. York.

Sa. a cher. ending in the middle point with a fleur-de-lis arg. KEx.

Sa. a chev. ensigned with a cross patty arg. FatRFIELD.

Sa. a chev. counterembattled arg. CAPELI, Kent.

Sa. a chev, engr. arg. Astwicke. H $\triangle$ THORPE.

Sa. a chev. wavy arg. HaNkFORDE, co. Devon; Harl. MS. 1386, fo. $34 b$.

Sa. a chev. barry nebuly arg. and gu. HANCKFord.

Sa. a chev. chequy arg. and az. M'MAUGHT, Scotland.

Sa. a chev. erm. Baynard, Norfolk. Wysse, Ireland, $V$.

Sa. a chev. or. Bainer or Baynar. Baynard, Norfolk, $V$. Coney. Cornay, Low Hall, co. York. Hewit, Ridenshall. Sr. .... de Riduedishell, $V$. RYDMEDIShell, $V *$ * Thornton.

Sa. a chev. engr. or. Hagthorpe, $V$. Halthorpe, $V$. Hathorpe, $V$. Hathonp. Robert Hatthorp, $Y$.

Sa. a chev. vairy arg. and gu. HANKFord.

Vair a chev. arg. APSEX.

Vairy arg. and sa. a chev. gu. AsHbroke or AsHBRook.

Vert a chev. arg. Cuckie or Cugley. Curle. $\mathrm{H}_{\text {ALL. }}$.

Vert a chev. erm. JoBbER, co. Stafford.

Vert a chev. or. CurLe, Hatfeld, co. Hertford; confirmed 17 December 1586. CurLe, V. Walter CURLE, Bishop of Rochester 1628, Bath, etc. 1629, Winchester 1632-47.

Vert a chev. engr. or. Curde, Soberton, co. Hants.

\section{CHEVRON and in chief....}

Az. a chev. and fess arg. in chief three annulets or. HaDleY, London.

\section{Bar see Fess}

Beast

Az. a chev. arg. in chief a lion pass. guard. or. HANBERE.

Az. a chev. or in chief a lion pass. guard. arg. HAMBORY.

Az. a chev. and in chief a lion pass. guard. or. HANBURY.

Az. a chev. and in chief a lion pass. reguard. or. HANBURY.

Gu. a chev. arg. in chief a lion pass. or. Bourch, Ireland.
CHEVRON and in chief....cont.

Gu. a chev. or in chief a lion pass. arg. TanfeILD, $V$. TANFIELD, $V^{*}$.

Gu. a chev. arg. in chief a lion ramp. crowned or. Brooke.

Per fess or and az. a chev. counterchanged in chief a lion pass. guard. of the second. SKEGES, St. Ives, co. Huntingdon; granted 29 August 1568. Sleggs, Aynesbury, co. Huntingdon.

Per pale vert and gu. a chev. indented erm. in chief a lion pass. betw. two martlets arg. SOMER, co. Salop ; granted 17 February 1651.

Sa. a chev. erm. in chief a lion pass. arg. crowned or. Hustock or Hustoke. Hustwick, Hull. Sa. a chev. and in chief two lions ramp. or. HyNDSTOKE.

Vert a chev. and in chief three lions ramp. or. Hens, Wingfield, co. Berks.

\section{Bend see Canton, and on a Canton; but see 2 CHEv. and in chief....Quarter.}

Bird

Arg. a chev. and in the dexter chief a bird sa. HARLSTON.

Gu. a chev. vairy arg. and sa. in the dexter chief a bird of the second. KNEVET.

Or a chev. and in the dexter chief a bird sa. HARDESTON.

\section{....Pelican}

Per chev. (vert) and erm. a chev. .... and in chief a pelican (or) vulning ber breast (ppr.). JoYNER or Jorner, about 1550, in Norton Disney Church, co. Lincoln.

Canton

.... a chev. .... and a canton .... RoDwell.

Arg. a chev. erm. a canton gu. SHAWE, Liverpool; Singleton Lodge, co. Lancaster; Soutbgate House, Middlesex; and Kesgrave Hall, Suffolk; quartering Wingfield.

Arg. a cher. canton and bend gu. Hable or HABLFY,

Arg. a chev. canton and bend gu. Keryell, Kent.

Arg. a cher. surmounted with a bend gu. a canton of the last. Werberton.

Arg. a chev. sa. and canton erm. BolensitH. BoLHALT, $V *$.

Arg. a chev, bend and canton sa. DaLBY.

Arg. a chev. and bend engr. sa. a canton of the last. Dalby.

Arg. \& plain chev. with over all a bend engr. sa. a canton of the last. Dalbye, Harl. MS. 1404.

(? Az.) a chev. arg. and canton engr. or. DEDEN. Az, a chev. erm. a canton and bend or. Reyes.

Az. a plain chev. and a canton engr. or. DEDHAM, Harl. MS. 1386, fo. 34 .

Az. a chev. engr. and canton or. Dedham.

Az. a chev. engr. and a canton indented at the bottom or. Dedhami, $V$.

Gu. a chev. and canton erm. Thодrs, Lelant, and Cury, Cornwall. Thonss, co. Glamorgan; and Chiverton, Cornwall; the heiress $m$. Peter.

Or a chev. gu. and canton erm. Grafton. HADSTOCKE. Sr. Humfrey STAFFoRd, Coddreth, co. Hertford, V. StafFond, Bradfield, co. Berks; Tottenho, co. Buclingbam; MorleWood, co. Gloucester; Blatherwick, co. Northampton; and Frodesham, co. Stafford, temp. Elizabeth. STAFroRd's InN, Office of the Remembrancer of the Exchequer, London.

Or a chev. fess and canton gu. Fitz-Richard or Fitz-Roand; but (?) the chev. in base.

Or a chev. gu. a canton vert. PIPE.

Sa. a chev. and canton arg. Boschall or Bosthali. 
CHEVRON and in chief.... cont.

Canton cont.

Sa. a chev. arg. and canton erm. Bormati, $V$. Bolmalthe, $V$. Bolmalth. Boschall or Bosthall. Boschall or Boshall, $V$. Bostall. Ferrar, London. Harper, Amerly, co. Hereford. Harper, $V$. Langtree, co. Lancaster, $V$. Langtree, Langtree, and Walton, co. Lancaster. Langtre, $V^{*}$. Roshall, $V^{*}$.

Sa. a chev. and canton erm. Bolhalth. HaRPER, co. Hereford. Thomas, Folkington, Sussex; Baronetcy 1660, extinct 1706 . Thomas, Wenvoe Castle, co. Glamorgan, Baronetcy 1694.

$\mathrm{Sa}$. a chev. or and canton erm. HeEper or HePER. LANGMORE Or LONGMORE.

on a Canton.... Beast (Lion)

Arg. a bend and chev. gu. on a canton like the second a lion pass. (another ramp.) of the first. Orbaston.

Bendy of three arg. and gu. a chev. as the last on a canton like the second a lion pass. of the first. ORBaston, Harl. MS. 1404.

$$
\text { ..... (Sheep) }
$$

Az. a chev. arg, over all a bend or on a canton of the last a holy lamb gu. ErNELL, Harl. MS. 1404 , fo. 108 .

$$
\text { ..... Bird }
$$

Arg. a chev. sa. on a canton of the second a mart. let of the first. WanTon.

$$
\text { .... Cross }
$$

Arg. a cher. oppressed by a bend gu. on a canton of the last a cross patty or. Boold, co. Lancaster.

$$
\text { .... Head (Boar) }
$$

Or a chev. az. on a canton of the second a boar's head couped betw. three fleurs-de-lis of the first. EDMoNDs, co. Devon; granted 1600.

Or a chev. sa. on a canton of the second a boar's head of the first. EDMonds.

$$
\text { .... ( } \left.\mathbf{D}_{0 \mathrm{~g}}\right)
$$

Arg. a chev. ermines on a canton gu. a talbot's head erased or. SHaw, Ardesley, co. York; granted 4 December 1707.

Sa. a chev, erm. on a canton or a talbot's head erased gu. Shaw alias SHaw-Lefevre.

$$
\text { .... (Lion) }
$$

Or a chev. gu. on a canton sa. a lion's head crowned of the first. STAFFORD.

$$
\text { ..... (Human Figure) }
$$

Or a chev. gu. on a canton sa. a man's head full faced crowned of the first. Bromisiall. STAFFORD.

\section{.... Heads}

Or a bend and chev. gu. on a canton of the secoud three leopard's faces of the first. Romenall.

\section{.....Fleur-de-lis}

Arg. a bend and chev. gu. on a canton az. a fleur. de-lis or. Freby.

Bendy of three arg. and gu. a chev. of the last on a canton az, a fleur-de.lis or. Frebye, Harl. MS. 1404, fo. 102 .

Or a chev. az. on a canton of the last a fleur-delis of the first. EDMONDs, temp. Charles I.

$$
\text { ....5-Foil }
$$

Arg. a chev. gu. on a canton sa. a 5-foil erm. Robert Tyas, London, $W$. The 5-foil pierced. Tyas or Tres, London.

Arg. a chev. gu. on a canton of the first a 5-foil sa. Tyers.

$$
\text { .....Mullet }
$$

Arg. a bend and chev. gu. on a carton of the second a pierced mullet or. Pope.
CHEVRON and in chief....cont.

on a Canton cont. Mullet cont.

Or a chev. and fess gu. on a canton of the last a muliet as the first pierced sa. Fitz-Rorand.

Or a chev: and bend gu. on a canton sa. a pierced mullet arg. POPE.

\section{Chessrooks}

Arg. a chev. and in chief three chessrooks sa. ANDELBY.

\section{Chief}

Arg. a chev. engr. az. a chief gu. Stayley.

Arg. a chev. gu. and a chief az. MaIrstoun, Park; quartering arg. an eagle displ. sa. Mastertoun, Parkmilne, Scotland.

Arg. a chev, and chief gu. Masterton, Gogar. And with a crescent upon the chief or. Malterstone, Scotland.

Arg. a chev. gu. and chief indented sa. Basingthorpe, $V^{*}$. Sire Richard de Boselingthorp, $N$. Sr.RichardBoslingthorr, co. Lincoln, $V$. BosLinthoRne, $V^{*}$. BosLinthoRP, $V^{*}$.

Arg. a chev. sa. a chief gu. Tierney.

Arg. a chev. sa. a chief indented gu. Thornton, co. Lincoln.

Arg. a chev. and a chief indented sa. THonnton, Laughton, co. Lincoln.

Arg. a chev. and chief vert. Gabell.

Erm. a chev. gu. a chief indented sa. John Rynel, $Y$. Monsire John Rivet, $Y$.

Erm. a chev, and chief sa. over the bottom line of the chief a leopard's head or. Poundon, co. Derby, $V$.

Gu. a chev. arg. a chief chequy or and az. LamibarT, co. York. Lambent, Pinchbeck, co. Buckingham.

Gu. a chev. engr. and a chief arg. Themelby, $V$. THIMBIEBY.

Gu. a chev. or and chief erm. Blayne, co. Berlss. Bleney or Blawney, co. Hereford. Davies, Caerben. Thomas Daties, Bishop of St. Asaph 1562.73. Sir Griffith LLOYD, living 1284. Sir Jevan LLwro.

Gu. a chev. vair a clief or. Panton. Sr. Hugh Paunton, $V$.

Or a chev, gu. a chief az. M. Nicol de StafFord, $S$. Nicolas Stafford, Froddeswall, $V$.

Or a chev. engr. gu. a chief arg. Foulcantex.

Or a chev. gu. a chief vair. HARPER. QUINTIN. ST. Quintin, Harpham, Lowthorpe, and Scamston, co. York; Baronetcy 164l, extinct 1795. St. Quinton, $V$. M. William Seint Quyntorne, $S$. Geffrey ST. Quintyn, $Y$. Sr. Geffray Saynt Quintyn, $M$. Sire William de St. Quintyne, $Y$. William St. Qunntyne, $Y$.

Sa. a chev. and chief arg. Thonnton.

Sa. a chev. arg. and a chief dancetty of the last. Thornton, Newcastle-on-Tyne, $V$. But the chief indented. Thonnton, Witton or Whitton Castle, Northumberland; the coheirs m. 'Tre. velyan and Witham. Thornton, $V^{*}$.

Sa. a cher, or a chief parted per (chief, $V^{*}$.) fess sa. and or. Sr. Roger BAYNARD, $V$.

on a Chief.... Annulets

Or a chev. sa. on a chief gu. three annulets or. BAYNARD.

$$
\text { ....Bar }
$$

Arg. a chev. sa. on a chief of the last a bar dan. cetty or. Selington. But the bar engr. Sillington, Harl. MS. 1386, fo. 36 .

Or a chev. sa. on a chief of the second a fess engr. of the first. Solington. Solyngton, $V$. 
CHEVRON and in chief....cont.

on a Chief cont. Beast

Erm. a chev. or on a chief arg. a lion pass. gu. Cadivor ap Selyf.

\section{.....Birds (Crows)}

Az. a chev. erm. on a chief arg. three Cornish choughs ppr. Dawson, Penrith, Cumberland; granted 1761 .

\section{.....(Martlets)}

Arg. a chev. az. on a chief as the second three martlets of the first. Sr. Henry $\mathrm{T}_{\Delta Y}, \boldsymbol{V}$. TAX, Essex. The martlets erm. TAY, Essex. The martlets or. TAY, Essex.

Arg. a chev. engr. ermines on a chief sa. three martlets of the first. WILDE, Long Whatton, co. Leicester ; granted 1743.

Arg. a chev. sa. on a chief gu. three martlets of the first. WuD.

Arg. a chev. sa, on a chief as the second three martlets of the first. WILD, Canterbury; and Lewisham, Kent; granted 1583 . WyLdE, $V$.

Sa. a chev. engr. arg. on a chief as the second three martlets of the first. WiLDE, co. Nottingham. Wyude, Nettleworth Hall, co. Nottingham; granted 15 June 1575.

$$
\text { ....Canton }
$$

Gu. a chev. or on a chief erm. a canton arg. charged with an eagle displ. with two heads sa. Lloyd, Croghan, co. Roscommon; derived through Meuric LIwyd, from Hedd Molwynog; quartering arg, a bend within a bordure engr. sa. .... Castles

Erm. a chev. gu. on a chief vert two towers arg. Horncastue, Dublin; granted 9 June 1683.

$$
\text { ....Crescent }
$$

Arg. a cher. gu. on a chief of the last a crescent or. Malterstone, Scotland.

$$
\text { ..... Crescents }
$$

Arg. a chev. gu. on a chief az. three crescents of the first. Crean.

$$
\text { ..... Cross }
$$

Arg. a chev. lozengy gu. and az. on a chief of the third a cross formy fitchy betw. two mullets or. Reynords, Suffolk.

$$
\text { .... Crosses }
$$

Arg. a chev. az. on a chief gu. three crosses croslet or. CurtarN.

$$
\text { .... Escallops }
$$

Arg. a chev. engr. gu. on a chief az. three escallops of the first. KEBILL.

Arg. a chev. engr. gu. on a chief of the last three escallops as the first. Simon de Cronbe, $E$; (and in a later hand) $F$.

$$
\text { .....Estoile }
$$

Sa. a chev. erminois on a chief indented arg. an estoile betw. two mullets gu. KerrLL, Croft Castle, co. Hereford.

$$
\text { ..... Estoiles }
$$

Arg. a chev, az. on a chief of the second three estoiles or. Port, Eardisley Castle, co. Hereford.

\section{....Fess see Bar}

.....Fleurs-de-lis

Gu. a chev, engr. erm. on a chief or three fleursde-lis sa. Cashire, Norfolk.

$$
\text { .....Flowers }
$$

Or a chev. sa. on a chief of the second three roses gu. Hartus.

$$
\text { ....5-Foils }
$$

Sa. a chev. arg. on a chief of the last three 5-foils gu. Dickey or Dichie.

$$
\text { .....Fret }
$$

Erm. a chev. gu. (sometimes sa.) on a chief az. fretty or. PRYE, Horwell, co. Devon, 1620.
CHEVRON and in chief.....cont.

on a Chief cont. Head

Gu. a chev. arg. on a chief sa. a griffin's head erased or betw. two bezants. GarTon, Sussex. .....Heads (Beast) Deer

Az. a chev, engr. erm. on a chief arg. two (buck's another) stag's heads cabossed gu. NiBBs; Island of Antigua; granted 13 October 1759.

$$
\text { .....Leopard }
$$

Erm. a chev. gu. on a chief or two leopard's heads of the last. Prescott, $V^{*}$.

Erm. a chev. sa. on a chief or two leopard's faces gu. Prescor, Prescot, co. Devon; the heiress m. Almescombe. Prescot, $V$.

Erm a chev. sa. on a chief of the second two leo. pard's heads or. Prescot, Dreby, co. Lincoln. .... Leopard

Arg. a chev. sa. on a chief of the second three leopard's faces or. Mary Cowper, wife of William Smith, London; granted by Cooke, $W$. Smith, $V^{*}$.

Erm. a chev. sa. on a chief of the second three leopard's heads or. Powerdon, co. Derby.

Gu, a chev, arg. on a clief az. three leopard's faces or. Cheydew, $V^{*}$. Cheynew, $V$. But leopard's heads. Cheynew, $V^{*}$.

$$
\text { .... ox }
$$

Arg. a chev. sa. on a chief of the second three bull's heads cabossed of the first. BEVERLEY, co. York.

\section{.... Leaves}

.... a chev, on a chief .... three leaves .... Huyshe Hiwis Huish, or Hewish, Lod Hiwis, Lynch, Doniford, Aller, and Taunton, co. Somerset; Sand and Clisthydon, co. Devon; co. Derby ; and co. Nottingham.

$$
\text { .....Mascles }
$$

Arg. a chev. gu. on a chief as the last three mascles of the first. PELLEW.

$$
\text { ..... Mullets }
$$

Arg. a chev. az. on a chief of the last two pierced mullets of the first. Bassing, $V$.

Arg. a chev. az. on a chief of the second three mullets or pierced sa. KEBBELL or KEByLL, London.

Arg. a chev. engr. gu. on a chief az. three mullets or. KeBLe, Lord Mayor of London 1510. The mullets pierced of the second. KEBYLL, $V$.

Arg. a chev. gu. on a chief as the last three mullets of the first. Fowle, Sandhurst, Kent; and Salhurst, Sussex.

Arg. a chev. gu. on a chief as the second three pierced mullets of the first. Fowke, Elmsthorpe, co. Leicester. Fowke; granted by Camden, $W$.

Arg. \& chev. engr. gu. on a chief or three mullets az. pierced of the second. KeBYLL, $V^{*}$.

Arg. a chev. sa. on a chief gu. three mullets of the first. Fowel; Collinson, Somerset, iii, 256.

Arg. a chev. sa. on a chief gu. three pierced mullets of the first. FowelL, Corsham, co. Wilts ; descended through Fowell, Black Hall, and Diptford, co. Devon; quartering Trevaze, Hallwell, Hayes, Glanville, Hele, Newton, Hawkins, Digby, Pakeman, Clarke, Ellis, Warwick, Knowling, Kirkham, Dennys, Scobbahal, Milleton, Ferrers, and Malherb; like Fowers, Plymouth ; and Harewood Honse, Cornwall ; from Fowell, Fowel's Combe, Ugborough, co. Devon; Baronetcy 1661, extinct 1692 ; the coheirs m. Parker, and Campernowne; quartering Trevaze, Hallwell, and Hayes. 
CHEVRON and in chief cont.....

on a Chief cont. Mullets cont.

Arg. a chev, sa. on a chief gu. three mullets or. Sr. Philip Barnard, V. The mullets pierced. Foowele, co. Devon; $V$. Fowle.

Arg. a chev. sa. on a chief of the last three mullets or. WILDE; Baronetcy 1060; the heiress m. Cockman.

Or a chev. gu. on a chief az. three mullets of the first. Aldiani, Suffolk.

Or a chev. engr. gu. on a chief sa. three mullets arg. Keeble, East Leach, co. Gloucester.

Sa. a chev. or on a chief arg. three mullets gu. KEVILL.

Sa. a chev. engr. or on a chief arg. three mullets gu. KeBELI, $V$. The mullets of the first. KEBLE.

\section{....Roundles (Ogresses)}

Az. a chev. erm. on a chief embattled or three ogresses. WaLL, Eryche, co. Derby. WaLL, Garter King of Arms, ob. 1536-7.

$$
\text { .... (Plates) }
$$

Arg. a chev. gu. on a chief as the second three plates. Travers.

$$
\text { ..... Swords }
$$

Arg. a chev. gu. on a chief sa. two swords in sal. tire of the first. NANBY.

Arg. a chev. gu. on a chief sa. two swords in saltire of the first (pomelled, $V^{*}$.) hilted or. NANBY, $V$.

\section{Comet see Estoile \\ Crescents}

Or a chev, and in chief three crescents az. WESTWROW or Westrow, London; granted 24 March 1613.

Per pale vert and arg. a chev. erm. in chief three crescents all counterchanged. Bugden. Cross

Sa. a chev. aud in the dexter chief a cross croslet arg. Pares, Kirby Frith, co. Leicester, temp. Elizabeth ; and Hopwell Hall, co. Derby, 1780, quartering Lightbody.

Sa. a chev. erm. in the dexter chief a cross croslet fitchy arg. RANDS. Crosses

Arg. a chev. gu. in chief two crosses croslet of the last. Byrton.

Arg. a chev. sa. in chief three crosses moline az. Blizard or Blizzard.

Az. a chev. and in chief three crosses patty arg. Barclay, Surrey; and Suffolk.

Az, a chev, erm. in chief three crosses formy fitchy vert. Reynolds.

Arg. a chev. and in chief four crosses formy fitchy az. Hollins, Mosseley, co. Stafford.

\section{Escallop}

Arg. a chev. purp. in the dexter chief an escallop sa. Marler or Marlex, Knavestock, Essex; and Crayford, Kent.

Per pale arg. and sa. a chev. counterchanged in chief an escallop of the seeond. Lawson, London.

\section{Escallops}

Arg. a chev. and in chief three escallops gu. Levins, co. Cambridge.

Az. a chev. and in chief three escallops or. Dabernon, Dunsland, co. Devon; extinct temp. Henry VI.; the heiress m. Arscott. Dabernon or D'Abernoun, Stoke Dabernon, Surrey.

Vert a chev. or in chief three escallops arg. Levings or Leving, co. Derby ; and co. Warwick; granted 10 September 1611. Levinge, High Park, now Knockdrin Castle; Baronetcy
CHEVRON and in chief....cont.

Escallops cont.

.... ; quartering Corbyn, Greene, and Kennedy. Lovinas or Levinge, co. Derby ; and Colsell, co. Warwick.

\section{Escucheons}

Per chev. sa. and arg. a chev. counterchanged in chief three escucheons of the second. WooDcnor, Newport, co. Salop; and Kilronane, co. Kilkenny, as quartered by Hoare, Factory Hill, co. Cork.

\section{Estoile}

.... a chev. .... in chief a blazing star (or comet) .... and a sinister canton .... MYHuL.

Vert a chev. and in the dexter chief an estoile or. StaLket, $V$.

\section{Estoiles}

Per chev. erm. and ermines a chev. per chev. sa. and arg. on the first three estoiles or. Wigston, $V *$.

\section{Fess and Fillot}

Arg. a chev. and a fess enhanced gu. MAck.

Arg. a chev. sa. in chief a bar engr. gu. Freme, Lippiat, co. Gloucester.

Sa. a chev. humetty reversed arg. a fillet .... BADRICK.

\section{Fleurs-de-lis}

Erm. a chev. gu. in chief two fleurs-de-lis vert. EADY.

Arg. a chev. chequy sa. and or in chief three fleurs-de-lis of the second. Botreney BotmLly or Botley.

Arg. a chev. engr. and in chief three fleurs-de-lis sa. ErLes.

Az. a chev. and in chief three fleurs-de-lis arg. Kinnimond, Scotland.

\section{Flowers}

Arg. a chev. and in chief three roses gu. HAYLES.

Arg. a chev. per pale engr. az. and gu. in chief two roses of the second and two of the third. Weston, Weston, co. Dorset.

\section{3-Foil}

Arg. a chev. .... in the dexter chief a 3 -foil sa. Foot, Lord Mayor of London 1651.

Arg. a chev. in the dexter chief a 3 -foil slipped sa. Foote, Loudon.

Or a chev. and in the dexter chief a 3-foil slipped sa. Foot. Foote, Tiverton, co. Devon.

\section{3-Foils}

Or a chev, and in chief three 3-foils slipped sa. Holings, co. Salop ; in St. Augustin's Church, Bristol.

\section{5-Foil}

Arg. a chev. sa. in the dexter chief a 5 -foil gu. RICARD, London, 1634. RICHARDS.

Arg. a chev. and in the dexter chief a 5 -foil sa. Kempstone. Rampston. The 5.foil pierced. Rempston or Rampston (K.G., ob. 1406). Garbs

Arg. a chev. sa. in chief three garbs vert. Tuson. Head.... (Beast) Leopard

Erm. a chev. sa. in chief a leopard's head or langued gu. a chief of the second. Fourden.

Per chief sa. and erm. a chev. as the first over the partition line a leopard's face or. POURDON, co. Derby, $V$.$$
\text { ....Human figure }
$$

Or a chev. engr. erm. in chief a Moor's head full faced couped at the shoulders sa. Mone, Suffolk.

Per chev. or and sa. a chev. engr. erm. in chief a Moor's head full faced couped of the second wreathed about the head arg. More. 
CHEVRON and in chief....cont.

Heads cont. (Beasts) Leopard

Gu. a chev. and in chief two leopard's heads arg. HePton.

Gu. a chev. and in chief two leopard's heads or. SiIngsir, co. York.

Or a chev. and in chief two leopard's heads gu. Harvey, co. Cambridge; and Storbrook, Suffolk.

Per chev, arg. and erm. a chev. and two leopard's heads in chief gu. Prescot.

Per chev. arg. and erm. a chev. sa. in chief two leopard's head gu. Wood, co. Somerset.

(Per pale a chev. sa. and arg. in chief two leopard's heads or?). CrMerewe, Thomas, Worcester, p.11. .... Dog

Gu. a chev. erm. in chief three talbot's heads erased or. CHITTY, Lord Mayor of London 1760. .....Horso

Arg. a chev, gu. in chief three nag's heads erased sa. Cooke, Essex.

Sa. a chev, or in chief three horse's heads erm. Coore, Essex.

.... Leopard

Sa. a chev. and three leopard's heads in chief arg. Ormes, (in a later band than) $W$. But the heads gu. Orniesley, co. Lancaster.

$$
\text { ....Wolf }
$$

Arg. a chev. gu. in chief three wolf's heads erased .... Richard Cuniberiand, Bishop of Peterborough 1691.1718.

Arg, a chev. and in chief three wolf's heads erased sa. CuMrBerland.

Horn

Az. a chev. or in chief a buglehorn betw. two leopard's heads arg. Foster, $W$.

Legs

Az. a chev, arg. in chief three lion's paws erased and erect or. WHITWANG.

Mascles

Arg. a chev, and in chief three mascles gu. Petoe, Suffolls.

Monsters.... Dragons

Or a chev. and in chief two dragons sa. Folborne, co. Cambridge.

\section{.....Wiverns}

Or a chev. and in chief two wiverns respecting each other sa. Folbonse, $V^{*}$. Sr. John Folbourne, co. Cambridge, temp. Edward I, $V$.

Or a chev. and in chief two wiverns pass. displ. respecting each other sa. Foleburne. Mullets

Arg. a chev. sa. in chief two mullets gu. Maton.

Gu. a chev. and in chief two mullets arg. Storiyn, co. Chester, $V$.

Gu. a chev. vairy arg. and sa. in chief two mullets or. Stockton.

Arg. a chev. chequy purp. and az. in chief three mullets gu. HAMPTON.

Arg. a chev. gu. in chief three mullets sa. Toole, Ireland.

Gu. a chev. vairy arg. and sa. in chief three mul. lets or. Stockton. Palo

$\mathrm{Gu}$. a chev. and pale conjoined in point at the top of the chev. erm. KELDoN, Kelvedon, Essex.

Per pale gu. and or a chev. and pale conjoined in point at the top of the chev. all counterchanged. Nosworthy, Ince Castle, Cornwall.

\section{Portcullis}

Gu. a chev. erm. in chief a portcullis or. Fishbrook.
CHEVRON and in chief.....cont.

Quarter

Per pale gu. and arg. a chev. per pale of the se. cond and sa. a quarter erm. LANGMORE.

Sa. a chev. arg. a quarter erm. LaNGTree, co. Lancaster.

Roundle

Gu. a cher. arg. in chief a bezant betw. two lion's heads erased of the second. FaIrbrother.

Roundles (Bezants)

Gu. a chev, arg. in chief three bezants. Latooche or LA Touche, England. The chev. or. Latouche or Latnuch, Ireland. .....(Torteaux)

Arg. a chev. gu. in chief three torteaux. Robert de Wixston, Y. Monsire William de Wistowe, $Y$. Sr. William Wrxton, $V$.

\section{CAEVRON and in base....}

\section{Annulet}

Arg. a chev. and in base an annulet sa. WANTON. Bars

Arg. in chief a chev, and in base two bars sa. HolbEame.

Az. in chief a chev, and in base two bars or. SPRIE or SPRy, glass in S. German's Priory Church, Cornwall: see 2 Bars, etc., p. 24.

$$
\text { Beast..... Lion }
$$

Arg. a chev, and in base a lion ramp. az. Richards, Reading. Richards, Brambletye House, Sussex; Baronetcy 22 February 168.3-4.

Per chief or and az. a chev. of the first in base a lion ramp. arg. OLHIER. Crescents

Gu. a chev. or in base a crescent arg. Alshoner, Scotland.

Per pale arg. and sa. a chev. and in base a crescent counterchanged. Alexander, Powis. co. Clackmannan, quartering or a galley sails furled sa. betw. three crosses croslet fitchy gu.; derived from Alexander, Menstrie, Earl of Stirling 1633, quartering Mac Donald.

Per pale arg. and sa. a chev. bruised at the top and in base a crescent connterchanged. Alexander, Kinglassie.

Cross

Arg. a chev. indented gu. and in base a cross croslet fitchy sa. KENNEDr, Lochen, Scotland.

Cup

Sa. a chev. erm. in base a covered cup. arg. HOLDEN.

Flower....Rose

Gu. a chev. erm. in base a rose or. Richard Marten, $V$.

$$
\text { ....Thistle }
$$

Or a chev, az. in base a thistle stalked and leaved ppr. Pinkerton, Scotland.

$$
\text { 3-Foil }
$$

Arg. a chev, and in base a 3 -foil slipped sa. Flete, $V$. Flote, $V$. Floelte.

Arg. a chev, and in base a 3 -foil vert. SLene or SLete.

5-Foil

Per fess arg. and sa. a chev. counterchanged in base a 5 -foil of the first. BaLnewis. BanNers, Scotland.

Heart

Arg. a chev. and in base a heart gu. Methen, Scotland.

Piles

Erm. a chev. gu. in base three piles issuing from the chev. sa. Nodrs, England. 
1 CHEVRON betw. or within....

\section{Anchors}

Az. a chev. betw. three anchors erm. Manlove, Ashborne, co. Derby.

Az. a chev. erm. betw. three anchors or. MaNLow.

Az. a chev. erm. betw, three anchors ppr. BATTEN, Aldon, near Yeovil, Somerset.

Az, a chev. or betw. three grappling-irons each of as many points and double-ringed arg. Stewins, $V^{*}$. Stewyne, Harl. MIS. 1386, fo. 95 . Stewyns, $V$.

Az. a chev. betw. three grappling-irons doubleringed or. Stewins.

Gu. a chev. erm. betw, three anchors or. Mancovk, co. Stafford.

Sa. a chev. betw. three anchors arg. HoLDER, South Wheatly, co. Nottingham, Collinson, Somerset, i, 119.

Sa. a chev, betw. three anchors erect or. ANCRam, Hill House, Frome, co. Somerset.

\section{Angles see Squares}

\section{Annulets}

... a chev. engr. .... betw. three annulets .... Dennison, Enniscorthy.

.... a chev. debruised by a fess charged with a crescent all betw. timree annulets .... HEDLEY, Newcastle-on-Tyne.

Arg. a chev. betw. three annulets az. John Soureby, $V$. Webrer, Scotland.

Arg. a chev. erm. fimbriated sa. betw. three annulets gu. Clutron.

Arg. a chev. betw. three annulets gu. Monsire de Chanceux, $Y$. Chancey. Sire Felip de Chaunsy, $N$. Dobins. Dobyns. Goreing, Kinston, co. Stafford, 1730. GorING, $V^{*}$. GonIng, Earl of Norwich, 1644-71. Gorynge, Sussex, V. Prenton, Prenton, co. York.

Arg. a chev. sa. betw. three annulets az. Hatr or Hatte.

Arg. a chev. sa. betw. three annulets gu. SECRofr.

Arg. a chev. sa. voided erm. betw. three annulets gu. CuUtron.

Arg. a chev. betw. three annulets sa. Boffrey, $V$.

Az. a chev. arg. betw, three annulets or. HODGE, Scotland; and Sunderland, co. Durham.

Az. a chev. betw. three annulets or. DoByns, co. Hereford. DoByns; quartered by Yate.

Az. a chev. surmonnted of a fess betw. three annulets or. HADLEY, London, Harl. MS. 1404, fo. 7. John Hadley or Hallex, Alderman, $V$, Lord Mayor of London, $W$. HARDLP, London.

Az. a chev. betw. three annulets or over all on a fess of the second as many martlets gu. HaDLEY, Lord Mayor of London 1379 and 1393. HaLLEy, London.

Gu. a chev, betw. three annulets or. HALDIMAND.

Or a cher. betw. three annulets gu. Goring, Highden, Sussex; Baronetcy 1627. Goring, Kingston, and Frodley Hall, co. Stafford; derived from Goring, Ovingdene, Sussex. Goring or Le Goning, Sussex. Goning, Kent; and Whiston Park, Sussex. Sutron.

Or a chev. betw. three annulets gu. over all a fess arg. Harteley, Middleton Lodge, co. York. HARTLEy, Scotland.

Sa. a cluev. betw. three annulets arg. Manson. NANFAN or NANSON.

Sa. a chev, betw. three gem-rings arg. Nanfan, $V$.

Sa. a chev. betw. three annulets compony arg. and az. Bery. Bury.

Sa. a chev, erm. betw, three annulets arg. Gregory Davy, Gonthorp, Norfolk, $V$.
1 CHEVRON betw. or within....cont.

Annulets cont.

Sa. a cliev. engr. erm. betw. three annulets arg Davy, Ingoldsthorpe, Norfolk. DAvY, Ufford.

Vert a chev. erm. betw. three annulets or. Planner (in a later band than), $W$.

Vert a chev. or betw. three annulets arg. Minifie, Collinson, Somerset, iii, 290.

Az. a chev. erm. betw. six annulets two two and two linked together or. CoRne, $V^{*}$. JANES.

Or a chev. az. betw. three pairs of annulets conjoined gu. Moncaster, co. Devon, Harl. MS. 1386.

Or a chev. az. betw. six annulets linked together two two and two (as leashes, $W$.) gu. within a bordure of the second. Moncaster, $V^{*}$. Monkaster, $V$.

Per pale gu. and sa. a chev. arg. betw. six annulets two two and two linked together palewise or. Huddeston or Hudson, Gyles-Clift, co. Warwick ; and Henvill, Sussex.

\section{Arrows}

Arg. a chev. betw. three arrows gu. TIngwire.

Arg. a chev. betw. three arrows (points upwards $\left.V^{*}.\right)$ gu. Tyngwicke, $V^{*}$. TYNGWYke, $V$.

Az. a chev. erm. betw. three broad arrows or feathered arg. Dawson.

Az. a chev, betw. three arrows or headed and feathered arg. Company of Fletchers, London.

Gu. a chev. betw. three birdbolts arg. Foster.

Sa. a chev. betw. three arrows arg. Floyer, Floyer Heys, co. Devon, $V$; and Mertrith, co. Somerset. Slayer, Morlick, co. Somerset.

Sa. a chev. betw. three broad arrows arg. ARCHER, Cornwall. Dennis, Orleigh, co. Devon, quartering Bolbay alias Boway, Esse Thorn and Giffard; the cobeirs m. Hanson, Glynn, and Dennis. Dennis, Bradford, and Holcombe Burnell; quartering Dabernon; the heiress $m$. Gifford.

Sa. a chev. betw. three darts points upwards shafts broken arg. AKENSIDE.

Sa. a chev. betw. tbree broad arrows headed and feathered or. Foster.

Sa. a chev. engr. betw. three arrows arg. Forster, Aldermaston, co. Berks ; co. Somerset; and co. Warwick. Foster, Aldermaston; Baronetcy 1620 extinct 1711 .

Sa. a chev. engr. arg. betw. three arrows or feathered and headed of the second. Fonster, $V$.

Sa. a chev. arg. betw. three arrows or. FLOYER, West Stafford; quartering Croke, Baphe, Loundes, etc.

Sa. a chev. engr. betw. three arrows or feathered arg. Fonster, $V^{*}$.

Sa. a chev. erm. betw. three arrows arg. Woouey. Sa. a chev. engr. erm. betw. three broad arrows or feathered arg. Hoster, co. Lincoln; and co. York.

Sa. a cbev. or betw. three arrows arg. Company of Fletchers, London, $V$, Cotton MS. Tiberius D 10.

Sa. a chev. engr. betw. three arrows or feathered arg. FORSTER

Sa. a chev. betw. three arrows or barbed and feathered arg. Cunate, Norwich.

Arg. a chev, sa. betw. in chief two sheaves of arrows gu. banded of the first and in base a buglehorn of the second stringed and garnished or. Duncanson, Scotland.

Arg. a chev. gu. betw. three sheaves of arrows .... Bess, Compton, Surrey. 
1 CHEVRON betw, or within....cont.

Arrows cont.

Az. a chev. betw. three sheaves of arrows arg. Nicholas Robinson, Bishop of Bangor 1560-85.

Az. a chev. or betw. three sheaves of arrows ppr. feathered and banded gu. BraKsDall.

Gu. a chev. arg. betw. three sheaves of arrows or barbed and banded of the second. Beste, Middleton Quernhow, co. York.

Sa. a chev. ern. betw. three sheaves of arrows arg. Sachertill, co. Devon.

Az. a chev. betw. three sheaves of five arrows or flighted and pheoued arg. pointed and banded gu. BrICKDALE, co. Somerset; and co. Gloucester; originally of Brickdale, co. Lancaster.

\section{Attires see Horns}

\section{Awls}

Az. a chev. betw. three awls points reversed arg. hafts or. AuLEs.

Axes

Az. a chev. engr. erm. betw. in chief two battleaxes and in base a garb or. FInTH, Hartford Lodge, Northwich, co. Chester.

Az. a chev. or betw. in chief two battle-axes the blades towards each other and in base a mallet .... a crescent for diff. .... DuRAND DE STE. Rose, impaled by Caton.

Gu. a chev. arg. betw. in chief two chipping-axes of the last and in base a mullet or. Company of Marblers, London.

Arg. a chev. betw. three pole-axes az. maunched or. Symonds, co. Devon.

Arg. a chev. gu. betw. three pole-axes az. handles or. Srmonds, co. Devon.

Arg. a chev. gu. betw. three battle-axes ppr. CoNgreve.

Arg. a chev. gu. betw. three pole-axes sa. Serman.

Arg. a chev. purp. betw. three (battle-axes, $V^{*}$.) halberts the blades to the sinister az. lanceheads gu. staves or. Symond, Exeter, $V$.

Arg. a chev. purp. betw. three pole-axes az. handles or. Srmond, co. Devon.

Arg. a chev. purp. betw, three (battle-axes, $V^{*}$.) halberts the blades to the sinister sa. Drake, co. Devon, $V$.

Arg. a chev. sa. betw. three battle-axes az. Batten.

Arg. a chev, betw. three battle-axes sa. BatTrn, Exeter. Congrill, $T^{*}$. But brown-bills, Congriml, $V$.

Arg. a chev. embattled betw. three battle-ases sa. BaInBRIgG or Bambridge, co. Leicester.

Arg. a chev. betw, three pick-axes sa. Hamerton, co. Stafford. Killicke.

Arg. a chev. betw. three poleaxes sa. Symonds, Exeter, co. Devon.

Az. a chev, betw. three battle-axes arg. Wrrght, Wright's Park, Scotland.

Gu. a chev, arg. betw. three battle-axes of the second staves or. Byseley, $V^{*}$. Dyseley, $V$.

Gu. a chev, betw. three carpenter's axes or hafted arg. Penfold.

Gu. a chev, betw. three halberts arg. staves or. HALBERDYN.

Sa. a chev, betw. three battle-axes arg. Congreve, Congreve, co. Stafford; and Aldermanston, co. Berks. Congreve, Walton, co. Stafford; Baronetey 1812. Mosely or Mosley, co. Derby; co. Lancaster' ; co. Stafford, etc.; but these are mill-piclss as below. Mossey, London.

Sa. a chev. betw. three halberts arg. Maseley, London.
1 CHEVRON betw, or within.... cont.

Axes cont.

Sa. a chev. betw. three mill-picks (or pickaxes) arg. Moseley, Leaton Hall; derived from Moseley or Mosley, The Mere, co. Stafford and Buildwas Park, co. Salop, quartering Acton; descended through Moscey, Owsden (now of Great Glemham), Suffolk, and Moscey, Wittington, like MosLey, Bolesworth, co. Chester, Park Hill, and Burnaston House, co. Derby; Houghend and Anconts, co. Lancaster; and Rolleston, co. Stafford ; Baronetcies 1640, 1720, and 1781, quarteing or a fess betw. three eagles displ.sa.; from Mosecey, of Mollesley or Moseley, co. Stafford. But with an estoile for diff. Mosley, Lord Mayor of London 1599.

Sa. a chev. arg. betw. three halberts or. Congreve, co. Stafford.

Gu. a chev. embattled counterembattled betw. six balberts in pairs saltirewise or. Fonse, Crokernwell, co. Devon. Furse, Fnrse, and Halsdon, co. Devon.

\section{Bag see Purse \\ Bag or Bale see Cushion \\ Bands}

Gu. a chev. betw. three hatbands arg. MaYnes.

Sa. a chev. arg. betw. three hatbands wreathed of the second and az. Bury.

\section{Banners}

Az. a chev. betw. three flags displ. arg. Drumson.

Barrel see Tub or Tun

Basket see Bouget

Baskets

Or a chev. betw. two fish-baskets weels or eelpots sa. Folebarne, $V$.

Arg. a chev. erm. betw. three fish-baskets weels or eelpots hoops upwards vert. WYLLEY, 1716. Or a chev. betw. three fish-baskets weels or eelpots sa. Foleborne.

\section{Baton see Staff}

\section{Beast}

Gu. a chev. or betw. a lion pass. in chief of the last and three crosses croslet in base two and one arg. Mablethorpe.

$\mathrm{Gu}$. a cher. betw. a lion pass, in chief and three crosses croslet in base or. Mablethorpe.

Beasts .... Bats

Gu. a chev. betw. two bats or. Stowlex, $V^{*}$.

$$
\text { ....Deer }
$$

Vert a chev. engr. arg. betw. in chief two stags statant at gaze or semy of torteaux and in base a stirrup leather of the third. Rouinson, Kirby Frith, co. Leicester.

$$
\text { .... Dogs }
$$

Sa. a chev. betw. two talbots arg. Howls, co. Nottingham.

$$
\text { ..... Hares }
$$

Az. a chev, erm. in chief two conies courant or in base a sun of the last. John Watson, Bishop of Winchester 1580-4. WaTsON, Stratton, co. Gloucester.

$$
\text { .... Lions }
$$

Arg. a chev, betw, in chief two demi-lions and in base a mullet gu. EGERTON.

.... a chev. betw. in chief two lions ramp. and in base a boar pass. .... DonaGH, Newtown, co. Louth, 1721 .

.... a chev. betw. in chief two lions ramp. combatant and in base a (beast) statant .... M'Donachy, and O'Donnager, Ballinascreen, 1775.1800 . 
1 CHEVRON betw. or within.... cont.

Beasts cont. Lions cont.

Arg. a chev. sa. betw, in chief two lions pass. and in base an annulet of the second. TAYLOR, Stechworth, and Lidgate, co. Cambridge ; Cole MS. xi, 219. TayLor, Marridge, co. Devon.

Erm. a chev. sa. betw. two lions pass. guard. or. Bewris.

Or a chev. gu. betw. two lions pass. guard. sa. Cooke, Owston, co. York; quartering Puleston, Davies, etc. Cooke, Wheatley, co. York; Baronetcy 10 May 1661 .

Or a chev. gu. betw. two lions pass. guard. sa. armed of the second. Cook, Doncaster, co. York; confirmed 27 August 1635. Cooke, Wheatley, co. York; Baronetcy 10 May 1061.

Or a chev. betw. in chief two lions pass. and in base an annulet sa. TAYLOR, Worcester Park, Surrey. TAYLOR, Strechworth, and Lidgate, co. Cambridge. Taylor, Marridge, co. Devon. TAYLOUR or TAYLOR, London; and Sussex.

Or a chev. betw. two lions pass. guard. sa. Cook, Northumberland; and co. York.

Or a chev. betw. in chief two lions ramp. and in base a lozenge sa. TaYLodr, London.

Per chev. gu. and sa. a chev. vair betw. in chief two lions ramp. double tailed or each holding in the forepaws a plate thereon an ermine spot and in base a 5 -foil .... SALOMIONS, Lord Mayor of London 1855.

Sa. a chev. erm. betw. two lions pass. arg. RicH, Otford, Kent.

Sa. a chev. erm. betw. two lions pass. arg. crowned or. Huystock, $V$.

Sa. a chev, betw. in chief tro lions pass. and in base an annulet or. TAYLOR.

$$
\text { ..... Wolves }
$$

Or a chev. az. betw. in chief two wolves pass. and in base a crossbow gu. Horton.

\section{.....Antelopes}

Az. a chev. betw. three antelopes salient arg. Durning, Bisphan, co. Lancaster.

$$
\text { .....Apes }
$$

Sa. a chev. or betw. three apes arg. chained of the second. LoBLEY.

$$
\text { .....Badgers }
$$

Arg. a chev. betw, three (brocks or) badgers pass sa. Brockhole, co. Lancaster. Brockholes, Claughton Hall, co. Lancaster; quartering Fitzherbert, Hesketb, and Heneage. The brocks statant. BrockноL, $V$.

Gu. a chev. betw. three brocks statant arg. Brocton or Broughton, co. Stafford, $W$.

$$
\text { .... Bats }
$$

Arg. a chev, betw. three bats displ. gu. Backomb, co. Devon, $V$.

Arg. a chev. purp. betw. three bats displ. az. Symonds.

Arg. a chev. betw. three bats displ.sa. Batiscombe. Cloberx, Bradstone, co. Devon; the heiress m. Glyn. Clyburx, $W$. Collier alias Dimock, Puddle, co. Dorset. Collowtery.

Gu. a chev. betw. three bats displ. or. Slouy, Sloly, Fremington, co. Devon. Slowley, Fermington, co. Devon. Stowly, Slowley, co. Devon, $W$.

Sa. a chev. erm. betw. three bats displ. arg. Phimlipson. Phipson, Selley Hall, near Birmingham, co. Warwick.

Sa. a chev. erm. betw. three bats expanded or. Philimiron.

\section{CHEVRON betw. or within....cont.}

Beasts cont. Bears

Arg. a chev.betw. three bears pass. sa. Brockноце, $V^{*}$. EgIoKe, Appesley, co. Warwick.

Arg. a chov. engr. betw. three bears pass. sa. muzzled or. Barrett, co. Cambridge.

Az. a chev. betw. three bears pass. gu. BonefIELd.

Az. a chev. betw. three bears or. Bronfield.

Gu. a chev. betw, three bears statant within a bordure arg. Brocton alias Broughton, co. Stafford, $W$.

Gu. a chev. betw. three bears pass. or. Brocton, $V^{*}$. Brovghton, $V^{*}$. And within a bordure arg. Brocton, $V^{*}$.

$$
\text { ..... Boars }
$$

Arg. a chev. betw, three boars pass. az. armed crined and langued or. MAC GAN, Ireland.

Arg. a chev. betw. three boars pass. gu. Herrays, co. Lancaster.

Arg. a chev. betw. three boars sa. Berham, $V^{*}$. SWYNEY, $V^{*}$.

Arg. a chev. betw. three 'porcs' sa. Thomas SWYNeTHWAYTe, $Y$; or SWYNyTHWaIt, $Y$.

Arg. a chev. betw. three boars pass. sa. BerHam, co. Lancaster. Bryam, Ireland. The boars statant sa. Berfam, co. Lancaster, $V$. Swynex, $V$.

Az. a chev. erm. betw. three boars or. HerRIs.

Az. a chev. gu. betw. three boars pass. sa. Lrnalr, St. Kew, Cornwall.

Erm. a chev. betw. three boars pass. sa. armed or. BeтнаM, co. Buckingham.

Erm. a chev. betw. three boars statant sa. Thomas Betham, Rowington, co. Warwick. $W$.

Gu. a chev. betw. three boars pass. or. Trewile.

Sa. a chev. betw. three boars (arg. $V^{*}$, but) statant arg. armed gu. BucHe, $V$.

$$
\text { ....Camels }
$$

Arg. a chev. betw. three camels sa. Cammel.

$$
\text { ..... Cats }
$$

Arg. a chev. betw. three cats pass. sa. Catherike.

Sa. a chev. betw. three cats arg. Catheryke or Catryke.

Sa. a chev. betw. three cats pass. guard. arg. Catricke, $V^{*}$. Catrick, $V$.

Sa. a chev. erm. betw, three mountain cats pass. arg. HitL.

Sa. a chev. erm. betw. three cats pass. arg. HoLDERMAN.

Sa. a chev. erm. betw. three spotted cats pass. arg. Harthorp, London, Harl. MS. 1404.

Sa. a chev. erm. betw. three cats pass. guard. arg. HiLl, $V^{*}$. HiLl, Harl. MS. 1404, fo. 130.

Sa. a chev. erm. betw. three cats statant guard. arg. Hru, $V$.

Sa. a chev. erm. betw. three cats pass. guard. or. Hirl, London, $W$.

Sa. a chev. or betw. three wild cats pass. guard. .... HinL, Stallington Hall, co. Stafford; quartering Clarke.

Sa. a chev. or betw. three cats arg. Hru, London.

Sa. a chev. or betw. three cats pass. arg. Huls, London; granted 15 March 1580.

Sa. a chev. betw. three cats (pass. $V^{*}$.) statant guard. or. John Hill, London, $W$; granted by Cooke, Harl. MS. 1359, fo. 109 b.

$$
\text { .... Deer }
$$

Arg. a chev. az. betw. three roebucks trippant sa. attired or. Rogers, Kent.

Arg. a chev. betw, three stags courant gu. Kogers, Pilton, co. Devon; quartered by Griffiths and Studdy. 
1 CHEVRON betw. or within.... cont.

Beasts cont. Deer cont.

Arg. a chev, betw. three buclss lodged gu. Higgs, Collesborne, co. Gloucester. Higas, Charlton Jings, co. Gloucester; quartering gu. a dexter arm embowed vambraced or. WOLSTUN, $V^{*}$. But harts. Wolston, $V$.

Arg. a chev. gu. betw. three roebucks courant sa. attired and gorged with ducal coronets or. Rooers, Wisdome, and Blackford, co. Devon; Baronetcy 1698.

Arg. a chev. gu. betw. three harts trippant sa. Lever, co. Lancaster.

Arg. a chev. engr. sa. betw. three stags courant .... Ellicombe, co. Devon.

Arg. a chev, sa. betw. tinree bucks springing gu. attired or. HEYFORD, $V^{*}$. But harts. Sir Humfrey Herford, Alderman of London, $V$.

Arg. a chev. sa. betw. three bucks trippant gu. HEIFORD. HEYFonde, Lord Mayor of London 1477.

Arg. a chev. engr. sa. betw. three stags courant ppr. Ellacombe; quartering Grene, Myddelton, and Rous. EliIcoube.

Arg. a chev. sa. betw. three stags trippant ppr. RoBInson, Haveringate Bower, Essex.

Arg. a chev. betw. three bucks sa. Rogers, Chelmsford, Essex; Purton, co. Gloucester ; Kent; and Evesham, co.Worcester. Tregodeck, Cornwall.

Arg. a chev. betw. three stags sa. Clebury.

Arg. a chev. betw. three stags sa. attired or. Rogers, Eent; and Bradford, co. Wilts.

Arg. a chev. sa. betw. three stags of the second chained and spotted or. Rogers, Rainscombe, co. Wilts.

Arg. a chev. betw. three bucks in full course sa. Rogers, Connington, co. Somerset.

Arg. a cbev. sa. betw. three roebucks comrant of the second attired or. Christopher Rogers, Sution, Kent, 1593, $\mathrm{W}$.

Arg. a chev. sa. betw. three bucks in full course of the second attired or collared gu. Rogers, Kient; granted 1593.

Arg. a chev, betw. three bucks pass. sa. Progers; Collinson, Somerset, i, 236 ; ii, 39 .

Arg. a chev. betw, tbree roebucks pass. sa. Rogers, Corninton, co. Somerset.

Arg. a chev. betw, three hinds statant sa. Norton, $W$.

Arg. a chev. sa. betw. three bucks springing of the second attired or. Rogens, $V^{*}$.

Arg. a chev. betw. three bucks trippant sa. Lever, co. Lancaster. Rogers; in Cheam Church, Surrey. Rogers, Penrose; quartering Heydon; descended from Rogers, Lanke, Cornwall,; quartering Bawden.

Arg. a chev. betw. three stags trippant sa. Rogers, Lota, and Ashgrove, cc. Cork.

Az. a chev. erm. betw. three bucks trippant arg. Green.

Az. a chev. erm. betw. three stags trippant or. Green, Lawford Hall, Essex.

Az. a chev. embattled betw. three bucks or. Green, London; and Norwich.

Az. a chev. betw. three bucks trippant or. GreEN, Norfolk.

Gu. a chev. .... betw. three stags (? arg.). Protheroe, North Wales; and Norfolk; for SARDDUR.

Gu. a chev, engr. alg. betw. three (bucks $V^{*}$.) harts springing of the second attired or Ciaxton, $V$.
1 CHEVRON betw. or within....cont.

Beasts cont. Deer cont.

Gu. a chev, engr. betw. three bucks trippant arg. Claxton.

Gu. a chev. engr. arg. betw. three harts trippant of the second attired or. Claxton, co. Chester.

Gu. a chev. or betw. three hinds trippant arg. Samuel Hinds, Bishop of Norwich 1849-57.

Gu. a chev. betw, three bucks or. GreEN.

Gu. a chev, engr. betw. three bucks or. Claxton. Gu. a chev. betw. three binds or. HIND. HyNd, Hesore, co. Buckingham, granted 1583.

Gu. a chev. betw. three hinds statant or. Rowland Hisd, Hedgewortb, co. Buckingham, $W$.

Gu. a chev. betw. three bucks trippant or. Twiss. Gu. a chev. betw. three hinds trippant or. Hind, Hodgeworth, co. Buckingham; and Laxton, co. Nottingham; granted $\mathbf{1 5 8 3 .}$

Or a chev. barry nebuly arg. and az. (now vair) betw. three roebucks courant ppr. SwYFT, Darnel, quartered by Harrison; and Rotberbam. But three bucks vert. SwIFr, co. Hereford.

Or a chev. gu. betw. three bucks pass. ppr. Ronne, Hounslow, Middlesex.

Or a chev. vair betw. three bucks in full course ppr. Swift SwIFTe or SwyFt, Broom Hall; the beiresses m. Jessop, Wortley, and Leke: and Rotherham, co. York; Viscount Carlingford 1627 ; granted 10 May 1561 . SwiFt, Lion's Den, co. Meath ; and Goderich, co. Hereford.

Or a chev. vair betw. three roebucks courant ppr. SwyFt, Doncaster, Rotherbam and Streettborpe, co. York; quartered by Jessop, in Sheffield Church. Swirt, Darnel, quartered by Harrison. Or a chev, vair betw, three bucks vert. SwIFT, co. Hereford.

Per pale az. and gu. a chev. betw. three (bucks, $\left.V^{*}\right)$ harts trippant or. Green, $V^{*}$. GReEne, Wilby, Norfolk, $W$.

Per pale gu. and az. a chev. betw. three bucks trippant or. Tliomas Green, Bishop of Norwich 1721, Ely 1723-38. But harts. Grene, Norfolk, E.arl. MIS. 1404, fo. 67.

Sa. a chev. arg. betw. three bucks of the second attired or. Rogers, $V^{*}$.

Sa. a chev. betw. three buclss pass. arg. BUCKLEY.

Sa. a chev. arg. betw. three roebucks statant of the second attired or. Rafe Rogers, London, granted $1586, \mathrm{~W}$.

Sa. a chev, arg. betw. three bucks trippant of the second attired or. Rogers, London.

Sa. a chev. betw. three bucks pass. or. BoKELL.

Sa. a chev. betw. three binds tripping or. CoLeT.

Vert a chev. arg. betw. three roebucks in full course or. Robertson, Boston, co. Lincoln.

Vert a chev. arg. betw. three harts pass. or. RoBERTSON, London.

Vert a chev. arg. betw. three roebucks trippant or. Royston.

Vert a chev. erm. betw. three stags trippant or. Crohan or Croghat, Ireland.

Vert a chev. betw. three bucks or. RoBinson.

Vert a chev. betw. three harts pass. or. Robertson, England.

Vert a chev. betw. three bucks at gaze or. Robinson, Viscount Goderich 1827, Earl of Ripon 1833, De Grey andRipon 1859. Robrsson, Newby, co. York; Baronetcy 1660-89.

Vert a chev. betw. three bucks trippant or. Rorinson, Trethevas, and Nansloe, Coruwall. Robinson, Kingston-upon-Hull, co. York; the heizess m. Rogers. Robinson, Rokeby, co. York. 
1 CHEVRON betw, or within.... cont.

Beasts cont. Deer cont.

Vert a chev. or betw, three bucks trippant ppr. Robinson, London.

Vert a cher. betw. three stags trippant per pale erm. and erminois. Greenty, Titley Court, (n. Hereford.

$$
\text { ....Dogs }
$$

Arg. a chev.gu. betw. three talbots az. Tregasawe, Cornwall.

Arg. a chev. betw. three greyhounds courant gu. Jordan de CANTINGTON, afterwards JORDAN, quartering Dompledale. JoRDAN, Neeston, co. Pembroke; a heiress m. Harries. Jonden, Welynton, co. Salop.

Arg. a chev. betw. three hounds courant gu. Pykin or Pynkney.

Arg. a chev. betw. three talbots pass. gu. Honrwood, $\mathrm{J}^{*}$. Howwood. Pykis, $V^{*}$. But statant. Honywood, $V$. PYKIN, $V$.

Arg. a chev. betw. three spaniels sejant gu. Homisng, Homlingstown, Harl. MS. 1441.

Arg. a chev. gu. betw, three greyhounds in full course sa. GaINSFORD, Kent; and Idbury, co. Oxford. Macham. The greyhounds collared or. Sr. John Gainsfond, Crowhurst, Surrey, $V$. Gaynsford, Surrey. Gaynsrorth, $V^{*}$.

Arg. a chev. gu. betw. three talbots pass. sa. Thomas TALBotT, Wyndam, Norfolk; granted 1584, $\mathrm{W}$; descended from Talbot of Bashall.

Arg. a chev. gu. betw. three greyhounds pass. sa. collared arg. GAYNESFORD; in several churches, as Ling field, Crowhurst, etc., Surrey.

Arg. a chev. betw. three talbots sa. Counderowe. Thomas Thoms or Tonyns.

Arg. a chev. betw. three greyhounds courant sa. Gaynsford, Kent. Prentis, Scotland. Whelpdall, $V$. Whelpedall, $V^{*}$.

Arg. a chev. betw. three hounds pass. sa. Chantrell. Talbot, co. Devon; and Suffolk; granted 1584.

Arg. a chev. betw. three talbots pass. sa. Carveth, Carveth, Mewsom, and Cowsawse, Cornwall. Couderons, $V *$. 'TALBOT.

Arg. a chev, engr. betw. three talbots pass. sa. Carvetil, Carveth, Mewdon, and Cowsawse, Cornwall.

Arg. a chev. betw. three talbots statant sa. Couderow, $\boldsymbol{V}$. Sr. William 'l'albot, $\boldsymbol{V}$.

Az. a chev. betw. three hounds arg. Gower, Durham.

Az. a chev. betw. three talbots couchant sinister arg. Trasaher, Trevethan, Cornwall.

Az. a chev. betw, three greyhounds courant arg. Gwion Benarw.

Az. a chev. betw. three talbots (pass. $V^{*}$.) statant arg. Gower, $V$.

Az, a chev. erm. betw. three talbots pass. arg. Gilmer, Sussex.

Az. a chev, erm. betw, three talbots .... or. Archdale, Norton Hall, Norfolk; Castle Archdale, co. Fermanagh: and Trilic, co. Tyrone; quartering Montgomery and Newyn. Tbe talbots pass. Archedare, London.

Erm. a chev. wavy gu. betw. three greylounds courant sa. KNesworth or KNeysworTH, Lord Mayor of Loncion 1505; Cornwall; and co. Stafford. 'The greyhounds collared or'. Sr. Thomas KNeyswonth, Alderman of London, temp. Fdward IV, $V$.

Erm. a chev. embattled gu. betw. three grey. lounds courant sa. collared or. KNErsworth, I.
1 CHEVRON betw, or within.... cont.

Beasts cont. Dogs cont.

Gu. a chev. betw. three talbots sejant arg. HoUNDGATE.

Gu. a chev. engr. betw, three hounds sejant arg. Houndgate. Hungate or Hungatt, Saxton, Saudhutton, Burnby, and North Dalton, co.York. Gu. a chev. engr. betw. three talbots sejant arg. John Hungate, co. York, in Charlewood Church, Surrey.

Gu. a cluev, arg. betw, three hounds comrant or. Marrant, London. Morant Mordant or Morhant.

Gu. a chev. arg. betw. three hounds pass. or. Mohan or MoHant.

Gu. a chev. arg. betw, three talbots pass. or. Morant. Edward Mornant, of the Exchequer; granted $1575, W$. Murnant, London; granted 1575.

Gu. a chev. vair betw. three talbots pass. arg. GoodHugr, Scale, Kent.

Or a chev. chequy arg. and az. betw, three greybounds courant sa. collared gu. Dowse, Broughton, co. Hants.

Or a chev. chequy arg. and sa. betw. three greyhounds of the last. Dowse, Broughton, co.Hants.

Or a chev. wavy gu. betw. three greyhounds in full course sa. KNEsworTH or KNEYswontH.

Or a chev. betw. three bloodhounds upon the scent sa. Allen, Kent.

Or a chev. sa. betw. three bloodhounds pass. as the second armed gu. and collared of the first. Allen, Grove, near Maidstone, Kent, I610.

Paly of eight arg. and sa. a chev. of the first betw. three dogs as the secoud spotted like the first. Gooch, Norfolk.

Per pale arg. and sa. a chev. engr. betw. three talbots .... counterchanged. ALLEN, London.

Per pale arg. and sa. a cbev. betw. three talbots pass. counterchanged collared or. ALLEN, Whetston, co. Leicester. The talbots sejant. AlLEN, London.

Per pale sa. and arg. a chev. betw. three talbots pass. counterchanged. Goche, Norfolls.

Sa. a chev. betw. three talbots pass. arg. Lampergy. Lanpergy, $V^{*}$.

Sa. a chev. betw. three talbots statant arg. Lanhergy, Cornwall, $V$.

Sa. a chev. erm. betw. three terriers arg. Buther, Staplehurst.

Sa. a chev. erm. betw. three greyhounds courant arg. FaIRstead, quartered by Hussey.

Sa. a chev. erm. betw. three talbots pass. arg. Hunton, co. Wilts; granted 1578.

Sa. a chev. erm. betw. three spotted dogs of the second. Hartham, co. Leicester.

Sa. a chev. erm. betw. three talbots pass. or. Bucher, Middlesex.

Vert a chev, betw. three greyhounds courant arg. Keigwin, Mousehole, Cornwall.

Vert a chev. betw. three hounds pass. arg. HounEHILL HowNDHILl or HownHILL.

Vert a chev, betw. three talbots (pass. Hounhils, $V^{*}$.) statant arg. Sr. John HownHIL, $V$. .....Goats

Gu. a chev, betw. three goats arg. Brlusw.

Gu. a chev. betw. three goats two in chief respectant and one in base salient arg. Chruens or Chevers.

Or a chev. betw. three goats statant arg. ALwiN, London, Harl. MS. 1404, fo. 138.

Or a chev. betw. three goats pass. sa. ALwvn. Sa. a chev. betw. three goats .... arg. Alwyn. 
1 CHEVRON betw, or within....cont.

Beasts cont. Goats cont.

Sa. a chev. betw. three goats pass. arg. Ronwin, Wales. Ronwyne, $V^{*}$.

Sa. a chev, betw. three goats statant arg. Ronwyne, Wales, $T$.

Sa. a chev, engl. betw. three goats statant arg. Trethewr ; Collinson, Somerset ii, 130.

Vert a chev. betw. three goats arg. I'Rethews, St. Stephen's Brannel, Cornwall.

\section{.....Hares}

Arg. a chev. gu: betw. three leverets courant sa. Leyvis. co. ILancaster, $V$.

Arg. a chev. betw. three hares sa. LEver, co. Lancaster. Quadring.

Arg. a chev, betw, three conies courant sa. Quaderin, $V^{*}$. STrode, co. Devon, quartering Newenham and Courtenay.

Arg. a chev, betw, three leverets courant sa. Leverett, Great Chelsea, 1062. Quaderin, $V$.

Arg. a chev. betw. three conies courant palewise sa. ConingesBy, $V$.

\section{....Hedgehogs see Urchins .....Horses}

Arg. a chev. betw. three horses pass. sa. Berryman, co. Devon. Borman.

\section{.... Leopards}

Az. a chev. betw. three leopards arg. Wyistrope, The leopards 'estants'. John WILLEsthorp, $X$.

Az. a chev. betw. three leopards or. BenEley.

Sa. a chev. erm. betw. three leopards or. Bourcher, co. Worcester; granted 1587. DeYFe, co. Gloucester.

Sa. a chev. erm. betw. three leopards pass. or. Bourchier or Burchar, London; and Essex.

Sa. a chev. erm. betw. three leopards pass. guard. or. Bouchen, Salisbury. .... Lions

Arg. a chev. hetw. three demi-lions gu. within a bordure of the last bezanty. FisHer.

Arg. a chev. betw. three demi-lions ramp. purp. Inevette, Coventry; granted 1558. Kevett, co. Warwick.

Arg. a chev, vair betw. three demi-lions ramp. erased gu. Sir Clement Fisher, co. Northampton, $W$. FisHer, Hartwell Park, co. Northampton.

Arg. a chev. wavy vair betw. three demi-lions ramp. gu. Fishen, Packington, co. Warwick ; the heiress $m$. Finch.

Az. a cher. betw, three demi-lions or. Bedrcke. Sire Johan de Hamme, $N$. Hamme, $V^{*}$. Hames or Hammes.

Az. a chev. betw. three demi-lions ramp. or. Hames, Nash Court, Kent. Hame, $V$. HaMner. HaNey or Hanney.

Gu. a chev. betw. three demi-lions ramp. arg. Bennet, $V *$. John Bennett, Vintner, London; granted by Cooke, $W$. BEweT.

Gu. a chev, betw. three demi-lions ramp. arg. armed and langued az. BenNet, Harl. MIS. 1603.

Or a chev. betw. three demi-lions ramp. erased az. crowned or. Steward; Noble, Durbam.

Or a chev. betw. three demi-lions gu. IIGFIeLD and LYFIEID, in Stoke Dabernon Church.

Sa. a cher. erminois betw. three demi-lions ramp. or erased gu. armed and langued of the same. Bennet, London; granted 24 June 1633.

.... a chev. erm. betw. three lions ramp. .... OrWELL, Isle of Ely.

Arg. a cher. az. betw. three lions ramp. guard. sa. Turner, Wakestown, Essex.
1 CHEVRON betw. or within.... cont.

Beasts cont. Lions cont.

Arg. a chev. barry az. and of the first betw. three lions ramp. as the second. Payne.

Arg. a chev. cliequy or and gu. betw. three lions ramp.sa. BOORNE.

Arg. a chev. gu. betw. three lions couchant of the second. Newman, Dromore, eo. Cork; descended from Newinan, Wincanton.

Arg. a chev. betw. three lions pass. coward gu. Topps or Torpes, Norfolk.

Arg. a chev. betw. three lions pass. guard. gu. LYonstopPe, $V$.

Arg. a chev. betw. three lions ramp. gu. Flatesbury, Ireland, $V$. Fiatterdury or Flatebury, Ireland. Flattesbery, Ireland. JocE. TOPPES.

Arg. a chev. embattled betw. three lions ramp. gu. Baspoole, $V^{*}$. Flatesbury, $V^{*}$.

Arg. a chev. gu. betw. three lions pass. sa. Bourne, $V^{*}$. JoHnson.

Arg. a chev. gu. betw. three lions ramp. sa. (?) Boorde or Bourde, Suffolk. Boonne. Sr. Thomas Borne, Q, Ashmol. MS. 1120. Bourne, $V$. Richard Bourne, $Y$. Nicholas Bourde (in margin Bourne), $Y$. Sr. Thomas Bourne alias Broun, Q. Sir Thomas Bowrne, $Q$, Cotton. MS. Tiberius E 9 , fo. $86 \mathrm{~b}$. The lions armed and langued of the second. Sr. Jhon (Browne altered to) Bowrne; Q, Harl. MS. 6595.

Arg. a chev. sa. betw. three lions dormant coward gu. Lyons ; Collinson, Sonterset, ii, 299,3 32.

Arg. a chev. engr. counterengr. sa. betw. three lions dormant tail coward hanging down the two in chief respectant gu. Gabriell LyoN, I.ondor, 1633-4; Harl. MS. 1358, fo. 40.

Arg. a chev. sa. betw. three lions ramp. gu. Meere, co. Wilts.

Arg. a chev. betw. three lions sa. Burthe, co. Lincoln.

Arg. a chev. engr. betw. three lions pass. sa. Sir Thomas Smith, Westenlanger; ob. 1591, in Ashford Church, Kent.

Arg. a chev. betw. three lions ramp. sa. Thoressr, co. York, $V$. John Thoresby, late Keeper of the Privy Seal, Q; Harl. MS. 6589. Hugh and Piers de Thonesbx, $Y$. Henry ThonesBy, at the Charter House, 1619. Thoresby now Thursby, Abington Albey, co. Northampton; the heiress $m$. Harvey; and Ormerod House, co. Lancaster. THonIsbye.

Arg. a chev. embattled betw. three lions ramp. sa. Baspoole, Beston, Norfolk.

Arg. a chev. engr. betw. three lions ramp. sa. Bartholomew. Sr. William Suwardby, $V$.

Arg. a chev, betw. three lions ramp. sa. armed and langued az. Hugh de Thoresby, $P$. But langued gu. William Thoresby, late Keeper of the Privy Seal, Q, Harl. MIS. 6595. John THoresbr, Bishop of St. David's 1347, Worcester 1349, Archbishop of York 1353-73. Thoresby, Leeds, co. York; and Hay, co. Brecon. Arg. a cher. betw. three lions sejant sa. Lrons.

Arg. a chev. vair betw. three lions ramp. az. Payne, Ittringham, Norfolk. Payne, Sulby Hall, co. Northampton.

Arg. a chev. betw. three lions ramp. vert. Clarke, co. Hereford.

Az. a chev. betw. three lions pass. arg. WIILESTHORP or WOLSTHORP, co. York.

Az. a chev. betw. three lions pass. guard. arg. Sr. Oswald Willistrop, co. York, $V$. W Yustrope. 
1 CHEVRON betw. or within.... cont.

Beasts cont. Lions cont.

Az. a chev. betw. three lions ramp. arg. Brightalan or Briztman, Paris Garden, Surrey. Gore. HyDE. Benedictine Monastery at Lindisfarne or HoLY IsLand, afterwards Priory at DurhaM. WillFrey.

Az. a chev, engr. betw. three lions ramp. arg. ThonPe, Conysthorpe, co. York.

Az. a cliev. belw, three lions estants (? statant) guard. arg. John Willesthorp, $X$.

A\%. a chev. betw. three lions ramp. or. Hyde. Brightmian or Briztman, Palis Garden, Surrey.

Az. a chev. erm. betw, three lions ramp. arg. Wolmington, co. Dorset.

Az. a chev. gu. betw. three lions pass. guard. arg. Willistrop, $V *$.

Az. a chev. or betw. three lions ramp. arg. RADCLIFF,

Az. a chev. betw. three lions pass. or. INGray. Waringe, co. Warwick.

Az. a chev. engr, betw. three lions pass. or. SMrthe, Corsham, and Baydon, co. Wilts.

Az, a chev. betw. three lions pass. guard. or. Bereley. SMith.

Az. a chev. engr. betw. three lions pass. guard. or. LLEWELLYN, as quartered by Whichcord. Siryth or Syrthe, Leeds Castle, and Bounds, Kent; derived from \мҮтнE, Ostenhanger or Westonhanger, Kent; granted 1591 ; quartering Judde witl Chichele; Viscount Strangford 1628 , Haron Penshurst 1825.

Az. a chev. betw. three lions ramp. or. BrighaMr. Benedictine Monastery at Lindisfarne or Holy Island, afterwards Priory at Durham. Thomas HatField, Bishop of Durham 1345-81, Noble, Durham. Prewert.

Gu. a chev. betw. three lions pass, arg. WILIESTHORP Or WOLSTHORP.

Gu. a chev, arg. betw. three lions ramp. or. Heeley or Heely. Langton.

Gu. a chev. erm. betw. three lions ramp. arg. Langton, co. York. Sr. John Langton, $V$.

Gu. a chev. erm. hetw, three lions ramp. or armed and langued az. Langton, Ferneley, co. York.

Gu. a chev, or betw. three lions .... double tailed arg. GoAD, Cruston.

Gu. a chev, or betw. three lions ramp. arg. Gooche Googe or Gond. WenLock, Wenlock, $V$.

Gu. a chev. or betw. three lions ramp. guard. arg. Wenlock, Wenlock, co. Salop.

Gu. a chev. betw. three lions ramp. or. BoLns, T'rerddot, Wales. Совнaа. Hwfa ap Cynddelw, 1]50. EILIs, Bodychau. Elits, Gwynfryn, co. Carnarvon, as descended from Howell-y-Pedolad. Good, Girlby, and Oneby, co. Lincoln. Griffites, Chwaen, Isle of Anglesey. Joln Owen, Bishop of St. Asaph 1629-5]. Owen, Bodeon, Anglesey. Owen, Bodsilin. Owen, Orielton, co. Pembroke; Baronetcy 1041 and 1813. Owen, Clenneney, co. Carnarvon; and Porkington, co. Salop; quartering Maurice; the heiress m. Ormsby. OWen, Penrhos, co. Montgomery. Wynne, quartered by Pendarves.

Gu. a chev. betw. three lions salient or. Gwxw, Fakenham, Norfolk.

Gu. a chev, vair betw. three lions ramp. or. Fardier. Fermor, Welches, Sussex. White, Wallingwells, co. York; and 'Tuxford, co. Nottingham; Baronetcy 1812. WhIte, Searnagh, co. Wexford, quartering Lce.
1 CHEVRON betw. or within.....cont.

Beasts cont. Lions cont.

Or a chev. erm. betw, three lions ramp. sa. Walter Mnuclerc, Bishop of Carlisle 1223-46.

Or a chev, ermines betw. three lions ramp. sa. $M_{A N}$, Hatfield Broadock, Essex ; and Kent.

Or a chev. engr. ermines betw. three lions rump. sa. Man, Surrey, W. Man, Hatfield Broadock, Essex ; and Kent. MaNN.

Or a chev. gu. betw. three lions ramp. az. Wyrtex, Dodford, co. Nortbampton; and co. Stafford.

Or a chev. betw. three lions ramp. gu. Lewrs, Wales.

Or a chev. gu. betw. three lions pass. sa. armed and langued of the second. WyrLer, co. Stafford.

Or a chev. gu. betw. three lions pass. guard. sa. Cooike.

Or a chev. gu. betw. three lions ramp. sa. Burridge, Halden. Kent.

(? Or) a chev. gu. betw. three lions ramp. vert. WyrLEY, co. Stafford.

Or a chev. betw. three lions .... sa. Burre, London.

Or a chev. per chev. engr. arg. and gu. betw. three ljons ramp. sa. BaRTLEME.

Or. a chev. betw. three lious ramp. sa. Burthe, co. Lincoln.

Or a chev. engr. betw. three lions ramp. sa. MaN, líent.

Or a chev, vair betw, three lions ramp. az. Parne.

Per chev, arg. and gu. a chev. betw. three lions ramp. counterchanged. Brockdon, Brockdon, co. Devon.

Per chev. gu, and az. a chev. engr. or betw. three lions ramp. arg. Haskins, Oxted, Surrey.

Per pale arg. and gu. a chev. betw. three lions ramp. counterchanged. LIMBERY or LYMBREY, co. Dorset. Limbury, Limehouse, Middlesex; and co. Dorset.

Per pale az. and gu. a chev. betw. three lions ramp. or. Wren-Hoskyns, Wroxhall Abbey, co. Warwick, quartering Wren; descended from Hoskyns, Harewood, co. Hereford; Baronetcy 18 December 1676 .

Per pale gu. and az. a chev. engr. or betw. three lions ramp. arg. Hoswins, Oxted, Surrey. Hoskyns ; Collinson, Somerset, ii, 133. Hotchis, Hoxwood, co. Salop. Suwardir, $V^{*}$; and Noble, Durham.

Per pale or and az. a chev. arg. betw. three lions pass. guard. counterchanged. Sмттн, London; and Ryall, Surrey.

Per pale or and az. a chev. erm. betw. three lions pass. guard. counterchanged. SMYTR, Henlow, co. Bedford.

Per pale or and az. a chev. betw, three lions ramp. of the first. HAWkINS.

Sa. a chev, betw, three lions pass. arg. HaLEs. Sa. a chev. betw. three lions ramp. arg. HALES, Mychurch, co. Somerset. HaLes, Hales, co. Norfolk. M. Steven de Hales, $S$. Raines, Fitling, and Flinton, co. York. Raymes, $V$.

Sa. a chev. betw. three lions ramp. reguard. arg. Henry de Merewell alias Woodlock, Bishop of Winchester 1305-16.

Sa. a chev. betw. three lions sejant arg. Woodock, Ireland.

Sa. a chev. betw. three lions sejant guard. arg. LYoNs, Island of Antigua.

Sa. a chev. betw. three lions sejant reguard. arg. WOODSTOGKE. 
1 CHEVRON betw. or within.... cont.

Beasts cont. Lions cont.

Sa. a chev. arg. betw. three lions ramp. or. Wiliason, Sugwas, co. Hereford. The lions donble tailed. Willason, $W$.

Sa. a chev. chequy or and az. betw. three lions pass. ary. Warkand, Westhorpe, co. Nottingham. Sa. a chev. erm. betw. three lions pass. guard. arg. Hill, Lord Mayor of London 1481.

Sa. a chev. erm. betw. three lions ramp. arg. Hinstock. Raynes, $V$.* Reynes or Reymes, Overswood Kettlestone, Norfolk. Spitty, Rekınden, Essex.

Sa. a chev. erm. betw. three lions ramp. arg. crowned or. Hinstoke, $V *$. Thomas HyNsTock, Rymes, $V$. Reynes or Reymes, Overswood Kettlestone, Norfolk.

Sa. a chev. betw. three lions pass. guard. erm. Hux, Kent ; and London.

Sa. a chev. erm. betw. three lions pass. guard. or. Boucher, Salisbury. Bourchier or Burchar, London; and Essex. Bourcher, co. Worcester; granted 1587. DE yFE, co. Gioucester. Sa. a chev. wavy erm. betw. three lions ramp. or. Cooper, Surrey.

Sa. a chev. betw. three lions ramp. or. Willason.

Sa. a chev, betw. three lions ramp. double tailed or. Willason, $V^{*}$. Willison, co. Hereford.

Vert a chev. betw. three lions ramp. or. Woolmerston; Collinson, Somerset, i, 256.

$$
\text { ..... Moles or Wants }
$$

Arg. a chev. betw. three moles sa. Twisleton, Dartford, Kent. Twisleton, Drax, and Goole, co. York; and Osbaston, co. Leicester. Twisleton, Baron Saye and Sele; quartering Fiennes. But with a mullet .... for diff. Twisleton, Barley, co. York; granted $22 \mathrm{Nc}$ vember 1602 .

\section{.... Otters}

Arg. a chev, betw, three otters pass. az. O'HALLORAN.

Sa. a chev. betw. three otters pass. arg. HaRTor, Bucliminster, co. Leicester; granted by Segar. Sa. a chev. erm. betw. three otters arg. HARTOP, Little Dalby, co. Leicester; derived from Buckminster and Freathby. The otters statant. Thomas Hartopp, co. Leicester, $W$.

Sa. a chev. erm. betw. three otters pass. arg. Cradock-Hartopp, Freathby, co. Leicester; and Four Oaks' Hall, co. Warwick; Baronetcy 12 May 1796; quartering Cradock. Hartopp, co. Cambridge; anu co. Leicester; granted 18 May 1596, Harl. MS. 1359, fo. 32 .

Sa. a chev. betw. three otters pass. erm. HARTopP, co. Cambridge; and co. Leicester; granted 18 May 1596.

Sa. a chev. vairy or and gu. betw. three otters pass. of the second. Lotyshas, Chiph, and Fornington, co. Somerset.

$$
\text { .....0xen }
$$

Arg. a cher.gu. betw. three bulls sa. OxEnden, $V^{*}$.

Arg. a chev, gu. betw. three calves sa. DuncaLF, Otringham, co. York.

Arg. a chev. gu. betw, three oxen sa. OxEnDEN, Brook, Kent. T'be oxen pass. Oxenden, Dene, Kent; Baronetcy 8 May 1678.

Arg. a chev. gu. betw. three oxen pass. sa. armed or. OXENDEN.

Arg. a chev. gu. betw. three bulls statant sa. Oxenden, Wingham, Kent, $V$.

Arg. a chev. betw. three bulls sa. Torner, Boclihill, Kent. Tournay, $V^{*}$. Wintersells. Wintersills, $V *$.
1 CHEVRON betw. or within.... cont.

Beasts cont. Oxen cont.

Arg. a chev. betw. three calves sa. Dunscalfe. LESQUET, $V^{*}$.

Arg. a chev. betw. three bulls pass. sa. Sutron, Kensington. Middllesex. William Tournar, $V$, Harl. MS.1392. Turnay. Turney, co. Buckingham, 1716.

Arg. a chev, betw. three calves pass. sa. Lesque. Arg. a chev. betw. three oxen pass. sa. Bragge. OXENDEN.

Arg. a chev. betw. three bulls pass. sa. armed or. Sellenge, Kent. Wintersells.

Arg. a chev 'betw, three bulls pass. sa. attired or. Turner, Cavenby, co. Lincoln. Turney; Collinson, Somerset ii, 225.

Arg. a chev, betw. three bulls statant sa. WyNTERSILS, $V$.

Arg. a chev, betw. three calves statant sa. Lesquet, $V$.

Arg. a chev. vert betw, three bulls pass. gu. Bragg, co. Somerset. Bragge, Sadborough, in Thorncombe, co. Devon. BraGgE; Collinson, Somerset, ii, 562.

Or a cbev. az. betw. three bulls sa. Bragge, $V^{*}$. But the bulls gontty d'or. Fleminge, $V^{*}$.

Or a chev. az. betw. three bulls pass. sa. goutty d'or. Sr. Thomas Flemynge, $V$.

Or a chev. gu. betw, three bulls pass. sa. Bragge, West Clandon, Surrey.

Or a chev. betw. three bulls sa. Brage, Essex; and London. Braggr, Hatfield Peverell, Essex; Collinson, Somerset, ii, 77.

Or a chev. betw. three oxen sa. RoDBArD; Collinson, Somerset, ii, 171.

Or a chev. betw. three bulls pass. sa. Tournay, Eastry, and Canterbury, Kent; quartering Bargrave.

Or a chev. betw, three calves pass. sa. Lesque. Or a chev. betw. three bulls sa. attired arg. RADBARD, Lambrook, co. Somerset.

$$
\text { ..... Sheep }
$$

Arg. a chev. engr. gu. betw. three lambs pass. sa. LAMrB.

Arg. a chev, betw, three rams sa. Sydnam, $V^{*}$.

Arg. a chev. betw. three rams pass. sa. a mullet for diff. Sydenham, Langford, co. Somerset.

Arg. a chev. betw. three rams statantsa. Sydnar, $V$. Az. a chev. betw. three paschal lambs couchant arg. Row, Totnes, and Kingston, co. Devon.

Az. a chev. betw. three rams pass. arg. HaRHAN, Ireland.

Az. a chev. arg. betw. three rams pass.or. RAMSEY, Kent.

Az. a chev. engr. erm. betw. three golden fleeces. Jennings, The Shrubbery, Dover.

Az. a chev. or betw. three paschal lambs couchant arg. RURDE.

Az. a chev, hetw, three rams or. Rarsey, $V^{*}$.

Az. a chev. betw. three rams pass. or. Ramsey, Kent.

Az. a chev. betw. tliree rams statant or. Ramser, $V$. Ramsey, Kent, $W$.

Gu. a chev. betw. three lambs arg. LAmbert, $V^{*}$. Gu. a chev. betw. three lambs pass. arg. LAMBERT, co. York.

Gu. a chev. erm. betw. three lambs pass. arg. Layrart, Stockton, Durham.

Gu. a chev. vair betw. three lambs arg. LAmBand, Sevenoaks, Kent; quartering Beale. Lambard or LaMtBarde.

Gu. a chev, vair betw. three lambs statant arg. LAMBERT, Sheriff of London (i.e. 1551), $V$. 
1 CHEVRON betw. or within.... cont.

Beasts cont. Sheep cont.

Per pale wavy arg. and erminois a chev. betw. three lambs pass. sa. Burges-Lani, Burville, co. Berks, Baronetcy 1795 ; quarterıng Burges.

Sa. a chev. betw. three rams arg. Crosbx, $V *$ * Parsons, Ireland.

$\mathrm{Sa}$. a chev. erm. betw. three rams pass. arg. Crosiy, Lord Mayor of London, 1771 .

Vert a chev. betw. three rams arg. Milleh, co. Dorset.

Vert a chev. betw. three rams statant arg. MALLARD.

Verta chev. erm. betw. three rams pass, arg. attired or. Wetherby, Norfolk.

Vert a chev.erm. betw, three rams or. WeTHEBy. WeTHERAY, $V$ * WHETHERBY, $V^{*}$.

Vert a chev. erm. betw. three rams statant or. Wetherey, $V$. Whetheriy, temp. Henry $6, V$.

$$
\text { ..... Squirrels. }
$$

Arg. a chev. az. betw. three squirrels gu. LoveLI, Addington Church. Gregory Loveli, Merton Abbey, ob. 1597.

Arg. a chev. az. betw. three squirrels ga. each cracking a nut. Loves., Cole Par'i, Malmesbury, co. Wilts. The nuts or. LovelL, $V^{*}$.

Arg. a chev, az. betw. three squirrels sejant gu. cracking nuts or. Sr. Gregory LovelL, Norfolk, $V$.

Arg. a chev. az. betw, three squirrels sejant cracking nuts sa. Loveli.

Arg. a chev. chequy or and az. hetw. three squirrels sejant gu. WARREN, London.

Arg. a chev. betw. three squirrels sejant gu. Goosetree ur Goosetrey, co. Buclingham. KENSING.

Arg. a chev. betw, three squirrels sejant cracking nuts gu. Trewithian.

Arg. a chev. betw. three squirrels sejant gu. cracking nuts or. Sr. John Holt, $V$. Kenfing, $V^{*}$. Kensing, $V$. The nuts stalked and leaved vert. KingseY or KYNSEY, co. Chester.

Arg. a chev. gu. betw. three squirrels sa. cracking nuts or. Scobisgton, $T^{*}$.

Arg. a chev. gu. betw, three squirrels sejant sa. crack!ng nuts or. CHOBINGTON, $V$. SchOBINGTON, co. Buckingham, $V$.

Arg. a chev. engr. (lozengy $V^{*}$.) countercompony az. and gold betw. three squirrels sa. each holding a branch vert and cracking a nut or. Lawrence W ARREN, Bygrave, co. Hertford, $W$.

Arg. a chev. or betw. three squirrels sejant gu. (ancient arms of) 'TwEMLow, Twemlow, Alsager, Buerton, and Northwich, co. Chester; and The Elms, near Bettley, co. Stafford.

Arg. a chev. sa. betw. three squirrels sejant gu. Litler, London. Littler, Middlesex.

Arg. a chev. sa. betw. three squrrels cracking nuts ppr. Burye, co. Warwick.

Gu. a chev, erm. betw. three squirrels or, GreENFORD, $V^{*}$. GRENSTED, $V^{*}$.

Gu. a chev. erm. betw. three squirrels sejant or Grenford or Grensted. Greenford, $V$. John de GRENEFond, Bishop of Chichester 117 $1-80$.

Or a chev. az. betw. three squirrels sejant gu. Loves, , Barton, and Harling, co. Norfolk.

$$
\text { ....Tigers. }
$$

Arg, a chev. az. betw. three tigers vert. LEIGHWOOD, London.

Arg. a chev. az. betw. three tigers statant vert reguard. a glass or. William LIGHTwOod or LizThed, London, $V$.

\section{CHEVRON betw, or within....cont.}

Beassts cont. Tigers cont.

Gu. a chev. betw. three tigers couchant reguarl. arg. Otuell Butteller, Calais, $V$. Butler, $V^{*}$.

Gu. a chev. betw. three tigers reguard. arg. ButLER.

Sa. a chev, erm. betw. three tigers arg. HaRTor, $V^{*}$.

Sa. a chev. betw. three tigers arg. reguard. a glass or. Tatersalis, $V^{*}$.

Sa. a chev. betw. three tigers pass. reguard. a glass arg. Tatershali.

Sa. a chev, betw. three tigers statant arg. reguard. a glass or. Tatersald, $V$.

\section{.... Urchins}

Arg. a chev, ermines betw. three urchins sa. Byrom, London.

Arg. a chev. erminois betw. three hedgehogs or a label .... for diff. HARRIS.

Arg. a chev, betw. three urchins sa. Birom, co. Lancaster.

Az. a chev. betw. three hedgehogs arg. Marnstone alias Mayneston, Urchingfield, co. Hereford; and Londou, temp. Edward III.

Az. a chev. arg. betw. three hedgehogs or. Harris, Stockton, co. Salop.

Az. a chev. erm. betw. three hedgehogs or. Harris, abcot, co. Salop. Harris or Harreys. Harris, $V^{*}$. Henreys, $V^{*}$. Heriz.

$\mathrm{Az}$. a chev. erm. betw. three hedgehogs statant or. James Herreys, $V$.

Az. a chev. erm. betw. three hedgehogs ppr. HaRris.

Gu. a chev, betw. three hedghogs arg. Craxton, Durham; Norfolk; and co. York. Laxton, co. York.

Or a chev. engr. az. betw. three hedgehogs sa. HARD.

Sa. a chev. betw. three hedgehogs arg. Harris, Surrey.

Vert a chev. betw. three hedgehogs or. MaYnstone, Langaran, co. Gloucester; and co. Hereford.

\section{....Weasels}

Sa. a chev. erm. betw. three weasels pass. arg. Byrtwysell, Amcote Hall, co. Lancaster.

$$
\text { .....Wolves }
$$

Gu. a chev. erm. betw. three wolves the two in chief combatant or. GRENFord.

Sa. a chev. erm. betw. three wolves or. Bourchier, London,

Vert a chev. erm. betw. three wolves .... arg. Ririd Flaidd, Penllyn. Vaughan, Glanllyn. Wynne, Hazlewood, co. Sligo.

$$
\text { .... Lions }
$$

Az. a chev. erm. betw. six lions ramp. or. Powle.

Gu. a chev. indented arg. betw. six lioncels ramp. or. Griffith, Wales.

$$
\text { ..... Sheep }
$$

Az. a chev. betw. six rams accosted countertrippant two two and two arg. attired or. Harian, Rendlesham, and Mulford, Suffolk. Harman, Antigua, quartering Cahusac.

\section{Bells}

Arg. a chev. gu. betw. three bells sa. Eriter.

Arg. a chev. gu. betw. three church bells sa. Exeter, $V$.

Az. a chev. betw. three bells arg. Rud or Rudde, Bishop of St. David's ; granted 1597. Rudd, $V^{*}$.

Az, a chev. erm. betw, three bells arg. Anthony RudD, Bishop of St. David's 1594-1615. RudD or RudDE. 
1 CHEVRON betw, or within.... cont.

Bells cont.

Az. a chev. betw. three falcon's bells or. ENT, Sandwich, Kent; and Westmiuster.

Sa. a chev. betw. three church bells arg. BeLr, Westmoreland; and Cumberland. William BELL, $Y$.

Sa. a chev. erm. betw. three churcl bells arg. Bell, Sunderland, co. Durham.

Sa. a chev. betw. three hawl's bells or. Srene. Billets

Arg. a chev, betw. three billets az. Sire Ricbard de Mouncanesy, $O$.

Arg. a chev. chequy gu. and or betw. three billets sa. Decres, Horsham ; Harl. MS. 5673, fo. 15.

Arg. a chev. betw. three billets (blocks or delves) gu. Delaland or De la Lannde. Delaward. Deltes. Deraunt. Derwick or Derawnt. Dreant. Irrires, $V$. Jerires, $V^{*}$. Kelle, Cornwall. Kerty; Collinson, Somerset, iii, 332 . KeLly, Kelly, co. Devon; quarteling Drewe and Godwin. Kylle, Cornwall, $V$. Krlley, $V^{*}$.

Arg, a chev. betw. three billets gu. withiu a bordure az. DERAW.

Alg. a chev. gu. betw. three billets (blocks or delves) sa. Delner or Delver. Delves, co. Chester, $V$. Exeter, $V^{*}$. Exiten, $V$.

Arg. a chev. gu. betw. three billets (blocks or delves) barwise sa. Delves, co. Lancaster, $V$. Cotton. MS. Tiberius D, 10, fo. 616 .

Arg. a chev.sa.betw. three billets erm. Englomise.

Arg. a chev. betw, three billets sa. Monsire John de Mounchensy, $Y$.

Az. a chev. erm. betw. three billets or. James Usher or Ussher, Primate of Ireland:

Az. a chev. betw. three billets (blocks or delves) gu. Woodwand, $V$ *

Az. a chev. betw. three billets (blocks or delves) or. Usher. Woodward, Norfolk, $W$.

Erm, a chev. az, betw. three billets gu. Eustace, Bishop of Ely 1198.1215.

Gu. a chev. betw. three billets (blocks of delves) or. Montesey or Montisey. Montessey, $V^{*}$. Montissey, $V$.

Or a chev. betw. three billets erni. Ushrr.

Or a chev. betw, three billets gu. Delaunr.

Per pale arg. and sa. a chev. betw. three billets counterchanged. MASON, Monkton, Isle of Thanet; and Bury St. Edmonds, Essex; Add. MS. 550\%, fo. 306 .

Arg. a chev. betw. tive billets (blocks or delves) and three crosses croslet fitchy sa. Sr. John Westres, Norfolk, $V$.

Arg. a chev. engr. betw. six billets gu. Artworth.

Arg. a chev. betw. six billets and three crosses croslet fitchy sa. Westiey.

Gu. a chev. erm. betw. six tillets arg. Repington, co. Lincoln; and Amington, co. Warwick.

$$
\text { Bird .... (Mragpie) }
$$

Arg. a cher. gu. betw. in chief a (magpie ?) ppr. and in base a bar of three lozenges conjoined gu. Pye or Pyes, Harl. MS. 140t, fo. 110.

$$
\text { ..... (Swan) }
$$

Az. a chev. arg. in chief a swan in base a 4-foil stalked and leaved of the secoud. Dry.

Birds .... (Cocks)

Arg. a chev. az. betw. in chief two cocks and in base a buckle gu. AITisis.

$$
\text { ... (Crows) }
$$

Arg. a chev. sa. betw. two ravens ppr. CoRbetr.

Or a chev. gu. betw. in chief two Cornish choughs aud in base a cannon mounted on a carriage sa. LEA, afterwards Tonisis, Merthen.
1 CHEVRON betw, or within.....cont.

Birds cont. (Eagles)

Az. a chev. erm. betw. in chief two eagles reguard. wings displ. and in base a dolpbin naiant embowed or. Stupart, Scotland; granted 176 ?

Az. a chev. betw. in ubief two eagles volant and in base a sun or. JoHnson, Goldington, co. Bedford.

Quarterly gu. and az. a cbev. erm. betw. in chief two eacles displ. arg. and in base a lion pass. or. Lidsgird, Plumsted, Kent ; and Rougham, Suffolk; granted $17 \pm 0$.

\section{.....Falcons}

Gu. a cbev. vair betw. in chief two falcons with wings expanded and in base a dolphin arg. all within $\mathbf{a}$ bordure engr. of the last. Fisher, co. Warwick.

\section{.... Martlets}

Per chev, arg. and or a cbev. gu. betw. in chief $t$ wo martlets sa. and in base $a$ crescent of the third. Devizmes, Lisbon.

\section{.....swans}

Az. a chev. betw. in chief two swaus and in base a pair of shears arg. Delaney. Lannoy, H ammerswith.

\section{Birds}

.... a chev. engr. .... betw, three birds .... Yon, Barrow, and Filmingham, co. Lincoln.

.... a chev. .... betw. three birds close .... membered gu. Duke, Benhall Lodge, and Brampton, Suffolk.

Arg. a chev. .... betw. three birds .... WALEER, Salisbury.

Arg. a chev. betw. three birds volant.az. RosBy, co. York.

Arg. a chev, az. betw. three birds wings expanded sa. Howywood.

Arg. a chev, engr. az. betw. three birds rising sa. within a bordure engr. of the second. Gethyn, $V^{*}$.

(? Arg.) a chev. ermines betw. three barnacle birds (probably solan or Orkney geese) close ppr. WYKE, Harl. MS. 1078, fo. 40 .

Arg. a chev. ermines betw. three birds sa. OwEN, co. Oxford.

Arg. a chev. gu. betw. three birds az. Evans, Wales.

Arg. a chev. gu. betw. three birds (perhaps seapies) rising overt inverted brown. TREvenour, Harl. MS. 1404, fo. 147.

Arg. a chev. betw. three birds gu. O'Merren.

Arg. a cher, gn. betw. three birds (probably Cornish choughs) rising overt (sa. beaked and legged of the second $i . e$.$) ppr. Trevenorth,$ Cornwall, $V$.

Arg. a chev. lozengy gu. betw. three birds (perliaps cocks, crows, ol moorcocks) sa. Ringwood, Norfolk.

Arg. a chev. bumetty gu. betw. three birds sa. in their beaks a sprig of laurel vert. CoвBETT, Edmonton, Middlesex.

Arg. a chev. gu. betw, three birds rolant sa. bealsed and legged of the second. Trevenothe, $V^{*}$. The birds probably Cornish choughs, or seapies. Trevenouthe.

Arg. a chev, gu. betw. three birds (probably Cornish choughs) sa. beaked and legged or. Thornhull, co. Wilts; co. Dorset; and co. Buclingliam.

Arg. a cher. gu. betw. three birds (probably pol injays) vert. KuLLINGwiKe. 
1 CHEVRON betw, or within.....cont.

Birds cont.

Arg. a chev. or betw. three birds (perhaps duclis) sa. the breast of the first and eye gu. HerLe, Harl. MS. 1404, fo. $] 44$.

Arg. a chev. betw. three birds sa. Hawnins, as quartered by Whitshed. Norman, Honyngham, Norfolk. Thomas, $V^{*}$. The birds perhaps Cornish choughs. Tномas. The birds perhaps crows. Baynard or Baynyard, Suffolk. The birds perhaps doves. DuFrelde or DuFrJeld, co. Buckingham. The birds perhaps magpies. KIngdom. 'T'he birds perhaps martlets. Baynard or Baynyard, Suffolk. DuFFelde or DuFField, co. Buckingham.

Arg. a chev. betw. three birds (? ravens or popinjays) sa. within a bordure engr. gu. BRAY, $V^{*}$.

(Arg.?) a chev. engr. betw. three birds (martlets or ravens sa?). De Brkele; Collinson, Somerset, iii, 15.

Arg. a chev. engr. betw. three birds sa. Beykle, $V^{*}$. The birds perhaps martlets. BEYKLE.

Arg. a chev, betw. three birds (probably Cornish choughs) sa. membered gu. MERYFeLDE, $V^{*}$. Thornhill, co. Dorset.

Arg. a chev, engr. betw. three birds (probably Cornish choughs) sa. beaked and legged gu. Bystley, $V *$.

Arg. a chev, betw. three birds (perhaps Cornish choughs) sa. beaked and legged or. WALDOURE.

Az. a chev. ... . betw. three birds (perbaps eagles close) .... Whitцоск.

Az. a chev. .... betw. three birds .... Tonme Penzance, and Rosebill, Cornwall.

Az. a chev. betw. three birds arg. Stanford, $V^{*}$.

Az. a chev. betw. three birds arg. beaked and legged gu. DnEwry, Brampton, Suffolk. STANFORD, $V$. The birds perbaps storks. STAMFORD.

Az. a chev, arg. betw, three birds (perhaps choughs or falcons) or. Austen, Norfolk.

Az. a chev. betw. three birds (perbaps choughs or falcons) or. Austen, Tenterden, Kent; and Guildford, Surrey. Austyne, $V$. The birds perhaps eagles close. Whitelock. Whitlock.

Az. a chev. engr. betw. three birds (perbaps eagles or falcons close) or. WHitelock. Whiтlock, London.

Az. a chev. betw. three birds (perhaps choughs or falcons) or beaked and legged gu. Austrn.

Gu. a chev. betw. three birds arg. ERLEy or EnLy. Ridley, $V^{*}$. The birds called seapewits. SAYER, Preston, co. Durham; and Worsall, co. York. The birds perhaps falcons or goshawlss. Redley or Redleigh. Ridley, Surrey. The birds probably falcons or goshawks close. Hugh Reduex, $V$. Nicholas RIDLEY, Bishop of Rochester 1547, London 1550-3, V, Harl. MS. 1392 fo. 49.

Gu. a chev, betw. three birds arg. beaked and legged or. Hudeley, $V$.

Gu. a chev. betw. three birds wings expanded arg. Ludkin, Ipswich, Suffolk.

Gu. a chev. arg. betw. three birds (probably wild ducks) volant recursant brown. WORLYCH, Harl. MS. 1404, fo. 147.

Gu. a chev. engr. arg. betw. three birds or. Wodex, $V$.

Gu. a chev. az. betw. three birds (perhaps hawlis) arg. W $\triangle$ LTHAM.

Gu. a chev. betw. three birds or. GeDING. The birds perhaps lapwings. Trnwerr.
1 CHEVRON betw. or within....cont.

Birds cont.

Or a chev. az. betw. three birds (see Gulls) brown. Seyer, co. Wilts, Harl. MS. ]404, fo. 146.

Or a chev. az. betw. three birds (i.e. ravens) ppr. SEgar, $V$.

Or a chev. az. betw. three birds purp. SEgar, $V^{*}$. SEger. SEYRE.

Or a chev, betw. three birds (perhaps hawks) sa. WALTHAD.

Or a chev. vert betw. three birds (perhaps hawlis) sa. Waltho, Nantwich, co. Chester.

Per pale arg. and sa. a chev. betw. three birds close counterchanged beaked and legged gu. Rotham, Kent.

Per pale or and vert a chev. betw. three birds (probably choughs) counterchanged. STEPHENS, Whippingliam, Isle of Wight.

Sa. a chev. betw. three birds arg. Icham, $V^{*}$. The birds perhaps doves. DuFField, Ashmol. MS. 763. Gervis, Isle of Ely, and co. Worcester. The birds perhaps eagles close. Gervis, Isle of Ely, and co. Worcester. The birds perhaps bawks. Gervis, Isle of Ely, and co. Worcester. ICHAM, $V$. The birds probably beronshaws storks or lapwings. Gervis, Isle of Ely, and co. Worcester. The birds perhaps martlets. Dufrield, Ashmol. MS. 763. Gervis, Isle of Ely, and co. Worcester.

Sa. a chev. betw. three birds close arg. Seafowle. Sa. a chev. arg. betw. three birds (perhaps doves) of the second beaked and legged gu. Duffelde, $V$.

Sa. a chev. arg. betw. three martlets or. (? WaLI,POOL.)

Sa. a chev. erm. betw. three birds within a bordure engr. arg. Stanlex, Horningsham, co. Wilts.

Sa. a chev. erm. betw. three birds arg. beaked and legged gu. in the dexter chief a crescent for diff. Hathye, $V$.

$$
\text { .....Auks }
$$

Or a chev, sa. betw. tbree murrs (or auks) ppr. Carthew, Canaligee, Cornwall ; Benacre, and Woodbridge, Suffolk; and East Dereham, Norfolk.

$$
\begin{aligned}
& \text {... Baldcoots see Coots } \\
& \text {... Barnacle Birds see Geese } \\
& \text {... Blackbirds see Thrushes } \\
& \text {... Buntings see Finches } \\
& \text {....Bustards }
\end{aligned}
$$

Arg. a chev. gu. betw. three sea-pies rising overt inverted brown. (? Trevenour, Harl. MS. 1404, fo. 147.)

Arg. a chev. betw. three bustards gu. Кгтching, co. Hereford.

Arg. a chev. gu. betw. three sea-pies ppr. Trevenok, Appledore, Cornwall. The birds volant ppr. Trevenour. The birds volant sa. beaked and legged of the second. (? Trevenouthe.)

Arg. a chev. sa. betw. three sea-pies ppr. Pentıne, Pentire, Cornwall.

Gu. a chev. betw. three sea-pies arg. SAYER, Pulbam, Norfolk. Robert SAER, $V$. SAYER, $V$. Gu. a chev. arg. betw. three sea-birds sa. bellies arg. Here.

Or a chev. sa. betw. three bustards vert. Landon. Sa. a chev. betw. three seafowl close arg. Searowle.

$$
\text { ....Cannet see Duck }
$$$$
\text { .... Chough see Crow }
$$ 
1 CHEVRON betw, or within.... cont.

Birds cont. Cocks cont.

Arg. a chev, az. betw. three cocks gu. Cockworthy or Cookworthy. Croasdatle, in Brasted Church, Kent, 1831. Kirkeby. KIrkLex, $V$.

Arg. a chev. engr. az. betw. three cocks gu. DyLderne, $V^{*}$.

Arg. a chev. erm. betw. three cocks sa. beaked and legged gu. Henshaw, Great Marlow, Essex; and London.

Arg. a chev. betw. three cocks gu. CoBBes, Bury, Suffolk. Cockington, co. Devon. John de Conerington, $Y$. Cokeworth, Cornwall. Crow or Crowe, Ireland.

Arg. a chev. gu. betw. threo cocks of the last combed and armed az. John de Cokerington, $X$.

Arg. a chev. betw. three cocks gu. combs and wattles or. CoBB, New Romney; descended through СовB, Reculver, from Совв, Cobb's Court, and Aldington, Kent.

Arg. a chev. gu. betw. three cocks sa. Cocktree, co. Devon.

Arg. a cher. lozengy gu. betw. three coclis sa. (? Ringwood, Norfolk.)

Arg. a chev. gu. betw. three cocks sa. armed crested and jelloped of the second. COAD Codd Codde or Coode, Cornwall.

Arg. a chev. lozengy sa. and or betw. three cocks of the first armed gu. RivGwoon, co. Hants.

Arg. a chev. sa. betw. three cocks gu. Cockworthy or Cookworthy. REsprin, Resprin, Cornwall ; the heiress m. Carminow.

Arg, a chev, engr. sa. betw. three cocks gu. Cockworthy or CoOzworthy.

Arg. a chev. betw. three cocks sa. armed gu. John Googh, $V$. Googe, $V^{*}$. Merifield, $V^{*}$.

Arg. a chev. betw. three cocks sa. armed gu. within a bordure compony of the second and first. Coket, $V$.

Az. a chey. betw. three cocks arg. Meuric, King of Dyfed.

Az. a chev, betw. three cocks arg. armed crested and jelloped gu. SPurcock, $V$. Jevan VOELL, Penkally, quartered by Eyton, 1674.

Az. a chev. betw. three cocks arg. armed crested and jelloped or. OwEN, Garth-Angharad, Cae'rbellan, etc., co. Merioneth; quartering gu. three snakes nowed az.

Az. a chev.or betw.three cocks arg. Jenkin ap DAvn.

Erm. a chev. betw. three cocks az. armed crested and jelloped or. Grascock, Much-Dunmow, Essex; granted $14 \mathrm{July} 1571$.

Erm. a chev.gu. betw. three cocks az. GLAscocz, High Easter, Essex.

Erm. a chev, betw. three cocks gu. GLascock, Essex.

Gu. a chev, betw. three cocks arg. CAPENHURST. LODWICK.

Gu. a chev. betw. three cocks crowing arg. Crow, Suffolk.

Gu. a chev. erm. betw. three cocks or. CockenNe, Kent. Gockyn Goken Gokin or Gookrn, Bekesborne, and Ripple Court, Kent; quartering Durant, 1575, Hasted, Kent, iv, 132.

$\mathrm{Gu}$. a chev, or betw, three cocks arg. (Allowed 1586 to) Crow, Brasted, Kent; from Suffolk; ancestor of Crowe, Llanherne, co. Carmarthen; Baronetcy 1627, extinct ....

Gu. a chev, or betw. three dunghill-cocks arg. armed of the second. Crow or Crowe, Brasted, Kent.

Gu. a chev. betw. three cocks or. Cockeine, Ickham, Kent; granted 1619. Moses.
1 CHEVRON betw. or within....

Birds cont. Cocks

Or a chev. az. betw. three cocks gu. Cockington, $V$.

Or a chev. gu. betw. three cocks sa. armed gu. MERIFID, $V$.

Or a chev, betw. three cocks sa. armed gu. with. in a bordure compony arg. and of the second. Cocket, $V^{*}$.

Sa. a chev. betw. three cocks arg. combed and wattled gu. Coxon, co. York.

Sa. a chev. betw. three cocks arg. combed legged and wattled gu. Hancoke, Gregory Stoke, co. Somerset. HANDCOCK.

\section{.....Coots}

Arg. a chev, az. betw. three bald coots close sa. heads arg. beaks tawny. KILBURne, Hawlehurst, Kent; and London.

Arg. a chev. sa. betw. three coots ppr. Coolis or Cowlin. Cootes, Blew-Norton, Norfolk. Coote, Ballyfin, Queen's County ; Baronetcy 2 April 1661 ; Baron Coote and Earl of Mountrath 1660 extinct 1802; Farl of Bellamont 1696 extinct 1766, and 1767 extinct 1800 ; Baron Castlecoote 1800 extinct 1827; Coote, Mount Coote, co. Limerick; derived from Coote, Killester. But membered gu. CoLrn, Boscarne, and Helland, Cornwall, temp. Richard II.

Arg. a chev. betw. three coots sa. Southcote, Southcote, co. Devon; Collinson, Somerset, iii, 179,332 .

Arg. a chev. betw. three coots within a bordure wavy sa. CooTe, Donnybrook, and Bellamont Forest, Ireland; Baronetcy $18 \mathrm{May} 1774$.

Arg. a chev. eng. betw. three coots sa. Coote, Baron Coote and Earl of Mountrath 1660 extinct 1802 .

Arg. a chev. betw. three coots sa. membered gu. Coote, Ireland; and Middlesex. .... Cormorants

Arg. a chev. chequy az. and vert betw. three gannapies ppr. WIKES, co. Devon.

Arg. a chev. (compony az, and vert $V^{*}$.) coun. tercompony vert and $\mathrm{az}$. betw. three gannapyes of the last membered gu. WYKEs, temp. Henry III, $V$.

Arg. a chev. between three cormorants gu. WaRburton, co. Lancaster.

Arg. a cher. sa. betw. three gannapies az. YEo, Colliton, co. Devon.

Arg. a chevron betw. three cormorants sa. William WARBURToN, Bishop of Gloucester 1760-79, quartering Dutton. Dutron afterwards WaRBURTON, Arley, and Warburton, co. Chester; temp. Edward II.; quartering Dutton and Winnington with (ancient) Warburton.

\section{....Cranes see Herons}

....Crows including Chonghs

.... a chev. .... betw. three Cornish choughs .... Kurwan, Blindwell, co. Galway; quartering Staunton.

Arg. a chev. .... betw. three Cornish choughs ppr. Krrwan. Tregos, Cornwall. Wise, Ireland.

Arg. a chev, engr, az. betw. three crows ppr. Croner, Norfolk.

Arg. a chev, counterengr. az. betw. three (birds rising $V^{*}$.) ravens statant exparsed sa. within a bordure engr. (of the second, $V^{*}$.) gu. Gethyn, $T$.

Arg. a cher. gu. betw. three Cornish choughs ppr. COADE or CODE, Gidley Castle, co. Devon; and Morval, and St. Austell, Cornwall. CoDD or Conde, Cornwall. Jackson. Merefield. 
1 CHEVRON betw. or within.....cont.

Birds cont. Crows cont.

Arg. a chev. gu. betw. three crows ppr. Croker. irampton or Kranton.

Arg. a chev. gu. betw. three Cornish choughs ppr. within a bordure az. charged with eight bezants. WHighт, Hunton, Essex.

Arg. a chev, engr. gu. betw. three choughs ppr. Lambert, Lord Mayor of London 1532; and Maiden Bradley, co. Wilts. Lambert, London.

Arg. a chev. engr. gu. betw. three Cornish choughs ppr. Croker, Cornwall (in error).

Arg. a chev, engr. gu. betw, three ravens ppr. Croker, temp. Richard II, V. Croker or Crocker, Croker's Hele, Crokern Tor, and Lineham, co. Devon; quartering Churchill; a heiress m. Bulteel. Crorer, St. Agnes, co. Devon. Croker, Trevillas, Cornwall, 1600; and its descendants, Ballyanker, co. Waterford; Tallow; Ballynagard, co. Limerick; and Dublin, Ireland.

Arg. a chev. gu. betw. three Cornish choughs rising overt ppr. (? Trevenonth, Cornwall, $V$.)

Arg. a chev. gu. betw. three Cornish choughs ppr. each standing on a mount vert. SpLatr, Brixton, Yealmpton, quartering Collius.

Arg. a chev. gu. betw. three Cornish choughs volant ppr. (? TREvenouthe.)

Arg. a chev. gu. betw, three Cornish choughs sa. KInwan, Castle Hacket, Cregg, and Hillsbrook, co. Galway; and Dalgin, co. Mayo.

Arg. a chev. lozengy gu. betw. three crows sa. (? Ringwood, Norfolk.)

Arg. a chev, engr. gu. betw. three ravens sa. Croker, temp. Richard II, $V$.

Arg, a chev. gu. betw. three choughs sa. beaked and legged or. (? THonnhull, co. Buckingham; co. Dorset; and co. Wilts.)

Arg. a chev. gu. betw. three Cornish choughs sa. beaked and legged or. WISKARD, Framlingham or Fraunsham, Norfolk.

Arg. a chev. lozengy sa. and or betw. three ravens close of the second. Thomas, London.

Arg. a chev. lozengy sa. and or betw. three rooks of the second. Ringewoon or Ringwood.

Arg. a chev. sa. betw. three Cornish clioughs ppr. Bartlet, Kent. Burnell. Collins or Collyn, Cornwall. Cowleigh, co. Devon. Cowling, Kerthen, Trevareneth, and Trengwainton, Cornwall. Kindon or Kingdon. Merefield, St. Columb, Cornwall. Merpfedde, V. Griffith ap Nicholas, co. Hereford. ReEs, Llandovery, co. Carmarthen; quartering Jenkins. Rookesbe, co. York. Thomas, temp. Henry VII. (? Thorneml, co. Dorset.) Tregoz, $V$. Warburton, co. Salop. Whirams, Llanidan, and Craig-y-Doc, Anglesey; and Temple House, co. Berks. Worteer, co. Derby, 1716.

Arg. a chev. betw. three crows close ppr. RICE, Baron Dynevor.

Arg. a chev. sa. betw. three ravens ppr. Bowen, Lechdwyny. Corbet. Corbett. Elinor, Wales. Protheroe Prytherch or Ap Rhydderch, Hawksbrook, and Llangharne, co. Carmarthen. Protheroe, Dolwilym. Rees, Llandovery, co. Carmarthen, quajtering Jenkins. REEs or Rhys, Killymaenllwyd, co. Carmarthen; derived through Elidir Ddu, from Urien REGED; quartering Hughes.

Arg. a chev. sa. betw. three ravens close $\mathrm{ppr}$. Rice. Rice, Baron Dynevor 1780, quartering T'albot and Cardonnel. Sir Rhys ap Thomas Urian Ryed. Llywarch Rhirid ap URIEN.

\section{CHEVRON betw, or within.... cont.}

Birds cont. Crows cont.

Arg. a chev. sa. betw. three rooks ppr. RoKeBY, Arthingworth, co. Northampton; derived through Rokeby, Barnby, from Rokeby, Skiers, co. York; Baronetcy 1661; derived through Rokeby, Hotham, from Roweby, Mortham, co. York. M. Thomas de RokeBy, $S$.

Arg. a chev. sa. betw. three ravens ppr. within a bordure invected gu. bezanty. JoHnes, Dolecotby, co. Carmarthen; descended from JoH NES, Llanvairclydoge and Hafodychtryd; derived through JoHNEs, Llanbadarn-fawr, co. Cardigan, from JoHnes, Albemarles, co. Carmarthen.

Arg. a chev. sa. betw. three Cornish choughs ppr. within a bordure engr. of the second. JOHN. Arg. a chev. sa. betw. three crows ppr. within a bordure of the second charged with eight bezants. Jones, Ratcliffe, Middlesex.

Arg. a chev. engr. sa. betw. three Cornish choughs ppr. Beckley or Bistley, $V$. Bisley or Bistlex. Bystley, $V$. Croker. Hope, Grangefield, co. Derby.

Arg. a chev. engr. sa. betw. three crows ppr. Cromar Cromer Crovmar or Crowner, Lord of London 1413, ob. 1423. Cromer, Mayor Tonstall Court, Kent.

Arg. a chev. engr. sa. betw. three ravens ppr. Croker. Cromer, Tonstall Court, Kent.

Arg. a chev. invecked sa. betw. three ravens ppr. Bysley, York Herald, temp. Henry VIII.

Arg. a chev. sa. betw. three Cornish choughs ppr. in the beak of each an ermine spot. LEwIs, Bodjor, Anglesey; quarterly with Roberts and quartering Hampton.

Arg. a chev. betw. three choughs sa. Fitz-Vrian, Wales. (? Thomas).

Arg. a chev. betw, three corbeaus sa. Thomas Rookby, Y. M. Thomas de Rokeny, $Y$.

Arg. a chev, betw, three crows sa. (? BAYNARD or Baynyard, Suffoll.) Merefield. Rice, Dynevor 17 October 1780.

Arg. a chev. betw. three ravens sa. CAwThonne. Enyon, Flore, co. Northampton; Baronetcy 1642. Norris, Ireland. RICE, Wales. John Streliting, $V$. Sir Rhes ap Thomas, $V$.

Arg. a chev, betw. three rooks sa. Sr. Robert de Rookвy, R. Rokesy, Rokeby, co. York. Roxpy, Monkwearmouth, Durham.

Arg. a chev. betw. three ravens sa. within a bordure engr. gu. Bray, $V$.

Arg. a chev. engr. betw. three crows sa. Cromer, Kent, 1730. Sir William Cromar Cromer Cronmar or Crowner, Lord Mayor of London 1413. Crowman. Crowmer, $V^{*}$.

Arg. a chev. engr. betw. three ravens sa. BECKLEY, Northcott, co. Devon, $V$. BeckLY, $V^{*}$. (? DE Brkele, Collinson, Somerset, iii, 15. BYrkLE, $V$. Croware, Kent, $\boldsymbol{V}$. Enron, Flore, co. Northampton; Baronetcy 1642.

Arg. a chev. betw. three crows sa. each bearing in the beak an ermine spot. Hughes, Plas Cock. William Grifith ap JENkIN. Llowarch AP Bran, quartered by Eyton, 1674. Lloyd, Bishop of St. Asaph 1680, Lichfield, etc., 1692, Worcester 1700-17.

Arg. a chev. betw, three ravens sa. each bearing in the beak an ermine spot. David Gowe, $V$.

Arg. a chev. betw. three rooks volant sa. Crowmer, $V^{*}$.

Arg. a chev. betw. three ravens expansed sa. Rookesy, $V$. 
1 CHEVRON betw. or within.... cont.

Birds cont. Crows cont.

Arg. a chev. betw. three crows (ravens, $V^{*}$.) sa. beaked and legged a7. Coltry, Cornwall, $V$.

Arg. a chev. betw. three rooks sa. membered az. Alisander de Rokeby, $P$. Rookesby, co. Lincoln.

Arg. a chev. betw. three ravens sa. beaked and legged gu. Strelining, $V^{*}$. Tregooz, $V^{*}$.

Arg. a chev, engr. betw, three ravens sa. beaked and legged gu. Beckley or Bistuey, $V^{*}$.

Arg. a chev. betw. three choughs sa. beaked and legged or. (? WALDounE.)

Az. a chev. betw. three rooks arg. RookesBy.

Az. a chev. arg. betw. three choughs or. (? AUSTEN, Norfolk.)

Az. a chev. arg. betw. three Cornish choughs or. Austen, Shalford, Surrey.

Az. a chev, arg. betw, three rooks or. Rooke.

Az. a chev. betw. three choughs or. (? AUSTEN, Tenterden, Kent; and Guildford, Surrey.) (? Austyne, V.)

Az. a chev. betw. three choughs or beaked and legged gu. (? Austrn.)

Or a chev. .... betw. three choughs .... KNowsLEY.

Or a chev. az. betw, three (birds purp. $V^{*}$ ) ravens ppr. Segar, $V$. (? Seger.) (? Seyre).

Or a chev. engr. barry wavy of six arg. and az. betw. three ravens ppr. Cromer, Norfolk.

Or a chev. engr. gu. betw. three ravens ppr. Cromer, Norfolk.

Or a chev. per pale az. and gu. betw. three Cornish choughs ppr. CaRDALE.

Or a chev. sa. betw. three Cornish choughs ppr. Tredignie.

Or a chev. betw. three Cornish choughs sa. Wrke.

Or a chev. engr. betw. three choughs sa. Jones, Barrow, and Filmingham, co. Lincoln.

Or a chev. engr. betw. three Cornish choughs sa. within a bordure az. bezanty. Jones, Walpole, and Marshland, Norfolk.

Or a chev. vair betw. three (crows, $V^{*}$.) ravens sa. Cromer, Yarmouth, Norfolk, $V$.

Per pale arg. and sa. a chev. betw. three Cornish choughs counterchanged beaked and legged gu. Tноmas, Wrotbam, Kent, 1574.

Per pale or and vert a chev. betw. three choughs counterchanged. (? STEPHENS, Whippingham, Isle of Wight.)

Per pale or and vert a chev. engr. betw. three Cornish choughs counterchanged. STEPHEns alias Stone, Trevegoe, and Bodmin, Cornwall. Whiteling, Cornwall.

Sa. a chev. engr. betw. three Cornish choughs arg. Gervays, Isle of Ely. .... Doves

Arg. a chev. betw. three turtle doves az. Wintoun, Strathmartine, Scotland.

Arg. a chev. sa. betw. three pigeons gu. ELD, co. Stafford.

Arg. a chev. sa. betw. three doves ppr. Cooper. Searle or Serrall, Cornwall; the heiress $m$. Treffry.

Arg. a chev. sa. betw. three wood-doves ppr. Scareld, Thanks, Cornwall ; confirmed 16 June 1602.

Arg. a chev. betw. three doves sa. or DUFFIELD, co. Buckingham.)

Az. a chev. betw. three doves arg.

Phorpe, co. Gloucester.

Az. a chev. betw. three pigeons arg. Wychand.
1 CHEVRON betw. or within....cont.

Birds cont. Doves cont.

Az. a chev. arg. betw. three doves ppr. NaIsH, 1740.

Az. a chev. betw. three pigeons or. WINDIBANEE, Kent.

Gu. a chev. (plain) betw. three doves within a bordure engr. arg. ZEKETH.

Gu. a chev. betw. three pigeons volant arg. Smaliman, Kinnardesley Castle, co. Hereford.

Gu. a chev. betw. three doves arg. membered sa. PAGE.

Gu. a chev, erm. betw. three doves volant arg. Francis.

Gu. a chev. engr. erm. betw. three doves arg. Child, Essex.

Gu. a chev. engr. erm. betw. three pigeons rising arg. legged or. Francis, Suffolk.

Gu. a chev. betw. three pigeons within a bordure or. Whatiey.

Gu. a chev, betw. three pigeons volant or. Smallman, Elton, co. Hereford; co. Hertford; and Wildertop or Wilderhop, co. Salop.

Per pale indented az. and gu. a chev. betw. three doves arg. WADE, Tottington Bury, co. Lancaster.

Sa. a chev. betw. three doves arg. Compton. DUFFIELD, Ripon and Coverdale, co. York; quartering Dawson. (? DUFFIELD, Ashmol. MS. 763.) (? GervIs, co. Worcester; and Isle of Ely.)

Sa. a chev. betw. three doves arg. beaked and membered gu. (? DUfFelde, V.) Duffield, Coverham, co. York; Medmenham, co. Buckingham; and Ireland; confirmed 12 January 1848, quartering Dawson, as confirmed $21 \mathrm{De}-$ cember 1858.

Sa. a chev. arg. betw. three doves ppr. Jervis, co. Stafford.

Vert a chev. betw. three doves arg. Foote, Veryan, Lambesso, and Truro, Cornwall; and Wood, Tavistock, Devon.

Vert a chev, arg. betw. three doves or. Martin, East Court, Kent.

\section{..... Ducks}

Arg. a chev. gu. betw, three cannets sa. DuBIsson. Du Bisson.

Arg. a chev. betw. three ducks az. WoLrige or WOLRIDGE.

Arg. a chev. betw. three shovellers az. YEo, $V^{*}$. Arg. a chev. az. betw. three Muscovy ducks ppr. STock.

Arg. a chev. engr. az. betw. three ducks vert. Mooneton.

Arg. a chev. gu. betw. three ducks ppr. Carthew, Canaleggy, Cornwall, as given in most books, but see a CHev. betw. 3 AUKs ; incorrectly quartered by Tanner.

Arg. a chev, or betw. three ducks sa. the breast as the first and eye gu. (? HerLe, Harl. MS. 1404, fo. 144 .

Arg. a chev. sa. betw. three drakes az. beaked and membered or. Yeo, Heyampton or Highampton, Hewys or Hewes, and Sachevill, co. Devon.

Arg. a chev, sa. betw. three mailards ppr. Joseph Henshaw, Bishop of Peterborough 1663-79.

Arg. a chev. sa. betw. three shovellers ppr. HYMERFORD.

Arg. a chev. betw. three drakes sa. YEo.

Arg. a chev. betw. three shovellers sa. Sr. John Warberton, co. Chester, $V$. Warburton, $V^{*}$. Arg. a chev. betw. three drakes sa. collared gu. HEMENFond or HenFond, Estocke, co. Somerset. 
1 CHEVRON betw. or within....cont.

Birds cont. Ducks cont.

Az. a chev. betw. three wild ducks volant arg. Wolrich, co. Salop, 1716.

Az. a chev. betw. three mallards wings elevated arg. Wolrich, Cowling, and Wickornbroke, Suffolk; Alconbury, co. Huntingdon; and Armley House, Leeds; a heiress m. Stansfeld; derived like Woolrych, Dyumore, co. Hereford, from Wolrich or WoLRYche, Dudmaston, co. Salop, quartering Dudmaston; Baronetcy 1611, extinct 1723 .

Az. a chev, engr, or betw, three sheldrakes arg. Tumor.

Gu. a chev. betw. three drakes arg. M. Robert HERLE, $S$.

Gu. a chev. betw. three ducks arg. LIarr, $V^{*}$.

Gu. a chev. betw.three ducks rising arg. CARIE, $V^{*}$.

Gu. a chev. arg. betw, three (sheldrakes volantrecursant of the second, WOLRICH, in a later hand than $W$, but) wild ducks brown. (? Worlych, Harl. MS. 1404, fo. 147.)

Gu. a chev, arg. betw. three wild ducks volant ppr. Wolrich. Woolrudge, Garlenick, Cornwall ; descended from Wolridge, Dudmaston, co. Salop.

Gu. a chev, or betw. three shovellers arg. Herde, co. Devon.

Or a chev. betw. three shovellers az. Yer or YeO.

Or a chev. engr. gu. betw. three ducks ppr. Loveis, Heunock, co. Devon.

Or a chev. engr. gu. betw, three shovellers ppr. Louris or Lowns, Ogberry, Beardon, and Trantock, Cornwall ; and co. Devon.

Or a chev. sa. betw. three shovellers az. YER or YEO. YEO, $\boldsymbol{V}$. Yoo, $\boldsymbol{V}$.

Sa, a chev. betw. three shovellers arg. Pyтy, $V$. Sa. a chev. erm. betw. three shovellers arg. Compton, Compton Castle, co. Devon; the co-heiresses m. Gilbert and Chiderlegh. Poplesham, $V$.

Sa. a chev, erm. betw, three ducks arg. within a bordure engr. of the second. STanter, Horningsham, co. Wilts.

$$
\text { ..... Eagles }
$$

Arg. a chev. betw. three eagles displ. .... membered gu. Chauncey, Essex.

Arg. a cher. az. betw. three eagles displ. with two beads. J J J Is, Humbleton, co. York.

Arg. a chev. betw. three eagles displ. az. CLOPтоN, Clopton, co. Buckingham, $V$. Frances, Scotland. Kneveson, $V *$. Neveson, $V *$. Sr. Roger Nevison, Kent, $W$. Nivison, Scotland.

Arg. a chev. betw. three eagles displ. az. beaked and legged gu. Nevenson, Rainthorp Hall, and Haddam, co. Hertford; and Eastry, Kent. Nevinson or Nevison, Estres, Kent; granted 1570.

Arg. a chev, az. betw. three eagles displ. sa. Wimbleton, Wimbleton, Surrey.

Arg. a chev. embattled erm. betw. three eagles displ. or. Essex, $V^{*}$.

Arg. a chev. betw. three eagles displ. gu. John and William Beaufoy, $Y$. Monsire Beauroy, Y. Beausy. Beaufy or Beaiffoy. Blondell, $V$. Franceis, Fornwerke, co. Derby, $V$. Franceis, Coxliench. Franceis Francis or Fraunceis, Foremark, co. Derby, 1360; the heiress m. Burdett. Franceys, Harl. MS.6829, fo. 32. Frances, $V^{*}$. Francis, co. Stafford. Tarrant, London. Terront or Terwyn, co. Devon. Trewent, $V$.

Arg. a chev. betw. three eagles displ. gu. armed az. M. Robert Frauncers, $S$.
1 CHEVRON betw. or within.... cont.

Birds cont. Eagles cont.

Arg. a chev, gu. betw. three eagles within a bordure sa. Eagleshan, Scotland.

Arg. a chev. dancetty betw. three eagles displ. gu. ConNocke, Coruwall.

Arg. a chev. betw. three eagles displ. double bearled gu. T'rewent, co. Devon. Estiene de Trewent, $X ; Y$. Trower.

Arg. a chev. gu. betw. three eagles displ. sa. Francis or Fraunces, co. Derby. Shelley. TOWERT or TROWERT.

Arg. a chev. gu. betw. three eagles double-headed displ. sa. Sr. de Towert, $V$. Trowert, $V$.

Arg. a chev. gu. betw. three eagles displ. vert. Bewfoy. Blundell.

Arg. a chev. betw. three eagles displ. sa. DYNcE or Dyncey. Sr. John Dynge, $V$. Smyth, co. Devon. Suytr, co. Devon; granted $30 \mathrm{March}$ 1583.

Arg. a cher. betw. three eagles displ. within a bordure sa. bezanty. Wynne, co. Carmarthen.

Arg. a chev. wavy betw. three eagles displ. sa. SHAW, $V$ *

Arg. a chev, vair betw. three eagles displ. vert. Chalimeston.

Arg. a chev. betw. three eagles displ, vert. Blewet, co. Gloucester; and Grenham, co. Somerset. Blondell. Sr. John Charleston, $V$. Charlston. Charliton.

Az. a chev. .... betw. three eagles close .... (? WhitLock.)

Az. a chev. betw. three eagles displ. doubleheaded arg. ducally crowned or. RyTon.

Az. a chev. wavy arg. betw. three eagles displ. or. Gerard Cosen, Keninghall, Norfolk ; granted by Cooke, $W$.

Az. a chev, arg. betw. three eagles close ppr. PhmLIPs, Garendon Park, and Grace Dieu Mauor, co. Leicester ; quarterly with March and quartering Lisle.

Az. a chev. erm. betw. three eagles displ. arg. Essex, co. Berks.

Az. a chev, embattled erm. betw. three eagles displ. arg. Essex, London. But embattled on the top only. Edmund Essex, London, granted by Cooke, $W$.

Az. a chev. erm. betw. three eagles displ, arg. beaked and legged or. Colebx, co. Hants.

Az. a chev. erm. betw. three eagles displ. or. Sr. Edward Essex, ob. 1599. GHBERT, London; Suffolk ; and Mayfield, Sussex.

Az. a chev. erm. the outer edges fimbriated engr. betw. three eagles displ. or. Sr. William Essex, $V$.

Az. a chev. or betw. three eagles displ. double headed arg. Ashbee, $V$.

Az. a chev. betw. three eagles (perhaps close) or. (? WhITEIOCK.) (? WHITLOCK.)

Az. a chev. engr. betw. three eagles (perhaps close) or. (WHITELOCK.) (? WHITLOCK, LOndon.)

Az. a chev. engr. betw. three eagles close or. WhITELocke, co. Berks.

Az. a chev. betw. three eagles displ. or. AsHBy, Middlesex; and co. Leicester. (? Michelu.) NICHELI.

Az. a chev. wavy betw. three eagles displ. or. Cosen, Kinninghall, Norfolk. Cossen, Remmingham, Norfolk; granted 1585.

Az. a chev. betw. three eagles rising or. JoHnson, co. Bedford; and London. 
1 CHEVRON betw. or within.... cont.

Birds cont. Eagles cont.

Erm. a chev. gu. betw. three eagles displ. of the second. BEYARD.

Gu. a chev. betw. three eagles displ. arg. CASTER, Norfolk. Caston, Norfolk. Caston, V. Catson or Causton. Sr. Nicholas Eton, co. Warwick, temp. Edward I, V; or de Etone, $N$. Snelimo, Snelling, Surrey.

Gu. a chev. engr. betw. three eagles displ. arg. Daston, $V$. Paston, $V$.

Gu. a chev. erm. betw. three eagles close arg. Chun, Wanstead, Essex; Earl of Tylney ; the heiress $m$. Long. CHIIDE, Kinlet, co. Salop, quartering Lacon and Baldwin. CHILD, Newfield Hall, co. Stafford. CHuD, Yaxley, co. Hants ; and Middlesex. CHind, Bigelly House, co. Pembroke.

Gu. a chev. engr. erm. betw. three eagles close arg. CHILD; Baronetcy 18 July 1678; Baron of Newtown and Viscount Castlemaine 17 April 1718; Earl Tylney 11 January 1732 ; extinct 17 September 1784 .

Gu. a chev. engr. erm. betw. three eagles close arg. each gorged with a ducal coronet or. CHIrD, London; and co. Worcester; granted 28 January 1700.

Gu. a chev, erm. betw, three eagles perched or. CHind, Wanstead, Essex ; Earl of Tylney; the heiress m. Long.

Gu. a chev, or betw. three eagles displ. arg. DISTER.

Gu. a chev. or betw. three eagles displ. doubleheaded erm. Dyster, $W$.

Gu. a chev. or betw. three eagles displ. doubleheaded erm. each head crowned with a ducal coronet of the second. Disher or DIsker, London; granted 23 November 1704.

Gu. a chev. betw. three eagles displ. or. Francis.

Gu. a chev. or betw. three eagles displ. doubleheaded or. Drster, $V^{*}$.

Gu. a chev, rair betw. three eagles displ. or. (The ancient arms of) Bretres., Brettell Lane; Dudley; and Finstall House, co. Worcester; quartering Henzey; Nash, Worcester. Merlyon. Sr. William Willmer, Sywell, co. Nortbampton, $W$. WILMER or Wulsuere, Rayton, co. Warwick; confirmed 16 February 1582. WILMER, Sywell, co. Nortbampton; and Meriden, and Starton, co. Warwick. Wrimore, co. Northampton, 1716 .

Or a chev, wavy betw. three spread eagles az. ByRche.

Or a chev. gu. betw. three eagles displ. az. De la Tremoumle, impaled by Stanley, $Z, 542$.

Or a cher. betw. three eagles displ, gu. CHancey or Channsy, Essex.

Or a chev. iuvecked pean betw. three eagles displ. sa. SHaw, Woodbouse, co. Stafford.

Or a cher. wavy betw. three eagles displ. sa. SHaw, Colchester, Essex; and London, 1586. Jobn SHAWE, Clerk of the Chamber of London granted by Cooke, IV.

Or a chev, betw. three eagles vert. BLEwit, co. Devon.

Or a chev. betw. three eagles displ. vert. Bifuetr, $V^{*}$. Sr. Walter Blewet, co. Gloucester, temp. Edward I, $V$; or Bluet, $N$. Biewet, Grenham, co. Somerset. Roliert BLOET, Bishop of Lincoln 1093-1123. BLUET, Holcombe-Regis, co. Devon; descended from Bluett, Lord of Ragland; quartering Chiselden; Collinson, Somerset iii, 29,260 .
1 cHEVRON betw. or within....cont.

Birds cont. Eagles cont.

Or a chev. dovetailed betw. three eagles displ. vert. Buewits, Llantarnam Abbey, co. Monmouth, quartered by Morgan.

Paly of six arg. and az. a chev. erm. betw, three eagles displ. or armed gu. JoBson, Ilford, Essex; granted temp. Edward VI.

Paly of six or and az. a chev. erm. betw. three eagles displ. or. JoBson, $Z, 45 \%$.

Purp. a chev. betw. three eagles displ. arg. Crueli.

Sa. a chev. betw. three eagles close arg. JervoISE, Idsworth Park, co. Hants; Baronetcy 1813. quartering Clarke. (? Genvis, Isle of Ely; and co. Worcester.) Jenvis, Bally Ellis, co. Wexford; Baronetcy ....; quartering White. Jervolse, Herriard, co. Hants ; quartering Purefoy.

Sa. a chev, betw. three eagles displ. arg. Mrchend, $V$.

Sa, a chev. arg. betw. three eagles displ. doubleheaded or. WADESDON, $V^{*}$. WADESON, London, $W$.

Sa. a chev. erm. betw. three eagles close arg. GaIIES, co. Leicester; granted 1614.

Sa. a chev. betw. three eagles displ. or. KENTBURY. Postuer.

Vert a chev. betw. three eagles displ. arg. crowned gu, Fineaux, Langham, Kent.

Vert a chev, arg. betw. three eagles displ. or. FineaUX.

Vert a chev, betw, three eagles displ. or. Feneux, Kent. Sr. .... Fineaux, Kent, $V$.

Vert a chev. betw. three eagles displ. or armed and langued gu. Frnney, Cheddleton, co. Stafford.

Vert a chev. betw, three eagles displ. or crowned gu. Fineaux, Langham, Kent.

\section{....Falcons including Hawks}

Arg. a chev. betw. three falcons close az. MoIENICK, Cornwall.

Arg. a chev, betw. three falcons gu. ELde, co. Stafford.

Arg. a chev. sa. betw, three falcons rising or. Kesteli, Kestell in Egloshayle, Cornwall.

Arg. a chev. betw. three falcons sa. beaked and legged or. Worsolter, $V^{*}$.

Arg. a chev. betw. three falcons close sa. beaked and legged or. Sr. Thomas Worceley, $V$.

Arg. a chev. sa. betw. three falcons of the last beaked legged and belled or. Worsiey, Gatcombe, Isle of Wight; the heiress $m$. Glynn and Campbell; descended from Worssex, Appuldercombe; Baronetcy 1611; extinct 1825 ; quartered by Simpson and A'Court; descender from Worsley, co. Lancaster, quartering Leigb.

Arg. a chev. betw. three hawks sa. Worsuer.

Arg. a chev. betw. three hawks rising sa. O'Beirne.

Arg. a chev. vairy sa. and of the first betw. three falcons as the second. Winsard or WinsLade, co. Devon.

Az. a chev. betw. three falcons arg. PHILIPS, London.

Az. a chev, betw. three falcons close arg. JEPPE, Sutton's Court, co. Somer'set.

Az. a chev. betw, three falcons arg. armed and jessed or. Pintey.

Az. a cliev. arg. betw. three falcons close .... belled of the last. PHiLrirs.

Az. a chev. arg. betw. three falcons or. (? AUsTEN, Norfolk.) 
1 CHEVRON betw, or within....cont.

Birds cont. Falcons cont.

Az. a chev, arg. betw, three falcons close or. Austyn, $V$.

Az. a chev. arg. betw. three falcons ppr. ducally gorged beaked and membered or. PHILLIPs.

Az. a chev. erm. betw. three hawks arg. Harewood, co. Devon.

Az. a chev. betw. three falcons or. (? Austen, Tenterden, Kent; and Guildford, Surrey.) (? Austyne, $V_{\text {. }}$ (? Whitelock.) (? WhitLock.)

Az. a chev. betw. three falcons close or. WHITLOCK, co. Berks, $W$.

Az. a chev. or betw. three falcons of the second beaked and legged gu. (? Austrn.)

Az. a chev. engr. betw. three falcons close or. (? Whitelock.) (? WhitLock, London.)

Az. a chev. betw. three falcons volant or. Windibanke, Haines, co. Wilts.

Gu. a chev. betw. three falcons arg. (? REDLEY or Redleigh.) (? Rrdiey, Surrey.) The falcons close. (? Hugh REDLEY, $V$ : and Nicholas Ridiey, Bisbop of Rochester 1547, London 1550-31, V, Harl. MS. 1392, fo. 49.)

Gu. a chev. betw. three falcons arg. HadLey, co. Hertford. George HadLex, East Barnet, 1730. Urry, Afton, Gatcombe, and Thorley, Isle of Wight.

Gu. a chev. betw. three goshawks arg. (REDLEIGH or Redley.) (? Ridley, Surrey.) The goshawks close. (? Nicholas Riduey, Bishop of Rochester 1547, London 1550-3: and Hugh Redley, V, Harl. MS. 1392, fo. 49.) WaLE, Ridley Hall, co. Chester; and Willymoteswick, and Walton, co. Northumberland; quartering Ridley.

Gu. a chev. betw. three falcons arg. beaked and legged or. Hedley, Newcastle-on-Tyne. The falcons close. HedLer, $V$.

Gu. a chev. arg. betw, three hawks or. WAREAURst.

Gu. a chev. arg. betw. three hawks close or. Ridley, co. Salop.

Gu. a chev. az. betw. three hawks arg. (? Waltham.)

Gu. a chev. engr. or betw. three falcons close arg. TOMORE.

Gu. a chev. betw. three falcons rising or. Smalman, Quatford Chaunby, co. Salop; quartering Barney, Wainwright, and Pountney. Siraimitan.

Or a chev. az. betw. three falcons close ppr. Falcon, Workington, Cumberland; and Garston House, co. Hertford.

Or a chev. gu. betw. three falcons ppr. (attributed to CARTHEW.)

Or a chev. betw. three hawks sa. (? WaLthanr.)

Or a chev. vert betw. three hawks sa. (? WaLtнo, Nantwich, co. Chester.)

Or a chev, vert betw. three hawks close sa. Walthali, Wistaston, co. Chester.

Sa. a chev. betw. three hawks arg. (? Gervis, Isle of Ely; and co. Worcester.) (? ICHAM, $V$.

Sa. a chev. betw. three hawks arg. belled or. ICHAM.

Sa. a chev. betw. three falcons wings expanded arg. Menwrwick or Menwinnick, Menwywick, Cornwall, temp. Henry IV; the heiress m. Coplestone.

Sa. a chev. engr. betw. three falcons arg. Ion, Harl. MS. 6829 , fo. $50 \mathrm{~b}$.

Sa. a chev. erm. betw. three hawks arg. Gerris, Great Pettley, co. Leicester; granted May 1614. JarveIs, Pratling, co. Leicester.
1 CHEVRON betw, or within.... cont.

Birds cont. Falcons cont.

Sa. a chev, erm. betw. three hawks close arg. Jervis, Petling, co. Leicester; granted by Camden.

Sa. a chev. betw. three falcons volant or. Hodsow, co. Cambridge; granted 1590.

Sa. a chev. betw. three hawks volant or. HADson, co. Cambridge.

Vert a chev. betw. three falcons or. SPARchForn.

\section{.... Finches including Buntings}

Goldfinches and Linnets

Arg. a chev. purp. betw. three buntings az. Buntinge.

Arg. a chev. sa. betw. three bunten birds ppr. Bunten, Buntenhall, Scotland.

Arg. a chev. sa. betw. three goldfinches ppr. Molenick, Molenick, St. German's, Cornwall.

Az. a chev. arg. betw. three linnets ppr. CARDALE, Hagley, 1590, and Dudley, 1670.

Gu. a chev. arg. betw. three linnets ppr. Cardonnay, Normandy, 1668.

\section{....Gannapies see Cormorants \\ .....Geese}

(? Arg.) a chev. ermines betw. three barnacle birds ppr. Wykss, Harl. MS. 1078, fo. $40 \mathrm{~b}$.

Gu. a chev. betw. three geese volant arg. WorkLYCH, Suffolk ; and Sussex.

\section{....Gulls including}

Sea-fowl and Sea-Pewits

Az. a cher. or betw. three sea-gulls arg. HODLDITCH.

Gu. a chev. betw. three sea-pewits arg. SAyer, Preston, co. Durham ; and Worsall, co. York.

Gu. a chev. erm. betw. three sea-gulls arg. SAYER.

Or a chev. az. betw. three seagulls (or sea-pewits) brown. SEYER, co. Wilts; Harl. MS. 1404, fo. 146 .

Sa, a chev. betw. three sea-fowls close arg. SEAFOWLE.

\section{....Hawks see Falcons \\ ....Heathcocks see Moorcocks \\ ....Herons including Cranes}

Arg. a chev, betw. three cranes az. Cranisley. Cranmer, co. Nottingham.

Arg. a chev. az. betw. three cranes sa. Thomas Cranmer, Archbishop of Canterbury 1533-56.

Arg. a chev. gu. betw. three cranes az. Cranestey. Cranley, $V$.

Arg. a chev. gu. betw, three herons az. Crowhey, $V^{*}$.

Arg. a chev. betw. three cranes gu. BRownE.

Arg. a chev. sa. betw. three herons ppr. IlıBery, Biscay, Spain; Reading, co. Berks; London; and Calcutta.

Arg. a chev. betw. three heronshaws sa. Henshaw, Bassets Fee, and Billinghurst, Sussex; the heirs $m$. Tipping and Wroughton. HeNsHaw, Hershaw, co. Chester; the heiress m. Thornycroft. The birds called heronshaws or storks. Howhit $V$. TwYNeHo, $V$.

Arg. a chev. vairy sa. and or betw. three heronshaws or storks wings expanded sa. WinsLade, $V$. Wyrdeslade, co. Devon, $V$.

Arg. a chev, vert betw, three cranes az. Crawley.

Arg. a chev. vert betw. three herons az. CrawLEY. Az. a chev. betw. three storks arg. membered gu. StamFond. (? Stanford, $V$.)

Az. a chev. betw. three heronshaws or storks or. FOWLER, $V$. 
1 CHEVRON betw. or within.... cont.

Birds cont. Herons cont.

Gu. a chev. betw. three herons arg. M. John Heron, $S ; X$. Heron, Newark, co. Nottingham; Chilham Castle, Kent; Bokenfield, Northumberland, 1660; and Stubbers, co. Lincoln ; Baronetcy 1778 ; extinct ....

Gu. a chev. engr. betw. three herons close arg. Heron, Bokenfield, Northumberland; Croydon, Surrey; and of Agecome, now Addiscombe, 1568. M. William Heron, $S ; Y$.

Gu. a chev. erm. betw. three herons arg. Herne, Godmanchester. co. Huntingdon.

$\mathrm{Gu}$. a chev. or fimbriated engr.sa. betw. three heronshaws or storks arg. Limyngton, co. Chester, $V$.

Or a chev, engr. barry wary of (six Browne) eight az. and arg. betw. three craves of the second. Browne, Islington.

Per pale az. and gu. a chev. hetw. three herons arg. HearNe, Harl. MIS. 140t, fo. 14l.

Sa. a chev. betw. three cranes arg. Browne, co. Buckingham.

Sa. a chey, betw. three heronshaws or storks arg. Janvis, co. Worcester, $V$. (? Gervis, Isle of Ely ; and co. Worcester.)

Sa. a chev. engr. betw. three herons arg. HERNE.

Sa. a ches. erm. betw. three herons arg. Hearne, Maidenhead, co. Berks; descendant of Sir John Hearne, London, 1618. Heron, Treasurer of the Chamber to Henry VIII.; Nicholls, Coll. Top., ii, 166.

Sa. a chev. erm. betw. three herons close arg. Herne or Heron, Panfield Hall, Essex; London; and Shacklewell, Middlesex, 1600.

$$
\text { ....Jays see Popinjay }
$$

.... Lapwings including Pewits

Arg. a chev. betw. three pewits gu. STANnEx, Porkington, co. Salop.

Arg. a chev. betw. three lapwings sa. Hewer. Howhits, $V^{*}$. TwyneHo, $V^{*}$. TwYNiho; Collinson, Somerset, ii, 189. Whistormead, $V^{*}$. Whistoxuead, $V$. WhitToxmead. WHIZTOZMEAD, $V$ *.

Arg. a chev. betw. three lapwings close sa. TwINiHaw or Twinino, Tunworth, co. Dorset.

Arg. a chev. betw. three pewits sa. membered and wattled gu. Penfound, Penfound in Poundstock, Cornwall.

Arg. a chev, vair betw. three lapwings sa. Winsiade, Tregarrick in Pelynt.

Arg. a chev. vairy sa. and of the first betw. three lapwings volaut as the second. WYDESLADE, $V^{*}$. WrindesLade. Wrinslade, $V^{*}$.

Az. a chev. betw. three lapwings or. Fowlen, $V^{*}$.

Gu. a chev, arg. betw. three pewits ppr. SArER, Bourchers Hall, Essex, 1650 ; and Pett, Charing, Kent; the heiress m. Marsham.

$\mathrm{Gu}$. a chev. or fimbriated and engr. sa. betw, three lapwings arg. Lrintington, $V^{*}$.

Gu. a chev. or voided and engr. sa. betw. three lapwings arg. LNNNington, co. Leicester.

Gu. a chev. betw. three lapwings or.(? TInwHIt.)

Or a chev. betw. three lapwings sa. WhitтоXme $\Delta D$.

Sa. a chev. betw, three lapwings arg. (? GERvis, Isle of Ely; and co. Worcester.)

Sa. a chev. betw. three lapwings arg. Jarvis, $V^{*}$.

$$
\text { .... Linnets see Finches }
$$

Arg. a chev. az. betw. three magpies ppr. HORLET.
1 CHEVRON betw. or within.....cont.

Birds cont. Magpies cont.

Arg. a chev. sa. betw. three magpies ppr. KrngDow, Launcells, Cornwall; and Compton Hall, otherwise Castle Hartley, co. Devon, quartering Boughton. Pentrer, Harl. MS. 1404, fo. $14 b$. Arg. a chev. betw. three magpies sa. (? Krngdow.) Arg. a chev. betw. three magpies sa. PIPER, Cornwall.

Gu. a chev. arg. betw. three magpies ppr. JACKSON, co. York.

\section{....Mallards see Ducks \\ ....Marlions see Martlets \\ .... Martins see Swallows \\ ....Martlets}

.... a chev, betw, three martlets .... HOLBRook, 1390.

.... a chev. erm. betw. three martlets ... Samuel PeploE, Bishop of Chester 1726-52.

Arg. a chev. betw. three martlets az. GYLwike, $V$.

Arg. a chev. engr. az. betw. three martlets sa. Pevensey, co. Lincoln.

Arg. a chev. chequy purp. and az. betw. three martlets gu. Hayrptos.

Arg. a chev. compony az. and purp. betw. three martlets gu. HaMPToN, $V^{*}$. But purp. and az. HADIPTON.

Arg. a chev. countercompony purp. and az. betw. three martlets gu. Hanipton, $V$.

Arg. a chev. erm. betw. three martlets sa. WerLs, $V *$.

Arg. a chev. ermines betw. three martlets gu. BAYLX.

Arg. a chev, ermines betw. three martlets sa. Werls, Buckstede, Sussex, $W$. Willis.

Arg. a chev. betw. three martlets gu. ARTHORP or Ashorp. Cheldeworth, co. Devon. Daveli, co. York. Edward WaDdington, Bishop of Chichester 1724-31. Wadington, co. York. Walington, Castle of Wallington, Nortbumberlaud.

Arg. a chev. betw. three martlets within a bordure gu. Borrownan, Scotland.

Arg. a chev. gu. betw. three martlets sa. $M$. John Bagot, $S$. Sr. Loys Bagot, $V$. Baggot, $V^{*}$. Bagot, Bagots Bromley, co. Stafford. Bigotte. Barkeley. Brenton, co. Hertford. Elvin, East Dereham, Norfolk. Elwin, Thorpe, Norfolb. Harne, co. Devon. HaYn. HAXNE, Hayne, co. Deron; the heiress m. Harris. Hayne, Haddon, Jamaica ; and Burderop Park, near Marlborough, co. Wilts. Soutнсоте, co. Devon; and Bliborough, co. Lincoln. Monsire Tenpest, $Y$.

Arg. a chev. sa. betw. three martlets gu. Colmpepper, $V^{*}$. Hardrishail, $V^{*}$. Proctor, Middlesex; granted 1761; and London. WAKEHURST.

Arg. a chev. betw. three martlets sa. AGON, Apton. ARgan, $V^{*}$. ARgud or ARgCNE. ARgun, $V$. AsHThORP. AspthoRP, $V *$. AsSETHORP. ASSETHORPE, $r$. AstHORP, $V$. Bagot, Bagots Bromley, co. Stafford. BARON, Preston, Scotland. Baron or Barron, Scotland. Bartlet, Kent. (? Baynard or Baynyard, Suffolk.) Bentlex. Brinton. Comberton, co. Lincoln. Croton. Cunberton. William CRYOM, $Y$. (? DUFFELDE or DUfFIeld, co. Buckingham.) ERNYON. ERION. KRAMPTON. LAWson, Brougb or Burgh Hall, co. York; Baronetcy .... LAwson, Cramlington, Northumberland ; quarterly with De Cardonnel and quartering Hylton. LAwson, Longhirst, North- 
1 CHEVRON betw, or within.....cont.

Birds cont. Martlets cont. umberland, 1610. Madesson, Wardale, $V$. MaDYson, Durham; Fonby, co.Lincoln; and Newcastle-on-Tyne, Northumberland. MarkLand. Marley. Merefield. Merrifield. Proctor, Langley Park, Norfolk; Barouetcy 1744; quartering Beauchamp. Ram. Ramsbery or Ramisury. Ramesbury, $V$. Romesbury, $V^{*}$. Romisbury, $V$. Rombure. Samford, Halberton, co. Devon; and Bicknel, co. Somerset. M. William Trionie, $Y$. Upthomas. Ward, London. Wrmondesold, Southwell, co. Nottingham.

Arg. a chev. betw. three martlets sa. within a bordure engr. gu. Fitz-Vrian, Wales.

Arg. a chev. engr. betw. three martlets sa. (? Beykle.) (? De Bykele, Collinson, Somerset, iii, 15 ).

Arg. a chev, engr. betw. three martlets sa. Bickford, Dunsland, co. Devon; the heiress m. Cohara. Beckley Beckly or Bickiey, co. Devon. Bicklex. Bykeley, co. Devoli.

Arg. a chev. sa. betw. three martlets vert. Penrith.

Arg. a chev. vairy sa. and of the first betw. three martlets as the second. WINSARDE or WINSLADE, co. Devon.

Arg. a chev. vert betw. three martlets gu. within a bordure of the last. BonekiLl, Scotland.

Az. a chev. betw. three martlets arg. Deraley or Denley. Duke, 1730. Honte. Hunt.

Az. a chev. engr. betw. three martlets arg. HoLlywood or HoLYwOOd. Sr. NicholasHunt, $V$.

Az. a chev. arg. betw. three martlets or. Burghill, co. York. Wichard, co. Leicester. WychaRd, Osbaston, co. Leicester.

Az. a chev. arg. betw. three martlets volant or. Byers or Byres.

Az. a chev, flory counterflory arg. betw. three martlets or. HaLleLey HaLleLY or Halimex, Hackney, Middlesex.

Az. a chev, erm. betw. three martlets arg. Harwood, Deane, co. Hants.

Az. a chev. erm. voided or betw, three martlets of the third. Northen, Essex.

Az. a chev. or betw. three martlets arg. Shralz. Bourchier, Barnesby, co. Gloucester.

Az. a chev. embattled or betw. three martlets arg. Baynes, co. Chester. And with a crescent for diff. Bateman, Essex.

Az. a chev. betw. three martlets or. Beckford. Bourchier, Barnesley, co. Gloucester. Bradesley. Demylux, France.

Az. a chev, betw, three (? eagles) merlions or. MICHELI.

Az. a chev. embattled betw. three martlets or. Brayn or Brayne.

Az. a chev, engr. betw. three martlets or. Holywood, $V$. Hunt.

Gu. a chev. betw. three martlets arg. Chedworth, co. Devon. Gidersh or Giderchs. Page. Seeres. Waleington, co. Chester. Walkenton, $V$. WALIINGTON, $Z, 340$.

Gu. a chev. betw. in chief three martlets and in base a cresceut arg. Martin.

Ga. a chev, arg. betw. three martlets or. Manynghalr.

Gu. a chev. engr. erm. betw, three martlets arg. BAYISY, $V$.

Gu. a chev.embattled counter-embattled erm. betw. three martlets or. Withins or WyTHENs, Wantaway, co. Berks; Eltham, Kent; and London; granted 1649. (? John WrTHines, Dean of Battle, 1615)

\section{CHEVRON betw. or within.....cont.}

Birds cont. Martlets cont.

Gu. a chev. or betw. three martlets arg. Donithorn, Cornwall. Manyngham.

Gu. a chev, betw. three martlets or. CangILI, Scotland. FynneE.

Or a chev. betw. three martlets az. Hodson, Ireland.

Or a cbev. chequy az. and arg. betw. three martlets of the second. Hanson, Gilstead Hall, near Brentwood, Essex.

Or a chev. chequy az. and arg. betw. three martlets sa. Houstoun, Johnston, co. Renfrew; derived from Houstoun, That Ilk; Baronetcy 1688.

Or a chev. chequy sa. and arg. betw. three martlets of the second. Houston.

Or a chev. counter-compony az. and arg. betw. three martlets sa. Hanson, Peckham, Surrey; and Rastricke and Woodhouse, co. York.

Or a chev. gu. hetw. three martlets az. STAFford. Or a chev. betw. three martlets gu. STAFFord. Or a chev. gu. betw. three martlets sa. BREYDON, Blackbouse. M. Edmon StafFond ('clerk'), $S$. StaFFond, Bootham Hall, co. Derby; and co. Stafford.

Or a chev. sa. betw. three martlets gu. within a double tressure flory counter-flory of the last. Baron, Kinnaird, Scotland.

Or a chev. betw. three martlets sa. Baron, Preston, Scotland. Sr. Thomas Comberton, co. Lincoln, V. Covelu, co. York. Estatrord, $V$.

Per pale arg. and sa. a chev. betw. three martlets counterchanged. WORDEs.

Per pale or and vert a chev. betw. three martlets counterchanged. HODSON HUDSON or Hudgeson, Middlesex.

Sa. a chev. betw. three martlets arg. CHEder. (? Duffield, Ashmol. MS. 763.) (? Gervis, Isle of Ely, and co. Worcester.) PAgE, Middlesex. Tompson, $V^{*}$. Torson. Touton, $V$. Toutson, $V^{*}$.

Sa. a chev. arg. betw. three martlets or. GILDERcH, $V$. Gilderche, $V^{*}$. Walpole, $V$. (? Wallpool.) Sa. a chev. erm. betw. three martlets arg. Tenrpe, co. Buckingham ; Kent; and co. Leicester; granted 1576. Welles, Wells and Bambridge, co. Hants.

Sa. a chev. erm. betw. three martlets or. Jervis, Chatculme, or Chatkyll, Eccleshall, co. Stafford. from which descended Jenvis, Darlaston; JERVIS, Trowbridge, co. Wilts; and JeRvis, co. Stafford, from whom came Jervis, Baron Jervis and Earl St. Vincent 1797, extinct 1823; Viscount St. Vincent 1801 .

Sa. a chev. betw. three martlets or. BIRTON or Brinton. Hodson, Hollybrooke House, co. Wicklow; and Green Park, co. Westmeath; Baronetcy 1787.

Vert a chev. betw. three martlets arg. Foore, Cornwall, temp. Henry VI; and Chariton Place, Kent; quartering Hatley. GreneLr, $V$. SADINGTON, co. Leicester; 1327.

\section{.... Moorcocks}

Arg. a chev. betw.three moorhens ..... Loxnoone, Southweek, co. Devon.

Arg. a chev. az. betw. three moorcocks ppr. John Luxmore, Bishop of Bristol 1807, Hereford 1808, St. Asaph, 1815-30.

Arg. a chev. chequy or and sa. betw. three moorcocks ppr. beaked and legged gu. RiNGwOoD, Barshfield, co. Hants. 
1 CHEVRON betw. or within.....cont.

Birds cont. Moorcocks cont.

Arg. a chev. compony sa. and or betw. three moorcocks of the second. RYNawoon, $V^{*}$.

Arg. a chev. countercompony sa. and or betw. three heathcocks of the second. RYNawood, $V$.

Arg. a chev. betw. three heathcocks gu. TALlets, $V$.

Arg. a chev, betw. three moorcocks gu. Совв, Aldington, Kent. Talletrs, $V^{*}$.

Arg, a chev. gu. betw. three moorcocks sa. membered and wattled of the second. Coone, Pensipple in Liskeard; Methleigh in Breage; St. Austell, and Morval, Cornwall; the heiress m. Buller.

Arg. a chev. lozengy gu. betw. three moorcocks sa. (? RING wood, Norfolk.)

Arg. a chev. sa. betw. three heathcocks (moorcocks, $V^{*}$.) az. Maningham, $V$.

Arg. a chev. betw. three moorcocks sa. Moore, Canterbury. More, co. York. Moreton, quartered by Fulford. MORTON, Cornwall. RALPH.

Arg. a chev. engr. betw. three heatheocks Sa. Heath, co. Stafford. Sr. John Moore, Loudon, $V$.

Arg. a chev. engr. betw. three moorcocks sa. More, London. More, $V^{*}$.

Arg. a chev. engr. betw. three moorcocks sa. combs wattles and legs gu. MorE, Barnborough, co. York.

Erm. a chev. betw. three moorcocks sa. armed gu. Heath, co. Oxford.

Gu. a chev. (plain) betw. three heathcocks (moorcocks, $V^{*}$ ) within a bordure engr. arg. Zekethe, $V^{*}$. ZeкHethe, $V$.

Or a chev. betw. three heathcocks gu. TALi,ET, $V^{*}$.

\section{$\ldots$...0wls}

Arg. a cher. betw. three owls az. AstLow. Atrow. Hookes, co. Denbigh. Hucks.

Arg. a chev. betw. three horned owls sa. FINN, Ireland.

Az. a chev. betw. three owls arg. membered or. APHIARD APPLEYARD or APPULYARD, East Carltov, Norfolk.

Az. a chev. gu. betw. three owls arg. AppLEYard, Norfolk.

Az. a chev. or betw. three owls arg. ApPLEYARD, Shotsham, Norfolk; quartering Speak and Whyte. And with a crescent for diff. APLEYARD, Norwich; and co. York.

Az. a chev. or betw. three owls arg. in chief a fleur-de-lis (? for diff.) erm. APLEGATH or Aplegarth, Rapley, co. Hants.

Az. a chev. or betw. three owls arg. legged of the second. Lemanchant, Isle of Guernsey; granted 27 May 1689; and Chobham Place, Surrey; Baronetcy 1841.

Az. a chev. betw. three owls or. Oldarave, co. Chester, 1716.

Az. a chev. engr. betw. three owls or. NichoLas, London; and Ashton-Keynes, and Roundway, co. Wilts.

Bendy of six gu. and vert a chev. betw. three owls arg. Westerdale.

Gu. a cher. betw, three owls arg. Fleming, Essex; co. Hants; Kent; and co. Salop. Fleming, Soutbampton, $V$. Fleming. Hewet. Slex, $V$. Suie.

Gu, a chev. engr. betw. three owls arg. HEwEtT, Tir Mab Ellis, Llantrissant, co. Glamorgan; descended from HEwet, Headley Hall, co. York. Hewet Hewit or Hewit, Pishio-
1 CHEVRON betw, or within.....cont.

Birds cont. 0wls cont.

bury, co. Hertford; Baronetcy 1660, Barony and Viscounty 1689, extinct 1689. Hewit, Alveston, co. Warwick ; granted 1704. HEwitT, Lord Lifford, Barony 1768, Viscounty 1781.

Gil. a chev. betw. three owls arg. beaked and legged or. Sleian, Ashe, co. Derby. Sleigh, quartered by Batburst and by Sutton. SLEY, co. Derby.

Gu. a chev. embattled betw. three owis arg. beaked and membered or. Sleigh, Ashe, co. Derby ; the coherrs m. Cotton and Chetham.

Gu. a chev. betw. three owls arg. crowned or. RADNEY, co. Devon.

Gu. a chev, arg. betw. three owls ppr. Hercey. Hersex.

Gu. a chev. erm. betw. three owls arg. HEwET, London.

Gu. a chev. or betw. three owls arg. Woods, Llanwyfhan, and Rhosinor, Wales.

Gu. a cher. betw. three owls or. Sleigh, co. Derby. Sley.

Gu. a chev, engr. betw, three owls or. LOBEnHAM. Sa. a chev. betw. three owls arg. Broughton, co. Salop. Burton, $V^{*}$. D'Oulepen. Hewetr. Griffith ap JenkIN. Prescot, co. Lancaster; London; and co. York, 1627. Prescott, Theobald's Park, co. Hertford; Baronetcy 1794; and co. Hants. Prescotr, Suffolk, 1716. Walter PrescotT, temp. Edward III, $V$. WoodLey. Sa. a chev. counterembattled betw. three owls arg. Hewet, Ampthill.

Sa. a chev. engr. betw. three owls arg. HEwIr, co. Stafford.

Sa. a chev. betw. three owls arg. crowned or. Borton. M. Thomas Buron (in pencil Burton), $X$. M. Thomas de Burton, $S$. Sr. Thomas Burton, Kensley, co. York, $V$. Burton, Tolethorp, Rutland; and Stockerston, co. Leicester; Baronetcy 1622 ; extinct ....

Sa. a chev. erm. betw. three owls arg. Prescot. Sa. a chev. erm. betw. three crowned owls arg. Burton, Sacketts' Hill House.

Sa. a chev. or betw. three owls arg. APPLEYARD, $V$. Griffith ap JeNKYN, quartered by Mytton.

Sa. a chev. or betw. three owls arg. crowned of the second. BurTon.

Sa. a chev. betw. three owls or. Hathorpe.

Vert a chev. betw. three owls arg. HoLCREw or Holgrate.

\section{.... Parrots seo Popinjays \\ .... Partridges}

Arg. a chev, gu. betw. three partridges ppr. Gregor, Trewarthenick, Cornwall.

Arg. a chev. sa. betw. three partridges ppr. ELD, London, 1753 ; and Syford, co. Stafford, 1574. ELLD.

Vert a chev, erm. betw, three partridges rising or. Partridae.

\section{....Peacocks}

Arg. a chev. sa. betw. three peacocks az. Manninghami, $V$.

Gu. a chev. betw. three peacocks in pride arg. Peacock, London.

Gu. a chev. or betw. three peacocks arg. Downer. .....Pelicans

.... a chev. .... betw. three pelicans. Pope, co. Oxford.

Az. a chev. erm. betw. three pelicans vulning themselves or. Culme, Wynckley, co. Devon. Culme or Cllmer, co. Devon. 
1 CHEVRON betw, or within..... cont.

Birds cont. Pelicans cont.

Az. a chev. erm. betw. three pelicans or vulned gu. Cullum or Culme, Hastede, Suffolk. Cullum, Hawsted, and Hardwick House, Suffolk; Baronetcy 1660. OsBorne, London.

Az. a chev. betw. three pelicaus or vulning themselves gu. JEGON.

Gu. a chev. erm. betw. three pelicans vulning themselves or. Stone, Holme, juxta Mare, Norfolk.

Sa. a chev, betw. three pelicans arg. vulning themselves gu. MEADE. MEad.

Sa. a chev. erm. betw. three pelicans with wings endorsed or. MEDDowes.

Sa. a chev. erminois betw. three pelicans vulning themselves or. MEAD.

Sa, a chev. betw. three pelicans or. MEade, co. Leicester. The pelicans with wings expansed vulning themselves. MEADE, $W$.

Sa. a chev. betw. three pelicans or vulned gu. Meade, Essex.

\section{....Pewits see Lapwings \\ .....Pheasants}

Arg. a chev. az. betw. three pheasant cocks vert beaked and legged gu. breast yellow. Richard Chopre, Alderman of London, $W$.

Arg. a chev. gu. betw. three pheasants (of the second another) ppr. (? O'MERREF.)

Az. a chev. betw. three cock pheasants or. Tomins, Webley, co. Hereford.

Gu. a chev. (plain) betw. three pheasants and a bordure engr. arg. ZeKeTH, Harl. MS. 1404.

Sa. a chev. betw. three pheasants arg. JERveIs, co. Worcester.

\section{.... Plovers}

Arg. a chev. erm. betw. three plovers ppr. Wуке. Az, a chev, arg, betw. three plovers or. Wychand.

$$
\text { ..... Popinjays }
$$

Arg. a chev, az. betw. three jays ppr. JAY, co. Devon.

Arg. a chev. gu. betw. three popinjays vert. KUILINGWIKE, $\boldsymbol{V}$.

Arg. a chev. gu. betw. three popinjays vert within a bordure sa. bezanty. WHIтE.

Arg. a chev. gu. betw, three popinjays vert beaked and legged of the second. THeweng.

Arg. a chev. gu. betw. three popinjays vert beaked legged and collared of the second witbin a bordure az. bezanty. WHite, Hutton, Essex. White, South Wainborough, co. Hants; and Okingham.

Arg. a chev. betw. three parrots (or popinjays) sa. within a bordure engr. gu. BRAY.

Arg. a chev. engr. sa. betw. three popinjays vert membered gu. PeEBLEs, Scotland.

Arg. a chev. betw. three popinjays vert membered gu. Cinfri, co. York.

Arg. a chev, betw. three popinjays vert membered gu. within a bordure az. bezanty. WHITE.

..... Seafowls see Gulls

.... Seapewits see Gulls

.... Seapies see Bustards

.....Sheldrakes see Ducks

.....Shovellers see Ducks

.....Storks see Herons

.... Swallows

Arg. a chev. betw. three martins sa. Martinson, Newcastle-on-Tyne.

Or a chev. engr. betw. three swallows sa. within a bordure az. bezanty. JosNes, Walpole, Norfolk.
1 CHEVRON betw. or within.... cont.

Birds cont. Swans

Arg. a chev. betw. three swans close sa. Soter. Az. a chev. betw. three swans arg. Crarlton. Mitchell, Deptford, Kent; quartering Pell and Clarke. Worlych, Cawling, Suffolk.

Az. a chev. betw. three swans arg. membered gu. Charcedon.

Az. a chev. betw. three swans arg. beaked and membered sa. CASIER or CAZter, London; from Flanders.

Az. a chev. betw. three swans wings elevated arg. WoLrich, Cowling, aud Wickorubroke, Suffolk: Alconbury, co. Huntingdon; and Armley House, Leeds; a heiress m. Stansfeld. WoLryche or Woolrych, Dynmore, co. Hereford; as descended from Wourich, Dudmaston, co. Salop; quartering Dudmaston; Bartey. 1641, ext.1723.

Az. a chev. erm. betw. three swans arg. Swan, Southfleet, and Denton Court, Kent.

Az. a chev. erm. betw. three swans rising arg. Wolrich, co. Salop.

Az. a chev. or betw. three swans arg. Charledon, $V$. Charleton, $V^{*}$. Charlton. Swan or SWANNE.

Gu. a chev. betw. three swans arg. CARY, co. Devon. Light, $V$. Lyte, Lytescary, co. Somerset. LyTE, Collinson, Somerset, iii, 193. MichelL, Garmstreet, co. Somerset. Micheli, Collinson, Somerset, iii, 133. Mrtcheld, Collinson, Somerset, ii, 39.

Gu. a chev. betw. three swans close arg. BRYse. $\mathrm{Gu}$. a chev. betw. three swans rising arg. LIGHT, Horley, co. Oxford; and Lites Cary, co. Somerset.

Gu. a chev. betw. three swans (ducks rising, $V *$.) wings elevated arg. CARY, $W$.

Gu. a chev. engr. erminois betw. three swans arg. wings elevated or. ReEs, Cholwell House, co. Somerset.

Per chev. gu. and sa. a chev. betw. three swans arg. Micheld, Glassell, co. Kincardine; and Forcet Hall, co. York.

Per chev. sa. and gu. a chev. betw. three swans arg. Michels, Cannington, co. Somerset. Mrchen, Salcombe Regis, and Seaside House in Branscombe, co. Devon.

Sa, a cher, embattled betw. three swans arg. Browne, London. The swans beaked and legged gu. Brown, London, Harl. MS. 1404, fol. 153 .

Sa. a chev. engr. betw. three swans arg. BADBY or BADLEY, Suffolk.

Sa. a chev. engr. erm. betw. three swans arg. BADBY, Nortb-Okenden, Essex.

Sa. a chev. or betw. three swans wings elevated arg. membered gu. Swan, Collinson, Somerset, i, 161; iii, 401, 404 .

\section{....Thrushes}

including Blackbirds

Arg. a chev. betw. three blackbirds ppr. TREwOOFE. Arg. a chev. gu. betw. three blackbirds sa. SANGSTer or Songster, Scotland.

Arg. a chev. sa. betw. three blackbirds ppr. Chantmarle. Sangster.

$$
\text { ....Turkeys }
$$

Arg. a chev. chequy az. and vert betw. three turkeys ppr. Wikes, co. Devon.

Arg. a chev. compony az, and vert betw. three turkeys of the second. Wross.

Arg. a chev. sa. betw. three turkeys in pride ppr. YEo, North Petberwyn, co. Devon, 1716.

Arg. a chev. betw. three turkeys in pride sa. YoE. 
1 CHEVRON betw. or within.... cont.

Birds cont. Wrens

Arg. a chev. sa. betw. three wrens close (brown, Harl. MS. 1404, fo. 147 ; but another, back vert and breast gu., and another) sa. Wrenbury.

$$
\text { ..... Crows }
$$

Arg. a chev. gu. betw. five Cornish choughs ppr. MEREFIELD.

Arg. a chev. sa. betw. five Cornish choughs ppr. Merefreld, St. Columb, Cornwall.

$$
\text { .....Eagles }
$$

Arg. a chev. betw. five eagles displ. sa. Dxnge or DYNGEY.

$$
\text { .....Martlets }
$$

Arg. a chev. sa. betw. five martlets three and two gu. M. Thomas CoLPEPER, $S$, quartering arg. a beud engr. gu.

$$
\text { .... Eagles }
$$

Or a chev. betw. six eagles displ. vert. BLEwet, co. Devon; and Cornwell, $V$. Blewetr, $V^{*}$.

$$
\text { .....Lapwings }
$$

Sa. a chev. betw. six lapwings arg. JARvis.

$$
\text { ..... Martlets }
$$

Gu. a chev, betw. six martlets arg. BELToN.

Or a chev. sa. betw. six martlets gu. HaRTSHHI.

Per pale arg. and sa. a chev. erm. betw. six martlets counterchanged. Agane.

Per pale arg. and sa. a chev. ermines and erm. betw. six martlets counterchanged. Griftith Amane Amaney or Amanne, $V$. Airand amane or AMARME.

Per pale or and sa. a chev. betw. six martlets counterchanged. GrIFFr.

$$
\text { .... Swans }
$$

Az. a chev. betw. six swans arg. membered gu. Charlton.

$$
\text { .... Martlets }
$$

Arg. a cher. sa. betw. nine martlets gu. Colepepper, $V:$ Sr. John HARDREDISHILL, V. HaRdYSHILi or HARDYSHULl. Limborne.

Or a chev, betw. nine martlets sa. STAFFORD, $V^{*}$.

Arg. a cbev. sa. betw. martlets gu. Sire Jobn de HARDESHULLe, $O$. The martlets in orle. Thomas Hardeshold, $Y$. Monsire de HARDESHILL, $Y$.

Sa. a chev. betw. martlets arg. Richard BEnEFELD. Bits

Az. a chev. or betw. three horsebits arg. Stanier, Lord Mayor of London, 1714.

Per pale or and sa. a chev. betw. three horse-bits counterchanged. MILNer or MiLiner, NunAppleton Hall, co. York; Baronetcy 1716. Milner, confirmed June 1772.

Sa. a chev. betw. three snaffle-bits or. MrLner, co. Lincoln. Milner, Burton Grange, Attercliffe, etc., co. York. Millner.

\section{Bordure}

Arg. a chev. az. within a bordure of the last entoury of mullets as the first. Loketon, Harl. $M S .1404$, fo. 110.

Arg. a chev. az. within a bordure engr. of the last entoury of mullets or. LockToN.

Arg. a chev. az. within a bordure of the second bezanty. Bromley.

Arg. a chev. engr. and a bordure az. ALANBY, $V^{*}$.

Arg. a chev. engr. within a bordure engr. az. AlanBy, $V$; quartered by Medleton, 1575.
I CHEVRON betw. or within.... cont.

Bordure cont.

Arg. a chev. az. and a bordure engr. sa. HoLme, Stapleton, co. Gloucester. Holme, $V$. Hulin. Sr. William Hulym, London, $V$. Hulye, Lord Mayor of London, 1459. Hulyn, $V^{*}$.

Arg. a chev. and a bordure engr. gu. KrMBERLEy. Trewythenick.

Arg. a chev. gu. within a borduro sa. bezanty. Bavent, Norfolk. Sire John de Bavent, $O$. Beaghan. BenN. Chancex, co. Lincoln. Thomas Chancy, Baron of Skirpenbeke, $Y$. Chauncey. Sr. Philip Chadncy, co. Lincoln, temp. Edward I, $V$. Sire Felip de Chaunscy, N. Chawsy, co. Lincoln. Delapoole. Exilby. Sire .... Peche, N. Pechex. Vanneli, Norfolk.

Arg. a chev. gu. within a bordure sa. platy. Sr. John Bavent, Norfolk, $V$.

Arg. a chev. gu. within a bordure compony az. and or. ChIlton, Wye, Kent; and Cadiz, Spain.

Arg. a chev. gu. within a bordure engr. sa. Bagworth. Watevile or Watervile, Essex.

Arg. a chev. gu. within a bordure engr. sa. bezanty. Bavent, Norfolk.

Arg. a chev. gu. within a bordure recercely sa. bezanty. John Bavent, $Y$.

Arg. a chev. sa. within a bordure engr. az. STAPLEHILI.

Arg. a chev. and bordure sa. Krmbalu. Trewartheneck, Cornwall.

Arg. a cher. sa. within a bordure of the second bezanty. Boyley, co. Buckingham. Bors, co. Buckingham; and Kent.

Arg. a chev. sa. within a bordure engr. of the second. KYMBERI,Ee, $V$.

Arg. a chev. and a bordure indented sa. Trewarthenick or Trewithenick, Cornwall; a coheiress $\mathrm{m}$. Trejago.

Az. a chev. vairy arg. and gu. within a bordure engr. of the last. MAHEWE.

Arg. a chev. vert within a bordure sa. bezanty. VANNELL.

Az. a chev. erm. within a bordure engr. arg. LIDDERDALE, London; from Scotland.

Barry of three sa. and or a chev. arg. within a bordure erm. HaYLES.

Erm. a chev. gu. within a bordure engr. sa. Mallere. Mallory.

Erm. a chev. gu. within a bordure engr. sa. Revelu, $V^{*}$. Sr. John Rrvele, $V$.

Erm. a chev, within a bordure engr. sa. Revel, co. Warwick.

Gu. a chev. within a bordure engr. arg. DENT, co. Leicester.

Gu. crusily patty a chev. and a bordure arg. BARKELEY, co. Hants.

Gu. a chev. arg. within a bordure engr. sa. Bachworth, $V$. Batchworth, $V *$.

.... a chev. .... within a bordure .... STAFFond, Collinson, Somerset, i, 263.

Or a chev. gu. within a bordure az. clịarged with mitres of the first. Edmund STAFFoRD, Bishop of Exeter 1395 to 1419, brother of Ralph Earl of Stafford.

Or a chev, and bordure gu. M. Hughe Stafford, $T$.

Or a chev. gu. within a bordure sa. William de Kimbe, $B$. Stafford, Sutbwyck, co. Dorset.

Or a chev. gu. within a bordure sa. bezanty. Payier. Vanes. 
1 CHEVRON betw, or within....cont.

Bordure cont.

Or a chev. gu. within a bordure engr, sa. M. Umffrey de StaFford, $S$. StaFford, Hook, quartered by Willoughby, $U$. STAFFond, Hook, and Suthwyck, co. Dorset; and Frome, co. Stafford. Stafford, Southwyke, co. Dorset, $V$. Or a chev. gu. within a bordure invecked sa. STAFFORD, Frome, co. Stafford; and Hook, and Suthwyck, co. Dorset.

Sa. a chev. engr. erm. within a bordure arg. HatTon.

Sa. a chev. or within a bordure arg. Thonnton, co. Larıcaster.

Sa. a chev, or within a bordure engr. arg. Thornton, Laughton, co. Lincoln.

Bottles

Vert a chev. betw. three phials (in shape of lacrymatories) or. Eisone, $V$, fo. 236 . Bougets

Arg. a chev. chequy sa. and or betw. three water bougets of the second. Ross, Renfrew, Scotland, which coat passed by marriage, 3408, to Coulthart of Coulthart, Collyn, and Ashtonunder-Lyne, chief of the name.

Arg. a chev. erm. betw. three water bougets gu. HuL.

Arg. a chev. betw. three buckets gu. FITzWALTER.

Arg. a chev. gu. betw. three water bougets sa. Burshell, co. Devon. Herd, London. Huld, Cornwall, $V$. HoLL, co. Stafford. YARD or YEARD, Cornwall; Bradley, and Newton Bushell, co. Deron; and Crosby, co.Leicester. Yerde, $V$.

Arg. a chev. betw. three water bougets sa. Bushell, Newton Bushell. Bushell or Bussheli, co. Chester. Busseld, co. Warwick. Farriy, That Ilk, Scotland. HiLL, Shilston in Modbury, co. Devon. Hoveneli. Hownylu. HuLl, co. Stafford.

Arg. a chev. betw. three buckets (or pails) sa. Pemberton, co. Lancaster. But hooped or. Pemberton, Lord Major of London, 1611 ; and Rushdon, co. Northampton. And handled or. Penterton, Millichope, co. Salop; descended from a family seated at Pemberton, co. Lancaster, and at Wrockwardine, co. Salop; now represented by C. O. Childe Pemberton, Esq., quartering Childe, Lacon, and Baldwyn. Pemberton, Milton, co. Northampton, quartering arg. three dragon's heads erect sa. couped and langued gu.

Arg. a chev. sa. betw. three water bougets vert. Staterdon, co. Buckingham.

Arg. a chev. vert betw. three buckets (or pails) sa. Pemberton, $V^{*}$. But hooped and handled or. Pemberton, Pemberton, co. Lancaster. Penierton, $V$.

Arg. a chev. betw. three water bougets vert. Staverton, Staverton Manor, Strodehall, and Waroyle, co. Berks; and Dreley, co. Hants.

Az. a chev. erm. betw. three water bougets arg. Rose or Rosse, Waddesten, co. Buckingham.

Az. a chev. betw. three water bougets or. EMsone.

Gu. a chev. betw. three water bougets erm. Meares, co. Lancaster.

Gu. a chev. betw. three buckets (or pails) or. Whitewell, $V^{*}$. WhitWell, $V$.

Or a chev. chequy sa. and arg. betw. three water bougets of the second. Ross, Haulkhead, Scotland.
1 CHEVRON betw. or within.....cont.

Bongets cont.

Or a chev. betw. three water bougets sa. FARBY or FARELY.

Or a chev. counterembattled betw. three water bougets sa. Ross, Henning, co. Ayr.

Sa. a chev. betw. three water bougets arg. Bushell, co. Warwick, $V^{*}$. HownILLYARD, co. Devon, $V^{*}$. Hownyld, $V$. Yerd, co. Devon. $V$.

Sa. a chev. or betw. three buckets (or pails) arg. Sutton, Sussex, $V$.

Sa. a chev. or betw. three water bougets erm. MeEr, co. Dorset; and Durham.

\section{Bows}

Arg. a chev. betw. three crossbows unbent az. Hureld, $V$. Hurle. HurRell, $V^{*}$.

Arg. a chev. betw. three stone bows sa. HuRLESTONE.

Gu. a chev. erm. betw. three crossbows arg. handles or. Trimmer.

Or a chev. betw. three bows bent in pale gu. Bowman, Hethleton, co. Dorset.

Sa. a chev. betw. three bows arg. Buche.

\section{Boxes see Pounce-boxes \\ Brogues see Legs \\ Brooms}

Arg. a chev. betw, three besoms gu. Brome.

Arg. a chev. engr. betw. three brooms sa. Browne, co. Oxford.

Buckles

Az. a chev. or betw. in chief a round buckle with a griffin's head erased and in base an escallop arg. LuHSDAINE.

Az. a chev. or betw. in chief a wolf's head couped with a buckle and in base an escallop arg. LUMISDEN, Innergelly, Scotland.

Arg. a chev. gu. betw. three square buckles tongues pendent palewise. sa. Moorton or Moreton, Moorton, co. Stafford. Moreton, Baron Ducie 1763, Viscount Moreton and Earl Ducie 1837. Morton.

Arg. a chev. sa. betw. three buckles gu. Fitz-WateR, Cumberland.

Arg. a chev. sa. betw. three round buckles gu. Fitz-Water. Grace. The tongues fesswise. Tregodick, Tregodick, Cornwall. The points to the sinister. Fitzwalter, Cornwall, $V$, Cotton. MS. Tiberius D, 10 . Fitzwater, $V$.

Arg. a chev. betw. three buckles sa. MaLLET, co. Buckingham. Morton, Houghton, co. Salop. Sire Robert de Norton, $O$. Sutton.

Arg. a chev. betw. three round buckles points to the sinister sa. CROXFORd, $V$.

Arg. a chev. betw. three square buckles tongues fesswise sa. Tregodorck, Treguddick, Cornwall. The tongues pendent. MoretoN.

Arg. a chev. vert betw. three round buckles az. BowkELL, Scotland.

Gu. a chev. alg. betw. three lozenge buckles or. Chester. William Chestre or Chestree, $Y$. The points dexter. Caster, $V$, Cotton. $M S$. Tiberius D, 10.

Gu. a chev, arg. betw. three round buckles points dexter or. Caster, $V$.

Gu. a chev. erm. betw. three round buckles or. BARBER, $V^{*}$. The points sinister. Dalby, $V$.

Gu. a chev. betw. three buckles or. BuknIL. Caster. The tongues pendent. HighField, co. York. 


\section{CHEVRON betw. or within.... cont.}

Buckles cont.

Gu. a chev. betw. three round buckles points dexter or. KINCH or KINTch, Ireland. KNIT, Daneslowne, Ireland, Harl.MS. 1441.

Or a chev. betw. three round buckles sa. TrEcothick, Lord Mayor of London, 1770.

Sa. a chev, betw. three buckles arg. BokLE. Buckie, London. Sire Robert Mariex, $N$. Martin, co. Buckingham.

Sa. a chev. betw. three round buckles arg. M ALLET, co. Buckingham; and Normanton, co. York. Mallets, $V^{*}$. The tongues to the sinister. Sr. Robert MALETT, co. Buclingham, temp. Edward I, $V$.

Sa. a chev. erm. betw. three buckles tongues pendent arg. Bradbury, $V^{*}$.

Sa. a chev. erm. betw. three round buckles tongues pendent arg. Sr. Thomas Bradbery, Alderman of London, $V$. Bradbury, Essex; and Suffolk.

Sa. a cbev. erm. betw. three buckles arg. a fleurde-lis for diff. or. BraDburx, co. Derby; and London.

Buildings, etc.

Arg. a chev. sa. betw. three round wells gu. Cristr, $V^{*}$. Crystr, $V$.

Gu. a chev. betw. three round wells arg. TIPPER, Tippers, co. Kildare, Harl. MS. 1441.

Sa. a chev. or betw. three dovecotes arg. Shapcotr, Shapcott, co. Devon.

\section{Bundles}

Arg. a chev. sa. betw. three bundles of laths (as the second, 1716) vert. Company of Woodmongers, London, $V$, Cotton. MS. Tiberius $\mathrm{D}, 10$, fo. 885 .

\section{Camelion see Reptile Canton}

Per chief indented sa. and arg. a chev. pean betw. a canton erm. and in base a lion ramp. of the tirst. Davis, Leytonstone, Essex.

Per pale arg. and sa. a chev. betw. on a canton az. a harp or and in base a crescent counterchanged. Alexander, Baron Caledon 1790, Viscount Alexander 1797, Earl of Caledon 1800. And with in the sinister chief point a mullet of the last. Alexander, Dublin; Baronetcy 1809 .

\section{Caps and Hats}

Arg. a chev. gu. betw. three chapeaus (? caps of maintenance) points to the dexter az. Lord BRUdNELI, $W$.

Arg. a chev. gu. betw. three morions or steel caps full faced az. BRUDENELL, Baronetcy 1611, Barony 1627, Earl of Cardigan 1661.

Arg. a chev. gu. betw. three steel caps points to the dexter az. Brudenell, Stanton Wyvile, co. Leicester; and co. Northampton.

Arg. a chev. gu. betw. three chapeaus (? caps of maintenance) points to the sinister az. turned up erm. BRODNELL, Harl. MS. 1404, fo. 156.

Arg. a chev. gu. betw. three morions (or steel caps) ppr. BRUDENELI, $V^{*}$.

Arg. a chev. betw. three ducipers sa. LAKINGLEECH.

Arg. a chev. betw. three steel caps sa. Brudenall or BRUDENELI.

Arg. a chev, sa. betw, three chapeaus (? caps of maintenance) points to the sinister of the last turned up erm. Lakenlech, Harl. MIS. 1404 , fo. 155 .

Arg. a chev. sa. betw. three caps of the last turned up gu. M. John LakYNGhithe, $S$.
1 CHEVRON betw. or within.....cont.

Caps and Hats cont.

Arg. a chev. sa. betw. three chapeaus (? caps of maintenance) points to the sinister of the last turned up gu. LAKENLYCHE, $V$.

Arg. a chev. betw. three bats sa. brims turned up gu. LakenLeEch or Lakinlioh. Lakinhethe, Harl. MS. 1386, fo. 85 .

Erm. a chev. gu. betw. tbree caps of maintenance az. BURDENELL.

Sa. a chev. betw. three hats arg. Bery. Castles

Or a chev. betw. in chief two castles and in base a griffin segreant gu. SCARBROW, granted ....

Per chev. gu. and or a chev. barry wavy of six arg. and vert betw. in chief two castles of the third and in base a bomb fired ppr. Watson, Ireland; granted 1767.

.... a chev. .... betw. three castles tripletowered .... Casteld, Castle Bromwich, co. Stafford.

Arg. a cher. betw, three castles gu. Castleford. Arg. a chev. betw. three towers gu. Trevilla.

Arg. a chev. betw, three towers triple-towered gu. CASTLEFORD, $V$.

Arg. a chev. betw. three triple towers gu. CAstLEFORD, $V^{*}$.

Arg. a chev. sa. betw. three castles triple-towered gu. Sumpter, Essex.

Arg. a chev, betw. three castles sa. flaming with fire gu. MaDocks, Middlesex; confirmed 26 March 1592.

Arg. a chev. betw. three towers triple-towered sa. Bronwich. Trevilla, Cornwall.

Az. a chev. betw. three castles arg. CAstriford, Essex.

Az. a chev, or betw. three towers arg. RENTON, That Ilk.

Az. a chev, betw, three castles or. Duncr, Charlton, co. Wilts. Veliey, Hartland, co. Devon; the coheirs m. Hamlyn and Ley. VILE.

Az. a chev. betw. three towers or. Walter DE LA WyLe, Bishop of Salisbury 1263-71. WyLE, $V$.

$\mathrm{Gu}$. a chev, betw. three triple towers arg. ONEBY, co. Leicester.

Gu. a chev. betw. three towers .... Jenkin ap Ernon, Hendar.

Or a chev, betw. three castles gu. Scarborgh, Northweltham, Norfolk; confirmed 10 Septem. ber 1614 .

Or a chev. betw. three castles triple-towered gu. Hibbings, Redmorley. Hовbins, Redmarsley, co. Hereford.

Or a chev. betw. three towers triple-towered gu. SCARBOROUGH, Norfolk.

Or a chev. sa. betw. three towers triple-towered gu. Dorstell, $V$. Scarbourge, $V$.

Or a cher. sa. betw. three triple towers gu. Dorsteli, $V^{*}$. Scarbourgh, $V^{*}$.

Sa. a chev. betw. three towers triple-towered arg. Dunch, Little Witnam, co. Berks; in Charlton Church, co. Wilts. SPICER, Exeter; and Weare in Topsham, co. Devon.

Sa. a chev. erminois betw. three (castles, 1716) towers triple towered or. Captain Christopher SPICER, co. Devon, 17I6. SPYCER.

Sa. a chev. engr. or betw. three towers tripletowered arg. Dunch, co. Berks.

Chessrooks

Arg. a chev. betw. three chessrooks erm. WaLcot, Wallingford, co. Berks; a branch of WaLCOT, Walcot in Lydburs, and Bitterley Court, co. Salop, quartering (ancient) Walcot. 
1 CHEVRON betw, or within.... cont.

Chessrooks cont.

Arg. a chev. erm. betw. three chessrooks ermines. Pinchieck, $V$.

Arg. a chev. betw. three chessrooks ermines. WALLCOT, $V^{*}$. WALLCOTT, $V$.

Arg. a chev. betw. three chessions gu. WaLcot, co. Lincoln. WALLCOTT, $V$.

Arg. a chev. gu. betw. three chessroolss sa. OrRock, Scotland.

Arg. a chev. betw. three chessrooks sa. ANLABY, Elton in Harthill, co. York. ANLABY, $V$. ANLeby or ANSElby, Eaton, co. York. Rokele, $V^{*}$. Rokell, $V$. WaRter or Wartur, co. Stafford.

Arg. a chev, engr. betw. three chessrooks sa. Rook. Walter, Cundall, co. York. Wallter, $V$.

Az. a chev. betw. three chessrooks arg. Spurrock.

Az. a chev. arg. betw. three chessrooks or. Scekley Scepley or Schapley, Middlesex. Shapley. Schipley, Middlesex, $V$. Shiplex, $V$.

Az. a chev. betw. three chessrooks or. Schiplex. SHIPLEY, $V *$.

Chevrons

Erm. a chev. gu. betw. two chevrons sa. GaLLoT, France.

Gu. a chev. arg. betw. one in chief or and another in base of the second. BAwDE, co. Lancaster.

Gu. a chev. vairy arg. and az. betw. two chevrons and three crosses croslet fitchy or. BLakey, Huntingfield, Suffolk.

\section{Chief}

Arg. a chev. pean betw. a chief indented sa. charged with a canton erm. and in base a lion ramp. of the third. Davis, Leytonstone, Essex.

Az. a chev, or betw, a chief of the second and in base a lion ramp. arg. OLLIER.

Or a chev. engr. erm. betw. a chief vert charged with two garbs of the first and in base a lion ramp. gu. Frоноск, co. Cambridge; and London; granted 1764.

Arg. a chev. gu. betw. on a chief az. three bezants and in base a crescent of the second. Conon or Codur, Suffolk. The crescent or. CoDun, Suffolk, $V$.

Arg. a chev. wavy gu. betw. on a chief az. a thunderbolt enclosed by two mullets or one concealed by a canton gold charged with a saltire engr. sa. betw. four crosses patty of the second and in base a seahorse in sea ppr. supporting a flag of the third. Thompson, Virbees, Sussex ; Baronetcy ....

Arg. a chev. betw. a chief sa. and in the fess point a leopard's face gu. Pourdon.

Gu. a chev. erm. betw. a chief chequy arg. and az. and in base a plate. Dopping, Lotown co. Westmeath; and Colmolyn, co. Meath.

Az. a chev. erm. betw. on a chief arg. a pale gu. charged with a garb or betw. two leopard's (faces or) heads of the first, and in base a sword as the third hilt and pomel gold. BLaYDs, Oulton, co. York. And with a mullet arg. in the dexter chief for diff. Thomas BlayDs.

Arg. a chev. gu. betw. on a chief of the second three mascles of the first in base an oakwreatb vert tied az. Pellew, Treverry, Cornwall, 1796.

\section{Chisels}

Arg. a chev. sa. betw. three chisels or handled of the second. CHESELDON or ScHESELDON, $V$. Sheseldon, Harl. MS. 1386, fo. 95.
1 CHEVRON betw, or within.....cont.

Chisels cont.

Arg. a chev, betw. three chisels sa. CHEseldon or Chesselden,

Arg. a chev. sa. betw. three chisels of the second handled or. Cheserdon, $V$.

Sa. a chev. betw, three chisels arg. Cheselten, Harl. MS. 1404, fo. 105 .

\section{Clarion see Rest}

Claw see Leg

Closet

Arg. a chev. betw. two closets gu. Malbise. Clove see Fruits Coaches

Az. a chev. betw. three coaches or. Company of Coachmakers and Coach-Harness Makers, London.

Combs

Arg. a chev. gu. betw. three currycombs ppr. HaRMTAN.

Arg. a chev. betw. three currycombs sa. Harman, Kent.

Gu. a chev. betw. three combs arg. Botel, Prior of St. John of Jerusalem in England, $V$. Bothell or Botell, Essex. Botteld, $V^{*}$. Fraxines. Fraxinis, $V$. Ponsonby, Baron Bessborough 1721, Ponsonby 1749, Duncannon, 1834, Viscount Duncannon 1723, Earl of Bessborough 1739. Ponsonbr, Barony 1806, Viscounty 1839. Ponsonby, Baron de Mauley 1838. PonsonBy, Cumberland and Ireland. Ponsonby, Crotto, Kent ; a branch of Ponsonby, Ponsonby, and afterwards Haugh or Hale, Cumberland.

Sa. a chev. betw. three combs arg. Butue. Cours or Combe, Scotland. Tunstall, co. Lancaster; Everton, co. Nottingham; and Hatchford, Richmondshire. Tunstall, 1716. Compasses

Arg. a chev. (another engr.) betw. three pairs of compasses expanded at the points sa. Company of CARPENTERs, London.

Cord

Or a chev. erm. betw. three cords erased at each end and tied in knots vert. CI.EAvER.

Coronels see Heads (of Spears)

\section{Coronets}

Arg. a chev. az. betw. in chief an Eastern crown $\mathrm{gu}$. enclosed by two chaplets of laurel vert and in base a lion ramp. of the third. Richards.

Arg. a chev, erm. betw, three ducal coronets sa. Robert Folman, $\boldsymbol{V}$. The chev. ermines. Toulmin.

Arg. a chev. gu. betw. three crowns sa. KNow'Ton. Arg. a chev. engr. sa. betw. three ducal coronets of the second. ByKelex.

Arg. a chev. engr. (? sa.) betw, three crowns (in error for crows) ppr. Cromar Cromer Cronmar or Crowner, Lord Mayor of London, 1413 and 1423 .

Az. a chev. arg. betw. three crowns or. CoRONA, $V^{*}$.

Az. a chev. betw. three ducal coronets or. Brona. Thomas de Corona, $V$. Corona, Adlington, co. Chester.

Az. a chev. betw. three mural crowns or. Walthait, co. Devon.

Az. a chev. dancetty betw. three mural coronets or. Curtess Curters and Curtiss. Curtis, Tuddenham Hall, Suffolk.

Az. a chev. vair betw. three crowns arg. within a bordure engr. or. MAHEwe or MATHEw, Clipsby, and Byllockegsby, Norfolk. 
1 CHEVRON betw. or within....cont.

Coronets cont.

Az. a chev, vair betw, three crowns or within a bordure engr. gu. MAHEwE, Essez.

Az. a chev. vairy arg. and gu. betw. three ducal coronets of the second within a bordure engr. or. Mathew, Billokesby, Norfolk.

Az. a chev, vairy arg. and gu. betw. three ducal coronets or within a bordure engr. of the last. MaYHewe, Clippesby, Norfolk; confirmed 9 November 1563.

Gu. a chev. betw. three ducal coronets arg. Cotterell, Ireland.

Gu. a chev. erm. betw. three mural coronets az. out of each a talbot's head or. Hodges, Overne, co. Leicester.

Gu. a chev. engr. erm. betw. three ducal coronets or. Austin.

Gu. a chev. engr. erm. betw. three antique crowns or. Grant, Glenlochy, Kilgraston, and Pitcaithly, co. Perth; confirmed I783.

Gu. a chev, betw, three antique crowns or. Grant, Auchnanie, Scotland.

Gu. a cher. vair betw. three ducal coronets or. Folman. Manew, $V^{*}$. Manewe alias Heller or Mayow, Lestwithiel, Cornwall. May Mayow or MarHew, High Cross in St. Austell, Looe, and Bray, Cornwall. Mayhew, $V$. Mayo, co. Dorset.

Gu. a chev. vair betw, three crowns or. MayHew, Hemington, Suffolk.

Vert a chev. erm. betw. three ducal coronets or. BlackBourn.

\section{Couplecloses}

Arg. a chev. (plain) az. betw. two couplecloses engr. on the outer edge sa. STALEY or Staveley, $V$.

Arg. a chev. az. betw. two couplecloses engr. sa. Staley or Stateley, $V^{*}$.

Arg. a chev. erm. betw. two couplecloses gu. and three leuves vert. Cooper.

Arg. a chev. erm. fimbriated sa. betw. two couplecloses of the last and three annulets gu. Cooper, Southwark.

Arg. a chev. erm. betw. two couplecloses sa. and three chaplets gu. John BURGH or BORNE, Middlesex, $\boldsymbol{V}$.

Arg. a chev. ermines betw. two couplecloses sa. and three annulets gu. ClotTon, Clutton, Nantwich, and Chorlton, near Chester.

Arg. a chev. ermines betw. two couplecloses and three ravens sa. RICE.

Arg. a chev. gu. betw. two couplecloses az. and three torteaux each encircled by two branches of oak ppr. Crutchler, Surninghill Park, Chertsey.

Arg. a cher. betw. two couplecloses gu. Langlond, $V$. (? Malbise, closets).

Arg. a chev. betw. two couplecloses gu. betw. three lions ramp. sa. Boorne. Browne, Esser.

Arg. a chev. betw. two couplecloses with in chief as many pheons and in base a unicorn's bead erased (? gu.). MaIN, Easter House.

Arg. a chev. betw. two couplecloses and three pheons gu. MaIN, Scotland.

Arg. a chev. sa. betw. two couplecloses az. and three pierced mullets of the second. CoLer, co. Derby. Cour, co. Derby, Harl. MS: 1404, fo. $78 \mathrm{~b}$.

Arg. a chev. betw. two couplecloses and three martlets sa. TANFIELD.

Arg. a chev. betw. two couplecloses and three escallops sa. Chamberlayn, co. York.
1 cHEVRON betw. or within.... cont. Couplecloses cont.

Arg. a chev. betw. two couplecloses and three bear's heads erased barwise sa. muzzled of the first. LANGDON, Wolterton, Norfolk.

Arg. a chev. betw. two couplecloses sa. and three (buck's beads in Aubrey, Surrey) stag's heads cabossed gu. John Marshall aliter Martial, founder and endower, 16:1, of Christchurch Church, Surrey, Add. MS. 6049.

Arg. a chev. betw. two couplecloses and three stag's heads cabossed sa. Martiall, London, 1690.

Arg. a chev. betw. two couplecloses sa. and three six-pointed mullets gu. pierced or. YAxIEY, Norfolk.

Arg. a chev, betw. two couplecloses engr. (i.e. the outer edge of the couplecloses engr. Harl. MS. 1386, fo. 34 b.) sa. Denston.

Az. a chev. betw. two couplecloses arg. SuUter.

Az. a chev. arg. betw. two couplecloses or and three crescents of the second. HoLYoks.

Az. a chev, erm. betw. two couplecloses arg. and three falcons or. ButLer. Butron.

Az. a chev. erm. betw. two couplecloses or and three eagles displ. arg. Essex, co. Berks; and Middlesex.

Az. a chev. betw. two couplecloses and three escallops or. ChaMeERLaYN.

Erm. a chev. betw. two couplecloses or and three roses gu. Browne, Chapel Allerton, co. York ; and Bishop's Canning (temp. Elizabeth), and Monkton Farleigh, co. Wilts.

Erm. a chev. sa. betw. two couplecloses gu. and three birds az. their eyes red. Drewe, Harl. MS. 1404, fo.143. Drew, Cornwall; and co.York.

Gu. a chev. betw. two couplecloses and three leopard's faces arg. Coles, co. Dorset.

$\mathrm{Gu}$. a chev. erm. betw. two couplecloses and three griffin's heads erased (? arg.) CORDALL, London.

Gu. a chev. erm. betw. two couplecloses or and three escallops of the second. Browne,co.Devon.

Gu. a chev. erm. betw. two couplecloses and three escallops or. Browne, co. Devon.

Gu. a chev. vairy or and az. betw. two couplecloses arg. and three roses of the last barbed and seeded ppr. ReEves, Leadenbam House, co. Lincoln.

Or a chev. arg. betw. two couplecloses and three 5-foils sa. Starchley, Harl. MS. 1404, fo. 94. Or a chev. sa. betw. two couplecloses gu. and three birds az. Drew, Cornwall ; and co. Wilts.

Or a chev. sa. betw. two couplecloses gu. and three (moorcocks, $V^{*}$.) heatbcocks of the second. Drewe, $V^{*}$. DRwe, $V$.

Or a chev. betw. two couplecloses sa. and three roses gu. slipped vert. (Confirmed $\mathbf{3 6 1 7}$ to) Miles Smitr, Bishop of Gloucester 1612-24. The roses stalked and leaved vert, $W$. And seeded gold. SmrтH, co. Gloucester; and Lambeth, Surrey.

Or a chev. betw, two couplecloses and three 5-foils sa. Stracheley.

Or a chev. betw. two couplecloses and three griffn's beads couped the two in chief respectant sa. HANCOCK.

Or a cher. betw. two couplecloses and three demigriffins segreant couped sa. SмгтH, Broxtow, co. Nottingham. The demi-griffins in chief respectant. Smitr, Gadesby, and Asblyn's Hall, co. Hertford; the senior branch of SwritH, afterwards Bromley, Nottingham, and East Stoke, co. Nottingham, Baronetcy 1757. 
1 CHEVRON betw. or within.... cont.

Couplecloses cont.

Or a chev. betw. two couplecloses and three demigriffins segreant reguard. sa. SнrтH, quartered by Sargent.

Sa. a chev. erm. betw. two couplecloses or and three swans the two in chief respectant arg. beaked and membered of the third. Eastwoon. Flockton Nettus, co. York; granted 1747. EAsTwOod or EsTwOod.

Sa. a chev. erm. betw. two couplecloses and three bull's heads cabossed or. SAUNDERS; granted 3 May 1761.

Sa. a chev. betw. two couplecloses and three 5foils or. Raynton, Lord Mayor of London 1632, ob. 1666; and Enfield, Middlesex. Renton.

Arg. a chev. betw. four couplecloses and three crosses patty gu. Smith or Smythe, Surrey.

Sa. a chev. betw. four couplecloses and three 5 -foils arg. Ratnton, Lord Mayor of London 1632.

\section{Crescent}

Arg. a chev, az. betw. in chief a crescent enclosed by two mullets of the last and in base a demiotter issuing out of water $\mathrm{ppr}$. ORD, Scotland.

\section{Crescents}

Arg. a chev. gu. betw. in chief two crescents az. and in base a martlet sa. Luteroot, Scotland.

Arg. a chev. betw. in chief two crescents and in base a dexter arm embowed couped fesswise wielding a sword gu. HEaps.

Arg. a cher. sa. betw. in chief two crescents gi. and in base an arm armed couped fesswise holding a sword in pale ppr. hilt and pomel or. JACK, Glasgow, Scotland.

Az. a chev. arg. betw. in chief two crescents and in base a mullet or. Docminique, London.

Gu. a chev. erm. betw. in chief two crescents arg. and in base a fleur-de-lis or. SHevind, Bishopwearmouth, co. Durham SHover; granted 1691. Sir Cloudesly Shovel, portrait.

Gu. a chev. erm. betw. in chief two crescents and in base a garb within a bordure engr. or. Smrt, Jordan Hill, co. Renfrew. The border invecked or. Sirith, Carbeth Guthrie, co. Stirling.

Or a chev. gu. betw. in chief two crescents and in base an escallop az. Henniker; Baronetcy 1765, Barony 1800. Henniker, Newton Hall, Essex; Baronetey 1813.

Sa. a chev. betw. in chief two crescents and in base a pelican vulning itself or. Criche.

Sa. a chev. betw. in chief two crescents and in base a 3-foil slipped or. Western, Baron Western 1833-44. Westerne or Western, Essex. Westerne, London.

Arg. a chev. betw. three crescents az. NETHERMILL, co. Warwick. Norton, Charlton, co. Berks; Fulham, Middlesex; Kent; London; and Coventry, co. Warwick. Norton, Leeds, Kent, $V$. WALKER, Leeds, co. York.

Arg. a chev, betw. three crescents ermines. (LFA, $V^{*}$ ); quartered by Framyngham, Suffolk, $W$.

Arg. a chev. gu. betw. three crescents .... impaled with az. a right hand the fingers and palm spread open in base two fetters with chains broken ppr. HochePIED, quartered by Larpent.
1 CHEVRON betw. or within.....cont.

Crescents cont.

Arg, a chev. betw. three crescents gu. Ipstans Ipstanes and Ipstanes. Ipstanes, $V$. M. John (Bonatlem in a later hand), $S$. Marshali, Chelsea, Middlesez. Pole, Radbourn, co. Derby; quartering Wakebridge, Lawton, Chandos, Fitz Walkelyn, Twyford, Brailsford, Basset, Colville, Moton, etc. Poole, Radburie, co. Derby, $V$. Rroer or Rither. Ypstarnus. And with a mullet in chief for diff. az. Poue, Wolverton Park, co. Hants. Baronetcy 28 July 1791.

Arg. a chev. betw. three crescents gu. over all a bend sinister.... Poole.

Arg. a chev. betw. three crescents gu. within a bordure erm. Assent, $V$.

Arg. a chev. gu. between three crescents or. Carson, Scotland.

Arg. a chev. gu. betw, three crescents sa. Wither, Hall Place, co. Hants; derived from Wither, co. Lancaster; and Manydown, co. Hants ; temp. Edward III; a heiress m. (1684) Bigg. Wither, $V^{*}$. Withers, Lord Mayor of London 1708. Sr. Thomas Wrther, $V$. Wythers, Colchester, Essex; and Manydown, and Theden, co. Hants.

Arg. a chev. betw. three crescents purp. Raufe Poole, $V$.

Arg. a chev. sa. betw. three crescents gu. PoLLARD, Kelve, co. Somerset. Speney, $V$. Whithers, co. Wilts. Withers, Porcullis Pursuivant of Arms, temp. Mary I. Wythers, co. Hants.

Arg. a chev. betw. three crescents sa. BEaUchamp. Lee. Masizy. WatKer, co. York.

Arg. a chev. betw. in chief three crescents and in base a buglehorn sa. Lemington,

Arg. a chev. betw. three crescents sa. flammant gu. Ingelton, $V^{*}$. IngILTON, Harl. MS. 1386, fo. 36 ; and $V$.

Arg. a chev. engr. betw, three crescents sa. Rous, $V$.

Arg. a chev, vert betw. three crescents gu. Marshali, $V$; Northumberland.

Az. a chev. betw. three crescents arg. Cotton. Durie or Drury. Hodges. Rider, Man. chester.

Az. a chev. betw. three crescents out of each an estoile issuing arg. MinshuLL.

Az. a chev. engr. betw. three crescents arg. Palmer, Wadesden, co. Buckingham; and Stockdale, co. Northampton; granted 1579.

$\mathrm{Az}$. goutty d'eav a chev. raguly betw. three crescents arg. KNотsHuLL.

Az. a chev. arg. betw. three crescents or. DURY, Dury, Scotland. Sr. John Stakepoul, $V$. Stakepoule, $V^{*}$. Stakepowle Stakepold or STAKEPOOLE.

Az. a chev. arg. betw. three crescents within a bordure invecked or. Durx, Grange, Scotland.

Az. a chev. erm. betw. three crescents arg. GLover (in St. Sepulchre's Church, London).

Az. a chev. or betw. three crescents arg. Sr. William Berkerolies, Lord of Coytie, temp. Edward I, $V$. Berkerolis, $V^{*}$. Chorlott. Colby. Sr. William Hetrote, co. Gloucester, $V$. Hetrots, $V^{*}$. Hollffe Hollet Holrfe Hoote Hotie Hoton HototT or Hotrot, co. Gloucester. Sire William de Нотот, $N$.

Az. goutty d'or a chev. of the last betw. three crescents arg. KNotr, Suffolk. 
1 CHEVRON betw, or within.... cont.

Crescents cont.

Az. a chev. betw. three crescents or. BAREE. Barkerolles, co. Gloucester, $\boldsymbol{V}$. Beckeroli.es. Berkerolles, quartered by Stradling. Sire William de Berieroles, $N$. Berkrall or Berkrolls, co. Gloucester. Catife Catift or CatTrFfe. Cayimf.

Az. a chev. betw. three crescents or each charged with an ogress. MoIgne or Moyne, Essex; and Norfolk.

Az. goutty d'or a chev. betw. three crescents of the last. Knotr, Sussex.

Erm. a chev, betw, three crescents gu. Fudde.

Erm. a chev. betw. three crescents or. Durward, Bocking, Essex. Lilborne, $V^{*}$. Lylborne, $V$.

Erm. a chev, quarterly per chev. or and sa. betw. three crescents gu. Wincold or Wincoll, co. Leicester: and Suffolk. WyncoLL, Twinstead, Essex, 1010; quartering .... a fess .... betw. three birds ....

Ermines a chev. betw. three crescents or. LILBORNE. Gu. a chev. betw. three crescents arg. Cothan $V^{*}$. Cottan. Sr. John Cotton, $V$. Richard Denton, Y. Foulston, co. Devon. Gostling. Martin. Oriphant, Bachiltoun, Scotland. Alfred Ollivant, Bishop of Llandaff 1849. Poole, co. Derby.

Gu. a chev. arg. betw. three crescents of the second each charged with a crescent sa. within as many martlets az. DETTON, $V^{*}$.

Gu. a chev, embattled betw. three crescents arg. OLIPHANT, Langtoun, and Classbiny, Scotland.

Gu. a chev, arg. betw. three crescents or. LYNDOWNE, $V$.

Gu. a chev. betw. three crescents erm. Goselyn or Gosling, London. Gosselin, Island of Jersey; Bengeo Hall, co. Hertford; and Mount Ospringe, Kent; granted temp. Edward III.

Gu. a chev. or hetw, three crescents arg. HoтотT. Maxey, Medley, co. Huntingdon. Parner.

Gu.achev.or betw.three crescentserm.Gosselyn, $V$.

Gu. a chev. betw. three crescents or. GooseLING. Gosling. John Maxe, Commendator (1520) of Welbeck and Bishop of Elphin 15l1-36, V. MaXey, $V^{*}$. M MXXeY, co. Huntingdon.

Gu. a chev. sa. betw. three crescents arg. The learned Snietrus, 1716

Gu. a chev, vair betw. three crescents arg. GODDARD, Norfolk; co. Hants; and (temp. Jobn) co. Wilts, with branches in the latter county at Albourn, Basset, Berwick, ClyffePypard, Hartham, Purton (the heiress $m$. Wilsonn), Standen Hussey, Swindon, Upham, etc. GodDard, co. Wilts, and Norfolk, $W$. GodDART, Scotland.

Gu. a chev. vair betw. three crescents erm. GoD $\triangle R D$, Eastwood, co. Hauts.

Gu. a chev, vair betw. three crescents or. DARE, Tournay, France.

Or a chev. betw, three crescents az. Blaydes.

Or a chev. betw. three crescents gu. Stradilng.

Per pale arg. and or a cher. betw. three crescents gu. Pembrooke.

Per pale az. and sa. a chev. engr. arg. betw. three crescents or. Craigre, Dumbarnie, Scotiand; the heiress $m$. Halkett. Craigie, Kilgraston.

Sa. a chev, betw. three crescents arg. BABтноRP. BABTHORPE, Babthorp, and Osgodby. FLYNT. Martin, Meadhop, Scotland. Southworth, co. Lancaster, $V$. Spiney or Spinney.

Sa. a cher. betw. three crescents arg. within a bordure of the last. GLover, 1606.
1 CHEVRON betw, or within....cont.

Crescents cont.

Sa. a chev, betw. three crescents arg. each charged with another crescent gu. DEToN, $V^{*}$. But within a bordure compony of the second and third. Deton, $V$. Dexfe, co. Worcester. Sa. a chev, arg. betw. three crescents of the second each charged with a crescent sa. within as many martlets az. DetTon, $V$.

Sa. a chev. embattled betw. three crescents al'g. KNotShuLl.

Sa.a chev. engr. betw. threecrescents al'g. Ass AKAR orAssakur. Palmer, Stokedale,co.Northampton.

Sa. a chev. indented betw. three crescents arg. MaRTin.

Sa. a chev. invecked betw. three crescents arg. MarTin, Anstruther, Scotland.

Sa. a chev. arg. betw. three crescents erm. Babthorp. Flint. Glover, Scotland.

Sa. a chev. arg. betw. three crescents or. SPrne. Sa. a chev, erm. betw. three crescents arg. Glover, Ashford, Kent; and Coventry, co. Warwick; granted 4 March 1577. GLover, London; granted April 1604. Glover, Norfolk 1611 ; Romney, Kent; and London. Robert Glover, Somerset Herald, temp. Elizabeth, $V$. Grover, Scotland. Lex, quartered by Fremlingham, Harl. MS. 1484, fo. 50 .

Sa. a chev. erm. betw. three clescents arg. and a bordure or. GLover, London; granted 1602.

Sa. a chev. betw. three crescents erm. BaBTHonP, co. York. Derse. West, $Y$.

Sa. a chev, betw, three crescents erminois. Framinghay.

Sa. a chev. or betw. three crescents arg. Babthorp, $V^{*}$, and co. York. Sr. de Babthorpe, $V$. PAlMER, Kilmare, co. Kerry; a branch (through Pasmer, Rockingham) of Parmer, Carlton, co. Northampton, Baronetcy 1660.

Sa. a chev, or betw. three crescents erm. BABтHORP, co. York. Sr. de BABтHORPE, $V$. Sa. a chev. betw. three crescents or. Babthorp. Bolington. Dakenfield. Duckenfeld, $V$. Duckenfield.

Sa. a chev. betw. three crescents or each charged with another of the first. Derse.

Sa. a chev. vair betw. three crescents arg. Martin, Gilliston, Scotland.

Vert a chev. betw. three crescents or. Copherst. Gu. a chev. betw. six crescents or. Kense. Cross

Or a chev. sa. betw. in chief a cross patty of the last and in base a beart gu. Litrleman or Litrmiran, Scotland.

Arg. a chev. gu. betw. in chief a cross croslet fitchy sa. enclosed by two 5 -foils of the second and in base a saltire couped az. AGNEW, Sheuchan: descended from Agnew, Lochnew; quartered by Vans.

Crosses and see Sails

Arg. a chev. gu. betw. in chief two crosses patty fitchy of the second and in base a suake coiled vert. WhitвY, co. Chester; and co. York.

Arg. a chev. gu. betw. in chief two crosses croslet fitchy and in base a boar's bead erased sa. Kennedy, Kirkmichael, Scotland.

Arg. a chev. betw. two crosses botonny fitchy sa. over all a bend gu. WiLtshire.

Arg. a chev. betw. in chief two crosses patty flory fitchy and in base a pierced mullet sa. RYPoN, London; granted 1590. The mullet within a crescent of the last. Rispos, Water Ville, North Sbields, Northumberland. 
1 CHEVRON betw. or within.... cont. Crosses cont.

Arg. a chev. betw. in chief two crosses patty and in base a saltire sa. Beaupeny, co. Somerset. GreEnhan.

Gu. a chev. betw. in chief two crosses croslet fitchy and in base a battleaxe arg. Sisrs, Scotland.

Gu. a chev. betw. in chief two crosses patty fitchy and in base an annulet or. 'Twycross. WotTon.

Sa. a chev. arg. betw. in chief two crosses croslet of the second and iu base a helmet ppr. SouthwerTH, Ireland.

Sa. a chev. erm. betw. two crosses croslet engr. or. Essex.

Arg. a chev. betw. three demi-crosses gu. Toret'T. .... a chev. .... betw. three crosses patonce .... Matthew de Sothworth, seal 1394, $V$.

Arg. a chev. betw. three crosses croslet fitchy az. Chardelow, Spratling, Norfolk. Scardiow.

Arg. a chev. az. betw. three crosses croslet fitchy gu. Sir John Buckworth, London 1730 . Sherlaw or Sherley, Norfolk.

Arg. a chev. chequy az, and gu. betw. three crosses botouny fitchy of the second. ReYNoLds, 1711, in St. Mary's, Lambeth.

Arg. a chev. chequy az. and or betw. three crosses croslet fitchy sa. Richard ReynoLd, Bishop of Bangor 1721, Lincoln 1723-44.

Arg. chev. chequy gu. and az. betw. three crosses croslet fitchy of the third. REYnoLds, Carshaltou, Surrey.

Arg. a chev. compony gu. and az. betw. three crosses croslet fitchy of the last. Peynolds.

Arg. a chev. erm. betw. three crosses patty fitchy (gu. another) sa. BARDOLPHE or BARDUlfe, co. Bedford.

Arg. a chev. ermines betw. three crosses croslet fitchy sa. Hulme, Ball-Hay House, Leek, co. Stafford.

Arg. a chev. ermines betw. three crosses patty fitchy sa. Boughton, Essex, 1595.

Arg. a chev. gu. betw, three crosses botonny fitchy az. Schardelow.

Arg. a chev. gu. betw. three crosses fitchy those in chief croslet and that in base botonny $a z$. Shardelow, Shardelow, Suffóll.

Arg. a chev. gu. betw. three crosses croslet fitchy az. Scardelow or Shardelew, Cotton. MS. Tiberius D 10. Shardelow, Schimpling, Norfolk.

Arg. a chev. betw. three crosses gu. Chrpchase and Chiphase.

Alg. a chev. betw. three crosses botonny gu. BUR'TON.

Arg. a chev. betw. three crosses croslet gu. Chesseldon, $V$. Christian. Copildyke Copledyke or Copuldike, co. Lincoln. Copoldike, West Wickham, Kent. M. John Copuldick, $S$. Copuldike, co. Lincoln, $V$. Holbrooke, Suffolk. Kirton. Sirith, Suffolk. Southwerth. Richard Stern, Whitecliff, co. York, 1730, son of Richard Stern, Archbishop of Yolk. Robert WycLiff, $P$.

Arg. a chev. betw. three crosses croslet fitchy each held in a dexter hand fesswise couped gu. McRorie or Rorie, Scotland.

Arg. a chev. betw. three crosses moline gu. Brucrshaw or Bruckshow. Cheselden, $V$. Cheseldon or Cheseldyne, Chippisham, Rutland. Chiseidine. Chiselden, Cotton MS. Tiberius D 10.

Arg. a chev. betw. three crosses patty gu. Átoste, $V$. Barclay, Wavertree Lodge, Liver-

\section{CHEVRON betw, or within....cont.}

\section{Crosses cont.}

pool; Burford Lodge, Surrey; Collairnie, co. Fife; quartering Brockhurst. BARKIEY. NEWBY, Hooton, co. York.

Arg. a chev. betw, three crosses patty fitchy gu. TOFTE. WOODROF or Woodrow, Bolton-uponDeane, co. York. Woodruffe, Wolley, co. York.

Arg. a chev. gu. betw. three crosses botonny su. Chardelowe, $V^{*}$. Shardelow, $V^{*}$. Shythe, Cotton MS. Tiberius D 10. Tonds, $V^{*}$.

Arg. a chev. gu. betw. three crosses botonny fitchy sa. Chardelow, $\boldsymbol{V}$. Thomas Sitardelowe, $\boldsymbol{V}$; but Shardelewe and Scardelow, Cotton $M S$. Tiberius D, 10 .

Arg. a chev. ga. betw. three crosses croslet sa. Gully, Trevennen, Cornwall; quartering Slade, Powne, Coryn, etc. Smyte, $V$. Suyth, Walsocken, Norfolk.

Arg. a chev. gu. betw. three crosses croslet fitchy sa. Cardelon or Cardejyon. Cardelou, $V$. Cardeton. Kennedy, Bennane; and Finnarts in Carrick, co. Ayr ; quartering as an augmentation, granted 1420 , az. three fleurs-de-lis or. Kennedy, Ardmillan, Scotland. Schandelow, Schimpling, Norfolk. Shardelot, $V$. Sirte, Sussex.

Arg. a chev. gu. betw. three crosses croslet fitchy sa. all within a double tressure flory counterflory of the second. Kennedy, Baltersan, Scotland. KenNedy, Kirkhill, Scotland, quartering as an augmentation az. three fleurs-de-lis or. Kennedy, Barouetcy 1632, Baron Kennedy 1453, Earl of Cassilis 1502, Baron Ailsa 1806, Marquis of Ailsa 1831. And with two crescents in flank and one in base. KenNedy, Knocknalling.

Arg. a chev. gu. betw. three crosses moline sa. WIKE, Collinson, Somer'set, ii, 268. WYке, Cotton MS. Tiberius D, 10; and Ninehead, 1400.

Arg. a chev. gu. betw. three crosses resarcelly sa. Wyke, co. Somerset; and Cotton MS. Tiberius $\mathrm{D}, 10$.

Arg. a chev. lozengy gu. and az. betw. three crosses croslet fitchy of the third. REANOLDS or REIgNolds, co. Devon; and co. Somerset; granted 1607 .

Arg. a chev. lozengy or and az. betw. three crosses croslet gir. REYNoLDs.

Arg. a chev. sa. betw. three crosses croslet fitchy az. on a bordure (sometimes engr.) gu. bezants alternately with escallops or. RussesL, Swallowfield House, co. Berks; Baronetcy 1812.

Arg. a chev. sa. betw. three crosses botonny gu. Robert Wycliff, $Y$; and Cotton MS. Tiberius D, 10 .

Arg. a chev. sa. betw. three crosses croslet gu. Elisden Elisdon or Elitisdon, Essex. WyckLIfF, Wyckliff, co. York, $V$. WycLIfF, $V^{*}$. Arg. a chev. sa. betw. three crosses croslet fitchy gu. WICKLIFF or WYCLIFFE.

Arg. a chev. sa. betw. three crosses patonce gu. Elesden or Ellispen, Essex.

Arg. a chev. sa. betw. three crosses patty gu. Elisden Elisdon or Ellisden, Essex.

Arg. a chev. betw. three crosses botonny fitchy sa. Bongheon. Sr, John Russeld, co. Worcester (in the margin of), $V$; and Cotton $M S$. Tiberius $10,10$. Rydels, co. York. Wiltsmire.

Arg. a chev. couped betw. three crosses botonny fitchy sa. Boughton. 


\section{CHEVRON betw, or within.... cont.}

\section{Crosses cont.}

Arg. a chev. debruised betw, three crosses botonny fitchy sa. BARDOLPH alias BEDOLPHE, co. Stafford, Harl. MS.1386, fo. 36. Bougrton, and Finderne, Cotton MS. Tiberius D, 10.

Arg. a chev. indented betw. three crosses botonny fitchy sa. BodghtoN.

Arg. a chev. betw. three crosses croslet sa. Anderson, Penley, co. Hertford; Baronetcy 1643 extinct 1699 ; the heiress m. Harcourt. Anderton, co. Salop. Can, Scotland. Kierkionell. Lakebourne, $V^{*}$. Lekeborne, co. Lincoln. Lekebourne, co. Lincoln, $V$. Russell, Strensham; Baronetcy 1620-1705. Southworth, Sandbury, co. Lancaster; and co. Somerset. Southworth, quartering Dayes, Harl. MS. 1445, fo. 107, and Collinson, Somerset, i, 219. Treage, Colnwall, $V$. Tregothnan, Tregotbnan, Cornwall; the heiress m. Boscawen. Wyclifr. Aud with an annulet for diff. CACHenors, Staveley, Woodthorpe, co. Derby; the heiress $m$. Rodes.

Arg. a chev. betw. three crosses croslet within a bordure sa. Fitz-Williast. The bordure bezanty. Fitz-Williar, Mablethorp, co. Lincoln, $V$. MABI,ETHORPE.

(Arg.) a chev. betw. three crosses croslet fitchy (sa.). Emport, Calveley, co. Chester.

Arg. a chev. betw. three crosses croslet fitchy sa. Bromehall. Davenport, Blackhurst, and Broughton; descended like Davenport, Capesthorne and Calvely, co. Chester; and Court Garden, co. Buckingham, quartering Davenport; through Daven PORT, Woodford; like DavenPort, Henbury; the heiress m.Lucy; and Davenport, Bromhall: through Davenport, Wheltrough, from Davenport, Davenport, co. Chester; extinct 1677 ; the heiresses $m$. Davies and Deane. Davenfort, Calveley; extinct 1771; derived like Davenport, Chorley, co. Chester; and Davenport House, co. Salop; from Davenport, co. Chester. Davenport, co. Chester (but croslets in the margin), $V$. Foxwest, London. Pardoe, Park House, Bewdley; quartering Acton. Laiton, co. Salop. Rippon, Stanhope Castle, Durham. Thomas Russelu, $X$. Russeli, Strensbam, co. Worcester; Baronetcy 1626, extinct 1705. Sir John Russeld, co. Worcester (but botouny in the margin), $V$. Sambesbury, co. Lancaster. Trege, co. Cambridge. Damport, co. Chester, Cotton MS. Tiberius D, 10.

Arg. a chev. betw. three crosses croslet fitchy sa. over all a (bend $V^{*}$.) baston dexter gu. Wiltshire, $V^{*}$. Wiltechire, $V$.

Arg. a chev. betw. three crosses croslet fitchy and five delves sa. Sr. Jobn Westles, Norfolk, $V$. But six hillets sa. Westrey.

Arg. a cher. betw. three crosses croslet fitchy sa. within a bordure engr. compons of the first and second. ARDERNE.

Arg. a chev. betw. three crosses croslet fitchy sa. within a bordure engr. gu. DAMPORT, co. Chester; granted 1582.

Arg. a chev, betw. three crosses croslet fitchy sa. within a bordure engr. gu. bezanty. Russelu, co. Hereford; and Little Malvern, co. Worces. ter. The bordure charged with four bezants and as many escallops or alternately. Rosseri, Howton, Essex; Baronetcy ....

Arg. a chev, debruised betw. three crosses croslet fitchy sa. BEDOLPHE, co. Stafford; Harl. MS.
1 CHEVRON betw, or within .....cont.

Crosses cont.

1404, fo. 114. Greenway, $V^{*}$. Sr. Joln Grentay, $V$.

Arg. a cliev. engr. betw. three crosses croslet fitchy sa. Cooke, Darfield.

Arg. a chev. betw. three crosses croslet botonny fitchy sa. Russell, co. Worcester.

Arg. a chev. betw. three crosses croslet patty fitchy sa. Bradman. Finderne, co. Leicester.

Arg. a chev. betw. three crosses flory sa. Anderson, Broughton, co. Lincoln; Baronetcy 1660, Anderson, Eyeworth, co. Bedford ; Baronetcy 1664 ; extinct 1773 . ANDERSON, St. Ives; Baronetcy 1628, extinct 1630. ANDERSON, Penley; Baronetcy 1643, extinct 1699. Muston.

Arg. a chev. betw. three crosses flory fitchy sa. Pixpon, co. Lancaster.

Arg. a chev. betw. three crosses moline sa. MrLL, granted 3 July $108 t$

Arg. a chev. betw. three crosses patonce sa Moston, $V$.

Arg. a chev. betw, three crosses patty sa. Anderson, Penley, co. Hertford; Baronetcy 1643 extinct 1699 ; the heiress $m$. Harcourt. Beaf. Beaurey. William de Muscon, $X$.

Arg. a chev. betw. three crosses patty fitchy sa. Broniehall. Bromhali, V. Finden. Finderne, $V^{*}$. Finderne or Frndenne, Finderue, co. Derby, temp. Edward III, co. Cambridge; and co. Stafford. Sr. de Fynderne, $V$. Russeli, co. Salop; and co. Worcester. Tofte or Toft. Trrgotr, Sonth Kirby, co. York.

Arg. a chev. couped betw. three crosses patty fitchy sa. CoNwaYe or Conway, Harl. MS. 1386, fo. 36. Goreway, Harl. MS. 1404, fo. 115. GONEWAY or GonWay.

Arg. a chev. engr. betw. three crosses patty fitchy sa. Finden, co. Leicester. Finderne or Fynderne, Finderne, co. Derby, temp. Edward III, co. Cambridge ; and co. Stafford.

Arg. a chev. betw, three crosses patty fitchy flory sa. Rippon.

Arg. a chev. betw. three crosses pomelly fitehy sa. Treage, Cornwall, $V$.

Arg. a chev. debruised betw. three crosses pomelly fitchy sa. Richard, son of William de GIENEWAY, 1403, $V$.

Arg. a chev. betw. three crosses sarcelly sa. in chief a fleur-de-lis gu. ANDERson, London.

Arg. a chev, betw. three crosses tau sa. Morngs, co. Lincoln, $T$.

Az. a chev. betw. three crosses croslet arg. MABLETHORPE.

Az. a chev. hetw. three crosses croslet fitchy arg. PARKBY, That Ilk.

Az. a chev. betw. three crosses moline arg. Molyneux.

Az. a chev. betw. three crosses patty arg. EMIPSON, co. York.

Az. a chev, arg. betw, three crosses croslet fitchy or. Writington, co. Lancaster.

Az. a cher. arg. betw. three crosses moline or. Glanton.

Az. a chev. erm. betw, three crosses croslet fitchy arg. ReYnolds.

Az. a chev. erm. betw. three crosses patty arg. AINGE, London.

Az. a chev, nebuly erm. betw. three crosses croslet or. Caston, Harl. MS. $] 386$, fo. 36 .

Az. a chev. or betw. three crosses moline arg. Gulby, $V$. Tulby, $V$. Tullby, $V^{*}$ * 


\section{CHEVRON betw. or within....cont.}

\section{Crosses cont.}

Az. a chev, or betw. three crosses patty arg. within a boldure chequy of the second and first. BARKLEY, Scotland.

Az. a chev. or betw. three crosses sarcelly arg. GuLBY.

Az. a chev. betw. three crosses or. Catbor, Norfolk. Calibut. Calybut, $V$.

Az. a chev. betw, three crosses croslet or. Babepull. KyMe,co. Lincoln, $V$. Macklethorp.

Az. a chev. betw. three crosses croslet fitchy or. Prx, Crayford, Kent. Tourges, $V^{*}$. Turges, $V$; and Bingham's Melcombe, co. Dorset, glass, fifteenth century. Turgis, co. Somerset.

Az. a chev. embattled on the top betw. three crosses croslet fitchy or. Parkins.

Az. a chev. betw. three crosses croslet fitchy within a bordure engr. or. Sturges, co. Hants. Tourgeis or Towergyes, co. Dorset. Turgeis.

Az. a chev. betw. three crosses croslet crossed and fitchy within a bordure engr. or. Estourges, $V^{*}$. Stourges, $V^{*}$. Tovroies, co. Dorset, $V$.

Az. a cher. betw. three crosses flory (anotber patonce) or. DABorne, Guildford, Surrey.

Az. a chev. betw. three crosses patty or. Barclay, Brechin.

Az. a chev. betw. three crosses sarcelly or. Tulby.

Bendy of six gu. and vert a chev. erm. betw. three crosses patty or. WESTERDALE.

Gu. a chev. betw. three long crosses fitchy arg. Hading, Scotland.

Gu. a chev. betw. three crosses botonny fitchy (tricked croslet) arg. Pakeman, $V$.

Gu. a chev. betw. three crosses croslet arg. Barkeley. Cros, $V$. Cross, $V^{*}$. Crosse. Southex, Collinson, Somerset, ii, 495 ; and Cott. MS. Tiberins D, 10. SotrHworTH, Soutbworth, co. Lancaster.

Gu. a chev. betw. three crosses croslet fitchy arg. Bonant. Bonham, Petersfield, co. Hants. Sr. .... de Coruldike, $Y$. Myles Pakenhair, $X$. Peckam. Suyth, Harwich, Essex.

Gu. a chev. betw. three crosses patty arg. ADDIS or ADDyes, Great Barr, co. Stafford, 1521 . Adis, Middlesex. Barkeley. Fitz-Harding. Maciseill, Scotland. Tost.

Gu. a chev. betw, three crosses patty fitchy arg. Dineston, Southouse, Scotland.

Gu. a chev, engr. betw. three crosses patty fitchy arg. Bonham, Orsett House, Essex; descended from Bouliam, Valence.

Gu. a chev. engr. betw. three crosses patty each fitchy at the foot arg. BonHanr, Essex, Harl. MS. 1083

Gu. a chev. wavy betw. three crosses patty each fitchy at the foot arg. BonHaM, Essex, $V$; and Harl. MS. 1542. Boynam or Buynhasi, Essex, Cotton IIS. Tibertus D, 10.

Gu. a chev. betw. three crosses pometty fitchy arg. Padenham.

Gu. a chev. arg. betw, three crosses or. Bisseldi, co. Berks.

Gu. a chev. arg. betw. three crosses croslet or. Barhdery. Heldershau, Suffolk.

Gu. a chev. arg. betw. three crosses croslet fitchy or. Coupledike, $V^{*}$. Duddingstoun, Sand. foord, Scotland.

Gir. a chev. arg. betw. three crosses patty or Barkeley. Sire Johan de Berkeleye, $N$. William Lutron, $V$. Lutron, Knapton, co. York.
1 CHEVRON betw. or within....cont.

Crosses cont.

Gu. a chev. countercompony or and arg. betw. three crosses croslet of the last. CowLEY.

Gu. a chev. erminois betw. three crosses Calvary arg. Coopey, Collinson, Somerset, iii, 160.

$\mathrm{Gu}$. a chev. erminois betw. three crosses botonny or. Rrcн, Rose Hall, Suffolk; and Shirley House, co. Hauts; Baronetcy 1791.

Gu. a chev. or betw. three crosses croslet arg. Crosse.

Gu. a chev. betw. three long crosses or. AUsTiN, Walpoole, Norfolk.

Gu. a chev. betw. three crosses botonny or. Windsor, Earl of Warwick and Holland. RicH, Baron Rich 1547, Earl of Warwick 1618, Baron Kensington 1622; Earl of Holland 1621, extinct 1759. RICH, Hornden Hill, Essex; Austy, co. Hertford; London; Mulberton, Norfolk; and Lambeth, Surrey. RicH, Stondon, Essex; Baronetcy 1675 , extinct 1785 ; Baronetcy 1791.

Gu. a chev. betw. three crosses croslet or. Norton. Rich, Earl of Warwick 1618-1759.

Gu. a chev. betw. in chief three crosses croslet and in base a lion pass. or. WABLETHORP.

Gu. a chev. wavy betw. three crosses croslet or. RICH, Dublin. HoLden (in a later hand than) $W$.

Gu. a chev. betw. three crosses croslet fitchy or. Sr. Thomas Hungerford, $V$.

Gu. a chev. betw, three crosses flory or. RIcH. STERNE.

Gu. a chev, betw. three crosses patonce or. RICH. Alderman Sir Peter Rich, 1692, St. Mary's, Lambeth, $A d d$. MS. 6409 (the field now seems arg. the charges gu.).

Gu. a chev. betw. three crosses patty or. LaYTon, co. York, Lutron.

Gu. a chev. betw. three crosses sarcelly or. SLOUGH.

Gu. a chev. paly of six arg. and or betw. three crosses croslet of the second. Cross, $V^{*}$. Crosse, $V$.

Gu. a chev. vair betw. three crosses croslet fitchy or. Blackuey or Blakey, Blackley Hall, co. Laucaster.

Or a chev. chequy erm. and gu. betw. three crosses patty fitchy sa. Broadlex, Kirke E.lla, Hull, quartering Jarrett. BroadLEx, Ferriby, co. York.

Or a chev. gu. betw. three crosses patty fitchy az. Maxton.

Or a chev, betw, three crosses croslet gu. CoPoldyKe, Harrington, co. Lincoln; quartered with lozengy each alternate spot ermine (Fitzwilliam ?) seal of John Copuldyk, xvth century. HoLEBRoore, Suffolk.

Or a chev. betw. three crosses croslet fitchy gu. Redike. Hugh Redyke, co. Lincoln, $V$.

Or a chev. gu. betw. three crosses patty fitchy sa. Maxton, Scotland.

Or a chev. betw. three crosses croslet sa. Richard Sterne, Bishop of Carlisle 1060, Archbishop of York 1664-83. JAGO, St. Erme and Helston, Cornwall, 1500. JAGo, Launceston; Ennis in St. Erme; and co. Warwick. (The mo. dern arms of) Trejago, Trejago, Cornwall; the heiress m. Mynors.

Or a chev, betw. three crosses flory sa. STERne, Grendon, co. Buckingham ; Carling, co. Cambridge; Hoddesdon, co. Hertford; and Skey. ton, Norfolk. Strane, Barkway. Richard STERNE, Kilvington, co.York, descended through Sterne, Archbishop of York, from Sterne, Nottingham. 
1 CHEVRON betw. or within.... cont.

Crosses cont.

Or a chev, betw. three crosses patonce sa. Sterne, Malton. Richard Sterne, Bishop of Carlisle 1660, Archbishop of York 1664-83.

Or a chev. betw. three crosses patty fitchy sa. Riley. Thomas Smith, Bishop of Carlisle 1684-1702.

Sa. a chev. betw. three crosses croslet arg. DAYES, quartered by Southworth, Harl. MS. 1445, fo. 107, and Collinson, Somerset, i, 219 . Sr. William de Pares, co. Lincoln, $V$. Paris. Southworth, co. Lancaster, $V$. Southworth or Southworth, Smalesbury, co. Lancaster.

Sa. a chev, engr. betw, three crosses croslet arg. AsTWYKe, $V$.

Sa. a chev. betw. three crosses croslet fitehy arg. Buckworth, Sheen, near Richmond, Surrey; since of Broxbourne, co. Hertford; Baronetcy 1697. RaND or Randes. Writington.

Sa. a chev, engr. betw. three crosses croslet fitchy arg. Astwicke or AstwykF.

Sa. a chev. wavy betw. three crosses croslet fitchy arg. BoneHAM or BONHAM.

Sa. a chev. betw, three crosses patonce arg. $M$. Thomas Southworth, $S$.

Sa. a chev. betw. three crosses patty arg. Forward, co. Lancaster.

Sa. a chev, arg. betw. three crosses erm. Champney, $W$.

Sa. a chev. arg. betw. three crosses patty engr. erm. Champney, London.

Sa. a chev. arg. betw. three crosses croslet or. Peckhali.

Sa. a chev. arg. betw. three crosses croslet fitchy or. Strutt, Baron Rayleigh 1821. Strutt, Little Warley Hall, Essex; Baronetcy 1641, extinct 1618. WORTHINGTON Or WRIGHTINGTON, co. Lancaster, $V$.

Sa. a chev. arg. betw. three crosses patty fitchy or. Writtington, co. York.

Sa. a chev. erm. betw. three crosses croslet arg. Carrier, Gosport, co. Hants.

Sa. a chev. erm. betw. three crosses croslet fitchy arg. Randes, Radwell, co. Bedford. Randes, $V$. Reynolds.

Sa. a chev, erm. betw. three crosses patty arg. GreENwood, co. Lancaster.

Sa. a chev. erm. betw. three crosses patty fitchy arg. Bardolfe, co. Hereford, $V$.

Sa. a chev. betw. threecrosses engr.erm. CHAMPNEY.

Sa. a chev, betw. three crosses roided erm. ChaMpNer.

Sa. a chev. erminois betw. three crosses croslet fitchy or. Strut, Westminster, Middlesex; granted 1772 .

Sa. a chev. or betw. three crosses botonny fitchy arg. Peckadr, Kent.

Sa. a chev, engr. or betw. three crosses croslet arg. KenIAM.

Sa. a chev. or betw. three crosses croslet fitchy arg. Denter, Essex. PEckham, Suffolk. Peckhair, $V$. Writington, eo. Lancaster.

Sa. a chev. engr. or betw. three crosses fiory arg. KenYon, Baronetcy 1781 ; Baron Kenyon, 1788. KEYNION, co. Laucaster.

Sa. a chev. engr. or betw. three crosses patonce arg. Sr..... de Kenyau, $V$.

Sa. a chev. or betw, three crosses erm. Chanpaney, London.

Sa. a chev. betw. three crosses croslet or. Hildershaji, Suffolk. Southby, Collinson, Somerset, ii, 492 .
1 CHEVRON betw. or within.... cont.

Crosses cont.

Sa. a chev. betw, three crosses croslet fitchy or. Packam, Kent. Whitington, co. Lancaster.

Sa. a chev. engr. betw. three crosses croslet fitchy or. Astwicke or Astwyke.

Sa. a chev. betw. three crosses patonce or. Fondham, Bishop of Durbam 1382, Ely 1388-1425. Hirdershai, $V$; and co. Cambridge.

Sa. a chev. hetw. three crosses patty or. Sothald or Sotheohald, $V$. Stothald, $V^{*}$. Stothehall, $V^{*}$.

Sa. a cluev. betw. three crosses patty flory or. Hildershan, co. Cambridge.

Vert a chev. betw. three crosses botonny fitcliy arg. Henry Maye, $V$.

Vert a chev. betw. three crosses croslet fitchy arg. MAY.

Vert a chev. betw. three crosses patonce or. Boydell, Pulcroft, co. Chester.

Az. a chev. erm. betw. four crosses patty arg. ANGE.

Or a chev. betw. four crosses croslet fitchy gu. Parsons, Clanclewedog, and Presteign, co. Radnor; quartering Hanmer, Jeffreys, and Morgan.

Arg. a chev. betw. five crosses croslet fitchy two two and one sa. Sydinton, Harl. MS. 1404, fo. 117 .

Arg. a chev. sa. betw. five crosses croslet fitchy of the second and three griffin's heads erased az. INGILTON, $V$.

.... a cher. .... betw. six crosses croslet ... Grerndor, Collinson, Somerset, i, 142.

Arg. a chev. betw. six crosses patty fitchy gu. WoodrofFe, Hoope, co. Derby; and co. York.

Az. a chev, betw. six crosses croslet arg. in the dexter chief a 5 -foil or. LATYMER, $V$.**

Az. a chev, arg. betw. six crosses croslet fitchy or. Cramp, Dudinghurst, Essex.

Gu. a chev. betw. six crosses patty arg. Sr. Morice de Berketey, $J$.

Gu. a chev. betw. six crosses croslet or. KYME, Kesteven, co. Lincoln; temp. Henry II, as borne by the Barons Kyme. Sire Philip de Kyne, $J$; but Keme, $J$, Harl. MS. 6137.

Gu. a chev. compony arg. and or betw. seven crosses croslet of the second. Cresse.

Gu. a chev. betw. seven crosses patty arg. Sr. Morice de Berrelex, J, Harl. MS. 6137.

Gu. a ohev. erm. betw. seven crosses croslet fitclyy arg. Longfield, Longueville, co. Cork; Viscount Longueville 1795; extinct 1811.

Gu. a chev. betw. eight crosses patty arg. Barkeley.

Arg. a chev. gu. betw. nine crosses croslet sa. Proctor, Collinson, Somerset, ii, 345 .

Gu. a chev. arg. betw, nine crosses croslet .... Kyмe, Cotton MS. Tiberius D, 10.

Gu. a chev. betw, nine crosses patty arg. BARKELEy.

Gu. a chev. betw. nine crosses croslet or. Krme, Kesteven, co. Lincoln. temp. Henry II, as borne by the Barons Kyme.

Or a chev. gu. betw. nine crosses croslet sa. Mereworth, Cotton MS. Tiberius D, 10.

Sa. a chev. betw. nine crosses croslet az. Richard Paris, Cotton MS. Tiberius D, 10.

Arg. a chev. betw. ten crosses croslet gu. $\mathrm{H}_{\mathrm{AGH}}$ $V$. Hawe, $V$. Haugh or Haw. Hawes. Hogh. Holmrook, Suffolk. Holbrow. SHaw. 
1 CHEVRON betw. or within.... cont.

Crosses cont.

Arg. a chev. gu. betw. ten crosses croslet sa. Malemayne, $V$. Malmaynes. Mereworth or Menworth. William M'wine, $A$; but Merwre, A, Harl. MS. 6137.

Arg. a chev. betw. teu crosses croslet sa. Kenebourne, Cotton MS. Tiberius D, 10. Lekebourne, $V$. Paris. Shellis.

Arg. a chev, betw. ten crosses patty sa. Kebonne.

Az, a chev. betw, ten crosses croslet arg. in the dexter chief three obscured by a pierced 5 -foil or. Latymer, Suffolk, $V$.

Az. a chev. or betw. ten crosses patty arg. Berkeley, Scotland.

Az. a chev. betw. ten crosses croslet or. BaBepull. BaKEPULL, $V$.

Gu. a chev. betw. ten crosses croslet arg. Fitz-Handing. Le S. de Berkele, $S$.

Gu. a chev. betw, ten crosses patty arg. Sir Thomas Barcley, L. Barkley. Monsire Morris de Berkeley, $Y$. Berieley, Baron Berkeley, 1416; Viscount Dursley and Earl of Berkeley, 1679; Collinson, Somerset, iii, 143, 166, 590. James, Lord Berkeley, $Z, 212$. Berkeley, Cotheridge, and Spetchley, co. Worcester. Sr. .... de Bencely, $V$; but de Barkelay, Cotton MS. 'Tiberius $\mathrm{D}, 10$. BERKELEY, $V^{*}$. BERKIEY.

$\mathrm{Gu}$. a chev. betw. ten crosses patty within a hordurearg. Barkeley, Harl.MS.1603. Berkeley, Beverstone.

Gu. a chev. erm. betw. ten crosses patonce arg. M. Moris de Berkele, $S$.

Gu. a chev. erm. betw. ten crosses patty arg. Barkeley or Berkeley, Collinson, Somer'set, i, 217 ; ii, 279 ; Viscount Fitzbarding aud Earl of Falmouth, Barons Boteourt and Berkeley; Stoke, and Stratton; quartered by Portman. Berkley. Callow, as quartered by Hussey.

Gu. a chev. betw. ten crosses croslet or. Horbroake. Kyмe, V; Kesteven, co. Liucoln, temp. Henry II.

Gu. a chev. betw. ten crosses croslet flory or. KInG, co. Lincoln.

Or a chev, betw. ten crosses croslet gu. Brockhole, Essex. Sr. James Holbroke, Suffolk, temp. Edward I, $V$. Holbrook. Holebrooke.

Or a chev. gu. betw. ten crosses croslet sa. Mereworth, $V$. Merworth.

Or a cbev. betw. ten crosses crosletsa. Proctor. Shelietoe. Shelit. M. Robert Sleght, $S$. Sleight, $V$. Shileyt, Cotton $M I S$. Tiberius $\mathrm{D}, 10$.

Sa. a chev. betw. ten crosses croslet arg. Paris, co. Lincoln.

Sa. a chev. erm. betw. ten crosses croslet fitchy arg. Rands.

Sa. a chev. or betw. ten crosses croslet fitchy arg. Peckham, co. Buckingham; and Kent.

Sa. a chev. betw. ten crosses croslet or. Richard Paris, $V$. Parys, $V^{*}$.

Arg. a chev. betw. twelve crosses croslet gu. BrokeHole or BrokHole.

Arg. a cbev. gu. betw. crosses croslet sa. William de M'Wire, $A$. John Meneworth, $Y$. 'The croslets potent. William de Merwre, $A$, Harl. MS. 6137.

Arg. a chev. betw. crosses croslet sa. Sir Henry de Lekburne, $M$; or de Lekebounne, $N$. Monsire de Lekeborne, $Y$. Hugh Lekeburne, $Y$. Lekyborne. Sir John de Mereworth, $R$.

\section{CHEVRON betw. or within.... cont.}

\section{Crosses cont.}

Az. a chev. betw. crosses croslet or. BABEPULL, Cotton MS. Tiberius D, 10. Rauf de Bakepuz, $E$. Simon de Krmbe, $G$; or de Kyme, $N$.

Gu. a chev. betw. crosses croslet arg. Sir Thomas de Berkeley, $G$; or de Barkeley, $H$. Thomas Benkeley, $Y$. But with a label az. (as Thomas was alive.) Sr. Thomas (? Maurice) Barkeley, the son, $H$.

Gir. a chev. betw. crosses patty arg. Sir Thomas de Barkley, L, Harl. MS. 6137. Sire Moris Barkley, Q. Morice de Barklex, $K$, Harl. MS. 6137, 6589; $Y$. Le Sr. de Barikey, T. Sire Moris de Berkeleye, $N$; and his descendants, Earls of Berkeley. Berkeleye. Berkeley, $V^{*}$. Sire Morice de Berkeley, $J$. Sr. de Berkiy, $V$. And with a label az. Moris de BarkLey, $K$; the label sometimes sa., $K, H$ arl. $M S .6589$. Gu. a chev. betw. crosses croslet within a bordure arg. Barkeley, co. Hertford.

Gu. a chev. erm. betw. crosses croslet arg. Maurice Berneler, Stoke Gifford and Brimpsfield, ob. 1347, and bis descendants, Barons Berkeley of Stratton, Baron Botetourt, Barons Berkely of Rathdown, Viscounts Fitzharding and Earl of Falmouth; Collinson, Somerset, iii, 279; Baronetcy 1660; all extinct.

Gu. a chev. betw. crosses croslet or. Kyse, $V$. Pbillipe de Krne. $A$; or de Krne, $E$; or de Kymbe, $G$; or de Krme or Kyme, $J$. Philippe, Sieur de Krmes, $K$. Sire William de Krme, $N$. William Kyne, $Y$. And with a label arg. Sir William de Krne, $L$; $O$. The label az. Sr. William de Kyme, $M$.

Or a chev. betw. crosses croslet gu. Thomas de Brokehole, $E$. Richard de Holebroc, $F$. Sire .... de Holebrok, $N$.

Sa. a chev. betw. crosses croslet arg. Sire William de Paris, $N$; or de Parys, O. Monsire de Paris, $Y$. William Parys, $Y$. Cups

Arg. a cbev. betw. two pots sa. within a bordure engr. gu. Bray.

Sa. a chev. betw. two covered cups or. Folchard. .... a chev. hetw. three covered cups .... Jobn HoDde R, Irelaud, seal, 1655.

Arg. a chev. betw. three covered cups gu. StraUnge, $W$.

Arg. a chev. gu. betw. three pots vert. KuLLINGWORTH.

Arg. a chev. betw. three ewers (flagons of the first Deckling or Dreckling, $V^{*}$.) sa. Decking, $V$. Arg. a chev. betw. three ewers (another, porridge pots) sa. DERI.ING.

Az. a chev. betw. three ewers arg. Todwell, $V^{*}$. Az. a chev, arg. betw. three standing cups or. Boteler, London.

Az, a chev, arg. betw. three covered cups or. Butler, co. Chester; and co. Lancaster. Butler, Middlesex.

Az. a chev. betw. three covered cups or. M. John Boteler, $S$. Butler, The Lodge, Upper Clapton. Samuel Butler, Bishop of Lichfield, 1836-9; quartering Taylor. Freckleton, Essex. Hall. Halles. And with a crescent for diff. Butler, Bishop Auckland, Durham.

Az. a chev, betw. three covered cups or. Botteller, Kerland, co. Lancaster, $V$. Pellet, $V$. Pellet $V^{*}$. Pillett, co. Lincoln. Rawcliffe. St. Alban, $V^{*}$. And with a cross croslet or in chief for diff. ButLer, quartered by Bowdon. 


\section{CHEVRON betw. or within.... cont.}

Cups cont.

Az. a chev. potent counterpotent or and gu. betw. three ewers with handles of the second. Bureau.

Az. a chev. humetty betw. three covered cups or. Christian, Unerigg Hall, Cumberland; de. scended from $\mathrm{M}$ Christen, Isle of Man.

Ermines a chev. betw. three covered cups arg. Boteller, Gillinge, $V$.

Gu. a chev, betw, three covered cups arg. SALLERs, $V$. Sollers or Sellers.

Gu, a chev. arg. betw. three bowls or. ARTHur.

Gu. a chev. betw. three cups covered or. Boteler, V*. Boteller, co. York, $V$.

Sa. a chev, betw. three covered cups arg. Warcur.

$\mathrm{Gu}$. a chev. betw. three fleshpots or. WeTHERED, Ashlins, Great Berkhampstead. Wethened or Wetherid, co. Buckingham; and co. Hertford. Or a cliev. betw. three covered cups .... Butler, Aston in the Vale, co. Northampton.

Sa. a chev, betw. three cups arg. Thomas de WARCOP, $Y$.

Sa, a chev, arg. betw. three covered cups or. Pillett.

Sa. a chev. erm. betw. three corered cups or. Felmyngham, $W$. Fildinghair, Fillingham, Norfolk. Fremyngham, $V^{*}$.

Sa. a chev. or betw. three (uncovered cups, $V^{*}$.) drinking pots arg. Candishe, $V$; and Suffolk.

Sa. a chev. betw. three covered cups or. BotLer, London; quartering or a lion az. a crescent for diff. Freckelton or Freckleton, co. Huntingdon. Odiard. Odyearne.

Vert a chev, or betw. three covered cups arg. STRAUNGE, $V$.

Vert a chev, betw, three covered cups or. STrange. Cuirasses

Az. a chev, erm. betw. three breastplates arg. Swatliman, Kent.

Cushions

Arg. a chev, betw. three lozenge cushions gu. Randall, Scotland.

Arg, a chev. betw. three cushions erm. Morron, $V^{*}$.

Arg. a chev. betw. three cushions sa. Roger de Norton, $Y$. Monsire John de Norton, $Y$. St. Michael, Bramson, Scotland.

Arg. a chev. betw, three lozenge cushions sa. Sr. Robert NonTon, $V$.

Az, a chev. betw. three cushions (or woolpacks) or. LOAT.

Gu. a chev. arg. betw. three lozenge cushions erm. tasselled or. M. Mays Redmane, S. Redman, Tulford, co. York. RedMan, co. York, $V$.

Gu. a cher. betw, three lozenge cushions erm. tasselled or. Reduan, $V^{*}$.

Sa. a chev. betw. three packs or cushions arg. tied of the first. Company of Dyers, London.

Sa. a chev. chequy or and gu. betw. three cushions of the second. Brisbane, Bishoptown, Scotland. All within a bordure chequy arg. and sa. Brisbane, M.D. The bordure vair. Brisbane, Scotland, Judge Advocate.

Sa. a chev. engr. arg. betw. three bags of madder of the last corded or. Company of Dyers, London.

\section{Delves see Billets}

Dice

Arg. a chev, betw. three dice sa. each charged with a cinquefoil of the first. Fitz-Willuams, Malton, co. York. Winliars.
1 CHEVRON betw. or within.....cont.

Dice cont.

Arg. a chev. betw. three dice sa. each charged with four spots .... Englowes, Collinson, Somerset, iii, 159 .

\section{Dorsers see Bougets}

Escallops

Arg. a chev. betw. in chief two escallops and in base a cross croslet fitcliy gu. DaLDERBY, $V$. The cross botonny fitchy. John DaLderby, Bishop of Lincolu, 1300.20.

Arg. a chev. engr. gu. betw. in chief two escallops of the last and in base a bandsaw palewise az. handle or. Sawers, Scotland.

Az. a chev, engr. erm. betw. in chief two escallops of the last and in base a paschal lamb ppr. Townshend, Stony Stanton, Hinckley, co. Leicester.

(Sa.) a chev. betw. in chief two escallops and in base a boar's head fesswise couped (arg.) Netby, Netby, co. Lancaster. Raufe Noteby, $V$. Thapers, co. Lancaster; co. Devon; and Garyycloyne and Birchill, co. Cork. Travers, Netby, co. York.

... a chev, betw, three escallops .... Down Darr, Ireland.

.... a chev. betw. three escallops over all a pilgrim's staff in pale (another without the staff) ... Fortington, Tewksbury, 1253.

Arg. a chev. betw, three escallops az. Champron. Donstable. Garneys Garnish or Garnys, Laxfield, Suffolk, temp. John; and Boyland Heveningham, Kenton Hall, Mukfield, and Radsham, Suffolk; and Gelderton, Norfolk. Sr. William Littilton, $V$. Littleton, $V^{*}$.

Arg. a chev. engr. betw, three escallops az. BADEL. Ganneys or Garnys, Mukfield and Radsham, Suffolk.

Arg. a chev. az. betw. three escallops gu. Pollard, $V$.

Arg. a chev. az. betw. three escallops sa. CARNESH or GARNESH, Suffolk. Gervis. Robert Gerveys, $X$. Tremayne, $V$.

Arg. a chev. engr. az. betw. three escallops sa. Garneshe or Garnishe, Suffolk.

Arg. a cher. chequy of the first and gu. betw. three escallops as the last witbin a bordure gu. bezanty. ExMEW or ExMERE, London.

Arg. a chev, compony of the first and gu. betw. three escallops sa. within a bordure as the third charged with six leopards' heads and so many bezants alternately. ExiEw, $V^{*}$.

Arg. a chev. compony or and gu. betw. three escallops sa. a bordure of the third charged with leopards' heads and annulets as the second alternately. ExMew, Wales.

Arg. a chev. compony purp. arid of the first betw. turee escallops gu. within a bordure of the last charged with three leopards' faces or and as many bezants alternately. ExMEwE, Lord Mayor of London 1517.

Arg. a chev. countercompony gu. and of the first betw. three escallops within a bordure gu. charged with six leopard's faces or and as many bezants alternately. Sr. Thomas Exmew, Alderman, $V$.

Arg. a chev. betw. three escallops ermines. Riman.

Arg. a chev. ermines betw. three escallops gu. Erre, Suffolk.

Arg. a chev. gu. betw. three escallops az. within a bordure engr. of the last. CoLBY. 


\section{CHEVRON betw, or within....}

\section{Escallops cont.}

Arg. a chev. betw. three escallops gu. ARDBorodg ARDEBorough and ARDBow. Roger Breton, $Y$. Dorthorpe. Kinmarton. Orme, co. Northampton. Perin. TAngred or Tanckard, Boroughbridge, co. York; Baronetcy 1663.

Arg. a chev. engr. betw. three escallops gu. Andeburo, $V$. Ardeburow, $V^{*}$.

Arg. a chev. gu. betw. three escallops sa. Gervais or Gerveis. Longstoder. Longstrother, $V$. Pussell, Falmouth, Cornwall.

Arg. a chev. gu. betw. three escallops sa. within a bordure engr. of the last. HanRYson, $V$.

Arg. a chev. sa. betw. three escallops erm. Raynham, Apledram, Sussex.

Arg. a chev. sa. betw. three escallops gu. Pollard, Trelligh, Cornwall; Waye and Horwood, co. Devon; co. Oxford; and co. Worcester. Pouldrd, King's Nympton, co. Devon; Baronetcy 1627, extinct 1693. PoLLARD, $W$. Woodjuan.

Arg. a chev. betw. three escallops sa. Alnotr, Suffolk. ARDBorough ARDEborough and ARdBow. Aspilon, $V$. Cottrell, co. York. Defenshire, co. Buckingham; and Cornwall. Donstabtie. Dunstable, $V$. Fairway, Lon. don. Faraway or Farraway, Penbellam, Cornwall; with four quarterings, quartered by Sotowell, Stawell, or Stowell; Harl. MS. 1415, fo. $193 ;$ 1385, fo. 2 : FARwey, Harl. MS.1141, fo. 8. Littleton Luttelton or Lyttleton, quartering Frankley; the heiress $\mathrm{m}$. Westcote, and her son was Sir Thomas Littueton, ancestor of Lyttleton, Baronetcy 1618, Baronies 1776 and 1794 , quartering Burley, Plantagenet through Talbot, Crompton, and 'Temple: of Litrleton, Pillaton, co. Stafford; Baronetcy 1627 , extinct 1812 ; the beiress $m$. Walhouse, afterward Litrueton, Baron Hatherton, 1835 ; and of Littueton, Spetchley, ancestor of Littleton, StokeMilburgh; Baronetcy 1 642-1710,quartering Litrleton, Mounslow, Barony 1640.5. Charles LytTleton, Bishop of Carlisle, 1762-8. REyMaN, Sussex. Tregantrian, Tregarthian, Cornwall. Tregarthon, Cornwall. Trregathan, Cornwall, $V$. WASKatT. And with a crescent for diff. .... Thomas Wrnniffe, Bishop of Lincoln, 1642-54.

Arg. three escallops sa. the one in base debruised by a pale gu. over all a chev. of the second. DARDES, Ireland.

Arg. a chev. sa. voided az. the inner edges engr. betw. three escallops of the second. Thomas Winniffe, Bishop of Lincoln, 1642-54, Harl. $M S .2275$, fo. 20 .

Arg. a chev. betw. three escallops within a bordure sa. Litrieton. The bordure engr. Richard Harrison, $V$.

Az. a chev. betw. three escallops arg. Hakewood. Hawkewood. Tayler or Taylor. M. Jolln TrELLOWE, $S$.

Az. a chev, betw. three escallops arg. within a bordure engr. gu. Sr. John Brone, temp. Edward IV, Harl. MS. 6137, fo. 44.

Az. a chev. arg. betw. three escallops or. TAYLoR, co. York.

Az. a chev, erm. betw. three escallops arg. Sr. Roger Townesende, Norfoik, $V$. Townsend, $V^{*}$. Townshend, Rainham; Baronetcy 1017, Baron 1661, Viscount 1682, and Marquis Townshend, 1786. Townshend, Baron 1783, and Viscount Sydney 1789. Townsend, co. Cork, a
1 CHEVRON betw. or within.... cont.

Escallops cont.

branch of Townshend, Wretham, Norfolk; and co. Worcester. And with a mullet for diff. Townshend, Baron Bayning, 1797.

Az. a chev. engr. erm. betw. three escallops arg. Townsend, Hem, and Trevallyn, co. Denbigh. Townhend, Wincham, co. Chester.

Az. a chev. engr. betw. three escallops erm. Townsend.

Az. a chev. betw. three escallops or. BAYARD. Browne, Walcot, co. Northampton. Browne, London; quartered by Cave. Browne, HortonKenby, Kent. Colbey. Lagherne, Cornwall. LANGHERne, Tregavethan, near Truro; and St. Erme. Langherne or Langhorne, Cornwall. Az. a chev. betw. three escallops or a bordure gu. Browne; Harl. MS. 1404, fo. 26.

Az. a chev. betw. three escallops or a bordure engr. gu. Browne, quartered by Cave. Sr. John Browne, Lord Mayor of London, $V ; 1513$. Brown, Harl. MS. 1404, fo. 20.

Az. a chev. betw. three escallops within a bordure engr. or. Browne, Lord Mayor of London 1480 ; ancestor of Browne, Walcot. CoLBy, Kensington, Middlesex; Banham, Norfolk; Brundish, Suffolk; and Finone, co. Pembroke. Az. a chev, engr, betw. three escallops within a bordure engr. or. CoLbx, $V$.

Erm. a chev. betw. three escallops sa. Shelly. $\mathrm{Gu}$. a chev. betw. three escallops arg. BEDELL. Carem. Carron. Charon. Sire Richard Charonne, temp. Edward I, $V$; or de Charonne, $N$. Charrone, $V^{*}$. Richard Charron, $Y$; or de Charron, $P$. Guichard de Charroun, $Y$. Dacres. Genton, Cumberland. Martin, Anstey Pastures, co. Leicester (for Richards). Milborne, $V$; and co. Derby; Dunmow and Markes, Essex; 'Tylington, co. Hereford; and co. Stafford. Tankakd, i. e.tT TANCRED, co. Pem. broke. Wormer, Bloxholme, and Swinsted, co. Lincoln. Woolmer, Stratford-on-A von, co. Warwick. And with a crescent for diff. WoLMer, Spalding, co. Lincoln.

Gu. a chev. engr. betw. three escallops arg. Bedell, Hamerton, co. Huntingdon, Baronetcy 1622, extinct 1663. GOODBUCK. GoodLOCK. Pedeld, co. Huntingdon.

Gu. a chev. arg. fimbriated or betw. three escallops of the second. TAYLOUR, Westminster; granted 14 Feb. 1714-15.

Gu. a chev. erm. betw. three escallops arg. Milibonne.

Gu. a chev, erm. betw, three escallops or. ARnoLd, co. Gloucester.

$\mathrm{Gu}$. a chev, engr. or betw. three escallops arg. LANGLEY, Essex.

Gu. a chev. betw. three escallops or. Browne, London. Chamberlayn, $V^{*}$, and Sherborne, co. Oxford. Chamberleyn, Tankerville, $V$. Sire Richard Chaumberlein, $N$; ol Chameerleyn, $S$. Chinkerlin, Scotland. Wolmer.

Gu. a chev. betw. three escallops or a label of as many points arg. Chamberlaine.

Gu. a chev, engr. betw. three escallops or. ALDBorougr. GoodBuck. Goonlock.

Gu. a chev. vair betw. three escallops arg. Chipmanden, $V$.

Or a chev. betw. three escallops az. ARMYN, Cornwall. Coltambe. Enmind or Ermine, Cornwall. Ermind, Coruwall, $V$. ERney or Erneys, Cornwall. Gay, co. Devon. Tremayne, $V$, and Cornwall ; and co. Devon. Wolmacombe, co. Devon. 
1 CHEVRON betw, or within.... cont. Escallops cont.

Or a chev. engr. az. betw. in chief three escallops and in base a buck's bead gu. LEwrs, Kent.

Or a chev. betw. three escallops gu. Branling, $V$. Sire Johan de YLE (in errov).

Or a chev. betw. three escallops sa. Exmies. Eymes, Cornwall.

Per chev. sa. and arg. a chev, erm. betw. three escallops or. GreEnwood.

Per fess indented arg. and or a chev. betw. three escallops gu. Browne.

Per pale arg. and or a chev. betw. three escallops gu. Browne, London; and co. Hereford.

Per pale indented arg. and or a chev. betw. three escallops gu. Browne, Kent. Sr. William Browne, Lord Mayor of London, $V$; 1507; Harl. MS. 1404, fo. 26 .

Per pale gu. and az. a chev. erm. betw. three escallops arg. $\mathrm{M}^{\prime} \mathrm{C}$ unsock, Drumcar, co. Louth; and Dunmore, co. Donegal. NorHan.

Per pale indented or and arg. a chev. betw, three escallops gu. Browne, Lord Mayor 150\%.

Per pale or and gu, a chev. betw. three escallops counterchanged. Bendesley, $V$.

Per pale or and sa. a chev. betw. three escallops counterchanged. Bradesley. Brendesley, $r$. Brindesley. Lowis, Lowis, co. Nottingham.

Per pule sa. and or a chev. betw. three escallops counterchanged. Worrall, Stourton, co. Stafford, as quartered by Grazebook; but this coat was assumed from some marriage with a heiress of a branch of BRYNDLEY, from co. Nottingham settled near Kynfare about 1550 .

Sa. a chev. betw. three escallops arg. Arryas. Bateman. Cheder or Chedder. Cheddar, Collinson, Somerset, ii, 156-7, iii, 176, 575-9. Fairway, co. Devon. Fanel. Fannelu Faraway or Farwey, Penhallam, Cornwall; with four quarterings; quartered by Sotowel, Stawell, or Stowell, Harl. MS. 1445, fo. 22 and 193. FAREwAY, $V$. FAREWAYE, quartered by Tryvett, Harl. MS. 1385, fo. 15. FARwelL, Hillbishops and Holbrooke, co. Somerset, Harl. MSS. 1385, fo. 5 ; and 1445 , fo. 148 . Farrwell, Barrington, co. Somerset; and Westminster; $Z, 451$. Favell, Craven, co. York, $V$; and KirbyHall,Catterick. KingE,Gainsborough, co. Lincoln. Maтthew. Michell, $V^{*}$; and Stamerham, and Horsham, Sussex; the heiress $m$. Shelley. Milbourne, Armathwaite Castle, Cumberland. Mrснe, $V$. STRICkLAND, Dorchester. Sire Jobn de Wolaston, $O$. And with a mullet for diff. Micheli, Houghton, Sussex.

Sa. a chev. betw. three escallops arg. within a bordure engr. or. Brise.

Sa. a chev. engr. betw. three escallops arg. Farewel Farewerd or Farwell, Hill Bishop, co. Somerset, Harl. MS. 1559, fo. $126 \mathrm{~b}$; and Collinson, Somerset, iii, 255.

Sa. a chev. arg. betw. three escallops or. GAY, Bath, co. Somerset. Graham, Morphy, Scotiand.

Sa. a chev, arg. betw. three escallops ppr. Michel, Codicote, and Standon, co. Hertford.

Sa. a chev. erm. betw. three escallops arg. CHEDDER, $V^{*}$. FarwaY, co. Devon. FARWeY, with four coats, quartered by Sotowell, Stawell, or Stuwell, Harl. MS. 1559, fo. 9] b.

Sa. a chev. or betw. three escallops arg. CHadder, $V$. Faveli. Mrchell, Lord Mayor of London 1424 and 1436. Mitcheld, Stapleton Mitchell, co. Dorset; and co. York.
1 CHEVRON betw, or within....cont.

Escallops cont.

Sa. a chev. betw. three escallops or. (? FAREwELL.) FAVELL, co. York.

Vert a chev. betw. three escallops arg. Richard Milbourn, Bisbop of St. David's 1615-21. Shapleigh, co. Devon.

Vert a chev. arg. betw. three escallops or Shapleigh, $W$. Trevenour.

Vert a chev. erm. betw. three escallops or. Mudgan, Mudgan, Cornwall; the beiress $\mathrm{m}$. Chynoweth.

Vert a chev. betw. three escallops or. Akenthorp, Akenthorp, co. Derby.

.... a chev, engr. .... betw. six escallops .... Thomas WARDE, 1641, in Blechingley Church. Arg. a chev. gu. betw. six escallops sa. over all a fess of the second. Bendish, Essex.

Az. a chev. betw. six escallops arg. Catcher, co. Lincoln. Hacher. Hatcher, Carby, and Bytham, co. Lincoln.

Arg. a chev. ermines betw. eight escallops gu. Eyre, Suffolk.

\section{Escucheons}

Arg. a chev. .... betw. .... three escucheons .... voided .... HALL, Pitcombe; quartering Ruddock; Collinson, Somerset, ii, 345 .

Arg. a chev. az. betw. three escucheons gu. euch charged with a leopard's face or. Hayes, Westminster; Baronetcy 1797, quartering Macnamara.

Arg. a chev. betw. three escucheons gu. Hay, Futhie, and Seafield, Scotland.

Arg. a chev. sa. betw. three escucheons gu. HaY, lreland.

Arg. a chev. sa. betw. three escucheons gu. each charged with a griffin segreant or. James Eryssy, ob. 1522, brass in church at Grade, Cornwall. Gressy, Harl. MS. 1302.

Arg. a chev. betw. three escucheons sa. each charged with a griffin ramp. or. GREssy, $V$.

Az. a chev. betw. three escucheons or each charged with a thunderbolt .... En Eronds.

\section{Estoiles}

Arg, a chev. embattled and ensigned on the top with a banner betw. in chief two estoiles and in base a sun gu. Euene.

Gu. a cher, arg. betw. in chief two estoiles and in base a crescent or. KIRKaldie, Scotland.

Arg. a chev. betw, three demi-estoiles couped per fess rays in base sa. Jenynges, London.

.... a chev. .... betw. three estoiles .... John Shirwode, Bishop of Durham 1488-94.

Arg. a chev. az. betw. in chief three estoiles and in base a crescent gu. Fontain or Fontaine.

Arg. a chev. gu. betw. three estoiles az. Brody, That Ilk.

Arg. a chev. engr. gu. betw. three estoiles az. Keure, Sparishall, Essex; and Suffolk. KeмP, $V^{*}$. Keмpe, Finchenfeld, Essex, $V$.

Arg. a chev. engr. gu. betw. three estoiles of twelve (another sixteen) points six wavy and six straight az. REveley, Bryn-y-gwin, co. Merioneth; a branch of Reveley, Newton Underwood and Newby Wisk, Northumberland, quartering Willey; a heiress m. Mitford.

Arg. a chev. betw. three estoiles gu. ARDALI Ardoll ARDon ARDonfF and Ardonse, Essex. Ardouffe, Essex, $V$. Arner. Colchester, London; granted 20 December 1626. WILson, Plewlands, Scotland.

Arg. a chev. betw. three estoiles of eight points wavy or. Wisenan, Scotland. 
1 CHEVRON betw. or within....cont.

Estoiles cont.

Arg. a chev. betw. three estoiles sa. Sr. John Mordant, $V$. Mondant, Turvey, co. Buckingham. Mordaunt, 1730 ; Baron Mordaunt 1529, Baron Reigate and Viscount Mordaunt, 1659, Earl of Peterborough 1628, Earl of Monmouth 1689, extinct 1814. Mordaunt, Massingham, Norfolk; and Walton, co. Warwick; Baronetcy 1611.

Arg. a chev, betw. three eight pointed estoiles sa. Mordaunt.

Az. a chev. betw. three estoiles and a crescent in chief (? for diff.) arg. ARNET.

Az. a chev. betw. three estoiles each enclosed by a crescent arg. MiNSHUL.

Az. a chev. arg. betw. three estoiles or. Crutendon or Cruttendon. Eyre, co. Wilts. Az, a chev. erm. betw. three estoiles arg. BREwster, co. Nortbampton; and Withfield, Essex.

Az. a chev. or betw. three estoiles arg. CARR.

Az. a chev. betw. three estoiles or. Davies, Salisbury.

Erm. a chev. per pale sa. and arg. betw. three estoiles or. WIGsToN, co. Leicester, Harl. MS. 1404 , fo. 78 .

Gu. a chev. betw. three estoiles alg. Pynsent, Carleton Curlieu, co. Leicester; and Urchfout, co. Wilts.

Gu. a chev. engr. betw. three estoiles arg. John Pynsent, in Croydon Church, ob. 1668.

Gu. a chev. engr. betw. three six-pointed estoiles arg. Pinson, London.

Gu. a chev. arg. betw. three estoiles or. ABERDEEN, Cairnbuly.

Gu. a chev. betw. three estoiles or. Lesturmy.

Gu. a chev. betw. in chief three estoiles and in base a crescent or. KIRkaldie, Grange, Scotland.

Gu. a chev. betw. three estoiles or. CHITwis, London. Griffith.

Or a chev. az. betw. three sixteen-pointed estoiles .... PARDY, That Ilk.

Or a chev. betw. three estoiles gu. CoLchester, $V^{*}$; London ; co. Somerset; and co. Warwick; granted 1626.

Or a chev. betw. three estoiles sa. Sterle or STERIEx.

Per chev, vert with the base per pale or and erm. a chev. ermines betw. in chief three estoiles gold and in the dexter base a lion ramp. gu. SHANLY.

Sa. a chev. betw. three estoiles arg. Holliard. LaNGDale, Houghton, co. York; the senior branch of LANGDALE, Baron Langdale 1658, extinct 1777; the heirs m. Butler, Stourton, and Clifford. Langdale, Langdale, cu. York. WaLTHAM.

Sa. a chev, betw. three estoiles arg. within a bordure engr. or. INGOLDISBY, $\boldsymbol{V}$. INGOLDSBY, co. Lincoln.

Sa. a chev. arg. betw. three estoiles or. Powkeswell. Pownsweld, $V *$. Powkysweld, $V$. Sa. a chev. erm. betw. three estoiles arg. Bewster, Wrentham Hall, aliter Brewster, $W$. LaNGDale. But the estoiles with six points. Brewster, Suffolk.

Sa. a chev. betw. three estoiles or. Pockeswen co. Dorset. Paxweld, Cornwall.

Sa. a chev. engr. betw. three estoiles or. STatr. Eyes

Az. a chev. or betw. three eyes arg. LFGLer. Iwers see Cuys
1 CHEVRON betw. or within.... cont.

\section{Faggot:}

Arg. a chev. sa. betw. three faggots of the second. Company of Woopmongers, London, 1716. But bundles of laths vert, Cotton. MS. Tiberius D 10 , fo. 885 .

\section{Feathers}

Gu. a chev. betw. three ostrich feathers arg. Fetherston-Haugh, Bracklyn Castle, co. Westmeath; descended from Cumberland.

Gu. a chev. or betw. three ostrich feathers arg. Fetherston or Fetherstone, Ireland.

Vert a chev. betw. three ostrich feathers within a bordure arg. Penkins, Fishlake, co. York.

Vert a chev. betw. three ostrich feathers arg. within a bordure or. Perkins, Fishlake, co. York. Perkins, co. Lincoln.

\section{Feet see Legs \\ Fetterlocks see Shackles \\ Fire}

Arg. a chev, voided az. betw. two flames of fire ppr. Wells. But three flames. Wells, Piercefield, co. Monmouth. WeLLs, 1716. WeLLS, co. Worcester.

\section{Fireballs}

Arg. a chev. az. betw. three freballs ppr. Fursdon, Fursdon, co. Devon, temp. Henry III. Arg. a chev. betw. three fireballs gu. BaLIs, Balle-Hayes in Axminster, and Mamhead, co. Devon.

Arg. a chev. sa. betw. three fireballs of the last fired pyr. Ball. Williams, Chichester, Sussex. Az. a chev, erm. betw, three fireballs .... Attributed to Richard Caton, Maryland, North America (? in error).

Gu. a chev. arg. betw. three fireballs ppr. BaLL, co. Devon.

\section{Fishes}

Arg. a chev, az. betw. in chief two fishes naiant fesswise sa. and an oak-tree growing out of a mount in base vert. Glasgow, Scotland.

Arg. a chev. betw. three demi-fishes valant gu. SHambrooke.

Gu. a chev. betw. three fishes erect arg. BraHam, Braham, Cumberland.

$$
\text { ..... Cods }
$$

Sa. a chev. betw. three cods naiant arg. CoD.

$$
\text { .....Crabs }
$$

Arg. a chev. engr. az. betw. three crabs gu. Bridger or Briger, co. Gloucester; and Combe, Sussex.

Arg. a chev. betw. three crabs gu. Bridger. Arg. a chev. engr. betw. three crabs gu. BrIdger or Briger. Bryger, $V$.

Arg. a chev. engr. sa. betw. three crabs gil. BrIDger, Warminghurst, Sussex; the heiress m. Shiffuer. BRIDGER or BRIGER, co. Gloucester ; and Combe, Sussex.

$$
\text { .....Dolphins }
$$

Arg. a chev, erm. betw. three dolphins naiant az. Hasset.

Arg. a chev, erminois betw, three dolphins naiant embowed gu. Sergeant, co. Gloucester.

Arg. a chev. engr. gu. betw. three dolphins embowed sa. Coclston, St. Ives, co. Huntingdon. Arg. a chev. betw. three dolphins sa. Fryer. Kedall Keydali, or Kiddali, Cornwull. Sargeaunt, Michel-Dean, co. Gloucester.

Arg. a cbev. betw. three dolphins embowed sa. Sargant ol Skrgeant, co. Stafford. Sargent, Wool-Lavington, Sussex; quartering Smith, Orme, and Garton; the beiress $m$. Wilberforce. 
1 CHEVRON betw, or withn.... cont.

Fishes cont. Dolphins

Arg. a chev, betw. three dolphins naiant sa. Kendale, $V^{*}$. Krdale, $V^{*}$. Sargent, Halsted Place, Kent.

Arg. a chev. betw. three dolpbins naiant embowed sa. Kendalc, Treworgy, and Pelyn, Cornwall. Kandale, co. Devon, $V$. Kydale, $V$, co. Devon; Cotton. MS. Tiberius D, 10. Sergeant, Cotes, co. Stafford.

Az. a chev. betw. three dolphins arg. Trahaern Goch, Llyn.

Az. a chev. betw. three dolphins naiant arg. Freer. Frier, Scotland.

Az. a chev. betw. three dolphins hourient arg. Edmund Griffith, Bishop of Bangor 1634-7. Wynne, Lees Wood, co. Flint ; Baronetcy 1731 ; extinct ....

Az. a chev, hetw. three dolphins haurient arg. the head back fins and tail or. CArreg, Carreg, Cefnmine, etc., co. Carnarvon ; from Trahaiarn Gocr, Lleyn.

Az. a chev. or betw. three dolphins naiant embotred arg. TREWORTHGAN.

Gu. a chev. betw. three dolphins embowed arg. Caipnam, co. Hereford.

Gu. a chev. erm. betw. three dolphins embowed arg. Blennerhasset, Blennerville; Baronetcy 1809; and Ballyseedy; descended from Buennerhasset, Blennerhassett, Carlisle, and Flimby Hall, Cumberlard. Blaverhassett, Suffolk, $V$. Blenerhayset.

Gu. a chev. erm. betw. three dolphins naiant embowed arg. Breverhasset, Lowdham, Suffolk, temp. Edward III ; quartering Lowdham.

Per pale arg. and sa. a chev. betw. three dolphins counterchanged. Hubey or Hulbey. The dolphins naiant embowed. HALL. HuLL, $V$.

Sa. a chev. betw. three dolphins arg. Freere or Fryer, Essex; and Charlton, co. Salop.

Sa. a cher. betw. three dolphins embowed arg. Arnord, Cromer, Norfolk; Ballesford, Suffolk; and co. Devon. Fryer, Clan, Essex; London; and co. Worcester.

Sa. a chev. betw. three dolphins naiant embowed arg. DarCY, Norfolk.

Sa. a chev. arg. betw. three dolphins or. DARE, Norfolk.

Sa. a cher. arg. betw. three dolphins naiant ppr. Freer, Stratford-upon-Avon, co. Warwick.

Sa. a chev, or betw. three dolphins arg. LEVERSEDGE, Vallis, co. Somerset.

Sa. a chev. or betw. dolphins naiant embowed arg. Leversedge, $V^{*}$. Letersege, $V$.

Vert a chev. embattled or betw. three dolphins embowed arg. Brand, Wherstead, and Wood. bridge, Suffolk.

$$
\text { .....Eels }
$$

Gu. a chev, betw. three griggs (or young eels) with tails in the mouth arg. GRIGG.

$$
\text { .....Gournets }
$$

Arg. a chev. sa. betw. three gournets haurient gu. TuBB, Trengoff, and Guinop, Cornwall ; granted 1571.

\section{.....Hakes}

Arg. a chev. betw. three hakes haurient gu. HAKE, co. Devon.

$$
\text { ..... Iucies }
$$

Gu. a chev. betw. three lucies arg. Brougram, Brougbam, Westmoreland; quartering Vaux of Catterlen, Vaux of Tryermane, and Delamore; Barony 1830 aud 1860 .
1 CHEVRON betw. or within.... cont.

Fishes cont. Pikes

Gu. a chev. or betw. three Jucies haurient arg. $W_{A Y}$, co. Devon, $V$. WAYE, $V^{*}$.

Sa. a chev. betw. three pikes haurient arg. OLney or ONELEY, Thackbroke, co. Warwick.

$$
\text { ....Powets }
$$

Arg. a chev. gu. betw. three powets (or tadpoles) haurient sa. Russel, quartered by Ramsay.

$$
\text { .....Salmons }
$$

Arg. a chev, betw. three salmons haurient ppr. WAYTE, Lostwithiel.

Gu. a chev, betw. three salmons naiant arg. Milleton, Cornwall. Milington, co. Devon. Gu. a chev. or betw. three salmons naiant arg. Miraton. Militon, Pengersick, Cornwall; the co-heiresses $m$. Erisey, Parker, Lanyon, Trefusis, Tregodick, Trenwith, Arundell, and Hearle, Bonithon, and Abbot. Millington, $V^{*}$. Mrilington, $V$.

Sa. a chev. erm. betw. three salmons arg. Krna. Sa. a chev. erm. betw. three salmons haurient arg. Cater, London ; co. Leicester; co. Berks ; and co. Huntingdon, 1582. Cornelius Cater, London; granted 1584, W. CARTER, London. ORD.

Sa. a chev. gu. betw. three salmons arg. KINGE, London.

\section{....Smeits}

Az. a chev. betw. three smelts naiaut arg. SMELT, co. York.

Az. a chev, or betw. three smelts naiant ppr. Smeit, Slindon, Sussex

$$
\text { .....Soles }
$$

Arg. a chev. gu. betw. three soles haurient within a bordure engr. gu. Sole, Bobbing Place, Kent.

Arg. a chev. gu. betw, three soles hanrient ppr. within a bordure engr. sa. Soles, Brabanne, co. Cambridge. Sole, 1716. Soley, co. Worcester.

$$
\text { ..... Spaldirgs }
$$

Arg. a chev, sa. betw. three spaldings az. SPRAT, co. Dorset.

\section{.... Sprats}

Arg. a chev. sa. betw. three sprats az. SpRat, $V^{*}$. Sprott, $V$. Sprotr (but in pencil Fote), Harl. MS. 1404, fo. 41 .

Arg. a chev. sa. betw. three sprats naiant (az. another) ppr. Thomas Sprat, Bishop of Rochester 1684-1713.

\section{.....Trouts}

Sa. a chev, or betw. three trouts haurient arg. Foreman, Forman. Scotland.

$$
\text { ....Whelks }
$$

Arg. a chev. gu. betw. three whelks sa. SHELIy, co. Lincoln.

Az. a chev. betw. three whelks or. WILKINson, Old Buckenham, Norfolk; and Bantam, Westmoreland.

Gu. a cbev, vair betw. three whelk shells or. Wilkinson, Dorrington, co. Durbam; granted 18 Scptember 1538; and Middlesex.

Gu. a chev. vairy or and az. betw. three whelks of the second. Wrikinson, Bishopwearmouth, co. Durham; quartering Stote.

Sa. a chev. betw. three whelk shells arg. JoHN.

Sa. a chev. erm. betw. three whelk shells or. WYLDE, co. Worcester.

Flagons see Cups

Flaunches

Arg. a chev, betw. two flaunches sa. Halbayne, co. Devon. HALBEYN. 
1 CHEVRON betw, or within.... cont. Fleams

Arg. a chev. gu. betw. three fleams or. Chetham, Asl, co. Derby; and Smedley, co. Lancaster; quartering Sleigh.

Arg. a chev. gu. betw, three fleams sa. Chetrum, Suffolls. Sнетнам, co. Lancaster.

Sa, a chev. betw. three fleams arg. Company of Barbers, London, temp. Henry VI; Cotton. MS. Tiberius D 10, fo. 888 .

\section{Fleur-de-lis}

Az. a chev. or betw, in chief a fleur-de-lis arg. enclosed by two brick axes palewise gold and in base a bundle of laths as the last. Company of Bricklayers aNd THERs, London.

Fleurs-de-lis

Arg. a chev, gu. betw. in chief two fleurs-de-lis and in base an eagle az. Bellas.

Az. a chev. arg. betw. in chief two fleurs-de-lis and in base a crab or. CraB, Robslaw, Scotland.

Az. a chev. betw. in chief two fleurs-de-lis and in base a lion ramp. or. Gogh. Rbys ap Meredith, Tywyn.

Az. a chev. betw. two fleurs-de-lis in chief and a crab in base or. CrabB.

Erm. a chev, engr. az. betw. in chief two fleursde-lis ard in base a 5-foil sa. Browne, Everton, near Liverpool.

Gu. a chev. betw. in chief two fleurs-de-lis and in base a crescent arg. SHovel.

$\mathrm{Gu}$, a chev. betw. in chief two fleurs-de-lis and in base a rose arg. CEwEr, Surrey.

Az. a chev. betw. three demi-Heurs-de-lis or. Fribourg.

.... a chev. .... betw. three fleurs-de-lis .... Welsteed, Collinson, Somerset, ii, 231.

Arg. a chev. betw. three fleurs de-lis az. Dirwell.

Arg. a chev. az. betw. three fleurs-de-lis sa. Derwell. Dinweli. Dexwell or Dixweil, Essex.

Arg. a chev. betw. three fleurs-de-lis erm. Richard de YheDingham, $Y$.

Arg. a chev. embattled erm. betw. three fleurs-delis sa. Daveru, co. Devon.

Arg. a chev. gu. betw. three fleurs-de-lis az. Belasyse, Baronetcy 1611, Baron Belasise 1641-92, Baron Faulconberg 1627, Viscount 1642, extinct 1815; Earl 1689-1700, 1756-1802; the heirs m. Wrnn, Wombwell, Howard, and Bingham. Bellassis, $V$. Bellasiz, co. York, $V$. Dyrwell. York, Clothwood.

Arg. a chev, wavy gu. betw. three fleurs-de-lis az. Denne, Kent.

Arg. a chev. betw. three fleurs-de-lis gu. BerLasis, co. York. Caladmount, Cornwall. Carewell. Chaumond, Cornwall, $V$; or Chamond, Trenworth Chamond, and Launcells, Cornwall. quartering Tregarthian; a heiress $\mathrm{m}$. Arundel, Trevanion, and Gerveys. CHAwmond, $V^{*}$. Clamond, Lansells, Cornwall. Davall or Davell, co. York. Dennis, Kent. Dilderby. Fleming, co. York. Griffith, Wales. Holt, V. Hughes.

Arg. a chev. engr. betw. three fleurs-de-lis gu. WooD, Brockthorp, co. Gloucester.

Arg. a chev. gu. betw. three fleurs.de.lis sa. Delves, Dierwell, $V$. Dixwell, Brome House, and Barham, Kent; and co. Warwick.

Arg. a chev. per chev. or and sa. betw. three Heurs-de-lis erminois: MuLso, $V$.

Arg. a chev. sa. betw. three fleurs-de lis gu. Moreyne or Monyne, Essex. Morin. Morin, $V$. SHaDForth.
1 CHEVRON betw, or within.... cont.

Flenr-de-lis cont.

Arg. a chev. engr. sa. betw. three fleurs-de-lis gu. Wood, Cirencester, co. Gloucester.

Arg. a chev. betw. three fleurs-de-lis sa. Anstom, $V^{*}$. Anston. Anstum, $V$. Ascum. Aynscomb, Mayfield,Sussex; and Cowdon, Kent. Bonithon, Bouithon, Cornwall. Bonychon, Cornwall. Bonytham. Bonythan, $V$. Dexwels, $V$. Dixwell, Church Over, co. Warwick. Green, $V^{*}$. Glees or Grene, Newby, co. York. Green, Stock Newton. John Greene, Mewby, co. York, $W$. Prxwell, $V^{*}$. Randolfe, $V^{*}$. Randolff, $V$. Randolphe. M. Jolen Walsh, $S$. Wrnne, Asluford, Middlesex. Yedingham. Arg. a chev. embattled betw. three fleurs-de-lis sa. Davells.

Arg. a chev. engr. betw. three fleurs.de.lis sa. Afton, co. Devon. Aston, Cornwall. Aughton, co. Devon. Sturh Stuyth Stwyth or Stwythe. Thomas Stwyth, $V$. Styrch.

Arg. a chev, voided betw, three fleurs-de-lis sa. Fanshaw, Barking, Essex.

Arg. a chev. betw. three fleurs-de-lis vert. Spring, Suffolk. SPRiNGes, $V$.

Az. a cher, betw. three fleurs-de-lis arg. CrabB. Gerdeliey or Gerdilley. Goodsir, Scotland.

Az. a chev, betw. three fleurs-de.lis arg. Hint, Kent, $W$. Lanacre, co. York. Linarce, co. York. Moone, Austhorp, co. York.

Az. a chev. engr. betw. three fleurs-de-lis arg. GARDELL.

Az. a chev, arg. betw. three fleurs-de-lis or. Brayer or Brayor. Fremonstratensian abbey at Hales.Owen, co. Salop. Huil or Hules. Hulu, Ireland. Hules or Hulles. Hulls, $\boldsymbol{V}$. Krnynmound, quartered by Murray.

Az. a chev. arg. betw. in chief three fleurs-de-lis or and in base a lion ramp. ppr. HaLL-JoY, Hartham Paik, co. Wilts; quartering Hall, Joye, and Hall.

Az. a chev. engr. arg. betw. three fleurs-de-lis or. GARDELL.

Az. a chev. chequy arg. and gu. betw. tbree fleursde-lis or. Brown, Edinburgh.

Az. a chev. chequy arg. and gu. betw. three fleursde-lis or and a bordure erm. Brown, Edinburgh. Az. a chev. (compony, $V^{*}$ ) countercompony arg. and sa. betw. three fleurs-de-lis or. STanes, $V$. Az. a chev, engr. erm. betw. three fleurs-de-lis arg. John Woodward, Kent, $V$.

Az. a chev. gu. betw. in chief three fleurs-de-lis and in base a demi-lion ramp. arg. Joy, Ireland.

Az. a chev. or betw. three fleurs-de-lis arg. GARDELL, $V$.

Az. a chev, betw. three fleurs-de-lis or. Brown, Fordel, Scotland. Hulu, $W$. Huldes, $V^{*}$, or HuLus, $V^{*}$.

Az. a chev. invecked betw. three fleurs-de-lis or. Brown, Kingside, Scotland.

Az. a chev. betw. in chief three fieurs de-lis or and in base a pen arg. Gilmour, Craigmillar, Scotland.

Az. a chev. wavy betw. three fleurs-de-lis or. Brown, Horn, Scotland.

Az. a chev. quarterly per chev. or and arg. betw. tbree fleurs-de-lis of the second. MARDock, co. Hertford. Matoke or Mattick, co. Hertford; and co. York. Matтick, quartered by Wilton. The fleurs-de-lis seeded. Mатоке, Hychen, co. Hertford, $V$. Mаттоск, $V^{*}$. 
1 CHEVRON betw. or within.....cont.

Fleurs-de-lis cont.

Az. a cliev. quarterly or and of the second betw. three fleurs-de-lis gold. Simonds, co. Worcester.

Erm. a chev. az, betw. three fleurs-de.lis or. Curtis.

Erm. a chev. betw, three fleurs-de-lis gu. Barber, Lord Mayor of London 1733.

Erm. a chev. or betw. three fleurs-de-lis gu. Barber, Lord Mayor of London 1733.

Erm. a chev. betw. three fleurs-de-lis or. Fromond or Fromount.

Erm. a chev. sa. betw. three fleurs-de-lis .... Curtis, Teignmouth, co. Devon, quartering Savage.

Gu. a chev. betw. three fleurs de.lis arg. ENGs, $V^{*}$.

$\mathrm{Gu}$. a chev. engr. betw. three fleurs-de.lis ar.

Raynford, Hadley, Essex. Raynsford, Bradfield, Essex. Sr. Jobn Raynsford, Essex, $W$, but Sussex, V, Cotton MS. Tiberius D 10, quartering gu. six eagles displ.three and three or.

Gu. a chev. arg. betw. three fleurs-de-lis or. Gullan, Scotland. Guven.

Gu. a chev. (compony, $V^{*}$.) countercompony arg. and sa. betw. three fleurs-de-lis or. Sr. Jolin Scherley, $W$, but Sherley, $V$, Cotton $M S$. Tiberius D 10. Shirley, London; confirmed 10 September 1609 .

Gu. a chev. erm. betw. three fleurs-de-lis arg. Crome, Mayden Early, co. Berks.

Gu. a chev. engr. erm. betw. three fieurs-de-lis arg. Crome, Ockingham, co. Berks; and Bromton, Middlesex.

$\mathrm{Gu}$. a chev. betw. three fleurs-de-lis erm. ALLWENT.

$\mathrm{Gu}$. a chev. erm. betw, three fleurs.de-lis or. $\mathrm{Sr}$. Thomas Montgomery, Essex, $V$. Rise, Suffolk.

$\mathrm{Gu}$. a chev, engr. erm. betw. three fleurs-de-lis or. Wolgar, co. Hauts.

$\mathrm{Gu}$. a chev. erminois betw. three fleurs-de-lis or. Brown, Westminster; Baronetcy 1732, extinct 1830.

Gu. a chev, lozengy arg. and sa. betw. three fleurs-de-lis or. SHERLEY or ShirLey.

$\mathrm{Gu}$. a cliev. or betw. three fleurs-de-lis arg. Hayneliles, Norfolk. Hayvilus.

$\mathrm{Gu}$. a chev. engr. or betw. three fleurs-de-lis arg. Mymyng Mynors or Mynos. Ralnefort.

$\mathrm{Gu}$. a chev. or betw. three fleurs-de-lis in chief two of the second and in base one arg. READ, London; granted 1599.

Gu. a chev. betw. three fleurs-de-lis or. Brows, Balquharn, Scotland. Browne, Westmunster; Baronetcy 11 March 1732, extinct 1830 . Croudace, Durbam. Lambert. Pickering, $V^{*}$. Sr. William Prkering, Kyrkby Kendall, and Oswaldkirk, $V$. StenNetT or StenNitT.

Gu. a chev. wavy betw. three fleurs-de-lis or. Hickes, Peddington, co. Gloncester, ob. 1746.

Or a chev. embattled erm. betw. tbree fleurs.de. lis gu. Davils.

Or a chev. per chev. gn. and sa. betw. three fleurs. de.lis seeded erm. Moulso, Calais, $V$; but seeded arg. $V^{*}$.

Or a chev. betw. three fleurs-de-lis per pale arg. and gu. Freeiran, Norfolk, $W$.

Or a chev. betw. three fleurs.de-lis purp. Swert or SwiFt ; granted 16f5. SwiFt, Ireland.

Or a chev. sa. betw. three fleurs-de-lis az. Millecent, Barkham Hall, co. Cambridge. Mirlicent, Linton, co. Cambridge. Mylsent. YAwKINs, Scotland.

\section{CHEVRON betw. or within.... cont.}

Fleurs-de-lis cont.

Or a chev, betw. three fleurs-de-lis sa. Brown, Carslaith, Scotland. Fanshaw, Ireland, Vis. count Fanshaw, derived from Fanshaw, Fan. shawgate, co. Derby; and Parsloes, Dengy Hall, and Barking, Essex. Fanshaw, West Park, co. Hertford.

Or a chev, engr: betw. three fleurs-de-lis sa. Brown, Dolphington.

Per chev. arg. and sa. a chev. erm. betw. three fleurs-de-lis counterchanged. LofTus.

Per chev. erm. and gu. a chev. betw. three fleursde-lis or. Fromonns, Cheyham, Surrey; and Hadlow, Kent. Jobn Fromoundes, ob. 1580, in Cheam Church. Frromond. Feomound or Fromount, Surrey, $W$; but Fremond, $V$, Cott. MS. 'Tiberius D I0.

Per chev. erm. and vert a chev. engr. counter. changed betw. three fleurs-de.lis or. STokes, $V$.

Per pale arg. and sa. a chev. betw. three fleursde-lis counterchanged. Christopher NELSON, Grimston, co. York, $V$. Nelson, London.

Per pale az. and arg. a chcv. betw. tliree fleursde.lis counterchanged. Weltes, $\boldsymbol{V}$.

Per pale az. and gu. a chev, or betw. three fleursde-lis arg. HuLl, Durham.

Per pale az. and sa. a chev. betw. three fleurs-delis or. OWEN, co. Gloucester.

Purp. a chev. betw. three fleurs-de-lis or. Ossan. Purp. a chev, engr. betw. three fleurs-de-lis or. Osam, Cotton. MIS. Tiberius D, 10. Usan. Osanne, $V$. Ossaur.

Sa, a chev. hetw. three fleurs-de-lis arg. BoDwind. Ediwwain ap Bleddin, Prince of Ardidwy. Bodwrdar, Bodwrdar. Caradoc. Cansey. Cowcey Cowcie or Cowcy. Eliss, Ystmyllyn, co. Carnarvon. Ellis, Bronbwil. Evans, Tau y bwlch. Gettenes. Griffith. Howeli, Prinknash Yark, co. Gloucester. Hughes, Betshanger, Kent; Oxford; and Newhery, co. Berks. Hughes, Cheltenham; and Trostrey, co. Monmoutb. Jenkins. Jenkinson. Powelt, Llwydarth, Lanharen, and Maesteg, co. Glamorgan: Powell (quartering Vaughan) quartered by Ollney. Prytherch, Tregaian. Richards, Isle of Wight, co. Hants. Richards, Solsborough, Rathaspock, and Ardemine, co. Wexford. Einion ap Collwyn AP TANGRo, 12th century, lord of Efionydd. VAUGHAN, Aberkain. VAUGHAN, Baron Vaughan and Viscount Lisburne 1695, and Earl of Lisburne 1776. Richard VAUGHaN, Bishop of Bangor I596, Chester 1597, London 1604-7. VaUGHaN, Wales. White, Anglesea, $Z, 320$. Williams, Aberarch, co. Carnarvon. Wynne, Gwynfryn, and Glynllivon; Baronetcy 1742, Baron Newborough 1776. Wyns, Bodrean, and Blodwell, co. Carnarvon. And with a crescent for diff. Moone, Wollington, co. Hereford. Richands, Goodnestone, Kent.

Sa. a chev. engr: betw, three fleurs-delis arg. AsHFIELD. DIGBY.

Sa. a chev. wavy betw. three fleurs.de-lis arg. Walter FisH, Stowmarket, Suffolk, $W$.

Sa. a chev, arg. betw. three fleurs-de lis or. HART, Lord Mayor of London 1589.

Sa. a chev, or betw, three fleurs-de-lis arg. Bonighair, $V$.* Sr....de Boningham, $V$. Thomas Cawsse, Norfolk, $V$. Hart, London; and co. York. Jenkins, Ireland. Penwarn, Penwarn, and Mullyton, Cornwall. 
1 CHEVRON betw. or within.... cont.

Fleurs-de-lis cont.

Sa. a chev. betw. three fleurs-de-lis or. BusfeILD, Upwood, co. York. Ellis, Carmarthen. EvaYne, Evens, Essex. Ewen, Essex, $V$. Fanshawe. Hughes, Brecon. Pichands, Corner House, co. Glamorgan, quartering sa. a chev. betw. three fleurs de-lis arg., and per pale az. and gu. three lions ramp. arg., with or on a chev. gu. betw. three buglehorns sa. stringed of the second as many crosses croslet fitchy of the first. Vaughan, co. Salop.

Vert a chev, betw. three fleurs-de-lis or. CruL or KyrLE, Altone, or Old Town, and Hornme, now Hom Green, near Ross, 1295; and Walford Court, co. Hereford, temp. Henry VII, quartering Abraball. KirLe, co. Salop. KyrLe, Much Marcle, co. Hereford, quartering Money.

Az. a chev. betw. four fleurs-de-lis and over all a pile or. Coutry, Broxbourne.

Flowers .... Bluebottles

Arg. a chev. gn, betw. two bluebottles ppr. stalked vert. BотнELL.

\section{.... Roses}

....a chev. betw. in chief two roses and in base a fleur-de-lis.... Lancelot du Lac, Chevalier, seal 16 or 17 century.

.... a chev. betw, in chief two roses and in base a talbot.... Pope, Collinson, Somerset, iii, 404. The talbot pass. Jobn Pope alias TaLBot.

Arg. a chev. az. betw. in chief two roses gu. and in base a bunting horn sa. stringed of the third. Jowsie, Scotland.

Arg. a chev. az. betw. in chief two roses gu. and in base a sword point downwards of the second. M'Lure, Scotland.

Arg. a chev, az. betw. in chief two roses gu. barbed ppr. and in base a bear's head erased sa. GEEkIE, London.

Arg. a chev. az, betw. in chief two roses gu barbed vert and in base an eagle close of the second. Chardin, Benley Park, co. Leicester.

Arg. a chev. gu. betw. in chief two roses of the last and in base a fish naiant az. Roscares, Ireland, $V$. Roscarreck, Roscarreck, Corluwall, $V$. Roscarick, $V^{*}$. Roscarrick. Roscarrock, Cornwall.

Arg. a chev. sa. betw. in chief two roses and in base a holly leaf gu. KaDrow, Scotland.

Arg. a chev. betw. in chief two roses and in base a hunting horn sa. Jossey or Jousey, Scolland.

Az. a chev. or betw, in chief two roses arg. barbed and seeded ppr. and in base an eagle displ. with two heads of the same. Lrevre.

Az. a chev. or betw. in chief two roses arg. leaved vert and in base a cock of the third combed beaked and legged gu. Srmond, Austin Friars, London; granted 30 June, 1760.

Az. a chev. or betw. in chief two roses slipped and in base a sun ppr. Dreux, Paris.

Erm. a chev. vairy gu. and or betw. in chief two roses of the second barbed vert and in base a lily (iris) stalked and leaved ppr. (i.e. white seeded gold with leaves vert). WAPSHoTT. WHAPSHOT.

Gu. a chev. betw. in chief two roses and in base a fleur-ile-lis arg. Cure, Kensington, Middlesex.

Gu. a chev. betw, in chief two roses and in base a boar's head erased arg. Boggie, Scotland.

Gu. a chev. betw. in chief two roses arg. barbed vert seeded or and in base a fleur de-lis of the second. Codre, France.
1 CHEVRON betw, or within.... cont.

Flowers cont. Roses cont.

Gu. a chev, arg. betw. in chief two roses or and in base a cross patty of the second. Doge, Doge, Scotland.

Gu. a chev. arg. betw. in chief two roses or and in base a fleur-de-lis of the (first, $V^{*}$.) second. George Cure, London, granted 1588, W. Cure, Blalse Hall, near Ongar, Essex.

Or a chev. gu. betw. in chief two roses of the last and in base a fish naiant az. Roscarrock, Roscarrock, Cornwall.

Or a chev. gu. betw. in chief two roses ppr. and in base a dolphin embowed of the last. IAANGSTON or LANGSTONE.

Or a chev. vair betw. in chief gu. two roses and in base a ship ppr. Bogle, Scotland.

Per chev. arg. and az. a chev. per chev. sa. and of the first betw. in chief two roses gu. seeded and barbed ppr. and in base a garb or. Coxed, co. Oxford, 1737.

Per pale gu, and vert a chev inclented erm. betw. two roses and as many fleurs-de-lis all counterchanged. Somer, Newland, Kent. .....Bluebottles

Arg. a chev, betw. three bluebottles az. cupped vert. Chorlex, Cott. MS. Tiberius D, 10, But slipped. Cherley.

Arg. a chev. gu. betw. three bluebottles az. Bothell, $V^{*}$.

Arg. a chev. gu. betw. three bluebottles az. cupped vert. Chorley, $V$. But slipped. Cherley, $V *$. Chorley, Chorley, co. Lancaster ; and Leek, co. Stafford. Juckes, quartered by Clifton.

Arg. a chev. gu. betw. three haydoddes az. slipped vert. DODD; Harl. MS. 2151, fo. 110.

Arg. a chev. gu. betw. three bluebottles $\mathrm{ppr}$ stalked vert. BотHELL.

\section{....Columbines}

Arg. a chev. betw. three columbines pendent az. barbed gu. slipped vert. Timothy HaLL, Bishop of Oxford, 1688.90.

Arg. a chev. engr. gir. betw. three columbines ppr. stalked and leaved vert. Company of Coors, London.

Arg. a cbev. sa. betw. three columbines az. Coventre, $V^{*}$. Coventreye.

Arg. a chev. engr. sa. betw. three columbines pendent az. Company of Cooks, London, Cotton. MS. Tiberius D 10 , fo. 885 .

Arg. a chev. sa. between three columbines pendent az. slipped vert. Sir John Coventre, Alderman of London, $\boldsymbol{V}$.

Arg. a chev. sa. betw. three columbines ppr. Coventry, Lord Mayor of London, 3425. Hall, co. Worcester.

Arg. a chev. sa. betw. three columbines slipped ppr. HaIL, Coventry, co. Warwick.

Arg. a chev. betw. three columbines pendent and slipped each of four leaves vert. Clarke, $W$.

Or a chev. sa. betw. three columbines az. Chipderden.

\section{.... Gilliflowers}

Arg. a chev. gu. betw. three gillifiowers az BothelL, V.; (slipped, Cotton MS. Tiberius D, 10.)

Arg. a chev. gu. betw, three gilliflowers of the second cupped vert. BothelL, $V$.

Arg. a chev. sa. betw. three gilliflowers ppr. Thomas Pace, alias Skeffington or Skevington, Bishop of Bangor 1510-33.

Or a chev. betw. three gilliflowers gu. John de Lisle or Sire Johan de Lysley, in error. 
1 CHEVRON betw. or within.... cont.

Flowers cont. Marigolds

Gu. a chev. or betw. three marigolds of the last stalked and leaved vert. GoLDMan, Sandford. ....Primroses

Az. a chev, arg. betw. three primroses slipped ppr. Carstans, Kilconquhar.

$$
\text { .... Roses }
$$

.... a chevron betw. three roses... Cambridge.

Arg. a chev. betw. three roses az. Inwin IRWINE or IRWYNE, Ireland.

Arg. a chev. betw, three roses az. within a bordure gu, GifFard, co. Leicester.

Arg. a chev. az. betw. three roses gu. M 4 ckusw, Garden. Rosagan, Kenegie, Cornwall. Rossel. Rutland.

Arg. a chev. embattled az. betw. three roses gu. slipped and barbed or. Asruun. But the roses stalked and leaved ppr. AsLin, London.

Arg. a chev. betw. three roses gu. Alisen. Ashton. Coop or Coope. Knolt. Lacke, that Ilk. Leckie, Scotland. LECKY, that Ilk. Lyne, Cornwall. Pearson. Phillips. Norley, co. Devon. Ressuggan, St. Earne, Cornwall. Resuggan, Cornwall, $W$. Rugeley, Shenstone and Smallwood, co. Stafford, and Downton Rugeley, co. Warwick. Ruggelay. Roggeisy, Shenton, and Hanksyard, co. Stafford, $W$. John Rugley, co. Warwick, $V$. Russell. Thirkeil, Shenstone, co. Stafford. Upton, Gaydon, co. Warwick. WedderbURn, Ruthven, Scotland, quartering Colvil. Wrdoerurn, London; and Easter Pawrie, Scotland. Wiard, London. Philip WYARD, $V$. WYWARD, $V^{*}$.

Arg. a chev. engr. betw. three roses gu. Manigfond. Mannyord, co. Dorset. Manningforde, 1352. White, $V^{*}$. Whyte, Ireland, $V$.

Arg. a chev, wavy betw. three roses gu. Manfold Mannyfold or Manyfold. Manyfold, Cornwall, $V$.

Arg. a chev. betw, three roses gu. seeded or. Roscrowe, Roscrowe, Cornwall.

Arg. a chev. gu. betw. three roses of the last seeded or leaved vert. Puelirs, Briggins Park, co. Hertford; descended through PHELIPS or Philups, Montacute, Collinson, Somerset, iii, 314; the heiress m. Farquharson; from Phelips, Barrington and Corfe Mullen, co. Dorset; the heiress m. Hareham. Powell, Hinton, Hereford. RugGles, Spains Hall, Essex; and Clare, Suffulk; descended from Rogyli or Ruggles, Sudbury, 1547.

Arg. a chev. betw. three roses gu. seeded or barbed vert. White, Treland.

Arg. a chev. engr. betw. three roses gu. seeded or barbed of the first. WHITE, Ireland.

Arg. a chev. sa. hetw. three roses az. slippea and barbed vert. Browne.

Arg. a chev. sa. betw. three roses gu. Roger de Clifton, $Y$. John Holyman, Bishop of Bristol 1554-8. Polives. Norleighe. Northleigh, Northleigh, co. Devon. Smit н, co. Lancaster, $W$. Smyth, co. York. Tresithney, Penryn, Cornwall; the cu-heiress m. Treffry. Wickнам.

Arg. a chev. sa. betw. three roses gu. seeded az. stalked and leaved or. Browne, $V^{*}$.

Arg. a chev. sa. betw. three roses gu. seeded az. stalked and leaved vert. Browne.

Arg. a chev. sa. betw. three roses gu. seeded or harbed vert. Sinth, Curdley, co. Lancaster.
1 CHEVRON betw. or within.... cont.

Flowers cont. Roses cont.

Arg. a chev. sa. betw. three roses gu. seeded and leaved ppr. Nicholas WEst, Bishop of Ely, 1515-33.

Arg. a chev. sa. betw. three roses gu. barbed and seeded vert. William Smith, Bisbop of Lichfield, etc., 1491, Lincoln 1496-1513; and Brazen Nose College, Oxford, as founded by him.

Arg. a chev. 8a. betw. three roses ppr. Sirith, Farnworth, co. Lancaster. Smith, Bishop of Lichfield, etc. 1491; Lincolu 1496-1513.

Arg. a chev. betw. three roses sa. Raynstone, co. Devon. Smith.

Arg. a chev, betw. three roses erochees sa. Thomas Murrell, Scrimby, $Y$.

Arg. a chev. betw. three pierced roses vert. TyLesLey.

Az. a chev. betw. three roses arg. Prentisse, $V^{*}$. John Prentysse, $V$.

Az. a chev. wary arg. betw. three roses gu. slipped or. GiriLispie, Newton.

Az. a chev. engr. arg. betw. three roses or. Lower, Colnwall.

Az. a chev. engr. or betw. three roses arg. Lower, Cornwall. Lowne, Cornwall, $W$.

Az. a chev. betw. three roses or. LandHam or Laneam. Laudham, $V$. Russeli, co. Rut. land.

Erm. a chev. sa. betw. three roses gu. seeded and leaved ppr. FARMor.

Erm. a chev. vairy or and az. betw. three roses gu. seeded of the second. ADAMs, Cheaton, co. Salop.

Erminois a chev, betw. three roses gu. Rickers. Gu. a chev. betw. three roses arg. Barkelex, co. Gloucester. EDwands, Maes-yr-hen-llys, co. Denbigh; Gouldgrieve, co. Flint; and Old Court, co. Wicklow; quartering Kynastou. Einion ap Geraint. Geydon. Knei.l. Elias de KNoLL, Lord of Knollsmere, Wigglesworth, and Hellifield Peel, co. York; coheirs m. Hamerton and Halton. RHoDrI Mawr. WADHAM, co. Devon; and Merifield, co. Somerset. Sir Nicholas WadHam, $V$; and Collinson, Somerset, i, 8, with thirteen quarterings, ob. 1609. And with a mullet for diff. WaDHant, Cotherston, co. Dorset. Woodhan, Catherston, Cornwall.

Gu. a chev. betw. three roses arg. barbed vert. Wadhair College, Oxford, founded 1613 by Nicholas Wadham, of Merefield, co. Somerset, and his wife, Dorotby Petre, impaling Petre.

Gu. a chev. betw. three roses arg. seeded or barbed vert. RODERICK the Great, King of all Wales (Rhodri MaUR).

Gu. a chev. engr. betw. three roses arg. WHite, Bristol.

Gu. a chev. arg. betw. three roses or. Lockenby, That Ilk.

Gu. a chev. erm. betw. three roses or. Dicome, co. Livcoln.

Gu. a chev. betw. three roses or. Strton, Salis. bury, co. Wilts.

Gu. a chev, vair betw. three roses arg. Reve, Malden, Suffolk; granted 1590.

Gu. a chev. vairy or and az. betw. three roses arg. Rene, Hubbart's Hall, Essex. Francis Reve, Molden, Suffolk; granted 1590, $W$.

Or a chev. az. betw. three roses gu. Mac Clany, Gardin, Scotland. M'LEY, Strathconath. Sire Geffrey Rosser, $N$. Sr. William Rosseli, 
1 CHEVRON betw. or within.....cont.

Flowers cont. Roses cont.

Northampton, $V$. Thomas Russell, $X ; Y$. And witb a label arg. M. Hugh Russeli, $X ; Y$.

Or a chev. az. betw. in chief three roses gu. and in base a dolphin naiant embowed of the second. Langston, $V$. Langstone, $V^{*}$.

Or a chev. betw. tbree roses gu. Bish. Bisshe, Essex. Bysshe, Surrey; and Sussex, $W$. Brshe, $V^{*}$.

Or a chev. embattled betw. three roses gu. stalked with two leaves vert. AsLin or Assiam, $V$.

Or a chev. gu. betw. in chief three roses ppr. and in base a dolphin embowed of the last. Langston or Langstone.

Or a chev. quarterly az. and gu. betw. three roses of the third. Dismoes or Dismos. Dysmars, Harl. MS. 1404, fo. 99.

Or a chev. sa. betw. three roses gu. William WICKHAM or WrkeHAM, while Archdeacon of Lincoln, 1366; Louth, p. 10.

Per pale arg. and gu. a chev. engr. betw. three roses counterchanged. WHITE.

Per pale arg. and or a chev. engr. betw. three roses counterchanged. Drewe.

Sa. a chev. arg. betw. three roses or (? surmounted of as many gu. seeded of the third). William Smith, Bishop of Lichfield, etc., 1491, Lincoln 1.96-1513.

Sa. a chev. betw. three roses arg. Consish, Collinson, Somerset, iii, 40l. Lownr, Trelaske, Cornwall, $W$. Lowen, St. Winnow Barton, Trelaske, Polmawgan, Tremeere, Lezant, and St. Judie, Cornwall. Roderick the Great (? in error). Moyne, Charter-House, Hinton, and Mendip, co. Somerset. Rose. Roys. Russeli, of the North, $W$.

Sa. a chev. betw. three roses arg. barbed rert. HOPTON.

Sa. a chev. betw. three roses or. Bonnington, Barrowcote, co. Derby.

Vert a chev. betw. three roses arg. HoLmas.

Sa. a chev. embattled or betw. three roses arg. Connish, Sharnbroke, co. Berks; Baronetcy 1766; extinct 1770. ConNish, Essex; and Kent. Cornishe, $V *$. Cornyshe, $V$. Forneche or Fornech.

\section{....Thistles}

Arg. a chev. az. betw. three thistles slipped of the second leaved vert. ChORLEy, 1730.

Vert a chev. betw. three thistles or. Skewis, Great Skewis, in St. Wenn, Cornwall; the co. heirs m. Mohun and Courtenay.

\section{....Teazles}

Arg. a chev. sa. betw. three teazles stalked and leaved ppr. FULHAM.

Sa. a chev. erm. betw. three teazles or leaved vert. BENNETt, Harl. MS. 1603.

$$
\text { ....Roses }
$$

Gu. a chev. betw, eight roses arg. Sir Thomas BarCley, $L$.

Gu. a ehev. betw. ten roses arg. barbed or. Bankeley or Barkley, co. Leicester.

Gu. a chev. hetw. roses arg. Sire Thomas Barcley, L, Harl.MS. 6589 ; or de'Berkeleye, $N$ (? of Wymondhan).

\section{3-Foils}

Arg. a chev. az. betw. in chief two 3 .foils slipped vert and in base a chaplet ppr. Becker, London.

Arg. a chev. gu. betw. in chief two 3.foils slipped and in base a 5 -foil vert. Gouldie, Scotland.

\section{CHEVRON betw. or within.... cont.}

\section{3-Foils cont.}

Arg. a chev. betw. in chief two 3-foils vert and in base a bull's head couped at the neck gu. horned and crined or. NEate, London; and Swindon, co. Wilts.

Arg. a chev. betw. in chief two 3-foils slipped vert and in base a tortoise gu. Goupie, Scotland. Sa. a chev. arg. betw. in chief two 3 -foils slipped and in base a bezant on the top a cross patty or. Lefevre, Old Ford, Middlesex; granted $7 \mathrm{July,} \mathrm{1789.} \mathrm{Shaw-Lefevre,} \mathrm{Heckfield,} \mathrm{co.}$ Hants; quartering Shaw.

Vert a chev. betw. in chief two 3-foils slipped and in base a fleur-de-lis arg. Plendercleith, Blyth, and Peebles, Scotland.

.... a chev. betw. three 3 foils .... a crescent for diff. .... Thomas Wicrins, 1694, Banstead Church.

Arg. a chev. betw. three 3-foils az. Robert Frost, in Tankersley church, co. York.

Arg. a chev. betw. three 3-foils slipped az. Tradwick.

Arg. a chev. az. betw. three 3-foils gu. CHamber, Wolsticastle,Cornwall; Hacton, Essex; and Middlesex. Rowe, Kingston, and Bearton, co. Devon. Arg. a chev. az. betw. three 3-foils slipped gu. Crambers, London; and Barkway, co. Hertford. Arg. a chev. az. betw. three 3-foils slipped per pale gu. and vert. RoE or Row, co. Devon; granted 1595. Rowe, London.

Arg. a chev, az. betw. three 3-foils slipped vert. Treadway.

Arg. a chev, voided az. betw. three 3-foils slipped vert. DE CARDONNEI.

Arg. a chev. gu. betw. three 3-foils slipped and erased at the foot az. Frost, co. York, $V$.; but not erased in Cott. MS. Tiberius D 10.

Arg. a chev. betw, three 3-foils slipped gu. Chambers, London. Goold or Gould, Scotland.

Arg. a chev, gu. betw. tbree 3 -foils vert. Blomefield.

Arg. a chev. gu. betw. three 3.foils slipped vert. GOI.DIE, England; and Craigmue, Scotland. SLEFORD, Wilsthrop, co. Lincoln.

Arg. a chev. engr. paly sa. and or betw. three 3 -foils of the second. Cray, Fulwell Lodge, Middlesex; Baronetcy 1841.

Arg. a chev. purp. betw. three 3-foils slipped sa. Richard Moreton, co. Salop, quartering gu. a cock or, $W$.

Arg. a chev. sa. betw. three 3-foils slipped gu. Hesill. HesYil, $V$.

Arg. a chev. betw. three 3-foils sa. Fitz-LEwes. FletT.

Arg. a chev. betw. three 3-foils slipped sa. CAPps, Kent. Roger Cappus, Kent, $V$. Capys, co. Gloucester, V. Flote. Lewr.s, Norwich. Moneton, $V$. Monton, co. Salop. Moneton, quartering gu. a cock or; $V$, in Cott. MS. 'Tiberius D 10 . Ronsfond or RowsFond. Rufford, $V$; and co. Buckingham. Adam WaLche, Wales, 1460, V. Wines, co.Gloucester. Arg. a chev. engr. betw. three 3 -foils slipped sa. Claye or Cley, Cryche, co. Derby; the coheirs m. Brailsford, Pwisey, and Clarke. Clay, Bridgehouses, Sheffield; impaling Greaves.

Arg. a chev. sa. betw. three 3 -foils vert. HEsiLL. Arg. a chev. sa. betw. three 3 -foils slipped vert. BeckFord. Frost, co. York. HaLYAN, $V^{*}$. William HAIYAX, V. UNDERHIL, Hounslow, Middlesex; Wolverhampton, co. Stafford; and Ettington, co. Warwick. UNDERHILL, $V$. 
1 CHEVRON betw. or within..... cont.

3-Foils cont.

Arg. a chev. engr. sa. betw. three 3 -foils slipped vert. BREWIN.

Arg. a chev. betw. three 3-foils vert. Peverell, Cornwall. Markes, Essex.

Arg. a chev, betw. three 3-foils slipped vert. Rotten.

Az. a chev, betw. three 3 -foils arg. $\mathrm{M}^{6} \mathrm{CHEAN}$, Scotland.

Az. a chev, betw. three 3-foils slipped arg. M'Hanaz, Scotland.

Az. a chev. arg. betw. three 3-foils slipped or. BeARD, Beard Hall, co. Derby.

Az. a chev. erm. betw. three 3-foils arg. Parsons, Hemerton, co. Gloucester.

Az. a chev. erm. betw, three 3-foils slipped arg. MEADE, Baronetcy 1703, Baron Gilford and Viscount Clanwilliam 1766, Baron Clanwilliam 1828, Earl of Clanwilliam 1776.

Az. \& chev. betw, three 3-foils slipped or. Bloss, Ireland. Bothweis, Baron Holyrood House. Bothwel, Bishop of Orkney 1562-93. Lrnch, Galway, Ireland. Lynch, Castle Carra, co. Mayo; Baronetcy 1622.

Az. a chev. engr. betw. three 3-foils slipped or. Symonds.

Erm. a chev. betw. three 3-foils slipped arg. a bordure engr. sa. Mallony, Harl. MS. 1404, fo. 62 .

Gu. a chev. betw. three 3-foils slipped arg. Duddin, Scotland. Dunnage. Mead.

Gu. a chev. arg. betw. three 3-foils stalked or. Nicholls, Baynham, Suffolk.

Gu. a chev. arg. betw. three 3-foils stalked (couped $V^{*}$ ) slipped and raguly or. George Nicoll, Southold, Suffolk, $V$.

Gu. a chev. erm. betw. three 3-foils arg. MEdE or MEaDE, co. Cambridge; and Cornwall. MODEY.

Gu. a chev, erm. betw. three 3-foils slipped arg. MeADE, co. Cambridge; and co. Somerset. Mede, $V$.

Gu. a chev. engr. erm. betw. three 3-foils slipped arg. Lorft, Troston, Suffolk.

Gu. a chev. erm. betw. three 3-foils slipped or. MEUGH, Ireland.

Gu. a chev. or betw. three 3-foils slipped arg. Thomas de Insula or de Lisle, Bishop of Ely 1345-61.

Or a chev. betw. three 3 -foils slipped az. CHaRlewood,

Or a chev. az. betw. three 3-foils slipped vert. Sirytre, Cotton. $M S$. Tiberius $\mathrm{D} 10$.

Or a chev. chequy gu. and arg. betw. three 3.foils slipped vert. DAN or DANN.

Or a chev, betw. three 3-foils slipped gu. Chicheley, $V$; and co. Cambridge. Williamson, East Markham, oo. Nottingham; (? an error).

Or a chev. embattled betw. three 3 -foils slipped gu. Simon Langham, Bishop of Ely 1362, Archbishop of Canterbury 1366-68.

Or a chev. gu. hetw. three 3-foils slipped sa. Williamson, Walkeringham, and Burton, granted 1602 ; and Great Markham and East Markham, co. Nottingham; Gainsborough, co. Lincoln; and Whitburn Hall, Monkwearmouth; Baronetcy 1642.

Or a chev. gu. betw. three 3-foils slipped vert. Slater, Barlborough, and Durant Hall, near Chesterfield, co. Derby.

Or a chev. sa. betw. three 3-foils az. Treshewy St. Stephen's, Cornwall.
1 CHEVRON betw, or within..... cont.

3.Foils cont.

Or a chev. betw. three 3-foils slipped sa. ABDY, Essex. Holworther.

Or a chev. engr. betw. three 3-foils slipped sa. Wrliramson, Melbeck Hall, Cumberland; granted 1670.71 ; and Mount Vernon, Liverpool.

Or a chev. sa. betw. in chief three 3-foils slipped vert and in base a mullet gu. ALsworthy.

Per pale arg. and gu. a chev. az. betw. three 3 -foils slipped counterchanged. Pike, co. Devon.

Per pale arg. and gu. a chev. betw. three 3-foils counterclianged. PrTts, co. Bedford.

Per pale az. and gu. a chev. betw. three 3-foils one and two in chief and an orb and cross in base or. Lefevre, Stepney Green, Middlesex.

Per pale or and gu. a chev. az. betw. three 3-foils slipped counterchanged. PIKE.

Per pale or and vert a chev. voided betw. three 8-foils counterchanged. WICKENS, Stochtbrewen, co. Northampton; confirmed 23 May 1640. The three 3-foils slipped. WIGGins.

Sa. a chev. betw. three 3-foils arg. LEw Is, Essex; co. Hertford; and co. York.

Sa. a chev. betw. three 3 -foils slipped arg. JoHN, $W$. Sr. Richard IEwEs, temp. Edward IV, Harl. MS. 6137, fo. 44; but LEwYs, $V$. Trayfray, $V$.

Sa. a chev. engr. betw. three 3-foils slipped arg. LOFTHOUSE.

Sa. a chev. erm. betw. three 3-foils slipped arg. MEADE.

Sa. a chev. engr. erm. betw. three 3-foils slipped arg. Lortus, (the elder branch) Viscounty 1622 extinct 1725; derived from LofThous, Swineshead, co. York; like Adam Lof rus, Archbishop of Armagh 1561 (but he bad, 1567, a grant of another coat which bis descendants abandoned), and Dublin, 1567-1605; Viscount Lisburne Baron Rathfarnham 1685 ex tinct 1691 , Baron Loftus 1751 and 1785 , Viscount 1756 , Earl of Ely 1761 and 1771 extinct 178:3. Loftus, Mount Loftus, co. Kilkenny; Baronetcy 1768. Loftus, Woolland, co. Dorset; and Fincham, Norfolk; derived from Loftus, Kilbride, co. Kildare, Ireland; quartering King. TotTenhan, afterwards Loftus, Baron 1785 and 1801, Visconnt Ely 1789, Earl of Ely 1794, Marquis of Ely 1800.

Sa. a chev. betw. three 3-foils or. Lewis, Marre, and Ledston Hall, co. York; Baronetcy 1660 ; extinct 1671 . LewEs, Ledstone, co. York, $Z, 443$.

Sa. a chev, betw. in chief three 3 foils and in base an orb and cross or. Lefevre, Stepney, Middlesex.

Sa. a chev. betw, three 3-foils slipped or. LEwrs, Doncaster; confirmed 1586 ; and co. Monmouth. WARLOD.

Vert a chev, betw. three 3-foils slipped arg. BEECHEY or BEECHY.

4-Foils

Arg. a chev. gu. betw. in chief two 4 -foils and in base a 3-foil slipped vert. BEDFORD.

Arg. a chev. betw. three 4-foils az. KYME. (Assumed by) KEM. But stalked vert. HoNOR or Honnor. KYME, Friskeney, $V$. And leaved vert. Friskney. KyMes, $V^{*}$.

Arg. a chev, az. betw. three blind 4-foils of the second stalked vert. Honour of Krmes, $V$. Kyme, Harl. MS. 1386, fo. 66. And leaved vert. KyMes, $V$.

Arg. a chev. betw. three 4-foils gu. ManNing. The 4-foils slipped. Le BoN. 
1 CHEVRON betw. or within.....cont. 4-Foils cont.

Arg. a chev. gu. betw. three 4-foils slipped vert. Matford, co. Devon.

Arg. a chev. betw. three 4-foils sa. AIR. WINToRd, co. Worcester. The 4-foils voided. WANDFORD, $V$, and Harl. MS. 1404, fo. 93. WANDEFORD, $V^{*}$.

Az. a chev. betw. three 4-foils slipped arg. a crescent for diff. Vincent, co. Stafford; and co. Worcester.

Az. a chev. betw. three 4-foils or. LyNcH, Ire. land; and Southampton.

Erm. a chev. gu. betw. three 4-foils or stalked and leaved vert. Goonson.

Gu. a chev. betw. three 4 -foils arg. CRumpe Cromp or Crompe, Kent.

Gu. a chev. betw. three 4-foils or. Crompe, Stonelinch, Sussex.

Sa. a chev. betw. three 4-foils voided arg. Rodghton, $V^{*}$.

Sa. a chev, betw. three pierced 4-foils arg. Radghton, co. York, Harl. MS. 1394, fo. 171.

Sa. a chev, betw. three 4 -foils or. Crompe, $V^{*}$. 5-Foil

Az. a chev, arg. betw. in the dexter chief a 5 -foil of the last pierced or and in base three crosses croslet as the second. Latrmer, Harl. MS. 1404 , fo. 111.

Az. a chev, arg. betw. in chief a 5 -foil of the second pierced or and in base three crosses croslet of the last. Latimier, Suffoll.

Az. a chev. betw. in the dexter chief a pierced 5 -foil in the sinister three crosses croslet and in base four arg. Latydier, Freston, Suffolk.

Az. a chev. betw. in the dexter chief a pierced 5 -foil or in the sinister three crosses croslet and in base (three $V^{*}$ ) four arg. Latymer, Suffolk, $V$.

\section{5-Foils}

Vert a chev. erminois betw. in chief two pierced 5 -foils and in base a stag trippant or a bordure engr. of the last. Robinson, Sunderland; granted ....

Vert a chev. betw. in chief two 5-foils and in base a buck pass. or. RoBINson.

Vert a chev. betw. in chief two pierced 5-foils and in base a stag trippant or. RoBInson, Middlesex; and Herrington and Sunderland, co. Durbam, quartering Appleton.

Arg. a chev. gu. betw. in chief two 5-foils and in base an eagle displ. sa. DE BEAUvoIr; quartering Benyon, 1822; quartered by Browne, 1825.

Or a chev. betw. in chief two 5-foils and in base an estoile sa. Richard KeLtawe, Bishop of Durham 1311-16.

Arg. a chev. gu. betw. in chief two 5-foils and in base a boar's head couped and erect az. Bogue.

Arg. a chev. betw. in chief two 5 -foils and in base a boar's head erased and erect gu. Bog Boag or Bogg, Scotland.

Arg. a chev. gu. betw. in chief two 5 -foils and in base a boar's head sa. Bog, Burnhouse.

Gu. a chev. or betw. in chief two 5-foils and in base a hunting-horn arg.garnished az. DunCan, Seaside and Lundie, Scotland.

Or a chev, betw. in chief two 5 -foils and in base a mullet sa. Kewro, Kellio in Corvely, Cornwall; the heiress m. Tredenham. KrLlowe, Dale, Cornwall.
1 CHEVRON betw. or within....cont.

5-Foils cont.

Gu. a chev. betw. in chief two 5-foils and in base a sword palewise arg. DOEG.

Arg. a chev. betw. in chief two 5 -foils gu. and in base a bawthorn tree vert. HAWTHORN or Haw thorne, Castlewig.

Arg. a chev. betw. in chief two 5-foils gu. and in base a saltire couped az. AGNEw, Lochnaw, co. Wigton; Baronetcy 1629. Auchmenan. But within a bordure of the second. AGNEw and AgNeU, Lochryan.

Arg. a chev. gu. betw. three 5-foils of the field. Prestwood, Prestwood, co. Salop (an error).

Arg. a chev. betw. three 5-foils az. Lockey.

Arg. a chev. engr. betw. three pierced 5 -foils az. Occle.

Arg. a chev. compony az. and gu. betw. three 5 -foils of the last. CookE.

Arg. a chev. gu. betw. three 5-foils az. HAMrтon, co. Stafford; Norwood, Middlesex; and London. Richard Sclerys, $V$. WyBaston.

Arg. a chev. betw. three 5-foils gu. Acton, Acton, co. Worcester. AGNew. ALLEN or ALLEYN, founder of Dulwich College, Surrey, 1566, 1620. Alleyn, Essex, $W$. Beauvoir, Guernsey; and Loudon. Beaver. Bevers, 1716. Bevers, Hogsdon. Chamber. Charteray. Henry Chicheley, Bishop of St. David's 1408, Archbishop of Canterbury 1414-43. De Beauvotr. Durren. Hajtpton. Langton or Langhan. Swetebr. Warsteed.

Arg. a chev, betw, three pierced 5-foils gu. WARSTED or WARSTEEDE.

Arg. a cher.gu. betw. three 5-foils vert. Pererell. Arg. a chev. sa. betw, three 5-foils gu. CLIFTon. RICAAD, Londoll.

Arg. a chev. sa. betw. three pierced 5-foils gu. Roger de Cimftone, $E$.

Arg. a chev. betw. three 5-foils sa. Chambencayn, co. York. Floracke. Folringham, Bartou, co. York. Folmingham, $V^{*}$. Keterton. John Kotterton, $V$. Rempston.

Arg. a cher. betw. three 5-foils sa. within a bordure compony or and az. CuIfToN.

Arg. a chev. betw. three pierced 5-foils sa. WANDEFORD.

Arg. a chev. engr. betw. three 5-foils sa. Hatfield or Hitfield.

Az. a chev. betw. three 5.foils arg. M'HaN, Scotland.

Az. a chev. embattled betw. three 5-foils or. LANGHAM, co. Leicester. LANGHAMr or LANGHorme, Coinsholme, co. Lincoln.

Erm. a chev. betw. three 5 -foils or. Connnaes, Harl. MS. 1404, fo. 93 .

Erm. a chev, sa. betw. three 5-foils or. Coring or CoRINGe.

Erm. a chev. betw. three 5-foils sa. Fermour, $\boldsymbol{V}$. Erm. a chev. engr. betw. three 5-foils sa. Hatfeld, $V^{*}$. Haytefeld. Haytfeld, $V$.

Gu. a cher. betw. three 5-foils arg. Acton, Wolverton; quartered by Pardoe; and Ombersley. Acton, Acton, co. Worcester, $V$. Crompe. Gedon. John Langton, Bishop of St. David's 1447, Add. MS. 12443.

Gu. a chev. betw. in chief three 5 -foils and in base a bugle arg. Donkin, Rippon.

Gu. a chev. engr. betw. three 5-foils arg. Bircut, Scotland. WreAOKe alias OcLe, Dabenbam, Suffolk.

Gu. a chev. betw. three 5.foils arg. stalked and leaved vert. 'THoms. 
1 CHEVRON betw. or within..... cont. 5-Foils cont.

Gu. a chev, arg. betw. three 5-foils or. BoDYAR, Coruwall. WadHanr.

Gu. a chev, erm. betw. three 5-foils arg. MEADE or Mede, co. Cambridge; and Cornwall.

Gu. a chev. betw. three 5-foils erm. Hamrtutos, Reddles. Hanilton, Pencaitland, Scotland; a scion of Presmanan.

Gu. a chev. betw. three pierced 5-foils erm. Smrth alias KENT, More End, co. Northampton. Gu. a chev. erm. betw. three 5-foils or stalked and leaved vert. KERSHAW.

Gu. a chev. erminois betw. three 5 -foils or. Tarleton, Leintwardine, co. Hereford; Baronetcy 1818, extinct 1833. TARJETON, Colling. wood Hall, Northumberland; quartering Col. lingwood.

Gu. a chev. or betw, thres 5-foils arg. TaRLeton.

Gu. a chev. engr. or betw. three 5-foils arg. LiCETON. IyCTON, $V$.

Gu. a chev. betw. three 5-foils or. Chambar, $V$. Chamber, $V^{*}$. Chambers, Studley, co. Warwick. Chanrbers, Bredgar House, descended from Selling, Kent. Chamber, Gaddesby, co. Leicester; Harl. MS. 1431, fo. 24, 6125, fo. 111, as if descended from CHAMBER, Kendal, co. Westmoreland; and Cleadon, co. Durham. And with a crescent for diff. CHamber, Dagenham, Essex.

Gu. a chev. voided betw. three 5-foils or. CHIEsty, Kersewell.

Or a chev. chequy arg. and gu. betw. three 5-foils az. Cooke.

Or a cher. chequy az. and gu. betw. three 5-foils of the second. Sr. Plilipp Cooke, temp. Edward IV, Harl. MS. 6137, fo. 44.

Or a chev. chequy gu. and az. betw. three 5 -foils of the third. CORkE.

Or a cbev. chequy gu. and az. betw. three 5 -foils of the second. Cooke, Essex.

Or a chev. compony gu. and az. betw. three 5 -foils of the third. Cooke, $V^{*}$. CoOkE, Lord Mayor of London 146\%.

Or a chev, countercompony gu. and purp. betw. three 5-foils az. Sr. Anthony Cooke, Giddy Hall, Essex, $V$.

Or a chev. betw. three 5-foils gu. Chichele; from whom descended Henry CHICHELE, Bishop of St. David's 1408, Archbishop of Canterbury 1414-43; and bis two brothers, Sir Robert Chichele, Lord Mayor of London 1411 and 1421, and William Chichele, London, Sheriff 1411. Chichele or Chichley, Wimple, co. Cambridge; descended from William, youngest brother of the Archbishop; the heiress $\mathrm{m}$. Griffiths. Sr. .... de CHICHLEY, V. ALL Souls College, Oxford.

Or a chev. betw. three 5.foils slipped gu. LE Bow.

Or a cher. sa. betw. three 5-foils gu. CuIfton, $V^{*}$. Geoffrey de Clystone, $V$.

Per fess arg. and sa. a chev. betw. three 5-foils counterchanged. Balnaves, Carnbody.

Per fess gu. and arg. in chief a chev. betw. three 5 -foils or in base a rose of the first stalked leaved and barbed ppr. VANHECK, London.

Sa. a chev, betw. three 5-foils arg. WaLtham.

Sa. a chev. embattled betw. three 5-foils arg. pierced or. SHadLPIEcE, Hockering, Norfolk.

Sa. a chev, engr. betw. three 5-foils arg. Syadpece or Smalidpiece, Worlingham, Suffolls. Robert Smallpeece, Hockering, Norfolk; granted $1590 ; W$. Stone, Framfield, Sussex; granted 14 December, 1628 .
1 CHEVRON betw. or within.... cont.

5-Foils cont.

Sa. a chev. engr. betw. three pierced 5-foils arg. Smallpeice, Norfolk; and Hockling, co. Salop; granted 1586.

Sa. a chev. betw, three 5-foils arg. pierced or. WALSINGHAMr.

Sa. a chev. arg. betw, three 5-foils or. WALsInghalr, $V$; and Kent. Walthadr, $V$. Roger de WoLsinghan, $Y$.

Sa, a chev. arg. betw, three pierced 5.foils or. M. Roger de WaLsHam, $S$. Roger Wolsingham, $X$

Sa. a chev, betw, three 5.foils erm. Daviss.

Sa. a chev. erm. betw. three 5-foils or. ThonLey. Sa. a chev. or betw, three 5-foils arg. Davies. Sa. a jehev. betw. three 5 -foils or. Chambers, Selling, Kent; Halsted, iii, 25. Kenton, $V$.

Sa. a chev. betw, three pierced 5-foils or. WALSING HAM.

Sa. a chev. engr. or betw. three 5.foils of the last pierced gu. Hildersham, Molton, Suffolk.

Sa. a chev. pean betw. three 5-foils arg. WoodHouse, London.

Vert a chev. betw. in chief three 5-foils and in base (a cross or) crosses croslet fitchy arg. UMPHRAY.

Arg. a chev. betw. six 5.foils sa. Freston, Suffolk.

Gu. a chev. betw. ten 5-foils arg. Barketer, Norfolk. Berkeley, Wymondham, co. Leicester; Baronetcy 161l, extinct ....., quartering Hamlyn, Delalaunde, Welles, Engaine, and Waterton, Harl. MS. 6183, fo. 5. Berkuey, Routland, co. Lincoln, $V$.

Gu. a chev. betw. ten pierced 5-foils arg. M. John de Berkele, $S$.

Gu. a chev. betw. 5.foils arg. Sire John Barkeley, $Q$. Berkeley, Wymondham; Baronetcy 1611 ; quartering as above.

\section{6-Foils}

Arg. a chev. sa. betw. three pierced 6 -foils gu. Roger de Clifton, $F$.

$$
\text { 7-Foils }
$$

Arg. a chev. betw. three 7 -foils (seitfoiles) gu. John Charteray, $Y$.

8-Foils

Sa. a cher. betw. three double 4-foils arg. MEDEGS.

\section{Fountains see Roundles}

\section{Frets or Gimlets}

Arg. a chev. az. betw. three frets (wine piercers) of the second screws or. Butler, $V$.

Arg. a chev. az. betw. three gimlets of the second the handles or. Butrer, Sussex. The handles of the second and the screws or. William Buteller, Harl. MS. 1386, fo. 94.

Arg. a chev. gu. betw. three gimlets sa. CrapHan. Arg. a chev. engr. betw. three frets (wine piercers) or the haudles sa. banded gold. Boteller, Harl. MS. 1404, fo. 105.

Arg. a chev. betw. nine gimlets sa. Clapharr.

\section{Fruit ... Acorns}

Arg. a chev. betw. three acorns gu. SEnNocke or Sevenocke, Layston, co. Hereford.

Arg. a chev, sa. betw, three acorns gu. Boyes. Boys.

Arg. a chev. sa. betw. three acorns ppr. Boyes.

Arg. a chev. sa. betw. three acorns vert budded or. Boys, $V^{*}$.

Arg. a chev. sa. betw. three slipped acorns or cupped vert. Boys, Cornwall, $V$. 
1 CHEVRON betw, or within.... cont.

Fruit .... Acorns cont.

Az. a chev, erm. betw. three acorns slipped or. Parier, Wales.

Az, a chev, betw, three acorns or husked vert. IFIELD.

Az. a chev. or betw, three acorns pendent of the last cupped and stalked vert. IFELD, of the North, $V$. MusheleEner.

Az. a chev. or betw, three acorns pendent of the last slipped vert. Dryfieid. Ifeld, $V^{*}$.

Az. a chev. or betw. in chief three acorns of the last husked and slipped vert and in base a bull's head erased arg. STork.

Az. a chev, betw. in chief three acorns and in base a bull's head erased or. STARK, Killermont, Scotland. And with a bordure arg. STARK, America.

Erm. a chev. gu. hetw. three acorns slipped and pendent ppr. DauBuz.

Gu. a cher. arg. betw. three acorns or. Hignfield, Suffolk.

$$
\text { .... Apples }
$$

Or a chev. betw. three apples gu. Southiey or Sourhby, Carswell, co. Berks; quartering Hayward.

Or a chev. per pale arg. and vert betw. three apples gu. Messariry.

Or a chev. per pale gu. and vert betw. three apples (they are cherries) of the second slipped of the third. Messarney, $V *$.

Or a chev. vert betw, three apples gu. stalked of the second. Messewy.

Vert a chev. engr. betw. three apples arg. Appolton. The apples gu. Appulton. .....Bean-pods

Arg. a chev. gu. betw. three bean-pods vert. RISE, Trewardreva, Cornwall; the heiress m. Trewren and Glynn.

\section{....Cherries}

Or a chev. per pale gu. and vert betw. three (apples $V^{*}$ ) cherries of the second slipped as the third. Messarney, $V$.

$$
\text { ..... Cloves }
$$

Sa. a chev. betw. three cloves or. Duffierd. .... Corn

Arg. a chev. gu. betw. three ears of rye (? ppr.) slipped and bladed vert. RIDALE RIDDALE Riddell Ridel or Ridele, Scotland; Baronetcy 14 May 1628.

Az. a chev. arg. betw. three ears of corn as the second slipped and bladed or. Thomas Erre, co. Buckingham, $V$; granted 1476.

$$
\text { .....Garlick }
$$

Sa. a chev. betw. three heads of garlick (pomegranates $V^{*}$ ) pendent arg. Garwynton, $V$.

$$
\text { ..... Gourds }
$$

Az. a chev. betw. three gourds (pears Steukele, $\left.V^{*}\right)$ pendent slipped or. Stukere, Cotton. $M S$. Tiberius D 10 .

$$
\text { ....Grapes }
$$

Arg. a chev. betw. three bunches of grapes (an. other, gu.) ppr. Bradway, Potsclip, co. Gloucester.

$$
\text { .....Nuts }
$$

Or a chev. sa. betw. three hasel nuts erect slipped gu. John Tarseli, $V$.

$$
\text { .....Pears }
$$

Alg. a chev. betw. three pears az. Perneys or Pernis.

Arg. a chev, az. betw. three pears gu. Parnham. Aro. a chev. az. betw. three pears vert. Peanne.
1 CHEVRON betw. or within.... cont:

Fruit .... Pears cont.

Arg. a chev. az. betw. three pears pendent bendwise sinister vert. Perneys, $V$.

Arg. a chev. gu. betw, three pears az. Crawley, co. Dorset.

Arg. a chev. gu. betw. three pears ppr. PyPand, Cornwall.

Arg. a chev. gu. betw. three pears (? ppr.) leaved vert. W ARDEN, Scotland.

Arg. a chev. sa. betw, three pears or. AтHLL.

Arg. a chev. betw. three pears vert. Perneys or Pernys.

Az. a chev. arg. betw. three pears or. OrchaRD, co. Devon; quartered by Portman, Collinson, Somerset iii, 275 .

Az. a chev. betw. three pears pendent or. Calmady, Calmady, Cornwall ; and Langdon, co. Devon; quartering Strode, Moreton, Gayer, Penwarne, Cavil, Nick, Courtenay, Shilston, Waldo, Potter, Fursland, Pollexfen, etc.; the heirs m. Hamlyn and Everitt. Bonfield. Steukele, $V^{*}$. (they are gourds). But with a crescent sa. on the chev. Boneferd, Cotton. MS. Tibe. rius $\mathrm{D} 10$.

Az. a chev. sa. betw, three pears or. Orchand, Scotland.

Gu. a chev. arg. betw. three pears or. Peareth, Usworth House, co. Durbam.

Gu. a chev. betw. three pears pendent or. ABBotT, $V^{*}$. (? PeRRot).

Gu. a chev. reversed betw, three pears or. WESTON.

Gu. a chev, betw. three pears pendent stalked or. Aвво T, Lord Mayor of London 1638. Robert Aввот, Bishop of Salisbury 1615-8. Aввот, Bishop of London; Archbishop of Canterbury 1611-33, at the Charterhouse 1619. Авотт, Alderman of London, $W$. Авотт, Guildford, $W$. Авотт, Archbishop of Canterbury, $W$. But each pear slipped with two leaves vert. Perenton, $V$.

$$
\text { ....Pine Apples or Pine Cones }
$$

Arg. a chev. betw. three pine apples gu. APPULEY. APPURLEY, $V *$.

Alg. a chev. betw. three pine cones slipped erect gu. ApPURLEY, $V$.

Arg, a chev. betw. three pine apples pendent gu. Grove. But pendants tenons. John APperLeY, $Y$.

Arg. a chev. betw. three pine apples gu. leaved vert. Christophers, $V^{*}$.

Arg. a chev. gu. betw. three pine apples vert. Paprecl, Cornwall. Peperecr, $V^{*}$.

Arg. a chev. gu. betw. three pine cones slipped erect vert. Peperein, Cornwall, $V$.

Arg. a chev. gu. betw. three pine apples vert stalked or. Pepenrell or Perperell, Cornwall.

Arg. a chev. betw, three pine apples or slipped vert. Pepenrell or Perperell, Cornwall.

Arg. a chev. sa. betw. three pine cones slipped erect gu. each with two leaves vert. Christopher, 1730. Christophers, $V$.

Arg. a chev. sa. betw. three pine apples vert. Cristofer.

Gu. a chev, engr. betw. three pine apples arg. PYNSON.

Gu. a chev. arg. betw. three pine apples or. Prow, Essex. William Prowe, Harl. $M S$. 1432.

Gu. a cluev. arg. betw, three pine cones or. Thomas de Pin, $\boldsymbol{E}$. 
1 CHEVRON betw. or within.... cont.

Fruit .... Pine Apples cont.

Gu. a chev. .... betw. three pine cones erased stalks erased or. De ta Pyne, Kent, $W$.

Gu. a chev. erm. betw. three pine apples arg. Penner.

Gu. a chev. erm. betw. three pine apples or. Delapine, Kent. Gube. Penner. Pine or Pyne. Pyne, Ham, Cornwall; and East Downe, co. Devon; quartering Downe.

$\mathrm{Gu}$. a chev. erm. betw. three pine apples erect or. Pine, 1730.

Gu. a chev. erm. betw. three pine cones slipped pendent or. GebBe alias ...., $V$. GeLbe, $V^{*}$. Penner, Cotton MS. Tiberius D, 10 . Pymes or Pynes, Cornwall, $V$.

Sa. a chev. betw. tbree pine apples or. Wesor.

$$
\text { ....Pomegranates }
$$

Arg. a chev. gu. betw. three pomegranates ppr. Richard Gardenar, Himbleton, co. Worcester, $W$. The pomegranates leaved vert. Gardiner, co. Worcester, 1592.

Gu. a chev. betw. three pomegranates or. MAHER, Ireland.

Sa. a chev. betw. three pomegranates (they are heads of garlick) pendent arg. Garwinton, $V *$.

Vert a chev. in point embowed or voided gu. betw. three pomegranates slipped and leaved ppr. Livius.

$$
\text { ....Quinces }
$$

Arg. a chev, betw, three quinces lying fesswise or. BONEFELD, $V^{*}$.

Az. a chev. betw. three quinces pendent bendwise dexter or. Bonefeid, $V$.

$$
\text { .....Cloves }
$$

Arg. a cher. gu. betw, (seven sometimes) nine cloves three three and three sa. Company of Grocers, London; granted 1531-2, Cotton MS. Tiberius D 10 fo. 886 .

$$
\text { ..... Corn }
$$

Sa. \& chev. erminois betw. nine ears of wheat tied in three parcels or. BENNET.

\section{Fusils}

Arg. a chev, az. betw, three fusils sa. Staley.

Arg. a chev. betw. three fusils erm. SHaw, Kenward and Eltham, Kent; Baronetcy, 1665.

Arg. a chev. betw. three fusils ermines. SHaA, Essex; and London, 1501. Shaw. And with a bordure az. StraA, Loudon, 1490.

Arg. a chev. gu. hetw. three fusils erminois. Sir John Shaw, Bart., Eltham, 1730.

Arg. a chev. betw. three fusils sa. Lermouth.

Arg. a chev. betw, three spindles of silk sa. Dardas.

Arr. a chev. betw. three wharrow-spindles sa Trefusis, Baron Clinton. Trefusis, Cornwall.

Arg. a chev. betw. three fusils sa. within a bor. dure of the last. MARTYN, Lord Mayor of London 1567 ; and Suffolk.

Az. a chev. betw. three fusils or. DE LA HIDE.

Or a chev. betw. three fusils az. LeIth, OverBarns, Scotland.

Or a chev. betw, three fusils gu. Hyde.

Or a chev, sa. betw. three fusils az. Parker, Norfolk.

\section{Gambs see Legs}

Garbs

Az. a chev. arg. betw. in chief two garbs or and in base a spaniel pass. ppr. in the centre chief point a cross croslet fitchy of the second. Bukder.
1 CHEVRON betw, or within....cont.

Garbs cont.

Per chev. arg. and gu. a chev. counterchanged betw. in chief two garbs ppr. and in base a horse arg. Whitenurst, co. Denbigh; co. Salop; and co. Hereford; confirmed 1748.

Per chief vert and or a chev. engr. erm. betw. two garbs of the second and in base a lion ramp. gu. Froноск, co. Cambridge; and London; granted 1761.

Vert a chev. engr. erm. betw. in chief two garbs and in base a lion ramp. or. Frovde, Kingston, co. Devon ; granted 1765.

Az. a chev. betw. in chief two garbs and in base a fleece or. NotTidge, East Hanningfield, Essex.

Vert a chev. arg. betw. in chief two garbs or and in base a bouse ppr. Newhouse, co. Lancaster.

Vert a chev. quarterly or and gu. betw. in chief two garbs and in base a sun of the second. Higginson, Middlesex; granted 1764.

.... arg. a chev. .... betw. three garbs .... Flatman, London, 1682, quartering paly of six .... and ... with .... a chev. ....

Arg. a chev. betw. three garbs az. YEO.

Arg. a chev. az. betw. three garbs bound or. Blake or Rich, Collinson, Somerset, i, 260. SARrEll.

Arg. a chev. gu. betw. three garbs az. Bothelt. Arg. a chev. betw. three garbs gu. Edmund. Sr. Thomas Sheffeitde, $V$. Sheffiedd, $V^{*}$. Arg. a chev. betw. three garbs gu. witbin a bordure compony az. and of the first. SHEFFIELD, Normanby, co. Lincoln; Baronetcy 2l March 1755. Sheffield, Barony 1547, Earl of Mnlgrave 1626, Marquis of Normanby 1694, Duke of Buckinghamshire 1702, extinct 1735.

Arg. a chev. gu. betw. three garbs vert. PILLAND. Powell, Surrey. Pyland, $V$. Shakerley, co. Derby.

Arg. a chev. betw. three garbs sa. Antron or De Antrenon. Barby, co. Devon; and Northampton. Benning ham, Ireland. Biage, $V^{*}$. Blake, co. Wilts. BLAKE, Taunton, co. Somerset. Sr. William Darby, $W$. Gervers, Helston, 1329 ; quartering Bonathlac and Trevanion; the beiress m. Grylls.

Arg. a chev. betw. three sheaves of beans sa. BLAEE, Northumberland.

Arg. a chev. betw. three garbs sa. banded or DarbY, Benington, co. Lincoln. DarBY, $V^{*}$. Arg. a chev. eng. betw. three garbs sa. Dardex. Arg. a chev, engr. sa. betw. three garbs .... Derly, co. Chester, temp. Henry VI.

Arg. a chev. betw. three garbs within a bordure sa. the second charged with eight fleurs-de-lis of the first. BLAKE, London; and Bunwell, Scottow, Horstead, and Swanton Abbots, Norfolk.

Arg. a chev. betw. three garbs sa. banded of the first. Blake, co. Wilts, $W$.

Arg. a chev. betw. three garbs vert. Hartstonge or HARTSTRONGE, Ireland.

Az. a chev, betw, three garbs arg. BurnetT.

Az. a chev. erm. betw. tbree garbs or. Conys, Durham; and Essex. HatTon, Ireland.

Az. a chev. or betw. three garbs arg. Preston. PRESTWOLD.

Az. a chev, betw. three garbs or. Boultber or Boultbie. Cuming or Comming. Cumiing, Pitully. Hatton, Cambridge; co. Chester; co. Gloucester; co. Northampton; Shrewsbury, 
1 CHEVRON betw, or within.....cont.

Garbs cont.

co. Salop; and Harringham, co. Warwick. Hatton, co. Chester, $V$. Sir Richard Hatton, 1677 in Thames Ditton church, and Hatron, 1680 in Banstead church. Hatton, Barony 1643, Viscounty 1682, extinct 1762. FinchHation, Earl of Winchilsea I628; quartering Finch.

Az. a chev. betw. three sheaves of cumin or. Comyn or Comin, co. Durbam.

Az. a chev. per pale or and erm. betw. three garbs of the second. HEYWARD, Loudon; granted 1 December 1768.

Az. a chev. quarterly per chev. gu. and arg. betw. three garbs or. Company of INNHOLDERs, London, $V$, Cotton $M S$. Tiberius D 10 fo. 885.

Erm. a chev. az. betw. three garbs or. Masterson, Nantwich, co. Chester. Masterson, Ferns, co. Wexford; the co-heiresses m. Devereux, Butler, Shee, and Synnott.

Erm. a chev. gu. betw, three garbs or. Thomas de Schefeird, $Y$. Thomas Scheffeild, $Y$.

Gu. a chev, arg. betw. three garbs .... BURKIT.

Gu. a chev. betw. three garbs arg. and six crosses croslet fitchy or. RoYToN.

Gu. a chev. betw. three garbs within an orle of eight crosses croslet fitchy arg. Royson or Ruton, $V$.

Gu. crusily fitchy or a chev. betw. three garbs arg. Ruton.

Gil. a chev. engr. betw. three garbs arg. HiLL, Bridgewater, co. Somerset.

Gu. a chev. engr. betw. three reed sheares arg. REDHAM, $V$.

Gu. a chev, arg. betw. three garbs or. Bannon. Eden. Waldsheafe, co. Huntingdon.

Gu. a chev. compony arg. and az. betw. three garbs or. Baron, $V^{*}$.

Gu. a chev. countercompons arg. and az. betw. three garbs or. BARON, temp. Edward IV, $V$. BarRon.

Gu. a cher. betw. three garbs erm. HiLl, Cornwall.

Gu. a chev. erm. betw. three garbs or. Banon, Bradwell, and Skirmby, Essex. Hill, Pounsford; and Taunton, co. Somerset; and Denham Place, co. Buckingham.

Gil. a chev. engr. erm. betw. three garbs or. HILL, co. Somerset.

Gu. a chev. betw. three garbs or. DADE, Tannington, Suffolk; and Woodton, Norfolk, temp. Edward IV. SHefFeld, $V *$.

Gu. a chev. betw. three garbs or within a bordure arg. HrLl, Pounsford, co. Somerset.

Or a chev. betw. three garbs az. VANDELEUR, Ireland. Yatton, $V$. Yeo. Yoe, $V$.

Or a chev. gu. betw. three garbs az. Yatron.

Or a chev. betw. three garbs gu. Cosgrave.

Or a chev. sa. betw. three garbs az. YatTon, $V$. YEO, $V^{*}$. YoE, $V$.

Purp. a chev, betw. three garbs arg. Fensux, $W$.

Purp. a chev. arg. betw. three garbs or banded az. Berew, $V^{*}$. Berewe, $W$.

Sa. a chev. betw. three garbs arg: Blake. Felde, $V$. Fieid, co. Oxford; and Irelaud. Fieid or Feld, Ardestow, co. York. Greenaker. Morgan OwEN, Bishop of Llandaff 1640-5.

Sa. a chev. engr. betw. three garhs arg. Field, Stanstedbury, co. Hertford; granted 9 March 1653.
1 CHEVRON betw. or within....cont.

Garbs cont.

Sa. a chev. arg. betw. three garbs or. BermeEad, Crestwhite, Cumberland.

Sa. a chev. erm. betw. three garbs arg. Fiedd. FroLd.

Sa. a chev. erminois betw. nine ears of wheat tied in three parcels or. BenNet.

Sa. a chev. or betw. three garbs arg. BendisH, co. Cambridge. Cowlson, Scotland. Halton. Hatieton. Harteton, $V$. Hariemin.

Sa. a chev. betw. three garbs or. ACLEWARD or ACKLEWARD. ACLEWARD or AYLWARD, $V$. AILEWARD, $V^{*}$. AYteward. AYLWorth. Theophilus Field, Bishop of Llandaff 1619, St. David's 1627, Hereford 1635.6. Segrave. Wicrs.

Sa. a chev. or voided az. betw. three garbs of the second. DANSON.

Vert a chev, betw, three garbs arg. (? AMYAND). Greenaker. Grenacre, $V^{*}$. Grenaker, $V$. Greynor.

Vert a chev. betw. three garbs arg. banded or. Charles DARBY, St. Edmondsbury, Suffolk; granted $1588, W$. Derby.

Vert a chev. arg. betw. three garbs or. Crose or Closs. Tapperell.

Vert a chev. betw. three garbs or. AMYaNd, granted 1771; Moccas Court, co. Hereford; Baronetcy 1764; quartered by Cornewall.

Vert a chev. betw. three garbs or over all a bend gu. ALDRIgH.

\section{Gimlets see Frets}

Gouttes

Or a chev. betw. three gouttes de sang. Samuel Goodenough, Bishop of Carlisle 1808-27.

Arg. a chev. voided sa. betw. gouttes de larmes. St. MaURe.

Az. a chev. raguly betw. gouttes d'eau and three crescents arg. KNotsHULL.

Az. a chev. gold betw. gouttes d'or and three erescents arg. KNotT, Suffolk. The crescents or. Knotr, Sussex.

Gridirons

Arg. a chev. betw. three gridirons dexter bendwise handles upward sa. Sr. Thomas Scort, Alderman of London, $V$. Thomas Scotte, Harl. MS. 1386, fo. 95 .

Arg. a chev. betw. three gridirons erect handles downward sa. LAURENCE, $V$. LaURencig, Harl. MS. 1386, fo. 95 .

\section{Guns}

Arg. a chev. erm. fimbriated sa. betw. three chamber pieces of the last fired ppr. Chamber or Chambers. Delechamber, Radmill, Sussex.

Arg. a chev. betw. three matcblocks sa. Levenage. LEVERSEGE, $V *$.

\section{.....Habbicks}

Sa. a chev. erm. betw. in chief two habbicks arg. and in base a teazle slipped or. Company of Shearmen or Crothworrers, London, Cotton MS. Tiberius D, 10 fo. 887, as granted 1530 .

Az. a cher. erm. betw. three habbicks arg. Company of Shearmen, London, Cotton MS. Tiberius D 10 fo. 887 .

\section{Hammers}

Arg. a chev. betw. three mallets gu. Some, Suffolk.

Arg. a chev. betw. three hammers sa. crowned or. Company of Bracksmitrs, London.

Gu. a chev. betw. three hammers or. Soame.

Gu. a chev. betw, three mallets or. Sos sis, Sheen, Surrey; Baronetcy 1697; quartering Buckwortl. 
1 CHEVRON betw. or within.... cont.

Hammers cont.

Soame, Lord Mayor of London 1598; Norfolk; Suffolk; co. Cambridge; co. Hertford; and Essex; granted 1572; quartering Knighton; Baronetcy 1681-5, extinct 1798. SoAMrE, $V *$ * Thomas Soane, Budley, Suffolk, $W$.

Sa. a chev, arg. betw. three hammers az. crowned and bandled or. Company of Blacksmiths, London; granted 12 April 1490; Cotton MS. Tiberius $\mathrm{D} 10$ fo. 885 .

Sa. a chev. or betw. three hammers arg. handled of the second ducally crowned as the last. Company of Blacksirites, London.

Vert a chev, betw. three mallets or. Sirrt.

\section{Hands}

Arg. a chev. az. betw. three dexter hands gu. Hand, Maynard, $V *$.

Arg. a chev, az. betw. three sinister hands gu. Marnard, Wicklow, Ireland.

Arg. a chev. az. betw. three dexter hands apaumy couped gu. Herury MaYNard, Esten, co. Northampton; granted $1590 ; W$. MANARD; granted 1590.

Arg. a chev. az. betw. three sinister hands couped at the wrist gu. Maynard. Maynard, Estaines, Essex; and Wicklow, Ireland; confirmed 1621; Baronetcy 1611, Baronies 1620 and 1628 , ex. tinct 1775 , Baronetcy 1681 , Barony and Vis. county 1766 .

Arg. a chev. (compony or and az. $V^{*}$ ) counter. compony az. and or betw. three sinister hands apaumy couped sa. GodHand, $V$.

Arg. a chev. betw. three sinister hands gu. MaINARD, co. Devon.

Arg. a chev. betw. three dexter hands couped and erect gu. a crescent for diff. MAYNARD, Ham mersmith, Middlesex. Maynard, Mosely, co. Leicester ; confirmed 1770.

Arg. a chev. betw. three dexter hands fesswise couped gu. each holding a cross croslet fitchy az. M'Ronte or Rorie, Scotland.

Arg. a chev. betw, three sinister bands couped at the wrist each holding a truncheon or. Stevenson.

Arg. a chev, quarterly per chev, az. and gu. betw. three dexter hands apaumy of the last. Manerd, Harl. MS. 1404 , fo. 156.

Arg. a chev. quarterly gu. and az. betw. three sinister hands couped of the second. MaYNaRD, St. Alban's, co. Hertford.

Arg. a chev. sa. betw. three sinister hands couped at the wrist gu. Maynard, Kent.

Arg. a chev. betw. three sinister hands sa. BREN, $V^{*}$. Brenne.

Arg. a chev. betw. three dexter hands couped sa. BERNEY.

Arg. a chev. betw. three dexter hands couped at the wrist sa. Bren. O'Burinna.

Arg. a chev. betw. three dexter hands each bolding a billet sa. STEventon.

Arg. a chev. betw. three dexter hands clenched sa. each holding a purse of the first. Stevenson, $V^{*}$.

Arg. a chev. (? sa.) betw. three dexter hands sa. each holding (? u stone) of the first. STEvenson, V.

Arg. a chev. betw. three sinister hands apaumy couped sa. Bren, $V$.

Az. a chev. betw. three dexter gauntlets or. Conway, London.

Erm. a chev. betw. three dexter hands sa. BremiNer.
1 CHEVRON betw. or within....

Hands cont.

Gu. a chev. betw. three gauntlets arg. GaNruet, Netherhampton, co. Wilts; granted 1670.

Gu. a chev. betw. three dexter hands couped at the wrists arg. Brrne, Timogue, Queen's County, and Cabinteely, co. Dublin.

Gu. a chev. betw. three arms armed arg. bent at the elbows or. ARMORER, $V^{*}$.

Gu. a chev. betw. three sinister arms fesswise bent the hands open gauntletted the back part outward armed arg. the elbow-pieces or. ArHorer, Belford, co. Northampton, $V$.

$\mathrm{Gu}$. a chev. erm. betw. three dexter gauntlets back outwards erect or. WAYNE, $V$.

Gu. a chev. erm. betw. three inside gauntlets or. WAYNE.

Or a chev. betw. three dexter hands apaumy couped sa. Thomas Brand, West Moulsey, Surrey; granted $1591 ; W$.

Sa. a chev. betw. three hands erect couped at the wrist arg. Bromborougr. Hardware, Peel, and Bromborough, co. Chester.

Sa. a chev. betw. three dexter hands couped arg. BatT, Lord Mayor of London 1240. HaLL, co. York.

Sa. a chev. betw. three sinister hands couped arg. AтHAEL, Sherborne.

Sa. a chev. betw. three sinister hands couped and erect arg. MaYNe, Littington, co. Devon; and London.

Sa. a chev. betw. three dexter hands apaumy erect and couped arg. HaLL, Clifton; Leeds; and Scarborough, co. York; Heaton-Norris; and Manchester, co. Lancaster.

Sa. a chev. erm. betw. three gauntlets arg. RoBinson; impaling gu. three spears or; Collinson, Somerset, iii, 370 .

Sa. a chev. or betw. three sinister hands couped arg. LEY or Leys, co. Huntingdon.

Sa. a chev. betw: three gauntlets fingers clenched or. Gunter, co. Brecon. James, Shwynbered, co. Brecon. Watkins, Llanigen, co. Brecon.

Sa. a chev. erm. betw. three pairs of men's hands couped at the wrist holding as many bodyhearts gu. Wheatley Wheatly or Whetsy.

\section{Handcuffs see Shackles}

\section{Hanks}

Az. a chev. betw. three hanks of cotton erect arg. Hugh Cotron, co. Stafford, $V$. Cotton; Collinson, Somerset, i, 164. Corron, co. Worcester; co. Salop; London; and Cotton Hall, Hampshire. Henry Cotron, Bishop of Salisbury 1598-1615.

Az. a chev. erm. betw. three hanks of cotton erect arg. Corron, Alkington, co. Salop, $W$.

Az. a chev. or betw. three hanks of cotton fesswise arg. PARker, Sussex, $W$.

Sa. a chev, betw. three hanks of cotton arg. Cotron.

\section{Harrows}

Arg. a chev. betw. three harrows sa. Harvey, Hale, Cornwall.

Az. a chev. betw, three harrows or. HaRrower, Enzievar.

\section{Hats see Caps}

Hatbands see Knots Torces and Wreaths Gu. a chev. betw. three hatbands arg. Maynes, $V$.

Sa. a chev. arg. betw. three hatbands wreathed az, and of the first. Bury, $V$. 
1 CHEVRON betw. or within.... cont.

Head..... (Beast)

Az. a chev. or betw. in chief a wolf's head couped and a buckle with in base an escallop arg. LUMSDEN, Innergelly, Scotland. And within a bordure engr. or. Lumsden, Scotland.

$$
\text { .....Spear }
$$

Arg. a chev. gu. betw. in chief a spear's point and a pheon with in base a horseshoe az. Sexton, Ireland.

\section{....(Beasts) Boar}

Arg. a chev. betw. in chief two boar's heads couped and in base a crescent gu. LAIRD, England.

Arg. a chev. gu. betw. in chief two boar's heads erased ppr. and in base a crescent of the second. Larro, Glenhuntly, Scotland.

Arg. a chev. sa. betw. in chief two boar's heads erased and in base a heart gu. More, Scotland.

Per chev. az. and gu. a chev. erm. betw. in chief two boar's heads couped or and in base a demi. griffin arg. WILLIAMs.

Az. a chev. betw. in chief two boar's heads erased gu. and in base a bezant. French, Scotland.

$$
\text { .... Deer }
$$

Arg. a chev. gu. betw. in chief two buck's heads cabossed and in base on a mount an oak tree ppr. Edwands, London.

Or a chev. betw. two stag's heads erased az. (another, of the field). STAGG (? an error).

$$
\text { ..... Leopard }
$$

Az. a chev, arg. betw. in chief two leopard's heads and in base a cross patty fitchy or. Gooduaw, Aspall, co. Lancaster.

Arg. a chev. arg. betw. in chief two leopard's faces and in base a fish haurient or. (Perhaps) Gloucester, stone in St. Mary, Mounthall, Harl. MS. 1096, fol. 114.

Gu. a chev. arg. betw. in chief two leopard's faces or in base a fish haurient of the second. John de Gloucester, Alderman of London, Sheriff 1345-6; Harl. MS. 1319, fo. 63 .

Arg. a chev. gu. betw. in chief two leopard's heads of the last and in base a buglehorn sa. Forester, co. York. Forrester. The bugle. horn stringed az. SirisgsBr, co. York.

Az. a chev. betw. in chief two leopard's faces and in base a buglehorn (or, Harl. MTS. 1392). Foster, $V$; and Northumberland.

Gu. a chev. betw. in chief two leopard's faces and in base a buglehorn arg. Shugesby. Scriven, quartering Slingsby, Scriven Park, co. York; with Markington, Walkingham, Caperon, Stodleigh, and Nesfield; Baronetcy 1628, extinct 1630; and Vavasour aud Cradock; Baronetcy 1635.

Gu. a chev. betw. in chief two leopard's heads arg. and in base a buglehorn of the second stringed or. Sirngesby, co. York, $V$.

Gu. a chev. or betw. in chief two leopard's faces and in base a hunting-horn arg. SclyngsBy, co. York. The buglehorn stringed of the second. Slingsiy, $V^{*}$.

Gu. a chev. or betw. in chief two leopard's heads .... and in base a buglehorn arg. stringed or. Slyngesiy, co. York, $V$.

Az. a chev, betw. in chief two leopard's heads and in base the stern of a ship or. PARklR.

$$
\text { .....otter }
$$

Arg. a chev. sa. betw. in chief two otter's heads couped gu. and in base an escallop vert. Lumsden, Couland, Scotland.
1 CHEVRON betw, or within..... cont. Heads ..... (Monsters) Griffin

Sa. a chev. erm. betw. in chief two griffin's heads erased and in base a cross formy or. GARDINER, 1670.

$$
\text { .... Unicorn }
$$

Sa. a chev. wavy arg. betw. two nnicorn's heads erased or. Peance or Peanse, Kent.

$$
\text { ....Axe }
$$

Arg. a chev. betw. three heads of brown bills (matchlocks $V^{*}$ ) sa. LEvensege, $V$.

$$
\text { .....(Beasts) }
$$

Arg. a chev. betw. three beast's heads with short ears couped sa. SEED; (these seem bears).

$$
\text { .....Antelope }
$$

Arg. a chev. betw. three antelope's heads erased gu. Beckwith, Thurcroft, co. York.

Arg. a chev. betw. three antelope's beads erased sa. AdLington, Harl. MS. 1468, fo. 81 .

Sa. a chev. betw. three antelope's heads erased arg. attired and crined or langued gu. Adlington, Adlington, co. Lancaster.

$$
\text { .....Badger }
$$

Arg. a chev. betw. three badger's beads erased sa. M. Geffrey Brokenoles, $S$.

$$
\text { .... Bear }
$$

Arg. a chev. az. betw. three bear's heads couped sa. muzzled or. Ellwyn, Wigenhall St. Germains, Norfolk; quartered by D'Oyly.

Arg. a chev. erm. betw. three bear's heads erased sa. muzzled or. Werdiam, Charleton, co. Berks.

Arg. a chev. engr. gu. betw. three bear's heads sa. muzzled or. BaRRETT, Tregarden or Tregarne, Cornwall.

Arg. a chev. sa. betw. three bear's heads couped gu. muzzled or. Steed. Steede, Kent, 1588.

Arg. a chev. betw. three bear's heads couped sa. Lea or LeE alias KempthoRne, Cornwall ; and co. Wilts. LEY, Baronetcy 1619, Barony 1625 , Earl of Marlborough 1626, extinct 1679: Collinson, Somerset, $i, 129$. LEY, Combe Martin; and Marwood, co. Devon.

Arg. a chev. betw. three bear's heads erased sa. Aberton. Alberton, $V^{*}$. Galbreath, That Ilk. LANGDON, formerly LizaRD, Keverell, Cornwall. Ludiow, Hill Deverill, co. Wilts.

Arg. a cbev. betw. three bear's heads erased erect sa. AlbERTON, $\boldsymbol{V}$.

Arg. a chev. betw. three bear's heads erased sa. muzzled arg. BenFond, Harl. MS. 1603.

Arg. a chev. betw, three bear's heads erased sa. muzzled gu. Pemartue, Cornwall. Penarth, $V^{*}$. Penrith, Cumberland. The heads erect. Penarthe, Cornwall, $V$.

Arg. a chev. betw. three bear's heads and necks sa. muzzled or. STEAD.

Arg, a chev. betw. three bear's heads couped sa. muzzled or. BarnBy, Towthorp, co. York. Barwis, Iselekirk, Cumberland. Steade, Onesacre, co. York, temp. Edward III. STEEdE, Hariesham, Kent.

Arg. a chev. betw. three bear's heads couped and bendwise sa. muzzled or. Kempthorne, Morestow, Cornwall.

Arg. a chev. betw. three bear's heads erased sa. muzzled or. AMBORROW ANBOROW or ANBURY. Birford. Pennarth.

Arg. a chev. betw. tbree bear's heads couped sa. muzzled and collared or. BAFRÉ or BARREY.

Arg. a chev. betw. three bear's heads erased sa. muzzled or and langued gu. ALEERToN. 
1 CHEVRON betw. or within....cont.

Heads cont. (Beast) Bear cont.

Az. a chev. betw. three bear's beads couped arg. Baronby or Baroughis.

Az. a chev. betw. three bear's beads erased arg. Baronby or Baroughis.

Az. a chev. betw. three bear's heads couped erect arg. muzzled .... Baronby, $V$.

Az. a chev. betw. three bear's heads erased arg. muzzled of the first. BaronBY, $V^{*}$.

Az. a chev. betw, three bear's heads couped arg. muzzled sa. Baronby, 1730.

Gu. a chev. hetw. three bear's heads couped arg. muzzled of the first. M. William Birlande, $S$.

Gu. a chev. betw. three bear's heads and necks arg. muzzled of the first. Galbreate, Scotland.

Gu. a chev. betw. three bear's heads couped arg. muzzled of the first within a bordure engr. as the second. Whiet or White, $V^{*}$. The beads erect. Whiте, $V$.

Gu. a chev. betw. three bear's heads erased arg. muzzled sa. BERELAND or BEERLAND, $V^{*}$. The heads erect. Bereland, $V$.

Gu. a chev. betw. three bear's heads couped arg. muzzled sa. within a bordure engr. or. WHITE.

Gu. a chev. erm. betw. three bear's heads couped arg. muzzled sa. within a bordure engx. of the last. John WIGHT, Jondon, 1716.

Or a chev. engr. gu. betw. three bear's heads sa. muzzled or. Barrett, co. Warwick.

Sa. a chev. betw. three bear's heads erased arg. muzzled gu. Furford, co. Devon; and Pol. lard, co. Dorset; granted 1623. Fulfond, $V *$. Linnet. The heads erect. Sr. Humfry FULFORD, $V$.

Sa. a chev. arg. betw. three bear's heads couped or muzzled gu. SMackborough.

Sa. a chev. betw. three bear's heads couped or. M. William Smalberough, $S$.

Sa. a chev. betw. three bear's beads couped or muzzled gu. Shackborovah. Smalborougr, $V^{*}$. The heads erect. Smalborougr, $V$.

$$
\text { .....Boar }
$$

.... a chev. betw. three boar's heads fesswise couped .... Lawrence Travers, seal, $V$.

Arg. a chev. betw. three boar's heads couped az. ABACORNe or ABERCorne, Scotland.

Arg. a chev. betw. three boar's heads erased az. Rouso.

Arg. a chev. az. betw. three boar's heads erased sa. Rollo, Duncruib, Scotland.

Arg. a chev, erm. betw. three boar's heads erased sa. muzzled or. Windnam, Charlton, co. Berks.

Arg. a chev. ermines betw. three boar's beads couped sa. BaGworth, $V^{*}$. The heads fess. wise. Bagworth, $V$.

Arg. a chev. gu. betw. three boar's heads erased az. Abercromby, That Ilk, Pitmedden, Ley, and Birkenbog, co. Banff; Baronetcy 1637 . Cochrane ; Baronetcy 1675, Barony 1647, Earl of Dundonald 1669

Arg. crusily fitchy az. a chev. gu. betw. three boar's heads couped of the second. ALDworth.

Arg. a chev, engr. gu. betw. three boar's beads erased az. ABERcrombY, Fetternier; Baron Glassfoord 1685; extinct ....

Arg. a chev. indented gu. betw. three boar's beads erased az. ABERcrombY, Glasshaugh.

Arg. a chev. gu. betw. three boar's beads erased az. within a bordure of the second. Cochran, Ochiltree, Scotland. And with a crescent in chief for diff. .... Coceran, Waterside, Scotland.
1 CHEVRON betw, or within....cont.

Heads cont. (Beast) Boar cont.

Arg. a chev. gu. betw. three boar's heads couped within an orle of eight crosses croslet fitchy az. Aldworth, Bristol; and co. Wilts.

Arg. a chev. betw. three boar's heads gu. Couryn. Jones, Hartsheath, and Cefn Coch. Iddon ap Rice Sais. Davies, Doddleston, and Middleton. Enwardes, Kilbendrie, and Shrewsbury. Sire Auketyn Salveyn, $O$. Adam Salvayne, $Y$. Monsire Amias Salveyn, $Y$. Vaughan, Burlton, and Shrewsbury.

Arg. a chev. betw. three boar's beads couped gu. Burgate. Canbrore. Shambrooke. Willians.

Arg. a chev. betw. three boar's heads erased gu. Redpath, Scotland. Shouster, Whiston, Scotland. VenschOYLE.

Arg. crusily a chev. betw. three boar's heads couped gu. SwrnFond, quartered by Rokewode, 1440.

Arg. a chev. engr. betw. three boar's heads erased gu. Ridpatr, Angelran, Scotland. Ridpatr Rippet or RuppetH, Berwick, 1776.

Arg. a chev. gu. betw. three boar's heads sa. Prynn formerly Resprynn.

Arg. a chev. gu. betw. three boar's heads couped sa. Agard, co. Lancaster. Saperton. Steadman. Stedman, co. Salop. Stedman, Aston, and Rindleford, 1775-80. Trotter, The Merse, and Charterball, co. Berwick; and Gatchilraw, Scotland. Wrovghton, $V^{*}$. Wroughton, co. Berks; and Bradington, co. Wilts. The heads fesswise. Sr. Christopher Wroughton, co. Wilts, $V$.

Arg. a chev. gu. betw. three boar's heads erased sa. Nesbitt, Lismore, co. Cavan; quartering Cosby. Nisbett, Dean, Mid-Lothian, Baronetcy 1669. Stedman.

Arg. a chev. engr. gu. betw. three boar's heads couped sa. AGARD, $V^{*}$. AGARD, co. Lancaster. Agard, Foston, co. Derby, temp. Charles II ; a coheiress m. Stanhope. Swynton, $V^{*}$. The heads fesswise. AaArd, Foston, co. Derby, $V$. John Swyn'ron, $V$.

Arg. a chev. gu. betw. three boar's heads sa. lan. gued of the second. JuDKIN, quartered by Fitzgerald.

Arg. a chev. gu. betw. three boar's beads sa. lan. gued and armed of the second. Trotrer, Charterhall, co. Berwick.

Arg. a cbev. gu. betw. three boar's heads erased sa. armed or. Wrotinton.

Arg. a chev. sa. betw. three buar's heads erased az. WADE, Essex.

Arg. a cbev. sa. betw. three boar's heads erased gu. ErpHinstone, Baron Elphinstone 1509. Elphinstone, Baroness Keith 1803. ElphINSTON.

Arg, a chev. engr. sa. betw. three boar's heads erased gu. Elphinston, Leys, Scotland.

Arg. a chev. sa. betw. three boar's beads erased within a bordure gu. ELPHinston, Airth, and Calderhall, Scotland.

Arg. a chev. sa. betw. three boar's heads erased within a bordure engr. gu. Elphinston, Melyholm, Scotland.

Arg. a chev. sa. betw. three boar's heads couped ppr. Jones.

Arg. a chev. betw. three boar's heads sa. Griniston, co. Devon. 
1 CHEVRON betw. or within.... cont.

Heads cont. (Beast) Boar cont.

Arg. a chev, betw. three buar's heads couped sa. Ennowain Bendew, Lord of Tegaingle, 1079; from whom descended Lloyd, Wygfair; Davies, Denbigh ; Griffiths, Rhual; Hughes, Halkyn; Hughes, Bagillt; Griffiths, Plas-1ssa Caerwys; Wynne, Gabdlom, and Caerwys; Piers, Llanasaph, and Merton Yoglan; Williams, Merton; Parry, Coleshill, and Bassingwerk; Ffachnalt, Ffachnalt; Griffith, Pant y Llowndwy ; Griffith, Caerwys Hall; Hanmer, Caervallweh; and Jones, Sandford. Benndew. Bradestone, $V^{*}$. Bradeston or Bradston. Richard Davies, Bishop of St. Asaph 1559, St. David's 1561-82. Evans, Northope, co. Flint; and co. Salop. Evans, Llaneurgain, co. Flint. Gabot. Great Grimsey, co. Lincoln. Mosel, Norfolk. Oglethorpe, co. York. Norcop, Belton, co. Salop. Pigg. Posilethwaite. Powill, quartered by Clough. SEwster, Steeple Morden, co. Cambridge. Swinford, co. Hereford. Turner. Tyack, Polmary, St.Breock. The heads fesswise. Bradestone, $V$. James Reading, 1694, in St. Mary's church, Newington Butts.

Arg. a chev. betw. tbree boar's heads erased sa. Brikes, Choner. Kirk, Retford, co. Nottingham. Sir Theophilus OGLethorp, 1730. Reading, London, 1697.

Arg. a chev, embattled betw, three boar's heads sa. Oglethonpe, Oglethorpe, Rawden, and Thorp Ash, co. York.

Arg. a chev. engr. betw. three boar's heads sa. EtTun.

Arg. a chev, engr. betw. tliree boar's heads couped sa. Burton, $V^{*}$. Egar, temp.JamesII. Eton, $V^{*}$. The beads fesswise. Burton, $V$. Etun, $V$.

Arg. a chev. betw. three boar's heads couped within a bordure sa. CARDEGAN, $V *$. The heads fesswise. CARDEgan, $V$.

Arg. a chev, betw. three boar's heads couped sa. armed or. Burton, co. Derby.

Arg. a chev. betw. three boar's heads erased sa. langued gu. armed or. AGARD, co. Lancaster.

Arg. a chev. vairy or and vert betw. three boar's heads sa. couped gu. a label of as many points .... Oglethorpe, Newington, co. Oxford.

Az. a chev. betw. three boar's heads couped arg. Baronby, $V *$ * Barroughby. The heads fesswise. Baronby, $V$.

Az. a chev. engr. betw. three boar's heads erased at the neck arg. EDwands, co. Salop.

Az. a chev, arg. betw. three boar's heads couped (another, erased) or. Gordon.

Az. a chev. erm. betw. three boar's heads couped or. Robson.

Az. a chev. erm. betw. three boar's heads erased or.- Robson, Newcastle, 1700; and Bishopwearmouth, Durham. Rosson, $V^{*}$.

Az. a cher. betw. three boar's heads erased erminois. Robson, West Morton, Durham.

Az. a chev. betw. three boar's beads or. LONGEFORD or LONGFORD. LUDFORD.

Az. a chev, betw. three boar's heads couped or. Baronby or Barrodghby. Ferguson, England. Lunsford, $V^{*}$. Luxford. The beads fesswise. Lunsford, Sussex, $W$.

Az. a chev. betw. three boar's erased or. FRENCH, Thornidikes, and Frenchland, Scotland.

Az. a chev. betw. three boar's heads erased or within a bordure countercompony of the second and first. Gondon, Glenbucket, Scotlaud; a cadet of Rothemay.

\section{CHEVRON betw. or within.... cont.}

Heads cont. (Beast) Boar cont.

Az. a chev, betw. three boar's beads or couped gu. Lunsfond, Battle, and East Hotheley, Sussex. Erm. a chev. chequy sa. and arg. betw. three boar's heads couped of the last muzzled gu. within a bordure nebuly of the second. Forbes, Pitscottie; which coat passed by marriage 11 April 1575 to Coulthart of Coulthart, Collyn, and Ashton-under-Lyne, chief of the name.

Erm. a chev. betw. three boar's heads sa. Brockholes.

Gu. a chev, betw. three boar's heads couped arg. Bethell, Londoll. Davis, co. Salop; quartering Hart. Thirkwald. Thirlway, Cumberland. Treshar, $V^{*}$. Francis White, Bishop of Carlisle 1621, Norwich 1629, Ely 1631-8. White or Whyte, Fretenbam, Norfolk, 1435. Whyte, $V^{*}$. Wight, Scotland. The heads fesswise. William Thressher, co. Devon, $V$. Sir John Wпyтk, Norfolk, temp. Edward I, $V$. Whyte.

Gu. a chev. betw. three boar's heads erased arg. Badeley, Suffolk. Davis. Mee, London. Thirlwali.

Gu. a chev. engr. betw. three boar's heads erased arg. Davis, $V^{*}$. Stowex, co. Hertford. The heads fesswise. Davis, Middleton, co. Salop, IV.

Gu. a chev, engr. betw. three boar's heads erased at the neck arg. EDwards, co. Flint; and Shrewsbury, co. Salop,

Gu. a chev. betw. three boar's heads couped and a bordure arg. WHITe, Tunstall, Suffolk; Shottisham, and Maidenton, Norfolk.

Gu. a chev. betw. three boar's heads couped within a bordure engr. arg. Francis White, Bishop of Carlisle 1621, Norwich 1629, Ely 1631-8. White or IVhyte, Shottisbam, Norfolk.

Gu. a chev. engr. betw. three boar's heads couped and a bordure engr. arg. White, Norfolk.

Gu. a chev. betw, three boar's heads couped arg. armed or. Whrte, London, 1634; Hackney, Middlesex; and Norfolk.

Gu. a chev. betw. three boar's heads erased arg. muzzled sa. Barlande.

Gu. a chev. arg. betw. three boar's beads couped or. Bradeley or Bradley. The beads couped at the neck or. Bradlex, $V^{*}$. The beads also erect. Bradley, $V$.

Gu. a chev. betw. three boar's heads couped erm. withn a bordure engr. arg. Philirson, Swadderden Hall, Westmoreland.

Gu. a chev, betw. three boar's heads couped erm. within a bordure or. Phillirson.

Gu. a chev. betw. three boar's heads couped erm. tusked or. Phillipson alias Thelwall, Crook . Hall, and Colegarth, Westmoreland.

Gu. a chev. betw. three boar's heads or. Bradley.

Gu. a chev. betw, three boar's heads couped or. Burton. Wight, Norfolk.

Gu. a chev. betw. three boar's heads erased or. John LANGDON, Bishop of Rochester 1422-34.

Gu. a chev. betw. three boar's heads couped erect or. Bradiey.

Or a chev. betw. three boar's heads erased az. Pozlo, Baron Rollo 1651.

Or a cliev. betw. three boar's heads erased within a bordure engr. az. Rollo, Powhouse, Scotland. 
1 CHEVRON betw. or within.... cont.

Heads cont. (Beast) Boar cont.

Or a chev. betw. three boar's heads gu. Trahaiarn, Rhôs. Wroughton.

Or a chev. gu. betw. three boar's beads erased at the neck ppr. Grice.

Or a chev. betw. three boar's heads couped sa. Bradeston or Bradston. Warner, $V^{*}$. 'The heads fesswise. Warner, co. Warwick; and co. Leicester, $W$.

Or a chev. betw. three boar's heads erased sa. Warner, Ratcliff, and Rowington, co. Warwick.

Sa. a chev. betw. three boar's heads arg. Buche.

Sa. a cher. betw. three hoar's heads couped arg. Baronry, $V^{*}$. Bradstone, $V^{*}$. Linnet, $V^{*}$. Connop Thinlwall, Bisbop of St. David's 1840. The beads fesswise. Baronbr, $V$. Bradstone, $V$. Lynnet, $V$.

Sa. a chev. arg. betw. three boar's heads or Thunwall, Thurwall, Northumberland; and Suffolls.

Sa. a chev. arg. betw. three boar's heads couped or. Hares, Hayes, co. Hants. ThinLwals, Norfolls.

Sa. a chev. or betw. three boar's heads couped arg. IWhiteiaw, That Ilk.

Sa. a chev. or betw. three boar's heads couped fesswise arg. Burssme, Whitlaw, Scotland.

Sa. a chev, or betw. three boar's heads erased arg. Denson, Deuson, Scotland. Dunse, Dunse Scolland. Swinton, Swinton, co. Berwick; and Swinton Bank, co. Peebles. Whitelaw, That Ilk.

Sa. a cher. or betw. three boar's heads and necks erased arg. WoLvEIDoN.

Sa. a chev, or betw. three boar's heads erased arg. within a bordure indented of the second. Swinton, Scotland.

Sa. a chev. betw. three boar's heads erased or. Duns, Duns, Scotland.

Sa. a chev. vairy or and gu. betw. three boar's heads arg. couped of the third. IPEHONGER, co. Lancaster ; and co. Salop.

$$
\text { ..... Camel }
$$

Gu. a cbev, arg. betw. three camel's heads erased of the second collared and lined or. Burston, $V^{*}$.

Gu. a chev. arg. betw. three camel's heads erased or collared az. and stringed of the second. Burston, $V$.

\section{..... Cat}

Arg, a chev, engr. betw. three cat:s heads guard. gu. Beauchatt.

Arg. a cher. engr. betw. three cat's faces erased gu. Beacatt, Harl. MS. 1404, fo. 130.

$$
\text { .....Deer }
$$

Arg. a chev. betw. three hind's heads gu. DOWRISH.

Arg. a chev. betw. three stag's heads gu. PARkER.

Arg. a chev. betw. three unck's beads cabossed gu. BECKINGHAdr.

Arg. a chev. betw. three hind's heads cabossed gu. Hurysse, quartered by Dowriche, Douriche, co. Devon, Cotton MS. Tiberius D 10, fo. 705. 'Thomas Hurysse, $V$.

Arg. a chev. betw. three stag's heads cabossed gu. HaRWOOD HERWARD HORWODE and WHORWOOD, co. Stafford; Hagbourn, and Streatley, Berkshire; Crickheath, and Tern, co. Salop.

Arg. a chev. betw. three bucls's heads couped gu. Piagax.
1 CHEVRON betw. or within.....cont.

Heads cont. (Beast) Deer cont.

Arg. a chev. betw. three hind's heads couped gu. Beciwith, co. York, $V$. Redesweli.

Arg. a chev. betw. three bind's lieads erased gu. MALBIE or MALBYSSE, changed the name, 12:0, which was allowed, 1339 , to Beckwrth, deton; Clint; Aldborough, Baronetcy 1681-1743; and Thurcroft, co. York; and Trimdon, Durham. Whitbread, Soutbill, co. Bedford.

Arg. a chev. betw. three byse's heads (i.e. ser. pents, but in the margin, hinds) heads erased gu. William MaLBYs, $Y$.

Arg. a chev. betw. three stag's heads erased gu. Collinawood, Esslington; Chirton; Dis. sington, the heiress $m$. Stanbope; Lilburne Tower; and Glanton Pyke; Northumberland. Collingwood, Barony 1805 , extinct 1810 .

Arg. a chev. betw. three buck's heads gu. attired or. Bellingham. Parker.

Arg. a chev. betw. three buck's heads cabossed gu. attired or. Becringhan, Kent, $V$.

Arg. a chev. flory gu. betw. three stag's beads cabossed ppr. Jones, Copeldavi, and Ystrad, co. Carmarthen; a branch of Llansadalal; quartering Jones.

Arg. a chev. gu. betw. three stag's heads couped ppr. hinvett.

Arg. a chev. gu. betw. three buck's heads cabossed sa. Hartshorne. Parker.

Arg. a chev. sa. betw. three buck's heads cabossed gu. GenNon, $V^{*}$.

Arg. a chev. sa. betw. three stag's heads cabossed gu. William Pariser, Copenole, co. Chester, $V$.

Arg. a chev. sa. betw. three hind's heads couped gu. Redesweli, $V$. Rydwell, co. York. York, $V^{*}$. Roger Yorke, Serjeant-at-Law, $V$. Arg. a cher. sa. betw. three hind's heads erased gu. Whitbread, Whitknotley. Essex, $V$. Whitpred, Writtle, Essex. Whitebread, Great Baddow, Essex.

Arg. a chev, embattled sa. betw. three hart's heads cabossed gu. PARKER, co. Chester.

Arg. a chev. betw. three buck's heads sa. Elinerton. Lacy, Beverley, co. York. Trethurffe, Curnwall.

Arg. a chev. betw. three roebuck's heads sa. Buny.

Arg. a chev. betw. three stag's heads sa. Roger de Ellerton, Swaldale, $X$. Gorney.

Arg. a chev. betw. three buck's heads cabossed sa. Harwood Herward Horwode and WHORWOOD, co. Oxford; and co. Stafford. Farker, Collin. son, Somerset, iii, 362. WORHEAD.

Arg. a chev. betw. tbree stag's heads cabossed sa. Geruin, Powershall.

Arg. a chev. betw. three buck's beads couped sa. Gernon. Gorxon, $V^{*}$. Henteey. Huntley. James Reading, 1694, in St. Mary's Church, Newington Butts, Surrey.

Arg. a chev. betw. three hart's heads couped sa. Germin or Germyn. Ragon.

Arg. a chev. betw. three stag's heads couped sa. GonNon, $V$.

Arg. a chev. betw. three stag's beads erased sa. ColiLingwood. Northumberland.

Arg. a chev. sa. betw. three stag's heads cabossed of the second attired or. Gernon, $V$.

Az. a cher. betw. three bucls's heads cabossed arg. HARTESHORN.

Az. a chev. betw, three buck's heads arg. attired gut. Duke, Suffoll. 
1 CHEVRON betw, or within.... cont.

Heads cont. (Beast) Deer

Az. a chev. betw. three stag's heads cabossed or. Chipleigh, Collinson, Somerset, iii, 260.

Az. a chev. betw. three buck's heads couped or. LANSFORD.

Erm. a chev. betw. three buck's heads couped sa. HUNTLEY.

Gu. a chev. betw. three hart's heads .... HARTFORD OY HERTFORD.

Gu. a chev. betw. three buck's heads cabossed arg. CowUEI.L.

Gu. a chev. betw. three stag's heads cabossed arg. Coytmore, Coytmore, co. Carnarvon.

Gu. a chev, betw. three stag's heads couped arg. Coldon, Coldon, Scotland.

Gu. a chev. betw. three bind's heads erased arg. York, Exeter.

Gu. a chev. betw, three stag's heads erased arg. Coldon, Coldon, Scotland. Covidon, Scotiand.

Gu. a chev. betw. three stag's heads cabossed arg. armed or. CoYTMORE.

Gu. a chev. arg. betw. three buck's heads el'm. FREINDE.

Gu. a chev, arg. betw. three stag's heads cabossed per pale of the second and or. Grifrith, Wales.

Gu. a chev. erm. betw. three huck's heads cabossed arg. Frend, co. Cambridge. Friend.

Gu. a chev. betw. three buck's heads cabossed erm. Frend, $V^{*}$. But attired or. Frend, $V$. Gu. a chev. erm. betw. three stag's heads couped or. Williams, London.

Gu. a chev, or betw. three hind's heads erased arg. Malbech Malbesh or Malbish. Malbish, $V$.

Gu. a chev. or betw. three stag's heads cabossed arg. attired of the second. (? Griffith, Penrhyn, co. Caernarvon.)

Gu. a cher, betw. three buck's heads or. HARTFORD.

Gu, a chev, betw, three buck's heads crbossed or. Chelliswoth. Hugget, Kent.

Gu. a chev. sa. betw. three stag's heads cabossed arg. attired or. FFrene, Harl. MS. 1404, fo. 70.

Or a chev. gu. betw. three deer's heads .... HAYTHORN.

Or a chev. sa. betw. three hind's beads couped gu. Redeswell or Redswell.

Or a chev. betw. three stag's heads cabossed sa. each lolding in the mouth a sprig of oak ppr. fructed as the first. HARWOOD alias WHORWOOD, co. Salop.

Or a chev. engr. sa. betw. three buck's heads cabossed vert within a bordure az. CHARILTON, $V$.

Per pale az. and or a chev, betw. three buck's beads counterchanged. Tayler, Surrey.

Per pale az. and vert a chev. betw. three buck's heads erased or. HIGDEN.

Sa. a chev. betw. three buck's beads cabossed arg. Buckley, Kent. Bulkeley or Bulkely, Ireland.

Sa. a chev. betw. three stag's heads cabossed arg. Cox, Beaminster; quartering Symes.

Sa. a chev, betw. three hart's heads erased arg. SPENCER, co. York.

Sa. a chev. engr. betw. three buck's heads cabossed arg. Fernfold or Fernwold, $V^{*}$.

Sa. a chev, engr. betw. three buck's beads erased arg. Fernefold or Fernwold, Sussex, $V$. Fernewold, Sussex.

Sa. a chev. engr. betw. three buck's heads erased arg. attired or. Farnefold.

Sa. a chev. or betw. three luck's heads cabossed arg. Broughton, co. Somerset.
1 CHEVRON betw. or within....cont.

Heads cont. (Beast) Deer cont.

Sa. a chev. betw, three buck's heads cabossed or. HutTon. White, London.

Sa. a chev. betw. three stag's heads cabossed or. White, Henllan, co. Pembroke.

Vert a chev. betw. three hind's heads couped arg. Conran.

Vert a chev, betw. three buck's heads cabossed or. HICEFORD or HUCKFORD. HITFORD. PARKer.

Vert a chev. betw, three stag's heads cabossed or. Paliker, Horrockford, and Browsholme, co. York; quarterıng Redmaine, Parker, and Tempest. PARKer, Alkincoats, Newton, and Browsholme; quarterung also Blakey, Parker and Goulborne.

Vert a chev. betw. three hind's heads couped or. Snelling, co. Dorset; and Portslade, Sussex.

$$
\text { ....Dog }
$$

Arg. a chev. betw. three talbot's heads erased .... Dunscombe, co. Cork.

Arg. a cher. betw. three talbot's heads couped az. withın a bordure gu. KEILOCK, Scotland.

Arg. a chev. betw. three talbot's heads erased gu. LEDRED, co. Somerset.

Arg. a chev. sa. betw. three talbot's heads erased pean. HALL, London.

Arg. a chev. betw. three greyhound's beads sa. WHEIPDALE.

Arg. a cbev. betw. three talbot's beads couped sa. HaLl, co. York.

Arg. a chev, betw. three greybound's heads erased sa. Tuck.

Arg. a chev. betw. three talbot's heads erased sa. CaMPION, Witham, Essex ; and London. Ellerker. Hall, High-Merdow, co. Gloucester.

Arg. a chev. engr. betw. three talbot's heads erased sa. HALL, Gretford, co. Lincoln.

Arg. a chev. engr. betw. three talbot's heads erased sa. all within a bordure gu. HALL, Spalding, co. Lincoln.

Az. a chev. betw, three talbot's heads couped arg. Phillir, Scotland. Philps, Amyrcloss, Scotland.

Az. a chev. betw. three talbot's heads erased arg. collared gu. AlEXANDER; a label of three points or: Leland, Collect., ii, 688. And with the same label. Thomas Alexander, Gray's Inn, ob. 1658.

Az. a chev. erm. betw. three greyhound's beads arg. Liggins.

Az. a chev. betw. three greybound's heads erased or. CHEDWORTH.

Gu. a chev. betw. three talbot's beads erased arg. Hull, co. Devon.

Gu. a chev. erm. betw. three talbot's heads erased or. William WHITtell, London; granted 1587, W.; Over-Helmesley, co. York.

Gu. a chev. $\in$ rm. betw. three talbot's beads or each issuing out of a mural coronet az. HoDGEs, Overne, co. Leicester.

Gu. a chєv. erm. fimbriated betw, three talbot's heads erased or. Whitile, co. Lancaster; con. firmed 1694 .

Gu. a chev. betw. three talbot's beads erased or. ClIFFORD.

Gu. a chev. vair betw. three talbot's heads erased or. Isted, Framfield, Sussex; and Ecton, co. Northampton; quartering Buck and Percy. Whittis, co. Lancaster; granted 13 Sept. 1688. 
1 CHEVRON betw, or within.... cont.

Heads cont. (Beast) Dog cont.

Or a chev. betw. three greyhound's heads couped sa. SHeIncliff, Shirecliff, co. York.

Sa. a chev. betw. three greyhound's heads erased arg. BEURY or BewYl. John BeuYr, $V$.

Sa. a chev. betw. three talbot's heads erased arg. HaLl, co. Devon, $W$. Hull, Lurckbere, co. Devon; St. Leonard's, Cornwall; and co. Oxford.

Sa. a chev. embattled betw. three talbot's heads erased arg. HuLL, Hammersmith, Middlesex.

Sa. a chev. erm. betw. three talbot's heads erased arg. Hill, London, 1616. Huin, co. Buckiugham; Larkbury, co. Devon; Osterley, co. Durbam; and London, $₫ 616$. Holl, Battersea, Surrey; confirmed 25 Jan. 1624.

Sa. a chev. betw. three greyhound's heads erased erm. BeLson.

Sa. a chev, or betw. three talbot's heads erased arg. Weston, Effingham, and Weston-Ockluam, Surrey.

\section{....Elephant}

Gu. a chev. or betw. three elephants heads erased ppr. Husisisson, Earth, Sussex.

\section{....Fox}

.... a chev. embattled betw. three fox's heads erased .... LEgatT, London; in Croydon Church.

Arg. a chev. az. betw. three fox's heads erased gu. John FoxalL, London; granted $1579, \mathrm{~W}$.

Arg. a chev. betw. three fox's heads couped gu. Awys.

Arg. a chev, betw. three fox's heads erased gu. William Awys, $V$. FaIrfax. John Fox, $V$. Fox, Gwernoga, co. Montgomery, $Z, 344$. Fox, Osmaston Hall, co. Derby ; co. Hereford; co. Leicester; co. Salop; and Ireland. Fox, Brambam Park, co. York; Baron Bingley, 1762, extinct 1773. Lane-Fox, quartering Lane. Tynslow. Whitbread, London.

Arg. a chev. betw. three fox's heads erased gu. collared or. John Fox, London; granted 1586 , TV.

Arg. a chev. sa. betw, three fox's heads erased gu. FAIRFAX.

Arg. a chev. betw. three fos's heads erased sa. Ludow, Barony 1755 and 1831 , Earldom 1760 , extinct 1842. LUDLOW, Ireland.

Az. a cher. betw. three fox's heads erased or. Chedworth, $V$. Reynold, Stratford, co. Warwick.

Erm. a chev. az. betw. three fox's heads erased ppr. Fox, London; and co. York.

Ermmois a chev. betw. three fox's heads erased gu. langued arg. Fox, High Holborn; Middlesex; granted 12 June 1632.

Or a chev. gu. betw. three fox's heads crased az. Fox, Youlgrave, co. Derby.

Or \& chev. betw. three fox's heads erased gu. Edward Fox, Bishop of Hereford 1535-8, Add. MIS. 5802, fo. 92 b. Fox, Bromfield, co. Salop; quartering Stoke, Steventon, Ped. warden, Daniell, G winnett, Picken ham, Barrington, Whichcott, and Donne; Harl. MS. 6110, fo. $14 \mathrm{~b}$.

Sa. a chev, betw. three fox's heads erased arg. Rathenale, $V$. Rodnale, $V^{*}$. Sr. John Rodnale, $V$. Rodnali. Rothenale, $V^{*}$. fiudnalie, $V$. Rudnali, $V *$.
1 CHEVRON betw. or within.....cont.

Heads cont. (Beast) Goat

Arg. a chev. betw. three goat's heads erased gu. Cheryton.

Arg. a chev. betw. three goat's heads erased sa. Beny. Bunney or Bunny, co. York; and co. Durham. Bunny, $V$; co. York, $W$. Bunny, Speen Hill, co. Berks.

Arg. a chev. vert betw, three goat's heads erased sa. White, Truro, Cornwall.

Az. a cher. betw. three goat's heads arg. within a bordure .... Company of CoRDonners or Shoemakers, London, Cotton. MS. Tiberius D 10 , fo. 887 .

Az. a chev. arg. betw. three goat's heads erased of the second armed or. Richard HIIL, Bishop of London 1489-96, W. William Marwood, Plymouth, and Plumstock, co. Devon; granted by Lee (? 1596), W. Plumstock, $V^{*}$.

Az. a chev, or betw. three goat's heads erased arg. GetForth, $V$.

Az. a chev. or betw. three goat's heads erased arg. attired of the second. Company of CordwaIners or Shoemakers, London. Company of Cordwainers, Exeter.

Gu. a chev. betw. three goat's heads erased arg. Company of Cordwainers, London. Filtelton. Filtilton, $V^{*}$. Sr. John Fyltilton, $V$. Merwood. Tintilton, $V^{*}$. Whight or White. White, Bere, co. Dorset; and Duffield, co. Derby; quartering Talbot.

Gu. a chev. betw. three goat's beads couped arg. attired or. White, co. Derby ; co. Dorset; and co. Hants.

Gu. a chev. betw. three goat's heads erased arg. attired or. Springhair, W. Thomas Whight, co. Hants, $V$. Witehors. Whitehorse.

Gu. a cbev. engr. betw. three goat's heads erased arg. armed or within a bordure engr. of the second. Marwood.

Gu. a chev. arg. betw. three goat's heads erased erm. attired or. Marwood, West Marwood, co. Devon; coheiresses $\mathrm{m}$. Chichester and Wichalse. Meriwood, $\boldsymbol{V}$.

Gu. a clrev, erm. betw. three goat's heads erased arg. Marwood or Monwood, Little Bushby, co. York; Baronetcy 1660; extinct 1740. Merwood, Widworthy, co. Devon; coheirs m. Stevens, Wolcot, and Elton.

$\mathrm{Gu}$. a chev. elm. betw. three goat's heads erased arg. attired or. MEE, 1702-85; Bigland, Gloucester. ii, 68 .

Gu. a chev. or betw. three goat's heads erased arg. armed of the second. Wytchers, $V$.

Or a chev. az. betw. three goat's heads of the second attired as the first. ALWYNE.

Or a chev. sa. betw. three goat's heads erased az. BENDISH.

Or a chev. vert betw. three goat's heads erased sa. White, London. White, $V^{*}$.

Sa. a chev, betw. three goat's heads erased arg. LAPPESLODE, co. Devon. YARKER, Westmoreland; and co. York.

Sa. a chev. or betw, three goat's heads erased arg. armed of the second. Crossman, Cross, Cornwall.

Sa. a chev, betw. three goat's heads or. Jthel Telyn, Yale, living 1000. Madoc ap Bleddy, Leeswood, living 1440.

Vert a cliev. betw. three goat's heads erased arg. ar'med or. Gathpath, $V^{*}$. Gatpath, V. 
1 CHEVRON betw. or within....cont.

Heads cont. (Beast) Hare

Arg. a chev. flory counterflory az. betw. three bare's heads erased purp. each having in the mouth an oak leaf vert. Collingwood, North. umberland.

Sa. a chev. betw. three coney's beads erased arg. SPENCER, $V$.

Sa. a chev, betw. three bare's heads erased arg. Spencer, Witton, co. Salop; and co. Stafford.

\section{.....Horse}

Arg. a cliev. az. betw. three nag's heads sa. Meirion GocH, Llyn. The beads erased. Jones, Castle March.

Arg. a chev. erm. betw. three horse's heads erased sa. EAsT.

Arg. a chev. ermines betw. three nag's heads erased sa. Edwards, co. Bedford.

Arg. a chev, betw. three horse's heads erased gu. Wymor, $V$.

Arg. a chev. sa. betw. three horse's lieads couped gu. LEWCAR. Redeswell or Redswell.

Arg. a chev. sa. betw. three horse's heads erased gu. Cason, Steeple Morden, co. Cambridge; and co. Hertford. Lucar, $V^{*}$. The heads bridled or. Emanuel LUCAR, Bridgewater, co. Somerset quartering auother coat (for LUCAR?), W.

Arg. a chev. sa. betw. three nag's heads erased gu. bridled or. LuCar, Madenbrook, co. Somerset.

Arg. a chev. betw. three horse's heads erased sa. Upwoon, Lovell's Hall, Terrington St. Clement's, Norfolk.

Az. a chev. or betw. three borse's beads arg. Rhys ap MarCHaN.

Gı. a chev. erm. betw. three horse's heads erased arg. SIADER, Bath and Barbam-Downs, Kient.

Gu. a chev. betw. three nag's loeads erased or. bridled sa. 'TRIPP, Tripham, Kent; and Lon. don.

Sa. a chev. betw. three horse's heads erased arg. East, co. Buckingham.

Sa. a chev. erm. betw. three horse's heads erased arg. Slader, co. Devon.

Vert a chev, betw. three horse's (or mule's) heads or. SNellinge.

Vert a chev. betw. three horse's heads erased or. Stling, Kent.

\section{.... Leopard}

.... a chev. betw. thrce leopard's heads .... John LE Bray, London, 1327; Cotton MS. Julius C., vij, fo. 184. The hearls bearded. William de Farington, seal temp. Fdward III.

Arg. a cher. betw. three leopard's heads .... STraFFord.

Arg. a chev. betw. three leopard's heads az. Houson, Shipley, Sussex. Lawler, England. SiFATNBand, $V$.

Arg. a chev. engr. betw. three leopard's heads az. Edward Copleston, Bishop of Llandaff 182849. Copleston, co. Devon.

Arg. a chev. az. betw. three leopard's beads ru. Welstead, co. Cork.

Arg. a chev. engr. az. betw. three leopard's leads gu. Copleston.

Ar'a. a chev. chequy or and sa. betw. three leopard's heads erased az. collared and lined gold. Monck, Caeuby, co. Lincoln.
1 CHEVRON betw. or within.... cont.

Heads cont. (Beast) Leopard cont.

Arg. a chev. betw. three leopard's heads erm. crowned or. Thomas PYNNER, 1583, in church at Mitcham, Surrey.

Arg. a chev. gu. betw. three leopard's heads az. Chamberlaine, $V$. Gibis. Gibons or Gibus, $V *$. 'Thomas GyBons, $V$.

Arg. a chev. engr. gu. betw. three leopard's heads az. Copleston, co. Devon, $V$.

Arg. a chev. betw. three leopard's heads gu. (in error). Briket or BukEt, $V^{*}$. BuCKETT. Chambert,yn, $V$ * . Chamberleyn, $V$. Farrington (in error). Halsam, co. Lincoln. Halsham. Syith, London, 1716. Nere. Peter, $V^{*}$.

Arg. a chev. betw. in chief three leopard's heads gu. and in base a bugleliorn .... Serrven, Seriven, co. York, temp. Henry III.

Arg. a chev. engr. betw. three leopard's heads gu. Halsham, Suffolk. Robert Halsham, $V$. Heliston. John Herliston, $V$. Heylston, London.

Arg. a chev. betr. three leopard's heads erased gu. Peter Briket, $V$. Buket, $V$.

Arg. a chev. gu. betw. three leopard's heads sa. Blakenex or Brakney. Farindon, Wierden, co. Lancaster, Harl. MS. 1468, fo. 94. Farington, Worden, co. Lancaster, quartering, Faringdon, Benson, Rufine, Bradshaw, Aspul, Fitton, Carden, Malvoisin, Brereton, Nowell, Fitton, Lonsdale, and Hargraves. Farningdon, co. Lincoln. Ferington, Ferington, co. Lancaster, $V$. Ferrington, $V *$. Harrington (in errol"?) LEE, Nantwich, and Newport, co. Salop, $W$. Newport, Worcester. Newport, High Ercall; quartering Ercall; Barony 1612, Viscounty 16r5, Earl of Brad. ford 1694, Extinct 1572; the beiress $m$. Bridgeman.

Arg. a chev. gu. betw. three leopard's heads sa. quartering gu. three 5.foils arg. over all a martlet for diff. ("A patent granted 16 December 1560 to") William FARINGton, Worden, co. Lancaster, Harl. MS. 1437. But with a crescent for diff. az. Farington, Little Farington, and Lingard, co. Lancaster, Harl. MIS. 1549 and 6]59. But with a mullet for diff. az. Farington, Ribbleton, co. Lancaster, quartering also Lawrence; Harl. MS. 1549 and 6159 .

Arg. a chev. gu. betw. three lenpard's heads erased sa. Farrington, London; Gwillim, 1724, i, 261. Arg. a chev. purp. betw, three leopard's heads sa. WYRDEN, quartering gu. three 5-foils arg. for Farington or Farrington, co. Lancaster. And with over all a crescent for diff. Farington, Lyngarde, co. Lancaster; and Farington or Farrington, Little Fariugton, co. Lancaster, Harl. MS. 2080 fo. 47 and 66. But with the same quartering, and Lawrence, with over all a mullet for diff. Farington or Fanrington, Ribbleton, co. Lancaster, Harl. MS. 2086 fo. $45 \mathrm{~b}$. But with the same diff. and gu. three 5-foils arg. also in the fourth quarter. Farington, Ribbleton, Harl. MS. 891 .

Arg. a chev. sa. betw. three leopard's heads az. TyCHEWELL, $V$.

Arg. a chev. betw. three leopard's heads sa. LeA, Lea, $V^{*}$. LeE, Lee, and Darnhall, co. Ches. ter; the heiress m. Townshend. LeE, Langley, co. Salop. Nornian, co. Somerset. Rich. ald De Newport, Bishop of Loudon 1317-8. Siert, $V$; and co. Devon. 
1 CHEVRON betw, or within.... cont.

Heads cont. (Beast) Leopard cont.

Arg. a chev. engr. betw. three leopard's heads sa. Copleston, co. Devon; coheirs m. Elford and Bampfylde. Edward Copleston, Bishop of Llandaff 1828-40. Dabgreene. Dabgreyne, $V^{*}$. Richard Dabgreyn, $V$. Lee, co. Chester. LeIGH, Ingoldsby, co. York, $V$. LeYGH, $V^{*}$. LEY, Ley, co. Chester, $V$.

Arg. a chev. betw. three leopard's heads sa. mouth tongue and eyes or. THInkill, in chureh at Sprotborough, co. York.

Arg. a chev. betw. thiee leopard's heads vert. LANGTON.

Az. a chev. betw, three leopard's heads arg. Chambers. Frowicke, Wysley, co. Herts; Oldford, Surrey; North Mims, Middlesex. Savage, Sussex. Savaige, Sussex, $T^{\prime}$. WILFRAY.

Az. a chev. engr. betw. three leopard's heads arg. EAdEs, Middlesex; and Saxmundhan, Suffolk. EDE, Saxmunảbam. EDEs, co. Bedford.

Az. a chev. arg. betw. three leopard's heads or. Iarvili. Blafener, $V$.

Az. a chev, arg. betw. threo leopard's heads in chief or and a fish haurient in base of the second. GLowster.

Az. a chev. erm. betw. three leopard's heads or. Nicholas Ashbr, Bishop of Llandaff 1441-58. Ashby, Quenby Hall, co. Leicester; quartering Ashley, Burdet, Zouch, and Shukburgh. Basket, Isle of Wight; and co. Dorset. William Baskert, $V$. And with a bordure of the second. Joln GAUDEN, Bishop of Exeter 1660, Worcester 1662.

Az. a chev. erm. betw. three leopard's faces salient ppr. Hingston, Aglis, co. Cork.

Az. a chev. betw. three leopard's heads or. BenLEr, Irelaud. Frowicke, Oldford, Surrey; Wyley, co. Herts; and North Mims, Middlesex. The heads erased. Frowicke as quartered by Doyley. Fronye, $T^{>*}$.

Az. a chev. betw. in chief three leopard's heads and in base a crescent or. Foster, Northumberland.

Az. a chev. betw. three leopard's heads or tongued gu. Berley.

Az. a chev. or betw. three leopard's heads erased of the second charged with pellets. Surth, co. Derby.

Az. a chev, engr, betw. three leopard's heads or langued arg. HUGH, $V$.

Erm. a chev. compony arg. and az. betw. three leopard's heads of the third. Auscot.

Erm. a chev. compony az. and or betw. three leopard's heads of the second, HENSCOT, ea. Devon.

Erm. a chev. sa. betw. three leopard's beads gu. Buсктнолght, co. Somerset.

Ermines a chev. betw. three leopard's beads arg. LECHFORD, $W$. LEECHFORD, $V *$.

Erminois a chev. engr. betw. three leopard's heads gu. Harvey, Wormersley, co. York.

Gu. a chev. betw. three leopard's heads arg. Belke, Copesham, Sole. Bilk, Coperham, Kent. Cole. Coles, co. Dorset. Heuxton, co. Bedford. Hexton, $V^{*}$. Karvell, Norfolk. Petтet, Shalmisford, Kent. PEтүт, Kent, W. Thensted, $V$. Thowested, $V *$. And with a crescent for diff. Ciriac Petir, Colkins, Kent, 1691.

Gu. a chev. engr. betw, three leopard's heads arg. Wilwoord, co. Worcester.
1 CHEVRON betw. or within....cont.

Heads cont. (Beast) Leopard cont.

Gu. a chev. betw. three leopard's heads crowned arg. SLINGSBY.

Gu. a cher. arg. betw. three leopard's heads or. Farvell. Kerwell or Carvme, Norfolk. Ludbrough. John de Ludburgh, $Y$. Monsire de Loghtburgh, $Y$. Lughborough. Wilford, Kent.

Gu. a chev. engr. arg. betw. three leopard's heads or. Wilford, London.

Gu. a chev. erm. betw. three leopard's heads arg. Keye, Kent, $W$. Keyes, Kent.

Gu. a chev. erm. betw. three leopard's heads or. Cole, co. Somerset. Godwin, co. Dorset. Goodwr, Wells, co. Somerset. Hill. Keyes, Kent. WiIford, Exeter, $V$. WILLESFord or Willford, co. Devon.

Gu. a chev. or betw. three leopard's heads arg. Carvill, $V^{*}$, and Norfolk. Carvele or Carwell. Harvill, $V^{*}$. Karvill, Marchland, $V$. Kervill, Norfolk. Kervyle, Wiggenball, Norfolk. Steward. Thewisted. Edgar, 1716.

Gn. a chev. betw. three leopard's heads or. Carwell or Carvele. Carveli. Fanner. Hesketh. Justice. Monsper, co. Devon, $V$. Monsder Monster or Mounser, co. Derby. Parker, $V$ *. Parker, Park Hall, co. Stafford; a branch of Parier, Norton Lees, co. Derby, the leiress m. Parker. Thewisted. Wilforn, Kent. Witford. And with a crescent for diff. Parmen, Whitley Hall, co. Lincoln; quartering gu. a tower or and perched thereon a bird arg. And also with a crescent for diff. PARKER, Barony 1715, Viscounty 1721, Earl of Macclesfield 1721 .

Gu. a chev. betw. three leopard's heads or in the mouth of each au arrow fesswise arg. PARkER, Cuerden, and Extwistle, co. Lancaster; quartering Townley and Banaster.

Gu. a chev, engr. betw, three leopard's heads or. Justice. Parker, $\boldsymbol{V}$. Parker, co. Derby; and Whitley Hall, co. Lincoln. Periani, Collinson, Somerset, ii, 495. Perian, Fulford, co. Devon. Peryam. Wilford, Kent, $V$. Wilsford, Harteridge, and Dover, Kent.

Gu. a chev, vair betw, three leopard's heads or. Memes or Mennys, Kent; and London; granted 1616. Mennis, $V^{*}$. Rice, Essex. Rys, Essex, $V$. Rice, Ireland.

$\mathrm{Gu}$. a chev, vairy or and az. betw, three leopard's heads of the second. Mennes. Menns Minnes or Mrnnes, Kent; and Middlesex; granted July 16]6. MENNYs, $W$.

Or a cher. az. betw. three leopard's heads gu. WELSTED.

Or a cher. az. betw, three leopard's heads sa. a bordure gu. Fourbins.

Or a cher. gu. betw. three leopard's heads az. Gibins.

Or a chev. betw. three leopard's heads gu. Aleyn, $V$. Allen or Alleine. Beckett. Chamberlayn. Harvey, Essex; and London. Hervy, co. Stafford, $V$. Sr. James Hervy, Alderman of London, $V$. NEcke or Nere. Richard NYkkE or NYx, Bishop of Norwich 1501-36. Nix.

Or a chev. engr. betw. three leopard's heads gu. Harver, Alvington, Isle of Wight; and Wor. mersley, co. York; granted 1688.

or a chev. gu. betw. three leopard's heads sa. Newport, New Park, co. Killenny; Baronetcy 1789 . 
1 CHEVRON betw. or within.... cont.

Heads cont. (Beasts) Leopard cont.

Or a chev. betw. three leopard's heads sa. WHEELER, London; granted by Coolie (? 1585), $W$. WhEeler or Wheler, Martin Hussingstre, and Burbury, co. Worcester; and Leamington Hastang, co. Warwick; granted 1585 ; Baronetcy 1666. WheELER, Waterford; the heiress $m$. Glasse and Bremer.

Or a chev. engr, betw, three leopard's heads sa. Marvel.

Per pale az. and gu. a chev. erm. betw. three leopard's heads arg. AsHBy.

Purp. a chev. vairy or and gu. betw. three leopard's heads of the second. Farnden, Sedlescomb, Sussex; granted February 1634.

Sa. a chev. betw. three leopard's heads arg. Blyke, co. Hereford; London; and co. Salop. Deyis. Dyes or Diss. Hawes, Juondon. Hexton. Lechford, Shelwood, Surrey. LECHFORD, $W$. LEECHFORD, $V^{*}$. LICHFORD. LYcHFORD, Charlwood, Surrey.

Sa. a chev. betw. three leopard's heads erased arg. Monsire William de Rednesse, $Y$.

Sa. a chev. arg. betw. three leopard's heads of the second langued gu. BLomner.

Sa. a chev. arg. betw. three leopard's heads or. Funingley. Hase. Hawes, Weston, and Stoke Albany, co. Nortbampton; co. Stafford; and co. Warwick. Hay; granted by Camden, $W$. The beads erased. NoBLE, Thristle Dermot.

Sa. a chev. engr. arg. betw. three leopard's heads or. Farwell. Fylingley, $V$.

Sa. a chev. (arg.) betw. three leopard's faces ppr. Blomney.

Sa. a chev. erm. betw. three leopard's heads arg. DefFe or DerfF, $V$. John Hilt, London, Auditor; granted by Cooke, $W$. Hill, Teddington, Middlesex.

Sa. a chev. engr, erm. betw. three leopard's heads arg. Hrus, Thornton, co. York.

Sa. a chev. erm. betw. three leopard's heads or. Blackley. Blackney, Norfolk. Blakeney, $V$. Eaton. Etton, Fresbe, $V$. Godwin, $V^{*}$. Sa. a chev. erm. betw. three leopard's heads within a bordure or. Browne, $V^{*}$. Goddin, Kent. GODDYN, $W$.

Sa. a chev. erminois betw. three leopard's heads arg. HiLl, Brook Hall, co. Londonderry; Baronetcy 1779 .

Sa. a chev. or betw. three leopard's beads arg. Prenne.

Sa. a cher. betw. three leopard's heads or. Pollington. Wentworth, co. York, $V$. WENTworTH, Woolley, co. York; quartering Downes; the heiress m. Armytage; a branch from Mendam Priory, Suffolk; and like Wentworth, Bretton, co. York ; Baronetey 1664 extinct 1792; descended like WentworTH, Nettlested, Suffolk, Barony 1529, Earl of Cleveland 1625-67; the beiresses $\mathrm{m}$. Noel and Curzon; and its branch at Gosfield, Essex; Baronetcy 1611-31 ; through Wentworth, North Elmsal or Empsale, co. York; quartering Bisset; Baronetcy 1692, extinct 1741 ; the heiress $\mathrm{m}$. Cholmley; from WINTERWADE WrNTWORD or WENTWORTH, Wentworth Woodhouse, Strafford, co. York; Baronetcy 1611, Baronies 1628 and 1640 , Viscounty 1628 and 1711 , Earl of Strafford 1640 and 1711 , extinct 1569 and 1799 ; the heiresses m. Watson, Conolly, Howrda, and Vernon. Wentwonth, Wentworth Castle, co. York, quartering Vernon and Vernon.

\section{CHEVRON betw. or within.... cont.}

Heads cont. (Beasts) Lion

Sa. a chev. betw. three lerpard's heads or within a bordure arg. Wentworth, Grimsby, co. Lincoln; and Bretton, co. York.

Vert a chev. betw. three leopard's heads or. Ffytche or Fitch. Ffytche or Fytche, Thorpe Hall, co. Lincoln; a branch of the family of Ffytche, Danbury Place, and Woodham Walter, Essex. FiтcH, Hudsell, Essex; Eltham, and Mount Mascal, Kent. Sr.... Kynardsby, $V$. Kynardysby. Mad Curdy, America : Ireland; and London. And with a crescent for diff. Fytche, Canfeld, Essex, 1578.

Vert a chev. betw. three leopard's heads or within a bordure gu. Fiтch, Woodham Waiter, Essex. The bordure bezanty. FIYcH, Ramsden, Essex.

Arg. a chev. az. betw. three lion's heads erased .... witbin a bordure engr. of the second. HaNderside.

Arg. a chev. az. betw. three lion's beads couped gu. Scotland, Scotland.

Arg. a chev. az. betw. three lion's beads erased gu. Bucket.

Arg. a cbev. betw. three lion's heads erased gu. Albemarle. Bucket. Collis, Ireland. Denman. Lovell, co. York. Luccombe, Collinson, Somerset, iii, 491. RiDon. Rockley or Rocuiff, Cowthrep, co. York. Rouclif, Rouclif, co. York. John de Roucliffe, $Y$. Rowchiffe. 'Tence, Ireland. TIFfin.

Arg. a chev. betw. three lion's heads erased within a bordure gu. RowClIFFe.

Arg. a chev. betw. three lion's heads erased gu. crowned or. JoHnson, North Luffenham, co. Nottingbam; and South Luffenham, Rutland. Edward Jomnson, $W$.

Arg. a chev. gu. betw. three lion's heads erased sa. crowned or. Petit or Pettit, Kent.

Arg. a chev. sa. betw. three lion's beads gu. Lovelu, co. York.

Arg. a chev. sa. betw. three lion's heads erased gu. Cranbuil. Reydon. Thomas de Routhe, $Y$. Routr, co. York. Rowe, Lewes, Sussex; confirmed 21 May 1614.

Arg. a chev. sa. betw. three lion's heads couped gu. crowned or. Robert JoHnson, Preacher, NorthLuffenham,Rutland; granted by Cooke, $W$. Arg. a chev. sa. betw. three lion's heads erased gu. crowned or. Gison, $V^{*}$.

Arg. a chev. betw. three lion's heads sa. Thomas LampLogh, $X$.

Arg. a chev. betw. three lion's heads erased sa. Allerton. William Driffield, 'de la Walde,' $X$. Gumars or Gunas, Witham, Essex. Gumras, $V^{*}$. GunNas, $V$.

Arg. a chev. engr. betw. three lion's heads erased sa. Fereby, $V$. Tommond, $V$. Tolmond.

Arg. a chev. betw. three lion's heads erased within a bordure sa. Rancliffe.

Arg. a chev. betw. three lion's heads erased sa. crowned or. GREY.

Az. a cher. betw. three lion's heads erased arg. FAIRFORD.

Az. a chev. betw. three lion's heads erased arg. goutty de poix ducally crowned or. Pinder, co. Lincoln; granted 1538.

Az. a chev. arg. betw. three lion's heads erased erm. crowned or. Pindall or Pinder, London, and Axholme, co. Lincoln. Pindar. Pinner, London; granted 12 August 1577. 
1 CHEVRON betw, or within.... cont.

Heads cont. (Beast) Lion cont.

Az. a clier. or betw. three lion's heads arg. Dudley, Clupton, co. Nurthampton.

Az. a chev, or betw. three lion's heads erased arg. Pest (in a later hand than) $W$.

Az. a chev. or betw. three lion's heads couped arg. langued gu. O'Enos, alias MAcGenIs, Lord Iveach.

Az. a chev. betw. three lion's heads erased or. Denman, London, Dudley. Stark or Starie. Steward, $V^{*}$. Sr. Thomas Wyndhadi, Norfolk; and Suffolk, $V$. Wyndham, Baronetcy 1661 ; Baron Cockermouth and Larl of Egremont 1749, extinct 1845 , descended like WyndhaM, Ash. combe, the heiress m. Aruudel; and WrNDHAI, Denton, and Hawling, co. Wilts, quartering Stratford and Smith; and WrNDHAM, Salisbury, quartering Hearst, throngh WyNDHAM, Nol:rington, co. Wilts, from Wyndham, Orchard, Collinson, Somerset, ii, 235; iii, 260, 455, 491, from whom also descended WyndHas, Kents. ford, aud Trent, co. Somerset, Baronetcy 1673 , extinct 1719, the heiresses $m$. James and Bromley; and Pilsden Court, co. Devon, Baronetcy 1641-63: WrNdHAMr, Cathanger, co. Somerset ; and 'Tale, co. Devon; Silton, co. Dorset. WyndHaM, Cromer, Norfolk, quartering Davy, Hobart, Dalton, and Wrighte. WyndHam, Felbrigg, Norfolk. WrNDHAM, Hunnıngton, co. Wilts, quartering Scrope, A bell, Gurney, Moyns, and Sydeubam.

Az. a chev, engr. betw, three lion's beads erased or. Pope, $V$. WyndhaM.

Az. a chev. betw. three lion's heads erased or langued gu. WINDHam, Collinson, Somerset, i, 258 .

Gi. a chev. betw. three lion's beads erased arg. Burham, Leversedge, Essex. Le Moxne or Monke, $V$, co. Devon, $W$; or Monck or Monk, Potheridge, co. Devon; $Z, 450$, Baron Moncl, Earl of Torrington, and Duke of Albemarle 1660 . 88; quartering Tilley, Estcott, Pishford, Trenchald, Crukerne, Grant, Champernowne, Wood, and Plantagenet. And with a crescent for diff. MoNck, Earl of Rathdown; and MoNck, Coley Park, Berkshire; derived from Monk, Hatherby, co. Devon. James Henry Monk, Bishop of Gloucester 1830, and Bristol 1836-56.

Gu. a chev. embattled betw. three lion's heads erased arg. BispHam, Bispham, and Billing, co. Lancaster; granted 1640.

Gu. a chev. arg. betw. three lion's heads erased erminois crowned of the second. PyNdan, Kempley, co. Gloncester; granted ....

Gu. a chev. erm. betw. three lion's heads erased arg. Goodwri, Winnington, co. Warwick.

Gu. a chev. engr. erminois betw. three lion's heads erased erm. ducally crowned gold. PINDAR or PYNDAR, afterwards LYGON.

Gu. a chev. or betw. three lion's beads erased arg. Burnham, $V$.

Gir. a chev, betw. three lion's heads erased or. Burnham. Chassereau. Leversedge, Essex. STEWARD.

Gu. a chev. vair betw. three lion's heads erased or. PAGE, Middlesex.

Or a chev. betw. three lion's lieads erased az. WENDY, Norfolk. The same arms within a bordure az. WeNDEY, Hastingfield, co. Cambridge. The bordure engr. az. WENDIE or Wend, Clan, Suffolk. Wende, $V^{*}$. Thomas WENDY, $V$.
1 CHEVRON betw, or within.... cont.

Heads cont. (Beast) Lion cont.

Or a chev. gu. betw. three lion's heads couped az. Gibon, $V$.

Or a chev, betw. three lion's heads erased gu. Brcket. Belet. Behell. Lovell, 0. York. Sr. Henry Halshum, T.

Or a chev. gu. betw. three lion's heads erased sa. GIBON, $V^{*}$. JowETT.

Per chev. gu. and az. a chev. betw. three lion's heads erased or. Sr. John Stewand, $V$.

Sa. a chev. betw. three lion's heads erased arg. Cotton. Peers. Stanton, Clovelly, co. De. von; the heiress $m$. Crewkern. Weston, Ockham, Surrey, 1700.

Sa. a chev. betw. three lion's beads erased arg. crowned or. Bieauchamp, $V$. Beauchampe.

Sa. a cher. erm. betw. three lion's heads erased arg. Pearse, Norfolk. Pearee, Harlington, co. Bedford. PeEres. Yiens. Sr. William Standon, Alderman of London, $V$. Staunton. Sa. a chev. erm. betw. three lion's heads erased or. Unetr, Castle Frome, Ledbury, Fearns Court, and Marden Court, co. Hereford; and Broadward Hall, co. Salop; quaitering Lingen.

Sa. a chev. or betw. three lion's beads erased arg. Jeauchanip. Bewchad, $V$. Beweham. WESTON.

Sa, a chev. betw. three lion's heads erased or. Benington, $V^{*}$. Benyngton, $V$.

Vert a chev. betw. three lion's heads erased or on eacb as many gouttes (another, four bil. lets) gu. Plomer, co. Bedford; and Radwell, co. Hertford.

\section{.....Martin}

Arg. a chev. betw, three martin's heads erased sa. LudLow, Baronies 1755 and 1831, Earldom 1760 , extinct 1842 .

$$
\text { .....otter }
$$

Arg. a chev. betw. three otter's heads gu. Fullerton, Craighall, Scotland.

Arg. a chev. betw. three otter's heads erased sa. (The old arms of) Bas Foun, Balfour, co. Fife; the heiress m. Bethune.

$$
\ldots .0 x
$$

Arg. a chev. betw. three bull's heads cabossed .... (The ancient arms of) Prestland, Prestland, and Wardle, co. Chester.

Arg. a chev. az. betw. three bull's heads cabossed gu. William de WeLLs, $V$.

Arg. a chev. az. betw. three bull's heads cabossed sa. Bullen.

Arg. a chev. ermines betw. three bull's heads couped sa. armed gu. WaLDRoN or WaLroN, Langridge, co. Somerset; and co. IVilts.

Arg. a chev. ermines betw. three bull's beads erased sa. Williadis.

Arg. a chev. ermines betw. three bull's heads sa. armed or. WaLrond, co. Somerset.

Arg. a chev. betw. three bull's heads gu. Courtors. Ipres, $V$ *.

Arg. a chev. betw. tbree bull's heads cabossed gu. CunTEIs, Canterbury; and Great Knello, Sus. sex. Sr. Rauf Ippres, $V$. lpres, co. Lancas. ter. M. John de YPRE, $S$.

Arg. a chev. betw. three bull's beads couped gu. IpEns.

Arg. a chev. gu. betw. three bull's heads couped at the neck ppr. Bulles, co. Brecon.

Arg. a chev. gu. betw. three bull's heads sa, Noribury 
1 CHEVRON betw. or within.... cont.

Heads cont. (Beast) Ox cont.

Arg. a chev. gu. betw. three bull's lieads cabossed sa. Botter, $V$.

Arg. a chev. gu. betw. three bull's heads couped sa. Boleyn, Lord Mayor of London 1457 , quartering sa. three mullets or and a chref dancetty erm. Bollen. Bullayn. Geffrey Bullen, Alderman of London, $V$. Bulley. Bulleyne.

Arg. a chev. gu. hetw, three bull's heads couped at the neck sa. horned or. Aune Boleys, second wife of Henry VIII. Bolerne, 1780. BULlien.

Arg. a chev. sa. betw. three bull's heads gu. Courtors. Curtoys.

Arg. a chev. sa. betw. three bull's heads cabossed gu. Curteis, Appledore, and Tenterden, Kent. Curteis, Otterden Place, Kent; the berress m. Wheler, and Walcot. Frend. Wragby, $V$.

Arg. a chev. betw. three bull's heads sa. Llewelly ap Biedri. Bulclogh or BulKeley, Bulkeley, co. Chester, the heiress m. Holford.

Arg. a chev. engr. betw. three bull's heads sa. Norbuny.

Arg. a chev. betw. three bull's heads cabossed sa. Boyvili. Browneshin. Curtis, Kent. Doods. Wood, co. Warwick, $V$.

Arg. a chev. betw. three bull's heads couped sa. Bolen or Bullein, 17li. Brownshin, $V^{*}$. Brownshyn, $I$. Norbury, co. Chester.

Arg. a chev. engr. betw. three bull's heads couped sa. Norbury.

Arg. a chev. betw. three bull's heads erased sa. Alberton.

Arg. a chev. hetw. three cow's heads erased sa. Newenton, Essex.

Arg. a chev. betw. three hull's heads cabossed sa. armed or. Woos, co. Warwick.

Az. a chev. arg. betw. three bull's heads of the second attired or. Richard HILL, Bishop of Loudon 1489-96.

Gu. a chev. betw. three bull's heads arg. Barman. BuLLOCK.

Gu. a chev. wavy betw. three bull's heads arg. Sandon, Asluby, co. Lincoln, $V$.

Gu. a chev. hetw. three bull's beads cabossed arg. Baynham, $V$. Bernham, Kent. Bulloci, $V^{*}$. and co. Hants. Scoffield or Scofield, Scoffield, eo. Lancaster; granted 1582 .

Gu. a chev. wavy betw. three bull's heads cabossed arg. SANDON.

Gu. a chev, betw. three bull's heads couped arg. SCOFFIELD or SCOFIELD, co. Laucaster; granted 1582.

Gu. a chev. betw. three bull's heads arg. attired or. Ketfond, co. Gloucester.

Gu. a chev. betw. three bull's heads cabossed arg. armed or. Bayngan, Kent; and co. Glouces. ter. Bullock, $V$. Bulloke, Essex.

Gu. a chev. betw. three bull's heads erased arg. armed or. BOLLOCKE.

Gu. a chev. erm. betw, three bull's heads cabossed arg. Bullock, Essex; confirmed 9 February $1602, W$. And with a crescent for diff. SANDERS, London.

Gu. a chev. erm. betw. three bull's heads cabossed arg. armed or. Bullock, Great Wighorough, and Faulkbourn Hall, Essex, quartering Wutson; a branch, like Bullocr, Shipdhan. Norfolk; quartering Berney, 'lownshend, Baldock, Bacon, and Flewelyn; of Bullock, Arborfield, co. Berks.
1 CHEVRON betw. or within.... cont.

Heads cont. (Beast) $\mathbf{O x}$ cont.

Gn. a chev, varr betw. three bulls's heads arg. Countors, London.

Gu. a chev. vair betw. three bull's heads arg. armed or. Countoys.

Gu. a chev. vair betw. three bull's heads cabossed arg. Counteis. Robert Countrs, Auditor, $V$. Curtw1s, $J^{Y *}$

Gu. a chev. vaur betw, three bull's heads or. Courtors, London.

Gu. a chev, vairy arg. and sa. betw. three bull's heads of the second. Courtoys, London.

Or a chev, az. betw. three bull's beads sa. goutty d'or. FlifiIng.

Or a chev. erm. betw. three cow's faces sa. CWWLEXGH.

Or a ches, sa. hetw. three bull's heads cabossed gu. armed arg. Frend, $V$. Frende, $V^{*}$.

Or a chev. hetw. three bull's heads cabossed sa. Frend. Stowfond, Stowford; co. Devon; the heiress $\mathrm{m}$. Walrond.

Sa. a chev. betw. three bull's beads arg. Buckeley or Bulkley, co. Hants; and Ireland. Bulkely, $V^{*}$. Norbery. Norbury, glass in church at Stoke I)abernon.

Sa. a chev. wavy betw. three lıull's hears arg. SANDON.

Sa. a chev. betw. three bull's heads cabossed arg. Buckley, Woolcombe Hall, co. Dorset; Minesteed Lodge, co. Hants; and co. Chester. Arthur BulKeley, Bishop of Bangor 1542-53; Bulkeley, Standlow, co. Stafford; descended like Bulleisy, Baron Beaumaris and Viscount Bulkeley, extunct 1802, from Bulkeley, Eaton, co. Chester, $V$; derived from a second son of Bulkeley, of Bulkeley. Morgan. John Norbery, $V$. Norbury, Norbury, co. Chester; dersved from a third sou of Bulkeley of Bulkeley. Norway. Sanders, Ireland. Worbury. WrIGHT, Nantwrch, and Mottram St. Andrew, co. Chester; quartering Leeche, Wynington, Offerton, Rolinson, Shipton, and Adderley.

Sa. a chev. engr. betw. three bull's heads cabossed arg. Nonbury, Droltwicb, and Sherridge, co. Worcester, from co. Chester. SANDER, $V^{*}$.

Sa. a chev. engr. betw. three bull's heads couped arg. Bucrei or Buckle, London. Buckiey. Nonbury.

Sa. a chev. betw. three bull's heads arg. attired or. WRIGHT.

Sa. a chev. erm. betw. three boll's heads cabossed arg. SAnder, Surrey, $W$. Sanders, Sandersted, and Charlwood, Surrey; and Lullington, Caldwell, and Little Ireton, co. Derby; a beiress m. Goodere. Saunders, Pentre, co. Pembroke; the heiress m. Davies. Saunders, Glanrbwdw, co. Carmarthen; quarterıng Hughes.

Sa. a cbev. gu. betw. three bull's heads or armed of the second. Gornex, $V^{*}$.

Sa. a chev. betw. three bull's heads or. Gunnar. Sa. a chev. betw. three hull's heads cabossed or armed gu. Sr. John GonNex, $V$.

Sa. a cbev. per pale aror. and or hetw. three bull's hearls cabossed of the second armed as the third. Clavelshex, Collinson, Somerset, iii, 73. Clayesley, co. Somerset.

$$
\text { .....Seal }
$$

Arg. a chev. betw. three seal's heads bendwise couped sa. Ley, co. Wilts, Burony 1025, Earl of Marlborongh 1626, extinct 1679. LEx, Combe Martin, and Ley House, Marwood, co. Devon. 
1 CHEVRON betw. or within.... cont.

Heads cont. (Beast) Sheep

Arg. a chev. betw. three ram's heads erased az. a crescent for diff. Bendish, Topesfield Hall, Suffolk; descended from Steeple Bumstead.

Arg. a chev. betw. three ram's heads erased gil. attired or. Cheriton. Chenyton, V. Churton, co. Salop.

Arg. a chev. sa. betw. three ram's heads couped az. Bendish, $V^{*}$.

Al'g. a chev. sa. betw. three ram's heads erased az. Bendish alias Westley, Steeple Bumstead, Essex; Baronetcy 1611-1717. Bendyshe, Barrington, co. Cambridge.

Az. a chev. erm. betw. three ram's heads cabossed arg. Rar, Hornchurch, Essex.

Gu. a chev. betw. ihree lamb's heads cabossed arg. Lampton, Keut.

Gu. a chev. betw. tbree lamb's heads couped arg. LanBTon, $V$.

Gn. a chev. erm. betw. three ram's heads cabossed arg. Coldalf, $V^{*}$. Coldall, $V$.

Gu. a chev. or betw. three lamb's heads couped arg. Hedlam, Stainton, Durbam; the heiress m. Bowes and Bowes. HedLame, $V$.

Per pale arg. and sa. a chev. betw, three ram's heads erased counterchanged. Chester.

Per pale arg. and sa. a chev. betw. three ram's heads erased counterchanged attired or within a bordure engr. gu. bezanty. Chester, Chiche ley $\mathrm{Hall}$, co. Buckingham.

Per pale arg. and sa. a chev. engr. betw. three ram's heads erased counterchanged within a bordure engr. gu. bezanty. Sr. William Chester, Lord Mayor of London 1560, $V$. Chester, London, temp. Edward IV, $V$.

Quarterly arg. and sa. a chev. engr. betw. three ram's heads erased countercluanged. Schester.

Sa. a chev. betw. three ram's heads couped arg. Ranser, Hitcham, co. Buclingham, temp. Richard II. RanseY, quartered through Writele by Walsingham. RaASEY, $V$.

Sa. a chev. betw. three ram's heads erased arg. attired or. Ramsey, Norfolk, 1716.

Sa. a chev. erm. betw. three ram's beads erased arg. Rausay, Newcastle.

Sa. a chev. erm. betw. three ram's heads erased arg. attired or. RAMSEY, Lord Mayor of London 1577.

Sa. a cher, betw. three ram's heads erased or. RAJISEY.

$$
\text { .... Tiger }
$$

Arg. a chev, engr. gu. betw. tbree tiger's heads erased of the second collared or. Cooke, $V *$.

Arg. a chev. engr. gu. betw. three tiger's heads erased .... charged on the neck with a bar or. Cooke, Norfolk, $W$.

Arg. a chev. gu. betw. three tiger's heads erased ppr. JACOB, London, $W$; Newhall, co. Oxford. $\mathrm{J}_{\mathrm{ACOB}}$, Horseheath, co. Cambridge; Bromley, and Bow, Middlesex; and Ubbeston, Suffolli the coheirs m. Oakes and Morley.

Arg. a chev. engr. gn, betw. three tiger's heads erased sa. langued of the second each charged on the neck with a gemel or. Cook, Mildham, Norfolk.

Arg. a cher, betw. three tiger's heads sa. erased and langued gu. HAYEs, Windsor, co. Berks; and London; granted 13 May 166\%.

Arg. a chev, engr. betw. three tiger's heads sa. maned of the first collared or. Cооке, Mild. bam, Norfolk.
1 CHEVRON betw, or within.....cont.

Heads cont. (Beast) Tiger cont.

Az. a chev. erm. betw. three tiger's heads erased arg. crined und armed or. SwIFT, London.

Gu. a chev. engr. betw. three tiger's beads erased arg. EDwardes, Shrewsbury; aud Frodesley; Baronetey 21 March 1645; quartering Bray and Mathews. EDwardes, 'Trefgarne, co. Pembroke.

Gu. a chev. betw. three tiger's heads erased or. Robert Gardner, Chardacre, surrey, $W$. GardNer, Lord Chief Justice of Ireland, $W$. GARDINer, Londun; and Beceles, Norfolk.

Gu, a chev. engr. betw. three tiger's heads erased or. Trtr, Denington.

\section{....Wolf}

Arg. a chev. betw. three wolf's heads erased az. Meredyth, Greenhills, co. Kildare; Baronetcy 1600 , quartering az. a lion ramp. or. And with a crescent for diff. Meredyth, Carlandstown, co. Meath; Baronetcy 1795.

Arg. a chev, betw. three wolt's heads erased gu. Caston. Loveli, Norfolk. 'White, Holcott, co. Bedford.

Arg. a chev. betw. three wolf's heads erased gu. ducally gorged .... Woolf F, Bridlington.

Arg. a chev. gu. betw. three wolf's heads erased ppr. JACOB.

Arg. a chev. gu. betw. three wolf's heads erased sa. White. Wilson.

Arg. a chev. sa. betw, three wolf's heads erased gu. Causton, Caustor, Issex. Causton, $V$; Esses, $W$. Cock. Lovell, co. York, $V$; and Skelton, co. York. Piers de Routhe, $P$.

Arg. a chev. betw. three wolf's heads couped sa. How, Essex ; and Suffolk.

Arg. a chev. betw, three wolf's heads erased sa. Abberton. Alberton, $V$. Brokhole. Cock or Cox. Galbreath, Scotland. Maurice, Astrad, co. Denbigh; descended from Ririd Flaidd. Satart. Warde, $V$. White, Ireland, $V$.

Arg. a chev. engr, betw. three wolf's heads erased sa. Raise.

Arg. a cher. betw, three wolf's heads erased sa. each gorged with a mural coronet of the first. WoLFE, 1759. But with a ducal coronet or. Wolf, $V$. WOLFE, $V *$.

Az. a chev. betw. tbree wolf's heads arg. Eignion ap Ithell ap Ryrid VtaItH, Rhiwaedog in Penllyn, North Wales; quartered by Eyton, 1674 .

Az. a chev. erm. betw. three wolf's heads erased or. Swift, London.

Az. a chev. betw. three wolf's heads erased or. John CHEDworth, Bishop of Lincoln 1452-71. Gownr, Essex; and co. Worcester. Gower, Glandovan, co. Pernbroke.

Az. a cher. engr. betw. three wolf's heads erased or. Robert Wolveden, 1432.

Erm. a chev, vairy or and gu. betw, three wolf's heads erased az. Milier, Addington, and Ryersh, Kent.

Gu. a chev, betw, three wolf's heads erased arg. Golding, Kent. Pettit, Kent.

Gir. a chev, arg. betw. three wolf's heads or each transfixed by a dagger palewise of the second liilted and pomelled gold. Srene, Fintray, Scotland.

Gu. a chev. betw. three wolf's heads erased or. WoLf, co. Salop.

Or a chev, engr. betw. three wolf's beads erased sa. Bath. 
1 CHEVRON betw. or within....cont.

Heads cont. (Beast) Wolf cont.

Sa. a chev. betw. three wolf's heads arg. Wolveidon, Comwall.

Sa. a chev. arg. betw. three wolf's heads of the second couped gt?. M. Richard Norlande, $S$. Sa. a chev. hetw. three wolf"s heads erased arg. Beal or Beall. Golding, Kent. Goldoury, 1528.

Sa. a chev. or betw. three wolf's heads erased arg. Goldourg, $V^{*}$. Goldodny, $V^{*}$. Wolf, $V$. WOLFDON, $V^{*}$. WOLFEDON. WOLVEIDON, Cornwall. Wolverstone. Woolfe. Woulf, $V^{*}$. WOULFDON, $V$.

Vert a chev. betw. three wolf's heads arg. Floyd or FuUds, Millgate, Kient; granted 10 November 1572 .

Vert a chev. betw. three wolf's heads crased arg. Frood, Flood Hall, Farmley, Newton Ormonde, Paulstown Castle, and Viewmount, Ireland; confirmed, temp. Elizabeth, to FLIDD, Kent. Lroyd, Whittington, co. Salop. Midleton, co. Salop. Owen, co. Salop. Pothan Viaydd, Lord of Penlyn, co. Merionetl, Havl. MS. 1507, fo. 383. Rend Vlaith (Eynion ap Ithell), Pealyn, co. Mersoneth, ob, 1108

Vert a chev, erm. betw, three wolf's heads arg. John Thomas, Bishop of St. Asaph 1743, Lincoln 1714, Salisbury 1761-6. Pirid FlaIDD, Lord of Penlyn. Wrnne, Hazlewood, Sligo.

Vert a chev. erm. betw. three wolf's heads erased arg. langued gu. Evans, Erbistock, co. Flint.

Vert a chev. betw. three wolf's heads crased erm. Lloyd, Whittington, co. Salop.

Vert a chev. or betw. three wolf's heads erased arg. Conran, Harl. MS. 1441 .

Vert a chev, betw. three wolf's heads erased or. Jones, Buckland, co. Brecon.

Vert a chev. betw. three wolf's heads erased or. langued gu. Jonts.

Vert a chev. sa. ( $\left.V^{*}\right)$ betw. three wolf's heads erased or. Selling, Kent, $V$.

Heads (Bird)

Arg. a chev. betw, three bird's heads sa. SEARLe, Cornwall.

Arg. a chev. betw. three bird's heads couped sa. LEY.

Arg. a chev. engr. betw. three bird's (probably daw's) beads erased sa. John de Dalston, $X$.

Arg. a chev. betw. three bird's (probably Cornish choughs) beads sa. heaked gu. DANT Dante or Daunte, anciently Dauntre, co. Gloucester; and Cork, Ireland, quartering D'Oulepen.

Gu. a chev. az. hetw. three bird's heads erased arg. Wrathaw, Harl. MS. 1404, fo. 150.

\section{.... Bittern see Heron$$
\text { ....Chongh see Crow }
$$$$
\text { ....Crane see Heron }
$$$$
\text { . . Cock }
$$

Arg. a chev. engr. az. betw. three cock's heads erased gu. Dildarne. Dyiderne, $V$.

Arg. a chev. chequy or and sa. betw. three cock's heads erased of the third beaked and combed gil. Ringwood.

Arg. \& chev. (compony or and sa. $V^{*}$ ) countercompony sa. and or betw. three cock's heads erased sa. combed and wattled gu. RYNGwood, T

Arg. a chev. betw. three cock's lieads erased gu. lieaked and wattled as the first. ALcock, Badly, Sutfulk.
1 CHEVRON betw, or within.... cont.

Heads cont. (Bird) Cock cont.

Arg. a chev. betw. three cock's heads erased gu. crested and jelloped or. Coxeter, Letchlade, co. Gloucester.

Arg. a chev. sa. betw. three cock's heads erased gu. Hugh Redhigh, $V$. Redley.

Arg. a chev. betw. three cock's heads sa. AIKEN. Az. a chev. betw. three cock's heads erased or. John CHEDworTH, Bishop of Lincoln 1452-71.

\section{..... Crow}

Arg. a chev. gu. betw. three raven's heads erased ppr. Thomas Ravis, Bishop of Gloucester 1604, London 1607-9.

Arg. a chev. gu. betw. three crow's heads erased sa. Newenton. Norton.

Arg. a chev. gu. betw. three raven's heads erased sa. Ravis, co. Worcester.

Arg. a chev. betw, three raven's heads erased sa. Bendish. NorRis or Norreys, as heir of Ravenscroft, $V^{*}$; and co. Chester; Bretton, co. Flint; co. Lancaster; and Horsham, Sussex. Ravenshaw, quartering Wither.

Arg. a chev. embattled betw, three raven's heads sa. ChynoN.

Arg. a cluev. betw. three raven's heads erased sa. within a bordure engr. of the second. Cooke, co. Devon.

Arg. a chev, betw. three chough's heads erased sa. beaked gu. BEwLEY.

Arg. a chev. betw, three Cornish chough's heads erased sa. beaked gu. blood dropping from their bills ppr. (? Dant Dante Daunte and Datintre, co. Gloucester.)

Arg. a chev. (sometimes engr.) betw. three daw's beads erased sa. bealied or. Dalston, Acornbank, Westmoreland; a branch of DALSTON, Dalston Hall, Cumberland; quartering Kirkbridge; descended from DE VAUX; Baronetcy 1640 , extinct 1765 ; a herress m. Dillon. (? Joun de Dalston, $X$.)

Arg. a chev. embattled counterembattled quarterly sa. and gu. betw. three raven's heads erased az. billety of the first. HanwOOD or HANroOD.

Or a chev. betw. three raven's heads erased sa. Brikes. WiLk.

\section{....Daw see Crow$$
\text { ....Dove }
$$

Arg. a chev. betw. three pigeon's heads az. WADE, Middlesex.

Sa. a chev. betw. three pigeon's heads erased arg. Ghest or Guest. Just, Monkwearmouth, co. Durham.

Sa. a chev. engr. or betw. three pigeon's heads erased arg. Pigeon, Beckham, and Yockthorpe, Norfolk.

$$
\text { .... Duck }
$$

Arg. a chev. sa. betw. three drake's heads erased az. Drakeley, $V^{*}$.

Arg. a chev. sa. betw. three drake's beads erased of the second beaked az. Drakelow, Essex.

Az. a chev. arg. betw. three shoveller's heads erased of the second ducally gorged gu. Tho. mas Herbert, Calais, $V$.

$A z$. a chev. or betw, three shoveller's heads erased ppr. Gheast or Guest.

Sa. a chev. engr, betw. three shoveller's heads erased arg. Symer, $V$.

Sa. a chev. engr. or lietw. three shoveller's heads erased arg. Symer or Symers. 
1 CHEVRON betw, or within .... cont.

Heads cont. (Bird) Eagle

Arg. a cbev. betw. three eagle's lueads erased az. Honrwood, Mark's Hall, Coggeshall, Essex; Evington, Elmested, and Sibton near Folkestone, Kent. JuPP.

Arg. a chev, betw, three eagle's heads erased gu. Newenton. Rowcliff, co. York, J716.

Arg. a chev. gu. betw. three eagle's heads erased sa. Walton, co. Lancaster, $V^{r}$.

Arg. a chev. betw. three eagle's heads erased sa. Bewlex, lient.

Az. a chev, arg. betw. thrce eagle's heads erased or. CASEr, Ireland.

Az. a cher. or betw. three eagle's heads erased arg. Saunders, Pentre, co. Pembroke.

Az. a chev. betw. three eagle's heads erased or. Aubrey, Broom Hall, co. Salop; the heiress $m$. Tozer. Aubrey, Lantrithyd Park, co. Glamorgan; Baronetcy 1660, extinct .... AwBREY. Cheselborne, co. Dorsetshire.

Gu. a chev. betw, three eagle's beads erased arg. BERCHE.

Gu. a chev. or betw. three eagle's heads erased arg. Elltson, Hebburn, co. Durham.

Gu. a chev. betw. three eagle's heads erased or. Eilison, Thorne, co. York. Giddrng, Icklingham, Suffolk.

Or a chev. iudented gu, betw. three eagle's beads erased sa. JAckson, Harraton, co. Durham.

Per pale or and arg. a chev. betw. three eagle's heads erased sa. Wrukes, Leighton-Buzzard, co. Bedford.

Vert a chev, betw, three eagle's heads erased arg. ducally gorged gu. HuBBARD.

$$
\text { ..... Falcon }
$$

.... a chev. .... betw, three hawk's heads ... Kent.

Arg. a chev. betw. three hawk's heads erased az. Honrwood, Evington, Kent; Baronetcy 1660.

Arg. a chev. betw. three falcon's heads erased az. beaked or. Honrwood, Pette, and Send-Newington, near Hythe, Kent; granted 10 Novem. ber 1576 .

Arg. a chev. az. betw. three hawk's beads couped sa. Honswood, Kent.

Arg. a chev, betw. three hawl's heads erased gu. CASLE or CASSY, co. Gloucester.

Arg. a chev. betw. three falcon's heads erased gu. bealsed or. CASEY, $V^{*}$. Casse. Cassey, co. Gloucester, $V$; and Deerhurst, co. Gloucester.

Arg. a chev, gu. hetw. three falcon's heads erased sa. Ravis, co. Worcester, $V$. Walton, $V^{*}$.

Arg. a chev. gu. betw. three hawk's heads erased sa. WALTON, Walton, co. Lancaster ; and Lacock, co. Wilts.

Arg. a chev. gu. betw. three hawk's heads erased sa. membered of the second. WoLton or Wolston.

Arg. a chev. embattled counterembattled quarterly sa. and a\%. betw. three hawk's heads erased of the last. Honerwill. Honrwood.

Arg. a chev. embattled counterembattled quarterly sa. and gu. betw, three hawk's heads erased az. billety of the first. HoNYwood.

Arg. a chev. betw. three hawk's heads sa. SAUL or SAULE.

Arg. a chev. betw. three falcon's heads erased sa. Bani, $V$. Bryckes, $V$. Brykes, $V *$. Norris, $V$. Norris alias Banks, $V$. Ravenscroft, $V$.

Arg. a chev, betw. three hawk's heads erased sa. WaLTON, Walton.
1 CHEVRON betw, or within....cont.

Heads cont. (Bird) Falcon cont.

Arg. a chev. embattled betw. three falcon's beads erased sa. Chamoun, $\boldsymbol{V}$.

Arg. a cliev. betw. three falcon's heads erased within a bordure engr. sa. Cock, co. Devon, $V$.

Arg. a chev. hetw. three falcon's heads crased sa. beaked gu. Bewley, $V$. SNayth, $V$.

Arg. a chev. betw. three hawk's heads erased sa. beaked gu. BEwLey.

Az. a chev. betw. three hawk's heads erased or. ConRan, Ireland.

Az. a chev. betw. three lite's heads erased or. Keete, Chellesburne, co. Dorset. Keyt, Collinson, Somerset, i, 77. KEYT, Ebrington, co. Gloucester; Baronetcy 1660, extinct 1784. Keyte or Krte, Cheselborne, co. Dorset; co. Worcester; and Lord Mayor of London 1767.

Gu. a chev, arg. betw. three hawk's beads erased or. Diliss or DYiLies.

Or a chev. betw. three hawk's heads gu: Nrcholson, Scotland.

Or a chev, betw. three falcon's heads erased gu. Casey, Treland. Nrcielson.

Or a chev. gu. betw. three falcon's heads erased sa. Banke, co. Yorls, $V$.

Or a chev. betw. three hawk's heads erased sa. Wyise, co. Hertiord.

Sa. a chev. betw. three falcon's heads couped arg. Haliop, Kent.

Sa. a chev. arg. betw. three hawk's heads erased or. Barret, co. Dorset, $V$. Barrette, $V$ *

Sa. a chev. betw. three hawk's hearls or. BARRETT, co. Dorset; and Ealing, Middlesex.

$$
\text { .... Heron }
$$

Arg. a chev. gu. betw. three crane's heads erased sa. 'ToPHAM, London; and co. York.

Arg. a chev. betw. three bittern's heads erased sa. BOWLE.

Arg. a cher. betw. three heron's heads erased sa. Bewley, $V *$. SNayth, $V *$.

Arg. a chev, betw. three heron's beads sa. beaked gu. LEWrEY.

Arg. a chev. betw. three heron's heads erased sa. beaked gu. Hewley, $V$. SNaythe, $V$.

Az. a chev. arg. betw. three bittern's lueads erased or. CASYE.

Az. a chev. arg. betw. three crane's beads erased or. HAIs, Dunglass, co. Huddington, Scotland; Baronetcy 1687 .

Gu. a chev, betw, three crane's heads erased arg. DENHARI.

Gu. a chev. betw. three heron's heads erased arg. Fowlen, co. Leicester.

Gu. a chev. arg. betw. three crane's heads erased or. Denham, Fairwood Park, co. Fermanagh, 1815; a branch of Denham, West Shields, 1693.

Or a chev. betw. three heron's heads erased gu. Hackshaw, Hutton, co. Salop.

Sa. a chev. betw. three stork's heads erased arg. WARING.

\section{.... Kite see Falcon .... Lapwing}

Arg. a chev. gu. betw. three pewit's heads erased sa. Topham, Caldbergh, Kildwick, and Middleham Hall, co. York; quastering Lupton, Bateman, and Bulmer.

Arg. a chev. betw. three lapwing's heads erased sa. Richard Bowle, $V$.

Arg. a chev. betw. three pewit's heads erased sa. Toplas, London; and Calverley, co. York. 
1 CHEVRON betw. or within.... cont.

Heads cont. (Bird) Peacock

Arg. a chev. gu. betw. three peacock's heads erased az. Pitis or Pitrs, Kent.

Erm. a chev. betw. three peacock's heads erased az. Pitson, Guildford, Surrey.

Erm. a chev. gu. betw. three peacock's heads erased az. beaked or. Pitis, $\vec{V}$.

Gu. a chev. betw. three peacock's heads erased or. Company of Painters, London; quartering az. three escucheon: arg.

Sa. a chev. betw. three peacock's heads erased arg. Overton. Quahton, $V$.

\section{....Pelican}

.... a chev. embattled .... betw. three pelican's heads erased .... Jobn Scory, Rochester 1551, Clichester 1552-4, Hereford 1559-85.

Arg. a chev. betw. three pelican's heads erased sa. Norris, co. Hants. Cuthbert Scotr, Bishop of Chester 1556-60.

Sa. a chev. betw. three pelican's heads vulning themselves or. GoDFrEY, descended from Godfrey le Fauconer, Hurst, Rumney, Lydd, Heppington, Hodiford, Norton Court, etc., Kent; Old Hall, East Bergholt, Suffolk; and Ireland. Sa. a chev. betw. three pelican's heads and necks erased or vulned gu. Godfny, Kerit, $W$. ....Pheasant

Erm, a chev. gu. betw. three cock pheasant's heads erased az. Petytr, Shep Meadow,Suffolk.

\section{.... Pewit see Lapwing} .... Popinjay

Arg. a chev. gu. betw. three parrot's beads erased az. Ridgeway, co. Devoll.

Arg. a chev. gu. betw. three parrot's heads erased vert. Lethieuliter or Lethulier, Alder. stock, Essex.

Arg. a che'v. gu. betw. three parrot's heads couped vert beaked of the second. LETHIEULLIER or Lethuiter, Acton, Middlesex.

Or a chev. gu. betw, three parrot's heads erased ppr. Dunnage.

\section{....Raven see Crow ....Shoveller see Duck .... Stork see Heron .... Swan}

Arg. a chev. gu. betw. tbree swau's heads couped sa. TATHAM, London.

Arg. a cher. sa. betw. three swan's heads erased (sa. or) az. Drakley, $Y$.

Arg. a chev. betw. three swans heads erased sa. Bransby or Brasley, Kent.

Az. a chev. arg. betw. three swan's heads erased of the second ducally gorged gu. HuBART, Calais, $V *$.

Az. a chev, or betw. three swan's heads crased arg. beaked (gv. another) of the second. Edmund GHEAST, Bishop of Rochester $1560, \mathrm{Sa}$ lisbury 1571-7. The heads pir. Guest.

Gu. a chev. betw. three swan's heads couped arg. Brightiere or Brightmore.

Gu. a chev. betw. three swan's heads erased arg. Brightuere or Brightrore. Bristuere.

Sa. a chev. betw. three swan's heads erased arg. Squire, Felstead, Essex.

Sa, a chev. engr. betw. three swan's heads erased arg. SQume, Londou. Symer, $V^{*}$.

Sa. a chev. el'm. betw. three swan's heads erased at the neck arg. Cawley, Rumbleswick, Sussex, 1604 .
1 CHEVRoN betw. or within.... cont.

Heads cont. (Bird) Swan cont.

Sa. a chev. or betw. three swan's heads erased arg. Gest or Gist.

... (Fish)

Arg. a chev. betw. three fish's (? conger's) heads couped gu. Canbroor.

Arg. a chev. gn. betw. three fish's heads erased sa. JENYNGES, London.

Al'g. a chev, betw. three fish's heads erased sa. FULFORD.

$$
\text { ..... Conger }
$$

Arg. a chev. betw. three conger's heads erased gu. Canbroke, $V$. Canbrook. Shambroke, $V$. ....Dolphin

Az. a cbev. erm. betw. three dolphin's heads or. Basket, Isle of Wight, and cn. Dorset.

$$
\text { .... Whale }
$$

Arg. a chev, betw. three whale's heads erased sa. WhaLLEY.

\section{....Human Figure}

Arg. a chev, erm. betw. three Moor's heads couped ppr. Gilbert.

Arg. a cliev. ern. betw. three Moor's heads in profile couped ppr. crined or. Blajen, Portslade, Sussex; granted 19 February 1016.

Arg. a chev. erm. betw. three Moor's heads in profile conped at the neck sa. wreathed of the first and az. BLACKER.

Arg. a chev. dancetty betw. three cherubs gu. ADYER, Kent.

Arg. a chev. gu. betw. three helmets ppr. Basnetr, $V^{*}$, and The Cloughs, Newcastleunder-Lyne.

Arg. a chev. gu. betw. three Moor's heads sa. SANDES. WenLOCK.

Arg. a chev. gu. betw. three Moor's heads in pro. file erased sa. Godrevy, Godrevy, Gwithian, Cornwall; the heiress $\mathrm{m}$. Tregendar.

Arg. a chev. sa. betw. three infant's heads couped at the shoulders each entwined round the neck with a suake ppr. VAUGHAN, Kington, co. He. reford; and Woodstone, co. Huntingdon; quartering Wrigbt.

Arg. a chev. sa. betw, three maiden's heads erased ppr. ducally crowned or. CARDwell.

Arg. a chev. sa. betw. three nun's heads couped at the shoulders ppr. Davenex, Colton, Norfolk. Arg. a chev. betw, three helmets sa. Massenger Massinger or Messenger, co. Gloucester.

Arg. a chev,sa. betw. three perulses ppr. Hareman, Add. MIS. 5507 , fo. 341 . HarMan, Kent.

Arg. a chev. betw. three buman skulls sa. De la 'lombe, London, Harl. MS. 1486, fo. 4 b.

Arg. a chev. betw, three Moor's heads couped sa. Bern. CAPs, Cornwall. Coker or CoKers. Hedon, Morton, Holderness. Ives. JEw, Whitfield, co. Devon. Jewes or Jues. More, co. Derby.

Arg. a chev. betw. three Moor's heads in profile erased sa. Iveson, Hedon, Hull. WENLOCK, co. Gloucester. Sr. John WenLOck, K.G., $V$.

Arg. a chev. betw, three Saracen's heads erased sa. Thenkeke or Thentkeke.

Arg. a chev. betw. three Moor's heads in profile couped sa. with round caps vert fretty or. IREYS, $V$. JeREYS, $V *$.

Arg. a cher. betw. three Moor's heads in profile erased sa. wreathed and tied of the first and az. Threthe ke or Tretheke, $V$. Trethecke, $V *$ * Arg. a chev. vair betw. three Moor's heads in profile couped at the neck ppr. HuLLock, Barnard Castle, Durham. 
1 CHEVRON betw, or within.....cont.

Heads cont. Human Figure cont.

Az. a chev. arg. betw. three boy's heads couped ppr. crined or. Holcombe, co. Devon.

Az. a chev, arg. betw. three men's heads in protile couped at the shoulders or wreathed of the second. Hогсомв or Holcombe, Hole, co. Devon.

Az. a chev, erm. betw, three Moor's heads in profile couped sa. Blacker, co. Buckingham.

Az. a chev, erm. hetw. three savage's heads in profile couped .... wreathed .... EDIngtoun, Garcunnock, Scotland.

Az. a chev. betw. three esquire's helmets or. Alexander Edeyn, Sussex, $V$. Iden, Kent, $W$.

Az. a chev. betw. three belmets close or. Bassnet. Eden Edon or Iden, Sandwich, Kent ; and Suffolk.

Gu. a chev. arg. betw. three men's heads in profile couped at the neck.... VYchan, Wales.

Gu. a chev. betw. three belmets arg. Cholmeley or Choliley, co. Yurk. Owen ap Meredith ap Tudor, $Z, 285$.

Gu. a chev, betw. three Saxon's heads in profile the two in chief couped and one in base erased arg. GriffitH. But with each of the two heads in chief charged with an ermine spot. GrifTiths.

Gu, a chev, butw. three Saracen's heads couped at the shoulders arg. SARES, Fulham, Middlesex; and Billinghurst, Suffolk. But proper. SARIS, co. York; and Sussex.

Gu. a chev. betw. three helmets close arg. plumed or. Framlingham or Fremin, Hartlip, Kent. Framlingham, $V^{*}$.

Gu. a chev. arg. betw. three Saracen's heads of the second the two in chief couped the third erased crmed and bearded or wreathed az. and sa. Sr. William Griffith, North Wales, $V$.

Gu. a chev. arg. betw. three Saracen's heads the two in chief couped or wreathed az. and sa. the one in base erased of the second haired and bearded as the third. Griffith, $V^{*}$.

Gu. a chev. arg. betw. three men's heads or. Claudius Crigan, Bishop of Sodor 1784-1813.

Gu. a cher. arg. betw, three St. Paul's leads ppr. Paulsworth or Pilsworth.

Gu. a chev. arg. betw. three boy's heads couped ppr. crined or enwrapped about the neck with suakes vert. VAUGHAN, Shapwick, co. Dorset; Just, co. Gloucester; and Falstone, co. Wilts.

Gu. a chev, erm. betw, three esquire's belmets arg. Sr. Davy Owen, $V$. Owen ap Meredith ap Tudor ap Grono, lord of Trefgastell, Anglesey, eldest son of Ednyfed Vychan.

$\mathrm{Gu}$. a chev. erm. betw. three men's heads armed arg. goutty de sang. OwEN.

Gu. a chev. erm. lietw. three Saxon's heads in profile couped (ppr. $i . e$.) arg. hair and beards sa. Ednyfed VYchas, lord of Brynffenigl, tenth in descent from Marchudd ap Cynan; his descendants were Griffith, Llanbedr y Trennau: Griffith, Penrhyn: George Griffith, Bishop of St. Asaph 1660-6: Hughes, Prestatyn: Lewis, Glanrafon: Lloyd, Nant; Gydros; Plymog, co. Denbigh; Gwerclas, and liymmer in Edeirnon, co. Merioneth; and Bashall Hall, co. Yorls: Mongax, Golden Grove, co. Flint: Owen, Penmyuedd: and Williams-Buliketex, Baronetcy 17 June 1661, with its branches Lumley-WiLi Ians: Williams, Vaenol, Baronetcy 1622-93: Williams, Meillionydd; the heiress m. Vaughan: and Jolın

\section{CHEVRON betw. or within.... cont.}

Heads cont. Human Fignre cont.

Wirliams, Aberconway, Cochwillan, and Penrhyn, co. Caernarvon, Bishop of Lincoln 1621, Archbisbop of York 1640-50, quartering gu. a chev. or betw. three stag's heads cabossed arg. attired of the second. Howen, Sussex.

Gu. a chev. erm. betw. three Saracen's heads full faced couped at the shoulders ppr. WiLliams, Penryn, co. Carnarvon; Baronetcy 17 June ]661.

Gu. a chev. erm. hetw. three men's heads or crined sa. Williams, Veynol, co. Carnarvon; Baronetcy 1622-93.

Gu. a chev. ermines betw. three helmets arg. Owen ap Merideth.

Gu. a chev. embattled or betw. three helmets ppr. Bromage, co. Worcester.

Or a chev. betw. three esquire's helmets az. Bulkyn, Otham, Kent; certified 3 April 1641. Buskin, Goore Court, Ottlam, Kent; granted hy Cooke, $W$.

Or a chev. az. betw. three Moor's heads in profile couped sa. banded about the temples .... Tregenna, Tregenna, Cornwall.

Or a chev, engr. erm. betw. three Moor's heads couped at the shoulders sa. wreathed about the temples arg. and az. and the ends of the wreath tied in knots. Mone, Suffolk.

Or a chev. gu. betw. three Moor's heads in profile couped sa. banded about the temples .... Tregenna, Cornwall.

Or a chev. pean betw. three men's heads in profile couped ppr. crined sa. BLAcker; granted 1613. Blaker, Salisbury, 1613.

Or a chev. embattled betw. three Moor's heads couped sa. BLACKMORE, London; granted 1706.

Per pale gu. and az. a cher, erminois betw. three helmets ppr. IDLE.

Sa. a chev. betw. three boy's heads couped at the shoulders arg. crined or enwrapped about the neck with as many snakes (ppr. $i, e$.) vert. Parry, Hamsted Marshall, co. Berks. VAUGHaN, Shapwick, co. Dorset; Just, co. Glourester; Falstone, co. Wilts; Treverwyn, co. Hereford ; Wales; and Sutton, co. York. $V_{A U G H A N}$, Withline, 1716.

Sa. a chev. erm. betw. three maiden's heads couped at the shoulders arg. hair dishevelled or. Eastfield, Lord Mayor of London 1429 and 1437. Estefield. Sr. William EstFeld, Iondun, $V$. Estrield, Lord Mayor of London 1530 and 1538 .

Sa. a chev, erm. betw. three maiden's heads or. EASTFIELD.

Sa. a chev. betw. three cherub's heads or. Challoner, Durham. Chaloner, Steeple Clayton, co. Buckingham; and Guisborough, co. York; Baronetcy 1620-40. CHawner, Newton Manor House, Alton, co. Hants; and Muslane, co. Derby.

Sa. a chev, engr. betw. three cherul's heads or. Challen, Doing, Selsey, and Shermanbury Park; a branch of Challen, Shopwhyke, Sussex; the heiress $m$. Miller.

Sa. a chev. vairy or and gu. betw. three maiden's heads couped ppr. crined of the second. Worley, Riber, and Allen Hill, co. Derby.

Tert a chev. gu. betw. three Turk's heads comped ppr. turbaned or. Sмiтн; granted 1623. 
1 CHEVRON betw. or within....cont.

Heads cont. (Monster) Dragon

.... a chev. betw. three dragon's heads erased .... Hugh Lluyd, Bislop of Llandaff 16t0-7.

Arg. a chev. gu. betw. three dragon's heads .... Nind, Tewkesbury, co. Gloucester; and Reading, co. Berks.

Arg. a chev. betw. three dragon's bends erased gu. Locken, quartering arg. a fess betw. three lozenges az.

Arg. a chev. gu. betw. three dragon's heads couped sa. Pemberton, $V^{*}$. Pemerton, $V$.

Arg. a chev. sa. betw. three dragon's heads of the last erased gu. HaYes.

Gu. a chev. erm. betw. three dragon's heads erased arg. Peires, co. Cambridge.

Or a chev, betw. three dragon's beads couped erect az. Cooke, London.

Or a chev. betw. three dragod's heads erased gu. langned az. JACrson.

Or a chev. purp. betw. three dragon's heads erased vert. JuDson.

Sa. a chev. erm. betw. three dragon's heads erased arg. Pearse or Peyrse, Nortbwold, Norfolk.

Vert a chev. betw. three dragon's heads erased or. Seliting, Kent.

\section{....Griffin}

Arg. a chev, engr. betw. three griffin's heads erased az. WALDEN or WALDEW.

Arg. a chev. chequy az. and erm. betw. three griffin's heads erased gu. membered of the second. WANToN, London. W WNTon, Stoughton, and Great Yarmouth, Norfolk.

Arg. a chev. compony erm. and sa. betw. three griffin's heads gu. goutty or. Laxton, Lord Mayor of London 1544.

Arg. a chev. compony ermines and of the first betw. three griffin's heads gu. goutty d'eau. Laxton, London.

Arg. a chev. erm. betw. three griffin's heads erased gu. Conderi, Long Melford, Suffolk; Baronetcy 1660 , extiuct 1704 ; the beiresses $\mathrm{m}$. King and Firebrace.

Arg. a cher, erm. betw. three griffin's heads couped sa. Peniberton, Aislaby, Durhain ; derived from Peuberton, Stanbope, Pemberton, Bainbridge Holme, and Barnes, Durham.

Arg. a chev, ermines betw. three griffin's heads erased sa. langued gu. PeMberton.

Arg. a chev, hetw, three griffin's heads erased gu. Tirney, Wisbeach, co. Cambridge; and Norfolk.

Arg. a chev. betw. three griffin's heads erased gu. armed or. Tillney, $V^{*}$. Tilney, $V$. Tylney, Norfolk; and Suffolk.

Arg, a chev, gu. betw. three griffin's heads erased sa. Dracelow or Drakelow, Essex. Sr. Thomas Drakelowe, $V$. Ellison. Payne, London. And with the two heads in chief sometimes respectant. Scawer, Arden in Stoke Climstand, a branch like Scawen, Trehane in Probus (quartering Trehane) of Scawen, St. Germains, Cornwall; and Surrey; quartering Molenick, and Russell; the heiress $\mathrm{m}$. Bathurst.

Arg. a chev. or betw. three griffin's heads erased sa. in chief a mullet .... for diff. Sisynner, Collinson, Somerset, i, 96.

Arg. a chev. engr. pean betw. three griffin's heads erased sa. beaked ppr. the neck charged with an erm. spot (arg. another) or. RaIKEs, Lon. don: Walthamstow, Essex; Welton House, aud East Dale, co. York.
1 CHEVRON betw. or within.... cont.

Heads cont. (Monster) Griffin cont.

Arg. a chev. engr. .... betw. three griffin's heads vert. Raikes, co. York.

Arg. a chev. sa. betw. three griffin's heads erased az. and five crosses croslet fitchy of the second. INGILTON, $V$.

Arg. a chev. betw. three griffin's heads couped sa. Howes or Howse, Moruingthorpe, Norfolk.

Arg. a chev. betw. three griffin's heads erased sa. Adeanr, Babraham, co. Cambridge. Cobylstonf or Coplestone, co. Devon, $V$. Condall. Cotton. Hayss, Drumboe Castle, co. Donegal ; Baronetcy 1789, quartering Basil. Sirynner. Snathe or Snayth, co. Wilts.

Arg. a chev. embattled betw. three griffin's heads erased sa. BeEtley, Attleburgh.

Arg. a chev. einbattled counterembattled betw. three griffiu's beads erased sa. BICKLIFE, London.

Arg. a chev. engr. betw. three griffin's heads erased sa. Charleton, $V^{*}$. Rake. Raye. Scarleton, $V^{*}$. Scharleton, $V$.

Arg. a chev. embattled counterembattled betw. three griffu's heads erased sa. each charged with a plate. Bickiey, Bickleigh, co. Devon; Sussex; co. Cambridge; Middlesex; and Norfolk. Bicklex, Attleborough ; Baronetcy 1661 , extinct ....

Arg. a chev. embattled counterembattled betw. three griffin's heads erased sa. beaked gu. langued az. each charged with a bezant. Thomas Bickley, Bishop of Chichester 1586-96.

Az. a chev. betw. three griffin's heads erased arg. JENNINGS, $V^{*}$.

Az. a chev, erm. betw. three griffin's heads erased arg. (another, or). Garniner, co. Oxford, 1578 .

Az. a chev. betw. three griffin's heads couped or eacb transfixed with a dagger the blade ppr. pomel gold. BAWDEN.

Az. a chev. betw. three griffin's beads erased or. Cassy. Jenninges, $V^{*}$. Jennyns, $V$. Jenynges.

Az. a chev. paly of six arg. and gu. betw. three griffin's heads erased of the second. JENNINGS, Ireland.

Erm. a chev. gu. betw. three griffin's heads az. beaked or. PrTis.

Erm. a cliev, engr. betw. three griffin's heads erased gu. Laxton, London.

Gu. a chev. betw. three griffin's heads erased arg. Aj.dred. Bridges. Gedding.

Gu. a chev. engr. betw. three griffin's heads erased arg. ALDRED.

Gu. a chev, betw. three griffin's heads erased arg. armed or. AllRed, $V$; and Holderness, co. York. ALREDE, $V^{*}$.

Gu. a chev, arg. betw. three griffin's heads erased or. GedDING, Norfolk. Sr. Robert GEDDINGE, Lecford, $V$. Goddinge, $V^{*}$.

Gu. a chev, erm. betw. three griffin's heads erased arg. Condarl, Norfolk; and Suffolk. CordaIl, $V *$. Cordeld. Drakelow, $V^{*}$.

Gu. a chev. erm. betw. three griffin's heads erased arg. langued az. CоттоN, Kent.

Gu. a chev. engr. betw. three griffin's heads erased erm. Condais, London.

Gu. a chev. or betw. three grifin's heads erased arg. William Gedding, temp. Henry IY, $V$.

$\mathrm{Gu}$. a chev. betw. three griffin's heads erased or. Gedding. Tilney.

Or a chev, erm. betw. three griftin's heads erased gu. Condelu, Melford Hall, Suffolk. 
1 CHEVRON betw. or within....cont.

Heads cont. (Monster) Griffin cont.

Or a chev. betw. three griffu's heads erased gu. Winde, Northumberland.

Or a chev. gu. betw. three griffin's heads erased sa. Ashritel, quartering Hurst.

Or a chev. betw. three griffin's heads erased sa. Aspinali, Preston, co. Lancaster. Cobiston or Corleston, co. Devon.

Or a chev. embattled betw. three griffin's heads erased sa. Bickler, Chidham, Sussex.

Or a chev. engr. betw. three griftin's heads erased sa. WarRen, London.

Per fess gu. and sa. a chev. rompu betw. three griffin's heads erased erm. AlLEN, London, 1620.

Sa. a chev. betw, three griffin's heads erased arg. CaMP. CAMPE, $V$; and London. Sr. John Cotton, Landware, co. Cambridge, $V$. Cotron, Landwade, and Madingley, co. Cambridge; $\mathrm{Ba}$ ronetcy 1641. GordneE. Quarton.

Sa. a chev. chequy or and az. betw. three griffin's beads erased arg. Quicke, co. Devon.

Sa. a chev. or betw. three griffin's heads erased arg. Cotton. Strynner, London; and Shel. field, co. Warwick. And with a mullet for diff. SkINNER, Wanstead, Essex; and London ; descended through Robert Skinner, Bishop of Bristol 1637, Oxford 1641, Worcester 1663-70, from Skinner, Le Burtons, co. Hereford; a heiress m. Clarke; Cofton, co. Worcester; a heiress $\mathrm{m}$. Joliffe; and Ledbury. and Under. down; a heiress $m$. Miles.

Sa. a chev. betw. three griffin's heads erased or. Camp, $V^{*}$. Campe, London, $V$.

Sa. a chev. per pale arg. and or betw. three griffin's heads erased of the second. Boume.

Sa. a chev, vairy or and of the first betw. three griffin's heads erased as the second. QuIck, Westwanke, co. Buckingham; Newton, St. Seeres, co. Devon; and West Monkton, co. So. merset, 1623.

Vert a chev. erm. betw. tluree griffin's heads erased arg. Berindon. Beringdon, $V$.

Vert a chev. erm. betw. three griffin's heads erased or. Berindon. Beringdon. BerJugdeN.

\section{.... Unicorn}

Arg. a chev. ermines betw. three unicorn's heads couped sa. HeaD, Hermitage, Kent; Baronetcy 1676 and 1837 .

Arg. a chev. engr. gu. betw. three unicorn's heads erased az. Edmund Honne, Oxford, $V$.

Arg. a chev. betw. three unicorn's heads couped gu. Colliar or Collyer, London; Wroxham, Necton, Hachford Hall, Norwich, and Girmingham, Norfolk.

Az. a chev. erm. hetw. three unicorn's heads couped arg. Oventon, co. Lincoln, $V$.

Az. a chev. erm. betw. three unicorn's heads erased arg. attired and crined or. Oventon, Somersham, co. Huntingdon; co. Lincoln; and Loversal, co. York. William Overton, Bisbop of Lichfield, etc. 1580-1609.

Gu. a chev. arg. hetw. three unicorn's heads of the second attired and crined or. Bevilt or Boyvilu.

Gu. a chev. or betw. three unicorn's beads couped arg. Blundelt, $V$, and Harlington, co. Bedford.

Per pale arg. and sa. a chev. betw. three unicorn's heads erased counterchanged. DoBers or DoBbs, co. York.

\section{CHEVRON betw, or within....cont.}

Heads cont. (Monster) Unicorn cont.

Per pale arg. and sa. a chev. engr. betw. three unicorn's heads erased counterchanged. DABBS, co. Warwick. Sir Richard DabBs or DoBBs, Lord Mayor of London 1551 ; descended from Doвbes, Baitby, co. York.

Per pale arg. and sa. a chev. engr. lietw. three unicorn's heads erased goutty counterchanged. Doвbes, Lord Mayor of London 1551.

Per pale sa. and arg. a chev. engr. betw. three unicorn's heads erased counterchanged. Dosis, Castle Dobbs, co. Antrim; quartering Dalway and Osborrie.

Sa. a chev. betw. tbree unicorn's heads erased arg. HEAD, London; and co. Berks, quartered by Baily.

Sa. a chev. erm. betw. three unicorn's beads couped arg. Hede or De Hedesa, quartered by Daries. Hede or Hedesa, London; and Kent. Hede, $V$.

Sa. a chev. betw. three unicorn's heads erased or. Conradus, London.

$$
\text { ....(Reptile) Lizard }
$$

Arg. a chev. betw. three lizard's heads sa. LANGDON.

Arg. a chev. betw. three ( $\ddot{b y s}$ 's $i$. e.) serpent's heads erased gu. Monsire William Madurs, $Y$.

$$
\text { ..... Spear }
$$

.... a chev. .... betw, three spearbeads .... Rice, quartered by Davis, Collinson, Somerset, iii, 165 .

Arg. a chev. betw.three spearheads .... RotesEy, co. Worcester.

Arg. a chev. gu. betw. three spearheads az. tasseled or. Armistead.

Arg. a chev. gu. betw. three spearbeads ppr. Jefferyes, London.

Arg. a chev. gu. betw. three spearheads sa. ST. Low.

Arg. a chev. gu. betw. three spearheads the dexter and sinister inclining to the middle chief point sa. Hamon BeLE or DaLe, Canterbury, $V$. Hanion, $V^{*}$.

Arg. a chev. gu. betw. three spearheads reversed sa. Sulliard, Essex; and Haughley, Suffolk.

Arg. a chev. betw. three spearheads sa. PrICE. Pryce, $V$.

Arg. a chev. engr. betw. three coronels sa. BYKELEY, $V$.

Az. a chev. betw. three spearheads arg. Howel Coetmore.

Az. a chev. betw. three spearheads arg. embrued ppr. within a bordure or. Gwinnet, Moreton Hall, co. Hereford; and Penlline Castle, co. Glamorgan.

Az. a chev. arg. betw. three spearheads ppr. embrued gu. Gwinnet, Cheltenham, and Brockhampton Park, co. Gloucester.

Az. a chev. betw. three coronels or. Scoplex, Middlesex.

Az. a chev. betw. three spearheads broken from the staff near the joint or. BurLy, Depeden, Suffolk, granted 4 April 1597. 'Thomas BurLi, Depeden, Suffolk; granted 1597, $\mathrm{W}$.

Gu. a chev. betw. three spearheads arg. BEATson, Scotland; and Innowle Farm, Sussex. Betson, Killie. Yeoman. Zerde.

Gu. a chev. betw. three spearheads embrueu arg. Watkins, co. Brecon. 
1 CHEVRON betw. or within....cont.

Heads cont. Spear cont.

Gu. a chev. erm. betw. three half-spears broken staves or beaded arg. Pennyman, Ormsby, co. York; Baronetcy 1628-43 and 1663; extinct.....

Or a chev. betw. three spearheads gu. WHIDDon, Chagford, co. Devon.

Or a chev, betw. three spearheads sa. Price, co. Brecknock.

Per pale .... and .... a chev. erm. betw. three coronels arg. Simon Wysseman.

Sa. a chev, arg. betw, three spearheads .... JEFFERIS.

Sa. a chev. betw. three coronels arg. Thomas Wiseman, Felsted, Essex; granted 22 February $1574, W$. Wiseman, Rivenhall, and Upminster, Essex; Yeamans or Yeomans, Redland, co. Gloucester, and Bristol, co. Somerset.

Sa. a chev. betw. three heads of (tridents bit) eelpiclss points downward arg. Stratele, Harl. MS. 1386, fo. 95 b. Stretele, $V$. STRETTELL.

Sa. a chev. betw. three spearheads arg. Anmeston or Armestone, co. Leicester. Gartherne. Jones, Wales. Margan, Kent, $\boldsymbol{V}$. Morgan alias Pryce. Price, Ireland. Urmestone, Westley, co.Lancaster; and co. York. WatkINs, Pennoyre, co. Brecon. And with a crescent for diff. Armeston, Burbage, co. Leicester.

Sa. a chev. betw. three harpoon heads arg. Strattile.

Sa. a chev. betw. three spearheads arg. within a bordure gu. ORMEston or ORneston, Essex. ORMESTON, $V$.

Sa. a chev. betw. three spearheads arg. embrued gu. Drombenog, Maynerch, Lord of Brecknock. Game. Sr. Davy Gamme, $V$. Ido, Wyllt, Wales. Jefferys. Jeffreys. Jeffries. Jefrryes, Priory, co. Brecon. Jefrrys. Jenkins. Jones, Fonmon Castle, co. Glamorgan; quartering Morgan, Gwys, and Llewellyn. Charles LLOYD, Bishop of Oxford 1827-9. MADOC, Llanfryneich, co. Brecon. Morgan, Kent; and Wales. Price, The Priory, and Fonmon, co. Brecknock. Price, $V$. Rees ap Rosser. Aneas Seys. Seys, Boverton, co. Glamorgan, and Caerleon, co. Monmouth, quartering Voss. Caradoc Vreichfras, about 795, quartered by Eyton. Watins, Pennoyre, co. Brecon, quartering Vaughan. Williams, Bristol.

Sa. a chev. embattled betw. three spearheads arg. embrued gu. JefFreys, Slywell, co. Brecon.

Sa. a chev. (? arg.) betw. three spearheads embrued ppr. GaMs, Newton, co. Brecknock.

Sa. a chev. erm. betw. three coronels arg. Wrseman, Rivenhaill, Essex; Baronetcy l66092, the heiress m. Honywood and Rebow; Thundersley, Essex; Baronetcy 1628, extinct .... ; Canfield Hall, Essex; Baronetcy 1628. Wisentan, $V^{*}$. Wisenan, quartered by Long. land. Wyseman, $V$; Essex, $W$.

Sa. a chev. erm. betw. three spearheads arg. LEwIs, Bristol; and London.

Sa. a chev. erm. betw. three spearheads arg. within a bordure az. bezanty. PEnToney.

Sa. a chev, erminois betw, three spearheads arg. embrued ppr. PrICE, Jamaica; Baronetey 1768-88; and Trengwainton, Cornwall; Baronetcy 1815 .

Sa. a chev, betw. three spearheads or. JEFfreys, co. Brecknock.

Sa. a chev. betw. three spearheads or embrued gold. Powelt, Castle Madoc, co. Brecknock.
1 CHEVRON betw. or within....cont.

Heads cont. Bird

Az. a chev. betw. four bird's heads erased or. IRMYNGES.

..... (Monster) Griffin

Az. a chev. betw. four griffin's heads erased three and one or. Jennyns, Middlesex. .....Bird

... a a chev. wavy betw. six bird's heads crossed (sic in orig.? erased) .... GY GномNe, impaled by Gresham, 1579, in church at Titsey, Surrey. ..... Spear

Sa. a chev. betw. six spearbeads arg. Rusken, $V$. Ruskyn.

$$
\text { ..... (Beast) Tiger }
$$

Arg. a chev. purp. betw. seven tiger's heads erect erased vert each devouriug a cross croslet fitchy gu. Mitchell.

\section{... Monster) Dragon}

Arg. a chev. purp. betw. seven dragon's heads erect erased close to the bead vert each devouring a cross croslet fitchy four in chief and three in base gu. Mrchel, Calne, co. Wilts. Mrtchelt. The chev. sa. Michel, Truro, Cornwall.

Sa. a chev. betw. seven griffin's heads erect couped arg. langued and each devouring a cross or. BowDEn, co. Devon (in a later hand than) $W$.

\section{Heart}

Per pale arg. and gu. a chev. betw. in the dexter chief a heart transfixed with a dagger in bend and in the sinister a leopard's head discharging water and in base a crescent.all counterchanged. DUdGEON, Leith. But with a mullet instead of the crescent. Dudaeon, Marionville.

Hearts

Arg. a chev. betw. three hearts within a bordure gu. Henry Rosce, $V$. Roscey.

Arg. a chev. betw. three bearts gu. crowned or. Trewran, co. Devon. Trueman or Truman.

Arg. a chev. gu. betw. three hearts ppr. NEMBHARD or NEMPHARTZ.

Arg. a chev. betw. three hearts sa. Baron, co. Devon. De Baronia, Buckland Baron. Barron, $V *$. Barune. Barwen, $V$.

Arg. a chev. vair betw. three hearts gu. each charged with a lion's gamb erased in bend sinister of the first. HOGGaRT, London.

Arg. a chev. engr. vairy or and gu. betw. three hearts of the third each charged with a lion's paw erased as the second. Hogan. But with a lion's gamb erased in pale paw downwards as the second. Hoggart, Tooting, Surrey.

Az, a chev, betw, three hearts or. WAGER.

Gu. a chev. arg. betw, three hearts of the last each pierced through with a dagger. NEwLE. But with a sword in bend sinister ppr. hilt and pomel in chief or. Newte, Tiverton, co. Devon; the heiresses m. Holwell and Pitman.

Gu. a cbev, arg. betw. three hearts or. FreEBody. Frebony, Udimore, and East Grinstead, Sussex; granted 16 April 1634. Frebody, $V$.

Gu. a chev. sa. betw. three hearts or. Frrebodr, Harl. MS. 1404, fo. 156.

Or a chev. betw. three hearts gu. ducally crowned of the first. Truman.

Sa. a chev. erm. betw. three hearts held in as many pairs of men's hands couped at the wrist gu. Wheatley Wheatly or Whetley.

$\mathrm{Sa}$. a chev. betw. three hearts or an annulet in chief for diff. Baytex, Temple, London, $W$. 
1 CHEVRON betw. or within.... cont. Hillocks

Arg. a chev. .... betw. three molehills with grass ppr. each charged with an annulet of the first. TYLDESLEY.

Arg. a chev. gu. betw. three molehills vert. Shatserley, co. Derby; and Wrotham, Kent.

Arg. a chev. sa. betw. three (monticuli scirparum iu margin) hillocks of rushes vert on each an annulet .... Shakenuey alias TmuesLey, $V$.

Arg. a chev, betw. three billocks vert. SHakeriey, Somerford Park, co. Chester; Baronetcy 1838. But molehills. Shakerley, co. Chester; and co. Lancaster; granted 1610 . Tinlessey alias Shaiserley, $V^{*}$. But turfs. Shakertey, Hulme, co. Chester, 1730.

Arg. a chev. betw. three molehills vert within a bordure engr. gu. bezanty. Shakerley, Holme, co. Chester.

\section{Hives}

Az. a chev. betw. three beehives or. JERrys, Letheringset, Norfolk.

Sa. a chev. erm. betw, three beehives ppr. LEHOOK or IEHOOP, Londen.

\section{Hooks}

Sa. a chev, betw, three fishing-books arg. Medville.

\section{Horns}

Arg. a chev. lozengy gu. and or betw. in chief two bugles strung and in base a 5 -foil sa. SEMPLE, Ireland.

Arg. a chev. az. betw. in chief two hunting-horns vert stringed gu. and in base a buruing mount ppr. M'Tirk, Scotland.

.... a chev. .... betw. three bugle-horns .... Russeld, and afterwards VernaI, Fairfield Collinson, Somerset, i, 258.

Arg. a chev, betw. three bugle-horns .... WaLTON.

Arg. a chev. betw. three stag's attires fixed to the scalps az. Cocks.

Arg. a chev, az. betw, three bugle-horns sa. Bassett, $V^{*}$. Durant. But stringed sa. Bassetr, Wales, $V$.

Arg. a chev, az. betw. three bugle-horns sa. stringed of the second garnished or. Durrant, Ireland.

Arg. a chev, betw. three bugle-horns stringed sa. Bassetr, Wales.

Arg. a cher. chequy gu. and of the first betw. three bugle-horns sa. stringed as the second. Senple, Cathcart, co. Renfrew, Scotland. But garnished or. SEMPILL, Barony 1489.

Arg. a chev. chequy or and gu. betw. three buglehorns sa. WOODLestone, co. York.

Arg. a chev. compony or and gu. betw. three bugle-horns sa. Wodmston, $V^{*}$.

Arg. a chev. compony sa. and of the first betw. three bugles as the last. WOODYLSTON.

Arg. a chev. countercompony gu. and of the first betw. three bugle-horns sa. stringed as the field. Semple.

Arg. a chev. countercompony gu. and or betw. three bugle-horns stringed sa. WoDILston, Wolverston, $V$.

Arg. a chev. engr. betw. three bugle-horns gu. Walshage, $V^{*}$.

Arg. a chev. gu. betw: three bugle-horns of the last stringed or. WALTON, $V$.

Arg. a chev, engr. betw. three bugle-horns gu. stringed or. WALTON, $V^{*}$.

Arg. a cher. gu. betw. three bugle-horus sa. WAYTE.
1 CHEVRON betw. or within.... cont.

Horns cont.

Arg. a chev. engr. gu. betw. three bugle-horns sa. stringed az. WALSHAGE, co. Lancaster, $V$.

Arg. a chev. gu. betw. three bugle-horns sa. stringed of the second. Foster. Petrit, Hexstall, co. Stafford ; granted 1583.

Arg. a chev. gu. betw. three bugle-horns sa. garnished or. Foxton, co. Cambridge; and Loudon.

Al'g. a chev. engr. gu. betw. three bugle-horns sa. garnished or. Foxton, co. Cambridge; and London.

Arg. a chev. gu. betw. three bugle-horns sa. stringed or. Fexton. Foxton, Dodworth, $V$. Pinchpoole, $V$.

Arg. a chev. engr. gu. betw. three bugle-horns sa. stringed or. Foxton, $V^{*}$. PinchPoole, $V^{*}$.

Arg. a chev. engr. gu. betw. three hunting-horns sa. stringed or. Petit.

Arg. a chev. gu. betw. three bugle-horns stringed sa. WaYTe, co. Hants, $V$.

Arg. a chev. engr. gu. betw. three bugle-horns stringed sa. РетTET.

Arg. a chev. gu. betw. three bugle-horns stringed sa. garnished or. WAIT or WAYTE, co. Hants.

Arg. a chev. gu. betw. three hunting-horns vert stringed of the secoud. HATHORN, Overairies; quartering Stewart, with in chief a bugle ....

Arg. a chev. gu. betw. three bugle-horns vert stringed or. Foster, co. Northampton, $V$.

Arg. a chev. (? or') betw. three stag's attires fixed to the scalps az. Cocks.

Arg. a chev. (? or) betw. three buck's horns affixed to the scalp sa. Daduey.

Arg. a chev. betw. three horns sa. Conderow.

Arg. a cliev. betw. tbree stag's attires sa. Nancannow, Nancarrow, Cornwall.

Arg. a chev. betw. three stag's attires affixed to the scalp sa. Cockes, 1730. 'TINker.

Arg. a chev. engr. sa. betw. three bugle-horns gu. WALShage, $V^{*}$.

Arg. a chev. betw. three bugle-horns sa. Bradford, co. York. Cornew Corney or Connue, co. Devon. Thomas, aud his son Robert, Foster, ob. 1603, Judges of King's Bench, quartering arg. on a bend sa. three martlets or, in Egham church. HORNBY. Sнттн, co. Lincoln, quartering arg. a chev. betw. three crosses croslet sa. Sutron, $V^{*}$. WAYTE, $V^{*}$.

Arg. a chev. engr. betw. three trumpets sa. THounder. Thunder, 1716.

Arg. a chev. engr. betw. three bugle-borns sa. CoRney, $V^{*}$. Walshage, $V^{*}$. Wrarly or WrrLey, co. Northampton; and Hampstead Hall, co. Stafford.

Arg. a chev. engr. sa. betw. three bugle-horns of the last stringed az. WalshagH, co. Lancaster, $V$.

Arg. a chev. betw. three bugle-horns sa. garnished gu. Forrester, Scotland.

Arg. a chev. engr. sa. betw. three bugle-horus of the last lip gu. stringed or. Wrreley, co. Stafford, $V$.

Arg. a chev. betw. three bugle-horns sa. stringed gu. Belisfgham. Foster. Hornby.

Arg. a chev. betw. three bugle-horns sa. garnished or. WaITE.

Arg. a chev. engr. betw. three bugle-horns sa. tipped and chaiued or. WrrLey, co. Leicester; and co. Stafford. 
1 CHEVRON betw. or within.....cont.

Horns cont.

Arg. a chev, engr. sa. betw, three bugle-horns of the last garnished or stringed az. Durants, $V^{*}$.

Arg. a chev. sa. betw. three bugle-horns of the last lip and mouthpiece or stringed az. Durants, $V$.

Arg. a chev. betw. three bugle-horns sa. stringed or. ColmRond or Colmbovrne, Colbrand in Tipton, Rowley Regis, and Dudley, co. Stafford; Groby, co. Leicester; and Coventry, co. War. wick.

Arg. a chev, engr. betw. three bugle-horns sa. stringed or. WYRELEY, $V^{*}$.

Arg. a chev. betw. three bugle-horns stringed sa. Bassett, Wales, Carney. Crosholmy. Dodsworth, co. Salop; and co. York. Foster, co. Berks. Sutton, co. Chester, $V$. Wayte, co. Hants, $V$.

Arg. a chev. engr. betw. three bugle-borns stringed sa. Corney, $V$.

Arg. a chev, betw, three bugle-horns stringed sa. garnished or. WAIT, Woodborough, Bath. WAYTE, Southampton, and Waytecourt, Isle of Wight.

Arg. a chev. vert betw. three bugle.horns sa. Forster, Bamborough Castle, Nortbumberland. Folsster or Foster, Island of Jamaica: The Grange and Grove House, co. Bnckingluam; Brickhill, co. Bedford ; etc. Forster, Egham, Middlesex; and Battle, Sussex. Sir Thomas Forster, at the Charterhouse, 1619. Foster, Pliory, co. Lancaster. Foster, Collinson, Somerset, ii, 436 .

Arg. a chev. vert betw. three bugle-horns within a bordure sa. bezanty. Foster.

Arg. a chev. vert betw. three bugle-horns sa. stringed gu. Forster, Alnwick, Northumberland. Foster, Stonehouse, co. Louth ; Baronetcy 1831.

Arg. a chev. vert betw. three bugle-horns stringed sa. Forster, Westminster.

Arg. a chev. betw. three bugle-horns vert stringed or. Foster, cr. York.

Az. a chev, betw. three bugle-horns arg. Gardner, Kirkton, co. Lincoln. Whithene, $V^{*}$.

Az. a chev. betw. three bugle-horns arg. WhIтнEDE, $V^{*}$. But stringed arg. WHчtheDE, $V$.

Az. a chev. or betw. three bugle-horns stringed arg. Whythene, $V$.

Az. a chev. embattled counterembattled betw. three bugle-horns or. PepLoE, co. Salop.

Erm. a chev. betw. three hunting-horns strung sa. Carnie.

Gu. a chev. engr. arg. betw. three trumpets or. Trumpeter.

Gu. a chev. erm. betw. three bugle-horns arg. stringed or. DoDworTh, London.

Gu. a chev. indented erm. betw. three bugle-horns sa. Cotarave, Malpas, co. Chester.

Ga. a chev, or betw. three bugle-horns arg. HoERne, $V^{*}$.

Gu. a chev. or betw. three stag's attires affixed to the scalps .... Coxs, co. Lincoln; quar. tering az. a tow er with two sidepieces arg. within a bordure or charged with eight mullets sa.

Gu. a chev. or betw. three bugle-horns arg.

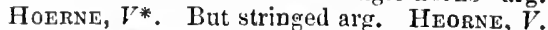
HorRne, $\mathrm{W}$.

Gu. a chev. betw. three bugle-horns stringed or. BIEACH, Cirencester.

\section{CHEVRON botw. or within.....cont.}

Horns cont.

Or a chev. chequy gu. and of the first betw. three hunting-horns sa. garnished of the second within a bordure of the same. SEmple.

Or a chev. betw. three bugle-horns sa. HounBy, Dalton Hall, Westmoreland.

Per pale gu. and az. a chev, betw, three buglehorns stringed or. Town of BRADFord.

Sa. a chev. betw. three buck's scalps arg. Cox, $V$.

Sa. a chev. betw. three stag's attires fixed to the scalps arg. Cocks, co. Gloucester; and Suffolk.

Sa. a chev. betw. three bugle-borns arg. STanfiedd, co. Leicester. Stanford, $V^{*}$.

Sa. a chev. betw, three bugle-horns stringed arg. Gardner, Middlesex. Stanford, $V$.

Sa. a chev. betw. three bngle-horns arg. garnished or. William GaRDINER, London, $\ddot{Z}, 293$.

Sa. a chev. erm. betw. three buglthorns arg. stringed or. Gardener, Berwick-on-Tweed; granted 24 April 1580.

Sa. a chev. or betw. three stag's attires fixed to the scalps arg. Cocks, Baronetcy 19 September 177.2, Barony 17 May 1784, Viscount Eastnor and Earl Somers, 1821.

Sa. a chev. betw. three bugle-horns stringed or. Thurston, Cranbrook, Kent.

\section{Iorsepickers}

Vert a chev. betw. three horsepickers (or dog. hooks or hay-hooks) arg. Metringhair, $V$, and Harl. MS. 13\&6, fo. 95 .

\section{Horseshoes}

Arg. a chev, gu, betw, three horseshoes sa. Marshall, $V$. Pochen or Poching, Barklny, co. Leicester. Pochin, $V^{*}$.

Arg. a chev, betw, three borseshoes sa. EDEnsor or Exson, Cumberford, co. Stafford; Willencote, co. Warwick; and Rollesby Hall, Norfolk; quartering Mapes and Blunt. MarshaiL, $V$.

Gu. a chev. betw. three horseshoes arg. Maynes. Ga. a chev. or betw. three horseshoes arg. Ferounces. Ferounes, $V$.

Gu. a chev. betw, three borseshoes or. FEARON, Sussex. Feronnes.

Or a chev. gu. betw. three horseshoes sa. Pochin, Barkby Hall, co. Leicester; quartering Willoughby, Luncoln, Palmer, Brett, Wineope, Hussey, Hodgkins, etc., etc. Pouchun, $W$.

Or a chev. betw. three horseshoes sa. FEARoN.

Vert a chev. betw, three horseshoes reversed arg. Metringham, Harl. MS. 14n4, fo. 140.

\section{Inkmolines}

Arg. crusily sa, a chev, ermines betw. three inkmolines of the second. Kingsmil, Millbrook, co. Hants.

Arg. crusily fitchy sa, a chev. ermines betw, three inkmolines of the second. KINGSAILL, co. Hants.

Arg. a chev. betw. three inkmolines sa. Fulferd, $V$. Fullford, $V^{*}$. JaMES, $V^{*}$. Milles, Duloe, Cornwall; and Exeter. Milles, Bishop of Waterford and Lismore 17 10. MrILEs, Suffolk. MiLls.

Arg. a chev. betw. three inkmolines fesswise sa. JAMES, Upminster, Essex ; and Kent; granted 18 November 1611. James, Surrey, W. None, co. Leicester.

Gu. a chev, erm. betw. three inkmolines or. ONION.

Per pale arg. and sa. a chev. betw. thrce inkmolines comnterchanged. LOWDELL.

Sa. a chev. erm. betw. three inkmolines or. Turner, co. Salop. 
1 CHEVRON betw, or within.... cont. Insects.... Bees

Per pale or and az. a chev. betw. in chief two bees volant and a 5 -foil in base counterchanged. Lambert, Brixton, Surrey; granted ....

Arg. a chev. erm. betw. three bees (or butterflies) gu. Deane, co. Devon, 1404, fo. 159.

Arg. a chev. betw. three bees sa. GenLinston or Girlington, 'Thurland, co. Lancaster; and Girlington, co. York.

Arg. a chev, vert betw. three bees ppr. Muschamp. Az. a chev. arg. betw. three bees ppr. SEwELL.

Az. a chev. betw. three bees volant or. BEe, Basingstoke, co. Hants. BeEBEE, Willey Court.

Sa. a chev. betw. three bees arg. Gerlinston or Girlington, Thurland, co. Lancaster; and Girlington, co. York.

Sa. a chev. hetw. three bees volant arg. Sewell, Newport, Isle of Wight.

Vert a chev, betw. three bees arg. Foster, 7730. .. Beetles

Arg. a chev. vert betw. three beetles ppr. Muschadip.

\section{.....Butterflies}

Arg. a chev. erm. betw, three butterflies (volant $V^{*}$.) gu. Deane, $W$.

Arg. a chev. betw. tbree butterflies sa. Van.

Arg. a chev. betw. three buttertlies (volant $V^{*}$.) sa. Girlington, $V^{*}$. Maskham, $V^{*}$. Musmaam, $V$.

Arg, a chev, vert betw, three butterfies ppr. Muschaup.

Az. a chev. betw. three butterfies volant arg. Papillon, Acrise, Kent.

Or a chev. per pale gu. and az. betw. three butterflies sa. Spacriey.

Sa. a chev. betw. three butterflies volant arg. Sewale. Sewayli, $V$. Sewell, $V^{*}$.

Sa. a chev. or betw. three buttertlies volant arg. VAN, Wales.

Vert a chev. betw. three hutterflies (volant $V^{*}$.) arg. Robert Foster, $V$.

$$
\text { .....Flies }
$$

Arg. a chev. betw. three flies sa. Muskenar.

Arg. a chev. vert betw. three (bees or beetles or butterflies or) flies ppr. Muschamp, the heiresses m. Bulmer, Ford, Strathearn, and Huntercombe. Muschamp, Brotberlee, Dirham; a branch of Muschamp, Barmoor.

$$
\text { .....Gadflies }
$$

Gu. a chev. betw. three gadflies arg. Seewelu, Thingdon, co. Northampton.

Per pale arg. and gu. a chev. betw. three gadflies counterchanged. ADAIS.

Sa. a chev. betw, three gadflies arg. Sewale, co. Chester, ]716.

\section{....Grasshoppers}

Arg. a chev. sa. betw. three grasshoppers ppr. Wrdoward, Kent.

Arg. a chev..sa. betw. three grasshoppers vert. Woodward, Woodmarsh, Kent.

$$
\text { .....Butterflies }
$$

Arg. a chev. betw. four butterflies sa. MI. John de Travers, $S$.

Instruments see Fleam Fret Gridiron Habick and Horsepicker

Arg. a chev. betw. three plumber's soldering-irons sa. Shrigley, V, and Harl. MS. 13\&6, fo. 95 Sa. a chev. betw. three hurling-ironsarg. Burland.

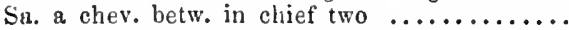
arg. and in hase as many soldering-irons in saltire arg. Company of Pludbers, London.
1 CHEVRON betw, or within....cont. Keys

Az. a chev. or betw. three keys fesswise arg. Hairstanes, Craiges, Scotland; quartering Gladstanes.

Gu. a chev. betw. three keys erect wards upward arg. PARKER, Lambeth, Surrey, assigned 1572.

Gu. a chev, betw. three keys arg. Parker. Royston, $V^{*}$.

Gu. a chev. betw. three keys reversed heads to the sinister arg. RoYston, $V$.

Gu. a chev. betw. three keys within a bordure arg. Parker, $V$.

Gu. a chev. engr. erm. betw. three keys or. KENNARD, Ireland.

Gu. a chev. or betw. three keys erect wards upward arg. PARken, Lambeth, Surrey ; assigned 28 May 1572 .

Gu. a chev, betw. three keys erect sa. Cosyn.

Vert a chev. betw. three keys or. Rohantied, Suffolk.

Arg. a chev. engr. betw. three pair of keys erect addorsed az. Mynshawe.

Knots see Hanks Hatbands Torces \& Wreaths Gu. a chev. betw. in chief two truelove knots in hase a lion ramp. or. Sir Jamys ap Owain.

Arg. a chev. betw, three wreathed chaplets sa. Sr. Richard de Hoo, Kent, $V$.

Ga. a chev. betw. three chaplets (or wreaths) twisted and tied arg. Maynes, $V$.

Gu. a chev. betw. three hatbands arg. Maynes, $V$. MAYNs, Harl. MS. 14(1), fo. 112.

Gu. a chev. betw. three tristram or truelove knots arg. Sir James ABowen. AP OWen. Bowen or Bower, quartered by Bowen of Pentre Jevan Tre Llwyn. D'Elwys, Earl of Worcester.

Or a chev. erm. betw. three cords erased at each end and tied in linots vert. Cleaver.

Sa. a chev. arg. betw. three chaplets (or wreaths) twisted az. and of the second. Bury, $V$.

\section{Lamps}

Sa. a chev. arg. betw. three lamps of the last flaming ppr. FARHER, co. Leicester; granted 1663.

Sa. a chev. or betw. three lamps the two in chief one light each facing each other the lamp in base with two lights arg. garnished or illuminated ppr. Company of Tinplate Wonkens AND WIREWOREERS, London.

\section{Lancets see Fleams}

\section{Leaves}

Az. a chev. or betw, three half elm leaves of the last. Hasimy.

Arg. a chev. betw. three leaves gu. Garwinton. Probably hazel leaves. Joos, $V$. Perbaps bur-leaves. SIPDENE, $V$.

Arg. a chev. gu. betw. three (probably bazel) leaves vert. Tumly, $V$.

Arg. a chev. betw. three (probably walnut) leaves vert. Tuystale, $V$.

Arg. a chev, engr. betw. three leaves pendent .... KIDSON.

Arg. a chev. engr. betw. three (perhaps walnut) leaves vert. John PERson, $V$.

Gu. a chev. betw. three leaves arg. Ross.

Gu. a chev, arg. betw. three leaves or. Ross.

Gu. a chev, erm. betw. three (perbaps hazel) leaves or. Thomas Gow Br, $V$.

Ga. a chev. betw. three (probably gletver) leaves or. John de LyLe, lord of Layburn, $P$. But nerhans pine-leaves. Thomas de Pin, $F$.

Or a chev. erm. betw. three leaves vert. LENr. 


\section{CHEVRON betw, or within.... cont.}

Leaves cont.

Or a chev. betw. three (perhaps gletver) leaves gu. Garwinton. LiLe, $W$. Lisle, $V^{*}$. Sr. John de Lrue, co. Hants, $V$. Sir John d'el Yle, N, Harl. MS. 4033, fo. 34. And with a label az. Sr. Walter de LyLe, $M$.

Vert a chev. erm. betw, three leaves arg. Lent. .....Bay

Arg. a chev. gu. betw. three bay leaves vert. BAYFORD or BYFORD.

Arg. a chev. betw. three bay leaves vert. SHore, co. Derby.

......Bur

Arg. a chev. betw. three bur leaves gu. (? SIPDENE, $V_{\text {.) }}$

Or a chev. erm. betw. three bur leaves ppr. a crescent for diff. Burwell, Woodbridge, Suffolk. ..... Elm

Arg. a chev. gu. betw. three elm leaves vert. Tumlyn, $V^{*}$.

....Gletver (perhaps Claver)

Or a chev. betw. three 'foilles de gletvers' gu. Sire Johan d'el YLE, $N$. .....Hawthorn

Arg. a chev. sa. betw. three hawthorn leaves vert. Thomnton, Estnenton, co. York. .... Hazel

Arg. a chev. betw. three hazel leaves gu. (? Joos, $V_{\text {.) }}$

Arg. a chev. gu. betw. three hazel leaves vert. (? TUMiLyn, $V_{\text {.) }}$

Arg. a chev. sa. betw. three hazel leaves vert. Hesilrigge.

Arg. a chev, betw. three hazel leaves vert. Haselrig, Weteslade, and West Brunton, Northumberland. Sr. Thomas Haselrigge, co. Leicester; Baronetcy ....W. HAZLERIGG or Hesilrigge, Nosely, co. Leicester; Baronetcy 1622 .

Gu. a chev. erm. betw. three hazel leaves or. (? Thomas Gowby, $V_{\text {.) }}$

Or' a chev. betw. three hazel leaves gu. (? Irru,

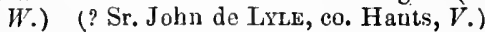
..... Holly

Arg. a chev. betw, three holly leaves gu. Joce.

Arg. a chev. gu. betw. three holly leaves vert. BiLILEge.

Arg. a chev. sa. betw. three bolly leaves ppr. Shove, quartered by Chalk.

Arg. a chev. sa. betw. three bolly lesves vert. Sнone, Baronetcy 1792, Baron Teigumouth 1797. Richard SHone, $V$.

Arg. a chev. sa. betw. three holly leaves vert. SHore, Sbeffield, Mearsbrook, and Norton Hall, co. Derby; and Castle Hill, co. Dorset, quartering Offley. Stoke. Trelawney, Cornwall, $V$.

Arg. a chev. betw. three bolly leaves vert. Invine, Inchray, Scotland.

Arg. a chev. betw. three holly leaves erect vert. Parsons, Langley, co.Buckingham; Baronetcy 1661-1812.

Erm, a chev, az. betw. three holly leaves vert. Hassey, Normandy. Husey or Hussey, Normandy, $V$.

Or a chev. betw. three holly leaves gu. LyLe, co. Hants.

Sa. a chev. betw. threc bolly leaves arg. Weston, V. Woston.

\section{....Laurel}

.... a chev. engr. .... betw. three (? laurel) leaves .... Guy de Mons, Dishop of st. Duvid's 1397-1407.

\section{CHEVRON betw. or within.....cont.}

Leaves cont. Laurel cont.

Arg. a chev, erm. betw. three laurel leaves ppr. Pearson.

Arg. a chev, erminois betw, three laurel leaves vert. John Pearson, Bishop of Chester 1673. 86.

Arg. a chev. sa. betw. three laurel leaves vert. Haselrigge, Haselrigge, and Nowesley, co. Leicester; and Swarland, Northumberland. Trelawner, Cornwall, 1716. Sir Jonatban Trelawney, Bishop of Bristol 1685, Exeter 1689, Winchester 1707-21.

Arg. a chev. engr. sa. betw. three laurel leaves vert. Sirminick, Lees-Langley, co. Hertford. Or a chev. betw. three laurel leaves gu. Robert de Insula, Bishop of Durbam 1274-88, $A d d$. MS. 12143.

\section{.... Linden}

a chev. .... betw. three linden (or limetree) leaves .... John IrNDEwode; brass, 1421, at Linwood, co. Lincoln.

$$
\text { .....Nettles }
$$

Or a chev. gu. betw. three nettle leaves ppr. Maluenbe, Fenyton, co. Devon; the heiress m. Ferrers. Netrles, Nettleville, and Beareforest, co. Cork; and Toureen, co. Waterford.

Or a chev. gu. betw. three nettle leaves vert. Malmerbe, $V$. The leaves joined in the fess point vert. Malmerbe or Marherbe, $V^{*}$.

$$
\text { ....0ak }
$$

Arg. a chev, az. betw. three oak leaves vert. Trelawny, co. Devon.

Arg, a chev. az. betw. three oak leaves vert each charged with an acorn or. Sиттн Sмхтн or Smythes, London. George Smithes, Aldernian and Sheriff of London 1611, W, granted by Camden. Smythes, Collinson, Somerset, iii, 463.

Arg. a chev. betw. three oak leaves gu. Sipdene, $V *$.

Arg. a chev. gu. betw. three oak leaves vert. Shennowe, $W$.

Arg, a chev. sa. betw. three oak leaves slipped ppr. Trelawney, Trelawny, Cornwall; temp. Henry V; Baronetcy 1 July 1628: of this family was Sir Jonathan Trelawney, Bishop of Bristol 1685, Exeter 1689, Winchester 1707.21 .

Arg. a chev. betw. three oak leaves sa. QUARRELL.

Arg. a chev. sa. betw. three oak leaves vert. Shore, $V^{*}$. Trerawney, $V^{*}$.

Arg. a chev. engr. sa. betw. three oak leaves vert. Silithson.

Arg. a chev, vert betw. three oak leaves ppr. Tombins, St. Leonard's.

Arg. a chev. betw. three oak leaves vert. Haselirig or Haslerigge, co. Leicester. Haselrigge. 'Tomlin. Tuystale, $V *$ *

Arg. a chev. betw. three oak leaves slipped vert. HuCKel.

Arg. a chev. engr. betw. three oak leaves vert. Person, $V^{*}$.

$$
\text { .....Pine }
$$

Gu. a chev. betw. three pine leaves slipped arg. Joyce.

Ga. a chev. betw. three pine leaves or. (? Thomas de Pin, F.)

$$
\text { .... Rose }
$$

Gu. a chev. arg. betw. three rose leaves of the secoud (another, or). Sr. Jobn Rose, $V$. ....Trefoil Grass see Gletver 
1 CHEVRON betw, or within....cont.

Leaves cont. Vine

Arg. a chev. az. betw. three vine leaves slipped vert. Tomlins, Bromley, Middlesex.

$$
\text { .... Walnut }
$$

Arg. a chev. betw. three walnut leaves vert. (? Tuystale, $V$.)

Arg. a chev. engr. betw. three walnut leaves vert. (? John Person, V.)

Sa. a chev. erm. betw. three walnut leaves arg. Wisearan, Suffolk.

\section{.... Woodbine}

Gu. a chev. erm. betw. three woodbine leaves or. (? GowBY, $V^{*}$.)

\section{Legs .... (Beast) Badger}

Arg. a chev. betw. three badger's legs erased sa. YarmoUth, $V$.

$$
\text { ....Bear }
$$

Arg. a chev. betw. three bear's gambs erased sa. Brecknock, $V^{*}$. Brecknoy. Sr. David BREKNOK, $V$.

Sa. a chev. betw. three bear's feet erased or. TrEBARFoot, Trebarfoot, Cornwall; the heiress m. Burgoyne.

$$
\text { .....Lion }
$$

Arg. a cher. erm. betw. three lion's gambs erased or armed gu. Whirwange, Harl. MS. 1404, fo. 120.

Arg. a chev. ermines betw. three lion's gambs fesswise erased gu. Whiteway, co. Dorset.

Arg. a chev. betw. three lion's gambs gu. RosHILL, $V^{*}$.

Arg. a chev. betw. three lion's gambs erased gu. Ploshiri, $V$.

Arg. a chev. betw. three lion's paws erased gu. ROSHILL or ROWSEHELL.

Arg. a chev. betw. three lion's gambs erased sa. Brecknock or Brecknoy. Town of Littile Yaraouth. Yarworth, Suffoll.

Arg. a chev. betw. three lion's paws erased sa. Treviodos. Yarmovth, Norfolk; and Blond. ston, Suffolk.

Arg. a chev. betw. three lion's paws fesswise erased sa. Whuteway, Ireland.

Az. a chev. erm. betw. three lion's gambs erased or. Stempe, co. Hertford.

$\mathrm{Gu}$. a chev. betw. three lion's gambs within a bordure arg. Browne, $V^{*}$.

Gu. a chev. betw. three lion's paws erased arg. Wetherton or Whetarton, Northumberland.

Gu. a chev. betw. three lion's gambs bendwise erased arg. WODERTON, $V$. WOODERTON, $V^{*}$.

Gu. a chev. betw. three lion's gambs inverted erased arg. WEThERTON, $V$.

Gu. a chev. betw. three lion's gambs erased within a bordure arg. Browne, $V$; and co. Devon.

Gu. a chev. betw. three lion's gambs arg. within a bordure erm. Browne.

Gu. a chev. betw. three lion's paws erased arg. armed az. within a bordure of the second. Browne.

$\mathrm{Gu}$. a chev. erm. betw. three lion's gambs erased arg. Browne, Essex.

Gu. a chev. betw. three lion's gambs erased erm. Denham.

Gu. a cher. betw. three lion's paws erased erm. Worthasi, co. Devon.

Gu. a chev. betw. three lion's gambs erased the two in ehief bending to each other erm. Wortham, co. Devon, $V$.
1 CHEVRON betw, or within.....cont.

Legs cont. (Beast) Lion cont.

Gu. a chev. or betw. three lion's paws erased statant of the second. Weatherston.

Or a chev. betw, three lion's gambs couped .... erased or. Powet., co. Hereford.

Or a chev. betw. three lion's gambs erased gu. Poweld, Hurdcott House, co. Wilts. Poweil, Pengethley, co. Hereford ; Baronetcy 1622-53, and 1660-80. Poweld, Penkelly, co. Hereford.

Or a chev. gu. betw. three lion's gambs erased sa. armed of the second. Austen, Taywell; granted 20 April 1603; Grovehurst, and Broadford, Kent.

Sa. a chev. arg. betw. three lion's paws erased or. WETEERTON OO WHETHERTON.

Sa. a chev, arg. betw. three lion's gambs erased and erect or. WHETERTON, $V$. WODERTON, $V$.

Sa. a chev. erm. betw. three lion's gambs erased the two in chief bending to each other and that in base to the sinister arg. SELSON or Selston. Selston, $V$.

Sa. a chev. betw. three lion's gambs erased or. Wheterton, $V^{*}$. Woderton, $V^{*}$.

$$
\text { ..... Seal }
$$

Arg. a chev. betw. three seal's feet erased sa. Town of Yarmouth, Norfolk.

$$
\text { ..... (Bird) Crow }
$$

Arg. a chev. betw. three raven's legs erased sa. Chamberlain. At the thigh. Owen, co. Worcester.

Arg. a cher. embattled betw. three raven's legs elased sa. Chamond.

$$
\text { ....Eagle }
$$

Arg. a chev. betw. three eagle's legs erased gu. a bordure engr. sa. M. John de Lancastre, $S$.

Arg. a chev. sa. betw. three eagle's legs couped gu. Pedicrew, Cornwall. Pedegrew, $V$. Predeux, Cornwall, $V$. At the thigh. Pedegrew, $V^{*}$. Predeux, $V^{*}$.

Arg. a chev. betw. three eagle's legs erased sa. Chamberiayn.

Arg. a chev. betw. three eagle's legs erased at the thigh sa. armed gu. BraY or Braye, co. Northampton; co. Bedford; Surrey, etc. BraYe, Eaton Braye, co. Bedford; Barony 1529. Sir Reginald Bray, glass at Malvern. Brays, Sbere, Surrey. Brays, Barrington, co. Gloucester.

Arg. a chev. betw. three eagle's legs erased sa. Braye, $V$.

Sa. a chev. betw. three eagle's legs erased or. TaLLANT, Cornwall.

$$
\text { .....Falcon }
$$

Arg. a chev. betw. three falcon's legs couped gu. PEDEGREW.

$$
\text { .....Popinjay }
$$

Arg. a chev. betw. three parrot's legs erased sa. within a bordure engr. gu. BRAY.

$$
\text { .....Fish }
$$

Arg. a chev. betw. three lobster's claws gu. Kerne.

$$
\text { ....Human Figure }
$$

Gu. a chev. betw. three lrish brogues or. ARTHURE, Ireland. ARTORE, Harl. MS. 1603.

Az. a chev. betw. three legs arg. Duffe.

Sa. a chev. betw. three legs couped at the knee arg. Shrigley, Beriscall, and Shrigley, co. Chester.

\section{Letters}

Arg. a chev, betw. three taus (of the first $V^{*}$ ) sa. MoIgns, $V^{*}$. Moyngs, co. Lincoln, $V$.

Arg. a cher. betw. three text T's sa. TOFтE. 
1 CHEVRON betw, or within.... cont. Locks

Arg. a chev. erm. betw. three staples sa. Stapues, England.

Arg. a chev, betw. three door-staples gu. Breton. Arg. a chev. gu. betw. three door-staples sa. KeIRdiff or Kerdiffe, Ireland.

Arg. a chev. betw. three door-staples sa. Cardiffe, Ireland. Donstarie. Kímpdff, harl. MS. 1441. Kendffee. Stapleford, co. Leicester. Sa. a chev, engr, betw. three padlocks arg. Fagger alias Silverlock, Sussex; and Essex; Harl. MS. 1432, fo. 9 .

Or a chev. erm. betw. three staples sa. Stapde.

Sa. a chev. betw. three door-staples arg. Dunstaple, co. Cambridge.

Sa. a chev. erm. betw. three door-staples arg. Dunstable, $V$.

Lozenges

Arg. a chev. ermines betw. in chief two lozenges sa. in base a dolphin embowed of the last finned or. Shewersden, Fssex.

Arg. a chev, betw. three demi-lozenges sa. Bellesex, co. Lincoln.

Arg. a chev. betw, three demi.lozenges couped per pale sa. Bruesiy, Bylesby, co. Lincoln.

Arg. a chev. betw. three lozenges az. STasey, Cornwall.

Arg. a chev. az. betw. three lozenges sa. John Staveley, $V$. Stayley. Staley, $V^{*}$.

Arg. a chev. betw. three lozenges ermines. Shas, Chaterbouse Henton, co. Somerset. ShaA, Lanham, Norfolk. Sr. John Shawe, Lord Mayor of London, $V$. Shaw or SHawe.

Arg. a chev. betw. three lozenges ermines a bordure gu. SHaw, Alderman of London 1500.

Arg. a chev. betw. three.lozenges gu. Fratesbury, Ireland. Flattesbury, Ireland, $V$. Ibenworth or IDYNEWORTH.

Arg. a chev. gu. betw. three lozenges of the second each charged with a cross croslet sa. AsLin.

Arg. a cher. gu. betw. three lozenges sa. Hru..

Arg. a chev. sa. betw. three lozenges gu. Cres'ry.

Arg. a chev. betw. three lozenges sa. Lermouth, V. Massey, Sale, and Wimincham or Winsham, co. Chester; Harl. MIS. 1424, fo.100 b. Morion, co. York. Mosley. Staveley.

Arg. a chev. ensigned on the top with a cross patty betw. three lozenges sa. Strang, Balcaskie, Scotland.

Az. a chev, arg. betw: three lozenges of the last. HELFORDES.

Az. a chev. erm. betw. three lozenges arg. each charged with a fleur-de-lis sa. Miles, Leigh Court, Bristol, co. Sumerset.

Az. a chev. erm. betw. three lozenges or each charged with an antelope's head erased ppr. attired of the third. GERD or GIRD.

Az. a chev, betw. three lozenges or. Hide. Honede. Hovered. John and Thoms Hyde, $V$. Hyde, Norbury, and Hyde, co. Chester; Denton. and Urmeston, co. Lancaster; Westhatch, co. Wilts; and Castle Hyde, co. Cork; the heiress m. Clark. Alexander Hyve, Bishop of Salistury 1665-7. HyDE, Earl of Rochester, Z, 644; Barony 1660, Viscount Cornbury and Earl of Clarendon 1661, extinct 1753, Barony and Viscounty 1681, Earl of Rochester 1682, extinct 1753. Hyde, Great Hadhan, co. Herts; and co. Salop. Mackey, England. Strang, Petgorthie, Scolland.
1 CHEVRON betw, or within.....cont.

\section{Lozenges cont.}

Az. a chev. betw. three lozenges or a file of three points in chief gu. HuYde or Hyde.

Az. a chev. betw. three lozenges or each charged with an anchor sa. Fiote.

Erm. a chev. vair betw. three lozenges az. on each a lion's gamb erect erased arg. HugGINs, London.

Gu. a chev. betw. three lozenges arg. MASSY, co. Chester. Town of Wotron-Basset, co. Wilts. And with a crescent on the chev. for diff. MAScy, Wymincham, co. Chester, 1396, V. MASEY, $V^{*}$.

Gu. a chev. erm. betw. three lozenges arg. each charged with a goat's head erased of the first. Girdeler, Clarke, co. Wilts.

$\mathrm{Gu}$. a chev. erm. betw. three lozenges or each charged with an ermine spot sa. Stone, Bad. bury, co. Wilts; granted 22 December 1722.

Or a chev. betw. three lozenges gu. Asun or AsLuN.

Sa. a chev. arg. voided gu. betw, three lozenges of the second each charged with a Cornish chough ppr. CaBORNE or CaBOURNE.

Sa. a chev. betw. three lozenges erm. SHaw. And with a bordure gu. SHaw.

Arg. a chev. engr. az. betw. four lozenges gu. each charged with a cross or. HOBson.

\section{Iures}

Arg. a chev. betw, three lures sa. Browwich.

Gu. a chev. betw. three lures or. WINGHAM, $V$.

Sa. a chev. betw. three lures arg. AP.M $\triangle$ DDOCK or Madoke, Wales. Struenton. Strverton, $V$.

Sa. a chev. arg. betw. three lures of the second stringed or. AP-MADOCK, $V^{*}$. AP-RAEN, $V^{*}$.

Sa. a chev. or betw. three lures arg. LiE. Prene or Prenue. Prenue, 1716.

Sa. a chev. or betw. three lures arg. stringed of the second. Thomas ap Madoc ap RaEN, $V$. Henry Skeynert, $V$.

Sa. a chev. betw. threo lures or. Skeynert, $V^{*}$. Sa. a chev. betw. three lures stringed or. Madoc ap RAEN.

Mascles, etc.

Or a chev. engr. betw. in chief two mascles and in base a ducal coronet gu. Mitchell, En. derby Hall, co. Leicester.

.... a chev. .... betw. two mascles in chief .... and a 3-foil slipped in base .... ALLAN, Corstorphine, near Edin burgh.

Az. a chev. betw. in chief two mascles and in base a 3-foil slipped within a bordure wavy arg. Trail.

Az. a chev. betw. in chief two mascles or and in base a 3-foil slipped arg. Trail TramLi or Trayle, Ballylough, co. Antrim; descended through James 'Trarl, Bishop of Down, ete., 1765, from Trail, Blebo, co. Fife.

Or a chev. betw. in chief two maseles and in base a boar's head az. Livie.

Arg. a chev. betw. three mascles az. Whitacre. Arg. a chev. ermines betw. three mascles az. Parker, Finglesham, Kent.

Arg. a chev. betw. three mascles gu. Aston, $V$; and co. Chester. HondFORD or HONFORD, co. Chester, $i$. Spring or Springe, Pakenham, Suffolk; Baronetcy 1641-1769.

Arg. a chev. gu. betw. three mascles sa. Philps, Seotland.

Arg. a chev. sa. betw. three mascles az. Parizer, Honyng, Norfolk, $V$. 
1 CAEVRON betw. or within.... cont.

Mascles, etc., cont.

Arg. a chev. sa. betw. three mascles voided erm. SHAA.

Arg. a chev. sa. betw. three mascles gu. Ashion, Crofton, co. Lancaster; quartering arg. two bars sa.

Alg. a chev. betw. three mascles sa. LermoutH. Massey. Martyn, Suffolk. Parker, Aldborough, Norfolk.

Arg. a chev, betw, three mascles sa. within a bor. dure engr. gu. Martis, Long Melford, Suffolk; and Burnham, Norfolk; Baronetcy 1667; extinct ....

Arg. a chev. betw. three mascles within a bordure sa. Martin, Scotland. Martrn, Suffolk.

Az. a chev, arg. betw. three mascles or. Chalenor, Kenwardes, Lindfield, Sussex. CHANDLER or Chaundler. Segar.

Az, a chev. erm. betw. three mascles or. PARIser, Kent.

Az. a chev. betw. three mascles or. Chaloner. YELLOWLEY.

Erm. a chev. betw. three mascles gu. Thomas Everdon, $V$.

Erm. a chev, betw, three mascles sa. Shaw, Ireland.

Gu. a chev, arg. betw. three mascles erm. Belgrate, $V$; and co. Leicester.

Gu. a chev. erm. betw. three mascles arg. Belgrate, Preston Hall, Rutland; a branch of Belgrave, North Kilworth, and Belgrave, co. Leicester.

Or a cher. sa. betw. three mascles az. PARkER, Norfolk.

Per chev. sa. and arg, a chev, betw. three mascles counterchanged. THORN or THORNE.

Per chief gu. and arg. a chev. of the first betw. in chief three mascles as the second in base an oak wreath vert tied az. PELIEw, Treverry, Cornwall, 1796.

Sa. a chev, betw. three mascles arg. 'Whitacre, Henthorne, co. York.

Sa. a chev, betw. three mascles or. Mrtchael, Alderstoun, Scotland.

\section{Maunches}

Arg. a chev. sa. betw, three maunches az. Stafferton, co. Berks.

Arg. a chev. betw, three maunches sa. MANFIELD, West Leake, co. Nottingham. Sr. Rice MAUNCEL, co. Glamorgar, V. Maunsell, Oakley Park, co. Kildare; derived from Maunsele, BallyWilliam, Plassy, and Bank Hall, co. Limerick. MaUnsel or MANSEl, Margam, co. Glamorgan, $Z$, 316 ; Baronetcy 1611; Barony 1712 ; extinct 1750. MANSEL, Trimsaren, derived from Mansel, Muddlescombe, co. Carmarthen; Baronetcy 1621. William Lort ManseL, Bishop of Bristol 1888-20. Mounsel.

Arg. a chev. sa. betw. three maunches vert. Stafferton, co. Berks. Sr..... de Staverton, $V$.

Arg. a chev. betw. three maunches vert. Stafferton or Staperton, Wingfield, co. Berks; and co. Hants. Stawton, Warnill, co. Berks.

Or a chev, erminois betw. three maunches .... Staple, Hacliney, Middlesex.

Sa. a chev, betw. three maunches arg. Mansell.

Vert a chev. betw. three maunches erm. Staterton, $V$.

Mermaids see Monsters
1 CHEVRON betw, or within.... cont. Mitres

Az. a chev. composed of chain and couped betw. three mitres all arg. at the dexter end of the chain a padlock of the last. Benedictine Abbey at Eveshair, co. Worcester.

\section{Molehills see Hillocks}

Monsters.... Cockatrices

Sa. a chev. or betw. three cockatrices arg. SEYnes.

\section{.... Dragons}

Arg. a chev. gu. betw. three demi-dragons couped erect vert. Heygers, $V$.

Or a chev. betw. three dragons sa. Folborne.

$$
\text { ....Griffins }
$$

Gu. a chev, vair betw, in chief two griffins se. greant or and in base a bunch of purple grapes. De Vitre.

Arg. a chev. engr. gu. betw. three griffins segreant az. armed and membered sa. crowned or. Fonsyth, That Ilk, Scotland.

Arg. a chev. betw. three griffins segreant gu. Forsyth.

Arg. a chev. gu. betw. three griffins segreant vert. Foresight, Scotland.

Arg. a chev, engr. gu. betw. three griffins segreant vert armed and membered of the second. Fonsyth, Tailzerton, and Nydie, Scotland.

Arg. a chev, betw, three griffins pass. sa. Frnch, Baron Guernsey 1702, Earl of Aylesford 1714 . Arg. a chev. betw. three griffins pass. wings endorsed sa. FincH, quartered by Hatton.

Arg. a cliev. engr. betw. three griffins pass. sa. Finch, Kent, $\boldsymbol{V}$.

Arg. a chev. betw. three griffins segreant sa. FincH.

Arg. a chev, engr. betw. three griffins segreant vert armed and ducally crowned or. Fonsrrh, Scotland.

Az. a chev. wavy betw. three griffins segreant or. Newman, London, 1610.

Gi. a chev. erm. betw. three griffins segreant those in chief combatant (of the second, $V^{*}$.) or. ALDAY, $V$.

Or a chev. betw. three griffins pass. gu. Pengeldy, Pengelly, Cornwall; the heiress m. Beare.

Or a chev, vert betw. three griftins pass. gu. armed of the second. Brompton. BRUMrton, $V^{*}$. Brympton, $V^{*}$. But armed and winged of the second. Brompton, $V$. Brympton, $V$.

Or a chev. betw. three griffins segreant vert. Brompton.

Per pale or and sa. a chev. betw. three griffins pass. counterchanged. Eveleigh, West Eveleigh, St. Lawreuce, and Holcombe, co. Devon, Collinson, Somerset, ii, 474.

Sa. a chev, betw. three griffins segreant arg. SPANEy, $V$.

Sa. a chev. betw, three griffins or. ERISA ERISAY (signature) ERISE ERIsee (signature) Erissa Erisy Erysey Nrysie Erysy Erysye HeriseI or HenIsy, quartering Ere, Durant, and Milliton; the heiress m. West. Eryse. The griffins segreant. ERIscy, Eriscy, Cornwall, $W$. ERISEY, $V^{*}$.

$$
\text { .....Mermaids }
$$

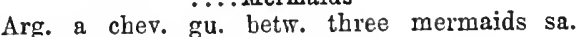
Tregarthian.

Or a chev, betw. three mermaids sa. Sr John de Folebourne (an error in) $N$, sloane $M S$. 1429.

.... Seadogs see Seawolves 
1 CHEVRON betw. or within.... cont.

Monsters cont. Seahorses

Az. a.chev. betw. three seahorses or. Tucker, Kent.

\section{....Seawolves}

Arg. a chev. engr. gu. betw. three marine wolves (or seadogs) naiant sa. finned ventred and dented of the first langued of the second. Fennor, Sussex; granted 10 November 1557.

$$
\text { ....Unicorns }
$$

Arg. a chev. betw. three unicorns salient sa. Monington, Sarnesfield Court, co. Hereford.

$$
\text { .....Wiverns }
$$

Or a chev. betw. two wiverns sa. Sire Johan de Forebourne, N, Harl. MS. 4033 ; but three, $N$, Nicolas, p. 155 .

\section{....Wivern-Serpents}

Arg. a chev. sa. betw. three wivern-serpents vert. LANDON, $V$.

\section{Mullets}

Gu. a chev. erm. betw. two mullets arg. TELFER

Arg. a chev. betw. in chief two pierced mullets and in base ar annulet sa. Pludiptre, co. Nottingham; and Fredville, Kent.

Gu. a chev, arg. betw. in chief two mullets and in base a halbert or. Syme, Holinbush.

Gu. a chev. arg. betw: in chief two pierced mullets and in base a halbert or within a bordure sa. Sim, Scotland.

Gu. a chev. betw. in chief two spur-rowels and in base a halbert or. Syme, Scotland.

.... a chev. .... betw. in chief two mullets .... and in base a lion ramp. ....

Thomas Mordon, Fladbury, co. Worcester.

Az. a chev. or betw. in chief two mullets and in base a lion pass. arg. DuPREE.

Az. a chev. betw, in chief two mullets and in base a lion ramp. arg. M'BeAtB.

Sa. a chev. or betw. in chief two mullets of the last and in base a lion pass. arg. crowned gold. CoRderat.

Sa. a chev. or betw. in chief two mullets of the last and in base a lion pass. arg. ducally crowned of the second within a bordure gold a label of three points for diff. CORDEROY.

Sa. a chev. betw. in chief two mullets and in base a lion pass. ducally crowned or within a bordure arg. Cordray, Chute, co. Wilts.

Or a chev, betw. in chief two mullets and in base a stork gu. WRIGHT.

Arg. a chev. betw. in chief two mullets and in base a crescent az. Wilson, Croglin, Scotland.

Arg. a chev. gu. betw. in chief two mullets and in base a crescent az. Scroggy, Scotland.

Arg. a chev. betw. in chief two mullets gu. and in base a crescent az. WILSON.

Arg. a cher. betw. in cluief two mullets and in base a crescent gu. Wilson, Fraserburgh, Scotland.

Arg. a chev. sa. betw. in chief two mullets and in base a crescent gu. Annet. Bцаск, Temple, Scotland.

Az. a chev. betw. in chief two mullets and in base a crescent arg. M'Beath, MackbeatH, Scotland. M'Neath.

Per pale arg. and sa. a chev. betw. in chief two mullets and in base a crescent counterchanged. Alexander, Auchmull, Scotland.

Or a chev. betw. in chief two mullets and in base a cross croslet fitchy gu. Fetres, Whamphrey, co. Dumfries, and Comelybank, Edinburgh; Baronetcy 1804-30.

\section{CHEVRON betw, or within....cont.}

Mullets cont.

Arg. a chev. betw. in chief two mullets and in base a 5-foil gu. Hrde, $V^{*}$.

Arg. a chev. gu. betw. in chief two mullets sa. and in base a 5 -foil of the second. HxDE, Essex, $V$.

Arg. a chev. sa. betw. in chief two mullets and in base a fret couped gu. in the interstices four 4 -foils of the last and charged with so many hearts as the field. Arnut, Scotland.

Arg. a chev. chequy sa. and or betw. in chief two spur-rowels az. and in base a hammer ppr. Lorimer, Scotland.

Az. a chev, arg. betw. in chief two mullets or and in base a dexter gauntlet lying fesswise of the second holding a mace erect gold. MAcE, Exeter. Mace, Tenterden, Kent. Macie, Collinson, Somerset, i, 162. The mullets pierced. MACEY.

Az. a cher. arg. betw. in chief two mullets or and in base a buck's head cabossed of the second attired gold. EDward. Ellwood, co. York. Euwood, Clayton Priory, Sussex.

Gu. a chev, arg. betw. in chief two mullets and in base a stag's head erased or. EлIotH, Middleton, co. York.

Arg. a chev, embattled az. ensigned with a flag gu. cantoned of the field betw. in chief two mullets and in base a sun of the third. EסEN, Craigton, Scotland.

.... a chev. .... betw. three mullets ... LEEKY, Treland.

.... a chev. vair betw. three mullets .... SiLver. Arg. a cbev. betw. three mullets az. BRaINCH or Brance. Brethie or Brothe, Scotland. Crockat and Crocketr, Scotland. Pasleire.

Arg. a chev, az. betw. three mullets gu. Poluard, co. Devon.

Arg. a chev. az. betw, in chief three mullets and in base a cross croslet fitchy gu. Rejd, Pitfoddles, Scotland; quartering or a fess chequy az. and arg.

Arg. a chev, az. betw. in chief three mullets and in base a cock gu. Cock.

Arg. a cher, az. betw. in chief three mullets of the last and in base a crescent gu. Crockatr, Scotland.

Arg. a chev, az. betw, three mullets sa. Wodor. Arg. a chev. erm. betw. three mullets gu. Freeland, Gretham, co. Hants. Ireland, Surrey.

Arg. a chev. erm. betw. three pierced mullets gu. Davies, Tredrea, Cornwall; the heiress $m$. Giddy.

Arg. a chev. erm. betw. three pierced mullets sa. Gresham Coliege. Gresham, Gresham, Norfolk; Osterley, Middlesex; and Titsey, Surrey, Add. MS. 6193, fo. 7.

Arg. a chev, ermines betw. three mullets gu. BAYLY.

Arg. a chev. erminois betw. three mullets sa. Greshant, Surrey.

Arg. a chev. gu. betw. three mullets az. Brodie, Brodie, co. Moray.

Arg. a chev. betw. three mullets gu. Sir Robert Brougrton, temp. Edward IV, Harl. MS. 6137, fo. 44 ; and Warbrightesley, Stoodleigh, co. Devon. Sr..... deBroughton, $V$. Broughton, Essex. M. Adar de Creting, $D$. Sr. Adam de Cretinge, $I$. Sr. John Cretinge, $V$. Cretinge, Suffolk; quartered by Wauton. John de Cretinges or Cretings or de 
1 CHEVRON betw. or within....cont. Mullets cont.

Cretingues, $K$. Frances. Ingledew. Ipstans. Kibble, Scotland. Kunerson. Kynerston. Plessetts. Skelton, co. York. Sutton, $V^{*}$. Wirson, Croglin, Scotland. Wilson, Ireland. Wilson, Cleugh, and Wilson Town, co. Lanark; London; Bruutsfieldbirks, Edinburgh; and Loudwater, co. Hertford.

Arg. a chev. betw. in chief three mullets gu. and in base an ermine spot ppr. BERTHon, Walthamstow, Essex; from Portugal and France.

Arg. a chev, engr. betw. three mullets gu. Frauncers, Fraunceis Court, Broad Clist, co. Devon; and Combe Flory, co. Somerset; a coheir m. Prideaux.

Arg. a chev. betw. three mullets gu. each charged with a bezant. Robert Creting, $Y$.

Arg. a chev. betw. three pierced mullets gu. Cretina, 1299. Monsire de Cretino, Y. Adam de Creting, A, Harl. MS. 6137. John Creting, $Y$. Davie, Baronetcy 1846. Francis, co. De. von; and Combflory, co. Somerset. Esmond Gretyng, $X$. Rugeley, co. Stafford.

Arg. a chev, engr. betw. three pierced mullets gu. Frances, co. Somerset.

Arg. a chev. betw. three mullets with six points gu. Creting; quartered by Wauton, in church at Great Staughton, co. Huntingdon. Adam de Cretingges, $F$.

Arg. a chev. betw. three pierced mullets with six points gu. Crering, Kent. Adam de Cretingaes, $E$; or Cretinge, $G$.

Arg. a chev. betw. three rowels gu. Sire Johan de Cretunge, $N$.

Arg. a chev. gu. betw. three mullets sa. BOAdLE. Kinnerton. Kirton. Kronton. Kynerston. Plessells, $V$.

Arg. a chev, engr. gu. betw, three mullets sa. ANNERING.

Arg. a chev. gu. betw. three pierced mullets sa. Davie Delawey Devie or Dewy, Creedy, co. Devon; Baronetcy 1846. Davie, Durham.

Arg. a chev. engr. gu. betw. three pierced mullets sa. Kynnerton, $V$.

Arg. a chev. sa. betw. tbree mullets az. BLACKeTt.

Arg. a chev. engr. sa. betw. in chief three mullets and in base a crescent az. ensigned on the top with a fleur-de-lis of the last. Cushner, Aberdeen.

Arg. a chev. sa. betw. three spur-rowels az. Loriner, England.

Arg. a chev. sa. betw. three mullets gu. Abercorn. Branch. Danes or Daneys. Daveys, co. Devon. Dency Deng or Dengis. Denys, $V$. Keverell, co. Warwick. Pollard, co. Devon. Rosmer, co. Devon. Samborne, Montesford, co. Berlss; co. Hants ; and co. Somerset. ? Samborne, adopted by Flower on m. with the beiress; Collinson, Somerset, ii, 220. Secroft. Shenock, Cornwall. Sherwood, Collinson, Somerset, i, 204. SHerwood, Newcastle. WakEHURST. Willes. Edward Willes, Bishop of St. David's 1743, Batb, etc. 1743-73. Willies or Willis, Fenny Compton, co. Warwick. Richard Willis, Bishop of Gloucester 1715, Salisbury 1721, Winchester 1723-34. Willis, Hungerford Park, co. Berks. YAXLEY.

Arg. a chev. sa. betw. three mullets gu. within a bordure indented of the second. AnNer.
1 CHEVRON betw, or within....cont.

Mullets cont.

Arg. a chev. sa. betw. three mullets gu. within a bordure indeuted of the second charged with crescents of the first. ARNET.

Arg. a chev. sa. betw. in chief three mullets and in base a crescent gu. BLack, Westminster.

Arg. a chev. embattled sa. betw. three mullets gu. WiNgrove.

Arg. a chev. sa. betw. three mullets gu. pierced or. Danis, $V^{*}$. Davies, Vive Hall, Sussex. Davis, V. Samborne, Timsbury House, Bath. Arg. a chev. sa. betw. three pierced mullets gu. Davies, Vine Hall, Sussex. Davy, $W$. Deneys, Suffolk. Denny, Eye, Suffolk; quartered by Carthew. Poluard. And (?) John Denys, Chesterton, co. Huntingdon, 1352. And with a vordure ....; his brother Thomas. But with a bordure engr.....; their brother Philip: Cotton MS. Julius F viii, fo. 36 .

Arg. a chev. engr. sa. letw. three pierced mullets gu. Francise, $V^{*}$. Fraunces, $V$.

Arg. a chev. betw. three mullets sa. Arnote, Scotland. BIRch, co. Lancaster; and co. Salop. Breche. Browne, Stroud, co. Gloucester, 1739. Bryche. Monsire Hugh de Cuilly; $Y$. Hugh de Coyly Tumly or Tuysy, $Y$. Fletcher, $W$. Fletcher, Ireland. Francey. Hamond, co. York. M'Millan, England. NefFeld, Armeforth, Scotland. Nefield or Nesfield, co. York. Nessffield, Flasby. Pollard, $V$. Quelly. Rigg. Salt. Sherwood. Silallbrook. Tooley or Towley.

Arg. a chev. couped betw. three mullets sa. Sabtey. Salt, Yoxley. Salte, Harl. MS. 1404, fo. 28. SatTs, Harl. MS. 1386, fo. 35 .

Arg. a chev, engr. betw. three mullets sa. BEDo. Kinnersley. Kynaston or Kynerston, Ryton Stokes, co. Shrewsbury; Woodhouse, and Shotter, co. Salop; granted 19 April 1569. Maveson, Maveson, co. Salop.

Arg. a chev. rompu betw. three mullets sa. SALT. SAULT.

Arg. a chev. betw. three pierced mullets sa. Browne, V. Coffis, Portland, co. Dorset. Coffyn, $V$. Conley or Conylye. Cosen, co. Devon. Culfy or Culy, co. Derby. Sr. Hugh de Culy, co. Derby, temp. Edward I, V. PASHley, Stainton, co.York. PAShley or PASLEY, co. Lincoln; and co. York. PasLey, co. York. Riggd, co. Iincoln. Richard Smallbrooke, Bishop of St. David's 1724, Lichfield, etc. $1731-49$.

Arg. a chev. debruised betw. three pierced mullets sa. Salter, $V$.

Arg. a cher. voided betw. three pierced mullets sa. Romney, co. Berwick.

Arg. a chev. betw. three pierced mullets with six points sa. CuIL, co. Leicester, 1158.

Arg. a chev, betw. three mullets sa. each charged with a bezant. Tullly or TwLLly.

Arg. a chev. sa. betw. three mullets with six points of the second each charged with a bezant. Deveris or Devers, Suffolk.

Arg. a chev. betw. three mullets within a bordure sa. Kemble, co. Gloncester.

Arg. a chev, betw. three rowels sa. Sire Huge de Culy, $N$.

Arg. a chev. sr. betw. three mullets vert. Penrith. Az. a chev. betw. three mullets arg. ARnotT. Ceely, St. Ives, Cornwall. Hildyard, co. York; and Suirey. Hillitard, Durham. Portington. 
1 CHEVRON betw, or within....cont.

Mullets cont.

Az. a chev. betw. in chief three mullets arg. and in base the sun or. Fatrweather.

Az. a chev. engr. betw. three mullets arg. Pysent. Az. a chev. wavy betw. three mullets arg. Puger. Az. a chev, arg. betw. three mullets or. HELLIAR, Exeter. Heisyard or Hildeyard, $V$. Himliard, Collinson, Somerset, ii, 448. Hyldeyard, $V^{*}$. Az. a chev. flory counterflory erm. betw. three pierced mullets arg. Briers, co. Bedford.

Az. a chev. erm. betw. three mullets with six points or. Draper, New castle.

Az, a cher. or betw. three mullets arg. Seary.

Az. a chev. betw. three mullets or. Ceely, used by Sicly, Trevelver, and Heligan, Cornwall; the heirs m. Sheppard, Martyn, Stoggett, Jackson, and Lyddon. CELy, Collinson, Somerset, i, 77. Cely, Essex. Monsire de Chatwinde, $Y$. Sire Johan Chedewynt, $O$. Chetwynd, Baron Rathdowne aud Viscount Chetwynd 1717, quartering de Mutton and de la Roche. Chetwrnd, Grendon, co. Warwick; Baronetcy 1795; with the same quarterings and Grendon with Meverett Sparrow and Moreton. M. Chetwynd, Ingestre, co. Stafford, 1730. William Chetwynde, $S$. John Creting, $Y$. John Eston, $V$. Hillier. Hyllyard. Moliens, $V^{*}$. Mulliens or Muluins. Pudsey, Bolton.

Az. a chev, rompu betw. three mullets or. SAIT, London.

Az. a chev. betw. three pierced mullets or. Sr. Philip Chetwyn, co. Stafford, $V$. M. William Chetwynde, $S$.

Az. a chev. betw. three mullets with six points or. Meer, Sherborn, co. Dorset. Murman, London; and Debden Hall, Essex; granted 8 November 1772 ; quartering Mulencar.

Az. a chev. betw. in chief three mullets with six points one and two and in base a hedgehog pass. or. DORRELy.

Az. a chev. betw. in chief three mullets with six points or and a porcupine in base ppr. Dayrolles, Henley Park, Surres.

Az. a chev. or betw. in chief three pierced mullets with six points as the last and in base a dove holding in the beak a sprig of laurel ppr. SaptT, Codiscote Lodge, co. Hertford.

Errn. a chev. gu. betw. three mullets az. GATONBY, co. York.

Erm. a chev. betw. three pierced mullets gu. Butrs, Norfolk.

Erm. a chev. or betw. three mullets az. GatonBy, Gatonby, co. York.

Erm. a chev. sa. betw. three mullets gu. DAxuEY, Bickerton, co. York. Yaxuey, Bawthorp, and Yaxley, Norfolk. Yaxuey, Norfolk, V; and Harl. MS. 1392.

Erm. a chev. sa. betw. three pierced mullets gu. Yaxuey, Yaxley, Suffolk; and Boston, co. Lincoln.

Erm. a chev. sa. betw, three mullets or. YAxLEx.

Erminois a chev. betw, three mullets arg. Pristow.

Gu. a chev. betw. three mullets arg. Apris. Sire Walter de BAA; co. Bedford, temp. Edward I, $V$. BAa or BAO, co. Bedford. Fullwood, Middleton, co. Derby ; co. Stafford; and co. Warwick ; confirmed 1579. FuLWOOD, co. Warwick, $W$. Howell. Millington, co. Dorset. Molton. Prnsent, Carleton Curlieu, co. Leicester; aud Urchfrout, co. Wilts. SToneryn, $V$; and co. Chester. SutherLand.
1 CHEVRON betw. or within.... cont.

Mullets cont.

Gu. a chev. counterembattled betw. three mullets arg. WILson, Queensferry, Scotland. WIIson, Transy, co. Fife, Scotland.

Gu. a chev. engr. betw. three mullets arg. Busheli.

Gu. a chev. betw. three pierced mullets arg. Monsire de Chanon, $Y$ (probably an error for escallops). Futwood, co. Lancaster ; Middleton, co. Derby ; Holborn, Middlesex; Hemington, co. Leicester; and co. Hants.

Gu. a chev. betw. three pierced mullets arg. within a bordure or. FuLlwood.

Gu. a chev. engr. betw. three pierced mullets arg. Rugge, Felmingham, Norfolk. William RugGE alias Reppes, Bishop of Norwich 1536-50.

Gu. a cher. betw. three mullets with six points arg. Joan le Estrume, $E$; or Strum, $E$, Harl. $M S$. 6137.

Gu. a chev. betw. three pierced mullets with six points arg. BAa or BAO, co. Bedford. Howel ap Res, $\boldsymbol{E}$. WaLkINGTON, $V$.

Gu. a chev. betw. three rowels arg. ABRIs. Apris. Alons. Sire Walter de BAA, N. Sr. Roger Stonmyn, $N$.

Gu. a chev. arg. betw. three mullets or. Bannatine, Scotland.

Gu. a chev. arg. betw. three pierced mullets or. RugGE, 1568.

Gu. a chev. compony or and sa. betw. three mul. lets of the second. Moulson, Lord Mayor of London 1634.

Gu. a chev. or betw. three mullets arg. MILLINGTON.

Gu. a chev. betw. three mullets or. Anmers or Anners, co. Chester. Anvers, co. Chester, $V$. D'Anvers, Cothorp, Oxford. Dawes or Downes. Fullwood. Milisngton. Podsey,co. Orford; and Langley, co. Warwick. Rotpert, 1370. Soame,Norfolk; and Little Thurlow, Suffolk, 1370. George Surron, GentlemanUsher to the Queen, $V$.

Gu. a chev. betw. in chief three mullets in one and two or and in base an anchor arg. Delacharois.

Gu. a chev. betw. in chief three mullets and in base a lion ramp. or. SoTwell, Grenham, co. Berks ; and Chate, co. Wilts.

Gu. a chev. betw. three pierced mullets or. DAMTVRS, $V$.

Gu. a cher. betw. three mullets with six points or, Anvers, co. Chester. Danvers, Dantsey, co. Wilts, $Z$, 345; co. Nortbampton; co. Oxford; and co. Warwick.

Gu. a cher. betw. three pierced mullets of six points or. Danvers, Cothorp, co. Oxford, quartering Brancestre and Verney, from whom descended Danvers, Chamberhouse, co. Berks ; Upton and Blisworth, co. Warwick; Prescote, co. Oxford ; and Culworth, co. Northampton, quartering Stradling, from whom descended Danvers, Baronetcy 1642-76, quartering Rainsford, Pope, and Barker; and Danvers, Baron Danvers 1603, Earl of Danby 1626, extinct 1644, quartering Latimer. D'ANvERS, Swithland, co. Leicester; Baronetcy 1746-96; quartering Bracester, Morewood, and Watson; the heiress $m$. Butler.

Gu. a chev. betw, three rowels or. Ambers. Sire Thomas de Anvers, $N$.

Gu. a chev. paly of eight or and az. betw. three mullets arg. Everetr, Biddesdon House, co. Wilts. 
1 CHEVRON betw. or within.....cont.

Mullets cont.

Gu. a chev, vair betw. three mullets arg. 'TuRvill, $V$.

Gu. a chev. vair betw. three mullets with six points or. Turvill, $V$.

Gu. a chev. vairy arg. and sa. betw. three mullets or. Stockton, $V$.

Gu. a chev. vairy sa. and arg. betw. three mullets of the last. Stockton, Lord Mayor of London 1470.

Or a chev. betw. three mullets az. Crakenthorpe. Helliard. Seager. Segar, co. Hants, 1716.

Or a chev. betw. three mullets az. each charged with a plate. Crakenthorp, $V$.

Or a chev. betw. three pierced mullets az. Davies, in St. Sepulchre's church, London.

Or a chev. betw. three pierced mullets az. each charged with a plate. Crakenthorp, $V^{*}$.

Or a chev. az. betw. three pierced mullets sa. Purdie or Purdy. Purdie, Scotlaud.

Or a chev. err. betw. three pierced mullets sa. BotT, co. Stafford.

Or a chev. ermines betw. three pierced mullets az. Lane.

Or a chev. gu. betw. three pierced mullets az. Hyde, co. Stafford. LANE, Hyde, and Bentley, co. Stafford.

Or a chev.betw. three mullets gu. CRUSE, co. Devon.

Or a chev. embattled betw. three mullets gu. ENGLEDUE, $V^{*}$; and (?) $W$.

Or a cliev. betw. three mullets sa. Langdale, Langdale, Wbilbistrond, co. York.

Or a chev. rompu betw. three mullets sa. SALT, Yoxall, co. Stafford.

Or a cher. betw. three pierced mullets sa. Crackenthorp, New biggin, Westmorelaud; and Bank Hall, Cumberland. Crakenthorpe. Danwicke. John Davies, Cressingtemple, Essex; third son of Sir Thomas Davies, Lord Mayor of London 1677. Dawikes or Dawkes.

Or a chev. sa. betw. three pierced mullets vert. Crakenthorpe.

Sa. a chev. betw. three mullets arg. Ap-Ronerts. Burreis, Northumberland. I ANGDaIe, co. York. Lroyd, Kimmel. George Lloyd, Bishop of Sodor, etc. 1599, Chester 1604-15. Mansei, co. Dorset. Sr..... de Maunsel, $V$. Rhys ap Fotpert. ShUckburgh, Shuckburgh, co. Warwick; Baronetcy 1660. ShUkesburghe, co. Hereford.

Sa. a chev. betw. three pierced mullets arg. Beanvill. Beavill, co. Huntingdon. Benville, Bevile. John Maunsell, $X$. Shakisburgh, V. Shugbonotgh, $V^{*}$.

Sa. a chev. engr. betw. three pierced mullets arg. SHuckburgh, Downton House, co. Wilts.

Sa. a chev. betw. three mullets with six points arg. Hilliand, co. York.

Sa. a chev. arg. betw. three mullets or. Estmond, co. Dorset.

Sa. a chev. arg. betw. three pierced mullets with six points or. Poxweld, Stroud, co. Dorset.

Sa. a chev. betw. three mullets erm. Chamberiayn, London.

Sa. a chev. erm. betw. three mullets arg. GREsHanI, Walsingham, Norfolk.

Sa. a chev. erm. betw. three mullets or. Blage.

Sa. a chev. wavy erm. betw. three pierced mullets or. MILdRed.

Sa. a chev. betw. three mullets or. CAPON.

Sa. a chev. rompu betw. three mullets or SAturt. SAvil, London, 17$] 6$.
1 CHEVRON betw. or within.... cont.

Mullets cont.

Sa. a chev. betw. in chief three mullets and in base a lion ramp. or. Gorrie or GorRY, Scotland. Sa. a cher. betw. three pierced mullets or. Manseli.

Vert a chev. betw. three mullets or. Sr. Richard Pudsey, Belton, co. Lancaster, $V$. Pudsey, Stonefield, co. Bedford; co. Lancaster; Ellesfield, co. Oxford; co. Stafford; and co. York. Puddesey or Pudsky, Barford, co. York.

Vert a chev. betw. three pierced mullets or. John Pudsay, Y. Pudsey, Bolton, co. Lancaster. Vert a chev. betw. three mullets or each charged with a torteau. Spurstow, co. Chester.

Arg. a chev. betw. four mullets gu. Bannatrne. Arg. a chev. sa. betw. six mullets gu. HarteshuI. Az. a chev. sa. betw. eight mullets three two two and one or. CUDFORD or KUDFORD.

Az. a chev. betw. nine mullets four two one and two or. KUDFORD, $V$.

Or a chev. embattled betw. nine mullets gu. ENGLEDUE.

Az. a chev, betw. ten mullets six in chief and four in base or. KNEFORD. RUDFORD.

Nails, etc.

Arg. a chev. betw. three demi-lozenges couped per pale sa. Bellesby, co. Lincoln. Bilesby, Bylesby, co. Lincoln.

Alg, a chev, gu. betw. three nails sa. CLEw or Clewe. Seint Clowe, $V$. Saint-Low. Samteil.

Arg. a chev. betw. three nails sa. Serntclowe, $V^{*}$. Arg. a chev. betw. three stone bills sa. BILlEsBy. Arg. a chev. betw. three (piles or) wedges $\mathbf{8 a}$. PegG or Pegge, Beauchieff Abbey, Hunter, Sheffield, 199 ; Yeldersley, and Osmaston, co. Derby. Or a chev. erm. betw. three nails az. HARRIS alias PrICKI.

Sa. a chev. erm. betw, three piles arg. Cater, London.

\section{Orle}

Arg. a chev. within an orle sa. Bentick. Orles

Arg. a chev. .... betw. three orles .... HaLL, Pitcombe; quartering Ruddock; Collinson, Somerset, ii, 345 .

\section{Packs}

Az. a chev. betw. three woolpacks or. LOAT.

Gu. a chev. betw. three woolpacks arg. Wools, Rugby.

Sa. a chev. betw. three packs arg. corded of the first. Company of Drers, London.

Sa. a chev. engr. arg. betw. three bags of madder of the last corded or. Company of Drens, London.

\section{Padlock see Lock}

Pails seo Bongets and Tubs

Arg. a chev. betw. three pails (or buckets) gu. FitzWalter.

Arg. a chev. betw. three pails (or buckets) sa. Pemberton, co. Lancaster. But hooped or. Pemberton, Lord Mavor of London 1611 ; and Rushdon, co. Northampton. And bandled or. Pemberton, Millichope, co. Salop; descended from a family seated at Pemberton, co. Lancaster; and at Wrockwardine, co. Salop; now represented by C. O. Childe Pemberton, Esq., quartering Childe, Lacon, and Baldwsn. Pemberton, Milton, co. Northampton, quarter. ing arg. three dragon's heads erect sa. couped and langued gu. 
1 CHEVRON betw. or within.... cont.

Pails, etc. cont.

Arg. a chev. vert betw, three pails (or buckets) sa. Pemberton, $V^{*}$. But hooped and handled or. Penberton, Pemberton, co. Lancaster. Pemerton, $V$.

Gu. a chev. betw, three pails (or buckets) or. Whitewell, $V^{*}$. Whitwell, $V$.

Sa. a chev. or betw. three pails (or buckets) arg. Sutton, Sussex, $V$.

Palo

Per chief arg. and az. a chev, betw. in chief a pale gu. charged with a garb or enclosed by two leopard's (faces or) heads of the first and in base a sword as the third hilt and pomel gold. Blayds, Oulton, co. York. And with a mullet arg. in the dexter chief for diff. Tho. mas BLAYDS.

\section{Pegs see Nails \\ Pen}

Per pale arg. and sa. a chev. betw. in chief a writing-pen fesswise and in base a crescent counterchauged. Alexander, Boghall.

\section{Perukes see Heads}

\section{Pheons}

Arg. a chev, engr. betw. two pheons gu. TrNwike. Arg. a chev. gu. betw. two pheons reversed sa. SULYARD.

Arg. a chev. roided gu. betw. in chief two pheons sa. and in base a fleur-de-lis within a bordure wavy az. MAYNE, Powis, and Lngie, co. Clackmannan; derived from Lockwood. MaYNE, Viscount Newhaven, 1776.

Arg. a chev. voided gu. hetw. in chief two pheons and in base a unicorn's head erased sa. MAIN, Lochwood, Scotland.

Arg. a chev. az. betw. three pheons of the second. Cropall.

Arg. a chev. betw. three pheons gu. WHydon, Chagford, co. Devon; granted 12 November 1564.

Arg. a chev. engr, betw. three pheons gu. TYNWTKE.

Arg. a chev. gu. betw. three broad arrow-heads sa. WaLsH, Castleboel.

Arg. a chev. gu. betw. three pheons the two in chief lying fesswise point to point and that in base erect sa. KIfFin, co. Salop.

Arg. a chev. gu. betw. three pheons sa. CADwgan, Bachan; quartered by Watkins of Pennoyre. Cadwgan ap RHIRYDD, quartered through Bromfield by Eyton, 1674. Sulliard, co. Devon; and Essex. And with a mullet on the chev. KyFFIN, $V$.

Arg. a chev. gu. betw. three pheons reversed sa. Sulyard, $V$. The pheons pointing to the centre. Kadwgan ap RHYRIDD.

Arg. a chev. voided gu. betw. in chief three pheons and in base a dexter hand couped sa. MAIN, Lochend.

Arg. a chev. sa. betw. three pheons gu. Nichols, in church at Maltby, co. York.

Arg. a chev. betw. three pheons sa. Archer, quartered by Shee. Price, London. Siliard. Smart or Smerte, London; and Scotland. Smert, Garter King at Arms, $V$; cc. 1450. SMert, Colnwall; granted 1579. SMert, London; confirmed 13 May 1610. WaLSH, seal. WELSH.

Arg. a chev. betw. three pheons the two in chief lying fesswise point to point sa. Beale, co. Hereford; and co. Northampton.
1 CHEVRON betw. or within.....cont.

Pheons cont.

Arg. a chev. betw. three pheons reversed sa. SULLIARD or Sullyard.

Az. a chev. betw. three pheons arg. Cropall, $V^{*}$. Cropeli, $V$.

Az, a chev. erm. betw. three pheons arg. MADY. MOODIE.

Az. a chev. erm. betw. three pheons and a bor. dure arg. Mudie, Arbreckie.

Az. a chev. betw. three pheons or. Flaxal, Waxhall, $V$; but WaIsall, Cotton $M S$. Tiberius D 10.

Az. a chev. betw. three pheons or within a bordure erm. Swayne, Gundvile, and Blandford, co. Dorset.

Gu. a chev. betw. three pheons arg. Cantenen. Egerton, Walgrange, co. Stafford; and Adstock, co. Berks. William de Malopasse, $V$.

Gu. a chev. betw. three pheons arg. and a bordure of the last charged with 5.foils gu. MaLpasse. Gu. a chev. erm. betw. three pheons arg. Canthen, $V$.

Gu. a chev. erm. betw. three pheons or. ARNoLD, Armswell, co. Dorset; and Ashby Lodge, co, Northampton. ARNoLd, co. Gloucester; granted 1653; Harl. MS. 1041, fo. 54 b. Sir Nicholas AnNold, Bigland, Gloucester, i, 537; and quartering Apraen, ii, 67.

Gu. a chev. ermines betw. three pheons or. Sr. Nicholas Arnoud, co. Gloucester, $V$.

Gu. a chev. betw. three pheous or. AnNold. Goslett, Marshfield,co.Gloucester. Malopasse, $V *$.

Gu. a chev. engr. betw. three pheons reversed or. WotToN, $V$.

Gu. a chev. quarterly erm. and ermines betw. three pheons or. AnNoLd, Chilwick, cn. Hertford.

Sa. a chev. betw. three pheons arg. EGERTon, co. Chester; and London. Egrrton, $V^{*}$. Eggerton, $V$. Foster. Newport. Now.

Sa. a chev. engr. arg. betw. three pheons or. Ancher, Trelewick, and Trelaske, Cornwall.

Sa. a chev. erm. betw. three pheons arg. John Foster, $V$. Foster, co. Huntingdon. Foster, Lord Mayor of London 1454. GADSBX. And with a crescent for diff. Fosten; quartering Hill.

Sa. a chev. engr. erm. betw. three pheons arg. Foster.

Sa. a chev. (another, engr.) betw. three pheons or. Foster.

Vert a chev, arg. betw, three pheons or. Holman, $W$. Vert a chev. or betw. three pheons arg. Holman, London. Holman, $W$. Holman, Banbury, co. Oxford; Baronetey 1663-1700. Homan, Dunlum, co. Westmeath; Baronetcy 1801. And with a fleur-de-lis on the chev. for diff. gu. HoLMaN, $V$.

Vert a chev. betw. three pheons or. Holman, Surrey, $W$. Holman, Godeston, Surrey. Phials

Vert a chev. betw. three bottles or. Emsone, $V$. Piercers see Frets

Piles see Nails Pillars

Sa. a chev. betw. three pillars or. BollingBroke. Pipes

Arg. a chev, erminois betw. three boatswain's whistles az. HAWKE, Barony 1776 ; quartering Harvey.

Ploughs

Arg. a clev. betw. three coulters sa. Dor, Sanghall, co. Lancaster, 1749. 
1 CHEVRON betw. or within....cont.

Ploughs cont.

Arg. a cbev. betw. three laver cutters (or ploughshares also called scythe-blades) sa. LEVERSEDGE or LYversage, Leverseck, and Wheelock, co. Chester; confirmed 24 September 1580; quartering Wheloke.

\section{Plummets}

Arg. a cher. gu. betw. three plummets sa. Sr. Stephen Jenings, Lord Mayor of London 1508, $V$. Jennings, co. Stafford; and co. York. Jennings, $V^{*}$. Jennyns. Jenyns, Harl. MS. ]386, fo. 96 .

Arg. a chev. hetw. three plummets sa. JEnnings, Ripon, co. York. Jennins, Milford, co. Hants.

Arg. a chev, engr. betw, three plummets sa. Jennings, Lilesden, co. York; granted 26 May 1611.

\section{Pots see Baskets and Cups \\ Pounceboxes}

Gu. a chev. betw. three writing sand-boxes reversed issuing sand or. SANDON, Horton.

Portcullises

Gu. a chev, erm. betw. three portcullises or. Clement, $V^{*}$. Fichcocke, $V^{*}$. Fiscoke. Clement FishcockL, Harl. MS. 1386, fo. 94 ; or Fychсоске, V; or Fycherocke, Cotton MS. Tiberius D 10.

\section{Pouches or Purses}

Arg. a chev, betw. three purses of the first each held in a dexter hand clencbed sa. STEvenson, $V *$.

Arg. a chev. betw. three (bags or) purses sa. garnished of the first. TAsburan, Suffolk.

Arg, a chev. betw. three (postscrips or) palmer's scrips sa. tassels and buckles or. Palmer, Howlets, Kent, 1586. Paluter, Wood Court, co. Somerset; descended from Leigh, Kent.

Arg. a chev. vert betw, three palmer's staves and scrips sa. galnished (gu. auother) or. Palmer, Castle Lackin, co. Mayo; Kenure Park, co. Dublin, etc.; Baronetcy 1777.

Az. a chev. or betw. three open wallets arg. buckles and buttons of the second. Towgood, Axminster, co. Devon; granted 1770.

\section{Reedsheaves}

Gu. a chev, engr. betw. three reedsheaves arg. ReDHair, $V$.

Gu. a cbev. engr. arg. betw. three reedsheaves or. REDHAH.

\section{Reptiles ..... Alligators}

Gu. a cbev. arg. betw. three alligators .... HiтCHCOCE.

\section{-...Cameleons}

Arg. a chev. sa. betw. three cameleons vert. LANDON, $V^{*}$.

\section{....Frogs}

Arg. a chev. gu. betw. three (powets or) tadpoles haurient sa. Russels, quartered by Ramsay.

Arg. a chev. betw. three (powets or) tadpoles sa. Russei.L, That Ilk.

Arg. a chev. hetw. three (powets or) tadpoles sa. a bordure of the last. RusserL, Kingseat.

Az. a chev, arg. betw. tbree tadpoles or. GuLdes, Scotland.

Or a cher. betw. three frogs displ. gu. Trevronck or Trerroneck, Sancreed, Cornwall.

$$
\text { .... Lizards }
$$

Arg. a chev. gu. betw. three demi-lizards couped vert. HeYnes.

Arg. a chev. sa. betw. three lizards vert. LANGTON.
1 CHEVRON betw. or within.... cont.

\section{Reptiles cont. Snakes}

Arg. a chev. betw. three scolpions reversed gu. Cole, co. Devon; and Walden, Essex.

Arg. a chev. gu. betw. three serpents ppr. CoTTER, Rockforest, co. Cork; Baronetcy 1763, quartering Rogerson and Lombard.

Arg. a chev. engr. gu. betw. three snakes nowed their heads toward the sinister ppr. RADLEY, Halton, and Yarborough, co. Lincoln.

Arg. a chev. gu. betw. three scorpions erect sa. Cols.

Arg. a chev. gu. betw. three scorpions reversed sa. Cole, $V$. Coley, $V^{*}$.

Arg. a chev, sa. betw, three scorpions gu. CoLE, co. Salop, 1730.

Arg. a chev, betw. three adders nowed sa. Padley, co. Lincoln, 1716.

Arg. a chev. betw. three scorpions sa. CoLe, Rill, co. Devon; an heiress m. Drake.

\section{Rests}

Gu. a chev, arg. betw. three rests or. Sir Thomas Anthur, T. Arrhur, Collinson, Somerset, iii, 177, 179. ARTHURE.

Gu. a chev. arg. betw. three rests or each charged with as many hurts. ARTHur, Dublin.

Gu. a chev. arg. betw. three organ-rests ppr. Myles, Dartford, Kent.

Gu. a chev. erm. betw. three clarions or. Hickes. Gu. a chev. betw, tbree rests or. Williain Arteur, co. Somerset, $V$. Arthur, Springfield, Essex. Arthur, Clopton, co. Somerset. Arthur, Glanomera, co. Clare; quartering Butler.

\section{Rocks see Chess-rooks and Stones} Roundles

Per pale az. and or a chev. arg. betw, in chief two roundles and in base a crescent counterchanged. Britten.

\section{....Bezants}

Sa. a chev. betw. in chief two bezants and in base a lion ramp. or. LAIDLAW.

Az. a chev. betw. in chief two bezants and in base a cross croslet fitchy or. Ismaye.

Gu. a chev, arg. betw. in chief two bezants and in base a griffin's head erased or. Garton, $V$.

Gu. a chev. betw. in chief two bezants and in base a griffin's head erased or. BLACKetT, co. Somerset. Blanchard, co. Somerset, Collinson, Somerset, i, 139; co. Wilts; and Grimsargh Hall, co. Lancaster. Garton, Suffolk.

$$
\text { ..... Ogresses }
$$

Arg. a chev, sa. betw. in chief two ngresses and in base a cross croslet of the second. WALFORD. WELFORD, co. Hereford. Wilimesford or Willford, Wosterton, co. Hereford.

Arg. a cher, sa. betw. in chief two ogresses and in base a fish gu. Oliver.

$$
\text { ....Plates }
$$

Az. a chev, engr. or betw. two plates. OATES, Perran Zabuloe, and St. Agnes, Cornwall.

\section{Roundles}

Quarterly or and az. a chev. betw. three roundles counterchanged. RicH, co. Lancaster.

Quarterly or and az. a chev. betw. three roundles each cbarged with a lion ramp. counterchanged. Rисн.

\section{....Bezants}

Az. a chev. arg. betw. three bezants. Hотоғт.

Az. a chev. engr. erm. betw. three bezants on each a 3-foil slipped vert. Anthony WaLKER, co. York; granted 1563, W. WaLker, Compton Basset, co. Wilts. 
1 CHEVRON betw, or within.... cont.

Roundles cont. Bezants cont.

Az. a chev. or betw. three bezants. AввEтот, co. Warwick. Hope, Deepdene, Surrey ; a branch of Hope, Kerse, Baronetcy 1672, extinct .... ; derived from Hope, Craighall, and Pinkie, co. Fife; Baronetcy 1628. Hope, Netley, co. Salop, quartering Edwardes. HutToLfe, Essex. Jenings, $V *$. OTOFT, $V$. OTOST.

Az. a chev, betw. three bezants within a bordure or. HOPE, London, quartering Williams. Hope, Rankeillor, Scotland.

Bendy az. and arg. a chev, or betw. three bezants. Coldmbers, Collinson, Somerset, iii, 264.

Gu. a chev. arg, betw. three bezants. BAcY. Golden, Gainsborough, co. Lincoln. Golding, Suffolk, $V$. Golding, Essex; Cavendish, and Postingford, Suffolk.

Gu. a chev. arg. betw. three pierced bezants. KNOLLE or KNOLLS.

Gu. a chev. or betw. three bezants. Anriers or Anners, co. Chester. Anners. Sr. Thomas ANVERs, co. Chester, $V$. ANvers or ANVERy. AvERy, Wells, co. Somerset; quartering az. a ram's head cabossed arg. attired or, Harl. MS. 1385. Bevell, co. Huntingdon. Bevile. Bevile, $V$. G八RTON, co. York. Golding, Maiden Erlegh, co. Berks; Halsted, Essex; Suffolk; and Norfolk.

Gu. a chev. paly of four arg. and sa. betw. three bezants each charged with a lapwing of the third. Kттсніл, Meales, co. Lancaster.

Or a chev, gu, betw, three bezants. Brshe.

Or a chev. sa. betw. three bezants. Beurce.

Per chief az. and arg. a chev. gu. betw. in chief three bezants and in base a crescent of the third. CoDon or Conds, Suffolk. The cres. cent or. Codun, Sutfolk, $V$.

Sa. a chev. .... betw. three bezants. Pellouer, Cornwall.

Sa. a chev. or betw. three bezants. LaIdLaw. PeLL, co. Hants.

Vert a chev. or betw. three bezants. GREen, Suffolk.

\section{.... Fountains}

Arg. a chev. sa. betw, three fountains. Sykes, Kirk Ella, co. York; descended through Sykes, Sykes Dyke, Cumberland, from Sykes, Sledmere, co. York, Baronetcy 28 March 1783. (Assumed by) Sikes, Chauntry House, Newark, co. Nottingham, quartering Burton and Chambers.

$$
\text { ....Golpes }
$$

Or a chev. gu. betw. three golpes. Glenham.

$$
\text { ..... Hurts }
$$

Arg. a chev. az. betw. three hurts. ReneU. Ritssell, co. Northampton.

Arg. a chev. betw. three hurts within a bordure az. charged with as many fleur-de-lis or. BRUZEAD.

Arg. a chev. betw. three hurts each charged with a fret of the first. Gratwick, Ham, Surrey.

Arg. a chev. gu. betw. three hurts. Sire Richard de Bascrevile, $N$. Water de Baskervil, $E$. Sir Richard Baskervile, I. Baskervile, co. Hereford, and co. Warwick. BaskervilL, $V$. Sir Ralph Baskervill. Baskerville, Eardis. ley Castle, co. Hereford; the heiress m. Talbot. Baskenvilie, Lawton, and Pickthoru, co. Salop; Netherwood, Goodrest, Aberedow, and Lambedr. BaSkervyle, old Withington, and Gayton, co. Chester. Beverly. Lucas.
1 CHEVRON betw, or within.....cont.

Roundles cont. Hurts cont.

Arg. a chev. gu. betw. three hurts within a bordure compony az. and of the first. BASKERvILLE, Pontrilas, co. Hereford, 1730.

Arg. a chev. sa. betw. three hurts each charged with an escallop of the first. Dacres, Loudon. Arg. a chev, vairy or and gu. botw, three hurts each charged with a lion's gamb erased of the first. Hoogan, Castleacre, Norfolk.

Or a chev. az. betw. three hurts. Clepolf, Narborough, co. Nottingham. James ClePole, Nor. bourne, co. Northampton; granted by Cooke, $W$. .....0gresses

Arg. a chev. .... betw. three ogresses. GOODENOUGH.

Arg. a chev. gu. betw. three ogresses. Barfoot, Midlington Place, co. Hants. Barroot or Barford, Bereford or Borefeld, $V$. BERFORD. BorefEILd. John Borefeld, $Y$. Monsire de Borstle, $Y$.

Arg. a chev.gu. betw. three ogresses each charged with an escallop of the first. Dacres, $V^{*}$.

Arg. a chev. gu. betw. tliree ogresses each charged with a fleur-de-lis of the first. STonyng, Lichfield, $V$.

Arg. a chev. sa. betw. three ogresses. BeverLey, co. Derby, $V$. Coley, co. Nottingham. Mrrton, Cambo, Fife, Scotland. OULane, co. York. Place, Yngton, Cornwall, V. Playse. Singleton or Shingleton, co. York. Singleton, Brockhall, co. Lancaster. Sr. Henry Vane, $V$. And with over the point of the chev, a crescent for diff. counterchanged. MYreton, Scotland.

Arg. a chev. sa. betw. three ogresses within a bor. dure engr. gu. BRAY, $V$.

Arg. a chev. engr. sa. betw. three ogresses. Creting, Suffolk.

Or a chev. engr. gu. betw. three ogresses. GRATWICH or GROTWICK.

Or a chev. sa. betw. three ogresses within a bordure engr. gu. BraY.

Az. a chev. engr. or betw. three plates each charged with a martlet sa. Nicholas HeatI, Bishop of Rochester 1540, Worcester 1544, Archbishop of York 1555-60.

Az. a chev. engr. erm. betw. three plates each charged with a 3-foil slipped vert. Walker, Killingbeck, Leeds, and Wilsick, co. York. WALKER, co. York; granted 12 March 1554; confirmed 12 June 1562 .

Az. a chev, arg. betw. three plates each charged with an erm. spot gu. Cozens.

Gu. a chev. arg. betw. three.plates. ANwrIs. BaA, co. Bedford. Bacey. Basse. Beasley. Befils. Besill. Besills, $V^{*}$. Besils, $V$. Dister. Dunholme. Mader Gloddatth. Griffith ap RHys, Gloddoeth, Cryddyn; the heiress m. Howel ap Evan Vychan. Stormyn. STURMYN, co. Chester, $V$.

Gu. a chev. arg. betw. three plates over all a fess az. HadLEY. HARDLY.

Gu. a chev. or betw. three plates. Bocie. Or a chev. gu. betw. three plates. Robart.

Per pale az. and sa. a chev, engr. erm. betw. three plates. Woornouse, Glapwell, co. Derby ; granted 1611; Harl. MS. 1093, fo. 111 .

Per pale az. and sa. a chev. engr. erminois betw. three plates. WorLbouse; granted 9 February 1611 to Robert, son of Anthony WoLHousE WooLHowse or Woodhouse, Glapwell, co. Derby; Harl. MS. 1486, fo. 57; 1537, fo. 104. 
1 CHEVRON betw, or within.....cont.

Roundles cont. Plates cont.

Sa. a chev. arg. betw. three plates. Sr. Henry Stoner, $V$. The plates each charged with a palet gu. Docwra, $U$. Dockwray, Foulborne, co. Cambridge, 1619. But with a pile. Docwra.

Sa. a chev, engr. arg. betw, three plates. Dockwray. The plates each charged with a palet gu. Docwna, Puttridge, co. Hertford. Docwra, Ashmol. MS. Wood F 33, fo. 96. But with a pile. Docwra.

Sa. a chev. or betw. three plates each charged with a cross patty gu. BERRY or BuRY, Bury, co. Lancaster. The chev. engr. Berrey or Berry, Teddington, co. Bedford. Burye, Bed. ford, 1566.

Tert a chev, or betw. three plates. Polden, $V$. .....Pomeis

Arg. a chev. vert betw. three pomeis. Bloer, London. Henry Felde, $V$. Field. Fild.

Arg. a chev, vert betw. three pomeys on each a hind lodged of the first. William Tillessey, Burbam, co. Buckingham, $V$. ....Torteaux

Arg. a chev. az. betw. three torteaux. Andreu de Bascervile, $F$; or Baskervile, $E$. Baskervill, V.

Arg. a chev. gu. betw. three torteaux. Walter de Bascrevile, $B$. Baskervile, co. Gloucester; co. Hereford; and co. Hertford. Joan de Baskervile, $E ; F$. Beberbort, Cornwall. Bennett. Beverley, Cornwall. Blake. BouILE. Sr. Richard CAPEIL, V. Sir Richard de CaPele, N, Harl.MS.6137. CaPELL, co.Hereford. Sire Richard CAPELL or de CAPILL, $L$; or de Caple, $N$. Cromwell. Cruchley or Crutchley. Etclum, $V$. Glenham. Ribo. Richard Riboo, Newbiggyng, $P$; or Rxbo, $Y$. SHerard, Harl. $M S .6829$, fo, 49. Sherard or Glemham, $V$. Sherard, Baron Harborough 1714, Earl 1719 , extinct 1859, Baron Sherard 1627. Sherrard. Wipston or WIXton. De Wixton or Wrxton.

Arg. a chev. gu. betw. three torteaux a label of four points az. SHERRARD, co. Stafford.

Arg. a chev. sa. betw. three torteaux. BLAIR, Balthyock, co. Perth. Mertoon, That Ilk. And with a crescent for diff. BLaIR, Lethenty.

Arg. a chev. embattled sa. betw, three torteaux. BuAIR, Inchira.

Arg. a chev. invecked sa. betw. three torteaux. BlaIr, Overbury.

Arg. a chev. sa. betw. three torteaux within a bordure of the second. BLaIn, Balmill.

Arg. a chev. sa. betw. three torteaux each charged with an escallop of the first. Henry Dacres, Malfeld, co. Stafford; and London, $V$.

Alg. a chev. wavy sa. betw. three torteaux. BLAIR, France.

Arg. a chev. vert betw. three torteaux. Singleturne, Salisbury; and Isle of Wight.

Erm. a chev. sa. betw. three torteaux. Conselius.

Or a chev. az. betw. three torteaux within a bordure engr. vert. Claypoole or Cleypool.

Or a chev. gu. betw. three torteaux. BEANLEY or Beawley. Beurle, $V$. Beurley, $V^{*}$. Beverley, Cornwall, $V$. Bewelle. Bovile. Gleman Glemham or Glenham, Suffolk. Gremian, Suffolk, $V$. Henry Glemham, Bishop of St. Asaph I667-ro.

Or a chev. sa. betw, three torteanx each charged with an escallop arg. Dacres, Cheshunt, co. Hertford; and London.
1 CHEVRON betw, or within.....cont.

Ronndles cont. Bezants

Arg. a chev. az. betw. five bezants two and three. CODD or CODDE, Ireland, but? Az. the chev. arg.

Az. a chev. or betw. five bezants two and three. CuD, Ireland. And with a label of five points arg. Coov, Ireland.

$$
\text { .....0gresses }
$$

Arg. a chev, sa. betw. five ogresses. Coodd, Ireland, Lansdowne $M S .255$, fo. 27.

Or a chev. sa. betw. five ogresses two one and two. Codn. Codpe, Ireland, $V$.

$$
\text { .....Torteaux }
$$

Arg. a chev. gu. betw. five torteaux. ETcLuN. ....0gresses

Arg. a chev. .... betw. six ogresses three two and one. COD, Ireland.

$$
\text { .... Plates }
$$

Gu. a chev. arg. betw. six plates. Stormyn. .....Bezants

Gu. a chev, arg. betw. eight bezants. Zouch.

$\mathrm{Gu}$. a chev. erm. betw. nine bezants three two one two and one. Sir Oliver Zodch, co. Leicester, $V$. ZOUCHE, $V^{*}$. ..... Plates

Gu. a chev, arg. betw. nine plates. Dewe, Kent. .....Torteaux

Or a chev, gu. betw. nine torteaux. Bovrle. .....Bezants

Gu. a chev, arg. betw, ten bezants. Dees, Kent, $V$. Mounsyer John PopHaMr, quartering arg. on a chief gu. a bezant betw. two buck's heads cabossed or; $T$. Soणth. ZобсH.

Gu. a chev. erm. betw. ten bezants four two one two and one. SoutH. ZoठcH, co. Leicester.

Gu. a chev. or betw. ten bezants four two one two and one. ZoucH.

Gu. a chev. erm. betw, bezants, Sire Oliver la Soбche, $N$. Zouch.

Rowell see Mullet

Saddles

Az. a chev. betw. three manage saddles complete or. Company of SADDLers, London.

\section{Sails}

Az. a chev. or betw. three windmill sails crosswise arg. Minnes, Scotland.

Az. a chev. betw. three windmill sails crosswise or. Milnes, Ashford, Fryston Hall and Bawtry Hall, co. Derby, quartering Wilson, Poole, Pemberton, Busk, Rodes, and Rich; and Great Houghton, co. York. And with a mullet for diff. Minnes; Baronetcy 1801, extinct 1839.

\section{Saltires}

Arg. a chev. erm, betw, three saltires arg. GRENEWOOD, Harl. MS. 1404, fo. 125.

Arg. a chev. betw. three saltires gu. Acton, Acton, co. Warwick.

Arg. a chev. plain betw. three saltires engr. gu. Holt, Brereton, co. Chester. Holte, $V$. Houlte, Harl. MS. 1404, fo. 25.

Arg. a chev. gu. betw. three saltires engr. sa. Paternoster, co. Salop.

Arg. a chev. gu. betw. three saltires engr. sa. a bordure az. Paternoster, Harl. MS. 1404, fo. 125 .

Arg. a chev, betw, three saltires sa. NANTELEN. Az. a chev, betw. three saltires couped arg. Cromer, $V$.

Az. a chev. betw. three saltires or. Croner. Az. a chev, betw. three saltires engr. or. Crome. Or a chev, betw. three saltires gu. STAFFond, $V^{*}$. StafFord, Sydenham, co. Devon; granted by Borough. StafFord, Monkwearmouth, Durham. 
1 CHEVRON betw. or within.... cont.

Saltires cont.

Or a chev. betw. three saltires sa. Nanstalen.

Sa. a chev. erm. betw. three saltires arg. Greenwood, co. Derby ; co. York; Castleton, Greenwood, and Norton Bruin, co. Oxford; and Brookwood Park, co. Hants. Greenwood, Burgh Castle, Suffolk.

Scythes

Vert a chev. betw. three scytbes or. CopHonst. Shackles

Sa. a chev. betw. tbree shacklebolts arg. Anderton, Euxton, and Ince, co. Lancaster, quartering Ince; descended from ANDERToN, Anderton, co. Lancaster, Harl. MS. 1468, fo. $42 \mathrm{~b}$, and 96 . Ships

Az. a chev. betw. three sterns of ships arg. Duke, Suffolk.

\section{Spades}

Arg. a chev, betw. three balf spades sa. STANDElFe, $V$.

Sa. a chev. betw, three half spades arg. GARDENER, $V$. Standiffe.

Sa. a chev. betw. three spades arg. Gardner, co. Somerset.

\section{Spectacles}

Gu. a chev. betw. three pairs of spectacles arg. Stormyn. Sturmyn, V; and Harl. MS. 1386. Spears

Arg. a chev, betw. three salmon spears sa. Guinne, Cornwall.

Arg. a chev, betw. three spears sa. points az. MoRdant.

Az. a chev. erm. betw. three tilting spears or. SPEARHAN.

Az. a chev. erm. betw. three broken spears erect or headed arg. Spearman, Eachwick; derived like Spearman, Thornley, and Old Acres, Durham, the beiresses m. Fenwick, Wilkinson, Swinburne, and Bewicke; from Spearman, Preston. Spearman, Dunnington, co. Salop.

Gu. a chev. erm. betw. three half spears splintered or headed arg. Pennyaran, Ormsby, co. York Baronetcy 22 February 1663: and Marske, co York; Baronetcy 6 May 1628-43; extinct 22 August 1643.

Sa. a chev. betw. three (? heads of) eel-spears arg. Stratele or Stratley. Stretele. Spheres

Gu. a chev. erm. betw. in chief two mounds and in base a talbot pass. or. DAvIs, Bristol. Spindles

Arg. a chev. betw. three spindles of silk sa. DARDAS.

Arg. a chev. betw. three wharrow-spindles sa. Trefusis, Cornwall. Treyusis, Baron Clinton. Sprigs

Arg. a chev. vert betw. three bunches of ashenkeys ppr. Estwrey.

Arg. a chev. betw. three bunches of ashenkeys vert. AsHFord, Cornwall.

Vert a chev. betw. three keys or. ? RoHantred. Arg. a chev. ermines betw. three hazel sprigs vert. BIIDWIN.

Gu. a chev. betw. three sprigs of (mallow, $V^{*}$, but? nettle) leaves arg. MaLHerbe, $V$.

Arg. a chev. az. betw. three rose branches slipped gu. leaved vert. Coup, Essex; and co. Northampton.

Arg. a chev. countercompony gu. and of the first betw. three rosebranches slipped gu. leaved vert. Deacons, co. Bedford; co. Buckingham; and co. Warwick.
1 CHEVRON betw. or within.... cont.

Sprigs cont.

Arg. a chev. erm. betw. three oak branches ppr. Baldwin, co. Cork. The chev. ermines. BALDwin, Wilton, Beaconsfield, co. Buckingham. Az. a chev. erm. betw. three oak slips or. HawkINS, co. Devon.

Az. a chev. erm. betw. three oak slips within a bordure engr. (or sometimes) arg. AmIDAs, London.

Az. a chev. erm. betw. three oak branches each with three acorns and four leaves slipped or tied with a wreath (or fillet) within a bordure engr. of the last. Robert Amedas, London, $V$.

Az. a chev. erm. betw. three oak slips acorned ppr. Arrades, Plymouth, co. Devon. Amedas, 1730.

Az. a chev. betw. three palm branches or. ARNALD or ARNAULD.

Arg. a chev. sa. betw. three teazels slipped ppr. BowDEN.

Arg. a chev. sa. betw. three teazles stalked and leaved ppr. FulHam.

Spurs

Arg. a chev. gu. betw. in chief two spurs and in base a battleaxe az. shaft or. CONNELL or ConNely.

Arg. a chev. betw. three spurs az. Connel or CoNNELL, Ireland.

Squares

Arg. a chev. betw, three carpenter's squares points to the sinister gu. Sydal, alias DIGBY. Elias Sydal.L, Bishop of St. David's 1731, Gloucester 1731-33.

Arg. a chev. betw. three carpenter's squares sa. Aтноw, $V^{*}$. Atlow, 1730. Atlowe, Harl. MS. 1386 , fo. 95 ; and $V$, points dexter.

Per pale arg. and sa. a chev. betw. three mason's squares connterchanged. Mason.

Sa. a chev. betw. tbree carpenter's squares points to the dexter arg. ATHowe, Brysley, Norfolk. Staves

Arg. a cher. betw. three truncheons each held in a sinister hand couped at the wrist or. STEVENSON.

Arg. a chev. erminois betw. three flag-staves ppr. HAWKE.

Arg. a chev. gu. betw. three crosiers .... THOMPSON-COLLEGE.

Arg. a chev, betw, three measuring yards gu. INEREIS INREYS Or INRYS.

Arg. a chev. betw. three pilgrim's staves each supporting a pouch (or palmer's scrip) sa. garnished or. TASBOROUGH or TASBROUGH, Southelmam, Suffolk.

Arg. a chev. betw. three measuring yards sa. $Y_{\text {ARD. }}$

Arg. a cher. vert betw. three palmer's staves and scrips sa. garnished (gu. another) or. Palmer, Castle Lackin, co. Mayo; Kenure Park, co. Dublin, etc. ; Baronetcy 1777.

Az. a chev. betw. three quarter staffs arg. LONGSTAFF.

Az. a chev, erm. betw. three batons (another billets) or. James Usher or Ussher, Bishop of Meath 1621, Archbishop of Armagh 1625, Bishop of Carlisle 1641-55. The chev. or. Usher, Dublin, Harl. MS. 1425, fo. 220.

Gu. a chev. betw. three measuring yards arg. YARD or YEARDS, Kent; and co. Stafford.

Gu. a chev, betw. three cross staves (another, hammers) or. Soame.

Gu. a chev. betw. three yards erect or. YARD, Yard, co. Devon. Yard or Yeakds. 
1 CHEVRON betw, or within....cont.

Stares cont.

Gu. a chev. betw. three pastoral staves or. Abbey of Premonstratensian Canons at Torne, co. Devon, Ashmol. MS. 763.

Or a chev, erm. betw, three batons palewise az. James Usher, Bishop of Meath 1621, Archbishop of Armagh 1625, Bishop of Carlisle 1641-55.

Or a chev. betw. three batons (or billets) erm. USHER.

\section{Stirrups}

Arg. a chev. betw. three stirrups pendent on as many palmer's staves sa. TASBonovgE TASBRough, Southelmam, Suffolk.

Az. a chev. betw. three stirrups with leathers or within a bordure engr. arg. charged with eight torteaux. GIFrond, Barony 30 January 1824.

Gu. a chev. betw. three stirrups leatbered or. SkIDDY, Ireland.

\section{Stones}

Arg. a chev. betw. three flagstones sa. Company of PAVIoURS, Loudon.

Arg. a chev. (? sa.) betw. three (? stones) of the first each beld in a dexter hand sa. Stevenson, $V$.

Az. a chev. betw. three rocks (another chessrooks) arg. SPURRock.

Or a chev. quarterly az. and gu. betw. three flintstones of the last. Stone, Lechlade, co. Gloucester.

Or a chev. quarterly az. and purp. betw. three flintstones of the second. STONe, co. Gloucester, Harl. MS. 1386 , fo. 96 .

Sa. a chev. engr. betw. three flintstones arg. STONE, $V$.

Vert a chev. betw. three flintstones arg. FuInt, Scotland.

\section{Stonebills see Nails \\ Suns}

Arg. a chev. betw. three suns gu. Ranson.

Az. a chev. engr. erm. betw. three suns in splendour ppr. ALDERson.

Az. a chev. betw. three suns or. Hissos, co. Devon; and co. Gloucester.

Az. a chev. betw. three suns or within a bordure erm. Henson or Hinson afterwards PowelL, Fulham, Middlesex ; and Pengethley, co. Hereford; Baronetcy 1661-81; the heiress m. Williams.

Sa. a chev. betw. three suns arg. WaLthair, Keene, co. Devon. Sr. John Waltham, $V$.

Sa. a chev. or betw. three suns in splendour. John de WaLtham, Bishop of Salisbury 1388-95.

Sa. a chev. engr. betw. three suns in splendour arg. WALTHANI.

\section{Sword}

Az, a chev, or betw. in chief a flaming sword fesswise ppr. hilt and pomel gold and in base a castle arg. masoned sa, portcullis gu. M'KindLay.

Per pale arg. and gu. a chev. betw. in the dexter chief a dagger in bend transfixing a heart with in the sinister a lion's face discharging water and in base a crescent counterchanged. DUDGEON, Leith.

\section{Swords}

Az. a chev. or betw. in chief two swords blades wavy palewise and in base a castle arg. Mackennal, Cloverbank; and Merk.

Arg. a cher. betw. three dirks az. hilted or with those in chief pointing downward. GLASHAN, Scotland.
1 CHEVRON betw, or within.... cont. Swords cont.

Arg. a chev. gu. betw. three dirks palewise az. hilted and pomelled or. M'Glashan, Scotland. Arg. a chev. betw. three swords point downwards each supporting a purse (or pouch) sa. the pomels and tassels or. TASBorough, Suffolk.

Az. a chev. betw. three daggers bludes wavy pointing downward arg. Cleather, St. Cleather, Cornwall.

Az. a chev. betw. three daggers the blades ppr. pomel gold each passing through a griffin's head couped or. BAwDEN.

Gu. a chev. arg. betw. three daggers palewise of the second hilted and pomelled gold each passing through a wolf's heed or. Skene, Fintray, Scotland.

Gu. a chev, arg. betw, three daggers .... each transfixing a heart of the second. Newle.

Gu. a chev. betw. three swords in bend sinister ppr. hilt and pomel in chief or each passing tbrough a heart arg. Newte.

Gu. a chev. chequy or and az. betw. three swords palewise arg. hilts and pomels or. Kinnoss, Scotland.

Sa. a chev. or betw. three swords erect arg. Balliawle, $V$.

Sa. a chev, or betw, three swords erect arg. hilted gold. BeLLEWELL.

\section{Tails}

Arg. a chev. gu. betw. three beaver's toils erect ppr. Lewes, Fossendon-in-Bleane, Kent.

Arg. a chev. gu. betw. three ermine spots sa. Jerard, Samford, co. Somerset; seal 9 Henry V; Visitation, Somerset, Harl. MS. 1385. JERARD or JERRARD.

Arg. a chev. gu. betw. three ermine spots. Potter, co. Chester.

Arg. a chev, betw. three ermine spots sa. BAnT, Cornwall.

\section{Teasel see Sprig}

Tents

Arg. a chev. betw. three royal tents sa. Tinten, St. Tudy, Cornwall.

Az, a chev. betw. three tents arg. Maybank.

Sa. a chev. betw, three tents arg. Tenton, $V$, and Harl. MS. 1386, fo. 94. Tenton, Norfolk, 1716. Tops

.... a chev. .... betw, three pegtops .... TopclyfF, in church at Topcliffe, co. York, 1391 . Trees, etc.

Az. a cher. or betw. two scrogs in chief and a man's heart in base arg. Scroggie or Scrogie. Or a chev, az, betw. two scrogs $(i$. $e$. branches without leaves) in chicf and a man's heart in base ppr. Scrogie, Scotland.

Arg. a chev. betw. three stocks raguly gu. TrEVENNARD.

Arg. a chev. engr. gu. betw. three stumps of trees eradicated and erased ppr. Grove, Shenston Park, co. Stafford; quartering arg. on a chev. betw. three mullets gu. as many estoiles or.

Gu. a chev, betw, three stumps of trees or. Skewis, Cury, Cornwall; the heiress m. Denzell. Or a chev. engr. betw. three stocks of trees eradicated sa. Rutrer, Exeter, co. Devon.

Arg. a chev. gu. betw. three willow trees ppr. Willis, Dean of Worcester, ob, 1596.

Arg. a chev. gu. betw. three trees ppr. fructed of the second. RoDIcr, Gateacre and Woodclose, co. Westmoreland. The trees called rodey (or rowan) i.e. mountain-ash. RodIE, Liverpool, quarteling arg. three escallops gu. 
1 CHEVRON betw. or within.....cont.

Trees, etc. cont.

Arg. a chev. gu. betw, three oak trees eradicated vert. SPотswood, That Ilk.

Arg, a chev. pean betw. three hollen brushes fructed ppr. Bushnan, London; and Stratford, Essex; granted 13 November 1784 ; quartering Hills and Lloyd.

Arg. a chev. sa. betw, three hawthorn trees ppr. Thornton, Some, co. Cambridge; Windham, Norfolk; and co. York.

Arg. a chev. betw. three trees rert. DarrocH.

Az. a chev. arg. betw. three trees eradicated or. Sr. John Trewyn, $V$.

Az. a chev. betw. three oak trees or. Mosuan, Auchtefardell, Scotland.

Az. a chev. betw. three trees eradicated or. TREWYn, $V^{*}$.

Gu. a chev. betw. three pine trees eradicated or. Pyne, $V^{*}$.

Sa. a chev, betw, three hawthorn trees arg. Trefrery, Treffry, and Place, Cornwall; quartering Boniface; a heiress $\mathrm{m}$. Trefusis. TrefFry, Rooke, St. Kew; the beiresses m. Toller and Austen.

Tressure

Arg. a chev. within a double tressure flory counterflory gu. Fleming, New Court, Skibbereen, Ireland. Fleding, Brompton Park, Middlesex.

Gu. a chev. within a double tressure flory counterflory arg. Flemaing, Scotland.

Gu. a chev. embattled within a double tressure flory counterflory arg. FleEMiNG, Fern, Scotland.

Or a chev. within a double tressure counterflory gu. Fleeming.

Trivets

Arg. a chev. gu. betw. three trivets az. BaskerviL.. Arg. a chev. betw. three trivets sa. Trivetr.

Tubs or Tuns

Arg. a chev, betw. three tuns gu. Butron, co. Glamorgan.

Arg. a chev. gu. betw. three (tuns or) barrels standing on their bottoms sa. hooped or. Norton, $V$.

Arg. a chev. betw. three barrels sa. Company of VINTNERS, 1716.

Arg. a chev. betw. three tuns sa. fire issuing from the bungholes ppr. INELEDON or INKLETON, Buckland, co. Devon. INkELDON and INELEDON.

Arg. a chev. engr. betw. three tuns sa. fire issuing from the bungboles ppr. INCLEDEN or INGLETON. INCLEDON, Incledon in Braunton, co. Devon; the heiress m. Webber. Incledon, Yeotown House, in Goodleigh, co. Devon.

Arg. a chev, betw. three tuns sa. hooped or. Norton.

Az. a chev. betw. three tubs (half-tuns) or. John SAINT-ALBon, $V$.

Sa. a chev. betw. three tuns arg. Fпrotr. Pнillot.

Sa. a chev, betw. three (barrels or) tuns arg. Company of Vintners, London, Cotton MS. Tiberius D 10.

\section{Wedges see Nails \\ Weel see Basket \\ Wells}

Arg. a chev. betw. three wells gu. Christie.

Arg. a chev. sa. betw. three round wells gu. Cristy, $V^{*}$. Crysty, $V$.

Arg. a chev. betw. three wells sa. Christre. Chrystie. Cristy.
1 CHEVRON betw, or within.....cont.

Wells cont.

Gu. a chev. betw. three round wells arg. TIPPER, Tippers, co. Kildare, Harl. MS. 1441.

\section{Wheels}

Arg. a chev. betw. three catharine wheels gu. Wiard, Wiard, Norfolk.

Arg. a chev. sa. betw. three catharine wheels gu. William Sinte, Bishop of Lichfield (1491, Lin. coln 1496-1514), $W$.

Arg. a chev. betw. three catharine wheels sa. Fablye. Faslake, $V$. Wheelock, Wheelock, co. Chester.

Arg. a chev. betw. three cartwheels vert. CARTER, London; granted 16]2.

Az. a chev. erm. betw. three catharine wheels arg. AsElOCKE or AsLake, Suffolk.

Gu. a chev. betw. three catharine wheels arg. StORMEY.

Gu. a chev. erm. betw, three catharine wheels or. Hastake.

Sa. a chev. erm. betw. three catbarine wheels arg. Aslack Aslake or Asloke, Holme, Norfolk. AsHLock, as quartered by Bennett. Asrake, Norfolk, $V$. Asselock. Hasiack. Laney, Pulham. Sa. a chev. or betw. three catharine wheels arg. HASLACK.

Sa. a chev. betw. three catharine wheels or. Charles Dodgson or Dodson, Bishop of Ossory 1765, Elphin 1775-95.

Sa. a chev. engr. betw. four catharine wheels three in chief and one in base arg. CARTwright, Brimley House, West Teignmouth, co. Devon ; granted ....

Wings

Arg. a chev, betw, three sinister wings gu. AMSDEN or AJISDON.

Gu. a chev. betw. three wings or. MicheLL.

Sa. a chev, erm. betw. three wings arg. Sr. Thomas Nanfant, $V$.

Sa. a chev, erm. betw, three dexter wings arg. NanpHan, Bruch Norton, co. Worcester. Nanfan or Nanphan. The wings displ. Nanfan, Nanfan, Cornwall. Nanfan, Trethewell, St. Evall, Cornwall ; the heiress m. Trenowith.

Sa. a chev. erm. betw. three wings or. NANFant. Az. a chev. betw. three pairs of wings conjoined and endorsed or. Reve.

$\mathrm{Gu}$. a chev, betw. three pair of wings in lure or. EAST.

\section{Woolpacks see Packs}

Wreaths

Arg. a chev. az. betw. three chaplets gu. HoLme, Huntington, co. York.

Arg. a chev. erm. fimbriated sa. betw. three chap. lets of flowers gu. Bonowe.

Arg. a chev. gu. betw. three chaplets az. BRUdENELI.

Arg. a chev. betw. three chaplets gu. Asmeton, Hampton Court. AsHeton or Ashton, (Crofton, co. Lancaster) and Askyton, co. Lancaster. Asheton, Crofton, co. Lancaster, Cotton MS. Tiberius D 10. Ashton, $V^{*}$, and co. Lancaster, $W$. Arg. a chev. sa. betw. three chaplets gu. AsHeton or Ashton (Crofton, co. Lancaster) and AskYTon, co. Lancaster.

Arg. a chev. betw, three chaplets sa. Croxford. Fitz-Water, co. York. Lakenlich or LAKINGLEECH.

Arg. a chev. sa. voided erm. betw. three chaplets gu. BorovgH.

Arg. a chev. betw. three wreathed chaplets sa. Sir Richard de Hoo, Kent, $V$. 
1 CHEVRON betw, or within.... cont.

Wreaths cont.

Arg. a chev. sa. betw. three chaplets of the second flowered gu. LACKINGBICH, $V^{*}$. LAKINLICH, $V^{*}$. LAKXNGLICHE, $V$.

Az. a cher. arg. betw. three chaplets or. Hawl, co. Devon, $\boldsymbol{W}$. Hull, co. Devon.

Az. a chev. erm. betw. three chaplets or. Clotworthy, Ireland. Clotworthy, Clot. worthy, co. Devon. HaIr, $V^{*}$; and co. Somerset. HALLE, $V$, co. Somerset, $W$.

Gu. a chev. betw. three wreathed chaplets tied arg. Maynes, $V$.

Per chev. arg. and az. a chev. betw. three chaplets counterchanged. YARBOROUGH, co. York, 1716.

Per pale arg. and az. a chev. betw. three chaplets counterchanged. YARBORougH, Heslington Hall, co. York; quartering Hesketh; descended from Yarborovah or Yerburgh, Yarborough, and Wilmsby, co. Lincoln. YarbURGH, $V$. And with a crescent .... Y YRBorougH, North Carlton, co. Lincoln.

Sa. a chev. betw. three chaplets arg. BuckLe, Burgh, Westmoreland; and Nork House, Surrey. Sir Cuthbert BuckLe, Lord Mayor of London, 1579 ; granted by Cooke, $W$. BuckLE, New Hall, co. Haddington; and Rogate Lodge, Sussex. Mallet, co. Buckingham.

Sa. a chev. arg. betw. three chaplets or. HaLL, Bassam, Norfolk; and co. Oxford, $W$.

Sa. a chev. arg. betw. three wreathed chaplets twisted and tied az. and of the second. Burr, $V$.

Sa. a chev. erm. betw. three chaplets or. CLOTwORTHY; quartered by Skeffington.

\section{Yards see Staves}

\section{CHEVRON betw, or within....}

and in chief....

\section{Banner}

Arg. a chev. embattled az. betw. three suns gu. in chief a banner of the second charged with on a canton as the first a cross like the third. EwING. (Beast) Dog

Arg. a chev. or betw. three martlets and in chief a talbot pass. sa. 'ГАLBOT.

$$
\text { ..... Lion }
$$

$\mathrm{Gu}$. a chev. betw. three crosses botonny and in chief a lion pass. guard. arg. MABLETHORPE.

Az. a chev. betw. three crosses croslet arg. in chief a lion pass. or. Mablethorpe.

Az. a chev. arg. betw. three crosses croslet and in chief a lion pass. or. Thetoft,Boston, co.Lincoln.

Gu. a chev. betw. three crosses croslet or in chief a lion pass. arg. Wyrrall, Barnwood, Bicknor, and Wirrall, co. Gloucester.

Gu. a chev. betw. three crosses croslet and in chief a lion pass. or. HONDON, Lincoln.

\section{Canton}

Arg. a chev. betw. three bulls pass. and a canton sa. Sutron.

Arg. a chev. betw. three cormorants sa. a canton gu. William Warburton, Bishop of Glouces. ter 1760-79.

Arg. a chev. gu. betw. three (ravens, $V^{*}$ ) berons sa. a canton barry of eight or and az. TreHeron, $V$.

Arg. a chev. pean betw. a chief indented and a lion ramp. sa. a canton erm. Davis, Leytonstone, Essex.

Arg. a chev. betw. three.crescents gu. a cantou az. Pore, Park Hall, in Barlborough; descended through Pose, Wakebridge, co. Derby; the heiress m. Morphy ; from Pole, Radbourn.
1 CHEVRON betw. or within....

and in chief..... cont.

Canton cont.

Arg. a chev. betw. three crescents and a canton gu. Poue, Heage, co. Derby.

Gu. a chev. or betw. three crescents arg. a canton of the last within a bordure erm. Cooke.

Arg. a chev. betw. three crosses croslet fitchy s8. a canton az. DavenPort, Bramall Hall, co. Chester.

Sa. a chev. betw. three dolphins embowed arg. a canton erm. Fryer, London; granted 10 April 1572. The dolphins naiant. Fryer, Lord Mayor of London 1721.

Sa. a chev. arg. betw. three dolphins embowed or a canton erm. FrIER, St. Martin's, co. Stamford ; and Baron, co. Lincoln.

Az. a chev. betw. three fleurs-de-lis and a canton or. HIL, Kilmarnock, co. Limerick ; and Doneraile, co. Cork. HILL alias Hur., Littlepipe, (of the Pipe, $W$, ) co. Stafford; granted 1560.

Arg. a chev. sa. betw. three torteaux a canton or. BuaIR, quartering Stopford.

Az. a chev. betw. three broken spears or a canton erm. STAFFord.

on a Canton .... Anchor

Arg. a chev. engr. gu. betw. three eagle's heads erased sa. on a canton az. an anchor or. Cocke, co. Lancaster; and Cornwall.

Arg. a chev, engr. betw. three eagle's heads erased sa. on a canton az. an anchor or on the chev. a crescent for diff. Cock, Plymouth, co. Devon.

Arg. a chev. engr. betw. three griffin's beads erased gu. on a canton az. an anchor or. Cocke, Plymouth.

\section{..... (Beast) Lion}

Arg. a chev. sa. betw. three choughs ppr. on a canton barry of six arg. and az. a lion ramp. gu. Traherne, Saint Hilary, Codriglan, and Coytrehen, co. Glamorgan.

Gu. a chev. erm. betw. three pelicans vulning themselves ppr. on a canton .... a lion sejant .... and in chief a label of three points .... Meadows Medewe or Medows, Witnesham Hall, and Great Bealings, Suffolk; quartering Brewster.

Arg. a chev. gu. betw. three storks sa. on a canton barry of seven or and az. a lion ramp. of the third. Traherne or Treheron, Cornwall.

Az. a chev. betw. three herons or on a canton barry of seven as the second and gu. a lion ramp. like the third. John TrEHEARNE, 1618, in St. Saviour's Church, Southwark.

Az. a chev. betw. three lozenges or on a canton gu. a lion ramp. betw. two crosses croslet fitchy of the second. HYDE.

\section{..... Lions}

Az, a chev, betw. three owls or on a canton gu. as many lions pass. guard. in pale of the second. DEsse. The chev. engr. DEss.

Per fess or and az. a chev. gu. betw. three mullets counterchanged on a canton of the third three lions pass. guard. in pale as the first. LANE, Hyde, Bentley, and King's Bromley, co. Stafford; with more than thirty quarterings.

$$
\text { ..... (Bird) Dove }
$$

Arg. a chev. betw. three crescents sa. on a canton of the second a dove with an olive branch ppr. WALKER, co. Leicester; Loudon; \& co. Warwick. Az. a chev. or betw. three sceptres lying bendwise on the dexter side of the escucheon in pale on a canton arg. a dove with an olive branch in its beak ppr. 'TIPPING. 
1 CHEVRON betw, or within.... and in chief.... cont.

on a.Canton cont. (Bird) Martlet

Arg. a chev. betw. three pilgrim's staves with scrips hanging to them sa. garnished or on a canton of the second a martlet as the last. TasBurgh, Bodney, Nortolk.

$$
\text { ....Cross }
$$

Per fess gu. and sa. a chev. rompu betw. three griffin's heads erased erm. on a canton arg. a cross potent betw. four crosses patty or. ALLYN.

$$
\text { .....Escucheon }
$$

Az. (another sa.) a chev. erm. betw. three pelicans with wings endorsed or vulned ppr. on a canton of the third an escucheon gu. charged with a lion pass. guard. or. Meadows.

$$
\text { ....Fleur-de-lis }
$$

Arg. a chev. gu. betw. three pinecones vert on a canton az. a fleur-de-lis or. Peppereld, London.

Arg. a chev. gu. betw. three pine cones vert on a canton of the second a fleur-de-lis of the first. Peperelu, Boston, Massachusetts, New Eng. land; Baronetcy 1746, extinct 1759; the heiress m. Sparhawk afterwards PePPERELL, Baronetcy 1774 , extinct 1816; the heiresses m. Hutton, Congreve, and Palmer.

$$
\text { .... Fleurs-de-lis }
$$

Gu. a chev. betw. three laurel leaves er ect arg. on a canton per bend sinister vert and az. as many fleurs-de-lis or within an orle of eight bezants. Fisher or Fletcher, co. Lancaster; London; and Woodstock, co. Oxford; granted 26 April 1613.

\section{.....Flowers}

Gu. a chev. betw. three lion's beads erased arg. on a canton or a rose of the first barbed and seeded as the second. Bispram, co. Lancaster. .....Fret

Arg. a chev. betw. three garbs sa. on a canton az. a fret or. Blake, Twisel Castle, Durham; Baronetcy 1774, quartering Blake and Ayton.

$$
\text { ....Harp }
$$

Az. a chev. erm. betw. three lions ramp. or armed and langued gu. on a canton vert a harp of the third stringed arg. Chinnery, Flintfield, Ireland; Baronetcy 1779.

$$
\text { ....Heads (Deer) }
$$

$\mathrm{Gu}$. a chev. betw. three crosses patty arg. on a canton erm. a buck's head erased sa. STRICKLAND.

Gu. a chev. or betw. three crosses patty arg. on a canton erm. a buck's head erased and attired sa. Strickland, Boynton, co. York; Baronetcy 30 July 1641 .

Gu. a chev. or betw. three crosses patty arg. on a canton erm. a stag's head couped ppr. STRICKTAND.

$$
\text { .... Hive }
$$

Arg. a chev. sa. betw. three mullets pierced gu. on a canton az. a beehive or. HANSARD, London. ....Pales

Arg. a chev. betw. three hinds trippant sa. on a canton or two pales gu. InNYNOE.

$$
\text { ..... Saltire }
$$

Arg. a chev. betw. three leopard's faces sa. on a canton or (another, per sultire or and arg.) a saltire vert betw. a cross croslet in chief gu. a lizard (another, a newt) erect in the dexter with a salmon naiant (another, hauriant) in the sinister fess point of the fourth and a dexter hand couped erect in base gu. CosBy, Hermaston, co. Lincoln; and Stradbally Hall, Queen's County, Ireland; quartering Sidney. CoSBY, Baron Sydney 1768, extinct 1773.
1 CHEVRON betw. or within....

and in chief....cont.

on a Canton cont. Saltire cont.

Per chief az. and arg. a chev. wavy gu. betw. in chief a thunderbolt enclosed by two mullets or and in base a seahorse in sea ppr. supporting a flag of the third upon the chief a canton gold charged with a saltire engr. sa. betw. four crosses patty of the second. Trompson, Virhees, Sussex; Baronetcy 23 July 1797.

\section{Cantons}

Quarterly arg. and gu. (another gu. and arg.) a chev. counterchanged witbin a bordure silver in chief two cantons counterchanged and over all an escucheon as the bordure. LONDON or LONDONS.

Quarterly or and az. two piles meeting in the centre point from the base (sometimes called a chev.) counterchanged in chief two cantons over all an escucheon arg. within a bordure of the last. LONDONS, $V$.

\section{Castles}

Arg. a chev. engr. betw. three martlets and in chief three towers triple-towered sa. WeBBER; Collinson, Somerset, iii, 20, in crror.

Chief

Arg. a chev. betw. three annulets and a chief sa. Nurse.

Arg. a chev. betw. three lions ramp. gu. a chief erm. Bonne, London; and co. Berks.

Arg. a chev. gu. betw. three lions ramp. sa. a chief erm. Borne. John Bourne, co. Worcester, $W$.

Arg. a chev. gu. betw. three lions ramp. sa. langued and armed of the second a chief erm. Gilbert Bounne, Bishop of Bath, etc. 1554-69; confirmed 1591.

Arg. a cher. gu. betw. three lions ramp. sa. a chief ermines. Bourne, Wells, co. Somerset.

Gu. a chev. betw. three lambs pass. arg. a chief chequy or and az. LAMBERT, co. Buckingham; and Owton, co. York. The lambs statant. Lambert, Skipton, in Craven, co. York, $V$.

Gu. a cher. or betw. three lambs pass. arg. a chief chequy of the second and az. Lambert.

Gu. a chev. betw. three seapies arg. a chief erm. Sayer or Sayre, Worsall, co. York.

Gu. a chev. betw. three seamews arg. a chief erm. Sare or Seers, Kent. Sawyer, in St. Sepulchre's Church, London.

Gu. a chev. arg. betw. three seamews or a chief erm. Sares, Kent.

Arg. a chev. betw. three martlets sa. a chief engr. vert. BrickLeY.

Arg, a chev. sa. within a bordure erm. over all a chief dancetty sa. Thonton, co. Chester, Harl. MS. 1535, fo. 28.

Gu. a chev. betw. two couplecloses arg. enclosed by three bees volant or a chief of the last. WestmacotT.

Arg. a chev. betw. three escallops gu. a chief chequy az. and or. Fitz-Andrew.

Or a chev. betw. three escallops gu. a chief chequy az. and gold. Fitz-ANDREW, $V$.

Sa. a cher. betw, three escallops arg. a chief or. LINACRE.

Sa. a chev. betw. three dolphins naiant embowed arg. a chief or. CoBB, Adderbury, co. Oxford; and Sandringham, Norfolk; quartering Floyd and Langton; Baronetcy 1662, extinct 1762 ; the coheir m. Methuen. COBB, Collinson, Somerset, ii, 344. 
1 CHEVRON betw, or within.... and in chief.... cont.

Chief cont.

Sa. a chev. arg. betw. three dolphins naiant embowed or a chief of the last. COBB, Adderbury, co. Oxford; Baronetcy 1662, extinct 1762 ; the heiress m. Methuen; descended from Cовв, Sandringham, Norfolk.

Arg. a chev. sa. betw. three roses and a chief or. MAY.

Or a chev, betw, three roses and a chief sa. HAYLIS, $V^{*}$.

Or a chev. sa. betw. three roses gu. a chief of the second. Sr. .... de HAYLIS, $V$.

Sa. a shev. betw. three roses arg. a chief or. Mayo, Middlesex.

Vert a chev. betw. three roses arg. a chief in. dented erm. MAY.

Arg. a chev. betw. three thistles leaved vert a cliief az. ENNis, Ireland.

Arg. a cher. betw. three 3-foils and a chief sa. Moodie, England.

Arg. a chev. betw. three fusils ermines a chief gu. SHaw, Bristol ; confirmed 1602.

Per pale gu. and az. a chev. betw. three boar's heads couped or a chief arg. Garstyde, co. York.

Sa, a chev. betw. three elephant's beads erased arg. a chief or. Sandens, Uxbridge, Middlesex. The chief embattled or. Sanders, Maid. stone, Kent.

Gu. a chev, betw. three leopard's heads or a chief erm. John BANGoR; granted 1457, W.

Arg. a chev. sa. betw. three lion's beads erased ppr. a chief gu. Vivian, $V^{*}$.

Gu. a chev. erm. betw. three lion's heads erased or a chief per fess wavy az. and gold. Fox.

Gu. a cher. betw. three lion's heads erased or a chief arg. Fox.

Sa. a chev. betw. three lion's beads erased arg. a chief or. Peers, Chislehampton Lodge, co. Oxford; quartering Knapp. PeErs, Lord Mayor of London I716.

Sa. a chev, erm. betw. three lion's heads erased arg. a chief or. Peeres.

Gu. a chev. vair betw. three bull's heads erased arg. a chief or. SANDON, co. Lincoln.

Vert a chev. betw. three wolf's heads erased arg. a chief erm. Henry Rowlands, Bishop of Bangor, 1598-I616.

Arg. a chev. engr. betw. three griffin's heads erased and a chief az. WALDEN.

Az. a chev. betw. three griffin's heads erased and a chief or. Jennings, Ipsley, co. Warwick. JENNINGS, Lancaster Herald, I485-1526.

Gu. a cher, betw. three griffin's hearls erased arg. a chief embattled or. Gardiner, co. Berks; and co. Buckingham.

Arg. a chev. betw. three horseshoes sa. a chief gu LocksMith.

Arg. a chev, ermines betw. three inkmolines sa. a chief of the second. KingsiLL, co. Warwick.

Arg. crusily botonny fitchy sa. a chev. ermines betw. three inkmolines and a chief of the second. KINGSMHL.

Arg. crusily fitcby sa. a chev. erm. betw. three inkmolines of the second a chief as the third. Kingsmill, Aston, co. Gloucester; and Sidmanton, Hants; Baronetey 24 November 1800, extinct 18\%3. KingsirmL, Hermitage, co. Dublin; quartering Kingsmill.

Arg. crusily fitchy sa. a chev. ermines betw. three inkmolines of the second a chief erm. KiNgsmill, Hants.
1 CHEVRON betw, or within....

and in chief..... cont.

Chief cont.

Or a chev. (? erm.) betw. three inkmolines and ten croslets fitchy sa. a chief ermines. Sr. Wil. liam Kingesmyll, Hants, $V$. Kyngsmill, $V^{*}$.

Arg, a chev. sa. betw. three laurel leaves vert a chief of the second. ShaberY or Shauberie, London.

Or a chev. sa. betw. three (? hazel) leaves vert a chief of the second. Owesie, $V$. But holly leaves. Ouselex, Claramount, and Woolmers, co. Hertford; Baronetcy 3 October 1808. But oak leaves. Owesle, $V^{*}$.

Or a chev. betw. three holly leaves vert a chief sa. Ouseler, Courteen Hall, co. Nortbampton; derived from Shropshire.

Gu. a chev. betw. three lion's gambs erased erect arg. a chief and bordure of the second. Browne, Essex, Harl. MS. 1404, fo. 120.

Or a chev. sa. betw. three mascles gu. a chief arg. MegGs, Kent.

Sa. a chev, betw. three griffins segreant and a chief or. Syrth, London, 1588.

Arg. a chev. betw. three mullets gu. a chief az. GaMAGE. (? BETAGHF, Ireland.)

Gu. a chev. vair betw. three bezants a chief indented or. Sybelles, Essex.

Arg. a chev, az. betw. three hurts a chief of the second. Hobson, Merington, Durbam ; confirmed $16 \mathrm{~J}$ anuary 1657 .

Arg. a chev, vert betw. in chief two spears of the last and in base on a mount a pear tree ppr. fructed or a chief erm. Purrier.

on a Chief..... Anchor

Arg. a chev. engr. betw. three griffin's heads az. on a chief of the last an anchor or betw. two bezants. Walikedend, Hadley, Middlesex.

$$
\text { ....Axe }
$$

Gu. a chev. betw. three wheels or on a chief arg. an axe fesswise ppr. Company of WheELWRights, London.

$$
\text { .....Baskets }
$$

Arg. a chev. az. betw. three lion's heads erased gu. on a chief sa. three baskets or. WITWANG, Northumberland.

$$
\text { .....(Beast) Dog }
$$

Arg. a chev. sa. betw. three cocks gu. on a chief az, a greyhonnd courant or. Abbey of Augustinian Canons at Missenden, co. Buckingham.

Or a chev. az. betw. three mascles gu. on a chief sa. a greyhound courant arg. MEGGs, Bradford Peverel, co. Dorset. The chev. engr. William MEGGs, London; granted 4 June $1579, W$.

Gu. a chev. or betw. three bezants on a chief in. dented of the second a greybound in full course sa. SIBEsDen, Essex.

Gu. a chev, vair betw. three bezants a chief in. dented or charged with a greyhound in full course sa. SELESDON.

$\mathrm{Gu}$. a chev, vair betw. three bezants on a chief or a talbot courant sa. SELESDON or SILLESDEN, Finchley, Middlesex.

Gu. a chev, vair betw. three bezants on a chief engr. or a talbot courant sa. SILLESDEN, $V^{*}$. Thomas Silisdon, Finchiugfeld, Essex, $V$. Gu. a chev. vair betw. three bezants on a chief engr. or a talbot pass, sa. Silyden, Essex.

Gu. a chev, vair betw. three ogresses on a chief dancetty or a greyhound courant sa. EGLESDEN, Essex, Harl. MS. 1404, fo. 110. 
1 CHEVRON betw, or within.... and in chief.....cont.

on a Chief cont. (Beast) Fox

Arg. a chev. sa. betw. three cocks gu. on a chief az. a fox courant or. Fox, Missenden, co. Buckingbam.

\section{....Lion}

Gu. a chev, erm. betw. three plates each charged with a fleur-de-lis az. on a chief or a demilion naissant of the first betw. two anchors in pale as the third. Goghe, Ireland.

Sa. a chev. betw. six leopards or on a chief of the second a lion pass. gu. holding in the dexter paw a serpent. HonT, Ireland.

Gu. a chev. betw. three birds close arg. armed or on a chief of the last a lion pass. as the first. GoldsmitH.

Sa. a chev. engr. betw. three eagles displ. arg. on a chief or a lion pass. of the first. CARNUS.

Gu. a cher. betw. three goldfinches arg. on a chief or a lion pass. of the first. Gouldsmitr, Crayford, Kent.

Az. a chev. hetw. three croslets arg. on a chief gu. a lion pass. or. MABLETHORE. MABLETHORP, $V$.

Az. a chev. betw. three crosses croslet or on a chief arg. a lion pass. gu. Mapletoft, co. Lincoln.

Gu. a chev, betw, three crosses croslet or on a chief of the second a lion pass. as the first. Holden. Houdon or Howdon. The lion guard. HoNDON, co. Lincoln, $V$.

Arg. a chev. betw. three escallops az. on a chief of the second a lion pass. as the first. HINDE, Bishopwearmouth, Durham. HINDE, co. Lancaster.

Az. a chev. betw, three fleurs-de-lis or on a chief of the last a lion pass. guard. gu. Overman, Norfolk; and Southwark, Surrey.

Arg. a chev. betw. three roses gu. barbed vert seeded or on a chief of the second a lion pass. guard. betw. two bibles palewise or clasped and garnished of the last the clasps to the dexter. Trinitr Coilege, Cambridge.

Or a chev. engr. gu. betw. three 5-foils az. on a chief of the second a lion pass. arg. Cooke, Linstead, Suffolk.

Arg. a chev. betw. three stag's heads erased sa. and as augmentation on a chief wavy gu. a lion pass. guard. navally crowned or with the word Trafalgar over the lion of the last. Collingwood, Barony 1805, extinct 1810.

Az. a chev. betw. three griffin's heads erased arg. on a chief or a lion pass. gu. betw. two tor. teaux. Gennings. Jennyns, Middlesex; and Speachley, co. Worcester. The lion pass. guard. Jennyns, Lancaster Herald, 1485$1556, W$.

Az. a chev. or betw. three griffin's heads erased arg. on a chief or a lion pass. gu. betw. two annulets az. JENNINGS.

Gu. a chev. or betw. three griffin's heads erased arg. on a chief of the second a lion pass. as the first betw. two torteaux. GEDDing, $V^{*}$.

Sa. a chev, erm. betw, three inkmolines or on a chief arg. a lion pass. gu. Oliver. Torner, $V$. Oliver Turner, $V$. Turner, Wareham, and Yarmouth, Norfolk. The lion holding in the dexter foot a branch of laurel vert. Turnen or TURNOR, Halberton, co. Devon; and London.

Sa. a chev, erm. betw. three iukmolines or on a chief of the last a lion pass. gu. Turner, $V^{*}$.
1 CHEVRON betw. or within....

and in chief..... cont.

on a Chief cont. (Beast) Lion cont.

Or a chev. sa. betw. three holly leaves vert on a chief of the second a lion pass. guard. betw. three fleurs-de-lis arg. CoBBoLd, Ipswich.

Arg. a chev. betw. three lozenges or on a chief of the second a lion pass. erm. HINDE, co. Cambridge.

Gu. a chev. betw. three lozenges arg. on a chief of the first a lion pass. as the second. HYENDE.

Az. a chev. or betw. three mullets arg. on a chief gu. a lion pass. of the third. Montague. The lion pass. of the second. Montague.

Az. a chev. or betw. three mullets arg. on chief gu. a lion pass. guard. of the second. MoNTague. Bastian Montaguta, $V$.

Arg. a chev. gu. betw. three ogresses each charged with a talbot or on a chief az. a lion pass. enclosed by two crescents of the first. ALLEN, St. Dunstan's, co. Kildare. John ALEN ALLAN or ALLEN, Archbishop of Dublin 1528.35.

Arg. a chev. engr. sa. betw. three ogresses on a chief az. a lion pass. guard. or. Benolt, Calais, $V$.

Arg. a chev. sa. betw. three ogresses on a chief gu. a lion pass. or. EgHair or ENGHAM, Kent. The lion pass. guard. or. EDINGHAM or Engham, Goodneston, Kent. Engham, Great Chard, Kent, V. Engham, quartered by Nourse. The lion pass. reguard. HugHaM or Inghair. $\ldots .0 x$

Or a chev. betw. three pears vert on a chief erm. a bull pass. sa. COLE, Exeter, granted .... .....Squirrel

Sa. a chev. betw. three taus arg. on a chief of the second a squirrel cracking nuts gu. TAW, Middlesex.

$$
\text { .... Wolf }
$$

Or a chev. az. betw. three mascles gu. on a chief sa. a wolf courant arg. Thomas MEgGES, Darnam, co. Cambridge, $V$. MEgas, $V^{*}$.

Or a chev. betw. three mascles gu. on a chief of the second a wolf arg. MEGGs, Kent; and co. Cambridge.

Or a chev. betw. three mascles sa. on a chief of the second a wolf courant arg. MEGGES or Mygaes, $V$.

\section{.....(Beasts) Boars}

Sa. a cher. betw. three eagles displ. arg. on a chief .... three boars pass. .... Raymond, Collin. son, Somerset, iii, 222.

$$
\text { ....Dogs }
$$

Per pale az. and or a chev. betw. three buck's heads counterchanged on a chief gu. two hounds respectant arg. collared of the second. TAYLOR, Linfield, Surrey. TAYLOR, Walton-onTrent, co. Derby.

Per pale az. and or a cher. betw. three buck's heads cabossed counterchanged on a chief gu. two greyhounds (pass. $V^{*}$ ) statant respectant arg. collared of the second. TAYLOUR, Lingfeld, Surrey, $V$. TAYLoure, $V^{*}$.

$$
\text { ..... Lions }
$$

Arg. a chev. betw. three buglehorns sa. stringed gu. on a chief of the second so many lions ramp. as the first. Hinchman. The lions ramp. guard. HENCHMAN or HiNCHITAN, co. Northampton.

Or a chev. betw. three buglehorns stringed sa. on a chief gu. as many lions ramp. of the first. Humphrey Henchinan, Bishop of Salisbury 1660, Loudon 1663-75. 
1 CHEVRON betw, or within...

and in chief.....cont.

on a Chief cont. Bend

Sa. a chev. betw. three eagles displ. arg. on a chief of the last a bend engr. enclosed by two hirds (some say martlets) as the first. RayMoND, Essex, $W$.

$$
\text { ..... (Bird) Cock }
$$

Arg. a chev. gu. betw. three ogresses on a chief az. a cock enclosed by two crosses croslet fitchy of the first, Luke LongLand, $V$. The cock or. LONGLAND.

Arg. a chev. sa. betw. three torteaux on a chief az. a cock of the first enclosed by two crosses croslet fitchy or. Lucas, Fenton, co. Cam. bridge.

$$
\text { ..... Crow }
$$

Az. a chev. erm. betw, in chief two annulets and in base a bow fesswise arg. surmounted with a pair of arrows in saltire points downward or feathered as the third on a chief like the fourth a Cornish chough ppr. enclosed by a couple of crosses croslet fitchy gu. LuKIs, Guernsey.

Arg. a chev. chequy or and az. betw. three boar's heads erased sa. on a chief erminois a mount vert thereon a raven sa. a canton gu. charged with a sword or. RABAN.

$$
\text { .... Eagle }
$$

Vert a chev. betw. three bucks trippant or in the middle chief point a bezant on a chief per fess gu. and arg. an eagle displ. counterchanged. Pease, Hull, co. York.

Az. a chev. erminois betw. three hedgehogs or on a chief arg. the eagle of Prussia displ. sa. beaked legged and langued gu. on the breast the cypher F.R. and over it the electoral cap over its bead the same cap in the dexter claw a sceptre in the sinister a mound all or and on each wing a 3.foil arg. Harris, Barony 1788, ViscountFitzharris andEarl of Malmes bury 1800 .

Or a chev. betw. three books gu. clasped of the first on a chief of the second a dove descending from clouds arg. nimbed and radiated gold. John Best, Bishop of Carlisle 1561:70; granted by Dethicke.

Arg. a chev. betw. in chief two crescents and in base a mullet gu. on a chief az. an eagle displ. or. Mastenton, Grange, co. Perth.

$A z$. a chev, betw. three 5-foils or on a chief of the second an eagle displ. sa. ducally crowned as the last. Le Buanc, Middlesex; and Rouen, Normandy; granted 1753.

Gu. a chev. or betw. in chief two lion's gambs arg. and in base four hands conjoined of the second on a chief engr. gold an eagle displ. sa. Brown, Brandon, co. Warwick; and Richmond Hill, near Liverpool.

Gu. a chev. betw. three lion's gambs erect and erased arg. on a chief of the second an eagle displ. sa. armed and crowned or. Browne, Weald Hall, Essex. Browne, Adlington, quartered with Clayton; descended through Browne, Browne's Hill, co. Carlow, from Browne, Wickham.

Gu. a chev. betw. three lion's gambs erect and erased within a bordure arg. on a chief of the last an eagle displ. sa. Sir Humfrey Browne, Harl. MS. 1401, fo. 120. The eagle crowned or. Sir Wiston Browne, Essex, $V$. The bordure engr. Browne.

Gu. a chev. betw. three lion's gambs arg. on a chief of the last an eagle displ. sa. membered or all within a bordure az. Browne, Suffolk.
1 CHEVRON betw, or within.... and in chief.....cont.

on a Chief cont. (Bird) Eagle cont.

Arg. a chev. betw. three lozenges az. on a chief gu. an eagle displ. or. HmE, Albury, co. Hertford; the heiress $\mathrm{m}$. Osborne.

$$
\text { ....Pelican }
$$

Arg. a chev. betw. three fleur-de-lis az. on a chief of the last a pelican in her nest enclosed by two mullets as the first. Sterenson, Edin. burgh.

Arg. a chev, erm. betw, three pierced mullets sa. on a chief gu. a pelican vulning herself en. closed by two lion's gambs erased of the first. Gresham, Norfolk. The pelican close enclosed by two lion's legs erased or armed az. Sir Richard Greshadr, Lord Mayor of London 1537. The pelican vulning itself enclosed by two eagle's legs erased or. GREsham, London, Add. MS. 6193, fo. 7 .

Arg. a chev. ermines betw. three pierced mullets sa. on a chief gu. a pelican vulning herself enclosed by two lion's gambs erect erased or. Sr. Richard Gresham, Alderman of London, $V$. The pelican close enclosed by two lion's legs erased or armed az. Sir Richard GREshaM, Lord Mayor of I,ondon 1537; grant, 30 November 1537, in Aubrey, Surrey, v. 373. The pelican enclosed by two griffin's claws couped (another two hind's heads erased) or. Grestani, London.

$$
\text { ..... Moorcock }
$$

Arg. a chev. gu. betw. three ogresses on a chief az. a moorcock enclosed by two crosses croslet fitchy or. Lucss.

Erm. a chev. engr. gu. betw. three annulets sa. on a chief az. a moorcock enclosed by two crosses croslet or. Lucas, Hasland, co. Derby. ..... (Birds) Ducks

Gu. a chev. wavy betw. three cob-fishes naiant arg. on a chief of the last two shovellers sa. beaked and legged or. Совв, co. Bedford.

$$
\text { ..... Crows }
$$

Az. a chev. erm. betw, three arrows or barbed and feathered arg. on a chief of the last as many birds (daws) sa. a canton gu. charged with a mullet of the third. Dawson, Barony 1770, Viscount Carlow 1776, Earl of Portarlington 1785. The birds beaked and membered gu. Dawson, Coverham, co. York; confirmed 21 December 1858, quartered by Duffield. Dawson, $V^{*}$. But Cornish choughs ppr. Dawson, Spaldington, co. York; Wharton, co. Lancaster; and Chelmsford, Essex.

$$
\text { .... Ducks }
$$

Gu. a cher. wavy betw. three cob-fishes naiant arg. on a chief of the second as many shovellers sa. beaked and membered or. Совв, $V *$. Cosbe, co. Bedford, $W$.

\section{.....Herons}

Az. a chev. engr. betw. three salmons arg. on a chief gu. as many storks of the second ducally crowned or. Hibss, Tunbridge Wells, Kent.

Gu. a chev. engr, betw. three fishes naiant arg. on a chief of the second so many herons sa. beaked and membered as the first. HOBBS, Middlesex.

$$
\text { ..... Martlets }
$$

Az. a chev. erm. betw. three annulets arg. on a chief or as many martlets gu. CHater, Chasthall, co. York.

Az. a chev, erm. betw. three battle-ases or handles arg. on a chief of the last as many martlets gu. WRET. 
1 CHEVRON betw. or within....

and in chief.....cont.

on a Chief cont. (Birds) Martlets cont.

$\mathrm{Gu}$. a chev. or betw. three talbots pass. arg. on a chief embattled of the last as many martlets az. Burgoyne, co. Cambridge; Sutton, and Potton, co. Bedford; and Wroxall, and Handley, co. Warwick; Baronetcy 164l. Burgoyne, co. Bedford, $V$.

Per pale az. and or a chev. betw. three lozenges counterchanged on a chief gu. as many martlets of the second. Jordan, co. Wilts.

Per pale or and az. a chev. betw. three lozenges counterchanged on a chief gu, as many martlets arg. JoRDAN. JURDEN, $V$.

Az. a chev. engr. erm. betw. three scimetars that in base fesswise or on a chief of the last as many martlets sa. RAY.

Az. a chev. engr. erm. betw. three scimetars ppr. on a chief or as many martlets gu. RAY, Heanor Hall, co. Derby.

Sa. a chev. betw. three hilts of broken swords arg. on a chief embattled as the second as many martlets gu. LAWRENCE, $V$.

\section{..... Crows}

Az. a chev. erm. betw. three arrows or barbed and feathered arg. on a chief of the last four birds (? daws) sa. a canton gu. charged with a mullet as the third. Alexander Dawson, Spaldington, co. York; granted $1563, W$.

$$
\text { .... Book }
$$

Arg. a chev. az. betw. three plieons gu. on a chief of the second an open Holy Bible ppr. edged and sealed or inscribed "Proverbs, chap. xxii, v. 6 " enclosed by two crosses flory of the last. JoHNSON

\section{Bowls}

Arg, a chev, az. betw. three lion's gambs erect erased the two uppermost turned to each other gu. on a chief sa. as many open bowls or. George Whitewonge, $V$. Whitwong, $V^{*}$.

$$
\text { .....Crescent }
$$

Az. a chev. or betw. in chief two roses of the last and $1 \mathrm{n}$ base a lion ramp. arg. on a chief gu. a crescent enclosed by two estoiles as the third. SaVARY; certified May 1779.

Erm. a chev. betw. three bear's heads couped sa. on a chief vert a crescent in the dexter angle or. OtTerborne, Scotland.

Arg. goutty de poix a chev. betw. three otter's heads couped sa. on a chief az. a crescent or. Ottarburn, Red Hall, Scotland.

Erm. a chev. wavy az. betw. three blackamoor's beads couped below the shoulders sa. habited fretiy or on a chief chequy arg. and gu. a crescent sa. enclosed by two ogresses each charged with a lion pass. guard. of the fourth. DoDiser. or DoDMonE, $V^{*}$. The crescent of the fourth enclosed by two ogresses each charged with a talbot pass. gold. Sr. Raufe DodHone, Lord Mayor of London, $V$. The chev. sa. Dooner, Lord Mayor of London 1529.

$$
\text { ....Cross }
$$

Az. a chev. quarterly gu. and arg. betw. three garbs or on a chief arg. a St. Julian's cross sa. Company of InNHOLDERS, London.

Sa. a chev. engr. arg. betw. three plates each charged with a pale gu. on a chief of the second a cross as the third. DOCKWRAY, London.

Sa. a chev. (sometimes) engr. arg. betw. three plates each charged with a pale (sometimes a pile) gu. on a chief of the last a cross of the secoud. Thomas Docwra, Prior of St. Jobn of
1 CHEVRON betw. or within.... and in chief....cont.

\section{on a Chief cont. Cross}

Jerusalem in London 1504, $U$; sometimes impaling a buglehorn stringed betw. three goat's heads erased: sometimes impaling or a cross flory sa. with the chief over all.

Arg. a chev..... betw. three torteaux eash charged with a pale of the first on a chief gu. a cross as the field. Dockwrax.

\section{....Crosses}

Arg. a chev. betw. three ravens sa. on a chief of the last so many crosses croslet es the first. Cawthorne, co. Lincoln.

Arg. a chev. betw. three martlets sa. on a chief of the last as many crosses croslet or. CaI,DRon.

Az. a chev. erm. betw. three roses .... on a chief dancetty arg. as many crosses croslet fitchy .... Mee, East Retford, co. Nottingham.

Arg. a chev. betw. three lion's heads erased az. on a chief gu. as many crosses croslet or. Wren, Wroxhall Abbey, co. Warwick; the beiress $m$. Hoskyns.

Arg. a chev. betw. three lion's lieads erased gu. on a chief sa. as many crosses croslet of the first. Matthew Wren, Bishop of Hereford 1634, Norwich 1636, Ely 1638-67.

Arg. a chev. sa. betw. three lion's heads erased az. on a chief gu. as mauy crosses croslet or. Sir Christoplier Wren, 1632-1723. The heads sa. Wnen, Binchester, Durham, 1723.

Arg. a chev. sa. betw. three ogresses on a chief of the second as many crosses croslet fitchy of the first. Pate, Cheltenham, and Masterden, co. Gloucester.

\section{..... Crown}

Arg. a chev. countercompony or and sa. betw. three griffn's heads erased gu. on a chief vert a ducal crown of the first enclosed by two bezants. Yonge.

Arg. a chev. countercompony sa. and of the first betw. three griffin's heads erased gu. on a chief .... a ducal coronet ppr. betw. two bezants. YONGE, $r$.

\section{....Diamond}

Or a chev. betw. nine links of a chain each division consisting of three links sa. on a chief gu. a large diamond set in the midst of a triangle within a double row of brilliants ppr. Mrgnot. ..... Escallop

Arg. a chev. voided betw. three wolf's heads sa. on a chief of the last an escallop betw. two round buckles of the first. Clibborn, Moate Castle, co. Westmeath.

$$
\text { .....Escallops }
$$

Per pale or and gu. a chev. betw. three 5-foils counterchanged on a chief per pale of the second and first two escallops counterchanged. TEACH or TASH, London.

Az. a chev. betw. three lions ramp. or on a chief of the second as many escallops gu. the whole within a bordure compony or and gu. GRAUnge, Harl. MS. ]404, fo. 109.

Arg. a chev. betw. three boar's heads sa. on a chief of the second as many escallops or within a bordure az. (another vert) bezanty. Bowles, co. Herts.

\section{.... Escucheons}

Erm. a chev. gu. betw. three partridges ppr. on a chief of the second two escucheons each charged with an eagle displ. vert. GREGor, Trewarthenick, Cornwall. 
1 CHEVRON betw. or within....

and in chief.....cont.

on a Chief cont. Escucheons cont.

Arg. a chev. betw. three lion's gambs erect erased gu. on a chief sa. as many escucheons or. Whitwange, Dunson, Northumberland.

$$
\text { .....Estoile }
$$

Arg. a chev. gu. betw. three 3-foils slipped sa. on a chief of the second an estoile or. Phillip $J_{A C O B}$ London, $W$.

$$
\text { .....Estoiles }
$$

Arg. a chev. betw. three annulets sa. on a chief as the last so many estoiles of the first. NAIZON.

Az. a chev. or betw. three crescents arg. on a chief gu. as many six-pointed estoiles pierced of the second. LANGLoIs.

Gu. a chev, engr. arg. betw. three pineapples pendent of the second on a chief az. as many estoiles or. Prnson, $V$.

$$
\text { .....Fess }
$$

Gu. a chev. erm. betw. three lion's heads erased arg. on a chief of the second a fess nebuly charged with a griffin's head of the first. Fox, co. Northampton.

Gu. a chev. erminois betw. three lion's heads erased or on a chief of the last a fess nebuly purp. over all on the chief a pale arg. charged with a fox's head erasel of the first all within a bordure gold charged with hurts. Fox, Cha. combe, co. Northampton.

$$
\text { .....Fish }
$$

.... a chev. betw. in chief two leopard's heads .... and in base a garb .... on a chief .... a fish naiant .... Robert ELY, London, 1330.

Barry wavy of .... arg. and sa. a chev. or betw. three bezants on a chief of the third two dolphuns haurient endorsed enclosed by as many anchors az. Curteis, Lord Mayor of London 1557.

Barry wavy of six arg. and sa. a chev. .... betw. three torteaux on a chief az. two dolphins baurient encloserl by as many anchors or. CuRTEIs, London.

\section{.....Fleur.de-lis}

Or a chev. engr. betw. three falcon's heads erased az. on a chief gu. a tleur-de-lis enclosed by two suns of the first. Williadrson, Keswick, Cumberland.

Sa. a chev. gu. betw. three swan's necks or on a chief of the third a fleur-de-lis as the first. Davies, co. Stafford.

$$
\text { .....Fleurs-de-lis }
$$

Az. a chev. betw. three estoiles or on a chief em battled arg. as many fleurs-de-lis of the first. Burgoyne, $V$.

Gu. a chev. betw. three griffins segreant or on a chief of the last so many fleurs-de-lis as the first. Sмiтн or Siyth, co. Bedford.

Arg. a chev. engr, betw, three scorpions erect sa. on a chief az. as many fleurs-de-lis of the first. Cole, Newcastle-on-'Tyne.

$$
\text { … (Flower) Rose }
$$

Sa. a chev. betw. three eagles displ. arg. on a chief or a rose enclosed by two fleurs-de-lis gu. Parmond, London; granted 20 September 1581 . Raymond, Cornwall.

Az. a cbev. betw. three pelicans in piety or on a chief arg. a rose gu. enclosed by two butterflies Hugh Jones, Bishop of Llandaff 1566-7.

Arg. a chev. sa. betw. three roses gu. on a chief of the last a rose as the first. Brietr.

Per pale az, and vert a cher. betw. three stag's heads cabossed or on a chief arg. a rose gu.
1 CHEVRON betw, or within.... and in chief.....cont.

on a Chief cont. (Flower) Rose cont. enclosed by two leopard's beads of the first. Hygdon, Harl. MS. 1404, fo. 109.

Arg. a chev. chequy erm. and gu. betw. three coronels sa. on a chief az. a rose enclosed by a leopard's head and a buck's head or. Essex.

Arg. a chev. gu. betw. three bees volant $\mathrm{ppr}$. on a chief az. a rose of the field seeded or and barbed rert enclosed by two billets erect gold. Pitter, Croydon, Surrey.

Sa. a chev. engr. or betw. three bezants on a chief of the second a rose gu. enclosed by two fleursde-lis az. Homfrey, London; granted June 1562 .

\section{.... (Flowers) Columbines}

Sa. a chev. chequy or and az. betw. three bezants on a chief arg. so many columbines as the third. Cooke, Kent.

$$
\text { ....Roses }
$$

Erm. a chev. az. betw. in chief two eagles rising sa. and in base a sea.lion sejant ppr. on a chief or three roses gu. barbed vert seeded gold: RIGLEY, co. Nottingham.

Arg. a chev, vairy a 2 . and or betw. in chief two eagles displ. sa. and in base a merchant ship under sail ppr. on a chief of the second three roses as the first. EGLn, Kingston-uponHull.

Az. a chev. or betw. three owls arg. on a chief of the second as many roses gu. OLDON, Exeter.

Paly of three sa. and arg. a chev. betw. three owls counterchanged on a chief erminois as many roses gu. barbed and seeded ppr. OLDHAM.

Sa. a chev. betw. three owls arg. on a chief of the second as many roses gu. OLDham, $V$.

Sa. a chev. betw. three owls arg. on a chief or as many roses gu. OKenley. Richard Oldham, Bishop of Sodor, etc. 1481-6.

Sa. a chev. arg. betw. three owls ppr. on a chief of the second as many roses gu. seeded or and barbed vert. OLDHaH.

Sa, a chev. or betw. three owls arg. on a chief of the last as many roses gu. Hugh OLDHalr or Ordon, Bishop of Exeter 1505-19.

Sa. a cliev. or betw. three owls arg. on a chief of the second as many roses gu. Oldentary or Old нам, Oldham, co. Lancaster, OLdhav, $V *$.

Vert a chev. betw. three crosses croslet fitchy or on a chief of the last as many roses gu. MEY, Houldham Abbey, Norfolk.

Az. a chev. betw. three 3-foils slipped or on a chief arg. as many roses gu. seeded and barbed vert. LyncH, Teddington, Middlesex.

Az. a chev. betw. tbree pheons or on a chief arg. as many roses gu, seeded of the second barbed vert. Swayne, London.

$$
\text { ....3.Foil }
$$

Arg. a chev. .... betw. three pierced mullets sa. on a chief (? or) a 3 -foil az. (another vert) enclosed by two hind's heads (another greyhound's; another griffin's) erased .... collared gemel .... Greshair, Lord Mayor of London 15.7. But on a chief or a ü-foil betw. two hare's heads erased of the third. Gresham, Norfolk, Add. MS. 6193, fo. 7 .

Arg. a chev. betw. three pierced mullets sa. on a chief or a 3-foil slipped gu. enclosed by $t w c$ fux's heads erased of the secoud. Gresharr. 
1 CHEVRON betw, or within.... and in chief.... cont.

on a Chief cont. 4-Foil

Az. a chev. betw. three crosses patty or on a chief arg. a 4-foil purp. Dickinson, Lord Mayor of London 1757.

$$
\text { ....5-Foil }
$$

Az. a chev. betw, three crosses patty or on a chief arg. a 5-foil vert. DICKESON or DICKINSON, Londou.

$$
\text { ...5-Foils }
$$

.... a chev. .... betw. three pelicans vulning themselves .... on a chief .... as many 5 -foils .... William Blethin, Bishop of Llandaff 1575-90.

Az. a chev. or betw. three bezants on a chief erm. as many 5-foils gu. Jensings, Burton, co. Somerset; and Pynsent, co. Devon. Jennings, Collinson, Somerset, i, 27. John Jenings, co. Salop, $W$. Jennins. Jenninges, $V *$. JENynges, Wallyborne, co. Salop, $V$.

Az. a chev. or betw. three bezants on a chief of the second as many 5 -foils gu. Junor, London. ..... Fruit

Arg. a chev, betw. three boar's heads fesswise couped sa. on a chief of the last as many gourds or. Wardali, $V$.

$$
\text { ..... Fusils }
$$

Per pale az. and arg, a chev. engr. betw, three 3 -foils slipped and on a cbief per pale as many fusils counterchanged. Moody, Aspley, co. Bed. ford; quartering Sadleir, Chute, Trott, \& A'Leigh.

Az. a chev. betw. three mullets or on a chief erm. as many fusils sa. Pigotr, Chetwynd, co. Salop.

$$
\text { ..... Head (Beast) Boar }
$$

Sa. a chev. betw. three escallops arg. on a chief or a hear's head muzzled sa. LiNAcRe.

$$
\text { .....Lion }
$$

Arg. a chev. gu. betw. three mullets sa. on a chief az. a lion's head erased enclosed by two lozenges or. Bolle or Bolles, Worthin, Suffolk; granted 1528. The chief of the second. Bollys. But of the third. Borles Booles or Bowles, Suffolk; and co. Stafford. William Bolis or Bolies, Worthem, co. Stafford, $V$.

$$
\text { ....Human Figure }
$$

Gu. a chev. betw. three griffin's heads erased or on a chief of the second a close helmet sa. enclosed by two ogresses. Paynter, Twidall, Keut.

$$
\text { .....Heads (Beasts) Deer }
$$

Az. a chev, engr. erm. betw. two bees volant in chief and a beehive in base or on a chief of the last as many buck's heads cabossed sa. CAPPER, Ashurst, Kent; quartering Sinallwood. CAPPER, Birmingham; and co. Stafford.

$$
\text { .....Boar }
$$

Lirm. a chev. az. betw. three mullets sa. on a chief of the lust as many boar's heads and necks erased arg. Folier, Scotland.

$$
\text { ....Deer }
$$

Or a chev. engr. betw. three lions ramp. sa. on a chief indented of the second as many stag's heads erased of the first. SKINNER or SKYNNER, Essex; and Lincoln.

Arg. a chev. betw. three crosses croslet sa. on a chief of the last as many stag's heads cabossed of the first. WALKER, Ireland.

Gu. a chev. betw. three crosses croslet arg. on a chief of the last as many stag's heads cabossed of the first. WALKER.

Arg. a chev. betw. three mullets gu. on a chief az. as many (buck's, $V^{*}$ ) stag's heads cabossed or. William P'ARKer, London, $V$.
1 CHEVRON betw, or within.... and in chief.....cont.

on a Chief cont. Heads (Beasts) Deer cont. Arg. a chev. gu. betw. three pierced mullets sa. on a chief $8 \mathrm{z}$. as many buck's beads cabossed or. Parker, co. Derby ; and co. Lancaster.

Arg. a chev. gu. betw. three mullets sa. on a chief of the last as many buck's lieads cabossed or. Penketh, co. Lancaster.

Arg. a chev, pean betw. three mullets sa. on a chief az. as many buck's beads cabossed or. Parker, Woodthorpe, and Streetthorpe, co. York; descended from Parker, Little Norton, co. Derby.

$$
\text { .....Dog }
$$

Sa. a chev. betw. three escallops arg. on a chief or as many greyhound's beads erased of the first. Linacre, Linacre Hall, co. Derby. Linacre, $V^{*}$. Lynacre or Lynaker, co. Derby, LYNACRE, $V$.

\section{.....Leopard}

Per pale arg. and sa. a chev. betw. three talbots (courant, $V^{*}$.) pass. (statant, $V_{\text {.) }}$ counterchanged on a chief gu. as many leopard's heads or. John GoocH, London, $V$. GoocH, Benacre Hall, Suffolk ; Baronetcy 1746. Gooch, Brompton, Midalesex. Gooche, $V^{*}$. Goche or Goocne, London; and Mettingham and Bungay, Suffolk. Gouar, $V$. The chief sa. Thomas Gooch, Bishop of Bristol 1737, Norwich 1738 , Ely 1748-54.

Per pale sa. and arg. a cbev. betw. three talbots (pass. $V^{*}$.) statant counterchanged on a chief gu. as many leopard's faces or. GooGE, Wales; and London, $V$.

Arg. a chev. gu. betw. three buglehorns vert on a chief of the second as many leopard's heads or. Foster.

\section{.... Hnman Figure}

Az, a chev, betw. three pheons or on a chief gu. as many maiden's heads couped ppr. crined of the second. Swatn or Swayne, London; Sewardstone, Essex ; aud co. Somerset; granted $29 \mathrm{June} 1444$; confirmed $10 \mathrm{July} 1612$. William Swayne, co. Somerset, $W$. The heads veiled of the second. SwaYN, $V^{*}$.

Az. a chev. betw. three pheons or within a bordure engr. erm. on a chief gu. as many maiden's heads couped at the breasts .... SWAYNe, Gunvile.

$$
\text { ..... (Monsters) Griffin }
$$

Gu. a chev. betw. three covered cups or on a chief arg. as many griffin's heads erased az. Greenway, co. Devon. Greenway, London, $V$. The heads beaked or. GRENEWAY or Grenoway, London. Greenaway, Barrington Grove, co. Gloucester; and co. Oxford.

Gu. a chev. betw. three covered cups or on a chief of the last as many griffin's heads az. Greenway, Warwick, quartering Kelynge. The heads erased az. Greenway, co: Buckiugham; and London.

Arg. a chev. betw, three cocks gu. on a chief sa. as many spearheads of the first sanguinated. Willians, Gweruevet, co. Brecon; and Rose Hall, co. Hertford.

... a chev. engr. .... betw. three fleurs-de-lis .... on a chief .... as many spearheads .... Wright, Sedgefield, Durham.

Az. a chev, betw, three fleurs-de-lis or on a chief gu. as many spearheads arg. WrigHT, co. Hants. 
CHEVRON betw, or within....

and in chief.....cont.

on a Chief cont. (Heads) Spear cont.

Sa. a chev. betw. three fleur-de-lis arg. on a chief of the second as many spearheads az. Wright, co. Hants.

Sa. a chev. engr. betw. three fleurs-de-lis arg. on a chief of the second as many spearbeads gu. Wright, Bradbury, Durham.

Sa. a chev, arg. betw. three fleurs-de-lis or on a chief of the second as many spearheadss az. WRIGHT.

Sa. a chev, engr. arg. betw. three fleurs de-his or on a chief of the third as many spearheads az. Wright, Little Buckenham, Weeting, and Kilverstone, Norfolk; and Downham, Wangford, and Brent, Suffolk.

Sa. a chev. engr. arg. betw. three fleurs-de-lis or on a chief of the last as many spearheads erect ppr. the whole within a bordure wavy erm. Wright, South Carolina; Baronetey 1772; and Carolside, co. Berwick.

Sa. a chev. betw. three leopard's heads or on a chief arg. as many spearheads of the first em. brued gu. Price, co. Hereford.

\section{....Human Figuro}

Sa. a chev. betw, three antelopes statant (another, goats pass.) arg. girthed gu. ou a chief or a demi-man holding a club over the shoulder bendwise enclosed by two 5-foils all of the third. Battie, Cusworth, Wadsworth, and Warmsworth, co. York. WRightsworTH.

Sa. a chev. betw. three goats arg. each goat charged with two ogresses on a chief of the last a demi-woodman with a club erect ppr. enclosed by two 5-foils gu. BatTie, afterwards Wrigerson, Cusworth, Wadsworth, and Warmsworth, co. York.

Sa. a chev. betw. three bulls pass. arg. charged with two golpes on a chief or a demi-woodman with a club betw. two 5 -foils gu. Baty.

\section{.... Insects}

Sa. a chev. erm. betw. three acorns ppr. leaved vert on a chief arg. as many bees ppr. Connor. .....Lozenges

Per fess or and az. a chev. betw. three eagles displ. counterchanged on a chief gu. as many lozenges erm. FAYerY or FAYRY, Portcullis Pursuivant temp. Edward VI.

Per pale or and az. a chev. betw. three eagles displ. counterchanged on a chief gu. as many lozenges erm. ALcock.

Sa. a cher. betw. three fleurs-de-lis arg. on a chief gu. as many lozenges or. Crask, 1700.

$$
\text { .....Lure }
$$

Or a chev, az. betw. three gillyflowers gu. slipped and leaved vert on a chief of the third a hawk's lure enclosed by two popinjays of the first. JEWEI,L, Scotland.

$$
\text { ..... Mascles }
$$

Arg. a cher. betw. three eagle's heads erased sa. on a chief of the second so many mascles as the first. Clanke, Kettleston, Suffolk; confirmed 20 January 1559.

\section{.... Monster}

$\mathrm{Gu}$. a chev. betw. three escallops or on a chief of the second a griffin pass. az. enclosed by two torteaux each charged with a fleur-de-lis gold. Sinewse, Cornwall.

Gu. a chev. betw. three lion's heads erased or on a chief of the second a griffin pass. az. unguled gu. Walter Turk, Alderman of London, ob. 1352; Lansdowne MS. 874, fo. 8 .
1 CHEVRON betw. or within....

and in chief.....cont.

\section{on a Chief cont. Mullet}

Arg. a chev. betw. three fleurs-de-lis az. on a chief of the last a pierced mullet as the first. Hugres, Alltwwy, co. Cardigan.

Arg. a chev. engr. sa. betw. three griffin's heads erased az. on a chief gu. a mullet betw. two martlets or. HARE, Walsoken, Norfolk.

$$
\text { ..... Mullets }
$$

Arg. a chev. lozengy gu. and az. betw. three crosses fitchy vert on a chief sa. two mullets of the first. Reignolds or Reynor,ds, Suffolk.

Or a chev. betw. three arrows sa. on a chief embattled az. as many mullets of the first. Heynes, Turston, co. Buckingham. Heynes, Wilden Hall, Suffolk; confirmed 1575.

Arg. a chev, engr. betw, three stags courant sa. attired or on a chief of the second so many mullets as the third. Rogers, Coulston, Norfolk.

Arg. a chev. betw. three birds rising gu. on a chief sa. as many mullets of the tirst. ALuноUSE Aldous or Aldus, Suffolk.

Gu. a chev. betw. three martlets or on a chief of the second as many mullets sa. Thynne, Kent. Arg. a chev. chequy az. and gu. betw. three crosses patty fitchy vert on a chief embattled sa. as many mullets or. Reynolds, Shotley, Suffolk.

Arg. a chev. (compony, $\nabla^{*}$ ) countercompony gu. and az. betw. three crosses patty fitchy vert on a chief embattled sa. as many pierced mullets or. Raynolds. Robert Regnold, East Bar. bolth, Suffolk, $V$.

Arg. a chev. lozengy gu. and az. betw. three crosses patty fitchy vert on a chief sa. as many mullets of the first. REYNoLDS.

Arg. a chev. betw. three fleurs-de-lis az. on a chief of the last so many mullets as the first. Sterenson, Scotland.

Arg. a chev. betw, three fleurs-de-lis az. a bordure gu. on a chief of the third so many mullets as the first. Stevenson, Mount Grenan, Scotland.

Arg. a chev. betw. three fleurs-de-lis gu. on a chief of the last as many mullets or. Stevenson, Hermishiels, Scotland.

Arg. a chev. engr. betw. three talbot's heads erased az. on a chief of the second as many mullets or. HaLL, Newsham and Great Chilton, Durham; descended from Hall, Greatford.

Arg. a chev. engr. az. betw. three talbot's heads sa. on a chief of the second so many mullets as the first. HaLL, Newsham, Durham.

Gu. a chev. or betw. in chief two six pointed mullets of the last the edges issuing rays pierced like the first and in base a crescent arg. on a chief az. three mullets as before. LAYARD, Westminster; quartering Groze anciently Croissy, and Balaire.

$$
\text { ....Pale }
$$

Sa. a chev. betw. three (fleams or) lancets arg. on a chief (? of the last) a pale (? vert) in the dexter side a spatula in pale az. oppressed by a rose gu. regally crowned ppr. Company of Barber-Chirurgeons, London, until 1560, Cotton MS. Tiberius D 10.

Gu. a chev. erm. betw. three liorl's heads erased (arg. $V^{*}$.) or on a chief barry nebuly of four (five $V^{*}$.) arg. and purp. on a pale az. a pelican all within a boldure of the third. John Fox, Ropesiy, $V$. 
1 CHEVRON betw, or within.... and in chief.....cont.

on a Chief cont. Pale cont.

Gu. a chev. betw. three lion's beads erased or on a chief per fess nebuly arg. and az. a pale like the last charged with a pelican close of the third vulning her brelist as the first. CAREr.

Gu. a chev. arg. betw. two pairs of compasses in chief extended at the points and a sphere in base or on a chief of the last on a pale az. betw. two roses gu. seeded of the third, barbed vert an escallop of the second. Company of Jolners, London.

\section{.....Roundle}

Per pale az. and vert a chev. betw. three buck's heads or on a chief arg. a torteau betw. two leopard's heads of the first. HIGDEN. The torteau charged with a lion's head erased arg. HIGDEN.

Per pale az, and vert a chev. betw. three stag's heads cabossed or on a chief arg. a torteau betw. two leopard's heads az. langued gu. on the torteau a griffin's head arg. HygDoN; Harl. MS. 1404 , fo. 71 .

$$
\text { .....Roundles }
$$

Erm. a chev. wavy betw. three negro's heads couped at the breast sa. on a chief chequy or and az. two plates on each a talbot pass of the second. Dodmer, London ; and co. York.

Per pale arg. and az. a cbev. betw. three eagles counterchanged on a chief gu. as many bezants. Feyry, co. Bedfordshire.

Or a chev. sa. betw. three crosses patty fitchy gu. on a chief of the secoud as many bezants. Stanard, London. Stannard.

Arg. a chev. gu. betw. three fleurs-de-lis sa. on a chief az. so many bezants. Chatteris.

Arg. a chev. betw. three boar's heads couped sa. on a chief vert as many bezants. WARDELL, Norfolk; and Caen, Normandy ; granted 1584.

Arg. a chev. gu. betw. three laurel brauches vert on a clief az. so many bezants. Creagh, Newcastle-on-Tyne; granted 3 March 1684.5.

Az. a chev. erm. betw. three eagles displ. arg. on a chief embattled or as many ogresses. WALL, Crich, co. Derby, $V$.

Or a chev. betw. three leopard's faces gu. on a chief sa. as many plates each charged with an erm. spot of the last. BANGER.

Gu. a chov. betw. three fleurs-de-lis arg. on a chief of the last as many torteaux. Rew, Irelaud.

$$
\text { .... Saltire }
$$

Az. a chev. betw. three lozenges or on a chief arg. a saltire engr. gu. enclosed by two buds sa. HydF, Harl. MS. 1404, fo. 109.

Or a chev. betw. three lozenges az. on a chief gu. a saltire engr. enclosed by two birds of the first. HYDE, Harl. MS. 1 104 , fo. 109. Jown Hyde, co. Dorset $V$. Hyde, Hydon, co. Dorset. But martlets. HYdE, Noriolk.

$$
\text { .... Ship }
$$

Az. a chev, betw. two fleurs.de-lis in chief, and a Camperdown medal in base or pendent by a ribbon struped arg. az. and arg. with the word "Camperdown" uuderneath and on a chief a representation of H.M. ship Venerable engaging the Dutch Admiral's ship Vrgheid at the battle of Camperdown. FalrFax, The Holmes, co. Roxburgh; Baronetcy 1836.

$$
\text { ..... Staples }
$$

Sa. a chev. or betw. three wolf's heads erased crm. on a chief of the second as many door. staples gu. Cooke, Fulwell, Sussex.
1 CHEVRON betw. or within....

and in chief.....cont.

on a Chief cont. Sword

Arg. a chev. gu. betw. three bucks trippant ppr. on a chief az. a sword erect of the first hilt or enclosed by two double keys endorsed and linked of the third. Rominson, Loudon.

Arg. a chev. betw. three elephant's beads erased sa. on a chief gu. a broken sword ppr. hilt and pomel or the point hanging down betw. two plates. Saunders, London; Largay, co. Cavan; and Saunders Grove, co. Wicklow.

Erm. a chev. az. betw. three towers gu. on a chief embattled vert a sword erect betw. two leopard's faces ppr. Woop.

$$
\text { .....Tree }
$$

Vert a chev, gu. betw, two couplecloses erminois and three Turk's heads couped ppr. turbaned or on a chief arg. a silphiurn plant ppr. issuant from a mount vert inscribed with the letters KrPA gold. Sнутн.

Per pale arg. and gu. a chev. betw. three lion's heads erased counterchanged on a chief or a thorn-ti ee ppr. Thornthwaite, Cumberland. ....Wings

Or a chev. gu. betw. in chief three doves respect. ant ppr. beaked and legged of the second and in base a serpent nowed silver on a chief gu. three sinister wings arg. RENEU, London.

\section{Cross}

Az. a chev. arg. betw. in chief two garbs or and in base a spaniel pass. ppr. in the centre chief point a cross croslet fitchy of the second. Burder.

Arg. a chev. betw. three cormorants sa. m chief a cross croslet for diff. Warburton, Arley, co. Chester; Baronetcy 1660, extinct 1813; quartering Winnıngton and Dockwra.

Az. a chev. betw. three cotton hanks palewise arg. in chef a cross patty suspended by a ribbon. CotTon; Baronetcy 1677, Barony 1814, Viscounty 1826 ; quartering Stapleton.

Arg. a chev. sa. betw. three ogresses in chief as many crosses patty fitchy .... PATEs, co. Gloucester.

\section{Escucheor}

Vert a chev. couped gu. betw. three fleurs-de-lis or un chief on an escucheon arg. as many of the same in bend sa. Samuel Terrick, London, 1633, Harl. MS. 1358, fo. 83.

\section{Estoile}

Arg. a chev. wavy sa. betw. three lozenges az. in the centre chief point an estoile gu. STronge, Tynan Abbey, co. Armagh; Baronetcy 1803, quartering Manson, Tew, and Maxwell.

Arg. a chev. betw. three crows sa. in chief a star of the order of the crescent. Jones-BrydGes, Ioultibrook, co. Hereford; Baronetcy 1807: and for augmentation on a chiet vert a lion couchant in front of the sun in splendow ppr. Fleur-de-lis

Sa. a chev. erm. betw. three crescents arg. in chief a fleur-de-lis or. Glover.

Flower

Arg. a chev. chequy gn. and of the first betw. three buglehorns sa. garnished or stringed as the second in chief a gilliflower .... for diff. Semple, Belltrees, Scotland. And with a bordure .... charged with eight crescents gold. Semiple, Stockholm, Sweden.

\section{6-Foil}

Arg. a chev. sa. betw. three boar's heads .... a (j-foil (sitfoile) on the dexter chief .... Thomas Swyniort, $Y$. 
1 CHEVRON betw, or within....

and in chief.... cont.

Gun

Per saltire or and gu. a chev. betw. three owls arg. beaked and legged of the first in chief a culverin lying bendwise az. fired ppr. on the month a ball sa. Sir Francis FuEMrng, Lieutenant of the Ordnance; granted $1550, \mathrm{~V}$.

Horn

Az. a chev, erm. betw. three arrow-beads arg. in chief a hunting horn or. Moodie or Mudie, Mulsetter, Orkney Isles.

\section{Quarter}

Arg. a chev. betw. three hinds trippant sa. a quarter paly of four or and gu. JENNing, $V^{*}$. JENNYNG, $l$.

on a Quarter

Gu. a chev. hetw. three hedgehogs statant arg. on a quarter barry of five arg. and az. a canton as the first charged with three martlets or. Claxton, $V$.

Pile

Arg. a cher. sa. betw. three fleurs-de-lis gu. in chief a pile of the second. Moore.

Arg. a chev, betw. three fleurs-de-lis and in chief a pile sa. Richard More, Awstrop, $V$.

Arg. a chev. betw. three 3-foils slipped and in clief a pile sa. Rufrond, Nethersope, co. Worcester.

Az. a chev. or betw. in chief two mullets and in base a lion pass. arg. from the centre chief a pile issuant of the second. DU PRE, Wilton Park, co. Buckingham.

on a Pile

Sa. a chev. betw. three buglehorns stringed arg. in chief on a pile of the second a covered cup gu. all within a bordure or charged with eigbt pellets. Gardinen, Leatherhead, Surrey.

Gu. a chev. betw. three owls arg. in chief on a pile or a cannon az. discharged ppr. Fleming.

Sa. a chev. betw. three buglehorus stringed arg. in chief on a pile of the last another buglehorn stringed as the first all within a bordure or charged with torteaux. Gardner, of the Cellar, Harl. MS. 1404, fo. 129.

\section{Roundle}

Sa. a chev. chequy or and gu. betw. three cusbions of the second in the collar point a gold medal suspended by a red riband striped blue. Brisbane, Brisbane and Makerstoun, Scotland, Baronetcy 1830; quartering Macdougal.

Arg. a chev. vert betw. three Heurs-de-lis gu. in chief a torteau. REDE.

Arg. a chev. sa. betw. three pineapples vert in chief a torteau. CHristopher.

\section{Roundles}

Arg. a chev. betw. three unicorn's heads erased sa. in chief as many hurts. More.

Arg. a chev, vert betw. three fleurs-de-lis gu. in chief as many torteaux. REID, England.

\section{Ship}

Arg. a chev. gu. betw. three crosses croslet fitchy sa. in chief a galley sails furled like the last flags as the second in the sinister chief point a mullet of the same. Kennedx, Barclanachan, Scotland.

\section{CHEVRON betw, or within...} and in base...

A rg. a chev. within a bordure engr. and in base an annulet sa. THonNтoN.

\section{On 1 CEEVRON}

\section{Anchors}

Sa. on a chev. arg. three anchors of the first: 'Tibes.

\section{Annulet}

Arg. on a chev. gu. an aunulet or. THомas or Tommas, co. Northampton. Thomas or Thomes. William Tonnes, $V$. Tonnes or Tonnis, co. Northampton; and co. Nottingham.

Arg. on a chev. sa. an annulet or. Simon de Walton, Bishop of Norwich 1257-66.

Annulets

Arg. on a chev. gu. three annulets or. HALGHweLI or Halwell, Halwell, co. Devon; the coheiresses m. Bray, Brooke, Verney and Catesby, Pecham, Bruges, and Lifield. Tommes, Norfolk.

Arg. on a chev. sa. three annulets of the first. Hallewell. Round, Birch Hall, Essex; quartering Creffield.

Chequy gu. and arg. on a chev. sa. three annulets or. Pomeroy.

Chequy or and gu. on a chev. az. three annulets of the first. GILDRIDGE, Eastborne, Sussex; the heiress m. Eversfield.

Erm. on a chev. gu. three annulets or. RIGG, Cumberland. Rigge.

Erm. on a chev. sa. three annulets or. John Durward, $V$.

Gu. on a chev. or three annulets of the first. OfFERTON (? in error).

Or on a chev. sa. three annulets of the first. LEARMOUTH.

Bar

Sa. on a chev. arg. a fess wavy gu. HankFord, co. Devon.

\section{Bars}

Or on a chev. gu. three bars sa. Proud, co. Salop; and Westminster, 1605.

Sa. on a chev. arg. three bars wavy gu. HANKFord. Arg. on a chev. sa. four bars wavy of the first in chief a label gu. Prideaux, Notewell, co. Devon.

Gu. on a cbev. arg. three bars gemells sa. Frogmorton. ThrockMORTON, quartering Spineto; Coughton Court, co. Warwick; Baronetcy ]642, quartering Olney, Whorwood, Monson, und Yate. Throckmorton, Tortworth, co. Gloucester; Baronetcy ]611-82, quartering Spineto, Bruges, Matthew, Whittington, Baynham, and Hopton. Throckirorton, Molland, co. Devon. Throkmenton, $V$. Throkmorton, $V^{*}$. Gu. on a cbev. or three bars gemells sa. THROCKHORTON.

Gu. on a chev. arg. bars nebuly sa. HANEFORD. Or on a chev. engr. az. bars wavy arg. Browne.

Or on a chev, gu. bars sa. Lewis Proude, at the Charterhouse, 1619.

Sa. on a chev. arg. bars nebuly gu. HANCKFord. Beast .... Dog

Arg. on a chev. gu. a hound courant or. MARTrn. .....Lion

Arg. on a chev. or a demi-lion ramp. gu. HeglifFe.

Arg. on a chev. az. a lion ramp. betw. two flowers of the first. WAYNWRIGHT.

Arg. on a chev. engr. ga. a lion ramp. crowned or. Pinell. Pynell.

Erm. on a chev. or a lion .... vert. Heglise.

Gu. on a chev. arg. a lion ramp. sa. Broore, London, 1601.

Gu. on a chev, arg. a lion ramp. sa. crowned or. Sr. Thomas Brooke, co. Somerset, $V$. CoвHaM. 


\section{On 1 CHEVRON .... cont.}

Beast cont. Lion cont.

Gu. on a chev. arg. a lion ramp. sa. crowned or. armed and langued of the first. Brooke, Aspall, and Ufford Place, Suffolk.

Gu. on a chev. or a lion pass. sa. crowned of the second. MALEFONT.

Sa. on a chev. arg. a lion ramp. az. betw. two torteaux. MactYre, Westrea, Chief of the Clan Lendrice.

Beasts.... Lions

Erm. on a chev. sa. two lions pass. respectant or. Beuris Bewris or Bewrys. Bewrys, $V$.

Sa, on a chev. or two lions ramp. combatant .... GARDNER, Ireland.

$$
\text { .... Dogs }
$$

Arg. on a chev. gu. three talbots of the first. Marten, $V^{*}$.

Arg. on a chev. gu. three bloodhounds pass. of the

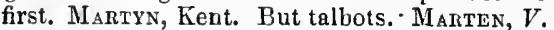

Arg. on a chev. gu. three bloodhounds pass. or. Martyn, Kent. But talbots. Martyn.

Gu. on a chev. arg. three talbots sa. Morant, Essex. Moraunt, $V *$.

$\mathrm{Gu}$. on a chev. arg. three talbots pass. sa. Broker, Kent.

$\mathrm{Gu}$. on a chev, arg. three talbots statant sa. Morraunt, $V$.

Gu. on a chev. or three bloodhounds pass. sa. Martin, Plymouth, co. Devon. But talbots. Martin, co. Devon, $W$. Martyn, Plymouth. .....Lions

Arg. on a chev. az. three lions ramp. of the first. Bickenor Bicknor or Bykenobe.

Arg. on a chev. az. three lions ramp. or. ATHLowe Essex.

Arg. on a chev. gu. three lions pass. guard. of the first. BoLTos, co. York, $V$.

Arg. on a chev. gu. three lions pass. guard. of the first. Bolton, Mount Bolton, co. Waterford ; co. Lancaster; and co. York.

Arg. on a chev. gu. three lions couchant (aliter pass.) or. Bozton.

Arg. on a chev. gu. three lions pass, guard. or. Bolton, Mount Bolton, co. Waterford; co. Lancaster; and co. York. Robert de Boidton or de Bolton or de Boulton, $Y$. Thomas Hastaaton, $X$; or Heslerton, $Y$. Gough. KING.

Arg. on a chev, gu. three lions ramp. or. Bourne.

Arg. on a chev. sa. three lions ramp. of the first. Thursby, co. York.

Gu. on a chev. or three lions ramp. sa. Thomas Brooke, Lord Cobham, $U$. Brooke, Collinson, Somerset ii, 300. Совнам, Barony 131:3-1409. Coвнam, Cobbam, co. Berks. Le Sr. de Coвmam, $T$, quartering arg. a tower sa. $\mathrm{Sr}$. .... de Cobrait, $S$; and Kent, $V$.

Or on a chev. az. three lions ramp. of the first. LISLE.

Or on a chev. gu. three lions pass. guard. arg. Bolton.

Or on a chev. sa. three lions ramp. arg. LEe. But with an annulet in the dexter chief for diff. of the second. LEIGH, Adlington, Surrey, 1609.

Or on a chev. sa. three lions ramp. of the first. SPENSER.

Or on 9 cher, vert three lions ramp. of the first. Reynolds, Axleborough, Norfolk.

Per pale .... and .... on a chev..... three lions couchant .... BoLToN.

\section{Billets}

On 1 CHEVRON .... cont.

Arg. on a chev. az. six billets of the first. Francheville.

\section{Bird..... Eagle}

Arg. on a chev. sa. an eagle displ. of the first. Woely. Wolin. Woolley, Comberworth, co. Lincoln.

Paly of seven az. and or on a chev. of the first an eagle rising overt inverted as the second. Locke, London, Harl. MS. 1404, fo. 144.

$$
\text { ..... Martlet }
$$

Or on a chev. az. a martlet betw. two pheons of the first. Warton. Wharton, Beverley, co. York.

Per pale arg. and or on a chev. per pale sa. and az. a martlet of the second. FlegGH, $V$. The chev. engr. FLEGGH, $\boldsymbol{V}$.

\section{Birds}

Az. on a chev. arg. three birds sa. HoLdict.

Az. on a chev, or three birds (probahly magpies) sa. HoLdich, $V^{*}$. With white breasts. Holdiche, Rainworth, Norfolk, $V$. ....Bustards

Arg. on a chev. or three seapies ppr. HoLdiche or Holditch, Raworth, Norfolk. .....Cocks

Arg. on a cliev. vert three cockerells of the first membered gu. Chickerin, Norwich.

$$
\text { ..... Crows }
$$

Az. on a chev. or three ravens sa. HoLdicne, Ranworth, Norfolk, $V$.

Gu. on a chev. or three ravens sa. Corbetr, Halghton, $V$.

Or on a chev. sa. three Cornish choughs arg. Hammon, Ellingham, Norfolk.

$$
\text { .....Eagles }
$$

Arg. on a chev. az, three eagles displ. or. Candos.

Arg. on a chev. sa. three eagles displ. of the first. Charlston, Essex.

Arg. on a chev. sa. three eagles displ. or. Sir William de Wantone, $L$. William de Wanton, $X$. Wanton, $V^{*}$, and co. Gloucester. Watton. Sr. William WaUton, co. Gloucester, temp.Edward $I, V$. Sire William de Wautone, $N$.

Arg. on a chev. vert three eagles displ. of the first. Charlston, Essex.

Arg. on a chev. vert three eagles displ. or. John Charleston, Essex, temp. Edward I, $V$. Sire Johan de Chariestone, $N$. Charlston.

Gu. on a chev. or three eagles displ. sa. Совнавт, Blackbury.

Or on a chev. indented sa. three eagles displ. of the first. Brrchet, Kent.

Or on a chev, vert three eagles displ. of the first. Carleston. Sr. Johan de Charlestone, $N$.

$$
\text { .....Magpies }
$$

Az. on a chev. or three magpies ppr. HoLbiche, Suffolk. HoLdiche or Holditc Norfolk.

\section{.... Martlets}

Arg. on a chev. gu. three martlets of the first. Chessendon, co. Dorset, $V$.

Arg. on a chev. gu. three martlets or. Mandevine.

Arg. on a chev. dancetty gu. three martlets or. Mandevile, Essex.

Arg. on a chev. sa. three martlets of the first. Cheseldon, co. Dorset. Hogan, Ireland.

Arg. on a chev. sa. three martlets or. BrisBon, $V *$. Brisbone. Brysbon, $V$. 
On 1 CHEVRON.... cont.

Birds cont. Martlets cont.

Barry wavy of ten arg. and az. on a chev. sa. three martlets of the first. Ferman.

Barry nebuly of ten arg. and az. on a chev. sa. three martlets or. Ferrejan, London.

Erm. on a chev. gu. three martlets or. Parre, co. Devon.

Gu. on a chev. arg. three martlets of the first. Rode, $V$.

Gu. on a cher. erm. three martlets of the first. Topsfield, Sussex.

Gu. on a chev. erm. three martlets sa. Copfield, Suffolk. TopsField, Norfolk; and Suffolk, And with a mullet in chief or. TopsFiesd, Frisingfield, Norfolk.

Gu. on a chev, or three martlets sa. Auduex. Sr. John Cobman, $Q$. Coвнam, $V$.

Or on a chev. gu. three martlets arg. Chedleworth Childworth or Chilworth, co. Devon. Chedword, $V$. Cheldeword, co. Devon, $V$. Cheseldon, Holcombe, co. Devon.

Paly of six or and gu. on a chev. arg. three martlets sa. BELCHER.

Per pale or and az. on a chev, three martlets counterchanged. LUDHAM, Londow; granted 1726.

Sa. on a chev, arg. three martlets vert. Deton or DetTon.

$$
\ldots .0 \mathrm{wls}
$$

Arg. on a chev. sa. three owls of the first. Prescott, $V$.

\section{Birds}

Arg. on a chev. sa. five hirds of the first beaked and legged gu. Temple, $V$.

$$
\text { .... Eagles }
$$

Gu. on a chev. arg. five eagles displ. of the first. DEGGs, Suffolk.

$$
\text { ..... Martlets }
$$

Erm. on a chev. sa. five martlets arg. Hinton. Hoyntoun, $V$. Hynton, $V$. Temple, Temple, and Whellesburgh, co. Leicester.

Per pale arg. and or on a chev. sa. six martlets of the second. Sleggs.

\section{Blocks}

Arg. on a chev, engr. az. three blocks or each charged with a cross of the second. HoBson, Harl. MS. 1404, fo. 118 .

\section{Brushes}

Arg. on a chev, az. three brushes of the first. Penwalis.

Caps

Arg. on a chev. sa. three steel caps of the first. Clatel or Claveli.

\section{Castles}

Arg. on a chev. gu. three towers triple-towered of the first. VIoLet, Norfolk.

Chessrook

Gu. on a chev, arg. a chessrook sa. Brunbury. Chevrons

Arg. goutty de larmes on a chev. sa. unother of the first. St. MAURE.

Arg. on a chev. engr. az. another plain sa. Stalee, $V$. Staley, $V^{*}$.

Arg. on a chev. gu. another of the first. STEER, Ireland.

Arg. on a chev. sa. another of the first. HuGHAM.

Arg. on a chev. sa. another of the first charged with three Moor's heads couped as the second. Fondre.

Arg. on a chev. sa. another of the first cliarged with three bunches of ashen keys ppr. AsHFORD, co. Devon.
On 1 CHEVRON.... cont.

\section{Chevron cont.}

Arg. on a chev. sa. another gu. charged with three escallops of the first. JERnYNGHAM, $W$.

Az. on a chev. or anotber gu. charged with five escallops arg. ? KrNGE, Essex.

Az. on a chev. engr. or another plain of the first. Dudley, co. Berks and co. Buckingham. Duley, co. Buckingham, Harl. MS. 1386, fo. 34 b. DuLY.

Gu. on a chev. or another arg. charged with three escallops sa. HaRDING, King's Newton, co. Derby.

Or on a chev. sa. another arg. charged with three 5 -foils of the second. Strechley, $V$.

Sa. on a chev, arg. another gu. Bawdrick, co. Nottingham.

Sa. on a chev, arg. another nebuly gu. Hankford, co. Devon, $V$.

Sa. on a chev. arg. another gu. charged with three 3-foils slipped or. WAPLODE, $V$.

Arg. on a chev. gu. two chev. (turned up erm. $V^{*}$.) couchant dexter and sinister or. CHENEw, $V$. Cheynew, $V$. Chennow.

\section{Couplecloses}

Arg. on a chev. gu. two couplecloses or. CANne. Canon or Chanon. ChaUn. Crescent

Arg. semy of martlets gu, on a chev. of the last a crescent as the first. MaBUISSON, $V$.

Erm. on a chev. sa. a crescent or. WeLingHam.

Gu. crusily patonce arg. on a chev. of the last a crescent az. M. James Berkele, $S$. Crescents

Arg. on a chev, gu. two crescents of the first. BYGONDS.

Arg. on a chev. az. three crescents of the first. Rush.

Arg. on a chev. az. three crescents or. DENNIS. Thomas Hodgetrs, Rector of Kingswinford, 1741, son of John HodGetTs, Shuttend House, co. Stafford. Stockbreghe. Stockeridge. Storebridge, $V^{*}$. Sr. Denis Stokebrige, $V$.

Arg. on a chev. gu. three crescents or. ATTHILL, Brandiston Hall, Norfolk. Sutron, Lykelnecher, co. Lincoln, $V$.

Arg. on a chev. sa. three crescents of the first. Darward, $V *$. Dyrward Ol Dyrwarne. Falluar, $V$. Fallun or Falyn. Fullumb. Hogh or Hoghe, co. Chester. Mascy, Hogh, $V$. Massey, Houghe. Massey, Hoo, co. Chester. Masseye. 'TaILUM, $V *$. Toncheis. Tothill. The chev, engr. Foston, $V$.

Arg. on a chev. sa. three crescents or. DURward, Norfolk. Durward, Essex, $V$.. Dyrward or Dyrwarne. Fallew. Fallun. Massey, $V^{*}$. Spyney. Syney.

Arg. on a chev. vert three crescents or. Monnies or Morrys. Morris.

Erm. on a chev, ermines three crescents or. WILLINGHAMI.

Erm. on a chev. gu. three crescents .... WALLINGHAII.

Erm. on a chev. sa. three crescents arg. DERTARD.

Erm. on a chev. sa. three crescents or. DEREWARD. DERWARd. DuRward, Essex; and Cloughton, co. York. Disward, $V$.

Gu. on a chev, arg. three crescents of the first. Comham. Dilwyn, until 1731. Norton, Kent.

Gu. on a chev. arg. three crescents sa. Fogelston. John de Foghelston or Foulstone, Kent, $V$. Norton, Kent. 
Crescents cont.

Gu. on a chev. erm. three crescents sa. Norton, Kent.

Gu. on a chev. or three crescents sa. CовналI, Hoo, and Beluncle, Kent, $V$. How, Kent.

Or on a chev. az. three crescents arg. TothiLI. TitTtall, Norfolk.

Or on a chev. az, three crescents of the first. Denrs or Dennys.

$\mathrm{Or}$ on a chev. gu. three crescents of the first. SutTon.

Or on a chev. sa. three crescents arg. Merfyn or Mervyn, lient. Morffin, Kent, $V$. Tottehull or Toutehill, $V$.

Paly of six arg. and gu. on a chev, sa. three crescents as the first. Finche, Ireland.

Cross

Paly of six arg. and sa. on a chev. gu. a cross croslet or. Allestowe, $V$. Cresson, $V$. Curson, $V$. Hareston. Hallestowe, $V$. Crosses

Arg. on a chev. gu. three crosses croslet of the first. Norwood. The crosses patty. PECK, co. Derby ; and Wakefield, co. York.

Arg. on a chev. engr. gu. three crosses couped of the first. Camas.

Arg. on a chev. engr. gu, three crosses croslet of the first. Peake or Peke, co. York. The crosses patty. Pate, Essex. Peake or Peke, co. York. PEck, co. Leicester; and co. Lincolv. Peck, $V^{*}$. Pecke, co. Derby. Serjeant Peck, Norfolk, temp. Charles II. John PEck, Scole, 1655. John Peke, Wakefield, co. York, $V$.

Arg. on a chev. sa. three crosses botonny of the first. William Shorthose, co. York, $V$.

Arg. on a chev. sa. three crosses croslet of the first. Atтowne, Kent, $V$. Shorthose, $V^{*}$. 'Towne, $V$.

Arg. on a chev, sa. three crosses patty or. Beaufeu or Beaufoy, $V$. Beawson. Martin Benson, Bishop of Gloucester 1735-52.

Az. on a chev. engr. sa. three crosses potent or. Robert Gilbent, Bishop of London 1436-18, Add. MS. 12413.

Az. on a chev. erm. three crosses croslet fitchy gu. Reynolds.

Az. on a chev. or three crosses potent sa. Hadsley, Essex.

Gu. on a chev, arg. three crosses croslet fitchy of the first. Drayton. M. John de Wilton, $S$. Wilton, Norfolk. The crosses patonce fitchy. Wilton, $V^{*}$. John Wylton, $V$.

Gu. on a chev. arg. three crosses croslet fitchy sa. Braituwait, Catterick, co. York; and Westmoreland. Brathwayte, Westminster, 1591. Studley, co. Salon.

Gu. on a chev, arg. three crosses tau sq. Prisetr.

$\mathrm{Gu}$. crusily or on a chev. of the last three irosses croslet as the first. Gregorie, Lenton, co. Nottingham. Gregory.

Gu. on a chev. or three crosses patonce of the first. HaDLEY, $V$ *.

Gu. on a chev. or three crosses hotonny sa. AdDelley, $V^{*}$. Adeilley, $V$. The crosses croslet sa. Adley or Adelley, co. Somerset. CobHa d.

Gu. on a chev. engr. or three crosses croslet fitchy sa. SnYTH.

Gu. on a chev. or three crosses croslet flory sa. Hewick or Hewike. The crosses patonce. HADLEY, $V$.
On 1 CHEVRON.... cont.

Crosses cont.

Gu. on a chev. per pale or and arg. thrce crosses croslet fitchy sa. WiLton, Snaresbrook, Es. sex; granted 1768.

Or on a chev. arg. three crosses tau sa. PrISETT, co. Salop.

Or on a chev. gu. three crosses patty of the first. PEck, Samford Hall, Essex; and Wood-Pelling, and Methwould, Norfolk.

Paly of six arg. and az. on a chev. gu. three crosses croslet as the first. Richard Carpenter, Coleford in Newland, co. Gloucester, Harl. MS. 1543, fo. 54. HaLstow.

Paly of six arg. and gu. on a chev. az. three crosses croslet or. CARPenter, London; co. Hertford; co. Gloucester; and Kent. Carpenter, Barony 1719, Viscount Carlingford and Earl of Tyrconnell 1761, extinct 1853 .

Paly of six arg. and gu. on a chev. as the last three crosses croslet or. WYKE, Newport, Es. sex; and Stanton Wyke, co. Somerset.

Paly of six arg. and az. on a chev. sa. three crosses botonny or. Carpenter, co. Hereford and London; Harl. MS. 1442. But crosses croslet. Carpenter, London, Harl. MS. 1358.

Sa. on a chev. arg. three crosses croslet gu. WAISINGHAMT.

Sa. on a chev, arg. three crosses patty fitchy gu. Wilton. But of the first. WiLTon.

Sa. on a chev. or three crosses croslet gu. CoRney.

Az. on a chev, embattled erm. four crosses croslet fitchy gu. RaynoLd, co. Leicester.

Per pale indented sa. and erm. on a chev. gu. five crosses patty or. Mackworth, Gnoll, co. Glamorgan ; Baronetcy 1776; quartering Bulkeley, Evans, Morgan, Deere, and Maddocks. Cup

Erm. on a chev. sa. a covered cup. arg. Chichester, Juord Mayor of London 1369. Cups

Arg. on a chev. sa. three covered cups or, Backwelr, London.

Escallop

Arg. on a chev, az. an escallop of the first. FLEE'TWOOD.

Arg. on a chev. sa. an escallop of the first. John Feewood or Frewod, $V$. Freewood.

Arg. on a chev. sa. an escallop or. NewLand, Essex. Escallops

Arg. on a chev. compony of the first and gu. three escallops of the first. ExMEw.

Arg. on a chev. gu. three escallops or. Sire Neel de Salford, $O$. Tully, Ireland.

Arg. on a chev. gu. fimbriated engr. sa. three escallops of the first. JERnynghadi, $W$.

Arg. on a chev, per pale az. and gu. three escallops of the first. Joce, Suffolk.

Arg. on a chev. per pale vert and gu. three escallops of the first. Jove.

Arg. on a chev. sa. three escallops of the first. Ballowe, Collinson, Somerset, iii, 176. HaNCKWOOD. HaRECOURT, $V^{*}$. M. John HAWkEWODE, $S$. HAWKEWOOD, $V^{*}$. Oliver KING, Bishop of Exeter 1493, Bath, etc. 1496 1503, Add. MS. 12443. Sir William Merynge, Harl. MS. 6137, fo. 44 .

Arg. on a chev. sa. three escallops or. Gunvill. Harconte, $V$. Harecort, $V$. Hatiewood, $V$. Mearing Meering Mering or Meryng, co. Nottingham. Mering, $V^{*}$. Sr. William Merynge, $V$. 


\section{On 1 CHEVRON....cont.}

Escallops cont.

Arg. on a chev. indented sa. three escallops of the first. Burton, Ireland, $W$; and Harl. MS. 1404, fo. 27.

Az. on a chev. arg. three escallops of the first. Prinole, Clifton, co. Roxburgh; and The Haining, co. Selkirk.

Chequy arg. and gu. on a chev. sa. three escallops of the first. M. Thomas Bekerynge, $S$. The escallops or. Beckering. Bekering, $W$.

Chequy or and az. on each piece an ermine spot counterchanged on a chev. gu. three escallops ppr. WaLKER, Uppingham, co. Rutland.

Erm. on a chev. gu. three escallops arg. Atgrove. Bellew, co. Chester. Bellewe, $V$. boldsworth. Golbore, $V^{*}$. Golborne, $V$. Grove, co. Buckingham, $V$. Groves, $V *$. The chev. engr. Grove, Grove Place, co. Buckingham; and London.

Erm. on a chev. gu. an escallop or betw. two others arg. Brodnell. The chev, engr. Grove, Dunhead, co. Wilts.

Erm. on a chev. gu. three escallops or. Betray. Grove, Shaftsbury, co. Dorset; Agmondesham, co. Buckingham; Fern House, co. Wilts; Woodford, and Walbury, Essex; and Groveshot. The cbev. engr. GLover, co. Wilts; Edmondson. Grove, Odstock, co. Wilts. Robert Grove, Bishop of Chichester 1691-6.

Erm. on a chev. sa. three escallops arg. RETBX. Thomas de Retrond, Asby, $X$.

Or on a chev. sa. three escallops arg. Mering, co. York.

Or on a chev. engr. sa. three escallops of the first. Robert KING, Bishop of Oxford 1542-57.

Per pale arg. and sa. on a chev. three escallops counterchanged. William Crakey or Crokey alias JoHnsone, co. York; granted 4 June 1496 , Harl. MS. 6169 , fo. 1 .

Per pale gu. and sa. on a chev. engr. arg. three escallops az. Browne, Harl. MS. 1404, fo. 26.

Sa. on a chev, arg. three escallops of the first. King, $V^{*}$; and co. Leicester. Kynge, Suffolk, $V$. The chev. engr. KING, co. Wilts. King, Ashby Hall, co. Lincoln. Kinge, co. Lincoln. Ring.

Sa. on a chev. erm. three escallops gu. KING, $V^{*}$, and London. Alexander KINGE, London; granted $15.92, W$.

Gu. on a chev, arg. three escallops of the first. Handing, King's Newton, co. Derby.

$\mathrm{Gu}$. on a chev. arg. fimbriated or three escallops sa. Harding, King's Newton, co. Derby; granted $3 \mathrm{July} 1711$.

Az. on a chev. gu. voided or five escallops arg. KINGe, Essex.

Escucheon

Gu. on a chev. arg. three shields of the first. Wardrop, Torbanhill, Scotland.

\section{Estoile}

Vert on a chev. or an estoile of eight points betw. two roses gu. CrawLix. The roses seeded and barbed ppr. Crowley.

Vert ou a chev. or an estoile of sixteen points betw. two roses gu. Crawley or Crowley, Middlesex; granted 14 June 1707.

\section{Estoiles}

Arg. on a chev. az. three estoiles or. EDmonds, co. Oxford.

Arg. on a chev. gu. three estoiles of the first. LANGLANDS, That Ilk.

Arg. on a chev. sa. three estoiles or. Sire Ieignold Cobhair, Q, Harl. MS. 6595 .

\section{On 1 CHEVRON.... cont.}

Estoiles cont.

Erm. on a chev. per chev. sa. and az. three es. toiles or. Wigston or Wiaton, co. Worcester. Gu. on a chev. arg. three estoiles sa. Bog. Carr or Carre, Hetton, and Ford, co. North. nmberland. KaSSYE or KaYRE, co. Northumberland. And with in chief a martlet or charged with a crescent sa. CARR, Bristol. But with only a crescent in chief for diff. $\mathrm{Sr}$. John Care, $V$. Carr, $V^{*}$.

Gu. on a chev. or three estoiles sa. Carr, Slea. ford, co. Lincoln; and co. Lancaster. Baron Совнам, $Z, 316$. Sr. Reginald Совнам, Ster. burgh, Surrey, $V$. Sire Rejnold Coвнам, $Q$, Harl. MS. 6589. And with a label of three points or. Syr John Cовнам, $Q$.

Gu. on a chev. or three estoiles vert. Coвнam, Kent.

Lozengy erminois and az. on a chev. gu. three estoiles or. Wraxald, Wraxall, co. Somerset; Baronetcy 1815 .

Or on a chev. az. three estoiles of the first. EDMonds, co. Oxford.

Per chev. erm. and ermines (anotber, sa.) on the upper part of a chev. per chev. sa. and arg. three estoiles or. William Wigston, Leunerlyda or Lunerleyda, co. Leicester, $V$.

\section{Fess see Bar}

\section{Fishes}

Arg. on a chev. az, three fishes naiant of the first. Penalles, $V *$. Pennalles, $V$.

Arg. on a chev. az. three fishes one haurient and two chevrouways respecting each other of the first. William Pennylues, Breksham, co. Devon, $i$. Penyless, $V^{*}$.

Arg. on a chev. az. three fishes or. Penniles, Lupton, co. Devon; the heiress m. Upton.

$$
\text { .... Dolphins }
$$

Gu. on a chev. engr. arg. three dolphins naiant embowed vert. Ralph Flambard, Bishop of Durham 1099-11:28. Flambert, $V$. Flambert, co. Cambridge; and Essex.

$$
\text { ......Trouts }
$$

Arg. on a chev, az. three tronts of the first. TROSSKILLIARD.

Fleur-de-lis.

Arg. on a chev. az. a fleur-de-lis or a label of three points gu. Sire Adam de Sueingrune, N. But tricked no fleur. Sr. Hewgh de Swerington, co. Yolk; Harl. MS. 6137, fo. 22.

Arg. fretty gu. on a chev. of the second a fleurde-lis or. HAMELYN.

Arg. on a chev. sa. a fleur-de-lis of the first. Alfray, Sussex, $W$. Alfrey, Gulledge, in East Grinstead, Sussex. WANTON.

Arg. on a chev. sa. a fleur-de-lis or. Carver. Flenrs-de-lis.

Arg. on a chev. az. three fleurs-de-lis of the first. Penwallis.

Arg. on a chev. az, three fleurs-de-lis or (corrected in margin to Arg. a chev. az. and a label ....). Sr. Adam de Swerington, co. York, $N$, Harl. $M S .6137$, fo. $21 \mathrm{~b}$.

Arg. on a chev, az. three fleurs-de.lis or. Bourghope. Bromsor Bronghore or Bronhop, co. Buckingham and co. Berlis. Burghepp or Burghopp, $V^{*}$. Burhope. Burghepp and Brovgheppe, $V$, Colton MS. Tiberius D 10. Burgher and Burghopp, $W$. Eluick, Middlesex. Elwick. Penrey. Peverell. Sire Roger Perve, N. And with a label of three points gu. Adam Suenigton, N, Harl. MS. 1380 , fo. 46 . 
On 1 CHEVRON.... cont.

Fleurs-de-lis cont.

Arg. on a chev. gu. three fleurs.de-lis of the first. Sr. John PEYer, co. Bedford, Cotton MS. Tiberius D 10.

Arg. on a chev. gu. three fleurs.de-lis or. Madoc ap Hendwr. Lloxd, Baron of Hendwr in Edeirnion, co. Merioneth. LLoyd, Tyfos ynEdeirnior, co. Merioneth. Paver, Braham Hall, and St. Nicholas Honse, co. York; quartering Markenfield, Woodburne, Woodroffe, Percy, Spencer, Beaufort, etc. Penrey. Peper. Pever, co. Bedford. Peyner. John Peyver, $Y$. Thomas Peyver, $Y$. Sire Johan Peyvre, $N$.

Arg. on a chev. engr. gu. three fleurs-de-lis of the first. Wansborousgh.

Arg. on a chev. sa. three fleurs-de-lis of the first. Alfrey, Sussex. Wevell.

Arg. on a chev. sa. three fleurs-de-lis or. PENN, co. Buckingham. Tracy. Tubb, Cornwall. WYKWAN.

Barry wavy of six erm. and gu. on a chev. az. three fleurs-de-lis or. MedLey, co. Somerset.

Chequy or and gu. on a chev. az. three fleurs-de. lis of the first. Boterells. Botrells, $V$. Bottrells, $V *$, or Botreld, co. Salop.

Chequy or and gu. on a chev. of the second three fleurs-de-lis as the first. Botreld, co. Salop.

Erm. on a chev. gu. three fleurs-de-lis arg. Buvd, Ireland.

Erm. on a chev. gu. three fleurs-de-lis or. DANBY, $W$.

$\mathrm{Gu}$. on a chev, arg. three fleurs.de-lis az. Coвнam, Kent.

Gu. crusily fitchy arg. on a chev. of the last three fleurs-de-lis as the first. BARLEY.

$\mathrm{Gu}$. crusily patty arg. on a chev. of the last three fleurs-de-lis sa. Berkeley, $V$.

Gu. on a chev. or three fleurs-de-lis az. Coвнair, Couling, Kent, $W$. Sire Henri de Coвhant, $N$. John Cobhant, $Y$. Thomas de Coвнait, Bishop of Worcester 1317.28.

Or on a chev. per pale arg. and gu. three fleurs. de-lis counterchanged. Freeman, $V^{*}$.

Sa. on a cbev. arg. three fleurs-de-lis .... Pendred, co. Northampton; and Broghelstown, Saunders Grove, and Barraderry, co. Wicklow.

Vair on a chev. gu. three fleurs.de.lis or. Budd.

Arg. on a chev. sa. five fleurs-de.lis of the first. BaBthoRPE. BaLTHORPE.

Or on a chev. sa. five fleurs-de-lis arg. Anton.

Arg. on a chev. gu. fleurs-de-lis or. William Peyter, $B$.

Flower .... Rose

$\mathrm{Gu}$. on a chev. arg. a rose betw. two lions pass. combatant of the first. Herbern, Humbie, and Wanghton, Scotland. Hepburn, Smeaton, co. Haddington; Baronetcy 1815 ; quartering Buchan and Beck. HePBund, Kent; quartering the same with Grabam and Rickard. Hepburn, Colquhalzie, co. Perth; quartering Stewart.

Gu. on a chev. or a rose of the first betw. two mullets sa. Spoure, Northill, co. Cornwall. The mullets pierced. Spoure, Trebartha, co. Cornwall; the heiress m. Bellot and Grylls.

Gu. on a chev. or a rose of the first betw. two spur rowels sa. SpurRe, Cornwall.

Flowers .... Roses

Arg. on a chev. az. two roses of the first. Cock. Arg. on a chev. gu. three roses of the first. Brooe. Brow, co. Devon, $V$. Browne, Marsh, co.Derby, 1582. Gilbert. Knolies, co.Chester.
On 1 CHEVRON.... cont.

Flowers cont. Roses cont.

Arg. on a chev, sa. three roses of the first. CARR. Gilbard, co. Devon. Gimbard or Gilbart. Gilbert, Greenway, co. Devon.

Arg. on a chev. sa. three roses or. WadHaM, co. Devon, $V$.

Arg. on a chev. sa. three roses or. Ralph Pansons, ob. 1478, in church at Cirencester.

Az. on a chev. arg. three roses gu. Blackader, Blackader, and Tulliallan; Baronetcy 1626; quartering Home or Hume, Pepdie, and Sinclair; the heiress m. Oliphant. Blackadder. Russeli.

Az. on a chev. arg. three roses vert. Merryton. Az. on a chev. or three roses gu. Sr. William Rossell, co. Rutland, temp. Edward I, $V$. Russell, $V^{*}$.

$\mathrm{Az}$. on a chev. or three roses gu. leaved vert. Gilbonne, Kent; and London.

Chequy arg. and gu. on a chev, az. three roses of the first. VAUX, Harowden; and (in error) Triermain.

Chequy az. and arg. on a chev. of the second three roses gu. Lard VAUX, of Harrowden.

Chequy or and gu, on a chev, az. three roses arg. VAUx, Triermain (in error). But the roses gold. Vaux, Harowden, as quartered by Lord Mostyn.

Erm. on a chev. az. three roses gu. Mower, Woodseats, and Holt House, in Darley, co. Derby ; Lysons. The roses or. Hays. MOORE, Devon, $V$.

Erm. on a chev. gut. three roses arg. Criduand, co. Somerset. The roses or. Fochebury, co. Bedford. Scepter. Skepper, Durham, 1615. Erm. on a chev, sa. three roses arg. GILBARD or Gilbert, co. Devon. Gilbert, $V$.

Gu. on a chev. arg. three roses az. Drayton, Norfolk.

Gu. on a chev. arg. three roses of the first. Blackader, Fallahall. Brooe. Brow or Browe, co. Hertford. Sr. Robert Knol.tes, $S ; V$. KNoLLys, Barony 1603 ; Viscount Wallingford 1616, Earl of Banbury 1626, extinct 1632. KNoLs KNOLLYS or KNowles, co. Chester, 1716. Robert Knowles, $X$. Sr. Robert Knowls, temp. Richard II, in church at Harpley, Norfolk. And with in chief a crescent or charged with a mullet sa. KNowles, Aylesham, Norfolls. The roses barbed and seeded of the first. KNoLLS or KNowls, co. Chester; Chisping, co. Lancaster; and Chipping and Harpley, Norfolk.

Gu. on a chev. arg. three roses of the first seeded or. M. Hugh de Browe, S. Drew. But barbed and seeded ppr. Drew, 1496. And wilh a crescent for diff. KNOLLES, in church at Sprowston, Norfolk.

Gu. on a chev. or three roses az. Drayton, Norfolk.

Or on a cliev. az. three roses of the first. HaDDow, Scotland. FinMPNEY, co. Worcester, 1716.

Or on a chev. embattled gu. three roses of the first slipped vert. AisLan Aslin or AsLyN.

Or on a chev. per pale az. and gn. three roses of the first. Rompney or RunpNey, Luldrey, co. Worcester. Rowney. RUMNEY.

Vert on a chev. arg. three roses gu. Crowley or Crowly, Middlesex.

Vert on a chev. or three roses gu. slipped and leaved of the first. InMan. The roses ppr. INIIAN, Chesterfield, co. Derby. 
On I CHEVRON...... cont.

Flowers cont. Thistles

Az. on a chev. or three thistles ppr. Robis, Grove Hill, co. Chester, and Tan-y-graig, co. Denbigh.

3-Foil

Erm. on a chev.gu. a 3-foil slipped or. MaLoree, $V^{*}$.

3-Foils

Erm. on a chev. engr. sa. three 3-foils or. HAYTFIELD.

Gu. on a chev. arg. three 3 -foils slipped of the first. Drulwyn, Burrough's Lodge, and Sketty Hall, Swansea, confirmed 1731 .

Gu. on a chev. arg. three 3-foils sa. Letrice.

$\mathrm{Gu}$. on a chev. arg. three 3-foils slipped sa. Dering. Dewin. Dewre, $V$.

Sa. on a chev, arg. three 3-foils slipped vert. Davies. Davrs, Baron and Viscount Mountcashel 21 January 1705-6, extinct 1736.

Sa. on a chev. gu. three 3-foils slipped or. WaPLODE. Whaplode.

Sa. on a chev. gu. fimbriated arg. three 3-foils slipped or. WAPLODE, $V$.

Vert on a chev. arg. three 3 -foils of the first. ShadForth, Eppleton, Durham.

Vert on a chev, arg. three 3-foils slipped of the first.

Balcaskte. Mickieton, Crook Hall, Durliam. 4-Foil

Arg. on a chev, sa. a 1 -foil of the first. TrewLove. 4-Foils

Arg. on a chev, gu. three 4-foils of the first. Matreew, $V^{*}$. 'The 4 -foils blind. Mathew, $V$.

Arg. on a chev. sa. three 4-foils of the first. Eyre, Earl of Newburgh; quartering Radcliffe and Livingston.

Arg. on a chev. sa. three 4-foils or. ArRe, co. Lincoln; and Isle of Ely. Erre, Bromham, Wedhampton, Chaltield, New Sarum, Brickworth, Chilhampton, Newhouse, etc., descended from Le Heyr, Bromham, co. Wilts. Eyre, Botley Grange, co. Hants. Eyres, Eyre Court Castle, co. Galway. Eyre, Mount Hedges, and Nacroom Castle, co. Cork ; quartering Maunsell. Eyre, Collinson, Somerset, i, 265. Eyre, Hope, Padley, Hirst, Hassop, Holm Hall, Chesterfield, Newbold, etc., co. Derby; Keveton and Laughton, co. York; and Rampton, and Grove, co. Nottingham. Erer or Hyer, co. Derby, Cotton MS. Tiberius D 10. Robert Trewlone (? Trewlore) $X$. The 4foils blind. EYER, co. Derby, $V$.

Arg. on a chev. sa. three 4-foils slipped or. EAKE. Erm. on a chev. sa, three 4-foils or. Winstow.

Erm. on a chev. engr. sa. three 4 foils or. Wynslow, $V^{*}$. The 4 -foils blind. Wynslowe, $V$. 5-Foil

Per pile az. and or on a chev. arg. a 5-foil of the first. MuLLER.

Gu. on a chev. arg. a 5 -foil betw. two lions counter-pass. of the first. HEBboRn. HEBORNE, co. Chester. And with in the dexter corner an annulet for diff. or. HEPBORNe alias Richardson, Tottenham High Cross, Middlesex, 1608. 5-Foils

Arg. on a chev. az. three blind 5.foils of the first. John Westby, Westby, co. York; and Mowberk, co. Lancaster; granted $1560, W$. The 5 foils pierced. Westby, Thornhill, co. Dublin; and High Park, co. Wicklow; quartering Neville; descended from Westby, Mowbreck, co. York; and Pawcliffe, co. Lancaster.
On 1 CHEVRON..... cont.

5.Foils cont.

Arg. on a chev. gu. three 5-foils ppr. Erres, Norfolk.

Arg. on a chev. 8a. three 5-foils of the first. Freston, Norfolk; and Suffolk. Froston, Suffolk, $V$. Richard Mayeli, $V$. Maynell. The 5-foils pierced. Gillibande.

Arg. on a chev. sa. three 5-foils or. Erre, Din. ston, Laughton, Kiveton, Rampton, Grove, etc., Richard Parcy, $V$. Trewlove.

Az. on a chev. or three pierced 5-foils gu. CruLL. Az. on a chev. or three pierced 5-foils sa. HAwEs.

Chequy arg. and gu. on a chev. az. three 5-foils (arg. Cotton MS. Tiberius D 10.) or. Lord Vaulx, Harowden, co. Northampton, $\boldsymbol{V}$.

Erm. on a chev. az. three 5-foils arg. John Moone, Bishop of Norwich 1691, Ely 1707-14.

Erm. on a chev. az. three 5-foils or. Moore, Collumpton, co. Devon, $W$; the heiress $m$. Blackmore.

Erm. on a chev. gu. three 5-foils or. More, co. Devon. SKEPPER, co. Lincoln, 1730.

Erm. on a chev. sa. three 5-foils arg. HatField. Hatfeild, Hatfeild Hall, co. York. Haytreid, V. HaYTFIELD.

Erm. on a chev. sa. three 5.foils or. CoRINGE, $V^{*}$. Robert Coryngs, $V$. Hadfield, The chev. engr. Hajipden. Hatfied, Twickenham, Middlesex. Hatrield, Hatfield, and Laughton en le Morthen, co. York. Haytfeid, $V$. Haytfield. Hercey, $V$. Hercy, $V^{*}$.

Gu. on a chev. arg. three 5.foils az. Coвнayr. The 5-foils pierced. Crofts. Crosth.

Gu. on a chev, arg. three 5.foils sa. Dewing, Carbrooke, Norfolk. DEwin or DEwYN. Levington. The 5-foils slipped. Dewen.

Gu. on a chev. arg. three 5-foils vert. G GFF.

$\mathrm{Gu}$. on a chev. or three 5 foils az. CoBHaM, $V$. SoMERFord, co. Chester. The 5-foils pierced. Cobhar.

Gu. on a chev. or three 5-foils of the first. CовнаM.

Gu. on a chev. or three 5-foils vert. CовдаM.

Or on a chev. arg. fimbriated sa. three 5-foils of the last. Strechiey, $V$.

Or on a chev, az. three 5-foils of the first. Froon, Bramber Hill, Honiton, co. Devon. StREchiy, co. Devon.

Or on a chev. sa. three 5-foils..... Stretchley, co. Dorset.

Paly of six arg. and sa. on a chev. gu. three 5foils or. Stradiing, Wales.

Vert on a chev. arg. three 5.foils gu. Crulise, $V$. Cunle, $V *$.

Vert on a chev. or three pierced 5-foils gu. Curley.

\section{Fret}

Arg. on a chev. gu. a fret (wine-broach or piercer) of the first. ClaphaM, $V$.

Per pale indented erm. and sa. on a chev. gu. fretty or. MACKWORTH, $V$. BERNARD's INN, London.

Per pale indented sa. and erm. on a cher. gu. fretty or. Mackworth, Mackworth Castle, co. Derby; Baronetcy 1619.

\section{Fruit....Acorns}

Arg. on a chev, az. two acorns or. Ataster.

Arg. on a chev. az. three acorns ..... Grosetr. Arg. on a chev. sa. three acorns or. AkAster, $V^{*}$. Codenley or Cudderley, co. Derby. The acorns slipped. Akaster, $V$. 


\section{On 1 CHEVRON.... cont.}

\section{Fruit cont. Acorns cont.}

Or on a chev. gu. five acorns of the first. PALmer, Stepney, Middlesex; co. Northampton; and Kingston-upon-Hull; confirmed 3 May, 1670.

$$
\text { .... Pears }
$$

Arg. on a chev. gu. three pears or. Penton, Barndsley, co. Salop. Purton, Faintree, co. Salop; quartering Pardoe; descended from Purton, Purton, co. Stafford.

$$
\text { .....Pomegranates }
$$

Or on a chev. gu. tbree pomegranates of the first. Colney, Hampshire.

\section{Garbs}

Arg. on a chev. az. three garbs or. CRadock ap Howell ap Grono, Iord of Newton in Rouse; quartering Delamere, from whom descended Sir Richard Cradock alias Newton, 1482; Baronetcy 16 August 1660; extinct 6 April 1743 ; quartering Delamere, Perret, and Barr. Another branch quartered Delamere, Perret, and Chedder. M. Richard Craddor, $S$. Sr. Davy Cradock, $V$. Newton, $V$; and Collinson, Somerset ii, 157 ; iii, 589 . Newton, Richmond Castle, co. Somerset; granted 12 Dec. 1569 ; quartering Sherborne, Angell, Pirot, Harry, Shedder, Hampton, Bitton, Furneaux, Gawdescot, Gurney, and Hawtrey.

Arg. on a chev, az. three wheat sheaves or. Clementson.

Arg. on a chev. gu. three garbs or. Combe, $V$. RUFFy.

Arg. on a chev, sa. three garbs or. HANCLER, Cotton MS.Tiberius D 10. Hanclow. Haneler. Haucler, $V$. Hutaker or Huttaker. Hwatacre, $V^{*}$. Hwataker, $V$. Watker, $V^{*}$. Erm. on a chev. gu. three garbs or. Chadiberlaine. Thomas Schefreild, $Y$. SHEFFIELD.

Gu. on a chev, arg. three garbs of the first. QUESTRED.

Gu. fretty arg.on a chev. az. three garbs or. BAnoN. Or on a chev. sa. three garbs of the first. WaLkER, co. Derby, $W$.

\section{Gonttes}

Arg. on a chev. sa. three gouttes d'eau. Notingham or NotTingham.

Arg. on a chev. sa. three gouttes d'or. AtHill, $V^{*}$. William AtHYLL, $V$. Hannoys, $V$. Harvys. And with a crescent in the sinister chief gu. Sr. Walter Hannoys, $W$. Walter Hernors, Cotton $M S$. Tiberius D 10.

Arg. on a chev. engr. sa. gouttes of the first. Notingham, $V^{*}$. Nottingham, Harl. MIS. 1386 , fol. 35. NotYNGHaM, $V$.

Arg. on a chev. sa. gouttes d'or. ÁtheL, co. Northampton. Harneys or Harnous, co. Bedforà. The chev. engr. sa. Nottingham.

Chequy or and sa. on a cher. arg. gouttes de sang. Colshili, $V^{*}$. COLSELL.

Hammers

Arg. on a chev. sa. three hammers with claws of the first. Haltom or Haltun. Halton, $V$. Hand

Or on a chev. gu. a hand extended fesswise arg. Mainstone.

\section{Hands}

Arg. on a chev. sa. three gauntlets or. Scot.

Erm. on a chev. gu. three sinister hands couped arg. Maldiaynes.

Head..... (Beast) Boar

Arg. on a chev. sa. a boar's head of the first. ROKEWELL.

\section{On 1 CHEVRON.....cont.}

Head cont. (Beast) Leopard

Arg. on a chev. gu. a leopard's face of the first. Boultoun, Suffolk.

$$
\text { .....Iion }
$$

Arg. on a chev. gu. a lion's head or. Bolton or Boulton.

$$
\text { ..... Otter }
$$

Arg. on a chev. sa. an otter's head erased of the first. BaIfour, Ireland, a branch through Balfour, Burleigh, Barony 1607, of Balfour, Pittendreich. BaLfoun, Balfour, co. Fife; the heiress m. Bethune. Balfour, Grange. Mecdnum, Segie, Scotland.

Sa. on a chev. or an otter's head erased as the first in chief a label of three points gu. BaLFour, Ballow.

$$
\text { .... Human Figure. }
$$

Arg. on a chev. wavy sa. a humau skull ppr. (The uncient arms of) Cust, Belton, co. Lincoln.

\section{Heads ..... (Beast) Boar}

Arg. on a cliev. sa. three boar's heads or. Sire Thomas de Swyneford, $N$. Norman Swynford, $X$. And with a 5 -foil for diff. in the dexter chief gu. Monsire Norman de Swinford, $Y$. Arg. on a chev sa. three boar's heads couped or. Norman, Kent. Swinford, co. Huntingdon. Swynboune. The heads fesswise. Sr. Thomas SwYNFord, co. Huntingdon, $V$. And with a 5-foil in the dexter chief gu. Sr. Norman SwYNFord, Essex, $V$.

$$
\text { ..... Deer }
$$

Arg. on a chev. sa. three buck's heads cabossed of the first. Elerton. Ellerton.

Arg. on a chev. sa. three stag's heads couped or. John Ragane, $X$.

Erm. on a chev. az. three buck's heads or. Ferington. The heads cabossed. Cervington. Servington or Serrinton, Tavistock, co. Devon; the co-heirs $m$. Croker and Savery. Scrivington, Southampton.

Erm. on a chev. sa. three stag's heads or. Servington.

Erm. on a chev.sa.three buck's heads cabossed or. Servington. Sermington or Syraington, $V *$. Erm. on a chev. sa. three stag's heads cabossed or. Sirmington, $V$.

Sa. on a chev. vert three buck's heads cabossed arg. BuckToN.$$
\text { ....Fox }
$$

Erm. on a chev. az. three fox's heads erased or. Fox, Little Eppleton, Durham.

Sa. on a chev, arg. three fox's heads couped gu. Colfox.

\section{.....Horse}

Arg. on a chev. sa. three horse's heads couped erect of the first. Corsen, $V$.

$$
\text { .....Leopard }
$$

Arg. on a chev. az. three leopard's faces or. Gower, London. Lovely. Pyrton. The faces langued gu. John Gower, 1400, in church of St. Saviour, Southwark.

Arg. on a chev. gu. three leopard's heads of the first. BoLton or Boulton.

Arg. on a chev. gu. three leopard's faces or. Bolton or Boulton.

Arg. on a chev. sa. three leopard's heads jessant fleurs-de-]is of the first. Canlery, $V$. CuUley, Cowley, $V^{*}$. Cowisy, Amsterdam, 1606.

Arg. on a chev. sa. three leopard's heads or. Coneley. Cowley, $V^{*}$. Leveroy. Norman. Weston, Heath Ham, co. Dorset. Weston, Couley, $V$. 
On 1 CHEVRON..... cont.

Heads cont. (Berst) Leopard cont.

Arg. on a chev. vert three lenpard's faces or. Foster, $\mathrm{W}$; and Northumberland.

Az. on a chev. or three leopard's heads gu. Gower.

Az. on a chev. embattled or three leopard's heads sa. Harvy, London.

Erm. on a chev. az. three leopard's heads or. Temperly, $V^{*}$. Temperley, $V$. Powerton, Essex. The chev. engr. PYrton, Essex, $V$.

Erm. on a chev. az. three leopard's heads jessant fleurs-de-lis or. Templey, Suffolk.

Erm. on a chev. gu. three leopard's heads or. Prestwich, London.

Erm. on a chev. gu. three leopard's heads jessant fleurs-de-lis or. Cantelow. Cantelupe, London, $V$.

Erm. on a chev. sa. three leopard's lueads jessant fleurs-de-lis or. Cautlow, London. Cooley.

Erm. on a chev. engr. sa. three leopard's heads or. CREEn, co. Wilts; granted 4 June 1663.

Or on a chev. vert three leopard's beads (arg. another) of the first. INGE, co. Leicester; and Thorpe Constantine, co. Stafford. INGE, $V^{*}$. JUGE, co. Leicester.

Per pale sa. and gu. on a chev. engr. or and erm. three leopard's frces of the second. Crend.

Sa. on a chev. arg. tluree leopard's faces jessant fleurs-de-lis of the first. Cowler.

Vert on a chev..... three leopard's faces .... O'KerIN.

$$
\text { .....Lion }
$$

Arg. on a chev. sa. three lion's beads erased of the first. Harbenger, $V^{*}$. WARD, $V^{*}$; and Berkshire. WaRDE, the Harbenger, $V$.

Az. on a chev, arg. three lion's beads erased .... HoRSEFIELD or HoRSFORD.

Gu. on a clev. arg. three lion's heads erased sa. TuRPIN, Knaptoft, co. Leicester.

Sa. on a chev. arg. three lion's heads erased erminois. Richarison, Ferring, Sussex.

Sa. on a chev. arg. three lion's heads erased of the first. Horspoole, Maidstone, Kent. Valentine, co. Hereford.

Sa. fretty or on a chev. az. three lion's heads erased of the second. BELEW or BELlowes, co. Lancaster.

$$
\ldots .0 x
$$

Arg. on a chev. sa. three bull's heads cabossed of the first. Hrllersdon, Hillersdon, and Membland, co. Devon. Hrhlesdon, Elstow, co. Bedford; and co. Devon. The heads armed or. Hillesdon or Hillesford, co. Devon. Hillersdon, $V^{*}$. Hillesdon, $V$.

Erm. on a chev. az. three bull's heads or. Servinton, co. Devon.

Erm. on a chev. sa. three bull's heads or. Servington.

$$
\text { ..... Sheep }
$$

Arg. on a cher. a7. three ram's heads couped or. WerdishaLLER, $V *$. WERDISSALLER, $V$.

Arg. on a cher. gu. three ram's beads (of the first, another) cabossed of the first attired or. Augustinian Abbey at Cirencester, co. Gloucester.

Gu. on a chev. arg. three ram's heads cabossed sa. attired or. Augustinian abbey at Cirencester, co. Gloucester.

$$
\text { ....(Bird) }
$$

Or on \& chev. vert three bird's heads erased or. Crawrurd, Northumberland.

\section{On 1 CHEVRON.... cont. \\ Heads cont. (Bird) Cock}

Or on a chev. gu. three cock's heads erased arg. combed and wattled of the first. Phillips, Chelmicke, co. Salop.

\section{..... Crow}

Arg. on a chev. az. three raven's heads couped or. WERDYSALLERE.

$$
\text { .... Eagle }
$$

Or on a chev. engr. sa. three eagle's heads erased arg. Philips or Phillips, co. Dorset; and London; confirmed 10 December 1633. Philips or Phillips, Barnstaple, co. Devon.

Or on a chev. vert three eagle's heads erased arg. Craford, Northumberland.

$$
\text { .... Falcon }
$$

Or on a cher, az. three falcon's heads erased of the first. FarhiLl, Chichester.

Or on a chev. gu. three falcon's heads erased arg. PhILIPs, Leominster, co. Hereford.

Or on a chev. sa. three bawk's heads couped arg. Hartridge, Kent; and Tyshurst, Sussex. The beads erased arg. Craford, Kent.

Or on a chev. vert three (falcous, $V^{*}$ ) hawk's beads erased arg. CrafoRD, Essex; and Mongham, Kent. Sr. Wm. Crafford, $V$.

\section{....Haman Figure}

Arg. on a chev. gu. three dead men's skulls of the first. Bolter.

Arg. on a chev. sa. three close helmets or. IRELAND.

Arg. on a chev. sa. three esquires helmets or. \кот, $V$.

Arg. on a chev. sa. three headpieces or. Scot.

Arg. a chev. voided sa. in the voidure three Moor's heads couped of the second. Fondre. Gu. on a chev, arg. three old men's heads ppr. affronty habited in close caps sa. SAGE.

Or on a chev. gu. three dead men's skulls of the first. BoLTER, 1730.

$$
\text { .... (Monster) Griffin }
$$

Arg. on a chev. sa. three griffin's heads erased of the first. Linley, Shegby', Scotland. Linley, $V^{*}$. Percivali, $V^{*}$.

\section{.... Unicorn}

Arg. on a chev. sa. three unicorr's heads erased of the first. Atkins, Fountainville, and Firville, co. Cork; quartering Ringrose, Prestwich, Going, Hastings, and Minnitt. ATKYNs, Yelverton, Norfolk.

Or on a chev. sa. three unicorn's beads erased arg. HoLl, Malton, Norfolk.

\section{Hearts}

Gu. on a chev. .... three hearts of the first. Thornton, Scotland.

\section{Horns}

Arg. on a chev. az. a pair of buck's horns or. SwILlington, co. Leicester.

Az. on a chev. or a pair of stag's horns affixed to a scalp sa. Vereker, Baron Kiltarton 1810, Viscount Gort 1816, quartering O'Connell, Prendergast, and Smith.

\section{Horseshoes}

.... on a chev. .... three horseshoes .... Cis. tercian Abbey at Fountains, co. York.

Arg. on a chev. sa. three borseshoes of the first. Tegall, $W$. Tegalile.

Arg. on a chev. sa. three horseshoes or. Crispe, London.

Chequy or and gu. on a chev. az. three borseshoes arg. Sire Renaud de Boterels. N. Reginald Botereux, $V$. Botreaulx or Botreux, co. Devon. Reinaud de Botereus, E, Harl. 


\section{On 1 CHEVRON.... cont.}

Horseshoes cont.

MS. 6137 ; but D'Estereus, F, Harl. MS. 6589. The borseshoes of the first. Boterell, Cornwall.

Erm. on a chev. sa. three horseshoes or. Tyghati, co. Hants.

Or on a chev. gu. three borseshoes arg. CRippis.

Vert on a chev, arg. three horseshoes sa. Crispe, Kent.

Arg. on a chev, sa. five horseshoes of the first. Chrisop or Kinsop. The horseshoes or. Crispe, Alderman of London, $W$. Crispe, Hammersmith, Middlesex; Baronetcy 1665; extinct 1740.

Or on a chev, sa. five horseshoes arg. Crisp, $V^{*}$. Sir Henry Crispe or Crippes, Thanet, Kent; $V$, and Cotton IIS. Tiberius D 10.

Or on a chev. sa. five horseshoes of the first. CrIspe, Queeks, and clive Court, Thanet, Kent.

Or on a cliev. vert five horseshoes arg. CRIPPS, Homestall, Sussex; granted $25 \mathrm{July} 1602$. The horseshoes of the first. CrIPPs, Cirencester.

Vairy or and gu. on a chev. az. three horseshoes arg. Renaud de Botereus, $F$.

Vert on a chev, arg. five horseshoes sa. CRISPE, Kent.

\section{Human Figures}

Arg. on a chev. sa. three angels kneeling habited in long robes close girt their bands conjoined elevated upon their breasts wings displ. or. MAELOR Cirwm, Lord of Llechwidd-isaf and Creuddyn, co. Caernarvon. MaLeock, Wales. Instrument

Arg. on a chev. gu. a fret (wive-broach or piercer) of the first. Clapham.

Keys

Arg. on a chev. sa. three keys each ensigned with a coronet or. IckAMr, Canterbury.

\section{Knot}

Or on a chev. gu. a true-lover's krot of the first. Town of STAFFord.

\section{Iozerges}

Arg. on a chev. gin. three lozenges of the first each charged with a cross croslet sa. AlLEN. Allyn, $V^{*}$. Aslyn, $V$. (? Cornish, London.)

Arg. on a cher. gu. three lozenges or. GERBRIDGE.

Arg. on a chev. gu. three lozenges or each charged with a cross croslet fitchy sa. Austen.

Arg. on a chev. sa. three lozenges of the first eacb charged with a cross croslet az. AsLYN, $V$.

Or on a chev. sa. three lozenges of the first. LEARMOUTH, Edinburgh.

Arg. on a chev. gu. five lozenges or. Ederstone. Lure

Arg. on a chev. gu. a lure the tassel waved or. Brooke, co. Devon.

Mascles

Or on a chev. az. three mascles of the first. IJARMAN or Lasitan.

Or on a chev. gu. three mascles arg. Murdoch. Or on a chev. sa. three mascles of the first. Learmouth, Balcomy, Scotland. And with a rose .... Learifouth, Darsy, and Esselment, Scotland.

Mitre

Paly of six arg. and gu. on a chev. sa. a mitre or. John Carpenter, Bishop of Worcester 144376, Add. MS. 12443.

\section{Monsters}

Arg. on a chev, engr. sa. two griffins combatant of the first. Pynell.
On 1 CHEVRON.....cont.

Monsters cont.

Arg. on a chev, az. three griffins gu. Sire Adam de Bloy, $O$.

Or on a chev. sa. three griffins segreant of the first. KNIGHT, co. Hants.

Mullet

Arg. on a chev. az. a mullet of the first. Toтr, $V$. The mullet pierced. ToTr.

Arg. on a chev. sa. a mullet of the first. Mixfine, co. Cambridge."

Arg. on a chev. sa. a mullet or in chief a label gu. Prideadx, Thuborough, co. Devon.

Erminois on a chev.sa. a mullet arg. Topper.

Or on a chev. sa. a mullet arg. MERFFYN or Mrnfyn, quartering Don, Cotton $M S$. Julius $F$, VIII. fo. 36 ; $H$ arl. $M S$. 1179 , fo. 77. MERFYN or Mervyn. Mirfin, Lord Mayor of London 1518.

Vert on a chev. arg. a mullet gu. Grogan, Ire. land.

\section{Mullets}

Arg. on a chev. sa. two mullets of the first. Kuelley or Kewley.

Arg. on a chev. vert two pierced mullets or. Druny.

Gu. on a chev. arg. two mullets sa. Bacon.

Arg. on a chev..... three mullets sa. Bearecroft, co. Worcester.

Arg. on a chev, az. three mullets of the first. WitTy.

Arg. on a chev, az, three mullets or. Bosvine.

Arg. on a chev. gu. three mullets of the first. LoNGLANDS, that Ilk.

Arg. on a chev. gu. three mullets or in chief an annulet sa. for diff. ? GAMBON or GAMON.

Arg. on a chev. sa. three mullets of the first. Tegwared y Baiswen, natural son of Llewellyn the Great. Ganiboun. Knell. KNelley, $V$. Regelite $\bar{y}, V^{*}$. Riggeley, co. Stafford.

Arg. on a chev. sa. three pierced mullets of the first. Gmiffith or GRyfFyd, Bach-y-saint, co. Carnarvon; and Tan-y-bwlch, co. Merioneth, the heiress m. Oakeley. Regeller, $V$. Ridgley, Abright-Hussey, co. Salop; and Longdon, co. Stafford.

Arg. on a chev. sa. three mullets or. ADAris, $V^{*}$. Adain de Saint Ivis, $V$. Robarts, Kent.

Arg. on a chev. sa. three pjerced mullets or. Adairs, St. Ives.

Arg. on a chev. sa. three mullets or each charged with a torteau. Gamboun, $V$.

Az. on a chev. arg. three mullets of the first. Roberts, Kent.

Az. semy of 5 -foils arg. on a chev. of the last three mullets gu. Carus, Kendall, Westmoreland. Crawe.

Az. on a chev. arg. three mullets sa. Robarts or Robehts. Robents, Borzell, Ticehurst, Stonehouse, and Warbleton, Sussex; a branch of RoBERTs, Glastenbury near Cranbrook, Kent; quartering Tyllye : Baronetcy 1620-17 15 . The mullets pierced. Roberts, Truro, Cornwall; granted 2 June 1614. RoBERTs, co. Lincoln ; London; and co. Worcester.

Az. on a chev. or three mullets sa. RoBERTs, Beechfield, Bromley, Kent.

Barry of (five, $V^{*}$.) six or and az. on a chev. gu. three six pointed mullets (arg. $V^{*}$.) or. 'Talworth, $V^{*}$. Talworthe, $V$.

Barruly .... and .... on a chev. .... three mul. lets. De La More alias Bythemore, Collinson, Somerset, i, 185. 
On 1 CHEVRON .... cont.

Mullets cont.

Chequy arg. and gu. on a chev. or three mullets sa. LoRD, Ireland.

Erm. on a chev, az. three mullets arg. PiEynolds.

Erm. on a chev. gu. three mullets arg. BELEw. Hatfiedd, Carlton, Norwell, and Willoughby, co. Nottingham. Heton. Hotton, $V$.

Erm. on a chev. or three pierced mullets gu. Liddiand alias Stratton, Rockley, co. Wilts ; quartering Stratton.

Erm. on a chev. sa. three mullets arg. HatFELD, $V$.

Gu. on a chev, arg. three mullets az. Shafto, Bavington, Benwell, and Whitworth, Northumberland; the heiress $m$. Adair. And with a 5 -foil or in the sinister chief for diff. Shafto, Whickham, and Swalwell, Durbam.

Gu. on a chev. arg. three mullets of the first. CAnR, quartered by Glyn. Lordship of JeDburgh. KER, Dalphington, Scotland; extinct .... Kenr, Kerrisland, co. Ayr ; and Saughfield, co. Lauark. And with in the sinister chief $a$ crescent of the second. Carke, Scotland.

Gu, on a chev. arg. three mullets sa. CARR, Scotland. CARR or CARRE, Bristol; co. Salop; and co. York. Robert James CARr, Bishop of Chichester 1824, Worcester 18:31-61.

Gu. on a chev, arg. three pierced mullets sa. Carr.

Gu. on a chev. az. three mullets arg. pierced of the first. Sir William WaLkINGToN, $R$.

Gu. on a chev. erm. three mullets sa. Rотн, co. Leicester.

Gu. on a chev. or three mullets az. Sire Renaud de Coвнam, $N$.

Gu. on a chev, or three mullets sa. Franiston.

Gu. a fret or on a chev, arg. three mullets of six points pierced sa. Fulsherst.

Or on a chev. sa. three mullets of the first. O'GAUN.

Paly of three az. and arg. on a chev, or three mullets of the first. GRIMwOOD.

Sa. on a chev. or three mullets of the first. O'GAON.

Sa. on a chev. or five mullets gu. Seynes.

\section{Pheons}

Arg. on a chev. gu. three pheons or. Rosseter, co. Somerset. Rossetur, co. Somerset, $V$.

Arg. on a chev. sa. three broad arrow-heads of the first. BATERTON or BECKERTON.

Arg. on a chev. sa. three pheons of the first. Bakerton or Bekeron, $V$. Bekerton, $V$. Bickerton, Essex; and Beeby, co. Leicester.

Vert on a chev, arg. three pheons sa. AYot. Charingworth. Kemmis, Ireland; derived from Kemers, originally DE CAMors, Kevanmably, co. Glamorgan; Baronetcy 1642-1735, quartering Began; the heiress m. Tynte. KenIs, Wickwick, co. Gloucester. KERNEx.

Vert on a chev. arg. three pheons sa. two of them pointing to the sides of the escucheon the other downwards. Kerys, co. Gloucester, $V$.

Vert on a chev. arg. three pheons of the first. ADAN.

Vert on a chev. or three pheons sa. Kemrs.

\section{Plummets}

Arg. on a chev. gu. three plummets or. Jennings, co. Stafford.

\section{Roundle}

on 1 CHEVRON .....cont.

Arg. on a chev. sa. a roundle betw. two roses of the first. BALDINGTON.

\section{Roundles}

Paly of $\operatorname{six} . .$. and .... on a cher. .... three roundles .... Ke Kene, Ireland.

Per pale erm. and gu. on a chev. three roundles counterchanged. SHEA.

\section{.....Bezants}

Arg. on a chev, az. three bezants. Bratr or Brett, co. Stafford. TODEFord or TODFord. Arg. on a chev. indented az. three bezants. TUnstal.L.

Arg. on a chev. gu. three bezants. Honevilu or Horvill. Nealewell. Vacye, Fenton Vacye, Cornwall. WaFF, Cornwall. WaFFe, Cornwall, $V$. Wass, Cornwall. John WaUgB, Bishop of Carlisle 1723-34, Cole MS. 5798, fn. 273.

Arg. on a chev. the upper part terminating in a cross patty gu. three bezants. Newland, New. lands, co. Southampton; and Totness, co. Devon. Newling.

Arg. on a chev. pean three bezants. Bond.

Arg. on a chev. quarterly gu. and sa. three bezants. Kitchinghair.

Arg. on a chev. sa. three bezants. Bond, Brookland, Mosbury, co. Devon, 1716. Bonde, co. Devon, $V$. John de Boys, $Y$. GOODCHIID, HaLleweli, $V$. Hullewell. And with a crescent for diff. (Berry says gu.) sa. Sir George Bond, Lord Mayor of London 1588; and his brother, William BoND, Alderman, ob. 1576; descended through Bond, Buckland, co. Somerset, from Bond, Cornwall, Harl. MS. 1096, fo. 88; and Visitation 1661, fo. 136. Bond; Barouetcy 1658-1767.

Arg. on a chev. embattled sa. three bezants. LEE, Isle of Wight.

Barry wavy of five arg. and az. on a cher. gu. three bezants. EsTer.

Erm. on a chev. .... three bezants. Skipper or SKIPPKER, Bradwell, Suffolk.

Erm. on a cbev. az, three bezants. JoHnson. And with a mullet for diff. JoHNson, Lon. don.

Erm. on a cher. gu. three bezants. BAXTer, co. Nottingham, granted ....; V. Sr. .... de DAGWorth, $V$. M. Tbomas DAGworTH, $X ; Y$. Gageworth or Gagworth.

Erm. on a chev. sa. three bezants. Delaleigh Delegey or Delegh. Sr. .... de Leigh, $V$. LEGH or LeIGH, Cumberland; and co. Lan. caster.

Gu, on a chev, az, three bezants. AnNering.

Lozengy arg. and vert on a chev. az. three bezants. YoNGE, co. Wilts; Harl. MS. 1401, fo. 102.

Or on a chev. gu. three bezants. Sire Robert de EstafFord, $N$. StafFord. And with a label of three points az. Robert StafFord, Eggin. ton, and Moginton, $V$.

Per pale gu. and vert on a chev. az. three bezants. RoE. Roo.

Pily of seven az. and arg. on a cbev. gu. three bezonts. Pillans.

\section{.....Fonntains}

Arg. on a chev. sa. three fountains. Casser, $V$. Cosh, co. Devon. Cosshe, $V^{*}$. And in the dexter chief a mullet of the second. CusH. Cushe, $V^{*}$. Cusshe, $V$. 
On 1 CHEVRON

Roundles cont. Fountains cont.

Erm. on a chev. sa. three fountains Cost, Baron Brownlow 1776, Viscount Alford and Earl Brownlow 1815 ; quartering Brownlow and Payne.

$$
\text { ..... Hurts }
$$

Pily of seven az. and arg. on a chev. counterchanged three hurts. Pillans, England.$$
\text { .....Plates }
$$

Erm. on a chev. sa. three plates. Leigh, Cumberland.

Or on a chev. gu. three plates. Le Baron de Stayford, $E$. Robert de Stafford, $X$. And with a label of five points az. Robert de StaFFond, $E ; F$.

Paly of six arg. and gu. on a chev. sa. three plates each charged with a cross patty gu. Carpenter, Barbadoes; granted 10 June 1647. Carpenter; granted 1601.

Pily of seven az. and arg. on a chev. gu. as many plates. Pillans, Leith, Scotland.

$$
\text { ....Torteaux }
$$

$\mathrm{Gu}$. crusily patty arg. on a chev. of the last three torteaux. Berkeley.

Lozengy or and az. on a chev. arg. three torteaux. BEG or BEGG.

\section{.... Bezants}

Arg. on a chev. gu. five bezants. EDErston, $V$. Ederstone, $V^{*}$. Erdeston, $V$. Hugh de Endeswike, co. Stafford, $V$. Harveli, $V^{*}$. Horevill or Horvill. Narvele, $V$. Somerford, co. Chester.

Arg. on a chev. sa. five bezants. Bayce or Bors, co. Buckingham. Sr. Nicolas de Boys, V. SOMTERFORD.

Erm. on a chev. gu. five bezants. Grant or Graunt, Nortbbroke, co. Warwick.

$$
\text { ..... Ogresses }
$$

Sa. semy of martlets arg. on a chev. of the last five ogresses. BARD, Middlesex; and Cavers. field, co. Buckingliam. BARD; Baronetcy 1644, Baron Bard of Drombey and Viscount Belmont 1646, extinct 1660. BARD or BEARD, North Kelsey, co. Lincoln, Harl. MS. 1550.

$$
\text { .....Plates }
$$

Arg. ou a chev, sa. five plates. Bond, Newland, co. Gloucester.

Arg. semy of martlets sa. on a chev. of the last five plates. BARD, co. Lincoln (an error).

Erm. on a chev. gu. five plates. GRAdNT, $V$.

Or on a chev. gu. five plates. Stafford.

Or on a chev. sa. five plates. Whitton.

Arg. on a chev. sa. seven plates. Bond, Newland, co. Gloucester; the heiress m. Nicholl.

$$
\text { ... Bezants }
$$

Arg. on a chev. sa. nine bezants. Severn or Severne, Shrawley, co. Worcester; co. Salop ; co. Northampton; and co. Montgomery.

Arg. on a chev. sa. bezants. Sire Nicholas du Boys, $N$.

Or on a chev.gu. bezants. Robertde Estafford, $B$. Scythes

Sa. on a chev. or two scythe blades of the first. LEY or LEYs.

$$
\text { Sprigs }
$$

Arg. on a chev. voided sa. three bunches of ashen keys ppr. Ashrond, co. Devon.

Erm. on a chev, sa. three withered branches arg. Frese, $V$.

Sa. on a chev. arg. three sprigs of broom ppr, Brome, Collinson, Somerset, ii, 339.
On 1 CHEVRON

...cont.

Sprigs cont.

Sa. on a cher. or three slips of broom vert. Broome, co. Hereford; granted 1670.

Sa. on a chev. arg. five slips of broom ppr. Broome. Swords

Gu. on a chev. arg. three daggers sa. Brathwaite, Brathy, and Warcup, Westmoreland. Tails

Or on a chev. gu. 'ermynee.' Le Baron de StaFfoRde, $P$.

Wheels

Arg. on a chev. az, three catharine wheels or. Witherden, Wisenden, Kent.

Az. on a chev, arg. three catharine wheels gu. Cotron, co. Leicester, temp. Edward III.

\section{Wings}

Paly of seven or and az. on a chev. of the second a pair of wings conjoined as the first. Locke or LokE.

Wreath

Az. on a chev, or a chaplet vert. Vereker, Baron Kiltarton 1810, Viscount Gort 1816; quartering O'Connell and Prendergast with Smith.

On 1 CHEVRON and in chief....

\section{Annnlet}

Arg. on a chev. sa. a crescent of the first in chief an annulet as the second. WANTON.

Arg. on a chev. gu. three mullets or in chief an anuulet sa. GaMBON or GaMon.

\section{Annulets}

Sa. on a chev. or three 5-foils of the first in chief two annulets arg. on a chief az. three columbines of the third. Cooke.

\section{Beast}

Arg. on a chev, gu. three escallops or in chief a lion pass. az. TuLLY, 1718. The lion vert. TuluY, Wetherall Abbey, Cumberland.

Arg. on a chev. engr. sa. three escallops of the first in chief a lion pass. guard. vert. TouLy. Torley. The lion bezanty. Tolney. But platy. Thomas Toldey, Ramessey, $V$. Toliye, $V^{*}$.

Or on a chev. engr. sa. three escallops arg. in chief a lion pass. vert. Tolur.

Arg. on a chev. az. three garbs or in chief a lion pass. sa. Cradock. Cradoke, $V$.

Gu. on a chev. arg. three mullets of the first in the dexter chief point a lion pass. or. Carr.

Gu. on a chev. arg. three (sometimes pierced) mullets of the first in the dexter chief point a lion pass. guard. or. C $A R R E$ or $\mathrm{KER}$, Baron Brancepeth 1613, Viscount Rochester '1611, Earl of Somerset 1613, extinct 1645 .

Gu. on a chev. arg. three mullets sa. in the dexter chief a lion pass. guard. or. Car., co. Salop.

\section{Beasts}

Or on a chev. sa. three annulets arg. in chief two lians pass. of the second. TAYLOR, London.

Gu. on a chev, arg. three ram's heads couped and affronted sa. attired or in the dexter chief quarter two lions pass. gliard. of the last. Augustinian Abbey at Cinencester, co. Gloucester.

\section{Birds}

Per pale sa. and arg. on a chev. three 3 -foils and in chief two martlets counterchanged. RowE, London.

\section{Canton}

Or on a chev. gu. a crescent of the field a canton erm. Stafford, co. Leicester.

... on a chev. .... three roses .... a canton .... Harris, Kent. 
On 1 CHEVRON and in chief.....cont.

\section{Canton cont.}

Arg. on a chev. gu. three roses of the first a can. ton .... Gilbert, Tredrea, Cornwall ; and Eastbourne, Sussex.

Az. on a chev, arg. three roses vert a canton erm. Meriton, 1716.

Az. on a chev, or three roses gu. a canton erm. Thomas Rands, co. Lincoln, 1599, $W$. Ranson, Suffolk. The roses barbed vert. Rands, co. Lincoln; confirmed $19 \mathrm{July} 1593$.

Gu. on a chev. arg. three roses of the first a canton erm. KNollys, Grove Place, co. Hants. KNowles.

Or on a chev. gu. three roses arg. a canton of the second. Capper, Bushey, co. Hertford.

Arg. on a chev. sa. three 4-foils or a canton vair. EYre.

Az. on a chev. arg. three 5-foils gu. a canton erm. HAwES, London.

Az. on a chev. or three 5-foils gu. a canton erm. Hawes, London.

Arg. on a chev. az. three garbs or a canton gu. charged with a fret of the third. EARDLEx, Lord Eardley. YaRdLEY, Upbery, Kent; and Yardley, co. Stafford. YARdeley, Kent, $W$. But fretty. YARDLEY, $V^{*}$.

Az. on a cher. arg. three torteaux a canton elm. Round.

on a Canton ..... (Beast) Cat

Erm. on a chev. az. three stag's heads erased ..... on a canton of the second a cat-a-mountain .... Hewlett.

\section{.....Lion}

Sa. on a chev. arg. three Cornish choughs ppr. a canton of the second charged with a demilion ramp. of the first. Parvis or Parvise, Unsted, Surrey; granted 12 January 1582, and 3 December 1597.

Az. on a chev, arg. three 5 foils purp. a canton of the last charged with a lion ramp. per pale gu. and sa. Hawes.

Az. on a chev. or three 5-foils gu. a canton arg. charged with a liun pass. of the third betw. two steel gads ppr. Hawes.

Az. on a chev. or three 5-foils gu. a canton arg. charged with a lion pass. Sa. Hawis, Harl. MS. 1404 , fo. 111.

Az. on a chev, or three 5-foils gu. a canton arg. charged with a lion pass. guard. (of the third, Harl. MSS. 1349) in a bordure engr. sa. HaWEs, Lord Mayor of London 1574.

Az. on a chev, or three 5.foils gu. a canton arg. charged with a liou ramp. sa. in a bordure engr. gu. Hawis, Harl. MS. 1401, fo. 111.

Az. on a chev, or three 5 -foils purp. a canton arg. charged with a lion pass. sa. Hawes, $V^{*}$.

Bendy of three sa. and or on a chev. arg. three mullets of the first a canton of the second charged with a lion ramp. gu. GILI or GYLL, co. Hertford, Harl. MS. 1404, fo. 109.

Sa. on a chev. arg. three pierced mullets of the first a canton or charged with a lion pass. guard. gu. BOKELAND, $V^{*}$.

$$
\text { ....Cross }
$$

Or on a chev. az. three leopard's heads of the first a canton gu. charged with a cross patonce arg. thereon five ogresses. ETON.

$$
\text { ....Cup }
$$

Erm. on a chev. gu. an escallop betw. a sinister and dexter hand couped in bend arg. a canton az. charged with a covered cup handled or. MaINe; granted 1765.
On 1 CHEVRON and in chief.... cont.

\section{on a Canton cont. Fleur-de-lis}

Arg. on a chev. gu. three castles of the first a canton az. charged with a fleur-de-lis or. ViLetT, London; granted 1572. VILLETT, Swindon, co. Wilts.

Arg. on a chev. gu. three towers triple-towered or a canton az. charged with a fleur-de-lis of the third. VILOT or VIOLOT, London; and Norfolk.

Gu. on a chev. arg. three roses of the first seeded or barbed vert a canton of the second charged with a fleur-de-lis a\%. a martlet for diff. KNOWLES.

Gu. on a chev, arg. three roses vert barbed and seeded of the first a canton of the second charged with a fleur-de-lis of the first. Knowses, Cule Ashby, co. Northampton; and Walton, Suffolk; granted 1580. KNowLys, Heysham Hall, co. Laucaster; and Stockwell, Surrey.

Erm. on a chev. az. three fox's heads erased or and for augmentation (30 October 1658) a canton of the second charged with a fleur-delis as the third. Strangways Fox; Baronies 1741 and 1747, Earl of Ilchester 1756, quartering Strangways; Collinson, Somerset i, 227. Fox, Foxley, co.-Wilts. Vassall Fox, Baron Holland 1762 ; extinct 1859 .

$$
\text { .....Flower }
$$

Arg. on a chev. gu. three sheldrakes of the first a canton as the second charged with a rose like the field. SHELDON, co. Worcester, 1663. The rose seeded or barbed vert. SHELDoN, Hampton Court, Surrey; granted 26 December 1681. The rose or. Gilbert SHELDON, Bishop of London 1660, Archbishop of Canterbury 1663-77; granted 1060.

$$
\text { -...3-Foil }
$$

Az. on a chev, arg. three millrinds sa. a canton or charged with a 3 -foil slipped of the third. Milnes, Beckingham Hall, co. Nottingham; quartering Wright and Gery.

$$
\text { .....Head }
$$

Or on a chev. gu. three roses arg. a canton of the second charged with a leopard's face as the first. Rumboud, Ferrand, co. York; Baronetcy 1779.

Sa. on a chev, arg. three broom sprigs vert a canton or charged with a spear's head az. embrued gu. Bromfiewd, Kent.

Sa. on a chev. arg. three broom branches vert budded ppr. a canton or charged with a spear headed az. embrued gu. broken in the truncheon .... Brouf IELd, Haywood, co. South. ampton, 1716, quartering Kempe.

Sa. on a chev. or three branches a canton of the second charged with a spear's head rompu as the first. BLOMEFIELD.

Sa. on a chev. az. a branch of laurel betw. two bombshells fired ppr.a canton or charged with a spear's bead az. embrued gu. BLOMEFIELD, Attleborough, Norfolk; Baronetcy 1807.

Sa. on a chev. erminois three pheons of the first a canton of augmentation gu. charged with a mullet and increscent fesswise in a bordure embattled or. BickerTos, Upwood, co. Huntingdon; Baronetcy ]778-1832. Chief

Arg. on a chev. az. three annulets of the first a chief of the second. FERRALL, Ireland.

Or on a chev. gu. a greybound current .... a chief vair. ST. QUINTYN, co. York. 
On 1 CHEVRON and in chief....cont.

Chief cont.

Or on a chev. gu. a martlet arg. a chief vair. St. Quintin. The martlet or. M. John SeINT Quintoyne, $S$. Thomas St. Quintyn, $Y$.

Az. on a chev. or three martlets sa. a chief arg. HolDICH or HolDICHE.

Erm. on a chev. sa. a crescent or a chief of the second. Mortlyne.

Az. on a chev, engr. arg. three buck's heads couped gu. a chief per fess ermines and erm. WOODROFFE, St. Edmundsbury, Suffolk.

Gu. on a chev. arg. three buck's heads erased sa. a chief per fess nebuly sa. and of the second. WoOdRoffe or WoOdRoff, Lord Mayor of London 1579; and Poyle, Surrey.

Az. on a chev, arg. three mullets sa. a chief indented or. Roberts, London.

Gu. on a chev. arg. three ogresses a chief of the second. CockLE or CoKYLL.

Gu. ou a chev, arg. three ogresses a chief in. dented of the second. Sr. Thomas Cokylu, $V$.

Gu. on a chev. arg. three ogresses a chief sa. Cockle or Cokrul. Cogrilu, Coghill, co. York; and Randall's Park, Surrey; Baronetcy 1778; quartering Cramer.

on a Chief (Beast) Dog

Az. on a chev. arg. a prerced 5-foil betw. two escallops gu. a chief or charged with a greshound courant sa. enclosed by a pair of ogresses. Quartered by NonTh, London, $V$.

Erm. on a chief gu. a bezant betw. two leopard's faces or a chief as the last charged with a talbot pass. sa. enclosed by a pair of fieurs-delis like the secoud. Ralph Prestwich, Hulme, co. Lancester ; granted ...., Harl. MS. 6159, fo. 62 .

$$
\text { ....Goat }
$$

Arg. on a chev. sa. three bucl's heads cabossed or a chief gu. charged with a goat trippaut of the first. Boughton.

$$
\text { .....Lion }
$$

Chequy arg. and az. on a chev. engr. or three anchors sa. a chief gu. charged with a lion pass. of the first. Emberx. TolLet, Betley Hall, co. Stafford.

Arg. ou a chev. az. a bird (? dove) betw. two pheons or a chief sa. charged with a lion pass. guard: enclosed by a pair of crescents as the first. Thomas WarTON, $W$.

Or on a chev. az. a hawk betw. two pheons arg. a chief sa. charged with a lion pass. as the first enclosed by a pair of crescents like the third. WARTON.

Or on a chev. az. a hawk (martlet, $V^{*}$.) betw. two pheons as the first a chief sa. charged with a lion pass. guard. enclosed by a pair of erescents arg. Thomas WARTON, $V$.

Barry wavy of six arg. and az. on a chev. sa. three martlets or a chief gu. charged with a lion pass. hetw. two anchors gold. Forman or Foreman, London; and co. Leicester.

Barry nebuly of six arg. and az. (seven az. and arg. Forman, $V^{*}$. Freman, $V^{*}$.) on a chev. sa. three martlets or a chief gu. charged with a lion pass. guard. betw. two anchors erect gold. Firmin, London. Sr. William Forman, Alderman of London, $V$. Freman, $V$. But barruly nebuly. Formian, co. Lincoln.

Gu. on a chev, arg. three crosses croslet sa. a chef or charged with a lion pass. of the first. Goudsiith, Exton, co. Hants.
On 1 CHEVRON and in chief....cont.

on a Chief cont. (Beast) Lion cont.

Arg. on a chev. az. three escallops as the first a chief of the second charged with a lion pass. like the field. Heende, Lord Mayor of London 1391 and 1404. Hende, co. Lancaster, $V$. Hendy or Hinde, co. Lancaster. Hinde, $V$.

Arg. on a chev. sa. three escallops of the first a chief az. charged with a lion pass. as the field. HIND, London.

Arg. on a chev. sa. three escallops or a chief of the second charged with a lion pass. guard. as the first. Surcott, $V$.

Arg. on a chev, sa. three escallops or a chief of the second charged with a lion pass. as the third. Suncotr.

Or on a chev. az. three escallops arg. a chief of the second charged with a lion pass. as the first. Stanbridge, Sussex.

Arg. on a chev. sa. three fleurs-de-lis of the first a chief az. charged with a lion pass. guard. or. SмYтнson, Kent; granted 1572.

$$
\text { ....Wolf }
$$

Erm. on a chev. gu. three leopard's heads (another bezants) a chief or charged with a wolf pass. sa. betw. two fleurs-de-lis of the second. Prestwich, Holme, co. Lancaster (an error).

$$
\text { .....Birds }
$$

Paly of six or and gu. on a chev. arg. an ancbor erect sa. a chief of the second charged with three martlets as the first. Martin, Wilderness, Surrey; and Stonefield, Cumberland; quartering Hutchinson, Richmond, Vaux, Vaux, Delamere, and Leybourne.

$$
\text { ....Cross }
$$

Purp. on a chev. arg. three escallops az. a chief of the third charged with a cross patty or betw. two griffin's heads erased as the second. GARDNER, London, Harl. MS. 1404, fo. $108 \mathrm{~b}$.

Purp. on a chev. arg. three escallops az. a chief embattled of the third charged with a cross potent or betw. two griffin's heads erased as the second. Gardiner, Lord Mayor of London 1478. GARDNERs, London, $V$.

Arg. on a chev. sa. three wolf's heads erased of the first a chief az. charged with on a cross patonce betw. two martlets or five (ogresses, W.) hurts. Thomas Warde, Benhams, co. Berks, Cotton MS. Tiberius D 10.

Arg. on a chev. sa. three wolf's heads erased or a chief az. charged with a cross patonce betw. two martlets of the third. W Bedford.

\section{.....Escucheon}

Arg. on a chev. sa. a gauntlet of the first betw. four swords in saltire as the last hilts and pomels or a chief of the second charged with on an oval shield like the field enclosed by a pair of peer's helmets ppr. garnished or a cross gu. encircled with a carved shield as the third. Company of Armourers, London, impaling the Braziers.

$$
\text { .....Estoile }
$$

Gu. on a chev. arg. three martlets of the first a chief az. charged with an estoile betw. two leopard's faces or. Dolestey or Dolseley, $V *$. Dolesly, $V$.

Gu. on a chev. arg. three mullets of the first a chief az. charged with an estoile betw. two leopard's faces or. Dulsey. 
On 1 CHEVRON and in chief.... cont.

on a Chief cont. Fleurs-de-lis

Az. on a chev. or three martlets sa. a chief gu. charged with a rose betw. two trunks of trees erased or. Thomas Brown, Bishop of Ro. chester 1435, Norwich 1436-45 (an error).

Or on a chev. gu. three horseshoes of the first a chief of the second charged with so many fleurs-de-lis as the first. Watrins, Silkstone, co. York.

\section{..... Flowers}

Fusily (another lozengy) az. and erm. (Lansdowne MS. 255, but another erm. and ermines and another erm. and sa.) on a chev. arg. a demi-lion ramp. (another betw. two lilies slipped) gu. a chief az. (another sa.) charged with (three lilies slipped ppr. but another) a rose betw. a lily slipped and a dove (another a pelican) or. John Storestey, Bishop of Lon. don 1530-39.

Sa. on a chev. or three 5-foils of the first a chief arg. charged with as many slipped columbines az. Cocke, Kent, $W$.

Sa. on a chev. or three 5 -foils of the first in chief two annulets arg. on a chief az. three colum. bines of the third. Cooke.

Arg. on a chev. sa. three passion nails (? closed lilies) of the first a chief as the second charged with three silver roses. Nicholas CLoos; granted 1450, Bentley, Excerpta, 361.

$$
\text { .....Lilies }
$$

Gyronny of eight gu. and sa. on a chev. arg. a grose (or drawing.board) betw. two adzes of the second a chief of the third charged with three lilies slipped and leaved az. Company of Coopers and Hellyars, Exeter.

$$
\text { ....5-Foils }
$$

Arg. on a chev, az. three bezants a chief gu. charged with two 5-foils or. Yonge or YounG, Basleton, co. Berlis ; granted 1607.

Arg. on a chev. engr. az. two griffins combatant as the field srmed and gorged with two bars gu. a chief of the second charged with three 5-foils like the first. John Tromas, Bishop of Peterborough 1747, Salisbury 1757, Winchester 1761-6, The 5-foils pierced and or. THomas, Llyn Madoc, co. Brecknock; granted 1 Febru. ary ....

Per pale arg. and gu. on a chev, engr. two griffins combatant counterchanged a chief wavy az. charged with three 5 -foils of the first. THorras, Wellfield House, co. Radnor.

$$
\text { ....Gun }
$$

Arg. on a chev. gu. three martlets of the first a chief as the second charged with a chamber. piece or. CowARD, Collinson, Somerset, iii, 468.

Arg. on a chev. gu. three martlets or a chief of the second charged with a culverin dismounted as the third. LEGH, co. Devon. LeIGH, Wells, co. Somer'set.

Or on a cher. gu. three martlets of the field a chief as the second charged with a chamberpiece like the first. Coward.

$$
\text { ..... Head }
$$

Gu. on a chev. erminois six 3-foils slipped vert (the erm. and 3-foils inclining the same way as the chev.) a chief or charged with a stag's head cabossed az. betw. two mullets of the first. HaRveY.

Lozengy arg. and vert on a chev. az. three bezants a chief gu. charged with a goat's head erased or betw. two 5 . fuils of the last. Willian Yonge, Wittenhaw, co. Berks, $V$. Young, $V *$.
On 1 CHEVRON and in chief.....cont. on a Chief cont. Heads

Arg. on a chev. az. three wrens of the first a chief gu. charged with as many horse's heads erased purp. WREN. But the chief or charged with as many heads erased brown. WRENNE, Harl. MS. 1404, fo. $111 \mathrm{~b}$.

Per pale or and az. on a chev. two dragons combatant counterchanged a chief ermines charged with three coronels of the first. Wiseman, Waltham, Essex; granted 18 May 1572.

\section{.....Monsters}

Az. on a chev. arg. three birds vert membered gu. a chief or charged with three griffins se. greant sa. GARD, Kent.

$$
\text { ..... Mullet }
$$

Gu. on a chev, arg. three martlets of the first a chief az. charged with a six-pointed mullet betw. two leopard's heads or. Dolescey or Dolseiny, $V^{*}$. Dolesly, $V$.

$$
\text { .... Mullets }
$$

Erm. on a chev. sa. a lion ramp. or a chief gu. charged with three mullets of the first. Triss, Newark, co. Nottingham. The mullets of the third. Trice, Godmanchester, co. Huntingdon.

Arg. on a chev. az. three mullets or a chief gu. charged with as many mullets of the third. LALEMAN, Ireland.

$$
\text { .....Pale }
$$

Arg. on a chev. az. a coney pass. betw. two fishes baurient of the first a chief chequy arg. and az. charged with on a pale of the second a rose or. Richard Caeyney, Bishop of Gloucester and Bristol 1562-79.

\section{....Roundle}

$\mathrm{Paly}$ of four gu. and vert on a chev. or a grey. hound's head erased sa. betw, two 5-foils az. a chief gold charged with on an ogress enclosed by a parr of crescents as the fourth each bearing three plates a demi-lion ramp. arg. Lawson, Popleton, Moreby, Aldborough Lodge, and Boroughbridge Hall, co. York.

Paly of four gu. and vert on a chev. arg. a bind's (fox's, $V^{*}$.) head erased (of the first, $V^{*}$.) betw. two 5-foils az. a chief or charged with on an ogress enclosed by a pair of crescents each bearing three plates a demı-lion ramp. as the third. Sr. George Lawson, co. York, $V$.

$$
\text { .... Roundles }
$$

Arg. on a chev. gu. three griffin's heads erased or a chief az. charged with as many bezants. Travers, Ireland, $V$.

Paly of six gu. and vert on a chev. arg. three wolf's heads erased sa. a chief or charged with as many ogresses. Lawson, co. York.

Gu. on a chev. .... two griffins segreant of the first a chief as the second charged with three torteaux. 'Тномаs.

$$
\text { ..... Ships }
$$

$\mathrm{Gu}$. on a chev. arg. fimbriated or three escallops sa. and for augmentation (1808) a chief wavy of the second charged with a dismasted French frigate towed towards the dexter by an English frigate in a shattered state. HARDINGE, Belleisle, co. Fermanagh: Baronetcy 1801.

$$
\text { .....Staples }
$$

Erm. on a cliev. gu. three escallops or a chief arg. charged with as many staples of the second. Coore, Essex.

Erm. on a chev. gu. three door-staples or on a chief arg. as minny of the second. Cooke, Fullwell Heath, Essex. 
On 1 CHEVRON and in chief.....cont. on a Chief cont. Suns

Arg. on a chev. gu. three mullets of the first a chief az. charged with as many suns or. Garling.

\section{.....Wreaths}

Arg. on a chev. betw. three demi-lions ramp. gu. a chief of the last charged with as many chap. lets or. HALL, Sawforth, and Harborough, co. Lincoln.

\section{Cross}

Or on a chev. sa. three martlets arg. in chief a cross croslet fitchysa. Hammon.

\section{Cups}

Per chev. sa. and erm. on a chev. or three 3-foils az. in chief as many covered cups or. Fran.

\section{Escallop}

Arg. on a chev. sa. three 4-foils or in the dexter chief an escallop gu. TreLow, $V$. Robert Treulowe, Cotton MS. Tiberius D 10. Truelove, $V$.

\section{Estoile}

.... on a chev. .... three crosses croslet .... in the dexter chief an estoile .... Ralph Cóham, 1402, Cobbam, Kent.

Fish

Az. on a chev. arg. three crescents gu. in chief a dolphin naiant embowed of the second. Bryan, $\boldsymbol{V}$.

Az. on a chev. or three crescents of the first in chief a dolphin naiant arg. Bryan, $V$.

Az. on a chev. or three crescents gu. in chief a dolphin arg. BRYAN.

3-Foil

Arg. on a chev. sa. three boar's heads or in the dexter corner a 3-foil slipped gu. Moncnensey.

Gouttes

Arg. on a chev. az. five estoiles or in chief six goultes de sang four and two. Brine.

\section{Head}

Gu. on a chev. or three martlets of the first in chief a leopard's head betw. two mullets as the second. Dolserey. Dunslay, co. York.

Az. on a chev. arg. three martlets sa. in chief a lion's head erased or. More, Newington, Surrey.

Az. on a chev. engr. or three martlets sa. in chief a lion's head erased of the second. More, London.

Sa. on a chev. arg. three roses gu. seeded and barbed ppr. in the dexter chief point a close helmet of the second. Rose, Hasland, co. Derby, 1730.

\section{Heads}

Arg, on a chev. gu. a molet or in chief two lion's heads erased gu.. Robert de RouclifFe.

Per chev. sa. and erm. on a chev. or an escallop gu. in chief two boar's beads couped of the third. Sandrord, Colchester.

Gu. on a chev. arg. three mullets of the first in chief two buck's heads erased as the second attired or. KETFORD.

Or on a chev. gu. three bezants in chief two lion's heads erased of the second. Somerton, Norfolk.

Erm. on a chev. engr. sa. three bezants in chief two eagle's heads erased of the second. ILLIDGE, Brixton, Surrey.

Arg. on a chev. engr. sa. two martlets or in chief thiee griffin's heads erased gu. Hane.
On 1 CEEVRON and in chief.....cont.

Label

Arg. on a chev. sa. four bars wavy of the first in chief a label gu. Prideaux, Notewell, co. Devon.

Sa. on a chev. or an otter's head erased as the first in clief a label of three points gu. BaLfour, Ballow.

Arg. on a chev. sa. a mullet or in chief a label gu. Prideaux, Thuborough, co. Devon.

on a Label

Arg. on a chev. az. five bezants in chief a label of three points as the second charged the same. Hopton, Suffolk.

\section{Mitre}

Paly of six az. and gu. on a chev. arg. three crosses croslet of the second in chief a mitre or. John Carpenter, Bishop of Worcester 1446-76. The crosses potent. Doctor Carpenter, Lansdowne MS. 255, fo. 7.

\section{Mullet}

Vert on a chev, arg. three crescents sa. in the sinister chief a mullet of the second. AULDERSTON, Scotland.

Arg. on a chev. sa. three fountains in the dexter chief point a mullet of the second. CusH or CusHe.

Arg. on a chev. gu. three hart's heads cabossed or in chief as many mullets az. PARKer, co. Derby.

\section{on a Quarter}

Az. on a chev. arg. three 5-foils purp. a quarter of the second charged with a lion pass. within a bordure engr. gu. HAwES or HAwSE, Lon. don.

Az. on a chev. or three pierced 5-foils purp. on a quarter arg. a lion statant sa. Robert and John HaWEs, London, $V$.

\section{Roundles}

Sa. on a chev. a lion ramp. az. betw. two torteaux in chief as many plates. MACTIER, Scotland.

\section{Scythe}

Arg. on a chev. sa. fretty or in chief a blade of a scythe barwise az. Thickness, $V^{*}$. Thickons, $V$; and Harl. MS. 1386, fo. 94. The blade gu. Tonchet-Thicknesse, Baron Audley, 1403 ; quartering Touchet and Audley. THickness, Bartley, co. Stafford.

\section{Sun}

Az. on a chev. arg. three pheons gu. in the dexter chief a sun or. JoHnson, London; and co. Yolk, 1634.

\section{On 1 CHEVRON and in base....}

\section{Bird}

Arg. on a chev. gu. three bezants in base a dove with an olivebranch in the beak .... GUID, Scotland.

Az. on a chev. arg. three mullets gu. in base an earn derouring a salmon or. LUMSDEN, Glenlie, Scotland.

Az. on a chev. arg. a buckle of the first betw. two mullets gu. in base a heron devouring a salmon as the second. Blanearn, Scotland; (? in error).

Vert on a chev. arg. three estoiles gu. in base a pelican vulning herself or. KER, Fernelie, Scotland. 


\section{On 1 CHEVRON and in base.....cont. Birds}

Gu. on a chev. arg. a rose betw. two lions counterpass. of the first in base three cannets as the second. Herburn, Bearford.

\section{Buckle}

Gu. on a chev, arg. a rose betw. two lions respectant as the first and in base a beart-shaped buckle as the second. HepBurn, Blackcastle, Scotland. The buckle or. BeLshes, Invermay; quartering Belches and Murray. Herbuns, Keith, and Rickarton, Scotland; quartering Congalton and (?) Bicksbery.

Flower

Arg. on a chev, sa. an otter's head erased of the first in base a rose gu. BaLfour, Balganvy.

Vert on a chev. arg. three pheons sa. two of them pointing to the side of the escucheon the other downwards in base a rose of the second. Kemys, co. Gloucester, $V$.

Head (Beast) Boar

Gu. on a chev. arg. a rose betw. two lions pass respectant of the first in base a boar's head erased as the second. Hepburs, Edinburgh.

Arg. on a chev. gu. a mulket of the first in base a boar's head couped as the second. TRATTER, Scotland.

$$
\text { ....Deer }
$$

Gu. on a chev. arg. three mullets of the first in in base a stag's head erased as the second. KARR, Zair, Scotland; granted 1698. But in base a buck's head erased .... in chief a crescent for diff. of the second. KER, Greenhead, Scotland.

Gi1. on a chev, arg. three mullets of the first in base a stag's bead erased or. Ker, Lord Jed. burgh, 1622 .

\section{..... (Monsters) Unicorns}

Vert on a chev, arg. three (stars or) mullets gu. in base a unicorn's head erased of the second. KER, Littledane, Scotland; quartering Ainsley. The whole within a bordure arg. KER, Moristoun, Scotland.

\section{Heart}

Arg. on a chev. sa. ensigned on the top with a cross patty gu. a crescent of the first in base a heart as the third. METHEN, Craiglownie, Scotland.

\section{Mullet}

Arg. on a chev. sa. an otter's head erased of the first and in base a mullet..... BALFoUr, Balmouth.

\section{Saltire}

Arg. on a chev. sa. an otter's head erased of the first in base a saltire couped as the second. Batfour, Monquhanny. Balfour, Baron Balfour of Clonawly 1619 ; extinct 1634. BALFOUR, Trenaby, co. Orkney; quartering Mac Duff, Ogilvy, Dury, Bruce, Baswell, Adamson, Sinclair, Mudy, Mackenzie, Trail, and Coventry. Ship

Sa. on a chev. arg. three crescents vert in base an open boat with oars of the second sailing in a sea ppr. M'NAB That Ilk, Acharne, Newton, Cowel, Jamaica, Inchewen, etc.

\section{Stone}

Gu. on a chev. arg. a rose betw. two lions counterpass. of the first in base a star-stone ppr. George Hepburs, Nisbet, i, 166.

\section{Tree}

Arg. on a cher. gu. three crosses croslet of the first in base an oak-tree growing out of a mount vert. BraIDWOOD.
On 1 CHEVRON betw. or within.....cont. Anchors

Erm. on a chev. az. betw. two anchors in chief .... and a crescent in base gu. a 5-foil betw. two escallops .... Harris, Kent.

Erm. on a chev. betw. three anchors az. as many escallops arg. TAYJoR, quartered by Gordon.

Erm. on a chev. gu. betw. three anchors sa. as many escallops arg. Taylor, Durant Hall, co. Derby ; the heiress m. Skrymsher.

Erm. on a chev. sa. betw. three anchors az. as many escallops arg. TAYLOR.

\section{Annulets}

Arg. on a chev. betw. three annulets gu. an an. nulet of the first. Harmer.

Gu. on a chev, betw. three annulets or as many of the first. Ritchie, England.

Or on a chev. betw. three annulets sa. as many lions ramp. arg. LEJGH.

Arg. on a chev. sa. betw. three annulets gu. anotber chev. erm. Clution.

Arg. on a chev, betw, three annulets gu. as many crescents of the first. ERISBY. The crescents or. Sutron.

Or on a chev. betw. three annulets gu. as many crescents arg. Sutton's Hospital or Charterhouse, London. The crescents of the first. Sutron, Burton, and Washingborough, co. Lincoln. Robert Sutron, co. Lincoln, $V$. Oliver Sutton, Bishop of Lincoln 1250-99.

Per pale or and az. on a chev. engr. betw. three annulets as many escallops counterchanged. Shadweld, Ripe, Sussex; quartering Lucas.

Per pale or and az. on a chev. betw. three annulets four escallops counterchanged. Thomas Shadwali, Lynedon, co. Stafford, $V$. Shadwell, $V^{*}$; and Lyndowne, co. Stafford; granted 1537.

Arg. on a chev. sa. betw. three annulets gu. as many estoiles of eight points of the first. Hales.

Arg. on a chev. sa. betw. three annulets gu. as many estoiles or. HaLes.

Arg. on a chev. betw. three annulets sa. as many estoiles as the first. Hales.

Arg. on a chev. betw. three annulets gu. as many 3-foils slipped or. FowLINGE, Ireland.

Az. on a chev. arg. betw. three annulets of the second fretty gu. Moulton.

Per pale or and sa. on a chev. betw. three annulets as many buck's heads counterchanged. PARKER; confirmed 20 April 1563.

Sa. on a chev. betw. three annulets or as many spearheads az. KELYNG.

Gu. on a chev. arg. betw. three annulets or as many torteaux. Richtie. Ritonie, Scotland.

\section{Antbills see Hillocks}

\section{Anvils}

Arg. on a cher. gu. betw. in chief two anvils and in base an anchor ppr. a bee of the last enclosed by two crescents as the first. WaLker, Blythe Hall, co. Nottingham; and Clifton House, Ro. therbam, co. York.

\section{Arrows}

Az. on a chev. gu. betw. in chief two sheaves each of six arrows interlaced saltiremise of the second flighted and phioned arg. and in base a bow stringed fesswise of the last three bezants. Shotter, Farnham, Surrey.

\section{Axes}

Sa. on a chev. engr. betw. three battle axes or as many eagles displ. of the field. HaLl. 
On 1 CHEVRON betw. or within.... cont.

Axes cont.

Sa. on a chev. embattled or betw. three pole-axes arg. as many ogresses. Frytн, co. Stafford.

Al'g. on a chev. betw. three woodbills (another wood-bill blades) palewise sa. as many pierced mullets of the first. Fust, Hill Court, co. Gloucester; Baronetcy 1682-1779.

Bands

Az: on a chev. betw. three hatbands or as many merillions sa. Company of Hatband-Makers, London.

Bars

Arg. on a cher. betw. two bars gu. three crosses patty or chequy or and gu. a lion ramp. erm. Hoex, Dublin; quartering chequy or and gu. a lion ramp. erm.

Beast ..... Lion

Arg. on a chev. betw. in chief a lion pass. guard. and in base an escallop arg. three roses gu. Shrtb, Guildford, Surrey. The roses barbed and seeded ppr. Sнrobв, Stoke, Guildford.

Per cbev. or and erm. on a chev. az. betw. a lion pass. guard. in chief and the Roman fasces erect in base ppr. three fleurs-de-lis of the first. KENSIT.

Or on a chev. vert betw. a lion pass. in chief and two mullets in base gu. three garbs or. KeLI.

\section{Beasts ..... Lions}

Gu. on a cher. betw. in chief two lions ramp. and in base an eagle displ. double headed or three crosses croslet az. BuTTERWORTH.

Arg. on a chev. az. betw. in chief two lions pass. guard. and in base a lymphad sa. on waves of the sea ppr. three annulets or. RFmFrx, Truro, Cornwall.

Arg. on a chev, erm. betw. in chief two lions pass. or and in base as many swords in saltire, points upward ppr. pomels and hilts of the third and entwined by a double chain gold, three catherine wheels of the last. WHEELTON, Manchester; London; and Surrey.

$$
\text { .....Bears }
$$

Arg. on a chev. engr. betw. three bears pass. sa. a mullet of the first. JUBBS.

$$
\text { .....Boars }
$$

Az. on a cher. betw. three grieces or five mullets of the first. Essington, Halsted, co. Lincoln.

Arg. on a chev. betw. three boars pass. sa. armed or a rose of the last. UPCOTT.

Arg. on a chev. betw. three boars pass. sa. as many roses of the first. UPCoTt, Upcott, co. Devon; a heiress m. Shilston.

Arg. on a chev. betw. three boars pass. sa. armed or as many roses of the last barbed vert. Hopcot, Cornwall.

Sa. on a chev. or betw. three boars pass. arg. as many eagle's beads erased of the first. RAYMOND.

Sa. on a chev. or betw, three boars pass. arg. as many falcon's heads erased of the first. IrEMoNGER, Wherwell, co. Hants; quartering Fryer.

Arg. on a chev. betw. three wild boars sa. maned and hoofed or langued gu. a bee enclosed by two bull's heads cabossed of the first in chief a crescent of the fourth for diff. Devas, Hern Hill, Surrey, 1811.

$$
\text { .... Cats }
$$

Per pale gu. and vert on a chev. betw. three cats pass. guard. or as many garbs of the first. JELTER.
On 1 CHEVRON betw, or within....cont.

Beasts cont. Cats cont.

Quarterly gu. and vert. on a chev. betw. three cats (pass. $V^{*}$ ) statant guard. or as many garbs of the first. Richard HEuer, Cookfield, V.

\section{.....Deer}

Sa. on a cher. betw. three hinds trippant arg. as many annulets of the first, CoLLET, $V^{*}$. Collett, Suffolk. Sr. Henry Colletr, $V$; Lord Mayor of London 1486. The chev. engr. CoLLeTT, Westerfield, Sutfolk ; granted 1644 .

Sa. on a cher. arg. voided of the first betw. three hinds pass. as many aunulets of the second. Colietr, Locker's House, Hemel Hempstead, Herts. The hinds statant ppr. Collert, Wendover, co. Buckingham.

Vert on a chev, arg. betw. three bucks or a crescent gu. Robertson, $V^{*}$. Robinson, $V^{*}$.

Vert on a chev. alg. between three stags those in chief trippant and the one in base statant or a crescent for diff. gu. ROBERTson, Boston, $V$.

Vert on a chev. betw. three bucks trippant or as many crosses patty az. RoBinson, Nansloe, Helston, Cornwall; quartering Vyvyan.

Vert on a chev. betw. three bucks pass. or as many estoiles gu. Robertson, Boston, co. Lincoln.

Arg. on a cbev, counter-embattled az. betw. three stags ppr. a salmon naiant of the first. Robinson, Moore Place, co. Buckingham; granted 25 October 1731.

Az. on a chev. betw. three (bucks, another) stags trippant arg. as many tleurs-de-lis of the first. Cely Cizeliex or Syceluy, Barking, Essex.

Per pale or and vert on a chev. betw. three stags trippant as many 3 -foils counterchanged. RoBinson, Tottenbam.

Vert on a chev. betw. three (bucks, another) stags trippant or as many 3-foils slipped gu. Lionel Robinson, Cowton, co. York, as quartered by Peytoll, 1684, in church at 'Thames Ditton. Robinson, Kentwell Hall, Suffolk; Baronetcy 1682-1743. And with a crescent for diff. RoBInson, Reading, co. Berks; Whatton, co. Leicester; and Suffolk.

Vert on a chev. betw. three roebucks trippant or as many 4-foils gu. RoBINson; Baronetcy 1730 ; Baron Rolseby, 1777.

Vert on a chev. or betw. three bucks trippant of the last pelletty as many 4-foils gu. Robinson, Rokeby Hall, co. Loutb; Baronetcy 1819.

Or on a chev. gu. betw. three stags trippant vert as many 5-foils of the first. Robinson, London ; and York, 1634.

Or on a chev. vert betw. three bucks trippant ppr. as many 5-foils of the first. John RoBrsson, Bishop of Bristol 1710, London 1714-23.

Vert. on a chev. arg. betw. three bucks trippant or as many. 5-foils gu. Robinson, Hendon Lodge, Durbam; quartering Clark.

Vert on a chev. betw. three (bucks $V^{*}$ ) stags statant or as many 5-foils gu. RoBinson, $W$.

Vert on a chev. betw. three bucks trippant or as many 5.toils (? az.). RoBinson.

Vert on a chev. betw. three bucks trippant or as many 5-foils gu. John RoBInson, Bishop of Bristol 1710, London 1714-23. RoBinson, Kentwell Hall, Suffolk; Baronetcy 1682-1745; quartering Laurence. Robinson, Hill Redware, co. Stafford. The 5-foils slipped. Robrnson, Southwold, Suffolk. 
On 1 CHEVRON betw. or within .... cont.

Beasts cont. Deer cont.

Vert goutty d'eau on a chev. betw. three bucks trippant or as many 5.fuils gu. Robinson, Silksworth Hall, Sunderland.

Vert on a chev. or betw. three bucks trippant of the last and charged on the side with ogresses as many 5-foils gu. Robinson, Rokeby Park, co. York; Baronetcy 1730, quartering Leyton and Wulters. But with an ermine spot instead of ogresses. Robinson, certified May 1779.

Vert on a chev. betw. three stags at gaze or each charged on the shoulder with a martlet sa. as many gates gu. RoBINson, Aigburth, Liverpool.

Gu. on a chev. betw. three hinds trippant or a lion's head erased az. enclosed by a pair of hurts each charged with a fleur-de-lis of the second. Hind Hinde or Hynd, London. Augustine Hynde, Alderman of London, $V$.

Vert on a chev. betw. three bucks or as many lozenges gu. Robinson, $V^{*}$. Robinson, Cranesley, Northumberland; and co. Nortbampton, 1611. But roebucks trippant. Robinson, London, $W$.

Vert on a chev. betw. three stags trippant or as many mullets gu. Robertson, Deisaprice, co. Lincoln.

Vert on a chev. betw. three bucks trippant or as mauy suns gu. Robinson, Boston, co. Lincoln.

Arg. on a chev. vert betw. three bucks courant sa. five ermine spots gold. Rogers, The Home, co. Salop; and Stanage Park, co. Radnor.

Vert on a chev. betw. three bucks trippant or a wreath of laurel betw. two 5-foils gu. RoBInson, Batb, co. Somerset; granted 1772 .

$$
\text { .... Dogs }
$$

Arg. on a chev. gu. betw. three greyhounds sa. collared or an annulet .... Nicholas GAYNESFORD, temp. Henry VII, in church at Carsibalton

Arg. on a chev. engr. sa. betw. three hounds gu. a 3-foil or enclosed by two fusils of the first. HARris, Essex.

Or on a chev. az. hetw. three greybounds cou. rant sa. as many 3.toils arg. Wright, Aldington, Kent; and St. Edmundsbury, Suffolk.

Per pole arg. and sa. on a cbev. engr. betw. three talbots sejant collared two cloves counter. changed. Allen, Londou, $W$.

Arg. on a chev. per pale gu. and az. betw. three talbots pass. sa. as many stag's heads cabossed or. Hunton, East Kuoyle, co. Wilts.

Az. on a chev. betw. three talbots pass. arg. a buglehorn sa. Horne.

$\mathrm{Gu}$. on a chev. betw. three talbots pass. arg. a buglehorusa. HorNe, Lord Mayor of London 1487 ; and co. Cambridge.

Sa. on a chev. betw. three talhots pass. arg. a buglehorn of the first stringed gu. Horne.

Gu. on a chev. engr. betw, three talbots ramp. arg. a mullet ..... HCNGATE, $V$.

Arg. on a chev gu. betw. three talbots courant sa. collared (and ringed $V^{*}$ ) or as many bezants. Hound, $V^{*}$. John Hownde, Mayor of Calais $1557, V$. But hounds pass. Hound or Hownd, Callis, co. Cambridge; and co. Here. fordshire. But talbots pass. Hind, Mayor of Calais 1557.

Sa. ou a chev. betw. three greyhounds courant arg. as many sprigs of ashen leaves ppr. NAShe.
On 1 CHEVRON betw. or within.....cont.

\section{Beasts cont. Goats}

Arg. on a chev. betw. three goats pass. sa. as many escallops of the first. Benson.

Az. on a chev. betw, three goats pass. arg. armed or as many fleurs-de-lis of the first. Clement Sysley, Barrow Hall; at Eastbury, Essex.

Vert on a chev. betw. three goats (pass. $V^{*}$ ). statant arg. as many fleurs-de.lis az. Syschey, Barrow Hall, Essex; granted $3 \mathrm{l}$ December $1560, W$. Syseley, $V^{*}$. But borned or. Sysuey, Fountains, co. York; Nortbam, Sussex ; Sevenoaks, Kent; and Bartoy (? Barrow) Hall, Essex; Add. MS. 7098, fo. 18.

Vert on a chev. betw. three goats pass. or as many lozenges gu. RoBinson.

\section{....Horses}

Sa. on a chev. betw, three horses passant .... as many annulets .... Swe Swing, London.

$$
\text { .... Leopards }
$$

Quarterly git. and vert on a chev. betw. three leopards pasa. or as many garbs of the first. Hever, Cuckfield, Surrey; the heiress m. Feners. .....Lions

Arg. on a chev. gu. betw. three demi-lions ramp. az. as many crescents or. CHACHEMAYD, $V$.

$\mathrm{Or}$ on a chev. gu. betw. three demi.lions ramp. sa. a cross croslet arg. betw. two towers of the first. Stephens; quartering Lyne.

Or on a chev. betw. three demi-lions ramp. gu. as many crosses arg. Stern, Scotland.

Or on a chev. gu. betw. three demi-lions ramp. gu. as many crosses croslet arg. Stephens, Burderop, co. Wilts.

Or on a chev. gu. betw. three demi-lions sa. as many crosses croslet arg. Stephens, Frox. field, co Wilts.

Vert on a chev. arg. betw. three demi-lions ramp. or as many crosses croslet sa. GrubB or Grubbe, Potterne, co. Wilts; no coat exists in the Visitation, 1623, for GRUBEE who had married the heiress of Stephens, of Froxfield.

Or on a chev. sa. betw, three demi-lions pass. guard. gu. crowned of the first so many covered cups as the field. Butler, Cotes, co. Lincoln.

Arg. on a chev. betw. three demi lions ramp. gu. as many escucheons of the first. Fisher, Lotsford, co. Hertford, $W$.

Arg. on a chev. sa. betw. three demi.lions erased vert as many 3 foils erm. Hamigston or Hammington, Dover, Kent. The chev. engr. Hamigston.

Erm. on a chev. betw. three demi-lions ramp.gu. as many 3 -foils slipped or. LifieLd, Surrey.

Or on a chev. betw. three demı lions ramp. gu. as many 3 -foils arg. Lisle, Surrey. The 3-foils slipped. Lyfield, Stoke Dabernon, Surrey; granted May 1568. Vincent, Surrey.

Or on a chev. betw. three demi lions gu. as many slipped 3-foils of the first. LAYFIEID; con. firmed 1639. LIfELDE, Surrey. Lyfeild, $V^{*}$. Gu. on a chev, arg. betw. three demi.lions ramp. or as many bunches of grapes ppr. Fisher, Londonderry; and London.

Arg. on a chev. betw. three demi-lions ramp. az. as many bull's heads cabossed or. Whitbroke, Bridgenorth, co. Salop; granted 20 March 1560.

Gu. on a chev. arg. betw, three demi.lions ramp. or as many sicliles sa. PEPPER, Thurmarston, co. Leicester; and co. York.

Arg. on a chev. gu. betw. three demi-lions ramp. az. as many bugles or. CATCHMAY, Buxmear, and Troy, co. Monmouth. 
On 1 CHEVRON betw. or within....cont.

Beasts cont. Lions cont.

Arg. on a chev. sa. betw. three demi-lions couped gu. as many buglehorns stringed or. BoND, Cawbery, co. Hereford; and Redbrook, co. Gloucester.

Or on a chev. betw. three (? demi) lions erased sa. as many pheons .... Hening, co. Worcester; and London.

Arg. on a cbev. az. betw. three demi-lions ramp. gu. as many bezants. HuLL, Hameldon, Sulrey.

Arg. on a chev. betw. three demi-lions ramp. gu. as many bezants. Sr. Michael Fisher, co. Bedford, $V$. Fisher, Cottesford, co. Hertford; and London.

Or on a chev. betw. three demi-lions gu. as many bezants. Fisher, Sidhamweek, co. Wilts.

Gu. on a chev. or betw. three demi-lions ramp. arg. as many hurts. DickMaN.

Arg. on a chev, az, betw. three demi-lions ramp. gil. as many plates. HuLL, Hameldon, Surrey.

Arg. on a chev. betw. three demi-lions ramp. gu. as many plates. Fisher, Cottesford, co. Hert. ford; and London.

Arg. on a chev. engr. sa. betw. three demi-lions ramp, vert as many plates each charged with a triplet of ermine spots. Hanington.

Or on a chev. betw. three demi-lions ramp. gu. as many plates a mullet for diff. FisHer, Lydenham, co. Wilts.

Arg. on a chev. betw. three demi.lions gu. nine plates. Fisher.

Arg. on a chev. betw. three demi-lions ramp. gu. two spear's in saltire of the first. Pickas.

Per pale arg. and az. on a chev. engr. erm. betw. three deni-lions erased counterchanged a wreath of uak ppr. enclosed by two escallops as the second. SHarp, Ulaybury, Brewsters, Maxwells, and Haynefields, Barbadoes.

Sa. on a chev. betw. three lions ramp. arg. an annulet of the first. Sr. Stephen Hallys, $V$. John Hasys, Essex, $V$.

Barry of six sa. and gu. on a chev, betw. three lions ramp. arg. as many annulets of the se. cond. Sowerby, Dalston Hall, Cumberland; and Putteridge-Bury, co. Hertford. Sowerby, Old Park, Durham; quartering Muschamp.

Arg, on a chev. sa. betw. three lions pass. ppr. as many arrows of the tirst. Foster, Barbadoes.

Arg. on a chev. betw, three lions ramp. az. bars of the first. PAYNe.

Az. on a cluev. flory betw. three lions pass. or as many lapwings ppr. HEWIT, co. Derby.

Arg. on a chev. sa. betw. throe lions ramp..... as many crescents of the first. Newlands, Scotland.

Arg. on a chev. sa. betw. three lious ramp. tails forked sa. crowned or as many crescents of the first. NEWLAND, eo. Hertford; granted 1693.

Az. on a chev. engr. betw. three lions pass. guard. arg. as many crosses moline sa. FowLER.

Az. on a chev. arg. (gu. $V^{*}$.) betw. three lions pass. guard. or as many crosses patty sa. Fowler, Windlesham House, Bagshot, Surrey; quartering Englefield, Mildmay, Ratcliffe, Burnell, Fitzwalter, and Devereux. Sr. Richard Fonvler, ricott, $V$. Fowler, Horton Hall, and Leek, co. Stafford. The lions langued end armed gi. Fowler, co. Salop.
On 1 CHEVRON betw. or within.....cont.

Beasts cont. Lions cont.

Az. on a chev. (another engr.) betw. three lions pass. guard. or as many crosses patty (another moline) sa. Fowler, Harnage Grange, co. Salop; Baronetcy 1704-73; quartering Loveday, Barton, Inglefield, and Lee; a heiress m. Jones; descended like Fowler, Pendeford, co. Stafford; through Fowler, St. Thomas, co. Stafford; from Fowler, Foxley, co. Buckingham.

Sa. on a chev, engr. arg. betw. three lions ramp. or as many crosses patty gu. Healy, quartering vert on a chief sa. three martlets or, Collinson, Somerset, iii, 407.

Arg. on a chev. betw. three lions ramp. sa. as many escallops of the first. NewLAND.

Az. on a chev. betw. three lions pass. guard. erm. as many escallops gu. J Ames, Haughton Hall, Hanover, Jamaica; quartering Haugbton, Halton, Fisber, Fowler, Drayner, and Parson.

Az. on a chev. betw. three lions pass. guard. or as many escallops sa. JAMES, Lord Mayor of London 1479; co. Salop; and co. Stafford. The lions reguard. JAmES, Foxley, co. Worcester.

Gu. on a chev. betw. three lions pass. guard. or as many escallops sa. James.

Per pale arg. and az. on a chev. betw. three lions pass. guard. as many escallops counterchanged. James, Cambridge. But the field per pale or and az. JAMES.

Az. on a chev. betw. three lions pass. guard. or ducally crowned of the last three grenades sa. fired ppr. James, Park Farm Place, Eltham, Kent.

Arg. on a chev. engr. gu. betw. three lions ramp. sa. as many fleurs-de-lis or. BIRD, Penrith. BYRDE, co. Lincoln.

Az. on a chev. betw. three lions pass. or as many fleurs-de-lis of the first. Warring, South Lutbroke, co. Devon.

Arg. on a chev. betw. three lions ramp. vert as many 3-foils slipped erm. Hanynton, Kent.

Az. on a cliev. engr. arg. betw. three lions ramp. of the second as many slipped 3-foils sa. BERIFFE.

Per pale gu. and sa. on a chev. or betw. three lions pass. guard. erm. crowned gold as many 4 -foils vert. Fow Fowler, Bishop of Gloucester 1691-1714.

Gu. on a chev. betw. three lions ramp. or as many 5-foils of the first. Goode, Whitstone, Cornwall ; the heiress m. Badcock.

Per pale gu. and az. on a chev. or betw. three lions pass. arg. as many 5 -foils .... Hosken, Carines, and Ellenglaze, Cornwall.

Sa. on a chev. betw. three lions ramp. or as many 5-foils az. Cooke, Cotton, Suffolk.

Arg. on a chev. sa. betw. three lions ramp. az. fretty or. HAII, $V^{*}$. The lions gu. BOCKIANDE.

Arg. on a chev. betw. three lions ramp. az. as many garbs or. ParRY.

Arg. on a chev. az. betw. three lions ramp. gu. as many buglehorns or. Hunter alias PERnY, Wotton-under-Edge, co. Gloncester.

Az. on a chev. arg. betw. three lions ramp. or as many ants fesswise ppr. LockYER, co. Devon; confirmed .... to LOCKYER, Plymouth.

Arg. on a chev. gu. betw. three lions pass. sa. bezanty as many lozenges of the first. ENaLISH. Arg. on a chev. gu. betw. three lions ramp. sa. as many lozenges of the first. ENGLIsH. 
On 1 CHEVRON betw. or within.... cont. Beasts cont. Lions cont.

Gu. on a chev. betw, three lions pass, arg. as many lozenges of the first. Cooper, Dowbiggen, co. York; and Pains Hill, Surrey.

Arg. on a chev. gu. betw. three lions pass. sa. bezanty as many mascles of the first. ENGLISH.

Arg. on a chev. gu. betw. three lions ramp. sa. as many mascles or. Borne, co. Worcester. The chev. engr. Bourne, London.

Gu. on a chev. betw. three lions pass. guard. arg. as many mascles of the first. CoOper or CowPer.

Erm. on a chev. az. betw. three lions ramp. guard. sa. each supporting betw. the forepaws an escallop erect gu. a mitre or enclosed by a pair of crosses croslet fitchy arg. Montaigne or Mountain, Hemel-Hemstead, co. Hertford; quartering Wale. George J.Mountain, Bishop of Montreal 1836, Quebec 1850.

Sa. on a chev. or betw. three lions arg. a mullet of the first. Thomas Hasfield, $Y$.

Az. on a cbev. betw. three lions pass. or as many mullets sa. WartNaBy.

Gu. on a chev, arg. betw. three lions pass. guard. or as many mullets az. Carre, Scotland.

Az. on a chev. arg. betw. three lions pass. or as many pheons gu. (The old arms of) WHITwick WHITWIKE or WignTwick, Whitwick, co.Stafford; granted 1612 .

Az. on a chev. betw. three lions pass. guard. or as many purses sa. Jaries, co. Gloncester.

Arg. on a chev. gu. betw. three lions ramp. sa. as many bezants. ENGLISH.

Arg. on a chev. betw. three lions ramp. the two in chief respecting each other sa. as many bezants. Morland. Nerland, $V$.

Arg. on a chev. betw. three lions ramp. sa. as many bezauts. NoRland or Norton, Ient.

$$
\text { .....0tters }
$$

Arg. on a chev. az. betw. three otters sa. each devouring a fish ( $i$. e. a salmon of the second) ppr. three barbed arrows or. GREIDEN, Scotland. But barbed pheons or. Gardin, Earns. law. Graden, Scotland.

Sa. on a chev. betw. three otters statant arg. a crescent gu. HarTOPP, co. Cambridge; confirmed 1617, Harl. MS. 6095, fo. 39.

$$
\text { .... Oxen }
$$

Arg. on a chev, engr. az. betw. three calves gu. another chev. or. LEMINGTON.

Arg. on a chev. gu. betw. three calves pass. sa. a mullet or. Dunalfe or Duncalfe.

$$
\text { ..... Sheep }
$$

Gu. on a cher, betw. three lambs statant arg. a crescent for diff..... LAMBERT, $V$.

Az. on a chev. or betw. in chief two lambs and in base a ram arg. three lamb's kidneys gu. KIDNEY, London; and Market Harborongh, co. Leicester; granted 1765.

Vert on a chev. or betw. in chief two lambs pass. arg. and in base a golden fleece another chev. erm. charged with three woolpacls ppr. KING, Broomfield, Essex; granted ....

Arg. on a chev. or betw. three lambs as many roses ppr. Crosby, London; confirmed 1821.

Arg. on a chev. az. betw. three squirrels sejant gu. an annulet or. Loveli, Norfolk.

Erm. on a cher. hetw. three squirrels gu, each with a nutbranch fructed or as mauy roses arg. Graytowyers.
On 1 cHEVRON betw. or within.... cont: Beasts cont. Squirrels

Erm. on a chev. sa. betw. three squirrels sejant gir. collared lined and ringed or (but ppr. with beads and chains of gold about their necks, Company of Tauyers, London;) as many roses arg. Greytawyers, $V$.

Arg. (another, or) on a chev. az. betw. three squirrels sejant each holding a nut ppr. as many acorvs or. WoODgate.

Az. on a chev. betw. three squirrels arg. as many trees vert fructed or a bordure engr. of the last charged with eight torteaux. STockwood.

\section{Bells}

Az. on a chev. or betw. three church bells arg. within a bordure erm. an eagle displ. enclosed by two lions ramp. gu. William BelHouse, Rygate, Surrey, $V$.

Erm. on a cbev..... betw. three cluurch bells .... an eagle displ. enclosed by two lions ramp..... BelHouse, (in a laterhand than) $W^{\prime}$.

Sa. on a chev. betw. three church bells arg. as many lion's heads couped gu. BELL, co. York. Billets

Arg. on a chev, az. betw. three delves sa. fretty or. Delves.

Arg. on a chev. gu. betw. three billets (or delves) sa. fretty of the first. Delves. But fretty or. Delues, $V$; and co. Chester; Kent; and co. Lancaster.

Or on a chev. gu. betw. three cubes pean as many horseshoes arg. Williams, Ivy Tower, co. Pembroke, quartering Harris and Ferrar.

Az. on a chev. arg. betw. three billets (or delves) or as many torteaux. TwEnTYDian.

Arg. on a chev. gir. betw. three steel gads az. as many swivels the middle one palewise the other two with the line of the chev. or. Company of lrondongers; granted 1455 .

\section{Birds}

Arg. on a chev. sa. betw. in chief two birds russet beaked and legged of the second and in base a book or in a black cover three pheons as the first. John Best, Bishop of Carlisle 1561-70; granted by Dalton.

Arg. on a chev, engr. gu. betw, in clitef two birds with wings erect and in base an anchor or five bezants. Boase, Cornwall.

$$
\text { .... Cocks }
$$

Arg. on a cher. az. betw. in chief two cocks and in base a buckle gu. a lion ramp. of the first crowned or. AIkIN, Liverpool.

$$
\text { .....Doves }
$$

Arg. on a chev. or betw. in chief two doves arg. beaked and legged gn. and in base a dragon's head erased of the third a red rose enclosed by a pair of books or in black covers. William Dounam or Downham, Bishop of Chester 156177 ; granted 5 May 1561, Harl. MS. 1359, fo. 50. Az. on a chev. or betw. in chief two doves arg. and in base an anclior erect of the second three roses gu. barbed and seeded ppr. DOVETON.

Az. on a chev, or betw. in chief two doves close arg. and in base an oak-tree ppr. a mullet .... HAGEN, Bermondsey.

$$
\text { .... Eagles }
$$

Az. on a chev, betw. two engles displ. or a lion pass. of the second. NICHOLAs, London.

Az. on a chev. erm. betw. in chief two eagles displ. and in base a lion pass. three estoiles or. Wildman, Newstead Abbey, co. Nottingham. Wirduan, Chilbam Castle, Kent. 
On 1 CHEVRON betw, or within.... cont. Birds cont. Eagles cont.

Az. on a chev. or betw. in chief two eagles displ. arg. and in base a lion's head erased of the second three estoiles gu. PoDE, Slade, co. Devon.

Az. on a chev. arg. betw. in chief two eagles displ. and in base a lion ramp. or three fleursde-lis gu. Snooke, Chichester.

Az. on a chev. betw. in chief two eagles displ. and in base a lion pass. or a burt charged with a leopard's head enclosed by two torteanx each bearing an escallop arg. John NicheLL, London, $V$.

Az. on a chev. betw. in chief two eagles and in base a lion pass. or a torteau charged with an escallop arg. Nicholas, Middlesex.

Az. on a chev. betw. in chief two eagles displ. and in base a lion pass. or three torteaux the middle one charged with a leopard's face and the other two with an escallop all arg. Nicholas, London.

Az. on a chev, betw. in chief two eagles rising and in base a liou pass. or three sprigs of oak fructed vert. BRANDFORD, London, late of Barbadoes.

\section{.....Falcons}

Arg. on a chev. az. betw. in chief two falcons ppr. belled or and in base a mount vert thereon the stump of an oak tree sprouting out a branch to the sinister also ppr. three roses of the first barbed as the folirth and seeded gold. BLock, Middlesex.

Arg. on a chev. embattled az. betw. in chief two falcons rising ppr. belled or and in base an anchor sa. the cable of the third an escallop as the first enclosed by a pair of bezants. RонDE, Middlesex; granted 1765.

$$
\text { .....Herons }
$$

Or on a chev. engr. gu. betw. in chief two storks rising az. beaked and membered of the second and in base on a mount vert an ash-tree ppr. three annulets as the first. FraIgneaU, Westminster; granted 1757.

$$
\text { ..... Lapwings }
$$

Az. on a chev. betw. two lapwings or as many 4-foils. Thomas and John AtsSTEN, Lincoln's Inn, 1658 ; St. Leonard's Church, Shoreditch. .....Martlets

Arg. on a cbev. gu. betw. in chief two martlets sa. and in base a book closed ppr. three pheons or. Best, Sedgley, Bilston, and Wedinesbury, co. Stafiord ; and Elmley Lovet, co. Worcester. .... Moorcocks

Erminois on a chev, az. betw, in cbief two moorcocks and in base a galley ppr. three estoiles of six points arg. Moonsom.

$$
\text { .... Partridges }
$$

Arg. on a chev. az. betw. in chief two partridges and in base a greylound comrant sa. a garb enclosed by a parr of luglehorns stringed or. Chard, Patbe House, co. Somerset.

\section{Birds}

Or on a chev. sa. betw. three birds (probably crows) az. membered gu. as many martlets of the first. CHAWNEY, London.

Per pale arg. and sa. on a chev. betw. three birds as mauy crescents all counterchanged. Rawlings.

Arg. on a chev, betw, three birds gu. as many fleurs-de-lis or. Downing.

Arg. on a chev, betw. three birds sa. within a bordure of the second platy a lion's head
On 1 CHEVRON betw, or within.....cont.

Birds cont.

erased betw. two 3.foils slipped or. JoNes, co. Monmouth.

Arg. on a chev. betw. three birds sa. within a bordure engr. of the second platy a lion's head erased as the first betw. two 3-fuils slipped vert. JoHnes, co. Monmouth.

$\mathrm{Gu}$. on a chev, betw. three birds arg. as many leopard's heads of the first. SмYTH.

Az. on a chev. engr. erm. betw. three birds arg. beaked and legged gu. as many buman hearts of the last. BeEDHaM, Ashfield, Kimbolton, co. Huntingdon.

\section{.... Blackbirds see Thrushes .....Bustards}

Arg. on a chev. quarterly gu. and sa. betw. three bustards of the second as many bezants. Ketchin, Scotland. Kitchiner. Кусhem, Harl. MS. 1404, fo. 14.

\section{.... Choughs see Crows .....Cocks}

Az. on a chev. arg. betw. three cocks or three crescents from each an estoile issuant of the first. TARTE, Westminster; granted ....

Erm. on a chev. sa. betw. three cocks az. legged and combed or a bezant. GLascock, Briseth, and High Easter, Essex.

\section{.....Cormorants}

Arg. on a chev. gu. betw. three cormorants sa. as mauy bezants. Ketching.

Arg. on a chev. sa. betw, three gannapyes az. membered gu. as many plates. YEo, $V$.

\section{....Cranes see Herons$$
\text { .....Crows }
$$

Arg. on a chev. sa. betw. three Cornish choughs ppr. an annulet of the first. WARD.

Arg. on a chev. sa. betw. three crows az. as many annulets or. Chaury, Lord Mayor of London 1494. The birds gu. Chawry, Kent.

Arg. on a chev. engr. betw. three ravens sa. as many annulets of the first. CroMrr, London. Or on a chev. sa. betw. three crows az. membered gu. winged or as many annulets arg. Sir Richard Chawrey, Lord Mayor of London, $V$; 1494.

Or on a chev. sa. betw. three crows az. membered gu. as many annulets of the first. CHawrEx, $V$. But winged or. Sir Richard CHawry, Lord Mayur of London, 1494.

Or on a chev. engr. betw. three ravens ppr. barry wavy of six arg. and az. Cromer, Norfolk. Arg. on a chev. gu, betw. three Cornish choughs ppr. a lion pass. guard. or. City of Canterbury. Or on a chev. betw. three ravens sa. two lions combatant arg. Nicholas or Nicholls, Prestbury, co. Gloucester; and Allcanning, and Roundway, co. Wilts.

Arg. on a chev. sa. betw. three crows ppr. and a bordure engr. gu. bezanty a crescent of the first. Fitz-Vrian, Llangadock, co. Carmarthen; granted 20 February 1526. The crows sa. Thomas Fitz-VRIAN, $V$.

Arg. on a cher. gu. betw. three crows ppr. as many crescents arg. KrowTon.

Arg. on a chev. sa. betw. three rooks ppr. as many chessrooks of the first. Rook, Kent. The chev. engr. and rooks sa. Rooke, Horton, Kent. Arg. on a chev. gu. betw. three Cornish choughs ppr. a crescent or. Dicker, Rotherfield Pipard, co. Oxford; and Bodebam and Salehurst, Sussex. PIPald. 
On 1 CHEVRON betw. or within.... cont. Birds cont. Crows cont.

Arg. on a chev. gu. betw, three birds (? crows) sa. as many crosses patty of the first. DeanE, $V^{*}$. The crosses or. Deane, Lord Mayor of London 1628.

Arg. on a chev. gu. betw. three ravens ppr. as many crosses patty or. DEANE.

Arg. on a chev. sa. betw. three Cornish choughs ppr. as many crosses croslet or. DEAN, London.

Arg. on a chev. engr. sa. betw. three ravens ppr. as many escallops or. Croker, London; and Batisford, co. Gloucester.

Arg. on a chev. sa. betw. three Cornish choughs ppr. as many estoiles or. Carhil.L. Carlile, Carlile, $V$. Carlill or Carlyle, Northumberland.

Or on a chev. sa. betw. three Cornish chougls ppr. as many estoiles of the first. CARLILES Cartiles, Northumberland.

Arg. on a chev. sa. betw. three rooks ppr. a fleurde-lis for diff. or. Rokeby, Maske, and Stanningford, co. York.

Arg. on a chev. gu. betw. three birds within a bordure engr. sa. as many fleurs-de-lis of the first. Thomas Massingham, Norfolk, $V$.

Arg. on a chev. betw. three crows sa. as many 5 -foils of the first. CALDEBECK.

Az. on a chev. engr. betw. three Cornish choughs or as many 5-foils of the first. WINCHCOMBE.

Arg. on a chev. sa. betw. three Cornish choughs ppr. five fusils of the first. Richard MAYEW or MAYo, Bishop of Hereford 150 $1-16$.

Arg. on a chev. betw. three choughs sa. as many gouttes d'eau. RICE, Dane Court, Kent.

Arg. on a chev. betw. three Cornish chonghs sa. as many stag's heads cabossed of the first. Baynbrigge. Blynbrige, Snatterton, co. Durham.

Arg. on a chev, sa. betw, three Cornish choughs ppr. as many leopard's heads or. URREN alias Currence. Wales, 1619.

Arg. on a chev. betw. three ravens sa. as many leopard's faces or. Corrance, Rendlesham, Parham $\mathrm{Hall}$, and Rougham, Suffolk ; descended from Urren alias Currance, London; granted 1619.

Arg. on a chev. gu. betw. three Cornish choughs ppr. as many lozenges or. TAUNTON, Somerton, co. Sumerset; Hilfield, co. Dorset; Liskeard, and Truro, Cornwall; and co. Oxford.

Arg. (another or) on a chev. sa. betw. three birds (? crows) of the last five lozenges as the first. Mayow, Dinton, co. Wilts.

Arg. on a chev, engr. gu. betw. three ravens ppr. as many mullets or. Croker, co. Oxford.

Arg. on a chev. sa. betw. three Cornish chonghs ppr. beaked and legged gu. as many mullets of six points or. Carleill, Sewerby, co. York.

Arg. on a chev. betw. three rooks sa. as many mul. lets arg. Rokeby, Rokeby Merton.

Arg. on a chev, betw. three rooks sa. as many mullets of the first. Tasiurgh, Clanny, co. Gloucester; granted 1739.

Arg. on a cher, couched sinister betw. three birds (? ravens) sa. five mullets of the first. Groys, $V^{*}$. GWyx, $V$. GWYNe, $V^{*}$. The field or. GWYN.

Arg. on a chev, voided sa, betw, three ravens ppr. each bolding in the beak an erm. spot as many ogresses. Flower, co. Nottingham; granted 1681. Flower, Baron of Castle Durrow 1733, Viscount Ashbrook 1751.
On 1 CHEVRON betw. or within.... cont.

Birds cont. Crows cont.

Arg. on a chev. gu. betw. three Cornish choughs ppr, as many pastoral staves erect or. Henry DEANe, Bishop of Bangor 1 496 , Salisbury 1500 , Archbishop of Canterbury 1501-3.

Arg. on a chev. engr. az. betw, three rooks ppr. as many suns or. Rook, London; granted 1755 .

Arg. on a chev. betw. three rooks sa. as many suns or. Rooke, Rookes'oth Bridge, Waverton, Akehead, Ruokes' Nest, Wigton, and Carlisle, Cumberland.

$$
\text { .... Doves }
$$

Per fess az. and gu. on a chev. engr. betw. in chief three doves and in base a fleur-de.lis or as many anuulets .... Hoderts, Hagley, Stourbridge.

Az. on a chev, or betw. three doves (? wood. wallises) ppr. another chev. as the first. PinfoLd, Dunstable, co. Bedford; granted 18 October 1501. The chev, charged wath so many plates. Pinfoln.

Az. on a chev. or betw. three wood pigeons ppr.each charged on the breast with an ogress another chev, couped sa. PENFord, Cissbury, Sussez. Arg. on a chev. betw. in chief three doves and in base a fleur-de-lis or three crescents vert. Hodgetts, Prestwood, co. Stafford; granted 6 October 1768.

Sa. on a chev betw. three doves arg. a fleur-delis az. Gervis, Master of the Pipe Office.

Az. on a chev. arg. betw. three doves of the second beaked and legged gu. so many fleurs-dtlis as the last. Plumerage.

Or on a chev. engr. between three doves az. as many fleurs-de-lis of the first. FuLmerton.

Az. on a chev. flory counterflory betw. three doves arg. as many 3 -foils vert. BARTHELET; granted l September 15 49 . The 3 -foils slipped vert pierced or. BARTLET, London.

Sa. on a chev. flory counterflory betw. three doves arg. as many slipped 3-foils ppr. BARTLET.

Sa. on a chev. betw. three birds (? doves) arg. as many pierced 3 -foils vert. BARTLYTT, London, Harl. MS. 1404, fo. 142.

Sa. on a chev. Hory counterflory betw. three birds (? doves) arg. as many 5.foils vert. BartLytr, Harl. MS. 1404, fo, 142 .

Az. on a chev. betw. three doves or as many 5 . foils vert. Austen, Derhams, Middlesex, 1714. Az. on a chev, arg. betw, three doves ppr. as many acorns of the last. HARWARD, Middlesex.

Sa. on a chev. betw, three doves arg. five gouttes de sang. Collens or Collins, Offwell, co. Durset. Collins, co. Devon.

Gu. on a chev. betw. three doves arg. as many pheons sa. PAGE, Donnington, Sussex, 1591 ; the heiress $\mathrm{m}$. White.

Gu. on a chev. betw. three doves arg. as many ogresses. RIDLEy, quartered by Lord Colborne.

Az. on a chev, betw. three doves reguard. arg. wings expanded or two sugar canes of the last spligged vert. LUSADA LOSADA aud LONSADA, Jamaica.

Az. on a chev. or betw. three doves ppr. as many laurel slips vert. MaIdman, lsle of Portsea, co. Southampton; granted 1765.

$$
\text { ....Ducks }
$$

Az. on a chev, engr. az. betw. three shovellers sa. as niany 3-foils or. Barnes Lord Mayor of London 1552.

Arg. on a chev. sa. betw. three shovellers az. membered gu. as many plates. YEo, $V^{*}$. 
On 1 CHEVRON betw. or within.... cont. Birds cont. Eagles

Arg. on a chev. engr. gu. betw. three eagles sa. an annulet or. LAMrBard, Lord Mayor of London 1531.

Arg. on a chev, gu. betw. three eagles displ. sa. as many annulets or. Cenly Celey or CeLy.

Arg. on a chev. betw. three eagles displ. sa. as many annulets of the first. SHERBorne.

Erm. on a chev. engr. betw. three eagles displ. double-headed gu. each gorged with a ducal coronet or as many annulets of the last. Eliwell. Elwill, Exeter; granted 11 December 1701; Baronetcy 1700-78; the heiress m. Hervey and Fremantle.

Arg. on a chev. gu. betw. three eagles displ. sa. five annulets or. Cinderowe. Clitherow, Lord Mayor of London 1635. A crescent for diff. .... Clithenow; certified 1779.

Sa. on a chev. betw. three eagles displ. arg. five annulets gu. Cliderow. The eagles doubleheaded. ClaEderow.

Sa. on a chev. (gu. $V_{\text {. }}$ ) or betw. three eagles displ. double headed arg. five annulets (or, $V_{.}$) gu. Clenerow, $V$. The eagles not double headed. John Cledenowe, Bishop of Bangor 1426-35.

Az. on a chev. arg. betw. three eagles rising or as many bars gemel gu. NiBLEtT, Haresfield, from Standisb, co. Gloucester.

$\Delta z$. on a chev. engr. betw. three eagles displ. or a plain cbev, erm. Sr. William Essex, $V$.

Arg. on a chev. betw. three eagles displ, gu. a crescent of the first. BlondelL.

Arg. on a chev. az. between three eagles displ. sa. as many crescents or. Thorpe, $V$. The eagles crowned gu. THORPE.

Gu. on a chev. betw. three eagles displ. arg. as many crosses croslet of the first. BarLAY, Barlay, and Barnsfield Woodhouse, co. Derby.

Gu. on a chev. arg. hetween as many eagles or three escallops sa. LoveKIN or LEWKYN, Lord Mayor of London 1348, 1358, 1365, and 1366.

Arg. on a chev. az. betw. three eagles close sa. as many estoiles or. Mansegles, $V$. The eagles displ. Nunsegles, 1615.

Arg. on a chev. wavy betw. three eagles displ. gu. as many estoiles of the first. Francis, co. Derby; and Cookmaines, co. Hertford.

Or on a cbev, engr. betw. three eagles displ. sa. as many 3 -foils slipped of the first. SHaw, Bushby Park, co. Dublin; Baronetcy 1821.

Gu. on a chev. betw. three eagles close reguard. or as many 5-foils sa. Dalling, alias Bulwer, Estwicke, Norfolk. Bulwer, Heydon, Norfolk; quartered by Bulwer Lytтon, Bart.

Arg. on a chev. betw. three eagles displ. az, a mullet or. Clopton, Clopton, co. Somerset, $V$.

Sa. on a chev. betw. three eagles displ. .... as many mullets .... LuFkys.

Gu. on a chev. engr. erm. betw. three eagles a serpent nowed enclosed by two ears of big ppr. Chul, Sireatham, Surrey.

Arg. on a chev. engr. betw. three eagles displ. gu. as many bezants. SHERBORNE.

Arg. on a chev. gu. betw. three eagles displ. sa. as many bezants each charged with a plate. Sr. Benet Cer.ey, $V$.

Az. on a cbev. erm. betw. three eagles displ. arg. as many ogresses. WaLL, co. Derby.

Arg. on a chev. betw. three eagles displ. gu. as many plates. Sr. Henry Cherbron, $V$. The eagles double headed. Eцрнick.

\section{On 1 CHEVRON betw, or within.....cont.}

Birds cont. Eagles cont.

Arg. on a chev. engr. betw. three eagles displ. gu. as many plates. Elswike or Elswyke, co. Lancaster. The eagles double headed. Rich. ard Elswike, Rebchester, co. Lancaster, $\boldsymbol{V}$.

Or on a chev. engr. betw. three eagles displ. gu. as many plates. Charbrone. The eagles double beaded. Elswell.

Gu. on a chev. betw. three eagles displ. or as many torteaux. Dycer, Hackney, from Wren. ham, Suffolk; granted 1660-1. The eagles displ. Dicor, Upball, co. Hertford.

\section{....Falcons and Hawks}

Az. on a chev. betw. three falcons volant arg. a crescent for diff. of the first. Primms, co. Leicester, 1716.

Per chev, az. and gu. on a chev. engr. or betw. three falcons close arg. beaked legged jessed and belled of the third collared gu. a plain chev. sa. GEPP, co. Somerset; and Chelmsford.

Gu. on a chev. betw. three falcons arg. membered and belled or a cross croslet fitchy sa. Headley or Hedley, co. Huntingdon.

$\mathrm{Gu}$. on a chev, arg. betw. three sparrow-bawks ppr, a cross croslet fitchy sa. Hetley, Bulbridge House, co. Wilts.

Erm. on a chev. vert betw. three falcons ppr. belled or as many crosses moline of the lust. MALYN.

Alg. on a chev. betw. three hawks sa, a cross tau or. O'BEIRNE.

Vert on a chev. betw. three falcons volant or as many 3 -folls slipped sa. WINDIBANKE.

Arg. on a chev. embattled betw. three hawks az. as many roses or. HоBBY, co. Hertford.

Az. on a chev. or betw. three falcons close arg. as many roses gu. Nicholas Close, Bishop of Carlisle 1450, Lichfield. etc, 1452-3.

Az. on a chev. betw. three birds (? hawks) arg. beaked and legged gu. as many talbot's heads sa. collared or. Morsen, co. York.

Az. on a chev. betw. three liawks close arg. belled and jessed or as many talbot's beads erased sa. collared of the third. Moyser, Farlington, co. York.

Arg. on a chev. sa. betw. three falcons close ppr. belled or as many pheons of the last. Tallis, Ireland.

$\mathrm{Gu}$. on a chev. betw. three falcons arg. as many ogresses. Ridery, Heaton Hall, Nortbumberland; Baronetcy 1756, quartering White. RideEy, Park End, Northumberland. Nicholas RidLey, Bishop of Rochester 1547, London 1550-53. The falcons close or. RIDLEY.

$\mathrm{Az}$. on a cher. betw. three falcons volant .... as many plates. Cregoe.

Sa. on a chev. or betw. three hawks rising arg. beaked legged and belled of the second five torteaux. DALE, Brentwood, Essex.

\section{....Heathcocks see Moorcocks .... Herons}

Az. on a chev. or betw. three herons close .... four bars of the first. Tномаs.

Gu. on a chev. or betw. three herons arg. four barrulets az. Thomas, Llettymaur, co. Carmarthen; granted 8 September 1768; a heiress m. Lloyd.

Or on a chev, engr. az. betw. three cranes of the second bars wavy arg. Browne, Islington.

$\mathrm{Gu}$. on a chev. betw. three hernshaws arg. as many lions ramp. of the first. Rowiet. 
On I CHEVRON betw, or within..... cont.

Birds cont. Herons cont.

Arg. on a chev, az. betw. three storks as many swans ppr. Company of Poulterers, London.

Gu. on a chev. engr. sa. betw. three (heronshaws or) storks arg. a plain chev. or. LyMington, co. Chester, $V$.

Az. on a chev. arg. betw. three herons or as many crosses patty gu. Fowlen, Islington.

Az. on a chev, arg. betw. three birds (? herons) or as many crosses patty sa. Fowler, Ricott, co. Bedford.

Arg. on a chev. sa. betw. three cranes close az. as many escallops or. Browne, Godmanstow, co. Dorset. Cranwelu.

Arg. on a chev. betw. three heronshaws (or storks) sa. as many estoiles or. Mansegles, $V$.

Az. on a chev, or betw. three storks arg. as many roses gu. barbed vert. FarnaBY, Wickham Court, Kent ; Baronetcy 21 July 1726.

Or on a cher. gu. betw, three cranes az, as many slipped 3-foils arg. Browne, co Stafford.

Gu. on a chev. engr. betw. three herons arg. a 5foil of the first. Horn, Norfolk.

$\mathrm{Gu}$. on a chev. betw. three herons arg. a 5-foil sa. Heron, East Thickley, co. Durham, 1575.

Arg. on a chev. az. betw. three cranes sa. as many 5 -foils or a crescent for diff. Thomas Cranmer, Archbishop of Canterbury 1533-56.

Per pale gu. and az. on a chev. betw. three herons arg. as many 5-foils sa. Heron, Agecome, now Addiscombe, Surrey, 1544. Sr. John HERoN, Chuston, $V$.

Or on a chev. az. betw, three herons ppr. gouttes d'or. Dry, Lincoln's Inn, London; and Fis. churst, Sussex.

Az. on a cbev. embattled or betw. between three herons arg. a leopard's head enclosed by a pair of fleurs-de-lis gu. Monnox, co. Hunting. don; and co. Nottingham.

Or on a chev. betw. three cranes az. a bezant. BRowne.

Az. on a chev. or between three berons arg. as many hurts. ClapcotT, Winterborn Abbas.

Gu. on a chev. betw. three herons or as many ogresses. Routhe, co. Leicester.

\section{.....Lapwings}

Gu. on a chev. engr. sa. betw. three lapwings arg. a plain chev. or. Lrmington, $V^{*}$.

Gu. on a chev. or betw. three lapwings arg. another chev. invecked sa. LYNNINGTON, co. Leicester.

Arg. on a chev, az. betw. three lapwings sa. as many estoiles or. Mansegles, $V^{*}$. Nanseglas Nansegles or Nansides.

Arg. on a chev. sa, betw. three lapwings close ppr. a rose stalked and leaved enclosed by a pair of 5-foils or. HeweTt, Heckfeld, co. Hants; granted 10 December 1597.

Az. on a chev. betw. three lapwings or as many 4-foils vert. Thomas Austin, 1634, in old church at Shoreditch.

$$
\text { ..... Magpies }
$$

Vert on a cher. engr. arg. betw. three magpies ppr. as many ogresses. Potale.

$$
\text { ..... Martlets }
$$

Arg. on a chev. gu. betw. three martlets sa. an annulet or. FreEBAIRN, Scotland.

Arg. on a chev. betw, three martlets sa. an annulet or. SANDFORD, Canterbury.

Arg. on a chev. sa. betw, three martlets .... an eagle displ. or. CHESEDon, co. Dorset.
On 1 CHEVRON betw, or within.....cont.

Birds cont. Martlets cont.

Gu. on a chev. betressed or betw. three martlets arg. an eagle displ. enclosed by two escallops sa. WeDdell, Leith, Scotland.

Vert on a chev. betw. three martlets .... as many eagles displ. .... Mrnrfie, Honiton, co. Devon; and Sarum, co. Wilts.

Per pale gu. and az. on a chev. arg. betw. three martlets or an eagle displ. su. BECKFORD, Basing Park, co. Hants, quartering Leigh, Freeland, and Love. But with a bordure of the fourth charged with a double tressure flory counterflory of the first. BECKFond, Fonthill, quartering Hamilton and Arran.

Az. on a chev. erm. betw. three martlets another chev. or. Northen, Essex.

Arg. on a chev. gu. betw. three martlets sa. a crescent of the first. BARROWMAN, Scotland.

Gu. on a chev. betw. three martlets arg. a crescent (of the first, WALKINTON, $V^{*}$; WALKINGTON,) .... Walkenton, temp. Edward III, $V$.

Arg. on a chev, engr, az. betw. three martlets sa. as many crescents of the first. WATSON, Ireland.

Arg. on a chev. az. betw. three martlets sa. as many crescents or. WATSON, co. Northampton. And with a crescent for diff. Thomas Watson, Bishop of St. David's 1687-99. The chev. engr. Watson, Conington, co. Cambridge. Watson, Dunse, Scotland. Watson, Silsden, co. York. Warson, Fulmer, co. Buckingham; Baronetcy 1760. Watson, $V^{*}$. Watson, Baron Sondes, 1760, quartering Monson. And with a crescent for diff. Thomas Watson, Bishop of St. David's 1687-99.

Arg. on a chev. engr. az. betw. three martlets sa. sometimes beaked gu.) as many crescents or each charged with a torteau. Edward Watson, Lydington, Rutland, $V$.

Arg. on a clev, engr. az, betw. three martlets sa. as many crescents or within a bordure engr. of the third. Watson, co. Lancaster.

Arg. on a chev. gu. betw, three martlets sa. as many crescents of the first. Crowton, $V$. Fatrbainn, Scotland.

Arg. on a chev, engr. betw. three martlets sa. as many crescents or. Watson, Rutlandshire.

$\mathrm{Az}$. on a chev. betw. in chief three martlets and in base a fleur-de-lis or as many crescents vert. Hodgets, Prestwood, and Shuttend House, co. Stafford; granted 1768.

Arg. on a chev. betw. three martlets vert as many crosses patty fitchy of the first. AsHaw. Ashawe, co. Lancaster; granted 1599. Ashow, co. Lancaster, $V$.

Or on a chev. betw. three martlets vert as many crosses croslet fitchy arg. AsHaw, co. Lancaster.

Arg. on a chev. gu. betw. three martlets .... as many croslets of the first. DEAN or DEANE, Terrenure, and Cromlin, co. Dublin.

Arg. on a chev. gu. betw. three martlets sa. as many fleurs.de-lis of the first within a bordure engr. of the third bezanty. Massingham, Norfolk.

Gu. on a chev. betw. three martlets arg. a rose enclosed by two lions pass. counterpass. of the first. HEPBurn, Smiton, Scotland.

Az. on a chev, betw, three martlets arg. a 3-foil slipped vert. Cromselin, Carrowdore Castle, co. Down; quarterıng De la Cherois. 
On 1 CHEVRON betw, or within.... cont.

Birds cont. Martlets cont.

Per pale arg. and sa. on a chev. betw. three martlets as many slipped;3-foils all counterchanged. Wood, Norwich. Wood, Norfolk, $W$.

Arg. on a chev. engr. az. betw. three martlets sa. as many 5-foils or. HEYMAN, Somerfield, Kent.

Arg. on a chev. hetw. three martlets sa. as many 5-foils of the first. HAYMON. The 5-foils pierced. Haymon, Kent, $V$.

Arg. on a chev. engr. (not engr. Harl. MS. 1392) betw. three martlets sa. as many 5-foils or. Hamond, Kent. Haymon, Kent, $V$. Sr. Peter HAYMON, $V$. HEYMAN.

Az. on a chev. counterembattled or betw. three martlets arg. as many 5-foils gu. BAYN, co. Chester, $V$. Baynes, co. Chester. The 5-foils pierced. BAME or BANY, co. Chester, Harl. MS. 891, fo. 98 b. The 5.foils sa.. BAYNes, co. Chester.

Vert ou a chev. embattled or betw. three martlets arg. as many 5-foils gu. BAYNE, co. Lancaster.

Arg. on a chev. betw. three martlets sa. five gouttes of the first. WooDs, Norwich.

Az. on a chev. betw. three martlets or five gouttes sa. WridDY.

Sa. on a chev. betw. three martlets arg. five gouttes de sang. Collins, quartered by Splatt, Brix. ton, near Yealmpton.

Arg. on a ehev. betw. three martlets gu. five lozenges erm. a bordure engr. vert. KIRKuBy.

.... on a chev. .... betw. three martlets .... as many (sometimes pierced) six pointed mullets ..... David Martin or Martyn, Bishop of St. David's 1293.1328.

Arg. on a chev. gu. betw. three martlets sa. as many mullets or. BAGot, Castle Bagot, Dublin.

Arg. on a chev. betw. three martlets sa. as many mullets or. Madeston, granted 1587. Madison Maddison or Maddrsson, Aldergill, and Unthank, Durham, 1575; quartering Marley, Harl. MS. 1540, fo. 39 ; MADYson, Funaby, cn. Lincoln; granted 1587, Harl. MS. 1539, fo. 109.

Gu. on a chev. betw. three martlets or as many mullets sa. Finney.

Sa. on a chev. betw. three martlets or as many mullets of the first. MonckTon or Monketon, co. Lincoln; Egbam, Surrey ; and Cabell, co. York. Monketon, Rebellhall, in Howden, co. York, $V$. Monton or Monkton, co. Lincoln.

Gu. on a chev. betw, three martlets arg. as many pheons sa. PaGe.

Aru. on a chev. betw. three martlets gu. as many bezants. Ethelstan, co. Loicester.

Or on a chev. betw. three martlets gu. as many bezants. Estatford, $V$.

Arg. on a chev. betw, three martlets gu. as many plates. Yeo, Coruwall; and co. Devon.

Arg. on a cher. gu. betw. three martlets sa. two swords in saltire ppr. pomels and hilts or entwined by a double chain gold. Evans, Lynnon, co. Carnarvon.

Arg. on a chev, vert betw. three martlets sa. five ermine spots of the first. Wells, Bambridge, co. Hants; and Isle of Purbeck, co. Dorset. Welises, Buckstead, Sussex.

Arg. on a a chev. engr. vert betw. three martlets sa. five ermine spots or. WELLES, Saltash, Cornwall.

Or on a chev. gu. betw. three martlets sa. two sugarcanes of the first. Fenwick.
On 1 CHEVRON betw. or within.... cont.

\section{Birds cont. Moorcocks}

Arg. on a chev. betw. three heathcocks sa. as many bar's nebuly of the first. WYNSLAOE, co. Devon.

Az. on a chev. betw. three moorcocks close or as many crosses croslet sa. Tompkins, Moning. ton, co. Hereford; and Arundel, Sussex.

$$
\text { .... Owls }
$$

Az. on a chev. arg. betw. three owls of the second another chev. gu. Hewat or Hewat, Scotland.

Gu. on a chev. embattled betw. three owls arg. each ensigned with an eastern crown or as many bombs fired ppr. Hewet, Netherseale, co. Leicester; and Alcomb, co. Somerset; Baronetcy 1813.

Arg. on a cher. sa. betw. three owls gu. a 3-foil slipped of the first. Fonest.

Arg. on a chev. sa. betw. three owls gu. a 4-foil (? of the first) az. Frost.

Arg. on a chev. gu. betw. three owls as many lozenges erm. HASLEWOOD, Haselbeech, co. Northampton, quartering Marmion.

Az. on a chev, betw, three owls arg. a mullet gu. APPLEYARD, Butterwyke in Exholme. Heslington, Frodingham, and Brastwick Garth in Holderness, co. York.

Az. on a chev. or betw. three owls arg. a mullet. Aplyand or APPleyard, Dunston, Norfolk.

Az. on a chev. betw. three owls arg. as many mullets sa. all within a bordure erm. HmL, Alveston, co. Gloncester. The bordure engr. Hill or Hull, Olneston, co. Gloucester.

Sa. on a chev. betw. three owls arg. within a bordure engr. erm. as many pierced mullets gu. Hill, co. Gloucester.

Gu. on a chev. betw, three owls arg. an ermine spot sa. Fleming, Stoneham, and Southampton, co. Hants ; confirmed 3 June, 1584.

$$
\text { .... Ostriches }
$$

Per pale arg. and .... on a chev. betw. three ostriches gu. as many crosses croslet of the first. Durdo, Gillingham.

Az. on a chev. or betw. three ostriches arg. as many mullets gu. WIGNaLL or WYDNELL, Tandridge, Surrey.

\section{.... Parrots see Popinjays}

.....Pelicans

Sa. on a chev. arg. betw. three pelicans vulning themselves or as many auchors of the first. Meades, London.

Az. on a chev. betw. three pelicans or vulning themselves gu. as many escallops of the last. Yong, Medhurst, Sussex.

Per pale az. and or (another, or and az.) on a chev. arg. betw. three pelicans vulning them. selves counterchanged as many escallops gu. Thomas Yonge or Young, Bishop of St. David's 1560 , Archbishop of York, 156:-70.

Arg. (anotber or) on a chev. az. betw. three pelicans sa. vulning themselves ppr. as many 5 -foils gold. Cranmer, Kent. Thomas Cranier, Archbishop of Canterbury 1533-56. Cranmure.

$$
\text { .....Popinjays }
$$

Arg. on a chev. sa. betw. three parrots vert beaked and legged gu. as many annulets or. Goodchild, Pallion, co. Durham.

Az. on a chev, or betw. three woodwallises ppr. another chev. couped of the tirst. Pinfouid, Dunstaple, co. Bedford; granted 18 October 1501 ; Harl. MS. 1359 , fo. 22 . 
On 1 CHEVRON betw, or within.....cont.

Birds cont. Popinjays cont.

Arg. on a chev. gu. betw. three popinjays vert membered of the second a crescent arg. within a bordure az. (gu, $V *$ *) bezanty. White, co. Hants; and London, $V$. The birds collared of the second. White, $V^{*}$.

Arg. on a chev. sa. betw. three popinjays vert beaked legged and collared gu. as many pears pendent or. Richard Penreth, $V$.

Per pale erminois and erm. on a chev. az. betw. three parrots rert beaked and legged gu. as many bezants. GoodchILD; granted 29 Sept. 1808.

\section{.... Ravens and Rooks see Crows .....Storks see Herons ..... Swans}

Az. on a chev. or betw. three swans arg. as many 5-foils gu. Charlton, London; Sandiacre, co. Derby ; and Chilwell, co. Nottingham; quarter. ing Sharpe, Strey, Dannet, Welles, and Orton.

Sa. on a chev. or betw. three swans close arg. as many lion's heads erased gu. HEBBs, Corton, co. Dorset. The lion's heads of the first. Hobbes, Sarum, co. Wilts.

Gu. on a chev. engr. or betw. three swans arg. as many bees volant ppr. SwaBEY, Langley St. Mary's, co. Bucks; quartering Birchfield.

Arg. on a chev. betw. three swans sa. as many plates. YEo, co. Devon.

$$
\text { .... Thrushes }
$$

Arg. on a chev. az. betw. three blackbirds ppr. a crescent enclosed by two 5 -foils or. SIEIGH, Haddington, Scotland.

$$
\text { .... Turkeys }
$$

Az. on a chev. or betw. three turkey cocks arg. as many mullets gu. WIDNELL.

\section{....Woodpecker's see Popinjays .....Wrens}

Arg. on a chev. betw. three wrens gu. as many mullets of the first. Manigham.

$$
\text { .... Crows }
$$

Arg. on a chev. gu. betw. four ravens sa. a crescent or. Crowton.

\section{.....Martlets}

Az. on a chev. betw. four martlets three in chief and one in base or three anuulets vert. BENNITT; granted about 1840 .

Arg. on a chev. vert betw. four martlets gu. a horse's head elased or. Wandr, Broke, Norfolk.

Arg. on a chev. betw. eight martlets sa. five plates. BARD, North Kelsey (in error).

Arg. on a chev. betw. nive (ten, $V^{*}$.) martlets gu. a crescent of the first. Mabuisson, $V$.

$\mathrm{Sa}$. on a chev. betw. ten martlets arg. five ogresses . Bard, Middlesex; and Caversfield, co. Buckingham. BARD or BEARD, Nortl Kelsey, co. Lin. colı, Harl. MS. 1550, fo. 51. BARD; Baronetcy 1644, Baron Bard of Dromboy and Viscount Belmont 1616; extinct 1660.

Bits

Az. on a chev. arg. betw. three mauage bits or as mauy bosses sa. Company of Lorimers Lorinors or Bitmakers, London.

Bordure

Arg. on a chev. within a bordure gu. an anvulet or. Hunt, Chalderston, co. Bedford.

Arg. on a chev, az. within a bordure engr. sa. a lion ramp. betw. two fleurs-de-lis of the first. WAINWRIGHT.
On 1 CHEVRON betw, or within .... cont.

\section{Bordure cont.}

Arg. on a chev, az. within a bordure gu. goutty d'eau three lions ramp. of the first. STokes.

Arg. on a chev. plain within a bordure engr.az. a martlet as the first. Lockton, co. Yorls.

Gu. on a chev. arg. within a bordure engr. or ogressy three ducks az. membered of the first. Fenrother, London.

Gu, on a chev, arg. within a bordure or three shields of the first. WARDROPE.

Gu. on a chev. arg. within a bordure chequy of the second and first three estoiles as the field. Carre or Ker, Cavers, Scotland.

Arg. on a chev. az. within a bordure engr. sa. three fleurs-de. lis of the first. MaudeEY, Wells, co. Somerset. The fleurs-de-lis or. Madeley, $V$. Maudele or Mawdeley, Wells, co. Somerset. Maydeley.

Gu. on a cher. plain within a bordure engr. arg. a rose betw. two lions pass. incontrant as the first. Hepburs, Nunram, Scotland. The bordure plain erm. HEPBURN, Clerkington.

Arg. on a chev. within a bordure gu. three roses of the first. GILBERT, Cornwall; Compton, co. Devon ; and Togenton, and Bleckington,Sussex. Arg. on a chev. gu. within a bordure engr. sa. three roses of the first. GubErt, co. Devon, $V$.

Arg. on a cher. sa. within a bordure gu. three roses of the first. Gilbard.

Az. on a chev. within a bordure or three roses gu. Gilborne, $V^{*}$. The roses slipped and leaved vert. Gilborne, Kent.

Erm. on a chev. gu. within a bordure engr. sa. a 3 -foil slipped or. Maloree, $V$.

Arg. on a chev, az. within a bordure gu. bezanty three 3-foils slipped of the first. SToKes, $V$. William Stokys, $V$.

Arg. on a chev. gu. within a bordure engr. sa. three 3-foils erm. Pievel, Newbold Revel, co. Warwick; and Ogston, co. Derby ; the coheirs m. Turbutt, Jenkinson, and Woodyeare. The bordure compony or and sa. Revel, co. Derby; granted 1700 .

Arg. on a chev. sa. within a bordure az. three 4-foils .... Eyre, co. Derby.

Arg. on a cher. plain within a bordure engr. sa. bezanty three 4-foils of the first. Eyers.

Arg. on a chev. plain within a bordure engr. gu. three pierced 5-foils of the first. GILBERT.

Arg. on a chev. plain within a bordure engr. sa. three bull's heads cabossed of the first. Hillerspen, Hocklife, co. Bedford; granted $1596, \mathrm{~W}$.

Arg. on a chev. gu. within a bordure engr. sa. a mitre of the first. John Stafrord, Bishop of Bath, etc. 1425, Archbishop of Canterbury 1443-52.

Arg. ou a chev. plain within a bordure engr. az. a mullet of the first. LokEton. The mullet pierced. Locton, $V^{*}$. LoLeton, co. York, $V$. Az. on a chev. within a bordure arg. three pierced mullets sa. Chilton.

Az. on a chev. arg. within a bordure sa. three mullets of the last. CHILton.

Erm. on a cher. gu. within a bordure engr. sa. three mullets or. Revel, Newbold Revell, co. Warwick.

Gu. on a chev. within a bordure arg. three mul. lets of the first. KERr, Bughtrigg; granted $178 \%$.

Gu. on a chev. within a bordure az. three mullets or. Совнан1. 
On 1 cHEVRON betw, or within.....cont.

\section{Bordure cont.}

Gu. on a chev. arg. within a bordure chequy of the second and first three mullets of the field. $\mathrm{C}_{\triangle \mathrm{RR}}$, Caverse, co. Roxburgh; granted ....; quartering Riddell.

Arg. on a chev. sa. within a bordure az. bezanty three bezants. Boys, $V^{*}$.

Arg. on a chev. sa. within a bordure engr. gu. three bezants. Hellwell or Helwell.

Arg. on a chev. within a bordure sa. bezanty three bezants. Boys, co. Buckingham, $V$.

Arg. on a chev. within a bordure gu. five bezants. Hunt. And with a label of five points az. Matthew de Chetelton, $V$. Chetilton, $V^{*}$.

Arg. on a chev. plain witbin a bordure engr. gu. five bezants. Sr.William Chetelton, $V$. Chetilton. Chettleton.

Arg. on a chev, gu. within a bordure engr. of the second (another, sa.) five bezants. BromLey.

Arg. on a chev. plain within a bordure engr.sa.five plates. Whitron, Netbercott, co. Oxford.

Bendy of six or and gu. on a chev. az. within a bordure purp. three plates. CoPINGER, Lord Mayor of London 1512 .

Sa. on a chev. within a bordure arg. three bunches of broom plants vert seeded or. Brone, Halton, co. Oxford.

\section{Bottles}

Arg. on a cher. betw. three leather bottles sa. as many buglehorns stringed of the first. Company of BotTLE-MAEERS and Horners.

Arg. on a chev.sa. betw, three flasks (or jars, they are veels) ppr. five ermine spots of the first. Willard, Eastbourne, Sussex, an error.

\section{Bougets}

Or on a chev. counterembattled betw. three water bougets sa. a thistle slipped of the first enclosed by two 5 -foils erm. Ross, Portivo, Scotland; and Ireland.

Arg. on a chev, betw. three water bougets sa. as many estoiles or. Lilgrave or Lillgrave, co. York.

Or on a chev, sa. betw. three water bougets gu. as many estoiles of the first a bordure engr. az. William LyLGRave, co. York, $V$.

Or on a chev. betw. three water bougets sa. as many estoiles of the first. Lilluegrane, co. York.

Arg. on a chev, betw. three water bougets gu. two pair of keys in salire or. Beuedictine Priory at Penwortham, co. Lancaster.

Arg. on a chev. betw. three water bougets sa. a mullet of the first. Dove.

Gu. on a chev. erm. betw. three water bougets arg. three hurts. Bushel, Myerscough Cottage, co. Lancaster.

\section{Brushes see Fans \\ Buckles}

Arg. on a chev. gu. betw. three demi-buckles tongues pendent sa. a mullet or. Morton, Quarendon, and Bosworth, co. Leicester; and Ingleton, co. Stafford.

Arg. on a clıtv. gu. betw. three square buckles tongues pendent sa. a crescent .... Morexon, Newton, and Church Hill, co. Chester.

\section{Buildings}

.... on a chev. .... betw, three dovecotes .... as inany escallops ..... SAPCote, Harl. MS. 6829, fo. 49 .

Árg. on a chev. engr. az. betw. three wells ppr. as many 5-foils of the first. NEwELL, Adwell, co. Oxford; granted 1755 .

\section{On 1 CHEVRON betw. or within.... cont. Caltraps}

Arg. on a cher, az. betw. three caltraps sa. as many annulets or. WeBsten, London.

\section{Candlesticks}

Az. on a cher. betw, three mortcours arg. as many roses gu. (but another az. on a chev. arg. betw. three mortcours or as many roses gu. seeded of the third barbed vert). Company of WaX-Chandlers, London; granted by Holland. Caps

Arg. on a cbev. gu. betw. three (morions or) steel-caps looking to the sinister az. au escallop or. Baron Brudeneld, $V$.

Erm. on a chev. betw. three felt-bats with strings sa. as many escallops arg. Company of Hatter-Merchants, London.

\section{Castles}

Gu. on a chev. betw. as many towers arg. issuing out of each a demi.lion ramp. or three (grapers i.e.) grappling-irons sa. Priesteer, Whitewindows, Sowerby, co. York. But castles. Prislet, or Prisley.

Sa. on a chev. betw. three towers arg. a pair of compasses extended as the first. Society of Free and Accepted Masons alias Freemasons. Sa. on a chev. (engr., Cotton. MS. Tiberius D 10 ) between three castles arg. a pair of compasses extended as the first. Company of MASONS, London; granted 1473.

Sa. on a chev. engr. betw. three towers arg. as many fleurs-de-lis gu. BerILL, London. But triple towered. Burwell, Wrigley, Essex.

Or on a chev. embattled betw. three towers gu. from the portal of each a doe issuant ppr. three 5 -foils of the first. PARDoe, Hailes Park, co. Worcester.

Or on a chev. embattled on the top betw. three castles gu. as many gouttes of the first. HibBeNs or Hibbyns, Weo, co. Salop.

Sa. on a chev. betw. three castles arg. as many leopard's faces gu. Hardcastle.

Sa. on a chev. betw. three towers arg. as many ogresses a mullet for diff. Towers, London; from co. Lancaster.

Per chev. vert and arg. on a chev. or betw. in chief two castles of the secoud in base another surrounded by a fortification ppr. three torteaux. Green, Marass, Kent, Baronetcy 17861825.

\section{Chessrooks}

Arg. on a chev. engr. betw. three chessrooks sa. as many crescents or. WALTER, co. York, 1603.

Sa. on a chev. engr. betw. three chessrooks arg. as many crosses croslet fitchy of the first. WARTER, Warter, co. York; co. Salop; co. Stafford; and London.

\section{Chief}

Or on a chev. sa. betw. a chief az. charged with a cross patty enclosed by gouttes or and in base a holly branch fructed vert leaved gu. two cats respectant arg. GIBBEs, $V^{*}$.

Sa. on a chev. arg. betw. a chief or charged with a demi-dragon gu. enclosed by a pair of battle. axes the heads to the dexter az. and in base a cross patty fitchy silver three escallops of the fifth. KING, co. Somerset.

\section{Combs}

Gu. on a cher. engr. betw. three combs arg. as many crosses patty fitchy of the first. Bootue. 
On 1 CHEVRON betw. or within.... cont. Compasses

Arg. on a chev. betw. three pair of compasses slightly extended sa. a joiner's square or and a golden reel of line as the first. Company of Carpenters, London; Cotton MS. Tiberius D 10.

\section{Coppers}

Az. on a chev. or betw. in chief two coppers of the secoud and in base two points in saltire arg. a drawing iron betw. two rings sa. Company of Gold and Silver Wire Drawe tes, London.

\section{Coronets}

Arg. on a chev, betw. three crowns sa. as many estoiles or. CARBILL.

\section{Couplecloses}

Erm. on a plain chev. az. betw. two couplecloses engr. and three garbs gu. an anchor erect or enclosed by two bezants. SHEFFIELD.

Az. on a cbev. betw. two couplecloses or and three crescents arg. two bars gemel of the first. Sr. John Hotror, $V$. Ноттот, co. Gloucester, $V$.

Arg. on a chev. betw. two couplecloses and three crosses patty gu. as many martlets or. Surth or SMYTH.

Gu. on a chev. betw. two couplecloses arg. three lions ramp. of the first. Rawlet. Rowlett.

Arg. on a chev. betw. two couplecloses sa. and three annulets gu. another chev. erm. Cooper, Southwark.

Arg. on a chev. betw. two couplecloses sa. and three Cornish choughs ppr. as many crescents of the first. Merninian, Marlborough; confirmed 21 December 1833 .

Paly of six or and az. on a chev. betw. two couplecloses erm. three crosses patty gu. HIGGINs.

Az. on a chev. betw. two couplecloses and three hanks of cotton arg. an escallop enclosed by a pair of crosses croslet fitchy gu. CotToN, Leatherbead, Surrey.

Arg. on a chev. bctw. two couplecloses sa. three escallops or. Healing. Hellinges, $V$.

Arg. on a chev. betw. two couplecloses indented sa. three escallops or. GoNriLL, Terrington, and Rushworth, Norfolk. Gonvill and CaIUs College, Cambridge, impaling CaIus.

Erm. on a chev. betw. two couplecloses sa. three escallops arg. Browneld, Derby, 1682.

Arg. on a chev. betw. two couplecloses sa. three pineapples or. AsHFORD.

Arg. on a chev. sa. betw. two couplecloses gu. and three fleurs-de-lis of the second gouttes d'or. Belitha, Londor; and Kingston, Surrey.

Erminois on a chev. sa. betw. two couplecloses gu. and three 5-foils .... gouttes d'eau. Secretan.

Alg. on a chev. sa. betw. two couplecloses and three estoiles gti, as many leopard's heads or. Creed.

Arg. on a chev. betw. two couplecloses sa. three leopard's heads or. MYNs, Cratfield, Suffolk.

Erm. on a chev. sa. betw. two couplecloses and three estoiles gu. as many leopard's heads or. Creed, London.

Or on a chev. betw. two couplecloses and three demi-griffins those in chief respectant sa. a mullet for diff. SMiTh, now Carrington, Baron Carrington, 1796 and 1797.

Sa. on a chev. arg. betw. two couplecloses or three pierced nullets of sis points as the first. Ronerts, Glassenbury, Kent; and Brightfieldstown, co. Cork; Baronetcy 1809 . RoBerTs, Kilmoney, and Ardmore, co. Cork.
On 1 CHEVRON betw. or within....cont.

Couplecloses cont.

Arg. on a cliev. betw. two couplecloses sa. three portcullises with chains and rings of the first. Hovell-Thuncow, Baron Thurlow 1792 ; quartering Hovell. And with a crescent in the sinister chief for diff. Thomas 'THurLow, Bishop of Lincoln 1779, Durham 1787-91.

Az. on a chev. arg. betw, two couplecloses or and three dove's beads erased ppr. an ogress enclosed by four cross croslets sa. NaIsH.

Arg. on a chev. betw. two couplecloses and thrce demi-lions ramp. gu. as many hezants. Fisher, The lions guard. Fisher. Frsher, Lidhamwicke, co. Wilts; granted 10 October 1608.

Arg. on a chev. sa. betw. two couplecloses gu. and in chief so many mullets of the second pierced as the third in base a hurt charged with a fleur-de-lis or three bezauts. Bonner, France; and London; granted 1751.

Arg. on a chev. sa. betw. two couplecloses gu. three fountains ppr. CASs, Hackney, Middlesex.

Gu. on a chev. betw. two couplecloses and three leopard's heads arg. as mauy torteaux. CoLE, co. Devon.

Arg. on a chev. betw. two conplecloses with in chief as many 3.foils and in base a bear's head erased sa. collared and muzzled or a sun in splendour enclosed by two crosses croslet of the last. Benson, North Cray Place, Kent.

Arg. on a chev. gu. betw. two couplecloses az. and six martlets of the second three wings as the first. Roger WALDEN, Bishop of London 1405-6.

Arg. on a chev. betw. two couplecloses gu. three chaplets or. HaLL, co. Salop, $W$.

\section{Crescent}

Gu. on a chev. betw. in chief a crescent and in base a buck's head erased arg. three mullets of the first. KER, Greenhead, Scotland. And with a bordure az. KER, Chatto, Scotland.

\section{Crescents}

Arg. on a chev. gu. betw. in chief two crescents sa. and in base a dove with an olive branch ppr. three bezants. Goodwright.

Arg. on a chev. betw. in chief two crescents and in base a cross botonny fitcby sa. a mullet of the first. GEGGE, Harl. MS. 6829, fo. 52.

Or on a chev. gu. betw. in chief two crescents and in base an escallop az. three estoiles alg. Henniker; granted with Baronetcy 1765 ; Barony 1800 ; quartering Major.

Arg. on a chev, wavy az. betw. in chief two crescents and in base a dexter hand couped gu. a fleur-de-lis enclosed by a pair of mullets of the first. Stevens, Scotland.

Arg. on a chev. betw. in chief two crescents and in base a dexter hand couped at the wrist erect gu. a pair of mullets as the first. Stephen. But a sinister hand. Steven, Nisbct, i, 269. But three mullets. Stephen, Scotland.

Gu. on a chev. betw. three crescents arg. an anchor erect with a piece of cable ppr. MARTIN, Lockynge, co. Berks; Baronetcy 28 July 1791. Arg. on a chev. gu. betw. three crescents az. as many annulets or. WALKER, Sund Hutton, co. York; quartering Porter.

Per pale al'g. and sa. on a chev. betw. three crescents as many annulets counterchanged. Walker, Bow, Middlesex. But the field per pale sa. and arg. Walker, Mitchell Grove, Arundel, Sussex. WaLIJER, Bow, 1716.

Az. on a chev, or betw. three crescents arg. two bars gemel sa. Нотот, co. Gloucester, $V$. 
On 1 CHEVRON betw, or within.... cont.

Crescents cont.

Vert on a cliev. arg. betw. three crescents or each charged with an ermine spot sa. a lion ramp. gu. enclosed by two crosses patty fitchy az. GosLing.

Sa. on a chev. engr. arg. betw. three crescents or each charged with a mullet two lions combatant of the first. Flint.

Sa. on a cluev. engr. or betw. three crescents erm. two lions combatant gu. FI,YNT, Norfolk.

Sa. on a chev, betw, three pierced crescents arg. as many martlets vert. Deton, $V ; W$.

Arg, on a chev. sa. betw. three crescents gu. five martlets of the first. TEMPLE, co. Warwick.

Per pale az. and sa. on a chev. betw. three crescents arg. a cross moline pierced of the first. Crargie, Glendoick.

Gu. on a chev, engr. betw. three crescents or as many crosses croslet sa. Muldeswell, $V$.

Sa. on a chev, betw. three crescents or as many crosses croslet of the first. Duckenfirid. The chev, engr. Mulswell.

Sa. on a chev. betw. three crescents or as many crosses patty of the first. Duckenfeld, $V$. The crosses fitchy. Ducisenfield.

$\mathrm{Az}$. on a chev, betw. three crescents arg. as many escallops sa. SHorthose, $V$.

Sa. on a chev. betw. three crescents arg. as many escallops gu. SHorthose. The escallops of the first. Shorthose, co. York.

Arg. on a chev, ringed at the point betw. three crescents sa. an estoile .... W WaLKER.

Per pale or and gu. on a chev. arg. betw. three crescents counterchanged as many 5-foils az. SANDELI.

Arg. on a chev, az. betw. three crescents and a double tressure flory counterflory gu. a boar's head couped or. SEATON, Kyllsimunne, Scotlaud.

Yert on a chev. arg. betw. three crescents or an otter's head erased sa. BALFoUR, Kirktoun.

Arg. on a chev. betw. three crescents sa. as many dragon's heads couped or. WaLizER, Leighton Buzzard; and London; granted 1748.

Sa. on a chev. betw. three crescents arg. a mascle of the first. Martin, Edinburgh, Scotland.

Arg. on a chev. ending on the top with a stock and ring betw. three crescents sa. two plates. WALKER, Harl. MS. 1445, fo. 92.

Az. on a chev. or betw. three crescents arg. as many olive sprigs vert. DoLliffe, London.

\section{Crosse}

$\mathrm{Az}$. on a chev. betw. three crosses patonce arg. an annulet for diff. sa. Glanton, $V$.

Arg. on a chev, betw. three crosses croslet fitchy az. as many annulets of the first. BaBELAKE.

Arg. on a chev. az. betw. three crosses croslet fitchy gu. a lion pass. or. M'Crummes or M'Crumirn, Scotland.

Gu. on a chev. betw. three crosses croslet fitcby or a lion ramp. of the first. Hawden, Scotland.

Or on a chev. betw, three crosses croslet fitchy gu. a lion pass. guard. of the first. Bolt or Boult.

Gu. on a chev. betw. three crosses croslet fitchy or two demi-lious pass. respectant sa. BarLow.

Arg. on a chev. betw. three crosses croslet sa. two lions pass. counterpass. of the first. Barrowe. The chev. engr. and the croslets fitchy. Barlowe, Slebetch, co. Pembroke.

Arg. on a chev. (sometimes engr.) betw. three crosses croslet fitchy sa. two lions pass. guard. incontrant of the first. William BARrow, Bishop of St. Asaph 1536, St. David's 1536, Bath ctc. $1548-53$.
On 1 CHEVRON betw, or within....cont.

\section{Crosses cont.}

Arg. on a chev. engr. betw. three crosses patonce fitchy sa. two lions (combatant BaRLow, $V^{*}$.) pass. guard. incontrant of the first. John BARLOWE; granted temp. Henry VI, $V$.

Or on a chev. engr. betw. three crosses patty fitchy sa. two lions ramp. reguard. combatant arg. BANCROFT.

Erm. on a chev. engr. gu. betw. three crosses patty fitchy sa. a Cornish chough enclosed by two crescents arg. Fleming, The Wergs, co. Stafford; the heiress m. Fryer.

Arg. on a chev. betw. three crosses patty gu. as many doves of the first. William SANCrofT, Archbishop of Canterbury 1678-91. SANDCRoFT. Arg. on a chev. engr. sa. betw. three crosses patty .... as many martlets of the first. CanoN, $V^{*}$.

Az. on a chev. betw. three crosses croslet saltirewise or as many martlets ppr. Crosier.

Or on a chev. engr. sa. betw. three crosses patty gu. as many martlets of the first. GuL.es.

Gu. on a chev. betw. three crosses patty fitchy arg, a chev. wavy sa. Bonham, $V$.

Arg. on a chev. engr, gu. betw. three crosses croslet fitchy az. an eastern crown supported by two lions counterpass. or. BarLow, Calcutta, East Indies; Baronetcy 29 June 1803.

.... on a chev. betw. three crosses croslet fitchy .... a crescent. Nicholas, Lazy Hill, in Dublin.

Arg. on a chev. betw. three crosses patty fitchy gu. a crescent for diff. of the first. Torte, $V^{*}$. Robert Toste, $V$. Thomas Wonerowe, $V$. Arg. on a chev. sa. betw, three crosses croslet gu. a crescent for diff. of the first. Ellisdon, $V^{*}$. Ellysden, $V$. Elysden. Etysden, $V^{*}$.

Gu. on a chev. wavy betw, three crosses patty fitchy az. a crescent of the first. Bonam, Hampshire.

Arg. on a chev. betw. three crosses croslet sa. as many crescents or. Denzell.

Arg. on a chev. engr. betw. three crosses croslet sa. as many crescents or. Mulleswell. The crosses patty. MULSweLL.

Arg. on a chev. betw. three crosses croslet (another crosses pometty) sa. five crescents of the first. Scopenam Scopham or Scopyn, co. Lincoln.

Arg. on a chev. betw. three crosses croslet sa. five crescents or. Richard Skорнал, $V$.

Arg. on a chev. betw, three crosses botonny fitchy sa. as many covered cups of the first. LANGFIELD.

Arg. on a chev. betw. three crosses croslet fitchy sa. an escallop or. Russeru, Arnabie, Cumberland; and Brancepeth Castle, Durham; quartering Harrison. Russell, Stubbers, in North Ockendon, Essex; Towcester, co. Northampton; and Southwark, Surrey.

Sa. on a chev. betw. three crosses croslet arg. as many escallops of the first. KINGE.

Sa. on a chev. betw. three crosses croslet or as many escallops of the frst. KrNG, London; granted by Camden. KING, Towcester, co. Northampton; Loxwood House, and Midhurst, Sussex.

Arg. on a chev. gu. betw. three crosses croslet fitchy sa. a fleur.de-lis or. KENNEDY, Auchtifordell, Scotland.

Or on a chev. betw. three crosses (clechy, i. e.) entrailed sa. a fleur-de.lis enclosed by two stag's heads cabossed of the first. Carver. 
On 1 CHEVRON betw. or within.....cont. Crosses cont.

Arg. on a chev. betw, three crosses croslet az. as many fleurs-de-lis of the first. Binties, Birtles, co. Chester. The croslets fitchy. Bertuey, co. Chester.

Arg. on a chev. az. betw, three crosses croslet fitchy sa. as many fleurs-de-lis or. Bunchali, Broudfield Court, Leominster, co. Hereford.

Arg. on a chev. sa. betw. three crosses croslet gu. as many fleurs-de-lis or. Ellerden, Carmouth.

Arg. on a chev. betw. three crosses botonny sa. as many fleurs-de-lis of the first. BATYForD, Suffolk.

Arg. on a chev, betw. three crosses croslet sa. as many fleurs-de.lis of the first. Birchells or Birchills. The croslets fitchy. Birchill, Birchill, co. Chester.

Arg. on a chev. betw. three crosses croslet fitchy sa. in the dexter side as many fleurs-de-lis and at the sinister side so many martlets or. Killuhurst or Killuhust, i.e. Kilnhurst, quartered through Montfort, 1304, by Darley, Kilnburst, co. York, 1562-1616.

Arg. on a chev. gu. betw. three crosses croslet fitchy az. as many roses of the first. DAvENPORT, Darnwell Bank.

.... on a chev. .... betw, three crosses croslet fitchy .... as many 3 foils .... Meskell, co. Cork.

Sa. on a chev, arg. betw. three crosses croslet or as many 4-foils gu. Mottershed.

Arg. on a chev. gu. betw. three crosses croslet sa. as many 5 -foils of the first. Sнiтh. The crosses flory. Siryth, Norfolk.

Gu. on a chev, arg. betw. three crosses croslet or as many 5-foils az. BLAND, London; granted 10 May 1563. Marsie, co. York.

Sa. on a chev, arg. betw. three crosses croslet or as many 5 -foils gu. Motrran, Newcastle.

$\mathrm{Az}$. on a chev. or betw. three crosses patonce arg. fretty gu. Bartholomewe (but Ricarde, Harl. MS. 6137) de Pevenesi, $A$.

$\mathrm{Az}$. on a chev. or betw. three crosses croslet arg. fretty sa. WALLER, lient. The crosses moline. LANDESDUKE.

Gu. on a chev. or betw. three crosses flory arg. fretty sa. WALLER, co. Huntingdon.

Arg. on a chev. gu. betw. three crosses croslet fitchy sa. a pineapple or leaved vert enclosed by two plates. KENNEDY.

Az. on a chev. betw. three crosses croslet fitchy or as many boar's heads couped gu. Botrry Buttey or Buttrey, Suffolk. The crosses patty fitchy. ButrRY, Suffolk.

Arg. on a chev. betw. three crosses fitchy sa. as many buck's heads cabossed or. Boughton.

Az. on a chev, betw. three crosses croslet sa. as many buck's heads cabossed of the first a mullet for diff. Wrchiffe, Offerton, Durham.

Sa. on a chev. betw. three crosses croslet fitchy arg. as many leopard's faces .... STRUTT, Baron Rayleigh 1821.

Gu. on a chev. engr. betw, three passion crosses or as many lion's heads erased of the first. Acstin.

Arg. on a chev. sa. betw. three crosses croslet gu. five buck's heads cabossed of the first. John WickLIFF, co. York, $V$. WYCLIFF, $V^{*}$.

Arg. on a chev. sa. betw. three crosses botonny gu. six buch's heads cabossed of the first. Wicklffe, Wickliff, co. York.
On 1 CHEVRON betw, or within.... cont.

Crosses cont.

Arg. on a chev. gu. betw. three crosses croslet fitchy az. as many lozenges of the first each charged with a cross croslet of the second. AsLyn.

Gu. on a chev. arg. betw. three crosses croslet fitchy or and as many garbs of the second a mullet sa. Ryton, quartered by Dryland. The garbs or. DRYLand, $W$.

Gu. on a chev. arg. betw, three crosses croslet fitchy or as many mullets sa. Roberts.

Arg. on a chev. gu. betw. three crosses croslet fitchy .... as many roundles .... Crossing, Exeter, 1009-20.

Arg. on a chev. gu. betw. three crosses patty sa. as many bezants. Smrte, Braxted, Essex.

Az. on a chev. betw. three crosses croslet arg. as many bezants. Chedington.

Or on a chev, betw. three crosses patty fitchy gu. as many bezants. SuIth, Leicester; and Northampton.

Or on a chev. sa. betw. three crosses patty fitchy gu. as many bezants. SPeEring.

Arg. on a chev. betw. three crosses croslet fitchy az. five bezants. BaBALAKE, $V$.

Sa. on a chev, betw. six crosses patty fitchy arg. three fleurs-de-lis az. SuItH, Kedcliffe, co. Buckingham; Baronetcy 1661.

Sa. on a chev. engr. betw. six crosses croslet fitchy or three fleurs-de-lis az. Smith, $V^{*}$.

Sa. on a chev. engr, betw. six crosses patty or three fleurs-de-lis az. SmIrH, Pajnswick, co. [i]oncester; quartering Crawfurth. The crosses fitchy. SHart, London. Sirtr, Sheriff of London $1509, \boldsymbol{V}$. And each fleur.de.lis charged on the top with a plate. Sarтth, North Nibley, co. Gloucester; and Thedlethorp, co. Lincoln, 1776. Sirth, Nibley, co. Gloucester. Gu. on a chev. betw, nine crosses croslet fitchy arg. three fleurs-de-lis of the first. BarLey.

Gu. on a chev, betw, ten crosses patty arg. an annulet .... James de Berkely, Bishop of Exeter 1327.8.

Gu. on a chev. betw. ten crosses patonce arg. a crescent az. M. James Berkele, $S$.

Gu. on a chev. betw. ten crosses croslet or three of the first. Gregorie, Lenton, co. Nottingham. GREGory.

Gu. on a chev. betw. ten crosses patty arg. three fleurs-de.lis sa. BERKELEY, $V$.

Gu. on a chev. betw. ten crosses patty arg. a rose gu. Gilbert Berkeley, Bishop of Batb, ete. 1560-80, Cotton MIS. Cleopatra C iii, fo. 36 b. But on the chev. a 5 -foil enclosed by two lions counterpass. guard. gu., $A d d$. MS. 12413.

Gu. on a chev. betw. ten crosses patty arg. three torteaux. BERLELEy.

Cubes

Or on a chev. gu. betw, three cubes pean as many horseshoes arg. Williass, Ivy 'Tower, co. Pembrolie; the heiress $\mathrm{m}$. Harris. Cups

Sa. on a chev. betw. two cups with handles arg. three martlets sa. Whyте.

Sa. on a chev. betw. three ewers arg. as many martlets gu. WhITE, Lord Mayor of London I489, in church at 'Ticlihill, co. York.

Sa. on a chev. erm. betw. three flagons the two in chief with spouts arg. as many martlets gu. Whiте, Ashford, Jent, $V$.

Sa. on a chev. elm. betw. three jugs arg. as many martlets of the first. WhITE. 
On 1 CHEVRON betw, or within.... cont. Cups cont.

Az. on a chev. betw. three corered cups arg. as many 5-foils gu. J $\mathrm{ACKSON}$, Christ Church, Surrey; granted 16 October 1700.

Arg. on a chev, gu. betw. three pewter pots sa. fretty or. Delves, co. Chester.

Az, on a chev. or betw. in chief two ewers (i.e. beakers) and in base a tripod pot with two handles of the second three roses gu. seeded or barbed vert. Company of Braziers.

Gu. on a chev. arg. betw. three silver singlehandled cups each containing so many sprigs of lilies ppr. the Virgin accompanied by four cherubs or enclosed by two pair of limbecks as the second. Company of Pewterers, London. Delves see Billets Diapers

Arg. on a chev. gu. betw. three diapers (in error for didappers) az. a crescent or cluarged with a mullet sa. Bredner, London.

\section{Dice see Cubes}

\section{Escallops}

Gu. on a chev. arg. betw. three escallops or an annulet sa. WoLrrer, co. Worcester.

Arg. on a chev. az. betw. three escallops sa. as many annulets or. GERNECH or GERNISH.

Arg. on a chev. betw. three escallops gu. as many annulets of the first. 'TANCKERT, Cotton $M I S$. Tiberius D 10. Tankard or Tankert, co. York. TANEARD, $V^{*}$. TANKaRde, co. York, $V$. And with a mullet in chief. Tankarde, $V^{*}$. The chev, engr. Tancred or Tankard, Pannell, co. York.

Arg. on a chev. betw. three escallops gu. as many annulets or in chief a mullet of the last. TANKERDE, $V$.

Arg. on a chev. betw. three escallops sa. a lion pass. or. Surcole.

Arg. on a chev. engr. sa. betw, three escallops .... as many eagles displ. .... Reeves, Ireland.

Arg. on a chev, engr. sa. betw. three escallops az. as many eagles displ. or. Reave, Breade, Sussex; confirmed 13 July 1633.

Or on a chev. engr. betw. three escallops az. as many eagles displ. of the first. Reve or Reeves, Ireland; quartering Spaight.

Gu. on a chev. betw. three escallops or a tower sa. Chamblayn alias Spicen, co. Notts, $W$.

Arg. on a chev. betw. three escallops sa. a chev. invected az. Thomas WINNIFFE, Bishop of Lincoln 1642-54, Harl. MS. 2275, fo. 20.

Gu. on a chev. or betw. three escallops arg. another chev. of the third. TAYLoUR, Westminster; granted 14 February 1714-15.

Arg. on a chev, az. betw. three escallops sa. a crescent or. Sr. Christopher Garnish, Suffolk, $V$.

Sa. on a chev. or betw. three escallops arg. a crescent for diff. Mrcael., $V *$. Mxchel.L, Cokfeld, Sussex, $V$.

Az. on a chev, engr, betw. three escallops erm. a cross croslet fitchy enclosed by a pair of annulets as the first. Townsend, Honington Hall, co. Warwick; quartering Gore.

Arg. on a chev. betw. three escallops sa, as many crosses patty or. PERIN.

Or on a chev. gu. betw. three escallops arg. as many crosses croslet of the first. Pearirain.

Arg. on a chev. betw. three escallops az. as many estoiles of the first. Townshend, Coggeshall Magna, Essex; granted 5 June 1718.
On 1 CHEVRON betw. or within....cont.

Escallops cont.

Or on a chev. betw. three escallops gu. an ostrich feather arg. BateMaN, Bartholey, co. Monmouth; a branch of Bateman, Oak Park, co. Kerry.

Gu. on chev. betw. three escallops arg. a fleurde-lis of the first a bordure as the second. BEDELL or BEDLE, London.

Sa. on a chev. betw. three escallops arg. a 3-foil slipped for diff. of the first. Simon Farewei. or Farwell, Hilsbushop, co. Somerset.

Gu. on a chev. betw. in chief three escallops and in base a dolphin arg. as many 3 -foils sa. a double tressure engr. of the second the outer bordure or. EARL.

Az. on a chev. betw. three escallops arg. a boar's head couped sa. enclosed by two spur-rowels gu. Moultrie or Moultry, Seafield, and Rosescobie, Scotland. But two mullets gu. and a bordure of the second. Moutrie, Scotland. Az. on a chev. betw. three escallops arg. a boar's head erased close sa. langued gu. enclosed by two estoiles of the last. Moultrie, Aston, Shiffual, co. Salop.

Arg. on a chev. betw. three escallops sa. as many boar's heads couped. Aspilon.

Pean on a chev. betw. three escallops arg. as many (dragon's beads ppr. but another) griffin's heads erased of the first langued gu. HARDy, Holcott, co. Northampton ; and Potes. ham, co. Devon; Baronetcy 1806, extinct 1839 .

Sa. on a chev. betw. three escallops or as many dragon's beads erased of the first. HARDY, Toller Wilmer, co. Dorset. HARDY or LE HARDY, Jersey; as impaled by Lysons.

Sa. on a chev. erm. betw. three escallops arg. as many griffin's heads erased of the first. HARDY.

Arg. on a chev, betw. three escallops gu. as many leopard's faces or. Benington, Essex.

$\mathrm{Az}$. on a chev. betw. three escallops arg. as many leopard's faces gu. John PLATT, Wiggin, co. Lancaster; granted 1559, $W$.

Sa. on a chev. betw. three escallops arg. a mullet for diff. gu. FanNell. The mullet sa. Fartell, a branch of Farwell, Hillbishop, co. Somerset, Harl. MS. 1445 fo. 198.

Gu. on a chev, betw. three escallops arg. as many mullets of the first. Scoules or Scowles, Charlton in Wantage, co. Berks; granted 10 July 1613 .

.... on a chev. betw. three escallops arg. an ogress. Wolmer, co. Worcester. The field gu. Tokye, co. Worcester.

Az. on a chev. betw. three escallops arg. a torteau. HaWKEWOOD. HAUKEWOOD, $V^{*}$. HaUKWOOD, $V *$.

Arg. on a chev. sa. betw. three escullops .... as many bezants. Freaston.

\section{Estoiles}

Az. on a chev. or betw. in chief two estoiles and in base a lion ramp. arg. three torteaux. CoRThine, co. York.

Arg. on a chev, engr. gu. betw. three estoiles az. an annulet or. Kenrpe, Cavendish, Suffolk. The field erm. KEmPE, Norfolk.

$\mathrm{Gu}$. on a chev, betw. three estoiles arg. a cross patty of the first. Bennet, Grubet; Baronetcy 1670. But as many crosses patty of the first. BENNET ; Baronetcy 1671. 
On 1 CHEVRON betw. or within....cont.

\section{Estoiles cont.}

Sa. on a chev. betw. three estoiles or as many crosses (croslet, sometimes) patty fitched at the foot gn. William (LAUD alias) LAWD, Bishop of London 1628; Archbishop of Canterbury $1633.45, W$.

Tert on a chev. arg. betw. three estoiles or an human eye ppr. enclosed by two lozenges of the first. STARr, Longbridge-Deverell, co. Wilts.

Az. on a cher. betw. three estoiles or two roses gu. Skippe, Ledbury, co. Hereford. The roses stalked and leaved ppr. John SKIP, Bishop of Hereford 1539-52.

Arg. on a chev. gu. betw. three estoiles (? of the second) as many buck's heads cabossed of the first. (? OlyfF or Olyve). OlyfF.

Arg. on a chev. engr. sa. betw. three estoiles gu. streaming on the dexter side downwards in bend or as many buck's faces of the first. AYLIFfe, London and Brinksworth, co. Wilts.

Arg. on a chev, engr. sa. betw, three estoiles gu. as many stag's heads cabossed of the second. IluFF; Collinson, Somerset, ii, 70.

Erm. on a cher. engr. sa. betw. three estoiles gu. as many leopard's faces or. Crade or Crode, $V$.

Az. on a chev. arg. betw. three estoiles within a bordure .... as many lozenges gu. Hopkinson, Bonsol, co. Derby; quartering Dakeyne and Wolley.

Az. on a chev, arg. betw. three estoiles within a bordure or as many lozenges gu. Hopkrnson, Alford, co. Lincoln; granted temp. Elizabeth.

Az. on a chev. betw. three estoiles or as many lozenges gu. Robert Butrs, Bishop of Norwich 1733, Ely 1738-48. Butrs, Norfolk, $W$.

Az. on a chev. betw. three estoiles or as many lozenges sa. Stubbes, Essex.

$\mathrm{Gu}$. on a chev. betw. three estoiles or as many lozenges of the first. Butrs, Norfolk.

Per pale gu. and az. on a chev. embattled betw. three estoiles or as many lozenges sa. GwLt.

Arg. on a chev. betw. three estoiles sa. a mullet of the first. STIRLEY, co. York.

Arg. on a cher. betw. three estoiles gu. as many bezants. WALIPOoL, Sussex. WALPULL, Sussex, $V$. Wastorle, Essex.

\section{Faggots}

Arg. on a chev. gu. betw. three bundles of rushes vert bauded or a mullet of the last. Shakeriex, Longstone, co. Derby, temp. Henry VI.

Arg. on a chev. betw. three fascines (or bundles of faggots) sa. as many bezants. StalwortH, $V$.

\section{Fans}

Arg. on a chev. betw, three (? fans or brushes) gu. as many catherine wheels or. Company of HABERDASHERs, anciently called Hurners and Miranels, Cotton. MS. Tiberius D 10.

\section{Feathers}

Gu. on a chev, betw, in chief two ostrich feathers endorsed and in base a saltire couped arg. three torteaux. Parkinson.

Gu, on a chev. betw. three ostrich feathers arg. as many annulets sa. Fetherston, Packwood, co. Warwick; granted by Dugdale.

Gu. on a chev. betw. three ostrich feathers arg. a martlet of the first. Fetherston, Ardagb, co. Longford; Baronetcy 26 June $17 \% 6$.

Az. on a chev, arg. ensigned with a thistle or betw. three pens in full feather of the second as many crescents of the first. Pendax.
On 1 CHEVRON betw. or within.... cont.

Feathers cont.

Gu. on a chev. engr. betw. three ostrich featbers erect arg. a fleur-de-lis az. enclosed by two ogresses. Parinson, East Ravendale, co. Lincoln.

Gu. on a chev. betw. three ostrich feathers erect arg. as many mullets sa. PArkinson, Kinnersley Castle, co. Hereford; Sunnibanks, co. Brecon; Eppleton Hall, co. York; and co. Louth; eo. Clare; and co. Dublin, Ireland.

Gu. on a chev. betw. three ostrich feathers arg. an ogress. Fetherston, Blacksware, co. Hertford; Baronetcy 4 December 1660, extinct 17 October 1746. FETHERSTONHADGH, Fetherstonhaugh, Northumberland; Baronetcy 1747 , extinct .... FethersTON-BAUGH, Kirk Oswald, Cumberland; the heiress m. Smallwood.

Gu. on a chev. betw. three ostrich feathers arg. as many ogresses. Fetherston alias Perkinson, Beaumondhill, co. Durham.

\section{Fetterlocks see Shackles}

\section{Fish..... Crabs}

Arg. on a chev. engr. sa. betw. three crabs the claws towards the dexter gu. faces erect surmounting two swords in saltire and encircled by a chaplet or. Bythesea, Axbridge, Compton Bishop, and Week House, co. Wilts; quartering Chiver's, Viner, Long, Bromley, De Chetilton, De Clifton, and Broc.

$$
\text { ....Dolphins }
$$

Arg. on a chev. sa. betw. three dolphins naiant embowed ppr. as many towers of the first. GUILlaAi.

Sa. ou a chev. betw. three dolphins naiant embowed arg. as many towers of the first. Thomas Freare, M.D.; granted by Camden, $W$. The towers triple towered. Frear Frene or Frier, London.

Sa. on a chev. arg. betw. three dolphins or as many castles of the first. Frear, London; granted February 1602.

Arg. on a chev, az, betw. three dolpbins embowed .... as many crosses croslet of the first. Tipper, Truro, and Falmouth, co. Cornwall.

Arg. on a chev. embattled az. betw. three dolphins embowed sa. as many estoiles or. CoLE, Mal. don, co. Essex.

Az. on a chev. engr. arg. betw. three dolphins naiant embowed as the second finned or a fleur-de-lis enclosed by two greyhounds courant respectant of the first. Thomas TAYLOUR, $W$.

Barry wavy of eight erm. and gu: on a chev. betw. three dolphins naiant embowed or a rose sa. enclosed by two gilliflowers vert. William Atwater, Bishop of Lincoln 1514.21.

Or on a chev. betw. three dolpbins naiant az. as many 5 -foils of the first. TIPPETTs, co. Devon.

Arg. on a chev, betw. three dolphins naiant embowed sa. a plate enclosed by two fleurs-de-lis of the first. Sergison, Cuckfield Place, co. Sussex.

Gu. on a chev. betw, three dolphins embowed arg. an erm. spot sa. Chippenhai or ChIPMAN, co. Hereford. The dolphins turned round with their tails in their mouths. Chippenham, co. Hereford.

Sa. on a chev, or betw, three dolphins embowed ppr. as many bowers vert. GiLlaM, Essex. 
On 1 CHEVRON betw, or within.... cont.

\section{Fish cont. Prawns}

Barry wavy of six erm. and gu. on a chev. betw. three prawns or a rose of the second barbed vert seeded gold enclosed by two lilies in chev. as the rose slipped vert. William AtTwater, Bishop of Lincoln 1514-21; granted by Wriothesley $1509: U$.

\section{.... Whelks}

Gu. on a chev. betw. three whelks arg. a demi. lion enclosed by two martlets sa. WILKIN, Kent.

Gu. on a chev. arg. betw. three whelks or a demilion of the first enclosed by two martlets az. WintLe.

Gu. on a chev. arg. betw. three whelks or a demi-lion ramp. guard. enclosed by two martlets sa. Wilkins, Kent.

Gu. on a chev. arg. betw. three whelks or as many demi-lions ramp. sa. WrLkins, Kent.

Gu. on a chev. arg. betw. three whelks or a fleurde-lis sa. Wilkins, Northumberland.

Flames and see Leaves

Arg. on a chev. az. betw. two flames of fre ppr. another chev. as the field. Wells. But three fiames. Werts, Piercefield, co. Monmouth, and co. Worcester.

Arg. on a chev. gu. betw. three flames of fire a lion ramp. enclosed by two estuiles of the first. Backie or BaIckis, Tankerness, Orkney.

\section{Fleur-de-lis}

Gu. on a chev, arg. betw. in chief a fleur-de-lis or and in base a dove of the second beaked and membered gu. three mullets as the first. KERR.

Gu. on a chev. betw. in chief a fleur-de-lis and in base a martlet arg. three mullets of the first. KER, London; granted 1800.

Gu. on a chev. betw. in chief a fleur-de-lis and in base a mullet arg. three mullets of the first. KERR, Northampton; granted 1787. The chev. embattled. KerR; granted 1806.

\section{Fleurs-de-lis}

Arg. on a chev. betw. two fleurs-de-lis sa. a lion ramp. of the first a bordure engr. as the second. WAYNWRIGHT.

Arg. on a chev. betw. in chief two fleurs-de-lis az. and in base an anchor sa. three mullets or. LAFOREy, Whitby, co. Devon; Baronetcy 1789, extinct 1835; quartering arg. a cross engr. sa. betw. four torteaux.

Gu. on a chev. betw. three fleurs-de-lis or as many annulets sa. Pickering, Coram in Coverdale, co. York.

Arg. on a chev. betw, three fleurs-de-lis az. a lion ramp. of the first a bordure engr. sa. WAINWRIGHT WAYNEWRIGHT and WAYNWRIGHT, Dudley, co. Worcester.

Sa. on a chev. embattled arg. betw. three fleurs de.lis or two lions pass. counter-pass. gu. Bowen, London.

Gu. on a chev. engr. or betw. three fleurs-de-lis arg. as many cocks sa. Mymyng or Mynons.

Gu. on a chev. engr. or betw. three fleurs-de.lis arg. as many rooks sa. Middlemore. Mymyng or MYNORS.

Arg. on a chev. gu. betw. tbree fleurs-de-lis vert as many martlets or. Eucotrs, co. Lincoln.

Arg. on a chev. betw. three fleurs-de-lis vert as many martlets or. Hiltoft, co. Lincoln.

Or on a chev. gu. betw. three fleurs-de-lis vert as many martlets arg. Hiltoft, Boston, co. Lincoln. The martlets of the first. ELTOFT, co. Jincoln. Entotts, $V$.
On I CHEVRON betw, or within.... cont.

Fleurs-de-lis cont.

Gu. on a chev. engr. betw, three fleurs-de-lis arg. as many chess-rooks sa. MynNs, co. Gloltcester. The chev, or. Mymuys, Middlesex, $V$. Arg. on a chev. betw. three fleurs-de.lis sa. another chev. of the first. FansHaw, Barking, Essex.

Arg. on a chev. betw. three fleurs-de-lis sa. as many crescents or. DeRwell.

Per pale or and vert on a chev. betw. three fleursde-lis as many crosses croslet countercharged. ShippHaRD, Natland, co. Westmorland; granted 16 th August 1794.

Arg. on a chev. betw, three fleurs-de-lis sa. as many escallops of the first. Grees, Horsforth Green, co. York. Greene, York, $W$

Per pale az. and gu, on a chev, arg. betw. three fleurs-de-lis or as many escallops of the second. JoHnson. The chev. or. JoHNSON.

Az. on a chev. betw. three fleurs-de-lis arg. as many estoiles gu. SHEPHEARD, Ixning, Suffolk.

Az. on a chev. or betw. three fleurs-de-lis arg. as many estoiles gu. Sheppard, Balcot in Tugford, 1700. SHEPPARD; Baronetcy 1809. The chev. wavy. ShePard, Whittell, co. Salop.

Az. on a chev. or betw. three fleurs-de-lis (arg. another) of the second as many estoiles gu. Shapard or Shepperd, Chelsbury, and Roulwright, co. Oxford.

Gu. on a chev. or betw. three fleurs-de-lis az. (sic) as many estoiles sa. Monsire John de CobHali, $Y$.

Vert on a chev. or betw. three fleurs-de-lis as many counterchanged. DIxwell.

Az. on a chev. wavy betw. three fleurs-de-lis or a thistle slipped vert. Browne, Angus, Scot. land; and London.

Vert on a chev. betw. three fleurs-de-lis or a 5-foil gu. CerLe or KYrLE, London.

Az. on a chev. betw. three fleurs-de-lis or as many 5 -foils of the first. SHIPpard.

Arg. on a chev. betw. three fleurs-de-lis sa. fretty or. Delves.

Arg. on a chev. betw. three fleurs-de-lis sa. as many (talbots?) lieads erased of the first. Town of Huddersfield.

Arg. on a chev. sa. betw, three pierced fleurs-de-lis az. as many goat's heads erased of the first. IREFORD, London.

Arg. on a chev, betw. three fleurs.de-lis sa. as many ram's heads erased of the first. RAMrSDEN, Byrom, co. York; Baronetcy 30 November 1689.

Sa. on a chev. betw. three fleurs-de-lis or as many coronels of spears az. ReEve, 'Thwayte, Suffolk. But spearheads az. Ryves or WrIGHT, Twayte, Suffolk.

Per pale erm. and ermines on a chev. betw. three fleurs-de-lis four lozenges counterchanged. ADdington, High Bickington, co. Devon; the cobeirs m. Incledon, Docton, and Willyams. But countercoloured (arr. and sa. $V^{*}$.) sa. and arg. Thomas ADdington, London, $V$.

Per pale erm. and ermines on a cher. counterchanged betw. three fleurs-de-lis or five lozenges also counterchanged. ADDINGTON, Viscount Sidmouth 1805 .

... on a chev, sa. betw. three fleurs-de-lis .... a mitre or. William de Sancta Barbara, Bishop of Durbam 1143-52.

Gu. on a chev. arg. betw. three fleurs.de-lis or a mullet of the first. Gurdise. 
On 1 CHEVRON betw. or within.... cont.

Fleurs-de-lis cont.

Arg. on a chev, betw. three fleurs-de-lis gu. as many mullets of the first. JuDE, London, 1592. JuDp.

Az. on a chev. or betw. three fleurs-de-lis arg. as many mullets gu. BogGIE or BogIE.

Az. on a chev. or betw, three fleurs-de-lis arg. as many six-pointed mullets sa. Sheppard, Thornton Hall, co. Buckingham; Baronetcy 29 Sept. 1809, quartering Cotton; extinct ....

Az. on a chev, betw. three fleurs-de-lis or as many pierced mullets of the first. GrDE, Avening, Painswick, Rodborough, Straid, Uley, etc., co. Gloucester.

Az. on a chev. betw. three fleurs-de.lis or as many mullets gu. Sheppard, Keyford House, and Frome, co. Somerset; Folkington Place, Sussex; Shrewton Lodge, co. Wilts; and Ruislip, and Hampstead Heath, Middlesex.

Gu. on a chev. betw. three fleurs-de-lis arg. as many mullets az. Sr. Stephen Coвнam, $W$.

Or on a chev. betw. three fleurs-de-lis az. a bezant. Brown, Bonnyton, Scotland.

Az. on a chev. engr. (arg. Cotton MS. Tiberius D 10 ) or betw. three fleurs-de-lis arg. a hurt. Gerdillex, $V$.

Arg. on a chev. engr. sa. betw. three fleurs-delis gu. as many bezants. Wood, Leonard Stanley, co. Gloucester, ] 759.

Or on a chev. betw. three fleurs-de-lis sa. as many bezants. Humrrey, $W$.

Az. on a chev. betw. three fleurs-de-lis arg. as many burts. Ginderer.

$\mathrm{Gu}$. on a chev, arg. betw. three fleurs-de-lis or as many hurts. Pickering. The chev. or. Pickering, Nottingham.

Gu. on a chev. arg. betw. three fleurs-de-lis or as many ogresses. Pickering, co. Nottingham. The chev, or. Pickering, co. York.

Arg. on a chev, betw, three fleurs-de.lis gu. as many plates. Sylver, co. Cork; granted 21 August 1663.

\section{Floats}

Sa. on a chev. betw. three floats arg. (or, Burke) as many (sometimes pierced) mullets of the first. Company of Bowyers, London, Cotton MS. Tiberius D 10.

\section{Flowers .... Columbines}

Arg. on a chev. sa. betw. two columbines ppr. fretty or. HALL.

\section{....Roses}

Az. on a chev. betw. in chief two roses arg. and in base an anchor or three thistles slipped ppr. Pastey, Craíg, co. Dumfries; Baronetcy 1794.

Or on a cher. betw. in chief two roses and in base a lion pass. reguard. gu. four barrulets wavy az. Richter alias Rider, London; granted 1 August 1759.

Arg. on a chev. betw. in chief two roses slipped gu. stalked and leaved vert and in base a tower of the second a dolphin embowed as the first. Roscroge, Cornwall.

Or on a chev. betw. in chief two roses gu. and in base a dolphin ppr. three crosses croslet of the first. Langston, Sarsden, co. Oxford.

Az. on a chev. arg. betw. in chief two roses of the last and in base an ananas leaved or a pair of palm branches vert. Pauminer, co. Devon.

Az, on a chev. arg. betw. in chief two heraldic roses and in base an acorn stalked and leaved or a pair of palm branches vert. PAMIURE.
On i CHEVRON betw, or within....cont.

\section{Flowers cont. Carnations}

Or on a chev, az. betw, three carnations arg. stalked and leaved vert as many lion's heads erased of the first. Pepwat, Bristol; and co. Gloucester. YEPWALL, Harl. MS. 1559.

\section{....Columbines}

Or on a chev. gu. betw. three columbines arg. as many flowerpots ( $V^{*}$; but ? baskets) of the first. Colnet, co. Hants, $V$. ColnetT.

Arg. on a chev. betw, three columbines az. stalked and leaved vert a six pointed mullet or. HALL, Salisbury.

Arg. on a cher. sa. betw. three columbines az. slipped vert a bezant. Coventry, London.

$$
\text { .... Gilliflowers }
$$

Arg. on a chev. sa. betw. three gillyflowers ppr. fretty or. Furbusher.

Or on a chev. az. betw. three gillyflowers ppr. as many lion's heads of the first. Poplewell. The heads erased. Popplewel.

$$
\text { ..... Lilies }
$$

Az. on a chev. betw. in chief three lilies slipped arg. and in base a pineupple slipped and leaved or a grappling-iron enclosed by two martlets of the first. Virgin.

Sa. on a chev. or betw. three lilies arg. two (scythes, $V^{*}$.) scythe-blades crossing each other at the points (arg. $V^{*}$.) of the first. LEers, $V^{*}$. LEYs, $V$.

$$
\text { ..... Marigolds }
$$

Or on a chev. az. betw. three French marigolds slipped ppr. two lions respectant of the first. Tyssen, London; and Hackney, Middlesex; granted 24 November 1687. Tyssen, Foley House, Kent; and Foulden Hall, Norfolk; quartering Amberst.

$$
\text { .... Roses }
$$

Arg. on a chev. betw. three roses gu. an annulet or. WARDE, Lord Mayor of London 1375. The roses budded or. Sr. Jobn WV Yar.D, Alspath. Arg. on a chev. engr. az. betw. three roses gu. a martlet of the first. M'LuRE or MAC LURE, Scotland.

Or on a chev. az. betw. three roses slipped ppr. an eagle displ. of the first. DEAcLe, London; granted 1704.

Or on a chev. betw. three roses gu. barbed and seeded ppr. an eagle displ. of the first. Deacle, Aylesbury, co. Buckingham.

Arg. on a chev. a\%. betw. three roses gu. a water bouget enclosed by two six-pointed pierced mullets of the first. Rose; quartering Holden.

Gu. on a chev. or betw. three roses arg. as many towers with spires az. DACombe, $V$. But spires. Dackсомве, Stepleton, co. Dorset. Dicair, Cowlby, co. Lincoln.

Arg. on a chev. betw. three roses gu. barbed vert a crescent of the first. WEDDERBURN, Blackness, co. Linlithgow, and Ballindean House, co. Perth; Baronetey 1704-46, and 1803 .

Arg. on a cher. sa. betw. three roses gu. a crescent for diff. .... Northieigh, Matford, co. Devon.

Az. on a chev. or betw. three roses arg. as many escallops sa. Templeman, Dorchester. The roses or. Templeman, co. Dorset.

Arg. on a chev, betw, three roses gu. barbed vert a fleur-de-lis of the first. WEDDERBURN.

Per fess gu. and arg. on a cher. betw. three roses of eight leaves counterchanged a fleur-de-lis or. BREEK. 
On 1 CHEVRON betw. or within.... cont.

Flowers cont. Roses cont.

Arg. on a chev. betw. three roses az. as many fleurs-de-lis of the first. COPE, Ireland.

Arg. on a chev. az. betw. three roses gu. stalked and leaved vert as many fleurs-de-lis of the first. CoApe, Duffield, co. Derby. Cope, Essex ; Middlesex ; co. Northampton; Northumberland; and co. Stafford.

Arg. on a chev, az. betw. three roses gu. as many fleurs-de-lis or. Couppe, co. Northampton.

Arg. on a chev. az. betw. three roses gu. slipped ppr. as many fleurs-de-lis or. Cope, Hanwell, co. Oxford; and Bramshill Park, co. Hants; Baronetcy 1611. Cope, Brewern, co. Oxford. (The ancient arms of) COPE, co. Oxford; and co. Northampton; 1730 .

Arg. on a chev, az. betw, three roses gu. stalked and double leaved vert as many fleurs-de-lis per fess or and of the first. Anthony Coope, co. Northampton, $V$. Cope, $V^{*}$.

Arg. on a chev. betw. three roses gu. another rose of the first. WhIте, co. Wexford.

Arg. on a chev. sa. betw. three roses gu. slipped vert another rose of the first (sometimes slipped as the fourth). Nicbolas West, Bishop of Ely 1515-33.

Sa. on a chev. arg. betw. three roses or as many gu. seeded of the third. William SмiтH, Bishop of Lichfield, etc. 1491, Lincoln 1496 . 1531.

Arg. on a chev. sa. betw. three roses az. stalked slipped and barbed ppr. fretty or. Dikons, co. Bedford.

Arg. on a chev. gu. betw. three roses as the second slipped with two leaves vert fretty of the first. Dicom or Dicons, co. Bedford. But fretty or. Robert Decons, Wasperton, co. Warwick; granted 1619, W. Dicom or Dicons, co. Bedford.

Or on a chev. betw. three roses gu. as many thistles of the first. Gound.

Arg. on a chev. gu. betw. three roses of the second barbed vert fretty as the first. Willoughby, co. Nottingham.

Arg. on a chev. gu. betw. three roses of the second harbed stalked and leaved vert fretty or. Dotchen, Wich, co. Worcester.

Arg. on a chev. sa. betw. three roses az. gu. slipped or fretty of the last. Browne, London, $I W$.

Arg. on a chev. sa. betw, three roses gu. slipped vert fretty or. Browne.

Or on a chev. betw. three roses az. as many pineapples of the first. Gord, Alarston, co. Wilts.

Arg. on a chev. az. betw. three roses vert as many bunches of grapes pendent or. Gos, $V$.

Arg. on a chev. sa. betw. three roses gu. as many bunches of grapes ppr. GooLd, co. Dorset.

Or on a chev. az. betw. three roses vert so many bunches of grapes as the first. GoLD, co. Somerset. GOULD, 1730 .

Or on a chev. betw, three roses gu. a garb of the first. Mac Laws, Garden, Scotland.

Sa. on a chev. arg. betw. three roses of the second an otter's head erased of the first. Bacfour, Lalethan.

Arg. on a chev. sa. betw. three roses gu. seeded or barbed vert a wolf's head erased gold. BELLFORD.

Arg. on a chev. betw. three roses gu. a mullet of the first. PHILLIP.

Gu. on a chev, arg. betw, three roses or five mullets of the first. Drew.

\section{On 1 CHEVRON betw. or within.... cont.}

Flowers cont. Roses cont.

Arg. on a chev. betw. three roses gu. as many bezants. Sydenhani.

Arg. on a chev. sa. betw. three roses gu. as many plates. EDGELL, Middlesex.

Arg. on a chev. az. betw. three roses gu. two daggers chevronwise points downward of the first hilted or. FindLAy, Scotland.

Arg. on a chev. betw. three roses gu. two swords points downwards conjoined at the pomel of the first hilted and pomelled or. Findlax.

Erminois on a chev. betw. three roses gu. two swords in chev, ppr. pomels and bilts or their points crossing each other in saltire the dexter surmounting the sinister. RICards or Ricketrs, Jamaica; and Combe, co. Hereford; granted 3 November 1773.

$$
\text { .... Violets }
$$

Arg. on a chev. sa. betw. three violets (az. or) purp. stalked and leaved vert barbed az. fretty or. Dikens, $V^{*}$. Dyckons, co. Bedford, $V$.

$$
\text { ....Roses }
$$

Arg. on a chev. sa. betw. four roses gu. three square buckles or. Fitz-WATER.

$$
\text { 3-Foils }
$$

Arg. on a chev. engr. az. betw. in chief two 3-foils slipped and in base a crescent sa. a 3-foil also slipped enclosed by a pair of crescents or. Williamson, Peckham, Surrey ; granted ....

Or on a chev, sa. betw, in chief two 3 -foils vert and in base a lion ramp. gu. an otter's head erased arg: BaLfour, Forret, a scion of Balfour of Monquhanny. (Three 3-foils ; Burke.)

Or on a chev. sa. betw. in chief two 3-foils and in base a garb vert banded or an otter's head erased arg. BALFoUR, Rauderston; a scion of Monquhanny. (Three 3-foils; Burlee.)

Az. on a chev. engr. arg. betw. three 3-foils slipped erm. as many lions ramp. sa. BERIFFE, Essex. The lions armed and langued gu. BARIFF.

Az. on a chev. engr. arg. betw. three 3-foils slipped pean as many lions ramp. sa. BarrifF, co. Northampton. The field vert. BarrifF, co. Northampton.

Arg. on a chev. az. betw. three 3 -foils slipped vert another chev. of the first. DE CARDonNEL.

Az. on a chev. betw. three 3-foils slipped arg. another chev, or. BLOWFIELD.

Per chev. vert and or on a chev. betw. three 3 -foils slipped another chev. couped counterchanged. WICKENS, $V^{*}$.

Per pale or and vert on a cbev. betw. three 3-foils another chev. counterchanged. WICKENS, Stochtbrewen, co. Northampton; confirmed 23 May 1640. The 3-foils slipped. WIGGINS.

Az. on a chev, betw. three 3-foils slipped or a crescent gu. John Buthwell, Lord Holyroodbouse; Nisbet, i, 400 .

Or on a chev. gu. betw, three 3.foils slipped sa. a crescent for diff. Williamson, Hayton, co. Nottingham.

Arg. on a chev. engr. betw. three 3-foils slipped az. as many clescents or. Wilutamson, New Hall, Cumberland.

Arg. on a chev. az. betw. three 3-foils slipped sa. as many crescents or. Williamson, Durham; co. Oxford; and Harnes Feader. co. York.

Arg. on a chev, engr. az. betw. three 3-foils slip. ped sa. as many crescents or. Williamson, $V$; and Middlesex ; and Denford, co. Northampton. But with a bordure engr. of the second. 
On 1 CHEVRON betw. or within.... cont. 3-Foils cont.

Eure. Thomas (John, Cotton. MS. Tiberius D 107) Williamson, Scarborough, co. York; W; granted 1557; confirmed 1565 (? WILKINSON.).

Arg. on a chev. engr. az. betw. three 3 -foils vert as many crescents or. Williarson, Westmoreland.

Arg. on a chev. betw. three 3 -foils slipped sa. an escallop of the first. CAPPS.

Arg. on a chev, betw. three 3-foils sa. as many escallops of the first. Juhn SaLonte, alias CAPON, Bishop of Bangor 1534, Salisbury 1539 57. The 3-foils slipped. Cappos, Kent, $V$. Cuppus, $V^{*}$.

Or on a chev. betw. three 3.foils slipped sa. as many estoiles arg. HoLworthy.

Per pale arg. and gu. on a chev. betw. three 3-foils slipped a fish naiant counterchanged. John Pykey, Bramton, co. Devon, $V$.

Per pale or and gu. on a chev. az. betw. three 3-fuils counterchanged a pike arg. PrKey or Pyise, co. Devon.

Arg. on a chev, az. betw. three 3-foils slipped vert as many fleurs-de-lis of the first. GiLBERT, Scotland.

Arg. on a chev, az. betw. three 3-foils vert as many fleurs-de-lis or. Gilmor or Gilmoun, Scotiand. The3-foils slipped. GILBERT,Scotland.

Arg. on a chev. sa. betw. three 3 -foils slipped vert two of the first. FOOT or Foote, Ireland.

Arg. on a chev, az. betw. three 3-foils slipped per pale gu. and vert as many 4 -foils or. RoE, Brundish, Suffolk; Baronetcy 1836.

Az. on a chev. betw. three 3-foils arg. as many lozenges gu. a bordure of the tbird. Horkinson.

Arg. on a chev. az. betw. three 3 -foils gu. a mullet or. Chambers, London; and Hackney.

Az. on a chev. betw. three 3 -foils slipped or a mullet .... $J_{\mathrm{ACK}}$, Scotland.

Az. on a chev. betw. three 3-foils slipped or a mulletgu. Bothwel, Scotland, 1534; Nisbet, App. 243.

Arg. on a chev. az. betw. three 3-foils slipped vert as many mullets of the first a bordure sa. Alvas or Alves.

Or on a chev. betw. three 3-foils slipped sa. as many mullets of the first. AlwORTHY. Holworthey, Palsgrave, Norfolk.

Or on a chev. betw. three 3.foils slipped sa. as many palets arg. Slater; quartered by Rebow.

Arg. on a chev. engr. betw. three 3.foils sa. palets or. Clay, Fulwell Lodge, Middlesex; Baro netcy 1841 .

Arg. on a chev. betw. three 3-foils slipped az. as many bezants. Rowe, Norton Place, Sussex.

Arg. on a chev. az. betw. three 3 -foils slipped per pale gu. and vert as many bezants. Robert Rooe or Roo, Charket, Kent, $V$. RoE or Roo, Dartford, Kent; and London. Rooe ol. Rowe. Sir Thomas Rooe, London, Harl. MS. 1404, fo. 63. Rowe, co. Devon. The :3-foils per pale vert and gu. Rowe, Colchester, co. Northampton.

Arg. on a chev. sa. betw. three 3.foils slipped vert as many bezants. UNDERHILI, Hunningham, co. Warwick. The chev. vert. Johu UnderHILI, Bishop of Oxford 1589-92.

Gu. on a chev. betw. three 3-foils slipped arg. as many ogresses. Plesley, in church at Thribergh, co. York, impaled by Reresby, Hunter, S. Yorkshire, ii, 43. Searle, London; and co. Worcester.
On 1 CHEVRON betw, or within.... cont.

\section{4-Foils}

Arg. on a chev, betw. three pierced 4-foils sa, a crescent of the first. WANDISFORD, co. Hereford; and co. York.

Arg. on a chev. betw. four 4 -foils gu. as many fleurs-de-lis or. CAPIE, Scotland.

Arg. on a chev. engr. gu. betw. three 4 -foils vert as many mullets or. ANDrews, co. Hants. The mullets pierced. ANDrewes, $V$. Andrews. And with a bordure compony gu. and arg. Andrewes, co. Hants, $V$. Andrews, $V^{*}$.

Arg. on a chev. engr. betw. three 4-foils slipped vert as many mullets or. ANDREws, London; and co. Hants.

Sa. on a chev. betw. three 4-foils arg. as many ogresses. CroAd or Croade.

Arg. on a chev. az. betw. three 4.foils .... two daggers points to the dexter and sinister base of the first hilts or a bordure engr. gu. Finlay, Wallyford.

Az. on a chev. engr. or betw. nine 4-foils arg. three mullets gu. CArus, Kirkby Lonsdale; quartered by Wilson.

\section{5-Foils}

Gu. on a chev, betw. in chief two 5 -foils and in base a hunting-horn or three buckles az. Duncan, Mott, Scotland. The horn viruled and stringed az. Duncan, Ardounie, Scotland.

Arg. on a chev. betw. in chief two 5.foils vert and in base a Moor's bead couped sa. a mullet of the first. M'Aluaine, Scotland.

Az. on a chev. arg. betw. three 5-foils erm. two lions combatant of the first armed gu. Cooke, Norfolk. The lions ppr. Снооке or Cоот, $V^{*}$. Az. on a chev. arg. betw. three 5-foils erm. two lions pass. respectant ppr. William CHооке (or Cooke, $W$, ) Middlesex, $V$.

Az. on a chev. engr. arg. betw. three pierced 5 -foils erm. two lions pass. sa. Coper.

Az, on a chev, engr. arg. betw. three 5-foils erm. two lions combatant sa. CowPER.

Az. on a chev, engr. arg. betw. three 5-foils erminois two lions pass. respectant sa. Tho. mas Couper, Thurgarton, co. Nottingham, $V$. COWPER, $V^{*}$.

Arg. on a chev. engr. gu. betw. three 5-foils az. as many martlets or. Hamound, co. Salop.

Gu. on a chev. or betw. three 5-foils arg. pierced az. billety of the first. WoodHouse, Suffolk. Sa. on a chev. or betw. three 5 foils arg. billety of the first. WoODHouse, Suffolk.

Sa. on a chev. or betw. three 5 -foils erm. billety gu. Woodhouse, Norfolk. Sr.... de Woophouse, $V$.

$\mathrm{Gu}$. on a chev. betw. three 5-foils arg. a buckle az. enclosed by two ermine spots a bordure of the second charged with eight 5-foils slipped vert. Hanilton, Barnton, and Binning, Scot. land ; Baronetcy 1692 , extinct ....

Gu. on a chev. betw, three 5-foils arg. a buckle az. enclosed by two ermine spots a bordure or charged with eight thistles ppr. Hamilton, Byres, as borne by Hamilon, Baron Binning and Byres 1611, Earl of Melrose afterwards Haddington 1619; quartering Melros and Baillie.

Gu. on a chev. betw. three 5-foils erm. a buckle az. a bordure embattled or charged with eight thistles vert flowered of the first. HamILTON, Call, Scotland; descended from Hamilton, Reidhouse, Scotland. 
On 1 CHEVRON betw, or within.... cont.

\section{5-Foils cont.}

Gu. on a cher. letw. three 5-foils arg. as many buckles az. Hamilton, Little Preston.

Gu. on a chev. betw. three 5-foils arg. five buckles az. Hamilton, Priestfield.

Gu. on a chev. betw. three 5-foils or another chev. of the first. Chiesty, Kersewell.

Or on a chev. betw. three 5 -foils sa. two chev. arg. Stretchley, Stretchley, co. Devon.

Gu. on a chev. betw. three 5-foils or as many eastern crowns az. Chambers, Overgrass, Northumberland ; granted ....

Arg. on a chev. betw. three 5.foils az. as many escallops of the first. Hawkins.

Gu. on a chev, betw. three 5-foils or as many estoiles of the first. CAREw.

Gu. on a chev. betw. three 5.foils arg. a rose supported by two lions pass. respectant of the first. HERBURN.

Az. on a chev. betw. three 5-foils arg. as many thistles ppr. Pasley, Craig, Scotland.

Sa. on a chev. or betw. three 5-foils erm. gouttes de sang. Woderouse, Baronetcy 1611, Barony 1797. Woodhouse, Kimberles, Norfolk. Sr. Thomas WoopHouse, $V$.

Arg. on a chev. betw. three 5-foils gu. a leopard's head cabossed or enclosed by two bezants. YALDIN. YALDWYN, Blackdown, Sussex; granted $15 \mathrm{March} 1651$; and Surrey.

Or on a chev. sa. betw. three 5-foils vert an otter's head erased of the first. B $\Delta$ LFour, Denmill.

Arg. on a chev. sa. betw. three 5-foils gu. as many boar's heads fesswise couped or. Tho. mas SWYNFord, $V$.

Gu. on a chev. betw. three 5-foils arg. as many leopard's faces sa. SмrтH, co. Wilts, Collinson, Somerset, ii, 294, 312 ; iii, 336,350. Sнгтн, Long Ashton, co. Somerset; Baronetcy 1859.

Gu. on a chev. betw. three 5 -foils arg. as many leopard's faces vert. ALDERSON.

Vert on a chev. engr. betw. three 5-foils or as many griffin's heads erased sa. Farncomb, Kennington, Surrey.

.... on a chev, betw, three 5-foils .... as many dart's heads broken at the shaft .... Paclin, Odcombe, co. Stafford, 1348.

Arg. on a chev. sa. betw, three 5.foils gu. as many horseshoes of the first. Ferrers, Newton Park, Cornwall; the heiress $m$. Coryton.

Arg. on a chev. sa. betw. three 5.foils gu. as many horseshoes or. Ferrers, Cornwall, $V$. Ferreys, Cotton MS. Tiberius D 10.

Gu. on a chev, arg. betw. three 5-foils or five mullets az. DREw. DRw, $V^{*}$. The 5-foils bliud. DRw, $V$.

Gu. on a chev. betw. three 5-foils or as many mullets az. Kingston, Isle of Wight, $V$.

Arg. on a chev. gu. betw. three 5-foils az. as many bezants. HaMpton, Wolverhampton, co. Stafford. Sr. .... de Hampton, co. Stafford, $V$.

Arg. on a chev. betw. three 5 -foils gu. as many bezants. EDGERLEY or EDGLEY, Wrenbury, co. Buckingham; and Milton, co. Oxford. Egerley, Milton, co. Oxford.

Arg. on a chev. gu. betw. three 5.foils or as many bezants. EgMORE.

Arg. on a chev. sa. betw. three 5-foils gu. as many bezants. EDGILI.

Arg. on a chev. embattled sa. betw. three 5-foils gu. as many bezants. EDGELL, Standerwick Court, Beckington, co. Somerset; Collinson, Somerset, ii, 202.

\section{On 1 CEEVRON betw, or within ...cont.}

\section{5-Foils cont.}

$\mathrm{Gu}$. on a chev. arg. betw. three 5-foils erm. as many hurts. Browne.

Arg. on a chev. gu. betw. three 5-foils az. as many plates. Prestwood.

Erm. on a chev. sa. betw. three 5-foils gu. as many catharine wheels arg. GreY.

Az. on a chev, betw. nine 5-foils arg. three mullets gu. Carus, Kendall, Westmoreland.

Az. on a cliev. betw. ten 5 -foils arg. three mullets gu. Crawe.

\section{6-Foils}

.... on a chev. .... betw. in chief two 6 -foils and in base a six-pointed mullet .... three slipped 3 -foils .... John Money, seal circa 1315.

\section{Fruit .... Corn}

Sa. on a chev. betw. three ears of wheat or an annulet enclosed by a pair of pheous pointing to it as the first. VILLE BOIs.

Arg. on a chev. gu. betw. three ears of wheat stalked and leaved ppr. so many fleurs-de-lis as the second. RIDELl, Ridell, co. Roxburgh.

Arg. on a chev. betw. three ears of wheat vert so many mullets as the first. Provan, Scotland.

Arg. on a chev. betw. three ears of wheat stalked and leaved vert as many mullets or. Provan, Scotlaud.

$$
\text { ..... Nuts }
$$

Arg. on a chev, betw. three filberts sa. two cats combatant of the first. GIBBs.

$$
\text { .....Pears }
$$

Gu. on a chev. betw. three pears or as many crosses raguly az. a tressure flory of the second. AвBOT, Baron Colchester, 1817.

Arg. on a chev. gu. betw. three pears pendent slipped and leaved ppr. as many fleurs-de-lis or. WARDOR.

Az. on a chev. betw. three pears pendent or a crescent for diff. sa. BoNEFELD; Cotton MS. Tiberius D 10.

Az. on a chev. betw. three pears or as many roses gu. Benrield, Middlesex.

Az. on a chev. gu. betw. three pears or as many bezants. Pearton, co. Stafford.

\section{.....Pine Apples or Pine Cones}

Sa. on a chev. betw, three pine cones slipped or as many martlets of the first. Wood, Kent, $W$. Arg. on a chev. betw. three pineapples vert as many crescents or. Brodway, Portslip, co. Gloucester ; granted 9 January 1661.

Arg. on a chev. sa. betw. three pineapples gu. as many stag's heads erased of the first. WILKIE, Blackheath, Kent.

Arg. on a chev. sa. betw. three pineapples vert as many leopard's head of the first. PERRYN, co. Derby; co. Gioucester ; Ashby, co. Leicester; Acton, Middlesex; and Brockton, co. Salop.

Arg. on a chev. sa. betw. three pineapples slipped reversed vert as many leopard's faces gold. Perring, Membland, co. Devon; Baronetcy 1808.

\section{....Pomegranates}

Vert on a chev. in point embowed or betw. three pomegranates slipped and leaved ppr. another chev, of like form gu. Lrvius.

$$
\text { .....Corn }
$$

Gi1. on a chev. arg. betw. three bandsfull of barley-ears (each containing five) or three bees ppr. Sirith, Yarmouth, Norfolk; granted 1722 . 
On 1 CHEVRON betw. or within.... cont.

\section{Fusils}

Per pale arg. and sa. on a chev. betw. three fusils as many birds counterchanged. CotTon.

Az. on a chev, betw. three fusils or as many mullets sa. CastelHull.

\section{Gads see Billets \\ Gambs see Legs \\ Garbs}

Sa. on a chev. or betw. three garbs arg. banded gold an annulet .... A A THYL, $W$.

Sa. on a chev. betw. three garbs or an annulet .... ATHYLL, $V^{*}$.

Arg. on a chev. betw. three garbs gu. banded or as many buckles of the last. Makelfeld or Mekelfeld, Bolton, co. York.

Sa, on a chev. betw, three garbs or another chev. az. Danson.

Arg. on a chev. betw, three garbs sa. a crescent of the first. BLAKE, co. Wilts.

Erm. on a chev. az. betw. three garbs or a cres. cent arg. Matsterson.

Gu. on a chev. arg. betw. three garbs of the second as many crosses croslet fitchy sa. DRILAND.

Gu. on a chev, arg. betw. three garbs or banded vert as many escallops sa. EDEN, West Auckland, and Windlestone, co. Durham; Baronetcy 1072, quartering Lambton and Johnson. And with an annulet for diff. EDEN, after. wards Henley, Baron Henley 1799. And with a crescent for diff. EDEN, Truir, co. Durham; Baronetcy 1776, quartering Lambton, Calvert, and Smith. And witb a mullet for diff. EDEN, Baron and Earl of Aucliand 1839, extinct 1849 ; Baron Auckland 1789 and 1793. Robert John EDEN, Bishop of Sodor, etc. 1847, Batb, etc. 1854.

Arg. on a chev. sa. betw. three garbs vert banded or as many estoiles of the first. W therby, co. Leicester ; and London.

Gu. on a chev, eugr. erm. betw. three garbs arg. a 5-foil of the first. HiLL, $V^{*}$. The 5-foil pierced. HnL, Spakestone, co. Stafford, $V$.

Az. on a chev. or betw. three garbs arg. fretty gu. Prestwold, $V$.

Gu. on a chev. arg. betw. three garbs or a fret az. Barron.

Gu. on a cher. betw. three garbs or fretty az. Baron.

Sa. on a chev. or betw. three garbs arg. fretty gu. Preston, Bawton, Suffolk. Monsire de Prestwald, $Y$. Prestwold, co. Leicester. Hugh de Prestwolid, $Y$.

Sa. on a chev. betw. three garbs or as many acorns gu. OpIE, Cornwall.

Or on a chev. betw. three garbs gu. as many ears of wheat stalked and leaved arg. READE, Close, Northumberland. REED, Troughend, and Prestwick Lodge, Newcastle-upon-Tyne, Northumberland.

Vert on a chev. arg. betw. three garbs or as many boy's heads couped ppr. LITTLEFIELD.

Erm. on a chev. az. betw. three garbs or a mullet for diff. arg. Matsterson, co. Chester, $V$. Maisterson, Nantwich, co. Chester.

Gu. on a chev. arg. betw. three garbs of the second and as many crosses croslet fitchy or a mullet sa. PrTon, quartered by Dryland. The garbs or. Dryland, $W$.

Gu. on a chev, arg. betw. three garbs or five palets and another chev. az. BAnow, temp. Henry VI, $V$.
On 1 CHEVRON betw, or within.... cont.

\section{Garbs cont.}

Arg. on a chev. betw. three garbs gu. as many bezants. Tobias Eden, 1730.

Sa. on a chev. betw. three garbs or as many hurts. Opie, Pawton in St. Breock; St. Erme; and Penhargard, Cornwall.

Gu. on a chev. betw. three garbs arg. as many tortenux. Duer.

Az. on a chev. gu. betw. three garbs or as many barrels arg. Company of Brewers, London.

Gu. on a chev. betw. three pairs of wheat sheaves saltirewise arg. as many butts. Cloake.

Gu. on a chev. arg. betw. tbree pair of barley garbs in saltire or three tuus sa. hooped as the thrrd. Company of Brewers, Exeter. And the same coat sometimes impaling Canterbury and Beckett. Company of Brewers, London, granted 1468 .

Gouttes

Arg. on a chev. sa. betw. gouttes-de-larmes another chev. of the first. ST. MAURE.

\section{Guns}

Arg. on a chev. sa. betw. three chambers placed transverse of the escucheon as the second fired ppr. another chev, erm. Chamber or Chambers. Chambers, co. Worcester. Delechamber, Radmill, Sussex.

Sa. on a chev, arg. betw. three matchlocks or as many roses gu.barbed vert seeded or. Hopkins, Oving House, co. Buckingbam; and Coventry, co. Wurwick. Hopkyns, Sybford liower, Swalcliffe, co. Oxford; and Weycliffe, Guildford, Surrey; seal.

Sa. on a chev, erminois betw. three pistols or as many roses gu. barbed and seeded ppr. Hopk1Ns ; confirmed 20 January 1773, quartering Bond.

Sa. on a chev, betw. three pistols or as many roses gu. Hopkins, co. Stafford, 1583; and Collinson, Somerset, ii, 437 .

\section{Hammers}

Vert on a chev. betw. three mallets or an eagle displ. sa. Abraham Surth, London, $W$.

Arg. on a chev. betw. three mallets gu. as many lions paws erased or. ParHan, Collinson, Somerset, ii, 377 .

Arg. on a chev, engr. betw. three mallets gu. as many lion's paws erased (? or) a bordure engr. sa. bezanty. Parram, co. Wilts, temp. Richard III, $V$. The mallets ppr. Parham.

\section{Hands}

Arg. on a chev. betw. three dexter hands apaumy couped at the wrist sa. a cross croslet or. BERne, $V$. Osborn, Ireland.

Arg. on a chev, betw. three dexter hands couped sa. a cross tau or. Binne.

Sa. on a chev. betw. three dexter (another sinister) gauntlets or as many roses gu. seeded and barbed vert. Hopkins, Atbboy, co. Meath; Baronetcy 1795 .

Arg. on a chev. betw. threo sinister gauntlets gu. as many 5 -foils or. CHIBborne.

Per pale arg. and gu. on a chev. engr. betw. three gauntlets as many 5 -foils counterchanged. Chllborne or Chilbourne, Essex.

Gu. on a chev. betw. three dexter hands arg. a garb gu. enclosed by a pair of 3.foils slipped ppr. O'Cullen. 'The chev. sometimes or. O'Culles. Arg. on a chev. betw. tbree sinister hands couped sa. as many spearineads of the first. BRENDE, Norfolk; and Suffolk. Browne, co. Devon. The hands bendwise sinister. BRINDE. 
On 1 CHEVRON betw. or within.... cont. Hands cont.

Arg. on a chev. az. betw. three arms in armour ppr. fesswise embuwed as the second so many mullets of the first. Anmour, Scotland.

Gu. on a chev. arg. betw, three sinister gauntlets or two palets amongst three half fleurs-delis split palewise .... Anmorer, London.

Arg. on a cher. betw. three dexter hands gu. as many bezants. Le Mesurier.

Arg. on a chev. vert betw. three sinister hands erect gu. five ermine spots or. MAYNARD, Chesterfield, co. Derby ; quartering Lax.

Head .... (Monster)

Vert on a chev. embattled betw. in chief a unicorn's head erased and in base a stag's head arg. three mullets sa. KEIR, Linlithgow, Scotland.

Heads.... (Beast) Boar

Az. on a chev. or betw. in chief two boar's heads erased and in base a padlock arg. a lozenge enclosed by a pair of keys fesswise wards uppermost sa. DunN, quartered by Gardner.

$$
\text { .... Deer }
$$

Gu. on a chev. betw. in chief two buck's heads erased with golden horns and in base a cat pass. arg. three mullets of the first. KELFORD.

Gu. on a chev. arg. (or, $V^{*}$.) betw. in chief two buck's heads erased of the second horned gold and in base a cat stat. or three mullets of the first each charged with a bezant. KeTford, co. Gloncester, $V$. But with a talbot pass. in the base. LETFORD, co. Gloucester.

Per chev. or and erm. on a chev. az. betw. in chief two stag's beads erased ppr. each holding a mullet in the mouth sa. and in base the Roman fasces in bend sinister surmounted by a sword saltirewise ppr. entwined by a double chain gold three 5-foils arg. Rogers, Bromp. ton Park, Middlesex ; and Calcutta.

Or on a chev. vert betw. iu chief two lion's heads erased az. and in base a fox courant ppr. a stag's head cabossed enclosed by a pair of wreaths of oak gold. BRADDICK, Boughton Mount, Boughton Monchelsey, Kent.

Gu. on a chev. betw. two lion's heads erased or ten ogresses. CoLEs, Ireland; granted 1648.

$$
\text { ..... Otter }
$$

Gu. on a chev. betw. in chief two otter's lieads and in base a fleur-de-lis or an otter's head erased as the first. BALFoUR, Carriston.

$$
\text { ....0x }
$$

Arg. on a chev. betw. in chief two bull's heads erased and in base a lion pass. az. a tower ensigned by a ducal coronet or enclosed by a pair of boar's heads couped as the first. JoNes; granted ....

Arg. on a chev. engr. az. betw. in chief two bull's heads erased sa. armed or and in base an un. chor of the third .... estoiles gold. BoLCOLE. Bolcotr, Waltham, Essex.

$$
\text { ....Tiger }
$$

Per chev, arg. and or on a chev. gu. betw. in chief two tiger's faces ppr. and in base an eagle displ. sa. a boar's head erased as the second enclosed by a pair of spearheads erect like the first. Grour, Hackney, Middlesex. .....(Birds)

Per chev. or and erm. on a chev. sa. betw. in chief two eagle's heads erased gu. and in base a garb of the first a harrow gold betw. two fountains. CAss, Little Grove, East Barnet, co. Hertford.
On 1 CHEVRON betw. or within.... cont.

Heads cont. (Birds) cont.

Arg. on a chev. gu. betw. in chief two eagle's heads erased of the last and in base an anchor az. three bezants a bordure of the third. Broadley, London.

\section{....(Monsters)}

Erm. on a chev. sa. betw. in chief two dragon's heads erased ppr. and in base a buglehorn as the second stringed gu. a griffin's head couped enclosed by a pair of buglehorns stringed or. Tunnard, Frampton House, co. Lincoln.

Sa. on a chev. arg. betw. in chief two unicorn's heads erased of the second armed and maned or and in base on a pile as the last issuing from the chevron a unicorn's head erased like the field three spearheads gu. WRIGHT,Mapperley, co. Nottingham.

$$
\text { ..... (Beasts) Bear }
$$

Sa. on a chev. betw. three bear's heads erased arg. as many swans close of the first. Bearcroft, co. Worcester.

Sa. on a chev. betw. three bear's heads erased arg. muzzled gu. a 5 -foil of the first. LENY; quartered by Buchanan.

Sa. on a chev. betw. three bear's beads arg. muzzled gu. as many 5 -foils of the last. LenNie or Leny, Scotland.

Az. on a chev. or betw. three bear's heads of the last muzzled gu. two hands each holding a dagger chevronwise ppr. $\mathrm{I}^{\prime} \mathrm{K} \mathrm{AY}$, England.

Per pale az. and gu. on a chev. betw. three bear's heads arg. muzzled counterchanged a sinister and dexter arm chevronwise issuing from the sides of the shield each holding a dagger meeting in point .... MACKAY, Edinburgh.

Az. on a chev. betw. three bear's head couped arg. muzzled gu. a roebuck's head erased enclosed by two hands issuant from the ends of the chev. each holding a dagger ppr. MAcKaY; Baronetcy 1627; Baron Reay 1628.

$\mathrm{Az}$. on a chev. or betw. three hear's heads couped arg. muzzled gu. a roebuck's head erased of the last enclosed by two hands couped at the wrist each holding a dagger ppr. MACKIE, Scotland.

Per fess az, and arg. on a chev. betw. three bear's heads couped muzzled gu. a stag's head cabossed enclosed by two daggers chevronwise counterchanged. MAcKay, England.

Az. on a chev. betw. three bear's beads couped arg. muzzled gu. as many unicorn's heads erased sa. Forbes, Culloden, co. Inverness. Forbes, Pittencrief, Scotlaud.

Az. on a chev. betw. three bear's heads couped arg. muzzled gu. a heart of the last. Fories, Pitsligo, co. Aberdeen, quartering Forbes, Eraser, and Stuart. And with a bordure engr. of the second. Formes, Kirknockie.

Az. on a chev. betw. three bear's heads arg. muzzled gu. a beart of the last betw. two daggers meetung in point ppr. Forbes, Alford, Scotland. The dagger's pomelled or. Forbes, Balfluig, Scotland.

Az. on a chev. betw, three bear's heads couped arg. muzzled gu. a heart ppr. with wings or. Forbes, Monimusk, Scotland; descended from Forbes, of Carsindae.

Arg. on a chev. gu. betw. three bear's heads erased sa. as many bezants. Petri, Kent.

Sa. on a chev. invecked betw. three bear's heads erased arg. as many ogresses. HILI, Ireland; granted 1648 . 
On 1 CHEVRON betw, or within.... cont.

Heads cont. (Beast) Boar

Arg. on a chev. engr. betw. three boar's heads couped sa. an annulet or. Brock.

Sa. on a chev. arg. betw, three boar's heads fesswise couped or armed az. an annulet gu. Thlrwall, Norfolk, $V$.

Sa. on a chev. engr. betw. three boar's heads couped arg. as many billets of the first. Burbage.

Gu. on a cher. betw. three boar's heads couped or a buckle arg. Peters, Angus.

Arg. on a chev. sa. betw. three boar's heads erased gu. as many buckles of the first. ElpHrnston.

Arg. on a chev. betw. three boar's heads couped gu. armed or a crescent of the first within an annulet gold. VADOHAN, Burlton Hull, co. Salop; quartering Tudor Trevor, Chambré, Gouldisbrough, and Bolas.

Arg. on a chev. betw. three boar's heads couped sa. a crescent or. Bethell or Bythell, Winchester.

Gu. on a chev. engr. betw. three boar's heads erased at the neck arg. a crescent. EDWARDs. The heads erect erm. EDwards, Shrewsbury, $W$.

Per chev. gu. and az. on a chev. betw. three boar's heads couped arg. a cross flory enclosed by two grasshoppers respectant vert. TreacHir, Stamford Hill, Middlesex; granted 1820.

Arg. on a chev. gu. betw. three boar's heads and necks erased az. crined and armed or as many crosses croslet of the last. DERmotr.

Or on a chev. gu. betw. three boar's heads couped az. as many crosses croslet of the first. MaC Dermot, Coolavin, co. Sligo. Mac Dennotr Roe, Alderford House, co. Roscommon.

Az. on a cbev. arg. betw, three boar's heads fess. wise erased erm. as many single-bandled ewers with spouts gu. John Hayes, $V$.

Arg. on a chev. betw. three boar's heads gu. as many escallops or a bordure of the second bezanty. Bowles.

Arg. on a chev. sa. betw. three boar's heads fesswise couped gu. armed or as many escallops of the fourth a bordure engr. vert bezanty. Bowles, Walington, co. Hertford, $V$.

Arg. on a chev. betw. three boar's heads sa. armed or as many escallops of the third. Bowldes or Bowles, co. Hertford; and co. Hereford. And with a bordure vert bezanty. Bowles, co. Hertford; and co. Hereford.

Arg. on a chev. betw. three boar's heads couped sa. a six-pointed estoile of the first. BETHELL.

Arg. on a cher. betw. three boar's heads couped and erect sa. an estoile of the first. Bоoтв, Baronetcy 1835 .

Arg. on a chev. betw. three boar's beads conped sa. an estojle o:. Bethel., Rise, co. York; and co. Hereford. Christopher Betnell, Bishop of Gloucester 1824, Exeter, 1830, Bangor 1830 .

Arg. on a cher. gu. betw. three boar's heads couped sa. a fleur de-lis or. AGArD, Sudbury, co. Derby.

Az. on a chev. betw. three boar's heads couped or as many fleurs-de-lis gu. LUDFORD, Ansley Hall, co. Warwick; granted 1808 ; quartering Newdegate.

Gu. on a chev. betw. three boar's heads couped arg. armed and langued or as many 3 -foils vert. Thenwall, North Wales.
On 1 CHEVRON betw, or within.....cont.

Heads cont. (Beasts) Boar cont.

Gu. on a chev. arg. betw. three boar's heads sa. as mauy 3.foils of the first. THELWALL.

Gu. on a chev. or betw. three boar's heads arg. as many i3foils vert. THELWALL.

Arg. on a chev. gu. betw. three boar's heads erased sa. as many 5 -foils of the first. NisBet, Craigintnie, Scotland. The chev. ensigned on the top with a thistle ppr. NISBET, Dirletoun, Scotland.

Or on a chev. betw, three boar's heads couped sa. as many 5.foils of the first. AMBERshar.

Arg. on a chev. az. betw. three boar's heads couped sa.five 5-foils of the first. AGMONDISHAI, Surrey.

Arg. on a chev. az. betw. three boar's heads couped sa. langued or five 5-foils of the last. Agmondesham, Horsley, Surrey. Ambersham.

Arg. on a chev. az. betw. three hoar's heads fesswise couped sa. five 5.foils or. AgMONDESHAM, $V^{*}$. Ambersam, $V^{*}$. The 5 -foils pierced. Agmondesham, $V$. The beads each bolding a 5 -foil or. Agmondestam, $V$. Ambersam, $V$.

Or on a chev. betw. three boar's heads couped sa. five 5 -foils of the first. AmBERSAMr.

Arg. on a chev, az. betw. three boar's heads ppr. as many garbs or. CARADOC or CraDOCE, Baron Howden, 1819.

Sa. on a chev, engr. or betw. three boar's heads couped arg. gouttes de sang. Burbyche, Middlesex; and co. Hertford.

Az. on a chev. betw. three boar's heads couped or a hand grasping a sheaf of arrows ppr. Gordon, Avachie, Scotland. And with a bor. dure of the second charged with eight cres. cents gu. Gordon, Gordonbank, Scotland.

Az. on a chev. erm. betw. three boar's heads erased or a buck's head erased gu. GoRDON Millig, co. Ayr; granted 1807.

Arg. on a chev. betw. three boar's heads erased az. a man's heart within a fetterlock or. Lockhart, Kirktoun, Scotland.

Az. on a chev. or betw. three boar's heads arg. a lozenge gu. enclosed by two keys sa. DunN.

Arg. on a chev. sa. betw. three boar's heads erased gu. a mitre of the first. Elphinston, Glacok, Scotland. And with a bordure for diff. gu. Elphinston, Edinburgh.

Or on a chev. sa. betw. three boar's heads erased of the second armed and langued gu. a mullet arg. Avern, co. Warwick.

Arg. on a chev. sa. betw. three boar's heads couped (? of the second) so many mullets as the first. Augusta Rrsso, daughter of Henry Frederick, Duke of Cumberland, as quartered by Dalton.

Arg. on a chev. engr. betw. three boar's heads fesswise couped sa. a bezant. Edmond Burton, London, $W$. Stapilford, of the North, $W$. But a plate. Borton, Stapleford.

Per pale or and arg. on a chev. az. betw. three boar's heads sa. three roundlets .... Nethercoat, Moulton Grange, co. North. ampton.

Arg. on a chev. betw. three boar's heads couped az. five bezants. BroxнoLME, Lincoln.

Arg. on a.chev. gu. betw. three boar's heads erased erect vert as many bezants. Hayes, Essex.

Arg. on a cher. betw. three boar's heads sa. as many bezauts. WARDALL. 
On 1 CEEVRON betw, or within....cont.

Heads cont. (Beasts) Boar cont.

Per pale or and arg. on a chev. az. betw. three boar's heads couped fesswise sa. as many bezants. Robert Wright, Bishop of Bristol 1623, Lichfield etc. ]632-43. WRIGHT, Nantwich, Harl. MS. 1535, fo. 29.

Az. on a chev. betw. three boar's heads arg. langued and couped gu. as many ogresses. Goonford, Chilton Cantelo, co. Somerset.

Arg. goutty de sang on a chev. embattled sa. betw. three boar's heads erased gu. two swords ppr. pomels and hilts or. Elphinstone, Sow. erby, Cumberland; Baronetcy 1815.

$$
\text { ....Deer }
$$

Arg. on a chev. gu. betw. three buck's heads sa. an annulet of the first. Booke, London.

Vert on a chev. arg. betw. three hind's heads erased of the first as many martlets gu. Conran.

Arg. on a chev. betw. three (buck's, $V^{*}$.) stag's heads cabossed sa. a crescent or. Horwood, co. Stafford. Horwood, $V$.

Gu. on a chev. betw. three buck's heads cabossed arg. a crescent of the first for diff. RoeErTs, Bodjor.

Arg. on a chev. betw. three bnck's heads cabossed sa. as many crescents or. WHORWOoD, Bobington, co. Stafford.

Sa. on a chev. or betw. three stag's heads cabossed arg. as many covered cups gu. Cantis, Can. terbury.

Arg. on a chev. betw. three buck's heads erased sa. as many 3 -foils or. Collingwood, quartering Giffard.

Arg. on a chev. engr. sa. betw. three reindeer's heads erased gu. as many 5 -foils erm. Rice, Boemer, co. Buckingham; granted 2 May 1555.

Arg. on a chev. sa. betw. three (buck's, $V^{*}$.) roebuck's (another', stag's) beads couped gu. fretty or. Ragon, Kent. Ragon, $V$.

Arg. on a chev. betw. three stag's heads couped sa. as many stringed buglehorns of the first. Mertingham, Frocester, co. Gloucester.

Arg. on a chev. betw. three (buck's, $V^{*}$.) stag's heads erased sa. as many stringed buglehorns of the first. John Huntuey, $V$. The heads erased sa. Huntlex, Boxwell, co. Gloucester; descended from Huntcey, Standish and Boxwell.

Arg. on a chev. betw. three buck's heads erased sa. as many buglehorns or (another the horns arg.). Huntuey, Dorking, Surrey ; and Wales.

Sa. on a chev. betw. three buck's heads cabossed - arg. as many stringed buglehorns of the first. Huntley, Treowen, co. Monmouth, temp. Edward III. MАYHUGH.

Sa. on a chev. or betw. three (buck's, $V^{*}$.) stag's heads cabossed arg. as many huglehorns of the first. Sr. Mayhugh Sorne, Wales, $V$.

Gu. on a chev. arg. betw. three buck's heads erased or as many mullets of the first. CARr. KARR.

Vert on a chev. betw. three buck's beads cabossed or as many mullets gu. HICKFonD, $V^{*}$, and Twiring, co. Gloucester. Thomas Higford, $V$. Huggeford, Dicklestone alias Dixton, co. Gloucester ; and co. Warwick. HugGForD, co. Worcester. Higford, formerly HugFord, Aldrington and Dickleston, co. Gloucester. Pudder, Gloucester, 220, quartering sa. a pile arg.
On 1 CHEVRON betw. or within.... cont.

Heads (Beasts) cont. Deer

Vert on a chev. betw. three buck's heads or as many mullets sa. HIGFORD, co. Worcester.

Vert on a chev. betw. three buck's heads cabossed or as many mullets sa. Higford.

Arg. on a chev. betw. three stag's heads cabossed sa. as many sprigs of broom or. WHORWOOD, Headington House, near Oxford.

$$
\text { .... Dog }
$$

Arg. on a chev. az. betw. three talbot's heads erased gu. an anchor of the first. M'KILLOP.

$\mathrm{Gu}$. on a chev. hetw. three talbot's heads erased or another chev. erm. WhitTue, co. Lancaster, confirmed 1694.

Arg. on a cher. gu. betw. three greybound's heads erased sa. each gorged with a ducal coronet and chain reflexed or as many crosses croslet of the fourth. Bass.

Arg. on a chev. az. betw. three greyhound's heads erased sa. as many estoiles or. SмIтн.

Arg. on a chev. engr. az. betw. tliree greybound's heads erased sa. collared or ringed gu. as many estoiles of the fourth. SMrTH, Mitcham, Surrey.

Arg. on a chev. betw. three talbot's heads erased sa. an estoile or. HALL, Grantham, co. Lin. coln, $W$. The chev. engr. HaIL, Greatford Hall, co. Lincoln; Jamaica; and Arrow's Foot, co. York. HaLL, Skelton Castle, co. York. HaLl, Wratting Park, co. Cambridge; quartering Carter and Thompson; the heiress $m$. Morse-Boycott.

Arg. on a chev. betw. three talbot's heads erased sa. as many estoiles or. HaLL, Grantham, co. Liucoln.

Erm. on a chev. engr. az. betw. three greybound's heads erased sa. collared or as many estoiles of the last. SмrтH, Lenton, co. Bedford, 1580 .

Per pale arg. and erm. on a chev. engr. betw. three talbot's heads erased sa. as many estoiles or. HaLL, Weston Colville, and Wratting Park, co. Cambridge, quartering Carter and Thompson; the heiress $m$. Morse-Boycott.

Sa. on a chev. betw. three talbot's heads erased arg. so many fleurs-de-lis of the first. within a bordure engr. as the second. Chedioke or Chidioke, Westbury, co. Wilts. Chideok Warder, Westbury, co. Wilts; W. WARDEN WARDER WARDOR or WARDOUR, Westbury, co. Wilts; granted 1585. WARDOR, co. Hants.

Arg. on a chev. az. betw. three talhot's heads erased gu. a rose and a crescent of the first. M'Killop, Scotland.

Arg. on a chev. az. betw. three talbot's heads erased gu. a rose of the first a bordure as the last. M'KeLLip, Scotland.

Per pale indented az. and sa. on a chev. engr. erm. betw. three talbol's heads erased or as many roses gu. barbed and seeded ppr. Culley, Coupland Castle, and Fowberry Tower, Northumberland.

Arg. on a chev. engr. or betw. three talbot's heads erased gu. as many 3 -foils slipped vert. BEIL, Baughton, Suffolk.

Per pale arg. and or on a chev. betw. three talbot's heads erased sa. collared with mural crowns or three hawk's lures of the first stringed as the second. Hall, Llanover Court, and A bercarn, co. Monmouth; Baronetcy 1838, Baron Llanover, 1859 . 
On 1 cHEVRON betw, or within.....cont.

Heads cont. (Beast) Dog cont.

Gu. on a chev, arg. betw. three talbot's heads erased or as many mullets sa. Bratam, Che. dington, co. Buckingham, V. Breame, London.

Arg. on a chev. gu. betw. three greyhound's heads erased sa. as many bezants. Caurche, Betton, co. Salop.

Per pale gu. and sa. on a chev. engr. betw. three greybound's heads erased arg. each with a collar gu. ringed at the back or three hurts. BELson, $V$. The chev. sometimes not engr. and the collars gold. BeLsoN.

Arg. on a chev. betw. three greyhound's heads erased sa. as many plates. Tooke. The heads collared and ringed or. Toocke, $V^{*}$. TоOKE, Magna Chard, Kent, $V$.

$$
\text { .....Elephant }
$$

Or on a chev. betw. three elephant's heads erased gu. as many mullets arg. Hovg Has, Wedington, Kent. Lewrs, Northborne Court, Kent.

$$
\text { ....Fox }
$$

Sa. on a chev. or betw. as many fox's heads erased erm. three doorstaples gu. Cooke, Essex.

Arg. on a chev. betw. three fox's heads erased gu. a mullet or. Fox, Bosworth, co. Leicester.

Arg. on a chev. az. betw. three fox's heads erased gu. collared and ringed or as many bezants. Fox. ....Goat

Arg. on a chev. sa. betw. three goat's beads erased az. as many billets or. YARFORD. YeRford, London.

Or on a cluev. vert betw. three goat's heads erased sa. a crescent for diff. .... John W WrTE, London; granted by Cooke, $W$.

Arg. on a chev. sa. betw. three goat's beads erased az. armed or as many escallops of the first. Bendishe, $V$.

Arg. on a chev. betw. three goat's heads erased sa. three escallops of the first. BENSON. BEwson.

Per chev. gu. and az. on a chev. or betw. three goat's heads erased arg. as many fleurs-de-lis of the second. BagGallay, Lambeth, Surrey.

Arg. on a chev. indented gu. betw. three goat's heads erased sa. as many 5 -foils of the first. Nisbet, Bourdeaux.

Arg. on a chev. sa. betw. three goat's heads erased az. as many bezants. YerFord, London.

Sa. on a chev, betw. three goat's heads couped arg. as many ogresses. Cow PER, co. Gloucester.

$$
\text { ....Hors } \theta
$$

Sa. on a chev. or betw. three horse's hearls erased arg. two crosses calvary heads toward the centre point of the first. EAsT, Stradford Place, Middlesex; Baronetcy 1823.

Sa. on a chev. betw. three horse's heads erased arg. as many borseshoes of the first. $\mathrm{E}_{\mathrm{AST}}$, Hall Place, co. Berks; Baronetcy 1766-1828, and 1838 ; quartering Clayton. EAst, Rading, co. Buckingham.

\section{..... Leopard}

Arg. on a chev, gu. betw. three leopard's heads sa. an annulet .... F Fanington, London, 1634, Harl. MS. 1476, fo. $205 b$.

Arg. on a chev. betw. three leopard's heads sa. as many annulets of the first. CALLOW. CAYLOWE, V. Kaloway. Tallowe.

Arg. on a chev. betw. three leopard's heads sa. as many aunulets or. Kelley. Tallowe.

Sa. on a chev. engr. or betw. three leopard's faces arg. as many annulets of the first. Forser, Kelboe, and Harberhouse, co. Durbam ; granted 1575. Lonsor or Lovsor, Kellow, co. Durham.
On 1 CHEVRON betw. or within.....cont.

Heads cont. (Beast) Leopard cont.

Gu. on a chev. arg. betw. three leopard's faces or two arrows in saltire az. barbed and flighted ppr. enclosed by a pair of bows chevronwise as the fourth stringed like the first. MEADE; quartered by King.

Gu. on a chev. betw. three leopard's heads arg. four bars of the first enclosed by twelve torteaux. Colles, Croke-Burnell, co. Devon.

Arg. on a chev. gu. betw. three leopard's faces sa. as many castles triple-towered or. Saumarez; Baronetcy 1801, Baron de Saumarez 1831.

Arg. on a chev. gu. betw. three leopard's faces sa. a crescent for diff. ... Newpont, Baron Tor. rington 1716-19.

Arg. on a chev. engr. betw. three leopard's faces sa. a crescent or. LEE, London; descended from co. Chester; confirmed 25 October 1583.

Sa. on a chev. betw. three leopard's heads or a crescent gu. Hanvy, London. Hayes, Wardrobe, and Litley, co. Chester; granted 1015.

Per pale or and gu. on a chev. betw, three leopard's heads as many crescents counterchanged. WILFORD, London. The chev, engr. WILFORD, $V^{*}$. Wylford, Enfield, $V$.

Arg. on a chev. betw. three leopard's heads sa. as many crosses croslet of the first. SNassell. The crosses croslet fitchy. SNaSELL or SNawseld, Biltoa, co. York. Seth Snassell, co. York, $V$.

Arg. on a chev. betw. three leopard's heads sa. as many crosses patty fitchy of the first. Pormonth, Todlethorp, co. Lincoln.

Az. on a chev. betw. three leopard's heads arg. as many crosses patty fitchy sa. SNASSELL, co. York.

Vert on a chev. betw. three leopard's faces or as many crosses croslet gu. FITCH, Eltham, and Mount Mascal, Kent; Baronetcy 1088-1736.

Az. on a chev. betw. three lenpard's heads or as many escallops sa. James, $W$.

Gu. on a chev. betw. three leopard's heads arg. as many escallops az. Browne, London, $W$; granted 28 February 1615. Piverne.

$\mathrm{Gu}$. on a chev. betw. three leopard's heads or as many escallops of the first. Heary Erre, London; granted $1589, W$.

Per bend gu. and sa. ou a chev. engr. arg. betw. three leopard's heads or as mauy escallops az. Browne, Newark, co. Nottingham.

Per pale gu. and or on a chev. engr. per pale arg. and az. betw. as many leopard's heads three escallops counterchanged. Browne, co. Nottingham.

Per palo gu. and sa. on a chev. engr. arg. betw. three leopard's heads (counterchanged, $V^{*}$.) or as many escallops az. Browne, Newark-onTrent, $V$.

Erm. on a chev. gu. betw. three leopard's faces sa. as many bombs or fired ppr. FARRINGToN, Blackbeath, Kent; Baronetcy 1818.

Arg. on a chev. betw. three leopard's heads sa. as many fleurs.de-lis of the first. CoNELEY.

Az. on a chev. arg. betw. three leopard's heads or as many fleurs-de.lis gu. GAY. Gux, Oundle, co. Northampton; and co. Wilts. GuY, $V^{*}$. GYE, of the Cellar, $V$.

Gu. on a chev. or betw. three leopard's faces arg. as many fleurs-de-lis az. Pelreat, London.

Or on a chev. betw. three leopard's faces gu. a rose of the first. Richard Nyxe, Bishop of Norwich 1501-66, Lansdowne MS. 255, fo. 7 . 
On I CHEVRON betw, or within.... cont.

Heads cont. (Beast) Leopard cont.

Per pale gu. and az. on a chev. or betw. three leopard's heads arg. cliarged with torteaux a rose purp. seeded ppr. enclosed by two cocks sa. membered of the first. Richard Rawlings, Bishop of St. David's 1523.36.

Arg. on a chev. sa. betw. three leopard's heads az. as many roses or. Gilbert, Brent Ely, Suffolk. And with a crescent for diff. Gilbert, Woodford, Essex.

Arg. on a chev, betw. three leopard's faces sa. as many roses or. Gilbert, Woodford, Essex; confirmed 1609 .

Az. on a chev. arg. betw. three leopard's heads each holding a shuttle or as many roses gu. seeded of the third barbed vert. Company of Weavers.

Erm. on a chev. sa. betw. three leopard's heads az. as many roses arg. Gilbert de Clare, Suffolk, $W$.

Az. on a chev. betw. three leopard's faces or as many 3-foils slipped .... FroHOck.

Gu, on a chev. betw. three leopard's heads or as many 3 -foils slipped gu. Hervey, Ireland.

Gu. on a chev. betw. three leopard's heads or as many 3-foils slipped vert. Henvex.

Or on a chev. betw. three leopara's faces gu. as many 3-foils slipped arg. Harvey, Middlesex.

Or on a chev. betw. three leopard's heads gu. a 5 -foil for diff. .... Richard Nix or Nyx, Bishop of Norwich 1501-66; $U$; sometimes spelt NrkKe or Nyxe.

Az. on a chev, or betw. three leopard's heads arg. as many 5-foils pierced gu. Pettrt, Kent.

Az. on a chev. or betw, three leopard's heads arg. as many 5 -foils gu. each charged with a pomey. Petite, $V$.

Az. on a chev. or betw. three leopard's beads arg. as many 5-foils vert. Petrte, $V^{*}$. Pettet.

Gu. on a chev. betw. three leopard's faces or as many 5-foils of the first. InPEx, Hammersmith, Middlesex.

Gu. on a chev. betw. three leopard's faces arg. gouttes de poix. Heartston. Hewston, $V$. Hoxтon, Sutterton-Hoxton, Suffolk. Sr. $\ldots$ de Lughteburgh, $V$. Lutburgh, $V^{*}$. The cher. sa. goutty arg. HEwsToN, $V^{*}$. LUGHTEBURGH, $V^{*}$.

Az. on a chev. alg. betw. three leopard's heads erased or three spearheads sa. Price, Bryn-yPys, co. Flint; and Castle Lyons, Ireland. PrICE; Baronetcy 1813, quartering Cleveland and Puleston.

Sa. on a chev, engr. or betw. three leopard's faces arg. two antique keys bows to the centre wards upwards az. Wenrwonte, Parlut, co. Lincoln; Baronetcy 1795 , extinct ....

Arg. on a chev. gu. betw. three leopard's faces sa. a mullet of the first. Farington, Chichester; Baronetcy 1697, extiuct 1719; Harl. MS. fil64.

Az. on a chev. betw. three leopard's heads or a mullet gu. Frowicke, Lord Mayor of London 1435 and 1444. The mullet sa. Frowrke, Justiciarius Angliæ, $V$.

Arg. on a chev. betw. three leopard's heads sa. as many mullets of the first. Pormort, Saltfletby, and Kenington, co. Lincoln.

Arg. on a chev. betw. three leopard's heads sa. as many mullets or. BRICKIEToN.

Gu. on a chev, betw. three leopard's heads or as many mullets of the first. Davers, Rougham, Suffolk.
On 1 CHEVRON betw. or within .....cont.

Heads cont. (Beast) Leopard cont.

Gu. on a chev. betw. three leopard's heads or as many mullets sa. Pearle, co. Hereford.

Arg. on a chev. betw. three leopard's beads az. as many pales of the first. HEwscotT, co. Devon.

Arg. on a chev. betw. three leopard's heads az. as many palets or each charged with an ogress. Tristram Hingscot, co. Devon, $V$.

Erm. on a chev. betw. three leopard's beads az. four palets arg. HeNscotT, $W$.

Arg. on a chev. betw. three leopard's heads erased az. a bezant. HaLL, Horton Hall, co. Buckingbam; and London.

Or on a chev. betw. three leopard's faces gu. a bezant. Richard Nykke or Nyx, Bishop of Norwich 1503-36.

.... on a chev. .... betw. three leopard's faces .... as many roundles. HugHes.

Arg. on a chev. betw. three leopard's heads az. as many bezants each charged with an ogress. HENGSCOTT, $V^{*}$.

Or on a chev. engr. gu. betw. three leopard's heads jessant-de-lis .... as many bezants. Cathrow.

Arg, on a chev. compony az. and or betw. three leopard's heads of the second as many hurts. Henscot, co. Devon.

Sa. on a chev. engr. or betw. three leopard's faces arg. as many ogresses. Forcer.

Erm. on a chev. betw. three leopard's heads az. four plates. Hengscot, co. Devon. But ogresses. HensCOTT, $V^{*}$.

Arg. on a chev. betw. three leopard's heads gu. goutty d'or a sun of the last. HeILy or HELY.

Or on a chev. betw. three leopard's heads gu. as many suns of the first. NIxoN, Blechingham, co. Oxford.

Gu. on a chev. betw. three leopard's beads arg. an ermine spot. Coles or Colles, co. Somerset.

$$
\text { ....Lion }
$$

Or on a cher. az. betw. three lion's heads erased purp. as many annulets of the first. Benedictine Priory at BoDmin, Cornwall.. (? Benedictine Priory at S. Gerians, Cornwall ; Monasticon.) Arg. on a chev. betw. three lion's heads erased gu. as many battle-axes of the first. TIFFIN, Whitrigg, Cumberland.

..... on a chev. .... betw. three lion's heads erased of the second three battle-axes as the first. TIPping, Preston, co. Lancaster.

Arg. on a chev. gu. betw. three lion's heads erased sa. bars and plates of the first. Collis.

Gu. on a chev. arg. betw. three lion's heads erased or four bars of the first and ogresses. Core, co. Hants. The bars gemel. Colles, co. Worcester.

Az. on a chev. engr. betw. three lion's heads erased or as many leopards pass. ppr. collared .... 'T Tabers, Heard's Hill, Essex.

Az. on a chev. arg. betw. three lion's heads erased or each gorged with a collar as the first charged with a triplet of bezants so many cluurch bells like the field ornamented as the third. BeLr, London.

Az. on a chev. betw. three lion's heads erased arg. as many martlets gu. BoLdero or BOLDEROWE.

Az. on a chev. arg. betw. three lion's heads erased or as many martlets sa. Luntuey. 
On 1 CHEVRON betw. or within.... cont.

Heads cont. (Beast) Lion cont.

Az. on a chev. betw. three lion's heads erased or as many martlets of the first. Plomer.

Az. on a chev. betw. three lion's heads erased or as many martlets sa. Moore. Thomas Moore, Newington, Middlesex, $W$; granted 1576.

.... on a chev. .... betw. three lion's heads erased .... as many buckles. Thomelin DREFFELD; seal.

Arg. on a chev. betw. three lion's heads erased gu. a chessrook or. RocclyFr, Calthorpe. Rociliffe. Sr. Davy Rowcliff, V. Geofferey Rowcliff, Carthorp, $V$.

Arg. on a chev. betw. three lion's heads erased gu. a cross croslet or. Tenche, Shrewsbury ; and London; granted 1 July 1628.

Vert on a chev, arg. hetw, three lion's heads erased or as many crosses botonny sa. WILDgoose, Kent.

Vert on a chev. arg. betw. three lion's heads erased or as many crosses croslet az. PEAKE or PEkE, Warton, co. Lincoln.

Vert on a chev. betw. three lion's heads erased or as many crosses croslet az. PEak, co. Lin. coln; and Acburch, co. Nortbampton. Sir William PEAE, Lord Mayor of London 1668.

Yert on a chev. betw. three lion's heads erased or as many crosses croslet gu. PEAKE, Bilton, co. lincoln.

Arg. on a chev. sa. betw. three lion's heads erased gu. an estoile or. JoHnson, London, $W$. And with a bordure engr. gu. Jonnson, Willing. ball, Essex, $W$.

Arg. on a chev. sa. betw. three lion's heads erased gu. bezanty an estoile or. JoHnsons, $V$. The estoile of eight points. JoHnson, London.

Arg. on a chev. sa. betw. three lion's heads erased gu. an estoile of sixtecn points or. JoHnson, Essex.

Arg. on a chev, betw. three lion's heads erased sa. an estoile ppr. HaLL.

Or on a chev. betw. three lion's heads erased gu. a fleur-de-lis of the first. BEKETT, $V$.

Or on a chev. betw. three lion's heads erased gu. a fleur-de-lis enclosed by two annulets of the first. Bechett, co. Wilts.

Arg. on a chev. gu. betw. three lion's beads erased sa. as many fleurs-de-lis or. SlegGe, co. Cam. bridge.

Arg. on a chev, sa. betw. three lion's heads erased gu. as many fleurs-de-lis of the first. Bawtre, co. Cambridge.

Sa. on a chev, arg. betw. three lion's heads erased or as many roses gu. STony.

Or on a chev, betw. three lion's heads erased sa. as many 4 -foils of the first. WIIDGoose or Wilgos.

Vert on a chev. arg. betw. three lion's heads erased or as many 4 -foils sa. WILDGoOSE, Kent.

Sa. on a chev. beiw. three lion's heads erased arg. as many 5 -foils gu. Stray, $V$ *.

Sa. on a chev. engr, arg. betw, three lion's heads erased or as many pierced 5 -foils gn. Thomas Stray, Doncaster, co. York, $V$.

Sa. on a chev. betw. three lion's heads erased or as many 5 -foils of the first. STAUN'ON.

Gu. on a chev. betw. three lion's heads erased arg. fretty sa. Brunham, $V$. Bunnham, $r$.

Erm. on a chev. vert betw. three lion's heads erased gu. as many acorns or. Halfacre, Whiston, Cornwall.
On 1 CHEVRON betw. or within.... cont.

Heads cont. (Beast) Lion cont.

Sa. on a chev. betw. three lion's heads erased arg. seven cloves .... STondon, Lord Mayor of London 1392 and 1407.

Sa. on a chev. betw. three lion's heads erased arg. nine cloves ppr. Standon.

Az. on a chev, engr. betw, three lion's heads erased or as many leopard's faces of the first. Sir Robert TABOR, temp. Charles II, in church of Holy Trinity at Cambridge.

Arg. on a chev. engr. betw. three lion's heads erased or langued gu. as many leopard's faces sa. TABER.

Arg. on a chey. gu. betw. three lion's heads erased sa. as many gadbees volant of the first. Muned or Mynd, co. Salop. Mynde, Mynde, co. Salop. Mynds, Mynd Town, co. Salop.

Per pale az. and gu. on a chev, engr. arg. betw. three lion's heads erased erminois as many holly leaves slipped vert. HoLligaN, Barbadoes; granted ....

(Arg.) on a chev. betw. three lion's heads erased (gu.) as many lozenges (or). SHERGoLd, in church at Bishop's Canning, co. Wilts.

Gu. on a chev. betw. tluree lion's heads erased arg. a mollet for diff. Nicholas Moncke, Bi. shop of Hereford 1660-1.

Arg. on a chev. az. betw. three lion's heads erased gu. as many mullets or. ENNEw, Colchester, Essex.

Arg. on a chev. betw. three lion's heads erased sa. as many pierced mullets of the first. WESTBY.

Gu. on a chev. erm. betw. three lion's heads erased (arg. $V^{*}$.) or a pale az. charged with a pelican vulning herself gold a bordure of the third charged with hurts. Jobn Fox, Ropes. les, $V$.

Arg. on a chev. betw. three lion's faces az. as many piles or each charged with a triplet of ogresses. Hengscot, co. Devon.

Or on a chev. betw. three lion's heads erased sa. as many pheons .... Hening, co. Worcester; and London.

Arg. on a chev, betw. three lion's heads erased gu. crowned or as many bezants. William Wyrcestre, calling himself by his mother's name, Botoner.

Arg. on a chev. gu. betw. three lion's heads erased sa. crowned or as many bezants. Petit or Petryt, Dent de Lion, Kent.

Arg. on a chev. betw. three lion's heads erased sa. as many bezants. Jobu FisHer, Bishop of Rochester 1504-35.

Or on a chev. betw. tbree lion's heads erased gn. as many bezants. Butnor. Love. Somerton, $V$; and co. Worcester.

Per chev. erminois and arg. on a chev. betw. three lion's heads erased az. five bezants. Scot or ScoTT.

Arg. on a chev. sa. betw. three lion's heads gu. bezanty a sun in splendour. JEPHson, Froyle, co.Herts; and Mallow, co. Cork. Jephsos, quartered by Norreys.

Arg. on a chev. betw. three lion's heads erased gu. as many ermine spots or. DENMAN, Baron Denman 28 March 1834.

\section{.....Ignx}

Arg. on a chev, az. betw, three lynx's heads erased sa. as many crescents erm. Nicolls, Mersh. land. Norfolk. 
On 1 CHEVRON betw. or within.....cont.

Heads cont. (Beast) Otter

Arg. on a chev. betw. three otter's heads couped gu. a crescent enclosed by two stars of the first. Fuluarton, co. Forfar.

$$
\text { .... } 0 \mathrm{x}
$$

Gu, on a chev. betw. three bull's heads cabossed arg. an estoile sa. BAYNHAM, co. Gloucester, 1631.

Arg. on a chev. engr. sa. betw. three bull's heads cabossed of the second a fleur-de-lis as the first. John Nonbery, co. Chester, $V$.

Sa. on a chev. betw. three bull's heads cabossed arg. a fleur-de-lis of the first. John Monburye, $T$; but Norburre, Ashmol. MS.

Arg. on a chev. engr. gu. betw. three bull's heads cabossed sa. a rose enclosed by two tleurs.de. lis of the first. Willians, Llwyny Wormwood, co. Carmarthen; Baronetcy 1815; quartering Griffies.

Sa. on a chev. erm. betw. three bull's heads cabossed arg. a rose (gu. sometimes) of the first. Sanders or SaUnders, Sandersted and Char]wood, Surrey; and Lullington, Caldwell, and Little Ireton, co. Derby ; granted 1615.

Gu. on a chev. betw. three bull's heads couped arg. as many roses of the first. BuLL, London.

Arg. on a chev. betw. three bull's heads cabossed sa. a mullet for diff. of the first. IM. Rauff de IPRE, $S$.

Sa. on a chev. betw. three bull's heads cabossed arg. as many mullets gu. BuckLey.

Vert on a chev. betw. three bull's heads cabossed or as many pierced mullets gu. HUGFORD, $V^{*}$. HUOGEFORD, $V$.

Sa. on a chev. betw. three bull's heads couped arg. armed or as many pomeys. WRIGHT.

$$
\text { .....Rabbit }
$$

Arg. on a chev, betw. three rabbit's heads couped sa. each charged at the breast with a goutte d'or five such gouttes. RABET, Bramfield Hall, Suffolk.

$$
\text { .... Tiger }
$$

Arg. on a chev. az. betw. three tiger's heads erased sa. as many cresceuts erm. Nicholas.

Or on a chev. engr. betw. three heraldic tiger's heads erased sa. as many falcons rising arg. GEORGE, afterwards EDwARDs, Manor House, Bishop's Lavington, co. Wilts.

$$
\text { .....Wolf }
$$

Gu. on a chev. betw. three wolf's heads erased arg. a billet of the first. ROBERTson, Aberdeen.

Vert on a chev. or betw. three wolf's heads erased arg. as many birds sa. Conran.

Arg. on a chev. engr. betw. three wolf's heads erased gu. a plain chev. or charged with a battle-axe erect enclosed by two bows stringed each surmounting as many arrows in saltire barbs downwards sa. PoRcH, Edgarley, co. Somerset; quartering Reeves.

Sa. on a chev. betw. three wolf's heads erased arg. a crescent .... Reginald GoLdoung; 1582, V; but 1528, Cotton. MS. Tiberius D 10.

Erm. on a chev. betw. three wolf's heads erased az. as many crosses croslet fitchy or. Heighington, Graystone, and Mesbett, co. Durham.

Gu. on a chev. betw. three wolf's heads erased arg. as many roses of the first stalked and leaved vert. COLLYER, co. Dorset.
On 1 CHEVRON betw. or within....cont.

Heads cont. (Beast) Wolf cont.

Gu. on a chev. arg. betw. three wolf's heads erased or as many roses of the first. CoLLYER.

Az. on a chev. arg. betw. three wolf's heads erased .... as many 3 -foils slipped .... Scafe.

(Arg.) on a chev. (sa.) betw. three wolf's heads erased (gu.) as many 5 -foils .... Thomas LovelL, Skelton, co. York; seal 1388.

Sa. on a chev. betw. three wolf's heads erased or as many 5-foils of the first. Beal or BEall.

Arg. on a chev. betw, three wolf's heads erased sa. a wolf's head or. White, Newton Flatman, Norfolk.

Sa. on a cher. betw. three wolf's beads erased arg. a falcon's head couped of the first. AIRD or ARD.

Arg. on a chev. engr. betw. three wolf's heads erased sa. a lozenge or enclosed by two fishes of the first. Harries or Harris, Loughton, Essex ; and Prickwell, Sussex.

Sa. on a chev. betw. three wolf's heads erased arg. a mullet enclosed by two crescents gu. Barcroft, Meer Green, co. Worcester.

Per pale arg. and gu. on a chev. invecked betw. three wolf's beads erased as many mullets counterchanged. Wilson, Stratford-le-Bow, Middlesex.

Sa. on a chev. betw. three wolf's beads erased arg. as many ogresses. Beverley. Golding. But Law, as impaled by Burton, quartering Bamforth, in church at Sheffield 1772; Hunter, Sheffield, p. 144.

Gu. on a chev, betw. three wolf's heads erased arg. as many oak-trees eradicated ppr. fructed or. Colyear, Earl of Portmore.

Gu. on a chev. betw. three wolf's heads erased arg. as many trees vert fructed of the first. Coldyear, Ireland.

$$
\text { ....(Bird) }
$$

Arg. on a chev. bretessed quarterly per chev. gu. and sa. (another, sa. and az.) betw. three birds heads erased az. ten billets of the first. HoNYwOOD, Harl. MS. 1404, fo. 149.

$$
\text { .... Cock }
$$

Arg. on a chev. betw. three cock's heads sa. a rose enclosed by two mullets arg. Llewelyn ap Madoc ap Einion.

\section{.....Cormorant}

Or on a chev. az. betw. three cormorant's heads erased sa. as many acorns slipped of the first. Chideriegr, Cornwall; and co. Devou.

$$
\text { ..... Crow }
$$

Arg. on a chev. betw. three raven's heads erased sa. five crescents or. NonRIs.

Arg. on a chev. betw. three raven's heads erased sa. a 3-foil slipped or. SNeith alias Parker, Iushell, co. Wilts.

Arg. on a chev. betw. three daw's heads erased az. as many 5 -foils or. JACKson, $V^{*}$.

Arg. on a chev. gu. betw. three raven's heads erased sa. as many pierced mullets or. WARner, London.

Az. on a chev. betw. three raven's heads erased arg. an ogress betw. four crosses croslet sa. Nash, Lord Mayor of London 1772. NasH, Woodstock, co. Oxford; and Old Stratford, co. Warwick.

$$
\text { .... Eaglo }
$$

Oron a chev. em hattled az. betw. three eagle's heads erased gu. an easteru crown enclosed by two wreaths of laurel of the first. NichOLsON. 
On 1 CHEVRON betw, or within.... cont.

Heads cont. (Bird) Eagle cont.

Arg. on a chev. gu. betw. three eagle's heads erased sa. as many cresceits or. HARADON. The heads beaked or. Drakelow, $V$.

Arg. on a chev. embattled gu. betw. three eagle's heads erased az, as many fleurs-de-lis or. SADLER, Edmonton, Middlesex.

Arg. (another or) on a chev. Sa. betw. three eagle's heads erased az. as many 5-foils arg. Jaclison, Cumberland; and Combhay, co. Devon.

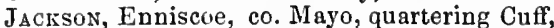
Aungier, and Rutledge; the heiress m. Pratt; and Carramore, co. Mayo, also quartering Vaughan.

Arg. on a chev. betw. three eagle's heads erased Sa. as many acorns or. CUDDERLEY.

Gu. on a chev. betw. three eagle's heads erased arg. as many lozenges of the first. ALDRIDGE.

Vert on a chev. betw. three eagle's heads erased or five mullets sa. DEane.

Sa. on a chev. (sometimes engr.) betw. three eagle's heads erased arg: as many hurts. Henry BeLey, Abbot of Tewksbury, $U$, elected 1509.

$$
\text { .....Falcon }
$$

Arg. on a chev. gu. betw. three hawk's heads erased sa. as many crescents of the first. DrAKELOW.

Arg. on a chev. sa. betw. three falcon's heads erased az. as many pierced 5 -foils of the first.

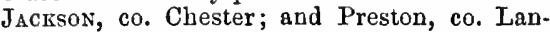
caster.

Az, on a chev. or betw. three hawk's heads erased arg. each beak holding a slip of the second two roses gu. leaved vert. Henry HolbeacH or RANDES, Bishop of Rochester 1544, Lincoln 1547-51. Randes, Bliton, co. Lincoln.

Az. on a cher. betw. three (kite's, $V^{*}$.) hawk's heads erased or as many tulips flowered gu. leaved vert. Krte, $V$. But gilliflowers (sometimes roses). John KITE, Archbishop of Armagh 1513, Bishop of Carlisle 1521-37.

Arg. on a chev. gu. betw. three hawk's heads erased sa. as many slipped 3-foils or. Walton, co. Lancaster.

Az. on a chev. betw. three kite's heads erased or as many slipped 3-foils gu. KEYTE or KITE, Ebrington, co. Gloucester.

Arg. on a chev. sa. betw. three hawk's heads erased az. as many 5-foils or. Jackson, Hereford ; quartering Webster, Carpenter, Baskerville, Coningsby, and Scudamore.

Arg. on a chev. betw. three hawk's heads erased sa. as many (blind, $V$ ) 5 -foils of the first. $\mathrm{J}_{\mathrm{ACKSON}}$, Gatenby, co. York; $V$; granted 1563 , Harl. MS. 1487, fo. 371. The 5-foils pierced. J AcKson, Sunderland, co. Durham.

Arg. on a chev. sa. betw. three falcon's heads erased az, as many acorns slipped erect or. Chelderlex, $V$.

Arg. on a chev. betw. three falcon's heads erased sa. as many acorns erect or. CHELDERLEy, Cornwall, $V$. Chiderslet, co. Devon. Cudderly, $V$. Or on a chev. gu. betw. three hawk's heads erased sa. as many acorns slipped arg. Anderson, Newcastle, Northumberland.

$$
\text { ..... Heron }
$$

Arg. on a chev. betw. three stork's heads erased gu. as many roses of the first. Graye, Maldon, Essex.

$$
\text { .... Lapwing }
$$

Sa. on a chev. betw. three pewit's heads erased arg. as many annulets of the first. Gillers.
On 1 CHEVRON betw. or within.... cont.

Heads cont. (Bird) Lapwing cont.

Sa. on a chev. arg. betw. three pewit's heads erm. beaked gu. as many annulets of the first. Gylour, quartered by Pratt.

$$
\text { ..... Martlet }
$$

Arg. on a cher. betw. three martlet's heads erased gu. as many mullets .... BLAck for FuRNIVAL, Liverpool.

$$
\text { ....Peacock }
$$

Arg. on a chev. gu. betw. three peacock's heads erased az. ducally gorged or as many slipped 3-foils of the last. RIDGEwaY alias Peacock, co. Devon. The chev. engr. or and the beads crowned not gorged or. RIDGEwaY, co. Devon.

$$
\text { .... Pelican }
$$

Sa. on a chev. betw. three pelican's heads erased or vulning themselves ppr. as many crosses croslet gu. GoDfrey, co. Stafford; and Tamworth, co. Warwick; granted 1765.

Arg. on a chev, betw, three pelican's heads erased az. vulned gu. an estoile or. Perne, Ely, co. Cambridge; granted 15 June 1575.

Or on a chev. betw. three pelican's heads erased at the neck az. vuluing themselves gu. a pierced mullet of six points of the first. PERN, co. Cambridge; granted 1575.

$$
\text { .... Swan }
$$

Sa. on a chev. betw. three swan's heads erased arg. as many crescents of the first. WhipLey or WHIPPLE, Norfolk.

Az. on a chev. or betw. three swan's heads erased ppr. as many crosses moline sa. GuEst, Dowlais, co. Glamorgan; Baronetcy 1838.

Per pale gu. and sa. on a cbev. engr. erminois betw. three swan's heads and necks erased erm. as many fleurs-de-lis az. Gist, Wormington Grange, co. Gloucester.

Sa. on a chev. betw. three ducal cygnet's heads erased arg. as many ogresses. Troughton, Leach Hall, co. Lancaster; descended from Troughton, Great Lynford, co. Buckingham; granted 30 October 1566. Troughton, Bodlew.

$$
\text { .... Wren }
$$

Arg. on a chev. gu. betw. three wren's beads erased ppr. as many escallops or. Penneck, Cornwall; granted 2 August 1712.

$$
\text { ..... Fish }
$$

Arg. on a chev. betw. three whale's heads erased sa. as many birds with wings expanded of the first. WhaLEy, Dalton, co. York. .....Human Figure

Sa. on a chev. betw. three women's heads erased arg. crined or as many roses gu. seeded of the third. EILIS.

Az. on a chev. engr. betw. three knight's helmets or as many millinds sa. Miles, Narborough, co. Leicester; quartering Pares. Myald.

Gu. on a chev. betw. three esquire's helmets plumed of three feathers one or within two arg. a mullet charged with a crescent for diff. .... FramLINGHAM; granted by Cooke, $W$.

Or on a chev. pean betw. three Moor's heads in profile couped at the neck ppr. wreathed about the temples arg. and sa. a pheon of the first. Moore, Grimeshill, Westmoreland ; quartering Cragg and Middleton.

Arg. on a chev. sa. betw. three Moor's heads in profile couped of the second clothed on the shoulder gu. collared vert two swords the points (crossing, $V^{*}$.) touching each other of the first hilts and pomels or. John Moore, 
On 1 CHEVRON betw. or within....cont. Heads cont. Human Figure cont.

Bishop of Bangor 1775, Archbishop of Can. terbury 1783-1805. Moone, $V$.

Erm. on a chev. betw. three Moor's heads couped sa. two swords in saltire arg. Moore, Berwick St. John, co. Wilts. The swords only conjoined in point arg. hilts or. More, co. York.

\section{(Monster) Dragon}

Arg. on a chev. betw. three dragon's beads erased az. as many roses or. Clark, Werk, Northumberland.

Arg. on a chev. gu. betw. three dragon's beads erased vert as many bezants. Hayes, Rockingdon, Essex.

Erm. on a chev. embattled counterembattled betw. three dragon's heads erased az. a chaplet enclosed by two roses or. ClakK, Belford, Northumberland.

\section{.... Griffin}

Arg. on a chev. gu. betw. three griffin's heads erased az. an anchor enclosed by two lions pass. combatant or. Gardiner. Gardner; Baronetcy 1794, Baronies 1800 and 1806.

Arg. on a chev. gu. betw. three griffin's heads erased az. two lions counterpass. of the first. Gardiner, Roche Court, Farnham, co. Hants; Baronetcy 1660-1779 and 1782; quartering Whalley and Smith. The lions ramp. or. GARDNER, Stoke-Ash, Suffolk.

Or on a chev. gu. betw. three griffin's beads erased az. two lions pass. incontrant arg. Gardener or Gardner, Callis, $V$. William GARDENER, co. Lincoln, $W$. But pass. guard. incontrant. William GARDENER, Northball, co. Lincoln, $V$. GarDner, $V^{*}$.

Or on a chev. gu. betw. three griffin's heads erased az. two lions combatant arg. GaRDENER or Gardner, Wallingham and Bishop's Norton, co. Lincoln.

Or on a chev. gu. betw. three griffin's beads erased az. two lions pass. respectant of the first. GARDENER, Northall, co. Lincoln. Gardiner, London; and Wigan, co. Lancaster.

Or on a chev. gu. betw. three griffin's beads erased az. as many lions ramp. of the first. GARDINER.

Sa. on a chev. betw. three griffin's beads erased arg. a martlet gu. CotTon, Suffolk.

Az. on a chev. betw. three griffin's heads erased arg. as many martlets sa. Gardner, Tunbridge Wells, Keut.

Az. on a chev. arg. betw. three griffin's heads erased or as many martlets sa. GARDNER, Ruspar, Sussex, 1634.

Sa. on a chev. or betw. three griffin's heads erased arg. (another, of the second) so many martlets like the first a bordure compony silver and as the field. BaLLE.

Arg. on a chev. betw. three griffin's heads erased gu. as many castles of the first. Sir Richard Browne alias Moses, Lord Mayor of London 1661.

Arg. on a chev. az. betw. three griffn's heads erased sa. as many crescents erm. Nicolls, Tilney, Norfolk ; Harl.MS. 1177, fo. 104.

Arg. on a chev. betw. three griffin's heads erased gu. an escallop or. Braye. Cotron.

Per fess embattled az. and purp. on a chev. or betw. three griffin's heads erased arg. as many escallops sa. Gardiner, Blaudford, co. Dorset.
On 1 CHEVRON betw. or within..... cont.

Heads cont. (Monster) Griffin cont.

Or on a chev, az. betw. three griffin's heads erased vert as many estoiles of the first. EDMONDS, Dodington, co. Oxford.

Sa. on a chev. betw. three griffin's beads erased arg. as many estoiles .... ADEANE, Babraham, co. Cambridge; quartering Jones, Brydges, and Chandos.

Sa. on a chev. betw. three griffin's heads erased arg. as many estoiles gu. Beale, London; and Cork.

Sa. on a cbev. .... betw, three griffin's heads era. sed ppr. as many estoiles of the first. Correy.

Sa. on a chev. or betw. three griffin's beads erased arg. as many estoiles gu. Beale, Maidstone. Beate, Farningham Court, Kent; Baronetcy 1660, extinct 1684 . Beare, Walton, co. Buckingham; and Heath House, co. Salop.

Sa. on a chev. betw. three griffin's heads erased or as many estoiles gu. CARY, London; confirmed 1612. Cone, Bromerton, Norfolk. Coney, London; granted 1612. Cox, Bromerton, Norfolk.

Per pale or and az. on a chev. betw. three griffin's heads erased as many fleurs-de-lis counterchanged. PoPE, co. Oxford.

Sa. on a chev. engr. betw. three griffin's beads erased arg. as many fleurs-de-lis of the first. SKYNNER.

Sa. on a chev. wavy arg. betw. three griffin's heads erused or as many fleurs-de-lis az. Skynner, Ryegate, Surrey.

Per pale or and az. on a cher. betw. three grif. fin's heads erased four fleurs-de-lis counterchanged. POPE, Wroxton, and Wilcote, co. Oxford; Earl of Downe, 1629 68; the coherrs m. Boughton, Soames, North, and Hyde. Trinity College, Oxford.

Arg, on a chev. betw, tbree griffin's heads erased sa. as many roses of the first. SPENCER, $V$.

Or on a chev. az. betw. three griffu's heads erased gu. as many roses arg. barbed vert. DREren, Orkney ; granted 1809.

Gu. on a chev. betw. three griftin's heads arg. a 4-foil vert. PRIDDLE.

Arg. on a cher. betw. throe griffin's heads erased sa. as many 5-foils of the first. SPEncer, Chester; descended from Sr. James SPEncer, Lord Mayor of London 1527; Stow.

Sa. on a chev, arg. betw. three griffin's heads erased or a boar's head fesswise couped enclosed by two pheons gu. Hugh Beckworth alias SmitH, Callis, $V$.

Sa. on a chev. betw. three griffin's heads erased or a boar's bead couped enclosed by two pheors gu. BeckwitH or Beckworth, co. York.

Arg. on a chev. betw. three griffin's heads erased sa. a leopard's head or. SION COLLEGE,London.

Erm. on a chev. engr. arg. betw. three griffin's heads erased .... as many lozenges ..... ALDRICH, Suffolk.

Arg. on a chev. gu. betw. three griffin's heads erased of the second armed as the first a mullet or. TILney.

Arg. on a chev. betw. three griffin's beads erased sa. a mullet of the first. Cotron, Kent, $V$.

Sa. on a chev. or betw. three griffin's beads erased arg. a mullet for diff. .... SkINNER, quartering Walker; descended through Robert SkInner, Bishop of Worcester 1663-71, from Skinner, Le Burtons and Ledbury, co. Here. ford ; an heiress m. Clarke. 
On 1 CHEVRON betw. or within.... cont.

Heads cont. (Monster) Griffin cont.

Gu. on a chev. arg. betw. three griffin's heads erased or as many mullets az. Hughes, Archerstown, co. T'ipperary; and Corranbrook, co. Carmarthen, etc., quartering Annesley.

Or on a chev. sa. betw. three griffin's heads ernsed gu. as many pierced mullets of the first. Hughes, Ballytrent, and St. Margaret's, co. Wexford.

Sa. on a chev, betw. three griffin's heads erased or as many mullets of the first. BEALE, Surrey.

Vert on a chev. betw, three griffin's heads erased or beaked gu. five mullets sa. DEane, Mattingley, co. Hauts.

Az. on a chev. erm. betw. three griffin's heads erased or two serpents in saltire as part of a caduceus ppr. BARritt, Jamaica.

$$
\text { .... Unicorn }
$$

Arg. on a cher. sa. betw. three unicorn's heads couped az. as many annulets or. KiLLINGBECK, $V^{*}$; and Leeds, co. York. Wm. KILLINGBERK, Chappell-Allerton, co. York; granted $1585, \mathrm{~W}$. Kylimabeck. The heads erased. KyLlingBeck, Talworth, Heningham, and Leeds, co. York.

Az. on a chev. arg. betw. three unicorn's heads erased or as many crescents gu. Clowes, London.

Az. on a chev. betw. three unicorn's heads erased or as many crescents gu. Clowes, London: co. Warwick; and co. Stafford; confirmed 1576.

Vert on a cher. betw. three unicorn's heads erased or as many crescents gu. Clowes, Sutton, near Macclesfield; Whiteley, and Langley, co. Chester; and Delaford, co. Buckingham.

Vert on a chev. betw. three unicorn's heads erased arg. as many estoiles gu. KER, Faldonside, Scotland; quartering Halyburton. The estoiles sa. KER, Cessford, Scotland.

Sa. on a chev. betw. three unicorn's heads erased arg. as many 3 -foils vert. CHodgh or Clowes.

Per pile reversed sa. and arg. on a chev. of the second betw. three unicoru's heads erased counterchanged those in chief armed and maned or as many spearheads gu. (? WRIGHT, Mapperley, co. Nottingham.)

Sa. on a chev. betw. three unicorn's heads or as many spearheads gu. WRIGHT, Longston, co. Derby ; and co. Stafford.

Vert on a chev. betw. three unicoln's heads erased arg. as many mullets sa. KerR. The heads armed and maned or. KER, Duke of Roxburghe, quartering Weapont. KER, Gateshaw, co. Roxburgh.

$$
\text { .....(Reptile) }
$$

Arg. on a chev. az. betw. three snake's heads erect erased vert as many bezants. Heres, Ratington, Essex; granted 2 August 1563.

Arg. on a chev. gu. betw. three serpent's beads erased vert as many bezants. WARD.

$$
\text { .....(Spear) }
$$

Gu. on a chev. betw. three spearheads arg. as many annulets of the first. Sysicock, London.

Sa. on a chev. engr. betw. three spearheads arg. as many annulets gu. Sracotrs, co. Bedford.

Or on a chev, betw. in chief three spearheads and in base a martlet sa. as many crescents of the first. WILIIAMs.

Sa. on a chev. betw. three spearheads arg. as many crosses croslet of the first. Coys, Hatfield Peverell, Essex. Quose or Quoys, North Kendon, Essex.
On 1 CHEVRON betw. or within.... cont.

Heads cont. (Spear) cont.

Gu. on a chev. betw. three spearheads arg. a mullet of the first. Betson, Glassermount.

Sa. on a chev. or betw. three spearheads arg. as many torteaux. Srmcoats, co. Liucoln; and London.

Sa. on a chev. betw. three spearheads arg. two staves of Asculapius chevronwise each en. twined by a serpent ppr. Jones, Glan Helen, co. Carnarvon.

\section{Hearts}

Arg. on a chev, betw. three hearts gu. as many martlets or. BAYLIFF, $V$. BAYLIFFe.

Az. on a chev. betw. three hearts arg. as many escallops gu. Pateshull or Patteshall, co. Hereford.

Az. on a chev. arg. betw. three hearts or as many escallops gu. Pateshull, co. Hereford, $W$.

Az. on a chev. betw. three hearts or as many escallops gu. Pateshad, Allensmore, co. Here. ford, quartering Allen; the heiress $\mathrm{m}$. Lechmere, quartering Burnam.

Gu. on a chev. arg. betw. three hearts or as many escallops of the first. Pateshati, Laford, co. Hereford.

\section{Hillocks}

Sa. on a cbev. betw. three anthills or each charged with four ants ppr. as many holly leaves az. Benedictine Abbey at Pershore, co. Worcester.

\section{Horns}

Az. a chev. erminois betw. in chief two bugle. horns and in base a stag's head erased or. Forster, St. Pancras, Middlesex; granted 28 June, 1784.

Arg. on a chev.gu. betw. three buglehorns stringed sa. as many crosses croslet fitchy of the first. Birte, co. Devon. Bilt or Burt, CandellMarsh, co. Devon. Byrt or Byrtt.

Arg. on a chev. gu. betw. three buglehorns sa. stringed of the second as many crosses croslet fitchy or. BURT.

Arg. on a chev. betw. three buglehorns sa. stringed gu. as many crosses croslet of the first. Burt, Maiden-Earleigh, co. Berks.

Gu. on a chev. betw. three buglehorns arg. stringed or as many crosses croslet fitchy of the second. Crukerne, Childhoy.

Per pale gu. and az. on a chev. betw. three buglehorns stringed or as many crosses croslet fitchy sa. Cramphorne, Ambury, co. Hertford; granted 29 January, 1700.

Arg. on a chev. betw. three buglehorns sa. five crosses croslet of the first. BASSETT, Essex.

Arg. on a chev. vert betw. three buglehorns sa. stringed or an escallop of the last. Forster, Cumberland and London.

Erm. on a chev. vert betw. three stringed bugle. horns sa. an escallop or. Foster, Draycot Foliot, co. Wilts.

Arg. on a chev. gu. betw, three stringed bugle. horns sa. as many estoiles or. Honne, Kent, $V$.

Arg. on a chev. betw. three buglehorns sa. as many estoiles of six points or. HoRne, Kent.

Arg. on a chev. az. betw. three buglehorns stringed sa. as many roses or leaved ppr. RoDwar, London.

.... on a chev. betw. three buglehorns as many lozenges .... Wermeston, Northumberland. Arg. on a chev. betw. three buglehorns stringed gu. as many lozenges or. RUDD. 
On 1 CHEVRON betw. or within.... cont. Horns cont.

Arg. on a chev. sa. betw. three stringed buglehorns gu, as many mascles or. Sr. Amand de RUDA, $V$. Rudd. St. Amand.

Az. on a chev. counterembattled betw. three stringed buglehorns or a mitre with labels of the first. Samuel Peploe, Bishop of Chester 1726-52.

Sa. on a chev. betw. three (buck's, $V^{*}$.) hart's scalps and attires arg, a mullet for diff. Thomas Cox, Tilmanstone, Kent, $\boldsymbol{V}$.

Arg. on a chev, engr. gu. betw. three buglehorns sa. as many pierced mullets of the first. Horne, London.

Arg. on a chev, engr. gu. betw. three buglehorns sa. stringed of the second so many mullets as the first. Horne.

Arg. on a chev. gu. betw. three buglehorns sa. stringed of the second as many mullets or. Hoerne. Horune, Kent, Cotton MS. Tiberius D 10. The mullets pierced. Colborne, Barony 1839-54; quartering Ridley.

Arg. on a chev. gu. betw. three stringed buglehorns sa. as many mullets or. Holne, $V$.

Arg. on a chev. betw, three buglehorns sa. as many mullets or. Honne, Kent.

Arg. on a chev. betw. three stringed buglehorns sa. garnished or as many mullets of the last. Colborne, Bruton, co. Somerset.

Sa. on a chev. arg. betw. three buglehorns or as many pierced mullets gu. Honne, Kent.

Arg. on a chev, betw. three buglehorns sa. a pheon arg. Forster, Isondon.

Arg. on a chev, vert betw. three buglehorns strung sa. a pheon or. Forster, London.

\section{Horseshoes}

.... on a chev. .... betw. three horseshoes .... five crosses patty .... Cistercian Abbey at Fountains, co. York.

$\mathrm{Gu}$. on a chev. or betw. three horseshoes arg. as many roses of the first. Rose, $V^{*}$. William Rosse, $V$. (but? the field sa., $W$.)

\section{Hourglasses}

Vert on a chev. betw. three hourglasses arg. as many 3-foils slipped of the first. Shadforth, Red Barns, and Darras Hall, Northumberland. Inkmolines

Sa. on a chev. betw. three inkmolines arg. as many mullets gu. Mosfler, Moseley, 'and Bilston, co. Stafiord. Mosley, Newcastle-onTyne.

\section{Keys}

Or on a chev, betw. in chief two keys and in base a dagger sa. three roses arg. Bronscombe.

Or on a chev. betw. in chief two keys palewise and in base a sword sa.three (4-foils sometimes) 5-foils of the first. Branscomb or Bronscomb. Walter Brownscomb, Bishop of Exeter 1258-80.

Gu. on a chev. betw. three keys arg. as many estoiles of the first. Matthew Parken, Archbishop of Canterbury 1559-75, $\mathrm{V}$.

Gu. on a chev. betw. three keys or as many estoiles sa. PArker, Kent.

$\mathrm{Gu}$. on a chev. betw. three keys erect arg. as many fleurs-de-lis of the first. Parrer, Bassingbourn, Essex; Baronetcy 1782; quartered by Elwes. PARKer, $V^{*}$. PARKER, Sandwich, and Margret, Kent; granted by Borongh.

Gu. on a chev, arg. betw. three keys erect or as many fleurs-de-lis az. PARKer; granted 1772 .
On 1 CHEVRON betw, or within.... cont.

Keys cont.

Gu. on a chev. betw. three keys or as many estoiles of the first. Parker, $V^{*}$.

$\mathrm{Gu}$. on a chev. betw. three keys arg. as many mullets of the first. Parker, Kent. The keys erect or. PARKER, Kent.

Gu. on a chev. betw. three keys the wards to the sinister or as many six-pointed mullets of the first. Parker, $W$.

Gu. on a chev. betw. three keys the wards to the sinister or as many mullets sa. Parker, Kent, $W$.

\section{Lamps}

Az. (another, sa.) on a chev. arg. betw. three lamps or burning with a flame ppr. a leopard's head gu. enclosed by two estoiles of the first. Farier, Ratcliff, co. Leicester.

Leaves.....Cinnamon

Or on a chev. gu. betw. in chief two cinnamon leaves erased vert and in base a negro girt with white linen striped blue carrying on a bamboo yoke two bundles of cinnamon $\mathrm{ppr}$. three cinnamon leaves as the first. PyBus, Barnet, co. Hertford; granted $\mathbf{I} 768$.

$$
\text { .... Holly }
$$

Az. on a chev, arg. betw. in chief two holly leaves ppr. and in base an unicorn's head erased of the second three mullets gu. KeIR, Knock, Scotland.

\section{.... Grass}

Or on a cbev. engr. az. betw. three tufts of grass vert as many crosses croslet of the first. Sykes, The Berlss in Wyersdale, co. Lancaster; and Leatherhead, Surrey.

$$
\text { .... Holly }
$$

Vert on a chev. betw. three holly leaves arg. as many mullets gu. KER, Blackshiels.

Arg. on a chev, sa. betw. three bolly leaves vext as many bezants. DaLLING.

$$
\text { .....Laurel }
$$

Or on a chev, gu. betw. three laurel leaves slipped vert the two in chief inclining to each other another chev. erm. Couper; Baronetcy 1841. Arg. on a chev. betw. three laurel leaves vert as many plates. Foulis, Ratho.

$$
\text { ....0ak }
$$

Az. on a chev. arg. betw. three oak leaves or as many crosses couped gu. Parsons, co. Buckingham. Jolnn Parsons, Bisbop of Peterborough 1813-19.

Arg. on a chev. az. betw. three oak leaves slipped vert each charged with an acorn or as many leopard's faces jessant-de-lis of the first. Smirk, Willesden, Middlesex.

Arg. on a chev. sa. betw, three oak.]eaves vert as many bezants. Monnoux, Wotton, co. Bed. ford; Baronetcy 1600-1814.

$$
\text { ..... Staff-tree }
$$

Az. on a chev. arg. betw. three staff-tree leaves slipped or as many bees volant ppr. LEAF, Streatham, Surrey.

$$
\text { ....Vine }
$$

Or on a chev. betw. three vine leaves vert five gouttes d'eau. Joye, Benefield, co. Northampton; granted 1738. JoY, London. JoY, Hart. ham Park, co. Wilts.

$$
\text { .... Woodbine }
$$

Or on a cher. betw, three woodbine leaves gu. a ducal coronet of the first. Garwynton, $V$.

Arg. ou a chev. sa. betw. three woodbine leaves vert as many bezants. Dalling. 
On 1 CHEVRON betw. or within.... cont. Legs ('Beast) Bear

Arg. on a chev. embattled at top gu. betw. three bear's gambs erased and erect ermines armed of the second as many crescents erminois. Harvey, Eastry, Kent; with an escucheon of pretence for Maundy; descended, like Harver, Cowden, from Harvey, Eythorne. And with a martlet for diff. az. William-Manndy Harvey, Colonel 79th, or Cameronian Highlanders, ob. 1813.

$$
\text { ..... Lion }
$$

Alg. on a cher. gu. betw. three lion's gambs erased bendwise sa. as many crescents or. Austen.

Or on a chev. betw. three lion's gambs couped erect sa. as many crescents of the first. Asketine, West Peckham, Kent.

Arg. on a chev. betw. three lion's gambs erased sa. as many bezants. AusTrN, co. Somerset.

$$
\text { .... (Bird) }
$$

Arg. on a chev. sa. betw. three eagle's legs couped gu. a book or purfled vert enclosed by two bow. knots of the first. Prydeux, Nutwell, co. Devon; granted 16 May 1558.

\section{Letters}

.... on a cher. .... betw. in chief two letters iv and in base a cross patty .... another chev. .... charged at bottom with a pair of annulets .... (Ascribed to) William WANDLESWORTH, (but with) ANDISWORTH in the margin, seal .....

\section{Limbecks}

Az. on a chev. or betw. three limbecks arg. as many roses gu. stalked and leaved vert seeded gold. Company of Pewterers.

\section{Lozerges}

Arg. on a chev. betw. three lozenges sa. a lion pass. or. Massex, co. Chester. Massex, Baron Clarina ..... Ms Msy, Baron Massy ..... Massey, Doonas, co. Clare; Baronetcy ..... And with a bordure gu. Massey.

$\mathrm{Gu}$. on a chev. betw. tluree lozenges arg. as many church bells sa. Henshawe.

Arg. on a chev. betw. three lozenges gu. as many martlets or. WELBECK, co. Derby.

Arg. on a chev. gu. betw. three lozenges sa, as many martlets or. NAYLOR. WELBEck, co. Derby, $V$.

Sa. on a chev. betw. three lozenges arg. each charged with an ermine spot another chev. gu. Cabron, $V$. Caperoun or CAPron, quartered by Slingsby; in chapel at Scaglethorp, co. York.

Sa. on a chev. betw. three lozenges arg. each charged with a Cornish chough ppr. another chev. gu. Caborne. Cabourne, $V$.

Sa. on a chev. gu. betw. three lozenges erm. another chev, arg. CABron, Cotton MLS. Tiberius D 10.

Gu. on a chev, engr. arg. betw, three lozenges chequy or and az. as many crosses botonny sa. WARREN, Long Milford, Suffolk.

Arg. on a chev. az. betw. three lozenges gu. as many fleurs-de-lis or a bordure engr. sa. MAUdLex, Wells, and Nunnys, co. Somerset; granted 1537.

Az. on a cher. betw. three lozenges or as many fleurs-de-lis gu. HYDE, St. liatharine's, Middlesex; confirmed 5 August 1037.

Per pale or and az. on a cher. engr. betw. three lozenges counterchanged in the dexter side as many gouttes d'eau and in the sinister three ermine spots. HrDE, London.

\section{On 1 CHEVRON betw. or within.... cont.}

Lozenges cont.

Arg. on a chev. betw. three lozenges az. as many buck's heads cabossed of the first. STavelEx, Buckland, co. Devon.

Arg. on a chev. betw. three lozenges az. as many hart's heads cabossed or. Staveley, Glanduff Castle, co. Limerick.

Arg. on a chev. az. betw. three lozenges sa. as many buck's heads cabossed or. STAveler, $V$. But stag's beads. Staveley.

Arg. on a chev. betw. three lozenges sa. as many hart's heads erased or. Staveley, co. York.

Az. on a chev. arg. betw. three lozenges or as many mullets gu. Cateshull, $V$.

Az. on a chev. betw. three lozenges or as many mullets gu. CastleHUL Castlehyld Cateshali or Cateshull. The mullets pierced. Castelhili. Casthehylu, $V$.

\section{Mascles}

Arg. on a chev. gu. betw. in chief two mascles az. and in base a laurel branch slipped vert an. other chev. erm. Mitchell, England.

Az. on a chev. arg. betw. in chief two mascles of the last and in base a boar's head erased or a mullet gu. KinLoch, Scotland.

Per pale arg. and sa. on a chev. betw. three mascles as many martlets counterchanged. Ryvetr, Suffoll.

Arg. on a chev. betw. three mascles gu. as many roses of the first seeded az. SPRING, Suffoll. Az. on a chev. or betw. three mascles arg. a 5-foil Sa. ChaLLONER.

Arg. on a chev. betw. three mascles gu. as many 5 -foils of the first. Spring, Pakenham, Suf. folk, 1730 .

Arg. on a chev, betw. three mascles gu. as many 5 -foils or. Spring, Cockfield, Suffolk. But each 5-foil charged with five annulets of the second. Spring, Suffolk.

Or on a chev, betw. three mascles gu. as many pierced 5-foils of the first. Spring.

Az. on a chev. betw. three mascles arg. as many 5 -foils of the first (another, gu.) Punvis.

Az. on a chev. betw. three mascles arg. a boar's bead erased of the first in chief a fleur-de.lis (? for diff.) or. Kinloch, Gourdie, Scotland.

Arg. on a chev. betw. three mascles az. as many buck's heads cabossed or. STANLEx, Barnstaple, co. Devon.

Per fess gu. and vert on a chev. arg. betw. in chief three mascles or and in base a unicorn's head erased of the third as many mullets of the first. KER, Newbottle, Scotland.

Arg. on a chev. betw. three mascles sa. as many bezants. Wingar. Winger, $V^{*}$. John WYNGER, co. Leicester, $W$.

\section{Monster}

Arg. on a chev. az. betw. in chief a griffin pass. gu. wings erminois and in base a boar's head erased fesswise ppr. three garbs or. Caradoc, Baron Howden 1819.

\section{Monsters.... Cockatrices}

Sa, on a chev. betw, three cockatrices or five mullets gu. Sermes, $V^{*}$. Henry Sexnes, Newark, $V$.

\section{.... Griffins}

Sa.-on a chev. or betw. three demi-griffus couped the uppermost respectant erm. as many martlets gu. Sr. Thomas BaLdry, London, $V$.

Sa. on a chev. engr. betw. three demi-griffins couped or as many martlets gu. BALDRY, Lord Mayor of London 1523. 
On 1 CHEVRON betw. or within.....cont.

Monsters cont. Griffins cont.

Arg. on a chev. betw. three demi-griffins erased gu. as many towers triple towered of the first. Browne, Kent; and London.

Sa. on a chev. engr. betw. three griffins segreant erm. as many martlets gu. BALDREY.

\section{..... Seahorses}

Az. on a chev. embattled counterembattled or betw. three sealiorses naissant arg. five gouttesde-poix. Tucrer, Woodland, co. Dorset; and Tenterden, Kent.

Barry of nine az. and arg. on a chev. embattled betw. three seahorses or five gouttes-de-poix. Tooker.

Barry wavy of ten arg. and az. on a chev. em. battled betw. three seahorses naissant or five gouttes.de-poix. Tucker, co. Devon.

Barry wavy of twelve (thirteen az. and arg. Harl. $M S .1149$, fo. 64) arg. and az. on a chev. embattled or betw. three seaborses silver finned and unguled gold seven gouttes-de-poix. Tooker, Exeter. Tucker, co. Devon; and Cornwall.

\section{.... Unicorns}

Arg. on a chev. sa. betw. three demi-unicorns courant gu. a lion pass. of the first crowned or. Collier alias Dymock, co. Stafford.

Arg. on a chev. az. betw. three demi-unicorns courant gu. as many acorn slips or. Colliar or Collyar, Darlston, co. Stafford. The acorns slipped and leaved ppr. Collyer, London.

Gu. on a chev. betw. three unicorns pass. or as many human hearts of the field. YARKER, as confirmed, 32 George II, to John YARKER, Esq., of The Hall, Leyburn, North Riding, co. York; and his descendants, and the descendants of his grandfather, Luke Yarker, Esq., derived from Reinhold von Yarcläer, a knight of Flan. ders, who came to England during the wars of the Roses, cc. 1440; and quartering Forster, South, Brabazon, Braddyll, Risbton, Dodding, Sandys, and Rawson. YARKER, Conynger Hurst, Ulverston, co. Lancaster, descended from a younger branch of YARKER, Leyburn; quartering Leyburn, Barker with Smith in a canton, Woodburne, and Letbam. YaRker, Oakenclough, Ashton-under.Lyne.

\section{Mullets}

Per chev. arg. and or on a chev. vert betw. in chief two mullets gu. and in base a portcullis sa. three pigeons ppr. DYER.

Az. on a chev. arg. betw. in chief two mullets and in base an earn (i.e. hawk) perching on a salmon or a buckle of the first. Lumisnes, Blenearn, Scotland.

.... on a chev. or betw. in cbief two mullets arg. and in base a cock of the same beaked gold a chain sa. GatuY.

Gu. on a chev. betw. in chief two mullets or and in base a lion ramp. arg. three crosses croslet fitchy az. WARDrop, Strathavon, Linlithgow, and Edinburgh.

Arg. on a chev. az. betw. in chief two pierced mullets and in base a lion pass. gu. three 5-foils or. Davey, Redruth, Cornwall.

Gu. on a chev. betw. in chief three mullets and in base a crescent arg. an anchor sa. MARTiN.

Per pale gu. and arg. on a chev. betw. three mullets as many talbots counterchanged. Martyne, Crekars, co. Bedford.

\section{On 1 CHEVRON betw, or within.....cont.}

IIullets cont.

Or on a chev. betw. three mullets sa. as many lions pass. guard. (arg. sometimes) or. BarRetT, Lee Priory, Kíent.

Arg. on a chev. engr. betw. three mullets sa. a martlet for diff. or. Krnaston, Thorington, Essez.

Arg. on a chev. betw. three mullets gu. an eagle displ. (of the first, another) or. LEMON, Carclew, Cornwall; Baronetcy 1774.

Arg. on a cher. betw. three mullets sa. an eagle displ. or. BaKETT. BLAKET.

Or on a chev. betw. three mullets sa. an eagle displ. of the first. BLAKET, $V$.

Gu. on a chev. betw. three mullets arg. as many ducks sa. Russell, $V^{*}$.

Or on a chev. betw. three mullets sa. as many eagles displ. of the first. Blake't.

Gu. on a chev, arg. betw. in chief three rowels and in base a halbert or as many ravens sa. SYM, Scotland.

Arg. on a chev. gu. betw. three mullets sa. as many martlets or. WELBECK, $V$.

Gu. on a chev. betw. three mullets arg. as many swans sa. Russell, $V$.

Az. on a chev. betw. three mullets or a buckle of the first. Lumsden, That Ilk, co. Berwick.

Sa. on a chev. betw. three mullets art. as many chessrooks of the first. OrRock, That Ilk.

Arg. on a chev. engr. gu. betw. three mullets sa. another chev. az. charged with as many 4 -foils of the third. ANDros.

Arg. on a chev. betw. three pierced mullets sa. another chev. of the first. Romney, co. Berwick.

Arg. on a chev. betw. three mullets gu. a crescent of the first. WILson, West Wickham, Kent; confirmed $20 \mathrm{July} 1762$.

Arg. on a chev. sa. betw. three pierced mullets gu. a crescent of the first. M. Philip DaveYe,S.

Arg. on a chev. gu. betw. three six-pointed mullets of the second a crosss patty or. WILLIS, London.

Or on a chev. betw. three six-pointed mullets gu. a cross patty of the first. Willis, London.

Gu. on a chev. arg. betw. three mullets or as many crosses croslet fitchy sa. Dryland, Norfolk.

Arg. on a cher. betw. three pierced mullets sa. as many escallops of the first. BLACKETT, Matson Hall; Baronetcy 1673; descended from Blackett, Woodcroft, and Wylam, Northumberland. Thomas Browne, Harwood, co. Hertford, $V$.

Az. on a chev. betw. three mullets or as many 3 -foils slipped vert. Cousmaker or Coussmaker, Brabant; certified May 1779; quartering az. two chev. interlaced one issuing from the chief and the other from the base betw. eight sixpointed mullets or.

Arg. on a chev. engr. gu. betw. three mullets sa. as many 4-foils or. Andrews, $V$. The 4-foils each charged with a hurt. DE ANDRews, $W$.

Arg. on a chev. engr.gu. betw. three mullets vert as many 4 -foils or. ANDrewes, $V$.

Or on a chev. betw. three mullets sa. as many 4-foils of the first. Roger de Sinerning or Srenwyng, Bishop of Norwich 1266-78.

Arg. on a chev. sa. betw. three mullets gu. as many 5-foils or. Scarming.

Arg. on a chev. sa. betw. three mullets of the second fretty of the first. MORLeton. 
On 1 CHEVRON betw, or within.... cont. Mullets cont.

Gu. on a chev, arg. betw. three mullets of the second each charged with an ogress fretty sa. Motlton, $V$.

Gu. on a chev. arg. betw. three mullets or fretty sa. Moulson.

Gu. on a chev, arg. betw, three pierced mullets or fretty sa. Moulson or Moulton, London.

Sa. on a chev. arg. betw. three mullets or fretty of the first. Moulson or Moulton, London.

Sa. on a chev. betw. three mullets or as many acorns slipped and leaved vert. DAwes, Mid. dlesex.

Az. on a chev, arg. betw, three mullets or gouttesde-sang. Hellier, Woodhouse, co. Stafford; granted 1763, quartering Shaw.

Az. on a chev. or betw. three pierced mullets of six points arg. gouttes-de-poix in chief a cres. cent of the last. Cruttendon.

Arg. on a chev. betw. three mullets gu. a talbot's head erased of the first. WrLson, Edinburgh, Scotland.

Arg. on a chev, engr. sa. betw. three mullets gu. an otter's head er'ased of the first. Batfour; certified May 1779.

Arg. on a chev. engr. betw. three mullets sa. a selch's head erased of the first. BaLFour, Balbirny.

Arg. on a chev. betw. three mullets az. and in the dexter fess point a bear's bead erased .... muzzled .... with in the siuister an anchor erect .... cabled .... a talbot's head of the first. WILsON.

Arg. on a chev. betw. three mullets gu. a griffin's head erased of the first. Secroft.

Arg. on a chev. sa. betw. three mullets gu. a griffin's head erased of the first. William Secroft, $V$.

Az. on a chev. betw. three mullets or as many lozenges gu. Burts, Esses; and Norfolk.

Gu. on a chev. arg. betw. three mullets or as many mascles az. BASSENDEN.

.... on a chev. .... betw. three mullets .... another mullet .... Bolingerore, seal 1330, Harl. MS. 1487, fo. 306 .

Arg. on a chev. sa. betw. three mullets gu. as many of the first. Tingcombe, Cornwall.

Gu. on a chev. or betw. three mullets arg. five palets az. a bordure wavy of the second. Everetr, Heytesbury, and Upton Lovell, co. Wilts.

Arg. on a chev. betw. three pierced mullets of six points sa. a bezant. CuILX, co. Leicester.

Gu. on a chev. arg. betw. three mullets or two torteaux each charged with a mullet of the second. Rialph Baines or Bayne, Bishop of Lichfield, etc. 1554.59.

Arg. on a chev. sa. betw. three mullets gu. as many bezants a bordure of the third. Macmilian, Scotland.

Arg. on a chev. betw. three mullets sa. as many bezants. Mac Millan, Scotland.

.... on a chev. betw. three pierced mullets .... five saltires couped ..... Simon de Feltone, seal ....

Az. on a chev. arg. betw. three mullets or a stirrup enclosed by a pair of buglehorns ppr. stringed gu. CuOSE, co. York; and Drumbanagher, co. Arrnagh.

Az. on a chev. betw. three mullets arg. as many civic wreaths vert. Brodie; Baronetcy 1834.
On 1 CHEVRON betw. or within.... cont.

\section{Nails}

Arg. on a chev. betw. three wedges sa. five mullets of the first. WADGE, Upton Lewanneck. Packs

Arg. on a chev. betw, three woolsacks az. as many garbs or. Wolsay, Norfolk.

Pattens

Gu. on a chev. arg. betw. three pattens or tied of the second the ties lined az. two cutting-knives conjoined sa. Company of Patten-Makers, London.

\section{Pheons}

Arg. on a chev. gu. betw. in chief two pheons sa. and in base a fleur-de lis az. another chev. of the first a bordure wavy as the last. MAYNe, Powis, and Logie, co. Clackmannan; derived from Lockwood. MaYne, Viscount Newhaven, 1776.

Arg. on a chev. gu. betw. in chief two pheons and in base a unicorn's head erased sa. another chev. of the first. MAIN, Lochwood, Scotland.

Arg. on a chev. gu. betw. in chief three pheons and in base a dexter hand couped sa. another chev. of the first. MaIN, Lochend.

Arg. on a chev. per pale gu. and sa. betw. three pheons of the second as many crescents or. KuTchin.

Az. on a chev. arg. betw. three pheons or as many crosses patty gu. Whiтwicke, Marle. ston, co. Berks; and Whitwicke, co. Stafford; granted 1613. Whirwick, York Herald, ob. 1722. Wightwick, Surrey; Coventry; co. Berks; and co. Stafford.

Az. on a chev. betw. three pheons or as many escallops of the first. Westcar, co. Oxford; and Surrey.

Sa. on a chev. arg. betw. three pheons or as many escallops of the first. Forster, Trotton, Sussex; co. Salop; and co. Worcester. Foster, Wich, co. Worcester; and Stourton Castle, co. Warwick.

Vert on a chev. or betw. three pheons arg. a fleurde-lis gu. Horman, $V$.

Arg. on a chev, betw. three pheons sa. a 5 -foil or. Sirart, London.

Vert on a chev. arg. betw. three pheons or gouttes-de-sang. Hallian, co. Devon, 1607. Holman, co. Devon; granted June 1608.

Sa. on a cbev. betw. three pheons arg. a wolf's head erased enclosed by two mullets of the first. BYRD or BYRE, co. Northampton. But a griffin's head. Byen or Byens, co. North. ampton.

Arg. ou a chev. betw. three pheons gu. as many

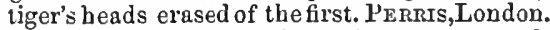

Arg. on a chev. gu. betw. three pheons sa. a mullet of the first. KYFrin, $V$.

Sa. on a cher. betw. three pheons arg. as many mullets gu. Newport, $V$. (? Richard Neoport, 1471, seal.) The mullets of the first. NEwPORT.

Arg. on a chev. gu. betw. three pheons sa. as mauy frogs or. UverEND.

Portcullis

Gu. on a chev. betw. three portcullises or five roses of the first. Port, Poole, co. Dorset.

Az. on a chev. or betw. three antique limbecks arg. as many roses gu. seeded of the second barbed vert. Company of Pewterers, London.

\section{Rests}

Gu. on a chev, erm. betw, three rests or a cres. cent .... William ARthur, co. Somerset, Harl. MS. 1386 , fo. 94. 
On 1 CHEVRON betw, or within.....cont.

Roundles....Bezants.

Per chev. gu. and az. on a chev. engr. betw. in chief two bezants and in base a fleur-de.lis arg. a lion pass. ppr. enclosed by a pair of crosses croslet sa. PePpercorne.

Arg. on a chev. sa. betw. in chief two ogresses each charged with a martlet as the first and in base a wreath of oak-leaves ppr. three escallops of the first a bordure engr. vert. Hastond, Holly Grove, co. Berks ; Baronetcy 1783 ; quartering Græme.

$\mathrm{Az}$. on a chev. or betw. three bezants a roebuck courant of the first. Hore, Kers, Scotland.

Sa, on a chev. or betw. three bezants each charged with a talbot pass. of the first so many crescents az. AlLeN, Essex.

Gu. on a chev. arg. betw. three bezants as many crosses formy fitchy sa. Sмүтн, co. Berlzs; Bosworth, co. Leicester; and London.

Gu. on a chev. or betw. three bezants as many crosses croslet fitchy of the first. Sмгтв.

Gu. on a chev. or betw. three bezants as many crosses croslet sa. Sirrth, Leeward Islands; quartered by Matbew.

Gu. on a chev. or betw. three bezants as many crosses patty fitchy sa. Smith alias Heriz, Withcock,co.Leicester; and Weald Hall, Essex; quartering Heriz. Sнгтн, Edmondthorpe, co. Leicester; Baronetcy 1661-1721. Smith, Walcot, co. Lincoln. Sмхтн, Middlesex; Kelmarsh, co. Nortbampton; co. Lincoln; and co. Chester.

Gu. on a chev. arg. betw. three bezants a 3 -foil slipped of the first. Golding, Colston Basset, co. Nottingham.

Az. on a chev. or betw, three bezants a rose gu. Hope, Granton, Scotland.

Az. on a chev. or betw. three bezants a laurel leaf slipped vert. Hope, Baron Hope Viscount Aithrie Earl of Hopetoun 1703, Baron Hopetoun 1809, Baron Niddry 1814.

Az. on a chev. arg. betw. three bezants as many palets gu. HoPe, Balcomy, Scotland.

$$
\text { .....Hurts }
$$

Arg. on a chev, az. betw. three hurts as many annulets of the first. WEBBER. The chev. engr. (? Wenber, Amell, Cornwall.)

Arg. on a chev. engr. az. betw. three hurts as many annulets or. WEBBER.

Arg. on a chev. az. betw. three hurts a lion ramp. enclosed by two fleurs-de-lis of the first. WAINWRIGHT.

Arg. on a chev. gu. betw. three hurts each charged with a fleur-de-lis three birds with wings expanded of the first. Streeter, Kent. The birds volant. STONYNG, co. Stafford; and Suffolk.

Arg. on a cliev. gu. betw. three hurts each charged with a fleur-de-lis or as many martlets of the first. Stoning, London.

Arg. on a chev. az. (another, gu.) betw. three hurts as many (another, six) crosses croslet or. Baskervile, co. Gloucester.

Arg. on a chev. gu. betw. three hurts as many crosses croslet or. Sr. Richard Baskervili, $V$.

Arg. on a chev. gu. betw. three hurts crosses croslet or. Sire Walter Bascrevile, $N$.

Arg. on a chev. gu. betw, three hurts as many fleurs-de-lis or. John Baskervile, $Y$. Monsire de Baskerville, $Y$.

Arg. on a chev. gu. betw. three hurts as many mullets or. Sir Walter de Baskenvile, $L$.
On 1 CHEVRON betw. or within.... cont.

Roundles cont. Hurts cont.

Arg. on a chev. vairy or and gu. betw. three hurts a burt charged with a lion's head erased of the first. HUGON.

\section{..... Ogresses}

Arg. on a chev. gu. betw. three ogresses a cock of the first. Longland.

Arg. on a cher. sa. betw. three ogresses an eagle displ. arg. BaILE, co. Devon.

Arg. on a chev. gu. betw. tliree ogresses each charged with a fleur.de.lis of the first so many birds volant as the field. STONYNG, co. Stafford; and Suffolk.

Arg. on a chev. sa. betw. three ogresses as many crescents of the first. WALKER, co. Lancaster.

Arg. on a chev. gu. betw. three ogresses as many escallops of the first. LoNGLAND, Toymoke, co. Buckingham.

Arg. on a chev. sa. betw. three ogresses each charged with a martlet of the first as many escallops or a bordure engr. vert. Hammond, St. Alban's Court, Kent.

Or on a chev. sa. betw. three ogresses each charged with a lark arg. a sixteen-pointed pierced estoile of the first. LaRKe or LaRKE. The larks or. LARKE, co. Lincoln.

Or on a cher. gu. betw. three ogresses as many ostrich feathers arg. Perinson.

Arg. on a chev. engr. sa. betw. three ogresses a fieur.de.lis enclosed by two conies of the first. Flegh or Flight, London. The ogresses each charged with a mart]et or. FIEGH.

Or on a chev. engr. sa. betw. three ogresses each charged with a bird of the first a fleur-de.lis enclosed by a pair of conies courant incontrant arg. FLIGHT, Caistor, Norfolk, quartered by Harrison. Flye or Flyght, $V$. The conies sejant. John Flye or Flight, $V$.

Or on a chev. engr. sa. betw. three ogresses each charged with a martlet as many fleurs-de-lis of the first. FLY, co. Hants.

Arg. on a chev. sa. betw. three ogresses as many roses of the first. Babington. BaLdington, $V$. Boldington.

Or on a chev. az. betw. three ogresses each charged with a woolsack arg. as many garbs of the first. Wolsey, Newton, Norfolk.

Arg. on a cher. sa. betw. three ogresses as many mascles or. PratT.

Arg. on a chev. sa. betw. three ogresses each charged with a martlet of the first as many mascles or. BABER, co. Somerset; and co. Oxford. Pratr, Norfolk; and co. Salop. Pratt, Thurloxton, Collinson, Somerset, i, 77.

Arg. on a chev. sa. betw. three ogresses each charged with an escallop as many mascles or. Pratt, Suffolk.

Arg. on a chev. sa. betw. three ogresses the two in chief charged with a bird of the first and that in base with an escallop .... as many mascles or. William Pratt, Ryston, Norfolk, $V$.

Arg. on a cher. sa. betw. three ogresses the two in chief charged with a martlet of the first and that in base with a 3-foil slipped arg. so many mascles or. Pratr, Ryston Hall, Norfolk. Erm. on a chev. sa. betw. three ogresses a pierced mullet of six points as the first. CHerwoon.

Arg. on a chev. sa. betw, three ogresses each charged with a leopard's face of the third two palets or. Hengott or Henscots, co. Devon. Arg. on a chev. sa. betw. three ogresses as many bezants. Killegrave. 
On 1 CHEVRON betw, or within..... cont. Roundles cont. Plates

Gu. on a chev. engr. betw. three plates as many annulets of the first. WEBter.

Az. on a chev. or betw. three plates each charged with a griffin's head erased sa. a lion pass. enclosed by two 5 -foils gu. Lyon.

Az. on a chev. engr. or betw. three plates each charged with a greyhound courant sa. collared as the second so many crescents as the last. William Aleyn, Rayley, Essex, $V$. Alueyn, $V^{*}$.

Or on a chev. engr. az. betw. three plates each charged with a greyhound courant sa. collared gu. so many crescents of the first. Allen, Essex.

Az. on a chev. betw. three plates as many crosses croslet sa. Cheddington.

Gu. on a chev. arg. betw. three plates as many crosses patty sa. LeADBITter, Deptford, near Sunderland, co. Durham.

Sa. on a chev. arg. betw. three plates as many lion's heads erased of the first. Trmins.

Vert on a chev. arg. betw. three plates each charged with a pyncheon (or goldfinch) as many pansies (? beraldic roses) slipped ppr. Henry Morgan, Bishop of St. David's 1554-50; granted 1553.

\section{.... Pomeis}

Or on a chev. betw. three balls vert a crescent gold. BLOWER.

\section{....Torteaux}

Arg. on a chev. sa. betw. three torteaux as many annulets of the first. KiLlegrew, Cornwall.

Az. on a chev, arg. betw. three torteaux as many Cornish choughs ppr. Benedictine Priory at Tywardreth, Cornwall.

Arg. on a chev. gu. betw, three torteaux as many 4 -foils or. Comport, Eltham, Kent; granted 1 December 1663.

Arg. on a chev, engr. az. betw. three torteaux as many 5 -foils of the first. HoBson, Chicbester, Sussex.

Arg. on a chev. az. betw, three torteaux as many 5 -foils or. HOBSON.

Arg. on a chev. gu. betw. three torteaux as many mullets of the first. CranaCH or Cranadge, Cranach, co. Chester; the heiress m. Needham.

Arg. on a chev. sa. betw. three torteaux as many bezants. Boleche. Boleigh, $V^{*}$. Boleighe, $V$. BoLoch. Boligh, Lansallos, Cornwall ; the heiress $m$. Kellio.

Arg. on a chev. sa. betw. three torteaux as many bezants. Bolley. Killegrew, Coruwall.

Arg. on a chev. sa. betw, three torteaux five bezants. (The ancient arms of) TrEJAGo, Fentongollan, Cornwall; derived from TrejaGo, Trejago, Cornwall.

Sa. on chev. betw. four plates three in chief and one in base a pellet. Timsins.

\section{Rowels see Mullets Saltires}

Gu. on a chev. betw. three saltires arg. an annulet sa. GoLdston or Goulston, co. Salop.

\section{Shackles}

Gu. on a chev. betw. six shackles in pairs or three heathcocks az. (moorcocks sa. Fenvotier, $V *$.) a bordure engr. of the second ogressy. FenRother, London, $V$.

Gu. on a chev. or betw. three fetterlocks arg. a pheon enclosed by two pierced mullets sa. KIrEwood, Pilrig, Scotland.
On 1 CHEVRON betw. or within.... cont. Ships

Arg. on a chev. gu. betw. three ships of as many masts sn, a lion ramp. or. MAY.

Spears

Az. on a chev. erm. betw. three broken spears erect or headed arg. as many bells sa. Sreardian, Preston, co. Durbam; and Easlewick Hall, Northumberland

\section{Sprigs}

Arg. on a cher. az. betw. three bolly branches vert fructed ppr. as many (doves of the last, another) woodpigeons of the first beaked and membered gu. HoLlis, London; Rotherham, etc., Hunter, Sheffield, 183.

Arg. on a chev. gu. betw, three sprigs of laurel each consisting of three leaves vert another chev. erm. Coopen, Wortlington House, Suffolk. Couper, Cogar, Scotland.

Arg. on a chev. az. betw. three branches of mountain ash vert as many crescents of the first. Rowntree.

Arg. on a chev. gu. betw. three branches of rowan tree (i.e. mountain ash) ppr. as many crescents or. RodIE, Liverpool ; from Scotland.

Arg. on a chev, engr. sa. betw. three sprigs of oak fructed ppr. a Malteso cross as the first. OAEES; Baronetcy 1815.

Per pale az. and purp. on a chev. betw. three oak branches arg. (a rose enclosed by two pinks, another) as many marigolds (another pinks) ppr. Augustinian Priory at Llanthony, co. Monmouth.

\section{Square}

Arg. on a chev. betw. three pairs of open compasses sa. a joiner's square or and a reel as the last stringed az. Company of Carpenters.

\section{Staves}

Arg. on a chev. betw. three pilgrim's staves each supporting a pouch (or palmer's scrip) sa. gar. nished or a crescent for diff. TASBURGH, St. Andrew's, in Ilkensall, Suffolk, Harl. MS. 1103 , fo. $83 \mathrm{~b}$.

Sa. on a chev. arg. betw. three staves raguly of the last inflamed ppr. a fleur-de-lis enclosed by two Cornish choughs (gu. another) sa. Merrick, Monkton, and Rush, co. Pembroke; descended from Rowland Meryck, Bishop of Bangor 1559.66.

Sa. on a chev. arg. betw. three staves raguly or inflamed ppr. a fleur-de-lis az. enclosed by two Cornish choughs ppr. Rowland MERYCK, Bi. shop of Bangor 1559-66. Owen ap MEYrick, Bodeon, co. Anglesey; and his son John Mericke, Bishop of Sodor, etc. 1575-99. Merric or Meyrick, Bodorgan, co. Anglesey; quartering Meredith ap Cadwgan; descended from Einion Sais ap Cadaval Yuad. The chev. or. CaDafuel YNFYD, 1200.

Az. on a chev. betw. three pilgrim's staves or as many mullets of the first. EuINToN, co. Lincoln, $\mathrm{W}$; granted by Camden. Evinron.

Az. on a chev. betw. three mariner's cross-staves or five mullets of the first. Evingron, Spalding, co. Lincoln.

\section{Stones}

Az. on a chev. betw. three flint-stones arg. two lions combatant gu. Fuint, Norwich.

Or on a chev. gu. betw. three flint-stones az. another chev. arg. StoNe, London. 
On 1 CHEVRON betw, or within.....cont. Suns

Az. on a chev. arg. betw. in the dexter chief quarter a sun in splendour ppr. and in base two swords points upwards in saltire encircled with a double chain or three pheons gu. JoHnson, Lord Mayor of London 1841.

Arg. on a chev. sa. betw. three suns gu. as many buck's heads cabossed of the first. OLrET, London.

Az. on a chev. arg. betw. three suns or as many pierced mullets (gu. $V^{*}$ ) sa. Sonnclene, $V$. ST. CleRE.

\section{Swords}

Arg. on a chev. gu. betw. three dirks az. hilted or those in chief points downward ppr. as many water bougets gold. GLasham, Scotland.

Arg. on a chev. betw. three swords points downwards each supporting a pouch (or purse) sa. the pomels and tassels or a crescent of the last. Tasburgh, St. Andrew's, in Ilkensall, Suffolk, Harl. $M I S .155$, fo. 25 .

Arg. on a chev. betw. three falchions palewise sa. as many pierced mullets of the first. FusT, Hill, co. Gloucester; Baronetcy 1682-1779.

Gu: on a chev. betw. three dirks arg. hilted or a torteau enclosed by two crescents gu. M'Cormicis.

$\mathrm{Gu}$. on a chev. betw. three daggers palewise those in chief points downwards ppr. as many torteaux. M'Cormack, Scotland.

Tails

Chequy or and az. on a chev. gu. betw. ermine spots one in each piece counterchanged three escallops ppr. WALKER, Uppingham, Rutland.

\section{Tents}

Sa. on a chev. or betw. three tents (without poles) erm. lined az. (another, 1730, gu.) as many roses gu. UPHOLSTERERS.

\section{Trees}

Sa. on a chev. betw. three oak-trees eradicated or as many martlets of the first. Wood, Sandwich, Kent.

Sa. on a chev. betw. three pine-trees or as many martlets of the first. WooD, $V^{*}$.

Arg. on a chev. sa. betw. three cherry trees eradicated vert fructed gu. five gouttes of the first. Thonnton, Clapham, Surrey.

Or on a chev. gu. betw. three trees ppr. a boar's head arg. SPotriswood.

Arg. on a chev. gu. betw. three trees eradicated vert as many bezants. Boys, co. Somerset. SpotTiswood, Dunipace, Scotland.

\section{Tressure}

Gu. on a chev. within a double tressure flory counterflory arg. three 5-foils az. FLeming, Board, Scotland.

\section{Tubs or Tuns}

Sa. on a chev. betw. three tuns arg. a chessrook

az. Winter, Northington, co. Leicester.

Wells see Buildings

Wheels

Arg. on a chev. betw. three catharine wheels sa. as many 5-foils of the first. CARTER, $V^{*}$.

$$
\text { Wings }
$$

Gu. on a chev. betw. three wings or as many griffin's heads erased of the first. Micheli, co. Wilts.

Arg. on a chev. betw. three wings az. as many bezants. Cosowarth, Coruwall.

Arg. on a chev. az. betw. three wings sa. as many bezants. TODEFORD or TUDFORD.
On 1 CHEVRON betw. or within.....cont.

Wings cont.

Sa. on a chev. or betw. three wings arg. as many torteaux each charged with an eagle's head or. BABEHAMr.

Sa. on a chev. betw. three dexter wings arg. as many torteaux each charged with a pheon or. Richard Babenam, Cokham, co. Berks, $V$. Babeham or Babehaw, London.

Arg. on a chev. betw. tbree falcon's wings az. five bezants. Coswarth, Coswarth, Cornwall ; the heiress $m$. Mynard, and the heiress of Mynard m. Vivian.

Arg. on a chev. az. betw. three sinister wings elevated sa. five bezants. Conkord, $V$. Cosworth, $V$.

Arg. on a chev, az, betw. three sinister wings elevated gu. five plates. CoDeford, $V$. CODFORD.

\section{Woolsacks see Packs \\ Wreaths}

Az. on a chev. arg. betw. in chief two chaplets of oak and in base a lion sejant guard. or tbree buglehorns stringed sa. JowITT, Eltofts Thorner, co. York.

Arg. on a chev. sa. betw. three chaplets of flowers gu. another chev. erm. Borovgr. Borowe. The roses seeded or. BonNE.

Az. on a chev. arg. betw. three wreaths of oak or an Eastern crown gu. Vivease, Calne, co. Wilts.

Arg. on a chev. betw. three chaplets sa. as many roses gu. LAKINGLEECH.

Gu. on a chev. arg. betw. in chief three chaplets of hazel or and in base a plough ppr. three shakeforks sa. PEER, Hazelwood, near Kings. bridge, co. Devon; granted 1832.

\section{On 1 CHEVRON betw. or within...} and in chief....

\section{Bird}

Az. on a chev. or betw. three bibles fesswise clasps downwards gu. garnished and leaved of the second an eagle rising ppr. enclosed by two red roses seeded or barbed vert from the chief a demi-circle of glory edged with clouds ppr. therein a dove displ. and nimbed arg. Company of Stationers, London; incorporated 1556 .

Sa. on a chev. betw. three doves arg. as many (pinks or) gilliflowers gu. slipped vert in chief three annuiets or. Thomas Skevyngton, Bishop of Bangor, 1510-33, $U$, alias SkEF FINGToN or PACE.

.... on a chev. betw. three martlets .... as many cherries stalked .... in chief three annulets .... Thomas ChentTon, Bishop of Bangor 1436-47.

\section{Canton}

Gu. on a chev, embattled betw. three martlets arg. an eagle displ. enclosed by two escallops sa. a canton erm. Wedpecl, Newby, and Ripon, co. York.

Gu. on a chev. engr. betw. three ostrich featber's erect arg. a fleur-de-lis az. two ogresses enclosed by a canton or. Parkinson.

Az. on a chev. engr. arg. betw. three dolphins or another chev. gu. a canton erm. Fryer.

Gu. on a chev. betw. three fleurs-de-lis or so many annulets of the first a canton chequy as the second and az. Dennis, Fort Granite, co. Wicklow. 
On 1 CEEVRON betw. or within.... and in chief..... cont.

Canton cont.

$A z$. on a chev. betw. three boar's beads couped or as many fleurs-de-lis gu. a canton erm. LUDFORD; quartered by Chetwode.

Arg. on a chev, betw. three fox's heads erased sa. as many crescents erm. a cantou of the second. Nichols.

Az. on a chev. erminois betw. three tilting spears erect arg. headed or three bells sa. a canton erm. Spearain, Eachwick Hall, Northumberland. on a Canton..... Bird

Arg. on a chev. embattled gu. betw. three bear's gambs erased erect ermines armed of the second as many crescents erminois a canton gu. charged with an eagle displ. arg. ducally crowned or standing on a serpent nowed in fret ppr. HarveY.

$$
\text { .....Birds }
$$

Arg. on a chev. vert betw. three hawk's heads erased sa. so many thistles slipped and leaved of the first a cauton as the third charged with three martlets like the field. ANDERSON.

Or on a chev. gu. betw. three hawk's heads erased sa. so many acorns slipped arg. a canton as the third charged with three martlets of the fourth. ANDERSON, Newcastle; granted 3 November 1547 .

$$
\text { ..... Cup }
$$

Erm. on a cher. within a bordure flory az. three fox's heads erased or a canton of the same charged with a drinking cup as the third bearing three fleurs-de-lis ppr. on the urn and in the centre a rose gu. Fox, Grove Hill, Ealmouth, Cornwall.

$$
\text { ..... Head }
$$

Arg. on a chev. gu. betw. three wolf's heads erased az. as many roses of the first a canton sa. charged with a lion's head erased or. Clarke, Knedlington, co. York.

$$
\text { .... Human Figure }
$$

Gu. on a chev. arg. betw. three buckles or as many storks az. a canton of the second charged with a man in red breeches on the top of a tower sa. holding a Dutch banner on it a bordure engr. of the first pelletty. Fenrother, in Chobham Church 1573.

$$
\text { ..... Mullet }
$$

Arg. on a chev. engr. sa. betw. three sprigs of oak fructed ppr. a Maltese cross as the field a canton gu. charged with a mullet of eight points within an increscent like the first. OAKEs, Mitcham Hall, Surrey; Baronetcy 1815.

$$
\text { .....Pheon }
$$

Arg. on a cbev. az. betw. three wolf's heads erased sa. so mauy crescents erm. a canton of the third charged with a pheon as the first. Nichol., Islington, Middlesex. The pheon or. Nicholls, Saffron Walden, Essex.

$$
\text { .....Saltire }
$$

Arg. on a chev. betw. three heathcocks az. as many 5.foils of the first a canton per pale or and sa. charged with a saltire couped counterchanged. David Pole or POOLE, Bishop of Yeterborough $1557-9$; granted 1557 .

Arg. on a chev. betw. three leopard's faces sa. a crescent as the first a canton or charged with a saltire vert betw. in chief a dexter hand couped at the wrist in base a cross croslet gu. in the dexter fess a lizard .... and in the sinister a salmon of the fourth. CosBr, quartered by Nesbitt.
On 1 CHEVRON betw. or within.... and in chief..... cont.

on a Canton cont. Staff

Az. on a chev. counterembattled betw. three stringed bugleborns or a mitre with labels of the first a canton erm. charged with a crosier as the second surmounted in saltire by a sword gu. Samuel Peploe, Bishop of Chester 1726-52 and his descendants, Peplor, Garnstone, co. Hereford.

$$
\text { ....Treo }
$$

Az, on a chev. embattled betw. in chief two bear's paws erased and in base an anchor erect or a bom $b$ on fire enclosed by a pair of crescents sa. a canton as the second charged with a slip of oak fructed ppr. grasping a crescent gold. Harver, Ramsgate, Kent.

\section{Chief}

Arg. on a chev. betw. three bombs sa. fired ppr. as many bezants a chief of the second. HEald.

Arg. on a chev. betw. three martlets gu. as many annulets or a chicf engr. erm. Cooper, Bengeworth, quartering Beale, Hayward, and Emms.

Arg. on a chev. counterembattled betw. three castles sa. as many bombs of the first fired ppr. a chief az. Pandoe, Welwyn, co. Herts.

Or on a chev. sa. betw, two couplecloses gu. three martlets of the first a chief rair. HUNGERFORD, Dingley ; for HoLdich or Holditch, Maidwell Hall, co. Northampton; granted 1824.

Arg. on a chev. gu. betw. three fishes naiant az. a rose of the field a chief chequy as the second and first. MACBRIDE.

Sa. on a chev, betw. in chief two pistols or and in base a silver medal of Louis XV tied at the top with a red ribbon a laurel chaplet enclosed by a scalp on a staff and a tomahawk ppr. a chief em. hattled arg. HopkINs, Maryland; granted 1764.

Arg. on a chev. gu. betw. three leopard's beads erased sa. as many lozenges erm. a chief az. HASEllWOOD. HASELWOOD or HASSELWOOD, Suffolk.

Arg. on a chev. az. betw. three torteaux so many roses of the first a chief countercompony as the second and or. Hopson.

Arg. on a cher, az. betw. three torteaux so many 5 .foils of the first a chief chequy as the second and or. AOPSON. HoBson, $V$. HoBson, Middlesex. The chev, engr. Hobson, Wingwood, Isle of Wight. HoBson, $V^{*}$. Thomas HOBSONN, $V$.

Per pale arg. and or on a chev. engr. az. betw. three torteaux so many 5 -foils of the first a chief engr. chequy as the second and third. Hopson, Minster, Isle of Sheppey.

on a Chief.....Anchor

.... on a chev. quarterly .... and .... betw. three garbs .... a balance suspended by a hand ppr. issuing from a chief barry wavy .... and .... charged with an anchor fesswise stock to the sinister .... Company of BrownBakers, London; Stow.

Arg. on a chev. sa. betw. three holly (another, roodbine) leaves vert as many hezants a chief gu. charged with an anchor enclosed by two martlets of the first. DALLING.

Sa. on a chev. betw. three lion's heads erased or as many towers like the field a chief barry wavy of six as the first and arg. charged with an anchor enclosed by two frets gold. Boyer. 
On 1 CHEVRON betw, or within.... and in chief....... cont.

on a Chief cont. Anchor cont.

Vert on a chev. betw. three lion's heads erased or so many slipped 3 -foils of the first a chief barry wavy az. and arg. charged with an anchor enclosed by two frets as the second. Bowyer, Lord Mayor of London 1543.

Arg. on a chev. sa. betw. three eagle's heads erased az. so many 5-foils like the first a chief or charged with two anchors in cross as the third enclosed by a pair of 3-foils slipped of the last each charged with twelve bezants. JAcksoN, co. York.

\section{..... Annulets}

Arg. on a chev. sa. betw. three demi-lions pass. az. fretty or a chief gu. charged with as many annulets of the first. HaLL, Brittly, co.Durham.

Arg. on a chev. gu. betw. three hawk's heads erased sa. as many lozenges erm. a chief of the third charged with three annulets or. Haselwood, co. Northampton.

$$
\text { .....(Beast) Antelopo }
$$

Arg. on a chev. engr. gu. betw. three spearheads sa. as many bezants a chief paly of six gu. and az. charged with an antelope courant or. Marshall, London.

Arg, on a chev, engr. gu. betw. three lozenges sa. as many plates a chief paly of four gu. and az. charged with an antelope courant or. MarshaII. -....Beaver

Per pale gu. and az. on a chev. or betw. three 5 -foils arg. as many leopard's faces sa. a chief of the third charged with a beaver pass. ppr. Sмiт, Upper Canada, and Preston, Northumberland; Baronetcy 1821.39.

$$
\text { ....Dog }
$$

Az. on a chev. arg. betw. three crosses patty fitchy or a pierced 5 -foil within two escallops gu. a chief of the third charged with a greybound courant sa. enclosed by two ogresses. NortH, Feltham, Middlesex, $V$.

Az. on a chev. arg. betw. three lozenges (arg. Stow) or so many griffin's heads erased as the first a chief chequy of the third (arg. Stow) and gu. charged with a greyhound courant erm. WARREN, Lord Mayor of London 1537 and 1544.

Or on a chev. az. betw. three hurts fretty of the first a chief sa. charged with a hound pass. arg. enclosed by two mullets as the field. BARker, Norfolk.

\section{....Goat}

Arg. on a chev. betw. three crosses botonny fitchy sa. as many (buck's, $V^{*}$.) roebuck's heads crbossed or a chief gu. charged with a goat courant arg. (armed gold, $V^{*}$.). Boughton, co. Warwick, $V$.

Arg. on a chev. betw. three crosses pomelly sa. as many buck's heads cabossed or a chief of the second charged with a goat pass. as the first. Broughton, co. Devon.

Arg. on a chev. betw. three 3-foils slipped sa. as many stag's heads cabossed or a chief gu. charged with a goat pass. of the first. BodGHTON, Lawford Hall, co. Warwick; Rouse Lench, co. Worcester; and Downton Hall, co. Salop; Baronetcies 4 August 1641 and 28 July 179l, quartering Rouse and Boughton.

$$
\text { .... Leopard }
$$

Az. on a chev. betw. three lozenges arg. as many griffin's heads erased of the first a chief chequy or and gu. charged with a leopard pass. as the second goutty de poix. Warren, London.
On 1 CHEVRON betw. or within ... and in chief.........

on a Chief cont. (Beast) Lion

Or on a chev. sa. betw. as mauy ogresses each bearing a talbot (pass. $V^{*}$.) statant of the first three martlets arg. a chief az. charged with a demi-lion ramp. issuant enclosed by two dragon's heads erased or. ALLEN. Thomas ALYN, $V$.

Gu. on a chev. betw. three goldfinches arg. as many crosses croslet sa. a chief or charged with a lion pass. of the first. GoLDsMrтH,Ireland.

$\mathrm{Gu}$. on a chev. betw. three goldfinches arg. so many roses sa. a baton of the third a chief as the second charged with a lion pass. like the first. Gooldsurt, Kent.

Arg. on a chev. betw. three escallops az. so many escallops of the first a chief as the second charged with a lion pass. like the field. Hinde, Evelith, co. Salop.

Gu. on a chev. arg. betw. three pears stalked and leaved or as many crosses couped sa. a chief erm. charged with a lion pass. of the fourth. Whieldon, Springfield House, co. Warwick; and Weltou Place, co. Northampton.

Arg. on a chev. betw. three goat's heads erased az. attired or as many lozenges of the third a chief sa. charged with a lion pass. guard. erm. Chicheley.

Arg. on a chev. gu. betw. three goat's heads erased az. attired and collared or as many lozenges of the first a chief sa. charged with a lion pass. guard. of the fourth. Hind, Kent. Sir Francis Hynde, co. Cambridge, $\boldsymbol{V}$.

Arg. on a chev. gu. betw. three goat's heads erased az. attired and collared or as many lo. zenges of the last a chief sa. charged with a lion pass. guard. erm. Hinde, co. Cambridge. Alg. on a chev. betw. three goat's heads erased gu. collared or so many lozenges of the third a chief as the second charged with a lion pass. like the first. HINDE.

Or on a chev. sa. betw. three roundles (? sa.) each charged with a martlet arg. an estoile of the first on a chief gu. a lion pass. as the third. LARKe, $V$.

$$
\text { .... Billets }
$$

Arg. on a chev. betw. three mullets gu. a crescent or a chief' az. charged with three ingots of gold in fess crossed by another in bend ppr. WILson, Sneaton Castle, co. York.

$$
\text { ..... Bird }
$$

Arg. on a chev. sa. betw. three (elm or hazel, $V)$ leaves vert as many bezants a chief gu. charged with a dove enclosed by two anchors of the first. MoNnox, Chorley Woods, co. Herts. Monox, Walthamstow, Essex; granted 1561. Sr. George Monoux, Alderman of London, $V$.

Arg. on a chev. sa. betw. three (oak, $\left.V^{*}\right)$ leaves vert as many annulets (but $V^{*}$, bezants) a chief gu. cbarged with a (bird, $V^{*}$ ) martlet enclosed by two anchors of the first. Monnoux or Monnox, co. Bedford; Essex; and London. Monnox, $V^{*}$. ..... Birds

Arg. on a chev. betw. three spearbeads gu. five plates a chief az. charged with three birds or. Rice or Rise, London. Rrce, $V^{*}$. Symon Ryse, London, $V$.

$$
\text { ..... Cocks }
$$

Sa. on a chev. betw. three leopard's heads arg. as many spearheads of the first a chief of the second charged with three cocks gu. APRICE, co. Hereford. The cocks combed wattled and legged or. Price or Pryce, Wrotham, co. Herts. 
On 1 CHEVRON betw. or within.... and in chief.....cont. on a Chief cont. Martlets

Az. on a chev. betw. three escallops arg. as many acorns ppr. slipped vert a chief embattled or charged with three martlets gu. NEDEHam, $V^{*}$. Nedham, Wimeley, co. Hertford. John Nydehair, London, $V$.

Erminois on a chev. sa. betw. three lion's heads erased purp. as many plates a chjef engr. gu. charged with three martlets or. Vrvian, Pencalenick, Cornwall; the heiress m. Tippet. Vivian, St. Columbe, and Key, Cornwall.

Or on a chev. az. betw. three lion's heads erased ppr. as many annulets of the first a chief gu. charged with three martlets arg. Vivian, Bod. min, Cornwall. The heads ppr. and the mart. lets of the first. Vivian, Cornwall.

Az. on a chev. or betw. three griffin's heads erased arg. a chaplet of oak vert a chief of the second charged with three martlets gu. Humpenry, Clapham, Surrey.

$$
\text { .....Buildings }
$$

Arg. on a chev. betw. three fleurs-de-lis az. as many mullets of the first a chief silver charged with amongst the sea and rocks the Bell-Rock Lighthouse with temporary lighthouse men at work and ships in offing ppr. STEVENSON, Edinburgh.

Vert on a cher. embattled erminois betw. three hedgehogs or as many bombs sa. fired ppr. \& chief charged with the gates and fortress of Seringapatam ppr. Harris, Baron Harris, 1815 .

\section{....Canton}

Per chev. the upper part per pale erm. and arg. the lower arg. on a chev. sa. betw. in chief on the dexter side an eagle displ. double beaded silver holding a gauntlet gu. and a scimetar hovering over an inperial crown on the sinister side a turbaned Turk's head in profile couped fesswise face downward the neck towards the edge of the escucheon issuing drops of blood over a Turk's banner staff in bend sinister inverted tasseled and headed with a crescent and in base a $Z$ top and bottom indented sa. enclosed by two ash trees vert from the under part of the chev. a pile az. thereon a sun or six ostrich feathers each turned towards the centre ppr. a chief az. charged with on a canton gu. a peer's helmet. Hesse, Paddington, Middlesex; confirmed 12 June 1772.

$$
\text { ....Chevron }
$$

Sa. on a chev. betw. three greyhounds statant arg. as many sprigs of ash ppr. on a chief vert a chev. betw. three greyhounds courant arg. NASH, co. Worcester; granted ....

$$
\text { ......Coronet }
$$

Arg. on a chev, az. betw. three roses gu. barbed and seeded a wreath of laurel gold fretted with a dexter sword surmounted by another sinister in saltire ppr. hilts and pomels or a chief of the second charged with a naval crowu enclosed by two anchors erect or. Rickets, The Elms, co. Gloucester; Baronetcy 1827.

Or on a cbev, az. betw, three lions ramp. gu. an anchor of the first surmounted by a sword in saltire ppr. pomel and hilt gold a chief wavy of the second charged with a naval crown or betw. the cross of the Russian Order of St.George and that of the Swedish Order of the Sword each pendent from the ribbons ppr. Marshali, Rochester, Kent.
On 1 CHEVRON betw, or within.... and in chief.... cont.

\section{on a Chief cont. Cross}

Or on a chev. sa. betw. three holly branches vert fructed gu. two cats pass. respectaut arg. a chief az. goutty d'or charged with a cross patty of the last. Thomas Gibies, $V$. Gibes.

Arg. on a chev. betw. three wolf's heads erased sa. langued gu. as many lilies of the first leaved vert a chief gu. charged with a cross tau enclosed by two escallops or. Lupton, co. York; granted temp. Henry VII; and Thame, co. Oxford.

Sa. on a chev. engr. betw. three eagle's heads erased arg. as many hurts a chief or charged with a cross patty fitclyy enclosed by two annulets gu. Henry BELEY, elected 1509 Abbot of Tewksbury; U, Ashmol. MS.

Sa. on a chev, betw. three maiden's heads arg. crined or so many lilies gu. leaved vert a chief of the third charged with a cross tau enclosed by two roses as the fourth. John TAYLOR, Bishop of Lincoln 1552-4, Cole MS. xlix, fo. 251, correcting Browne Willis.

Sa. on a chev. arg. betw. three griffin's heads erased or as many Moor's beads couped ppr. filletted of the second a chief as the last charged with a cross potent enclosed by two fleurs-de-lis gu. John BELL, Bishop of Worcester $1539-43$.

Arg. on a chev. betw. three buglehorns stringed sa. as many mullets of the first a chief embattled gu. charged with the Peninsular gold cross and clasps suspended from the ribbon ppr. enclosed by two mural crowns or. Colborne, Baron Seaton, 1839.

$$
\text { .... Crosses }
$$

Arg. on a chev. sa. betw. three lion's beads erased az. as many wrens of the first a chief gu. charged with three crosses croslet or. Matthew Wren, Bishop of Hereford 1634, Norwich 1636, Ely 1638-67; Parentalia. The beads purp. Wranne, $V$. Wren, Bilby Hall, co. Durham. WRENne, $V^{*}$.

$$
\text { .....Escallop }
$$

Arg. on a cber. betw, three wolf's heads sa. another chev. of the first a clijef of the second charged with an escallop enclosed by two round buckles as the field. Clibions, Moate Castle, co. Westmeath.

Az. on a chev. betw. three griffin's beads erased arg. so many crosses croslet fitchy gu. a chief of the second charged with an escallop of the first enclosed by two 5 -foils as the third. Shedden, Paulerspury Park, co. Northampton; and Knockmarloch, co. Ayr ; Brooklands, Eastonton, and Efford, co. Hants; London; and Aldham Hall, Suffolk; each with due diff. as descended through SHEDDEN, Roughwood, Auchingree, and Kerse, from Shedden, Beith, Scotland.

\section{.... Escallops}

Per pale or and vert on a chev. betw. three bucks courant as many pheons counterchanged a chief az. charged with three escallops of the first. SwIFT, co. York. The bucks trippant. Swift, Rotherham.

Az. on a chev, betw. three griffin's heads erased arg. as many crosses croslet fitchy gu. a chief as the second charged with so many escallops of the first. SHednen, Auchinmede, Kilwinning, co. Ayr. 
On 1 CHEVRON betw. or within.... and in chief.....cont.

on a Chief cont. Escallops cont.

Gu. on a chev. betw. three dexter wings or as many griffin's heads erased of the first a chief arg. charged with three escallops sa. Richard Wilter, $V$.

\section{.....Feathers}

Arg. on a cher. sa. betw. three fleurs.de-lis each within a chaplet gu. as many estoiles arg. a chief az. charged with three writing.pens or. John Har.es, Nakingden, Kent, Cotton MS. Tiberius D 10.

$$
\text { .... Fleur-de-lis }
$$

Sa. on a chev. engr. betw. three doves arg. so many pierced 5 -foils of the first a chief like the second charged with a fleur.de-lis enclosed by two escallops as the field. Jarvice, Patting, co. Cambridge.

Az. on a chev. engr. betw. three eagles close or so many 5 -foils of the first a chief like the second charged with a fleur-de-lis enclosed by two spearheads as the field. WxNchoombe, Bucklebury, co. Berlss.

$$
\text { .... Fleurs.de-lis }
$$

Az. on a chev. betw. three birds or so many 5 -foils of the first a chief like the second charged with three fleurs-de-lis as the field. Tideman de WinchсомB, Bishop of Llandaff 1394, Worcester 1396-140l.

\section{.....Flower}

Az. on a chev. or betw. three martlets arg. as many sa. a chief gu. charged with a rose enclosed by a pair of trunks of trees eradicated or. Thomas Brown, Bishop of Rochester 1435, Norwich 1436-45; Blomefield, Norfolk, $1739, \mathrm{ii}, 379$.

Gu. on a chev. or betw. two escallops arg. a Cornish chough ppr. euclosed by so many 5 -foils az. a chief as the second charged with a rose enclosed by a pair of fleurs-de-lis like the first seeded or barbed and leaved vert. Peter or Petre, co. Devon; and Essex.

Arg. on a chev. sa. betw. three buck's hends erased gu. attired or as many mullets of the last a chief gold charged with a rose of the third enclosed by two 3 .foils slipped vert. Buck, co. Hants.

\section{.....(Flowers) Columbines}

Sa. on a chev. or betw. three plates as many 5 -foils of the first a chief arg. charged with three columbines ppr. Cooke, Kent.

$$
\text { ..... Lilies }
$$

Gyronny of eight sa. and gu. on a chev. betw. three annulets or a grose enclosed by two adzes az. a chief vert charged with three lilies slipped stalked and leaved arg. Company of Conpers, London; and co. Chester.

$$
\text { .... Roses }
$$

Arg. on a chev. sa. betw. three lions ramp. as the second fretty or a chief gu. charged with so many roses of the third barbed and seeded vert. HaIJ, co. Lancaster.

$$
\text { ....5-Foils }
$$

Arg. on a chev. sa. betw. three hurts as many estoiles or a chief gu. charged with three 5 -foils of the first. Bonde, Coventry, $V$.

$$
\text { ..... Fruits }
$$

Arg. on a chev. gu. betw. three owls sa. as many lozenges erm. a chief gu. charged with three hazel nuts or. HASIEWOOD, a branch of Haslewood, Haselbeech, co. Northampton.
On 1 CHEVRON betw, or within.... and in chief.....cont.

on a Chief cont. Hands

Arg. on a chev. engr. sa. betw. three 3 -foils slipped vert as many lozenges or a chief az. charged with two arms issuing from clouds ppr. vested bendy or and gu. holding in the hand a rose of the last. MOODYe, Ipswich, Suffulk. ..... Head

Arg. on a chev. sa. betw. three crosses croslet fitchy gu. two doves like the first on a chief as the third a griffin's head erased enclosed by a pair of serpents nowed or. Thomas Watson, Bishop of Lincoln 155\%-9.

$$
\text { ..... Heads }
$$

Gu. on a chev. betw. three falcons close arg. as many crosses croslet fitchy of the first a crescent for diff. a chief erm. charged with three spearheads sa. points embrued ppr. GaskerL.

$$
\text { ..... Heart }
$$

Az. on a chev. or betw. in chief two lions counter. ramp. arg. baronially crowned and in base a lymphad sails furled gold three mullets of the field a (canton, another a) chief per pale as the third and second charged on the dexter side with a human heart regally crowned and on the sinister with a thistle leaved and seeded ppr. Douaras, Castle Douglas, co. Kircudbright; Baronetcy 1801-9.

$$
\text { ..... Horseshoes }
$$

Az. on a chev. erm. betw. three lions ramp. or a bee ppr. enclosed by two bezants a chief arg. charged with three horseshoes sa. WYatr.

$$
\text { ..... Ieaves }
$$

Az. on a chev. betw. three lions pass. guard. or as many crosses sarcelly sa. a chief az. charged with the same number of laurel leaves vert. Leveson Fowler, Harnage Grange, co. Salop, $Z, 444$; (in error ?).

$$
\text { ...... Iegs }
$$

Sa. on a chev. betw. three men's heads couped sidefaced or as many crosses croslet fitchy gu. a chief arg. charged with three bird's legs erased of the first. Sandes, Cumberland; and Surrey, 1512.

Gu. on a chev. or betw. three Saracen's heads in profile couped arg. so many crosses patty fitchy of the first a chief as the third charged with three eagle's legs erased at the thigh sa. Dame Juliana Bray, impaled by Fenrother, $\vec{V}$. FENRODER.

\section{.....Lozenge}

Gu. on a chev. betw. three lions pass. arg. holding a battleaxe in the forepaw or so many lo. zenges sa. a chief engr. gold charged with a lozenge of the field betw. two martlets as the fourth. Cooper, Toddington Park, co. Bed. ford; and Highgate, Middlesex.

$$
\text { ...... Lozenges }
$$

Az. on a chev. betw. three eagles rising or as many bars germel gu. a chief gold charged with five lozenges of the first. LOPEs, Maristow House, co. Devon; Baronetcy 1805; quartering Franco.

\section{.... Letters}

Arg. on a chev. az. betw. in chief two ducks ppr. and in base a naval crown as the second a bomb fired enclosed by a pair of estoiles or a chief wavy az. charged with the word St. Domingo within a branch of laurel entwined with another of oak gold. Duckworta, Fenteroon, Cornwall; and Wear, near Exeter; Baronetcy 1813. 
On 1 CHEVRON betw. or within.... and in chief....cont. on a Chief cont. Lure

Arg. on a chev. betw. three hawk's bells gu. two bars gemel as the first a chief of the second cbarged with a hawk's lure enclosed by a pair of martlets like the field. Sr. Thomas BELL, co. Gloucester, $V$.

Or on a chev, az. betw. three (pinks, $V^{*}$ ) gilli. flowers gu. stalked and leaved vert a woman's head of the first hair dishevelled as the third a chief sa. charged with a lure double-stringed enclosed by two birds (falcons, $V^{*}$ ) arg. (bil. led, $\left.V^{*}\right)$ legged like the field. John JEwELL, Bowden, co. Devon, $V$. The head ducally crowned gu. with the birds beaked sa. JEWELL or Jule, Bowden, co. Devon. And the lure or. John JEwEL, Bishop of Salisbury 1560-71.

\section{....Mascles}

Gu. on a chev. arg. betw. three martlets or as many mullets sa. a chief of the second charged witl three mascles as the first. Thame, Chi. nor, co. Leicester. The mascles pierced. Thynne.

Gu, on a chev, arg. betw. three martlets or as many mullets sa. a chief of the third charged with three mascles of the first. Thynne, $V^{*}$. The mascles pierced. W. THinne, Clerk of the Kitchen temp. Henry VIII, $V$.

Gu. on a chev. betw. three martlets or as many mullets sa. a chief of the second charged with three mascles as the first. Finte.

$$
\text { .... (Monster) Dragon }
$$

Or on a chev. betw. three roses az. as many es. callops of the first a chief per pale gu. and sa. charged with a dragon pass. wings endorsed erm. HaWkINS.

$$
\text { .....Griffin }
$$

Or on a chev. betw, three 5-foils az. as many escallops arg. a chief gu. charged with a griffin pass. of the third. Hawkins, Marsham, Berks. The griffin of the first. HawkINs, co. Berks.

Or on a chev, betw. three 5-foils az. as many escallops gu. a chief per pale gu. and sa. charged with a griffin pass. erm. Hawnins, co. Gloucester; and Sherington, co. Hereford. The 5-foils pierced. Richard Harokins, Shering. ton, co. Hereford, $V$.

Az. on a chev. arg. betw. three bezants as many martlets sa. a chief or charged with a griffin pass. wings endorsed per pale gn. and sa. Collin or Collins. But per pale sa. and gu. Colinins, Essex.

$$
\text { .... Mirullets }
$$

Arg. on a chev. betw. three fleurs-de-lis az. a cross moline of the first a chief gu. charged with as many mullets or. STEvenson, co. Chester.

$$
\text { ....Pale }
$$

Sa. on a cher. or betw. three lions ramp. arg. a buck pass. enclosed by a pair of crosses croslet fitchy as the first a chief chequy or and $a z$. charged with on a pale betw. two salmons haurient arg. a rose gu. seeded or. Richard Cheney or Cheynex, Bishop of Gloucester and Bristol 1562-79.

$$
\text { .... Piles }
$$

Arg. on a chev, az. betw. three demilions pass. gu. as many bezants a chief sa. charged with two piles of the first. John HuLl, Hameldon, Surrey, $V$.
On 1 CHEVRON betw. or within.... and in chief.....cont.

on a Chief cont. Portcullis

Az. on a cbev. arg. betw. three fleurs-de-lis or a cross clechy gu. a chief of the last charged with a portcullis chained as the second. Byrce, Sussex; and Kent.

$$
\text { .... Saltire }
$$

Arg. on a chev. betw. three hind's heads erased gu. fretty or a chief as the second charged with a saltire (both engr.) enclosed by two roses in pale and as many demi-fleur-s-de-lis joined to the dexter and sinister sides gold. Becrwith, co. York.

$$
\text { .... Sprigs }
$$

Arg. on a chev. gu. betw. three owls sa. as many lozenges erm. a chief az. charged with three acorn branches or. FoulKe, co. Worcester.

Arg. on a chev. gu. betw. three owls sa. as many lozenges erm. a chief az. charged with three hazel branches of nuts or. HASELWOOD, Med. well, co. Northampton; co. Oxford; and Wykewaren, co. Worcester. Haselwood, $V^{*}$. But the chief az. charged with three bazel branches eradicated vert each carrying as many nuts arg. Edmund HASEI,WOOD, $V$.

Arg. on a chev. gu. betw. three owl's heads frontfaced erased sa. as many lozenges erm. a chief az. charged with three hazel branches or. HaSElWood, co. Northampton, $V$.

Gu. on a chev. betw. three griffin's heads erased arg. as many lozenges az. a chief embattled of the second charged with three nine-leaved birch branches vert. Brrch, Essex; and co. Bedford. The chief or. BIRch, Garnstone, co. Hereford. Byrche, Essex, $V$.

$$
\text { .....staves }
$$

Or on a chev. betw. tbree fleurs-de-lis az. as many crosses clechy of the first a chief gu. charged with two staves of Esculapius in saltire or en. twined by a serpent ppr. Birch,Croydon,Surrey.

$$
\text { .....staples }
$$

Ermines on a chev. or betw. three bear's heads erased erm. as many escaliops gu. a chief of the second charged with three door-staples as the (third, $V^{*}$ ) fourth. John Cooke, Fulwell Hacche, Essex, $V$.

$$
\text { ....swords }
$$

Arg. on a chev. engr. gu. betw. three fleurs.de-lis az. as many ermine spots or a chief of the third charged with two swords in saltire as the first enclosed by a pair of maunches erm. Norton, Suffolk.

$$
\text { .....Wreath }
$$

Or on a cher. az. betw. three lion's heads erased ppr. as many annulets as the first a chief embattled gu. charged with a wreath of oak like the first betw. the gold medal and clasp for Saha. gren etc. and the silver Waterioo medal. Vivian; Baronetcy 1828, Barony 1841.

$$
\text { ....Wreaths }
$$

Or on a chev. sa. betw. three demi-lions pass. az. five barrulets arg. a chief gu. charged with three chaplets of the fourth. HaLL, London; granted 18 May 1768.

Arg. on a chev. gu. betw. three demi-lions ramp. az. fretty of the first a chief of the second charged with as many chaplets or. HaIJ., Ha. ninsley, and Streatham, co. Cambridge.

Or on a chev. sa. betw. three demi-lious passant az. fretty of the first a chief gu. charged with as many chaplets arg. a martlet for diff. HaLL, co. Durham; Dublin; and co. Antrim. 
On 1 cHEVRON betw. or within.... and in chief........ cont.

on a Chief cont. Wreaths cont.

Arg. on a chev. sa. betw. three demi-lions ramp. erased az. fretty or a chief gu. charged with as many chaplets of the (fourth, $V^{*}$ ) first flowered as the third. John HaLL, Salford, co. Lancaster, $V$. HaLL, co. Lincoln; Middlesex ; and MiddleWalton, co. York.

Arg. on a chev. sa. betw. three lions ramp. az. fretty or a chief gu. charged with as many chaplets of the first the roses or. HALL, Middlesex, $V$. Crescent

Az. on a chev, or betw. three spur-rowels arg. five gouttes sa. in chief a crescent of the third. (? Cruttendon). Holden, Cruttenden.

Cross

Az. on a chev. arg. betw. in chief two eagles displ. and in base a garb gold gouttes de sang in the centre chief point a cross croslet or. Sinebotrom, Harewood Lodge, Mottram, co. Chester.

Fillet

Arg. on a chev. gn. betw. three ogresses a cock of the first in chief a fillet vert and a double rose as the second enclosed by two leopard's faces az. John Longland, Bishop of Lincoln 1521-47; Lansdowne MS. 255. But two fillets, Add. MS. 21074.

Fleur-de-lis

Az. on a chev. betw. three mascles arg. a boar's head erased of the first in chief a fleur-de-lis or. KinLocH, Gourdie, Scotland.

\section{Flower}

Arg. on a chev. gu. betw. three boar's heads erased sa. as many 5 -foils of the first the chev. ensigned on the top with a thistle ppr. Nisbet, Dirletoun, Scotland.

\section{Head}

Arg. on a chev. betw. three mullets az. a talbot's head of the first in the dexter fess (? chief) point a boar's head erased muzzled and in the sinister an anchor in pale cabled .... Wilson. Heads

Az. on a chev. or within a bordure compony as the second and gu, a crescent for diff. of the last in chief two leopard's faces gold. Foster, $W$. Heart

Arg. on a chev. gu. betw. three crosses croslet fitchy sa. a boar's head erased as the first and in chief a heart of the second. KEnNeDY, Garvinmains, Scotland.

\section{Letters}

Arg. on a chev. betw. three cock's heads erased the two in chief respectant sa. an escallop-shell or in chief the letters A L az. Alcock.

Level

Or on a chev. sa. betw. in chief two plummets az. and in base a level reversed of the second two soldering-irons in saltire enclosed by a cutting linife on the dexter and a shave-hook on the sinister arg. in chief a cross-staff fesswise of the second. Company of Plumbers.

on a Quarter

Az. on a cher. betw. three estoiles or as many lozenges gu. on a sinister quarter per pale arg. and az. two lion's gambs erased in saltire of the third. Butrs, Norfolk.

Roundle

Erm. on a chev. az. betw. three bull's heads erased sa. two swords arg. pomels and hilts or surmounted by a wreath vert in chief' the 'Frafalgar medal. Bullen.
On 1 CHEVRON betw. or within....

and in chief....... cont.

\section{Sprigs}

Arg. on a chev. engr. gu. betw. three crosses croslet fitchy az. an eastern crown supported by two lions counterpass. or in the centre chief a branch of olive saltirewise with another of palm ppr. Barlow, Calcutta, East Iodies; and Fir Grove, Surrey; Baronetcy 1803.

Trowel

Az. on a chev. engr. or betw. in chief two plaisterer's hammers arg. handled of the second and in base a treble flat brush of the third handle upward like the third a rose gu. seeded or barbed vert enclosed by two fleurs-de-lis of the first in chief a trowel fesswise handle to the sinister as, the third. Company of Platsterers, Lóndon.

\section{On 1 CHEVRON betw. or within.... and in base....}

\section{Head or Horn}

Gu. on a chev. within a bordure invecked arg. three stars of the first in base (a stag's head erased ...., another) a huntung horn or stringed arg. KER, Sutberland Hall, Scotland. Shackle

Gu. on a chev. az. within a bordure engr. ogressy three ducks and in base a shacklebolt arg. Farnother, London.

\section{1 $\frac{1}{2}$ CHEVRON betw. or within....}

Arg. a chev. and in base a dexter half chev. sa. all betw. three chaplets gu. AsHeton, $V$. Ashton, $V^{*}$; quartered by Becousall, Harl. $M S .1519$, fo. 35 ; and by Preston, Arton in Craven, co. York, Harl. MS. 1487, fo. 140. The half chev. sinister. AsHTON, quartered by Beconshall, Harl. MS. 1535 , fo. 48 b. Beterenshall, co. Lancaster.

\section{CHEVRONS}

.... two chev. .... and over all a cross croslet fitchy .... Walter de Merton, Bishop of Rochester 1274-7; Nichols, Leicester, ii, 649.

Arg. two chev, az. BAGED. William BAGOD, $E$; F. Bagod, $V$. Bagot, co. Stafford. Tyrreli, Essex; and Norfolk.

Arg. two chev. gu. Chetwyn. De Brendon. Erndon. Fallesby. Fettiplace, Rudder, co. Gloucester, 220. Sir Rafe Grandene, $I$. Grandon, $V^{*}$. Sire Rauf de Grandone, $N$. Sr. Rauft Grendon, $H$. Sr. de Grendon, $V$. Grendon, Grendon, co. Warwick; quartered by Chetwynd. Robert de Grendone, $E ; F$. Grey. Langborne. Langton, Baron of Malton, co. Lancaster. More, co. Devon. Mower, co. Devon, $V$. Moyer, Petsey Hall, Essex; Baronetcy 1701-15. Sir Robert Peche, $H$; but Perche credo Peche in margin, $Y$. Robertfeld, $V^{*}$. St. Maur or Seymour, St. Maur, co. Gloucester; quartering or a lion ramp. within an orle of eight crosses croslet az. St. Maure. (? Steer, Ireland.) Sully, Iddesleigh, co. Devon.

Arg. two chev. gu. a 5-foil for diff. az. Fallesby. Arg. two cher. gu. a label az. GRENDON, co. Leicester. The label of three points. AlBini, co. Lincoln. But of four points. Hue de Seymors, $G$. But of five points. St. Maure. Lawrence de Seintmone, $A$, Harl. MS. 6137. 


\section{CHEVRONS cont.}

Arg. two chev. gu. a label az. floretty. ST. MaUR. The label of five points az. charged with fifteen fleurs-de-lis or. Nicol de Sernmor, $E$.

Arg. two chev. gu. a label of five points three az. betw. a pair vert. Laurence de Seintmore, $A$.

Arg. two chev, and a label of three points gu. GRENDON.

Arg. two chev. gu. a label vair. Sire Robert de Grandone, $N$. John GrendoN (in margin), $Y$. Monsire de Grindone, $Y$. The label vairy arg. und sa. Grandon.

Arg. two chev. gu. a label vert. Monsire Thomas le Arcedyakne, $Y$. Juhn Grendon, $Y$. Laurence Seymore, $P$. Sire Nicolas de Seinmor, N. St. Maur, co. Gloucester. Monsire de ST. Moore, $Y$. The label of three points. Sr. de Grandon, co. Gloucester, V. St. MaUr, North Molton, co. Devon; a heiress m. Drury. St. Maun, co. Gloucester; and Castle Cary, co. Somerset, Collinson, Somerset, ii, 54. Sr. Laurence dé St. Macre, I. Sr. Nicoles SaINT Madre, co. Gloucester, $V$. The label of five points. Lorenz de Seinaror, $E$.

Arg. two chev. gu. over all a lion ramp. sa. Winthorp, Groton, Suffoll.

Arg. goutty de sang two chev. gu. Moore, Sandon, and Haddon, co. Hertford; and London.

Arg. goutty de poix two chev. gu. ST. MaUre.

Arg. two chev. engr. gu. GaIRden or Gaudine, That Ilk. GraIDEN, Scotland.

Arg. two chev. reversed gu. Newron, Norfolk; as (without tinctures) $\mathrm{Harl} . \mathrm{MS} .1386$, fo. 35 . Arg. two chev. paly of six az. and or. BIRT.

Arg. two cher. paly of six or and az. Bint. Tregareck or Tregarrick, Tregarrick, Cornwall; the beiress $\mathrm{m}$. Trenowth.

Arg. two chev. sa. Ash or AsHe, Twickenham, Middlesex; and Downton, co. Wilts; Baronetcy 1660-1734. AsHe or Esse, co. Somerset; and Sowton, co. Devon. Ashe, $V^{*}$. Ashe, Freshford, co. Somerset; Fifield, Heytesbury, and Langley Burwell, co. Wilts; co. Trim; Asbgrove, co. Limerick: Ashfield, co. Meath, originally Esse or Essecourt, Clyst Fornyson, co. Devon. Crodchisan, $V^{*}$. Esse, quartered by Yeo, Harl. MS. 3288, fo. 56 . Grigg, $V$. (? Hugham.) Kine. William de Kylaby, $V$. KYLahy. Krnn. Sire William de Lamboure, $N$. Milo de Lamburn, $F$. Sr. William Lamborn, Essex, $V$. William de LaBORNE (or LamBorNe, Harl. MS. 6137, A, or Lamburne, $E$. Lamborne. M'Laren or Mac Laren, Scotland. Rosethe. Stacnton; Cargins, co. Galway; Baronetcy .... ; and co. Nottingham. Trreell, Suffolk.

Arg. two cher. sa. a label of three points az. Kittelby or Kittleby, Steple, co. Salop. The label gu. KettlebY, co. Glaucester; co. Lincoln; and Steple, co. Salop.

Arg. two chev, and in the dexter chief a martlet sa. Stanton. But a mullet .... Ashe or Esse, co. Somerset.

Arg. two chev, and over all a pile voided sa. A TwiLt, Exeter, Harl. MS. 1538, fo. 1.

Arg. two chev. conjoined in fess sa. Halfenide; granted 1560 .

Arg. goutty de larmes two chev. sa. (? SAINT MaURe.)

Arg. two chev. couped sa. AtTElodxde.

Arg. two chev. of the first fimbriated sa. LaNgham, altered to Lugham (? for Hugham), Harl. MS. 1386, fo. 34 b.)
2 CHEVRONS cont.

Arg. two chev, coucbed vert. Codohmaster.

Az. two chev. arg. CHawers or CHaworth. Lathadi. Lathom. Lathum.

Az. two chev. arched couched and fretted arg. Bracegirdle.

Az. two chev. erm. WaLL, Suffolk. WALI, $V$. WALLIS.

Az. two chev. or. Sr.de Alfreton, $V$. Alfretton, $V^{*}$; the coheirs $m$. Latham and Chaworth. AIradlt, quartered by Piper. AufFenton. Breton, Leyrbreton, Essex, $V$. Sire Thomas de Chauworde, $N$. Chawells. Chawers. Chaworth, $V$. Thomas de Chaworth, $A$. Sr. Thomas Chaworte, $I ; J ; X$. Sir Christopher Chaworth, $R$. M. William Chaworth, S. Monsire de Chaworth, Y. Chaworth, Suffolk; Alfreton, co. Derby; and Kempsford, co. Gloucester. Thomas de Chelwinch, $A$, Harl.MS. 6137. Cheyney. Fitz-Randlph, co. Derby; and co. Nottingham. LathaM, quartering arg. an inescucheon within an orle of eight pierced 5-foils sa. LATHAM, quartering gu. a fess dancetty betw. six billets or. Lathum, $V$. RaNDolph, Ireland. Sheworth. Az. two chev. or a label gu. Monsire de Chinnorche, $Y$. The label of three points. Sir William de Chaworth, $I$.

Az. two chev. and in the dexter chief a mullet or. M. John Lyssoures, $X$; or Lysours, $Y$.

Chequy or and gu. two chev. sa. Clayton. Clayston, $V$.

Erm. two chev. az. BAGoT; Baronetcy 1627, Barony 1780. BaGoT, Pype Hall, co. Stafford. BAGOT, Blithfield, co. Stafford; Baronetey 1730. Lewis BaGot, Bishop of Bristol 1782, Norwich 1783, St. Asaph 1790-1802. Richard Bagot, Bishop of Oxford 1829, Bath and Wells 1845-54.

Erm. two chev. gu. Fanner. Fesrynor Fenmer Ferimor and Fermer, Norfolk; and Suffolk. Sr. John de St. Maure, R. St. MAUR or Sermour, Suffolk. Sille or Silley. Somer or Somner, Kent; and Suffolk. Charles Richard Sonner, Bishop of Llandaff 1826 , Winchester 1827. John Bird Sumner, Bishop of Chester 1828, Canterbury 1848-62.

Erm. two chev. gu. a label of four points az. Rauf de Seyrors, $G$.

Erm. two chev. gu. a label of five points az. Sire de Setnmor, $N$. .... de Semmatre, $F$. Sire Rauf le SEMIURe, $\ddot{J}$.

Erm. two chev. gu, a label of five points vert. Rauf de Seinmor, $E$. The label charged with as many fleurs-de-lis or. Nicholas de $\mathrm{S}$. Maure, $F$.

Erm. two chev, or. Sumner, Puttenham Priory, Surrey. Sonner, Hatchland Park, Surrey, quartering Holme.

Erm. two chev. paly of eight or and gu. RoPEr, late Viscount Baltinglass, 1716.

Erm. two chev. purp. Sr. John Selly, $V$.

Erm. two chev. sa. Sr. Richard Fenner, Suffolk, $V$. Illeign, Northumberland. Sr. de Iltey, $V$. St. Maure or Seymour, $V$. Sire John de Ylee, $O$.

Erm. two chev, engr. sa. HodghtoN.

Gu. two chev. arg. BAWde, co. Lincoln. Fentman. Sr. de Fetiplace, $V$. Fetiplace, co. Worcester. Fetriplace, $V^{*}$; and Chilrey, and Fern. ham, co. Berks; Baronetcy 1661-1743; the coheirs m. Pitts, Lacy, Bushel, and Broderick. Hyde, South Denchworth, and Kingston Lisle, 


\section{CEEVRONS cont.}

co. Berks. Hxde, Pangborne, co. Berks; derived from Alnwickes, in Letcombe Regis. Lawrence,Cirencester,co.Gloucester. Pannelu, Norfolk. Parnell, Baron Congleton, Rathleague, Queen's County. 'PAYNeLL, impaled by Sykes in church of St. Andrew Undershaft, London. Paynel, Bootbby, co. Lincoln. Pennell.

Gu. on a chev, arg. interlacing (another reversed) or. Sheddan, Scotland.

Gu. two chev. that in chief or the other arg. Wilus, Botesfleming, and Saltash, Cornwall.

Gu. two chev, arg. a bend sa. Parnell.

Gu. two chev. arg. on a label of five points az. five fleurs-de-lis or. Edmund de Waldeseuf, $F$. But fifteen. Alain de (WALDESEFTH, Harl. MS. 6137) WaLdefest H, $A$.

Gu. two chev. chequy arg. and az. Fitz-Piers. Gu. two chev. erm. Dominus de Cheveron, $V$. Ceneverton, $V *$.

Gu. two ehev. lozengy arg. and az. Fitz-Piers.

Gu. two chev. or. Counte de EsTerne or Strathern; $D$. Fallesle or Fallvesle, Northampton. Grendon. Mare. Le Counte de Stratherne, Scotland, $Y$. Waldescheff, $V$. WaLdSheFF. And with a label of three points az. WALDESCHEFE, $V$.

Gu. two chev. that in clief or the other arg. Wruls, Botesfleming, and Saltash, Cornwall.

Gu. two chev. vair. Monsire de Turnell or Turvelu, $Y$. Robert Turville, $Y$.

Lozengy arg. and sa. two chev, or. Oram.

Or two chev. that in chief gu. the other az. PoPe, Shrewsbury.

Or two chev. gu. Sir Thomas Daventer, $V$. Daventree, $V^{*}$. M. John de Fallesle, $S$. John Fallestey, $V$. Faldesley, co. Buckingham. Falvesley, $V^{*}$. Sr. Walter Fitz.Robert, $V$; and Northumberland. Sire Walter le Filz-Rouert, N. Monson, Reson, South Carleton, and Burton, co. Liucoln; Baronetcy 1730, Baron Monson 1728; quartered by Watson now Milles Baron Sondes. Mounson. Mounsor. RoBertfeld, Northumberland, $V$. Robartfierd. Le Counte de Stracherne, $Y$.

Or two chev. gu. in the dexter' chief a crescent sa. Sr. Thomas Faidesley, $V$. Salesley or Salkesley. But a 5-foil az. Fallestey, $V$. But a mullet sa. Sir William Robert, $W$.

Or two chev. sa. Alche. Greike. Kyme, $V$. Lamborne, Essex. M'Lelian. Mackleld. Maclellan, Bomby, Baron Kirkcudbright, 1633 , extinct ...., quartered by Lee. Manny.

Per chev. arg. and sa. two chev. counterchanged. GrymsBy.

Per chev. az. and arg. on each side of the chev. point a chev. of the second. Grimsir, $V^{*}$.

Per chev. gu, and arg. two chev, counterchanged. SAWLE.

Per chev. gu. and arg. two chev. in chief or. Tuckex, Ireland.

Per chev. gu. and erm. two chev. counterchanged. HaNKWELL, $V^{*}$. HaNkEwEll or SaNkewel, $V$. SANCEWELt or SANKWELl.

Per chev. sa. and arg. in chief two chev. arg. Grymsey, Cotton MS. Tiberius D 10, fo, 753 .

Per chev. sa. and arg. on each side of the chev. point a chev. of the second. Grymsby, $V$.

Per chev. sa. and arg. two chev. counterchanged. Grimsby, $V$. Gryissy.

Per chev. sa. and arg. two chev. in chief or. Grymsey.

\section{2 cHEVRONS cont.}

Per fess arg. and gu. on the first a chev. sa. and on the second another or. BEARDMone or BERDMore.

Per pale or and az. two chev. gu. Flashman. Purp. two chev. arg. Sr. de BAwDE, $V$.

Sa. two chev, arg. Butvillain and Butvlulan. Burlyn. Cecill, $V^{*}$. Thomas Cecylu, $V$.

Sa. two chev. erm. Miliard.

Sa. two chev. or. Burlyn.

Vair two chev. gu. Balner. Bellanx. Bellenx, $W$.

\section{CHEVRONS and in chief....}

\section{Annulet}

Arg. two chev, and in chief an annulet sa. Browne.

Beast

Or two cher, and in chief a lion pass. gu. Fitz-Ronard or Fitz.Roward, co. Buckingham.

Beasts

Sa. two chev, arg. in chief as many lions com. batant or. Chipeninam.

Birds

Az. two chev. or in chief as many martlets arg. BRITAIN or Briton, Lord Mayor of London 1294-97.

Gu. two chev. or in chief as many martlets arg. WiLLs, Ireland.

Canton

Arg. two chev. az. a canton gu. Dexter.

Arg. two chev, and a canton gu. Bertram D'ORL ....; in margin 'Credo OrLanston vel Cryoll,'E. Crioli, Croxton. Feton or Fitton, co. Chester. Fytton, $V^{*}$. Gawseworth. (? Hable or Hablex.) (? Keryell, Kent.) Kiriel, co. Leicester. Kyreli. Orby, Gos. worth, co. Chester. Orneby, $V^{*}$; adopted by Fitron on marriage with the heiress. Titron, $V^{*}$. Waspale or Waspoole. (" Werberton.) Arg. two chev. and a canton sa. (? DALBY.) The chev. engr. DaLBY, $V^{*}$.

Az. two chev, and a canton or. Rees, $V^{*}$.

Or two chev. gu. a canton az. Gegon Gigon or Jegon, $V^{*}$. Pope, co. Salop.

Or two chev, and a canton gu. Bevelu. Criell, $V^{*}$, or Kerriell. Criol, Albury, co. Hertford. Cryolll, $V^{*}$. Kenell, Kent. Kirriell, $V^{*}$. Kyreil, Sutton, Kent. Kxriall, $V^{*}$.

Or two chev. gu. a canton sa. M'Leise, Scotland.

on a Canton..... Anchor

Chequy arg. and az. two chev. gu. on a canton or an anchor sa. CLERKE; granted 1761.

$$
\text { ..... Annulet }
$$

Arg. two chev. sa. on a canton erm. an annulet of the second. Browne, Lord Mayor of London 1438 and 1448 .

$$
\text { .....Annulets }
$$

Or two chev. gu. on a canton of the last three annulets arg. Cryer.

$$
\text { .... Beast }
$$

... two chev. .... on a canton .... a lion pass. .... Cassior.

Arg. two chev. gu. on a canton of the second a lion pass. as the first. Orbaston. The lion ramp. De Orbaston, $V^{*}$.

Arg. two chev. gu. on a canton of the second a lion ramp. or. OLDSTON or OLlaston.

Erm. two chev. gu. on a canton of the last a lion pass. or. Orreby. 
2 CHEVRONS and in chief.... cont.

on a Canton cont. Beast cont.

Or two chev. gu. on a canton of the second a lion pass. arg. Fitz-Ronard. ORLEston. Reynard. Rohandes and Fitz-Rohandes, co. Leicester.

Or two chev. gu. on a canton of the second a lion pass. guard. as the first. KrrieIL.

$$
\text { .....Bends }
$$

Or two cher. gu. on a canton arg. three bends of the second. BaLas, $V^{*}$.

$$
\text { .....(Bird) Eagle }
$$

Arg. two chev. gu. on a canton az. an eagle wings endorsed or. JEGGINS or JEGoN.

Arg. two chev. sa. on a canton of the last an eagle displ. as the first. Pienson, co. Gloucester; Westminster; and Hitchin, co. Hertford; granted 157\%. The eagle displ. or. Pearson or Piefison, Westminster.

$$
\text { ....Falcon }
$$

Arg. two chev. gu. on a canton az. a falcon rising or. Jobn JEGoN, Bishop of Norwich 1603-18.

$$
\text { .....Crescent }
$$

Arg. two chev. gu. on a canton of the last a crescent as the first. (? HALL). HanLo, $V^{*}$.

Or two chev. gu. on a canton of the last a crescent arg. M. Nicholas Hanlo, $D$. Hawle.

$$
\text { ....Cross }
$$

Arg. two chev. on a canton of the last a cross bo. tonny fitchy or. MoDfERLEY.

Arg. two chev. gu. on a canton of the last a cross croslet as the first. Boolde or Bould.

Arg. two chev.gu. on a canton of the last a cross croslet fitchy gu. MOBERLY or MODBURLEY, $V^{*}$. Mobdurley.

Arg. two chev. gu. on a canton of the last a cross patonce or. BoLd, $V^{*}$. The cross patty. BALd Bold or BAwd; Cotton MS. Tiberius D 10. BoLd, $V^{*}$. 'The cross pometty fitchy or. Modberley, $V^{*}$.

$$
\text { ....Cup }
$$

Arg. two chev, gu. on a canton of the last a covered cup or. WATERBULToN or WATERBUSTON, Surrey.

$$
\text { .... Escallop }
$$

Arg. two chev. gu. on a canton of the last an escallop or. Pope, Collinson, Somerset, ii, 436.

Or two chev. gu. on a canton of the last an escallop as the first. CLAREE, East Barebolt, Suffolk.

$$
\text { ....Fleur-de-lis }
$$

Arg. two chev. gu. on a canton az. a fleur-de-lis or. Frebr. Freche, $V^{*}$.

$$
\text { ....4-Foil }
$$

Arg. two chev. sa. on a canton az. \& 4-foil .... Staunton, Staunton, co. Nottingham; the beiress $\mathrm{m}$. Charlton.

$$
\text { ....Hammer }
$$

Or two cher. gu. on a canton sa. a mallet arg. POPE, $V^{*}$.

$$
\text { ....Head }
$$

Or two cher. vert on a canton gu. a lion's bead erased arg. Henshall.

$$
\text { .....Heads }
$$

Or two chev. gu. on a canton of the last three leopard's heads as the first. Romenal, $V^{*}$. RoMeNALI, $V^{*}$.

$$
\text { ..... Key }
$$

Or two chev. gu. on a canton of the last a key as the first. Criall. De Cryoll alias Deicrow, Londou; and Enfield, Middlesex, 1634.
2 CHEVRONS and in chief....cont.

on a Canton cont. Mascle

Or two chev. engr. gu. on a canton of the second a mascle arg. ReYnardson, Plymouth, co. Devon; and Lord Mayor of London 1649; granted 1632. Reynardson, Holywell, co. Lincoln.

$$
\text { .... Mullet }
$$

Arg. two chev. gu. on a canton of the second a mullet as the first. Stanley. Stanlow, $V^{*}$. The mullet pierced. Staniey. Stanlow.

Arg. two chev. gu. on a canton of the last a mullet or. Pope, London. Warbilton, Cotton. $M S$. Tiberius D 10 . Warburton, $V^{*}$.

Or two chev. gu. on a canton of the last a mullet of the first. POPE, Hendall, Sussex; quartering Weston. POPE, $V^{*}$.

$$
\text { .... Roundles }
$$

Or two chev. gu. on a canton of the last five plates. Bronex, Kent.

$$
\text { ....W Wreath }
$$

Arg. two chev. gu. on a canton of the second a chaplet as the first. HaLL, $V^{*}$.

Chief

Az. two chev. or a chief chequy of the second and first. SHIEL, Ireland.

Or two chev. gu. a chief vair. St. Quints, $V^{*}$; and co. York. St. Quinton, $V$.

on a Chief..... Beast

Arg. two chev. sa. on a chief of the last a lion pass. as the first. INGLE.

$$
\text { .... Billets }
$$

Arg. two chev, gu. on a chief or three billets of the second. StapLL, $V$.

$$
\text { ..... Escallop }
$$

Arg. two chev. gu. on a chief of the last an escallop or. Pope.

$$
\text { ....5-Foil }
$$

Arg. two chev. gu. on a chief of the last three 5 -foils as the first. Bradnox.

Or two chev. gu. on a chief of the last three 5-foils arg. Broadnax. Brodnax, Kent; and co. Chester.

$$
\text { .... Palets }
$$

Arg. two chev. gu. on a chief or three palets of the last. STaylt.

$$
\text { .... Roundles }
$$

Arg. two chev. gu. on a chief of the last three bezants. SkILliNg, co. Hants; and Draycot, co. Wilts.

\section{Crescents}

Or two chev. gu. in chief as many crescents az. SingletoN, Ireland.

\section{Escallops}

Gu. two chev. and in chief three escallops arg. Parneli, Baron Congleton, 20 August 1841.

Gu. two chev. arg. in chief as many escallops or. Fettiplace, co. Hants.

\section{Heads}

Arg. two chev. sa. in chief as many hart's beads cabossed gu. LAVERING.

Fleurs-de-lis

Or two chev. gu. in chief thrce fleurs-de-lis of the last. BARBER, $W$.

\section{Mullets}

Az. two chev. or in chief as many mullets of the last. Sr. de Breton, $V$; and Hassted, Essex. The mullets six.pointed. Breton.

Az. two chev. or in chief three mullets of the last. Breton, $V$.

Quarter

Arg. two chev. and a quarter gu. Chrelle, Kent, Cotton MS. Tiberius D 10, fo. 645. FxtToN, 
2 CHEVRONS and in chief.... cont.

Quarter

Gawsworth, co. Chester, $V$. John KyneLL, $X$. OrRedy, $V$. Touch. Roger de WapaIL, $E$. Roger WapaILle, $X$. And with a mullet for diff. sa. Roger WAPPAYLE, $X$.

Arg. two chev, engr. and a quarter sa. Walter Dalby, co. Chester, $V$.

Az. two chev, and a quarter or. Rees, $V$.

Or two chev. gu. and a quarter az. Gigon or JEGON, $V$.

Or two chev. and a quarter gu. Robert (Bertram, Harl. MS. 6137) de CrIELL, $A$. B ertram de Criole, B. Cryoill, $V$. Sir Nicolas de Kyriel, $N$. Kyriell, Kent, $\boldsymbol{V}$. M. Nicole Krryell, $S$. Bertram D'ORL .... (credo OnLeston vel Cryoli, $E$; but De Crues, $E$, Harl. $M S$. 6137.)

on a Quarter.... Beast

Arg. two chev. gu. on a quarter of the last a lion ramp. as the first. William de Orbaston, $V$.

Or two chev. gu. on a quarter of the last a lion pass. arg. Sire Fitz-Ronard, $N$. The lion ramp. M. William de OrLanston, $D$. William de Orleston, $A$.

Or two chev. gu. on a quarter of the last a lion ramp. as the first. William de OrLanstone, A, Harl. $M S .6137$.

\section{.....Beasts}

Arg. two chev. gu. on a quarter of the last so many lions pass. in pale as the first. John de Orbebi, $F$.

\section{.....Bendlets}

Or two chev. gu. on a quarter of the last three beudlets arg. Sr. George BaLas, $V$.

$$
\text { .....Crescent }
$$

Arg. two chev. gu. on a quarter of the last a crescent as the first. Nicolas HaNDLo, $V$; or Hanlo, Cotton MS. Tiberius D 10, fo. 645 .

Or two chev. gu. on a quarter of the last a crescent arg. Nicolas de Haulo, $A$.

$$
\text { .....Cross }
$$

Arg. two chev. gu. a quarter of the last a cross croslet fitchy or. MoberLey, $V$. Sr. John Modburiey, co. Chester, $V$.

Arg. two chev.gu. on a quarter of the last a cross patonce or. Sr. John de BoLd, co. Lancaster, $V$. The cross patty. BoLd, $V$.

$$
\text { ....Fleur-de-lis }
$$

Arg. two chev. az. on a quarter of the last a fleurde-lis or. Esteven Streche, $X$.

Arg. two chev. gu. on a quarter az, a fleur-de-lis or. Freche, $V$.

\section{..... Heads}

Or two chev. gu. on a quarter of the last three leopard's faces as the first. Raffe (Romenal, Harl. MS. 6137) Romenalle or Romevalle, A. Romenati, $V$. Romney, Middleton, Kent; granted 1615

$$
\text { ..... Mullet }
$$

Arg. two cbev. gu. on a quarter of the last a mul. let as the first. Stanlaw, $V$. The mullet or. M. Gefferey Wariminon, S. Sr. Gefferey Warburton, co. Chester, $V$.

Or two chev. gu. on a quarter sa. a mullet arg. Pope, $V$.

\section{....Wreath}

Arg. two chev. gu. on a quarter of the second a chaplet as the first. HALL, W.

Roundles

Arg. two chev. sa. in chief three ogresses. McLaggan, Scotland.
2 CHEVRONS betw. or within...

Annulets

Arg. two chev. sa. betw. three annulets gu. Spaxon or Spaxton, Scotland.

Beasts.... Deer

Per fess embattled az. and gu. two chev. or betw. three bucks trippant arg. attired and hoofed of the third. Robinson, Batt's House, co. Somerset; Baronetcy 11 November 1823.

$$
\text { ....Lions }
$$

Per pale indented az. and sa. two chev. betw. three lions ramp. or. CURTLER, Bevere House, Worcester.

Birds .... Eagles

Az. two chev. betw. in chief as many eagles and in base a crescent or. BRettell; granted 1850 to W. Edwards, Burway, near Ludlow, on taking the name and arms of Brettell and Vaughan.

\section{....Falcons}

$\mathrm{Gu}$. two chev. betw. in chief as many falcons belled rising or each charged on the breast with a cross patty fitchy az. and in base a cross as above of the second. Masters, Ewdon, co. Salop.

\section{.....Doves}

Az. two chev. or betw. three doves (? wood. wallises) ppr. Pinfotd, Dunstable, co. Bedford.

$$
\text { .... Ducks }
$$

Arg. two chev. betw, three drakes the backs sa. bellies arg. Ynys Enlli yn LLYN.

$$
\text { .....Eagles }
$$

Gu. two chev, erm. betw. three eagles displ. or. Parsons, Barbadoes. Sir Jobn Parsons, Lord Mayor of London 1704; and Humphrey Parsons, Lord Mayor 1731.

$$
\text { .....Falcons }
$$

Gu. two chev. betw. three falcons arg. beaked legged and belled or. HADLEY, co. Hereford; and London; granted 1685.

$\mathrm{Gu}$. two chev. or betw. three hawks belled arg. HEDLEY, quartered by Dent.

$$
\text { .....Herons }
$$

Sa. two chev. or betw. three lierons arg. Heron. ..... Martlets

Arg. two chev. gu. betw. in chief three martlets sa. and in base a heart crowned ppr. Oliver, Scotland.

Arg. two chev. betw. three martlets sa. TANFietD or Tansfield, Copswood, Essex. Tanfietd, Essex ; co. Northampton; and co. York. Sr. Robert Tanfeild, $V$. TanfiLd, temp. Edward IV, $\mathrm{Harl}$. MS. 6137, fo. 44 .

Az. two chev. betw. three martlets arg. Hunt, Speckington, co. Somerset.

Sa. two chev. or betw. three martlets gu. BALDRY, London.

Sa. two chev. betw. three martlets or. Caseborne, Caseborne, Kent.

$$
\text { .... Popinjays }
$$

Az. two chev. or betw. three woodwallises ppr. PINFOLD, Dunstable, co. Bedford ; granted $\mathbf{I 5 0 1}$. .....Eagles

Arg. two chev, gu. betw. six eagles displ. az. Tusses.

\section{.... Martlets}

Arg. two chev. betw. six martlets gu. Cooke, co. Worcester. Cookes, Bentley; descended from Cookes, Nargrove, co. Worcester ; quartering Jennetts and Denham. Gennet or Jennet, Nargrave, co. Worcester. Jennets, $V^{*}$. But the martlets two three and one. JENETs, $V$. 
2 CHEVRONS betw. or within.... cont.

Birds cont. Martlets cont.

Arg. two chev. gu. betw. six martlets three two and one sa. Gennett. Jennet.

Or two chev. gu. betw. six martlets sa. Worcester College, Oxford; for its founder, Cookes, Norgrove, co. Worcester; quartering sa. a buck's head cabossed or ; Baronetcy 1604-1701.

\section{Bordure}

Arg. two cbev, az. within a bordure engr. gu. Rockiey. Tirreli, Thornton, co. Buckingham; Heron, and Spingfield, Essex ; Gepynge, Suffolk; and Ryegate, Surrey. Tyren, Boreham House, Essex; Baronetcy 1809. Sir Ro. bert Trrele, temp. Edward IV, Harl. MS. 6137 , fo. 44. Sr. Thomas 'Tyrrell, $V$. T'yrrell, Stanford, co. Berks ; the heiresses m. Hatch and Nicholl.

Arg. two chev. gu. within a bordure engr. az. Tykreli, Rushton, co. Staffurd, 1583.

Alg. two chev. within a bordure gu. Crioll or Keriell, co. Leicester. Grandon.

Arg. two cher. within a bordure engr. gu. Kymber. Macklelian, Barclay, Scotland.

Arg. two chev. gu. within a bordure engr. sa. Grendon.

Arg. two chev. sa. within a bordure engr. gu. Tirrell. 'I'yrrell.

Arg. two chev. within a bordure sa. M'Lares, Scotland. Staunton, co. Nottingham.

Arg. two chev. sa. within a bordure engr. of the last. Staunton, Longbiidge, co. Warwick; quartering Crynes. M. Tbomas de Staw'Ton, $S$.

Erm. two chev. gu. within a bordure az. Mushet, Burnbank. The bordure charged with eight crescents arg. Mushet, Holland.

Erm. two chev. gu. withiu a bordure sa. Musentr. Gu. two chev. within a bordure arg. Dean, co. Lincoln; and Saltingstall, co. York; usurped by Deane. Deane or Deene, co. Liucoln. Deen, co. Lincoln, $V$. M. John Paynel, $S$.

Gu. two chev. within a bordure arg. over all a bend sa. Parnell, Harl. MS. 1404, fo, 110. Pavnell. But a bendlet. Paynell, $Y$.

Gu. two chev, arg. within a bordure engr. of the last. Pannell, Norfolk. Paynell, $V$.

Gu. two chev, arg. within a bordure or. 'TonnILI.

Gu. two chev. arg. within a bordure or over all a bend sa. Parnell.

Gu. two chev, within a bordure or. Thomas de Charneles, $E$. Charnells, co. Leicester. Daubeney. Tharnel, $V$. Thornell, $V^{*}$. TORNILL.

Or two chev. within a bordure az. MUSAnD, Stavely, co. Derby.

Or two chev. gu. within a bordure engr. az. Brewas.

Or two chev. within a bordure gu. Albany. Sr. de Barmoyt, Cotton MS. Tiberius D 10, but Beauvorre, $r$. Dalbenay or Darbenay. William Dadbeny, Beauvoir, $B$, or Beauvaire, $P$. Dawbeny. DaWBNex.

Or two chev. gu. within a bordure engr. of the last. DABIGNi, $V^{*}$.

Or two chev. gu. witbin a bordure sa. bezanty. Chauncey. Chauncy, $V^{*}$. Vannell, $V^{*}$.

Or two chev. sa. within a bordure gu. $\mathrm{M}_{\mathrm{AC}}$ LAGAN or M'LAGAN, Scotland.

\section{Buildings}

Or on two chev. betw. three wells az. watered arg. as many lion's gambs erased gu. I'OWELL, co. Oxford.
2 CHEVRONS betw, or within.....cont.

Buckles

Or two chev. gu. in chief as many buckles az. in base a horn of the last stringed of the second. Orue, Magdrum, co. Fife.

Sa. two chev. or betw. four buckles three in chief and one in base arg. Bradbury, co. Lancaster. Castle

Arg. two chev. betw. three castles gu. Castle. Chevrons

Erminois two chev. az. betw. as many gu. Every, Egginton, co. Derby ; Baronetcy 1641.

\section{Crescents}

Az. a chev. gemel or betw. three crescents (of the second, Harl. MS. 1008, fo. 45) arg. Sire Johan de Hotor, co. Gloucester; $N$.

Escallops

... two chev. .... betw. three escallops .... William de Wrkehame, Bishop of Winchester 13fi7-1404, seal " in Curia Ward."; Add. MS. 5538 , fo. 1 .

Erm. two chev. engr. az. betw. three escallops gu. Hope, Northall Court, Middlesex.

Gu. two chev. betw, three escallops arg. Parkinges. Parisins. Perinins.

Gu. two chev, betw, three escallops or. DeEves. Sa. two chev. betw. three escallops arg. Bove, Feversham, Kent. With six escallops two three and one. BOADE. But with twelve escallops six three and three. Boode, Essex.

Fire

Arg. two chev. az. betw. as many flames of fire ppr. Welis. But three flames. Wells, Piercefield, co. Monmouth. Wells, 1716. WeLLS, co. Worcester.

\section{Fleurs-de-lis}

Arg. two chev. betw. three fleurs-de-lis gu. Barbor; Upcot, co. Somerset; and Fremington, co. Devon. And with a bordure of the last. Barber.

Arg. two chev. wavy gu. betw. three fleurs-de-lis sa. Pilland, co. Devon. (? Prllande, co. Devon, Harl. MIS. 1386, fo. 35 b.)

Arg. two chev. betw. three fleurs-de-lis sa. Fanshaw, Barking, Essex.

Arg. two chev. wavy betw, three fleurs-de-lis sa. Pilland, co. Devon. Pilland, $V^{*}$. Pyllond, co. Devon, $V$. Pyllonde, $V^{*}$.

Gu. two chev. engr. betw. three fleurs-de-lis or. Carruthers, Howmains. Caruthers or Carruthers, Scotland. And with a bordure arg. Carruthers, Annandale.

Or two chev. erm. betw. three fleurs-de-lis sa. Fanshaw, co. Derby.

Or two chev. ermines betw. three fleurs-de-lis sa. Fanshaw.

Or two chev, betw, three fleurs-de-lis gu. BarBer, Suffolk; and co. Hertford.

Flowers

.... two chev..... betw. as many roses and a crescent .... FeLstead, Great Yarmouth.

Gu. two chev. betw. in chief as many roses and in base a fleur-de-lis arg. WIDIrore, Hockington, co. Buclingham.

Arg. two chev, betw, three roses gu. Wrтенam, Baroness Wenman 1834, heiress of WYкенаנ, Swalcliffe, co. Oxford; (? an error).

Arg. two chev. sa. betw. three roses gu. Wickнam, Collinson, Somerset, ii, 373. WYkeHå, $V *$. Sr. Thomas Wrktam, $V$. The roses seeded or barbed vert. DREw, Collinson, Somerset, ii, 312. Pynk. St. Mary Winchester or New Coliege, Oxford; and College of the 
2 CHEVRONS betw, or within.... cont.

Flowers cont.

Vurgin, Winchester; for the founder William de WIKEHAME (signature 1367), Bishop of Winchester 1367-1404. WICKHAMI Or WYKEHAM, Swalcliffe, and Tythrop House, co. Oxford, quartering Wenman; Sherborne, co. Dorset; Horsington, and Frome, co. Somerset; Abung. don, co. Berks; and Kent.

Arg. two chev, gu. and sa. betw, three roses ppr. JEANE, jmpaling erm. on a bend gu. three bezants, Collinson, Somerset, j, 95.

Az. two chev. or betw. three roses arg. John Roscel or Russelu, Bishop of Rochester 1476, Lincoln 1480-94.

Or two chev. engr. vert betw. three roses gu. harbed and seeded ppr. lLBERT, Rill in Buckfastleigh, Bowlingsleigh, and Horswell House, co. Devon; quartering Roope.

Sa. two cher. betw. three roses arg. Weicer, Kingsgate House, Rolvendon, Kent.

Sa. two chev. erm. betw. three roses arg. barbed and seeded ppr. WELLER.

$$
\text { 3-Foils }
$$

Arg. two chev, az. betw, three 3 -foils (sometimes slipped) vert. De Cardonnel, Churton, Northumberland; granted 1773; quartering ermines on a chief or tbree griffins segreant sa.; quartered by Lawson, and by Rice through Talbot. The chev. vert. CARDONNEL (in error).

Or two chev. az. betw. three 3-foils slipped vert. SPIERS, Oxford. Thomas SPYer, Huntercombe, co. Oxford, $W$. SPYER, Walgrove, and Shortletts, co. Berks; and co. Oxford ; granted 1500. SPYRE, $V^{*}$

Or two chev. betw. three 3-foils slipped sa. ABDAy, Kent, $W$. ABDy, Albins, Essex; Baronetcy 1(i60-1759, quartering Abdy; and Baronetcy 1849; descended like ABDY, Moores, Essex, Baronetcy 1660-62, from ABDY, co. York; Felix Hall, Essex; and Chobham Place, Surrey; Baronetcy 1641 .

Per pale or and vert two chev. hetw. three 3-foils counterchanged. Wickens, Stochtbrewen, co. Northampton; confirmed 23 May 1640. The 3 -foils slipped. Wiggins.

\section{5-Foils}

Arg. two chev, betw. three 5-foils gu. Florack. Az. two chev. betw. three 5.foils or. CuIpsham.

Gu. two chev. betw. three 5-foils or. ChiesLy, Kersewell.

\section{Fusils}

Az. two chev. arg. betw. three fusils or. Chalons. Sussex.

Sa. two chev. or betw. three fusils arg. each charged with a martlet of the first. CABorne.

\section{Garbs}

Az. two clet. betw, in chief as many garbs or in base a pair of swords in saltire ppr. pomels and hilts gold. REeD, quartered by Cresswell.

Gu. two chev. compony az. and arg. betw. three garbs or. BARON, $V^{*}$.

\section{Gouttes}

Arg. two chev. gu. betw. three gouttes-de-poix. Pitches.

Arg. two chev. sa. betw. gouttes-de-larmes. St. MaURe.

Heads .... Human Figure

Per chev, gu. and arg. two chev. counterchanged betw. in chief as many helmeted beads in profile vizor up ppr. garrished or and in base a lion ramp. sa. GRIFFith. The lion regual. Griffith, Llwynduris, Cardigan.
2 CHEVRONS betw, or within.....cont.

Heads cont. Beasts (Boar)

Az. two chrev. betw. three boar's heads erased or. Cotin.

$$
\text { .... (Deer) }
$$

.... two chev. .... betw. three stag's heads ca. bossed .... John de Beckingham, seal 1385. Arg. two chev. gu. betw. three liuck's heads ca. bossed sa. Bucknall. Bucknell, Crowcombe, co. Somerset.

Arg. two chev. sa, betw. three (buck's, $V^{*}$, another hart's) stag's heads cabossed gu. LaVERING, $V$.

Arg. two chev. betw. three buck's heads cabossed sa. Buckworth, London : and co. Hertford

$$
\text { ..... (Dog) }
$$

Sa. two chev. erm. betw. three greyhound's heads erased arg. collared gu. RELF, Wore, and Ashburnham, Sussex. The collars ringed or. RaLPH. WatTS.

$$
\text { .....Birds (Eagle) }
$$

Arg. two chev. sa. betw. three eagle's beads erased gu. EDwards.

$$
\text { ....Human Figure }
$$

Arg. two chev. gu. betw. three Moor's heads sa. SANDES.

Arg. two chev, betw. three Moor's heads sa. Sandes or Sondes, Jees Court, Kent.

\section{.....spears}

.... two chev. .... betw, three coronels .... Frenie, feodary, or land-steward, of the Berkeley estates while in the hands of Henry VIII; formerly on brass in church at Berkeley, co. Gloucester.

Heart

Arg. two chev. gu. betw. in chief a human heart of the last and in base a hat sa. with an ostrich feather ppr. Huth, London.

Leaves

Arg. two chev. az. betw. three leaves erect vert. Pierson, Loudon.

Arg. two chev. sa. betw. three oak leaves erect ppr. Pierson; confirmed 21 October 1577.

Arg. two chev. betw. three oak leuves vert. Hokele or Hokle, $V$. Huckley or Hukeley. OCCLE or O'KuLL.

\section{Legs.... Beast}

Ermines two chev. betw. three lion's gambs erased and erect or. Pawson, Allerton Gledhow, near Leeds, co. York; and Shawdon, Northumberland; quartering Hargrave.

Or two chev. betw. three lion's gambs erased gu. Poweld, Penkelly, co. Carmarthen.

$$
\text { .... Human Figure }
$$

Az. two chev. betw. three legs couped at the thigh arg. Gámon, Minchenden House, Middlesex.

$$
\text { Letters }
$$

Arg. two chev, betw. three text T sa. Tofre.

$$
\text { Lozenges }
$$

Sa. two chev. arg. betw. three lozenges of the second each charged with a martlet of the first. Cabourne or Cabron, Thrasthrop, co. Lincoln. Mascles

Erm. two chev. betw. three mascles sa. ScHaw, England. SHaw, London.

\section{Monsters}

Or two chev. az. betw. in chief as many griffins segreant gu. and in base on a mount vert an oak tree ppr. Cohen, Brixton.

Per pale or and sa. two chev. letw. three griffins pass. counterchanged. Eveleigh.

Mullets

Az. two chev. betw. as many mullets or. Brayton. 
2 CHEVRONS betw, or within.... cont.

Mullets cont.

Gu. two chev. betw. in chief as many mullets and in base a rose arg. seeded or. Swete, Trayne, and Oxton, co. Devon. SWEet.

Alg. two chev. betw. three pierced mullets gu. SANDES.

Arg. two chev. gu. betw. three pierced mullets sa. SANDES.

Arg. two chev. sa. betw. three mullets gu. DAvY, Beaford, co. Devon.

Arg. two chev. betw. three mullets sa. Francey. Norтн,Walkeringham,co. Notingham; granted 1600. North, $V^{*}$. The mullets pierced. Frainceis, $V^{*}$. Fraunseys, $V$. Rominey, co. Berwick. The chev. engr. John SranBURx, Bishop of Bangor 1448, Hereford 1453-74.

Az. two chev. betw. three mullets arg. Brayton, Thomas Sutton, $V$.

Az. two chev. arg. betw. three mullets or. SuTton.

Az. two chev. betw. three mullets or pierced gu. Breton.

Erm. two cher. one sa. the other az. betw. three mullets in pale of the last. Paxton, Watford, co. Herts; and Middleton Hall, co. Carmarthen; granted 13 May 1806.

Gu. two chev. betw. three mullets arg. Northe, $V$.

Or two chev. "betw. three mullets in pale gu. Paxston.

Per pale arg. and sa. two chev. betw. three pierced mullets counterchanged. Monse; Sprowston Hall, Norfolk; quartered with Boycott. Pheons

Arg. two chev. gu. betw. in chief as many pheons sa. and in base a fleur-de-lis all within a bordure wavy az. Mayne, Powis, and Logie, co. Clackmannan; derived from Lockwood. Mayne, Viscount Newhaven, 1776.

Arg. two chev. betw. in chief as many pheons sa. and in base a fleur-de-lis az. within a bordure engr. of the last. Mayne, Farley Hill, co. Berks.

Arg. two chev. gu. betw. in chief as many pheors and in base a unicorn's head erased sa. MaIN, Loch wood, Scotland.

Arg. two chev. gu. betw. in chief three pheons and in base a dexter hand couped sa. MAlN, Lochend.

\section{Roundles}

Az. two chev, arg. betw. three bezants. Kydermaster, Sussex.

Az. two chev. erminois betw. three bezants. Kydermaster, London; and Coushall, co. Warwick.

Az. two chev. or betw. three bezants. Kidderminster. Richard Kydermester, Abbot of Winchcounbe, $U$.

\section{Wreaths}

Arg. two chev. vert betw. three chaplets or. Burrough, Suffolk.

Arg. two chev, betw. three chaplets vert. Burroughes, Long Stratton, Norfolk; quartering Ellis; a branch of Burrovghes, Bur. lingham Hall, Norfolk, quartering Negus and Burkin.

Erm. two chev. sa. betw. tbree chaplets gu. Borovgh, Middlesex, $V$.

Per chev. arg. and erm. two chev. sa. betw. three chaplets gu. Borovgr. Wings

.... two chev. .... betw. three dexter wings erect .... Richard YIveley, seal 1357, V.
2 CHEVRONS betw. or within....

and in chief...

\section{Canton}

Az. two cliev. erm. betw. three martlets arg. a canton or. Hunt, Compton l'auncefoot, co. Somerset, quartering Husey. on a Canton

Or two chev. az. betw. three ravens sa. on a canton of the second a staff erect as the first en. twined with a suake ppr. Crowfoot, Beccles. on a Chief

Arg. two chev. within a bordure gu. on a ohief of the second an escallop or. Pope, Marnehull, co. Devorn; and co. Dorset.

Arg. two chev. betw. three wolf's beads sa. on a chief of the last an escallop enclosed by two round buckles as the first. Cumborn, Moate Castle, co. Westmeath.

on a Quarter

Arg. two chev. gu. within a bordure or on a quarter of the second an escallop gold. William PoPE, $V$.

\section{On 2 CHEVRONS}

\section{Annulets}

Or ou two chev. sa. as many annulets of the first. M`Clemlan, Edinburgh.

Birds

Gu. on two chev. arg. as many martlets of the first. Paynell, $V$.

Arg. on two chev. az. four birds ... Polgreen, Polgreen, near Fowey, Cornwall.

\section{Chevrons}

Arg. on each of two cher. sa. another chev. couped of the first. LanghaM, altered to LughaM (? for Hugham), Harl. MS. I386, fo. 34 b.

Arg. on two chev. az. four couched dexter and sinister or. CHEYNEY.

Crescents

Or on two chev. sa. as many crescents arg. M'Clellan, Gutton.

\section{Fleur-de-lis}

Gu. on two chev. arg. a fleur-de-lis in the uppermost az. Hyde, Romsey, co. Hants.

Gu. on two chev. arg. a fleur-de-lis in the uppermost of the first. Fother.

\section{Fleurs-de-lis}

$\mathrm{Gu}$. on the uppermost of two chev. arg. three fleurs-de-lis as the first. John Fotherby, $V$.

Or on two chev. gu. three fleurs-de-lis of the first. BARBER or BARBERY.

Erm. on two chev. sa. six fleurs-de.lis or. Smrth, Kent; granted by Camden, $W$.

\section{Flowers}

Arg. on two chev. sa. six roses or. Monnis.

5-Foils

Vert on two chev, arg. six 5-foils gu. MusweiL; granted by Lovel.

Millet

Az. on two chev. or a mullet in the uppermost sa. Breton, Essex.

\section{Mullets}

Arg. on two chev. sa. as many mullets of the first. Esse, Esse Ralph; from which derived Ashe, co. Devon.

Arg. on two chev. sa. as many mullets or. Sr. de Esse, co. Devon, $\boldsymbol{V}$.

Quarterly az. and arg. in the second and third quarters a chev. sa. charged with three mullets of the second over all on a bend sa. as many eagles displ. of the first. Howghton. 
Nails

\section{Ou 2 CHEVRONS cont.}

Arg. on two chev, sa. ten horse-nails or. Cleveley. Clovel or Cloveli. Clovile, $\boldsymbol{V}$. Ciovyie or Clonvyle, West Hanfield, Essex. Pales

Arg. on two chev. az. four palets or. Bretr, Cornwall.

Roundles

Arg. on two chev. sa. as many plates. Mackielian, Ediuburgh. M'Clemiand, Scotland.

Arg. on two chev. engr. sa. six bezants. Rothwel., Ewerby, and Stapleford, co. Lin. coln.

Arg. on two chev, engr. sa. ten (bezants. Rothweli, $V^{*}$.) plates. Poshweli. Rotheweli, co. Lincoln, $V$. RoTHWELL, $V$.

\section{On 2 CHEVRONS and in chief....}

on a Canton.....Beast (Lion)

Sa. on two chev, arg. six mullets of the first a canton or charged with a lion pass. gu. Gill, co. Hertford.

\section{.....Coronet}

Arg. on two chev. sa. six bezants a canton gu. charged with a mural crown of the third. RothwelL, Southampton; granted $1 \mathrm{Marcb}$ 1687.

on a Chief.... Beast (Lion)

Arg. on two chev. sa. as many fleurs-de-lis or a chief az. charged with a lion pass of the third. Syyte, Essex.

Arg. on two chev. sa. six fleurs-de-lis or a chief az. charged with a lion pass. of the third oppressed on the shoulder by a lozenge gu. Sr. John Smith, Baron of the Exchequer, $V$.

\section{on 2 cHEVROINS betw. or within....}

on a Canton.... Beast (Lion)

Sa. on two chev. arg. betw. in chief a canton gu. charged with a lion ramp. guard. or and in base a 5 -foil of the second three mullets in the upper chev. as the field. GILI.

Sa. on two chev. arg. betw. in chief a canton or charged witb a lion pass. guard. gu. and in base a pierced 5 -toil of the second three pierced mullets in the lower chev. as the field. (iIII. Bokeland, co. Hertford, $W$.

Sa. on two chev. arg. betw. in chief a canton or charged with a lion pass. guard. gu. and in base a 5.foil of the second six mullets as the field. GrLI, co. Cambridge; Wyddial Hall, co. Hertford; and Wraysbury, co. Buckingbam; quar. tering Canon.

\section{Birds}

Arg. on two chev. betw. three escallops sa. six martlets or. Draper, co. Leicester.

\section{Bordure}

Gu. on two chev. within a bordure arg. six crosses patty sa. Deane, Tilney Marsh, Norfolk. Escallops

Arg. on two chev. betw, as many escallops sa. six martlets of the first. Draper.

\section{Flowers}

Erm. on two chev, engr. az. betw. three roses gu. barbed and seeded ppr. ten bezants. RотнWELL, Sunning Hill, near Bolton, quartering Heywood and Crompton.

\section{Heads}

Arg. on two chev. engr. vert betw. three talbot's heads erased gn. six slipped 3 -foils or. BELL, Haughley, Suffolk.
On 2 CHEVRONS and in chief.... cont.

\section{Roundles}

Az. on two chev. .... betw. three plates eight ogresses. KIDderminster InN or Six Clerks' OFFICE.

\section{Wells see Buildings}

\section{CHEVRONS}

.... three chev. .... Amundevile, Cotton MS. Julius F 8, fo. 59. Eıworthe, Collinson, Somerset, iii, 525.

.... three chev, arg. Froghal..

Arg. three chev. braced .... DEAsE, Ireland.

Arg. three chev, az. Sir John Lewknor, $Q$; (? in error, Harl. MS. 6589 and 6595.)

Arg, three chev, engr, az. CoTHER.

Arg. three chev, braced az. Bracinenbury.

Arg. three chev. gu. ARCHDEckne ARchDEkne or Erchdekin. Sr. Robert Banastre, lord of Newton in Makerfield, and Walton-le-dale, co. Lancaster; the heiress $m$. Langton. BANESTER, co. Lancaster. Sire William Banestre, $J$. BOLD or BOLDE, quartering sa. a cross arg. Erchedederne. Granden. Grandon, co. Lejcester. Houghton. John de Langton, Bisbop of Chichester 1305-37. Langton, Langeton, co. Leicester, temp. Edward I ; quartering arg. a cross flory (anotber, moline) sa.; a heiress $m$. Fleetwood. Sr. .... LdnGton, Baron of Walton, co. Lancaster, $\ddot{R} ; V$. Tho. mas Langton, Baron of Newton, $Y$. Langton, Lowe in Hindley, co. Lancaster; quartering arg. an eagle displ. with two heads vert. Langton, Ledall, co. Lancaster. Langton, Walton, co. Chester. Richard Lovghen, Tytleston, co. Glamorgan, 1730. LovgeER, Tythegston, co. Glamorgan. Peyting, co. Lincoln. Ravensberg, $Z, 489$. St. Maure. Singleton, co. Lancaster. Sullie, co. Devon. Talbot. Monsire de Waceville, $Y$. Waternili, Essex. Sire Johan de Watevile, $N$. Watevili,e. WatVill, Essex.

Arg. three chev. gu, an anumlet for diff. Langton, Heton, Cumberland.

Arg. three chev. gu. a martlet in the dexter chief for diff. sa. Sir Roger Watevile, $L$; or DE Watevile, $N$.

Arg. three chev, gu. a label of as many points az. Barantine, Essex. Sr. Nicolas de Barington, Essex, temp. Edward I, $V$; or Baringtone, $N$. Barrington, Limerick; and Cullinagh, Queen's County ; descended from Barrington, Barring ton Hall, Essex ; Baronetcy 16 11-1833; $Z, 444$. Barrington, Barony and Viscounty 1720. Shute Barrington, Bishop of Llandaff 1769 , Salisbury 1782, Durham 1791-1826. Gerard. M. Christopher de Langeton, $S$.

Arg. three chev, and a label of as many points gu. Gerard. The label vair. Grandon, co. Leicester.

Arg. tbree chev, gu. over all a lion ramp. sa. WINTHORP.

Arg. three chev, gu. over all as many lions ramp. or. Cromwers, co. Huntingdon.

Arg. three chev, over all a fess gu. ANDBLy, $V$. A NDBY or' AnDly. AUDelbye, Harl. MS. 1404, fo. 4. AUNDBY.

Arg. three chev. engr. gn. Sr. John Wareyn, $V$. WARYNe, Harl. MS. 1386 , fo. 34 b.

Arg. three chev, per ebev. sa. and gu. Sr. Theobald FERIEY, $V$.

Arg. tiree chev. per pale az. and gu. Merton. 


\section{CHEVRONS cont.}

Arg. three chev. sa. Adam de Arcedeacon, $A$. Sr. de Archdeacon, Wigmore, co. Devon, $V$. Archdeacon, co. Devon; and co. Hertord. Archidecknie. Blackburn. Chambers. John Creseley, $V$. Deoyle. Deyle. Edfrby (rightly in pencil ENDERBY) impaling the same coat, $V$. Grymesby. I,ane, Ipswich Suffolk. Ede Lercedeakne, A, Harl. MS. 6137, fo. 94. Sire Thomas Le Ercedekne, $N$. Lowdham. Mancy. ManNey, Harl. MIS. 1407, fo. $73 \mathrm{~b}$. Ness, Scotland. Newnarch. Trecarreld, Trecarrell,Cornwall; a heiress m. Harris. Wrgmore.

A rg. three chev. sa. a label of as many points gu. Geffery. Kettreby, co. Salop. The label of five points. Gefrai le ERcederEne, $E, F$

Arg. three chev, and in the dexter chief a fleurde-lis sa. WIKe, $V^{*}$. WyKe, $V$.

Arg. three chev. the uppermost couped in the centre chief sa. A quartering of Golldesburgh, co. York; Harl. MS. 1487, fo. 125.

Arg. three chev, braced sa. Brackenbury, Sellaby, co. Durbam; quartering Bellewell, Josley, Denton, Wickliffe, and Elerton. Brackenbury, Scremby Hall, co. Lincoln. BRAKINGBERY, $V$.

Arg. three cher, braced sa. Hedworth, Durham. Arg. three chev. voided sa. Hung HAM.

Alg. three cher. sa. over all a bend erm. Enderbie, co. Bedford.

Arg. three chev. sa. over all a pale erm. ENDERBY, co. Bedford; Harl. MS. 1404, fo. 103.

Arg. three chev. sa. over all ten martlets gu. 'Trenewita.

Az, three chev, arg. Aspall, co. Northampton. Thomas De la Leie, $E$. Leukenur, $V^{*}$. Sire Thomas de Leukenore, $N$. Thomas Leuknor, $Y$. Roger de Lewkenor, $A$. Sir John Lewknor, $Q$. Sr. de LewhNor, $V$. Lewknor, West Dean, Sussex; and co. Worcester. Lurnor. And with a label of five points or. M. Roger de Lewryor., $D$.

Az. three chev, or. AsHroole. Sire Robert Aspal, N. Sr. de Aspall, Suffolk, temp. Ed. ward I, $V$. Chaworth, Suffolk. Latham. Lewrior, West Dean, Sussex; and co. Worcester. Sir Roger LEwknore, temp. Edward IV, Harl. MS. 6137, fo. 44. WALDEN.

Az. three chev. or a label of as many points arg. St. Almerizth.

Az. three chev. braced or. Friz-HugB, temp. Henry V. WICKENDEN.

Az. three chev, or over all a fess gu. Town of Monvoutr.

Barry of eight arg. and or over all three chev. engr. sa. Harpeley, Suffolk, $V$.

Erm. three chev. ermmes. Postred.

Erm. three chev, one gu. betw. two sa. Gallot, France.

Erm. three chev. gu. Monsire de Clare, $Y$. Patian or Pathyne. Pioger le Pectenin, $F$. PetMryn or Petoryn. Sr. Roger le Pertevin, co. Lincoln, $V$; or Paytenyn, Cotton MS. Tiberius D 10 ; Peyteum or Pictanieny, $V^{*}$. Sir Roger Peyteiyn, N. Peyton. Roger Peytouin, N, Harl. MS. 6589, fo. 39 b. St. MaUr or Sermour, Suffolk. Bartholomew de Saquevile, $B$. M. Thomas Sakevill, $S$. SeickMore. Selfe. Selie. Monsire John Selley, 'Breton,' Cotton MS. Tiberius D 10. Selley, Cornwall. Sille or Silley. Silly, St. Wean, Trevelver, and Heligan, Cornwall. Suller. Sully.

\section{CHEVRONS cont.}

Erm. three cher, engr. gu. Telfatr, That Ilk.

Erm. tliree chev, sa. Langtree, Langtree, co. co. Lancaster. Langtrey, co. Lancaster; and Howlett, co. Northampton; quartering erm. three bars az. Postred. Repes or Repps, West Walton, Norfolk. Sr. deReppes, Norfolk, $V$. John Reppis, 1 . Sr, de Ripes, Cotton MIS. Tiberius D 10. Siraluman. Wise, co. Devon. Gu. thiree chev, one arg. betw. two or. BAwDE, co. Lancaster.

Gu. three chev, two arg, and one or. Bawde, co. Lancaster.

Gu. three chev, arg. DE Avan, afterwards Williajs, Aberpergwm, co. Glamorgan, quartering Einion ap Collwyn. Aven Aveney or Avery, co. Gloucester. Sire Leysen de Avene, $N$. Avery, co. Gloucester, $V$. Sire William Banastre, $N$. Banester, Westminster. Bannister. John BaUd (son of William BaUd, Knight), buried in church at Rawreth, Essex, temp. Henry IV, $V$. M. William Baude, $S$, or Bawde, Essex; Y. Bawd. Bawde, Curringham, Essex; and co. Bedford. Bladen, Glastonbury, co. Somerset. Chalzhil, Middlesex. Finerbeke. Evans, co. Somerset. Evans, Gnoll Castle, co. Glamorgau (as arms of Jestyn ap $\mathrm{Gwrgant}$ ) quartered by Mackworth. Gedinge. Gurgant, Bishop of Llandaff 1149 . 8:3. Nicholas ap Justine or Justrne. Sire Leysen de Arene, co. Gloucester, temp. Ed. ward I, $N$; descendant of Morgan Vychan ap Morgan ap Caradoc (lords of Avon) ap Jestyn (Prince of Glamorgan, 1090) ap Gwrgant ap Ithell; from this stock descended LErson, Neath, co. Glamorgan, through Rees ap Morgan Vychan; and Lysons. Hempsted Court, co. Gloucester, through Jobn Lrsons, ob. 1587, son of Jobn ap Lyson ap Thomas (lord of Avon) ap John ap Leyson ap Morgan Vychan. LleWELLEN (quartering Davis) ap Griffith Vaur ap Jevan ap Llewellyn ap Kinyrig ap Madog second son of Jestyu. Llewellyn, quartering Turberville. Llewerars, Peterstone-super-Ely-Coedriglan, and Stockland, co. Glamorgan. Lluelis, co. Hertford. Lyson (in error Liyne, Noble, Life of Crommell.) From Jestyn (quartered by Nicholl) also descended Jones, Dol-yn-Edeirnion; MytTley, Myttley; and Newton, Haithly. MeEk. Meeke. Mikelley or Milkiliy, $V^{*}$. Sire Robert Milkeleye, $N$. Milkeley or Mrkeley, co. Hereford. Mykelley or Mylkeley, co. Herl. ford, temp. Edward I, $V$. NunE, Thorp, co. Northampton. Parker. Nicholas Singleton as claimant against Thomas BACDE, 1393-5, Harl. MS. 1178 fo. 5. Thomas, Michael's Town, co. Glamorgan. WILlia is, formerly de AraN, A berpergwm, co. Glamorgan, quartering Einion ap Collwyn. And with a crescent for diff. Bruce Pryce, Dyffryn, co. Glamorgan; quartering Bruce and Knight with Lewis.

Gu. three chev, braced arg. Mathews, Ireland. $\mathrm{Gu}$. three chev. arg. over all as many lions ramp. or. Richard WrLlians alias Cromwell, $V$.

Gu. three chev. chequy arg. and az. Frrz. Piers. But compony. Fitz-PeIrs, $V^{*}$. But countercompony. Fitz-Piers, $V$. Fitz-Piers, Earl of Essex 1199-1227.

Gu. three chev. erm. Sr. de BArNard, $V$. Bayinam. Elderbeke, Essex. Hankewell or SANEE TELL, $V^{*}$. And with a label of three points or. BaYNarD. 


\section{CHEVRONS cont.}

$\mathrm{Gu}$. three chev. the first or the others arg. BAWDE, co. Lancaster.

Gu. three chev. one or betw. two arg. Bawde, co. Lancaster.

Gu. three chev. or. Town of Cardiff, co. Glamorgan. HoRn or Horne, co. Uxford, 1730. LeE, Middlesex; granted 1592. Mathews, England. Matruews, London; Swansea; and Down. Monfichetr, Essex. Montfichetr. Sr. de Mount-Fichet, $V$. Mount-Fychett, $V^{*}$. St. Owen, co. Gloucester. Monsire St. OWen, $Y$. Sire Gilberd de Seint Ouweyn, $N$. Sir.de Seynt Owen, co. Gloucester, $V$.

Gu. three cliev. or a label az. Richard de Montfichet, $B$. The label of three points. Montfichets, Stansted Moutfichett, Essex. But five points. Clary. But seven points. Richard de Monfichet, seal, Cotton MS.Julius, C 7, fo. $136 \mathrm{~b}$.

Gu. three chev. vair. Fitz.Geffrex. 'Torneld, co. Worcester. Sire Nicholas Torvile, $N$. Sr. de Torvil, $V$. Turvile, quartered by Leveret. Turvile, Aston Flamville, and Husband's Bos. worth, quartering Fortescue; and Normanton Turvile, co. Leicester, extiuct $17 \% 6$.

Or three chev. az. Askeby. Sr. de Whelple, $V$. Or three chev. ermines. ClaRE, co. Salop.

Or three chev. gu. Augustinian Priory at ANGLEsex, co. Cambridge, impaled with or a cross gu. Town of CAkDIFF, co. Glamorgan. Clare, Earl of Gloucester, $V$; and co. Glou. cester; quartered by Nevill, $U$. Gilbert de Ciare, Conte de Gloucestre, $P ; Y$. Sr. de Everx, of France, $V$. Fitz-Gilbert. Countee de Glocestre, $D ; F$; $J$; or Glojcestre, $E$; $G ; L ; N ; Y$. Le Conte de Gloster, $B$; impaled by Ralph, Baron Montbermer, for the Earldom of GLoUcester, $K$; Earl of Clare, Gloucester, and Hertford, $Z, 49,101,140,141$, $379,441,442,444,445$, quartering Despenser 379. City of Glovcester: assumed for the see ly Giles Thompson or Touson, Bishop of Gloucester 1611-2. IVERYE, Harl. MS. 1407, fo. $73 \mathrm{~b}$. O'Brien, Earl of Clare. WadHULL.

Or three chev. gu. a crescent az. Crare, Pembroke; quartered by Mathew.

Or three chev, gu. a label az. William de Clare, $B$. Sr. Richard de Clare, $L ; N$. Thonas de Clare, $C$. Every. The label of three points. Clare. Fitz-Clare or Gloucester. Gerard. But five points. Sire Gilbert de Clare, $J$. M. Thomas de Clare, $D, E, F$.

Or three' chev. gu. over all a lion ramp. of the secoud. HASARD, Syngleton, Essex, temp. Edward IJI. Sr. Haslard de Sinaleton, Essex, temp. Edward I, $V$.

Or three chev. gu. over all a fess arg. John de Monemuth, $C$; or Monemue, $Y$. The fess az. John de Monemu, $F$; or Monemue, $B$; or Monemuth, $E$; but Guy de Monemueth, $Y$. But the fess gu. charged with three griffins se. greant arg. Sr. Thomas Filtold, Essex, temp. Edward $\mathbf{I}, V$.

Or three chev. gu. over all a crosier in bend arg. and sometimes a label of three points .... Cistercian Abbey at Langthorne at Bogh, Stratford, ol Stratford Langthorne, Essex.

Or three chev. engr. gu. CHancey or Chanceys, Edgcott, co. Northampton; granted 1546. Chauncer. Chauncy, co. Northampton, $V$.

Or three chev. per pale az. and gu. Malitin (in error for) MERToN, Bishop of liocheeter.

\section{CHEVRONS cont.}

Or three chev. per pale one gu. and az. betw. two az. and gu. Merton College, Oxford, for its founder, Walter de Menton, Bisliop of Roches. ter 1274- $\tau$.

Or three chev. sa. Berton, $V^{*}$. Richard de Breon, $V$. Man, Kent. Manny, $Z, 207,2118$. Terry de Manny, $Y$. Sr. Walter Manney, $Q$, Harl. MS. 6595. Sr. Walter Manney, Essex, $V$. Manny's Carthusian Priory in London, afterwards Sutron's Charterhouse Hospital. Mawne, Cotton MS. Tiberius D 10. Sutton, Norfolk. Sr. John de Sutron, $R$. M. John Sutton, $S$. Richard Sutron, Nolfolk, $Y$. WatTon. Yer.

Or three chev. vert. CoRnell or Connull. Connwall, co. Warwick. Sr. Richard Cornyll, co. Warwick; $V$. Cornille alias Tornille, Harl. MS. 1407, fo. 73 b.

Per pale arg. and gu. three chev. fimbriated counterchanged. SAY.

Per pale arg. and or three chev, gu. LANGTON, Broughton Tower, co. Lancaster.

Per pale arg. and sa. three chev. counterchanged. Littleborne.

Per pale az. and gu. three chev, as the field fimbriated arg. SAY, co. Devon, Harl. MS. 1538; fo. $17 \mathrm{~b}$.

Per pale az. and gu. three chev. counterchanged of the field and fimbriated arg. Sr. Willian SAX, V. But fimbiriated or. Sir John SAY, brass at Broxbourne, co. Hertford, Waller.

Per pale az. and gu. three chev. arg. voided of the tield. SAr, Weston-Favell, co. Northampton, and Blechingdon, co. Oxford.

Per pale az. and sa. three chev. or. Bounninge, Harl. MS. 1385, fo. 53. Bowring.

Per pale erm. and gu. three chev. counterchanged. Willey, Houghton, Northumberland.

Per pale erminois ard gu. three chev. counterchanged. Weluex, Houghton, co. Durham.

Per pale gu. and az. three chev. counterchanged of the field and fimbriated arg. SAY.

Per pale gu. and az. three chev. couped (arg. and voided counterchanged, or) counterchanged and fimbriated arg. GEX alias SAYE, Essex, Harl. MS. 1465, fo. 6 b.

Per pale gu. and sa. three chev. arg. MEe.

Per pale gu. and sa. three chev, errn. Wise, Hinton, co. Cambridge.

Per pale or and arg. three chev. sa. over all a label of as many points gu. СноLwick, Chol. wich in Holberton, Oldstone in Blackawton, and Farringdon House, co. Devon; the coheirs m. Lear, Fowell, and Cholwich.

Per pale or and sa. three chev. counterchanged. SHerlock, Surrey.

Per pale sa. and arg. three chev. counterchanged. CHolwich.

Sa. three chev. arg. John ARUndell, Gwarnick, Cornwall, 1613 ; in church of S. Mary, Lambetl, Add. MS. 6409. Carewell, $V$. Carwell. Cecill or Cessell. Ereedeeke. Kerlelaynon and Lanlayron, Cornwall; Cotton MS. Tiberius D 10. Lalerion, co. Devon. Lambaron, CoInwall. LANDSIEYDOWN LANLEYRON LANLAIRON or. Langlaron, Cornwall. Sire Serle Le Lanleyeroun, $N$. Sr. de Lansladron, Cornwall, temp. Edward $I, V$. LANSLADRON or Nansladron, temp. Edward $I$. Nastadran, Cornwall. Trerice, Trence, Newlyn, Cornwall; the beiress m. Arundel. Treris, $V$. Wxse, co. Devon. 
3 CHEVRONS cont.

Sa. three chev. erm. Gwiss or Wise, Mount Wise in. Stoke Damarell; quartering Brett; and Sydenham, co. Devon; the heiress $m$. Tremayne. Proysted, Norfolk. Trebet. Wise, Ford House, and Wonwell Court; quartering Ayshford. Wise, St. Olave's, 1714. Sr. de Wyse, Cornwall, $V$.

Sa. three chev. erm. a crescent or. Wise.

Sa. three chev. or. Archdeacon. Sr. John Sutton, Wyvenhall, Essex, V. Synton, (in pencil in) W. Walton. Watton.

Vair three cliev. gil. Balner. Bernall.

\section{CHEVRONS and in chief ...}

\section{Beast}

Arg. three chev, and in chief a lion pass. gu. Penkeveli, or Penkevill, Penlievell, Cornwall, temp. Fdward 11 .

Or three cher, and in chief a lion ramp. gu. St. Gulton.

Per pale or and sa. three chev. counterclianged in the dexter chief a lion ramp. of the second. FRJER, ' of the mountains of Dublin,' Harl.MS. 1441.

\section{Beasts}

Or three chev. gu. in chjef two lions ramp. sa. Lacy. Longespee, Earl of Ulster, Harl. MS. 1407 , fo. $\mathrm{T4}$.

Canton

Arg. three chev, and a canton gu. Crioll or KeRIOLL.

Arg. three chev. gu. a canton sa. Hardiman or HaRDYMaN.

Arg. three chev. gu. a canton vair. Langton, Broughton Tower, co. Lancaster.

Az. three chev. arg. a canton erm. Gainsborough, Crowburst, Surrey.

\section{on a Canton.... Beast}

Erm. three chev. gu. on a canton of the second a lion pass. or. Oreby. OrReBY, $V^{*}$; aud co. Chester.

Erm. three chev. gu. on a canton of the second a lion pass. guard. or. Orbx, Croyland ; Baronetcy 1658-1724; the herress $m$. Hay, and Hunter.

Erm. three chev. gu. on a canton of the second a lion ramp. or. OrRery, co. Chester.

Erm. three chev. sa. on a canton gu. a lion pass. guard. or. ORBY or ORREBY, co. Lincoln.

\section{...Castle}

Arg. three chev. sa. on a canton of the second a tower as the first. Carvalle, Harl. MS. 1047 , fo. $74 \mathrm{~b}$.

\section{.....Saltire}

Vert three chev. arg. on a canton az. a saltire of the second. BOCKLEY. Chief

Arg. three chev. braced and a chief az. Thomas Beitoft, $V$.

Arg. three chev, gu. a chief chequy of the first and second. Truscoat or Truscutr.

Arg. three chev. braced gu. a chief chequy of the second and first. ConRie or CoRry.

Arg. three chev. gu. a chiei vair. St. Quintin.

Arg. three chev, sa. a chief gi. FIELDS.

Arg. three chev, and a chief sa. RatFond.

Arg. three chev, braced and a chief sa. Cleborne, Kellerby, co. York. Cribunne, Cliburne, Westmorland.

Az. three chev. braced and a chief or .. M. Henry Fitz-Hugr, $S$. Dominus Fitz-Hugr, $\bar{V}$.
3 CHEVRONS and in chief.... cont.

Fitz-Hugi, $Z, 490$. Robert Fitz-Hugi, Bishop of London 1ł31-6. FIт\% HugH, co. Oxford, and co. York, temp. Edward III ; quartered by Catherine Parr, sixtb wife of Heniy VIII; $Z, 490$. And with a label of three points gu. Sr. Henry FItz-HewgH, L, Harl. MS. 6137.

Gu. three chev. braced or a clijef arg. Munton. Gu. three chev. braced vair a chief or. WyveLL, Croydon, Surrey, and Little Burton, co. York. (The new cost of) Wyvell, Osgodby, co. York, Harl. MS. 1487, fo. 322 b. Wrvill, Burton Constable, co. York; Baronetcy 1611. WyviL, Nesham, co. Durham; quartering Pigot, FitzRandall, and Scroop.

Gu. three chev. each emhattled on the top arg. a chief or. (The ancient arms of) WYVELL, Osgodby, co. Yurk, Harl. MS. 1487, fo. 322 b.

Or three chev, braced and a chief gu. Pilcher. Or. three chev. gu. a chief vair. HERBERT. Le Sire de St. Quintine, $Y$. Edward St. Quintrine, $Y$. Herbert de St. Quintin, $Y$. Sr. Herberd SAYNT Quintyn, $M$. Herbert de Seinquintyn, $E ; N$. Sentquint, $E$. Herehert de St. Quinton, $F$. Quintin. Robert de St. Quinten, $A$; but the chief vairy in four rows arg. and az., $A, H a r l$. MS. $613 \%$.

Or three chev. gur. a chief vert. ST. QUintyn, Harl. MS. 1407, fo. 74 .

Vert three chev, braced .... a chief or. ALLEsLEY, co. Warwick.

\section{on a Chief.... Annulets}

Sa. three chev. braced or on a chief of the last as many annulets sa. EwBANK.

$$
\text { ....Bar }
$$

Or three chev. giu. on a chief arg. a har wavy az. Robert de ST. Quintin, Llan Blethian.

$$
\text { ....Lion }
$$

Arg. three chev. braced gu, on a chief of the second a lion pass. betw. two mullets as the first. MaLLOM, Walter-Acton, Norfolk; granted 4 May, 1685.

$\mathrm{Gu}$. three chev. braced arg. on a chief or a lion pass, az. Ellishake, co. York. Malmam, Elslake, co. York, $V$. And with a fleur-de-lis or in the centre fret. MaLHome, Elslake, co. York; Harl. MS. 1487, fo. 144.

Gu. three chev. braced arg. on a chief or a lion pass. guard. az. Elsake, co. York.

Gu. three chev. vair on a chief arg. a lion pass. guard. az. Allaton Allatton or Alton.

$\mathrm{Gu}$. three chev. vair on a chief arg. a lion pass. of the first. Sr. Jobn Alation, $V$. Allation, $V^{*}$.

Sa. three chev. braced arg. on a chief or a lion ramp. gu. HaRHER.

\section{..... Crescent}

Az, three chev. braced or on a chief of the se. cond a crescent sa. charged with a mullet arg. Hewston, Wigtoft, co. Lincoln.

$$
\text { .....Crosses }
$$

Sa. three chev, arg. on a chief of the second three crosses croslet as the first. Parnther.

$$
\text { ..... Mullet }
$$

Gu, three chev. braced compony arg. and sa. on a chief or a mullet of the third. WYvell, co. York, Harl. MS. 1404, fo. 103.

Sa. three chev. braced vair on a chief or a mullet of the first. Wrveln, Little Burton, co. York. 
3 CHEVRONS and in chief.... cont. on a Chief cont. Mullets

Arg. three chev. braced sa. on a chief gu. as many mullets of the first. $D_{A N B Y}, V^{*}$.

Arg. three chev. braced sa. on a chief of the second so many mullets as the first. DanBy, Thorpe. DANBY, co. York, Harl. MS. 1487, fo. 275. DanBY, Danby, and Yafford ; the heiresses m. Acklom, Rokeby, and Strangwayes.

$$
\text { .... Roundles }
$$

Arg. three chev. braced sa. on a chief of the last as many bezants. Sr. Raufe Chadiberlyn, Gedding, Suffolk, $V$.

Sa. three cbev. braced or on a chief of the last as many ogresses. EwBank or EwBancke, Durham.

$$
\text { .....sun }
$$

Gu. three chev, arg. on a chief az. a sun in splendour or. Fonneread, Edmonton, Middlesex; and Christ Church Park, Suffolk; de. scended from La Rocbelle.

\section{Coronet}

Vert three chev, erm. in chief a naval crown betw. two lion's heads erased or. DomINICK, Great Marlow, co. Buckingham; granted 1720.

Fillet

Arg. three chev. braced sa. in chief a fillet and as many mullets of the second. DANBY: Yafford, co. York, $V$. The mullets pierced. DANBY, quartered by Hawkesworth, Harl. MS. 1487 , fo. $172 \mathrm{~b}$.

\section{Flowers}

Az. three chev. or in chief two roses arg. Trent, Collinson, Somerset, ii, 264, impaling paly arg. arg. and sa. two fleurs-de-lis counterchanged. 5.Foils

Arg. three chev. braced gu. in chief as many 5 -foils az. a chief of the last. LaURENCE or LAWRENCE, Ireland.

\section{Hands}

Arg. three chev. and in chief two dexter hands couped gu. Span.

\section{Head}

Gu. three chev. braced or in chief a lion's bead erased arg. Bousfield. Mullets

Arg. three chev. braced sa. in chief as many mullets of the last. DawBy alias Danbye, Harl. MS. 1407, fo. 74 b. The mullets pierced. Stamps, Norfolk.

\section{Roundles}

Or three chev. sa. in chief as many ogresses. MAN, Long Sutton, co. Lincoln. Sun

Arg. three chev. braced az. in chief a sun gu. FITZ-HUGH.

\section{CHEVRONS betw, or within....}

\section{Beasts ..... Deer}

Sa. three chev. betw. as many roebucks tripp. arg. Rogers, Netherthorpe, co. York.

$$
\text { ..... Lions }
$$

$\mathrm{Gu}$. three chev. arg. betw. as mayy lions ramp. or. Cromwell alias Williadis.

\section{Birds}

Arg.threechev. betw. as many birds sa. WALDoure. .... Martlets

Arg. three chev. gu. betw. as many martlets sa. Singleton, Laucaster, $V$. Singleton, Broughton, Lancaster; Dykelborough, and Mendlesham, Norfolk; Suffolk, 1716; and Cornwall. Singleton, Aclare, co. Meath; quarteringCorbet.
3 CHEVRONS betw. or within.....cont.

Birds cont. Martlets cont.

Arg. three chev. betw. as many martlets sa. Singleton, $V^{*}$.

Gu. three chev. betw. as many martlets arg. Singleton, Singleton Hall, co. Lancaster.

Arg. three chev. gu. betw. six martlets sa. Singleton.

\section{Bordure}

Arg. three chev. az. within a bordure engr. gu. ARderne.

Arg, three chev. witbin a bordure gu. WiLLs.

Arg. three chev. gu. within a bordure sa. Sire Robert de WADEville, $O$.

Arg. three chev. gu. within a bordure engr. sa. Sr. Alexander Selieey, $V$. Watervill, $V *$ Sr. Robert Watevise, $L$; or de Watevilue, temp. Edward I, $V$. Wille.

Arg. tbree chev. gu. within a bordure indented sa. Sire Robert de Watevile, $N$.

Arg. three chev. gu. a bordure vair. LANGToN.

Az. three chev. or within a bordure arg. Aspalc, Suffolk. Thomas de Aspal, seal.

Gu. three chev. within a bordure arg. DEane or DeEne, co. Lincoln.

Gu. three chev. arg. within a bordure engr. sa. Rande.

Gu. three chev, arg. within a bordure 'risercele' sa. William Rande, $Y$.

Gu. three cbev. or within a bordure engr. az. in the dexter chief a mullet of the second. Brewes.

Gu. three chev. one vair enclosed by two or betw. three crosses croslet fitchy of the last. BIAKEY, Huntingfield, Suffolk.

Or three chev. gu. within a bordure engr. az. W. Breus, $F$. Brewase, $\boldsymbol{V}$. Johan de Brewase, $E$. Winyand.

Or three chev. gu. within a bordure indented az. John de Brusse, $C$.

Or three chev. gu. within a bordure az. bezanty. Clane', co. Leicester.

Or three chev, gu. within a bordure s\&. Clane, Dabiton, co. Worcester. The bordure engr. Sr. Nicolas de Clare, $L$.

Or three chev. gu. within a bordure indented sa. Sire Nicholas de Crare, $N$.

Escallops

Gu. three chev. betw. as many escallops arg. MACBRIDE, Fingland.

Fleurs-de-lis

Arg. three chev. betw. as many fleurs-de.lis .... Minchin.

\section{Flowers}

Arg. three chev. sa. betw. as many roses gu. WICKHAM, Harl. MS. 1407, fo. 74 .

\section{4-Foils}

Az. three chev. arg. betw. as many 4-foils or. Aspin, co. Buck!ngham.

5.Foils

Per pale arg. and sa. three chev. betw. as many 5 -foils counterchanged. MaNey, Linton, Kent. John Maney, Biddendon, Kent, $V$. Mayne, Essex. MaYNe, Harl. MS. 1404, fo. 94 ; MAINY or MaYnye, $A d d$. MS. 5507, fo. 208; Kent. Mayney. Myne, Kent. Ommanney.

\section{Heads.... (Beasts) Deer}

Az. three chev. betw, as many hart's heads cabossed or. HARTFORD.

$$
\text { .....Goats }
$$

Sa. three chev. betw. as many goat's beads erased arg. Bulkiey, co. Stafford. 


\section{CHEVRONS betw. or within.....cont. Mullets}

Az. three chev. betw. as many mullets or. DeLafosse.

Sa. three chev. betw. as many mullets arg. TiRRey, London; confirmed 13 June, 1616.

Sa. three cher. arg. betw, as many mullets or. Sherys or Smeys, $V$.

\section{Reptiles}

Sa. three chev, erm. betw. as many adders arg. Wise, Warwick Priory. The adders erect or. Wise, Brompton Park, Middlesex. But serpents embowed vert. WISE.

\section{Roundles}

Arg. three cher. sa. betw, as many ogresses. Cuthbert, Ireland. Singleton, Ireland. UMEIER Or UNNELER, $V$. UMENER. UMLER, $V^{*}$. UNNESTER, $V^{*}$.

Or three chev. gu. betw. ten torteaux three three three and one. City of GLOUCESTER, assigned 15 August 1652 . Sprigs

Arg.three cher. betw. as many pine slips vert. FIG.

\section{On 3 CHEVRONS}

\section{Annulets}

Erm. on three chev. sa. as many annulets in the uppermost arg. Plonsted, Plomsted, Norfolk.

Sa. on three chev. arg. as many annulets or. BUTHALL.

Arg. on three chev. sa. fifteen annulets or. Convile or Colwatl, Kent (in error).

\section{Beast}

Or on three chev. (? braced in base) sa. a lion pass. in the centre one as the first. Monsire Walter de MaUncy, $Y$.

Or on three cbev. sa. a lion pass. guard. "in the top of one of them' as the first. Sr. Walter Manney, Q, Harl. MIS. 6589. But in the uppermost chev. Walter Mannye, founder of the Carthusian Monastery of the Salutation at London: at the Charterhouse 1619.

Or on three chev. sa. a lion ramp. in the centre one as the first. Sr. Walter Manney, $Q, A s h$. mol. MS. 1120.

\section{Chevrons}

Per pale arg. and gu. on three chev. as many couped and counterchanged. SAY.

Per pale az. and gu. on three chev. arg. as many of the field. SAY, Weston Favell, co. Northampton; and Blechingdon, co. Oxford.

Per pale az. and gu. on three chev. arg. as many conped of the field. SAY, co. Devon, Harl. MIS. 1538 , fo. $17 b$. SAY, Weston-Favell, co. Northampton, Harl. $M I S .1094$, fo. 198 b.

Per pale az. and gu. on three chev, arg. as many couped and counterchanged of the field. Sr. William $\mathrm{S}_{A Y}, V$. Sir John SAY, and SAY, Dodington, and Weston-Favell, co. Northampton, Harl. MS. 1553 , fo. 142 b.

Per pale az. and gu. on three chev, or as many couped and counterchanged of the field. SAY, Harl. MS. 5803, fo, 59. Sir John SAY, brass at Broxbourne, co. Hertford; Waller.

Per pale gu. and a\%. on three chev, arg. as many couped and counterchanged. SAY. But all the chev. couped. GEY alias SAYE, Essex, Harl. MS. 1465, fo. 6 b.

\section{Escallops}

Arg. on three chev. sa. as many escallops of the first. MaYne, Ireland.

Arg. on tbree chev. sa. as many escallops in the centre cher. or. Hellysges, $V$.

\section{On 3 CHEVRONS}

\section{Fleurs-de-lis}

Or on three chev. gu. nine fleurs-de-lis .... John Feltgrave (in pencil Fitz-Rafe), $\ddot{X}$. The fleurs-de.lis arg. Sire William Frtz RAFE, $N$, Harl. MS. 6589 ; or Fitz RAFFe, $N$, IIarl. MS. 6137 , or Fitz.Rauf, N, Harl. MS. 4033; Fitz Raufe, $V^{*}$. Fitz Raulf, Suffolk. The fleursde-lis as the field. Fitz-RaUlF, Suffolk.

Or on three chev. gu. eleven fleurs-de-lis five three and three arg. Sr. William Fitz.RAUFE, Pebmersh, Suffolk, $V$. But unnumbered. Sir William Firz-RAUF, $N$; and Lansd.MS. 855 ; or Fitz RAFE, Harl. MS. 5803.

\section{5-Foils}

Arg. on three chev. az, as many 5-foils of the first. Alderson.

Fretty

Or on three chev. gu. fretty arg. Fitz RaLPH. Leaves

Sa. on three chev. arg. fifteen leaves vert. WISE. Mitre

Or on three chev. gu. a mitre in the centre chev. arg. See of Grodcesten, as borne by Bishop Fowler, ]691-1714. Mullets

Az. on three chev. or as many mullets $\mathrm{gu}$. Croasdatle.

Or on three chev. vert as many mullets arg $\mathrm{H}_{\mathrm{AG} \text { AR. }}$.

Gu. on three chev. arg. nine mullets sa. Bairnsfather or Barnesfather, Scotland. Nails

Arg. on three cher. sa. fifteen nails or. Cronvrle Clovell Clovile or Clovyin, West Hanfield, Essex.

\section{Roundles.....(Bezants)}

Arg. on three chev. sa. thirteen bezants five five and three. Thomas LE ARCHDEACON or ARCHDEKIN, $E$.

Arg. on three cher. sa. fifteen bezants. Archmiacre. Collingwood, Northumberland. Cutbert Colvyle, Cornwall, $V$. Colwell, $V$. Cuthbert or Cuthburst. Cutbert, $V^{*}$.

Or on three chev. sa. fifteem bezants. CoLvile Colvyie or Colwell.

$$
\text { .....(Plates) }
$$

Arg. on three chev, sa. fifteen plates. MAIABASSELL. The chev. engr. Rotherell.

Or on three chev. sa. fifteen plates. MaLabasseld, $V$.

$$
\text { ....(Bezants) }
$$

Arg. on three chev. sa. bezants. Coliser, Northumberland. Colvile or Colyvill, Cumberland; Kent; co. Lincoln; co. Northampton; and Northumberland. Cutbert. Thomas L'ERCHDIACRE, $Y$.

Or on three chev. sa. bezants. Malabasse.

On 3 CHEVRONS and in chief...

\section{Canton}

Arg. on three chev. gu. so many mullets of the first a canton as the second. CAsson, Millom, and Frith Hall, Cumberland; Newfield in Seathwaite, co. Lancaster; and Blaenyddol, Festiniog, co. Merioneth.

Sa. ou three chev. arg. as many ogresses a canton or. Colquitr.

on a Chief.... Mullets

Arg. on three chev. sa. so many escallops as the first a chief of the second charged with three mullets like the field. Mayne. 


\section{CHEVRONS}

Erm. four chev. gu. Every. Orebye, Harl. MS. 1465 , fo. $122 b$.

Erminois four chev, two az. betw, as many gu. Everx, Egginton, co. Derby; Baronetcy 1641. Or four chev. gu. Everid. Every, Egginton, co. Stafford, impaling Mosley, Shaw, Stafford, 12; Devon; and Somerset; Collinson, Somerset, iii, 24, 302: (? assumed by) Fewtreld; Collinson, Somerset, i, 18.

Or four chev, engr. gu. Chancer or Chanceys, Edgcott, co. Northampton; granted 1546.

Or four chev. sa. Mamdye, Harl. MS. 1407, fo. $74 b$. MANNDy, Harl. MS. 1465, fo. $122 b$.

\section{CHEVRONS and in chief....}

Erm. four chev. gu. on a canton of the last a lion (passant, OrEBY, $V^{*}$ ) statant or. Sr. Phillip OrREbY, temp. Henry III, $V$.

\section{CHEVRONS}

Arg. five chev. sa. Hougham, London. Sutton. Az. five chev. or. DENEw. And with a label of as many points gu. Creythorns.

Or five chev. az. Avering. Evening (in error for) Evering, Evering, Kent.

Or five chev.gu. Abrincis or Averinges, Folkestone, Kent. Strongbow, Earl of Clare.

Or five chev. sa. Every, Kent.

\section{CHEVRONS and in chief....}

Erm. five chev. gu. on a canton of the second a lion pass. or. ORREBY, Hagneby, co. Lincoln, temp. Henry III ; and co. Chester.

\section{CHEVRONS}

Arg. three pair of chev. interlaced fesswise at each end an annulet (az. WASTLEY, gu. WASTLAY, $V$.

Arg. six chev. alternately gu. and sa. Fartegh, co. Devon.

Arg. six cher. three sa. and as many gu. FARLEGH or FerLey.

Arg. six chev. sa. Robert de Hughasr, $A$. HunghaM.

Per pale az. and gu. six chev. arg. SAY, WestonFavell, co. Northampton; and Blechingdon, co. Oxford.

\section{CHEVRONELLY}

Chevronelly of four arg. and gu. Whithorse.

Chevronelly of six arg. and sa. Grywsey.

Chevronelly of six giv. and arg. Chalkhill, Middlesex. SAWLE.

Chevronelly of six gu. and erm. HaNkEweli or Sankewell, $V$. SanckWEll or Sankwell. Chevronelly of six sa. and arg. Grinisiy, $V$.

Chevronelly erm. and gu. Roger Peitwyn, $Y$.

\section{CHIEF}

(For coats with a chief and a charge over all, see the charge with a field 'per chief'.)

\section{See also Per Fess.}

.... a chief indented .... Thomas de Appueby, Bishop of Carlisle 1363-95. And with a label of three points. Sir James Dormont, Captain of Gournay, 1441; seal.

Arg. fretiy gu. a chief of the first. CunEON.

Arg. a chief az. Aubominster, Cornwall. Beltoft. Bicknor or Byrenor. Checky. Chester, Gough, cxlviii,; and i, 40. Cheverell. Clinton, co. Wilts. Cuun, $V$. Clune or Cloun. Fitz-Alan, Clun, co. Salop. Fitz-Alluan Fitz-Alin litz-Flaald or Fitz-Flade, co. Salop. Glanvil, Earl of Suffolk. LockTon, co. Lincoln. Monstrell. Saluce. Santon, San-

\section{CHIEF cont.}

ton, co. Devon; the heiress m. Stockhey, SAUnton, co. Lincoln. WhitMore, Thurstanton, co. Chester. And with a martlet for diff. or. Whitmore, $V$. But with a label of five points gu. Roger de Lokintone, $E$.

Arg. fretty of six and a chief az. Curwen.

Arg. fretty and a chief az. Sire Roger de Beltoft, $N$. Beltofts, co. Lincoln, $V$. Elerker, $V^{*}$. Sr. William Eltercar, $V$. ElLerker, co. York.

Arg. fretty engr. and a chief az. Robert BELTOFT, $Y$. Arg. fretty gu. a chief az. Christofer CNowENE (in pencil Corowen), $X$. Corwex. Thomas Cospatrick, Weirkington, $Y$. Curwen, Workington, Camberland; as descended from Gospatric, Earl of Northumberland; the heiress m. Christian. Morleigh, co. Lancaster. M. Gilbert Oulwenne, $S$. Wyrkington.

Arg. fretty sa, a chief az. CuRwIN.

Arg. a chief dancetty az. CRAWFURde. Robert Fitz-Elys, Netrton, $P$. Glanviue, Earl of Suffolk.

Arg. a chief indented az. Boteler. Cranford, South Newton, co. Northampton. GlanviLe or Glanvill, Snffolk; and Broomball, co. York. Glanvill, $V$. Gilbert de Glanvill, Bishop of Rochester 1185-1214. John de Sanduiz, A, Harl. MS. 6137, fo. 90. Henry de SANDWTCH, Bishop of London 1263-73. Vaience. Valens, $V$.

Arg. a chief chequy az. and or. W Arg. a chief chequy gu. and or. JERBALL, $V$.

Arg. a chief chequy or and az. HASTED. WAREN, $V^{*}$. WARREN.

Arg. a chief chequy or and gu. Irball, co. Lancaster. Jerball, $V^{*}$. JerbaLl, co. York. Jerbaz, Sussex.

Arg. a chief indented erm. Saxsarr.

Arg.a chief gu. Pers de Campaine, $F$. Champaigne. Pers Champaine or Perse de Champaine, $E$. Maheu de Columbers, B. Durward, Nisbet, i, 74. De Fontibus. Forts or De Fortibus. Fonse, Norfolk. William de Fontz, Vivonia, $B$. But William (Fors, $X$ ) de Forz, Coup land, Earl of Albemarle, $P$. Honstey co. Nor thampton. Alein Lasser, $C$. Massey, Tatton, co. Chester. Menzies, Castle Menzies, co. Perth; Baronetcy 1665. Menzies, Pitfaddles. Munsemberg. Werkesley, $V^{*}$. Worsley, Worslay, co. Lancaster. Worslex, Hovingham Hall,co. York; Baronetcy 1838. Geoffrey de Wyrkesley, co. Lancaster, $V$. And with an annulet for diff. or. Worseley, Depingate, co. Northampton. But with a crescent for diff. arg. Worceley, co. Lancaster, $V$. Worceldex, $V$. The crescent or. Worseley, co. Northampton. But with a label of five points or. Fortibus. But with a mullet for diff. or. Worsley, co. Lancaster.

Arg. fretty and a chief gu. Thomas Curwene, $Y$. Sr. Richard Salkeld, $V$. Salieled, Baslington, Northumberland; and co. York.

Arg. fretty of sir su. a chief gu. CockBORNE.

Arg. fretty sa. a chief gu. Murcaunt, $V^{*}$. A quartering of Rogers, co. Dorset, $V$. TALMACH, $V^{*}$. Sr. William Talmache, Suffolk, $V$.

Arg. a chief dancetty gu. Roger de Brome, $E$. M. Edmond Hengrave, S. Hengrave, Suffolk. Arg. a chief indented"gu. Brightly or Brigiey, co. Devon. Brome, Norfolk. Brony, Suffolk. Heingrave. Osmond de Heingrave (in pencil in margin Herngrave), $Y$. Sire Edmon 


\section{CHIEF cont.}

de Hevegrate, $N$. Hejgrave, $V^{*}$. Hemingham, Norfolk. Hempgrate or Hengrate. Herman. Heringrate, $V^{*}$. Sr. Edmund Herngrave, Norfolk; and Suffolk, temp. Edward I, $V$. Heyngrave. Mandevile, Essex. Mergrant. Mortaine. And with a slipped 3-foil for diff. of the first. MaUNDEVILL, $V$.

Arg. goutty de poix a chief nebuly gu. RoydenHaLL, 1716.

Arg. fretty sa. a chief or. Curwen.

Arg. a chief or bordured az. Broderuey.

Arg. a chief paly of seven (eight, Barrington) as the first and gu. KeITH, Baron Keith 1380, Earl Marischal 1455; Nisbet. But later, the chief paly of six (or of eight) gu. and or (aliter or and gu.).

Arg. a chief sa. Arrth, Scotland; the heiress m. Bruce. Barent. La Porest. Le Forest. Penley. Velayn, $V$. Velayne, co. Chester. Viluane, co. Chester.

Arg. fretty and a chief sa. Aymer de St. Aront, $B$. Sr. Henry de RADFord, $V$. M. Henri de RYDFORD, $S$.

Arg. a chief dancetty sa. Bannetr, Suffolk. Sir Roger Baudwyn, $L$. Adame Bevent, $A$. Hilicke. Le Poer. Power, Ireland.

Arg. masoury and a chief embattled sa. Reynel, co. Devon, 1716.

Arg. a chief indented sa. Arsnick. Arsycke. Sir Roger Baldwy or Baudwy, $L$. Bament. Adam de Bavent, A, Harl. MS.6137. Bavent, $V$. Sire Roger de Bavent, $N$. Monsire Roger. Bavent, $Y$. Sir John HaRseck or Harsick, 1384, quartering Calthorp and Gestingthorp; in church at South Acre, Norfolk; Gough, i, 140. Harsick, Norfolk. Hilicke. Hillick or HILLOCK, HILLOCK. LA POER, Ireland. LE Poer, Curraghmore, co. Waterford. DE LA PoEr, Baronies 1375, 1452, 1535, Viscount Decies and Earl of Tyrone 1673, extinct 1704 ; the heiress $\mathrm{m}$. Beresford. Pooke, Ireland. Dominus de Power, Ireland, $V$. Power, co. Oxford. And with a crescent arg. on a crescent gu. for diff, Baron PoER.

Arg. masonry and a chief indented sa. RAYNELL, Malston, co. Devon, Harl. MS. 4199, fo. 62. Reynell, Pyttney, co.Somerset; Trumpinoton, co. Cambridge; and Ogwell, co. Devon; quartering Trumpington and Strighull. REYNeLL, Castle Reynell, Reynella, Woodfort, and Killy. non, Ireland; descended from Reynell, East Ogwell, and Malston, co. Devon. Rernelu, Laleham, and Shepperton, Middlesex; descended from Rerneli, West Ogwell, quartering Spiller; the beiresses m. Reynell and Williams, Reyneli, Newton Abbot, co. Devon; descended like Reynell, Rivershill, co. Hants; from Reynell, East Ogwell. Carew Reyneld, Bishop of Down 1739, Derry 1741-5. Rernell; Ba. ronetcy $1837-48$.

Arg. a chief wavy sa. Aston.

Arg. a chief vairy or and gu. Frtz-Henbert, co. Derby.

Arg. a chief vairy or and vert. Broors.

Arg. a chief vert. LuMLEy, Lord Mayor of London 1623. Meyler, Ireland. Mruer.

Arg. fretty and a chief vert. BELTOFT.

Arg. a chief bevily vert. BEVERLEY.

Arg. a chief indented vert. Poore.

Az. a chief arg. Clun. Beanvill. Kilpatiok. Maunstrell, $V^{*}$. Monstrell. Mounstrell, V. Provis, co. Somerset.
CHIEF cont.

A z. fretty and a chief arg. AlLesley. Elloker. Holtby, Tryton, co. York. Sire Robert de Holteby, $N$. Sr. de Holtesby, co. Lincoln, $V$. Thomas Seint Leger, $Y$. Rauf St. Legeir, $Y$. Sr. Thomas Sutron, $V$.

Az. a chief indented alg. Bechorn. Duc, $V$. DUE, $V^{*}$.

Az. a chief chequy arg. and gu. Irelinge, $V^{*}$. Ikeling or IkLing. Pienpoint, Sussex.

Az. a chief chequy gu. and arg. IKelinge, $V$. Perpount, $V$.

Az. a cbief chequy or and gu. IKELING or IKLING. Pierpoint, co. York.

Az. a chief countelcompony gu. and or. Robert de Porponne, A, Harl. IIS. 6137, fo. 92 ; but or and gu. Robert Perpount, $A$.

Az. a chief erm. Claus. Seyliard Suliard or Sylyard, Delaware, Braxted, and Ighton, Kent. Sulliard, $V^{*}$.

Az. a chief erm. over all an escucheon or a chev. gu. Erlescairp, $V^{*}$. Erllescaip; $W$.

Az. bezanty a chief erm. KEIGNES or KEYNES. Az. a chief gu. William de Sentlegar, $A$

Az. fretty arg. a chief gu. CAvE. Sire Johan de Sein Leger, $N$. St. Leger, $V$.

Az. fletty of six or a chief gu. WILLOUghBY.

Az. a chief lozengy or and gu. Scobie.

Az. a chief or. BEANEveILl or BeAvill. Si.

Rauf Beaurill, V. Beltoft. Benevill.

Benville. Bonvile. Bovile. Donham.

Hasellwali. John de Lusers, $V$. John

Lusures, $Y$. Raffe de Seintleger, $A$. Sleger, Kent. And with a label of three points arg. DonHali, Harl. MS. 1550 , fo. $17 ; 6829$, fo. 63 .

Az. billetty and a chief or. Dromer.

Az. fretty of six arg. a chief or. William de SENTLEGER, $F$.

Az. fretty arg. a chief or. BRIDGes. Sr. Raufe St. Leger, Kent, $\boldsymbol{V}$. M. Rafe de S. Leger, $D$. Sire Rauf de SFin Leger, N. St. LEger, Annery, and Canouleigh, co. Devon. the coheiresses m. Grenville, Stucley, Tremayne, and Arscott. St. LEGER, Castlemore, and Heyward's Hill, co. Cork. ST. LEGER, Ulcomb, Kent; and Doneraile, co. Cork, Baron Kilmadow and Viscount Doneraile 1703-67, Baron 1776, Viscount 1785. M. Rauffe SEYNT LEGGER, $S$. And with a crescent for diff. gu. St. Leger, $V$. But a mullet gu. Sire 'Thomas de Seint Leger, $N$. The mullet of six points gu. M. Renold Seynt LegaEre, $S$.

Az. fretty and a chief or. Randolf Fitz-HenRr, $P$. Sire Henry Fitz-Henry, $R$. Hue Fit'hary or le Fitz-Henry, E. Sir Henry Fitz-Hugh, $I$, or le Fitz-Hugh, M. Sire Henri le Fız-HuE, $N$. Le Sire Fitz-HugH, $Y$. Henry le Fitz-Randolfe, temp. Edward I, $V$. And with a label gu. Sir Henry le Fitz Hugh, $L$.

Az. a chief dancetty or. FItz-RADLF. M. Randolff FrTz-JOHN, S. ORMOND, Ireland, Harl. MS. 1441.

Az. a chief indented or. Donhanr, co. York. Sr. Joln Dunham, Karlington, $V$. Dunham, co. Lincoln. Randolf Fitz.John, Wodhalle, $P$. John Fitz-Randolf, Spenythorne, Y. Monsire Randolf Fitz-Raufe, $Y$. Fitzrandall. M. Rauf de Sanduiz, A, Harl. MS. 6137.

Az. flory or a chief paly arg. and gu. Henry de Bennad, $C$.

Barry of four arg. and gu, a chief of the second. Salier, co. liutlaud. 


\section{CHIEF cont.}

Barry of four arg. and gu. a chief vair. Prmpe, $V$.

Barry of four or and az, a chief gu. Manners, Baron Ross, 1616-32.

Barry of four (or and sa. Add. MS. 14307, fo. 18.) sa. and or a chief arg. Frogenhall, Kent.

Barry nebuly of five arg. and gu. a chief chequy or and sa. ADrian, quartered by D'Oyley.

Barry of six arg, and az, a chief erm. WIGLEY.

Barry of six arg. and az. a chief gu. Lampkyn.

Barry wavy of six arg. and az, a chief per pale erm. and gu. BarLowe, co. Derby, Cotton MS. Tiberius D 10.

Barry of six arg. and gu. a chief vair. Sr. Thomas Pympe, Kent, $r$.

Barry nebuly of six az. and arg. a chief or. BYDEFORD, $\boldsymbol{V}$.

Barry of six gu. and or per pale counterchanged a chief the dexter side per bend as the first and second the sinister per bend sinister like the second and first over all an escucbeon arg. Hageiey.

Barry of six or and az. a chief erm. TALWORTH.

Barry of six or and gu. a chief erm. BoRDeux, Harl. MS. 1424, fo. 105 b.

Barry of six or and sa. a chief paly of six as the first and second. EDFYN, Harl. MS. 1404, fo. 104. But paly of ten. EDEFin. But paly of the same. EDEFYNe or EDFYNE.

Barry of six sa. and or a chief paly of ten of the first and second. EDEFIN.

Barry of ten gu. and arg. a chief or. Malephant, Harl. MS. 1441; and of Ireland, $W$.

Barry of twelve (twenty-one, Harl. MS. 6137) arg. and az. a chief indented gu. Elles de RochFord, $A$.

Barruly arg. and az. a chief gu. RochFord.

Barry wavy arg. and az. a chief or a label of three points .... De Biderord.

Barry nebuly arg. and sa. a chief chequy or and az. ADRYAN.

Barry bendy sa, and arg. a chief or. Ralph de WiLLINGTON, 1230 .

Bendy of six arg. and gu. a chief or. BALDWYN, $V^{*}$. Baldwyn de Betun, Earl of Albemarle, temp. Richard I, $W$.

Bendy of six az. and arg. a chief sa. Little, Ireland.

Bendy of six az. and or a chief erm. Hankes. HAWKE, Treveven, Cornwall. Howkes, $V$.

Bendy of six gu. and arg. a chief az. Coleridge. Bendy of six gll. and or a chief az. Danford.

Bendy of six or and az, a chief erm. Hownes, $V^{*}$.

Bendy of six sa. and or a chief gu. LINGHaM.

Bendy of six vair and gu. a chief or. Cowcey.

Bendy of six vert and arg. a chief erm. LOAT.

Bendy gu. and arg. a chief or. Baudwin de Betun, brother of the Count of Flanders, was Earl of Albemarle and De L'Isle, lord of Skipton in Craven, m. Hawise, Countess of Albemarle, $Y$.

Chequy arg. and az. a chief gu. PALMer, Barton, co. Warwick, and co. York. And with a crescent in the dexter corner for diff. .... Palmer, co. Warwick, $1619, \mathrm{~W}$.

Chequy arg. and az. a chief iudented or. WALTON, co. Devon.

Chequy arg. and gu. a chief az. Gospatrick, Cumberland.

Chequy arg. and gu, a chief indented az. Micklethwait, Iridge Place, Sussex; Baronetcy 1838.53; Taverham, and Beeston, Nor-
CHIEF cont.

folk; and Maresfield, Sussex; quartering Peckham; derived from MicklethwaIt, Kimberworth, co. York. MicklethWAYT or Micklethwaite, co. Lincoln; and Swayne, Holderness, co. York. Mucklewaite.

Chequy arg. and gu. a chief erm. Richard Fitz.JoHn, $Y$.

Chequy arg. and gu. a chief or. Colshrus. NEHAir, $V^{*}$. NeHUN.

Chequy arg. and gu. a chief engr. or. Walton, $V^{*}$.

Chequy arg. and gu. a chief per chev. wavy of the second and or. HAUBERKE, $V^{*}$.

Chequy arg. and gu. a chief vair. ChIohester, 1730 .

Chequy arg. and sa. a chief erm. Colshril.

Chequy arg. and sa. a chief or. Brooke. CAwod. Cawood, $V$. Colshill, co. Devon. Hankepenny. HAWKEPENNY.

Chequy arg. and sa. a chief of the last on the second cheque a crescent or. M. Thomas Colshill, $S$.

Chequy arg. and sa. a chief vairy of the first and gu. Fulkeram.

Chequy az. and arg. a chief engr. or. WaLton, $V$.

Chequy az. and or a chief pel chief nebuly of the first and second. Tavestoke, $V^{*}$. TAvystock, $V$.

Chequy az. and or a chief per fess wavy of the last and sa. TAVISTOCK.

Chequy gu. and arg. a chief or. NEHAMr, $V$.

Chequy gu. and arg. a chief engr. or. WALton, $V$.

Chequy gu. and arg. a chief per cher. wavy of the first and or. Sr. Nicolas HaUBERKEs, $V$.

Chequy gu. and or a chief arg. Forsham.

Chequy gu. and or a chief az. Hamond de Bonet, $A$. Symon de Porpoune, A, Harl. $M S$. 6137 , fo. 92 .

Chequy gu. and or a chief erm. Robert de ateshale, $F$. Sire Roberd de Tatteshale, $J$, Harl. MS. 6137 , fo. $58 \mathrm{~b}$. And with a label or. Roger Tateshalle le filz, $Y$.

Chequy or and az. a chief arg. Garreig. Sr. William GaWre (GAREN le filz), in margin "credo GWAREN", $R$. WaRREN. And with a crescent for diff. gu. Garein, $V^{*}$. Gruarein, $V^{*}$. Thomas Garen or GarRenne, $V$. Warren, $V^{*}$. But a mullet az. Clifford, Bartcy. 1838. Chequy or and az. a chief erm. Clinton.

Chequy or and az. a chief gu. Palmer, Barton, co. Warwick; and co. York.

Chequy or and az. a chief of the first. Garan. But with a erescent in the dexter chief gu. GarRIG.

Chequy or and gu. a chief arg. Comberworth. Hamberbras.

Chequy or and gu. a chief az. Hamon Bonet, $\boldsymbol{A}$; Harl.MS.6137. Bonett. Brooke. Symone Perpount, $A$. Pierpoint.

Chequy or and gu. a chief indented az. MitTlewelL.

Chequy or and gu. a chief (barry) wavy az. and arg. John RALEY, $Y$.

Chequy or and gu. a chief erm. Casharc. Roger de Cuinton, Bishop of Lichfield etc. 1129-48. M. Rauf Cromwels, Lord of Tatir. sale, quartering per chief gu. and arg. over all a bend sa., $S$. Giney or Gynney, Norfolk. Grnty, $V$. Stedman, Dolgoer, co. Brecknock. Tatershald, Norfolk. Robert de Tateshale, $B ; K$; or Tatishale, $C$; or Tateshall, $E$. Sire Robert Tatershall, $H$. Sire Roberd de Tatseshale, $J$. Sire Roberd de Thatrshale, $N$. Robert, Baron of Tateshall, $V$. Robert 


\section{CHIEF cont.}

Tateshale, $P$; or Tatteshall, $Y$. Sr. de Tattersali, $V$. And with a label az. Sr. Robert Tatraesaric le filz, $H$.

Chequy or and gu. a chief ermines. TatTersald, $V *$.

Chequy or and gu. a chief vair. Chichester, quartering Hopton. Sr. William Chichester, co. Devon, $V$. Robert Chichester, Bishop of Exeter 1138-55. Chichester, Arlington, co. Devon; Baronetcy 1841; descended like Chichester, Hall, co. Devon; quartering Hall; from Cirencester or Chichester, Ra. leigh, co. Devon: Baronetcy 164l. Chichester, Greencastle, co. Donegal; Baronetcy 1821. Chichester, Collinson, Somerset, iii, 541, 549. Chichester, Baron Belfast 1612-24, Baron and Viscount 1625, Earl of Donegal 164\%, Baron Fisherwick 1790, Earl of Belfast and Marquis of Donegal 1791, Baron Eunishowen 1841; quartering Itchingham. RALEIGH, Raleigh, co. Devon.

Chequy or and sa. a chjef arg. Colshul. Muscanpe.

Chequy or and vert a chief arg. Brockley, Lord Mayor of London 1433.

Chequy sa. and arg. a chief or. Richard Colsull, $V$. Sr. de Hinkpenne, $V$.

Chevronelly of six or and gu. a chief erm. Tatershall.

Erm. a chief az. Arches.

Erm. a chief dancetty az. LiTToN.

Erm. a chief engr. az. Askeley. Scaley.

Erm. a chief indented az. Nevill, Reresby, co. Iueicester. Rauf Nevile, Cletham, Y. Monsire Rauf de Nevill, Clechin, $Y$.

Frm. a chief wavy az. Kitchener.

Erm. a chief bendy of six or and (az. another) sa. Dabetot, co. Worcester.

Erm. a chief bendy of six sa. and or. Dabetote, co. Worcester, Harl. MIS. 1404, fo. 104.

Erm. a chief bendy or and az. Sire Rauf le Fitz-RICHARD, $O$.

Erm. a chief bendy or and sa. Sire William Dabetoot, $N$.

Erm. a chief chequy arg. aud gu. WILcock (in St. Sepulchre's Chur'ch, London).

Erm. a chief chequy az. and or. ARDEN, $V$. Wilcocrs.

Erm. a chief chequy or and az. ARDEN, $V^{*}$. ARderne. Dode.

Erm. a chief chequy or and gu. Nowers, Knossington, co. Leicester. Wilcox.

Erm. a chief chequy or and sa. Nowers alias Wilcox, co. Leicester, 1732. Joseph WrLcocks, Bishop of Gloucester 1721, Rochester 173]-56, with chequy sa. and or; portrait.

Erm. a chief gu. Bullock, Brecon. Burdeloys, co. Cambridge; and Norfolk. Button. Esmond, Ireland. Harcourt. Menzies, Weems. William de Morriton, $E$. Mortaine, $V$ * Mortayne, $V^{*}$. Sr. Williain Morteyne, $V$. Robert de Morteyn, "Breton", B. Morteyne, Eyam, and Risley, co. Derby; the heiress $m$. Willoughby. William de Morteyns, $X$. Narburgh, (in peucil), $F$. Newburr, Ireland.

Erm. a chief gu. a label of five points or. Bullock, Norton, Onston, and Darley, co. Derby; quartered by Mower through Latham, and by Dale through Hayne.

Erm. fretty and a chief gu. John Thornborovgh, Bishop of Limerick 1593, Bristol 1603, Worcester 1617.41. Thornborovgh or 'THORnbUry,

\section{CHIEF cont.}

co. Hants; Westmoreland; and co. York. Thornborowe, Selsheyd, co. Cumberland. Thornburgh, Shesbeyd, $V$. William de Thonnburgh, $X$.

Erm. fretty of six sa. a chief gu. Gerard.

Erm. a chief dancetty gu. Astell de Basset, $A$. Wat de Einegrove, E, Harl. MS. 6137 ; or Enegrove, E, Harl. MS. 6589. Moreton, co. Bedford.

Erm. a chief embattled gu. Aiskell Aiskil and Askili.

Erm. a chief indented gu. Ansel Bassetr, A, Harl. MS. 6137. Brone, Broom Hall, Suffolk; and Norfolk. Browne, Broomhall, Norfolk. Montaine, Earl of Cornwall 10681]04. Sire Johan de Mortein, $N$. Sr. John Morteighe, $V$. Morteine, $V^{*}$. Morton or Morteyne, co. Bedford, Moreton. Rincester. Turbervile, co. Buckingham.

Erm. a clijef lozengy gu. aud erm. Chardes, $\boldsymbol{V}$. Erm. a chief paly az. and arg. BeCKet.

Erm. a chief paly of (eight $V^{*}$ ) ten sa. and or. Sr. William BeKETOT, $V$.

Erm. a chief paly sa. and or. BeckToL.

Erm. a chief per (chief $V^{*}$ ) fess indented gu. and or. Brone, $V$.

Erm. a chief indented per fess or and gu. Brome, $V$.

Erm. a chief indented per pale gu. and or. Browne.

Erm. a chief per pale indented or and gis. Browne. Shotesbroor, $V$. And with a rose of the last in the dexter chief for diff. SHorTESBROOKE.

Erm. a chief indented per pale or and gu. SHORTESBROOKE Or SHOTISBROOKE, Kent; sometimes an annulet, sometimes a rose, of the second for diff.

Erm. a chief quarteriy gu. and or. Peckhad, Kent; and Little Green, Upmarden, and Lordington, Sussex; the heiress m. Phipps. St. Nicolas, Kent.

Erm. a chief quarterly or and gu. Fitz-Nicholas, $V^{*}$. Pecham or Peckeam, Chichester, and Franfield, Sussex; and Kent. Peckhasr, Nyton, Sussex; the heiress m. Smith. John PeckhaM, Archbishop of Canterbury 1279.92. PECEHAII, Kent, $V$. St. Nicholas, Kent, $V$.

Erm. a chief potent quarterly or and gu. Peckham.

Erm. a chief sa. Angus. Belfield, co. Lincoln. OKESLEY Or ORKESLEY.

Erm. a chief dancetty sa. Banner.

Erm. a chief indented sa. Ban or Banne. Bon, Essex. Bonner. Gent, Moyns, Essex; quartering Moyns. Nevili.

Fusily erm. and sa. (sometimes in error, or and az.) a chief of the second. William PATTYN or Waynflete, as provost of Eton College.

Fusily or and gu. a chief sa. Brooke, London.

Gu. a chief arg. Bewford. Hampsted. Hansted. Hercy, $S$. Hercy, Cruchfield, co. Berks. Hercy, Grove, co. Nottingham; quartering Arches, Leke, Somers, Staveley, and Talbot. Sir Thomas Hersay, Grove, co. Nottingham, $V$. Kent. Kersa. Gilbert de Wawton, Kesperby, $P$. John Wawton, 1411-2, $V$. Woriesley. Worselley, co. Lancaster, $V$. Worsley, co. Chester; and co. York. And witb a crescent of the first. Kency. But a label (of three points, $V_{.}$) az. Sire Huge de Hercy, $N$. Hersey, Kent. 
CHIEF cont.

Gu. a chief embattled arg. Bincester, $V^{*}$. Sr. Richard Byncester, V. Ryncester, 1716; and Harl. MS. 1386, fo. $34 b$. Sr. Richard Ryncestre, Cotton MS. Tiberius D 10, fo. 765. Gu. a chief indented arg. BaRetT. BRIGHLEY, $V$. Sarcester. Surcester, $V$.

Gu. fretty or a chief az. John de Fleming, St. George ; Enderbie.

Gu. a chief bendy of eight az. and arg. HonaN, Ireland.

Gu. a chief chequy or and az. Sr. William HANSTED, co. Northampton, $V$. Hansted or Hasted, co. Nurthampton; and Northumberland. Le Sire de Hausted, $Y$. Sire Robert de Haustede, $N$. Hawsted, co. Northampton. Hunsted.

Gu. a chief chequy or and sa. Hasteed.

Gu. a chief erm. Charless. Chastelin D'Aras, A; Harl. MS. 6137 ; but Cheselen de Daras, A. Davy, Kent. Narborough Narburgh or Newborouge, Norfolk. Norburgh, Norburgh, Norfolk, $\boldsymbol{V}$. Speluan.

Gu. bezanty a chief erm. KeIanes or Keynes.

Gu. fretty of six or a chief erm. Dewre. William MaILot, E, Harl. MS. 6137.

Gu. fretty or a chief erm. Fouleshurst, co. Chester; Essex; and co. Leicester. Sr. Thomas Fouleshurst, Essex, $V$. Fulleshohst or Fodlthurst, co. Chester. William Mailott, $E$, Harl. MS. 6589.

Gu. a chief indented erm. Chames. Charles, $V$. Goldington. Michaell. Seynt Michaeli, Ireland, $V$.

Gu. a chief nebuly erm. Goldington.

Gu. a chief or. CARON or CARRON, Scotland. Nicholas de Criell, $A$. Fatesend, co. Chester. Fitz-Henry, (co. Wexford, $W$, and Harl. MS. 1441), Ireland, V. Fitz-Srmon. KeMor or Kenur, co. Glouc.; Kent; Middlesex; Gissing, Norfolk; Suffolk; and Sussex. Veriet or Weriet. Walton. Wanton, $V$. Worsley, co. York.

Gu. crusily and a chief or. Sr. Jolnn ARDERNa or de Arderna, $L$; or de Arderne, $N$.

Gu. fretty arg. a chief or. BrogDEN.

Gu. fretty vair a chief or. WYNAJLL. WYviLE, Stanton Wyvile, co. Leicester. Robert Wyvilue, Bishop of Salisbury 1330.75. John Wyville, $Y$.

Gu. a chief dancetty or. Grovall. Kinner.

Gu. a chief indented or. Crowale or Cruall. Grovill, $V$. Grovyli, $V^{*}$. Kayrois or Lamois. Borough of Kinver, co. Stafford. Kumer. KYNeR. KYNVE1, $V$.

Gu. billetty and a chief indented or. Garton. Sr. Thomas Gerton or Gonton, $\boldsymbol{V}$.

Gu. a chief per fess (indented, Thonelys, $V^{*}$, ) dancetty of the first and or. THORLEYs, $V$.

Gu. a chief vair. Gernes or Joynes.

Gyronny of eight gu. and arg. a chief or. KEEFE, Ireland.

Gyronny of eight gu. and sa. a chief or. Matrhews, Scotland.

Gyronny of eight or and az. a clief gu. Sturdy. Gyronny of eight or and sa. a chief gu. LAUGHER.

Gyronny of eight sa. and arg. a chief erm. DOBREE or DOBREY.

Gyronny of eight sa. and arg. a chief or. "PAUL, Ireland.

Lozengy .... and .... a chief .... Sr. Walter Kilningeholme, co. Lincoln, seal 1254, V.

Lozengy az. and arg. a chief or. ADErson.

Lozengy gu. and arg. a chief erm. JOEL.
CHIEF cont.

Lozengy gu. and arg. a chief or. Tutrn.

Lozengy or and gu. a chief arg. Brokr.er, London.

Lozengy or and gu. a chief az. Broke, $V$. BRokeley or BRoOK.

Lozengy or and sa. a chief of the second. BRETON. Lozengy sa. and arg. a chief erm. Merrivan.

Lozengy sa. and arg. a chief per fess indented or and az. STOcker.

Lozengy sa. and or a chief erm. Mears.

Or a chief az. Arderne. Aston. Beavill. Beltost, Samton, $V$. Dewar, Scotland. Randolf Fitz-Robert, Midelham, $P$. Gascoigne. Lesoures, $V$. Lysers or Lysotrs, co. Lincoln, Lysures, $V$. Menne. Meune. Muschampe. Muschanc, $V$. Muschance, $V^{*}$. Sampton or Samton. Sandier. Santon, $V^{*}$. Sire Johan de Saunton, $N$. Sr. de Saunton, co. Lincoln, $V$. Staunton, co. Lincoln.

Or fretty gu. a chief az. Novelle or Nowelr. Or a chief dancetty az. Boteler, Earl of Or. mond and Ossory, $V$. Tebaud (Richard, Harl. $M S .6137$ ) le Botruer, $E$. Sire Tebaud le Botuler, J. Richard Boulers or Butler, Bishop of Hereford 1451, Lichfield, etc. 1453-9. Midreham. Le Counte de Ormaund or Ormounde, $T$. ORmond, Ireland, Harl. $M S$. 1441.

Or a chief indented az. Boteler, $V^{*}$. Monsire le Botiller, Ireland, $Y$. Theobald Butelier, Conte d'Ormond, $X$. Butler, Viscount Tulloch and Earl of Arran 1663-85, and 1693 ; extinct 1758. Butrer, Earl of Tipperary, cc. 1300. Butler, Viscount Tulachphelim. Butler, Baron of Aghrim, Viscount Clonmore, and Earl of Gowran 1675-6. Butler, Viscount Butler 1603-13. Butler, Polestown; Baronetcy 1643. 1723. Butlen, Earl of Ormond and Wiltshire, Duke of Ormond, $Z, 333,371,543$; quartering Rochford, Brotherton, and Warren 487 . ButLER, Baron Arklow, Earl of Carrick-mac-griffin 1315 , Earl of Ormond 1328, Earl of Ossory 1527 , Viscount Thurles 1535, Baron of Ormond 1821 , Marquis 1642-1758, 1800-1820, 1825. Earl of Wiltshire 1449-61, Baron Rochford 1495-1515, Duke of Ormond 1661-1758, 1682-1721, Earl of Brecon 1673-1721, 1800-20; Baronies 1665 and 1673-1721, 1800-20. Butler, Barony and Viscounty 1550, Earl Mountgarret 1723. Augustinian Priory at ButLey, Suffolk. Premonstratensian Abbey at CorHam or Coverham, co. York. Rauf le Fitz-RANDOLF, $B$. Fitz-Randolph, Northumberland. Rauf' Fitz-RaUf, Middelham, $Y$. Randolf de Glamivile, $Y$. Glanvile or Glanville. Sr. de Midleham, $V$. M. Joln de Sandwis, $D$. And with a crescent for diff. ButLer, Viscount Mountgarrett temp. Edward VI. ButLer, Viscount Ikerrin 16:9, Earl of Carrick $17 \pm 8$. But a fleur-de-lis for diff. Buther, Earl of Kilkenny. But a label arg. Boterer.

Or a clijef bendy of six arg. and gu. KEnERam or Keverais.

Or a chief bendy of ten gu. and arg. Kendram, Harl. MS. J404, fo. 103.

Or a chief chequy arg. and gu. Ineling, $V$.

Or a chief chequy of the first and gu. Labibard.

Or a chief countercompony erm. and az. HrLton. Or a chief gu. ABLeHall. M. Thomas Fitz-Simonde, $S$. Fitz-Symon, $V$. FitzSymond. Launce. Lomelyna alias Lumley, 
CHIEF cont.

Great Barfield, Essex. Lomuex, Bradfield, Essex; Baronetey 1610-1771. Molton. City of Naples. Seuaer, Scotland, Nisbet, i, 74 . WoRSLEY.

Or fretty az. a chief gu. WyLoughвy, $V$.

Or a chief indented gu. Brighley, $V^{*}$. Bryohley, $V$. Augustinian Priory at Butley, Suffolk (in error). DIER, W. DYer, Tottenham, Middlesex; and Spains Hall, Essex; Baronetcy 1678. Dren, Middlesex; quartering Moreton, Ducie, Knightly, Hardy, and Prestwich. Dyer, Wincauston, and Roundhill, co. Somerset; and Alpington, co. Devon. SWYNERTON, London.

Or a chief lozengy (arg. and gu. $V^{*}$.) az. and gu. Sendesing, $V$.

Or a chief lozengy gu. and az. SENDEFrng or Sendling. Sendesing, Harl. MS. 1401, fo. 61. Or a chief per pale az. and gu. ArchIE (Nisbet) or A RThie, Scotland.

Or a chiefsa. Browne, Deptford, Kent. Forneaux, co. Devon. Penley.

Or fretty and a chief sa. Phillipp Breton, $V$. Bretton, $V^{*}$.

Or a chief indented sa. ARsYcke. Harsack or Harseck, Norfolk. John de Harsick, $Y$. Le Sire de Harsike, $Y$. Sire Roger Harsike, $V$. Hersetr, Norfolk. Power, Ireland. Skeretr, co. Devon.

Or a chief vair. Copis. Coppin, co. Hertford, 1608.

Or a chief vert. Henry Vernay, $V$. Verney.

Paly of six arg. and az. a chief of the last. LANGFORD.

Paly of six arg. and az. a chief or. GoLL, Kent; and Hoppey. Hopper.

Paly of six arg. and az. a chief sa. AcwELL. HACKHELL, France.

Paly of six arg. and gu. a chief of the first. Patishall, co. Devon.

Paly of six arg. and gu. a chief az. Auchincloss, Scotland. Kellali. Keliull.

Paly of six arg. and gu. a chlef erm. Filpot.

Paly of six arg. and gu. a chief or. ANSDELL.

Paly of sis arg. and gu. a chief dancetty or. Gonsel Gonsell or Gonsley. Goshell or GowSLEY.

Paly of six arg. gu. or sa, as the first and az. a chief erm. DAGLEY.

Paly of six arg. and sa. a chief az. Swinford, Essex.

Paly of six arg. aud sa. a chief wavy az. Burman.

Paly of six arg. and vert a chief sa. SAvORY.

Paly of six az. and arg. a chief of the first. Gull, Sandwich, Kent.

Paly of six gu. and arg. a chief az. Kelhuld, $V$. Kellum. Kethall.

Paly of six gu. and or a chief vert. Witney, $V^{*}$. Paly of six gu. and vair a chief or. FERINGTON. Paly of six or and az. a chief erm. Clinton. PAyne, co. Dorset; and Medborne, co. Leicester.

Paly of six or and az. a chief gu. Brossett. Degneall. Foston, co. York.

Paly of sis or and az. a chief vair. Whitney.

Paly of six or and az. a chief inderited vert. Pelytoe or Pelytot, Woodhall, co. Hertford; the heiress $m$. Boteler.

Paly of six or and gu. a chief arg. Jenny, Norfolk; and Suffolk. Mountney. Patesole. And with a mullet sa. in the dexter chief for diff. Sr. Robert Monteney, $V$.
CHIEF cont.

Paly of six or and gu. a chief az. Hedigan.

Paly of six or and gu. a chief erm. Burdeaux. Sr. Peirs Filiol, $V$. Filliol, $V^{*}$. Geney, Norfolk, $V$. Genney, Norfolk. M. John Gery, $S$. JeNNr, Norfolk; and Suffolk.

Paly of six or and gu. a chief as the last. Haversedge.

Paly of six or and gu. a chief as the first. Haversage.

Paly of six or and gu. a chief sa. SHelley.

Paly of six or and gu. a chief vair. Francis Atterbury, Bishop of Rochester 1713-23; ob. 1731. Belches, Scotland. Wytteney, co. Chester.

Paly of six or and gu. a chief vert. Sr. Eustace de Witney, co. Chester, $V$. Wrtteney, co. Chester.

Paly of six or and sa. a chief of the first. Guds, Sandwich, Kent.

Paly of six or and sa, a chief indented vert. Peltot, temp. Edward I.

Paly of six or and vert a chief as the second. PeLcot. But with a mullet for diff. of the first. Phillip Peltot, 1452, $\mathrm{V}$.

Paly of six or and vert a chief indented of the second. Paietoot Pelytoe or Pelytot, co. Hertford. PELTot, London.

Paly of eight arg. and az. a chief gu. BenweL. Paly of eight or and az. a chief erm. Payne, co. Hereford. Sr. Edward PAyNe, $V$.

Paly of eight or and gu. a chief az. RusserL, $V$. Paly of eight or and sa. a chief vair. ATterbury, IT.

Paly arg. and az. a chief gu. Richard CALDECOTT, $Y$.

Paly arg. and gu. a chief of the first. Matheu de Hayersegge, $B$.

Paly or and gu. a chief erm. Sire Roger Grner, $N$.

Paly or and gu. a chief vair. Sire Eustace de Witteneye, $N$.

Per fess dancetty arg. and sa. a chief gu. Bluffeld, Harl. MS. 1404, fo. 5 .

Per fess indented arg. and sa. a chief gu. Blufield, co. Stafford.

Per fess az. and or a chief paly of six as the last and gu. Fawconbridge, Harl. MS. 1401, fo. 103.

Per fess gu. and arg. a chief per chief indented of the same. Hachet, $V^{*}$. HaNCHET, $V^{*}$.

Per fess or and gu. a chief dancetty of the last. Thorelys, $V$.

Per fess dancetty or and sa. a chief gu. BlythFeld, Harl. MS. 1401, fo. 5.

Per fess indented or and sa. a chief gu. Blythfield.

Per pale arg. and gu. a chief or. Barshay.

Per pale arg. and sa. a chief indented per palo of the second and first. LaING; Nisbet, $j, 70$.

Per pale engr. arg. and sa. a chief indented counterchanged. LAING.

Per pale indented arg. and sa. a chief or. Willington, temp. Henry V.

Per pale indented arg. and sa. a chief indented per pale of the second and first. LANG, Scotland.

Per pale az. and or a chief dancetty counterchanged. Raffe Perot, A, Harl. MS. 6137.

Per pale gu. and arg. a chief or. Barsham, Norfolk.

Per pale or and arg. a chief duncetty sa. GILL or Gille, London. 


\section{CHIEF cont.}

Per pale or and az. a chief gu. CALDEcot, $V^{*}$ Sr. Ellys Caldecote, $V$. Caldicot.

Per pale dancetty or and gu. a chief az. Bermincham.

Per pale indented or and gu. a chief az. Berming Hair.

Per pale or and gu. a chief of the first. Barshani, Colkirk, Norfolk.

Per pale sa. aud arg. a chief indented per pale of the second and first. Fitz-Warren.

Per pale sa. and or a chief dancetty arg. LAING, England.

Purp. a chief indented or. Sire Randolf FrtzRAUF, $O$.

Quarterly gu. and erm. a chief duncetty of the first. Gataker.

Quarterly gu. and or a chief indented of the second and first. Fitz-WARIEN.

Quarterly per fess indented or and gu. a chief indented of the second and first. Fitz-Warren.

Sa. a chief arg. Sr. William Penlay, $V$. Penley.

Sa. a chief iudented arg. Barent.

Sa. fretty erm. a chief chequy arg. and of the first. GigGe, Suffolk. Robert GyGGEs, Norfolk; or Suffolk; $V$.

Sa. fretty erm. a chief counter'compony arg. and sa. Dixes, Norfolls.

Sa. a chief or. Boyvili. Penley, $V$.

Sa. fretty arg. a chief or. Philip Breton, Colboume, $Y$.

Vair a chief chequy arg. and gu. Slayne or Sleyne, Ireland. But chequy gu. and arg. Robert Fleminge, $Y$.

Vuir a chief chequy or and gu. Fleming, Landith, Cornwall; and Ireland. Flening, Bratton Fleming, co. Devon; the coheirs m. Bellew and Dillon. Fleme, Landithy in Madron, Cornwall. Fuenyng, Baron of Slane, Ireland, $V ; 1613$. Slayne or Sleyne, Ireland.

Vair a chief counter'compony arg. and gu. (another or and gu.) FLEMING.

Vair a chief erm. Bickworth, $W$.

Vair a chief gu. Bigwaies. ClavmL, co. Dorset. William D'Estoke, $E$; or de Estokes, $F$. Rauf le Fitz-Roger, $E$. Stoke, Stoke, co. Dorset. STOKES.

Vair a chief or. Fishborne. Thicheborne. Tichborne, Tichborne, co. Hants; Baronetcy 1620; Kent; and Norfolk. Tichborne, Beau. lieu, co. Louth; Baronetcy 1697, Baron Fer. rard 1715, extinct 1731. John Tichbotmene, seal, 1391. TrchbourNe, co. Hants, $V$. Tychebourne, $V^{*}$. Tycheburne.

Vairy az. and erm. a chief chequy or and gu. SLEY, Ireland.

Vairy or and gu. a chief sa. Sir.William Estoke, co. Dorset, $V$. Fitz-Henry, Ireland, $V$. Stokes, $W$.

Vert a chief erm. Doner. But with a label of five points gu. DoNAY.

Vert semy of fleurs-de-lis and fretty of eight or a chief erm. Perbo, co. Chester; and Middlesex; granted 1620.

Vert a chief or. Tychborne, co. Hants, $V$. VERNEY.

\section{CHIEF and in base...}

Arg. a chief gu. in base a point indented sa. BLITHEFILD, $V$.

Per pale barry of six erm. and gu. with az. over. all a chief engr. of the third in base a point indented arg. ACTONLEY.

\section{CHIEF and BORDURE}

Arg. a chief az. a (? bend over all) bordure engr. gu. Pembridge.

Arg. a chief gu. a bordure chequy az. and of the first. Menzies, Skein.

Az. a chief and bordure or. DaLBY

Arg. a chief paly of six gu. and or within a bordure engr. sa. KerTH, Inverugie, Scotland, Nisbet, i, 74; ij, app. 5 .

Gu. a chief dancetty arg. within a bordure az. Baret, $V$. The chief indented. William Barrat, Harl. MS. 6076, fo. $22 b$; or GarratT, Harl. MS. 1049, fo. 53 b, Sheritf of London 1379 Barrett, London, 1383.

Gu. a chief engr. arg. a bordure indented or a label barry of the second and az. Sire Pbilip de Neville, $O$.

Gu. a chief arg. within a bordure gobony of the last and az. Hercy.

Gu. a chief or within a bordure az. Harington, co. Leicester.

Gu. a chief or within a bordure erm. Ardenus, $V$.

Or a chief indented az. within a bordure engr. gu. Boteler. Butler, Viscount Mountgarrett.

Or a chief indented az. within a bordure vert. Butler, Viscount Galmoye, 1646; quartering gu. three covered cups or with arg. a lion ramp. sa. on a chief gu. a swan wings expanded of the first betw. two annulets or and erm. a saltire gu.

Or a chief indented az. within a bordure engr. vert. ButLER.

Or a chief gu. a bordure sa. Harington.

Or a chief sa. a bordure az. charged with three crescents arg. Erthe, Scotland.

Bendy of six or and az. a chief erm. with a label gu. a bordure of the first charged with three fleurs-de-lis of the second. PAGAN, Scotland.

\section{On a CHIEF}

\section{Anchors}

Barry wavy of six arg. and az. on a chief gu. two anchors or. SisH.

Arg. on a chief az. three anchors or. PACk. Annulet

Erm. on a chief gu. an annulet betw. two billets or. WatTs, Hockswold, Norfolk, 1610.

Erm. on a chief dancetty gu. an annulet betw. two coronets or. LEEcH; $A d d$. MS. 5507, fo. $188 \mathrm{~b}$.

Erm. on a chief jndented sa. an annulet or betw. two slipped 3-foils arg. Bamme, Lord Mayor of London 1390.

Arg. on a chief gu. an annulet betw. two mullets or. ST. JoHN.

Annulets

Arg. on a chief gu. two annulets braced ov over all a bend engr. az. LAKE, co. Devon.

Barry of four sa. and arg. on a chief like the second three annulets as the first. BEardoe, Manchester. Burdeux, $V$.

Barry of five az. and arg. on a chief as the second three annulets gu. De Grir, Baron Walsingham, 1780. The annulets sa. CromuIngton.

Barry of six arg. and sa. on a chief like the se. cond three annulets as the first. John Moulton, $V$.

Barry of six arg. and sa. on a chief as the se. cond three annulets or. Sermarke, $V$. Seynakes, $V$.

Barry of six az. and arg. on a chjef as the second three annulets gu. Cooke. DE Grex, Baron Walsingham, 1780 . 


\section{On a CHIEF cont.}

Annulets cont.

Barry of six sa. and arg. on a chief of the se. cond three annulets gu. Cookes, $V$.

Barry of six sa. and or on a chief arg. three annulets gu. Vismill, France.

Barry of six sa. and or on a chief of the second three annulets gu. Sr. John de la Vifiulde, France, Cotton MS. Tiberius D 10. Vismil, France.

Gu. on a chief indented arg. three annulets az. Hirst or Hirste.

Gu. on a chief arg. three annulets of the first. Collys, $V^{*}$

Gu. on a chief indented arg. three annulets of the first. Colls. Coluys, $V$.

Gu. on a chief or three annulets of the first. OFFERTON; Edmondson.

Gyronny of eight erm. and sa. on a chief gu. three annulets or. Rolfe, Hadleigh, Suffolk.

Gyronny of ejght or and az. on a chief sa. three annulets arg. RoLfe, Heacham Hall, Norfolk; quartering Neville.

Or on a chief dancetty az. three annulets arg. Robert D'Hereford, $E$; or de Hereford, $F$. The chief indented. Hereford.

Or on a chief sa. three annulets of the first. OGAN.

Or fretty vert on a chief of the second three annulets of the first. MARDOCK, Owlton, Norfolk.

Paly of six or and az. on a chief of the last three annulets of the first. HiNCEEs HINCKS or Hinks.

Sa. on a chief or three annulets of the first. HOGAN OGAN Or OUgAN.

\section{Arrows}

Barry nebuly (wavy, Fordam or FordHaM) of six or and az. on a chief gu. two arrows in saltire betw. as many towers arg. Fond HaM, $V$.

Erm. on a chief az. three bird bolts arg. Bollen (in error for) Bolter, Bolterscombe, co. Devon, quartered by Hooker.

\section{Axes}

Arg. on a chief gu. three battle-axes or. Shepard or SHepherd, Norfolk. Sheppeard or Shepperd. The chief dancetty. Robert ShEPPARD, Kirby Bedon, Norfolk ; granted 1598. The chief indented. Rober't ShepHaRd, ]661, in church at Thames Ditton. SHepherd, Norfolk. But poleaxes. SHEPPERD, Kirby Bedon.

Erm. on a chief sa. three battle-axes arg. Shephard, Pesmarch, Sussex. Sheppard, $V^{*}$. But halberts. Robert Sheppard, Pesmarch, Sussex; granted 1574, $W$. But poleaxes. ShePard, Battersea, Surrey ; and Peasmarshe, Sussex; granted 1574.

Erm. on a chief embattled sa. three battle-axes arg. ShePpard, 1674, in church at Hempsted; Bigland, Gloucester, ii, 67 .

Erm. on a chief sa. three battle-axes ppr. SHEPHERD, London.

Bar

Bendy of six arg. and gu. on a chief sa. a bar indented or. WITTEWRONGE, Stantonbury, co. Buckingham; and Rothamstead, co. Hertford; Collinson, Somerset, ii, 26.

Chequy or and gu. on a chief az. a bar wavy arg. RAYIEY, $W$.

Erm. on a chief arg. a bar indented gu. Shotesbroke, Harl. MS. 1404, fo. 102.

Erm. on a chief gu. a bar of four lozenges conjoived throughout as the first. Chardes, $V$.

Erm. on a chief or a har dancetty gu. SHOTtEBROEE.

\section{On a CHIEF cont.}

Bar cont.

Gu. on a chief or a bar dancetty sa. Shortrand. Paly of six arg. and gu. on a chief az. a barrulet dancetty or. Goshell. John Gousile, $Y$. But a fess dancetty. Gansell or Gonsel.. Goushili. Hathersage or Hathersege.

Paly of six arg. and gu. on a chief az. a bar indented or. Sr. Walter Gouseli, V. But a barrulet indented. Gousel.

Paly of six az. and or on a chief of the second a bar (anotlier a fess) dancetty gu. Heather, co. Derby ; and Surrey.

Paly of six or and az. on a chief gu. a bar in. dented arg. Blíset, $V$. But a fess dancetty. Bleset, $V^{*}$. Blesset.

Paly arg. and gu. on a chief az. a bar dancetty or. Le Sire de Goushill, $Y$.

Paly arg. and gu. on a chief or a bar dancetty az. Rauf Gousile, $Y$.

\section{Bars}

Erm. on a chief (indented, $V^{*}$ ) dancetty gu. a bar gemel or. Sr. Nicholas Brome, Norfolk, temp. Edward I, $V$.

Paly of six arg. and gu. on a chief indented or two barrulets wary az. Gousell.

Gu. on a chief arg. two bars gemel az. Richsiond. Barnacles

Barry wavy of six arg. and az. on a chief gu. three pairs of barnacles extended or. Sмiтн, $(W)$, Surtu or Suytue, Dartmouth, co. Devon.

Beast .... Badger

Chequy arg. and sa. on a chief or a brock pass. ppr. Brooke.

$$
\text { .....Beaver }
$$

Barry wavy of nine arg. and sa. on a chief as the last a beaver like the first. Town of BEvERLEY, co. York; Cotton MS. Tiberius D 10, fo. 846 .

$$
\text { .... Deer }
$$

Arg. fretty az. at each joint a bezant on a chief sa. a buck trippant or betw. two mullets of the last each charged with a torteau. William Grexe, Mylton Clyffedon, near Bruton, $V$.

Chequy arg. and sa. on a chief or a stag pass. ppr. Brooke.

Sa. on a chief vert a buck (couchant, another) current reguard. arg. attired or. Btickton, $V$.

$$
\text { ....Dog }
$$

Barry of five arg. and gu. on a chief as the last a greyhound current per pale or and erm. William Skipwith, St. Alban's, $V$.

Barry of six arg. and gu. on a chief as the last a greyhound current per pale or and erm. collared az. William Sripwitk. St. Alban's, co. Hertford; granted 1507, $W$.

Barjy of six gu. and arg. on a chief as the lnst a greyhound current az. Reskixiner, Cornwall.

Barry of six gu. and arg. on a chief as the last a greybound current sa. Colndeke, $V$. Skipwith, Skipwith, co. York; Hever, and Ormesby, co. Lincoln; and Snowers, Norfolk; Baronetcy 1670-1790. The greyhound collared or. Kepwith, co. Warwick. Skipwith, Prestwould, co. Leicester; Baronetey 1622; Newbold, co. Warwick; Barouetcy 1671-90: and Metheringham, co. Lincaln; Baronetcy 1678-1756.

Barry of eight gu. and arg. on a chief as the last a greshound current sa. MaPOWDER, Haselworthie or Holsworthy, and Pyeworthy, co. Devon, 1620. Sr. William Skipwiтн, $V$.

E rm. on a chief az. a talbot pass. arg. Richard KELLEFET, 1595 ; in church at Egham. 


\section{On a CHIEF cont.}

Beasts cont. Dog cont.

Erm. on a chief sa. a talbot pass. arg. and in the honour point an annulet for diff.gu. MORDEN or Murden, Branston, co. Northampton; and Morten Morell, co. Warwick; confirmed 1618. The dog or. MARDEN or MORDEN, co. Warwick. Paly of six or and vert on a chief gu. a greyhound current ern. Popingay, Portsmoutb.

\section{.....Ermine see Weasel ....Goat}

Chequy az. and or on a chief arg. a goat current gu. Colshilu, $V$.

Chequy or and az. on a chief arg. a goat current gu. attired or. CoIshill, $V^{*}$. The goat salient gu. Corshilu, London.

$$
\text { .... Leopard }
$$

Paly of six arg. and az. on a chief gu. a leopard pass. or. Acweis.

$$
\text { .... Lion }
$$

Arg. masoned sa. on a chief az. a demi lion issuant of the first. BEAU. The lion or. William BEaw, Bishop of Llandaff 1679-1706.

Arg. on a chief gu. a demi lion ramp. as the first in the centre a 5-foil for dift. of the second. Wejoon, Cookbam, Bray, and Shaftes. broke, co. Berks; Swanscombe, Kent; and Newcastle-on-Tyne, co. Northumberland. Wilding, Hackney, Middlesex. But with a mullet in the centre for diff. gu. WELDON, Kent. Wilding, Hackney; and co. Chester.

Arg. on a chief gu. a demi hon of the first armed or langued az. Weudon, Kent.

Arg. on a chief gu. a deni lion ramp. issuant or in the centre a 5 -foil for diff. of the second. Weldone. Weutden, Weltden, Northumberland. The 5 foil pierced. Welnone, $V$.

Arg. on a chief or a lion ramp. issuaut gu. Powell, Packnall or Parkhall, co. Salop.

Az. on a chief arg. a demi lion ramp. gu. DENiBAND, as quartered by Lemprière of Rozel. Deynband. D'urban or Durban. Karbyll. The lion issuant. Denband or Denbaud. Markham, Northampton.

Az. on a chief erm. a demi lion ramp. issuarit gn. Geffrey de GenNevile, $A$, Harl. MS. 613\%.

Az. fretty or on a chief of the second a demi lion issuant gll. William Fitzherbert, Archbishop of 'York 1153-4.

Az. on a chief or a demi lion ramp. issuant gu. MaRkHam, Sedgebrooke, co. Nottinghám; Baronetcy 1642-1779. MARKHaM, Coatham, co. Nottingham; and Becca Hall, co. York; descended from William MARKHal, Bishop of Chester 1771, Archbishep of York 1777-1807. Sr. Richard Markham, $V$.

Az. billety arg. on a chief or a demi lion ramp. issuant sa. Donner, $V *$. Sr. Robert Dornone, $V$.

Az. billety and on a chief or a demi lion ramp. issuant sa. Sr. Robert Dormer, Eythorpe, co. Oxford, $V$. Donder, Ascot, co. Buckingham. Dormer, $Z, 357$ (the.lion sometimes incensed gu.). Donmer, Lee Grange, and Purston, co. Buckingham; Buronetcy 1661-1726, ancestor of Dormer, Rarunetcy 1615, Barony 1653, Viscount Ascott and Earl of Carnarvon 1621-1709. Dormor, $V^{*}$. William Dormore, West Wycomb, $V$. And with a crescent for diff. Michael Dorner, Lord Mayor of London 154l. The crescent on the lion. Michell Dormore, Thumley, $V$.

\section{On a CHIEF cont.}

\section{Beasts cont. Lion cont.}

Barry of four gu. and erm. on a chief as the last a demi lion ramp. issuant like the first. Draton, $V$.

Barry wavy of six az. and or on a chief as the last a demi lion ramp. issuant with two tails vert armed and langued gu. Suttie, Balgone, co. Haddington; Baronetcy J702, quartering Semple.

Barry of six gu. and arg. on a chief erm. a demi lion ramp. issuant az. Turrell, Harl. MS. 1441 , fo. 45 .

Barry of seven az. and arg. on a chief as the last a demi lion ramp. issuant gu. EgnenHaJ, $V$.

Barry of eight gu. and erm. on a chief as the last a demi lion ramp. issuant like the first. Sr. .... FreYNe, $V$.

Chequy arg. and gu. on a chief or a demi lion ramp. issuant az. Robert de Bruere, $A$; or De La Bruere, A, Harl. MS. 6137.

Chequy arg. and gu. on a chief or a demi lion ramp. sa. LABORNE.

Erm. on a chief az. a demi lion ramp. or. Bromhali. But issuant and with a label of three points arg. charged with as many erm. spots sa. Bromhali, $V$.

Erm. on a chief gu. a lion ramp. issuant or. Elwood, Ireland; and co. York.

Frm. on a chief or a demi lion ramp. issuant vert. HegLISE, $V$.

$\mathrm{Gu}$. on a chief or a demi lion ramp. issuant erm. WHERTON, $Y$. But the lion vert. Wharton.

Or on a chief gu. a demi lion ramp. arg. AbNeY.

Paly of six sa. and $\mathrm{nr}$ on a chief of the second a demi lion ramp. of the first. Manwood, Kent.

Sa. on a chief arg. a demi lion ramp. gu. Branes, Kent.

Sa. on a clijef arg. crusily and a lion ramp. issuant gu. Boddington. Bodington, $V$.

Sa. bezanty on a chief arg. a demi lion ramp. issuant gu. JADWYN,$V^{*}$. JADWIN aliter JAUIN, $V$. JUYN, $V$.

Sa. on a chief arg. a demi lion ramp. of the first. Manters, $V$. Mastels.

Sa. on a chief arg. a demi lion ramp. issuant of the first. Manlery. Manters, $V^{*}$. Mantery, V. Matres.

Sa. on a chief ur a demi lion ramp az. Mantony or Mantres.

Sa. on a chief or a demi lion ramp. gu. MarkhaM, Nottingham.

Sa. on a chief or a demi lion ramp. of the first. Mantory or Mantres.

Vair on a chief gu. a demi lion ramp. issuant or. T'ERELL.

Vert on a chief arg. a demi lion ramp. gu. GISE. Vert on a chief gu. a deini lion ramp. or. Terroll, co. Hants. Tirrell. The lion issuant. Terell, co. Hants, $V$.

Arg. on a chief az. a lion pass. of the first. Aston. co. Stafford.

Arg. on a chief az, a lion pass. or. Sir William St. George, temp. Edward I, V. Standen. STAWNDON, $V$.

Arg. fretty gu. on a chief az. a lion pass. or. ORMESTONE.

Arg. on a chief indeuted az. a lion pass. or. Sir Hugh Croft, $L$. Standon.

Arg. on a chief gu. a lion ramp. of the first. Chatjcer, Suffolk. But crowned or. Granell (? France). 


\section{On a CHIEF cont.}

Beasts cont. Lion cont.

Irg. goutty de poix on a chief gu. a lion pass. guard. of the first. Drope, co. Huntingdon; and London.

g. goutty de poix on a chief engr. gu. a lion pass. guard. of the first. Foller.

$\therefore$ on a chief gu. a lion pass. or. Bray. Morand, co. Stafford. Roger de Molend aliter LoNGESPEF, Bishop of Lichfield, etc. 125\%-95, Harl. MS. 6128, fo. 5*. Noble, Reresbie, co. Leicester.

Arg. fretty sa. on a chief gu. a lion pass. or. Mapertshall, $V^{*}$. Mepertishall, $V$. Mepertshald. The lion pass. guard. Pursthall.

Arg. on a chief dancetty (indented, $V^{*}$ ) gu. a lion pass. or. Sr. Thomas Chamber, $V$.

Arg. on a chief gu. a lion pass. guard. or. BRey.

Arg. goutty de poix on a chief gu. a lion jass. guard. or. Sr. Robert Drope, Lurd Mayor of London 1474 .

Arg. goutty de poix on a chief (engr. Gwillim) indented gu. a lion pass. guard. or. City of Chichester, Sussex.

Arg. on a chief gu. a lion ramp. guard. or. LANCASTER.

Arg. fretty gu. on a chief or a lion pass. az. UTHESTONE.

Arg.fretty gu. on a chief or crusily and a lion pess. of the second. Breti, co. Devon, $V$.

Arg. fretty gu. on a chjef or crinsily and a lion ramp. of the second. BRERETon, co. Devon. The croslets fitchy. Bretr, co. Devon.

Arg. on a chief sa. a lion pass. of the first. Bamburgh, Kent, $V$. Cardemen. Cardenew, V. Cardmene or Cardmewe. Gardemow.

Arg. on a chief sa. a lion pass. or. CARDIMEW or Cardinden. Nanscute.

Arg. fretty of six sa. on a clinef as the last a lion pass, or. MILCOMBE.

Arg. on a chief sa. a lion pass. guard. or. Malifant.

Az. on a chief arg. a lion pass. of the first. VALE, Ireland, $V$. WaLL, Ireland.

Az. on a chief arg. a lion pass. guard. of the first. VALE.

Az. on a chief arg. a lion pass. gu. John de Betune, $A$. Gapper.

Az. fretty or on a chief arg. a lion pass. gu. JeFFeray, Malling, Sussex, quartering Melwari. JefFryes, Chiddingley, Sussex.

Az. on a chief arg. a lion pass. guard. gu. GEFFry.

Az. (? gu.) on a chief arg. a lion pass. guard. gu. and in the centre a fleur-de-lis for diff. or. Brock.

Az. on a chief arg. a lion ramp. betw. two squirrels sejant gu. Sutron.

Az. on a chief erm. a lion pass. guard. of the first. HaLL (in error for) Wall, Hoxtou, Mid. dlesex; granted by Camden 1613; Add. IIS. 4964 , fo. 45

Az. on a chief or a lion pass. gu. GLANVILE. Lancaster, Ireland. Sir John Sucton or Sutton, $L$.

Az. on a chief or a lion ramp. gu. Markham, co. Leicester; and co. Worcester. Sutron.

Az. on a chief or a lion ramp. betw. two squirrels sejant gu. Sutton.

Az. fretty or on a chief of the last a lion ramp. betw. two mullets gu. Lementon.

Az. on a chief or a liun pass. sa. MarkHant.

Az. on a chief engr. or a lion ramp. vert. LIZARs, Edinburgh.

\section{On a CHIEF cont.}

Beasts cont. Lion cont.

Barry of four arg. and az. on a chief gu. a lion pass. or. Derardestone. Deneston, $V$. But pass. guard. Demardeston Denardestun Deneston or Deveston.

Barry wavy of four arg. and az. on a chief as the second a lion pass. guard. or. TAYLOUR, London.

Barry wavy of four arg. ard az. on a clief sa. a lion pass. guard. as the first. Mole, Molton, co. Devon; grauted 1592.

Barry of four az. and arg. on a chief as the first a lion pass. or. MARDESTON.

Barry of four gu. and arg. on a chief as the second a lion pass. guard. like the first. BURNBY, $V$.

Barry of four or and gu. on a chief as the second a lion pass. arg. HiLl, co. Somerset, $V$. The lion gold. John ToringtoN, $V$. Robert TREGOZ, $V$.

Balyy of four or and $\mathrm{gu}$. on a chief as the second a lion pass. like the first in the centre an annulet for diff. gold. VYeLL (but ? Massie,) Havl. MS. 1543 , fo. 126.

Barry of five arg. and gu. (? gu. and arg. Harl. MS. 1392) on a chief as the first (sic) a lion pass. like the second. Sr. Adam Lowthe, $V$.

Barry of five gu. and arg. on a chief or a lion pass. as the first. Marbrax, $V$.

Barry of six arg. and az. on a chief gu. a lion pass. or. Lanisn. But pass. guard. Lamkyn, $V$.

Barry (nebuly or) wavy of six arg. and az. (an. other, sa.) ou a chief gu. a lion pass. guard. or. Merchants of the Staple, London.

Barry nebuly (or wavy) of six arg. and az. on a chief quarterly gu. a lion pass. guard. gold with or two roses in fess gu. barbed vert. Merchant Adventurers of the Old Trade, or Hambrough Merchants. But barry wavy with the same chief and an escuclieon az. charged with a sceptre or. Merchant Adventurens of the New Trade, or FrencH Merchants.

Barry of six arg. and gu. on a chief az. a lion pass. or. INGLEFIEID.

Barry wavy of six az. and arg. on a chief or a lion pass. sa. Prilips. The Jion collared or. Phillifs, Ireland ; granted 1600.

Barry of six gil. and arg. on a chief or a lion pass, az. Eglesfield, $V^{*}$. Sir Francis Englefeild, co. Berks, $V$. Englefield, En. glefield, and White Knights, co. Berks; and Wotton Basset, co. Wilts; Baronetcy 1612 . 1822. ENGLESFIELD, $V^{*}$. And with over all a bend sa. ENFIEID.

Barry of six gu. and arg. on a chief or a lion pass. sa. ENGLEFIEI, Harl. MS. 1241, fo. 12?.

Barry of six ol and az. on a chief as the last a lion pass. like the first. Treoose, Cornwall.

Barry of six sa. and arg. on a chief or a lion pass. gu. Phillips, Ireland.

Barry of seven az. and arg. on a chief or a lion pass. guard. gu. WALLERON, $V$.

Barry of eight arg. and gu. on a chief or a lion pass. az. Inglefield, co. Berks.

Barry of ejght gu. and or on a chief per pale as the second and first a lion pass. arg. InKEPENNe, $V^{*}$.

Barry of eight or and gu. on a chief as the second a lion pass. like the first. ENKPEN. But pass. guard. Si..... SPygornelL, $V$.

Barry of eight or and gr. on a chief per pale as the same a lion pass. arg. INKEPENNE, $r$. 


\section{On a CHIEF cont.}

Beasts cont. Lion cont.

Barry of ten gu. and arg. on a chief or a lion pass. sa. Sr. Thomas Malefant, Ireland, $V$. Malefont.

Barry of twelve arg. and az. on a chief or a lion pass. gu. Wallerain de Leceinboch, $A$, Harl. MS. 6137.

Barry of twelve az. and arg. on a chief or a lion pass. gu. William de Lucenburth, $A$.

Barry arg. and az. on a chief or a lion pass. az. Sire Roger de Ynglefeld, $N$.

Barruly gu. and arg. on a chief or a lion pass. sa. INGLEFIELD.

Chequy or and gu. on a chief arg. a lion pass. sa. Sr. Thomas Comberworte, $V$. But pass. guard. COMBERWORTH.

Chequy or and gu. on a chief of the first a lion pass. az. COMBERWORTH.

Chequy or and purp. on a chief sa. a lion pass. guard. of the first. AlFred, the King.

Chequy or and sa. on a chief of the last a lion pass. guard. as the first. HIgHAM, Higham, co. Chester; and Essex.

Erm. on a chief az. a lion ramp. arg. AGER or Awger, Kent; and co. Gloucester. The lion or. ANger or ANGier, Keut.

Erm. on a chief gu. a lion pass. or. Clyssele. Dealchamber., co. Oxford. Landeth. LoNDETH, $V$.

Erm. on a chief gu. a lion pass. guard. or. Bordeley Bordeleys or Bordeloys, co. Cambridge. Sire Gefferey de Bordeleys, $N$. Sr. Thomas Bordeleys, co. Cambridge, $V$. Sr. Geoffrey Bondleys, temp. Edward I, $V$. Burdeleys, Delechamber.

Erm. on a chief gu. a lion ramp. or. Brodess.

Erm. on a chief or a lion pass. guard. gu. Grancester. Grauncester, $V$.

Erm. on a chief per pale arg. and gu. a lion pass. counterchanged. KEn, Earl of Ancram, quartering Kerr.

Gu. on a chief arg. a lion pass. of the first. Laurens de Broc, $E$. Broc, $V$. Brock, $V^{*}$. Brock or Brocke, Upton, co. Chester. But pass. guard. Brock or Brocke, Upton, co. Chester. Brook or Brooke.

Gu. on a chief arg. a lion pass. guard. of the first. Brooks, Whalley, co. Lancaster.

Gu. fretty arg. on a chief of the second a lion pass. guard. of the first over all a bend az. Spigernell. Spygernell. Spygournell.

Gu. on a chief arg. a lion pass. sa. Manscuke, co. Devon.

Gu. fretty of six .... on a chief arg. a lion pass. guard. as the first. JEFFREY, Suffolk.

Gu. on a chief or a lion pass. az. PACEFord. PACiford, $V$. PATFORD.

Gu. fretty of six arg. on a chief or a lion pass. as the first. Spigerneld, co. Buckingham.

Gu. fretty arg. on a chief or a lion pass. of the first. Bretr, co. Devon, $V$. Le Sire Spigurneli, $Y$. Spygerneril or Spyngourneld, Essex.

Gu. fretty arg. on a chief or a lion pass. guard. of the first. SPIGERNELI. SPIGORNEIL, $V^{*}$. Sire Henri SpIgoonnel, $N$. Sr. Henry Spigurneli, temp. Edward I, $V$. And with over all a baton az. SPIgernelL. Sire Johan Spigornel, $N$. Spygerneli. Spygourneli.

Gu. fretty or on a chief of the second a lion pass. as the first. T'wyFord.

Gu. on a chief or a lion pass. sa. Drmock or Dумотт, co. Lancaster. Sire Dary Dyнot, $N$.
On a CHIEF cont.

Beasts cont. Lion cont.

Dyмотт, Westminster, $V$. Hower,, $V$. Sr

David Veryet, $V$. Weriet. Weirswall.

Gu. fretty arg. on a chief or a lion pass. $\mathrm{s} 1$

Yesten, $V$. Yeston, $V^{*}$. Yescon or YestC

Wales.

Gu. on a chief dancetty or a lion pass.

Glincester. Glowcester, $V$. The chief indented. Gloucester, London.

Gu. on a chief dancetty or a lion pass. guard. sa. Gloucester, Harl. MS. 1556, fo. 108.

Lozengy or and az. on a chief gu. a lion pass. of the first. Kipping, Tewdley, Kent. The lion betw. two bezants each charged with a fleur-delis of the second. Keppyng.

Or fretty az. on a chief of the second a lion pass. guard. arg. betw. two martlets as the first. ST. AMOND, $V *$.

Or fretty sa. on a chief az. a lion pass. guard. arg. betw. two martlets of the first. Anthony St. Amand or St. Amond, $V$.

Or on a chief az. a lion ramp. gu. Asconm.

Or on a chief az. a lion pass. of the first. Aston, co. Stafford. Aston, $V$.

Or on a chief dancetty az. a lion pass. of the first. RandulPH.

Or on a chief indented az. a lion pass. of the first. Midle Hadr. Ribald, Middleham, co. York.

Or on a chief az, a lion pass. of the first armed gu. Canton, Ireland.

Or a chief az. a lion pass. guard, of the first. Aston, Tixall, co. Stafford; Erdeswick. Brasham, $V$.

Or on a chief az. a lion ramp. of the first. Aston, $V^{*}$. LanNCELOT.

Or on a chief gu. a lion pass. arg. ABNEY, Abney, co. Derby; and co. Leicester. ABney, Masham Hall, co. Derby. IngWardby, Willesley, co. Derby; a coheiress m. Abrey.

Or on a chief dancetty gu. a lion pass. arg. a crescent for diff. Glenester.

Or on a chief embattled gu. a lion pass. guard. of the first. (Augmentation granted, 1665, to) Trtus, Bushey, co. Hertford.

Or on a chief sa, a lion pass, arg. Megas, co. Warwick.

Or on a chief sa. a lion pass, of the first. Sмгтн, London.

Or fretty sa. on a chief of the second a lion pass. guard. arg. betw. two martlets as the first. Anthony Sr. Amand, $V$. St. Amond, $V^{*}$.

Or fretty sa. on a cbief of the second a lion pass. as the first. Milconbe.

Or fretty sa. on a chief of the second a lion pass. guard. as the first. Gygges, $V^{*}$. Multecombe. MyLtecombe, $V$.

Paly of six arg. and az. on a chief gu. a lion pass. as the first. BAGWELL, Ballyloughane, co. Tipperary; and Burgagery, near Clonmel.

Paly of six arg. and az. on a chief gu. a lion pass. or. BACKWELL, Middlesex. 'Thelion pass. guard. (? AcWEll). BlackWell. Lodington, $V$. Lonington, Weldingworth, co. Lincoln. Lodyngton, Chief Justice of the King's Bench 1416-19, brass at Gonby, co. Lincoln. Ludington, co. Lincoln.

Paly of six arg. and az. on a chief or a lion pass. guard. sa. GoLdFincH ol GouldFincH, Kent. GoLDSMiTH.

Paly of six nebuly arg. and gu. on a chief as the first a lion pass. guard. like the second. ArMory, Kerry, Ireland. 


\section{On a CHIEF cont.}

\section{Beasts cont. Lion cont.}

Paly of six arg. and gu. on a chief as the first a lion pass. sa. Langford, Bratton, co. Devon.

Paly of six arg. and gu. on a chief az. a lion Ar pass. as the first ducally crowned or. LEwis. Wenham, Moorball, Sussex. And with a cres. Ar cent for diff. Wenhar, Laughton, Sussex.

raly of six arg. and gu. on a chief az. a lion pass. or. LANGFond, co. Wilts ; and co. Berks. Sr. Christopher (? Thomas) de LangFond, $R$.

Paly of six arg. and gu. on a chief az. a lion pass. guard. or. CARDEMEN. LANGeFord, $V$. Le Sire de Langford, $Y$. Langford, Langford Hill, Cornwall; the heiress m. Wollacombe. LangFord, Tremabe, in Liskeard. Langford, Trungle, and Penzance, Cornwall. LANGFORD, Hallatrow, co. Somerset, 1620 ; descended from LANGFORD, co. Wilts. The lion reguard. LANGFORD, co. Devon.

Paly of six arg. and gu. on a chief as the last a lion pass. like the first. Stormyn, $V$. Winyard.

Paly of six arg. and gu. on a chief as the second a lion pass. gliard. or. BECKWELL.

Paly of six arg. and sa. on a chief gu. a lion pass. guard, or. LAXTON.

Paly of six arg. and sa. on a chief as the second a lion pass, like the first. UFTWAYTE or Ustewayte. Thomas UstewaIte, $V$. Ustewayt, $V$. Vustewayte, $V *$.

Paly of six erm. and az. on a chief gu, a lion pass. or. Barnes. The lion guard. Althair, London; and Essex.

Paly of six erm. and az. on a chief gu. a lion ramp. or. Althali, Baron of the Exchequer, at the Charterhouse, 1619.

Paly of six gu. and vair on a chief or a lion pass. sa. Devereux.

Paly wavy of six or and az. on a chief gu. a lion pass. guard. or. Allanson, quartered by Preys. Allenson.

Paly of siz or and az. on a chief sa. a lion pass. guard. as the first. HIGHAMI, Echingham, Sus. sex.

Paly of six or and gu. on a chief arg. a lion pass. sa. LANGSFORD, $W$.

Paly of six or and gu. on a chief of the last a lion pass. arg. Sr. Phillip Preys, $V^{*}$. PHillip. The lior pass. guard. Preys, $V^{*}$.

Paly of six or and sa. on a chief vert a lion pass. of the first. LANGSFORD, Cornwall.

Paly of eight arg. and gu. on a chjef az. a lion pass. (guard. $V^{*}$ ) or. REDLEFELD, $V$.

Paly of ten arg. and az. on a chief gu. a lion pass. guard. (as the first, $V^{*}$ ) .... BELLwELI. Sr. John Bellwelie, $V$.

Paly arg. and az. on a chief gu. a lion ramp. guard. or. Sire Johan de BAKWELLE, $N$.

Paly arg. and gu. on a chief az. a lion pass. or. Sire Johan de Langeford, $O$. The lion pass. guard. Thomas LaNGForde, $Y$.

Per pule arg. aud gu. on a chief sa. a lion pass. or. KInkBy, Stainbridge, co. Hants. KIRKEBE, $V$. KIRKEBY, $V^{*}$. KIRELEY.

Per pale erm. and ermines on a chief indented or a lion pass. vert. GoDMAN, Leatherhead, Surrey; granted 1579. Godian, Wevilsfield, and Chichester, Sussex.

Per pale indented erm. and sa. on a chief gu. a lion pass. guard. or. MACKWORTH.

Per pale pily of sis gu. and arg. on a chief as the second a lion pass. like the first. M'Deriot or M'DERHOTT, Ireland.

\section{On a CHIEF cont.}

Bessts cont. Lion cont.

Per pale or and gu. on a chief sa. a lion pass. of the first. KirELEY.

Purp. on a chief dancetty (indented, Skipton, $V^{*}$.) arg. a lion ramp. of the first. Skypton, $V$. Sa. on a chief arg. a lion pass. gu. Diable Dibble or Dible. Gerard de Giable, $D$.

Sa. fretty or on a chief of the first a lion pass. guard. as the second. Mrltecombe, $V$. MYTTECombe, $V *$.

Vairy purp. and erm. on a chief gu. a lion pass. or. TASWELL.

$$
\text { .... Wolf }
$$

Barry of six gu. and arg. on a chief of the last a wolf courant az. RESKYHER or RoskYMER, Reskymer, Cornwall; the coheiresses $\mathrm{m}$. Trelawney, Mohun, Courtenay, and Lower. Roscomours, $V^{*}$. But pass. Reskinner, Hailsford, Cornwall. Roscomours, $V$.

\section{.... Weasel}

Or on a chief vert an ermine pass. ppr. WATSON, Newport, co. Salop.

\section{Beasts ..... Ieopards}

Barry wavy of six arg. and az. on a chief sa. two leopards pass. as the first betw. so many an. ehors or. Bond, London.

Gyronny of eight sa. and or. on a chief as the first two leopards like the second. Crow, Bil. ney, Norfoik.

$$
\text { .... Lions }
$$

Az. bezanty on a chief arg. two lions pass, respectant sa. Preston, Crickett, Harl. MS. 1385.

Erm. on a chief az. two lions ramp. or. DYPDEN, $V *$.

Erm. on a chief indented az. two lions ramp. or. BUREs, co. Somerset.

Erm. on a chief indented gu. two lions ramp. or. Bowres.

Erm, on a chief dancetty sa. two lions ramp. or. Bures.

Erm. on a chief indented sa. two lions ramp. or. Bery. Sire Robert de Bourrel, $N$. Bures, Essex; and Suffolk, 1730. Burr, Ramsay, Dover Court, and Wrabnese, Essex. Bowens, Essex. Bures, Essex, temp. Edward III, $V$.

Or on a chief az. two lions ramp. of the first. Dypden, Suffolk, $V$.

Or on a chief sa. two lions ramp. combatant arg. Cownterle, $V$.

$$
\text { .... Deer }
$$

Gu. on a chief arg. three harts of the first. HaRT, Grimmons. And with a fleur-de-lis in the centre for diff. silver. HarT, Ireland.

Or on a chief indented arg. three harts gu. HART or HERT.

$$
\text { .... Leopards }
$$

Arg. fretty gu. on a chief of the second three Jeopards or. LTDwell, Dromard, Clonmore, and Cormackstown, co. Tipperary.

$$
\text { .... Lions }
$$

Arg. on a chief az. three lions ramp. of the first. Sire Johan de Brkenore, $N$. Sr. John BickNor, Kent, temp. Edward I, $V$. And with over all a baston gu. Sire Thomas de BIKENoRe, $N$.

Arg. on a chief az. three lions ramp. of the first crowned or. John de Bikenor, $A$.

Arg. on a chief az. three lions ramp. or. M. John DEPDEN, $S$. 


\section{On a CHIEF cont.}

Beasts cont. Lions cont.

Arg. on a chief gu. three lions ramp. of the first. Yonge, $V^{*}$.

Arg. on a chief gu. three lions ramp. guard. of the first. Yonge, $V$. Younge, Metbeley, co. York.

Arg. on a chief gu. three lions ramp. or. Frame.

Arg. on a chief indented sa. three lions ramp. of the first. Poone or Power, Baron of Dunoyle, 1327.

Erm. on a chief az. three lions ramp. arg. Henry Fitz-Aucher, $V$. Johan Sauvage, $G ; N$. Raffe Savage, $A$. Savage, Kent, $V$. Sir John Savage, $L$.

Erm. on a chief az. three lions ramp. or. ARcher, Bishopsburn, Kent; Baronetcy 1666-1723. Archer, Essex. Sr. Anthony Aucher, Otterden, Kent, $V$. Henri Aucher, $E ; F$. Bunes. Depden, Suffolk. Fitz-Archer. Henry Fitz-Aucher, $Y$. Sire Auger le Fitz-Henri, N. Fitz-Henry, Essex. Aucher Fitzhenky, $Y$. Monsire Richard Fitzhenry, $Y$. Young, Westminster.

Erm. on a chief az. three lions ramp. palewise or. ANCHER or ANCHOR, Kent.

Erm. on a chief dancetty az. three lions ramp. or. OnMesley.

Erm. on a cbief embattled az. three lions ramp. or. Acher, Kent.

Erm. on a chief indented az. three lions ramp. or. Norkesley, Essex. Sr. William Orkeley, Essex, temp. III, $V$. Sire William Orkesileye, $N$.

Erm. on a chief az. three lions ramp. or armed and langued gu. AUcher, Losenham, Otterden, and Bishopsbourne, Kent; Baronetcy 1666-1723; the coheiresses $\mathrm{m}$. Corbett, and Blomer.

Erm. on a chief indented az. three lions ramp. or. ORKELEY or ORKESLEY.

Erm. on a chief gu. three lions ramp. arg. Franckcheney, co. Devon.

Erm. on a chief gu. three lions pass. or. LoNDE'TH, $V^{*}$. Sir Thomas Londeth, $V$.

Erm. on a chief gu. three lions ramp. or. Oliver, Wollescott Hall, co. Worcester, quartering Milward. Oliver, Croombill, Kent. Quinton alias Omver, Heyborne, and Leyborne, Kent; and Boulton, co. Wilts. Quintin, co. Wilts, 1716 .

Erm. on a chief sa. three lions ramp. arg. Greane, Norwich, and Hardwick, Norfolk. Oliver, Exeter, co. Devon. Wheleer, London.

Erm. on a chief indented sa. three lions ramp. arg. Bowers, Essex; and Suffolk.

Erm. on a chief sa. three lions ramp. or. LoXDALE, Ryton Grove, Shrewsbury. OLIVER, Ireland.

Lrm. on a chief indented sa. three lions ramp. or. Bowers, Essex.

Erm. on a chief vert three lions ramp. or. Edward Oliver, 1697, in church of St. Mary, Newington, Surrey; Add. MS. 6409.

Erm. fretty or on a chief sa. three lions ramp. of the second. Treslove or Truslewe, co. Northampton; Aubery, co. Wilts; and Beverley, co. York.

Erminois on a chief az. three lions ramp. or. Lile or Lisle, Middlesex.

Gu. on a chief indented arg. three lions ramp. az. WormLey, co. York, 1716. The lions sa. Wormley, Halfield, co. York.
On a CHIEF cont.

Beasts cont. Lions cont.

Gyronny of eight arg. and sa. on a chief or three lions ramp. gu. CoLMER, Wyghton, or Tolwy, Nighton, i. e., Tolwin, Aylsham, and Wighton, Norfolk.

Lozengy or and az. on a chief gu. three lions ramp. of the first. BAKER, co. Lincoln; and Sinallborough, Norfolk.

Or an a chief az. three lions ramp. arg. Nicol de Menne, $E, F$; but De Incule, $E$, Harl. MS. Sandwell or Sandwrel. Viennus.

Or on a chief az. three lions ramp. arg. crowned or. Jon de Birenone, A, Harl. MS. 6137.

Or on a chief az. three lions ramp. of the first. De Insula or Lisle, Moyles Conrt, and Wodeton, co. Hants; the coheirs m. Taylor, Manley, and Taylor. Sir John Del Yıe, N. Samuel LISLE, Bishop of St. Asaph 1744, Norwich 1748-9. Sir John LisLe, $I$; and co. Hants, temp. Edward I, $V$. John Lisley, $E$. LisLey, Collinson, Somerset, ii, 443. Thomas de SandUns, A, Harl. MS. 6137, fo. 91.

Or on a chief gu. three lions ramp. of the first. Thomas de Sandair, $A$. Saunder.

Or on a chief vert three lions ramp. of the first. Raynolds or Reynolds, Attleborough, Norfolk; confirmed 14 October 1576.

Paly of six or and gu. on a chief az. three lions ramp. of the first. KIDDELL alias Benner, i. e., Ridell or Ryddell alias Bonner, Camden, co. Gloucester; and Swalford, co. Oxford; granted 1574.

Per pale or and arg. on a chief indented sa. three lions ramp. of the first. BEEvor, Hetbell, Norfolk; Baronetcy 1784; descended from BEEvoR, Heckmondwicke, co. York.

Sa. (on a chief .... in error) three lions pass. betw, two bendlets engr. arg. Browne, $V^{*}$.

Sa. on a chief or three lions ramp. of the first. VyNaII, Kingston, near Lewes, Sussex.

Varr on a chief gu. three lions ramp. or. Younge, Grenford, Middlesex; and Dunford, co. Wilts.

Bells

Arg. fretty gu. on a chief of the second three hawli's bells of the first. RaDFord, $V$. RATFORD, $V$.

Az. fretty or on a chief arg. three hawk's bells gu. RADFORD, $V^{*}$.

Az. fretty or on a chief gu. three hawk's bells arg. RaDFond, $V$.

Az. fretty or on a chief gu. three bells of the second. RADFORD.

Erm. on a chief sa. three church bells arg. BELL, Essex.

Gu. on a chief arg. three church bells sa. BeLL, Cumberland, $V$. Richard BELI, Bishop of Carlisle 1478-95. Beld, Northumberland.

\section{Bend}

Gu. on a chief az. a bend nebuly out of which issue rays of the sun ppr. (An error for) Lysons, Hempsted Court, co. Gloucester.

Gu. tretty arg. on a chief or (a lion pass. guard. of the first over all) a bend az. Sir John Spygunneli, Harl. MS. 2116, fo. $38 \mathrm{~b}$.

\section{Bendlets}

Erm. on a chief or two bendlets az. Claypoli. And with an annulet in the centre for diff. .... Claypoole, $V$.

Az. on a chief arg. three bendlets gu. BunsLaM or Burslem. 


\section{Bendlets cont.}

On a CHIEF cont.

Az. on a chief gu. three bendlets arg. Mawrice. Erm. on a chief or three bendlets sa. BaBETote, $V^{*}$. Sr. William DaBetote, $V$.

Or on a chief arg. three bendlets gu. Kinneray. Billet

Arg.onachief az. a billet fesswise or. BroderLer.

Barry of five or and sa. on a chief of the second a billet betw. two esquires based dexter and sinister of the first on an escucbeon (? gu.) a fess and chief erm. Butler.

Billets

Erm. on a chief gu. two billets or. WATTs, Nor. folk.

Erm. on a chief gu. two billets or gads engr. or. Wattrs, $V$.

Erm. on a chief gu. three billets or. Wattrs. The tillets engr. WatTrs.

\section{Bird}

Per pale arg. and sa. a chief dancetty counterchanged in the dexter quarter a bird arg. legged gu. Brasy.

\section{..... Crow}

Arg. on a chief or a Cornish chough (another a raven ) ppr. HOARD. Richard Hurd, Bishop of Lichtield etc. 1774, Worcester 1781.1808. The bird sa. Hurd.

$$
\text { .... Eagle }
$$

Paly of six or and az. on a chief of the first a demi-eagle displ. sa. Cover't or Court, co. Somerset.

Arg. on a chief gu. an eagle displ. or. Cabipion or Campyon, London; Combwell; and Colchester; and Danny, Sussex; quartering Courihope. Canpron, Essex, $W$.

Arg. on a chuef wary gu. an eagle displ. or. Charles, $V$. Charles, Tavistock, co. Devon.

Barry wavy of six arg. and az. on a chief gu. an eagle displ. betw. two fleurs-de-lis or. Town of Burton-upon.Trent.

Barry of six sa. and or on a chief as the second an eagle displ. like the first. CATENYS.

Erm. on a chief wavy gu. an eagle displ. or. Charles, Tavistock, co. Devon. Southmead, Wrey ; perhaps from marriage with CHARLIs, Moreton, co. Devon, Harl. MIS. 3288, fo. 23.

Err. on a chief sa. an eagle displ. double-headed or. Greffry or GreFfY, co. Warwick. Gressr.

Gu. on a chief arg. an eagle displ. sa. Burgees.

Gyronny of eiglit vert and arg. on a chief of the last an eagle displ. gu. Crowgay Crowgey or CrowgIE.

Gyrouny of twelve arg. and gu. on a chief az. an eagle displ. double.headed of the first. Nicholas Lemprew, $V$. Lempietur, $V$.

Paly of six az. and arg. on a chief as the first ao eagle displ. like the last. A'Court.

Paly of six or and az. on a clijef as the first an eagle displ. sa. Courte, $V$. Conrt or Covert, co. Somerset. Court, Collinson, Somerset, is, 470.

Paly arg. and az. on a chief as the first an eagle displ. double-headed sa. Court, Collinson, Somerset, i, 222.

Per chev, az, and or on a chief engs. of the second an eagle displ. sa. HENNEBER.

Vert on a chref arg. an eagle displ. sa. SALTHOUSE.

$$
\text { .... Falcon }
$$

Arg. on a chief or a hawk sa. Hoond Hond or Hownd, Parkbromage, co. Salop.
On a CHIEF cont.

Bird cont. Falcon cont.

Paly of six sa. and or on a chief arg. a falcon close ppr. Fauiriner.

$$
\text { .....Finch }
$$

Per saltire erm. and ermines on a chief gu. a goldfinch ppr. betw. two roses or. GoLdsmid. ..... Kingfisher

Arg. on a chief gu. a kingfisber of the first belled or. Geffrey Wanton, $V$.

$$
\text { .....Martlet }
$$

Az. on a chief or a martlet ppr. DE Honde, co. Salop. Horde. Hooard. Howard, Surrey. Gu. on a chief az. a martlet sa. Resrys, $V$.

Per saltive or and az. on a chief of the first a martlet as the second charged with a 5 -foil gold. Harlow.

\section{....Peacock}

Barry wavy of six arg. and az. on a chief gu. a peacock in pride ppr. betw. two fleurs-de-lis or. 'Town of NEwark, co. Nottingham.

\section{Birds}

Per pale .... and .... on a chief .... two birds .... O'HAGAN; in old church at Ballinascreen.

$$
\text { ..... Eagles }
$$

Erm. on a chief iudented az. two eagles displ. arg. Dar, London.

Erm. on a chief indented sa. two eagles displ. or. GENT, Doddinghurst, and Steeplehumstead, Essex.

Per chev. sa. and arg. on a chief az. two eagles rising or. WYBERD, Walrish Hall, Essex.

$$
\text { .....Martlets }
$$

Arg. on a chief or two martlets with wings displ. sa. FISHER.

Erm. on a chief az. two martlets or. HaYn; granted 1628.

\section{....Moorcocks}

Erm. on a chief indented sa. two heathcocks (moorcocks $V^{*}$ ) arg. BANNE, $V$.

$$
\text { .... Swallows }
$$

Gu. on a chief or two swallows rising overt ppr. SPEED, London; Harl. MS. 6095, fo. 9.

\section{Birds}

Az. billety and on a chief or three birds of the first. Dormer, Wing, co. Rutland. The birds sa. Dormer, $V^{*}$. Sr. Robert Doriore, Wyng, co. Rutland, $V$.

Arg. on a chief gu. three birds or. Bartholmewe de Morston, $A$.

Arg. on a chief sa. three birds or. CORBEN, $V^{*}$. The birds either ravens or jays. Tregean Tregian or Tregyan, Cornwall.

Barry nebuly of six sa. and or on a chief arg. tbree birds as the first. Griarsere, Brachlowe, co. Leicester, temp. Henry VIII.

Chequy or and gu. on a chief of the first three birds az. FLEMING.

$$
\text { .... Cocks }
$$

Barry of four gu, and arg. on a chief as the last three cocks like the first. Blackstone or Buagestone, $V^{*}$. Plackeston, Newcastleupon-Tyne, $V$.

Gu. on a chief arg. three cocks of the first. Hancocke, Comb Martin, co. Devon; granted 1588 .

Paly of six sa. and or on a chief as the second three cocks like the first. Galliers, Stapleton Castle, co. Hereford; quartering Vaughan.

Arg. on a chief or three ravers sa. Corben, co. Stafford, $V$. Corben Corbin or CoRbyn, co. Stafford; and Sufioll. 


\section{Birds cont. Crows}

On a CHIEF cont.

Arg. on a chief sa. three ravens or. Tregean, V. Treaian Tregean or Tregian, Cornwall. Az. on a chief or three ravens ppr. Corbyn, as quartered by Levinge.

Per pale gu. and az. on a chief engr. or three ravens ppr. each charged on the breast with an ermine spot of the third. Corbin, La Porte, Guernsey.

Sa. on a chief or three ravens ppr. Corby .... Doves

Or on a chief az. three doves arg. Frederick, Westminster, and Burwood House, Surrey; Baronetcy 1723. The doves ppr. Frederick, Hampton, Middlesex.

$$
\text { .... Ducks }
$$

Barry wavy of four sa. and or on a chief urg. three ducks (or swans) as the first. Grimesiy.

Per pale or and gu. on a chief arg. three shovellers sa. Calcot or Caldecot, Willscot, co. Oxford. .....Eagles

Az. on a chief or three eagles displ. sa. Harrison, Norton Place, co. Lincoln; quartered by Cholmeley.

Chequy arg. and gu. on a chief sa. three eagles displ. or. Kyrle-Moner, Much Marcle, co. Hereford; Whetham, co. Wilts ; and Pitsford, co. Northampton; Baronetcy 1838; quartering Kyrle, Washbourne, Dabitot, Ernle, Malwyn, Finamore, Kyrle, Scudamore, Gifford, Tregoz, Ewyas, Windsor, Stoughton, Thorold, Richmond, etc.

Erm, on a chief indented az. three eagles displ. or. Gent, Essex.

Or on a chief gu. three eagles displ. of the first. Harrison, London; and North Riding, co. York. HaRrison, of the North; granted 1574.

Or on a chief sa. three eagles displ. of the first. Harrison, Hurst, and Finchamsted, co. Berks; granted 1623 .

Paly of six gu. and or on a chief az. three eagles displ. arg. WeEkes, Gloucester, $V$.

Paly of six gu. and vair on a chief or three eagles displ. sa. DE AQUiLIS.

Paly of eight or and gu. on a chief az. three eagles displ. double-headed as the first. WEEKS.

$$
\text { .....Falcons }
$$

Or on a chief az. three falcons jessed and belled or. Loke, London.

$$
\text { .....Herons }
$$

Sa, on a chief arg. three storks of the first. HoBBs, Ireland.

\section{.... Martlets}

Arg. on a chief az. three martlets of the first. Frederick, London.

Arg. on a chief az. three martlets or. Blanford. Arg. on a chief indented az. three martlets ol. Martyn.

Arg. on a chief gu. three martlets of the first. Wray.

Arg. on a chief gu. three martlets or. Morston, Kent, $V$. Wogan.

Arg. on a chief indented gu. three martlets or. Mandevile or Mandeville, co. Buckingham; and Nottley, Essex. Sire Thomas de Mandefile, $N$. Speyes or Spyes, Essex. Sr. Thomas Speys, Essex, temp. Edward I, $V$.

Arg. on a chief sa. three martlets of the first. Hogan, Wales.

Arg. on a chief indented sa. three martlets of the first. Levins.

\section{On a CHIEF cont.}

Birds cont. Martlets cont.

Arg. on a chief sa. three martlets or. WoGAN, Wiston. Sir Walter Wogan, cc. 1190. WyLdE, Kempsey, co. Worcester.

Az. on a chief arg. three martlets gu. WraY.

Az. on a chief or three martlets gu. RAY, co. Lincoln. WEBB. WeBBe, Bottisham, co. Cembridge. Wray, co. Lincoln, W. Wray, Beamish, co. Durham. Wray, Asbby, co. Lincoln; Baronetcy 1660; ext..... Wray, Cusworth, co. York. Wray, Kelfield, co. Lincoln; descended from WraY, Glentworth, co. Lincoln; Baronetcy 1612-1809; quartering Casey; thecoheirs m. Innes, Dalton, and Arthington.

$\mathrm{Az}$. on a chief or three martlets gu. in base a mullet for diff. WraY, Chester-le-Street Church, co. Durham.

Az. on a chief indented or three martlets gu. RAY, Howleigh, Suffolk; granted 8 March 1770.

Az. billety or on a chief of the second three martlets sa. Dormer.

Barry of six gu. and arg. on a chief as the second three martlets az. Moulton, Norfolk.

Erm. on a chief indented az. three martlets or each bolding in the beak a 3-foil slipped arg. RIDER, Lichfield; granted 1722.

Erm. on a chief gu. three martlets or. Fitz-Hugh or Fits-Hewe, Wanendon, co. Buckingham.

Erm. on a cbief sa. three martlets or. Treasan or Tregyan, Wolfedon, Cornwall.

Gu. on a chief arg. three martlets sa. Chabnor, co. Hereford. Toulmin.

Gu. on a chief indented arg. three martlets sa. Barrett. Lovelace, Kent.

Gu. on a chief indented or three martlets sa. Lovelace.

Gu. on a chief sa. three martlets arg. LUkE, Corrıwall.

Gu. on a chief indented sa. three martlets arg. Lovelace, Hurley, co. Berks; Lovelace, and Canterbury, Kent. Sir Richard Lovelas, $V$. Lovelass, $\boldsymbol{V}^{*}$.

Gu. on a chicf indented sa. three martlets or. Lovelace, Barony 1627-1736.

Or on a chief gu. three martlets of the first. OWGaN, $V^{*}$. SEYNGER, $V$.

Or on a chief sa. three martlets of the first. Ongawyn. John OWgan, Wiston, $V$. Sr. Henry Owaan, Boliston, $V$. Owgan or Ougan, co. Pembroke. Pareman. Worgan, impaling arg. a chev. betw. three pierced mullets gu. Collinson, Somerset, i, 168.

Or on a chief vert three martlets of the first. Seynger. Watson, Hughfield, Middlesex; and Gisborough, co. York.

Paly of six arg. and az. on a chief or three martlets gu. Cheneld. Cheynel, $V^{*}$. Cheyneli, $\boldsymbol{V}$.

Paly wavy of six arg. and az. on a chief sa. three martlets or. Ferman or Feryman, London.

Paly of six az. and or on a chief as the second three martiets gu. Cherneli, $V^{*}$.

Paly of six gu. and compony arg. and sa. on a chief or three martlets gu. CHawryn.

Paly of six or and az. on a chief gu. three martlets arg. Martys. The martlets gold. MaRtyn, London; granted 10 January, 1572.

Paly of six or and az. on a chief of the first three martlets gu. CheynerL, $V$.

Paly of eight arg. and az. on a chief or three martlets gu. Chevill or Cheynel.L. 


\section{On a CHIEF cont.}

Birds cont. Moorcocks cont.

Arg. on a chief or three (moorcocks, $\nabla^{*}$.) heathcocks sa. Corben, co. Stafford, $V$.

\section{.... Owls}

Arg. on a chief gu. three owls of the first. Cropley, Middlesex; co. Cambridge ; Harl. IIS 6095 , fo. 3 ; and Offord-Cluney, co. Huntingdon.

Barry of six arg. and sa. on a chief of the second three owls like the first. WAKEFIELD.

Erm. on a chief gu. three owls arg. CopLey, London; and Soham, co. Cambridge; 1730.

$$
\text { .....Popinjays }
$$

Erm. on a chief sa. three jays or. TregeAN Tregian or Tregyas, Tregian, and Golden, Cornwall.

$$
\text { .... Swallows }
$$

Barry wavy of six arg. and az. on a chief or three swallows with wings expanded sa. Moriskines.

$$
\text { ..... Swans }
$$

Barry wary of four sa. and or on a chief arg.three (ducks, or) swans as the first. Grimesby.

$$
\text { .... Eagles }
$$

Erm. on a chief indented az. six eagles displ. arg. DAY, London.

$$
\text { .....Martlets }
$$

Or on a chief gu. six martlets of the first. SEYNGER. Blades

Or on a chief gu. three scythe-blades erect arg. Sethington, V.; and Harl. MS. 1385, fo. 94. Book

Or on a chief sa. an open bible proper clasped betw. two ink-molines of the first. WOOD, Singleton Lodge, co. Lancaster.

\section{Bordure}

Arg. on a chief or a borduro az. BroderLey. Bougets

Arg. on a chief az. two flesh-pots or porridge pots without handles or. Potter, $V$.

$A z$. on a chief arg. three water-bougets gu. Du-Vernet or Duvernette.

$$
\text { Buckle }
$$

Arg. on a chief paly of six gu. and or a buckle .... Kertr, Auquhorsk, Scotland ; Nisbet, i.75. Backles

Arg. on a chief gu. three round buckles or Stryvelin. The points dexter. Sir John Strevelyn, $Q$

Arg. on a chief sa. three buckles or. STERLYN. Sternilng.

Arg. on a chief sn. three round buckles or. Streveling. The points sinister. John de STREVELyNe, $V$.

Az. on a chief arg. three lozenge buckles points dex. ter of the first. THOROGOOD or THOROWGOOD, Thorowgood, and Shartfield, co. Hertford; granted 1594. Throgood, $V^{*}$. Throogood or Troogood,Thornhall, co.Northampton; 1594.W.

Erm. fretty or on a chief of the last three buckles points fesswise gu. Rowley, Highley, co. Stafford.

\section{Canton}

Barry of five az. and arg. on a chief per fess dancetty erm. and as the second a canton or. Hотнам, $V$.

Barry of six arg. and az. on a chief erm. a canton (of the first, another) or. Нотнам.

Parry of six arg. and az. on a chief indented erm. a canton or. Hotha

Barry wavy of six arg. and sa. on a cbief gu. a callon erm. Banlow, co. Derby; $V$. The chief gu. flory or. Barlow, Bramfield, co. Chester.

\section{On a CHIEF cont.}

on a Canton.... Bird

Arg. a chief erm. on a canton gu. an owl of the first. Barton, co. Buckingham.

$$
\text { ..... Estoile }
$$

Erminois on a chief indented gu. a gold medal pendent from a ribbon of the last fimbriated $a z$. betw. two crescents arg. and below it "Orthes" on a canton erm. the Order of the Tower and Sword pendent from a ribbon. Harvey.

$$
\text { .... Roundle }
$$

Arg. on a chief vert two mullets or on a canton gu. a bezant pierced by a pair of arrows saltirewise of the third. DREwry.

$$
\text { .... Saltire }
$$

Arg. on a chief gu. a canton az. charged with a saltire arg. oppressed by an escutcheon of Scotland ensigned by a regal crown. MenzIes, That Ilk; Baronetcy 1665.

$$
\text { ..... Wreath }
$$

Paly of six or and gu. on a chief of the first a demi lion issuant .... on a canton as the second a garland gold. GarLand.

\section{Cantons}

Barry of five or and az. (but six az. and or, Ferne, $202)$ per pale counter-changed on a chief paly per fess two cantons gyronny of eight transmuted over all an escucheon arg. Pressionie.

Barry of six gu. and or (? per pale counterchanged) on a chief per pale two cantons one per bend the other per bend sinister transmuted over all an escucheon arg. Sr. de HAgeley, $\nabla$.

Chequy gu. and arg. on a chief of the second two cantons one dexter the other sinister az. Hamberkers, Harl. MS. 1404, fo. 59.

\section{Caps}

Erm. on a chief az, three (dncipers or) caps of maintenance .... BRADSHAW.

\section{Castles}

Per chev. erm. aud vert on a chief gu. three towers arg. Honncastue.

\section{Chessrook}

Erm, on a chief quarterly or and gir. a chessrook in the dexter corner sa. Barrokes, V. Parrock, Parrock, Kent.

Chessrooks

Arg. fretty sa. on a chief of the second three chessrooks as the first. CHAMrBERLAYN.

Sa. on a chief arg. three chessrooks az. VERDON, V.

Sa. on a chief arg. three chessrooks of the first. Arthosy. ARthorig, $V^{*}$. ARthory, $\boldsymbol{V}$.

Chief

Barry of five az. and arg. on a chief as the se. cond another dancetry erm. a canton or НотнАM, $V$.

Chequy az. and or on a chief of the second another nebuly as the first. TAVESToke, $V^{*}$. Tavystock, $\nabla$.

Chequy az. and or on a chief sa. another wavy of the second. Tavistock.

Erm. on a chief or another indented gu. Brous, $V$.

Erm. on a chief indented gu. another plain or. Brome, $\nabla$.

Gu. on a chief or another dancetty (indented, Thorelys, $V^{*}$.) of the first. Thorleys, $V$.

Lozengy sa. and arg. on a chief az. another indented or. Stocker.

Paly of six arg. and gu. on a chief az. another indented or. Gousell, $\nabla$.

l'er fess gu. and arg. on a chief of the second another indented as the first. Hachet or HaNCHET, V* 


\section{on a Chief}

\section{On a CHIEF cont.}

Arg. fretty gu. on a chief az. charged with three crosses (croslet, another) patty of the first another chief arg. charged with so many leopard's faces like the second. Michael Carvenem, $V$.

Bendy of nine or and gu. on a chief erm. another arg. charged with three fleurs-de-lis sa. Draper, Strond Green, granted 1613, Harl. MS. 6095. Cloud see Cloud

\section{Coronet and Crown}

Arg. on a chief gu. a mural coronet or. WorsLEy, Overton Hall, co. Derby.

Chequy arg. and az. on a chief gu. a ducal coronet or. Plomer, Ireland.

Erm. on a chief dancetty sa. a ducal coronet or betw. two escallops arg. TAYLor, $W$.

Vairy sa. and or on a chief wavy of the second an eastern coronet gu. betw. two mullets of the first. Benyon, quartered by De Beauvoir.

\section{Coronets}

Arg. gontty de larmes on a chief az. three baron's coronets or. Kington, Harl. MS. 1401, fo. $102, b$.

Arg. goutty de sang on a chief az. three ducal coronets or. EARLEsMan, in Hampshire. Kinoton, $V^{*}$. Kyngton, $\boldsymbol{V}$. But crowns. Kingston.

Arg. goutty de sang on a chief indented az. three ducal coronets or. KINGTON, $V^{*}$.

Arg. goutty de sang on a chief wavy per pale gu. and vert three ducal coronets or. Kington, Charlton House, co. Somerset.

Arg. goutty de poix on a chief indented az. three Saxon crowns or. ErLisman, Westover, Isle of Wight.

Erm. on a chief az, three ducal coronets or. LitTon, Ireland.

Erm. on a chief indented az. three ducal coronets or. Letton, Hertford. LitTon, $V^{*}$. Sir Edward Lytton, $V$. Lytron, Lytton, co. Derby; and Knebworth, co. Hertford; the heiress $\mathrm{m}$. Bulwer, now Lytton, quartering Bulwer, Baronetcy 1838 .

Erm. on a chief gu.three regal (or imperial) crowns ppr. Company of Glovers and SkINNers, Exeter.

Erm. on a chief gu. three prince's coronets or with caps the first tasselled of the third. Company of SkInNers, London; granted 1551.

Erm. on a chief dancetty gu. three ducal coronets or. Leech, co. Lincoln; Kent; and Surrey.

Frm. on a chief indented gu. three coronets or. Ackworth. But crowns. Leach, Cornwall; and Crediton, co. Devon. Leach or Leache. Leche, co. Derby ; and Carden, co. Cliester ; quartering Cawarden. Leche, Chatsworth, co. Derby. Sir Philip Leche, $\boldsymbol{\nabla}$. Leche, $\nabla^{*}$.

Erm. on a chief sa. three crowns or. LEACH, co. Devon.

Erm. on a chief sa. three ducal coronets or. Barksteade, Tower of London, 1654. Stephen de Berkstead, Bishop of Chichester, 1262-87.

Erm. on a chiet engr.sa. three antique crowns or. John EARLE, Bishop of Worcester 1662 ; Salisbury 1663.65.

Erm. on a chief indented sa. three eastern crowns or. EarLes; granted 1 Aug. 1660.

\section{Crescent}

Arg. on a chief indented gu. a crescent betw. two mullets or. ST. JoHN, co. York, $V$.

Arg. on a chief vert a crescent of the first betw. two mullets or pierced gu. Oroway.

\section{Crescent cont.}

Arg. on a chief or a crescent .... SAmore. The crescent gu. Samoure.

Erm. on a chief per pale or and az. a crescent gu. Peckham.

Gu, on a chief az. a crescent arg. Danderler.

Per pale arg. and gu. on a chief indented per pale a crescent and a leopard's face counterchanged. RitoN, Harl. MS. 1465, fo. 17.

Per pale arg. and or on a chief indented vert a crescent betw. two mullets .... ORDWAY.

Per pale (dancetty or) pily sa. and arg. on a chief gu. a crescent betw. two ermine spots or in the centre a rose for diff. of the third. HENDERson, co. Chester.

\section{Crescents}

Arg. on a chief gu. two crescents of the first. BIGWOOD.

Arg. on a chief gu. two crescents or. BELET, Lord of Marham, Norfolk. Bigwon, $V^{*}$. Bygwod, $V^{*}$.

Arg. on a chief sa. two crescents or. BIGwov.

Per pale .... and .... on a chief per pale two erescents all counterchanged. John de Nectone, seal.

Per pale or and az. on a chief per pale two crescents all counterchanged. FARNHAM, Quorndon, co. Leicester.

Per pale or and gu. on a chief per pale two crescents all counterchanged. Nicholas de Farniram, Bishop of Durbam, 1241-9.

Vairy on a chief .... two crescents. Bockland. Arg. on a chief az. three crescents of the first. Symson, Polton.

Arg. on a chief az. three crescents or. DAGGETT. Sir John Dudley, $V$.

Arg. on a chief gu. three crescents of the first. Bigwood. Lamorley or Lamatorle, Norfolk; and co. York.

Arg. on a chief gu. three crescents or. BIGWoD or Bigwood, $\boldsymbol{V}$. Bygonds.

Arg. on a chief indented sa.three crescents or. Preston, Ireland.

Arg. on a chief vert three crescents of the first. Simison, Udock, Scolland. Henry Simpson or Sympson, London, 1716. The chief indented. Srmpson, Thorntoun, Scotland.

Az, on a chief gu. three crescents arg. DaMarelL, North Huish, co. Devon: the heiress $m$ Trenchard; and Milton Damarell, co Devon. Moone or MOYNE.

Az. on a chief or three crescents gu. Samore; this is apparently an error in Burke, Armory, through confusing two entries in Berry, Dict.

Barly of (five $V^{*}$ ) six arg. and gu. on a chief of the second three crescents or. Frampton.

Erm. on a chief az. tbree crescents or. HEBDEN, Easthorpe Park, and Appleton, co. York. The chief indented. HEBDON, co. Oxford.

Erm. on a chief sa. three crescents arg. WinchINGHaMr.

Erm. on a chief sa. three crescents or. Preston, Becston St. Lawrence, co. Norfolk, Baronetcy, 1815. Preston, Suffolk, $\boldsymbol{V}$. The chief indented. Preston, Stanfield Hall, Norfolk.

Ermines on a chief arg. three crescents gu. Preston, Ireland.

Erminois on a chief indented gu. three crescents arg. Harvey, Beacham Well, and Thorpe Lodge, Norfolk.

Gi1. on a chief arg. three crescents of the first. Goldfrap.

Gu. on a chief az, three crescents arg. Damerley. 


\section{On a CHIEF cont.}

Crescents cont.

Or on a chief indented az. three crescents of the first. Rauf PikenhaM, Thorneton Watlous, $Y$. Harvey de Watlons, $Y$. Hervey de Watlous, $P$. Or on a chief sa. three crescents arg. ANDERLEY. Or on a chief indented sa. three crescents arg. Harvey, Comb-Nevile, co. Surrey ; descended like Harvey, Rolls Park, Cbigwell; the coheiresses m. Lloyd, Eustace, Tower, Drummoud, Bramston, and Fane, from Harvey, Folkstone. HaRrey, Kyle, Wexford; quartering Champney and Hutchinson; a branch of Harvey, Bargy Castle, Wexford ; descended from Harvey, Bosworth, co. Leicester.

Or on a chief sa. three crescents of the first. Preston, Ireland; and Preston, co. Lancaster. Preston; quartered by Ludlow. Preston, Viscount Gormanston 1478; quartering O'Brien with Landres and az. a saltire betw. four leopard's heads arg.; but quartering Birming. ham, Harl. MS. 1603. 'The chief indented. Preston, Ireland.

Paly of six arg. and az. on a chief gu. three crescents as the first. MENCE or Mens. Meus, $V$.

Paly wavy of six arg. and sa. on a chief as the second three crescents like the first. BEAwshiN. BEwSHIN.

Paly wavy of six or and sa. on a chief as the second three crescents arg. Lambroke, co. Somerset.

Quarterly or and gu. on a chief sa. three crescents of the first. Preston.

Paly of six arg. and gu. on a chief as the first so many crescents like the second. SnLeto, Italy.

Paly of six arg. and gu. on a chief paly as many crescents all counterchanged. BURLEIGH. Cross

Arg. on a chief vert a tau betw. two mullets pierced or. Drony, Thurston Rougham, etc., Suffolk ; Colne, co. Huntingdon ; Riddlesworth, Norfolk; Beronetcy 1627-1712 ; and Oierstone, co. Northampton; Baronetcy 1739-59.

Barry of six erminois and gu. on a chief az. a cross patty arg. betw. two suns in splendour. Nicholson, Roundhay Park, co. York.

Chequy or and gu. on a chief az. a cross wavy arg. RALeigh.

Gu. on a chief arg. a cross engr. of the first. Bacon, $V$.

Or on a chief az, a long cross arg. Lizars, Scotland.

Or on a chief sa. a cross moliue fitcliy of the first. HALL, London.

Paly of six or and az. on a chief gu. a cross croslet arg. ANwTCK, London.

Sa. on a chief arg. a cross patonce of the first. John Boluron, $T$.

Vair on a chief gu. a cross patonce arg. Rauf le Fitz-Barnard, $E$.

\section{Crosses}

Arg. on a chief gu. two crosses croslet of the first. Farrand or Farrant, Charlton, co. York.

Arg. on a chief gu, two crosses patonce chequy of the first and az. Farnant, Surrey.

Arg. on a chief gu. two crosses flory vair (with properly) a 5-foil for diff. az. Ferrand, St. Ives, and Harden Grange, co. York; quartering Walker and Dale.

Arg. on a chief gu. two crosses patonce vair. Ferrant, Mitcham, Surrey; and Harden, co. York. Ferrand, St. Ives, and Harden Grange, co. York; quartering Walker and Dule.
On a CHIEF cont.

\section{Crosses cont.}

Arg. on a chief sa. two crosses or. Cistercian Abbey at Tame or Thane, co. Oxford.

Arg. on a chief per pale gu. and sa. two crosses patonce vairy or and az. Farrant, Nortbsted House, Chelsfield, Kent.

Bendy of six or and az, on a chief of the second two crosses patty as the first. MEDDEw, Great Yarmouth. Meddus or Medowes, co. Chester.

Erm. on a chief indented sa. two crosses croslet arg. Bame or Baum.

Arg. on a chief az. three crosses croslet fitchy of the first. Fitz-Oseert.

Arg. on a chief az. three crosses patty of the first. Fitz-Osbert. The crosses patty fitchy, Clare, Pembrole. Marshall. Ogie. Ogye. Osbert. Strongbow, i.e. Gilbert and Richard de Clare, Earls of Pembroke, 1138-70.

Arg. on a chief az. three crosses patty fitchy or. Strongrowe, $V^{*}$. StrongBow, $V$.

Arg. on a chief dancetty gu. three crosses croslet fitchy of the first. John de Otterburne, $Y$. The chief indented. Gargrave, co. Lancaster. Gargrave, Craven, co. York, $V$. Otterbourne, $V$. Otterburne, $V^{*}$

Arg. on a chief gu. three crosses patty of the first and in the centre point a 5 foil for diff. of the second. Drall, Mile End, Middlesex; granted 1758.

Arg. on a chief indented gu. three crosses patty of the first. Perceval, Royton, co. Lancaster; the heiress $m$. Pickford afterwards Radclitfe; descended from Perceval, co. Somerset. Perceval, Temple House, co. Sligo; quartering Crofton and Carleton; descended, like Percival, Kilmon Hill, co. Waterford, Annefield, co. Dublin, Cappaheaden, co. Kilkenny, and Kilcunart, co. Cork, froln Perceval, Tykeuham, and Weston, ancestor. of Penceval, Barony 1715, Viscounty 1722, Earl of Egmont 1733, Baron Arden 1770; quartering Lovel: Collinson, Somerset, iii, 173-6.

Arg. on a chief gu. three crosses patty fitchy of the first. Dyall, Berkswell, co. Warwick.

Arg. on a chief indented gu. three crosses tau of the first. THurland, co. York, Harl. MS. 1404 , fo. 118 .

Arg. on a chief. engr. gu. three crosses croslet fitchy or. OtTerbonne, co. York.

Arg. on a chief indented gu. three crosses patty or. Perceval, Barntown, co. Wexford.

Arg. ou a chief gu. three crosses putty vair. Ferrard, Skipton, co. York ; granted 1586.

Arg. fretty gu. on a chief per fess of the first and az. in the upper part three leopard's heads as the second in the lower so many crosses patty like the field. Michael Carteneld, $V$.

Arg. on a chief sa. three crosses croslet fitchy or. Fitz-Osbert. The chief indented. Orwer, Orwey, co. Devon; Leiress m. Hampton.

Barry of four sa. and arg. on a chief or three crosses croslet as the first. AUNDELIGH.

Barry lozengy or and az. on a chief gu. three crosses croslet of the first. George MoNTEIGNe Mountagne Mountaigne or Mountaine, Bishop of Lincoln 161\%, London 1621, Durham 1627 , Arch bishop of York 1628; granted 1613.

Bendy of six arg. and az. on a chief sa. three crosses patty or. Calbreath, Scotland.

Bendy of six arg. and sa. on a chief gu. three crosses croslet or. Heritage, Britams, co. Warwick. 


\section{Crosses cont.}

Chequy arg. and gu. on a chief or three crosses botonny az. Burges.

Chequy gu. and or on a chief arg. three crosses croslet az. Burges, Cornwall.

Erm. on a chief gu. three crosses .... fitchy arg. SHEPPARD.

Erm. on a chief gu. three crosses tau or. Prifer. Prosert. The chief indented. Therrand or Thurland, Ryegate, Surrey; and Garnstone, co. York. THUnLaNd. $V$; and Harl. MS. 1404, fo. 117 ; and co. Nottingham. Totorell, $V$.

Erm. on a chief indented gu. three crosses wavy or. Thurrand.

Erm. on a chief sa. three crosses botonny arg. DiMOCKE.

Erm. on a chief indented sa. three crosses croslet arg. Bamme or Baum.

Erm. on a chief sa. three crosses patty arg. Newman. Wichingham or Witchingham, Yoxford, Suffolk. Wickinghall. Wychingeon, $V^{*}$. WYcHINGTON, $V$.

Erm. on a chief sa. three crosses patty or. NewMaN, London. WICHINGHAM or Witchingham, Yoxford, Suffolk.

Erm. on a chief indented sa. three urosses patty fitchy or. Orway.

Er.m. on a chief indented sa. three crosses tau arg. ThurLand, Harl. MS. 1404, fo. 118.

Gu. on a chief arg. three crosses patty of the first. DeBbeIG.

Gu. on a chief arg. three crosses patty sa. Prisotr, $V^{*}$. Prysetr, $V^{*}$. Sr. John Prysott, $\boldsymbol{V}$.

Gu. on a chief arg. three crosses tau sa. Prisetr or Prosser. Profetr, Harl. MS. 1404, fo. 118.

Gu. on a chief az. three crosses croslet fitchy arg. Damerley.

Or on a chief .... three crosses tau of the first. Prescop. The chief arg. Prisetr, co. Salop.

Or on a chief dancetty arg. three crosses patty of the first. CoRDEler.

Or on a chief (dancetty Harl. MKS. 6595) indented az. three crosses croslet of the first. Syr William (or Galyon) Conder, $Q$.

Or on a chief indented gu. three crosses croslet fitchy arg. Gararave, co. York.

Or on a chief sa. three crosses formy of the first. TANNER, Ireland; granted 1613.

Paly of six arg. and az. on a chief gu. three crosses formy as the first. Peter MEw or MEws, Bishop of Bath etc. 1672, Winchester 1684.1706.

Paly of six az. and or on a chief gu. three crosses croslet as the first. Almeware or ALNwICK.

Paly of six az. and or on a chief gu. three crosses patty as the second. Alnewick, $V$. Alnewren, $V *$.

Puly of six or and az. on a chief gu.three crosses croslet arg. Meres. The croslets fitchy. Sr. John de Mews, $V$.

Paly of six or and az. on a chief gu. three crosses patty arg. MEwes, Isle of Wight. Sr. Walter Mrws, of the Wight, $V$. The crosses fitchy. DEMEws, $V^{*}$.

Paly of six or and az. on a chief gu. three crosses patty of the first. Meres or Meros. Meaux or MEUx. Kingston, Isle of Wight; quartering Drew; Baronetcy 1641-1706; quartered by Worsley through Miller. Meux, Theobald's Park, co.Hertford; Baronetcy 1831 . MEwes, $V^{*}$.

Arg. on a chief gu. four crosses croslet or. LATIMER.

\section{Crosses cont.}

On a CHIEF cont.

Arg. on a chief indented az. five crosses croslet or. WILTSHIRE.

Arg. on a chief (ampty) enty az. crosses or. M. Raphe de Wilshire, $Y$.

Cups

Arg. on a chief az. two fleshpots (or porridge pots) without handles or. Porter, $\nabla$.

Arg. on a chief sa. tbree covered cups or. Boteler, Teston, Kent; Baronetcy 1641-1772. Boteller, $V$. Nicholas Butrer, Hailes in Over Rawcliffe, co. Lancaster; and London, 1730. BoterKER.

Arg. on a chief indented sa. three covered cups or. Butler.

Az. on a chief indented or three covered cups of the first. Lawlesse or Lawley.

Barry of four gu. and or on a chief arg. three goblets or drinking cups (open bowls $V^{*}$ ) of the first inside silver feet gold. HaLghton, $V$.

Or on a chief indented az. three cups covered of the first. Boterer. Butler, Baron of Kayre, Harl. MS. 1607. LAWLES.

\section{Cushion}

Arg. on a chief gu. a cushion betw. two spurrowels of the first. MarjonIBanks, Lees, co. Berwick; Hallyards, Mid Lothian; Baronetey 1814. Marjoribanis, Leuchie, Scotland.

Arg. on a chief sa. a cushion or in the centre a mullet for diff. gu. MarJoribanks, Bowbardie, Scotland.

\section{Cushions}

Arg. on a chief gu. three cushions or. JоHnston, quartered by Murray.

Gu. on a chief arg. three lozenge cushions of the first. RaNDALI, Scotland.

\section{Escallop}

Arg. fretty gu. on a chief az. an escallop of the first. John Curwen, Cumerton, $V$; co. York.

Arg. fretty gu. on a chief az. an escallop or. Cutsing.

Erm. on a chief gu. an escallop arg. UMroner.

Erm. on a chief sa. an escallop betw. two bells arg. BeLl, Essex.

Paly of six or and gu. on a chief as the second an escallop like the first. BAYONS or BAYos.

Vair on a chief gu. an escallop betw. two pierced mullets or. BARNARD, $V$.

\section{Escallops}

Erm. on a chief indented gu. two escallops arg Rous or Rosse, Suffolk. Sire Thomas le Rous, $N$. Geffry Rous, $V$.

Erm. on a chief gu. two escallops or. Raw, London; and Skipton, co. York; confirmed 1563. $R_{\mathrm{Aw}}$, Sandwich, Kent; and Rishangles, Suffolk. Arg. fretty gu. on a chief az. three escallops of the first. KENDALL.

Arg. on a chief indented az. three escallops of the first. Strickland, Suffolk.

Arg. on a chief az. three escallops or over all on $\mathrm{a}$ bend gu. as many lozenges of the first. GAMAGE, Harl. MS. 1404, fc. 31 .

Arg. fretty gu. on a chief az. three escallops or. Conwen, $V$. Sr. Gilbert Curwen, Camerton, $V$. Arg. on a chief gu. three escallops of the first. Brovghton.

Arg. on a chief gu. three escallops or. Ps. de Bronton, $F$

Arg. on a chief indented gu. three escallops or. Bassett, co. Gloucester.

Arg. on a chief sa. three escallops of the first. TAyLer, Middlesex. 


\section{On a CHIEF cont.}

Escallops cont.

Arg. on a chief indeuted sa. three escallops of the first. Burton, Ireland. Negus, Bedford. (Attributed to) John TAYLoR, Bishop of Lincoln 1552-4.

Arg. on a chief sa. three escallops or. Patrick de Graham, $V$. Graeam, Scotland. And with a crescent of the third surmounted by a mullet as the second for diff. Graham, Dumblane, Scotland.

Arg. on a chief dancetty sa. three escallops or. Greme. But indented. Greme, Scotland.

Az. on a chief arg. three escallops gu. Plays, $V$. Playse.

Az. on a chief indented arg. three escallops sa. BARRETT.

Barry of four az. and or. on a chief of the second three escallops like the first. Clarke.

Barry of eight or and arg. on a chief indented sa. three escallops or. Henry du Boys of Use. burne, $X$.

Bendy of six .... and .... on a chief .... three escallops .... John EgLeshed ; seal. $V$.

Erm. on a chief nebuly az. three escallops or. Negus, Norfolk; and Brome, Eye, Suffolk.

Erm. on a chief gu. three escallops arg. BeLLEw, co. Chester.

Erm. on a chief indented gu, three escallops arg. Rouse, $V^{*}$. Sr. Thomas Rous, temp. Edward I, $V$. Sir Thomas Roose, $L$; or de Roux, $L$; but de Ronye, L, Harl. MIS.6137. TAYLeR, Grafton, co. Oxford.

Erm. on a chief dancetty gu. three escallops or. Sr. Edmond Basset, co. Gloucester, $V$. The chief indented. Basset, $V^{*}$. Edmund (the second son of) Basset, $K$. Sire Edmon Basser, $N$. Bassetr, co. Gloucester. CHLD, $V^{*}$. TayLour, co. Lancaster; and Middleton Cheney, co. Northampton.

Erm. on a chief sa. three escallops arg. Tayleur, Rodington, and Buntingsdale, co. Salop; quartering Skrymshire.

Erm. ou a chief dancetty sa. three escallops arg. TAYLOR, Strensham Court and Mosely Hall, co. Worcester. The chief indented. TAYLER, $V$. TAYLOUR.

Erm. on a chief sa. three escallops or. TAYLOR, quartering Wheeler.

Erm. on a chief indented sa. three escallops or. TAYLOR, co. Lancaster; and London; granted 24 December 1674

Erminois on a chief arg. three escallops sa. KING, Middlesex.

Gu. on a chief indented arg. three escallops of the first. Baret, $V$. Barretr, co. Hereford.

$\mathrm{Gu}$. on a chief indented arg. three escallops sa. Barrett, co. Hereford; co. Salop; and co. Oxford.

Gu. on a chief arg. three escallops vert. Glasco, lreland.

Gu. on a chief indented or three escallops of the first. l'OER.

Gu. on a chief indented or three escallops sa. Andrew Barrett, Bishop of Llandaff 1395-6.

Or on a chief dancetty az. three escallops arg. Reginald Boulers or Butler, Bishop of Hereford 1451, Lich field etc. 1453.9.

Or on a chief inderted az. three escallops (arg. Stratton, Suffolk, $V$; but) of the first. Stratton, Suffolk.

Or on a chief sa. three escallops arg. GRAHAM, Scotland; and York, 1718.

\section{Escallops cont.}

Or on a clivef sa. three escallops of the first. Graham, Barony 1445, Baron and Earl Graham 1722, Earl of Montrose 1504, Marquis $16 \pm 1$, Duke 1707. Graham, Esk, Cumberland; Burovetcy 1629 ; quartering Stewart; Viscount Preston, 1680-1739. GraHaM, Norton Conyers, co. York; Barouetcy 1662. Gräan, Netberby, Cumberland; Baronetcy 1783. Graham, Airth; quartering arg. a fess embattled betw. three roses gn.; Killern; Mossknow, co. Dumfries ; Petham, Kent; and Sewerby House, co. York.

Or on a chief embattled sa. three escallops of the first. Gramam, Meickle, Scotland; descended from Montrose. The chief engr. Graham, Braco, Scotland; a scion of Montrose.

Paly of six arg. and az. on a chief gu. three escallops of the first. HIoHaM, co. Bedford. The escallops or. Heighan, $V^{*}$. Sr. Roger HerHaM, co. Bedford, temp. Edward I, $V$. Higham, co. Bedford.

Paly of six arg. and gu. on a chjef of the second three escallops arg. Robert Chamberlays, $V$.

Paly of six erm. and erminois on a chief indented sa. three escallops or. TAYLOR, Hollycombe, co. Sussex; Baronetcy 1828.

Paly of six or and az. on a chief gu. three escal. lops arg. Nevill. Newport. The escallops as the second. Nenrle; Edmondson.

Paly of six or and gu. on a chief as the last three escallops like the first. BaYE. BaYeaux, co. Lincoln; temp. Henry III. Bayons, $V^{*}$. Bayos. Bayous, $\boldsymbol{V}$. Boys, or Boras, london. Paly arg. and az. on a chief gu. three escallops or. Sire Roger de HexHam, $N$.

Per pale indented erminois and sa. on a chief per pale of the last and or three escallops connterchanged. GraHay, Kirkstall, co. York; and Edmond Castle, co. Cumberland; Baronetcy 1808.

Sa. fretty arg. on a chief or three escallops of the first. THOMPSON.

Or on a chief indented az. four escallops of the first. Robert Stretion, Bishop of Licbfield etc. $1360-85$.

Arg. on a chief sa. five escallops or. GreLY.

\section{Escucheon}

Erm, on a chief gu. an escucheon arg. UmMoner. Esquires

Barry of six gu. and or per pale counterchanged on a chief per pale of the first and second two esquires based dexter and sinister transmuted over all an escucheon arg. HAGELEY (in error).

Estoiles

Arg. on a chief indented gu. two estoiles or. Edward ST. JoHN, seal, 1345.

Chequy arg. and sa. on a cluef gu. two estoiles or a crescent for diff. .... Bonwick, Surrey.

Erm. on a chief az. two estoiles or. RarNon; granted 1588. The chief indented. Rayner, East Drayton, cu. Nottiugham.

Erm. on a chief gu. two estoiles arg. Dougras, Whittingham, Scotland.

Gu. on a chief arg. two estoiles sa. Prust, Gorver, and Hartland, co. Devon. Prust, $W$.

Arg, on a chief az. three estoiles or. Dymoke, $V$. Arg. on a chief gu. three estoiles or. Monison. Arg. on a chief sa. three estoiles or. Dimocke. Dymock, Drmok, or Dymoke, co. Devon.

Barry lozengy arg. and gu. on a chief az. three estoiles or. Payntell or Poyntell, London; granted June 1611. 


\section{On a CHIEF cont.}

Estoiles eont.

Barry of six or and az. on a chief as the second three pierced estoiles like the first. PItT, Cure. yard, co. Salop; and co. Worcester.

Erm. on a chief az. three estoiles or. Raynor.

Erm. on a chief indented gu. three estoiles arg. Escourte. Estorlls, $V$.

Erm. on a chief dancetty gu. three estoiles or. Eastcourt, W. The chief indented. Bassett, co. Gloucester. Escourte. Estcourt, Estcourt, co. Gloucester. Estcourt, Newton, co. Wilts; and co. Gloucester, 1623.

Erm. ou a chief per pale gu. and az. three estoiles or. Edward RaInBow, Bishop of Carlisle 1661-84.

Or on a chief az. three estoiles of the first. LAWES or LAWsE, Kent; and Norfolk; granted 1584. Lawes, Rothamsted Manor Honse, co. Hertford; quartering Bennet and Wittewronge.

Or on a chief sa. three estoiles of the first. LEwis, Canterbury.

Sa. on a chief arg. three estoiles gu. Priest. Eyes

Barry (nebuly, Gwillim) of six az. and arg. on a chief of the second turee eyes gu. Delahax, Ireland.

\section{Feathers}

Chequy or and az. on a chief gu. three ostrich feathers in plume issuant of the first. Drax, Middlesex; co. Somerset ; and co. York ; confirmed 1561. Drax, Charborough Park, co. Dorset; and Ellerton Abbey, co. York; quartering Erle and Sawbridge. Drax, Sibsey, co. Lin. coln; and Barbadoes.

Fess see Bar and Lozenges

Fetterlocks see Shackles

Fireballs

Gn. on a chief arg. three fireballs ppr. BoDycoAT or Bоусотт. But three grenadoes ppr. Вочсотт, Boycott, Buildwas, and Ruclge Hall, co. Salop.

Paly of six or and gu. on a chief engr. erm. three hand grenades ppr. BoycotT, Sprowston Hall, Norfolk; the beiress m. Morse; and the two coats are now borne by John Hall MorseBoxcotr, Sennowe Lodge, near Great Ryburgh, Norfolk; and Semnoweville, near Bushey, co. Hertford; quartering Hall, Carter, and Thomp son.

\section{Fish.... Dolphin}

Arg. on a chief gu. a dolphin naiant of the first. FISCHER.

Arg. on a chief gu. a dolphin embowed naiant of the first. Fisher, Maidstone, Kent. John Fisher, Bishop of Rochester 1501-35.

Arg. on a chief gu. a dolpbin embowed or. Fisher, Maidstone, Kent, $W$.

Gu. on a chief or a dolphin az. Elmore.

$$
\text { ..... Salmon }
$$

Sa. fretty arg. on a chief cousu gu. a salmon naiant or. Salmon, France.

\section{Fleur-de-lis}

Arg. on a chief az. a fleur-de-lis betw. two pierced estoiles or. SAULT, 1786.

Arg. on a chief gu. a fleur-de-lis or over all a bend engr. az. LEEke, Ludlow, and Longford, Salop.

Arg. on a chief gu. a fleur-de-lis or betw. two lozenges of the first. WEYMAN, quartered by Gascoigne, Harl. MS. 1487, fo. 268b. WymeN, in church at Sprotborough, co. York.

Arg. on a chief gu. a flenr-de-lis or in the centre a mullet for diff. sa. Rogers, Dowdeswell ; and Castle Hale, in Panswick, co. Gloucester, 1730.

\section{On a CHIEF cont.}

Fleur-de-lis cont.

Arg. on a chief or a fleur-de-lis gu. Roger, $V$. Rogers, co. Dorset. And with a mullet in the centre for diff. of the last. Rogers, $V$. The mullet sa. Rogeps, Bryanstone, co. Dorset. Rogers, Cadbury House, co. Somerset.

Arg. on a chief or a fleur-de-lis sa. Rogers, Brianston; Collinson, Somerset, iii, 532.

$\mathrm{Az}$. on a chief arg. a fleur-de-lis of the first. HORDE.

Erm. on a chief gu. a fleur-de-lis betw. two boar's beads couped erect or. TAYLor, Baronetcy 1704, Barouies 1760, 1831, Viscounty 1762, Earl of Bective 1766, Marquis of Headfort 1800.

Erm. on a chief indented gu. a fleur-de-lis betw. two boar's heads erased erect or. TAYLOUR, Dublin; granted 1668 .

Gyronny of eight az. and or on a chief arg. a fleur-de-lis betw. two crescents gu. Prentice.

Paly of six gu. and vair on a chief or a fleur-delis issuant sa. M. Henry de Basones, $D$.

Paly vair and gu. on a chief or a fleur-de-lis issu. ant sa. Robert de Basseches or Basseges, $C$. Quarterly arg. and erm. on a chief or a fleur-lelis gu. Rogers, co. Dorset.

Sa. on a chief arg. a fleur-de-lis gu. Saschant or Sasthant. The fleur.de-lis issuant. Sire de Susane, $A$; or Susat, A, Harl. MS. 6137 ; but Sr. de Saschant, Harl. MS. 6137, fo. $71 b$. Fleurs-de-lis

Arg. on a chief az. two fleurs-de-lis of the first. MountFond, Norfolk.

Arg. on a chief az. two fleurs-de-lis or. Clinton, co. Warwick. Sir John Clinton or de Clinton alias Quingeton or QUINGenton, $L$. Sire Johan de Clintone, $N$. Monford, $V$.

Arg. on a chief sa. two fleurs-de-lis or. Tracx.

Per fess indented sa. and or on a chief arg. twc flenrs.de-lis of the first. HINTON.

Arg. on a chief az. three fleurs-de-lis MOUNTFORD.

Arg. on a chief' gu. three fleurs-de-lis or. : Robert WaSHINGLEY, $V$. WaSINGLEY, $V$.

Barry of four gu. and arg. on a chief as the second three fleurs-de-lis like the first. Seniser. Barry of -six or and gu. on a chief arg. three fleurs-de-lis sa. Norman, Shipton Mallet, co. Somerset; the heiresses m. Bremer, Roby, and Elphinstone.

Bendy of six .... und .... on a chief three fleursde-lis .... John de TrumLeck or TrLuLEK, Bishop of Hereford 1344-60.

Bendy of six gu. and or (or and gu. $V^{*}$ ) on a chief per chief sa. and erm. in the upper part three fleurs-de-lis arg. Nonman, $V$.

Bendy of eight or and gu. on a chief arg. three fleurs-de-lis az. FARMER.

Bendy of nine or and gu. on a chjef per fess arg. and erm. three fleurs-de-lis in the upper part sa. URAPER, Strond Green, granted 1613; Harl. MS. 6095, fo. 28.

Erm. on a chief az. three fleurs-de.lis arg. Brown, Hartrigg, Scotland.

Erm. on a chief indented az. three fleurs-de-lis arg. Washingley, co. Huntingdon.

Erm. on a chief indented sa. three fleurs-de-lis arg. BaYMrN.

Or on a chief az. three fleurs-de-lis arg. FLERIor, $V$. WILLY, $V$.

Or on a chief indented az. three fleurs-de-lis of the first a canton erm. Cramer. 
On a CHIEF cont.

Flears-de-lis cont.

Arg. on a chief az. fleurs-de-lis of the first. Skinner, Cowley, co. Devon.

Arg. on a chief az. fleurs-de-lis or. Skinner, Cowley, co. Devon; granted 1587; W. Skinnen or Skinhur, Cowlegh.

Erm. on a chief indented az. fleurs-de-lis or. AUBEMOND Or AUBEMUNDE.

Flower.... Rose

Chequy arg. and sa. on a chief or a rose gu. leaved vert seeded of the third. HaLFPENny.

Erm. on a chief per pale indented arg. and gu. a rose in the dexter side of the last. SHOTISBROOKE.

Flowers .... Roses

Arg. on a chief az, two roses of the first. Cock, $V^{*}$. Cock, Scotland.

Arg. on a chief sa. two roses of the first. Priory of Austin Canons at SourHwick, Hampshire.

Erm. on a chief indented az. two roses arg. Glyborne.

Or on a chief indented sa. two roses arg. Sir John Careti, $V$.

Fusily erm. and sa. on a chief of the second three lilies slipped arg. William PATTEN or Pattrn or Barbour, commonly called William of Waynflete; founder of Magdalen College, Oxford; Bishop of Winchester 1447-87.

Lozengy erm. and sa. on a chief of the last three lilies slipped arg. Magdalen College, Ox. ford; for the founder, William (BARBOUR or Patten or Pattyn) of Waynflete.

$$
\text { .... Roses }
$$

Arg. on a chief gil. three roses of the first. Sillborne or Sinborne. SWInborne. Sr. William Swynburne, $V$. The roses barbed vert. Becket, Norfolk.

Arg. on a chief indented gu. three roses of the first. SWINBORNE, $V^{*}$.

g. on a chief indented gu. three roses or. Roser, $V$. Rosier.

g. on a chief sa. three roses of the first. Darrell. Hill, London.

Arg. on a chief indented sa. three roses or. Rosien, co. Rntland.

Arg. fretty sa. on a chief of the first three roses gu. leaved vert. Fortescue.

Arg. fretty vert on a chief az. three roses or barbed of the second. Younge, London; and Drayton, co. Stafford; confirmed by Segar.

Erm. on a chief gu. three roses arg. Sichebery or SichenBury, co. Bedford.

Erm. on a chief gu. three roses or. Atwater. Fadkethbery, Ferontbery, or Fountiery, co. Bedford. Sr. John Foulthebury, co. Berlford ; temp. Edward I, $V$. Sichebery or Sicherbury co. Bedford. Sire Johan di Southburi, $N$. SoUTHBury.

Iirm. on a chief embattled gu. three roses or GrubB, North Minms Parsonage, co. Hertford. GRUBB, Horsenden, co. Buckingham, quartering Ratcliffe.

Erm.on a chiefsa. three roses arg. SatherTHWAYTE, co. Lancaster.

Or on a chief indented sa. three roses arg. Carett, $V^{*}$. Caret or Carrett.

- Per pale az. and or on a chief gu. three roses arg. 'l'Alcot, $V$ *

Sa. fretty arg. on a chief of the last three roses gu. Fitz-Chamberiarn, V*. (Quartered by Fortescue) $r$.
On a CHIEF cont.

Flowers cont. Roses cont.

Vairy arg. and sa. on a chief of the last three roses of the first. William Partrich, London, W. Patrick, $V^{*}$. The roses seeded or barbed vert. Partridoe, Kent, 1630.

Arg. on a chief gu. five roses of the first. Lacer. 3-Foil

Erm. on a chief indented sa. a 3.foil slipped betw. two annulets arg. Adam Bayme or Bawne, Lord Mayor of London 1390. Bamme, Kent, $\boldsymbol{V}$.

Erm. on a chief dancetty sa. a 3 -foil slipped betw. two annulets or. BArme, Kent, quartered by Walsingham.

Gu. on a chief erm. a 3-foil slipped vert betw. two hurts. Walmsiey, Foston Hall, co. Derby. 3-Foils

Erm. on a chief indented arg. two 3 -foils slipped sa. BaWne.

Erm. on a chief indented sa. two 3-foils slipped arg. BAMHE, $W$.

Arg. on a chief gu. three 3-foils slipped of the first. Gamuell or Gamvill, Storton.

Arg. on a chief indented gu. three 3-foils of the first. Mandevilie.

Arg. on a chief gu. three 3 -foils slipped ppr. Bonville.

Arg. on a chief indented sa. three 3-foils slipped of the first, Maundevil, $V^{*}$. Maundevyle, $V$.

Erm. on a chief az. three 3-foils slipped or. Mucham, Norfolk.

Erm. on a chief indented sa. three 3-foils of the first. TAYLER. TAYLOUR.

Erm. on a chief indented sa. three 3-foils or. TAYLOUR.

Gu. on a chief arg. three 3.foils slipped vert. COORE.

Or on a chief gu. three 3-foils slipped arg. GanUBI, Aud with over all a baston in bend sinister company arg. and sa. GanUBLE, Spalding, co. Lincoln.

Or on a chief indented gu. three 3.foils arg. MaNDEvile.

Or on a chief gu. three 3-foils slipped of the first. Bairfeld or Bawhefield. Baytile, Chester.

Or fretty gu, on a chief of the last three 3 -foils slipped as the first. Slade, Ireland.

Per pale arg. and sa. on a chief three 3-foils slipped all counterchanged. MrcheLL, $V^{*}$.

Per pale arg. and sa. on a chief per pale three 3-foils slipped counterchanged. MrcheLL, $W$.

\section{4-Foil}

Per pale gu, and az. on a chief erm. a 4-foil of the second betw. two burts. Walmesley.

$$
\text { 4-Foils }
$$

Gu. on a chief or three 4-foils vert. WeDson or Winson, Loudham, co. Nottingham; granted 1574 .

\section{5-Foil}

Or on a chief sa. a 5 -foil betw. two annulets of the first. Cooke, Norfolk.

\section{Foils}

Arg. on a clief gu. two 5 -foils of the first. Bellet. Arg. on a chief gu. two 5-foils or. Belet.

Az. on a chief arg. two 5 -foils (another pierced) gu. Vickire, Donkeswell.

Or on a chief az. two 5 -foils of the first. BeLETt. Sa. on a chief arg. two 5-foils gu. Ticarr, Dunkeswell, co. Devon, and Warminster, co. Wilts; granted 1558. VICAREY or VICrARY, co. Devon. Arg. on a chief gu. three 5 -foils of the first. Becket, Norfolk. Sire Ingram Belet, $N$. Belet, co. Worcester, $V$. Beliet Beliet 


\section{On a CHIEF cont.}

5.Foils cont.

or Bextot, Moreton, co. Chester, Baronetcy 1663.1714. BeLLot, Corsham, co. Wilts, and Bechym, co. Cornwall; the beiress $\mathrm{m}$. Hawkins and Hele. Birnet, Ashe, co. Devon; the heiress m. Drake. GAYER.

Arg. on a chief sa. three 5-foils of the first. Bellett, Norfolk; and Wiltshire. Palmer, Dorrington, and Lymington, co. Gloucester ; and co. Warwick.

Barry of four arg. and az. on a chief as the second three 5-foils like the first. Srocвwyтн, Harl. MS. 1404 , fo. 96 ,

Barry of four arg. and sa. on a chief as the second three 5-foils like the first. WALDEN, Harl. MS. 1404 , fo. 96 .

Barry of six arg. and az. on a chief as the second three 5-foils or. Brown, Collinson, Somerset, ii, 135.

Bendy indented of six arg. and az. on a chief sa. tbree 5-foils or. RIGBY, Burgh, co. Lancaster. Chequy arg. and gu. on a chief az. three 5-foils or. Thomas ChaBnor, Mowsley, co. Hereford, $1586, W$.

Erm. on a chief gu. three 5-foils arg. GAX, $V^{*}$. John Gaye, Fowey, $V$. Fowex.

Erm. on a chief embattled gu. three 5-foils arg. BuRLAND.

Erm. on a chief gu. three 5-foils or. Sir John SodBery or Sudburye, $L$.

Erm. fretty or on a chief gu. three 5-foils of the second. RowLEY.

Gu, on a chief or three 5-foils vert. WYDDowson.

Lozengy gu. and arg. on a chief of the second three 5-foils of the first. BagGs.

Lozengy gu. and arg, on a chief or three 5-foils az. BAgGE, Stradsett, Norfolk.

Or on a chief az. three 5-foils of the first. Mocket, Kent.

Or on a chief gu. three 5 -foils of the first. Hugh Bellot, Bishop of Bangor, 1586, and Chester, 1595-7.

Or on a chief sa. three 5-foils arg. pierced gu. Gentur, co. Lancaster.

Or on a chief indented sa. three 5-foils of the first. Launce, Penair, Cornwall ; and Suffolk. Payne, Great Marlow, co. Huntingdon.

Paly bendy of six arg. and gu. on a chief or three 5-foils az. BagGe, Plymouth, co. Devon: granted 1607, Harl. MS. 6095, fo. 9.

Paly of six or and sa. on a chief as the second three 5. foils like the first. Potman, Kent.

Per fess gu. and az. on a chief arg. fretty of the second. MorRys, Harl. MS.1404, fo. 110 .

Sa. on a chief arg. three 5.foils of the first. VICKERY.

Vairy az. and arg. on a chief of the last three 5. foils gu. Partheriche or Parthericke, Middlesex.

Vert on a chief arg. three 5.foils az. HeatH. 6-Foils

Paly arg. and sa. on a chief gu. three 'sit-foyles' or. Hubert MoNFER'ANT, $Y$.

Fret and Fretty

Arg. on a chief sa. fretty ol:. Jefrrey. Fitz Piers, as quartered by Viscount Townshend.

Arg. on a chief indented sa. fretty or. Firz Piers.

Az. on a chief arg. a fret gu. M'Carlie.

Erm. on a chief gu. a fret arg. RiBford, co. Leicester.

Erm. on a chief gu. a fret or. Swrnerton, co. Stafford.
On a CHIEF cont.

Fret and Fretty cont.

Erm. on a chief gu. fretty or. ABBEFonn, co. Leicester. RIBBEFond. RIPPESFond, co. Leicester. Henry de RIBEsFond, $E$; or RIBEFond, $F$. Sire Henry de Ribbesfoed, $N$. Sywnerton, co. Stafford, $V$.

Erm. on a chief or fretty gu. RIPPESFORD, co. Leicester.

Frm. on a chief sa. fretty or. Henry de Ribbesford, temp. Edward I, $V$.

Or fretty sa. on a chief of the first fretty like the second. Bretron, $\nabla^{*}$.

Paly of six arg. and sa. on a chief as the first a fret betw. two crescents like the second. Ginson, East Beckham, and 'Thorpe, co. Norfolk; granted 1591.

Fruit.....Pears

Erm. on a chief gu. three pears or. HoLdes, Hockridge, Kent; granted 20 May, 1663. ....Whrat

Az. on a chief arg. three ears of wheat $v t_{1}$ Levinge, Ireland.

\section{Fusils}

Erm. on a chief gu. three fusils or. GERBRIDGE.

Erm. on a chief sa. three fusils or. CHEEKE or Chene, Burton, co. Somerset ; and Suffolk.

Gu. on a chief arg. three fusils sa. BLewer.

Or on a chief az. three fusils of the first. LaNCELOT. LANSELATT.

Fusils

Or on a chief gu. three fusils arg. Sarellyng, $V$.

Sa. on a chief arg. three fusils gu. Molines. Richard Mor.lins, $Y$. Monsire de Molins, being the arms of Montagu in the chief, $Y$.

Erm. on a chief gu. five fusils of the first. Charles, Bridgeuball.

Garb

Barry of four arg. and sa. on a chief as the last a garb or. WEAVER.

Erm. on a chief az. a garb or. Howd.

Paly of four or and gu, on a chief az. a garb erect as the first betw. two escallops arg. PIPER, Ridgewell, Essex.

Garbs

Arg. on a chief indented az. three garbs of the first. WAKEFIEID. The garbs or. WaKEFIELD. Arg. on a chief gn. three garbs .... Whateley, quartering Thompson.

Arg. on a chief gu. three garbs of the first. Richard Wetley, $\nabla$. Wheatley, $V^{*}$. Witley or Whiteley, co. Salop.

Arg. on a chief gu. three garbs or. WHIterey or Wituex, co. Salop. Whituey.

Arg. on a chief indented sa. three garbs. Lawless, Baronetcy, 1776 ; Barou Cloncurry, 1789.

Az. on a chief or three garbs gu. Woods, Ireland. Erm. on a chief vert three wheatsheaves arg. Prosser.

Or on a chief sa. three garbs arg. Cartuand, Ireland.

Paly of six arg. and gu. on a chief az. three garbs or. DaLe, Rutland; confirmed 1602.

Paly of six arg. and vert on a chief az. three garbs or. PAIN.

Sa. on a chief arg. three wheatsheaves vert. Kearney, Ireland.

\section{Gouttes}

Chequy arg. and sa. on a chief of the first four gouttes de sang. Coushill, Devonshire.

Chequy or and az. on linf urg. gouttes de sang. Colshull. 
This book is a preservation photocopy.

It is made in compliance with copyright law and produced on acid-free archival

$60 \#$ book weight paper

which meets the requirements of ANSINISO Z39.48-1992 (permanence of paper)

Preservation photocopying and binding

by

Acme Bookbinding

Charlestown, Massachusetts

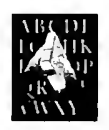

2003 


$$
\text { , }
$$




BOSTON PUBLIC LIBRARY

39999048531568 
